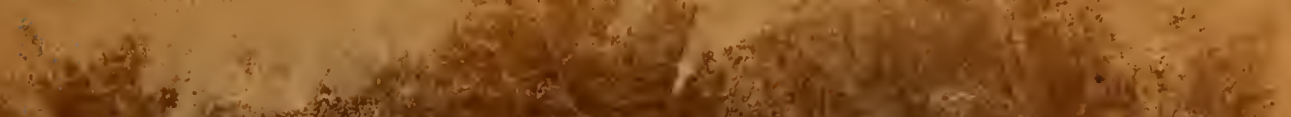

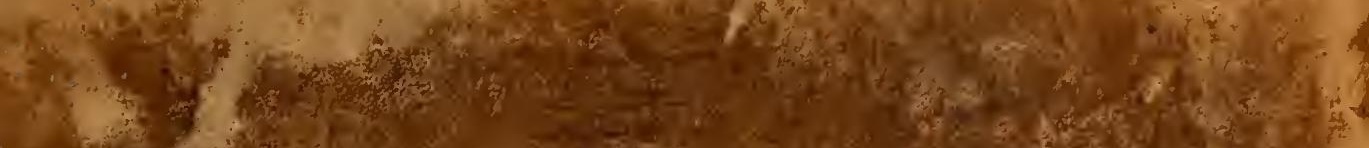

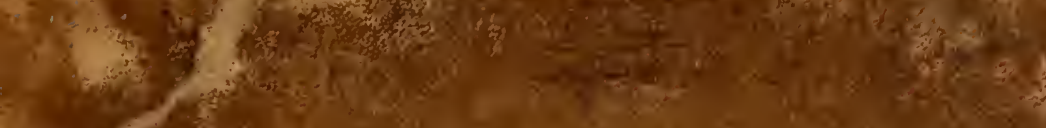

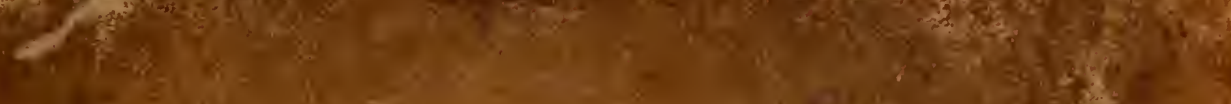

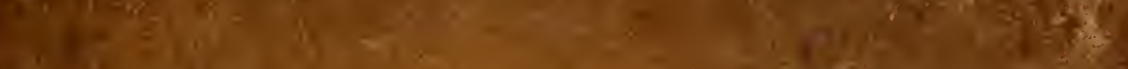

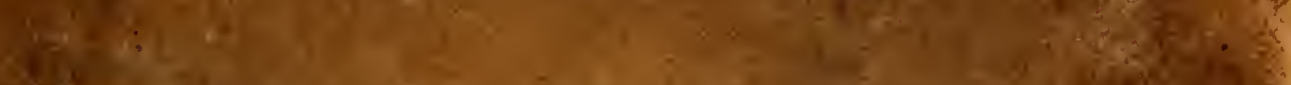
a

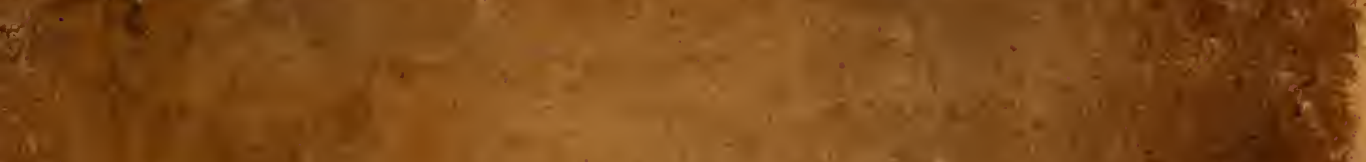

t, $\left(x+x^{3}\right.$

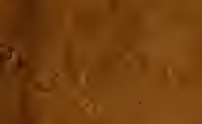

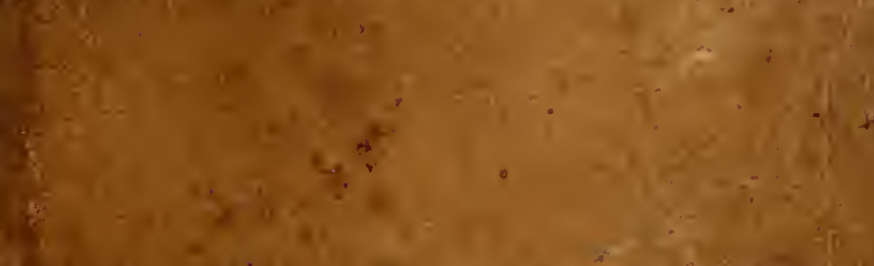
3 $\left\{\begin{array}{l}x \\ 2\end{array}\right.$

$3 \times$ $\operatorname{lig}^{2}$

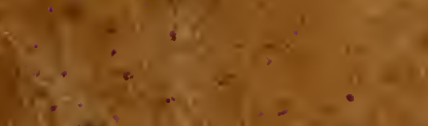
6. 8 if

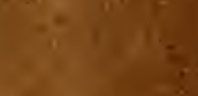
in 7 
$10-5$

Physiology 


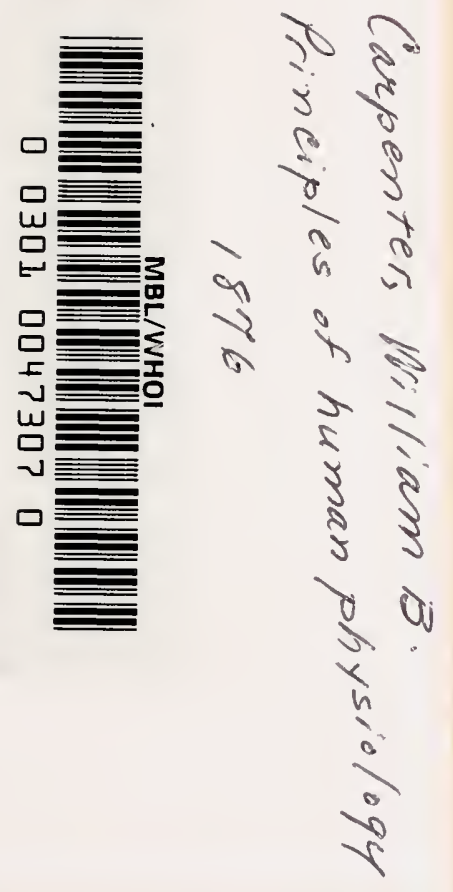







\section{HUMAN PHYSIOLOGY.}

BY

WILLIAM B. CARPENTER, M.D., F.R.S., F.G.S., F.L.S., REGISTRAR TO THE UNIVERSITY OF LONDON, ETC., ETC.

EDITED BY

HENRY POWER, M.B. LOND., F.R.C.S.,

EXAMINER IN YATURAL SCIENCES, UNIVERSITY OF OXFORD, AND IN NATURAL SCIENCES AND IN MEDICINE, LNIVERSITY OF CAMBRIDGE; LATE LECTURER ON PHYSIOLOGY AT THE WESTMINSTER HOSPITAL; OPHTHALMIC SURGEON TO ST. BARTHOLOMEW'S HOSPITAL;

SURGEON TO THE ROYAL WESTMINSTER OPHTHALMIC HOSPITAL.

A NEW AMERICAN, FROM

THE EIGHTH REVISED AND ENLARGED ENGLISH EDITION,

IVITH NOTES AND ADDITIONS,

BY

FRANCIS G. SMITH, M.D.,

PROFESSOR OF INSTITUTES OF MEDICINE IN THE UNIVERSITY OF PENNSYLVANIA. FELLOW OF THE COLLEGE OF PHYSICIANS, PHILADELPHA.

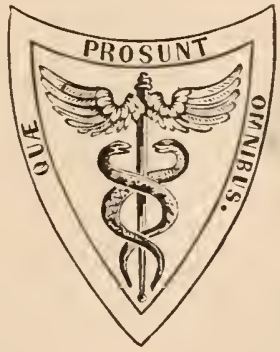

P H I L A D E P H I A :

$\begin{array}{llllllllllll}\mathrm{H} & \mathrm{E} & \mathrm{N} & \mathrm{R} & \mathrm{Y} & \mathrm{C} . & \mathrm{L} & \mathrm{E} & \mathrm{A} \text {. }\end{array}$

1876. 
Entered according to Act of Congress, in the year 1876, BY HENIIY C. LEA,

In the office of the Librariau of (ongress, at Washington, D.C.

PIIIA DEI. PII I A :

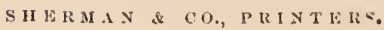




\section{AMERICAN EDITOR'S PREFACE.}

Is again presenting to the American profession Dr. Carpenter's standard work on Human Physiology, the Editor has made such additions as seemed advisable to supply the material which has accumulated both in Europe and this country since the publication of the English Edition. The additions will be found distinguished by brackets [-], and the volume, it is believed, now accurately represents the existing state of physiological knowledge.

The Editor desires to express his acknowledgments to Dr. J. Ott, Demonstrator of Physiology in the University of Penusylvania, and to Dr. Robert M. Smith, Assistant Demonstrator in the sane institution, for valuable aid in preparing the matcrial for the press.

\section{Philadelphia,}

September, $18 \% 6$. 



\section{EDITOR'S PREFACE.}

The Editor trusts that the present Edition of this Work will be found to embody the principal results of the Physiological investigations that have been undertaken during the last four or five years.

Both normal and pathological Histology and Histo-chemistry have lately undergone extraordinary development, which has been accomplished not only by improvements in the construction of the microscope, but by the introduction of new means of investigation, as by Stricker's warmed stage, the application of various agents to harden and stain the tissues, and of new methods of obtaining sections, as by the freezing microtome of Rutherford, by imbedding in paraffin, wax, gum, and pith. A reference to the great works of Stricker and Frey on the microscopic anatomy of the tissues; to those of v. Gorup-Besanez, and 'Kühne, on physiological chemistry, and to that of Rindfleisch on pathology, will show at once that it is impossible, even in a work of this magnitude, to give more than an outline of the more important results of recent research. " In the additions that have been made, the Editor has endeavored to keep in view the practical character of the work as originally intended by the Author; and he has preserved, with such alteration as appeared to be requisite, those sections that especially bear on the relations between physiology and pathology. In future editions, which will be superintended by other hands, the extension of physiological knowledge will probably render necessary a subdivision of the work into two or more volumes, one of which will deal with minute anatomy, another with pure physiology, and perhaps a third with the relations of physiology to pathology.

In the Section on the Blood the results obtained by Brozeit and Steinberg on its quantity; of Gamgee on its specific gravity; of Jacobson, Bernhardt, Albert, Stricker, Körner, and Heidenhain on its tempera- 
ture; of Paquelin and Joly on its coloring matters; of Mathieu and D'Urbain, and of Estor and St. Pierre on its gases ; of Richardson and Brücke on the structure of the red corpuscles ; of Malassez on their number; and of Foster and Balfour on the mode of thcir development; of Klein on the structure and movenents of the white corpuscles; of Binz and Geltowsky on the action of reagents on them ; and of Hoppe-Seyler on their composition; of Obermeier, Lewis, Nepveu, Lostorfer, and others, on spores, germs, and entozoa in the blood, have been given under their appropriate headings.

So in the Section on the Liver, the results of Prof. Flower's researches on its form and divisions, with those of Steffan on its relative weight; of Weber, Asp, Hering, Heidenhain, Flint, Schiff, and Schenk on its structure; of Kowalewsky on the pressure under which the Bile is excreted; of Bogoljubow on the gases of the Bile; of Dalton on its Spectrum; of Maly, Jaffe, Vanlair and Masius, Bernard, and Thudichum, on its coloring matters; of Brunton, on the Action of Calonel on the Liver; of Pflüger, Röhrig, and Munk on the Action of the Nerves on its Secretory Activity; and of Bernard, v. Wittich, Luchsinger, Dock, Salomon, Cyon and Aladoff, Eckhard, Weiss, Seheremetjewsky, and Senator, on its Glycogenic Funetion, have all been noticed at greater or less length.

And again, in the Section on the Kidney and its secretion, the observations of Spiegelberg, Gscheidlen, and others, on uræmia; of Pollack, on the quantity and character of the urine in infants; of Ustimowitsch, on the conditions of its secretion in adults; of Schiff and Brown-Séquard, on the influence of the nervous system upon its composition; of Flint, on the effects of violent exercise; and of Heynsius, Gréhant, and others, on various circumstances modifying the amount of urea, have received due notice.

It would be tedious to go throngh the other subjects in the same way, but it may be stated that, in the aceount of the Nervous System, due space las been given to the consideration of the interesting researches of Fritsch and Hitzig, and of Dr. Ferrier in regard to the action of Electricity applied directly to the surface of the Cerebral Convolutions. In writing the Section on this subject, the Editor has not only had the advantage of Dr. Ferrier's assistance, but has also had several opportuni- 
ties of witucssing his experiments. The views of Hermann and Radcliffe on Electrotonus, and of Kü̈ss on Reflex Actions, are fully given, and an attempt has been made to supply an outline of Mcynert's observations on the Structure of the Brain.

In the account of the Circulating System considerable pains have becn taken to give a connected account of the numerous expcriments that have been madc within the last few years on the Action of the Nervous System upon the Heart, and the Editor must acknowledge the kindness of Dr. Brunton in revising the proof shcets of this part.

Free use lias been made of the Elements of Embryology by Dr. Foster and Mr. Balfour, in describing the earlier stages of development, and several of the drawings have been borrowed from this excellent and instructive work.

The Editor regrets that the Memoir of Dr. Buchanan on the Forces which carry on the Circulation of the Blood was overlooked when this subject was under consideration, or he would have been disposed to accord a somewhat greater influence to the respiratory actions in promoting the flow of Blood through the Heart than is admitted in the text. And, again, in regard to the circumstances affecting the frequency of the Pulse, reference should have been made to Mr. Garrod's observations. Mr. Garrod maintains that the Pulse rate varics inversely as the arterial capillary resistance, and is not affected by the arterial blood-pressure, grounding this essentially on the fact that no effect is produced on the blood-rate in an animal bled to death under chloroform, from which he deduces the law that the heart recommences to beat after the diastole, when the blood-pressure has fallen a certain invariable proportion-a law, the possible hydrodynamical complications of which are much simplified by the verified observations of Poisseuille, who demonstrated that the flow of fluids through capillary tubes varies directly as the pressure.

A considerable number of woodeuts, most of them of a diagrammatic character, have been added, and a few of the older ones have been replaced by others giving better representations of the objects described in the text.

Henry Power.

Great Cumberland Place,

Nov. 1875. 



\title{
TABLE OF CONTENTS.
}

\author{
CHAPTER I. \\ OF LIFE AND ITS CONDITIONS, \\ CHAPTER II. \\ OF THE DISTINCTIVE CHARACTERISTICS OF MAN, . \\ CHAPTER III. \\ ON THE MINUTE ANATOMY OF THE CONNECTIVE TISSUES, CELLS, AND \\ THEIR DERIVATIVES, . . .
}

CHAPTER IV.

CHEMICAL COMPOSITION OF THE BODY, 80

\section{CHAPTER V.}

OF FOOD AND THE DIGESTIVE PROCESS.

1. Of Food and Drink, their Nature and Destination, . . . . 100

2. Of Hunger and Thirst; Starvation, . . . . . . . . 120

3. Movements of the Alimentary Canal, . . . . . . . . 127

Prchension and Ingestion, . . . . . . . . . . 127

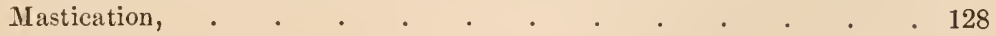

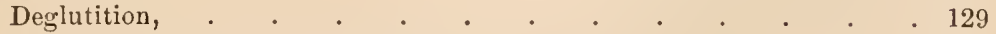

Movements of the Stomach, . . . . . . . . . 133

Peristaltic Movement of Intestines, . . . . . . . 137

Defecation, . . . . . . . . . . . . 141

4. Of the Changes which the Food undergoes, during its passage along the

Alimentary Canal, . . . . . . . . . . 143

Salivary Secretion, and Buccal Digestion, . . . . . . 144

Gastric Juice, and Gastric Digestion, . . . . . . . . 151

Intestinal Digestion; Pancreatic Secretion, . . . . . . 167

Biliary Secretion, . . . . . . . . . . . 173

Intestinal Secretion, . . . . . . . . . . . 177 


\section{CHAPTER VI.}

OF ABSORPTION AND SANGUIFICATION.

1. Of Absorption from the Digestive Cavity ; Intestinal Villi, . . . . . 186 Osmosis, . . . . . . . • . • . . . 194

2. Absorption from the Body in General, . . . . . . . . 200

3. Of the Elaboration of the Nutrient Materials, . . . . . . . 205

Assimilating action of Liver, . . . . . . . . . . 206

Structure of Lymphatic Glands and Serous Membranes, . . . . . 206

Assimilating action of Absorbent System, . . . . . . 210

Composition and Properties of Chyle and Lymph, . . . . . . 212

Vascular or Duetless Glands, . . . . . . . . . 218

\section{CHAPTER VII.}

OF THE BLOOD; ITS PHYSICAL CHARACTERS, CHEMICAL COMPOSITION, AND VITAL PROPERTIES.

1. General Considerations: Quantity of Blood, . . . . . . . 230

2. Of the Physical, Chemical, and Structural Characters of the Blood, . . 233

Corpuscular Elements. of Blood, . . . . . . . . 235

Spectrum Analysis of the Blood, . . . . . . . . 248

Chemical Composition of the Blood, . . . . . . . 252

Pneumatology of the Blood, . . . . . . . . . 257

Alterations of the Composition of the Blood in Disease, . . . . . 264

3. Of the Vital Properties of the Blood, and its Relations to the Living Or-

ganism,. . . . . . . . . . 270

Coagulation of the Blood,. . . . . . . . . 270

Relation of the Blood to the Nutritive Proeesses, . . . . . 280

Relation of the Blood to Morbid Actions, . . . . . . 28.2

\section{CHAPTER VIII.}

OF THE CIRCULATION OF THE BLOOD.

1. Of the Cireulation in General, . . . . . . . . 292

2. Aetion of the Heart, . . . . . . . . . . . 297

Source of its Rhythmieal Movements, . . . . . . . 297

Succession of its Actions, . . . . . . . . . . 298

Sounds of the Heart, . . . . . . . . . . . 304

Action of Nervous System upon the Heart, . . . . . . . 306

Excito- or Cardio-motor System of the Heart, . . . . . 306

Effects of Variations of Temperature upon the Heart's Aetion, . . 307

Nerves lictarding or Inluibiting the Action of the Heart, . . . . 309

Nerves Aceclerating the Action of the Heart, . . . . . . 314

liate and Force of its Pulsations, . . . . . . . . 319

2. Movement of the Blood in the Arteries, . . . . . . . . 323

4. Movement of the Blood in the Capillaries, . . . . . . . . . 343

5. Novement of the Blood in the Veins, . . . . . . . . . 353

6. Peculiarities of the Circulution in different P'arts, . . . . . . . 35: 
CHAPTER IX.

OF RES P I RA TION. Relation of the Nervous System to the Respiratory Acts, . . . 374

Respiratory Movements, . . . . . . . . . . 369

Sources of Production of Carbonic Acid in the Living Body, . . 361

Structure of the Lungs, . . . . . . . . . . 369

2. Effects of Respiration on the Air, . . . . . . . . . 384

Circumstances affecting the Exhalation of Carbonic Acid Gas, . 388

Exhalation and Absorption through the Lungs, . . . . . 400

3. Effects of Suspension or Deficiency of Respiration, . . . . . . 404

Asphyxia, . . . . . . . . . . . . 406

Predisposition to Zymotic Diseases, . . . . . . . . . 408

\section{CHAPTER $X$.}

OF NUTRITION.

1. General Considerations-Formative Power of Individual Purts, . . . 415

2. Of the Balance of the Vital Economy, . . . . . . . . . 421

With Ordinary Diet, . . . . . . . . . . 423

In Fasting, . . . . . . . . . . . . 425

On Pure Meat Diet, . . . . . . . . . . . 428

On Meat and Fat Diet, . . . . . . . . . . . . . 428

On Meat and Starch or Sugar Diet, . . . . . . . . . . 429

Disintegration of various Organic Compounds, with accompanying De-

velopment of Force, . . . . . . . . . . . 430

Degeneration of Tissues, . . . . . . . . . . . . . 438

3. Varying Activity of the Nutritive Processes, . . . . . . . . 441

Hypertrophy; Tumors, . . . . . . . . . . 441

Atrophy, . . . . . . . . . . . . . 445

Reparative Process, . . . . . . . . . . . . 447

4. Abnormal Forms of the Nutritive Process, . . . . . . . 453 .

Inflammation, . . . . . . . . . . . . 454

Emigration of White Corpuscles and Diapedesis of White, . . . 459

Tuberculosis, . . . . . . . . . . . . 463

Cancer, . . . . . . . . . . . . . 464

CHAPTER XI.

OF SECRETION AND EXCRETION.

1. Of Secretion in General,. . . . . . . . . . . 465

Excretory Operations, . . . . . . . . . . 466

Metastasis of Secretion, . . . . . . . . . . . . 467

2. The Liver.-Secretion of Bile, . . . . . . . . . 469

Structure and Actions of the Liver,. . . . . . . . 471

Composition and Sources of Bile, . . . . . . . . . . . . . 476

Glycogenic Function of the Liver, . . . . . . . . 482 
3. The Kidneys.-Secretion of Urine,

Structure and Actions of the Kidneys, . . . . . . . 490

Composition and Sources of Urine, . . . . . . . . . . . 497

4. The Skin.-Cutaneous Transpiration, . $\quad$ c c . . . $\quad$. $\quad$. 520

Structure of Sudoriparous Glandulæ, . . . . . . . 521

Sudoriparous Excretion, . $\quad . \quad$. . . . . . . 521

\section{CHAPTER XII.}

OF THE EVOLUTION OF HEAT, LIGHT, AND ELECTRICITY.

1. General Considerations, . . . . . . . . . . 527

2. Evolution of Heat,. . . . . . . . . . . . . . . . 928

Temperature of the Human Body, . . . . . . . . $\quad$. 529

Sources of Calorifying Power, . . . . . . . . . . 541

Absolute amount of Hcat produced in the Body, . . . . . . 542

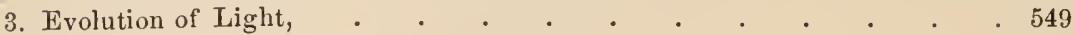

4. Evolution of Electricity, . . . . . . . . . . . . 550

\section{CHAPTER XIII.}

ON THE FUNCTIONS OF THE CEREBRO-SPINAL NERVOUS SYSTEM.

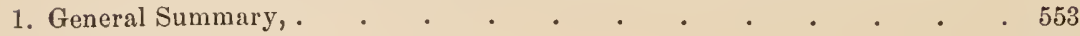

Structure of the Nervous System, . . . . . . . . . 558

Regeneration and Chemistry of Nervous Tissue, . . . . . 553

Cerebro-Spinal Nervous Centres, . . . . . . . . . 565

Cerebro-Spinal Nerve-Trunks, . . . . . . . . . . 571

Determination of the Functions of Nerves, . . . . . . 574

Rapidity of Transmission of Motor and Sensory Impressions, . . 581

Electrical Currents in Nerves, . . . . . . . . . 583

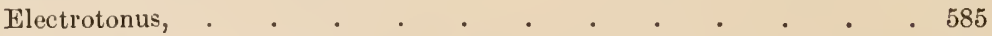

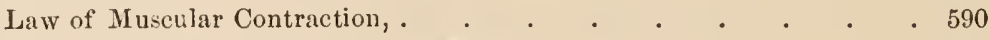

2. Of the Spiral Axis (Spinal Cord and Medulla Oblongata), . . . . 597

Structurc and Relations of the Spinal Cord, . . . . . . . 597

Nerves of the Spinal Axis, . . . . . . . . . 601

Structure and Relations of the Medulla Oblongata, . . . . . 605

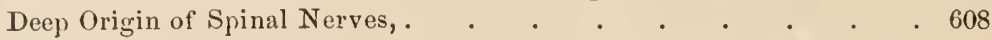

The Spinal Cord as a Conductor of Sensory Impressions and Motor Impulses, . . . . . . . . . . . . . . 627

The Spinal Cord as an Independent Centre, . . . . . . . 633

3. Of the Sensory Ganglia,. . . . . . . . . . . . . 649

Structure and Relations of the Sensory Ganglia, . . . . . . 649

Nerves of Special Sensation, . . . . . . . . . 651

Nerves of Common Sensation, . . . . . . . . . 655

Functions of the Sensory Ganglia: Sensori-Motor Actions, . . . 656

Muscular Scnse, . . . . . . . . . . 668

4. Of the Cercbellum, . $\quad . \quad$. . . . . . . . . . 673

Structure and Relations of the Ccrcbellum, . . . . . . 674

Functions of the Cerebcllum.-Co-ordination of Muscular Action, . 675

Supposed Relation to Sexual Propensity, 680

5. Of the Ccrebrum, . . . . . . . . . . . 685

Structure and Relations of the Ccrcbrum, . . . . . . 686

Functions of the Ccrebrum.--Intelligence as contrasted with Instinct, . 695 
PAGE

Dreaming, . . . . . . . . 716

Somnambulism, Spontancous and Induced, . . . . . . . 718

Hypnotism, . . . . . . . . . . . . 719

CHAPTER XIV.

OF SENSATION AND THE ORGANS OF THE SENSES.

1. Of Sensation in General, . . . . . . . . . . 721

2. Sense of Touch, . . . . . . . . . . . . . . . . . 724

3. Sense of Taste, . . . . . . . . . . . . . . . . . 733

4. Sense of Smell, . . . . . . . . . . . . . . . . 740

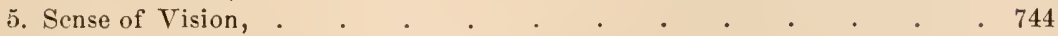

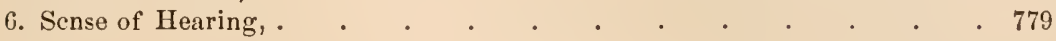

\section{CHAPTER XV.}

ON THE STRUCTURE AND FUNCTIONS OF MUSCULAR TISSUE.

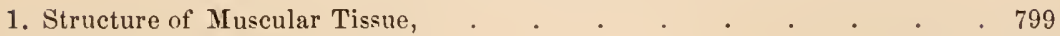

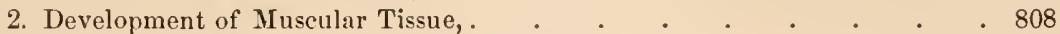

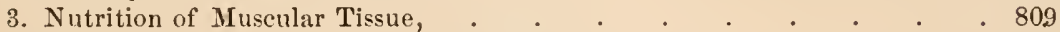

4. Phenomena accompanying Contraction, . . . . . . . 813

5. Electrical Relations of Muscle, . . . . . . . . . . 813

6. Mechanism of Muscular Contraction, . . . . . . . . . . 814

7. Rigor Mortis, . . . . . . . . . . . 827

8. Voluntary and Involuntary Movements, . . . . . . . . . 828

9. Symmetry and Harmony of Muscular Movements, . . . . . . 830

Movements of Locomotion, . . . . . . . . . . . 831

Movements of the Eye; Strabismus, . . . . . . . 834

10. Energy and Rapidity of Mluscular Contraction, . . . . . . . 838

Absolute Force of Muscle, . $\quad$. $\quad$. $\quad$. $\quad$. $\quad$. . . . 839

\section{CHAPTER XVI.}

OF THE VOICE AND SPEECH.

1. Of the Larynx and its Actions, . . . . . . . . . . . . 844

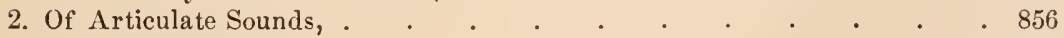

Stammering, . . . . . . . . . . . . . 856

\section{CHAPTER XVII.}

OF THE INFLUENCE OF THE NERVOUS SYSTEM ON THE ORGANIC FUNCTIONS.

1. Sympathetic Nervous System; its Structure and Relations,

2. Influence of Nervous Agency and of Mental States on Contractions of Organic Muscles, . . . . . . . . . . . .

3. Influence of Nervous Agency and of Mental States on Nutrition and Secretion,. . . . . . . . . . . 875 


\section{CHAPTER XVIII.}

OF GENERATION.

1. General Character of the Function,

2. Action of the Male, . . . . . . . . . . . 882

Structure of Testes.-Spermatic Fluid, . . . . . . 884

Coitus; Emissio Seminis, . . . . . . . . . 885

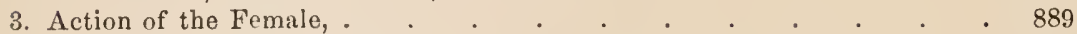

Structure of Ovary, Ovisac, and Ovum, . . . . . . . $\quad$. $\quad$. 889

Puberty; Menstruation, . . . . . . . . . . 892

Maturation of Ova; Corpus Luteum, . . . . . . $\quad$. 896

Fecundation of Ovum, . . . . . . . . . . . . . 899

Formation of Decidua, . . . . . . . . . . 902

Formation of Placenta, . $\quad . \quad$. $\quad . \quad$. . . . . $\quad$. 904

Parturition; Duration of Gestation, . . . . . . . 909

4. Development of the Embryo, . . . . . . . . . . 921

5. Of Lactation, . . . . . . . . . . . . . 970

\section{CHAPTER XIX.}

OF THE DIFFERENT BRANCHES OF THE HUMAN FAMILY, AND THEIR MUTUAL RELATIONS.

1. General Considerations; Differentiation of Species, . . . . $\quad 982$

2. General Survey of the Principal Varieties of the Human Species, . . 1000

\section{CHAPTER XX.}

OF THE MODES OF VITAL ACTIVITX CHARACTERISTIC OF DIFFERENT AGES.

1. General Considerations; Germinal Capacity, . . . . . . 1014

2. Pcriod of Growth and Development, . . . . . . . . 1017

3. Period of Maturity, . . . . . . . . . . . . . 1028

4. Period of Decline, . . . . . . . . . . . . . . 1029

\section{CHAPTER XXI.}

OF DEATH, 



\section{TABLE OF ILLUSTRATIONS.}

\section{PLATE I.}

FIG.

1. Spermatozoa of Man; A, viewed on the surfaee; $\mathbf{3}$, viewed edgeways (3 731).

2. Vesieles of evolution from the seminal fluid of the $\operatorname{Dog} ; \mathbf{A}, \mathbf{B}$, $\mathbf{C}$, single vesieles of different sizes; $\mathrm{D}$, single vesiele within its parent-eell; $\mathbf{E}$, parent-cell inelosing seven vesicles of evolution $(\xi 732)$.

3. Development of Spermatozoa within the vesieles of evolution; A, B, vesieles containing spermatozoa in proeess of formation; c, D, spermatozoa escaping from the vesieles $(\& 732)$

[The three preeeding figures are after Wagner and Leuekardt (Cyclop. of Anatomy and Physiology, Art. "Semen").]

4. Thin slice of the ovarium of a Sow three weeks old, showing the Graafian vesicles or ovisaes imbedded in a fibro-cellular stroma. The ovisaes are filled with cells, in the midst of which one large one may be espeeially distinguished; this, which is the germinal vesiele, is surrounded by minute granules, which eonstitute the first indieation of the yolk ( 8737$)$.

5. Ovum of a Rabbit, showing the vitelline mass almost entirely eonverted into distinct eells, of which those at the surface are pressed against each other and against the zona pellucida, so as to assume a hexagonal form. The dark portion eonsists of a mass of vitelline spheres, which has not undergone this conversion $(\& 776)$.

6. Ovum of the Rabbit, seven days after impregnation, viewed on a black ground. The outer membrane is the chorion, on whieh are seen ineipient villosities. Within this is the blastodermic vesicle, at the summit of which is the projeetion formed by the area germinativa; and from this, the mucous layer of the germinal membrane is seen to extend over about one-third of the surface of the eontained yolk $(\& 776)$.

7. Portion of the germinal membrane, taken from the area germinativa, to show the two layers of whieh it is composed; the serous, or animal layer (epiblast) is turned back, so as to show the mucous or vegetative layer (mesoblast and hypoblast) in situ. In the latter is seen the primitive trace (\& 776).

8. Portion of the serous layer of the germinal membrane, highly magnified; showing that it is made up of nucleated cells, united by intercellular substance, and filled with minute molecules $(\xi 776)$. 
FIG.

9. Portion of the mucous layer of the germinal membrane, highly magnified; showing that it is made up of cells, whose borders are more distinct and more closely applied to each other than those of the serous layer, and whose contents are more transparent $(\& 776)$.

[The six preceding figures are after Bischoff (Entwickelungsgeschichte der Säugethiere, etc. (1842), 一 des Kaninchen-eies - (1842) - des Hunde-eies (1845).]

10. Gravid Uterus of a Woman who had committed suicide in the seventh week of preguancy, laid open : $a$, os uteri internum; $b$, cavity of the cervix; $c, c, c$, $c$, the four flaps of the body of the uterus turned back; $d, d, d$, inner surface of uterine decidua; $e, e$, decidua reflexa; $f, f$, external villous surface of the chorion; $g$, internal surface of the chorion; $h$, amnion; $i$ umbilical vesicle; 7 , umbilical cord ; $l$, embryo; $m$, space between chorion and amnion $(\xi 752$ et seq.). [After Wagner (Icones Physiologice).]

\section{PLATE II.}

11. Utcrine Ovum of Rabbit, showing the Arca Pellucida, with the primitive trace (\& 776$)$.

12. More advanced Ovum, showing the incipient formation of the Vertebral column, and the dilatation of the primitive groove at its anterior extremity ( 8776$)$.

13. More advanced Embryo, seen on its ventral side, and showing the first development of the Circulating apparatus. Around the Vascular Area is shown the terminal sinus $a, a, a$. The blood returns from this by two superior branches $b, b$, and two inferior, $c, c$, of the oinphalo-mesaraic veins, to the heart, $d$; which is, at this period, a tube curved on itself, and presenting the first indication of a division into cavities. The two aortic trunks appear, in the abdominal region, as the inferior vertebral arteries, $e, e$; from which are given off the omphalo-mesaraic arteries $f, f$, which form a network that distributes the blood over the vascular area. In the cephalic region are seen the anterior cerebral vesicles, with the two ocular vesicles, $g(\& 777)$.

[The three preceding figures are from the works of Bischoff previously cited.] 
PLATE II

Fig II

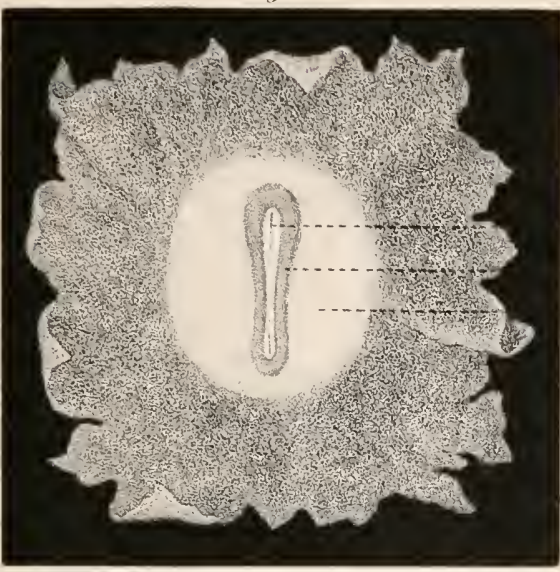

Fig.12

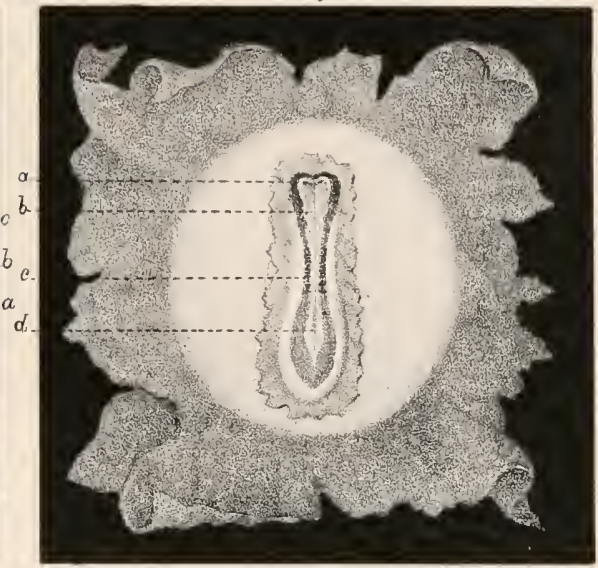

Fig.13.

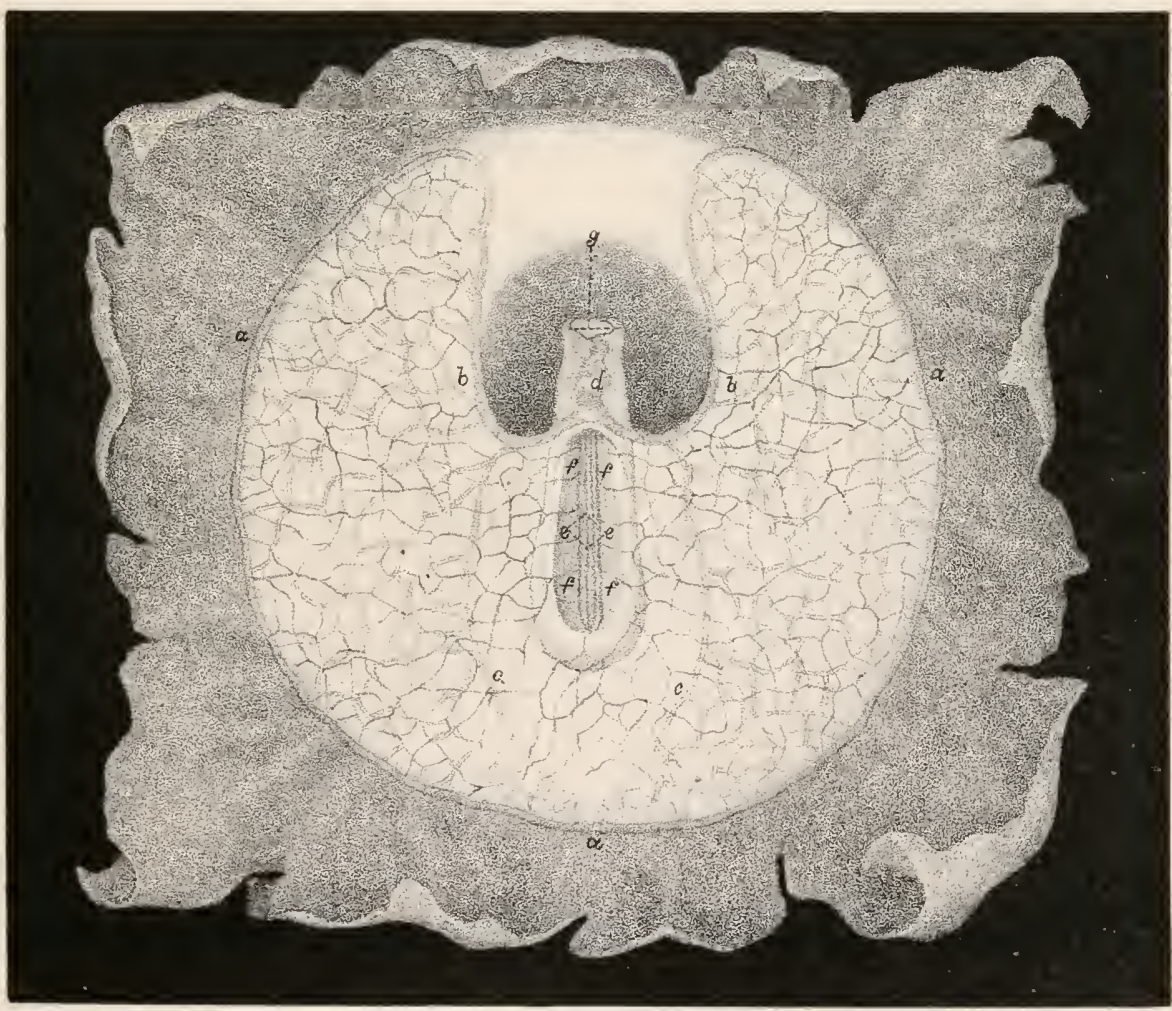





\section{LIST OF WOOD ENGRAVINGS.}

FIG.

PAGE

1. Hand of Man, compared with anterior extremity of Orang; after Gervais, 41

2. Foot of Man, compared with posterior extremity of Orang : after Gervais, 43

3. Base of Skull of Man, compared with that of Orang; after Owen, . . 44

4. Vertical Section of Skull of Adult Orang; after Owen, . . . . . 45

5. Vertical Section of Skull of Young Orang; after Owen, . . . . . 45

6. Tertical Section of Skull of Papuan Negrito; after Owen, . . . . . 45

7. Skeleton of Gorilla ; after Gervais, . . . . . . . . . 48

8, 9. Comparative view of the Skeleton of Man, and that of the Orang-Outang, 50

10. Brain of Man; after St. George Mivurt, . . . . . . . 53

11. Brain of Orang-Outang, . . . . . . . . . . . 53

12. Brain of Chimpanzee, "

13. Brain of Mandrill, 4 . . . . . . . . 54

14. Tesscllated Epithelium; after Klein, . . . . . . . . 60

15. Section of Epidermis, . . . . . . . . . . . . 61

16. Ribbed Epithelial Cell ; after Frey, . . . . . . . . 61

17. Section of Villus; after Klein and Verson, . : . . . . . . 61

18 Cup or Goblet Cell ; after Klein, . . . . . . . . . . 62

19. Ciliated Epithelium, . . . . . . . . . . . 62

20. Pigment Cells of Hexagonal Form, . . . . . . . . 62

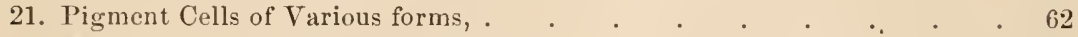

22. White or Non-elastic Fibrous Tissue, . . . . . . . . . 63

23. Caudal Tendon of Riat; after Bruce, . . . . . . . . . 65

24. Transverse Section of 'Tendon; after Bruce, . . . . . . . 65

25. Yellow or Elastic Tissue, . . . . . . . . . . . . . . . 66

26. Areolar and Adipose Tissue, . . . . . . . . . . . . . 66

27. Development of Fat; after Czajewicz, . . . . . . . . . 67

28. Example of Endogenous Cell-formation; after Czajewicz, . . . . . 67

29. Section of Branchial Cartilage of Tadpole, . $\quad . \quad$. . . . . . $\quad$. 69

30. Elementary part from Cartilage of Frog; after Beale, . . . . . 69

31. Lacunæ of Osseous Tissue, . . . . . . . . . . . $\quad$. 70

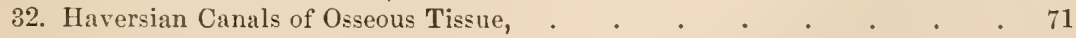

33. Transverse Section of Bone, . . . . . . . . . . . . 71

34. Process of Ossification in Cartilage, . . . . . . . . . . . $\quad$. 73

35. Vertical Section of Tooth, . . . . . . . . . . . . . 75

36. Transverse Section of Tooth, . . . . . . . . . . . . $\quad$. 76

37. Transverse Section of Enamel, . . . . . . . . . . . . 76

38. Vertical Section of Upper Jaw of Fœtal Sheep; after Waldeyer, . . 77

39. Section of Jaw of Pig; after Frey, . . . . . . . . . 77

40. Section of Jaw of Human Fœtus; after Waldeycr, . . . . . . 77

41. Section of Dentine, . . . . . . . . . . . . . 78

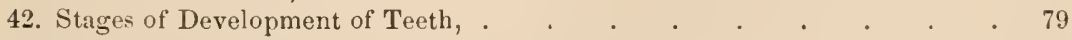

43. Myelin; after Frey; . . . . . . . . . . . . . 87

44. Leucin, " . . . . . . . . . . . 87 
FIG.

45. Tyrosin, after Frey,

46. Kreatin. This with the suceeding 13 figures are taken from Kühne,

47. Kreatinin,

48. Uric Acid,

49. Hippurie Acid,

50. Allantuin,

51. Uystin, .

52. Urea,

53. Hydrochlorate of Guanin, .

54. Nitrate of Hypoxanthin,

55. Hydrochlorate of Hypoxanthin, . . . . . . . . . . . 92

56. Hydrochlorate of Xanthin, . . . . . . . . . . . . 92

57. Taurin, . . . . . . . . . . . 9 9

58. Succinic Acid, . . . . . . . . . . . . . . 96

59. Nervous Supply of Intestines; after Küss, . . . . . . . . 138

60. Lobule of Parotid Gland of Infant ; after IVagner, . . . . . . 143

61. Subnaxillary Gland of Dog; after Frey, . . . . . . . . 143

62. Modes of Termination of the Nerves in the Salivary Glands; after Ptlügrer, 144

63. Capillary Network round Follieles of Parotid Gland; after Berres, . . 145

64. Submaxillary and Sublingual Glands; after Bernard, . . . . 149

65. Vertical Section of Mucous Membrane of Stomach; after Warner, . . 152

66. Capillary Network of Stomach, with Oritices of Gastric Follieles; after Kölliker,

67. Peptic Gastric Gland; after Kölliker, .

68. Portion of Gastric Gland, more highly magnified; after Kölliker, _ . 153

69. Transverse Section through Cluster of Gastric Cæca; after Kölliker, . . 154

70. Mucous Gastric Gland; after Kölliker, . . . . . . . 154

71. Transverse Scetion through Fundus of Stomach; after Klein and Irerson,. 154

72. Capillaries of Lining Membrane of Stomach, showing Rudimentary Villi and Orifices of Follicles; Original, . . . . . . . 155

73. Portion of Brïnner's Gland; after Allen Thomson, . . . . . . . 177

74. Section of Villus from Rabbit; after Klein and Verson, . . . . 187

75. Villi of Huruan and Sheep's Intestine; âter Teichmann, . . . . 188

76. Section carried through Mucous Membrane of small Intestine; alter Teichmann,

77. Section carried through Mucous Membrane of large Intestine; after Teichmann,

78. Diagram of Origin of Lacteals in Villi ; after Funke, .

79. Urigin of Lacteal; after Letzerich,

80. Colummar Epithelium; after Klein and Verson, .

81. An Endosmometer,

82. Diagram to show Influence of Pressure on Osmosis; altered from liobinson,

83. Cells of Cornea; after Rollett,

84. A Lymphatic Rete Mirabile; ufter Teichmann, - 207

85. Section of Lymphatic Gland; after Kölliker, . . . . . . . . 208

86. Section of Simple Lymphatic Gland; after Teiehmann, . . . . . 208

87. Section of the Medullary substance of the Mesenteric Gland of an $O x$; after Kölliker,

88. Portion of a Peyerian Jateh; after Boehm,. . . . . . . 210

89. Distribution of Bluodvessels in Peyerian Glandule; after Fölliker, . . 211

90. Formation of Lympl-corpuscles; after Gulliver, . . . . . . 212

91. Molecular Base and Corpuseles of Chyle, . . . . . . . . 214

92. Chyle-corpuscles in Varions Phases; after Gulliver, . . . . . 215

93. Malpighian Corpuseles attached to Splenic Artery ; after Kölliker, . . 220 
94. Malpighian Corpuseles from Spleen of IIedgrehog; after WV. Müller,

95. Vertical Section of Suprarenal Capsule; after Eberth,

96. Portion of 'Thymus of Calf', unfolded; after Kölliker,

97. Section of Human Thymus; after Kölliker,

98. Section through Lobule of Thymus; after Kölliker, .

99. Thymus Juiec; after Gulliver, . . . . . . . . . 225

100. Gland-vesicles of Thyroid; after Kölliker, . . . . . . . 226

101. Red Corpuscles of Human Blood; after Donne, . . . . . . 235

102. Red and Whit: Corpuscles of Human Blood; after Beale, . . . 237

103. Corpuscles of the Blood of Mai and other Mammals; after Gulliver, . 238

104. Tarious Forms assumed by Blood-corpuscles after withdrawal from body ; after Gulliver, . . . . . . . . . . . . . . . 239

105. Red and Colorless Corpuscles of Hının Blood; after Gulliver, . 240

106. Blood-corpuscles of Man; after Gullivor, . . . . . . . 240

107. White Corpuscles of Blood; after Kilein, . . . . . . . . 241

108. "6 6 6 . . . . . . . . 241

109. A Granular Corpuscle of the Newt, showing changes assumed in fifteen minutes,

110. Small venous trunk from Frog's Foot; after Wagner, . . . . . 243

111. Formation of Blood-crystals; after Beale, . . . . . . 245

112.

113. Blood-crystals from Human Blond; after Funke,

114. Crystals of Hydrochlorate of Hrmatin ; after Kühnn,

115. Crystals of Hæmin ; after Kühne,

116. Speetrum Analysis of Blood; by Sorby,

117. Segment of Human Senilunar Valve of Pulmonary Artery; after Pettigrew,

118. Seument of Human Mitral Valve; after Pettigrew, .

119. Cardiac Muscular Fibres; after Eberth,

120. Diagram of Movements of Heart ; after Sibsnn,

121. Similar Diagram, profile view, .

122. Chauveau's Cardiograph,

123. Traeing of Pulse obtained by Sphygmograph ; after Chauveau and Marey,

124. Marey's Cardiograph, .

125. Tracing of Heart's Action on Exposure to Heat; after Cyon, .

126.

"6

127. Diagram of Nerves of Heart, 6

128. Tracing, showing effects of stimulating Vagus or Pulse; after Rutherford, 311

129. Bloodressels of Web of Frog's Foot; after Wagner,. . . . . . 323

130. Narey's Sphyomograph; after Longet, . . . . . . . . 330

131. Modification of Marey's Sphygmograph, . . . . . . . . . 331

132. Tracing of Pulse; after Galabin, . . . . . . . . . 331

133. A tracing from Marey's Sphygmograph ; after Longet, . . . . 332 134.

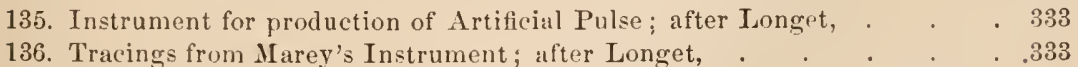

137. Instrument for showing variations of Pressure with variations of Resistance; after Longet, . . . . . . . . . 334

138. Differential Manometer; after Bernard, . . . . . . . 335

139. Hrmadynamometer of Poisseuille, . . . . . . . . . 336

140. Mereurial Kymograph, . . . . . . . . . . . 337

141. Tracing of Mercurial Kymograph, . . . . . . . . . 337

142. Fick's Spring Kymograph, . . . . . . . . . . . 338

143. Spring Kymograph Tracing, . . . . . . . . . 338 
144. Ludwig's Stromuhr, .

145. Tracing showing effect of Respiration on the Pulse; after Einbrodt, . . 340

146. Hremodromometer of Volkmann; after Dalton, . . . . . . 341

147. Hæmatochometer of Vierordt; after Longet, . . . . . . . . 341

148. M. Lortet's Hæmatochometer; after Lortet, . . . . . . . . 341

149. Tracing obtained by M. Lortet's Instrument, . . . . . . . . 342

150. Capillary Plexus of Web of Frog's Foot, highly magnified; after Wagner, 343

151. Structure of Capillaries; after Eberth, . . . . . . . 344

152. Distribution of Capillaries in Skin of Finger ; after Berres, . . . 346

153. " " around follicles of Mucous Membranc; after

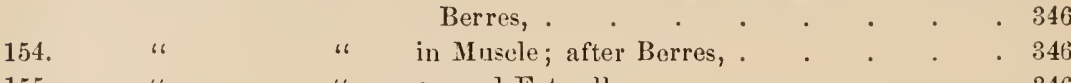

155. " " . . . . . . 346

156. Ciliated Epithelium from Bronchial Twig ; after E. Schultze, . . . 363

157. Transverse section of Bronchial Tube; after E. Schultze,. . . . . 364

158. Air-sacs of Human Lung; after Waters, . . . . . . . . 365

159 Air-cells of Human Lung; after Kölliker,. . . . . . . . . . 365

160. Capillaries and Air-cells of Human Lung; original, . . . . . . 365

161. Apparatus to show Mechanism of Respiration; after Donders, . . . 368

162. Tracing of Respiratory Movements ; after Marey, . . . . . . 370

163. " " " . . . . . 377

164. Pettenkofer's Respiration Apparatus, . . . . . . . . . 414

165. Hepatic cæcum of Cray-fish; after Leidy, . . . . . . . 470

166. Connection of lobules of Liver with Hepatic Vein; after Kiernan, . . 471

167. Plan of arrangement of Bloodvessels in lobules of Liver; after Kiornan, 471

168. Section of lobules, showing distribution of intralobular veins; after

Kieruan, . . . . . . . . . . 472

169. Section of Injected Liver from Rabbit; after Ewald, . . . . 473

170. Biliary Capillaries and Ducts; after Irminger and Frey, . . . . . 474

171. " " a after Hering, . . . . . . 474

172. Portion of Hepatic Column, with secroting cells; after Leidy, . . 475

173. Spectrum of Green Bile; after Dalton, . . . . . . . . 478

174. Spectrum of Pettenkofer's Test; after Dalton, . . . . . . . . 479

175. Diagram of punctures required to produce Glycosuria ; after Küss, . . 487

176. Section of Cortical Substance of Kidney ; after Ecker, . . . . 491

177. Scction of Kidney of new-born Infant; after Wagner, . . . . . 491

178. Portion of Tubulus Uriniferus, with secreting cells; after Wagner, . 491

179. Course of Tubuli Uriniferi ; after Hertz, . . . . . . . . 492

180. Structure of Malpighian Body, . . . . . . . . . . 492

181. Diagram of the Circulation in the Kidney; after Bowman, . . . 493

182. Sudoriparous Gland, with its duct; after Wagner, . . . . . . 521

183. Microscopic Ganglion from Heart of Frog; after Ecker, . . . . . 553

184. Bipolar Ganglionic cells and Nerve-fibres; after Ecker, . . . . . 553

185. Funieulus of Mousc; after Ranvier, . . . . . . . . . . 554

186. Nerve-fibre of Mouse; after Ranvier, . . . . . . . . 554

187. Diagram of structure of Nerve-fibrc, . . . . . . . . . 554

188. Axis-cylinder of Nerves; after Max Schultze, . . . . . . . 555

189. Primitive Nerve-fibrils; after Max Schultze, . . . . . . 555

190. Ganglion-cell from Spinal Cord ; after Max Schultzc, . . . . . 556

191. Stcllate Ganglionic Cell; after Beale, . . . . . . . . 558

192. Structure of Ganglionic Cells; after Beale and Arnold, . . . . 558

193. Brain of Cod; after Leurct, . . . . . . . . . 567 
194. Apparatus to measure rapidity of Transmission of Electric Stimulus through Motor Nerves; after Budge, . . . . . . . . 581

195. Diugram of Nerve-current in II uscle; after Du Bois-Reymond, . . 583

196. Plan of apparatus to exhibit the nervous electrical current; after Du Boislieymond,

197. Plan of apparatus to exhibit the nervous electrical current; after Du BoisReymond,

198. Plan exhibiting Electrotonic condition of a Nerve during Passage of Electrical Currents of various strength ; ufter Funke, . . . 587

199. Plan explanatory of extrapoliır centripetal Cathelectrotonus; after Funke, 200. " "entrifugal extrapolar Anelectrotonus; after Funke, 201. " " " " Cathelectrotonus; after Funke, 202. " " centripetal " Anelectrotonus; after Funke, . 203. Plan showing direction of Centrifugal Currents; after Budge, . . . 590 204. " " Centripetal Currents; after Budgc, . . . 590 205. Diagram of Electrotonic state of Nerve; after Radeliffe, . . . . . 595 206. Electrotonus of Nerre, . . . . . . . . . . 595 207. Magnified vicw of Transverse Scetion of Spinal Cord; after J. L. Clarke, 598 208. Section of Gray Substance of Spinal Cord ; original, . . . . 600 209. Transverse section of Centre of Spinal Cord ; after Gerlach, . . . . 60 210. Longitudinal Scction of Spinal Cord; after J. L. Clarke, . . . . . 602

211. Antcro-posterior Section of Lumbar Enlargement of Spinal Cord; after Gerlach,

212. Lateral view of Medulla Oblongata ; after Lockhart Clarke, . . . . 606 213. Disscction of Medulla Oblongata ; after Solly (altered), . . . . . 607 214. Section of Cord through the first pair of Cervical Nerves, . . . 608 215. " " through the upper fibres of origin of the first pair of Nerves, 216. Section passing a quarter of an inch below Olivary Bodies, . . . 608

217. Section immediately below Olivary Bodies, . . . . . . . 609

218. Section through lower part of Olivary Bodies, . . . . . . . 610

219. Section through point of Calamus Scriptorius, . . . . . . . 610

220. Position of Nuclei in Medulla Oblongata, . . . . . . . . 611

221. Section through upper part of Medulla Oblongata, . . . . . . 611

222. Longitudinal Section through Medulla Oblongata, . . . . . . 611

[The preceding nine drawings were made by the Editor from sections madc and kindly lent to him by Mr. Lockhart Clarke ]

223. Section made through the summit of the Medulla Oblongata, after an unpublished Memoir of Lockhart Clarke,

224. Course of the Sensory Tract in the Medulla Oblongata; after Sir C. Bell, 613

225. Course of the Motor Tract in the Medulla Oblongata; after Sir C. Bell, . 614

226. Nerves of the Orbit; after A rnold, . . . . . . . . . 618

227. Distribution of Facial Nerve; after Erasmus Wilson, . . . . . 619

228. Diagram of Distribution of Eighth Pair ; after Erasmus Wilson, . . 621

229. Diagram of section of part of Spinal Cord ; after Küss, . . . . 627

230. " " " " . . . 6 " 627

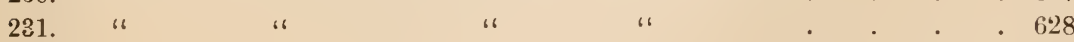

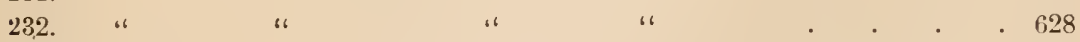

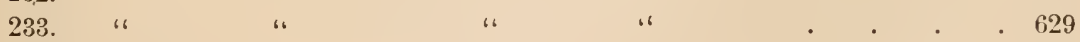

234. " "

235. " "

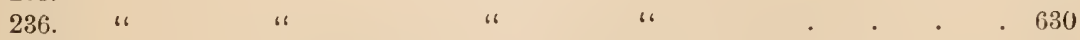

237. " "

238. Plan of course of Roots of Spinal Cord, " " . . . . 632 
FIG.

239. Plan of eourse of Motor and Sensory Fibres in Spinal Cord ; after BrownSéquard,

240. Diagram showing course of Sensory and Motor Impulses,

241. Seetion of Cortex of Cerebellum ; after Meynert,

242. Convolutions of Brain,

243. Diagram of mutual relations of principal Eneephalie Centres; original, .

244. Diagram of cour-e of Cerebral Fibres,

245 Section of Cortex Cerebri ; after Meynert,

246. Diagram of Brain of Monkey; to illustrate Ferrier's researehes; after Ferrier,

247. Diagram of Brain of Monkey; to illustrute Ferrier's researehes; after

Ferrier; . . . . . . . . .

248 Diagram to illustrate the phenomena of Speeh,

249. Vertieal Section of Skin, showing distribution of Nerves; after Ecker, .

250. Tuetile corpuseles of Cutaneous Papill:e; after Eeker, . . . .

251. Capillary Network at Margin of Lips; after Berres, . . . .

252 Plan of Sensory Circles of Skin; after Fick, . . . . . .

253. Capillary Network of Fungiform Papilla of Tongue; after Berres, . .

254. Gustatory Bulbs; after Engrelmann, . . . . . . . . . 737

255 Seetion of Gustatory Papilla; after Engelmann, . . . . . . $\quad 737$

256. Termination of Gustatory Nerve; after Engelmann, . . . . . 737

257. Fibres of Olfactory Norve; after Eeker, . . . . . . . . 741

258. Olfuetory Cells; after Lockhart Clarke and Sehultze, . . . . . . 742

259. Distribution of Olfaetory Nerve; after Erasmus Wilson, . . . . 743

260. Plan of the Eve,. . . . . . . . . . . . . . . 746

261. Plan of ehanges in the Eye during Aeeommodation; after Helmholtz, . 747

262. Scetion of Ciliary Region of Eye in Man; after Iwanofi, . . . 749

26:. Diagram of course of Purallel Rays in Emmetropic Eye. . . . $\quad 752$

264. " " " in Hypermetropic and Myrpic Eye, .

265. Seheiner's experiment,

725

754

266. Vertieal Section of Retina; after H. Müller, . . . . . . . $\mathbf{7 5 4}$

267. Diagram of structure of lietina; after Sehultze, . . . . . 755

268. Rod and Cone from Rutina of Man ; after Sehultze, . . . . . . 755

269. Conneetive Tissue of Retina; after Schultze, . . . . . . . 755

270. Section through Macula Lutea; after Schultze, . . . . . . 758

271. Muscular strueture of Iris ; after Kölliker, . . . . . . . . 759

27.2. Stereoseopic figures; original, . . . . . . . . . . 765

273. Stereoscopie projections of Pyramid; after Wheatstone, . . . . . 766

274. Diagram illustrating Visual Angle; original, . . . . . . . . 769

275. Vistal illusion produced by peculiar arrangement of lines, . . . 772

276. Diagram of mode of termination of Auditory Nerve in Ampulla of Ear; after liüdinger,

277. Seetion of Lamina Spiralis of Cochlea, . . . . . . . . . 784

278. Section through organ of Corti; after Waldeyer, . . . . . . 784

279. Direction of movements of Tympanic Bones; after Helmholtz, . . 787

280. Vertical Seetion of Interual Ear; aftr. Milne-Edwards, . . . . . 791

281. Diagram to illustrate Fechner's Psycho-physical Law, . . . . . 799

282. Cells forming smooth muscular tissue; after Bowman, . . . . . 801

28\%. Striated muscular tissue fibre; after Bowman, . . . . . . . 801

284. Structure of striated muscle; after Engelmann, . . . . . . 804

285. " "

286. Museular fibre undergoing eontraetion ; after Engelmann, . . . 804

287. Structure of Muscular Fibres; after Schäfer, . . . . . . . 805 
FIf.

PAGE

288. Termination of nerves in muscular fibre; after Kühne,

805

289.

66

after Cohnleim,

806

290.

16 6

after Beale,

807

291. Diagram of Muscle Curve, .

815

292. Striated Muscular Tissue in contraction ; after Buwman, . . . 816

293. Continuous traeing obtained from a Muscle made to contract till nearly exhausted; after Marey,

294. Tracing obtained from a Muscle in contraction,

295.

"

6

819

296.

6

in Tetanus,

298. Latcral View of Larynx; after Willis, . . . . . . . . 845

299. Sectional Yiew of Larynx; after Willis, . . . . . . . . 845

300. Bird's-eye View of Larynx from above; after Willis, . . . . 846

301. Direction of Museular Forces of Larynx; after Willis, . . . . 848

302. Tiew from above of the Glottis during Life in the quieseunt state; after Czèrmak,

303. Similar Vicw, during the emission uf grave notes ; ufter Czermak, . $\quad 848$

304. " " " " acute notes; after Czermak, . . 819

305. Artificial Glottis; after WVillis, . . . . . . . . . . . 852

306. Human Testis, injeeted with Mereury; aftrl Lautl, . . . . . 882

307. Diagram explanatory of Human Testis, injected with Mercury, . . 883

308. Spermatozoa of various Animals, . . . . . . . . . . 885

309. Section of Ovary of Bitch; after TValdeyer, . . . . . . . 889

310. " Primordial Ovum; after Waldeyer, . . . . . . 890

311. Constituent Parts of Mammatian Ovum; after Coste, . . . 891

312. Ovarium of the liabbit at the Period of Heat; after Pouchet, . . $\quad 892$

313. Cells forming Substance of Corpus Luteum ; after Pouehet, . . . 896

314. Diagram of Formation of Corpus Luteum; after Pouchet, • . 896

315. Section of Lining Membrane of Uterus, showing Glandular Follieles; after Weher,. . . . . . . . . . . . . . . 902

316. Portion of the same, more highly magnified; after WVeber, . $\quad . \quad 902$

31\%. First Stage of Formation of Decidua Ruflexa; afrer Coste, . • 903

318. Second Stage of Formation of Decidua Ruflexa; after Coste, . . . 903

319. Human Ovum of eighth week, howing Tufts of Churion; after Ecker, . 903

320. Portion of Uttinate Pamifieations of Umbilical Vessels; original, . 904

321. " " one of Fotal Villi ; after Ecker, . . . . . 901

322. Diagram of Placental Villus; aftr.r Turner, . . . . . . . 905

323. Seetion of Portion of Placenta ; after Ecker, . . . . . . . . 906

324. Diagram of Strueture of Fowl's Eggr; after Foster and Bulfour, . 925

325. First Stages of Segmentation of Egg of Bird; after Foster and Balfour, . 926

326. Formation of Blastodermic Vesiele; after Foster and Balfour, . $\quad .926$

327. " " " "

328. Pellucid Area, with primitive trace; after Foster and Balfour, . 927

329. Formation of Hrad Fold; after Foster and Balfour, . . . . 928

330. Plan of Early Uterine Ovum ; after Wagner, . . . . . . . 929

331. Diagram of Ovum at commencement of formation of Amnion; after IVagner,

332. Fecundated Egg, showing formation of Amnion and Allantuis; after Dalton, .

333. Fecundated Egg, with Allantois nearly completed; after Dalton, . . 334. Section of Embryo Chick on third day of Ineubation; after Kölliker, 335. First Stages of Segmentation of Mammalian Ovum; after Coste, 
FIG.

336. Later Stages of Scgmentation of Mammalian Ovum; after Coste,

337. Section of Embryo Chick at end of first day of Incubation; after Kölliker,

338. Section of Embryo Chick on fifth day of Incubation; after Kölliker, .

339. Plan of First System of Vessels of Embryo ; after Kölliker, . . .

340. Diagram of Circulation of the Yolk-sac of the Chick at end of third day; after Foster and Balfour,

341. Embryonic Heart at an early period; after Kölliker,

342. Later Stage of Formation of Amnion, and Origin of Allantois; after Wagner,

343. Completion of Amnion, and further Development of Allantois; after Wagner,

344. Diagram of Circulation in Human Embryo, as seen in Profile; after Coste,

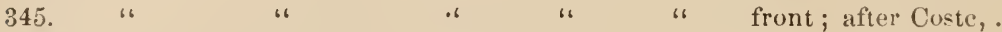

346. Plan of the Aorta and its Arches in the Embryo at an early poriod; after Kölliker,

347. Diagram of the Føtal Circulation; after Erasmus Wilson,

348. Embryo of Dog at twenty-five days; after Bischoff, .

349. Origin of the Liver from Intestinal Wall, in Embryo Chick, after Müller,

350. First Appearance of the Lungs; after Wagner,

351. Urinary and Genital Apparatus in Enbryo Chick ; after Müller, . . 946

352. Section of Embryo Chick on the first day of Incubation; after Kölliker, . 951

35\%. " " " second day of Incubation; after Kölliker, .

354. Plan of Chorda Dorsalis at period of formation of Vertebræ; after Kölliker,

355. Plan of Vertebra at an eurly period of Development; after Kölliker, .

356. Typical Vertebra and Thoracic Vertubra of Bird; after Owen, . . . .

357. Plan of Cartilaginons Basis Cranii ; after Huxley, . . . . .

358. Plan of Transverse Section of Anterior Portion of Primordial Basis Cranii; after Huxley,

359. Plan of Head of Human Embryo at the close of the third week; after Huxley, .

360. Plan of Head of Human Embryo at the close of the tifth week; after Huxley, .

361. Plan of the First and Second Visceral Arches of Human Embryo; after Huxley, .

362. Development of Cercbral Vesicles; after Foster and Balfuur, .

368. Encephalon of Human Embryo at twelfth week; after Tiedemann, . .

364. Plan of Development of Eye; after Kölliker, . . . . . . . 962

365. Diugram of Comparative Viability of Male and Female; after Quetclet, . 366. " " Heights and Weights of Male and Femule; after Quetelet, 


\title{
HUMAN PHYSIOLOGY.
}

\author{
CHA P'TER I.
}

\section{OF LIFE, AND ITS CONDITIONS.}

1. The term Life has been used by different writers, Physiological and Ontological, in a great varicty of significations; but thesc are for the most part capable of reduction to three categories-Life being regarded either (1) as the aggregate of the phenomena exhibited by any Organized being from the commencement to the conclusion of its individual existence, or (2) as the mode of activity peculiar to such beings, whereby they arc distinguished from inanimate bodies, or (3) as the special agency supposed to be inherent in every organism, and to be the efficient cause alike of its first development and of its subsequent maintenance. The first is the sense in which the term is understood by Philosophers of the "Positive" school, who refuse to concern themselves with anything save phenomena that are immediately cognizable by the senses; while the last is the meaning attached to it by such as think that a great deal of trouble is saved by the assumption of a hypothetical entity, whose agency may at once account for everything not to be otherwise explained. To both these definitions it may be objected that they tend to limit inquiry into the essential nature of Vital Action. For by taking the former as a starting-point, we are led to fix our attention ton exclusively on the material conditions presented in the structure of the Organism, and to ignore the forces by which its activity is maintained; just as if, in studying the operations of a cotton factory, we were to limit our attention to the mechanisn of the carding, spinning, weaving, and other machines by whose instrunentality its products are elaborated, and were to neglect, as a condition not directly cognizable by our senses, the Motive Power without which those machines would all be inert. On the other laand, by resting in the assumption of a "Vital Principle" or "Organic Agent" as afforling a sufficient account of all that is mysterions in the nature of Life, we really remove it from the domain of scientific inquiry; just as if the visitor to a cotton factory were to give up in despair any attempt to acquaint himself with the meaning of the several processes that go on before his eyes, and were to regard it as a sufficient account of the transformation of raw cotton into woven calico, that it takes place by the agency of a "calico-making principle."

2. But if, on the other hand, the Physiologist takes as his standpoint the conception of Life as a peculiar modc of activity, he at once finds himself on a pathway of inquiry markerl out for him by the antecedent researches of the Physical philosopher. For as, in the study of that great cycle of 
mutually-related changes which may be designated the Life of the Universe, the Physicist has been led in the first instance to recognize several distinct modes of activity, e.g., Mechanical and Chemical, Electrical and Thermal ; and then, prosecuting his analysis under the guidance of that idea of Power which he finds in his own sense of effort, has been brouglit to refer every effect to a causative Force of some kind, acting through a certain Material instrumentality: so the Physiologist who makes the living organism his study, is led in the first place to refer its peculiar phenomena to a set of catcgories as distinct from the preceding as they are from each other; and thence to distinguish between their instrumental and their dymamical conditions, the Organic Structure and the Vital Forces which animate it. But further, as the Physicist, in proportion to the elevation of his standpoint and the comprehensiveness of the survey he can thence take of the phenomena of the Inorganic Universe, is enabled to discern, first the mutual relation, and at last the essential unity, of all those Forces whose manifestations appeared so diverse when separately contrasted: so may the Physiologist, in proportion to the insight lie gains into the peculiar characteristics of Vital Activity, come in the first instance to recognize the mutual relation of the agencies which underlie its diversified phenomena, next to perccive their fundamental unity as so many expressions of one and the same Vital Force acting through different material instrumentalities, and finally to discern the essential identity of this force with that which maintains the ceaseless cycle of activity in the Universe at large.

3. If, now, we inquire what it is that essentially distinguishes Vital from cvery kind of Physical Activity, we find this distinction most characteristically expressed in the fact, that a germ endowed with Life develops itself into an Organism of a type resenbling that of its parent; that this organism is the subject of incessant changes, which all tend in the first place to the evolution of its typical form, and subsequently to its maintenance in that form, notwithstanding the antagonism of Chenical and Physical agencies which are continually tending to produce its disintegration; hut that, as its term of cxistence is prolonged, its conscrvative power declines, so as to become less and less able to resist these disintegrating forces, to which it finally succumbs, leaving the organism to be resolved by their agency into the components from which its materials were originally drawn. The history of a Living Organism, then, is one of incessent chinge; $;^{2}$ and the conditious of this change are to be found partly in the organism itself, and partly in the external agencies to which it is suhjected.

4. But the Life of any conuplex organism, such as that of Man, is the aggregate of the Vital Activity of all its component parts; and we nust

1 See the Author's Memoir, On the Mutual Relutions of the Vital and Physieal Forees, in the Philosophicul Transactions for 1850

2 If ehange be essential to cur idea of Life, it may be asked what is the condition of a seed, which may remain unaltered during a period of many centuries, vegetating at last, when placed in favorable eireumstances, as if it had only ripened the year before. The can scareely call it alive, for it is not performing any vital operation. But it is not dead; for it has undergone no disintegration, and retains its capacity for living, which is anulogous to the potential energy of the Physicist. The most eorrect designation of such a state (which can only be maintuined under a complete seclusion from disintarming agencies) seems to bo domant vitality. Certuin Animals maty be reduced to it: as the Frog by cold, and the Wheel-animaleule by slow desiceation Organisms capable of molergoing such a suspension of atetivity may be kept in a durmant eonditun so long as disintegrating :uencies are excluded; but the very enaditions (as heat in the one case, moisture in the other, and both combined in the ease of the seed) whos presence is followed by the renewal of active life if the organiom las undergone no injurious clange, insure its speedy decan if it be not able to resume its proper vital activity. 
ascertain the conditions on which the activity of eaeh of these is depcndent, before we can rightly comprehend their united action in the Life of the whole. No fact has becn nore clearly ascertained by modern Physiological research than this, - that as the germ derives from its parent certain independent endowments, in virtue of which it is enabled to develop itself (under appropriate conditions) into an organism which may be composed of a vast number of dissimilar parts, so each of those parts derives from the germ in which it had its origin an independent capacity for development and maintenance, in virtue of which it goes through its own course of vital activity, and by the ultimate cessation of which its own term of existence is limited. Of this mutual independence we have illustrations in the pcrsistence of the "molecular life" of individual parts long after "somatic" death (or death of the body as a whole) has taken place;-in the fact that not only may vital activity be sustained in a part completely separated from the body by the maintenance of the circulation of bloorl through it, but vital endowments which had partially or completely ceased to manifest themselves in consequence of the cessation of the circulation, may be restored by its re-establishment; - and in the occasional reunion of members which have becn entirely separated. But notwithstanding the wonderful diversity of structurc and of endowments which we meet with in the study of any such complex organism, we encounter a harmonious unity or co-ordination in its entire aggregate of actions, which is yet more wonderful. It is in this harmony of co-ordination, whose tendency is to the conservation of the organism, that the state of Health or Normal Life essentially consists. And the more profound is our investigation of its conditions, the more definite becomes the conclusion to which we are led by the study of them,- that it is fundamentally based on the common origin of all these diversified parts in the same germ; the vital endowments of which, equally diffused throughout the whole fabric in those lowest forms of organization in which every part is but a repetition of every other, are differentiated in the highest amongst a variety of organs or instrumental structurcs more or less dissimilar, acquiring in virtue of this differentiation a much greater intensity.

5. In the lowest forms of Vegetable life, the primordial germ multiplies itself by duplicative subdivision into an apparently unlimited number of cells, each of them similar to every other, and capable of maintaining its existence independently of them. And in that lowest (Rhizopod) type of Animal life, the knowledge of which is among the most remarkable fruits of modern biological research, "the Physiologist has a case in which those vital operations which he is elsewhere accustomed to see carried on by an elaborate apparatus, are performed without any special instruments whatever; a little particle of apparently homogeneous jelly changing itself into a greater variety of forms than the fabled Proteus, laying hold of its food without nembers, swallowing it without a mouth, digesting it without a stomach, appropriating its nutritious material without absorbent vessels or a circulating systen, moving from place to place without muscles, feeling (if it has any power to do so) without nerves, propagating itself without genital apparatus, and not only this, but in many instances forming shelly coverings of a symmetry and complexity not surpassed by those of any testaceous animals " " whilst the mere separation of a fragnient of this jelly is sufficient to originate a new and independent organism, so that any number of these beings may be produced by the successive detachment of

1 See the Author's Introluction to the Study of the Foraminifera, published by the Ray Sueiety, 186\%, Preface, p. vii. 
such particles from a single Rhizopod, each of them retaining (so far as we have at present the means of knowing) the characteristic endowments of the stock from which it was an offiet.

6. When, on the other hand, we watch the evolution of any of the higher types of Organization, whether Vegetable or Animal, we observe that althongh in the first instance the primordial cell multiplies itself by duplicative subdivision into an aggregation of cells which are apparently but repetitions of itself and of each other, this homogeneous extension has in each case a definite linit, speedily giving place to a structural differentiation which becomes more and more decided with the progress of development; until, in that nost heterogeneous of all types-the Human Organism - no two parts are precisely identical, except those which correspond to each other on the opposite sides of the borly. With this structural differentiation is associated a corresponding differentiation of function ; for whilst in the Life of the most highly-developed and complex organism, we wituess no act which is not foreshadowed, however vagnely, in that of the lowest and simplest, yet we observe in it that same "division of labor" which constitutes the essential characteristic of the highest grade of Civilization. For in what may be termed the elementary form of Human Society, in which every individual relies upon himself alone for the supply of all his wants, no greater result can be atiained by the aggregate action of the entire community, than its mere maintenance; hut as each individual sclects a special mode of activity for himself, and aims at improvement in that specialty, he finds himself attaining a higher and yet higher degree of aptitude for it ; and this specialization tends to increase as opportunities arise for new modes of activity, until that complex fabric is evolved which constitutes the most developed form of the Social State, wherein every individual finds the work - mental or bodily-for which he is best fitter, and in which he may reach the highest attainable perfection; while the mutual dependence of the whole (which is the necessary result of this specialization of parts) is such that every individual works for the benefit of all his fellows, as well as for his own. As it is only in such a state of Society that the greatest triumphs of Human ability become possible, so it is only in the most differentiated types of Organization that Vital Activity can present its highest manifestations. In the one case as in the other does the result depend upon a process of gradual development, in which, under the influence of agencies whose mature constitutes a proper object of scientific inquiry, that most general form in which the fabric-whether Corporeal or Social-originates, evolves itself into that most special in which its development culminates. And hence we are distinctly justified in the conclusion, that the special endowments of the several components of the organism, however dissimilar to each other, are nothing else than differentiated and proportionately intensified expressions of those which are common to every part of the originally homogeneous fabric; - a conclusion which derives a remarkable confirmation from the indication afforded by the phenomenon of "Metastasis of Secretion," that the gencral structure, even in the most highly-specialized organism, retains somewhat of its primitive community of finction.

7. 'Thus, then, we may take that mode of Vital Activity which manifests itself in the Evolution of the germ into the complete organism repeating the type of its parer $t$, and in the subsequent maintenanec of that organism in its integrity, -in both cases at the expensc of materials derived fron external sources, - as the most universal and most fundancutal characteristic of Life; and we have now to consider the nature and somree of the Force or Power by which that evolntion is brought about. The prevalent opinion has until lately been, that this power is inherent in the 
germ; which has been supposed to derive from its parent not merely its material substance, but a nisus formativus, bildung-stricb, or germ-force, in virtue of which it builds itself up into the likeness of its parent, and maintains itself in that likeness until the force is exhausted, at the same time imparting a fraction of it to each of its progeny. In this nocle of viewing the subject, all the organizing force required to build up an Oak or a Palm, an Elephant or a Whale, must be concentrated in a minute particle only discernible by microscopic aid; and the aggregate of all the germ-forces appertaining to the descendants, however numerous, of a common parentage, must have existed in their original progenitors. Thus, in the case of the successive viviparous broods of Aphides, a germ-force capable of organizing a mass of living structure, which would amount (it has been calculated ${ }^{1}$ ) in the tenth brood to the bulk of five hundred millions of stout men, must have been shut up in the single individual, weighing perhaps the ${ }_{100}{ }_{0}$ th of a grain, from which the first brood was evolved. And in like nanner, the germ-force which has organized the bodies of all the individual men that have lived from Adam to the present day, must have been concentrated in the body of their conmon ancestor. A more complete reductio ad absurdum can scarcely be brought against any hypothesis; and we may consider it proved that, in some way or other, fresh organizing force is constantly being supplied from without during the whole period of the exercise of its activity. When we carefully look into the question, we find that what the germ really supplies is not the force, but the directive agency; thus rather resentbling the control exercised by the superintendent builder who is chargerl with the working-out the desigin of the architect, than the bodily force of the workmen who labor under his guidance in the construction of the fabric. The actual constructive force, as we learn from an extensive survey of the phenomena of life, is supplied by Heat; the influence of which upon the rate of growth and developnent, both Animal and Vegetable, is so marked as to have universally attracted the attention of Physiologists; who, however, have for the most part only recognized in it a vital stimulus that calls forth the latent power of the gerns, instead of looking upon it as itself furnishing the power that does the work. It has been from the narrow limitation of the area over which Physiological research has been commonly prosecuted, that the intinuacy of this relationship between Heat and the Organizing force has not sooner become apparent. Whilst the vital phenomena of Warm-blooded Animals, which possess within themselves the means of maintaining a constant temperature, were made the sole, or at any rate the chief ohjects of study, it was not likely that the inquirer would recognize the full influence of external Heat in accelerating, or of Cold in retarding, their functional activity. It is only when the survey is extended to Cold-blooded Animals, and to Plants, that the immerliate and direct relation between Heat and Vital Activity, as manifested in the rate of growth and development, or of other changes peculiar to the living body, is unmistakably manifested. To some of those phenomena which afford the best illustrations of the mode in which Heat acts upon the living organism, attention will now be directed.

8. The agency of Heat as the "efficient cause" or "motive power" to which the phenomena of growth and development are to be referred, is peculiarly well seen in the process of Germination. The Seed consists of an embryo which has already advanced to a certain stage of development, and of a store of nutriment laid up as the material for its further evolution; and

"See Prof. Huxley on the "Agamic Reproduction of Aplis," in Linnæan Transa tions, vol. xxii, p. 215 . 
in the fact that this evolution is carried on at the expense of organic compounds already prepared by extrinsic agency, until (the store of these being exhausted) the young plant is sufficiently far advanced in its development to be able to elaborate them for itself, the condition of the germinating enbryo resembles that of an Aninal. Now the seed, as already pointed out ( $\$ 3$ note), may remain (under favorable circumstances), in a state of absolute inaction during an unlimited period. If secluded from the free access of air and moisture, and kept at a low temperature, it is removed from all influences that would on the one hand occasion its disintegration, or on the other would call it into active life. But when again exposed to air and moisture, and subjected to a higher temperature, it either germinates or decays, according as the embryo it contains has or has not preserved its vital endowments, - a question which only experiment can resolve. The process of germination is by no mcans a simple one. The nutriment stored up in the seed is in great part in the condition of insoluble starch; and this must be brought into a soluble form before it can be appropriated by the embryo. The metamorphosis is effected by the agency of a ferment termed diastase; which is laid up in the immediate neighborhood of the cmbryo, and which, when brought to act on starch, converts it in the first instance into soluble dextrin, and then (if its action be continued) into sugar. The dextrin and sugar, combined with the albuminous and oily compounds also stored up in the seed, form the "protoplasm" which is the substance immediately supplied to the young plant as the material of its tissues; and the conversion of this protoplasm into various forms of organized tissue, which become more and more differentiated as development advances, is obviously referable to the vital activity of the germ. Now it can be very easily shown experimentally that the rate of growth in the germinating embryo is so closely related (within certain limits) to the amount of Heat supplied, as to place its dependence on that agency beyond rcasonable question; so that we seem fully entitled to say that Heat, acting through the germ, becones the constructive force or power by which the Vegetable fabric is built up. ${ }^{1}$ But there appears to be another source of that power in the Seed itself. In the conversion of the insoluble starch of the Seed into sugar, and probably also in a further metamorphosis of a part of that sugar, a large quantity of carbon is eliminated, by combining with the oxygen of the air so as to form carbonic acid; this combination is necessarily attended with a disengagement of heat, which becomes very sensible when (as in malting) a large number of germinating seeds are aggregated together; and it cannot but be regarded as probable that the heat thus evolved within the seed concurs with that derived from without, in supplying to the germ the force that promotes its evolution.

9. 'The condition of the Plant which has attained a more advanced stage of its development, differs from that of the germinating embryo essentially in this particnlar, that the organic compounds which it requires as the materials of the extension of the fabric are formed by itself instead of being supplied to it from without. The tissues of the green surfaces of the leaves and stems, when acted on by light, have the peculiar power of gencrating at

1 The effect of Ileat is doubtless manifestud very differently by different seeds; sueh variations being partly specific, partly individual. But these are no greater than we see in the Inorganic world; the increment of temperature and the augmentation of bulk exhibited by different substances when subjected to the same absolute measure of heat, being as diverse : the substances themselves. The whole proeess of "malting." it may be remarked, is based on the average regularity with which the seeds of a partieular speeies may be at any lime foreed to a definite rate of germination by a definite inerement of temperature. 
the expense of carbonic acid, water, and ammonia, various ternary and quaternary Organic counounds, such as chlorophyll, starch, oil, and albumen; and of the compounds thus generated, a part are appropriated by the constructive force of the Plant (derived from the heat with which it is supplied) to the formation of new tissues; whilst a part are stored up in the cavities of those tissues, where they ultimately serve either for the evolution of parts subsequently developed, or for the nutrition of Animals which employ them as food. Of the source of those peculiar affiuities by which the components of the Starch, Albumen, etc., are brought together, we have no right to speak confidently; but looking to the fact that these compounds are not produced in any case by the direct union of their elements, and that a decomposition of binary conpounds seems to be a necessary antecedent of their formation, it is scarcely improbable that as suggested by Prof. Le Conte, ${ }^{1}$ that source is to be found in the chemical forces set free in the preliminary act of decomposition, in which the elements would be liberated in that "nascent condition" which is well known to be one of peculiar encrgy. The influence of Light, then, upon the Vegetable organisn appears to be essentially exerted in bringing about what may be considered a higher mode of chemical combination between oxygen, hydrogen, and carbon, with the arddition of nitrogen in certain cases; and there is no evidence that it extends beyond this. That the appropriation of the materials thus prepared, and their conversion into organized tissue in the operations of growth and development, are dependent on the agency of Heat, is just as evident in the stage of maturity as in that of germination. And there is reason to believe, further, that an additional source of Organizing force is to be found in the retrograde metamorphosis of organic compounds that goes on during the whole life of the plant; of which metamorphosis the expression is furnished by the production of carbonic acid. This is peculiarly remarkable in the case of the Fungi, which being incapable of forming new compounds under the influence of light, are entirely supported by the Organic matters they absorb; corresponding in this respect on the one hand with the germinating Plantembryo, and on the other with Animals. Such a decomposition of a portion of the absorbed material is the only conceivable source of the large quantity of carbonic acid they are constantly giving out; and it would not seem unlikely that the force supplied by this retrograde metamorphosis of the superfluous components of their food, which fall down (so to speak) from the elevated plane of "proximate principles" to the lower level of comparatively simple binary compounds, constitutes the power by which another portion is raised to the rank of living tissue; thus accounting in some degree for the very rapid growth for which this tribe of Plants is so remarkable. This exhalation of carbonic acid, however, is not peculiar to Fungi and germinating embryos; for it takes place during the whole life of Flowering Plants, both by day and by night, in sunshine and in shade, and from their green as well as from their dark surfaces. It is not improbable that, as in the case of the Fungi, the source of this exhalation lies partly in the Organic matter absorbed; Plants being able to take up and assimilate soluble humus, which, being a more highly carbonized substauce than starch, dextrin, or cellulose, can only be converted into compounds of the latter kind by parting with some of its carbon. ${ }^{2}$ But it may also take place at the expense of compounds previously generated by the Plant itself, and stored up in its tissues, of which

1 See his very suggestive Memoir, On the Correlation of Physical, Chemical, and Vital Force, in the Philosophical Mragazine for 1860 , vol. xix, Ser. ir, p 137.

2 See the Memoir of M. Risler, On the Absorption of Humus, in the Bibliothèque Universelle, N.S., 1858, tom. i, p 305. 
we seem to have an example in the unusual production of carbonic acid which takes place at the period of flowering, especially in such plants as have a fleshy disk or receptacle containing a large quantity of starch; and thus, it may be surmised, an extra supply of force is provided for the maturation of those generative products, whose preparation seems to be the highest expression of the vital power of the Vegetable Organism.

10. The entire aggregate of Organic compounds contained in the Vegetable tissues, then, may be considered as the expression not merely of a certain amount of the material elements oxygen, hydrogen, carbon, and nitrogen derived (directly or indirectly) from the water, carbonic acid, and ammonia of the atmosphere, but also of a certain amount of force which has been exerted, in raising these from the lower plane of simple binary compounds to the higher level of complex "proximate principles;" whilst the portion of these actually converted into organized tissue may be considered as the expression of a further measure of force, which, acting under the directive agency of the germ, has served to build up the fabric in its characteristic type. This constructive action goes on during the whole Life of the Plant, which essentially manifests itself either in the extension of the original fabric (to which in many instances there seems no determinate limit), or in the production of the germs of new and independent organisms. It is interesting to remark that the development of the more permanent parts involves the successional decay and renewal of parts whose existence is temporary ; the "fall of the leaf" being the effect, not the cause, of the cessation of that peculiar functional activity of its tissues, which consists in the elaboration of the nutritive material required for the production of wood. And it would seem as if the duration of the existence of such temporary parts stands in an inverse ratio to the energy of their action; the leaves of "evergreens," which are not cast off until the appearance of a new succession, effecting their functional changes at a much less rapid rate than do those of "deciduous" trees, whose term of life is far more brief.

11. Thus the final cause or purpose of the whole Vital Activity of the Plant, so far as the individual is concerned, is to produce an indefinite extension of the dense, woody, almost inert, but permanent portions of the fibric, by the successional revelopment, decay, and renewal of the soft, active, and transitory cellulal parenchyna; and, accorling to the principles already stated, the descent of a portion of the materials of the latter to the rondition of binary compounds, which is nanifested in the largely increased exhalation of carbonic acid that takes place from the leaves in the later part of the season, comes to the aid of external Heat in supplying the force by which another portion of those materials is raised to the condition of organized tissue. The vital activity of the Plant, however, is further manifested in the provision made for the propagation of its race by the production of the germs of new indivirluals; and here, again, we observe that whilst a higher temperature than that which suffices to sustain the orlinary processes of vegetation, is usually required for the development of the flower and the maturation of the seer, a special provision appears to be marle in some instances for the evolution of force in the sexual apparatus itselt, by the retrograde metamorphosis of a portion of the organic compounds prepared by the previous nutritive operations. This seems the nearest approacl presented in the Vegetable organism, to what we shall find to be an ordinary mode of activity in the Animal. That the performance of the generative act involves an extraordinary expenditure of Vital force. appears from this rem.rkable firct, that blossoms which wither and rlie as soon as the ovnles have been fertilized, may be kept fresh for a long period if fertilization be prevented by cutting off the stamens before the bursting of the anthers. 
12. We are now prepared to inquire into the manifestions of Vital Aetivity in the Animal, and into the sources of the power by which the various formis of that activity are sustained. The first of the manifestations is, as in the Plant, the building up of the organism by the appropriation of material supplied from external sources under the directive agency of the germ. The ovum of the Animal, like the sced of the Plant, contains a store of appropriate nutriment previously elaborated by the parent; and this store suffices for the development of the embryo, np to the period at which it can obtain and digest alimentary materials for itself. That period occurs in the different tribes of animals at very dissinilar stages of the entire developmental process. In many of the lower classes, the embryo comes forth from the egr, and commences its independent existence, in a condition which, as compared with the adult form, would be as if a Human enbryo were thrown upon the world to obtain its own subsistence only a few weeks after conception; and its whole subsequent growth and development take place at the expense of the nutriment which the embryo ingests for itself. We have examples of this in the class of Insects, many of which come forth from the egg in the state of extremely simple and minute worms, having scarcely any power of movement, but an extraordinary voracity. The eggs having been deposited in situations fitted to afford an ample supply of appropriate nutriment (those of the flesh-fly, for example, being laid in carcases, and those of the cabbage butterfly upon cabbage leaves), each larva on its emersion is as well provided with alimentary material as if it had been furnished with a large supplemental yolk of its own; and by availing itself of this, it spcedily grows to many hundred or even many thousand times its original size, without naking any considerable advance in development. But liaving thus laid up in its tissues a large additional store of material, it passes into a state which, so far as the external manifestations of life are concerned, is one of torpor, but which is really one of great developmental activity; for it is during the pupa state that those new parts are evolved, which are characteristic of the perfect Insect, and of which scarcely a trace was discoverable in the larva; so that the assunıtion of this state may b. likened in many respects to a re-entrance of the larva into the ovurs. Oir its termination, the Imagro or perfect. Insect comes forth complete in all its parts, and soon manifests the locomotive and sensorial powers by which it is specially distinguished, and of which the extraordinary predominance seems to justify our regarding Insects as the types of purely Animal life. There are some Insects whose Imago-life has but a very short duration, the pcrformance of the generative act being apparently the only object of this stage of their existence: and such for the most part take no food whatever after their final emersion, their vital activity being maintained, for the short period it endures, by the material assimilated furing their larva state. ${ }^{1}$ But those whose periud of activity is prolonged, and upon whose energy there are extraordinary demands, are scarcely less voracious in their Imago than in their Larvacondition; the food they consume not being applied to the increase of their bodies, which grow very little after the assimption of the Imago-state, but chiefly to their maintenance,-no inconsiderable portion of it, however, being appropriated in the female to the production of ova, the entire mass of which deposited by a single individual is sometimes enormous. That the performance of the generative act involves not merely a consumption of Material,

1 It is not a little curious that in the tribe of Rotifera, or Whecl-animaleules, all the males ret discovered are entirely asplanchnic: not only the whole of their development within the egg. but the whole of their active life after their emersion from it, being carried on at the expense of the store of yolk provided by the parent. 
but a special expenditure of force, appears from a fact to be presently stated, corresponding to that already noticed $(\$ 11)$ in regard to Plants.

13. Now if we look for the source of the various kinds of Force,-which may be distinguished as eonstructive, sensori-motor, and generative,- that are manifested in the different stages of the life of an Inseet, we find them to lie, on the one hand, in the Heat with which the organism is supplied from external sources, and, on the other, in the Food provided for it. The ageney of heat, as the noving power of the constructive operations, is even more distinetly shown in the development of the Larva within the egg, and in the development of the Imago within its pupa-case, than it is in the germinating seed; the rate of each of these processes being strietly regulated by the temperature to which the organism is subjected. Thus ova which are ordinarily not hatched until the leaves suitable for the food of their larva have been put forth, may be made, by artificial heat, to produce a brood in the winter; whilst, on the other hand, if they be kept at a low temperature, their hatehing may be retarded almost indefinitely without the destruction of their vitality. The same is true of the pupa-state; and it is remarkable that during the latter part of that state, in which the developmental process gocs on with extraordinary rapidity, there is in eertain Insects a special provision for an elevation of the temperature of the embryo by a proeess resenbling incubation. Whether, in addition to the heat imparted from without, there is any addition of foree developed within (as in the germinating sced) by the return of a part of the organic eonstituents of the food to the condition of binary compounds, eamnot at present be stated with eonfidence; the probability is, however, that such a retrograde metamorphosis does take place, adequate cvidence of its occurrenee during the incubation of the Bird's egg being afforded by the liberation of earbonic acid whieh is there found to be an essential eondition of the developmental process. During the larva-state there is very little power of maintaining an independent temperature, so that the sustenanee of Vital Aetivity is still mainly due to the heat supplied from without. But in the active state of the perfeet Insect there is a production of heat quite comparable to that of warm-blooded animals; and this is effected by the retrograde metamorphosis of eertain organic constituents of the food, of which we fiud the expression in the exlralation of carbonic acid and water. Thus the food of Animals becomes an internal souree of heat, which may render them independent of external temperature. Further, a like retrograde metamorphosis of eertain constituents of the food is the source of that sensori-motor power which is the peculiar characteristic of the Animal organism; for on the one hand the demand for food, on the other the amount of metamorphosis indicated by the quantity of carbonic acid exhaled, bear a very close relation to the quantity of that power which is put forth. This relation is peeuliarly manifest in Insects, since their eonditions of activity and repose present a greater contrast in their respeetive rates of metamorphosis, than do those of any other animals. Of the exercise of generative foree we have no similar measure; but that it is only a special modification of ordinary vital activity appears from this circumstance, that the life of those Insects which ordinarily dic very soon after sexual congress and the deposition of the ova, may be considerably prolonged if the sexes be kept apart so that congress cannot take place. Moreover, it has been shown by reeent inquiries into the Agamic reproduction of Inseets and other animals, that the process of Generation differs far less from those Reproductive acts whieh must he referred to the category of the ordinary Nutritive processes, than had been previously supposed.

14. 'Thus, then, we find that in the Animal organism the demand for food 
has reference not mercly to its use as a material for the construction of the fabric; fool serves also as a generator of force; and this force may be of various kinds,-Heat and Motor-power being the principal but by no means the only modes under which it manifests itself. We shall now inquire what there is peculiar in the sources of the Vital Force which animates the organisms of the higher animals at different stages of Life.

15. That the Developmental force which occasions the evolution of the germ in the higher Vertebrata is really supplied by the heat to which the orum is snbjected, may be regarderl as a fact established beyond all question. In the Frog and other Amphibia, which have no special means of imparting a high temperature to their eggs, the rate of development (which in the early stages can be readlily determined with great exactness) is entirely governed by the degree of warmth to which the ovum is subjected. But in Serpents there is a peculiar provision for supplying heat; the female performing a kind of incubation upon her cggs, and generating in her own body a temperature much above that of the surrounding air. ${ }^{1}$ In Birds, the developmental process can only be maintained by the steady application of external warmth, and this to a degree much higher than that which is needed in the case of cold-blooded animals; and we may notice two results of this application as very significant of the dynamical relation between Heat and Developmental Force,-first, that the periorl required for the evolution of the germ into the mature embryo is nearly constant, each species having a definite period of incubation,--and second, that the grade of development attained by the embryo before its emersion is relatively much higher than it is in cold-blooded vertebrata generally; the only instances in which anything like the same stage is attained without a special incubation, being those in which (as in the Turtle and Crocodile) the eggs are hatched under the influence of a high external temperature. This higher development is attained at the expense of a much greater consumption of nutrient material ; the store laid up in the "food yolk" and "albumen" of the Bird's egg being many times greater in proportion to the size of the animal which laid it, than that contained in the whole egre of a Frog or a Fish. There is evidence in that liberation of carbonic acid which has been ascertained to go on in the egg (as in the germinating seed) during the whole of the developmental process, that the return of a portion of the organic substances provided for the sustenance of the embryo, to the condition of simple binary compounds, is an essential condition of the process; and since it can scarcely be supposed that the object of this metamorphosis can be to furnish heat (an aniple supply of that force being afforded by the body of the parent), it seems not unlikely that its purpose is to supply a force that concurs with the heat received from without in maintaining the process of organization.

16. The development of the embryo within the body, in the Mammalia, imparts to it a steady temperature equivalent to that of the parent itself; and in all save the implacental Orders of this class, that development is carried still further than in Birds, the new-born Mammal being yet more complete in all its parts, and its size bearing a larger proportion to that of its parent, than even in Birds. It is doubtless owing in great part to the constancy of the temperature to which the embryo is subjected, that its rate of development (as shown by the fixed term of utern-gestation) is so uniform.

I In the Viper the eggs are usually retained within the oviduct until they are hatched. In a Prthon, which went through the proecss of incubation in the Zoulogical Gardens, the egres were imbedded in the coils of the body; the temperature to which they were sulijeeted (as aseertained by a thermometer placed in the midst of them) averaging $90^{\circ} \mathrm{F}$, whilst that of the cage averaged $60^{\circ} \mathrm{F}$. 
The supply of organizable material here afforded by the ovum itself is very snall, and suffices only for the very earliest stage of the constructive process; but a special provision is very soon made for the nutrition of the embryo by materials directly supplied by the parent; and the imbibition of these takes the place, during the whole remainder of fotal life, of the appropriation of the materials supplied in the Bird's egg by the "food yolk" and "albumcn." To what extent a retrograde metanorphosis of nutrient material takes place in the foetal Mamnal, we have no precise means of determining; since the products of that metamorphosis are probably for the most part returned (through the placental circulation) to the blood of the mother, and got rid of through her cxeretory apparatus. But sufficient evidence of such a metamorphosis is afforded by the presence of urea in the amniotic fluid and of biliary matter in the intestines, to make it probable that it takes place not less actively (to say the least) in the foetal Mammal than it does in the Chick in ovo. Indeed, it is impossible to conceive of the growth of any of the higher organisms - which not merely consists in the formation of new parts, but also involves a vast anıunt of interstitial change-without perceiving that in the remodelling which is incessantly going on, the parts first formed must be removed to make way for those which have to take their place. And such removal can scarcely be accomplished without a retrograde metamorphosis, which, as in the numerous cases already referred to, may be considered with great probability as setting free constructive force to be applied in the production of new tissue.

17. If, now, we pass on from the intrauterine life of the Mammalian organism to that period of its existence which intervenes between birth and maturity, we see that a temporary provision is made in the acts of lactation and nursing for affording both food and warmth to the young creature, which is at first incapable of adequately providing itself with aliment, or of resisting external cold without fostering aid. And we notice that the offspring of Man remains longer dependent upon parental care than that of any other Mammal; in accordance with the higher grade of development to be ultimately attained. But when the period of infancy has passed, the child that is adequately supplied with food, and is protected by the clothing which makes up for the deficiency of other tegumentary covering, ought to be able to maintain its own heat, save in an extremely depressed temperature; and this it does by the metamorphosis of organic substances, partly derived from its own fabric, and partly supplied directly by the food, into binary compounds. During the whole period of growth and development, we find the producing power at its highest point; the circulation of blood being more rapid, and the amount of carbonic acid gas generated and thrown off being much greater in proportion to the bulk of the body, than at any subsequent period of life. We find, too, in the large amount of other excretions, the evidence of a rapid metamorphosis of tissue; and it can hardly be questioned (if our general doctrines be well founded) that the constructive force which operates in the completion of the fabrie will be deriver in part from the heat so largely generated by chemical change, and in part from the descent which a portion of the fabric itself is continually making from the higher plane of organized tissuc to the lower plane of dead matter. This high measure of vital activity can only be sustained by an ample supply of Food; which thus supplies both material for the construction of the organism, and the force ly whose agency that construction is accomplished. How completely dependent the constructive or organizing process still is upon Heat, is shown by the phenomena of reparation in coldblooded animals; since not only can the rate at which they take place be experimentally shown to bear a direct relation to the temperature to which 
these animals are subjected, but it has been ascertained that any extraordinary act of reparation (such as the reproduction of a limb in the Salaniander) will only be performed under the influence of a temperature much higher than that required for the maintenance of the ordinary vital activity.

18. After the maturity of the Organism has been attained, there is no longer any call for a larger measure of constructive force than is requirer for the maintenance of its intcgrity; and if there were no other source of retrograde metamorphosis than that which is inherent in the peculiar composition of the tissues, the demand for food would be reduced to very little more than would suffice, by its ultimate conversion into water and carbonic acid, to keep up the Tensperature of the body. But the conditions of Animal existcnce involve a constant expenrliture of Motor force through the instrumentality of the Nervo-muscular apparatus, as well as a liberation of Heat; and the exercise of the purely Psychical powers through the instrumentality of the Brain constitutes a further expenditure of force, even when no bodily exertion is made as its result. We have now to consider the conditions under which these forces are developed, and the sources from which they are derived.

19. That the Motor force which is put forth in the contraction of a Muscle, is generated by the oxygenation of the component elements, either of the muscle itself, or of the blood which circulates through it, may be considered as demonstrated by these two facts: (1) that while the blood which circulates through a Muscle at rest is returnerl by its veins in an almost arterial condition, its hue changes to renous as soon as the muscle is thrown into action ; and (2) that the quantity of Carbonic acid exhaled bears a constant relation, cateris paribus, to the amount of muscular exertion put forth, as has been especially shown by the experiments of Mr. Newport and Dr. Edward Smith; the former upon Insects, the latter on the Human subject. It is interesting to note the different ways in which this oxygenation is brought about in the two cases. In the Insect the aeration is quite independent of the blood-circulation; being provided for by the direct penetration of air, through the ramifications of the trachea, into the substance of the muscles. But in Man as in Vertebrata gencrally, the Blood is not only the mutrient but is also the orygenating medium; and while, in the Organic compounds with which it is charger, it has a store of "potential energy," it is only by the presence of the free Oxygen which it carries with it, that those changes can be maintained wherehy "potential energy" is converted into "actual energy." When the doctrine now known as that of the "Conservation of Energy" "was first worked out in regard to the production of Animal Force,

1 The earliest distinet general expression of this doetrine is to be found in the very renalkable treatise of Dr. Mayer (Die organische Bewegung in iliren Zusammenlange mit dem Stoffwechsel, Heilbronn, 1845), in whicl he worked out from the two fundamental axioms, "E.x nihilo nil fit," and "Nil fit ad nihilum," the whole system of doetrine which has since eone to be known as that of the "Correlation of Forces," and the "Conservation of Energy," in its application alike to Physies and Chemistry and to Physiology. Sur William Grove was simultaneonsly enuaged in the development of the doctrine of the "Correlation of the Physical Forees" as Prof. Helmholtz was in that of the "Conservation of Enerry ;" and without any knowl'dge of the previous labors either of Dr. Mayer or of Prof. Ilelmholtz. the Author of this Treatise developed a similar duetrine in his Memoir. On the Mrutual Relattions of the Vital and Physieal Forces, published in the Philosopical Transaetions for 1850. [In a published Introductory Lecture, delivered liy Prof. Samue! Jackson, of the University of Pennsylvania, at the opening of the Sescion of 18:371838, he uses these words: "Physicail phenomen:1, recording to the class they belong to, are relerred to a few simple laws, as gravity, caloric, affinitv, galvanism, electricity, magnetism, all of which, it can now be scarcely doubted, are nodifications of one great law or forec." ] 
it was supposed that every exertion of muscular power involved a metamorphosis of the tissue of the muscle itself, sufficient in its amount to produce the mechanical equivalent of the heat that would be otherwise liberated by the combustion of its Hydrocarbon. But the obscrvations of MII. Fick and Vislicenus on the increase of the urea and other nitrogenons products of the disintegration of muscle, which shows itself in the Urine during and after prolonged muscular exertion-confirmed, as they have been, by the results of many similar inquiries - seem to place it beyond doubt that the amount of Motor energy put forth is so completely out of proportion to that of the muscular tissue which we can suppose to have been consumed, that we camnot do otherwise than attribute it in great part to the oxygenation of the non-azotized components of the Blood during its passage through the muscle. What is the peculiar condition which determines this oxidation, is at present undetermined; but it would seem not improbably related to the electric changes of which (as will be shown hereafter) the contracting muscle is the scat.

20. The case seems differcnt; however, in regard to the generation of Nerve-force; for there is great reason to believe that its production is mainly, if not entirely, dependent upon the oxygenation of the Nerve-substance itself. Its rapid metamorphosis, particularly in the cortical substance of the brain, is indicated alike by many histological characters, and by the appearance of the special products of that metamorphosis in the Urine; where the quantity of the alkaline phosphates, whose production may fairly be attributed to the oxidation of the phosphorized fats of the nerve-tissue, bcars a very close relation to the quantity of Brain-work executed. The enormous supply of Blood which the Brain receives-as much as one-fifth part of the whole Arterial stream being sent to an organ whose weight does not exceed one-fortieth that of the entire body-is another evidence of the activity of the changes continually in progress between the Blood and the Nerve-substance. We may roughly liken the Brain to a Galvanic battery, and the Blood to its exciting liquid. When the circuit is closed, a rapid oxygenation of the Nerve-substance, as of the zine of the battery, takes place; and a corresponding equivalcnt of Nerve-force (which seems closely related to, but not identical with, Electricity) is generated. But the Blood also serves for the nutritive renewal of the Nervc-substance in its intervals of repose; thus supplying it with the "potential energy," which is converted into "actual energy" by the oxygenation that destroys it as a living tissue. How intimate is the dependence of the generation of Nerve-force on the supply of Blood to the Brain, is proved by the cffect of its suspension ; for if this be complete, there is an immediate cessation of consciousness and motor power. And that this cessation of activity is due rather to the want of the Oxygen supplied by the Blood, than to that of its nutricnt material, appears from the recent experiments of Professor Bert, of the Collége de France. For having, by means of an apparatus capable of including the entire human body, and of being exhausted of its air to any required degree, brought on the fitintness and exhaustion-proceeding even to a state resembling asphyxia-which is known as the mal des montegnes, he found that this was inmediately and completely relicved by the inspiration of air highly charged with oxygen. And two aeronauts, MIM. CrocéSpinclli and Sivel, having inspired from bags containing snch a mixture, found thenselves in possession of their conscionsness and power of exertion, under a diminution of pressure which had reduced Mesirs. Glatisher and Coxwell to a state of inscusibility. 
21. To sum up: The Life of Man essentially consists in the manifestation of Forces of various kinds, of which his Organism is the instrument; and these Forces are developed by the retrograde metamorphosis of the Organic Compounds gencrated by the instrumentality of the Plant, whercby they ultimately return to the simple binary forms (watcr, carbonic acid, and ammonia) which scrve as the food of plants. Of these organic Compounds, one portion $(a)$ is converted into the tissucs of the living body, by a constructive forec which (in so far as it is not supplied by the direct agency of external Heat) is developed by the retrograde metamorphosis of another portion (b) of the food. And whilst the ultimate descent of the first-named portion $(a)$ to the simple condition from which it was originally drawn, becomes one source of the peculiarly Animal powers-the psychical and the motor-exerted by the organism, another source of these may be found in a like metamorphosis of a furtler portion (c) of the food which has never been converted into living tissue. The gencrative force, as in the Plant, is evidently an cxpression of the ordinary constructive force; and there seems reason, moreover, for regarding it as a very high expression, its too rapid expenditure producing a peculiarly depressing effect upon the vital power of the organism, which tends to its dissolution. But whilst we find the ultimate source of the whole vital power of the organism in the supplies of Food and of Heat which it derives from external sources, it must never be forgotten that its capacity to avail itself of those supplies depends upon its own original constitution; and that as the form into which the Germ develops itself depends upon its own specific endowments, so the particular modification of that form presented by each individual must depend (all external conditions being the same) upon its own individual cndowmentsthe differences between these being at present only vaguely referable to antecedent conditions of the parental organism.

\section{CHA PTER II.}

\section{DISTINCTIVE CHARACTERISTICS OF MAN.}

22. Ix entering upon the study of that aggregation of phenomena which constitutes the Life of Man, it seens appropriate in the first instance to consider his relations to other types of Animal organization; and to examine what there is in his corporeal and psychical characters, which most distinctiy differentiates him from the beings he most nearly resembles. All Zoologists are agreed that his place is at the hear of the Mammalian class of the Vertebrate subkingdom; and that as regards both the general plan of conformation and the details of anatomical structure, there is a very close approximation betwcen the genus Homo and the semierect tailles Apes belonging to the genera Trogloclyles and Pithecus. But there is a considerable difference of opinion as to the morle in which this relationship should be expressed. By Linneus, the Apes and Man were included witl Lemurs and Bats in one and the same Order Primates; and in this non-separation of Man from the Apes, he has been followed by several modern Zoologists of great eminence. On the other hand Blumenbach, who in this was followed by Cuvier, maintained that the distinctive characters of the genus 
Homo are sufficient to entitle man to rank as the type of a separate Order, to which he gave the name of Brmana, considering it to be specially distinguished by the possession of two hands from the QUadrumasa, which possess four nearly similar handlike extremities. And Prof. Owen has recently gone a step further, by raising Homo into a snbclass Archencepinata, on the ground that his "psychological powers, in association with his extraordinarily developed brain, entitle the group which he represents to eqnivalent rank with the other primary divisions of the class Mammalia, founded on cerebral characters." Although the discnssion of questions of systematic arrangement is the proper business of the Zoologist, yet the inquiry into the exact nature and amount of the differences between Man and the (so-called) Quadrumana falls legitimately within the province of the Physiologist, and nay therefore be appropriately dealt with in this place. In the pursuit of this inquiry, it is most important to distiuguish between those structural peculiarities of which alone the Anatomist can take cognizance, and those psychical manifestations of which the sources are altogether beyond his ken ; for these two orders of facts cannot be legitimately brought into the same category, and any attempts to blend them can lead to nothing but confusion. It is the province of the Comparative Anatomist to deal with Man's corporeal organism, as if he knew nothing more than the facts brought nnder his observation in the dissecting-room; serntinizing every peculiarity in its structure in exactly the same spirit, and valuing it according to exactly the same measure, that lie wonld bring to the investigation of the peculiarities of some newly discovered type, known to him only by dead specimens. And although he might safely assign to the genus Homo a structural capacity for the erect posture,- a specialty in the conformation of the anterior and posterior extremities, imparting to the former a peculiar power of varied and minute prehension, and fitting the latter for biped progression,- and a relatively larger and more complex brain, rendering it probable that the psychical faculties of which it is the instrument wonld be more elevated and nore predominant,-yet there he must stop ; since he cannot discover in Man's corporeity the fintest indication of those Intellectnal and Moral attributes by which he holds himself to be spccially distinguished from the brute creation, of that Progressive Reason which draws even the Infinite within its scope, of that upward aspiration after Truth and Gooduess which ranges even beyond his intellectual conception, of that yearning after a purely Spiritual existence which refises to recognize in bodily decay anything but the liberation of the imprisoned Soul. 'These are fucts of Man's nature not less necessary to be taken into account in the estimation of his position in the Universe than those which are snpplied by his bodily organization; and it is not surprising that by a too exclusive regard to them, many eminent Naturalists, from Aristotle downwards, have been led to maintain that Man ought not to be included in the Animal Kingdon at all, but should be ranked in a kingdom by himself. 'This, however, is a position which cannot be consistently held by any one who recognizes Anatomical structure as the true basis of 'Zoological classification. For granting that Man is distinguished from every other form of terrestrial being by psychical at tributes which bring him into relation with Infinite Intelligence, he does not the less belong to the Animal Kingdom in his present stage of existence, in virtue of his possession of every attribute by which an Animal is characterized, and the absence of any peculiarity whatever in his organization which can be shown to renove him from that category. And since it is only as an animal that he is taken

1 On the Charactrs and Classification of the Mammalia, in Journal of the Procredings of the Linuacan Society, vol. ii, 1857, p. 33. 
cognizance of by the Zoologist, it is only with his structural characters that the Zoologist should concern himself. In this point of vicw it appears to the author clearly demonstrable that the structural distinctions by which Man is separated from the higher $A$ pes are mnch smaller in amount than those by which the latter are separater from the lower Quadrumana; and hence that the Linnean association of Man and the Quadrumana in the same primary group is much more correct than the ordinal separation of the Bimana and Quadrumana maintined by Cuvier, and a fortiori than the proposition of Prof.' Owen to rank Man in a distinct sub-class.

23. As the ordinal separation of the Bimana from the Quadrumana has come to be gencrally accepterl upon the authority of Cuvier, it will be desirable to begin by examining into the valiclity of the characters on which it rests ; comparing, in the first place, the hand and the foot of Man with the corresponding extremities of the higher Apes; and then inquiring whether the differences which they respectively present, either surpass in degree those with which we meet in a like comparison between the cxtremities of the higher Apes and those of the lower Monkeys, or cau be justly held to depart from them in kind. There is in Man, what we observe in none of the Mammalia which approach him in other respects, a complete distinction in the character of the anterior and posterior extremities; the former being adapted for prehension alone, and the latter almost exchusively for support and progression: and thus each function is performed with much greater completeness, than it can be when two such opposite purposes have to be united. "That," says Cuvier, "which constitutes the hund, properly so called, is the faculty of opposing the thumb to the other fingers, so as to seize upon the most ninute objects; a faculty which is carried to its highest degree of perfection in Man, in whom the whole anterior extremity is free, and can be employed in prehension." The peculiar prehensile powcr possessed by the Hand of Man, is chiefly dependent upon the size and power of the thumb; which is more developed in him, than it is in the highest Apes (Fig. 1). The

FIG, 1,
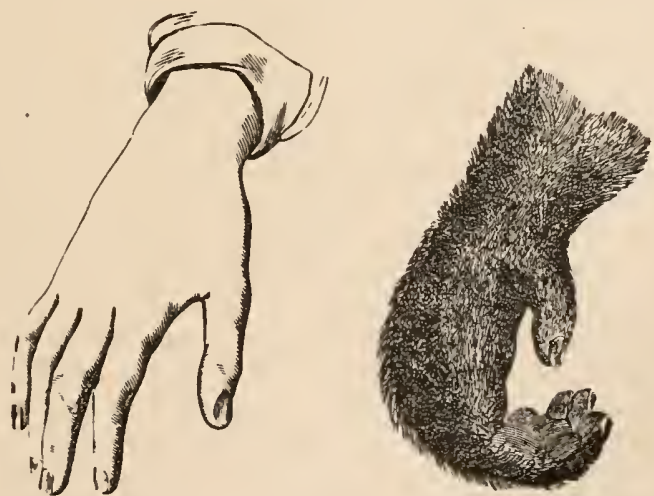

Hand of Man, compared with anterior extremity of Orang.

thumb of the Human hand cau be brought into exact opposition to the extremities of all the fingers, whether singly or in combination; while in those Quadrumana which most nearly approach man, the thumb is so short, and the fingers so much elongater, that their tips can scarcely be brought into opposition; and the thumb and fingers are so weak, that they can never be 
opposed to each other with any degree of force. Hence, although well suited to cling round bodies of a certain size, such as the small branches of trees, etc., the anterior extremities of the Quadrumana can neither seize very minute objects with such precision, nor support large ones with such firmness, as are essential to the dexterous performance of a variety of opcrations for which the hand of Man is admirably adapted. This adaptation, however, is not obtained by means of any new instrumentality ; for the anterior extremity of the Orang or Chimpanzee possesses not only every bone, but every muscle, which is found in that of Man; and its only structural differences consist in the proportionate development of the several components of these organs respectively. But the functional powers of the anterior extremity are not related solely to its own structure; since the use that can be made of the limb depends in part upon its relations to the body at large, the general conformation of which must be adapted to turn its special capacity to advantageous account. Thus, while the arm of the higher Apes has as wide a range of motion as that of Man, so far as its articulation is concerned, it is only when the animal is in the erect attitude that the limb can have free play. And even the most perfect organization of the land as an instrumental structure would be comparatively valueless, without the mind by which its actions are prompted, and the senses by which they are guided.

24. The Foot of Man, in like manner, differs from that of the higher Apes, in those characters which specially adapt it to the support of the body in the erect posture, and to biped progression; in which adaptation it loses much of that prehensile power which the posterior extrenities of the higher Quadrumana possess almost equally with their anterior. The Human foot is, in proportion to the size of the whole body, larger, broader, and stronger, than that of any other Mammal save the Kangaroo. The surface of the Astragalus, which articulates with the tibia, looks almost vertically upwards, and hardly at all inwards when the sole is flat upon the ground, and the lateral facets are more nearly at right angles to this surfice than in any Ape. The plane of the foot is directed at right angles to that of the leg; and its sole is concave, so that the weight of the body falls on the summit of an arch, of which the os calcis and the metatarsal bones form the two points of support. This arched form of the foot, and the contact of the whole plantar surface with the ground, are peculiarly noticeable in Man; most of the Apes having the os calcis small, straight, and more or less raised from the ground, which they touch, when standing erect, with the onter side only of the foot (Fig. 2). The function of the hallux, or great-toe, moreover, is strikingly contrasted in Man and the Apes; for whilst in the latter it is nearly as oppowable as the thumb, and can be used to almost the same degree as an instrument of prehension, it chiefly serves in the former to extend the basis of support, and to advance the body in progression. But neither in its osteology nor in its myology is there any esiential difference between the foot of Man and the posterior extremity of the higher Apes; for every bone and every muscle in the one has its counterpart in the other; and there is nothing which really assimilates the posterior to the anterior extremity of the $\Lambda$ pe, or entitles the former to be considered as a hand, save the opposahility of the great-toe. It is certain, moreover, that this finculty is not originally "anting in Man, although it may be destroyed by the disuse prodnced by the habit of inclosing the foot in rigid investments; for among nations by whom that loabit is not practiced, we often find that the great-toe can be sufliciently opposed to the other toes to render the foot a useful instrmment of prehension, and that many actions are commonly perforneal by its means, which we are accustomed to regard as requiring manual agency. And in the case of individ- 
uals among ourselves, who have either been congenitally deficient in the anterior cxtremities, or who have subsequently lost them, practice only has been requircel to enable the posterior to be turned to the like account.

FIf. 2.

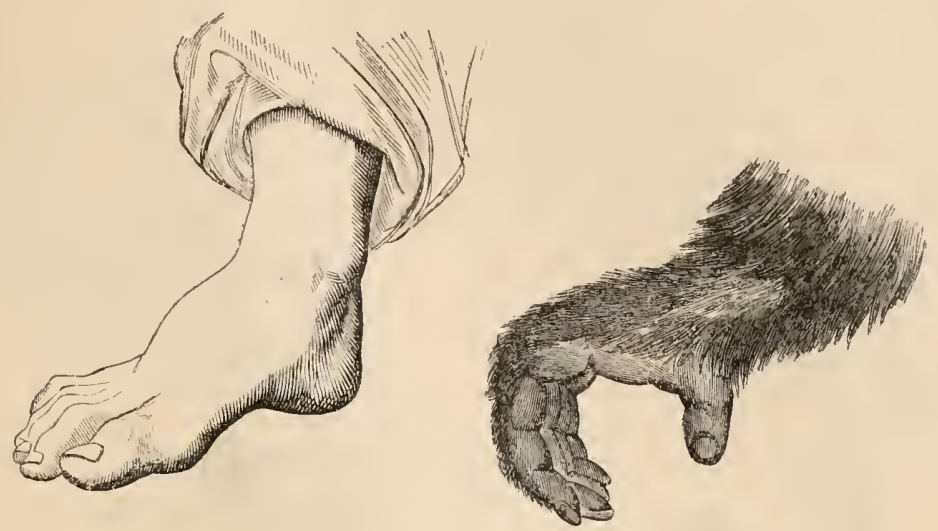

Foot of Man, compared with posterior extremity of Orang.

25. When the comparison, of which the leading points have now been sketched, is extcuded further, we meet with differences that cannot but be accounted of far greater importance, both in degree and in kind, than those already cutumerated. Thus in the entire group of Platyrrhine Monkeys, we find that the thumb is not opposable, but ranges with the other digits, so that it can only be used consentaneously with them in the act of prehension; while in the Ateles, or Spider-Monkey, the thumb is altogether wanting, and although a great-toe is present, it can neither be used like that of Man for support, nor be opposed to the other digits as in the higher Quadrumana, the posterior and anterior extremities being strikingly assimilated in structure, and being alike adlapted to serve only as claspers. Among the Baboons and Lemurs, moreover, we find that the conformation alike of the anterior and of the posterior extremities is such as to assimilate them at least as much to the lower quadrupedal as to the higher quadrumanous type; so that between the two extremes of the series of which the anthropoid Apes are the highest and the Baboons and Lemurs are the lowest members, there is a far willer interval, as regards the conformation of the extrenities, than that which separates the former from Man.

26. The next serics of distinctive characters to be considered, are those by which Man is adapted to the erect attitude-On examining his Cranium, we remark that the occipital condyles arc so placed, that a perpendicular dropped from the centre of gravity of the head would nearly fall between them, so as to be within the base on which it rests upon the spinal column. The foramen magnum is not placed in the centre of the base of the skull, but just behind it; so that the greater specific gravity of the posterior part of the head, which is cntirely filled with solid matter, is compensated by the greater length of the anterior part, which contains many cavities. There is, indeed, a little over-compensation, which gives a slight preponderance to the front of the head, so that it drops forwards and downwards when all the nuscles are relaxer ; but the muscles attached to the back of the head are far larger and more numerous than those in front of the condyles, so that 
they are evidently intended to counteract this disposition; and we accordingly find ourselves able to keep up the head for the whole day with so slight and involuntary an effort that no fatigue is produced by it. Moreover, the plane of the foramen magnum and the surfaces of the condyles have a nearly horizontal direction when the head is upright; and thus the weight of the skull is laid vertically upon the top of the vertebral column.If these arrangements be compared with those which prevail in other Mam. malia, it will be found that the foramen and condyles are placed in the latter much nearer the back of the head, and that their plane is more oblique. Thus, whilst the foramen magnum is situated in Man just behind the centre of the base of the skull, it is found in the Chimpanzee and Orang-outang to occupy the middle of the posterior third (Fig. 3) ; and, as we descend through the scale of Mammalia, we observe that it gradually approaches the back of the skull, and at last comes nearly into the line of its longest

FIG. 3.
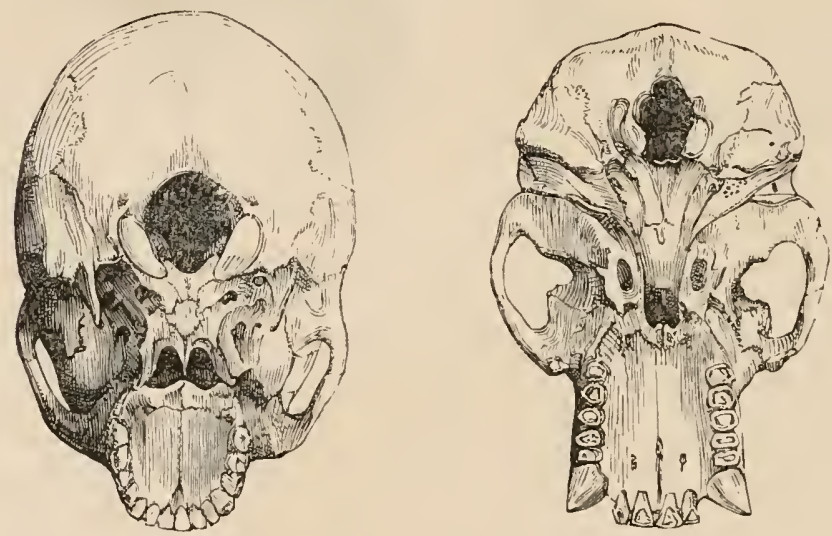

View of the base of the Skull of Man, compared with that of the Orang-outang.

diameter, as we see in the Horse. Again, in all Mammalia except Man, the plaue of the condyles is oblique, so that, even if the head were equally balanced upon them, the force of gravity would tend to carry it forwards and downwards; in Man, the angle which they make with the horizon is very small; in the Orang-outang, it is as much as $37^{\circ}$; and in the Horse, their plane is vertical, making the angle $90^{\circ}$. If, therefore, the natural posture of Man were horizontal, the plane of his condyles would be brought, like that of the Horse, into the vertical position; and the head, instead of being nearly balanced on the summit of the vertebral column, would hang at the end of the neck, so that its whole weight would have to be supported by some external and constantly acting power. But for this, there is neither in the skeleton, the ligamentous apparatus, nor the muscular system of Man, any adequate provision; so that in any other than the vertieal position, his head, which is relatively heavier than that of most Mammalia, would be supported with more difficulty aud effort than it is in any other animal.

27. The position of the Face immediately beneath the brain, so that its front is nearly in the same plane as the forehead, is peculiarly characteristic of Man; for in the skulls of the Chimpanzee and Orang, which approach nearest to that of man, the cranial portions are rather posterior to, than 
above, the facial (Figs. 4, 7). The projection of the muzzle, taken in connection with the obliquity of the condyles, is another evidence of want of perfect adaptation to the erect posture; whilst the absence of prominence in the face of Man shows that none but the ereet position ean be natural to him. For supposing that, with a head formed and situated as at present, he were

FIG. 4.

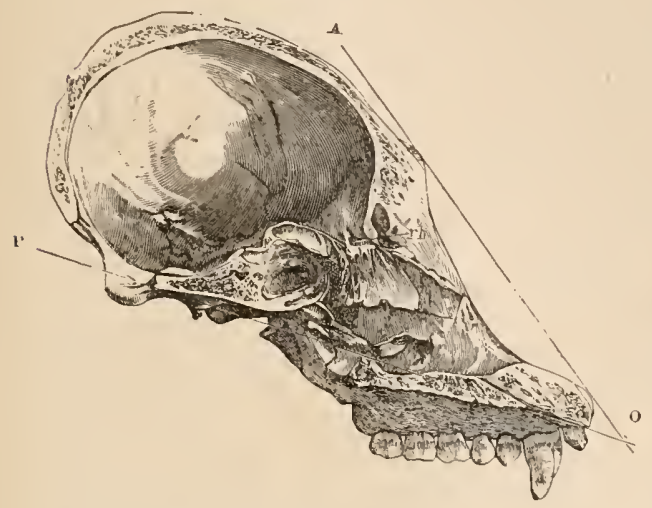

Vertical section of skull of Adult Orang.
FIG. 5.

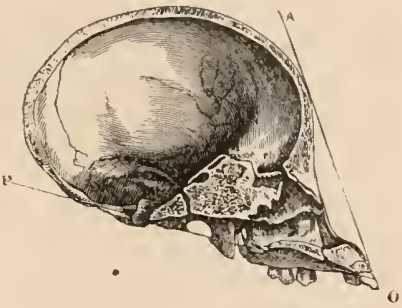

Vertical section of Skull of Young Orang.

FIG. 6.

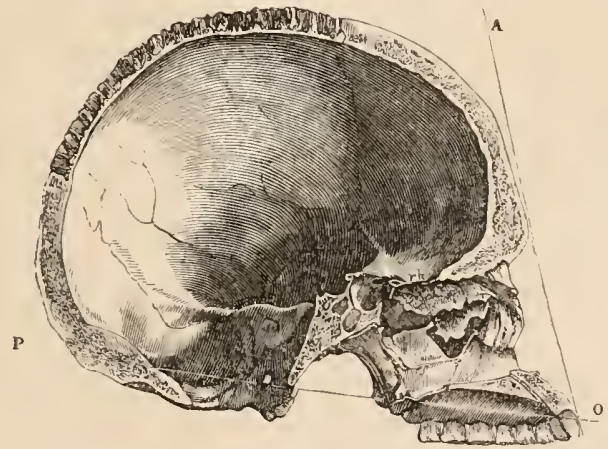

Vertical section of Skull of Papuan Negrito.

to move on all-fours, his face would be brought into a plane parallel with the ground; so that as painful an effort would be required to examine with the eyes an object placed in front of the body, as is now necessary to keep the eyes fixed on the zenith; the nose would then be incapacitated from receiving any other odorous emanations than those proceeding from the earth or from the body itself; and the mouth could not touch the ground without bringing the forehead and chin also in to contact with it. The oblique position of the condyles in the Quadrumana enables them, without much difficulty, to adapt the inclination of their heads either to the horizontal or to the erect posture; but the natural position, in the highest among them, is unquestionably one in which the spinal column is inclined, the body being partially thrown forwards so as to rest upon the anterior extremities; and 
in this position, the face is directed forwards withont any effort, owing to the mode in whieh the head is obliquely artieulated with the spine (Fig. 7).

28. The Cranium of Man is further distinguished from that of the anthropoid A pes, uot merely by its great capaeity, but also by its smoothness; its surface being almost entirely defieient in those ridges for the attaehment of muscles, whieh are remarkably strong in both the Chimpanzee and the Orang, and which impart to its eonfiguration somewhat of a carnivorous aspeet. This aspeet is strengthened by the great depth of the temporal fossa, and by the extent and strength of the zygomatic arch; features that are most remarkably developed in the Troglodytes gorilla (Fig. 7). The breadth of the upper part of the face, is a noticeable feature in Man; the eyes being set widely apart, and the interorbital spaee oceupying one-fourth of the interval between the outer walls of the orbits. ${ }^{1}$ The inner walls of the orbits formed by the ossa plana of the ethnoid are nearly parallel to one another. Moreover, the jaws in even the most degraded races of Man projeet far less from the general plane of the faee, than they do in the Apes; and his teeth are arranger in a entinuous series, without any hiatus or any considerable differenee in length; whilst all the Apes, in their adult state at least, are furnished with eanine teeth of extraordinary length, between the sockets of which and those of the adjoining teeth (anteriorly in the upper jaw, and posteriorly in the lower) there is a vaeant space or "diastema." Even in the most prognathous Human skulls, moreover, the incisor's meet each other much more nearly in the same axis than they do in the anthropoid Apes, in which they form an angle with eaeh other that is not nearly so divergent. The fusion of the intermaxillary or premaxillary bones with the superior maxillary, at an early period of foetal life, is a remarkable character of the Human cranium, as distinguishing it from that of the Apes, in whieh the intermaxillary bones remain separate to a much later period, sometimes differing also very eonsiderably both in size and shape. Thus, in the Troglodytes gorilla, the bones are not only remarkable for their prominenee, but also for their upward extension round the nostrils, so that they completely exclude the maxillary bones from their borders, and from the basis of support for the nasal bones; and althongh they coalesce with the maxillaries at and near the alveolar portion, they renain separate elsewhere. The lower jaw of Man is remarkable for that prominence at its symphysis whieh forms the chin ; and although this, also, is least developed in the most prognathous Human crania, yet it is never so defieient as it is in the lower jaw of the Chimpanzee and Orang.-It is eurious to observe that the skulls of the young of Man and of the anthropoid Apes resemble one another mueh more than do those of the adults ; each tending to diverge, in its advanee towards full development, from a type which seemed almost similar in both (Figs. 4, 5, 6). It is at the time of the seeond dentition, that the muzzle of the anthropoid Apes aequires its peenlial elongation and conserquent projection in front of the forehear (Figs. 5, 4); and the whole east of the featnres is altererl at the same time, so that it approaches much more to that of the lower Quadrumana than would be supposed from observation of the young animal only. ${ }^{2}$ In the Human subject, on the other hand, we see that althongh in the advanee from childhood to ardult age, there is a progressive enlargement of the faee in proportion to the capacity

1 Huxley's Anatomy of the Vertebrate Animals, 1871, p. 489.

2 None but young specimens of the Chimpanzee and Orang-outang have ever been brought alive to this country; and they have never long survived the period of their second dentition. 
of the cranial cavity, this augmentation is comparatively small in amount, and but little aflects the gencral configuration of the cranium.'

29. The great sizc of the cranial portion of the skull in Min, as compared with the fucial, prodnces a marked (hifference between his "facial angle" and that of even the higrlest Quadrumana. According to Camper, who first applicd this methor of measurement, the "facial angle" of the average of European skulls is $80^{\circ}$; whilst in the ideal hearls of the Grecian gorls it is increased to $90^{\circ}$; on the other hand, in the skull of a Kalmuck he found it to be $75^{\circ}$, and in that of a negro only $70^{\circ}$; and applying the same system of measurement to the skulls of Apcs, he found them to range from $6 t^{\circ}$ to $60^{\circ}$. But these last measurements werc all taken fiom young skulls, in which the forward extension of the jaws, which takes place on the second dentition, had not yet occurred. In the arlult Chimpanzee, as Prof. Owen has shown, the "facial angle" (Figs. 4, 5, 6, А O $\mathrm{P}$ ) is no more than $3.5^{\circ}$, and in the adult Orang only $30^{\circ}$; so that instcad of the Negro being nearer to the Ape than to the Europcan, as Campcr's estimate would makc him, the intcrval between the most degraded Human races and the most clcvated Quadrumana, is considerably greater than between the highest and the lowest forms of Humanity. It must be borne in mind, however, that the "facial angle" is so much affected by the degrce of prominence of the jaws, that it can never afford any certain information concerning the elevation of the forehead and the capacity of the cranimm; all that it can in any degree serve to indicate, being the relative proportion between the facial and the cranial parts of the skull. This proportion is far more correctly determined, as Prof. Owen has shown, ${ }^{2}$ by vertical sections of the skulls to be comparerl, through their median planes (Figs. $4,5,6$ ); and from an cxtenderl comparison of such sections, it appears that whilst the rlfference between the cranial cavity of the higher Apes and that of Man is rather one of relative size than of conformation, there is a far more strongly marked difference, not only in relative size but also in conformation, between the cranial cavities of the higher and those of the lower Quadrunana, the latter being not only far less capacions in proportion to the size of the body, but being also disposed in such a manner that its long dianeter comes to be continuous (as in Quadrupeds generally) with the axis of the spinal canal, instead of crossing it nearly at right angles as in Man. The length of the cerebral cavity in Man is more than twice that of the basi-cranial axis. Its capacity in the healthy adult is invariably more than forty cubic inches, and may rise to more than a hundred cubic inches (Huxley).

30. The Vertebral Column in Man, although not absolutely straight, has its curves so arranged, that, when the body is in an erect posture, a vertical line firom its summit would fall exactly on the centre of its base. It incrcases considerably in size in the lumbar region, so as altogether to be somewhat pyramidal in form. The lumbar portion in the Chimpanzec and Orang is not of the same proportional strength, and contains but four vertebra instcad of five. The proccsses for the attachment of the dorso-spinal muscles to this part are peculiarly large and strong in Man; and this arrangement is obviously adapted to overcome the tendency which the weight of the viscera in front of the column would have to draw it forwards and downwards. On the other hand, the spinous processes of the cervical and lorsal vertebræ, which in other Mammalia are large and strong for the attachment of the

1 See Prof. Owen's Papers on the Anatomy of the Orang and Chimpanzee, in the Zuological Transactions, vols. $\mathrm{i}$ and iii; and Prof. Vrolik in the Art. Qual,umana in the Cyclopredia of Anatomy and Physiology, vol. iv.

2 Zoological Transactions, vol. iv, p. 77 et seq. 
ligaments and muscles that support the head, and which are peculiarly pronounced in the Gorilla (Fig. 7), have eomparatively little prominenee in Man, his head being nearly balaneed on the top of the column.-The base of the Human vertebral column is placed on a saerum of greater proportional breadth than that of any other animal ; this saerum is fixed between two widely-expanded ilia; and the whole pelvi.s is thus peculiarly broad. In

Fig. 7.

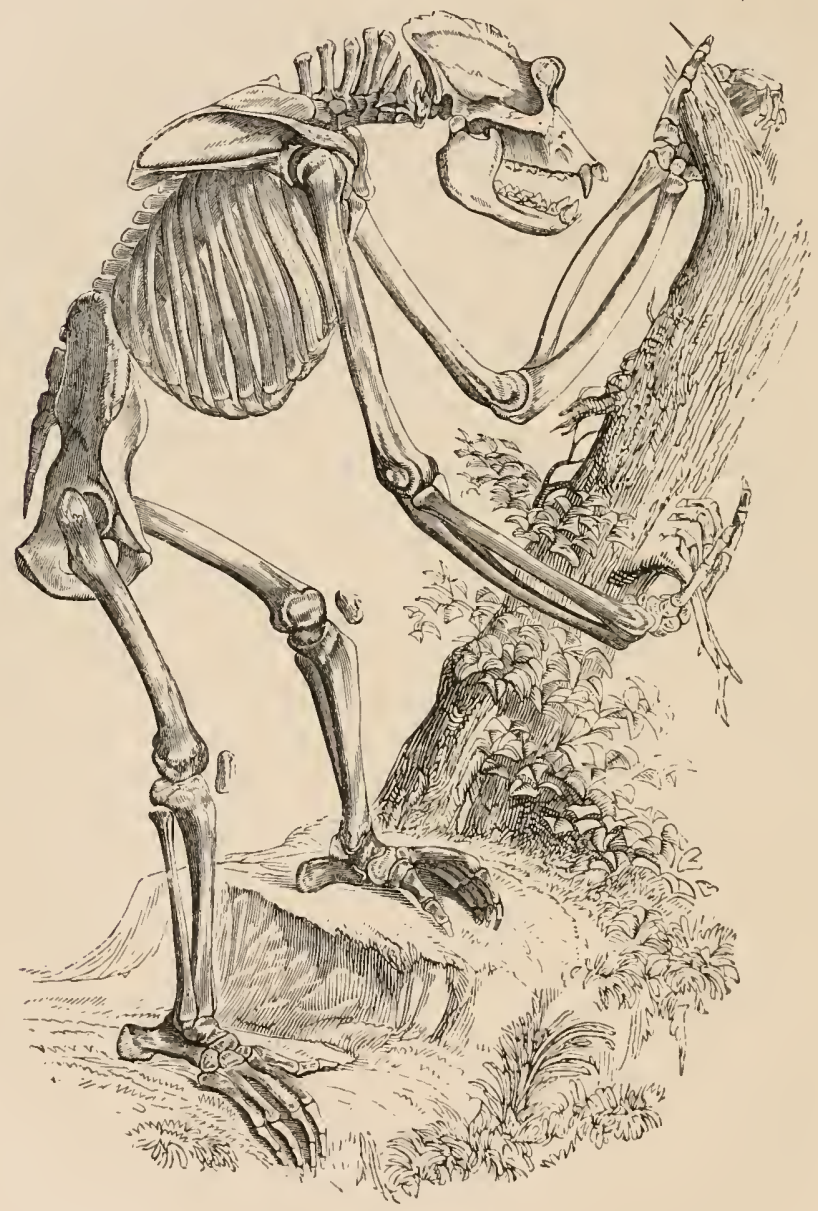

Skcleton of Troglodytes Gorilta.

this manner, the femoral articulations are thrown very far apart, so as to give a wide basis of support and by the oblique direction of the pelvis, the weight of the hody is transmitted almost vertically from the top of the sacrum to the upper part of the thigh boncs. The pelvis of the anthropoid Apes is very difierently constructed, as will he seen in the subjoined euts, in which the skeleton of the Orang is placed in proximity with that of Man. It is much larger and narrower; its alse extend upwards rather than outwards, so that the space between the lowest ribs and the erest of the iliac 
bones is much less than in Man ; their surfaces are nearly parallel to that of the sacrum, which is itself longer and narrower; and the axis of the pelvis is nearly parallel with that of the vertebral column. The position of the Human femur, in which its head is most securely retained in its deep ace-

FIG. 8.

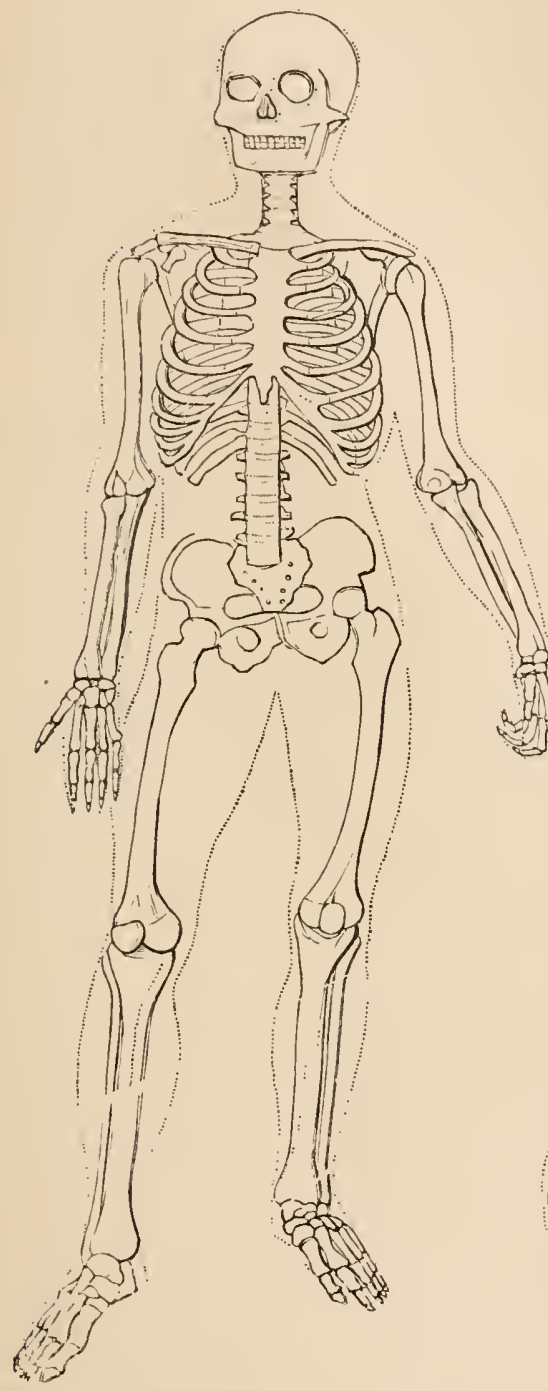

FIG.9.

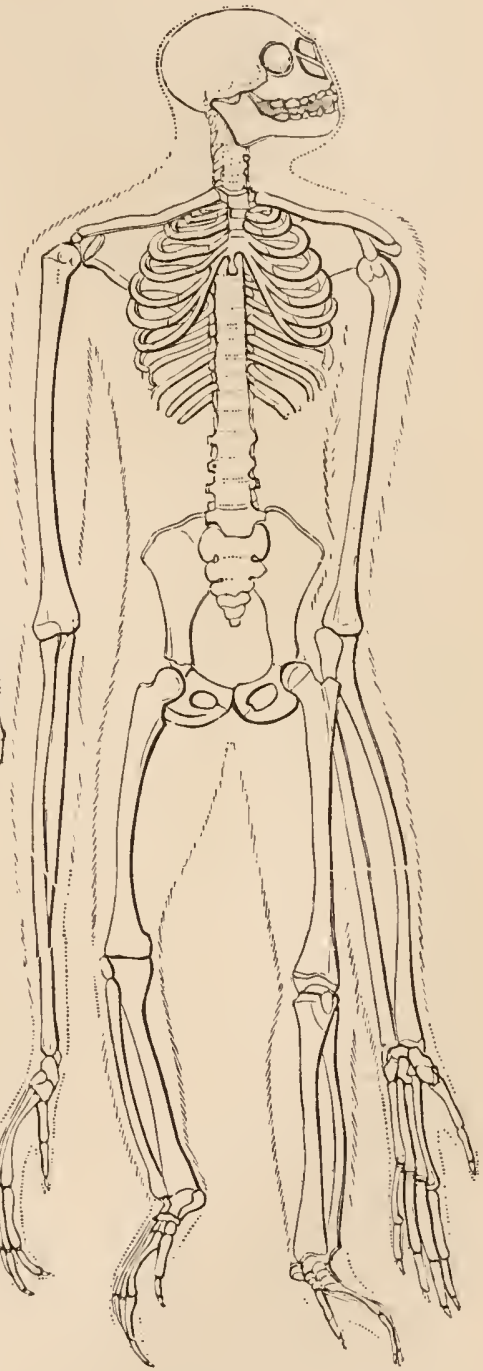

Comparatire View of the Skeleton of Man, and that of the Orang-outang.

tabulum, is that which it has when supporting the body in the erect attitude; in the Chimpanzee and Orang its analogous position is at an oblique angle to the long axis of the pelvis, so that the body leans forwards in front 
of it; in many Mammalia, as in the Elephant, it forms nearly a right angle with the vertebral eolumn; and in several others, as the Horse, Ox, ete., the angle which it makes with the axis of the pelvis and vertebral eolumn is acute. In these respects, then, the skeleton of Man presents an adaptation to the erect posture, which is exhibited by that of no other Mammal; but that of the anthropoid Apes presents a far nearer approximation to the Human model in all the foregoing particulars, than it does to that of the lower Quadrumana.

31. There is a considerable differenee in the form of the trunk, between Man and most other Mammalia : for his thorax is expanded laterally, and flattened in front, so as to prevent the eentre of gravity from being carried too far forwards; and his sternum is short and broad. Between the bony walls of the thorax and the margin of the pelvis, a eonsiderable space intervenes, whieh is oeenpied solely by museles and tegumentary membranes; and these would he quite insufficient to sustain the weight of the viseera, if the habitual position of the trunk had been horizontal. In these particulars, however, the most anthropoid Apes agree more or less eompletely with Man.

32. The lower extremities of Man are remarkable for their relative length, which is greater than that whieh we find in any other Mammalia, except the Kangaroo tribe. The ehief differenee in their proportions between Man and the seni-ereet Apes, is seen in the thigh; and it is from the relative length of this part in him, that the middle point of the height of the body is in the adult as low as the symphysis pubis, and further, from the eomparative shortuess of his anterior extremities, his hands only reaeh the middle of his thighs, whilst in the Chimpanzee they hang on a level with the knees, and in the Or:ang they descend to the ankles (Fig. 9). The Human femur is distinguished, however, by its form and position, as well as by its length. The obliquity and length of its neck still further inerease the breadth of the hips; whilst they eause the lower extremities of the femora to be somewhat obliquely directed towards eaeh other, so that the knees are brought more into the line of the axis of the body. This arrangement is obviously of great use in facilitating the purely biped progression of Man, in whieh the entire weight of the body has to be alternately supported on eaeh limb; for if the knees had been kept further apart, the whole body must have been swung from side to side at each step, so as to bring the eentre of gravity over the top of each tibia; as is seen to a certain extent in the female sex, whose walk, owing to the greater breadth of the pelvis and the separation between the knees, is less steady thin that of the male: There is also a marked difference between the knee-joint of Man and that of even the highest $A$ pes. In the former, the opposed extremities of the femur and the tibia are so expanded as to present a very hroad artieulating surface, and the internal condyle of the femur being the longer of the two, the two eondyles are in the same horizontal plane in the usual oblique position of that bone; so that by this arrangement the whole weight of the body, in its ereet posture, falls vertieally on the top of the tibia, when the joint is in the firmest position in which it ean be placed. The knce-joint of the Orang, on the other hand, is comparatively defieient in extent of alticulating surfice; and its whole conformation indicates that it is not intended to serve as more than a partial support.-In regard to the general conformation of the bones of the extremities, it may be most explieitly affirmed that the differences which undoubtedly exist between Man and the anthropoid Apes are much less eonsiderable than those which present themselves between the latter and those Baboons and Lemurs whose ordinary mode of progression is quadrupedal. And thus, after eontrasting one part 
after another of the skeleton of Man with the corresponding parts of the skeleton of the higher apes, we are led in every instance to the simc conclusion. It is quite true that between Man and those $A$ pes which approach him most closely, there is a widler hiatus than we usually meet with between the members of the Quadrumanous series, which as a whole presents a remarkably gradational position between its higher and lower forms ; and the existence of this hiratus has been used as an argument for ranking Man in a distinct Order. But since, as we ascend that series, we witness a gradual tendency towards the anthropoid form, and since in passing from the highest A pes to Man we only come somewhat abruptly upon the culmination of that ascent without being led off in any other direction, it would be contrary to the whole idea of Zoological classification to place Man in a distiuct category from then as regards his corporeal structure, whatever we may think it right to do when we take his psychical constitution into account. And it is to be borne in mind that this hiatus-like many similar gaps in our classification of existing animals which have been filled up by the progress of palceontological research - may be simply due to that extinction of intermediate forms which (there is constantly increasing reason to believe) has taken place in past ages of the Earth's history, to an extent of which the remains hitherto known to us afford but a very imperfect idea. That it may not be completely bridger over by such intermediate links, no one has any right to affirm upon negative evidence only; more especially in the fice of the positive evidence afforded by the recent discovery of a very remarkable fragnent of a skull, which, while unquestionably Human, resembled that of the Gorilla in the comparative lowness of its vault, the smallness of its capacity, and the extraordinary prominence of its superciliary ridges."

33. The most characteristic peculiarity of the Human Myology, is the great development of those muscles of the trunk and limbs, which contribute to the maintenance of the erect posture. Thus, the gastrocnemii, and the other muscles which tend to keep the leg erect upon the foot, form a much more prominent "calf" than is seen either in the most anthropoid Apes, or in any other animal. The soleus is attached to the tibia as well as to the fibula. So, again, the extensors of the leg upon the thigh are much more powerful than the flexors; a character which is peculiar to Man. The glutri, by which the pelvis is kept erect upon the thigh, are of far greater size than is elsewhere seen. 'The superior power of the muscles tending to draw the head and spine backwards, has been already referred to. Among the differences in the attachment of individual muscles, it may be noticer that the "flexor longus pollicis pedis" proceerls in Man to the great-toe alone, on which the weight of the body is often supported; whilst it is attached in the Chimpanzee and Orang to the three middle toes also. All four heads of the flexor brevis digitorum pedis arise from the Calcaneum, and the second toe has two dorial interossei. The "latissimus dorsi" is destitute in Man of that

1 We meet with a similarly abrupt transition at the other extremity of the series, in the Cheiromys or Aye-aye; an animal which Zoologists now agree to rank among the Quadrumana in virtue of its general Lemurine affinities, although in dentition and several other particulars it bears so strong a resemblance to the Rodents as to have been placed among them by Cuvier.

2 See Natural History Review, vol i, 1861, p. 155; and Prof. Huxley "On some Fossil Remains of Man," in his Evidence as to Man's Place in Nature, 1863. The anatomical peculiarities of Man are very completely given by Prof. Huxley, in his Anatomy of Vertebrated Arimals, 1871, p. 488, et seq.; and the student will find an admirable exposition of the structural resemblances and differences between Man and Apes in St. George Mivart's little work, entitled Man and Apes, 1873. In this work Mr. Mivart strongly opposes the doctrine of the descent of Man and Apes from a common ancestor. 
prolongation attached to the olecranon, which is found in the lower Mammalia, and which exists even in the Chimpanzee, probably giving assistance in its climbing operations. The larger size of the muscles of the thumb, is, as might be expected, characteristic of the hand of Man; although the number of muscles by which that digit is moved, is the same in the Chimpanzee as in the Human subject. The separation of the "extensor digiti indicis," however, as a distinet musele, is peculiar to Man.

34. The Visceral apparatus of Man presents very few characteristic peculiarities, by which it can be distinguished from that of the higher Quadrumana; among the most rentarkable is the absence of the laryngeal pouches, which exist even in the Chimpanzee and Grang-outang, as dilatations of the laryngeal ventricles. Of the anatomy of the last-named animals in their adult condition, however, we know as yet too little to enable its conformity to that of Man to be confidently pronounced upon.

35. The Brain of Man does not differ so much in conformation from that of the Chimpanzee and in this respect still more highly developed Orang, as the superiority of his mental endowments might have led us to anteipate. The following are the principal differences which it seems to present: 1 . The mass of the entire brain is considerably larger in proportion to that of the body, and in proportion also to the diameter of the spinal eord and of the nerves which are connected with it.-2. In the external configuration of the Cerebrum, we notice that its anterior lobes are larger, project further beyond the Rhinencephalon, or Olfactive Ganglion, than they do in the highest Quadrumana; a difference which is well narked in the sectional contour of the brain-case, the rhinencephalic fossa of the Orang (Fig. 4, rh) being at its most anterior part; whilst even in the least elevated forms of the Human skull, this fossa (of which the cribriform plate of the ethmoid bone constitutes the floor) has no inconsiderable part of the cranial cavity in front of it (Fig. $6, r h$ ).-3. The Cerebrum as a whole projects further beyond the Cerebellum than in the Quadrumana generally, which is due not to any inerease in size of the occipital Convolutions, but to the great development of the "bridging convolutions" interposed between the parictal and occipital lobes.-4. The Convolutions are more numerous and eomplex, and usually more or less unsymmetrical, and the sulci are deeper. It appear's, however, that in the lower races of Mankind, the brain presents, both in the simplicity and the precise symnetry of its convolutions, a much eloser approximation to the Quadrumanous type than it does in the higher.-5. On examining the internal structure it is found that the peripheral layer of gray matter is thicker, the corpus callosum extends further backwards, and the posterior cornua of the lateral ventricles are relatively longer and larger than they usually are in Quadrumana. ${ }^{1}-6$. The Cerebellum, also, is proportionally larger. The relative development of the Cerebrum in Man and the three highest apes is well shown in the aceompanying drawings (Figs. 10, 11, 12).

36. The small size of the face of Man, compared with that of the cranium,

1 It has been asserted by Prof. Owen (Journal of the Proeedings of the Linnaan Soeiety, vol. ii, p. 19) that the existenee of the posterior lobes of the Cerebrum, of the posterior eornua of the lateral ventrieles, and of the hippocanpus ininor, which projeets into each eornu, is peeulinr to the genus Homo. How strangely ineonsistent is this assertion with the well-kuown and eertninly aseertained facts of the ense, has been conelusively shown by Prof. Iluxley in his Memoir "On the Zoologienl Relations of Mun with the Lower Animals, "in the Natural History Review, January, 1861, 11. 71 et seq.; nnd the ehief points of the controversy hnve sinee been sueeinetly stuted in his Evidenee as to Man's Plaee in Nuture, 1863. For nn exeellent deseripition of the Convolutions of the Human Cerebrum, see W. Turner, Edin. Med. Jour., June, 1866, and Eeker. 
is an indication that in him the senses are subordinate to the intelligence. Accordingly we find that while he is surpassed by many of the lower ani-

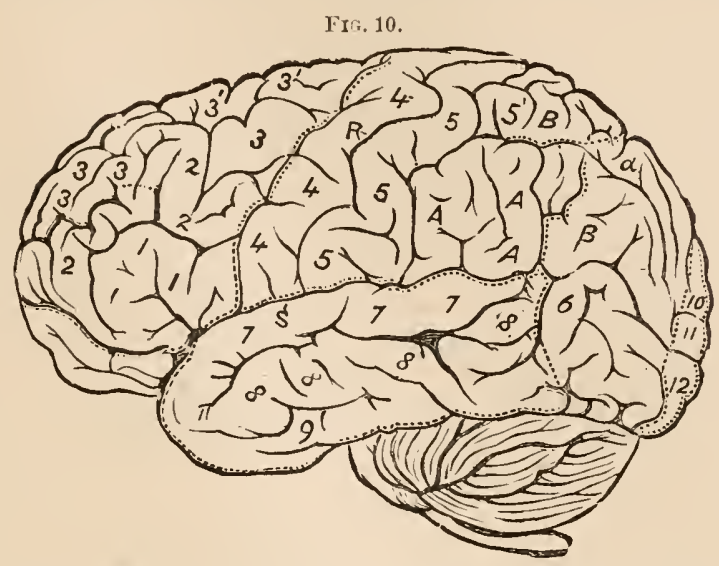

Brain of Man. [The same lettering applies to all the four figures.]

1, 2, 3, Frontal convolutions. 4,5, 6, A and B, Parictal convolutions. 7, 8, 9, Temporosphenoidal convolutions. 10,11, 12, Occipital convolutions. A is the supramarginal lobule; $\mathrm{B}$ is the postero-parietal lobule; and $\beta$ on the bridging or annectent convolutions; $\mathrm{R}$, fissure of Rolando; E, parieto-occipital fissure.

mals in acuteness of sensibility to light, sound, etc., he stands pre-eminent in the power of comparing and judging of his sensations, and of thence drawing conclusions as to their objective sources. Moreover, although none of his senses are very acute in his uatural state, they are all noderately so;

Fig. 11.

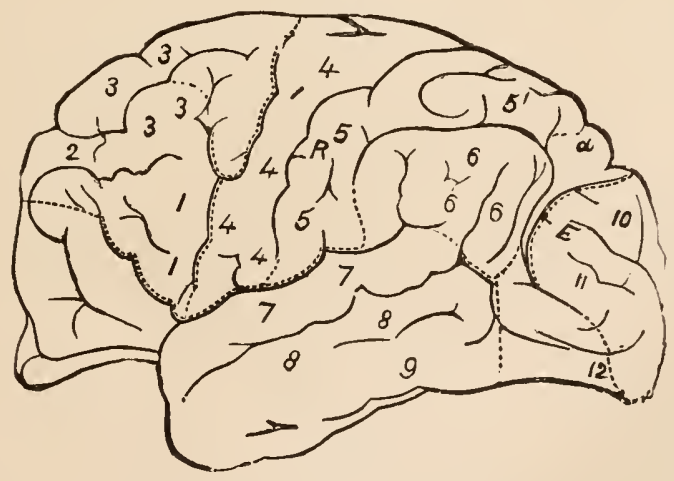

Brain of Orang (Simia). Left side.

and they are cajable of being wonderfully improved by practice, when circumstances strongly call for their exercise. This seems especially the case with the tactile senze, of which Man can make greater use than any other animal, in consequence of the entire freedom of his anterior extremities; although there are many which surpass him in their power of appreciating certain classes of tactile impressions. So, again, Man's nervo-muscular power is inferior to that of most other animals of his size: the full-grown 
Orang, for example, surpasses him both in strength and agility; and the Gorilla, aecording to the statements of the Negroes who have encountered it, is more than a match for any single man, and is almost certain to de-

FIG. 12.

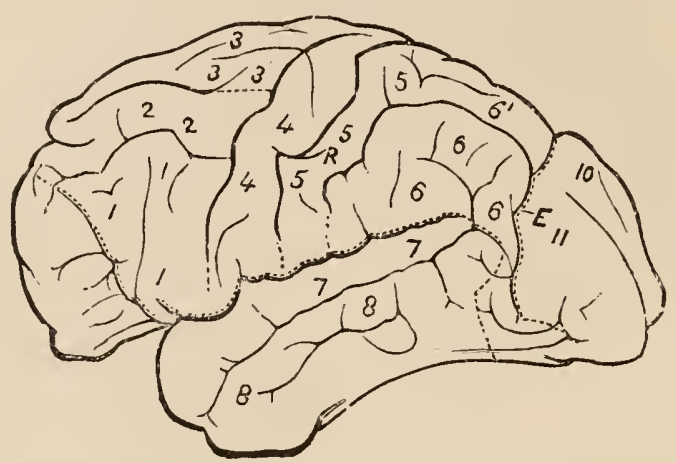

Brain of Chimpanzee (Troglodytes). Left side.

stroy any human opponent onee within his grasp.-The absenee of any natural weapons of offence, and of direct means of defence, are remarkable characteristics of Man, and distinguish him not only from the lower Mammalia, but also from the most anthropoid Apes; in which it is obvious (both from their habits and general organization) that the enormous canines have no relation to a carnivorous regimen, but are instruments of warfare. On those animals to whiel Nature has denierl weapons of attack, she has bestowed special means either of passive defenee, of eoncealment, or of flight;

FIG. 13.

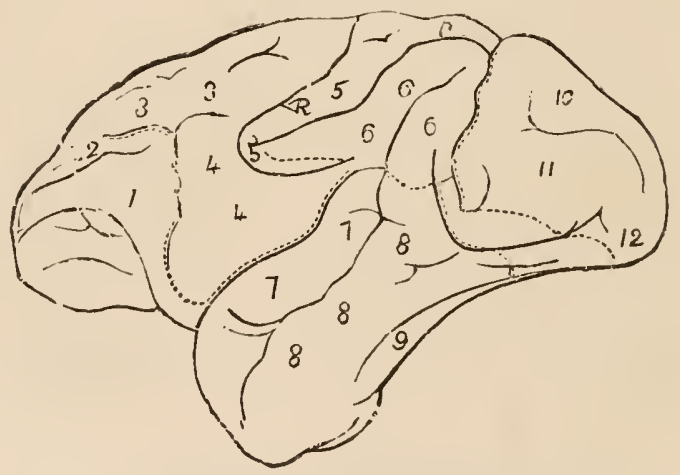

Brain of Mandrill Baboon (Cynocephalus), Left sirle.

in each of which man is relatively defieient. Tet by the superiority of his reason he has been enabled not only to resist the attacks of other animals, but even to bring then into suljection to himself. His intellect ean seareely suggest the mechanism which his hands camnot frame; and he has devised and constructed arms more powerful than those which any ereature wields, and defences so secure as to defy the assaults of all but his fellow-men.

37. Man is further remarkable for his extraordinary power of adaptation 
to varicties in cxternal condition, which renders him to a great extent independent of them. He is capable of sustaining the highest as well as the lowest extremes of temperature and of atmospheric pressure. In the former of these particulars, he is strikingly contrasted with the anthropoid $A$ pes; the Gorilla and Chimpanzee being restricted to the hottest parts of Africa, and the Orang-outang to the tropical portions of the Indian Archipelago; and neither of these animals being capable of living in temperate climates without the assistance of artificial heat, even with the aid of which they have not hitherto long survived their sccond dentition. So, again, although man's diet seems naturally of a mixed character, he can support himself in health and strength either on an exclusively vegetable diet or on an almost exclusively animal regimen.

38. The slow growth of Man, and the length of time during which he remains in a state of dependence, are peculiarities that remarkably distinguish him from all other animals. He is unable to obtain his own food during at least the first three vears of his life; and he does not attain to his full bodily stature and mental capacity until he is more than twenty years of age. 'This retardation of the developmental process seems to have reference to the high grade which it is ultimately to attain; for everywhere, throughout the Organized Creation, do we observe that the most elevated forms are those which go through the longest preparatory stages, and of which the evolution is most dependent upon the assistance afforded by the parental organism during its earlier periods. The peculiar prolongation of this state of dependence in the Human species, has a most important and evident effect upon the social condition of the race; being, in fact, the chief source of fimily ties, and affording the opportunity for those processes of education, direct and indirect, which transmit to the rising gencration the influence of the intellectual culture and moral training of the past.

39. Still, however widely man may be distinguished from other animals by these and other particulars of his structure and econony, he is yct more distinguished by those mental endowments, and by the habitudes of life and action thence resulting, which must be regarder as the essential characteristics of Humanity. It is in adapting himself to the conditions of his existence, in |roviding himself with food, shelter, weapons of attack and defence, etc., that Man's intellectual powers arc first called into active operation; but when thus aroused, their development has no assignable limit. The Will, guided by the intelligence, and acted on by the desires and emotions, takes the place in Man of the instinctive propensities which are usually the inmediate springs of action in the lower animals; for although, among the most elevated of these, a high amount of Intelligence is exhibited, yet its operations seen to be always directly attributable to external suggestions, present or remembered; and the character never rises beyond that of the child. In fact, the correspondence between the psychical endowments of the Chimpanzee, and those of a Child of three years old who has not yet began to speak, is very close.-One of the most inportant aids in the use and development of the human mind, is the capacity for articulate speech; of which, so far as we know, man is the only animal in possession. There is no doubt that many other species have certain powers of communication between individuals; but these are probably very linited, and of a kind more allied to "the language of signs" than to a proper verbal language. In fact, it is obvious that the use of a language composed of a certain number of distinct sounds, combined into words in a multitude of different modes, requires a power of intellectual abstraction and generalization, in which it appears that the lower animals are altogether deficient. So, again, verbal language affords the only means whereby abstract ideas can be communicated; and 
those who have perused the interesting narrative given by Dr. Howe of his successful training of Laura Bridgeman, will remember how marked was the improvement in her mental condition, from the time when she first apprehended the fact that she could give such distinct expression to her thoughts, feelings, and desires, as should secure their being comprebended by others.

40. The capacity for intellectual progress is a most remarkable peculiarity of Man's psychical nature. The instinctive habits of the lower Animals are limited, arc peculiar to each species, and have immediate reference to their bodily wants. Where a particular adaptation of means to ends, of actions to circumstances, is made by an individual, the rest do not seem to profit by that experience; so that, although the instinets of particular animals may be modified by the training of Mian, or by the education of circumstances, so as to show themselves after a few generations under new forms, no elevation of intelligence appears ever to take place spontaneously, no psychical improvement is manifested in the species at large. In Man, on the other hand, we observe not merely the capability of profiting by experience, but the determination to do so; which he is enabled to put into action by the power which his Will (when properly discipliner) comes to possess, of directing and controlling his current of thought, by fixing his attention upon any subject which he desires to keep before his mental vision. This power, so far as we know, is peculiar to Man, and the presence or absence of it constitute the difference between a being possessed of power to determine his own course of thought and action, and a mere thinking automaton.

41. Man's capacity for progress is connected with another element in his nature, which it is difficult to isolate and define, but which interpenetrates and blends with his whole psychical character. "The Soul," it has been remarked, "is that side of our nature which is in relation with the Infinite;" and it is the existence of this relation, in whatever way we may describe it, which seems to constitute one of the most distinctive peculiarities of Man. It is in the desire for an improvement in his condition, occasioned by an aspiration after something nobler and purer, that the main-spring of human progress may be said to lie; anong the lowest races of mankind, the capacity exists, but the desire seems dormant. When once thoroughly awakened, however, it seems to "grow by what it feeds on ;" and the advance once commenced, little external stimulus is needed ; for the desire increases at least as fast as the capacity. In the higher grades of mental development, there is a continual looking upwards, not (as in the lower) towards a more elevated Hunan standard, but at once to something beyoud and above Man and Material Nature. This seens the chief source of the tendency to belicve in some unseen existence; which may take various forms, but which seems never entirely absent from any race or nation, although, like other innate tendencies, it may be deficient in individuals. Attempts have been made by some travellers to prove that particular nations are destitute of it ; but such assertions have beei based only upon a limited acquaintance with their habits of thonght, and with their outward observances; for there are probably none who do not possess the idea of some invisible Power, external to thenselves, whose favor they seck, and whose anger they deprecate, by sacrifice and other ceremonials. It requires a higher mental cultivation than is commonly met with to eonceive of this power as having a spiritual existence; but wherever the idea of Spirituality can be defined, this seems connected with it. The vulgar readiness to believe in ghosts, denons, ete., ant the vagaries of the so-called "Spiritualists" of recent times, are only" irregular, or depraved manifestations of the sane tendency. Closely connected with it is the desire to participate in this spiritual existence, of which 
the germ has been implanted in the mind of Man, and which, developed as it is by the mental cultivation that is almost necessary for the formation of the idea, has been regarded by philosophers in all ages as one of the ehief natural arguments for the immortality of the soul. By this immortal soul Man is connected with that higher order of being, in which Intelligence exists untrammelled by that corporeal mechanism through which it here operates; and to this state-a state of more intimate conmunion of mind with mind, and of creatures with their Creator-he is encouraged to aspire, as the reward of his inprovement of the talents here committer to his charge.

\section{CHA P TER I I .}

\section{ON THE MINUTE ANATOMY OF THE CONNECTIVE TISSUES.} CELLS AND THEIR DERIVATIVES.

42. The whole substance of the body in many of the lower forms of Animal Life, and the elementary parts from which the several tissues are formed in the higher, is composed of a soft gelatinous substance which was named Sarcode by Dujardin, Protoplasm by v. Mohl and Remak, Cytoplasm by Kölliker, Germinal matter by Beale, and in its various kinds represents the "Physical Basis of Life," of Huxley. It is transparent and homogeneous and may be compared to white of egg. It usually presents a number of minute granules distributed through its substance, which are derived in part at least from the materials it has absorbed. It may exist in the form of separate masses, varying in size from points scarcely perceptible with the microscope, to such as are visible to the naked eye, or in the form of layers or sheets lining the interior of cells and vessels. "When at rest it is probable that masses of protoplasm assume a spherical form, but under all ordinary circumstances they are more or less flattened, and exhibit certain movements, and present the phenomena of growth, nutrition, and reproduction. The movements witnessed in Protoplasm are of two kinds, both of which are rendered conspicuous by the molec:ules in its substance. The first is a vibratory, quivering, or dancing movement of the granules, resembling closely those trembling movements of resinous and other inorganic particles suspended in fluids, which, having been first described by Robert Brown, are sometimes called Brunonian motions. Such vibratory movements are chiefly seen in spherical masses of Protoplasm, and cease when these are undergoing changes of form or place. The second kind of movement demonstrates the contractility of protoplasm, which, as is shown by experiments on the pigment cells of the Chameleon and various Amphibia and Fishes in which the sarcode contains colored granules, is under the control of the nervous system. The masses change their shape, becoming elliptical or ovoid, and flattenerl or irregular, owing to the thrusting out of processes, and these may be either withdrawn or may drag the rest of the body after them, so that a veritable change of place is effected. The processes may vary in

1 The best account of Protoplasm is given by Kühne in his essay entitled Das Protophasm, Leipzis, 1864; but the reader may refer with advantuge to the essay on Cells by Stricker in his Ilanual of Histology, Syd. Soc. Translation, vol. i, p. 1, where the chief authorities on this subject are cited; to Huxley's lecture on The Physical Basis of Life, in his Lay Sermons and Addresses; and to Hacckel's work on General Morphology. 
shape from rounded elevations or swellings but slightly projecting from the general surface, to long and extremely delicate threads, and the rapidity with which they are shot out and retracted differs with the surrounding conditions, and especially with variations in the temperature. The activity of the movements is greatest at about $100^{\circ} \mathrm{F}$. At $32^{\circ}$ they usually become extremely sluggish or cease altogether. The ova of trout, however, which may be regarded as a kind of Protoplasm, undergo segmentation perfectly in iced water, whilst they soon cease to move at ordinary temperatures. The contractile property of Protoplasm can be brought into play by mechanical and electrical irritation, and by the application of chemical stimuli. The locomotive powers of the masses of Protoplasm enable them to search for, and procure, the materials required for their nutrition. When such niaterials are met with, the Protoplasm extends itself over and embraces them, the opposite surfaces coalescing, so that the foreign body is entirely included ; its nutritive parts are then extracted, and the remainder, if any, is cast away by the retreat of the Protoplasm from it. The reproduction-or rather, multiplication of such masses-is effected by the detachment of a larger or smaller portion of the parent mass, the two parts separating to obtain the substances requisite for their own growth and nutrition. Chemical examination of Protoplasm shows that it contains a considerable proportion of myosin, and in some instances, protagon, glycogen, and cholesterin have been found to be present. Protoplasm, presenting slight but unimportant differences from the general description above given, is found to form the contents of all Vegetable cells, at least in their early condition, to constitute the essential part of a great group of organisms which have been associated together by Haeckel under the name of Protista, and include such forms as the Flagellata, Diatomaces, Myxomycetie, and Foraminifera, the last of which recent researches have shown to form a thin, but very widely spread, layer on the bed of the ocean at all depths. And, finally, it forms the living material in the interior of all animal cells, and to its presence the active processes they exhibit are essentially due. In the very simplest forms of Animal Life, as in the Monera, no differentiation of structure is visible in the Protoplasm of which they are composed. But in most of the Amobre and Foraminifera; in the ovum at an early stage of its development; in the free floating corpuscles known as the white corpuscles of the blood; in granulation cells and pus-corpuscles; in the corpuscles of the ductless glands; in osteoblasts and elsewhere, the small nuasses of Protoplasm contain a nucleus; and such bodies may be conveniently designated by the term employed by Haeckel of Cytodes. In most cases the outer surface of the Protoplasm has undergone a certain, though often very slight, degree of consolidation. And when this consolidation has proceeded so far as to form a thin membrane around the protoplasnic mass and nucleus, a cell is formed, the various forms and characters of which we shall now proceed to consider.

43. Every perfectly formed and active cell is composed of three parts, a cell-wull, a mucleus, and protoplasmic, or other cell-contents. Of such bodies, more or less modified, most of the tissues of the body are composed; and each in maintaining its own nutrition ministers to the functional activity of the special tissue to which it belongs, and is subservient to the well-being of the organisin at large. The ccll-rull in the majority of instances is a thin and transparent, but resistant membrane, through which osmntic processes (an readily occur. It presents, however, in different instances, the most various degrees of density and consolidation, sonetimes, as in the hepatic cells, being only slightly firmer than the rest of the cell; whilst in cartilage cells it acquires great firmness and thickncss, beconing ultimately, by the deposition of calcareous salts, converted into bone. Occasionally it presents 
pores, as in the cells of the chorda dorsalis (IV. Mäller), or is theficient at some part of the surface, as in the cells covering the intestinal villi. It is sometimes prolonged in the form of cilia, or of processes rendering it more or less stellate in form. The mucleus is a minute oval borly, situated either near the centre of the cell or in contact with the cell-wall, and never absent in the higher animals in the first stages of the development of the cell. Originally soft, it becomes more consistent with age, and appears to be of an albuminous nature, resisting the action of acids and alkalies better than the protoplasmic contents of cells generally. Like these, however, it stains with carmine, and hence is regairder by: Beale as germinal matter-a view which is supported by the fact that it appears to be specially related to the formative activity of the cell, the division of the nucleus in most instances preceding that of the cell itself: The nucleus often contains one or more extremely minute particles termed nucleoli; and Rollett, who consirlers the nuclei to be vesicular, has described certain lacune or vacuole in their interior. The cell-contents, apart from the nucleus, whilst consisting essentially of protoplasm, mingled in young cells with cholesterin and lecithin, and in many cases also with glycogen, vary as they advance to maturity with the special tissue or organ of which they form a part; being sometimes transparent and colorless, sometimes charged with pigment, sometimes containing the special secretion of a gland; whilst at others the protoplasm becomes almost wholly converted into fat, or acquires the highly differentiated properties of nerve and muscle. The mode of origin or genesis of cells has been the subject of much controversy, and takes place in several ways. One of the commonest methods is that in which the contents of a cell divide, whilst the cell-wall remains unaltered till it is burst asunder by the growth of the new cells in its interior. In this endogenous mode of cell genesis, which occurs in fat-cells (Fig. 28), and in cartilage, the nucleus usually first divides, and the two halves, or if there are more divisions, the several segments, retreat from each other to the opposite ends of the cell. The protoplasmic contents then undergo a process of differentiation, accumulating to form separate masses around the segments of the nucleus, and each acquiring a cell-wall; the whole being ultimately set free by the rupture of the membrane of the parent cell. In other instances the parent cell divides as a whole (fission), the cell-wall becoming inflected. The bridge between the two parts then becomes gradually attenuated, and the parts at length separate. The white corpuscles of the bloorl have been seen to divide in this manner. A third mode is that of gemmation, or budding, in which a swelling appears on one or more parts of the circumference of a cell, and gradually increasing is nipped off by the constriction of the base. This is well seen in the yeast fungus. Lastly, cells may develop independently in a blastema that has been formed by pre-existing cells, free-cell formation. Broca, Robin, Bennett, and Bastian are strong supporters of this view, ${ }^{1}$ and it seems to be certain that in the Myxomycetæe, spore-cells make their appearance in the blastema-like mass of which the whole organism is composed without the previous existence of cells. In 1867 Legros and Onimus, in their experiments on the generation of leucocytes, ${ }^{3}$ pointed out that if little sacs of goldbeaters' skin, filled with the serum of blisters, filtered to remove all morphological elements, be placed beneath the skin of rabbits, a large number of leucocytes appear in the fluid in the course of twenty-four hours, which, they were of opinion, must have been formed in the fluid.

I See Bennett's Text Book of Physiology. Bastian, Beginnings of Life, 1872, vol. i, p. 169. Robin, Anat. et Physiologie Cullulaires, 1873. Broca, Traté des Tumeurs.

2 De Bary, Die Mrectozoen, 1864.

3 Journal de la Anatumie, 1867. 
Lortet of Lyons, however, as well as MII. Cornil and Ranvier, objected that the lencocytes observed might have penetrated by virtue of their amoboid movements from without; to which Onimus replied by making experiments with very resistant membranes, as with parcliment paper, when he found that leucocytes still inade their appearance. It is to be observer that in one case where cells appear to arise de novo in a blastema, namely, in the fluid poured out upon the surfiace of a wound,' late experiments ${ }^{2}$ have rendered it probable that snch cells really take origin from the budding of the cells at the borders of the wound. Vrarious forms of cells will be described when the subjects of the skin, the alimentary, respiratory, and genito-urinary mucous tracts, the nerves, muscles, and glandular organs are under consideration ; and it will be advantageous to consider here the principal forms which occur in a free state, and are collectively known as Epithelial and Epidermoid structures, and the following sections will be devoted to the description of those textures which result from the metamorphosis of cells, and are now generally included under the title of Connective Tissues, embracing: 1 . Areolar, fibrons, tendinous, and ligamentous tissues; 2. Elastic tissue; 3. Fat; and 4. Cartilage and Bone. These tissues all present the features in common of originating in cells, of presenting a low type of orgauization, of possessing an indifferent supply of bloodvessels and nerves, of being easily repaired when injured, whilst they frequently present forms that are intermediate to one another, and finally, as their name implies, they all subserve the purpose of eomecting or supporting the other textures of which the borly is composed.

Lipitheliun. - The skin, mucous and serous membranes, the interior of the vessels, and of the ducts of many glands, arc covered with one or more layers of cells, which give to these parts a smooth and uniform surface, and enlable them to supply, by structures capable of easy renewal, the losses they experience from the friction to which they are constantly subject. The innermost recesses of glandular organs are also lined by cells, the function of which appears to be the separation from the blood, or the formation from the materials supplied by that fluid, of the secretion proper to each. Four principal kinds of cells have been distinguished by microscopists, forming,

FIG, 14 .

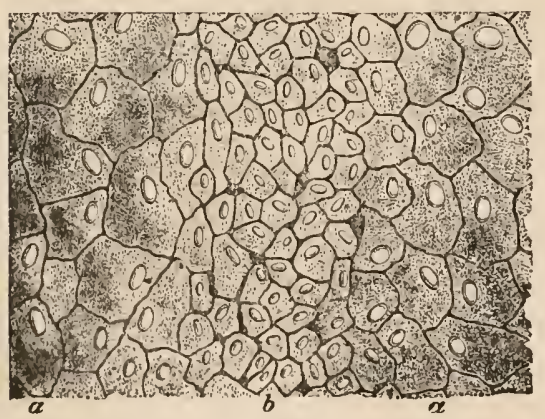

Tessellated Ejithelium firun the abdominal surface of eentrum tendinum of rablit, strongly culomd with nitrate of silver; $a$, dark silver lines of the interstitial substance of the condothelial cells; $b$, cell-substance; c, nucleus. The snaller cells lie over a capillary lympluatic. by their juxtaposition, tessellated or pavement, cylindrical or columnar, spheroidal or glandular, and ciliated epithelium, and the contours of the cells may be bronght into view by immersing the fresh nembrane for a few minutes in a one-half" or one-quarter per cent. solution of nitrate of silver, and then washing in distilled water. The first-named form is found as a single layer of flattened cells in the interior of the vessels and synovial and serous membranes (Fig. 14). The cells are therc seen to be flat, and are oftell either sinnous in ontline, or are rendered polygonal by mutnal pressure. illey possess a cell-wall, and a

1 See Arnold, Virchow'- A rehiv, Band xlvi.

2 See Everth and Hoffmann, Virchow's Archiv, Band li. 
distinct nucleus. As a multiple layer this form is well seen in the skin, where it constitutes the thick epidermis. The action of a blister splits the epidermis iuto two portions; a deeper one-the rete mucosum-in which the cells, being in an early stage of their development, are more or less soft and rounded, and remain attached to the dermis; and a superficial portion -stratum corneum - which forms the blister, and is composed of flattened cells firmly cohering together (Fig. 15). The cells of the rete mucosum are the chief seat of the pigmentary deposit characteristic of the skin of the negro and of the darker portions of the body of fair-skimed races. In some parts the cells are serrated at their margin (Fig. 16). The second

FIG. 15.

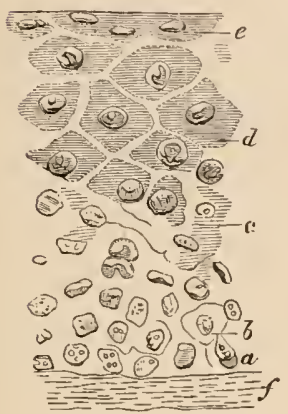

Fig. 15.-Oblique section of Epidermis, showing the progressive development of its component cells: $\alpha$, nuclei, resting upon the surface of the cutis rera, $f$; these nuclei are seen to be gradually developed into cells, at $b, c$, and $d$; and the cells are flattened into lamelle, forming the exterior portion of the epidermis at $e$.
FIG. 16.

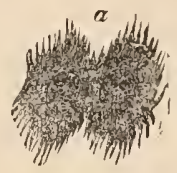

Epitheliai Cell (ribbed cell of the Rete Malpighii).

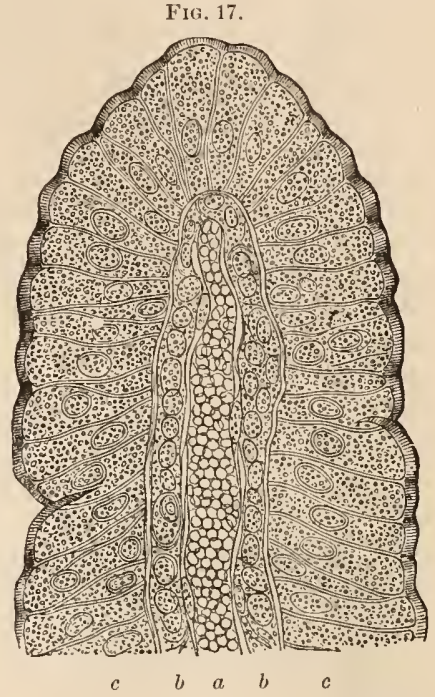

FIG. 17.-Section of a Villus from the intestinc of a rabbit: above $(a)$ is the central canal, bounded on either side by the matrix $(b)$, which again is covered by long columnar cells $(c)$, containing a nucleus and granules. The outer surface of these cells is seen to be striated.

form of cell--the columnar-occurs throughout nearly the whole of the alimentary canal. The cells are arranged vertically to the surface, as seen in Fig. 17, and are attached to the subjacent membrane by their small extremity. They possess a distinct nuclens, cell-wall, and cell-contents, and their mouth in those lining the small intestines is closed by a striated membrane, the strice being by some believed to represent fine pores, permitting the passage of oily and albuminous fluids. Spheroidal epitheliun is best seen in the acini of glands. The shape of the cells is expressed by their name; but the presence of a cell-wall is, in many instances, doubtful. They appear to be masses of germinal matter, and have been observed to execute spontaneous movements. The fourth and last kind of cell-the ciliatedvaries much in form, though perhaps the cylindrical or subcylindrical is the most common. It is characterized by the presence of a number of minute cilia, or hairlike processes of the conthined protoplasm of the cell, which perforate the basal border of the cell-wall, varying from one or two to fifty for each cell. These, during life, are in continual motion, performing rapid vibratory or lashing movements, the effect of which is to drive any small body in contact with them towards the outlet of the body. Such cells are found in the respiratory passages, with the exception of the finest 
ramifications of the bronchial tubes; in the upper part of the vagina, the uterus, and the Fallopian tubes; and lastly, on the choroid plexus of the lateral ventricles. In some vertebrata they also exist near the commencement of the urinary tubuli. The cause of the movement is unknown; it is rentarkable that it should persist long after the general death of the body. A very peculiar form of cell, termed Cup, or Goblet-Cell (Fig.

FIg, 18.

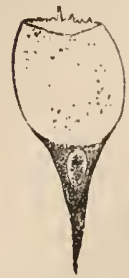

Cup, or Goblet-Cell. 18), appears scattered over parts that are usually covered by columnar and ciliated cells. According to Klein ${ }^{1}$ they are only the empty shells of the ordinary ciliated cells. In certain parts of the body-as in the choroid coat of the eye, the lungs and bronchial glands, and in the deep or Malpighian layer of the epidermis of the negro-cells are found loaded with black pigment or melanin. The shape of these cells varies from the most regular hexagonal to extremely irregular branched and caudate forms. They usually possess a distinct nucleus, and the melanin is scattered through the otherwise clear protoplasmic cell-contents in the form of minute grauules. Some pigment cells, as those in the skin of the Frog, ${ }^{2}$ are capable of undergoing remarkable changes in their form and in the distribution of the pigment-granules in their interior. They may contract into spheroids, or may expand into a stellate form, with numerous irregular, branched, anastomosing, and gradually attenuating processes; and the pigment-granules may either accumulate around the central nuclcus, or be distributed through the protoplasm. According to Lister, their

FIG, 19,

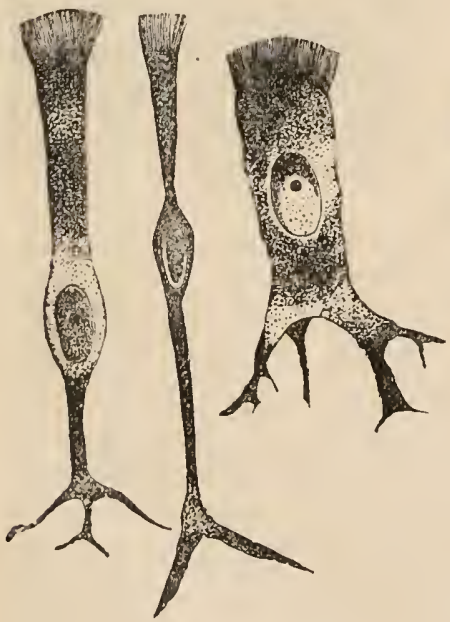

Various forms of Ciliated Epithelial Cells from the trachea of a cat.
FIG, 20.

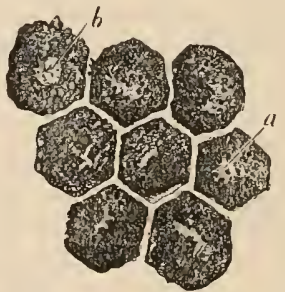

Cells from Pigmentum Nigrum! : $a$, pigmentary grauules concealing the nueleus; $b$, the melens distinct.
FIG, 21.

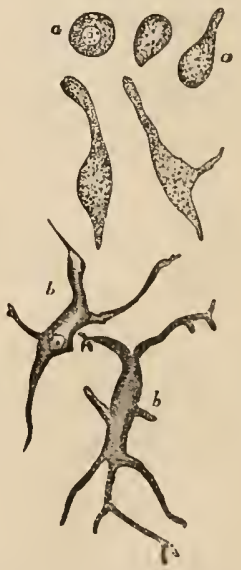

Pigment-Cells from tail of Tad pole: $a, a$, simple forms of recent origin; $b, b$, more complex forms subsequently assumed.

concentration follows cxposure to the action of light, section of the nerve, and the rleath of the aninial. On the other hand, the molecules diffuse thenselves through the cell-processes, when the animal is kept in dirkness, and when the skin is irritated. Hering and Hoyer think the movements of

1 Hundbook for the Physiological Liboratory, 1873, 1. 23.

2 Swe the paper of Lister, in Phil. Trans., 1858; of M M. Hering and Hoyer, in the Centralblatt, 1869, p. 49. 
the granules are essentially dependent upon disturbances or variations of the circulation. Saviotti ${ }^{1}$ las obscrved the migration of the pigment cells of the wall of the frog's foot into the bloodvessels after irritation, and the tiunc occupicd in the transit of the cells through the walls of the bloodvessels, was about twelve hours. M. Tschaussow ${ }^{2}$ observed, on the contrary, the passagc of a jigment cell out of a vein and its division into two in the tissues. ${ }^{3}$ When the cell is crushed, the black particles escape and exhibit peculiar vibratory or quivering movements. 'The coloring matter or melanin is insoluble in water and most reagents, but it dissolves in weak alkalies. It is not bleached by chlorine. It contains iron and nitrogen.

44. Areolar, Fibrous, and Erastic Tissurs. - Ordinary connectivetissue in its fully developed for'm, may be shortly defined to consist of plasmatic corpuscles scattered through a fibrillar matrix. The corpuscles, though presenting a general resemblance to a cell, possess no cell-wall, are very variable in form, and have occasionally been observed to undergo spontaneous changes of form (Kühne).-They may be regarder as small masses of "germinal matter," preserving their original activity, whilst the matrix consists of "formed material," proceeding from the modified cell-walls and intercellular substance. In many cases a third morphological element, the elastic, enters into the composition of this tissue, conferring properties upon it which are of great importance in the discharge of the functions that in some situations it has to perform. Amongst the principal examples of ordinary connective tissue met with in the body we may include with Bouchard the various structures termed tendons, ligaments, fascix, aponeuroses, periosteum, and perichondrium; the investing membranes of many organs, as the dura mater, pericardium, tunica albuginea of the testis and of the ovary, and the sclerotic and corneal coats of the eye. It also forms the basis of the true skin, of mucous, serous, and synovial membranes, the chorion, vascular sheaths, and tunics, and amorphous membranes, as the lyaloid humor of the eye, and the envelopes of glandular follicles. These all present a general similarity of structure and chemical composition, though differing in minor details. The most common form, or that met with in fibrous

FIG. 22.

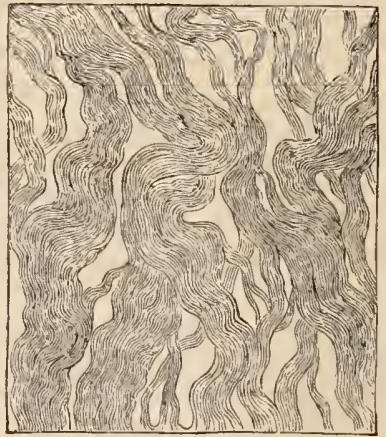

White or Non-elastic Fibrous Tissue. membranes, appears when examined with the microscope to be composed of bundles of wavy filaments (Fig. 22), which either run parallel to one another with but few cross fibres as in tendons, or decussate with one another in every direction as in the sclerotic, leaving irregular interspaces, lacunse or areolie, the imperfectly bounded walls of which permit the passage of fluids in every direction. The individual fibres do not exceed $\frac{10}{10}$ th $_{0}$ of an inch in diameter. The addition of a little acetic acid, by its different action on the three elements that commonly enter into the composition of the tissue, enables them to be easily distinguished. The white wavy filaments swell

\footnotetext{
1 Centralblatt, 1870 , pp. 145 and 161.

2 Ib., p. 309.

3 The movements of the pigment in the skin of the Chamrleon have been well described by Brücke in his Vorlesungen über die Physiologie, 1874, P. 440.

4 For good papers on Connective Tissue see S. Martyn, in Dr. Beale's Archives of Medicine, vol. ii, p. 99 ; and Dr. Beale in idem, vol. iii.
} 
up and become transparent, losing in great measure their fibrillar character. The corpuscles appear as dark granular bodies, and the elastic tissue when present appears in the form of fine dark fibres with well-defined borders, which pursue a tortuous course, and often branch and anastomose. Such tissue presents few or no bloodvessels and nerves, those seen in any section being in all probability on their way to other parts. In many localities, as beneath the skin, the areolie of the connective tissue are filled with lobules of fat. Tendons and ligaments may be regarded as modifications of connective tissue, and a considerable amount of discussion has lately arisen in regard to their structure. ${ }^{1}$ Boll and Mitchell Bruce, who are supported by all the more recent inquirers, consider the cell-elements of tendinous tissue to be quadrilateral plates, which bend round the fasciculi of fibrils, two forming an investment for each fasciculus at any given height. The cellelements as a whole (Ciaccio), or a certain portion of each only (elastic stria of Boll), stain deeply with Carmine. Ciaccio maintains in addition, that besides the cells each fasciculus of fibres is inclosed in a delicate sheath containing fine elastic fibres. The opposed surfaces are moistened with a thin fluid which closely rescmbles the serum of blood in its composition. In the case of the serous and synovial membranes, which as Klein has shown are dilatations of the lymphatic system, the connective tissue is so arranged as to constitute bags or sacs, the inner surface of which is, for the most part, lined by a single layer of flattened epithelial cells, forming an exquisitely smooth and polished surface, that materially facilitates the constant gliding movements to which these parts are subjected. Besides these, more rounded cells, termed germinating endothelial cells by Klein, are found in certain regions, as will be more fully explained in the section on the lymphatic system. In the vitreous humor of the eye, and in the substance which constitutes the greater part of the umbilical cord, there exists a peculiar form of connective tissue, termed mucous or gelatinous tissue. The structure of the vitreous is difficult to determine, but it appears to be composed of a jelly-like fluid, contained in the meshes of a network of exquisitcly fine filaments; it is doubtful whether any cells are present. In the cord, the matrix is soft, transparent, and homogeneons as in the vitreous, but presents round, fusiform, or stellate cells, with branched and communicating prolongations scattered through it. This kind of connective tissue is found only in enbryonic structures, or in organs retaining their embryonal characters. In mucous membranes the layer of connective tissue is much thicker and more vascular than in serous, frequently contains minute glands, and instead of a single layer, is covered by many layers of epithelial cells, of a morc or less rounded or columnar form. In all instances mucous membranes con-

1 The following being some of the more important papers that have been published upon them:

Ranvier, Brown-Séquard's Archives de Physiologie. t. ii, p. 471.

Rollett, Stricker's Manual of Histology, Syd. Soc. Trans., 1870, p. 47.

Giiterbock, Centralblatt, $1870, \mathrm{p} 33$.

Boll, Schultze's Archiv f. Microseop. Anat, Band vii, pp. 28 and 275, 1871.

Krause, Deutsche Klinik, 1871

Ianzilotti Buonisanti, Pamphlet. Milan, 1871.

Mitchell Bruce, Quart. Journ. of Mic Sei., vol, xii, p. 129.1872.

Ciaccio, Memorie del Academia di Bologna, ser. iii, t. ii. 1872.

Adickes, Centralblatt, 1872, p. 597.

Gerlach, Sitzungsher. d. Phys. Merl. Societät zu Erlangen, July, 1872.

V. Törok, Centralblatt, 1872, pp. 66 and 675.

Kiein and Sanderson, Centralblitt, 1872, p. 33, and Handbook, 1873.

Ditlevsen, Centralblatt, 1873, p. $(370$ ( $\Lambda$ bstract).

Dr. G. Thin, Edin. Med. Journ., Sept. 1874. 
stitute the walls of tubes or eavitics having free outward communication. The interspaces between the fibres of connective tissue are believed by many to constitute the commencement of the lymphatic system, receiving the superfluous material poured out by the bloodvessels for the supply of the

FIG. 23.

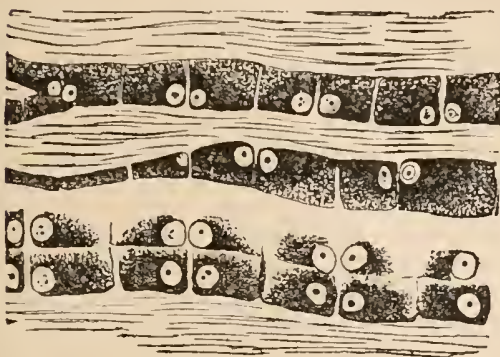

Caudal Tendon of young rat, showing the arrangenent, form, and structure of the tendon cells.
FIG. 24.

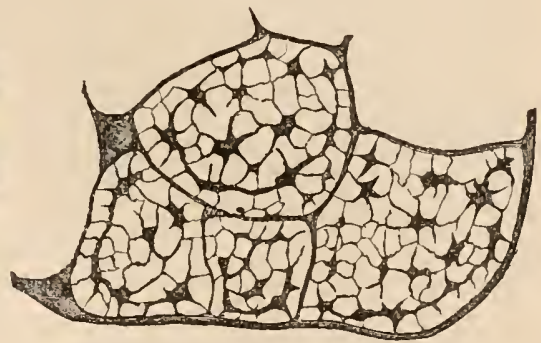

Transverse section of Tendon, showing branched cells, inclosing spaces which, here left blank, are naturally filled with tendinous fasciculi.

sevcral textures, and gradually conveying it, at first through irregular spaces partially filled with protoplasmic masses or cells, but subsequently through proper tubes, to the thoracic duct, from whence it is again discharged into the blood. On boiling with water this tissue yields gelatin.

The mode of development of connective tissue has been much elucidated by the recent researches of Rollett, ${ }^{1} \mathrm{Boll},{ }^{2}$ and others. It seems to be ascertained that, as Schwamn originally maintained, the primary cells of the tissue become greatly elongated and slightly branched, and their protoplasmic substance assumes a finely fibrillated aspect; at the same time, however, in various forms of connective tissue, as in the peritoneum for instance, the intermediate homogeneous matrix, as was strongly maintained by Virchow, Donders, and others, also undergoes fibrillation, the bundles thus formed constituting the fasciculi of fibrils of the fully-developed tissue. The elastic fibres are commonly believed to be the result of a direct deposit, or differentiation of the matrix, though Virchow thought they were the remains of the cells. Besides the cells which become fusiform and fibrillated, connective tissuc always contains wandering cells.

45. Elastic Tissue.-The elastic tissue that we have just seen to be mingled in small quantity with white fibrous tissue in situations where it is requisite that the latter should accommodate itself to changes of form, bulk, or position in the organs it invests, is sometimes met with in an almost pure state. In the vocal cords and the ligamenta subflava good examples are seen of this tissue, with scarcely any intermixture of white fibrous tissue. In the ligamentum nuchæ and the suspensory ligament of the penis, in the stylo-hyoid, thyro-hyoid, and crico-thyroid ligaments, and in the coats of the bluodvessels and lymphatics, both kinds of tissue are present in nearly equal proportion, though perhaps the elastic predominates; whilst in the subcutaneous and submucous areolar tissue, the elastic fibres, though numer-

1 Stricker's Manual of Histology, Syd. Soc. Transl., 1870, p 84, where the student will find a résumé of all modern views up to that date.

2 Archiv f. Microscop. Anatomie, Band vii, p. 28, 1871, which article also contuins numerous references. 
ous, form only a small part of the general mass. When examined under the microscope, it is found to consist either of separate fibres, of bundles of fibres,

FIG. 25.

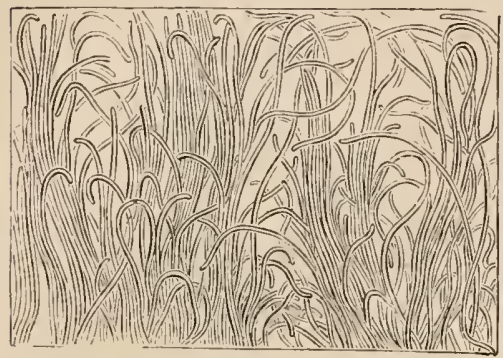

Yellow or Elastic Fibrous Tissue, from ligamentum nuche. or of broad membranous bauds of a highly refractile and elastic substance. The fibres vary indefinitely in size, but have sharply-defined dark borders, and appear to be abruptly broken off at their extremities. They may anastomose and branch, and where the fibres are broad and membraniform, and the anastomoses close, a thin tissue results, as in the lining or fellestrated membrane of the arteries, which presents a continuous sheet with only here and there minute holes or spaces. The arrangement of its bloorlvessels and nerves, which are very few in number, is not accurately known. The fibres are reddened with Millon's reagent, and give the xanthoproteinic reaction. When long boiled, they yield a little modified gelatin. Elastic tissue fulfils important functions in the vascular system - to which attention will hereafter be called-aud it frequently occurs in situations where its physical properties enable muscular tissue to be dispensed with, as in the ligamentum nuchæe of the larger quadrupeds. Occasionally, though more rarely, it appears as the antagonist of muscular effort, as in the chordæ vocales, and typically in the hinge of the conchifera.

46. Adipose Trssue.-This form of tissue is extensively distributed through the animal kingdom, and consists of large cells filled with oil, which in good specimens are individually separated from one another, as well as collected into lobnles by delicate trabeculae of connective tissue (Fig. 26). It is more freely supplied with blood than most of the other forms of cellular or connective tissue. The cells, thongh varying much in size, average the $\frac{{ }_{5}^{3}}{5} \overline{0}$ th of an incl in diameter, and are rendered polygonal by mutual pressure; they are composed of a cell-wall of considerable thickness, lined by a layer of protoplasm, in which an eccentric nucleus with

FIG. 26.

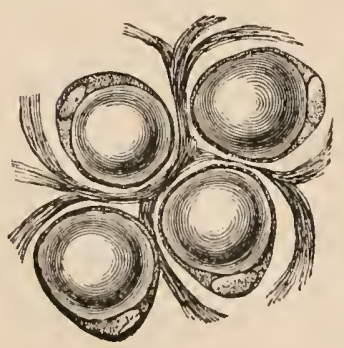

Four fat-cells, with intervening connective tissues. several nucleoli is imbedded, and which surrounds a clear, perfectly transparent, and highly refractile drop of oil. The connective tissue uniting the lobules is sometimes small in quantity, and exceedingly delicate, as in the fat that surrounds the kidney, and in the marrow of bones; whilst in other instances, as in the subcutaneous layer of fat, it is possessed of much firmmess, and is very dense. No nerves have been discovered to terminate in fat, nor do any lymphaties appear to take origin in $i$. Adlipose tissue is absent in the brain, lnugs, liver, and in the delicate skin of the eyelids, of the prepnce, scrotum, and nymphre. In all these regions, however, oily globules may be seen on making fine sections. The absolute amount of fat in a well-nourished nnan amounts to abont $\frac{1}{20}$ th of the weight of the hody. Infancy, mid-age, warmth, abundant food, especially of a saccliarine or oleaginous nature, freedom fron mental anxiety, castration, indolent liabits, and inherited constitutional peculiarities, are all circumstances pre- 
disposing to the accumulation of fat. It is probable that every form of cell nuay become infiltrated with fit, as a stage or form of degencration. Fat fulfils the following important objects in the animal economy: It liffuses pressure, and is, therefore, largely developed on the palms of the hands, soles of the feet, buttocks, and female breast. By its disposition beneath the skin generally, it forms a warm investment for the body that matcrially diminishes the loss of heat by radiation and conduetion; at the same time it gives a smooth, flowing, and agreeablc contour to the surface which otherwise, especially near the joints, would present hard and angular outlines. It forms an elastie pad, or cushion, in the orbit, on which the eye ean rotate; and in the heart, by filling up the interstiees of the vessels and the irregularities of its surfaee, it fulfils a similar function, enabling this organ to perform its ceaseles movements with the least possible amount of frietion. It confers lightness, and probably a ccrtain degree of elastieity, on the bones-as well, indeed, as on all other tissues into the eomposition of whieh it enters. It constitutes a storehouse or reserve fund of hydroearbonaceous material, which, when required by the economy, can readily be absorberl into the blood; the proeess of absorption being faeilitated, as Matteucei has shown, by the alkalinity of the fluid that moistens the outer surface of the cells. Lastly, if we may judge from its constant presence when these are taking place, it plays an important part in the processes of growth and development.

Aecording to M. F. Czajewicz, ${ }^{1}$ the eells of adipose tissue originate in the corpuscles of ordinary eonneetive tissue. These, in any part that is about to beeome the seat of deposit of fat, increase in size, assume a spherical form, and become filled with a mist of small fat-drops ( $a$, Fig. 27). At a stage slightly more advaneed $(b)$, the mist becomes condensed into sniall drops,

FIG. 27.

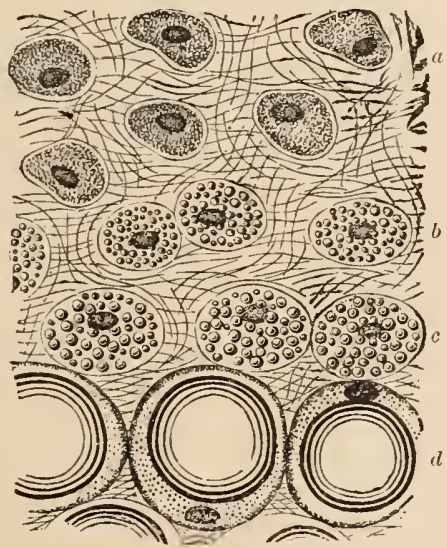

FIG. 28 .

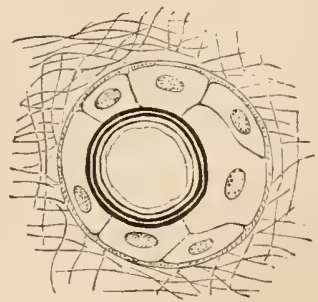

Successive stages in the Development of Fat.

Example of Endogenous Cell-formation.

whieh gradually acquire a larger size and greater distinctness (c), and ultimately blend into one large oil-globule $(d)$. Toldt, however, maintains that fat-eells in the earliest stages of their development have no eell-wall, and constitute a tissue quite sui generis and distinct from connective tissue. In 
the later stages, the nuclei of the corpuscles, though still discoverable on careful examination, are to a great extent obscured by the oily contents of the cells; and Toldt ${ }^{1}$ and Flemming ${ }^{2}$ from experiments with picro-carmine as a coloring agcnt, believe they can demonstrate the persistence of a thin layer of protoplasm immediately beneath the cell-wall, in perfectly mature fat-cells, and this they regard as possessing the power of secreting the oil contained in the cell. When an animal is starved, the oily material is continuously withdrawn from the cells, and its place is supplied by a serous fluid, the cells still preserving their round form. If now abundant food be given, a series of changes similar to those above described may be observed, the cells becoming filled at first with minute oil-globules, which afterwards coalcsce to form one of large size. If inflammation is established in adipose tissue by the injection of solution of iodine,or other irritant, the endogenous formation of cells can be very distinctly seen (Fig. 28).

47. Cartilage.-Cartilage presents two forms: the temporary and the permanent; the former exists in considerable quantity in the fotus, occupying the position and constituting the foundation of the principal bones of the skeleton, certain portions of the vault of the cranium alone being excepted. In all instances, the microscopical structure is essentially similar, the tissuc presenting cells separated from one another by a greater or less amoint of intercellular substance or matrix. In some situations, as in the chorda dorsalis, the cells appear to be in direct apposition with one another, their cell-walls, slightly thickened, alone representing the matrix; in other cases, as in ordinary articular cartilage, the cells appear to be scattered through the intercellular substance, which forms a large proportion of the whole mass. W. Müller ${ }^{3}$ describes the central cells of the chorda dorsalis as presenting fine punctations, which are probably the expression of porous canals. Heitzmann ${ }^{4}$ describes processes given off from the cells which travcrse the matrix in all directions. The matrix in the permanent cartilages of the joints and ribs, appears as a homogeneous and structureless material; but in the cartilages connected with the organs of sense-as in the cartilages of the nosc, eyelids, and ear, and in the epiglottis-it is of a yellowish color, and is pervaded by elastic fibres, and from this form of tissue the transition is easy to the fibro-cartilages, exemplified in the symphysis pubis, the intervertebral substance, the interarticular cartilages of the knee and other joints, the glenoid and cotyloid ligaments, and the cartilages lining the grooves for tendons, in all of which the matrix is almost entirely converted into firm and close-set interlacing connective-tissue fibres. Dr. Beale has show that, if a thin section of cartilage be carefully examined whilst in course of development, it is impossible to discover any distinct line of demarcation between the substance of the matrix and the contents of the cavities or cells which are distributed through it. The gradation between the two may, lowever, be made obvious by soaking the section in carminc, which scarcely tinges the peripheral portion, whilst it deeply dyes the central, staining the intervening zones less and less strongly in proportion to their distance from it (Fig. 30). Thus it appears that the truc view of the nature of cartilage is to regard it as made up of an aggregation of spheroidal segments of protoplasmic substance or "grerminal matter," cach of which has the power of being converted, at its surface, into that kind of formed material which is termed "chomlrin," so that these particles become separated from each

1 Wiener Sitzungs-berichte, Band lxii, p. 465.

2 Schultze's Archiv, Band vii, p. 328.

3 Jenaische Zeitsch., Band vi, p. 327.

4 Wien. Med. Zeitsch, 1873, p. 38. 
other by an intervening deposit of that substance, which holds to them very much the same relation that the gelatinous substance, copiously interposed between the so-called "cells" of seaweers, holds to those elcmentary parts. In both cases, it is to be borne in mind that the intervening substance

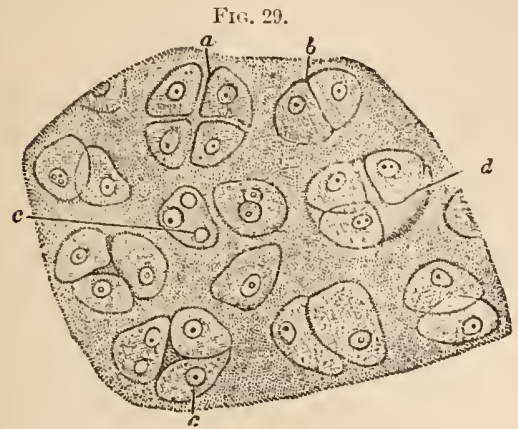

Section of Branchial Cartilige of Tadpole: $a$, group of four cells, suparating from each other; $b$, pair of cells in apposition; $c, c$, nuclei of cartilage-cells; $d$, cavity containing three cells.
FIg. 30.

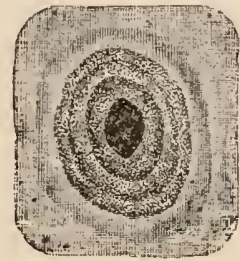

Elementary part from Cartilage of Frog, treated with carmine, showing successive stages of conversion of germinal matter into matrix.

represents the cell-wall of such cells as have a distinct limitary membrane, but that the essential constituent of the cell is the scgment of protoplasmic substance, which is thus isolated. Ordinary articular cartilage is thickest where the pressure is greatest, and the cells are found to be somewhat flattened near the free surface, irregularly distributed in sets of from eight or more near the centre, and perpendicularly placed in that part which lies nearest the bone.

The mutrition of cartilage, when it attains considerable thickness, is provided for by the passage of a few large vessels through channels in its substance, that are lined throughout by prolongation of the perichondriun. Beneath the articular cartilage the vessels of the bone form loops, the bight of which is dilated into an enlargenent, or sinus, which must cause a retardation in the current of blood. Mr. Barwell' has described a peculiar arrangement by which he believes the nutrition of articular cartilage is maintained. This consists of an osseous lamella intervening between the cartilage and the shaft of the bone, penetrated, like the dentine of the teeth, with numerous fine canaliculi, rumning, in a wavy course, parallel to one another and perpendicular to the surface. Through these the nutritive materials are conveyed to the cartilage from the above-naned sinuses. The costal, and most of the fibro-cartilages, are invested by a firm layer of connective tissue, termed the perichondrium. Though the two tissues may be separated by prolonged maceration, they are structurally continuous with one another. No nerves or lymphatics have been hitherto tracerl into the substance of cartilage, and it appcars to be nearly insensible; hence the exquisite pain accompanying ulceration of joints may probably be referred to irritation of the nerves supplying the subjacent bone.-The chemical composition of cartilage has not been accurately determined. On drying it loses about 70 per cent. of water; on being subjected to prolonged coction in water it yields chondrin, a substance that gelatinizes on cooling, and generally resembles gelatin, except that it is precipitated by acetic acirl. The organic basis from which the chondrin is derived constitutes about 30 per

1 British and Foreign Med.-Chir. Rev., 1859, p. 489. 
cent. of fresh cartilage, and the inorganic substances, of which the sulphates of potash and sodla constitute the major part, do not amount to more than 2.5 per cent. (Hoppe-Seyler.) Permanent cartilage is employed in the construction of the body chiefly ou account of its resiliency, and on account of the extremely smooth surface which it presents, permitting free movement in the joints, where it is lubricated by the albuminous synovial fluid, with the least possible amount of friction.

48. Boxw-The boues constitute the organs of support for the softer tissues, and with the muscles form a system of levers by which locomotion, prehension, mastication, and various other movements are effected. They more or less perfectly inclose the cavities of the head, chest, and pelvis, and by their hardness and elasticity constitute an efficient protection to the important organs therein contained. They are divided according to their form into long, short, irregular, and flat boncs. In the long bones the shaft is pierced by a central canal, which ruus coutinuously from one extremity to the other, and the hollow cylinder which surrounds this is very compact in its structure. On the other hand, the dilated ends of the bone are composed of a spongy or cancellated structure, which is made up of osseous lanella and fibres interwoven together; the arrangement of which has been shown by $\mathrm{H}$. Meyer ${ }^{1}$ and $\mathrm{W}_{\mathrm{olf}}{ }^{2}$ to be by no means irregular or fortuitons, but exquisitely adapted for the mechanical funetions they have to perform and in exact accordance with theoretical requirements; ${ }^{3}$ a multitude of minute chambers or cancelli freely communicating with one another and with the cavity of the shaft are thus formed, whilst the whole is capped with a thin layer of solid bone. In the flat bones of the head, and less distinctly in the scapula and ilium, we find the two surfaces composed of solid osseous texture, with more or less of cancellated tissue, called the diploë, interposed bctween the layers. This, however, is sometimes deficient, leaving a cavity as in the frontal sinuses. Finally, we frequently mcet (especially in the ethmoid and sphenoid bones) with thin lantelle of osseous substance, resembling those which elsewhere form the boundaries of the cancelli. These consist of but one layer of osseous substance, and are not penetrated by vessels, but are nourished by those ramifying on their surfaces; and they consequently exhibit the clemcnts of the osseous substance in their simplest form. It will be desirable, therefore, to commence with the description of these.

49. When a thin natural lamella of this kind is examined, it is found to belong to the doubly refracting tissues, and to be chiefly composed of a sub-

FIG. 31.

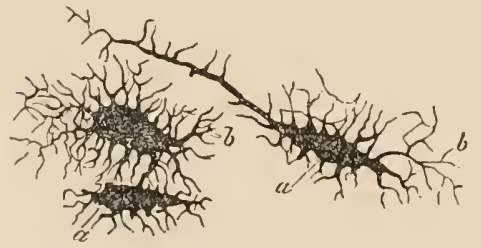

Lacunac of Osseous substance, magnified 500 diameters; $a$, central cavity; $b$, its ramifications. stance which is nearly homogeneous, though sometimes exhibiting indistinct traces of a fibrous arrangement. In the midst of this granular substance a number of dark spots are to be secn, presenting an oval form, and giving off, from their sides and extremities, numerous radiating prolongations of extreme minutencss, and frequently of considerable length. The dark spots are small eavitics, termed lucume, and the branched prolongations or cancliculi, are tubular channels, which, though far too small to convey blood-corpuscles, yet bring the fluid elcments of the hlood, or matters secreter from them, into close relation with

1 Die Arehitectur der Spongriosa, Reichert and Dubois-Regmond's Arehiv, 1867.

2 Virchow's Arebiv, Band 1, 1). 389.

3 On this point see also Culmann, Die graphische statik. Zurich, 1866. 
every part of the tissne. The size of the lacuns is to some extent proportionate to that of the blood-corpuscles, being large in reptiles and fish, and small in the ligher classes of the vertebrata. In man their long diameter is about $\frac{1}{800}$ th of an inch, and their short $\frac{1}{600} \mathrm{t}_{\text {th }}$ of an inch. Every lacuna is occupied in the living bone by a corpuscle of "germinal matter," which is the nutritive centre of the surrounding osseous substance. If, instead of a thin lamella of bone, sections of one of the long bones be examined, it will be found that the penetration of the tissue by bloodvessels renders a peculiar arrangement of the lacuma and canaliculi requisitc. The solid osseous texturc which forms the shaft is covered by a strong and firm layer of connective tissue termed the periosteum, in which numerous bloodvessels ramify, and is lined by a very thin and delicatc layer of the same tissue, to which the term endosteum is applied. This also is freely supplied with small vessels derived from the nutrient artery or arteries of the bone. From both the external and internal membranes numerous small bloodvessels penetrate the bone, occupying a series of canals that wcre first described by Clopton Havers, and have been named after him the Haversian canals. These for the most part run parallel to the central cavity, communicating however with onc anther by frequent transverse branches, so that the whole system forms an irregular network, pervading every part of the solirl texture, and adapted for the establishment of vascular communication throughout. The diametcr of the Haversian canals varies from $\frac{1}{250} 0_{0}$ th to $\frac{1}{2} 00$ th of an inch or more; their average dianeter may be stated at about $\frac{1}{50} 0_{0}$ th of an inch. The Arteries and Veins usually occupy separate

FIG, 32.

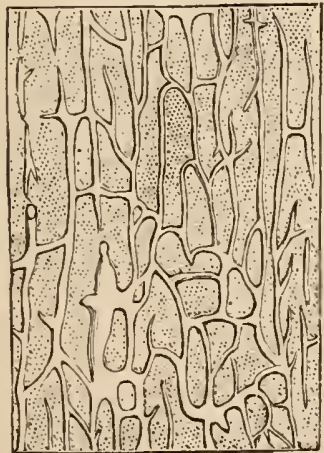

FIg, 33.

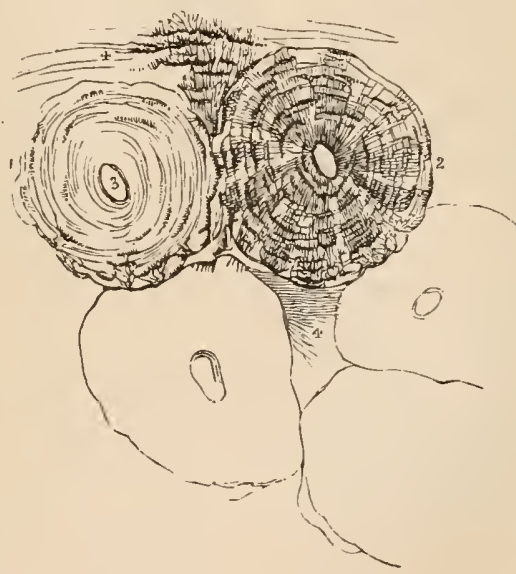

FIG. 30.- Tertical section of Tibia, showing the network of Haversian canals.

FIG. 31.-Minute structure of Bone, as shown in a thin section cut trausversely to the direction of the Haversian canals: 1, One of the Haversian canals surrounded by its concentric lamellæ; the lacunæ are seen between the lamelle; but the radiating tubuli are omitted; 2, an Haversian canal with its concentric laminæ, lacunæ, and raliating tubuli; 3 , the area of one of the canals; 4,4 , intervening lamellæ; between these lanelle at the upper part of the figure, several very long lacune with their tubuli are seen. In the lower part of the figure, the outllues of two other canals are giren, in order to show their form and mode of arrangement in the entire bone.

channels, and those inclosing the latter are, in some instances, as in the diploë of the flat bones of the skull, of extraordinary amplitudc. When a transverse section of a long bone is made, the open orifices of the longitudinal 
canals present themselves at intervals, sometimes connected by a transverse canal where the section happens to traverse this. Around these orifices the osseous matter is arranged in the form of cylindrical lamellæ, producing the appearance of concentric circles, the number varying from five to twenty for each Haversian canal. Each lamella presents a clearer internal and a darker external part. In the clearer portion of the lamella, or in the spaces intervening between the lamellæ, numerous lacunæ are situated, the canaliculi from which penetrate the adjoining lamellae, producing, as Dr. Sharpey ${ }^{1}$ has stated, the same appearance as would be scen on boring holes to some depth in a straight or crooked direction through, the leaves of a book, excepting only that the passages have proper parietes. On minute examination of bones softened in acid, the lamella are found to present a well-marked fibrous structure, the fibres being transparent and decussating with each other to form an extremely fine network, and those lamella that are formed by the periosteum as well as the outer lamellae of the Haversian system are often comnected or bolted together by perforating bundles of fibres of white fibrous or of yellow elastic tissuc. The spongy flat bones contain from 12 to 30 per cent. of water, the compact tissue from 3 to 7 per cent. The chemical analysis of dried bone shows that it consists of from 30 to 34 per cent. of animal matter, which, on boiling yields gelatin, and from 66 to 70 per cent. of mineral matter, of which about 57 parts are composed of calcium phosphate, 8 parts of calcium carbonate, 1 part of calcium fluoride, and 1 part of magnesium phosphate. ${ }^{2}$ The degree of hardness of bones does not altogether depend, as shown by the experiments of Dr. Stark, ${ }^{3}$ on the proportion of mineral deposit they nay contain; for the flexible, semitransparent, easily-divided bones of fish contain as large a proportion of earthy matter as the ivory-like leg bones of the deer or sheep. As a general rule, the bones of the extremities contain nore calcium carbonate and phosphate than those of the trunk, and the larger long bones more than the smaller ones. 'There is no difference in the composition of the corresponding bones of the two sides of the body, ${ }^{5}$ and within certain limits ( $\left.20-80\right)$ age has little or no influcnce upon it. It is also but very slightly influenced cither by the proportion or the nature of the salts centained in the food. ${ }^{6}$ The power of resisting pressure possessed by bone is very great, being nearly thrce times more than elm or ash, and twice as much as box, yew, or oak. 'The weight of the skeleton is to that of the whole body about as $10.5: 100$ in man, and as $8.5: 100$ in woman. The specific gravity of bone varies from 1.898 to 1.964 . The natural process of absorption which parts of various bones and the fangs of the first set of teeth undergo is effected by nucins of many nucleated cells, to which Kölliker ${ }^{8}$ has recently applied the term of osteoclasts or osteophagous cells. These present a close brush of hairs on that part of the cell which is turned towards the bone undergoing absorption, and it is by their action that all foramina, canals, and grooves in bone are produced. In the long bones of Man and of most Mammalia, the centra]

1 Introduction to Quain's Anatomy, Tth edition, $\mathrm{p} 96$.

2 For further details, and for the percentage composition of the Ashes of Bones and Treth, sce Aeby, Centralblatt, 1871, p. $51 ; 1 ; 1873$, p. 97.

3 Edinbureh Ileclical and Surgical Jourmal, April, 1845.

4 Fossil bones sometimes contain a very large amount of Calcium fluoride. Lassaigne, for example, found 15 per cent. in a tooth of the $A$ noplotherium.

5 Acby, Centrallalut, 1871, 1. 561.

6 sece Wreisere \%eits. t'. Biologie, Band vii, pp. 179 and 333 , viii, 239, and ix, 54l; and Papillon, Rubin's Journal de l'Anat., t. vi, 153 Heitzmann (Wien. Anzeig., $1873, \mathrm{p} .113$ ) shows that cither feeding with, or subeutaneous injection of anctic acid frodues Rachitis and Osteomalacia in Carnivora.

7 lobinson, in Lancet, 184f, vol. i, p. 346.

8 Verhandlung der Wurzburger Physik und Gesellechaft, N. F., Band ii, 1872. 
cavity, which nua be considered as an enlarged Haversian canal, is filled with the fatty matter known as marrow. This substance differs from ordinary adipose tissue in the nearly complete abscnce of connective tissuc, the cclls being supported by the spiculie and lamellie of bone which project into the cavity of the shaft. It is composed of 96 parts of fat, 3 parts of fluid, and 1 part of connective tissue. In the cancellous tissuc forming the expanded extrenities of the bones, a peculiar reddish fluid is found, to which the term marrow has also, though incorrectly, been applied, since it contains only a trace of fat. Its percentage composition is: Water, 75 parts; albumen, fibrin, and salts, 25 parts. Bones are but feebly supplied with sensibility. A few small nerves may, however, be seen to enter the shafts of the long bones with their nutritious arteries, and to be distributed in the endosteum.

50 . The development of Bone $\mathrm{e}^{1}$ consists in the conversion either of fibrous membrane, or of cartilage into osseous tissue. In the former case the ossification is said to be intramcmbranous, in the latter, intracartilaginous. The intramembranous form of ossification principally occurs in the flat bones of the hcad, and is also the mode by which the long bones increase in girth. The primary tissue presents the appearance of ordiuary fibrous membrane, in the meshes of which are numerons nuclei, osteoblasts, or corpuscles of "germinal matter." In the process of ossification, the fibres become the seat of calcareous deposit, which radiates out from a central point, advancing along the fibres, and rendering them opaque and granular. By the devclopment of commecting spiculis between the first-formed radiating strix, irregular areolæ are soon produced, in many parts partially or wholly inclosing bloodressels. The bone then increases, in thickness, by the deposition of new bone proceeding either from the calcification of successive generations of osteoblasts, which line the areola like an epithelial layer, or of a material excreted by and exterual to the osteoblasts; and in extent, by the lateral development of the radiating strice. In intracartilaginous ossification certain preparatory changes occur in the cartilage, which consist in its becoming vascular, and in its cells undergoing repcated division, so as to form cylindrical piles or columns, separated from each other by intercellular substance (Fig. $34)$. It is in this substance that the ossific matter is first deposited, appearing in the form of dark granular spicule, which shoot up between the rows of cells from the surface of the subjacent bone, or radiate from a central point. If the cartilaginous and the osseous substance be separated at this period, the ends of the rows of cartilage-cells will be found to be received into deep

FIG. 34 .

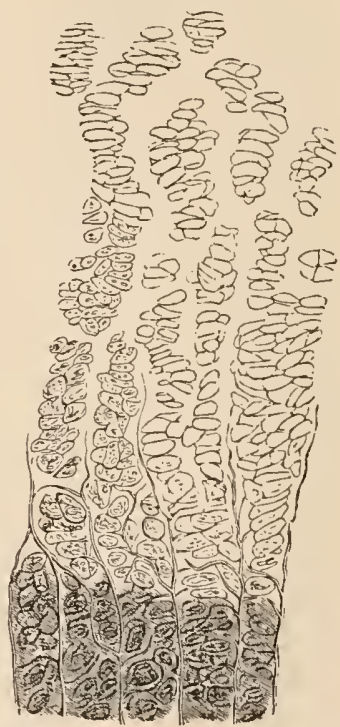

Cartilage at the seat of Ossification, showing at its lower portion the elusters of cells arranged in columns, each of which is inclosed in a sheath of calcified intercellular substance. narrow cups of bone; and the nuclei in immediate contact with the ossi-

1 For good papers on the development of Bone see C. Kutsehin in Pollett's Untersuch. aus dem Instit. für Phys. und Histologie in Graz, 1870; Kölliker, Die normalem Resolption des Knochrngewebe, Leipzig, 1873; Wolff, Klin. Wochenschrift, 1863, No 6; Ollier, Brown-Séquard's Archives de Physiolngie, 1873; TVegner in Virchow's Archiv, 1874, Band 1xi, p. 44; Strelzoff, Centralblatt, 1872, p. 449, and 1873, p. 273. 
fying surface, which were previously in close apposition, separate considerably from one another by the incrcase of material within the cells, the nuclei themsclves becoming larger and more transparent. Small connecting spicule of bone then form between the vertical ones, and the groups of original cartilage-cells come to be inclosed within oblong loculi or arenlæ, which constitute the primary medullary spaces. The young cells occupying these spaces may be divided, according to Waldeyer, into two groups, one of which aids in the formation of the osseous tissue, whilst the other develops into medullary tissue. The former may be appropriately termed "osteoblasts," and consist of masses of granular protoplasm, or germinal matter apparently destitute of any investing membrane, but each containing a nucleus, which arrange themselves side by side, like an epithelial layer, on the inner surface of the primary areolie of bone-substance. Many of these osteoblasts may be seen undergoing calcification, and half buried in the newly-formed yellowish but homogeneous bony deposit, that appears as an cdging to the darker and more granular primary trabecule, whilst in other parts they may be seen to communicate with one another by long processes. After the first set, which proceed directly from the cartilage-cells, have been used up, fresh osteoblasts are developed from the cells of the young medullary tissue. Dr. Sharpey, Waldeyer, and others, believe that some of the osteoblasts become wholly converted into bone, in which case the nuclei vanish, whilst others only undergo partial calcification, the ccntral portion of the protoplasmic mass remaining with the nucleus to form the contents of the bone lacunæ. Gegenbaur, however, thinks the laniellie are formed from a material excreted by the osteoblasts, ${ }^{1}$ and Kölliker" ${ }^{2}$ seems inclined to adopt this view. Whilst these processes are occurring, the bony tissues become vascular, partly by bloodvessels from the investing membrane of the bone penetrating or pushing their way in from without by absorption, and partly by vessels lying on the surface becoming surrounded by deposits of new osseous substance, which form by degrees the series of inclosing lamellæ that constitute an Haversian system. Of the bouy spiculie and lamella bounding the primary areols, some have been shown by Dr. Sharpey to be speedily absorbed again, and thus to form larger areole, which are to be scen on making a transverse section a little below the ossifying surfitce. Even after the completion of the bone, moreover, interstitial changes are continually taking place in its substance, as in that of the softer tissucs, old Haversian systems being partially or entirely removed by absorption, and new ones being developed in their place. And it is to the persistence of portions of those older Haversian systems, which have undergone partial absorption, that we are to attribute the prescuce of those intervening lamine which fill up the spaces between the existing Haversian systems. The clavicle and lower jaw are the first bones to ossify, their osseous centres or points of ossification appearing at the close of the first month of foetal life. Increase in the length of a bone-as may be shown in experiments marle by feeding an animal with madder, the newly formed bone being cleeply tinged -takes place almost entirely between the cpiphyses and the shaft; but probably also results in part from the interstitial cleposition of new material; ${ }^{3}$ inciease in girth, by ossification immediately beneath the periostcum; absorption from within and deposition from without going on continually. The former takes place by intracartilaginous or endosteal, the latter by intramembranous or ectosteal ossification.

1 Jenaischen Zeitschrift, Band iii, 1866.

${ }^{2}$ Gewebelehre.

3 For arguments for and arainst the latter point see IVolfr, Cl)1, 1869, p. 849; 1870 , p. 641 ; Volkmann in Centralblatt, 1870 , p. 129; Jieberkuhn, Centralblatt, 1872, N. 420 ; Ranvier, Comptes Rendus, 1873, t. 77, p. 1105. 
51. TEETH.- Is soon as solid food is introduced into the mouth it is divided and comminuted by the Tcctl. Partly in accordance with the general fact thit epithelial growths die and are cast off' to be replaced by other's formed heneath them, but chiefly to allow for that enlargenent of the jaws which oceurs in the passage from infancy to adult age, two sets of thesc organs are developed - the first, temporary or milk teeth, which last up to the seventh or eighth rear, arc 20 , the second, or permanent set, are 32 in number. Both are firmly imbediled in sockets or alveoli of the upper and lower jaws. The front or incisive teeth ( 8 in number) are, as their name implies, provided with a cutting edge for the prehension and division of morscls of food of appropriate size for mastication. The sharp-pointed canines ( 4 in number) pierce and cut the firner aud tougher constituents of our ordinary aliment, whilst the bicuspids ( 8 ) and the molars (12) triturate and bruise the food, till, with the aid of the saliva, it is reduced to the consistence of pulp; it is then fitted for deglutition. Every tootil consists of a crown, a neck, and one or more fangs (Fig. 35), and in all teeth thrce structures are found-the dentine, which gives the general form and size to the tooth; the enamel, which caps the crown; and the crusta petrosa, which invests the fang. On examining a thin longitudinal section of a tooth, the dentine is found, like the shaft of the loug bones, to be hollowed out into a pulpcavity, containing a little connective tissue, with bloodvessels and nerves. These enter by a minute orifice at the extremity of the fang. The dentine which surrounds the pulp-cavity is composed of a matrix, which is traversed by numcrous tubuli that radiate from the pulp-cavity towards the external surface of the tooth, and which pursue a gently undulating course, dividing dichotomously, and sending off minute branches. In dry sections the tubuli, having a diameter of about $\frac{1}{4500}$ th of an

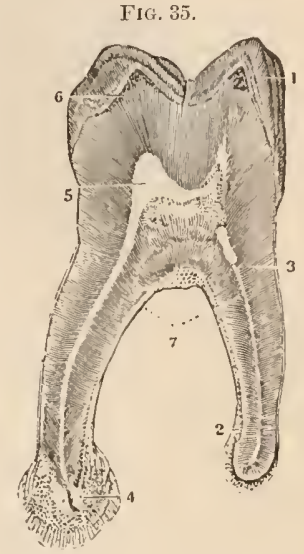

Vertical section of IIuman Molar Tooth: 1 , enamel; 2,7 , cementum or crusta petrosa; 3 dentine or ivory ; 4 , osseous excrescence, arising from hypertrophy of cementum; 5 , cavity. subsequently filled with osteodentine; 6 , osseous lacunse at outer part of dentiue. inch, are seen to open into the pulp-cavity by one extrenity, and by the other to terminate either by exquisitely fine branches or in similar cavitics in the dentine, or overstepping the limits of this to end in the enamel, or crusta petrosa. The tubuli are most closely set near the crown of the tooth. In the living state they are occupied by prolongations of the protoplasmic substance which fills the pulp-cavity. These processes are not in direct contact with the matrix, but are invested by sheaths - the dentinal sheaths of Neumann. The matrix intervening between the tubuli is clear and homogeneous, and in softened specimens gives evidence of being deposited in lamelle, concentric with the pulp-cavity (Sharpey). Near the outer surface of the dentine, and also forming certain arched contour lines at the crown of the tooth, is a peculiar modification of the matrix, which appears to be broken up into spaces bounded by glohular masses perforated with dentinal tubuli-the so-called interglobular layer. The enamel (Fig. 28) is composed of solid hexagonal prisms of about the $-\frac{1}{5} 0$ th of an inch in diameter, arranged vertically to the dentinal surface on which they rest, and firmly adherent to one another. The course of these prisms is generally wavy, and their surfaces, in section, are marked by transverse strix. Enamel is the hardest of all the tissues of the body. The crustc petrosa, or cementum, corresponds in all essential particulars with bone, pos- 
sessing its eharacteristie laeunæ and canaliculi. It is destitute, however, of any lamellar strueture. It is thiekcst at the extremity of the fang, and becomes gradually thinner towards the neck of the tooth, where it terminates.

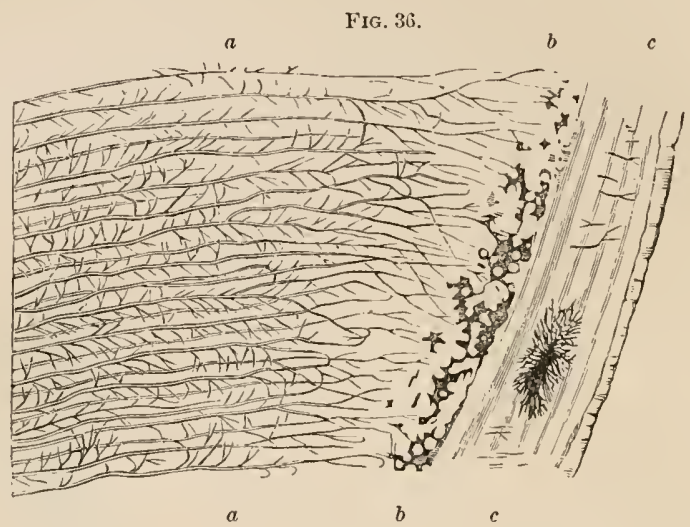

Section through the fang of a Molar Tooth: $a, a$, dentine traversed by its tubuli ; $b, b$, nodular layer; $c$, $c$, eementum.

A.

FIG. 37.

B
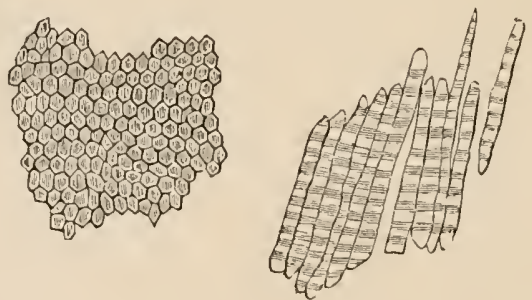

A. Transverse section of Enamel, showing the hexagonal form of its prisms; B, separated prisms.

The following are the results of Von Bibra's analysis of the component struetures of human tceth :

Incisors of Adult Man.

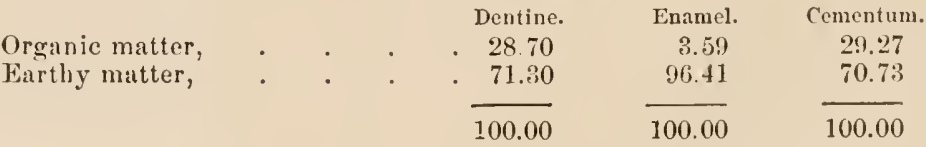

In tracing the development of the teeth, they are found to be essentially dermal structures, which have undergone caleification, the epithelium forming the enamel, and the mucous tissue the dentine and cement. At the sixtl week of foetal life a deep, narrow groove may be perceived in the upper jaw of the human embryo, between the lip and the rudimentary palate. This is speedily divided into two by a ridge, which afterwarls becomes the external alveolar process; and it is in the inner groove, which is termed the primitive dental groove, that the germs of the teeth subsequently appear. The groove is at first completely covered and filled with the epithelium of the oral eavity, so that on a surface view it is scarcely perceptible. From the bottom of the dental groove a narrow process of the oral 
epithelium dips into the subjacent nucous tissue, presenting on section the form of a short tubular gland (Fig. 38), but really constituting an epithelial fold along the whole length of the jaw. As this fold deepens and enlarges a projection of the mucous tissue takes place in the opposite direction. (Fig. $39 \mathrm{f}$.) This projection or papilla is the dentine germ. By its growth it

FIG, 3S.

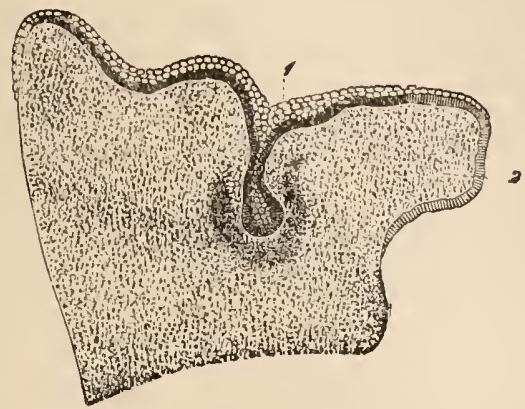

FIG. 39.

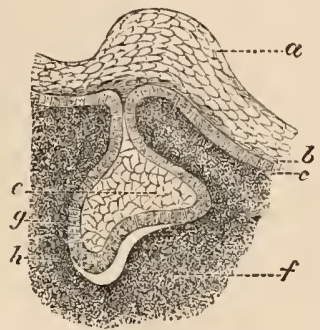

FIG. 38.- Vertical section of the Upper Jaw of a Fotal Sheep, about 23/4 inches long, sliowing the enamel germ, with the semilunar rudiments of the dentine germ and dental sac in transverse section. 1. Dental groove; 2 , palatal process, magnified 50 diam.

FI(i, 39.- $a$, Epithelium. $b$, younger layer of Epithelium. $c$, inferior layer of the Epithelium. $e$, enamel organ. $f$, dentine germ or papilla. $g$ and $h$, inner and outer layers of the sacculus that is about to form.

assumes the form of a club-shaped mass, and the enamel organ invests it like a cap. (Fig. 40.) The first papilla appears at the end of the seventh week,

FIG. 40.

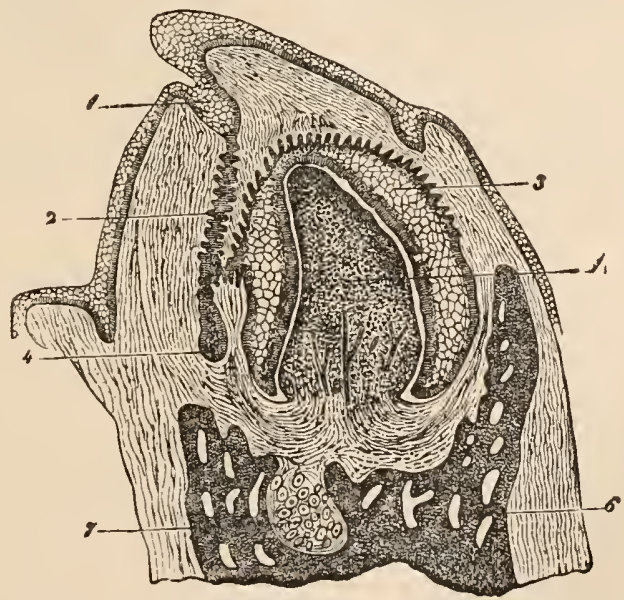

Vertical section of the Lower Jaw of a II uman Fotus, measuring about four iuches in length, magnified 25 diam.: 1, dental groove; 2, remains of the enamel germ; 3, enamel organ, presenting epithelium on both its outer and inner surface, $i . e$, where it lincs the sacculus and where it covers the papilla; 4 , enamel germ of the permanent tooth; 5 , dentine germ; 6 , section of inferior maxilla; 7 , Ifeckel's eartilage. The dental sacculus will be observed to present a number of fine papillæ opposite the dental pauillax.

and is the germ of the anterior temporary molars; at the eighth week that for the canine tooth appears; at the ninth those for the central and lateral in- 
cisors; and at the tenth week that for the posterior milk molar tooth. The dental ridges now coalesce ( $f$, Fig. 41), orring to the meeting and fusion of two (incisors), three (canine), or four (molar) processes (opercula) from their margins, which takes place at the fourteenth week. The tooth-germs are now inclosed in sacculi, and on section the characters seen in Fig. 40 are presented.

Between the papilla or dentine germ and the comnective tissue forming the wall of the sacculus is seen a spongy tissue (3) composed of cells, which forms the entmel organ. The innermost layer of cells, which are in immediate contact with the papilla, are columnar and regularly hexagonal in section. Their extremities are destitute of a cell-wall, though elsewhere it is well defined. Near the base of the papilla the cells become more cubical, and are reflected at its base upon the inner surface of the wall of the sacculus. The polygonal cells intervening between these two layers become stellate and anastomose with each other, the interspaces being filled with a gelatinous substance, which appears to form a kind a pabulum for the growth of the columnar enamel cells. At all events, it undergoes atrophy, so that the

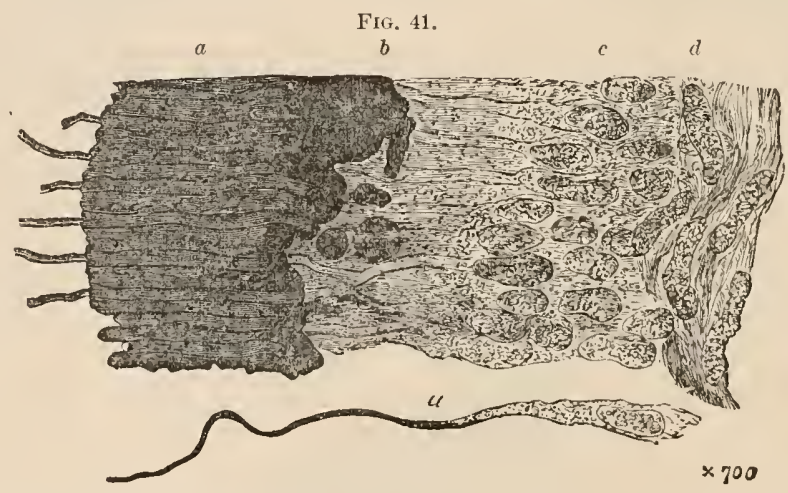

Thin section of the inner portion of the Dentine, and of the surface of the Pulp, of an adult Incisor Tooth : $a$, portion in which calcification is complete, showing separate glubular masses at the line of junction with the uncalcified substance, $b$; at $c$ are seen oval masses of germinal matter (eells), with formed material on their outer surface; $d$, terminal portions of nerve-fibres.

outer and inner epithelial layers come into close apposition; and in tceth examined just at the period of eruption a membrane can be detached from the enamel, composed of one or more layers of very flat epithelial cells, which Waldeyer entertains no doubt represents the outer epithelium, with more or less of the stratum intermcdium. The enamel itself proceeds from the direct calcification of the long columnar cells, the deposition of the calcareous salts taking place with tolerable uniformity in their outer ends. When the calcification has proceeded to a certain extent, the calcified part may be raiser in the form of a membrane (Raschkow's membrana preformativa) from the subjacent softer tissue; and thus, as Huxley first demonstrated, the enamel is a petrified cpithelium. 'The first germ of the dentine appears as a dark semilunar area at the base of the enamel germ. As development proceeds the papilla is gradually formed by the differentiation of the mucous tissue, and is composed of cells lying in delicate connective tissue. The cells or odontoblasts lying near the surface become elongated, and arranged vertically to the surface, the more deeply situated extremes of each communicating with other odontoblasts lying nearer the axis of the papilla. Calcification first invades the outer extremities of these cells. A 
central rod always remains uncalcified. The layers of matrix immediately surrounding the fibres undergo conversion into elastic tissue, and form the dental sheaths of Neumann. Fach dentinal tube is thus made up of several odontublasts arranged end to end. The formation of the cement is identical with the process of intramembranous ossification in bone. 'The matrix of

F1G. 42
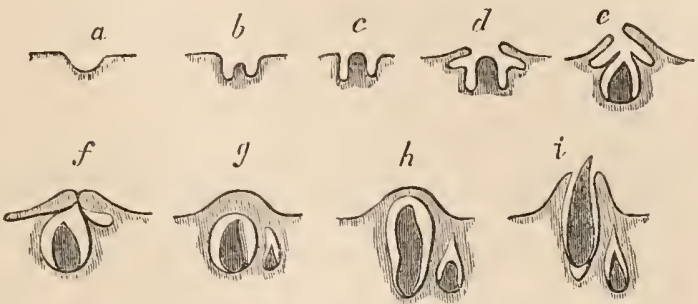

Successive stages of the Development of the Deciduous or Temporary Teeth, and of the origin of the capsules of the Purmanent set: $a$, ptimitive dental groove, seen in transverse section; $b$, origin of dental prapilla from its fluor, the pit being, in the recent state, roofed in by, and filled with, epithelium cells; $c$, papilla projecting from the mouth of its follicle; $d, e$, formation of the opercula, which meet over the papilla ; $f$, incipient formation of cavity of reserve; $g, h, i$, formation of capsules and papilla of permanent tectl from cavity of reserve, and eruption of milk teeth.

the cement is the loose myxomatous connective tissue of the dental alveoli immediately surrounding the teeth. ${ }^{1}$ As early as the fifth mouth, before the calcification of the primitive pulps commences, a provision is made for the production of the "permanent" teeth, the capsules of which originate in burls or off'sets from the upper part of the capsules of the "temporary" or milk teeth ( $f, \mathrm{Fig} .42)$. 'These offsets are at first in the condition of open follicles communicating with the eavity of the primitive tooth; but they are grarlually closed in, and detached altogether from the capsules of the inilk teeth $(g, h, i)$. The three permanent molars, which are superadded in the adult to the milk teeth of the infant, are produced by a precisely sinilar process of budding from the sac detached from that of the last milk molar.

The following are the principal dates connected with the development and eruption of the teeth :

\begin{tabular}{|c|c|c|}
\hline \multicolumn{2}{|c|}{ Temporary or Deciduous Teeth. } & \multirow{2}{*}{$\begin{array}{c}\text { Permanent Teeth. } \\
\begin{array}{c}\text { Period of eruption. } \\
\text { Years. }\end{array}\end{array}$} \\
\hline $\begin{array}{l}\text { Period of formation of rapilla. } \\
\text { Week of intrauterine life. }\end{array}$ & $\begin{array}{l}\text { Period of eruption. } \\
\text { Month after birth. }\end{array}$ & \\
\hline 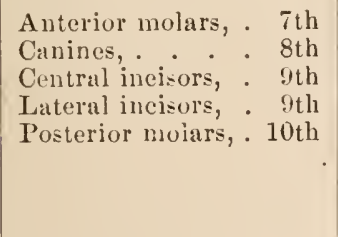 & $\begin{array}{l}\text { Central incisors, } 8 \text { th } \\
\text { Lateral incisors, 8-10th } \\
\text { Anterior molars, 12-13th } \\
\text { Canines, . . . 14-20th } \\
\text { Posterior molars, 18-36th }\end{array}$ & 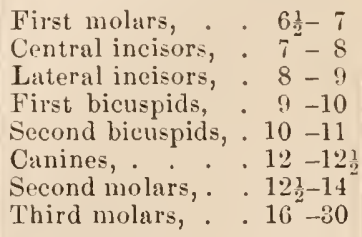 \\
\hline
\end{tabular}

1 For a full account of the structure and devclopment of the teeth, see Waldeyer's Essay in Strieker's Human and Comparative Histology, 1870; Syd. Soc. Trans. vol. $i$, p. 463 , to which an excellent bibliography is attached. Also Quain and Sharpey, vol.ii, p. 780. Wenzel, Pamphlet, Leipzig, 1871. For the resorption of parts of the tceth see Kölliker, Centralblatt, 1872, pp. 353 and 369. 


\section{CH A P T E R I V.}

\section{CHEMICAL COMPOSITION OF THE BODY.}

52. Trie elements which enter into the composition of the various fluids and solids of the body are Oxygen, Hydrogeu, Nitrogen, Carbon, Sulphur, Phosphorus, Chlorine, Fluorine, Potassium, Sodium, Lithium, Calcium, Silicum, Magnesium, and Iron. Lead and copper are occasioually, but perhaps only accidentally, present. ${ }^{1}$ The combinations of these elementary bodies are divisible into two great groups: the Inorganic, represented by the saline coustitueuts, in which they are united for the most part in a binary manner, and the Organic. in which the chemical constitution is much more complicated, but which are again easily subdivisible into the azotized compouuds represented by the albuminous substances and their derivatives, and the nonazotized compounds, which include the oleaginous and the saccharine substances. The inorganic compounds are commonly associated with the organic in sufficient quantities to maintain the body in health, if the food be sufticiently varied, though in one or two instauces-as in those of the use of water and of conmon salt-an additional supply is taken in the pure state. The organic group is primarily and entirely derived from the Vegetable Kingdom, the office of which is to produce, from the surrounding air, water, and soil, the complex materials of which the bodies of auimals are constructed. The inorganic compounds uudergo comparatively little change in passing through the body, but the organic - and especially those belonging to the azotized or albuminous type, which have a complicated constitution, their molecules being larger, and containing many atoms held together by comparatively feeble affinity-are correspondingly liable to break down under the influence of disintegrating causes, and by their oxidation to yield the various forms of force which the animal body exhibits. If, for instance, we follow the changes undergone by the albuminous group we shall find that they no sooner enter the stomach than they are placed under conditions, uancly, warmth and moisture, that are particularly favorable to decomposition. 'The peculiar properties of the gastric juice, however, retard aud, at the same tinı, modify the changes they would otherwise undergo. By rendering them soluble it enables them to be absorbed into the blood, where they are exposed to the action of oxygen, in a very active state, dissolved in an alkaline fluid. A portion is probably inmediately applied to the maintenance and reconstruction of the tissues, and to the formation of the albuminoid constituents of the various secretions, which, in the form of Mucin, Collagen, Spcrmatin, etc., may be regarded as the immediate derivatives of albumen, whilst a part remains in solution in the blood. Both portions alike - that which forns part of the tissues, and that which forms part of the blood-sooner or later unitc with oxygen, and appear to break np into two groups of compounds, the azotized and the nonazotized. The former include

1 See Blasius, Zeits. f. Rat. Med., B. xxvi, p. 250; and Lossen, Journal f. Chemie, 1866, P. 460. 
such substances as Leucin, Glycin, and Taurin; the Biliary and Urinary acids, Kreatin, Kreatinin, and Urea; and the azotized pigmentary substances. The latter-or nonazotized group-are divisible into those which contain less oxygen than the albuminous compounds, as the fats; or more oxygen, as the carbo-hydrates, glycogen, nilk, sugar, and the like. The ultimate results of the further oxidation of both classes of compounds are carbonic acid and water.' The fats and carbo-hydrates ingested into the stomach, after some preparatory processes, are absorbed into the blood, and undergo the same changes as the corresponding compounds resulting from the breaking up of albunen and its allies. The tissues therefore, as Dr. Marcet has recently pointed out," may be regarded as formed of three different classes of substances, namely, those which constitute the nature or functionally active tissue, and are characterized by being insoluble in water; next, those on their way to form the living tissuc-which are soluble in water but of colloidal nature, i.e., incapable of diffusion; and, finally, those which are effete, having performed their function, and are on the road to be eliminated. These are soluble in water and crystalloid. It will thus be seen that Plants and Animals are directly opposed to each other in their chemical relations: Plants forming organic compounds, decomposing carbonic acid, fixing the carbon and setting free the oxygen, and, so to speak, absorbing force; whilst Animals effect the decomposition of the organic compounds, taking up oxygen, and eliminating carbonic acid, water, and urea, and giving off force in the form of heat, motion, etc. In consiclering the proximate principles entering into the composition of the body, we shall first describe the albuminous compounds and their derivatives; secondly, the hydro-carbonaceous, and thirdly, the mineral compounds, following as far as possible the order of descent from the higher to the lower planes of complexity of constitution which experiment and observation render probable.

53. Albumnous Compouxis. ${ }^{3}$ - As already stated, Plants alone are capable of producing albuminous substances or "Proteids" from the direct union of their elements; and from this source are derived all the supplies required for the maintenance of their bodies by the Herbivora, which again yield them up to the Camivora. The chief facts deserving of attention in the chemical history of the Proteids are, that they are all composed of Carbon, Hydrogen, Nitrogen, Oxygen, and Sulphur, and so complex is the grouping of their atoms that it is almost impossible to represent them by any rational formula. No less than sixteen different forms of albumen have been described by chemists, viz., Serum-albumen, Ov-albumen, Paralbumen, Paraglobulin, Fibrinogen, Serum-Casein, Alkali- (Sodium-or Potassium-) Albumen, Casein, Myosin, Syntonin, Coagulated Albumen, Fibrin, Vitellin, Ichthin, Amyloid and Prot-acid. The differences between these are, however, comparatively slight, and are chiefly referable to their greater or less solubility in saline or acid solutions, or in the temperature at which they coagulate by heat. A knowledge of their percentage composition is more easily attained,

1 The successive steps may be traced, perhaps, most distinctly in the case of guanin $\left(\mathrm{C}_{5} \mathrm{H}_{5} \mathrm{~N}_{5} \mathrm{O}\right)$ which is a constituent of the pancreas, through hypoxanthin $\left(\mathrm{C}_{5} \mathrm{H}_{4} \mathrm{~N}_{4} \mathrm{O}\right)$ and xanthin $\left(\mathrm{C}_{5} \mathrm{H}_{4} \mathrm{~N}_{4} \mathrm{O}_{2}\right)$ to uric acid $\left(\mathrm{C}_{5} \mathrm{H}_{4} \mathrm{~N}_{4} \mathrm{O}_{3}\right)$; uric acid again, when acted on by oxidizing agents, yielding urea $\left(\mathrm{CH}_{4} \mathrm{~N}_{2} \mathrm{O}^{\prime}\right)$, allantoin $\left(\mathrm{C}_{4} \mathrm{H}_{6} \mathrm{~N}_{4} \mathrm{O}_{3}\right)$, oxalic acid $\left(\mathrm{C}_{2} \mathrm{O}_{2} \mathrm{OH}_{2}\right)$, and carbonic acid.

${ }_{2}^{2}$ An Experimental Inquiry into the Nutrition of the Animal Tissue, 1874.

3 See Eichwald, Beiträge zur Chemie der Gewebebildenden Substanzen und ihre Abkömnlinge. Berlin, 1873. Nasse Studien über die Eiweisskorpen, Pfüger's Archiv, Band vi, 187:, p. 589, and Band vii, 139. 
and the following table ${ }^{1}$ will show the close similarity in the composition of those that have been most carefully determined. They are all very unsta-

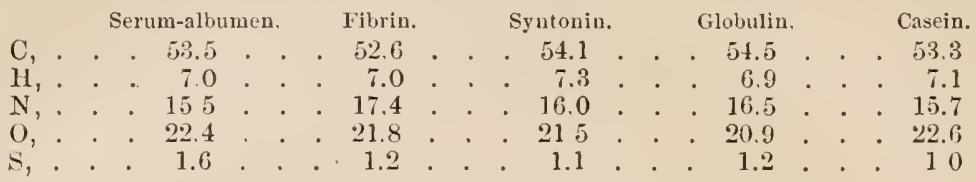

ble, and not only easily decompose themsel ves, but act as excitors of fermentation to other bodies. Most of the Proteids exist in two states-a soluble, and an insoluble. The former may be obtained by evaporating the fluids in which they are contained at a comparatively low temperature to dryness, when the albuminous substance appears as a semi-transparent yellowish material, resembling gum-arabic, free from taste and smell, neutral to testpaper, and with the exception of Hamoglobin, quite destitute of any tendency to crystallize. The insoluble form is obtained by heat or by precipitation with various chemical reagents, and forms whitish floceulent masses, which present a granular aspect under the microscope. A moderately strong solution of ov-albumen in water becones turbid at $140^{\circ}$; completcly insol alble at $145^{\circ}$; and separates in flakes at $167^{\circ}$; when exccssively diluted, however, no turbidity can be produced by a less heat than $194^{\circ}$. After having been dried in vacuo, or at a temperature below $120^{\circ}$, albumcn may be heated to $212^{\circ}$ without passing into an insoluble condition. The albuminous compounds belong to the group of Colloids, founderl by Professor Graham, which possess an extremely low power of diffision through animal membranes. To this peculiarity their feeble taste may in all probability be attributed. They have little or no smell. They dissolve in concentrated acetic and phosphoric acids, and with partial decomposition in caustic alkalics. They are precipitated by alcohol, ether, tannic acid, corrusive sublimate, and most of the mineral acids. Concentrated nitric acid stains them yellow, and concentrated hydrochloric acid dissolves them, the solution assuming a blue color. They are precipitated by potassium ferrocyanide. Solution of iodine stains them of a yellow color, and they all become red at $212^{\circ} \mathrm{F}$. when acted on by Millon's reagent, which consists of a solution of the proto- and pernitrate of mercury. Sulphuric acid holding molybdenic acid in solution stains them of a dark blue (Frolude's reaction), and when treated with sugar and sulphuric acid under the microscope, they give a beautiful violet color (Schultze's reaction). Ton Gorup Besanez observes that when acted on by powerful oxidizing agents, the albuminous compounds yield formic, acetic, propionic, butyric, valerianic, capronic, and benzoic acids, the aldehydes of these acids, ammoniat, and volatile bases; whilst by the action of acids, alkalies, and during putrefaction, they give rise to volatile fatty acils, leucin, tyrosin, grycin, ammonia, volatile lases, sulphide of ammonium, and a volatile erystallizable substance having the odor of fieces. It is worthy of notice that some of there, as the azotized compounds, leucin, and tyrosin, and the nonazotized substanec, glycin, can be extracted from those parts of the body as the glands in which active processes of metamorphosis are taking place. It is reasonal)le to suppose, therefore, that the successive stages molergone by the albuminons substances within the body are essentially similar to those through which they pass when acted on by chemical agents without the body. The arqueous solutions of albumen rotate the plane of polarization to the left.

1 Frey, Histochemie, 1873, p. 13.

2 Phys. Chemie, 18it, pp. 39 and 117. 
The albuminous componnds, as the following table taken from the same author will show, are widely distributed through the body, and in fact may alluost be said to be everywhere prescut.

In 1000 parts of-

Fluids

Cerebro-spinal fluid,

Aqueous humor,

Liquor amnii,

Intestinal juice,

Pericardial fluid,

Lymph, .

Pancreatic secretion

Synovia,

lilik,

Chyle,

Blood,

are
0.9
1.4
7.0
9.5
23.6
246
33.3
39.1
39.4
409
195.6

Tissues

are

Spinal cord,

74.9

Brain, . . . . . . . . 86.3

Liver, . . . . . . . 117.4

Thymus (of ealf), . . . . . 122.9

Egg (of fowl), . . . . . . 134.3

Muscle, . . . . . . . . 1618

Middle coat of arteries, . . . 273.3

Crystalline leus, . . . . . . 383.

Fibrix appears to be a compound formed by the union of two kinds of albumen-fibrinogen and paraglobulin-under the influence of a fernent; the two former of which are constantly present in the blood, and in inflammatory cxudations, whilst the ferment forms in the blood after its removal from the body.' Its properties, as well as those of hrematocrystallin, or the albuminous constituent of the blood-corpuscles, will be found detailed in the section devoted to the consideration of the blood. A substance presenting numerous points of similarity to Fibrin, if not identical with it, has been obtained by Mr. A. Smee, ${ }^{2}$ by passing oxygen through defibrinated blood to which ordinary ov-albumen lias been added, or through albumen shightly acidified with acetic acid, and also by transunitting fceble currents of electricity through an albuminous fluid, when it accumulates around the positive pole, where oxygen is eliminated. The substance to which the term CAsEIN was formerly applied, and which is so abundant in milk, has lately been shown to be only a combination of albumen with soda, the albumen playing the part of an acid. ${ }^{3}$

Mrosis. - The term Myosin is applied to the coagulum which forms in the juice expressed from living muscle. It liffers from fibrin in its transparency and in its remaining gelatinous, without any tendency to assume a fibrous character, but resembles that substance in its remarkable power of quickly decomposing peroxide of hydrogen; it loses this property at a temperature of $140^{\circ} \mathrm{F}$. It separates from the muscle plasma or juice very slowly at $33^{\circ} \mathrm{F}$, but with great rapidity at $104^{\circ} \mathrm{F}$. An immerliate coagulum occurs in the plasma on dropping it into cold distilled water, or on the addition of diluted acids or solution of conmon salt (ten to twenty per cent). The coagulum thus formed renains insoluble in water, but it is easily dissolved in dilute acids and alkalies, and in five to ten per cent. solutions of common salt. In a state of purity, myosin has no action on vegetable colors. In the act of solution in dilute acids, it is converted into syntonin. Külne considers that to the coagulation of the myosin, the condition of the muscles termed Rigor mortis is to be referred.

Srxtoxix can be extracted in large quantities from muscles and other albuminous compounds by the action of a solution of hydrochloric acid, containing onc part of the acid to 1000 of water. Syntonin is precipitated

1 See Schmidt, Pfluger's Archiv, Band vi, 187-2, p. 413.

2 Procedings of the Royal Socicty, January $15 t h, 1863$.

3 Kühne, Physiolog. Clsemie, 1868, pp. $175^{\circ}$ and 565. See also Kelırer, Arehiv f. Gynæcologie, Band ii, 1871, p. 1. 
from its solution by exact neutralization, is easily solnble in dilute acids and alkalies, and in solutions of the alkaline carbonates, but it is quite insoluble in solutions of common salt, and the chlorides of ammonium and calcium. It does not decompose peroxide of hydrogen. The acid solutions of syntonin do not coagulate at a boiling temperature.

54. Derivatives of Albumen.-In close relationship with the albuminous compounds, stand a series of substances into which albumen is either converted in the act of digestion, as peptone, or which may be obtained from various secretions and tissues, as ptyalin, pepsin, and pancreatin, which constitnte the organic bases of the salivary, gastric, and pancreatic fluids, respectively; muein, contained in mucus; spermatin, from the spermatic fluid ; elastin, keratin, collogen, cerebrin, and choudrin, which are severally found in elastic, horny, and connective tissue, in the nervous tissue, and in cartilage. These are all azotized. Most of them contain sulphur and, like albumen, have a great tendency to imbibe water and swell up. They have but little disposition to undergo putrefaction.

PTYalin is obtained by acidulating saliva with phosploric acid, and precipitating with lime-water. The Ptyalin falls with the phosphate of lime, from whence it may be extracted by distilled water. It contains nitrogen, and is thrown down from its watery solution by alcohol, but its reactions show conclusively that it is not identical with albumen. Great interest is attached to it in consequence of its remarkable power of eonverting starch into sugar.

Persin may be obtained from the gastric juice, in a pure or nearly pure state, by a method suggested by v. Wittich," which consists in making an extract of the mucous membrane of the stomach with glycerin, after coagulating the albuminous compounds with alcohol. Pepsin is a grayishwhite, amorphous, nitrogenous substance, which is not lyggrometrie, and is incapable of assuming the crystalline form. It dissolves witl difficulty in water, but more easily in dilute acids, and then possesses powerful digestive properties. It is a colloid, i.e., is non-diffusible per se, ${ }^{2}$ but its acid solution readily diffuses. ${ }^{3}$ It is precipitated by platinum chloride, and by the neutral and basic acetates of lead, but not by concentrated nitric acid, iodine, tannic acid, or biehloride of mercury. The pepsin of the shops is very impure, containing, with some pepsin, much peptone and starch; yet its activity is considerable. Pepsin acts energetically when combined with from 0.1 to 7 per cent. of hydrochloric or sulphuric acid; with 0.2 to 12 per cent. of ordinary phosphoric acid ; with 0.1 to 5 per cent. of nitric acirl; and with from 1 to 5 per cent. of acetic, lactie, and oxalic acids. In order that its solvent powers should be exerterl, it is imperatively necessary that it should possess an acid reaction; the neutralization of its normal acidity with sodium carbonate having been shown by Bernard to effect the immediate arrest of the digestive process. An exceedingly small quantity of pepsin, in the first instance, will suffice to dissolve a very considerable amount of fibrin, providing fresh atditions of diluted acid be constantly marle; the pepsin appearing to deternine the solution of the albuminoid substance in the acid. The temperature most fivorable for the performance of artificial digestion is between $95^{\circ}$ and $112^{\circ} \mathrm{F}$. A boiling temperature, and even one not exceeding $140^{\circ} \mathrm{F}$., deprives pepsin of its peculiar properties; and searcely any digestion oecurs at a temperature of $40^{\circ} \mathrm{F}$.

Griatin of: Collagen.-This substanee is not an original constituent

'Pflügrer's Archiv, Band v, 1873.

${ }^{2}$ Wolfthiigel, Pllïure's Archiv, 1873, Band vii, p. 188.

3 See v. Wittich, P'flüger's Archiv, 1872, Band v, p. 435. 
of the horly, but may be obtained hy hoiling connective tissue, articular fihro-cartilage, or bone, with water. The solution gelatinizes on cooling, even when the gelatin is only present in the proportion of 1 per cent. It is precipitated by alcohol and ether, but not by acids, with the cxception of tamnic acid, which constitutes its most delicate test. It is also precipitated by chlorine water and corrosive sublimatc, but not by other salts of mercury, nor by those of silver, copper, lead, or alum, nor by potassium ferro or ferricyanide. Its percentage constitution when procurer from tendon is C 50.9, H 7.2, N 18.3, O .23, and S .56. When acter on by oxidizing agents, it furnishes the same products of disintegration as the alhuminated compounds, and with sulphuric acids and alkalies, it yields Leucin and Glycin.

Elastre is the basis of elastic tissue, and may be obtained from it by boiling it successively with alcohol, ether, water, concentrated acctic acid, diluted alkaline lye, and hydrochloric acid. When the residue is thoroughly washerl it forms a yellowish fibrous mass still possessing great elasticity, which dissolves only in concentrated allalies. When heated on platinum, it burns away without leaving any residue. It differs from albumen in being destitute of sulphur. The composition of a portion taken from the liganientum nuchr, as given by $\mathrm{WV}$. Müller, is C $55.72, \mathrm{H} 7.67, \mathrm{~N} 15.71$, $\mathrm{O} 20.7$.

CHONDRIx is obtained by boiling cartilage or the cornea of the eye with water, and appears to be a modification of gelatin, from which it differs in being precipitated by acetic acid, diluted mineral acids, and the salts of alum, iron, lead, silver, and copper; whilst its solutions are only rendered slightly turhid by tannic acid. When boiled with sulphuric acid it yields no glycin, but only leucin. It is not as yet accurately ascertained whether gelatin and chondrin pre-exist in the tissues from which they are obtained, or are produced in the act of boiling, for on the one hand they cannot be obtained by maceration in cold water, whilst on the other the action of tannic acid on the tissues seems to be of the same nature as on the solution; and when exerted upon the connective tissucs of the skin, effects its conversion into leather. Its percentage composition is $\mathrm{C} 49.9, \mathrm{H} 6.6$, O 28.6, S 0.4 .

KERATIx constitutes the basis of the various horny tissues, as epithelium, epidermis, nails, hoofs, claws, hom, wool, hair, and feathers. It is characterized by swelling and becoming soft in boiling water, though it neither dissolves in this fluid, unless the temperature is much raised by pressure, nor in ether or alcohol. With the exception of hair the tissues in which it is contained are soluble in acetic acid and in alkalies. It is colored vellow by nitrie acid, and under the action of sulphuric acid develops much leucin and tyrosin. The horny tissues in their early state are all composed of soft cells, which subsequently become morlified in form, and nuch firmer in consistence. They contain C, H, N, O, and S in proportions that, whilst closely similar to those of the albuminous compounds from which they are derived, have not yet been accurately determined.

Mucre.-A substance possessing in a high degree the power of absorbing water, and swelling up to a gelatinous and sticky mass of semifluid consistence. No precipitate or coagulation occurs in mucin at a boiling heat, nor is any produced by acetic acid, the mineral acids, or potassium ferrocyanide. It occurs in the body in the mucous fluids, and may be obtained by boiling water from the foetal connective tissue. It is contained in the fluid of Ranula. It differs from albumen. in being free from sulphur, and in containing a smaller amount of carbon and nitrogen.

Prin presents features closely analogous to those of mucin, except that 
it is precipitated by corrosive sublimate and by neutral acetate of lear. On boiling with sulphuric acid, it yields leucin and tyrosin.

Frastry is characterized by its stability and insolubility. It yields no gelatin even on protracted boiling in water, and is not acted on by acetic acid. It is, however, disonlved by boiling alkalies and by sulphuric acid at ordinary temperature, which at last decomposes it, giving rise to leucin. Nitric acid gradually dissolves it with the xantho-proteinic reaction. It is obtained in an almost pure state from the ligamentum nuche, but is generally associated with much comnective tissue.

Globulin or Cristalin is obtained from the crystalline lens. It dissolves in acctic acid, but it is precipitated by exact neutralization with ammonia, and vice verkit, it is dissolved by ammonia, but is precipitated by exact neutralization with acetic acid. It is completely precipitated from its solutions by carbonic acirl.

H.moglobin, Heintocrystallin, a coloring substance closely allied to the albuminous compounds will be fully described in the chapter on the blorel.

Nuclem has been obtained by Miescher from the uuclei of lymph-corpuscles. It is soluble in alkalies and in alkaline bicarbonates, and is precipitated arain by acids.

Cerebrix, $\mathrm{C}_{17} \mathrm{H}_{33} \mathrm{NO}_{6}$, is a white powder which can be obtained from the nervous and some other tissues; it is soluble in warm ether and alcohol, but insoluble in water and in anmonia. It swells up remarkably in cold water. When boiled with acids it yields a kind of sugar, and is, therefore, a glycosicle. ${ }^{1}$,

Pertone, Metapertone.-These terms are applied to the substances resulting from the action of gastric juice on the various albuminous compounds, which they resemble in some points but differ from in others. They are yellowish-white, amorphous, and hydroscopic bodies, soluble in water, not precipitated by heat nor by potassium ferrocyanicle. They are precipitaterl by tannic acid, iodide of mercury-potassium, nitrate of silver, corrosive sublimate, and, when added in large excess, by alcohol. They rotate the plane of polarized light to the left. They are crystalloids, diffusing easily through animal and vegetable membranes. Peptone-like bodies are producer by the action of ozone and of protracted boiling in water, or albumen.

Lecitinx is an imperfectly crystalline body resembling wax, easily fusible and soluble in hot alcohol and ether, and forming combinations with acids and salts. In warm water it swells up like cerebrin. It is very unstable. After protracted boiling with alcohol, and more easily on the aldition of

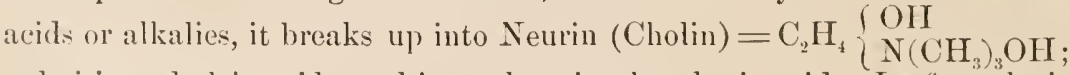
palnitic and oleic acids, and into glycerin-phosphoric acid. Its formula is very complicated, being thus given by Frey:

$$
\mathrm{C}_{3} \mathrm{H}_{5} \begin{cases}\mathrm{O} . \mathrm{C}_{16} & \mathrm{H}_{31} \mathrm{O} \\
\mathrm{O} . \mathrm{C}_{18} & \mathrm{H}_{33} \mathrm{O} \\
\mathrm{O} . \mathrm{PO} & \left\{\begin{array}{l}
\mathrm{OH} \\
\mathrm{O} . \mathrm{C}_{2} \mathrm{H}_{4}\left(\mathrm{CH}_{3}\right)_{3} \mathrm{~N} . \mathrm{OHI}
\end{array}\right.\end{cases}
$$

Besicles heing a constituent of the nervous system, Lecithin occurs in the yolk of the fowl's egre, in the blood-corpuscles, hile; semen, and pus ; according to Danilewsky ${ }^{2}$ it is generated in muscular tissues during tetanus.

I See Liaconow, Centrall,latt, 1868, p. 3. Strecker, Zeitschrift für Chemie, 1868, p. 437 ; and Frey, Histochemie, 1873, p. 29.

2 Centralblatt, 1872, 1). 433 . 
Protucos, which Liebreich and Bayer regarded as a constituent of nervetissuc, is stated by Frey to be a mixture of (erebrin and Lecithin.

[J. L. W. Thudichum says that nerve-matter contains an abundance of water termed "water of colloidation." He says there are three groups of nervematter in the brain: phosphorized bodics, nitrogenized bodies, and oxygenized bodies. Phosphorized bollies contain the phosphorus in the shape of phosphoric acid, proximately combined with glycerin; and they may be subdivided as follows: kephalins, which have a free aftinity for oxygen; myclins, which have none, and lecithins. The nitrogenized bodies imitate the phosphorized, but in a lesser degree, and are cerebrin, phrenosin, and kerasin. The oxygenized bodies consist mainly of alcohols. Jour. of Physiology.]

II Yelis.-The term Myelin was applied by Virchow ${ }^{2}$ to the substance which constitutes the medullary portion of the nerves, but which he, Gobley, and others, also obtained from the blood and bile, spleen, thymus gland, the yolk of egg, the testes and spermatic fluid of the bull, and the ovary of the calf. It is a viscid substance, assuming a variety of forms, that present the most deceptive resemblance to nerve-fibres. It is ensily soluble in. ether, chloroform, turpentine, and hot alcohol, but separates from the latter on cooling. In water it swells up like sago. It is only slowly decomposed by acids or alkalies. Beneke ${ }^{3}$ observing that myelin gave a red color with sulphuric acid and sugar (Pettenkofer's test) regarded it as the glyceride of cholic acid, and consirlered the presence of cholesterin to be a necessary condition of its production, and both he and Neubauer ${ }^{*}$ obtained forms similar to myelin fron an emulsion of cholesterin in soap and water, and from a mixture of oleine, ammonia, and water, and it seems very doubtful whether it can be regarded as a truc chemical compound of constant composition.

Axrloid Substance. - A peculiar form of degeneration sometimes takes place in certain tisues and glands, known as waxy degeneration, in which a homogcneous dull gray substance is deposited differing from other albuminoid compounds in turning of a bluish violet, or mahogany red color, when acted upon by iodine. In some iustances corpuscles are met with resembling starch-grains in presenting concentric striation. These laminated concretions are believed by Rindflcisch ${ }^{5}$ to be the result of successive de-

FIG, 43.

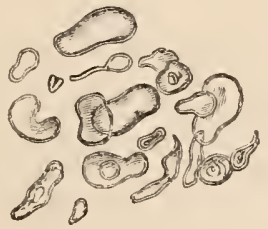

Myelin.
FIG. 44.

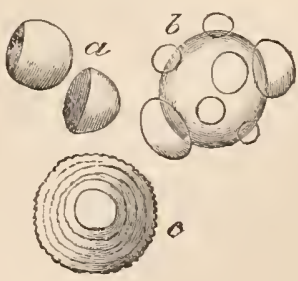

Leucin.

posits of fibrin in cells, or on hremorrhagic deposits or other normal or abnormal elements of the tissues.

Leucin, $\mathrm{C}_{6} \mathrm{H}_{12} \mathrm{~N}_{2} \mathrm{O}_{2}$, or Anido-capronic acid, $\mathrm{C}_{6} \mathrm{O}_{11}\left(\mathrm{~N}_{2} \mathrm{H}\right) \mathrm{O}_{2}$, appears in the form of iridescent scales, which are made up of fine microscopic needles,

1 Virchow's Archiv, Band xxxix, 1867, p. 183.

3 Studien üb. d. Torkom. v. Gall. in Thier. u. Pflanz, 1862.

4 Beneke, in Archiv f. wissensch. Heilkunde, 1865, p. 375; and Neubauer in Virchow's Archiv, xxxvi, p 303.

- Pathological Histology, Syd. Soc. Trans., 1872, p. 44. 
but often also in the form of spheroid or hemispheroidal masses, or of an aggregate of one large spheroid with several smaller ones adherent to it. The spheroids either present a concentric lamination or are destitute of this and resemble fat-cells. It is destitute of taste and smell, is soluble in 27 parts of cold water, but is nearly insoluble in cold ether or alcohol. Its aqueous solution is neutral. It unites both with acids and with bases. It is largely present in the pancreas and pancreatic juice, and is also found in the salivary glands and saliva, in the spleen, kidneys, and suprarcnal bodies; in the thymus, thyroid, and lymphatic glands, in the fluids of the lungs, and in pus, and occasionally in the urine, especially in cases of acute atrophy of the liver. It is either absent or only traces of it can be found in the healthy liver, brain, and muscles. It is in all probability a product of the retrogressive metamorphosis of gland tissue. It has been artificially obtained by Kühne from the action of the pancreatic ferment on albumen. Frerichs and Städeler have shown it to be probable that it undergoes decomposition in the alimentary canal, into anmonia, and the volatile fatty acids.

Trrosin, $\mathrm{C}_{9} \mathrm{H}_{11} \mathrm{NO}_{3}$.-This substance is likewise an amido-acid and forms delicate white silky needles, which have no taste or smell, are soluble with

FIG. 45.

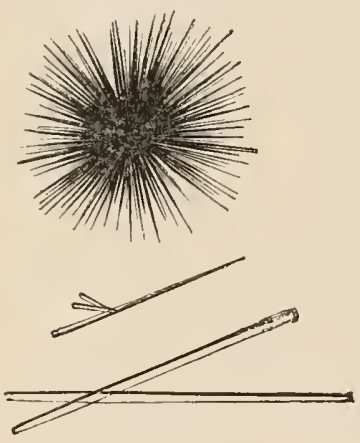

Tyrosin. difficulty in cold water, and are insoluble in alcohol and ether. When boiled with Millon's reagent, the solution first assumes a beautiful red color, and then quickly throws down a darkbrown red precipitate. Tyrosin is said to be found in the spleen and pancreas, and in acute atrophy of the liver in that gland, in the brain, and in the urine; but it is probable, from Radziejewsky's researches, ${ }^{1}$ that it never occurs in any organ in a normal condition, with the single exception of the contents of the small intestines, where it results from the decomposition of albuminous compounds under the influence of the pancreatic juice. Heated with concentrated sulphuric acid it forms Tyrosin-sulphuric acid together with other acids. The former gives a beautiful violet color, with iron and its salts (Piria's test). Tyrosin, like Leucin, is to be regarded as a product of the disintegration of the albuminous compounds.

KriEstin, $\mathrm{C}_{4} \mathrm{H}_{9} \mathrm{~N}_{3} \mathrm{O}_{2}+\mathrm{H}_{2} \mathrm{O}$. - This substance is a constant constituent of muscular tissue, both of the striped and smooth variety, in the proportion of from 2 to 4 parts in 1000; and is found in the blood, brain, urine, and amniotic fluid. It crystallizes in oblique rhombic prisms, which are soluble in hot water, but are deposited again on cooling. It dissolves with difficulty in alcohol, and is insoluble in ether. It is prepared by exact precipitation of the phosphates in the jnice of meat with acetate of lead; separation of the lead by means of sulphuretted hydrogen and careful craporation. On boiling it with baryta water, it is converted into sarkosin-a substance closcly related to the glycin of the bile-and urca, which immediately splits up into ammonia and carbonic acid. When heated with acids, or eren after long exposure to the action of lot water, it loses two atoms of water and becones converted into kreatinin. Under other circumstances, instead of producing sarkosin and urea, it may decompose into oxalic acid and a substance termed methyl-uramin, which stands in close connection with guanin, xanthin, hypoxanthin, and urie acirl; all of which relations 
are full of interest, in reference to the successive stages or plans of disintegration suffered by the albuminous compounds in their passage through

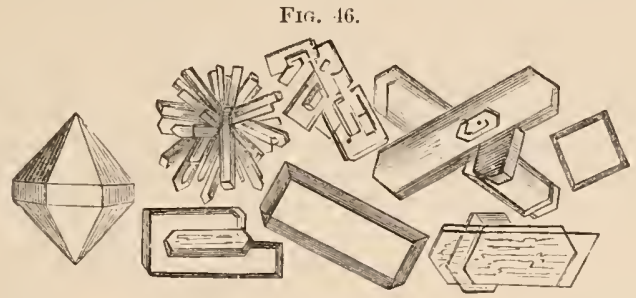

Kreatin.

the body, since ncarly all of them are found in onc or other of the several fluids or tissues.

Kreativis, $\mathrm{C}_{4} \mathrm{H}_{7} \mathrm{~N}_{3} \mathrm{O}$, is usually associated with kreatin, and consequently occurs in muscular aud nervous tissue, and in the blood and urine, but is not found in the glandular textures. Nawrocki, ${ }^{3}$ however, believes his experiments prove satisfactorily that kreatinin is not a constituent of muscle, and that no conversion of kreatin into kreatinin occurs during exercise. As just shown, it may be obtained from the action of acids ou kreatin. It is a porrerful base, and crystallizes in oblique rhombic prisms, which are soluble in water and in boiling alcoliol.

Lutein.-This term has been ap-

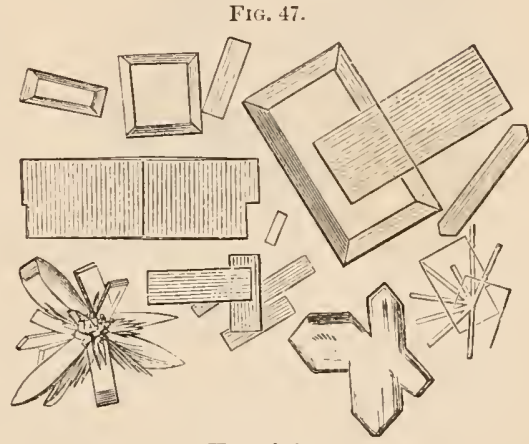

Kreatinin. plied by Dr. Thudichum ${ }^{2}$ to a yellow substance crystallizable in rhombic plates, which can be obtained from various parts of animals and plants. It is normally present in the vitellus of the egg, in the corpora lutea of the ovary, and in the serum of blood, the cells of fat, and under pathological conditions in ovarian tumor's and in serous effusions. It is also contained in the seeds, roots, leaves, and stamens of many plants. It is easily soluble in alcohol, ether, and chloroform, but is insoluble in water. Its spectrum presents three absorption bands in the blue, indigo, and violet portions of the spectrum. It crystallizes and exhibits strong attraction both for fatty and for albuminous substances. The substance termed Hrmatoidin by Holer and Städeler is Lutein; but the Hrematoidin of Valentiner, Robin, Ruhe, and Mercier is Bilirubin or Cholophrein.

Unic AcID, $\mathrm{C}_{5} \mathrm{H}_{4} \mathrm{~N}_{4} \mathrm{O}_{3}$. - When perfectly pure, uric acid appears in the form of colorless, microscopic, rhombic crystals, occasionally in six-sided plates, and sometimes in rectangular four-sided prisms; but as they are usually seen in the urinary deposit of rheumatic patients, the angles of the rhombic plates are rounded off' and stained, more or less deeply, by the coloring matters of the urinc. It is nearly insoluble in water, aud completely so in alcohol and ether. It is dissolved by conceutrated sulphuric acid, and can 
be precipitated unaltered on the addition of water. On subjecting it to a higl temperature, it decomposes and yields urea and cyanuric acid; with oxidizing agents, as ozone and peroxide of lead, it gives allantoin, urea, oxalic and carbonic acids. When acted on by nitric acid, and evaporated to dryness, the residue slightly moistened with amnonia, assumes a beautiful purple tint from the formation of murexide. Uric acid is found in the urine, the blood, the juice of flesh, and in glandular structures, in all of which it probably exists in the condition of urate of soda. It proceeds from the decomposition of the albuminous compounds, and contains 33 per cent. of nitrogen. The proportion of $\mathrm{N}$ to $\mathrm{C}$ is as $1: 2 \frac{1}{2}$.

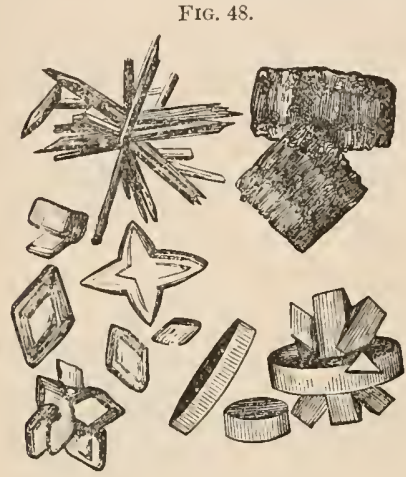

Uric acid.
FIG, 49.

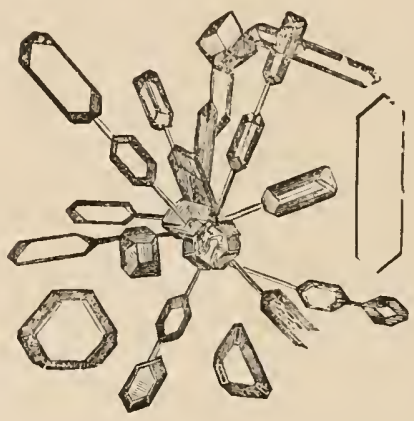

Hippuric acid.

Hippuric Acin, $\mathrm{C}_{9} \mathrm{H}_{9} \mathrm{NO}_{3}$, is one of the constituents of human urine, though, like the last-named acid, it exists only in small quantity. It is always more abundant in the urine of the herbivorous than in that of carnivorous animals. It may be obtained from the urine of the cow or horse by simple addition of hydrochloric acid, when it crystallizes out; by resolution and filtration through animal charcoal, it appears in the form of beautiful, transparent, colorless, four-sided prisms, which belong to the rhombic system. They are soluble with difficulty in cold water and in ether, but more easily in hot water and in aleohol. When benzoic acid is ingested, it is eliminated from the body as hippuric acid-a change that probably takes place at the liver, since benzoic forms hippuric acid by taking up glycin and giving off ten equivalents of water, and it is remarkable that all the herbivora secrete bile which is rich in glycin. Hippuric acid also appears in the urine after the ingestion of bitter-almond oil, cinnamic acid, chinic acil, and toluol into the stomach. Mcisner and Shephard have shown that the hippuric acid of the herhivora is directly dependent on the nature of the aliment, since on feeding them with non-albuminous compounds-fart, sugar, and starch-they ccased to pass this acid in the urine, whilst it reappenred when they were fed on hay, straw, or clover. They bclieve this to be duc to the presence in the latter of a body belonging to the benzole atomic gromp, and by a process of exchusion, that it was the thickcned and infiltrated cell-walls of the cpidermis cells which furnished the primary substance that by conversion yiclded the acid. Thudichum² has recently described another acid, the Kryptophanic, to the presence of which he attributes the normal acid reaction of the urine. It is amorphous, re-

1 Untersuchungen über d, Entstehen der Hippursäure, im Thier. Organismus, 1866.

2 Centralblatt, 1870, p. 195. 
sembling gum arabic when dried, soluble in water, less in alcolol, and still less in ether. It gives a precipitate with many metallic salts. It forms the chicf mass of the so-called Fxtractive of the urine, and its reactions explain the statements that lave been made in regard to the presence of sugar in the urine. It is quadribasic, and has a composition represented by the formula $\mathrm{C}_{10} \mathrm{H}_{18} \mathrm{~N}_{2} \mathrm{O}_{10^{\circ}}$

Aluantorn, $\mathrm{C}_{4} \mathrm{H}_{6} \mathrm{~N}_{4} \mathrm{O}_{3} .-\mathrm{As}$ its name implies, this substance is found in the allantoic fluid of the cow, but it also appears in the acid urine of foctal

FIG. 50.

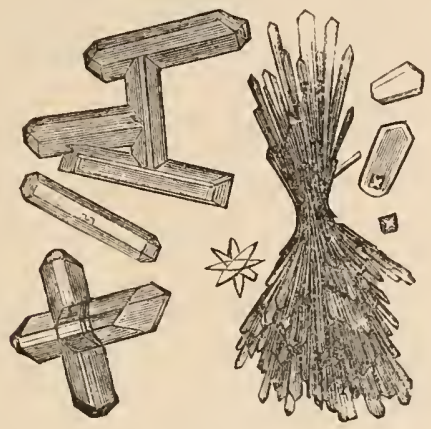

Allantoin.
FIG. 51.

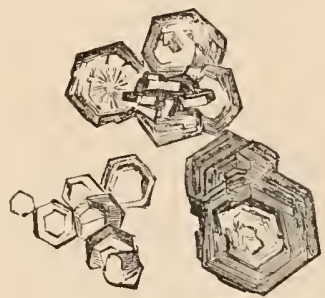

Cystin.

and sucking animals-that is, during the period of life when the herbivora are subsisting on animal food. It has also been found in human urine after the free use of tannic acid. It forms transparent prismatic crystals, soluble with difficulty in cold, but more easily in lot water and in boiling alcohol. It is insoluble in ether. It is closely allied to uric acid and to urea-in fact, under the influence of yeast it breaks up into urea and salts of ammoniaand is consequently one of the terminal products of the disintegration of albumen. It is not precipitated by corrosive sublimate nor by the salts of lead. It has heen found in the urine of dogs suffering from diseases of the lungs, apparently in eonsequence of the deficient supply of oxygen impering the formation of the uric acid ordinarily present.

Crstix, $\mathrm{C}_{3} \mathrm{H}_{6} \mathrm{NO}_{4} \mathrm{~S}_{2}$. $-\mathrm{A}$ rare constituent of the urine of apparently healthy persons, and of renal and vesical ealculi. It is normally present in the killneys of oxen. It forms transparent, colorless, six-sided plates or tables, insoluble in water and aleolol, but soluble in mineral acirls, in oxalic acid, and in caustic and carbonated alkalies. It is, however, precipitated by ammonium carbonate from its acid, and by acetic acid from its alkaline solutions. Like the foregoing substances, it is in all probability a transition stage of the decomposition of albumen or other nearly allied sulphur-holding compound. Its rarity shows that it is the result of a morbid process.

Ures, $\mathrm{C}_{2} \mathrm{H}_{4} \mathrm{~N}_{2} \mathrm{O}_{2}$, crystallizes in white silky, four-sided prisms, which frequently present oblique or diherlual summits. It possesses a bitter cooling taste, like saltpetre, is deliquescent, and very soluble in water and alcohol, hut somewhat less so in ether. It has no action on vegetable colors. It is decomposed at $212^{\circ} \mathrm{F}$., giving off ammonia. It is not affected by potassium permanganate or ozone, but by nitric acid it is decomposed into water, nitrogen, and carbonic acid. Strong mineral acids, and the hydrates of the alkalies, as well as contact with albuminous compounds undergoing putrefaction, effect its conversion into anmonium carbonate. It unites witl nitric and oxalic acids to form salts. It is isomeric with ammonium cyanate, contains 46 per cent. of nitrogen, and is one of the terminal products of the 
retrogressive metamorphosis of the albuminous compounds in man. Its extreme solubility, and the facility with which as a "crystalloid" it permeates

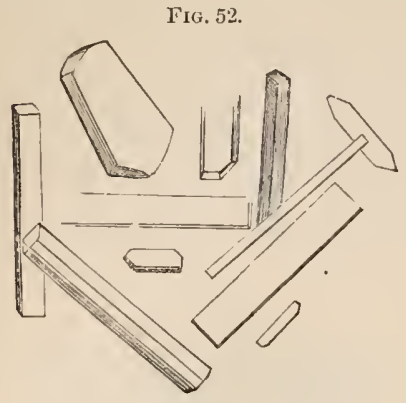

Urea.

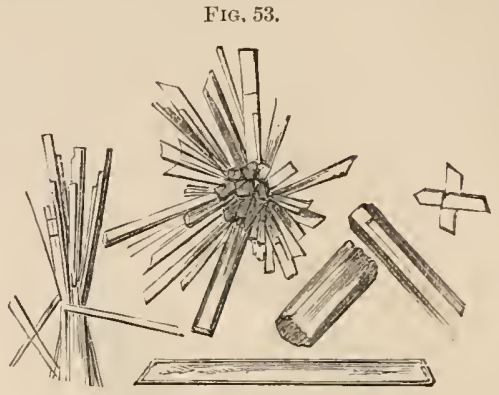

Hydrochlorate of guanin.

animal membranes, permit it to be readily discharged by the urine, of which it is the most important constituent.

Guaxin, $\mathrm{C}_{5} \mathrm{H}_{5} \mathrm{~N}_{5} \mathrm{O}$.- An amorphous, yellowish-white substance, nearly insoluble in alcohol, ether, and water; ensily soluble in acids and alkalies. By oxidation with potassium permanganate, guanin is converted into urea, oxalic acid, and oxyguanin. It constitutes the greater part of the excrements of spiders, but has also been found in the pancreas and liver, and, as its name imports, in guano. It forms crystalline combinations with various acids, one of which is represented in the adjoining woodcut, and also with lime and soda.

Hrpoxanthix (Sarkin), $\mathrm{C}_{5} \mathrm{H}_{4} \mathrm{~N}_{4} \mathrm{O}$, appears in the form of colorless, microscopic, crystalline granules, of no recognizable shape, which are soluble in 300 parts of cold and 76 of hot water, and readily dissolve in acids and alkalies. By nitric acid it is converted into xanthin. It has been found

FIG. 54.

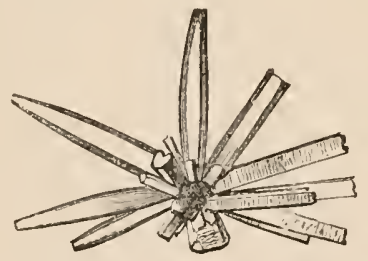

Nitrate of hypoxanthin.
FIG. 55.

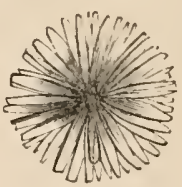

Hydrochlorate of hypoxanthin.

in the blood and urine, especially of leukimic patients, in the juice of flesh, in the liver, spleen, thymus, thy roid, kidney, and brain. It unites with acids to form salts, which, as in the accompanying woodent, form well-defined erystals:

Xavonin, $\mathrm{C}_{5} \mathrm{H}_{4} \mathrm{~N}_{4} \mathrm{O}_{2}$. - This substance, which was first found in certain rare urinary calculi, is amorphous, and presents both in its chemical consti-

FiG. 56.

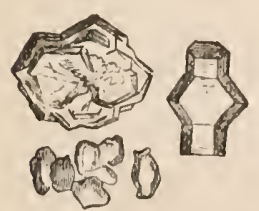

Hyilrochlorate of xanthin. tution and in the places where it is found, the closest analogy to hypoxanthin. It is soluble in 1400 parts of boiling and 14,500 parts of cold water. It is soluble in ammonia, from which solution, by slow evaporation, it is again deposited in confused crystalline scales. It combines with acids, and then presents characteristic crystalline forms. The very intimate connection which exists between the thrce last-mentioned substances and uric acid, $\mathrm{C}_{5} \mathrm{H}_{4} \mathrm{~N}_{4} \mathrm{O}_{3}$, is deserving 
of cspecial attention. They all clcarly constitute successive steps in the downward or retrogressive process of metamorphosis of the albuminoms compounds.

Anmal Qunoidse.-From the experiments of Dr. Bence Jones and M. 1. Dupré, it appcars there exists in the bodies of man and other vertebrata a substance which can be extracter from any of the tissucs by the same process as quinine, when that alkaloid has been ingesterl and absorbed. It possesses nearly the same chemical properties as quinine, and its solutions give the well-known flnorescence charactcristic of quininc.

CHOLIC $\Lambda$ CID, $\mathrm{C}_{24} \mathrm{H}_{40} \mathrm{O}_{5}$, is obtained from glycocholic acid by the action of alkalics. It crystallizes cither in four-sided prisms with dihertral summits, in nctahedra, or in tetrahedra, which are easily soluble in alcohol, but not readily in water or ether. On boiling with acids it yields dyslysin $\left(\mathrm{C}_{24} \mathrm{H}_{36} \mathrm{O}_{3}\right)$, which is only soluble in ether. Cholic acid has a pure bitter taste, and when treated with nitric acid it yields acetic, valerianic, capronic, oxalic, and cholesterinic acids.

Thuris, $\mathrm{C}_{2} \mathrm{H}_{7} \mathrm{NO}_{3} \mathrm{~S}$, is found as a constant constituent of the bile in combination with cholic acid. It has also been occasionally discovered in the blood and nrine, in the tissue of the kidney, lungs, and of the striated muscles. It forms large tasteless and colorless four or six-sided prisms, with four-sided pyramids at their extremi-

FIG, 57.

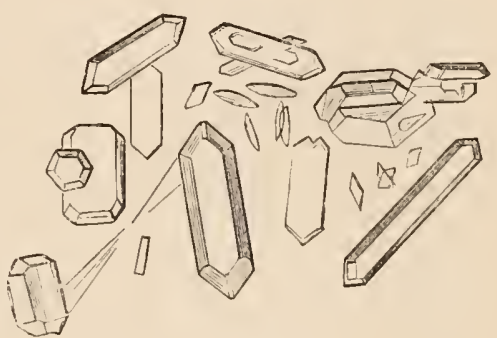

Taurin. ties. It dissolves in fifteen parts of cold watcr, and the solution is ncutral to test-paper. Taurin is decomposed when subjected to a heat greater than $46 t^{\circ} \mathrm{F}$.

Grycis (Glycocol or Gum Sugar), $\mathrm{C}_{2} \mathrm{H}_{3}\left(\mathrm{NH}_{2}\right) \mathrm{O}_{2}$, is chiefly found in combination with cholic acid in the bile, but it also occurs conbined with benzoic acid, as hippuric acid, in the blood and urine. It crystallizes in large colorless rhombohedral crystals, which melt at $354^{\circ} \mathrm{F}$., are easily soluble in water, but with difficulty in alcohol. The solutions are acid to test-paper, and sweet to the taste. It acts both as a base to acids, and as an acid to alkalies. It originates as the product of the disintegration of gelatin and of albumen, and has been artificially formed.

Glycociolic and Taunocholic Acins, $\mathrm{C}_{26} \mathrm{H}_{43} \mathrm{NO}_{6}$ and $\mathrm{C}_{26} \mathrm{H}_{44} \mathrm{NO}_{7} \mathrm{~S}$.When to a solution of crystallized ox-bile neutral acetate of lead is adder, a precipitate of glycocholic acid in combination with the oxide of lead falls, and when this has bcen removed by filtration, the addition of the subacetate of lead to the mother liquid causes the precipitation of the taurocholate of the same metal. The amount of glycocholic acid containcd in the bile of man and of the carnivora is small, but in that of the ox it is abundant. Both acids rotate the plane of polarized light to the right. Taurocholic acid is easily soluble in water, and tastes very bitter. Glycocholic acid dissolves with difficulty. Glycocholate of soda crystallizes in acicular radiating needles. Taurocholate of soda forns resinous drops. Dr. Dalton ${ }^{2}$ observes that the biliary acid or acids of the human subject are precipitated by both the acetate and subacetate of lead. Pettenkofer's test for bile consists in the addition of a little cane sugar, and then of a drop of sulphuric acid to the 
suspected liquid, when, if either of the biliary acids be present, the fluid assumes a bright cherry color, which gradually deepens to purple. Nothing is accurately known respecting the origin of the biliary substances just noticed; part is probably preformed in the bloorl, and is only filtered off by the liver, but part, there can be little doubt, is formed in the liver, and results from the decomposition of albuminous and oleaginous compounds.

55. Hydrocanionaceous Compounds. - The non-azotized or hydrocarbonaceous organic compounds which enter into the composition of the borly may be divided into two groups, the saccharine and the oleaginous. The principal saccharine substances are milk and grape sugar, inosite, glycogen, and the acids resulting from their fermentation. The chief olcaginous compounds are olein, stearin, palmitin, and cholesterin. Both the oily and the saccharine groups are of great importance in the processes of nutrition and development, and are scarcely ever absent either in the food, the bloorl, or the tissues. There can be little question that the saccharine compounds contained in the body are partly derived from the farinaceous and saccharine, and partly from the decomposition of the albuminous compounds, the latter process occurring especially in the liver. That a grcat part of the saccharine and anyloid compounds is derived directly from the foor is clearly shown by the fillowing experiment of M. Bernard. ${ }^{1}$ The muscular tissue of a fasting horse was found on careful examination to be perfectly free from anyloid substances; but in the muscles of the same animal, a few hours after a full meal, clear evirlence of their presence was obtaincl. It seems to be well established that compounds presenting a close analogy to sugar may be obtained by the metamorphosis of oleaginous, as well as of albuminous substances within the body, of which we have examples in their continued formation in the liver, when completely absent in the food, and even during the last stages of inanition, and in their presence and gradual increase in the egg during incubation. The smali quantity of sugar naturally present in the blood aids in retaining the carbonate and phosphate of line in solution, and, according to Hoppe, ${ }^{2}$ assists that metanorphosis by which fitt is generated from the albuminous compounds. Most of the saccharine compounds are soluble in water and alcohol, rotate the plane of polarized light to the right, can be obtained in crystals, lose their water of crystallization at a temperature of $212^{\circ}$, at a little higher temperature are converted into a blackish substance termed caramel, and at a red heat are completcly decomposed into carbonic oxide, carbonic acid, carburetted hyclrogen, acetic acid, acetone, and other products. With oxide of lead and some other bases they play the part of an acid; on fermentation, they either yield alcohol and carbonic acid, or lactic, butyric, and formic acids.

Grape Scgar, $\mathrm{C}_{6} \mathrm{H}_{12} \mathrm{O}_{6}+\mathrm{H}_{2} \mathrm{O}$, crystallizes in warty masses which are found under the microscope to consist of rhombic tablets. It is capable of fermentation, and is especially characterized by its power of reducing all easily reducible metallic oxilles, as those of copper, bismuth, tungsten, and molybdenum in alkaline solutions. It occurs naturally in the alimentary canal as the product of the conversion of starch into sugar through the action of the salivary, pancreatic, and intestinal juices, and from thence by absorption it gains entrance into the chyle and blood. It exists in small quantities in the egre of the bird, in the amniotic and allantoic fluids of the lierbivorat, and oceasionally in the urine of man. It is the chicf or only saccharine constituent of the urine in diabetes, and it may also be made to appear in the urine by injury of the medulla oblongata. 
Ille Sunar, $\mathrm{C}_{12} \mathrm{H}_{22} \mathrm{O}_{11}+\mathrm{H}_{2} \mathrm{O}$, exists in the proportion of from 3 to $5 \mathrm{or}$ 6 per cent. in the milk of various animals. It is feebly saccharine to the taste, and is gritty to the teeth. Like grape sugar it rerluces the salts of copper in an alkaline solution, and rotates the plane of polarization to the right.

GLycones, $\mathrm{C}_{6} \mathrm{H}_{10} \mathrm{O}_{5}$ (Liver sugar).-This remarkable substance was first obtaincel by C. Bernard by immersing the livers of various animals, within a few seconds of their death, in hot water, to coagulate the albumen, then bruising the mass in a mortar and filtering the liquid through animal charcoal. On the addition of alcohol or of glacial acetic acid, the glycogen is precipitated as a white and tasteless amorphous material soluble in water, but incapable of effecting the reduction of the salts of copper. Brücke ${ }^{1}$ has lately recommended the double iodide of mercury and potassium as the best means of completely precipitating pure glyeogen. The solution is prepared by precipitating solution of corrosive sublimate with potassium iodide, washing the precipitate and dissolving it in hot solution of potassium iodide till the latter is saturated with it. Pure glycogen is obtained by first placing the liver in boiling water, then bruising it in a mortar, returning it to the same water, and boiling it for a few minutes; filtering and rapidly cooling the solution with ice or a refrigerator. Hydrochloric acid and the mereurial solution are then alternately added as long as any precipitate falls, the fluid is filtered and spirit of wine adrled to the filtrate till an abundant precipitate of glycogen takes place. This is washed with weak alcohol and finally purified with ether. Glycogen thus obtained is free from nitrogen and leaves no ash when burnt. It is colored red with iodine, not brown. It rotates the plane of polarization to the right. Glycogen was found by Brücke to be constantly present in the muscles, but only very small traces of a substance, the identity of which with glycogen was somewhat doubtful, could be obtained from the blood, spleen, kidneys, or secreting mammary gland, so that it could not be admitted that it was stored up in the body as a preliminary stage of the formation of milk sugar.

All muscles yield sugar, part of which appears to present identity of composition with grape and liver sugar, whilst part possesses distinctive charicters, and has received the name of Inosite. Weiss ${ }^{2}$ found that muscular activity was associated with a marked decrease in the percentage of glycogen in the case of frogs, amounting to a quarter of the total normal quantity. 'The heart, however, in spite of its constant activity, contains (in the dog) two-thirds as much glycogen as ordinary muscular flesh.

Inosite, $\mathrm{C}_{6} \mathrm{H}_{12} \mathrm{O}_{6}+2 \mathrm{H}_{2} \mathrm{O}$, is a kind of sugal which has been found in the expressed muscle-juice of the heart; in the pancreas and thymus glands; in the lungs, kidners, liver, and spleen $;^{3}$ in the brain (Iüller) and suprarenal capsules of the ox. In disease, as in diabetes and Bright's disease, it occurs in the urine. It is identical with the Phaseomannite found in beans, and is found elsewhere in the vegetable kingdom. It crystallizes in long rhombohedra, which are at first transparent but subsequently become opaque. It possesscs a feebly saccharine taste, and has no power of rotating the plane of polarized light, nor does it, like some other kinds of sugar, reduce the salts of bismuth, copper, or silver in an alkaline solution. A good test for it, suggested by Scherer, consists in heating to dryness the supposer mass with a little nitric acid in a porcelain dish, then moistening it with chloride of calcium, and again evaporating it, when a rose-red mass remains. It does not undergo alcoholic fermentation, but when in contact with decomposing albuminous bodies it yields lactic and butyric acids.

1 Wien. Akad. Ber., Band lxii, Feb. 18i3. ${ }_{2}^{2}$ Wien. Akad. Ber., Band lxiv, ii.

3 Cloetta, Vierteljahr. der nat. for Gesells. in Zürich, Band i, p. 205. 
LACTIC ACID, $\mathrm{C}_{3} \mathrm{H}_{6} \mathrm{O}_{3}$, is a compound of considerable ehenical and physiologieal interest, for it is related not only to the saeeharine, but also to the oleaginous and albuminous groups. It may be obtained from the fermentation of milk sugar, in the form of a eolorless syrupy fluid, of pure acid taste, but free from snell, which dissolves in all proportions in alcohol, ether, and water. It also crystallizes in the form of brushes of very fine needles. It is not volatile, and can therefore displaee some of the stronger mineral acids, as the hydrochloric, at a high temperature; when still more strongly heated, however, it yields lactide, carbonie aeid, and carbonic oxide gases. It is connected with the albuminous compounds, of which it may be regarded as a product of the regressive metamorphosis, through alanin, which is isomeric with sarcosin, a derivative of kreatin. To the oleaginous eompounds it is related by the similarity of its composition to propionic acid, which is a prorluet of the oxidation of oleic acid, and it is thus associated with formic and butyrie aeids. Proeceding from one or other of these sourees, it is found widely distributed through the tissues of the body, and is of almost constant oceurrenee in the various parenchymatous juices, especially in that of muscle, the proportion present being considerably inereased after exercise. It appears to be rapidly decomposed in the blood (earbonie acid being left in combination with the bases), since a few minutes

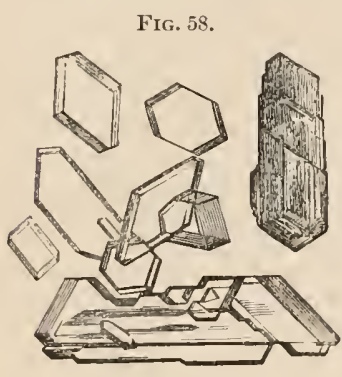

Succinic acid. after the introduction of considerable quantities of the alkaline lactates into the stomach the urine is found to be alkaline from the presenee of their earbonates.

Succinic Acid, $\mathrm{C}_{4} \mathrm{H}_{6} \mathrm{O}_{4} \cdot-\mathrm{A}$ very stable organie acid, crystallizing in rhombic prisus and rhombohedrie plates; it is tasteless, and dissolves easily in water. It oecurs in the parenchynatous juiees of the spleen, thymus, and thyroid glands, of the $x$, in the urine of the herbivora, in the eontents of cysts containing echinoeoeci, in man, in the fluid of hydrocelc, and in considerable quantity in the blood of the rabbit, goat, $0 \mathrm{x}$, and hurse. It appears to belong to a series of acids obtained by the aetion of powerful oxidizing agents on fats, and is one of the terminal produets of thcir disintegration. It ean be obtained from the oxidation of butyric acid, malie aeid, and asparagin, to the use of which last substanee its oecurrence in the urine is probably usually due.

Oxalic AcID, $\mathrm{C}_{2} \mathrm{O}_{2}\left(\mathrm{OH}_{2}\right)$, is frequently found in urine after the use of certain kinds of regetable food. In combination with lime, it constitutes a formidable variety of caleulus. It is a eonstantly-occurring product of the oxidation of organie bodies, and stands in elose relation with uric acid.

56. Olenginous Compounds.-The animal fats are glycerides, i.e., compound cthers of the trivalent aleohol glycerin, and the fitty acids. Those usually present are tripalmitin, tristearin, and triolein, which are represented by the formula:

$$
\begin{aligned}
& \text { Tristearin (Tristearie Aeid Glyeeride), } \\
& \text { Tripalmitin (Tripalmitinie Acid Glyceride), } \\
& \text { Triolein (Triolcinie Aeid Glyceride), } \\
& \left.\begin{array}{r}
\left(\mathrm{C}_{18} \mathrm{H}_{33} \mathrm{O}_{3}\right) \\
\mathrm{C}_{3} \mathrm{H}_{5} \\
\left(\mathrm{C}_{16} \mathrm{H}_{35} \mathrm{O}_{3}\right) \\
\mathrm{C}_{3} \mathrm{H}_{5} \\
\left(\mathrm{C}_{18} \mathrm{H}_{33} \mathrm{O}_{3}\right) \\
\mathrm{C}_{3} \mathrm{H}_{5}
\end{array}\right\} \begin{array}{l}
\mathrm{O}_{3} \\
\mathrm{O}_{3}
\end{array}
\end{aligned}
$$

These are assoeiated in human fat in the proportion of about three-fourths of stearin and palmitin and one-fourth of olein. The substance formerly called 
margarin is a mixture of tripalmitin and tristearin. A separation of these proximate principles within the cells may occisionally be observer at low temperatures; the more solid fats, tripalmitin and tristeariu, appearing as a minute stella of erystalline form, surrounded by the still fluid triolein. The mean percentage composition of luman fat is $\dot{\mathrm{C}} 76.62$, H $11.94, \mathrm{O} 11.44$. expressed by the empirical formula $\mathrm{C}_{62} \mathrm{H}_{99} \mathrm{O}_{6}$. Exposed to the action of supcrheated steam, they break up into the fatty acils and glycerin. All the animal fats are soluble in hot alcohol, in ether, fluid oils, benzole, carbon disulphide, and in chloroform. They are distinguished from one another by the tenmperature at which they respectively solidify, and by the salts that they form with the alkalies.

The following table shows about the proportion in which they are found in some of the fluids and tissues of the body :

\begin{tabular}{|c|c|c|c|c|c|}
\hline & $\begin{array}{l}\text { Percentage } \\
\text { of fat. }\end{array}$ & & & $\begin{array}{l}\text { Percentage } \\
\text { of fitt. }\end{array}$ & $\begin{array}{l}\text { Pereentage } \\
\text { of fat. }\end{array}$ \\
\hline Swent, & . 0.001 & Blood, & & $0 . \pm$ & .4 .3 \\
\hline Vitreous humor & 0.002 & Cartilage, & & 1.3 & Cortex of Brain, \\
\hline Salira, . . & . 002 & Bone, . . & & 1.4 & Brain (whole), . 8.0 \\
\hline Lymph, & .0 .05 & Bile, ... & & 14 & Hen's Egg, : . 11.6 \\
\hline Synovia, : & 0.06 & Crystalline & Lens, & 2. & Medulla of Brain, 20. \\
\hline $\begin{array}{l}\text { Liq. Amnii, . } \\
\text { Chyle,. }\end{array}$ & 0.06 & Liver, . & - & 24 & Nerves, . . . 2.2.1 \\
\hline $\begin{array}{l}\text { Chyle, . } \\
\text { Mueus, }\end{array}$ & - $\quad 0.2$ & Muscles, & - & $\begin{aligned} 33 \\
4\end{aligned}$ & Spinal Cord, \\
\hline Mueus, & 0.0 & Hatr, & & & Adprose Tlssue, \\
\hline
\end{tabular}

Cholesterix, $\left.\quad \mathrm{C}_{2 \ell} \mathrm{H}_{43}\right\} \mathrm{O}+\mathrm{H}_{2} \mathrm{O}$ (or biliary fat), is a hard spermaceti-

like substance, which separates from its solutions in nacreous scales, that are found under the microscope to have the form of rhombic tablets, the obtuse angle being $100^{\circ} 30^{\prime}$, the acute $79^{\circ} 30^{\prime}$ : it is quite insoluble in water, but is soluble in ether, and also in boiling alcohol, from which, however, the greater part separates on cooling. It does not melt until heated to $298^{\circ}$, and it solidifies again and becomes perfectly crystalline at $275^{\circ}$. It is not decomposed by coucentrated alkalies even when the mixture is subnitted to prolonged heat. It is found in plants, ${ }^{1}$ and is constantly present in the blood, in the proportion of about two parts in ten thousand; its quantity seems to be augmented in old age. It is found also in the lymph, in most glands, and is stated to be a constituent of the nervous tissue, being probably a product of the disintegration of the nerve-substance. It is frequently separated from the bloor as a morbid product; thus it is often present in considerable quantity in dropsical fluids, and particularly in the contents of cysts. It is occasionally secn in disorganized eyes, floating in detacher scales in the fluid vitreous, and is sometimes depositerl in the solid form in degenerated structures, tubercular concretions, etc. Strong arguments have been adduced by $D_{r}$. Austin Flint ${ }^{2}$ for regarding it as an excrementitious principle discharged by the liver, and hardly second in importance to urea. He has found it always more abundant in the blood returning from the brain than clsewhere; also that its quantity is exceedingly small in the venous blood of the paralyzed side in hemiplegia ; and that in cases of serious structural disease of the liver, accompanied by symptoms pointing to blood-poisoning, cholesterin accumulates in the blood, constituting a condition which he has called Cholesteræmia.

Stercoris.-This term has been applied by Dr. Austin Flint to a peculiar substance, crystallizing in needles, which may be extracted from normal freces by the successive action of ether, alcohol, and a hot solution of caustic potash, by which all the saponifiable fats are removed. On largely diluting

2 Physiology of Man, vol. ii, p. 402. 
the mixture with water, filtering, acting on the residue with ether and alcohol, and evaporating, pure stercorin may be obtained. It resembles cholesterin in many points, and is believed to proceed from that substance. Its crystalline form is, however, different, and it fuses at a lower temperature $-96.8^{\circ} \mathrm{Fahr}$. About ten grains are eliminated per diem.

57. Inorgaxic Compounns.-The prineipal inorganic compounds that form part of the tissues and fluids of the borly, are water, carbonic acid, and ammonia; the carbonates, chlorides, sulphates, and phosphates of the alkalies and alkaline earths, and potassium sulphocyanide. Wuter is the most widely distributed of all the constituents of the body, and forms rather more than half its weight ( 59 per cent.), the different tissues, however, containing very various amounts, from the enamel of the teeth, which has only 2 per 1000 , to the reual tissue, which has 827 per 1000 . Fat contains 209 per 1000 ; the tissues of the liver 693 ; of the spinal eord, 697 ; of the skin, 720 ; of the brain, 750 ; of the muscles, 757 ; of the spleen, 758 ; of the thymus, 770 ; of the nerves, 780 ; and the heart, 792 parts in 1000 . It is for the most part directly ingested, but a small portion is probably also found in the body, as one of the terminal products of the various chemical changes undergone by the more complex substances used as food. It is discharged from the body by the kidneys, skin, lungs, and bowels. It confers elasticity, extensibility, and transparency on the several tissues. It is a general solvent, and is essential for all processes of imbibition, diffusion, and of movement in general, both in a chemical and physical sense. By its evaporation, a large amount of heat is rendered latent, and it hence serves as thc chief heat regulator of the body. The physiological significance of the various saline constituents, except in so far as they form part of the bony skeleton, has not been satisfactorily ascertained, though in some instances, it is probable they serve to retain in solution some of the organic compounds. With the exception of common salt, they are rarely taken into the body in their chemically pure state, being usually combined with the organic constituents of the food, and are no less important than these in the general processes of nutrition. In some few instances, they appear to be formed in the body, as in the case of the alkaline sulphates and phosphates, the former of which, whilst partially consumed with the foor, are in part derived from the oxidation of the sulphur contained in the albuminous compounds, whilst the latter in part proceed from the oxidation of phosphorus in organic compounds. The saline compounds are eliminated for the most part unaltered by the kidneys and bowels. The chief exceptions to this rule arc found in the salts of the vegetable acids as the tartrates, malates, and citrates, which undergo decomposition in the hlood, and are discharged in the condition of carbonates. The most widely distributed, as well as perhaps the most important salt in the body is sodium-chloride, or common sult. The blood contains rather more than 4 parts of it in 1000 , and the proportion undergoes but little variation, whether an excess or a deficiency be ingester with the food-in the one case the superfluous quantity being quickly eliminated by the urine, and in the other, the system retaining its lold of the salt with such pertinacity that the quantity discharged fidls to a minimum, or its elinimation is altogether arrested. Dr. Broalbent has pointed out that this retention can only be in virtue of a special chemical relation between the salt and the animal tissues and fluids, and it is in consequence of such atfinity that it, as well as other salts, are of service in the organic processes. It is present in considerable quantity in chylc, lymph, and white of eggs; in the

1 An Attempt to apply Chemical Principles in Explanation of the Action of Rimedies and Poisons. i869. 
salivary and gastric fluids; in mucus, pus, and inflammatory exudates; whilst it is remarkably deficient in the yolk of ergs, in the juice of muscles, and in the secretion of some glands. Its uses are numerous. It exerts an important influence on all the diffusion processes that take place in the borly, affecting in this way the absorption and interchange of matcrial; whilst by conferring, in association with other salts, a certain density upon the blood plasma, it plays an important part in the conservation of the morphological clements of the blood in their natural condition. It also seems to be essential to the performance of many of the metamorphic and histogenetic operations to which the organic constituents of the food are subjected in the animal economy. It was demonstrated by Bonssingault, ${ }^{1}$ that when, of two sets of oxen, one was allowed the unrestricterl use of salt, whilst the other was as far as possible deprived of its usc, a marked contrast was observable in the course of a few weeks between them, and manifestly to the advantage of the former. The desire for common salt on the part of animals and man is extremely powerfil, leading the former, especially if they be vegetable feeders, to traverse great distances to reach saline deposits: whilst strong evidence of the necessity for its use in man is afforded by the fact mentioned by Brïcke, that many military deserters who live a wild life in the mountains of Salzburg, Upper Austria and Carinthia, risk their liberty and even lives to obtain it in town or village. Sodium phosphate $\left(\mathrm{Na}_{2} \mathrm{HPO}_{4}\right.$ and $\mathrm{Na}_{4} \mathrm{H}_{2} \mathrm{PO}_{4}$ ) and carbonate, the latter of which is partly ingested with the food, and partly results from the decomposition of the salts of malic, citric, and tartaric acids, would seem to have as their chief purpose the maintenance of the alkalinity of the blood, on which depends not merely the solubility of its albumen, but the facility of its passage through the capillaries, and the readiness with which its combustive materials are oxidized, whilst they also increase the absorptive power of the serum for gases, and thus play an important part in the respiratory process. The salts of potash appear to be specially required for the nutrition of the muscles and nerves, since they are largely present in the fluids and aslies of those tissues, but they probably exert the same general influence as those of soda. The quantity present in the blood cannot exceed certain limits, since the observations of Grandeau and others ${ }^{2}$ have shown that the injection of potassium salts, and especially of potassium chloride, are even in dilute solution highly poisonous, paralyzing the heart and striated muscles. It is remarkable that when injected into the stomach the action of the chloride is different, increasing the frequency and force of the heart's action, and the pressure of the blood." The presence of the earthy salts, on the other hand, would seem to have reference almost exclusively to the composition of the tissues, into which some of them enter very largely. Culcimm phosphate, in particular, must be regarder alnost in the light of a histogenetic substance so constantly is it present in newly forming tissues, whilst it is also in great demand as the principal consolidating material of bone and tooth. Whether the calcium carbonate, magnesium phosphate, the calcium fluoride, and the silicu of the blood, are of any other use than to supply consolidating materials for the tissues, there is at present no evidence whatever. Iron, like the alkaline salts, is an essential constituent of the blood itself, forming a large percentage of the hrematoglobulin of its red corpuscles, and it is supplied by the blood to various tissues, especially the muscles and the hair, of which also it may be eonsidered an essential component. Estimating the quantity of

1 Mémoire de Chemie Aıricole, 1854, p. 271.

2 Traube, Bernard, Ranke, Podcapäw, and Guttmann.

3 Kemmerich, Archiv f. Phys., Band ii, p. 49. 
blood with Bischoff (highly) at 7.7 per ccnt. of the whole weight of the body, the total quantity of iron contained in the blood of a man, weighing about $150 \mathrm{lbs}$., would be 45 grains. The normal proportions of all these substances are essentially maintained by means of the excretory apparatus, which filters off (so to speak) any surplus, it being through the urinary organs that they are chiefly elimiuated. And it is by them too that the normal proportion of water in the blood is maintained; the Malpighian apparatus of the kidneys apparently acting ats a kind of safety-valre, through which any surplus that remains after the cutaneous, pulmonary, and intestinal exhalants have performed their appropriate duties, is allowed to make its escape.

\section{CHA PTER V.}

\section{OF FOOD, AND THE DIGESTIVE I'ROCESS.}

\section{Of Food, its Nature and Destination.}

58. From the forcgoing obscrvations regarding the composition of the tissucs and fluids of the borly, it may be concluded that the substances which are required by animals for the development and maintenance of their fabric are of two kinds, the Organic and the Inorganic. The Organic alone are commonly reckoned as aliments: but the latter are really not less requisite for the sustenance of the body, which speedily disintegrates if the attempt be made to support it upon any Organic compounds in a statc of purity. In all orlinary articles of diet, however, the Inorganic matters are present in the requisite proportion; and hence it is that the necessity which exists for their employnent has very commonly escaped notice.

59. The Organic compounds usually employed as food by Man are partly derived from the Animal, and partly from the Vegetable Kingdom; and they may be conveniently arranged under the three heads already mentioned of the Saccharine, the Oleaginous, and the Albuminous-under which last. gelatin is included. There are many other substances, however, which, though truly alimentary and consumed to a considerable amount, cannot be legitimately placed under either of the above heads-such are, for example, the vegetable acids, and pectin, or vegetable jelly. The compounds belonging to the Saccharine group ${ }^{1}$ consumed as food, though existing in suall pro-

1 By far the most important of the hydrocarbonaceous eompounds is stareh, which exists in the roots, tubers, stems, leaves, fruit, and seeds of plants, both as an anorphous and as a morphological constituent. In the former eondition it is comparatively rare, but in the latter it appears in the form of separate granules, presenting, as muy be well seen in potato starch, a series of coneentrie lamina arranged around an eceentrically situated point. Every stareh-granule eonsists of three kinds of substince-of granulase, which is eolored blue by ioline; of erythrogramulose, which is eolured red by it; and of cellulose, which is not colored by it. If iudine be added to a stareli-granula, it becomes of a deep-blue tint, beeause the granulose is by far the liurest constituent; but if very little iodine be added the grarula becomes of a reddish color, beeatuse the erythrogramuluse has the strongest aflinity for it, and sei\%ces upon it. On boiling with a 2 per cent, solution of sulphuric acid, stareh is rendered soluble, and is convertul into Nasse's amilulin, which still turns blue with jodine. On longer boiling it undereroes a further change into erythrodertrin, or ordinary dextrin, which colors red with iodine; and after a still longer time it becomes converted into another kind of dextrin, achroodextrin, whieh tastes sweet and does not culor with iudine, and into a kind of sugar termed glycose (stareh sugar, dextrin sugar, grape sugar). All the abovementioned bodies rotate the plane of polarization 
portions in the animal tissues, are principally derived from the vegetable kingdom, in which they are frequently present to a large anount. The pure sugars undergo little change before absorption, though they are sometimes partially decomposed into lactic and butyric acids. It is probable that cane-sugar undergoes conversion into grape-sugar either at the liver or soon after it has entered the blood. Starch is for the most part converted into dextrin and grape-sugar; and by a further process of oxidation or combustion, these compounds generate carbonic acid, which is chiefly eliminated by the lungs, and thus become directly subservient to the generation of nervo-muscular force, and to the maintenance of the heat of the body. That the saccharine substances are per se insufficient for the maintenance of life has been shown by numerous experiments upon animals, and by the interesting experiments of Dr. Hammond, ${ }^{1}$ who on one occasion limited himself to a diet of $1 \frac{1}{2} \mathrm{lb}$. of gum per diem, and on another to a similar quantity of starch and water. In both sets of experiments hunger, debility, and febrile excitement were soon experienced, and he was finally compelled to discontinue the gum diet on the fourth day, though he was able to persevere in the use of the starch till the tenth-a circumstance which was probably partly due to its still retaining a small proportion of gluten, and partly to its not producing such serious disorder of the stomach and bowels as the gum.

60 . The Oleaginous compounds $(\$ 56)$ which enter so largely into the composition of the body-being not only stored up in masses in the adipose substance, but also forming constant and important constituents of the muscular, nervous, and other tissues-are partly introduced into the system from without, and are also partly the result of the chemical metamorphoses effected within the body upon the albuminous and saccharine compounds: by which means the latter become subservient to the nutrition of the several nitrogenous as well as non-nitrogenous tissues. In the diet of the Carnivora, the fits almost entirely replace the carbohydrates consumed by the Herbivora. Previous to absorption the oleaginous substances undergo fine division, and, perhaps, to some extent saponifieation; whilst after their entrance into the circulation they are partly applied to the purposes of nutrition, partly to the production of nervo-muscular force, and partly, there is good reason for believing, combine immediately with oxygen, and thus sup)port the animal heat. Like the saccharine, the oleaginous compounds when consumed alone are wholly incapable of supporting life; and the only benefit that a starving animal obtains from their consumption is the maintenance of its temperature, and a consequent slight prolongation of its life; death occurring, as has been shown by Mr. Savory, when non-nitrogenous food is freely supplied, ${ }^{2}$ not from loss of temperature, as in inanition, but from loss of tissue. The experiments of Dr. Ed, Smith on the elimination of carbonic acid, and of MIM. Fick and Wislicenus, and Dr. Parkes, on the excretion of nitrogen during rest and exercise, as well as the more theoretical considerations adduced by Professor Frankland, alike tend to show that during the period of active exertion the nitrogen-holding substance of the muscles undergoes comparatively trifling increase in the disintegration to which it is constantly subject, whilst a marked increase occurs in the

to the right Changes essentially sinilar to those just described as moduced in stareh by boiling with acid, are effeeted by the action of a ferment termed diastase, which is developed in germinating seeds. Diastase breaks up starch into glycose and achroodextrin, and if fermentation continues the latter is gratually almost wholly eonverted into glycose. See Brücke, Vorlesungen, 1874.

1 Experimental Researches on Fuod, Philadelphia, 1857.

2 Proeeedings of Royal Society, Maty 1st, 1862. 
oxidation of the hydrocarbonaceous constituents; the union of these with oxygen, or their combustion, appearing to generate the force which is rendered apparent in locomotion or manual labor. Hence it is found that considerable, and with healthy muscles even prolonged, exertion can be made on fond containing little or no nitrogen-as, for instance, on biscuits made of starch and sugar, or starch and fat. General experience, however, as well as the experiments of Dr. Hammond and Mr. Savory-as we have already seen-and especially those of Dr. Parkes, which will hereafter be more fully discussed, show conclusively that there is a limit to the muscular force which can be exerted under such circumstances; and that when food has been administered which is either altogether deficient in nitrogren, or which contains an insufficient supply of that substance, sooner or later the power of the muscles diminishes, and at length altogether fails. It may therefore be regarded as a well-established fact that when severe and sustained muscular exertion is required to be performed, the food must contain not only a due supply of hydrocarbonaceous and easily oxidizable substance which may develop the muscular force, but also a sufficient amount of nitrogenous material to repair the waste of tissue which occurs in the act of contraction.

61. The substances forming the Albuminous group (\$53) are applicable to the support of the Animal body, both by aftording the materials for the nutrition and re-formation of its tissues, and also by serving for the maintenance of its heat, and the production of muscular force, through the decomposition of which they are susceptible, into hydrocarbonaceous matters capable of undergoing direct oxidation, and highly azotized compounds which ultimately pass off by the kidneys. The proportions of carbon, hydrogen, oxygen, and nitrogen, of which all these substances are composed, appear to be very similar; and they seem all capable of being reduced by the digestive process to a like condition. Hence it is a matter of little consequence, except as regards the proportion of inorganic matters with which they may be respectively united, whether we draw our histogenetic materials from the flesh of animals (myosin, syntonin), from the white of egg (albumen), from the curd of milk (casein), from the grain of wheat (gluten), or from the seed of the pea or bean (legumin). Neither of these substances, however, can long sustain life when it is used by itself; for it has been experimentally ascertained, that by being made to feed constantly on the same substance. (boiled white of egrg, for instance, or meat deprived of the osmazome that gives it flavor), an animal may be effectually starved; its disgust at such food being such, that even if this be swallowed, it is not digested. Thus Dr: Hammond limited himself' for a period of ten days to a diet of about $1 \frac{1}{2} \mathrm{lb}$. of albumen obtained from the serum of bullock's blood, and 4 lbs. of distilled water per dienr. Little inconvenience was experienced until the fourth day, when loss of appetite, headache, and debility were felt. The severity of these symptoms rapidly increased, and the disgust which the monotony of the diet occasioned was so great, that it was with much difficulty the albminen could be eaten. On the seventh day, albumen appeared in the urine; and on the ninth, such severe diarrloa set in that lie was compelled to give up the experiment. There was no failure in the maintenance of the temperature of the body, though its weight was notably diminished at the end of the experiment, and the mental ficulties remained clear throughout.-The organized fabric of Animals contains also a large quantity of Gelutin-yielding tissues. It secms certain that these tissues may be produced out of fibrin and albumen; since in animils that are supported on these, or at least consume no gelatin with their food, the nutrition of the gelatinous tissues does not scem to be inipaired. The experiments of 
Bischoff and Voit, ${ }^{1}$ when taken in conjunction with the inquiries of the conmissioners appointed to investigate the subject in Paris and Amsterdam, ${ }^{2}$ appear to have establisher that, though gelatin is not destitute of nutritive value, it camnot permanently replace albunen as an article of diet. For a short period it may indeed be serviceably, perhaps even advantageously employed; and the nutritive value which experience has long assigned to soups and broth, whilst partly attributable to the albuminous matters which they hold in solution, may also in some measure be due to the readiness with which their gelatinous constituents can be absorbed and applied to the purposes of nutrition and calorification. The very large quantity of gelatin which Bischoff and Voit found it necessary to make their dog consume in order to maintain its weight-a quantity of dry gelatin, in fact, equal to the weight of moist flesh on which the animal was ordinarily fed-is worthy of particular notice, and furnishes an explanation of the negative results which were obtained by previous inquiries. ${ }^{3}$ That it rapidly undergoes a decomposition analogous to that of the albuminous compounds, is evident from the observations of Frerichs on the result of the ingestion of large quantities of pure gelatin: this being a marked increase in the proportion of urea in the urine, with an elevation of its specific gravity from 1018 to 1030 or even 103t. It is very interesting to remark (with Dr. Prout) that, in the only instance in which Nature has provided a single article or food for the support of the animal body, she has mingled articles from the first three of the preceding groups. This is the case in Mill, which contains a considerable quantity of albuminous substanse, casein, which forms its curd; a good deal of oily matter, the butter; and no inconsiderable amount of sugar, which is dissolved in the whey. 'The proportions of these vary in different Mammalia, and they depend in part upon the nature of the food supplied to the Animal that forms the milk; but the substances are thus combined in every instance.

62. Up to a comparatively recent period, attempts were made to divide all kinds of food, in accordance with their supposed application in the body, into two great classes, called respectively the "histogenetic" or tissue-forming, and the "respiratory" or heat-producing aliments. It was imagined

1 Gesetze der Ernährung, 1860, p. 215.

2 See the Report of the French Gelatin Commission, in the Compt. Rend., Aout, 1841 ; that of the Amsterdam Commission in Het. Institut, No. 2, 1843; Gazette Mélicale, Mars 16,1844; Toit's paper in the Zeitschrift für Biolugie, Band viii, 1872 , p. 297 ; and Etzinger in idem, Band $x$, p. 84.

3 That Gelatin is not destitute of nuiritive value is shown by the fuct that in one of Bischotf and Toit's experiments a dorg, weighing abont $80 \mathrm{lbs}$, lost in four days one pound in body weight when fed with 500 grammes ( $1 \mathrm{lb} .1 \mathrm{oz}$. avoir.) of meat alone, but gained in three day: 134 grammes (2069 grains) when the same: quantity of meat was given together with 200 grammes (3088 grains) of gelatin. That gelatin, even when given in eonsiderable quantities, will-not sujport lile, is shown by the results of another experiment, in whieh a dog weighing over $50 \mathrm{lbs}$. died on the 31 st clay when supplied witl 3088 grains of gelatin, 2316 grains of stareh, 1544 grains of fat, and 185 grains of flesh extract. Etzinger has recently shown (Zeits. f. Biologie, B. $\mathrm{x})$ that ligament, cartilage, and bone, are all largely soluble, with loss of their gelatinifying power, in gastric juice, and are all capable of absorption. Liebig's essence of meat contains from $16-21$ per eent. of water, $18-\div 2$ per cent. of ash, and $56-60$ per eent. of substanees soluble in atcolol of 80 per cent. strength (Thudichum, on the Origin, Nature, and Uses of Liebig's Extract of Mrat, Pamphl('i, 1869) and no gelatin or fat. In regard to the physological action of beef tea and the extract of meat, the reader may refer to the pamphlets on this subject by Kommerieh, Beljawsky, Bogoslowsky (Centralblatt, f. d. Med. Wiss., No 32, 1871, und Archiv f. Anat. v. Phys., 1872), and to Bunge (Cbl., 1871, p. 636). Kemmerich attributed these good effects to the influence of the alkaline salts they eontain exclusively, a vicw that is not supported by the results of experiments pertormed by other observers. 
that a definite line could be drawn between the non-azotized, including the oleaginous and saccharine substances, on the one hand, and the azotized, embracing the albuminous group and gelatin, on the other; the former being subservient to the production of heat, the latter to the repair and development of the different tissues. To a certain extent this division is unquestionably based on correct principles. The presence of a large proportion of Nitrogen in all the higher tissues of the Animal body clearly indicates that for their due nutrition some substance containing Nitrogen should be consumed as food; and the justice of this inference has been fully borne out by experiment. In this selise, then, the albuminous and gelatinous substances are truly histogenetic. On the other hand, the large proportion of Carbon and Hydrogen in saccharine and oleaginous compounds naturally suggests that the chief purpose to which they are applied in the body is the maintenance of its temperature by their combination with oxygen. But the muscular, nervous, and glandular tissues are not composed of albuminous substances alone; they contain, as an essential constituent of their structure, a certain portion of fat, without which their composition would be imperfect, and the performance of their functions impossible. Such fitt, then, must be considered as "histogrenetic" and not as "calorifacient" fat; though like that which exists in the free state in the blood, or is stored up in the adipose tissue, after having fulfilled its functions, it may be applied by its combustion to the support of the animal heat and the production of nervo-muscular force. In a manner essentially sinilar, the albuminous substances ingested, whilst partly becoming assimilated and applied to the nutrition of the tissues, are partly also directly decomposed in the blood; the products of their disintegration in both instances combining with oxygen, and yielding a certain amount of heat or other force; so that, like the oleaginous and saccharine substances, they are applied to the carrying out of both provisions, the formation of tissues, capable of generating nervo-muscular, or other form of activity, and the maintenance of an elevated temperature, though undoubtedly in each case to a very unequal degree. It is, however, impossible to measure the value of any particular kind of food for either purpose by a consideration merely of its ultimate or even of its proximate constitution; since its fitness as an article of diet will also depend upon the facility with which it may be reduced by the digestive process, and afterwards assimilated. Thus an aliment abounding in nutritive unatter, may be inferior to one which really contains a mucl smaller proportion, if only a part in the first case, and the whole in the second, be readily taken up by the system.

63. It is obvious that the most economical diet will be that in which there is the most perfect apportionment of the several classes of constituents to the wants of the system; and these will vary with the amount of muscular exertion put forth, and with the elevation or depression of the extemal temperature. Thus, for a man of ordinary habits, and living under a medium temperature, a diet composed of either bread or of animal flesh alone is far from being the most econonical. No doubt there are particular conditions of existenee, under which life may be advantageously supported upon animal fool alone. Thus the Guachos of South America, who pass the whole dily in the saddle, and lead a life of constant activity resembling that of a carnivorous animal, searcely ever taste anything but beef; and of this their consumption is by no means great; for the temperature of the surromeding atmosphere is so high, that the body has no occision to generate more heat than is supplied by the eombustion of the hydrocarbonaceons portion of the albumen of the food or of "waste" of the tissues. Here, then, the demand for histogenetic material being at its maximum, and that for combustive materials at its minimum, the former supplies all that is requisite for the 
latter. $\Lambda$ gain, the Esquimaux and other dwellers upon the Aretic seas find in the bodies of the whales, seals, etc., whereon they subsist, that special supply of the very best combustive material, which alone can enable them to maintain their existence in a climate where the thermometer is for many weeks or months in the year at $-40^{\circ}$ or even lower, and where the amount of heat which must be generated within the body is four or five times that for which a diet of bread will sufficc.-On the other hand, the general experience of the inhabitants of warm climates seems in favor of a diet chiefly or entirely regetable; and its peculiar suitableness appears to consist in its affording an adequate supply of the plastic alimentary substances, in combination with farinaceous matters that give the requisite bulk to the food, without affording more combustive material than the system requires, - the quantity of starch which undergoes conversion, and which is introduced as sugar into the circulation, being apparently governed rather by the demands of the respiratory process than by the anount ingested; and the remainder being roided again unchanged.

64. In a well-arranged system of diet, the proportion that the non-azotized substances ought to bear to the azotized should be determined by the proportion of Carbon and Nitrogen which are eliminated in the excreta of a healthy man in a given period. Now we know fron various experiments that with active exertion about 300 grains of Nitrogen and 4600 grains of Carbon are daily discharged by the several channels of the lungs, skin, kidners, and bowels; the proportion of the Nitrogen to the Carbon eliminated being, therefore, nearly as $1: 15$. Now, if we compare the composition of bread and of meat, we shall see what is their relative value as aliments, by the proportion which the $\mathrm{C}$ holds to the N. According to Palyen, ${ }^{1} 1000$ grains of Bread contain, in round numbers, 300 of Carbon, and 10 of Nitrogen; hence, to obtain the 300 grains of Nitrogen required by the system, 30,000 grains (or more than 4 lbs.) of Bread must be consumed; but the 4600 grains of Carbon required are contained in 15,000 grains of Bread; so that to obtain the requisite supply of Nitrogen a quantity of Bread must be consumed containing exactiy double the quantity of Carbon required. Hence it is adrantageous to add to a bread diet a small quantity of cheese or other highly nitrogenous food. Again, in the case of Meat, 1000 grains contain 100 of Carbon and 30 of Nitrogen; therefore to obtain the 4600 grains of Carbon, no less than $6 ., 2$ lbs. must be consumed, whilst the requisite 300 grains of Nitrogen are contained in $1 \frac{1}{2} \mathrm{lb}$. of Meat; consequently three or four times more meat must be consuned to supply the Carbon than is necessary to furnish the Nitrogen. Here then we see again the economy of the mixed diet which is so generally employed by Man, whether in a barbarous or highly-civilized state; and the following table will show how an admixture of bread and meat would require a much less consumption of both, than if each were taken separately:

15,440 grains of Bread contain 4,630 grains of Meat contain

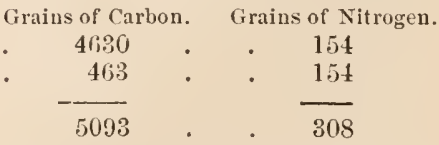

Thus about $2 \mathrm{lbs}$. of bread and $\frac{3}{4} \mathrm{lb}$. of meat are amply sufficicnt to compensate the daily losses of the system of a healthy man. ${ }^{2}$ Hence we

1 Des Substances Alimentaires, Paris, 1854.

2 See Béclard, Traité Elémentaire de Physiologie, p. 570 et seq. 1862. G. Mryer (Zeits. f. Biol, Band vii, Heft 1) has made a series of interesting observations on the effects of exclusive bread diet on man and dugs. White bread furnished a snaller 
see the immense advantage as to economy of food which a fixed agricultural population possesses over those wandering tribes of hunters which still people a large part both of the Old and New Continents. The mixed diet, to which the inclination of man in temperate climates seems usually to lead him (when circumstances allow that inclination to develop itself freely), appears, moreover, to be fully conformable to the construction of his dental and digestive apparatus, as well as to his instinctive propensities. And whilst on the one hand it may be freely conceded to the advocates of "Vegretarianism" that a well-selected regetable diet is capable of producing (in the greater number of individuals) the highest physical development of which they are capable, it may on the other hand be affirmed with equal certainty that the substitution of a moderate proportion of animal flesh is in no way injurious, whilst, so far as our evirlence at present extends, this seems rather to favor the highest mental development. If indeed we take a comprchensive survey of the conditions of the rarious races of Man at present inhabiting the earth, we cannot help being struck with his adaptiveness to a great variety of circumstances, as regards climate, mode of life, diet, etc. And we can scarcely avoid the conclusion, that the Creator, by conferring upon him such an adaptiveness, intended to qualify him for subsisting on those articles of cliet, whether animal or vegetable, which are most readily attainable in different parts of the globe; and thus to remove the obstacle which a necessary restriction to any one kind of food would have otherwise opposer to his universal diffusion.

65. It is exceedingly difficult to give even an approximation to the composition of the ordinary butcher's meat userl as food, since the analyses of different chemists vary considerably; some selecting the muscles alone and the heart, others taking the whole body. The average constitution of entire carcasses of butcher's meat, as given by Messrs. Laws and Gilbert, the fat being included, is :

\begin{tabular}{|c|c|c|c|c|}
\hline $\begin{array}{l}\text { Animals as fattened for the } \\
\text { butcher. }\end{array}$ & Water. & $\begin{array}{c}\text { Dry nitrogenous } \\
\text { substance. }\end{array}$ & Fat. & Mineral matter. \\
\hline $\begin{array}{l}\text { Calf, } \\
\text { Bulloek, } \\
\text { Lamb, }\end{array}$ & $\begin{array}{l}625 \\
500 \\
505 \\
440 \\
385\end{array}$ & $\begin{array}{l}165 \\
160 \\
110 \\
125 \\
100\end{array}$ & $\begin{array}{l}166 \\
300 \\
350 \\
400 \\
500\end{array}$ & $\begin{array}{l}45 \\
50 \\
35 \\
35 \\
15\end{array}$ \\
\hline
\end{tabular}

Moleschott gives the following as the composition of the principal animal foods:

\begin{tabular}{|c|c|c|c|c|c|c|c|}
\hline $\begin{array}{l}\text { In } 1000 \text { par } \\
\text { Water, . }\end{array}$ & & $\begin{array}{c}\text { Mammals. } \\
7: 875\end{array}$ & $\begin{array}{l}\text { Birls. } \\
7: 99.83\end{array}$ & $\begin{array}{c}\text { Fish. } \\
740.82\end{array}$ & $\begin{array}{l}\text { Liver. } \\
720 \text { o6 }\end{array}$ & $\begin{array}{l}\text { Eggs. } \\
735.04\end{array}$ & $\begin{array}{l}\text { Milk. } \\
861.563\end{array}$ \\
\hline Albuminous col & ounds, & $17+.22$ & 202.61 & 137.40 & 128.20 & 194.34 & 3943 \\
\hline Collagen, . & . $\quad$. & 31.59 & 1400 & 4388 & 37.33 & - & - \\
\hline Fut, & . & 37.15 & 1946 & 45.97 & 35.04 & 116.37 & 4983 \\
\hline Carbohydrates, & . & - & - & - & - & - & 43.23 \\
\hline $\begin{array}{l}\text { Extractives, } \\
\text { Silts, }\end{array}$ & . & 1690 & 21.11 & 16.97 & 65.26 & 3.74 & \\
\hline Silts, . . & . & 11.39 & 12.99 & 14.96 & 14.06 & 10.51 & 5.92 \\
\hline
\end{tabular}

amount of feces, containing also less nitrogen than Munich rye bread, North German black bread, or the Horsford Liebig's bread, but the feeling of homger after four day: was much greater than with the nther kinds of breand. It was found imposibile to grive sufficient bread to maintuin the individual at his full weight, though no less than, 94.4 per cent. of the dry material was aboorbed. See also Dr. Pavy on the Physiolugy and Therapenties of Food. Laneet, 1871-72. 
And the following as representing the composition of the principal Vegetable foods:

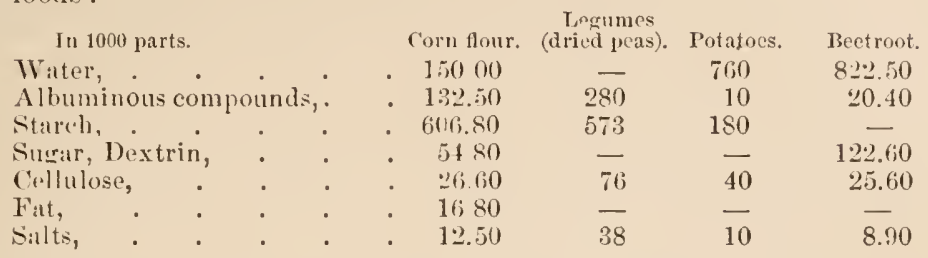

According to Dr. Lankester, ${ }^{1} 21 \mathrm{oz}$ of wheat are required to make $1 \mathrm{lb}$. of flour; and in the $1 \mathrm{lb}$. of flour there are contained-of watcr $2 \frac{1}{4} \mathrm{oz}$., gluten 2 oz., albumen $\frac{1}{4}$ oz., starch $9 \frac{1}{2}$ oz., sugar 1 oz., gum $\frac{1}{4}$ oz., fat $\frac{1}{8}$ oz., fibre $\frac{1}{4}$ oz., ashes $\frac{1}{4} \mathrm{oz}$. The carbon contained in $1 \mathrm{lb}$. of flour amounts to 7 oz. Payen ${ }^{2}$ gives the composition of ox heart as follows:

Water,

Nitrogenous compounds,

Fits,

Mineral substances, .

74.674

17.911

6.155

1.260

And he states that grilled beefsteak contains:

Wrater,

Nitrogenous compounds,

Futs,

Nineral substances,

Non-nitrogenous compounds, sulphur, and loss,

6989

22.9 .3

5.19

1.0 .5

104

10000

Oysters. which are very digestible and highly nutritions, contain 80.4 parts of water, 14 parts of nitrogenous compounds, 1.5 parts of fat, salts 2.7 , nonnitrogrenous compounds and loss 1.4. According to M. Chevreul, the composition of good beef tea per litre (1.76 English pint) is :

Watter,

985.600

Solid organic substances, dried in vacuo at $68^{\circ} \mathrm{F} ., . \quad . \quad 16917$

Silts,

11.263

Liebig has given a receipt for making beef tea without the aid of heat, which is statel to be highly nutritious: 250 grammes ( 3862 grains) of fresh beef or chicken are finely minced and macerated for an hour in 560 grammes (8652 grains) of water, to which 4 or 5 drops of hydrochloric acid and about 15 grains of salt have been added. At the end of this time the fluid is filtcred throngh a hair sieve withont pressure. The residuc is washed with 250 grammes more water. About 500 grammes (a pint) of a reddish, agreeably smelling and tasting fluid is thus obtained, which must be taken cold. It readily decomposes. Dr. Marcet ${ }^{3}$ has suggested that in cases where the digestive powers are feeble the process of digestion should be carried on to some extent prior to its introduction into the stomach, and for this purpose recommends that to $1 \mathrm{lb}$. of roast meat finely minced, $10 \mathrm{oz}$. of a weak solution of hydrochloric acid (containing 232 grains of the pure acid, sp. gr. 1.1496 , to one pint of water), $10 \mathrm{oz}$. of water and 15 grains of pepsin should be added; the whole being kept for three hours in a stone jar immersed in boiling water. The meat is thus reduced to a pulp, which will keep for a day or two. When required for use 51 grains of dry Sodium Carbonate, or 81 grains of crystallized Sodium bicarbonate must be added. Of late years

1 Guide to the Fond Collection in the South Kensington Museum, p. 39.

2 Jules Cyr, Traité de l'Alimentation, p. 47.

${ }^{3}$ A New Process for Preparing Meat for Weak Stomachs, 1867. 
a preparation knowu as Liebig's Extraet of Meat has been largely introduced, and with beneficial results, into the military eommissariat and into the dietary of the sick. It is made at Fray Bentos from the flesh of fouryear old cattle, of the Spanish long-horned breed, greatly iniprover by crossing with English breeds, reared-on the grassy plains or pampas of Uruguay. A full-grown ox yields from 8 to $10 \mathrm{lbs}$. of extract of standard eomposition-that is to say, every $34 \mathrm{lbs}$. of pure muscle eorresponding to 45 lbs. of meat as obtained from the butcher (including fat, tendons, ligaments, eellular or eomnective tissue, and horus), yields on an average $1 \mathrm{lb}$. of extract. The extract contains no gelatin and no fat. One pound is sufficient to produce 70 pints of good beef tea, of which each pint contains the soluble ingredients of $\frac{1}{2} \mathrm{lb}$. of beef.' Sueh extract can eommunicate a strong flavor of meat to vegetable soups, and contains the more important salts of flesh; but it must not be supposed that it can supply the place of a eorresponding quantity of meat to that from which it is prepared, sinee it eontains but a small proportion of albuminous compounds. ${ }^{2}$

66. When the results of Experience, then, are eombined with the teaehings of Seienee, they seem to justify the following eonclusions :

I. That a due adjustment of the Albuminous, Oleaginous, Sacchariue, and Saline constituents of the food to the varying conditions under which Man exists is of the first importance; whilst the question of the derivation of the first two of these constituents from the Animal or from the Vegetable kingdom, is one of seeondary character; each being eapable of yielding them in adequate amount, and the only condition being that the articles of food shall be so selected as to supply the needful quautity. At the same time it will obviously be requisite that differenees should be made in the diet, in aceordance with climatie and seasonal variations. For when the external temperature is low, an ample supply of oleaginous matter is indicated, and may be advantageously taken in the form of butter, eneoa, fat meat, or maize-bread. On the other hand, during the heat of summer, the more nearly the diet is assinilated to that of the natives of tropical climates, in the substitution of fruits and farinacea for oleaginous articles, the less will be the liability to disordered health in the autumn. ${ }^{3}$

II. Experience teaches, however, that it is not a matter of entire indifference, whether the Albuminous constituent be drawn from the Animal or from the Vegetable kingdom; for the use of a highly-animalized diet has a tendencr to raise, and that of a vegetable diet to lower, the proportion of red corpuseles in the Blood; whilst, by a due adjustment of the proportion of the two elasses of eomponents, the evil effeets of the exclusive use of either may be prevented.

III. So, again, Experienee teaches what eould scarcely have been anticipated theoretieally: namely, that notwithstanding the power which the liv-

1 See a famphlet by J. L. W. Thudichum, On the Origin, Nature, and Uses of Liebic's Extract of Meat, 1869.

2 See Edward Smith on Foods, in King's Intermational Scientific Series, 1873.

3 There can bes no doubt that a latge proportion of the disenses of the direstive apparatus, which are so fatal among European residents in India and other tropical climates, result from the habitual ingestion of a much larger quantity of food, and this especially of a rieh and stimulating eharacter, than the system requires. The loss of appetite eonsequent upon the diminution of the dematnd for enmbustive mitterial, is set down to the deleterions influmee of the climate; and an attempt is made to meutralize this by artificial provocutives. - So, it seems probable that many of the "bilious attacks," which, in this country, are so frequent in oarly atumn, and which are commonly set down to the account of fruit (althoush the subjects of them have often abstained entirely from that article), are renlly the result of the presence of an excess of hydroeabonateous matter in the system, eonsequent upon overfeeding during the summer, and must be looked upon as the natural means by which it is got rid of. 
ing body posscases, of converting saccharine compounds into olcaginous, the ingestion of a certain amount of Oleaginous matter as such is necessary, or at least is favorable, to the maintenance of health. We sce this provided in lare quantity, in the first aliment prepared by nature for the offipring of the Manmalia; in the yolk of the eger of all Oviparous animals; whilst, as the laborious investigations of Messrs. Lawes and Gilbert have slown, the amount of fat contained in ordinary butcliers' meat of good quality, to which such a high percentage of nitrogen is usually attributed, is exceedingly great, varying from one-third to one-half of its weight. In the ordinary diet of every nation on the globe,-whether this be animal, regetable, or mixcd,-we find one or more articles of an oleaginous nature; and there is a natural craving for such substances when they are completely withheld, which indicates that they serve some important purpose in the economy. Although this craving is so far affected by climate that it leads to the largest consumption of oily matter where the extreme of cold has to be enclured, it exists with no less intensity even in tropical regions; and we find the Hindoo adding his modicum of "ghee" (or rancid butter made from bisons" mill) to the rice which constitutes his staple article of diet, with the same relish that the Esquimaux feels for his massive lumps of blubber.-It does not seem difficult $t o$ understand the rationale of this fact. For whilst the Arlipose and Nervous tissues are the only portions of the Animal fabrie in to which fitty matter enters in any considerable proportion, yet its presence has an important influence on the assimilation of albuminous mattcrs, and seems essential to every act of tissue formation. There is strong and increasing reason to believe that a deficiency of oleaginous matter, in a state fit for appropriation by the nutritive processes, is a fertile source of diseased action, especially of that of a tuberculous character; and that the habitual use of it in a larger proportion would operate favorably in the prevention of such maladies, as the employment of cod-liver oil unquestionably does in their cure. A most remarkable example of this is presented by the population of Iceland; which, notwithstanding the concurrence of every one of the circumstances usually considered fiavorable to the scrofulous diathesis, enjoys a most remarkable immunity from it, - without any other assiguable cause than the peculiarly oleaginous character of the diet usually employed.

rv. Another of the results of Expcrience, of which Science has not yet given a definite rationale, is the necessity of employing fresh regetables as an article of Diet; the almost invariable consequence of the entire omission of them, being the development of that peculiar constitutional disorder which is known as Scurvy. ${ }^{2}$ That the deficiency of something which fresh vegetables can alone supply is the essential cause of this disease (its operation being promoted, however, by other conditions, such as absolute deficiency of food, confinement, bad ventilation, depression of spirits, ete.), may now be regarded as a well-established fact; and it is one which onght to have an important influence on our dietetic arrangements. For if the total withdrawal of these articles be productive of such a fearful depravation of the blood as perverts every function to which the blood is subservient, a diminution of them below the standard requisite for the maintenance of health must necessarily involve a depravation similar in kind though less aggravated in degree; and this, if slight, may be expecterl to nuanifest itself, not so much in the production of idiopathic disorders, as in firvoring any peculiar tendency to disease which may exist in the system, and in preventing or retarding recovery. ${ }^{3}$ The employnent of fresh fruits and of green

1 Phil. Trans., 1859, pt. ii, p. 495.

2 For a full inquiry into this subject, see the Brit. and For. Med.-Chir. Rev., vol. ii, p. 439.

"This "scorbutic tendency" was fully recognized by the past generation of Phy- 
vegetables seems especially indicated, where a general chronic disorder of nutrition indicates a perverted condition of the circulating material; and especially where there is a disposition to chronic inflammation, induration, and ulecration, in lifferent parts of the body.

v. Finally, then, a well-arranged dietetic scheme ought to consist of such a combination of the Albuminous, Oleaginous, and Farinaceous constituents, as is most appropriate to the requirements of the system;-a larger measure of both the albminous and furinaccous or oily being supplied, when an unusual amount of nervo-muscular exertion is put forth, and this supply being in the latter case most advantagenusly derived from animal tlesh; - a larger measure of the ole aginons being required for the sustentation of the heat in a frigid atmosphere, and this being supplied equally well by the Vegetable kingdom as by the Animal; - and a larger proportion of the furinaceous, as a substitute for the oleaginous, being most favorable to health under a high atmospheric temperature. An habitual excess in the use of either of these constituents, above what the demands of the system require, tends towards the production of a particular "diathesis" or constitutional state, which may manifest itself in a great variety of modes. Thus, an excess of the albuminous components, such as is only likely to occur when too large a proportion of animal food is employed, undoubtedly farors the arthritic diathesis, which seems to consist in the presence of imperfectly assinilated histogenetic substances and wrongly metamorphosed products of disintegration, that are not duly eliminated through the kidneys; and this diathesis not only displays itself in gout and gravel, but modifies the course of other diseascs. So again, an excess of the oleaginous constituents of the food tends to the production of the bilious diathesis, in which, through the insufficient elimination of hydrocarbonaceous matters, the blood becomes charged with the elements of bile. The excess of farinaceous matters, moreover, especially when combined with a deficiency of the albuminous (as it too frequently is among those who are obliged by necessity to live chiefly upon a "poor" vegetable diet), tends to the production of the rheumatic diathesis; which seems to consist, like the arthritic, in the mal-asimilation and wrong metamorphosis of the components of the tissues, but to be especially favored by the presence cither of lactic acid, or of some other product of the metamorphosis of the saccharine compounds. And, as alrearly pointed out, the deficiency of oleaginous matters seems to tend to the development of the scrofulons diathesis; and that of fruits and fresh vegetables to the production of the scorbutic. ${ }^{1}$

sicians, who practiced in those good old times when potatoss were a luxury and green vegetables in the winter almost unknown, when the middle classes fed ilpon salted meat during a great part of the year, and when sagacious old women prescribed ncttle-tai and scurry-grass, with a eourse of lenitive "spring-physie," for the "clcansing of the blood."

1 It is worthy of remark that in the times when even the wealthy lived during four or five months of the year almost exelusively upon meat, breat, and flour-putdings, and when, therefore, the diet was far too highly azotized, as woll as defieient in fresh vecuetables, Arthritic, Caleulous, and scorbutic disorders were much more common than at present. The introduction and universal employment of the potato has unquestionably done much to correct these two tenchencies; on the one hand, by diluting the azotized constituents of the food, so that, with the same bulk, a much smallev proportion of these is now introduced; and on the other, by supplying to the blowl some rement which is essential to the mantenance of its healthy condition. But with the diminution of the Arthritic diathesis, which the exprerienes of our older practitioners, and tlie medical writings of the last eentury, inclicate as having taken place during that period, there has been an inerease in the lihenmatic;-a change which scems to have a close relation to tlis alteration in diet. And it sems not improbable, too, that this alteration has also much to do with that diminished power of sustaining aetive depletory treatment, which, according to the observations of practi- 
67. The absolute quantity of Food required for the maintenance of the Hnman body in health, varies so much with the age, sex, constitution, and habits of the individual, and with the eireumstances in which he may be placed, that it would be absurl to attempt to fix any standard which slould apply to every particular case. 'The appetite is the ouly sure guide for the supply of the wants of each; but its indications must not be misinterpreted. To eat when we are hungry, is an evidently natural disposition; but to eat as long a.s we are humgry, may not always be prudent. Since the feeling of luunger does not depend so nuch upon the state of fulness or emptiness of the stomach, as upon the condition of the general systenl, it appears evident that the ingestion of food cannot at once produce the effect of dissipating it, though it will do so after a short time; so that, if we eat with undue rapiclity, we may continue swallowing food long after we have taken as mueh as will really be required for the wants of the system; and every superfluous particle is not merely useless but injurious. Hence, besides its other iuportant ends, the process of thorough mastieation is important, as prolonging the meal, and thus giving time to the system to be made acquainted (as it were) that the supply of its wants is in progress; so that its demands may be abated in due time to prevent the ingestion of more than is required. It is very justly renarked by Dr. Beaumont, that the cessation of this demand, rather than the positive sense of safety, is the proper guide. "There appears to be a sense of perfect intelligence conveyed to the encephalic centre, whieh, in health, invariably dictates what quantity of aliment (responding to the sense of hunger and its due satisfaction) is naturally required for the purposes of life; and which, if noticed and properly attended to, would prove the most salutary monitor of health, and effectual preventive of disease. It is not the sense of satiety, for this is beyond the point of healthful indulgence, and is Naturc's earliest indication of an abuse and overburden of her powers to replenish the system. It occurs immediatcly previous to this; and may be known by the pleasurable sensations of perfect satisfaetion, ease, and quiescence of borly and mind. It is when the stomach says, enough; and it is distinguished from satiety by the difference of sensations,-the latter saying too much." Every medical man is well aware how generally this rule is transgressed; some persons making a regular practice of eating to repletion; and others paying far too little attention to the preliminary operations, and thus ingesting more than is good for them, even though they may actually leave oft with an appetite.

68. Although no universal law can be laid down for individuals, it is a matter of much practieal importance to be able to form a correct average estimate. But even this is given somewhat differently by different observers. Dr. Dalton, for instance, ${ }^{1}$ states that the entire quantity of food required every 24 hours by a man in full health and taking tree exercise is, of meat $16 \mathrm{oz}$. ar., bread $19 \mathrm{oz}$., fat $3 \frac{1}{2}$ oz., and of water $52 \mathrm{fl}$. oz., that is, about $2 \frac{1}{2}$ lbs. of solid food, and rather more than 3 pints of fluid. Vierordt ${ }^{2}$ considers the adult to be well nourished if, with moderate exercise, he receives daily about $4 \mathrm{oz}$. of dry albumen, $3 \mathrm{oz}$. of fat, $11 \frac{1}{2} \mathrm{oz}$ of some starchy substance, and about $1 \mathrm{oz}$. of salts, which gives a proportion of one part of

tioners of long experience, charaeterizes the present generation as compared with the preceding. But whilst there is a diminished capability of bearing large bloodlettings, viulent purgation, etc., there is at the sume time such an increased tendeney to a favorable termination in many of those diseases for which they were formerly accounted necessary, as should remove all regret at this change of constitution.-On the question of "Vegetarianism," the author may refer to his articlus on that subject in the Brit. and For. Med.-Chir. Rev., vol. vi, pl. 76 and 399.
1 Physiology, 1861, r. 97.
${ }^{2}$ Grundriss d. Phys., 1860, p. 192. 
nitrogenous to three and a half parts of non-nitrogenous food. If to this about 6 pints of water, and the oxygen taken up in the act of respiration, which he estimates at $1 \frac{1}{2} \mathrm{ll}$., be added, we shall obtain a total of about $\frac{1}{2}$ th of the weight of the body consumed in 24 hours. It is from the experience afforded by the usual enusumption of food by large bodies of men that our best data are obtained; and these data are sufficient to enable us to prediet with tolerable accuracy what will be required by similar aggregations, though they can afford no guide to the consumption of iudividuals. We shall first eonsider the quantity sufficient for men in regular active exercise; and then inquire low far that may be safely reduced, for those who lead a more sedentary life.-The Diet-scale of the British Navy may be advantageously taken as a specinen of what is required for the first class. It is well known that an extraordinary improvement has taken place in the liealth of seamen during the last eighty years; so that three ships can now be kept afloat, with only the same number of men as were formerly required for two. This is due to the improvement of the quality of the food, in combination with other prophylactic means. At present, it may safely be affirmed that it would not be easy to construct a diet-scale more adapted to answer the required purpose. The health of crews that have long been afloat, and have been exposed to every variety of external conditions, appears to be preserved (at least when they are under the direction of judicious officers) to the fuil as well as that of persons subject to similar vicissitudes on shore; and there can be no complaint of insufficiency of food, although the allowance cannot be regarded as superfluous. It consists of from 31 to $35 \frac{1}{2} \mathrm{oz}$. of dry nutritious matter daily; of this, $26 \mathrm{oz}$ are vegetable and the rest animal; and it contains, as does also that of the English soldier, 5 oz. of Nitrogenous eompounds and $10 \mathrm{oz}$ of Carbon. The ordinary diet of the Dutch soldier contains 5 oz. of Nitrogen compounds and $10 \frac{1}{2}$ oz. of carbon in war, but in peace only $3 \frac{1}{2} \mathrm{oz}$. of the former; the French soldier, $4 \frac{3}{4} \mathrm{oz}$. and $12 \mathrm{oz}$; Greenwich pensioner, $3 \frac{1}{2} \mathrm{oz}$ and $10 \mathrm{oz}$; Chelseal pensioner, $4 \mathrm{oz}$ and $9 \frac{3}{\mathrm{oz}} \mathrm{oz}$; the old men of Gillespie's hospital, in Edinburgh, 3 oz. and $10 \mathrm{oz}$. Paupers.Taking the average of all the workhouses in the kingdom, $3 \frac{1}{7}$ oz. of Nitrogenous compounds and $8:$ oz. of Carbon. The boys of the Roval Naval School, at Greenwich, $2 \frac{1}{2} \mathrm{oz}$ and $7 \frac{1}{2} \mathrm{oz}$; and, finally, the boys of Christ's Hospital, in London, have only $2 \frac{1}{2}$ oz. of Nitrogenous compounds and $7 \mathrm{oz}$. of Carbon in their frod. ${ }^{1}$ Liebig ${ }^{2}$ estimates that a laborer of $140 \mathrm{lbs}$. weight requires for his sufficient uourishment 2025 grains of albuminates daily. The English navies who constructed the railway at Balaclara, and astonished both the French and English soldiers by the amount of work they accomplished, consumed daily from 2:35-2462 grains of albuminates. The men in the Munich breweries consume on an average 2558 grains of albuminates per dien. In the case of Prisoners, the diet should be, of course, as spare as possible, consistently with health; but it should be earefully modified, in individual cases, according to several collateral circumstances, such as depression of mind, compulsory labor, previous intemperate habits, and especially the length of confinement. It has been supposed by some, that prisoners require a fuller diet than persons at large; this is probably erroneous; but more variety is certainly desirable, to counteract, as far as possible, the depresing influence of their condition upon the digestive powers. The evil effect of an undue reduction in the supply of food, and of insufficient attention to its quality, lats unfortunately been too frequently displayed in our prisons; a notalile example of which will be hereafter alluded to $(\$ 81)$.

1 Lankester in Guide to the Food Collection of the South Kensington Museum.

2 Lancet, 1869, vol. i, p. 5. 
From the information eolleeted by Dr. Edward Smith for the Govermment, ${ }^{2}$ it is ascertained that some people eat ten times more food, in point of nutriment, than others, and that in whole elasses of the eommunity a differcnee of one-lialf in the amonnt obtained by the lowest fed is common. From the extended experiments which he has made on the amount of Carbon daily eliminated by men in good licalth during the middle period of life when at perfect rest, it appear's that it amounts to $7.9 \mathrm{oz}$, with the cstimated excrtion of the middle and light laboring elasses to $9.5 \mathrm{oz}$. , and with the estimated exertion of the hard laboring classes to 12.5 ounces. On an examination of the nature of the food actually consumed by these classes, it was foumd that the proportion of Carbon present was approximatcly represented by the above numbers; indoor laborers, as cotton and silk operatives, needlewomen, and shoemakers, consuming about $10.5 \mathrm{oz}$, and agricultural laborers in England, 13.2 oz. ; in Great Britain and Ireland, $14.1 \mathrm{oz}$. Hence it may be stated that the adult body requires an arerage minimum daily amount of Carbon of $9 \frac{1}{2}$ to $10 \frac{1}{2}$ ounces in the middle and light laboring classes, and of $12 \frac{1}{2}$ to 14 ounces in the ordinary hard laboring classes, that is from 2.5 to 30 grains per lb. weight of the whole body. It is interesting to notice that the infant consumes no less than 136 grains of Carbon for caeh pound of body weight, a proportion three to four times greater than that actually obtained by the poor in adult life. As regards the amount of Nitrogen, Dr. Smith's observations show that about 200 grains of Nitrogen are used up daily in the working of the body by the light laboring classes, whilst in the middle and well-fed classes the total evaeuation by all the excretions was 260 grains. The actual amount obtained in food by the indoor classes was 183 grains, and by the outdoor laborers in England 242 grains; and hence we may place the requirements of the adult body daily at 200 grains with light oecupation, and 250 grains for ordinarily hardworking laborers, or from 1 to $1 \frac{1}{2}$ grain per lb. of body weight. 'The proportion of Nitrogen to the body weight eonsumed by the infant appcars to be about six times greater than that of the adult. The amount of mineral eonstituents including chlorine, phosphoric and sulphuric acids, potash, soda, lime, and magnesia daily required, as estimated by the amount excreted, varies from about 200 to 600 grains. Lastly, about $6 \mathrm{lbs}$, or nearly five pints, of water per day are neeessary with moderate exertion and temperature. The following is a dictary furnished by D. Smith, ${ }^{2}$ whieh he considers may be taken as the substantial part of a proper and moderate quantity of food for a man in good health with a good appetite, and making a moderate degree of cxertion : Birenkfast.- ${ }_{4}^{3}$ pint of milk; $\frac{1}{4}$ pint of water with coffee or tea ; bread, 4 oz. to $6 \mathrm{oz}$.; butter, $\frac{3}{4} \mathrm{oz}$; sugar, $\frac{3}{4}$ oz.; bacon, $3 \mathrm{oz}$, or eggs, 4 oz., or eooked meat, $3 \mathrm{oz}$. Dinmer.-Cooked meat, 4 oz. to $6 \mathrm{oz}$; potatoes, $8 \mathrm{oz}$; bread, $3 \mathrm{oz}$. to $4 \mathrm{oz}$; pudding, $8 \mathrm{oz}$. ; cheese, $\frac{1}{2}$ oz. ; soup, 6 oz. ; water or beer, $\frac{1}{2}$ pint. Tea.- Water with tea, $\frac{3}{4}$ pint; sugar, $\frac{3}{4}$ oz.; milk or crean, 2 oz.; bread, 3 oz.; butter, $\frac{1}{2}$ to $\frac{3}{4}$ oz. Supper.-Milk, $\frac{3}{4}$ pint ; oatmeal, 1 oz., and bread $3 \mathrm{oz}$. to 4 oz., or eggs, 4 oz., or cooked meat, $3 \mathrm{oz}$, and bread, $3 \mathrm{oz}$; ; butter or cheese, $\frac{1}{3} \mathrm{oz}$; water or beer.

69. The smallest quantity of food upon which life is known to have been supported with vigor during a prolonged period, is that on which Cornaro state himself to have subsisted; this was no more than $12 \mathrm{oz}$ a a day, ehicfly of vegetable matter, with $14 \mathrm{oz}$. of light wine, for a period of 58 years. There is another well-kuown case (that of Thomas Wood, the miller of Billericay, reported to the College of Physicians in 1767 by Sir George Baker), in which

1 Sce Practical Dietary, 1864, p. 20.

2 For numerous other dietaries, see Pavy, A Treatise on Food, 1874. 
a remarkable degree of vigor was sustained for upwards of eighteen years, upon no other nutriment than $16 \mathrm{oz}$ of flour (containing about $14 \mathrm{oz}$ of dry solids) made into a pudding with water, no other liquid of any kind being taken. 'There are probably few, however-at least among those whose avocations require much mental or bodily exertion-who could long persevere in such a diet. Still it is certain that life with a moderate amount of rigor may be preserved for some time on a very limited allowance of food; this appears from the records of shipwreck and similar disasters. In regard, howerer, to those who have been stated to fast for a period of months or even ycars, taking 110 nutriment, but maintaining an active condition, it may be safely asserted that they were impostors, probably possessing unusual powers of abstinence which they took means to magnify.

70. Of the quantity which can be deroured at one time, this is scarcely the place to speak; since such feats of gluttony only demonstrate the extraordinary capacity which the stomach may be made to attain by continual practice. Many amusing instances are related by Captain Parry in lis Aretic Toyages; in one case a young Esquimaux, to whom he had given (for the sake of curiosity) his full tether, devoured in four-and-twenty hours no less than $35 \mathrm{lbs}$. of various kinds of aliment, including tallow andles. A case has more recently been published of a Hindoo, who can eat a whole sheep at a time; this probably surpasses any other instance on record. The half-breed voyageurs of Canida, according to Sir John Franklin, and the wandering Cossacks of Siberia, as testified by Captain Cochranc, habitually devour a quantity of animal food which would be soon fatal to any one unused to it. 'The former are spoken of as very discontented, when put on a shoit allowance of $8 \mathrm{lbs}$ of meat a day; their usual consumption being from 12 to $20 \mathrm{lbs}$.- That a much larger quantity of food than that formerly speeified, may be habitually taken with perfect freedon from injurious consequences, under a particular system of exercise, etc., appears from the experience of those who are trained for feats of strength, pugilistic encounters, etc. The ordinary belief that the Athletic constitution cannot be long naintained, appears to have no real foundation; nor does it appear that any ultimate injury results from the system being persevered in for some time. That "trained" men often fall into bad health on the cessation of the plan, is probably owing in part to the intemperance and other bad hibits of persons of the class usually subjected to this discipline. The effects of trainers' regimen are liarlness and firmmess of the muscles, clearness of the skin, capability of bearing continued severe exercise, and a feeling of freetom and lightness (or "corkiness") in the limbs. During the continuance of the system, it is found that the body recovers with wonderful facility forom the effects of injuries; wounds lieal very rapidly; cutaneous eruptions usually disappear. Clearness and vigor of mind, also, are stated to be results of this plan.' The injurious efleets observed in those who suddenly engage in trials of strength and endurance, as in rowing, running, and gymulstics, are

1 The method of training employed by Jackson (a colebrated trainer of prize fighters in modern times), as deduced from his answers to questions put to him by Joln Bell, was to begrin on a elatr foundation by an emetic and two or three purges. Beef and intent the lean of fat meat boing preferred, constituted the principal foul; veal, lamb, and pork wore sajd to be less ligestible ("the last purges some men"). Fisli was said to be a "watery kind of diet :" and is employed by jockegs who wish to reduce weight by sweatine. Stale breal was the only vegetable ford allowed. The quantity of flud prermited was $3 ?$ pints per diem; but fermented licguors were strietly furbidden. Two full meals, with a light supper, were usually taken. The quantity of exercise employed was very considerable; and such as fow men of ordinary strength could endure - I'his acenut corlesponds very mush with that which IIunter gave of the North Anerican Indians, when about to set forth on a long march. 
probably attributable to their being undertaken by young persons who have undergone an insufficient amount of training, and who exhanst themselves by exerting their whole nervous energies, or who induce some plyysical derangement of the vascular or respiratory system, by the violent muscular efforts put forth. ${ }^{1}$

71. It is not enough for the healthy support of the body, that the Food ingested should contain an adequate proportion of alimentary constituents; it is important that these should be in a wholesome or undeconposing state. 'Thus from Mr. Giangee's inquiries it appears that the sale of neat derived from animals who have suffered from the recently prevalent diseases, pleuropneumonia and typhoid fever, is lamentably common even in the Lundon markets; and it has been well stated ${ }^{3}$ that "although it may be difficult to prove it by actual cases, there can he no doubt that unwholesome meat is one cause amongst many of the debility and cachexies, the poverty of blood and intractable maladies of the poor who flock to the dispensaries and parochial medical officers, and especially of diarrhoa during hot weather." Many instances of this kind have been recorded ; ${ }^{4}$ and the risk is quite sufficient to justify a strict prohibition of the use of any such article.-That meat which is simply putrescent is to be considered as injurious per se, when habitually employed, is scarcely a matter of reasonable doubt. It is true that some nations are in the habit of keeping their meat until it is tainted, having a preference for it in that condition, which seems to have grown out of the supposerl necessity for thus employing it; a preference which has its parallel among the epicures in our own country, who consider the laut gout essential to the perfection of their venison or woodcock. One of the most remarkable eximples of this kind among a civilized people, is furnished by the inhabitants of the Faroe Islands; who, according to the report of Dr. Panum, who has investigated their Sanitary condition, live during a large part of the year upon meat in a state of incipient decomposition, and introduce rast, or half decayed maggoty flesh, fowl, or fish, as a special relish at the end of a meal. ${ }^{5}$ The result of such a diet is (as might be anticipater) a continual disorder of the digestive organs, manifesting itself especially by diarthea, which also complicates the course of other disenses, and even becomes, from its obstinacy and exhausting character, their most serions occurrence. MIoreover, the Faroese are peculiarly liable to suffer severely from epidemics, when these are introduced among them. Hence, notwithstanding that the usual rate of mortality is very low (only 1 in $64 \frac{2}{3}$ annually), it is obvious that there is a certain constitutional condition among them which peculiarly favors the reception and propagation of zymotic poisons; and it is quite conformable to the principles elsewhere laid down, to attribute this to the liabitual introduction of putrescent matter with the food. It is probable, indeed, that if it were not for the active lives of the Faroese, and their habitual exposure to a low external temperature, the direct effects of their diet would be far more prejudicial than they are; but a large part of these are probably neutralized by that activity of respiration which the habits of life of this hardy people induce, much of the noxions matter being decom-

1 See Skey's Letter and subsequent discussion in Times of Uctober, 1867.

${ }^{2}$ Cattle Plague and Diseased Meat. Letter to Sir George Grey, 1857, quoted in Med.-Chir. Riev., 1858.

${ }^{3}$ In a Report of the Committee of the Metropolitan Association of Medical Officers of Health.

4 See Ann. d'Hygiène, 1829, ii, p. 267 ; 1834, ii, 69; also Taylor in Guy's Hospital Reports, April, $1 \dot{1} 13$.

5 See Dr. Panum's Observations on an Epidemic of Measles in the Färoe Islands, in the Bibliothek for Legr., 1846; of which an analysis is given in the Brit. and Fur. Med.-Chir. Rev., vol. vii, p. 419. 
posed and eliminated by the combustive process. Hence it may well be conceived, that the effects of putrescent food would be much more decidedly manifested amongst individuals dwelling in close, ill-ventilated apartments; and although the same means of comparison do not exist, since there is no part of our town population habitually subsisting on such a diet as that of the Faroese, yet there is no want of evidence with regard to the injurious effects of even the occasional employment of putrescent food, especially when any zymotic disease is epidemic. ${ }^{1}$

72. That it is Water which constitutes the natural drink of Man, and that no other liquor can supply its place, is apparent from the most cursury glance at its uses in the system; and it is only necessary here to remark, that the purity of the water habitually ingested is a point of extreme importance. A very minute impregnation with lead, for example, is quite sufficient to develop all the symptoms of chronic lead-poisoning, if the use of such water be sufficiently prolonged. In the case of the ex-royal family of France, many of whom suffered in this manner at Claremont, ${ }^{2}$ the amount of lead was only about one grain per gallon; and in a case subsequently published, in which also the symptons of learl-poisoning were unequivocally developerl, the anount was no more than $\frac{1}{9}$ th of a grain. ${ }^{3}$ So again, an excess of the saline ingredients which appear to be innocuous in snitll quatntities, may produce a marked disorder of the digestive organs, and (through then ) of the system generally." Moreover, as in the case of fond, the presence of a very small amount of putrescent matter is quite sufficient to produce the most pernicious results, when that matter is habitually introduced into the system; and these results, on the one hand, manifest themselves in the production of certain disorders which appear distinctly traceable to the direct action of the poison so introduced; whilst, on the other, they become apparent in the extraordinary augmentation of the liability to attacks of such zymotic diseases as may at the time be prevalent. ${ }^{5}$ The quantity of water daily consumed is about four or five pounds; and a slight excess, indicative of its formation in the system, is daily eliminater. The ingestion of large quantities has been shown by Mosler ${ }^{6}$ to cause a considerable increase in the discharge of urea and salts in the urine, which appears to be the result of an increased metamorphosis of the albuminous constituents of the blood and tissues. The quantity of alcoholic liquids consumed in the United Kingdom is extraordinarily great. A recent writer (Rev. W. Crane) ${ }^{7}$ states that, in $1873,28,908,501$ gallons of home spirits; $10,223,709$ gallons

1 Facts of this kind have been abundantly furnished during the visitations of Cholera. Sre the Report of the General Board of Health on the Epidemic Cholera of 1848 and $1849, \mu .63,64$. An instance of a very remarkable kind occurred at Bridgewater, towards the close of that epidemie, as related to the Author by Dr. Brittan. A cargo of spoiled oysters having been brought to the town, and the sale of them having been prohibited on account of their putrescent condition, they were griven awy to any who would receive them; and several ebildren in a neighboring school partook of them plentifully. In the eourse of the following night, all who hat daton of the oysters (so far as Dr. Brittan could ascertain) were at acked with cholelia and choleraic diarrhoa, and eleven of the children bied the next day.

2 See the account of this case, which presents many features of great interest, in the Jublin Quarterly Journal of II edieal Seience, vol. vii, $\mathrm{n} 415$.

3 See Herapath in Medical Gazette, Sept. 20th, 1850, p. 518.

4 Of this a very instructive ease, which oceurred at Wolverton, has been published by Mr. Corfe in the Pharmatentical Journal, July, 1848.

5 For ample evidence to this effect, see Dr. P'ereira's Treatice on Food and Diet, 1p. 8!-91; and the Report of the General Board of Health on the Epidemic Cholera (t) 1848 and 1859, pl. 59-63, Appendix A, p. 14, and $\Lambda_{p} p$ endix B, pp. 91-95.

6 Arehiv des Vereins f. gemeins Arbeit., Bd. iii, 1857, \}). 398.

7 In a paper read before the Bellast Neeting of the $\Lambda$ ssociation for the Advancement of seicnce, $\Delta$ ug. $26 \mathrm{th}, 1874$. 
of foreign spirits; $18,327,104$ gallons of wine; $1,076,844,942$ gallons of beer; and about 18,509,900 gallons of cider and British wine were consumed. The proportion of Aleohol in Beer varies from 1 to 12 per cent.; in the light wines of France and Germany from ${ }^{k}-15$ per cent., and in the stronger Spanish wines from 15 to 25 per cent. Besides Aleohol, all wines contain certain volatile Ethers, and more or less of the Acetic, Tartaric, and Tamnic Acids. Sugar and Extractives are also commonly present. The use of Aleohol, in combination with water and with organic and saline compounds, in the various forms of "fermented liquors," deserves particular notice, on account of the numerous fallacies which are in vogue respecting it.-In the first place, it may be safely affirmel that Alcohol cannot answer any one of those important purposes for which the use of Water is required in the system; and that, on the other hand, it tends to antagonize many of those purposes, by its power of precipitating most of the organic compounds, whose solution in water is essential to their appropriation by the living body. Secondly, the ingestion of alcoholic liquors cannot supply anything which is essential to the due nutrition of the system: since we find not only individuals, but whole nations maintaining the highest vigor and activity, both of body and mind, without ever employing them as an article of diet. Thirdly, there is no reason to believe that Alcohol, in any of its forms, can become directly suhservient to the mutrition of the tissues; for it may be certainly affinied that, in common with non-azotized substances in general, it is incapable of transformation into albuminous compounds; and there is no sufficient evidence that even Fatty matters can be generated in the body at its expense. Fourthly, the experiments of Anstie and Dupré show that when Alcolol is consumed in noderate quantities, as of two ounces in divided doses, in the conrse of the day, the merest traces only are eliminated by the excretions. There can be little doubt, therefore, that it underoes oxidation in the system. ${ }^{1}$ And M. Dupré has shown that weight for weight Alcohol evolves about four times the amount of heat or actual energy that is evolved by lean beef." Fifthly, the operation of Alcohol upon the living body is essentially that of a stimulus; increasing for a time, like other stimuli, the vital activity of the body, and especially that of the nervo-muscular apjaratus, so that a greater effect may often be produced in a given time under its use than can be obtained without it; but being followed by a corresponding depression of power, which is the more prolonged and severe in proportion as the previous excitement has been greater. The results of the researches of Ringer, ${ }^{3}$ Anstie and Dupré, Binz, and others, show that Alco-

1 And this accounts for the faet that some persons who consume large quantities of fermented liquors become very fat; the hydrocurbonaeenus matters in tlic system being prevented from undergoing the combustive process to which they would otherwise be subjeet. Ifuch of the fatty deposit in intemperate persons has the eharacter of "fatty degeneration;" the tendency to which is very marked in persons of this class.

2 MII. Durny, Lallemand, and Perrin, Du rôle de l'Aleool et des A nesthétiques dans l'Organisme, 1860, Dr. Mareet, Chronie Aleoholic Intoxication, 1862, and Dr. E. Smith, Cyelieal Changes, and more recently, Dr. Ssubutin, Zeitsehrift für Biologie, Band vii, 1871, p. 361, thought that a considerable quantity of the aleohol ingested was discharged unchanged ; but as Anstic and Dupré have shown in their papers in the Lancet, 1815, and Practitioner, 1872, 1873-in which references will be found to the principal authors on this interesting subjeet-this view arose cither from crroneous obscrvations and inefficient modes of testing for ulcohol, or to very large doses being administered to small animals like the rabbit, in which ense, no doubt, a ronsiderable quantity is eliminated unelanged. See also in ralation to this subject Dr. Richardson, Reports Brit. Assoc. for the Adv. of Sei., 1864 and 1869 ; Sehulinus, Archiv f. Heilk., 1866; Parkes and Wollowicz, Proeeed. Roy. Soc., 1870.

3 Lancet, 1866, rol. i, p. 208. 
hol in tolerably full doses lowers the tempcrature of the body, although it incrcases the force and frequency of the pulse; and the experience of Arctic voyagers is most decided in regard to the comparatively low value of Alcohol as a heat-producing material. It is certain that Aleohol is not without its value under various corporeal conditions; and the views expressed by Dr. Hammond, ${ }^{1}$ that its effects, injurious or salutary, are in a great measure dependent upon the quantity of food consumed with it, are probably true. When the food is ample in quantity and varied in quality, and the digestion good, Alcohol is unnecessary, exciting the circulation, and tending to produce a plethoric condition of the system $;^{2}$ but when the diet is insufficient, or the digestion feeble, the effects of Alcohol, when taken in moderate quantitics, seem decidedly beneficial, the body not only ceasing to lose, but actually gaining in weight: the Alcohol either taking the place of the food, or retarding the metamorphosis of the tissues. In conditions of exhaustion it often proves of the greatest utility, and there is reason for believing that it can excrt an antiscptic power in certain states of bloodpoisoning, whilst it excrts a powerful influence over the formation of pus in the inflamed parts; partly perhaps by restraining the movements of the white corpuscles of the blood, partly by hardcning the walls of the vessels and preventing their eseape, and partly by its general power of lessening tissue-change and cell-genesis. The Pliysiological objections to the habitual use of Alcoholic liquors rest upon the following grounds. First, they are universally admitted to possess a poisonous character, exhibited when they are taken in tolerably large doses by loss of appetite and diminished muscular power and control over the voluntary movements, with partial paralysis of the sympathetic nervous system, leading to dilatation of the smaller vessels; whilst death is the speedy result of very large doses through the suspension of ncrvous power, which their introduction into the circulation in sufficient quantity is certain to induce. Secondly, when habitually used in excessive quantities, universal experience shows that Alcoholic liquors tend to produce a morbid condition of the body at large, and especially of the nervous system; this condition being such as a knowledge of its modus operandi on the body would lead the Plyysiologist to predicate. Thirdly, the frequent occurrence of more chronic diseases of the same character, among persons advanced in life, who have habitually made use of Alcoholic liquor's in "moderate" amount, affords a strong probability that they result from a gradual perversion of the nutritive processes, of which that habit is the cause. This perversion manifests itself peculiarly in the tendency to "fatty degeneration" of the muscular substance of the heart, of the walls of the arteries, of the glandular substance of the kidney and liver, and of many other parts; and thus gives rise to a great variety of forms of disease. Fourthly, the special liability of the intemperate to zymotic diseases, seems an indication that the habitual ingestion of Alcoholic liquors tends to prevent the due elimination of the azotized products of the disintegration of the system, and thus to indnce a "fermentable" condition of the blood. Fifthily, extended experience has shown that, notwithstanding the temporary augmentation of porrer which may result from the occasional use of fermented liquors, the capacity for probonged endurance of mental or bodily labor, and for resisting the extremes of heat and

I Amer. Journ. of Med. Sciences, Oct. 1856.

2 According to Dr. Ed. Smith (Trunsace of Roy. Med. Society of London, vol. i, pt i, p. 1, 18(i1), alcolol interferes with alimentation, diminishes the exeretion of ureat and the action of the skin, and increases the greneral activity of the vascular system. Rum increases, but brandy and gin kessen the exeretion of carbonic acid by the lungrs. 
cold, as well as other depressing agencics, is diminished rather than increased by their habitnal employment; aud the reason of this, so far as cold is concerned, is sufficiently obvious. Inder ordinary circumstances of exposure to cold the circulation of blood through the vesscls of the surface, owing to the contraction of the cutaneons capillaries, is greatly reducerl, and much less heat is lost by conduction and radiation, the skin alone being a very barl conductor. ${ }^{1}$ When, however, considerable quantities of $A$ lcohol are taken, more or less conplete paralysis of the vaso-motor nervous system is the result: the vessels of the skin no longer respond to the stimulus of colrl, and the blood traversing them loses a large anount of heat; so that whilst in all instances where the quintity of Alcohol consumed excecls the moderate limits of $1 \frac{1}{2}-2$ ounces per diem, there is diminished power of resistance to cold, this is felt much more acutely in extreme cases, and reath may cven take place from the general reduction of the temperature. ${ }^{2}$ On these grounds, the Author has felt himself fully justified in the conclusion, that, for Physiological reasons alone, habitual abstinence from Alcoholic liquors is the best rule that can be laid down for the great majority of healthy individuals; the exceptional cascs in which any real benefit can be derived from their ase being comparatively few."

73. The very extensive employment of Tobacco by men of almost every rank in society in this country, and the large consumption of Tea and Coffee by both sexes throughout the community, render the study of their effects upon the animal cconomy particularly interesting, though up to the present time cxcedingly few observations have been made. Thic effects of Tobaceo are chiefly due to the absorption of the extremely poisonous liquid alkaloid Nicotia," which exists in the plant in combination with Citric and Malic acids, and from its remarkable volatility, is contained in and inhaled with the smoke of the smouldering leaves. Its chemical composition is represented by the formula $\mathrm{C}_{10} \mathrm{H}_{1:} \mathrm{N}_{2}$. Dr. Hammond's conclusions (Op. cit ) from his experiments upon the use of Tobacco are, that whilst it only slightly affects the excretion of carbonic acid from the lungs, it diminishes the quantity of freces, urine, aqueous vapor, and of chlorine, but it increases the amount of uric, phosphoric, and sulphuric acids eliminated by the kicheys,circumstances which seem to indicate that there is an increasc in the interstitial changes taking place in the brain and nervous tissue, of which there are other indubitable signs, as wakefulness, trembling, and nervons cxcitement. The quantity employed in the experiment was two cigars thrice a day.-These results accord with general experience; and there are few who will not coincide with the moderate tone of Sir B. Brodie's well-known letter to the Times on this subject, dated August 27th, 1860, in which he observes that when used in limited quantity, and under circumstances of privation, Tobacco may be not only harmless but absolutely beneficial by soothing and tranquillizing the nervous system, allaying hunger and the uneasy feelings produced by mental and bodily exhaustion; but that in too many instances it is only a bad habit, producing a greater or less degree of derangement of the nervous system, and indisposing to both mental and bodily exertion. Tea and Coffee, though derired from different classes of the Vegetable king-

I See Klug., Zeits. f. Biologie, Band x, 1874, p. 73 .

2 A very remarkable cxample of the effects of cold on whisky and non-whisky drinkers is recorded in the Lancet, vol. $i, 1871, \mathrm{p} .636$.

${ }^{3}$ See his Physiology of Temperance and Tutal Abetinence; also the important Treatise on Alcoholimmus Chronicus, by Dr. Huss of Stockholm. of which an abslract is griven in the Brit. and For. Med.-Chir. Rev., vols. vii and ix.

4 See Heubel, Exp. Beitriige, Centralblatt f. d. Med. Wiss., 1872, p. 641. 
dom, appear to contain nearly the same organic constituents, but in different proportions, as shown in the following analysis:

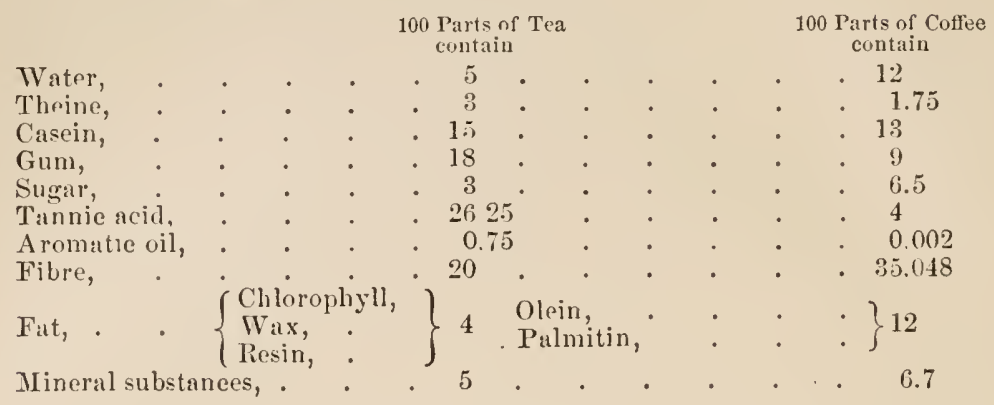

In making "Tea" and "Coffee," the Theine, Gum, Sugar, and Tannic acids are chiefly extracted, the Casein, unless a little soda be added to the water, being undiscolved. It is a singular circumstance that the Alkaloid contained in Tea and Coffee, as well as that in Maté, the shrub used for tea in Paraguay, should have the same chemical composition $\left(\mathrm{C}_{5} \mathrm{H}_{10} \mathrm{~N}_{4} \mathrm{O}_{2}+2 \mathrm{Aq}\right.$. $)$. Strong decoctions of both fluids counteract the tendency to sleep, excite the nervous system and heart, and produce contractions and tremor's in the muscles. ${ }^{1}$ Tea is a respiratory excitant, while coffee depresses this function. Lehmann ${ }^{2}$ and Böeker ${ }^{3}$ consider that tea and coffee diminish the excretion of urea, and consequently the disintegration of the albuminous tissues, whilst they effect an increase in the amount of water dischargerl. Voit, ${ }^{4}$ however, from observations on a dog, and Squarey, ${ }^{5}$ from experiments on men, conclude that coffee possesses little or no influence on the general nutrition of the body.

\section{Of Hunger and Thirst-Starvation.}

74. The want of solid Aliment, arising from the demands of the system for the materials requisite for the growth and maintenance of the body, and for the combustive process, is indicated by the sensation of Hunger; and that of liquid, by Thirst. The former of these sensations is referrerl to the stomach, and the latter to the fauces; but although certain conditions of these parts may be the inmediate cause of the sensations in question, they are really indicative of the requirements of the system at large. For the intensity of the feeling bears no constant relation to the amount of solid or liquid alinent in the stomach; whilst, on the other hand, it does correspond with the excess of demand in the system, over the supply afforded by the blood; and it is caused to abate by the introduction of the requisite material into the circulating fluid, even though this be not accomplished in the misul manner by the ingestion of food or drink into the stomach.

75. That the sense of hunger, however, is immediutely dependent upon some condition of the Stomach, seems to follow from the fact, that it may be temporarily alleviated by introducing into the digestive eavity matter which is not alimentary. Of the precise nature of that condition, we have no cer-

1 Sre M. I errn in Brown-Séquard's Archives de Physiologic, t. i, p. 179.

2 Liebig's Ammalen, Band lxxxvi, $p$ 205.

3 Arehiv d. Vureins f. uemeins, 1853.

4 If Archive. Thysulogie, Band v, 1872. p 589.

${ }^{5}$ See Dr. Parlies's Practical Hygiene, 4th edit., p. 287. 
tain kunwlelge. It is easy to prove that nany of the causes which have bcen assigned for the sensition, are but little, if at all, concerned in producing it. 'Thus, merc emptincss of the stomach cannot occasion it ; since, if the previous meal have hcen ample, the food passes from its cavity some time before the uncasy fecling is renewed; and this emptiness maly continne (in certain disordered states of the system) for many hours or even days, without a return of desire for food. Besides, the stomach may be filled with food, and yet IIunger may be intensely felt, if, from disease of the pylorus or any other cause, there be an obstacle to the passage of the aliment into the intestine, and to the completion of the processes of chylification and ahsorption, so that the system needs that which the digestive apparatus is unable to provide for it. Again, the sense of Hunger cannot be due, as some have supposed, to the action of the gastric fluid upon the coats of the stomach themselves; since this fluid is not poured into the stomach, except when its production is stimulated by the irritation of the secreting follicles. Nor is it conveyed through the priemmogastrie nerves, since, as shown by Dr. Joln Reid, ${ }^{+}$after section of these nerves animals take food with no less avidity than previously; indeed, the sense of satiety lather than that of Hunger seems to be abolished, the animals often continuing to gorge themselves with food long after the stomach has been adequately filled.- It may, perhaps, be a more probable supposition, that there is a certain condition of the Capillary circulation in the Stomach, which is preparatory to the secretion, and which is excited by the influcnce of the Sympathetic nerves, that communicate (as it were) the wants of the general system. This condition may be easily imagined to be the proximate cause of the sensation of hunger, by acting on the nerrous centres. When food is introduced into the stomach, the act of secretion is directly excited; the capillary vessels are gradually mloaded; and the immediate cause of the impression on the nervous system is withdrawn. ${ }^{2}$ By the conversion of the alimentary matter into materials fit for the nutrition of the system, the remote demand also is satisfied; and thus it is, that the condition of the stomach just referred to, is permanently relieved by the ingestion of substances that can serve as food. But if the ingested matter be not of a kind capable of solution and assimilation, or the digestive apparatus cannot effect its preparation, the feeling of hunger is only temportrily relieved, and soon returns in grcater force than before.-The theory liere given seems reconcilable with all that has heen said of the conditions of the sense of Hnnger; and particularly with what is known of the effect produced upon it by ncrvous impressions, which have a peculiar influence upon the capillary circulation. It also corresponds exactly with what we know of the influence of the nervous systen, and of mental impressions, upon other secretions (chapter $\mathrm{x}$ vii).

76. The sense of Hunger, like other sensations, may not be taken cognizance of by the mind, if its attention be strongly directed towards other objects; of this fact, almost every one engaged in active operations, whether mental or bodily, is occasionally conscious. 'The nocturnal student, who takes a light aud early evening neal, and after devoting himself to his pursuits for several hours uninterruptedly, retires to rest with a wearied head and an empty stomach, but without the least sensation of hunger, is frequently prevented from sleeping by an indescribable feeling of restlessness and deficiency; and the introduction of a small quantity of food into the

1 Phys. Anat. and Path. Researches, pp. 234-239.

2 'These views seem to be contirmed by the observations of M. Bernard on the condition of the gastric follicles during the intervals of their functional activity. 
stomach will almost instantaneously allay this, and procure comfortable rest. Many persons, again, who desire to take active exercise before breakfast, are prevented from doing so by the lassitude and even faintness which it induces, the bodily exercise increasing the demand for food, whilst it draws off the attention from the sensation of hunger.

77. The conditions of the sense of Thirst appear to be very analogous to those of hunger. This sense is not referred, however, to the stomach, but to the fauces. It is probably even more immediately connected with the state of the general system than that of hunger; for the inmediate relief afforded by the introduction of liquid into the stomach is fully accounterl for by the instantaneous absorption of the fluid in to the veins, which is well known to take place when there is a demand for it. This demand is increased with almost equal rapility, by an excess in the amount of the fluid excretions; and it may be satisfied, or at least alleviated, without the introduction of water in to the stomach, this having been one of the results observed after the use of saline injections into the veins in cases of Asiatic Cholera, as well as after immersion in a warm bath in eases of extreme dysphagia. Thirst may also be produced, however, by the impression made by peculiar kinds of food or drink upon the walls of the alimentary canal; thus salted or highly spiced meat, fermented liquors when too little diluted, and other similarly irritating agents excite thirst; the purpose of which is obviously to cause ingestion of fluid by which they may be diluterl.

78. The results of an entire deficiency of Food, or of its supply in a measure inadcquate for the wants of the system, constitute the phenomena of Inanition or Starvation. These have been experimentally sturlied by M. Chossat on Birds and Mammals; and the infornation thence gained leads us to a better comprehension of what is (unfortunately) too frequently exhibited in the Human subject.-The following were the general sympitoms noted by MI. Chossat. The animals usually remain calm during the first half or two-thirds of the period; but they then hecome more or less agitater ; and this state continues as long as their temperature remains elevated. On the last day of life, however, whilst the temperature rapidly falls. this restlessness ceases, and gives place to a state of stupor. 'The animal, when set at liberty, sometimes looks round with astonishment, without attempting to fly; and sometimes closes the eyes, as if in a state of sleep. Gradually the extremities becone cold, and the limbs so weak as no longer to be able to sustain the animal in a standing posture; it falls over on one side, and remains in any position in which it may be placed, without attempting to move. The respirations become slower and slower; the general weakuess increases, and the insensibility becomes more profound; the pupil dilates; and life becomes extinct, sometimes in a calm and tranquil mamer, sometimes after convulsive actions producing opisthotonic rigidity of the budy. After the first day, in which the freces contain the residue of the fiond previously taken, their amount is very small ; and they seem to consist principally of grass-green biliary matter. 'Towards the close of' life, they contain a much larger quantity of water, even when none has heen ingested hy the aninal; and include much saline matter in addition to the biliary.-The average loss of weight in the warm-blooded anintals experintented on by M. Chossat, between the commencement of the period of Inanition and its termination by death, was 40 per cent. ; hut he met with a considerable variation in the extremes, which seened to depend chiefly on the amount of fat previously aecumulated in the body; those animals losing most weight, in

1 Recherches Expérimentales sur l'Inanition, Paris, 1843 See also Panum, Virchow's Archiv, Band xxix, p. 241; and Voit, Zeitschrift f. Biologie, Band ii, p. 307 . 
whieh the fat had been most abundant, which were also those that lived the longest. ${ }^{1}$ Tilking 40 per ecut. as the mean, M. Chossat obtained the following curious results, as regards the relative diminution of the several tissues and organs of the body; those which lost more than the mean, being distinguished from those which lost less:

Parts which lose more than 40 per cent.

Fat,

Blood,

Spleen, .

Panereas,

Liver,

Heart,

Intestines,

Murcles of loeomotion, .
Parts which lose less than 40 per cent.

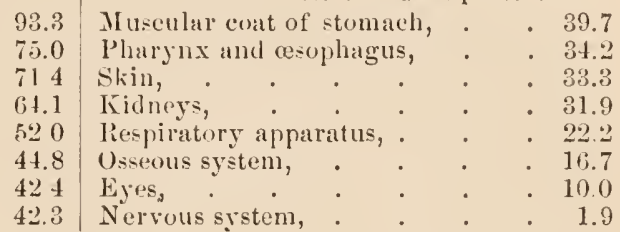

The points most worthy of note in the above table are the almost complete removal of the fat, and the reduetion of the blood to threc-fourths its normal amount, the diminution, as has since been shown by Valentin and Panum, espeeially affecting the albumen of the scrum; whilst the nervous system undergoes searcely any loss. It would seem, in faet, as if the supervention of death was eoineident with the eonsumption of all the disposable combustive material; and that up to that point, the whole remaining energy of nutrition is eoncentrated upon the nervous system. And it will be shown hereafter that there is adequate ground for considering death by starvation as really death by cold; since the temperature of the body is maintained with little diminution until the fat is thus eonsumed, and then rapidly falls, unless it be liept up by heat externally applied.-As might be expected from the comparative rapidity of interstitial change at the earlier periods of life, it was found by Chossat that the diurnal loss was much the most rapid in young animals, and that the duration of their lives when deprived of food was consequently fir less than that of adults. He further ascertained that the results of insufficient alimentation were in the cud the same as those of entire deprivation of food; the total amount of loss being almost exaetly identical, but its rate being less, so that a longer time was required to produce it. Neither he nor Scheffer ${ }^{2}$ found that much influence was exerted on the duration of life, by permitting or withdrawing the supply of water; the latter cxperimenter found that in a dog wholly deprived of water the loss in weight of the different organs was nearly the same as in deprivation of solid food, with the exception of the brain, fat, and glandular organs, which were not materially diminished. All the tissues beeame mueh drier; the skin, tendons, muscles, intestines, and blood, containing from 4 to 11 per cent. more solid residue thin in health. It appears, however, that in Man death supervenes mueh earlier when liquid as well as solid aliment is withheld; and the indifferenee observed by Chossat in the ease of Birds is probably due to the faet that they ordinarily driuk very sparingly, and eliminate very little water in their various exeretions. The experiments of Blundel and Panum show that the life of a dog deprived of food cannot be prescrved by the frequent transfusion of the blood of other healthy dogs.

1 There is a well-known ease of a fat pig, which was buried in its sty for 160 days, under thirty feet of the chalk of Dover cliff; and which was dug out alive at the end of that time, redueed in weight from $160 \mathrm{lbs}$, to $40 \mathrm{lbs}$, or no less than 75 per cent. (Trans, of Linn. Soc., vol, xi, p. 411.) This extraordinary prolongation of life in this ease may be attributed to the retention of the heat of the body by the non-condueting power of the chalk, and to the retention of its moisture by the saturation of the air in its immediate vicinity, and restriction of its movements.

2 Ludwig, Physiologie, 1861, vol. ii, p. 683. 
79. The most prominent symptoms of Starvation, as they have been noted in the Human subject, are as follows: In the first place, severe pain in the epigastrium, which is relieved on pressure; this subsides after a day or two, but is succeeded by a feeling of weakness and "sinking" in the same region; and an insatiable thirst supervenes, which, if water be with held, thenceforth becomes the most distressing symptom. The countenance becomes pale and carlaverous; the eyes acquire a peculiar wild and glistening stare; and general emaciation soon manifests itself. The body then exhales a peculiar fetor, and the skin is covered with a brownish, dirty-looking, and offensive secretion. The bodily strength rapidly declines; the sufferer totters in walking, his voice becomes weak, and he is incapable of the least exertion. The mental powers exhibit a similar prostration; at first there is usually a state of stmpidity, which gradually increases to imbecility, so that it is difficult to induce the sufferer to make any effort for his own benefit; and on this a state of maniacal delirium fiequently supervenes. Life terminates either in the mode described in Chossat's observations, or, as occasionally happens, in a convulsive paroxysm. ${ }^{1}-\mathrm{O} n$ post-norten examination, the condition of the boly is found to be such as the results of Chossat's observations would indicate; namely, extreme general emaciation and disappearance of fat, ${ }^{2}$ diminution in the bulk of the principal visceri, and almost complete bloodlessness, save in the brain, which still receives its usual supply. It is especially morthy of note, that the coats of the small intestines are peculiarly thinned, so that they become almost transparent; and that the gall-bladder is almost invariably turgid with bile, the cadaveric exudation of which tinges the surrounding parts. And further, the body rapidly passes into decomposition.

80. Now it is peculiarly wortly of note, that the deficient supply of new histogenetic materials appears to check the elimination and removal of those which have become effete; for in no other way can we accomt for that tendency to putrescence, which is so remarkably manifested during life in the fetid exhalation and in the peculiar secretion from the skin, and which is shown after death in the rapidity with which putrefaction supervenes. Moreover, towards the close of nuny exhausting diseases, the fatal termination of which is really due to a chronic inanition, it frequently happens that a "colliquative diarrhoea" comes on, which must be consilered as a manifestation of the general disintegration that is making progress eren during life. Now, referring to the conditions hereafter to be enumerated, as those which favor the operation of zymotic poisons in the body, it is obvions that no state could be more liable to it than this; since we have not merely that general depression of the vital powers, which is a prerlisposing cause of al most any kind of malady, and pre-eminently so of zymotic diseases, but also the presence of a large amount of disintegrating matter in the blood and general system, which forms the most favorable nidus possible for the reception and multiplication of such poisons. And thus it happens that pestilential diseases must certainly follow in the wake of a famine, and carry off a far greater number than perish from actual starvation.

81. Another class of phenomena, however, results from such a deficiency of alimentation as is not arleguate to produce the results just described ; provided this deficiency be prolonged for a considerable length of time, and especially if it be conjoined with other unfavorable conditions. Of this, a

1 See Rostan in Diction. de Médecine, art. Abstinence; and I)r. Donovan's account of the Irish fanine of 1847 in the Dublin Medicul Press, Feb. 1848; ulso a paper by Martin, Med. 'T. and Gaz., April, 1861.

2 In cases of acute starvation, as Dr. Fowler has shown in reference to the case of the $1 \mathrm{Velsh}$ fasting girl (Lancet, vol. ii, 1870, p. 150), a considerable amount of fat may be present in the body, and emaeiation may not be marked. 
remarkable example was presenterl at the Millbank Penitentiary in 1823. The prisoners confined in this establishment, who lad previously received an allowance of from 31 to $33 \mathrm{oz}$ of dry mutriment daily, lad this allowance suddenly rerluced to $21 \mathrm{oz}$, animal food being almost entirely excluded from the diet scale. They were at the same time subjected to a low gralde of temperature, and to considerable exertion; and were confined within the walls of a prison situated in the midst of a marsh which is below the level of the adjoining river. The prison had heen previously considered healthy; but in the course of a few months, the healtl of a large proportion of the inmates began to give way. The first symptoms were loss of color, and diminution of flesh and strength; subsequently diarluea, dysentery, and scurvy ; and lastly adynamic fevers, or headache, vertigo, convulsions, naniacal delirium, apoplexy, etc. The smallest loss of blood produced syncope, which was frequently fatal; and after death, ulceration of the mucous lining of the alimentary canal was very commonly found. Out of 860 prisoners, no fewer than 437 , or 52 per cent., were thus affected. The influence of concurrent conditions, especially of previous confinement, was here renarkably shown; for those were found to he most liable to disease who had been in prison the longest. That the reduction of the allowance of food, however, was the main source of the epidemic, was proved by the two following facts: the prisoners employed in the kitchen, who had $S$ oz. of bread additional per day, were not attaclied, except three who had only been there a few days; and after the epidemic had sprear to a great extent, it was found that the addition of $8 \mathrm{oz}$. to the daily allowance of vegetable food, and $\frac{1}{2} 0 z$. to the animal, greatly facilitated the operation of the remedies which were used for the restoration of health. ${ }^{1}$ Very similar observations to these were made by Dr. Jones ${ }^{2}$ on the prisoners confined in Camp Sumter, one of the Southern prisons, during the late American civil war. The prisoners numbered upwards of 30,000 , and were confined in a space of 27 acres, with little or no shelter from the intense heat of a Southern sun, or from the rain and dew, with festering masses of filth at the very doors of their rude dens and huts, and with the greater portion of the banks of the stream flowing through the stockade, a filthy quagmire of human excrements alive with magrgots. The diet consisted of only $\frac{1}{3} 1 \mathrm{~b}$. bacon and $1 \frac{1}{4} \mathrm{lb}$. of meal, and even this was sometimes reducerl. As a consequence of exposure to these conditions, in less than seven months 10,000 Federal prisoners died, the chief causes of this frightful mortality being diarrhcea, dysentery, scurvy, and hospital gangrene, the last often supervening on the slightest scrateh of the surface, or even on the bites of small insects. It is curious to notice that contagious fevers were rare, and typhus unknown. Dr. Jones remarks, in full confirmation of Chossat's experiments on birds, that whilst large numbers of the Federal prisoners were utterly disgusted with the Indian corn supplied to them, in which, for the most part, the husk was not separated from the meal, vet that an urgent feeling of hunger was not a prominent symptom, and that even when it existed at first, it soon disappeared, the muscular strength at the same time becoming rapidly diminished, the tissues wasted, and the mental faculties to the last degree lethargic. The diminished power of resisting deleterious influences produced hy insufficient aliment was well shown on a large scale by the statistics cullected by Dr. Chenu, of the rel-

1 See Dr. Latham On the Diseases in the Millbank Penitentiary, 1824. A similar example of the effects of prolunged insufficiency of diet wat furnished at the Maison Centrale of Nînes, for a highly instructive account of which by M. Buileau-Castelnau, chief physician to the Iraison Centrale, see Ann. d'Hyciène Publ., Janv. 1849.

2 See Dr. Austin Flint's Physiology of Man, vol. ii, p. 39, 1867. 
ative mortality of the French and English contingents in the Crimean war. During the first winter (1855) the English army lost 5.79 per cent. of its effective force, whilst the French only lost 2.31 per cent. Great changes were immediately introduced into the diet and general regimen of the English army, with the result that in the following winter, only 441 soldiers succumbed to disease, out of an effective of 50,000 , whilst the French troops, badly fed and badly clothed, had no less than 106,000 sick, of whom 20,000 died, out of a total force of 130,000 men. The effects of insufficient alimentation were also exhibited on a large scale during the siege of Paris. The mortality among the feebler member's of the community-old people and children-being very great. Besides the soldiers killed in action, upwards of 42,000 persons died in the course of the five months of siege, in excess of the number dying in the corresponding period of the preceding year. ${ }^{2}$ The proportion steadily rose week by week as the supply of food decreased, with only one or two exceptions, from the number $127 \%$, who died in the week ending 24 th September, 1870 , to the number of 4671 , who died in the week ending the $3 d$ February, 1871, the numbers in the three subsequent weeks being rather less. ${ }^{2}$

82. It is a curious effect of insufficient nutriment, as shown by the inquiries of Chossat ( $\mathrm{O}_{\mathrm{p}}$. cit.), that it produces an incapability of digesting even the small anount consumed. He found that when turtle doves were supplied with limited quantitics of corn, but with water at discretion, the whole amount of food taken was scarcely ever actually digested ; a part of it being rejecterl by vomiting, or passing off by diarrhoea, or accumulating in the crop. It seens as if the vital powers were not sufficient to furnish the requisite supply of gastric fluid, when the body began to be enfeebled by insufficient nutrition; or perhaps we night well say, the materials of the gastric fluid are waiting. Hence the loathing of food, which is often manifested by those who have been subjected to the influence of an insufficient diet scale in our prisons and poor-houses, and which has been set down to caprice or obstinacy, and punished accordingly, may be actually a proof of the deficiency of the supply which we might expect to have been voraciously devoured, if really less than the wants of the system require.

83. It is extremely important that the Medical Practitioner should be aware, that many of the phenomena above described may be induced by the adoption of a system of too rigid abstinence in the treatment of various diseases; and that they have been freruently confounded with the symptoms of the malady itself, and have led to an entirely erroncous method of treating it. "Many cases," says Dr. Copland, " "have oceurred to me in practice, where the antiphlogistic regimen, which had been too rigidly pursucd, was itself the cause of the very symptoms which it was employed to remove. Of these symptoms, the affection of the head and delirium are the most renarkable, and the most readily mistaken for an actual disease requiring abstinence for its removal." The experience of those, cspecially, who are largely engaged in consulting practice, must have furnished numerous illustrations of the above statement. Dr. Copland mentions the following: "A professional man has been seized with fever, for which a too rigid abstinence wits enforced, not only during its continuance, but also during convalescence. Delirium had been present at the height of the fever, and recurred when the paticnt was convalescent. A physician of cminence in maniacal cases was called to

1 Le Bon, La Vie, ete, Paris, 1874, p. 71. From 18th Sopt. 1869, to 24th Feb. $1870,21,978$ persons died; whilst from 18 th Sept. 1870 , to 24th Fet. 1871 (period of siege), the number of deaths was 6.4.154.

2 See M. Le Bon, La Vir, cte., 1874.

3 Dictionary of Practical Medicine, vol. i, p. 26. 
him, and recommended that he should be removed to a private asylum. Before this was carricd into effect, I was requested to see him. A different treatment and regimen, with a gradual increase of nourishment, were adopted, and he was well in a few days, and within a fortnight returned to his professional avocations."

84. The time during which life can be supported under entire abstinence from food or drink, is usually stated to vary from eight to ten days ; the period may be greatly prolonged, however, by the oceasional use of water, and still mise by a very small supply of food; or, even, it would seem, by a moist condition of the surrounding atmosphere, which obstructs the exhaliatiou of liquid from the body. Thus, Forleré mentions that some workmen were extricated alive, after fourteen days' confinement in a cold damp vault, in which they had been buried under a ruin. Dr. Sloan has given an account $^{2}$ of the case of a healthy man at. 65 , who was found alive after having been shut up in a coal-mine for twenty-three days, during the first ten of which he was able to procure and swallow a small quantity of foul water; he was in a state of extreme exhaustion, and rlied three days afterwards, notwithstanding the attempts marle to recover him. It would scem as if certain conditions of the nervous system, especially those attended with peculiar emotional excitement, are favorable to the prokmgation of life under such cireumstances. Thus, in a case recorded by Dr. Willan, of a young gentleman who starved himself under the influence of a religious delusion, life was prolonged for sixty days; during the whole of which time, nothing else was taken than a little orange juice. In a somewhat similar case which occurred under the Author's notice, in the person of a young French larly, more than fifteen days elapsed between the time that she ceased to eat regularly, and the time of her being compelled to receive nourishment; churing this period she took a good deal of exercise, and her strength seened to suffer but little, although she swallowerl solid food only once, and then in small quantity. Again, in cerrain states of the system commonly known as "hysterical," there is frequently a very remarkable disposition for abstinence, and power of sustaining it. It niay be well to remark that, under such circumstances, the continual persuasions of anxious friends are very injurious to the patient, whose return to her usual state will probably take place the earlier, the more completely she is left to herself.

\section{Movements of the Alimentary Cunal.}

85. The motions by which Food is conveyed to the Mouth and introduced into its cavity, constituting the acts of Prehension and Ingestion, are ordinarily consilererl to be voluntary, at least in the adult; and it is indubitable that the Will has entire control over them. Nevertheless, they belong to the class of "secondarily automatic" movements; and like those of locomotion, may be kept up when the will is in abeyance, by the suggesting and guiding influence of sensations, thus being performed under the same essential conditions as the purely "consensual" or "sensori-motor" actions." The necessity

1 There secm, adequate evidence, that a state which may be eharacterized as one of Syncope,-the animal functions being entirely suspended, and the organic functions heing redueed to an extremely low ebb-may be prolonged for many days, or even weeks, provided the temprature of the budy be not too nuch reduced. This class of facts, however, will be more appropriately considered hereafter (chap. xxi).

2 Medical Gazette, vol. xvii, p. 389.

3 This, the Author thinks, will be conformable to the experience of most of his readers; who will find, if they analyze their own eonsciousness, that they continue to eat while their whole atlention is given to some abstract train of thought, or to some external object. But a remarkable case has been placed on record by Mr. Dunn 
of "guiding sensations" for their performance is made evident by one of Sir C. Bell's experiments, the wrong interpretation of whose results originally led him to an erroneous view of the functions of the Fifth pair of nerves. He found that an Ass, in which the infraorbital branch of this nerve had been divided, made no attempt to pick up oats with its lip, although the animal saw them, bent down its head with the obvious purpose of ingesting them, and brought its lip into absolute contact with them; hence he concluded that the power of motion was destroyed in the lip, when it was in reality only the gmiding sensation that was deficient, the motor power being supplied by the Facial nerve or Portio dura.

86. The food thus introduced into the mouth, is subjected (unless it be already in a state which needs no further reduction) to the process of Mustication. This is evidently an operation of great importance, in preparing the substances to be afterwards operated on for the action of their solvent; and it exactly corresponds with the trituration to which the Chemist would submit any solid matter, that he might present it in the most advantageous form to a digestive menstrum. The complete disintegration of the alimentary matter is, therefore, of great consequence; and, if imperfectly effected, the subsequent processes are liable to derangement. Such derangement we continually meet with; for there is not, perhaps, a more frequent source of Dyspepsia than imperfect mastication, whether resulting from the haste with which food is swallowed, or from the want of the instruments proper for the reducing operation. The mechanical disintegration of the food is manifestly aided by Insalivation; but the adnixture of Saliva also exerts, as we shall hereafter see, a very marked influence on the chemical composition of certain of its constituents. The movements of Mastication, still more than those already adverted to, although under the complete coutrol of the Will, and originally dependent upon it for their excitation, come at last to be of so habitual a character, that they continue when the direct influence of the will is withdrawn, the influence of the guiding "sensation," however, being essential to their performance. Every one is conscious that the act of mastication may be performed as well, when the mind is attentively dwelling on some other object, as when directed to it; but, in the former case, we alre rather apt to go on chewing and rechewing what is already fit to be swallowed, simply because the will does not exert itself to check the action, and to carry the food backwards within the reach of the muscles of deglutition. This conveyance of food backwards to the fauces, is a distinctly voluntary act; and it is necessary that it should be guided by the sensation, which there results from the eontact it induces. If the surface of the pharynx were as destitute of sensation, as is the lower part of the osophagus, we should not know when we had done what was necessary to excite its muscles to uperation.-The muscles depressing the lower jaw are the genio-hyoid, the mylo-hyoid, and the anterior belly of the digastric. The omo-hyoid, stemo-hyoid, and thyro-hyoid muscles, also aid. The upward movenent is effected by the combined action of the masseter, temporal and internal pterygoid muscles. The forward movenent is clue to the action of both pterygoids, and the lateral or grinding movement to the external pterygoid of one sidc. 'The Tongne is moved downwards and forwards by the hyo-glosens and genio-glosess, upwards and backwards by the stylo-glossus, whilst its changes of form are due in great measure to its intrinsic longitudinal and transverse fibres. The more inportant muscles concerned in

(Lancet, Nov. 15th and 29th. 1845), which fully confirms the view here advanced; the movements, not merely of the lips and jaws, but those by which fond was conveyed to the mouth, having been (arried on antomatically, when once (so to speak) the spring was touched by which they were set in action. 
the mastication of food are supplied by the third branch of the Fifth pair, which is wcll known to be a nerve of mixed cndowments; but some, especially those of the cheeks, are also supplied by the Facial nerve; and yet, if the former be paralyzed, the latter camnot stimulate them to the necessury combined actions. Hence we see that the movements are of an associated character, their due performance being dependent on the part of the nervous centres from which the motor influence originates. If the Fifth pair, on the other hand, be uninjured, whilst the Portio dura is paralyzed, the movements of mastication are performed without difficulty; whilst those connected in any way with the Respiratory function, or with Expression, are paralyzed. If again, the sensory portion of the Fifth pair be paralyzel, the act of Mastication is very imperfectly performed, even though the motor power be not in the least impaircd; for the muscles cannot be marle to perform the requisite associated movements without the guidance of sensations; so that the morsel lodges between the teeth and the cheek, or beneath the tongue, and can with difficulty be kept in the appropriate position.

87. When the reduction of the food in the mouth has been sufficiently accomplished it is carried into the Pharynx, and is thence propelled down the esophagus into the stomach by a set of associated movements, which taken together constitute the act of Deglutition. These movements were first described in detail by Magendie; but his account requires some modification, through the more recent observations of Dzondi, ${ }^{1}$ Butge, ${ }^{2}$ Bidder, ${ }^{3}$ Czermak, ${ }^{,}$Schuh, ${ }^{5}$ and Moura ${ }^{6}{ }^{6}$ The first stage in the process is the carrying back of the food until it has passed the anterior palatine arch; this is effected by the contraction of the nuylo-hyoid, and of the longitudinal and transverse muscles of the tongue, which together render the tongue shorter and thicker, pressing it against the roof of the mouth, whilst the stylo-glossi draw it somewhat backward; those movements are purely voluntary. The second stage now commences, during which the entrance of foorl into the uasal cavities and trachea is most jealously guarded against by certain reflex actions, which have only been clearly recognized since the introduction of the laryngoscope by Czermak. During this stage the tongue is carried still farther backwards, the larynx riscs, its orifice being covered by the epiglottis, which is at the same time somewhat depressed, and placed horizontally, so that its upper border tonches the posterior wall of the pharynx. The cushion at the base of the epiglottis becomes applied to the arytenoid cartilages, and the vocal cords, both true and false, are closely approximated; a triple protection against the entrance of the food into the trachea being thus afforded. Coincidently with these movements, the lower border of the velum palati becomes applied to the walls of the pharynx, and the muscles of the posterior palatine arch contract in such a manner as to cause the sides of the arch to approach each other like a pair of curtains, so that the passage from the fauces into the posterior nares is nearly closed by them; and to the cleft between the approximated sides the uvula is applied like a valve. A sort of inclined plane, directed obliquely downwards and backwards, is thus formed; and the morsel slides along it into the pharynx, which is brought up to receive it. Though some of these acts may he performed voluntarily, the combination of the whole is automatic. ${ }^{7}$ The third stage

1 See Prof. Müller's Elcments of Physiology (translated by Dr. Baly), p. 501.

2 Phys., 1860, p. 157.

4 The Laryngoscope, New Syd. Soc. Translation, 1861, vol. ix.

5 On the Laryngoscope, Canstatt, 1858.

6 Robin, Journal de l'Anatomie, 1867, p. 157.

- The observation of Schuh (Canstatt, 1858) upon the movements of the soft palate during deglutition seem to show that this part is somewhat more active during 
of the process, the propulsion of the food down the esophagus, then commences. This is accomplished, in the upper part, by means of the constrictors of the pharynx ; and in the lower, by the muscular coat of the esophagus itself, which has been shown by Gillette ${ }^{1}$ to be consposed in its upper part of striated muscular tissue alone, in its middle part of exclusively unstriated muscular tissue, and near the cardiac orifice of the stomach of a mixture of striated and unstriated tissue. When the morsels are small, and are mixed with much fluid, the undulating movements from above downwards succed each other very rapidly, as inay be well observed in Horses whilst drinking; large morsels, however, are frequently some time in making their way down. Fach portion of food and drink is included in the contractile walls, which are closely applied to it during the whole of its transit. The gurgling sound which is observed when driuk is poured down the throat of a person in articulo mortis, is due to the want of this contraction. The whole of the third stage is completely involuutary.-In order to ascertain the parts implicated in the deglutition of liquids, Dr. Moura employed the laryngoscope after ink had been swallowed, and fornd that the parts tinted were the whole internal surface of the mouth, the velum palati, uvula, pillars of the fauces, anterior surface of the epiglottis, and the pharynx generally, with the posterior surfaces of the cricoid and arytenoid cartilages. On the contrary, the parts that preserved their natural color were the interior of the laryux to within a very short distance of the free edge of the epiglottis and the anterior portion of the lateral grooves of the fauces. At the point where the oesophagus enters the stomach, the "cardiac orifice" of the latter, there is a sort of sphincter, which is usually closed, but which opens when sufficient pressure is made on it by accumulated food, closing again, when this has passed, so as to retain it in the stonach.

88. The purely automatic nature of the act of Deglutition is shown by the fact, that no attempt on our part will succeed in performing it really coluntarily. In order to excite it, we must apply some stimulus to the fauces. A very smali particle of solid matter, or a little fluid (saliva, for instance), or the contact of the back of the tongue itself, will be sufficient; but without either of these, we camnot swallow at will. Nor can we restrain the tendency, when it is thus excited by a stimulus; every one knows how irresistible it is, when the fauces are touched in any unusual manner; and it is equally beyond the direct control of the will, in the ordinary process of eating,- - voluntary as we conmonly regard this. Moreover, this action is performed, like that of respiration, when the power of the will is suspenderl, as in profound slecp, or in apoplexy affecting only the brain; and it does not seen to be at all affected by the entire removal of the brain, in an animal that can sustain the shock of the operation; being rearlily excitable, on stimulating the fauces, so long as the nervous structure retains its functions. This was experimentally proved by Dr. MI. Hall; and it harmonizes with the natural experiment sometimes brought under our notice in the case of an anenceph-

the second stage than it was described to be by Dzondi. He had an opportunity of observing them in a woman, the left side of whose fitce hat been removed by an operation. When the patient drauk, the soft palate raised itself above the horizonal line, as som as the glass was approximated to ler lips. It renained in this position whilst the fluid was being sucked in; but as soon as swallowing commenced it very suddenly descendecl, so as to press the fluid into the wophlagus. It then agaiu elevated itself with even greater tension, and again deseended. In swallowing solid food the same suddeu ascent and descent of the velum upon the deglutition of each morsel was observable.

1 Gillatte, Journ. de I'Anatomie, 1872, p. 617. See also for the Histology of the Alimentary Canal, Klein and Verson in Stricker's Manual of Histology, Syd. Soe. Transl., vol. i. 
alous infunt, in which the power of swallowing seems as vigorous as in the perfect one. But if the "nervous" circle be destroyed, either by division of the trunks, or by injury of any kind to the portion of the nervous centres connecter with them, the action can no longer be performed; and thus we see that, when the effects of apoplexy are extending themselves from the brain to the spinal cord, whilst the respiration becomes stertorous, the power of Deglutition is lost, and then respiration also speerlily ceases.

89. Our knowledge of the nerves specially concerned in this action, is principally due to the very careful and well-conducted experiments of Dr.J. Reil, ${ }^{1}$ which have been fully corroborated by the more recent observations of MII. Yulpian ${ }^{2}$ and Jolyet. From a careful examination of the actions of deglutition, and of the influence of various nerves upon them, Dr. Reid drew the following conclusions: The excitor impressions are conveyed to the Medulla. Oblongata chiefly through the Glosso-pharyngeal, but also along the branches of the Fifth pair distributed upon the fauces, and along the superior laryngeal branches of the Pncumogastric distributed upon the pharynx. 'The motor influence passes chiefly along the pharyngeal branches of the Pneumogastric, which are probably originally derived from the Spinal Accessory; along the branches of the Hypoglossal, distributed to the muscles of the tongue, and to the stemo-hyoid, stemo-thyroid, and thyrohyoid muscles; along the motor filaments of the Recurrent laryngeals; through some of the branches of the Fifth, supplying the elevator muscles of the lower jaw; along the branches of the Facial, ramifying upon the digastric and stylo-hyoid muscles and upon those of the lower part of the face; and probably along some of the branches of the Cervical plexus, which unite themselves to the descendens noni. It was further observed by Dr. Reid, that the stylo-pharyngeus muscle is usually thrown into contraction, when the roots of the Glosso-pharyngeal nerve are irritated; and as this - has been also noticed by Mayo, Volkmann, and others, we are probably to consider the Glosso-pharyngeal a notor nerve, in so far as that muscle is concerner. ${ }^{3}$

90. When the food has been propelled downwards by the Pharyngeal muscles, so far as their action extends, its further progress through the Esophugus is effected by a kind of peristaltic contraction of the muscular coat of the tube; and Dr. J. Reid found, by repeated experiment, that the continuity of the cosophageal branches of the Pneumogastric with the Me-

1 Edin. Med. and Surg. Journ., vol. xlix; and Physiologieal, Anatomical, and Pathological Researches, chap, iv.

2 Revue de Cours Soientifiques, $1866, \mathrm{t}$. iii, p. 754.

3 Op. cit., pl. 258-200. It seems not improbuble that the diserepant resul ts obtained by different experimenters on this point, are partly to be explained by differences in the distribution of the nerves in the several species of animals operated on. Thus in the experiments of Prévost and Waller on the Rabbit (Brown-Séquard's Archives de Physiologie, 1870, p!. 185 and 343), it appeared that in this animal the glossopharyngeal nerve takes no part in the reflex phenomena of deglutition, the fifth being the principal sensory nerve, and the superior laryngeal braneh of the pneumogastric contributing to the reflex movement by its sensory branches distributed to the mucous mombrane eovering the epiglossus, the arytrno-epiglotidean folds, the superior borders of the laryngeal orifice, and the cartilages of Santorini. In Chauveau's experiments on the IIorse (Journal de la Pliysiologie, t. v, pp. 190 and 323), direct irritation of the upper ronts of the vagus caused eontraction ehiefly of the inferior constrictor of the cosophagus; of the middle roots, contraction of the pharynx; and of the lower roots, contraction of the upper eonstrictor and levator ; thougl all aeted to some extent upon the whole pliarynx and cosphagus. The spinal accessory, glossopharyngeal, facial, hypoglossal, and eervical sympathetic nerves, had little or no action on the movements of the pharynx osolhagus, or stomali in this animal. See also Goltz (Studien, ete., in Pfüger's Archiv, 1872, vi, p. 616), for the movements of the csopliagus in the Frog. 
dulla Oblongata is necessary for the rapid propulsion of the food; from whence it appears that an impression made upon the mucous surface of the nesophagus, conveyed by the afferent fibres of these nerves to their ganglionic centre, and reflecterl downwards along the motor fibres, is the real cause of the muscular contraction. The following are the general results of Talentin, ${ }^{1}$ so far as they apply to this part of the subject: The lower part of the osophagus in the neck is made to contract peristaltically from above downwards, by irritation of the roots of the first three cervical Spinal nerves, and of the cervical portion of the Sympathetic, through which last the former evidently operate. The thoracic portion of the resophagus is made to contract, by irritation of the lowest Sympathetic ganglion of the neck, and of the higher thoracic ganglia, and also of the ronts of the lower cervical Spinal nerves. Muscular contractions of the Stomach are produced in the rabbit, by irritation of the roots of the 4 th, 5 th, 6 th, and 7 th cervical Spinal nerves, and of the 1st thoracic, so that a distinct furrow is evident between the cardiac and pyloric portions of the viscus; and the lower the nerve is irritated, the nearer to the pylorus do the contractions extend. If the Pneumogastric be divided in the rabbit, on each side, above the osophageal plexus, but below the pharyngeal branches, and the animal be then fed, it is found that the food is delayed in the nesphagus, from spasmodic contraction of the cardiac sphincter, which becomes greatly distended. Further, if the lower extremity of the Pneumogastric be irritated, distinct contractions are scen in the asophageal tube, proceeding from above downwards, and extending over the cardiac extremity of the stomach. We have here, then, a distinct case of reftex action, without sensation, occurring as one of the regular associated movements in the natural condition of the animal body; and it is very interesting to find this following upon a reflex action with sensation (that of the pharynx), and preceding a movement which is but slightly connected with the Spinal Cord (that of the lower part of the alimentary canal). The use of sensation in the former case his been already shown. The muscular fibres of the Csophagus are also excitable, though usually in a less degree, by direct stimulation; for it appears that, in sone animals (the Dog, for example), section of the pneumogastric does not produce that check to the propulsion of the food, which it occasions in the Rabbit; and even in the Rabbit, as Dr. M. Hall has remarked, ${ }^{2}$ the simple contractility of the muscular fibre occasions a distinct peristaltic movement along the tube, after its nerves have been divided; causing it to discharge its contents when cut across. Such a movement indecl, seems to take place in something of a rhythmical manner (that is, at short and tolerably regular intervals), whilst a meal is being swallowed; but as the stomach becomes full, the intervals are longer, and the wavelike contractions less frequent. The reopening of the cardiac orifice, on pressure from vithin (which is usually resisted by the sphnincter, as in the acts of defecation, parturition, ete.), is one of the first of that series of reversed actions which constitutes the act of Vomiting; and this is accompanied by a reversed peristaltic action of the resophagnis. The independence of these actions, one of another, and their relation to a common cause, is remarkably shown by the fact, that when vomiting takes place as a consequence of the injection of tartar emetic into the veins, the reversed peristaltic action of the oesophagus is performed even after its separation from the stomach.

91. The food which, thus propelled along the osopliagus, enters the Stomach through its cardiac orifice in successive wares, is immediately subjected

1 Valentin, De Funct. Nerv. Cereb. et Nerv. Sympath, book ii, chal. ii.

2 Third Memoir on the Nervous System, 8201. 
to a peculiar peristaltic movement, which has for its object to produce the thorongh intermixture of the gastric fluid with the alimentary mass, and so to separate the portion which has been sufficiently reduced from the remainder. The fasciculi composing the muscular wall of the Human stomach have recently been shown by Dr. J. B. Pettigrew ${ }^{1}$ to be so disposed as to form long spirals or figure-of-cight loops, of which the most external and most internal fibres are nearly longitudinal, whilst those most centrally situated are nearly circular. The contraction of these fibres lessens the cliameter of the stomach in every direction; and whilst the cavity is empty they are uniformly contracted, so as to reluce the organ to its smallest dimensions. When food is introduced, the contraction of the parietes as a whole still continues, to such a degree as to make them closely apply themselves to its surface; but the contraction of the individual fasciculi alternates with relaxation, in such a manner as to induce a great variety of motions in this organ, sometimes transversely, and at other times longitudinally. "These motions;" remarks Dr. Beamont, who has enjoyed a peculiar opportunity of observing them," "not only produce a constant disturbance or churning of the contents of the stomach, but they compel them at the same time to revolve about the interior from point to point and from one extremity to the other." I 11 addition to these movements, there is a constant agitation of the stomach produced by the respiratory muscles. The nature of these, and indeed of all peristaltic movements, has been stated by Dr. Brinton ${ }^{3}$ to resemble very closcly those producer by the descent of a perforated piston in a closed tube containing fluid, for here there would be peripheral currents passing in the same direction as the piston, and a central current flowing in the olposite direction, through the perforation in the piston. 'The direction which the particles of food take, as described by Dr. Beaumont, corresponds very finly with this view. He says: "The bolus as it enters the cardia turns to the left, passes the aperture, descends into the splenic extremity, and follows the great curvature towards the pyloric end. It then returns, in the course of the smaller curvature (or as Dr. Brinton supposes, through the axis of the stomach), and makes its appearance again at the aperture in its descent into the great curvature, to perform similar revolutions. These revolutions arc completer in from one to three nimutes. They are probably induced, in a great measure, by the circular or transverse muscles of the stomach. They are slower at first than after chymification has considerably adranced;" at which time also there is an increased impulse towards the pylorus. It is probable that, from the very commencement of chymification until the organ becomes empty, portions of chyne are continually passing into the duodenum; for the bulk of the alimentary mass progressively diminishes, and this the more rapidly as the process is nearer its completion. The accelerated expulsion appears to be effected by a peculiar action of the transverse muscles; and especially of that portion of them which surrounds the stomach at about four inches from its pyloric extremity. This band is so foreibly contracted at the latter part of the digestive process, that it almost

1 Proced. of the Roy. Soc., Lond., Jume 20th, 1867.

2 See the Case of Alexis St. Martin, with Ubselvations and Experiments by Dr. Beaumont, republislsed in this country by Dr. Andrew Combe.-This patient had a large fistulous orifice in his stomach, remaining after a wound which had laid open the cavity; but his general health had been completely restored.

3 Cyclop. Anut. and Phys., vol. v, pp. 313 and 345 . See also, supporting Dr. Brinton's views, the observations of Dr. v. Bram Houckgeest (PAüger's Archiv, 3872, Band vi, p. 300). In these experiments the belly of the animal was opened whilst the animal was immersed in a solution containing $\frac{6}{10}$ ths per cent. of common salt in water, at bloud heat. 
separates the two portions of the stomach into a sort of hourglass form; and Dr. Beaumont states that, when he attempterl to introduce a long thermometer tube into the pyloric portion of the stonach, the bulb was at first gently resisted, then allowed to pass, and then grasped by the muscular parietes beyond, so as to be drawn in: whence it appears that the contraction has for its object, to resist the passage of solid bodies into the pyloric extremity of the stomach, at this stage of digestion, whilst the matter which has been reduced to the fluid form is pumped away (as it were) by the action of that portion of the viscus. These peculiar motions continue until the stonach is perfectly empty, and not a particle of food or of chyme remains; and when they are nearly brought to a close, the contraction of the pyloric orifice also gives way to an extent sufficient to allow not only the undigested residue of the food, but also large solid bodies that may have been swallowed (such as coins and the like), to pass into the intestinal canal.

92. With regard to the degree in which these movements of the Stomach, whose share in the Digestive operation is so important, are dependent upon the Spinal cord, and are consequently of a "reflex" nature, it is difficult to speak with certainty, owing to the contradictory results obtained by different experimenters. These contradictions, however, seem partly due to a diversity in the nature of the animals experimented on, and partly to a difference in the stage of the digestive process at which the observations were made. The nerves supplying the Stomach are derived from the Pneumogastrics, and from branches of the solar plexus of the Sympathetic, and it seems to be well established by the researches of Reid, Valentin, and others, ${ }^{1}$ that distinct movements commencing at the cardiac orifice, and extending peristaltically towards the pylorus may be excited, when the stonmach is distended with food, by irritating the Pneumogastric. The movements, however, are comparatively feeble when the stomach is empty. When the Pneumogistrics are divided in the neck, the cardiac orifice of the stomach becomes spasmodically contracted ${ }^{2}$ - a condition which, after lasting for about thirty-six hours, generally passes off: If previously to that period the animal be allower to eat, the food accumulates in the lower part of the osophagus, and death results from suffocation. 'The contraction of the cardiac sphincter appear's, therefore, to be induced by other nerves than the Pneumogastric; but there is abundant evidence to show that all the ordinary movements of the stomach are governed by the Pneumogastrics (or, perhaps, as Schiff believes, by the fibres of the Spinal Accessory coursing in the Pneunogastrics), since if these be divided, complete paralysis of the muscular walls results, whilst lively movements can still be induced by irritation of the lower or distal cut extremity. Irritation of the splanchnic nerves, or of the sympathetic cord, is not followed by any very obvious movements, the former nerves being in fact essentially vaso-motor, and therefore as when stimulated they thus caluse contraction of the bloodvessels, they rather tend to inlibit any movements that may be present than to incite them if they are absent. It is found that after the section of the Pneumogastrics, if small portions of food be introduced into the stomach, these can be still propelled onwards, which we must con-

1 See Dr. Reid's Physiological, Anatomical, and Pathological Researehes, ebap. v; Valentin, De Funetionibus Nervorum Cerebralium, etc., chap. xi ; also Longet, Anat. et Physiol. du Système Nerveux, tom. i, p. 323 ; and Physiolurie, rol. i, p. 234, 1861; and Biscloff' in Müller's Arehiv, 1843. P'incus, Exp. de vi Nervi Lagi, Wratislaw, 1856; Harting, Ucber die Nervi Vagi, Giessen, 1858; Sehitl, Hhyshlugie, 1859, p. 420; and Scliweiz, Monats. f Pralit. Mecl., 1860; Bernard, Med."Times and Gaz., 1860 , vol. ii, p. 1; Ratvitsch, Müller's Archiv, 1861, p. 779; Henle, Handb. d. System. Anat. des Mensclen, Baud ii, 1866; O. Nasse, Beiträge zur Physiologie d. Darmbewegumg, 1866 .

2 Bernard, Mlied. 'Times and Giz., 1860, vol. ii, p. 1. 
sider to be due either, as Ludwigr and Schiff ${ }^{2}$ supposc, to the reflex action of the ganglia of the Sympathetic, which are very numerons in the conneetive-tisue layers of its parietes, or possibly to the contractions of the muscular fibres proluced by direct irritation, a view which, originally andranced by the author, has been lately strongly advocated by Engelmann. ${ }^{3}$ 'The moderate excitement of pleasurable emotions is favorable to the operation of digestion ; not only by giving firmness and regularity to the action of the heart, and thus promoting the circulation of the hlood and the increase of the gastric secretion; but also in all probability by inparting energy and regularity to the muscular contractions of the stomach. The movements of the stomach ccase during sleep (Busch).

93. If uch discussion has taken place upon the question, how far contraetion of the parietes of the Stomach itself actually participates in the operation of Vomiting; and many experiments have been made to determine the facts of the case. Some, like Magendie, have gone so far as to affirm that the stomach is essentially passive; grounding this inference upon the fact experimentally ascertainel, that when the stonach was removed, and a bladder was substituted for it, this was emptied of its contents by the conpression of the parietes of the abdomen, when tartar emetic was injected into the vcins. ${ }^{*}$ But this fact by no means disproves the active co-operation of the stomach; and judging from the analogy of the uterus, bladder, and rectum - whose muscular walls are all actively concerned in the expulsion of their contents, though that expulsion is in great part due to the contraction of the abdominal muscles-we should be led to concur with the common opinion, of which our own sensations during the act would indicate the correctness. From the careful experiments of Schiff $^{5}$ on dogs, as well as from ohservations made on man in cases where, from injury, the stomach has been exposed, ${ }^{6}$ it appears that under ordinary circumstances the cardiac aperture is firmly closerl but that when vomiting is about to take place, a full inspiration occurs, which scrves, as Dr. M. Hall first pointed out, to fix the diaphragm and to supply a firm surface against which the stomach can be pressed. Then, an instant before the contraction of the abdominal walls occurs, the cardiac orifice is suddenly dilated by the contraction of special bands of muscular fibres, which are probably continuous with the longitudinal fibres of the resophagus. The muscles of expiration-i.e., the abdominal muscles - then contract with great vigor, and the glottis being closed, so that the escape of air from the chest and the elevation of the diaphragm are prevented, the stomach is subjecterl to considerable pressure, and its contents are immediately ejected. The importance of the contraction of the abdominal muscles is sufficiently evidenced by the fact, demonstrated by Giannuzzi, that no vomiting can be induced in animals, whose voluntary muscles have been paralyzed by woorara. When peristaltic movements of the stomach, which have occasionally been observed to be reversed in direction, are already present, their activity is generally intensified; but if the stomach be quiescent before vomiting commences, it may remain perfectly passive throughout. The pylorus is almost always firmly closed, so that but little of the food escapes into the intestines. The flow of

1 Physiologie, p. 614 .

3 Pflüger's Archiv, Band iv, 1871, p. 1

4 Schiff has pointed out that for Magendie's experiment to succesd, the cardiac orifice and lower part of the oesophagus must also be removed, the contraction of these parts otherwise preventing the escape of the contents of the bladder.

5 Moleschott's Unters., Bd. x, 1867, p. 353.

6 Lepine, Bullet. de l'Acad. Roy. de MIéd., 1844; and Patry, in Allgem. Med. Centralblatt, 1863, No. 62 . 
bile is usually inereased. The interesting observation was made by Rühle, that if a manometer be fastened into the stomach, and vomiting be excited, instead of an elevation there is a deseent of the mercury, momentarily preeeding the expulsion of the contents; this must doubtless be referred to the sudden and active opening of the cardiac orifice produced by the dilatator fibres described by Sehitf, which oceurs just anteeedently to the pressure exerted by the muscles of the abdomen. There can be but little doubt that the violent but fruitless efforts at vomiting whieh we oceasionally witness (two or three such efforts frequently preeeding the effeetual one), are prevented from emptying the stomach by the obstinacy with which the cardiae sphincter is kept closed; just as the expiratory effort which assists in emptying the stomach, is prevented, by the firmness with which the glottis is held shut, from expelling the contents from the chest. The immediate eauses of vomiting may be redueed to several different eategories. 1st. The contaet of irritating substances with the mucous membrane of the stomach itself; these, however, cannot act by direct stimulation upon more than its own inuscular coat; and their operation upon the associated museles must take plaee by reflexion, through the "nervous eircle" furnished by the pueumogastrics and the motor nerves of expiration. 2d. Irritations applied to other parts of the body, likewise operating by simply reflex transmission; as in the vomiting which is eonsequent upon the strangulation of a hernia, or the passage of a renal calculus. 3d. To the direct irritation of the nerrous eentres by certain irritants (Tartar Emetic, Apomorphine); and perhaps we may add, the voniting that oecurs after division of both pneumogastricsthe division of one having but little effeet. ${ }^{l}$ 4th. Inpressions reeeived through the sensorial centres, which may be either sensational or emotional, but which do not operate unless they are felt. In this mode seems to be excited the vomiting that is induced by tickling the fauces, which first gives rise to the sensation of nausea; as well as the vomiting eonsequent upon disgusting sights, odors, or tastes, and upon those peculiar internal sensations which are preliminary to "sea-sickness." The recollection of these

1 This appears to be demon-trated by the experiments of Choupne (Société de Biologie, Séance, 18th July, 1874), who observed that after section of both pnemmoratstrics in dogs, the intravenous injection of tartar cmetic and of apomorphine catused free vomiting, whilst Ipeacuanba or its atctive principle, Emetine, had no action; from whence the conclusion may be drawn that the two first-named drugs aet on the vagal centre as well as upon the peripheric cxtremities of the vagi in the gatric muens membrane, whil-t the aetion of emetine seems to be contined to the latter. Hermann (Pflügere's Archiv, Band v, 1872, p. 280) grounding his opinion on the result of an experiment made by Grimm (Idem, Band iv, 1871, p. 20.5), showing that tartar emetic injected into the veins takes a longer time to act than when injected into the stomach, believes that this salt has a speeific action on the parictes of the stomach; but it may be remarked that, as above stated, IIagendic long argo slowed that "fforts to vonit followed the injection of tartar cmetic, after the ablation of the cntirr stomach. (See D'Urnellas's Bulletin Généralu de Thérupeutique, 1873, p. 193 et sey.) D'Ornellas considers that vomiting may be produced by three kinds of effort-: 1. Intrinsice, or by the contraction of the stonach alone; 2 , Extrinsie, or by the contraction of the expiratory muscles; and 3 , by mixed or combined and coordinated, intrinsic and extrinsie etforts; and the nerves impliented may be either the puremongastries, the nerves of special sense, or the sympathetic. In meningitis, in cases of cerebral tumor, and in lamorrhage, the feeling of natsen is probably conveyed by the sensory branches of the ghosso-pharyngeal nerve. The natuseating principle of some drugs, though gencrally, is not always idcutical with that producing their emetic eflect. Thus in the cars of Ipecaleuahat the natuseating principle is an odorous substance, capable of separation hy ether, in which it is soluble, whilst the emetic principle is soluble in alcohol. 'The turmer can produce vomiting inmediately on being swallowed, or even before by its action on the olfactory and glosso-phiryngeat nerves, whilst the latter acts as above stuted on the vagal branches distributed to the stomacl. 
sensations, conjoincd with the cmotional state which they originally excited, may itsclf become an efficient cause of the action, at least in individuals of peculiarly irritable stomachs or of highly sensitive nervous systems; for this plays downwards upon the sensorial ccutres, in such a manner as to excite in them the same condition as that which was originally produced through the medium of the sensory nerve when the object was actually present. (See chap. xiii, sce. 3.)

94. Thic passage of the Chyme, or product of the gastric digestion, through the pyloric orifice, into the commencement of the Intestinal tube, is at first slow; but when the digestive proccss is nearly completed, it is transmitted in much larger quantities. The pyloric orifice, like the cardiac, is furnished with a sphincter muscle; but low far its contractions are dependent upon "reflex action," has not yet been ascertained. The ingestcd matter, which undergoes further changes of a very important character within this portion of the canal, is gradually propelled onwards by the peristaltic contractions of its walls; and these are excited by the contact, either of the products of digestion or of the secretions poured in by the various glands that discharge their products into the intestinal tube. ${ }^{1}$ In its progress along the small intestines, the nutritious portion of the ingested matter is gradually taken up by the bloodvessels and absorbents; and the residue, combined with excrementitious matters separated from the blood, begins to assume the fecal character. A further absorption takes place during the passage of the fecal matter through the large intestines; and thus by the time it reaches the rectum it has acquired a considerable degree of consistency.

95. The nervous supply of the intestines is derived essentially from the sympathetic system; though a few fibres may be derived from the pneumogastrics. The sympathetic fibrcs proceeding from the coliac, mesenteric, and other plexuses accompany the bloodvessels to the intestines, and form a chain of nerves and nervous ganglia, the Plexus myentericus, one portion of which has been shown by Auerbach, to lie between, and to supply both the circular and longitudinal layers of muscular tissue of the small intestines, and to be situated on the outside of the longitudinal layer in the large intestinc, whilst another portion, discovered by Meissner, lies in the submucous areolar tissue, and is probably destined for the supply of the muscularis mucose, or muscular layer of the mucous membrane." "It might at first sight appear to be easy to determine the precise influence of the nervous system upon the muscular walls of the intestines, but experience has shown that the investigation is amongst the most difficult in experimental physiology, various results having been obtained according to the animal experimented on; the nature of the stimulus applied; the precise part stimulated;

1 The Bile seems to have an important share in producing this effect; since, when the ductus choledochus is tied, constipation always occurs. M. Legros and Onimus (Robin's Journal de l'A nat., 1869, pp. 37 and l63) have shown by tracings taken from a caoutchouc ball introduced into the intestines, that the peristaltic contractions move more rapidly in the duodemum (sometimes traversing eight inches in the minute) than in the crecum (six inches) of the dog.

2 Auerbach, Canstatt's Jahresbericht, 1862, p. 174; Manz, Die Nerven und Ganglien des Sungethierdarms, 1859; Krause, Studien des Phys. Instit. zu Breslau, 1863, P. 41 Unters. ub. einig. Ursach. der peristalt. Beweg des Darm-canals; and Virchow's Archiv, 1864, p. 457. According to Gerlach (abstract in Humpliry and Turner's Journ. of Anat., vol. viii, 1874, p. 173) the myenteric piexus of Auerbach contains higlily vascular ganglia and fusciculi of tibres, forming primary and sccondary networks. From the secondary plexuses tine tibres arise, each of which ends in a corpuscle that may give off one or two processes, ending between the muscular fibes. Klewn (Quart. Juurn. of Mic. Sci., Oct. 1873) describes, in addition to the above, isolated ganglion-cells, between the circular and longitudinal muscular coats. 
the state of distension of the tube; the fulncss or emptiness of the bloodvessels; the venous or arterial condition of the blood circulating through the tissues, and the temperature at which the experiments are conducted.

FI(*. 59.

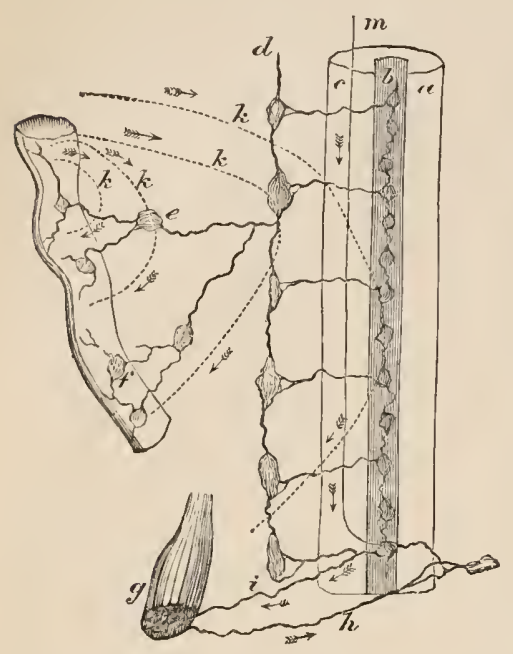

Nervous supply of the Intestines. $-a$, is the posterior colum of the spiual cord; $b$, the gray substance with its chain of ganglion cells; $c$, anterior column; $d$, great sympathetic; $e$, nervous ganglion of mesentery ; $f$, ganglion of nerve plexus in the walls of the intestine; $g$, sphincter aui; $h$, sensory filament running centripetally to the ano-spinal centre by the posterior column ; $i$, motor root with fibre, rmuing centrifugally from the ano-spinal centre to the sphineter; $m$, encephahic fibre, conducting the mandates of the will to this centre; $k$, curres of suceessively wider and wider area showing the implication under stronger and stronger stimuli, of a progressively increasing number of ganglia, tili the cord is at length reached, when pain and various reflex cffects on distant parts may be experienced. tant ccrebro-spinal and sympathetic centres, but the precise channels through which their influence is transmitted are still undeternined. Schiff" and Budge, ${ }^{3}$ in experiments on cats, observed movements of the intestines follow irritation of the corpora striata, pons Farolii, medulla oblongatu, and other parts of the encephalon; and the remarkable influcnce of certain emotions, as fear, in increasing peristalsis, as well as the history of many pathological cases, supports the view that the cerebro-spinal nervous systeni can atct more or less directly upon the intestines. Good evidence that the fibres by which irritation of the more remote sympathetic ganglia act upon the intestines are contained in the spinal cord, is afforded by the following experiment of M. C. Bermard. The spinal cord is divided below the medulla oblongata, to abolish the influence of the IVilt. 'The chest is then opened, and the inferior ccrvical the firct that the splanchnic nerves, which are the vaso-motor nerves of the vessels supplying the abdominal viscera, appear also, under certain circumstances, to cxert an inhibitory influence on the intestinal movements. It may be certainly stated that in the collapsed state, the intestines are quiescent, or at most their movements are extremely slow and feeble; but as soon as food is propelled into them from the stomach, peristaltic contractions commence, which force the contents onwards. These movements are of a reflex nature, the circuit consisting of centripetal sensory ncrve-fibres distributed to the mucous menbrane, which convey the impression produced by the presence of food to the ganglia of the plexuses of Auerbach and Meissner, from whence an impulsc is reflected to the muscular tissues of the in(Fig. 59) may aid in rendering the influence of the nervous system on the intestines intelligible. Coincidently with the entrance of food into the intestines, the bloodvessels become turgid with blood, a condition that appears greatly to heighten the irritability of the nervomuscular apparatus, for stimuli which provoke no response when the vessels arc comparatively empty, will produce well-marked effects when they are full. ${ }^{1}$ A large amount of evidence has been accumulated, showing that the peristaltic movements nay be influenced by dis-

The inquiry is further complicated by 
ganglion galvanized. After a few seconds, active movements of the small intestines takes place. The cord connceting the inferior cervical with the first thoracie ganglion is now divided, and the lower extrenity galvinized. The intestines remain quiescent. But if the upper extrenity be galvanized, active intestinal movements again occur. ${ }^{1}$ The Pneumogastrics are believed by many to be also a channel by which impulses proceeding from the cerebrospinal centres are transmitted to the intestines, since electrical excitation of these nerves usually, though not always, produces contractions which commence in the stomach, and are most crident when the splanchnics hatve been divided, ${ }^{2}$ and also at a short interval after death. It must be admitted however that the effects of stimulating the pneumogastrics are very inconstant. ${ }^{3}$

96. The Splanchnic nerves are now well known to be the vaso-motor nerves of the abdominal viscer:a, and it is difficult to say whether when irritated, they act directly upon the muscular fibres or nervous ganglia of the intestincs, or whether their influence is exerted indirectly by modifying the size of the vessels, and the quantity of blood supplied to these parts. According to some experimenters, ${ }^{4}$ when irritated by the application of exceedingly feeble currents of electricity, the splanchnies act like ordinary motor nerves, and produce contraction of the muscular coats. If, however, the current be of moderate strength, so far from causing contraction, these nerves are declared by Pflüger, to restrain or inhibit the peristaltie movements, and many excellent observers corroborate his statements. ${ }^{5}$ On the other hand there seems to be little doubt that shortly after death, irritation of the splanchnics will produce peristaltic movements. To explain these phenomena, Nasse has suggested that the splanchnics may contain both motor and inhibitory fibres, the former being more irritable than the latter; that is to say, responding to a feebler stimulus, and at the same time retaining their irritability for a longer period after death. Nasse, experimenting on rabbits, found that the inhibitory effect of irritating the splanchnics immediately after death, was limited to the small intestines; the movements of the stomach, colon, and rectum renaining unaffected. The arrest of movement took place so quickly after the application of the stimulus to the nerves, as to lead him to the conclusion that it was a direct effect, and not secondary to contraction of the bloodvessels, and of the

1 Experiments made like those of Pincus, Budge, Adrian, and Lamansky, with a view of determining the functions of the celiac and mescnteric plexuses by noticing the effects of their ablation can scarcely be of any service, since the operation required is accompanied by much hamorrliage and is so severe as to cause death in a few hours. However, the chief phenonena observed have been congestion, and ecchymoses in the mucous membrane of the stomach and small intestine, with lyyersecretion of mucns, liquid fieces, and more or less severe peritonitis. M. Morean, Comptes Renzlus, 1868 , p. 554 , has shown that section of the nerves supplying a fuld of intestine leads to effusion into it.

2 Houckgeest, Pflüger's Archiv, 18i3, Band vi, p. 266.

3 Legros and Oninus, Rubin's Jurnat de l'Anat. et de la Physiologie, 1869, p. 196 , state that the application of interrupted currents of electricity to the prieumogastrics produces relaxation and immobility of the intestines, whilst continuous currents exert but little action upon then. Sanders Ezn (Humphry and Turner's Journal of Anat., vol. vi, p. "242, 1872) states that irritation of the right pnenmogastric chiefly causes novement in the duodenum, and irritation of the left, movement in the ilium. Goltz (Pflüger's Archiv, 1872, p. 616) has shown that in the frog the excitubility of the myenteric ganglia is very greatly augmented when, by destruction of the brain and spinal cord or section of the pneumogastries, they are cut off from the central nervous system, which therefore in this animal appears to exert an inhibitory infiuence upon them.

4 Lister, Proceed. Roy. Soc, 1858; Nasse, Beiträge zur Physiologie der Darmbewegungen, 1866; Wundt, P'hysiologie, 1873, p. 191.

5 See Ludwig and Spiess, Sitzungsberichted. k. Akad. der Wiss zu Wien, B. xxr, 1857, p. 580; Kölliker; Honckgeest, Pfluger's Archiv, B. vi, p 266; and others. 
circulation. Kölliker, who admits the inhibitory power of the splanchnics, states that it is destroyed by woorara; and Brunton ${ }^{1}$ was unable to perceive it in several animals narcotized by chloral.

97. The movements of the intestines appear further to be powerfully affecter by the quantity of blood supplied to them, as well as by its arterial or venous.quality. Nasse observed lively movements, both when the vessels were rendered anæmic by pressure on the aorta, and when blood was injected at a ligh-pressure. S. Mayer and $v$. Basch ${ }^{2}$ remark that compression of the thoracic aorta usually, but not always, causes vigorous contraction both of the longitudinal and circular muscular fibres of the intestines, which they attribute to the excitation either of the peripheral extremities of the splanchnic and vagi, of the solar plexus, of the ganglia of the myenteric plexus, or possibly even of the muscular fibres themselves, by the carbonic acid or other product of disintegration, which accumulates in the stagnating blood. They maintain that when such products are present, lively movements can be induced by irritation either of the splanchnics or of the pneumogastrics; but that when absent, no amount of irritation of these nerves has any effect. Both nerves, therefore, contain motor fibres for the intestines, which, however, only act under certain conditions. ${ }^{3} \quad$ Hermann $^{4}$ remarks simply that saturation of the blood with oxygen arrests the movements of the intestines, whilst saturation with carbonic acid excites them, which explains to some extent their activity shortly after death. The whole subject requires to be reinvestigated, since Horvath ${ }^{5}$ has shown that tempcrature has a very powerful influence in determining the reaction of the intestinal walls to electric stimulation. No movements occur in the intestines according to this observer, when they are cooled below $66^{\circ} \mathrm{F}$, whilst they exhibit spontaneous movements, and contract on the application of electricity between $66^{\circ} \mathrm{F}$. and $106^{\circ} \mathrm{F}$., at which last temperature the movements are sometimes very vigorous and rapid, supporting in Rabbits and Guinea-pigs a column of water 18 ccntimetres in height. Horvath, in opposition to the statements of Nasse, Legros, and Onimus and Mayer, maintains that a certain fulness of the vessels is absolutely necessary; no contractions occuring in anæmia even at a high temperature. The action of many aperient nedicines, as Senna and Croton oil, has been demonstrated ${ }^{6}$ to be due to their producing increased peristalsis : if pushed too far, however, and if their action be very violent, they diminish the irritability of the intestines and even cause paralysis, a fact not to be overlooked in the administration of purgatives for the relief of constipation.

1 Handbook for the Phys. Laboratory, 1873, p. 526 .

2 Sitz. d. k. Akad. zu. Wien, B. lxii, 1870, p' 809.

3 It is to be noted, however, that although the absence of arterial blood causes lively eontractions, none are produced by an excess of venous blood in the mesenturic veins, such as may be oceasioned by pressure on the vena porta. This faet is admitted by Mayer and Basch, and has also been demonstrated by Legros and Onimus (Robin's Jourual de Physiol., 1869, pl. 37 and 163). It should also be stated that Van Bram Hunekgeest (P'flüger's Arehiv, 1872, p. 298), who operated earefully by opening the abdomen whilst the animals experimented on were immer-ed in water eontaining 0.6 of common salt, at blood heat, maintains that andenic conditions prevent, arrest, or weaken the movenents of the intestines, and that whilst distension of the vessels with either arterial or venous blood favored contraetion in the small intestines, the latter eondition alone seened to increase the irritability of the nervo-muscular apparatus of the large intestines in Rabbits. Sanders Ezn (Humphry and Turner's Journal of Anat., vol, vi, 1872, p. 242), operating in the same way as Houckgeest, maintains that the amount of blood in the vessels has no influenee on the in testinal movenents.

- Physiologie, 1874, p. 136.

5 Centrablatt f. d Med. Wiss., 1873, p). 597 et seq.

By ladzicjewsky, Archiv f. Anat. v. Physiolog., 1870; and Legros and Onimus, loe. cit. 
Saline aperients, if given in a sufficient state of concentration, probably act chicfly by producing endosmosis; but partly also by causing increased secretion, not by increasing peristalsis. ${ }^{1}$ Certain poisons exeite lively intestinal movements. Nasse observed that injection of nicotin and of sulphocyanide of potassium caused violent tetanic spasms of the small intestines in rabbits. Opinm acted but slightly, and strychnia and woorara were totally inoperative. Carbonic acid intoxieation caused general contraction, but no active movements of the walls of the intestincs.

98. The rapidity with which the food traverses the intestinal tube is subject to great variations. In a case of duodenal fistula in a man, recorded by Kühne, ${ }^{2}$ portions of uncoagulated milk, and small fragments of meat, were observed to make their appearance within ten minutes of their being swallowed. In a case of artificial anus which opened into the upper part of the jejunum, reported by Dr. Busch, ${ }^{3}$ the first portions of food usually appeared in from fifteen to thirty minutes after ingestion. Whilst in another case reported by Dr. Braune, ${ }^{4}$ in which the artificial anus communicated with the intestine a few inches above the ileo-colie valve, the first appearance of the food presented itself three hours after ingestion, and the last about six hours after, so that we may consider the time occupied by the food in traversing the small intestine, to be about $2 \frac{1}{2}$ hours. The food having traversed the small intestine, enters the excum by an aperture guarded by a valve (the Ileo-crecal), whose lateral position is elearly a provision for preventing the whole weight of the Freces, as the renıains of the food here begin to be called, by which it might be forced back, from resting upon it. The Freces, in their ascent, are lodged in the sacculi of the colon, by which they are supported during the intervals of the peristaltic action of the Muscular Coat. In their course through the descending colon, they pass through its remarkable sigmoid flexure, by which they are prevented from directly pressing against the anal orifice. ${ }^{5}$ According to the observations of M. Voit, ${ }^{6}$ in cats and $\log s$ the evacuation of freces, known by their characters to proceed from particular kinds of food previously given, almost invariably occupies 24 hours.

99. On examining the outlet by which the freces are voided, we find that it is placed, like the entrance, under the guardianship of a ganglionic eentre describer by Masius, termed the ano-spinal centre, situate in the lower part (opposite the sixth lumbar vertebra in the Rabbit) of the Spinal Cord ; subject, however, to some eontrol on the part of the will. In the lowest animals, the act of discharging excremcntitious matter is probably as involuntary as are the acts immediately concerned in the introduction of nutriment; and it is performed as often as there is allything to be got rid of. In the higher classes, however, such discharges are mueh less frequent, and reservoirs are provided, in which the excrementitious matter may accumulate in the intervals. The associated movements required to empty these are completely involuntary in their eharacter, and are excited by the quantity, or stimulating quality, of the contents of the reservoir. But, had volition no control

Legros and Onimus, op cit.

2 Physiologischo Chemie, 1868, p. 53.

3 Virchow's Archiv, vol. xiv, p. 140. 4 Archives Générales de Méd., 1861, p. 610.

5 For some further observations on Defecation, the reader is referred to O'Bcirne, New Views of the Process of Defecation, Washington, 1834; and to vol. ii, p. 406, of Dr. Austin Flint's Physiology of Man, both of whom agree in bclieving that under ordinary circumstances the rectum is contracted, and contains neither faces nor gas, whilst the condition which immediately prceedes the desire for defecation is probably the descent of the contents of the sigmoid flexure of the colon into the rectum. They admit, however, that under certain circumstances frees must accumulate in the lower and dilated portion of the rectum.

6 Zeits. f. Biologic, Bd. ii, p. 6. 
over them, great inconvenicnce wonld ensue; hence, sensation is excited by the same stimulus which produces the movements, in order that, by arousing the will, the otherwise involuntary motions may be restrained and directed. There can be little doubt, from the experiments of Dr. M. Hall, as well as from other considerations, that the associated movements by which the contents of the rectum and bladder are discharged, correspond much with those of Respiration; being in their own nature excito-motor, but being capable of a certain degree of voluntary restraint and assistance. The act of Defecation (as of Urination) chiefly depends upon the combined contraction of the abdominal muscles, similar to that which is concerned in the expiratory movement; but, the glottis being closed so as to prevent the upward motion of the diaphragm, their force acts only on the contents of the abdominal cavity; and so long as the sphincter of the cardia remains closed, it must press downwards upon the walls of the rectum and bladder-the contents of the one or the other of these cavities, or of both, being expelled, according to the condition of their respective sphincters. These actions are doubtless asisted by the contraction of the walls of the rectum and bladder themselves, for we sometimes find their agency sufficient to expel the contents of the cavities, when there is a total paralysis of the ordinary expulsors, provided that the sphincters be at the same time sufficiently relaxed. This is more especially the case, when their power is augmented by increased nutrition. For example, in many cases of disease or injury of the Spinal Cord, the bladder ceases to expel its contents, through the interruption of the circle of reflex action; but after a time, the necessity for drawing off the urine by the catlieter is found to exist no longer, the Huid being constantly expelled as soon as it has accumulated in small quantities. In such cases, the mucous coat is found after death to be thickencd and inflamed, and the muscular coat to be greatly increased in strength, and contracted upon itself. It would seem, then, that the abnormal irritability of the mucous membrane, and the increased nutrition of the muscular substance which appears consequent upon it, enable the latter to expel the urine without the assistance of the ordinary expulsors.

100. On the other hand, the sphineters which antagonize the expellent action are usually maintained in a state of moderate contraction, so as to afford a constant check to the egress of the contents of the cavities; and this condition has been fully proved by Dr. M. Hall to result from their connection with the Spinal Cord, ceasing completely when this is interrupted. But the sphincters are certainly in part controlled by the will, and are made to act in obedience to the warning given by sensation; and this voluntary power is frequently destroyed by injuries of the Brain, whilst the Spinal Cord remains able to perform all its own functions, so that discharge of the urine and freces occurs. In their state of moderate excitement, the expulsors and the sphincters may be regarded as balancing one another, so far as their reflex action is concerned, the latter having rather the predominance, so as to restrain the operation of the former. But, when the quantity or quality of the contents of the cavity gives an excessive stimulus to the former, their action predominates, unless the will be put in force to strengthen the resistance of the splincter; this we are freqnently experiencing, sometimes to our great discomfort. On the other hand, if the stimulus be deficient, the will must aid the expulsors, in order to overeome that resistance which is due to the reflex contraction of the splineters; of this also we maly convince ourselves, when a scuse of propriety, or a prospective regard to convenience, occasions us to evacuate the contents of the rectum or bladder witlout a natural call to do so. 


\section{Of the Changes which the Food undergoes during its passage along the Alimentary Cunal.}

101. The object of the Digestive process, as already pointed out, is to reduce the Alimentary matters to a condition in which they can be introduced by Absorption into the Circulating system. This reduction is partly effected, as we have seen, by Mechanical means; but it is chiefly due to the Chemical agencies which are brought to bear upon the ingested substances, during their transit through the mouth, the stomach, and the upper portion of the intestinal tube. The first of these is exerted by the Salivary fluid, which is incorporater with the food in the act of mastication, and of which a large quantity descends with it to the stomach. For the secretion of this fluid, it will be renembered that three pairs of glands of considerable size are provided, namely, the parotid, the sublingual, and the submaxillary. But in addition to these there is a small pair situated just at the tip of the tongue, whilst a very important part of the fluid is furnished by the lingual and palatine glands, and by the numerous follicular glands lodged in and beneath the buccal mucous membrane. The larger Salivary glands are all constructed upon the type of tubular glands, the principal features of which are shown in Figs. 60 and 61 . The excretory ducts (d, Fig. 61), which are

FIG, 60

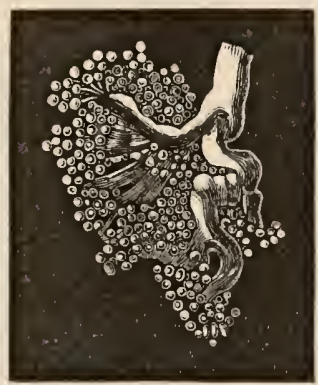

FIG. 61.

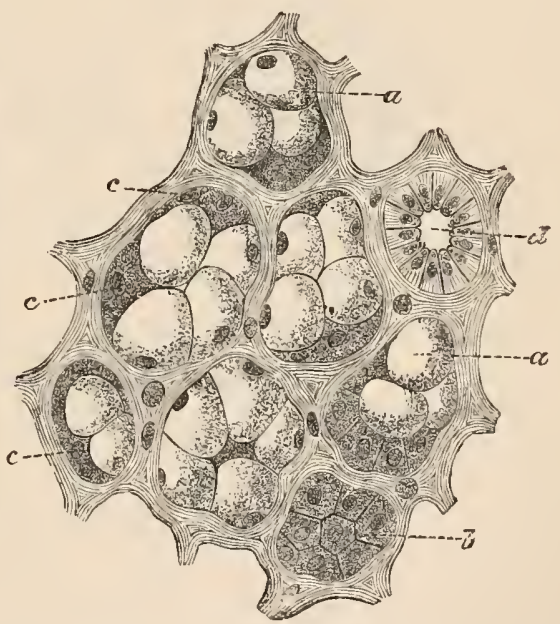

FIG. 60.-Lobule of Parotid Gland of newborn infant, injected with mercury. Magnified 50diameters. FIG. 61.-Submaxillary Gland of the Dog. $a$, nucous cells; $b$, protoplasm cells; $c$, demilune of Giannuzzi ; $d$, transverse section of an excretory duct, with its peculiar columnar epithelial cells.

lined by columnar epithelium, divide and subdivide till they terminate in a series of follicles, which contain (to a greater extent in the case of the submaxillary than of the others) large transparent non-granular cells, with an eccentric nucleus $(a \quad a)$; and in addition a mass of what appears at first sight to be granular protoplasm, with interspersed nuclei, the "demilune" of Giannuzzi ${ }^{1}(c)$, but later investigations show that this is composed of many closely-compressed cells. Other vesicles contain these protoplasm cells alone. ${ }^{2}$ Ewald and others have observed a fine plexus surrounding the individual

2 Pflüger, Schultze's Archiv, Bd. v, p. 203. 
cells, which they believe to be the origin or ultimate termination of the Salivary ducts. 'The follicles are surrounded by a rich plexus of bloodvessels, the interstices of which form spaces from which the lymphatics take origin (Giannuzzi). Pflüger ${ }^{2}$ believes he has been able to follow nerve-fibres into direct continuity with the cells lining the acini and ducts of the salivary glands, and describes no less than four morles of termination. In the first (1 and 2, Fig. 62), a cerebro-spinal nerve-fibre loses its sheath as it passes through the basement-membrane of the acinus, with which the sheath becomes continuous, whilst the medulla passes on between the gland-cells and divides into finer fibres, each of which, regaining a sheath, perforates the

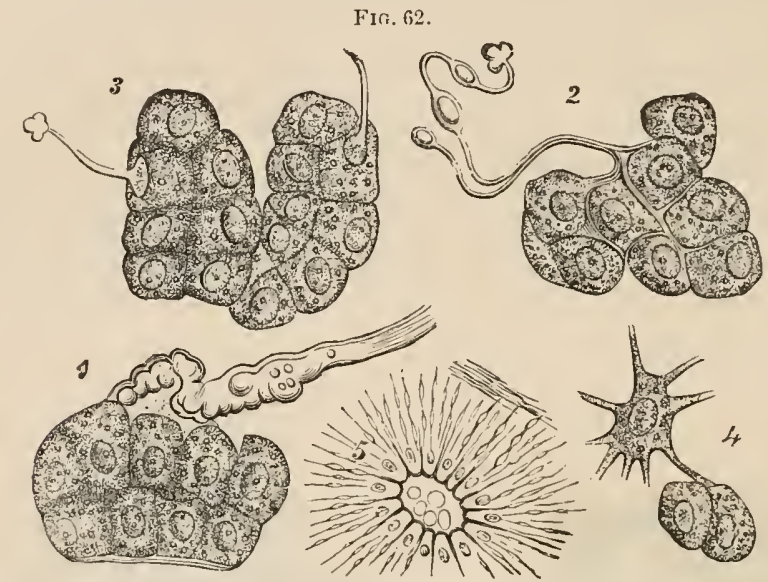

Modes of Termination of the Nerves in the Salivary Glands. 1 and 2, branching of the nerves between the salivary cells; 3 , termination of the nerve in the nucleus; 4 , union of a ganglion cell with a salivary cell; 5 , varicose nerve-fibres cutering the cylindrical cells of the excretory ducts.

wall of one of the secreting cells, and terminates in the nucleus. In the second mode (4, Fig. 62), the nerve-fibres, which probably belong to the sympathetic system, terninate in multipolar ganglion cells, some of the offsets or caudate prolongations of which in like manner penetrate the secreting cells, and terminate in the nuclei. In the third mode (3, Fig. 62), a nervefibre, invested with a sheath containing nuclei, within which are numerons varicose axis cylinders covered by a thin layer of medullary substance, terminates periphically in a conical enlargement, which he terms a "protoplasma-foot or expansion," and which he regards as a kind of intermediate organ between the nervous and glandular substance. Lastly, he has observed certain nerve-fibres distributed to the cylindrical cells lining the salivary ducts (5, Fig. 62). The attached extremity of these cells is often marked with longitudinal strix, and is continued for some distance as a varicose prolongation. The nerve-fibres lie beneath the basement-membrane,

1 Boll has deseribed an intra-alveolar retieulum of eonnective tissue whieh is perhaps identieal with it.

${ }_{2}$ Pamphlet, On the Terminations of the Seeretory Nerves of the Salivary Glands, 1866; and Medicin. Centralblatt Nos. 10 and 14, 1866; see also Palladino (A bstraet in Centralblatt, $1873, \mathrm{p} .782$ ), who, however, was only able to traee non-medullated nerve-fibres into the secretory eells of the submaxillary gland in the Horse. Asp (Abstract in Centralblatt, 1873, p. 565), Mayer, Hering, Frause, Schweigger-Seidel, Henle, lilein, Eivald, and many others, express grave doubts as to the aeeuraey of Pflügrer's statements of the mode of termination of the nerves in the salivary glands, and the subjeet may be regarded as being still sub judice. 
and form exquisitely fine threads, with swellings or varieosities upon them, which he has been able to trace into direct continuity with the above-mentioned prolongations of the epithelial cells, several passing into cach cell. The development of the salivary glands commences during the seeond half of the scond month, in accordanee witl the general plan of the acinous glands, by a simple protrusion of a part of the wall of the oral eavity, whieh subsequently gives off budlike proecsses.

102. Numerous researches lave shown, that the eharaeters of the fluids poured forth respeetively from the three principal glands are by no means identical; and that the buceal mucus has a very important share in the operations of that mixed product, which constitutes the ordinary Saliva. The speeific gravity of this fluid may vary with in the limits of health from 1002 to 1009 . The variations appear to be partly referable to the amount of solids and liquids ingested, and partly to the amount of the sceretion previously poured out; but it may be in some measure attributed to a difference in the proportions of the fluids poured into the mouth by the

FIG. 63.

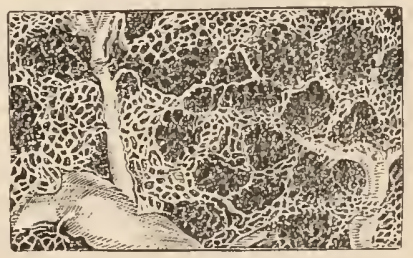

Capillary Network around the Follicles of the Parotid Gland. several glands which secrete them. Mixed Saliva is found to contain a few epithelial scales thrown off by the buccal mucous membrane, and a small number of minute corpuscles proceeding chiefly from the lingual and tonsillitie glands, which perform curious spontaneous and Amoeba-like movements. ${ }^{1}$ Its reaetion is always alkaline in health, which is due to the presence of the tribasie phosphate of soda; but the degree of alkalinity varies, being greatest during and after nicals, and least after prolonged fasting, when the fluid is almost neutral. Its temperature at the moment of secretion is always from $1^{\circ}$ to $2^{\circ} \mathrm{Fahr}$. higher than the arterial Blood supplying the gland. ${ }^{2}$ Aecording to Oehl, ${ }^{3}$ the saliva is secreted and discharged by the parotid duct, under a pressure amounting at its nraximum to a eolumn of water of six inches in height. The following are some of the ehief analyses of this fluid that have been made:

\begin{tabular}{|c|c|c|c|c|c|}
\hline In 1000 parts. & Simon. ${ }^{4}$ & Berzelius. ${ }^{5}$ & Frerichs. ${ }^{6}$ & Jacubowitsch. ${ }^{\top}$ & Harley. \\
\hline $\begin{array}{l}\text { Water, } \\
\text { Solid residue, : . : . }\end{array}$ & $\begin{array}{r}991.22 \\
8.78\end{array}$ & $\begin{array}{r}992.9 \\
7.1\end{array}$ & $\begin{array}{r}99410 \\
5.90\end{array}$ & $\begin{array}{r}995.16 \\
4.81\end{array}$ & $\begin{array}{r}993.331 \\
6.69\end{array}$ \\
\hline $\begin{array}{l}\text { Ptyalin, } \\
\text { Mucus, epithelium, } \\
\text { Fat and cholesterin, } \\
\text { Water extract, witl salts, } \\
\text { Alcoholie extract,. } \\
\text { Potassium sulphocyanide } \\
\text { Salts,. . . . . . }\end{array}$ & $\begin{array}{r}4.37 \\
1.40 \\
0.32 \\
2.45 \\
\cdots \\
\cdots\end{array}$ & 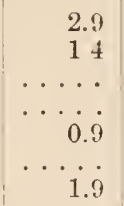 & $\begin{array}{l}1.41 \\
\because .18 \\
0.07 \\
\cdots \cdots \\
\cdots \quad .10 \\
0.10 \\
2.19\end{array}$ & $\begin{array}{r}134 \\
162 \\
\ldots \\
\cdots \\
\cdots \\
\cdots \\
0.06 \\
1.82\end{array}$ & $\begin{array}{c}\text { Organic matters. } \\
3.91\end{array}$ \\
\hline & 1000 . & 1000. & 1000. & 1000. & 1000 . \\
\hline
\end{tabular}

${ }_{1}$ Brueke, Sitzungsberieht d. Wiener Akad, Bd. xlv.

2 Kühne, Phys. Chemie, 1866, p. 6. $\quad{ }_{3}$ La Saliva Umana, ete, Pavia, 1864.

4 Simon, Animal Chemistry, vol. ii, p. 4. ${ }^{5}$ Donders's Phys., p. 188, 1859.

6 See Canstatt's Jahresbericht, 1850 , p. 136.

7 Inaug. Diss., De Salivâ, Dorpati, 1848.

${ }^{8}$ Brit. and For. Med.-Chir. Rev., 1860, p. 207. 
According to the researches of Pflüger ${ }^{1} 100$ c.c. of the saliva of the $\mathrm{dog}$ contains about 0.5 per cent. of its volume of oxygen, about 0.7 or 0.8 per cent. of nitrogen, and from 49.2 to 64.7 per cent of carbonic acid, of which one-third is free, whilst the rest is eliminated on the ardition of phosphoric acid. The substance to which the designation of ptyalin is given, is that on whose presence the peculiar properties of the Saliva appear to depend; and it seems, as regards its chemical nature, to be an albuninous compound, since it coagulates by heat, nitric acid, and electricity; the precipitate is insoluble in water and in alcohol, but soluble in concentrated hydrochloric acid with the production of a beautiful violet-red color, and it gives a violet color when treated with sulphate of copper and caustic potash. A large proportion of this albuminous substance is present in the saliva of the horse, but only traces of it exist in that of man, and it appears to be in such a state of unstable equilibrium that it acts the part of a "ferment." ${ }_{2}$ Potassium Sulphocyanide, considered by Bernard ${ }^{3}$ to be only occasionally present, and attributed by some to the presence of carious teeth, and by others conceived to have been mistaken for Nicotin, the essential oil of Tobacen, has been found by Harley and Longet to be a constant constituent of the Saliva in persons possessing perfectly sound teeth, and not addicted to smoking. It is absent in the Saliva of the Herbivora. Its use may possibly be that suggested by Kletzinsky, ${ }^{4}$ to prevent the formation of fungoid spores between and in the cavities of the teeth. In a medico-legal point of view, the existence of a sulphocyanide in the saliva has a special importance; since, if in a state of sufficient concentration, it causes the saliva to exhibit the same blood-red color, when treated with a persalt of iron, as that which is produced by meconic acid. (The difference between the two, however, is easily made apparent, by adding a solution of perchloride of mercury; for this causes the color produced by the sulphocyanide to disappear, whilst it has no action on that which is due to the presence of meconic acid.) To determine the nature of the differences in the composition and physical characters of the secretion of the several salivary glands, Bernard inserted tubes into their ducts, and found, on placing a few drops of vinegar on the tongue of a dog, that the submaxillary saliva was immediately secreted, speedily followerl by that from the parotid, and at a later period by that from the sublingual. The parotidean saliva was clear and watery, with a specific gravity varying from 1003 to 1006 , and containing only 0.47 per cent. of solid residue in the Dog, and 0.76 in the Horse (Lehmann). The fluid discharged by the sublingual gland was thick and riscid, whilst that of the submaxillary was intermediate in this respect to the others, having a specific gravity of 1005 . Hence Bernard was led to suggest that the submaxillary gland ministers to the sense of taste, whilst the parotid is connected with mastication, and the sublingual witin deglutition. The size of the parotid in animals is proportionate to the degree in which the mastication of their foor is performed. It is large in the horse, which lives on comparatively dry food, less in carnivora, and still less in the aquatic mammals, as the seal. It is absent in birds, which swallow their food whole. ${ }^{5}$ The submaxillary gland is largely developed in the carnivora, but is again reduced to a minimum in birds. The Salts, ac-

I Y'lüger's Archiv, Band i, 1868, p, 688.

2 v. IVittieh (Pflüger's Archiv, Band iii, 1870, p. 339), in order to obtain it, reenmmends the fincly-clivided tissue to be trated with absolute alcohol for 24 hours, after which the rosidue is to be extracter with gryerin. Korowin (Centrulblatt, 1873, p. 305) and Jul. Sehifler (Archiv f. Anat. v. Pliysiol., 1872, p. 464) show that it is present in the saliva immediately after birth.

3 Leceons, 1859 , t. ii, 1). 243

5 Sec Bernard's Lectures, in the Rev. Scientifique, 1873.

4 IIeller's Archiv, 1833, p. 39. 
corling to the andyes of Schmidt, consist chicfly of potassium and sodium chlorile, sodium phosphate (to which the alkaline reaction of the saliva appears to be due), calcic carbonate-giving it its cloudy appearance when its reaction is neutral (Oehl)-earthy phosphates, and oxide of iron. Bernard has shown that various salts, after their introduction directly or indirectly into the Blood, rapidly make their appearance in the saliva; this is particularly the case with Iodide of Potassimm, which ean often, though not always (Harley), be detected in the saliva long before its appearance in the urine. The Tartar which collects upon the teeth, and the salivary concretions which occasionally obstruct the ducts, consist chiefly of the earthy phosphates held together by about 20 per cent. of animal matter. The fluids which are secreted by the three principal glands appear (from the experiments to be presently cited) to have very different degrees of efficacy, in producing that chemical change in the food which it is the peculiar attribute of this secretion to cxert.

103. Of the quantity of Saliva which is secreted daily, it is impossible to form an exact estimate, since it varies greatly with the character of the food ingesterl, and the frequency with which that food is taken; the secreting process being, indecd, almost suspended when the masticating muscles and tongue are completely at rest, unless excited by a nervous stimulus. The taste, the sight, or even the idea, of savory food, is sufficient to cause a flow of saliva, especially after a long fast; but it is by the masticatory movements that this flow is chiefly promoted, so that the amount poured forth will in a great degree depend upon the duration of these movements, - this, again, heing governed by the degree in which the food requires mechanical reduction. Harley, with great probability, estimates it at from 1 to 2 lbs. in man. Oehl found the quantity obtained by catheterization from the subinaxillary gland, as compared with the parotid, to be as $3: 1$. He obtained only 26 grains per hour from a fasting man, and still less (15 grains) after fond had been taken. The influence of the kind of food upon the quantity secreted was well shown by Lassaigne, ${ }^{1}$ who found on abstracting the Bolus of food, as it passed down the cesophagus in Horses, that 100 parts of green stalks were mingled with 49 parts of saliva, the same quantity of oats and barley with from 113 to 186 parts, and of dry hay with 406 parts of saliva. Dr. Dalton, however, did not observe such difference in Man, ${ }^{2}$ since 10 parts of fresh conked meat gained 48 per cent., whilst dry wheaten bread did not gain more than 55 per cent. of its weight after thorough mastication. In II. Oehl's experiments, Salt, Pepper, Vinegar, and Quinine excited the flow of saliva from the parotid and submaxillary glands to about an equal degree. Honey chiefly effected an increase of the submaxillary saliva. Butler Stoney ${ }^{3}$ found in a woman with parotid fistula, that the flow of saliva from this gland was stimulated by mastication alone, but much more by the mastication of any sapid substance, especially if acid (tartaric acid). Potassium iodide ingested by the mouth, appearerl in the saliva in $29 \mathrm{~min} .30 \mathrm{sec}$.

104. Besides the preparation of the food for the ulterior changes which it has to undergo, by promoting its mechanical reduction in the act of mastication, and by facilitating the subsequent admixture of other watery fluids, and besides the material assistance which it affords to the act of deglutition, the Saliva fulfils other and perhaps still more important purposes. Without its solvent action on many of the solid constituents of our food, their taste would be either greatly diminished in intensity or altogether lost. Moreover, by lubricating the surfaces of the mouth and tceth, it prevents the adhesion of

1 C. Rend., xxi, p. 362.

2 Human P'hysiology, 1861, p. 112.

3 Humphry and Turner's Journ. of Anat. and Phys., 1873, vol. vii, p. 161. 
viscid substances, whilst its presence is of great importance in enabling the tongue to perform the rapid movements requisite for distinct articulation, as is clearly indicated by the thick and almost unintelligible utterance of those in whom from any cause the mouth and tongue have becone dry and parched. Lastly, there can be no doubt that it has a powerful chemical action upon the farinaceous constituents of food, the influence being of a continuous nature, and resembling the action of a ferment, so that a suall proportion of Ptyalin will convert a considerable, though, according to Paschutin, ${ }^{1}$ not an indefinite quantity of starch into sugar. In Mialhe's experiments, one part of Ptyalin was found to effect the conversion of 2000 parts of starch, first into dextrin and then into grape sugar. If the starch be crude or raw the time required is considerable, ${ }^{2}$ amounting to two or three days even at blood heat, but the rapidity with which it takes place under favorable circumstances is very great; thus Vintschgau ${ }^{3}$ found that if well boiled, thin starch paste, which had been rendered blue by the addition of Iodine, were added drop by drop to Saliva at a temperature of $98^{\circ}$ or $99^{\circ} \mathrm{F}$., the color instantly disappeared; and Dr. Dalton found traces of sugar in starch-paste which had been kept in the mouth within 30 seconds. The temperature at which the action is most intense is from $100.4^{\circ} \mathrm{F}$. to $105.8^{\circ} \mathrm{F} .^{4}$ This power is not peculiar, however, to the Saliva; for M. Bernard has shown that many azotized substances in a state of incipient decomposition, exert a similar agency : still it appears to he possessed by Ptyalin in a much greater degree than any of these (save the pancreatic fluid, which resembles saliva in this property), the transformation of starch under its influence commencing immediately, and continuing energetically until it is entirely effected. The activity of Ptyalin is destroyed by a boiling temperature. Its presence has been ascertained in man in the saliva secreted by all the glands; but in the dog it is absent in the parotidean fluid, and it exists only in small quantities in the secretion of the other salivary glands, which is in accordance with the nature of the food of this animal. In man, the transforming process is certainly not checker on the passage of the food into the stomach, as it is in the dog, which is partly owing to the larger proportion of Ptyalin his saliva contains, and partly to the acidity of the gastric juice being much less. It would appear that the Saliva has little or no chemical action on either the oleaginous or on the azotizer constituents of the food, and its operation on then, if it have any, must therefore be purely physical.

105. The secretion of the saliva takes place remittingly under nervous influence, the conditions of which have been very carefully investigated by Bernard, ${ }^{5}$ Ludwig, ${ }^{6}$ Eckhard, ${ }^{7}$ Schiff, ${ }^{8}$ v. Wittich, ${ }^{9}$ and Bidder. ${ }^{10}$ In the dog, the submaxillary and sublingual glands are supplied by the Sympathetic and by a nervous circle formed by the Glosso-pharyngeal and Fifth as sensory nerves, and the facial as a nerve exciting secretion, the active fibres of the latter passing into the chorda tympani nerve, and proceeding to the submaxillary ganglion. The different action of the sympathetic fibres, and of those coursing in the chorda tympani, when stimulated, is very curious, effecting actually a change in the character of the Saliva secreterl. If the two glands above mentioned are cleanly dissected out, they may be seen at

\footnotetext{
1 Centralblatt, 1871, p. 372.

${ }^{2}$ Sehiff, Pliysiologie de la Digestion, 1867, p. 153.

3 Atti del Instituto Veneto, t. iv, 18:9.

4 Paschutin, Centralblatt, 1870, p. 577.

5 Leetures, Med. Times and Gaz., vol. i, 1860, pp. 288-361.

6 Lehrbuch der Physiologie, Band ii.

7 Beitrïge, Bd. ii, p 205; iii, 186i2, p. 41 ; iv, 1867, Heft 2.

8 l'hysiologie, 1859 , p. 393. 9 Virehow's Arehiv, Bd. xxvii and xxxix.

10 Reichert and Dubois-Reymond's Arehiv, 1866, p. 339.
} 
rest, secreting little or no saliva, whilst the venous blond retnrning from them is of a dark tint. If a drop of vinegar be now placed upon the tongue of the animal, the arterial twigs supplying the gland immediately enlarge, the rapidity of the current of blood is increased, the veins pulsate and convey scarlet blood, the pressure of which on their inner surface is considerably increased, and there is an abundant ${ }^{1}$ discharge of limpid, highly alkaline saliva, containing small quantities of albumen (Globulin) and mucin. (This is termed chorda tympani saliva.) These conditions are brought about by an action transmitted through the sensory branches of the fifth and glossopharyngeal nerves to the Medulla oblongata, from which it is reflected through excito-secretory nerves contained in the chorda tympani, and primarily derived from the facial. If either of these latter nerves be cut, the current of

FIG. 64.

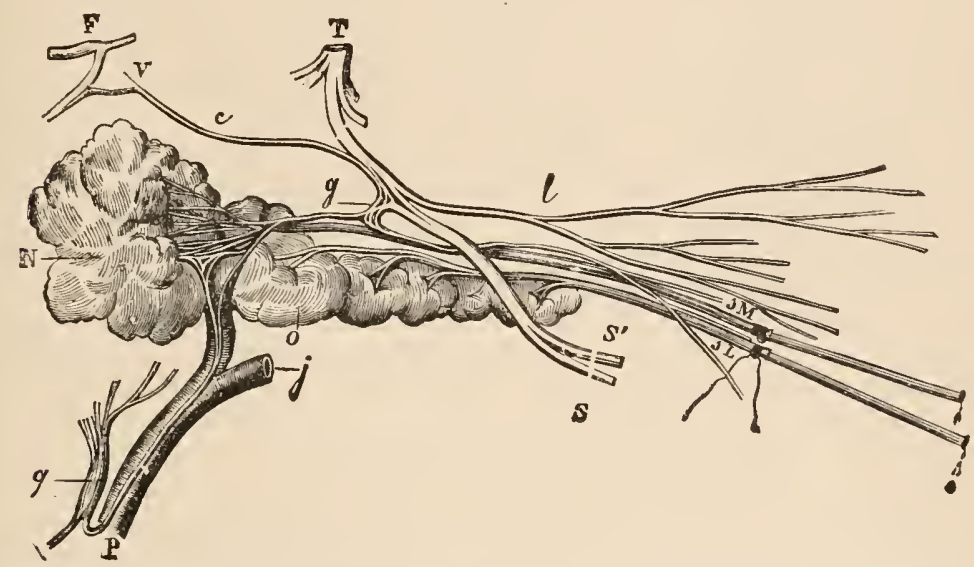

The Submaxillary and Sublingual Glands of the dog, with the nerves and vessels in relation to the submaxillary gland; to show the mechanism of the secretion in this gland.

N, submaxillary salivary gland ; $O$, sublingual, JM, Wharton's duct ; JL, duct of sublingual, pach with a canula tied into it; $\mathrm{T} \mathrm{ss}^{\prime}$ lingual branch of the inferior maxillary division of the Fifth nerve; $\mathrm{ss}^{\prime}$, branches distributed to the uucous membrane of the mouth; $F$, fucial nerve; $c$, chorda tympani; $a$, branch of the Facial distributed to the submaxillary gland after runuing for a short distance with the lingual of the Fifth; $g$, submaxillary sympathetic ganglion; $q$, superior cervical ganglion; $\mathbf{P}$, branch from this ganglion to the submaxillary gland; $j$, internal maxillary artery; $v$, vidian nerve; $l$, branch of the lingual nerve ramifying in the buccal nucous membrane.

blood becomes slower, its color in the veins black, the secretion of Saliva diminishes, and vinegar placed on the tongue no longer excites the secretion; whilst, if their distal cut extremities be again irritated, all the former phenomena recur. On the other land, if the sympathetic branches proceeding to these glands be directly irritated, the current of blood becomes very slow, in consequence of the contraction of the vessels, its color in the veins very dark, and the secretion of Saliva, whilst it diminishes in quantity, becomes at the same time cloudy and remarkably viscous, contains more albumen and mucin, and, according to Eckhard, a remarkable number of sarcode-like bodies possessing the power of spontaneous movement. (This is termed sympathetic saliva.). That the secretion does not wholly cease after section of the chorda tympani, is believed by Bernard to be due to the reflex action of the submaxillary ganglion, ${ }^{2}$ but even when the sympathetic fibres are divided, it

1856 grains in one hour in a dog (Ludwig).

2 Though this is rendered very doubtful by the experiments of Schiff, Leçons sur la Physiologie de lu Digestion. Florence, 1866. 
is not entirely stopped, a small quantity of so-called paralytic saliva continuing to be secreted when the tip of the tongue is excited by induced elcetricity. The nervous circle stimulating the parotid glands to activity in the dog appears to be completerl by the scnsory fibres of the Glosso-pharyngeal and gustatory of the Fifth, which transmit the impressions of taste to the Cerebrospinal nervous centres, firom whence a motor impulse, inducing increased secretory activity, is reflected through the Facial and the nervus petrosus superficialis minor to the otic ganglion, and from thence to the gland through motor fibres contained in the auriculo-temporal branch of the fifth. It is possible also that the otic ganglion may be the centre of reflexion without the cerebro-spinal centre being in any way implicated, the sensory impression passing by the Glosso-pharyngeal and the nervus petrosus superficialis minor, and being reflected at the ganglion upon the gland through the auriculotemporal. Section of the Nervus petrosus superficialis minor in the rabbit ${ }^{1}$ causes an immediate increase of the flow of saliva from the parotid gland, which lasts for ten minutes, and then subsides gradually, though it does not entirely cease. Schiff believes it to be the vaso-motor dilator nerve of the gland. Section of the Auriculo-temporal nerve, which is also a dilator nerve for the vessels, abolishes the reflex salivation of the parotids. (Schifi, Bernard.) Eckhard ${ }^{2}$ maintains that in the sheep the Parotid glands act unintermittingly, and are not under the influence of any cerebral nerve, since no change was effected in the secretion by stimulation of the fifth, or of the portio dura of the seventh, or of the sympathetic nerve. Division of this last in the neck was also devoid of influence, and no increase in the quantity discharged was produced by brushing the mucous membrane of the mouth with vinegar. Ludwig has pointed out, and this is an extremely important point in the physiology of secretion, as showing the direct influence of the nervous system upon gland tissue and cells apart from any action on the bloodvesscls, that if the circulation be suppressed and either the sensory or excito-secretory nerves be irritated, a considerable amount of Saliva is secreted. He also observed a fact which tells in the same direction, namely, that the pressure under which the saliva is secreted by the submaxillary glands as measured by a canula attached to a manometer, and introduced into Wharton's duct, is grcater than the pressure of the blood in the carotids. In the former amounting to $190 \mathrm{~mm}$. of mercury (or nearly 8 inches), whilst in the latter it was only $108.5-112.3 \mathrm{~mm}$. (or about $4 \frac{\mathrm{i}}{2} \mathrm{in}$.). The temperature of the saliva he found to be $1.5^{\circ} \mathrm{C}$., or nearly $3^{\circ} \mathrm{F}$. warmer than the blood of the Carotid artery. The partial independency of secretory activity upon increased flow of blood through the gland is further shown by the experiments of Giannuzzi, ${ }^{3}$ in which the glands were paralyzed by the injection into the duets of a 4.9 per cent. solution of Carbonate of Soda, nr of a 0.5 per cent. solution of hydrochloric acid. On stinulating the chorda tympani all the ordinary vascular phenomena made their appearance, but no increase in the amount of saliva secreted occurred and the gland soon becane adematous, the fluid which should have been nsed up in the formation of saliva apparently acemulating in the lymphatic system. Obviously, therefore, secretion is not a purely pliysical action; and as Ranket remarks, although a large supply of blood aflords abundant material for secretion, it is requisite before this act can be accomplished that sone change should occur in the grand eclls themselves, which it is the special province of the nervons

1 Schifl, Leçons sur la P'hysiol. de la Digest., 1867, p. 228.

2 Henle and P'feuffer, Keits., Bd. xxix, 1867, Heft 1, p. 74.

3 Ber d. k. sachs Gesells. d. Wiss., 1865, p. 68.

4 Grundzüge der Physiologie, 1868, p. 181. 
system to induce. Heidenhain ${ }^{1}$ has described at length the changes which tike place in the salivary glands which have been excited to secrete for a considerable time by irritation of their nerves. These changes consist in the breaking down of the large salivary cells to furnish the secretion, and their replacement by a growth of small granular cells, which he belicves to take place from the protoplasmic "demilune" of Giannuzzi (c c, Fig. 61); Ranvier," however, whilst adnitting that the secretion proceeds from the large cells, maintains that they do not entirely break down, but merely yiekd up their contents, their nuclei and the protoplasm surrounding the nuclei remaining to repair the loss. ${ }^{3}$

The several conditions under which a flow of saliva may be made to occur, arc - 1. By the reflex action of the submaxillary and otic ganglia, and of the ccrebro-spinal centres, excitcd by impressions conveyed through the glosso-pharyngeal and gustatory of the fifth, and taking effect through the motor branches of the facial, rumning in the chorda tympani and auriculotemporal nerves. 2. By calling into play the muscles of mastication, the effect being probably due to coincident excitation of the nerves supplying the glands with those distributed to the muscles. 3. By mental stimuli, as by the sight or thought of sapid food. 4. By poisons circulating in the bloorl, as Camphor, Woorara, Chloroform, and the Salts of Mercury. 5. By lesion of certain parts of the encephalon, as the floor of the fourth ventricle; by irritation of the upper extremities of the sympathetic or pneumogastric nerves divided in the neck, or of the central extremity of the divided sciatic nerve, which is not due (entircly at least) to the effects of this irritation in producing increase of blood pressure.

106. On its cntrance into the Stomach, the food is subjected to the operation of the Gastric Juice, which is secreted loy the follicles in its walls, or by a certain part of them. This follicular apparatus is extremely extensive, and makes up the chief part of the thickness of the gastric mucous membrane. If this be divided by a section perpendicular to the surface (Fig. $65)$, it is scen to be ahmost entirely composed of a multitude of parallel tubuli closely applicd to each other, their caecal extremities abutting against the submucous tissue, which here contains a considerable quantity of the unstriated form of muscular tissue that constitutes the muscular layer of the submucous tissue of Kölliker, and their open ends being directed towards the cavity of the Stomach. Between the tubuli, bloodvessels pass up from the submucous tissue, and form a vascular network on its surface, in the interspaces of which the orifices of the tubes are seen (Fig. 66). These tubular glands, the number of which is estimated by Sappey at nearly five millions, ${ }^{5}$ do not everywhere present the same structure. In that which may be considered as their most characteristic form, and which presents itself over the greater part of the area of the membrane, the wide open orifice leads to a pit of no great depth (Fig. 67, a), lined by columnar-epithelium ${ }^{6}$ resembling

1 Studien des Physiol. Inst. zu Breslau, 1868, p. 1.

2 Notes to the Freneh translation of Frey's Histology, p. 439, quoted in Küss, Physiolngie, 1873 , p. 265 .

3 See also for a similar view, Ewald, Centralblatt, 1870, p. 375.

4 see P. Grutzner, Pfüger's Archiv, Bd. vii, 1873, p. 52\%. Heidenhain has slown that the fibres of the chorda tympani nerve exciting the submaxillary crland to increased seeretion, are aistinct from the inhibitory vaso-motor fibres, sinee the administration of atropine faralyzes the former, but leaves the latter funetionally intaet.

5 Henle, Anatomie, 1862, p. 159.

6 Heidenhain's Hauptzellen (ehief or principal eells); Rollet's adelomorphous cells; Jukes's conical cells. See Jukes, in Centralblatt, 1872, No. 47. 
that of the surface with which it is continuous; and from the bottom of this pit, two or more passages $(b, b)$ branch off, still lined by columnar epithelium, which speedily subdivide into the proper glandular cæca $(c, c)$. Each of

FIG. 65.
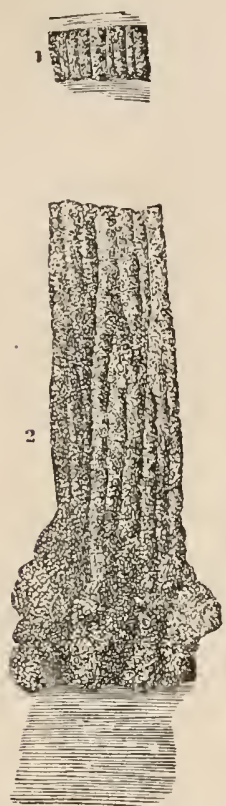

FIG. 66.

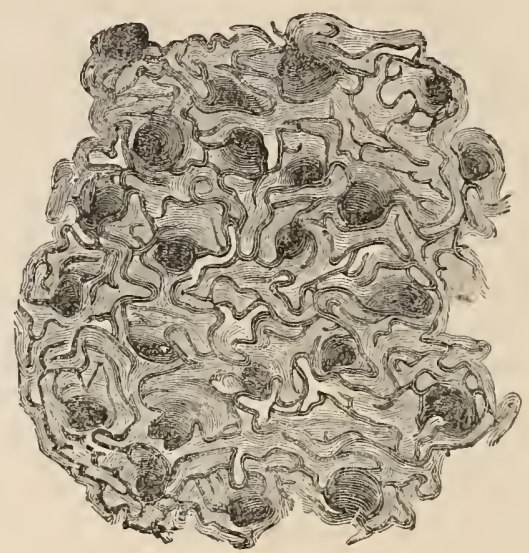

FIG. 65.-Vertical section of the Mucous Membrane of the Stomach, near the pylorus; magnified 20 times.

Fig. 66.-Capillary network of the lining membrane of the Stomach, with the orifices of the gastric follicles.

these crea, when sufficiently magnified (Fig. 68), is found to be composed of a delicate basement-membrane $(a)$, inflected over a scries of nearly globular cells $(b)^{1}$ which occupy ahmost the whole eavity of the tubc, and which contain a finely granular matter; the narrow passage left vacant in the centre, however, still surrounded by a layer of epithclial cclls (c), whose small size is in striking eontrast to the large dimensions of the gland-cells. "When a transverse section is made through a eluster of creea connceted with a single external orifice, they are found to be held together in a bundle (Fig. 69) by the interposition of areolar tissuc, a thicker layer of which surrounds the whole faseiculus, and isolates it from others: whilst between the crea are observed the orifices $(a, a)$ of the divided capillary vessels which pass up amongst them.-A different type of glandular structure presents itself in an annular zone around the eardia, and cspecially also in the region of the pylorus; the supcrficial orifice leading into a long and wide follicle (Fig. 70 , a), lined witl cylinder epithelinn, and branehing out, as it approaches the subnueous tissue, into a small number of short follicles $(b, b)$, still lined by an epithelium of the same kind. The columnar cells found in botl kinds of glands probably produce the mucous secretion of the stomach; but the pepsin there is erery reason for belicving is chicfly

1 Heidenhain's Belegzellen (investing cells) ; Rollet's delomorphous cells ; Jukes's polygonal cells. 
formed in the larger granular and more spheroidal gland-cells. ${ }^{1}$ Klein, however, has shown that the two extreme forms of glands are connected by so many intermediate forms, that it is impossible to draw a very definite line between those secreting mucus exclusively, and those which produce both pepsin and mucus. ${ }^{2}$ According to M. Cl. Bernard, ${ }^{3}$ when the stomach is

FIG, 67.

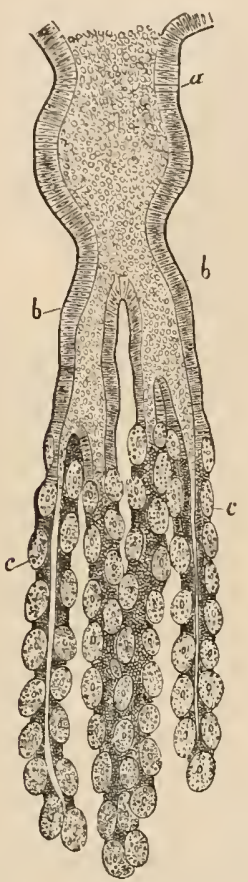

FIG. 68.

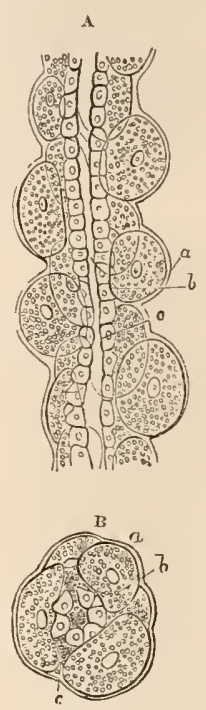

Fig. 67.-Peptic gastric gland;- $a$, common trunk; $b, b$, its chief branches; $c, c$, terminal cæca with spheroidal gland-cells.

FIG. 68.-Portions of one of the ceca more highly magnified, as seen longitudinally (A), and in transverse section (B); $a$, basement-membrane; $b$, large glandular cell ; $c$, small epithelium cells surrounding the cavity.

empty, the columnar epithelium which lines the neck of the glands completely blocks up their orifices, so that during fasting these appear as slightly prominent papillæ; but when the secretion of gastric fluid commences, this epithelium is cast forth by the pressure from beneath. The matrix of the mucous membrane of the stomach in which the glands are imbedded, consists of adenoid tissue, or a fibrous network containing cells and nuclei. This is more dense in some parts than in others, which has led various observers to admit the existence of lenticular or solitary glands in the region; but these

1 See Kölliker, Microscop. Anat., 1860, p. 321 : and Heidenhain, Schultze's Archiv, Bd. vi. Ebstein und Grützner, however (Pfüger's Archiv, 1872, Bd. vi, p 1), think that the columnar cells form the pepsin. See also Rollet, Untersuch. aus. der Phys. Inst. in Graz, Band ii.

${ }_{2}$ The best accounts of the structure of the mucous membrane of the stomach, and of the gastric glands, are given by Messrs. Todd and Bowman, Physiological Anatomy, vol. ii, pp. 190 et seq.; by Prof. Kölliker, Mikros. Anat., Bd. ii, \& 163; by Dr. Brinton, in the Supp. to the Cyc. Anat. and Phys.; and in Med.-Chir. Rev., July, 1862 , p. 189; by Henle, Eingeweidelehre, p. 152 ; and by Dr. Klein, Stricker's Histologv, 1870, p. 543 .

3 Gaz. Méd., Mars, 1844. 
spots differ from the lenticular glands, in being destitute of a limiting membrane. ${ }^{1}$ The interior surface of the stomach, thrown by contractiou when

FIG. 69.

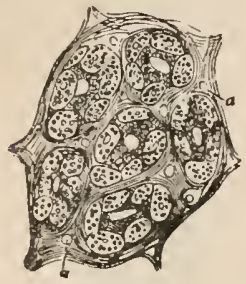

FIG. 70.

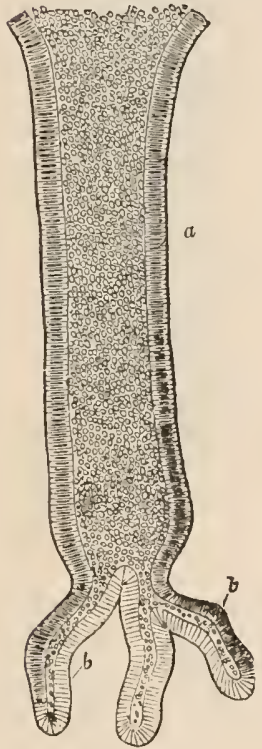

FIG. 71.

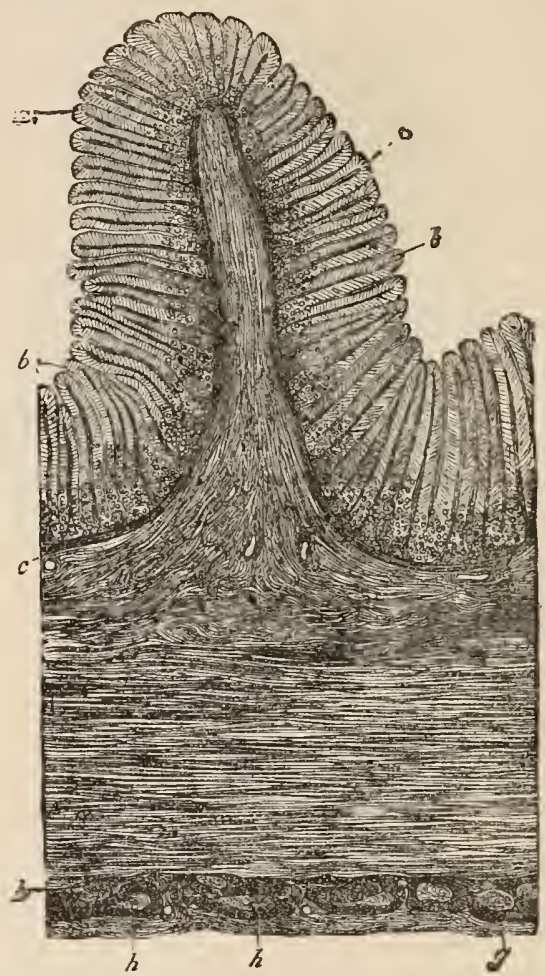

FIG. 69.-Transverse section passing through a cluster of gastric crea, separated and surrounded by fibrous tissucs; $a$, $a$, orifices of divided capillaries.

FIG. 70.-Mueous gastric gland, with cylinder epithclium; $a$, wide trunk; $b, b$, its ceeal appendages.

FIG. 71.-Trausverse section through the fundus of the stomach in a child: $a, a$, columnar epithelium : $b, b$, peptic gland-tubes; $c, c$, muscularis mucosa, about 1-250th of an inch in thickness, chicfly composed of longitudiual fibres; $d, d$, submucous tissue; $e$, circular muscular layer; $g$, peritoneum ; $h$, ganglia of Auerbach.

the viscus is empty into irregnlar folds or rugre (Fig, $72, \mathrm{~A}$ ), presents throughout the greater part of its extent, and especially near the Pylorus, small vascular processes or prolongations of the mucous membrane (B), ${ }^{2}$ resembling the villi of the small intestine, of which they must be considered as the rudimentary condition, but differing essentially from them in the circunstance that they contain no lacteal vessels. The lymphatics of the stomach are stated by Teichmann, ${ }^{3}$ to form two layers, a superficial and close network surround-

1 See Klein, Op. cit., 1. 548.

2 'This fat was first brought into prominent notice by $\mathrm{Dr}$. Neill, in his Memoir, On the Structure of the Mlucous Membrane of the Human Stomach, in the Aner. Juur. of Med. Sei., January, 1851.

3 Dus Saugader System, 1861, p. 76. 
ing the cxeal extrenities of the peptic glands, and a deeper layer with larger meshes lying in the submucous areolar tissue, and separated from the first by the thin stratum of unstriated muscular fibre, known as the muscular

A

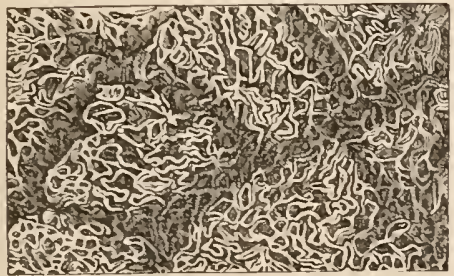

FIg. 72.

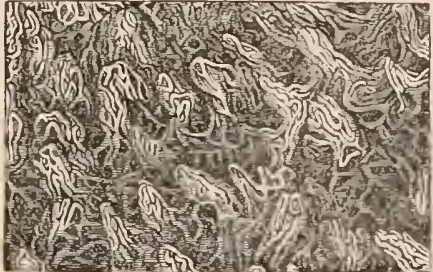

Appearance of the lining memlirane of the Stomach, in an injected preparation: A, from the convex surface of the rugr; $B$, from the neighborhood of the pylorus, where the orifices of the gastric follicles occupy the interspaces of the deepest portions of the vascular network.

layer of the mucous membrane, through which many vessels connecting the two strata pass. The nerves of the stomach are derived from the pneumogastric, or rather from the branch of the spinal accessory that joins the pneumogastric, and from the great sympathetic. They are divided into two layers; one of which forms a plexus in the submucous tisue (Meissner's plexus), whilst the other lies amongst the fasciculi of the longitudinal muscular coat (Auerbach's plexus; Fig. 71, h). In the former, ganglia are somewhat sparingly distributed ; in the latter they are abundant. ${ }^{1}$

107. The nature and composition of the Gastric Juice which is secreted and poured forth by the peptic follicles, have been the subject of much discussion among Chemists. When obtained without admixture with saliva, it is a clear, transparent, colorless or slightly yellow fluid with very little viscidity. Microscopio examination indicates the persistence of a fer of the cells exuviated from the interior of the gastric follicles; but these for the most part leave no other traces than their nuclei and a fine molecular matter arising from their disintegration. The proportion of solid matter which the Gastric Juice contains, and the proportion which its chief organic constituent-the pepsin-bears to the inorganic residue, seem to vary greatly in different animals. The following table shows the composition of the Gastric Juice as obtained from the best analyses in man and some animals:?

\begin{tabular}{|c|c|c|c|c|c|}
\hline & \multirow{2}{*}{$\begin{array}{l}\text { Max, } \\
\text { mixed with } \\
\text { salisa. } \\
\text { C. Schmidt. }\end{array}$} & \multicolumn{2}{|c|}{ DOG. C. Schmidt. } & \multirow{2}{*}{$\begin{array}{l}\text { SHFEP. } \\
\text { Schmidt. }\end{array}$} & \multirow{2}{*}{$\begin{array}{l}\text { Horse. } \\
\text { Frericlis. }\end{array}$} \\
\hline & & $\begin{array}{l}\text { Without } \\
\text { saliva. }\end{array}$ & With saliva. & & \\
\hline $\begin{array}{l}\text { Water, } \\
\text { Solid residue, }\end{array}$ & $\begin{array}{r}994.40 \\
5.60\end{array}$ & $\begin{array}{r}973.0 \\
27.0\end{array}$ & $\begin{array}{r}971.2 \\
28.8\end{array}$ & $\begin{array}{r}986.15 \\
13.85\end{array}$ & $\begin{array}{r}98.2 .8 \\
17.2\end{array}$ \\
\hline $\left.\begin{array}{l}\text { Organic matters, } \\
\text { (Ferment: Pepsin, }\end{array}\right\}$. & 3.19 & 17.1 & 17.3 & 4.05 & 9.8 \\
\hline $\left.\begin{array}{l}\text { Inorganc matters. } \\
\text { Podium chloride, } \\
\text { Calcium chloride, : } \\
\text { Ammonium chloride, } \\
\text { Free hydrochloric acid, } \\
\text { Calcium phosphate, } \\
\text { Magnesiur phosphate, } \\
\text { Ferric phosphate, }\end{array}\right\}$ & $\begin{array}{l}1.46 \\
0.55 \\
0.06 \\
0.20\end{array}$ & $\begin{array}{l}2.5 \\
1.1 \\
06 \\
0.5 \\
3.1 \\
1.7 \\
0.2 \\
0.1\end{array}$ & $\begin{array}{l}3.1 \\
1.1 \\
1.7 \\
0.5 \\
2.3 \\
2.3 \\
0.3 \\
0.1\end{array}$ & $\begin{array}{l}436 \\
152 \\
0.11 \\
0.47 \\
1.23 \\
118 \\
057 \\
0.33\end{array}$ & 7.4 \\
\hline
\end{tabular}

I For the mode of termination of the nerves in the stomach of the Frog, see $K$. Trütschel, Centralblatt, 1870, p. 115.

2 v. Gorup-Besanez, Phys. Chem., 1862, p. 460. 
108. The most characteristic feature of the Gastric Juice is its decided acidity, which is very perceptible to the taste, and is constant throughout the animal kingdom. With regard to the nature of the acid, however, there has been much discrepancy of opinion amongst Chemists; for simple as the problem of its determination might seem, it is complicated by the very peculiar property which lactic acid possesses, of decomposing the alkaline chlorides at a certain elcvation of temperature, the degree being partly determined by the strength of the solution. Hence, supposing lactic acid to be present in the stomach with sodium chloride, the fluid which passes over by distillation will at first be destitute of liydrochloric acid; but, as the liquor becomes more concentrated, and the temperature rises, hydrochloric acid will appear. This, it has been alleged by Bernard and other Chemists, is the true sourcc of the hydrochloric acid which may be always obtained from the gastric juice by this method; and it is affirmed by theni that lactic acid is the real agent in the solvent process to which that fluid is subservient, the prcsence of free lactic acid in the stomach liaving been dctermined by other means. In like manner, Dr. F. G. Smith, ${ }^{1}$ on examining the contents of the stomach of Alexis St. Martin, two and a half hours after a small quantity of bread had been eaten, obtaincd evidence of the presence of lactic, and of the absence of all but the slightest trace of hydrochloric acid. [These experiments have since been confirmed by Dr. Robert M. Smith in some investigations made in the Physiological Laboratory of the University of Pennsylvania, upon the contents of the stomach of a recently exccuted criminal. In these experiments, lactic acid was undoubtedly present, while no trace of free hydrochloric acid could be detected.-Plita. Med. Times, Feb. 13th, 1875.] On the other hand, the great readiness with which hydrochloric acid was obtained many years ago by Prof. Dunglison from the pure gastric fluid drawn from the stomach of Alexis St. Martin, and the fact that the smell of hydrochloric acid may be distinctly recognized in the fresh juice, ${ }^{2}$ are strong evidences in favor of the belief that (as originally maintained by Dr. Prout) free hydrochloric acid is present in this fluid, and that it is the principal, if not the only, source of its acidity. And an opportunity having bcen afforded to Dr. Bence Jones, of obtaining a fluid continually vomited in large quantities from the stomach of a patient affected with Sarcina ventriculi, and this fluid, which presented all the ostensible characters of gastric juicc, having been placed in the hands of Prof. Graham for examination, this distinguished Chemist succeeded in separating hydrochloric acid from it by his method of "liquid diffusion," which is not open to the objection that applies to distillation; and although he found free lactic acid to be also present, its quantity was comparatively small. ${ }^{3}$ It appears, then, to be a reasonable conclusion, that whilst hydrochloric acid is originally poured forth, and is thereforc the acid obtained by those cxperimenters, who liave employed mechanical irritation to the empty stomachs; other acids, as the lactic, butyric, or even acetic, may be formed during digestion, and may thus have been obtained by those who have examined the contents of the stomach only during or towards the close of that process. Allowance must also be made for differences existing in different animals, and perhaps also at

1 Experiments upon Digestion, Philadelphia, 1856.

2 See Prof. Dunglison's Human Physiology, 8th edit, vol, i, p. 152.

3 For his knowledge of this fact, the Anthor is indebted to Prof. Graham. That hydrochloric acid is the source of the acidity of the gastric juice has also been maintained by Enderlin (Canstatt's Jahresbericht, 1843, p. 149), by Hubbenet (Disquisitiones de Suceo Gastrico, Diss. inaug., Dorpat, 1850), by Bidder and Schmidt (Die Verdaungssaefte und der Stoffweehsel), and by Gruenewaldt and Sehroeder in their Theses on this subjeet. 
different ages, since MI. Wasnann has remarked that the pepsin of the stomach of the pig is entirely destitute of the power to coagulate milk, although the pepsin of the stomach of the calf possesses it in a very high degree; from which he is led to suppose that the power of the latter depends upon a particular modification of pepsin, or perhaps upon another substance accompanying it, which ceases to be formed when the young animal is no longer nourished by the milk of its mother. ${ }^{2}$

109. The peculiar organic constituent of the Gastric juice, to which the name of Pepsin ( $\$ 54)$ has been given, and which, according to Brücke, is neither an albuminous substance nor a ferment, appears to be sccreted and stored up in the cells of the stomach in a neutral state during the intervals of digestion, and to be only mingled with the acid at the moment of discharge. $^{3}$ Brücke noticed, that if the stomach of an animal were thoroughly washed with water till all trace of acidity was removed, a fresh portion of pepsin, possessing a perfectly neutral reaction, could be obtained on further maceration; and Bernard found that on injecting successively lactate of iron and ferrocyanide of potassium into the jugular vein of a rabbit, no blue discoloration of the blood, secretions, or tissues generally was observable on account of their alkaline reaction, though this could be immediately produced by the addition of sulphuric or other acid. On examining the stomach, however, he found that whilst the gastric follicles were free from color, the surface of the mucous membrane was uniformly tinted. From these experiments, the inference may be fairly drawn that the pepsin of the gastric juice is secreted by the cells lining the gastric follicles, whilst the acid is formed, or at least excreted, by the most superficial cellular layers of the mucous membrane. ${ }^{*}$ It nust not be supposed that the whole of the albuminous compounds introduced into the stomach under ordinary circumstances are converted into peptone. Some forms of albumen, as white of egg, undergo, in part, direct absorption, whilst a part is absorbed as soon as it is converted into syntonin (Brücke). The solvent power of the gastric juice in the living body is difficult to determine, since it differs with the animal and with the nature of the food. The gastric juice of Camivora is the most active, then that of Herbivora, whilst that of man appears to be comparatively feeble; and in this point, therefore, he appears to be most closely allied to the Herbivora. Lehmann and Corvisart estimated that on the average $20 \mathrm{oz}$. of the gastric juice of the $\log$ were required to dissolve 1 oz. of coagulated albumen; but M. Koopmans showed that whilst the strongly acid gastric juice of the Carnivora was best adapted for the solution of animal albumen, the weakly acid gastric juice of the Herbivora was far more efficacious in dissolving vegetable albumen or gluten. In Brücke's experiment with artificial gastric juice, ${ }^{6}$ it was found that at a temperature of $65^{\circ} \mathrm{F}$., the most active fluid for raw fibrin contained $12 \frac{1}{2}$ to 15 grains of muriatic acid in one litre (1.76 pints), whilst the most active fluid for albumen, coagulated by

1 See Prof. Graham's Elements of Chemistry, pp. 1031-1033.

2 Torlesungen über Physiologie, 1874, p. 295.

${ }^{3}$ See Bernard, Leçons, 1859, p.376; and Schiff, Physiologie de la Digestion, 1868, Leçons 21-:24.

"Schiff" considers that, as in the case of the Pancreas, a lind of "charging" of the glandular follicles occurs during the intervals of digestion, the pepsin being derived from certain peptogenic materials in the blood supplied by the previous digestion of albuminous compounds, or of dextrin. This vicw is strongly opposed by Fick (Verliand. d. Phys. Med. Gesells, N. F', B. ii, 53), who found that the stomaeh of a dog secreted active gastric juice fifteen hours after the last full meal, and that in rabbits, fusting did not diminish the digestive activity of the stomach, whilst the ingcstion of dextrin did not augment it.

5 Nederland. Lancet, t. v, 1856.

Op. cit., p. 300. 
heat, contained from 18.5 to 24.7 grains of this acid in the litre. When fibrin or other albuminous compound is acted on by artificial gastric juice, it swells up, and according to Brücke, ${ }^{1}$ becomes converted in to a substance identical with syntonin, which is gradually changed into peptone, and subsequently undergoes solution. The conversion of albumen into peptone, Brücke regards as complete, when it is no longer capable of being precipitated by potassium ferrocyanide. Meissner's description of the process is more complicated. He cousiders the first product of the artificial digestion of fibrin to be a substance insoluble in water, which soon splits up into parapeptone (= syntonin) and into peptone (of which last he recognizes three modifications, termed respectively, $a, b$, and $c$ peptone); small quantities of dyspeptone, and of metapeptone, are also occasionally found. All these substances are distinguished from one another by their relative solubility in acids or in neutral solutions, and their precipitability by nitric acid and potassium ferrocyanide. Gelatin and gelatin-yielding tissues, as connective tissue, tendons, ligaments, etc., are only slowly acted on by the gastric juice, the fluid resulting from their solution retaining for some time its porrer of solidifying; ultimately, however, they are reduced to a syrupy fluid, the osmotic powers of which are somewhat increased. ${ }^{2}$ From the experiments of Dr. Snith on Alexis St. Martin, it appears probable that the conversion of starch or dextrin into glycose may be effected in the stomach to some extent, since evidence of the presence of grape-sugar was found an hour and a half after bread and water had been introduced through the fistulous orifice, the man carefully aroiding to swallow his saliva during that period. There seems also to be good evidence that cane-sugar may be converted into grape-sugar. In both instances the active agent is probably the mucus of the stomach. It has been noticed by Hoppe-Seyler, that when large quantities of cane-sugar are taken, a condition of gastric catarrh, attended with the secretion of much mucus, is induced, and that the cane-sugar then undergoes, probably in consequence of its rapid transformation into grapesugar, speedy absorption. Oleaginous substances appear to be merely liquefied and finely divided, in which state they are diffused through the pulpy chyme.

110. It is only when either alimentary or some other substances capable of exciting irritation are present iu the stomach, that the gastric juice is poured forth. So long as it is empty, the secretion which moistens its walls is neutral or even alkaline; but as soou as food is taken, acid is poured forth, and this in increasing quantities, until a certin time after the commencement of the digestive process, when the acidity of the stomach is at its maximum. In proportion as the alimentary matter is dissolved, however, and is either at once absorbed, or escapes through the pyloric orifice, the acidity of the stomach diminishes; and as soon as its cavity is emptied, the secretion of its walls is neutral again. ${ }^{3}$ The circumstance that the stomach does not itself undergo digestion, even when that process is being actively performed on its contents, is of considerable interest, and must be attributed to the saturation of the whole mucous membrane with blood containing a large proportion of alkaline salts, for it has been shown by Dr. Pavy, that if one or two vessels of the stomach be tied, the parts thus deprived of the circulation of the blood rapidly undergo digestion, and perforating ulcers occur,

1 Vorlesungen über Physiologie, 1874, p. 301.

2 See Henle and Meissner, Bericht, 1860 , p. 269 ; and Henle and Pfeuffer's Zeitschrift, Bd. xiv, 1862, p. 303; Mohlenfeld, P'llüger's Arehiv, 1872, Bd. v, p. 381 ; v. Wittieh, idem, p. 435.

3 See Dr. Bence Jones, in the Medical Times, June 14th, 1852; and Dr. Marcet, Journal of the Chemical Soc., 1862. 
precisely analogous to those described by Hunter as seen in the bodies of men killed by accident during the digestion of a full meal. It must be remembererl, also, that the pepsin prescnt in the glands of the stomach is inoperative till it las mingled with the acid secreted on the surface. It is difficult to give even an approximative cstimate of the quantity of fluid poured forth from the walls of the stomach, since it is certain that it varies considerably, according to the nature of the substances ingested. Corvisart, from experiments on dogs, estimates it at about $\frac{1}{20}{ }^{1}$ th of the weight of the animal per diem; Harley," at $\frac{1}{15}$ th ; Lehmann, at $\frac{1}{10}$ th; whilst Gruenewaldt obtained ncarly $\frac{3}{4} \mathrm{lb}$. avoird. from a woman of $116 \mathrm{lbs}$. weight, with a gastric fistula, in fiftcen minutes $;^{3}$ and Schmidt gives as the mean of experiments on the same wonan, about 9000 grains hourly during activc digestion. ${ }^{4}$

111. A very important series of observations on the conditions under which the gastric juice is secreted, was made some years since by Dr. Beaumont, in the remarkable case of Alexis St. Martin, already several times referred to. " "The inuer coat of the stomach (as seen through the fistulous orifice) in its natural and healthy state, is of a light or pale pink color, varying in its hues according to its full or empty state. It is of a soft or velvet-like appearance, and is constantly covered with a very thin, transparent, viscid mucus, lining the whole interior of the organ. By applying aliment or other irritants to the internal coat of the stomach, and observing the effect through a magnifying glass, inuumerable lucid points, and very fine [nervous or vascular] papilla can be seen arising from the villous membrane, and protruding through the mucous coat, from which distils a pure, limpid, colorless, slightly viscid fluid." (The papilla here described appear to be the orifices of the gastric follicles, which are usually closed by their epithelial cells during fasting, and which would seem to become prominent when the vis a tergo of the secreted fluid first causes this plug of cells to be cast forth.) "The fluid thus excited is invariably distinctly acid. The mucus of the stomach is less fluid, more viscid or albuminous, semi-opaque, sometimes a little saltish, and does not possess the slightest character of acidity. The gastric fluid never appears to be accumulated in the cavity of the stomach while fasting; and is seldom, if ever, discharger from its proper secerning vessels, except when excited by the natural stimulus of aliment, mechanical irritation of tubes, or otler excitants. When aliment is received, the juice is given out in exact proportion to its requirements for solution, except when more food has been taken than is necessary for the wants of the system." The observations of Dr. Beaumont have been confirmed by those of M. Blondlot ${ }^{6}$ and of M. Cl. Bernard, ${ }^{7}$ which were made upon dogs in whose stomachs fistulous openings were maintained for a length of time. They found that the flow of gastric fluid is more excited by pepper, salt, and soluble stimulants, than it is by mechanical irritation; and that if mechavical irritation be carried beyond certain limits, so as to produce pain, the secretion, instead of being more abundant, diminishes or ceases entirely; whilst a ropy mucus is poured out instead, and the movements of the stomach are considerably increased. The animal at the same time appears ill at ease, is agitated, has nausea, and, if the irritation be continued, actual vumiting; and bile has been observed to flow into the stomach, and escape by

1 Longet, Physiologie, 1861, p. 182, vol. i. ${ }^{2}$ Med.-Chir. Review, 1860, p. 211.

3 Quoted by II. Edwards, Leçons, t. vii, 1862, p. 24

4 Annal. der Chemie, von Liebig und Wöhler, vol. xcii, p. 42.

5 See Dr. Beaumont's Experiments and Observations on the Gastric Juice and the Physiology of Digestion, reprinted with Notes by Dr. Andrew Cumbe, Edinb., 1838.

$6^{*}$ Traité Analytique de la Digestion.

7 Archiv. d'Anat. Gén. et de Physiol., Jan. 1846. 
the fistulous opening. Similar disorders of the functions of the stomach result from violent pain in other parts of the body; the process of digestion in such cases being suspended, and sometimes vomiting excited. When acidulated substances, as food rendered acid by the addition of a little vinegar, were introduced into the stomach, the quantity of gastric fluid poured out was much smaller, and the digestive process consequently slower, than when similar food, rendered alkaline by a weak solution of carbonate of soda, was introduced. If, however, instead of a weak solution, carbonate of soda in crystal or in powder was introduced into the stomach, a large quantity of mucus and bile, instead of gastric fluid, flowed into the stomach, and vomiting and purging very often followed. When very cold water, or small pieces of ice, were introduced into the stomach, the mucous membrane was at first rendered very pallid; but soon a kind of reaction followed, the membrane became turgid with blood, and a large quantity of gastric fluid was secreted. If, however, too much ice was employed, the animal appeared ill, and shivered; and digestion, instead of being rendered more active, was retarded. Moderate heat, applied to the mucous surface of the stomach, appeared to have no particular action on digestion; but a high degree of heat produced most serious consequences. Thus, the introduction of a little boiling water threw the animal at once into a kind of adynamic state, which was followed by death in three or four hours; the mucous membrane of the stomach was found red and swollen, whilst an abundant exudation of blackish blood had taken place into the eavity of the organ. Similar injurious effects resulted, in a greater or less degree, from the introduction of other irritants, such as nitrate of silver or ammonia ; the digestive functions being at once abolished, and the mucous surface of the organ rendered highly sensitive.

112. That the quantity of the Gastric Juice secreted from the walls of the stomach depends rather upon the general requirements of the system, than upon the quantity of food introduced into the digestive cavity, is a principle of the highest practical importance, and cannot be too steadily kept in view in Dieteties. A definite proportion only of aliment can be perfectly digested in a given quantity of the fluid; the action of which, like other chemical operations, ceases after having been exercised on a fixed and definite amount of matter. The cessation of the action is due, however', not to the pcpsin losing its solvent power, since a comparatively minute proportion will convert an almost indefinite quantity of albumen or fibrin into peptone, but rather to the presence of a great excess of the dissolved peptone interfering with further action, just as the presence of alcohol or lactic acid in large quantity interferes with those processes of fermentation in which these substances are respectively formed; in accordance with this, it is found that when the gastric juice is saturated with peptone and ceases to digest, the addition of a little diluted acid will immediately enable it to effect the conversion of a fresh portion of albumen. ${ }^{1}$ Nevertheless, the statement of Dr. Bcaumont is perfectly true as regards the living subject, that "when

\footnotetext{
1 Aceording to Brüeke, Pepsin is not destroyed during digestion, but Sehiff maintains that it is. Brücke, Op. eit., p. 29.5; Schiff, Or. eit., vol. ii, Leçon xxi. Between two sueh skilful observers it is diffieult to deeide. In a recent paper on the subjeet (Cenno sulle Rieerche futte del Prof. Schifr, ete, abstract in Centralblatt, 1872, p. 788), Schiff states that the stomach of a healthy dog in good physiologieal eondition requires 200 litres (about $4 \frac{1}{2}$ gallons) of water to develop its full digestive power, and the infusion of the stomach of a large dog in this quantity of water will digest $162 \mathrm{lbs}$. of albumen I Bennett (Text-book of Pliysiology, 1872, p. 203) observes that one part of pepsin dissolved in 60,000 parts of water still possesses a distinet digestive atetion.
} 
the juice has beeome saturated, it refuses to dissolve more; and, if an excess of food has been taken, the residue rentains in the stomach, or passes into the bowels in a crule state, and becomes a source of nervous irritation, pain, and disease for a long time." The unfavorable effeet of an undue burden of food upon the Stomach itself, interferes with its healthy action; and thus the quantity really appropriate is not dissolved. The febrile disturbance is thus increased; and the nueous membrane of the stomach exhibits evident indications of its morbid eondition. The description of these indications given by Dr. Beaumont, is peculiarly graphie, as well as hygienieally inportant. "In disease or partial derangement of the healthy funetion, the mucous membrane presents various and essentially different appearances. In febrile conditions of the system, oecasioned by whatever eause, - obstructed perspiration, undue excitement by stimulating liquors, overloading the stomaeh with food, fear, anger, or whatever depresses or disturbs the nervous system, - the villous eoat becomes sometimes red and dry, at other times pale and moist, and loses its smooth and healthy appearanee; the seeretions beeome vitiated, greatly diminished, or even suppressed; the eoat of mucus seareely pereeptible, the follicles flat and flaeeid, with secretions insufficient to prevent the papilla from irritation. There are sometimes found, on the internal coat of the stomaeh, eruptions of deep-red pimples, not numerous, but distributed here and there upon the villous membrane, rising above the surfice of the mueous coat. These are at first sharp-pointed, and red, but frequently beeome filled with white purnlent matter. At other times, irregular, eircumscribed red patches, varying in size and extent from half an inch to an inch and a half in circumferenee, are found on the internal coat. These appear to be the effeets of eongestion in the minute bloodvessels of the stomach. There are also seen at times small aphthous crusts in eonneetion with these red patehes. Abrasion of the lining membrane, like the rolling up of the mucous eoat in to small shreds or strings, leaving the papilla bare for an indefinite space, is not an uneommon appearance. These diseased appearanees, when very slight, do not always affect essentially the gastrie apparatus. When considerable, and particularly when there are eorresponding symptoms of disease, - as dryness of the mouth, thirst, accelerated pulse, ete.-no gastric juice can be extracted by the alimentary stimulus. Drinks are immediately absorbed or otherwise disposed of; but food taken in this eondition of the stomach remains undigested for twenty-four or fortyeight hours, or more, inereasing the derangenent of the alimentary eanal, and aggravating the general symptoms of disease. After excessive eating or drinking, ehymification is retarded; and, though the appetite be not always impaired at first, the fluids beeome aerid and sharp, exeoriating the edges of the aperture, and almost invariably producing aphthous patches and the other indications of a diseased state of the internal membrame. Vitiated bile is also found in the stomach under these eircumstanees, and floeeuli of mucus are more abundant than in health. IVhenever this morbid eondition of the stomaeh oeeurs, with the usual aceompanying symptoms of disease, there is generally a eorresponding appearance of the tongue. When a healthy state of the stomach is restored, the tongue invariably beeomes clean."1

1 Dr. A. Combe's commentary on the above passage is too apposite to be omitted. "Miny persons who obviously live too freely, protest against the fact, because they feel no immediate incunvenicnce, either from the quantity of food, or the stimulants in which they habitually indulge; or in other words, because they experience no pain, sickness, or headache,-nothing, perhaps, except slight fulness and oppression, which soon go off. Observation extended over a sufficient length of time, however, shows that the conclusion drawn is eutirely fullacious, and that the real amount of injury is not felt at the moment, merely because, for a wise purpose, nature has de- 
According to the experiments of Dr. Severé, ${ }^{1}$ the process of alcoholic fermentation is materially interfered with by fresh gastric juice, the obstructing agency being exerted upon the ferment, and not upon the fermentable substance. The lactic acid fermentation is not checked by fresh gastric juice; but this fluid, as Spallanzani long ago showed, is capable of completely stopping the progress of putrefactive fermentation. The Temperature of the Stomach rises with the increase of vascular and secretory activity which takes place during digestion. Dr. F. Smith found the ordinary temperature of St. Martin's stomach while fisting to be $98^{\circ}-99^{\circ}$ Fahr., whilst during digestion it rose to $100^{\circ}-101^{\circ} \mathrm{F}_{\mathrm{ah}} \mathrm{r}^{2}$

113. That the sccretion of Gastric Juice is affected in a very marked manner by couditions of the Nervous system, is indicated by the effect of mental enotions in putting an immediate stop to the digestive process, when it is going on with full vigor. It does not appear to be exactly deternined by what channel such influence is conveyed. Experiments which have been made upon animals with a view of ascertaining the share which the nervous influence conveyed by the Pneumogastrics takes in digestion, have led to different, though perhaps when all the conditions are considered, to reconcilable results in the hands of different experimenters. The immediate result of the division of these nerves is to arrest the movements and the secretion of the stomach. The organ becomes pale and flaccid, ${ }^{3}$ the reaction of the juice feebly acid or neutral, and the quantity of pepsin produced diminished. ${ }^{4}$ Any food that may be contained in it consequently undergoes only slight and supcrficial digestion. If the animal survives the respiratory and circulatory troubles resulting from the operation, a re-establishment of the digestive power manifests itself after an interval of some days; and the experiments of both Dr. Reid ${ }^{5}$ and Schiff show that when life is sufficiently prolonged, the power of assimilation and absorption is almost complctely restored: the evidence of this restoration consisting in the recovery of flesh and blood by the animals, the acidity of the contents of the stomach, and the disappearance of a considerable quantity of alimentary matter from the intestinal canal, with the existence of chyle in the lacteals. ${ }^{6}$. Longet ${ }^{7}$ found that milk was congulated on the second day after the division of the pneumogastrics, and that small quantities of meat or other food were digested casily enough, though large masses were only superficially affected. The experiments of Schiff ${ }^{8}$ seem to prove that the chief permanent effect of section of the pueumogastries is to prevent the stomach from co-operating in the atct of vomiting, whilst it does not interfere with the reflex movements of digestion.

prived us of any eonseiousness of either the existence or the state of the stomach during health. In accosdanee with this, Dr. Beaumont's experiments prove, thut exten-ive erythematic infammation of the mueaus eoat of the stomach was of frequent weeurence in St. Martin atter excesses in eating, and especially in lrinking, even when no marked general symptom was present to indieate its existence. Occasionally, febrile heat, nausea, headaehe, and thirst were eomplatined of, but not always. IIad st. Martin's stomach, and its inflamed patches, not been visible to the eye, he too inight have pleaded that his temporary excesses did him no harm; but, when they presented themselves in such legible characters that Dr. Beammont could not miss seeing them, argument and supposition were at $n \mathrm{n}$ end, and the broad fact could not be denied.'

1 Hopre-Seyler's Med. Chem. Untersueh., 1867, p. 257.

2 Loe. eit.

3 Bernard, Leçons, 1859, vol. ii, p. 81. Scchitf, Op. eit., Leçon xxxii.

5 Edinb. Med. and Surg. Journ, A pril. 18s9; and Physiolorical, Anatomical, and Patlological Researches, chap v.-Dr. lieid's results have been confirmed as to this important particular by Häblenet (OP. cit.), and more recently by Bidder and Schmidt. Ill. Ned. Zoitung, 1852, Heft viii, p.112.

6 For corroborative evidence, see Budge, Physiologie, 1862, p. 175.

7 Physiologie, vol. i, p]. 236-7, 1861 .

8 Loc. cit., Leçons $x \times x i$ and $x \times x i$. 
Both Budge and Schiff maintain that these nerves are the eonduetors by which sensory and painful impressions affecting the stomaeh, are eonveyed to the mind. The inquiries which have been made in reference to the aetion of the Sympathetic upon the secretion of the gastric juice, are, owing to the difficulties which attend experiments upon this point, comparatively few. Budge extirpated the coliac and meseraic ganglia, as well as divided the pneumogastrics, and still found (with one exception) that after the lapse of nine hours the stomach gave an acid reaction; and his results were fully corroborated by Ravitsch, ${ }^{1}$ who found that seetion of the vagi at the œsophageal opening, involving seetion of the sympathetic, had little or no influence upon either the secretion of the gastric juiee or the absorption of the chyme, though the latter was somewhat prolonged; and by Schiff, who divided the splauchnic nerves without effect. Adrian ${ }^{2}$ only obtained negatire results as regards the gastric seeretion after extirpation of the Coeliac Plexus, which he must have aecomplished with great dexterity, as the animals lived for montlis after the operation. ${ }^{3}$ What influenee is exerted by these nerves is probably effected by their vaso-motor action. It must be held as demoustrated by these experiments, then, that all the arguments which have been drawn from the effects of lesion of the Pneumogastric and Sympathetic nerves upon the funetions of the Stomach, in favor of the doctrine that Seeretion depends upon Nervous agevey, must be set aside. That these nerves have an important influence on the gastrie seeretion, is evident from the defieieney in its amount soon after their section, as well as from other facts. But this is a very different proposition from that just alluded to, and the difference has been very happily illustrated by Dr. Reid. "The movements of a horse," he observes, "are independent of the rider on his back-in other words, the rider does not furnish the eonditions necessary for the movements of the horse-but every one knows how mueh these movements may be influeveed by the hand and heel of the rider."

114. Our knowledge of the nature of the proeess of Gastric Digestion has been greatly advanced by recent inquiries; and we are now in a eondition to state with considerable preeision what it is, and what it is not, the province of the gastrie juice to effect.-There ean no longer be any doubt, that the operation is one essentially of chemical solution; and that the vital attributes of the Stomach are only exercised in the preparation of the solvent, and in the performanee of those movements which promote its action on the alimentary matter's submitted to it. The first series of facts which clearly demonstrated this position, were those that resulted from the very painstaking observations made by Dr. Beaumont, in the ease of St. Martin already referred to. By introducing a tube of india-rubber into the empty Stomach, Dr. B. was able to obtain a supply of gastric juice whenever he desired it, the tube serving the purpose of stimulating the follicles to pour forth their secretion, and at the same time conveying it away; and with the fluid thus obtained, he was able to make various experiments, which showed that the change which it effects upou alimentary matter, when it is kept at a temperature of $98^{\circ}$ or $100^{\circ}$, and frequently agitated, is not less eomplete than that which takes place when the same matter is submitted to its operation within the stomaeh, but requires a longer time. This is readily accounted for when we remember that no ordinary agitation can produce the same effeet with the

1 Phỵsiologie, p. 421, 1861; and Leçons sur la Phys. de lat Digestion, 1868, Leçon xxxii, p. 347.

2 Eckhard, Beiträge, Bd. iii, 1862.

3 Bernard, however, states (Med. Times and Gazette, 1860, vol. ii) that on gal. vanizing the sympathetic nerves distributed to the stomaeh, a sudden arrest of the secretion occurred. 
curious movements of the stomach; and that the continual removal, from its cavity, of the inatter which has been alrearly dissolved, must aid the operation of the solvent on the remainder. The following is one out of many experiments detailed by Dr. Beaumont. "At $11 \frac{1}{2}$ o'elock A.x., after having kept the lad fasting for 17 hours, I introduced a gum-elastic tube, and drew off an ounce of pure gastric liquor, unmixed with any other matter, except a small proportion of mucus, into a three-ounce vial. I then took a solid piece of boiled recently-salted beef, weighing three drachms, and put it into the liquor in the vial; corked the vial tight, and placed it in a saucepan filled with water, raised to the temperature of $100^{\circ}$, and kept at that point on a nicely-regulated sand-bath. In forty minutes digestion had distinctly commenced over the surface of the meat. In fifty minutes, the fluid had become quite opaque and cloudy ; the external texture began to separate and become loose. In sixty minutes, chyme began to form. At 1 o'clock P.M. (digestion having progressed with the same regularity as in the last half hour), the cellular texture seemed to be entirely destroyed, leaving the muscular fibres loose and unconnected, floating about in fine small shreds, very tender and soft. At 3 o'clock the muscular fibres had diminished one-half since the last examination. At 5 o'clock, they were nearly all digested; a few fibres only remaining. At 7 o'clock the muscular texture was completely broken down, and only a few of the small fibres could be seen floating in the fluid. At 9 o'clock, every part of the meat was completely digested. The gastric juice, when taken from the stomach, was as clear and transparent as water. The mixture in the vial was now about the color of whey. After standing at rest a few minutes, a fine sediment of the color of the meat subsided to the bottom of the vial.-A piece of beef, exactly similar to that placed in the vial, was introduced into the stomach, through the aperture, at the same time. At twelve o'clock it was withdrawn, and found to be as little affecterl by digestion as that in the vial; there was little or no difference in their appearance. It was returned to the stomach; and, on the string being drawn out at 1 o'clock P.nr., the meat was found to be all completely digested and gone. 'The effect of the gastric juice on the piece of meat suspended in the stomach was exactly similar to that in the vial, only more rapid after the first half hour, and sooner completed. Digestion commenced on, and was confined to, the surface entirely in both situations. Agitation accelerated the solution in the vial, by removing the coat that was digested on the surface, enveloping the remainder of the meat in the gastric fluid, and giving this fluid aceess to the undigested portions." Many variations were made in other experiments; some of which strikingly displayed the effects of thorough mastication, in aiding both natural and artificial digestion.

115. The attempt was made by Dr. Beaumont, to determine the relative digestibility of different articles of diet, by observing the length of time requisite for their solution. ${ }^{2}$ But, as he himself points out, the rapidity of digestion varies so greatly, according to the quantity eaten, the nature and amount of the previous exercise, the interval since the preceding meal, the state of health, the condition of the mind, and the nature of the weather, that a much more extended inquiry would be necessary to arrive at results to be depended on. Some important inferences of a general character, however,

1 Experiments 2 and 3 of First Series.

2 It is important to bear in mind, that the digestibility of different substanees bears no relation to their nutrient value, which is entirely dependent on their chemieal eomposition. Of course, however nutritious a substance may be, it is valueless as an urticle of diet if it eannot be dissolved; but, on the other hand, substanees which are very easily digested (such us farinaceous matters) may luve a low nutritive value, through eontaining but a very small proportion of azotized eonstituents. 
may be drawn from his researches.-It seems to be a general rule, that the flesh of wild animals is more easy of digestion than that of the domesticated races which approach them most nearly. This may, perhaps, be partly attributed to the small quantity of fatty matter that is nixech up with the flesh of the former, whilst that of the latter is largely pervaded by it. For it appcars from Dr. B.'s experiments, that the presence in the stomach of any substance which is difficult of digestion, interferes with the solution of food that would otherwisc be soon reduced. It seems that, on the whole, Beef is more spcedily reduced than Mutton, and Mutton sooner than either Veal or Pork. Fowls are far from possessing the digestibility that is ordinarily imputed to them; but Turkey is, of all kinds of flesh except Venison, the most soluble. Perhaps the average period required for the digestion of an ordinary meal, and the complete emptying of the stomach, may be roughly estimated at from 3 to $4 \frac{1}{2}$ hours.-Dr. Beaumont's experiments further show that bulk is as necessary for healthy digestion, as the presence of the nutrient principle itself. This fact has been long known by experience to uncivilized nations. The Kamschatclales, for example, are in the habit of mixing earth or sawdust with the train-oil on which alone they are frequently reduced to live. The Veddahs or wild hunters of Ceylon, on the same principle, mingle the pounded fibres of soft and decayed wood with the honey on which they feed when meat is not to be had; and on one of them being asked the reason of the practice, he replied, "I cannot tell you, but I know that the belly must be filled." It is further shown by Dr. B., that soups and fluid diet are not more readily chymified than solid aliment, and are not alone fit for the support of the system; and this, also, is conformable to the well-known results of experience; for a dyspeptic patient will frequently reject chicken-broth, when he can retain solid food or a richer soup.-Dr. Beaumont also ascertained, that moderate exercise facilitates digestion, though severe and fatiguing exercise retards it. If even moderate exercise be taken immediately after a full meal, however, it is probably rather injurious than beneficial; but if an hour be permitted to elapse, or if the quantity of food taken have been small, it is of decided benefit. The influence of temperature on the process of solution is remarkably shown in some of Dr. B.'s experiments. He found that the gastric juice had scarcely any influence on the food submitted to it, when the bottle was exposed to the cold air, instead of being kept at a temperature of $100^{\circ}$. He obscrved on one occasion, that the injection of a single gill of water at $50^{\circ}$ into the stomach, sufficed to lower its temperature upwards of $30^{\circ}$; and that its natural heat was not restored for more than half an hour. Hence the practice of eating ice after dinner, or even of drinking largely of cold fluids, is very prejudicial to digestion.

116. It is far from being true, however, that (according to the older views of its power) the Gastric juice is capable of acting upon all the nutritive components of the food. The mistake probably arose from the reduction to which these matters are subjected in digestion, the alimentary bolus being completely disintegrated, and its particles saturated with the fluids of the stomach, so that the whole forms a homogeneous liquid of pultaceous consistence, to which the name of chyme is given. This chyme will of course vary greatly in its composition, according to the proportion of the different alimentary substances that have cntered into the composition of the food; and its appearance, also, is far from uniform, being sometimes like gruel, but sometimes more creamy, always, however, having a strong acid reaction. All the more recent and accurate experiments of those who have studied the chemistry of digestion, lead to the conclusion, that the solvent powers of the Gastric juice are chiefly exerted upon azotized substances; and that its action is comparatively slight upon starchy, saccharine, and ole- 
aginous natters. Although the change in the starchy particles, which commences in the mouth, is usually continued in the stomach, yet its continuance is cssentially dependent upon the presence of the salivary fluid; being materially checked, when, by tying the osophagus, that fluid is prevented from passing into the stomach. ${ }^{i}$ [The experiments by the American editor upon Alexis St. Martin, alluded to in the text on page 156, confirm the statements here made as to the office of the Gastric juice in digesting albuminous articles of fond, by a previous conversion into albuminose or peptones. So, also, that Gastric juice has no action upon oleaginous food, other than to liberatc the oil by dissolving away the albuminous enrclopes of the fat-vesicles. With regard to amylaccous constituents of food, these experiments upon St. Martin, as well as others more recently performed, through the kindness of Dr. E. Brown-Sequard, who, it will be remembered, has the faculty of vomiting at will, showed distinctly the presence of grape-sugar in the products of Gastric digestion as determined by Trommer's test; and this in much larger quantity than could be obtained by the action of saliva for the same length of time npon a portion of the same arrowroot swallowed by Brown-Sequard, and which had been previously tested for glueose without the response usual when this substance is present. That the glucose thus found in the products of Gastric digestion is the result of the action of Gastric juice upon the amylaceous food is not contended for. The change has been most probably produced by the action of the mucus secreted by the mucous follicles of the stomach, as it is well known that mucus from any of the mucous membranes has this effect. Thus, an injection of starch in the rectum, when evacuated, is found to respond to Trommer's test for grapesugar.] Its conversion into dextrin and sugar is completed in the small intestine by the action of the gastric juice. The experiments of Dr. Dalton ${ }^{2}$ on the introduction of the garden snail and slug into the stomachs and gastric juice of $(\operatorname{logs}$, show that no living animals, at least of this grade of development, can long resist the digestive process, death occurring in the course of a few minutes, which is speedily followed by the disappearance of all traces of their bodies. The action of the gastric juice seens essentially to stand in the place of a high tempcrature and a powerful oxidizing agent; but though albuminous substanees are converted into peptones during digestion, yet as no peptones are found in the fluids of the body, but simply albumen, this conversion seems to be only accomplished for the purpose of promoting its absorption. For, as Prof. Graham has shown, albumen has a very low diffusive power, and a very high endosmotic equivalent; aud although, when subjected to considerable pressure, its solutions will filter slowly through animal membranes (thus affording a rationale of its occasional appearance in various transudations), yet it is obvious that unless some such preliminary change took place, a very insufficient supply of this material would gain cutrance into the blood.

117. This action of the gastric solvent upon the azotized constituents of the food, is dependent upon several accessory conditions. One of the most important of these is temperature. A heat of from $96^{\circ}$ to $100^{\circ}$ is required to keep up the solvent process, which is retarded according to the depression of the thermometer below this standard; so that at the ordinary temperature of the atmosphere it is completely suspender, to be renewed, however, with an increment of heat. On the other hand, a trifling elevation of temperature above $100^{\circ}$ occasions a decomposition in the gastric juice, which entircly destroys its solvent power. The next condition, which specially

1 See Frerichs, in Wagner's IIandwörterbuch, Bd. iii, Art. Verdauung.

2 Amer. Juurn. of Med. Science, $\Lambda_{\text {pril, }} 1865$, p. 334. 
affects the time required for the process of solution, is motion. This docs not act mechanically, by way of "trituration," as was once supposed ; for food is found to be digested, when inclosed in netallic balls perforated to admit the access of gastric juice to their interior. But it answers the purpose of thoronghly subjecting the whole of the alimentary bolus to the agency of the gastric solvent, by bringing each part successivcly into contact with the lining membrane of the stomach, from the surface of which the fluid is effused. The remomal of the matters already reduced or dissolied, also, has a most important effect in facilitating the solution of the remainder. This removal is due in part to the absorption of the natters in a statc of solution, into the bloodressels of the walls of the stomach; and in part to the successive escape of the reduced portions through the pyloric orifice. The importance of the previous state of minute division and incorporation with aqueous fluid, in promoting the action of the gastric solvent, has been already dwelt on $(\$ 101)$.

118. Although the Chyme, or product of gastric digestion, which escapes through the pyloric orifice into the duodenum, contains much azotized matter in a state of actual solution, a considcrable proportion of it is still only reduced and mechanically suspended; and the solution of the latter is continued in the intestinal tube. In the farinaceous part of the food, moreover, no great amount of change has hitherto been effected; and the sugar which has been generater by the agency of the salivary ferment, is probably absorbed in to the bloodvessels nearly as fast as it is formed. In the condition of the fatty matters, no important change is perceptible, except such as results from the solution of the membranes, etc., that incloscd them. Hence we see that the process of Digestion, so far from being completed in the stomach, has only been carried one stage further. Soon after its entrance into the Duodenum, the chyme is subjected to the actions of the Bile, the Pancreatic fluid, and that secretion from the glandule in the walls of the intestine itself (proceeding from the glands of Brunner, $\S 114$, and Lieberkühn), which is known under the name of the "Succus Entericus." Of these, the Pancreatic fluid will be first noticed. The structure of the Pancreas closely resembles that of the Salivary glands ( $\$ 95)$, for it consists of racemose clusters of secreting follicles, which form the terminations of the ramifying divisions of the duct; each cluster, with its bloorlvessels, lymphatics, nerves, and connecting tissue, forming a lobule; and the separate lobules being held together by areolar tissne, as well as by the vessels and ducts. The cells of the secreting part of the gland are, according to Latschenberger,' large, and contain a succulent mass of protoplasm in their interior. If the gland be injected from the duct of Wirsung, a dendritic series of branches are brought into view, which has led various observers ${ }^{2}$ to believe that the secretory cells of the pancreas, like those of the liver, are surrounded by extremely fine ducts, which convey the secretion into the larger excretory passages; but Latschenberger has shown that there are no such independent tubes, the appcarance being due to the injection forcing its way not only in the axis of the canal, but through the interspaces between the adjoining cells. The nerves of the Pancreas are derived from the sympathetic system, and terminate, according to Pflüger, in the same way as in the salivary glands, by penetrating the secretory cells. Like both the liver and the salivary glands, the development of the pancreas commences by

I Quoted in Brücke's Physiolngie, 1874, p. 325.

2 See Langerhans, Inaug. Dissert., 1869; Centralblatt, 1870, p. 261 ; and Pflüger's Archiv. Band v, p. 203: Giannuzzi, Comptes Rendus, t. Ixviii, 1869, p. 1280; Saviotti, M. Schulize's Archiv, Band v, p. 404. 
a sort of budding forth of the alimentary canal at a particular spot upon which a mass of cells has previously accumulated. The secretion of this gland resembles saliva in its general appearance, being clear and colorless, free from smell, alkaline in its reaction, and very viscid; the only morphological constituents it contains are numerous granules of oil. Upon the application of heat, or upon the addition of any of the stronger mineral acids, it coagulates into a solid mass like the white of an egg. This appears to be due to the presence of alkali-albumen and serum-albumen, as well as to a peculiar form of albumen, which is precipitated in a gelatinous condition at a temperature of $32^{\circ}$ Fahr. from the concentrated secretion. ${ }^{\prime}$ The properties of the secretion seem to vary according to the period of digestion at which it is collected, being at first very tenacious and coagulating completely, and at a later period becoming thimer, more alkaline, and less perfectly coagulable by heat; its solvent powers upon various constituents of the food are, at the same time, less strongly marked. The composition of the Pancreatic juice of the Dog is represented in the following Table ; ${ }^{2}$ the term pancreatic including all the albuminous constituents:

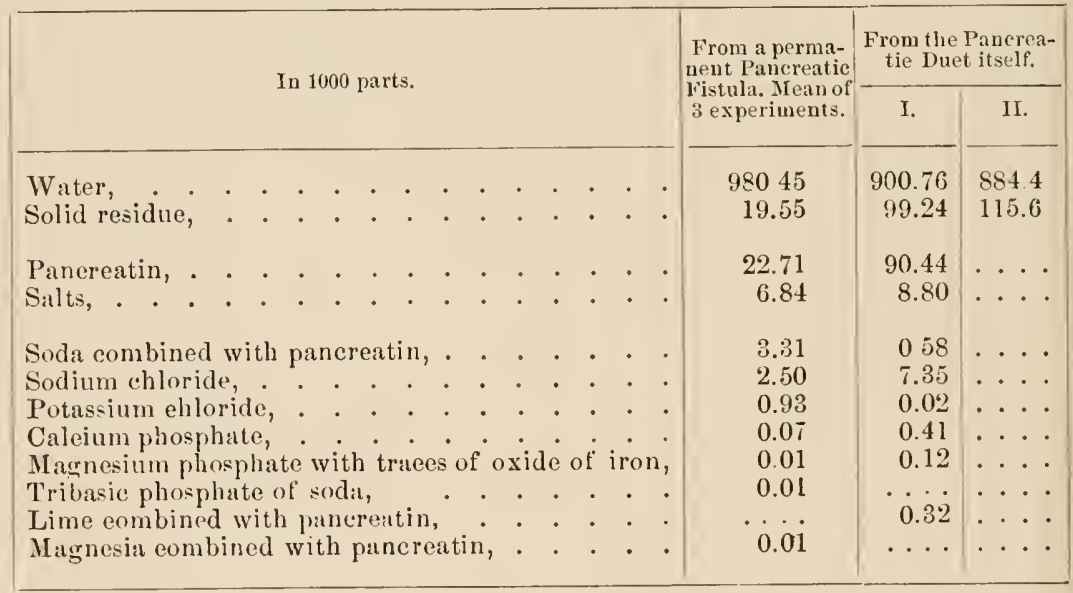

Leucin, Guanin, and Tyrosin, have been stated to be constant constituents of the substance of the gland, and Leucin and Xanthin have occasionally been found in the secretion. Reeent experiments, however, ${ }^{3}$ render it probable that these substances proceed from the action of the secretion on the albuminous constituents of the food, or even on the tissue of the gland itself.

119. The nature of the organic substance which forms so large a part of the solid residue of the pancreatic juice, and which is so singularly prone to decomposition, has not been aceurately determined. Bernard states that it resembles albumen in being precipitated by heat, acids, alcohol, and metallie salts, but differs in being thrown down by sulphate of magnesia, and by the circumstance that, after being precipitated by alcohol, it ean be redissolved in water. 'The quantity of the secretion which is poured forth in twenty-four hours, has been varionsly estimated; and perhaps the differences

1 Wundt, Physiologie, 1873, p. 217.

2 Gorup-Besanez, Physiol. Chemic, 1862, p. 487.

3 Külne, Centrablatt f. d. Med. Wiss., 1867, p. 420, and Fudakowski, idem, p. $5+6$. 
are due, as Bernard has suggested, to the circumstance that when the operation for the formation of a pancreatic fistula has been attended with much violenec, when the ghand has become inflamed, and the health of the animal has in consegucnce suffered, the fluid secreted is abnormal, and differs both in quantity and in many of its most essential properties, from the healthy secretion. From these considerations, and from the probably intermittent character of the secretory act, it is manifest that only an approximate estimate of the absolute quautity can be made. Bernard estimates the quantity secreted per hour in the dog, for every $1 \mathrm{lb}$. weight of the animal, at about 15 grains; Schmidt and Kröger at from 20 to 35 grains; Skrebitzky and Bidder at from 21 to 35 graius. If this last estimate were applied to man, it would give from $12 \mathrm{ozs}$. to $16 \mathrm{ozs}$. av. as the total quantity of pancreatic juice secreted per diem. Bernard describes the gland as palc and flaccid during the period of fasting, and as rosy, but not deep red, some time after food has been taken, when the secretion is rapidly poured forth. The activity of the gland seems to be greatest at the middle or towards the close of gastric digestion, ${ }^{2}$ and at the period, thercfore, of the passage of the contents of the stomach into the small intestine. Corvisart attributes the secretion to a kind of charging of the pancreas with albuminous compounds absorbed during gastric digestion, for on the intreduction of food, or of the products of gastric digestion below the entrance of the pancreatic duct, no increase in the flow of the secretion occurred. [Bernstein has shown that with the entrance of food into the stomach the pancreatic secretion rapidly increases, and soon reaches its maximum; then slowly decreases, and towards the sixth hour again increases. Heidenhain, in a long paper, has put forth the following: During the state of hunger the granular interior portion of the pancreatic cell occupies a larger part, whilst the homogeneous exterior of the cell occupies a smaller part; that during the first period of digestion, when the most active secretion takes place, there is a lessening of the size of the whole cell through a using up of the granular interior. Whilst new materials are added to the exterior of the cell, this portion of the cell is increased in size; that during the second period of digestion, when the secretion siuks and stops, there is a renewal of the granular interior of the cell at the expense of the homogeneous exterior, extreme diminution of the latter, and incrcase of the size of the whole cell; that, during long fasting, there is a gradual increase of the external portion of the cell to its origival size, with a small decrease of the interior granular portion; the cells during their physiological activity use up their gramular interior, whilst there is au addition of new material; - in other words, there is a metamorphosis of the granular matter into secretory elements with the increase of nutritive materials in the formation of the homogeneous part of the cell, which, in its turn, is converted into the interior granular material. The general shape of the cell depends on the relative rapidity with which these processes are accomplished.

1 See M. Edwards, Leç. sur la Physiul., 1860, p. 52*. Colin obtained about 10 oz. per hour from a cow of medium size and from a horse, but only 3 drachms from a pig.

2 Weinmann observed in a dog during the first hour after a full meal 1510 grains secreted, whilst after a 45 hours' fast only $7 \frac{1}{2}$ grains (Henle and Pfeuffer's Zeitschrift, N. F., Band ii, p. 247). Kröger ubtained 384 grains during the first hour, 271. in the $2 d, 225$ in the $3 d, 4$ th, 5 th, and 6 th; 176 in the $71 \mathrm{~h}, 8$ th, and 9 th; 165 from the 10 th to the $1 \mathrm{fth}$; and 103 from the 19 th to the 2 th (Archiv. Gén. de Méd., i, 1861, p. 533). Bernstein (Leipziger Arbeiten, 1870, j. 6) obtained scarcely any from fasting dogs, but remarked a eunsiderable inerease $(0.6-2 \cdot 2$ e.e. in 10 min.) during the first hour after feeding, the quantity attaining its maximum at the $2 \mathrm{~d}$ and $3 \mathrm{~d}$ hour (ahout 5 e.e. in 10 min.), then diminishing to the 5 th hour, when a slight inerease tuok place till the 7 th hour, after which it gradually fell to zero. 
In the first period of digestion there is a more rapid using up of the interior of the eell, and a more rapid addition to the exterior. In the second period, when the greatest ehanges take plaee, the homogeneous exterior is metamorphosed into the granular interior; whilst during the stage of hunger, the using up of materials is smaller, the addition of new materials is slower, but it eauses visible widening of the exterior portion of the eell. Heidenhain believes that in no other organ are the interior ehanges shown with such marked mieroseopie distinctness. He also deseribes a body obtained from the panereas, whieh he ealls zymogen, which is soluble in coneentrated glyeerin without suffering any ehange. Its eonversion into panereatin oecurs in watery solution quieker in warmoth, slower at the usual temperature. Aeids eause these changes, but salts, sueh as ehloride of sodium and carbonate of soda, retard this metamorphosis. The quantity of this borly in the panereas during digestion varies with the ehanges in the eell; it increases and decreases aceording as the degree of formation of the granular interior of the eell inereases and decreases. Irritation of the medulla by induetion eurrents inereases this seeretion probably through its eonneetion with the intraglandular ganglia. The seeretory nerves of the panereas have a direet influenee not only on the amount of water, but of the solid elements in that seeretion.-Pflïger's Archives.] Distinct evidenee of the indirect influence of the nervous system upon the aetivity of the gland has been obtained. Seetion of the nerves aecompanying the vessels eauses eongestion of the gland, greatly augments the quantity of the seeretion (paralytic seeretion), whieh eontinues when the animal is kept fasting. If, whilst these nerves are uninjured, the pneunngastries are divided, and the eentrie ends exeited, the secretion is diminished, and a similar inhibitory effeet is observed at the commeneement of efiorts to vomit. From these faets the eonelusion may be drawn that the nerves distributed to the gland exert an inhibitory or restraining influence upon the secretory aetivity of the gland, which is removed by reflex aetion, through the spinal eord and sympathetie nerve, when the pneumogastrie, or its peripherical terminations in the stomach, are exeited. ${ }^{1} \mathrm{~N}_{0}$ evidenee has been obtained that any nerves directly excite the secretion. Under the toxie influenee of woorara, the secretion is greatly augmented. As the organ is of eonsilerable size, is very eonstant amongst the Vertebrata, and uniformly discharges its seeretion into the duodenum, it is natural to suppose that it must exert an important influenee in preparing the food for absorption; aud this is fully borne out by our knowledge of the serious interferenee to the due performanee of this operation, resulting from disease of this organ, and of the extreme instability of the organie matter eontained in its seeretion.

120. From the researehes of many experimenters, it appears to be well aseertained that probably owing to the presenee of three separate ferments," the panereatic juiee ean-1. Like liastase, convert stareh into sugar; 2 . That it can emulsify the fats and oils and effect their deeomposition into glyeerin and the fatty acids; 3 . That it ean, like pepsin, eonvert albumen into peptone. ${ }^{3}$ Its action differs from pepsin, however, in continning in alkaline and neutral solutions, whilst it is arrested by a moderate excess of aeid. 'The first and second of the above aetions are possessed by all speei-

1 See Bernstein, Arbeiten nus der Leipziger Anstalt, 1870, p. 1.

2 Sre Danilewsliy, Archiv f. Path. Anat., Bd. xxv.

3 Liversidge and Clowes (Journal of Anat. and Phys., vol. viii, p 25) have shown that pepsin and pancreatic ferment have a very similar chemical composition. The percentago compusition of the probahly impure forment obtaned by macerating the puncreats in aloohol to precipitate the albuminons componnds, extracting with glyorin and precipitating with aleohol, was C. 34925, N. 11.02 3 , Ash 15.170; that of P'epsin was C. 39.792, N. 10.106, Ash 16.48. 
mens of pancrcatic juice, the last is only displayed with certainty by the juice and extract of the rosy gland, obtained during digestion.' In addition to its emulsifying power over fats, the pancreatic juice can exert a chenical action, effecting the disintegration of the more easily decomposable fats into glycerin and the fatty acids, and this, according to Brücke, materially facilitates the formation of a permanent emulsion. ${ }^{2}$ The sacchurifying influence of the pancreatic juice upon starch was first observed by Valentin, and may be proved by adding the healthy secretion obtained by a fistulous opening, or even an infusion of the gland-substance, to either crude or boiled starch; for though the energy of the action is much greater in the latter casc, yet even in the former the starch-grains become rapidly altered in form, disintegrate, and dissolve, grape-sugar being at the same time produced.". The necessity which exists for the conversion of starch into sugar before it can be absorbed, renders evident the advantage which attends the presence of a gland possessing a similar transforming power to that of saliva, at some dis. tance from the mouth, where it may act upon crude starch, now softenerl, swollen, and otherwise affected by the combined heat and moisture of the stomach, and which would otherwise escape being acted on. The amylolytic power of the pancreatic fluid has been shown by Dr. M. Fostert not to depend on the pancreatin it contains; and Cohnheim and Danilewsky believe they have isolated the substance possessing this peculiar power, and have satisfied themselves it is not a proteid. The action exerted is undoubtedly that of a ferment, since an indefinite quantity of starch can be converted into sugar by a definite quantity of the ferment. Its operation is not interfered with by the presence of the gastric juice. The pancreatic juice is not, however, exclusively destined for this function, sharing it with the "succus entericus," which has been shown by Frerichs and Hübbenet, and especially in the interesting case recorded by Busch, ${ }^{5}$ to be also possessed of this converting power.

121. But secondly, it has been affirmed by MI. Cl. Bernard, and strong evidence has been adduced by him in support of his statement, that the essential purposc of the Pancreatic fluid is to promote the absorption of fatty matters, by reducing them to the state of an emulsion, which is capable of finding its way into the lacteals. That this fluid possesses the emulsifying power in a peculiar degree, may be considered as having been fully demonstrated by his experiments; for on mixing it with oil, butter, or any variety of fat, at a temperature sufficiently high to render the fatty substance liquid, and then stirring the mixture for a few minutes, an emulsion is produced, bearing a strong resemblance to chyle. This emulsion does not cease to present its peculiar aspect, even when left standing for some time; whereas, although bile, saliva, gastric juice, blood-serum, and other animal fluids, have a certain emulsifying power, yet, after a short time, the oil-particles run together again, almost as if they had been merely shaken up with water. Further, it is asserted by Bernard, that in the Rabbit (in which the pan-

1 Wundt, Physiologie, 1873, p. 217. Bernstein, Leipziger Arbeiten, 1870, p. 33, states that lie could ohtain little or no secretion from healthy fasting dogs, but that the pancreatic juice $(?, 105)$ always acted well in dissolving Fibrin.

2 See Brücke, Physiologie, 1874, p. 329.

3 In unhealthy conditions, it is not unlikely that the same changes may takc place as occur when pancreatic juice is allowed to runain long upon starch-paste at a moderately high temperature; these changes being accompanied with the evolution of hydrugen, nitrogen, and carbonic acids, indicating the occurrence of the lactic, butyric, or even alcoholic fermentation.

4 Humpliry and 'Turner's Journal of Anat. and Physiol., rol. i, 1866, p. 108.

5 Virchow's Archiv f. path. Anat. und Physiol., vol. xiv, p. 140. See also Canstatt's Jahresbericht, $186 \%$, p. 112. 
creatic duct discharges itself some inches lower down in the intestine than does the bile-duct), when fatty matters have been introduced into the alimentary canal, they undergo no considerable change, until they have passed the orifice of the pancreatic duct; an oily emulsion being then for the first time found in the intestinal canal, and the opaque whiteness of chyle showing itself in the contents of those absorbents only which originate in the intestinal villi below that orifice. Sn, again, M. Bernard affirms that by putting a ligature round the pancreatic duct, the digestion of oleaginous matter is so completely prevented, that it is found unchanged in the lower part of the intestinal tube, and no opalescent chyle is found in the lacteals. This position is further strengthened by the fact ascertained by clinical observation, ${ }^{1}$ that there is a close relation between disease of the pancreas, and the discharge of fatty matters per anum. Frerichs, Lehmann, Lenz, ${ }^{2}$ and others, endeavored to show that the statements of MI. Bernard were too exclusive in their character, and that the digestion and absorption of fatty matters took place after the paucreatic duct had been tied (sufficient time having been given for the evacuation of any pancreatic fluid that might have been in the alimentary canal previously to the operation), and even in the lower part of the small intestine, into which the substances had been conveyed by injection, after it had been completely separated by a ligature from the upper part into which the pancreatic fluid was poured. Bernard replied with great acumen to these observers, that after tying the duct they did not in most instances take care to ascertain whether a second duct was present or not, a circumstance of common occurrence in some animals; and secondly, that when the expcriments were in other respects satisfactorily performed, the enulsification of the fats might still have been effected by the increased activity and development of certain glands which he has observed between the coats of the duodenum, in immediate proximity to the entrance of the duct of the pancreas, and the secretion of which he found to resemble very closely that of the pancreas itself. It must be observed however that Bérard has dissected out these glands, and ascertained that their collective weight does not exceed $\frac{1}{325}$ th that of the pancreas; and, therefore, the function of that gland can, in the first instance, at least, bc but imperfectly discharged by them. Colin ${ }^{3}$ (of Alfort), moreover, made some ingenious experiments, in which he determined the quantity of fat contained in the chyle of cows and other animals, both before and after ligature of the pancreatic duct, and after extirpation of the gland. He was unable to discover any remarkable difference in its composition. Similar experiments were made by Herbst, Schiff, and Donders, from which the conclusion may be fairly drawn, that though the pancreatic juice is of considerable importance in the emulsification of fatty bodies, yet that its action is not indispensably requisite for their absorption; and it is possible, either as Frerichs and Hübbenet state, that the Succus Entericus may possess an emulsifying power of considerable energy, and quite suffieient, in the absence of the pancreatic juice, to prepare a due amount of fat to supply the demands of nutrition; or, as M. Peyrani, ${ }^{4}$ Voit, ${ }^{5}$ and Schiff $^{6}$ contend, that the bile is an important agrent in the digestion of this class of alimentary substances. In Busch's

1 See Dr. Bright's researches on this point, in Med.-Chir. Trans, vol. xviii ; also an Article on Pancreatic Discase and Fatty Diseharges, in Brit. and For. Med.-Chir. Rev., vol. xii, p. 154.

${ }^{2}$ De Adipis Concoctione et $\mathrm{Absorptione,} \mathrm{Dorpat,} 1850$.

3 Comptes liendus, 1856.

5 See Brüeke, Vorlesungen, 1874, p. 329.

6 Centrablatt, 1872, p. 790, Schiff oceludes the duet of Wirsung with paraffin, and finds the digestion of fats in no way interfered with. 
case, however, already referred to, the digestive action of the fluid poured forth by the lower part of the Jejunum and Ileun upon fatty bodies introduced into them through the fistulous orifice, was exceedingly imperfect.

122. If the part plaved by the pancreatic fluid in the digestion of fatty bodies is still in some measure doubtful, its capability of effecting a solution and metamorphosis of albuminous borlies is still more difficult to determine. There appears, however, to be good reason for believing that the view originally held by Corvisart ${ }^{1}$ is correct, to the effect that healthy pancreatic juice, or the infusion of a healthy pancreas, or cven a solution of precipitated pancreatin in distilled water, pussesses a distinctly solvent action on albuminous compounds, converting them into peptones without the supervention of any signs of putrefaction. The following experiment, performed by Meissner, affords material confirmation of the accuracy of the views eutertained by Corvisart. The duodenum in a dog was thoroughly washed out with a stream of warm water, and surrounded by a ligature above and below the point of entrance of the large duct of the pancreas. By this proceeding the entrance of the secretion of the superior duct, and of the bile through the ductus communis cholcdochus, was excluded. And now, the animal having previously been kept fasting for fifteen hours, 34 grammes of hard-boiled white of egg were introduced into the lonp of intestine, confined between the ligatures, whilst 20 grammes were at the same time introduced into the stomach, to supply the ferment with which he believes it is requisite that the pancreas should be charged. After the lapse of fifteen hours the duodenum was examined, when 150 grammes of neutral fluid were found quite free from any odor of putrefaction, with 4 grammes of undissolved albumen; 30 grammes of this substance had consequently been dissolved. Pancreatic peptones differ, according to Diakonow, "from those produced by the gastric juice, in their precipitability by acids, and by most acid salts; (the acid phosphate of soda, however, being especially excepted). Kühne ${ }^{3}$ has shown that by the continued action of the juice on the newly formed peptone, lencin and tyrosin appear in the fluid, indicating that regressive metamorphosis of alhumenor a kind of luxus-consumption-may occur previous to absorption in the intestinal canal, since these same substances can be obtained from albumen by the action of acids at a boiling temperature. Indol (a substance belonging to the indigo series) and Naphthylamin have also been discovered in pancreatic chyme. All observers are agreed that the most active pancreatic juice is obtained from an animal in full digestion, as it is only at that time that the gland is thoroughly charged with the pancreatic ferment that is capable of digesting albuminous compounds. In a remarkable and wellobserved case of atrophy of the liver and pancreas described by Dr. J. A. Flés, a considerable quantity of fat and undigested muscular fibre was found to pass away in the freces, but after the daily arlminstration of a calf's pancreas nearly all the fot and a great proportion of the muscular tissue disappeared."

123. The Duodenum receives not only the Pancreatic, but also the Biliary secretion; and from the constancy with which this fluid is poured into the upper part of the intestinal tube, or even into the stomach itself, in all animals which have any kind of hepatic apparatus, it seems a legitimate infer-

1 Sur unc Fonetion peu connue du Pancreas, Paris, 1857-58.

2 Hoppe-Seyler's Med. Chem. Untersuch., 1867, p. 243.

3 Kühne, Physiolog. Chemie, 1865, p. 118.

4 Donders's Árchiv, 1862, Bd. iii, pt. ii, p. 187. A practical application of the digestive powers of the pancreatic secretion has been made by Dr. Dobell, who uses an emulsion of the fresh gland in certain forms of indigestion. A combined solution of pepsin and pancreatin has also bcen used with good effect by Mr. Kinkead. Sec Lancet, 1870 , ii, p. 667 . 
enee that this seeretion is not purely excrementitious, but serves some important purpose in the digestive process. ${ }^{1}$ It is not easy, however, to state with preeision what this purpose is. The results of many of the experiments whieh have been made to determine it, are vitiated by the fact, that the panereatic duet in most cases discharges itself into the intestinal tube at the same point with the hepatie, and has thus been frequently involved in operations performed upon it.-As the most important constituents of Bile, and the agency of the Liver as an assimilating and depurating organ, will be more appropriately eonsidered elsewhere (chaps. vi and xi), we shall here limit ourselves to the consideration of what may be regarded as the bestestablished facts in regard to the uses of the biliary seeretion in the digestive process.

124. When Bile is mingled with fresh or artificial gastrie juice, a precipitate falls whieh partly consists of glycoeholie acid, ${ }^{2}$ partly of albumen rendered insoluble by the taurocholic acid, of muein and the eoloring matter of the Bile, and partly of pepsin, whieh attaehes itself to the precipitate. ${ }^{3}$ Dr. Dalton, ${ }^{4}$ however, states that Bile does not form a precipitate with gastrie juice holding albuminose (peptones) in solution. These fluids are therefore not finally antagonistic to each other in the digestive process, though at first they produce a precipitate on admixture. ${ }^{5}$ When its aetion is tested out of the body, by mingling it with the different constituents of food, it is found to exert a slight but distinet action in eonverting starch into sugar. ${ }^{6}$ It has no action upon cane-sugar, until it has stood a eonsiderable length of time; but then it converts it into laetie acid. This change it speedily exerts, as do many other animal substanees, upon grape-sugar. It has no aetion on albuminous substances, even when acidulated. And although it will form an emulsion with and saponify oleaginous matter, and especially the fatty aeids, yet the cmulsification is less complete than that which is effeeted by the panereatie fluid alone. ${ }^{7} \quad$ But if the action of the Bile is only subsidiary to that of the Pancreatic Juiee, it is eertain that it very materially aids the absorption of olcaginous bodies by enabling them to pass more easily through the eoats of the intestine, Wistinghausen ${ }^{8}$ and Hoffmann ${ }^{5}$ having shown that the foree requisite to effect the filtration of an oily substance through an animal membrane is much less when the membraue is moistened with an alkaline fluid, or with bile, than when it is moistened with pure water. Bile appears to be defieient in any materials corresponding to the peeuliar ferments of the saliva, gastrie juice, and pancreatie seeretion; and henee its office in digestion must be of a different charaeter from that of cither of those fluirls. Bile certainly possesses an antiseptic power, for Mr. Bernard found that when two similar pieces of meat had been immersed for three months, one in a bottle of gastrie juiee alone, and the other in a mixture of

1 See Princ. of Comp. Phys., 4th edit., 8? 40.5-411.-The simplest condition of the Liver, such as we meet witli in the higher Radiata, and in the lower Articulata and Mollusca, consists in a series of follicles lodged in the walls of the stomach and of the upper part of the intestinal tube.

2 See Burklart, in P'lürer's A rchiv, 1868.

3 Hammarston, Pflüger's Archiv, 1870, p. 53.

4 Iluman Phyiology, 5th edit., 1871, p. 181.

5 Sec also Schiff, Pflüuser's Arehiv, 1870, p. 620.

6 v. Gurup-Besarez, 1862, 1). 467. Sce v. Wittich, Pfü̈rcr's Archiv, 1872, Band vi, p. 184 .

7 Dr. Bence Jnnes, in the Medical Times, July 5th, 1851.

8 Endosmoticeh Versuche, Dissert. inaug., Dorput, 1751. See also Dr. Charles Williams, in Prize Essay of the Boylston Med. Suc., 1874. Supplement to Boston Med. Surg., I, 1874.

9 Ueber die Aufnahme von Qucelisilber, 1854, Wurzburg. 
gastric juice and bile, a strong ammoniacal odor resulting from decomposition was emitted from the former, whilst the latter was pure and free from any smell whatever. And it was remarked by MIM. Tiedemann and Gmelin (and also recently by Hoffinamn), that when the bile was prevented from passing into the alimentary canal, the contents of the latter were more fetic than usual. Noreover, it is found that the admixture of bile with fermenting substances checks the process of fermentation; and M. Bernard ${ }^{1}$ has shown by ingeniously-contrived experiments, that this power is exerted also to some extent in the living body. Hence we can understand how the reflux of bile into the strmach shonld seriously interfere with the process of gastric digestion; and how, when there is a deficient sccretion of bile, or more food is swallowed than the bile provided for it can act upon, or the character of the biliary secretion itself has undergone any serious perversion, there should be much more than the normal anount of putrefactive fermentation, as is indicated by an erolution of flatus, and very frequently by diarrhea. Schiff ${ }^{2}$ and Budge ${ }^{3}$ have shown that the bile produces energetic, and indeed almost tetanic spasms of the muscles, both voluntary and involuntary, when applierl cither to the tissue itself or to the nerves supplying it. Its importance, therefore, in maintaining the peristaltic action of the intestine is probably considerable, whilst by exciting the involuntary muscular fibre-cells of the villi it very probably materially aids the movement of the chyle in the lacteals. Moreover, the presence of a proper quantity of bile in the intestine seems to promote the secreting action of the intestinal glandule: this appears from the tendency to constipation which is usually consequent upon deficiency of the secretion, and from the diarrhoa which proceeds from its excess; and is confirmed by the purgative proplerties which inspissated ox-gall has been found to possess. Notwithstanding all its uses, however, it must be arlmitted that the prevention of the discharge of bile into the alimentary canal is not attended with the deleterious results which might have been anticipated from it for it has been found by the experiments of Schwann, Blondlot. and Bernard, that if the bile-duct be divided, and a tule be inserted in it in such a manner as to convey away the secretion through a fistulous orifice in the abdominal parietes, the animals thus treated may live for weeks, months, or even years, ${ }^{4}$ although they usually die at last with signs of inanition.

125. The best evidence that has hitherto been obtained of the quantity of Bile daily poured into the alimentary canal of man has been aftorded by patients suffering from fistula of the cystic, or of the common bile-duct. In one of these cases which was under the observation of $\mathrm{v}$. Wittich ${ }^{5}$ the quantity discharged amounted to 22.2 c.c. per hour, or 532.8 c.c., which are equivalent to one pint, in 24 hours. In another case observed by Westpha$\operatorname{len}^{6}$ a man weighing abont $140 \mathrm{lbs}$. discharged almost exactly the same quantity (7703 grains $=1 \mathrm{lb} .703 \mathrm{gr}$. av., or about one pint) with but small variation daily for 10 days. Nasse and Plattner ${ }^{7}$ obtained from a dog 105 grains, and Stack mann 108 grains per diem for every $1 \mathrm{lb}$. of borly weight. Birder and Schmidt, from experiments on a dog, estimaterl the quantity in

1 Amer. Journ. of Med. Sci., Oct. 1851, p. 351.

2 Archiv für Phys. Heilk., B. ix, p. 60.

3 Physiologie, p. 195, 1861.

4 At the meeting of the French Academy, June 28d, 1851, M Blondlot gave the history and an aceount of the post-mortem examination of a dog that had lived five years without the passage of any bile into the intestinal tube. For efficts of Ligature of Bile-ducts see Legg, St Barth. Hosp. Rep., vol. ix, 1873, p. 161.

5 Pflüger's Archiv, B. vi, 1872, p 181

6 Deuts. Archiv. f. klin. Med., 1873, B. xi, p. 588.

7 Béclard's Physiologie, 1862, p. 501. 
man at $3 \frac{1}{2}$ lbs. daily, but such experiments have been shown by the Edinburgh Committee of the British Medical Association to afford no reliable data for comparative estinates, since the size and weight of the auimals have no relation to the amount of bile sccreted. In one instance a large dog weighing $42 \mathrm{lbs}$. secreted on an average only 1036 grains daily, while a dog weighing $11 \mathrm{lbs}$. secreted 1857 grains daily. ${ }^{1}$ Schiff ${ }^{2}$ has shown that a much larger quantity of bile is discharged into the duodenum under normal conditions than can be collected from a biliary fistula, the reason being that the bile is reabsorbed with great rapidity, and is again excreted, together with fresh bile, by the liver. This observation has been confirmed by Laffter, ${ }^{3}$ under Heidenhain's direction, the evidence relied on being the injection of bile in to the duodenum, when its quantity was observed to be increased, and the injection of colored bile or rhubarb into the intestine, which reappeared in the course of a minute in that flowing from the canula. Wolf found that the amount of secretion in dogs was proportional to the size of the liver; that it was more active in small and young animals; that it was most abundant on mixerl diet (rising with the quantity of meat); less on a diet of bread or rice, and least on a diet of fat; and that it was greater by day than by night. Wolf in Man and Arnold ${ }^{5}$ in dogs found that the activity of the secretion obtained its maximum an hour or two after food, Voit ${ }^{6}$ two hours after, Kölliker and Müller between the 6th and 8 th hours, Bidder and Schmidt ${ }^{\text {? }}$ about 10 or 12 hours after a full meal, and Dr. Austin Flint from the $2 d$ to the 8th hour.-As Dr. Dalton has remarked, a distinction should be drawn between the time at which the largest quantity of bile is discharged into the intestine, and that at which the secretory activity of the liver is at its height. In his own experiments on a dog, which appear to have been conducted with much care, a considerable quantity of bile was discharged into the intestine soon after feeding, as is shown in the following Table: ${ }^{9}$

\begin{tabular}{|c|c|c|c|c|}
\hline $\begin{array}{l}\text { Time after } \\
\text { feeding. }\end{array}$ & $\begin{array}{l}\text { Quantit } y \text { of fluid in } \\
15 \text { niuutes. }\end{array}$ & $\begin{array}{l}\text { Dry residne of the } \\
\text { same. }\end{array}$ & $\begin{array}{l}\text { Quantity of } \\
\text { biliary matter. }\end{array}$ & $\begin{array}{l}\text { Proportion of biliary } \\
\text { matter to dry residue. }\end{array}$ \\
\hline $\begin{array}{l}\text { Inmediatcly. } \\
1 \text { hour } \\
3,6,9 \text { hours } \\
12,15 \\
21,24,25 "\end{array}$ & $\begin{array}{l}640 \text { grains. } \\
1990 \text { " } \\
780,750,860 \text { grs. } \\
325,347 \\
384,163,151 \text { "، }\end{array}$ & $\begin{array}{l}33 \text { grains. } \\
105 \text { " } \\
60,73,78 \text { grs } \\
23,18 \text { " } \\
11,9 \frac{1}{2}, 5 \text { ". }\end{array}$ & $\begin{array}{l}10 \text { grains. } \\
44 \text { " } \\
4,3 \frac{1}{2}, 4 \frac{1}{2} \text { grs. } \\
3 \frac{3}{4}, 4 \\
1,3 \frac{1}{4}, 3\end{array}$ & $\begin{array}{c}.30 \\
.03 \\
.07, .05, .06 \\
.16,22 \\
.09, .34,60\end{array}$ \\
\hline
\end{tabular}

The secretion diminishes considerably when fool is withheld for some time; the quantity poured out after ten days' starvation being only about oneeighth of what it is when at its maximmm. Still it is obvious, that although

1 See Report by Drs. Bennett, Rutherford, and Gamgec, in 'Trans, of British Assoc. for the Advancement of Suience, 1868 The experiments of this Committec, which wits appointed for the purpose of determining the action of Mereury, etc, on the Liver, showed conchusively that in dogs witl biliary fistule the administration of mereury does not eause any increase in the amount of bile secreted or discharged, while if it eause purgation or impaiment of beulth, the quantity is diminished. Noither lordoplyllin and 'Taraxacum aumented the secretion. Purgation, however proluced, invariably diminished the quantity. S'ec also Brunton on P'urgation in Practitioner, 1874.

2 P'fügcr's Archiv, 1870, p. 568. 3 See Iaffter, Intug. Dissert., Breslau, 1873.

- Centralblatt, 1869, 1, 86.

6 Phys. Chem Untersulumwen, Augsburg, 1857, p. 41.

7 Verdaumgssilte und Stoftiwechsol, 83. 114-209.

8 P'hysiolocy of Man. 1867, part ii, p. 375.

9 Dalton, Pliys., 1871, p. 178.-The dog in these experiments weighed $36 \frac{1}{2}$ lbs. 
its rate is thus greatly influenced by the stage of the digestive proeess (whicl is the less to be wondered at, when it is remembered that the seeretion is formed from blood that is charged with newly-absorbed and imperfectlyassinilaterl matters), the exerementitious eharacter of the seeretion requires that its elimination shall be eonstantly going on to a eertain degree; but a receptacle is provided in Man, as in most others among the higher animals whose digestion is performed at intervals, for the storing up of the fluid until it can be usefully employed in that proeess. The intestinal orifice of the ductus choledochus is closed by a sort of sphineter; and the fluid seereted during the intervals of digestion, not being propelled with a foree sufficient to dilate this, flows back into the gall-bladder, which dilates to receive it. The prescnee of food, and especially of the acid products of gastrie digestion, in the duodenum scems to excite the walls of the gall-bladder and of the bliary duets $^{1}$ (which eontain a large quantity of non-striated museular fibre), to a contraction sufficiently powerful to propel their contents into the intestine, in spite of the opposition of the sphineter; but whether this takes place through a reflex action of the nervous system, or through the direct stimulation of the muscular eoat of the duet by the passage of alimentary matters over its orifice, we have at present no means of satisfactorily determining. It will be recolleeted that the gall-bladder is usually found distended with bile, in cases of death from starvation ( $\$ 79)$, notwithstanding the diminution in the amount actually secreted. Ot the bile which is poured into the intestinal tube, by far the greater proportion seems to be reabsorbed $(\$ 129)$, or at least to be so altered that the presence of the biliary acids can no longer be reeognized.

126. Besides the biliary and pancreatic secretions, there is poured into the Intestinal eanal a fluid secreted in its own walls, which has reeeived the designation of Succus Enterieus. The secretion of this fluid is partly the function of the Glands of Brünner, which are small racemose clusters of follicles ${ }^{2}$ (Fig. 73), imbedded in the walls of the duodenum, extending also to the commeneement of the jejunum, and partly of the follicles of Lieberkühn, with which the intestinal canal is furnished throughout its entire length. These are straight narrow crea, standing side by side, with a little adenoid intervening substance (except where the Peyerian bodies lie amongst them), and corresponding in length with the thickness of the mucous membrane. Their orifices are seen in the interspaces between the villi, where they are so elosely set together as to seem like the apertures of

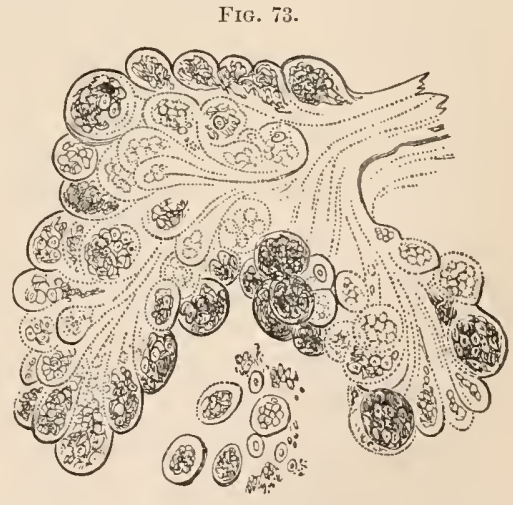

Portions of one of Brünner's Glands, from the Human Duodenum.

1 Bernard and Küthe (Canstatt's Jahresbericht, 1861, p. 131) found that touehing the point of entranee of the biliary duct into the intestine with an alkaline fluid had little or no effect, whilst brushing it lightly over with an aeid solution immediately eaused a discharge of bile to take plaee.

2 Puky Akos and Schlemmer (Wien Akad. Sitzungsber., 1869, Band lx, p. 31 and $\mathrm{p} .169)$ regard these glands as belonging rather to the tubular than to the racemose type, whilst Schwalbe considers them to be intermediate tr both. See Max Schultze's Archiv, Band viii, p. 92. Toldt (Mittleil. der ärtz. Vereins in Wien, Band i, p. 33) holds them to be racemose glunds. 
a sieve; and they are arranged in rings around the Peyerian glandulæ. The secretion of Brïnner's glands cannot be obtained separately fiom that of the small intestine generally, but the glycerin extracts of the glands dissected out from their attachments was found by Krolow to be capable of converting starch into sugar and of dissolving fibrin. The Intestinal juice appears, from the researches of Birlder and Schmidt, ${ }^{2}$ to be a colorless viscid liquid, invariably alkaline in its reaction, and containing from 3 to $3 \frac{1}{2}$ per cent. of solid matter. The total amount daily secreted in Man is estimated by these experimenters at about $7 \mathrm{oz}$; the rate of its secretion seems to be most rapid five or six hours after a meal; and its quantity is considerably increased shortly after the ingestion of fluid, and this without any diminution in the proportion of its solid constituents. The most satisfactory observations that have been made in regard to the property of the succus entericus or secretion of the Lieberkühnian follicles and columnar epithelium covering the general surface of the mucous membrane of the small intestine are those of Busch upon a patient with an intestinal fistula. In this interesting case, in which the contents of the stomach and duodenum were completely prevented by a fistulous opening from entering the small intestine, it was clearly determined by accurate chemical analysis of the freces, as well as indicated by the great improvement in the health which resulted from introducing food into the lower part of the intestine, that the fluids secreted by the jejunum, ileum, and large intestine were capable of dissolving albumen (though with the evolution of a putrefactive odor, probably due to the absence of the bile), and of converting starch into sugar. There seemed, however, to be little or no emulsifying power exerterl on the fats, which were also but very slightly absorber, the greater part reappearing in the freces. In this case the woman lived for six weeks, previous to her coming under the care of M. Busch, upon the absorption which had taken place in the stomach and duodenum. A great portion of the products of digcstion, which presented a variable reaction to test-paper, flowed off by the fistulous orifice, and she had become much emaciated. The treatment adopted was the reintroduction of this discharged fluid into the lower orifice of the fistulous opening, and she rapidly regained her health and strength. Experiments upon animals (cliefly dogs) have been much less satisfactory in their results. Thiry ${ }^{3}$ isolated a loop of the small intestine, preserving the vascular supply intact, and established a fistulous opening between it and the surface. The quantity of fluid obtained in this way from the loop, if calculated for the whole length of the intestine, amounted to about $1 \mathrm{lb}$. in five hours, and was of a clear straw-yellow color, alkaline reaction, and exceedingly constant specific glavity (1.0115). It contained about 2.5 per cent. of solids, less than one-half of the amount obtained by M. Busch from his patient, of which about 1.5 consisted of albumen and other organic matters, the remainder being salts. In experimenting on the physiological effects of this fluid upon the different constituents of food, little more than negative results were obtained, no action being apparently exerted either on starch, fat, or albumen, and only a feeble power (when alkaline) of dissolving fibrin. Paschutin, operating in a similar manner, obtained a fluid which had little or no action on fats, or on the various albuminous compounds. The infusion of the small intestine converted starch and cane-sugar

1 Berlin klin. Wochenschrift, 1870.

2 Op. eit., ?? 260-282; and Lehmann's Physiologiselen Chemie, 2 d edit., Bd. ii, рp. 95-99.

3 Sitz. d. k. Akad. zu Wien, Bd. 1.

- Centralblatt, 1870, P. 561. 
into grape-sugar. ${ }^{1}$ Dobroslawin, ${ }^{2}$ pursuing Thiry's method in Dogs, found that the fluid secreted possessed a diastatic action on starch, requiring, however, about two hours to operate, and a slow and feeble action on raw fibrin, which at a temperature of $100^{\circ} \mathrm{F}$. was converted into peptone in the course of from 20 to 48 hours, without the occurrence of any putrefactive orlor. It had no action on oleaginous compounds. Schiff," also operating after Thiry's method upon Dogs, found that small portions of albumen, casein and fibrin, generally underwent conversion into peptones, and that starch was rapidly converted into sugar. Occasionally, however, perhaps owing to peculiar states of the animal's liealth, or to the immediate effects of the operation, these actions failed to take place. Quincke ${ }^{4}$ also frequently observed the solvent action of the succus entericus upon fibrin to fail. Lastly, Costa ${ }^{5}$ found that in Horses the glycerin extract (v. Wittich's method) of Brünner's glands, and of the Lieberkühnian follicles, though capable of converting starch into sugar had no action on albumen or fat. Brücke $^{6}$ remarks, that although in normal digestion cane-sugar is converted into grape-sugar, this is effected not by any of the intestinal fluids per se, but by the acids found in the stomach.

127. Notwithstanding the negative results of some of the above experiments, it must be remembered that under normal conditions the fluid of the small intestines is a mixture of the biliary and pancreatic secretions with the salivary and gastric fluids, and with the secretion of the intestinal glandule, and there can be little doubt that in this part of the alimentary canal all the principal constituents of our food are reduced to a soluble condition. Here the conversion of starchy into saccharine matter is completed, the oleaginous compounds are enulsified and in part saponified, and a powerful solvent agency is exerted even upon albuminous substances which have not been submitted to the previous agency of the gastric fluid (as has been slown by experimentally introducing pieces of meat, through a fistulous orifice, directly into the duodenum), and it thus completes the solvent process which had been very far from perfected in the stoniach. ${ }^{7}$ It is obvious that the amount of each kind of alimentary substance that can be thus prepared for absorption in a given time, will vary with the amount of the secretion by whose agency this preparation is specially effected; and as there are many indications that the quantity of each that is taken up in absorption is limited, and that it bears a relation to the wants of the system, it is probable that the amount of the solvent or reducing fluid secreted by each glandular apparatus, is regulated, as we have seen it to be in the case of the gastric juice $(\S 110)$, by the demand set up by the nutrient operations, rather than by the amount of alimentary matter that is waiting to be digested.-The processes of digestion and conversion are probably continued during the entire transit of the alimentary natter along the small intestine, and at the same time the products of that conversion are grad-

1 The infusion of the small intestine of the sheep and ealf is ineapable of eonverting eane-sugar into grape-sugar.

${ }^{2}$ Untersuch. aus d. Instit. für Physiologie in Graz, 1870. Dobroslawin obtained in one case 34 grains of fluid per hour from a loop of intestine about 13 inches in length; and in another ease 28 grains of fluid from a loop about 19 inches in length. The rapidity of seeretion was augmented by the passage of a eurrent of electricity.

3 Abstraet in Henle and Meissner's Berieht, 1868, p. 168.

4 Arehiv f. Anat. v. Physiol., 1868.

5 Centralblatt, 1873, p. 310.

6 Vorlesungen üb. d. Physiol., 1874, p. 332.

7 See the aeeount of M. Cl. Bernard's researehes in the Amer. Journ. of Med. Sei., Oct. 1851, p. 356 ; Zander, De Suceo Enterieo, Inaug. diss., Dorpat, 1850 ; and Frerichs, art. Verdauung, in Wagner's Handwörterbueh, Bd. iii. 
ually being withdrawn by absorbent action; so that, by the time it reaches the crecum, the undigested residue contains little else than the innutritious or insoluble components of the food, together with the excrementitious portion of the bile and of other secretions. Up to this time the contents of the canal appear generally to possess an acid reaction; for in the two patients, each with an artificial anus opening into the lower part of the ileum, examined by Dr. Brauns ${ }^{1}$ and Lossnitzer, ${ }^{2}$ the chyme was still acid, though the nucous membrane was alkaline to test-paper. In the crecum, the acidity seems to become still more marked, at least in the Herbivora, owing to the formation of lactic acid from the starchy materials of the food ${ }^{3}$ but in Carnivora, according to Bernard, ${ }^{4}$ the contents of the crecum are alkaline, owing to nitrogenous fermentation. That digestion will still take place, though imperfectly, in the large intestine, is shown by the observations of Steinhanse ${ }^{5}$ upon a woman who had an artificial anus communicating with the large intestine. When food was introduced into the lower part of the bowel, it was for the most part discharged unaltered; but albumen was to some extent dissolved. Czerny and Latschenberger ${ }^{6}$ have more recently had a similar opportunity in a patient who, after Hernia, had a fistulous orifice in the sigmoid flexure. Their experiments led them to the conclusion that although the lower part of the sigmoid flexure and the rectum in Man have no digestive power on albumen or fibrin, and no power of emulsifying fits, yet that soluble albumen and fat in the state of emulsion may there undergo absorption in an unaltered condition. Starch paste was also absorbed, but they were unable to satisfy themselves whether it was first converted into sugar. The addition of common salt or of magnesiun sulphate checked or altogether prevented absorption. " In Eichhorst's ${ }^{8}$ experiments on Dogs, it was shown by the augmentation of urea in the urine that the casein of milk, the white of egg, gelatin, and the nitrogenous compounds contained in Liebig's extract of meat, underwent absorption when introduced into the large intestine. On the other land, blood-fibrin, the peptones, syntonin, and myosin were not absorbed to a sensible extent. Leube ${ }^{9}$ found in a patient with Cancer of the Intestine, that whilst albumen underwent no digestive action, when introduced per se in the raw starch, a mixture of finely-minced meat and pancreas acquired the smell, consistence, and appearance of ordinary fieces after it had been retained in the bowel for about twenty-four hours, and in a later communication, ${ }^{10}$ he recomments the employment of the glycerin extract of the pancreas, especially during the summer months, when the juice of the gland soon loses its digestive properties by putrefaction. The fact that absorption will take place is of impor-

1 Archiv. Gén. de Médecine, 1861, p. 610.

2 In Lossnitzer's case (Henle's Bericht, 1864, p. 250), the opening was twelve inches ahove the ileo-caeal valve. After a meal of milk, bread, meal-broth, and a little meat, the chyme was troubled, floceulent, bright-yellow, more or less strongly acid, fouming, smelt of volatile fatty aeids, and on standing quickly developed gasbubbles. The fluid contained biliary acids and peptone, but no parapeptone or sugar.

3 Blondlot, Truité de la Digrestion, p. 103.

- I.iquids of the Organism, p. 39, 1859.

6 See Milne-Edwards, vol. vii, p. $136,1862$.

6 Virchow's Archiv, Bd. lix, 1874, p. 1162.

7 In Voit and Bauer's Experiments on a dog (Zeitschrift f. Biologie, Band v, 1869, p. 536), white of egg underwent little or no absorption unless a little eommon Ealt were added: blood-serum, syntonin, and peptone were taken up in larger but still small quantities. The amount of oil absorbed was also small, and life, they observe, rould not be persistently maintained by injeetions.

8 l'flüger's A rehiv, 1871, y. 570 .

9 Sitzungshericht d. Plyys.-Med. Suc. zu Erlangen, 5th Dec. 1871.

10 Centralblatt, 1872 , p. 465. 
tance, as showing the mode in which injections of nutrient substances per anum act in prolonging life in cases where the passage of food along the upper part of the intestimal tube is interrupted.

128. The undigested residue of the food, mingled with the products of secretion that have been poured into the alimentary canal, gradually acquires, in the large intestine, the ordinary consistency of Freces, through the continuance of the absorbent process, whereby the superfluous fluid is removed. The condition of this residue has been particularly studied by Dr. Rawitz and Dr. Marcet. ${ }^{1}$ By the former observer, muscular fibres are stated to be almost entirely dissolved, especially in the flesh of fish and hares, though less rapidly in that of poultry and other animals, only a few fragments remaining. Dr. Marcet, however, found muscular fibres, exhibiting clearly their well-marked structure, almost constantly present and in considerable quantities; and he is inclined to believe that when meat is daily taken, only the juices are extracted, the fibres themselves undergoing but little digestive action. The cells of cartilage and fibro-cartilage, the fibres of elastic tissuc, ${ }^{2}$ and fatty matter if taken in excess, are frequently found unchanged in the freces; and crystals of cholesterin may usually be obtained, especially after the use of pork fat.-_"As regards vegetuble substances, Dr. Rawitz states that he frequently found large quantities of cellmembranes unchanged in the foees; also starch-cells (which were rarely seen by Dr. Marcet), deprived of only part of their contents. The green coloring principle, chlorophyll, was usually unchanged. 'The walls of the sap vessels and spiral vessels were quite unaltered by the digestive fluid, and were usually found in large quantities in the freces; their contents, probably, were removed."'3-Besides the undigested resillue of the food, the microscope enables us to recognize the brown coloring matter of the bile, epitheliumcells and mucus-corpuscles, and various saline particles, especially those of the ammoniaco-magnesian phosphate, ${ }^{4}$ whose crystals are well defined; most of which are derived from the secretions.- The quantity of fecal discharge which is daily passed by an adult seems to vary from 2 to $10 \mathrm{oz}$. Dr. Edward Smith found the average weight in prisoners at the Coldbath Fields Prison to be $8.55 \mathrm{oz}$. These men were fed upon a full dietary with brown bread, and the proportion of the freces to the solid food was as $1: 4.5$. Severe labor on the treadmill was found to diminish the quantity of freces, whilst the rest of Sunday occasioned a considerable increase. The proportion of water was very uniform, viz., 73.5 per cent.; and an average of 41.8 grains of nitrogen was daily eliminated from the system by this channel. ${ }^{5}$ The absolute quantity of solid matter discharged in the freces in the twenty-

1 Med. Times and Gaz., July 31st, 1858.

${ }^{2}$ It has becn pointed out to the Author by his friend Mr. Queket, that elastic fibres are occasionally to be met with in the Human freces, which present an appearance of transverse division (probably resulting from incipicnt decomposition) closely resembling that which is normal in the ligamentum nuch:e of the Giraffe. So distinct, indeed, does the transverse division then become, that these fibres, when pectliarly abundant (as they are in the freces of persons who have for some time been living upon mutton-chops, and have not put aside the scrment of the aorta which each chop includes), have actually been mistaken for a confervoid growth in the fieces.

3 Quoted from Dr. Kirkes's Physiology. See also the Memoir of Dr. Rawitz, Ueber die Einfachen Nahrungsmittel, Breslau, 1816; and the Analysis of Wehsarg and Ihring's Inaugural 'Theses in Brit. and For. Med.. Chir. Rev, vol. xiv, p. 528.

4 Crystals of this salt sometimes occur in perfectly normal frecs; and in those cases in which the secreted fluids and the contents of the intestine readily undergo decomposition, as in typhus, cholcra, and certain forms of dysertery, they are found in large numbers and of considerable size.

5 Smith and Milncr, Rep. on the Influence of Pris. Discip., Syd. Soc. Year-Book, 1861, p. 83. 
four hours is about 460 grains, of which only 10 per cent. consists of undigested matter. Of the dry fieces, from 23 to 31.5 per cent. (the proportion being highest when an abundant meat diet has been consumed) consists of an inorganic ash; the composition of which is stated by Enderlin ${ }^{1}$ to be as follows:

Allialine chlorides and sulphates,
Bibasic phosphate of soda,
Phosphates of lime and magnesia,
Phosphate of iron,
Sulphate of lime, .
Silica, .

$\left.\begin{array}{r}1.367 \\ 2.633 \\ 80.372 \\ 2.090 \\ 4530 \\ 7.940\end{array}\right\}$ Soluble in water.
Insoluble in water.

The potash generally predominates greatly over the soda, but especially when the diet has chiefly consisted of muscular flesh. The reaction of the Fieces is usually acid, but sometimes neutral or alkaline. The study of the composition of the Organic portion of the Fæces is attendell with so much difficulty and unpleasantness, that it has hitherto been scarcely prosecuted systematically. According to the inquiries of Dr. Marcet, ${ }^{2}$ healthy Human excrements contain,-1. A peculiar substance crystallizing in acicular, silky, four-sided prisms usually grouped into stellæ, not subject to spontaneous decomposition, possessing feeble affinities, fusing at about $203^{\circ} \mathrm{F}$., containing Sulphur, and having a composition expressed by the formula $\mathrm{C}_{78} \mathrm{H}_{78} \mathrm{~S}_{1} \mathrm{O}_{2}$; this he proposes to call Excretin. In infants cholesterin may take the place of excretin in the Fieces. ${ }^{3}$ 2. Stearic and Margaric Acids in combination with bases. 3. A coloring matter similar to that of blood and urine. 4. Pancreatin or an analogous form of albumen. And 5. An acid olive-colored substance of a fatty nature, termed Excretolic acid, which is probably united in fieces with Excretin or a basic substance closely allied to it. Neither butyric nor lactic acid can be discovered in healthy Human excrement; although the former presents itself in the excrements of Carnivorous Mammalia, which contain also a substance allied in its nature to excretin, but not identical with it. Dr. Austin Flint ${ }^{4}$ has obtained a substance he terms Stercorin $(\$ 56)$, which results from the decomposition of Cholesterin, and Vanlair and Masius ${ }^{5}$ have isolated a coloring matter which they have named Stercobilin. ${ }^{6}$

129. Of the degree in which the Bile, as a whole, normally enters into the composition of the freces, it is difficult to speak with precision. Its principal constituents can be easily recognized in the upper part of the small intestine; but the further we descend in the intestinal canal, the less of them do we meet with; and in the contents of the large intessine, and in the evacuated fieces, they are only to be discovered in small quantity. How far this result depends upon their removal from the alimentary canal by reabsorption, and how far upon the loss of their characteristic properties by decomposition, cannot be stated with certainty. According to Bischoff, Jr., in the luman subject about 45 grains of the biliary acids are daily discharged by the ficces, whilst, according to Voit's estimate, about 170 grains are secreted by the liver, consequently about 125 grains must be either reabsorbed or destroyed in their course through the intestinal tube. From the experiments of Hoppe-Seyler, it would appear that in dogs, whose bile chiefly

I Ann. der Chem. und Pharm., 1844. Porter in do., t. lxxi, and Fleisehmann in Pocgendortf's Annalen, 1849.

2 P'oeeclings of the lioyal Socicty, June 15th, 185t, and Mareh 12th, 1857.

3 II urcet, Journ. of Chem. Suc, 1862.

1 Physiolugy of Man, part ii, 1867, p. 399.

5 Centralblatt, 1871 , p. 369.

- Jaife, however (Centralblutt, 1871, 1). 465), regards it as identical with lis urobilin. 
contains taurocholic acid, this acid undergoes changes in passing through the alimentary canal which are identical with those produced by boiling with acids, or with alkalies, or which oecur in the act of putrefaction, cholalic acid, dyslysin, and choloidinic acid being produced. On the other hand, in the fieces of those animals that, like oxen, secrete bilc of which glycocholic acid is the chief constituent, this acid, being comparatively stable and scarcely destroyed even by putrefaction, may be found in considerable quantity. That the coloring matter of the fieces is in great part derived from the bile, is shown by their paleness when that secretion is not duly poured in to the intestinal tube. And it is probable that the peculiar fatty substances usually present, are products of the metamorphosis of its oleaginous and resinous mattcrs. The similarity which has been fonnd to exist between the odor of certain components of putrefying bile, and that of freces, has led Prof. Valentin to suppose that the matter which gives to the latter their characteristic smell, is entirely derived from decomposing bile. We shall prescntly see, however, that other sources of this matter probably exist $(\$ 131)$; and the recent researches of Bidder and Schmidt upon the amount of sulphur in the freces, appear to show that not above one-eighth of the solid matter of the bile is normally excreted under this form. The indications of the presence of bile are especially distinct when the freces liave remained for only a short time in the large intestine, and when there has consequently been less time for its reabsorption.

130. Planer ${ }^{1}$ examined the Gases dercloped in the alimentary canal of Dogs after different kinds of food, and in Man after death. The gas contained in the stomach consisted chiefly of air swallowed with the food, and was usually small in quantity. The Oxygen soou disappeared. In the small intestines, Carbonic Acid and Hydrogen are developed in nearly equal proportion, whether the diet be Animal or Vegetable. The experiments of Pastenr $^{2}$ affurd some explanation of their appearance, at least in Herbivora, by showing that with the development of munerous infusory animalcule in the intestines, starch and sugar are converted into lactic and butyric acids, and that with the development of the latter there is an evolution of Carbonic Acid and Hydrogen: thus, one equivalent of Sugar $\mathrm{C}_{12} \mathrm{H}_{12} \mathrm{O}_{12}=\left(\mathrm{C}_{8}\right.$ $\left.\mathrm{H}_{7} \mathrm{O}_{3}\right) \mathrm{HO}+4 \mathrm{CO}_{2}+\mathrm{H}_{4}$. In the large intestinc, Carbonic Acid is chiefly present, but is mingled with Sulphuretted Hydrogen (after Animal diet), and if the food have been long retained in the body, with Carburetted Hydrogen $\left(\mathrm{C}_{2} \mathrm{H}_{4}\right)$. It is more than doubtful whether gases can be disengaged from the blood, and excreted or sccreted into the intestines, as Magendie supposed; but there seems no reason to doubt that if gas were already developed, exchange, according to the ordinary laws of diffusion, might take place between it and the gases of the blood. In a dog which had been fed for 6 days on pure animal diet, and was killed 5 hour's after a meal, he found-

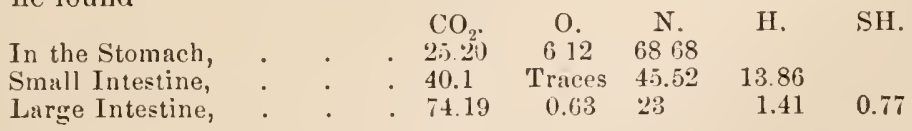

In another dog fed with bread for 8 days, there was only sufficient gas for analysis in the small intestine; it consisted of-

$\begin{array}{cccc}\mathrm{CO}_{2} & \text { O. } & \mathrm{N} . & \mathrm{H} . \\ 38.78 & \text { Traces } & 542 & 6.33\end{array}$

1 Henle and Meissner's Bericht für 18ti0, p. 274.

2 Annales de Chemie, 1858, p. 404 et seq.; Comptes Rendus de l'Académie des Sciences, 1860. p. 849. See also, for Analysis of the Gases of the Intestines in Dugs and Rabbits, K. B. Hofmann, Wiener Med. Wochens., 1872, p. 24. 
Ruge ${ }^{1}$ has carefully examined the Gases of the large intestine in the Human subject after different kinds of food, and finds their composition tolerably constant,-Nitrogen Gas preponderating after the use of flesh, Hydrogen after milk, and Carburetted Hydrogen after Vegetable (Leguminous) diet. Though the gases were sometimes offensive, they never gave more than a trace of Sulphuretted Hydrogen. The following table includes his chief results:

Composition of the Gases of the Large Intestine after the use

\begin{tabular}{|c|c|c|c|c|c|c|c|c|c|c|}
\hline \multicolumn{3}{|c|}{ Of Milk, for } & \multicolumn{5}{|c|}{ of Vegetables (Leguminous), for } & \multicolumn{3}{|c|}{ Of Animal Diet, for } \\
\hline & $\begin{array}{c}48 \\
\text { hours. } \\
1\end{array}$ & $\begin{array}{c}72 \\
\text { hours. } \\
2\end{array}$ & $\begin{array}{c}48 \\
\text { hours. }\end{array}$ & $\begin{array}{c}72 \\
\text { hours. }\end{array}$ & $\begin{array}{c}96 \\
\text { hours. }\end{array}$ & $\begin{array}{l}\text { Second } \\
\text { exper } \\
\text { on sam }\end{array}$ & $\begin{array}{l}\text { ies of } \\
\text { ents } \\
\text { erson. }\end{array}$ & 24 hours. & 48 hours. & 72 hours. \\
\hline $\mathrm{CO}_{2}$ & 16.82 & 9.06 & 3400 & 3840 & 21.05 & 35.43 & 17.6 & 13.62 & 12.46 & 8.45 \\
\hline $\mathrm{CH}^{\mathrm{N}}$ & 38.38 & 36.71 & 19.11 & 10.67 & 18.96 & 21.78 & 32.2 & 4.) 96 & 57.85 & $6+.41$ \\
\hline $\begin{array}{ll}\mathrm{CH} \\
\mathrm{H}\end{array}$ & 0.92 & 009 & 44.55 & 49.86 & 55.96 & 42.79 & 50.2 & 37.41 & 27.58 & 26.45 \\
\hline $\mathrm{H}$ & 4388 & 54.20 & 234 & 1.67 & 4.03 & 0.00 & 0.0 & 3.01 & 2.09 & 0.69 \\
\hline
\end{tabular}

131. Although it cannot be stated with certainty what is the precise portion of the Glandular apparatus connceted with the Intestinal canal, which is concerned in the elimination of that peculiarly putrescent matter, which gives to the freces their characteristic odor, yet it may be stated, almost with certainty, that this natter is not derived from the decomposition of the undigested residue of the food. For, in the first place, this residue consists of matters whose very inaptiturle for undergoing chemical change is the source of their indigestibility; and it is scarcely possible, therefore, to imagine that in so short a period they should acquire a character so peculiarly offensive. But, further, we observe that fecal matter is still discharged, even in considerable quantities, long after the intestinal tube has been completely emptied of its alimentary contents. We see this in the course of many diseases, when food is not taken for several days, during which time the bowels liave been completely emptied of their previous contents by repeated evacuations. Sometimes a copious flux of putrescent matter continnes to take place spontaneously; whilst it is often prodnced by the agency of purgative medicine. "The colliquative diarrhea," which frequently comes on at the close of exhausting diseases, and which usually precedes death by starvation, appears to depend, not so much upon a disordered state of the sccreting organs themselves, as upon the general disintegration of the solids of the body, which calls them into extraordinary activity for the purpose of separating the decomposing matter which has accumulated in it to a most unusual amomnt.These views (which have long been tanght by the Author) derive a remarkable confirmation from the experiments of Prof. Licbig on the production of artificial fecal matter. For he has ascertained that if albuminous or gelatinous compounds be heated with solid hydrate of potash, and the heat be continned until the greater part or the whole of the nitrogen has becn dissipated as ammonia, and hydrogen begins to be given off, the residue, when supersaturated with dilnte sulphuric acid, and distilled, yields a liquid containing acetic and butyric acids, and posscssing in a very intense degree the peculiar and characteristic odor of human fieces. The odor varies accord-

1 Beiträge zur Kenntniss der Darm-Gase, Sitzungsbericht d. k. Akad. d. Wissenschaften (Wien), 1862, p. 729. 
ing to the snbstance employerl; and in this way all varieties of fecal smell may be obtained. As the action of caustic potash at a ligh temperature is siniply a linited or incomplete oxidation or combustion, this curious result confirms the view which had been previously put forth by Prof. Liebig, that the proper fecal matter is the product of the imperfect oxidation which a portion of the histogenetic constituents of the food undergo in the course of their retrograde metamorphosis, being comparable to the soot or lampblack of a furnace or lamp.- It is further urged by him, that the condition of fieces differs in many particulars from that of substances in a state of fermcntation or putrefaction; that their peculiar odor is entirely unlike any that is generated by the ordinary decomposition of organic compounds, whether azotized or non-atonized; and that, by contact with air, they themselves undergo a sort of fermentation or putrefaction, in which their peculiar fetor disappears, - - a fact, as he justly remarks, which is full of significance.' This view is of great practical importance; for if it be true that the intestiwal canal receives and discharges the products of the secreting action of a glandular apparatus, whose special function is the elimination of certain products of decomposition from the blood, the facility with which we can stimulate this to increaserl action by certain kinds of purgative medicine, gives us a most valuable means of augmenting its depurative action. Seeing, as no observant Medical Practitioner can avoid doing, how frequently Naturc herself employs this means of eliminating morbific matter from the system, - as is shown by the immense relief often given by an attack of diarrhoa,-we may look upon this apparatus as one which, like the Liver, the Kidney, or the Skin, may frequently, with propriety, be stimulated by medicines that have a special action upon it, and one through which some morbific matters may be got rid of more certainly and more speedily than through any other channel.-It is not inteuded by these observations to encourage the system of violent and indiscriminate purgation; but to show that purgatives, judiciously administered, often constitute our best means of eliminating injurious matters from the system.

132. If we now cast a retrospective glance at the changes undergone by the several groups of substances employed as food in their passage through the alimentary canal, we shall find that,-1. The oleaginous compounds are melted and finely divided in the stomach, and may, under certain conditions, undergo decomposition indicated by acid eructations, etc. On entering the small intestine they are emulsified, and in small part also decomposed by the action of the pancreatic juice and bile, and are gradually almost entirely absorbed before reaching the large intestine. 2. The starchy compounds are converted into dextrin and sugar, first by the saliva, secondly by the pancreatic juice, and thirdly by the succus entericus. They in part undergo lactic acid fermentation from the mere heat and moisture of the stomach and intestines, and this again is capable of effecting the conversion of other portions of the starch into dextrin and sugar. Ample provision thus exists for the digestion of starchy substances, and they may hence be consumed without harm under circunstances in which the digestion of albuminous compounds or of fats can only be accomplished with difficulty, if at all. By far the larger portion of the starch thus converted into sugar, and almost ail the purely sacchtrine compounds are dissolved and absorbed in the small intestine. A considerable quantity of starch, however, if this be eaten raw as in the form of unripe apples or other regetables, passes off by the bowels unaltered; and this is the case even in the Herbivora, which have very long

I See Prof, Liebig's Animal Chemistry, 3d edit., pp. 148-154. 
and capacious alimentary tracts. Bischoff, Meyer, and Voit ${ }^{1}$ have shown that a bread diet given to $\operatorname{logs}$ causes a great increase in the amount of freces; and Brucke ${ }^{2}$ points out that the remarkably different effects observed by different persons who havesubmitted themselves to the so-called Banting's cure-some of whom complain of constipation, while others suffer from diarrhea - is referable to the fact that whilst an exclusive meat diet is apt to cause diarrhøa, it always causes great diminution in the amount of fieces excreted ; readily giving rise to the idea that constipation is present. 3. The albuminous compounds are in part absorbed directly into the blood, but for the most part undergo conversion into peptone in the stomach by the gastric juice, and this change is continued in the small intestines by the action of the pancreatic fluid and succus entericus; so that in the case of muscle but few and small remains enter the large intestine. The gelatin-yielding tissues, especially when they have been previously cooked, appear to be readily dissolved and absorbed ; as are also such substances as brain, and the tissue of glands generally (liver, pancreas, thymus, and kidney). Such portions as escape the action of the above-mentioned fluids, and reach the large intestine, are subject to a kind of secondary digestion, effected, as Blondlot supposes, by the lactic and other acids that are there developed; so that but small quantities are discharged with the fieces. Lastly, mineral compounds, and the various fermented beverages, are but little altered in their passage through the alimentary canal, being directly taken up by the blootvessels and lymphatics.

\section{CHA P TER VI.}

\section{OF ABSORPTION AND SA NGUIFICATION.}

\section{Of Absorption from the Digestive Cavity.}

133. So long as the Alimentary matter remains in the Digestive cavity, however perfect may be its state of preparation, it is as far from being conducive to the nutrition of the system, as if it were in contact with the external surface. It is only when absorbed into the vessels, and carried by the circulating current throngh the very substance of the body, that it becomes capable of being appropriated by its various tissues and organs. In Man, as in nearly all Vertebrated animals, a set of vessels is interposed between the walls of the intestine and the sanguiferous system, for the purpose, as it would seem, of taking up certain components of the nutritive matter, of which part at least are not in a state of perfect solution, and of preparing them for being introduced in to the current of the blood. These are the $A b$ sorbents of the intestinal walls; of which those that are found, after the performance of the digestive process, to contain the white opalescent fluid known as "chyle," are distinguished as lacteals; while the remainder, like the absorbents of the system generally, are known as lymphatics. The distinction is a purely artificial one for the "lacteals" and the "lymphatics" of those parts of the intestinal walls which they supply, as is sliown by the fact that, churing the intervals of the digestive process, they contain a transparent fluid in all respects similar to the "lymph" of other parts.-The ab-

1 Zeit-chrift für Biologie, Band v, vi, vii, viii, 1869-73.

2 Vorlesungen, 1874, 1). 336. 
sorbents form a minute plexus bencath the mucous lining of the alimentary canal along its whole extent; but in the small intestine they cuter the villi, at the extrenities of which, indeed, they may be said to commence. Those only are cutitled to the designation of "lacteals," which originate from the intestinal canal below the point at which the biliary and pancreatic ducts pour their contents into it; for above that point, the fatty constituents of the alimentary matter are not in a state of sufficiently fine division to enter them ; and the absorbed fluid is consequently pellucid, instead of possessing the milky aspect. Thus, then, we are to consider the lucteal portion of the Absorbent system to be that part of it which is specially adapted, by its prolongation into the villi, for the reception of an Olcaginous fluid, which we shall prescntly see to be taken up from the contents of the alimentary canal, and to be prepared for entrance into the absorbents, by the epithelium-cells at the radical extremities of those organs ( $\$ 134)$.

134. The Villi are extensions of the mucous lining of the Intestinal canal, which thickly beset its surfice from the pyloric orifice to the ceecum, that is, through the entire length of the Small Intestine, to which they are limited in Man. They have usually somewhat the form of the finger of a glove, being sometimes nearly cylindrical, sometimes rather conical, whilst they not unfrequently become flattened and extended at the base, so that two or more coalesce. Their length varies finm $\frac{1}{4}$ th to $\frac{1}{3} \mathrm{~d}$ of a line, or even more; and the broad flattened kinds are about $\frac{1}{6}$ th to $\frac{1}{8}$ th of a line in brcadth. - In the upper part of the small intestine, where they are most numerous, it has been calculated by Krause that there are not less than fronı 50 to 90 in a square line; and in the lower part, from 40 to 70 in the same area.-The details of their structure are of extrcme interest in reference to the mechanism of absorption. If the plan pursued by Teichmann, that of injection, be adopted, the appearances presented are those shown in Figs. 75 and 76 , taken from the beautiful plates which accompany his work on the Lymphatic System. ${ }^{1}$ From these it appears that the lacteals commence either by a simple closed cxtremity, or by a loop, though in broad villi a network is sometimes visible. The tube or tubes occupying the centre of the villus

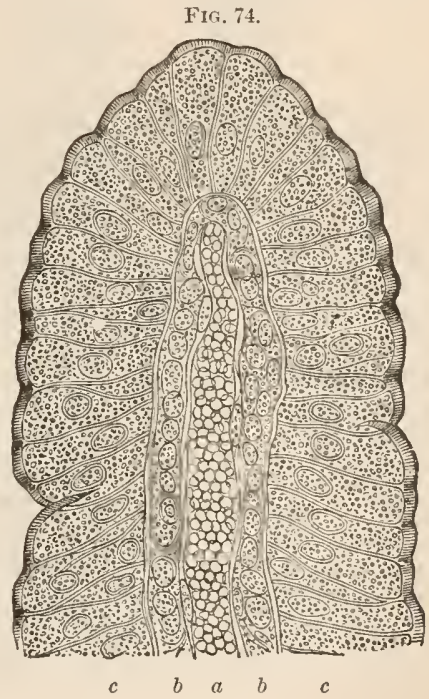

Section of a Villus from the intestine of a ralbit: above $(a)$ is the central canal, bounded on either side by the matrix (b), which again is covered by long columnar cells $(c)$, containing a nucleus and granules. The outer border of these cells is seen to be striated. appear to possess perfectly definite walls, and are larger than the numerous capillary bloodvessels which surround and are external to them. Their average diameter is about $\frac{1}{80} \overline{0}$ th or $\frac{1}{1} 0_{0}$ th of an inch; but they present here and there slight dilatations and contractions, and at the base of the villus terminate in a network of lacteal vessels immediately subjacent to the Lieberkühnian follicles (Fig. $76, b$ ), termed by Teichmann, from the closencss of the meshes, the Rete angustum. This plexus communicates with another possessing larger vessels, which are supplied with valves, are 
more deeply situated in the sulmucous areolar tissue (Fig. 76,c), and constitute the so-called Rete amplum. Besides these plexuses, Auerbach ${ }^{1}$ has more recently called attention to other plexuscs of lymphatics, situated in and between the muscular coats of the intestines. In the longitudinal muscular layer one such plexus, and in the circular layer several may be found, to which he has applied the name of interfascicular capillaries of the lymphatics, and all of which pour their contents into a median system of larger channels, possessing valves, and occupying the space betwcen the circular and longitudinal muscular coats, which he has termed the interlaminar network. This last he considers represents the subserous or' subperitoneal layer of other observers, a layer which is only present at and in the inmediate

FIG. 75.

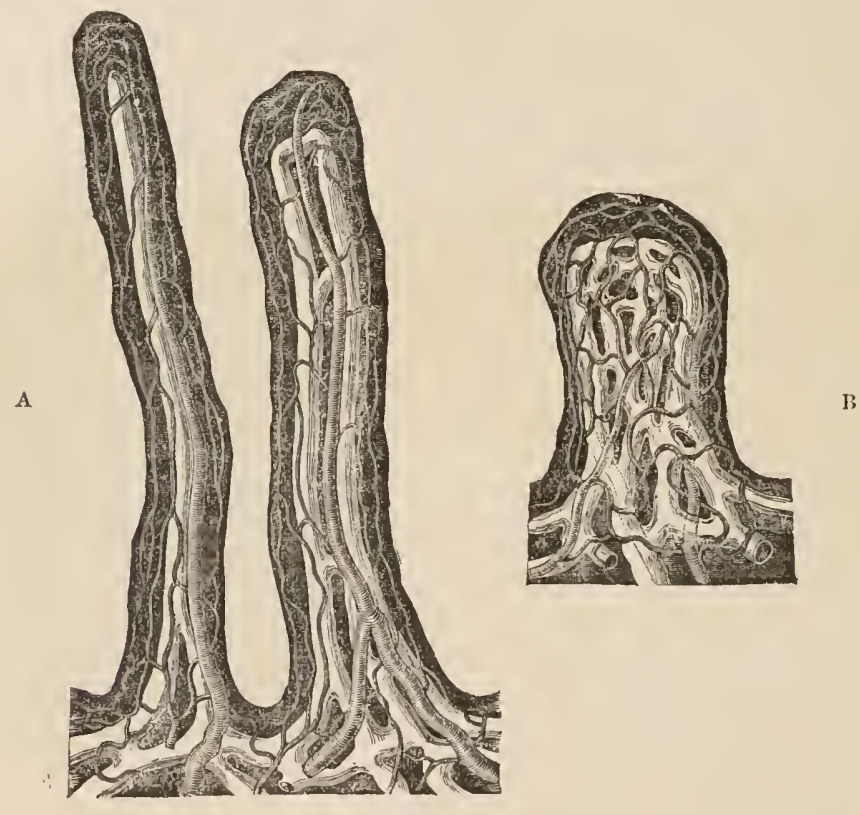

A, Villi of Man, injected, showing the bloodvesse's, an the lacteals. B, Villus of a Sheep.

vicinity of the attachment of the mescntery. Some of the fincst of these capillary lymphatics appear to have no other parietes than such as may be formed by the athesion of a single layer of sinuously-contoured tessellated epithclium-cells. In addition to the central lacteal, each villus is composed of a matrix of areolar tissuc, ${ }^{2}$ without any intermixture of elastic fibres, containing in its interstiecs numerous branched and communicating cells with nuclei, and frequently also fat-granules in their interior. The arrangement of the bloodressels, according to Heller, ${ }^{3}$ is that in man cvery villus rontains an artery, which begins to lose itself in a capillary plexus, about

1 Siebold and Kölliker, Zeits. f. Wiss. Zool., Band xv, 1865, p. 127.

2 Kölliker, Manual of Iluman II istology, p. 325.

3 Ludwig's Arbeiten, Band vii. 
the middle of the villus. The vein returning the blood begins at the point of the villus, and generally goes directly into the submucous tissues, without recciving any lateral branches. No nervous elements have been traced into the villi; but a layer of muscular fibre-cells has been shown by Kölliker and others to surround the lacteal tubes, the contraction of which has been frequently observed whilst absorption is going on, and has an important influence on the propulsion of the fluids contained within those vessels.

135. When the Villi are examined at such a period after a meal containing oleaginous matters as has sufficed for its partial digestion, their lacteals are seen to be turgid with chyle, the extremity of each being imbedded in a collection of globules presenting an opalescent appearance, and giving to the end of the villus a somewhat mulberry-like form. It was supposed by Prof. Goodsir, ${ }^{1}$ by whom this appearance was first observed, that these globules were cells developed within the basement-membrane luring the act of absorption, from what he considered to be granular germs visible in the same situation fluring the intervals of the process; but there can now be little doubt that the appearance in question is really due to the distension of the

FIG. 76 .

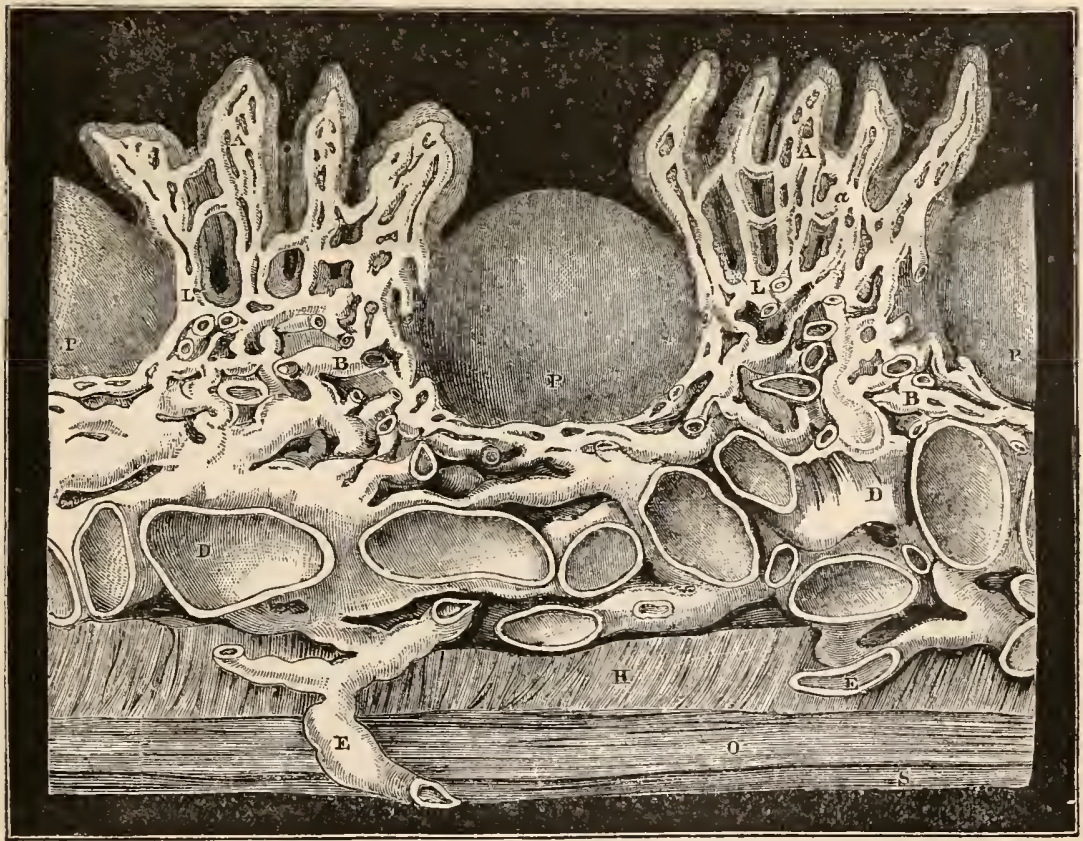

Perpendicular section through one of Peyer's patches in the lower part of the ileum of the Sheep. A, Lacteal vessels in the villi. $\mathbf{L}$. The superficial layer of the lacteal vessels (rete angustum). D. The deep layer of the lacteals (rete amplum). E. Efferent vessels, provided with valves. $a$. Lieberkühn's glands. P. Peyer's glands. F. Circular museular layer of the wall of the intestine. o. Longitudinal miscular layer. s. Peritoneal layer.

cylindrical epithelial cells investing the villi with the lacteal fluid. As it is a matter of much interest to examine and explain the morle in which absorption in this, its first stage, is effected, the attention of many observers has

1 Edin. New Phil. Journ., July, 1812, and Anatom. and Pathol. Observ., py. 5-10. 
been directed to the structure of these columnar investing epithelial cells; and if the observations of $\mathrm{v}$. Thanhoffer ${ }^{1}$ be correct, our knowledge of the mode of absorption of various substances, and especially of those of an oleaginous nature, will be materially simplified. According to these investigations, the investing cells ${ }^{2}$ of the villi (c, Figs, 78 and 79, $a$, Fig. 80) are

FIG, 77,

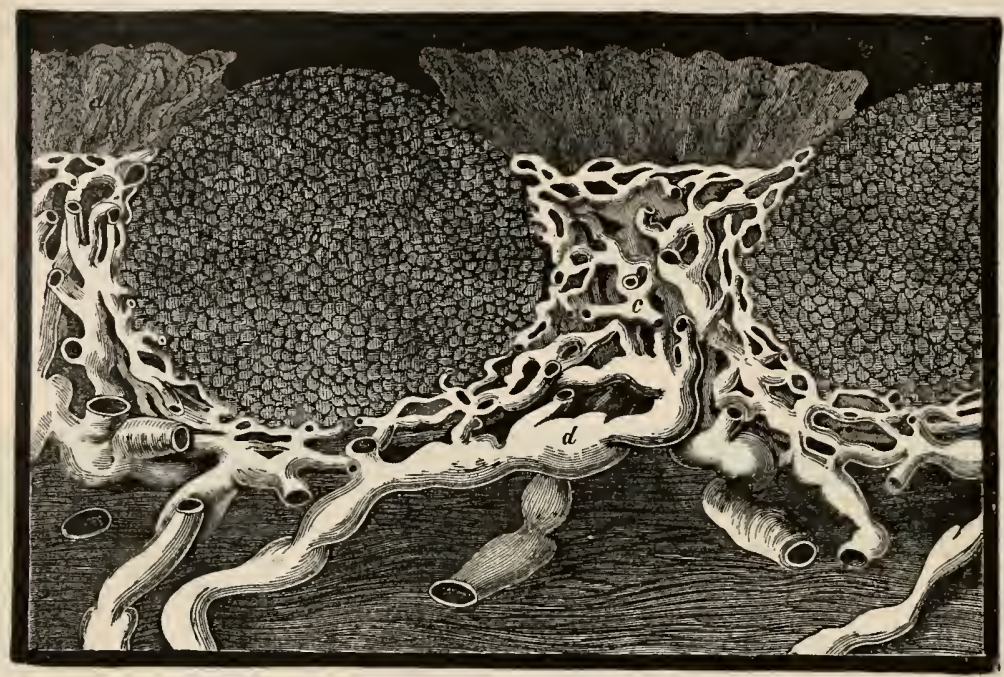

A perpendicular section through the wall of the Proeessus Vermiformis (Man). a. Lieherkühuian glands. b. Solitary follicle. c. Lacteal vessels, surrounding but not penetrating the follicles. At $d$, are seen the larger cfferent vessels, provided with valves.

of columnar form, with a broad free, and a narrower attached extremity. The free extremity presents a thickened, bright, and highly refractile border

1 v. Thanhoffer, Pfliger's Arcliv, 1874, p. 391.

2 See Heidenhuin in Moleschott's Untersuchungen, Bd. iv, 1858, P. 2.51; and Brüeke in id. Bd. viii, 1862, p. 495; and in Denkichrift. d. k. Akad. d. Wiss. \%u Wien. Bd. vi, p. 105. Also Verson in Strickrer's Human and Comparative Histolorgy, Syd. Sue. Transl., vol. i, 1870, p. 573. Ranvier, art. Epitheliun in the Nouveau I)ictionnaire de Médecine, t. iii, 1870. v. Thanhoffir, l'flüger's Arehiv, 1874, p. 391. These epithelial cells were deseribed by M M. Grulyy and Delafond (C. Rendus, 1843, 1195), as possessing cilia on their free margin; but Kölliker, Funlie, and morr r'cently sehultze, eousidered this appearanee as illusory, and produecd by the thick mombrane elosing the free extremity of the eell being perforated by very delicate pores or ('anals, whilst after death it split up in sueh a manner as to resemble a bundle of eilia (Kölliker, Mikroseop. Anat., 1860, p. 329). Balogh, agrering with Kölliker as to the lines in question being eamals, differed from him in believing them to be not pre-existent, but merely the indications of the passuges made by the molecules of fat in penetrating the delicate tissue oeeluding the mouth of the cell (Moleschott's Unters, Bd. vii, 1861, p. 556). Brettauer and Steinach, on whose obscrutions the statements of Brileke, Heidenhain, and other later authors are founded (Brettauer and Steinach, Sitzungsbericht d. k. Akad. d. wissen. zu Wien, 1857, J3l. xxiii, p. $303)$, maintained that the apparent eilia are prolongations of the eell-eontents, the eells themselves terminating with a smooth circular margin. They deseribed the columnar ur rangement as broadest and most distinct in fasting animals, whilst in eells filled with fat it diminishes to one-half or ome-third of its former bradth. and the striae disappear, so that only a hright narrow rim or border is left. Lastly, WVicgandt is stated in Canstatt's Jahresbericht for 1862,1 . 32 , to view the eilia as inerely the optieal expression of striw or wrinkles. 
surrounding the open mouth of the cell. The border varies in thickness and breadth in different cells, even of the same villus; and when the cells atre examined from above, their margins secm to be continuous with catch other, so that a kind of mosaie is formed. Immediately internal to the border is a row of processes formed of the protoplismie contents of the eell, which in nammals are rod-like, but in frogs, especially when examined in winter, are eiliaform. The proeesses stand ereet during life, but quickly disappear after death, being replaced by a globular swelling projecting from the mouth of the eell, occasioned by the imbibition of water.

The contents of the eells during fasting are a mass of clear protoplasm, and a bright nucleus with nueleolus; but during digestion, especially of substanees eontaining fat, the protoplasm beeomes eloudy or granular, from the entrance of the molecules of oil into its substance; a process that is ficilitated by the movement of the processes above deseribed. The attached extremity runs out into two kinds of processes, one of which is continuous with stellate eorpuscles (d, Fig. 78), forming a lymph eanalicular system in the conneetive-tissue matrix of the villus, which opens into the central lacteal vessel $(e)$, thus aftording a direet means of entrance for the fat-molecules into the absorbent system, and explaining the oeeasional introduetion of solid
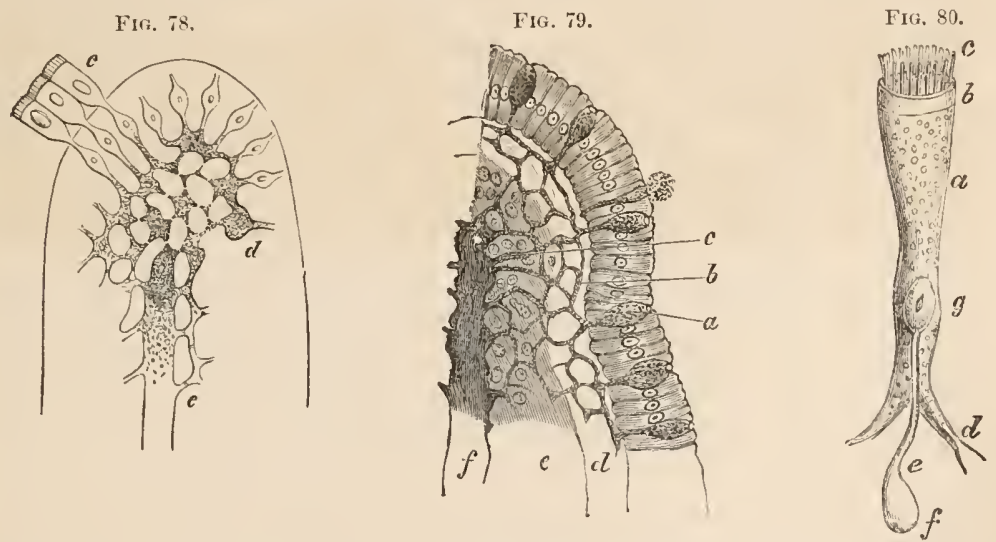

FIG. 78.-Diagrammatie representation of the Origin of the Lacteals in a Villus, according to Funke: $e$ Central lacteal; $d$. Connective-tissue corpuseles wilh communicating branches; $c$. Ciliated columuar epithelial cells, the attached extremities of which are directly eontiguous witl the connective-tissue corpuscles. After Funke.

FIG. 79.-Origin of the Lacteals according to Letzerich. The cells marked $n$, are cup or goblet-cells, and are seen to he intercalited amongst the columnar epithelial cells, and to communicate with a delicate plexus, $b$, that opens at various points into the central lacteal, $c, f ; d$, Layer of clear eonneetive tissue; $e$, connectire tissue with numerous nuclei.

Fig. 80.-a. Body of Columnar cell from small intestine. $b$. Smooth border of cell. c. Protoplasmic processes. $d$. Connective-tissue processes. e. Nerve-fibre penetrating the cell to join the nucleus. $g, f$. Ganglion cell.

particles into the cireulating eurrent, whilst the other (e, Fig. 80) appears to be nervous tissuc, sinee it is connected with a corpuscle resembling a ganglion-cell, and has the chemical relations of nerve. It penetrates the foot of the cell, and has been traced to the nucleus. Interposed at variable distances between the ordinary columnar cells, are peculiar oral eells, known as Cup, or Goblet-cells ( Fig. 79, a). These have been regarded by Letzerich " as the true commencements of the absorbent system, and he traces a connection 
between their attached attenuated extremities, with a vascular network lying between the basement-membrane of the villus, which joins the central lacteal, and he states that after a meal containing oleaginous material the flaskshaped bodies, or cup-cells, the delicate and more internally situated plexus of absorbent vessels, and the central lacteal may all be seen charged with oily particles. ${ }^{1}$

136. In regard to the degree in which the function of Nutritive Absorption is performed by the Lacteals and by the Sanguiferons system respectively, considerable difference of opinion has prevailed. When the Absorbent vessels were first discovered, and their functional importance was perceived, it was imagined that the introduction of alimentary fluid into the vascular system took place by them alone. Such an idea, however, would be altogether inconsistent with the facts of Comparative Allatomy $;^{2}$ and it is completely negatived by the results of experiment. For that Absorption is effecterl to a very considerable amount by the agency of the Bloodvessels, is shown in the first place, by the readiness with which aqueous fluids and even alcohol are taken up fron the parietes of the Stomach, and are carried into the general circulation. Thus in a case of extroversion of the bladder, observed by Mr. Erichsen, ${ }^{3}$ in which the urinary secretion could be collected immediately on its passing from the kidney, when a solution of ferrocyanide of potassium was taken into the stomach, this salt was detected in the urine in one instance within 1 minute, and in three other instances within $2 \frac{1}{2}$ minutes. In the interesting experiments of Dr. Bence Jones and M. Dupré, the rapidity of absorption of certain salts from the stomach was shown to be very great, a few grains of lithium chloride given to a fasting guinea-pig diffusing itself through all the vascular textures, and even into the cartilage of the hip-joint, in the short space of 15 minutes, and permeating every part of the lens, even in old animals, in four hours. In like manner, from experiments on cataractous lenses in man, it appears that traces of quinine may be discovered in the lens in about $2 \frac{1}{4}$ hours after its ingestion. In the analogous experiments of Eulenberg ${ }^{5}$ and of Colin ${ }^{6}$ iodide of potassium, when injected into the stomach, could be detected in the parotidean saliva in from 20 to 45 minutes, and when into the small intestine of a horse in so short a period as 6 minutes in the chyle. In all these cases, however, the stomach may be presumed to have been empty, and the vascular system in a state of aptiturle for absorption; since the experiments were made either after a long fast, or at least four hour's after a light meal. When, on the other hand, the salt was introduced into the stomach soon after the ingestion of alimentary substances, a much longer period elapsed before it could be detected in the urine; thus, when a substantial meal lad been taken two hours previously,

1 These statements of Letzerich have met with much opposition. Lipsky (Wiener Sitzungsber., Bd. lv, p. 183), Erdmann (Die Resorptionswege, ete), and Suehs (Vir chow's Archiv, Bd. xxxix, p. 493), regald the enp-cells as the results of manipulation, and deny their original existenee altogether. Others, as Oeffinger (Reichert's Archiv, 1867, 1). 337), and Thanhofter (op. cit.), whilst admitting their presuce during life, believe they proeeed from natural changes oceurring in the ordinary (ppithelial cells, steh as imbibition of wrter, ete. Others, agrin, us Schultze (Arehiv f. Mikroskop. Anat., Bd. iii, Pl. 145) and 204), and Theod. Eimer, in whose little pamphlet (Die Becherzellen) the reader will find an interesting epitome of all the essuys (thirtyseven in number) on this sulject 11, to 1868 , are of opinion that there is a real and primary difference brtween the eolumiar cells and the eup-cells, and they regard the latter is mucus-secreting organs. Verson (op. cit.) leaves the question undeeided.

2 Sec Prince of Comp. Phys, ehap. iv.

3 Nledienl Gazette, vol. xxxvi, p. 363

4 Pruceedings of the Rioy. Soc, vol xiv, p. 220 , and $x \mathrm{v}, \mathrm{p} .73$.

5 Hermann in Madiein Centralblatt, 1865, p. 5:9.

6 Canstatt's Bericht, 1865, p. 104. 
the interval was 12 minutes; when tea and bread and butter had been takeu one hour previously, the interval was 14 minntes; a similar meal having been taken twenty-four minutes previously, the interval was 16 minutes; when only two minutes had passed since the conclusion of such a meal, the interval was 27 minutes; and when a solid meal had been concluded just before the introduction of the salt, the interval was 39 minutes. These fircts are of great importance, in showing the very marked influence which the state of the stomach excreises upon the absorption of matters introduced into it. Not less important, however, is the state of the vuscular system in regard to turgescence or cmptiness ; for it was found by Magendie, that when he harl injected a considerable quantity of water into the veins of a dog, poison was absorbed very slowly; whilst, if he relieved the distension by bleeding, there was speedy evidence of its entrance into the circulation. The rapidity with which not only aqueous but alcoholic liquids introduced into the stonach may pass into the general circulation, has been shown by the experiments of Dr. Percy ; who found that when strong alcohol was injected into the stomach of dogs, the animals would sometimes fall insensible to the ground $\mathrm{im}$ mediately upon the completion of the injection, their respiratory and cardiac movements ceasing within two minutes ; and that on post-mortem examination in such cases, the stomach was nearly empty, whilst the blood was highly charged with alcohol; thus rendering it almost certain, that not merely the final destruction of nervons power, but the immediate loss of sensibility, was due to the action of alcoholized blood upon the nervous centres. Finally, numerous experiments have becn made by various physiologists, which have demonstrated that absorption of alimentary and other substances may take place from the walls of the Stomach ; these substances having been prevented firom passing into the intestine by a ligature around the pylorus. Now, as the Absorbent system does not present that peculiar arrangement in the coats of the stoniach which it does in those of the intestinal tube, there can be little doubt that the introduction of such substances into the system must be effected chiefly, if not entirely, through the medium of its sanguiferous capillaries.

137. That the Bloodvessels of the Intestinal tube largely participate in the introduction of soluble alimentary matter into the system, has been clearly proved by various observations upon the constitution of the blood of the Mesenteric veins; these having shown, that after the digestion of albuminous and farinacenus or saccharine substances, albuminose, dextrin, grape-sugar, and lactic acid, are detectible in that fluid, whose usual composition is greatly altered by the presence of these substances, as well as by the augnented proportion of water which it contains. Moreover, it is asscrted by Bruch, ${ }^{2}$ that so large a quantity of fat is absorbed into the bloodvesscls, that the superficial capillary network sometimes presents an opalescent whiteness. We may consider the Sanguiferous vessels, then, as affording the usual channel by which a large part of the nutritive materials are introdnced into the system; but these are not allowed to pass into the general current of the circulation, until they have been subjected to an important assimiluting process, which it appears to be one great office of the Liver to perform, whereby they are rendered more fit for the purposes they are destined to serve in the economy. Of this we shall have presently to speak.-But the absorbent porver which the bloodvessels of the Alimentary canal possess, is not linited to alimentary substances; for it is through them almost exclusively, that soluble matters of every other description are received into

1 Exprimental Inquiry concerning the Presence of Alcohol in the Ventricles of the Brain, p. 61 .

2 Siebold and Kölliker's Zeitschrift, April, 1853. 
the circulation. This, which may now be eonsidered a well-established fact, was first clearly shown by MM. Tiedcmann and Gmelin, ${ }^{1}$ who mingled with the food of animals various substances, which, by their color, odor, or chemical properties, might be easily detected in the fluids of the body: after some time the animal was examined; and the result was, that unequivocal traces of such substances were not unfrequently detected in the venous blood and in the urine, whilst it was only in a very few instances that any indication of them could be discoverced in the chyle.

138. The process of absorption by the bloodvessels is effected by the operation of forces of a purely physical character, the chief phenomena of which are embraced under the gencral term of Osmosis, and which may here be briefly noticed. When two fluids, miscible with one another, are placed on the opposite siles of an animal membrane or other porous septum, currents are generally established in opposite directions, the activity of which is esscntially dependent upon the nature of the scptum and the affinity of the fluids for one another. The instrument by which these effects are best shown, is termed an Endosmometer, and consists (Fig. 81 ) of a tube $\mathrm{B}$, whose wide extremity is partially filled with the fluid to be experimented on, and is then immersed in

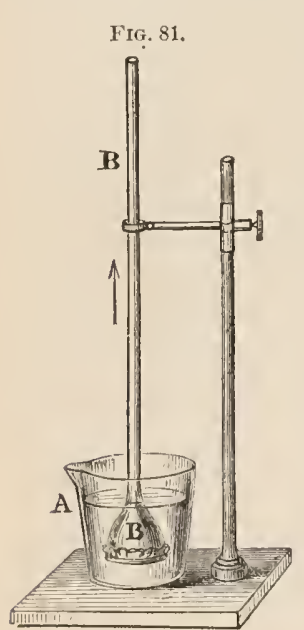

An Endusmometer.

a vesscl of pure water, $A$, the height of which is accurately kept at the same level as that to which the fluid rises or falls within the tube, in order to avoid the effect of uncqual hydrostatic pressure. In the najority of experiments of this nature the membrane is capable of being wetterl by the fluids on both sides, as when water and a solution of some salt are employed. It is then found that a strong current sets from the water to the saline solution, termed the cudosmotic current, the energy of which is within certain limits proportional to the density of the solution, ${ }^{2}$ whilst the amount of water entering will, of course, vary with the extent of surface prescnted by the membrane. On the other hand, the water without becomes impregnated with a portion of the salt from the establishment of a counter current, hitherto termed the exosmotic current, which will continue until the density of the fluids on the two sides of the membrane is equal. The experiments of Prof. Graham, Brücke, and others, however, render it probable that the passage of two fluid currents in oppositc directions through the membrane is only apparent, and that the phenomena may in reality be cxplained by the admission of only a singlc current setting inwards from the pure water to the saline solution, the apparent exosmotic current being clue to the particles of salt passing outwards by a process of solution in successive layers of the pure water contained in the pores of the membrane until the outer surface is reached, when they immediately diffuse

1 Versuehe uber clie Were anf welehen Substanzen aus dem Magen und Darmkanal ins lilut gelangen, Jleidelbere, 1820.

2 It is considered by Liebig, that the purgative effects of coneentrated saline solutions are to beaceomiced for on this principle, - the establishment of an osmotic current frem insteal of towards the cirenlating system. It $i$ - difficult, however, thus to accoint fior all the phenomena of saline pureqution; and the Author wreatly doubts the validity of the cxplanation. Some experimants performed by Aubert are also strongly opposed to it, for he found that the injection of solutions of many of the? neutral salts into the veins produced active purging; and here, of couree, the explanation sugrgetel by Licbig is inamissible. (See Zeitschrift für rat. MLed., 1832, t. ii, 1. 2.25.) 
into that liquid, giving rise to the appearance of a fluid current in the opposite direction. The great importance of the nature of the septum and of its capacity for imbibing or for being permeated by the liquids, is shown by the facility with which the experinent can be arranged in such a manner that a current shall only pass in one direction; for if the mouth of the instrument be closed with bladder, and alcohol be placed within it, on immersing it in water a current is immediately established from the water to the alcohol, the increased bulk of which can be ascertained by a scale attached to the upper part of $\mathrm{B}$, but there will be no evidence of a counter current passing from the alcohol to the water. If on the contrary, the mouth of the instrument be closed with a thin lamina of caoutchouc, a current soon sets from the alcohol to the water, and therefore in the opposite direction. We may explain thesc plrenomena by supposing that in the former instance the water possesses a superior attraction for the membrane, enters its pores by imbibition and capillary attraction, and driving the alcohol. before it, reaches the inner surface of the membrane, whence it instantly diffuses into that fluid, partly in consequence of the mutual repulsive force of its own particles, and partly from their affinity to those of the alcohol. In the latter case the alcohol exerts the same influence by virtue of its superior affinity for the caoutchouc. Professor Graham, indeed, considers that the water movement in osmosis is simply an affair of hydration and dehydration of the substance of the membraue or other colloid septum, and that the diffusion of the saline solution placed within the osmometer has little or nothing to do with the osmotic result otherwise than as it affects the state of hydration of the septum.'

139. It is not absolutely necessary that the septum should be of a solid nature, since the same phenomena are observed where, as in L'Hermite's experiment, ${ }^{2}$ a layer of water constitutes the diaphragm, being marle to separate a subjacent and heavier layer of chloroform from a supcrjacent and lighter layer of ether. The water is impermeable to chloroform, but permeable to ether, which, therefore, gradually penetrates through the water to the chloroform, and from its affinity for the latter, immediately diffuses into it, ultimately, in opposition to the force of gravity, entirely disappearing from the surface of the water. The importance of the miscibility of the fluids is clearly shown by the complete absence of currents which occurs when the fluids on the opposite sides of the septum have no affinity for one another, as in the case of oil and water, or of water and chloroform. But even when such affinity really exists, and when, as is usually the case in the animal body, there is more or less tendency in the fluids on the opposite sides of the septum to diffuse into one another, many circumstances may interfere to modify the force and direction of the osmotic currents besides those already noticed. Amongst these may be mentioned temperature, ${ }^{3}$ pressure, electricity, ${ }^{4}$ the specific heat of the fluids, ${ }^{5}$ the process of evaporation, the previous impregnation of the membrane with acids, ${ }^{6}$ or alkalies, ${ }^{7}$ and lastly, one which is in constant operation in the living body, viz., the movement of one of the fluids, the effects of which may be clearly exhibited by means of an apparatus essentially the same as that constructed by Dr. Robinson, and shown in Fig. 82, where $\mathrm{B}$ is a vessel containing colored fluid; $\mathrm{C}$ a piece of intestine attached to the stopeock of $B$ on the one hand, and to a siphon on the other, and immersed in a vesscl of water, $A$. If the siphon be of

1 For a theory which is in close accordance with this, see Buchheimer (Beiträge) Archiv f. Phys. Heilk., 1853, t. xii.

2 Comptes Rendus, 1855, p. 1179.

4 Brooke, Nat. Phil., 1860.

3 Eckhard, Beiträge, 1858, p. 95.

6 Harzer, Archiv f Phys. Ifeilk., 1856, t. xv.

7 Wistinghausen, Dissert., Durpat, 1851. 
smaller diameter than the portion of intestine, $\mathrm{C}$, as in the figure, the fluid will discharge itself with difficulty, the intestine will become tight, and an effusion of the colored fluid into the pure water contained in the vessel, $A$, will become apparent; but if the diameter of the siphon be greater than that

FIG. 82.

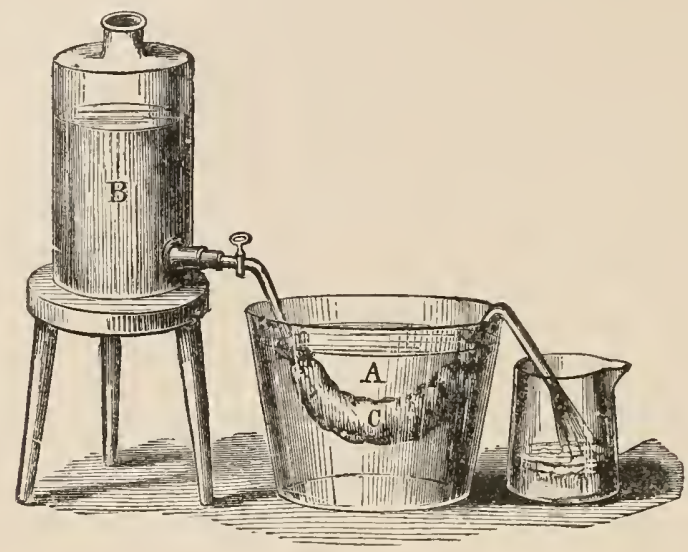

of the intestine attached to it, the discharge of the fluid will take place easily, the membranous tube will become flaccid, and a rapid process of absorption of the water or of any saline solution in $\mathrm{A}$ will occur. ${ }^{1}$ In a recent paper by Professor Graham, ${ }^{2}$ of great interest in reference to the phenomena we are now discussing, that chemist shows that some substances, as the salts of the metals, gencrally pass through porous septa with facility; and these and all substances so diffusing themeclves he proposes to call crystalloids; whilst others, as alumina, hydrated silicic acid, gum dextrin, gelatin, albuminous substances, etc., pass with great difficulty, or not at all. These he denominates colloids. ${ }^{3}$ The latter are characterized by possessing feeble chemical reactions; by diffusing very slowly in water; by having so weak an affinity for that liquid that they are easily precipitated from their solution; by being unable to pass through (by means of diffusion) any colloidal septum; by their consequent insipid taste, since they probably never reach the scntient extremities of the gustatory nerves; and by their high equivalent numbers, unstable nature, and ready passage into decomposition. The crystalloids, on the other hand, present characters which are precisely the reverse.

[While it is true that colloids are of low diffusibility in their natural condition, they may, however, be caused to undergo certain chemical or physical changes, in consequence of which they become capable of osmosis, and thus become practically crystalloids. As examples of this metamorphosis, may be mentioned the conversion of the colloid albumen into the crystalloid albuminose in the process of gastric or intestinal digestion, and the change which occurs in oily matters by contact with the panereatic juice, whercby an emulsion is formed and absorption rendered possible. These changes, however, are alluded to at considerable length in the text.

Crystalloids not only diffuse among themselves, but they will gradually

1 Robinson, Contributions to Physiology , 1857, p. 98.

2 Trans. Roval Soc., 1861, part i.

3 Redwood, Dialysis, Pharm. Journ., April, 1862. 
diffuse themsclves through collnids. A simple experiment slowing this fact may be thus performed: In the centre of a nass of any colloid substance, as boiled starch, let there be placed any highly colored crystalloid, as potassium bichromate; in a short time it will diffuse itself throughout the entire mass, giving it a bright yellow color; or, for the bichromate, substitute a crystal of potassium iodide, and in a short time upon touching the starch with a drop of some concentrated mineral acid, as sulphuric, a potassium sulphate will be formed, the iodine liberated, and the starch colored blue from the formation of the iodide of starch. If, on the other hand, a colloid, as burnt sugar, or caramel, be placed in the centre of a similar mass, at the end of many day's it will be found to have diffused itself scarcely at all.

In consequence of this property, when crystalloids and colloids are mingled, as in the egg, the former may be caused to diffuse themselves away from the latter. This fact is easily demonstrated in the cgg-endosmometer, which is prepared by removing the shell from one end of an egg. in such a manner as to leave the membrane intact. In the opposite end a small opening is made, around which is cemented a glass tube. The egg is then placed in a wineglass of distilled water, with the cud upon which the membrane is intact downward. Soon the contents of the egg will begin to appear in the tube, showing that water has passed through the animal membrane, and caused the displacement of the egg's contents. That the diffusion of the crystalline contents of the egg has taken place can be proved by adding a drop or two of a solution of silver nitrate to the water in the wineglass, when a copious precipitate of the silver chloride will be thrown down, thus demonstrating the passage of soluble chlorides from the interior of the egg through the animal membrane into the water. By this experiment also, the nou-diffusibility of colloids may be proved, as no test whatever can detect the presence of albumen in the water in the wineglass. - It is this diffusion of crystalloids away from colloids through an animal membrane which is termed, by Prof. Graham, dialysis.]

140. There seems to be no reason for doubting that the absorption of the various nutritive and alimentary materials takes place according to the ordinary rules of Osmosis; for on the one hand is the aliment always more or less perfectly reduced to the liquid state, the density of which is generally less than that of the blood, in consequence of the very copious discharge of aqneous fluid into the alimentary canal during the operation of digestion; and on the other is the blood or lymph in rapid movement, posscssing a high specific gravity, at a temperature of $99^{\circ}$ or $100^{\circ} \mathrm{F}$.; whilst between them is the septum, of immense extent and great tenuity, formed by the mucous membrane, and the walls of the blood or lymph vessels: the tendency is, therefore, in accordance with the facts alrealy stated, in favor of the passage of the aliment from the intestinal tract towards the circulating fluids. As regards such substances as albumen, gum, and gelatin, which belong to the "colloid" class of substances, and therefore transude with extreme difficulty, it appears at first sight difficult to explain how they pass throngh the intestinal mucous membrane. ${ }^{1}$ The experiments of Funke, however, show that the act of digestion essentially effects a conversion of the "colloid" group into the "crystalloid;" for that as soon as the albuminous substances intro-

1 Mialhe (Chimie appliquée à la Physiologie, 1856) broke the shell from the end of an egg, leaving the mernbrane intuct, and immersed it in water. After 5 hours it had increased in weight upwards of $30 \mathrm{grains}$, and the inembrane was tight and prominent. The water in which the egg liad been immersed became alkaline from the exosmose of the salts, but no albumen had escaped. So Graham and Eckhard (Beiträgc, Bd. iii, $\mathrm{pp}$ " 51 and $85,186 \%$ ) state that in analogous experiments-with solutions of gum no exosmosis of that substance occurred. 
duced into the stomach have undergone the modification into peptones, they have acquired the power of traversing animal membranes with comparative facility. As the conditions for the absorption of these substances are alike prescnt in the stomach and intestines, it is probable that this process takes place through the whole length of the alimentary tube, though chiefly in the intestine, as the presence of acids is unfavorable to its active performance; a view which receives support from the experiments of Busch ${ }^{1}$ upon the woman with a duodenal fistula, in whom it was found that a considerable portion of the saccharine, and about one-third of the albuminous compounds taken as food, were absorbed before reaching the intestines. Funke ${ }^{2}$ ubservel, also, that when solutions of peptone were introduced and secured by ligature in determinate lengths of the intestines of living rabbits, and permitted to remain for two, four, and six hours, the more concentrated the solution, the greater was the activity with which the absorption was accomplished in a given time; but that a remarkable difference occurred from what might have been anticipated, where a definite quantity of the solution of peptone was presented to double the extent of surface, very little more being then absorbed, or at least nothing like double the amount in the same time. He further found that the amount absorbed in the living animal by no means stands in direct relation to the duration of the experiment, the process taking place with far more energy during the first hour than subsequently; and the same facts were also observed in experiments upon the absorption of sugar made by Becker. ${ }^{3}$

[In absorption by the blondvcseels, change of place or motion on the part of at least one of the fluids separated by the animal membrane is of primary importance. Were this not the case an equilibrium would soon be obtained and the current be discontinued; but the rapidity of the circulation in the capillaries carries away the materials or fluids which have been absorbed, and leaves room for the absorption of more; as demonstrated in the cxperiment of Dr. Robinson, Fig. 82.

On the same principle, fulness of the capillaries retards osmosis; whence an important practical deduction follows with regard to the treatment of poisoned wounds. If by any means at our disposal we can bring about a congestion of the bloodvessels surrounding the wound, the tendency to the absorption of the poison will be greatly diminished. And this is the principle upon which the application of a cupping-glass to the wound, as revived by Sir D. Barry, or a ligature placed between the wound and the central organ of the circulation, or even suction applied to the wound itself, will sometimes prevent the action of the poison. facts.

The experiments of Christison and Magendie are illustrations of these

The former, after tying a ligature about the limb of a dog, introduced some poisonous material into the connective tissue beyond the ligature. So long as the ligature was allowed to remain, very little absorption took place; but immediately on the renoval of the ligature and the renewal of the circulation, the animal succunbed. (Christison on Poisons, p. 39.) Magendie injected a colored liquid into the cavity of the peritoneum of an animal, having first also produced a plethoric condition of the bloodvessels by injecting them with water. So long as the plethoric condition remained, the colored fluid was not absorbed from the peritoneal cavity; but immediately on opening a bloodvessel, the colored fluid disappared rapidly by absorption. 
An important therapeutic application of this fact is scen in the treatment of dropsies, or at least those involving the great serous cavities, where the absorption of the effused serum is accelerated by drawing away a portion of the fluid constituents of the blood, by the aid of diuretics and hydragogue cathartics.]

141. The difficulty which formerly existed in regard to the absorption of fatty bodies into the absorbent ressels, since these traverse moist animal membranes with great difficulty, is in some neasure set aside by the obscrvations of MIM. Heidenhanin and Brücke, already detailed, though there are still some points which have not received explanation. ${ }^{1}$ The entrance of fatmolecules into the bloodvessels may be aided, as Béclard ${ }^{2}$ supposes, by the direct pressure of the muscular coats of the intestines; for though great force is requisite to drive oil through the entire thickness of the walls of the small intestine, a much slighter one will suffice to impel it throngh the delicatc structure of the mucous nembrane alone, cspecially if the oil be finely divided or emulsionized; the yolk of egg, for instance, mingled with two or three times its weight of water, traversing such a membrane at a temp. of $100^{\circ}$ F., and under a low pressure, with great ease; though, in other experiments made by M. Morin, ${ }^{3}$ nuch difficulty was experiencerl with milk, on account of the much larger size of the molecules of oil contained in that fluid. It is certain, moreover, that the presence of a weak solution of soda or potash in the pores of the membrane, which effects a saponification of the oil, materially facilitates its passage $;^{4}$ and $W$ istinghansen and Hoffmann ${ }^{5}$ have observed that the force requisite to drive oil through an animal membrane is materially diminished by first inpregnating the latter with bile; an important observation in reference to the phenomena of the absorption of these substances by the bloudvessels, since it renders it probable that, as in the case of the albuninous compounds, it is in the small intestine chiefly, the surface of which is rendered alkaline by its own secretion, and by the fluids discharged by the Liver and Pancreas, that the absorption of fat is accomplished. ${ }^{6}$

142. It is a very remarkable fact, which has recently been fully substantiated, that not merely soluble natters, but insoluble substances in a state of minute division, may find their way from the alimentary canal and from the serous cavities into the current of the circulation. Thus it was found by Oesterlen," that particles of finely-divided charcoal, introduced into the

1 For a very full and interesting critique upon the whole question of the absorption of Fats, see Funke, Physiolugrie, 1863, th edit., p. 357-372. Dr. Broadbent (Journal of Anatomy and Plyysiolong, 1870, vol. iv, p. 14) has pointed out that the extremely delicate layer of celis forming the walls of the roots of the lacteals and lymphatics present but little resistance to the entranee of fat-molecules. He eontends that these vessels may be regarded as intertextural spaces; and whilst the more diffusible substances, as sugar, peptones, salts, ete., pass by osmosis through the walls of the eapillary bloodvessels to en ter the blood, the greatly inferior diffusibility of the fats causes them to be left behind in these intertextural spaces, from which they slowly nake their way into the lymphatics possessing proper walls. It must be admitted, however, that the columnar cells of the intestine scem to have a special predilection for, and power of, absorbing finely divided and emulsionized fut.

2 Physiologie, 1862, p. $181 . \quad 3$ NI émoires de la Société de Genève, 1854.

4 Mattencei, Leetures on the Pliys. Phenom. of Living Beings, Pereira's edit., p. 111.

${ }_{5}$ Dissert. Inaugur, Dorpat, 1861.

6 For the best recent account of the various phenomena of imbibition, eapillarity, nsmosis, and ditfision of liquids, see Milne Edwards, Leçons sur la Physiolugie, vol. $v, 1852$, in which the literature of the subjeet is given in a singularly perfect manner. See also Prof. Graham's Menoirs in the Phil. Trans. for 1850, 1854, 1857, ete.

7 Heller's Arehiv, 1847. 
alimentary canal, conld be distinguished in the blood of the mesenteric veins; and similar results were obtained by Eberhard, and by Mensonides and Donders, ${ }^{1}$ not only with charcoal, but also with sulphur and even with starch, the latter substance being at once detcetible in the blood by the iodine-tcst. There can be little doubt that such substances enter the lactcal system through the epithelial cells of the villi; as the presence of psorosperms in the interior of these has becn distinctly pcrceived by Klebs. ${ }^{2}$ In like manner, Ludwig and others in the Physiological School of Leipsic ${ }^{3}$ have noticed the penetration of particles of coloring matters from the interior of the abdominal or thoracic cavities into the lymphatics of the central tendon of the diaphragm, and into those of the pleura respectively; Auspitz ${ }^{4}$ describes a similar absorption of starch-corpuscles from the peritoneal cavity, and it seems probable that this is effected through certain openings (stomatu) first noticed by Oedmannson, ${ }^{5}$ and since fully deseribed by Klein and others, which occupy interspaces between the ordinary tessellated epithelium-cells lining the scrous carities. These openings, therefore, establish a direct communication between the serous cavities and the lymphatic vesscls, and the cavities themselves maly reasonably be regarded, in one sense, as merely colossal dilatations of the vessels, analogous to those large lymph-sacs or reservoirs which are found in the frog, fish, and other animals. ${ }^{6}$

\section{Absorption from the Body in general.}

143. The Mucous Membrane of the alimentary canal is by no means the only chamnel through which nutritive or other substances may be introduced into the circulating apparatus from external sourecs. The Lymphatic system is present in all animals which have a lacteal system; and the two, as ahready pointed out, evidently constitute one set of vessels. The Lymphatics, however, instead of commencing on the intestinal walls, arc distributed through most of the vascular tissues of the body, and especially in the. Skin; but their number bears no proportion whatever to the vascularity of the several tissues, or to the amount of interstitial change which these undergo ; and it would rather seem to be related to the amount of Connective tissue interposed between the other constituents of the fabric. Thus we find the Nervous centres entirely destitute of them, unless indeed they are represented by the lacunar spaces filled with nuclei, which have becn described by Robin ${ }^{7}$ and $\mathrm{His}^{8}$ as surrounling the capillaries; and they are very scanty in the substance of Muscles. After passing, like the lacteals, through a serics of glandular bodies (the precise nature of which will be presently considered), they cnipty their contents into the same recptacle with the lacteals; and the mingled products of both pass into the Sanguiferous system.-We find

1 Nederlandsch Laneet, Band iv.

2 For further information on this point the reader is referred to Mroliseliott's Untersuehungen, Bd. ii, p. 119; and Wien Med. Wochenschrift, 18.4, 1) 817; Hollander, Quiestiones de Conp. solid. e tratet. intest., ete., Dorpat, 18.4i; Tolehmann,

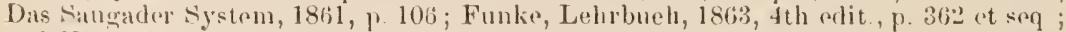
and Klrols, in Areh. f l'ath. Anat., Bd. xvi, p 188; and especially to Auspitz, bsaty in the Wien. Iled. Jahrb., N. F., 1871, p. 283, in which the history of the subject is fully given.

3 Sice the several papers by Judwig, Sohweigner-Sicdel, Dogiel, and Dybliowsty in the Verhatd. d. Satehs. Gerehl. d. Wiss, 1866.

- Wien Med. Jahr., N. F., 18i1, p. 583.

6 Virchow's Archiv, Bal. xxviii, $p$ \$6l.

6 see M. Jourdain, Ann. des sei. Nat., 1867.

7 Brown-sioguard, Journat de la I'hysiol, vol. ii, 1859, p. 537.

${ }^{8}$ Zeits. f. wiss. Zoologie, 1865, p. 127. 
in the Skin, also, a most copious distribution of capillary bloodvessels, the arrangement of which is by no means unlike that of the bloodvessels of the alimentary canal; aud its surface is further extended by the elevations that form the sensory papillie, which are in nany points comparable to the intestinil villi, although their special function is so different.

144. In the lowest tribes of animals, and in the earliest condition of the higher, it would seem as if Absorption by the external surface is almost equally important to the maintenance of life, with that which takes place through the internal reflcxion of it forming the walls of the Digestive cavity. In the adult condition of most of the higher animals, however, the special function of the intestinal tract is so much exalted as usually to supersede the necessity of any other supply; and the function of the cutaneous and pulmonary surfaces may be considered as rather that of exhalation than of absorption. We have a remarkable exception to this general statement, however, in the case of Frogs and other Batrachia, which are characterized by the softness of their skins and the thinness of their epidermic covering; for cutaneous absorption seems in them to be no less active than their cutaneous exhalation and respiration are well known to be. And even in the higher animals there are peculiar conditions of the system in which the imbibition of fluid through these surfaces is performed with great activity, supplying what would otherwise be a most inportant deficiency. It may take place either through the direct application of fluid to the surface, or even through the medium of the atmosphere, in which a greater or less proportion of watery vapor is usually dissolved. This absorption occur's most vigorously when the systcm has been drained of its fluid, either by an excess of the excretions, or by a diminution of the regular supply.

145. It may be desirable to adduce some individual cases, which will set this function in a striking point of view; and those may be first noticed in which the Absorption took place through the contact of liquids with the skin. It is well known that shipwrecked sailors and others who are suffering from thirst, owing to the want of fresh water, find it greatly alleviated, or altogether relieved, by dipping their clothes into the sea and putting them on whilst still wet, or by frequently inmersing their own bodies. ${ }^{1}$ - In a case related by Dr. Currie, of a patient laboring under dysphagia in its most advanced stage (the introduction of any nutriment, whether solid or fluid, into the stomach, having become perfectly impracticable), an attempt was made to prolong his existence by the administration of nutritive enemata, and by immersion of the body, night and morning, in a bath of milk and water. During the continuance of this plan, his weight, which had previously been rapidly diminishing, remained stationary, although the quantity of the excretions was increased. How much of the absorption, which must have been effected to replace the amount of excreted fluid, is to be attributcd to the baths, and how much to the enemata, it is not easy to say; but it is important to remark that "the thirst, which was troublesome during the first days of the patient's abstinence, was abated, and, as he declared, removed by the tepid bath, in which he had the most grateful sensations." "It cannot be doubted," Dr. Currie observes, "that the discharge by stool and perspiration exceeded the weight of the clysters;" and the loss by the urinary excretion, which increased from $24 \mathrm{oz}$. to $36 \mathrm{oz}$. under this system, is only to be accounted for by the cutaneous absorption. ${ }^{2}-$ Dr. S. Smith mentions

1 See a collection of such cases in Dr. Madden's Experimental Inquiry into the Physiology of Cutaneous Absorption, p. 47.

2 Medical Reports, vol. i, pp. 308-326. Eichhorst (Pfüger's Archiv, Band iv, part xii) classes various peptones, muscular flesh, casein of milk, salified egg-albumen, and 
that a man, who had lost nearly 3 lbs. by perspiration, during an hour and a quarter's labor, in a very hot atmosphere, regained $8 \mathrm{oz}$. by immersion in a warm bath at $95^{\circ}$ for half an hour. ${ }^{1}$ - The experiments of Dr. Madden ${ }^{2}$ on his own person show that a positive increase usually takes place in the weight of the body, during immersion in a warm bath, even though there is at the same time a continual loss of weight by pulmonary exhalation, and by transudation from the skin. ${ }^{3}$ This increase was, in some instances, as much as 5 drachms in half an hour; whilst the loss of weight during the previous half hour had been $6 \frac{1}{2}$ drachms: so that if the same rate of loss were continued in the bath, the real gain by absorption must have been nearly an ounce and a half. Why this gain was much less than in the cases just alluded to, is at once accounted for by the fact that there was no deficiency, in the latter case, of the fluids naturally present in the body.

146. There are certain phenomena, which, if accurately recorded, cannot be accounted for in any other way, than by admitting that, under particular circunstances, a considerable amount of water may be absorbed from the vapor of the atmosphere. The following are among the most satisfactory and circumstantial observations, that have been adduced in support of this position. Lining observed that his body on one occasion increased in weight, during two hours, to the amount of $8 \frac{1}{2} \mathrm{oz}$; ; allowance being made for the amount of fluid ingested during that time, and for the quantity passed off by the urine and by cutaneous transpiration. ${ }^{4}$ Dr. Jurin affirms that he ascertained an increase of $18 \mathrm{oz}$. to have taken place during a night passed in a cool room, after a day's exercise and abstinence. ${ }^{5}$ It is stated by Dr. Watson, ${ }^{6}$ that a lad at Newmarket, having been almost starved, in order that he might be reduced to a proper weight for riding a match, was weighed at 9 A.M., and again at 10 A.M.; and he was found to have gained nearly $30 \mathrm{oz}$. in weight in the course of this hour, though he had only drunk half a glass of wine in the interim. A parallel instance was related to the Author by the late Sir G. Hill, then Governor of St. Vincent: a jockey had been for some time in training for a race, in which that gentleman was much interested, and had been reduced to the proper weight; on the morning of the trial, being much oppressed with thirst, he took one cup of tea ; and shortly afterwards his weight was found to have increased $6 \mathrm{lbs}$., so that he was incapacitated for riding.-Nearly the whole of the increase in the former case, and at least three-fourths of it in the latter, must be attributerl to absorption from the vapor of the atmosphere; probably, however, rather through the lungs than through the skin. If the possibility of such absorption be admitted, we are probably to attribute to it the chief part of the excess of watery fluid which cannot be otherwise accounted for, in the following instances.-Dr.

gelatin among substanees eapable of being absorbed when injeeted in to the large intestine. On the other hand, amongst the substances not so absorbed he mentions pure egg-albumen, eoagulated fibrin, and preparations of syntonin and myosin. Batuer (Sitz. d. k. Bayer Akad., 1868, Band ii, p. 511) states that whilst little or no albumen is absorbed even when it has been well whipped, by the large intestine, a eonsiderable quantity is taken up if a solution of eommon salt be added to it. See note, p. 180 .

1 Philosophy of Health, vol. ii, p. 396.

2 Op. eit., pp. 59-63.

3 That part of the funetion of Cutaneous Transpiration whieh eonsists in simple Exhalation, is of eourse eompletely cheeked by such immersion; but that which is the result of an aetual Seereting process in the eutaneous glandula (chap. xiv, sect. 4) is inereased by heat, even though this be aeeompanied with moisture.

4 Philosophical Transactions, 1743, p. 496.

6 Klapp, Inaug. Dissert., p. 30, eited by Dr. Madden.

6 Chemieal Essays, vol. iii, p. 100. 
Hill ${ }^{1}$ relates the case of a diabetic patient, who for five weeks passed 24 lbs. of urine cvery twenty-four hours; his ingesta during the same period amounted to $22 \mathrm{lbs}$. At the commencement of the disease, he weighed $145 \mathrm{lbs}$; and when he died, 27 lbs. of loss had been sustained. The daily excess of the excretions over the fluid ingesta could not have been less than $t \mathrm{lbs}$; ; making $140 \mathrm{lbs}$. for the thirty-five days during which the complaint lasted. If from this we deduct the amount of diminution which the weight of the body sustained during the time, we shall still have $113 \mathrm{lbs}$. to be accounted for, which can only have entered the body from the atmosphere.-A case of ovarian dropsy has been recorded by Mr. Ford ${ }^{2}$ in which it was observed that the patient, during eighteen days, drank $692 \mathrm{oz}$ or 43 pints of fluid, and that she discharged by urinc and paracentesis $1298 \mathrm{oz}$. or 91 pints, which leaves a balance of $606 \mathrm{oz}$. or 38 pints, to be similarly accounted for. ${ }^{3}$

147. The capacity of the Skin to absorb saline or other substances in solution, though formerly generally admitted, has lately been called in question by various observers. In experiments performed by Murray Thomson, ${ }^{4}$ with which those of Parisot ${ }^{5}$ and Kletzinsky are in accordance, it was found that no trace of iodine could be detected in the morning urine, when a bath, containing half an ounce of iodide of potassium dissolved in 80 gallons of water had been taken the previous night after six hours' abstinence from all food. Homolle, ${ }^{6}$ whilst admitting that pure water is certainly absorbed, and that saline solutions and some organic mixtures are sometimes decomposed by the skin, apparently by that tissue exerting an elective affinity for one of the constituents, to the exclusion of the others, states that in many instances in which he remained for an hour or more at a time in baths containing $3 \mathrm{oz}$. of cyanide or iodide of potassium, nitrate of potash, or chloride of ammonium, he was unable to discover any trace of those salts in the urine, nor did he perceive any physiological effect from the employment of baths in which 1 lb. of belladonna or of digitalis leaves had previously been infused. M. Willemin, and others, ${ }^{7}$ on the other hand, maintain that the healthy skin is capable of absorbing not only water, but small portions of various substances soluble in water; the process of absorption varying under different circumstances, and often taking place very slowly, but being favored by a delicate skin, and by exhaustion, though it does not take place when the skin is actively perspiring from cxercise. The occasional serious effects upon the urinary organs of the application of a blister, the poisonous action of solutions of Strychnine, Nicotin and Digitalin, ${ }^{8}$ the tinging of the urine with madder, rhubarb, and turmeric after bathing in infusions of those substances, ${ }^{9}$ and lastly, the remarkable experiment of Schreger, who found on immersing the hind leg of a puppy for 24 hours in tepid milk, after having previously applied a bandage, that the lymphatics were full of milk, though the veins

1 Trans, of Med. Chirurg. Soc. of Edinb., vol. ii.

2 Medical Communications, rol. ii, p. 130.

s In this case, however, as in others of a similar kind, something is to be allowed for the quantity of water contained in the solid food ingested; but this may be fairly considered not to exceed the quantity lost by pulmonary and cutaneous exhalation, and discharged in the fecal evacuations.

4 Edin. Mled. Jour., 1862, p. 1017. 5 Archiv. Gén. de Méd., 1863, p. 376.

6 De l'A bsorption par la Tégument externe, L'Union Médicalc, 18.33, p. 462, et seq. See also Reveil, Recherches sur l'Osmose, 1865; Oré, Gaz. Médicale, 1865, p. 731; Mongeot, Revue Médicale, 1865, t. ii, p. 536.

7 Archiv. Gén. de Méd., 1863, pp. 5, 105, 325 ; Delore, Ibid., p. 376 ; Hoffmann, Comptes Rendus, 1867 , p. 722 ; Clemens, Archiv f. wiss. Heilk., Bd. iii, 1867, p. 211;

Brémond, Lancet, 1870, i, 495.

8 Chrzonsezewsky, Berlin Klin. Wochenshrift, 1870.

9 Medical Communications, vol. ii, p. 130. 
contained none, are all favorable to the latter opinion. The experiments of Auspitz ${ }^{1}$ show that the absorption of solid bodies (rice starch) and mercury can be effected by rubbing them strongly into the skin, and that it is materially facilitated by the addition of any oily substance. When absorption does take place, we should expect that the absorbed substances would be more readily discoverable in the absorbents than in the veins; for their imbibition takes place entirely according to the physical laws already mentioned, in conformity with which they pass most readily into the vessels which present the thinnest walls and the largest surface. ${ }^{2}$

148. Our inferences with regard to the ordinary functions of the Lymphatic system, however, must be rather drawn from the nature of the fluid which it contains, and from the uses subsequently made of it, than from such experiments as the preceding. We shall presently see that there is a close correspondence in composition between the Chyle of the Lacteals and the Lymph of the Lymphatics; the chicf difference being the presence of a considerable quantity of fatty matter in the former, and of a larger proportion of the assimilable substances (albumen and fibrin) which are equally characteristic of both $(\$ \S 152,153)$. This evident conformity in the nature of the fluid which these two sets of vessels transmit, joincd to the fact that the fluid Lymph, like the Chyle, is conveyed into the general current of the circulation, just before the blood is again transmitted to the system at large, almost inevitably leads to the inference that the lymph is, like the chyle, a nutritious fluid, and is not of an excrementitious character, as maintained by Hunter and his followcrs. On the other hand, the close resemblance between the contents of the Lymphatics and diluted Liquor Sanguinis seems to indicate that the former are chiefly derived from the fluid portion of the blood, which has transuded through the walls of the capillary vessels, and has permeated the tissues, giving up to them the materials required for their nutrition. And we shall presently see reason to believe that this transudation answers the additional purpose of subjecting the crude materials, which may have been taken up direct into the bloodvessels, to an elaborating or preparatory agency, such as it seems to be the especial object of the Lacteal system to exert upon the nutritive substances which it serves to introduce into the circulation.--But it seems not impossible that there may be another source for the contents of the Lymphatics. We have already had to allude, on several occasions, to the disintegration which is continually taking place within the living body; whether as a result of the limited duration of the life of its component parts, or as a consequence of the dccomposing action of Oxygen. Now the death of the tissues by no means involves their immediate and complete destruction; and there seems no more reason why an animal should not derive support from its own dead parts than from the dead body of another individual. Whilst, therefore, the matter which has undergone too complete a disintegration to be again employed as nutrient matcrial, is carriel off by the excreting processes, that portion which is capable of being again assimilated, may be taken up by the Lymphatic system. If this be the case, we may say with Dr. Prout, that " a sort of digestion is carried on in all parts of the body." - It may be stated, then, as a general proposition, that the function of the Absorbent Systcm is to take up, and to convey back into the cireulating apparatus in a state of higher elaboration,

1 Op. eit., vol. ii., p. 320.

2 For much interesting information respecting the inereased energy, rapidity, and eertainty of action of various poisons introdueed directly into the eirculation by the hypodrrmie mode of injection, as eompared with the effects of the same substanees when administered by the stomach, see the Report of a Committee of the MedieoChir. Soe. in vol. $v$ of the T'ransactions of that Society. 
sueh snbstanees as are eapable of appropriation to the mutritive process, whether thesc substanees be directly furnished by the external world, or be derived from the disintegration of the organism itself. We have seen that, in the Lacteals, the seleeting power is sueh, that these vessels are not disposed to convey into the system any substanees but such as are destined for this purpose; and that readily diffusible matters are absorbed in preference by the mesenteric Bloodvessels. The ease is different, however, with regard to the Lymphatics; for there is reason to believe that they are more disposed than the venous capillaries to the absorption of other soluble matters, espeeially when these are brought into relation with the skin, through which the Lyinphatic vessels are very profusely distributed.

\section{Of the Elaboration of the Nutrient Materials.-Sangnification.}

149. The alimentary substanees, taken up by the Bloodvessels and Absorbents, seem very far from being capable of immediate application to the nutrition of the body; for we find that they are not conveyed by any means direetly into the circulating eurrent, but that those which enter the Gastrointestinal veins are submitted to the operation of the Liver, whilst those whieh are received into the Laeteals are subjected to a kind of glandnlar

FIG. 83.

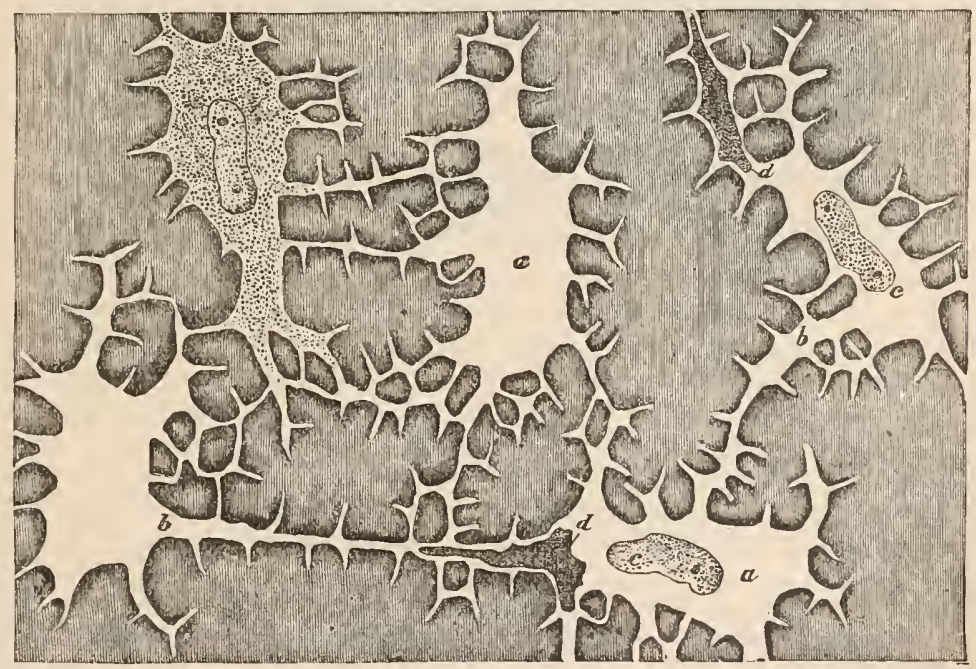

Cornea of Frog treated with lunar caustic. a, canalicular system. In one place a branched flattened corneal corpuscle with its nucleus is seen; in two others are lacunze of the canalicular system, containing nuelei, $c$, of corneal corpuscles, and $d$, migrating or wandering cells; $b$, branched channels, which connect the lacunæe of the canalicular system. Oc. 3, Obj. 9.

aetion within their own system; the newly absorbed materials in both eases undergoing eonsiderable ehanges, whieh tend to assimilate them to the eomponents of the Blood.-The Lymphatie System ${ }^{\mathrm{L}}$ eonsists of an extensive network of vessels very generally distributed throughout the body, but present in remarkable abundance beneath the Skin and Mucons membranes. In regard to their origin it has been shown $(\S 134)$ that in the villi the lym-

1 For an exhaustive account of the Anatomy of which, see v. Recklinghausen, Stricker's Human and Comp. Histology, 1870, vol. i, pp. 297-346. See also Klein, Anatomy of the Lymphatic System, 1873-4, I. Serous Membranes. 
phatics end in processes like the finger of a glove, which, however, are probably connected laterally with irregular passages, containing stellate cells, through which the fluids absorbed gain entrance into their interior. In other parts of the body, as in fibrous and tendinous tissues, in membranes and fascix, a peculiar system of branched cavities is almost always visible when proper methods of preparation and observation are adopted. Each of the cavities contains a nucleated mass of protoplasm, which completely fills it; and both the cavities and their contents are in continuity with eacl other, so as to form a network which is now known under the name of lymph-canalicular system, ${ }^{1}$ and the more or less branched cells contained in them are termed lymphatic cells. ${ }^{2} \quad$ The large cavities and vessels with which the lymphcanaliculi communicate appear to be always lined, whilst their walls are sometimes exclusively formed by a delicate layer of flattened epithelial cells. ${ }^{3}$ An external membrane is in the latter case gradually acquired, as the vessels become larger, on which again is superimposed a layer of dense connective tissue, in which a few transverse muscular fibres may be distinguished. It is a peculiarity of the Lymphatics that they do not present the same smooth and regular contour, nor the same definite mode of branching, that is met with in the Bloodvessels; on the contrary, they run irregularly, and the walls of the vessels often present dilatations or reservoirs in their course, whilst the larger vessels formed by the reunion of several smaller ones, often again subdivide and reunite. The principal communication between the lymphatics and the bloodvessels is at the point where the great trunks empty themselves into the junction of the subclavian and jugular veins. It is not improbable, however, that in certain regions, as the cornea, the lymphatic canaliculi form channels by which the fluid parts of the blood, without its morphological constituents, can enter the rootlets of the lymphatic system. ${ }^{4}$ In many parts, especially in the central parts of the nervous system, the bloodvessels run in the interior of the lymphatic vessels, which form, as it were, an additional sheath to them, the space between the wall of the lymphatic vessel and that of the bloodvessel being occupied with fluid containing lymph-corpuscles. At certain parts of the body, as the bend of the knee and elbow, and in the neck, the larger stems suddenly break up into a dense interlacing network of capillary vesscls, most distinct in young subjects, forming a rete mirabile, as is shown in Fig. 84. This is surrounded by condensed connective tissue, and is penetrated by bloodvessels, constituting, so to speak, the first towards the formation of a lymphatic gland. From this simple structure we can readily ascend through a series of glandlike organs, gradually increasing in complexity, composed of several of these little retia, arranged either continuously or in groups, until at length, by steps of easy transition, we arrive at the complex structure of the truc lymphatic glands.

The details of the structure of the lymphatic glands have been most laboriously investigated and excellently described by His, ${ }^{5}$ Kölliker, ${ }^{6}$ Teich-

1 Saftcanälchen of Recklinghausen.

2 See Klein, in Handbook for the Physiological Laboratory, 1873, p. 114 ; also Teichmann, Das Saugader System; Belajeff, Journal de l'Anat., t. iij, pp. 465 and 594; Ludwig, in the Medizinischer Jahrbucher of A. Juchek and A. Schauenstein, 1863, Heft ix, pp. 35-77, Wien; Giannuzzi, Ber. d. S. Gesells. zu Leipzig. Nov. 1865; Wywodzoff on the Lungs, Wi'n. Med. Jahrb., Bd. xi, Heft iii ; Genersich, in Ludwig's Arbeiten, B. v, 1871, p. 53.

3 Auerbach, Kölliker's Zeitschrift, Bd. xv, 1868, p. 172.

4 See Dr. T. A. Carter, Journal of Anatomy and Physiology, 1870, vol. iv, p. 97.

- Untersuchungen über den Bau der Peyerschen Drüsen, Leipzig, 1862.

6 Gewebelehre, 1866. 
mann, ${ }^{1}$ Frey, ${ }^{2}$ and v. Recklingliausen. ${ }^{3} \quad$ From their investigations we learn that each gland is invested by a vascular sheath or capsule of condensed comnective tissue, which is continuous with the coats of the afferent and efferent vessels, sending inwards a number of thin lamelke, so disposed and connected together as to constitute a tolerably regular alveolated framework pervading the gland, excepting usually near the centre. 'The septa thus formed contain, in Man and many other animals, but especially the Rumi-

FIG. 84.

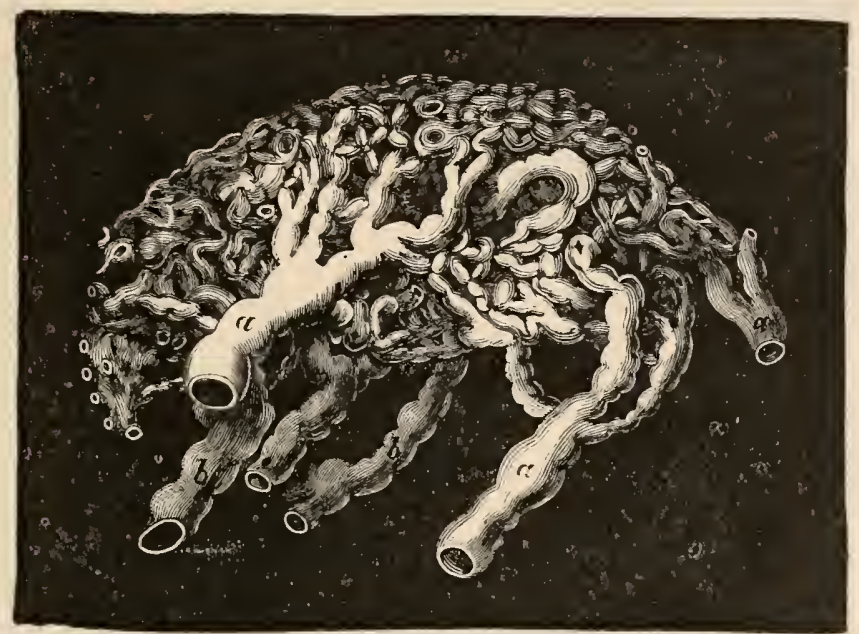

A section of a simple Rete Mirabile, viewed from the surface, $a, a$, afferent vessels; $b, b$, efferent ressels, only partially risible, from the popliteal space. (Man.)

nants, numerous muscular fibre-cells, $d, d$, Fig. 85 . The alveoli are most distinct wear the surface of the gland, $c, c$, Fig. 85 ; towards the centre, in consequence of the breaking up and irregular disposition of the septa, they are not very apparent. The centre of the gland is occupied by the medullary substance, varying considerably in amount in different instances, but always most abundant in childhood, and in the more deeply-seated glands. Its relation to the alveoli may best be understood by conceiving it to be a plastic substance, accumulated in mass at the centre, and sending out on all sides prolongations of the most irregular form and shape, which do nearly, but not completely, fill the alveoli, spaces being consequently left between the septa which form the alveoli, and the processes of medullary substance partially filling them. These are termed by Frey the investing spaces of the follicle, and are represented by $b$ in Figs. 86 and 87 . They are traversed by irregular fibres, formed of nucleated cells with anastomosing prolongations, $c, c$, Fig. 87. According to v. Recklinghausen, ${ }^{7}$ they are lined by epithetial cells of a rounded polygonal form, and certainly contain numerous lymph-corpuscles. They are directly continuous with the afferent and efferent vessels, and may be filled with injection propelled from either of those sets of tubes; though, of course, on account of the valves, more readily

1 Op. cit.

2 Untersuch. üb. die Lymph-drüsen des Mcnschen, Leipzig, 1861.

3 Stricker's Hum. and Comp. Hist., Syd. Soc. Trans., 1870.

4 See also Bizzozero, Centralblatt, 1873, p. 110. 
through the former than the latter. The course which the lymph takes in traversing these somewhat lacunar spaces around the medullary substance contained within the alveoli, is termed by Frey the superficial lymph-path. The central or medullary portion consists of a close network or reticulum of connective-tissue fibres, $a$, Fig. 87 ; in the interstices of which are nu-

Fig. 85
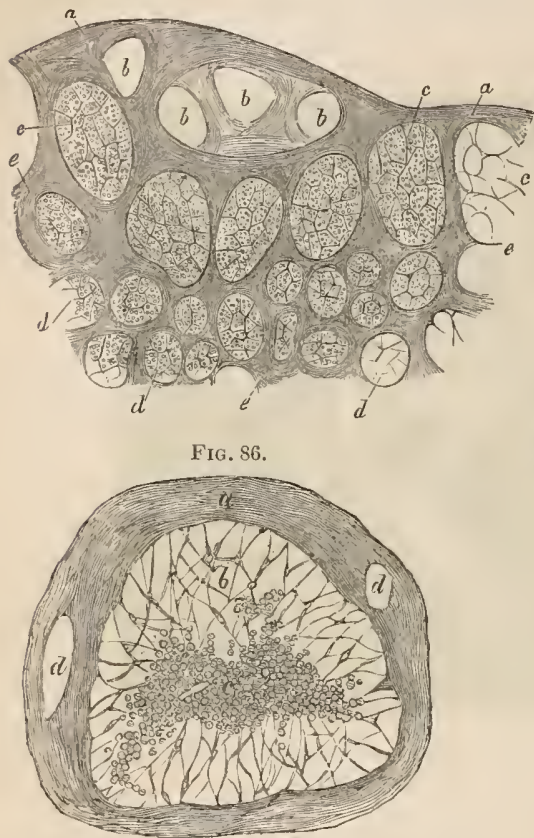

FIG. 87.

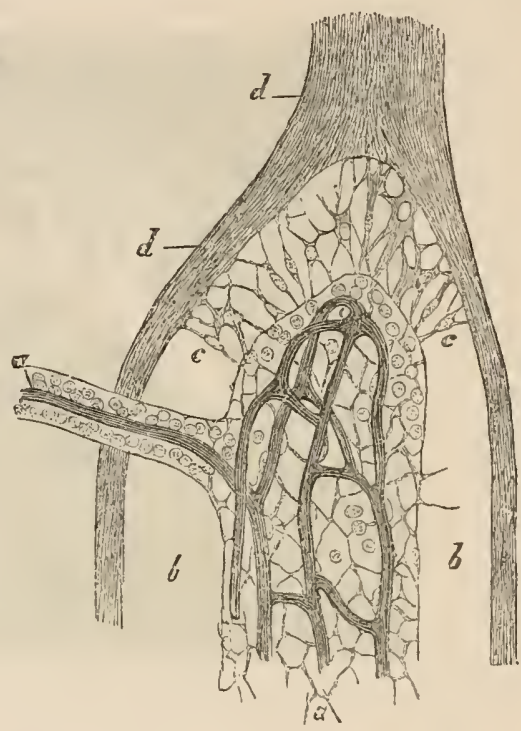

FIG. 85.-Seetion of Lymphatic Gland, showing, $a, a$, the fibrous tissuc which folms its cxterior; $b, b$, superficial vasa iuferentia; $c, c$, larger alveoli, near the surface; $d, d$, smaller alveoli of the interior; $c, e$, fibrous walls of the alveoli.

FIG. 86.-Simple Lymphatie Gland. $a$, the eapsule, with sections of lymphatics, $d$, $d$, coursing through it. $b$, lacunar and intercommunicating passages, permeated by tlic lymph, and forming the superficial lympli-path of Frey, $c$, nucleus or mcdullary portion of the gland, in the eentre of which the section of a bloodressel may be secn. The path pursued by the lymph through the medullary portion constitutes the deep or secondary lymph-path of Frey.

Fig. 87.-Portion of the Medullary substance of the Mesenteric Gland of an ox. The artery injected with Cliromatc of Lead $\times 300$. a, medullary substanee with eapillary network, finc retieulum of connective tissue, and a few lymph-corpuseles; $b, b$, superfieial lymph-path, traversed by a retieulum of nucleated cells $(c, c)$ with numerous anastomosing prolongations. The lymph-eorpuseles have for the most part been removed witl a camel-hair brush; $d, d$, trabeculre, composed almost cxelusirely of unstripel musenlar tissue; $g$, a small medullary cord or bridge, containing a bloodvessel and numcrous lymph-corpuseles.

merous lymph-corpuscles. It is not bounded by any definite membranc, though a kind of investing wall is formed by the connective-tissue fibres being much more closely arranged near the surfice; fluids, therefore, which are circulating through the superficial lymph-path (b), Figs. 87 and 88 , may also slowly percolate through the medullary portion, and this constitutes the deep lymph-path of Frey. The medullary portion is freely supplicd with bloodvessels. It thus appears that the lymph or chyle entering one of the mesenteric glands passes, under ordinary circumstanecs, from the afferent to the effercut vessels, through the superficial lymph-path, that is, chiefly through the investing follicular spaces around and between the alveoli; 
though partly also through the interstices of the tissue forming the medullary portion of the gland, where it comes into intimate relation with the bloodvessels, and takes up a certain proportion of lymph-corpuscles. When, however, the activity of the gland is at its height, as regards both the circulation of the blood and that of the lymph, as aftcr food, the pressure of the increased quantity of the lymph effects the dilatation of the minute pores, by which the spaces between the connective-tissue corpuscles and their prolongations communicate with the alveolar investing spaces. A much more rapid percolation of the newly-absorberl fluid is thus permitted through channels in which lymph-corpuscles are abundantly contained, effecting the first steps in its assimilation to that fluid, into which it is subsequently poured, and of which it is obvious that it constitutes the pabulum. Oidtmann analyzed a lymphatic gland from the inguinal region of an old woman and found it to consist of water 71.5, and solids 28.5 , of which last 1.2 parts were salts.

1.50. In immediate connection with the lymphatics arc the large sacs or cavities known as the Serous membranes, which, as the researches of Klein ${ }^{1}$ have shown, may be regarded as lymphatic glands that have been unravelled or opened out, and which present many points of interest in reference to the processes of sanguification. The serous membranes, typical examples of which are presented by the Pleura, Peritoneum, Pericardium, and Arachnoid, as well as by the synovial membranes of joints, are composed of a matrix of connective tissue, lined by a single layer of cells termed the cndothelium. They form elosed sacs, existing between parts that are subject to friction, the movements of which they facilitate by the extreme smoothness and lubricity of their surfaces. The endothelium for the most part consists of a layer of flattened nucleated hyaline cell-plates, the sinuous outlines of which can be brought beautifully into view by staining with nitrate of silver. In many places, however, the cells present a different character, being polyhedral, club-shaped, or even short-columnar with granular contents and oroid nucleus, which is often constricted or divided into two. These germinating or young endothelial cells sometimes form projecting and pedunculated masses, and some of them, closely rescmbling lymph-corpuscles, may be seen either simply attached to the general surface, in the act of separating from it, or actually free in the cavity of the membrane. The matrix of the serous membranes, best seen in such a part as the omentum, is composed of a homogeneous substance, in which are imbedded cells of various kinds. These according to their form and arrangement present (in the omentum of the rabbit for example) two kinds of lymphangeal structurcs. In one there are patches of more or less flattened branched cells lying in the lymph-canalicular system, multiplying by division and growing up into lymphoid cells, which are also contained in the lymph-canalicular system. In the second kind there are patches and tracts, the matrix of which consists of a reticulum, containing in its meshes a variable number of lymphoid corpuseles. These patches are usually vascularized, but the former do not originally contain bloodvessels, though they subsequently become highly vascular; by coalescence they ultimately form large tracts. It is thus apparent that there is a considerable amount of adenoid tissue imbedded in, or rather forming the walls of, the serous membranes. The proper lymphatics of the serous membrane form wide vessels, partly accompanying and sometimes invaginating or surrounding, and partly running independently of the bloodvessels, the walls of which consists of only onc layer of fusiform endothelial plates. The larger ones have valves and sacculated dilatations. The existence of 
stomata or openings on the surface of the serous membranes leading into lymphatic vessels, and forming therefore a communieation between the eavity of the serous sac and the interior of the lymphatie vessels, was demonstrated by the experiments of v. Reeklinghausen and Dybkowsky, and their eharacters and relations have been very carefully described by Dr. Klein. He distinguishes two kinds, the true and the false. The true are cither the mouths of vertical lymphatie ehannels, which are lined by a speeial layer of polyhedral eells eontaining granular protoplasm, and lead in to the lumen of a superfieial lymphatie vessel, or they represent a diseontinuity betwecn the endothelium of the surface leading into a simple lymphatie sinus near the surface, lined on one side only with epithelium. The false or pseudo-stomata are perpendieular proeesses whieh extend from the superfieial cells of the cell-network of the matrix of certain nodules, and pass up betwcen the endothelial cells of the surface.

151. The whole of the Lacteal Lymphutic system, with the serous cavities in connection with it, may thus be looked upon as eonstituting one great Assimilating Gland, dispersed through the body at large; for it does not differ in any essential partieular from what the Kidney or the Testis would be, if it were simply unravelled, and its convoluted tubuli spread through the entire system, yet still all discharging their seereted produets by a common outlet. In the eold-blooded Vertcbrata, the Absorbent system appears to attain a relatively greater development than it does in the higher elasses; but the difference really lies in the greater extension, in the former, of those

FIG, 88.

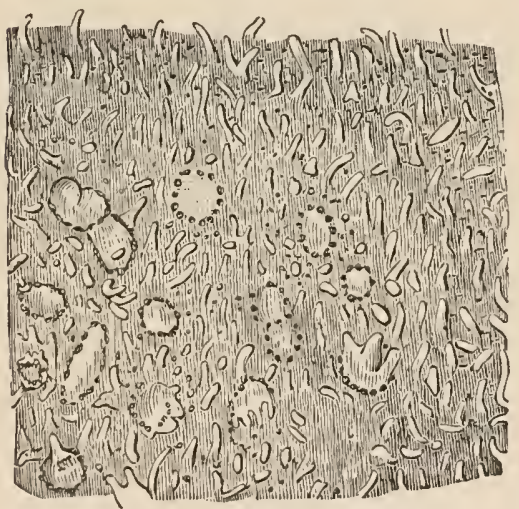

Portion of the mucous surface of the end of the Human Ileum, moderately magnified, showing the Pcyerian Glands, the orifices of the follicles, and the villi. glandular elements whieh are more eoneentrated in the latter (see Prixc. of Comp. Phys., $\S \S 184-187)$. - Scattered through the whole length of the intestinal mucous membrane, from the Stomaeh to the Reetum, are eertain peeuliar bodies, which are known as Peyer's Glands. These may be either "solitary" or "agminated ;" the former being very generally distributed throughout the intestinal eanal, whilst the latter are restrieted to the small intestine, being most abundant at the lower part of the ileum. In whatever portion of the canal they may occur, they are always limiterl in situation to that part of its periphery which is opposite to the mesentery. Eaeh "Peyerian gland," in a healthy mueous membrane, presents the appcaranee of a cireular, white, slightly-raised spot, about a line in diameter, over whieh the membrane is usually less beset with villi, and is very often entircly destitute of them; and it is surrounded by a ring of openings, whieh are the orifices of a set of creal follicles disposed in a zone around it (Fig. 88). The "Peycrian patches" (Figs. 88, 89) present aggregations of these spots, varying in number from two upwards, but every one of their individual eomponents having preeisely the same strueture as the solitary gland. This appears, from the researches of Brïeke, Kölliker, and others, to be a sort of eapsulc, whosc walls arc composed of indistinetly fibrillated conneetive tissue with interspersed nuclei, and whose eontents are thus but imperfectly differentiated from the tissues in which the gland is imbedded. The eontents of 
the glands are made up of an adenoid or cytogenous tissue, the meshes of which contain lymph-corpuscles, and fatty anrl albuminous molecules of various size; altogether presenting an appearance of being the seat of rapid changes of progressive metamorphosis. Each follicle is surrounded by a large lymphatic sinus, ${ }^{1}$ beneath which is a close vascular network; and according to the observations of Frey, which have been confirmed by Kölliker, ${ }^{2}$ capillary vessels pass freely into the midst of its contents, and then return loops, as shown in Fig. 89. The researches of Teichmann ${ }^{3}$ show

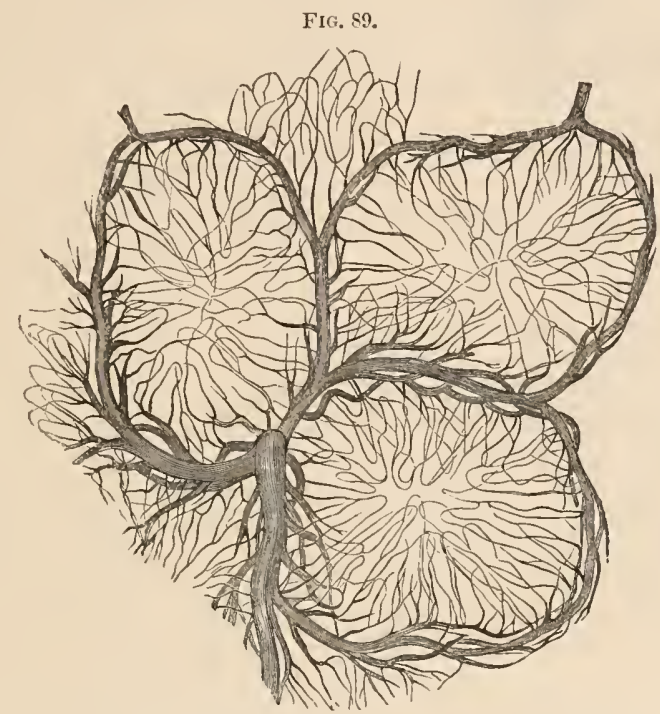

Horizontal Section through the middle plane of three Peyerian Glands in the Rabbit, showing the distribution of the bloodvessels in the interior.

that these bodies are never penetrated by any lacteal vessels, though their presence in the mucous membrane occasions considerable disturbance in the usual arrangement of the lacteal system. The figures on page 189-190 show clearly the relations which they hold to the surrounding vessels, together with the general structure of the small (Fig. 76) and large intestine

1 Klein, in Handbook for the Physiological Laboratory, 1873, p. 125.

2 Mikroskopische Anatomie, Band ii, ? 171.

3 Teichmann's investigations were chiefly made by means of injections; but His, who examined thin sections of the intestinal mucous membrane after merely washing them with water and a camel-hair brush (Untersuch. über den Bau der Peyerischen Drüsen, Leipzig, 1868, p. 7), maintains tle elaborate system of vessels described by Teichmann to be only splits or fissures in the membrane between the follicles, traversed by fibrous cords and bands, and containing bloodvessels. At the same time he agrces with the view that they serve as channels for the conduction of the chyle. He considers that the proper substance of the parietes of the follicles is continuous with that of the villi and subjacent portion of the mucous membrane; both consisting of a matrix of areolar tissue with nucleated cells imbedded in it, and of capillaries, the latter being sparingly distributed to the follicles, causing them to appear like clear spaces in finc sections. He applies the term adenoid tissue to the matrix of the follicles, and to the surrounding tissue of the intestinal mucous membrane. The Lieberkülnian Glands are imbedded in this adenoid substance, and immediately cxternal to them is the muscular layer (Brücke) of the mucous membrane. He believes lastly, that the cells imbedded in the adenoid substance become blood-corpuscles. 
(Fig. 77). In their course through the mesentery, the Lacteals pass into the bodies known as the Mesenteric Glands, which stand in the same relation to them that the Absorbent Glands of the body generally do to the Lymphatics.

152. Composition and Properties of the Chyle and Lymph.-The chief chemical difference between these fluids consists in the much smaller pro-

FIG. 90.

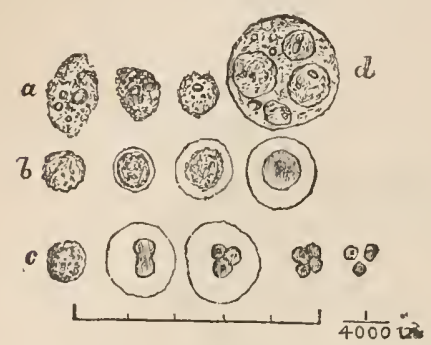

$a$, Formation of lympll-corpuscle, - first a shapeiess aggregation of moleculcs in a very finelygraular basc, next acquiring shape, which is completed in the third object. At $d$ is an endogenous brood of lymph-corpuscles. $b$, the perfect lymph-corpuscle acquiring a cell-wall, closely adhering at first, and distended and madc clearer in the last object by dilute acetic acid. c, first, the perfect lymph-corjuscle, scarcely affected, after having been soaked in strong acetic acid; then pale cells, from the lymph of the thoracic duct, showing the double, triple, and quadruple division of the nucleus under the action of the same acid. they now show indications of cleavage under the influence of acetic acid, which previously exerted little or no influence upon them. The stages of formation of the lymph-corpuscles are well shown in the adjoining diagram after Mr. Gulliver.' The oil-globules found in the lymph are always espeportion of solid matter in the Lymph, and in the almost entire absence of fat, which is an important constituent of the Chyle. Lymph is, in general, a colorless transparent fluid, sometimes yellowish, and sometimes turbid or opalescent, having a faint odor, salt taste, and alkaline reaction. Its chemical characters, according to Lud wig, vary considerably at different periods, and even in different parts of the system at the same time; so that of the fluids taken from the two sides of the neck, it will sometimes happen that one will coagulate spontancously, whilst the other remains fluid. A considerable, though variable, number of corpuscles and minute oil-globules are generally present; the lymph-corpuscles are nuclei, which may acquire a coating that gradually assumes the form of a cell-wall, the whole then becoming the pale cell of the blood. In the act of acquiring this envelope, however, the nuclei undero some alteration, since

\begin{tabular}{|c|c|c|c|c|c|c|c|}
\hline \multirow{2}{*}{\multicolumn{2}{|c|}{ In 1000 parts of Lymph. }} & \multicolumn{2}{|c|}{ Gubler and Quévenne. } & \multirow{2}{*}{$\begin{array}{c}\begin{array}{c}\text { Marchand } \\
\text { and Colluerg. }\end{array} \\
\text { III. }\end{array}$} & \multirow{2}{*}{$\begin{array}{c}\text { Scherer. } \\
\text { IV. }\end{array}$} & \multirow{2}{*}{$\frac{\text { Nasse. }}{\text { v. }}$} & \multirow{2}{*}{$\frac{\text { Dähnhardt.? }^{\text {VI. }}}{\text { V. }}$} \\
\hline & & I. & II. & & & & \\
\hline $\begin{array}{l}\text { Water, } \\
\text { Solid residue, }\end{array}$ & $\begin{array}{ll}\cdot & \cdot \\
. & .\end{array}$ & $\begin{array}{r}939.87 \\
60.13\end{array}$ & $\begin{array}{r}934.77 \\
65.23\end{array}$ & $\begin{array}{r}969.26 \\
30.74\end{array}$ & $\begin{array}{r}957.60 \\
42.40\end{array}$ & $\begin{array}{r}940.60 \\
60.50\end{array}$ & $\begin{array}{r}985 \\
15\end{array}$ \\
\hline $\begin{array}{l}\text { Fibrin,. } \\
\text { Albumen,. } \\
\text { Fut,. } \\
\text { Extractives, } \\
\text { Salts, }\end{array}$ & 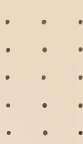 & $\begin{array}{r}0.56 \\
42.75 \\
3.82 \\
5.70 \\
7.30\end{array}$ & $\begin{array}{r}063 \\
42.80 \\
9.20 \\
4.40 \\
8.20\end{array}$ & $\begin{array}{r}5.20 \\
4.34 \\
264 \\
3.12 \\
15.44\end{array}$ & $\begin{array}{r}0.37 \\
34.72 \\
\ldots \ldots \\
\cdots \\
7.31\end{array}$ & $\begin{array}{l}1.65 \\
\ldots \ldots \\
\ldots \ldots \\
\ldots \ldots\end{array}$ & 10 \\
\hline
\end{tabular}

cially abundant after food. The preceding table shows the results of some of the most accurate analyses that liave been made upon human Lymph : ${ }^{3}$

3 v. Gorup-Besanez, Physiol. Chem., 1862, p. 358. 
The Lymph examined in the analyses numbercd I and II was obtained from the thigh of a healthy woman, 39 years of age; that in No. III from a wound on the dorsum of the foot; that in No. IV from a saccular dilatation of a Lymph-vessel of the spermatic cord ; that in No. V from a lymphatic fistula; and No. VI from the thigh of a patient suffering from Barbadoes leg. Leucin, Sugar, and Urea have been found in the Lymph; the latter in the very perceptible proportion of 0.1 to 0.2 parts per 1000 (Wurtz). The gases containcd in the Lymph of man were long ago in vestigated by Hensen, ${ }^{1}$ but the recent researches of Hammarsten" are morc rcliable, though they were made upon lymph obtained from the dog. Hammarsten found about 30-32 per cent, of gas in the lymph, of which nearly the whole was carbonic acid, the quantity of nitrogen being 1 per cent., whilst there was only a trace of oxygen.

153. In fasting animals, the composition of the Chyle appears to resemble very closely that of the Lymph, but during digestion its qualities sensibly altcr. The following analyses, compared with the table above, will enable a comparison to be made between the Chyle and Lymph of man:

\begin{tabular}{|c|c|c|c|c|c|c|}
\hline & Man. & Cow, & $\begin{array}{l}\text { Horse } \\
\text { Thoracie Duct. }\end{array}$ & $\begin{array}{l}\text { Ass. } \\
\text { Tho racic Duct. }\end{array}$ & Dog. & Cat. \\
\hline & Owen Rees. & Lassaigne. & Simon. & Owen Rees. & Schmidt. & Nasse. \\
\hline $\begin{array}{l}\text { Water, } \\
\text { Solid residue, }\end{array}$ & $\begin{array}{r}904.8 \\
95.2\end{array}$ & $\begin{array}{r}964.40 \\
35.60\end{array}$ & $\begin{array}{r}92823 \\
71.57\end{array}$ & $\begin{array}{r}902.37 \\
97.63\end{array}$ & $\begin{array}{r}916.65 \\
83.35\end{array}$ & $\begin{array}{r}905.7 \\
94.3\end{array}$ \\
\hline $\begin{array}{l}\text { Fibrin,. } \\
\text { Albumen,. } \\
\text { Fat, } \\
\text { Extraetives, } \\
\text { Salts, : }\end{array}$ & $\begin{array}{c}\text { Traees. } \\
70.80 \\
9.20 \\
108 \\
4.4\end{array}$ & $\begin{array}{c}0.95 \\
28.0 \\
0.40 \\
0.55 \\
5.70\end{array}$ & $\begin{array}{r}0.72 \\
49.89 \\
489 \\
11.42\end{array}$ & $\begin{array}{r}3.70 \\
3516 \\
36.01 \\
15.65 \\
7.11\end{array}$ & $\begin{array}{r}2.12 \\
35.75 \\
33.02 \\
4.03 \\
8.39\end{array}$ & $\begin{array}{r}1.30 \\
48.90 \\
32.70 \\
\because \cdots \\
11.40\end{array}$ \\
\hline
\end{tabular}

The small proportion which the oleaginous bear to the albuminous substances (as in the case of the lymph), in the first three of the preceding analyses, is probably due to the circumstance that in these instances but little food had been taken for some hours before death. The characters of the Chyle drawn from the largcr absorbent trunks, near their entrance into the Receptaculum chyli, are very different from those of the fluid first absorbed into the Lacteals; for during its passage through these vessels and the Mesenteric glauds, it undergoes important alterations, which gradually assimilate it to Blood. The chyle drawn from the lacteals that traverse the intestinal walls contain Albumen in a state of complete solution; but it is generally destitute of the power of coagulation, no Fibrin being present in it. The salts, also, are completely dissolved; but the Oily matter presents itself in the form of globules of variable size. ${ }^{3}$ It is generally supposed that the milky color of the chyle is owing to these ; but Mr. Gulliver has pointed out ${ }^{4}$ that it is really due to an immense multitude of far more minute particles, which he describes as forming

1 Virehow's Arehiv, Band xxxix.

2 Ludwig's Arbeiten, 1872, p. 121.

3 These oily globules are more abundant in the Chyle of Man and of the Carnivora than in that of the Herbivora; their diameter lias been observed to vary from $\frac{1}{250} \overline{0}$ th to $\frac{1}{2} \frac{1}{60}$ th of an inch.

4 Gerber's General Anatomy, Appendix, p. 88; and Hewson's Works (Sydenham Soeiety Edition), notes to pp. 82-88; and College Leetures in Med. Times and Gazette, 1863. 
the molecular base of the ehyle ( $a$, Figs. 91, 92). These molecules are most

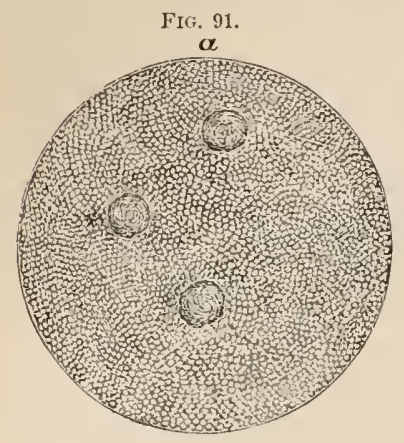
abundant in rich, milky, opaque chyle; whilst in poorer chyle, which is semi-transparent, or opaline, the particles float thinly or scparately in the transparent fluid, and often exhibit the vivid motions common to the most minute molecules of various substances. Such is their minuteness that, even with the best instruments, it is impossible to form an exact appreciation either of their form or their dimensions. They seem, however, to be generally spherical; and their diameter may be estimated at between $3 \frac{1}{3000}$ th and $5 \frac{1}{4000}$ th of an inch. Though remarkable for their unchangeableness, when subjected to the action of numerous reagents which quickly

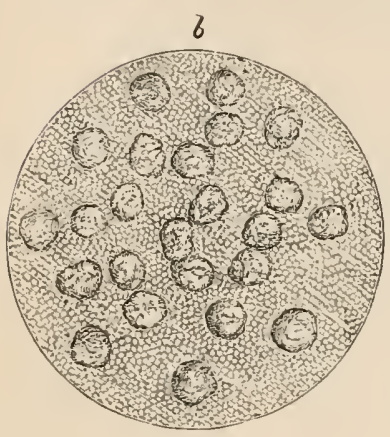
affect the proper Chyle-corpuscles, they are readily soluble in ether, the addition of which causes the whole molecular base instantly to disappear, not a particle of it remaining; whence it may be inferred that they consist of oily or fatty matter. That they do not ordinarily tend to coalesce, is probably due to the coating of albumen which they obtain through their diffusion in an albuminous fluid; if, however, this be dissolved by acetic acid, or even when water is added, many of the molecules are lost sight of, and oil-drops appear in their place. The milky color which the Serum of blood always exhibits in healthy subjects during the most active period of digestion, is due to an admixture of this molecular base with the circulating fluid.

154. During the passage of the Chyle through the absorbents on the intestinal edge of the mesentcry, towards the Mes. enteric Glands, its character changes in several important particulars. The presence of Fibrin begins to manifest itself by the slight coagulability of the fluid when withdrawn from the vessels; and a few Chyleor Cytoid-eorpuscles make their appearance; though these may occasionally be observed in the chyle from a lacteal on the wall of the intestine. The corpuscles are most abundant in the chyle of the mescnteric glands, and beeome less numcrous again in the fluid of

Molecular Base and Corpuseles of Chyle. At $a$, from a lacteal on the intestine; $b$, from a mesenteric gland; $c$, from the recetaculum chyli. From a man.

the thoracic duct (compare $a, b, c$, Fig. 91). The average diameter of these bodies is about $\frac{1}{4} \sigma_{0}$ th of an inch. During digestion they are scen to be accompanied by much of the fatty molecular base of the chyle (a, Figs. 91, 92), sonie particles of which have coalesced to form larger oncs, surrounded by a thin layer of albumen (b, Fig. 92). Two, three, or more of the eorpuscles may be sometimes seen inclosed within a eommon 
cell. The smaller Chyle-corpuscles appear like the Lymph-corpuscles to be in the condition of nuclei (d, Fig. 92); in those a little larger, the cell-wall is beginning to be differentiated from the nucleus; whilst in those of greatest diameter the cellular character is very distinct, and the nuclens may be plainly seen in the interior, especially after the addition of a little water or acetic acid. They occasionally exhibit curious

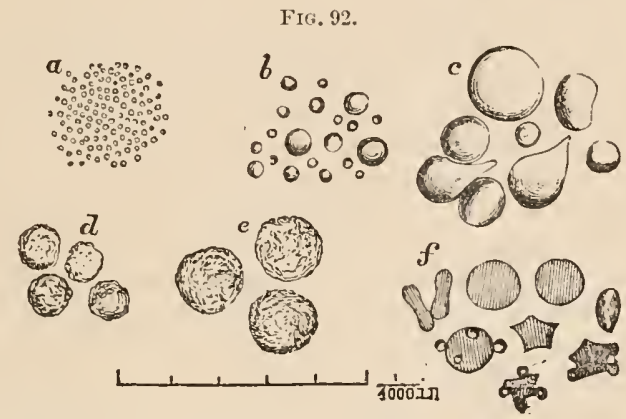

At $a$, primary molecules of chyle; $b$, secondary molecules of chyle; $c$, fatty globules; $d$, chylecorpuscles; $e$, pale cells ; $f$, red corpuscles.

changes of form; in this respect corresponding with the colorless corpuscles of the blood, which are probably the sane bodies in a more advanced stage. The Chyle drawn from the lacteals that intervene between the Mesenteric glands and the Receptaculum, possess a pale reddish-yellow color; and, when allowed to stand for a time, it undergoes a regular coagulation, separating into clot and serum. The former is a consistent gelatinous mass, which, when examined with the microscope, is found to include the Corpuscles, each of them surrounded by a delicate film of oil; the Fibrin of which it is principally composed differs remarkably from that of the Blood in its inferior tendency to putrefaction; whence it may be inferred that it has not yet undergone its complete vitalization. The serum contains the Albumen and Salts in solution, and a proportion of the Corpuscles suspended in it. It is curious, however, that considerable differences in the perfection of the coagulation, and in its duration, should present themselves in different experiments. Sometimes the chyle sets into a jelly-like mass, which, without any separation into coagulum and serum, liquefies again at the end of half an hour, and remains in this state. The Chyle from the Receptaculum and Thoracic duct coagulates quickly, often almost instantaneously; and few or none of the corpuscles remain in the scrum. The fluid drawn from the Thoracic duct, and from the Absorbent vessels which empty their contents into it, is frequently observed to present a decided red tinge, which increases on exposure to the air. This tinge appears to be due to the presence of Red blood-corpuscles in an early stage of formation. ${ }^{1}$ The ordinary corpuscles, moreover, have a more distinctly eellular character than have those of the chyle and lymph, and they are of larger size, their diameter usually ranging from about $\frac{1}{2} \frac{1}{900}$ th to $\frac{2}{260}$ th of an inch: in these particulars they correspond with the colorless corpuscles of the Blood; as also in the change they exhibit on the action of acetic acid, which brings into view two, three, or four distinct central particles. The quantity of lymph which can be ob-

1 See Gulliver, Med. Times and Gaz, vol. ii, 1863, p. 449. 
tained from the head and neck of the dog is estimated by Krause ${ }^{1}$ at onethird, and by Weiss ${ }^{2}$ at one-fifth of the weight of those parts; but these proportions are probably too high for the body generally; other experiments of TWeiss showing that it varies from one-fifth (after an abundant supply of milk) to one-twelfth of the total weight. Bidder and Schmidt ${ }^{3}$ estimated that in man nearly thirty pounds of mingled lyniph and chyle are daily poured into the subclavian vein.

155. The movement of the fluids taken up by the Absorbent vessels seems to depend upon a combination of different agencies. The lower Vertebrata are provided with "lymphatic hearts," " or pulsatile cavities, by which important assistance is given to the onward flow; but no such aid is afforded in Man or in the Mammalia; yet it is obvious that a considerable vis a tergo must exist, since, if the thoracic duct be tied, it is speedily distended below the ligature, even to bursting. In the Lymphatics as well as in the Lacteals of the higher animals, the onward course of the contained fluids is probably aided by the contraction of the unstriped muscular tissue in their walls, assisted by the action of the valves; and to this perhaps we may attribute the emptiness of the absorbent system which usually presents itself some little time after death. Moreover, in all the movable parts of the body, material assistance is afforded (as it is to the circulation in the veins) by the occasional pressure exercised upon the lymphatic ressels by the surrounding tissues (as the nuscles, Paschutin); for while this pressure is operating it will tend to empty them of their contents, which are only permitted by the valves to pass in one direction; and when the pressure is relaxed, they will be refilled from behind. In the lacteals, special agents for the propulsion of the chyle exist in the muscular fibres contained within the vilii, which constitute so many minute force-pumps that are perhaps stimulated to action (as suggested by Schiff) by the irritating properties of the bile. When the lacteal and lymphatic fluids have arrived at the thoracic duct, besides the forces already mentioned, their flow receives an additional impetus from a vis a fronte derived in part from the suction-power exerted by the rapid movement of the blood in the subclavian veins, the influence of which may readily be proved experimentally, and partly from the negative pressure exerted upon the walls of the duct during the period of inspiration, the opposing influence of expiration being neutralized by the valves. ${ }^{5}$ Noll ${ }^{6}$ found the pressure in the larger lymphatics of the neck in cats and dogs to be equal to that of a column of water varying from $\frac{1}{2}$ to $1 \frac{1}{4}$ inch in height $(10-30 \mathrm{~mm}$.), but it is probably much higher in the smaller vessels. The rapidity of the current in the lymphatics of the neck is stated by Weiss to be about one-sixth of an inch per second.

156. Since the bloodvessels constitute a closed system of canals interposed between the histological elements of the various organs, a continual process of transudation must take place through their walls, in order that the fluids appropriate to the nutrition of the different tissues may be supplied in due proportion to their requirements. This effect is probably in part the result of the operation of the laws of Osmosis, which are here made subservient, not only to the passage of the nutrient materials of the blood outwards, but also to the introduction of the products of disintegration into the circulating

1 \%eits f. rat. Med., Bd. vii, p. 148.

2 Virchow's Archiv, B. xxii.

3 Verdauungssäfte und Stoffwechsel, 33 224, 285.

4 See Wharton Jones on Lymphatic Heart of Eel, Proc. Roy. Soc., Nos. 98 and 101,1868

6 Dybkowsky, Bericht. d. Suchs. Greell., 1866.

6 Ludwig, Physiologie, vol. ii, p. 581. 
fluid for the purpose of being ultimately discharged by the excretory organs. But the main agent in the process appears to be the constant and considerable pressure exerted by the blood against the inner surface of the vessels, effecting a filtration of its fluid portions into the irregular cavities and intcrispaces of the connective tissue which are now believed to constitute the true origin of the Lymphatics. This view receives support from the experiments of Tomsa, ${ }^{1}$ who has shown that the injection of serum into the vessels immediately after death, at the ordinary pressure of the blood, is followed by the filtration of a fluid closely analogous to lymph in its characters, which can readily be obtained from the lymphatic vessels. And there is abundant evidence to show that those circumstances which tend to increase the pressure in the capillaries, either by forcing more blood into the part, ${ }^{2}$ or by preventing its return by ligature or pressure applied to the veins (provided that complete stoppage of the current of the blood is not produced), are followed by an increased discharge of lymph, as well as of lymph-corpuscles, ${ }^{3}$ from the larger absorbent vessels. It is easily intelligible that various other causes besides pressure may influence the quantity and quality of this fluid, which, as Milue-Elwardst observes, is poured forth to irrigate the various organs of the body; for besides the important condition of the quality of the blood (with the effects of variations in which we are but imperfectly acquainted), differences in the thickness of the walls of the vessels and of the external pressure to which they are subjected, may to some extent be the causes of those differences in the nature of the transudate observed in $\mathrm{Hy}$ drocephalus, Ascites, and Hydrocele. ${ }^{5}$ - That the central nervous system excrcises considerable influence over the process of absorption is clearly shown by the cxperiments of Goltz. ${ }^{6}$ In these, which were marle upon frogs, rendered motionless by woorara, the brain and spinal cord were removed in some instances, whilst in others they were left intact. In both sets of frogs fluid was injected into the dorsal lymph-sac, and it was found that the fluid was rapidly carried off in those in which the brain and spinal cord were uninjured, whilst little or no absorption took place in those in which those organs had been removel. Nasse, who has also investigated this subject, found that irritation of sensory nerves caused increase in the flow of lymph. Excitation of the pneumogastric trunk, or of its centric extremity when di-

1 The serum used in Tomsa's experiments containcd from 677 to 6.26 per cent. of solid residue, and that obtained from the Lymphaties from 6.12 to 4.36 per cent, which is about the proportion in ordinary lymph. Paschutin, however, has arrived at a different conelusion, and believes that variations in the arterial pressure have no influence on the flow of lymph. The secretion is increased, and its composition altered by the administration of woorara. His experiments were made on the lymphaties of the fore leg of the dog. Sitz. d. König, Sächs. Gesellsch. d. Wis., 1873, p. 95. For corroborative observations see Genersich in idem, 1870, and Emminghaus, Ludwig's A rbeiten, 1873 , B. viii, p. 51.

2 As was effected by Mr. Robinson in his experiment recorded in the Med.-Chir. Trans., vol. xxvi, p. 51, when the aorta just above its division into the common iliaes, and also one of the renal arteries, were tied, and ulbumen immediatcly made its appcarance in the urine, being as it were forced, by the increased pressure in the remain. ing renal artery, through the delicate filter formed by the walls of the vessels in the Malpighian tufts.

3 See Cohubeim, Virchow's Archiv, 1867, Bd. xl, p. 1.

4 See his excellent chapter on Transudation in the Leçons sur la Physiologie, vol. iv, $1859, \mathrm{pp} .391-446$.

5 See Hales's Hiemastatics, pp. 118-119.

6 Pflüger's Archiv, Band v, p. 53. See also Bernstein, Berliner klin. Woehens., 187.2, Nu. 28, and E. Heubel Virehow's Archiv, 1872, Bd. lvi, p. 248.

7 Centralblatt, 1873 , p. 155. 
vided, augmented the flow. The influence of the nervous system is, however, in all probability only indirect, being due, in Goltz's experiments, to the circumstance that in the uninjured animals the circulation was maintained, whilst in those deprived of their nervous system the vessels of the body generally had lost their tone, and the blood accumulated in the veins of the abdomen and in other parts to such an extent indeed that little blood escaped even when the aorta was divided. In Nasse's experiments, again, the effects of the irritation of the sensory nerves was doubtless to cause contraction of the small vessels. 'The results of Krause's and Tomsa's experiments likewise learl to the conclusion that the influence of the nervous system is indirect, for whilst Tomsa found that irritation of the nerves proceeding to the testicle produced no alteration of the quantity, Krause obtained both upon irritation of the mucous membrane of the mouth, that is to say on irritation of the fifth pair of nerves, as well as on excitation of the portio dura, a considerable increasc in the flow; the different effect in the two eases being clearly the result of the intermittent pressure of the muscles in the parts traversed by the lymphatics in the one instance, and the entire absence of muscles in the other.

157. Vascular or Ductless Glands.-There is reason to believe that the office performed by certain bodies connected with the Sanguiferous system, which possess the essential elements of the Glandular structure without any efferent ducts, is to restore to the circulating current any substances which they may withdraw from it; and there seems adequate ground, therefore, for the conclusion, that their action, whatever it may be, is subsidiary to the process of Sanguification,-being exercised, perhaps, upon that portion of the nutrient materials more especially, which did not traverse the A bsorbent system when first introduced, but which was directly taken up by the Bloodvessels. The organs in question are the Spleen, and the Thymus, Thyroid, and Suprarenal bodies. Of these the Spleen deserves especial notice, on account of its size and its obvious functional importance in the adult; the others appearing to minister more particularly to the requirements of the system at the earlier periods of life.

The minnte structure of the Spleen has recently been made the subject of careful research by many excellent microscopic observers; and the following arc the most important points which may be considered to have been established by their labors: ${ }^{1}$

I. The fibrous coat in Man is composed of white fibrous tissue, with an intermixture of yellow or elastic fibres, and perhaps a few fusiform non-striated muscular fibre-cells; which, however, are much more numerous in many of the lower animals. The trabecular tiszue consists of bands and threads of fibrous tissue, which arise from the inner surface of the fibrous envelope, and

1 See Kölliker, Cyel. of Anat. and Plysiol, vol. iv, Art. Spleen; and Mikroskop. Anat., Bal. ii, 多 183-189; Sanders, Gnodsir's Annals of Anat. und Physiol, No. I, and Edin. Jonthly Journal, March, 185\%, p. 286; Wharton Jones, Brit and For. Hed.-Chir. lieviow, vol. xi, p 32; Huxley, Quart. Journ, of Mieroscop. Sci., vol. ii,p 74; and 'Transl. of Kölliker's Manuat of Hunan Histohgy (Sydenhum Socirty), vol. ii, P. 144; Grav, On the Structure and Use of the Spleen (Astley Cooper Prize Essay, 18.54); Romak, Muller's Archiv, 1852; Leydig, Anatomische-Histolugische Untersuchungen uber Fi-che und Reptilico, 1853; Billroth, Arehiv für Path. Anat.,

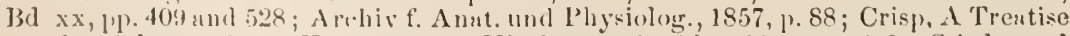
(1) the spleen, 1857; Kownlowsky, Virchow's Archiv, 1861, P. 2013; Stieda and Schwrigger-Siedel, id., bil. xxiv, 23, p. 457; Peremeschko, sitzungsber. d. k. A kind. zu Wien, Bd. Iv und lvi, and Muller in Gott Nach, 1862-1863; W. Müller, Monocraph on the Spleen, Leipsic, 1865, and Stricker's Manual of Histology (Syd. Soc. Transl.), vol, i, p. 348. 
form a network that extends through the cntire organ, becoming connected also with the fibrous sheaths of the vessels which penetrate it. These bands are partly muscular in those animals which have muscular fibres in the external envelope; but elsewhere they are simply fibrous. The spaces left by their interscetion, which are by no means regular as to either form or size, are occupied by the splenic corpuscles and splenic parenclryma.

II. Of the Arteries of the Splecn, it is chiefly to be observed that their branches form no anastonoses, but subdivide and ramify like the branches of a tree, with the Malpighian corpuscles attached to them as fruit (Fig. 93). Beyond their conncetion with these, however, they enter the general mass of the splenic parenchyma ; and here each twig subdivides into a tuft of arterioles still more minute, which either pass directly into capillary veins (Billroth) or again subdivide in to the true capillaries. At their entrance into the hilus of the organ, the arterics receive a sheath from the capsule composed of fibrillar connective tissue, with numerous elastic fibres, and a moderate proportion of cell elements. Where the arteries separate from the veins, and are not more than $7_{75}^{1}$ th to $\frac{1}{12} 5$ th of an inch in diameter, the sheaths become much looser and converted into a cytogenous tissue.-The Capillaries, bounded only by their very thin walls, pass in every direction through the spleen-pulp, both in the general mass of the organ, and also in the interior of the Malpighian corpuscles. But it is affirmed by Mr. Gray, with whom Stieda and W. Müller, and still more recently Stoff and Hasse, agree, that in the Spleen of Man and of many other animals, the walls of the capillaries frequently disappear, and that the blood, in passing from the minutest arteries to the minutest veins, moves in great part through lacunce, or mere channels in the pulp-tissue.-Of the Veins, the idea has been generally entertained, that they are dilated into cavernous spaces or sinuses; but this, though true of many of the lower Mammalia, especially of ruminants and diving animals, is the case to only a very limited extent in Man. Their mode of ramification closely resembles that of the arteries; and they are unprovided with valves.

III. The Parenchyma of the Spleen essentially consists of cells in various stages of evolution, imbedded in a granular plasma (the periplast of Huxley); thus corresponding in every essential particular with the contents of the Peyerian and absorbent glandulæ ( $\$ 156)$, and giving evidence, as they do, of being in a state of rapid developmental change. The amount of this colorless parenchyma is stated by $\mathrm{Mr}$. Gray to undergo a marked increase towards the end of the digestive process, when a large quantity of new alimentary material is being introduced into the sanguiferous current; whilst, in the intervals of this operation, it undergoes a gradual diminution.-The peculiar Splenic Corpuscles, or "Malpighian bodies of the Spleen," are whitish spherical bodies, which are connected with the smaller arteries by short peduncles, like grapes with their fruit-stalks, or are sessile upon their sheaths (Fig. 93). Their diameter usuaily varies between one-third and one-sixth of a line; smaller bodies, however, are met with, which appear to be Malpighian corpuscles in an earlier stage of evolution. The boundary of each is an indistinctly fibrous membrane, which appears to be partly formed by the metamorphosis of the extcrnal cells of its contained parenchyma, and to be partly derived from the fibrous coat of the artery to which it is attached. ${ }^{2}$ And its contents correspond, in every essential particular, with

1 Centralblatt, 1872 , p. 753 .

2 It has been commonly supposed that the Malpighian corpuscles are invested by a distinct limitary membrane, like the acini of ordinary Glands; but such, from the ubservations of Wharton Jones and Huxley, would clearly seem to be not the case. 
the colorless parenchyma in which they are imbedded. Their walls are

FIG. 93.

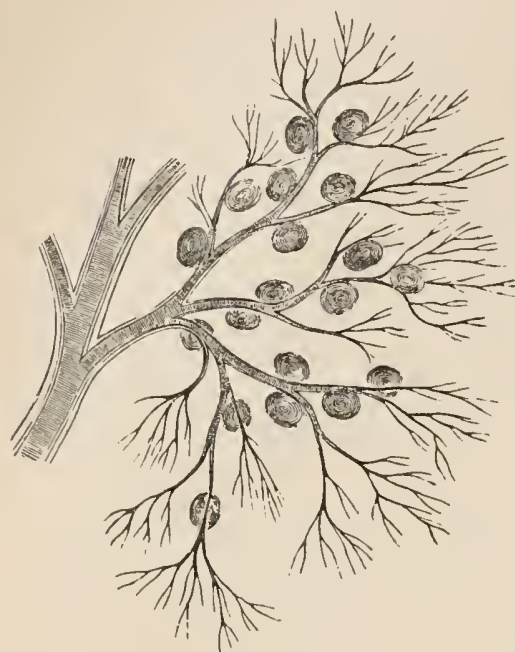

Branch of Splenic Artery, the ramifications of which are studed with Malpighian corpuscles. covered with a plexus of capillaries, and branches from these traverse their interior, just as in the case of the Peyerian and Absorbent glandulx. The number and size of the Malpighian corpuscles bear a remarkable relation to the general state of nutrition; being much the greatest in healthy well-fed animals, whilst in those that have been illfed they diminish extremely, and in those that have been starved they disappear altogether. Hence it has happened that their existence in the Human species has been denied; the opportunity of examining subjects not reduced by previous abstinence, being one that comparatively seldom occurs. There is no doubt, however, of their normal presence in the spleen of Man, as in that of other Mammalia.-Diffused amidst the colorless parenchyma, but in very variable amount, colored cells are found, some of which are unchanged blood-corpuscles, whilst others appear to be blood-disks in various stages of retrograde metamorphosis; these gradually diminishing in size, and assuming a golden-yellow, brownish-red, or even blackish color, or having the pigmentary matter crystallized in a rod-like form in their interior; or,

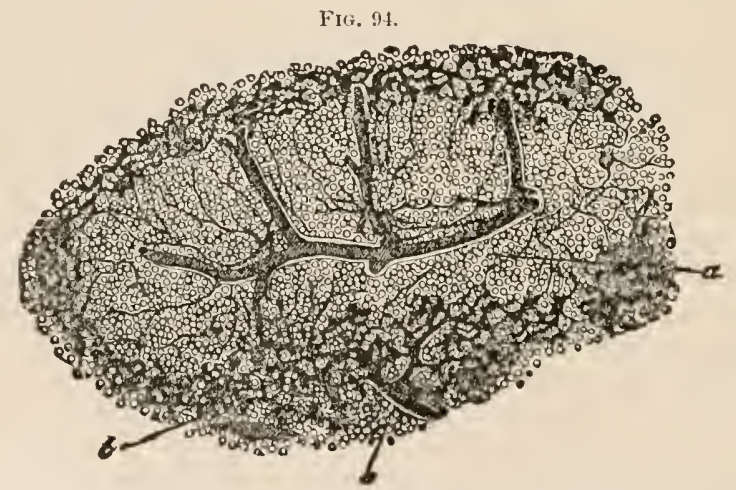

Malpighian corpusclc from the spleen of the Hedgehog, with its vaseular supply: $b$, splenic pulp, with the intermediary blood-passages; $c$, the rootlets of the reins.

again, breaking up into detached pigment-granules. Occasionally (though very rarely in the Human subject) little clusters of from 1 to 20 of such degencrating blood-corpuscles are found, included in a vesicular envelope, originally figured by Mr. Gulliver.' Several of these bodies are seen in the blood

1 Lond. and Edin. Phil. Mag., 1842, p. 169, Fig. 2. 
of the Splenic vein; and it has been hence concluded by some, that they do not constitute aormal elements of the Splenic parenchyma, but that they are cither contained in its capillaries, or, if actually diffused through the pulp, are so as a result of an abnormal extravasation. These conflicting views may be reconciled, if, as stated by Mr. Gray and W. Müller, the splenic blood, in its passage firom the arterics to the veins, ordinarily escapes from the walled vessels into indefinite channels traversed by connective tissue, so that its corpuscles may become diffused through the parenchyma without any departure from its regular course; and it is a confirmation of this view, that the amount of colored corpuscles in the splcen-pulp augments with the general turgescence of the vascular system, and diminishes with the poverty of the blood, so that in animals reduced by ill-feeding, it disappear's altogether.

IV. The Lymphatics of the Spleen are few and inconsiderable in Man; being less numerous than in other glandular organs, such as the liver and kidneys. In some of the lower animals, as in the horse, ${ }^{1}$ they are more abundant, and form two systems, one of which may be followed into the interior of the organ acompanying the larger arteries and veins, and investing the smaller vessels with a distinct sheath, between which and the parietes of the bloodvessels numerous lymph-corpuscles may be found, whilst the other forms a plexus in the trabeculæ. ${ }^{2}$

v. The Nerves of the Spleen are apparently very large in some animals, especially in the Ruminants; but the great size of their trunks and branches is chiefly due to the large proportion of ordinary fibrous tissue which enters them ; the number of real nerve-fibres being extremely small.

vi. The chemical composition of the Spleen is indicated by the following analysis of Oidtmann: In 1000 parts were, water, 750.31, solid residue, 249.69 ; of the latter, 242.32 parts were organic substances, and 7.37 inorganic. A mongst the organic substances, albumen, fats, inosite, lactic, formic, succinic, acetic, butyric, and uric acids, sarkin, xanthin, leucin, pigment, and much choleștcrin have been distinguished. The most remarkable circumstances respecting the inorganic constituents are the large relative quantity of soda salts and of oxide of iron. ${ }^{3}$ From the observations of Mr. Dobson, ${ }^{4}$ which have been corroborated by other observers, it appears that the Spleen attains its maximum volume at the time that the process of chymification is at an end, namely, about five hours after food is taken; and that it is small and contains little blood seven hours later, when no food has been taken in the interval. The removal of this organ from the body has been performed even in man without serious effects; whilst in some instances in animals perfect regeneration has occurred, which is probably attributable to the hypertrophy of the little splenculi so often present in the immediate vicinity of the Spleen $;^{5}$ in others, enlargement of the lymphatic glands in various parts of the body, as the neck and axillie, have been observed. Maggiorani ${ }^{6}$ noticed a deficiency in the amount of iron containcd in the blood-corpuscles; and in the dogs operated on by Dr. Dalton ${ }^{7}$ an unnatural appetite and ferocity of disposition were exhibited, which may perhaps be attributed to imperfect assimilation of the food they consumed.

158. The history of the development of the Spleen, which was studied with

1 See Tomsa, in Sitz. d. k. Akad. zu Wien, Bd. xiviii.

2 See Kyber, in Max Schulte's A rehiv für Mikroscop. Anat., Bd viii, 1872, p. 568.

3 v. Gorup-Besanez, Physiolog Chemie, 1862, p. 600.

4 Lond Med. and Phys. Journ., Oct. 1821.

5 Phillipeaux and Maver, C Rendus, 1861, p. 547.

6 Comptes Piendus, 1861, p. 319.

7 Human Physiology; 1871, p. 203. 
mueh care by Mr. Gray, ${ }^{1}$ presents facts of great interest as aiding in the determination of the functional character of this organ, and of the nature of its component parts.- It arises in the Chick between the fourth and fifth days of incubation, in a fold of membrane which connects the intestinal canal to the spine (the "mesogastrium"), as a small whitish mass of blastema, perfectly distinct from both the stomach and the pancreas; from the former of which it has been said by Bischoff, and from the latter by Amold, to take its origin. The external capsulc and the trabecular tissue are developed between the eighth and ninth days: the former as a thin membrane composed of nucleated fibres; the latter consisting of similar fibres, which intersect this organ at first sparingly, and afterwards in greater quantity. The bloodrcssels of the organ are formed within itself, independently of those which are exterior to it; and hlood-corpuscles are also observed to originate in the substance of its blastema, their formation continuing until its conncction with the general vascular system is completed, at which period their development appea:s to ceasc.-The pulp-tissue, at an early period of its formation, closely corresponds with that of the Suprarcnil and Thyroid bodies in their earliest stages of evolution; consisting of nuclei, nucleated vesicles, and a fine granular plasma. Peremeschko ${ }^{2}$ and Cohnheim ${ }^{3}$ have also noticed peculiar ancebiform cells or protoplasmic bodies to be constantly present in the embryonal spleen, and in the splenic pulp, but their function is unknown. When the splenic ressels are being formed, many of the above-mentioned nuclei arc surrounded by a quantity of fine dark granules, arranged in a circular mode; and these appear to be developed into nucleater vesicles, of which, when the splenic vein is formed, nearly the whole pulp is composed; the nuclei of these subsequently break up into a mass of granules, which fill the cavities of the vesicles. The Malpighian corpuscles are developed in the pulp at the angles of division of the smaller bloodvessels, by the aggregation of nuclei into circular masses, around which a fine membrane is subsequently formed.-Thus during foetal life we have evidence of a process of ccll-growth and maturation, followed by cell-destruction, in the colorless parenchyma. The largest proportional size and the greatest functional activity of the Splcen, howevcr, seem to be exhibited during adolescence and the most vigorous period of adult life, its proportionate weight to the whole body being then as $1: 320$ or 400 .

159. The Suprarenal bodics in Man and most Mammalia present, like the kidneys, a division into cortical and medullary substances; the inner portion of the former having a remarkably dark-brown hue. The cortical substance, divided by Arnold into three zones, named Z. glomcrulosa, fasciculata, and reticularis, is principally formed of a stroma of comnective tissue, so arranged as to leave a series of oval spaces lying cnd to end with some indistinct indications of a tubular structure; the spaces or tubes are filled with a finely granular plasma containing a large number of fat-particles, nuclear corpuscles, and cclls, somc of which are small, spherical, or cubical, with large muclei and finely granular contents, whilst others are large, coarsely granular, with indistinct nuclei, and much fat in their interior. The medullary sulostance consists of a basis of fibrous tissuc which is continuous with processes that come off from the sheath of the eortical substance, and supports a plexus of tubes filled with finely stellate or polygonal grauular cells, together with numerous bloodvessels and nerves." Holm, in the

1 On the Development of the Ductless Glands in the Chick, in Philosophical Transactions, 1852, p. 295; see also his Pri\%e Essay

2 Wien Acrd. Sitzungsher., 1897, Bal lv and lvi.

3 Virchow's Arehiv, Bal, xxxiii, p. 311

4 Sce Art. Suprarenal Capsule in Cyclop. of Anat, and Plysiol., vol. iv; Fölliker, 
suprarenal bodics of oxcn, found, amongst other ehenieal constitucnts, inosite, with hypoxanthin, taurin, probably lenein, and an alkaline eoloring matter. The suprarenal bodies arc more highly supplied with nerves than any other glandlike structure in the body. Kölliker counted no less than thirty-threc branches procecling to one of these bodies, derived from the sympathetic, pnemmogastrie, and phrenic nerves, and whieh, after passing through the eortieal, formed a dense plexus in the medullary portion. In both parts, multicaudate ganglion-cells are prescnt.

160. Though Brown-Séquard ${ }^{1}$ found that ablation of the Suprarenal Capsules was uniformly fatal, yet Phillipeaux, ${ }^{2}$ Harley, and Gratiolet ${ }^{3}$ have shown that this effect is rather attributable to hremorrhage and the unavoidable injury to the nerves, and espeeially to the semilunar ganglia, atteridant upon the operation, than, as Brown-Séquard believed, to the retention of some poisonous substance in the eirculation, whieh it is the officc of these bodies to remove. Of late years much importanee has been attaehed to the study of the diseases of these organs, from the observation of Dr. Addison, that sueh cases are frequently associated with the deposition of pigment in the skin, causing it to assume a deep bronze color. Harley, Parkes, ${ }^{5}$ and many others have, however, shown that bronzing of the skin may be present and yet the suprarenal eapsules be heal thy; whilst Dr. Kirkes, ${ }^{6}$ Davy, and others have recorded cases in whieh disease was present in one or both of these organs, yet no bronzing of the skin oeeurred. Further

FIG. 95.

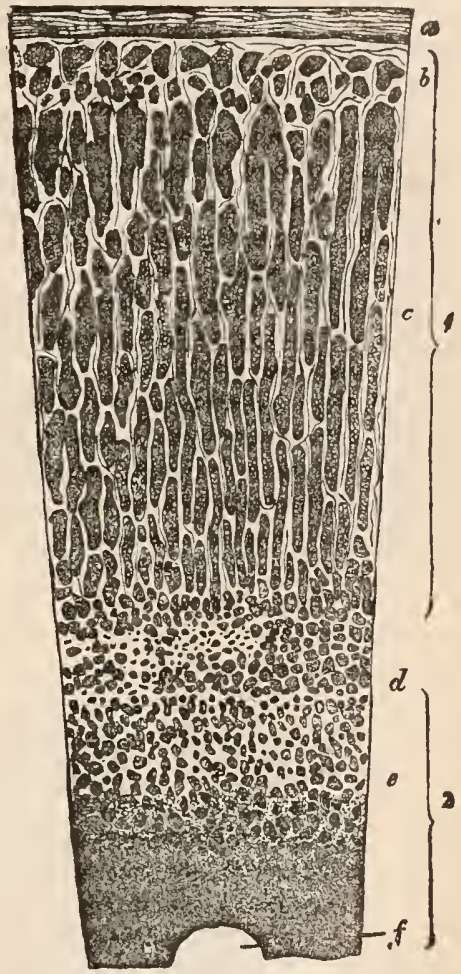

Vertical section of Supratenal Capsule of Man: 1 , cortex; 2 , medulla ; $a$, capsule; $b$, layer of external cell masses; $c$, columnar layer (Zona fasciculata); $d$, layer of the internal cell masses; $e$, m.dullary substance; $f$, section of a vein. inquiry is therefore requisite to determine whether the disease of the eapsules and the discoloration of the skin really stand in the relation of eause and effect.

161. The development of the Suprarenal bodies also has been studied by Mr. Gray (loc. cit.). ${ }^{7}$ They arise in the mesoblast before the seventh day of incubation, as two separate masses of blastema, situated between the upper end of the Wolffian bodies and the sides of the aorta; being totally independent

Mikroskup. Arat. ; Henle, Handbuch der System. Anat., Bd. ii, 1866, p. 561; also Gulliver's Appendix to Gerber's Anat., p. 103, and Figs. 266 and 267 ; Holm, Moleschott's Untersuch., 1867, Bd. x, p. 456; Arnold. Virchow's Archiv, 1866; Eberth, in Stricker's Humnn and Comp. Histolory, vol. ii, 1872, , 110.

1 Journal de la Phys, vol. i, 1858, p. $160 . \quad 2$ Comptes Rendus, $1856-57$.

3 Ied.-Chir. Rev., 1858, vol. i, p. 209.

4 Comptes Rendus, 1856.

5 Med. Times and Gaz., 1858, p. 564.

6 Ib., 1857, p. $85 ; 1859$, p. 30.

7 For a good account of the development of the suprarenal capsules see $A$. v. Brunn, in šchultze's Archiv, Band viii, 1872, p. 618. 
(as concerns their development) of those bodies and of each other. The cortical and medullary portions have a distinct origin. From an early period their minute structure bears a close resemblance to that of the spleen, consisting of the same elements as that gland, excepting in the existence of more numerous dark granules, which give to the organ at a later period an opaque and darkly-granular texture; and the general history follows a very similar course: the Suprarenal capsules, however, acquiring their characteristic structure, and attaining their largest relative size, so early in foetal life, as to surpass the Kidneys in dimension up to the tenth or twelftl week of Human embryonic development; though they afterwards diminish so much relatively to the Kidneys, as to possess in the adult condition only $\frac{1}{2} \frac{1}{8}$ th part of their bulk.

162. The general structure of the Thymus Gland may be best understood from the simple form it presents when it is first capable of being distinguished in the embryo. It is then solid, ${ }^{1}$ but soon breaks down in the central part so as to form a single tube, closed at both ends, and filled with granular matter; and its subsequent development consists in the lateral growth of branching-off shoots from this central tubular axis. In its mature state, therefore, it consists of an assemblage of hollow glandular lobules, united together by connective tissue; and their cavities all communicate with the central reservoir, from which, however, there is no outlet (Figs. 96, 97).

FIG. 96.

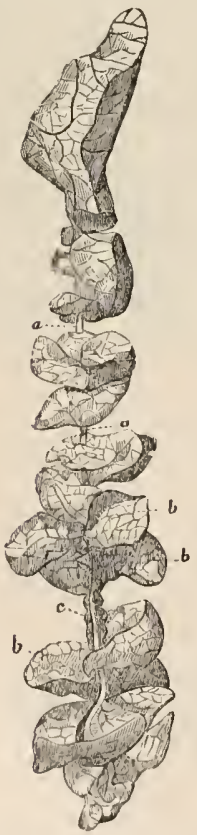

FIG. 97.

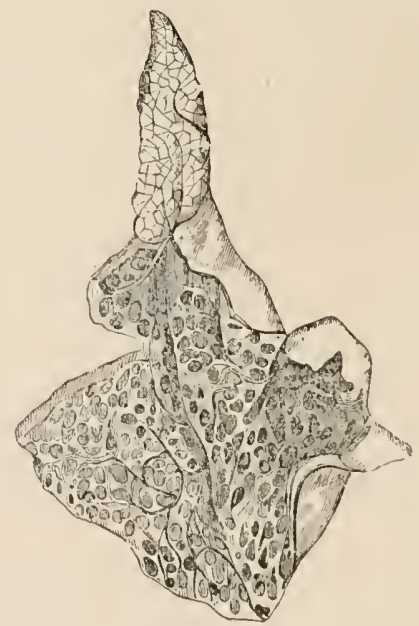

Fifi, 96.-Portion of Tlyymus of Calf, unfolded: $a$, main eanal; $b$, glandular lobules; $c$, isolated gland-granules scated on the main canal.

Fri. 97.-Section of llmman Thymus, showing the large eavity in the wide portion, and ummerous orifiers leating to its lolular cavities.

Each lobule is bounder externally by an indistinctly fibrous or almost homogeneous membrane (Fig. 96, a), which sends prolongations (b) into its 
substanee, that divide it into "aeini" or gland-granules. Isolater glandgranules of the same kind are frequently to be met with on the main canal (Fig. 96, c). The parenchyma of each lobnle or follicle is male up of a plexus of eonnective-tissue fibres with interspaces which eontain lympheorpuscles; larger coarsely granular spheroidal bodies composed of protoplasm, and containing one or several nuclei ; and Hassall's eoneentric corpuseles, whieh, as Ecker has pointed out, may be either simple or eompound. The former are spheroidal vesieles with a concentrically striated investment, and either eontain a homogeneous substanee exhibiting fatty lustre, or contain granular material and a nueleus in their interior. The latter are mueh larger bodies, and consist of several simple vesicles inclosed by a concentrically striated common investment. Both forms become more numerous as the gland advanees to eomplete maturity. The vessels, which are numerous, especially during the period of the functional activity of the organ, penetrate the follicles at many points of their surfiaee, and anastomosing frequently form a close plexus in the interior (Fig. 98). Between the vessels and attached to them as well as to the eonneetive tissue of the septa, an exceedingly eompact but very delieate network is extended, chiefly formed

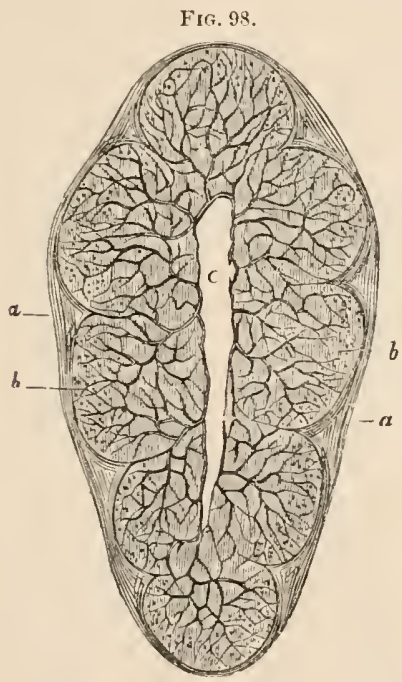

FiG. 99

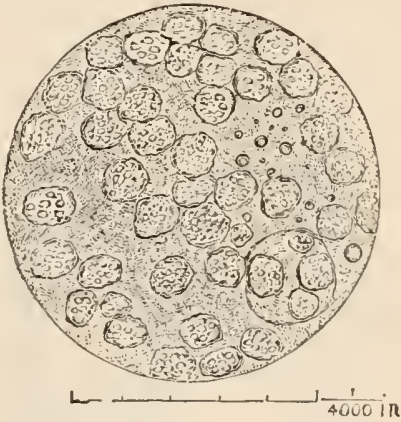

Fir. 98.-Transverse section through an injected lobule of the Thymus in a child: $a$, membranous investment of the Iobule; $b$, membrane of the gland-granules; $c$, carity of the lobule, from which the larger vessels branch out.

FIG. 99.-Thymus-juice rich in corpuscles, with a few sccondary molecules, and the structureless minutely granular base.

by the anastomosing branehes of multipolar eells, in the interstices of whieh are numerous lymph-corpuscles; in addition a narrow-meshed network may be observed, which is formed by the prolongations of the interfollieular lymphatic vessels. The whole structure of the follicles resembles that of the Peyerian bodies.

163. The lymphatics of the interior of the follicles open into cavities lined by endothelium surrounding the follicles, which again communicate with

1 See Prof. Kölliker's Mikrozen Anat., \& 208; Mr. Simon's Physiological Essay on the Thymus Gland; Peremeschko, Zeits fowise Zuol., Bd. xxviii, p. 147; Mr. Gulliver's Lecture, iv. Merl. Times and Guz., 1863. vol. ii, p. 503; and $\mathrm{K}$ lein in Stricker's Manuul of Histology (Syd. Suc. Trınsl.), vol. i, p. 365. 
elongated spaces imbedded in the trabeculie and capsule of the gland. The chemical constituents of the Thymus are water, albumen, gelatin, sugar, fats, leucin, and sarkin, with xanthic, formic, acetic, succinic, and lactic acids, and the ordinary inorganic salts. ${ }^{1}$ The expressed juice of the Thymus (Fig. 99) in young and healthy animals possesses a creamy consistence and opacity duc to the great abundance of corpuscles or free nuclei, identical in sizc, shape, and chemical characters with the corpuscles of the fluid of the lymphatic aud mesenteric glands. The nerves are not very numerous, but were observed by Peremeschko partly to accompany the arteries, and in part to enter separately. Mr. Sinon considers that they are mainly derived from the plcxus which surrounds the first part of the subclavian artery, and which has its chief origin from the inferior and middle cervical ganglia. It has been commonly stated, that the Thymus attains its greatest development in relation to the rest of the body, during the latter part of fotal life; and it has becn considered as an organ peculiarly comnected with the embryonic condition. But this is a mistake; for the greatest activity in the growth of this organ manifests itself, in the Human infant, soon after birth; and it is then, ton, that its functional energy seems the highest. This rapid state of growth, however, soon subsides into one of less activity, which merely serves to keep up its proportion to the rest of the body ; but its increase is continuous till the age of puberty is attained (Friedleben). From that time, during a variable number of years, it remains stationary in point of size; but, if the individual be adequately nourished, it gradually assumes the character of a mass of fat, by the development of the corpuscles of its interior into fat-cells, which secrete adipose matter for the blood. This change in its function is most remarkable in hibernating Mammals; in which the developinent

FIG. 100

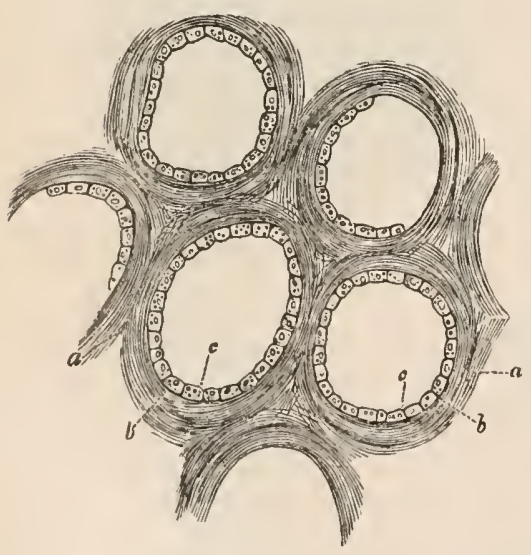

Group of gland-vesicles from the Thyroid Gland of a chill: $a$, cunnective tissue; $b$, membrane of the vesicles; $c$, epithelial culls. of the organ coutinues, even in an increasing ratio, until the aninal reaches adult age, when it includes a large quantity of fatty matter. The sanie is the case, generally speaking, among Reptiles.

164. The Thyroid body differs from the other Vascular Glands in its elementary structures; for it essentially consists of an aggregation of vesicles ${ }^{2}$ (Fig. 100,b,b), which scem to be furnished with a true limitary membrane, and therefore to be real gland-vesicles, imbedded in a stroma $(a, a)$ of connective tissue, which supports a vast caveruous lymphatic network. The vesicles vary in diameter, in the Human subject from $\frac{1}{20} 00^{\text {th }}$ to $3^{\frac{1}{5}}$ th of an inch; and they contain an albuminoid plasma, ${ }^{3}$ of cither

1 See Frielleben, in the Journal de la Physiologic, 1859, p. 137; and v. GorupBesanez, I'hys. Chemie, $1862, p 666$.

2 These vesicles were formerly stated to be closed, but P. A. Borehat (Contralblatt, 1871, p 81) has recently naintained, as the result of obsirvations made upon healthy chlands hardened in Pieric Aeid, subsequently placed in solution of grum, and finally" in alcobol, that they intereommunicate freely.

3 That the fluid does not cuntain true dlbumen in solution, but some albuminous comprounds, is indicated by the results of Dr. Beale's amalysis (Cyclop. of Anat. and Physiol., vol iv, p. 1106). 
a faintly granular or of a somewhat oily aspect, which may be seen to exurte from the epithelial cells $(c, c)$ lining their intcrior. ${ }^{1}$ The vascular supply of the Thyroid body is extremely abundant; and, as in the preceling instances, the subdivisions of its arteries form a very minute capillary plexus upon the membrane of the vesicles. The lymphatic spaces are lined by a layer of epithelium, which is often the only septum between the interior of the resicles and the lymphatic spaces. The nerves are scanty, accompanying the ressels, and are derived fiom the cervical parts of the svmpathetic. The development of the Thyroid body has been shown by Mr. Gray (loc. (it.), Mr. Callender, ${ }^{2}$ and $\mathbf{W}$. Müller, ${ }^{3}$ to be closely accordant with that of the "ductless glands" already described. This body originates on the third day in the Chick as an involution from the hypoblast of the throat opposite the point of origin of the second arterial arch. On the fourth day it forns a solid mass of cells, and on the fifth becoming independent of the epithelium of the throat, it presents a bilobed form, the two lateral masses being joined by a central portion or isthmus, with an outlying picce or pyramid of very variable form. The lateral lobes are situated on each side of the root of the neck, close to the separation of the carotid and subclavian vessels, and between the trachea and the branchial clefts, but quite independent, as far as regards their development, of either of those parts; their minute structure at an early period closely corresponds with that of the spleen and suprarenal glands. This body, like the Suprarenal and Thymus, is of larger relative magnitude during intrauterine existence and infancy, than in after life. According to Ecker ${ }^{4}$ and Peremeschko ${ }^{5}$ the Pituitury body has the same essential structure as the vascular glands in general; presenting vesicles containing a finely-granular blastema with nuclear particles imbedded in a fibrous stroma. A minute gland-like body, first described by Luschka, ${ }^{6}$ and termed by him the Coccygeul gland, is situated near the anterior part of the apex of the coccyx. It consists of a basis of connective tissue, in which are imbedded irregularly branched tubes, that here and there dilate into vesicles. The nerves proceed from the coccygeal ganglion. By Luschka and others the pituitary and coceygeal bodies have been regarded as the remains of the opposite extremities either of the chorda dorsalis or of the primary intestinal tube.

The recent lesearches of Neumann ${ }^{7}$ and others seem to demonstrate that the so-called "red marrow," occupying the cancellous tissue of the bones, constitutes a kind of adenoid tissue in which lymph-corpuscles are developed. The ressels of this tissue are very numerous and large, and are connected by a delicate web of stellate cells, with long processes, the interstices of which are filled by a homogeneous mucin-like material. Imbedded in this are large numbers of cells, presenting every grale of development between lymph and fully developed white and red blood-corpuscles. These must either gain entrance into the blood vascular system by penetrating the walls of the capillaries, or as Hoyer thinks, the whole tissue resembles the lacunar system of the lymphatic glank, and the corpuscles are generated by fission of previously existing cells within the dilated and anastomosing capillaries.

1 Sie Terson, Syd. Soc. Trans, of Stricker's Manual, vol i, p. 370 ; and Archives de Méd., 1874, June.

2 Proceed. of the Roryal Soc., vol. xvi, 1867, p. 2.5.

3 Jenaische, Zeitschrit, 1871.

4 Art. Blutgefässdrüsen in Wagner's Handwörterbuch, Bd. iv.

5 Loc. rit.

6 Virchow's Archiv, Bd. xviii, p 106.

7 Arehiv der Heilkunde, 1869, pp. 68 and 20 . Sice also Bizzozero, Centralblatt für dir Med. Wissenschatt. 1868, p. 885, and 1869, p. 149: Hoyer, Centrablatt, 1869, Pp. 244 and 257 ; Palladino, Centralblatt, 1869, p. 513 ; and Mosler, Centralblatt, 1871, p. 290. 
The large many-mucleated cells (myeloplaxes or giant cells) described by Robin as existing in the medulla of bones, may possibly, as Neumann surmises, represent the mother cells of the lymph-corpuscles, or as Bizzozero maintains, such many-nucleated cells with the pigment-granules that are often found in them indicate that destruction as well as development of bloorcorpuscles takes place in the medullary tissue of the bones. The whole subject has an important bearing on the Leuciemia, so often associated with disease of osseous tissue. Mosler ${ }^{1}$ observes that marked changes occur in the medulla of bones after extirpation of the spleen.

165. That the Ductless or Vascular Glands, of whose peculiar strueture and relations we have thus taken a general survey, liave some office of importance to perform in the preparation and maintenance of the blool, cannot any longer be reasonably questioned; and the determination of this point may be fairly regarded as a considerable step in the investigatiou. It is obvious; from the very copious supply of blood which they receive during the period of their functional vigor, and from the manner in which this is distributed by minute capillary plexuses on the exterior, and even through the interior, of the glandular vesicles, that it must be subservient to some process of active change; and the aspect of the contents of these vesicles, as well as of the substance in which they are imberded, indicates that cellgrowth is rapidly proceeding, at the expense of the materials thus afforded. But, on the other hand, that the preducts of this cell-growth are not substances, which, like those of the ordinary glands, must be separated from the blood, either for its purification, or to serve some special purpose in the economy, appears from the fact that they are not carried off by ducts; but are received again into the current of the circulation. With the exception of the Spleen, all the ductless glands thus discharge their products at once into the general venous circulation; so that, after having passed through the lungs, they will be carried by the systemic arteries through the system at large; but the spleuic vein, it will be remembered, forms one of the roots of the portal trunk; and its blood must pass through the liver before it enters the vena cava.

166. Whatever materials, then, are withdrawn from the blood by these organs, are returned to it again in an altered state; and it may fairly be inferred from this circumstance, that the change which they have undergone is one that prepares them for higher uses in the economy. For, as the blood which has received them is immediately transmitted to the system (except in the case of the splenic blood), without having passed through any other depurating organ than the lungs, it appears fair to conclude that the prorlucts which it has taken up in these organs are either combustive or nutritive, i. e., either serve to maintain the functional activity of the lungs, or of the system, or of the blood itself. Now that they are not destined to prepare a pabulum for respiration, appears from the very small quantity of fat which is found in their substance, except when their period of functional activity has gone by. On the other hand, the albuminous nature of the plasma, and the finely granular appearance which it presents, strongly indicate that a material is here in progress of preparation, which is to be rendered subservient to the formative operations. Various facts which have been noticed in regard to the changes in the bulk of the Thymus in young animals (and particularly its rapid diminution in overdriven lambs, and its subsequent gradual redistension during rest, if plentiful nutriment be afforderl), lead to the conclusion that such is almost undoubtedly the function of that body. And such would also seem to be the justifiable inference from the researches of Mr. 
Gray on the Spleen: for the correspondence in the amount of the colorless parenchyna of that organ (and especially of its Malpighian corpuscles) with the general state of nutrition of the animal, its regular increase (in wellfed animals) near the completion of the digestive process, and its gradual diminution in the subsequent interval, scem to indicate that the Spleen, like the Thymus of the young animal, is a storehouse of nutritive material, which may be draw upon according to the requirements of the system, just as the fat of the body is a storchouse of combustive substance. And of the exertion of an elaborating or assimilative action upon this albuminous matter, during its withdrawal from the current of the circulation in these organs, we seem to have dircet evidence, as regards the Spleen, in the large increase of the proportion of fibrin contained in the blood drawn from its veins. It was formerly supposed that the Spleen acted as a kind of reservoir or diverticulum for the portal circulation, the vessels of which were thus relieved from undue turgescence, when the alimentary canal was distended with food, and rapid absorption was taking place. Others again were of opinion that a process of disintegration took place in the bloorl-corpuscles which are found so abundantly in the splenic pulp, but the grounds on which both these views were supported are scarcely tenable in the present state of our knowledge. ${ }^{1}$

167. The results then of all the recent investigations on these organs tend to prove that equally with the Absorbent glands, they supply the germs of those cells which are ultimately to become blood-corpuscles. Such, it is well known, was the doctrine of Hewson ${ }^{2}$ in regard to the Spleen and Thymus gland; and there are many facts which lend it a considerable probability. In the first place, we have seen $(\$ 157$, II) that there is no difficulty whatever in the admission of snch corpuscles into the smaller veins of the Spleen, if Mr. Gray's account of its lacunar circulation, which appears to be fully confirmed by the more recent investigations of Billroth ${ }^{3}$ and Müller, ${ }^{4}$ be correct; and that there is no physical impossibility in the reception of particles of such a size into the interior of even a closed system of capillaries, is proved by the very curious facts already noticed in regard to the passage of starch-grains into the mesenteric veins $(\$ 142)$. Secondly, there is an unusual proportion of colorless corpuscles in the blood of the splenic vein ; so that whilst according to Hirt the proportion of colorless to colored corpuscles in the blood of the splenic artery is as $1: 2000$, in that of the splenic vein it rises to $1: 70$, and in some diseased conditions it has been known to amount to $1: 4 .^{5}$ Thirdly, if the spleen be extirpated, which has even been performed on man himself, showing that its functions are not indispensable for the preservation of life, the only effects observed have been increasc in volume and pigmentation of the lymphatic glands, ${ }^{6}$ probably in consequence of their taking on a vicarious action in the development of the white corpuscles. Fourtlily, the period of greatest functional activity of these glands generally, is duriug the state of early childhood, when the formative processes are going on with extraordinary activity; and there is at this time a

1 See Cycl. of Anat. and Physiology, vol. iv, p. 796.

2 See his Third Series of Experinental Inquiries, chaps. iii-v.

3 Mïller's Archiv, 1857, p. 88, and Virchow's Archiv, Bd. xx, p. 410.

4 See Funke, Physiologie, 1870, p. 241; and Gray, op. cit., p. 148. Dl. Silvester, in an ingeniously written essuy (The Discovery of the Nature of the Spleen, 1870), has adduced various arguments against the view that the spleen is a blood-making organ. He regards it as a sanguiferous gland, effecting certain changes in the blood traversing it, and as the left lateral homologue of a portion of the liver, which is itself a combination of a sanguiferous gland and a biliary apparatus.

5 Stricker's Manual of Histology, vol. i.

6 Fälıer and Ludwig, Archivf. Phys. Heilk., 1855, pp. 315 and 491, and others. 
larger proportion of colorless corpuscles in the blood than at any subsequent period, at least in the healthy state. Further, as Prof. J. H. Bennett has pointed out, that peculiar condition of the blood, which consists in the multiplication of its colorless corpuscles, is almost always associated with hypertrophy of one or other of these bodies; and in one case of this kind, in which the Thyroid was the organ affected, its cells and their included nuclei were observed to be considerably smaller than usual, and the same pcculiarity presented itself in the colorless corpuseles of the blood. ${ }^{1}$ Hence there seems a strong probability, that whilst the plasma of the blocd is being elaborated by these bodies, a constant supply of new blood-corpuscles is also afforded by them ; and that they thus effect for the nutrient materials directly absorbed into the Sanguiferous system, that which the glandula in connection with the $A$ bsorbent system accomplish for the substances which it has taken up.

\section{CHA PTER VII.}

OF THE BLOOD; ITS PHYSICAL CHARACTERS, ITS CHEMICAL COMPOSITION, AND ITS VITAL PROPERTIES.

\section{General Considerations: Quantity of Blood.}

168. Fron the materials supplied in the Food, there is prepared, by the Digestive and Assimilative processes described in the preceding Chapters, that general nutritive liquid, the Blood, which, in the organism of Man (as in that of all the ligher Animals) is constantly circulating through its vessels during the whole of life. From this liquid, each portion of the solid. tissues has the power of extracting, and of appropriating to its own use, the particular components of its substance; these either.pre-existing as such in the blood, or being capable of being readily formed from it by a process of chemical transformation. During its circulation, morcover, the blood draws into its current the effete particles which are set fice by the disintegration of the tissues (probably at the very time when it gives forth the components of the newly forming structures), and conveys them to the various organs which are provided for their elimination. Hence the Blood not only contains the materials for the renovation of the tissues, but also the products of their decay; but there is an important difference in the proportion of these two sets of components, for whilst the former make up the principal part of the mass of the Huid, the latter are only detectable in it with difficulty, so long as the excretory organs maintain their normal activity ; and only make their prescnec obvious, when they accunulate unduly, in consequence of the retardation or suspension of the eliminating operations.-But besides thus mceting the demand occasioned by the constructive operations, and preventing the results of the destructive fron exerting an injurious influence on the systcm, the Blood acts (so to speak) as the carrier of Oxygen introduced from the atmosplicre, to the Muscular and Nervous tissues, to whose peculiar vital

1 This fact is the more weighty, as, in another ease observed by Prof. Bennett, the colurless corpuseles of the blood were of two distinct sizes, the smaller corresponding with the nuclei of the harger oncs; and the lymphatic glands were found to be crowded with crorpuecles also of two distinct sizes, oxactly corresponding with those of the blood. (See Edin. Monthly Juurnal, Oetober, 18.1)

2 'This view has been abty supported by Prof. J. H. Bennett, in Edin. Monthly Journ., March, 1852; and in his treatise on Lencocythamia. 
activity its presence appears to be an essential condition, the same elenent being also required in various other metamorphoses which form part both of the constructive and of the destructive operations: whikt conversely it imhibes the Carbonic acid, which is one of the chief products of the action of oxygen upon the tissucs and fluids of the body, and conveys this to the lungs and skin for elimination. But in addition to the Histogenetic materials and Oxygen, on the one hand, and the various products of the disintegration of the tissues on the other, the blood contains those non-azotized substances, which are reccived into it for the purpose of supplying the pabulum of those combustive processes that are requisite for the production of heat and the generation of nervo-muscular cnergy ; and the union of their carbon with oxygen introduced from the atmosphere which is continually going on, becomes an additional source of the production of carbonic acid, and of its injurious accumulation if its elimination be checked.

169. From this variety in the operations to which the Blood is subservient, it naturally follows that the changes which it undergoes in different parts of its circulation are of a very diversified nature, and that the composition of the fluid in the several parts of its course will be far from uniform. Between the blood which is being distributed by the systemic Arteries to the body at large, and that which is being collected from it again by the systemic Veins, after having percolated the tissues, there is not only an obvious difference in hue, which indicates an important change, but there is also a considerable difference in composition, which is revealed by chemical analysis; and a differcuce of a converse nature presents itself, between the blood that is on its way to be distributed to the Lungs, and that which is returning from them. So again, although there is no obvious dissimilarity in physical characters between the blood which is transmitted to the Liver by the vena porta, and that which is carried off from it by the hepatic vein, yet chemical analysis reveals a very remarkable difference in their composition, and shows that the blood of the ascending vena cava (above the entrance of the hepatic vein), that of the right cavities of the heart, and that of the pulmonary artery, differs from all other blood in the body, in constantly containing air appreciable quantity of a peculiar substance readily convertible into sugar, which is formed in its passage through the Liver. In like manner the researches of M. Picard have shown that the blood of the renal vein contains a smaller proportion of the chief component of the urinary secretion, urea, ${ }^{1}$ than that of the renal artery; and in many other cases of blood returning from particular organs we know that important differences must exist, although they have not yet been detected by chemical analysis.-In the account to be presently given of the Blood, those most general characters and properties will be first described, which it presents in all parts of its circulation; the principal differences which have been substantiated in the composition of the blood in the several portions of its circuit will then be noticed; and lastly, a summary will be given of the most important of those pathological alterations which it exhibits in disease.

170. The quantity of Blood contained in the Human body is probably, for a man of average height, from 12 to $15 \mathrm{lbs}$; but its precise determination is more difficult than might at first be supposed, and the estimates which have been made of it have been most strangely discrepant. The entire amount which flows from a large arterial trunk freely opened, can by no means be taken as a measure; since, however readily it may be permitted to escape, a considerable quantity still remains within the bloodvessels, especially if the heart's action fail before the loss of blood has proceeded 
very far, so that it is not drawn from the venous system. A closer approximation may be made by opening several vessels at once, which was the method adopted by Herbst ; who estimated the proportion of the weight of the bloorl to that of the entire borly to be as $1: 12$ in the $0 \mathrm{x}$, as $1: 16$ in the Dog, as 1:18 in the Horse, as $1: 20$ in the Goat, Calf, Lamb, and Hare, as 1:22 in the Sheep and Cat, and as $1: 24$ in the Rabbit. With these estimates the conchusions drawn by Vanner, from observations made in the abattoirs of Paris, pretty closely correspond; for he was led by them to the belief, that for horned cattle in general, the proportion does not vary far from $1: 20 .^{2}$ It is obvious, however, that no such method can give more than a minimum; since, even after the most complete exsanguination that the freest opening of the vessels can permit, a considerable quantity of blood is still retained in them, and especially in those of the head. Various other methods have been suggested, none of which, however, can be considered as yielding more than approximations to the truth. That of Vierord $t^{3}$ consists in multiplying the quantity of blood which is expelled from the left ventricle at each pulsation of the lieart by the number of beats which occur whilst the blood performs one entire circuit of the body. He estimates the former (highly) at $6.3 \mathrm{oz}$. av., and the latter at 27.7 beats; consequently the total quantity of blood is about $11 \mathrm{lbs}$. av., or between one-twelfth and one-thirteenth of the wcight of the body. Welcker's method, termed also the " chromatic" or "color" method, gives nearly the same result for Man and the Dog. It consists in first roughly estimating the quantity of blood in the animal by rapidly bleerling it to death. The portion that still remains in the small vessels is then removed by the injection of pure water, and the whole body of the aninial is finely minced and infused. These liquids are mingled, and on comparing their tint with a series of previously prepared "color tests," the proportion of blood in which is accurately known, a practiced eye may discern variations in the color when the difference in the quantity of blood does not exceed 4 per cent. Welcker estimates that a man weighing 143 lbs. has $11 \mathrm{lbs}$, of blood. An interesting collection of cases has been brought together by Haller of the amount of blood lost by hamorrhage; and two remarkable instances are cited by Burdach, ${ }^{5}$ from iV risberg, who states that a female who died from violent metrorrhagia had lost 26 lbs. of blood, and that $24 \mathrm{lbs}$. were collected from the body of a plethoric female who had suffered deatl by decapitation. In the first of these cascs, it is probable that, as death could not have been immediate, some increase tonk place from the absorption of the fluils of the body; in the second, however, the suddenness of the discharge of blool, and its concurrence with the destruction of life, must have prevented any considerable augmentation from this source; and if any such increase did takc place, it probably did not exceed the amount of blood remaining undischarged in the vessels. An important observation has been made by Bernard, ${ }^{6}$ that the quantity of blood which can be obtaincd from a fasting animal is scarcely more than one-half of that contained in its vessecls shortly after a full meal: a point to which no other observer appears to have pail attention, but which may account for some of the discrepancies observable in the different estimates. ${ }^{7}$

I De Sanguinis quantutate, qualis homini adulto et sano convenit. Goettingre, 182:2.

${ }^{2}$ Comptes Rendus, tom. xxviii, p. 649.

4 Elomenta Physoluerio, vol. ii, pp. 3 and 4.

- Traité de Phỵsología, truduit pur Jourdain, tom. vi, p. 119.

6 Leçuns, 1s59, t. i, p. 419.

7 Valoutin's mothed is founded on the diminution in the specific gravity of the iblood after thu injection of a kuown weight of wat "r into the vessels, and gave for alugs the proportion of the weight of blood to that of body generally as $1: 4.2$ (Repert. 


\section{Physical, Chemical, and Structural Characters of the Blood.}

171. The Blood as it flows forth from an opening in a large vesscl, is an apparently homogeneous liquid, possessing a slight degree of viscidity, with a consistence and density somewhat greater than that of water, but especially distinguished by its color, which is usually of a bright scarlet when it is drawn from an artery, and of a dark purple, sometimes almost approaching to black, when it is drawn from a vein. This difference of color, however, is by no means constant ; for arterial blood may sometimes be unusually dark, whilst venous blood is occasionally so florid that it might almost be taken for arterial. The former condition is observable, when from any cause the respiratory process is imperfectly effected, as in the foetus, and it may be especially noticed during operations performed under the influence of anasthetic agents; it has also been remarked by Dr. John Davy, as usually characterizing the arterial blood of the inhabitants of hot climates, ${ }^{1}$ and it occurs in blood that has been allowed to stagnate either in arteries or veins; but in any of these cases, the ordinary arterial hue is acquired by the blood when it has been sufficiently exposed to the air. The florid hue is presented by the venous blood of animals which are made to respire pure oxygen; but it seems normal with some individuals whose respiration is peculiarly active. It is well marked in the blood returning from an actively secreting gland, and from a quiescent muscle. ${ }^{2}$ When ordinary venous blood is examined in thin layers, it presents a deep red or purple tint by reflected light, but by transmitted light it assumes a grecnish hue, thus presenting the phenomena of Dichroism; a peculiarity which is not possessed by arterial blood (Brücke); but when the gases of the blood are wholly removed by exhaustion, both arterial and venous blood assume a deep black color. ${ }^{3}$ The specific gravity of the Blood is stated by Nasse ${ }^{4}$ to vary (within the limits of health) between 1050 and 1059 ; the average being taken at 105.5 . The specific gravity of of the Corpuscles is about 1085, and that of the fluid in which they float about 1028. The chemical reaction of the blood is invariably alkatine, and very important purposes are served by this alkalinity. The temperature of the Blood, usually considered to be about $100^{\circ} \mathrm{F}$., has been found by Bernard, ${ }^{5}$ in an extensive series of observations made with extremely sensitive thermometers, to vary several degrees in different parts of the body. The

f. Anat. und Phys., Bd. iii, p. 281). Blake's method consisted in the injection of a detinite quantity of some saline compound, as sulphate of alumina, and its subsequent quantitative determination, in a portion of blood drawn from another part of the system. This means of estimation gives the proportion of blood to that of the body as $1: 8$ or as $1: 9$ (see Prof. Dunglison's Physiol., 8th edit., vol. 1, p. 3.57), and is in accordance witt the results obtained by Lehmann and Weber in their examinations of the quantity of blood discharged from two decapitated criminals (Lehmann, Lehrbuch, 2l edit, Bd. ii, p. 234). For recent papers on this subject, which, however, add little to our knowledge, see Brozeit, Pfinger's Archiv, 1870, p. 353 ; Steinberg in idem, 1873 , p. 101 ; and Gseheidleu, in idem, 1873, p. 350 . Brozeit obtains the Hrematin by means of ether and hydrochloric acid from a given quantity of the washings after venesection, compares it with that in the same quantity of blood, and makes the requisite calculation. Steinberg proceeds on the principle that solutions of hanoglobin, when of a certain strength, transmit green light.

1 Anatomical and Physiological Researches, vol. ii, p. 140. This fact, which harmonizes with the inference to be drawn from the observed results of a high external temperature in reducing the excretion of carbonic acid (ehap. ix), is of great practical importance.

2 Bernard, Leçons, 1859, vol. i, p. 324.

3 Setschenow, Sitszungsberichte d. Kais. Akad d. Wiss., xxxvi, 1859.

4 Wagner's Handwörterbuch der Phys., Art. Blut, Bd. i, p. 82.

5 Leçuns sur les Liquides de l'Organisme, 1859, iii, iv, v, vi. 
blood which has the lowest temperature under ordinary circumstances is that which has circulated through the cutaneous capillaries, where it has been exposed to the cooling influences of evaporation and radiation; though Bernard ascertained that on carefully enveloping the head or limbs of an animal in cotton-wool, the temperature of the arterial and venous blood in the large vcssels soon becomes equalized. The blood of the left ventricle again is, for similar reasons, generally ${ }^{1}$ of a lower temperature than that of the right. The highest temperature is attained in passing through the ghands, muscles, and nerves; for in all such parts, cspecially during the active performance of their functions, energetic processes of oxidation are bcing carried on. Hence the blood of the Vena Portre, which has traversed the capillaries of the intestines, spleen, etc., is warmer, especially during digestion, than even the arterial blood; and the blood which possesses the highest temperature in the body, and which is frequently $2^{\circ}$ or $3^{\circ} \mathrm{F}$. above the ordinary venous blood is that of the Hepatic Vein, which has been subjected to the active assimilative operation of the liver. The specific heat of the blood of the $\mathrm{Ox}$ is on the average 1.02." When we add that the Blood has a saltish taste, and a faint odor resembling that of the pulmonary and cutaneous exhalations of the animal from which it is drawn, we have enumerated all the characteristics which can be nuade out by the unassisted senses.

172. When the Blood is examined with the Microscope, either immediately upon being drawn, or whilst it is yet circulating in the vessels of the living body (as in the tongue or foot of the Frog, the wing of the Bat, the omentum of the Guinea-pig, ${ }^{3}$ or any other membranous expansion of similar transparency), it is seen that its apparent homogeneity is not real, but that it consists of two very different components. These are a transparent and perfectly colorless liquid which is known as the Liquor. Sanguinis, and a set of Corpuscles which are suspended in it: the great mass of these last present a distinctly red hue, and it is to their presence alone that the color of the blood is due; but there arc also to be seen, scattered among the red, a few which arc colorless, and which differ from the red in somc other particulars presently to be noticed. On the other hand, when the Blood has been drawn from the body, and is allowed to remain at rest, it undergoes at ordinary temperatures spontaneous coagulation, in the course of which it separates into a red Crassamentum, and a ncarly colorless Serum. The "crassamentum" or "clot" is composed of a network of Fibrin, presenting a more or" less distinct fibrous texture; in the meshes of which the Corpuscles, both red and colorless, are involved, together with a certain amonnt of serous fluid. The "serum," which is the same with the "liquor sauguinis" deprived of its fibrin, coagulates by heat, and is therefore known to contain Albumen; and if it be exposed to a high temperature sufficient to decompose the animal matter, a considcrable amount of earthy and alkaline Salts remains.Thus we have four principal components in the Blood; namely, Fibrin, Al-

1 See the variable results obtained in Colin's experiments, recorded in the Anu. d. Sei. Nat., Ser. v, t. vii, 1867, p. 83 . Jacobson and Bernhard found the temperature of the Left Heart to be from $0.12^{\circ}$ to $0.42^{\circ}$ Cent. warmer than the Right, as aseertained by the introduction of a compound needle connected with a thermometrie aplaratus through the parietes of the ehest into the eavity of the ventrieles (sec Centralbatt, 1868, p. 689)." Körner, however (Inaug. Dissert., Breslau, 1871), and IIeidenhain (l'flüger's Arehiv, Bd. iv, 558) support Bermard's statements. Albert and stricker (Stricker's Jahrbüeher, $1873, \mathrm{p} .29$ ) found a thermometer inserted into the substunce of the museular tissue of the left ventricle, stood $0.5^{\circ}-0.7^{\circ}$ Cent higher than when introdued in to the cavity of the same ventriele in the living animal, which may in part explain the diserepancy in the different experiments.

2 Gumece, Journ. of Anat. and Physiol., vol. ii, p. 139.

3 See Burdon Sanderson, Iandbook for the Physiologieal Laboratery, 1873, p. 231. 
bumen, Corpuscles, and Saline matter. In the circulating blood, they are thus combined:

\author{
Fibrin, \\ Albumen, $\}$ In solution, forming Liquor Sanguinis. \\ Salts, $\}$ \\ Corpuscles,-suspended in Liquor Sanguinis.
}

But in coagulated blood, they are combined as follows:

$\left.\begin{array}{l}\text { Fibrin, } \\ \text { Corpusales, } \\ \text { Albumen, } \\ \text { Salts, }\end{array}\right\} \begin{array}{r}\text { Forming Crassamentum, or Clot, which, however, al- } \\ \text { ways contains more or less serum in its meshes. }\end{array}$ Remaining in solution, forming Scrum.

The change from the one condition to the other is due to the fibrillation of the fibrin; which usually takes place so speedily as to involve the Corpuscles floating in the "liquor sanguinis," before they have time to subside; although, under various conditions hereafter to be described, it may occur in such a manner that the clot, or a portion of it, is left colorless.

173. The Red Corpuscles of the Blood (commonly but crroneously termed "globules") are minute, nearly transparent, yellowish bodies, of a flattened or discoidal form, which, in Man, as in most of the Mammalia, have a distinctly-circular outline (Figs. 101, 102). In the disks of Human blood, when this is examined in its natural condition, the sides are somewhat concave; and there is a bright spot in the centre, which has been regarded by many as indicating the existence of a nucleus; though it is really nothing else than an effect of refraction, and may be exchanged for a dark one by slightly altering the focus of the Microscope (Fig. 101). The Corpuseles of Man and Mammalia seem to be homogeneous masses of germinal matter, soft, elastic, transparent, and structureless, refracting light singly, and having a specific gravity of about 1088 . The appearances of a proper cell-wall and nucleus which they present when subjected to the action of certain reagents ${ }^{1}$ are probably deceptive, and arise either from physical or chemical changes occurring on their surface or in their substance. Mr. Wharton Jones, from considerations connected with their development, regards them as free nuclei, though they certainly possess neither the physical nor chemical characters of nuclei, but are very energetically acted on by numberless reagents, which are quite powerless on the nuclei of the red corpuscles of the blood of Birds, Reptiles or Fishes. Mr. Gulliver considers them to be peculiar bodies without any known homologues in the blood of these pyrenæmatous vertebrates. The form of the Red Corpuscles is very much altered by various reagents. Thus if they be treated with water, they first become flat, and then double-convex, so that the FIG. 101.

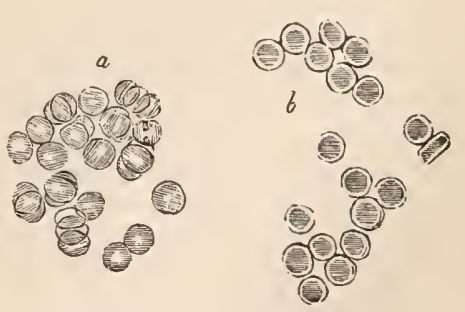

Red Corpuscles of Human Blood: represented at $a$, as they are seen when rather beyond the focus of the microscope; and at $b$, as they appear when within the focus. central spot disappears; and by a continuance of the samc process, they at last become globular, and so attenuated that a diffusion of their substance

1 Strong arguments have recently been adduced by Dr. J. G. Richardson of Philadelphia (On the Cellular Structurc of the Red Blood-corpuscle, Pamphlet, 1870), to show that the red corpuscles of the Menobranchus or Proteus (Batrachia), are truly ccllular. On division the contents escaped, and the cell-wall collapsed, and crystals were frequently found in the interior, over which the cell-wall appeared to be stretched like a tent over a tent-pole. 
scems to take place through the surrounding liquid." With dilute solutions of common salt they become prickly on the surface, so as to resemble the fruit of the horse-chestnut. ( $a$, Fig. 102 and $e$, Fig. 104.) The projections, seen in profile, give the corpuscles a stellate form, and those seen en face appear as black dots. With acetic acid the corpuscles become globular and pale, but their outlines remain distinct; with solutions of magenta they swell up and assume a faint rose color, a dark-red spot appearing on some point of their circumference. With (2 per cent.) solutions of Tannin, ${ }^{2}$ after the lapse of twenty or thirty seconds some point of the circumference of the red corpuscle appears to give way, and a small button of highly refractile yellowish-green substance projects, which sometimes contains a vesicular body that may again be retracted into the corpuscle by the action of acetic acid. The similar appearances produced by the action of a one per cent. solution of Boracic acid on the red corpuscles of Reptilia have led Brücke ${ }^{3}$ to regard the Blood-corpuscles in these animals as consisting of a transparent shell or case, the "cecoid," which is occupied by the "zooid," the latter being composed of the nucleus and hremoglobin. If carbonic acid gas be transmitted through a drop of blood which has been mingled with a little saline solution so that the corpuscles have become horse-chestnut shaped, the stellie disappear, and although there are many which do not reassume their natural biconcave form, remaining saucer-shaped, yet their surfaces become smooth and cven. On the transmission of air they again become horse-chestnut shaped, and this alternating effect may be repeated several times. Klcin ${ }^{4}$ suggests that the action of Tannin and Boracic Acid is due to phenomena of coagulation, and that of carbonic-acid gas to the resolution of a spontaneously coagulated constituent. Bile and Urea, according to Kühne, dissolve the red blood-cells, though Jurasz maintains that they only swell up and burst; the addition of Urine seems to exert no other influence upon them than a saline solution of equal density would do, as was long since ascertained by Hewson. Alkalies cause the corpuscles to swell and to become cup-shaped, after which they lose their color and disappear. The passage of a current of electricity produced by the discharge of a Leyden jar (having a surface of 500 square centimetres) at intervals of from three to five minutes, causes the eircular disks to become slightly crenatc, then rosette-shaped and horsechestnut-shaped; still later the processes are withdrawn and the corpuscles become round and pale, giving up their coloring matter to the surrounding fluid. ${ }^{6}$ If blood be exposed to a temperature of $140^{\circ}$ or $150^{\circ} \mathrm{F}$., or if it be frozen and then thawed once or twice, or if the whole of the gases be removed by the air-pump, the corpuscles disappear, the coloring matter staining the scrum of a lake color, and only a few floceuli remain (Rollett). Professor Lehmann has remarked ${ }^{7}$ that some of the red corpuscles resist the influcnee of reagents much more than others do, and he infers that the latter are the

1 A large number of experiments of this kind were made, and their results aeeurately reeorded, by IIewson (see his Inquiry into the Properties of the Blood, 1782, and his Deseription of the Red Particles of the Blood, 1788), who eorrectly drow from them the inferenee of the vesicular charaeter of the Red Corpuseles amongst the Pyr eniemata. See also the Leetures of Mr. Ancell on the Blood, in the Lancet for 1839 ; the Memoir of Dr. G. O. Rees and Mr. S. Lane, in Guy's Hosp. Rep., No. xiii ; and the exeellent Lectures by Mr. Gulliver, delivered at the College of Surgeons in 186263, in Med. 'Times and Gazette.

2 Roberts, l'roceed. of Roy. Soe, vol, xii, 1863, p. 481.

3 See his Vorlesungen über Physiolog., 1874, p. 73.

4 Hundbook to the Laboratory.

6 Klein, op, cit., p. 17. See aliso Bütteher, Virchow's Archiv, Bd. xxxix, 1867, p $4: 27$.

7 Op. eit, vol. ii, pp. 184. 
older cells as having the strongest tendency to disintegration. It is probable that the Blood-corpuscles, even whilst they are circulating in the living vessels, are liable to alterations of form firom variations in the density of the fluid in which they float; and that such alterations may be constantly connected with certain disorderer states of the system. ${ }^{1}$ Thus, even without such an alteration in the Blood as would constitute disease, its propor-

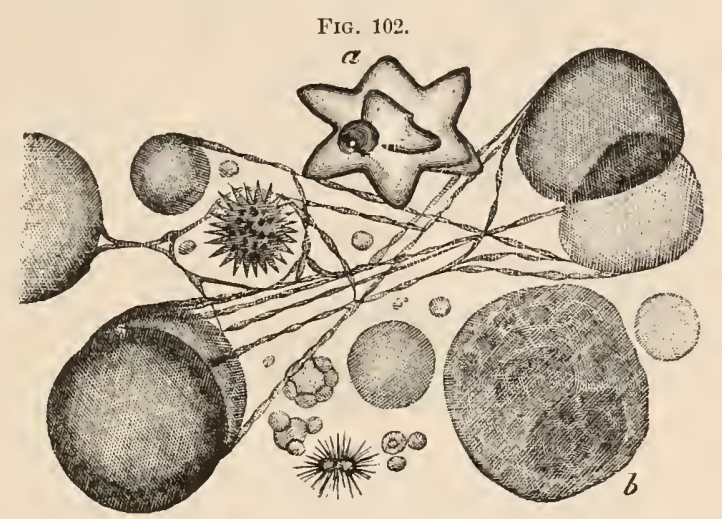

Red and white corpuscles in blood from the finger $\times 2800$ linear. The large, smooth, eircular bodies are the red corpuscles. Three very small red corpuseles are less than 1-8000th of an inch in diameter. The sma!lest particles are composed of matter like that of which the white blood-corpusele $(b)$ consists. Threads of fibrin undergoing coagulation are observed between the corpuscles. $a$, red corpuscle, exhibiting angular projectious; below it and to the left is another with still more pointed processes.

tion of water may be temporarily so much diminished by diuresis or cxcessive perspiration, unbalanced by a corresponding ingestion of liquid, that the corpuscles may be made to present a granulated cdge; which is rendered smooth again by the dilution of the liquor sanguinis with water. We hence see the necessity, in examining the Blood microscopically, for employing a fluid for its dilution, that shall be as nearly as possible of the same character with its ordinary "liquor sanguinis." In the following Fig. (103), which shows the form and size of the red blood-corpuscles of animals belonging to each division of the Vetebrate class, most accurately drawn to scale by Mr. Gulliver, ${ }^{2}$ it will be seen that whilst in Man and all Mammalia, witl the exception of the Camel tribe (4), they are circular, and destitute of a nucleus, or apyrensematous, ${ }^{3}$ in Birds, Reptiles, and Fish, except only some of the lowest forms of the last, the corpuscles are uniformly oval and nucleated, or pyrenrematous: in the Camel tribe, though the corpuscles are oval, yet they conform to the Mammalian type in being free from a nucleus, and in their small size. Mr. Gulliver has particularly insisted on this difference in the blood of the Mammalian and Oviparous Vertebrata, maintaining it to be the only single, universal, and characteristic difference between them. ${ }^{4}$

I See Dr. G. O. Rees's Gulstonian Lectures, in the Medical Gazette for 1845.

2 See Proceedings of the Zoolog. Soc. of London, 1862, p. 101.

3 a. not, $\pi v \rho \grave{\eta} v$, a nucleus, and ai $\mu a$, blood.

4 The following measurements of the blood of domestic animals (expressed in vulgar fractions of an English inch) have been sclected from Mr. Gulliver's observations, as the most likely to become of intercst in Juridical inquirics :

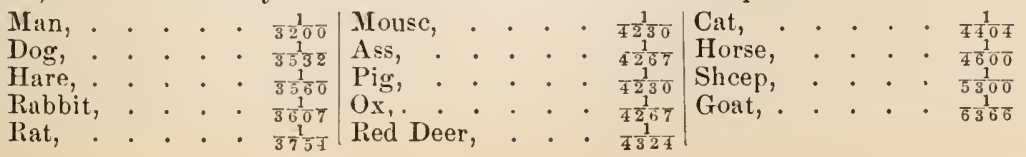


FIG. 103.

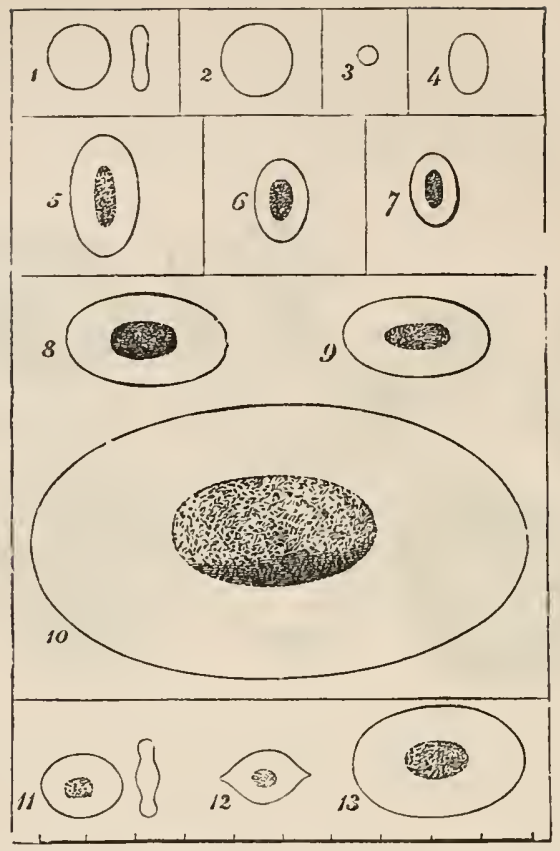

All the Corpuscles here shown are drawn to the uniform scale, at the bottom of the woodcut, of 1-4000th of an English inch, and the measurements are expressed in vulgar fractions of that inch. T. D. signifies transverse diameter; L. D. long diameter; s. D. short diameter.

\section{MAMMALIA.}

1. Red Corpuscle of Man, seen on the flat surface and also on the edge; 2. " "

4. " of Dromedary, thickness 1-15337.

\section{Aves.}

$\begin{array}{ll}5 . & \text { " } \\ 6 . & \text { " }\end{array}$

8.
9.

11.
12.

Pisces.

of Perch

of Shark.

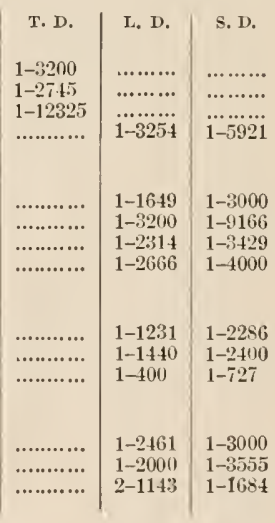

For a eritique slowing that too mueh relianee must not be plaeed upon them, see Woodward, MLontl. Mie. Journ., Feb. 1st, 1875.

A Tabular summary of Mr. Gulliver's very numerous and aceurate measurements of the hed Corpuseles of the Blood of different animals, from all the elasses aud most of the orders of the Vertebrate series, is eontained in the P'roeedings of the Zoological Soeiety, No. eii, and also in his edition of the Works of Hewson, already referred to, published by the Sydenham Society (p. ․37). Manassein (Centralblatt, 1871, p. 689 finds that agents or eonditions which lower the temperature of the body, as Muriate of Qunine, Aleohol and Aente Anamia effeet enlargement of the blood-corpuscles, whilst they are diminished in size by agents exalting the temperature of the body, as IIeat, Septicamie poisoning, and exposure to Carbonie $\Lambda$ eid. They enlarge under exposure to Oxygen. 
174. The form of the Red Corpuscles is not unfrequently seen to changc during their circulation; but this is generally in consequence of pressurc,

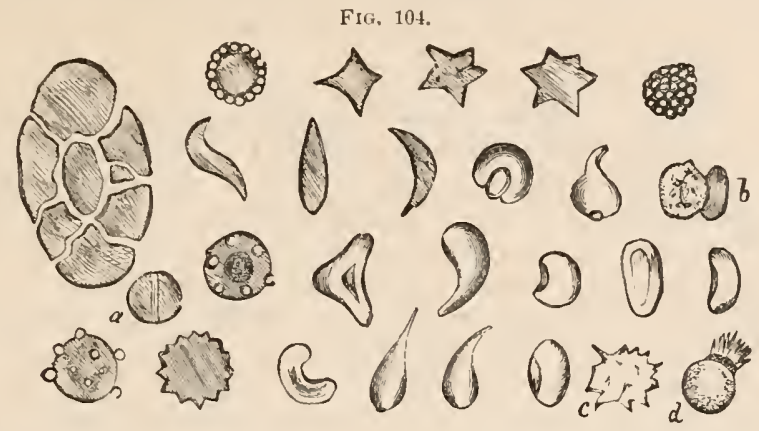

Various forms assumed by blood-corpuscles after withdrawal from the body. The first represents an oval corpusele of the frog breaking up into segments. The corpuscle marked $a$ exhibits the formation of a crystal within a red corpusele (Owsianuikow). $b, c, d$, forms represented by Böttcher. The remainder are from $\mathrm{Mr}$. Gulliver's drawing.

from the effects of which, however, they quickly recover themselves. In the capillary vessels they sometimes become suddculy elongated, twisted, or bent, through a narrowing of the channel; and this change may take place to such a degree as to enable the disk to pass through an aperture which appears very minute in proportion to its diameter.-The size of the blood-disks is liable to considerable variation, even in the same individual; some being: met with as much as one-third larger, whilst othcrs are one-third smaller, than the average. The diameter of the corpuscles bears no constant relation to the size of the animal, even within the limits of the same Class; thus, although those of the Elephant (2, Fig. 103) are the largest among Mammalia (as far as is hitherto known), those of the Mouse tribe are far from being the smallest, being, in fact, more than three times the diameter of those of the Musk Deer (3, Fig. 103). There is, however, as Mr. Gulliver has remarked, a more uniform relation between the size of the animal and that of its blood-disks, when the comparison is made within the limits of the same Order. In Min, their diameter commonly varies from about $\frac{1}{400} \overline{0}$ th to $\frac{1}{280}$ th of an inch, with still wider extremes; the average diameter is about $\frac{1}{3200}$ th ; and their average thickness, according to the same excellent observer, is about $-^{2} \frac{1}{400}$ th of an inch. According to the estimates of Vierordt, which have been corroborated by Mantegazza, a cubic centimetre of human blood contains about $5,000,000$ red corpuscles (in the male, 4,500,000 in the female), and about 14,000 colorless ones.-M. Malassez ${ }^{1}$ finds that the number of corpuscles varies in different parts of the circulation, the largest number being contained in the smaller arteries and capillaries $(4,300,000)$, and a smaller proportion in the larger arteries and veins $(4,000,000$, vein of arm). The richness of the blood, however, is not dependent alonc on the number of the corpuscles, but upon their volume and the quantity of hremoglobin they contain.-The color of the Red Corpuscles

1 De la Numération des Globules Rouges du Sang. Pamphlet, Paris, 1873 ; also Abstract by Dr. Ferrier in Medical Record, Jan. 8th, 1873. In this method of estimation the blood is drawn into a capillary glass-tube of known diameter, diluted with a definite quantity of serum, and the corpuscles counted. Among mammals the number varies from about $3,500,000$ (Rabbit) to $18,000,000$ (Goat) in the cubic centimetre. Camels possess about $10,000,000$; Birds (Cock), 2,000,000-3,300,000; Osseous Eishes, 700,000-2,000,000; Cartilaginous Fishes, 140,000-230,000. 
is very pale when they are lying in a single stratum; and it is only when we see three or four or more together in rolls or clumps, that the full, deep red tint of their contents becomes apparent. The cause of the difference in hue between the corpuscles of arterial and those of venous blood, will be considered hereafter.

175. The Red Corpuscles, when freely floating in the liquor sanguinis of blood no longer in motion, exhibit a marked tendency to approximate one another; usually coming into contact by their flattened surfaces, so that a number of them thus aggregated present the appearance of a pile of coins; or, if the stratum be too thin to permit them to lie in this manner, partially overlapping one another, or even adhering by their erlges, which then frequently become polygonal instead of circular. The corpuscles, when - thus adherent, resist the influence of forces which tend to detach them, and will even undergo considerable changes of shape, rather than separate from each other; if forced asunder, however, they resume their normal form. After thus remaining adherent for a time, they seem to lose their attractive force; for they are then seen to separate from each other spontameously. This peculiar tendency to aggregation is most strongly manifested in inflammatory blood, and assists in the production of the buffy coat; whilst, on the other hand, it seems to be neutralized by the action of most saline sub-

FIG. 105.

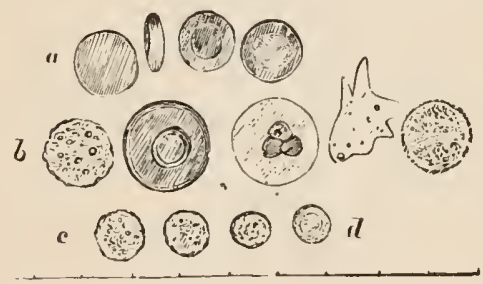

FIG. 106.

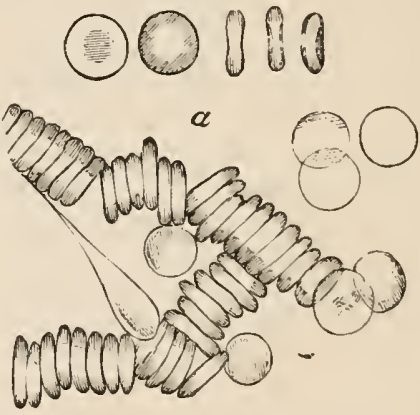

Fig. 105.-Red corpuseles and pale cells of blood and $1 \mathrm{mmph-globules.} \mathrm{At} a$, four red corpuscles; $b$, five pale globules; $c, d$, four lymph-globules. The first pale globule, at $b$, contains spherical granules, the last is only minutely granular, and the fourth is collapsed and sending off processes: these three globules are in the natural state, but the second shows its circular nucleus exposed by the action of weak acetic acid, and the third the nucleus divided after treatment by stronger acid. Of the lymphglolules (which are from an inguinal gland) at $c$, the first two are in their natural state; and at $d$, the last two, after having been long stceped in strong acetic acid. From a child, aged three, accidentally killed.

Fig, 106,-Red corpuscles of Man (on the same scale of one-four-thousand th of an inch, as marked at Fig. 103). At $a$, the corpuseles are seen flat, on edge, and in rolls; the two first corpuscles show the central spot or coneavity, lark and light; next are shown the biconcave and concaro-convex forms; among the rolls, one corpuscle is drawn out by virtue of its viscidity, and would resume its circular shape by virtue of its clasticity.

stances, since if these be added to the blood the corpuscles do not run together, or instantly scparate if they have already become adherent. It appears to be a purcly physical phenomenon, dependent on the relations of cohesion existing between the particles of solids and fluids. ${ }^{1}$

1 See Dr. Norris, of Birmingham, Proceed. of Roy. Soc., No. 112, 1869, who has shown that it ean be elosely imitated by partially immersing poised cork disks in water or other liquid, the particles of the solid outside the liquid having an attraction for each other, which, owing to the slight resistance oflered by the fluid, leads to movement through very sensible distances. Such disks exhibit no tendency to 
176. Besides the red corpuscles of the blood there are others which possess no color, and nua have an altogether different function. 'These are known as the White or Colorless corpuscles (b, Figs. 107, 108, 109). From

FIG. 107.

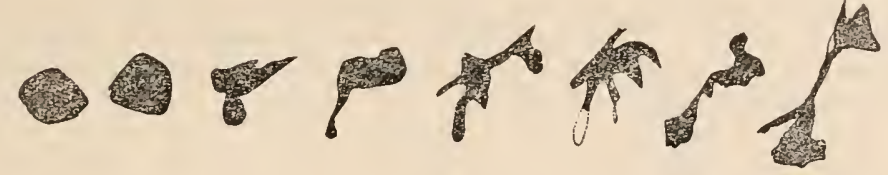

the researches of Dr. Klein on the blood of the Newt, there appears to be three varieties of white corpuscles in this animal.

1. The first is the common large colorless corpuscle. These, when examined immediately after they have escapea from a bloodvessel, are round and tramsparent, with a smooth surface. A few minute granules are scatterer through their substance ( $b$, Fig. 105). If means be taken to maintain the temperature of the microscope stage at about $100^{\circ}$ Fahr., and to prevent evaporation (as with a Stricker's warmed stage), ${ }^{1}$ the surface may be observed to become rough and prickly, one or two nuclei characterized by their duller aspect, and some perfectly clear spaces or vacuole, which are believed to be clear spaces filled with fluid, nake their appearance, and the whole corpuscle undergoes slow but continuous and most remarkable changes of form, closely resembling those of some of the lower organisms, and hence termed amoboid. These were first observed by Mr. Wharton Jones. ${ }^{2}$ Several such alterations of form are represented in the adjoining cut.

FIG. 108.
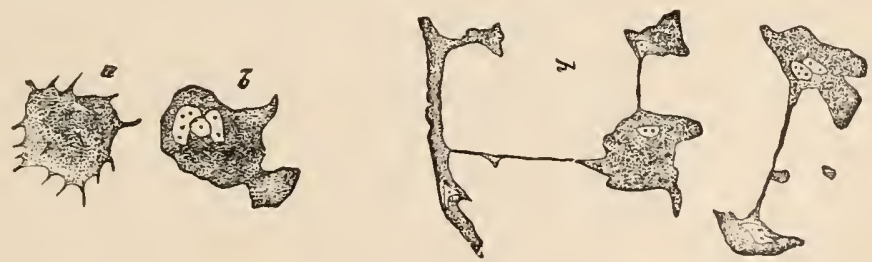

$a$, Common white corpuscle, soon after its withdrawal from the vessels.

$b$, The surface become prickly. $c$, Protrusion of larger processes, and apparition of nuclei.

The tips of the processes are usually rather more transparent and hyaline than the rest of the corpuscle, and a current seeming to carry some of the fine granules and one or more of the nuclei sets into them and urges them to further protrusion. Movements of locomotion as well as of mere change of form are thus effected, and after straying over the field of the microscope for some time the movements either become more and more feeble until they cease altogether, or the corpuscle may gather itself together again and resume its original nearly splierical form. ${ }^{3}$ Both the nuclei and the vacuolæ

run in to rouleaus if they are wholly submerged in a luid that will wet them, because then a cohesive equilibruim is established; but they can arain be made to do so by wetting them with some liquid that is unmiscible with the one in which they are submerged.

1 See Stricker's Human and Comp. Histology, New Syd. Soc. Translation, 1870.

2 Phil. Trans., 1846, pr. 64, 71, 90, etc.

3 According to Dr. Richardson, Report on the Structure of the White Blood-Cor- 
undergo constant ehange alike in their form and relative position. The size of these white eorpuseles is remarkably uniform in the different classes of the animal kingdom, being seldom much greater or less than $\frac{1}{3000}$ th of an ineh in the warm-blooded Vertebrata, and $\frac{1}{250}$ th of an inch in Reptiles.

2. A second kind of colorless Corpuscle in the blood of the Newt has been deseribed by Dr. Klein, ${ }^{1}$ under the term Granular corpuscles. These are larger but less numerous than the others, and are eharaeterized by the large dark granules they eontain.

FIG. 109.
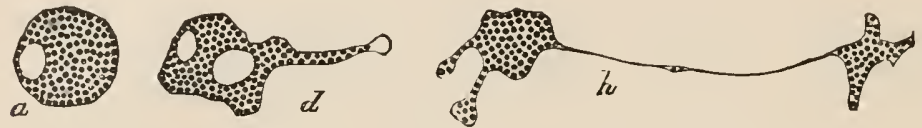

A granular corpuscle of the Newt, showing changes assumed in fifteen minutes.

Their movements are mueh more aetive than the former variety, but otherwise present a close general resemblanee to them.

3. Besides the ordinary eolorless corpuseles and the granular eorpuseles, other kinds ${ }^{2}$ are observable, whieh have been divided into, a, small, welldefined bodies resembling nuelei, $b$, large eorpuscles eonsisting of finely granular protoplasm, with jagged outline, eontaining three or four distinct nuclei, $c$, still larger irregularly-shaped masses of finely granular protoplasm inelosing from five to twenty nuclear-like bodies. The human eolorless eorpuseles are smaller than those of the newt, present less variety in aspeet, and are less aetive in their movements. They are either quite pale, or they eontain a variable number of dark granules. The Colorless eorpuscles possess a higher refrative power than the red; from which they are further distinguished by their greater firmness, their inferior elasticity, their softly shaded and granular aspeet, and the absenee of any disposition to adhere to each other; so that, when a drop of fresh blood is placed between two strips of glass, and these are gently moved over one another, the white eorpuscles may be at onee reeognized by their solitariness, in the midst of the rows and irregular masses formed by the aggregation of the red. This is still better seen in inflammatory blood, in which the Red eorpuseles have a peeuliar tendency to adhere to one another, so that the distinctness of the White is more marked. Colorless eorpuscles may be readily distinguished in the blood circulating through the small vessels of the Frog's foot; and it is then observable that they oeeupy the exterior of the eurrent, where the motion of the fluid is slow, whilst the red eorpuscles move rapidly through the centre of the tube (Fig. 110). The eolorless eorpuscles, indeed, often show a disposition to adhere to the walls of the vessels; whieh is manifestly inereased on the application of an irritant. Henee the idea naturally arises, that (to use the words of Mr. Wharton Jones) "there is some reeiprocal relation between the colorless corpuseles and the parts outside the vessels, in the process of nutrition." On the addition of distilled water the white eorpuscles swell up, beeome globular, and cease to move; one or several nuclei

pu-cle, pamphlet, 1872, some of the phenomena he has observed lend eountenanee to the theory that the white corpuseles of Man possess a cell-wall dotted with minute pores, which permit deliente threads of the soft protoplasm to be extruded. The psendopodia, he thinks, are invested to near their tip by the external cell-wall.

1 Handbook for the Physiological Laboratory, 1873, 1) 5.

2 See Gulliver, Med. Times, i, 1863, \}). 207 ; Nedsvetski, Centralblatt, 1873, p. 147. 
come into view and coalesee to form a vesicular body which begins to rotate, whilst the granules around it exhibit Brownian movements, and ultimately the wholc corpuscle disintegrates. When acted on by carbonic acid, the colorless corpuscles show their nuclei, but are otherwise unaltcred. After the action of acetic acid they present the appearance of globular bodies in which two, thrce, or more small shrunken nuclei are visible. In alkalies the colorless corpuscles swell and rapidly disappear, yet they exhibit remarkable resistance to the action of bile. ${ }^{1}$ When excited electrically during their amoboid movements, they assune the spheroidal form, but resume their activity on the cessation of the stimulus; after repeated excitation they expand and flatten, but still exhibit changes of form. Under the influence of successive shocks of greater intensity they swell, the granules exhibit molecular movements, and they tinally disappear. ${ }^{2}$ Binz ${ }^{3}$ and Geltowsky have shown that quinine has a remarkable power of arresting the movenients of the white corpuscles. The stroma of the white corpuscles contains a substance analogous to Myosin, with Lecithin, Cholesterin, Glycogen, and Fat. In addition to the alkaline albuminates and

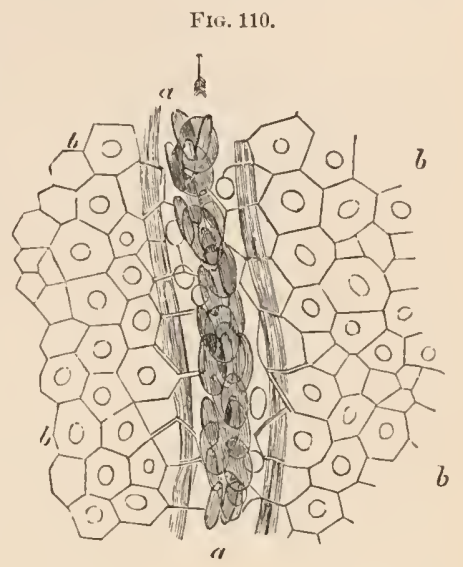

A small Venous trunk, $a$, from the Web of the Frog's foot; $b, b$, cells of pavement-epithelium, containing nuclei. In the space between the current of oral Blood-corpuseles and the walls of the ressel, the round transparent colorless corpuscles are seen. serum-albumen, the nucleus contains an albuminoid substance (Nuclein) which closely resembles mucin (Kühne, Brunton), and is perhaps intermediate to albumen and lecithin. ${ }^{*}$ Hoppe-Seyler finds that the white corpuscles only contain glyeogen as long as they exhibit movements, aud that when they become rigid they lose their glycogen and contain sugar. The inclosure of particles of coloring matter of carbon, or even of red corpuscles by the white corpuscles, has been frequently witnessed. ${ }^{5}$ The white corpuscles of the blood, both of the frog and triton, and of man, have been observed by Klein to multiply by fission. ${ }^{6}$

177. The proportion which the white or colorless corpuscles bear to the red, is very small in the blood of man and the higher Vertebrata; being, in the state of health, according to the cstimate of Moleschott (which is confirmed by Kölliker), ${ }^{7}$ not more than 2.55 to 1000 . It varies, however, to a very re-

1 Jurasz, Inaug. Diss. Greifswalde, 1871.

${ }^{2}$ Klein, op. cit., p. 18. See also Golubew, Wien. Akad. Sitz., lvii, p. 555, Math. Nat. Classe.

3 Practitioner, No. 51, 1872.

4 See Hoppc-Seyler and Micscher in Hoppe-Seyler's Med.-Chem. Untersuch., iv, 1871 , p. 486, quoted in Brunton and Ferrier's Report on Physiolory in Journ. of Anat. and Phy's, vol. vi, p. 45. Also Brunton's Paper on the Chemical Comp. of the Nuclei of Blood-Corpuscles in Journ. of Anat. and Phys., vol. iv, 1870, p. 91. The distinctive chemical charactcrs of "nuclcin" appear to constitute an answer to Mr. Savory's view that " the existence of a nucleus in the red corpuscles of Ovipara is due to changes after death or removal from the vessels." Sce his paper in Month. Microsp. Journ., 1869, vol. i, p. 235.

5 See Preyer, Virchow's Archiv, 1864, p. 417.

6 Centralblatt, 1870 , p. 17.

7 Manual of Human Histology (Sydenham Society's edition), vol. ii, p. 330. 
markable extent, as has been shown by Dr. Hirt, of Zittau, ${ }^{1}$ according to whether the examination be made before or after food. Thus in the morning before breakfast the proportions were one colorless to 716 colored corpuscles; half an lour after breakfast $1: 347$; between two and three hours after breakfast $1: 1514$; ten minutes after dinner $1: 1592$; half an hour after dinner $1: 429$; two hours and a half to four hours after dinner $1: 1481$; half an hour after supper $1: 544$; and between two and a half to three and a half hours after supper $1: 1227$. The white corpuscles are more abundant in children than in adnlts, and there is an increase during preguancy and in certain diseased conditions of the system. In the oviparous Vertebrata the proportion is higher; thus it has been observed by Wagner ${ }^{2}$ to be as $1: 16$ in the bloorl of a frog examined in February, and as 1:6 in similar blood examined in Angust. In one Vertebrated animal, the Amphioxus, the red corpuscles are wanting altogether; their place in the circulating blood being taken by the colorless. And in the Invertebrate series generally, the corpuscles of the circulating fluid correspond rather to the colorless corpuscles of the blood of Vertebrata, and to the corpuscles of Lymph and Chyle (which may be regarded as the same bodies in an earlier stage of development), than they do to the red corpuscles, which are peculiar to Vertebrata. ${ }^{3}$ Thus, in one of its most characteristic features, the blood of Invertebrata (and of Am. phioxus) may be likened rather to the Lymph and Chyle of vertebrated animals than to their blood; and this resemblance is strengthened by the fact that there is no distinction in the former between the absorbent and the sanguiferous vessels, which in the latter respectively contain the nutritious fluid in its earlier and in its later stages of development. Moreover, the earliest blood-corpuscles of the embryo of even the highest vertebrata are colorless; and long after the blood has acquired its cliaracteristic hue from the development of red corpuseles, the colorless corpuscles bear a very large proportion to the red, so as even to equal them in number (as the author is informed by Mr. Gulliver), in the blood of foetal Deer an inch and a half long, and absolutely to preponderate in the blood of still smaller embryos.

178. If the blood (of a Mammal) be exposed drop by drop to a cold of $8^{\circ}$ or $9^{\circ}$ Fahr., and then be rapidly warmed to $68^{\circ}$ Fahr., the corpuscles will be found to have lost their color, whilst the serum is deeply stained. A kind of analysis of the constituents of the blood may thus be effected. To the material of the corpuscles, which retain for some time their original form and elasticity, though devoid of color, the term Stroma has been applied, whilst the coloring matter has been named Hamoglobin, Hrematoglobulin, or Hiematocrystallin, and is characterized by its property of assuming under favorable circumstances the crystalline form. The stroma appears from its reactions to be chiefly composerl of certain albuminous compounds, the nature of which has not been clearly ascertained, lecithin and cholesterin. MI. Preyer has named one of these albuminous substances globin, and regards it as the purest form of albumen known, since it leaves no ash when burnt. It has no fibrino-plastic property. By the action of acids (acetic acid) acidalbumen, and of alkalies (potash) alkali-albuminate are formed. Syntonin

1 Müller's Archiv, 1856, p. 174; see also the Experiments of Marfels and Lorange, quoted in Ludwix, vol. ii, p. 38, 1861.

2 Elements of Physiolngy, translated by Dr. Willis, p. 246.

3 See Mr. Wharton Jones's Memoir on The Blood-Corpusele, ennsirlered in its different Phases of Development in the Animal Series, in the Philos. Trans., 1816; atso P'rine. of Comp. Phys., 4th edit. 2.? 379-382.

4 Preyer, Die: Bhut-Crystalle, 1871, p. 167, shows that the term globulin has been applied to twelve or fourteen different albuminoid compounds, suffieiently attesting the diffieulty ehemists experienee in isolating and discriminating the members of this extensive class of organie cumpounds. 
and Globulin are also products of the decomposition of the albuminous constituent of Haenoglobin.

The coloring matter of the blood, or liamoglobin, enters largely into the composition of the corpuscles. It is capable of assuming the crystalline form,

FIG. 111.

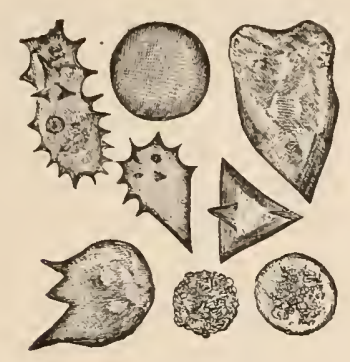

FIG. 112.

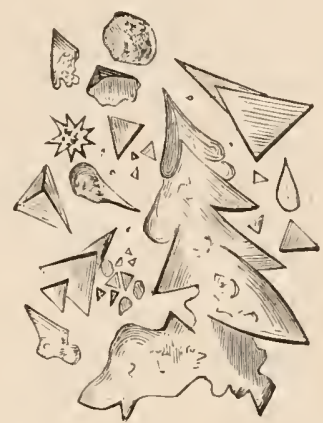

Frf. 111.-Spontaneous changes in form of Red corpuscles of Guinea-pig's Blood, within an hour after removal from the body.

FIG. 112.-Perfect Tetrahed ral Crystals formed from Guinea-pig's Blood. In many cases, one Corpuscle became one Crystal.

the crystals being obtained with the greatest facility from the blood of the dog, horse, guinea-pig, and goose, less easily from the blood of mau, and with the greatest difficulty from the mouse, the mole, and the bat. ${ }^{1}$ In some instances it is only requisite to dilute the blood and allow one or two drops to dry spontaneously. In others, an abundant crop may be obtained by transmitting air free from carbonic acid through the blood for several hours; or the blood after being defibrinated nay be frozen (Rollett's plan) and allowed slowly to thaw ; or (Böttcher's method) a considerable quantity of cold water may be injected into the veins of the animal whilst it is being killed by chloroform inhalation, the blood removed from the heart mixed with its own volume of cold water and some alcohol added, when the whole mass changes into a crystalline pap;

FIG. 113.

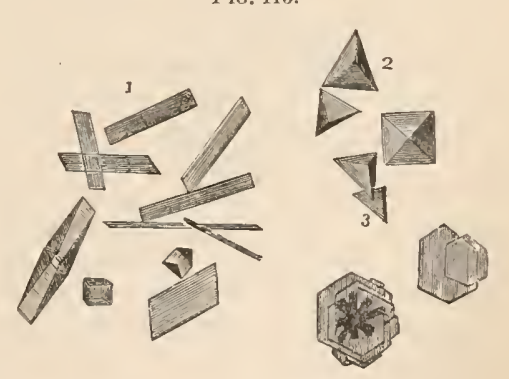

Blood-Crystals, (1) prismatic, from Humau blood, (2) tetrahedral, from Pig's blood, (3) hexagonal plates, from Squirrel's blood. or (Kühne's and 'Thiry's plan) the blood left after the formation of a clot is mingled with some 0.5 per cent. aqueous solution of crystallized ox-bile (tauro-and glycocholate of soda), and then with alcohol (90 per cent.) containing a little acetic acid. The method given by Preyer as the best adapted for microscopical investigation is that to a small quantity of blood free from fibrin, sufficient water should be added to give a clear sulution; if on evaporation in the cold a drop of the solution covered by a thin slip of glass give no crystals, about a quarter of its volume of alcohol must be added and the fluid placed in a freezing mixture: crystals will in alnost all instances be immediately formed. Speaking generally, in order to obtain good crystals, the corpuscles must be dissolved, and the coloring matter thrown down by 
alcohol, or by some salt or acid. Some of the chief forms of hæmoglobin crystals are exhibited in Figs. 111, 112, 113. It has been ascertained that with the exception of those of the squirrel, which are hexagonal, the crystals of the blood of other animals belong to the rhombic system. Those of man present the form of elongated rectangles, rhombs, and four-sided prisms, with dihedral summits. The crystals of the blood of the rabbit are very similar to those of man. Those of the dog are long four-sided needles, terminated by one plane surface. From cat's blood similar crystals may be obtained, together with thin rhombic and six-sided plates. In the guineapig tetrahedra, and in the rat tetra- and octahedra are found. Dr. Ray Lankester ${ }^{1}$ has shown that Hremoglobin is present in the plasma of the vascular fluid of various Invertebrata, as in that of the Annelids Lumbricus, Eunice sanguinea and Hirudo, in that of the Crustacean Phyllopod, Cheirocephalus diaphanus; in that of Chironomus amongst Insecta and the Planorbis amongst Mollusca.

Hiemoglobin crystals, from whatever animal they may be obtained, are always perfectly transparent, and doubly refracting, with silky lustre; the crystals of reduced hemoglobin are pleochromatic, alternating from red or purple to green; but those of oxygenated hremoglobin are not so, presenting the color of the blood from which they are got. When fresh they are soft and highly elastic, breaking with an uneven splintery fracture; exposed to the action of water they imbibe it and undergo various changes of form, never, however, assuming that of a red blood-corpuscle. The sp. gr. of hamoglobin probably varies from 1.3 to 1.4 . All the varieties are soluble in water, and the solubility increases with the temperature. They are insoluble in absolute alcohol, ether, in volatile and fixed oils, benzol, turpentine, chloroform, and carbon disulphide. They dissolve readily and for some time without undergoing decomposition in the alkalies and most alkaline salts (carbonates, phosphates, borates), but in a few days the solution becomes cloudy from decomposition. Solutions of most acids quickly dissolve them, but decomposition sets in in the course of a few hours. They remain long unchanged in healthy urine, in sacharine solutions, in bile, and serous transudates. Hrmoglobin, though a crystalline compound, is not diffusible, and when pure is not fibrino-plastic. The percentage composition of hamoglobin obtained from Schmid's and Hoppe-Seyler's analyses is C 54.0, H 7.25, N 16.25, iron (0.42, sulphur 0.63, O 21.45 , which accords with the formula: C $600, \mathrm{H} 960, \mathrm{~N} 154, \mathrm{Fe}_{1}, \mathrm{~s}_{3}, \mathrm{O} 179 .^{2}$ Hrmoglobin has a strong affinity for oxygen, one gramme absorbing at mean tenperature and pressure 1.3 cub. cent. of this gas, but at the same time it readily yields up the gas to other easily oxidizable substances.

179. Under the influence of warmth $\left(140^{\circ}-180^{\circ} \mathrm{F}\right.$.), of acids, or of caustic alkalics, hamoglobin undergoes decomposition; the color of the liquid changes from a beautiful red to a snutty tint, which appcars in thin layers and by reflected light, brown, and by transmitted light, green. This change of color is due to the breaking up of the hremoglobin into an albuminous compound, and a peculiar colored substance termed hematin. Evcry 100

1 Journal of Anat. and Physiology, 1868, p. 114, and 1871, p. 122, and P'roeeed. of Proy. Soc., 18\%2, Dee. 12th.

Aceording to the recent researehes of MII. Paquelin and Jolly (Séanee de l'Academie des Scienecs, 19th Uet. 1874), the corpuscles of the blood contain the iron in the form of tribasie phosphate of the protoxide, but the pure eoloring matter (their hrmatosin) contains no iron. Their hamatosin burns away without leaving any ash, is insoluble in pure water, slightly soluble in solutions of ammonia, potash, and soda, undergoing decomposition in the two latter; soluble in ether, ehloroform, benzin, and bisulphide of earbon. 
parts of hamoglobin treated with hydrochloric acid yield about 4 parts of liydrochlorate of hamatin (Fig. 114) and 96 parts of albumen. Hamatin was erroneously supposed to be the true coloring material of the blood by Berzelius, Mulder, Lccanu, Lehmann, and others. According to HoppeSeyler, its composition is represented by the formula $\mathrm{C}_{96} \mathrm{H}_{51} \mathrm{Fe}_{3} \mathrm{~N}_{6} \mathrm{O}_{15}$. When Aried it forms an amorphous bluish-black, or on being rubbed down, reddishbrown powder. It withstands without decomposition a temperature of $350^{\circ}$, but above that point, carbonizes. It is insoluble in alcohol, water, ether, or chloroform, but dissolves readily in acids and alkalies, and in acidified alcohol, by which last it is freed from the albuminous compound. Then treated with sulphuric acid, the iron can be wholly withdrawn, and the hamatin thus obtained, so far differs from oldinary hematin, that whilst it is insoluble in dilute acids, it presents the important chemical feature of being polymeric with bilirubin, or coloring matter of the bile, as shown by the following formuli:

$$
\mathrm{C}_{96} \mathrm{H}_{51} \mathrm{~N}_{6} \mathrm{Fe}_{3} \mathrm{O}_{18}+3 \mathrm{HO}=3\left(\mathrm{C}_{32} \mathrm{H}_{38} \mathrm{~N}_{2} \mathrm{O}_{6}\right)+3 \mathrm{FeO} \text {. }
$$

Teichmann's Hemin crystals, which are identical with Lehmaun's Hemotin crystals (Fig. 115), Virchow's Hematoidin crystals, and Preyer's Hamatoin crystals, are all products of the decomposition of Hremoglobin. Preyer has described two other crystalline compounds he has obtained from blood,

FIG. 114.

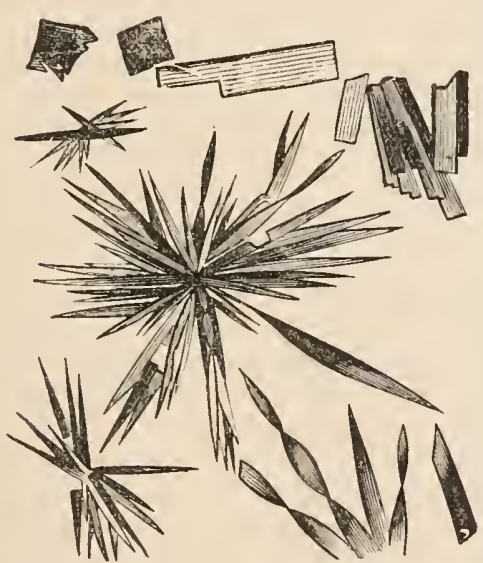

FIG. 115.

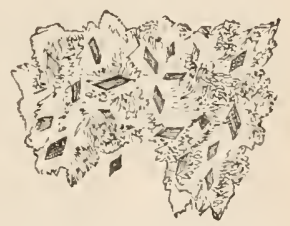

Hæmin Crystals, by Teichmann, in Hydrochlorate of Hrematin.

Rhombic Crystals of IIydrochlorate of Hrematin, obtained by Lchmann's method. They are obtained when blood is suhjected to the action of a mixture of 1 part of alcohol, 4 parts of ether, and 1-16th of oxalic acid, and appear as thin brownish and brownish-green, striated, transparent crystalline laminie, often curiously twisted upon their long axes, and soon spontaneously changing into flat rhombic octahedra.

Hematochlorin and Hcematolutein; and four non-crystalline substancesMethremoglobin, Hrematin, Hremathion, and Hrmatinin. The formation of the Hremin crystals of Teichmann is important in a medico-legal point of view, since they can be obtained fron a very minute speck of blood. 'The best method is to triturate the supposed dry blood-spot with a little common salt, and to add glacial acetic acid. The mixture is then to be warmed till bubbles appear, and set aside to cool. If blood be present, numerous himin, or hydrochlorate of hrematin crystals appear in the form of rhombic tablets, often arrangerl in stars or crosses of red, brown, or black color, becoming 
violet on exposure to oxygen, and losing thcir transparency on exposure to carbonic acid. Mingled with these arc colorless crystals of common salt, acctate of soda, and colorless scales of albumen in combination with acid. The Hematoidin crystals observed by Virchow, and stated by him to occur in blood that has long becn extravasated, as in old apoplectic clots, and in corpora lutea, appear to be identical with bilirubin, or the coloring mattcr of bile. The formation of these crystals takes place with considerable rapidity. If a little coagulated pigeon's blood be introduced beneath the skin of that bird, Hrematoidin erystals appear in the conrse of two days. ${ }^{1}$ The crystals are soluble in ammonia, insoluble in alcohol and acetic acid. Preyer $^{2}$ has recently described yet another form of crystal, to which he applies the term of Hrematoin crystals. They are acicular, frequently bent, partly grouped into stellie and donbly refractile. They are insoluble in alcohol, ether, and water; but very soluble in weak solution of potash or weak acetic acid. ${ }^{3}$

180. Spectrum Axalysis of the Blood.-The researches of Brewster, Herschel, and Müller showed that when solutions of various coloring matters are placed in the solar spectrum, certain portions of the light are absorbed, and dark strie or bands appear in the spectrum corresponding to those rays that have been arrested. F. Hoppe ${ }^{4}$ found that in a very diluted mixture of blood and water the spectrum exhibited two well-marked dark strise (2, Fig. 116) in the yellow and in the green, both lying between the Fraunhöfer lines, D and E. When less dilute, the two lines blend together, and with increasing concentration, the violet and blue, as well as the green and yellow, gradually vanished, till at length only the red remained. Arterial and venous blood alike showed the two strix, as did also dricd blood, and blood treated with $\mathrm{CO}_{2}, \mathrm{CO}, \mathrm{H}, \mathrm{SH}, \mathrm{NH}_{3}$, etc.; but the strie rapidly disappeared when acetic or tartaric acid, or caustic alkaline lyes were added to the blood. He further found that the ordinary absorption strice werc rendered most distinct by precipitating a mixture of blood and water with acetate of lead, and throwing down the lead with carbonate of sorla. Prof. Stokes, ${ }^{5}$ on repeating the experiments of Hoppe, confirmed them, and at once proceeded to inquirc whether it were possible to imitate the change of color of arterial into that of venous blood, on the supposition that it arose from reduction. This he accomplished by adding solntion of protosulphate of iron to the blood, with enough tartaric acid to prevent precipitation by alkalics, when the color of the solution immediately became much deeper, and the two absorption bands were at once replaced by a single band (4, Fig. 116) shaded off at the borders, and occupying an intermediate position between them. On exposure to air, the bands originally present reappeared. Hence he inferred that the coloring matter of the blond, like indigo, is capa-

1 Langhans, quoted in Fehling's Neues Handwörterbuch der Chemie, 1875, B. ii, 1. 112.

2 Centralblatt, 1871, p. 51.

3 For the best accounts of the crystals of blood see Teiehmann, Zeitschrift f. Rat. Med., N. F. ii, 375, viii, 141; Kölliker, Manual of Inman Histologs, 1860; Virchow, Collular Patholuey, 1840, Pl. 143-145; v. Gorup-Besanez, Phys. Chem., 1862, pp. 170-194; Funke, I'lysiologir. 4th edit, 1863, p. 45; Boja:oowski, siebold and Kölliker's Zeitschrift, Bd. xii, 181;2, p. 312: Rollett, Moleschott's Untersuchung.,

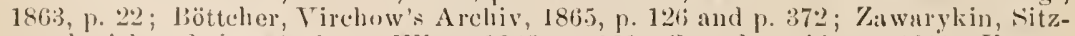
mngherichte d. k. Akad. zu Wien, 1865, p. 161; Gwosdew, idem, 1866; HoppeSerler, Med -Chem. Untersuch, 1867, p 298; Kühne, Plỵsiologr. Chemie, 1868, p. 188 et sıo ; Thudichum, Centralblatt, 1869, p. 1; P'reyer, Die Blutkrystalle, Jena, 1871, which last contains all the referenees up to that date, and gives the fullest aceount yet published.

4 Virchow's Archiv, Bd. xxiii, 18ti2, p. 446.

5 l'roceed. Roy. Soc., vol, xiii, 1863-64, p. 355. 
ble of existing in two states of oxidation, distinguishable by a difference of eolor and a fundamental difference in the action on the spectrum. To this eoloring matter he has applied the term Cruorin, suggested by Dr. Sharpey, its two states of oxiclation being termed searlet cruorin and purple cruorin respectively. Prof: Stokes showed also that hematin, which is the result of the action of weak acids on eruorin, was similarly capable of oxidation and reduetion, and that it shows well-defined and highly characteristic

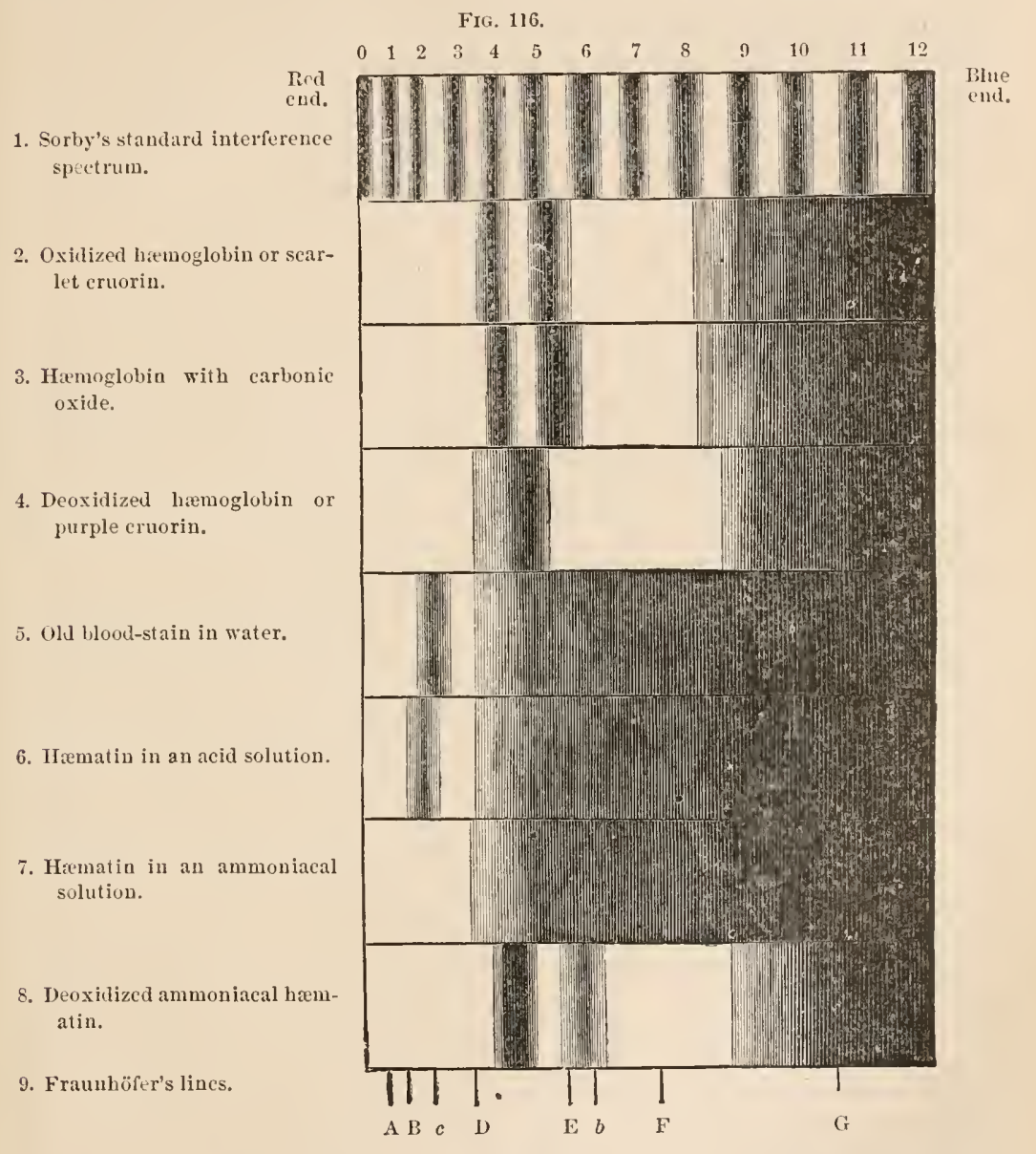

lines, which, however, are by no means identieal with those of eruorin. Prof. Stokes suggests, as a physiologieal deduction from his experiments, that cruorin is to be regarded as the carrier of oxygen to the tissues, sinee it absorbs that gas with extreme faeility; whilst under the influenee of redueing agents, it permits it again to be withdrawn from it. Both Hoppe and Stokes refer to the applieability of spectrum analysis for the detection of blood-stains in medieo-legal investigations. Mr. Sorby ${ }^{1}$ has greatly improved the meehanieal

1 Quart. Journ of Ści., 1865, vol. ii, p. 198; Pop. Sci. Review, vol. v, p. 66 ; Proceed. of Roy. Soc., vo!. xv, 1866-7, p. 433. For an account of Vierordt's method of notation see Dalton, N. Y. Mled. Journ., vol. xix, 1874, p. 579. 
arrangements by which the lines in question can be examined, and the foregoing woodeut, Fig. 116, is after a drawing by his hand. The uppermost scale represents Mr. Sorby's standard interference spectrum, and is obtained by transmitting light through two Nicol's prisms and an intervening plate of quartz or selenite, with its axis at $45^{\circ}$ to the plane of polarization. The number of the dark bands due to the interference of the luminous waves may be regulated by the thickness of the plate of quartz, and for the sake of convenience has been fixed at 12 , the unequal dispersion making the distance between the bands in the blue about twice as great as in the red. The dark bands are numbered $1,2,3,4$, etc., and the centre of the white spaces $1 \frac{1}{2}, 2 \frac{1}{2}, 8 \frac{1}{2}$, etc., which may be again subdivided, as into $1 \frac{1}{4}, 1 \frac{3}{4}$, etc. Definite narrow ahsorption bands are indicated by a * printed over their centre. On this notation the bands occurring in the several solutions mentioned may be described intelligibly and simply thus:

2. Oxidized hremoglobin,

3. Hremoglobin with $\mathrm{CO}$,

$$
\begin{array}{lcl}
* & * \\
3 \frac{5}{8}-4 \frac{3}{8} & 4 \frac{3}{4}-5 \frac{3}{4} & 8-9- \\
3 \frac{3}{4}-4 \frac{1}{2} & 4 \frac{7}{8}-5 \frac{7}{8} & 8-9-\text { and so on. }
\end{array}
$$

According to Mr. Gamgee, the nitrites cause blood to assume a chocolate color, the bands of oxidized hemoglobin becoming very faint, and an additional absorption band in the same position as in acid hrmatin appearing. The nitrites do not decompose the blood-coloring matter, nor discharge the oxygen. They appear to link themselves on to it, as is probably the case with hydrocyanic acid. ${ }^{2}$ Nitritized blood absorbs less oxygen, but it can convert into ozone what it does absorb.

181. There can be no doubt that both the red and the colorless corpuscles have, like other cells, a definite term of life; and that, whilst some are undergoing disintegration, others are in a state of advancing development to supply their places, so that the entire mass of both is undergoing continual clange. That a new production of red corpuscles may take place with considerable rapidity we have evidence in the rapid rcstoration of their normal proportion after it has been lowered by hemorrhage, and in the speedy increase which may be effected in their amount in blood in which they have been excessively diminished by disease, this heing especially promoted by the administration of iron, and by a generous diet. On the other hand, various appearances indicative of degeneration may be seen in the red corpuscles; and this especially in the blood of the Griparous Vertebrata, which usually contains corpuscles almost destitute of color, and having a shrunken or eroded aspect, their nuclei, however, prescnting a remarkable distinctness. That, under certain circumstances, such a degenerating process takes place with great rapidity in the blood which circulates through the Spleen, nray be considered as ascertained almost beyond a doubt $(\$ 157$, mi ). The duration of the individual corpuscles is unknown, the only evidence yet obtained being derived from the experiments of Bernard, who found that when the blood of birds was injected into the vessels of mammals, the elliptical corpuscles of the former, which were at first plainly visible, disappeared entirely in the course of a few weeks. The question now arises, in what manner the two classes of corpuscles are respectively developed, and whether they have any relationship to each other.

182. Development of the Blood-corpuscles.-That the fully developed Red corpuscles, when ceasing to exist as such, do not give origin to new corpuscles of the same kind, may now be asserted (notwithstanding the statements

1 Proceedings of Roy. Soc., No. 102, 1868.

2 Preyer, Virehow's Arehiv, Bd. xl, 1867; and Hoppe-Seyler, Untersuch., 1867. 
of former observers) to be the concurrent opinion of ncarly all who have in recent times specially devoted themsclves to this inquiry. The first lied corpuscles unquestionably have their origin, like the original cells of the solid tissucs, in the primordial cells of the germinal structure; and it is in the "mesoblast" or so-called "vascular layer" of the "blastodermic vesicle" (chap. xviii, sect. 4), and the mass of cells which constitute the ruriment of the heart, that this metamorphosis seems first to take place. The situation of the heart, and the course of the principal trunks of the "vascular area," arc early marked out, by the peculiar disposition of the aggregations of cells from which these orgaus are to be developed; and whilst the outer portions of these aggregations are transformed into the walls of the respective cavities, the inner portions seem partly to deliquesce, and partly to remain as isolated cells floating in the liquid thus produced. These isolated cells are the first blood-corpuscles; and the following account of then in the Oviparous Vertebrata or Pyrenzemata is given by Foster and Balfour, ${ }^{1}$ and differs but slightly from that by Klein. ${ }^{2}$ In the pellucid area, where the formation of bloodressels may be most easily observed, a number of mesoblastic cells are seen to send out processes which unite and form a protoplasmic network, with nuclei at the points from which the process started. The nuclei, which as a rule are much clongated and contain large oval nucleoli, increase very rapidly by division, and form groups at the nodal points. 'The majority of these acquire a red color and hecome converted into blood-corpuscles, but a few, generally on the ontside of the group, remain unaltered. The protoplasm in which the central reddened nuclei are imbedded becomes liquefied, whilst that on the outside of each group as well as that of the uniting processes remains granular and forms an investment for the unaltered nuclei which are imbedded in it. Each nodal point is thus transformed into a more or less rounded mass of blood-col'puscles floating in plasma, but enveloped by a layer of nucleated protoplasm, the several groups being united by strands of nucleated protoplasm. By the growth of the strands and the transformation of nuclei in their interior a series of communicating vessels are formed containing corpuscles which when removed from the vessels exhibit energctic amoboid movements, and probably increase by division. ${ }^{3}$

183. That after the Chyle and Lymph have begun to flow into the circulating current, the continued generation of Red corpuscles is due to the

1 Elements of Embryology, 1874, p. 69.

2 Sitz-ber. d. Wien. Akad., 1871, Bd. Lxiii, Abth. ii. For other accounts see Afanassieft in iden, Bd. liii, 1866, Goette, Sehultze's Archiv, 1873, and His, Neben die Erste Anlage des Wirbclthierleibs.

3 A different aeeount has lately been given by Dr. H. D. Schmidt, Monthy Mieroseopieal Journal, 1874 , p. 45, from observations made on a very early human embryo. In this case the young eolored eorpuseles appeared to be developed in the interior of mother-eells, at the expense of which they grew, and from whieh they ultimately beeame detached, leaving a dimple at the point of separation. One, two, or three, young corpuseles were sometimes scen in a parent corpusele, and the young ones themselves sometimes had a third generation in their interior prior to their own escape. 'This method of inerease forms, as Dr. Schmidt observes, the transition from endogenous development to generation. The parent-eells themselves appeared to be derived from the interior primary glandular follicles, formed of hexagonal cells in the walls of the umbilieal vesiele, and he is of opinion that the so-ealled nuclci of the first set of blood-cells are in reality the embryonie red blood-corpuscles which, when first formed, exaetly resemblc the eorpuseles of the adult, exeept that the eentral depression is less distinet. See also Sehäfer, Proceed. Roy. Soe, xxii, No. 151, who shows that blood-corpuseles arise in the interior of the vacuolated and nueleated eells of conneetive tissuc; the hemoglobin being deposited in the form of minute globules, whieh inerease in size and form the eorpuscles, whilst the cells elongating, branehing, and uniting with others form the vessels. 
progressive metamorphosis of the eorpuseles of those fluids, is an opinion whieh has come of late to be very generally received amongst Physiologists; it may be found, however, to require some modifieation. It rests upon facts of three different orders: 1st, the presenee in the blood of oviparous Vertebrata, of corpuseles exhibiting what appear to be intermediate gradations of development between Lymph-eorpuscles and their nucleated Red eorpuseles; and this espeeially in blood in whieh an unusually rapid developnent of red corpuseles is taking place, to make up for previous loss; $2 \mathrm{~d}$, frequent ruddiness in the hue of the fluid of the Thoracic duct, which seems to depend upon the incipient development of Hrmoglobin in some of its floating corpuseles; and $3 \mathrm{~d}$, the progressive transition from one form to the other, which may be observed in the ascending seale of animal existenee. As to the preeise mode, however, in which the non-nueleated Red corpuscles of Mammalian blood are produced, much difference of opinion still exists. The most probable view is that the ordinary lymph-globule, which is a nncleus, may either develop into a white corpusele, whieh is a nueleated cell, or into a red eorpusele. ${ }^{1} \mathrm{Mr}$. Wharton Jones still holds the view originally maintained by Hewson, that the red corpuseles of Mammalia proeeed from the nuelei of the pale eorpuscles, and it is almost eertain that amongst the apyrencmata the entire white corpuscle does not beeome the red eorpusele, though various observers have shown that the pale mucleated cells of the pyrenremata do pass into the colored nucleated red corpuscle of this seetion of vertebrata. 'Thus this differenee in the mode of development would appear as remarkable as the difference in the perfect structure, already described, of the red corpuscles of these two main divisions of Vertebrata. And thus also the Chyle and Lymph seem to be continually supplying, not merely the pabulum for organization, derived from the food, whereby the components of the liquid part of the blood are replenished as fast as they are withdrawn; but also the rudimentary corpuscles whieh are to be progressively metamorphosed into the partieles that float in its current. In one or two instances, under exceptional eircumstanees, the red blood-corpuscles have been seen to be undergoing fission.

184. Composition of the Blood.-The morphologieal or formed elements of the Blood having been thus separately described, we have now to inquire into the ehemical eharaeters of the various eomponents which are associated in the liquid as a whole, and the proportions in which they sererally present themselves. These are subject, even within the limits of health, to considerable variations; some of whieh seem to depend upon the eonstitution of the individual, his diet, mode of life, ete.; whilst others are probably referable to the period at which the last meal was taken, and the amount of bodily exertion made within a short time previous to the aualysis. Hence no single analysis could represent the average composition of the bloud, even if it were itself ehemieally accurate; but there are difficulties in the way of quantitatively determining with preeision the several components of the blood, which interpose a new source of uncertainty and error. Notwithstanding the numerous investigations which have been made upon the Blood, the means of separating the several constituents are not sufficiently exact to enable us to arrive at more than an approximative estimate of their respective proportions. The marked discrepancy observable between the results obtained by different analysts, especially in regard to the relative proportions of Albumen and Corpuscles, arises in great degree from the lifference of the methods of analysis employed, as has been proved by MI. v. Gormp-Besanez. ${ }^{2}$ For he found that when four samples of the same blood were ex-

1 See Dr. Bennett, Lancet, vol. i, 1863, p. 378.

2 Journ. für Prakt. Chem., Bd. i, p. 346. 
anined by the methods adopted by four different experimenters respectively, the results were as follows. 'The first specimen was the blood of a vigorous man fifty years old.

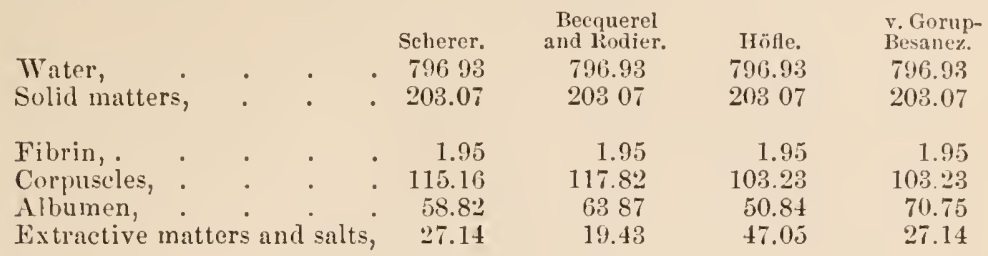

The sccond specimen was from a robust nan twenty years old:

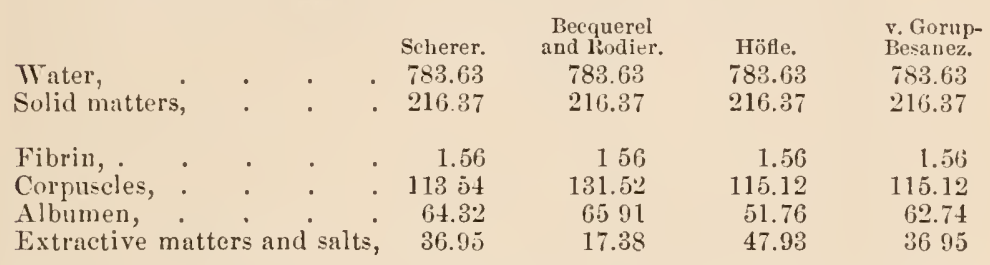

185. We have now to notice those less prominent components of the Blood which have not been hitherto described in detail. Under the general lead of Fatty Matter's are included several different kinds of fat; of which the most important are the saponifiable fats, stearin, palmitin, and olein; the phosphorized fats or glycerin-phosphoric acids, which appear to originate from the decomposition of Lecithin (\$54) in the blood, and cholesterin. The proportion of the saponifiable fats is always considerably increased after food, the increase proceeding from the entrance of the oleaginous chyle (\$153). The kind of food will, however, of course materially affect the quantity of fat contained in the blood. Nasse found 2.6 parts of fat in 1000 of the blood of a dog that had been kept fasting for four days. After bread diet it rose to 3.1 parts, after meat to 3.8 , and after suet and starch to $t .1$ parts in 1000 . The following table represents the mean, maximum, and minimum amounts of fatty substances in the healthy blood of Man (the proportion in that of the female being almost precisely similar), according to the analyses of MM. Becquerel and Rodier:

\begin{tabular}{|c|c|c|c|c|}
\hline Saponified fat, . & & $\begin{array}{l}\text { Mean. } \\
. \quad 1.004\end{array}$ & $\begin{array}{l}\text { Max. } \\
2.000\end{array}$ & $\begin{array}{l}\text { Min. } \\
.700\end{array}$ \\
\hline Phosphorized fat, & . & .488 & 1.000 & .270 \\
\hline Cholesterin,. . & - & .088 & .175 & .030 \\
\hline Serolin, . & . & . $\quad .020$ & .080 & inap \\
\hline
\end{tabular}

The source of the peculiar odor of the blood is probably a volatile fatty acid, too minute in its amount to admit of being separately estimated. This odor may be made much more apparent by treating the blood with sulphuric acil, even after it has been long dried; and in all those animals which are readily distinguishable by their odorous emanations, it may thus be made so perceptible as to admit of their blood being distinguished (at least by an individual possessed of a delicate sense of smell) tlirough its scent alone. Of this test use has been made with great advantage in juridical investigations. ${ }^{1}$

1 See MI. Barruel's researches on this subject in Ann. d'Hygiène, etc., tomes i, ii, and $x$. 
186. Under the vague term Ertractive, have been included many different substances which normally present themselves in only very small quantity, and which are consequently diffieult of detection; but which are extremely important in a physiological point of view, as the chief "factors" (to use the appropriate designation of Prof. Lehmann) in the metamorphosis of animal tissue, both progressive and retrograde. Amongst the latter, Urea, Creatin, and Creatinin; Uric, Hippuric, and Lactic Acids; Leucin, Tyrosin, and Hypoxanthin (or Sarkin), may be particularly mentioned. Besides the foregoing, the extractive of blood generally seems to contain Sugar, or an amyloid substance (Pary), that is waiting for elimination by the respiratory process, this substance being found most abundantly, however, in the blood of the hepatic vein, vena cava, and pulmonary artery. As might be expected, the proportion of sugar in the blood is greatly affected by the diet of the animal. Plosz and Tiegel ${ }^{1}$ have described a saccharifying ferment in the blood, and Hutson Ford ${ }^{2}$ maintains that alcohol derived from the decomposition of sugar is normally present. The very small amount in which the Blood-constituents of this class normally present themselves, is readily accounted for by the fact, that they are only en route between the tissues and the cxcretory organs which are destimed for their elimination; so that as long as the disintegrating processes taking place in the former are balanced (as they should be) by the activity of the latter, these substances are withdrawn from the blood-current as fast as they are introduced into it, and no sensible accumulation will occur. It can scarcely be doubted that the more attentive study of this part of the blond, prosceuted upon large quantities at once, will be attended with the discovery of many facts that would throw great light upon the Chemistry of the histogenetic operations, and of the retrograde metamorphoses of the effete materials of the tissues.

187. No list of the Inorganic Constituents of the Blond which has yet been given expresses the precise mode in which they are grouped together. The proportion which the Carbonates bear to the Phosphates, however, seems to be small in human blood, as is shown by the following table, founded on the analysis of $\mathrm{V}$ erdeil, ${ }^{3}$ of the percentage composition of the ash of the blood, after deducting the carbon still contained in it:

\begin{tabular}{|c|c|c|c|c|c|c|c|c|c|}
\hline Man. & $\mathrm{NaCl}$. & NaHO. & HKO. & $\mathrm{MgO}$. & $\mathrm{H}_{2} \mathrm{SO}_{4}$. & $\mathrm{P}_{2} \mathrm{O}_{5}$. & $\begin{array}{l}\mathrm{Ca}_{2} \mathrm{II} \\
\mathrm{PO}_{4} .\end{array}$ & $\mathrm{Fe}_{2} \mathrm{O}_{3}$. & $\mathrm{CO}_{2}$. \\
\hline$I, 3^{4}$ & 61.99 & 2.03 & 12.70 & 0.99 & 1.70 & 7.48 & 3.55 & 8.06 & 1.43 \\
\hline II,$^{5}$. & 55.63 & 6.27 & 11.24 & 1.26 & 1.64 & 9.74 & 3.21 & 8.68 & 0.95 \\
\hline
\end{tabular}

In Carnivorous animals the Phosphates, in Herbivorous the Carbonates, are in excess, which is obviously related to the difference of their diet. The proportion of Sodium Chloride in both classes exhibits a remarkable constancy. The normal presence of various metals in the blood has been alternately admitted and denied. Iron is unquestionably always present, and amounts to 0.42 per cent. of the hamoglobin present. ${ }^{{ }^{6}}$ Millon ${ }^{7}$ found in 100 parts of the insoluble residue of the ash of blood 1 to 3 parts of silicium, 1

1 Pflüger's Archiv, 1873, p. 391.

2 New York Med. Journal, vol. xv, 1872, p. 561.

3 Ann. der Chem. und Pharm., Bd. Ixix, p. 89.

- Man, forty-five years old, suffering from weak digestion.

5 Woman, twenty-two years old, sanguineous temperament.

${ }^{6}$ Ses Fudakowski, Centrablatt f. d. Mlediein Wiss., 1866, p. 705.

7 Annal. de Chim. et de P'hys., sér. iii, t. xxiii, p. 372. 
to 5 parts of lead, 0.5 to 2.5 parts of copper, and from 10 to 24 parts of manganese. ${ }^{1}$

188. We lave now to inquire into the principal modifications which the relative proportions of these constituents undergo in the state of health, under the influence of varying conditions of the system; and notwithstanding the want of absolute correctness in the analyses of which we are at present in posscssion, those that are male by sinilar methods give results sufficiently trustworthy to enable then to be compared together, and thus to give a tolerably correct inclication of the circumstances which determine the increase or diminution in the principal components of the Blood.- The first of these modifying conditions which requires special notice is Age. During the latter part of fotal life, the blood is remarkably rich in solid contents, as appears from the following comparative analyses of Denis: ${ }^{2}$

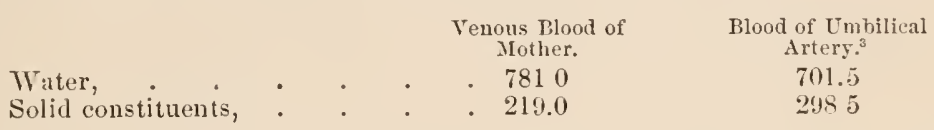

The larger quantity of solid constituents in the blood of the foetus is chiefly due to the increased proportion of corpuscles, which appears to continue for a short time after birth; but it gradully diminishes; and the whole amount of solid matter in the blood seems to fall to its lowest point during the period of childhood. Towards the epoch of puberty, however, the amount of solid matter increases again, the chief augmentation being in the corpuscles; and it remains at a high standard during the most vigorous period of adult life, after which it begins to decline. This is made apparent in the following table, deducerl from the analyses of Denis, which are confirmed by those of Lecann and Simon :

Solid Constituents.

In 5 individuals between 5 months and 10 years, . . 170

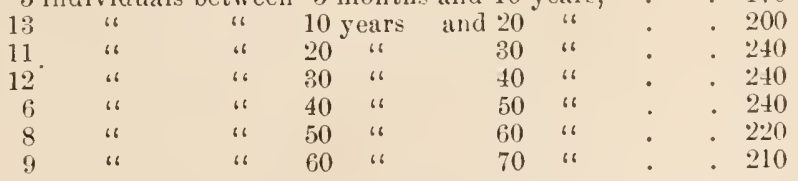

189. An appreciable difference exists between the blood of the two Sexes; that of the male being from 12 to 20 per cent. richer in solid contents than that of the female, the excess being particularly observable in the proportion of the corpuscles. There is no doubt, also, that the proportions of the constituents vary considerably with individual temperament and constitution; the proportion of the whole solid constituents, and especially of the corpuscles, being considerably greater in individuals of the plethoric or "sanguineous" temperament than in persons of the "lymphatic" temperament; and it appears from the analyses of Lecanu, that the sexual difference in

1 Melsens (Annal. de C. et de P., xxiii, p. 358) denies the presence of copper and lead; and Béchamp (Journ. de la Phys., 1860, vol. iii, p. 211) appears to think the occurrence of all or any of these metals to be merely accidental.

2 Recherches Expérimentales sur le Sang humain, and Simon's A nimal Chemistry, vol, i, p. 238; see also Panum, Virchow's Arehiv, 1864, Bd. xxix, p. 481.

3 Which has been shown by Poggiale to be identical with that of the body of the Fretus (Comptes Rendus, t. xxy, p. 198).

4 Animal Chemistry, vol. i, pp. $237-239$.

5 Etudes Chimiques sur le Sang luumain, p. 66, and Simon's Animal Chemistry, vol. i, p. 236 . 
the blood alnost disappears, when the blood of males and of females of the latter temperament is compared.

190. A considerable influence is exercised on the entire amount, and on the relative proportions, of the constituents of the Blood, by the previous ingestion of Food or Drink, and by the Diet habitually employed. When a full meal containing oily matter is taken after a long fast, and a small quantity of blood is drawn previously to the meal and at intervals subsequently, the serum, though quite limpid in the blood first drawn, shows an incipient turbidity about half an hour afterwards; this turbidity increases for about six hours subsequently, after which it usually begins to disappear. The period at which the discoloration is the greatest, however, and the length of time during which it continues, vary according to the kind and quantity of the food, and the state of the digestive functions. When such milky serum is examined with the nicroscope, the opacity is found to be due to the presence of an immense number of exceedingly minute granules, identical with those which form the "molecular base" of the chyle $(\$ 153)$. They seem to be composed of two chemically distinct substances; for when the milky serum is agitated with ether, a part is dissolved, whilst another portion remains suspended; and this latter is soluble in caustic potass. The former, therefore, appears to be identical with the "molecular base" of the Cliyle, and to be of an oily or fatty nature; whilst the latter belongs to the protein-compounds, and probably constitutes the haptogen membrane of Ascherson, by which all fatty particles floating in an albuminous fluid, immediately become invested. The Crassamentum of such blood often exhibits a pellucid fibrinous crust, sometimes interspersed with white dots; and this seems to consist of an imperfectly assimilated protein-compound, analogous to that found in the serum. The quantity of this varies according to the amount of the protein-compounds present in the food.-The increasc of saccharine matter in the blood (in which it forms part of the "extractive"), after the ingestion of a large quantity of saccharine or farinaceous aliment, has been noticed by many experimenters. Its proportion differs much in different parts of the body. - It might be fairly presumed that a temporary augmentation must take place in the aqueous constituent of the blood, whenever any considerable quantity of liquid is ingested; and yet this augmentation is much less considerable, under ordinary circumstances, than we should at first be inclined to suppose. For therc exist various provisions in the system (the peculiar Malpighian apparatus of the Kidneys being the chief ) for rapidly freeing the blood from any superfluity of water; and thus any excess of fluid absorbed is speedily drawn off again. But further, it is certain that when the ressels are already filled, absorption does not take place with nearly the same readiness as after long abstinence from liquids $(\$ 136)$; the rate of absorption being in great degree governed by that at which the liquid is disposed of. The influence of the Regimen upon the composition of the blood, however, appears to be more definite and coustant. An animal diet tends to increasc the whole amount of solid matter, but especially to augment the proportion of corpuscles. On the other hand, a vegetable diet tends to lower the whole amount of solid matter, occasioning a marked reduction in the corpuscles, whilst it seems rather to increase the albumen; thus showing that the decrease in the corpuscles is not due to a deficiency in the azotized pabulum, but depends on some other condition. The devclopment of fibrin appears to take place at least as readily on the vegetable, as on the animal regimen. Hence we sec what may, and what may not, be effected in the treatment of disease, by the adoption of a particular dietetic system; for we may promote or retard the development of 
the red corpuscles by the cmployment of an animal or a vegetable regimen, but can make little or no impression upon the fibrin. ${ }^{1}$

191. 'The effects of Loss of Blood and of Abstinence are very similar in their nature. Almost as soon as the strean begins to flow from a woumicd vessel, there seems to be a transudation of watery fluid from the tissues into the current of blood; for this undergoes a rapid diminution in density, so that the portion last drawn is of lower specific gravity, and contains a considerably smaller amount of solid matter, than that which first issued. The principal diminution occurs in the proportion of red corpuscles; the amount of fibrin, albumen, extractive and saline matters and fat being only slightly affected." We shall find, indeed, that in inflanmatory diseases the anount of fibrin undergoes an extraordinary incrcase, which is not checked in the slightest appreciable degree by the most copious venesection. It is remarkable that after very considerable losses of blood, a decided increase shows itself in the proportion of Colorless corpuscles, not only relatively (as to the red) but absolutely; so that, in the blood of a Horse from which 50 lbs. had been previously abstracted, the colored and the colorless corpuscles appear to exist in equal numbers. ${ }^{3}$

192. We have now to consider the differences which present themselves in the composition of the Blood drawn from different vessels of the same body; these, it is obvious, being dependent on the changes to which the fluid is subjected, during its passage through organs that will appropriate or change its several constitucnts in an unequal degree. And the first and nost important of these sets of differences, is that which exists between Arterial and Venous blood. The analyses alrearly cited having been made chiefly upon the latter, it will be sufficient here to state the general results of comparative inquiries into the composition of the former. The quantity of solid constituents pertaining to the Corpuscles is smaller; they contain relatively more hamoglobin and salts, but much less fat. The liquor sanguin is is somewhat richer in Fibrin; but it contains a larger proportion of water, and consequently less Albumen. The Fatty matters of the serum, as well as of the corpuscles, are considerably diminished; on the other hand, the Extractive and Saccharine matters are decidedly increased. The most remarkable difference between Arterial and Venous blood, however, lies in the amount of gases which they respectively contain. The observations of M. Malassez ${ }^{4}$ have shown that the relative amount of corpuscles in the blood varies considerably in different parts of the body, being really increased in the blood of the splenic vein, because new corpuscles are formed in the spleen and really diminished in the blood of the hepatic vein, owing to the destruction of the corpuscles in the liver. On the other hand, they are apparently diminished in the mesenteric veins during digestion owing to the absorption of fluid, and apparently increased in the blood returning from the skin, glands and tissues generally owing to the exosmose of the fluid parts.

193. Pnenmatology of the Blood.-The Gases contained in the blood principally consist of Oxygen and Carbonic acid, the former being chiefly combined with the red corpuscles, the latter wholly with the saline constituents

1 See on this subject the treatise of M. Emile Marchand. De I'Influence comparative du Régrime Végétul et du Régrime Animal sur le Physiquo et le Moral de l'Homme.

2 See the Observations and Analyses of Zimmerman (Heller's Archiv, Bd. iv, p. 385); Pulli (Med.-Chir. Review, Oct. 184i); J. Davy (A nat. and Plissiol. Researches, vul. ii, p. 28).

3 Kölliker's Manual of Human Histolugy (Sydenham Society's edit.), vol. ii, p. 330 .

4 See Pamphlet, 1873, and London Med. Record, 1874, p. 132. 
of the plasma. A small proportion of Nitrogen and traces of Ammonia are, however, constantly present. In 100 volumes of blood are found between 50 and 60 volumes of these gases collectively (namely, in arterial blood $\mathrm{CO}_{2}$ 30-35 vol., $\mathrm{O} 16-20$ vol., and $\mathrm{N} 1$ or 2 vol., in venous $\mathrm{CO}_{2} 40-50$ vol., $\mathrm{O} 12$ vol., $\mathrm{N} 1$ or 2 vol.); but their total quantity, as well as their relative proportions, present considerable variations in different parts of the body. From the results of numerous recent researches the conclusions may be drawn, that the affinity or capacity of absorption of the blood for the two first-named gases at least, is peculiar, follows laws of its own, and differs materially from that of other liquids. If we compare it, for instance, with water, we find that whilst 100 vol. of water will take up 2.97 vol. of Oxygen at standard temperature and pressure, the same quantity of blood, at $32^{\circ} \mathrm{F}$., will absorb from 16.882 vol. to 19.794 vol. $;^{1}$ and the amount absorberl appears to be but slightly affected by the degree of pressure to which the fluid is subjected (Bert), though according to the experiments of Bernard ${ }^{2}$ it raries to a considerable extent in blood drawn from different regions of the body. Thus whilst 100 vol. of arterial blood which already contained a considerable amount absorbed only 8.9 vol. of Oxygen, the same quantity of blood taken from the Jugular Vein absorbed 16 vol., from the Right Heart 21.1 vol., and from the Portal Vein 30 vol. of this gas, and Gréhant found that the arterial blood of a dog contained 16.3 vol. per cent. of Oxygen, but if the animal were made to breathe $\mathrm{O}$, the proportion rose to $23.3 \mathrm{per}$ cent., whilst if it were agitated with oxygen out of the body it contained 26.8 per cent. In ordinary air the tension of the oxygen is equal to a column of mercury $158 \mathrm{~mm}$. in height, corresponding to 20.8 per cent. by volume; but the tension of the oxygen in the blood is, in consequence of its affinity for hremoglobin, very low, amounting in the case of the arterial blood of the dog to a mean of only $22 \mathrm{~mm}$. of mereury, ${ }^{3}$ that is to say, it corresponds to the tension of oxygen in an atmospherc containing 2.9 per cent of this gas; in the venous blood it amounts to $29.6 \mathrm{~mm}$. (3.9 per cent.). For complete saturation the pressure of the oxygen in the atmosphere or in the blood must amount to between 20 and $30 \mathrm{~mm}$. With increase of temperature the affinity of hemoglobin for oxygen diminishes, whilst with diminished temperature it increases, or in other words the quantity of oxygen absorbed by the blood varies inversely with the temperature of the air inspired. ${ }^{4}$ In a similar manner, whilst 100 vol. of water will absorb about 100 vol. of Carbonic acid at ordinary temperature and pressure, Meyer ${ }^{5}$ found that 100 vol. of fresh defibrinated blood would take up 178.3 vol. of Carbonic acid at $48^{\circ} \mathrm{F}$, the quantity increasing, though not in direct proportion, with the pressure. The tension of the $\mathrm{CO}_{2}$ in ordinary air anounts to $0.38 \mathrm{~mm}$., corresponding to 0.05 per cent. by volume; but in arterial blood it amounts on its average to $21 \mathrm{~mm}$., i.e., to the tension of the gas in an atmosphere containing 2.8 per cent.; and in venous blood to $41 \mathrm{~mm}$., or to the tension of the gas in an atmosphere containing 5.4 per cent. ${ }^{6} \quad$ Even as regards Nitro-

1 Setschenow, Beiträige zur P'ncumatologie des Blutes, Sitzungsbericht d. k. Akad. d. Wissens., xxxvi, 1859, p. 298. See also Fernet, Annal. de Scien. Nat., 1858, tom. viii, p. 125. Gréhant, Comptes liendus, $1 \times x v$, p. 495.

${ }^{2}$ Leçons, 1859 , tom. i, p. 282.

${ }^{3}$ Sce Worm Müller, Bcricht. d. Sachs. Gesellschaft, 1870, p. 351. Sce also Hermann, Physiologie, 1874, p. 140.

4 Inathicu and D'Urbain, Archives de Plyssiologie, No. 5, 1872. See also Estor and St. l'icre, Journal de l'Anatomie, 1865.

5 Zeit.chrift t. Lat. Med., Bd. viii, p. 256.

6 See Hermann, op cit., p. 140, quoted from Strassburg. Wolffberg, Pflüger's Archiv, I3d. iv, Ifeft $x$, found the tension of the $O$ in the blood of the pulmotary capillaries amounted to $27 \mathrm{~mm}$. of mercury, and that of the $\mathrm{CO}_{2}$ to $24 \mathrm{~mm}$. 
gen, the Blood appears to possess a superior power of absorption than pure water, 100 vol. of the latter absorbing at ordinary temperature and pressire about 1.5 vol. of nitrogen, while 100 vol. of fresh defibrinated Blood depriver of gas by exhaustion will absorb about 5 vol. at a temperature of $65^{\circ}$ $\mathrm{F}$. and under a pressure of $0.6 \mathrm{~m}$. (Setschenow). It is very evident then that the absorption of these gases does not take place in accordance with the ordinary law established by Dalton and Henry, but that chemical affinity must come into play; and the investigations of Meyer, Fernet, Heidenhain, ${ }^{1}$ Prever, and Pfliiger ${ }^{2}$ and others indicate that the carbonic acid present in the blood may be divided into two portions, of which one follows the ordinary law of absorption, whilst the absorption of the other is only explicable on the supposition of there being certain substances in the blood for which it possesses a strong affinity, and with which it enters into combination. These substances appear to be the carbonate and phosphate of soda contained in the liquor sanguinis, for dilute solutions of both these salts in pure water exert a well-marked influence in increasing the quantity of carbonic acid which can be absorbed; in the former case a bicarbonatc of the alkali being formed, and in the latter case a peculiar double salt, represented, according to Fernet, by the formula $\mathrm{PO}_{4}+\mathrm{Na}_{2}+\mathrm{CO}_{2}{ }^{3}{ }^{3}$ As regards the Oxygen contained in the blood there seems every reason to believe that it is chemically combined with the hrmoglobin of the red corpuscles in which it exists in the active or ozonized condition, and from which it can be abstracted with the utmost facility by reducing agents, such as the sulphides of potassium, ammonium, and hydrogen, protoxide of nitrogen, carbonic oxide, and iron filings. The hromoglobir, therefore, plays a most important part as a carrier of oxygen from the air to the tissues, the affinity of which for ozone is still greater than that of hemoglobin. One gramme of hamoglobin takes up from 1.2 to 1.3 c.e. of oxygen, carbonic oxide, and protoxide of nitrogen at standard pressure and at $0^{\circ} \mathrm{C}$, but its affinity for protoxide of nitrogen is stronger than for carbonic oxide, and for carbonic oxide than for oxygen; so that by presenting blood to these gases in that order they may be made successively to replace each other. Carbonic oxide is commonly employed as a means of determining the amount of oxygen contained in blood, the coloring matter of which under its influence acquires optical and other characters which remarkably resemble those of oxyhrmoglobin. (3, Fig. 116.) The importance of the absorption of oxygen being dependent upon chemical affinity and not simply upon pressure is sufficiently obvious; since, by securing the introduction of a definite proportion of this gas, it enables animal life to be maintained without difficulty at all altitudes, and under the most various conditions of atmospheric pressure. Preyer ${ }^{4}$ states as the results of his experiments that Hiemoglobin forms no chemical compound with Carbonic Acid gas, nor does it materially alter the capacity of water to absorb this gas.

194. The actual quantity and relative proportions of the gases contained in the blood, as well as the exact ratio of the combined to the simply absorbed gases, is still a matter of question. The following table gives the most recent observations on this subject: ${ }^{5}$

1 Studien des Physiolog. Inst. zu Breslau, 1863, p. 103.

2 Centralblatt f́. d. Med. TViss., 1867, Nos. 21 and $t 6$.

3 Heidenhain's experiments show that this statement only holds for very dilute solutions. See Sertoli, Centralblatt f. d. Med. Wiss., 1868, No. 10.

4 Die Bluterystalle, 1871, p. 78. See also Claude Pernard, Leçons, 1875.

5 See Henle and Heissner, 1857, 1859, F. 308, 1860, p. 330; v. Gorup-Besanez, Phys. Chemie, 1862, p. 322. Irathieu and D'Urbain, Brown-Séquard's Archives, 1872. 


\begin{tabular}{|c|c|c|c|c|c|c|c|c|}
\hline \multirow[b]{2}{*}{ In 100 Vols. } & \multirow{2}{*}{ 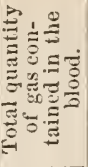 } & \multirow[b]{2}{*}{ 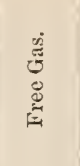 } & \multirow[b]{2}{*}{ 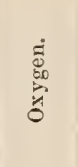 } & \multirow[b]{2}{*}{ 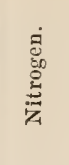 } & \multicolumn{3}{|c|}{ Carbonic Acid. } & \multirow[b]{2}{*}{ Observer. } \\
\hline & & & & & 夰 & 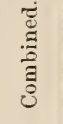 & 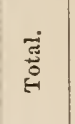 & \\
\hline Human blood, . . & 48.20 & 4588 & 16.41 & 1.20 & 28.27 & 2.32 & 30.59 & Setsehenow. \\
\hline Arterial blood of dog, & 46.22 & $\ldots$ & 11.39 & 4.18 & $\cdots$ & 1.90 & 30.08 & Sehotfer. \\
\hline " & 41.32 & $\cdots$ & 9.88 & 1.54 & $\cdots$ & . . & 29.90 & Nawroeki. \\
\hline " & $\cdots$. & & 16.9 & 1.4 & 26.2 & & & Pflüger. \\
\hline Venous & & & 4.15 & $\cdots$ & $\cdots$ & 5.49 & 29.32 & Schotfer. \\
\hline Arterial & 49.44 & 46.90 & 1505 & 119 & 30.66 & 2.54 & 3320 & Setschenow. \\
\hline " " of eat, & 32.81 & $\cdots$ & 9.92 & 0.98 & $\cdots$ & $\cdots$ & $\because 1.91$ & Hering. \\
\hline Carotid (arterial), . & & $\cdots$ & 28.45 & 1.64 & & . . & 48.18 & Mathieu. \\
\hline Crural " & & & 18.03 & 1.60 & & . & 44.23 & Urbain. \\
\hline
\end{tabular}

The percentage proportion of the gases of the blood amongst themselves, obtained from the mean of seven observations of Meyer and Setschenow, is

$$
\begin{aligned}
& \text { Oxygen, . . . . . . . . . . } 2820
\end{aligned}
$$

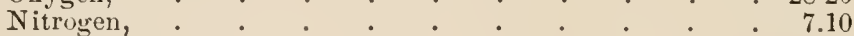

$$
\begin{aligned}
& \text { Carbonie Acid, . . . . . . . . } \quad \text {. } 64.70 \\
& 100.00
\end{aligned}
$$

In all experiments made to determine the proportions of the gases of the blood, the investigation should be commenced immediately after the blood has been withdrawn; since it is certain that the quantity of oxygen decreases, and of carbonic acid increases, with considerable rapidity. Thus Felix Nawrocki ${ }^{1}$ found the following differences in two equal and similar portions of blood drawn at the same time, one of which (I) was examined immediately, and the other (II) after the lapse of 24 hours, the mean temperature of the air in the room being $86^{\circ} \mathrm{F}$.

I.

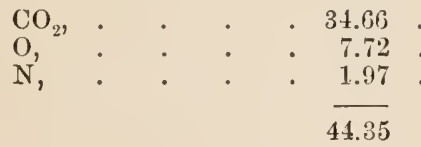

II.

40.95

1.02

0.67

$42.64 \mathrm{vol}$. in 100 of Blood.

MM. Mathieu and Urbain ${ }^{2}$ found that whilst blood taken from arteries of the same size contained equal amounts of oxygen, the proportion of this gas was slightly (2 or 3 per cent.) diminished in blood drawn from the smaller vessels. ${ }^{3}$ Hirschmann, however, found no remarkable differences in the blood of different arteries. The variations which occur in the venous blood returning from muscles at rest and in action, as compared with the arterial blood of the same animal, are well shown in the following results obtained by Sezelkow, ${ }^{4}$ where A indicates Arterial blood, MR the blood returning from muscles at rest, and MIA that returning from muscles in action:

1 See Studien des Physiolog. Institut zu Breslau, 1863, p. 144.

2 Op. eit., p. 200.

3 Ilirsehmann, Journal de l'A natomie, 1865, p. 302. See also Estor and Pierre, Arehiv f. Anat. u. P'hysiol., 1866, p. 502.

${ }^{4}$ Sitzungsberieht d. Wiener Akad., Bd. xlv, 1862. 


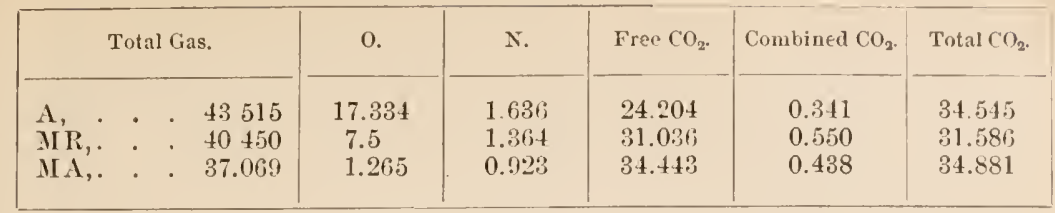

In other experiments Sezelkow found that the venous blood returning from muscles at rest contained on the average 6.71 per cent. more carbonic acid and 9 per cent. less oxygen than arterial blood, whilst that returning from muscles in action contained an excess of 10.79 per cent. of carbonic acid, and a deficit of from 12 to 14 or even 16 per cent. of oxygen; and similar results were obtained by Bernard. ${ }^{1}$ The experiments of Dr. Gairdner ${ }^{2}$ seem to show that increase in the relative proportion of oxygen in the blood increases the proportion of fibrin that may be obtained from it, thus the arterial blood of six healthy rabbits furnished the following mean percentage results, Fibrin 1.65, Corpuscles 82.35, Albumen 46.30. On the other hand, the analysis of the blood of three individuals which had been made to respire pure oxygen for half an hour, gave the following as the proportions of its components: Fibrin 2.40, Corpuscles 69.56, Albumen 40.23. It is further stated by Dr. Gairdner ${ }^{3}$ that a rabbit having been kept for half an hour under the influence of an electro-magnetic current between the chest and spine, which produced a great acceleration in the respiratory movements, its blood was found to contain as much as 2.9 parts of fibrin in $1000 .{ }^{4}$ - The larger quantity of fibrin in arterial blood of itself reuders its coagulum firmer; but independently of this there would seem to be a difference in the quality of the fibrin, which when separated by stirring or whipping, is more tenacious and compact in arterial than in venous blood. Bert ${ }^{5}$ found that when oxygen reaches the proportion of $28-30$ vols. for 100 vols. of arterial blood in a dog the animal is seized with convulsions, while a proportion of 35 rols. proves fatal.

195. The proportion of red corpuscles in arterial and venous blood respectively has been variously stated by different observers, and we may easily conceive it to be affected by several circumstances, which may produce a change in the whole proportion of the solid to the fluid constituents of the blood during the course of its circulation. Thus, the discharge of the contents of the thoracic duct into the venous system near the heart will tend to dilute the blood of the pulmonary and arterial circulation; whilst conversely, the escape of the watery part of the blood by the renal and cutaneous secretions and by transudation into the tissues, which takes place during its passage through the systemic capillaries, will tend to augment the proportions of the solids of the blood drawn from the systemic veins. On the other hand, if the discharge of fluid from the thoracic duct be suspended, and the amount absorbed from the tissues during the systemic circulation should exceed that which is transuded (as appears sometimes to happen, $\S 191$ ), then the proportion of solid matter will be less in venous than in arterial blood.-The difference in the color of arterial and of venous blood is undoubtedly due to

1 Leçons, vol. ii, 1859, p. 435.

2 Treatise on Gout, 2 d edit., p. 153.

3 Op. cit, p. 183 .

4 Jore reeently Mr. A. H. Smee (Proeeedings of the Royal Society, 1863), and $v$. Gorup-Besanez (Physiolog. Chemie, 1862, p. 137) have stated that they lave obtained a fibrin-like sub-tanee; the former, by transmitting Oxygen, and the latter Ozone, through an albuminous fluid.

5 Comptes Rendus, No. 8; Aug. 25th, 1873. 
the different absorptive powers of light possessed by blood charged respectively with oxygen and carbonic acid. Venous blood recently taken from the living animal, and containing only a small amount of oxygen, is dark, and in thin layers dichromatic, whilst its spectrum is materially different from that of arterial blood into which it is immediately changed, becoming brighter and monochromatic on shaking it with air or oxygen. The change in color which results from the addition of certain reagents to the blood is, however, partly to be attributed to an alteration in the form of the corpuscles, the tint being darkened by whatever tends to distend the corpuscles, so as to render them flat or biconvex, whilst it is brightened by whatever tends to empty them, so as to render them more deeply biconcave. Thus arterial blood is rendered dark by the addition of water, the corpuscles being swollen and more or less deprived of their coloring matter. Oxygen will not then restore the form of the corpuscles or the bright hne of the blood, but this is quickly effected by the addition of solutions of neutral salts. In like manner venous blood can be reddened by strong saline solutions, even without the contact of oxygen. The varying circumstances under which either arterial or venous blood may be at one time dark and at another scarlet in color, have been very fully discussed by $\mathrm{Wells}^{1}$ and Bernard. ${ }^{2}$ The latter obscrves that in the Fotus, and in the asphyxiated animal, the blood is everywhere dark or venous. On the contrary, during sleep, in the hibernants during the period of repose, and in animals dying by ansmia, the blood is everywhere scarlet or arterial. With high temperatures of the surrounding medium, whether this be air or water, there is little difference in the color of the two kinds of blood, the arterial being less and the venous more florid than usual. ${ }^{3}$ The difference between them is, on the other hand, best marked in cold weather. The Blood contained in the veins of muscles is dark, and always of a deeper shade in proportion to the energy and duration of the previous muscular contraction, whilst that returning from the glands is always brighter in proportion to the activity with which secretion is being performed; and in the latter instance, with the alteration in color, the amount of fibrin is found to be diminished, or so modified as to form a softer clot, from which a larger quantity of serum separates. It is remarkable that if the darkcolored clot of ordinary venous blood be immersed in the serum of the searlet venous blood, it rapidly assumes a brighter tint, and converscly the clot of scarlet venous blood changes to a dark color when imurersed in the serum of deeply-colored venous blood; from which we may conclude that the primary changes are effected upon the Liquor Sanguinis, and not upon the corpuscles. The influence of the Nervous System in inducing alterations in the color of the blood returning from the salivary glands has al ready been pointed out $(\$ 105)$.

196. Although but little difference except as regards the relative proportion of oxygen and carbonic acid gases present can be detected between samples of blood drawn from various parts of the Arteriul system of the sanle animal, very important variations exist, as might be expected, in the composition of the blood drawn from the several parts of the Venous system ; since the changes to which it has been subjected in the several organs throngh which it has passed, are of a very diversified character. The blood of the Vena Porte, for example, differs considerably from the blood of the Hepatic vein, and both of these differ from the blood of the Jugular. So, again, the blood of the Splenic as well as that of the Renal vein differs from all the

1 Phil. Trans., 1797.

2 Lecons, xi to xix, 1859.

3 See an neeount of Davy's and Crawford's Experiments, in Gulliver's Lectures, Med. Times and Gaz, 1863, vol, i, p. 1. 
precerling. The most important and best established of these diversities will now be enumerated. In speaking of the composition of the blood of the Tena Porte, it nust be remembered that this consists of two very distinct factors, nanely, the blood of the Gastric and Mesenteric veins, and the blood of the Splenic vein; the former having been altered by the introduction of solid and liquid alimentary matters, and the latter by its circulation through the spleen. These, therefore, ought to be separately studied; and this has been done by M. Jules Béclard. ${ }^{\text {" }}$ 'The characters of the blood returning by the Gastric and Mesenteric veins from the walls of the alimentary canal, are of course affected by the stage of the digestive process, and by the nature and amount of the absorbable nuatters. As compared with the ordinary venous blood, the total quantity of its solid constituents is lowered during the early part of the digestive process, hy the dilution it suffers through the imbibition of liquid; and this diminution is especially remarkable in the corpuscles, the relative proportion of albumen being increased by the introduction of new albuminous matter from the food. 'Towards the conclusion of the digestive process, however, the blood of the mesenteric reins gradually cones to present the ordinary proportions of these two components; and in an animal that has been subjected to long abstinence, it docs not differ from that of the venous system in general. The quantity of extractive is usually increased ; and in this part of the blood it must be, that sugar, dextrin, gelatin, and other soluble organic matters that are taken into the circulation, are contained. Some of these have in fact been detected in it. ${ }^{2}$ The fibrin of the blood of the mesenteric veins appears to be less perfectly elaborated than that of the blood in general; for the blood of the mesenteric veins coagulates less firmly (having been erroneously asserted by some not to coagulate at all); and its fibrin, when separated by stirring, shows a marked deficiency in tenacity, and liquefies completely in the course of a few hours. A part of the albuminous constituent of this blood does not present the characters of true albumen, for it is not precipitated by heat or by nitric acid, and the precipitate thrown down by alcohol is redissolved by water; like albumen, however, it is precipitated by the metallic salts, creasote, and tannin. This substance, which has been distinguished by M. Mialhe as albuminose, further differs from true albumen in the facility with which it traverses organic membranes; for these resist the passage of albumen, while they are freely transuded by albuminose. And it is affirmed by M. Mialhe, that the want of that conversion of albuminose into albumen, which ought to take place as part of the assimilating process, is one cause of the readiness with which albuminous matter transudes from the blood in albunimuria and in dropsies; this albuminous matter frequently having rather the characters of albuminose, than those of true albumen.

197. The Splenic blood is remarkable for the marked decrease it presents in the amount of solid matter it contains; the average of twelve experiments giving only 187.1 per 1000 of solid constituents in the splenic blood, whilst the arterial blood of the same animals contained 239 parts, and the jugular venous blood 201 parts. ${ }^{4}$ 'The decreasc depends upon the diminished proportion of red corpuscles. The albumen and fibrin, on the other hand, with the white corpuscles, are usually more or less increased in their relative

1 See his Memoir in the Arch. Gén. de Méd, $4^{\text {e }}$ série, tom. xviii, p. 322 et seq.; and his edition of his father's Elémens d'Anatomie Générale, pp. $265,266$.

2 See the Researches of MIM. Bouchardat and Sandras in the Supplément à l'Annuaire de Thérapeutique, 1846.

3 See the Cours de Physiologie of M. Paul Bérard, tom. iii, p. 87.

4 See the Analyses of Mr. Gray in his Essay, On the Strueture and Uses of the Spleen, 1854. 
proportions, the fibrin having been found in amounts varying from 2.5 to 11.53 parts in 1000 , and coagulation having been noticed to recur when the blood had already been freed from the fibrin by whipping. Hirt ${ }^{2}$ counted 1 colorless to 2179 colored corpuscles in the blood of the splenic artery, but 1 colorless to 60 colored in that of the splenic vein. The red corpuscles sometimes present crystals in their interior. Many comparative observations have been made upon the blood of the V'ena Portre and of the Hepatic vein; but a large part of them, according to M. Cl. Bernarl, are vitiated by the fiact, that, unless the vena portse be tied, a reflux of blood takes place into it from the liver, so that the blood which flows when it is wounded, is not so much portal as hepatic blood. The latter, like all blood which contains much carbonic acid and little oxygen, coagulates slowly and forms a bulky clot from which the serum imperfectly separates. It contains 8 or 9 per cent. less water than the portal bloor, owing apparently to the red corpuscles taking up solid materials in their passage through the liver. The blood of the hepatic vein is far richer in blood-cells, both colored and colorless, than that of the portal vein; Hirt estimated that the proportion of the colorless to the red corpuscles was in the portal venous blood as $1: 524$, in the hepatic as $1: 136$; the colored are scen in heaps of a distinct violet color, and they arc less readily destroyed by water than arc those of the blood of most other vessels. The corpuscles in the blood of the hepatic veins are poorer in fat and in salts, and especially in hematin, or at least iron, but somewhat richer in extractive matters. Their specific gravity is higher than that of the corpuscles of the portal blood, notwithstanding the diminished quantity of iron. The plasma of the blood of the hepatic veins is far denser than that of the blood of the portal vein, for it contains a much larger amount of solid constituents generally, although little or no fibrin is to be found in it. If we compare the solid constituents of the serum of hoth kinds of blood, we find less albumen and fat, and far less salts, in the blood of the hepatic vein, while the quantity of extractive matter, and espccially of sugar, unless the examination be made instantaneously after death, is perceptibly augmented. ${ }^{2}$ It cannot be doubted that when the secretion of urine is proceeding with rapidity, the blood of the Renal vein must contain a smaller proportion of water than that of the renal artery, and that the quantity of salines also must be diminished; since a separation of these ingredients takes place in the passage of the blood through the renal capillaries. So far as regards the quantity of water, this a priori conclusion has been confirmed by the analyses of Simon, who found 790 parts of water in 1000 of blood drawn from the renal artery, and only 778 in bloorl drawn from the renal vein of the same anima!. ${ }^{3}$ And Picurd ${ }^{4}$ found in the renal arterinl blood of two dogg 0.0365 and 0.04 per cent. of Urea, whitst in the venous blood returning from the kidneys the proportion was 0.0186 and 0.02 per cent. Poisscuille and Crobley, ${ }^{5}$ however, did not find the difference so wcll marked or constant.

1!18. Alterations in the Composition of the Blood in Disease.-Under this hend it is intended here to consider, not the state of the Blood in every principal type of discase (which it is the duty of the Pathologist to investigate), but the most important facts which the study of its morbid conditions has afforded, towards the determination of the conditions under which de-

1 Müller's Archiv, 1856.

2 Physiological Chemistry (Cavendish Socjety's ed.), vol. ii, p. 259; Lehmann, Leipziger Berichte, iii, 131; and Pharmaceut. Cuntrablatt, 1856, p. 433

3 Simon's Animal Chomistry (Sydenham Soeiety's ed.), vol, i, p. 214.

4 Pinar, Sur la P'rénence de l'U'lée daus le Sangr, Strasbourgr, 18.56.

5 Comptes Rendus, 1859, 1). 164. 
cided variations take place in the quantity or quality of its principal components, and of the effects which those variations produce upon the system at large. Many analyses have been made by excellent observers; but in consequence of the variations in the mole of analysis pursued, the results can only be given in general terms.

199. 'The first of these components whose variations we shall consider, is Fibrin: the estimate of which, however, is open to an important fallacy, that has not been sufficiently guarded against, namely, the admixture of the Colorless corpuscles. "These," as Mr. Paget correctly renurks, "cannot, by any moke of analysis yet inventer, be separated from the fibrin of mammalian blood; their composition is unknown, but their weight is always included in the estimate of the fibrin. In health they may, perhaps, add too little to its weight to merit consideration; but in many diseases, especially in inflammatory and other blood diseases in which the fibrin is said to be increased, these corpuscles become so numerous that a large proportion of the supposed increase of the fibrin must be due to their being weighed with it. On this account, all the statements respecting the increase of fibrin in certain diseases need revision. ${ }^{2}$ In the results of the analyses now to be stated, it must be borne in mind that the term "fibrin" really designates the "colorless coagulum" of spontaneous formation, whatever may be its composition. The following may be considered as the normal range of variation for the principal constituents of the blood in health, according to the mode of estimating them pursued by MM. Andral and Gavarret:

$\begin{array}{lcrrrrr}\text { Fibrin, from } & 2 & \text { to } & 3 \frac{1}{2} & \text { parts per } & 1000 . \\ \text { Red corpuscles, . } & \text { " } & 110 & \text { " } & 152 & \text { " } & \text { " } \\ \text { Sulids of serum, . } & 72 & \text { " } & 88 & \text { " } & \text { " } \\ \text { Water, - . } & 760 & \text { " } & 815 & \text { " } & \text { " }\end{array}$

200. The most important fact suhstantiated by Andral, is one that harl been previously suspected, - the invariable increase in the quantity of Fibrin during acute Inflammatory affections, as pleurisy and pneumonia, the increase being strictly proportional to the intensity of the inflammation, and to the degree of symptomatic fever accompanying it. "The augmentation of the quantity of Fibrin is so certain a sign of Inflammation, that, if we find more than 5 parts of fibrin in 1000 in the course of any disease, we may positively affirm that some local inflammation exists." The average proportion of Fibrin in inflammation may be estimated at 7 ; the minimum at 5 ; the maximum at 13.3 . The greatest augmentation is seen in Pneumonia and Acute Rheumatism. Such blood in general coagulates slowly. ${ }^{3}$ An increase is also commonly observable duriug the advanced state of Phthisis, in spite of the deterioration which the blood must then have undergone, and this is probably dependent upon the development of local inflammation around the tubercular deposits. In continued and Typhoid Fever's, whilst the proportion of Colpuscles is commonly increased, there is a decrease in the proportion of Fibrin, especially in the early stage; though the usual augmentation will take place if any local inflammation occurs. It appears from the experiments of Magendie, that one of the effects of a

1 See Andral and Gavarret, Essai d'Hxmatolngie Pathologique; Becquerel and Redier, Recherehes sur la Composition du Sang, etc.

2 Kirkes and Paget's Handbook of Plysiolugy, p. 57.

3 The white fibrinous elots found alter death in the heart and large arteries, in various diseases, appear to owe their origin to the slight disposition of the blood in these cases to coagulate, thus affording time for the sinking or separation of the red corpuseles. Miyer has augmented the amount of fibrin in the blood of dogs to nearly double its normal amount by repeated bleedings, repeated at stated intervals (quoted in Brucke's Vorlesungen, 1874, p. 117). 
diminution in the proportion of Fibrin is a tendency to the occurrence of Hiemorrhage or Congestion, either in the parenchymatous tissue or on the surface of membranes; and these conditions are well known: to constitute common complications, not only of febrile diseases, but also of Apoplexy and Purpura hæmorrhagica, in both of which there is a marked deficiency of Fibrin. It has been asserted that the proportion of Fibrin is diminished in Senrvy; but this, from the analyses of MLI. Becquerel and Rodier, Chatin and Bouvier, ${ }^{\mathrm{B}}$ and $\mathrm{Mr}$. G. Busk, ${ }^{2}$ appears not to be the case, the proportion of fibrin being rather above than below the normal average. In Cholera, however, a reduction in the coagulable element of the blood seems to be an almost constant occurrence; and in some instances the blond, although loaded with solid matter, has scarcely coagulated at all. Of the blood drawn during life, it has been observed that the clot is loose and grumous, often not shrinking and expelling serum; and that this change presents itself in a degree corresponding to the severity and advanced stage of the discase. And when the blood has been removed from the body after death, the clots have been found loosc and fragile in texture, sonetimes almost semifluid. ${ }^{3}$ How far the so-called exudation found in an inflamed part is dependent upon the accunulation of the white corpuscles on the exterior of the vessels, as described by Waller and Cohnheim, cannot as yet be stated with certainty.

201. The amount of Red Corpuscles seems to be subject to greater variation, within the limits of ordinary health, than is that of fibrin. It may even form a racial characteristic, for Mr. Bakewell ${ }^{t}$ states that he was able to distinguish the Mohammedan from the Hindoo by the proportion of corpuscles contained in their blood, and both of these races readily from the negro, the blood in the latter race being very highly corpusculated. In the condition which is ordinarily termed a highly sanguineous temperament, or Plethora, it is chiefly the entire mass of the blood that undergoes an increase; but whatever excess there may be in the proportion of its solid constitucnts, this affects the Corpuscles rather than the fibrin, the proportion of thesc, according to Nantegazza, ${ }^{5}$ rising from $5,000,000$, which is the normal amount, to 5,500,000 in a cubic centimetre. Plethoric persons are not more prone to Inflammation than are those of weaker constitution; but they are liable to Congestion, especially of the brain, and to apoplexy or other hemorrhage. The effect of bleeding in diminishing this tendency is now intelligible, since we know that loss of blood reduces the proportion of corpuscles.-On the other hand, in that temperament ${ }^{6}$ which, when exaggerated, becomes Ansmia, there is a marked diminution of the Corpuscles, the number contained in a cubic centimetre falling from 5,000,000, which is the normal amount, to about 2,000,000. This temperament may lead, on the one hand, to Chlorosis, in which the Red Corpuseles are diminished whilst the Fibrin remains the same, a condition of the system which is singularly improved by the remedial employment of Iron $;^{7}$ and, on the other, to Scrof-

1 Journ. de Chinie Médicale, Mars, 1848

2 Library of Medieine, vol. v, p. 90. See also Chalvet, Union Mediealé, 1871, p. 525 .

${ }_{3}^{3}$ See Dr. Parkes's Researelres into the P'athology and Trentment of the Asiatie or Algide Cholera, pp. 32, 73.

4 Med. Times and Gazette, Nov, 1872, p. 514. Also a paper read before the Anthropological Society.

5 Gat. IIrod. Itil., 1865, Nos. 28 and 25.

6 The term lymphatic has been applied to this temperament; by whieh term was meant a preduminunce of lympli in the absorbent vessels.

7 The records of Medicine searcely furnish a more notable example of the pernieious influence of theories founded upon a shallow Empiricism, and of the superiority 
ula, in which a diminution of Corpuscles coexists with a deficicncy in the amonnt or in the degree of elaboration of the Fibrin. A similar deficicncy in the proportion of Red Corpuscles lias bcen observed by Andral in other cachectic states induced by disease, as in Diabetes Mellitus, Aneurismal dilatation of the Heart producing Dropsy, and in Cachexia Saturnina. It occurs also in Scurvy, and in the advanced stages of Albuminuria, and Dr. Williams $^{1}$ has observed a similar total destruction of the blood-disks in a case of maliguant scarlatiua with purpura; and has met with indications of a partial destruction of them in acute purpura connected with jaundice, and in cases of functional derangement of the liver.

202. A marked increase in the proportion of the Colorless Corpuscles has been frequently observed in the blood of Inflammatory subjects; this increase is not, however, so characteristic of the Inflammatory state as some have supposed; for it is by no means constant in that condition, and is frequently seen in very different states of the system. ${ }^{2}-$ Attention has recently been drawn by Prof. J. H. Bennett ${ }^{3}$ to a condition of the.Blood which is espccially characterized by a marked excess of these bodies, and which he lias designated by the term Lencocythermia (white-cell blood). This condition has been detected in the blood of a considerable number of individuals suffering under diseases (most commonly enlargement) of the Spleen, Liver, and Lymphatic glands, either separately or in conjunction; but it has not yet been determined how far it is constantly associated with any of these abnormal conditions. In all cases in which such blood has been analyzed, its specific gravity has been found very low, and the total amount of corpuscles small; but the fibrin is almost invariably above the average, having in one instance risen to 7.08 .

203. The quantity of Albumen in the blood seems to vary less than that of most of its other constituents. The proportion which it bears to the water of the serum, is of course elevated by anything which diminishes the latter; and thus we find it high in cholera after profise discharges of fluid from the intestinal canal, and in other cases in which there has been an unusual drain upon the liquid part of the blood, provided that the albumen do not pass off with it, as sometimes happens. Where some special cause is in operation, which favors the escape of the albumen from the circulat-

of a Rational practice, based on a knowledge of the real facts of the case, than is afforded by the contrast between the former and the present treatment of Chlorosis. IVhilst the notion prevailed that the "buffy coat" is a sign of Inflammation, and that the most potent remedy for Inflammation is loss of blood, patients already redueed to a state of ancmia, who complained of pain in the left hypochondrium, palpitations, etc., were bled over and over again, every withdrawal of blood of eourse seriously increasing the mischief, by produeing a further reduction in the proportion of red corpuseles (\& 187). The Author well remembers that, when a pupil in the Bristol Infirmary in the years 1833-4, he was repeatedly directed by the estimable Senior Plyysician (long since dead) to draw eight, ten, or twelve ounces of blood from patients in this condition; and that the crassamentum, after coagulation, often resembled a small island floating in an ocean of serum. Yet, becuuse this minute clot exhibited the butty cout, the bleeding was considered to be "ortlodox" practiee, and the obstinaey of the symptoms was attributed to the severity of the disease. If MI. Andral had made no other contribution to Medical Seience than the demonstration of the real nature of this condition of the blood, and of the intluence of further depletion in promoting it, he would have rendered a most essential serviee to the multitude of females who are unfortunate enough to suffer from this kind of deterioration of their vital fluid.

1 Principles of Medicine, 2d edit, p. 115.

2 As in Scurvy. See Laboulbéne, La Revue Scient., ser. ii, an. 1, p. 43, 1871.

3 See his sueeessive Papers in the Edinb. Monthly Journal for 1851, his Treatise On Leucocythremia, and his Clin, Lectures On the Principles and Practice of Med., 4 th edit., 1865, p. $867 \mathrm{ct}$ seq. 
ing current (as happens in various forms of Albuminuria, but especially in the advanced stage of "Bright's disease"), the amount of albumen in the serum is rerluced below the normal standard. Thus Dr. Christison found the entire solids of the serum to be reduced in some instances to 55 or even 52 parts in 1000, his estimate of their normal amonnt being 83.4 ; and he found the specific gravity of the serum to fall as low as 1020 or even 1019 , the normal standard being from 1027 to 1031 . According to Andral, the diminution in the amount of Albumen in the Serum is exactly proportional to the quantity contained in the Urine. ${ }^{3}$ The proportion of albumen is not diminished in scurvy (Chalvet). The proportion of fatty matter in the serum, and especially of the cholestcrin, has been found by MM. Becquerel and Rodier to undergo an increase at the commencement of most acute diseases; and they have also observed an increasc of fat, and especially of cholesterin, in chronic diseases of the liver, in Bright's disease of the kidney, and in tuberculosis. The quantity of fat in the blood sometimes undergoes such an augmentation, as to give to the serum a constant "milkiness." This has been observed by Marcet in a case of diabetes, by Traill in hepatitis, by Christison in dropsy, icterus, and nephritis, by Zanarelli in pneumonia, and by Sion in mammary abscess. In Dr. Sion's case, the blood itself was quite milky; it underwent no coagulation; and only a very small quantity of coloring matter was deposited, when it was allowed to stand. This blood was found by Lecanu to contain 206 parts of solid constituents in 1000; but of these no less than 117 parts were fat, the remainder consisting of albumen (6t parts), and of extractives and salines (25 parts). ${ }^{2}$ No fibrin could be found, and the quantity of hamoglobin was inappreciable. ${ }^{3}$ Such a fluid must be considered rather as chyle than as blood; and in the entire absence of coagulating power, corresponds rather with chyle when first absorbed, than with that which is usually transmitted by the thoracic duct $(\S 154)$, - Little is known with certainty regarding the variations of the alkaline salts in the blood in different diseases. The analyses which have been made, however, are considered by Prof. Lehmann ${ }^{*}$ to

1 A ease is related by Andral, under this head, whieh afford; an interesting exemplifieation of the general fats that have been attained by his investigations. A woman who had been suffering from Erysipelas of the faee, and had lost blood both by venesection and by leeehes, beeame the subject of Albuminuria. The blood drawn at this time exhibited a eonsiderable diminution in the proportion of the red Corpuseles, as well as of Albumen, - a fact which the previous loss of bloed fully aceounted for. After a short period, during which she had been allowed a fuller diet, another experimental bleeding exhibited an inerease in the proportion of those Cor'puseles. Some time afterwards, when the Albumen had disappeared from the Urine, some more blood was drawn; and it was then observed that the Albumen of the Serum had returned to its due proportion, but that the Corpuseles had again diminished, whilst there was a marked increase in the quantity of Fibrin. This alteration was fully aeeounted for by the faet, that in the interval, several lymphatic ganglia in the neek had been inflamed and had suppurated; and that the patient had been again placed on very low diet. "Thus," observes Andral, "we were enubled to give a complete explanation of the remarkable oseillations which were presented in the proportion of the different elements of the blood, drawn at three different times from the same individual; and thus it is that, the more extended aro our inquiries, the more eusy does it beeome to refer to general prineiples the eauses of all those ehanges in the eomposition of the blood, which, from the frequeney and rapidily witl which they oeeur, seem at first sight to baffle all rules, and to take plane, as it were, at randon. In the midst of this aprarent disorder, there is but the fulfilment of laws; and, in order to obtain these, it is only neeessary to strip the phenomena of their complieations, and reduce them to their simplest form."

2 See also a case by Speek, Archiv f. wiss. Heilk., 1864, p. 232.

3 'This remarkable case is cited in Simon's Animal Chemistry, vol. i, p. 333, from the Lancette Française, 1835, No. 49.

4 l'hysiological Chemistry (Cavendish Society's ed.), vol, ii, p. 262. 
indicate that in very severe inflammations they are greatly diminished; whilst they are much increased in the acute exanthemata and in typhus, in dysentery, Bright's discase, and all forms of dropsy and hydramia ; and are often doubled in quantity in discases depending upon malarious influences, such as endemic dysentery, malignant forms of intermittent fever, etc. Although a large quantity of saline matter usually passes off from the blood in Cholera, yet the proportion of water discharged is so much greater, that, as appears from the analysis of Dr. Garrod, the percentage of salines in the blood is rather increased than diminished.' 'The proportion of Huter in the blood will of course vary reciprocally with that of the solid constituents; and will be specially augmented when there is a marked diminution in the amount of red corpuscles.

204. That the Blood is subject to a great variety of other morbid alterations, which are sometimes the causes, and sometimes the results, of Disease, cannot be for a moment doubted. But our knowledge of the nature of these changes is as yet very insufficient. ${ }^{2}$ The great amount of attention which is being directed by Chemists and Pathologists to the subject, however, will doubtless ere long produce some important results.-Among the most frequent causes of depravation in the character of this fluid, we must undibutedly rank the retention, in the Circulating current, of matters which ought to be removed by the Excretory proccsses. We shall hereafter see, that a total interuption to the excretion of Carbonic Acid by the lungs will occasion death in the course of a very few minutes; and even when only a slight impediment is offered to the elimination of the carbonic acid, so that the quantity of it always contained in arterial blood is augmented to but a small degree, a feeling of discomfort and oppression, increasing with the duration

1 London Journal of Mcdicine, May, 1849.

2 It seems not improbable that the phenomena of disease are sometimes caused by, though perhaps in other instances they may bc only associated with, the development of living organisms in the blood. 'Thus cxtremely fine, moving threadike bodies rescmbing spirillum, have bcen observed by Obermeier (Centralbiatt, 1873, p. 145) in the blood of patients suffering from recurrent fever, shortly before or during the crisis, but their nature is unkuown. Nedvetski (idem, 1872, p. 234) has seen moving particles, apparently derived from the white corpuscles, and bactcridia in the blood of chulcraic patients Nepveu (Guz. Med. de Paris, 1872, No. 3) has noticed bacteria in cases of erysipelas. Lewis (Pamphlet, 1872, Lancet, 1873, 1, 446) has described a peculiar kind of Filaria, as being constantly present in large numbers in the blood of patients (in India) suffering from chyluria; Riess (Rcichert's Archiv, 1872 , 1237 ), bright granules in scarlet fever; Birsch-Hirschfeld (Archiv d. Heilkunde, xiii, 187.2, p. 38), micrococci in pyæmia and puerperal fever; Hüter (Centralblatt, 1868, p. 177), sintilar forms in diphtheritis. Sre also Orth, Arehiv d. Heilkunde, 1872 , xiii, p. 265, and Hiller, Centralblatt, $1874, \mathrm{p} .833$. In the Biennial Retrospect of Physiology, of the New Syd. Soc. for 1875 , several other references will be found. Considerable interest attiches to a statement recently made by Lostorfer (Wien. Med. Jah.b., 18i2, Heft i, p. 96), and confirmed by Stricker, though vehemently denied by others, that the blood of syphilitic patients can be recognized by the presence of snall bright bodies, which present Brunonian movements, and in the course of a week after removal from the body, enlarge, sprout, become vacuolated, and die. Lostorfer's statements have been partially corroborated by Biesiadecki, who, however, regards the bright particles as pariglobulin (Untersuch. aus dem Path.-Anatom. Institute in Kraliau, Vicnna, 1872) precipitated by carbonic acid developed during the decomposition of the blood. Such particles are present in small numbers in all blood, but are uncommonly abundant in blood preparations from syphilitic patients, either because their blood contains more paraglobulin or jess fibrinogenous substance than other blood. See article by Klein in Iund Med. Record, April 9th, 1873. Halford, On the Condition of the Blood after Snakebite, 1867, has observed peculiar nucleated cells in thc blood after snakebite, which he belicves to be derived from germinal matter in the poison of the snake, and to lave grown at the expense of the blood. 
of the interruption, is speedily produced. The results of the retention of the materials of the Biliary and Urinary excretions will be hereafter considered (chap. xi); and at present it will be only remarked that such retention is a most fertile source of slight disorders of the system, that it is largely concerned in producing many severe diseases, and that, if complete, it.will most certainly and rapidly bring about a fatal result.

\section{Of the Vital Properties of the Blood, and its relations to the Living Organism.}

205. It cannot be doubted that the perfect and regular performance of the various actions to which the Blood is subservient, is dependent upon the admixture of its principal components in their due proportions, and upon its freedom from deleterious matters whether formed within the system, or introduced into the circulating current from without. And it is not difficult to see how any considerable alteration which affects its physical conditions merely, may thereby produce a most serious disturbance in the regnlarity of the circulation, and in the functions to which it ministers. Thus it has been shown by the experiments of Poisseuille, ${ }^{1}$ that a certain degree of viscidity is favorable to the motion of liquids through capillary tubes; a thin solution of sugar or gum being found to traverse them more readily than pure water will do. Hence any serious alteration in the proportion of the organic and saline compounds dissolved in the liquor sanguinis, and especially in that of the Fibrin (on which the viscidity of the hlood appears chiefly to depend), might be expected to produce obstruction in the capillary circulation, and to favor transudation of the fluid portion of the blood; and the numerous experiments of Magendie (Op. cit.) seem to favor this view, although they are far from manifesting that character for accuracy and discrimination, which would be required to afford an anthoritative sanction to it. A much more determinate influence, however, must be exerted upon the Red Corpuscles, by any cause which seriously affects the specific gravity of the liquor sanguinis $(\$ 173)$; and the perfect elaboration of the Albuminous constituent of the serum has been shown to be requisite, to prevent it from copiously transuding the membranous walls of the vessels which it traverses $(\$ 196)$. These and other physical and chenical relations of the Blood are quite subordinate to its vital reactions; and it is into them that we have now to inquire. Before proceeding, however, to inquire into the nature of the relation of the Fibrin and the Corpuscles - the two constituents of the blood that are most highly endowed with vital propcrties-to the "Life of the Blood," our attention may be advantageonsly directed to that remarkable change in the state of the blood when withdrawn from the vessels of the living body, which is commonly known as its "coagulation."

206. The Coaguilation of the Blood consists in the new arrangement of its constituents, which takes place when it is draw from the vessels and is left to itself, or when the body itself dics $(\$ 172)$. This new arrangement essentially depends upon the passage of the Fibrin (or of the constituents of Fibrin) from the soluble to the insoluble state, in which it forms, not an anorphous coagulum, but a network of fibres more or less definitcly marked out; in the meshes of which network arc included the Rerl corpuscles, usually grouped together in columnar masses resembling piles of money. Crassamention or Clot thus formed, gradually acquires a degree of firmness proportioned to the amount of Fibrin which it contains, and to the degree of its elaboration; and it undergocs a progrcssive contraction, by which the

1 See II. II agendie's Leçons sur les Phénomènes Physiques de la Vie, tom, iv, p. 57. 
Albuminous, Saline, and Extractive matters, still dissolved in the water, are more or less completcly expelled from it, constituting the Serum. This separation will not occur, however, if the coagulation take place in a shallow vessel; nor if the amount of Fibrin should be small, or its vitality low. A homogeneous mass, deficient in firmmess, presents itself under such circumstances; though the solid part of this may pass into a state of more complete condensation after a lapse of a certain time.-That the coagulation is due to the Fibrin, and that the Corpuscles do not take any active share in the process, appears from several considerations. ${ }^{1}$ A nicroscopical examination of the clot shows, that it has the same texture with Fibrin when coagulating by itself; the Corpuscles clustering together in the interspaces of the network, and not being uniformly diffused through the whole mass. Their specific gravity being greater than that of the Fibrin, they are usually most abundant at the lower part of the clot, and the upper surface is sometimes nearly colorless, especially when the coagulation has taken place slowly; yet this upper part is much firmer than the lower, showing that the fibrin alone is the consolidating agent. If, after the complete subsidence of the Corpuscles, a little of the colorless Liquor Sanguinis be skimmed off', it will undergo complete coagulation, forming a colorless clot, as was long ago shown by Hewson. The same fact may be experimentally demonstrated, by the use of methods which effect an artificial separation of the Fibrin from the Corpuscles. Thus Müller placed the blood of a Frog, diluted with water (or still better, with a very thin syrup), on a paper filter, when the Liquor Sanguinis, having passed through completely unmixed with the corpuscles, presented a distinct coagulum; although, from the diluted state of the fluid, this did not possess much consistency. Owing to the more minute size of the Blood-disks of warm-blooded animals, this experiment cannot be so readily performed with their blood. So, again, if fresh-drawn blood be continually stirred with a stick, the Fibrin will adhere to it in strings during its coagulation; and the Red corpuscles will be left suspended in the serum, without the slightest tendency to coagulate. MIoreover, if a solution of any salt that has the property of retarding the coagulation (such as carbonate of potash or sulphate of soda) be added to the blood, the Corpuscles will have time to sink to the lower stratum of the fluid before the clot is formed; the greater part of the crassamentum is then entirely colorless, and is found by the microscope to contain few or no red particles. $\Lambda$ curious observation has been made by Bernard, showing that, even during life, the Blood-cells gravitate to the lowest part of the fluid. Thus in a Horse, laid out on the ground in such a position that its long jugular vein was nearly horizontal, a small opening made in the upper surface allowed the escape only of yellowish serous fluid without red corpuscles, whilst from a similar small opening made at the lowest surface of the vein some very black blood issued. Both portions coagulated; the first, of course, giving a colorless clot; the second, as usual, a dark clot, with a well-marked buffy coat. ${ }^{2}$ It will be presently shown, however, that the difference of specific gravity is by no means the only cause of the separation of the Corpuscles from the Liquor Sanguinis. Generally speaking, the fibrillation is more perfect the more slowly it takes place; and the higher the previous vitalization of the

1 It is remarliable that this doctrine, elearly established by the older Physiologists, and especially by Hewson, should ever have been put aside, even temporarily, for the untenable hypothesis that the coagulation of the blood is due to a running together of its red corpuscles. - For an admirable summary of the history of opinion on this subject, see M. Gulliver's Introduetion to his Edition of Hewson's works (published by the Sydenham Soeietry).

2 Bernard, Leçons, 1859, p. 432. 
fibrin, the longer is it before it changes its state. Thus the eoagulation of sthenic infammatory blood, which produces a clot of remarkable firmuess, is mueh longer in taking place than the coagulation of ordinary blood; whilst the coagulation of the blood of cachectic subjects, which takes place very rapidly, is fecble and imperfeet. The plastic effusions poured out from the blood in these two opposite conditions, partake of the eharaeter of the blood itself; those of the inflammatory blood of a previously healthy subjeet being eonverter into fibrous membranes of eonsiderable firmness, which are subsequently penetrated by bloodvessels, and beeome regularly organized tissucs; whilst those proeeeding from the blood of cachectic subjects frequently undergo a certain degree of organization with great rapidity, but do not go on to the same perfection, and speedily degenerate. ${ }^{1}$

207. Instances oecasionally present themselves, in whieh the blood does not coagulate after death, or coagulates very imperfectly. It was affirmed by Hunter" that no coagulation occurs in the blood of animals hunted to death, or of those killed by lightning, by eleetric shocks, or by blows upon the epigastrium; and this statement has been generally received upon his authority. It is far, however, from being eonstantly true; for Mr. Gulliver has made observations, and eollected numerous eases in which eoagulation was found to have taken place in the blood of animals killed in cach of these modes; in some of them, however, the eoagulation was very imperfeet. ${ }^{3}$ It is not improbable that some of the instances of apparent absence of eoagulation were really cases of retarded eoagulation ( $\$ 208$ ); and Dr. Polli goes so far as to maintain, that the complete absence of eoagulating power is a phenomenon whieh has no real existence. He states that he has never met with an instanee in which the blood, when left to itself, and duly proteeted from external destructive influenees, did not coagulate before becoming putrid; and that he has more than onee found blood to coagulate, which had been taken in a fluid state from the vessels thirty-six or forty-eight hours after death. ${ }^{*}$ Still there seems no reasonable doubt that non-coagulation may oecur, when the blood has been previously subjeeted to conditions which affeets its vitality. Such appears to be the case, for example, when death occurs fiom Asphyxia, as by hanging, drowning, or breathing of irrespirable gases; ${ }^{5}$ and the same has been observed in eases of poisoning by hydrocyanic acid, in which asphyxia was probably the immediate eause of death. In certain diseased states, again, we have seen that the eoagulating power seems to be eompletely defieient $(\$ 200)$.

208. The rapidity of Coagulation, and the degree in which the elot solidifies, vary eonsiderably; in general, they are in the inverse proportion to each other. Thus, if a large quantity of blood be withdrawn from the vessels of an animal at the same time, or within short intervals, the portions that last flow coagulate much more rapidly, as originally proved by Hewson, but much less firmly, than those first obtained. In blood drawn during Inflammatory states, again, the eoagulation is usually slow, but the elot is preternaturally firm; especially at its upper part, where the Buffy coat $(\$ 199)$ or colorless stratum of fibrin gradually eontraets, and produees

1 See especially Mr. Datrymple's Memoirs, On the Lapid Organization of Lymph in Cachexia, in the $\mathbf{M}$ ed.-Chir. Trans., vol. xxiii; and On the Early Organization of Coagula and Mixed Fibrinous Effusions under certain Conditions of the System, op. cit., voi. xxvii.

2 The Works of John Hunter, edited by James F. Palmer, vol. iii, pp. 34, 114.

3 See Edinb. Med. and Surg. Journ., Uet. 1848, pp. 367, 418, and his Edition of Hewson's Works, pp. 20, 21.

\& Annali Universali, 1845; and Ranking's Abstract, rol ii, p. 337.

5 Sec Dr. J. Davy's Playsiological and Anutomical Researches, vol. ii, p. 191. 
the "cup," which may be generally considered to indicate a high degrec of Inflammation. The physical changes to which the blood is subjected when drawn from the vessels are, that it is brought to rest, that its temperature is reduced, and that it is exposed to the action of the air. It may easily be shown, however, that its coagulation cannot be attributed to either of these conditions. For in the first place if the blond be continually agitater in a bottle, though its coagulation is delayed, it will at last take place in shreds or insulated portions; that rest is not the cause of its coagulation (as some have supposed) is proved by the fact that, if a portion of blood be included between two ligatures in a living vessel, it will remain fluid for a considerable time; ${ }^{1}$ as it also will when effused into the midst of living tissues, or kept in a state of stagnation in parts affected with inflammation. Thus Mr. Gulliver, besides other instances, mentions a remarkable case witnessed by himself, in which a collection of blond which had been effused in consequence of a bruise on the loins, was found uncoagulated when let out twenty-eight days afterwards; it measured fivc ounces, was as liquid as blood just drawn from a vein, and showed the normal characters when examined microscopically; and it coagulated in a cup in less than thirty minutes. ${ }^{2}$ And Mr. Pagret mentions that he has known the blood remain fluid in the vessels of an inflamed part, though in a state of complete stagnation, for as long as three days. - Again, so far from coagulation heing pronoted by cold, it can be shown to be accelerated by moderate warmth, the natural heat of the body from which the blood is taken appearing to be most favorable to it; but the coagulating power appears to be destroyed by a temperature of about $150^{\circ}$, blood heated to that point remaining permanently fluid.* On the other hand, the coagulation is retarded by cold; but the coagulating power is not destroyed even by extreme cold ; for if blood be frozen immediately that it is drawn, it will coagulate on being thawed.Lastly, although coagulation is accelerated by exposure to air, it is not prevented by complete exclusion from it, as is proved by its taking place in a vacuum, or in a shut sac within the dead body: complete exclusion from the air, however, does retard the change; as may be easily shown by cansing blood to flow into a vessel containing oii, which will form an inpervious coating on its surface, and will occasion tlic coagulation to take place so slowly, that the red particles have time to subsile, and the upper stratum of the clot to be colorless. ${ }^{5}$ - The effect of the addition of strong solutions of neutral salts to fresh blood, is usually to retard, and sometimes even to prevent, its coagulation; and the same effect is produced by many vegetable substances, particularly those of the narcotic and sedative class, such as opium, belladonna, aconite, hyoscyamus, digitalis, and tea or coffee in strong infusion. ${ }^{6}$ The action of most of those substances, however, which preserve

1 The testimony of all experimenters is in accordance on this point, although they differ as to the length of time that elapses before coagulation commences. Mr. Gulliver states that out of many trials made by him, the coagulation commenced within two hours in only a few instances; more commonly, three, four, or five hours elapsed hefore any clot was forned; and in one instance, the coagulation was incomplete at the end of twenty-four hours. In all these experiments, the blood coagulated in the course of a few minutes, when withdrawn from the living vessels. - See Mr. Guliiver's edition of Hewson's Works, p. 23.

2 Op. cit., p. 17.

4 Gulliver, op. cit., pp. 4, 5.

5 Dr. Babington in Medico-Chirurgical Transactions, vol. xvi.

6 See Dr. J. Dary's Anatomical and Physiological Researches, vol. ii, pp. 101, 102 ; and Mr. Prater's Experimental Inquiries in Chemical Physiology, pp. 59, 63, etc. A copious table of the results of their experiments is given in Mr. Ancell's Lectures on the Physiology and Pathology of the Blood, in the Lancet for Dec. 2 Ist, 1839. 
the fluidity of the blood, only continues during such time as their solutions retain a certain strength; for if they be diluted coagulation will then take place, although in most cases less perfectly than it would have done at first. 'There appears to be no limit to the time during which the coagulation may be thus postponed; thus MI. Gulliver ${ }^{1}$ mentions that he has kept horse's blood fluid with nitre for fifty-seven weeks, and that it still readily coagulated when diluted with water. ${ }^{2}$ It is not so difficult, therefore, as it might otherwise seem, to give credit to the statement of Dr. Polli, that, in a case witnessed by himself, complete coagulation of the blood did not take place until fifteen days after it had been withdrawn from the body; and that fifteen days more elapsed before putrefaction commenced in it. The upper four-fifths of the clot were colorless, the red corpuscles occupying only the lowest fifth. It is additionally remarkable that the patient (who was suffering under acute pneumonia) being bled very frequently during the succeeding week, the blood gradually lost its indisposition to coagulate. ${ }^{3}$ Neither heat, ammonia, nor carbonic acid appear to be evolved, as was formerly supposed, during coagulation.

209. The vital condition of the walls of the bloodvessels appears to have an important influence upon the fluidity of the Blood. Thus it has been found by Sir A. Cooper and Mr. Thackrah, and the same point has been strongly insisted upon by Brücke, ${ }^{*}$ that whilst blood inclosed in a living vein may retain its fluidity for some time $(\$ 208)$, blood similarly inclosed in a dead vein, the atmosphere being completely excluded, will coagulate in a quarter of an hour. Morenver, inflammation of the walls of the bloodvessels (which is a condition of depressed vitality, chap. $\mathbf{x}$ ) promotes the coagulation of the blood which they contuin, and thus it is, that the trunks both of artcries and veins frequently become choked up by coagula. And, although there can be no doubt that a large proportion of the loose fibrinous masses found in the heart and large vessels after death, are the result of post-mortem coagulation, yct there is often adequate evidence, derived from the symptoms previously observed, and from the appearances presented by the coagula themselves, that the coagulation has conmenced during life; and in all cases of this kind there has been a marked depression of vital power for some time previous to the final extinction of life. Again, it was found by Schroeder Van der Kolk, ${ }^{5}$ that if the substance of the brain and spinal marrow be broken down, coagulation of the blood takes place whilst it is still moving within the vessels; clots being found in then, even within a few minutes after the operation. Further, that the contact of a dead substance promotes coagulation, ${ }^{6}$ even in the living and actively moving blood, is shown by the experiments of Mr. Simon, who carried a single thread (by means of a very

1 Mr. Gulliver considers this fact, together with the occurrence of coagulation on the thawing of blood which has been frozen whilst yet fluid, as conelusive against the vital character of the act; remarking that if we belicve the corgulation to be an effect of life, we must admit that we can freeze and pickle the life (op. cit., p. 21). No sueh admission, however, is neessary. We do not freze and pickle the life; but we simply preserve the vital properties of the substance by preventing it from undergoing spontaneous change; thus doing the same for the blood as may be done for seeds, eges, and even highly-organized bodies, which may bo kept in a state of "dormant vitality" for unlimiterl periods, by couling or drying them, or by secluding them from the atmosphere. (Sce Princ. of Gen. Physiol.)

2 Op. cit., p. 12.

3 Gazetta Mediea di Milano, Genn. 20,1844; cited in Mr. Paget's Report in Brit. and For. Med. licv., vol. xix, p. 252.

4 Vorlesungen, 1874, p. 81 ct seq.

5 Comment. de Sanguinis Coagulatione, Gröningen, 1820.

6 For various proofs of whieh see Lister, Crooniun Lecture on the Coagulation of the Blood, in Lancet for 1863 , vol. ii, p. 179. 
finc needle) transversely through an adjaccut artery and vein of a dog, and left it there, so that it might cut the stream, for a period of fron twelve to twenty-four honrs; the consequence of which was, that a coagulum was formed upon the thread more or less completely obstructing the vessel. There was, however, a marked difference in the coagula formed within the artery and the vein respectively, which may be attributed to the difference in the quality of the fibrin in the blood of the two vessels, or to the difference in the rate of its motion, or to both causes conjointly; for the thread which traversed the artery usually presented a "vegetation" on its surface, somctimes as large as a grain of wheat, always of a pyramidal shape, with its base attached to the thread, and its apex down stream; whilst the venous coagulum was a voluminous black clot, chiefly collected on that side of the thread remotest from the heart. ${ }^{1}$

210. A gain, the contact of dead animal matter with the Blood appears to promote the coagulation of its fibrin in a very remarkable degree, occasioning coagula to form, whilst it is yet actively moving in the vessels of the living body. Thus M. Dupuy found that the injection of cerebral substance into the veins of an animal occasioned its death almost as instantaneously as if prussic acid had been administered; the circulation being rapidly brought to a stand, by the formation of voluminous clots in the heart and large vessels. These experiments were repeated and confirmed by MI. de Blainville. ${ }^{2}$ The same effect is produced with still more potency, when the substance injected is rather undergoing degradation, than actually dead; for it then seems to act somewhat after the manner of a ferment, producing a marked diminution in the vitality of the solids and fluids with which it may be brought in contact. Such is pre-eminently the case with pus, as was long ago observerl by Hunter, and as Mr. H. Lee has since determined more precisely. It was found by the latter, that healthy blood received into a cup containing some offensive pus coagulated in two minutes; whilst another sample of the same blood, received into a clean vcssel of similar size and shape, required fifteen minutes for its complete congulation. When he injected putrid pus into the jugular vein of a living ass, coagulation took place so instantaneously as to produce an immediate obstruction to the current of blood, so that the vessel at once acquired a cord-like character; and in this mode, the pus was usually prevented from finding its way into the general current of the circulation. Whilst it thus remains circumscribed by a coagulum of blood, the pus so introduced seems to produce no other constitutional disturbance than is attributable to the local injury; but if the circumscription should be incomplete, and the pus should be carried into the general circulation, it becomes a source of extensive mischief, determining the formation of abscesses in various parts, and producing a most depressing influence on the system at

1 Lectures on General Pathology, p. 56.-Mr. Simon applies this fact to the explanation of the "vegetations" which so commonly present themselves upon the valves of the heart, in eases of rhemmatic endocarditis; maintaining that they are simple deposits from the fibrin of the blood, which is unusually abundant in this condition. This doctrine can only be substantiated, however, by a careful inicroscopic exanination of these substances; and if they should be proved to have the simple constitution which Mr. Simon imputes to them, the fact will in no degree set aside (as he seems to consider it must do) the existence of endocardial inflammation, but will rather confirm it, since the deposition of fibrin on those particular spots is likely to be specially deternined by inflammation of the subjacent membrane.

2 Gazette Medicale, 1834, p. 521.-There is no reason to suppose that cerebral substance possesses a more special infuence than would be exerted by any other tissue which could be as easily mixed up with the circulating current. The presence of a piece of flesh or of the clot of blond, as Prof. Buchanan has shown, often suffices to determine the coagulation of fibrin in a solution from which it would not otherwise have separated. 
large. ${ }^{1}$ The effect of certain animal poisons of a still more potent nature, when introduced into the current of the circulation (as by the bite of venomous serpents), appears to be, like that of a high temperature, the entire destruction of the coagulating power of the blood; possibly, as Dr. Halford ${ }^{2}$ has suggested, by the rapid development of corpuscles of germinal matter at the expense of the oxygen contained in it, as well as of the vital endowments of the tissues generally.

211. The proportions of Serum and Clot which present themselves after coagulation, are liable to great variation, independently of the amount of the several ingredients characteristic of each; for the crassamentum nay include, not only the fibrin and red corpuscles, but also a large proportion of the serum, entangled (as it were) in its substance. This is particularly the case when the coagulation is rapid; and the clot then expels little or none of it by subsequent contraction. On the other hand, if the coagulation be slow, the particles of fibrin usually seem to become more completely aggregated; the coagulum is denser at first, and its density is greatly increased by subseqnent contraction. When a firm fresh clot is remored from the fluid in which it is immersed, its contraction is found to go on increasing for 24 or even 48 hours, serum being squeezed out in drops upon its surface; and in order, therefore, to form a correct estimate of the relative proportions of Crassamentum and Serum, the former should be cut into slices, and laid upon bibulous paper, that the latter may escape from it as freely and completely as possible. According to the experiments of Mr. Thack rah, ${ }^{3}$ coagulation takes place sooner in metallic vessels than in those of glass or earthenware, and the quantity of serum separated is much less; in one instance, the proportion of serum to clot was as 10 to 24 , when the blood coagulated in a glass vessel; whilst a portion of the same blood, coagnlating in a perter vessel, gave nuly 10 of serum to 175 of clot. The specific gravity of Blood is no measure of its coagulating power; for a high specific gravity may be due to an excess in the amount of corpuscles, which form the heaviest part of the blood; and may be accompanied by a diminution in the quantity of fibrin, which is the coagulating element.

212. The surface of the Crassamentum not unfrequently exhibits, in certain disordered conditions of the blood, a layer that is nearly free from color ; and this is known as the Buffy Coct. Its presence has been frequently regarded as a sign of the existence of Inflammation, indicating an undue predominance of fibrin; but this idea is far from being correct, since, as occurs in chlorosis, it may result from an opposite condition of the blood. Its occurrence in the liuman subject, excepting in the female during the latter stages of utero-gestation, is certainly pathological; but in some animals, as in the horse, the blood-clot is ordinarily bnffy. Conclusive evidence that the formation of the buffy coat is due to the clumping together, and consequent more rapid sinking of the red corpuscles, is afforded by the facts that its appearance is hindered by artificially scparating the corpuscles, whilst it is hastence or increased as their aggregation increases. Thus, as shown in Gulliver's experiments, dilute solutions of neutral alkaline salts prevcut the ruming together of the corpuscles and retard the formation of the buffy coat. On the contrary, certain viscid matters facilitate the clumping of the corpuscles, and coincidently the quickness of formation and quantity of the buffy coat. But the most curious and decisive proof is the discovery by Gul-

1 See Mr. II. Lee's excellent Treatise On the Origin of Inflammation of the Veins, and on Purulent Deposits.

2 On the Condition of the Blood after Death by Snakebite. Melbourne, 1867.

3 Inquiry into the Nature and Properties of the Blood, 2d edit., p. 66. 
liver that in fluid blood the sinking of the red corpuseles increases in a kind of arithmetical ratio, being slowest when they first begin to collect into clumps, and fastest at the very time when these clumps are most fully formed ; so that the corpuscles would, in some instances, take two and a half minutes at first to sink through one-eighth of an inch of the liquor sanguinis, but only two and a half ninutes more to sink through a further three-eighths of an inch. It is remarkable, as Gulliver notices, that Hunter was well acquainted with the chumps of the red corpuseles in inflammatory blood.

213. The actual cause of the scparation and coagulation of the fibrin is still exceerlingly obsure. Dr. Buchanan" long ago remarked that fibrin might apparently be formed, or at least that coagulation could be induced, by miximg two serous fluids like those of Hydrocele and Ascites, or of Ascites and Pleurisy, neither of which had, separately, any tendency to coagulate; and that coagulation was equally caused by putting into the serum portions of blood, clot, or of fibrin, either fresh or powdered, muscular fibre, or other tissues. Schmidt, ${ }^{3}$ in more recent observations, attempts to cxplain the phenomena in question by attributing them to the combination of two substances existing in the liquor sanguinis under the influence of a ferment which is rapidly formed in the Blood after its removal from the borly. To one of these, which is contained in considerable quantity in the bloor-corpuscles, he has applied the name of Fibrinoplastic substance, Globulin or Crystallin, though it differs from the crystallin obtained from the lens of the eye in its non-precipitability by heat and alcohol, and has therefore been termed by Kühne Puraglobulin. It is precipitated when its alkaline solution is exactly neutralized. To the other substance, which is closely allied to ordinary albumen, and is chiefly, if not exclusively contained in the plasma, he has given the name of Fibrinogenic substance or Fibrinogen. This differs from the Fibrinoplastic substance in the circumstance that its alkaline solution must be rendered acid with acetic acid before precipitation occurs. Both compounds are precipitated from dilute solutions by carbonic acid, the latter with somewhat greater difficulty than the former. Both Schmirlt and Hoppe-Seyler have been successful in producing a coagulum differing in no respect from ordinary fibrin, by the admixture of these two substances in a condition as pure as it was possible to obtain them. A small quantity of Paraglobulin is capable of effecting the coasulation of a relatively large quantity of Fibrinogen. Schmidt appears to think that both of these substances are weakly acid, and are combined with a certain proportion of base, and that when brought into contact with one another under the influence of the ferment and also of oxygen, they unite, displacing a part of the base, which explains the increased alkalinity of the fluid in which the

1 See Lectures, Med. Times and Gaz., 1863, Oct. 17; Hewson's works.

2 Proeeedings of Glasgow Phil. Society, 1845.

3 Il üller's Arehiv, 1862, p. 543, and P'flüger's Arehiv, B. vi, 1872, p 413. See also Mantegazza, Annali Universali di Medicine, t. cexvi, April, 1871. In "pposition to schmidt, see Eichwald, Beiträge zur Chemie der gevebe-bildunden Substanzen und ihren Abliommlinge, 1873. Eiehwald regards the Fibrin as being normally dissolved in the plasma, but undergoing preeipitation when exposed to the ation of the carbonic aeid of the air. Denis divides the Albuminous compounds of the blood into Serine (amounting to 52 parts per 1000 of blood), whieb is eougulable by heat and aerds; and Plasmine (25 per 1000), which is preeipitated by $\mathrm{NaCl}$, but redissolves in from 10-20 parts of water. The plasmine is capable of breaking up spontaneously into eoncrete fibrin (3-4 per 1000 ) and soluble fibrin $(22$ per 1000$)$, the proportions of which bear an inverse ratio to each other. Hence, as Sée maintains, it is never a question in disease of excess or defect of fibrin, but simply of the relative proportions of the concrete and soluble fibrin. See Kiuss, Plusiulogie, 1873, p. 158, and Budge's Compendium de Physiologie, 1874, p. 260. 
coagnlation has occurred. Mr. Goodman ${ }^{1}$ has pointed out that ov-albumen suspended in cold and pure water for some time loses the characters of albumen, and assumes the nature, appearance, and constitution of Fibrin ; and he accounts for the formation of the Fibrin in Blood in this way. Smee, ${ }^{2}$ admitting that the changes described by Goodman occur, attributes it to the removal of the salts of the albumen by dialysis, and maintains that the coagulation of blood is a physical act, depending on the same laws which cause all soluble colloid substances to pass from a peptous or soluble state to a pectorous or insoluble state. Brown-Séquard ${ }^{3}$ has made the curious observation, that on injecting defibrinated blood into the separated limbs of animals, fibrin is formed, especially if the muscles are tetanized; which tends to show that, as some hold, fibrin is the result of the disintegration of the albuminous tissues-a view that is further supported by its excess in all inflammatory and febrile diseases. Similar results have been obtained by Bernard. ${ }^{4}$ It is remarkable that Splenic Venous Blood, when defibrinated, will, on exposure to the air, form a second coagulum. The blood returning from the kidneys and liver has little or no tendency to coagulate; hence, BrownSéquard has argued that fibrin is destroyed in these organs, and, from a calculation based on the quantity of blood transmitted through the renal arteries, estimates the total quantity of fibrin decomposed by the kidneys alone at from 8 to $10 \mathrm{lbs}$. per diem.

214. Of the particular purposes which are served by the fibrin of the blood in the vital economy of the system at large, it must be confessed that we have but little positive knowledge. But putting aside its presumed importance in maintaining that physical condition of the blood which is most favorable to its free movement througl the vessels, and to its due retention within their walls ( $\$ 205)$, we find that it is entirely on the coagulating powers of the blond that the cessation of hamorrhage from even the most trifling injuries is dependent; that the limitation of purulent effusions by the consolidation of the surrounding tissue, and the safe separation of gangrenous parts, can only take place in virtue of the same property; and that the adhesion of incised wounds, still more the filling up of breaches of substance, require as their first condition, that either the blood, or matter exuded from it should be able to assume the state of fibrous tissuc. On the other hand, we sce the consequences of excess of the proportion of fibrin, and of that increascd plasticity (or tendency to fibrillate) which usually accompanies its augmentation, in the tendeney to form those plastic effusions which are characteristic of the inflammatory state, and which, if poured out upon serous or mucous surfaces, constitute "false membranes" and "adhcsions," or, if infiltrated into the substance of living tissues, occasion their consolidation. This increased plasticity of the blood, however, may frequently be regarded in the light of an "effort of Nature" to antagonize the evil consequences of that depression or positive destruction of the vitality of the solid tissucs, which seems to form an esscntial part of the inflammatory condition; and thus it is, that whilst the central part of a mass of tissue, in which the inflammation has been nost intense, suffers complete death, and is carricd away in the suppurative process, the pcripheral part, in which the violence of the inflanmation has been less, becomes infiltrated with plastic matter poured out from the blood, and forms the solid and impermeable wall of the abscess. (See chap. $x$, scet. 3.)

215. Turning now to the corpuscles of the blood, we have to inquire into

1 Fibrin; its Origin and Sourees of Development. P'amphlet, 1871, p. 12.

2 Journal of Anat. and Physiol., vol. vii, pp. 210, 218.

3 Journal de la Physiol, tom i, p. 299, 1858. 4 Leçons, 1859, vol. i, p. 460. 
their special functions, and into the nature of their participation in the vital operations of the system at Iarge. Here, also, we are obliged to rely upon evidence of a far less satisfactory nature than could be desired; we may, however, look upon them as specially subservient to the vital activity of the Nervo-Muscular apparatus; since it is one of the most important conditions of that activity, that these tissues shall be supplied with duly oxygenated blood, and that the carbonic acid which is one of the products of their disintegration, shall be conveyed away. And this view is in complete harmony with the fact, that the proportion of red corpuseles in the blood bears a close relation to the amount of respiratory power (as shown in the quantity of carbonic acid set frec, and in the amount of heat generated) in clifferent classes of Vertebrata; both being greatest in Birds, nearly as great in Mammals, very low in most Reptiles, and varying considerably among fishes. ${ }^{1}$ Again, we observe that among carnivorous Manmalia, the proportion of red corpuscles is considerably greater than it is anong the Herbivorous tribes, whose nervo-muscular energy is (upon the whole) so greatly inferior; and it is in the condition of greatest animal vigor, in the Human system, that we find their amount the greatest, whilst the reduction of that vigor by chronic disease of any description, seems invariably attended with a more marked diminution in this constituent of the blood than in any other. And in those Anæmic states of the system, in which the proportion of red corpuscles is reduced to an extremely low point $(\$ 201)$, we invariably find that the animal powers are correspondingly depressed; the capacity for sustained exertion, either of the mental faculties, or of the motor apparatus, being almost destroyed, although both the nervous and muscular systems are very easily excited to feeble action.

216. The difficulty of precisely determining the functions of the Red corpuscles, is even surpassed by that of assigning the probable duty of the Colorless. The considerations already adduced appear to show, that the Colorless corpuscles are to be considered as cells of a lower grade than the Red; since they represent them among Invertebrated animals, and also in the incipient blood of Vertebrata; and also, because cells resembling the former (if not the very same) pass on to develop themselves into the latter. Still we find that this final change does not occur among the Invertebrata; and it is obvious, therefore, that even in their colorless state, the corpuscles have a function to discharge in the vital economy. The observations of $\mathrm{Mr}$. Newport seem to indicate, that the corpuscles of the bloor of Insects (some of them in the condition of "granule-cells," others in that of "nucleated colorless cells"), play an important part in the elaboration of nutrient material. For he found that the "oat-shaped" corpuscles (the "gramulecells" of $M[r$. Wharton Jones) in the Larva, a re most numerous at the period immediately preceding each change of skin; at which time the blood is extremely coagulable, and evidently possesses the greatest formative power; whilst the smallest number are met with soon after the change of skin,

1 A mong Invertebrated animals, as a general rule, the degrec of nervo-muscular energy that can be put forth, the quantity of carbonic acid produced in respiration, and the amount of heat generated in the body, are alike at a low standard; and the fluid constituents of the bluod, with the colorless corpuscles that float in it, would seem to convey oxygen to the tissues, and carbonic acid to the respiratory organs, with suflicient fucility. In inscets, however, the case is different; the nervo-muscular activity, capacity of respiration, and heat-producing powcr being all extraordinarily high. The want of red corpuscles would here scem to be compensated, so far as the respiratory process is concerncd, by the introduction of air, through the tracheal apparatus, into the tissues themselves. 
when the nutrient matter of the blood has been exhausted in the production of new epidermic tissue. ${ }^{1}$

217. That condition of the corpuscular element of the blood which is normal in the Insect, must be considered as dccidedly abnormal in the Vertebrated animal, in which the circulating fluid goes on to a higher phase of development; and the excess of Colorless corpuscles in the latter seems always to be associated (save in the early part of life) with an imperfect performance of their nutritive operations. Thus, according to the observations of Mr. Paget, ${ }^{2}$ they are especially abundant in the blood of frogs that are young, sickly, or ill-fed; and as regards the human subject, he confirms the statement of Mr. Wharton Jones and Prof. J. H. Bennett, that the increased proportion of Colorless corpuscles in inflamed blood is most frequent when the subjects of the disease are persons in weak health, or of the tuberculous diathesis. Mr. Paget has also furnished a remarkable confirmation of this view, in the observation, that the inflammatory cxudations produced in different individuals, by the application of the same stimulus on the sane tissue (e.g., by the action of a blister on the skin) are found to present a predominance of the fibrinous or of the corpuscular element, according to the general condition of the patient.- "The highest health is marked by an exudation containing the most perfect and uminixed fibrin; the lowest by the formation of the most abundant corpuscles, and their nearest approach, even in their early state, to the characters of pus-cells." From such evidence we seem forced to the conclusion, that, whether or not the Colorless corpuscles are to be regarded in any other light than as blood-cells not yet fully developed, their multiplication is not the source of increase in the fibrinous constituent of the liquor sanguinis.

218. The fitness of the Blood for circulation through the body is maintained partly by the action of the proper excretory apparatus, and partly by the power which every tissue possesses of withdrawing from the circulating fluid some particular material, or combination of materials, which constitutes its own special pabulum; and as the "pabulum" of each tissue is different, it follows that the normal composition of the blood can only be preserved, without waste of substance, by the existence of such a balance between the appropriative action of the several parts, as shall cause a certain equivalent of blood to supply, without deficiency or surplus, the materials which they collectively require. Such a balance is, in fact, ordinarily preserved ; and its maintenance is one of the most marvel lous of those exemplifications of Design, which the vital economy of the body presents in no less a degrec than its organized structurc; an exemplification, however, which becomes yet more marvellous, when it is shown that not only every kind of tissuc, hut every spot of every organ, has its own special "pabulum;" drawing something from the blood, which is different from that appropriated by every other part of the body, save the corresponding spot on the opposite side. This position secms fully established by the researches of Dr. W. Budd and of Mr. Paget on "Symmetrical Diseases,"3 the phenomena of which are full of interest, as illustrating the ordinary operations of Nutrition. From a general consideration of these as displayed in various rheunatic and syphilitic affections, the conclusion seems unavoidable, that, however closely onc portion of skin or bone may secm to resemble another, the only parts that are exactly alike are those which repeat each other symmetrically on the opposite sides of the borly; for, although no power of artificial chemistry may determine the difference,

1 Philosoph Magazine, May, 1845.

2 Surgian Pacholocy, vol. i, pp. 313, 314.

3 See their original essays on this subject in the Med.-Chir. Trans, vol. xxv. 
the chemistry of the living body makes it evident, the morbid material testing out the parts for which it has the greatest affinity, uniting with these alone, and passing by the rest. It luas been further pointed out by Dr. WV. Mudd, as indicated by the phenomena of these diseases, that next to the parts which are symmetrically placed, none are so nearly identical in composition as those which are analogous, such as the corresponding parts of the superior and inferior extremities. - All these facts tend to demonstrate the perfect and most minute exactness of the adaptation which must exist in the state of health between the hlood and all the tissues, as well as the almost inconceivable minuteness of the departure from this adaptation which may become a source of disease. And hence we are led to the conclusion, that, as 'Treviranus plirased it, " each single part of the body, in respect of its nutrition, stands to the whole body in the relation of an excreted substance;" or, in other words, each part of the body, by taking fiom the Blood the peculiar substances which it needs for its own nutrition, does thereby act as an excretory organ, inasmuch as it removes from the blood that which, if retained in it, would be injurious to the nutrition of the body generally. Thus, the phosphates which are deposited in our bones, are as effectually excreted firom the blood, and as completely prevented from acting injuriously on other tissues, as arc those which are discharged with the urine.-The applications of this doctrine have been greatly extended.by Mr. Paget, ${ }^{1}$ who hat given the following among other examples of its bearing upon the general relations between the blood and the tissnes. The hairy covering may be considered to serve, over and above its local purposes, for the removal of certain components of the blood, which would be injurious to its constitution if they remained and accumulated in it ; and accordingly we do not find that its development is delayed, until near the period when its protection will be required ; for a complete coat (the lanugo of the human foetus) is formed in the foetus of mammals generally, whilst they are still within the uterus, removed from all those conditions against which hair is a defence; and this coat is shed very soon after birth, being replaced by another of wholly different color, the growth of which had begun within the uterus. The same principle leads to the apprehension of the true import of the hair which exists in a kind of rudimental state on the general surface of our bodies; and thence to the real meaning of the existence of other organs which permanently remain in a rudimental state, such as the mammary glands of the male. For, as Mr. Paget justly remarks (loc. cit.), "these rudimental organs certainly do not serve, in a lower degree, the same purposes as are served by the homologous parts which are completely developed in other species, or in the other sex. To say they are useless, is contrary to all wc know of the absolute perfection and all-pervading purposes of creation; to say they exist merely for the sake of conformity to a general type of structure, is surely unphilosophical, for the law of unity of organic types is, in larger instances, not observed, except when its observance contributes to the advantage of the individual. No: all these rudimental organs must, as they grow, be as excretions, serving a definite purpose in the economy by removing their appropriate materials from the blood, thus leaving it fitter for the nutrition of other parts, or adjusting the balance which night otherwise be disturbed by the formation of some other part. 'Thus they ninister to the self-interest of the individual ; while, as if for the sakc of wonder, beauty, and perfect order, they are conformed with the great law of unity of organic types, and concur with the universal plan observed in the construction of organic beings."

219. But further, there are many examples in which the presence of a

1 Lectures on Surgical Pathology, Lect. ii. 
certain substance in the Blood, appears to determine the formation of the particular tissue, of which that substance is the appropriate pabulum. And thus, as the abstraction of the material required for each part leaves the blood in a state fitted for the nutrition of other parts, it seems to follow, as Mr. Paget has further renarked, ${ }^{1}$ that such a mutual dependence exists among the several parts and organs of the body, as causes the evolution of one to supply the conditions requisite for the production of another; and hence, that the order in which the several organs of the body appear in the course of development, while it is conformable to the law of imitation of the parent, and to the law of progressive ascent towards the higher grade of being, is yet the immediate result of changes effected in the condition of the blood by the antecedent operations. And this view is confirmed by many circumstances, which indicate that certain organs really do stand in such a complemental relation to one another as it implies; a large class of facts of this order being supplied by the history of the evolution of the generative apparatus, and by that of the concurrent changes in other organs (especially the tegumentary) which are found to be dependent upon it, although there is no direct functional relation between them. 'Thus, the growth of the beard in man at the period of puberty, is but a type of a much more intportant change which takes place in many animals with every recurrence of the period of generative activity. If the development of the male organs be prevented, the evolution of the beard does not take place; while the cessation or the absence of activity in the female organs is often attended by a strong growth of hair on the face, as well as by other changes that may be attributed to the presence of some special nutritive material in the blood, for which there is no longer any other demand. This, again, shows itself yet more strongly in Birds; among which (as Hunter long since pointed out ${ }^{2}$ ) it is no uncommon occurrence for the female, after ceasing to lay, to assume the plumage of the male, and even to acquire other characteristic parts, as the spurs in the fowl tribe. Moreover, it has been ascertained by the experiments of Sir Philip Egerton, that if a buck be castrated while his antlers are growing and are still covered with the "velvet," their growth is checked, they remain as if truncated, and irregular nodules of bone project from their surfaces; whilst, if the castration be performed when the autlers are full grown, these are sher nearly as usual at the end of the season, but in the next season are only replaced by a kind of low conical stumps. That these and similar changes in the development of orgaus are immediately determined by the condition of the circulating fluid, that is, by the presence or absence of the appropriate "pabulum" for the parts in question, rould further seem likely from the fact, that they may be artificially induced by circumstances which directly affect the condition of the blood. This has been shown by Mr. Yarrell, in regard to the assumption of the male plumage by the female; and a still nore remarkable and satisfactory proof is furnished by the conversion of the "worker" larva of the Bee into a perfect "queen," solely through a change of diet."

220. Thus, then, the precise condition of the Blood at any one time, is dependent upon a vast variety of antecelent circumstances, and can scarcely be the same at any two periods of life, nor, incleed, in any two parts of its course, even in one and the same individual. Yet we find that, taken as a whole, it exhibits such a remarkable constancy in its leadiug features, that we seem justified in the belief that, as Harvey and Hunter always main-

\footnotetext{
1 Op. cit., p. 32.

\& $\Lambda$ ceount of an Extraordinary Pheasant, in IIunter's Works, Palmer's edit, vol. iv, p. 44.

3 P'hilosophical Transactions, 1827.

4 Prine of Comp. Phys., \& 119.
} 
taincd, the Blood, like the solid tissues, has a formative power of its own, which it exerts in the appropriation of the new material supplied to it from the food; and that, like all the other parts descended from the component cells of the germinal mass, it goes through a succession of phascs, which are partly the cause, and partly the effect, of developmental changes in the organism generally. The self-maintaining power of the Blood is yet more shown in the phenomena of Disease; and espccially in its spontaneons recovery of its normal condition, after the most serious perversions; as we sce nore particularly in febrile discascs of definite type (such, for example, as the Lxanthemata, Typhoid, Typhus, etc.), of whose origin in the introduction of specific poisons into the blood, there is no reasonable ground for doubt. In studying the mode in which these and other "norbid poisons" act upon the bloud, and through it upon the system at large, we may derive important ascistance from a previous inquiry into the history of the action of such poisonons agents, which, from their being more readily traceable by chenical analysis, can be more satisfactory made out. Such an inquiry has a most important bearing, also, on the modus operandi of medicines. The operation of medicinal or poisonous substances for the most part depends upon the power which they possess, when introduced iuto the current of the circulation, of effecting sone determinate change in the chemical, and thercby in the vital condition, either of the components of the blood, or of some one or more of the tissues which it nourishes; and their determination to some special part or organ must be attributed to the same kind of elective affinity, as that by which the normal coustituents of the blood are so determined (\$217). Now of nearly all these substances it may be said, that the system if left to itself, tends to free itself from them, provided time be allowed for it to do so; and that, when death results from their introduction into it, the fatal result is to be attributed to the fact, that the disorganization of structure and disturbance of function are too rapid and violent to allow the eliminating processes to be set in efficient operation. When smaller doses are taken, their effects are evancscent, unless the abuormal action to which they may have given rise is of a kind to perpetuate itself; ${ }^{1}$ and their cessation is olvviously attributable to the removal of the agent from the system, whereby the continuance of its deleterious agency is prevented. Of this removal, we have of course the most satisfactory evidence in the casc of those substances which can be detected by ordinary chenical tests in the excretions, such as the alkaline and earthy salts, arsenic, tartarized antimony, and a variety of other metallic compounds, which may readily be detected in the urine for some days after they have been ingested; clearly showing that their elimination is a work of time. On the other hand, the salts of copper appear rather to be removed from the blood by the liver, and also by the bronchial secretion. And lead, which passes off but little by the ordinary excretions, is withdrawn from the circulation by various tissues aud organs, but particularly by certain parts of the muscular apparatus, with the substance of which it becomes incorporated, producing a most injurious influence upon its vital endowments. ${ }^{2}$ - The ouly exception to the geueral rule above stated, seems to be in the case of those mediciues

1 Such a perpetuation is scen in the chronic iuflammation, thiekening and contraction of the aesophageal walle, consequent upon tho deglutition of strong acids and caustic alkalies.

2 This has been shown by the analyses of M. Devergie (sce the Traite des Maladies de Plomb of M. Tanquerel, tom. if, pp. 401-6), and of Prof. Miller (see Dr. W. Budd's essay on The Symmetry of Direase, in the Med.-Chir. Trans., vol. xxv). M. Malassez (Gaz. Méd. de Paris, Nos. 1 and 2, 1874) has shown that under the toxic influence of lead the number of red corpuscles falls to $2,200,000$ : they at the same 
which have what is called a "cumulative" tendency; this tendency being, in fact, simply the result of their want of stimulating influence upon the excretory organs, whose functional activity is rather impeded than promoted by them. This is pre-eminently the case in regard to lead, which is probably the most cumulative poison with which we are acquainted; its continual introduction in doses of even extreme minuteness, being capable, if sufficiently prolonged, of causing the most serious disturbance in almost every function in the economy. Even here, it is rather in the tissues, than in the blood, that it accumulates, - as is indicated by a variety of facts, but more especially by the difficulty with which it is eliminated from the system by means that would be probably effectual in removing it from the circulating current.

221. There are some substances of this class which are, nevertheless, of a nature and composition which render them peculiarly susceptible of change, when subjected to the influences which they must encounter in the living body, and more especially when exposed in a state of very fine division to the agency of oxygen. We see exemplifications of this mode of elimination of poisons in the transient operation of moderate doses of Alcohol, Ether, Chloroform, Opium, Strychnia, Prussic Acid, Snake poison, ${ }^{1}$ etc., in all of which the question of life or death is one of time; for if the fatal result do not speedily follow the absorption of the poison into the blood, the patient gradually recovers from its effects; and the most effectual treatment consists in the artificial maintenance of the respiratory movements, which the influence of these poisons upon the nervous centres inight otherwise suspend. With regard to certain poisons of this unstable class, there is strong evidence that whilst in moderate doses they are partially or completely destroyed ${ }^{2}$ in the system; when taken in large doses they pass into the urine and are eliminated, without undergoing any change that impairs their physiological action; this cvidence being afforded in the effects of the reingestion of the urine, either by the individuals themselves, or by others. A very curious example of this kind is afforded by the intoxicating fungus Amanita muscaria, which is used by some of the inhabitants of the northeastern parts of Asia, in the same manner as alcoholic liquors by other nations. Its effects, like those of other excitants, have a limited duration; for a man who is intoxicated by it one day, "sleeps himself" sober" by the next. His restoration is due, however, not to his repose, but to the elimination of the poison which takes place during the interval; for if he drink a cup of his urine the next morning, he is yet more powerfully intoxicated than he was the preceding day; and this fluid has the same cffect upon any other individual into whose urine the active principle then passes; so that, according to the testimony of travellers, the intoxicating agent may be transmitted in this manner through five or six persons, a snall stock at the commencement thus serving to maintain a week's debauch. . Results of the same order have been obtained by Dr. Latheby, in regard to opium, belladonna, hemlock, aconite, etc.; the passage of these substances into the urine being proved by the induction of their characteristic effects, when that fluid was administered to other animals.

222. Between the substances which admittedly rank as poisons, and those which are reckoned as materies morborum, no definite line of demarcation

time become increased in size, and less liable to change under the influence of reagents.

1 See in particular the experiments of Brunton and Fayrer on the nature and physiological aetion of the poison of Naja tripudians, ete., Proeced. Roy. Soe., 1873, p. 358 , and 1874, p. 68 .

2 See the rescarches of Instie and Dupré on Alcohol, in the Practitioner. 
can be drawn; and the train of symptons produced by the opcration of the former, is really as much a disease as that which results from the presence of the lattcr. "The connection is, in fact, established by those "animal poisons" which are the result of decomposition either within ol without the body"; such as that of the "pustule maligue," or of the flesh of animals suffering under discase on the one hand, or the "chcese poison," etc., on the other.-It may be admitted that our belief in a specific material cause for a great part of the effects set down to the action. of "morbid poisons" is merely inferential; and there are many persons to whom their exhibition in a tangible form seems to afford the only convincing evidence of their existence. But it must be remembered that the germs of other ferments constantly exist in the state of suspension in the atmosphere, as is well shown by the experiments of Schröder ${ }^{1}$ and Pasteur, ${ }^{2}$ who found that the mere filtration of air through so coarse a micdium as a plug of cotton-wool placed in the mouth of the vessel, was sufficient to prevent the fermentation or putrefaction of almost any organic substance which had been heated to boiling, and it is easy to conceive that pus-cells, ${ }^{3}$ or the minute insoluble particles of albuminous substance believed by Chauvea ${ }^{4}$ to constitute the active agents in the conmunication of the vaccine virus, or the minute portions of the plasma of various diseases, may be taken up duriug evaporation and remain long floating in the atmosphere. In the case of those poisons which are capable of being introduced by inoculation, we have, indeed, the required proof of their material existence; and this proof is capable of being extended by a safe analogy to infectious diseases generally. For, if small-pox can be communicated by the inhalation of an atmosphere tainted with the exhalations of a person alreaty affected with it, as well as by the introduction of the fluid of the cutancous pustule into the blood of another, it can scarcely admit of a question, that the same poisonous agent is transmitted in both cases, although through different media, and that it has as real an existence in the transferred air as in the transferred liquir. Diseases, then, which are capable of being transmitted in both these methods, form the connecting link between those resulting from ordiuary toxic agents, and those which must be assumed to depend upon a subtle poison, of which the ail alone is the vehicle,-such, for example, as malarious fevers; this assumption being required by all the rules of logic, as the only one which will account for the phenomena to be explained, and therefore possessing a claim to be accepted as an almost certain truth. There is a strongly marked difference, however, between the modus operandi of the toxic agents whose action has been previously examined, and that of the norbid poisons we are now considering; for whilst the former possess a certain definite action, the intensity of which (coteris paribus) is proportionate to the quautity that is in operation, and which is usually determined, in virtue of the "elective affinity" already spoken of, to some particular organ or tissue,- the latter act primarily upon the blood, influencing the system at large through the changes which they produce in its constitution; and their potency depends rather upon the susceptibility of the blood to their peculiar influence, than upon the quantity of the poison that may be introduced into it.

223. Of the existence of such susceptibility as a "predisposing cause" of Zymotic ${ }^{5}$ disease there cannot be the slightest doubt. In the case of the Ex-

1 Liebig, Annalen, cix, Heft i.

2 Revue des Cours Seientifiques, 1864, No. 21.

3 See the experiments of Dr. Eiselt, of Prague, referred to in Med.-Chir. Rev., Oct. 1865 , p. 523.

4 Comptes Rendus, 1868 , and Revue Seientifique, t. x, 1872, p. 68.

5 The term zymotic is a very eonvenient designation, which, originally suggested 
anthemata and Hooping-cough, we see that it is congenital and is usually removed by the oceurrence of one attack of the disease (although this is not a mniform protection); but the liability even to these varies greatly in different individuals, and at different times in the same individual. And with regard to other zymotic diseases, the liability to which is not thus limited, all extended observation concurs in showing that it is augmented by anything which tends to depress the vital powers of the system, and more particularly by any eause which obstruets the due purification of the blood, by the elimination of the produets of deeomposition. Thus, it will be shown hereafter (chap. ix, sect. 3), that no antecedent ennditions have been found more effieacious in augmenting the fatality of Cholera than overcrowding and impure water; the former eompelling those who are subjected to it to be constantly breathing an atmosphere laden with putreseent emanations, thus favoring the aecumulation of decomposing matter in the blood, which serves as the most appropriate soil for the seeds of the disease; whilst by the latter sueh matter is introduced directly into the system. ${ }^{1}$ And what is true of Cholera has been found to be true of Zymotie diseases in general; the very same fermentable matter in the blood serving for the levelopment of almost any kind of zymotie poison that may be received into the system, whether from the atmosphere, or from the boclies of those who have alrearly been subjeets of the disease. That such eonditions are constantly present in all large towns is shown in the most satisfactory manner by the observations of 'Dr. Angus Smith ${ }^{2}$ who found that whilst on the hills above Manchester the proportion of organic matter was one grain in 200,000 c. in. of air, in the crowded eourts of the town there was one grain in every $8000 \mathrm{c}$. in., indieating but too surely the source of the various diseases of the lungs, brain, and alimentary canal, which the observations of Dr. Greenhow ${ }^{3}$ have shown to oeeur in sueh exeess in town distriets. Henee what has been here spoken of as "fermentable matter," is not a mere hypothetical entity, but has a real material existence; for in all those eonditions of the system in which we know that deeomposition is going on to an unusual extent, and in which there is a marked tendeney to putrescence in the excreted matters, we witness such a peculiar liability to zymotic diseases, as elearly indieates that the state of the blood is peculiarly favorable to the action of the zymotic poison. This is pre-eminently the case in the puerperal state, in whieh the tissue of the uterus is undergoing rapid disintegration, its vital force having been expended; for there is now abundant evidence that the contaet of deeomposing matters which would be innoeuous at other times, is eapable of so acting upon the blood of the parturient female as to induce that most fatal zymosis which is known as "puerperal fever." And her peculiar liability is in no respeet more manifest than in this: that the poison by which she is affected may liave lain dormant for weeks or months, for want of an appropriate

by Dr. W. Farr, has of late gained general currency, for that elass of diseases whose phenomena may be attributed to the operation of a morbid poison of the nature deseribed above; this operation bearing a strong amalogy to that of ferments.

I See the various papers of Pettenkofer in the Zeits. f. Biologie, B. v-x.

2 ()n the Air of Towns.

3 Papers on the Sanitary State of the People of England, by G. H. Greenhow, MI. D., 1859 .

4 For a most marked and eonvincing example of this kind, see Dr. Rontly's paper on 'The Causes of the Endemie Puerperal Fever of Vienna, in the Medieo-Chirurgicul Transactions, vol. $x x x i i$, p 27.-That the poison which develops puerperal fever may be eonveyed from patients haboring under almost any othel form of Zymotic disease tending to putreseence, that is propagable by eontaet,- such as searlatina, small-pox, or erysipelas, - is now the general opinion of most pathologists who have puid special attention to the subject. 
nidus, and will yet exhibit its full poteney on the very first case in which opportunity may be given for its introdnction into the system of a puerperal patient." 'The same kind of liability is displayed in the subjects of severe injuries, and in those exhitusted by long-continued nuscular exertion, among whom, also, there is not only a state of general depression of the vital powers, but also a special source of decomposing matter in the system; for there is evidenee that "surgieal fever" may be induced in them, by the introrluction of a zymotic poison derived from a variety of external sources (amongst others, from patients affected with puerperal fever), such as would have no effect upon a healthysubject; and, moreover, that overerowding in hospitals has a special tendency to increase this liability. ${ }^{2}$ Thus, then, we may affirm with strong eonfidence that the special liability to Zymotic diseases, whieh determines their selection of individuals when epidemieally prevalent, depends upon the previons condition of the blood of the subjeets who are thus "predisposed" to their invasion; and more especially on the presence of fermentable matters, resulting from the ordinary proeesses of disintegration, whieh, in the state of perfect health, are eliminated as fast as they are formed, but of which an accumulation is prone to take place, either when there are special sources of an augmented produetion, or when the excretory operations are imperfectly performed. ${ }^{3}$ And it would further appear that the eontinued accumulation of such matters may itself become a souree of certain forms of Zymotie disease, which may thus originate de novo in the system, and which may thence be propagated to other individuals in some of the modes already specified; of this we have notable exanples in erysipelas and the "pustule maligne."

224. It is not only, however, in the class of Zymotie diseases that we seem distinctly able to traee the operation of morbid poisons circulating in the blood ; for there are numerous other maladies, of whose origin in a like condition there ean be no reasonable doubt; and these are in some respects more closely analogous than the preceding to the disordered states induced by the introduetion of toxic agents. For in those of which we have now to speak, the action is destitute of any analogy to fermentation, and its potency is strictly proportionate, in each case, to the amount of the dose that is in operation. Here, too, we have a conneeting link afforded by those disordered states of the system, which depend upon an undue accumulation of poisons normally generated within it, in eonsequenee of some obstacle to their elimination. 'Thus, the retention of urea or of urie acid, of carbonie acid, biliary matter, lactic acid, or of other substanees which are normal products of the waste or disintegration of the body, in the blood, are as true instances of poisoning as if these substanees had been directly injected into the bloodvessels; and the evil is of eourse inereased, when (as frequently happens) augmented production is eoneurrent with imperfect elinination.

225. In all eases, therefore, one of the first questions which the intelligent Practitioner will feel called upon to deeide, is, whether the malarly he has to treat originates in the state of the Blood, or in a disorder purely local; and if he feel justified in referring it to the blood, whether it merely depends

1 This is shown by the instances, unhappily of no unfrequent oceurrence, in which practilioners who have unfortunately become the vehicles of the nuerperal poison, and have conveyed it to several patients in succession, have experienced the same direful results immediately on resuming obstetric attendance, after a lengthened interval of suspension from it, and even from professional employment of every kind.

2 See Prof. Simpson, On the Analogy between Puerperal and Surgical Fever, in the Edin. Monthly Journ., vol. xi, p. 414; and vol. xiii, p. 72. See also Bryden, Report on Cholera, 1869.

${ }^{3}$ For a fuller exposition of this doctrine, see the Brit. and For. Med.-Chir. Rev, vol. xii, p. 159 et seq. 
upon an alteration in the proportion of its normal constituents, as in plethora and simple ansmia, or whether its phenomena imply the presence of some toxic substance in the circulating fluid.-If the former be his conclusion, he has then to endeavor to rectify the excess or the deficicncy, by reducing the former, or by supplying the latter; as when he bleeds and prescribes low diet for Plethora, and employs iron and generous living in Ansemia. But it is his duty to take care that his means are applopriate to his ends; for there can be little doubt that the too copious venescetion which was formerly practiced almost indiscriminately in acute inflammations, had a pernicious tendency to postpone the final recovery from them, whilst it had often but a doubtful cfficacy in subduing the first violence of the disease. As a general rule, it may be stated that general bloodletting is likely to be rather injurious than beneficial in toxic inflanmations, in which the vitality of the blood as a whole is decidedly lowered, and to this rule, the results of careful and extended observation have recently shown that Rheumatism is seldom to be considered an exception, notwithstanding that this disease was formerly considered to be one of those in which the efficacy of copious depletion was most undoubted.-In diseases of toxic origin, the treatment must be conducted upon principles exactly the same as those by which the practitioner would be guided in his treatment of a case of ordinary poisoning; but as regards the two classes into which it has been shown that these maladies may be divided, a difference must be made in their application.

226. The "morbid poisons" of our second class (\$224) are distinguished by this, that there is a continual new generation of them within the system; and the first indication of treatment, therefore, will be to check their formation, so far as this may be possible. This is the rationale of the dietetic and regiminal treatment of the lithic, lactic, and oxalic diathesis, of lepra and psoriasis, of chrouic gout and rheumatism, and many other chronic diseases of toxic origin. - Secondly, we should endeavor to destroy or neutralize the poison, if we have any remedies which possess such an action upon it. Perhaps the curative influence of Ammonia in Australian snakebite, recommended by Prof. Halford, if supported by future investigations, ${ }^{1}$ would constitute one of the best examples of this kind.-Thirdly, where we cannot thus destroy the poison, we must endeavor to moderate its action upon the system; this is the rationale of palliative treatment of every description, in which the fons et origo of the malady is left unchanged.-But, fourthly, our main object nust be to eliminate the poison from the system as rapidly as possible, by the various chamnels of cxcretion; acting upon these by remedies which cither increase their activity, or which so alter the conclition of the norbific matter as to enable it to be more reaclily drawn off. 'The judgment of the well-informed practitioner, in the treatinent of diseases of this class, is more shown in his discriminative selection of the best means of thus aiding the Blood to regain its normal purity, than in any more apparently "heroic mcasures;" and a candid review of the nust approved systems of treatment, for diseases of the type here alluderl to, will show that the ratio of their efficacy is in accordance with that of their harmony with the above indications.

227. Among the Toxic riseases of the zymotic class, in most of which the poison is introduced from without, the conrse of the morbid phenomena to which this gives rise is usually more definite anul specific, and its duration more limited. There is no souree within the body, whence a new supply of

1 It has been tried and fund ineflectual in the case of Indian snakebites by Hilston, Ind. Med. Gaz., 1873. Fayrer, Proceci. Roy. Soc., Jan. 2:d, 1874. 
the poison is continually arising; and its operation ceases, therefore, as soon as it is entircly eliminated from the system. But there is this peculiarity in the action of many of the poisons in question, that they have the power of multiplying themselves within the body; thus, for example, when smallpox has been communicated by the inoculation of an excessively minute portion of the virus, humdreds or thousands of pustules are generated, each of them charged with a poison equally potent with that from which they originated. It is to this multiplication, that the extension of zymotic diseases, hy communication between individuals affected with them and healthy subjects, is chiefly due; and the question of the "contagion" or "non-contagion " of any particular disease of this class, is, therefore, essentially that of the multiplication or non-multiplication of the poison in the human body. This nultiplication of certain zymotic poisons is a yet stronger point of analogy to the action of "ferments," than that which is afforled by the violence of the changes they induce when compared with the amount in operation. Some of these poisons are of such potency, that, in however minute a quantity they are introduced, they will change the whole mass of the blood in a few minutes, and will act indiscriminately on all individuals alike; this is the case, for example, with the venom of serpents. On the other hand, there are many (as already remarked) which seem to require the presence of some special fermentable matter in the blood (\$223). And between these might probably be established a regular gradation-firom those most "pernicious" forms of malarious poison, which derive their potency from the intensity of vegetable decomposition under the influence of a high temperature; or those "malignant" types of typhoid poison, which owe their special intensity to animal putrescence engendered by filth and overcrowding; both of these attacking a very large proportion of those who are exposed to them-to those milder forms of zymotic poisons, which, though derived from the same sources with the preceding, act with so much less of uniformity upon different individuals, that we can scarcely fail to recognize as a "predisposing cause," or rather as a necessary concurrent condition, the presence of some readily-decomposable matter in the blood. The long-continued action of these poisons, in their milder forms, seems itself capable of inducing this condition; thus, a healthy person who settles in an aguish country, may remain free from intermittent fever for a considerable time, but his health gradually deteriorates, and at last he becomes the subject of the disease, which would have much earlier attacked him if his blood had been brought into the "fermentable" state by irregularity of diet, over-exertion, etc.; and the same may be observed in the case of those long exposed to the poison of typhoid or other fevers, which especially locates itself in animal miasmata, if it be not actually engendered by them.

228. In some of the diseases of this class, the change in the qualities of the Blood produced by the introduction of the poison is such as to give it a morbid action on certain organs or tissues only; their phenomena in this respect corresponding with those of ordinary poisons, and of the toxic diseases previously noticed. Such may be said of vaccinia, gonorrhaa, primary syphilis, etc., in which the general functions of the body seem to be disturbech chiefly or solely through the locil disorder. It may happen that, even where a specific poison is present in the blood, it may not be potent enough to manifest itself in any disordered action, either general or local, until the depressed state of the nutrition of some part or organ renders it more susceptible of a further perversion; thus it is very common for the first development of Cancer to follow upon some local injury; and where constitutional Syphilis may be presumed to exist, it often seems to lie dor- 
mant, until some appropriate part is rendered, by some such cause, peculiarly susceptible to this malady. ${ }^{1}$-But, in other cases, we find that the contamination of the blood is such as primarily to produce more or less disturbance in all the functions; as we especially witness in the severer forms of fever, in poisoning by vellomous serpents, etc. Even in this last class of cases, however, a special determination to one organ or system is frequently obvious; and this may be so constant as to be characteristic of the disease, as is the case with the skin affection in the Exanthemata generally, the affection of the throat and the kidneys in Scarlatina, and that of the airpassages in Measles. But in other instances, the local affections produced in different individuals by the same specific poison, rary in their relative intensity, and even in their seat, according to the previous conditions which their respective subjects afford; and whilst in some instances, this variation may be clearly traced to local peculiarities of nutrition, in others it seems only capable of being accounted for by supposing that the blood of each individual has some peculiar or personal character, which causes it to be differently affected in each subject. Of the determining influence of local deteriorations of nutrition, we occasionally meet with curious examples in the Exanthenata : thus, the eruption of Measles has been seen to be deepest and most diffused over a knee affected with chronic synovial inflammation and general swelling; and in a patient who became affected with Small-Pox soon after a fall on the nates, the pustules, though thinly scattered elsewhere, were crowded together on the injured part as thickly as possible. ${ }^{2}$ So, during an epidemic Infiuenza, it is evident that the local affection often manifests itself chiefly (if not solely) in what was previously regarded as the "weak point" of each patient's system. "The local determination of a morbid poison may frequently be regarded as one of the means whereby the blood and the system at large are fireed from its action. Of this, again, we have a most characteristic example in the Exanthemata: for it is a matter of constant observation, that the constitional symptoms, especially fever and delirium, are most severe before the cutaneous eruption comes out; that there is much greater danger to life, when the eruption does not develop

1 See Mr. Paget's Leetures on Surgical Pathology, vol, i, p. 492.

2 Paget, op. eit., p. 444.

3 Of those variations, on the other hand, which, as they cannot be thus attributed to purely local causes, must be referred to peeuliarities in the general state of the system, and especially of the blood, of each individual, we have a highly characteristic example in the following incictent, which fell under the notice of Prof. Huxley, when serving as Assistant-Surgeon on board H. M. S. Pattlesnake, whieh had been engaged on a surveying voyage about New Guinea and Australia. The erew seem to have aequired a predisposition to disease, by long confinement, exposure to tropical sunshine, unwholesome food, and other unfivorable influences; but no decided malady had shown itself among them, until one of them, after slightly wounding his hand with a beef-bone, had suppuration of the axillary lymphatic glands, with which typhoid symptoms and dolirimm were associated, and which proved fatal. A few days atter hi- death, the sailor who washed his clothes had similar symptoms of disease in the axilla; and for four or five months he suffered with sloughing of portions of the eellular tissue of the axilla, arm, and trunk of the same side. Near the sane time, a third sailor had diffose inflammation and sloughing in the axilla ; and after this, the disease ran in various forms through the ship's company, between thirty and forty of whom were sometimes on the sick-list at once. Some had diffise cellular inflainmation; some had inflanmation of the lymphatie glands of the hear, axilla, and lower extremities; one had severe idiopathic erysipelas of the head and neck; another had phlegumous erysipelas of the hatrid and arm after an accidental wound; others harl low fever with or without enlargement of glands. Finally, the disease took the form of mumps, which affected almost everybody on board. The epidemic lasted from May to July (the winter in the southern hemisphere), the ship being at sea during the whole time. 
itself fully; and that its premature repression induces a return of the severer constitutional affection. So in Syphilis and Camcer (as Mr. Paget remarks), the severest defects or disturbances in the whole economy niay coexist with the smallest amounts of speeific local disease; and it has becu laid down as a general law by Dr. Robert IVilliams, "that when a morbid poison acts with its greatest intensity, and produces its severest forms of disease, fewer traces of organic alterations of structure will be found, than when the disease has been of a milder character."

229. In nearly all the Toxic diseases of the zymotic class, there is a natural tendency to the self-elimination of the poison and of the products of its action on the blood, either hy the operation of the ordinary excretory organs, or by the peculiar local actions just adverted to; and this process takes place in mauy instances with such regularity, that not only the period which it will altogether require, but each of those successive epochs which nurk the stages of development and metamorphosis in the poison and in the products of its action, may be almost exactly predicted. There is not, in fact, a more renarkable indication of the "Life of the Blood," than is afforded by its extraordinary power of self-recovery, after having undergone the excessive perversion which is consequent upon the introduction of the more potent Zymotic poisons; and every philosophical physician is ready to admit that it is to this "vis medicatrix nature," rather than to any remedial agency which it is in his power to apply, that he must look for the restoration of his patient. The very uature of the action of zymotic poisons upon the blood, seems to forbid the expectation of our being able to neutralize or check that action by antidotes; and the objects of treatment wholly lie, therefore, in promoting the elimination of the morbific matters thus engendered, in keeping under any dangerous excess of local action, and in supporting the system during the continuance of the malady. In a large proportion of zymotic diseases, it is probable that the oxidation of the morbific matter by the aration of the blood, is the chief means of its removal ; ${ }^{2}$ and it is accordant with this view, that the encouragement of the respiratory function, both pulmonary and cutaneous, by a pure and cool atmosphere, and by keeping the skin moist (either by the administration of diaphoretic medicines, or by external applications), should be found one of the most efficient nieans of promoting recovery. ${ }^{3}$ Whilst mild purgatives may be employed with advantage for the same end, in the earlier stages of these diseases, care must be taken that the system be not too much debilitated by their action; and the same caution must be observed with regard to the use of local depletion or counter-irritation, for the purpose of subduing the violence of some local affection. In fact, the general tendency of these diseases to the adynamic type seems to indicate that, however beneficial the immediate results of re-

1 Elements of Medieine, vol. i, p. 12.

2 A praetieal applieation of the doetrine laid down, lus reeently been made by Drs. Fayrel and Brunton, who have reeommended the maintenanee of artifieial respiration in the treatment of snakebite, and there seems to be no reason why the subeutaneous or intravenous injection of Ammonia, advoeated by Prof. Halford of Melbourne as an agent neutralizing the poison, should not be conjoinad with it. See Fayrer and Brunton (op. eit.). Halford, Australian Med. Gaz., and Pamplilets, $18 \div 0-74$

3 Dr. Daniell, whose long familiarity with the most pernieious forms of Afriean fever, and with the various modes of treatment which lave been put in pratiee for its eure, gives a most deeided preferenee to the sudorific system in vogue among the natives, as laving a vast superiority over the venesections, saline purgatives, and large doses of ealomel, whieh most European pratitioners have employed. See lis Sketehes of the Medical Topography and Native Diseases of the Gulf uf Guinea, p. 120 . 
ducing treatment may appear to be, its remote effects are much to be dreaded. And when the results of a large and varied experience are brought together, the Author believes that those will be found most satisfactory in which the treatment has been moderately evacuant, and early sustentative. ${ }^{1}$

\section{CHA PTER VIII.}

\section{OF THE CIRCULATION OF THE BLOOD.}

\section{Of the Circulation in General.}

230. Tne Cireulation of nutritive fluid through the body has for its object, on the one part, to convey to every portion of the organism the materials for its growth and renovation, together with the supply of Oxygen which is requisite for its vital actions (especially for those of the Nervo-Muscular apparatus); and at the same time to carry off the particles which are set free by the disintegration or "waste" of the tissues, and which are to be removed from the body by the Excreting processes. Of these processes, the one most constantly in operation, as well as most necessary for the maintenance of the purity of the blood, is the extrication of Carbonic Acid through the Respiratory organs; and this is made subservient to the introduction of Oxygen into the system. In Man, as in other Vertebrated animals, there is a regular and continuous movement of the nutritive fluid through the salnguiferous vessels; and upon the maintenance of this, the activity of all parts of the organism is dependent. In conmon with Birds and Mammals, again, Man has a Respiratory circulation entirely distinct from the Systemic ; all the blood which has returned from the body being transmitted to the lungs, and being brought back to the heart again, betore it is sent forth afresh for the nourishment of the tissues and for the maintenance of their functional activity. The Heart is placed at the junction of these two distinct circulations, which may be likened to the figure 8 ; and it may be said to be formed by the fusion of two distinet organs, a "pulmonary" and a "systemic" heart; for its right and left sides, which are respectively appropriated to these purposes, have no direct communication with each other (in the perfect alult condition, at least), and seem merely brought together for economy of material. ${ }^{2}$ Each system has its own set of Arteries or efferent vessels, and of Veins or afferent trunks; these communicate at their central extrenity by the Heart, and at their peripheral extremity by the Capillary vessels, which are nothing else than the ninutest ramifications of the two systems, inosculating into a plexus.-Besides the systemic and pulmonary circulations, however, there is another which is no less distinct, although it has not an impelling organ of its own. "This is the "portal" circulation, which is interposed between the venous trunks of the aldominal viscera and the Vena Cava, for the purpose of distributing that blood through

1 ()n the subject of the latter portion of this section, see the treatise of Dr. Robert Williams on Morbid J'oisons, the Principles of Medicine of Dr. Charles J. B Williams, the Lectures on Goneral Pathology, by Mr. Simon, and the chapter on Specific Discases in Mr. Paget's Lectures on Surgicail Pathology, vul. i.

$2 \mathrm{At}$ an early preriol of toetal life, as in the permanent state of the Hugong, the linart is so deeply cleft, from the apex towards the base, as almost to give the idea of two separate organs. 
the Liver, in which organ its newly-absorbed materials undergo assimilation, whilst its excrementitious matters are separated by the secreting process. The Vena Porta, which is formed by the convergence of the gastrie, intestinal, splenie, and pancreatic veins, subdivides again like an artery, so as to form a capillary plexus which extends through the whole substance of the liver; and the Hepatic vein, collecting the blood from this plexus, conveys it into the Vena Cava. Thus the portal circulation is grafted (so to speak) upon the general cirenlation, in precisely the same mode as the respiratory cireulation is grafted upon it in Mollusca and Crustacea; and if the "sinus" of the Vena Portie had possessed contractile muscular walls, it would have ranked as the proper heart of the portal system. The really arterial character of the Vena Portie is well shown by comparing it with the Aorta of Fishes; which is formed by the convergence of the Branchial veins, and then distributes the blood which it has received from them to the body genelally.

231. That the movement of the Blood through the arterial trunks and the capillary tubes, is, in Man, and in other warm-blooded animals, chiefly dependent upon the action of the Heart, there can be no doubt whatever. It can be easily shown by cxperiment, that if the arterial current be checker, the capillaries will immerliately cease almost entirely to deliver the blood into the veins, and the venous circulation will be consequently arrested. And it has also been proved that the nsual force of the Heart is sufficient to propel the bloorl, not only through the arterial tubes, but through the capillaries, into the veins; since even a less force will serve to propel warm water through the vessels of an animal recently dead." But there are certain "residual phenomena" even in Man, which clearly indicate that this is not the whole truth; for not only is the general current of blood greatly modified in its passage through the circulating system, but there are many variations in its movement, which, being very limited in their extent, cannot be attributed to any central disturbance, and inust therefore be dependent on causes purely local. Hence we are led to perceive that forces existing in the Bloodvessels themselves must have a considerable influence, in prolucing both general and local modifications of the effects of the Hear's action. There are also indications of the existence of intluences in which the bloodvessels do not partake, arising from those changes occurring between the blood and the tissues, that constitute the processes of Nutrition, Secretion, etc. Of the nature of these influences, and of the degree of their operation, the most correct idea may be obtained by examining the phenomena of the Circulation in those beings, in which the moving power is less concentrated than it is in the higher Animals. Thus we find that in Plants and the lowest animals, as in the earliest embryonic state of the highest, a movement of nutritious fluid takes place through a system of minute passages or channels excavated in the tissues (representing a capillary plexus), without any vis a tergo derived from an impelling organ. Ascending a little higher in the series, we meet with a system of vascular trunks, distributing the blood to these plexuses, and collecting it again from them; and the walls of these trunks are so far endowed with contractility, as to assist, by a solt of peristaltic movement, in the maintenance of the current through them. Still passing upwards, we find this contractility manifesting itself especially in some limited portion or portions of the vascular system, which execute regular movements of contraction and dilatation; and this tendency to concen-

1 See Dr. Williams's Prineiples of Medicine, 2d edit., p. 185, note. 
tration is increasingly observed, until the whole movement is subordinated to the action of a principal propelling organ, the Heart. ${ }^{1}$

232. The elaborate dissections of Dr. J. B. Pettigrew ${ }^{2}$ have shown that the walls of the ventricles of the Heart are composed of a series of seren laycrs or strata of muscular fibres, of which three arc external, the fourth is central, and the remaining three are interual. The direction of the fibres constituting these layers gradually changes from a nearly vertical to a horizontal or transverse one, which is the course pursued by the fourth layer, and from this back again to a nearly vertical one. The fibres composing corresponding extcrnal and internal layers, such as layers one and seven, two and six, etc., are continuous in the left ventricle at the left apex, and in the right ventricle in the track for the anterior coronary artery, the fibres of both ventricles being for the most part continuous likewise at the base, forming, thereforc, a series of figure-of-eight loops. The outermost fibres of both ventricles, on reaching the apex of the heart, present two bundles, which, curving round in the form of a vortex, or whorl, become continuous with the fibres of the carnere columnæ and musculi papillares. Only the first and seventh layers are inserted into the auriculo-ventricular rings, to which they pass in a direction almost at right angles to their plancs. The object of these special arrangements appears to be, as Dr. Hensley ${ }^{3}$ has pointed out, to enable the muscular walls of the cavities of the heart to expel by their contraction the whole of their contents, whilst the shortening of the several fibres is both uniform in amount and moderate in extent.

233. There are, however, some important differences in the structure and functional actions of the two divisions of the Heart, which should be here adverted to.-The walls of the left Ventricle are considerably thicker than those of the right; and its force of contraction is much greater. The following are the comparative results of M. Bizot's measurements, ${ }^{4}$ taking the average of Males from 17 to 79 years:

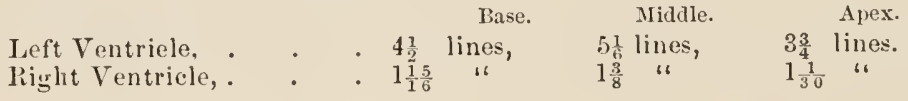

In the Female, the average thickness is somewhat less. It will be seen that the point of greatest thickness in the left Ventricle is near its middle; while in the right, it is nearer the base. The thickness of the former goes on increasing during all periods of life, from youth to advanced age; whilst that of the latter is nearly stationary. During pregnancy there is an hypertrophy of the left Ventricle to the extent of one-fourth or even one-third of the original thickness of its walls. ${ }^{5}$ The left Auricle is somewhat thicker than the right; the average thickness of the formcr being, according to Bouillaud, a linc and a half; whilst that of the latter is only a line. In regard to the relative capacities of the right and left cavities, much difference of opinion has prevailed. ${ }^{6}$ And so much fallacy may arise from the peculiar condition

1 See Prine, of Comp. Phys., chup. v. A very full and comprehensive aecount of the eirculation and the apparatus by whiel it is effeeted in plants, in the lower animals, and in Man, will be found in Dr. J. Bell Pettigrew's work on the Physiology of the Cireulation, 1874.

2 Phil. Trans., part iii, 1864, p. 415.

3 Jouru, of $\Lambda$ nat. and Pliysiology, vol. iv, 1870, p. 83.

4 Mém. de la Soe. Médie. d'Oloservation de Paris, tom. i.

6 Larcher, Comptes Rendus; Henle and Meissner's Berieht, 1857, p. 467.

6 WVinslow, Senae, Haller and Lientad, Boyer, Bizot, Legallois maintain that the disparity in the size of the Auricles and Ventrieles is considerable; Iaennee, Cruveillier, Gordon, Bonillaud, Meekel, and Portal that it is trifling; Lower, Sabatier, Weiss, Andral, and more reently Pettigrew, that there is no difference whatever. 
of the animal at the moment of death, that it is almost imposible to make any dircet measurement. - The average capacity of the cavities may, however, be estimated, in the full-sized Heart, at about four to five ounces. - The regurgitation of the blood is effectually prevented by valves, the structure of which has also been investigated by Dr. Pettigrew, ${ }^{1}$ and may be under-

FIG. 117.

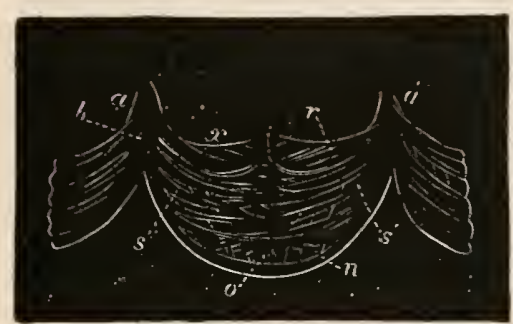

FIG, 118.

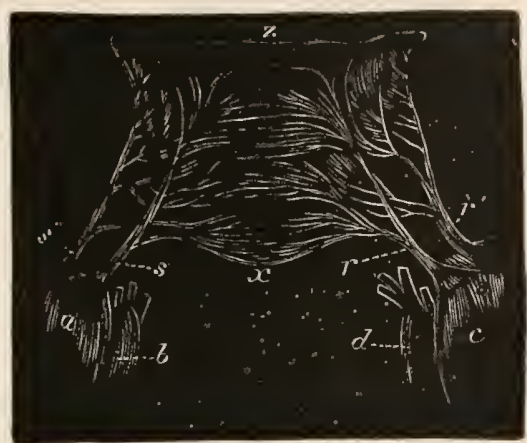

FIG. 117.-Segment of human semilunar valve from the pulmonary artery suspended from the fibrous band $a a^{\prime} . \quad x . r$, Lunula, which when the valve is in action become accurately applied to corresponding lunule in the two remaining segments. $c$, Corpus Arantii, or portion usually thickened in old, though not in young people; $n$, thickent convex border attached to fibrous ring of pulnonary artery ; 0 , thinner portion of segment, $s s^{\prime}$, Fibrous bands which break up in the mesial line of the segment to support and strengthen it.

Fic. 118.-Anterior segment of the human mitral valve, showing the threefold distribution of the chordie tendineæ from above down wards, and from the mesial liue towards the margins of the segments. $z$, base of segment ; $x$, apex ditto; $r r^{\prime} s s^{\prime}$, chordce tendinex from anterior portions $(a c)$ of right and left musculi papillares, bifurcating and losing themselves in margins of seguents; $b, d$. posterior portions of right and left musculi papillares which send chordæe tendinete to posterior segment of mitral valve.

stood by an examination of the adjoining figures. In the case of the valves of the pulmonary artery they appear to be not quite equal in size, nor are they cxactly upon the same plane; when made to act by pouring water into thein, and watching them from below, it may be seen, according to Dr. Pettigrew, that the smallest segment, which is situated highest, descends with a spiral movement, and first falls into position; the middle-sized segment, which is placed a little lower, descends in like manner, fixing the first segment by one of its lunulxe or crescentic surfaces; the third and largest segment, which occupies a lower position than either of the others, descends spirally upon the crescentic margins of the other two, wedging and screwing them more and more tightly into each other. 'The spiral movement is occasioned by the direction of the sinuses of Valsalva, which curve towards each other and direct the blood in spiral waves upon the mesial line of each segment.-The muscular fibres of the heart are peculiar in presenting an intermediate form between the striped and unstriped varieties of muscular tissue; the fibres are striated, but destitute of a sarcolemma, and according to Eberth ${ }^{2}$ are composed of broad cells that are often forked at their extremities or give off lateral prolongations which, being firnly adherent to each other, produce a deceptive appearance of anastomosis of the fibres. In a chemical point of

1 Transact. of the Roy. Soc. of Edinb., vol, xxii, part iii, 1864, p. 761.

2 Virchow's Archiv, Bd. xxxvii, Heft 1, p. 100. See also Schweigger-Seidel, Stricker's Histology, New Syd. Soc. Trans., vol. i, p. 248. 
view the muscular tissue of the heart is characterized by containing a larger amount of water than other muscles $(79$, insteald of 76 per cent.) ; a considerable quantity

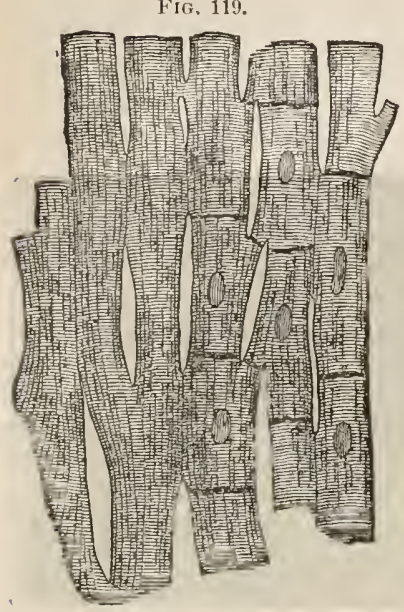

Anastomosing muscular fibres of the Heart seen in longitudinal section. On the right the limits of the separate cells with their nuclei are exhibited somewhat diagrammatically. of a peculiar kind of sugar, inosite, a very small proportion of creatin, and a large amount of creatinin. ${ }^{1}$ - The nerves of the heart are deriver from the cardiac plexus, which is formed by branches from the pnemmogastric and sympathetic nerves, and appear in the form of -1 . Minute ganglia and ganglionic cells, situated in the walls of the cavities, and especially in the auriculo-ventricular and interventricular furrows. Some of the ganglionic cells resemble those of the sympathetic in giving off from one and the same pole a straight and a spiral fibre; others are bipolar; and others again form bicelled ganglia, resembling two pears applied to each other by their broad ends, the stalks representing the nerves they give off. These have no spiral fibre. 2. Fibres derived from the cervical portion of the sympathetic, which pass to the cardiac plexus, between the aorta and pulmonary artery. 3. Cerebrospinal fibres which enter the inferior cervical or stellate ganglion and proceed to the same plexus, and are probably derived from a centre situated in the brain and spinal cord. And 4. Fibres coursing in the vagus, and originating in a centre situated in the medulla oblongata. The first three of these ganglia and fibres probably collectively constitute the excitomotor system of the heart, the fourth forms an inhibitory, restraining, or regulo-motor apparatus. The precise morle of termination of the nerve-fibres has not been made out, but they probably lose their double contours, aud continuing their course as pale fibres form loops and anastomoses around the muscle cells. ${ }^{2}$ It will be observed that in consequence of the absence of a sarcolemma the ultimate nervous plexus is in immediate contact with the contractile substance. The nerves of the parietal laycr of the Pericardium are derived according to Luschka from the right vagus (ramus recurrens), and phrenic, ${ }^{3}$ and Schweigger-Seidel has observerl a rich plexus of nerves in the endocardium. According to Eberth and Belajeff," the endocardium, especially in the ventricles, and both surfaces of the pericardium, present a meshwork of fine lymphatics, the walls of which in some parts consist only of a single layer of intimately-adhering cells. No lymplatics are traceable on the chordie tendinese, and very few upon the auriculo-ventricular and semilunar valves.- IVe shall now examine what agency in the Human Circulation may be attributed to the Heart, the Arteries, and the Veins respectively; and what other forces may be fairly presumed to operate in the Capillary circulation. ${ }^{5}$

1 Ranke, Grundzüge d. Physiologr., 1868, p. 307.

2 Langerhans, Virchow's Ärehiv, Band lviii, 1873, p. 71.

3 Frey, Barker's 'Translation, 1874, p. 403

4 Virchow's Arehiv, 1866, Bd. xxxvii, p. 55.

5 Many of the phenomena of the circulation can be conveniently studied, and praetice in the use of recording instruments, manometer, sphygmograph, kymographion, ete., obtained by means of an india-lubber model of the cireulatory system eonstrueted by Dr. Rutherford, and deseribed in the Journal of Anatomy and Physiology, vol. vi, p. 249. 


\section{Action of the Heart.}

234. The Heart is endowed in an eminent degree with the property of Irritability, by which is meant the capability of being easily excited to movements of contraction alternating with relaxation. Thus, after the Heart has been removed from the body and has ceased to contract, a slight irritation will cause it to execute, not one movement only, but a'series of alternate contractions and dilatations, gradually diminishing in vigor until they cease. The contraction bcgins in the part irritated, and then extends to the rest. It appears, however, from Mr. Paget's experiments, that it is necessary for the propagation of this irritation, that the parts should be connected by muscular tissue, of which a very narrow isthmus will suffice; and that the propagation will not take place if the comnecting istlmus be composed of tendon, even though this be a portion of the auriculo-ventricular ring, which has been supposed by some to be peculiarly efficacious in this conduction. Like the contractility of other muscles, that of the Heart can only be continuously sustained by a supply of arterial blood to its own tissue. This is shown not only by the serious cffects produced by disease of the coronary arteries, but also by the experiments of Erichsen ${ }^{2}$ and Schiff; ${ }^{3}$ the former of whom found that ligature of the coronary arteries rapidly produced cessation of the movements of the heart, especially if the cardiac veins were also opened; whilst the latter obtained a local paralysis of either ventricle, according as the artcry distributed to the one or the other was tied." The contractility of the Heart is much less speedily lost in cold-blooded animals than in warm-blooded; the heart of a Frog, for instance, will continue to pulsate for as many as twelve hours after its removal from the borly, particularly if kept in an atmosphere of oxygen, though it ceases in a few minutes if immersed in Carbonic acid gas. ${ }^{5}$ It has further been shown liy Mr. Tod, that the irritability of the heart is of great duration after death in very young animals; which, as was long since demonstrated by Dr. Edwards, agrees with the cold-blooded Vertebrata in their power of sustaining life for a lengthened period without oxygen.

235. It is difficult to account for the long continuance of the alternate contractions and relaxations of the muscular parietes of the Heart, after all evident stimuli have ceased to act upon it; and many theories have been offered on the subject, none of which afford an adequate explanation. ${ }^{6}$ The

1 Brit. and For. Med. Review, vol. xxi, p. 551.

2 Lond. Med. Gaz., 1842, vol. ii, p. 561.

3 Arch. f. Phys. Heilk., tom. ix.

$4 \mathrm{v}$. Bezold, however, found that ligature of the coronaries produced but little effect for a considerable period in rabbits.

5 Castell, Müller's A rehiv, 1854, p. 226.

6 The rhythmieal movements of the heart may in part be accounted for by regarding them as an expression of the pcculiar vital endowments of its muscular tissue, and as the ordinary muscles of the body may, under certain conditions, be conceived to contract spontaneously in consequence of being charged with motility or motor force engendered by previous acts of nutrition, so the rhythmical movements of the heart may be due to a simple excess of this motility, continually supplied by the nutritive operations, and as constantly discharging itself in contractile action. This view is supported by cases of muscular action where no nerves are apparent, as in the embryonic Heart at an early period, and the hearts of the lower animals (the Tunicata for instance), and also by cases of local cramp and spasm which cannot be fairly attributed to a perverted reflex action of the nervous system. M. Brown-Séquard has, however, attributed the intermittent action of the Heart and other muscles to the presence of venous blood in their capillaries, which he believes to exert a stimulant action on muscular fibre. (See Experimental Researches, etc., 1853, n. 114; Comptes Rendus, 1857; and Journal de la Physiol., 1858, p. 95 et seq.) Dr. Radeliffe, on the other hand, has adduced evidence to the effect that the true stimulus to the contrac- 
extraordinary tendency to rhythmical action, by which the heart is distinguished from nearly all other muscles, is shown by the fact, that not only do the entire hearts of cold-blooded or of hibernating aninals continue to act long after their removal from the body, but even separated portions of them will contract and relax with great regularity for a long time. ${ }^{1}$ Thus the auricles will persist in their rhythmical action, when cut off above the auriculo-ventricular rings; and the apex of the heart will do the same, when separated from the rest of the ventricle. There is strong reason for believing that the contact of the blood itself with the lining membrane of the Heart is, as Haller maintained, the ordinary stimulus inciting it to contract. As already stated, Schweigger-Seidel has observed a rich plexus of nervefibres in this membrane, whilst its sensitiveness to mechanical irritation was incidentally shown by an experiment of Bernard, ${ }^{2}$ in which the contact of the bulb of a thermometer with the interior of the ventricles immediately increased the number of pulsations. Schiff ${ }^{3}$ and Budge ${ }^{4}$ have, moreover, shown that the action of both auricles and ventricles rapidly ceases if they are placed on blotting-paper; but that they nay be called into action again, either by immersing them in blood, or by dropping a little blood into their cavities. And an ingenious experiment was made by Haller himself, showing that if arrangements are made, by which either the right or left side of the Heart remains filled with blood, whilst the other can discharge its contents and remains empty, that side which is stimulated by the presence of the blood continues to beat rhythmically long after the movement of the other has ceased. When the irritability of the heart is nearly exhausted, the usual rhythm is often a good deal disturbed, so that the contractions of the auricles and ventricles do not regularly alternate witl each other; and onc set frequently ceases before the other.

236. When the Heart is exposed in a living animal, and its movements are attentively watched, they arc seen to follow each other with grcat regularity. In an active and vigorous state of the circulation, however, they are so linked together, that it is not easy to distinguish them into periods; both Auricles contracting, and also dilating, simultaneously; and both Ventricles doing the same. The systole or contraction of the Ventricles corresponds with the projection of blood into the artcries; whilst the diastole or dilatation of the Ventricles coincides with the collapse of the arterics. The contraction of the Auricles and Ventricles run into each other, that of the Auricle immediately preceding that of the Ventricle. The entire period that intervenes between one pulsation and another, is nearly equally dividerl between

tion of the Uterus, Heart, and other rhythmically-acting organs, as well as indeed of all muscular tissue, is the absence of oxygenated or arterial blood (Epilepsy, 3d edit., p. 20 et seq.) ; whilst Mr. Paget has endeavored to explain the phenomena by referring them to an intermission in the proeesses of nutrition (Croonian Lecture, 185i). Lastly, v. Bezold, Untersuch. üb. d. Innervation des Ierzens, Laipzig, 1863, attributes the contractions to continuous excitations originating in the cardiac excito-motory ganglia, which meeting with continuous resistanees in the cardiac inhibitory gangliaonly periodically, that is to suy, after nvercoming sueh opposition - act on the muscular tissue. None of these theories, however, appear to afford a stiffieient explanation of all the facts, and the essential cause of the rhythmical action of the IIeart must still remain an unsolved question.

1 Reid, indeed, was of opinion (Cyc. of Anat. and Plysiology, vol. ii, p. 611), that the rhythmical action of the lieart in the frog could continue in the absence of any physical stimulus, for he observed contractions taking place even in vacuo: but his experiments lave been repeated on several oceasions with different results, the pulsirtions ceasing on the withdrawal of the air, and commeneing again when it was readmitted.

2 Leçons sur les Liquuides de l'Organisme, 1859, p. 124.

3 Vierordt's Archiv, 1850, p. 34. Arehiv f. Phys. Heilk., 1846, p. 561. 
the systole and diastole of the Ventricles, but the division is very unequal as regards the Auricles; about one-fifth of the whole being occupied in their contraction, and the remainder being taken up by their dilatation. ${ }^{1}$ The following tabular view will perhaps make the relations of the several parts of this series more intelligible:

\title{
A URICles.
}

\author{
f Dilatation. \\ $\frac{4}{5}\{$ Continued Dilatation. \\ $\frac{1}{5}$ Contraction.
}

\section{Ventricles.}

Contraction.

$\left.\begin{array}{l}\text { First stage of Dilatation, } \\ \text { Sccond stage of Dilatation. }\end{array}\right\} \frac{\frac{2}{5}}{5}$

In some very careful experiments, Donders ${ }^{2}$ ascertained that in different persons in whom, when at rest, the pulse varied from 74 to 94 per minute, the duration of the systole of the ventricles, $-i . e$., from the commencement of the first to the commencement of the second sound-varied from 0.327 to 0.301 of a second, and that it constituted from 40.6 to 45.6 per cent. of the time occupied by an entire cardiac revolution. In a man whose pulse was only 32 per minute, the duration of the ventricular action was still 0.307 to 0.325 of a second, though its proportion to the whole revolution had fallen to about 18 per cent. From whence it appears that the duration of the activity of the Ventricles, determined by the ganglia of the heart itself, is independent of the duration of the entire cardiac revolution, which is regulated by the Pneumogastrics. ${ }^{3}$ The systole and diastole of the heart are represented in Figs. 120, 121 (p. 300). ${ }^{4}$ An entire cardiac revolution may be described in the following terms, commencing with the systole or contraction. The Auricles and Ventricles are both filled with blood, which has flowed into them from the veins. The Auriculo-ventricular valves are open, and the arterial valves (both aortic and pulmonary) are perfectly closed. A sudden contraction of the Auricles now takes place, commencing at the entrance of the great veins, and extending, without appreciable pause, over the ventricles. By the contraction of the Auricles a portion of their contained blood is discharged into

I See Marey, Circulation du Sang, Paris, 1863, p. 68.

2 Nederlandsch Archief voor Genees-en Natuur-kunde, 1866, p. 139, of which paper a full translution is to be found in the Dub. Quart. Journ., vol. xlv, p. 225. See also some estimutes by Landois, Henle and Meissner's Bericht, 1866, p. 411.

3 See Sibson, IIedical Anatomy, 1869, and the instructive papers by Dr. Haiford, now Prof. of Physiology at the Univ. of Melbourne, On the Times and Manner of the Closure of the Auriculo-Ventricular Valves, and On the Movements and Sounds of the Heart, Lond., 1861; also Pettigrew's Lectures on the Physiology of the Circulation, Edin. Med. Journ., 1873.

4 The outlines of the cavities of the heart, and the great vessels, are here indicated, at the end of the systole of the heart, by continuous lines-at the end of the diastole by interrupted or dotted lines. (The drawing and descriptions are taken from Dr. Sibson's admirable treatise on Medical Anatomy, 1869, Col. 73. The dotted lines ure less accurate than the interrupted lines.) The systolic movements are everywhere shown by arrows, the extent of the movements being marked by the length of the arrows. As it is more difficult to watch and measure the movements of the heart from the side than from the front, the side view (Fig. 2) is not so accurate as the front view (Fig. 1). Brücke (Vorlesungen, 1874, p. 17:2), whose experiments wcre made by implanting needles into the hearts of rabbits, and watching the reversed motions of the heads, maintains that all parts of the ventricles move down wards in systole with the exception of the apex, the amount of movement increasing from below upwards. Halford (op. cit.) believes the apex of the heart is drawn up towards the base, but nevertheless undergoes less change of position than any other part, its upward movement being neutralized by the descent of the whole heart occasioned by the elastic recoil of the great vessels springing from the base. A condition of active dilatation has been admitted by many writers; there seems reason to believe that what gives rise to this impression is partly occasioned by the injection of the coronary arteries. See A. H. Garrod in Nature, Feb. 19th, 1874. 
the Ventricles, completing the distension of these eavities, and effeeting the closure of the Aurieulo-ventricular valves which float up into contact. The

FIG, 120 .

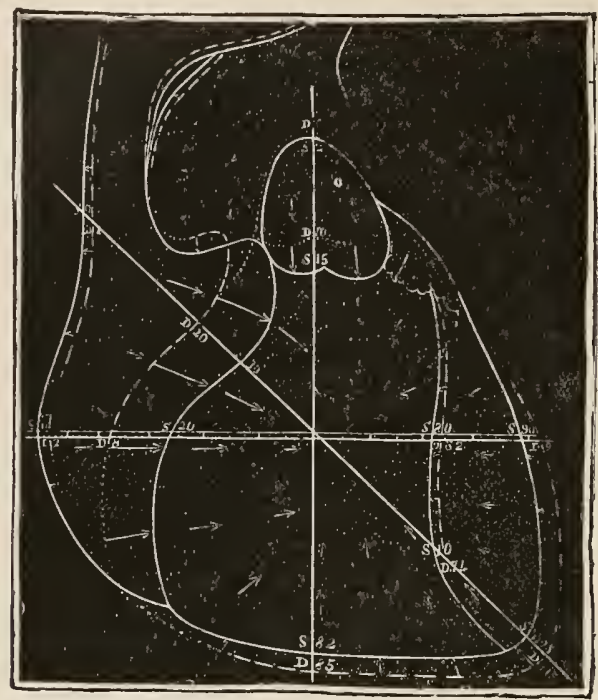

Front view of the movements of the heart in systole and diastole.

Ventrieles instantly contraet tightly, closing the Auriculo-ventrieular valves, and forcing open the arterial valves, through which the blood is propelled into FIg. 121.

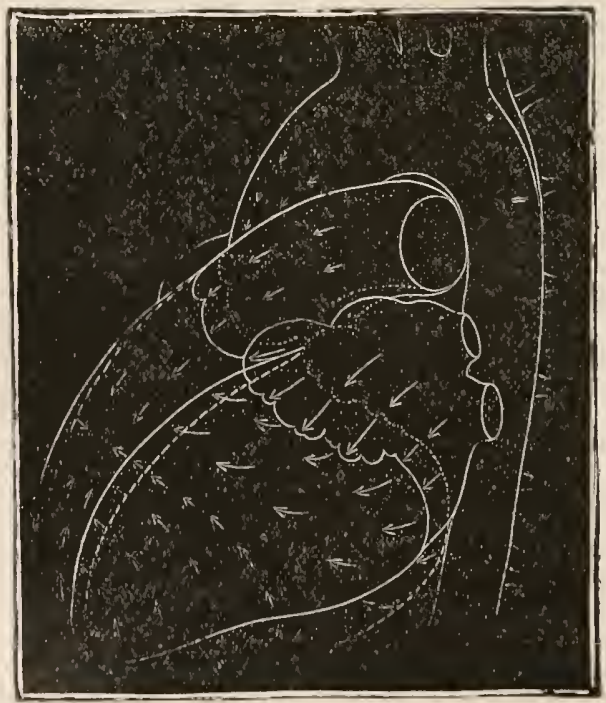

Profile view of the movements of the heart in systole and diastole.

the arteries. The great arteries, now distended with blood, recoil on their eontents and close the semilunar valves. As soon as the eontration of the Ven- 
tricles is completed, a sudden movement of relaxation takes place similar to that of an elastic bag when released from pressure, and this is followed by a brief interval of complete rest; during which both Auricles and Ventricles are rapidly filling with blood; contraction then again recurs. During the systole the heart becomes more globular, or, perhaps more correctly speaking, more conical in form. The chief movement observable in the Auricles is the sudden retraction of the appendices, which almost instantly become refilled with blood as the ventricles contract. The contraction of the two ventricles seems to take place simultaneously towards a centre or point of rest, which in the right ventricle, where the action is most easily observed, is situated about the middle of its length, near the septum and opposite the attachment of the anterior papillary muscle (Sibson). The base of the heart descends rather more than the apex ascends. There is a slight twisting movement of the whole heart during the systole, both on its longitudinal and on its transverse axis. By its rotation on its transverse axis the apex of the heart is tilted forwards; by its rotation on the long axis the left ventricle, which during the diastole looks backward, is turned forwards. The combination of the two movements gives to the apex a twisting movement from left to right and forwards. The apex beat is felt between the 5 th and 6 th ribs, and is caused by a part just above the apex. In the act of contraction the heart may be felt to become hard. During the diastole the heart undergoes a change in form, the converse of that which has been above described. The impulse is felt over every part of the Ventricles during their contraction, but most

Fig. 122.

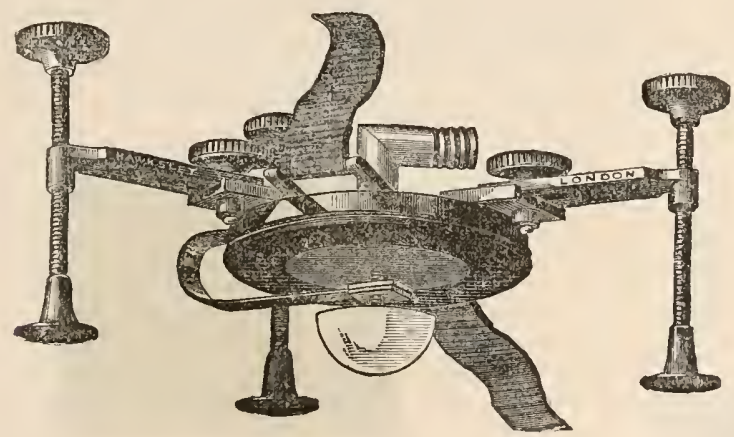

forcibly over their centre. The experiments of MIM. Chauveau and Marey, with a peculiar form of Cardiograph, represented in Fig. 122, in which levers of extreme lightness register the undulations of the air contained in elastic sacs applied to the surface of the Heart and Thorax, show clearly the sequence and duration of the movements of the Auricles and Ventricles, and the coincidence of the impulse with the contraction of the Ventricles (Fig. 124). The Cardiograph, as modified by Sanderson, consists of a hollow disk of brass, the front of which is closed by a thin india-rubber membrane called a tympanum. To the brass back a flat steel spring is serewed, which is bent twice at right angles in such a way that its extremity is opposite the centre of the tympanum. The extremity is perforated by a steel screw, the point

1 Annal. des Scien. Nat., 4th sér., Zool., tom. xvii, p. 374; and Mém. de la Soc. de Biol., sér. iii, tom. iii, pt. ii, 1862, p. 1. For other Cardiographie tracingrs and accounts of the instruments employed, see A. H. Garrod in Journ. of Anat. and Phys, Nov. 1870, and Kutherford's lectures in Lancet, 1871- 22. 
of which rests on the membrane, whilst its head is surmounted by an ivory knob. The tympanum is provided with three adjusting screws, by whieh when in use it rests on the wall of the chest with its face parallel to the sur-

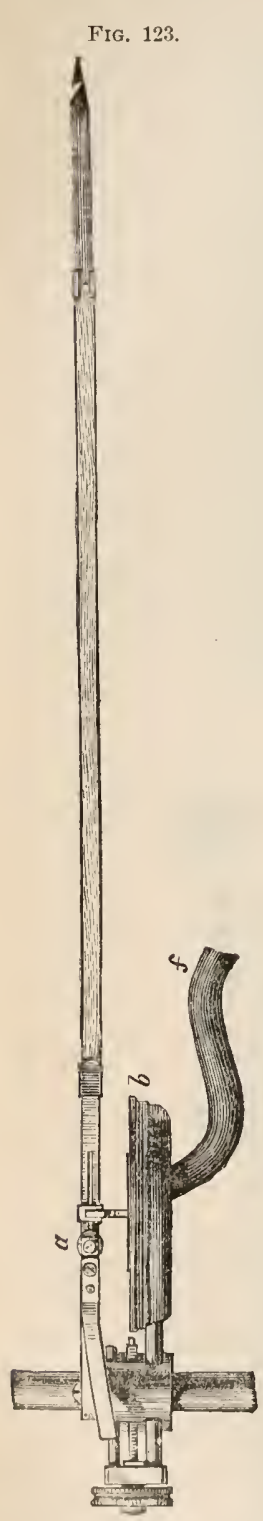
face, and ean be approximated or withdrawn at will. The cavity of the disk communieates by a vulcanized india-rubber tube with a second tympanum represented by $b$ in Fig. 123, in such a way that the two tympana and the tube inclose an air-tight cavity. The movement of the second tympanum is magnified and inscribed on a registering cylinder by a lcver. The causes of the impulse aceording to Sibson are, first, the rigidity of the museular walls during contraction; secondly, a lever movement forward, due to the thickening of the muscle, which oceurs during contraction, being resisted by the fibrous bed of the pericardium on which the heart rests; and lastly, to the outward pressure of the blood in the ventricles on the walls by which it is expelled, and through those walls on the ribs and intereostal spaces. The mechanical force put forth by the heart is wonderfully great. Houghton ${ }^{1}$ estimates the total daily work of both Ventrieles at 124.208 foot-tons, or admitting the weight of the heart to be nine ounces, it is capable of raising 20.576 pounds one foot in lheight per minute for every ounce of its weight, which considerably exceds the work done by the museles in a boat race. Dr. Andrew Buchanan, ${ }^{2}$ proceeding upon somewhat different data, cstimates the foree exerted by the heart per diem to be 42.3 foot-tons in the

FIG. 124.

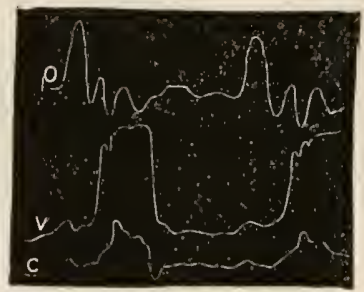

Tracing obtained by the Cardiograph of Mn. Chauveau and Marey.

In this tracing $o$ represents the short and abrupt contraction of the Auricles which immediately precedes the more energetic and protracted contraction of the Ventricles, represented by the line $v$. The line $c$ shows the impulse of the licart to be coincident with the V'entricular contraction.

twenty-four hours. Helmholtz ${ }^{8}$ calculates that the heart can raise its own weight, through 20,250 feet in onc hour, and Ranke ${ }^{4}$ cstimates that the force developed by the Ventricle alone anounts to 64,800 kilogrammes per diem, or that it would be suffieient to raise $142,560 \mathrm{lbs}$, a voir. through the space of 39.37 inches; the force of the Right Ventricle lic estimates at one-third of the above. Whichever estinnte is taken the power exerted is enormous, and greatly in excess of any effurt of

I Principles of Animal Merhanies, 1873, p. 145.

2 Lancet, 1870, vol. ii, p. 666.

- Grundzage der Physiologie, 1868, p. 332.

Med. Times and Gia., 1864, p. 629. 
the muscles under the control of the will. According to M. Marey, each systole of the heart is accomplished by a single shock or blow, and not by a series of shocks, as in the case of the muscles of animal life. The duration of the shock in the case of the heart of the frog is as much as fifteen times longer than that of the ordinary striated muscle.

237. The course of the circulating fluid through the IIeart, and the action of its different valves, will now be briefly described.-The Venous blood, which is returned by the ascending and descending Vena Cava, enters the right Auricle during its diastole, on the contraction of which it is propelled through the tricuspid valves into the Ventricle, which thus becomes completely distended. The reflux of blood into the veins during the auricular systole, is impeded by the contraction of their own walls, and is limited on the right side by the valves placed at the junction of the jugular and subclavian veins; but these valves are so formed as not to close accurately, especially when the tubes are distended; so that a small amount of reflux usually takes place, and this is much increased when there is any obstruction to the pulmonary circulation. Whilst the right Ventricle is contracting upon the blood that has entered it, the carnece columnce, which contract simultaneously with its proper walls, put the chorde tendinee upon the stretch, preventing the flaps of the Tricuspid valve from being driven back into the auricular cavity. The blood is now expelled by the ventricular systole into the Pulmonary artery, which it distends, passing freely through its Semilunar valves; but as soon as the vis a tergo ceases, and reflux might take place by the elastic recoil of the arterial walls, the valves are filled out by the backward tendency of the blood, and completely check the return of any portion of it into the ventricle. The blood, after having circulated through the lungs, returns as Arterial blood, by the Pulmonary Veins, to the left Auricle; whence it passes through the Mitral valve into the left Ventricle, and thence into the Aorta through its Semilumar valves. In the same manner with that on the other side, as just deseribed. ${ }^{1-}$ - There is a wellknown anatomical difference between the auriculo-ventricular valves on the two sides, which has given rise to the diversity of name; and this seems, from the researches of $\mathrm{Mr}$. King, ${ }^{2}$ to be connected with an important functional difference. The Mitral valve closes much more perfectly than the Tricuspid; and the latter is so constructed as to allow of considerable reflux, when the cavities are greatly distended. According to Dr. Flint, ${ }^{3}$ an equally weil-marked difference in sufficiency also exists between the arterial semilunar valves on the two sides, the closure of the pulmonary being much less perfect than the aortic. Many occasional causes tend to produce an accumulation of blood in the venous system, and in the right side of the Heart; thus, any obstruction to the pulmonary circulation, cold, compression of the venous system by muscular action, etc., are known to favor such a condition. This is a state of peculiar danger, from a liability which over-distension of the Ventricular cavity has to produce a state of muscular paralysis; and in the structure of the Heart itself there seems, as just stated, to be a provision against it. For, when the ventricle is thus distended, the Tricuspid valves do not elose properly; and a reflux of blood is permitted, not only into the Auricle, but also (through the imperfect closure of their valves under the same circumstances) into the large veins. This is proved by the fact, several times observed by Dr. J. Reid in his experiments upon Asphyxia, etc., that when the action of the right ventricle had ceased from over-distension,

1 For a full account of the mechanism of the Semilunar valves of the Hcart, sce Ceradini, abstract in Centralblatt, 1872, pp. 123 and 135.

2 Guy's Hospital Reports, vol. ii.

3 Physiology, 1866, p. 203. 
he could frequently re-excite it, not merely by puncturing its walls, but by making an opening in the jugular vein. ${ }^{1}$ This fact evidently affords an indication of great importance in the treatinent of Asphyxia; and it explains the reflux of blood, or venous pulse, which is frequently observed in cases of puhmouary disease, and which, according to $M r$. King, always exists even in health, though in a less striking degree. ${ }^{2}$

238. When the ear is applied over the cardiac region, during the natural movements of the Heart, two successive sounds are heard, each pair of which corresponds with one pulsation; there is also an interval of silence between each recurrence, and the sound that immediately follows this interval is known as the first sound, the other as the second.-The first sound is dull and prolonged, and is heard all over the left ventricle with equal intensity; it is evirlently syuchronous with the impulse of the Heart against the parietes of the chest, and also with the pulse, as felt near the heart; it must, therefore, be produced during the Ventricular Systole.-The second sound, which is short and sharp, ${ }^{3}$ follows so immediately upon the conclusion of the first, that it cannot take place during the anricular systole, as some have supposed, but must be assigned to the first stage of the ventricular diastole, when the auricles also are dilating. - With regard to the relative duration of the two soumds, and of the interval, widely different estimates have been formed. Thus Laennec considered the lengths of the periods of sound and silence to be respectively $\frac{3}{4}$ and $\frac{1}{4}$ of the whole interval between one pulse and another; by Dr. Williams, and by Barth and Roger, the relative lengths of these periods have been estimated at $\frac{2}{3}$ and $\frac{1}{3}$; whilst the experiment of Volkmann ${ }^{*}$ (made by adjusting two pendulums to vibrate precisely in the two periods) indicates that they are almost exactly equal.

239. The causes of the sounds, and more especially of the first, have been the subjects of much discussion. A number of very distinct actions are taking place during the period of the production of the latter; and each of these has been separately fixed on as competent to produce it. Thus we have (1) the impulse of the heart against the parietes of the chest; (2) the contraction of the muscular walls of the ventricles; (3) the rush of blood through the narrowed orifices of the aorta and pulmonary artery; (4) the general molecular collision of the particles of the blood anongst each other, and their friction against the walls of the rentricles; $(5)$ the sudden collision of the stream of blood issuing from the ventricles with the colunn of blood at rest on the semilunar valves of the aorta and pulmonary artery; (6) the friction of the heart against the pericardium; (7) the vibration of the walls of the chest from the sudden rigidity and pressure of the heart; and $(8)$ the sudden tension of the valves of the auriculo-ventricular orifices. An experiment made by Dr. Halford would seem, at first sight, to permit the first two of the above-mentioned events to be at once dismised. A large

1 Physiol, Anatom, and Pathol. Researches, chap. iii.

2 Dr. Herbert Davies (Proceed. Roy. Soc., No. 118, 1870, and pamphlet) maintains that the four chief orifices of the heart are cireular in form and constant in area during the entire periods of systole and diastole, and that they bear an exact mathematical relationship to each other, expressed by the formula-

$$
\frac{\text { Area of trieuspid }}{\text { Area of mitral }}=\frac{\text { Area of pulmonic }}{\text { Area of aortic }}
$$

but his enclusions have been controverted on mathematical grounds by Mr. Trotter, Jomrn. of Anat, 1870, p. 298.

3 The difference between these two sounds is well expressed (as Dr. C. J. B. Williams has remarlied) by articulating the syllables lubb, dúp.

4 Die IIämodynamik, nach Versuchen, p. 364. 
dog was chloroformed, and the heart being exposed, its movements were naintained by artificial respiration. In this state, the sounds being plainly audible, the superior and inferior vena cave, and the pulmonary veins, were suddenly compressed, so that the current of blood into both ventricles was arrested: "The heart continuing its action, a stethoscope was again applied, when neither first nor second sound was hearl; after a short space of time the veins were allowerl to pour their contents into both sides of the heart, and both sounds were instantly reproduced. The veins being again compressed, all sound was extingushed, notwithstanding that the heart contracted vigorously." Excellent observers, however, as Ludwig and Dogiel, Sibson and Broadbent, maintain that though much reduced in intensity the first sound is still audible during the contractions of an empty heart. It must not be overlooked that the susurrus of ordinary muscles is due to the vibration into which they are thlown during contraction, whilst Marey has shown that when the heart is excited to contract the shortening of the fibres is a single and sudden act. In regard to the third event considered as a cause, it has been well remarked, that there is no abupt contraction of the passages through which the blood flows from ventricles to vessels; and it may be added, that there would be no sound if there were; sound being only produced at that point in a vessel conveying a stream of fluid, where a sudden enlargement occurs. In regard to the fourth event, strongly advocated as a cause by Sibson and Broadbent, it may be argued that during other periods of the heart's rhythm, such collision produces no sound, as in the passage of the blood from the auricles to the ventricles; and in reference to the fifth eausc, which has been advanced by Dr. Leared, it appears from Dr. Halford's experiments, that at the moment when the systole of the ventricle is about to take place, the active and passive columns of blood, or those below and upon the semilunar valves, are not separated by any space; that there is no propulsion of the blood from a distance against the passive colunin, but that when the ventricles contract, the fluid pushes open the valves and communicates its force to the column in the vessels, a circumstance which does not appear likely to be accompaniel by much, if any sound. The sixth and seventh events doubtless materially aid in the production of the first sound, and on the whole its chief factors appear to be the sudden tension of the auriculo-ventricular valves, and the contraction of the muscular walls of the ventricle, aided, as just stated, by the vibration of the walls of the chest, and the friction of the heart against them.2

240. That the second sound is produced in the act of closure of the Semilunar valves, is now almost universally admitted; the simple hooking back onc of these valves by a curved needle against the side of the artery, so as to permit a reflux of blood into the ventricle, being sufficient to suppress this sound altogether. Whether it proceeds from the tension of the valves themselves, or from the recoil of the blood against them, or from both causes combined, has not been clearly determined; probably the' last is the true account of it.-When the first sound is altered by disease of the semilunar valves, occasioning obstruction to the exit of blood, the second sound also is affected

1 By a writer in the Med.-Chir. Rev, April, 1860, p 354.

2 Billing's remarks upon this sulject in his Principles of Medicine, Halford's pamplet, On the Sounds of the Heart, and the observations of Sibson and Broadbent in Sibson's Medical Anatomy, are deserving of careful perusal. For somc exceptional statements, as that the sccond sound is due to a contraction of the auricles, see Paton, On Sounds of Heart, in Dub. Quart. Journ., vol. xcix, p. 83 et seq. The various treatises on practical medicine and auscultation may alsu be referred to. Dr. Dunglison, Human Physiology, vol. i, 1856, p. 397, has tabulated the uninions of a large number of authors. They exhibit an extraordinary amount of discordance upun a matter of pure observation. 
in its eharaeter; and if the disease be of sueh a kind as to prevent these valves from effeetually elosing, a reflux of blood takes plaee into the ventriele at the tine of its diastole, eausing a rushing sound that is analogous to the ordinary first sound, or to some of its modifieations. Thus the second sound may eome to acquire so completely the eharacter of the first, that it is difficult to distiuguish the two in any other way, than by the synchronousness of the first with the heart's stroke and with the pulse in the arteries.

241. In regard to the influence of the Nervous system upon the Heart, there is abundant evidenee to show that its movements may be powerfully affeeted by eauses acting either upon the Cerebro-spinal or upon the Sympathetie system ; and whilst, upon the one hand, the energy and foree of its contractions may be augmented by stimuli applied to these eentres, it appears to be well ascertained that the Pneumogastric nerves, originating in the Medulla oblongata, may be the means of conveying an influenee of a preeisely contrary nature, serving to inhibit, restrain, or regulate the Cardiae movements. The fact that the Heart will continue to beat after its removal from the bory, or after the gradual renoval of the whole Cerebro-spinal axis, especially if the flow of bluod through the Lungs be kept up by artificial respiration, ${ }^{1}$ as well as the existenee of anencephalie monsters whieh possess a regularly pulsating heart, clearly show that this organ is not exclusively or essentially dependert upon the eentral nervous system for the eontinuanee of its rhythmical action. Its movements under these cireumstanees must be regarded as automatie, and governed by the Cardio-motor ganglia distributed through its substance. On the other hand, the well-known effects of mental emotions and of sudden and severe injuries of either the Sympathetie or Cerebro-spinal system upon the Heart's aetion, prove with equal eertainty that its action may be influeneed through nervous fibres in eonneetion with those centres.

242. Excito- or Cardio-motor System of the Heart.-The careful disseetions made by Remak, ${ }^{2}$ Bidder, ${ }^{3}$ Lee, ${ }^{4}$ Beale, ${ }^{5}$ and others, have shown that whilst small ganglia and nerves are very generally distributed through the substanee of the heart in the Frog, special colleetions of ganglia are found in three plaees: the first, known as the ganglion of Remal, is placed near the opening of the inferior vena eava; the seeond, termed the ganglion of Bidder, is imbedded in the left aurieulo-ventrieular septum; and the third, or ganglion of Ludwig, lies in the interaurieular septum. The relation between the ultimate nerve-fibres and the museular fibres has not been satisfactorily made out. The above-named ganglia do not appear to have the same funetion, and an experiment devised by Stannius ${ }^{6}$ seems to show that the first two are exeitor-or eardio-motor eentres, whilst the last is an inhibitory eentre: for if the heart be so divided that one segwent shall eontain the ganglion of Remak, whilst the other part contains the ganglion of Bidder and Ludwig, the former will continue to beat rhythmieally, whilst the latter remains motionless; but if this last segment be so divided as to separate the aurieles from the ventriele, the former commence to beat, whilst the latter remains quiescent. It would thus appear that rhythmical impulses originate in the ganglia of Remak and Bidder, whieh excite the muscular fibres of the heart to corresponding eontractions, whilst the ganglion of Ludwig acts as an inhibitory or restraiuing centre. It is right to adil that a different mode of explaining the phenomena.

1 See the Experiments of Dr. Wilson Philip, Experimentul Inquiry, ete., p. 56.

2 Müller's Archiv, 1844, p. $463 . \quad{ }^{3}$ Archiv 1. Anat. und l'hysiol., 1868, p. 1.

4 l'hilosophieal 'Transactions, 1869.

5 Quart. Journ. of Microscop. Sci., A pril, 1869 ; see also Friedländer, Unters. a. d. I'hysiol. Labor. in Wurzbïrg, 1867, and Schweigger-Seidel in Stricker's IIum. and Comp. Histology, vol. i, 1870 ; Art. Heart, p. 260.

6 Zwei Reihen Phys. Tersuch., 1851. 
observed in these sections has been proposed by Eckhard and Bidder, and by Dr. Michael Foster. Eckhard and Bidder, observing that the movements called forth by the last-mentionerl division sonn cease, attribute them not to the action of spontaneously acting ganglia, but merely to irritation of the accelerating fibres and ganglia, and this is supported by the fact that Stannius's experiment will succeed when the inhibitory centres are paralyzed by atropine. Dr. Foster again believes that the intracardiac ganglia of the heart exert a continuous influence, and that the rhythmical action is due to a peculiarity of the muscular tissue. The carlio-motor system of nerves represented in the figure on p. 310 , which is purely diagrammatic, by a single stellate ganglion, receiving and giving off afferent or excitor and efferent or motor nerres, may be excited by mechanical, chemical, electric, and thermic stinuli. Bernard, for example, observed acceleration of the heart's beats when the bulb of a therinometer, introduced through the superior vena cava, touched the endocardium; and a similar effect was unticed (in Mammals at least, though the opposite occurred in cold-blooded animals) by Lurwig when the blood-pressure was increased. Again, the presence of blood or serum in the chambers of the heart greatly prolongs its activity, partly by its mechanical excitation, but partly also by affording nutritive materials and a supply of oxygen. The heart may be tempora rily arrested, even during life, by a strong expiration, which appears to act by effecting the compression of its walls, and preventing the entrance of fresh blood, though perhaps other causes here co-operate. The importance of oxygen is well shown by an experiment made by Wündt, ${ }^{2}$ who observed that the heart of a frog continued to beat for twelve hours in oxygen, whilst it ceased to move in ordinary air after three hours, in nitrogen and hydrogen after one hour, and in vacuo in half an hour. Certain gases, as chlorine, sulphurous acid, hydrogen sulphide, and certain poisons, as strychnia, opium, Calabar bean, ${ }^{3}$ are capable of more or less rapidly arresting the movements of the excised heart when directly applied to it, by their chemical action on the cardio-motor system. Various salts, as those of sodium and rubidium (Grandeau and Bernard) when in large quantity, and those of the biliary acids (Röhrig) slow or arrest the heart's action; as do also certain acids, as acetic and citric acid (Bobrik), and phosphoric acid (Leyden and Munk). The action of electricity upon the heart is peculiar. The heart, as Eckhard has remarked, knows no tetauus. A single shock applied to it in situ increases the frequency of its beats, and if applied to the excited heart when its excitability is nearly exhausted, stimulates it to renerved rhythmical activity; but interrupted currents, which if applied to ordinary muscles would produce tetanus, abolish the rhythmical activity of the centres now under consideration, and ineffective peristaltic contractions necur, with great depression of the blood-pressure. ${ }^{*}$ Continuous currents have the same effect.

243. Effects of Variutions of Temperature upon the Heart's Action.-The effects of variations of temperature upon the heart have been studied by Pickforủ, ${ }^{5}$ Calliburcés, ${ }^{6}$ Tigrer, ${ }^{7}$ Liebermeister, ${ }^{8}$ Schelske, ${ }^{9}$ Panum, ${ }^{10}$ Cyon, ${ }^{11}$ and Brunton. ${ }^{12}$ From their experiments, which were chiefly made on the

1 Journ. of Anat. and Physiol., 1869, p. 400.

3 See Fraser, Trans. Roy. Soe. Edinb, vol. xxiv, p. 65.

4 Majer, quoted in Hermann's Physiologie, 1874, p. 75.

5 Henle and Pfeuff, Zeits., 1851. 6 Gaz. Hebdomad., 1857, p. 468.

7 Dissert., $1853 . \quad 8$ Deutseh. Archiv. f. Klin. Med., Bd. i, p. 464.

9 Ueber der Veranderungen der Erregbarkeit durch die Wärme, Heidelberg, 1860.

10 See Abstract in Schmidt's Jahrbücher, 1858.

11 Ludwig's Arbeiten, 1868, p. 77.

12 St. Bartholomew's Hosp. Peports, rol. vii, 1871, p. 216. 
frog, it appears that the heart only beats within certain limits of temperature, though these arc not very well defined; in regard to the lower limit of temperature, the hearts of some animals cease to beat at $32^{\circ} \mathrm{F}$., others not till exposed to a temperature of $25^{\circ} \mathrm{F}$; in regard to the higher limit of temperature the variation is still greater, some hearts being arrested at $86^{\circ} \mathrm{F}$., and others not till $104^{\circ}$. In ascending slowly from the lower to the higher limits the frequency of the heart's aetion steadily increases till it reaches a maximum, and then as the higher limit is approached it suddenly but somewhat irregularly falls, as is represented in the adjoining eut (from Cyon's Memoir), where the abseissa may be considered as divided into degrees of temperature, whilst the ordinates would represent the relative frequency of the heart's action. Near the higher limit, at which the heart's

FIG. 125 .

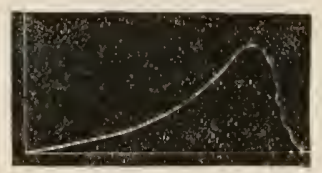

FIG. 126 .

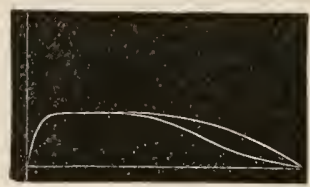

Fig. 125.-Curve showing the increased rapidity of the heart's action as the temperature to which it is exposed rises.

FIG. 126.-Curves showing force of the contraction of the heart with increase of temperature.

movements are arrested, the heart beats irregularly, so that the duration of the successive periods of diastole vary eonsiderably, and just before stopping the contraction of the heart is no longer sudden and eomplete, but progressive or peristaltie in charaeter. In regard to the variation in the force of the beats of the heart which oceurs with rise of temperature, Cyon has shown that the curve representing it attains its maximum very near the lower limits of temperature, and remains at the same height till a temperature of between $59^{\circ} \mathrm{F}$. and $66^{\circ} \mathrm{F}$. is reached, from which it progressively falls to null-point. At the higher temperature little or no fluid is propelled from the leart, owing to the peristaltic character of its contractions. The conclusion that may be drawn from the above facts is, that there is a certain temperature at which the combined frequency and force of the heart's action produees its greatest effect in driving the blood through the ressels. For the frog, this lies, according to Cyon, between $64^{\circ}$ and $72^{\circ} \mathrm{F}$. The phenomena in Cyon's experiments were somewhat different when the changes of temperature in the air surrounding the excised heart, and the serum flowing through it were sudden. Cyon found that if a heart that had been beating regularly at about $70^{\circ} \mathrm{F}$. were suddenly cooled to $32^{\circ} \mathrm{F}$, the force of the eontractions underwent great diminution, the movements assuming a peristaltic character, and the heart beeoming considerably dilated (heat diastole). After a time, however, it began to beat more strongly, and bchaved as if it had been gradually cooled. If after being kept at $32^{\circ} \mathrm{F}$. for some timc, it was suddenly exposed to air and scrum at a temperature of $10 t^{\circ}$, the beats succeeded one another more and nore rapidly till the whole organ passed into a state of tetanus (heat tetanus), lasting from 15-30 scconds. It then began to beat again, and passed through the same stages in the course of $1 \frac{1}{2}-2$ minutes that it presented in being gradually warmed. When a heart was suddenly heated, not from $32^{\circ} \mathrm{F}$., but from about $55^{\circ}$ to $104^{\circ} \mathrm{F}$., the beats insteat of becoming quicker beeame slower and fuller, and the traces rescmbled those of a heart in which the vagus is irritated. This state lasted 
for $1-2$ minutes, and then the heart passed through the same stages that it would otherwise have presented, if it had been gradually warmed It thus appears that if the temperature be raised above that of "heat-diastole" "heat-rigor" is produced, and the movements of the heart cannot again be restored by cooling it. The excitability of the inhibitory nerve apparatus is abolished during the arrest of the heart's action from the heat, for Cyon has shown that irritation of the sinus venosus, which invariably produces arrest of the heart's action in diastole under normal conditions, causes tetanus of the ventricle when applied to a heart that is in a state of arrest from heat. In warm-blooded animals the frequency of the heart's beats also increases with the temperature within certain limits (Panum, Brunton). In one instance, by means of registering apparatus, Dr. Brunton found that the heart of a rabbit, when the animal was exposed to a temperature of $105^{\circ} \mathrm{F}$., beat 472 times in a minute. After reaching a maximum the beats become slower, and the heart finally stops. The increase is not the same for each degree of rise in the temperature; and the number of beats at the same temperature, and also the amount of quickening for each degree of rise of temperature, differs in different animals. The upper limit at which the heart stands still in rabbits is about $113^{\circ}$ or $114^{\circ} \mathrm{F}$. (Brunton); as the temperature to which the heart is exposed rises, and the pulse quickens, the inhibitory power of the vagus diminishes, but when the temperature had risen in Dr. Brunton's experiments to nearly its upper limit, the power of the vagus was again observed to be increased, and-contrary to expectation-to be strongly marked just before the heart ceased to beat. It is not improbable that the increased frequency of the heart's action in febrile conditions of the system is in part due to the stimulating effect upon the heart of the increased temperature of the blood caused by augmented tissue-change.

244. Nerves Retarding or Inhibiting the Action of the Heart.-Some years ago (1846) the brothers Weber ${ }^{1}$ observed the important fact which proved the starting-point of numerous researches on the influence of the nervous system upon the heart, that irritation of the Vagus, or of its inferior cut

1 Archiv. d'Anat Gén. et de Physiol., Jan. 1846, and Waguer's Handwörterbuch, Bd. iii, p. 31 ; sre also Budge in Archiv. f. Phys. Heilk., 1846, Bd. v, p. 319 ; v. Bezold, Unters. üb. d. Innervat. des Herzens, 1863; Rutherford, Influence of the Vagus upon the Vaseular System; Transaet. of Roy. Soe., Edinb., vol. xxvi, 1870, p 1 (in this paper references will be found to all the more important antccedent memoirs); Goltz, Centralblatt, $1 \times 68$, p. 593 ; Meyer, Das Hemmungsnerven-system des Ferzens, Berlin, 1869; Abstract in Journ. of Anat. and Physiol., 1869, vol. iii, p. 445; Kowalowsky and Adamük, Centralblatt, 1868, p. 546; Bernhardt, Inaug. Dissert., 8vo., p. 32,1868; Aubert and Roever, Centralblatt, 1868, p. 578; Coats, Bericht d k. Sachs. Gesell. d. Wissensehuft, 1869 ; also the Effects of Irritation of the Vagus on the Internal Work of the Heart, Leipziger Arbeiten, Bd. iv, 1870, p. 176; Michael Foster, Fullerian Leetures, Rev. des Cours Scientif., 1869, Nos. 42, 43, and 45; P. Keuehel, Das Atropin, und die Hemmungsnerven, Inaug. Dissert., 1868; Donders, Centralblatt, 1870, p. 408; Masoin, Bull. de l'Aead. Roy. de Méd de Belgrique, t. vi, p. 4, 1872-3; Nuel. Pflüger's A rchiv, Bd.ix, p. 83; Boehm, Studien über Herzgiften, 1871; Arloin et Tripier, Arehiv. de Phys. Norm. et Path., 1872, Contribution à la Physiologie des Nerfs Vagues; Schiff, Herz- und Gefäss-nerven, abstrict in Centralblatt, 1873, Nos. 1, 2, 3; Metsehnikott and Setschenow, Ucber die Vaguswirkung auf das Herz, Centralblatt, 1873 , pp. 163 and 289 ; Schiff, Arehiv f. Physiol. Heilk., 8ter Jahr.; Molesehott, Wiener Med. Wochens., 25th May, 1861; and Lister, Proeed. Roy. Soe, vol. ix. p. 367, were led by their researches to consider the vagus as a motor nerve of cxtreme exeitability, but which was easily exhausted. They maintained that with very fceble currents applied to it, the heart's aetion is accelerated; but Pfüger, v. Bezold, Rutherford, Wündt, and many others hare becn unable to corroborate these statements. Later experiments have shown, however, that ccrtain accelerator fibres do run in the trunk of the vagus; sce Schiff's Physiologie, 1859, p. 417 et seq. 
surface in the neck, by means of an interrupted current of electricity caused the rhythmical movcments of the heart to become slower, and if the current were sufficiently strong arrested its movements altogether. Now in the case of any voluntary muscle the passage of such a current through the nerves supplying it produces either simple contraction, or if the shocks be sufficiently frequent, tetanus, but in the case of the heart the effect produced is,

FIG. 127.

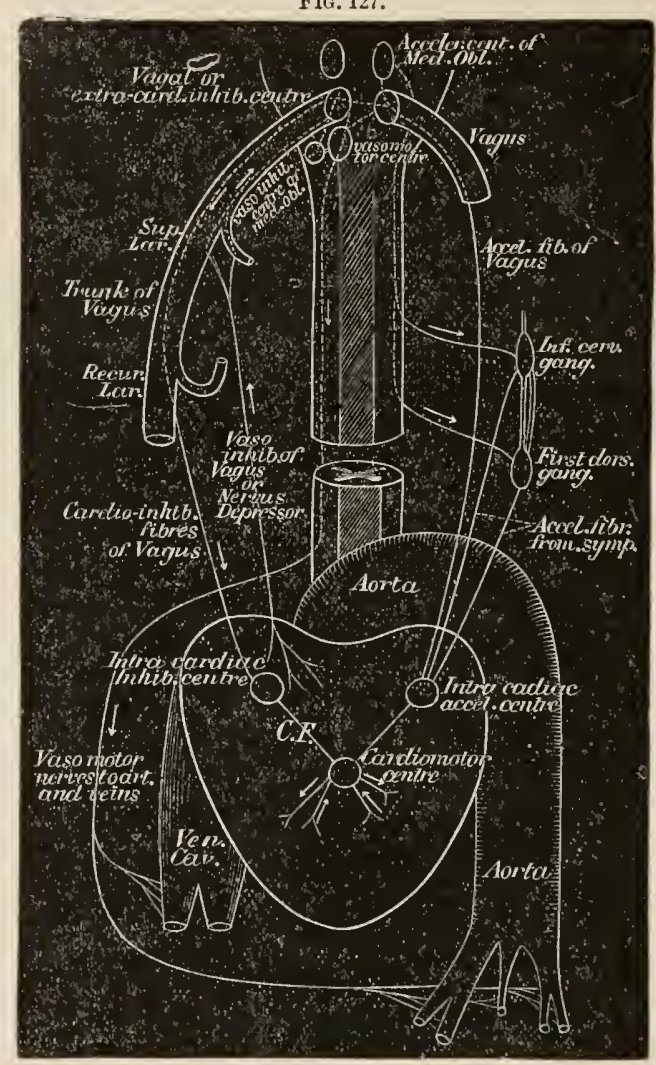

Diagram to aid in understanding the aetion of the nerves upon the Heart. The Right half represents the course of the inhibitory, and the Left the course of the accelerating nerves of the Heart; the arrows showing the direction in which impressions are conreyed. The ellipse at the upper extremity of the Vagus looking like the section of the nerve is intended to represent the Vagal nucleus or centre.

on the contrary, that of complete relaxation. The cessation of the rhythmical action in diastole is not, lowever, of long duration; contraction soon recommences, notwithstanding the continued application of the clcctrical stimulus, though it can be again arrested by passing the interrupted current throngh a fresh portion of the ncrve situated lower down or nearer the heart. Dr. Ritherford has shown that the indnced current obtained from Du BoisReymond's induction machine and a single Daniell's cell begins to slow the heart in the frog when the primary and sccondary coils are distant about 200-300 millimetres, and that arrest of the licart's action ocenrs when the distance is abont 100 millimetres. Comparative trials showed that a very much stronger irritant is necessary so to stimulate the Cardio-inhibitory 
fibres of the Vagus that the heart's action may be retarded than is required to stimulate the recurrent laryngeal fibres, so that the laryngeal muscles may be thrown into action. The accompanying woodeut will show by means of a tracing the effect of stimulation of the lower end of the Vagus in the rabbit. It will be observed that the undulations, cach of which represents

FIG. 128.

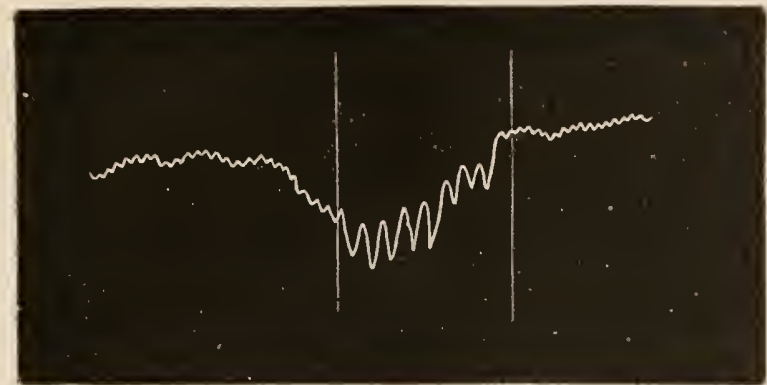

After.

During.

Before.

Tracing showing effect of stimulation of Vagus. The tracing must be read from right to left.

a cardiac contraction, are very rapid and small till the moment at which the stimulus was applied to the Vagus. They then become much slower, and la rger, whilst their mean level falls, indicating a diminution of bloodpressure. As soon as the stimulus to the Vagus is withdrawn the contractions present their former frequency, and the blood-pressure again rises. Further inquiry by Cyon and Ludwig soon showed that in the rabbit the Vagus gives off a branch immediately below the inferior laryngeal nerve, which may be called the Carlio-inhibitory of the Vagus (see Fig. 127), since when excited it is capable of exerting the same controlling, restraining, arresting, or inhibitory power over the Cardiac movements as the Vagus itself. In man this nerve is represented by the superior Cardiac branch of the Vagus. If this nerve be divided and its upper cut surface be irritated no effects are produced, but if the lower cut surface be irritated, the heart stops in diastole. The fibres of the nerve therefore appear to conduct impulses downwards (as indicated by the arrow in the figure). It might be supposed that these fibres pass to the Cardio-motor centre, and exert a direct inhibitory influence upon it, but several circumstances render it probable that an intermediate apparatus or inhibitory mechanism which we may term an inhibitory centre exists in the heart between the vagal branches rumning to the heart and the ultimate fibrils of their branches. For, in the first place, when the Cardio-inhibitory nerves are irritated it has been shown both by Pflüger and Donders that a very appreciable interval elapses before the inhibitory action is manifested. Thus Pflüger found that even when the stimulus applied was strong enough to produce complete arrest of the Cardiac movements, two entire beats always intervened before the cessation occurred, ${ }^{2}$ and in Donders's experiments, a period of 0.17 secs. elapsed before

I Ludwig's Arbeiten, 1867, p. 128.

2 Pfluger found that the first perceptible effect of slight irritation of the Vagi is a prolongation of the diastole of the heart, or a retardation of the motor impulse, induciug the next contraction. When violent or long-continued excitation is applied to the Yagi, producing stoppage of the heart's action, the first beats on its recovery are usually very feeble; but when only moderately strong currents are applied, the first beats are often as energetic or even more powerful than before. This would 
arrest occurrer. But in the case of ordinary muscles the period of latent excitation, or the time that elapses between the application of a stimulus to the nerve and the beginning of the contraction of the muscle, does not exceed $T_{00}^{1}$ th of a seconrl. Secondly, Meyer ${ }^{1}$ has been able by direct irritation of a particular part of the sinus venosus in the common eel by means of an interrupted current to arrest the heart's action for sixteen minutes, and in the frog he was occasionally able by persistent direct irritation to kcep the heart at rest for an hour. M. Foster ${ }^{2}$ has in like manner pointed out that in certain Molluses, Anodon and Helix, there is no nerve corresponding to the Vagus, but that the heart can be stopped in diastole by direct irritation when removed from the body. The inhibitory mechanism must in these instances be in the heart itself. Lastly, evidence of an intermediate apparatus such as is represented in the above figure as the intracardiac inhibitory centre is derived from the action of certain poisons. ${ }^{3}$ Thus Nicotin and Woorara when injected subcutaneously in very small doses ( $\frac{1}{8}$ th to $\frac{1}{3} \mathrm{~d}$ of a milligramme) appear to stimulate the inhibitory centres, and the heart beats slower; but they soon paralyze these centres, and the heart then beats faster, and when this occurs irritation of the Vagus will no longer inhibit the heart's action, but if whilst the lreart is beating fister Muscarin be administered or the sinus venosus be irritated the heart still stops in diastole. If, however, Atropin have been injected, not only does the heart beat faster, but it can no longer be stopped in diastole by irritation of the sinus venosus, or the adninistration of Muscarin. The explanation of this appears to be that whilst Nicotin and Woorara in certain doses and stages of their action paralyze the vagal centre, and the Cardio-inhibitory fibres of the Vagus, so that these can no longer transmit inhibitory impulses, they do not paralyze the Intracardiac inhibitory centres, as is indicated by the effect of clirect irritation on the sinus venosus. Atropin, on the other hand, not only paralyzes the Vagal centre, but it also paralyzes the intracardiac inhibitory centres, for the heart under its influence is no longer capable of being arrested in diastole, either by irritation of the -vagus or of the sinus venosus. ${ }^{4} \mathrm{Dr}$. Brunton is disposed to think that Atropin acts especially on the connecting filaments, C F, between the inhibitory and cardio-motor centres. ${ }^{5}$ In the course of an elaborate series of experiments upon the action of the nerves on the heart, v. Bezold observed that in animals under the influcuce of Woorara, in which therefore all muscular movements that might complicate the phenomena were prevented, on applying clectrical excitation to the upper cut surface of the divided Vagus, the blood-pressure fell, and lie also obscrved that similar irritation applied to the medulla oblongata caused considerable elevation of blood-pressure, which still occurred, even when the two Vagi had been divided. He concluded that the spinal cord contained fibres acting directly on the heart. He further noticed that on division of the spinal cord in the cervical region the blood-pressure immerliately fell, whilst if the posterior cut surfice of the cord was irritated the blood-pressure again rose. The conclusion drawn by v. Bezold was, that the medulla

seem to show that if the inhibitory influence is very strongly exerted it prevents the production of motor energy in the motor gunglin, whilst if it be moderately excited it doos not interfure with its genration, but only with its discharge.

1 Dis H(smununısnerven-system, 1869.

2 Piliger's Arehiv f. Phys.. Bd. v, p. 191.

3 See the papers of Trubart, Iuaug. Dissert., Beiträg. zur Nicotin-Wirkung, Dorpat, 1869 ; and Schmiedelerg, Iudwig's Arbeiten, Bd. v, 1871, p. 41.

4 'The effect of the udministration of $\Lambda$ tropin in man is to raise tlie number of the pulse from $72-89$ to $140-180$ in the minute.

s Brit. Med. Journ., Dec. 16ith, 1871, p. 689. 
oblongata eontains a eardio-motor eentre, the centripetal fibres of which rum upwards in the vagus, whilst the efferent or motor fibres descend through the spinal cord and are distributed to the heart. Irritation of the upper cut surfice of the vagus he thought excites the centre, which acting in a reflex mimner stimulates the heart to beat more energetically, and the blood-pressure rises, whilst section of the spinal eord divides the motor filaments proceeding from the ganglion, and the heart beats with less foree, and the blood-pressure consequently diminishes. Ludwig and Thiry on repeating v. Bezold's experiments substantiated their accuracy, but demonstrated the ineorrectness of his conclusions. They noticel that even when all the fibres passing from the spinal cord to the heart were destroyed by means of a galvano-caustic wire, the effects observerl by v. Bezold to result from irritation of the cord eould still be manifested, and they conchuded that the rise in the blood-pressure and augmentation in the frequency of the beats of the heart, were due to constriction of the small vessels in the body generally, and in this conclusion they were supported by the results of ligatures applied to the aorta or larger arteries. Further investigations, the details of which were published in Ludwig's Arbeiten in 1866, enabled them to announce their diseovery of the functions of a small nerve given off from the vagus, and to which they applied the uame of Nervus Depressor. This nerve arises in the rabbit from the vagus, immediately below the superior laryngeal nerve, from which part it often receives a reinforcing filament; and descending through the neck it is distributed to the heart. If this nerve be divided and the lower eut surface be irritated, no effeets are observed, but if the upper cut surface be irritated its inhibitory action immediately becomes manifest, and the animal gives indieations of pain. The direction in which it eonducts inpulses is therefore exactly the opposite to that of the cardioinhibitory nerve of the vagus: it is a sensory or afferent nerve. If the irritation be continued, the slowing aetion on the heart passes off, and the heart beats as fast or even faster than before, and eoincidently the blood-pressure in the vessels falls. The mechanism of the phenomena observed as deduced from their experiments seems to be that when a stimulus is first applied to the depressor nerve, an impulse is conducted straight to the vagal centres, from whence an inhibitory influence is directerl through the cardio-inhibitory nerves to the intraeardiac inhibitory centre, and the heart is slowed; but the depressor nerve also contains fibres terminating in a vaso-inhibitory eentre in the medulla oblongata, which exerts a restraining or inhibitory power over a vasomotor centre in close relation with it. Under ordinary eonditions a nervous influenee is discharged from the vaso-motor centre by fibres, which, descending through the spinal cord, emerge with the several roots of the spinal nerves, and are distributed to the smaller vessels throughout the body (one only being shown in the figure). This nervous influènce maintains the vessels in a state of permanent tonic contraction, which keeps up the blood-pressure to its normal height. But when the vaso-inhibitory of the vagus (depressor neve) is stimulated, an impulse is conveyed to the vaso-inhibitory centre of the medulla oblongata, which reacting on the vaso-motor eentre inhibits its action, and the downward current from this through the spinal eord being eonsequently arrested, the ressels dilate, the blood-pressure sinks to one-half or two-thirds of its normal amount, and the medulla receiving less blood, the ragal inhibitory centres become less active and the heart resumes its ordinary activity, or if the dilatation of the vessels and the eonsequent relief from the retracing power be very considerable, may even beat faster than before. It has been pointed out by Dr. Rutlerford, that the inlibitory fibres of the vagus may be excited to action by stimulation applied to: 1 . The central end of the vaso-inhibitory or superior eardiae braneh of the vagus 
(depressor nerve); 2. The central end of the vagus of the opposite side; 3 . Almost any sensory nerve in the case of warm-blooded animals, the fifth, according to Hering and Kratschmer, having a very special action; 4 . The abdominal viscera in the frog; 5 . The splanchnic and cervical sympathetic. In these instances the cardio-inhibitory nerves appear to be excited in a reflex manner. The inhibitory action of the right Vagus upon the heart is much more marked than the left in the tortoise. ${ }^{1}$ It may just be noticed that both Dr. Rutherford and Dr. Coates, ${ }^{2}$ of Glasgow, have shown that irritation of the vagus always diminishes the absolute amount of work done by the heart.

There is reason to believe that the depressing effects of shock may be exerted both through the vagus and through the sympathetic system of nerves, and that considerable disturbance may ensue from lesions of such branches of these nerves as are most nearly connected with the heart. For the wellknown fact of sudden death not unfrequently resulting from a blow on the epigastric region, especially after a full meal, without any perceptible lesion of the viscera, scems to indicate that a violent impression upon the widelyspread celiac plexus of Sympathetic nerves (which will be much more extensively communicated to them when the stomach is full, than when it is empty), may cause the inmediate cessation of the heart's action probably by a reflex action exerted on the pneumogastrics, in the same manner as a severe injury of the brain or spinal cord. And a case has been put on record, in which the heart's pulsations were occasionally checked for an interval of from 4 to 6 beats, its cessation of action giving rise to the most fearful sensations of anxiety, and to acute pain passing up to the head from both sides of the chest-these symptoms being connected, as appeared on a post-mortem examination, with the pressure of an enlarged bronchial gland upon the great cardiac nerve. ${ }^{3}$ Czermaks ${ }^{4}$ has produced all the usual effects of irritation of the vagus in his own person by carefully applied pressure over the vagus in the neck.

245. Nerves Accelerating the Action of the Heart.-The action of the heart cannot only be rendered slower or stopped by irritation of certain fibres running in the vagus, but by the irritation of other nerves its movements can be accelerated. V. Bezold observed that irritation of the cervical sympathetic is followed by increased frequency of the heart's beats, but that this effect is not constant. ${ }^{5}$ Much more marked increase follows irritation of the communicating filaments rumning between the spinal cord and the in-

1 Meyer (Op.eit.) in pigeons and rabbits. Masoin (Op. cit.) and Arloing and Tripier (Op. eit.) state that of the left. Though coursing in the trunk of the vagus, the inhibitory nerves seem really to be derived from the spinal accessory, since if the fibres of the spinal arcessory, which Bernard has shown spring from the medulla oblongata and join the vagus, be torn out, it will be found impossible to arres the Jealt's action by irritation of the vagus trunk, even as early as three days after the operation, that is before degeneration of the nerve's fibres could have set in (Brieke, Vorlesungen, 1874, Bd. ii, p. 94), though it can be inmediately produeed by irritation of the opposite vagus.

2 Ludwig's A rbeiten, 1869.

3 Mülker's Arehiv, 1841, Heft 8 ; and Brit. and For. Mred. Rev., Oet. 1841.-It may be surnised that in many cases of angina pectoris, in which no lesion adequate to iecount for death eould be cliseovercd, some affection of the cardiac plexus might have been traeed on nore careful examination.

4 Jenaische, Keits., 1865 , p. 384

5 Soe the researches and experiments of A, v. Bezold, Untersuehungen über die Innervation d. Inerz, Leipzig, 1863; Ludwig and Thiry, Sit\%. d. k. Akud. zu Berlin, J3d. xlix; Cyon, sitz. d. k. Sachs.-Gesell. d. Wiss, 186t, and Comptes Rendus, 1867, P1. 670 and 1049; Karl Bever, Würzlurg Medicin. Zeitsch., Bd. vii, p. 215; Rutherford, Tran-ilet. Roy. Soc. Edin., 1870, vol. xxvi, p. i, and his excellent Lectures in the Lancet, in 1871-7:. 
ferior cervical and first dorsal ganglia of the sympathetic. Irritation of the spinal cord itself, and of the medulla oblougata, causes increased frequency of the pulse, though this has been shown by Iudwig and 'Thiry to be a complicated phenomenon, and due in part to the effect of such irritation in producing' contraction of the smaller arteries. The accelerating fibres, however, secmed from these observations to arise from centres in the medulla oblongata and spinal cord, and emerging from the latter by the rami communicantes to enter the sympathetic ganghia, and to proceed from thence to the heart (see Fig. 126, right side). This view is supported by the experiments of v. Bezold and the brothers Cyon, ${ }^{1}$ who have eliminated the influence of vascular innervation by division of the spinal cord between the first and sccond dorsal vertebra. The vessels are then permanently paralyzed; but irritation of the spinal cord in the cervical region will still be found to produce considerable increase in the frequency of the pulse, though the variations of blood-pressure arc slight or nil. The course of the accelerating fibres has been much elucidated by the recent careful dissections of Schmiedeberg ${ }^{2}$ made upon the dog. In this animal the vagus and sympathetic run together as far as the inferior cervical ganglion. Here they scparate, and the vagus immediately gives off the recurrent laryngeal. The last cervical and first dorsal ganglion of the sympathetics are connected by two filaments, the upper one of which often joins the vagus. The inferior cervical ganglion gives off the superior cardiac nerve, and sometimes the inferior cardiac, though both not unfrequently come off from the vagus. One of them is sometimes absent, and both appear to act as accelerators (though they sometimes contain inhibitory fibres), and to reach the sympathetic through the roots connecting the sympathetic with the cord. In the rabbit, the fibres directly accelerating the action of the heart proceed from the medulla oblongata, or possibly from the brain, and descending through the cervical portion of the cord, emcrge as in the dog, opposite the inferior cervical and first dorsal ganglion of the sympathetic, which they enter, and then proceed to the heart. In the Frog the vagus contains accelerating as well as inhibitory fibres, for $W^{2}$ ündt ${ }^{3}$ has shown that, at a certain stage of poisoning with Woorara, irritation of the vagus no longer caused slowing but quickening of the heart's action; and the same has been noticed in the action of Atropin and Nicotin. On grounds similar to those which have led to the admission of an intracardiac inhibitory centre, the existence of an intracardiac accelerator centre, or series of centres, scems probable. The accelerating fibres appear to be less easily excited and less readily exhausted than the inhibitory fibres. ${ }^{4}$ They render the contractions of the heart more forcible as well as more frequent. ${ }^{5}$

246. During the last few years, the action of numerous poisons on the heart has been made a subject of special investigation, but the results at present obtained scarcely admit of being accurately classified. Some appear to act as paralyzers, others as excitors of the notor and inhibitory nerves respectively ; others, as the sulphocyanide of potassium, ${ }^{6}$ act directly on the

1 Archiv f. Anat. and Physiol., 1867.

2 Ludwig's Arbeiten, Bd. vi, 1871, p. 34.

3 Verhand des Naturhist.-11 ed. Ver, zu Heidelberg, 1859.

4 Schiff (Centralblatt, 1873, Nos. 1, 2,3) denies the existence of accelerator fibres, both in the sympathetic and the cervical portion of the spinal cord. He derives the accelerator fibres from the spinal accessory nerve, and maintains that they run in the vagus.

5 Badond, Verhand. d. Phys. Med. Gesellsch, zu Wülzburg, N, F., Bd, viii, p. 12.

6 C. Bernard, Leçons sur les Substances Toxiques, etc., 1857, p. 358; MM. OHivier and Bergeron in Brown-Séquard's Journal de la Physiol., 1863, pp. 35 and 47, and M. M. Dubreuil and Legros, Comptes Rendus, 1867, p. 1256. 
muscular tissue, rendering it incapable of responding to the strongest stimuli. And others, again, indirectly influence the force and frequency of the heart's action by thcir action on the respiratory, or upon the vaso-motor systems of nerves. When it is remembered that different animals are not affected in the same manner by particular poisons, and that there is frequently a difference between the effects of large and sniall doses, it may be conceived that the difficulty of explaining the phenomena observed is extreme. It may be observed, however, ${ }^{1}$ that some poisons, as the Antiaris toxicaria ${ }^{2}$ Tanghinia venenifera ${ }^{3}$ Digitalis; Helleborus niger; Helleborus viridis; the green resin obtained from the Nerium oleander; ${ }^{4}$ Squill ; Manganja, from the Zambesi River (Dr. Sharpey); and Carroval and Vao, from the river Darien $;^{5}$ most of which have becn examined by Drs. Fagge and Stevenson, produce in frogs a peculiar form of irregularity in the action of the heart, attended with protrusion of its walls at different points, and accelcration of its beat; then diminished frequency, caused by protraction of the ventricular systole; and finally, stoppage of the contractions by cessation of the dilatation of the ventricles, which remain contracted, white; and perfectly empty. The stoppage usually occurs in from five to twenty minutes after the administration of the poisonous dose, and the animal retains its control over the voluntary movements for a quarter of an hour or more after the heart has ceased to beat. Calabar bean, on the other hand, according to Dr. Fraser, is a poison that produces cardiac paralysis in an exactly reverse manner. It causes no acceleration; by exciting the vagal centres it diminishes the frequency of the contractions by prolonging the ventricular diastole; and it produces the final stoppage by cessation of the contraction of the ventricles, which then remain dilated, dark, and full of blood. ${ }^{6}$ The Atropin group of bases, viz., atropin, hyoscyamin (which is an

1 See T. R. Fraser, M.D., On the Physiologieal Aetion of the Calabar Bean, Plyssostigna venenosum, from the Transact. of the Roy. Soe. of Edinb., vol. xxiv, 1867, and the paper, On the Appticution of Physiological Tests for certain Organic Poisons, and espeeially Digitalin, by Dr. Fagge and Dr. Stevenson, in Guy's Hosp. Reports, 1846, p. 47.

2 Neufeld, Stud. des Physiul. Instit. zu Breslau, 1865, Heft 3.

3 Pelikin and Dybkowski, C. Rend., 1856, p. 1209.

4 Pelikan, ib., 1866, p. 237.

5 Hammond, Amer. Journ. of Mled. Sei., 1859, July, p. 13.

6 Arsenious Aeid (Cunze, Zeits. f. Rat. Med., Bd. xxviii, p. 33, and Sklarek, Reichert's Arehiv, 1866, p. 481), bromide of potassium (Eulenbergs and Guttmann, Comptes Rendus, 1867, p. 1281), the salts of barium and of oxalie acid (Cron, Reicher't's Archiv, 1866, p. 196), ehloroform (P. Q. Brondgeest, Nederland. Arehief, 1865, p. 473, and Dogiel, Reichert's Archiv, 1866, pp. 231 and 415), nicotin, quinine (Eulenberg, Comptes Rendus, 1867, p. 421, Solyet; ibid, 1867, p. 719), stryehnia (IIeineman, Virehow's Archiv, xxxii, p. 394), the arrow poison of Borneo (Braidwood, Edin. Mred. Journ, Aug. 1864), aconitina (Aehseharmow, Reiehert's A rehiv, 1866, p. 281), eaffein and thein (Leven, in Brown-Séquard's Arehives de Physiologrie, 1868, p. 481), delphinin (Böhm, Centralblatt, 1871, p. 586), muscarin (Sehmiedeberg, Ludwig's Arbeiten, 13d. v, 1871, p. 41 and Bd. vi, 1872, p. 34), and the gases sulphuretted hydrogen (Kaufmann and Rosenthil, Reiehert's Archiv, 1865, Heft 6), bydroeyanie aeid (Preyer, Arehiv f. P'ath. Anat., Bd. xl, p. 125), carbonie oxide (Pokrowsky, ibid., 1866, Heft 1, and 'Traube, Centralblatt, No. 10, 1866), earbonic aeid (Cyon, Comptes Rendus, 1867, p. 1049), or blood saturated with them, seem all to excreise a depressing influence upon the motor ganglia of the heart, eausing it to stop in diastole, in some instances (aconitina), with, in other (delphinin) without, a preliminary stage of aceelerated frequency of beat and augmented blood-pressure. When the stoppange in diastole is sudden, as oecurs when blood elatrged with earbonie aeid is transmitted through the heart, the eflect may with probability be referred to direct stimulation of the extremities of the pnemmogristric or inhibitury nerves. Cinehonin aceelerates the action of the heart (Elson, Amer. Journ. of Med. Seienee, 1866, July, p. 9). Atropin (v. Bezold and Blöbaum, Unters. aus der Physiol. Labor. 
atropin containing 1 eq. of methyl ammonium instead of 1 eq. of hydrogen), conium, daturin, together with physostigmin, aconitin, delphinin, veratrin, first, or in small doses, stimulate and then lower or abolish the excitalility of the inhibitory centres. ${ }^{1}$ The intracarliac inhibitory centres are stimulated by muscarin, and with suitable arrangements to prevent desiccation the heart of a frog may be kept motionless in diastole for hours under its influence, but if it be acted upon by a solution of atropin it soon again resumes its ordinary movements. Referring to Fig. 127, it may be said that the cardio-inhibitory fibres of the vagus are excited by nicotin and paralyzed by woorara, that the intracardiac inhibitory centre is excited by muscarin, and that the connecting filaments, $\mathrm{c}, \mathrm{F}$, between the intracardiac inhibitory and motor centres are paralyzed by atropin and excited by Calabar bean. [Lohelina, like conia and nicotina, paralyzes the pneumogastrics.] ${ }^{2}$

247. There seems adequate reason to believe that the whole, or very ncarly the whole, of the blood contained in the V'entricles is discharged from them at each systole; for the left ventricle is very frequently found quite empty after death; and if a transverse section be made through the heart, when in a state of well-marked rigor mortis (which may be considered as representing its ordinary state of complete contraction), the ventricular cavity is

zu Würzburg, 1867, p. 1), paralyzes the terminal branches of the vagus in the heart. The feeble influence excrtod by the vagus over the cardiac movements in rabbits explains in part their immunity from the injurious ellects of large doses of the poison (see Dr. Ogle, Med. Times and Gaz., 1867, p. 466). For other papers on the action of poisons on the heart, see Bochun Studien üb. Herzgifte, Pamphlet and Abstract in C'entralblatt, 1871, p. 581), Basch and Oser (Wirkungen des Nicotins, Wien. Hed. Jährb., 1872, p. 367), Polaillon et Carville (Les Effets Toxiques de l'Inée, Poisons de Pahoions), Gabor (Archiv d. Physiol, 1872, pp. 523 and 680), Ackermann (Wirkungen des Digitains, Deutsche Archiv f. Klin. Mled., 1872, B(l. xi, 12.i), and Volkmann's Sammlung Klin. Vorträge, No. 48; Brunton (On Digitalis, 1868), Fothergill (Digitalis, 1871), Oulmont and Laurent (On Hyosevamin and Daturia, Archiv. de Physiol., Nos. 2 and 3, 1870), Holmes (On Ergot, Arch, de Plys., 1870, p. 384), Fick (Die Wirkung des Sparteins, Archiv f. Experiment Path., Bd. i, 1873, p 397), Nunneley (Proc. Roy. Soc., Junc, 1869, and Practitioner, 1869, p. 347, action of atropin, digitalin, aconitin, strychnia, veratria, morphia, nicotin, conium, and bromide of potassium), Arnstein and Sustschinsky (Ueber die Wirkung des Culabar auf die Herznerven, in Würzburg Plivs. Untersuch., Bd. iii), Buchheim and Loos (Ncb. die Pharm. Gruppe des Curarins, Pamphlet), Wood (Viridia and Veratroidia, Amer. Journ. of II ed. Sci., 1870), Weyland (Vergleich Tnters. über Teratrin, Sabadillin, Delphin, Emetin, Aconitin, Saneruinarin, and Chlorkadin), Blake (Action of Inorganic Substances when introduced directly into the Blood, Journ. of Anat and Physiol., 1870 and 1873 ), and many others. Mucl discussion has arisen in regard to the question whether the inhibitory power of the pricumogatric nerves upon the heart is affected by the administration of woorara, Bernard (Leçons sur les Effets des Substances Toxiques, 1857, pp. 348, 352, 373), Köliker (Virchow's Archiv, Bd. $\mathrm{x}, 11,17,39,73$, and Med. Central Zeitung, 1858, No. 58), Heidenhain (Allg. Med. Central Zeit., 1858, No.64), Funke (Lehrbuch, 4th edit, 1863, pp. 959 and 979), Goltz (Virchow's Archiv, Bd. xxvi, p. 24), and Budge (Physiologie, 1862, p. 549), comsidering it to be proved that thesc nerves are rendered incapable of transmitting their inhibitory influence; whilst v. Bezold (Central. Zisit., 1858, Nos. 49 and 59), Tulpian (Gaz. Méd. de Paris, 1858, Nu. 27, p. 429), Meissner (Zeits. f. Rat. Med., 3 R., Bd. vi, p. 506), Bidder (Reichert's Archiv, 1865, No. 3, p. 337), contend that this agent does not paralyzc the vagi, no loss of regulatory or inhibitory power being obscrvable between poisonea and healthy animals. Bidder arrived at the latter conclusion in reference to the splanchnic nerves, and their influcnce upon the intestines. He noticed also, in opposition to Kölliker, that in poisoning by woorara great dilatation of the pupil, indicating the persistence of the agency of the sympathetic, occurred, and he perccived no indications of paralysis of the vuso-motor nerves. This contradictory testimony is probably referable to differences in the composition of the poison and in the quantity administered.

1 See Rossbach, Verhand. 1. Med., Verhand. zu Würzburg, and Boehm, op. cit.

2 [I. Utt, Physiolog. Action of Lobelina, Plila. Med. Times.] 
found to be entirely obliterated. ${ }^{1}$ The total quantity discharged from either ventricle of the Human heart at each systole is estimater by Valentin at $5.3 \mathrm{oz}$., by Volkmamn at $6.2 \mathrm{oz}$, and by Vierordt at $6.3 \mathrm{oz}$; but these amounts are deduced from calculation of the (supposed) total of the blood, divided by the estinated duration of its passage through the heart, rather than from actual admeasurement. The time occupied by the Blood in making an entire circuit of the body was attempted to be ascertained by Hering, ${ }^{2}$ by introducing prussiate of potass into one part of the system, and drawing blood from another. He states that he detected this salt in blood drawn from one of the jugular veins of the Horse in about 30 seconds after it had been introduced into the other; in which brief space the blood must have been received by the heart, have been transmitted through the lungs, have returned to the heart again, have been sent through the carotid artery, and have traversed its capillaries. These experiments have been fully confirmed by those of Poisenille, ${ }^{3}$ and of Mr. Blake, ${ }^{4}$ who found that a solution of nitrate of baryta injected into the jugular vein of a horse appeared in the blood of the carotid artery of the opposite side after an interval of 15 seconds. The same inquiry has been pursued, with improved means, by Vierordt. ${ }^{5}$ 'This observer affixed a number of small cups to a drum which was made to rotate at a certain velocity in front of the opened vein; analyses of the contents of the several vessels enabled him to ascertain with great accuracy the moment at which the salt injected made its appearance. In this way he determined the number of seconds occupied by the blood in performing one entire revolution to be, in Squirrels 4.39 , in Cats 6.69 , in the Hedgehog 7.61, in Rabbits 7.79, in the $\mathrm{Dog} 16.7$, in the Horse 31.5 , in the Cock 5.17, in the Duck 10.64, and in the Goose 10.86. He estimates the period in Man at 23.1 seconds (during which there are 28 beats of the heart), of which 2 seconds at most are occupied in traversing the larger arteries, $2 \frac{1}{2}$ to 3 seconds in passing through the smaller arteries, 3 seconds for the capillaries, and 4 or 5 seconds for the renous system, which numbers must be multiplied by two for the two circulations. MLreover, the coincidence between the cessation of the heart's action and the diffusion of the salt through the arterial blood bears a striking correspondence; and it may be hence inferred that the arrestment of its muscular movement is due to the effect of this agent upon its tisstre, when immediately operating upon it, through the capillaries of the coronary artery. -This conclusion is borne out by a variety of other experiments; which show that the time of the agency of other poisons that suddenly check the heart's action (which is the special property of mineral poisons), nearly coincides, in different animals, with that which is required to convey them into the arterial capillaries. And it seems to derive full confirmation from the fact, that poisons which act locally on other parts give the first iudications of their operation in the same period after they have been introduced into the venous circulation. Thus, in the Horse, the time that is required for the blood to pass from the jugular vein into the capillary terminations of the coronary arteries is 16 seconds, as is shown by the power of nitrate of potass to arrest the heart's action within that time; and nitrate of strychnia injected into a vein gave the first manifestation of its action on the Spinal Cord in precisely the same number of seconds. In the Dog, the heart's action was alrested by the nitrate of potass in 11 or 12 seconds; and the tetanic convulsions occasioned by strychnia

1 Kirkes and Paget's IIandbook of Physiology, 2d edit , p. 80.

2 Tiedemann's Zeitschrift, vol. iii, p. 85.

3 Annal. des sciences Nat., 1843, Zool., t. xix, p. 32.

4 Edin. Med. and Surg. Journ., Oct. 1811. ${ }_{5}$ Phys. d. Mensch., 1861, p. 111. 
also commenced in 12 seconds. In the Fowl, the former period was 6 seconds, and the latter $6 \frac{1}{2}$; in the Rabbit, the first was 4 , and the other $4 \frac{1}{2}$ seeonds.-From such experiments, it seems evident that the rapidity of the circulation is underrated, in any estimate that we found upon the capacity of the Ileart, and its number of pulsations in a given time; and it is difficult to see how the two sets of facts are to be reconciled. According to Hering, the rapidity of the circulation diminishes with age; and Vierordt has shown that with increased frequency of the heart's action there is in general an increased rapidity of the circulation, at least in the higher Vertebrata. Still it by no means follows that an increase in the frequency of the heart's action in a particular animal should be always acconpanied by an increased rapidity in the current of the circulation; in point of fact, the experiments of Hering ${ }^{1}$ show that, in the Dog and Horse, when inflammatory or febrile conditions, such as Pericarditis, are set up, a much longer period is occupied in the passage of the blood than before.

248. The number of contractions of the Heart in a given time is liable to great variation, within the limits of ordinary health, fiom several causes; the chief of these are diversities of Age, of Sex, of Stature, of Muscular exertion, of the activity of the Respiratory process, of the condition of the Mind, of the state of the Digestive system, and of the Period of the day.

a. Putting aside the other causes of uncertainty, the following table may be regarded as an approximation to the average frequency of the Pulse, at the several Ages specified in it, taking equal numbers of Males and Females:

\begin{tabular}{|c|c|c|}
\hline $\begin{array}{l}\text { Beats } \\
\text { r minute. }\end{array}$ & & $\begin{array}{l}\text { Beats } \\
\text { per minute. }\end{array}$ \\
\hline $140-150$ & From the 7 th to the 14 th year, & . $80-90$ \\
\hline $130-140$ & the 14 th to the elst year, & $75-8$ \\
\hline $115-130$ & From the 21 st to the 60 th year, & $70-7$ \\
\hline $\begin{array}{r}100-115 \\
95-105\end{array}$ & Old age, ${ }^{2}$. & \\
\hline
\end{tabular}

In the foetus in utero, Newly-born infant, During the 1st year, . During the 2 d year,. During the 34 year, .

$95-105$

$b$. The difference caused by Sex appears from the inquiries of Dr. Guy, ${ }^{3}$ to be such that the pulse of the adult Female is more frequent than the pulse of the adult Male, at the same mean age, by from 10 to 14 beats in a minute.

$c$. The influence of Stature is affirmed by Volknann to be tolerably well defined. The pulse being coteris paribus less frequent as the stature is greater; so that if the pulse of a man of $5 \frac{1}{2}$ feet high were 70 per minute, that of a man of 6 feet would be 66.7 , and that of a man of 5 feet 73.8 .

d. The effect of Muscular Exertion in raising the pulse is well known; as is also the fact, which is one exemplification of it, that the pulse varies considerably with the posture of the body. The amount of this variation has been made the subject of extensive inquiry by Dr. Guy; aut the following are his results. In 100 healthy Males, of the mean age of 27 years, in a state of rest, the difference between standing and siting was 10 beats, or about $\frac{1}{8}$ th of the whole number of beats per minute; the difference between sitting and lying was 5 beats, or $\frac{1}{3}$ th of the whole; and the difference between standing and lying was 15 beats, or $\frac{1}{5}$ th of the whole. In 50 healthy Females of the sane mean age, the difference between standing and sitting

1 Arehiv f. Phys. Heilk., 1853, t. xii, p. 133.

2 The rise in the average frequency of the pulse in very advaneed life, eontrary to the prevalent notion, has been determined by the observations of Levret and Mitivié (De la Fréquence des Pouls chez les Aliénés), Dr. Pennoek (Amer. Journ. of Med. Sei., July, 1847), and Prof. Volkmann (Op. eit., p. 427).

3 Guy's Hospital Reports, vol. iii, p. 312; and Cyelop. of Anat. and Physiol., vol. iv, Art. Pulse. 
was 7 beats, or $\frac{1}{13}$ th of the whole; that between sitting and lying was 4 , or $\frac{1}{2^{4}}$ th of the whole; and that between standing and lying was 11 , or $\frac{1}{8}$ th of the whole. Dr. Ed. Smith has made similar and very extender observations on Adults in Phthisis and on Children in health; and conjoined with them the influence of period of the day. He found in Phthisis, at 8 A.M., the increase, on assuming the sitting and standing postures, was in each case 10 pulsations per minute, but at 4 P.м. it was reduced to 7 , and on the whole a verage there was an increase of $8 \frac{1}{2}$ pulsations in each posture. In healthy Children, at 8 A.M., 12 (noon), 5 P.Mr., and 8 P.M., the increase in the sitting posture was $12: 9: 7.3: 3.5$ pulsations, whilst in the standing posture it was $27: 14.6: 12: 10$ pulsations per minute: results which seemed to show that the irritability of the heart, augmented by the rest and quiescence of sleep, undergoes a gradual diminution through the day. In both sexes, the effect produced by change of posture increases with the usual frequency of the pulse, whilst the exceptions to the general rule are more numerous, as the pulse is less frequent. The variation is temporarily increased by the muscular effort, involved in the absolute change of the posture; and it is only by the use of a revolving board, by which the position of the body can be altered, without any exertion on the part of the subject of the observation, that correct results can be obtained. That the difference between standing and sitting should be greater than that between sitting and lying, is what we should expect, when we compare the amount of muscular effort required in the maintenance of the two former positions respectively. A different explanation has, however, been offered by Ludwig, who considers that the slowing of the pulse which occurs in the recumbent position is due to excitation of the vagal roots from increased blood-pressure in the medulla, and Dr. Brunton has observed that if whilst in the recumbent position the head be hold much lower than the body the pulse becomes greatly accelerated, possibly from cxcitation of the accelerator centres in the medulla. It is stated by Lichtenfels and Fröhlich that the alternate contraction and relaxation of any set of muscles has a much greater effect than their simple tonic contraction in increasing the action of the heart. ${ }^{1}$

$e$. The pulse is well known to be nuch accelerater by Mental Excitement, especially by that of the Emotions; it is also quicker during Digestion. The ingestion of warm food produces this effect much more rapidly than cold; and accorling to Burlge, ${ }^{2}$ whilst animal food raises the frequency of the pulse more quickly than vegetable, the effect of the latter is nuch greater and more permanent. Lichtenfels and Fröhlich found that, an hour and a half after hreakfast, the pulse was 13 beats per minute quicker than before, whilst there was only an increase of 9 beats an hour after dimner. 'The pulse was less frequent in vegetarians, however, than in those who fed on animal diet, and was probably less energetic. The ingestion of large quantities of water diminishes the frequency of the pulse (Bocker). Dr. Eit. Smith ascertained the rate at each hour of the 24 hours for 3 days successively in health and for six days in Phthisis. He found that it was never stationary, but that there was a progressive increase after a meal and decrease before a meal, so that there were four maxima and four minima daily. The maxima occurred about two hours after a meal, and were the greatest after breakfast and after tea. The day minima inmediately precerled the meals, and all were nearly cqual. The pulse invariably fell after 9 P.M., so that supper produced but little effect; and the lowest point of the 24 hours was fiom 3 to 5 A.m. There was an increase in the norning with sunlight. The dif-

1 Denk, d. kais. Akad. d. Wissens. zu Wien, 18.j2, t. iii, pt. ii, p. 149.

2 Physiologie, 1861, p. 275. 
ference between the maximum of the day and the maximum of the night anomnted in health to from 14 to 34 pulsations, and in Phthisis to from 22 to 45 pulsations. The increase from that of the night to the breakfast maximum was, on the averagc, 27 pulsations in phthisis. Therc was a eonsiderable increase in ehildren whilst eating. During a fast of 24 hours the variation in the rate was small, but there was an increase during the usual meal hours and an increase at night.

f. The pulse varies also with the Season, and Dr. Ed. Smith has shown by dialy experiments throughout the year, that the rate of pulsation is greater in the Spring and Summer than in the Winter, both in health and Phthisis. In experiments nade upon Frogs, Budge and Calliburcés found that immersion of the exeised Heart or of the hind legs in warm water increased the frequency of the pulse $(\$ 243)$; the same result was obtained after section of the Crural Nerves, or after poisoning by Woorara, showing that it was not effected through the nervous system.

g. Variations in the pressure of the surrounding atmosphere exert a certain, but not very well-ascertained influence on the frequency of the Pulse. Alpine travellers are well acquainted with the increased rapiclity of the pulse which occurs on attaining great heights; but this is probably in great measure attributable to the great muscular exertion previously made. Salvatore 'Tommasi, however, observed an increase of $S$ in the number of his pulsations, after a good night's rest in the Alpi di Susa, at an elevation of between seren and eight thousand feet. ${ }^{2}$ In some experiments performed by Tivenot ${ }^{3}$ on the effects of compressed air, in which the barometer rose from $742 \mathrm{~mm}$. to $1060 \mathrm{~mm}$., the pulse was observed to rise 3.45 beats on an average of 79 . After exposure for an hour and a half to the maximum of pressure it rose to 6.33 beats, and to 7.31 beats on return to the ordinary pressure. In other experiments on the influence of rarefied air, the barometer falliug from 758 to $500 \mathrm{~mm}$., there were observed an increase in the amplitude of the rarlial tracings, as shown by the sphygmograph, indicative of diminution of vascular tension; increased feeling of warmth in the skin, especially of the face; congestion of the conjunctiva; uneasiness in the head, difficulty of thinking, and neuralgic pains in the forehead, neck, and teeth; all whieh symptoms appeared to arise from derivation of the blood to the cutaneous eapilharies. On gradual readmission of the air they soon vanished. Jaminet ${ }^{4}$ had the opportunity of examining the effects of compressed air on many workmen engaged in the construction of the Illinois and St. Louis Bridge over the Mississippi River. In this work the men were exposed to a pressure at one time of $50 \mathrm{lbs}$. to the square inch, exclusive of the $15 \mathrm{lbs}$. of the ordinary ambient atmosphere. It was found necessary at an early period to construct an air-lock or intermediate room, where the passage into air of ordinary pressure could be gradually effected, otherwise most serious symptoms, great muscular exhaustion, headache, cpigastric pain, sickness, paralysis, himorrhage, and even death resulted. M. Jaminet found an increased firequency of the pulse and respiration during the first few minutes, the pulse rising about 15 beats above the normal; but after remaining in the air-chambers for two hours, and whilst still exposed to the action of the increased pressure, the pulse fell about 15 beats below the normal. On issuing into the open air the pulse again rose to 15 or 20 beats above the normal, and slowly in the course of an hour or two returned to its usual state.

1 Physiologie, 1861, p. 272.

2 Fisiolngia, 1861, p. 244.

3 Virchow's Archiv, xxxiv, p. 515. See also the Essays of Buequoy and Pravaz, on this subject.

4 A. Jaminet, On the Physical Effects of Compressed Air on Man, etc. (Pamphlet) 1871, pp. 135. 
Glaisher, in his scientific balloon ascents (see his article on Aeronauties in the Encyclopadia Britannica, 9th edit., 1875, p. 197), found that the pulse, which was 76 before starting, inereased considerably at high altitudes, being 90 at 10,000 feet, 100 at 20,000 feet, and 110 at greater heights.

249. It may be advisable briefly to sum up the cireumstanees affecting the frequeney of the heart's aetion. As has already been pointed out, the heart not only possesses an internal system of ganglia and nerves by which its movements ean be maintained and regulated for some time after exeision from the body, but it is also under the control of centres situated in the medulla oblongata; and as there is reason for believing that there are both aecelerating and inhibitory centres in the heart and in the medulla, it is obvious that great diffieulty must exist in detcrmining the canse of any partieular variation in the frequency of its beats that may be observed. IVe have, however, evidenee that the heart may be influenced-

A. By eonditions affecting the intracardiac motor ganglia, whieh inay be (1) excited, and the frequeney of the pulsations inereased-a, by heat, $b$, by mechanical, chemical, and cleetrical exeitation, $c$, by increased blood-pressure, whieh is essentially a mechanieal irritant, $d$, by various poisons ; or (2), depressed, and the pulsations. lowered- $a$, by cold, $b$, by diminishech bloodpressure; $e$, by certain poisons, as ehloral.

B. By eonditions affeeting the intracardiac inhibitory ganglia, these being stimulated and the heart slowed or stopper in diastole by certain poisons (Muscarin) and paralyzed by others (Atropin).

c. By eonditions affecting the intracardiac accelerator ganglia, leading to increased frequeney of action. At present these cannot be satisfactorily distinguished from those affecting the intracardiac motor ganglia.

D. By conditions affeeting the eardiae inhibitory centres in the Medulla oblongata, sueh as increased blood-pressure, which acts directly upon them, or by irritation of the depressor nerve, or of various other sensory nerves, which act upon them in a reflex manner, or by the action of poisons (Digitalis), all of whieh exeite these eentres and cause slowing of the heart's aetion.

E. By certain conditions affecting the accelerator centres in the medulla, as diminished blood-pressure, mental processes, the aetion of poisons. They may also probably be excited in a reflex manner. It will be seen from the above that eertain conditions, inereased blood-pressure for example, exerts a double action on the cardiae norves. On the one hand, it excites the heart to inereased frequeney of action by direct irritation of its motor ganglia through filaments distributed to the Endoeardium; on the other hand, it stimulates the vagal centres in the Medulla, and thus causes slowing of the heart, the aetual result in any given case being dependent upon the preponderating influence of the cardiae motor or medullary inhibitory eentres. Usually the medullary centres are strongest, and inereased blood-pressure eauses slowing of the heart; but if the vagi be divided, so that they can no longer act on the heart, increased blood-pressure stimulates the heart to more rapid action. The increased rapidity of the pulse observed by $\mathrm{Asp}$ to follow exeitation of the central extremity of the divided spinal cord has not been found to be constant by Dittmar, ${ }^{1}$ the variation being probably dependent upon the complicated effects of the increased blood-pressure, which the latter experimenter has shown results from this operation. 


\section{Movement of the Blood in the Arteries.}

250. The Blood propelled from the Heart is distributerl to the body in general by a system of Arterics, which may be likened in its arrangenicnt to the trunk and branches of a tree, except that very frequent communications or anastomoses exist anong these branches, so that, by continual subdivision and inosculation, their distribution comes more and more to resemble the capillary network in which they terminate (Fig. 129). Although

F1G. 129.

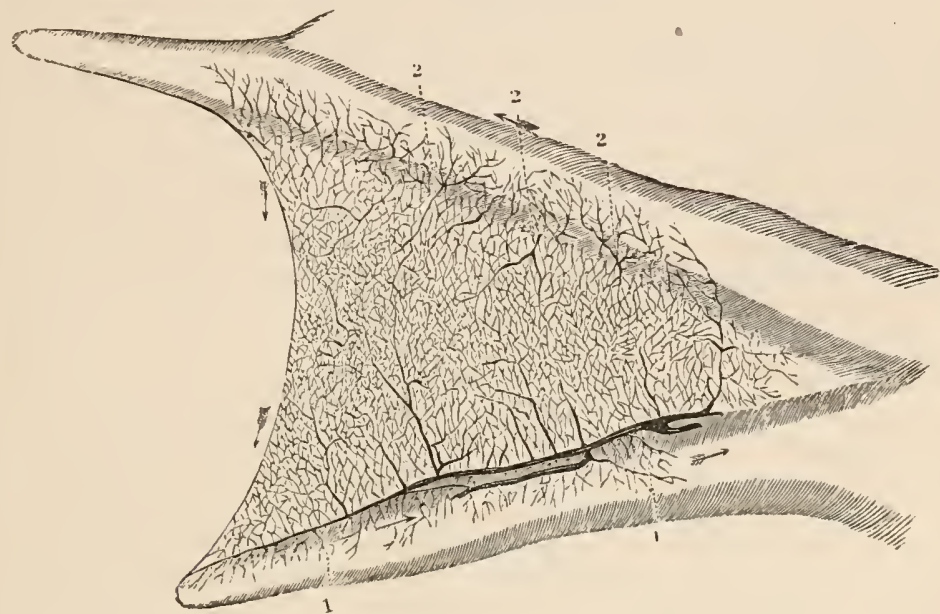

Web of Frog's foot, stretching between two toes, magnified three diameters: showing the bloodvessels, and their anastomoses : 1,1 , veins; $2,2,2$, arteries.

the diameters of the branches, at each subdivision, together exceed that of the trunk, yet there is but little difference in their respective areas. What difference docs exist, however, is with few exceptions, in favor of the branches; and thus it happens that there is a gradual increase in the capacity of the arterial system from its centre towards the capillaries, whose capacity is many times greater. The Arteries exert a most important influence upon the movement of blood through them, in virtue of the physical and vital properties of their walls, or rather of their middle or fibrous coat, which alone is possessed of contractile properties. We find in this coat a layer of yellow Elastic tissue, which is much thicker in the larger arteries, in proportion to their size, than in the smaller. On the inside of this is a layer of annular fibres composed of Muscular fibre-cells, mingled with areolar tissue; ${ }^{1}$ the muscular element being much more abundant in the smaller arteries, than in the larger. To the former tissue is due the simple elasticity ${ }^{2}$ of the arte-

1 See P'rof. Kölliker's Manual of Human Histology (Sydenham Society's edit.), vol. ii, p. 291, and Handbuch der Gewebelehre, 5 Auflag, p. 583. Eberth in "Strieker's Human and Comp. Hist., Syd. Soc. Trans., 1870, vol. i, Art. Blood vessels.

In some vessels, as in the splenic and umbilical, and in the dorsal artery of the penis, a few longitudinal muscular fibres are found in the external coat, whilst in others, as the renal, hepatic, splenic and crural, longitudinal fibres are found in the internal coat. (Remak, Eberth.)

2 Wündt (Physiologie, 1813, p. 287) finds the coefficient of elasticity of the arteries (i.e., the weight necessary to be applied to double the length of a given piece), to be 1120 grains, and that of the veins 1465 grains. In both sets of vessels the elas- 
rial walls, which is a physical property that persists after death, until a serious change takes place in their composition; whilst to the latter we are to attribute the property which they unquestionably possess (in common with proper muscular tissue), of contracting on the application of a stimulus, so long as their vitality remains. These two endowments are possessed in various degrees, proportional to the respective predominance of the elastic or of the muscular tissue, by the different parts of the Arterial system. Thus, as was justly remarked by Hunter, the elasticity, being the property by which the interrupted force of the Heart is made equable and continuous, is most seen in the large vessels more immediately connected with that organ; whilst on the other hand, the contractility is most observable in the smaller vessels, where it is more required for regulating the flow of blood towards particular organs. With the exception of the capillaries, nerves partly consisting of dark-edged and partly of pale fibres have been demonstrated in all vessels, even in the tunica adventitia of the non-muscular veins of the pia mater. The fibres, ${ }^{1}$ after they have traversed the tunica adventitia, break up into a fine network with here and there ganglionic cells and knots. It is to these ganglionic enlargements that the local contractions of the vessels are due, which take place when the main trunks from the sympathetics which supply them have been divided. They appear to be easily excitable, but soon exhausted.2

251. The chief purpose served by the Elasticity of the Arteries, is one of a purely physical character; its effect being to convert the intermitting impulses, which the blood receives from the heart, into a continuous current. The former are very evident in the larger trunks; but they diminish with the subdivision of these, until they entirely disappear in the capillaries, in which the strean is usually equable or nearly so. If a powerful force-pump were made to inject water, by successive strokes, into a system of tubes with unyielding walls, the flow of fluid at the farther extremities of thesc tubes would be as much interrupted as its entrance into them. But if the airvessel (like that of a fire-engine) were placed at their commencement, the flow would be in a great degree equalized; since a part of the force of each stroke would be spent upon the compression of the air includer in it; and this force would be restored by the elasticity of the air during the interval, which would propel the stream, until directly renewed by the next impulse. A much closer imitation of the natural apparatus would be afforded by a pipe which had elastic walls of its own; thus if water were forced by a syringe into a long tube of caoutchonc, for example, the stream would be equalized beforc it had proceeded far. 'This effect is found to be accomplished, at any point of the Arterial circulation, in a degree proportionate to its distance from the Heart; and in this mode it is, that the intermitting force of the ventricular contraction is almost equably distributed over the whole of the interval between one systole and another, by the contraction of the elastic tubes in the dilatation of which it was at first expended. Another effect of this elasticity is to distribute the pressure of the blood upon the walls of the arteries nuch more equally than would be the case if they formed a system of rigid tubes.

252. The contractility of the arteries fulfils several important purposes. It is the principal means by which hemorrhage from the smaller vessels is arrested after injury, and even in the case of so large an artery as the temporal,

ticity is greater in the longitudinal than in the transverse direction. The eoeflicient of clasticity of the aorta, taking the mean of several experiments, is 927 grains in the direction of its length and 588 grains in the direction of its breadth, whilst that of the jugular vein is 1503 grains in the former and $72.5 \mathrm{grains}$ in the latter direction.

1 Eberth, in Stricker's Hum. and Compar. IIistol., Syd. Soc. Transl., vol. i, p. 266.

${ }^{2}$ See Mohammed Lffendi IIafiz, in Ludwig's Arbeiten, 1871, Bd. v, p. 95. 
the complete division of the tube is often the readiest means of checking the flow of blood. Secondly, under the influenee of the nervous system it seems to regulate the supply of blood to the different tissues and organs of the body in accordance with the variations of their functional activity. And lastly, it enables the whole vascular system to accommodate itsclf to the very varying amount of fluid it contains at different times, so that the pressure under which it is distributed through the body is approximately the sanc. It may be readily demonstrated by experiment. Thus, when a ligature is plateed upon an artery in a living animal, the part of the artery beyond the ligature becones gradually smaller, and is empticd to a certain degree, if not completely, of the blood it contained. Again, when part of an artery in a living animal is isolated by means of two ligatures, and is punctured, the blood issues from the orifice, and the inclosed portion of the artery is almost completely cmptied of its contents. This contraction is much greater than could be accounted for by the simple elasticity of the tissue; and is more decided in small than in large vessels. The empty condition of the arteries, generally found within a short time after death, seems to be in part due to the samc cause; since their calibre is usually much diminished, and is sometimes completely obliterated. A remarkable example of the same slow contraction, is that which takes place in the end of the upper portion of an arterial trunk, when the passage of blood through it is interrupted by a ligature; for the current of blood then passes off by the nearest lateral branch, and the tube of the artery shrivels and soon becomes impervious from the point at which the ligature is applied back to the origin of that branch. This last fact is important, as proving how little influence the vis a tergo possesses over the calibre of arterial tubes, since without any interruption to the pressure of blood occasioned by it the tube becomes impervious. Other evidence of the contractility of the arteries may be readily obtained by observing the effects of various stimuli, mechanical, chemical, or electrical, upon the vesscls of a transparent membrane, such as the bat's wing or the frog's foot. Thus if, whilst we watch the movement of blood in a companion artery and vein, we draw the point of a fine needle across them three or four times, without apparently injuring them or the membrane over them, they will both presently contract and close; then, after remaining for a few minutes in the contracted state, they will begin again to dilate, and will gradually increase in diameter until they acquire a larger size than before the stimulus was applied. When in this condition, they will not again contract on the same stinulus as before; the needle may now be drawn across them much oftener and more forcibly, but no contraction ensues, or only a trivial one which is quickly followed by dilatation ; with a stronger stimulus, however, such as that of great heat, they will again contract and close, and such contraction may last more than a day, before the vessels again open and permit the flow of blood through them. The comparative effects of chemical and other stimuli have been especially studied by Mr. Wharton Jones, ${ }^{2}$ by whom they are thus classified. (1.) Constriction may slowly take place, and be slowly succeeded by the normal wid th; this is the action of the sulphate of atropia. (2.) Constriction may quickly take place, and be soon succeeded by the normal width, or a width not much

1 See Mr. Puget's Lectures on Surgical Pathology, vol. i, pp. 302, 303.-As Mr. Paget justly remarks, it is from the mechanical stimulus of the knife, that small divided vessels contract and close, so as speedily to cease bleeding; but this contraction lasts only for a time; and hrmorrhage would commence on their dilatation, if their mouths were not sealed by coagula of blood or lymph. When secondary hæmorrhage does occur from want of such coagulation, it is most effectually controlled by the application of such stimuli as, like the actual cautery, induce a more prolonged contraction of the vessels.

2 Guy's Hospital Reports for 1850, pp. 8, 9. 
exceeding the normal; this is the result of the moderate application of cold, and of mechanical and galvanic irritation. (3.) Constriction either does not take place at all, or when it does, it very rapidly gives place to great dilatation; this is the effect of a weak solution of sulphate of copper, of a strong solution of common salt, of wine, of opium, and of spirit of wine. (4.) Dilatation, preceded or not by momentary constriction, may slowly yield to constriction, which remains permanent; this is the effect of sulphate of copper, applied in strong solution, or in substance.-The electric stimulus is most effectual when applied by the magneto-galvanic apparatus. When the minute arteries of the mesentery of frogs, between $\frac{1}{7}$ th and $\frac{1}{17}$ th of a Paris line in diameter, are thus stimulated, they do not immediately respond to the irritation, but begin to contract after a few seconds, so that their diameter, in from five to ten seconds, is diminisherl by a third, and their sectional area consequently reduced to about half; by a continued application of the stimulus, the calibre is so much reduced, that only a single row of corpuscles can pass; and at last the vessels become completely closed, and the current of blood arrested, the original conditions being gradually restored on the cessation of the electric current (Weber). ${ }^{1}$ - Further, it has been ascertained by the experiments of Poiseuille (which confirm those of John Hunter), that when an artery is dilated by fluid injected into it, it reacts with a force superior to the distending inpulse; and that, if a portion of an artery from an animal recently dead (in which the contractility is preserved), and one from an animal that has been dead some days (in which nothing but the elasticity remains), be distended with an equal force, the former becomes much more contracted than the latter, after the distending force is removed.

253. There is no sufficient proof that the contractility of the arteries enables them to exert a propulsive action in any marked degree supplementary to that of the Heart; and yet, looking to the general facts already stated, as to the diffusion of the propulsive power through the arterial trunks in many of the lower animals, their cxperimentally proved reaction upon a distending force, and to the circumstance, that a kind of rhythmical action, occurring seven or eight times in the minute, has been observed by Wharton Jones in the vessels of the Bat, by Schiff in those of the ear of the Rabbit, by Lovén ${ }^{2}$ and Riegel ${ }^{3}$ in the saphenous artery of the Rabbit, which last contracts once or twice in the minute, and by Saviotti ${ }^{4}$ and Gunning ${ }^{5}$ in the vessels of the web of the foot in the Frog, it does not seem by any means improbable that some such power should be preserved, even where there is the greatest concentration of the propulsive force in the muscular walls of the Heart. It is important to notice that these systolic and diastolic movements of the vessels are not simultaneous on opposite sides of the body, and that they are quite independent of cerebro-spinal innervation, since they continuc even when the whole of the cerebro-spinal and sympathetic nerves have been divided, and even after division of the spinal cord itself in the neck. ${ }^{6}$

254. The infuence of the Nervous system upon the calibre of the vessels, which might be inferred to exist from the act of blushing and other analogous phenomena, is capable of experimental demonstration. Thus evidence has been afforded by the experiments of Dr. Aug. Waller that the application of galvanism to the sympathetic trunk on either side of the neck causes con-

1 Maller's Arehiv, 1847.

3 lingrel, P'flüger's A rehiv, 1871.

5 Gunning, Onderzoeckingen, etc., Utrecht, 1857.

6 See Brunton, in Ludwigr's A rbeiten, Bd. iv, 1870, p. 106.

7 See Comptes Rendus, 1853 , tom. xxxvi, p. 378.- Of this remarkable experiment, which first demonstrated the influence of the Sympathetic Nerve upon the smaller arteries, the Author, by the kindness of Dr. Waller, has himself been a witness. 
traction of the minute arteries on that side of the face, which can be well seen in those distributed to the external ear of the cat or rabbit. $A$ s in the case of the Heart, the nerves supplying the bloodvessels appear to have two centres, one of which is represented by the small ganglia distributed in the walls of the vessels, whilst the other is represented by a centre or a serics of centres, situated in the medulla oblongata and spinal cord. The activity of the local ganglia is rendered evident by the contractions that ma be produced by direct irritation after division of all the nerves supplying a part. 'The central ganglia governing the contraction of the vessels have received much attention during the last few years, ${ }^{1}$ the general result of which has been to show that an important centre is situated in the medulla oblongata, its lower limit in rabbits bcing about one-eightl of an inch above the level of the apex of the calamus scriptorius, whilst the upper limit is near the upper border of the corpus trapezoides, just below the corpora quadrigemina (Ludwig and Thiry, Owsjannikow and Dittmar). It occupies the antero-lateral part of the medulia oblongata on each side, and corresponds to the continuation through the medulla oblongata of the anterior part of the spinal cord. Brown-Séquard," Goltz, and others have pointed out that in some animals (Dog) the vasomotor centre or centres must extend for some distance down the spinal cord, since on division of the cord in the cervical region, which is followed by general dilatation of the vessels of the borly, section of such a nerve as the sciatic is followed by still further dilatation of the vessels of the posterior limbs accompanied by elevation of temperature. [Schlesinger ${ }^{3}$ found that after section of the spinal cord in the neck, strychnia elevated the bloodpressure very decidedly. He also established that it was due to an irritation of the vaso-motor centres situated in the cord. Under the direction of Dr. I. Ott, Dr. IV. H. Klapp has experimented on cats, and seen a similar rise of pressure in the Physiological Laboratory of the University of Pennsylvania.] Some experiments of Cyon seem also to show that the vaso-motor centre extends into the brain above the plane of the medulla oblongata ; still the most important centre is certainly placed in the medulla oblongata. This centre exercises a permanent tonic influence on all the smaller vessels, and especially upon the smaller arteries of the body, maintaining their muscular fibres in a state of general contraction. It receives centripetal or afferent, and gives off efferent or centrifugal fibres. Both sets of fibres, as Miescher ${ }^{4}$ and Nawrocki ${ }^{5}$ have shown, run in the lateral columns of the spinal cord, and enter into or issue from it with the roots of the several spinal nerves, at least as low down as the eleventh dorsal nerve. They run partly in the sympathetic cords, and partly with the branches of the spinal nerves. Thus the cervical cord

I Wiener Sitz-ber., Bd. xlix, and Zeit. f. Rat. Med., Bel i. Fur other papers on the infuenee of the nerves on the bloodvessels, see besides many of those mentioned in the note on p. 316, the essays of Ludwigr in conjunction with Cynu, Lovén, $\mathrm{A}$ sp, Hatiz, Owsjanniliow (1871), and Dittmar (1873), in Ludwig's Arbeiten, 1866-73, and Berichte der Sülis. Gesell., 1866-71. Also the papers of v. Bezold in conjunction with Stezinsliy, Bever, Breymann, Dreschfeld and Gescheidlen, in the Untersuch. aus der Plyyiol. Labor. zu WVürburg; Heidenhain, in Pflüger's Archiv, Bd. iii, iv, and v.; Röver, Nerven einfluss aut. d. Gefisse, 1869; Thiry and Kuwalewsliy, Centralblatt, 18t8, 1. 579; Saviotti, Virchow's Archiv, Bd. 1, 1870, p. 592; Budge, Plüger's Alchiv, 1872, p. 303 ; Goltz, Pflüger's Archiv, Bd viii, p. 460; Putzrys and Tarelianoff, Centralblatt, 1874, p. 641; Putnam, Boston Med and surgs. Journal, 1870 , p. 469 .

2 Juurnal de la Physiologie, t. i, 1858, p. 209. See also Vulpian, Leçons sur l'Appareil Vaso-moteur, 1875, p. 266; and Cyon, Hemmungen und Erreg, in Central Syst. d. Gefüssnerven, Bull. d. Petersb. Akad., Bd. xvi, p 97, and Centrilblatt, 1871, r. 407 .

3 [Wiener Med Jahrbuche, 1874.]

4 Ludwig's Arbeiten, 1870, p. 172.

5 Idem, 1871, 1. 89. 
of the sympathetic contains the vaso-motor nerves of the skin of the head, the conjunctiva, and salivary glands. The splanchnics, which are exceedingly important vaso-motor nerves, supply the very dilatable vessels of the abdominal viscera. The vaso-motor nerves for the upper extremities pass from the roots of the middle dorsal nerve to the sympathetic cord, and thus reach the first dorsal ganglion, from whence they pass into the brachial plexus (E. Cyon). Those for the lower extremitics proceed from the rami communicantes of the sympathetic into the anterior roots of the spinal nerves. ${ }^{1}$ The vaso-motor centre is capable of being excited and of being depressed. In the former case the smaller arteries either of a definite region or of the whole body contract, and the blood-pressure rises. In the latter case the smaller arteries of a territory of variable extent dilate or relax and the blood-pressure falls. This is usually accompanied by the accumulation of blood in the veins of the abdominal viscera. The excitation of the centre indicated by exaltation of the blood-pressure in the arteries can be effected by the circulation through its vessels of blood charged with carbonic acid or deficient in oxygen, and in a reflex manner by the irritation of almost any of the sensory nerves, as those of the skin, ${ }^{2}$ peritoneal layer of the stomach, ${ }^{3}$ dura mater, ${ }^{4}$ olfactory or nasal nerves ${ }^{5}$ (providing the brain is mninjured, Cyon); also by irritation of the cervical sympathetic nerve ${ }^{6}$ and by certain poisons, amongst which digitalis may be particularly mentioned. ${ }^{7}$ [Some poisons like thebain have the property of exciting the vaso-motor centre to increased activity, but unlike strychnia thebain does not act on the vasomotor centres situated in the spinal cord. $]^{8}$ The vaso-motor centre can be depresserl, or its action inhibited, by irritation of the depressor nerve of the vagus, and fibres having a similar depressing action run in the vagus below the origin of the nervous depressor from the vagus. The term "Traube's curves" is applied to the rhythmical variations of arterial pressure which were observed by Traube to occur iu animals under the influence of TVoorara during the gradual rise of pressure that arises after complete cessation of the respiratory movements and section of both vagi. Kowalewsky and Adamük and Hering have shown that the rise and fall of pressure constituting Traube's curves are independent alike of variations in the heart's action, of bloodpressure, and of asphyxia, and that they are referable to the circulation of non-arterialized blood through the respiratory centres, and to variations in

1 The nerves of the vessels supplying a muscle do not al ways aecompany the motor trunks of that musele. Thus the biceps femoris reeeives its motor nerves from the sacral plexus, but its vaso-motor nerves come from the lumbar plexus through the erural nerve.

2 Lovén.

3 Mayer and Pribram, Sitz.-ber. d. Wien. Akad., Bd. Ixri, 1872.

${ }^{4}$ Ludwig aud Dittmar, Ludwig's A rbeiten, 1870, p. 4.

5 Hering and Kratschmer; lutherford, Journal of Anat. and Phys., 1873, vol, vii, p. 283 ; Brown-Séquard, Arehiv. of Sirientific Meel., 1873, p. 90.

- Aubert and Riveven, Kritische Untersuch., etc. Rostock, 1869.

7 Bruston and Mayer, Journ. of Anat and Plyss, Nov. 1872. Callenfels (Zeits. f. Rat. Med., 1855, Bd. vii, 1. 191) las noticed eontractions of vessels of one ear of a rabbit oceur when the opposite ear wis pinched; and Brown-Séquard (Journ de la Physiol, 1858, p. 504) observed that on immersion of one hand in cold water, the temperature of the other uniformly fell, iu one instanee as mueh as $21^{\circ} \mathrm{F}$. : a result whieh may porhaps serve to explain the effects of the application of eold in controlling hamorrhage when applied to some distant part of the body.

${ }^{8}$ [I. Oti, Physioluny, Act. of Thebain, Boston MIed. and Surg. Journal.]

9 Allgemein. Mrd. Centralzeitung, Nos 9, 30, 89, 99, and Centralblatt, 1865, p. 881. See also 'Thiry, Sitz.-ber. d. Wien. Akad., 1864, p 32; Kowalewsky and Adanüi, Centralbutt, j868, p. 545; Itering, Sitz.-ber. d. k. Akad. zu Wien., Bd. 1x, 1869; Sandersoll, in Handbook to Phys. Lab., p. 317, 1873. 
the tonc of the ressels. There are certain nerves the irritation of which eauses dilutation of the vessels to which they are distributerl. This is the are with the chorda tympani and with the nervi erigentes of the penis (Loven), and there is considerable difficulty in explaining their action. The most reasonable view is that of Vulpian, who supposes that there are inhihitory centres in the walls of the vessels, which, when irritated, restrain or abolish the tonic influence of the vaso-motor centre, and dilatation is the inmediate consequence. ${ }^{1}$ The morle in which variations of pressure affect the pulie lias already been explained, \$249.

255. The distension of the Arteries that is consequent upon the intermittent injection of blood into their trunks gives rise to the pulsation, which is perceptible to the touch in all but the smallest arteries, and which is visible to the eye when they are exposed. It would secm to the touch, as if this were chiefly effected by an increase of diameter, and the experiments of Volkmann (Hämodynamik) led liim to belicve that the transverse dilatation is greater than the longitulinal; but these experiments were marle unler conditions so different from those of the living artery, that but little weight can be attached to them. It is to be remembered, however, that every increase in lengtl augments the capacity in only a simple ratio; thus a tube of 21 inches in length will only coutain one-twentieth more than a tube of 20 inches loug, of the same diameter. On the other hand, every increase in diameter augments the capacity of the tube in the ratio of the square of that increase; thus the capacity of a tube of 21 lines in diameter will be to that of a tube of 20 lines, as $441: 400$, or one-tenth more. Consequently, supposing the increase of capacity to take place equally in both directions, the increase in longitudinal dimension will be fir more apparent than the transverse enlargement. The total increase of capacity was estimated by Flourens, from experiments upon the carotid artery, at about $\frac{1}{2} \mathrm{r} l$ part; but it is affirmed by Volkmann² that this must not be considered by any means a constant ratio, since it varies in different arteries, and in the same artery under different circumstances. It has also been attributed to elongation of the artery, which was supposed to be lifted from its bed at each pulsation, and, when previously straight, to become enrved; the impression nade upon the finger by such displacement, not being distirguishable from that which would result from the dilatation of the tube in diameter. A very obvious example of this upheaval is seen in the prominent temporal artery of' an old person. 'The real cause of the pulse, however, may be considered to be the return of the artery to a cylindrical form under increased internal pressure, after it has been more or less flattened by the pressure of the finger against an unyielding structure, while in a comparatively flaceid condition.The fluctuations of the Pulse in the living body without exposure of the arterv can be rendered apparent by the use of an instrument originally invented by Vierordt, but materially morlificd and improved by Marey, termed the Sphromograph. The general arrangement of the instrument is shown in Fig. 130, where the part B B is applied to the forearm, whilst the pressure on the artery is effected by a very light steel spring, terminating in a

1 Vulpian, Leçon: sur l'Appareil Vrasu-moteur, 1875, p. 177 et seq. Other views that have bren advanced are: 1 . That of schiff, who belleves it to be possible that certain nerves may, instead of cauning contraction, cause elongation of muscular tibres. 2. That which attributes the ditatation of the arteries to increased bloudpressure caused by contraction of the veins; but this is enntrary to fact, the veins being dilated in all cases. 3. That of M. Legros (Thèse, 1873), who regards active conerestion as the result of inereased peristaltic action of the vessels. 4. That it is due to increased attraction of the tissues for the bloul, so that a suction force or vis a fronte is established.

2 Up. cit., chap. xiv. 
small plate of ivory $\mathrm{R}$ eapable of elevation or depression by the serew $\mathrm{V}$. The long arm of the wooden lever $\mathrm{L}$ terminates in a fine point tonehing the plate of smoked glass, or glazed card $P$, which is made to move gradually forwards by elockwork in the box II. The immediate deseent of the lever after its elevation is accomplished by the very delicate spring at $r{ }^{\prime}$ [Mr. Keyt, of Cineinnati, has substituted for the elastic spring of Marey, an elastic menibrane and water to communicate the movements of the artery to the tracing lever. This instrument ean also be used as a cardiograph. $\left.{ }^{2}\right]$ A modi-

FIG. 130.

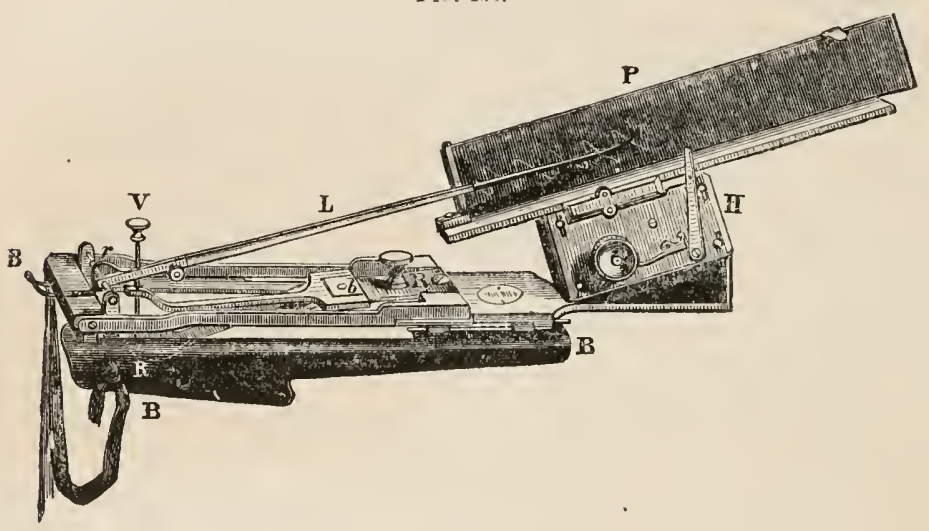

Mares's Sphygmograph.

fication of Marey's instrument is show'n in Fig. 131, by which the pressure exerted on the artery can be approximatively measured. The traeings made by either of these instruments show that under ordinary cireumstances the period of aseent or of inerease in the tension of the arterial walls is rapid ; whilst the pcriod of deerease, during which the elasticity of the larger arteries is acting, is eomparatively slow and prolonged. The line representing the period of ascent is straight, but that of deseent presents several seeondary undulations, which are not invariably present, vary much in their form and amplitude, and are partly natural and partly artificial, that is to say, due to defects of the instrument. 'The first of these has been termed by Maliomed and Galabin the tidal wave, though they interpret it differently; Mr. Mahomed considering it to be a wave of distension of the arterial walls, following the primary wave, which he regards as a vibration of the blood column, travelling with great rapidity, whilst Mr. Galabin, probably more correctly, loolds it to be due to an oscillation of the Sphygmograph, as a whole, caused by the inertia of the instrument. For when the spring employed in some forms of the Sphygmograph to depress the long lever is absent, no such waves are seen; whilst if it be prescut the tidal wave is sometimes broken into two, and if the spring has a short period of vibration a series of undula-

1 Mach, Sitzungsbericht d. k. Akud. zu Wien, 1868, p. 5i), Baker, of Hohorn, Dr. Foster, of Birmingham, Jomrnal of Anat. and Phys., ser. ii, vol. i, p. 62, BurdonSanderson, The Sphygmograph (pamplitet), Mahomed, Med. Times and Gazette, 1872, have all suggested modifications in the construction of the spring and lever. For various explanations of traciags see in addition to works quoted above, $\mathrm{A} . \mathrm{H}$. Garrod, in Jumn. of $A$ nat and l'hysiol, vol, vii, 1873, p. 98, Galabin, in idem, vol. viii, p. i, 1874; and Balthazar Foster, in Aitken's Practice of Medicine.

${ }^{2}$ [New York Mad. Journal, Janmary, 18i6.] 
tions may make their appearance. The presence of the tidal wave in a Sphygmographic tracing indicates, according to Galabin, high tension, diminished elasticity, and long, laborious action of the heart. It is typically seen in cases of Bright's disease. $\Lambda$ second wave that appears in the period of descent is termed the dicrotic wave. The cause of this is not accurately known. It has been held to be a reflection from the periphery, but tracings
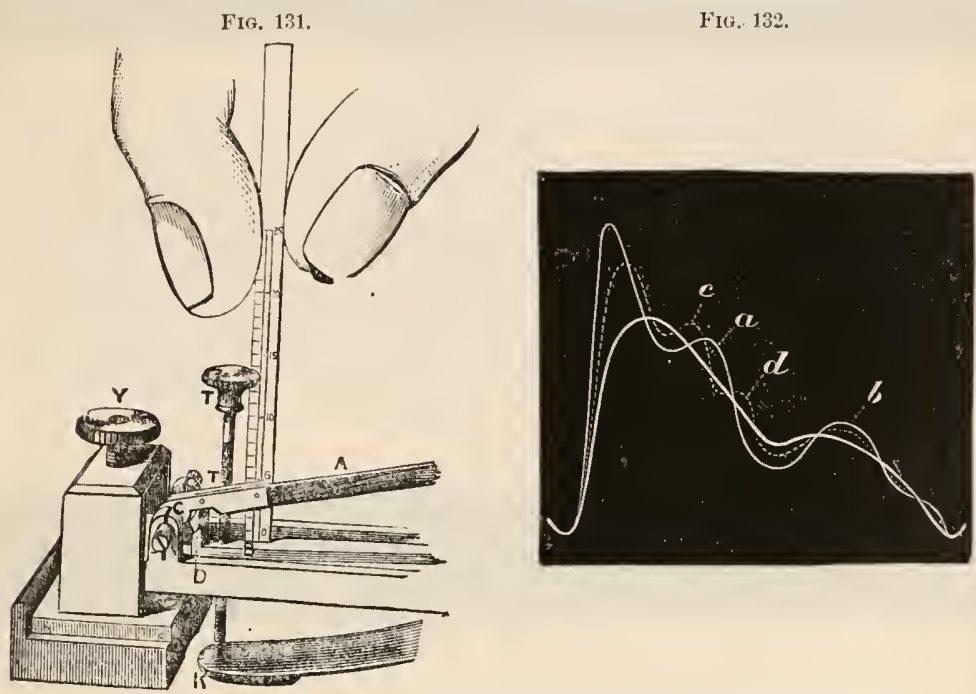

FIG. 131.-This figure shows a modification of Marey's Sphygmograph, by means of which the amount of pressure exerted on the artery can be approximatively measured. A, registering lever; $\mathrm{D}$, knife-edge on which it rests; $\mathbf{K}$, spring placed over the artery; $T$, screw regulating the pressure, the amount of which is ascertained by the index $\mathrm{B}$.

FIG, 132.-Diagram to illustrate the relation of the sphygmograplic tracing to the true pulse wave. The thick line represents the true pulsc wave, the thin line the sphygmographic tracing, the dotted line the tracing drawn by a sphymograph having a secondary spring to kcep down the lever. $a$, tidal or "first secondary wave ;" $b$, dicrotic or "prineipal secondary wave;" $c, d$, two small waves into which the tidal wave may be broken by the action of the secondary spring.

ohtained by Galabin show, that in cases where it is well marked, it is not nearer the primary wave in tracings taken from the foot than in those taken from the femoral artery, and he considers it to be due to the inertia of the arterial walls, the acquired velocity of their expansion with each influx of blood passing a little beyond the point of equilibrium, and again passing within it by recoil, so that a series of oscillations occur about the point of equilibrium. The feebler the tension of the vessels the more marked is the dicrotism of the pulse. It is perfectly obvious that the fulness of the pulse, or in other words the amplitude of the pulsation, is in inverse ratio to the tension of the walls of the vessel; whilst the hardness of the pulse is indicative of arterial tension, and may be produced either by the heart acting with great force and injecting more blood than the arteries can discharge through the capillaries, or by the contraction of the capillaries themselves preventing the escape of the blood from the arteries into the reins. M. Marey has clearly shown how these two conditions of the arterial system may be induced by acting upon the capillaries alone, and either facilitating the passage of the blood through them, or, on the contrary, rendering it more difficult. Thus the tracing obtained by his Sphygmograph, after exposure to a cold bath of one minute's duration, is shown in Fig. 133. It is that of a 
hard pulse, in which there is considerable tension of the arterial wall; for the contraction of the cutaneous capillaries constitutes an obstacle to the passage of the blood from the arteries. 'The line of ascent is accordingly

FIG. 133.

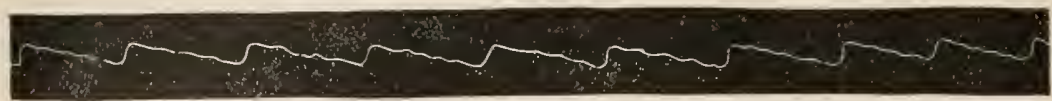

sudden and short, the limit of the elasticity of the vessel being soon reached, and the summit of the curve is rounded; whilst the line of descent is protracted and gradual, the resiliency of the vessel being only capable of reacting slowly on the contained blood, and there is no tendency to dicrotism. On the other hand, Fig. 134 shows the effects of a hot-air bath, and presents the characters of a soft full pulse; a pulse of deficient tension, in which the greater boldness of the curves, their sharper summits, and the marked tendency to dicrotism, may particularly be noticed; as well as the increased frequency of the heart's action, corresponding to the diminished

Fif, 134.

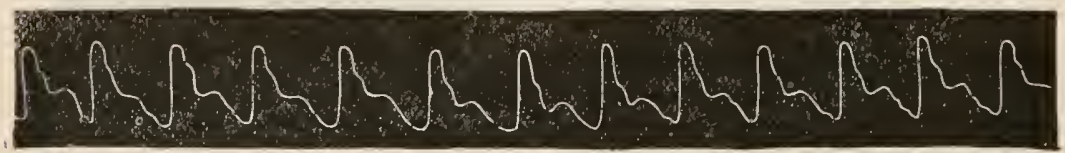

exertion which it has to make in propelling the column of blood through the same vessels. The variations in the curves presented by Sphygmographic tracings have for ages been partially and imperfectly recognized by the tactus eruditus, and depend on the vigor and frequency of the heart's action; the fulness of the bloodvesscls and degree of elasticity of their walls; and upon the state of relaxation or contraction of the smaller arteries. Thus amongst others may be mentioned:

1. The large compressible pulse of fever, in which the rise and fall of the primary wave curve are sudden. The tidal wave is absent, the dicrotic wave large, and the blood-pressure low. Here the heart's action is vigorous, but the smaller arteries and capillaries are rclaxed, allowing the blood injected into them to pass readily into the veins.

2. The large hard pulse of Bright's disease with contracted granular kidney. Here the lreart's action is vigorous, but the smaller vessels are contracted, and their walls less elastic. Hence the blood-pressure is high, the tidal wave large, and distinctly separated with well-marked dicrotic, and cven a third seconclary wave (Galabin).

3. The small hard pulse of peritonitis due to less vigorous action of the heart, with coincident contraction of sualler arteries.

4. The small, soft, and threaty pulse of collapse, in which the heart's action is feeblc, and the vesscls are relaxed, with perhaps diminution of supply of blood.

5. 'The irregular and the intermittent pulse are conditions associated with disease of the heart and disordered cardiac innervation.

256. The mode in which the pulse is propargated through the arteries, is male manifest by the following ingenious experiment devised by M. Marcy. A small cantchouc bag (Fig. 135, s) is fitted with valves which permit the contained fluid to move only in one dircetion, and is comnected with a long elastic tube forming a rude resemblance to the Heart and Arteries. At 
three different points of its length the tube is placed under the control of a Sphygmograph, the levers of which, $l l^{\prime} l^{\prime \prime}$, register their movements on the drum $\mathrm{C}$ in such a manner that thcir tracings may be exactly parallel and

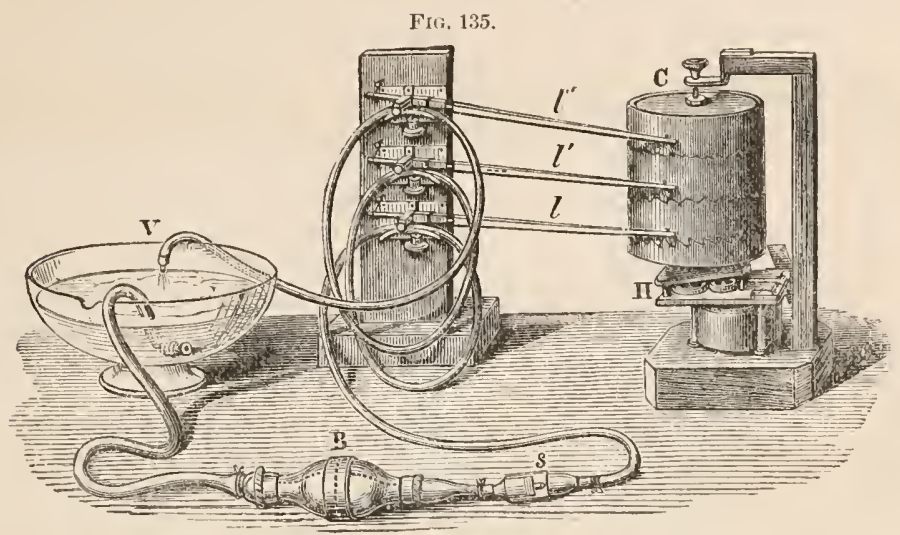

comparable with one another. Fig. 136 shows such a triple tracing after the india-rubber bag has been for a few times rhythmically compressed. It is here evident that, as indicated by the oblique dotted line, the period at which the maximum of tension is attained, is latest in that portion of the

FIG. 136.

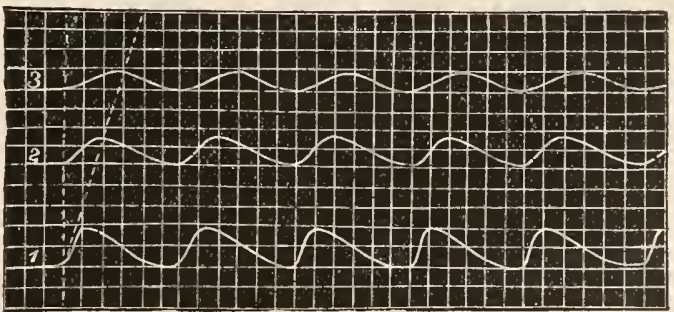

tube which is most distant from the impelling organ, and a certain, though minute retardation occurs in the passage of the wave through the column of liquid. The actual annount of this retardation has been carefully investigated by Czermak, ${ }^{1}$ with the aid of his photo-sphygmograph, in which the fluctuations of a ray of light reflected from a small mirror placed over the radial artery are registered on a screen of prepared photographic collodion. The mean of a series of twenty experiments, showed that the pulse in the radial artery at the wrist was 0.18 sec. earlier than in the dorsal artery of the foot; whilst the shock of the heart occurred 0.159 of a sec. earlier than the pulsation at the wrist, and 0.087 sec. earlier than the pulse in the carotid. It, therefore, takes about $\frac{1}{6}$ th of a second for the primary pulsewave to travel from the heart to the foot, and estimating this distance roughly at five feet, the rate of the pulse-wave is about thirty feet a second, with which Weber's estimate (28.5 feet) closely agrees. The rate of the pulse-wave is, of course, to be carefully distinguished from the velocity of 
the blood itself. (See $\$ 259$.) Again, in the above tracings it may be noticed that the force of the impulse, or the extent of the vertical movenient of the lever, diminishes with increase of distance from the impelling organ, producing the effect which Poiseuille described as "extinction of the wave."

257. Since the blood, like other fluids, is almost completely incompressible, all force applied to it becomes perceptible by movement, or if this be preventerl, by lateral pressure exerted against the sides of the vessels, and these two, the velocity of movement and the lateral pressure, however much each may vary in amount, always together represent the impelling force. The circumstances that chiefly affect the movement or velocity of the blood, independently of variations in the amount of the propelling force, are those which increase or dininish the friction between it and the vascular walls. Thus it will be retarded by diminution of the diameter of the tubes, ${ }^{1}$ or, as was observed by Hunter, by curves, angles or divisions in their course, ${ }^{2}$ or by their rigidlity, ${ }^{3}$ or by increased viscidity in the blood itself; or lastly, by augmentation of its attraction for the tissues, or for the walls of the ressels through which it is coursing. These constitnte the obstacles or resistance to the passage of the blood; and with their increase, if the impelling force remain the same, whilst the velocity of its movement is retarded, the amount of lateral pressure exerted is increased. The effects of diminished resistance in diminishing pressure may be understood from a consideration of Fig. 137.

FIG. 137 .

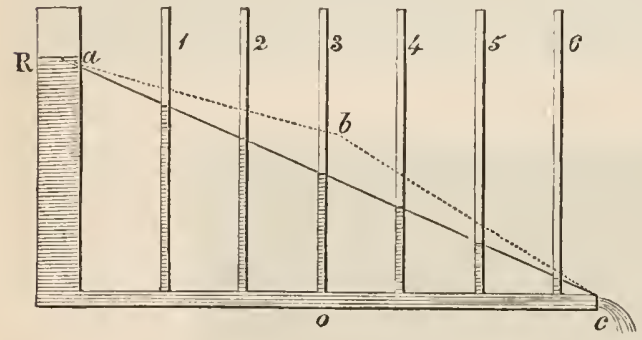

For here the height to which the fluid will rise in the small tubes numbered $1-6$, is the expression of the pressure of the liquid against the walls of the tube $\mathrm{R} o c$ at different points. If the fluid were stationary, from the closure of the orifice $c$, it would, according to a well-known law, rise to the same height in all; hut when a discharge is allowed to take place from $c$,

1 Thus Poiseulle (Mém. de l'Acad. des Sciences Sav. Etrang, t. ix, p. 513 ct seq.) found that the amount of fluid dischurged by small tubes increases, cateris paribus, in proportion to the diameters of these tubes raised to the fourth power; so that a tuhe of $\frac{1}{100}$ th $\mathrm{mm}$. in diameter will discharge 16 times more fluid in a given time, than une of $\frac{1}{20}$ th $^{0} \mathrm{~mm}$. in diameter. The following fucts are worthy of reeollection in connection with the physies of the eirculation :

The circumference of a cylindrieal tube

The sectional area of ditto

The amount of discharge from ditto

And bastly the velocity of the current (See Vierorit, Phys., 1861, p. 88 )

2 So Budge (Physiologie, 1862), p 309, found that a simple tube (a) would deliver more fluid in a given time than a bifid one $(b)$, the sectional arcas of whose arms were torather equal to $a$. and the hifid tube more than a triticl one $(c)$ in the proportion of (a) $3860:(b) 3400:$ (c) 3100 , the pressure being rounl in all three cases.

3 Thus Ilarey has shown that whilst elastic and rigid tubes of equal dianeters will discharge an equal quantity of fluid as long us the stream is continuous, the moment the stream becomes intermittent an advantage is anined by the elastic tuhes, apparently owing to the diminution of friction in the latter, and the conversion of the jetting movement of the fluid into a more continuous, uniform, and steady flow ; and herein perhaps we may pereeive an explanation of the hypertrophy of the Heart, so frequently observed as a coneomitant of a rigid aorta in old age. See Annal. des Sei. Nat. "\%ool., 1857, t. viii, p. 330 ; and Marey's Thèse Ynaugurale, 1859. 
a cradual diminution of pressure, indicated by the diagonal line $\mathrm{x} c$, may be observed as the outlet is approached. Now, if the bore of the tube be contracted at any part, as at $o$, an obstacle to the discharge of the fluid will be creater, through the increase of friction; the pressure against the walls of the preceding portion of the tube r to $o$ will increase, and consequently the line of levels will rise in that part, as indicated by the dotted line $\mathrm{R} b c$. If, on the other hand, the outlet be enlarged, the fluid will be discharged more easily, and the line of levels will fall with great rapidity. Upon these principles M. Marey ${ }^{1}$ has constructed an apparatus bearing some resemblance to the different systems of rescels in the body, a constricted portion at $o$ (Fig. 137) representing the capillaries, ${ }^{2}$ and being preceded by a wisler portion for the Arteries, and followed by a still wider one for the Veins. By this instrument it may be shown physically, that the pressure is highest in the Arterial vessels, whilst it is much less in the Capillaries, and is lowest in the Veins. ${ }^{3}$ It may also be shown that the mean tension of an Artery diminishes in proportion to its distance from the heart, and is by so much the less in proportion as the capillaries are dilated, and thus constitute a smaller obstacle to the passage of the arterial blood. These facts, at least as regards the

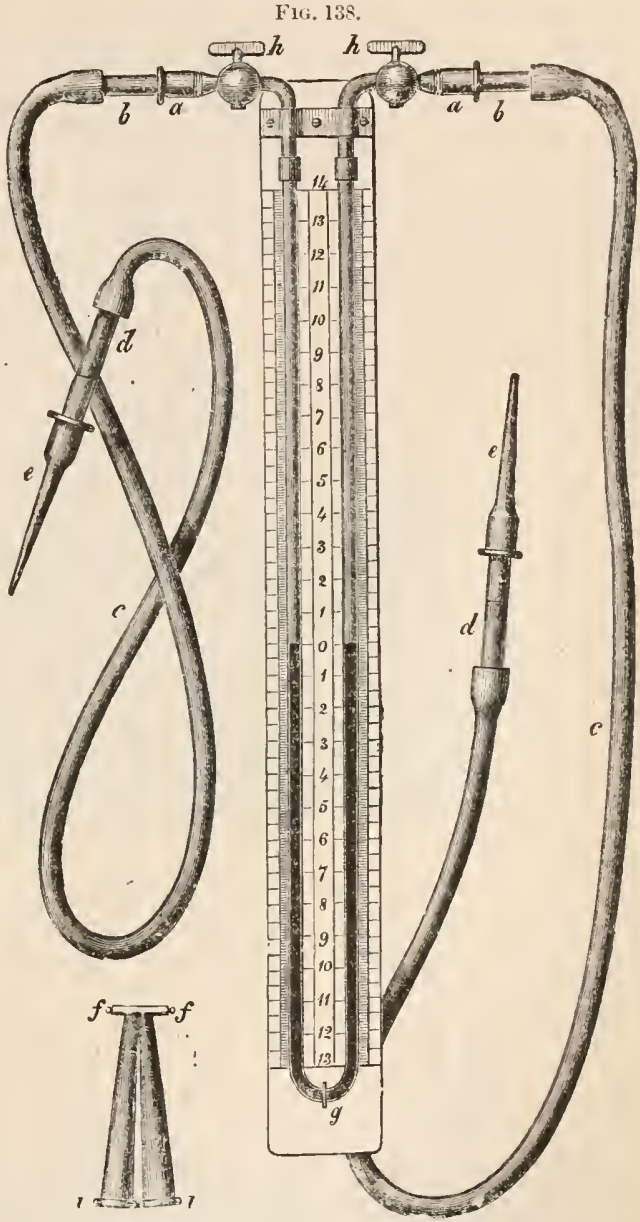

Diff reutial Hanometer of Bernard. ${ }^{4}$ difference of the pressure in the arterial and venous system, were clearly perceivel by Hales, and having been substantiated by Bernard with the differential Manometer, Fig. 138; the two mouthpieces of which, e e, being inserted into Arteries at the same distance from the heart, as the two caro-

1 Bruwn-Séquard's Journ. de la Physiol., vol. ii, p. 436. See also Rutherford's New Schune of the Circulation, Journ of Anat. and Phys., 1872, vol, vi, p. 219.

2 The capillaries of the body, though in their,agregatesectional area much larger than the aorta, yot by reason of their smallness, and the consequent great increase of friction against their walls, operate virtually as such a constricted portion.

3 In the living body the prissure rises again in the veins, as their collective calibre is mucli less than that of the capillaries, though greater than that of the arteries.

4 Bernard, vol. i, p. 20.5, 1859. 
tids or the two crurals, the level of the mercury on the two sides remains equal, indicating equality of pressure; whilst if one be placed in a more distant artery or into a Vein, the mercury constantly rises on that side, thus showing a diminution of pressure or tension. If the contracted or capillary portion of Marey's apparatus (Fig. 137) be enlarged, the fluid will pass through it with less resistance, and the pressure in the Arterial portion will diminish, and vice versa. This has actually been observed by Bernard in the living subject; for on placing the mouthpieces of his differential Manometer into the two facial arteries of a horse, the mercury stood at the same level in each arm of the instrument; but on division of one of the cervical synupathetic nerves, the mercury instantly rose on that side, indicating a diminution in the tension of the vessel. Now it has been ascertained by M. Brown-Séquard that section of the sympathetic causes a dilatation of the Capillary vesseks, and therefore facilitates the passage of the blond through them; and the counterproof is shown by galvanizing the cut extremity of the Sympathetic, which inducing contraction of the Capillaries, increases the resistance to the passage of the blond from the arteries, and augments the tension of their walls, as is indicated by the gradual falling of the nercury on the galvanized side, till the pressure there may even exceed that of the healthy one.

258. The absolute pressure of the blood in the living vessels has engaged the attention of many observers. Hales ${ }^{1}$ endeavored to ascertain it by inserting long pipes into the vessels of living animals, and measuring the height to which the blood rose. In a Mare, when the tube was introdnced into the crural artery, it rose $8 \mathrm{ft} .3 \mathrm{in}$; in two Horses, $9 \mathrm{ft} .8 \mathrm{in}$. and $9 \mathrm{ft}$. 6 in. From paraliel experiments upon sheep, oxen, dogs, and other animals,

FIG. 139.

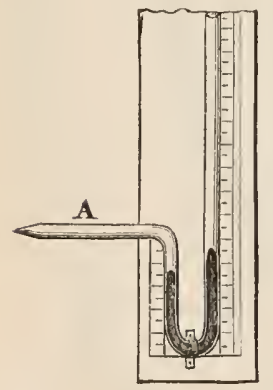

Poisenille's Ifamady namomcter: A, mouthpiece. and from the comparison of the calibre of their respective vessels with that of the human aorta, Hales concluded that the usual force of the heart in man would sustain a column of blood $7 \frac{1}{2} \mathrm{ft}$. high, the weight of which would be about 4 .Ihs. $6 \mathrm{oz}$. on the square inch. Poiseuille, improving on Hales's method, employed a much more portable instrument in the form of a doubly-bent tube (Fig. 139), containing mercury in the curve, and a solution of carbonate of soda in the mouthpiece, which prevented the formation of clots. A still further improvement was made by Ludwig and Volkmann, by placing Poiseuille's instrument in connection with a revolving drum, on which tracings indicating the fluctuations of the pressure could be taken. The instrument so modified is called the "Kymographion," and is represented in

Fig. 140. The tracing immediately below gives a normal tracing of arterial pressure obtained with the mercurial $K$ ymograph from a rabbit. Poiseuille estimated the pressure in the arteries at 6.3 inches of mercury on the square inch, which he assumed as the standard for all arteries, and for all Mammalia. But the tracings of Ludwig and Volkmann showed that the range of variation is very wide, being in the carotid of the Horse from 6 to 13 inches, in the Dog from 7-8 inches, and in the Rabbit from 2-33 inches; in man it is probably abont equal in the larger arteries to a column of nerenry 8 inches in height (Ranke, 5 or 6 Faivre). Bernard has invented a lighter instrument, termed the "Cardiometer," the indications given by which are somewhat higher than those obtained by Poiseuille's apparatus. 
The following table presents the results of Volkmanu's observations ${ }^{1}$ upon the relative lateral pressure at four points of the circulation in different

FIG. 140 .

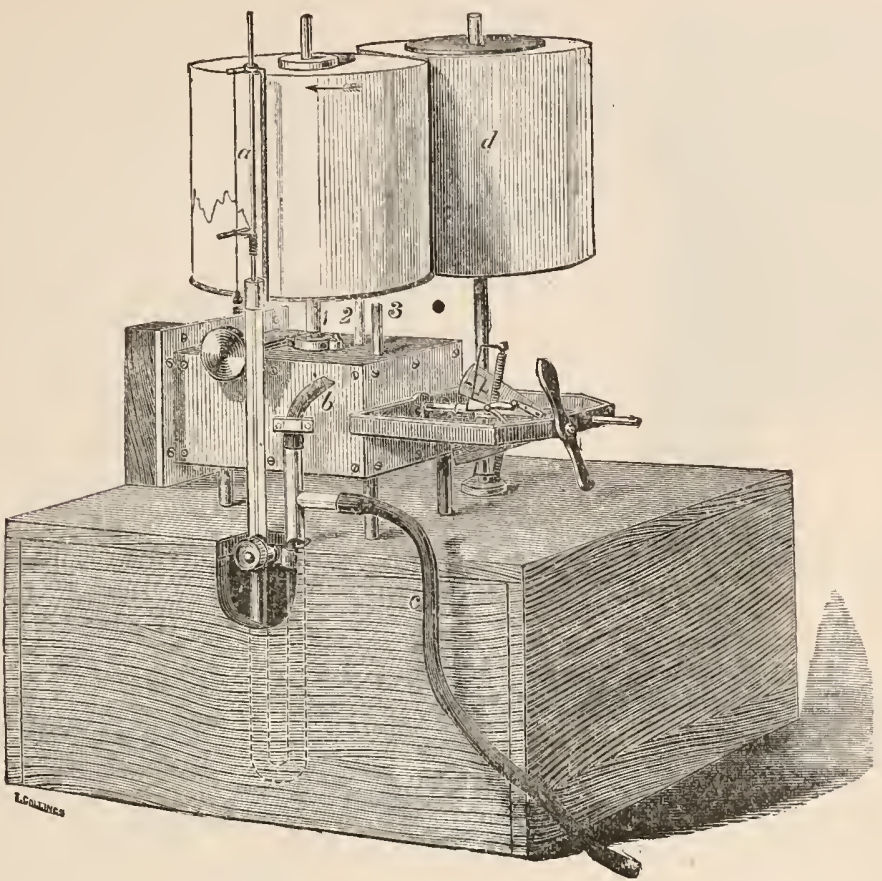

The Mercurial Kymograph: $a$, Vulcanite rod of floating piston; $b$, tuhe which communicates with the pressure-bottle; $c$, tube which communicates with the artery; $d$, feeding cylinder. 1 , first axis, which revolves once in a minute; 2 , second axis, which revolves once in ten seconds; 3 , axis, in a second and a half. The iustrument is furnished with other eylinders suitable for the reception of bands of paper, the surface of which can be blackened after they are fixed on to the cylinders, by causing the cylinder to revolve over the flame of a petroleum lamp, though more frequently the tracings are taken with a brush wetted with solution of anihn dye.

FIG. 141 .

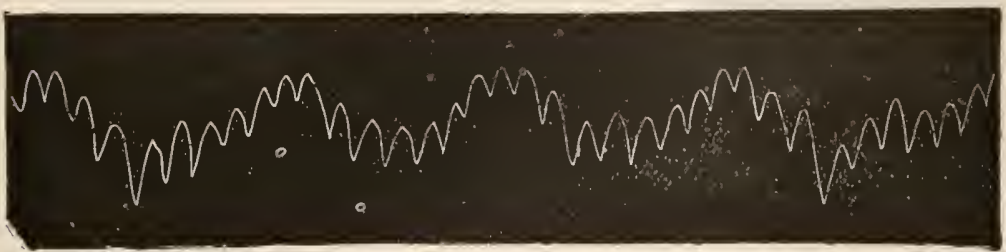

animals, expressed in millimetres, namely, (I) the carotid near its origin, (II) a peripheral branch of the carotid or some other artery, (III) a peripheral rootlet of a vein, and (Iv) a jugular vein:

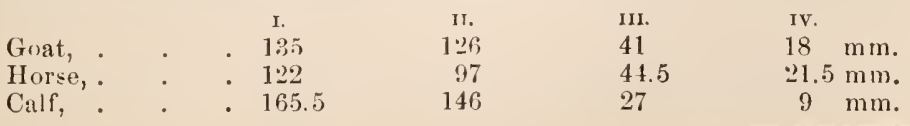


The periodic variations of the blood-pressure depend essentially on the frequency and vigor of the contractions of the heart. When the heart beats

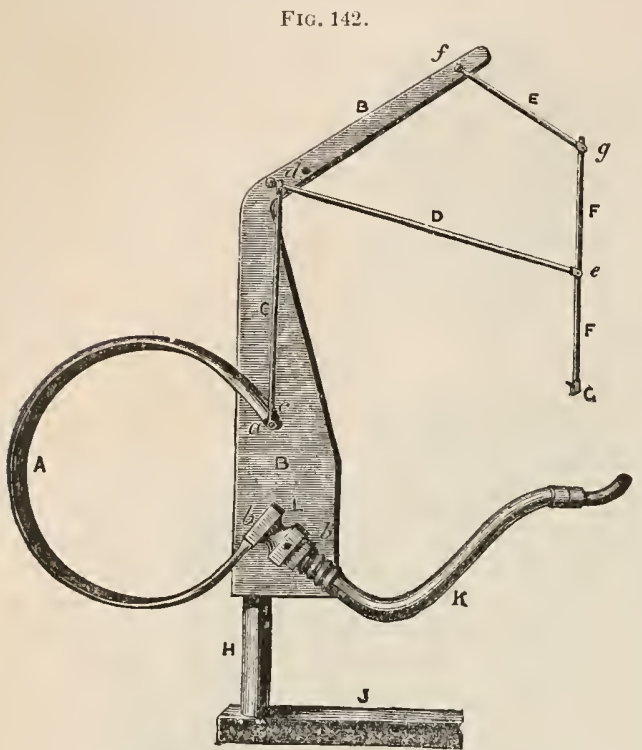

Fick's Spring Kymograph : A, C-spring; B B, support; C, rod which communicates the movements of the spring to the lever $D$, and thus to the writing-needle $G$, the verticality of the movement of which is s:cured by the second rod $\mathrm{E} ; \mathrm{R}$, leaden tube by which the cavity of the spring is in communication with the artery. his modified spring manometer (Fig. 142), found the pressure in the right auricle nil (= atmospherie pressure); during inspiration it sank to $10 \mathrm{~mm}$. of mercury below zero. In the right ventricle the pressure varied from 18-42

FIG. 143 .

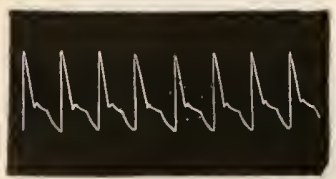

Normal arterial tracing obtained with the Spring Kymograph; dog under Curara. sion of the sirteris the tengreatly hetween systole and diastole, and the maxima and minima of the pressure represented by the lieight of the curves differ considerably from the mean pressure, and the pulse may become perceptible even in the eapillaries. When the eardiac beats are frequent, on the other hand, the maxima and minima of the pressure differ but little from the mean pressure; the eurves are smaller and more numerous, and the mean pressure is relatively high. These conditions may he induced at will through the Vagus; moderate stimulation of this nerve causing slow pulse with wide excursions of the tracings and low mean pressure, whilst section of the nerve causes quicker pulse with smaller excursions and higher mean pressure. Fick, ${ }^{1}$ from experiments made on the dog, with mm., and in the left ventricle the maximum was $140 \mathrm{~mm}$. The pressure of the blood in the arta rose as high during the period of systole as in the ventricle, but it did not fa!l so low during the diastole. Barloud, ${ }^{2}$ working under Fick and using his C-spring manometer, found the pressure of the blood in the pulmonary artery constantly helow $60 \mathrm{~mm}$. of mercury; after section of the spinal cord, it fell considerably, and when the cord was stimulated electrieally, it not only rose, as oceur's in the systemic arteries, but rose considerably ahove the normal, this being due to the muscular contraction excited in the body generally. Torm Müller ${ }^{3}$ has shown that when the tension of the vaseular system has heen lowered by the section of the spinal cord and cardiac nerves, the hlood-pressure cannot again be raised to its normal height by the injection of blood into the vessels. He also showed that blood to the extent of two per cent. of the body

1 Terhand. d. Würzhure Phys.-Med. Ges., Bd. iv, 1873, p. 2:3.

2 Inaug. Dissert, Würzburg, 1874.

3 Sitz.-ber. d. Süchs. Ges. d. Wiss., 1873, p. 578. 
weight can be withdrawn from the body without materially lowering the blood-pressure. The influence of the respiratory movements upon the pressure of the blood in the vessels is of much interest: after an ordinary expiration the heart and large vessels in the chest are exposed to a pressure acting through the tissue of the lung, which as Wündt has pointed out, is equal to the difference between the pressure of the air on the one hand $(=750 \mathrm{~mm}$. of mereury $)$ and the elasticity of the lungs acting in the opposite direction $(=7.5$ $\mathrm{mm}$. of mercury) on the other ; whilst on the vessels outside the full pressure of the air is exerted. The blood-cavities in the chest being thus exposed to less pressure than those of the rest of the body, have a tendency to dilate until restrained by the elasticity of their walls. The venous current is affected to a greater degrec than the arterial, since the walls of the veins arc thinner and less elastic than those of the arteries. In ordinary inspiration the elasticity of the lungs rises to $9.5 \mathrm{~mm}$. of mereury, and in extraordinary respiration it would even support a columm amounting to $30 \mathrm{~mm}$. of mercury in height, and the suction power of the cavities is correspondingly increased. In consequence of the descent of the diaphragm this is chiefly exerted upon the veins of the abdominal viscera. In expiration, on the contrary, the pressure on the thoracic vessels being increased, the escape of the blood by the arteries is facilitated, whilst there is a tendency to arrest the flow in the veins; the valves in the latter, however, offer an obstruction to a backward flow, even in extreme expiration, beyond certain limits. The general result of this is, that the pressure of the blood in the veins of the body at large, rises during expiration, and falls during inspiration. In the arterial tracing similar curves occur (complicated of course with those of the cardiac beats), but in the opposite direction, the ascending portion of the curve (corresponding to increase of pressure) occurring chiefly during the period of inspiration, the descending portion of the pressure-curve chiefly occurring during expiration. The rise of blood-d)ressure in the arteries during inspiration depends on the heart becoming filled with more blood frorn the veins at this period than during expiration, and hence acting more vigorously and at the same time more frequently. But inasnuch as the filling of the cardiac cavities with blood does not take place at the commencement of inspiration, nor the dininished supply of blood to them with the commencement of expiration, and since further the diminution of pressure within the thoracic cavity in expiration exerts a suctional power upon the contents of the arteries, whilst the incrcase of pressure during expiration tends to drive out the blood, it comes to pass, as was shown by Einbrodt, ${ }^{1}$ that the respiratory phases representerl by the dotted line in the following figure (Fig. 145) do not exactly correspond with the variations of pressure, but that the pressure continues to fall for a little while after the conmencement of inspiration, and continues to rise for a little while after the commencement of expiration. Curves essentially similar to those observed in normal respiration are seen when the animal is poisoned by

1 Sitz -ber. d k. Akad. zu Wien, 1859, n. 345. See also Funke, Physiologie, Band i, 1863, n. 135; Wündt, Phrsiologie, 1873; p. 314; Sanderson, in Handbook for the Physiological Laboratory, 1873, p. 314. 
woorara if artificial respiration be maintained; on suspending the artificial respiration the mean pressnre rises, and eurves (Traube's eurves) then begin to appear, whieh gradually beeome more and more marked, and are

FIG, 145,

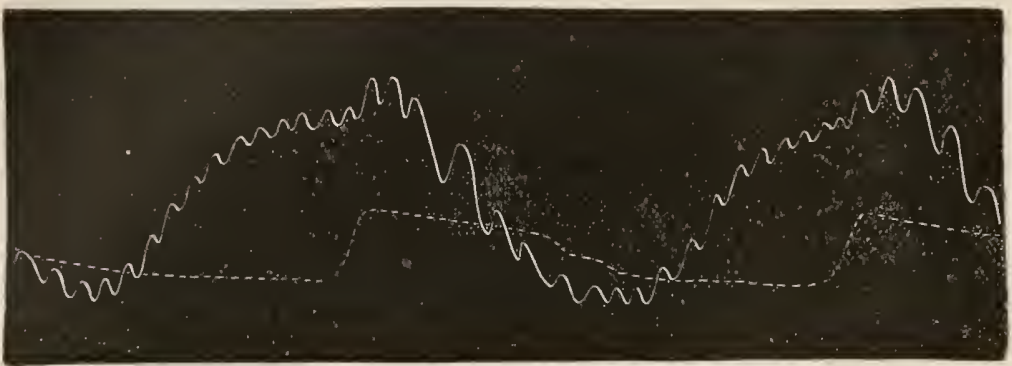

synchronous with the suppressed respirations; they are probably partly dependent on the relation of the gases in the blood to the vaso-motor centre, and partly to the direct action of the imperfeetly arterialized blood upon the vessels themselves.

259. The rate of movement of the blood in any artery can only be guessed at as regarts the human subjeet from the comparative results of experiments upon the lower animals; but several methods have been suggested, by which it may be ascertained in them with some approximation to truth. One of these, employed by Volkmann, and termed by him the Hromodromometer, is exhibited in Fig. 146, where A shows the instrument as it is inserter between the two cut extrenities of an artery or vein. In this position the blood continues to flow in the original direetion; but by a simple mechanieal arrangement its course ean be snddenly diverted (as in B), throngh the bent tube fillerl with serum in the direetion of the arrows. The rapidity of the eurrent may be readily estimated by timing its eourse along the scale at the side. Ludwig has suggested an instrument which he has namerl a "Stromuhr" or Meter, the prineiples of which are represented in Fig. 144. This consists of an arched glass ressel with two legs, of whieh $\mathrm{B}$ and $\mathrm{C}$ are considerably dilated, and the extremities of whieh are inserterl into the vessels; that directed towards the heart, c, being filled with pure olive oil, whilst the other direeted towards the eapillaries is filled with defibrinaterl blood. If the eapacity of the limb $\mathrm{C}$ up to the point a be known, and the time occupied in filling it be noted, it is easy to calculate the quantity of blood passing through the artery in a given period. At $\mathrm{n}$ is a mechanical arrangement by whiel the eurrent of bloor through the two limbs may be reversed, and the experiment repeated on the same animal. A third instrument adapted for measuring the rapidity of the blood-eurrent is that represented in Fig. 147, devised by Vierordt, and termed by him the "Hrenatochometer." This consists of a small glass cell filled with water, with two mouthpieces for insertion into the ressel, and a light vertically suspenderl and easily movable pendnhm, placed close to the point of entranee of the current from the upper extremity of the divided artery. The amount of deviation from the perpendicular producerl by the instreaming blood on the pendulum, as measured by the scale, indicates the veloeity of the current. Volkmann gave the rapidity of the stream in the carotid of the IIorse as from 12-17 inches per second, and in the Dog, at abont 12 inches per second. In the crural artery of the Dog, it had fallen to $6 \frac{1}{2}$ inehes, and in the metatarsal of the Horse, to $2 \frac{1}{4}$ inches per second. Vierordt estimated it at $10 \frac{1}{2}$ inches per 
second in the carotid of man, and at $2 \frac{1}{4}$ inches per second in the metatarsal artery. Chauveau, ${ }^{2}$ with a similar but somewhat improved instrument, estimated the rapidity of the blood in the carotid of the Irorse at 20.28 inches

FIG, 146.

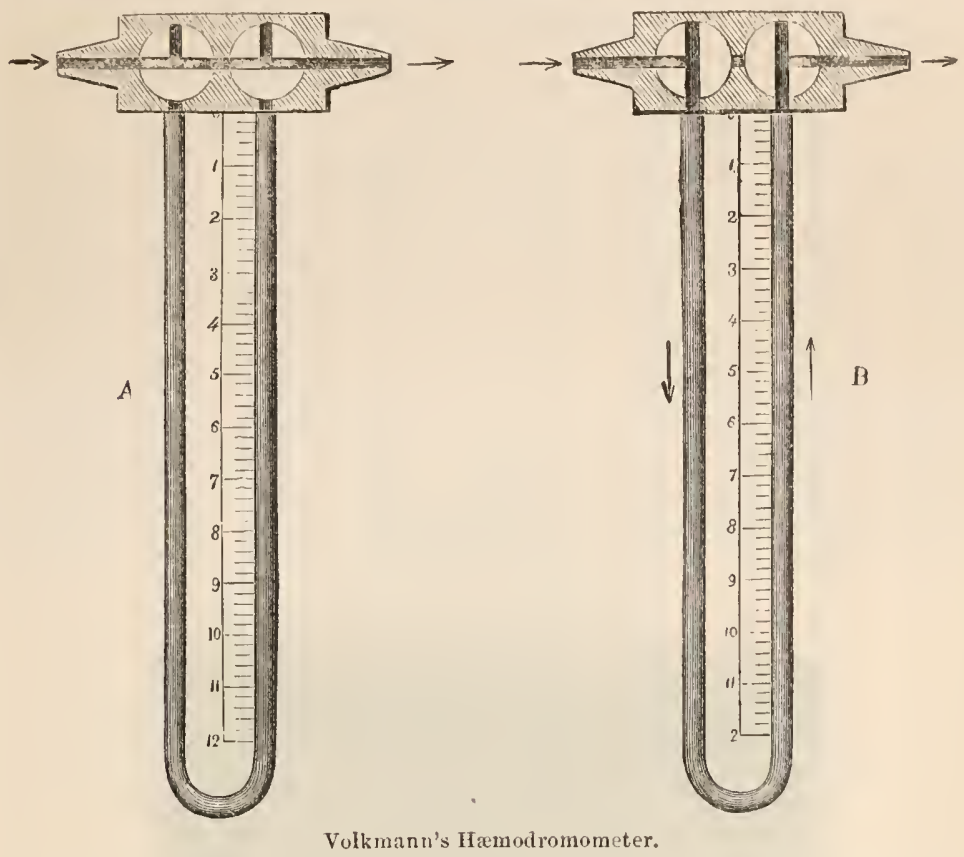

per second during the systole of the heart, falling to 8.78 inches during the diastole. Volkmann found the rapidity of the current in the jugular vein

FIG. 147.

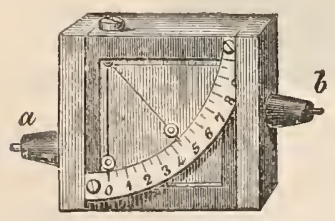

Hsematochometer of Vierordt : $a$ and $b$, mouthpieces.
FIG. 148.

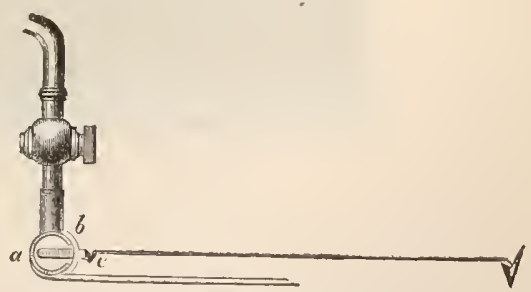

M. Lortet's Instrument.

of the $\operatorname{dog}$ to be 9 inches per second, and Ludwig and Dogiel ${ }^{3}$ found it to vary in the carotid of the rabbit from 4 inches to 9 inches, and in the carotid of the $\mathrm{dog}$ from 14 to nearly 30 inches, in the second. Cyon and Steinmann

1 Physiologie, p. 110, 1861.

2 A rehiv. Gén. de lléd., vol. i, 1861, p. 113 ; and Jour. de la Phys., 1860, p. 695.

3 Ludwig's Arbeiten, 1867, p. 196 ; see ulso Notes on some Experiments on the rate of flow of Blond, and some other liquids, through Tubes of Narrow Diameter, by Drs. Duncan and Gamgee, Journ. of Anat. and Phys., vol. v, 1871, p. 150 ; and Cyon and Steinmann, Bull. de l'Aead. Impériale de St. Pétersbourg, t. viii, p. 55. 
found that great diminution in the rapidity of the flow of blood follower section of the spinal cord, which was clearly due to the consequent paralysis of the vaso-motor nerves, and the accumulation of blood in the veins of the viscera. The instrument adopted by M. Lortet ${ }^{1}$ (Fig. 148) is founded on the same principle as the one suggested by MM. Chauveau, Bertolus, and Laroyenne. ${ }^{2}$ It consists of a short tube, open at both ends $(a)$, which is introduced into the artery. On one side, near the middle, is a square opening $(b)$, which is closed by a plate or ring of caoutchouc. The caoutchouc is pierced by a long and light lever (c), the short and somewhat broader end of which hangs in the current of blood, whilst the long end records its corresponding but opposite movements on a rotating drum, the fulcrum being the point where the lever is gripped by the sides of the opening in the indiarubber. Connected with the instrument is a sphygmoscope and a sphygmographic apparatus, with the object of obtaining traces of the pulsations, the tube of the former being soldered on the one hand into the side of the primary or hæmodromographic tube, and on the other being connected with an elastic cushion filled with air, and supporting a lever the movements of which are registered just below those of the lever indicating the rapidity of the movement of the blood. Fig. 149 shows a double normal tracing obtained from the carotid of a horse with a pulse of 40 per minute. Each complete trace, therefore, occupied a second and a half. From this it will be seen that the increase of the rapidity commences briskly, the line of ascent being

FIG. 149.

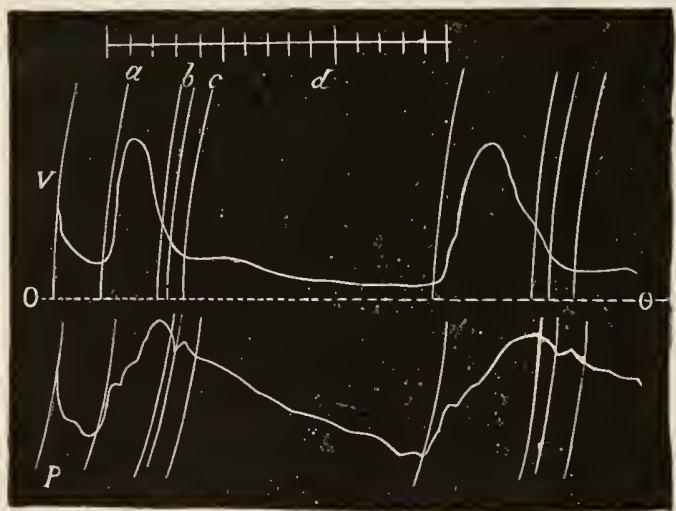

Tracing obtained by M. Lortet's Instrument.

The seale above indicates tenths of a second, $\mathrm{V}$, tracing indicating the variations in the rapidity of the blood. P, tracing of the pulse.

sharp, and reaching its acme in the space of two-tenths of a second. In the following tenth the line rapidly falls. In the fourth and fifth tentlis the rapidity diminishes insensibly, and in the sixth the line is almost horizontal, though still above the zero line. At the seventh tenth second is a slight elevation, showing a dicrotism of rapidity. During the succeeding eight-tenths of a second the line, though descending, presents undulations corresponding to oscillations of the rapidity. Amongst the more inportant results of his observations, M. Lortet believes he has shown that the blood at tains its maximum of rapidity shortly before the systole of the henrt, as indicated by the 
pressure in the arteries, reaches its greatest intensity. The closure of the sigmoid valves exerts little influence on the rapidity. The rapidity is greatest during expiration, and least during inspiration. Section of the spinal cord in the atlo-occipital region, or of the Pneunogastrics, increases both the speed of the blood and the pressure in the arteries. On ligature of one carotid the rapidity of the blood was found to increase in the other.

\section{Novement of the Blood in the Capillaries.}

260. In Man, as in all the higher Animals-in the adult condition at least-the Capillary circulation is almost entirely carried on through tubes having distinct membranous parietes, the only known exception being in the case of the spleen $\left(\$ 157\right.$, ii). ${ }^{1}$ These tubes commonly form a ninutelyanastomosing network (Fig. 150), into which the blood is brought by the ramifications of the arteries on one side, and from which it is returned by

FIG. 150 .

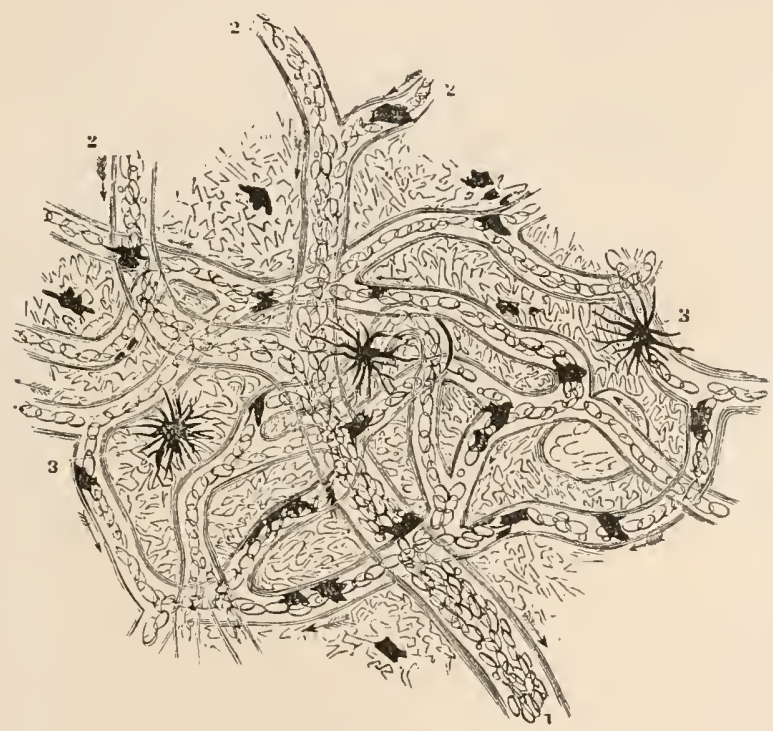

Capillary plexus in a portion of the web of a Frog's foot, magnified 110 diameters: 1 , trunk of vein; $2,2,2$, its branches; 3,3 , pigment cells.

the radicles of the veins on the other. The walls of the tubes are composed of a delicate membrane, on the inner surface of which is a single layer of epithelial cells possessing nuclei, and of fusiform shape, in this respect resembling the cells lining the smaller arteries, but differing from those in the interior of the veins, which are lozenge-shaped, with wavy outline. According to Eberth ${ }^{2}$ (Fig. 151), the walls of the very finest capillaries, as

1 The eapillary eirenlation may be well seen in the web of the foot, in the lung, mesentery, and tungue of the frog, the tail of tadpoles and of finh (see Caton, Quart. Journ. of Mic. Seience, 1870, p. 236 ), and in the puritoneum of mammats by the plan suggested by Strieker and Burdon-Sanderson, in which a guinea-pig is chloralized, the abdominal carity opened, and the omentum floated in a warm bath containing common salt in solution. (See Quart. Journ. of Mie. Sci., Oct. 1870.)

2 Wurzburg. Naturwiss. Zeit., Bd. vi, 18t5, p. 27, and Stricker's Hum. and Comp. Histology, Syd. Soc. Trans., Art. Bloodvessels. See also Chrzonszcoewsky, Vir- 
those of the retina and brain, arc composed of the intimately-adhering cells alone, without any basement-membrane, this last only becoming perceptible in those of larger diameter. It is possible that minute interspaces may exist between adjoining cells, through which, when the pressure of the blood is increased, the white and even the less-yielding red corpuscles may escape. ${ }^{1}$ Non-medullated nerve-fibres have been traced by Beale to the capillaries, and by the aid of the gold method of staining, Klem has followed still finer fibres into the substance of the capillary wall. ${ }^{2}$ The diameter of the capillaries varies in different animals, in accordance with that of their blood-corpuscles; thus the capillaries of the frog are, of coursc, much larger than those of Man. The ordinary diameter of the latter appears, from the measurements of Weber, Müller, and others, to vary from about the $\frac{1}{30} \overline{0}$ th to the $5 \frac{1}{500}$ th of an inch; the extremes, however, are siated by Kölliker at as little as $\frac{1}{5607}$ th and as much as $\frac{1}{1 \times 70}$ th of an inch. As the diameter of the human capillaries, however, can only be examined after death, it is probable that these statements may not be altogether corrcet, particularly as tubes of the

FIti, 151 .

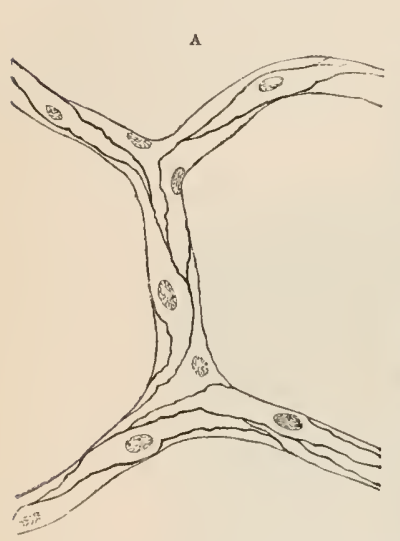

B

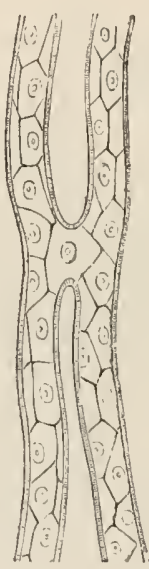

A. Fine capillaries from the misentery. B. Capillaries of larger size and with thicker walls, from the pecten of the eye of a bird. smallest of the above sizes would not admit ordinary blood-corpuscles. The dimensions of the individual vessels, indeed, are by no means constant; as may be secn by watching the circulation in any transparent part, for some little time. Putting aside those general changes in diameter which result from circumstances affecting all the capillaries of a part, it may be observed that a single capillary will sometimes enlarge or diminish by itself, without any obvious cause. Thus the stream of blood will sometimes be seen to run into passages which were not before perceived; and it has hence been supposed that they were new excavations, formed by the retreating or removal of the solid tissue through which it passes. But a more attentive examination shows, that snch passages are real capillaries, which dist not at the time of the first observation admit the stream of blood-corpuscles, in consequence of their small calibre, or of some other local impediment; ant that they are brought into view by the simple increase in their diancter. The compression of one of the small arteries will generally ocension an oscillation of the corpuscles of blood in the smallest capillaries, which will be followed by the disappearance of some of them; but when the obstruction is removed, the blood soon

chow's Archiv, 1866, Bd. xxxv, p. 171; Auerbach, Breshus. Zeitung, 1865; Aeby, Modicin. Centrabblatt, 1865, No. 14; Cohnhem, Virehow's Archiv, Bd. xv, p. 52, and Ranvier and Cornil, Brown-Séquard, Archiv de Physiol., t. i, 1868, p. 551.

1 See Amold, Virchow's Arehiv, Band Iviii, 1873, p. 220, and Frey, Barker's Transl, 1875, p. 364, Hig. 358.

${ }^{2}$ Klein, Distribution of Non-medullated Nerve-fibres, Quart. Journ. of Mie. Sei., No. Ixvi, 1872, p. 125. In appendix to this paper contains a list of thirty-eight memoirs on this subject. Beale, The Nerves of Capilhary Vessels, ete, Monthly Microscop. Jurn., 1872, vol. viii, p. 57. 
regains its previous velocity and force, and flows into cxactly the same passages as before. It is still doubtful whether the capjillaries possess any contractile power of their own, or merely vary in size owing to the elasticity of their walls, with the quantity of blood they contain. ${ }^{1}$ The capiliaries in certain regions, ${ }^{2}$ as the central parts of the nervous system and the mesentery, appear to be surrounded by a sheath between which and their own proper coat, lymph-corpuscles have been observed ; these spaces have consequently been regarded as extensions of the lymphatic system. Frey remarks, however, that it is not every adventitial tissue of a bloodvessel containing lymphoid cells that must be regarded as a lymph sheath. A circumstance that may frequently give rise to the deceptive appearance of sucl a sheath, is that a bloodvessel is often bounded on each side by lymphatic cantals, and this is most commonly seen in uninjected preparations.

261. The opinion was long entertaincd, that there are vessels adapted to supply the white or colorless tissues; carrying from the arteries the "liquor sanguinis," and leaving the corpuseles behind, through inability to receive them. Very well-narked examples of such non-vascular tissues are found in the cornea and hyaloid humor of the eye, and in the mucous tissue constituting the greater part of the umbilical cord. A considerable development has lately been given to this view by the investigations of Virchow ${ }^{3}$ and others; by whom it has been attempted to be shown that in the varions structures included under the term connective tissues, the corpuscles, which are almost constantly found disseminated through them, are to be regarded, like the latcuna of bone, as centres and storehouses of nutriment, which is again distributed by their caudate prolongations (frequently assuming the form of elastic tisue) to the most distant parts. The idea that Nutrition can only be carried on by means of Capillary ressels is, however, entirely gratuitous; for there is no essential difference between the nutrition of the non-vascular tissues, and that of the islets in the midst of the network of capillary vessels which traverse the most vascular. In both cases, the nutrient materials conveyed by the blood are absorbed by the cells or other elementary parts of the tissue inmediately adjoining the ressels, and are imparted by them to others which are further removed; and the only difference lies in the anount of the portion of tissue which has to be thus traversed, so that we are only required to extend our ideas, from the largest of the islets which we find in the rascular tissues, to the still more isolated structures of which the non-vascular tissues are composed.-The disposition of the Capillaries, both as to the degree of minuteness and the plan of the reticulation which they form, varies so greatly in the different vascular tissues, that it is possible to state with tolerable certainty the nature of the part from which any specimen has been detached, - whether a portion of Skin (Fig. 152), Mucous membrane (Fig. 153), Serous membrane, Muscles (Fig. 15t), Nerve Fat (Fig. 155), Areolar tissue, Glands, etc. The degree of minuteness is obviously in accordance with the copiousness of the supply of blood which is required for the purposes of its circulation through the part; thus the plexus is closest, where some change is to be cffected in the blood itself, as in the absorbent, respiratory, and secreting organs; whilst it is widest in those parts which receive the blood solely for their own nutrition,- the nervous centres and muscles having a more minute reticulation

1 See Eberth, op. cit., and Stricker, Wien. Sitz.-berichte, Bd. li and lii, for arguments in favor of the former view, which are vigurously contested by Beale, op cit., and Tulpian, Leçons sur l'A ppareil Taso-moteur, 1875, p. 73

2 Stricker, in II oleschott's Untersuch., Bd. x, Heft 2, p. 168.

3 See Cellular Pathology, pussim. 
than is seen in the generality of the last-named parts, in virtue of the peculiar activity of the moleeular changes whieh take place in them. But the arrangement of vessels peenliar to each, evidently has reference only to the convenience of the distribution of blood among the elementary parts

FIG. 152.

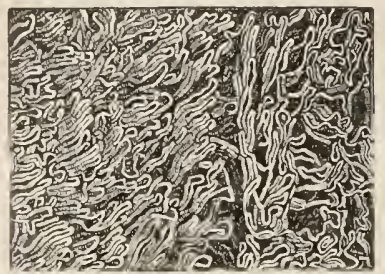

Distribution of Capillaries on the surface of the Skin of the finger.
FIG. 153.

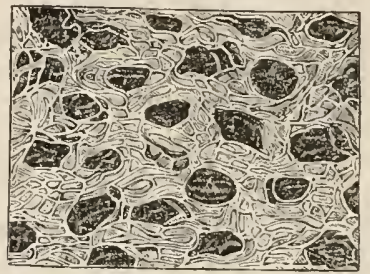

Distribution of Capillaries around follicles of Mrucous Membrane.

of the tissue, and varies with their form. It is not possible to imagine that it has any other relation than this to their functions; since the function of each separate element of the organ, of which that of the entire organ is

Fig. 154 .

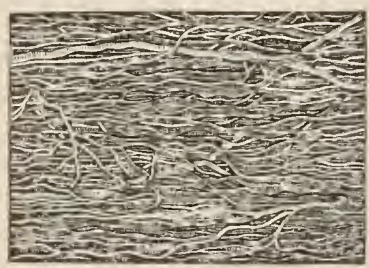

Distribution of Capillaries in Muscle.
FIG. 155.

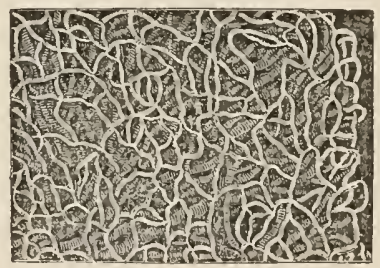

Capillary network around Fiat-cells.

the aggregate, is due to its own inherent vital powers,- - the supply of blood being only required as furnishing the material on which these are to be exereised.

262. The average rate of movement of the blood through the Capillary system, may be determined with tolerable preeision by microseopie measurement; and the observations of Hales, Valentin, and Weber coneur in representing it to average in the systemie capillaries of the Frog 1.2 inch per minute. In warm-blooded animals, however, the eapillary circulation is probably much more rapid than this; the observations of Volkmann upon the mesenterie arteries of the Dog making its rate about 1.8 ineh per minute; whilst Ludwig and Vierordt, from olservations on the movement of the bloot-corpuseles in the retinal eapillaries of their own eyes, estimate the rapidity at from one ineh in 41 seends to one inch in 28 seconds. The layer which is in immediate proximity to the wall of the ressels flows from 9 to 17 times more slowly if the movement of the white corpuscles is to be taken as a metus of estimating it (Weber). Assuming .03 ineh per second, however, as the rate, and comparing this with the rate of movement of the blood in the larger arteries, which seems on the average to be 11.8 inches per second, it is calculated by Volkmann that the aggregate area of the capillaries (being in an inverse ratio to the rate of the hlood's movement through them) must be nearly four humdred times that of the arterial trunks 
which supply them. ${ }^{1}$ Donders, on similar clata, estimates it at 500 times greater, and Vierordt at from 800 to 850 times. $^{2}$

263. That the movement of the blood through the Capillary system of vessels, is mainly dependent upon the force which it derives from the Heart and from the coats of the Artcries, is a matter altogether beyond dispute. But it is a most important question, not merely in itself, but in its hearing on one of the fundamental questions of Pathology, - the nature of inflammation,-whether the Capillary circulation is influenced by any other anency than the contractile power of the Heart and Arterial system; some Physiologists maintaining that this alone is sufficient to account for all the phenomena of the Capillary circulation; and others asserting that it is necessary to admit some supplementary force, which may be exerted cither to assist, retard, or regulate the flow of blood from the Arteries into the Veins. We shall first consider the evidence which may justify an affirmative conclusion as to the cxistence of such force; and shall then examine into its nature.-No physiological fact seems to the Author to be more clearly proved, than the existence, in the lower classes of Animals, as well as in Plants, of some power independent of a vis à tergo, by which the nutritive fluid is caused to move through their vessels. ${ }^{3}$ This power appears to originate in the circulation itself, and to be closely connected with the state of the Nutritive and Secreting processes: since anything which stimulates these to increased energy, accelerates the movement; whilst any check to them occasions a corresponding stagnation. It may be convenient to designate this motor force by the name of capillary power; it being clearly understood, however, that no mechanical propulsion is thence implied. On ascending the animal scale, we find the power which, in the lower organisms, is liffused through the whole system, grarlually concentrated in a single part; a new force, that of the heart, being brought into operation, and the Circulation placed, in a greater or less degree, under its control. Still there is evidence that the movement of blood through the Capillaries is not entirely due to this; since it may continue after the cessation of the Heart's action, may itself cease in particular organs when the Heart is still acting vigorously, and is constantly being affected in anount and rapiclity, by causes originating in the part itself, and in no way affecting the heart.The chief proofs of these statcments will now be adverted to.

264. When the flow of blood through the capillaries of a transparent part, such as the web of a Frog's foot, is observed with the microscope, it appears at first to take place with great evenness and regularity. But on watching the movement for some time, various changes may be observed, which cannot be attributed to the heart's influence, and which show that a certain regulating or distributive power exists in the walls of the capillarics, or in the tissues which they traverse. Some of these changes, involving variations in the size of the capillary tubes, have been already referred to $(\$ 260)$. Others, however, are manifested in great and sudden alterations in the velocity of the current; which cause a marked difference in the rates of the movement of the blood through the several parts of the area under observation. Sometimes this variation extends even to the entire reversal, for a time, of the direction of the movement, in certain of the transverse or communicating branches; the flow always taking place, of course, from the stronger towards the weaker current. Not unfrequently, an entire stagnation of the current in some particular tube precerles this reversal of its

1 Hämodynamik, pp. 184, 204.

2 Die Erscheinungen und Gesetze der Stromgeschwindigkeit des Blutes, 1858.

${ }^{3}$ See Principles of Comparative Physiology, chap. v. 
direction. Irregularities of this kind, however, are more frequent when the Heart's action is partly interrupted; as it usually is by the pressure to which the tadpole or other animal must be subjected, in order to allow microscopic observations to be made upon its circulation. Under such circumstances, the varieties in the capillary circnlation, inducerl by causes purely local, become very conspicuous; for when the whole current is nearly stagnated, and a fresh impulse from the heart renews it, the movement is not by any means uniform (as it might have been expected to be) through the whole plexus supplied by one arterial trunk, but is much greater in some of the tubes than it is in others; the variation being in no degree connected with their size, and being very different at short intervals.

265. The movement of the blood in the capillaries of cold-blooded animals, after complete excision of the Heart, has been repeaterlly witnessed. In warm-blooded animals this cannot be satisfactorily established by experiment, since the shock occasioned by so severe an operation much sooner destroys the general vitality of the system; but it nnay be proved in other ways to take place.. After most kinds of natural death, the arterial system is found, subsequently to the lapse of a few hours, almost or completely emptied of blood ; this is partly, no doubt, the effect of the tonic contraction of the tubes themselves; but the emptying is commonly more complete than could be thus accounted for, and inust therefore bc partly due to the continuance of the capillary circulation. It has been observed by Dr. Bennet Dowler, ${ }^{1}$ that in the bodies of individuals who have died from yellow fever, the external veins frequently become so distended with blood within a fero minutes after the cessation of the heart's action, that, when they are opened, the blood flows in a good stream, being sometimes projected to the distance of a foot or more, especially when pressure is applied above the puncture, as in ordinary bloodletting. It is not conceivable that the slowly-acting tonicity of the arteries should have produced such a result as this; which can scarcely, therefore, be attributed to anything else than the sustenance of the capillary circulation by forces generated within itself. Further, it has been well ascertained that a real process of secretion not unfrequently continues after general or somatic death; urine has been poured out by the ureters, sweat exuded from the skin, and other peculiar secretions formed by their glands; and these changes could scarcely have taken place, unless the capillary circulation were still continuing. In the early embryonic conrlition of the highest animals, the movement of blood seems to be unquestionably due to some diffised power, independent of any central impulsion; for it may be seen to commence in the Vascular Area, before it is subjected to the influence of the Heart. The first movement is towards, instead of from, the centre; and even for some time after the circulation las been fairly established, the walls of the Ileart consist merely of cells loosely attached together, and can hardly be supposed to have any great contractile power.

266. The last of these facts may be said not to have any direct bearing on the question, whether the "capillary power" has any existence in the adult condition? lout the phenomena occasionally presented by the foutus, at a later stage, appear decisive. Cases are of no very unfrequent occurrence, in which the heart is absent during the whole of embryonic life, and yet the greater part of the organs are well developed. In most or all of these cases, it is true, a perfect twin foctus exists, of which the placenta is in some degree united with that of the imperfect one; and it has been customary

1 liesearches, Critical and Experimental, on the Capillary Circulation, reprinted from the New Orleans 11 edical and Surgical Journal, Jan. 1849. 
to attribute the circulation in the latter to the influence of the heart of the former, propagated through the placental vessels. This supposition hats not been disproved (however improbable it might seem), until a case of this kind occurred, which was submitterl to the most eareful exanination by an accomplished anatomist ${ }^{1}$ when the decisive result was obtained, that it scemed impossible for the heart of the twin fortus to have occasioned the movement of blood in the imperfect one, and that some cause present in the latter must have been sufficient for the propulsion of blood through its vessels. It was a rery curious anomaly in this case, that the usual functions of the arteries and veins must have been reversed; for the Vena Cava, receiving its blood from the umbilical vein nearly as usual, had no communication with the Arterial system (the Heart being absent), except through the systemic capillaries; to which, therefore, the blood must have next proceeded, returning to the placenta by the umbilical artery. This view of the course of the blood was confirmed by the fact, that the veins were everywhere destitute of valves.-It is evident that a single case of this kind, if unequivocally demonstrated, furnishes all the proof that can be needed of the existence, even in the highest animals, of a "capillary power ;" which, though usually subordinate to the Ifeart's action, is sufficiently strong to maintain the circulation by itself, when the power of the central organ is diminished. In this, as in many other cases, we may observe a remarkable capability in the living system of adapting itself to exigencies. In the acardiac Fotus, the "capillary power" supplies the place of the heart, up to the perior of birth; after which, of course, the circulation ceases, for want of due aeration of the blood. It has occasionally been noticed, that a gradual degeneration in the structure of the Heart has taken place during life, to such an extent that scarcely any muscular tissue could at last be detected in it, but without any such interruption to the circulation as nust have been anticipated, if this organ furnishes the sole impelling force.

267. Further, it is a general principle, unquestioned by any Physiologist, and emborlied in the ancient aphorism, $U b i$ stimulus, ibi fluxus, that, when there is any local excitement to the processes of Nutrition, Secretion, etc., a determination of blood towards the part speedily takes place, and the motion of blood through it is increased in rapidity; and although it might be urgerl that this increased determination may not be the effect, but the cause, of the increaserl local action, such an opinion could not be sustained without many inconsistencies with positive facts. For it is known that such local determinations may take place, not only as a part of the regular phenomena of growth and development (as in the case of the entire genital system at the time of puberty and of periodical heat, the uterus after conception, and the mamme after parturition), but also as a consequence of a strictly local cause. Thus, the student is well aware that, after several hour's' close application, there is commonly an increased determination of blool to the brain, causing a sense of oppression, a feeling of heat, and frequently a diminished action in other parts; and, again, when the capillary circulation is being examined under the microscope, it is seen to be quickened by moderate stimuli, and to be equally letarded by depressing agents. All these facts harmonize completely with the phenomena, which are yet more striking in the lower classes of organized beings, and which are evidently in accordance with the same laws.

1 See Dr. Houston in the Dublin Medical Journal, 1837.-An attempt was made by Dr. M. Hall (Edinb. MIonthly Journal, 1813) to disprove Dr. Houston's inferences; but a most satisfactory reply was given by Dr. Iouston, at the meeting of the British Association, August, 1843, and published in the Dublin Journal, Jan. 1844. See also Edin. Med. and Surg. Journ., July, 1844. 
268. It is equally capable of proof, on the other hand, that an influence generated in the Capillaries may afford a complete check to the circulation in the part; even when the Heart's action is unimpaired, and no mechanical impediment exists to the transmission of blood. Examples of this may be seen in the loss of vitality prolucerl by the prolonged application of cold to a part; also in cases of spontaneous gangrene of the lower extremities, in which the death of the solid tissues is clearly connected with a local decline of the circulation, and in which it has been shown by examination of the limb after its removal, that both the larger tubes and the Capillaries were completely pervious; so that the cessation of the flow of blood could not be attributed to any impediment, except that arising from the cessation of some power which exists in the Capillaries, and which is necessary for the maintenance of the current through them. The most remarkable evidence on this point, however, is derived from the phenomena of Asphyxia, which will be more fully explained in the succeeding chalpter. At present it may be stated as a fact, which has now been very satisfactorily ascertained, that, if admission of air into the lungs be prevented, the circulation through them will be brought to a stand, as soou as the air which they contain has been to a great degree deprived of its oxygen, or rather has become loaded with carbonic acid; and this stagnation ivill, of course, be communicated to all the rest of the system. Yet, if it have not continued sufficiently long to cause the loss of vitality in the nervous centres, the movement may be renewed by the admission of air in the lungs. Now although it has been asserted, that the staguation is due to a mechanical impedimeut, resulting from the contracted state of the lungs in such cases, this has been clearly proved not to be the fact, by causing animals to breathe a gas destitute of oxygen, so as to produce Asphyxia in a different manner; for the same staguation results as in the other case.

269. If the phenomena which have beeu here brought together be considered as establishing the existence, in all classes of beings possessing a circulating apparatus, of a "Capillary power," which affords a necessary condition for the movement of the nutritious fluicl, through those parts in which it comes into more immediate relation with the solids, the question still remains open, what is the uature of that power?-It is very doubtful whether the Capillaries possess true contractility; for although their diameter is sul)ject to great variation, yet this may be due simply to the elasticity of their walls, which tends to keep them constantly contracted upou the stream of blood that passes through them; and there is no arlequate proof that the alterations in their size, which are consequent upon the local application of stimuli, proceed from any other source than the alteration in the quantity of blood delivered to them by the nimute arteries, the very considerable alterations in whose calibre under such influences have been already described $(\$ \$ 252,253)$. In the experiments of the Profs. Weber (loc. cit.), the application of the electric stimulus to the Capillaries produced no change in their diameter. Even supposing the Capillaries, however, to possess such an independent contractility, this could not exert itself in aiding the flow of blood through them, except either by rhythmical alternations of contraction and dilatation, or by sone kind of peristaltic movement; and observatiou completely negatives the idea of the existence of any such movement, since the strean of blood, now rendered continuous by the elasticity of the arteries, passes through the Capillaries as through tubes of glass. Hence the notion of any mechanicul assistance, afforded by the action of the walls of the Canpillaries to the movement of blood through them, must be altogether disminssed.

270. There is experimental eviclence, howerer, that the morement of the 
blood may be affected by any agency which alters the chemico-vital relations between the blood and the tissues which it permeates. Thus, when the interiupted electrie current was applied to the Capillaries by the Profs. Weber, they noticed that the blood-corpuscles showed a remarkable tendency to adhere to each other and to the walls of the ressels, so as to produce a great amomt of friction and a consequent retardation. A very similar set of phenomena has heen observed by Mr. Wharton Jones, ${ }^{1}$ as the consequence of the direction of a stream of carbonic acid against the capillary network. And the depression of the vitality of the part, by such injuries as tend to excite Inflammation in it, produces a like stagnation. This effect cannot be attributed to mechanical obstruction in the vessels, for they are usually dilated rather than contrated, when this condition exists; and without any change in the dimensions of a tube, the stream of blood through it may be seen decreasing from extreme velocity to complete stagnation. ${ }^{2}$ 'That alterations in the chemical state of the blood (involving, of course, important changes in its vital properties) are capable of excreising a most important effect on the Capillary circulation, is shown, not merely by the stagnation of the pulmonary Circulation in Asphyxia, but by the curious fact ascertained by Dr. J. Reid, ${ }^{3}$ that the bluod, when iniperfectly arterialized, is retarded in the systemic capillaries, causing an increased pressure on the walls of the arteries. He found that, when the ingress of air through the trachea of a Dog was prevented, and the Asphyxia was proceeding to the stage of insensibility, - the attempts at inspiration being tew and labored, and the blood in an exposed artery being quite veuous in its character, the pressure upon the arterial walls, as indicated by the hrenadynamometer applied to the femoral artery, was much greater than usual. Upon applying a similar test to a vein, however, it was found that the pressure was proportionably diminished; whence it became apparent, that there was an unusual obstruction to the passage of venous blood through the systemic capillaries. After this period, however, the mercury in the haemadynamometer applied to the artery began to fall steadily, and at last rapidily, in consequence of the diminished foree of the heart, and the retardation of the blood in the pulmonic capillaries; but, if atmospheric air was adnitted, the mercury rose instantly, showing that the renewal of the proper chemical state of the blood restored the condition necessary for its cireulation through the capillaries."

271. It appears from the preceding facts, that the conditions under which the power in question uniformly operates, may be thus simply and definitely expressed: Whilst the injection of blood into the Capillary ressels of every part of the system is due to the action of the Heart, its rate of passage through those ressels is greatly modified by the degree of activity in the processes, to which it should normally be subservient in them; the current being rendered more rapid by an increase in their activity, and being stagnated by their depression or total cessation. Or at any rate, to use the more guarded language of Mr. Paget (loc. cit.), we have ficts enough to justify the hypothesis, "that there is some mutual relation between the blood and

1 Brit. and For. Med. Review, vol. xiv, n. 600.

2 See Mr. Paget, Op. cit., P. 311. - The Author had lone previously satisfied himself that such was the fact; and is giad to be ablo to cite the far more extended observations of Mr. Paget on this point, in confirmation of his own.

3 Edimb. Med. and Surg. Journ., April, 1841 ; and Anat., Phys, and Pathol. Researches, chap. ii.

4 This last fact (as Dr. Reid has remarked) is sufficiont to nerative the idea of Mr. Erichsen, that the obstruction is eansed by the controtim of the capillaries under the stimulus of renous blood (Edinb. Med. and Surg. Journ., Jan. 1845); for all experiments agree in showing, that such contracticn can only be excited by the application of a stimulus for some minutes, and that relaxation takes place still noreslowly. 
its vessels, or the parts around them, which, being natural, permits the most easy transit of the blood, but, being disturbed, increases the hindrances to its passage." - A physical principle has been put forth by Professor Draper, ${ }^{1}$ which seems quite adequate to explain these phenomena. It appears fully capable of proof, that "if two liquids communicate with one another in a capillary tube, or in a porous or parenchymatous structure, and have for that tube or structure different chemical affinities, movement will ensue; that liquid which has the most energetic affinity will move with the greatest velocity, aud may even drive the other liquirl before it." Now rterial blood,-containing oxygen with which it is ready to part, and bcing prepared to receive in exchange the carbonic acirl which the tissues set fiee,-must obviously have a greater affinity for those tissnes than Venous blood, in which both these changes have already been effected. Consequently upon mere physical principles, the arterial blood which enters the Systemic capillaries on one side, inust drive before it, aud expel on the other side of the network, the blood which has become venous whilst traversing it; but if the blood which enters the capillaries have no such affinity, no such motor power can be developed.- On the other hand, in the Pulmonary capillaries the opposite affinities prevail. The venous blood and the air in the cells of the lungs have a mutual attraction, which is satisfied by the exchange of oxygen and carbonic acid that takes place through the walls of the capillaries; and when the blood has become arterialized, it no longer has any attraction for the air. Upon the very same principle, therefore, the venous blood will drive the arterial before it in the Pulmonary capillaries, whilst respiration is properly going on ; but if the supply of oxygen be interruptcd, so that the blood is no longer aerated, no change in the affinities takes place whilst it traverses the capillary network; the blood continuing venous, still retains both its need of a change, and its attraction for the walls of the capillaries; and its egress into the pulmonary veins is thus resisterl, rather than aided, by the force generated in the lungs. - The change in the condition of the blood, in regard to the relative proportions of its oxygen and carbonic acid, is the only one to which the Pulmonary circulation is subservient; but in the Systemic circulation, the changes are of a much more cemplex nature, every distinct organ attracting to itself the peculiar substances which it requires as the materials of its own nutrition, and the nature of the affinities thus generated being consequently different in each case. But the same law may be eonsidered to hold good in all instances. Thus the blood conveyed to the Liver by the portal vein, contains the materials at the expense of which the bile-secreting cells are developed; consequently the tissue of the Liver, which is principally made up of these cells, possesses a certain degree of affinity or attraction for blood containing these materials; and this is diminisherl, so soon as they have been drawn from it into the cells around. Consequently the blood of the portal vein will drive before it, into the hepatic vein, the blood which has traversed the capillatries of the portal system, and which, in doing so, has given up the elements of bile to the solid tissnes of the liver. ${ }^{2}$

27\%. The influence which the Nervous System is known to exert upon the functions of Nutrition and Secrction, which are very intimately related to the morement of the bloorl in the Capillarics, would lead us to expect that it should exercise some like influence over that movement itself. And two distinct channels for such an influence naty be assigned with nuch probability; 'first, the control exercised by the Sympathetic system over the diameter

1 Treatise on the Forces which produce the Organization of Plants, pp. 22-41.

2 For further information, the reader is referred to Mr. Savory's Review of the whole of this subject, with origrinal experiments, in the Brit. and Fur. Med.-Chir. Raview, vol. $x v, p, 372$, and vol. $x v i, p .12$. 
of the smaller arteries, which will thus regulate the rate at which the blood is supplied to the Capillary plexus; and, second, the direct agency of Nerveforce in stinulating, retarding, or molifying those molecular changes, in which the Nutritive and Secretory operations consist. (See Prix. of Gris. Pirs.) - That the ordinary action of this force is not required to sustain the Capillary circulation, is clearly prover by the continuance of the flow without any apparent alteration, after section of the nerves of the part, as has been observel by Müller, Wharton Jones, and others; and this corresponds witl the well-known fact, that the Nutritive and Secretory processes may take place after Nervous agency has becn thus suspended. But it seems indubitable that a sudden and violent "shock" to the nervous centres may exert the same antagonistic influcnce on the movement of blood in the Capillaries, as we have seen it to do on the Hcart's action $(\$ 244)$ : for this appears alike from the immediate and total annihilation of all vital activity which is consequent upon such an injury, and firom direct observation iu such an experinent as the following, made by Dr. Wilson Philip. "The web of one of the hind legs of a frog was brought before the microscope; and while Dr. Hastings observerl the circulation, which was vigorous, the brain was crusher by the blow of a hanmel. 'The vessels of the wcb instuntly lost their power, the circulation ceasing; an effect which cannot arisc, as we have seen, from the ceasing of the action of the heart. [Dr. Philip here refers to experiments, by which it was ascertained that the circulation in the capillary vessels of the frog will continue for several minutes atter interruption of the heart's action.] In a short time the blood again began to move, but with less force. This experiment was repeated, with the same result. If the brain is not completely crushed, although the animal is killed, the blow, instead of destroying the circulation, increases its rapidity."1

\section{Hovement of the Blood in the Veins.}

273. The Venous system takes its origin in the small trunks that are formed by the remion of the Capillaries; and it returns the blood from these to the Ileart. The structure of the Veins is essentially the same with that of the Arteries; but the fibrous tissuc of which their middle coat is made up, bears more resemblance to the areolar tissue of the skin, than it docs to the true elastic tissue, and prescuts the distinguishing feature of Lamine running longitudinally as well as transversely; and the muscular fibre-cells are usually much fewer in number, and arc sometimes wanting altogether. ${ }^{2}$ The elasticity of the Veins is shown by the jet of blood which at first spouts out in ordinary venesection, when, by means of the ligature, a distension has been occasioned in the tubes below it. Though the walls of the Veins are thinner, they yet resist pressure better than the Arteries. In an experiment of Wintringliam ${ }^{3}$ the Aorta burst when the pressure rose to $158 \mathrm{Sbs}$, whilst the Vena Cava only gave way when it reached $176 \mathrm{lbs}$. A slight contractility on the application of stimuli, and on irritation of the sympathetic nervous fibres, has been observed; but this is not so decided as in the Arteries. The whole capacity of the Venous system is considerably greater than that

1 Experimental Inquirv into the Laws of the Vital Functions, 4th edition, p. 5.)

2 The following, accorling to Prof. Kölliker (Manual of Human Hirtology, Syd. Soc., vol. ii, p. 307), are Veins which are unprovided with muscular structure: Thus veins of the uterine portion of the placenta; the veins of the cerebral substance and pia mater; the sinuses of the dura mater; Breschet's reins of the bones; the venous cells of the corpora cavernosa in the male and female; and probably the venous cells of the spleen. See also Eberth, art. Bloodvessels, in Stricker's Hum. and Comp. Histology, vol. i, $1870, \mathrm{p}, 275$.

3 Experimental Inquiry, ete., 1740. 
of the arterial; the former is usually estimaterl to contain from two to three times as much blood as the latter, in the ordinary condition of the circulation; and when we consider the great proportion which the Veins in almost every part of the borly bear to the Arteries, we shall searcely regard even the larger of these ratios as exaggerater. Of course the rapidity of the movement of the blood in the two systems will bear an inverse ratio to their respective capacities; thus if, in a given length, the Veins contain three times as much bloorl as the Arteries, the fluid will move with only one-third of the velocity. Speaking gencrally, circumstances causing diminution of blood-pressure by dilatation of the Capillaries, as division of the spinal cord, render the bloodeurrent slower in the Veins. ${ }^{1}$ Even at their origins in the capillary plexus, the Veins are larger than the Arteries which terminate in the same plexus; so that wherever the arterial and venous networks form distinct strata, they are readily distinguished from each other. The Veins are remarkable for the number of valves which they contain, formed of duplicatures, or loose folds of the internal tunic, between the componcnt laminse of which contractile fibres are interposed; and also for the dilatations behind these, which, when distended, give them a varicose appearance. The valves are single in the small veins, the free edge of the flap closing against the opposite wall of the vein; in the larger trunks they are double; and in a few instances they are composed of three flaps. The object of these valves is evidently to prevent the reflux of blood; and we shall prescntly see that they are of important use in assisting in the maintenance of the venons circulation. They are most numerous in those veins which run among parts affected by muscular movement; and they are not found in the veins of the lungs, of the abdominal viscera, or of the brain.

274. The movement of the blood through the Veins is, without doubt, ehiefly effected by the vis à tergo or propulsive iorce, which results from the action of the heart aud arteries; this, as already shown (\$258), is very greatly diminished by the time that it acts on the bloor in the reins; but the resistance to the onward movement of the blood is now so slight, that a very feeble power is adequate to overcome it. There are some concurrent causes, however, which are supposed by some to have much influence upon it, and of which the consideration must not be neglected.-One of these has been found by some physiologists, in the inspiratory movement; this is supposed to draw the blood of the Veins into the chest, in order to supply the vacuum which is createrl there at the moment of the descent of the diaphragm. That the movement in question has some influence on the flow of venous blood into the chest, is evident from the occurrence of the respiratory pulse, long ago described by Haller, which may be seen in the veins of the neck and shoulder in thin persons, and in those especially who are suffering from pulmonary discases. During Inspiration, the veins are seen to be partially emptied, whilst during Expiration they become turgid, partly in conseguence of the accumulation fom hehind, and of the check in fiont ; and partly (it may be) in some cases, through an absolute reflux from the veins within the chest $(\$ 237)$. The fat that in the immerlate neighborhoor of the chest the flow of blood towards the heart is ated by inspiration and imperled by expiration, is further provel by Sir D. Barry's experiurent, which eonsisted in introduciug one extremity of a tube into the jugular vein of a Horse, and the other into water, whieh exhibiter an alternate elevation and depresion witli inspiration and cxpiration; this has been repeated and confirmed by several Physiologists. On the other hand, the expiratory movement, while it

In regard to this point see Cron and Stcinmann, Bulletin de l'A ad. des Sciences de St. l'étersbourg, t. xit, 1871, p. 266 . 
directly canses accumulation in the reins, will assist the heart in propelling the blood into the artcries; and by the combined action of these two causes is produced, among other effects, the rising and sinking of the Brain, synchromously with expiration and inspiration, which are observed when a portion of the cranium is removed. Several consirlerations, however, agree in pointing to the conclusion, that no great efficacy can be rightly attributed to the Respiratory movements as excrting any general influence orer the Venous circulation. The Pulmonary circulation being entirely within the chest, cannot be affected by variations in atmospheric pressure; the entire venons circulation of the foctus, also, is independent of any such agency. Again, it has been shown expcrimentally by Dr. Arnott and others that no suction power, exerted at the farther end of a long tube, whose walls are so deficient in firmmess as are those of the Veins, can occasion any acceleration in a current of fluid transmitted through it, for the eflect of the suction is destroyed at no great distance from the point at which it is applied, by the flapping together of the sides of the vessels. 'This tendency may be counteracted, howerer, as Bérard ${ }^{1}$ maintains, by firm adhesions of the external surface of the Veins to the arljoining parts: such arlhesions unduubtedly take place in many parts, as for instance in the Hepatic and Innominate Veins, and in the lower part of the Jugular Vein; and therefore, to that extent at least, the venous circulation must be influenced by the respiratory movements. ${ }^{2}$ - Inother agency which certainly assists the renous circulation in some animals, is the rhythmical contraction of the walls of the Veins, which has been observed to occur 8 to 10 times per minute in the transparent membrane of the wing of the Bat, the amount of coutraction being about onefourth of the diameter of the vessel (Wharton Jones). The same phenomenon repeated 5 or 6 times per minute has been observed by Schiff ${ }^{3}$ and Vulpian ${ }^{4}$ in the veins of the Ear, and by $\mathrm{Wagner}^{5}$ in the ressels of the Iris of the Rabbit. It has also been shown by Mr. ITharton Jones ${ }^{6}$ that the Lymphatic Hearts of the Eel and Frog are to be regarded as exerting an auxiliary agency on the general circulation, propelling their contents at certain intervals into the Veins. The walls of these hearts are composed of unstriped rhythmically contractile muscular fibrils, which contract under the influence of the spinal cord.

275. One of the most powerful of the general causes which influence the Venous circulation, is doubtless the frequently recurring pressure of the muscles upon their trunks. When quiescent the circulation in muscles is extremely slow, but whenever contraction takes place, a portion of the Veins

1 Cours de Physiologie, t. ir, p. 62.

2 'The pressure of the blood in the reins has been earefully examined by M. M. Jacobson and Recklinghausen (Virchow's Archiv, Bd. xxxvi, p. 1), who found it to be as follows in the slicep, when the animal was breathing naturally:

Left vena innominata,

light subelavian rein, .

Left subclavian vein,

Right jugular vein,

Left jugular vein, .

External facial vein,

Internal facial vein

Brachial vein,

J 3 ranch of the brachial vein, .

Crural vein,.

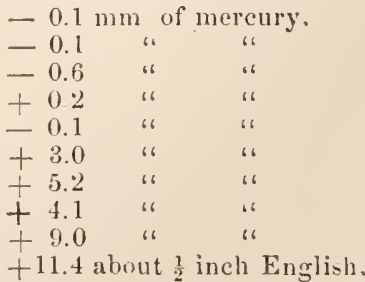

- $0.1 \mathrm{~mm}$ of mercury.

$+02$

$-0.1$

$+3.0$

$+4.1$

+11.4 about $\frac{1}{2}$ inch English.

3 Arehiv f. Physiol. Heilk, 18.54, t. xiii, p. 521.

4 Comptes Rendus de la Société de Biologie, 1856, p. 183.

5 Archiv f, Ophthalmol., Bel xii, Heft ii, p. 1.

6 Proeeed. of the Roy. Soc., 1868, Nos. 98, 101, and 102.

7 See Eckhard, Beiträge, No. vii, p. 167. 
of the part will undergo eompression: and as the blood is prevented, by the valves in the Veins, from being driven baek into the small vessels, it is neeessarily foreed on towards the heart. ${ }^{1}$ As each set of museles is relaxed, the Veins compressed by it fill out again, to be again eompressed by the renewal of the force. That the general Museular movement is an important agent in maintaining the eireulation at a point above that at which it would be kept by the action of the heart and arterial system alone, appears from several eonsiderations. The pulsations are diminished in frequeney by rest, aceelerated by exertion, and very much quiekened by violent effort $(\$ 248$, d). In all kinds of exercise, and in almost every sort of effort, there is that alternate contraction and relaxation of partieular groups of Museles, which has been just mentioned as affeeting the flow of blond through the veins; and there can be little doubt that the inereased rapidity of the return of blood through them is of itself sufficient eause for the aeeelerated movements of the heart. When a large number of museles are put in action after repose, as is the ease when we rise up from a reeumbent or a sitting posture, the biond is driven to the heart with a very strong impetus; and if that organ should be diseased, it may arrive there in a quantity larger than ean be disposed of; so that sudden death may be the result. Hence the neeessity for the aroidanee of all sudden and violent movements on the part of those who labor under either funetional disorder or structural disease of the eentre of the eirculation.

276. The Venous eirculation is mueh more liable than the Arterial, to be influenced by the foree of gravity; and this influenee is partieularly notieeable, when the tonieity of the vessels is defieient. - The following experiments performed by Dr. C. J. B. Williams," to elueidate the influence of defieient firmmess in the walls of the vessels, and of gravitation, over the movement of fluids through tubes, throw great light on the eauses of venous coingestion. A tube with two equal arms having been fitted to a syringe, a brass tube two feet long, having several right angles in its eourse, was adapted to one of them, whilst to the other was tied a portion of a rabbit's intestine four feet long, and of ealibre double that of the brass tnbe, this being arranged in eurves and eoils, but withont angles or erosings. When the two tubes were raised to the same height, the small metal tnbe discharged from two to five times the quantity of water diseharged in a given time by the larger but membranous tube; the difference being greatest when the strokes of the piston were most foreible and sudden, by which the intestine was much dilated at its syringe end, but conveyed very little more water. When the discharging ends were raised a few inches higher, the difference increased ennsiderably, the anount of fluid discharged by the gut being much dininished; and when the ends were raised to the height of eight or ten inches, the gut ceased to discharge, each stroke only moving the column of wates in it, and this subsiding again, without rising high enough to orerfow. When the foree of the stroke inereased the part of the intestine mearest the syringe burst.-From these experiments it is easy to understand how any deficiency of "tone" in the Venous system will tend to prevent the aseent of the blood from the depending parts of the body, and will eonsequently oecasion an inereased pressure on the walls of the vessels, and an angmentation in the quantity of blood they enntain. All these eomlitions are peeuliarly fiurorable to the eseape of the watery part of the blood from the small vessels; and this may either infiltrate into the areolar tissue, or it may

1 Sadler, Ueber den Blutstrom in den ruhenden, verkïrzten und ermüdeten Muskeln des lubendes 'Thieres, in Ludwig's Arbeiten, 1870, p. 77. Also Sezelkow, in Wiener Sit\%ungsberichte, Band xlv.

2 Principles of Medicine, 2 d edit., p. 188. 
be ponred into some neighboring serous cavity, producing dropsy. 'Thus it happens that such effusions may often be traced to that state of deficient vigor of the system, which peculiarly manifests itself in want of tone of the bloodressels; and that it is relieved by remedics which restore this. In many young females of lencophlegmatic temperament, for example, there is a tendency to swelling of the feet, by oedematous effusion into the areolar tissue, in conscquence of the flepending position of the limbs; the oedenia disappears during the night, but returns during the day, and is at its maximum in the evening. And the congestion which frequently manifests itself in the posterior parts of the body, towards the elose of exhausting diseases in which the patient has lain much upon his back, is attributable to a similar cause; of such congestion, effusions into the various serous cavities are frequent results; and such effinsions, taking place during the last hours of life, are often erroneously regarded as the source of death. To the same cause we are to attribute the varicose state of the veins of the leg, which is so common amongst persons of relaxed fibre, and especially in those whose liabits require them to be much in the erect posture; and this distension occasionally proceeds to complete rupture, the causes of which are fully elucidated by the experiments just cited.

\section{Peculiarities of the Circulation in different Parts.}

277. In several portions of the Human body, there are certain varieties in the distribution and in the functional actions of the bloodressels, which should not be omitted in a general account of the Circulation.-Of these, we have in the first place to notice the apparatus for the Prlmonary circulation; the chief peculiarity of which is, that venous bloor is sent from the heart, through a tube which is arterial in its structure, whilst arterial blood is returned to the heart, through a vessel whose entire character is that of a vein. The movement of the blood through these is consiflerably affected by the physical state of the lungs themselves; being retarled by any causes which can occasion pressure on the ressels (such as over-distension of the cells with air, ${ }^{1}$ obstruction of their cavity by solid or fluid depositions, or by foreign substances injected into them, etc.); and proceeding with the greatest energy and regularity when the respiratory movements are freely performed. - The Portal circulation, again, is peculiar, in being a kind of off'set from the general or systemic circulation, and also in being destitute of valves; and it may be surmised with much probability, that the purpose of their absence is, to allow of an unusually free passage of blood from one part of that system to another, during the very varying conditions to which it is subjected.-Another very important modification of the Circulating system, is that which presents itself within the Cranium. From the circumstance of the cranium being a closed cavity, which must be always filled with the same total amount of contents, the flow of blood through its vessels is attended with some peculiarities. The pressure of the atmosphere is here exerted, rather to keep the blood in the head, than to force it out; and it might accordingly be inferred, that, whilst the quantity of cerebral matter remains the same, the amount of blood in the cranial vessels must also be invariable. 'This inference appeared to derive support from the experiments of Dr. Kellie. ${ }^{2}$ On bleeding animals to death, he found that, whilst the remainder of the body was completely exsanguine, the wsual quantity of blood remained in the arteries and veins of the cranium; but that if an opening

1 See Quincke and Pfeiffor, Uebor den Blutstrom in die Lungen, Reichert und Du Bois-Revmond's Archiv, 1871, p. 90.

2 Edinburgh Medico-Chirurgical Transactions, vol, i. 
was made in the skull, these vessels were then as completely emptied as the rest. In the experiments performed by Küssmaul and Tenner, ${ }^{1}$ it was found on trephining the skull and compressing the carotids, that the brain, especially after removal of the dura mater, became very pale, and retreated from the opening to so great an extent as to form a cup $2 \frac{1}{2} \mathrm{~mm}$. in depth; whilst on releasing the pressure, it assumed a decp rose color and becane convex. When, however, they luted a piece of glass air-tight into the hole made by the trephine, as suggested by Donders, the phenomena were no longer the same, for no movement of any kind could then be perceived in the brain, which remained in all cases immovably in contact with the glass plate; but the sane changes in the tint of the cerebral substance, on checking and again restoring the current in the arteries, were observed. Observations of a similar nature were made by Mr. Durhan ${ }^{2}$ and Dr. Hammond, ${ }^{3}$ by whom it was noticed that the condition of the brain varied to a remarkable degree in the sleeping and in the waking states, being paler and ansmic in the former, and comparatively congested in the latter. These experiments, therefore, appear to furnish indisputable evidence that the circulation of blood through the Brain varies with the general conditions of the vascular system, and is not, as Dr. Kellie's experiments appeared to show, independent of them. In M. Jolly's experiments a manometer luted into the skull of dogs showed a positive pressure, which, rising with expiration and falling with inspiration, was sufficient in general to support a column of water varying from one to six inches in height. In rablits it was about half this amount, and occasionally became negative. The pulse in dogs caused a variation of from 5 to $10 \mathrm{~mm}$. Compression of the carotids produced but little effect, but the pressure slowly rose when the jugular veins were compressed. ${ }^{+}$Moreover, in disordered states of the circulation, the quantity of bloor in the ressels of the cranium may be for a time dininished by a sudden extravasation, either of blood or serum, into the eerebral substance; and the amount of interior pressure upon the walls of the vessels may also be considerably altered, cven when there is no difference in the quantity of fluid contained in them. It secms highly probable that in the delicate and extensive system of capillaries found in the pia mater and choroid plexus, a provision is made by which a large quantity of cerebrospinal fluid can be effused or absorbed in a short space of time, to compensate for sudden changes in the balance of the circulation.

278. The Erectile Tissues present another curious modification of the ordinary vascular apparatus. 'The chief' of these are the corpora cavernosia in the penis of the male, and in the clitoris of the female; the collection of sinilar tissues round the vagina and in the nymphe and uterus (Rouget) of the female; and the nipple in both sexes. In all these situations, crec-

1 See their Exsay (Syd Soc. Translution), p. 39 et seq., 1859.

2 Guy's Hosp. liep, 1860, p. 149.

3 New York Med. Journ., 1865, quoted in the Pliysiology of Man, by Dr. Austin Flint.

4 see F. Jolly, Untersuchungen über den Gellirndrïrk und über die Blutbewegung im šchïdel, Wurzburg, 1871; see atso G. Althaun, Beitrïge zur Physiolngie und Pathologie der Circulation, 1871. Pagenstedrer, Experiments und 'studien über Gehirudrick; and Caplie, The Relation of the Cranial Contents to the Pressure of the Atmosphere, 1874 .

6 The results of the experiments of Dr. G. Burrows (Medical Gazette, Aprit and May, 18.43) fully confirm the views stated above. Pagenstreher has shown that from 2.9 in 6.5 per cent. of the cubic eapacity of an animal's skull may be oceupied by injection of wax and tallow throurh a trephine aperture before symptoms of pressure supervene. In other words, that taking the eapacity of the skull to be $1300-1+00$ c c., from 37.7-40.fi c.e. as a mean, or 84.5-90.0 c.e. ats maximum of blood may be effused without evidence of pressure. 
tion may be produced, and in the rase of the penis, emissio seminis may be effected, by local irritation. The erectile tissue appears cscontially to consist of a plexus of veins with varicose cnlargements, inclosed in al fibromuscular envelope with trabccular partitions.' In the penis, as first pointed out by I'rof. Miiller, ${ }^{2}$ there are two sets of arteries; those of one set, destined for the nutrition of the tissues, communicating with the veins in the usual waty, through a capillary network; whilst the others, termed by him the "helicine arteries," are short, tendril-like branches which project into the veins (covered, however, by their endothelium), sometimes singly, and sometimes in tufts, ending abriptly by dilated extremities. These arteries are accompanied by a special system of longitudinal bundles of museles, the fibres of which become inserted into the midlle coat at various points (Stilling, Stein). The dilated ends of the helicine arteries usually communicate directly with the venous cavities, since injection thrown into the former generally fills the latter, and Kölliker states that he has frequently found them giving off delicate, almost capillary vessels, which discharge themselves into the venous spaces. The nerves implicated in producing erection in the dog were found by Ecklat ${ }^{3}$ to be, first, the $N_{n}$. pudend. communes proceeding from the sciatic plexus, and supplying the musculi ischio-carernosi, the corpora cavernosa of the penis, and membranous portion of the urethra ; and second, the Nervi erigentes proceeding from the sacral nerves and entering the hypogastric plexus. This plexus contains minute ganglia, communicates with the posterior mesenteric plexus, and furnishes branches to the bladder, prostate gland, rectum, and membranous portions of the urethra. After division of the former, or common pudendal nerves in the dog, Eckhard found it impossible to produce erection of the penis or emission of semen by direct irritation of the penis. The Nervi erigentes are, undoubtedly, the chief excitors to erection, for on exposing and irritating them, swelliug of the penis, gradually proceeding forwarls to the glans, immediately commencer. Erection may also nceur as a result of certain emotional conditions of the mind, the influence of which is probably transmitted through the Sympathetic nerve, as it may be experienced even in cases of paraplegia, whilst according to Legros, ${ }^{4}$ after section of the sympathetic fibres distributed to an erectile orgail no erection occurs. The precise mole in which the nerves act is still unknown, ${ }^{5}$ but there are grounds for believing that both the male and female organs are preserved in a quiescent state by a tonic influence exerted over the vessels by centres situated in the lower part of the spinal cord. In the venereal orgasm, however, inbibitory centres are excited, which restrain the action of the spinal cord and lead to dilatation of the vessels, and increased flow of blood through the organ; Eckhard, indeed, relates that in his experiments he obtained

1 See A. W. Stein, New York Med. Journal, June, 1872, for an aceount of the Histolngy and Physiology of the P('nis.

2 Entdeckung der bei der Ereetion wirksnmon Arturien, in Müller's Arehiv, 1835, p. 262. The views of Muller, though opposed by Valentin Müler's Arehiv, 1838, p. 182), W(abr, Arnold, Béclard, and others, as well as recently by Rouget, Journal de l'Anatomie, t. i, p. 326, and Laner, WVien. Sitz., xlvi, 1863, p. 120, who consider the helieine arteries to be for the most pirt, if not altogether, artificial produets consequent on the difficulty of foreing injection into the tortuous vessels of the trabecule, have been supported by the great authority of Hinle (Handluch d. Mensch. Anatom., 1866, p 40\%). See also Rohin, pamplilet, On the Erectile Tissues, and Vulpian. Legons sur l'A ppareil Vasomoteur, 1875, p 161.

3 Beitrạ̈ce zur Anat. und Phys., Giessen, 1863, and 1867, p. 71 .

* Gaz. Méd de Paris, 1866, Ño. 6.

5 For different views spe Kölliker, loe. eit.; Rnuget, Archives de Physiologit, 1868, p. 671; Goltz, Pflüger's Archiv, 3. vii, 1873, p. 346 ; Vulpian, Liccons sur l'Appareil V'asomoteur, 1875, p. 161 et seq. 
eight times more blood from the veins of the penis at the period of erection than during the intervals. The ischio-cavernosi and bulbo cavernosus muscles probably afford some assistance in completing and strcngthening the act of erection by compressing the veins which return the blood from the penis, but they are clearly unable to effect it by their own act, and it is obvious that no analngous power can be exerted in other erectile organs as the nipple. Their centres, according to Goltz, are situated in the lumbar region of the spinal cord, and here also is, in all probability, an inhibitory centre governing their action as well as that of the sphincter ani.

\section{CH A PTER IX.}

\section{OF RESPIRATION.}

\section{Nature of the Function; and Provisions for its Performance.}

279. The Nutritive fluid, in its circulation through the capillaries of the system, undergoes great alterations, both in its physical constitution and in its vital properties. It gives up to the tissues with which it is brought into contact, some of its most important elements; and at the same time it is made the vehicle of the removal, from these tissues, of ingredients which are no longer in the state of combination that fits them for their offices in the Animal Economy. To separate these ingredients from the greneral current of the circulation, and to carry them out of the system, is the great object of the excretory organs; the importance of whose respective functions will vary, it is very evident, with the amount of the ingredient which they have to separate, and with the deleterious influence which its retention would exert on the welfare of the system at large. Of all these injurious ingredients, Carbonic Acid is without doubt the one most abundantly introduced into the nutritive fluid; and it is also most deleterious in its effects on the system, if allowed to accumulate. We find, accordingly, that the provision for the removal of this substance from the blood is one of peculiar extent and importance, especially in the higher forms of animals; and further, that instead of being effected by an operation peculiarly vitul (like other acts of Excretion), its performance is secured by being made to depend upon simple physical conditions, and is thus comparatively little susceptible of derangement from disorder of other processes. All that is reguisite for it, is the exposure of the Blood to the influence of the Atmospheric air (or, in aquatic animals, of air disolved in water), ${ }^{2}$ through the metium of a membrane that shall permit the "diffusion of gases;" an interchange then taking place between the gatsons nutters on the two sides,-Carbonic Acid being exhaled from the Bhood, and being replaced by oxygen from the air. Thus the extrication of Carbonic acid is effected in a manner that renders it subservient to the introduction of that element which is required for all

1 Golt\%, I'flüurer's Arehir, Band vii, 1873, p. 58:2.

2 Whil-t nir contains about $\frac{1}{5}$ th of its volume of oxyen gas, water entuins only $3 \frac{1}{2}$ th of its volume The toebleness of the respiratory proceses which this implies in aquatic unimals is in part compen-ated for by the ready solubility of carbonic acid gats in water, which facilitates its escape from the syeteni, and the cirennstance that the respiratory organs are actually floating in the oxygenated medium. 
the most active manifestations of vital power; and it is in thesc two processes conjointly, not in either alone, that the function of Respiration essentially consists. - We shall now inquire into the sourees from which Carbonic acid is produced in the living body, and the causes of the demand for Oxygell.

280. The vital activity of the organism at large involves a continual change in its constituent parts; and those which (so to spcak) live the fastest, usually die the soonest, and pass most readily into decay (chap. $x$, sect. 1). Hence in the very performance of the Organic functions which concur to effect the Nutrition of the body, there is a constant source of disintegration; and one of the chief products of the decay of the tissues, which is consequent upon their loss of vitality, is Carbonic acid-Chus the most general object of the Respiratory process, which is common to all forms of organized being, is the cxtrication of this product from the system; and the demand for acration hence arising, will vary with the activity of the nutritive operations. Now the rate of life, and consequently the amount of disintegration, in any organized structure, depend in great measure upon the temperature at which it is maintained; and thus it happens that the produc. tion of Carbonic acid from this source, at the ordinary rate of vital activity, is much more rapid in "warm-blooded" than in "cold-blooded" auimals, and that the former suffer far more speedily than the latter from the privation of air. But when the temperature of the Reptile is raised by external heat to the level of that of the Mammal, its need for respiration increases, owing to the augmented waste of its tissues. When, on the other hand, the warm-blooded Mammal is reduced, in the state of hibernation, to the level of the cold-blooded Reptile, the waste of its tissues diminishes to such an extent, as to require but a very small exertion of the respiratory process to get rid of the carbonic acid, which is one of its chief products. And in thosc animals which are capable of retaining their vitality when they are frozen, or when their tissues are completely dried up, vital activity and disintegration are alike entirely suspended, and consequently there is no Carbonic acid to be set free.

281. But another source of Carbonic acid to be set frec by the Respiratory process, and one which is peculiar to animals, consists in the rapid changes which take place in the Muscular and Nervous tissues, in the very act of performing their peculiar functions; the development of the Muscular and of the Nervous forces involving, as the very condition of their production, a change in the substance of these tissues respectively ; in which change a large quantity of Oxygen is consumed, and a large amount of Carbonic acid is generated. Hence in Man, as in all Animals, in which the Nervo-Muscular apparatus constitutes the essential part of the organism, a powerful demand for Respiration is created by its activity; the amount of oxyen taken in, and of Carbonic acid exhaled, being determined, cateris paribus, by the degree in which this apparatus is exercised. - That Carbonic acid is set firec ready formed by the muscles, and is not exclusively generater by the oxidation of the products of their disintegration after the reception of these in to the blood-current, has been shown by the experiments of Dr. G. Liebig, who found that carefully preparcd frogs' muscles absorb Oxygen and exhale Carbonic acid so long as their contractility lasts, even when they have been completely deprived of blood. ${ }^{2}$ In the similar experiments more recently made by $M$.

1 Bericht d. Akad. d. Wissensch. zu Berlin, 1850, \&\& 339-347.

2 The statement of $\mathbf{M}$ M. Estor and St. Pierle, that the formation of carbonic acid is most cnergetic in the arterial system (Robin's Journal de l'A natomie, $1865, \mathrm{p} .302$ ), has been refuted by Hirschman (Du Bois-Reymond's Archiv, 1866, p. 502), and Hoppe-Seyler (Med. Chem. Untersuch, Berlin, 1867, p. 295). 
Paul Ber ${ }^{1}$ it clearly appears that whilst the muscular tissue on account of its large mass plays the most important part in those internal processes which he has termed the "respiration of the tissues," yet that analogous changes occur in every tissue and organ in the body. It must not, however, be too hastily assumed that the phenomena here witnessed are those of simple oxidation, since the absorption of Oxygen and the extrication of Carbonic acid are probably only the first and last links in a long series of decompositions.

282. Besides these sources of Carbonic acid which are common to all Animals, there is another which is restricted (or nearly so) to the two highest classes, Birds and Mammals; these being distinguished by their power of maintaining a constantly-elevated temperature. A part of this heat is generated by the oxygenation of the components of their disintegrating tissues, and of their blood, the metamorphosis of which takes place at a very rapid rate; but where this is not sufficient, their power of maintaining their temperature depends upon the direct combination of certain elements of the food with the oxygen of the air, by the combustive process. - The quantity of carbonic acid that is generated directly from the elements of the food, seems to vary considcrably in different animals, and in different states of the same individual. In the Carnivorous tribes, which spend the greater part of their time in a state of activity, it is probable that the quantity which is generated by the waste or metamorphosis of the tissues is sufficient for the maintenance of the required temperature; and that comparatively little of the carbonic acid set free in respiration, is derived from the direct combustion of the materials of the food. But in Herbivorous animals of comparatively inert habite, the amount of metamorphosis of the tissues is far from being sufficient; and a large part of the food, consisting as it does of substances that undergo combustion with great facility, is made to enter into direct combination with the oxygen of the air, and thus to compensate for the deficiency. In Man and other animals, which can sustain considerable variations of climate, and can adapt themselves to a great diversity of habits, the quantity of carbonic acid formed by the direct combination of the elements of the food with the oxygen of the air, will differ extremely under different circumstances. It will serve as the complement of that which is formed in other ways; so that it will diminish with the increase, and will increase with the diminution of muscular activity. It will also vary in an inverse ratio to the external temperature, increasing with its diminution (as more heat must then be gencrated), and diminishing with its increase; the effect of external heat being thus precisely opposite, in the warm-blooded aninal, to that which it exerts on the cold-blooded ( $\$ 281$ ). - In all cases, if a sufficient supply of food be not furnished, the store of fat is drawn upon; and if this be exhansted, the animal dies of cold.

283. To recapitulate, then, the sources of demand for Oxygen and pro-

1 P. Bert, Leçons sur la Physiologrie eomparée de lat liespiration, Paris, 1870, ]. 30 et seq. In these experiments M. Bert found that :

\begin{tabular}{|c|c|c|c|c|c|c|}
\hline Grammes. & & & & $\begin{array}{l}\text { Cub, cent. } \\
\text { Oxygen. }\end{array}$ & Cub & $\begin{array}{l}\text { cent. of Car- } \\
\text { onic Acid. }\end{array}$ \\
\hline 100 of musele, & . & · & \multirow{6}{*}{ Absorbed } & $(508)$ & \multirow{6}{*}{ Exlialed } & f 56.8 \\
\hline " of brain, & . & · & & 45.8 & & 42.8 \\
\hline " of kidney, & . & . & & 37.0 & & 15.6 \\
\hline of spleen, & . & . & & 273 & & 15.4 \\
\hline " of testis, & - $\quad$. & - $\quad$. & & 18.3 & & 27.5 \\
\hline " of bone and & marros & ushed, & & $(17.2)$ & & 8.1 \\
\hline
\end{tabular}

It is worthy of notiee that M. Bert finds in corroboration of Spallanzani's experiments that the latger the proportion of oxygen present in the air to which the tissues are exposed, the more freely it is absorbed; the proportion of carbonie aeid gas exhaled, however, is not eor respondingly increased. 
duction of Carbonic acid in the animal body are threefold.-I. The continual decay of the tissues common to all organized bodies, which is favored by whatever promotes their vital activity, and is retarded hy every influence that depresses it.-II. The metamorphosis peculiar to the Nervous and Muscular tissues, which is the very condition of the production of their power, and which therefore bears a direct relation to the degree in which they arc exerted.-II. The direct conversion of the carbon and hydrogen of the food into carbonic acid and water, which is peculiar to warm-blooded animals; and which varies in quantity, in accordance with the amount of heat to be generated.

284. The activity of the process of Respiration in auy Animal is, as a general rule, in direct proportion to the smallness of the Corpuscles of its blood; for these, as has already been shown ( $\$ 193)$, are the carriers of oxygen; and it is evident that a given weight of smaller globules will offer a larger surface for the absorption of oxygen, than an equal weight of larger Corpuscles. Hence in Fishes and Reptiles, which possess large Corpuscles, the provision for the aeration of the blood is much less perfect, and the amount of oxygen absorbed, and of carbonic acid eliminated, is considerably smaller than in the case of Mammals and Birds, the corpuscles of whose blood are remarkably minute. At the same time the size of the lungs in the latter classes is far less in proportion to their bulk than in most Reptiles; but this diminution is more than compensated by the minute subdivision of their cavities, by the peculiarity of the distribution of their bloodvessels, and by the arrangements whereby a continual and rapid interchange, both of the blood and of the air, is provided for.-The following are the points of most importance in the structure of the Human Lung. "The walls of the larger bronchi are composed independently of the tunica adventitia of four structurally distinct layers. Of these the outcrmost ( $\alpha$, Fig. 157) is a fibrous layer of dense comnective tissue in which cartilaginous lamina conferring firmness and elasticity on the tubes, ace imbedderl. The next $(b)$ is a muscular layer composed of compact circularly arrangerl fasciculi of smooth muscular tissue. The third is the internal fibrous layer (c), composed of tolerably legularly-arranged longitudinal bundles of thick elastic fibres, which on section give a sinuous outline to the interior of the tube. The innermost part of this layer is condensed into a hyaline layer', and upon this last or so-called basement-membrane rests the ciliated columnar epithelium that forms the fourth laycr. Intervening here and there anongst the ciliated columuar cells are $\mathrm{E}$. Schulze's cup, goblet, or chalice cells (b, Fig. 156). These are filled with a mucous mass through which numerous highly refractile granules are distributed. Imbedded in the outer fibrous layer of the larger bronchi are numerous mucous glands, the ducts of which run inwards, are lined with columnar epithelium, and open by trumpet-

FrG. 156

$$
\text { a b }
$$

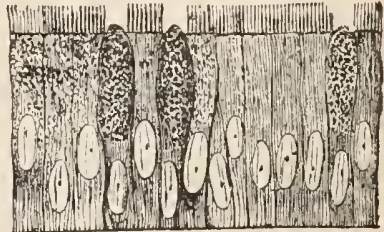

ciliated Eyithrlium from a bronchial twig 1-6th of an inch in diameter. $a$, ciliated columuar epithelial cells; $b$, goblet cells. From the Dog, magnified 320 diameters.

1 For an account of the principal forms of Respiratory apparatus among the lower Animals, see Princ. of Comp. Phys., clatp. vi; also the Menioir by Mr. Rainey in the Med.-Chirurg. Trans., vol. xxviii; and Prof. Kölliker's Manual of Human Microscopic Anatomy, 1860, Lond. For excellent general accounts of the structure of the Human Lung, see IVaters's Fothergillian Esaly, London, 1860; Williams in the Supplement of the Cycl. Anat. and Plyysiology; and F. E. Schulze in Stricker's Manual of Histology (Syd. Soc. Trans.), vol. ii, 1872, p. 63, on whose essay the following description is tounded. 
shaped orifices. They cease with the cartilaginous plates between which only they ultimately appear. The smaller bronchi, or those having a diameter of about one-fiftieth of an inch, differ from the foregoing chiefly in the thinness of their external fibrous coat, and the absence in it of either cartilages or mucous glands, whilst the columnar ciliated epithelium becomes

FIG. 157.

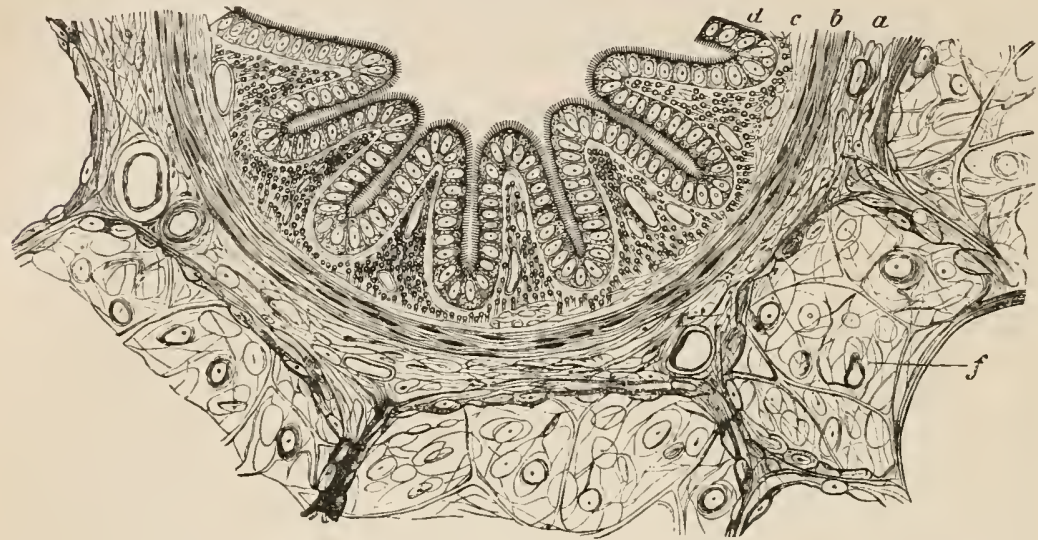

Part of a transverse section of a bronchial tube from the Pig, having a diameter of about 1-60th of an inch, magnified 240 diameters. $a$, external fibrous layer; $b$, muscular layer; $c$, internal fibrous layer ; $d$, epithelial layer; $f$, one of the surroundiag alveoli.

lower or more flattened, and finally at the termination of the bronchia in the alveolar passages the cells lose their cilia and the cup cells cease to appear. The bronchial tubes divide and subdivide, and at their termination (a, Fig. 158), open into canals known as the alveolar passages, the entrance of which is surrounded by a thick bundle of annular muscular fibre-cells forming a kind of sphincter. ${ }^{1}$ The alveolar passages, $c, c$, are rather wider than the bronchia, from which they spring, and, after dividing dichotomously at acute angles from two to four times, terminate cacally at a listance of from $\frac{1}{12}$ th to $\frac{1}{16}$ th of an inch from the extrenity of each bronchial tube. In cousequence of these ultimate processes gradually expanding towards their ceecal terminations they liave been termed infundibula. Both the alveolat passages and the infundibula (air-saes of Dr. Waters, which he describes rather differently from Schulze as forming a group of from six to ten in number clustered around the extremity of every bronchial tube) are beset with numerons small polyhedric cavities with rounded angles and borders termed the alveoli or air-cells (Fig. 158); from ten to twenty of each may be counted on the interior of each infundibulum or air-sac. 'The length of the alveoli of ordinary size are about equal to their brearth ; the total number has been estimated approximatively at 1700 or 1800 millions, with a surface equivalent to 200 square metres (Küss). ${ }^{2}$ The foundation layer of the alvcolar wall is composed of a transparent structureless membrane, which in the thickest part- exhibits a distinctly fibrous character, caused by the presence of numerous elastic fibres. ${ }^{3}$ The membrane is folded sharply at the margin of the air-vesicles ( $\mathrm{Fig} .159, c)$, so as to form a very definite border to them. The stronger septa divide off polyhedric portions of the alveolar parenchyma, which are known as lobuli.-The diameter of the Human air-cells is about

3 Hirschmann and Chrzonsczezewsky, Virchow's Archiv, 1866, p. 355. 
twenty times greater than that of the capillarics which are distributed upon their parietes; varying (according to the measurement of Weber) from the Io th to the $\frac{1}{7}{ }_{0}$ th of an inch. 'The inner surfice as well as the whole of the

FIG. 158 .

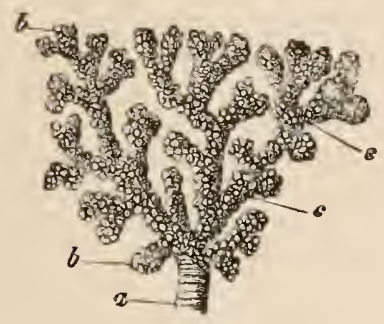

System of alreolar passages and infundibula from the margin of the Lung of a Monkey (Cercopthecus) injected with mereury, magnified 10 diancters. $a$, Terninal bronchial $t w i g$; $b, b$, infundibula; $c, c$, alveolar passages.

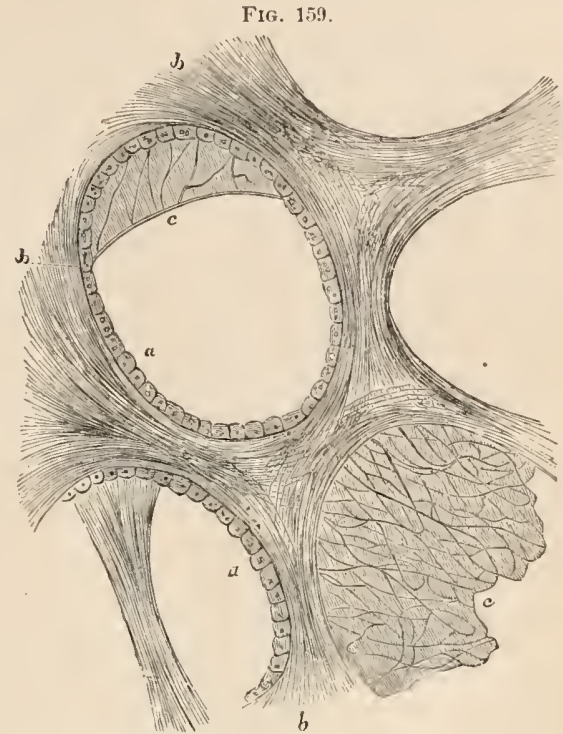

$b$

Air-cells of Human Lung, with intervening tissues: $a$, epithelium ; $b$, elastic trabecula; $c$, membranous wall, with fine elastic fibres.

infundibula and alveolar passages are invested by a continuous and in the foetus homogeneous epithelium. In adult mammals, however, it is not homogeneous. In the mature foetus the cells are flat, $4-6$ angled, with granular contents and a bright spherical nucleus. In the adult such cclls are arranged in groups of two or four separated by large transparent thin structureless cells, which are either irregularly angular or sinuous in ontline. These cover the capillaries and all the folds and prominent edges. The granular spheroidal cells cover the alveolar walls between the meshes of the capillarics, and in adults constantly contain spheroidal black pigmentgranules. The capillary plexus (Fig. $160)$ is so disposed between the two layers which form the walls of two adjacent air-cells, as to expose one of its surfaces to each ; by which provision the full influence of the air upon it is secured. The nctwork of vessels is so close, that the diameter of the meshes is scarcely so great as that of the capillaries which inclose them, and they often project into the cavity of the alveoli covered only by the

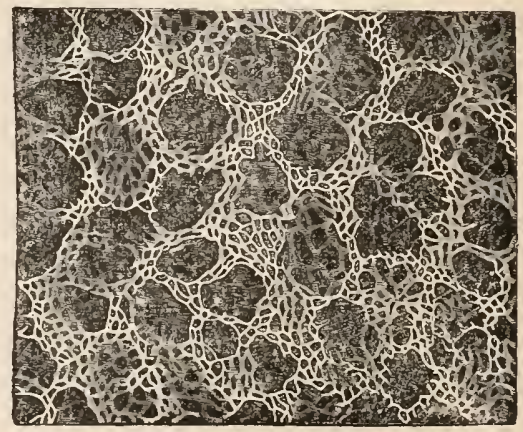

Arrangement of the Capillaries of the Air-cells of the Human Lung.

I The dimensions given by Moleschott (De Vesieulis Pulmonum Malpighianis) are very mueh less than these; the lange of dianeter being stated by him at between $I^{\frac{1}{2}}{ }_{0}$ th and $\frac{1}{200}$ th of an inch. The Author's own observations, however, lead him to regard Weber's and Kölliker's statements as very near the truth. 
flat cells above mentioned; indeed it would be impossible to conceive of a method by which blood, whilst still retained within vessels, should be spread over a larger surface for aeration. And if not restricted within vessels, it could not be ceaselessly and rapidly driven on by the propulsive power of the heart, which acts no less efficiently upon the pulmonary circulation than upon the systemic, although the force exerted is much inferior, the resisting power being far less, in consequence of the shortness of the circuit. Estimating the surface of the capillaries at three-fourths of the whole surface of the alveoli, a thin layer of blood of 150 square metres would be exposed to the air, representing about two litres of blood; and it has been further calculated that it is renewed 10,000 times in the 24 hours (Küss). ${ }^{1}$ Even making great allowance for error in these calculations, enough remaius to show how extensive is the surface for the interchange of gases between the air and the blood.- Two systems of vessels, the pulmonary and the bronchial, transmit blood, though in very different proportions, through the lungs. In the former, which is by far the largest, the blood received from the system, deficient in oxygen and charged with carbonic acid, is propelled by the right ventricle through the pulmonary artery to the minute plexus of capillaries just described on the walls of the air-sacs and vesicles. From thence, having undergone aeration, it is returned to the left auricle of the heart, through the pulmonary veins, to be distributed by the left ventricle and arterial systen to the body at large. The smaller system, which has been particularly examined by Prof. Turmer, ${ }^{2}$ consisting of the bronchial arteries and veins, with numerous minute branches of the intercostal, internal mammary, and other arteries; is distributed to the parts about the root of the lung, the large bronchial tubes, and the pulmonic pleura; some of its capillaries discharge themselves into the corresponding bronchial veins, whilst others terminate in the pulmonary system, and, there is reason to believe, play an important part in maintaining the circulation in cases where the pulmonary artery has been obliterated by disease. The lymphatics of the Lungs ${ }^{3}$ arise either from branched cells in the alveolar septa, one of the branches opening between the epithelial cells into the cavity of the alveoli (pseudo-stomata of Klein); or, as Sikorski maintains, from the goblet-cells of Schulze. In either case they form a plexus in the submucosa, and then run with, and partially or wholly invaginate branches of the pulmonary artery and vein. Cloetta found in the lung-tissue inosite, uric acid, taurin, and leucin, besides the ordinary chemical constituents of the glandular textures, as albuminous compounds, collagen, chondrin, protagon, elastin, and mucin. In the fretus, the tissue of the lungs contains a large number of cells rich in glycogen, which escape on pressure in the form of a milk-white fluid, but which are not found except under pathological conditions in the adult.

285. The contractility of the bronchial tubes (according to the experiments of Dr. C. J. B. Williams) may be excited by electrical, chemical, or mechanical stimuli, applied to themselves. It is chiefly manifesterl in the smaller bronchial tubes, those of less than a line in diameter having been seen to eontract gradually under the stimulus of galvanism, until their cavity was nearly obliterated; on the other hand, in the trachea and the larger bronchi, the cartilaginous rings prevent any decided diminution in the calibre of the tubes, and the muscular structure is much less distinct. It is doubtful whether the contractility can be called into play by irritation of the

1 Op. cit., 398.

2 Med.-Chir. Rev., 1865, p. 209.

3 See Wywodzoff, Wien. Med. Jahrbücher, Bd. xi, p. 3 ; Siliorski, Centralblatt, f. d Med. Wiss, 1870, p. 817; Klein, Proceed. Roy. Soc., Jan. 29 th, 1874.

4 lieport of the British Association for 1810, p. 411. 
Pnemmogastrics. ${ }^{1}$ It is remarked by Dr. Williams, that the contractility of the bronchial muscles is soon exhausted by direct stimulation; but that it may in some degrec be restored by rest, even when the lung is removed from the body. When the stimulation is long continued, however, as by intense irritation of the mucous membrane during life, the contractile tisine passes into a state which resembles the tonic contraction of muscular fibre. The contractility is greatly affected by the mode of death, and is remarkably diminished by the action of vegetable narcotics, particularly stramonium and belladonna; whilst it seems to be scarcely at all affected by hydrocyanic acid.-These facts are very important, as throwing light upon certain diseased conditions. It has long been suspected, that the dyspoea of Spasmodic Asthma depends upon a constricted state of the smaller bronchial tubes, excited through the nervous system, frequently by a stimulating cause at some distance; and there can be now little doubt that such is the case. The peculiar influcnee of stramonium and belladonna, in diminishing the contractility of these fibres, harmonizes remarkably with the well-known fact of the relief frequently afforded by them in this distressing malady. It seems not improbable that the contractility of the bronchial tubes may serve to regulate the supply of air to the lobules, in accordance with the wants of the system, just as the contractility of the minute arteries regulates the supply of blood to the organs to which they proceed; and it may possibly be through this channel, that the remarkable variation is effected in the amount of respiration, which adapts the quantity of heat produced to the depression of the external temperature $(\$ 282)$. It has been further suggested by Dr. W. T. Gairdner, ${ }^{2}$ that the contractility of the smaller bronchi may serve to expel collections of mucus which have accumulated in them, and which neither ciliary action nor the ordinary expiratory efforts suffice to displace.

286. The elasticity of the lungs, which in many animals, as the horse, is remarkably increased by the dense layer of clastic tissue by which they are invested, ${ }^{3}$ plays an important part in the respiratory acts. Donders ${ }^{4}$ estimates the expiratory force derived from the elasticity and muscular tension of the lungs, and coming into play in ordinary respiratiou, as equal to a pressure of about $5 \mathrm{oz}$. on the square inch; but the elastic tension is rapidly increased by the dilatation of the lungs with air, and the carefully conducted experiments of Dr. Hutchinson ${ }^{5}$ led him to estimate it at certainly not less than $\frac{1}{2}$ lb. upon each square inch of surface, when the lungs have been filled by the deepest possible inspiration; so that its whole amount (reckoning an average surface of $300 \mathrm{sq}$. in. for the male, and $247 \mathrm{sq}$. in. for the female) will be not less than $150 \mathrm{lbs}$. for the male, and $123 \frac{1}{2} \mathrm{lbs}$. for the female. This force is exerted in aid of the expiratory movement, and is directly antagonistic to the inspiratory ; so that the inspiratory muscles must overcome it, in order to produce complete distension of the pulmonary cavities.

1 Volkmann (Wagner's Handwörterbuch, Bd. ii, Art. Nervenphysiologie, p. 586), Longret (A nat. et Physiol. du Système Nerveux, tom. ii, p. 289), and P. Bert (Leçons sur la Physiologie comparée de la Respiration, Paris, 1870, p. 375) affirm that it ('an, whilst Rosenthal (Die Athembewegungen, p. 232), Rugenberg (Sudien des Phys. Institut zu Breslau, 186i3, pa 47), and Wintrich (Krankheit. d. Resp. Org. in Virehow's Handbueh der Patbol., 1855-57) maintain that if a manometer be inserted into the traehea, irritation of the peripherie extremity of the $V$ agus never produees any inerease of pressure, which would certainly oceur if the eapaeity of the bronehi diminished.

2 Edinburgh Monthly Journal, May, 18:31.

3 See G. Gulliver's Note to Willis's translation of Wagner's Physiology, 1844, p. 360 .

4 See his Essays in Henle and Pfeuffer's Zeitseh., Bd. iii and iv.

5 Cyelop. of Anatomy, Art. Thorax, vol. v, p. 1058. 
This disteusion is entirely accomplished by the action of the muscles external to the thorax, or partly forming its parietes.

287. The mechanism of the respiratory acts may be rendered clearly intellivible by the accompanying diagram, in which the trachea and lungs ( 5 , 6, Fig. 161) are inclosed in a glass vessel with three openings. The lower

FIG. 161 .

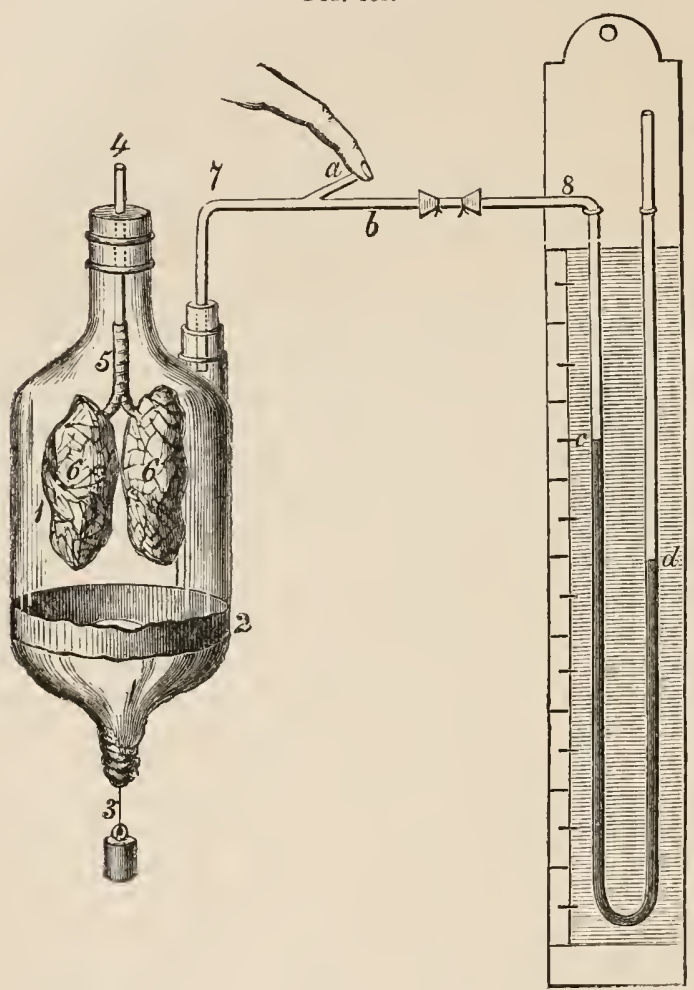

Apparatus constructed by Donders to show the Mechanism of Respiration.

opening (2) is closed by a bladder or piece of cantchouc, representing the diaphragm, and capable of being either pushed into the cavity of the vessel or of being drawn down by a weight. The upper opening is closed by a cork, through which a glass tube (4), firmly attached to the trachea, passes. The lateral opening ( 7$)$ is connected with a manometer $(c, d)$ by a tube $(b)$, having a smalt lateral branch $(a)$ opening to the air. If the openings ( $a$ and 4$)$ be now stopperl whilst the bladder is extended by the weight (3), the rarefaction of the air in the glass vessel will be made apparent by the rise of the mercury in the arm (c) of the manometer. It is obvious that the pressure of the air within and without the lungs will be different, and consequently, on opening the orifice of the tube (4) air will rush through it and the trachea to equalize the pressure as far as the elasticity of the lung will permit. Such, with the exception that in the living body no air intervenes between the surface of the lung and the walls of the thorax, and therefore no rarefaction, but only a tendency to a vacuum occurs, are the conditions present in the ordinary act of inspiration. On the contrary, with the same exception, the act of expiration may be imitated by pushing the bladder into the vessel; 
for then the pressure on the exterior of the lungs will be increased, the nercury in the arm (c) of the manometer will descend, and, aided by their own elastieity, the lungs will cont ratet upon and drive out the air contained within their carities.

288. The complete dependence of the expansion of the Iungs upon the enlargement of the cavity of the chest, is well shown by the efficet of admission of air into the pleural cavity. When an aperture is mate on either side (as by removing the finger from the orifice of the tube $\alpha$ in the apparatus represented in Fig. 161), so that the air rushes in at each inspiratory movement, the expansion of the lung on that side is diminished, or entirely prevented, in proportion to the size of the aperture. If air ean enter through it more realily than through the trachea, an entirc collapse of the lung takes place; and by making such an aperture on each side, eomplete asplyxia is produced. But if it be too small to admit the very ready passage of air, the vacuun produced by the inspiratory movement is more easily filled by the distension of the lungs, than by the rush of air into the pleural cavity; so that a sufficient amount of ehange takes place for the maintenance of life. This is frequently observed in the case of penetrating wounds of the thorax, in the surgical treatment of which it is of great importance to close the aperture as eompletely as possible; when this has been accomplished the air that had found its way into the eavity is soon absorbed, and the lung resumes its full play. Where one lung is obstructed by tubercular deposit, or is prevented in any other way from rightly discharging its function, an opening that freely admits air into the pleural eavity of the other side is neessarily attended with an immediately fatal result; and in this manner it not unfrequently happens that ehronie pulmonary diseases suddenly terminate in Asphyxia, a eommunication being opened by uleeration between a bronehial tube and the cavity of the thorax.

28\%. Of the Respiratory Movements.-Ivery complete act of respiration may be divided into-1, Inspiration; 2, Expiration. ${ }^{1}$ M. Marey has constructed an instrument by which the movements of respiration ran be registered, and to which he has applied the term pneumograph or atmograph; it eonsists of a spiral spring inelosed in a thin eaoutchouc evlinder, the extremities of which are conneeted by a band passing round the borly. A lateral tube places the interior of the eylinder in eommunieation with the registering apparatus, and the following cut (p.370) shows a traeing taken from a healthy subject. In ordinary tranquil breathing (especially in ehildren), the action of the diaphragm is alone nearly sufficient to produce the necessary exchange of air, and this musele is eonsequently the chief inspiratory agent; but when a full inspiration is required, the eavity of the chest is dilated laterally and antero-posteriorly, as well as inferiorly. ${ }^{3}$ The enlargement of the chest in both these directions is effected by the elevation of the

1 The pause which was admitted by Vierordt and others to oceur between Expiration and Inspiration, has been shown by Riegel (Wurzburg. Med. Gesell., Bd. vii, $1867, \mathrm{p} .321)$, with a self-rexisteriner apparatus, not to be present at least when the body is in a horizontal position. Sibson, Vierordt, and others believe they luve proved that the duration of the inspiration is to that of expiration as $10: 14$ in the ehild, femate, and old person, and as $10: 12$ in the adult male; but these statements hardly accord with the tracing shown on the next page. See Sibson in Med.-Chir. Transaet., rol. xxxi, and Medical Anatomy.

2 Revue des Cours Scient., 1867, p. 726.

3 Bert (Leçons, p. 352) has clearly shown by traeings witl his Tambour pour recueillir les Mouvements du Thorax, or Pneumograph, that iu the dog the diaphragm in eontraeting eauses the 6 th and lower ribs to rise, and thus to inerease the trainsverse diameter of the chest; whilst, on the contrary, the 5th and upper ribs tend to descend and diminish the transverse diameter. 
ribs; for whilst, in the undilated state of the thorax, the ribs form an angle with their cartilages, which becomes less and less obtuse as we pass from the first rib downwards, the elevation of the ribs tends to bring them and their cartilages more nearly into a line, and thus separates them more widely from the median plane, and at the same time causes them to push forward the

FIG. I62.

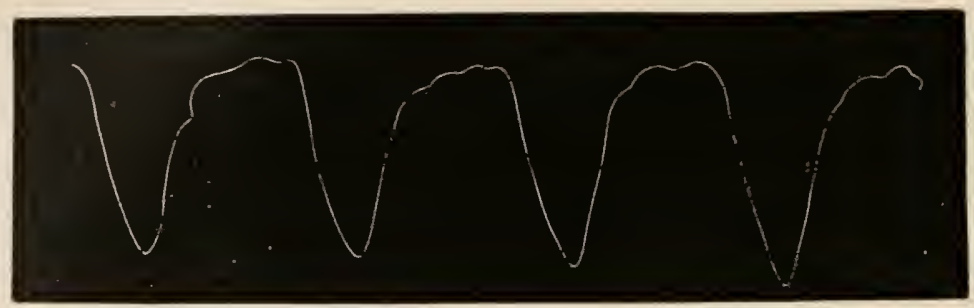

Tracing of the respiratory movements in a healtby man, taken by M. Marey's Pneumograph. The down-stroke represents the act of inspiration, the up-stroke that of expiration. The undulations at the apex of the curvc, which represents the period of pause of Longet, are due to the cardiac beats.

sternum. Owing to the greater length of the lower true ribs, and the greater obliquity of their junction with their cartilages, both these changes are more considerable in the lower part of the thorax than in the upper; and this is especially the case in adult men, whose respiration has been designated as "inferior costal," whilst in females the mobility of the first rib and of the whole of the upper part of the thorax is greater, so that their respiration may be designated as "superior costal."-The thoracic muscles whose contraction participates, with the diaphragm, in the ordinary movements of Inspiration, are, according to Dr. Hutchinson, ${ }^{1}$ the external inter-

1 Op. cit., p. 1055 See also Cleland, Journal of A nat. and Physiol, vol. i, 1867, p. 209. There is probably no point in the whole rangc of physiology respecting which such different opinions have been entertained by good observers as upon the action of the intercestal muscles, and it may be instructive to give the following enumeration of them, drawn from Beau and Massiat (Archiv. Gén. de Méd., 1842), Küss (Physiologie, 1873, p. 343), Budge (Compendium de Physiol. Humain, 1874, p. 55), and Colin ('Truité de Physiologic Comparée, 1873, p. 251 pt scq.): 1. Both the external and internal in terestals are inspiratory muscles (Borelli, Senac, Boerhat ve, Winslow, Hulter, Cuvicr, Colin, Wündt, Duchenne, Duval). Duchenne supports his opinion by reference to a case in which all the respiratory museles were paralyzed except the intereostals, and yet in which respiration was maintained; Duval rests his upon expriments made on decapitated criminals shortly after death. 2. Both sets of museles are expiratory (Vesalius, Dipmorbröck, Sabatier, Beau and II assiat, Longet). This view rests on the fact that in vivisections the muscles may be secn to contract in forced expiration, as in coughing or crying out. Norcover, the intercostals are present in Birds, in which the act of expiration alone is due to muscular effort. 3. The external intercostats are expiratory, the internal, respiratory muscles (Galen, Bartholinus). 4. The external intercostais are inspiratory. The internal, expiratory muscles (Spigelius, Vesling, Hamberger, and, with some modification, Sibson, Herrmann, and Cleland). According to Sibsom the extcrnal intereostals are inspiratory, except at their anterior part, in the five inferior intercostal spaces; the interual intereostals are inspiratory in the anterior part of the five first spaces, but have elsowhere an expiratory action. Hermann observes that the external muscles are inspivalory where they are attached to the osseous portions of the ribs, the internal where attaclied to the cartilaginous portions; but as this corresponds to the chief action of the two sets of fibres both may be regarded as inspiratory museles Cleland (Letter to Editor) remarks similarly that the external and anterior fibres of the internal intercostals are most advantageously disposed for elcvating the ribs, and that the remaining intercostals are most atvantageously placed for depressing the ribs; but that all the intercostals are capable of giving some assistance in inspira- 
eostals, with those portions of the, internal intereostals which pass between the cartilages, the levatores costarum, and a portion of the triangularis stemi, all of which lave the same aetion, that of elevating the ribs. On the other hand, the thoraeic Expiratory muscles are the proper eostal portion of the internal intercostals, with the infracostals, and a part of the triangularis sterni. The expiratory movement will be assisterl also by the abdominal museles, which antagonize the diaphragm by pressing back the abdominal viscera, and thus eausing its ascent so soon as it has beeome relaxed. There are mauy aecessory muscles, however, which take a share in violent respiratory movements, both inspiratory and expiratory. Thus all the museles whieh elevate the seapula, may act through it upon the ribs-the sternomastoid raises the elavicle, and the scaleni act direetly upon the first rib; whilst all those whieh ereet the spine fix more perfectly the origins of these and other museles which are to act upon the thorax. So, again, the expiratory movement is aided by the longissimus dorsi, sacro-lumbalis, and other museles which tend to depress the ribs. In diffieult respiration, almost every muscle in the body is made in some way subservient to the distension of the chest; thus, a patient suffering under urgent dyspnoea instinetively lays hold of some fixed object, so as to prevent his upper extremities from moving; and thus his scapula becomes a fixed point, from which the pectorales (major and minor) and serratus magnus can aid in elevating the ribs. The movements of the heart liave a slight influenee on the lungs, the systole aiding inspiration, the diastole expiration. ${ }^{1}$

290. The extent of movement of the several parts of the ehest during the respiratory acts may be registered by an instrument suggested by Dr. BurdonSanderson," and naned by him the "recording stethometer." From experiments made with this instrument, he finds that in the ordinary respiration of a healthy museular young man aged twenty-two, the upper antero-posterior diameter, which was equal to $146 \mathrm{~mm}$., varied one millimetre; the lower sternal diameter, which equalled 203 millimetres, varied 1.5 to $1.8 \mathrm{~mm}$.; and the transverse costal diameter at the level of the eighth rib, which equalled $228 \mathrm{~mm}$., varied 1.7 to $2.0 \mathrm{~mm}$. In forced respiration the variations of the antero-posterior diameters of the upper part of the chest were mueh more extensive, the ends of the upper ribs moving horizontally forward-i.e., in a plane parallel to the middle plane of the body, from 12-30 millimetres: the advanee of the third rib being greater by several millimetres than that of the fifth, and this Dr. Ransome attributes to an actual bending of the ribs. ${ }^{3}$ The extent of the respiratory movements is affeeted by various morbid eonditions. Thus, when dislocation of the spine takes place above the origin of the intereostal nerves, but below that of the phrenie, so that the

tion, as also in forced expiration, whilst ordinary expiration is aceomplished altogether by elasticity, and not by muscular effort at all. Aeby (Lehrbuch, 1871, p. 379 ) holds that both sets of muscles approximate the adjoining ribs, but whether this occasions an elevation or depression of the whole series is dependent on the coincident action of other muscles. 5. Mayo and Magendie regarded both sets of muscles as at once expiratory and inspiratory in their action. Lastly, Van Helmont, Arantius, Cruveilhier, Küss, and Jobelin considered that both sets of muscles are passive in the movements of respiration, and simply form an immovable wall to the chest, or rather they contract, not to produce the movements of inspiration or expiration, but to resist at both periods the pressure cither of the external or of the internal air.

1 See Voit and Lossen, Zeitschrift für Biologie, Bd. i; Ccradini, Vcrhand. des natur.-hist.-ned. Vereins zu Heidelberg, 1869. Also Landois, who, however, holds a different opinion (Berlin Klin. Wochens., 1870).

${ }_{2}$ Handbook for the Physiological Laboratory, p. 291.

3 See Arthur Ransome, On the Mechanical Conditions of the Respiratory MIovements in Man, Proceed. Roy. Soc., Nov. 1st, 1872. 
former are paralyzed, the respiratory movement is confined to the diaphragm : this is insufficient, and with the coincident paralysis of the vaso-motor nerves leads to the effusion of serum into the lungs, and slow asphyxia, which usually proves fatal in a few days. Even where the muscles and nerves are all capable of action, the full performance of the inspiratory movements is prcvented by the solidification or engorgement of any part of the lung which interferes with its free distension; or by adhesions between the pleural surfaces, which offer a still more direct impediment. When these adhesions are of long standing, they are commonly stretched into bands, by the continual tension to which they are subjected. If the impeding cause affect botll sides, the movements of both will be alike interfered with; but if one side only be affected, its movements will be diminished, whilst those of the other remain natural; and the physician hence frequently derives an indication of great value, in regard to the degree in which the lung has become incapable of performing its functions. It is to be remembered, however, that the action both of the diaphragm and of the elevators of the ribs may be prevented, by pain either in the muscles themselves or in the parts which they move; thus the descent of the diaphragm is checked by inflammation of the abdominal viscera or of the peritoneum; and the play of the intercostals by rheumatism, plcuritis, pericarditis, or other painful disorders of the parts forming the parietes of the thorax. In man the acts of respiration are properly effected through the nostrils, which are lined by a highly vascular membrane, kept constantly moist by numerous glands, and by the lachrymal secretion, whilst its surface is greatly extended by the sinuosities of the turbinal bones. The inspired air is thus rendered moist and warm before reaching the sensitive larynx and lungs, and the coughs and colds so prevalent in this country in the winter and spring months might often be avoided if care were taken, especially on sudden exposure to cold air, to breathe through the nostrils instead of the mouth. The passage of air into and from the lungs is acconipanied by a peculiar soft blowing sound, termed the respiratory murmur or bruit. The act of inspiration being more rapid and energetic than that of expiration, is attended by a louder sound, which is most distinctly audible in young children and in thin persons. It probably arises either, as Dr. Salter ${ }^{1}$ suggests, from the current of air striking against the angles of division of the bronchia, or, as indicated by Dr. Waters, ${ }^{2}$ from a slight constriction that exists at the mouth of each air-sac. Other causes that have been assigned to it are the separation of the moist septa of the alveoli, the general friction of the air against the walls of the bronchial tube, and the reverberation of the glottidcan bruit (Sabatier; Cornil, 1873). The expiratory murmur is exclusively due to the friction of the air against the glottis (Chauveau). ${ }^{3}$

291. The relative amount of muscular force which is required for the two respiratory movements respectively is affected in a very remarkible manner by the elasticity of the walls of the thoracic cavity and of the lungs themsclves; for this (like the elasticity of the lungs) supplies a force which greatly aids the expiratory movement, whilst it offers a corresponding opposition to the inspiratory. Here, also, the degree of force exerted incrcases very rapidly with the degree of distension. 'Thus in a body experimented on by Dr. Hutchinson, ${ }^{4}$ the following were the relations between the amount of air forced in, the resisting elasticity, as shown by the height of mercury supported, the actual pressure upon each square inch of surfice which this

Pamphlet on Cause of Respiratory Murmur, 1864.

2 Med..Chir. Rev., 1865, p. 2217.

3 See Budge, Compendium de la Physiologio, 1874, p. 69.

Up. cit., p. 1056 . 
indicated, and the total pressure over the surface of the chest, reckoning its area at 206 square inches:

Cubic inches.

$\begin{array}{lr}\begin{array}{c}\text { Pressure in height } \\ \text { of Mercury. }\end{array} & \begin{array}{r}\text { Pressure } \\ \text { persid. id. }\end{array} \\ 1.00 \text { inch. } & 78 \mathrm{oz} . \\ 1.50 \text { "6 } & 11.7 \text { "6 } \\ 3.25 \text { "6 } & 25.36 \\ 450 \text { "6 } & 35.16\end{array}$

Total
pressure.
104.4 lbs
1506 66
3263 "6
451.9 "6

To this $451.9 \mathrm{lbs}$. must be added at least $128 \mathrm{lbs}$. for the elastic force of the lungs themselves at that degree of distension, making altogether 580 lbs.; and as the subject of this observation could expire during life considerably more air than the highest amount forced into his chest after death, there can be little doubt (judging from the rapid ratio in which the elastic force increases when the distension is approaching its limits) that the muscular power required to overcome this, towards the close of a very deep inspiration, could not have been less than 1000 lbs. The co-operation of the elastic resistance with the expiratory movement, and its antagonism to the inspiratory, is doubtless the principal cause why the power of the expiratory muscles, as tested by the height of the columin of mercury supported by the air, should always be greater than that of the inspiratory muscles ; ${ }^{1}$ and why the expiratory power should be very much greater when the chest has been well filled with air, than when it is comparatively empty. 'The following is given by Dr. Hutchinson as the range through which these powers may vary within the limits of health:

Power of
Inspiratory Muscle
1.5 inch,
20 "6
4.5 "6
7.0 "6

$$
\text { es. }
$$

Weak, .

Ordinary

Remarkable,

Very extraordinary, .
Power of

Expiratory Muscles.

20 inches.

25 "

5.8 "

10.0 "6

The expiratory power may be augmented by the habitual performance of movements in which they participate; and thus the inspiratory power is the preferable test of the vis vitce. This has been found by Dr. Hutchinson to bear some relation to height, being greatest (on an average of a considerable number of cases) when the stature is 5 feet 7 or 8 inches; and diminishing above that height, as well as below it. Fick estimates that the work accomplished in effecting the inspiration of 600 e.c. is equivalent to $0.63 \mathrm{kilo-}$ grammetre, and Prof. Haughton estimates the daily work of the respiratory muscles at 21 foot-tons. ${ }^{2}$

292. It is impossible to form a correct estimate, by observations on one'sself, of the usual number and extent of the respiratory movements; since the direction of the attention to them is certain to increase their frequency and amount. In general it may be stated, that from 16 to 20 alternations usually occur in a minute $;^{3}$ of these, the ordinary inspirations involve but little novement of the thorax; but a greater exertion is made at about every fifth recurrence. According to Quetelet, the infant breathes

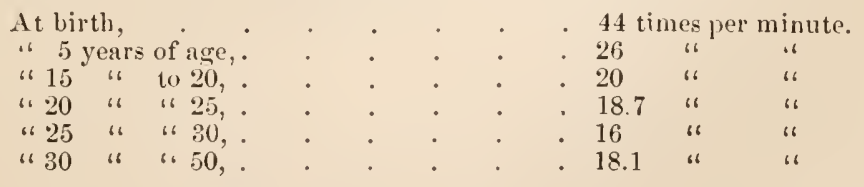

: See Dr. Hutchinson, op. cit., p. 1061.

2 Lecture delivered at the Mceting of Brit. Med. Assoc. at Oxford, August, 1868.

${ }^{3}$ Sec Dr. Hutchinson's 'Table, in Cyclop. of Anat. and Phys, vol, iv, p. 108.j. 
The average numerical proportion of the respiratory movements to the pulsations of the heart, is about $1: 5,1: 4 \frac{1}{2}$, or $1: 4$; and when this proportion is widely departed from, there is reason to suspect some obstruction to the aeration of the.blood, or some disorder of the nervous system. ${ }^{1}$ Thus in Pneumonia, in which a greater or less amount of the lung is unfit for its office, the number of respirations increases in a more rapid proportion than the acceleration of the pulse; so that the ratio becomes as 1 to 3 , or even 1 to 2, in accordance with the degree of engorgentent. ${ }^{2}$ In Hysterical patients, however, a similar increase, or even a greater one, may take place without any serious cause; thus Dr. Elliotson ${ }^{3}$ mentions a case in which the respiratory movements of a young female, through a nervous affection, were 98 or even 106, whilst the pulse was 104. On the other hand, the respiration in certain typhoid conditions and in narcotic poisoning becomes abnormally slow, owing to the torpid condition of the nervous centres, the proportion being 1 to 6 , or even 1 to 8 ; and in such cases the lungs not unfrequently become odematous, from a cause hereafter to be mentioned $(\S 303)$. II. Marey ${ }^{4}$ believes it may be shown that the frequency of the respiratory acts are, as in the analogous case of the heart, almost always diminished whilst they are at the same time rendered deeper by the existence of any obstacle to their due performance; so that there is an evident attempt made to effect within certain limits, the introduction of the same quantity of air into the lungs in a given time; and in an ingenious instrument he has devised, where, by the reversal of a valve, difficulty of breathing may be inducerl either during inspiration or expiration, he has observed that that act is prolonged in which the dyspnoa is made to occur.

293. We have now to inquire into the mode in which the Muscular movements of respiration are kept up by nervous power.--There can be no doubt that these movements, though partly under the control of the Will, are essentially "automatic" in their nature. Their chief centres consist of two ganglia placed on either side of the point of the Calamus Scriptorius, and connected by a gray commissure $:^{5}$ corresponding therefore to the origins of the Pneumogastric Nerves, which are the principal excitor nerves that convey the stimulus on which the movements are dependent, whilst from the adjacent parts of the Medulla Oblongata and Spinalis proceed the chief motor nerves by which they are carried into effect. And thus it happens that the whole of the Eucephalon may be rcmoved from above, and the spinal cord (as far up as the origin of the phrenic nerve) from below, without suspending the most essential of the respiratory movements; the destruction of these centres, however, causes their immediate cessation, and as the arrest of respiration is incompatible with life, they were named by Flourens the "nœud vital." The Respiratory Centres, as Duchenne ${ }^{6}$ has pointed out, are in immediate contiguity to the hypoglossal nucleus govern-

$1 \mathrm{~V}$. Ghert has shown that, during violent exertion, the respirations increase in frequeney more than the pulsations; but that in the subsequent period of rest, the increased activity of the cardiac movements is more persistent than that of the respiratory. For a list of the number of Resfirations per minute in a great number of different animals see P. Bert, Leçons, p. 393 et seq.

2 See a Paper by Dr. Hooker, an abstract of which will be found in the British and Foreign Medical Review, vol. iv, p. 263.

3 Physiology, p. 215 , note.

4 Mémoires de la Suc. de Biologie, 1865, p. 175. Bert (Leçons, p. 410) shows that many statements, though accurate when the obstacle to respiration is slight, must be accepted with some reservation when the obstacle is great, the amplitude then decidedly diminishing.

6 See Longet (Physiologie, 1861, vol. ii, P. 396), Flourens (Comptes Rendus, 18.51, p. 437, and 1858), Brown-Séquard (Journal de la Pliysiologie, vol. i, 1858, p. 232), Schiff' (l'hysiologie, 1859, p. 323).

- De l'Electrisation Localisée, 1872, p. 564. 
ing the movements of the tongue; to the inferior nuclens of the facial, regulating the movements of the lips; and to the uucleus from which the cardiac branches of the spinal accessory and pnemmogastric nerves arise. In the diseasc known as glosso-labio-laryngeal paralysis these centres are affected successively, the tongue being first affected; then the muscles of the palate; then the orbicularis oris, whilst the fatal termination of the disease is preceded by attacks of suffocation.

294. The respiratory ceutres are capable of being excited to action in two ways : directly, by changes in the quality of the blood traversing their capillaries; and reflectorially, by excitation of the sentient extrennities of the vagi and many other nerves. The condition of the blood by which they are directly excited, consists in the diminution of Oxygen and the accumulation in it of Carbonic acid, or possibly of other products of the disintegration of the tissues. Nasse maintains ${ }^{1}$ that it is not the diminution of oxygen which constitutes the stimulus, but that such diminution causes the Central ganglia to respond more readily to the ordinary and a fortiori to any extraordinary quantity of Carbonic acid in the blood; on the contrary, their irritability is lowered when the proportion of oxygen in the blood circulating through them is increased. In proportion as these alterations in the relations of the gases become more pronounced, the "besoin de respirer" is rendered more intense, and the respiratory movements becone nore and more energetic till Dyspnoe is established, which gradually passes into Asphyxia, in which the centres are paralyzed. If, on the other hand, the proportion of oxygen in the blood is rendered high either by the active performance of artificial respiration, or by the imhalation of oxygen, ${ }^{2}$ whilst at the same time, no obstacle is presented to the elimmation of carbonic acid gas, the activity of the ganglia is lessened, the respiratory movements become reduced in number and extent, and the animal passes into the state of Apnoca. ${ }^{3}$ Between these two states is that which exists in the normal aeration of the blood, and results in ordinary breathing, or Eupnoea. Dyspnoea from deficiency of oxygen can be produced by the inhalation of Nitrogen or Hydrogen ; in such cases Pflüger has shown, the oxygen is greatly diminished, whilst the carbonic acid is not materially increased, or may be even diminished.* Dyspnoea from excess of carbonic acid can be induced by making the animal breathe air surcharged with that gas, or by preventing its elimination from the system. Traube ${ }^{5}$ produced dyspnoea by making an animal breatle a mixture of 28 per cent. of carbonic acid gas, 32 per cent. of oxygen, and 10 per cent. of nitrogen. ${ }^{6}$ Dyspncea produced by such gases as carbonic oxide and nitrous oxide is due apparently to these gases withdrawing oxygen from the blood, whilst phosphuretted, arsenimetted, and sulphuretted hydrogen reduce the hiemoglobin, and after first exciting rapidly paralyze the respiratory centres. Hydrocyanic and hychrochloric acid gases, chlorine, sulphurous acid, and some other gases seem both to act destructively on the blood, and to destroy the functional activity of the vagal nuclei.

1 Centralblatt, 1870 , p. 275.

2 See the experiments of Czermak, Centralblatt, Jan. 3d, 1866; Pflüger, Pflüger's Archiv, 1868, p. 61 ; Schwarz, Beiträge

3 Ewald, Phüger's Archı, 1873, p. 575; Zur Kenntniss der Apnœa.

- See Pflüger's Essay in Band i, of his Archiv, 1868

5 Allgem. Med. Centralblatt, 1868, Nos. 38 and 39 See also Thiry, Rec. des Travaux de la Soc. Méd. Allemande de Paris, 1865; and Dohmen, Unters. aus dem Physiul. Lab. zu Bonn, 1865, p. 83.

6 M. Bert (Séance de la Soc. de Biolngie, Feb. 3d, 1872, Rev. Scient., $2^{\mathbf{e}}$ Sér., i Année, No. 37,1872 , p. $88^{\circ}$ ) has shown that the barometric pressure to which the animal is exposed is of great importance in such experiments in consequence of its effects on the diffusion of the gases. 
295. The reflectorial, as opposed to the automatic activity of the respiratory centres is chiefly excited through the Pneumogastric or vagal nerves, and especially through the branches of these nerves distributed to the larynx and lungs. Other sensory nerves, however, as the fifth, and the sensory nerves of the skin generally, may convey impressions which are reflected at the medulla to the muscles maintaining respiration. Under ordinary circumstances, that is to say, in tranquil breathing, it would appear that the deficiency of oxygen or the accumulation of Carbonic acid and other products of disintegration in the blood, acts as a stimulus to the sentient extremities of the Vagus distributed to the lungs; the excitation is conveyer through the trunks of thesc nerves to the vagal centres in the medulla oblongata, from thence it is reflected through the spinal cord and chiefly through its lateral columns ${ }^{1}$ to the phrenic nerves, and the diaphragm contracting an act of inspiration takes places. 'The Blood, now become uxygenated, ceases to be a stimulus to the vagal branches, the ragal centres become quiescent, the diaphragm relaxes, and the elasticity of the chest and lungs expels the air, and the act of expiration is effecter. ${ }^{2}$ The succession of these phenomena constitutes normal or ordinary respiration, but if from any circumstances, as the performance of active exercise, or exposurc to a high temperature, ${ }^{3}$ the consmmption of oxygen and production of carbonic acid are increased, the vagal centres and extremities are more strongly excited, they transmit a more powerful influence, and other motor nerves (such as the intercostals) besides the phrenics are excited. In cases where the blood is still less perfectly arterialized, as when the supply of air is insufficient, the vagal centres are still more strongly excited, and all the accessory muscles are then called into play.

296. The important part played by the Vagi in the respiratory acts may be experimentally shown by their division, and the application of a stimulus to their centric extremities. The trunks of the vagi are not endowerl with much sensibility, for if pinched or pricked the animal does not exhibit nearly such acute signs of pain as when the trunks of the ordinary spinal nerves or of the fifth pair are subjected to similar treatment. The effects of section of the vagi appear to differ considerably in different animals, which is doubtless in part due to the fact that in some animals, as the Cat and Dog, the vagus is united into one trunk with the sympathetic, the section of the latter leading to vaso-motor complications; whilst in others, as in Man and the Rabbit, these nerves are separate. When the section is made on onc side only in the Rabbit the efiects are not constant, ${ }^{4}$ but if the division be made simultaneously on both sides, the number of respirations per minute, as wits shown by Dr. Reid, ${ }^{5}$ diminishes from $120-140$ to $40-50$. The mechanism of breathing is at the samc time completely altered. Each respiration becomes much deeper than before, which is partly due to increased action of the diaphragm, and partly to the participation of the accessory muscles in the act of inspiration. The quantity of air breathed per minute is, however, not materially altered, being as great after as before the section, the diminished frequency being compensated for by increased depth of the respiratory act. Still it is to be particularly observed that although the vigor of the respiratory movements does not appear to be materially impaired, the blood

1 Sce Schiff, Pflüger's Archiv, Bd. iv, p 225.

2 Breuer, Sitz. d. Wien. Akad., 1868, Heft xii, attempts to show that the mere act of inspiration leads to relaxation of the respiratory muscles, and is a stimulus to the nerves suplying the expiratory muscles, and vice rersa. 156.

3 See Gohd-tein, Verhandlung Phys. Med. Gesell. zu Würzburg, Bd. ii, 1871, p.

4 Gilchrist, Med.-Chir. Rev., 1858, vol. ii, p. 495.

5 Op. cit. 
becomes more or less venous (Sanderson). ${ }^{2}$ In dogs the simultaneous division of the two ragi usually rerluces the number of the respiratory movements by one-half (Reid). In pigeons the number falls to one-eighth, whilst the depth of each inspiration is only increased as $1: 2.5$, the respiratory activity thercfore being diminished to about one-third of its original amount (Rosenthal)." In some cases, after division of the Vagi, the respiration alters in character, the inspiration beconing sudden and spasmodic, with long intervening pauses, but usually the difference is such as is expressed in the following tracing given by Dr. Sanderson, in which the movements are

FIG. 163.

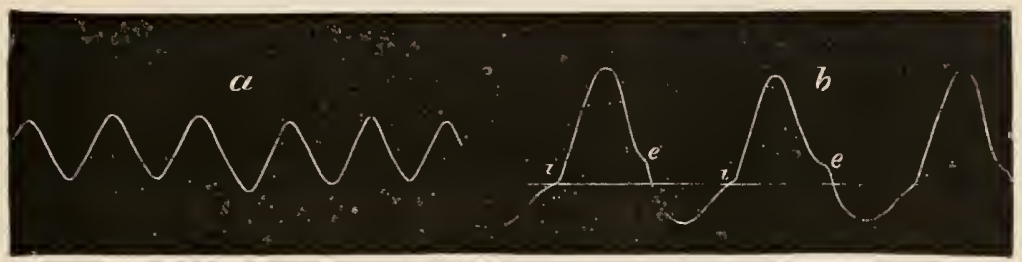

a. Tracing of the respiratory movements of the cat. $a$ before, $b$ after division of both vagi.

seen to be more slowly performed, but much deeper and fuller. The influence of the Vagi upon respiration may also be shown by the application of an electrical stimulus of moderate intensity to the centric extremity of the divided nerves of one side. The effect will be observed to vary according to whether the animal is breathing naturally, or is in a state of apnoea or dyspnœa. If it be breathing naturally, or be in a state of eupnoea, the inmediate effect of slight irritation is an acceleration of the respiratory movements, whilst if the stimulus be stronger temporary arrest of respiration in inspiration occurs, owing to contraction of the diaphragm without the participation of the other respiratory muscles. If the excitation be still stronger, the respiratory movements are completely suspended, the diaphragm passing into a tetanic condition, which lasts as long as the stimulus is applied. In apnoea, when the blood is surcharged with oxygen, the effect is negative; in dyspnoa, when the blood is deficient in oxygen, all the accessory muscles are brought into action, and the chest remains for a time in a state of tetanic expansion. ${ }^{3}$ When the animal is depressed by chloral, and its nerves are exhausted, stimulation of the ragi, instead of being followed by contraction, is followed by relaxation of the diaphragm, which is regarded as the effect of the stimulation of the inhibitory fibres probably contained in the recurrents. ${ }^{4}(\$ 297,301,302$.

297. The branches of the vagi supplying the larynx possess special attributes, which are comparable with those of the inhibitory nerves of the heart, for if moderate excitation be applied either to the superior or to the inferior laryngeal nerve the inspiratory movements arc diminished in extent and frequency, whilst if the excitation be more energetic, arrest of respiration with strong contraction of the expiratory muscles is produced (Brener) ${ }^{5}$. The superior laryngeal nerves are more sensitive to irritation than the inferior. The expcriments of various observers have afforded evidence that

1 See Sanderson's Chapter on Respiration in the Handbook to the Physiological Laboratory, 1873 .

2 Rosenthal, Comptes Rendus, 1861, p. 754. 3 Burdon-Sanderson, Op. cit., p. 311.

4 See Burkart, Pflüger's A rchir, Band i, 1868, p. 107.

5 Sitz.-ber. d. Wien. Akad, 1868, No. xii. 
the respiratory movements can be arrested in several ways by nervous influence. Thus it appears that this can be effected-(1), by irritation of the pneumogastric nerve (Traube), (2), by irritation of the larynx (Bernard, Burkart), and (3), by irritation of the nostrils-nasal branch of the infraorbital (Schiff and Kratschmer). ${ }^{1}$ Slight irritation of any sensory nerve augments the number of the respiratory movements (Schiff'). Strong irritation diminishes (Mantegazza) or altogether arrests them, especially if the excitant be heat, when inspiration-tetanus is produced (Schiff). According to M. Bert ${ }^{2}$ the arrest in the above instances may take place either in expiration or inspiration, though it is morc easily produced in expiration; coincidently with the arrest of the movements of respiration the general movements of the animal are arrested-it remains perfectly motionless.

298. The importance of moderate excitation of the general sensory nerves of the surface, and especially of the fifth pair, in exciting the respiratory movement, is easily shown. Thus Pflüger ${ }^{3}$ observed that, on opening the abdomen and uterus of a pregnant rabbit at the full time, the foetuses were brought into vicw enveloped in the membranes, and quiescent. On detaching the placenta a few feeble inspiratory movements occurred, especially when the animals were pinched; but death soon took place. When, however, the mombranes were laid open, lively inspiratory movements followed, which soon became rhythmical. In the same way it has long been a wellknown fact, that the first inspiratory effort of the new-born infant is most vigorously performed when the cool external air comes in contact with the face; and that impressions on the general surface, such as a slap of the hand on the nates, are often effectual in exciting the first inspiratory movements, when they would not otherwise commence. Dr. M. Hall relates an interesting case, in which the first inspiration was delayed, simply because the face was protected by the bed-clothes from the atmosphere; ${ }^{+}$and, on lifting up these, the infant immediatcly breathed. Dr M. Hall laas also mentioned the important fact, that although, if the cerebrum be removed, and the pncumogastrics be divided, in a young kitten, the number of acts of respiration will be reduced to four in a minute, yet by directing a stream of air on the animal, or by irritating various parts of the general surfice, we nay excite twenty or thirty acts of respiration within the same space of time. He further remarks that in the very young warm-blooded animal, as in the cold blooded animal, the phenomena of the excito-motor power are far more vividly manifested than in the older and warm-blooded. In the very young kitten, even when asphyxiated to insensibility, every touch, contact, or slight blow, every jar of the table, any sudden impression of the external air, or that of a few drops of cold water, induces at once cnergetic reflex movements and acts of inspiration. This nay be looked upon as Nature's provision for the first establishment of the respiratory function in the new-born animal.-But the influence of the nerves of the general system is by no means wanting in the adult; as many familial facts demonstrate. 'Thus every one knows that the first plunge into cold water, or the first descent of the streams of the shower-bath, or even the dashing of a glass of cold water in the fice, will produce inspiratory efforts; and this fact has many important practical applications. Thus in the treatment of Asplyyia, whether congenital or the result of narcotic poisoning, drowning, etc., the alternate application of cold and heat is found to be one of the most cfficacious means of restoring the respiratory movements; and a par-

1 Sit\% d. k. Akad. zu Wien, 1870, Bd. Ixii, p. 160.

2 lirown séquard, Arehives de Physiologrie, t. ii, pp. 179 and 322.

3 Pflüger's Arehir, 1868, p. 61.

- New Memoir on the True Spinal Marrow, ete., p. 29. 
oxysu of hysteric laughter may be cut short by dashing a glass of cold water in the face. It seems not improbable that even the sympathetic nerve, which derives many fibres from the cerehro-spinal system, and which especially communicates with the pncumogastric nerves, may be one of the cxcitors to this function; and this perhaps not only through its ranifications in the lungs, which are considerable, but also by its distribution on the systemic vessels; so that it may convey to the spinal cord the impression of imperfectly arterialized blood through these, such as the pneumogastric is believed to transmit from the lungs.

299. The motor or "efferent" nerves concerned in the function of Respiration, are those which Sir C. Bell has grouped together in his " respiratory system." The most important of these, the Phrenics, arise from the upper part of the Spinal Cord; the Intercostals much lower down; whilst the Facial Nerve and the Spinal Accessory, to the latter of which, as will be shown hereafter (chap. xiii, sec. 2), the motor powers of the Pneumogastric are chiefly due, take their origin in the Medulla Oblongata itself. M. Brown-Séquard ${ }^{1}$ has paid paricular attention to the rhythmical movements of the Diaphragm in Rabbits, which are observed to occur after section of the phrenic nerves, and even after destruction of the entire spinal cord. He attributes them to the minute ganglia described by Rouget, which are found on the filaments of the phrenic nerve. It is very remarkable that after such serious injury to the nervous system the two sides of the diaphragm, which are chiefly connected by tendon, should act synchronously ; and also that the inspiratory movenents of the Diaphragm should regularly alternatc with those of the expiratory muscles, which in Rabbits are chiefly the external oblique muscles of the abdomen.

300. That the respiratory movements, as ordinarily performed, are essentially independent of the IVill, appears not only from our own consciousness, but also from cases of paralysis; in some of which the power of the will over the muscles has been lost, whilst the movements have been kept up by the reflex action of the Medulla Oblongata or respiratory ganglion; whilst in others, some of the respiratory muscles have been motionless during ordinary breathing, and yet have remained under the power of the will. ${ }^{2}$ That consciousness is not a necessary link in the chain of causes which produce the respiratory movements, we are cnabled to judge from the phenomena presented by the human being in sleep and coma, by anencephalous foetuses, and by decapitater animals. This conclusion is confirmed by a case recorder by Dr. H. Ley, ${ }^{3}$ who liad under his care a patient in whom the pneumogastrics appeared to be diseased; the lungs suffered in the usual way in consequence, and the patient had evidently laborious breathing; but he distinctly said that he felt no uneasiness in his chest.-The experience of every one informs him, however, that the Respiratory movements are partly under the control of the will, though fiequently un restrainable by it. In ordinary circumstances, when the blood is being perfectly aerated, and there is a sufficient amount of arterial blood in the system to carry on the functions of life for a short time, we can suspend the respiratory actions during a few seconds without any inconvenience. If, however, we endeavor to prolong the suspension, the stimulus conveyed by the excitor nerves to the Merlulla Oblongata becomes too strong, and we cannot avoid making inspiratory efforts; and if the suspension be still further prolonged, the whole borly becomes agitated by movements which are almost of a convulsive nature,

1 Brown Séquard, Journal de la Physiologie, t. ii,'p. 115.

2 Such cases are mentioned by Sir C. Bell, in the Appendix to bis work on the Nervous Srstem of the Humun Budy.

3 On Laryngismus Stridulus, p. 417. 
and no effort of the will can then prevent the ingress of air. ${ }^{1}$ It is easy to understand why, in the higher animals at least, and more especially in Man, the respiratory actions shonld be thus placed under the direction of the will: since they are subservient to the production of those Sounds, by which individuals communicate their feelings and desires to each other; and which, when articulate, are capable of so completely expressing what is passing in the mind of the speaker.

301. The motor power of the Respiratory nerves is exercised, however, not only on the muscles which perform the inspiratory and expiratory movements, but on those which guard the entrance to the windpipe, and also on some other parts. Between the superior and inferior Laryngeal nerves there is an important difference, which anatomical and experimental researches have now very clearly demonstrated. It appears from the very careful and satisfactory observations anl experiments of Dr. J. Reid, ${ }^{2}$ that whilst the inferior laryngeal is the motor nerve of nearly all the laryngeal muscles, the superior laryngeal is an afferent nerve of extreme sensibility, conveying to the Merlulla Oblongata the impressions made on its peripheral extremities. The motor endownents of the latter are limited to the crico-thyroid muscle, to which alone of all the muscles its filaments can be traced, the remainder being distributed to the mucous membrane of the larynx ; and its sensibility is very evident, when it is pinched or irritated during experiments upon it. On the other hand, the motor character of the inferior laryngeal branch is shown by its very slight sensibility to injury, by its nearly exclusive distribution to muscles, and by its influence in exciting contraction of these when its separated trunk is stimulated. Burkart ${ }^{3}$ has, however, shown that certain sensory or centripetal fibres course in this nerve, on irritation of which an inhibitory influence can be exerted on the respiratory acts; slight irritation producing a prolongation of the interval between expiration and inspiration, and strong irritation conpletely stopping the respiratory movements.

302. It was also ascertained by Dr. "J. Reid, ${ }^{4}$ that, if the inferior laryngeal branches be divided, or the trunk of the pneumogastric be cut above their origin from it, no constriction of the glottis follows, but a paralyzed state of its muscles. After the first paroxysm occasioned by the operation, a period of quiescence and freedom from dyspnoea often supervenes, the respirations being performed with ease so long as the animal remains at rest ; but an 111 usual respiratory movement, such as takes place at the commencement of a struggle, induces immediate symptoms of suffocation, - the current of air carrying inwards the arytenoid cartilages, which are rendered passive by the paralyzed state of their muscles; and these, falling upon the opening of the glottis like valves, obstruct the entrance of air into the lungs. The more effort is made, the greater will be the obstruction: and accordingly, it is generally necessary to counteract the tendency to suffocation, when it is de-

1 It is asserted by M. Bourdon (Reeherehes sur le Mécanisme de la Respiration, p. 21), that no person ever eommitted suicide, thoush many have attempted to do so, by simply holding the breath; the eontrol of the will over the respiratory museles not being sufficiently great to antagonize the stimulus of the "benin de fesprirer," when this has beeome aggravated by the temporary cessation of the action. But such persons have sueceeded better by holding the face beneath the surface of water; beeause here another set of museles is ealled into ation, which are much nore under the eontrol of the will than are those of respiration; and a strong volition applied to these can prevent all aecess of air to the lungs, however violent may be the inspiratory efforts.

2 Ëhin. II d. and Surg. Journ., Jan. 1838; and Anat., Physiol., and Pathol. Ress, chap. iv

3 P'thinger's Archiv f. gesammte Physiol., Bł. i, p. 107, 1868.

4 Op. eit. See also abstract of Levens's Researches, in Lancet, vol, i, 1870, p. 357. 
sired to prolong the life of the animal after this operation, by making an opening into the traclea. Dr. Reid further ascertainerl, that the application of a stinulus to the inferior laryngeal nerves, when separated from the trunk, would occasion distinct muscular contractions in the larynx; whilst a corresponding stimulus applied to the superior laryngeal occasioned no muscular novenent, except in the crico-thyroid muscle. But when the superior laryngeals were cntire, irritation of the mucous surface of the larynx, or of the trunks themselves, produced contraction of the glottis and efforts to cough; effects which were at once prevented by divirling those nerves, and thereby cutting off their communication with the Medulla Oblongata. The observations of Dr. Reid have been fully corroborated by those of Rosenthal, ${ }^{1}$ who found in addition that moderate irritation of the Vagus caused increased fiequency of the respiratory movements, and strong irritation, inspication-tetanus, whilst if the superior laryngeal nerves were carefully isolated and stimulated with weak induction currents, the respirations fell in frequency, chiefly in consequence of the prolongation of the pause; and if the strength of the current were somewlat increased, complete reluxution of the diaphagm oceured, and expiration-tetams. The strength of the current to produce these effects must, however, be inuch less considerable than is required to produce increase of respiratory activity and tetanus of the diaphragm, when applied to the trunk of the Puemmogastric, on accomnt of the extreme sensibility of the superior laryngeal nerve. The inhibitory influence upon the respiratory function, and especially upon the movements of the diaphragm, thus attributed by Rosenthal, to the superior laryngeal branches of the Pneumogastric nerve, is so far different from that of the Cardiac and Splanchnic branches of the same nerve-wlose controlling power over nuscular movements has been already alluded to ( $\$ 244,95)$ - that it acts centripetally on the Medulla Oblongata, and not, like them, centrifugally. There can be no doubt then, that the superior and inferior laryngeal branches constitute the circle of incident and motor nerves, by which the aperture of the glottis is governed, and by which any irritation of the larynx is made to close the passige, so as to prevent the entrance of improper substances; whilst the superior laryngeal nerve also excites the muscles of expiration, so as to cause the violent ejection of' a blast of air, by which the offending gas, fluid, or solid, may be carried off. 'The effect of carbonic acid in causing spasmodic closure of the glottis is well known; and affords a beautiful example of the protective office of this system of nerves.- The mucous surface of the trachea and bronchi appears from the experiments of Valentin, to be endowed with excitability, so that stimuli applied to it produce expiratory movements; and this evidently operates through the branches of the pneumogastric distributed upon the membrane. Here, as elsewhere, we find that a stimulus applied to the surface has a much more deciderl influence than the irritation of the trumk of the nerve supplying it.

303. The actions of sighing, yawning, sobbing, langhing, conghing, and sneezing, are nothing else than simple modifications of the ordinary movements of respiration, excited either by mental emotions, or by some stimulus originating in the respiratory organs themselves.-Sighing is nothing more than a very long-drawn inspiration, in which a larger quantity of air than usual is made to enter the lungs. This is continually taking place to a moderate degree; and we notice it particularly when the attention is re. leased, after having been fixed upon an object which has excited it strongly, and which has prevented our feeling the insufficiency of the ordinary move-

1 Rosenthal, Die Athembewegungen und ihren Beziehungen zum Nerv. Vagus, Berlin, 1862; and Arehiv f. Anat. und Physiol, 1852, p. 226. 
ments of respiration. Hence this action is only occasionally connected with mental emotion.-Y Yuvning is a still deeper inspiration, which is accompanied by a kind of spasmodic contraction of the depressors of the lower jaw, and also by a very great elevation of the ribs, in which the scapula partake. The purely voluntary character of this movement is sometimes seen, in a remarkable manner in cases of palsy ; in which the patient cannot raise his shouldcr by an effort of the will, but does so in the act of yawning. Nevertheless this act may be performed by the will, though not completely; and is one that is particularly excited by an involuntary tendency to imitation, as every one must have experienced who has ever been in company with a set of yawners-Sobbing is the consequence of a series of short convulsive contractions of the diaphragm ; and it is usually accompanied by a closure of the glottis, so that no air really enters.-In Hiccough, the same convulsive respiratory movement occurs, and the glottis closes suddenly in the midst of it ; the sound is nceasioned by the impulse of the column of air in motion against the glottis. - In Laughing, a precisely reverse action takes place; the muscles of expiration are in convulsive movement, more or less violent, and send out the breath in a series of jerks, the glottis being open. This sometimes goes on, until the diaphragn is more arched, and the chest is more completely emptied of air, than it could be by an ordinary movement of expiration.The act of Crying, though occasioned by a contrary emotion, is, so far as the respiration is concerned, very nearly the same as the last. Every one knows the effect of mixed cmotions, in producing an expression of them which is "between a laugh and a cry."-The greater part of the preceding movements seem to belong ats much to the consensual or to the emotional, as to the excitomotor group of actions; for whilst they are sometimes the result of peculiar states of the respiratory organs, or of the bollily system in general, they may also be called forth by influences which operate directly through the senses, or which excite the emotions. Thus, whilst Sighing and Yawning often occur as simple results of deficient aeration, they may be brought on, - - the former by a depressed state of the feelings, - the latter by the mere sight of the act in another person. The actions of Laughter and Crying seem never to originate in the respiratory system ; but to be always either expressions of the emotions, or simple results of sensations, - as when crying arises from the sense of pain, - and laughter from that of tickling. 'The origin of the act of Hiccough does not seem very clear; but the movement is probably of a purcly reflex nature.

304. The purposes of the acts of Coughing and Sneezing are, in both instances, to expel substances from the air-passages, which are sources of irritation therc; and this is accomplished in both, by a violent cxpiratory eflort, which sends forth a blast of air from the lungs.-Coughing oceurs when the source of irritation is situated at the back of the mouth, in the glottis, trachea, or bronchial tubes. 'The irritation may be produced by acrid vapors, or by liquids or solids, that have found their way into these passages; or by secretions which have been poured into them in unusual guantity, as the result of disease; or by the simple entrance of air (especially if cold), when the membrane is in a peculiarly irritable state. Any of these causes may produce an impression upon the excitor fibres of the superior ${ }^{1}$ and inferior ${ }^{2}$ laryngeal branches of the P'neumngastrics, which, being conveyed to the Medulla Oblongata, gives risc to the transmission of a motor impulse to the several inuscles, that combines them in an act of expiration. The act of coughing consists, -1st, in a long inspiration, which fills the lungs; $2 d$, in the closure

\& Burkhart, Pfluger's Archiv, Bd. i, p. 107. 
of the glottis and of the larynx at its upper orifice by the approximation of the epiglottis to the walls of the pharynx (Ed. Smith), at the moment when expiration commences; and $3 d$, in the bursting open (as it were) of the glottis, by the violence of the expiratory movement; so that a sudden blast of air is forced up the air-passages, carrying before it anything that maty offer an obstruction.-The difference between Coughing and Sneezing consists in this, that in the latter, the communication between the larynx and the mouth is partly or entirely elosed by the drawing together of the sides of the velum palati over the back of the tongue; so that the blast of air is directed, more or less completely, through the nose, in such a way as to carry off any source of irritation that may be present there.-It is difficult to say how far these actions are independent of consciousness, or how fir they may require the stimulus of sensation for their performance.

30.5. Various alterations are produced in the Lungs by section of the Pneumogastric nerves; the inquiry into the nature and succession of which has been most carefully prosecuted by Dr. J. Reil ; ${ }^{1}$ and as his results have a very important bearing on several physiological and pathological questions of great interest, a summary of them will be here given.-In the first place, it has been fully established by Dr. Reid, that section of the Vagus on one side only does not necessarily, or even generally, induce disease of that lung; and hence the important inference may be drawn, that the nerve does not exercise any immediate influence on its functions. When both Vagi are dividerl, however, the animal rarely survives long; but its death frequently results from the disorder of the digestive functions. Nevertheless, the power of digestion is sometines restored sufficiently to reinvigorate the animals; and their lives may then be prolonged for a considerable time $(\$ 92)$. In fifteen out of seventeen animals experimented on by Dr. Reid, the lungs were found more or less unfit for the healthy performance of their functions. The most common morbid changes were a congested state of the bloodvessels, and an effusion of frothy serum into the air-cells and bronchial tubes. In eight out of the fifteen, these changes were strongly marked. In some portions of the lungs, the quantity of blood was so great as to render them dense. The degree of congestion varied in different parts of the same lung; but it was generally greatest at the most depending portions. The condensation was generally greater than could be accounted for by the mere congestion of blood in the vessels, and probably arose from the escape of the solid parts of the blood into the tissne of the lung. In some instances the condensation was so great, that considerable portions of the lung sank in water, and did not crepitate; but they did not present the granulated appearance of the second stage of ordinary pneumonia. In five cases in which the animal had survived a considerable time, portions of the lungs exhibiter the sccond, and even the third stages of pneumonia, with puriform effusion into the small bronchial tubes; and in two, gangrene had supervened.- One of the most important points to ascertain in an investigation of this kind, is the first departure from a healthy state; to decide whether the effusion of frothy reddish serum, by interfering with the usual change in the lungs, causes the congested state of the pulmonary vessels and the labored respiration; or whether the effusion is the effect of a previously congested state of the bloodvessels. The former is the opinion of many physiologists, who have represented the effusion of serum as a process of morbid secretion, directly resulting from the disorder of that function produced by the section of the nerve; the latter appears the unavoidable inference firom the carefully noted results of Dr. Reid's experiments. In several of these, only a very small quantity of frothy serum was found in 
the air-tubes, even when the lungs were found loaded with blood, and when the respiration before death was very labored. This naturally leads us to doubt whether the frothy serum is the cause of the labored respiration, and of the congested state of the pulmonary vessels, in those cases where it is present; though there can be no doubt that, when once it is effused, it must powerfully tend to increase the difficulty of respiration, and still further to impede the circulation through the lungs. Dr. Reid has satisfied himself of an important point which has been overlooked by others, namely, that this frothy fluid is not mueus, though occasionally mixed with it, but that it is the frothy serum so frequently found in cases where the circulation through the lungs has been impeded before death. From this and other facts, Dr. Reid concludes "that the congestion of the bloodvessels is the first departure from the healthy state of the lung, and that the effusion of frothy serum is a subsequent effect." The experiments of v. Boddirt ${ }^{1}$ are essentially confirmatory of those of Dr. Reid. He has shown, lowever, that effects, similar to those following division of both Vagi, result from paralysis of the inferior laryngeal nerve, which permits the entrance of foreign bodies into the air-passages. It has also been dentonstrated ${ }^{2}$ that tracheotomy performed after division of the Vagi prolongs life, the degree of prolongation depending on the efficiency of the means used to prevent the entrance of foreign bodies into the air-passages. If to these facts it is added that the injection of mucus into the trachea and bronchi of animals with intact Vagi produces serious effects, the inference, as Dr. Sanderson observes, is unavoidable that the inflammatory symptoms observed after section of the Vagi, are due to the abolition of the guard which the glottis constitutes at the entrance to the respiratory passages, and the entry of foreign bodies into their interior. ${ }^{3}$ "The experimental history of the Par Vagum," it is justly remarked by Dr. Reid, "furnishes an excellent illustration of the numerous difficulties with which the physiologist has to contend, from the impossibility of insulating any individual organ from its mutual actions and reactions, when he wishes to examine the order and dependence of its phenomena." In such investigations, no useful inference can be drawn from one or two experiments only; in order to avoid all sources of fallacy, a large number must be made; the points in which all agree, must be separated from others in which there is a variation of results; and it must be then inquired, to what the latter is due. ${ }^{4}$

\section{Effects of Respiration on the Air.}

306. The total amount of air which can be drawn into the Lungs by the deepest possible inspiratory movement, by no means affords a measure of the quantity which they ordinarily contain. It is in fact composed, as was first pointed out by Mr. Julius Jeffireys, ${ }^{5}$ of several different quantities, which may be distinguished as follows:

1 Journal de la Plyysiologie, vol. v, 1862, pr. 442 and 527.

2 sianderson, Handbook for the Physiological Laboratory, 1873, p. 308.

${ }^{3}$ Schiff (A rehiv f. Phys. Heilkunde, Bd. vi) suggests that the congestion results from vaso-motor paralysis.

4 On the important subject of the Mechanism of Respiration, the following Memoirs may be consulted in addition to those already referrel to: Dr. J. Reid's Art. Respirtion in Cyclop. of Anat. and Plhysiol, vol. iv; Dr. Hutchinson in Mr.d.-Chir. Trans., vol. xxix; Dr. Sibson in Phil Trans., 18tr, Med. Gaz., vol. xli, Med.-Chir. Trans, vol. xxxi, and Trans. of Prov. Med. Assoc., 1850); Beat and Mrussiat in Archiv. Gén., 1842; Mendelssohn, Der Mrehanismus der Respiration und Circulation, Berlin, 1845 and Vierordt, Art. Respiration in Wagner's Inandwörterbuch der Plyysiologic, Bd. ii.

$5^{2}$ Statics of the IIuman Chest, $18+3$. 
1. Residual Air; that which cannot be displaced by the most powerful expiration, which always remains in the thorax so long as the lungs retain their natural structure, and over which, therefore, we have no control.

2. Supplemental Air; that portion which remains in the chest after the ordinary gentle expiration, but which may be displaced at will.

3. Breuthing or Tidal Air; that volume which is displaced by the constant gentle inspiration and expiration.

4. Complemental Air; the quantity which can be inhaled by the deepest possible inspiration, over and above that which is introduced in ordinary breathing.-The amount which can be expelled by the most forcible expiration after the fullest inspiration, and which is consequently the sum of the $21,3 \mathrm{~d}$, and 4 th of these quantities, is designated by Dr. Hutchinson ${ }^{3}$ as the lital Capacity, being that volume of air which can be displacerl by living movements. "This "vital capacity" is less dependent than might have been supposed, upon the absolute dimensions of the thoracic cavity, being yet more influenced by its mobility. Thus of two scts of men of the same height, one measuring 35 inches round the chest, and the other 38 inches, the average vital capacity of the first was found to be 235 inches, and that of the second only 2.26 inches; for notwithstanding the greater absolute capacity indicated by the larger circumference of the latter, the inferior mobility of the chest caused more "residual air" to remain behind after the deepest expiration. By taking the average of nearly 5000 observations, Dr. Hutchinson has arrived at the very remarkable conclusion, ${ }^{2}$ that of all the elements whose variation might be supposed to affect the "vital capacity," Height alone seems to have any constant relation to it; and that this relation is capable of being expressed in a simple numerical form. It may be briefly expressed by the rule, that for every inch of stature, from five to six feet, eiglit additional cubic inches of air $\left(60^{\circ}\right.$ Fahr.) are given out by a forced expiration after a full inspiration: the vital capacity for a man from 5 feet to 5 feet 1 inch, being 174 cub. in.; from 5 feet 1 iuch to 5 feet 2 inches, 182 cub. in., and so on. ${ }^{3}-$ There is also a relation between "vital capacity" and Weight; but of a different kind from that which might have been anticipated. So far as the increase in weight is simply proportional to the increase in height, the relation is of conrse the same for the one as for the other. But if the excess of weight should depend upon corpulence, the vital capacity decreases in a very marked manner, being always very low in corpulent men. The general result of Dr. Hutchinson's observations on this point, is expressed by him as fillows: When the man exceeds the average weight (at each height) by 7 per cent., the vital capacity decreases $1 \mathrm{cub}$. in. per 16 . for the next 35 lbs. above this weight.-The influence of Age upon the "vital capacity" is less marked than might have been anticipated. The general fact seems to be, that the "vital capacity" undergoes a slight increase between fifteen and thirty-five years, and then gradually decreases, the decline being more rapid than the augmentation, so that by the age of sixty-six it has diminished to about $\frac{4}{5}$ ths of the maximum.-There does not seem to be as close a relation between the "vital capacity" and Muscular Vigor, as might a priori have been expected, and as an attempt has been made to establish." Cases are not unfrequent in which men of athletic constitution have an absolute deficiency, whilst others by $n$ means remarkahle for physical power present a large excess. ${ }^{5}$ In fact,

1 Oyclop, of Anat. and Physiol., vol. iv, Art. Thorax.

20 p. cit., p. $10 \% 2$.

3 For similar results obtained by an ingenious method suggested by M. Gréhant see Med.-Chir. Rev., Report on Physiology, Jan. 1865, P. 231.

4 See Dr. Jackson in American İedical Examiner, 185], p. 51.

5 See D. C. Radelyffe Hall in Trans. of Prov. Med. and Surg. Assoc., 1851. 
as Dr. C. R. Hall has justly remarked, this measure indicates, not what a person does breathe, but what he can breathe.-The maximum "vital capacity" met with by Dr. Hutchinson in his entire series of observations, was 464 cub. in.; this was in a man 7 feet high, whose weight was 308 lbs. The minimum was no more than 46 cub. in.; this was in a dwarf (Don Francisco), whose height was only 29 inches, and weight $40 \mathrm{lbs}$.

307 . But however constant the above averages may prove to be, when tested by a still larger number of observations, it yet remaius to be determined within what limits individual variation may range, without departure from the standard of health. It is considered by Dr. Hutchinson ${ }^{1}$ that a deficiency of 16 per cent. (unless the individual should be very corpulent) should excite suspicion of disease; but the observations of Dr. C. R. Hall (loc. cit.) seem to show that the range is considerably wider, cspecially in females. They also indicate that even a marked deficiency in vital capacity nust not be regarded as indicative of pulmonary disease ; for it may be dependent upon disorder of the abdominal viscera, especially upon congested liver.

305. In estimating, however, the effects of the Respiratory function upon the air which passes through the lungs, we are not so much concerned with the quantity which may be drawn in aud forced out, as with that actually cxchanged at each movement. The estimates of the earlier observers, Herbst, Valentim, ${ }^{2}$ etc., which ranged from 10 to 92 cub. in., are in general imperfect, having been based upon comparatively few respirations, and without taking into consideration the many circumstances we now know to exercise an influence upon the depth and frequency of the respiratory acts. Dr. Ed. Smith ${ }^{3}$ has arranged a spirometer, by which the quantity of air inspirecl may be registered from 1 to 1,000,000 cub. in., and therefore for any period. He has used it for 24 hours without intermission, except for meals, and ascertained the quantity of air inspired during sleep, and in almost every condition met with during the day. From numerous experiments upon scveral persons, each extending over a whole day, he found that the average depth of inspiration was 33.6 cub. in. when at rest, and when walking at $1,2,3$, and 4 miles per hour, 52, 60, 75, and 91 cub. in., and even 107 cub. in. when working the treadmill. If we take 30 or 40 cubic inches as the average quantity exchanger at each iucpiration, we cannot but observe how small a proportion it bears to the entire amount which the lungs usually contain : for the "residual air," which cannot be expelled, is estimated by Dr. Hutchiuson at from 75 to 100 cubic inches, aud the "supplemental air," which can only be expelled by a forced expiration, is about as much more; the sum of the two being from 150 to 200 cub. in., or from 5 to 7 times the "breathing volume." Now it is obvious that if no provision existed for nuingling the air inspired with the air already occupying the lungs, the former would penetrate no further than the larger air-passages; and as this would be again thrown out at the next expiration, the bulk of the air contained in the lungs

10 p. cit.. p. 1079.

2 Thu following are some of the amounts assigned by different observers:

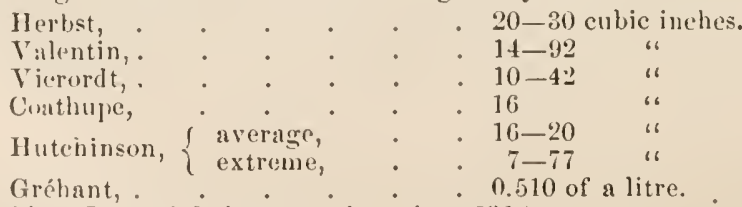

(Grétant, Robin's Jourual de t'Anatoinie, t. i, p. 523.)

3 Many of the following statements respecting Dr. Edward Smith's experiments were kindly communicated by himself. 
would renain altogether without renewal, and the cxpired air would not be found to lave undergone any change. ${ }^{2}$ 'That a change is effected, however, in the whole volume of the air contained in the lungs, with every inspiration. is indicated by the difference between the inspired and expired air ; and it. amount las bcen ascertained by Gréhant by means of his mothod, in which hydrogen gas is inspired, to be that about two-thirds of the pure air inspired remains in the lung, whilst the other third is expelled mingled with twothirds of vitiated air. ${ }^{2}$

309. The total amount of air which passes through the lungs in twentyfour hours, will of course vary with the extent and fiequency of the respiratory movements; and these are liable to be affected by many circumstances, but particularly by the relative degrees of repose and of exertion. Moreover, as any such computation must be based upon the datum of the ordinary volume of breathing or "tidal " air, it is obvious that the estimates of different observers nust vary with the amount they adopt. Dr. Ed. Smith found that during the day ( 6 A.m. to 12 night) the average quantity of air inspired by scveral persons at rest was 502 cub. in. per minute, or a total of 542,160 cub. in (nearly 314 cub. feet); and as the average quantity during the night was about $400 \mathrm{cub}$. in. per minute, the total daily amount was 686,000 cub. in. ( 397 cub. feet), which is in close approximation to the results of Valentin, who estimated the total daily amount at 688,348 cub. in. The quantity is largely increased by exertion, and Dr. Smith computes that the total anount actually respired by the unoccupied gentleman, the ordinary tradesman, and the hard-working laborer, would be 804,780 cub. in., $1,065,840$ cub. in., and 1,568,390 cub. in.; and with 12 hours of Alpine walking, as over the Wengern $A l p, 1,764,000$ cub. in. (1020 cub. feet). When carrying the weights, as by the soldier in his heavy marching order, Dr. Smith found an increase of 7 cub. in. per minute for every $l \mathrm{lb}$. weight carried.

310. The alterations in the $\mathrm{Air}^{3}$ which are effected by Respiration, consist in its satulation with aqueous vapor, the elevation of its temperature to $95.5^{\circ}$ or $97.43^{\circ}$ Fahr., ${ }^{4}$ and in the renoval of a portion of its oxygen, and the substitution of a quantity of carbonic acid usually rather less in bulk than the oxygen which has disappeared. Probably about 4.35 per cent. may be taken as the average anount of Carbonic acid added to the air, at the ordinary rate of respiration; whilst according to Vierordt, the amount of oxygen renioved is 4.782 por cent.; the absolute diminution in bulk of the expired air, when deprived of the moisture which it has acquired in passing through

1 See Mr. Jcfireys's Statics of the Human Chest, in which this important point first recived due consideration.

2 See for an account of his method Budge, Compendium de Physiologie, 1874, p. 78.

3 The composition of ordinary atmospberic air in England is thus given by Dr. Miller (Elements of Chemistry, vol, ii, p. 455):

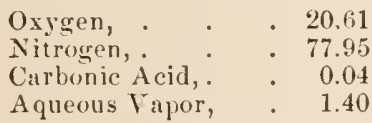

Nitric Acid, Ammonia, and Carburetted Hydrogen,. . . traces.

And in towns-Sulphuretted $\mathrm{Hy}^{\mathrm{r}}-$ \} traces.

When fully saturated, air at $50^{\circ} \mathrm{F}$. is stated by Pettenkofer to contain about 4 grains of water per cubic foot; at $68^{\circ} \mathrm{F}$. it contains about 7. The average hygrometric condition of the atmosphere at $50^{\circ} \mathrm{F}$. is such that it contains about 3 grains per cubic foot, or about 75 per cent. of its full saturation. At the ordinary temperature of the month of July, the atmosphere is capable of containing nearly three times as much aqueous vapor as in December; nevertheless the quantity of moisture actually present is gcnerally grcater in winter, owing to the greater rainfall.

4 Weyrich, Observations on the Insensible Perspiration of the Lungs and Slin, 1865. 
the lungs, being from $\frac{1}{40}$ th to $\frac{1}{50}$ th of its volnme, though its weight owing to the sp. gr. of carbonic acid being greater than that of oxygen is rather increased. Supposing the entirc amount of air respired per diem to be $1,000,000$ c. in., or 578 cubic fect, or 3600 gallons, as given by Dr. Smith for an ordinary tradesman, the absolute quantity of oxygen withdrawn from the air in the respiratory acts may be estimated at about 5000 cubic inches or 30 c. ft. (=5 per cent.); the weight of which would be about 18,000 grains, or rather more than $2 \frac{1}{2}$ lbs. avoirdupois. A curious calculation has been made by Welcker, to the effect that the surfacc presented for aeration, by the entire mass of the red corpuseles of the blocd, amounts to no less than 2816 square metres, or estimating the amount propelled throngh the lung in each second to be 176 cubic centimetres, the snrface presented by the corpuscles contained in that quantity of blood would amount to 87 square metres, or a square of 13 military steps to the side. It is deserving of notice in regard to the elimination of Carbonic acid, that if the air be already charged to some extent with this gas, the quantity exhaled is nuch diminished (Allen and Pepys).

311. The absolute quantity of Carbonic acid exhaled from the Lungs is liable to variation from so many sources, that no fixed standard can be assigned for it. The mean of a great number of obscrvations, however, made in different modes, and under different circumstances, would give about 160 grains of Carbon per hour as the amount set free by a well-grown adult man, under ordinary circumstances. Taking this as the average of the twenty-four hours, the total quantity of Carbon thus daily expircd from the Lungs would be 3840 grains, or $8 \mathrm{oz}$. troy, which is equal to 14,080 grains of Carbonic acid. ${ }^{1}$ According to Dr. Edward Smith, who has devised an apparatus by which all the Carbonic acid exhaled may be collected for a whole day without intermission except for food, the total amount evolved in 24 hours at rest (deduced from cxperiments on different persons) was 7.144 oz. of Carbon; and he estimates that it should be increased to $8.68 \mathrm{oz}$. and 11.7 oz. for the nou-laboring and laborious classes respectively, at their ordinary rate of exertion. The chicf causes of variation are,-the Temperature and Hygrometric statc of the surrounding Medium, Age, Sex, Development of the Borly, Nature and Quantity of Food and state of the Digestive process, Muscular Excrtion or Repose, Slecp or Watchfulness, Period of the Day, Season, and state of IIcalth or Disease. These will now be considered in detail :

I. Temperature of Survounding Medium.-The amount of Carbonic acid exhaled by warm-blooded animals, is greatly increased by external Cold, and diminished by IIeat. From Letellier's experiments it appears that the quantity of Carbonic acid exhaled by Mammals between $86^{\circ}$ and $106^{\circ}$, is less than half that sct free near the freezing-point; whilst that which is exhaled between $59^{\circ}$ and $68^{\circ}$ is but little more than tero-thirds of the same amount. The diminution oceasioned by heat is still more remarkable in Birds; which cxhale at the highest temperature scarcely more than one-third of that set free at the lowest. - The obscrvations of Vierordt ${ }^{3}$ upon himself show that the same is true of the Human subject; and a difference of $10^{\circ}$ Fahr., acecording to lim, producing a variation of rather more than two cubic inches in the amount of Carbonic acid hourly cxpired. Dr. Ed. Smith found that

1 Seharling estimated the hourly elimination of Carbonic Acid to be on the average 30 grammes, or 550 grains, and by Panum it is given as 34 grammes or 525 grains.

${ }^{2}$ Annales de Chimie et de Physique, 1815; and M. Boussingault's Mémoires de Chimie $\Lambda$ gricole et de Physiologie, 1854.

3 Pliysiologie des Athmens, j1. 73-82. 
sudden increasc of tempcrature occasioncl sudilen decrease, in an increasing ratio, in the quantity of Carbonic acid evolverl, amonnting to 1.3 grain per minute for $16^{\circ}$ Fahr. of temperature; but that in experiments continued over long periods, there was the greatest diversity in the proportion of Carbonic acid evolved to each degree of temperature.

II. That the Hygrometric state of the Air influences the rate of cxhatation of Carbonic acid, appears from some cxperiments by Lehmann made with this express view. For he found that while 1000 grammes' weight of Pigeons yielded, in dry air, 6.055 grammes of Carbonic acid per hour, at the temperature of $75^{\circ}$, and 4.69 grammes at the temperature of $100^{\circ}$, the same animals, in moist air, yielded 6.769 grammes at $73^{\circ}$, and 7.76 grammes at $100^{\circ}$. And while 1000 grammes' weight of Rabbits exhaled, in dry air, 0.451 gramme per hour, at a temperature of $100{ }^{\circ}$ they exhaled as much as 0.677 gramme in a moist atmosphere at the same temperature.

III. 'The amount of Carbonic acid exhaled increases in both sexcs up to about the thirtieth year; it remains stationary until about the forty-fifth ; and it then diminishes. Thus, according to Andral and Gavarret," at 8 years of age, $7 T$ grains of carbon are excreted per hour; at 14 years, 126 grains; at 20 years, 166 grains; at 48 years, 162 grains; and at 76 years, 92.4 grains.

IF. Sex.-At all ages beyond eight years, the exhalation is greatcr in Males than in Females. Nearly the same proportionatc increase takes place, however, in Females, up to the time of puberty; when the quantity abruptly ceases to increase, and remains stationary so long as they continue to menstruate. When, however, menstruation has ceased, the exhalation of Carbonic acid begins again to augnent; and then again diminishes, with the advance of years, as in men. Should menstruation temporarily cease at any time, the exhalation of Carbonic acid immediately undergoes an increase, precisely as at the final cessation of the function. And during pregnancy, the exhalation increases in like manner.

v. Develomment of the Body.-The more robust the individual, cateris paribus, the more Carbonic acid is exhaled; and the variation is much more influenced by the development of the muscular system, than by the height or weight, capacity of the chest, etc. Thus a very strong man of twenty-six years of age exhaled at the rate of 217.1 grains of carbon per hour; while a man of moderate muscular power set free but 169.4 grains in the same time. Another robust man of sixty years of age exhaled at the rate of 209.4 per hour ; and an old man of ninety-two years, who still preserved an uncommon degree of energy, and who in his younger days liar boasted of extraordinary muscular powers, exhaled at the rate of 135.5 grains per hour. So, also, a remarkably vigorous young woman of nineteen years exhaled at the rate of 107.8 grains per hour ; and a strong woman of forty-five years (who had ceased to menstruate), 152.4 grains.-On the other hand, a slender man of forty-five years in the enjoyment of good health, only exhaled at the rate of 132.4 grains per hour (Andral and Gavarret). In Dr. Ed. Smith's experiments the quantity of carbon expired per diem to each $1 \mathrm{lb}$. of bodyweight was 17.07 grains, 17.51 and 17.99 , at 48,39 , and 33 years of age respectively.

vi. Nature and Quantity of the Food, and State of the Digestive Process.It is well cstablished, that the exhalation of Carbonic acid is grcatly increased by eating, and that it is diminished by fasting. Thus Prof. Scharling states the hourly exhalation to have increased in one instance from 145 to 190 , after breakfast and a walk; in another from 140 to 177, after breakfast alone; and in another from 111.9 to 188.9 , after dinner. Dr. Ed. Smith on several

1 Lehmann, Op. cit., Bd. iii, p. 304. ${ }^{2}$ Annales de Chimie et de Physique, 1843. 
occasions fasted for more than twenty-four hours, and collected all the Carbonic acid exhaled during the whole period, or during ten minutes at each hour of the waking day. He found the total daily amount of carbou exhaled at rest and whilst fasting to be $5.923 \mathrm{oz}$; and there was scarcely any variation in the hourly quantity during the hours of the day. He noticed that there was a line below which the quantity of Carbonic acid did not fall, during waking hours in health; this, which he has termed the basal line, is that observed at rest and in the absence of food. The inerease above that line, which is caused by food, seldom exceeds one half of the basal quantity, or about 3 grains per minute. He has shown that the increase is from 2 to 3 grains per minute after break fast and tea, and from 1 to 2 grains per minute after early diuner, whilst he seareely found any increase after supper. $\mathrm{He}$ has examined the influence of numerous foods, as flesh, fish, albumen, gelatin, bread, rice, oatmeal, cane, grape, and milk sugar, milk, tea, coffee, cocoa, stareh, gluten, butter, olive oil, alcolıol, rum, gin, brandy, sherry, and port wiue, beer and spirits. All nitrogenous foods_gluten, easein, flesh, fish, albumen, and gelatin - inereased the evolution of Carbonic acid to the extent of $\frac{3}{4}$ to 1 grain per minute; but tea, eoffee, bread, rice, oatmeal, milk, and sugar increased it from $1 \frac{1}{2}$ to 3 grains per minute. Fats and starch did not increase it; aleohol, rum, and ales inereased it from $\frac{1}{2}$ a grain to 2 graius per minute, whilst brandy and gin decreased it, and 3 ounees of wiue exerted but little influenec. The inhalation of the aroma of wines decreased it. All Dr. Snith's experiments were made in the sitting posture, at rest, before breakfast, and upon one substance alone in moderate quantity, the dose of which was repeated every ten or fifteen minutes, until the maximum influence had been obtained. With sugar, alcoholie liquids, tea, coffee, the maximum influence was observed in from twenty to thirty minutes; but with bread, oatmeal, milk, and flesh, it was commonly later, and eontinued from $1 \frac{1}{2}$ to $2 \frac{1}{2}$ hours. With sugar and tea there was frequently an inerease of 1 grain per minute in less than ten minutes. The whole of the Carbonie acid exhaled during five minutes at a time for two hour's was eolleeted and weighed; the pereentage was not sought for. Dr. Smith has called attention to the separate action of the alcohol, aronias, sugars, and nitrogenous matters in each of the aleoholie compounds. Similar though less extended and perfeet observations have been made by Vierordt, Bidder, Schmidt, and Perrin, ${ }^{1}$ and others, which generally corroborate the conclusions drawn by Dr. E. Smith.

VII. Muscular Evertion or Repose.-The effect of bodily exereise, in moderation, is to produce a considerable increase in the amount of Carbonie acid exhaled, both during its eontinuance, and for some little time subsequently to its eessation. Aceording to the observations of Vierordt, the increase amounts to one-third of the quantity exhaled during rest, and it lasts for more than an hour afterwards; being manifested in the greater quantity of air respired, and in the larger percentage of Carbonic contained in it. If the exercise be prolonged, however, so as to oceasion fatigue, it is sueceeded by a diminished cxhalation.-Dr. Ed. Smith found that whilst walking at two and three miles per hour, the quantity of Carbouic acid evolvel was 18.1 grains and 25.83 grains per minute, which are respectively 1.85 and 2.64 times more than that eliminated in the quiet sitting posture. With tread wheel labor the quantity varied from 42.9 grains to 48.66 grains. After the excrtion hat eeased, the inerease continued for some time; and not the least exertion could be made, even when sitting, without disturbing the results.-In the experiments of Pettenkofer and Voit ${ }^{2}$ the following results

1 Comptes Rendus, 1864, p. 257.

2 Münchener Akad. Berichte, 186i, No. 10. 
were obtained in the case of a liealthy man, at. 28, weighing 132 lbs., fert on ordinary diet, engaged in reading and cleaning watches, and extending over twenty-four hours:

\begin{tabular}{|c|c|c|c|c|}
\hline Period of the day. & \multicolumn{2}{|c|}{$\begin{array}{l}\text { Elimination of } \\
\mathrm{CO}_{2} \quad \text { I Ho } \\
\text { through Skin and } \\
\text { Lungs in grains. }\end{array}$} & $\begin{array}{l}\text { Amount } \\
\text { of Oxygen } \\
\text { absorbed. }\end{array}$ & $\begin{array}{c}\text { Percentage of the } \\
\text { inspired Oxygen } \\
\text { in the Carbonic } \\
\text { Acid. }\end{array}$ \\
\hline $\begin{array}{c}\text { Day. } \\
6 \text { A.M. }-6 \text { p.M., . . } \\
\text { Night. } \\
6 \text { p.м. } 6 \text { A.M., . . . }\end{array}$ & $\begin{array}{l}826.0 \\
586.8\end{array}$ & 533.8 & 363.6 & $\begin{array}{r}271.2 \\
89.9\end{array}$ \\
\hline Total in 24 hours,. . & 1412.8 & 1283.6 & 1098.7 & 361.1 \\
\hline
\end{tabular}

A few days later the same man worked till exhausted.

\begin{tabular}{|r|r|r|r|r|} 
Day, . . . . . . & 1371.1 & 169.69 & 456.9 & 3879 \\
Night, . . . . & 619.4 & 146.83 & 1022.5 & 68.2 \\
\cline { 1 - 2 } & & & \\
\cline { 1 - 3 } & & & \\
\hline
\end{tabular}

The connection between muscular exertion and the exhalation of Carbonic acid, is most remarkably shown in Insects; in which animals we may witness the rapid transition between the opposite conditions of extreme muscular exertion and tranquil repose; and in which the effects of these upon the respiratory process are uot masked by that exhalation of Carbonic acid, which is required in warm-blooded animals simply for the maintenance of a fixed temperature. 'Thus a Humble-Bee was found by Mr. Newport ${ }^{1}$ to produce one-third of a cubic inch of Carbonic acid in the course of a single hour, during which its whole body was in a state of constant morement, from the excitement resulting from its capture; and yet, during the whole twenty-four hours of the succeeding day, which it passed in a state of comparative rest, the quantity of Carbonic acid generated by it was absolutely less.

viII. Sleep or Wutchfulness.-The amount of Carbonic acid exhaled during sleep is considerably less than that set fiee in the waking state. This is particularly shown by the experiments of Scharling; ${ }^{2}$ who confined the subjects of them in an air-tight chamber, within which they could sleep, take their meals, etc. Thus in one case the hourly exhalation sank from 160 to 100 , in another from 194.7 to 122.3 , and in another from 99 to 75.1 . With customary food and exercise Pettenkofer and Voit, in one experiment found that of the total amount of Carbonic acid eliminated during 24 hours, 58 per cent. was given off during the 12 hours of the day, and 42 per cent during the 12 hours of the night; whilst 33 per cent. of the oxygen was taken up by day, and 67 by night. Dr. Ed. Smith found that 4.88 and $4.99 \mathrm{grs}$ of Carbonic acid were exlated per minute during light sleep from 1 to 3 A.M., and he estimates the quantity in profound sleep at $1 \frac{1}{2}$ grs. He also observed that 5.7 grs., $5.94 \mathrm{grs}$, and $6.1 \mathrm{grs}$. per minute were evolved at $1.30,2.30$, and 6.15 A.M., whilst awake, the average amount during the waking day being $9.77 \mathrm{grs}$. per minute in the same person. The cause of this result is partly to be sought in the cessation of all muscular exertion (save that concerned

1 Philos. Transact., 183r.

2 Ann. der Chem. und Pharm., 1843; transl. in Ann. de Chim. et de Phys., 1843. 
in the maintenance of the respiration); and partly in the diminution in the dissipation of the heat of the body itself.

Ix. Period of the Day.-Independently of these variations, which have their source in the condition of the individual, there is reason to believe that there is a diurnal cycle of change in the quantity of Carbonic acid exhaler; the maximum being (cateris paribus) before and after noon, and the minimum before and after midnight. From the experinents of Scharling upon the Human subject, it would appear that the average proportion exhaled by day to that exhaled by night is as $1 \frac{1}{4}$ to 1 ; and this difference does not seem to be affected by sleep or wakefulness. Dr. Ed. Smith found that the quantity of Carbonic acid varied at every moment; and that there were similar hourly variations in the quantity of Carbonic acid evolved, as in the rate of pulsations to which we have already referred. There was the least during the middle hours of the night, a slight increase with sunlight, a large increase after the meals, and a decreasc before them, and a prolonged and inevitable fall after about 90 'clock P.M. The proportion in the night of six hours to the day of 18 hours was in himself as $1: 1.8$. Most persons are conscious of a greater difficulty in bearing exposure to cold between midnight and early morning, than at any other period in the twenty-four hours. ${ }^{1}$

x. Season.-Dr. Edward Smith has investigated the influence of season by determining the amount cvolved at rest, in the sitting posture, and before breakfast, daily throughout the year, and has found that the greatest amount occurs in April and May; that there is a decrease commencing in June, and continuing progressively throngh June, July, and August to September; and that in October, November, and December there is an increase. He considers that there is a maximum period (end of Winter and Spring), a minimum period (end of Summer to Autumn), an increasing period (Winter), and a decreasing period (early Summer). The extreme loss at the end of Summer was 3 grains of Carbonic acid per minute, or 33 per cent., and on the monthly average the loss was 17 or 18 per cent. He has applied this to the causation and treatment of disease, and has shown that the influence of the rotation of the seasons is a prime element in the vis medicatrix nature. Temperature and Barometric pressure to some extent, but very imperfectly, explained the results. A medium temperature was accompanied by the most diverse quantities of Carbonic acid at the different seasons, but extremes exhibited marked influence.

xI. Frequency of Respiration.--Vierordt ${ }^{2}$ found that, if he only respired six times in a minute, the quantity of Carbonic acid was 5.5 per cent. of the whole air exhaled; with twelve respirations, it was 4.2 ; with twenty-four, it was 3.3 ; with forty-eight, it was 3.0 ; and with ninety-six, it was 2.6 per cent. In some of the experiments of Messrs. Allen and Pepys, it was as much as 8 per cent. If the breath be held for 40 seconds (Vicrordt), or 100 seconds (Stefan), the proportion of Carbonic acid may rise to upwards of $7 \frac{1}{2}$ per cent., and if the same air be breathed over and over again, the proportion may attain 9 per cent. (Müller, Setschenow).

xIr. Stute of Health or Disease.-Upon this very important cause of rariation, few accurate rescarches have yet been malle. The pereentage of Car-

1 Perhaps the smaller quantity of $\mathrm{CO}_{2}$ exhaled by night than by day is due to less food being taken at this time. See the experiments of Henneberg, E. Schulze, Märkrr, Busse on Sheep, in Centralblatt f. d. Med Wiss. 1870, p. 3.3i.

2 Physiologie des Athmens, p). 112-149. Pantum (Pllüger's Archiv, Bd. i) and Berg (Arehiv f. Klin. NIed., Bd. vi) arrived at the same results as Vierordt, but Lossen ("eitsehrift f. Biologie) thinks that when the respirations are simply increased in number in a given time their greater shallowness compensates for their increased frequeney, and no more $\mathrm{CO}_{2}$ is given oft'. 
bouic acid in the expired air has been found to be unusually great in the Exantlemata, and in ehronic Skin-diseases (Mackregor) $;^{1}$ and it has becn staterl to be diminished in Typhus (Malcolm). ${ }^{2}$ - Thus, the average proportion in health being abont t.3 per cent. (Vierordt), it has been seen at 8 per cent. in confluent Simall-pox, at 5 per cent. in Measles, and at 7.2 per cent. in a severe case of Ichthyosis which terminated fatally; whilst in Typhus the percentage has been found to range from 1.18 to 2.50 . But these statements do not indicate the total quantity exhaled in each case.-The remarkable increasc of the exhalation in cases of Chlorosis has been already noticed; in four cases recorded by Hannover, the hourly expiration was 123.6, 118.6, 116.9 , and 106.3 grains; the absolute quantity diminishing as the respirations increased in rapidity. - In chronic diseases of the respiratory organs, as might be anticipated, the amount of Carbonic acid exhaled undergoes a sensible diminution ( $\mathrm{N}_{\text {ysten }}{ }^{3}$ and Hannover). ${ }^{4}$ - Further researches are much necled on this subject; but, for obvious reasons, they cannot be readily made in severe forms of disease.-The greater part, if not the whole, of the Oxygen absorbed in respiration is again eliminated in combination with Carbon as Carbonic acid. In the original experiments of Lavoisier on Guinea-pigs, 81 per cent. of the Oxygen thins reappeared, the remaining 19 per cent., which disappeared, were believed by him to unite with hydrogen to form water. 'The results of Regnault and Reiset's expcriments on various animals-mammals, birds, reptiles, insects, and annelids ${ }^{5}$-were almost precisely the same; the general average heing, that for each kilogramme of weight of the animal, there were absorbed per hour 3.0219 grammes of oxygen; whilst there were exhaled 3.2544 grammes of Carbonic acid; and they found that 80.5 per cent. of the Oxygen absorbed was discharged in combination with the Carbon, but considerable variations occurred connected with the nature of the food, a larger proportion of the Oxygen absorbed being combined with Carbon when the food was rich in Carbon, ${ }^{6}$ amounting in Ruminants to about 100 per ceut. Pettenkofer and Voit also found the proportion of Oxygen eliminated in the form of Carbonic acid varied, in a large dog, from 52.4 to 148.2 , according as he was kept altogether without food, or was fed upon a mixed diet of neat and sugar.

The table (p. 391) shows a remarkable excess of the diurnal against the nocturual elimination of Carbonic acid, especially after work, and a corresponding increase in the percentage of the absorbed Oxygen which is thus discharged. On the other hand, the absorption of Oxygen appears to take place most energetically during the night, whilst, taking the whole period of 24 hours into consideration, it appears that in both sets of experiments from 94 to $98 \mathrm{per}$ cent. of the oxygen absorbed is eliminated in combination with Carbon as Carbonic acid. In other and still more recent researches, the same difference was not observed ${ }^{8}$ between the day and night absorption of Oxygen and elimination of Carbonic acid, and no definite statement as to the exact proportion can therefore as yct be made. The elimination of Urea

1 Edinb. Monthly Journal, 1843.

2 Report of Brit. Assoc., 1813, p. 87.

3 Recherchos de Physiologie et de Chimie Patholonique, 1811.

4 De Quantitate relitiva et absoluta Acidi Carbonici ab Honine Sano et Egroto exhalati, 184.).

6 See Longet's Physiologie, 1861, t. i, p. 556.

- Kowalewsky, Arbeiten aus der Physiol. Anstalt zu Lcipzig, 1867, p. 33, was only able to obtain about 50 per cent. of the oxyan absorbed in the carbonic acid exhaled, by means of his new apparatus, in rabbits fed on eabbage leaves.

7 Prof. Haughton's Address, On the Relation of Foud to Work, Brit. Med. Association Meeting, Augu-t, 1868.

8 Op. cit., February, 1867. 
corresponded in its variations to that of the Carbonic acid, being 21.7 grammes by day and 15.5 grammes by night.

312. The effects of exposure to increased atmospheric pressure have been marle the subject of experiment by Vivenot, ${ }^{1}$ C. IV. Müller, ${ }^{2}$ Paul Bert, ${ }^{3}$ and Panum, ${ }^{4}$ hut have best been illustrated by the observations made by Dr. Jaminet $t^{5}$ on himself and on the workmen engaged in the construction of the Illinois and St. Louis Bridge over the Mississippi River. In the course of this work the men were engagerl in excavations conducted at a depth of 115 feet below the level of the surface of the river, the pressure of the air then amounting to upwards of fifty pounds on the square inch of their bodies, exclusive of the ordinary atmospheric pressure of fifteen pounds on the square inch. No ill effects were observed, even when the pressure was greatest, whilst the men were working in the air-chambers; it was only on suddenly emerging that great exhaustion, pain in the epigastrium and spine, sickness, paraplegia, involving the bladder and rectum, and even death occurred. Great care was taken that on entering and leaving the air-chanbers the workmen should remain for ten minutes or nore in lock chambers, in which the pressure was gradually increased or diminished. The pulse and respiration usually rose in fiequency on exposure to the augmented pressure, and free perspiration occurred ; but it nust be rememberer that the air-chambers were small, and the temperature in them was many degrees above that of the open air. The Urine and Urea were at the same time increased. Speaking generally, there seems to be reason for believing that under the conditions to which the men were here subject, with moderate pressure (20 lbs. to the square inch), the activity of the physiological functions was augmented, though there seemed to be a reaction on return to orlinary pressure. In the cases in which death occurred, the Brain and Spinal Cord were found to he highly congested, and their cavities filled with serum. MI. Vivenot's experiments found that an increase of pressure amounting to one-fifth of the normal decreased the respiration two, and the pulsations ten per minute. The proportion of gases contained in the blood is only to a slight extent dependent on the pressure. ${ }^{6}$ The recent experiments of M. P. Bert ${ }^{7}$ have, however, shown that when animals are made to respire pure oxygen gas under a pressure of five or six atmospheres (or, which is the sane thing, when the pressure of the ordinary air is raised to 20 atmospheres) it acts like a poison -convulsions rescmbling those produced by strychnia occurring. These set in, in dogs, when the blood contains about 10 per cent. more oxygen than nornal, and it is remarkable that the convulsions continue after the animal hats been withdrawn from the pressure and its blood only contains the usual proportion of oxygen. The effects of diminution of pressure in some respects resemble those of exalted pressure. Thus $\mathrm{Hoppe}^{8}$ observed that when rats were placed unler the receiver of an air-pump and exhanstion made till the presicure was reduced to 2 inches of mercury, fainting and convulsion were induced, and when it was reduced to $1 \frac{3}{4}$ in. (40 $\mathrm{mm}$.), death occurred, apparently from the evolution of gas in the capillaries of the lungs, which impeded the passige of the blood. The singular effects observed by Glaisher in his lofty

1 Virchow's Archiv, Bd. xxxiii.

2 Zeitschrift für rat. Med., Bil. xxxiii

3 Comptes liendus, t. Ixxiii, pl). 213, 503, and Leçons sur la Respiration.

4 Plliegrer's Archiv, Bd i.

5 Physienl Effects of Compressed Air observed in the Construetion of the Illinois and St. Louis Bridge, 1871.

6 Mathieu and Urbain, Comptes Rendus, 1871, p. 216.

7 Comptes liendus de l'Aend des Scienees, 187:-73.

8 Mïller's Arehiv, 1857, p. (i3.

9 Glaisher, Art. Aeronaties, Encyclop. Britanniea, 1875, p. 167. 
balloon ascents at an altitude of 7 miles, viz., loss of power in the arnis and legs, finlure of vision, and syncope, were probably due to the sudden and combined influence of cold, and an insufficient supply of oxygen. Less marked phenomena characterize the condition known to Alpine climbers as the Mal de montagne. 'They appear, lowever, at much lower levels than in aeronatic expeditions, on account, probably, of the muscular fatigue and want of sleep undergone. The symptoms of the affection-breathlessness, nausea or vomiting, pa!pitation, exhatustion, feeling of coldness, humming in the ears, and congestions of various parts, are usually experienced at a lieight of about 12-14,000 feet, and ascents of these altitudes should not be undertaken by those who suffer from disease of the heart, or who have a predisposition to apoplexy. The symptoms of the Mal de montagne are attributed by M. Lortet to the great consumption of heat that takes place in order to develop the amount of muscular force required. Nevertheless, both man and animals are capable of accommodating themselves to the diminished atmospheric pressure of great heights, the town of Potosi being 13,265 feet above the level of the sea, Ancomarco 15,258 feet, and Deba 15,920 feet.

313. The aeration of the blood may take place, not only by means of the Lungs, but also in some degree through the medium of the Cutaneous surface. In some of the lower tribes of animals, indeed, this is a very important part of the respiratory process; and even in certain Vertebrata the cutaneous respiration is capable of supporting life for a considerable time. This is especially the case in the Batrachia, whose skin is soft, thin, and moist; and the effect is here the greater, since, from the small proportion of the blood that has passed through the lungs, that which circulates through the system is very imperfectly arterialized. By the experiments of Bischoff it was ascertained that, even after the lungs of a Frog had been removed, a quarter of a cubic inch of Carbonic acid was exhaled from the skin in the course of eight hours. Experiments on the Human subject leave no room for doubt, that a similar process is effected through the medium of his general surface, although in a very inferior degree; for by confining the body in a close chamber, into which the products of cutaneous respiration could freely pass, whilst the pulmonary respiration was measured by a distinct apparatus, Prof. Scharling ${ }^{1}$ believed he had ascertained that the proportion of Carbonic acid given off by the Skin is from $\frac{1}{4}$ th to $\frac{1}{6} 0$ th of that exhaled from the Lungs during the same period of tine, or from 350 to 500 grains. The results obtained by more recent observers, however, render it probable that Scharling's estimate was too high. Dr. Ed. Smith inclosed the whole of his body, except the head, in a caoutchouc bag, passed a current of air through it, and collected the Carbonic acid. The whole quantity obtained in Summer, including that found in the air of the room, was 6 grains per hour, or somewhat more than 1 per cent. of the amount passing off by the Lungs. Reinhard, ${ }^{2}$ who had admirably constructed apparatus at his command, estinated it at from 34 to 35 grains per diem (2.23 grammes); and Aubert, ${ }^{3}$ whose experiments appear to have been very earefully conducted, estimates it at about 60 grains (4 grammes), a quantity that is not equivalent to $\frac{1}{2}$ per cent. of the amount eliminated by the lungs (13-14,000 grains). Moreover, it has been observed, not unfrequently, that the livid tint of the skin which supervenes in Asphyxia, owing to the non-arterialization of the blood in the lungs, has given place after death to the fresh hue of health, owing to the reddening of the blood in the cutaneous capillaries by the action of the atmosphere upon them; and it does not seem improbable that, in cases of obstruction to the due action of

1 Ann: der Chem. und Pharm., 1846. ${ }^{2}$ Zeitschrift für Biologie, Bd. v, 1869, p. 37.

3 Pflüger's Archiv, Bd. vi, 1872, p. 539. 
the lungs, the exhalation of Carbonie aeid through the skin may undergo a eonsiderable inerease; for we find a similar disposition to vicarious action in other parts of the exereting apparatus. There is also evidence that the interchange of gases between the air and the blood, through the skin, has an important share in keeping up the temperature of the body (chap. xii); and we find the temperature of the surfaee mueh elevated in many eases of pneunonia, phthisis, ete., in whieh the lungs seem to perform their funetion very insuffieiently.

314. The total amount of Carbonie aeid daily given off from the Skin and Lungs may be estimated in another mode, namely, by determining the total amount of Carbon eontained in the ingesta, and the amount exereted in other ways, making allowanee for the difference in weight (if any) of the body. In this mode, Prof. Liebig eame to the eonelusion, that the average amount of earbon exhaled by soldiers in barraeks was $13.9 \mathrm{oz}$. (Hessian), or very nearly $14 \mathrm{oz}$. troy. From similar eolleetive observations upon the inmates of the Bridewell at Mariensehloss (a prison where labor is enforeed), he ealeulated that eaeh individual exhaled ${ }^{\circ} 10.5 \mathrm{oz}$. of Carbon daily in the form of Carbonie acid; while in a prison at Giessen, whose inmates are deprived of all exereise, the daily average was but $8.5 \mathrm{oz}^{1}{ }^{1}$ A very exaet estimate, though based on more limited data, was made by M. Barral, ${ }^{2}$ who experimented upon himself (at. 29) in winter (A) and in summer (B), upon a boy 6 years old (C), upon a man 59 years old (D), and upon an ummarried woman of 32 years (E). The following table gives the results which he obtained, from an average of five days, in regard to the disposal of the Carbon of the food; those which relate to its Nitrogen, Hydrogen, and Oxygen will be noticed subsequently ( $\S 317,318$ ).

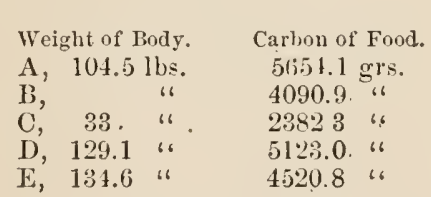

\begin{tabular}{|c|c|c|}
\hline \multicolumn{3}{|c|}{ Carbon excreted. } \\
\hline In Freces. & In Urine. & By exbalation \\
\hline $236.2 \mathrm{grs}$. & $234.6 \mathrm{grs}$. & $5183.3 \mathrm{grs}$ \\
\hline 137.4 & $211.5 "$ & $5741.1 " 1$ \\
\hline 149.7 & 67.9 & 2164.7 \\
\hline 210.0 & 327.3 & 45857 \\
\hline 64.8 & 216.1 & 4239.9 \\
\hline
\end{tabular}

Thus the average amount of the Carbon daily eonsumed in pulmonary and eutaneous exhalation by M. B. Barral himself, was in winter 5183.3 grains, or 10.8 oz. troy; whilst in summer it was but 3741.1 grains, 7.8 oz. troy; this differenee is quite conformable to what might liave been antieipated from the results of a different mode of experimenting $(\$ 311, \mathrm{I})$; and it throws some light on the diserepaneies in the results of other measurements, to find that the seasonal variation is seareely less than one-third of the mean between these two amounts. The other results eorrespond elosely with the statements of MII. Andral and Gavarret, in regard to the higher proportion of Carbonie aeid exhaled (as eompared with the bulk of the borly) by children, and the smaller proportion thrown off by men advaneed in years, and by women. In some experiments made on himself in Pettenkofer's apparatus, Rianke (weighing $161 \mathrm{lbs}$.) found that when at rest and fasting, 10,190 grains of Carbonie acid or 2779 grains of Carbon were eliminated in twenty-four hours by the Skin and Lungs, whilst with as full a diet as possible the amount was 13,278 grains of Carbonie aeil, or 3621 grains of Carbon.

315. It is not only by an oxygenated atmosphere that the removal of Carbonie acid from the blood may be effected. For although it was formerly supposed that the exhaled Carbonic aeid is generated in the lungs by the combination of atmospheric oxygen with the carbonaceous matters of the 
blood, and that the inhalation of oxygen is therefore immediately necessary for its production, yet it is now quite certain that this carbonic acid exists preformed in venous blood, and that the oxygen introduced is carried into the arterial circulation, instead of being at once returned to the air in a state of Carbonic acid ( $\$ 194)$. Hence an exhalation of Carbonic acid may continue for a considerable period (in cold-blooded animals especially) whilst the animal is breathing an atmosphere in which no oxygen exists. Thus it was shown by Spallanzani, ${ }^{1}$ that snails might be kept for a long time in Hydrogen, without apparent injury to them; and that during this period they disengaged a considerable anomnt of Carbonic acid. Dr. Edwards ${ }^{2}$ subsequently ascertained that, when Frogs were kept in hydrogen for several hours, the quantity of Carbonic acid exhaled was fully as great as it would have bcen in atmospheric air, or even greater; this latter fact, which however is very doubtful, might be accounted for by the superior displacing power which (on the laws of the diffusion of gases) hydrogen possesses for Carbonic acid. Collard de Martigny ${ }^{3}$ repeated this experiment in Nitrogen, with the same results. In both sets of experiments, the precaution was used of compressing the flanks of the animal, previously to immersing it in the gas, so as to expel from the lungs whaterer mixture of oxygen they might contain. These experiments have been since repeated by iIüller and Bergmann, who took the additional precaution of removing, by means of the airpump, all the atmospheric air that the lungs of the frog might previously contain, together with the Carbonic acid that might exist in the alimentary canal. They found, in one of their experiments, that the quantity of Carbonic acid exhaled in hydrogen was nearly a cubic inch in $6 \frac{1}{2}$ hours ; and in another, that nearly the same amount was given off in nitrogen, though this required rather a longer period. It appears from the table of their results, ${ }^{4}$ that the amount was not ordinarily greater in the experiments, which were prolonged for twelve or fourteen hour's, than in those which were terminated in half the time; hence it may be inferred, that the quantity which the blood is itself capable of disengaging is limited,.and that the absorption of oxygen is necessary to enable Cirbonic acid to be continuously set free from the body.-It is impossible, however, for an adult Bird or Manımal to sustain life for any considerable time in an atmosphere deprived of oxygen; since the greatly increased rapidity and energy of all their vital operations necessitate a much more constant supply of this vivifying agent, than is needed by the inferior tribes; and, as we shall presently see, the capillary action requisite for the passage of the blood through the lungs will not take place without it $(\S 321)$. But Dr. Edwards has shown that young Mamınalia can sustain life in an atmosphere of hydrogen or nitrogen, for a sufficient length of time to exhale a sensible amount of Carbonic acid ; so that the character of the process is clearly proved to be the same in warmblooded animals as in Reptiles and Invertebrata.

316. The seat of those changes which result in the formation of Carbonic acid has been the subject of much research and discussion. It may cither be conceived that the oxygen taken up by the blood-corpuscles, and feebly held in combination by their hæmoglobin, escapes by diffusion through the bloodvessels, and directly enters into combination with the constituents of the tissues, the Carbouic acid formed being given up in exchange for fresh oxygen; or we may suppose that the products of the disintegration of the

1 Mémoires sur la Respiration, traduit par Senebier, Genève, 1804.

2 De l'Influence des Agens Physiques sur la Vie, Puris, 1824.

3 Recherches Expérimentales, etc., in Magendie's Journal de Physiologie, tom. $x$.

- Müller's Eleménts of Physiology, transiated by Baly, vol. i, p. 338. 
tissues enter the blood, and there meeting with the loosely combined oxygen, abstract it from the corpuscles, which readily surrender it to the more oxidizable materials. In the one case, the oxidizing process and the production of Carbonic acid would take place chiefly in the tissues, in the other ehiefly in the blood. Various circumstances seem to point to the former as being the more correct statement of the facts. ${ }^{1}$ In the first place, the respiration of the tissues shown to occur by Liebig and P. Bert, leads to the development of Carbonic acid within them, and as they contain (at least in the case of the most important of all-the muscles) 110 oxygen capable of bcing removed by exhaustion, the oxygen contained in arterial blood will in obedience to physical laws diffuse into the tissues, and be replaced by Carbonic acid. Again, it may be shown that arterial blond loses its oxygen with extraordinary rapidity during its passage through the capillaries, and although this was attributed by Schmidt to the presence of easily oxidizable or reducing substances in the blood, chiefly associated with the corpuscles (A fonassieff), yet Pflüger ${ }^{2}$ has shown that the quantity of these oxidizable substances can be but small, since artcrial blood removed from the body only slowly acquires a venous character, whilst even in the case of asphyxiated animals, warmth and time are required for the production of a large amount of Carbonic acid; and so too, if an easily oxidizable substance, as sodium lactate, glycerin, or caproic acid, be added to blood after withdrawal from the body, no augmentation in the amount of Carbonic acid is observed, though if injected into the circulation such substances are quickly decomposed, and canse increased evolution of this gas. ${ }^{3}$ The fact noticed by Ludwig and Hammarsten, that the tension of the Carbonic acid in the lympl is lower than in venous blood, though higher than in arterial, constitutes no valid objection to the view that the gas is chiefly formed in the tissues and not in the blood, since the lymph examined by them had already had the opportunity of equalizing the tension of its gases with those of arterial blood in traversing the lymphatic glands and the lacunæ of the connective tissucs. At the same time, the phenomena of oxidation are materially affected by the integrity of the blood-corpuscles, since these are the carriers of the oxygen, or perhape, more properly speaking, of ozone; for, as Ritter ${ }^{4}$ has shown in his investigations on the influence of agents which modify the absorptive capacity of the globules for oxygen, the secretions undergo material alterations when the corpuscles have bcen profoundly altered by the action of antimonial and arsenical compounds, by phosphorus, or by the action of the biliary acids; these agents changing the form of the globules, and causing the appearance of crystals of Iremoglobin in the blood, coinciding with which the urine becomes albuminous, and contains various coloring materials. In connection with this, the observations of Manassem ${ }^{5}$ may be mentionerl, as showing that the red corpuscles diminish in volume when under the influence of abnormal activity of the disintegrating processes, as in febrile states, when they have to part with an increased amount of oxygen; or when any obstacle exists to the absorption of oxygen, as when they are exposed to the

1 See J. Worm Müller, in Ludwig's Arbeiten, 1870, p. 168. Ueber die Spanning des Sunerstoff's der Blutseheiben.

2 P'llïger, Ueber die Diffusion des Sauerstoffs, etc., Plüger's Archiv, Bd. vi, 1872, p. 43.

3 Ludwig and Sehremetjewsky (Ludwig's Arbeiten, 1868) have, however, shown that sugar passes through the eapillaries of the kidners unchanged.

4 Ritter, Des Modifieations ehimiques que subissent les seeretions sous l'influpnee de quelques agrnts qui modifient les globules sanguins. Paris, 1872. See Küss, Physiologie, 1). 380.

5 Unler die Dimensionen der rothen Blutkorperchen unter verschiedenen Einflüssen. Pamplet, 1872. 
action of carbonic acid or morphia; whilst they augment in size when they are exposed to a highly oxidized medimm, or when they are placed under conditions in which the oxygen escapes with difficulty, as after the arministration of refrigerants, quinine, alcohol, and hyrlocyanic acid. Whether the carbonic acid is chiefly formed without or within the vessels, it is certain that the amonnt developed bears a close relation in all parts of the borly with the energy with which cell growth and function take place, and with the activity of the interstitial changes coineident with these processes; the blood, which has then become charged with this gas and poor in oxygen, is conducted to the lungs, when the converse changes arc effected, the Carbonic acid diffusing through the vessel into the air contained in the pumonary alveoli, and being replaced by oxyen. The precise steps of this change are not certainly known. Wolffberg has demonstrater that the tension of the Carbonic acid in the alveoli of the lungs, and in the venous blood of the pulmonary artery, is nearly the same, and it is not clear why it should diffuse through the walls of the bloorlvessels. From some cause or other its tension in the blood must be raised as this traverses the pulmonary capillaries. Robin and others have attributed this elevation of tension to the formation of an acid-pneumic acid, whilst others have regarded it as the effect of the formation of oxyluenoglobin, the expulsion of the Carbonic acid being dependent on the absorption of Oxygen.

317. Much discussion has taken place with regard to the degree in which the proportion of Nitrogen in the air is affected by Respiration. It seems probable that the absorption and exhalation of this gas are continually taking place; but that the two amounts usually nearly balance each other." ${ }^{2}$ On the whole, however, there is adequate reason to believe that Nitrogen is ordinarily given off; this being the joint result of the analysis of the expired air, and of the comparison of the amount of nitrogen given off in the other excretions with that ingested as a constituent of the food. In some experiments made by Regnault and Reiset, on the composition of the expired air in various warm-blooded animals, they arrived at the following conclusions: (1.) That warm-blooded animals subjected to their ordinary regimen exhale nitrogen, but never in larger proportion than $\frac{1}{5}$ th, and sometimes in less than $\frac{1}{100}$ th, of the oxygen consumed; (2.) That in a state of inanition, animals usually absorb nitrogen ; (3.) That animals whose usual diet has been changed, usually absorb nitrogen until they are accustomed to their new fond. ${ }^{3}$ -Voit, ${ }^{4}$ in experiments on pigeons extending over 124 days, found that little or no nitrogen is eliminated by the lungs in these animals, since the amount contained in the urine and faces was equal to within 2.3 per cent. of that ingested. This result is in marked contrast to that obtained by Boussingault, who found a deficit of 35 per cent. of nitrogen in the freces and urine when compared with that contained in the food. From Seegen's researches on dogs, it appears that al though generally the greater part of the nitrogen is eliminated as urea, under certain circumstances, a large portion (one-half) may be discharged by other channels, a portion probably escaping by the lungs. Barral estimated that the amount of nitrogen which (being otherwise unaccounted for) must be considered to have passed off by the lungs

1 Wolff berg, Ueber die Athmung der Lunge, Pfüger's Arehiv, Bd. vi, 1872, p. 23 ; Strassburgh, Die Topog. der Gasspannungen im Thierisehen Organismus, in idem, p. 65

2 For the considerations whieh render this probable, see especially Dr. W. F. Edwards, On the Influence of Physical Agents on Life, part. iv, ehap. xvi, seet. 2, 3.

3 Ann. de Chim. et de Phys., 1849; and Mém. de Chin. Agrie., 1854, p. 31.

4 Irenle and Meissner's Bericht, 1862, p. 342, and 1866, p. 390.

5 Wiener Sitzungsberichte, 1867, Bd. Iv, March. 
and skin in Man, varied from $\frac{1}{75}$ th (in an adult) to $\frac{1}{1 \frac{1}{4}} \mathrm{~d}$ (in a child) of the oxygen consumed, the former proportion agreeing very well with that deduced by MM. Regnault and Reiset from their experiments on animals.

[The alterations effected in the Blood by Respiration have already been fully considererl. See $\$ \$ 193-194.7$

319. Exhalation and Absorption through the Lungs.-The Air expired from the lungs differs from that which was introduced in to them, not merely in the altered proportions of its Oxygen, Nitrogen, and Carbonic acid, but also in having received (under ordinary circumstances at least) a large ardition to its watery vapor. This it doubtless acquires in accordance with physical laws, through its exposure to the warm blood which is spread out over a very extensive surface, the intermediate membrane being extremely permeable; and the variations in its amount will depend upon the physical conditions under which that exposure takes place. The air expired in ordinary respiration is charged with as much watery vapor as saturates it at the temperature of the body $;$ and consequently the amount of watery vapor thus exhated will vary (for equal volumes of air at any given temperature) in the inverse proportion to that which the air previously contained. But when the air is very cold and very dry, and the respiration is unusually rapid, it may not remain sufficiently long in the air-cells to be raised to the temperature of the body, or to be fully saturated with moisture. The amount of watery vapor exhaled, morcover, will of course depend in part upon the quantity of air which passes through the lungs. And from these caluses of difference, it happens that the amount of watery vapor exhaled in twenty-four hours may vary from about $6 \mathrm{oz}$. to $27 \mathrm{oz}$; its usual range, however, being between 7 and $11 \mathrm{oz}$. Weyrich ${ }^{2}$ estimates the amount of insensible perspiration by the skin and lungs for a man weighing $125 \mathrm{lbs}$. at 14,500 grains or 2 lbs. avoirdupois per diem, and the proportion of water discharged by the skin to that by the lungs as $2: 3$. Dr. Ed. Smith found that during a long fast the quantity of vapor exhaled by the lungs was 2.02 grs. per minute, or .548 gr. in every 100 cub. in. of cxpired air. With food and at rest, the quantity varied from 3 grs. to 3.4 grs. per minute. The inhalation of alcoholic vapors increased the quantity of vapor exhaled; when alcohol was drunk the quantity was also increased, but it was decreased under the action of gin.-Of the fluid ordinarily exhaled with the breath, a part doubtless proceeds from the moist lining of the nostrils, fauces, etc. ; but it is indisputable that the greater proportion of it comes from the lungs, since, when the respiration is entirely performed throngh a canula introduced into the trachea, the amount of watery vapor which the breath contains is still very considerable. Of the proper pulmonary exhalation, there can be no doubt that the greater part is the mere surplus water of the blood, and especially of the crude fluid which has been newly introduced into the circulating current by the process of nutritive absorption. But there is strong evidence that Hydrogen as well as Carbon undergoes combustion in the system, and that a portion of the cxhated aqueous vapor is the product of that combustion. For of the hydrogen which the food contains, not more than from $\frac{1}{8}$ th to $\frac{1}{T}{ }^{1}$ th passes off by the other excretions, the remaining $\frac{7}{8}$ ths or ${ }_{10}^{3}$ ths being exhaled in the condition of watery vapor from the lungs. A portion of the oxygen which this vapor contains is supplied by the food; but there is usually a considerable surphis of hydrogen, and this

1 The tension of the watery vapor of expired air amounts, according to Weyrich, when redueed to $0^{\circ} \mathrm{C}$. and $760 \mathrm{~mm}$. pressure to $4.36 \mathrm{~mm}$. of mercury, which is nearly that of air saturated with aquenus vapor $(4.5 \mathrm{~mm}$.).

2 Ubservations, etc., Dorpat, 1865, 8ro. 
can only be converted into water at the expense of oxygen derived from the atnosphere.

319. The fluid thrown off from the lungs is not pure water. It loolds in solution, as might have becn expected, a considerable aunount of Carbonic acid, and also some animal matter, which, from the inquiries of Dr. R. A. Smith, ${ }^{1}$ would appear to be an albuminous substance in a state of decomposition. A small quantity of Ammonia is usually, but perhaps not always, thrown off." It has been suggested that this, when present, may be derived either from decomposing fragments of food or from carious tcetli ; but Thiry believed he had demonstrated it in air expired to avoid contamination throuch a ranta':a introciced into the trachea of a rabbit. The test used was Nessler's (solution of iodide of silver and iodide of potassium). Ransome estimates that an amount of Ammonia representing about 3 grains of organic matter are elininated by an adult man in twenty-four hours. According to Wiederhold, ${ }^{3}$ the Chloride of Sorliun and Ammonium, Uric Acid and the Urates of Soda and Ammonia, may be detected in the expired air. Ransome found a small quantity of Urea in one or two instances. If the fluid be kept in a closed ressel, and be exposed to an elevated temperature, a very evident putrid odor is exhaled by it. Every one knows that the breath itself has, occasionally in some persons, and constantly in others, a fetid taint: when this does not proceed from carious teeth, ulcerations in the air-passages, discase in the lungs, or other similar causes, it must result from the excretion of the odorous matter, in combination with watery vapor, from the pulmonary surface. That this is the true account of it, seems evident from the analogous phenomenon of the excretion of turpentine, (amphor, alcohol, and other odorous substances, which have been introduced into the renous system, either by natural absorption, or by direct injection; and also from the suddenness with which it often manifests itself, when the digestive apparatus is slightly disordered, apparently in consequence of the entrance of some malassimilated matter into the blood. Among the substances occasionally thrown off by the lungs, Phosphorus deserves a special mention, on account of the peculiarity of the form under which it is elininated; for it has been found that if phosphorus be mixed with oil, and be injected into the bloodvessels, it partly escapes in an unoxidized state from the lungs, rendering the breath luminous. ${ }^{4}$ And this luminous breath has also been observed in spirit-drinkers, in whom the oxidation of the effete matters of the system is impeded, in consequence of the demand set up by the alcohol ingested for the oxygen introduced $(\$ 311, \mathrm{vi})$.

320. Not only exhalation, but also (under peculiar circumstances) absorption of fluid may take place through the Lungs. Thus Dr. Madden ${ }^{5}$ has shown that, if the vapor of hot water be inhaled for some time together, the total loss by exhalation is so much less than usual, as to indicate that the cutaneous transpiration is partly counterbalanced by pulmonary absorption ;

1 Philosophical Magazine, vol. $\mathrm{xxx}, \mathrm{p} .478$

2 See Riehardson, The Cause of the Coagulation of the Blood, 1857, p. 360; Lossen, Zeits. f. Biologrie, Bd. i, p. 107: Thiry, Zeits. f. rat. Med., Bd. xvii, 1863, p. 166; Schenk, Pfüger's A rehiv, Bd. iii ; Kuhne and Strauch, Centrablatt, 1862. p. 578; Arthur liansome, Journal of Anatomy und Physiology, 1870, vol. iv, p. 209; Truchot, Comptes Reudus, 1873, t. ii, p. 1160. Bachi, however (Zeits. f. Biologie, Bd. v, p. 61), was unable to find any traees of it.

3 Deutsche Klinik, 1858. Schenk states that a small quantity of ammonia is eliminated by the lungs in the Rabbit, Guinea-pig, and Dog, but none by the skin. The nature of the food has no influenee on the quantity (Pfluger's Archiv, Bd. iii, p. $4 \pi 0)$.

- Casper's Wochenschrift, 1849, Bd xv .

5 Prize Essay on Cutaneous Absorption, p. 5.j. 
the pulnonary exhalation being at the same time entirely checked. It is probable that, if the quantity of fluid in the blood had been previously diminished by excessive sweating, or by other copious fluid secretions, the pulmonary absorption would have been much greater. Still in the cases formerly mentioned $(\$ 146)$, in which a large increase in weight could only be accounted for on the supposition of absorption of water from the atmosphere, it seems probable that the cutaneous surface was chiefly concerned; for it can only be when the air introduced into the lungs is saturated with watery vapor, that the usual exhalation will be checked, or that any absorption can take place.

321. That absorption of other volatile matters diffused through the air, however, is continually taking place by the Lungs, is easily demonstrated. A fimiliar example is the effect of the inhalation of the vapor of 'Turpentine upon the urinary excretion. It can only be in this manner that those gases act uyon the system, which have a noxious or poisonous effect when mingled in small quantities in the atmosphere; and it is most astonishing to witness the extraordinary increase in potency which many substances exhibit, when they are brought into relation with the blood in the gaseous form. The most remarkable example of this kind is afforded by Arseniuretted Hydrogen, the inspiration of a few hundredths of a grain of which has been productive of fatal consequences, the resulting symptoms being those of arsenical poisoning. Next to this, perhaps, in deleterious activity, is Sulphuretted Hydrogen; but it would seem that the effects of this gas upon the Human subject are scarcely so violent as they are upon animals; for though it has been found that the presence of $\frac{1}{500}$ th part of it in the respired air will destroy a bird in a very short time, that $\frac{1}{80} \overline{0}$ th part suffices to kill a dog, and that $\frac{1}{250}$ th part is fatal to a horse, yet M. Parent-Duchâtelet has affirmed that workmen habitually breathe with impunity an atmosphere containing one per cent., and that he himself has respired, without serious symptoms ensuing, air which contained three per cent. There can be no doubt, however, that the continued inhalation of air thus contaminated would be speedily fatal. Sulphuretted hydrogen and Hydrosulphuret of ammonia are given off from most forms of decaying animal and vegetable matter'; and it is undoubtedly to the accumulation of these gases, that the fatal results which sometimes ensue from entering sewers are to be chiefly attributed.Antimoniuretted and Phosphuretted hydrogen may also be included with the above as poisonous gases. These all oxidize themselves at the cxpense of the oxygen of the blood, ${ }^{1}$ and as a result of this appropriation, induce dyspnoea, convulsions, and asphyxia. Other poisonous gases, as Carbonic oxide, ${ }^{2}$ Deutoxide of Nitrogen, and Cyanuretted hydrogen, according to Hermann, ${ }^{3}$ form a group that displace the oxygen and enter into combination with the hemoglobin, producing a clear red solution, and inducing the same symptoms as the former. Deutoxide of Nitrogen is, however, properly included under the irrespirable gases. Other poisonous gases again, as Pro. toxide of Nitrogen, Olefiant gas, Chloroform, and Carbonic acid, are intoxicating in their properties, affecting the functions of the brain, and ultimately producing a narcotic effect. Amongst the irrespirable gases which, unless exceedingly diluted, induce spasm of the glottis, may be enumerated Car-

1 See the experiments of Kaufmann and Rosentlat on the action of Sulphuretted IIydrogen, in Reichert's Archiv, 1865, Heft vi; those of Hoppe-Seyler on the same, and on Antimoniuretted and Arseniuretted Hydrogen, Med. Chem. Unters., Heft i, p. 133, and those of Dybkowsky on Pliosphuretted Hydrogen.

2 See 'Traube, Gurlt's Verhand. d. Berlin. Gesellsch., 1866, p. 67, and C. Bernard, Rev. Seientif., t. vi, 1870; and Leçons sur les Anestliesiques.

3 Physiologrie, 1874 , pp. 45 and 161. 
bonic acid, Hydrochloric acid, Binoxide and Peroxide of Nitrogen, Ammonia, Chlorine, and Ozone. If introduced through a tracheal fistula, all of them act as poisons. Finally Nitrogen, Hydrogen, and perhaps Carburetted hydrogen, may be considered as indifferent gases, proving fatal when breathed in a state of purity, by permitting the accumulation of Carbonic acid in the blood, and by failing to supply oxygen.-Cyanogen is another gas which has an actively poisonous influence upon animals, when absorbed into the lungs; its agency is of a narcotic character, but has not been accurately investigated.

322. The respiration of pure Oxygen for short periods, $7-17$ minutes in man, ${ }^{1}$ produces $n 0$ effect either on the rapidity of the pulse or upon the temperature of the body, and scarcely any more of this gas is absorbed than under ordinary circumstances, which, as Pflüger has shown, is owing to the fact that arterial blood is charged normally with nine-tenths of the whole amount of oxygen it can take up." In small chambers ${ }^{3}$ the whole of the oxygen is used up, but if the chamber be large, the amount of Carbonic acid produced proves fatal before the complete consumption of the Oxygen. Thus Bert observed that when an animal was placed in an atmosphere of pure Oxygen with no provision for the removal of the Carbonic acid eliminated, death trok place when the proportion of this gas amounted to $20-30$ per cent., though the quantity of Oxygen was still from 70-80 per cent. When all the Carbonic acid eliminaterl was removed, ${ }^{4}$ death occurred in mammals when the amount of Oxygen had fallen to 2 per cent., and in birds when it was reduced to between 3 and 4 per cent. He further found that animals made to breathe Oxygen at a pressure of 5 or 6 atmospheres, or which are exposed to ordinary air at a pressure of 20 atmospheres, fall into violent convulsions, which last even after the pressure has been reduced to the normal. It would therefore appear that the Oxygen in entering the blood at this high pressure forms one or more compounds with some of its constituents, acting like strychnia. Death is also caused by the inhalation of several gases of an irritant character, such as Sulphurous, Nitrous, and Muriatic acids; but it is doubtful how far they are absorbed, or how far their injurious effects are due to the abnormal action which they excite in the lining membrane of the air-cells and tubes.-It cannot be doubted that Miasmata and other morbific agents diffused through the atmosphere, are more readily introduced into the system through the pulmonary surface than by any other; and our aim should therefore be directed to the discovery of some counteracting agents, which can be introduced in the same manner. The pulmonary surfice affords a most advantageous channel for the introduction of certain medicines that can be raised in vapor, when it is desired to affect the system with them speedily and powerfully; such is pre-eminently the ease with those Anresthetic agents, ether and chloroform, whose introduction into the various departments of Medical and Surgical practice constitutes a most important era in the history of the healing art; also with Mercury, ${ }^{5}$ Iodine, Tobacco, Stramonium, etc., and it has recently been shown

1 Naounoff and Béliaieff, Robin's Journal de l'Anatomie, 1875, p. 138. See also Kowalewsky, in Travaux du laboratoire physiologique de l'Univ. Imp. à Kasan, $1^{\text {ere }}$ sér. Kiasan, 1869.

2 This is difficult to reconcile with the statement made by MI. Gréliant (Comptes Rendus, 1872, 19 Août), that 100 c.c. of carotid blood of the dog eontains when air is breathed 16.3 per cent. of oxygen, and when oxygen is breathed 23.3 , and even 26.8 per cent.

3 See account of Muller's Experiments in Funke's Physiology, 1870, p. 281.

4 Paul Bert, Art. Asphyxia, Nouv. Diet. de Méd., t. iii.

5 The beneficial results of the introduction of Mercury by inhalation, are strikingly set forth in Mr. Langston Parker's Essay on the Treatment of Secondary, Constitutional, and Confirmed Syphilis. 
by M. Jousset that direct injection through the trachea is a means by which quinine may be made to enter the systen rapidly, when the state of the cutaneous circulation and the irritability of the stomach render it useless to administer it either by the stomach or by subcutaneous injection. ${ }^{1}$

\section{Effects of Suspension or Deficiency of Respiration.}

323. We have now to consider the results of the cessation of the Respiratory function, and the consequent deficiency in the supply of Oxygen and retention of Carbonic acid in the blood. If this be sufficiently prolonged, a condition ensues to which the name of Asphyxia has been given, the essential character of which is the cessation of muscular movement, and shortly afterwards of the Circulation; with an accumulation of bloor in the venous system. The time which is necessary for life to be destroyed by Asphyxia varies much, not only in different animals, but in different states of the same. Thus, warm-blooded animals are much sooner asphyxiated than Reptiles or Invertcbrata; on the other hand, a hibernating Mammal supports life for many months, with a respiration sufficiently low to produce speedy asphyxia if it were in a state of activity. And among Mammalia and Birds, there are many species which are adapted, by peculiarities of conformation, to sustain a deprivation of air for much more than the average period. ${ }^{2}$ Excluding these it may be stated as a general fact, that if a warm-blooded animal in a state of activity be deprived of respiratory power, its muscular movements (with the exception of the contraction of the heart) will cease within five minutes, often within three; and that the circulation generally fails within ten minutes. In the experiments made by the Committee of the Royal Medico-Chiqurgical Society, ${ }^{3}$ which are corroborated by the more recent ones of M. P. Bert, ${ }^{4}$ it was found that when death by drowning took place rapidly, it was due to the entrance of Water into the lungs; and that if the entrance of air into the lungs was prevented by suddenly inserting a cork into a glass tube tightly tied into the trachea, the average duration of the efforts to inspire was 4 minutes 5 seconds in dogs, and 3 ininutes 25 seconds in rabbits; whilst the average duration of the heart's action was 7 minutes 11 seconds in dogs, and 7 minutes 10 seconds in rabbits. It was found also that in simple occlusion of the trachea recovery might take place after deprivation of air for 3 minutes 50 seconds, whilst immersion for $1 \frac{1}{2}$ min. was usually fatal.-M. Brown-Séquard ${ }^{5}$ has shown by numerous experineents, that both newly-born animals and adults are capable of resisting the Asphyxia which results from submersion, by so much longer a period as their temperature is lower, providing it does not descend below $64^{\circ} \mathrm{F}$. As a general rule, the newly-born animal can survive submersion for a longer period than the adult; this, however, docs not hold in the case of guinea-pigs. Of 14 newly-born rabbits submersed in water at $77^{\circ} \mathrm{F}$., 5 had a temperature of $962^{10} \mathrm{~F}$., and survived, on the average, $12 \frac{1}{2}$ minutes; 4 hard a temperature of $82^{\circ}$ to $89^{\circ} \mathrm{F}$., and survived 17 minutes; lastly, 5 had a temperature

1 Claude Bernard, Leçons sur les Anesthesiques, 1875, p. 74

2 'Thus, the Cetaeea contain fur more blood in their vessels than do any other Manmalia; and these vessels are so arranged, that both arteries and veins are in eonncetion with large reservoirs or diverticula. The reservoirs belonging to the former are usually full; but when the Whale remains long under water, the blood which they eontain is gradually introdueed into the eireulation, and after beeoming venous, acconmulates in the reservoirs eonneeted with the venous system. $13 y$ means of this provision, the Whale can remain under water for more than an lour.

3 Truns., vol. xlv, p. 449.

5 Journal de la Phys., vol. ii, p. 98 et seq.

4 Gaz. Médicule, 1865, p. 79. 
of from $64^{\circ}$ to $70^{\circ} \mathrm{F}$., and these sulvived, on an average, $26_{2}^{7}$ minutes. $\Lambda$ newly-born dog will survive, if its temperature be low, an immersion of 50 minutes' duration. A duck is capable of resisting the privation of air for seven or eight minutes, while a chicken will die from submersion or strangling in two or three. A satisfactory explanation of these pecularities has been given by M. P. Bert, who has shown that they are dependent upon the amount of Oxygen in the blood, and the activity of the combustive processes in the tissues. As the blood-corpuscles constitute a magazine of Oxygen, the larger their number the longer will the animal be able to resist the privation of air; and so also life will be prolonged when from any cause the processes of oxidation in the tissues are lowered. M. Bart has elsewhere shown that the respiration of the tissues takes place less actively in young than in old animals, whilst it is obvious that a low temperature is less favorable for oxidation than a high one, and direct experiment has demonstrated that a duck contains one-third or even one-half more blood than a chicken. Many persons are capable of sustaining a deprivation of air for two, three, or even four minutes, ${ }^{1}$ without insensibility or any other injury; but this power, which seems possessed to the greatest degree by the divers of Ceylon, can only be acquired by habit. The period during which remedial means may be successful in restoring the activity of the vital and animal functions, is not, however, restricted to this. There is one well-authenticated case, in which recovery took place after a continuous submersion of fifteen minutes; ${ }^{2}$ and many others are on record, of the revival of drowned persons after an interval of half an hour, or even more; but there is not the same certainty in regard to these, that the individuals may not have occasionally risen to the surface and taken breath there. It is not improbable, however, that in some of these cases a state of Syncope had come on at the moment of immersion, through the influence of fear or other mental emotion, concussion of the brain, etc.; so that, when the circulation was thus enfeebled, the deprivation of air would not have the same injurious effect as when this function was in full activity. The case would then closely resemble that of a hibernating animal; for in both instances the being might be said to live very slowly, and would therefore not require the usual amount of respiration. The condition of the stillborn infant is in some respects the same; its tissues, as just stated, are the seat of much less active processes of combustion than those of the adult, and reanimatoin has been successfully attempted, when nearly half

1 Dr. Hutchinson states that any man of ordinury "vitul capacity" can pass two minutes without breathing, if he first makes five or six forcible inspirations and expirations, so as to cleanse the lungs of the old air, and then fills his chest as completely as he can. "For the tirst 15 seconds a giddiness will be experienced; but when this leaves us, we do not feel the slightest inconvenience from want of air." (See Cyclop. of Anat. and Phys., vol. iv, p. 1066.)

2 The following are the facts of this case, as narrated by Marc (Manuel d'Antopsie Cadavérique Nédico-Légale, p. 165) on the authority of Prater: A woman convicted of infanticide was condemned to die by drowning. 'l'his punishment was formerly inflicted in Germany according to the now obselete Caroline law, the culprit being inclosed in a sack with a cock and a cat, and sunk to the bottom of the water. In this instance, the woman, after havinir been submerged for a quarter of an hour, was drawn up, and spontaneously recovered hel senses. She stated that she had become insensible at the moment of her submersion; a circumstance which adds considerable weight to the supposition, based upon the post-mortem appearances in many cases of drowning, that death often takes place as mucl by syncope for primary failure of the heart's action, consequent upon sudden and violent emotion, or upon physical shock) as by Asphyxia. If the reality of this state of Syncopal Asphyxia be admitted, there does not seem any adequate reason for limiting the possible persistence of vitality in a submerged body, even to lalf an hour; especially if the temperuture of the water be such as not to cause any rapid abstraction of its lieat. 
an hour had intervened between birth and the employment of resuscitating means, and when probably a mueh longer time had elapsed from the period of the suspension of the cirenlation.

324. The phenomena presented in Asphyxia, ${ }^{1}$ whether produeed by suddenly eutting off the supply of air, or more slowly by permitting the animal to breathe through a narrow chink, are very similar, though in the latter ease, the successive stages ean be more easily followed. In the first instanee there are violent inspiratory, followed after a short time by equally violent expiratory efforts, whieh culminate in eonvulsions, the abdominal and other expiratory museles being those ehiefly affected. When the aceess of air to the lungs has been suddenly prevented, the expiratory convulsions with spasms of the museles of the limbs occur within the first minute, and are so marked and peculiar as to have been attributed to the excitation of an expiratory eonvulsive centre. During this period the tension of the blood in the vessels is greatly inereased. After the convulsions have lasted a few seconds they often eease suddenly, and are followed by a period of calm. The expiratory movements cease, efforts to inspire oecur with long but tolerably regular intervals between them, and at eaeh effort, when the occlusion of the trachea has been sudden, the blood-pressure falls, so that at the end of the seeond minute it is considerably less than natural; when, however, Asphyxia has been slowly produced, the bluod-pressure as well as the frequency of the heart's beats eontinuc to inerease during this period. Reflex movements now cease, and the pupil becomes widely dilated and insensible to light. In suddenly produced and complete Asphyxia death ensues in the course of three or four minutes, preceded by inspiratory movements which are slow, feeble, and irregular, two or three efforts being made suceessively, followed by a long pause. In the spasms whieh aecompany the final gasps the head is thrown baek, the trunk is straightened or arehed backward, and the limbs are extended, whilst the mouth gapes, and the nostrils dilate. These socalled stretching eonvulsions are of quite a different type from the previously mentioned expiratory convulsions. The augmentation of the blood-pressure which oceurs during the first period of Asphyxia, is occasioned by the eireulation of non-arterialized blood through the vaso-motor centre, the excitation of which eauses contraction of the smaller arteries. The effeet of this eontraetion is to fill the venous system, which beeomes still more distended by the obstaele to the onward movement of the blood, prescnted by the contraction of the expiratory muscles of the trunk and extremities. The heart being abundantly supplied with blood, fills rapidly during diastole and eontracts vigorously, in consequence of which, and of the inereased resistanee in front, the arterial pressure rises. This last effect is, however, temporary : the diastolic intervals being lengthened by the excitation of the inhibitory ncrvous systcm, and the heart itself weakened by defect of oxygen, the organ soon passes into a state of diastolic relaxation. Its contraetions beeome more and more ineffectual till thcy finally cease, leaving the artcries empty, the veins distended, and its own eavities relaxed and full of blood. The heart's eontractility is not finally lost, however, nearly as soon as its movements eease; for the action of the right ventriele may be renewed, for some time after it has stopped, by withdrawing a portion of its contents-cither through the pulmonary artery, their natural channel-or, more directly, by an opening male in its own parictes, in the auricle, or in the jugular vein $(\S 237)$. On the other hand, the left ventricle may be again set in action,

1 See Burdon-Sanderson in the Handbook for the Physiological Laboratory, 1873, p. 319 et seq. 
by renewing its appropriate stimulus of arterial blood. ${ }^{1}$ Hence, if the stoppage of the eirculation have not becn of too long continuance, it may be renewed by artifieial respiration ${ }^{2}$ for the replacenent of the carbonic acid by oxygen in the air-cells of the lungs, restores the circulation through the pulmonary capillaries; and thus at the same time relieves the distension of the right ventricle, and conveys to the left the due stimulus to its actions.-Of the mode in which the pulmonary circulation is thus stagnated by the want of oxygen, and renewed by its ingress into the lungs, no other consistent explanation can be given, than that which is based on the doctrine already laid down in regard to the capillary circulation in general $(\$ 269)$; namely, that the performance of the normal reaction between the blood and the surrounding medium (whether this be air, water, or solid organized tissuc) is a condition necessary to the regular movement of the blood through the extreme ressels. That no mechanical inpediment to its passage is created (as some have maintained) by the want of distcusion of the lungs, has bcen fully proved by the expcriments of Dr. J. Reid on the induction of Asphyxia by the respiration of nitrogen; at the same time it must be admitted that the contraction of the smaller arteries is a very important factor in the arrest of the circulation in the-pulmonary capillaries of the lungs, since it is in accordance with what is elsewhere seen when the vaso-motor centres are stimulated, and is very certainly deducible from the phenomena of pressure observed in the artcries and veins respectively. ${ }^{3}$

325. It is obvious that by the repeated passage of the same air through the lungs, it must, though originally pure and wholesome, become so strongly impregnated with carbonic acid, and must lose so much of its oxygen, as to be rendered utterly unfit for the continued maintenance of the aerating process; so that the individual who continues to respire it, shortly becomes asphyxiated. There are several well-known cases, in which the speedy death of a number of persons confined together has resulted from neglect of the most ordinary precaution for supplying them with air. That of the "Black Hole of Calcutta," which occurred in 1756, has acquired an unenviable pre-eminence, owing to the very large proportion of the prisoners123 out of 146 -who died during one night's confinement in a room 18 feet square, only provided with two small wiudows; and it is a remarkable confirmation of the views formerly stated $(\$ 223)$, and presently to be again adverter to, that of the 23 who were found alive in the morning, many were subsequently cut off by "putrid fever." Such catastrophes have occurred even in this country, from time to time, though usually upon a smaller

1 Setschenow has made some important researches on the amount and kind of gases contained in the blood of asphyxiated animals (clogs). He found that only traees of oxygen could be discovered in either the venous or arterial blond: the quantity of nitrogen varied from 1 to 2 parts, of free carbonic aeid from 28 to 38.8 parts, and of eombined carbonic aeid from 1.7 to 4 parts. (Henle and Meissner, Bericht, 1859, p. 30.5.$)$

2 Of the two chief modes of performing this operation, Dr. Silvester's method of alternately raising and depressing the arms, 15 or 16 times in the minute, of whieh Dr. Bains's is only a modification, appears to be far preferable to Dr. Marshall Hall's method of rotating the body half over, and pressing on its chest. See Marshall Hall's work on Drowning, Med. Times and Gaz., 1858, vol. i, pp. 147, 176 et seq., and Med.-Chir. Transact., vol. liii, 1870, p. 291.

${ }^{3}$ For a fuller discussion of the pathology of Asphyxia, see the Cyclop. of Anat. and Phys, art. Asplyxia, by Prof. Alison; the Library of Practical Medicine, vol. iii, art. Asphyxia, by the Author; Experimental Essays, by Dr. J. Reid, On the Order of Sueession in which the Vital Aetions are arrested in Asphyxia, in the Edinb. Med. and Surg. Journ., 1841, and in his Anat., Physiol., and Pathol. Researches; and the Experimental Inquiry by Mr. Erichsen, in the Edinb. Med. and Surg. Journ., 1845. 
scale; there has happened one at no distant date, however, which rivalled it in magnitude. On the night of the 1st of December, 1848, the deck passengers on board the Irish steamer Londonderry were ordered below by the captain, on account of the stormy character of the weather; aud although they were crowded into a cabin far too small for their accommodation, the hatches were closed down upon them. The consequence of this was, that out of 150 individuals, no fewer than 70 were suffocated before the morning.

326. It cannot be too strongly impressed upon the Medical practitioner, however, and through him upon the Public in general, that the continued respiration of an atmosphere charged in a far inferior degree with the exhalations from the Lungs and Skin, is amongst the most potent of all the "predisposing causes" of disease, and especially of those zymotic diseases whose propagation seems to depend upon the presence of fermentable matter in the blood. That such is really the fact, will appear from evidence to be presently referred to ; and it is not difficult to find a complete and satisfactory explanation of it. For, as the presence of even a small percentage of carbonic acid in the respired air is sufficient to cause a serious diminution in the amount of carbonic acid thrown off and of oxygen absorbed ( $\$ 310$ ), it follows that those oxidating processes which minister to the elimination of effete matter from the system, must be imperfectly performed, and that an accumulation of substances tending to putrescence must take place in the blood. Hence there will probably be a considerable increase in the amount of such matters in the pulmonary and cutaneous exhalation; and the unrenewed air will become charged, not only with carbonic acid, but also with organic matter in a state of decomposition, and will thus favor the accumulation of both these morbific substances in the blood, instead of effecting that constant and complete removal of them, which it is one of the chief ends of the respiratory process to accomplish.-It has been custonary to consider the consequences of imperfect respiration, as being exerted merely in promoting an accumulation of carbonic acid in the system, and in thus depressing the vital powers, and rendering it prone to the attacks of disease. But the deficiency of oxygenation, and the consequent increase of putrescent matter in the body, must be admitted as at least a concurrent agency; and when it is borne in mind that the atmosphere in which a number of persons have been confined for some time becomes actually offensive to the smell in consequence of the accumulation of such exhalations, and that (as will presently appear) this accumulation exerts precisely the same influence upon the spread of zymotic disease as that which is afforded by the diffusion of a sewer-atmosphere through the respired air, it scarcely admits of reasonable doubt, that the pernicious effect of overcrowding is exerted yet more through its tendency to promote putrescence in the system, than through the obstruction it creates to the due elimination of carbonic acid from the blood. For it is to be remembered, that whilst the complete oxidation of the effete matters will carry them off by the lungs in the form of carbonic acid and water, leaving urea and other liighly azotized products to pass off by the kidneys, an imperfect nxidation will only convert them into those peculiarly offensive products which characterize the fecal excretion $(\S 131){ }^{1}$

1 It is a remarkable confirmation of Prof. Liebig's analogy between the imperfect oxidation of etlete matters within the body, and that eombustion in a lamp or furnace insufliciently supplied with air which eases a deponit of soot and various empyreumatic produets, thint a set of acids have been found by Stadeler in the urine of the cow, bearing a close analogy to well-known products of destructive distillation, and one of them nctually identical with the carbolic acid previously known as one of the ingredients of smoke.- see Prof. Gregory's Handbook of Organic Chemistry, p. $t 50$. 
327. The determination of the cubic space which ought to be allowed for each person in workhouses, schools, and prisons, is a sulject of great pratetical importance. It is to be borne in mind that it is not suffieicnt for health that a room should contain the quantity of air requisite for the support of its inhabitants during a given time only, since after they have remained in it but a part of that time, the amount of carbonic acid and other products of disintegration which its atmosphere will contain will be large enough to interferc greatly with the due aeration of their blood; but care ought to be taken that the air is renewed so frequently that the amount of carbonic acid gas does not exceed at most one part per 1000 . A small room with several people in it may be better ventilated than a larger one with few inhabitants, if provisions for the renewal of the air in it are superior; and it is fortunate that a considerable amount of fresh air is introduced into all houses of modern construction by what nay be termed spontaneous ventilation, as distinguished from the special arrangements made by builders and architects. This spontaneous ventilation is effected through the crevices of the doors and windows, especially when open fireplaces are used as in England, and Pettenkofer has shown that a large and hitherto unsuspected interchange of air takes place even through the walls. Thus in one case where the roon hat brick walls, and its size was 2650 cubic feet, with a difference of temperature of $34^{\circ} \mathrm{F}$. $\left(66^{\circ} \mathrm{F}\right.$. in, $32^{\circ}$ outside), the contents of the room changed once in one hour, a quantity of air equal to 26.50 feet entering in that time. With the same difference of temperature, but with a good fire in the stove, the communication of which with the chimney was made as frec as possiblc, the cliange of the air rose to 3320 cub. feet, or about 25 per cent. When all openings, crevices in windows and doors, were thoroughly pasted up, there was still a change of 1060 feet per hour, or a fall of 28 per cent. With a difference of temperature of $71^{\circ} \mathrm{in}$, and $6 t^{\circ}$ outside, the change amounted to 780 cubic feet only per hour, and when a window of 8 feet square was opened the change rose to 1060 feet per hour. These quantities are instructive: they show that a difference of temperature of $34^{\circ}$ with carefully shut openings and crevices, is of greater influence than large conmunications with the outer air at a small difference of temperatnre, and that a large ward or room with one fireplace is not necessarily well ventilated. Pettenkofer found that in nne of his rooms whon the differcnce of temperature between the inside and outside was $9.5^{\circ} \mathrm{F}$. the spontaneous ventilation through each square yard of the wall amounted to about 7 cubic feet or 43 gallons per hour. The material of which the wall is constructed of course exerts a great influence on the spontaneous ventilation; thus Märker and Schultze found in their researches on the spontaneous ventilation of stables, that for one square yard of free wall at $9.5^{\circ} \mathrm{F}$. difference of temperature, the spontaneous ventilation amounted per hour-with walls of sandstone to 4.7 cub. feet, of quarricd limestonc to 6.5 , of brick to 7.9 , of tufaceous limestone to 10.1 , and of mud to 14.4 cubic feet. The renewal of air should, if possible, be so regulated that no draught or sensation of air in motion is experienced. The observations of Pettenkofer and Voit made in their great apparatus at Munich show that no resistance or sense of coolness is felt at ordinary temperature if the hand be moved at a less rate than 19 inches per sccond, and that as a rule the motion of the air is only felt distinctly when it amounts to $3 \frac{1}{4}$ feet per second. The velocity of the air as measured by the anemometcr in this climate, is about 10 fcet per second, which would make about 7 miles

1 See three Leetures, entitled The Air, in relation to Clothing, Dwelling, and Soil, delivered before the Albert Society of Dresden, and translated by Aug. Hess, M.D., 1874. 
per hour; consequently in one second about 90 cubic feet, in one minute 5400 cubic feet, and in one hour 324,000 cubic feet of air flow over one pcrson in the open. In experiments made in France in connection with the construction of the Hôpital Lariboisière with a ventilation of 350 cub. feet per bed per hour, the smell was so bad, that the authorities at once directed the quantity to be doubled; but then also the state of the air was anything but desirable, and it was only when the amount reached 2120 cubic feet per hour that the air was found to be free from perceptible taint. Pettenkofer and Voit thercfore conclude that this amount of fresh air per bed per hour, representing $-\frac{1}{1} \frac{1}{6}$ th of the air flowing over the body in the open, is necessary for the due ventilation of hospitals, school-rooms, etc. Pettenkofer and Voit ${ }^{1}$ found that no discomfort was experienced from long exposure to an atmosphere containing 10 parts of carbonic acid in 1000 parts, providing this had been added to the air in a pure state; but if the same quantity were present as a result of the respiration of several people, serious inconvenience was soon felt; and similarly Dr. Snow observed that the presence of carbonic acid in the atmosphere acts more deleteriously upon the system in proportion as the normal quantity of oxygen is reduced. Thus various birds and mammals introduced into an atmosphere containing only from $10 \frac{1}{2}-16$ per cent. of oxygen soon died, although means were taken to remove the carbonic acid set free by their respiration as fast as it was formed, whilst an increase in the proportion of carbonic acid to 12 or even 20 per cent.-the percentage of oxygen being kept to its regular standard of 21 per cent.- did not appear to enfeeble the vital actions more rapidly than did the reduction of the oxygen in the experiments just referred to. Bernard ${ }^{2}$ moreover found that a bird which lay exhausted from breathing in a limited quantity of air, recovered itself when the carbonic acid was partially absorbed by caustic potash. He observed also that the circulation of blood charged with carbonic acid, rapidly arrested the activity of the secretory organs, as the kidneys, which recommenced to discharge their function as soon as oxygenated blood was allowed to pass through then. The proportion of carbonic acid present in the air of large towns has been examined by Dr. Roscoe, ${ }^{3}$ by Dr. Angus Smith, ${ }^{4}$ and by MIr. Leigh. ${ }^{5}$ Dr. Roscoe found the usual proportion of carbonic acid in the air of London to be 3.7 parts in 10,000 ; whilst the proportion in Manchester, according to Dr. Smith, was 12 parts in 10,000, on a still day, and from 4.5 to 8 parts in 10,000 on a windy day. From experiments made with permanganate of potash, he ascertained that on the high grounds north of Manchester therc existed but 1 grain of organic matter in 200,000 cubic incles of air, whilst in close places in the town there was 1 grain in 8000 cubic inches. According to Braconnot, ${ }^{6}$ the black particles always floating in the atmosphere of large towns consist chiefly of carbon, bitumen, and sulphate of ammonia. Mr. Leigh finds a small quantity of sulphuretted hydrogen in the air of Manchester. The air of sewers, and gencrally air loaded with organic matters, has an alkaline rcaction, from the presence of ammonia and ammonium-sulphide. The numerous researches that have been undertaken both in this country and abroad, especially those by Pettenkofer, show that the poison both of cholera, and of typhoid, and

1 An abstraet of these observations will be found in the Med. Times and Gazette for 1862, p. 459 .

2 Bernard, Liquides de l'Organism, 18.59, vol. i, p. 505.

3 Quarterly Journal of the Chemieal Society, 1857; and Med.-Chir. Review, 1861, p. 429 .

4 On the $\Lambda$ ir of Towns, quoted in Med.-Chir. Rev., 1861, vol. ii, p. 433.

5 See 'Twenty-ninth Annual Report of the Regist. Gen, 1868.

6 Annal. de Chimie et de Phys., t. xxxiii. 
perhaps of typhus fever, is associated with decomposing excrements, which have either dried and then having become reduced to a pulverulent form float in the air, and are taken into the system by the lungs, or are held in suspension in water, and are thus introduced into the body. The remarkable experiments of 'Tyndall and of Cunningham demonstrate incontestably that a large number of organic particles are constantly floating in the air, some of which are probably the germs of infectious disease which only require a favorable soil on which to germinate. In all large towns difficulty is experienced in the removal of excrementitious mattcrs; cesspools, which are primitive means of disposing of such material, caunot be permanently used in large towns, though they are still far too commonly employed. Even direct draining into the sea, unless the sewers are carred out for a very long distance, has been found ineffective, the water near the shore soon becoming fetid and impure. When an extensive system of drains, as in London, is in operation, fresh and unlooked-for dangers arise: the houses warmed in winter constitute so many flues, which suck up the foul air of the cooler drains, and typhoid fever in a more or less virulent form makes its appearance. The adoption of eartli-closets, though practicable in country districts, is inapplicable in town. Probably little improvement will be made for a long period to come upon the plan which is now becoming general in London, of an unlimited water supply to each house, the water flowing into drains which conduct the fluid to a distance of several miles, where having discharged itself into large tanks, it is deodorized, and then applied to the fertilization of the surrounding soil. Pettenkofer has recently drawn attention to the importance of investigating the condition of the soil air as well as of the soil or ground water, in all investigations on the origin of zymotic diseases: he has shown that a few feet under the surface there is already as much carbonic acid as in the worst ventilated human dwelling-places. This quantity increases with the depth, so that at 156 inches there is more than at 58 inches, all the year round, except during the months of June aud July, when an inverse proportion arises. He attributes its formation to organic processes taking place in the soil, which demand further investigation.

328. Of the remarkable tendency of the respiration of an atmosphere charged with the emanations of the Human body, to favor the spread of zymotic diseases, a few characteristic examples will now be given: The dwellings of the great bulk of the population of Iceland seem as if constructed for the express purpose of poisoning the air which they contain. They are small and low, without any direct provision for ventilation, the door serving alike as window and chimney; the walls and roof let in the rain, which the floor, chiefly composed of hardened sheep-dung, sucks up; the same room generally serves for all the uses of the whole family, and not only for the human part of it, but frequently also for the sheep, which are thus housed during the severer part of the winter. The fucl employed in the country districts chiefly consists of cow-dung and sheep-dung, caked and dried; and near the seacoast, of the bones and refuse of fish and sea-fowl; produciug a stench, which, to those unaccustomed to it, is completely insupportable. In addition to this, it may be mentioned that the people are noted for their extreme want of personal cleanliness ; the same garments (chiefly. of black flannel) being worn for months without being even taken off at night. Such an assemblage of unfavorable conditions, combined with the cold, damp nature of the climate, might have been expected to induce tubercular diseases of various kinds; but from these the Icelanders appear to enjoy a special exemption ( $\$ 66$, iii). Syphilis, also, is wanting, or nearly so; and yet, notwithstanding that the number of births is fully equal to the usual a verage, the population is stationary, and in some parts actually dimin- 
ishing. This is partly due to the extent and fatality of the epidemie diseases, of which some one or other spreads through the island nearly every year; but it is chiefly owing to the extraordinary mortality of infants from Trismus nascentium, which carries off a large proportion of them between the fifth and the twelfth days after their birth. It is in the little island of Westmannoe and the opposite parts of the eoast of Iceland, where the birdfuel is used all the year round, instead of (as elsewhere) during a few months only, that this disease is most fatal ; the average mortality for the last twenty years, during the first twelve days of infantile life, being no less than $6+$ per eent., or nearly two out of three. ${ }^{1}$-Now it is not a little remarkable that the vely same disease should have prevailed, under eonditions almost identically the same, in the island of St. Kilda, one of the Western Hebrides; the state of which was made known by Mr. Maclean, who visited it in 1838 . The population of this island, too, was diminishing rather than increasing, in eonsequenee of the enormous infantile mortality; four out of every five dying, from Trismus nascentium, between the eighth and twelfth days of their existenee. The great if not the only eause of this mortality, was the eontamination of the atmosphere by the filth amidst which the people lived. Their huts, like those of the Icelanders, were small, low-roofed, and without windows; and were used during the winter as stores for the eollection of manure, whieh was earefully laid out upon the floor, and trodden under foot to the depth of several feet. On the other hand, the clergyman, who lived exaetly as did those around him, except as to the eondition of his house, had brought up a family of four children in perfeet health; whereas, aceording to the average mortality around him, at least three out of the four would have been dead within the first fortnight.-Of the degree in whieh this fearful disease is dependent upon impurity of the atmosphere, and is preventable by adequate ventilation, abundant proof is afforded by the experienee of Hospitals and Workhouses in our own eountry. Thus in the Dublin Lying-in Hospital, up to the year 1872, the mortality within the first fortnight, almost entirely from Trismus nascentium, was 1 in every 6 ehildren born. The adoption, under the direction of Dr. Joseph Clarke, of an improved system of ventilation, redueed the proportion of deaths from this eause to 1 in $19 \frac{1}{2}$. And further inprovements in ventilation, with increased attention to eleanliness, during the seven years in whieh Dr. Collins was Master of this Institution, reduced the number of deaths from this disease to no more than three or four yearly. ${ }^{2}$ - A sinilar amelioration took plaee about a eentury ago, in the eondition of the London Workhouses, in which 23 out of 24 infints had previously died within the first year, and a large proportion of these within the first month; for owing to a Parliamentary inquiry whieh was ealled forth by this fearful state of things, the proportion of deaths was speedily redueed (ehiefly by improvement in ventilation) from 2600 to 450 annually.

329. It appears, indeed, that in all climates, and under all conditions of life, the purity of the atmosphere habitually respired is essential to the maintenance of that power of resisting disease, which, even more than the ordinary state of health, is a measure of the real vigor of the system. For, owing to the extraiordinary eapability which the human body possesses of accommodating itself to eircunstanees, it not unfrequently happens that individuals continue for years to breathe a most unwholesome atmosphere, without apparently suffering from it; and thus, when they at last succumb to some Epidemie disease, their death is attributed solely to the latter; the

1 See Island undersört fra lagevidenskabeligt Synspunct. Af P. A. Schleisner, MI. D. Copenhagen, 1819 .

2 See Dr. Collins's Practical Treatise on Midwifery, p. 513. 
previous preparation of their bodies for the reception and development of the zymotic poison, being altogether overlooked. It is impossible, however, for any one who carcfully eximines the evilence, to hesitate for a moment in the conclusion, that the fatality of Epidemics is alnost invariably in precise proportion to the degree in which an impure atmosphere has been habitually respired; that an atmosphere loaded with putresecnt miasuata may afford a nidus wherein a zymotic poison undergoes a marked increase in quantity and intensity, the putrescent exhalations from the lungs and skin of the living subject being at least as effectual in furnishing such a "nidus," as are the emanations from fecal discharges or from other decomposing matters; that the habitual respiration of such an atmosphere tends to induce a condition of the blood, which renders it peculiarly susceptible of perversion by the introduction of zymotic poisons, and which favors their multiplication within the system ; ${ }^{1}$ and lastly, that by due attention to the various means of promoting atmospheric purity, and cspecially by efficient ventilation and sewerage, the rate of mortality may be enormously decreased, the amount and severity of sickness lowered in at least an equal proportion, and the fatality of Epidemies almost completely annihilated. The cffects of good drainage and water supply have been recently well exemplified in the case of Salisbury: the average number of deaths for the eight years preceding the completion of the drainage in this town (excluding the Cholera year) having been 27 in 1000 , and for the same period since 21 in 1000 ; an actual reduction of almost one-fourth of the whole number. ${ }^{2}$ And it cannot be too strongly borne in mind, that the eflicacy of such preventive measures has bcen most fully substantiated, in regard to many of the very diseases in which the curative power of Medical treatment has seemed most doubtful; as for example, in Cholera and Malignant Fevers. - The practical in portance of this subject may be estimated from the startling fact, which inquiries prosecuted under the direction of the Board of Health have brought to light ${ }^{3}$ viz., that the difference in the annual rates of nortality, between the most healthy and the most unhealthy localities in England, anounting to no less than 34 in 1000 , is almost entirely due to Zymotic diseases, which might be nearly (if not completely) exterminated by well-devised sanitary arrangements. The lowest actual mortality is 11 per 1009 , while the highest is 45 per 1000 ; and between these extremes, there is every intermediate degree of range. But what may be termed the inevitable mortality, arising from diseases which would not be directly affected by Sanitary improvements-is a nearly constant quantity throughout; namely, the 11 per 1000 of those districts which are free from Zymotic discase. The average mortality of all England, in ordinary years, is about 22 per 1000, or just double that to which it might be reduced; so that, taking the population of England and

1 A careful consideration of the very satisfactory evidence which has been of late years collected on this point, must (in the Author's opinion) satisfy any competent and unprejudiced inquirer, that endemic Fevers, originating in local causes (marsh miasmata and the like), and at first affecting those only who are exposed to such causes, may find, by the crowding together of infected subjects, a nidus for development within the Human system; so that these diseascs then become communicable by human intercourse, although not so originally.-For a discussion of this subject, see the Articles on Yellow Fever and the Fever of Boà Vista, in the Brit and For. Mred-Chir. liev., vols. i, ii, and iv.

2 See Times, Oct. 24 th, 186 ?.

3 See Summary of Experience on Disease, and Comparatirc Rates of Mortality, by William Lee, Superintending Inspector, 1851. Nearly similar numbers are to be found in the Twenty-ninth Annual Report of the Registrar-Gencral, 1868. Of 13 large towns, the mortality of Liverponl was the lighest (42 per 1000); that of Birmingham and Hull the lowest, 24 per 1000. 
Wales (as by the last Census) at 20,000,000, the average annual mortality must be 440,000 , of which only 220,000 is inevitable, an equal amount being preventible.

\section{Pettenkofer's Respiration Apparatus.}

The construction of Pettenkofer's apparatus, with which so many important investigations have been made, may here be bricfly given. A full description illustrated by three plates is given in the Physiologische Chemie of v. Gorup-Besanez. It eonsists essentially of a sheet-iron chamber (A), containing table, ehair, and bed, from which the air is slowly exhausted by two pumps $(G)$, worked by a small steam engine. Fresh supplies of air are admitted through ventilators. The greater part of the air is drawn through $\mathrm{R}$, and is conducted into a large receptacle (B) filled with wet

FIG, 164 .

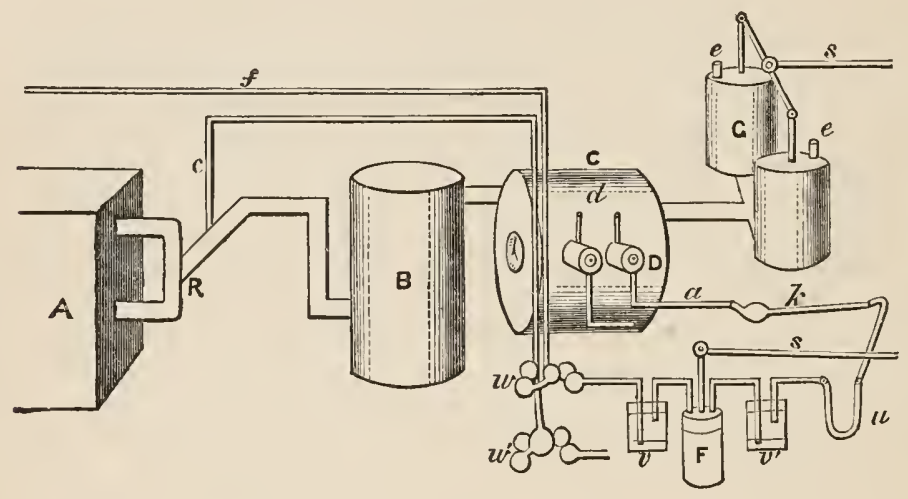

pumice-stone in order to saturate it with aquenus vapor, and then enters the gasometer, where its volume is measured. From this it is drawn by the suction of the pumps, and having passed through them cscapes into the air. For the analysiz of the air in the immediate vicinity of the chamber a tube $(f)$ conduets a certain quantity, which by means of a mercurial exhausting and pressure pump ( $F$ ) is drawn through the bulb apparatus containing sulphuric aeid $(w)$, it is then made to pass through an inspiratory mereurial valve $(v)$ into $F$, then through a similarly eonstructed expiratory valve $\left(v^{\prime}\right)$ into the $U$-shaped tube $(u)$, in which it is saturated with watery vamor by means of moistened pumiee-stone. It is then propelled through the tube $(\dot{k})$ filled with baryta water, by which the amount of carbonic acid gas present is determined. It then passes through the small meter (D), where its volume is deternined, and is finally discharged into the air through the small tube $(d)$. For the analysis of the air, contaminated with the cutaneous and pulnonary excretion of the subject of the experiment, a small tube $(c)$ is attaehed to the main discharge tube ( $\mathbf{r}$ ) ; the air thus obtained is conducted through a series of apparatus which is the precise duplieate of that just described, enabling an cxact eomparison to be instituted. The accuracy of the whole method of investigation was asecrtained by control experiments with wax candles, the products of the combustion of which were compared with the amount that direct analysis showed ought to have been obtained. The average error for the carbonic acid did not exceed 0.3 per eent, and for the water 1.5 per eent. for 24 hours. 


\section{CH A PTER X.}

\section{OF NUTRITION.}

\section{General Considerations.-Formative Power of Individual Parts.}

330. THE function of Nutrition, considered in the widest acceptation of the term, includes that whole series of operations by which the alimentary materials-prepared by the Digestive process, introduced into the system by Absorption, and carried in to its penetralia by the Circulation-are converted into Organized tissue; but in a more limited sense it may be understond as referring to the last of these operations only, that of Histogenesis or tissueformation, to which all the other organic functions, in so fir as they are concerned in maintaining the life of the individual, are subservient, by preparing and keeping in the requisite state of purity the materials at the expense of which it takes place. Every integral part of the living body possesses a certain capacity for growth and development, in virtue of which it passes through a series of successive phases, under the influence of the steady Heat, which in the warm-blooded animal is constantly acting upon it ; this capacity being an endowment which it derives by direct descent from the original germ (chap. i), but undergoing a gradual diminution with the advance of life (chap. xx), until the power of maintenance is no longer adequate to antagonize the forces that tend to the disintegration of the system. It has been also shown (chap. vii), that notwithstanding the diversities in the structure and composition of the several tissues, the Blood supplies the matcrials which each requires; every tissue possessing (so to speak) an elective affinity for some particular constituents of that fluid, in virtue of which it abstracts them from it, and appropriates them to its own uses.-But it has been shown, on the other hand, that the "formative capacity" does not exist in the tissues alone, but is shared by the Blood, which must itself be regarded as deriving it from the original germ ; for there are certain simple kinds of tissue, which appear to take their origin directly in its plastic components. Of others, which cannot be said thus to originate in the blood, the revelopment seems to be entirely determined by the quantity of their special pabula which it may contain. Thus, an increase of Adipose tissue takes place, when the blood habitually includes an unusual anount of fat; an augmentation in the proportion of the Red Corpuscles of the blood may be distinetly observed (especially if it has been previously diminished unduly), when an additional supply of iron is afforded; and when one of the Kidneys has been removed, or is prevented by disease from performing its normal function, the other, if it remain hcalthy, undergoes an extraordinary increase in size, so as to perform the duty of both organs, the augmented development of its secreting structure being here also fairly attributable to the accumulation of its appropriate materials in the blood. ${ }^{1}$ Even of those tissues which must be con-

1 This principle is one most fertile in Pathological applications; for there can be little doubt that the development of many morbid growths is due, not so much to a perverted local action, as to the presence of certain morbid matters in the blood, which determines the formation of tissues that use them as their appropriate pabulum. Such is pretty obviously the case with those disorders, which (like the Exanthemata) are universally admitted to be of "constitutional" character, and which ane dis- 
sidered as most independent and self-sustaining, the development is not only checked by the want of a due supply of their appropriate materials, but it is modified in a very remarkable degree by the presence of abnormal substances in the blood, which single out particular parts, and effect determinate alterations in their nutrition, in such a constant manner as to show the existence of a peculiar "elective affinity" between them.-In so far, then, as the process of Nutrition is dependent upon the due supply and normal state of the Blood, its conditions have been already sufficiently discussed; and we have now only to consider it in its relations to the Tissues.

331. The demand for Nutrition primarily arises from the tendency of the organism to simple Increase or Growth. Of this we have the most characteristic illustration in the multiplication of the first embryonic cell by the simple process of "duplicative subdivision ;" whereby a multitude of cells is produced, every one of which is similar in all essential particulars to the original. But after the difierent parts of this homogeneous embryonic mass have taken upon themselves their respective modes of development, so as to generate a diversity of tissues and organs, each one of these continues to increase after its own plan; and thus the child becomes the adult, with comparatively little change but that of growth (chap. xviii, sect. 4). An excess of growth, taking place conformably to the normal plan of the tissue or organ, constitutes Hypertrophy; whilst a diminution, without degeneration or alteration of structure, is that which is properly distinguished as Atrophy. -But Growth is not confined to the period of increase of the body generally; for it may manifest itself in particular organs or tissues, as a normal operation, at any subsequent part of life; as when an extraordinary demand for the functional activity of a particular set of muscles is supplied by an increase in the amount of their contractile tissue.-And further, even where there is no such manifestation of increase, there is really a continual growth in all the tissues actively concerned in the vital operations, and this even to the very end of life; although it may be so far counterbalanced, or even surpassed, by changes of an opposite kind, that instead of augmentation in bulk, there is absolute diminution.

332. The evolution of the complete organism from its germ, however, does not consist in mere growth; for by such a process nothing would be produced but an enormous aggregation of simple cells, possessing little or no mutual dependence, like those which constitute the shapeless masses of the lowest Algse. In addition to increase there must be Development, that is, a passage to a higher condition, both of form and structure; so that the part in which this change takes place becomes fitted for some special function, and is advanced towards the state in which it exists in the highest or most completed form of its specific type. Thus the development of tissue consists in the change from a simple mass of cells or fibres into any other form; as in the production of Dentine from the cellular substance of the tooth-pulp, or in the formation of Bone in the subperiosteal membrane. So, again, the developmental change is seen in the passage of an entire organ from a lower to a higher condition, by the evolution of new parts, or by a change in the

tinetly traecable to a poison introdueed tlrough the blood, whose first influence is exerted in modifyiner the physical and vital properties of that fluid; and the evidence has boen of late aceumulatinic, that it is true also of the various forms of Cancer, the loeal drvelopment of an abnormal structure being in this ease also, nothing else than the manifestation of the existence of that peeuliar matter in the blood, which is the appropriate nutriment of its eomponent tisues; or, as $\mathbf{M r}$. Simon appropriately desiguates it, "a new exeretory organ, which tends eserntially to acts of eliminative secretion, just as distinctly as lia liealthy liver or the lienlthy lichey." - See IIr. Simon's Leetures on General Patholory, p) 87, 152; and Mr. Paget's Lectures on Surgical l'atlology, vol. i, p. 44l, and vol. ii, pp. 528 et seq. 
relations of those already existing, even though the change in its texture should consist of little else than of simple increase: thus in the development of the heart, we have the original single cavity subdivided, first into two, and at last into four chambers; and in the development of the Brain, we find the sensory ganglia to be the parts first formed, the anterior lobes of the cerebrum to be evolverl (as it were) from these, the middle lohes sprouting forth from the back of the anterior, and the posterior from the back of the middle; yet with all this, there is no production of any new kind of tissue, the new parts being generated at the expense of histological components identical with those of the pre-existing.-Now it is in the early period of embrrnin life, that the der.lopmental process is most remarkably displayed; for it is then that we see that transformation of the primordial cells into tissues of various kinds, which originates a spccial nisus in each part, whereby the production of the same tissue, in continuity with that first formed, comes to be a simple act of growth; and it is then also that we observe that marking out of all the principal organs, by the development of tissue in particular directions, which makes all subsequent evolution but a completion or filling up of the plan thus sketched out. Thus, during the first dlays of incubation in the Chick, the foundation is laid of the vertebral column, the nervous centres, the organs of sense, the heart and circulating system, the alimentary canal, the respiratory apparatus, the liver, the kidneys, and many other parts; and at the termination of that period, the chick emerges in such a state of completeness of development, that little else than increase is wanting, save in the plumage and sexual organs, to raise it to its perfect type. The same nay be said of the Human organism; save that the period of its development is relatively longer, in accordance with the higher grade which it is ultimately to attain; its earliest stages being passed through, however, with extraordinary rapidity. The complete evolution of the generative organs, of the osseous skeleton, and of the teeth, constitute the principal derelopmental changes which the Human organism undergoes in its progress from the infantile to the adult condition; almost every other alteration consisting in simple increase of its several component tissues and organs, without any essential change in their form or structure. And when the adult type has been once completely attained, every subsequent change is one rather of degeneration than of development, of retrogression rather than of advance.

333. The difference between these two processes of Growth and Development is most characteristically shown in those cases in which there is a partial or complete arrest of one of them, without any corresponding impairment of the other. Thus a dwarf, however small in stature, may present a perfect development of every part that is characteristic of the complete human organism; the deficiency being solely in the capacity for grouth. On the other hand, the usual size at birth may be attained, and every organ may present its ordinary dimensions, and yet some important part may be found in a condition of arrested development: thus the Heart may consist of a single cavity, or the interventricular or interauricular septa may be incomplete, so that the organ has not passed beyond the grade of development which it had attained at an early perior of embryonic life, although its growth may have continued; or the Brain may in like manner exhibit a deficiency of the posterior lobes, or of the corpus callosum, or of some other part whose formation nominally takes place in the latter months of intrauterine life, although the parts already produced may have continued to grow at their usual rate.-Numerous instances of the same kind might be cited, but these must suffice.

334. The demand for nutrition arises, however, not merely from the exer- 
cise of the formative powers which are concerned in the building up of the organism, but also from the degeneration and decay which are continually taking place in almost every part of it, and the effects of which, if not antagonized, would speedily show themselves in its complete disintegration. As each component cell of the organism has to a certain degree an independent life of its own, so has it also a limited duration; and its duration usually bears an inverse ratio to its functional activity. This is particularly striking when we compare the ratio of change in the organisms of cold-blooded animals at low and at high temperatures; for they live slowly, need little nutriment, give off but a small amount of excretory products, and require a long time for the performance of the reparative processes, under the former condition; but live fast, require a comparatively large supply of nutriment, give off a far greater amount of carbonic acid and other excretions resulting from the "waste" of tissue, and exhibit a far more rapid reparation of injuries, in the latter state. The constantly high temperature of Man, as of other warm-blooded animals, prevents this difference from being displayed in him in a similar manner; but it is well seen when we contrast his different tissues with each other, and study their respective histories. For whilst there are some (I) which appear to pass through all their stages of growth, maturation, and decline, within a limited period, there are others (II) whose existence seems capable of almost indefinite prolongation, and others (III) again, which are liable to have a period put to their life at any time by the direction of their vital force into other channels.

I. Of those belonging to the first category, which are actively concerued in the purely vital operations of the organism, a characteristic example is presented by the Ovule; which, if not fertilized within a limited period after its maturation, speedily declines and decays; and the same law of limited duration doubtless extends to a large proportion of such tissues as are actively concerned in the maintenance of the organic functions; as for example, the Corpuscles of the Blood, the Epithelial cells of many glands which are instrumental in the process of Secretion, the cells forming the parenchyma of the Absorbent and Vascular Glands, and many others.

Ir. The contrary extreme to this may be found in those tissues whose functions are rather physical than vital; and especially in such as undergo consolidation by the deposit of solidifying matter, either in combination with the animal membrane or fibre, or in its interstices. Such tissues are more withdrawn from the general current of vital action; and there seems to be no definitc limit to the duration of some of them, cxcept such as is imposed by the chemical and mechanical degradation to which they may be subjected. This appears to be the case with the simple Fibrous tissues, especially the yellow, even in their soft or unconsolidated state; but it is far more obvious in the dentine and enamel of Teeth, which are formed by the combination of calcareous salts with an animal matrix, and which retain their condition apparently unchanged through the whole remainder of life, under circumstances which show that if any nutritive action takes place in them, its amount must be extremely small. In the dentinal structures of the young, however, there is obviously a determinate limit of existence; as is shown by the exuviation, at a certain definite epoch, of the first set of teeth, which exuviation is usually preceded by the death and partial disintegration of their texture. In Hair, Nails, and other Epidermic appentages, again, whose substance, when once it has undergone consolidation by the deposit of horny matter, may remain unchanged for centuries, we must recognize the same principle of indefinite duration, in connection with the cessation of vital activity; the chenical constitution of these textures, moreover, being such as renders them but little prone to be acted upon by ordinary decomposing 
agencies. The limit of existence seems more determinate, however, in Bone; for not only do we find that, in the first development of this substance, a considerable part of the tissue originally generated by the consoliclation of its osseous or cartilaginous matrix speedily disappears, and that during the whole periol of growth of the shaft of a round bone, there is a continual removal of its inner and older portions, wherely the medullary cavity is progressively enlarged; but there is strong evidence that, even after the bone has attained its full dimensions, a replacement of old Haversian systems by new is continually in progress.

III. In the case of the Muscular and Nervous tissues, however, we trace the operation of causes that differ from any of those al ready specified. These tissues are doubtless subject, like all others that are distinguished by their vital activity, to the law of linited duration; for we find that, when not called into use, they undergo a gradual disintegration or wasting, which is not adequately repaired by the nut ritive processes. But their existence as living structures appears to be terminable at any time, by the exercise of their functional powers; for the development of muscular contractility or of nervous force seems to involve, as its necessary condition, a metamorphosis (so to speak) of the vital power which was previously exercising itself in the nutritive operations; and the materials of these tissues, now reduced to the condition of dead matter, undergo those regressive changes which speedily convert them into excrementitious products. But the very manifestation of their peculiar vital endowments determines an afflux of blood towards the parts thus called into special activity; and from this it comes to pass, that the nutrition of these textures is promoted, instead of being impaired by the losses to which they are thus subjected; so that their constant exercise occasions an augmentation, rather than a diminution of their substance, a due supply of the requisite inaterials being always presupposed.

335. Thus it comes to pass, that during the whole period of active life, a demand for Nutrition is created by every exertion of the vital powers, but more especially by the evolution of the Nervous and Museular forces. The production and application of these, indeed, may be considered as the great end and aim of the Human organism, so far at least as the individual is concerned; the whole apparatus of Organic life being subservient to the building up and maintenance of the Nervo-muscular apparatus, and of those parts of the fabric (e.g., the bones, cartilages, fibrous textures, etc.), which it uses as its mechanical instruments. Thus the activity of all the Organic operations, when once the full measure of growth has been attained, is niainly determined by that of the Animal functions; and as the "rate of life" of all the parts which minister to the former will be proportioned to the energy with which they are called upon to perform their functions, their duration will diminish in the same proportion, and hence occasion will arise for their continual renewal. ${ }^{1}$ But since, in the attainnient of the adult condition, the productive

1 Sueh an exeellent illustration is afforded by the phenomena of Vegetation, of the doetrines here propounded, that it searcely appears desirable to pass it by in this place, although it has been elsewhere more fully referred to (PRrnc. of Comp. PuYs., 8,265 , 358). - The leaves of plants serve, like the absorbing and assimilating cells of Animals, for the introduetion and elaboration of the untritive materials which are to be applied to the extension of the fabric; the more permanent and inactive parts of which are thus generated at the expense of materials prepared by the vital operations of the more transitory and energetic. Now there is an obvious limit to the duration of the leaf-cells; but this limit is not preeisely one of time, being rather dependent upon the completion of their series of vital actions. Thus, although we are aceustomed to look upon the "fall of the leaves" (which is nothing else than an exuviation eonsequent upon death) as a phenomenon of regular seasonal reeurrenee, and to regard their replaeement by a new growth as oeeurring at a not less eonstant interval, yet experience 
capacity has undergone a gradual diminution, whilst the exercise of the animal powers has become vastly increased, the formative processes are only capable of maintaining the Organism in its state of completeness and vigor, by making good the losses consequent upon the continual disintegration to which it is subjected by its nervo-muscular activity. And with the advance of years, the further diminution of the productive capacity involves, - on the one hand, a progressive decrease in the substance of the tissues and organs most important to life (their bulk, however, frequently remaining unchanged, or even increasing, in consequence of the accumulation of fat), and on the other, a gradual weakening of its power of action. (See chap. xx.)

336. The performance of the function of Nutrition, the demand for which arises out of the causes that have been now discussed, is dependent, not merely upon a due supply of pure and well-elaborated blood, but also upon the normal condition of the part to be nourished, and especially upon its possession of a right measure of "formative capacity ;" in virtue of which, the newly produced tissues are generated in the likeness, as well as in the place of those which have become effete. The exactness of this replacement is most remarkably shown in the retention of the characteristic form and structure of each separate organ or part of the body, and thus of the entire organism, through a long series of years; no chaiges being apparent (so long as the state of health is preserved), but such as are conformable to the general type of that alteration which the organism undergoes with the advance of life. And not only is this to be noticed in the conservation of all those distinguishing points of structure which mark the species and are essential to its well-being, but it is still more remarkably displayed in the continuous renewal of those minor peculiarities which constitute the characteristic features of the individual, and which serve to distinguish him from his fellows. And how much this depends upon the formative capacity originally derived from the germ, is evident from this, that a similar moulding (so to speak) of the nutritive material takes place, in its original development, at first into the form characteristic of the species, and afterwards into that which marks the individual; and that the peculiarities of the individual are frequently such as have been distinctive of one or other of the parents, or present a combination of both. But it is curious that the formative power should often be exercised, not only in maintaining the original type, but also in keeping up some acqui red peculiarity; as, for example, in the perpetuation of a cicatrix left after the healing of a wound. For, as Mr. Paget has remarked, the tissue of a cicatrix grows and assimilates nutrient material, exactly as do its healthy neighboring tissues; so that a scar which a child might have said to be as long as his own forefinger, will still be as long as his forefinger when he becomes a man. And when the mode of nutrition in any part has been altered by disease, there is frequently an obstinate tendency to the perpetuation of the same alteration; or, if the healthy action be for a time restored, there is a peculiar tendency to the renewal of the morbid process of the part; and this is stronger the more frequently it recurs, until at last it becomes inveterately established. There is, however, in the Tissues generally, as in the Blood, a general tendency to a return to the normal type, after it has undergone a temporary perversion; and thus it is that we find the typical structure of parts generally restored, when the morbid tendency has been overcome; and that even cicatrices and indurations, notwithstanding

shows that these intervals are entirely regulated by temperature; for if one of the ordinary deciduous trees of temperate climates be transferred to a tropical climate, it will live much fuster, its leaves being shed far more frequently, and being replaced much more speedily; so that two, or even three, successive exuviations and reproductions of its foliage may take plaee within a year. 
their usual obstinate persistence, occasionally disappear. The normal type is, perhaps, less likely to be thus recovered, when the departure from it is very slight, and consists rather in the wrong plan (so to speak) on which the new matter is laicl down, than in a perversion of the nutritive process itself. It may be useful to conclude this section with a table showing the proportion which the several component parts of the boly bear to one another. It will be seen how large a percentage of the body is composed of the soft tissues, in which rapid processes of disintegration and reconstruction are constantly in course of performance:

\begin{tabular}{|c|c|c|c|c|c|c|}
\hline & \multirow{2}{*}{$\begin{array}{l}\text { Man, } \\
\text { ret. } 33 \\
\text { executed. }\end{array}$} & \multirow{2}{*}{$\begin{array}{l}\text { Woman, } \\
\text { ret. } 22, \\
\text { killed by } \\
\text { accident. }\end{array}$} & \multirow{2}{*}{$\begin{array}{l}\text { Youth; } \\
\text { suicide. }\end{array}$} & \multicolumn{2}{|c|}{ New-born. } & \multirow{2}{*}{$\begin{array}{l}\text { Fotus, } \\
\text { sixth, } \\
\text { month. }\end{array}$} \\
\hline & & & & Boy. & Girl. & \\
\hline $\begin{array}{l}\text { Weight of the whole body in } \\
\text { grammes, . . . - } \\
\text { Percentage proportion of- }\end{array}$ & 69,668 & 55,400 & $35,5+7$ & 2400 & 2969 & 643 \\
\hline Skeleton, . . . . & 159 & 15.1 & 15.6 & 17.7 & 15.7 & 20.3 \\
\hline Muscles, . . & 41.8 & 35.8 & 442 & 22.9 & 239 & 22.3 \\
\hline Thoracic Viscera, . & 1.7 & 2.4 & 32 & 30 & 45 & 2.7 \\
\hline Abdominal Viscera, & 7.2 & 8.2 & 12.6 & 11.5 & 12.1 & 12.3 \\
\hline Fat, . . . . & 182 & 28.2 & $18.9\}$ & 200 & $\{13.5\}$ & 14.8 \\
\hline Skin,. . . . . & 6.9 & 5.7 & $6.2\}$ & 200 & $\{11.3\}$ & 14.8 \\
\hline brain, . . . . · & 19 & 2.1 & 3.9 & 15.8 & 12.2 & 18.5 \\
\hline
\end{tabular}

The proportion of water in the body of adults is about 58.5 per cent.; in the newborn child, 66.4 per cent.; the muscles contain 75.7 per cent; the fat, 29.9 ; the skin, 72 ; the bloud, 83 ; the liver, 69.3 ; and the brain, 75 per cent. of that fluid.

\section{On the Balance of the Vital Economy, or the Relations which subsist between.} the Ingesta, the Metamorphosis of Tissue, the Work accomplished in and by the Body, and the Ingesta. ${ }^{2}$

337. During the last few years many laborious investigations have been undertaken, with a view to determine what may be called the "balance of the vital economy ;" or in other words, to ascertain not only the kind and quality of food requisite to maintain life under varying external conditions, but to gain an insight into the manner in which different kinds of foods are applied to the formation of tissue, the production of mechanical force, and to the maintenance of animal heat; and also the mode in which the results of their metamorphosis within the body are ultimately discharged by the various excretory organs. The average amount of food required by the

1 From Ranke, Grundzüge der Physiologie, 1868, p. 143.

2 The following are some of the more important recent works on this subject: Bidder and Schmidt, Dic Verdaumessäfte und der Stoffwechsel, 1852. Lawes and Gilbert, Philosoph. Trans., 1859. Bischoff and Toit, Die Gesetze der Ernährung des Fleischfressers, Leipzig, 1860. Hennebers and Stohmann, Beiträge zur liat. Futterung der Wiederkauer, Braunseluweig, 1860. Ranke, Archiv f. Anat. und Phys., 1862. Pettenkofer and Voit, Annal. d. Chemic und Pharmacie, 1862. Sehützenberger, Chimie appliqué à la Physiologie. Seegen, Sitz.-ber. d. Wien. Akad., Bd. lv, Ixiii, 1871. Voit in Zcits f. Biologie, Bd. ii, 1866, pp. 6 and 189, Bd. iii, 1867, p. 1. Bd. iv, p. 517 (über Luxus Consumption), and his experiuents either alone or in conjunction with Pettenkofor in the succeeding six volumes of this periodical, which contains numerous other articles on this subject by differcnt workers.-The Editor must herc acknowledge his obligations to the standard works of Funke, Ludwig, Vierordt, Budge, Longet, Milne-Edwards, W Wndt, Herrmann, and Runke; in each of which, exccllent sections on Nutrition will be found. 
body has already been given $(\S 68)$, and it has been shown that the ordinary diet of the working man contains between 250 and 300 grains of nitrogen, and between 4000 and 5000 grains of carbon; that he consumes besides about five pints of water and a very variable quantity (200-600 grains) of salts ; lastly, that he requires about 11,000 grains of oxygen. These collectively constitute the Ingesta. The Egesta are represcuted by the excretions of the Kidneys, Bowels, Lungs, and Skin, ${ }^{1}$ which are composed of the more or less completely oxidized constituents of the food and tissues, as well as in the case of the alvine evacuations of the indigestible residue of the food. If the weight of the boty remain stationary, the Egesta must necessarily be precisely equal to the Ingesta. But if the quantity of food consumed be greater than necessary, then one of several events may occur: either it fails to be absorbed, and is simply discharged by the bowels, as in an experiment of Ranke, who found that with $64 \mathrm{oz}$. of meat $22 \frac{1}{4} \mathrm{oz}$. were thus eliminated unaltered; or (as in the case of water and salts) it may be absorbed, and be immediately discharged by the kidneys and skin; or it may be absorbed and be deposited in the body (as often occurs with fat), increasing its weight; or lastly, it nuy minister to the performance of more work, and after undergoing oxidation may increase the Egesta generally. If again the supplies of food be insufficient in quantity the weight of the body must diminish, the excreta remaining the same, or the weight of the body heing maintained the excreta must diminish. Speaking generally, the increased demand for food and the increase of the Egesta are associated with increased activity of the cell functions throughout the body, which may express themselves in the formation of more abundant secretions, the more rapid circulation of the blood, and the greater energy of the nervo-muscular apparatus. Bidder and Schmidt estimate that the respective amounts of the various digcstive fluids which are daily poured into the alimentary canal of an adult Man weighing 14 stone, are nearly as follows:

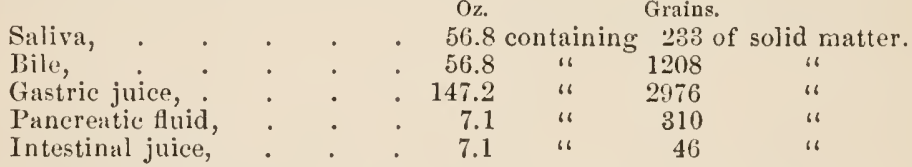

So that nearly $10 \mathrm{oz}$. (troy) of solid matter are separated from the blood in the digestive secretions, for the purpose of introducing new alimentary materials of not more than two or threc times the amount; and thus we see that a large portion of the food ingested and assimilated must be consumed in providing for the introduction of a further supply, in addition to that which, when duly assimilated, is applied by the nutritive processes to the repair of the solid tissues. All thesc processes imply the more active absorption of oxygen and a corresponding increase in the excreta, which are essentially products of combustion, so that when the muscles are powerfully exerted a larger amount of carbonic acid and water is excreted, whilst if the activity of the glands is increased more urca (containing the chief portion of the nitrogen of the ingesta) is eliminated. It must be understood, however, that it is not owing to the quantity of oxygen absorbed that the general activity of the cells throughout the body is augmented, but the activity of these regulates the amount of oxygen absorbed. This is well shown by the fact that whilst, as Fwald has pointed out, the oxygenation of the Hrmo-

1 To which may be added the fluids discharged at stated periods by the Mammary Glands, Testes, and Uterus. 
globin may be raised to saturation by sufficiently active respiration, this does not lead to any increase in the consumption of the oxygen by the economy (Pflüger). To augment the consumption of oxygen the growth and multiplication and functional activities of the cells of the organism must be increased. These activities are dependent upon the play of molecular forces in the cells, that is to say, upon the entrance into and exit of nutritive fluids from their interior, and the changes effected by the cells in such fluids and on their own walls. Albumen when abundantly supplied augments these changes. Fats and sugars diminish them, and they fall to a minimum in inanition. Voit has with some success endeavored to establish a distinction between "circulating albumen" and "tissue" or "organ albumen," the former of which supplies the new material required to replace the old in cell formation, and is much more susceptible of the action of oxygen. He estimatcs, indeed, that of the tissue-albumen only 1 per cent. is destroyed, whilst about 70 per cent. of the "circulating albumen" undergoes disinterration. Voit supports his views by a comparison of the amount of albumen decomposed in inanition with that in excessive consumption of meat, in which it may be as much as ten times greater. The following cxperiment by Pettenkofer may be selected as an example of the mode in which the balance of the Ingesta and Egesta is worked out in the apparatus he has constructed for the purpose, and a description of which has already been given (p.414). ${ }^{1}$ In considering experiments of this nature it may be accepted as a fact that all the nitrogen of the food is eliminated by the urine and freces; the quantity discharged by the lungs and skin ( 0.6 of a grain in 24 hours) being too small to interfere with the results (Parkes). The subject of the experiment was il strong and lively dog, weighing 33 kilogrammes (or $72 \mathrm{lbs}$, the kilogramme being $2.2 \mathrm{lbs}$. a voird.) which was found to maintain its weight nearly unaltered when fed with 1500 grammes $(2.3,160$ grains, the gramme being 15.44 grains) of meat per diem; whilst thus fed it absorbed from the air 477.2 grammes (7367 grains) of oxygen. Analysis of the excreta gave the following results :

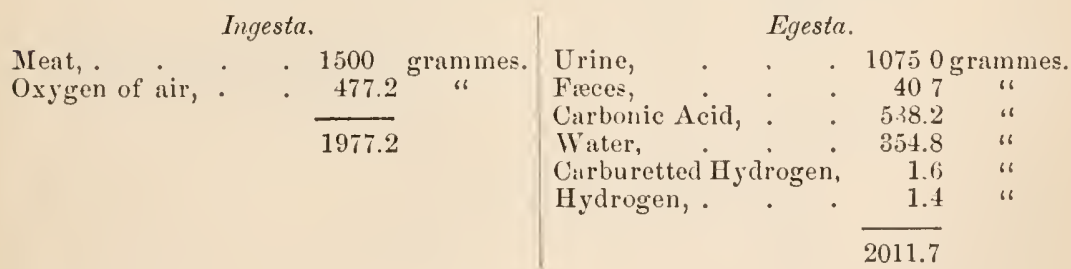

Analysis of the Ingesta showed that-

1500 grammes of meat contained 187.8 grammes of Carbon.

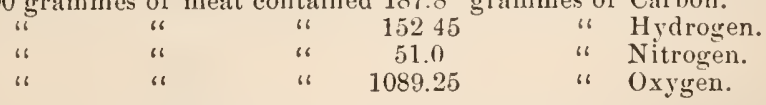

Of the 1089.25 grammes of Oxygen 7725 were contained in the dry meat and 1012 in the water, and of the $152.45 \mathrm{grammes}$ of Hydrogen 25.95 were contained in the dry meat and 126.50 in the water. In addition 477.2 of Oxygen were absorbed from the air. The total ingestion of Oxygen was, therefore, $1566.45 \mathrm{grammes}$

Analysis of the Egesta showed 1075 grammes of urine, containing with 152.2 of dry residue 107.9 grammes of urea and 16.3 grammes of salts. After 
dedueting the urea and salts from the total residue there remained for other urinary constituents 28 grammes, which further analysis showed to contain 9.6 grammes of carbon, 2.5 grammes of hydrogen, and 15.9 of oxygen. 40.7 grammes of moist fieces, which when dried weighed 11.2 grammes, contained 4.9 grammes of carbon, 0.7 of hydrogen, 0.7 of nitrogen, 1.5 of oxygen, and 3.4 grammes of salts. We have thus in the Egesta-

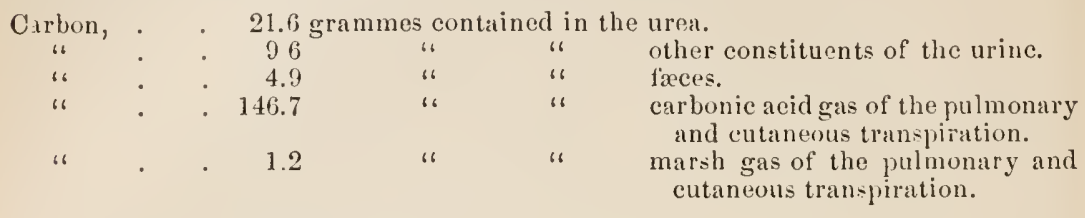

Total, . $184.0 \mathrm{grammes}$.

Hydrogen, - $\quad 7.2$ grammes contained in the urea.

\begin{tabular}{|c|c|c|c|c|}
\hline "6 & $\begin{array}{l}.2 \\
.\end{array}$ & 66 & 66 & unary eonstituents. \\
\hline "6 & . 102.5 & 66 & 66 & water of the urea. \\
\hline 16 & 0.7 & 66 & 66 & dry freces. \\
\hline 6 & $3 \cdot 2$ & 66 & “ & witer of the faees. \\
\hline 66 & 394 & 16 & "6 & water of the transpiration. \\
\hline 6 & 0.4 & "6 & " & marsh gas of the transpiration. \\
\hline 66 & 1,4 & 66 & 16 & hydrogen of the transpiration. \\
\hline
\end{tabular}

Total, . 157.8 grammes.

Nitrogen,. $\quad 50.4$ grammes contained in the urine.

Total, . $\overline{51.1}$ grammes.

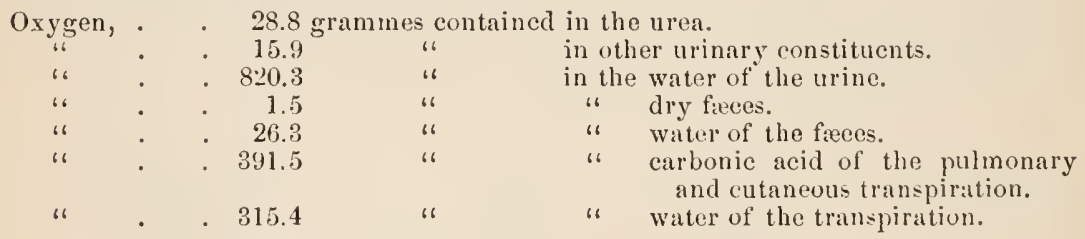

Total, . 1599.7 grammes.

Salts, . 16.3 grammes contained in the urine.

Total, . $\overline{19.7}$ grammes.

If the Ingesta and Egesta are now briefly compared, we get the following balance:

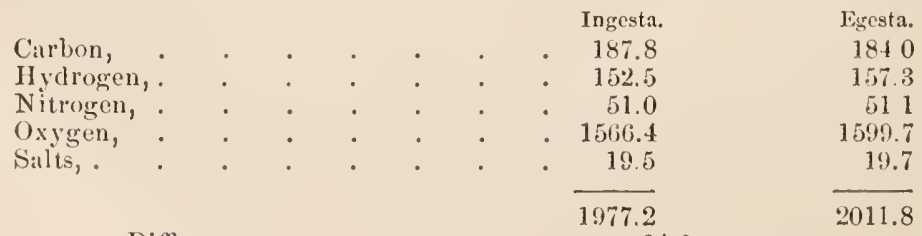

Difference, . . . . 34.6 grammes.

The excess of the Egesta over the Ingesta is nearly 35 grammes; this amounts to not quite 1 per cent. of the total weight of the Ingesta and 
Egesta. This cxcess is believed by Pettenkofer and Voit to be attributable to a slight excretion of water, which is rendered probable because the excess of oxygen and hydrogen is in the proportion in which they form water, and because if from the actual body weight the mean daily quantity of fieces were deducted, there was an actual diminution in the weight of the animal amounting to 34 grammes. The minus quantity of 3.8 grammes of Carbon they attribute to a small production of fiat from the meat. Numerous cxperiments of a similar nature have been made on the same principle on man and animals by Pettenkofer and Voit. The principal source of error in experiments conducted in this manner lies in the analysis of the flesh administered as food, especially in regard to the nitrogen which it contains. 'The estimate here taken was that of ${ }^{\text {Voit, }}{ }^{1}$ who considered it to contain 3.4 per cent. of nitrogen; but other observers ${ }^{2}$ have found that the proportion varies in the flesh of different animals, or when the composition of the flesh is determined by different methods of analysis, from 2.14 to 5.17 per cent., so that a surplus or a deficit of nitrogen would be found in the excreta according as the one or the other estimate is taken as the average. Another difficulty is in the analysis of the frecs, especially when the experiment is marle on one of the Herbivora or on an omnivorous animal, on account of the large amount of indigestible material they contain. In the Carnivora, on the other hand, the amount of indigestible substances is insignificant. Thus in eats it does not exceed 1 per cent. (Bidder and Schmidt). In man it amounts to 4-8 per cent. (Valentin, Barral, Hildesheim), in the pig 19.9 per cent. (Boussingault), in the cow 34.4 per cent. (Boussingault), and in the horse $40-50$ per cent. (Valentin).

338. Balunce of the Economy in Fasting.-Great interest attaches to the study of the excreta during inanition, for we may be sure from the care that we elsewhere see to be taken by nature in the preservation of life, that the animal then lives most econonically, for it is in fact living upon its own tissues, and no more is consumerl than is absolutely requisite for the maintenance of the internal work of the body, which becomes greatly reduced in amount, whilst after the first day or two there is little disposition to external work. The chief objection to this method of determining the minimum quantity of food required, and the minimum amount of Egesta discharged from the body is, that soon after the withdrawal of all supplies the activity of the principal organs, as the liver, pancreas, spleen, glands of intestine, etc., undergoes material diminution. The diminution in the general weight of the body and of the several excreta, begins on the very first day of fasting, and continues throughout, though of course, in consequence of the progressively smaller bulk of the body in a gradually lessening proportion. The most marked alteration in the excreta occurs in the Herbivora, since in fasting they live on themselves; in other words, change from a vegetable to an animal diet, and the urine conseruently contains for a time an increused proportion of nitrogen. Both in these animals, however, and in carnivora, the amount of urea gradually diminishes with the diminished bulk and lessened external and internal activities. Well-fed animals bear inanition for a longer period than ill-fed ones-lean young pigeons dying in three days, and after a loss of only a fourth of their weight, whilst old, well-nourished ones live for thirteen days, and do not die till their weight is reduced to one-half. The loss of weight falls very unevenly on different

1 Voit, Zeits. f. Biologie, Bd. i, p. 100.

2 Nowak, Leube, Siëwert, Petersen, Ritthausen, Zeitschrift f. Biologie, Bd. vii, 1871. Seegen, Wien. Akad. Anzeiger, 1870, p. 230. Schenk, Sitzungeber. d. k. Akad. zu Wien., Jan. 1870. 
organs, the store of fat, for example, being almost entirely used up, whilst the nerve-centres undergo scarcely any change, from which it would appear that some organs continue to be nourished at the expense of others. Ranke gives the following as the results of an experiment upon himself, in which no food or drink was taken :

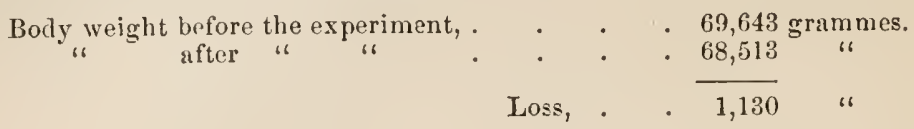

The ingesta (i.e., loss of weight of the body) were calculated for twentyfour hours of the second day of total abstinence from the loss of weight of the body:

\begin{tabular}{|c|c|c|c|c|c|}
\hline Egesta. & N. & C. & Ingesta. & N. & C. \\
\hline $\begin{array}{l}17.025 \text { Urea, } \\
0.236 \text { Uric acid, }\end{array}$ & $\begin{array}{l}7.9455 \\
0.0786\end{array}$ & $\begin{array}{l}3.5654 \\
0.0843\end{array}$ & $\left.\begin{array}{c}50.7 \text { grammes of } \\
\text { Aibumen. }\end{array}\right\}$ & 8.024 & 27.796 \\
\hline In the respiration, & 0 & 180.8500 & 1981 grammes of Fat, & 0 & 156.7 \\
\hline Total, & 8.024 & 181.5 & & 8.024 & 184.5 \\
\hline
\end{tabular}

The calculated loss of albunten and fat amounted to 248.8 grammes, to which must be added 7.7 grammes of extractives and salts excreted in the urine. The loss of solids amounted to 256.5 grammes; the remainder, therefore, 873.5 grammes of the total loss, was water. Seegen, ${ }^{1}$ from the amount of $N$. eliminated in the urine, found that in a young girl, who in consequence of stricture of the osophagns was only able to swallow about an ounce of milk per diem, the consumption of body albumen reckoned dry was about 386 grains per diem, and that since an excess of water was egested, the blood and tissues must have become poorer in water, or drier. The metamorphoses of the albuminates during fasting, so far as they were represented by the excretory products of the urine, bore the proportion to the normal metamorphosis of $1: 4$ or $1: 5$. It must be borne in nind, however, that we cannot conclude from analysis of egesta in the fasting state, or from calculation based on those analyses of the quantity of albumen or fat actually consumed in the acts of life, that we have obtained accurate data of the minimum required for the maintenance of an animal in its normal state; for numerous experiments have shown, that if the same amount of food be given as will exactly cover egesta in the fasting state, the excretions by skin and lungs, urine and frees, will exceed that quantity in weight; clearly showing that the animal still consumes a portion of its own body, or, in other words, that more than a minimum is required. According to Bidder and Schmidt, whilst the Ioss of weight sustained by an inanitiated Carnivorous quadruped is about 2.2 per cent. daily, nearly twice as much, or 4.4 per cent., is required to keep up its weight to the ordinary standard. The most important of the conclusions drawn by Schmidt in regard to the effects of fasting are-1. That whilst the daily quantity of fat undergoing oxidation, in a fisting animal, remains nearly constant; that of the albumen falls in the course of the first two days to one-half, then remains constant for eight days, then falls slowly, and during the last two days diminishes rapidly and considerably. 2. The quantity of expired aqueous vapor diminishes continually but unequally, falling more quickly at the commencement and at the end of the experiment. The proportion of aqueous vapor eliminated by the skin and lungs to that discharged by the urine and fieces remains constant as

1. Seegen, loc. cit., and abstract in Lancet, 1871, vol. i, p. 793. 
$10: 7$. The absorption of the oxygen is also found to diminish unequally, bcing much less at the commencement of the period of inanition and towards the close of life. The quintity of oxyen expired as carbonic acid also finls (from 80 to $7: 3$ per cent.). On the whole a fasting animal loses daily 1 per cent. of its body substance, calculated as free from water, of which 0.6 is albuminous and 0.4 fat. Bischoff and $V^{\top}$ oit have made sinilur series of rescarches on a $\log$, after having previonsly in one experiment fed him well; in a second, after having gradually diminished the amount of food; and in others, after having given him an excessive supply of meat and fat. The general conclusions at which they arrived were, that during inanition the amount of consumption of the animal's own tissue was dependent upon its size; since if it had been previously well fed, it lost more in a given time, and if it had been badly fecl it lost less; living in the latter case, as it were, more economically. And further, the consumption was found to fluctuate between the two chief fictors of the body, the muscular tissue and the fat, in such a manner that a very muscular animal consumed more flesh, and a very fat animal more fat; which result is attributable in part to the presence of a greater bulk or mass of the tissue, which is consequently more exposed to the action of the oxygen absorberl, and undergoes a greater amount of disintegration. In the experiment in which the animal had been previously well fed, and with a mean weight of $70 \mathrm{lbs}$, the proportion of nitrogen to that of carbon eliminated was as $1: 19$; the proportion of nitrogen eliminated per diem for each 1 lb. of borly weight being 2.1 grains, and of carbon 40 grains. In a second experiment, where the dog had previously becn fed on progressively diminishing quantities of meat, and weighed $70.7 \mathrm{lbs}$, the proportion of $N$ to $C$ was as $1: 24$, and there were eliminated for each $1 \mathrm{lb}$. of body weight 1.68 grains of $\mathrm{N}$ and 40 grains of $\mathrm{C}$. In a third experiment, where the $\operatorname{dog}$ had been so abundantly fed that its mean weight throughout the experiment was $8.5 \mathrm{lbs}$, the proportion of $\mathrm{N}$ to $\mathrm{C}$ was as $1: 16.3$, the quantity of $\mathrm{N}$ eliminated per diem to each $1 \mathrm{lb}$. of body weight being 1.54 grains, and 25.2 grains of C.- Sintilar observations have been made by Ranke ${ }^{1}$ on himself; and the influence of diet in Man, in effecting a variation in the composition of the excretions, is wcll shown in the following table, based on his experiments:

Proportion of

Nitrogen to Carbon in the collective excretions of the Skin, Lungs, and Kidneys.

With mixed food, .

$1: 12$

$1: 17$

$1: 25$

$1: 6$

Quantity of Nitro-
geu exereted per
dien for each l lb,
of body weight, in
grains.
1.817
1.000
.788
8.67

Quantity of Carbon exeretid per diem for each $1 \mathrm{lb}$. of body weight, in grailis. 45) 7 17.82 195

528

Ranke found in his experiments that Man required more carbon, i.e., more fat or starch, in his food to supply the wants of his economy, than appeared to be requisite in the Dog experimented on by Bischoff and Voit; and he further remarks that the quantity of nitrogen appearing in the excreta bears an inverse proportion to the carbon contained in the food: consequently, when the fat or starchy comstituents of the food are insufficient, the albuminous constituents of the body are drawn upon or are consumed to maintain the temperature. He found also-1. That the minimum quantity of urea (containing nearly all the nitrogen) is disclarged during hunger. 2. 
That whilst mere increase in the quantity of food, irrespective of its eomposition, has no effect in increasing the quantity of nitrogen eliminated by the kidneys, an increase in the proportion of nitrogenous diet is followed by an increaserl discharge of urea, though this does not rise proportionately for 24 hours at least; the effect, however, enduring for some time after the withdrawal of such food. 3. The same holds with regard to urie acid. In fasting animals Voit found the proportion of water in the several organs inereased in amount, so that in a starved eat the percentage of water in the muscles was 76.5 per cent., whilst in a well-nourished cat it only anounted to 74.6 per eent.; and Ranke found that in the muscles of Frogs in winter, when they obtained little or no food, the proportion of water was 83 per eent., whilst in summer, when they were well fed, it was only 79. Such inerease of the proportion of water has a powerful effeet in exhausting the muscles, and probably also leads to depression of the temperature by interfering with the proeesses of oxidation.

339. The eonclusions arrived at by Bisehoff and Voit upon the effect of feeding their Dog on pure meat-diet are espeeially interesting. They found that in order that the animal should neither lose nor gain in weight, a daily supply of meat equal to from $\frac{1}{20}$ th to $\frac{1}{25}$ th of the whole weight of its borly was required (a much smaller proportion than that found requisite by Bidder and Schmidt in the experiments on the Cat); and that if less than this were supplied, a loss of weight took plaee in eonsequence of the animal eonsuming some of its own flesh and fat; whilst if more than this proportion were supplied, a gain in weight occurred. But to produee a daily increase in weight-constantly inereasing weight-a relatively larger proportion of food was continually required, until at last a maximum was attained; the auimal then loathed its food, eonsumed no more, and rapidly returned to its standard weight. At the same time they found that the quantity of meat which the dog required to eover loss on the one hand, and to form flesh on the other, varied always with the mass of the body. In the well-fed animal, therefore, it required more, in the badly fed less, to produce the same effeet. They further eonclude that when large quantities of meat are eonsumed, the products of its retrogressive metamorphosis take up or combine with the oxygen of the blood, and that thus the fat of the animal is spared; the animal's temperature being suffieiently maintained by the eombustion of the secondary products of the disintegration of the albuminous eompounds.

340. These results have been verified by Ranke in experiments upon himself, with the exception that he found that he was unable to subsist entirely upon a meat diet, and still less, as Hamnoud had already shown (\$61) upon pure albumen. Large supplies of meat with diminution of hydrocarbonaeeous compounds invariably diminished the fat of the body. "The method of diminishing excessive obesity suggested by Mr. Banting, and which consisted in augmenting the use of flesh and redueing the eonsumption of firinaceous and oleaginous food to a minimum, is founded, therefore, on strict physiologieal prineiples. The economy that is effected by a varied diet, and the immense loss of material that results from restrieting man to an exclusively animal diet, have already been fully dwelt upon (ehap. v). An extraorlinary amount of albumeu undergoes disintegration on a pure meat diet. Thus Ranke ${ }^{1}$ found that whilst a healthy man ordinarily excreted about 570 grains of urea per diem, the amount rose to 1327 grains per diem on a pure flesh diet, and he draws particular attention to the fiet that so far from the increased exeretion of urea being due to augmented muscular work, the first effect of an excessive meat diet is not that of increased strength, but

1 Ranke, Grundzüge der Physiologie, 1874, p. 196. 
rather a fccling of heaviness and wcariness in the muscles, with ucrvous excitation often rising to sleeplessucss, which he attributes to the accumulation in the blood of the alkaline salts of the meat. The following gives the result ly Ranke of an experiment on his own person in Pettenkofer's Ricspiration apparatus when consuming as much pure flesh as possible:

$$
\begin{aligned}
& \text { Initial weight, } \\
& \text { Terminal weight, }
\end{aligned} \quad \text {. } \quad . \quad \cdot \quad \cdot 72.927 \text { kilogrammes. }
$$

Difference : a loss of weight of 146 grammes, notwithstanding the large amount of meat eonsumed.

Ingesta.

$832 \mathrm{grammes}$ of meat,

70

31

" of fat,

" of salts.

3371 c e. of water.
N. $\mathrm{C}$.

$62.29 \quad 22936$

$0 . \quad 50.27$
Eqesta.

N. C.

86.3 grammes of urea, . $4028 \quad 17.26$

195 " of urie acid, 0650.70

$\begin{array}{llll}99.0 \quad \text { " of frees, } \quad 3.26 & 14.88\end{array}$

In the respiration, . . . 0.231 .20 2073 e. c. urine.

26.6 grammes of eommon salt.

The differcnce in the amount of $\mathrm{N}=18.1 \mathrm{grammes}$ in favor of the ingesta, shows that about 523 grammes of albumen were retained in the body, and in order to cover the egesta about 23 grammes of fat must have been supplied by the body. The result of the addition of fat to the food of a carnivorous animal was found by Bischoff and Voit materially to diminish the disintegration of albuminous compounds, as shown by the diminished elimination of urea, so that only a third or fourth part is required. This is intelligible enough when it is rememberer that only a certain quantity of ozonized oxygen is present at any moment in the body, and that since the hydrocarbons possess a much higher affinity for oxygen than the albuminous compounds, they essentially spare or prevent the disintegration and oxidation of the latter. They do not, however, interfere with the ordinary decomposition and reconstruction of the muscular tissues. But if, with the fat, an increased proportion of meat be given, tlic proportion of urea also increases, obviously because when much more albuminous material is contained in the blood than is required for the maintenance of the tissues, and especially of the muscles, it undergoes oxidation, and instead of being applied to the tissues is used up for the production of heat. Sugar and starch consumed with a meat-dict seem to operate in precisely the same manner as fat, except that their action, in combining with oxygen, and thus sparing both the adipose and nitrogenous compounds, is in consequence of their greater affinity for oxygen, still more marked than fat ; and if large quantities of sugar be given with sufficient albumen, a deposition of fat invariably takes place.

341. The differences which exist between Carnivora and Herbivora, in regard to the mode in which the constituents of the Ingesta arc distributed through the excretions, are very striking. The first and most remarkable feature of difference between them, is the very large proportion which the fecal discharges of the Herbivora bear to the other excretions, which obviously proceeds from the indigestibility of a large part of the alimentary substances they consume. Of the water taken into the alimentary canal or formed within the body, nearly two-thirds passes off with the fieces in the Horse, whilst nearly the whole is absorbed in the Cat ; and of that which is absorbed by the Horse, little more than one-seventl passes into the urine, the remainder being exhaled from the lungs and skin; whilst in the Cat, the proportion which passes off by the skin is less than one-sixth of that which is absorbed, the remainder being eliminated by the urine. Of the carbon taken into the system, a relatively larger proportion passes off by the lungs 
in the Horse, while a relatively larger proportion enters the urine in the Cat: this is probably because the great bulk of the carbon in the food of the Horse exists in those non-azotized compounds, which can be readily converterl by oxygenation into carbonic acid and water, and which consequently yield little or nothing to the urine; whilst those products of the decomposition of albuminous substances which pass into the urine, though especially rich in nitrogen, carry with them a certain measure of carbon into that excretion. In the case of man, the researches of Pettenkofer and Voit show that with ordinary food 54 per cent. of the Water discharged from the body is eliminated by the kidneys, 5 per cent. with the feece, and 41 per cent. with the expired air. The amount of Carbon discharged per diem on mixed food by the skin and lungs is about 3900 grains, of which 4 per cent. is excreted by the kidnevs, 6 per cent. by the bowels, and 90 per cent. by the lungs. The amount of Hydrogen gas eliminated is small, and the major portion of this element passes away in combination with oxygen as water. The quantity of Nitrogen varies considerably, but with sufficient mixed diet is equal to 300.6 grains daily. Parkes ${ }^{1}$ finds that of this, 25 grains pass off by the bowels per diem, the remainder being eliminated by the urine. The proportion of the alvine to the total excretion of nitrogen varies from 8.1-11.45 per cent. (Parkes); according to Ranke it is 8 per cent. The amount of Oxygen absorbed with sufficient food is 12.845 grains, whilst during fasting it is 14,793 grains. In the fasting statc more oxygen is taken up than carbonic acid is climinated, the proportion being 106:100; when food is taken, on the other hand, the proportion of oxygen absorbed to carbonic acid eliminated is as $100: 90$; in the latter case the carbon is derived from the-hydrocarbons or carbohydrates in the food, whilst in the former it is derived from the tissues, in which case a much larger amount of oxygen is required, the carbohydrates containing much more oxygen.

342 . Thus, then, we see that, throughout life, a continuous interchange of material takes place in the very substance of the tissues, and the new material, derived from without, is being constantly laid down to replace the old and effete substance, which, in the act of devcloping force in one form or another, undergoes oxidation, and, as we shall hereafter see (chap. xi, sect. 3 ), is then taken up by the circulating current, to be removed by the excretory organs. In the earliest periorls of life, how active soever the oxidizing processes may be, the power of the fabric to seize and apply the substances employed as food is superior, and the results are seen in the processes of growth and development. In adult life the balance is more equally preserved, and all the ficulties of the body attain their highest state of efficiency. But in old are, with the increasing debility of all the vegetative processes, with diminished capability of absorption, diminished energy and rapidity of the circulating current, with more compact and drier tissues, there comes to be a gradual deficiency in the processes of nutrition, until at length the body censes to be able to nourish itself, the waste is greater than the supply, and the death of extreme old age may be justly compared, in the wasting oftentimes preceded by the degencration of the tissues and the gradual failure of the temperature, to death by inanition.

34:. Of all the constituents of the boly, none are of more complex chemical composition, and undergo more nmmerous and varied changes, than Albumen. ${ }^{2}$ 'The relations which this substance bears to the living body are

1 On the Elimination of Nitrogen from the Human Body, Croonian Lectures, Lancert, vol. i, 1871.

${ }^{2}$ The formulat given for it by v. Gorup-Besanez being $\mathrm{C}_{216} \mathrm{H}_{162} \mathrm{~N}_{27} \mathrm{~S}_{3} \mathrm{O}_{68}$, and by Theile $\mathrm{C}_{188} \mathrm{H}_{126} \mathrm{~N}_{17} \mathrm{~S}_{2} \mathrm{O}_{46}$. 
of the most important and fumdamental character; since, as elsewhere shown, it enters largely into the composition of the muscles, nerves, and glandular structures, whilst it also affords the chief material for the production of the fibrin, and hematoglobulin of the Blood. It appears, lowever, to be itself entircly lestitute of formative capacity; for in no exudation which is purely serous do we ever trace the slightest indication of organization; and its conversion into the various kinds of tissues, therefore, must be entirely due to their own power of appropriating and transforming it. The great function of the Albumen of the blood, then, is to supply the material for these various transformations; and we accordingly find that whatever other changes the fluid may nudergo, whether it loses it fibrin or its red corpuscles, or both, albumen is still present in abundance. Its ultimate source is to be found in the food; but the serous liquid which percolates the tissues of the body may be regarded as a reserve store, to be drawn upon in case of need, furnishing albumen to the blond when it might otherwise be deficient; and thus perhaps it is, that abstinence or repeated losses of blood do not produce the degree of depression in the proportion of albumen, which might bc expected from the very marked reduction they effect in that of the corpuscles. When an excess of Albuminous uatter is ingested as food, the injurinus effects which might follow the too great augmentation of this constituent of the Blood, appear to be averted by the readiness with which it undergoes retrograde as wcll as progressive metamorphosis; for, if not speedily subjected to the latter change, it appears in the ceaseless interchange which takes place between the contents of the cells of which the body is composed and the fluids, as the lymph and blood bathing their extermal surfaces, to be affected by decomposing agencies, and to be eliminated from the system by the excretory apparatus, under the form of urinary and biliary matter. Flom various considerations it would appear the albuminous compounds in their retrograde metamorphoses are capable of breaking up into two groups of substances, of which one contains the whole of the nitrogen, whilst the other is composed of carbon, hydrogen, and oxygen alone. The former are ultimately eliminated from the body as urea or some analogous compound; the latter are either stored up in the form of fat or are discharged after oxygenation in the form of carbonic acid and water. Of the former series, we know that whilst Leucin $\left(\mathrm{C}_{6} \mathrm{H}_{13} \mathrm{NO}_{2}\right)$, Tyrosin $\left(\mathrm{C}_{9} \mathrm{H}_{11} \mathrm{NO}_{3}\right)$, and Glycin $\left(\mathrm{C}_{2} \mathrm{H}_{5} \mathrm{NO}_{2}\right)$, can be artificially formed by the action of alkalies or acids upon albumen, or even appear during its spontaneous deconiposition; these same substances can also be obtained from various tissues of the body, and are always most abundant in those organs in which interstitial changes are most active, as in the spleen and liver. ${ }^{1}$ From muscular tissue, again, Inosinic Acid $\left(\mathrm{C}_{10} \mathrm{H}_{14} \mathrm{~N}_{4} \mathrm{O}_{11}\right)$, Creatin $\left(\mathrm{C}_{4} \mathrm{H}_{9} \mathrm{~N}_{3} \mathrm{O}_{2}\right)$, and the urinary constituent Creatinin $\left(\mathrm{C}_{4} \mathrm{H}_{7} \mathrm{~N}_{3} \mathrm{O}_{1}\right)$, can be directly obtained. The relation of Inosinic Acid and of Allantoin $\left(\mathrm{C}_{4} \mathrm{H}_{6} \mathrm{~N}_{4} \mathrm{O}_{3}\right)$, found in the urine of women during gestation and in new-born children, to Uric Acid and Urea, which are the ultimate products of the decomposition of the albuminous compounds, is very intimate; whilst as regards Creatin, the researches of Sarokow ${ }^{2}$ indicate that during active muscular exertion it is converted into Creatinin, or at all events that, in muscles exhausted by action, a greatly increased proportion of Creatinin is generated; and it is well known that both of them are convertible by chemical agents into Urea. ${ }^{3}$ The evidence of the

1 Glycin has not, indeed, been obtained in the separate state, but it enters into the composition of the glyccchulie acid of the bile. The further decomposition of leucin in the laboratory by fermentation and oxidizing agents, yields the volatile fatty acids well known to oceur in glandular organs and in the blood.

2 Virehow's Arehiv, 1863, p. 541. 3 Fownes's Chemistry, 1861, p. 670. 
derivation of the fatty compounds from the albuminous substances will be given in the next section, and, like that indicating the origin of the farinaceous and saccharine compounds from them, is chiefly of an indirect nature. In regard to the analogous compound glycogen, it may be observed that the formation of an amyloid substance is the natural function of the liver, and there is some reason for believing that this is an intermediate stage of the decomposition of albumen into fat; the formation of the glycogen being accompanied by the simultaneous appearance of highly nitrogenous substances, such as Glycocholic and Taurocholic acids, which have been shown by Liebig to be rearlily derivable from albumen, the latter containing an important element of albunen, namely, Sulphur. In regard to the albuminous, and as the experiments of Bischoff and Voit appear to prove, the gelatious constituents of our food also, it is probable that by far the largest part is applied directly to the formation of tissue, including under this term the contents of gland-cells, whilst a much smaller portion, if indeed there be any, termed the "Luxus consumption" by the Germans, is decomposed in the blood without forming tissue. In both instances a kind of decomposition or disintegration takes place under the influence of oxygen, by which, on the one hand, such compounds as Fibrin, Chondrin, Keratin, Taurin, Glycin, Leucin, Creatin, Creatinin, Guanin, Sarkin, Xanthin, Uric Acid, Urea, etc., are formed, which are, for the most part, discharged by the Urine and Freces; and on the other, certain fatty or saccharine substances are generated, by the further combustion of which the animal heat is maintained, their ultimate products, consisting of Carbonic Acid and Water, bcing eliminated chiefly by the skin and lungs.

344. As regards the fatty constituents of the body, a large proportion is doubtless derived from the oleaginous compounds consumed in the food, though it is certain that a part may also proceed from the metimorphosis or disintegration of both hydrocarbonaceous and albuminous compounds. Of the fats ingested a portion after reduction to the fluid state and minute division is directly absorbed, whilst a smaller portion appears to be decomposed by the pancreatic juice into the fatty acids and glycerin before absorption. It has been suggesterl by v. Gorup-Besanez that the fat directly absorbed would, under the influence of the active oxygen and alkalinc carbonates of the blood, also soon undergo decomposition into the fatty acids and glycerin, which again, by further oxidation, give rise to formic, propionic, and other acids. It seems reasonable to suppose that the stearates, oleates, and margarates are directly applied to the formation of adipose tissue. ${ }^{1}$ But that the adipose tissuc of an animal does not proceed exclusively from the fats ingested with the food is conclusively shown by the expcriments of Lawes and Gilbert, ${ }^{2}$ who found that in fattening pigs for every 100 parts of fat in the food, 400-500 parts of fat were stored up in the body of the animal. The question then arises, does the excess of fat laid down in the body over the fat ingested proceed from the hydrocarbonaceous or from the allouminous constituents of the food? The experiments of Liebig, Gundlach, Huber, Dumis, and Milnc-Edwards upon Bees, showing that if these animals be fed upon pure sugar they are yet able to furnish wax for the comb, and the observa-

1 Sre Hofmann (Zeits, f. Biologie, Band viii, p). 153). Radziejewski (Virchow's Archiv, Band $x$, liii) and Subbotin (Centralblatt, 1870, p. 675) are however opposed to this view, because they found that although when eertain fats with wellmarked chemical properties, as spermaceti, were introdueed into the alimentary eanal of a dog, they underivent absorption, yet they could not be subsequently detected in the subcutaneous fat.

2 Philosoph. T'ransact., 1859, p. 543. See also Pettenkofer and Voit, Zeitsehrift f. Biologie, Band ix. 
tions of Boussingault, Lehmann, Groner, and Lawes and Gilbert on ducks, gcese, pigs, and oxen, showing that on a diet rich in carbohydrates fat is abundantly formed, and either deposited in the tissucs or excreted in the milk or fieccs, coupled with the well-known fact that ncgroes rapidly fatten during the period of cutting the sugarcanes, lcar to the conchsion that the fat of the body may be derived from the carbohydrates, and this is supported by the observation of Pasteur, that in the alcoholic fermentation of sugar Glycerin is one of the products. Lawes and Gilbert indeed estimate that $2 \frac{1}{2}$ parts of starch must be consumed in the food to produce one part of fat, the proportion of sugar required being somewhat larger.' But evidence has also accumulated showing that the fat of the body may be derived from the albuminous compounds; thus Pettenkofer and Voit found that on very full or excessive meat dict their dog excreted considerably less carbon than he ingested, though the quantities of nitrogen ingested and egested were almost exactly equal, and as the animal gained in weight and fat was deposited in its tissucs, there was strong rcason for believing that it was due to the separation of a part of the albuminous compounds in the form of fat. Other facts which may be mentioned as tending to prove the same thing are the production of adipocere from muscle; the observations of Blondeau, Hoppe, Kemmerich and Fleischer, that fat can be deposited during a diet composed mainly of cheese, and the formation of fat during the maturing of cheese, and the development of fat in a fasting dog when the animal is slowly poisoned with phosphorus; the experiments of Subbotin showing that bitches secrete milk containing the largest amount of fat when the food has been abundant, though composed essentially of lean meat; the observations of Burdach ${ }^{2}$ upon the eggs of Limnzeus, showing that in the progress of incubation the fat increases apparently at the expense of the albumen, so that whereas in the early stage the amount of fat is about 7 per 1000 and of albumen about 9.53 , in the last stage the amount of fat has increased to about 22 parts, whilst the albumen has fallen to 9.18 in 1000 parts; and lastly, the rccent experiments of Pettenkofer and Voit ${ }^{3}$ all afford strong support to the view that the fats may be derived from the albuminous compounds, the observation of these investigators appearing to demonstrate that when a sufficient amount of albuminous food is supplied, fat ingested as such is stored up in the body, the carbohydrates burnt to maintain the animal heat being really derived from the disintegration of the albumen, which they estimate yields about 55 per cent. of its weight of fat. The phenomena presented in nerve-cells and muscular tissue during the pathological process of fatty degeneration may also be referred to as supplying additional evidence. - The quantity of fat contained in different parts of the body varies considerably, but it is almost universally present. The blood usually contains about 0.4 per cent., the muscles 3.3 , milk 4.3 , brain 8 , the nerves 22 , and adipose tissue 83 per cent.-The fatty matters of the Blood, besides being destined to furnish the contents of the Adipose and Nervous vesicles, appear also to be required in the early stages of the production of cells generally. The principal source of their expenditure, however, is that process of combustion by which the heat of the body is maintained; and the amount deposited in the tissues as fat, may be looked upon as the surplus of

1 The opponents of the view above given, that fat may be derived from the Carbohydrates, contend that the purely chemical evidence is weak, since only fatty acids, poor in carbon, and traces of Glycerin and Glycerides, make their appearance in saccharine fermentations.

${ }_{2}$ F. W. Burdach, De Comment Subst. Prot. in Adipem Dissert., 1853.

${ }^{3}$ Zeits. f. Biologie, Band ix, Heft 1. Weiske und Wildt, Zeits. f. Biologie, Band $\mathrm{x}, 1874, \mathrm{p}, 1$. 
the quantity ingested, that is not thus consumed. The quantity of fatty matter in the blood is liable to sudden augmentation, from the introduction of a large quantity furnished at once by the alimentary material; and this excess will continue until the surplus has been eliminated, either by the combustive, the nutritive, or the excretory operations. These last do not ordinarily remove the saponifiable fats from the body; for although the mammary secretion in the female draws off from her blood a large quantity of fatty matter, this is destined not for its purification, but for the nutrition of her offepring; and cholesterin appears to be the only fatty substance which is normally excreted for the purpose of being removed from the body. The ultimate disposal of the saccharine constituents of the body, which appear to be partly derived from without, and to be partly the result of the decomposition of the albuminous constituents of the blood, as will be hereafter more fully considcrerl (Glycogeny), is still unknown; though there seems to be some probability in favor of thcir being first converted into Lactic acid, and finally into Carbonic acid and Water, and as these are more easily oxidized than the fats, they spare the latter from combustion.

345 . The uses of the various Inorganic compounds, which, as being uniformly present in the Blood, nuust be considered among its integral constituents, have already been pointed out ( $\$ 57)$, and it need only here be remarked that the recent observations of Weisk $\mathrm{e}^{1}$ show that the bones retain their hold of the salts that enter into their composition with great tenacity, so that if food be supplied in which the proper salts are defective no material difference can be detected for a considerable period in the composition of the osseous tissue. Papillon ${ }^{2}$ has demonstrated that the Bones will contain a large proportion of strontium phosphate, or of magnesian phosphate, replacing the calciun phosphate, if these salts are liberally given with the food, and providing the calcium phosphate is deficient or altogether absent.

346. We may now proceed briefly to consider what is the amount and nature of the work done in and by the body, and endeavor to ascertain the mode in which the food consumed is applied to the production of that work. It has already been stated that the two principal circumstances occasioning a denand for alimentary material are the supply of the loss caused by the activity of the nervo-nuscular apparatus, and the production of the heat requisite to maintain the body at a uniform standard. The actual disintegration of the material substratum of the nervous and muscular tissues during exertion appears to be exceedingly small, since fasting animals, or animals fed on non-nitrogenous diet, can for a considerable period perform severe work without the occurrence of any considerable increasc upon the amount of nitrogenous excreta eliminated by the same animals when at rest with the same diet. Yet that the tissues really undergo disintegration during exertion, and that they require appropriate nitrogenous food for the repair of the loss occasioned by their wear and tear, is clearly shown by their incapacity for performing work except for a limited period without such supplies. It is reasonable then to suppose that whilst a certain small portion of the large store of albuminous and other nutritive material present in the body is applied to the nutrition and repair of the work-performing tissues, a very much larger proportion is applied to the developnent of the forces of various kinds which are excrted by them. The three principal classes of food, the albuminous, firrinaccous, and oleaginons, are all of them composed of easily oxiclizable material, and it is conceivable that in the act of com-

1 Zeitschrift für Biologie, vii, pp. 179 and 333.

2 Journal de l'Anatomie, 1873, No. 3 ; see also König, Zoits. f. Biologie, B. x, 1874, p. 68. The statement is contested by Weiske, ibid., 1872, Bd. viii, p. 239. 
bining with oxygen, or rather with ozone, the force may either become directly apparcnt as heat or electricity, or may, through the agency of muscle -glani-or nerve-tissue, produce movement, sccretion, or thought. We have only indirect means of estimating this last; but the quantity of food required for the mcchanical and calorific force developed by the body has been rendered capable of being estimater by the experiments of Frankland, Haughton, and others.

$: 34$. According to the observations of Prof. Frankland, one gramme (15.44 grains) of purifier albumen, when burnt in oxygen, yields 4.998 units of heat. Now each unit of heat ran be converted into mechanical force, expressed in kilogrammetres, by multiplying it by the number 423 ; that is to say, the lieat required to raise one kilogramme of water $1^{\circ} \mathrm{C}$. if converted into mechanical force would raise 423 kilogrammes one metre in height, or an amount of heat equivalent to $1^{\circ} \mathrm{C}$. wonld be produced by the expenditure of an amount of force equal to the raising of 423 kilogrammes to the height of one metre; hence one gramme of albumen in burning in oxygen yiclds $4.998 \times+23$, or 2117 kilogrammetres-that is, a force sufficient to raise 2117 kilogrammes to the height of one metre. But it is to be remembered that albumen, in passing through the body, is not so completely oxidized as when burnt in oxygen. It is only reduced to the condition of urea; and Professor Frankland has shown that urea can itself be burnt in oxygen, yielding 2.206 units of heat, which is equal to 934 kilogrammetres of force; and as it is found that one gramme of pure albumen in passing through the body, furnishes almost exactly one-third of its weight of urea, the effective force developed in the borly by its consumption is obviously less than when it is burnt in oxygen to the extent of the amount of force still produced when one-third of a gramme of urea is burnt in oxygren. Hence the effective force of one gramme of albumen is equivalent to 1803 kilogrammetres. ${ }^{1}$ Fat, on the other hand, is as completely burnt in the body as outside of it, and yields weight for weight a much larger amount of effective force than albumen. The following table contains some of the more important determinations made by Profcesor Frankland:

\begin{tabular}{|c|c|c|c|c|c|c|c|}
\hline \multirow{3}{*}{ Name of the Food. } & \multicolumn{5}{|c|}{$\begin{array}{l}\text { Effectire energy when one gramme of the } \\
\text { diffirent sulustances named is burnt in } \\
\text { Oxygell. }\end{array}$} & \multicolumn{2}{|c|}{$\begin{array}{l}\text { Effective energy when } \\
\text { consumed in the body } \\
\text { in kilogrammetres. }\end{array}$} \\
\hline & \multicolumn{2}{|c|}{ Units of IIeat. } & \multicolumn{2}{|c|}{$\begin{array}{l}\text { Kilogrammetres } \\
\text { of Force. }\end{array}$} & \multirow{2}{*}{$\begin{array}{c}\text { Per- } \\
\text { centage } \\
\text { of } \\
\text { water. }\end{array}$} & \multirow{2}{*}{ Dry. } & \multirow{2}{*}{$\begin{array}{l}\text { Natural } \\
\text { state. }\end{array}$} \\
\hline & Dry. & $\begin{array}{l}\text { Natural } \\
\text { state. }\end{array}$ & Dry. & $\begin{array}{l}\text { Natural } \\
\text { state. }\end{array}$ & & & \\
\hline Albumen, . & 4.896 & $6 i 1$ & 2074 & 284 & 86.3 & 1781 & 244 \\
\hline Lean Bref. . & 5.313 & 1567 & 22.50 & 664 & 70.5 & 2047 & 604 \\
\hline Fish (Mnckerel), & 6.064 & 1789 & 2568 & 758 & 70.5 & 2315 & 683 \\
\hline Fut of Beef, . & 9069 & & 3841 & & $\cdots$ & 3811 & \\
\hline Starch, . . & $\ldots$ & 3941 & $\ldots$ & 1669 & $\cdots$ & $\ldots$ & 1627 \\
\hline Sugar (white), . & $\cdots$ & 3348 & & 1418 & $\cdots$ & $\because \cdots$ & 1418 \\
\hline 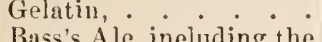 & 4.520 & $\cdots$ & 1014 & $\cdots$ & $\cdots$ & 1550 & $\cdots$ \\
\hline alcohol, . . . . & 3776 & 775 & 1559 & 328 & 884 & & \\
\hline
\end{tabular}

1 It must be acknowledged that the estimates of different experimenters in regard to the ealorifie value of different substanees vary eonsiderably. Thus, Franke estimates that the combuction of one gramme of starch produees 5292 units of heat, Lud wir 4568, Dulong 3232, Bischoff and Voit 5100, and Frankland 3941. The warming of one pound of water $1^{\circ} \mathrm{C}$. is equivalent to a mechanical force of 1390 footpounds. 
348. The amount of work done by the body may be divided into-1. Calorific work; 2. Internal mechanical work, such as is required for the maintenance of the circulation, respiration, digestion, etc.; 3. External mechanical work, expended in the movements of loconotion, lifting and carrying weights, etc.; 4. Mental work; and lastly, in youth, the work of growth. The absolute amount of heat units daily produced by an adult of average weight has been estimated by Ranke at 2200 (by Helmholtz at 2700), or sufficient to raise the temperature of $48.4 \mathrm{lbs}$. from the freezing to the boiling-point; $;$ or if converted into mechanical force, it amounts to 930,600 kilogrammetres, which would be sufficient to raise the body of a man weighing 68 kilogrammes (149.6 lbs. av.) through a vertical height of 8.5 miles. This heat is expended in conduction and radiation from the body, in warming the air inhaled, and the water and watery vapor exhaled by the skin, kidneys, and lungs, and in warming the food. Next as regards internal dynamical work. Professor Haughton ${ }^{2}$ states that the work done in maintaining the circulation and respiration may be estimated at 133 foot-tons, or 41,180 kilogrammetres (heart $=121$ foot-tons, muscles of respiration, 11 foot-tons). The same authority gives as the result of numerous observations on the external or daily work of various classes of laborers the mean of 353.75 foot-tons $(109,549$ kilogrammetres), which corresponds well with the results obtained by Coulomb (330 foot-tons), Lamandé (352 foot-tons), and Playfair ( 346 foot-tons). The work expended in grouth may be neglected for the adult; and that exerted in mental operations, as already stated, can only be indirectly estimated. From the foregoing calculation it would seem that the entire amount of force expended in maintaining the heat of the body of an adult weighing $150 \mathrm{lbs}$. and in the performance of his internal and external mechanical work is 1,044,267 kilogrammetres, of which ninetentlss is expended in maintaining the heat, and the remainder in external and internal dynamical work. ${ }^{3}$

349. It may be shown, either from an examination of Frankland's tables, or by calculating the amount of tissue decomposed to furnish the usual amount of urea, carbonic acid, and water eliminated from the body, that almost exactly the same amount of a million kilogrammetres of force are contained in the food. 'Thus, on Vierordt's estimate-

120 grammes of albumen, dry, of fat,

of furinaceous compounds,

$$
\begin{aligned}
& =213,720 \text { kilogrammetres. } \\
& =345,690 \\
& =536,910 \\
& =-1,096,320
\end{aligned}
$$

The close approximation of the expcrimental with the calculated values is of great interest. It may be objectcd that a very small margin is left for purely mental operations; but it inust be remembered that Professor Haughtou's estimate of 353.75 foot-tons, or 109,549 kilogrammetres, for cxternal or mechanical work, is very high, being cquivalent to that required to raise the body through one mile of vertical height, or to walking 20.74 miles per dicm, which is perhaps three times more than is usually accomplished; and

Grundzüge der Physiologie, p. 476, 1868.

2 Address delivered at the British Medieal Assoeiation at Oxford, Ang. 1868. Dr. Andrew Juchanan gives reasons for believing that the foree of the heart (Left Ventricle) does not exeed 42.3 foot-tons in the 24 hours. See Laneet, vol. ii, 1870 , p. 6iti5.

3 Prof. Haughiton, caleulating the amount of heat produced from the amount of Carbonie Acid gas eliminated, as shown in Ranke's experiments, estimates the ealorific work at five-sixths, and the internal and external mechanical work at one-six th of the whole amount of foree generated. 
that under such circumstances, citlicr little mental work would be done, or more food would be required. Supposing only scven miles were walked, 118 foot-tons of force would be requirer, leaving 236 foot-tons a vailable for mental work; but it must be remembered that both mental work and much of the internal mechanical work are again expended in the body. A part of the mechanical force cxerted by the heart is given up as heat from obstructed motion in the capillaries, and will be included in the heat given off from the body ; and although nothing positive can be stated as to the form taken by mental work and nervous action generally, it is highly probable that for the most part this is heat. There is every reason to believe that, although the tissue of the nerves and muscles cannot be built up from alimentary materials destitute of nitrogen, the force which can be exerted by those tissucs proceeds both from the disintegration and oxidation of nitrogenous as well as nou-nitrogenous substances. At any rate, it has becn clearly shown by Professor Haughton that the amount of urea (501 grains) eliminated after severe exercise does not represent the oxidation of a sufficient amount of nitrogenous material to account for the work done. Moreover, whilst in carnivorous animals the force inust proceed from the oxidation of nitrogenous constituents, since they can be nourished upon lean flesh, in herbivorous animals-and, as Verloren has pointed out, in mature insects, as bees and butterflies-it seems equally evident that the nervo-muscular force is generated from the oxidation of farinaceous compounds; and an examination of the excreta gives additional testimony to the same effect. Thus, Professor Haughton found the daily elimination of urea in a Bengal tiger to be 4375 grains, whilst in a sheep it was only 256 grains. It has also been shown by the same observer that in diabetes, where sugar is eliminated by the urine, instead of undergoing combustion and being discharged from the body in the form of carbonic acid and water, an increased quantity of food is required, which is accompanied by an increased discharge of urea, showing that the nitrogenous materials are consumed to maintain the tenperature and to furuish the force required for work, which is always small. Heaton suggests that the whole, or nearly the whole, of the force of the body is generated in the blood, and that Mayer was perfectly right in saying that the muscle produces nrechanical effect at the expense of the chenical action occurring in its capillary vessels. It is probable, however, that the oxidizing processes take place essentially in the tissues and intertextural fluids.

350. Of the mode in which the substitution of new tissue for that which has become effete, is effected in the process of Nutrition, our knowledgc is at present limited; but there can be little doubt that it nearly always takes place in a manner closely conformable to the first developnicnt of each tissue. In some instances there is an obvious replacement of the old and dead by the young and active elements: this is the case, for example, in the coustantly repeated production of the Epidermic and Epithelial layers; for whether they are developed from germs imbedded in the subjacent basement-membrane, or from nuclei formed de novo in the blastema ou its free surface, or by the duplicative subdivision of pre-existing cells, there is a continual succession of new cells, which take the place of those that are cast off as defunct and useless. So in the growth of Hair, the increase of which takes place only at its base, we can trace at any period the same development of newly-formed spheroidal cells into horuy fusiform fibres, as that which occurred when first the hair began to sprout from the aggregation of epidermic cells at the bottom of its follicle. So, again, in the vesicular tissue which constitutes the essential part of the Nervous centres, there are appearances which indicate that its peculiar cells are in a state of continual development, 
newly-formed ganglionic vesicles taking the place of those which have undergone disintegration. But there are other textures, whose nutrition is more conpletely interstitial; their elements being more closely coherent, and their newly-formed portions being developerl throughout the substance of the old, instead of (as in the case of the epidermis and its appendages) superficially or in mere continuity with it. Such is the e'se, for example, with Muscle, the mode of whose nutrition has not yet been elucidated. We can only infer from analogy, that here too each fibre or fibril will pass, in the course of its development, through the same stages which those of the embryo did when its muscles were first formed. And this analogy seems to derive support from the presence, in all well-nourished muscles, of bodies which bear the appearance of nnclei; for these, as Mr. Paget remarks, "are not the loitering inpotent remains of embryonic tissue, but germs or organs of power for new formation." And it is further confirmatory of this view, that losses of substance of muscle which involve the destruction of these centres of nutrition, are not replaced, like losses of cuticle, by new tissue of the same kind; the power to form it not being inherent in the blood or in the neighboring parts. Nevertheless it must be adnitted that no intermediate stages of development ean be traced in the fibres, even of those muscles of the adult which are in most constant use, and of which the nutrition is the most active, that are at all comparable to those which are met with in the muscular tissues of the embryo.-With regard, again, to the interstitial nutrition of Bones and Teeth, we have no certain knowledge. That some movement of nutritive fluid is continually taking place through them, is made apparent by the effects of madder in gradually tinging even the bones and teeth of the adult, though for such a change a much longer period is required in the adult than in the young animal; how far this movement, however, is subservient to any continual change of substance, still remains doubtful. If the supply of blood be withdrawn from a tooth or from a bone, or even from a part of the latter, the structures thus cut off from connection with the act of nutrition soon die, become detached from the living parts around, and are thrown out of the body. Of this we have a very good example in the annual exuviation of the antlers of the Deer, which is partly brought about by the choking up of the Haversian canals that give passage to bloodvessels, with concentric osseous deposit, and partly, as Lovenn, ${ }^{1}$ Kölliker, ${ }^{2}$ Morison, ${ }^{3}$ and others have shown, by the absorptive power of peculiar, nany-nucleated giant cells (the Myeloplaques of Robin, and Riesenzellen of Virchow). Something of this kind seems to be continually taking place in ordinary Bone, upon a more limited scale; individual Haversian systems being removed by absorption, leaving spaces termed the Lacunæ of Howship, and being replaced by new formations of the same kind, probably during its whole life, without any change in external configuration. So far as can be gathered from observation, the process of interstitial decline and death usually takes place too rapidly for its stages to be perceptible, and is immediately followed, in the normal condition of the system, by the removal of the effete particles; so that it is only when this removal is from any cause obstructed, as happens in the cases to be presently cited, that we see any indication of the stages through which the disintegrating tissues pass.

351. There is one remarkable form of degeneration, however, which is common to nearly all the tissues, and which seems to occur as a normal

1 Lovén, Würsburg Phys. Med. Verhand., N. F., 1873, Jand 4, p. 1.

2 Kölliker, idem, p. 34. See the Memoir by Messrs. T'omes and De Morgan, On the Structure and Development of Bone, in Philos. Transact., 1853, p. 111.

3 Edin. Mled. Journ., Uet. 1873. 
alteration in many of them at an advanced period of life; this consists in the conversion of their albuminous or gelatinous materials into fat, thus constituting what is known as futty degenerution. That this change is not due to the removal of the normal components of the tissucs, and the substitution of newly-deposited fatty matter in their place, but is (in most cases at least) the result of a real conversion of the one class of substances into the other, may now be considered as well ascertained. ${ }^{1}$ And there are certain facts which indicate that this kind of degeneration is a part of the regular series of processes, by which tissues that have served their purpose in the economy are prepared for being removed by absorption; one of the most remarkable being the observations of Virchow ${ }^{2}$ and Kilian ${ }^{3}$ with regard to the fatty degeneration of the muscular tissue of the uterus after parturition, and quite analogous phenomena are observed in muscles the motor nerves of which have been divided. ${ }^{4}$ So, as Mr. Paget has pointed out, the fibrinous and corpuscular products of inflammation are often brought into a state fit for absorption, by passing through this intermediate stage; the fibrinous substances being observed to be dotted by granules which are recognized as oil-particles by their peculiar shining black-edged appearance, and at the same time losing its toughness and elasticity, and being no longer rendered transparent by acetic acid; whilst the lymph-cells present a similar increase of shining black-edgred particles like minute oil-drops, which accumulate until they nearly fill the cell-cavity, their nuclei at the same time gradually farding and disappearing. ${ }^{5}$ Thus, then, if the fat, which is one of the products of this retrograde metamorphosis, be absorbed as fast as it is formed, and the effete tissue be replaced by a new production (as seems to be the case with Muscles in a state of healthy activity), there is no appearance of degeneration, and the nutrition is kept up to its normal standard. So if, from the alvance of age, or from the insufficient exercise of the muscles, their nutrition take place less rapidly than their waste, whilst the products of their degeneration are still removed, simple atrophy is the result. If, on the other hand, the general conditions being similar, the fat produced in degeneration be not absorbed, but remain in the tissue, an obvious "fatty degeneration" is the result. This seems most likely to happen either (1) when the fat is thus produced in such excessive amount, that the ordinary rate of its absorption (corresponding with that of its elimination by the combustive process) does not provide for its removal; which will occur when a large amount of tissue is undergoing degeneration at once, as in the case of the uterus after parturition; or (2) when the blood, being already highly charged with respiratory material, is indisposed to receive an additional amount of fat; and it is probably in part from this cause, that the habitual presence of Alcohol in the blood strongly predisposes to fatty degeneration, as is proved by the very large proportion of intemperate individuals among the subjects of the more

1 For an excellent account of the whole subject of Fatty Degeneration, see Dr. Handtield Jones's Articles in the Brit. and For. Med.-Chir. Rev., vol. xi, p. 327, and vol. xii, p. 30 . In this country, a substantial description of the importance of the fatty degerieritions was given, upwards of a quarter of a century ago, by Gulliver (Trans. Med.-Chir. Soe., 1843, vol. xxvi, and Edin. Med. und Surg. Journ., July, 1813 , p. 158), who thus early proved that these degenerations are a most frequent cause of the decay of the tissues, especially of aneurism of the arteries, and of that spontaneous bursting of their small branches, which is the proximate cause of the most frequent form of apoplexy in the brain.

2 Verhandlungen der Gesellschaft für Geburtshülfe, Berlin, vol. iii, p. 17.

3 Henle and P'feuffer's Zeitschrift, vol. ix, p. 1.

- See Erb, Centralblatt, 1868, p. 115; Bizzozero and Golgi, Stricker's Jahrbüeher, 1873 , p. 125 .

5 See Mr. Paget's Lectures on Surgical Pathology, vol, i, p. 374. 
aggravated forms of this disorder. For the special aptitude for the combustive process which is characteristic of Alcohol, may give it such a preference in this operation over the ordinary combustive material, that the conversion of the latter by oxidation into carbonic acid and water is kept back, so long as Alcohol is present; and thus the blood of drunkards becomes so highly charged with fat, that it might be itself considered to be in a state of fatty degeneration. ${ }^{1}$ 'This distinct evidence of the operation of Alcohol habitually received into the blood in large quantities, affords an obvious indication that the habitual consumption of even a much smaller amount will tend to produce fatty degeneration at more remote periods and in a less aggravated degree; and the participation which this state has been shown to have in the production of a large proportion of the diseases of Old Age,-especially by the changes it induces in the texture of the heart and of the walls of the bloodvessels (which are particularly liable to it), fully bears out this idea.

352. It may be stated as a general rule, that no absorption of the materials of tissues can take place, without a previous degeneration such as this, or a more complete decomposition. There is no evidence that any healthy tissue is ever thus absorbed, or that any preternatural activity of the absorbent vessels can ever (as formerly supposed) be the occasion of a loss of substance; in fact, so long as the vital force is in active operation in a part, and its processes of growth and development are being normally carried on, such absorption may be considered to be impossible. On the other hand, if a part die en masse, it is not removed by absorption, but becomes isolated by the separation and recedence of the living parts, and is then cast out altogether, even from the interior of the body, as we see in the case of a necrosed bone; its condition being then essentially the same as that of the outer layers of the tegumentary organs, which are cut off, by their distance from a vascular surface, from all further nutrient change. The difference between these two morles of removal is well seen (as Mr. Paget has rcmarked) in the case of the Teeth; for the fangs of the deciduous teetl undergo degeneration, when the current of nutrition is diverted towards those which are to succeed them, their materials being slowly decontposed, so as to beconc soluble, and being graduatly removed by absorption, so that nothing is left at last but the crowns of the teeth ; on the other hand, the permanent teeth, which are not to be succeeded by others, when no longer receiving their duc nutrition, die, and are cast out entire.

353. Among the conditions of healthy Nutrition, a due supply of Nervous power is commonly enumerated; and it cannot be questioned that the want of such a supply is frequeutly the source of a perversion of the normal operations. This, however, by no means proves that the formative power is derived from the nervous system; and such an idea is at once negatived by a number of incontestable facts. Yet it may be freely admitted that the right direction and application of this power in nutrition, may sometimes depend upon guidance and direction aftorded by the Nervous centres, in the same manner as the Secreting process is capable of being thus affected; in fact, we can scarcely explain in any other mode that influence of mental states upon the nutrient operations, which frequently leads to very important modi-

1 The quantity of fat in the blood of drunkards has been found in some eases to be as much as 11.7 parts in 1000 (Lecanu), the highest estimate of the quantity in health being 865 parts. Scharlau has found as much as 30 per eent. more carbon in the blood of a drunkard than in that of a healthy man.- See Dr. Huss's trentise on Alcoholismus Chronieus, Rokitansky's Handbuch der allgemeinen pathologischen Anatomie, Bd. iv, and Brit. and For. Med.-Chir. Rev., vol. xii, pp. 33, 34. 
fications of them.-The whole of this subject, however, will be more appropriately consirlered hereafter (chiap. xvii). ${ }^{1}$

\section{Varying Activity of the Nintritive Processes.-Reparative Operations.}

354. Without any change in the character of the Nutritive processes, there may be considerable variations in their degree of activity; and this, as regards either the entire orginuism, or individual parts, though most commonly the latter. 'These variations may be so considerable as to constitute Disease; though there are some which take place as part of the regular series of Physiological phenomena. Thus, as we have seen, it is to the excess of formative activity, that the increase of the organism in the earlier period of life is duc, its "waste" being at the same time extremely rapid ; whilst it is to a corresponding reduction in the regenerative power, and not to positive excess of "waste" or decay (this, indeed, taking place very slowly), that the gradual decline of the organism in adrancing years is to be attributed. So also we find that local as well as general variations may take place, as a part of the regular series of vital phenomena; and this during the period of adult life, as well as in the earlier and later epochs. Thus all those differences in the proportional development of the several parts of the organism, which mark the distinction between the adult and the child, even where (as in the case of a (lwarf) there is no difference in stature, result from a decline in the formative capacity of those which are peculiarly adapted to the wants of the earlier stage (the Thymus Gland, for example), and from an increased activity of mutrition in those which are destined to the use of the adult, the Generative organs more particularly. And the intermittent activity of the sexual apparatus of the female affords a remarkable example of the same principle; this being marked, not merely in the enormous development of the uterus and mamnary glands as a consequence of conception, but in the periorlical change which takes place in the ovaries, whereby the ova are matured and thrown off at certain regular intervals. The dechine in the formative power of these same organs, moreover, when as yet the organism in general shows but little indication of deterioration, is another characteristic example of the variation in Nutritive activity resulting from the inherent endowments of the part, and essentially irrespective of the condition of the blood, of the circulation, and of the organism as a whole; although, as formerly shown (\$219), the production and maintenance of other and apparently unconnected organs are complementally dependent upon the formative activity of the Generative apparatus.

355. The abnormal excess of Nutritive change which properly constitutes Hypertrophy, appears to depend upon a departure from one or other of the conditions, under which, as already specitied, the change normally takes place-namely, the right composition of the blook, a due supply of such blood, and a proper formative capacity in the blood itself.-Of the excess of nutrition resulting from the presence of an excess of the peculiar naterials of certain tissues in the circulating fluid, examples have already been given $(\$ 330)$; it is important to remark, however, that although hypertrophy may be thus induced in any of the tissues which constitute the instruments of organic life, yet there is no evidence that either the Nervous or the Muscular apparatus can be forced (so to speak) to an angmentation in bulk, by the

1 In the treatment of this subject, the Author has made use of many valuable illustrations contained in the first three of Mr. Paget's Lectures on Surgical Pathology; the general doctrines, however, being such as he had himself expressed on many previous occasions. 
mere abundance of their nutritive materials.- With regard, in the next place, to the supply of blood, there ean be no doubt that in general an increased flow of blood towards a part is consequent upon, rather than a cause of, an exeess in its nutritive aetivity; but still there are eases in whieh its causative ageney may be traced. Tarious examples of this have been supplied by the experiments and observations of John Hunter, the records of which are left in his Museum. Thus if the spur of a eoek be transplanted from the leg to the eomb, which is a part far more vascular than that with whieh it was originally eonnected, it undergoes an extraordinary augmentation in size; laving in one instanee grown in a spiral form, until it was six inehes long; and in another eurved forwards and downwards like a horn, so that its end needed to be often cut, to enable the bird to bring its beak to the ground in feeding. So, again, it was remarked by Hunter, and has been frequently observed since, that an inereased growth of hair often takes place on surfaces to which there is an increased determination of blood as a eonsequence of inflammation in some neighboring part, though not from the surfaee of the inflamed part itself. So it sometines happens, that when an ulcer of the integuments of the leg has long existed in a young person, the subjacent bone may share in the inereased afflux of blood, and may enlarge and elongate. And it seems not improbable that we are to attribute the increased thickness of the cuticle, on parts which are exposed to eontinual pressure or friction, to the augmented afflux of blood whieh is determined to the irritated surface. ${ }^{1}$

356. The greater number of cases of hypertrophy, however, must undoubtedly be referred to the preternatural formative eapaeity of the part itself, and this may either be congenital or aequired. Of this eongenital excess, we have a remarkable example in the abuormal growth of an entire limb, or of fingers or toes, ${ }^{2}$ whieh cannot with any probability be referred to an original excess in the supply of blood, the enlargement of the arteries leading towards such parts being almost eertainly eonsequent upon their unusually rapid growth, just as in the case of the uterine and mammary arteries of the pregnant female. The most remarkable instances of the aequirenent of increased formative aetivity, are presented to us in that augmented growth of the nervous and muscular tissues, whieh is consequent upon the exereise of their functional powers. This may be eonsidered as, to a eertain extent, a normal adjustment of the supply to the denand; but there are some instanees in whieh it takes plaee to such an extent as to beeome a positive disease. Thus it not unfrequently happens that if young persons who naturally show precocity of intellect, are encouraged rather than checked in the use of the brain, the inereased nutrition of the organ (which grows faster than its bouy case) oceasions pressure upon its vessels, it beeones indurated and inaetive, and fatuity and eona may supervene. Now although in such cases there may probably have been some eongenital tendency to preternatural activity of the brain, which manifested itself in the preeoeity of intellect, yet there is 110 doubt that this may be augmented by the "forcing system " of" education; whilst on the other liand, it may be controlled by a system of management adapted to the peculiar circumstances of the ease. Excess of muscular development is peculiarly prone to show itself in the involuntary muscles; but

1 It is ecmmonly said that local IIypertrophy may be indued by long-eontinued Congestion; but this is not true hypertrophy; for the bulk of the organ is not aug mented by the increased production of its nurmal tisitu, but by the addition of tissue of au inferiol type of organization, as in Inflammation.

${ }^{2} \Lambda$ case of hipertrophy of an entire limb was deseribed by Dr. John Reid in the Ediub. Monthly Jumn., is43, p. 198; and several cases of hypertrophy of the fingers were deccribed by AIr. Curling in the II d.-Chir. Trans., Vol. xxvifi. 
this production is in almost every instance the result of the demand for increased muscular exertion which is consequent upon some obstruction to the usual function of the part. Thus an extraordinary hypertrophy of the muscular coat of the urinary bladder is often seen as a consequence of obstruction to the exit of the nrine, through the presence of a stone in the bladker or of a stricture in the urethra ; so again hypertrophy of the muscular coat of the gall-bladder may take place as a consequeuce of obstruction of its duet by a gallstone; hypertrophy of the muscular coat of any part of the alimentary canal may be induced by the existence of stricture lower down; and even hypertrophy of the heart is generally, if not always, attributable to obstruction to the exit of the blood which it propels, resulting either from stagnation of the pulmonary circulation by the deficient aeration consequent upon disease of the lungs (in which case the hypertrophy is limited to the right side of the heart), or from thickening or incluration of the semilunar valves, or from narrowing of the erifices of the aorta and pulmonary artery. It is curious, moreover, to observe, that hypertrophy of nuscles frequently becomes a source of increased nutrition of the bones to which they are attached; this being manifested not merely in the augmented bulk of the bones of limbs that are specially exercised, but also in the increased proninence in the ridges and processes to which the nuscles are attached. This adaptiveness on the part of the formative activity of the osscous tissue, is curiously manifested also in the relation of the skull to the brain ; for if the bulk of the brain be not too rapidly augmented, the skull will enlarge accordingly, and this (in some instances) not merely by the extension of its normal bones, but by the intercalation of new osseous elements, the "ossa wormiana ;" whilst, on the other land, if there be a diminution in the bulk of the brain, the cranium may adapt itself to this also, by a thickening on its internal surface (or concentric hypertrophy), - this change, rather than a diminution in the entire substance of the skull, being more liable to take place in cases in which the cranial sutures lave already closed, and the nutrition of the bone has become inactive.

357. The production of Tumors nutust be considered as a manifestation of an excess of formative activity in individual parts, and as constituting, therefore, a species of Hypertrophy. For a tunior may be composed of the tissues which are normal to the part; as we see especially in the case of those tumors of the uterus, which are made up of an excess of its ordinary muscular and fibrous elements. But, as Mr. Paget has justly remarked, "an essential difference lies in this: the uterus (often itself" hypertrophied) in its growtl around the tumor maintains a normal type, though excited te its growth, if we nıy so speak, by an abnormal stimulus; it exactly imitates, in vascularity and muscular development, the pregnant uterus, and may even acquire the like power; and at length, by contractions like those of parturition, may expel the tumor spontaneously separated. But the tumor imitates in its growth no natural shape or construction; the longer it continues, the greater is its deformity. Neither may we overlook the contrast in respect of purpose, or adaptation to the general welfare of the body, which is as manifest in the increase of the uterus as it is improbable in that of the tumor." A gradation is established, however, between true Hypertrophies and Tumors, by those productions of glandular tissues, which are made up of the proper substance of the gland with which they are connected, as the mamniary, the prostate, or the thyroid, and which (though

1 See his Lectures on Surgical Pathology, vol. ii, p. 2 ; also Dr. Handfield Jones in Brit. and For. Med.-Chir. Rev., vol. xiii, p. 330; and Dr. Bristowe in Trans. of Pathol. Soc., vol. iv, p. 218. 
frequently encysted) are sometimes met with as outlying portions of the gland itself.-There is another class of objects, to which Tumors come into close relation, and which must be referred, like them, to a local excess of formative activity; these are the "supernumerary parts" which are not unfrequently developed during foetal life, as for example, additional fingers and toes. It seems absurd to refer these, formed as they are by simple outgrowth from the limbs to which they are attached, to the "fusion of germs" which has been hypothetically invoked to explain more important excesses, as those of additional limbs, double bodies, or double heads; and yet from the lower to the higher form of excess, the transition is so gradual, that what is true of the former can scarcely but be true of the latter. Hence even complete "double monsters" must be regarded, not as having proceeded from two separate germs which have become partially united in the course of their development, but from a single germ, which, being possessed of an unusual formative capacity, has evolved itself into a structure containing more than the usual number of parts, and comparable to that which may be artificially produced by partial fission of the bodies of many of the lower animals. ${ }^{1}$

358. We can scarcely fail to recognize, throughout this whole series of abnormal productions, the operation of a similar power. In the formation of a supernumerary part, this has been sufficient not merely to produce the tissues, and to develop them according to a regular morploological type, but to impart to the fabric thus generated a separate and even an independent existence; thus involving an additional finger or thumb on each hand, a double pair of arms or legs, a double head or trunk, or even a complete double body. In the hypertrophy of a regular or nornal part, the new tissues are still developed according to a regular morphological type; but they have not the power of individualizing themselves (so to speak), and are so incorporated with the normal elements as to augment the size of the existing organ. In the formation of a tumor, on the other hand, whilst its component tissucs are themselves perfectly formed, and have a marked power of independent growth, the mass composed of them is altogether anorphous, its configuration being usually determined rather by the physical conditions under which it is produced, than by any peculiar tendencies of its own; so that we recognize the action of the formative power, undirected by that morphological nisus, which normally models (so to speak) the growing tissues into the likeness of the organ to which they belong. But further, in many of the large class of tumors distinguished as "malignant," the development of tissue has not gone to the extent of producing any of those species of which the body is normally constituted; and in this respect, as well as in their tendency to rapid degeneration, the vital endowments of their elements must be reckoned as below those of the normal tissues. - It is not always easy to draw the line between certain tumors and supernumerary parts, especialiy when the production of the former is symmetrical ; but the first appearance of the latter never takes place save during embryonic life, and their structure is more complex, and is more conformed to the plan and construction of the body at large, than is that of tumors, whose production may take place at any period of life. And between those tumors which are known as "piliferous" and "dentigerous cysts," and those encysted embryos (usually incomplete in their formation) which are sometimes found in the bodies even of males, it is impossible to establish any line of demarcation sufficiently precise, to prevent our recognizing them as all having the same origin, and

1 See Princ. of Comp. Phys., \& 475, Prof. Vrolik in Cyclop. of Anat. and Phys., art. Teratology, vol. iv, p. 976 ; and Prof. Allen Thomson on Double Monstrosity, in Edinb. Monthly Journal, June and July, 1844. 
being expressions of the same power, - the simple cyst being a kind of rude attempt at the production of a distinct individual, - and the encysted enbryo being but the result of an unusually high development of a proliferous cyst.

359. The state of Atrophy is in all respects the very opposite of that of Hypertrophy ; consisting in such a reduction in the rate of formative activity of the parts, as compared with that of their "waste," that their nutrition is no longer naintained at its previous standard: so that they are gradually reduced in bulk, or degenerate into some inferior histological type, or (which is more common) undergo both dininution and deterioration at the same time. It is important to bear in mind, that Atrophy may take place, either locally or generally, from an unusually rapid disintegration of the tissues, uncompensated by a corresponding increase in the rate of their nutrition: of such local atrophy, we have a characteristic example in the rapid reduction of the bulk of the uterus after parturition, and of the mammary glands after the sudrlen cessation of lactation; of the general, we see an illustration in that rapid wasting of the system, which takes place in the irritable state that results from excessive and prolonged exertion of body or anxiety of mind, especially when accompanied with want of sleep, the increased disintegration being marked by the presence of an unusual anount of urea and of the alkaline phosphates in the urine. But in the ordinary forms of Atrophy, there is not merely a relative but an absolute reduction in the rate of the frrmative process, or a lowering of its standard of perfection; and here also we have to look for its causes, on the one hand, in the condition and supply of the blood, and on the other, in the formative capacity of the tissucs themselves.-The Atrophy dependent upon an insufficient supply of nutritive materials, may be either general or partial. General atrophy, or emaciation, is a necessary result of deficiency of food; but it may also proceed from an imperfect performance of the assimilating processes, whereby the nutritive materials do not receive their requisite elaboration, as in cases of disease of the mesenteric glands; or from an unusual energy of the metamorphic processes, whereby the azotized constituents of the food are decomposed into excrementitious products, without undergoing assinilation at all, as seems to be the case in diabetes. Of the atrophy of a particular tissue, consequent upon the deficiency of its proper materials in the blood, we have an example in the reduction of the adipose, when there is no surplus of fatty matter to serve for its nutrition, but on the other hand, a withdrawal of the contents of the fat-cells into the circulating current, whilst the nutrition of the nuscular and other azotized tissues may proceed with its usual vigor.-Instances of complete local atrophy, or gangrene, resulting from deficiency in the supply of blood to a part, are by no means unfrequent; but it is less common to meet with a prolonged diminution in the rate of nutrition from such a cause, since a partial obstruction to the circulation is usually removed after a short time by the enlargement of the collateral vessels. Yet there are peculiar circumstances under which this does not take place; thus Mr. Curling has shown that atrophy may occur in that portion of a fractured bone which is cut off from the direct supply of blood through the great medullary artery; the circulation being restored by anastomosis to such an extent as to prevent the death of the bone, but not so completely as to support vigorous nutrition. ${ }^{2}$

360. The most frequent cause of Atrophy lies, however, in the deficiency of fornative power in the tissues themselves, arising from the decline of that capacity which they inherit from the germ. This decline, as already 
shown, takes place in the body at large, as a part of the regular order of things with the advance of years, and also normally occurs in particular organs at earlier periors of life; but it sometimes takes place prematurely, either in the body at large, or in particular organs, so that they undergo a wasting or degeneration without any ostensible cause. Thus it is not at all uncominon for Articular Cartilages to be almost entirely destroyed through defect of nutrition, without any pain or other symptoms to call attention to the change in progress $;^{1}$ and many similar cases might be cited. There is reason to believe that "fatty degeneration," the form under which degeneration most commonly presents itself $(\$ 351)$, is in reality far more frequent than simple wasting; but it attracts less notice, because the bulk of the tissue is little or not at all dininished; and it is only when their function becomes impaired, that attention is seriously drawn to the change. This form of Atrophy can seldom be attributed to antecedent diminution in functional activity; for it is most common in organs upon which there is the most constant demand for the energetic performance of their respective duties, as, for instance, in the heart, the kidneys, and the liver. But the formative activity of Muscles and Nerves is so closely dependent, as already several times pointed out, upon the active exercise of their functional powers, that atrophy is certain to supervene if this be interrupted; and this atrophy may or may not present itself under the form of fatty degeneration; a shrinkage of the parts, concurrently with the production of an increased amount of fit in them, being perhaps the morle in which it most frequently takes place. Atrophy of one part, moreover, may be dependent upon atrophy or imperfect functional activity of another, if the two be so related in their normal functions, that a decline of one involves a corresponding decline in the other. Thus if a motor nerve be paralyzed, the muscles which it habitually calls into action will be atrophied; and this will equally happen, whether the want of motive power depend upon a deficient production of it in the nervous centres, or upon an interruption to its conduction through the trunks. ${ }^{2}$ On the other hand, if the muscles of a part undergo degeneration from want of use (as in disease of the hip-joint), the nerves which supply them also suffer. The same is the case in regard to the nerves and organs of sense; for atrophy of the eye will occasion atrophy of the optic nerve, and destruction of the optic ganglia will induce atrophy of the eyes and optic nerves. Even the bones of a limb will suffer, in cases of atrophy of the muscles consequent upon disuse; for in an experiment made by Dr. J. Reid, to determine the effect of artificial exercise in maintaining the nutrition of muscles whose nerves

1 See Redfern, On Abnormal Nutrition in Artieular Cartilages, p. 65.

2 The Author had some time ago under his observation a case in which three males of a family progressively beeame attieted, botween the ages of 3 and 5 years, with fatty degeneration of the museles, which proceeded in the most advaneed ease to the alnost eomplete obliteration of their normal structure. This change has been considered by many eminent praetitioners to be idiopathic ; that is, to have its primary origin in the inuseular tissue; and the measures which had been employed to arrest it bad been of no avail whatever. It was a strong argument, however, against sueb a view of the case that, in the heart of the eldest sun, who died of fever at the age of 16, no fatty deguneration could be diseovered; and on making inquiry into the history of the parents and of their families, ample evidenee was diseovered for the belief, that the disease was dependent upon the want of funetional power in the nerrous eentres. Aetinu on this view, it was reeommended that the nuseular system should be kept as much as possible in a state of aetive cxercise, and that a weak galvanic current should be frequently transinitted through the limbs from the spine. This trentment proved so far suecessful that the progress of the disease appeared to be arrested, in the most advineed case, whilst a deeided improvement took place in the eondition of n younger child, who was previously passing rapidly in to a state resembling that of his elder brothers. 
had been divided, the bones of the quiescent limb only weigherl 81 grains, whilst those of the exercised limb weighed 89 grains. - It is an inportant fact, which was first pointed out by Mr. Paget, ${ }^{2}$ that when fatty degeneration is conmencing in any tissue, which is characterized by the persistence of its nuclei, it is in the nuclei that the first alterations are seen ; for they become pale and indistinct, and may eren disappear altogether, alnost before any other change is disceruible in the contents of the cells or tubes to which they appertain; but in atrophy from mere decrease, this disappearance of the nuclei does not occur.

361. Reparative Process.-The nutritive operations take place with extraordinary energy and rapidity in the process of Reparation; by which losses of substance occasioned by injury or disease are made gond. In its most perfect form, this process is exactly analogous to that of the first development of the corresponding parts; and its results are as complete in the one case as in the other. In fact, among the lowest tribes of Animals, we find these two conditions blended, as it were, together; for the process of reparation may be carried in them to such an extent, as to reproduce the whole orcanisni from a rery small portion of it. In the Hydra, or Fresh-water Polyp, there would seem to be scarcely any limit to its power; for, even if the body of the animal be minced into small fragments, every one of these can produce a new and perfect being. In this manner, no less than forty have heen artificially generated from a single individual.- In ascending the Animal scale, we find this reparative power less conspicuons, because limited in its exercise to particular tissues and to comparatively insignificant parts of the body $;^{3}$ and in Man, as in other warm-blooded Vertebrata, the regenerative power is for the most part restricted in its exercise, as Mr. Paget has pointed out, to three classes of parts, namely: (1.) "Those which are former entirely by nutritive repetition, like the blood and epithelia (their germs being continually generated de novo in the ordinary condition of the body); (2.) Those which are of lowest organization, and (what seems of more importance) of lowest chemical character, as the gelatinous tissues, the areolar and tendinous, and the bones; (3.) Those which are inserted in other tissues, not as essential to their structure, but as accessories, as connecting or incorporating them with the other structures of vegetative or animal life, such as nerve-fibres or bloodvessels. With these exceptions, injuries or losses are capable of no more than repair in its limited sense-i.e., in the place of what is lost, some lowly organized tissue is formed, which fills up the breach, and suffices for the maintenance of a less perfect life."-Yet, even thus restricted, the operations of this power are frequently most remarkable; and are in no instance, perhaps, more strikingly displayed, than in the re-formation and remodelling of an entire Bone, when the original one has been destroyer by disease. That this porrer is intimately related to that by which the organism is normally built up and maintained, is evident, not merely from the peculiar mode in which it is exercised,-its tendency being always to reproduce each part in the form and structure characteristic of it at the particular perind of life, and not according to its embryonic type,-but also from the fact, that it is more effectual in the state of growth than in the adult condition, and that it can do far more in the embryonic state, when development as well as growth is taking place, than after the developmental process has ceased. In fact, as Mr. Paget has remarked (loc. cit.), its amount at different periods of existence, as in different classes of animals, seems to bear an inverse ratio

1 Physiological, Anatomical, and Patholorical Researches, p. 10.

2 Lectures on Surcical Pathology, vol. i, p. 106.

3 See Princ. of Comp. Phys, chap. xi, sect. 3.

4 Op. cit, p. 164. 
to the degree of development which has already taken place. Thus it is well known to every practitioner, how inuch more readily and perfectly the lesions resulting from accident or disease are repaired in childhood and youth, than they are after the attainment of the adult state. And there is evidence that, during embryonic life, the regeneration of lost parts may take place in a degrce to which we have scarcely any parallel after birth: for Prof. Simpson" has brought together numerous cases, in which, after "spontaneous amputation" of the limbs of a foetus, occurring at an early period of gestation, there has obviously been an imperfect attempt at the re-formation of the anputated part from the stump; and it seems probable from the history of normal development, that in the cases in which perfect hands and feet have been present without the corresponding limbs, these hands and feet have been secondary productions from the stumps of amputated limbs, since any original defect of development would liave affected the hands and feet rather than the arms and legs. There are occasional examples, moreover, in which this regenerative power has been prolonged to an unusually late period: thus an instance is recorded, on authority that can scarcely be doubted, of the twice-repeated reproduction of a supernumerary thumb, after it had been twice completely removed $;^{2}$ and the Author has been assured by a very intelligent surgeon, that he was cognizant of a case in which the whole of one ramus of the lower jaw having been lost by disease in a young girl, the jaw had been conpletely regenerated, and teeth were developed, and occupied their normal situations in it. ${ }^{3}$

362. It has been a general opinion anıng British surgeons (founded upon what they believe, but erroneously, to have been the doctrine of Hunter), that Inflammation is essential to the process of Reparation. There is no doubt that, as usually conducted, the healing of wounds is attended by a greater or less degree of Inflammation; but it does not thence follow that this morbid condition is essential to the renewal of the healthy state; and in fact it can be shown that, in the majority of cases, the occurrence of Inflammation is injurious rather than beneficial. It was by Dr. Macartney that the first clear enunciation of this important truth was made; and his conclusions, founded upon a philosophical comparative survey of the operations of Reparation and Inflammation as performed in the different classes of animals, namely, "that the powers of reparation and reproduction are in proportion to the indisposition or incapacity for inflammation; - that inflammation is so far from being necessary to the reparation of parts, that, in proportion as it exists, the latter is impeded, retarded, or prevented;-that, when inflammation does not exist, the reparative power is equal to the original tendency to produce and maintain organic form and structure; - and that it then becomes a natural function, like the growth of the individual, or the reproduction of the species," - may be regarded as substantially correct, although requiring some modification in particular cases.

363. The simplest of all the methods of healing of an open wound, is that

1 These cases were brought by Prof. Simpson before the Physiological Section of the British Association, at its meeting in Edinburgh, Aug. 1850. The Author, having bad the opportunity of examining two living cxumples, as well as Prof. Simpson's proparations, is perfectly satisfied as to the fact.

'See Mr. White's Treatise on the Regeneration of Animal and Trgetable Substances (1785), p. 16. A case was under Dr. Carpenter's observation, where the reproduction of a supernumerary digit, after renuval, oceurred once, and a second operation was postponed till the child had erased to grow.-ED.

3 For analoguus cases, seo Wagner, On liesections, Sydenham Society's transl., p. 137.

- Dr. Macartney's T'reatise on Inflammation, p. 7. 
which is termed by Dr. Macartney "immediate union." It is often seen in the case of small incised wounds, such as cuts of the fingers, or the incision made in venesection, in which the two edges can be bronght into close approximation, so that they grow together without any comnecting medium of bloorl or lymph; but it sometimes occurs in larger ones, ${ }^{1}$ and as it is the best intaginable process, the surgeon ought to favor it as much as possible, by procuring the most exact coaptation of the wounded parts, and by repressing any tendency to inflammation which will interfere with it. This is the morle of union which was spoken of by John Hunter as "healing by the first intention." He supposed that the mion takes place through the medium of the bloud intervening between the lips of the wound, which undergoes organization into a commecting tissue ; but it is now certain that although blood may become organized, especially when effused into a wound secluded from the air, yet that its intervention opposes, rather than favors, healing by immediate union.

364. That which is commonly known amongst British Surgeons as "healing by the first intention," is that which was rlcsignated by Hunter as " union by adhesion" or by "adhesive inflammation." This process takes place in the case of incised wounds, of which the edges are not brought into perfect coaptation, or in which some inflammatory action is present, which gives rise to the effusion of plastic lymph. In either case, the connection is finally reestablished by the organization of the lynph, into which vessels pass from both surfaces; but the intervention of this bond is manifested in the persistence of the cicatrix, which is quite distinguishable by its peculiar appearance from the surrounding tissue. A very good example of this process, as it takes place under favorable circumstances, is presented after operations for harelip; the wound left by which, lowever, may partly heal by "immediate union." Even the moderate effusion of lymph, to a degree that is altogether salutary, cannot be regarded as alone sufficing, under such circumstances, to constitute Inflammation. But it is well known that if a slight wound which is thus healing, be provoked to an increased degree of inflammation, its progress is interrupted; and all the means which the Surgeon employs to promote union are such as tend to prevent the accession of this state.-The only case in which the concurrence of Inflammation can be regarded as salutary, is that in which there is a deficiency of Fibrin in the blood, causing a deficient organizability of the lymph. It has been seen that the amount of fibrin is rapidly increased by inflammation (\$200); and the Surgeon well knows that a wound with pale flabby edges, in a depressed state of the system, will not heal, until some degree of Inflammation has commenced. But when the inflammatory state has developed itself, in however trifling a degree, there is always a risk of. its proceeding further, and occasioning a degeneration of the plastic material, so that the formation of pus-cells and the effusion of purulent fluid take place, instead of the development of uniting tissue.

365 . The regeneration of epithelium when the injury has been so slight as only to effect its abrasion has chiefly been studied in the case of the corneal epithelium, ${ }^{2}$ and appears to be effected chiefly by the adjoining cells thrusting out processes towards the wound and gradually bridging it over and covering it; but some new cells may also arise from the multiplication and devclop-

1 Mr. Paget mentions a case of extirpation of a mammary tumor, in which the greater part of the wound was found to have healed after this fushion; the slin and fuscia having so firmly adhered, that no indication existed of their previous detachment; and no effusion of coagulable lymph, or production of a connecting tissue, was detectable by nicroscopicexamination. (Lectures on Surgical Pathology, vol. i, p. 193.)

2 Sce Arnold, Virchow's A rehiv, Band xlvi, Heft 2; Hoffmann, idem, 1870, p. 373; Heiberg, Stricker's Jahrbücher, 1871, p. 7, and Küss, Cours de Physiologie, 1872. 
ment of the nuclei in the subjacent tissue, and there give rise to the formation of islands (Küss). The importance of the artificial aid that may be given to the efforts of nature in this direction are sufficiently shown in the remarkable results obtained by Reverdin in his method of treating ulcers by the transplantation of skin. ${ }^{1}$ "The reparation of somewhat deeper wounds in which there has been so great a loss of substance that neither immediate union nor adhesion by a thin layer of coagulable lymph can take place, is accomplished by the gradual development of new tissue from the "nucleated blastema" with which the eavity is first filled. But this may take place in different modes, according to the degree in which it is disturbed by the Inflammatory process; and it should be the great object of the Surgeon to procure the most favorable method of its performance. It has been shown by Mr. Paget ${ }^{2}$ that the mode in which the process of filling up is accomplished, differs essentially according as the wound is subcutaneous, or is exposed to air. In the former case, the nucleated blastema is gradually developed into fibrous tissues without any loss, and usually with freedom from local inflammation (beyond what may have been requisite for the production of the plastic fluid), as well as from constitutional irritation. In the latter case, the nucleated blastema is developed into cells; and those on its exposed surface are unable, either from degeneration or from imperfect development, to pass on to any higher form of organization, but take on the characters of pus-cells, and are only fit to be cast off. ${ }^{3}$ Hence there is a continual loss of plastic material, the amount of which in the case of an extensive suppurating sore, forms a most serious drain upon the system; whilst, at the same time the local inflammation gives rise to more or less of constitutional disturbance, and the formatian of new tissue is by no means so perfect as in the preceding case. In cold-blooded animals, however, the contact of air does not produce this disturbance; and we see wounds with extensive loss of substance gradually filled up in them by the development of new tissue, without any suppuration or other waste of material, very much as in the subcutaneous wounds of warm-blooded animals. This method of healing, which has been termed by Dr. Macartney the "modelling process," is nothing else than healing by granulations under the most favorable circumstances; and to procure this should be the endeavor of the Surgeon, who too frequently considers suppurative granulation as the only means by which an open wound ean be filled up. The difference between the two modes of reparation is often one of life and death, especially in the case of large burns on the trunk in children; for it frequently happens that the patient sinks under the great constitutional disturbance occasioned by a large suppurating surface, althougl he has survived the immediate shock of the injury.-Now the means adopted by Nature to bring this about, in warm-blooded animaks, is the formation of a scab; which reduces the wound more nearly to the'condition of a subcutaneous one, so that the reparative growth and formation of new tissue take place (under favorable circumstances) without any sup-

1 Reverdin, Arehives Gén. de Méd., 1872, Mars. Juin; Duval, Nouveau Dict. de Méd., 1873, t. xvi, p. 715; Demarquay, De la Régénération des Organes et des Tissueg, 1874, p. 61.

20 ). cit.

3 The organizable material or lymph contaning pus-corpuscles thus thrown out, eonstitutes a very favorable bed for the devolopment and multiplieation of the various spores which the resmathes of Tyndall (Nature, vol. i, 1869-70, p. 339, and vol. iv, p. 124), as well as those of Dr. Cumningham and Lewis (Reports Samitary Board of Calentta), have shown to be constantly floating in the air. At the temperature of the hody, Bacteria, Vibriones, and other organic forms soon make their appearanee in ineilculable numbers, and accompany, if they do not produce, the putrefietion whieh takes pluee in the fluid. 
puration, and with scarcely any irritation; the subsequent cicatrix, ton, being much more like the natural parts, than are any scars formed in wounds that remain cxposed to the air. In the Human subject, lowever, the process is far less certain than it is among the lower animals, owing to the liability to inflammation in the wounded part, and the consequent effusion of fluid, which produces pain, compresses the wounderl surface, or forces off the scab, with great discomfort to the patient, and retardation of the healing. Small wounds, however, in persons of good habit of borly, and in parts which can be completely kept at rest, readily heal in this manner; and large wounds have been known to close, in the same desirable mode, beneath a clot of inspissated blood. In fict, among "uncivilized" nations whose habits of life are favorable to health-their borlies being continually exposed to fresh air, thcir food wholesnme and taken in moderation, and their drink water or other unstimulating liquids-there seems to be as great a tendency to this method of reparation, as exists among the lower animals; and the difficulty of procuring it among the members of "civilized" communities, is owing, without doubt, to the unnatural conditions under which they too frequently live. Seeing as we continually do, the effects of foul air, of habitual excess in diet, and of the constant abuse of stimulants, in impairing that form of the reparative process which must be regarded as the least favorable, namely, the closure of a wound by suppurating granulations, it is very easy to comprehend, that, to induce the most favorable method, the most perfect freedom from all pernicious agencies should be required.

366. The most effectual means of promoting this kind of Reparative process, and of preventing the interference of Inflammation, vary according to the nature of the injury. The exclusion of air which almost invariably contains the germs of low organisms from the surface, and the regulation of the temperature, appear the two points of chief importance. The value of the former is well shown by the favorable results obtained by the plan suggested by Prof. Lister, ${ }^{1}$ of dressing wounds in an atmosphere saturated with carbolic acid spray and of the frec application of carbolic acid to wounds, fistulous passages, etc., and by covering them with a paste formed of whiting, boiled linseed oil, and carbolic acid. By Dr. Macartney, the constant application of moisture is also insisted on. ${ }^{2}$ He states that the immediate effects of injuries, especially of such as act scverely upon the sentient extremities of the nerves, are best abated hy the action of "steam at a high but comfortable temperature, the influence of which is gently stimulant, and at the same time extremely soothing." After the pain and sense of injury have passed away, the steam, at a lower temperature, may be continued; and, according to Dr. M., no local application can compete with this, when the Inflammation is of an active character. For subsequently restraining this, however, so as to promote the simple reparative process, WV ater-dressing will, he considers, answer sufficiently well; its principal object being the constant production of a moderate degree of Cold, which diminishes, whilst it does not extinguish, sensibility and vascular action, and allows the Reparative process to be carried on as in the inferior tribes of animals. The reduction of the heat in an extreme degrce, as by the application of ice or iced water, is not here called for, and would be positively injurious; since it not only renders the cxistence of Inflammation in the part impossible, but being a direct scdative to all vital activity, suspends also the process of restoration. The efficacy of water-dressing in injuries of the severest character, and in those which are most likely to be attended with violent Inflammation (especially wounds of the large joints), has now been established beyond all question; and its em- 
ployment is continually becoming more geueral. ${ }^{1}$-Other plans have been proposed, however, which seem in particular cases to be equally effectual. To Dr. Greenhow, of Newcastle, for instance, it was accidentally suggested, a few years since, ${ }^{2}$ to cover the surface of recent burns with a liquefied resinous ointment, so as to form an artificial scab; and he states that in this manner suppuration may be prevented, even where large sloughs are formed; the hollow being gradually filled up by new tissue, which is so like that which has been destroyed, that no change in the surface manifests itself, and none of that contraction, which ordinarily occurs even under the best management, subsequently takes place.-A plan has, moreover, been proposed for preventing suppuration "and promoting reparation by the "modelling" process, which consists in the application of warm dry air to the wounded surface. Although the experiments yet published have not been entirely satisfactory, they seem to show that whilst the process of healing may be slower under treatinent of this kind, it is attended with less constitutional disturbance than is often unavoidable in the ordinary method; and that it may, therefore, be advantageously put in practice in those cases in which the condition of the patient requires every precaution against such an additional burdell,-as after amputation in a strumous subject. ${ }^{3}$

367. When the process of healing of an open wound by Suppurative Granulation is attentively watched, it is seen that the first stage is the formation of a "glazing" on the exposed surface, which closely resembles the buffy coat of the blood, being composed of coagulated fibrin and colorless corpuscles: in this manner a sort of imperfect epithelium may be formed, within half an hour after the surface has been laid bare. The increase of this glazing is the prelude to the formation of granulations; but whilst it is going on, there is, in and about the wound, an appearance of complete inaction, a sort of calm, in which scarcely anything appears except a slight oozing of serous fluids from the wound, and which continues from one day to eight, ten, or more, according to the nature and extent of the wounded part, and the general condition of the body. "This calm," says Mr. Paget, "may be the brooding-time for either good or evil; whilst it lasts, the mode of union of the wound will, in many cases, be determined; the healing may be perfected, or a slow uncertain process of repair may be but just begun; and the mutual influence which the injury and the patient's constitution are to exercise on one another, appears to be manifested more often at or near the end of this period, than at any other time." The cessation of this period of calm, and the active commencement of the reparative operations, are marked by the restoration of the flow of blood in the vessels of the wounded part; but the current is not altogether normal, being slower but fuller than natural, so that on the whole more blood than usual passes through the capillary plexus. 'Th is increased afflux of blood is followed by effusion of plastic material in increased proportion; and it is from this effusion that the granulating process properly commences.

368. The process of Suppurative Granulation, then, appears to differ from the process of granulation as it takes place in closed wounds, or in a warm moist atmosphere (the "modelling process" of Dr. Macartney), essentially in this, - that a large part of the corpuscles thrown out on the womnded surfice rlegenerate into pus in the former case, whilst none are thus wasted in the latter; but that the existence of inflammation occasions a more copious supply of fibrin in the former case, and increases its tendency to

1 See an account of the results of this treatment by Dr. Gilchrist, in Brit. and For. Med. Rev., July, 1846, p. 242.

z Mledieal Grazte, Oct. 13th, 1838.

${ }^{3}$ See M. Jules Guyot, De l'emploi de la Chaleur dans le Traitement des Ulcères, etc. 
become organized; the filling up of a wound with granulations being thus a much more rapid process than that renewal of the completely formed tissues which may take place in the absence of inflammation. The inperfect character of the granulation structure is shown, by the almost complete disappcarance of it after the wound has closed over. The portion of it in immediate contact with the subjacent tissue, however, appears to undergo a higher organization; for it becones the medium by which the cicatrix is made to adhere to the bottom of the wound. It is very liable to undergo changes which end in its disintegration; as is evident from the known tendency to reopening, in wounds that have been been closed in this manner.

369. When two opposite surfaces of granulations, well developed, but not yet covered with cuticle, are brought into apposition, they have a tendency to unite, like the two original surfices of an incised wound. 'This method of union, which was noticed by John Hunter, has been appropriately termed "secondary arhesion" by Mr. Paget. 'The surgeon may frequently have recourse to it with great idvantage, when primary adhesion is impossible, and when the filling up of the wound with granulations would be a tedious process, and very exhausting to the patient. In applying it to practice, it is essential to success, first that the granulations should be healthy, not inflamed or profusely secreting, nor degenerated, as those in sinuses commonly are; and secondly, that the contact between them should be gentle but maintained: it seems desirable, also, that the granulation surfices should be as much as possible of equal development, and alike in character. ${ }^{1}$

\section{Abnormal Forms of the Nutritive Process.}

370 . Under the preceding head we have considered the chief variations in the degree of activity that are witnessed in the ordinary or normal conditions of the Nutritive process, - those conditions, namely, in which the products are adapted, by their similarity of character, to replace those which have been removed by disintegration. But we have now to consider those forms of this process in which the products are abnorinal,-being different from the tissues they ought to replace. We shall confine ourselves to a brief examination of a few of some of the most important of these states; and that which first claims our consideration, on account of the firequency of its occurrence and the importance of its results, is Infammation.-Although Pathologists have been accustomed to look for the "proximate cause" of the phenomena which essentially constitute the Inflammatory state, or, in other words, for the first departure from the normal course of vital action, in the enlarged or contracted dimensions of the bloodvessels of the inflamed part, or in the altered rate of movement of the blood through it, yet it may now be safely affirmed that these are only secondary alterations, depending upon an original and essential perversion of that normal reaction between the blood and the tissues, which constitutes the proper Nutritive process. This perversion manifests itself in the early stages by a disposition of the cellular elements to return to their embryonic condition, and in the later periods by (1) a diminution in the formative activity of the tissues, leading to their degeneration and death; (2) by an augmentation of the plastic components of the bluod, proceeding in all probability, as Virchow has suggested, from their increased local production, and subsequent conveyance into the circulating fluid by the lymphatics; and (3) by these

1 On the whole subject of the Reparative Processes, see Mr. Paget's admirable Lectures on Surgical Pathology (vol. i, Lect. vii-xii); from which many of the furegoing statements and doctrines are adopted. 
newly-formed materials appearing either in a state in which they may pass into a low form of organized tissue, or in such a degraded condition that they are altogether unorganizable, and are fit only to be cast out from the borly. Each of these phenomena requires a separate examination, both as to its causes and its consequences.

371. Although it has been customary to speak of Inflammation as a state of "increased action" in the part affected,- of which increased action, the augmentation in the bulk and weight of an inflamed part, and in the quantity of blood which passes through it, together with its higher temperature and more acute sensibility, would seem to furnish sufficient evidence,- - yet all these signs are found to be deceptive when they are more closely examined; and the conclusion is forced' upon us, that the vital power of the part is really dcpressed rather than exalted. For the increase in bnlk and weight is not due to such an augmentation of its proper tissue, as would truly constitute Hypertrophy ; on the contrary, even in the slightest forms of Inflammation there is such a diminution in the rate of its nutrition as really constitutes Atrophy; and such augmentation of the solid mass as may take place, is produced by the passage of the fluid which should properly have been applied to the nutrition of the part, into an organized tissue of the lowest kind, and this in virtue rather of its own plasticity than of the vital force which it derives from the tissues which it infiltrates. That there has been an atrophy rather than a hypertroply of the proper fabric of the part, becomes evident enough when the inflammation has passed away, and this newly-formed tissue undergoes degeneration and absorption. The only tissues in which there is any appearance of increased formation during the inflammatory state, are those which correspond in their low type of organization with the new tissue thus generated, namely, the areolar and other simple fibrous tissues, and also the osseous, in all of which, as Virchow has shown, the cells undergo a remarkable increase, constituting what he has termed Hyperplasia, or a formation of new elements, in opposition to Hypertrophy, or an increase in the nntrition of existing parts. ${ }^{1}$ When the Inflammation is more severe, the tendency to degeneration in the proper tissues of the part becomes very obvious; for it is by their interstitial decay and removal, that the cavity of all abscess is formed; it is by their superficial death and absorption or solution that ulceration takes places; and it is in the death of a whole mass at once that gangrene consists.

372. That a diminution in the formative activity of the Tissues is an essential characteristic of the Inflammatory state, further appears from the study of its Etiology; for whether the causes to which the inflammatory attack may be traced are local or general, acting primarily upon the tissues of the part, or first affecting the blood, their operation is essentially the same. 'Thus the local causes are all obviously such as tend either directly to depress the vital powers, or to clevate them at first, and then to depress them by exhaustion. Of the former kind are cold and mechanical injury; also mauy chemical agents, whose operation tends to bring back the living tissnes to the condition of inorganic compounds. Under the latter eategory are to be ranked all those agencies which produce overexertion of the functional power of the part; amongst which may be named heat, when not so excessive as to produce a directly destruetive effect. Now cold, heat, chemical agents, and mechanical injury, when operating in sufficient intensity, at once kill the part, by entirely destroying, instead of merely depressing, its vital powers; and it is on the borders of the dead part, where the cause has acted with less potency, that we find the inflammatory state subsequently pre- 
senting itself.-On the other hand, there can be no doubt that many inflammations have their origin in morbid eonditions of the Blood, which, without any other cause whatever, may determine all the other phenomena. This is nost obvious with regard to these of a "specific" kind; but it is also probably true of the majority of the so-called spontaneous or eonstitutional, as distinguished from trammatie inflammations. We seen, indeed, to be able to trace a regular gradation between inflammatory attacks which are entirely traceable to the introduction of a poison into the blood, and those which resnlt from eauses purely local. Under the first head, we may unquestionably rank such inflammatory diseases as are producible by inoeulation, the eruptive fevers for example; and scarcely less thoroughly demonstrated are the eases of rheumatism and gout, and many inflammations of the cutaneous textures, which, when occurring in the ehronie form, tend to exhibit a regular symmetry (\$218). In all such cases, the loeal affections are the external signs of the general affection of the blood, just as are the infianmations produced by the introdnction of arsenic or of other irritant poisons into the eirculation; and they may in fact be reasonably attributed to the impairment of the formative activity of the parts upon which these poisons fix themselves, in virtue of their "elective affinity" $(\$ 220)$, just as the peculiar functional aetivity of the nervous centres is affeeted by narcotie poisons. And this view of the really loeal action of what are primarily regarded as general or constitutional causes of inflammation, is confirmed by the fact that the loealization of the perverted nutritive eondition is often determined (as both Dr. W. Budd and Mr. Paget have remarkerl) by a previous or eoneurrent weakening or depression of the vital aetivity of the part. Thus a part which has been the seat of former disease or injury, and which has never recovered its vigor of nutrition, is always more liable than another to be the seat of loeal manifestation of blood disease; it is, in eommon language, the "weak part." And it frequently needs such a concurrent operation of a loeal depressing canse, to fix and develop the action of the eonstitutional cause, or blood disorder; thus, a rheumatie or gouty diathesis may exist for some time (as when, to use a eommon expression, the disease is "flying about" the patient), and yet the poison may not have sufficient poteney to produee an attack of acute inflammation, until the vitality of some particular organ becomes depressed by cold, overexertion, or some similar influence, which would not have itself engendered the diseased action, had it not been for the concurrenee of the morbic eondition of the blood.-Thus we seem justified in eoncluding that, whether the causes of Infiammation act directly upon the tissues of a part, or whether they aet upon it through the intermediation of the blood, their effect is to produce a depression in its vital powers, whieh manifests itself in a deficient us well as abnormally directed formative activity, and in an increased tendency to degenerction; and that this is one of the primary and essential conditions of Inflammation.

373. This view is by no means inconsistent with the oeeurrenee of other manifestations of Inflammation whieh have been supposed to indieate "increased action;" and, in faet, it is in such striking aeeordance with the phenomena presented by the movement of the blood, when these are inter-

1 Thus Impetigo appears about blows and scratehes in unhealthy ehildren, and Erysipelas first attacks the seat of loeal injury in men with unhealthy blood. Perhaps as good an example as any, is afforded by the uniform limitation of the inflammation eonsequent upon the introduction of Vaceine matter into the blowd, the the spots in which the puneture was made; notwithstanding that the whole mass of blood is affected by it, as is shown by its incapaeity for subsequently developing the poison of simall-pox. 
preted by the principles already laid down, as to afford a powerful confirmation to both doctrines. The usual condition of the vessels of an inflamed part, is one of dilatation; and this may be fairly attributed to the lowered vitality of their walls, whereby they yield too realily to the disteuding force of the current of blood. But this current moves too slowly; and its retardation may cradually increase, in the part most intensely inflamed, to the point of complete stagnation. Now this altered rate of movensent cannot be attributed to any general cause; nor ean it be accounted for by the change in the diameter of the vessels; for, on the one hand, it may oceur with a constricter state of the vessels, whilst, on the other, in the vessels surrounding the inflamed part, which yartake of the dilated condition, the flow of blood is so far from being retarded, that it usually takes place more rapidly than usual. But it may be fairly considered as the result of the lowered or suspended nutritive activity of the part, which will tend to retard or entirely check the motion of blood in the systemic eapillaries, just as the want of aeration retards or checks the pulmonary circulation $(\$ 266)$. It is quite true that a larger amount of blood passes through a limb, of which some part is in a state of active inflammation, than passes through the corresponting sound limb; but this is far from indicating "increased action" in the inflamel part, being dependent upon the augmented flow of blood through the tissues which surround it; and if the whole of a limb be in a state of inflammation passing on to gangrene (as necurs when a "frostbitten" limb has been incautiously warmed), the amount of blood which passes through it is diminished.-It would be just as erroneous to assume the elevated temperature of an inflamed part as a sign of "inereased aetion" in it; for this elevation is no doubt attributable in part to the angmented flow of blood through the surrounding vessels; and, so far as it depends upon local changes, it obviously indicates a more rapid disintegration of tissue, rather than a more energetic production of it; since it is in the former state, rather than in the latter, that the conditions of the levelopment of heat (on the chemical theory) are supplied, as we see that the heat of a muscle is the greatest when it is being disintegraterl by active exercise, not when it is being repaired by the formation of new tissue in the intervals of repose. But, as Mr. Paget justly remarks, "this phenomenon is involved in the same difficulty as are all those that concern the local variations of temperature in the body; difficulties which the doctrines of Liebig, however good for the general production of heat, are quite unable to explain." (See chap. xii.) - And lastly, with regard to the unusual tenderness of inflamed parts, this is obviously due to such a combination of causes, neither of which can be legitimately held to indicate an increase of its proper vital aetivity, that nothing ean be rested on this alone; especially as we see an augmentation in the susceptibility of the sentient nerves, under many circumstances (as in hysterical disorders), in which, far from an angmented, there is obviously a diminished activity in the parts from which they spring. - That neither an alteration in the circulation of a part, nor a departure from the normal condition of its nervous supply, can be regarded as one of the essential phenomena of inflammation, is obvious from this, that the most important phenomena of inflammation may present themselves, as results of injury or disease, in parts that have neither bloodvessels nor nerves: this is seen in the deposition of lymph in the eornea, in the ulceration of the cornea and of articular eartilages, and in other morbid actions in these parts, which, if ever they are vaseular, become so only after the effision of lympl in them, the new vessels being formed in this lymph, and not in the tissues themselves. Here it is obvious that the whole change eonsists in a perversion of the nutritive aetions which the tissues ought to earry on at 
the expense of the materials which they draw from the blood of the surrounding vessels.

374. Of the alterations in the condition of the Blond in Inflammation, an account has already been given $(\$ 199)$; and it is here only necessary to recapitulate then. The most characteristic is the augmentation, either of the organizable or plastic fibrin, or of the organized colorless corpuscles; the increased production of these two components seeming to bear in some degree a relation of reciprocity, the one to the other. The increase of Fibrin may be considered as the alteration most characteristic of a previously healthy and vigorous state of the system; and it is in the inflammations which occur in such subjects, that the effusions are most strongly disposed to become organized, and show the least tendency to undergo degenerative changes. On the other hand, the increase of the Corpuscular elements seems to occur in cachectic or otherwise unhealthy individuals; and the inflanmatory effusions which partake of the same character are far less plastic originally, and are extremely prone to undergo degeneration, either at the time of their effusion or subsequently. With this increase in the proportion of fibrin and colorless corpuscles, separately or in combination, there is a dininution in the proportion of the red corpuscles, albumen, and salts of the blood. None or these changes, however, can be legitimately regarded as originally or essentially characteristic of the inflammatory condition; they are, in fact, to be looked on rather as the results of its establishment, constituting that series of alterations in the circulating fluid which is of parallel order to that which occurs in the solid tissues wherein the inflammatory action has been set up.

375. The Inflammatory state is further characterized by the effusion and local production of certain of the components of the Blood, either upon the surface, or into the substance, of the inflamed tissues.-The effusion of pure serum cannot be regarded as characteristic of inflammation; since it may take place as a mere result of congestion, especially when this congestion is due to an obstruction to the return of the hlood; whilst, again, it may be due to an iltered condition of the albuminous constituent of the blood, which favors its transudation $(\S 196)$. The so-called serous effusions which are poured forth in inflammation, do in reality contain fibrin in solution ${ }^{1}$ but this fibrin may not manifest its presence by spontaneous coagulation, until its passage into the solid state is favored by the introrluction of a piece of the washed clot of blood, or of the buffy coat, or of muscle or some other animal tissue, which seems to act as a sort of nucleus of fibrillation. The presence even of fibrin in such an effusion, however, is not in itself a sufficient proof of the existence of inflammation; for it has been shown by the experiments of Mr. Robinson, ${ }^{2}$ Emminghaus, ${ }^{3}$ and others, that when the obstruction to the return of blood by the veins is so great as to occasion an excessive pressure within the capillaries, the fluid which transudes may contain enough fibrin to render it spontaneously coagulable.-The locally developed material which is most characteristic of Inflammation, is that which is known as coagulable lymph; it is much to be desired, however, that some other designation should be applied to it, since the term "lymph" can only be appropriately employed for the fluid contents of the lymphatic vessels. The peculiar characteristic of this inflammatory product, is its capability of spontaneously passing into the condition of an organized tissue, either fibrous or cellular, or a mixture of both; and of thus forming "fialse membranes"

1 This is denied by Virchow (Cellular Pathology, p. 392).

2 Iledico-Chirurgical Transactions, vol. xxvi, p. 51.

3 Emminghaus, Ber, d. k. k. Gesellschaft d. Wiss., 1873. 
on inflamed surfaces, or solidifying the inflamed part by the interstitial production of similar lowly organized textures. Although it has been too much the habit of Pathologists to speak of "coagulable" or "plastic lymph" as if it were always one and the sane thing, yet it really presents various gradations of character, which are mimifested in its different degrees of organizability, and in the diverse nature of the tissues developerl from it; and, as Mr. Paget has pointed out, ${ }^{1}$ there are two typical forms, the fibrinous, and the corpuscular, between which the others are intermediate. The former coagulates into a fibrous clot, resembling that of healthy blood, but usually showing a more distinct fibrillation. The latter" (the "croupous" exudation of Rokitansky) is characterized by the want of any proper coagulation, the fibrous clot being replaced by an aggregation of cells, which in their first appearance resemble very nearly the primordial condition of the corpuscles of the fluids of the absorbent vessels, and the colorless corpuscles of the blood. It is seldom, however, that either of these typical forms of lymph presents itself in a state of complete isolation from the other; they are much more commonly blended in various proportions, so that one or the other predominates; and it is mainly upon the preponderance of fibrin, that the "plasticity" of the fluid (or its capacity for organization) depends; whilst according to the preponderance of corpuscles, will be its tendency to degeneration. Thus the cxulation of fibrinous lymph is the symbol of the "allhesive" inflammation; whilst that of the "corpuscular" is similarly characteristic of the "suppurative" inflammation.

376. It is obviously of great consequence to ascertain the conditions which determine the production of one or other of these states; and these, as Mr. Paget has remarked (loc. cit.), may be considered under three heads, - (1) the previous state of the blood, (2) the seat of the inflammation, and (3) the degree and character of the inflammation. The condition of the blood, as determining that of the lymph, has been carefully studied by Rokitansky, who has shown that the characters of inflammatory deposits in different diathescs, correspond very generally and closely with those of the coagula found in the heart and pulmonary vessels after death. The results of Mr. Paget's experiments on the same subject have been already cited (\$217). And clinical observation fully confirms this doctrine by evidence of another kind; that, namely, which is afforded by the different course of the same specific disease, in different individuals, according to the previously healthy or abnormal condition of their blood. There can be no doubt that a very large proportion of what are called "unhealthy inflammations," especially those of the erysipelatous type, are to be regarded as owing their peculiarity to the low vitality of the components of the blood; which seems to be farored by the presence of decomposing matters, whose accumulation in the blood acts in many ways so prejudicially on the system at large, ${ }^{2}$ and though the evidence is as yet very faulty there is much reason for believing that the special form assumed by the inflummation in certain forms of disease is due to the development of the spores of various fungi and other low organisms which from their lightness are readily carried by the currents of the air, or may be ingested in drinking-water, and are ever rearly, when the conditions are fitvorable, to geminate. ${ }^{3}$ That the quality of the local product is in

1 Lectures on Surgieal Patholory, vol. i. p. 332

2 See Mr. Brooke Gallwey's papers on Unhealthy Inflammation, in the Laneet for $1849-50$, and the Medieal Guzette for $1850-51$.

${ }^{3}$ See the observations of Laptschinsly (Centralbiatt f. d. Med. Wiss., 1875, p. 84) on the accurrence of spirilla in the blood of patients sufferine from recurrent fever; of Luwis on the presence of II:matozon in Human blood in Chyluria (Report of the Sanitary Commission in India, 1872), and the numerous papers that have been pub- 
some degree determined by the seat or tissue in which the Inflammation occurs, appears from the different character of the products of the disordered actions that occur simultaneously in different organs of the same individual, and apparently under the operation of the same cause; thus it may happen that in plemro-pneumonia, the two surfaces of the pleura become connceted by an organized material of a fibrous character; whilst the effusion in the substance of the lung is rather of the corpuscular nature, and speedily passes into suppurative degeneration. Mr. Paget ingeniously proposes to account for the determining influence in question, on the idea that the inflammatory product is influenced at the time of its formation by the assimilative force of each part, so that it is to be regarded as a mixture of true lymph with its special product of assimilation; thus we observe that in inflammation of bone the lymph usually ossifies, in that of ligaments it is converted into a tough ligamentous tissue, and in that of secreting organs it contains a nixture of the ordinarily secreted product.-The mode in which the intensity of the Inflammation affects the character of the effused lymph, is twofold. For, in the first place, the nature of the original effusion is likely to vary according to the degree in which the ordinary nutritive process is in terrupted; since, the more intensc the inflammation, the less will be the assimilating force of the part, and the more will the nuatters effused from the vessels deviate from the natural plasma which would be drawn from them in healthy nutrition; whilst, on the other hand, when the inflammation is less severe, its product wili not differ so widely from the natural one, and will from the first tend to manifest in its developnent some characters corresponding to those of the natural formations of the part. But, secondly, the influence of the inflammation, or rather of the depressed vitality of the inflamed tissues, is shown in the tendency to degeneration which it impresses on the locally developed product; so that, even though this may be disposed to pass on under favorable circumstances to the complete formation of an organized tissue, its development is early checked, and it undergoes retrograde metamorphosis; or else, from the very commencement, its development takes place according to a lower or degraded type. The normal product of the organization of either fibrinous or corpuscular lymph, is undoubtedly a tissue closely allied to the ordinary areolar or connertive; it is of this that false membranes and adhesions are formed, and that the material of most thickenings and indurations of parts is composed $;^{1}$ and it is by the production of this tissue also, that losses of substance are in the first instance repaired, and that divided surfices are made to adhere. Various kinds of degeneration may subsequently take place in any of these products, according to the stage at which the developmental process is checked; and among these, in tissues which have once attained an advanced stage of development, the most common is the fatty.

377. Emigration of White Corpuscles and Diapedesis of the Red.-One of the most frequent results of the inflammatory process is the formation of Pus, a serous or albuminous fluid holding a large number of corpuscles in suspension, the origin of which has been the object of much recent investigation. The cells are spherical, about the size of the white corpuscles of the

lished during the last few years on the presence of Bacteria and other low organisms in the blood of patients laboring under various forms of zymotic disease, some of which are referred to in the year books of the New Sydenham Society.

1 The Author is much disposed, however, to agree with Dr. Handfield Jones, in believing that a chronic "fibroid degeneration," resulting from the substitution of a lowly organized tibrous tissue for the proper texture of the part, may take place, like "tubercular degeneration," without the occurrence of Inflammation, properly so called. See Brit. and For. Med.-Chir. Rev., vol. xiii, pp. 343, 349. 
blood, with softly shaded contours and numerous granules in their interior. They contain one, two, or more nuclei. By Virchow ${ }^{1}$ they were considered to be derived essentially from the proliferation of epithelial cells, and of connective-tissue corpuscles, and there can be no doubt that all intermediate stages between healthy epithelial cells and connective-tissue corpuscles, and pus-corpuscles, may be traced in inflammation, but numerous observers have noticed that under certain altered physical conditions of the circulation, an escape, both of the white and of the red corpuscles, takes place from the interior of the vessels into the adjoining tissues. This phenomenon was first observed in 1843, by Dr. W. Addison, ${ }^{2}$ and was noticed to occur in inflammation by Waller, ${ }^{3}$ who in a remarkable memoir fully corroborated Addison's observation, declaring that he had seen the corpuscles protruding half out of the vessels; whilst Addison had already arrived at the conclusion that pus-corpuscles of all kinds were only altered colorless blood-corpuscles. These statements, however, received little attention till the publication of Cohnheim ${ }^{4}$ of an essay on inflammation, in which he described the process of the passage both of the white and red corpuscles through the walls of the capillaries, and even of tolerably thick-walled veins, in detail. Cohnhein's observations immediately attracted great attention, and though they have been opposed by Feltz, ${ }^{5}$ Picot, ${ }^{6}$ and a few others, they have received the support of so niany good observers, as of Stricker, ${ }^{7}$ Prussak, ${ }^{8}$ Caton, ${ }^{9}$ Norris, ${ }^{10}$ Bastian, ${ }^{11}$ and Heller, ${ }^{12}$ that the main fact of the escape of the corpuscles from the vessels may be regarded as incontrovertible. In a recent essay, Cohnheim ${ }^{13}$ has given his latest views upon the point. The passage of the white corpuscles through the walls of the vessels appears to be due to some plysical alteration in the walls of the vessel, reducing their tenacity, and permitting the colloidal substance of the corpuscles to penetrate them in a mode essentially similar, as Norris showed, to that by which a solid body may be made to traverse the thin film of a soap-bubble. This process is probably aided by the amoboid movements of the white corpuscles, and in part also by the increased pressure of the blood. ${ }^{14}$ That neither the increased pressure of the blood, nor the mere dilatation of the vessels is sufficient per se to lead to the emigration of the corpuscles, seems to be demonstratel by the fict that if any slight injury, as a pinch of moderate severity, be inflictel on a transparent structure, as the tongue of a frog, the vessels in the vicinity may be seen immediately to enlarge (the arteries being first affected), permitting a more rapid current to flow through them. The veins then enlarge, and afterwards the capillaries. This condition is maintained for some minutes, when the arteries begin to contract, and with the capillaries return to their normal condition. The veins, however, do not follow this process of contraction, and hence the blood-current in them becomes slower.

1 See his Cellular Pathology, passim.

2 Exper. and Pract. Researches on Inflammation, 1843.

3 Plilosoph. Mragazine, Oet. and Nov. 1846. 4 Virelıw's Archiv, 1867.

5 liobin's Journ. de l'Anatomie, $7^{\text {me }}$ Année, 1870-71, pp. 33 and 505.

6 Idem, p. 4ijo. $\quad 7$ Stricker, idem, No. 6, 1867.

8 Prussak, Sitzungsber. d. WVien. Akad., Bd. Ixvi, p. 13.

9 Caton, Iournal of Inatomy and Physiology, 1871, vol. v, p. 35.

10 Norris, Proeeed. Roy. Society, 1871, No. 129.

1 Bastian, Transaetions of Pathologieal Society, 1868, vol. xix, p. 461.

12 II eller, Centralblatt f. d. Med. Wiss., 1870 , p. 310.

13 Cohnlieim, Neue Untersueluugen uber Entzundung, Berlin, 1873.

14 It is possible, as Purves (Centralblatt f. d. Med. Wis., 1874, p. 654), A rnold (Virchow's Arehiv, 1873, Bd. Iviii, 203), Thomas (Centralblatt, 1874, p. 344), and some writers maintain, that pores, whiel they believe are naturally present botween the epithelial cells of which the walls of the smallor vessels are composed may enlarge, but this requires further eonflrmation. 
As soon as this stage is reached, viz., dilated veins with retarded circulation, a very abundant adhesion of colorless blood-corpuseles to the walls of those veins is seen to take place sooncr or later; however, if the injury las not been too severe, the veins commence also to contract, in consequence of which the blood current bccomes quicker, and at the same time the number of adherent colorless corpuscles diminishes, until finally the normal condition is re-established. Now, notwithstanding there have been temporarily present the condition of dilated veins, slower blood-current, and marked adhesion of colorless blood-corpuscles to the walls of the veins, as well as increased pressure in the capillaries during the dilatation of the arteries, no colored or colorless corpuscles will be seen to pass through the walls of the vessels; on the other hand, by proceedings adapted to produce physical changes in the relations of the walls of the ressels to the blood, an abundant emigration of the white corpuscles can be produced almost at will. Thus, Stricker and Prussak have both shown, that after the subcutaneous injection of a small quantity of a ten per ceut. solution of common salt, under the skin of frogs and rabbits, a condition of the vessels is produced in which the red corpuscles readily escape from the vessels; the same occurs when the main vein of a limb is tied; and these observers regard the diapedesis of the red corpuscles as the result of some "active condition" of the capillary wall, a view that Colnheim also adopts, whilst Bastian attributes it to an "active condition," that is to say, to amœboid movements of the red blood-corpuscles themselves. The emigration of the white corpuscles may also be readily witnessed in the mesentery of a frog inflamed by mere exposure to air; under such circumstances the white corpuscles accumulate, apply themselves to the sides of the vessels, where they either remain stationary or slowly oscillate. In a little while small colorless projections are seen on the outer surface of the vascular coat. These subsequently become pyriform, and ultimately detach themselves from the vessels, appearing as colorless contractile amceboid corpuscles, with one or several nuclei; the whole process being accomplished in from one to two hours. ${ }^{1}$ That the presence of whitc corpuscles in large numbers in the tissues is not sufficient to constitute suppuration is shown well in the remarkable experiments of Tarchanoff ${ }^{2}$ upon the effects of woorara. On placing frogs under the influence of this poison, he found that the number of white corpuscles in the blood underwent great diminution, whilst the proportion of the red increased. ${ }^{3}$ The white corpuscles were found to be accumulated in the tissues and in the lymphatic vessels and sacs, which last were distended with lymph. These effects, which must be admitted to modify the statenıents of Goltz (see $\$ 155$ ), M. Tarchanoff attributes to augmentation of blood-pressure, owing to paralysis of the vaso-motor nerves, leading to dilatation and freer current of blood through the smaller arteries, and to repose of the muscles, and arrest of the contractions of the lymphatic hearts; yet, notwithstanding the exodus of the white corpuscles, no suppuration resulted, and on the animals recovering from the effects of the woorara, the white corpuscles quickly disappeared from the tissues, whilst the lymph-sacs returned to their normal condition. ${ }^{4}$

1 See Cornil and Ranvier, Manuel d'Histologie Pathologique.

2 Tarchanoff, Archives de Physiologie, 1875, p. 33 . See also Drozdoff, Journal de la Méd. Milit., 1872.

3 The proportion of red to white in a cubic millimetre in a healthy frog was as $200,375: 10,412$; in a curarized frog it was $514,436: 6759$ in the same quantity.

1 'Tarchanofl"s experiments are, as he himself points out, in accord with previous observations of Paschutin, to the effect that woorara causes an augmentation of lymph (Ludwig's Arbeiten, 1872, p. 197), of Genersich, that muscular movements favor the flow of the lymph through the lymphatics, of Ranvier (Comptes Rendus, Dec. 20th, 
In some instances the puriform fluid appears as a discharge on the surface of the membrane, as of the Urethra in Gonorrhøa, or of the Conjunctiva in Purulent Ophthalmia; in others it appears in the substance and between the ultimate textural components of the tissues themselves, and then constitutes an abscess. The anatomical changes that take place in a very well-defined though small abscess, that naniely of the small-pox pustule, have been made the subject of special study by Dr. Klein, ${ }^{1}$ and his observations show that the prineipal seat and origin of the changes occur on either side of the well-defined line which separates the rete Malpighii from the vascular tissues forming the papillary layer, the inflammation being apparently excited, or at least accompanied by the development in the finest lymphatics of a kind of fungus, consisting of a feltwork of delicate-branched filaments, giving off acrospores or conidia at the growing ends, like the fungi of the penicillium group, and which may be regarded either as resulting from the development of the poisonous agent to which the whole series of phenomena is due, or as some fungoid vegetation introduced from without and developing at this spot, because the conditions are favorable, coincidently with, or very soon after the appearance of the mycelium. The cells of the rete rapidly germinate and some enlarge, become vaculated, and unite with others to form cysts and cavities. 'The cysts are at first filled with clear fluid and granules, but subsequently with pus-cells and germinating fungus. Similar changes take place in the corium, and the whole tissue becomes infiltrated with leucocytes. When such a small abscess as this bursts, or when the discharge from the surface is accompanied by softening and breaking-down of the subjacent tissues, an ulcer is produced; but whetler the disintegrating tissues are entirely removed by absorption (having previously undergone that degenerative softening which is requisite for the occurrence of such process), or whether they are broken up and dissolved in the purulent fluid, is a point not yet determined. The conservative nature of the fibrinous exudation, and the consequent importance of fibrin as an element of it, are well shown by the results of its deficiency. Thus if there be no "sac" formed around a collection of pus, this fluid infiltrates through the tissues, and by its mere presence so impairs their nutrition, that a corresponding degradation takes place in the characters of the plastic material furnished for their assimilation; and hence the purulent effusion spreads without limit, and the tissues through which it percolates undergo rapid degeneration. So, again, when gangrene is spreading by contiguity (the proximity of the dead tissue tending to lower the vitality, and even to occasion the death, of that with which it is continuous), it is only when an inflammatory "reaction" occurs, or in other words, when a development of fibrinous lympl takes place in the substance of the tissues bordering on those which have lost their vitality, that a line of demarcation between the dead and the living parts is formed. And generally, it may be said, that, as the ultimate tendency of Inflammation is to produce the disintegration of the part, the ultimate tendency of the fibrinous material developed is to keep its elements together, and to repair the losses which have taken place, although with a very inferior material.It is only, however, with the subsidence of the inflammation, and the return to the ordinary type of nutrition, that the lighest development of the lymph can take place; and it is in proportion as this occurs more speedily, that

1869), and Emminghaus (Ludwig's Arbeiten, 1874), that seetion of the nerves of a limb inerease the flow of lymph, and lastly, of Hammarsten (Ludwig's Arbeiten, 1872 ), that dogs from whieh mueh lymph has been withdrawn eontain a larger amount of oxygen in their blood.

1 See Dr. Sanderson's Lectures, British Med. Journal, 1875, p. 405. 
the recovery of the organization proper to the part is more completely effected. ${ }^{1}$

378. In persons of that peculiar constitution, which is termed Scrofulous or Strumons, we find an imperfectly organizable or cacoplastic deposit, known by the designation of Tiberculur matter, frequently taking the place of the normal elements of tissue; both in the ordinary process of Nutrition, and still more when Inflammation is set up. A distinction must be drawn between the condition known as acute Tuberculosis and Phthisis, the latter being only one of the manifestations of the former. In 'Tuberculosis the adenoid tissue so extensively distributed through the body takes on new growth; the cells of which it is composed proliferate, and swellings and thickenings of the tissues composed of small cells and nuclei appear. In the latter stages, the cells are often separated by an amorphous or somewhat fibrous intermediate substance, and by their multiplication and pressure lead to occlusion of the vessels, and their own caseous degeneration and softening. The history of the formation of 'Tubercles in the lungs and other orgaus is essentially similar ; it appears, in the first instance, to be a kind of metamorphosis of the ordinary Nutritive process; and in this manner it may proceed insidiously for a long period, so that a large part of the tissue of the lungs shall be replaced by tubercular deposit, without any other ostensible sign than an increasing difficulty of respiration. In the semi-transparent, miliary, gray, and tough yellow forms of 'Tubercle, we find clear evidence of organization in the early stages in the form of cells and fibres, more or less obvious ; these bcing sometimes almost as perfectly formed as those of plastic lymph, at least on the superficial part of the deposit, which is in immediate relation with the living structures around; whilst they may be so degenerated as scarcely to be distinguishable. In no instances do such deposits ever undergo further organization; and therefore they must be regarded as cacoplastic. The larger the proportion of this kind of matter in a tubercular deposit, the more certainly does it compress the bloodvessels of the part, and. by cutting off the supply of nourishment lead to its own death, and conversion into cheesy matter, the surrounding lung-tissue almost always undergoing more or less fibroid change.-Thus it may now be lield as established with certainty that Tubercular matter is always, even in its most amorphous state, a product of cell-formation; and that the difference between the amount of organization which its several forms present, is due rather to a variation in the degree of its subsequent degeneration, than to an original diversity in histological condition. ${ }^{2}$

1 The Author has pleasure in referring to Mr. Paget's Leetures on Surgical Pathology (vol. $\mathrm{i}$ ), as eontaining, in his opinion, the best exposition of the subject of Inflammation yet made publie; and in acknowledging his obligations to them for much assistance in the short view of it given above.-The fundamental doetrines on which the Author would lay the greatest stress, however, are the same in all esscntial partieulars with those which he taught in the earlier editions of this Treatise. An exeellent aeeount of the general phenomena and pathology of Inflammation has been written by Mr. Simon in Holmes's System of Surgery, vol, i, p. i. The interesting paper of Mr. Lister, On the Early Stages of Inflummation, in the Philosophieal Transactions for 1858, will also well repay perusal. The work of Virchow, Cellular Pathology, translated by Dr. Chanee, contains a full aceount of the views of this author on the pathology of Inflammation. (See chaps. viii and $x$ vii.)

2 See Mr. Paget, in the Pathologieal Catalogue of the Hunterian Museum, vol. i, p 134; also Dr. Madden's Thoughts on Pulmonary Consumption. The subject of the nature and affinities of Tuberele will be found in terestingly given by Dr. Southey, in the Gulstonian Lectures for 1867; and the question of its inneulability has been the topie of diseussion in the Parisian Academy of Mcdicine for nearly two years past. Although it ean be scareely said that any definite eonelusion ean be drawn, the prefonderating opinion appears to be in favor of its inoeulability, especially in 
379. But although Tubercular matter may be slowly and insidiously deposited, by a kind of degradation of the ordinary Nutritive process, yet it cannot be doubted that Inflammation has a great tendency to favor it; so that a larger quantity may be produced in the lungs, after a pneumonia has existed for a day or two, than it would have required years to generate in the previous morle. But the character of the deposit still remains the same; and its relation to the plastic element of the blood is shown by the interesting fact, of no unfrequent occurrence,-that in a Pneumonia affecting a tuberculous subject, plastic lymph is often thrown out in one part whilst tubercular matter is deposited in another. Now Inflanmation, producing a rapid deposition of tubercular matter, is peculiarly liable to arise in organs which have been previously affected with chronic tubercular deposits by an impairment of the process of textural Nutrition; for these deposits, acting like foreign bodies, nuay of themsclves become sources of irritation; and the perversion of the structure and functions of the part renders it peculiarly susceptible of the influence of external morbific causes.

380. We frequently meet with abnormal growths of a Fatty, Cartilaginous, Fibrous, or even Bony structure; which result from the development of these tissues in unusual situations, and appear to originate in some perverted action of the parts themselves $(\$ \S 355,376)$.-But there is another renarkable form of disordered Nutrition, which is concerned in producing what have been termed heterologous growths-that is, masses of tissue that differ in character from any which is normally present in the body. Most of these are included under the gencral designation of Cancerous or Fungous structures; and it has been shown by Miiiller and succeeding inquirers, that the new growth consists of a mass of cells; which like the Vegetable Fungi, develop themselves with great rapidity; and which destroy the surrounding tissues by their pressure, as well as by abstracting from the Blood the nourishnient which was destined for them. These parasitic masses have a completely independent power of growth and reproduction; and some kinds of them can be propagated by inoctlation, which conveys into the tissues of the animal operated on, the germs of the peculiar cells that constitute the morbid growth, these soon developing themselves into a new mass. So it may be by the diffusion of the germs producerl in one part, through the whole fabric, by means of the circulating current, that the tendency to reappearance (which is one great feature in the malignant character of these diseases) is occasioned. But it would scem more probable, that this character rather depends upon the presence of a morbid matter in the blood, of which the formation of the Cancerous tissue is only the manifestation (\$330 note); the local discase thus being the consequence of a constitutional cachexia, rather than the constitional affection the result of the local disease. ${ }^{2}$

rabbits, as stated in the first instance by M. Villemin. It is certain that small partieles of tuberculous matter introduced beneatl the skin of these animals gradually travel ulong the lymphatics, affect the glands, and thence become disseminated through the body; but rabbits appear to be very liable to tubercular inflammation, and it has been found that many other materials besides tuberele when thus introdnced lead to the formation of tubercle, or masses which cannot be distinguished from tubercle. Experiments on other animals, though sometimes suceessful, have been upon the whole less satisfaetory. See Chauveau in Report of the second session of the Freneh Assoc. for the Advance of Science; Hering, II istologische und Experiment studien über der 'Tuberculosis, 187 :

I See Dr. Walshe on The Natrre and Treatment of Cancer; Mr. Simon's General Pathology, Lect. viii ; Mr. Paget's Lectures on Surgrical Pathology, vol. ii, Lect. xvi, and the discussion on Cancer in the Pathological Soeicty, reported in Lancet, vol. i, 1874 . 


\section{CHA P T R XI.}

\section{OF SECRETION AND EXCRETION.}

\section{Of Secretion in General.}

381. Tine literal meaning of the term Secretion is separation; and this is nearly its true acceptation in Physiology. But the ordinary processes of Nutrition involve a separation of certain of the components of the Blood, which are withdrawn from it by the appropriating power of the solid textures; and every such removal may be considered in the light of an act of excretion, so far as the blood and the rest of the organism are concerned $(\$ 218)$. Moreover, the separation of certain matters from the blood in a fluid state, either for the purpose of being cast forth from the body, or of being employed for some special purpose within it, which constitutes what is ordinarily known as Secretion, is effected by an instrumentality of the same nature with that whose operation constitutes an essential part of the nutritive process, namely, the production and subsequent agency of cells. Hence there is no other fundamental difference between the two processes, than such as arises out of the diverse destinations of the separated matters, and from the anatomical arrangements which respectively minister to these. For the products of the Secreting action are all poured forth, either upon the external surface of the body, or upon the lining of some of the cavities which communicate with it; and the cells by which they are separated from the blood, usually staud in the relation of epithelium-cells to those prolongations of the skin or of mucous membranes, that form the follicles or extended tubuli of which the Glandular organs are for the most part composed (Figs. $165,172)$. The act of Secretion appears to consist, in some cases, in the successive production and exuviation of the cells which minister to it, these cells giving up), by rupture or deliquescence, the substances which they have eliminated from the blood; such, for example, appears to be the mode of separation of the Sebaceous secretion of the skin, of the Mucous secretion of mucous membranes, of the secretion of Milk, and perhaps also of the Biliary secretion. On the other hand, there can be little question that those more liquid secretions, in which there is either very little solid matter (as is the case with the Cutaneous transpiration and the Lachrymal fluid), or in which the solids, though in larger amount, are in a state of such perfect solution as to be capable of easy transudation (as is the case with the Urine), are not formed in this mode; since neither are exuviated cells normally found in the secreted fluids, nor do the epithelial cells lining the glandular tubes or follicles present indications of being in a state of continual change. Still, even in these cases, it seems fair to conclude that the selective powers of the gland-cells are employed in drawing from the blood, on one side, the special products which are to be set free by transudation on the other. Each group of cells is thus adapted to separate a product of some particular kind, which constitutes its special pabulum; and the rate of its production seems to depend, cateris paribus, upon the anount of that pabulum: supplied by the circulating fluid. 'The substances at the expense of which the secreting cells grow, however, may not be precisely those which are subsequently cast forth; for it is very probable that some of them at least undergo a certain degree 
of chemical transformation by the agency of these cells; the characteristic materials of the several secretions not being always found to pre-exist as such in the blood.

382. A distinction may be drawn as regards this point, between those Excretions, the retention of whose materials in the Blood would be positively injurious, and those Secretions, which are destined for particular purposes within the system, and the suspension of which has no immediate influence on any other functions than those for which they are respectively destined. The solid matter dissolved in the fluids of the latter class, is little else than a portion of the nutritive constituents of the Blood; either so little altered as still to retain its nutritive character, as is the case with the casein of Milk, and with the albuminous constituent of the serous fluid of areolar tissuc and of serous and synovial membranes; or in a state of incipient retrograde metamorphosis, as seems to be the case with the peculiar "ferments" of the salivary, gastric, pancreatic, and intestinal secretions. On the other hand, the characteristic ingredients of the Excretions are very different in character from the normal elements of the blood. 'They are all of them completely unorganizable; and they possess, for the most part, a simple atomic constitution. Sone of them also have a tendency to assume a crystalline form; which, as Dr. Prout justly remarked, indicates their unfitness to enter into the composition of organized tissues. With regard to some of the chief' of these, there is sufficient evidence of their existencc, in small quantity, in the circulating Blood; but it is also clear that they exist there as products of decomposition, and that they are destined to be separated from it as speedily as possible. If their separation be prevented, they accumulate, and communicatc to the circulating fluid a positively deleterious character. Of this, we have already seen a striking example in the case of Asphyxia (\$32?); and the history of the other two principal Excretions, the Bile and Urine, will furnish evidence to the same cffect.-As a general fact, then, it may be affirmed, that the materials of the proper Excretions pre-exist in the Blood, in a state nearly resembling that in which they are thrown off by the secreting organs; and that, as their presence there is the result of the destructive clianges that have taken place in the system, they cannot be retained in it without injury; but that the materials of those Secretions which are destined to perform some particular function within the economy, are derived from the nutritive substances which are appropriated to its gencral purposes.

383. Notwithstanding that, under ordinary circumstances, the several parts of the Excretory apparatus are limited, each to its own special function, we find that there are certain complementary relations between them, which makes the action of one vicarious to a certain extent with that of another. Such a relation seems to exist, for instance, between the Lungs on one side, and the Liver and Intestinal glandulie on the other; for, the more active the respiration, the less bilc is secreted; whilst, if the respiration be lowered in amount by inactivity of body and a high external temperature, a larger proportion of unoxidized or imperfectly oxidized excrementitious matters acemulates in the blood, giving rise to that augmented production both of the biliary and of the fecal excretions, which constitutes diarrhoea.' And thus, on the other hand, when the liver is not adequately effecting the depuration of the blood from the constituents of bile, an augmentation of the respiration by active exercise in a low temperature gives most cffectual

1 Such is probably the occasion of the "bilious attacks" and "autumnal cholera," so previalent at the close of the summer; the subjects of these being most eommonly persons who have not redueed their consumption of food during the warm season, in accordanee with the diminished demand for the produstion of heat within the body. 
rclief.-Still more obviously vicarious, however, are the Kidneys and the Skin; for here we find that not only do the kidneys allow the transudation of whatever superfluous water may remain in the circulating current, after a sufficient amount has been exhaled from the skin to keep down the temperature of the body to its normal standard, but the skin actually assists in the elimination of one of those products of the metamorplosis of the azotized tissues, the removal of which has been until recently considered as the special function of the kidney. Consequently, whenever the due action of the skin as an excreting organ is interfered with, it is the kidney especially that will be called on to take its place; whilst, on the other hand, if it be thouglit desirable to relieve the kidney, this may be most effectually done by stimulating the skin to increased excretory activity. This vicariousness of function among the Excretory organs presents itself far more renarkably, however, in certain states of disease; in which a complete "metastasis of secretion" may exhibit itself. The capability of one organ thus to take upon itself the special action of another, appears to be relaterl to the "community of function" existing in the secretory surface among those lower auinals, which manifest none of tle "specialization" or setting apart for particular offices, that we see in the higher; for it seems to be a general law in Physiology, that, even where the different functions are most highly specialized, the general structure retains, more or less, that primitive community of action which characterized it in the lowest grade of development. ${ }^{1}$

384. It is in regard to the Urinary excretion, that the evidence on this point is most complete; for it seems to be established by a great mass of observations, that uriue, or a fluid presenting its essential characters, may pass off by the mucous membranc of the intestinal canal, by the salivary, lachrymal, and mammary glands, by the testes, by the ears, nose, and navel, by parts of the ordinary cutaneous surface, and even by serous membranes, such as the arachnoid tunic lining the ventricles of the brain, the pleura, and the peritoneum. A considerable number of such cases was collected by Haller $;^{2}$ many more were brought together by Nysten $;^{3}$ and more recently Burdach has furnished a full summary of the most important phenoniena of the kind; and Dr. Laycock ${ }^{5}$ has compiled a valuable collection of cases of urinary metastasis occurring as complications of hysteria. The following table of cases referred to by the last of these authors, will give some idea of the relative frequency of the different forms of this curious affection :

\begin{tabular}{|c|c|c|c|c|c|c|c|c|c|}
\hline Vomit. & Stool. & Ears. & Eyes. & Saliva. & Nose. & Mammæ. & Narel. & Skin. & Total. \\
\hline 34 & 20 & 4 & 4 & 5 & 3 & 4 & 34 & 17 & 125 \\
\hline
\end{tabular}

It is to be borne in mind, however, that cases of hysterical ischuria are frequently complicated with that strange moral perversion, which leads to the most persevering and ingeuious attempts at deceit; and there can be little doubt that a good many of the instances on record, especially of urinous vomiting, are by no means veritable examples of metastasis.-The proofs of the fact we are seeking to establish are, therefore, much more satisfactory when drawn from experiments upon animals, or from patlological observations, about which, from their very nature, there can be no mistake. 'Thus

1 See Princ. of Comp. Phys., $3 z$ 110, 428.

2 Elementa Physiologiæ, tom. ii, p. 370.

3 Recherches de Physiologie et de Chimie pathologiques, p. 265.

4 Traité de Physiologie (Jourdan's translation), vol. viii, p. 248 et seq.

6 Edinb. Med. and Surg. Journ., 1838; and Nervous Diseases of Women, p. 233. 
Mayer ${ }^{1}$ found that when the two kidneys were extirpated in the gninea-pig, the cavities of the peritoneum and the plenra, the ventricles of the brain, the stomach, and the intestinal canal, contained a brownish liquid having the odor of urine; that the tears exhaled the same odor; that the gall-bladder contained a brownish liqnid not resembling bile; and that the testes, the epididymis, the vasa deferentia, and the vesiculre seminales, were gorged with a liqnid perfectly similar to urine. Chirac and Helvetius are quoted by Haller as having tied the renal arteries in dogs, and having then remarked that a nrinous fluid was passed off from the stomach by vomiting. A remarkable case is quoted by Nysten from Zeviani, in which a yonng woman having received an incised wound on the external genitals, which would not heal, the urine gradually became more scanty, until none could be passed even with the assistance of the catheter; at last dropsy supervened, with sweats of a urinous odor, and vomiting of a nrinous fluid, which continued daily for thirty-th ree years; on post-mortem examination, the kidncys were found disorganized, the right ureter entirely obliterated and the left nearly so, and the bladder contracted to the size of a pigeon's egg.-In some other instances, the urine appears to have been secreted, and then reabsorbed in consequence of some obstruction to its exit through the urinary passages. Thus Nysten quotes a case from Wrisberg, in which, the urethra having been partially obstructed for ten years by an enlarged prostate, the bladder was so distended as to contain ten pounds of urine; and the serosity of the pericardium and of the ventricles of the brain exhaled a urinous odor. He cites other instances, in which the presence of calcnli in the bladder prevented the due discharge of the secretion; and in which a nrinons liquid was ejected from the stomach by vomiting, or was discharged by stool. A still more remarkable case is recorded, of a girl born withont either anus or external genitals, who nevertheless remained in good health to the age of fiftecn years, passing her urine from the nipples, and getting rid of fecal matters by vomiting. There are cases, moreover, in which it would seem that the mucous lining of the urinary bladder mnst have had a special power of secreting urine; the usual discharge having taken place to the end of life, when, as appeared by post-mortem examination, the kidneys were so completely disorganized that they could not have furnished it, or had been prevented by original malformation, or by ligature of the nreters, from discharging it into the bladder. A considcrable number of these have been collected by Burdach. ${ }^{2}$ In all the older statements of this kind, therc is a deficiency of evidence that the fluids were really urinous, nrea not having becn obtained from them by chemical analysis, and the smell having bcen chiefly relied on. The urinous odor, however, when distinct, is probably nearly as good an indication of the presence of the most characteristic constituent of human urine, as is the appcarance of the urea in its separated form. The passage of a urinous fluid from the skin has bcen frequently observed in cases in which the renal sccretion was scanty; and the critical sweats, by which attacks of gont sometimes terminate, contain urates and phosphates in such abundance as to form a powdery deposit on the surface.

385. The metastasis of the Biliary sccretion is familiar to every practitioner, as being the change on which jaundice is dependent. It is not, however, in every case of yellowish-brown discoloration of the tissues, that we are to imputc such discoloration to the presence of biliary matter; and we can only safily do so, when we have at the same time cvidence of concurrent obstruction of the biliary apparatus. The urinary apparatus then aftords the principal 
channel through which the biliary matter is eliminated $;^{1}$ the urine becomes tinged with the coloring principle of bile, being sometimes of a yellowish or orange hue, and sometimes of a brown color with a considerable sediment; and the presence of the most characteristic constituents of the bile has been determined in the urine. The same result presents itself, when the biliary duct has been artificially obstructed by ligature. Other secretions have been found tinged with the coloring matter of bile: thus the pancreatic fluid has been scen of a yellow color in jaundice; and the milk has presented not merely the hue, but the characteristic bitterness, of the biliary secretion. The cutaneous transpiration is not unfrequently so much impregnated with biliary matter, as to communicate its tinge to the lincn covering the skin; and even the sputa of patients affected with bilious fevers have been observed to be similarly colored, and have been found to contain biliary matter. The secretions of serous membranes, also, have been frequently seen to present the characteristic hue of bile; and biliary matter has been detected, by analysis, in the fluid of the plenral and peritoneal cavities. Biliary matter, however, when unduly present in the circulating current, is not removed from it by the secreting organs alone; for it seems to be withdrawn also in the ordinary operations of nutrition, entering into combination with the solid tissues. Thus, in persons affected with jaundice, we find the skin, the mucous and serous membranes, the lymphatic glands, the brain, the fibrous tissues, the cartilages, the bones and teeth, and even the hair, penetrated with the coloring matter of the bile, which they must have withdrawn from the blood, and which seems to have a particular affinity for the gelatinous tissues. It is impossible at present to say, however, to what extent the more characteristic ingredients of the bile are thus withdrawn from the blood f for the presence of its coloring matter cannot by any means be taken as an indication that its peculiar resinoid acids are also incorporated with the normal components of the tissues.

\section{The Liver.-Secretion of Bile.}

386. The Liver is probably more constantly present, under some form or other, throughout the entire Animal series, than any other gland. Its form and condition vary so greatly, however, in different tribes, that, without a knowledge of its essential structure, we should be disposed to question whether any identity of character exists among the several organs which are regarded as Hepatic. It is, in fact, the presence of bile-secreting cells, that must be held to constitute a Liver ; and these may be scattered over the general lining membrane of the alimentary canal, or may be restricted within follicles which are formed by depressions of it; these follicles, again, may be multiplied in some particular spot, so as to be aggregated into a mass, or may be extended into long tubes. In all the Invertebrata, however, the Liver is obviously conformable to the general type of glandular structures; the hepatic cells being in immediate relation with a basement-membrane, and being discharged npon a free surface. This will be readily understood from an examination of any one of the higher forms of it, such as that presented in the liver of the Crab, which, like the liver of the Mollusca generally, is a lobulated glandular mass, formed by the aggregation of a multitude of follicles with distinct crecal terminations; these follicles discharging their secreted products into cavities which occupy the centre of the lobules, whence they are collected by the ducts which convey them into the alimentary canal. On a careful examination of these follicles-(Fig. 165, p. 470), and a comparison of the size and contents of the cells at the bottom and to-

1 See J. W. Legg in St. Barthol. Huspital Reports, vol. ix, p. 161. 
wards the outlet, it becomes evident that the cells originate in the former

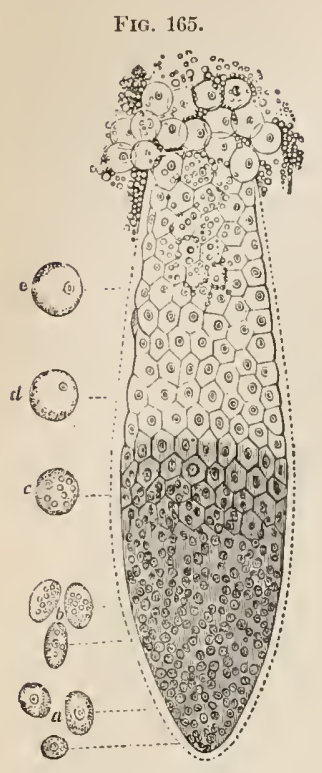

One of the Hepatic crea of Astacus affinis (Crayfish), highly magnified, showing the progress of development of the secreting cells from the blind extremity to the mouth of the follicles; specimens of these, in their successive stages, are shown separately at $a, b, c, d, e$. situation, and gradually increase in size as they advance towards the latter. It is also to be observed that the cells which lie deepest in the ceecum $(a$, $b)$, contain for the most part the yellow granular matter, which nuay be regarded as the proper biliary secretion; but as they increase in size, there is also an increase in the quantity of oil-globules which they contain $(c)$, until past the niddle of the follicle, where they are found full of oil, so as to have the appearance of ordinary fat-cells $(d, e)$. From this it happens, that when an entire cxecum is examined microscopically, its lower half appears filled with a finely-granular matter, intermingled with nucleated particles; and the upper half with a mass of fat-cells, whose nuclei are obscured by the oily particles. ${ }^{1}$-In vertebrated animals, the Liver seems to be constructed upon a similar plan. Its component cells, which have not been proved to possess a definite cell-wall, are still contained in distinct crecal follicles or elongated tubuli branching off from the excretory ducts; but in ascending through the Vertebrated series, it presents a more and more solid parencliymatous texture, which strikingly contrasts with its loosely-lobulated racemose aspect in even the highest Invertebrata. This character is very obvious in the liver of Man, which is peculiarily firm and compact, and has less of connective tissue between its clifferent parts than is found in that of many other Mammalia.-It is observable, moreover, in the Human liver, that certain portions are rudimentary, which are elsewhere fully developed. The liver in Mammalia, as in the lower vertebrates, is essentially a bilobed organ, but this character is usually more or less concealed by the various accessory fissures by which it is divided into many lobes; always, however, on the same general plan. The fissure in which the umbilical vein runs constitutes the primary division into right and left segments. In the most complex forms usually met with in the Quadrumana, Carnivora, Insectivora, Rodentia, Edentata, Marsupialia, etc., the left segment is further divided by the left luteral fissure into a left luteral and a left eentral lobe. The right segment is similarly divided into a right central and right lateral lobe; and it has moreover two accessory lobes on its under surface, the Spigelian and the caudate. When the gall-bladder is present it is attached to the under surface of the right central lobe. In most Ungulates, in Cetacea, in the highest Apes, and in Man, the lateral fissures are not present, and the liver appears of simpler form. In Man the simplicity is further increased by the caudate being hardly distinguishable from the right lateral lobe and the Spigelian lobe being but little developed."

1 Leidy, Amer. Journ of Med. Sei., Jan. 1848.

2 see $W$. H. Flower, On the Organs of Digestion of Mammalia, Med. Times and Gazette, March 9 th, 1872 , et seq. The weight of the Liver is from 48-58 oz. in the male, and from 40-50 oz. in the female. Its sp. $\mathrm{gr}$. is about 1.0.5 From the examination of a large number of bodies, Steffun (Jahrbueh f. Kinderheilk., N. F., Bd. v, p. 47) found that the ratio of the weight of the Liver to the body weight is greatest after birth, and that it diminishes during the first year, espeeia!ly in boys. In childhood the body weight and the liver weight inerease, but not in equal proportion, the former augnienting fastest. 
387. When the Liver is closely examined with the naked eye, it is seen to be made up of a great number of small granular bodies, about the size of millet-seeds, of an irregular form, and presenting a number of rounder projecting processes upon their surfaces. These are commonly termed lobules, although by some Anatonists they are spoken of as acini. ${ }^{*}$ When divided longitudinally, they have a somewhat foliated appearance (Fig. 166), arising from the rlistribution of the Hepatic Vein, which passes into the centre of each division. When transversely divided, the lobules are usually found to present somewhat of a peitagonal or a hexagonal shape, the angles being slightly rounded, so ats to form a series of passages or interlobular spaces: in these lie the branches of the Vena Portie (as well as of the Hcpatic Artery and Duct), from which are derived the plexuses that enter the lobules. The exterior of each lobule is covered by a process of the "capsule of Glisson," which is very dense in the Pig and other animals, but is so thin as to be almost undistinguishable in the Human Liver; the interspaces between the vessels are filled by the ulti-

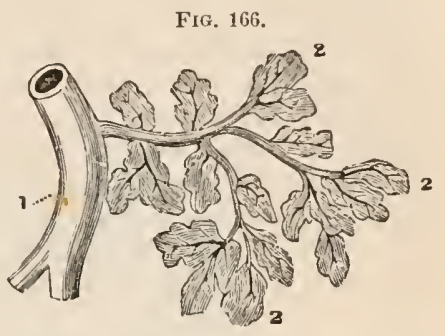

Connection of the Lobules of the Liver with the Hepatie Vein : 1, trunk of the Vein: $2,2,2$, lobules depending from its branches, like leaves on a trec; the centre of cach heing occupied by a venous $t w i s$, the Istralobular Vein.

mate terminations of the Hepatic biliary ducts, which contain large secreting cells. ${ }^{2}$ The structure of each lobule, then gives us the essential character's of the whole gland.

388. The Vena Porto, which is formed by the convergence of the veins that return the blood from the chylopoietic viscera, probably also receives the blood which is conveyed to the liver for the purposes of nutrition by the Hepatic Artery. Like an artery, it gradually subdivides into smaller and vet smaller branches; and at last it forms a plexus of vessels, which lie in the interlobular spaces, and spread with the freest inosculation throughout the entire Liver. To these vessels, the name of interlobular Veins was given by Mr. Kiernan. ${ }^{3}$ They ramify in the capsules of the lobules, covering with their ramifications the whole cxternal surface of these; and then enter their substance. When they enter the lobules, they are termed

lobular veins; and the plexus formed by their convergence from the cir-

1 The acini of Malpighi are the minute bodies of various forms and yellowish color, whieh are seen when any individual lobule is examined with the microseope; these are nothing else, however, than the irregular islets of parenehyma, left between the meshes of the plexus formed by the ultimate ramifieations of the portal vein.

2 See Prof. Beale's puper, On the Ultimate Arrangement of the Biliary Duets, in Phil Trans., 18.56, and Todd and Bowmun's Physioloc. Anat., p. 459, vol. ii, 1859.

3 See his admirable Memoir, On the Anatomy and Physiology of the Liver, in the Philosophical Transaetions, 1833. 
cumference of each lobule towards its centre (where their ultimate ramifications terminate in those of the intralobular or hepatic vein), is designated as the lobular venous plexus. - The Hepatic Artery sends branches to every part of the Liver, supplying the walls of the portal and hepatic veins, and of the hepatic ducts, as well as Glisson's capsule. The principal distribution of its branches, however, is to the lobules; which they reach, in the same manner with the portal vessels and biliary ducts, by spreading themselves through the interlobular spaces. There they ramify upon the interlobular ducts, and upon the capsular surface of the lobules, which they then penetrate, terminating for the most part in the portal venous plexus, though a very few small branches may be traced into the Hepatic plexus of capillaries. The whole of the blood, therefore, of the Hepatic Artery passes through the lobuli, and is subservient to the secretion of Bile.-It now only renains to describe the Hepatic Veins, the branches of which occupy the interior of the lobules, and are termed intralobular veins (Fig. 167, 1, 1; Fig. 168). On making a transverse section of a lobule, it is seen that the central

FIG. 168 .

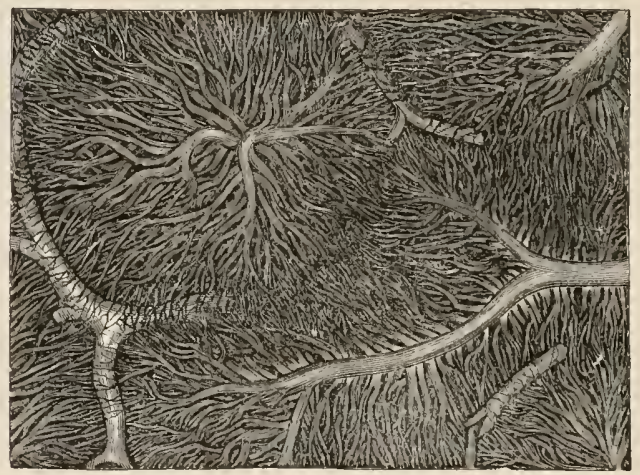

Section of a small portion of the Liver of a Rabbit, with the Hepatic or intralobular veins injected.

vessel is formed by the convergence of numerous minute venules, which arise from the plexus upon the surface of the lobule. The intralobular veins terminate in the larger trunks, which pass along the bases of the lobules, collecting from them their venous blood; thesc are called by Mr. Kiernan sublobular veins. The main trunk of the Hepatic Vein terminates in the ascending Vena Cava.

389. The Hepatic Duct forms, by its subdivision and ramification, an interlobular plexus very like that of the portal vein; the branches ramifying upon the capsular surface of the lobules, and ultimately penetrating into their interior. The trunk and larger branches of the biliary duct consist of an internal mucous membranc and an external fibrous sheath. The former is very vascular and is lined by tall columnar cells, the latter is believed by Hering to contain smooth muscular fibres, arranged longitudinally, and a few bloorlvessels; Asp, however, believes the spindle-cells and striated appearance relied upon by Hering, Heidenhain and others, as evidence of nuscular fibres, to be due to elongated nuclei and connective-tissue fibres, as they swell up and disappear in weak solution of hydrochloric acid and alcolol. At the point where the interlobular ducts become continuous with the network within the lobules, their diameter is very small, not exceeding $\sigma_{0}^{\prime} 0_{0}$ th to $\frac{1}{500}$ th of an inch; and here the epithelium, which in 
the medium-sized dincts remains columnar, passing in the smaller ducts into the tessellated variety, sudilenly becomes spheroidal, or assmmes the form of the true secreting cell. The tubes, of the diameter of $\frac{1}{81}$ th of an inch and larger, present many little saccular dilatations of the coats, the openings of which, according to Dr. Beale, are regularly arranged in two rows or lines on opposite siles of the ducts; and besides these are numerous small, irregular, and anastomosing canals, which run obliquely in the coats of the ducts, and ultimately open into their cavities. These tubes and cæea may be regarded as accessory gall-bladders, in which the Bile, secreted and stured up,

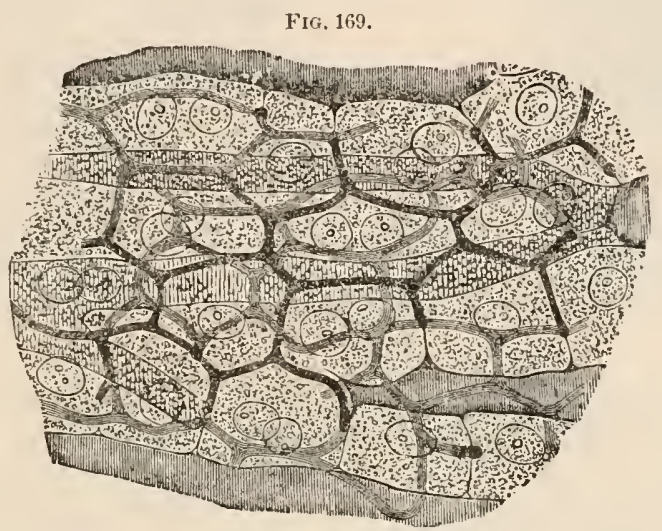

Section of an injected liver from the Rahbit. The slender and dark biliary ducts are seen to be arranged in the form of a plexus, each of the meshes of which incloses a biliary cell with one or two nuclei. The much wider capillaries are also shown.

comes into intimate relation with a fine plexus of capillaries, and may perhaps undergo further elaboration. In regard to the mode of termination of the finest biliary ducts it appears from the observations of Hering and others, ${ }^{1}$ that when injected the conals existing between the large secreting cells, firm a close plexus, the meshes of which appear to inclose the hepatic cells, though in reality the lines of injection follow the spaces between the large secreting cells (Beale). In the Rabbit these canals run exclusively, and in Mam and the Dog in by far the greatest number, not along the angles, but between the opposite surfaces (Fig. 171) of two adjacent cells, dividing their surfaces sometimes into two equal halves and at others unequally. The bloorl capillaries, on the other hand, chiefly run in the angles formed by the junstion of three or more cells. According to Hering, the biliary canals and passages do not possess any membrana propria, their walls being formed by the hepatic cells themselves, which succeed suddenly to the flattened polyhedric cells of the smaller biliary ducts, but MacGillavry and Chrzonsczsczewsky maintain that they have proper walls, the bile-secreting cells lying (Fig. 170) to their outside, though this is perhaps illusory, the snpposed vascular wall being only a thickening of the cell-wall. Both Weber and Asp, from injections with gamboge dissolved in spirit (Weber), and

1 Stricker's Manual of Histology, vol, ii, 1872, Syd. Soc. Trantlation. See also MacGillaviy, sitz-ber, d. k. Alidd. zu Wien., Bd l, 1864. Reichert, Reichert's Archiv, 1866, p. 734. Irminger and Frey, in Kölliker's Zeitschrift, 1866, p. 208. Uscar Wyss, in Virchow's Archiv, 1866, April, and Chrzon-c\%sczowsky's paper abstracted in Humphry and Turner's Journal, vol, i, 1867, p. 146. Kölliker, Handbuch der Gewebelehre, 1867. Eherth, Centralblatt, 1866, No. 57, and Sitz.-ber. d. Wien. Akad., Dec. 1866. A. Mryer, Strick. Med. Jahrbücher, 1872, p. 133, and Asp, l. c. 
alkanet in turpentine (Asp), have observed that under moderate pressure the fluid injeeted will often penetrate direetly from the smaller biliary duets into the biliary eells, the so-called biliary eapillaries then entirely disappear-

FIG. 170.

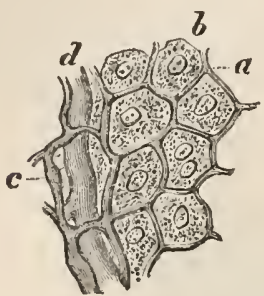

Fig. 171.

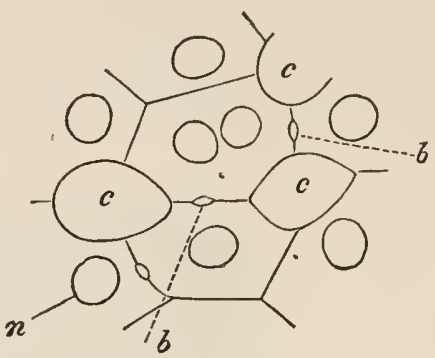

FIG. 170.- Injected Biliary capillaries of the Liver of the Rabbit. Part of a Lobule, showing the arrangenent of the biliary ducts in relation to the hepatic cells : $a$, capillaries of the biliary ducts; $b$, hepatic cells; $c$, biliary ducts; $d$, capillary bloodvessels.

FIG. 171.-Section of Rabbit's Liver injected: $c$, blood capillaries; $b$, bile passages; $n$, nueleus of hepatic cell.

ing, and the peripherie part of the lobules beeoming deeply stained; on subsequently injeeting Prussian blue, Asp found that it was retained in the passages it would under ordinary eircumstanees have run in, and did not enter the eells, prechuding, in his opinion, the idea that there are any coarse openings between the biliary duets and liver cells. The demonstration of their ultimate biliary eanals by the injeetion of eolored fluids is extremely diffieult in Man on aecount of the coagulation of their eontents. Soon after death they have, however, been very distinctly seen as the result of disease in animals, ${ }^{1}$ and may perhaps hereafter be in this way made apparent in the human subjeet.

390. The biliary cells of the Human liver (Fig. 172, в) are usually of a polyhertrie spheroidal form ehannelled at their angles by the eapillaries, and on their surfices by the biliary eanals, and are from $\frac{1}{500}$ th to $: \frac{1}{20} \sigma_{0}$ th of an inch in diameter. Each of them, generally, but not always (Asp), presents one or two distinct nuclei containing numerous granules; and the eavity of the cell is occupied by yellow amorphous biliary matter, usually having one or two large adipose globules, or five or six small ones, intermingled with it $(a, b)$. The size and number of these, however, vary considerably, aecording to the nature of the food, the amount of exercise reeently taken, and other eircumstanees. If an animal be very fat or be well fed, espeeially with farinaceous or oleaginous substanees, the proportion of adipose partieles (c) is much greater than in an animal moderately fed and taking much exereisc. The size of the oil-globules varies from that of mere points, searcely distinguisliable from the granular eontents of the eells except by their intense blackness, up to one-fourth of the diameter of the cell. A still greater aeeumulation of adipose partieles in the biliary eells gives rise, as was first pointed out by Mr. Bowman," to the peculiar condition termed "fatty liver." The fincly granular matter is the portion fiom which the color of the cell is derived; it seems to fill the space not occupied by the oil-globules; and it often obscures the nueleus, so that the latter eannot be distinguished until aeetic acid is added, which makes the granular matter more transparent

1 Texas Cattle Disease. Austin Elint, Physiology of Man, vol. iii, p. 245.

$\&$ Medical Grazette, Jan. 1842. 
without affecting the nucleus. ${ }^{1}$ The Liver, thereforc, belongs to the class of ramified tubular glands; and the matcrials of the biliary secretion formed from the blood by the colls lining the intrabobular extremities of the ducts are discharged into the interior of these canals either by exudation or by the

$\mathbf{A}$

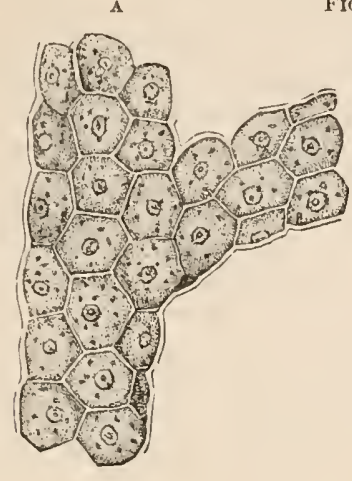

FIG. 172.

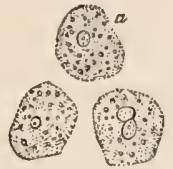

B
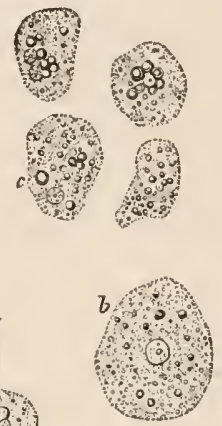

A, Portion of a Ilepatic Column, from IIuman Liver, showing its component secreting cells; $B$, secreting cells detached; $a$, in their normal state; $b$, a cell, more highly magnified, showing the nucleus and distinct oil-particles; $c$, in various stages of fatty degeneration.

deliquescence of the cells themselves. Teichmann ${ }^{2}$ describes the lymphatics as running with the portal venous branches, and the biliary ducts as forming a plexus with large, irregular meshes on the outsidc of the lobuli, and he believes he has even injected minute branches passing up their centre with the Vena intralobularis of the Hepatic Veins. MacGillavry ${ }^{3}$ describes the lymphatics of the liver of the rabbit as forming loose sheaths, and his statements have becn confirmed by Asp. Similar sheaths have been observed by Irminger and Frey around the bloodvesscls of the liver of the dog. A siugle layer of lymphatics exists on the peritoneal surface of the Liver, lying in the subserous areolar tissue. The nerves of the Liver have been

1 Sehiff (Archiv f Phys. Heilk., 1857, 263, and Untersuch. ub. die Zuckerbildung in der Leber, etc., Wurz., 1859) described two kinds of granules in the Liver eells besides the nueleus, one of these was dark-bordered and highly refractile, the other much smaller and pale. These last he thought were particles of Glyeoger. Buck and Hoflmunn (Virchow's Archiv, 1872, Bd. Ivi, p. 202) deny this on the grounds of their chemieal renetion and the want of relation between their numbers und the amount of Glyeogen in the Liver. For an aecount of the albuminous compounds of the Liver, see Plusz, P'flürer's Arehiv, 1873, Bd, vii, p. 371. Sichenk (Centralblatt, 1869, p. 865 ) laas described peculiar protoplasmic masses resembling anæba in possessing spontaneous movement, as being present in the embryonal Liver of mamnals, and Ptlüger (Arehiv f. ges. Physiol, Bd. ii, p. 459) states that the liver cells possess processes like those of the salivary cells, and appears to think there is some communication between the biliary camaliculi and the interior of the cells; since if the eapillary ducts of the biliary canals are injected with cold Prussian blue injeetion fine ducts may be seen to penetrate the protoplasm of the cells, whieh divide and surround the uncolored nucleus. MacGillavry had previously notieed that on injection of the lymphaties with eold Prussian bluc the nuclei of the colorless hepatie eells became deeply stained.

2 Silugader System, p. 94, Leipzig, 1861.

3 MacGillavry, Zur Anat. der Leber, Pamphlet, 1864. His statements arc corrolorated by Frey, Handb. der Histol. und Histochem., 4 Aufl., p. 524, and Biesiadecki, Wien. Sitzungsber., Bd. Iv. H. D. Schmidt in Month. Micros. Journ., 1870; Asp, Ludwig's A rbeiten, 1873, Bd. vii, p. 134. See also, for Lymphatics of Capsule of Liver, Wedl., idem, Bd. lxiv, Abth. 1. 
carefully cxamined by Drs. Robert Lee, ${ }^{1}$ Hering, ${ }^{2}$ and Pfï̈ger. ${ }^{3}$ Dr. Lce has shown them to be chiefly connected with the semilunar ganglion and sympathetic plexus surrounding the root of the hepatic artery, the minutest branches of which they accompany. Pfiuger believes he has been able to trace the nerves into connection with the hepatic cells, but Hering maintains that all demonstrable nerves lie on the other side of the lobules.

391. The first and most obvious function performed by the Liver is the secretion of Bilc. For this the arrangement of the cells and ducts appears to be primarily designed; and by their means a considerable quantity of matcrial, rich in carbon and hydrogen, is, temporarily at least, eliminated from the blood, whilst at the same time a liquid is provided, the utility of which in promoting the absorption of ford, and especially of oleaginous food, has been already sufficiently considered $(\$ 124)$. But the large size of this organ in comparison with the anount of secretion poured into the alimentary canal; its constant presence in almost all classes of animals, how various soever the nature of their food may be; its manifest activity in the foetus before the ingestion of any food has taken place; the large supply of bleod which it receives from different sources, as well as the peculiar relations which it holds to the blood returning from the placenta in the foetus, and from the abdominal viscera in the adult-are all cireumstances suggesting that other functions than the secretion of the Bile are here performed; and from the results of comparatively recent research, it may now be consilered as fairly established, that it exerts an assimilative or elaborating action on the freshly absorbed materials of our food, and especially upon the albuminous and saccharine constituents, whereby they become more fitted for the nutrition of the body; and that in the course of these assimilative changes, the activity of which is indicated by the high temperature of the organ, and perhaps as a consequence of them, a material analogous to sugar is formed, whose ultimate destination is still undetermined, but which there is sonte reason for belicving, in part either direetly or indirectly combines with oxygen, and thus becomes subservient to the maintenance of animal heat, and in jart is on the way to histological formation. The production of this substance is termed Glycogeny, and will be considered after the characters and mode of formation of the Bile have becn discussed. The following are analyses of the Bile contained in the human Gall-bladder, by Frerichs and v. GorupBesanez: ${ }^{*}$

\begin{tabular}{|c|c|c|c|c|c|c|}
\hline \multirow[b]{2}{*}{ In 1000 parts. } & \multicolumn{2}{|c|}{ Frerichs. } & \multicolumn{4}{|c|}{ V. GORUP-BESANEZ. } \\
\hline & $\begin{array}{c}\text { I. } \\
\text { Maur } \\
18, \text { kill-d } \\
\text { by it fill. }\end{array}$ & $\begin{array}{c}\text { II. } \\
\text { Man gat. } \\
22, \text { killed } \\
\text { by injury. }\end{array}$ & $\begin{array}{l}\text { I. } \\
\text { Man aet. } 49, \\
\text { criminal, } \\
\text { beheadeded. }\end{array}$ & $\begin{array}{l}\text { II. } \\
\text { Woman mt. } \\
\text { 29, eriminail. } \\
\text { beheadied. }\end{array}$ & $\begin{array}{c}\text { III. } \\
\text { Man ian. } \\
\text { 6s, killed } \\
\text { by a tall. }\end{array}$ & $\begin{array}{c}\text { IV. } \\
\text { Bor iet, 12, } \\
\text { killeed hy } \\
\text { anl injury. }\end{array}$ \\
\hline $\begin{array}{l}\text { Water, } \\
\text { Sulid residue, : }\end{array}$ & $\begin{array}{l}8600 \\
140.0\end{array}$ & $\begin{array}{l}8.592 \\
140.8\end{array}$ & $\begin{array}{l}8227 \\
1773\end{array}$ & $\begin{array}{l}898.1 \\
101.9\end{array}$ & $\begin{array}{r}9087 \\
91.3\end{array}$ & $\begin{array}{l}8: 28.1 \\
171.9\end{array}$ \\
\hline 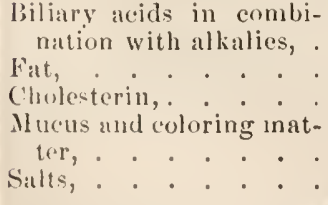 & $\begin{array}{r}72.2 \\
3.2 \\
1.6\end{array}$ & $\begin{array}{r}91.4 \\
9.2 \\
2.6\end{array}$ & \} $\begin{array}{r}107.9 \\
47.8 \\
\\
22.1 \\
10.8\end{array}$ & $\begin{array}{r}56.5 \\
30.9 \\
14.5 \\
63\end{array}$ & $\begin{array}{l}17.6 \\
\ldots\end{array}$ & $\begin{array}{l}23.9 \\
\ldots\end{array}$ \\
\hline
\end{tabular}

1 Procedings of Royul suciety, vol. xii, p 246.

2 Stricker's Human and Comparative Histology, Syd. Soe. Trans, vol. ii, p. 33.

3 Archiv f. Physiology, Bd. iv, p. 53.

4 Phys. Chem, 1875, 1. 529. 
Bile is a viscid, neutral or feebly-alkaline, somewhat oily-looking liquid, of a greenish-yellow color, and very bitter taste, followed by a sweetish aftertaste. It is readily miscible with water, and in solution froths like onc of soap. Its specific gravity in the human snbject is ahout 1018 , the extremes being 1.0105 and 1.032. According to Kowalewsky ${ }^{1}$ the pressure of the Bile in the ductus conmunis choledochus under ordinary circumstances in curarized cats, varies from 3.5 to $7.5 \mathrm{~mm}$. of mercury (2-4 in. of water), rising if the duct be ligatured to from 12 to $20 \mathrm{~mm}$. of mercury (6-11 in. of water). Heidenhain states that it is secreted under a pressure of a column of watcr, eight inches in height. The proportion of solid matter which it contains is nsually from 9 to 17 per cent., and nearly the whole of this consists of substances peculiar to Bile. 100 parts of human Bile purified and drice at $230^{\circ} \mathrm{F}$. contain about 1.5 parts of sulphur. Bogoljubow observes that whilst freshly secreted Bile may contain as much as 64 per cent. of combinel and 7 per cent. of free carbonic acil, the Bile which has long been stored up in the gall-bladder of fasting animals, may not contain more than 2 per cent. of the combinerl and 2 per cent. of the free gas. In the biliary matter, according to the researehes of Strecker (which are undoubtedly the most accurate and satisfactory that have been hitherto marle), the following substances nay be distinguished: Two resinous acids, the Glycocholic (which is the cholic acid of Strecker) in small quantity, and the Tuurocholic (which is the choleic acid of Strecker, and is nearly the same with the bilin of other chemists); these are formed, according to Lehmann, by the "conjugation" of cholic acid with glycin or glycocoll (gelatin-sugar) and taurin respectively; and they are united in the bile with soda as a base. It is in the taurocholic acid that the sulphur of the bile presents itself, no less than 25 per ccnt. of that element existing in taurin; so that the proportion which this acid bears to the glycocholic (which differs greatly in different animals) may be estimated by the amount of sulphur in the mixture of the two. ${ }^{2}$ Besides a variable quantity of the ordinary Fatty acids, Bile also contains Cholesterin, a non-saponifiable crystalline fatty substance; Lecithin, $\mathrm{C}_{44} \mathrm{H}_{90} \mathrm{NO}_{9}$; various products of the disintegration of albumen, as Leucin, Tyrosin, Xanthin, and Hypoxanthin ; and Cholin or Neurin, ${ }^{3} \mathrm{C}_{5} \mathrm{H}_{15} \mathrm{NO}_{2}$, which is one of the products of decomposition of Lecithin, and certain coloring matters, the nature of which has not been very accurately determined, for Städeler (1863) isolated five distinct compounds: Bilifulviu, Biliverdin, Bilifuscin, Biliprascin, and Bilihumin : whilst Maly ${ }^{4}(1864)$ finds only one substance, Cholepyrrhin; and Dr. Thudichum ${ }^{5}$ (1872) describes two, Cholophein or Bilirubin, $\mathrm{C}_{9} \mathrm{H}_{9} \mathrm{NO}_{2}$, and Bilifuscin, $\mathrm{C}_{9} \mathrm{H}_{41} \mathrm{NO}_{3}$. The relationship of these coloring matters to the coloring matter of the Blood, first suggested by Virchow ${ }^{6}$ has been rendered probable by the discovery of Zenker ${ }^{7}$ of crystals of Hrematoidin in inspissated Bile, by the circumstance that both contain iron, and by the observation of Gübler ${ }^{8}$ that Bilirubin and Hrmatin give the same play of colors with $\mathrm{NO}_{5}$, except that the green color is most persistent in the former and the violet in the latter. R. Maly ${ }^{9}$ has pointed out that there is

1 Pflüger's Archiv, Bd. viii, Heft xii.

2 For excellent accounts of the Liver and its Functions, see Dr. Dalton's Human

Physiology, 187l, and Austin Flint's Physiology of Man. 1870, vol, iii, p. 232.

3 O. Liebreich, Rev. des Cours Scient., tom. v, p. 648, 1848.

4 Bernard, Physiologie Générale, Revue Scientifique, 1873, p. 462.

6 Clinical Physiology, 1872, p. 18

6 Archiv f. Path. Anat., Bd. i, 1818, p 421.

7 Jabresbericht von der Gesellsch. f. Natur und Heilkunde in Dresden, 1858, p. 53.

8 Gaz. Méd. de Paris, 18599 , p. 469.

9 R. Maly, Centralblatt f. d. Med. Wiss., 1871, p. 849, and Annal. de Chemie v. Pharm., Bd̀. clxiii, p. 77, 1872. 
a close relation between Cholepyrrhin, or Bilirubin, and the coloring matter of the Urine obtained by Jaffe, ${ }^{1}$ and named by him Urobilin, and with the coloring matter of the freces obtained by Vanlair and Masius. ${ }^{2}$ Feltz and Ritter ${ }^{3}$ and Tarchanoff ${ }^{4}$ have shown that if the coloring matters of the Bile or of the Blood are directly injected into the Blood, they are rapidly excreted in a more or less modified condition by the Urine. These experiments rather tend to show that the biliary coloring matters a re not formed exclusively in and by the Liver, but rather that they are in part performed in the Blood, so quickly is their elimination from the body effected. It is remarkable that, notwithstanding the comparatively minute proportion in which cholesterin and coloring matters exist in ordinary bile, cholesterin should usually be the principal ingredient of the biliary concretions which are frequently found in the gall-bladdcr and bile-ducts; and that the bile-pigment with choloidinic acid and a calcareous base should also occasionally accumulate, so as to form solid masses which consist of little else. The Spectrum of Bile in man and various animals has been investigated loy Dr. Dalton. ${ }^{5}$ He states that it is very short, the light being totally absorbed at a considerable distance from the refrangible end, and that it terminates suddenly. It presents, as is shown in the accompanying diagram from his paper, an absorption-

FIG. 173.

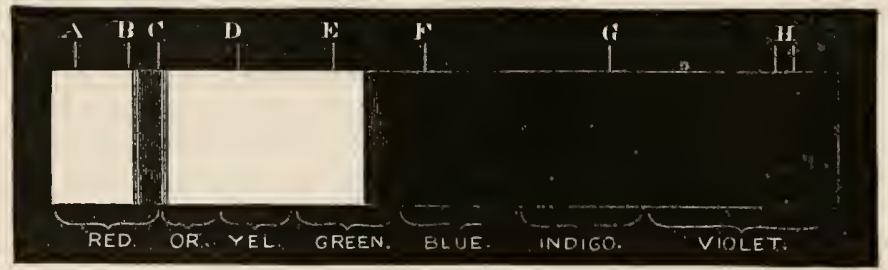

Spectrum of green bile.

band in the red at the situation of the line $\mathrm{C}$, which appears to be due to the green rather than the red coloring matter of the bile. ${ }^{6}$ And lastly, it presents as a rulc a remarkable diminution in quality of the orange and red colors. Both Dalton and Schenk ${ }^{7}$ obtained the spectrum (Fig. 174) from the purple fluid, resulting from the action of Pettenkofer's test on solutions of the taurocholate and glycocholate of Soda, cxhibiting two wide and dark absorption-bands, one at E, extending from D $50 \mathrm{E}$, to E $25 \mathrm{~F}$; the other at $\mathrm{F}$, from $\mathrm{E} 60 \mathrm{~F}$, to $\mathrm{F} 15 \mathrm{G}$, the spectrum terminating gradually about the line G. V. Wittich, in a case of biliary fistula in the human subject, found that the fresh bile contained a ferment capable of converting starch into sugar. ${ }^{8}$

392. We have now to inquire into the conditions under which the Secretion of Bile takes place; and one of the most important of these, is the supply of

1 Jaffe, Virchow's Arehiv, Bd. xlvii.

2 Tambir and Masius, Centralblatt f. d. Med. Wiss, 1871, p. 369.

3 Felt\% and Ritter, Robin's Jourmal de l'A natomie, 1875, p. 162.

4 'Tardhanoff, P'fliger's Archiv, 1874, Bel. ix, p. 329.

${ }^{5}$ New York Medical Journal, June, 1874.

6 Un Vierordt's system of notation, in which the eight principal lines of the solar speetrum are taken as fixed points, $A, B, C, D, E, F, G$, and $I$, and the spaces between these considered as divided into 100 equal parts, the exnct position of the band was in one case from B $20 \mathrm{C}$ to C $10 \mathrm{D}$, and in another from $\mathrm{B} 13 \mathrm{C}$ to $\mathrm{C} 18 \mathrm{D}$.

7 Anatom. Physiol. Unters., Wien, 1873.

8 l'flüger's Archiv, 1872, Bd. vi, p. 181. Ranke, Pliysiology, 1875, p. 287: 
Blood which the liver receives. How far the blood supplied by the Hepatic Artery is the inmodiate source of the secretion has not been quite satisfactorily determincd. Kottmeier ${ }^{1}$ and Küthe ${ }^{2}$ found that no bile was secreted

FIG. 174.

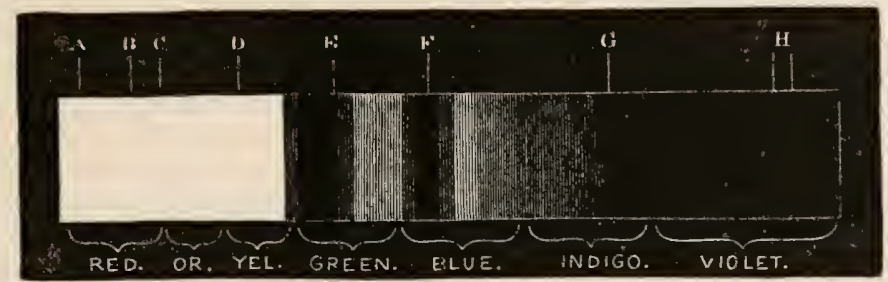

Spectrum of Pettenkofer's test with the biliary salts in alcoholic solution.

after ligature of this vessel, and they attribute the result to an alteration taking place in the nutrition of the cells destined to form the bile. Schiff, however, was unable to detect any diminution in a large dog upon which he had performed the same operation, and Röhrig ${ }^{3}$ found the secretion was only slightly lessened. It is certain that the Hepatic artery may indirectly furnish the supply of hlood necessary for the secretion; for although, if the Vena Porta be suddenly tied, the flow of bile is immediately stopped, and death ensues in the course of a few hours; yet if the obliteration be slowly effected, either by the gradual tightening of a ligature, ${ }^{4}$ or, as occasionally happens, from disease, the secretion of bile still continues, though in diminished quantity. In such instances it probably proceeds from the blood of the hepatic artery, the capillaries of which discharge themselves into the lobular plexus of veins, and in cases of malformation have been actually observed to pass into the ramifications of the umbilical vein, forming a plexus in the lobules that exactly resembled the ordinary portal plexus. ${ }^{5}$ Its secretion after such slow obliteration of the Vena Portæ may also sometimes be due to the presence and enlargement of the accessory Venæ Porta, which have been noticed by Sappey. ${ }^{6}$ According to Bernard, the engorgement of the Vena Porte consequent upon its slow obliteration, is relieved by the presence of small anastomotic branches with the Renal Vein corresponding to the Veuous system of Jacobson found in the lower Vertebrate classes. ${ }^{8}$ The fact that the secretion of Bile is normally formed, in great part at least, from venous blood, has been commonly connected with the hydrocarbonaceons nature of its chief components, which must exist (it is considered) in larger proportion in such blood than in that of the arteries. But it must be borne in mind, that the urinary excretion, which is undoubtedly formed at the expense of the products of the disintegration of the tissues, is secreted from arterial blood; and since the bile is, as it were, the complement of the urine (the ultimate components of the two together making up the composi-

1 Zur Kenntniss der Leber, Wurzburg, 1857.

2 Studien des Physiolog. Institut zu Amsterdam, 1861.

3 Röhrig, Stricker's Jahrbucher, 1873, p. 243.

4 Oré, Comptes Rendus, 1856, p. 463.

5 Such, at least, was found to be the ease in the only instance in which the Liver was examined with sufficient carc. Sec Kiernan, loc. cit.

6 Gaz. Mléd., 1859, p. 489.

7 Leçons sur les Liquides de l'Organisme, 1859, vol, ii, p. 195.

$\mathrm{s}$ Fur other anustomotic branches, see Schiff in Schweiz. Zeits. f. Heilkunde, Bd. i, 1862. 
tion of blood), there seens no reason why arterial blood should not furnish its materials as abundantly (or nearly so) as venous. The real explanation of the peculiar relation of the Liver to the Venous circulation, is probably to be found in the action of the organ upon the matters newly absorbed into the circulation from the alimentary canal. That this action is not only assimilative, as already shown (chap. vi, sect. 3 ), but is also to a certain extent depurative, appears from the fact that the liver tends to remove from the blood, and to store up in its orm substance, certain foreign matters of an injurious kind,-such as copper and arsenic,-which have found their way into the tributarics of the portal systent. This seems also to be the case with respect to pus, which, when taken up from ulcers in the intestinal walls, is stopped in the liver, and not unfrequently gives rise to abscesses in its substance. ${ }^{3}$

393. There is strong reason for believing that the chief constituents of the Bile arc elaborated in the liver itself and are not preformed in the blood, since although the tests for biliary acids are far more delicate than those employed for the detection of urea, no trace has been discovered of them in the blood of animals whose livers have been extirpated, though it might be expected, that if like the components of the urinary secretion, they pre-exist in the circulating current, and are merely eliminated from it by the action of the liver, they would accumulate in it when that elimination is checked by the removal of the secreting organ. Some of the constituents of this very complex secretion may undoubtedly be found in other organs or fluids of the body, thus cholesterin is found in the blood, lymph, most glands, and abundantly in the brain. Taurin is a constant constituent of the lungs and muscles of many animals, and Taurocholic acid is stated by Cloez and Vulpian to exist in the suprarenal capsules. Glycocoll can easily be obtained from hippuric acid, which is constantly present in the urine; and even the coloring natters bilirubin and biliverdin occur normally in the placenta of the dog. Still there can be little doubt that the pigmentary substances and the conjugated tauro- and glycocholic acids are formed in the liver itself, and that they are produced at the expense of substances of an excrementitious character, whose retention in the circulating current would be injurious; this being strikingly demonstrated by the disturbance of the functions generally, and especially of those of the Nervous system, which is consequent tipon the suspension of the secreting process. When the suppression is complete, the powers of the system are speedily lowered (almost as by a narcotic poison), the patient suddenly becomes jaundiced, and death rapidly supcrvenes. When then secretion is dininished, but not suspended, the saine symptoms present themselves in a less aggravated form. It is probable that much of the disorder in the functions of the brain, and it has been experimentally shown by Röhrig that the well-marked diminution of the frequency of the beats of the heart which so constantly accompanies deranged action of the digestive system, and especially jaundiec, are due to the less severe operation of the same cause, namely, the partial retention within the blood of certain constituents of the bile, which should have been eliminated from the circulating fluid. Such an abuormal accumulation, which may depend either on a deficiency in the functional activity of the liver, or on an excess

1 See Dr. (x. Budd's Treatise on Disease of the Liver, $2 d$ edit., ehap. ii, seet. 1.

2 See 1'rof. Alison in Edin. Mred. and Surg. Journ., vol. xliv; and Dr. Budd, op. cit, (hap) iii. Austin Flint (I'lysiology of Man, vol. ii, p. 288 et seq.) has suggested that it is the cholestrolin whieh nets as the poisonous agent, and has proposed the term "cholesteramia" for this form of blood-poisoning; but the observations of Feltz and Pitter (Robin's Journal de l'A natomie, 1875, p. 171) on the effects of the injeetion of cholesterin are opposed to Dr. Fint's view. 
of the excrementitious matters brought to it for elimination, is habitual in some persons; and it produces a degrec of indisposition to bodily or mental excrtion, which it is difficult to com teract. More, probably, is to be gained in such cases by the regulation of the diet, especially the reduction of its hydrocarbonaceous components, and by active exereise (which, by augmenting the respiration, will promote the climination of any superfluity of this kind through the lungs), than by continually inciting the liver to increased functional activity, by medicines which have a special power of temporarily augmenting its cnergy.-The excrementitious character of the Bilialy secretion is very strikingly indicated by its formation during foetal life; ${ }^{1}$ which, as it can then have reference neither to the function of Digestion nor to that of Respiration. must be regarded as having for its purpose to free the blood of the matter which would be injurious to it. And this matter can hardly arise from any other source than the "waste" of the tissues (consequent upon the limited duration of thcir existence), which takes place even when the life of the organism is most purely vegetative.

394. From what components of the Blood the materials of the biliary secretion are immediately derived, is a question that cannot yet be quite satisfictorily answered. The close rescmblance in composition between the resimous acicls of bile and the ordinary fits (especially olein), naturally suggests the idea that they are drawn from the fatty matters of the blood; an opinion which was supported by Lchmann, on the grounds-first, of the diminished proportion of fat contained in the Hepatic, as compared with the Portal Venous blood; secondly, of the increase in the quantity of bile observer after rich fat food; and thirdly, of the emaciation which occurs in animals as a consequence of the formation of a biliary fistula, in spite of abundant supply of albuminous foor. It must be acknowledged, however, that there are various objections to this view, both physiological and chemical. Thus it is maintained by Bidler and Schmidt, that the flow of bile is not increased by a predominance of fat in the food, and that animals fed exclusively on fit do not sccrete more bile than those entirely deprived of food: whilst it has been found by Nasse, that it is to the presence of a large amount of albuminous compounds in the food that any great augmentation in this secretion is duc. ${ }^{2}$ The increase of the secretion after each ordinary ingestion of food ( $\$ 125)$, and its marked and progressive diminution in animals entircly deprived of aliment (as detcrmined by MM. Bidder and Sehmidt), seen to indicate that its materials may be dircetly derived in part from albuminous materials which co not undergo metamorphosis into tissue; whilst, on the other hand, there is evcry reason to believe, that the production of the components of bile is a necessary part of those processes of retrograde metamos phosis, by which the materials of the effete tissues are removed from the system. The experiments and observations of Schiff,

I The gall-bladder begins to contain bile at about the sixth month of intraterine life, and it has bem shown lyy Simon and Frerichs, that the meconium which is eontained in the intestinal canal at birth, is chiefly composed of inspissated bile; and Kühne (Physiol. Chemie, 1868, p. 103), after referring to the results of various investigations, observes that the Bile undergoes the same changes in the intestines as when boiled with acids or alkalies, or when allowed to putrefy. These changes commence in the lower part of the ileum, and are completed in the cuecum and colon. Glycocholic acid, which is decomposed with difficulty, may frequently be found in the faces of animals, in which it constitutes the chipf biliary acid, whilst in the faees of Carnivora, whose bile is principally composed of Taurocholic acid, only cholalic acid appears. Accorcing to Bischoff, man discharges about 50 grains of the biliary acids by the fieces per diem, whilst Voit's estimates give 170 grains as the quantity daily formed by the liver; 1:0 grains must therefore be reabsorbed or otherwise disposed of:

2 Ser Prof. Lehmann's Pliysiologischen Chemie, $2 d$ edit., Bd. ii, pp. 64-66.

3 P'flüger's Archiv, 1870, p. 598. 
Lussana, ${ }^{1}$ and others have demonstrated that a constant circulation of bile takes place in healthy conditions, so that a large portion of that which has been secreted by the liver and discharged into the intestines is reabsorbed from thence and again separated by the liver. They found that on inserting a caunla into the gall-bladder after tying the ductus communis choledochus, the discharge of Bile was considerable for the space of half an hour, the liver during this period performing the part of a secreting as well as of an excreting organ, but rapid diminution then took place in the amount discharged from the canula, because Bile no longer entered, and could therefore no longer be absorbed from the intestinc. IVhen, however, Bile was injected into the blood, the ruantity eliminated quickly underwent increase, though it again diminished when the additional quantity had been excreted. The cholagogue action of calomel appears to be in part due to its effecting a diminution in the absolute quantity of Bile formed, as was shown by the experiments of the Edinburgh Committee of the British Association $;^{2}$ but chiefly, as Dr. Brunton maintains, to its stimulating action on the duodenum, which causes the rapid transmission of the Bile through this portion of the intestine; and if it be combined with sulphate of magnesia, or other saline purgative, it is rapidly expelled from the system ; so that the reabsorption of the excessive quantity resulting from too free living is effectually prevented, and the "biliousness" so often complained of is temporarily, at least, removed. [Rutherford and Vignal in experimenting with calomel on dogs state that it diminished the biliary secretion in three cases, and slightly increased it in one. $]^{4}$

395. In regard to the influence of the Nervous system on the secretion of Bile, the results of experiments are contradictory: thus, whilst Pflüger states that no effect is produced on the secretion-in regard to its quantity, at least -by section of the Pneumogastrics, Phrenics, Splanchnics, or Sympathetics, by destruction of the Coliac Plexus, nor after destruction of all the nerves entering the Porta Hepatis, provided the supply of blood be not interfered with, Röhrig ${ }^{5}$ found that section of the splanchnics or of the spinal cord, either of which causes dilatation of the abrlominal vessels, is followed by increased flow of Bile, whilst on the contrary reflex irritation of the cord (as by stimulating a sensory nerve) by contracting the vessels, diminishes it. The reason of this is that the most important factor in the secretion of Bile is the rapidity of the circulation through the vessels of the abdominal viscera. Irritation of the Spinal Cord is without effect if the splanchnics have been previously divided. ${ }^{6}$

396. But besides the secretion of Bile, it appears that another purpose is fulfilled by the Liver-the production of an amyloid substance termed Glycogen; and we shall now proceed to consider the chief' facts which have been ascertained in reference to this so-called "Glycogenic function of the Liver." It had long been well known that Vegetables were capable of producing Starch and Sugar from the inorganic materials of their food, but the presence of the former as a constituent of the animal body, in the test of one

Lu-sana, Lo Sperimentale, t. xxix, p. 337. See also Brit. Med. Journal, January 4th, 1873. liöhri乡, luc. cit.

2 See 'l'ransuctions of British Association for the Advaneement of Science for' 1868 , p. 214, and Bennett's Text-Book of Physiology, 18i2, p. 253. These experiments simply showed that the liver formed less bile.

3 Brunton, in Practitioner, 1874, p. 412.

4 [English .Jour. of Physiology, Oet. 1875. Reprinted in Boston Med. and Surg.

Journal, March 16th, 1876.]

5 Stricker's Jahrbucher, 1873.

6 See Hoidenhain, Centralblatt, 1867 , p. 662, and $1868, p .710$; and Munk, Pfäger's Archiv, Bd. viii, p 151, who think that there is a primary incrased flow of bile on irritation of the spinat cord, which is due to the contraction of the inuscular fibres they believe to be present in the biliary duets. 
of the Tunicata, announced by Dr. Schmidt, and corroborated by the observations of Löwig and Kölliker, ${ }^{1}$ was considered to be only interesting because it destroyed what har till then been looked upon as one of the most important means of distinguishing the tissues of the animal from those of the plant. In 1848, however, Bernard ${ }^{2}$ obscrved, that whilst the Blood of the system generally, and that of the Vena Portie in particular, in an animal ficd exclusively on meat, appcared to be destitute of Sugar, a very notable quantity could be detceted in the blood of the Hepatic Vcin and right heart-that is to say, in the blood which had passed through the Liver. He immediately inferred that a new function, the formation of Sugar, was to be attributed to the Liver; that the sugar so produced was thrown into the circulation, and then, by undergoing combustion, ministered to the maintenance of animal heat. He was supported in this view by the authority and analysis of Lehmann, ${ }^{3}$ who suggested that the Sugar might proceed from the decomposition of albuminous compounds, since there was a smaller quantity of albumen in Hepatic as compared with Portal Venous blood; and there were also good chemical grounds for supposing that albumen might split up into nitrogenous compounds, represented by the conjugated biliary acids (which also contain the sulphur), and into non-nitrogenous compounds replesenterl by Starch, Glycogen, and Sugar. Schmidt (of Dorpat) conceived that the Sugar might result from the decomposition of the fatty substances; whilst Frerichs thought that the albuminous substances might break up into Glycosc and Urea. Bernard himself, however, was disposed to consider that Bile and Sugar were produced in the Liver independently of one another; first, because the formation of Sugar was most active at a much earlier period after food than that of Bile; and, sccondly, because in one of the Mollusca (Limax flava) he found that the liver secreted sugar and bile alternately, the former during, the latter after, digcstion. The observations of Bernard, from their novelty and interest, attracted the attention of many chemists and physiologists, and it was soon shown that sugar, though in comparatively small proportion, was frequently present in the blood of the general circulation, and of the Vena Porix, as well as in that of the Hepatic vein. Thus Chauveau found in the arterial bloor of a Horse, which had fasted for six days, 0.06 per cent. of Sugar, and in the systemic venous blood, 0.05 per cent. Colin also detected traces of Sugar in the Chyle and Lymph. Very careful investigations were made by Dr. Harley, Poisenille, Lefort, ${ }^{6}$ and others to determine the proportion of Sugar in the Liver, and in the blood drawn from different parts of the body in animals under different circumstances, the general results of which appeared to be that sugar existed in the arterial blood of the Dog in the proportion of about 1.5 per 1000 ; in the Vena Cava inferior below the renal veins, 0.54 per 1000 ; and in the Tena Cava inferior, above the diaphragm, $i$.e., above the entrance of the Hepatic Vein, 1.12 per 1000 . In Herbivora, the quantity of Sugar in the blood of the Hepatic Vein amounted to about 1 per cent. during fasting, and from $1 \frac{1}{2}$ to 2 per cent. at a period of fill digestion, whilst the mean quantity found in the liver substance was said to be from $\frac{1}{2}$ to $2 \frac{1}{2}$ per cent. The much larger proportion of sugar obtained from the liver of Herbivorous as compared with Carnivorous animals, especially after a meal containing much amylaceous or saccharine material, naturally led to the supposition that these substances were derived from the aliment, and were merely

1 Annales des Siciences Naturelles, 1846.

2 Archives Gén. de Médecine.

3 Comptes Rendus de l'Acad. des Sciences, 1855, p. 587.

4 Lrçons, $1854-55$, p. 93 et seq., a view which has been supported on histologieal grounds by Accolas, Thesis, Strasbourg. 1867.

5 Gaz. IIéd, 1857 ; L'Union Méd., 1857.

6 Gaz. Méd., 1858. 
deposited in the tissue of the liver; and we accordingly find Figuier ${ }^{1}$ and Sanson ${ }^{2}$ arriving at the conclusion that vegetables alone are capable of producing starch, a part of which, when formed, is applied by the plant to the nutrition of its own tissues, whilst another part, stored up in cells, becomes subservient to the nutrition of Herbivorous animals. In these again, a portion of the starch is consumed in the vital processes, whilst another portion is distrihuted to the tissues, being especially abundant in the liver; and to this source they believed the sugar contained in the blood of Carnivora was traceable. This view, however, became untenable when it was shown that in animals ferl exclusively for months on ordinary butchers' meat, in which no trace of starch or sugar is present, the presence of sugar in the liver, though in much smaller quantity, could readily be demonstrated. In such cases it was obvious that the sugar could not be deriverk directly from the aliment, but must have been the result of metamorphoses taking place in the econony.

397. In the meanwhile Bernard, pursuing his investigations, was struck with the circumstance, that if the vessels of the Liver were thoroughly cleared of Sugar by the injection of water, a fresh supply of that substance could be obtained, after the lapse of a few hours, upon reinjection; showing not only that the production of sugar must be external to the vessels, and iu the very substance of the organ itself, but also that it is capable of taking place quite independently of all vital action. From a consideration of these facts, he was led to inquire whether there might not be some substance formed by and pre-existent in the hepatic tissue, from the metamorphosis of which the sugar proceeded; and he, coincidently with Hensen ${ }^{3}$ and Pavy, ${ }^{4}$ was soon successful in obtaining a peculiar substance possessing properties intermediate between those of starch and dextrin, and capable, under the action of ferments, of being readily converted into sugar, and of ultimately undergoing alcoholic or lactic acid fermentation. This substance was termed Glyengen by Bernard; Hepatin, or Amyloid substance, by Pavy; and Zoamylin by Rouget. It belongs to the group of colloidal or non-diffisible bodies (Pary). The great influence exercised by the nature of the food on its amount has been clearly shown by Dr. Pavy, ${ }^{5} \mathrm{MeDonnell,} \mathrm{and}$ Tscherinoff. ${ }^{6}$ Dr. Pavy found, on analyzing, the livers of dogs fed exclusively on animal diet, about 7 per cent. of amyloid substance; whilst in those fed on meat and sugar it amounted to 14.5 per cent.; and in. those fed on vegetable diet alone to 17 per cent. In cases where animals were fed on starch and sugar, the livers were pale and pulpy. No:anyloid suhstance was present in animals dying of starvation or wasting disease. ${ }^{7}$. The amount of Glycogen in the Liver of those animals in which the tissue of the organ

1 See Guz. Méd, Gaz. Hebdomad., and C. Rendus, 1867.

2 Journ. de la Physiol., 1858, p. 24t; 1859, p. 104.

3 Archiv f. Path. Anut, Bd. xi, p. 395.

4 Guy's Hospital Reports, 18.58, p. 291; 1859, p. 204; 1861, p. 197; Phil. Trans., 1860.

5 Phil Trans., 1860, p. 604.

${ }^{6}$ Sitz. d. k, Akad. zu Wien, Bd. li, 1865, p. 412. See also Doek, Plüger's Arehir, Bd. v, p. 571 .

7 This is not in aeeordance with Bernard's experiments (Revue Seient., t. viii, 187273, p. 115.5) who found grlycogen to be constantly present, even after prolonged fisting. Dock states tbat when in eonsequence of inanition all glyoogen had disappeared from the liver, the ingestion of sugar in to the stomaeh caused the appearance of harge quantities in the liver in the sourse of a few hours, but no such effect was produced in rabbits by the ingestion of albumen. See Tiegrel, idem, Bd. vi, p. 249. The differenees in the amount of glycomen found by different observers under apparenty similar conditions may perhaps be due to the circumstamee pointed out by v. Wittich (Centralblatt f. d. Med. IV 1 ss , 1875, p. 117), that the formation of glyeogen does not take place with equal energy in all parts of the liver, some produeing it more abunduntly than others. 
is compact, is much less than in those in which it is lonse. In the Horse, for example, it is at least thrce times less than in the Rabbit. In Fowls, Brücke found it might reach the high proportion of 12 per cent. of the total weight of the Liver. In rabbits submitted for several days prior to dcath to different dietarics, it lias been found that canc, milk, and grape sugar (though not mannite), 1 and starch always led to a large percentage of anyloid substance in the Liver, this organ appearing to scize upon these substances and store them up, so that the sudden cntry of a large quantity into the general circulation is prevented. If, however, a very considerable quantity of sugar be introduced into the stomach, especially if it be empty (as it commonly is in the dog), it is quickly absorbed, and though conveyed to the liver, this organ is unable to metamorphose the whole of it, and the portion which escapes entering the general circulation is discharged by the Kirheys, providing it exceeds three per cent. of the blood. The same quantity of Sugar may be disposed of without producing diabetes if it be incested slowly, or when the stomach is full (as it commonly is in rabbits), and thus Bernard accounts for the difference in regard to the appearance of Sugar in the urine after the administration of the same quantity to dogs and rabbits. ${ }^{2}$ Although, as the foregoing cxperiments show, the amyloid substance is much nore abundant in the livers of animals fed on starch and sugar, from which, therefore, it doubtless in part proceeds, it must not be overlouked that it is also prescnt in animals confined to a pure neat diet; in which case it is probable, that it proceeds from the disintegration of albuminous compounds into hydrocarbonaceous and nitrogenized substances. ${ }^{3}$ In Granivorous and Herbivorous animals, as in fowls and rabbits, the albuminous compounds do not appear to be well adapted for the production of glycogen. Thus IV eiss found only traces of Gly'cogen in the liver of fowls fer for a fortnight on flesh and fibrin, and Dock found none in rabbits fed with white of egg. The same conclusion may be drawn from the fact that the quantity of glycogen in the liver of animals starving to death, and when therefore they are living on animal diet, is greatly reduced. In 1859, Bernard ${ }^{5}$ detected the presence of anyloid substance in the placenta of ruminants, in which, or rather, as has been since shown, in patches of cells lying on the inner surfice of the amnion, it cxists in considerable quantities. Shortly afterwards, Rouget ${ }^{6}$ discovered it in various embryonic cellular tissues, as in the epithelium of the skin, and of the alimentary and genito-urinary mucous membranes. It is remarkable that it is not found in the liver till its histological development is completed, or until about the middle of intrauterine existence. Substances presenting the reactions of starch or of dextrin have recently been discovered by Jaffe in the substance of the brain, by Limpricht ${ }^{7}$ in the muscles, and by Kühne in various glands and pathological gruwths. Anyluid substance has been found also in the bodies of several invertebrate animals, as in the snail (Bernard), cockle $\left(\right.$ Bizio $\left.^{8}\right)$, tape and round worm (M. Foster $\left.{ }^{9}\right)$, mussel, and oyster $\left(\right.$ Pavy $\left.^{10}\right)$; but

1 See Luhsinger, Pflüger's Archiv, Bd. viii, and Salomon, Virchow's Archiv, Band Ixi, p. 352.

2 See Brunton, Lectures in British Med. Journal, 1874, pp. 1, 39, and 221; and Schöptfer, Archiv f Experiment. Path., 1873, i, p. 72 .

3 See Hnppe-Seyler, Ptlüger's A rchiv, Bd. vii, p. 399. Salomon (Virchow's Archiv, Bd. Ixi, 18i4, p. 352) has demonstrated clearly that glycogen is formed in the liver from gelatin as well as from albumen.

4 Sitzung.wer. d. Wien. Akad., Bd. Ixvii, abth. 3.

5 Brown-Séquard's Jourual de la Phỵ:jol., $18 ; 9$, p. 30.6 Id., p. 83.

7 Amalen der Chemie und Pharm., Bd. exxxiii, p. 293.

8 Comptes liendus, lxii, p. 675.

9 Procedings of the Roy. Suc., 1865, No. 79.

10 Op. cit., 1868, p. 77. 
in these instances it appears to have little tendency to become transformed into sugar. The "corpora amylacea " of Virchow, observed as pathological formations in the kidney, spleen, and other organs, and at one time considered to be identical with amyloid substance, differ from it essentially in containing nitrogen. ${ }^{1}$

398. After the presence of an amyloid material was shown to be constant in the liver, and to precede the formation of sugar, it was supposed that some ferment was requisite by which, either in the hepatic cclls themselves, or after the absorption of the starch into the blood, its conversion into sugar could be rapidty effected. Many efforts were made to ascertain the source of this ferment; and the spleen, thymus, thyroid, suprarenal, salivary, and pancreatic glands were successively extirpated by Schiff," without, however, his being able to determine whether any of them were instrumental in its formation. Bernard, ${ }^{3}$ Hensen, and Cohnheim ${ }^{4}$ maintain that the ferment is thrown down with the amyloid substance on the addition of alcohol to the cold aqueous infusion of the liver; that it is rendered inoperative by boiling; and finally, that it is contained in ordinary arterial blood, and in the blood of the vena portæ, the addition of such blood to a solution of glycogen effecting its conversion into sugar. The necessity for the existence of this ferment has been reudered doubtful by the investigations of Dr. Pavy, ${ }^{5}$ whose experiments have led him to the following conclusions: 1 . That the liver normally and during life, whatever may have been the nature of the food, contains little or no sugar, but a considerable proportion of amyloid substance; since if it be removed from the body instantly after death, and subjected to the action of caustic or carbonated potash or soda, or of extreme cold, no saccharinc reaction can be obtained, though the presence of the amyloid substance can casily be shown. 2. That, during life, there is under ordinary circumstances very little difference in the amount of sugar contained in different specimens of blood, whether withdrawn from the systemic arteries or veins, the portal vein, or (by means of a catheter introduced through the jugular vein $)^{6}$ from the right auricle; the latter of course containing a large proportion of hepatic venous blood; the quantity of sugar present in all instances being extremely small, and varying from -470 ths to 1730 ths of a grain per cent. 3. That during life, thereforc, very little amyloid substance is taken up by the blood in its passage through the liver, as indeed night be anticipated from its low power of dialyzing through animal membranes. On the contrary, after death, and frequently fron varions disturbing causes during life, such as violent muscular action or embarrassment of the respiration, a conversion of the amyloid substance into sugar takes placc in the substance of the liver itself, and the sugar so formerl then quickly appears in the blood, often to so great an extent as to occasion diabetes.

399. At an early period of the history of the glycogenic function of the Liver, it was found that the formation of glycogen could be influcuced through the nervous system. Bernard, for instance, observed that when the floor of the fourth ventricle between the origin of the Pneunogastric and Auditory nerves (see Fig. 175) was pricked with a needlc, ${ }^{\top}$ so great an in-

1 See Dr. Pavy's Gulstonian Leetures for 1863.

2 Unters. üb. die Zuckerbildung der Leber, Würzburg, 1859.

3 Revue Scientif., 1873, Leet. xviii. See also v. Wittich, Centralblatt, 1873, 1. 365.

4 Virehow's Archiv, Bd. xxvii, 1. 241.

5 Sce his work on Dinbetes, 1868. See Ritter, Zeitsehrift f. rat. Med., Bd. xxiv, p. 65; Schifl, Journal de l'Anatomie, Robin, 1866; MeDonnell, Observations on the Functions of the liver, 1865 .

6 See on this point also McDonnell, Proecedings of the Royal Irish Society, 1868.

7 Though not, aecording to Dock, if the animal has been kept fusting for several duys. P’lüger's Arehiv, vol, v, 1872, p. 583. 
crease was effected in the quantity of sugar gencrated, that that substance was discharged by the urine, a temporary condition of diabetes being established. The same condition could be established by irritation of the centre extremity of the divided vagus, and by irritation of the spinal cord (Schiff, Mons), ${ }^{1}$ and by section of the splanchnic (Grïfe, Eckhard, Hensen1), ${ }^{2}$ which led Schiff to admit a form of diabetes from irritation, and a diabetes from paralysis of vaso-motor nerves. Eckhard ${ }^{3}$ subsequently showed that after division of the splanchnics puncture of the fourth ventricle is no longer followed by diabetes. He further found that section of the inferior cervical ganglion was always followed by marked diabetes, and he arrived at the conclusion that the effects of pricking the fourth ventricle were transmitted through the inferior cervical and the upper thoracic ganglia. Diabetes was produced by Pavy after division of the sympathetic cord in the neck, and after division of the sympathetic plexus accompanying the vertebral arteries. ${ }^{4}$ The whole subject of the action of the nervous system upon the liver has been carefully worked out by Cyon and Aladoff: ${ }^{5}$ The cause of the diabctes in all the above-mentioned instances is the paralysis of the vaso-motor nerves, occasioned either by direct injury to their centres, as when the fourth ventricle is punctured, or by reflex irritation, as when the Pneumogastries are irritated and there is a consecutive dilatation of the branches of the hepatic artery, and a more rapid circulation of blood through the liver. The vaso-motor nerves for the liver arise for the most part from the vaso-motor centres in the medulla oblongata $(\$ 254)$, and descending through the cord, leare this by means of fibres which accompany the vertebral artery and enter the lower cervical ganglia. Thence they proceed contained in tro fasciculi, one of ' which passes on each side of the subclavian artery, forming the annulus of Vieussens, to the first thoracic ganglion, and so through the successive ganglia of the sympathetic, the splanchnies, celiac ganglion, and finally along the hepatic vessels to the liver. The experiments of Eckhard ${ }^{5}$ render it probable that in some instances the fibres descend through the cord to a lower level than that of the vertebral artery before they emerge to enter the splanchnics. As section of the hepatic vaso-motor nerves at any point between the fourth ventricle and the liver causes vaso-motor paralysis and increased flow of blood through

1 Moos, Archiv f. Wiss. Heilk., Bd, iv.

2 Hensen, Verhand. der Phys. Med. Ges. in Würzburg, Bd. vii.

3 Eckhard, Beiträge zur Anatomie v. Physiologie, 1867, Bd. iv.

4 See Guy's Hosp. Rep., 1859, p. 204.

5 Cyon and Aladofi', Bulletin de l'Académie Impériale de St. Pétersbourg, t. viii, p. 91. Abstract in Centralblatt, 1872, p. 152, and in Dr. Brunton's Lectures in Brit. IIed. Journ.

6 Eckhard, Beiträge, Bd. vii, 1873, p. 19. 
the liver, sueh seetion ought to be always followed by glyeosuria, but this is by no means the case, and a rational explanation of its non-oecurrenee has been given by Cyon and Aladoff to the effeet that although the section does really produee vaso-motor paralysis of the vessels of the liver, yet that the current of blood is not materially increased in vigor, beeause the same seetion, if marle high up, eoincidentally paralyzes the vessels of the abdominal viscera, which, owing to their great size, inprison as it were a large quantity of the blood. The reflex influenee of the pneumogastrie nerves on the liver is shown by dividing it and irritating the upper cut surface; sugrar then appears in the urine in eonsequenee of the paralysis of the vaso-motor centre. Irritation of the lower cut surface is without effeet. The pneumogastrics are therefore the sensory nerves of the liver. It may here be remarked that the close relationship of the secretion of bile with the formation of glycogen is demonstratel by the observations of Dr. Legg, ${ }^{1}$ who has shown that after ligature or eomplete obstruction of the Hepatic duets, glyeogen is no longer formed by the Liver, and that puneture of the fourth veutriele fails to produce dialietes.

400. The influenee of medicinal agents upon the glyeogenie funetion of the Liver hats received but little attention, though various substanees are known to be eapable of inducing diabetes. Cozé ${ }^{2}$ found the proportion of sugar nearly clouble both in the liver and in arterial blood after the adninistration of norphia. Pavy ${ }^{3}$ observed well-marked diabetes in animals after the atdministration of phosphorie acid, and atso after poisonous doses of strychnia, when the circulation was maintained by artificial respiration. Harley obtaincl the same result in himself after eating freely of asparagus. Certain poisons, as woorara (Schiff'), produce it, as well as very vigorous artificial respiration. Ewald ${ }^{4}$ obscrved it in Rabbits after the subcutaneous injection of nitro-benzole. The administration of large doses of eaustic potash, or of earbonate of soda, is stated by Dr. Pavy to prevent the occurrence of diabetes under circumstances in which it would otherwise have been indueed. Diabetes may be produced by disturbances of the respiratory processes. Thus it oceurs in Asphyxia, as in poisoning with earbonic oxide gas (Schiff), and Harley observed it in animals under the influence of ether, chlorotiorm, liquor ammonix, and methylated spirit. ${ }^{5} \quad$ Reynoso $0^{6}$ produced it by making animals respire the vapors of benzoin and acetoin, and found that it followed asphyxia slowly produeed by the inhalation of carbonic, hydrocyanic, and sulphuretted hydrogen gases. Diabetes may also be produced by disturbanees in the circulution. 'Thus Schiff found that retention of the blood or retardation of the blood-current in any part, such as ligature or eompression of the larger vessels, will lead to its oceurrence. Tieffenbach, however, found that the amount of sugar was increased by arrest of the eireulation through the aorta or vena porte. An experiment made by Winogradoff shows eonclusivcly that the Sugar is formed direetly or indireetly by the liver, for when diabetes has been produced by puncture of the floor of the fourth ventricle it at once ceascs on ablation of the liver, and a similar eonchision may be arrived at by puneturing the fourth ventricle in an animal to which arsenic has becn administered for some time, for this drug has been found to prevent the formation of glyeogen in the liver, and in eonsequence of the absence of glycogen in the liver, sugar is not produeed in sufficient quantity to lead to its climination by the kidncys.

1 Briti-h Med. Journal, 1874, p. 646, vol. i, and Archiv f. Experiment Pathologie, Bd. ii, II eft 5 .

2 Compttes Rendus, 1857.

1 Contrablatt, 1873, p. 819

6 Annal. d. Sui. Nut., 1855, p. 131.

3 Procedings of the Royal Society, No. 35.

5 See Procced. of lioy. Soc., 1860. 
401. The use of the amyloid substance developed in the Liver is involver in the greatest obscurity. By the earlier observers it was thought that it was immediately reconverted into sugar, and undergoing combustion in its passage through the Lungs, became subservient to the maintenance of animal heat. Various arguments have, however. been justly urged by Dr. Pavy against this view, and he is limself disposed to regard its production as representing the first step of assimilation of the starchy and saccharine elements of our food; and as these elements are known to proceed on into fat, he thinks there are grounds for believing that amyloid substance occupies an intermediate position between the two. The process of assimilation, he believes, may go on to the production of fat in the liver, or it may be that it stops short at the formation of another principle which cscapes from the liver, and is elsewhere transformed into fat, or into the resinoid matter of the bile. In accordance with this view are the researches of 'Tscherinoff, who, obtaining similar results to those of Dr. Pavy in regard to the amyloid substance, noticed also that the use of food coutaining nuch hydrocarbonaceous matter, as sugar, greatly increased the proportion of fat in the liver. Two theories have been advanced to explain why the amount of glycogen in the liver is increased after the use of the carbohydrates. On the one hand, it may be said that the carbohydrates are more or less completely couverted into glycogen within the liver, and that they are stored up in that organ ; and on the other it is maintained that the carbohydrates being readily oxidizable seize upon the oxygen of the blood and spare the glycogen derived from some other source. ${ }^{2}$ The probabilities seem in favor of the former view. In regard to the origin of glycogen from oleaginous compounds, the experiments of Bernard, and MIcDonnell, and Luchsinger with fat dietaries seemed to show that this diet is unfavorable to the formation of glycogen, and even Salomon, whose recent experiments ${ }^{3}$ are not quite in accordance with those of his predecessors, shows that the proportion of glycogen is very much less on a fat than upon a saccharine diet, and about half as much as upon a gelatin diet. The concordant results of Weiss, Luchsinger, and Salomon show that glycogen is abundantly formed, when glycerin is either administered alone in a diluted state or given with the food. Experiments with soap diet have been undertaken by Salomon, but have not enabled him to determine whether the glycogen iu neutral fat diet proceeds from the glycerin it contains. The circumstance that the blood which enters the Liver is rich in fibrin and albumen, whilst that which leaves it is poor in these materials, has led Dr. MeDomnell to suggest it as probable that these materials break upinto secondary hydrocarbonaceous compounds, which are partly eliminated by the bile-ducts, and are partly stored up as glycogen; and into nitrogenous compounds, which reunite with the hydrocarbonaceous amyloid substance, and leave the liver as a newly-formed protein compound, partly perhaps as globulin, and partly as a material resembling casein or albuminose. More recently, Dr. W. Ogle has advanced a similar view, and holds that before leaving the liver glycogen unites with some albuminous compound which enters the blood-corpuscles and from them is transferred to the muscles, where it undergoes decomposition with lactic

1 See Pavy, loc. cit. ; Tscherinoff, loc. cit. ; Dock, Pflüger's Archiv, Bd. v, p. 57.

2 Scheremetjewski (Ludwig's Arbeiten, 1869, p. 154) and Weiss (Sitz. d. WVien. Akad., Bd. lxvii, abth. 3) advocate this view, on the ground that after the administration of glycerin the proportion of glycogen in the liver is notably increased, glycerin being a substance not likcly to bc converted into glycogen. Both Kühne and Luchsinger (Pflügcr's Archiv, 1873, Bd. viii, p. 289) have shown that this is an assumption unwarranted by facts.

3 Virchow's Archiv, Bd. Ixi, 1874, p. 854.

4 Sce St. George's Hospital Reports, vol. iii, 1868, p. 149. 
acid and myosin: the former by its combustion yields muscular force, the latter is returned to the circulation to become again the carrier of a fresh portion of glycogen. That this is its destination, he thinks is supported by the fact that muscle naturally contains a not inconsiderable amount of glycogen, as well as by the circumstance that this disappears or is greatly reduced when this tissue is brought into action ; $^{1}$ and, lastly, it is in harmony with the fact that glycogen is abundant in most of the tissues of the embryo in which but little muscular energy is expended. ${ }^{2}$ Gaetghens ${ }^{3}$ from experiments with phosphorus on dogs, in which large quantities of fat are formed in the Liver, rising sometimes to 11 per cent., apparently from the metamorphosis of albumen, observes that there is no increase in the amount of glycogen, and is consequently opposed to this view. 'Taking, however, such information as we at present possess into consideration, we seem entitled to conclude that the Liver exerts a twofold action on the blood which is traversing its capillaries-an assimilative and a depurative. By its operation as an assimilating organ it helps to prepare histogenetic material for conversion into blood and solid tissue, in the course of which it is capable of producing and of storing up amylaceous and oleaginous material in its cells, both of which are capable of being called upon for the maintenance of muscular force and of animal heat; whilst by its depurative action it fiees the blood from the protein compounds which are destined to undergo retrograde metamorphosis, as being either superfluous or effete. A portion of these is again, in all probability, applied to the production of amyloid substance and fat; whilst the remainder, containing the nitrogen and sulphur, though a waste of product, is in the form of the bile made subservient to digestion, and the introluction of fresh matcrial into the blood before its final discharge from the body.

\section{The Kidneys.-Secretion of Urine.}

402. The Kidneys cannot be regarded as inferior in importance to the Liver, when considered merely as Excreting organs; but their fumction only consists in separating from the blood certain effete substances which are to be thrown off from it, and has no direct connection with any of the nutritive operations concerned in the introduction of aliment into the system. The following are the points in the minute structure of these organs, which are of most importance in their Physiological relations. ${ }^{5}$ Their glandular and - vascular elements are imbedded in a stroma composed of interlacing fibres (Fig. 176, $d d$ ); this is more abundant in the medullary than in the cortical substance; but at the surface of the gland it is condensed into a continuous membrane, which is loosely connected with the proper capsulc. The distinction between the cortical and the medullary part of the Kidney essentially consists in this,- that the former is by far the most vascular, and the

I See Wundt, Physiologie, 1873, p. 348.

2 See Weiss, Wien. Akad. Ber, lxiv, Heft. 2 ; also Flint, Plysiology, vol. ii, p. 315; Lusk, New York Med. Journ., July, 1870; Tyson, Introduetory Lecture delivered at Pennsyivania College, Nov. 7th, 1870 ; Senator, Centralblatt, 1871, p. 623.

${ }^{3}$ Centralblatt, 1871 , p. 623 .

4 See Huppert, Centralblatt, 1869, p. 349.

6 See especially Mr. Bowman's Memoir in the Philosophical Transaetions, 1842 ; also Goodsir in Edinb. Monthly Journal, 1842; Gerlach, Bidder, and Kölliker in Müller's Archiv, 1845; Toynbee in Med.-Chir. Trans., 1846; Johnson in Cyrelop. of Anat. and Phys, art. Ren.; Gairdner in Edinb. Monthly Journal, 1848; Frerichs, Die Bright'sche Nierenkrankheit und deren Behandluna, 1851; and Kööliker, Mikroskopische Anatomie, and Man. of Hum. IHistol. (Sydenham Soe.); Mieros. Anat. 1860 ; Isares, Trans. N. Y. Acad. of Med., vol. i, 1857; Henle, Göttingen Abhandlungeu, 1862; and Handbuch der Anatomie, Bd. ii, 1866; IIüfner, Zur veruleich $\Lambda$ nat. u. Pliys. d. Harncanälchen, Leipzig, 1866 ; Ludwig, Art. Kidney, in Strieker's Hum. and Comp. II istology, Syd. Soe. Transl., vol. ii, 1872, pp. 83-109; Frey's IIistology, translated by Barker, 1874. 
plexus formed by the tubuli uriniferi seems to come into the closest relation with that of the sanguiferous capillaries, so that it is probably the seat of the greatcr part of the process of secretion; whilst the latter is principally

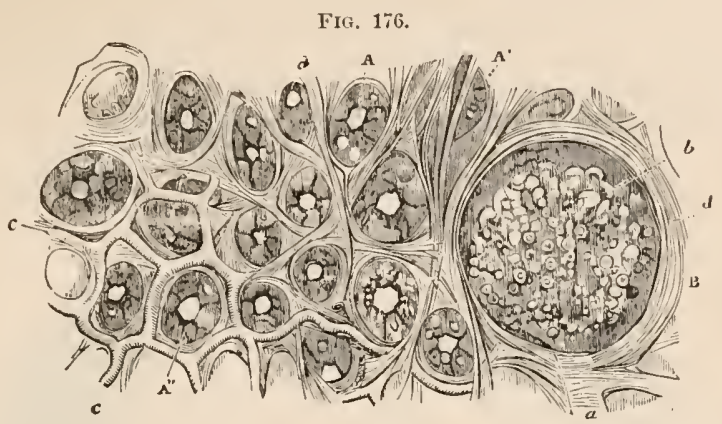

Section of the Cortical Substance of the Human Kidney: A A, tubuli uriniferi divided transversely, showing the spheroidal epithelium in their interior: B, Ifalpighian Capsule; $a$, its afferent branch of the renal artiry; $b$, its glomerulus of capillaries; $c c$, secreting plexus formcd by its efferent vesscls; $d$, fibrous strowa.

composed of tubes, passing in a straight line from the former towarls their point of entrance into the ureter. The tubuli uriniferi, in passing outwards from the Calices, frequently divide in a dichotomous manner, thus becoming greatly increased in number, whilst their diameter diminishes

FIG, $17 \%$.

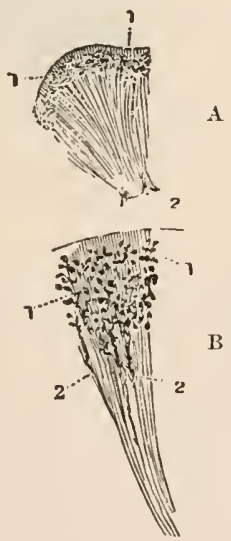

FIG. 178.

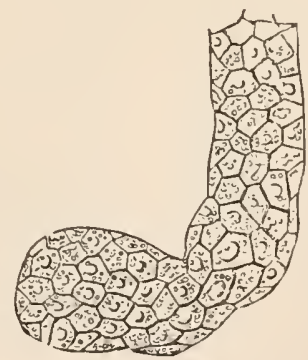

FIG. 177.-Portion of the Kidney of a new-born infant: A, natural size; 1, 1, Corpora Malpighiana, as dispersed points in the cortical substance; 2, papilla.-B, a small part magnificd; 1, 1, Corpora Malpighiana ; 2 , tubuli uriniferi.

FIG. 178.- Portion of one of the Tubuli Uriniferi, from the medullary substance of the kidney of an adult; showing its tessellated epithelium.

from $\frac{1}{300}$ to $\frac{1}{600}$ of an inch. Each branch, as it is given off, first enlarges and becomes tortuous, forming the intermediary portion of Ludwig, then contracts and (b, Fig. 179) runs towards the apex of the pyramid in the form of a very narrow tube, and after a course of variable length, loops back $(c c)$ towards the cortical portion, forming the loop of Henle, where it becomes wider and much convoluted, and terminates in a dilatation which has 
received the name of the Malpighian Capsule. ${ }^{1}$ The total number of the tubes is estimated by Huschke at about two millions. The epithelium presents very considerable changes in its character in the different parts of the tube. In the tortuous cortical part the cells are cloudy, and not very distinctly differentiated from one another, the nuclei lying in a pulpy substance, which is but loosely attached to the basement-membrane, slight pressure causing it to exude from the divided tubules under the microscope. These cells contain fat-drops and numerous dark granules that conceal the

FIG. 179.

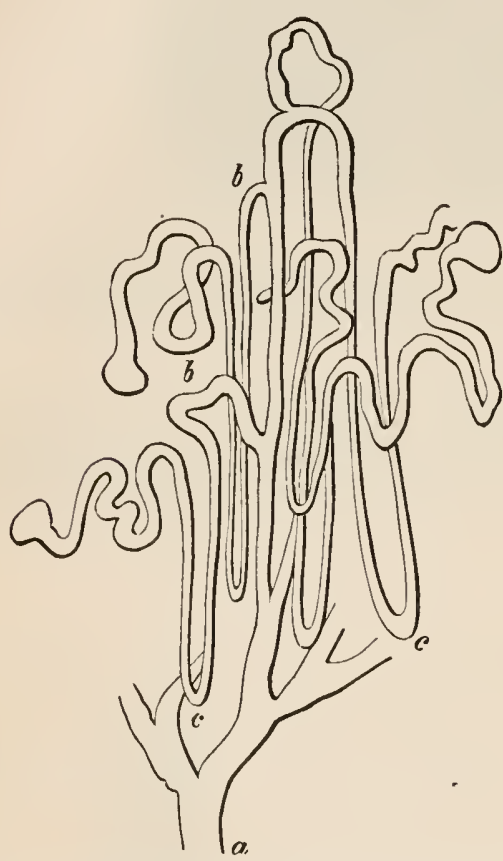

FIG. 180 .

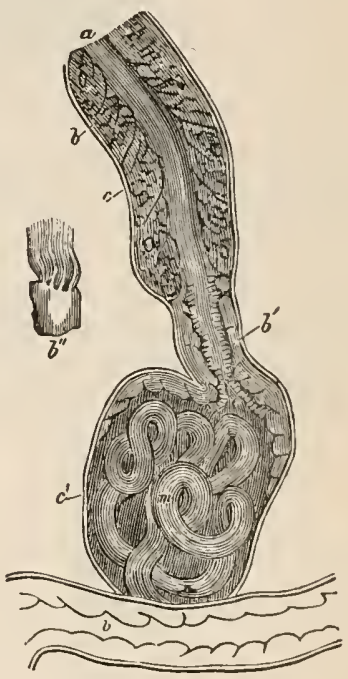

FIG. 179.-Diagram of the course of the Uriniferous Tubules : $a$, orifice of tubule at apex of Malpighian pyramid; $b$, intermediary portion, contiuuous with recurrent branches, which form loops, $c$, in the medullary portion of the kidney, and reascending, terminate in Malpighian capsules in the cortical portion.

Fig. 180.-Uriniferous Tube, Malpighian Tuft and Capsule, from Kidney of Frog: a, carity of the tube; $b$, epithelium of the tube ; $b^{\prime}$, ciliated epithelium of the reck of the capsule; $b^{\prime \prime}$, detached epithelium scalc; $c$, basement-membrane of tube; $c^{\prime}$, basement-membrane of capsulc; $m$, convoluted capillaries of the Malpighian tuft.

nucleus, but clear away with dilute acids. The capsular limb of the loop of Henle is lined by a thin and clear continuous layer, which is raised at regular intervals by nuclei. In the wider part of the opposite limb of the loop the pulp prescnts a fissure midway between cach pair of adjoining nuclei; so that the epithelium appears in the form of well-defined columnar cells

1 Ludwig states that the tubuli uriniferi change their diameter no less than seven times, viz.: 1. At the eonstrietion at the neek of the capsule; 2 . At the dilatation extending from the neek of the capsule through the tortuous portion; 3 , $\Lambda$ t the constriction through the greater part of the loop of Henle; 4 . At the dilatation in the ascending limb of the loop; 5 . At the constriction where it hecomes eontinuous with the windings of the intermediary portion; $6 . \Lambda$ the dilatation in these latter; and 7 . At the constrietion in the portion that extends from the intermediary portion to the excretory duets. 
arranged in an imbricated manner. In the windings of the intermediary portion, the epithelial lining reassumes the pulpy character it presented in the tortuous portion of the tubule. In the main ducts the cells are colummar and well defined, and are attached by their broad bases. In the papills themselves the ducts lose their basement-membrane, and are eomposed of the eells alone. ${ }^{1}$ On examining one of the Corpora Malpighiana with a high magnifying power, it is found to consist of a convoluted mass of minute bloodvessels (Fig. 180, $m$ ); and this is included in a flask-like dilatation of one of the tubuli uriniferi (Fig. 180, $c, e^{\prime}$ ). Aceording to Mr. Bowman, this dilatation proeeeds only from the termination of the tubulus; and this seems to be usually the ease, although it appears not improbable that it may sometimes be a lateral diverticulum, as deseribed by Gerlach (loc. cit.). The epithelium, whieh elsewhere lines the tube, is altered in appearanee where the tube is continuous with the capsular dilatation (Fig. 180, $b^{\prime}$ ); being there more transparent, and furnished with eilia (as shown at $b^{\prime \prime}$ ), which, in the Frog and other Reptiles, may be seen for many hours after death, in very active motion, direeting a current down the tube (Hüfner Meeznikow). Beyond this point the wall of the capsule is composed of a mosaie of eells like those forming the walls of the blood-and lymph-eapillaries strengthened on the outer side by a little eonneetive-tissue.

403. 'The absolute quantity of blood traversing the kidneys is wonderfully great, amounting, aeeording to the ealculations of M. Brown-Séquard, ${ }^{2}$ to nearly $2000 \mathrm{lbs}$. per diem. The Cireulation of Blood through the kidney presents a very remarkable peculiarity. The supply is derived in man (as in other Mammalia) direct from the arterial system; though in Fishes and Reptiles the urinary apparatus is eonneeted, as well as the biliary, with the portal renous system, and even in Birds a portion of its blood is derived from the latter. But although this organ is supplied from the Renal Artery, yet it is not to its proper secretory apparatus that the blood of the artery is distributed in the first instance; for, on entering the kidney, this vessel speedily and entirely divides itself into minute twigs, whieh are the afferent vessels of the Malpighian tufts (Fig. 176, a, 181, af). After it has piereed the capsule, each twig dilates; and suddenly divides and subdivides into several minute branches, terminating in convoluted capillaries, which are colleeted in the form of a ball (Figs. 176, b, 181, $\mathrm{mm}$ ); from the interior of the ball, the solitary efferent vessel, ef, arises, which passes out of the capsule by the side of the single afferent vessel. The examinations of Kölliker, ${ }^{3}$ and of Dr. Isaaes, ${ }^{4}$ show that the glomerulus is envered with oval nucleated eells. The efferent vessels on leaving the Malpighian bodies, separately enter the plexus of capillaries (Figs. 176, $c, 181, p)$ surrounding the tubuli uriniferi $(s t)$, and supply that plexus with blood; from this plexus the renal vein arises. ${ }^{5}$ Thus there is a striking analogy

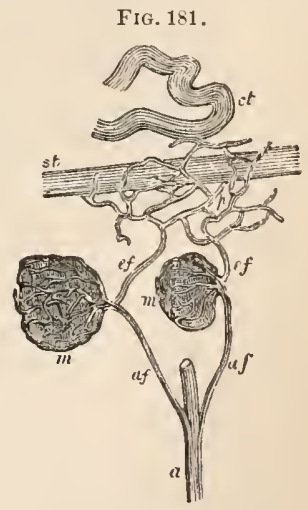

Distribution of the Renal vessels; from Kidueys of Horse;- $a$, brauch of Renal artery; $a f$, afferent vessels; $m, m$, Malpighian tufts; $e f, e f$, efferent vessels; $p$, vascular plexus surrounding the tubes; st, straight tube; $c t$, couvoluted tuke.

1 See Heidenhain, Alchiv f. Microscop. Anat., Bd. x; also v. Seng, Sitz. d. k. Akad. zu Wien, 1871, p. 354.

2 Journ de la Physiol., 1858, t. i, p. 305.

4 Trans of N. Y. Acad. Med., vol. i, 1857.

3 Man. Mic. Anat., 1860 , p. 408.

5 The reader will find a good summary of the opinions beld by Virchow, Ludwig, and others on the coturse of the vessels, by Dr. Reg. Southey, in the first volume of the St. Bartholonew Hosp. Reports, p. 177. 
between the mode in which the tubnli uriniferi are supplied with blood, for the purpose of elaborating their secretion, and the plan on which the hepatic circulation is carried on. For as the secretion of the Liver is formed from blood conveyed to it by one large vessel, the portal vcin, which has collected it firom the venous capillaries of the chylopoietic viscera, and which subdivides again to distribute it through the liver, so the secretion of the Kidney is claborated from blood which has already passed through oue set of capillary vessels, those of the Malpighian tufts; this blood is collected and conveyed to the proper secreting surface, however, not by one large trunk (which would have been a very inconvenient arrangement), but by a multiturle of small ones, the efferent vesscls of the Malpighian bodies; which may be regarded as collectively representing the portal vein, since they convey the blood from the systemic to the secreting capillaries. Hence the Kidney may be said to have a portal system within itself.-This ingenious view of Mî. Bowman finds support from the fact, that in Reptiles the efferent vessels of the Malpighian bodies (which receive their blood, as elsewhere, from the renal artery) unite with the renal branches of the Vena Portie, to form the sccreting plexus around the tubuli uriniferi. Here, therefore, the blood of the secreting plexus has a double source, the vesscls which supply it receiving their blood in part from the capillarics of the organ itself, and in part from those of viscera external to it; just as, in the Liver, the secreting plexus is supplied in part by the nutritive capillaries of the organ itself, which receive their blood from the hepatic artery, and in part by the blood conveyed from the chylopoietic viscera through the Vena Portæ.

404. These admirable researches of Mr. Bowman on the structure of the Malpighian bodies, and on the vascular apparatus of the Kidney, have thrown great light upon the mode in which the Urinary secretion is elaborated. One of the most remarkable circumstances attending this excretion, in the Mammalia particularly, is the large but variable quantity of water, which is thus eliminated, - the amount of which bears no constant proportion to that of the solid matter dissolved in it. The quantity of water which is passed of by the Kidneys depends in part upon that exhaled by the Skin, being greatest when this is least, and vice versâ; but the quantity of solid matter to be conveyed a way in the secretion has little to do with this, being dependent upon the amount of waste in the systen, and upon the quantity of surplus azotized aliment which has to be discharged through this channel.- The Kidney-contains two very distinet provisions for these purposes. The cells lining the tubuli uriniferi are probably here, as elsewhere, the instruments by which the solid matter of the secretion is eliminated; whilst it can scarcely be doubted, that the chief office of the Corpora Malpighiana is to allow the transudation of the superfluous fluid through the thin-walled capillaries of which they are composed. "It would indeed," Mr. Bowman remarks," "be difficult to conceive a disposition of parts more calculated to favor the escape of water from the blood, than that of the Malpighian body. A large artery breaks up in a very dircet manner into a number of minute branches; cach of which suddenly opens into an assemblage of vessels of far greater aggregate capacity than itself, and from which there is but onc narrow exit. Hence nust arise a very abrupt retardation in the velocity of the current of blood." The vesscls in which this delay occurs, lie in a capsule, from which there is but one outlet, the orifice of the tube. "This orifice is encircled by cilia, in active motion, directing a current towards the tube. These exquisite organs must not only serve to carry forward the fluid which is already in the cell, and in which the vascular tuft is bathed; but must 
tend to remove pressure from the free surface of the vessels, and so to eneourage the eseape of their more fluid contents." - Here we sec the essential difference which exists between the vital ageney coneerned in the truc Secreting process, and the physical powcr whieh oeeasions fluid cxhalation or transudation. This difference is preeiscly the same as that whieh exists between the vital aet of selective absorption, and the physical operation of endosmose or imbibition. By Imbibition and Transudation, eertain fluids may pass through organie membranes, in the dead as well as in the living body; and this passage depends merely upon the physical eondition of the part, in regard to the amount and the nature of the fluid it eontains, and the permeability of its tissues. There are two sets of lymphatics in the Kidneys, one of which emerges with the bloodvessels at the hilus, whilst the other arises amongst the fasciculi of the capsule. Little is known in regard to the nerves exeept that they belong to the sympathetie system, are eonnected with ganglion-eells, and eontain both scnsory and vaso-motor fibres. ${ }^{1}$ To ehemieal investigation the tissue of the kidney yields Inosite, Taurin, Leucin, Tyrosin, Kreatin, Xanthin, Hypoxanthin, Cystin, and sometimes Urea and Urie Aeid.

405. The Kidncy is liable to undergo alterations of its normal structure, from a perversion of its ordinary formative proeesses, which are of a nature very analogous to those neeurring in the Liver, though with differences arising out of the specialties of its conformation. ${ }^{2}$ Several different kinds, as well as degrees, of such alteration, have been deseribed (as it now appears) under the general term "Bright's discase," which has been applied almost indiscriminately to almost every kind of chronic disease of the strneture of the Kidney, whether produced by eongestion, inflammation, or fatty degeneration, that is attended with the presenee of Albumen in the Urine. It must not be supposed, however, that any of these lesions are invariably eoineident with the presenee of Albumen in the Urine: for it has been fully proved, on the one hand, that albumen may present itself in this excretion, without any alteration in the strueture of the kidney; whilst it has also been shown, that various forms of Bright's disease may exist, even in an advaneed stage, without any albumen bcing detectable in the urine. ${ }^{3}$ 'These variations may probably be attributed to two elasses of conditions, viz., the state of the albumen in the blood itself, and the state of the capillary circulation in the kidney. We have seen the weak form of albumen which is first taken up by absorption from the alimentary eanal, is distinguished by its proneness to transudation $(\$ 140)$; whilst, on the other hand, the strong albumen of the egg, if injeeted into the systemie blood-eurrent, or even if introduced in large quantities into the stomach, ${ }^{4}$ finds its way out again by the urine, as a forcign substance; an assimilating action being required, in the case of each, to give it the normal charaeter of blood-albumen. It is probably, in part at least, to the want of sueh perfeet assimilation of the newly absorbed albumen, that we are to attribute the increase of albumen in the urinc passed soon after meals, by patients suffering under Bright's disease; something,

1 See Lionel Beale, Kidney Diseases, ete., 1869, p. 17; Tyson, Ameriean Journal of Medieal Seienees, 1869, p. 395; Laneet, vol. i, 1870, p. 57.

${ }^{2}$ For full aceounts of the pathological eonditions of the Kidneys and of the Urine in "Bright's disease," the reader is referred to the recent works of Drs. Basham, Johnson, Diekinson, and Beale.

3 See Dr. Begbie in the Brit. and For. Med.-Chir. Rev., vol. xii, p. 46.

${ }^{4}$ See Hammond (Experimental Researches, Philadelphia, 1857, p. 31), who found on restricting himself' to a purely albuminous diet, that his urine first eontained a great exeess of urea, and on the eighth day albumen made its appearanee. Bernard also observed its presenee in his urine after eating six eggs fasting (Leçons, 1859, vol. ii, p. 138). 
however, may be due to the simple augmentation of the bulk of the blood, and especially of its solids. But, again, any cause which produces congestion of the vessels of the kidney, favors the passage of the normal albumen of the blood into the urine ${ }^{1}$ and thus we see how albuminous urine may be produced by the repulsion of blood from the cutaneous surface to the kidney, or by the determining influence of cantharides or other irritant diuretics, or by any obstruction to the return of blood from the capillary plexus by the renal veins."

406. The nature and purposes of the Urinary secretion, and the alterations which it is liable to undergo in various conditions of the system, are much better understood than are those of the Bile : this is owing, in great part, to the two circumstances, that it may be readily collected in a state of purity, and that its ingredients are of such a nature as to be easily and definitely separated from each other by simple chemical means. There can be no doubt that the chief purpose of this excretion, is to remove from the system the effete azotized matters, which the blood takes up in the course of its circulation, or which may have been produced by changes occurring in itself. This is evident from the large proportion of Nitrogen in the solid matter dissolved in the urine; and from the crystalline form presented by much of this solid matter when separated,-a form which indicates that its state of combination is such as to prevent it from conducing to the nutrition of the system. The injurious effects of the retention of the components of the Urinary secretion in the Blood, are fully demonstrated by the results of its cessation; whether this be made to take place experimentally (as by tying the renal artery), or be the consequence of a disordered condition of the kidney. The symptoms of Urcemia (as this condition has been appropriately termed) are altogether such as indicate the action of a specific poison upon the Nervous system; affecting either the Brain or the Spinal Cord, separately, or both together. In the first form, a state of stupor comes on rather suddenly, out of which the patient is with difficulty arouserl; and this gradually deepens into complete coma, with fixed pupils and stertorous breathing, just as in ordinary kinds of narcotic poisoning. In the second form, convulsions of an epileptic character, frequently affecting the wholc muscular system, suddenly occur; but there is no loss of consciousness. In the third form, coma and convulsions are combined. These effects have been attributed by Frerichs

1 See Robinson in Med-Chir. Transaet., vol, xxvi, p. 51.

8 Magendie, indeed, found that the mere injection of about a pint of water in to the veins of a large dog was suffieient to eause the urine quiekly to beeome albuminous, the effeet remaining for 10 or 12 hours (Bernard, Leçons, 1859, vol, ii, p. 139). Overbeek (Sitzungsbericht d. k. Akad. d. Wiss. zu Wien, 1868, F. 189) has also made the eurious observation, that eompression of the renal arteries, whilst it rapidly diminishes the quantity of urine and of urea seereted, also oeeasions the diseharge of ubumen in the urine; though if at the sume time a ligature be applied to the ureters, the appearance of abumen is eompletely prevented. Albuminous urine has been observed in eertain forms of heart disease (Rayer), and after certain lesions of the nervous system, as intracranial seetion of the tith pair of nerves (Longet, Physiologic, p. 95:), and seetion of the eerebral peduncles (Schitf); also in scurlet fever, measles, small-pox, erysipelas, pyamia, typhus, typhoid, rheumatic and matarial fevers, cholera, purpura, scurvy, diabetes, syphilis, eertain forms of pneumonia, pregnaney, post-parturient conditions, goit, ehronie aleoholism, and dyspepsia from excessive eating. See G. Johnson, British Med. Journal, January 11th, 1873. It lus been shown by Brown-Séquard, Schiff, and other experimenters, and espeeially by Ollivier (Archives Générales de Méd., 1874, February) that both puncture of the floor of the fourth ventricle, and hemorrhage into the substance of the hemispheres, is attended with great eongestion of the kidneys, and atbuminuria, but whether, as Schift thinks, this is due to paralysis of the vaso-motol nerves, or, as Brown-Séquard thinks, from spusm of the veins, or of the veins and arteries, leading to engorgement and rupture of the capillaries, eannot at present be stated with eertainty. 
and others ${ }^{1}$ to the conversion of urea in the blood into carbonate of ammonia, and in a case recorded by Spiegelberg not only was the quantity of urea in the urine greatly diminished, but the proportion of this substance in the blood was augmented to three times its nornal amount, whilst clear evidence was obtained by Dr. Gscheidlen that the blood contained a considerable excess of ammonia. Experiments on anintals in which carbonatc of ammonia has been injected into their veins, show that conditions precisely analogous to the urenic state can be established, the animals first becoming restless, and then exhibiting both tonic and clonic spasms, and finally passing into a state of deep coma. ${ }^{2}$

407. In order to form a correct opinion of the state of the Urinary secretion in morbid conditions of the system, it is desirable to be acquainted with every leading particular regarding its normal character.-Fresh healthy Urine is a perfectly transparent, amber-yellow-colored liquid, exhaling a peculiar but not disagreeable odor, and having a bitterish saline taste. The only morphological elements which it normally contains, are pavement epithelium-cells and mucous corpuscles from the lining of the urinary passages; which, however, are present in healthy urine to only a very small amount. But in certain morbid states of the urine, minute cylindrical bodies are seen in greater or less abundance, which are obviously derived from the tubuli uriniferi ; these are sometimes composed almost exclusively of the epithelial lining of the tubes, of which the cells remain adherent to each other, notwithstanding their detachment from the basement-membrane beneath; whilst sometimes they are fibrinous moulds of the interior of the tubes, formed by exudation of granular plastic material, and containing blood- or pus-corpuscles; whilst in other instances, again, they are perfectly transparent, or hyaline, and are then believed by Dr. Basham to correspond to the viscid mucous exudations poured out from all inflamed mucous surfaces. The first of these forms occurs chiefly in desquamative irritation of the kidneys, the second as a consequence of acute inflammation, and the last in the advanced stages of "Bright's disease," as well as in the gouty and atrophic kidney." In all natural conditions of the Human system (even when a vegetable diet is used) the urine possesses a well-marked acid reaction. When it is left to itself for some tine, slight nebulæ, consisting of inucus, are formed in it; and these gradually fall to the bottom. Soon afterwards an unpleasant odor

1 See Spiegelberg, Arehives of Gynæcology, 1870, and Ḧ̈mpeln, Dorpat Med. Zeits., Bd. iv, 1873, and Lond. Med. liecord, vol. i, 1873, p. 611.

${ }^{2}$ Voit (Henle and Meissner's Bericht, 1867, p. 358) is inelined from his experiments to hold that the effeets observed in uramic poisoning are due to the aetion of the various seeondary eompounds and alkaline sa?ts procceding from the disintegration of the albuminous constituents of the body which are retained in the blood in this disease upon the central parts of the nervous system, no ammonia being generated except on the intestinal mucous membrane (see also G. Johnson, Brit. Mifed. Journal, vol. i, 1873, p. 19:3); Mantegazza (Centralblatt, 1870, p. 576), on the other hand, finding that intravenous injeetion of urea or of urine produees convulsions both in eurarized frogs and even in muscles excised from the body, regards the aetion as peripheric, and not eentrie. Traube attributes the symptoms of uramic poisoning to too great fluidity of the blood and over-tension of the systemic vessels, leading to cedema and anremia of the brain; but Picot's experiments (Comptes Rendus, July 6th, 1874), in which water was injected at consideruble pressure, are opposed to this view. Rosenstein (Virehow's Archiv, Bd, lvi, 1872, p. 383), Oppler, and others contend that the symptoms caused by the injeetion of ammonia differ essentially from those of uramic poisoning. Urea ingested by the stomach is elininated unchanged. Siee Rabuteau in L'Union Médieale, 1872, No. 142. For an account of the effects of the injection of ammonia into the eirculation, see Tibbits, Med. Times and Gazette, 1872, Nio. 1166 .

3 See, for admirable drawings and descriptions of these, the work on Renal Dropsy, by W. R. Basham, M.D., 1866 . 
is developed; instead of an acid, an alkaline reaction is presented, in conscquenec of the decomposition of the urea into carbonate of ammonia; and a precipitation of earthy phosphates then takes place. A turbidity may bc produced, however, by the preeipitation of urates of soda and ammonia, on the simple cooling of the urine, without any sueh departure from its normal composition as would properly constitute disease, but under some of the eonditions hereafter to be specified ( $\$ 411$ ). But if the urine be turbid when it has first passed from the body, and has a temperature of $98^{\circ}$ or $100^{\circ}$, it must be considered as abnormal.

408. Quantity.-Dr. Parkes, ${ }^{1}$ who has collected the averages of many different observers, states that $52 \frac{1}{2}$ fluid ounces may be considered to represent the mean quantity of urine diseliarged in 24 hours by healthy male adults between 20 and 40 year's of age. ${ }^{2}$ The extremes given by different experimenters are, 35 ounces (Prout), and 81 ounces (Böcker). Almost every intervening number between these two remarkably different quantities hats been stated by one observer or another to be the usual average. Great differenees therefore exist, even in healthy adults; and the amount will vary with the quantity of fluid ingested, the extemal temperature and consequent activity of the cutancous transpiration, the nature and quality of the food, the temperament of the body, and perhaps even with national peeuliarities. Dr. Ed. Smith, from daily experiments made throughout the year, has shown that during a cold summer (half-year from May to Oetober) the average quantity was somewhat more, whilst during a hot summer it was somewhat less, than during the winter six months. With alcohol given to prisoners, therc was an average decrease of 20 ounees per day for three days, the quantity of water drank being unehanged. With a day of rest the quantity was less than on days of labor, and there was more on treadwheel days, notwithstanding that the quantity of water drank was the same. And there was more perspiration with the hard labor. Women secrete somewhat more urine than men, and children nearly twiee as mueh in proportion to the weight of the body. Some time, however, usually elapses after birth before the kidneys begin to discharge their function with activity, the urine up to the third day being usually seanty, albuminous, destitute of urea, and eontaining but a small proportion of solid ingredients. Pollaek t found that in infants from eight to eighty days of age the quantity of urine diseharged varied from 250 to 410 cub. eent. ( $\frac{1}{2}$ to $\frac{3}{4}$ of a pint) per diem, and that it was almost uniformly aeid.

409. The secretion of urine has been shown by various experimenters, ${ }^{5}$ and especially by Ustimowitsch, to be the product of two factors, one of which is the difference of pressure between the eirculating blood and the cxcreted urine, whilst the other is the amount of urinary material which the blood contains. When the blood-pressure is low the secretion is diminished, and if the pressure fall below $40 \mathrm{~mm}$. of mercury it is entirely arrested ; on the contrary, when the blood-pressure is high, the secretion is augmented. It may be observed, however, that the presure of the blood in the renal vessels is not always identical with that of the system generally, since, although it must nccessarily fall when the aortic pressure falls, it may be reduced considerably below that in the systemic arteries generally, by any cause leading to eontraction of the renal arteries. In accordance with this, diminution or arrest of the secretion has been noticed when the blood-pres-

1 On the Urine, p. 5.

2 This number agrees very exactly with the careful experiments of Drs. Ed. Smith and Kaupp, Areh. f. Phys. Heilk., Bd. xiv.

3 Donders, Physiologie, p. 485. Jahrb. f. Kinderheilk., N. F., Bd. ii, p. 27.

5 See Bernard, Leçons, 1859, t. ii, p. 155; Ludwig and Goll, Zeitsehrift f. ration. IIed., Bd. iv, p. 93 ; Hermann, Virehow's Arehiv, Bd. xxxiv; Ustimowitsch, Ludwig's Arbeiten, 1870, p. 198. 
sure has been diminished by bleeding or by compression of the renal arterics. In one of the expcriments recorded by Goll, the urine being discharged by the ureters at the rate of 30 or 40 drops per minute, the animal was bled, when the flow immediatcly diminished to 12 drops per minute, but upon transfusing into its veins some blood taken from another animal it rapidly rose to 188 drops per minute. The same cffect may be produced by acting on the renal circulation through the nervous system, as by irritating the pncumogastrics, which depresses the action of the heart, or by section of the spinal cord (Ustimowitsch), or of the sympathetic (Peyrani) at the lower part of the neck. Augnentation of the secretion, on the other hand, occurs when the prcssure of the blood is either increased gencrally, as during digestion (Bernard), or locally in the renal capillarics by ligature of the renal veins or of some of the larger systemic arteries, as the crural and axillary, or by the action of cold on the cutaneous capillaries. It may also be induced by division of the renal nerves, which, paralyzing the vaso-motor system, allows the arteries to dilate and leads to a fireer current of blood through the kidney. Section of the splanchnics is followed by similar, though less marked auginentation, because such section also paralyzes the vaso-motor system of the abdominal viscera generally, and though allowing of a fuller current of blood through the kidneys, lowers the blood-pressure as a whole. Increased sccretion of urine follows division of the pneumogastrics and puncture of the floor of the fourth ventricle. Hydruria is occasioned by mental emotions, fear being the one which most powerfully stimulates the kidneys to act, and the effect is observable both in animals and in man. It may act like cold by contracting the cutaneous arteries and producing congestion of the abdominal visccra generally, since diarrhoa is also frequently induced. The large flow of pale urine in Hysteria, as the attack is passing off, is well known; and occasionally this occurs as a critical discharge in some febrile affections. The importance of the other factor on which the secretion of urine depends is sufficiently demonstrated by the results of an experiment suggested by Ustimowitsch, who found that when the secretion of urine had been arrested by section of the spinal cord in the lower part of the neck, and common salt or urea was injected into the veins, secretion recommenced notwithstanding the great diminution of the blood-pressure consequent on the section, and with each additional gramme of sodium chloride injected a very definite quantity (15-16 grammes) of water was discharged. So also when a great excess of fluid has been ingested within a short space of time, it is rapidly discharged by the kidneys, nearly all having escaped at the expiration of $2 \frac{1}{2}$ lours after the last portions have been taken. ${ }^{2}$ Woorara administered in poisonous doses arrests or greatly diminishes the amount of urine secreted. The inhalation of carbonic oxide gas, on the contrary, increases it. It is a matter of common observation that injuries of the spinal cord are followed by changes in the constitution of the urine, which becomes ammoniacal and precipitates phosphates; but it appear's to be doubtful whether these changes are not the result of disordered secretion from the walls of the urinary bladder, the urine being secreted normally, but undergoing in its course through the urinary passages a kind of fermentation, which induces decomposition of the urea and the formation of carbonate of ammonia."

1 Comptes Rendus, t. $1 \times x$, p. 1300.

2 Thudichum, On the Pathology of the Urine, p. $26,1858$.

3 Schiff (Lezioni, 1873, p. 329) has pointed nut that injuries of the medulla oblongata cause hyper:mia of the kidneys, closely resenbling thc second stage of Bright's discase, which he attributcs to paralysis of the vasu-motor nerves, whilst BrownSéquard (Comptes Rendus de la Société de Biologie, 1871, t. iii, p. 101, and Lancet, 
410. The Specific Gravity comes to be a very important character in various morbid conditions of the urine; and it is therefore desirable to estimate it correctly. This also is of course subject to the like causes of variation; since, when the same amount of solid matter is dissolved in a larger or sinaller quantity of water, the specific gravity will be proportionably lower or higher; or, the quantity of water remaining the same, an increase or diminution in the anlount of solid matter will raise or lower the specific gravity. It has been commonly supposed that the amount of solid matters in the urine bears such a constant ratio to its specific gravity, that the former may be approximately deduced from the latter; this, however, is now ascertained to be by no means the case. ${ }^{1}$ Still, the determination of the specific gravity is of sufficient importance for diagnostic purposes, to make it desirable to possess an average standard, as nearly approaching to accuracy as circumstances will permit. The average, according to Dr. Prout, in a healthy person, taking the whole year round, is about 1020 ; the standard rising in summer (on account of the greater discharge of fluid by perspiration) to 1025 ; and being lowered in winter to 1015 . Simon, however, states the average specific gravity at no more than 1012. Dr. Roberts ${ }^{2}$ observed the specific gravity of his own urine, while in a healthy state, to vary from 1001 to 1036. Pollack ${ }^{3}$ found that in infants of a few weeks old it varied from $100 \overline{-}-1007$. That the specific gravity docs not bear any constant relation to the quantity discharged, has been shown by Dr. Hammond; who noticed that, although the afternoon and evening urine was most abundant, its specific gravity was very high, in consequence of its containing a large proportion of solid ingredients. The specific gravity of the urine probably depends mainly, in each individual casc, upon the amount of azotized solicls and of aqueous fluids habitually ingested, allowing for the portion of the latter that is dissipated by cutaneous exhalation; and it will also vary with the period that has elapsed since the last introduction of liquid into the stomach. From these and other causes, the amount of solid matter in 1000 parts of urine may vary from 20 to 70 parts; and hence the various recorded analyses of this liquid present very wide diversities in the proportion of its solid constituents. ${ }^{4}$ These discrepancies, however, being chiefly due to the fluctuating amount of water, become very much less (as Simon pointed out) when we calculate the proportion which each principal component bears to 100 of solid residue; as is shown in the following table:

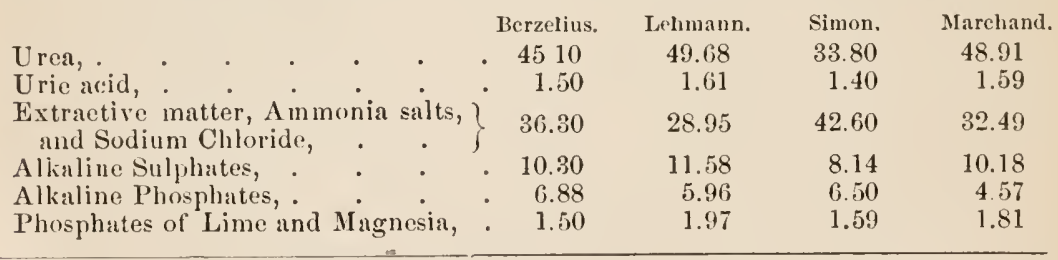

1871, vol. i, 1. 6) attributes the eongestion and hemorrhages seen in the kidneys and other abdoninal organs to contration of the veins, or to simultaneous eontraction of both arteries and veins. Ollivier (Archives de Médeeine, Feb. 18i4) gives various chemical observations showing the rapidity with whiel albumen appears in the urine ufter an attack of apoplexy.

1 See Lehmanu's Pliysiologieal Chemistry (Cavendish Soeiety), vol. ii, p. 436.

2 Eilinb. Med. Journ., 1860.

3 Loc. eit

4 It is remarked by Lehmann (op. eit., p. 44i), that the urine of the Freneh is poorest in solid constituents, especially in urea and uric acid, and that of the English the riehest, that of the Germans being intermediate between the two; the ratio in each nation being in eonformity with the proportion of animal food entering into its ordinary diet. 
We shall presently find the principal cause of some of the variations even here shown, to lie in the nature of the ingesta. The following table will show the usual constituents of lealthy urine, and the quantities excreted in 24 lours:

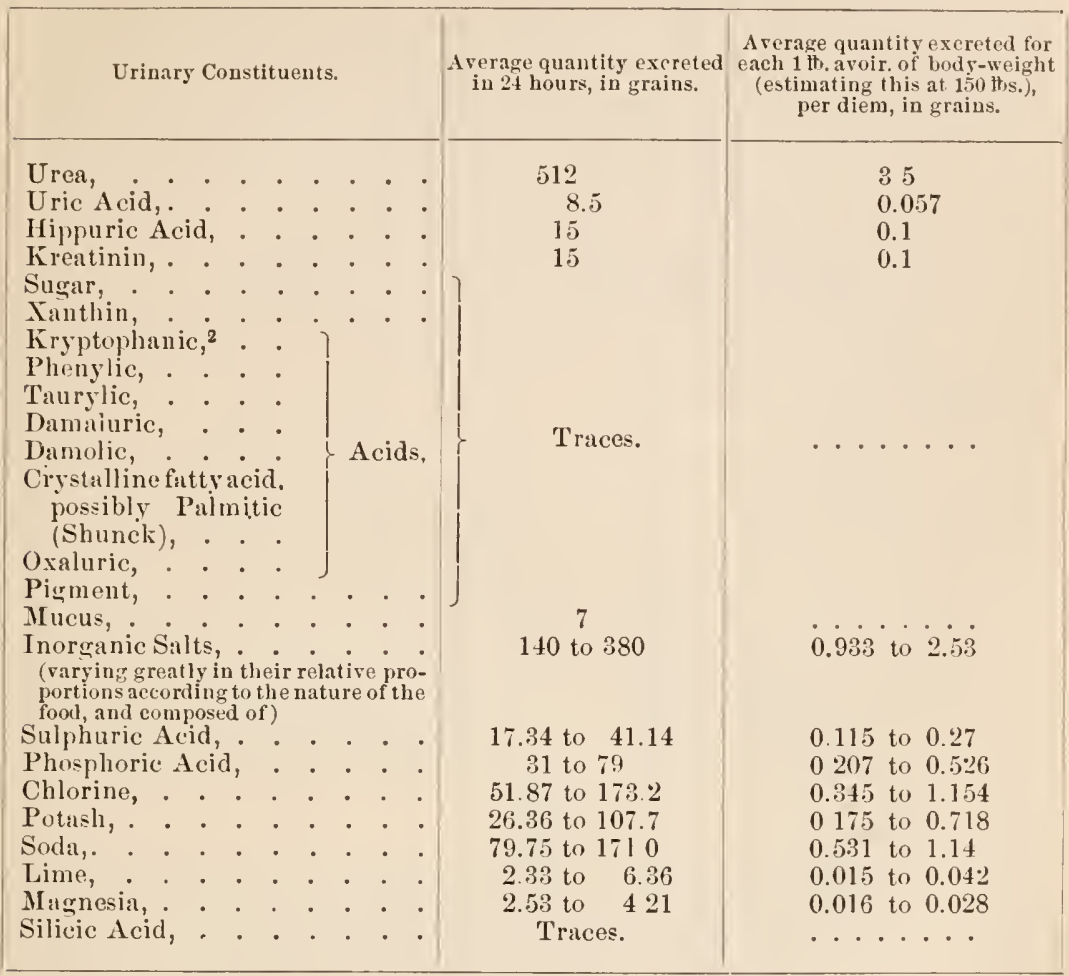

It is difficult, if not impossible, to determine the exact mode in which the acids are distributed amongst the bases, but the Chlorides and Phosphates seem to be eliminated in the following proportions:

Sodium Chloride,

Ammonium Chloride,

Magnesium Phosphate,

Calcic Phosphate,
Grains in 24 hours.

about 250

$\left.\begin{array}{lr}\text { " } & 35 \\ \text { " } & 5 \\ \text { " } & 10\end{array}\right\}$ Klehmann and

The relation between the two last is reversed by Neubauer.

The urine contains, in addition, free carbonic acid, oxygen, and nitrogen gases; together with a certain and not inconsiderable quantity of extractive matters, consisting of substances whose nature has not been accurately determined, as in the case of those containing sulphur and phosphorus, the

1 Chiefly drawn up from the works of Parkes, On the Urine, 1860, Lond. ; Thudichum, On the Pathology of the Urine, 1858, Lond.; and Neubauer and Vogel, On the Urine, Lond., 1863, New Sydenham Society's translation; to which excellent treatises the reader desirous of further information is referred.

${ }^{2}$ The presence of Kryptophanic Acid is given on the authority of Dr. Thudichum (Centralblatt, 1870, Nos. 13 and 14), but his statements have been called in question by Pircher, Centralblatt, 1871, p. 32\%. 
substance termed Oxide of Omichmyl by Scharling (which is apparently of a resinous nature), and others. The aggregate amount of the extractives is estimated by Dr. Parkes at 154 grains per diem, and constitutes a wide and very important field for future iuvestigations. It will thus be scen that the total quantity of solid material elimiuated by the kidneys does not fall far short of 900 grains in the 24 hours for a healthy alult man weighiug 150 lbs., the proportion of organic compounds being about 550 grains, and of inorganic about 300 grains.- -Under the head of constituents not constantly, or not certainly present, or perhaps present only in disease, may be enumerated albumen, fibrin, kreatin, xanthin, sarkin, grape-sugar, glycin in combination with benzoic acid forming hippuric acid, ${ }^{1}$ lactic and oxalic acids, fatty substances, biliary coloriug matter, salts of the biliary acids, allantoin, leucin, and tyrosin, cystin, inosite, taurin, hrematin, pus, spermatozoa, carbonate of ammonia, phosphate of ammonia and magnesia, and sulphuretted hydrogen, ${ }^{2}$ besides various substances consumed as food and eliminated by the kidneys, as the coloring and odorous matters of various vegetables and certain metals. The acid reaction of the urine depends essentially on the presence of the acid phosphate of soda.

411. The most important of the organic constituents of the Urine is that which, from its being the principal source of the characteristic properties of the secretion, is termed ureat. ${ }^{3}$ Its chemical relations are stated to be best explained upon the hypothesis that it is the amide of carbonic acid. ${ }^{4}$ This substance, as already mentioned $(\$ 197)$, exists preformed in the blood in the proportion of from 2 parts (in renal venous) to 4 parts (in renal arterial blood) in 10,000. It possesses the power of dialyzing through animal membraues with remarkable facility, almost equalliug carbonate of potash in this respect. ${ }^{5}$.The absolute quantity of urea eliminated in 24 hours, varies with age, seasom, weight of body, food, and occupation, and has been made a subject of examination by various chemists. The following table $e^{6}$ gives the results of some of the more recent analyses:

From an examination of such tables as this we may draw the conclusions, that the average quantity of urea discharged by a man of good bodily health, on full animal diet, is about 500 grains per diem; and that children of from 3 to 7 years of age excrete, proportionately to their wcight, about double the quantity of urea per dicm excreted by men in adult life, the quautity still further diminishing in old age. The minimum amount excreted by an adult whilst fasting and at rest is about 2 grains per $1 \mathrm{lb}$. of body-weight. In infants at the breast Pollack (loc. cit.), found the quantity to vary from 15 to 30 grains per dicm.

Season.-Dr. Ed. Smith, ${ }^{7}$ in the course of the year, found that the daily quantity (in himself) varied from 219 to upwards of 700 grains, the average

I Espccially in infants at the breast (Pollack, loc. cit.).

2 v. Gorup-Besanez, Phys. Chemie, p. 510.

ĆO

3 Urea, $\left.\begin{array}{r}\mathrm{CO} \\ \mathrm{H}_{2}\end{array}\right\} \mathrm{N}_{2}$, contains 46.7 per cent. of nitrogen, and is isomeric with ammo-

nium cyanate, $\left.\left.\mathrm{CNNH}_{4} \mathrm{O}=\stackrel{\stackrel{\text { Ć}}{\mathrm{II}_{2}}}{\mathrm{H}_{2}}\right\}\right\} \mathrm{N}_{2}$, and with carbamide, $\left.\stackrel{\mathrm{H}}{2}_{\mathrm{H}_{2}}^{\mathrm{O}_{2}}\right\} \mathrm{N}_{2}+\mathrm{CO}_{2}$.

4 Miller's Chemistry, vol. iii, p. 615.

6 See Weikart, Wagner's Archiv d. Heilkunde, 1862, p. 119.

6 Purtly taken from Dr. Day's Physiolog. Chemistry, 1860. tion.

7 Procecdings of the Royal Society for MIay $30 \mathrm{th}, 1861$, and a privatc communica- 
upon the whole being 519 grains. The proportion to each $1 \mathrm{lb}$. of bodyweight was, on the whole average, 2.76 grains. But in experiments in prison, either with or without hard labor, the proportion varied from 3.72 to 5.82 grains to each $1 \mathrm{lb}$. of body-wcight; so that he is of opinion that the relative proportion is of 110 scientific value. There was increase with diminished temperature and with increased atmospheric pressurc, and hence variations in the relations of these two agencies varied the results. The increase in the elimination of urca with cold was often deferred until the following day. The periorl of elimination is not that of production, and whatever increases elimination of urine increases that of urea also.

\begin{tabular}{|c|c|c|c|c|c|c|}
\hline & $\begin{array}{l}\text { Age in } \\
\text { Years. }\end{array}$ & $\begin{array}{l}\text { Weight in } \\
\text { tbs. avoir. }\end{array}$ & $\begin{array}{l}\text { Grains of } \\
\text { Urea exere- } \\
\text { ted in } 24 \\
\text { hours. }\end{array}$ & $\begin{array}{c}\text { Proportion of Urea } \\
\text { exereted to } 1000 \text { parts } \\
\text { of body-w eight in } \\
21 \text { hours. }\end{array}$ & $\begin{array}{l}\text { Ditto for } \\
\text { every } 1 \mathrm{tb} \text {. } \\
\text { of body- } \\
\text { weight. }\end{array}$ & Authority. \\
\hline Girl, ... & $3 \frac{1}{2}$ & 35.7 & 199.8 & 0.79 & 5.67 & \\
\hline Boy,... & $7^{2}$ & 492 & 281.8 & 081 & 5.72 & Scherer. \\
\hline Man,... & 22 & 137.8 & 415.8 & $0: 43$ & 2.94 & \\
\hline Man,... & 38 & 153.7 & 459.2 & 0.42 & & \\
\hline Boy, . . . & 3 & 29.8 & 2077 & 1.03 & 6.96 & \\
\hline Boy,... & 4 & 31.7 & 240.2 & 1.08 & 7.57 & \\
\hline Girl, . . & 5 & 36.9 & 280.2 & 1.08 & 7.59 & \\
\hline Youth,.. & 18 & 129.1 & 562.1 & 0.62 & 4.36 & Rümmel. \\
\hline Man,.. . & 31 & 163.7 & 604.9 & 0.51 & 3.69 & \\
\hline Man,... & 65 & 127.9 & 295.2 & 0.33 & 2.31 & \\
\hline Boy, . . & 3 & 35 & 65.7 & 0.53 & 1.9 & \\
\hline Youth,. . & 16 & 107 & 305.8 & $0.4 \mathrm{~L}$ & 2.85 & \\
\hline Girl, ... & 18 & 145 & 3109 & 0.30 & 2.14 & \\
\hline Woman,. & 43 & 107 & 389.9 & 0.28 & 3.63 & Blsenotf. \\
\hline Man... & 45 & 237 & 579.5 & 0.35 & 2.44 & \\
\hline Man,... & 42 & 196 & 519 & $\ldots$ & 2.73 & Ed. Smith \\
\hline
\end{tabular}

Period of the Day.-The greatest hourly elimination of urea, in Dr. Smith's experiments, occurred after the breakfast and tea-meals; whilst it was least during the hours of the night and early morning. Ranke found that it steatily diminished from the morning to the evening.

Sex.-Acerding to Dr. Parkes, the quantity of urea excreted every 24 hours, for $1 \mathrm{lb}$. of body-weight, is, for men, about $3 \frac{1}{2}$ grains; for women, about 3 grains. During menstruation, according to Beigel, the excretion of urea diminishes, but subsequently it is increased.

Food.-Variations in the quantity and quality of the food occasion great differences in the proportion of the urea. The following table gives the results in grains of some of the best observers:

\begin{tabular}{|c|c|c|c|c|c|}
\hline & Ranke. ${ }^{1}$ & Lehmann.? & Haughton. ${ }^{3}$ & Warnecke." & $\begin{array}{l}\text { Kölliker and } \\
\text { Franque. }^{\text {s }}\end{array}$ \\
\hline $\begin{array}{l}\text { I. Mixed diet, } \\
\text { II. Highly animal diet, } \\
\text { III. Vegetable diet, } \\
\text { IV. Non-azotized diet, }\end{array}$ & $\begin{array}{c}463-617 \\
1332 \\
264 \\
264\end{array}$ & $\begin{array}{l}50176 \\
821.37 \\
347.10 \\
237.90\end{array}$ & $\begin{array}{l}576 \\
394 \\
\ldots\end{array}$ & $\begin{array}{lc}\text { Man. } & \text { Woman. } \\
520 & 414 \\
3 \ddot{3} 9.6 & 310 \\
\ldots \ldots & \ldots\end{array}$ & $\begin{array}{l}586.7 \\
1420 \\
447.7 \\
262.48\end{array}$ \\
\hline
\end{tabular}

1 Grundzüge der Physiologie, 1872, p. 509.

2 Lehmann, Phys. Chem. (Cav. Soc. ed.), vol. ii, pp. 450-452.

3 Haughton, Dublin Quart. Journ., 1859.

5 Fierordt, Phys., 1860.

4 Dub. Med. Press, 1859. 
The immense amount discharged upon a highly albuminous diet is worthy of particular notice. The quantity of urea always increases after food, attaining its maximum usually about the $3 \mathrm{~d}$ or 4 th hour, and this would correspond with the perior when digestion and absorption being completed the interstitial changes in the cells and tissues throughout the body are being performed with the greatest activity. When an animal is fed on fat and water exclusively, or on starch and fat, with a very small admixture of albuminous compounds, or on sugar, the excretion of urea falls even below the proportion found in absolute starvation, ${ }^{1}$ apparently because when no food, or an inadequate quantity of flesh-food, is given, the animal consumes some of its own flesh in order to maintain its temperature, and thus more Nitrogen is eliminated than when fat is supplied; for this, by combining with the Oxygen, keeps up the temperature, and spares the tissues of the animal. It is certain that nearly the whole of the Nitrogen consumed as food is eliminated by the urine in the form of urea. Thus in an experiment made by Prof. Parkes, ${ }^{2}$ extending over sixteen days, two men who consumed in that period 313.76 grammes of nitrogen in their food, discharged by the urine in the same time 303.66 and 307.257 grammes of urea respectively, the difference being made up by the freces and other excretions. Every grain of urea may be regarded as proceeding from the disintegration of 3 grains of Protein, and represents the amount of work performed in raising 1.4 ton through one foot. So that on the supposition that 501.28 grains are eliminated in the day, the amount of work performed would amount to 218,786 kilogrammetres, or 704 foot-tons (Haughton). Genth ${ }^{3}$ has shown that an increase in the quantity of water drank is followed by a marked increase in the quantity of urea eliminated, and this especially if the water be taken, not between, but at, mealtimes. Certain substances consumed with the food increase the quantity of urea excreted; amongst these are Urea itself and Uric Acid, common Salt (Voit), Phosphoric Acid (Böcker), Glycin, Guanin, Theobromin, Cubebs, and Cantharides. ${ }^{4}$ On the other hand, it is diminished by Digitalis, Arsenic, Turpentine, and Alcohol.

Exertion.-The influence of muscular exertion on the excretion of Urea is a subject to which great attention has been directed during the last few years, as bcing likely to afford some insight into the source of muscular energy, and to show whetler the force exerted by muscle is derived from the disintegration and oxidation of its own proper substance, or whether it proceeds from the oxidation of certain constituents, and especially of the hydrocarbonaceous constituents of the blood, the heat derived from which the muscular tissue is capable of converting into mechanical force. In the former case we should naturally expect that the nitrogenous products of the disintegrated muscular tissue would appear in the urine, in the latter we should anticipate an increase in the amount of carbonic acid and water eliminated from the body, without material increase in the excretion of Nitrogen by the urine. The facts of the case, as will be seen, arc opposed to the view that the tissue of the muscle is materially disintegrated during excreise, and in favor of the view that the energy is derived from the oxidation of hydrocarbonaceous compounds. The experiments of Dr. Ed. Smith were amongst the first to show that muscular exercise was not attended with any notable increase in the amount of Urea eliminated. He found that with violent labor, as that of the treadwhcel, there was only an increase of 19 grains daily over that of light labor. On Sunday there was an increase with increase of food;

1. Ludwig, p. 381, vol. ii.

2 Proeedings of the Royal Soeiety, 1867, No. 94.

3 Untersuch. über den Einflüss des Wassertrink. auf den Stoffweehsel, 1856.

4 v. Gorup-Besinez, Physiolog. Chem., p. 540, 1862. 
but in prisoners without variation of food, with spare systems, and with increase in the fieces, there was a decrease. Sinilar results were ohtained by Voit, ${ }^{1}$ who, in consequence of the rery small differences that occurred in the quantities of urea eliminated in fasting animals (Dogs) with and without work, believed that suel slight increase of urea as really occurs after severe labor, is due to increased thirst and ingestion of water, together with inereased rapidity of the movements of the heart and lungs. Lelnmann's ${ }^{2} \mathrm{ex}$ periments also shower that 110 increase of urea took place in those engaged in active exercise. In 1866 an important experiment bearing on this point was made by MM. Fick and WVislicenus." These oberver's investigated the clianges oecurring in the elimination of Nitrogen by the Urine during the aseent of the Faulhorn, one of the peaks of the Swiss Alps, and about 6.500 feet in height. They took no albuminous food for seventeen hours previously, nor during the ascent, which occupied eight hours, nor for six hours after, their diet eonsisting of biscuits of stareh, fat, and sugar. The examination of the urine gave the following results:

1. Urine of the night previous to the ascent-a period of 12 hours,

2. Urine of the period of ascent-8 hours and $10 \mathrm{~min}-$ utes,

3. Urinc excreted for 6 hours after the ascent,

4. Urine of the night following the ascent, after a good meal had been taken-10 12 hours,

The average quantity of Nitrogen excreted per hour was, by Fick. Wislicenus.

0.63 gramme. 0.61 granme.

$041 \quad$ " 0.39 "

0.40 " 0.40 "

0.45 " 051 "

Here there was evidently a deerease in the exeretion of nitrogen during and after exercise, but it must be remembered that no nitrogenous food was consumed. Very sinilar results were obtained by Professor Haughton, ${ }^{4}$ who found that with about five miles of daily walk the amount of urea eliminated was 501.28 grains per diem, whilst when the exercise was inereased to 20.74 miles of horizontal walk for five conseeutive days, the amount of urea was 501.16 grains; actually less than the previous average. 'Two still more complete series of experiments liave been condueted by Professor Parkes ${ }^{5}$ on two solders, in the first series of which he investigated the elimination of nitrogen by the kidneys and intestines, during rest and exercise, on a diet without nitrogen; whilst in the second series the men were placed on a regulated diet of nitrogen. In the first series of experinents the men were kept for a first period of six days on ordinary diet and oceupation, in order to determine the conditions present in perfeet health, and to serve as a ground of comparison. 'Then for a seend period of two days' duration the men were kept on a non-nitrogenous diet and remained at rest. Under these circumstanees the urea fell from 35 grammes (which was about the usual daily amount with ordinary diet), to 16.7 in one nan, and in the other from 26 to 15 grammes, or in both to about one-half its ordinary amount. During the third period of four days the mea returned to their usual diet and occupation, by which time they were eonsidered to have regained their ordinary eondition, and the quantity of urea excreted rose to its ordinary amount. During the fourth period of two days the men were again placed on non-nitrogenous diet, but on this occasion were made to take severe exercise; walking on the first day 23.76 miles, and on the seeond day 32.78 miles. It was found that during the first thirty-six hours there was a decrease; but in the

1 Henle and Meissner, 1860, p. 373.

2 Archiv des Vereins für Wissenschaft. Heilkunde, vol. iv, p. 484, 1860.

3 Lond. Phil. Mag., 1866, p. 485.

5 Proceed. Roy. Soc., Nos. 89, 94, 1867.

4 Lecture, Brit. Meà. Assoc., 1868. 
last twelve, or rest hours of the forty-eight hours, an inerease in the amount of urea; and that, on the whole, the effeet of the exertion of walking fiftysix miles on a non-nitrogenous diet was a total inerease of only 1.589 gramme of nitrogen in one man, and in the other of only 0.223 granme in the forty-eight hours. In the fifth period the men onee more returned to their ordinary diet and oceupation for four days, in which a eonsiderable inerease of nitrogen over the average amount was observed; whieh however is referred by Dr. Parkes, not to the elimination of the produets of destroyed musele during the work period, but to an exeess of nitrogenous food eonsumed in the four days following the exereise. In the seeond series of experiments two men were kept on the same nitrogenized diet for sixteen days. For four days they were kept at their ordinary employment; during two days rested; returned to ordinary work for four days; took very aetive exereise for two days, walking twenty-four and thirty-five miles, and were then for four days more on ordinary oecupation. The ehanges that took plaee in the urea were almost identical with those in the total nitrogen eliminated, and so nearly equal to that in amount, that (allowanee being nade for what passed by the bowels) it was eertain none passed off, either during rest or exereise, by the skin or lungs. The results were, that in the first period the amount of urea was almost preeisely the same in the two men. In the rest period it inereased nearly two grammes daily in each man, fell during the third period to the former average, deereased greatly during the first thirty-six hours of the exereise period as eompared with the rest period, and inereased in the last twelve hours; in the last or after work period it also increased, though in a less proportion than the total nitrogen. The first series of these experiments undoubtedly eorroborate the statement of Fiek and Wislieenus, that on a non-nitrogenous diet exereise produees no notable inerease in the nitrogen of the urine; although, when the subsequent period is also eonsidered it does produee a slight inerease. The seeond series showed that, with an unehanged amount of nitrogen ingested, so far from there being any inerease, there was an actual diminution in the amount of urea eliminated both during ordinary and during severe exereise, as eompared with rest. There was, on the other hand, an exeess not great but long eontinued in nitrogenous exeretion after exereise; and there was a retention of the nitrogen in the system when it was again supplied after both rest and exereise, and greatest in the latter ease, showing that it is needed in the system, and that an insuffieient supply at one time must be subsequently made up. In some reeent experiments by Weigelin, ${ }^{1}$ it appeared that if, after two hours of strenuous museular exereise, the amount of urea eliminated during the sueeeding two hours were determined, an increase of as mueh as 50 per eent. on the ordinary average was sometimes observed. Persistent museular effort (tetanus) was found to produce more urea than the altermate eontraetion and elongation of musele. In 1870 and 1871 a very important and eomplete series of observations on the effeets of protraeted and severe museular exercise upon the exeretion of nitrogen were made by Dr. Austin Flint, aided by several other physiologists. ${ }^{2}$ The subjeet of the experiment was Mr. Weston, who, in the first instanee walked 100 miles in twenty-one lours and thirty-nine minutes, and subsequently attempted to walk 400 miles in five conseeutive days; which, however, he failed to aeeomplish. Dr. Flint made a eareful examination of the urine for five days preeeding the walk, for the five days of the walk, and for five lays after the walk. IIr. Weston was thirty-one years of age, and his weight was about 120 lbs. He smoked

1 Reichert's Archiv, 1868, p. 207.

2 See New Yurk Medical Juurnal, June, 1871, pp. 609-697. 
in moderation, and was an almost total abstainer from alcoholic fluids. On the first day of the walk he made 80 miles, on the sccond 48 , on the third 92 , on the fourth 50 , and on the fifth 40 . The failnre occurred on the fourth day from vertigo, partly induced by want of sleep. During the five days of the walk Mr. Wieston consumed in all 1173.80 grains of nitrogen in his food, and eliminated 1807.60 grains of nitrogen in the urine and fieces. This leaves 633.80 grains of nitrogen over and above the nitrogen of the ford, which must be attributcd to the waste of the tissues, and probably almost exclusively to the waste of the muscular tissue. Lean meat as has already been shown contains about three per cent. of nitrogen ( $\$ 337$ ). The loss of 633.80 grains of nitrogen would then represent a loss of 21.127 grains, or $3.018 \mathrm{lbs}$ of muscular tissuc. The actual loss of weight was $3.450 \mathrm{lbs}$., which allows $0.43 \mathrm{lb}$. loss unaccounted for, which might be fat or water. It would hence appear that there was a distinct consumption of mnscular substance during the immense exertion of the period of five days' walking. In two days after the walk the weight of the body had been made up to within four ounces of the normal weight. Schultzen and Nencki ${ }^{1}$ have shown that Leucin and Glycocol administered to dogs greatly increase the amount of urea eliminated. Tyrosin canses no increase, but is expelled unaltered. Cerebral activity ${ }^{2}$ and sexual excitement ${ }^{3}$ angment the quantity of urea.

Frequency of Micturition.-Kaupp has shown that with increased frequency of micturition there is an increase in the quantity both of urine and of urea discharged in twenty-fonr honrs.

Disease.-The anount of urea eliminated increases in the early stages of nearly all acute diseases,-meningitis, pneumonia, typhns, etc.,-indicating the rapicl disintegration of the nitrogenous tissues and constituents of the blood, and coinciding with the period during which increased heat of skin is usually complained of. 'This, though not more than $4^{\circ}$ or $5^{\circ}$ Fahr. above the average, represents (fron Newton's law of cooling), an increase of one-eighth of the total amount of heat produced-an amount equivalent to the force required to raise the body through one mile of vertical height per diem, ${ }^{5}$ and furnishing an adcquate explanation of the extrene exhaustion experienced by the sufferers at this period. Vogel and Warnecke found that in a case of typhoid fever no less than $1065 \frac{1}{2}$ grains of nrea were excreted daily, or more than donble the nsual average, and in a case of pyæmia the extraordinary quantity of $1235 \frac{1}{2}$ grains. Now, as every four grains of urea excreted correspond to five tons lifted throngh one foot, it is obvious that an enormous amount of force is spent in these diseases, fully accounting for the extraordinary debility induced in such patients. When the fever is over the quantity of urea falls below the normal amonnt, in spite of the augmented quantity of nitrogenous food ingested, which is doubtless appropriated to the repair of the wasted tissues, and it then after perfect recovery returns to the normal standard. During convalescence it gradually subsides, and may even fall below the normal amount. The proportion appears to be remarkably diminished in some forms of hepatic disease. 'Thus Frerichs, ${ }^{6}$ in a case of acute atrophy of the liver, fonnd no trace of urea in the urine, but in its place lencin and tyrosin. In another case, recorded by Vogel, of cancer of the liver, scarcely one-fourth of the normal quantity of urea was fonnd in the urine; and Heller has shown that the proportion of urea is diminished in chronic nervous affections, and in anæmia, however produced.

1 Zeits. für Biologie, 1872.

2 Byasson, Rev. d. Cours Scient., 1868, Thesis.

3 Haughton, loc. cit., found the ordinary quantity of urca to be in the sheep 256 grains per diem, but in the ram during the rutting season 1493 grains per diem.

4 A rchiv f. Phys. Heilk., 1856. ${ }^{5}$ Haughton, Op, cit.

6 Deutsche Klinik, 1855, p. 31. 7Gmelin, vol. viii, p. 325. 
412. Next in importance to urea among the organic products of the metamorphosis of the azotized constituents of the tissues or of the blood, but ordinarily bearing a very small proportion to it (1:45 or 50) in quantity, is Uric Acid $\left(\mathrm{C}_{10} \mathrm{H}_{4} \mathrm{~N}_{4} \mathrm{O}_{6}\right)$. This compound contains 33 per cent. of nitrogen. It probably exists in the urine, partly in the free state, and partly combined or conjugated with the alkaline phosphates. ${ }^{1}$ The variations in the daily quantity eliminated are considerable; and, according to Ranke, whilst in great measure independent of differences in age, sex, height, weight, or temperature, stand in close relation with the ingestion of food, diminishing to a minimum of 3.7 grains with abstinence, and rising to a maximum of 32.5 grains on a full meat diet. Prof. Haughton found the average quantity eliminated by those consuming animal food to be 4.55 grains per diem, whilst vegetarians discharged only 1.48 grains. Pollack ${ }^{2}$ found that the quantity was relatively large in infants at the breast, varying from 1.5 to 3 grains per diem. It is diminished after the use of Alcohol (Hammond), and after the administration of Quinine (Ranke), and is totally absent when large draughts of water have been taken (Genth). It is increased after the free use of Tobacco (Hanmond), and after the consumption of certain substances introduced into the foorl, as Glycin and Urea, but no influence is exerted on its quantity by mental activity or repose (Byasson). The effects of muscular exercise were found by Austin Flint ${ }^{3}$ to cause slight increase, the quantity passed by Mr. Weston in his long walk of $317 \frac{1}{2}$ miles in five days, being at the rate of three grains per diem, whilst during the five days previous to the walk it was 2.26 grains, but the quantity varied considerably on each day, without it being possible to connect this variation with the composition of the food or the amount of the exercise taken. A marked increase has been observed in intermittent fevers, in leukiemia, in peritonitis, phlebitis, and some chronic renal and spinal affections. Uric acid is found in the spleenpulp in considerable quantities, and also in the lungs, liver, pancreas, and brain; in the juice of muscles, and in small quantities in the blood (Garrod) in the form of an acid urate of soda or ammonia." It seems, therefore, to be very generally present where active interstitial changes are taking place. The precipitation of Uric acid (usually in combination with potash, soda, and ammonia, and perhaps sometimes with lime), which frequently takes place on the cooling of the urine, must not be regarded as indicative of the presence of an unusual amount of this substance; since it may depend upon other conditions. It seems to have becn clearly proved by Dr. Bence Jones, ${ }^{5}$ that there is no relation whatever between the acidity of the urine, and the absolute amount of Uric acid which it may contain ; for in the urine which is most acid, and which deposits the largest uric acid scdiment, very little uric acid may really exist; whilst that which contains most uric acid may hold it in perfect solution, and may have but a feeble acid reaction. The main cause of the deposit of Uric acid sediments, is doubtless the presence of some other acid; for the ardition of any acid to healthy urine passed soon after fond, is always sufficient to produce it. But the deposit takes place less readily if the temperature of the fluid be high, since the solvent power of the acid phosphate of soda is then more strongly exerted; so, on the other hand, a deposit often takes place in urine which would not otherwise exhibit it, through an unusual reduction in its temperature, as by exposure to the cold air of a sleeping-room in the winter. Again, the deposit of uric acid

1 Byasson, Rev. d. Cours Scient, 1867-8, p. 610.

2 Loc. cit.

3 New York Med. Journal, 1871, p. 687.

4 Thudiehum, Pathology of the Urine, p, 97.

5 See his Contributions to the Chemistry of the Urine, in Philos. Trans., 1849. 
sediment is favored by concentration of the liquid, which thus augments the proportion of the urate to the water, and at the same time intensifics the acid reaction; and thus urine whose constituents are otherwise normal, may throw down a copious deposit of this kind, merely from deficiency of water; whilst an unusual amount of uric acid nua be really present without being deposited,-the urine, too, cxhibiting its ordinary acidity,-if the proportion of water be largc. Thus the uric acid sediment may be regarded as dependent upon three concurrent conditions: (1) Decrease of temperature; (2) Increased proportion of uric acid compound to the water, positively or relatively ; (3) Increased acidity of the urine. Sometimes one condition is most influential, sometimes another; but they are all usually concerned in some dégree.-There are many diseascs, especially those of a febrile nature, in which the presence of an excess of uric acid is a very marked symptom; there is often, at the same time, a reduction in the proportion of urea; and thus it would seem that, with perhaps an augmented tendency to disintegration of the tissues, there is an incapacity for the performance of that higher process of oxidation, which is requisite for the genesis of urea; so that a larger proportion of the products of the "waste" passes off in the state of uric acid, as in animals whose respiration is feeble. - The proportion of $H$ ippuric Acid $\left(\mathrm{C}_{18} \mathrm{H}_{8} \mathrm{NO}_{5}+\mathrm{HO}\right)$ present in the urine appears to be in great measure dependent upon the nature of the food and upon the amount of exercise. According to the researches of Weissmann and Thudichum, it amounts to between 30 and 40 grains per diem on a mixed diet. On a purely animal diet, it falls to about 12 grains per diem; whilst it rises considerably when vegetables alone are consumed; and its origin has been attributed by Shepard and Meissner ${ }^{1}$ to the conversion at the kidney of a substance existing in the cuticle of plants having the formula $\mathrm{C}_{14} \mathrm{H}_{12} \mathrm{O}_{10}$ and ncarly allied to Kinic acid. As night be anticipated, therefore, a large quantity of this acid is constantly present in the urine of Herbivora, but only traces exist in that of Carnivora. Both Mack and Roussin found that horses at rest pass much urea and little Hippuric acid; but when at work, the quantity of Hippuric acid equalled or exceedcd that of urea, the absolute quantity of the latter undergoing a diminution equal to the increase of the Hippuric acid. As urea is one of the ultimate products of oxidation in the body, whilst Hippuric acid is very imperfectly oxidized, it would seem that during violent exertion the due oxidation of the secondary nitrogenous compounds produced by the disintegration of the tissues is interfered with, perhaps by the diversion of the oxygen to form carbonic acid, the quantity of which has been shown by Dr. Ed. Smith to be so notably increased by all kinds of muscular exertion; or we may, with morc probability, suppose that the lungs are unable to eliminate the whole of the carbon of the disintegrated tissues in the form of $\mathrm{CO}_{2}$, and that a part of the carbon is consequently discharged by the kidueys in the form of the richly carbonized compounds, Hippuric or Benzoic acids. The quantity of Hippuric acid eliminated can be greatly increased by the administration of Benzoic, Succinic, Cinnamic, or Kinic acids, or of Oil of Bitter Almonds. ${ }^{2}$ The transformation of Benzoic into Hippuric acid appears to take place at the liver, as it does not occur in jaundiced patients, or in dogs in whom the ductus communis choledochus has been tied, the Benzoic acid then passing off unchanged. The process is exceedingly simple. Benzoic acid $\left(\mathrm{C}_{14} \mathrm{H}_{6} \mathrm{O}_{4}\right)+$ Glycin $\left(\mathrm{C}_{4} \mathrm{H}_{5} \mathrm{NO}_{4}\right)$ producing Hippuric acid $\left(\mathrm{C}_{18} \mathrm{H}_{9} \mathrm{NO}_{6}\right)+2 \mathrm{HO}$. Kühne and Hallwachs, however, maintain that the conversion occurs in the blood, and Meissner and

1 Centralblatt, Nos, 43 and 44, 1866.

2 See Matschersky, Virchow's Archiv, 1863, p. 528. 
Shepard at the kidney.-Kreatin and Kreatinin may be obtained by the action of Chloride of Zinc on concentrated urine; but the researches of Heint $\mathrm{z}^{1}$ have shown that no Kreatin is present in fresh urine, that which was formerly obtained being in fact produced by the decomposition of the Chloride of Zinc compound, the Kreatinin of which takes up water and is converted into Kreatin. ${ }^{2}$ The quantity of Kreatinin daily eliminated by a healthy man, living on a good mixed dict, was found by Neubauer to vary from 9 to 20 grains. The maximum quantity is excreted on a flesh, the minimum on a farinaceous diet (Mcissner, Voit). In dogs exertion causes no increase. Kreatinin is the most powcrful organic base in the body. Kreatin can be converted by boiling with Baryta water into Sarcosin and Urea. ${ }^{3}$ - When ingested with the food it is either eliminated unchanged, or it is partially converted into Kreatinin. ${ }^{4}$ The coloring matters of the urine appear to be derivatives of the biliary acids, and not of the biliary coloring matters, since Bngomoloff $f^{5}$ and Heynsius and Campbell ${ }^{6}$ found that.injection of the biliary acids into the blood increased the quantity of urinary coloring matter, whilst injection of biliary pigments was without effect. Masius, and Vanlair thought they proceeded from the coloring matter of the bile which underwent conversion in the intestines into stercobilin, and was partially excrcted in the fieces and partially eliminated by the kidneys. Jaffe ${ }^{8}$ considered stercobilin to be identical with urobilin, since the absorption strie of its solutions is the same and it gives the same beautiful green fluorescence with chloride of zinc. Maly ${ }^{9}$ obtained from the intestines a substance to which he has applied the term Hydrobilirubin, which he considers to be a derivative of cholepyrrhin, and to undergo partial absorption. ${ }^{10}$ They may all be regarded as modifications of one substance, urobilin, which gives a yellow or rose color dichroizing into pink with mineral acids, and presents an absorption stria between $b$ and $\mathrm{F} .{ }^{11}$ Thesc bodies, as was also noticed by Carter, ${ }^{12}$ present close analogies to the series of compounds of which Indican forms the first member, and a blue coloring matter is sometimes gencrated in disease. The Extractives of the urine contain considerable proportions of carbon, whilst they are poor in nitrogen; so that their increase will be favored by an excess of carbonaceous food, an imperfect action of the liver, and a low degree of respiration; whilst on the other hand, a highly azotized dict, especially if combined with active exercise, will tend to their reduction. -The odor of the urine appears to be due to the presence of minute quantities of the volatile acids, termed by Städeler Phenylic (or Carbolic, $\mathrm{C}_{12} \mathrm{H}_{5} \mathrm{O}_{1}$, $\mathrm{HO})$, Taurylic $\left(\mathrm{C}_{14} \mathrm{H}_{8} \mathrm{O}_{2}\right)$, Damaluric $\left(\mathrm{C}_{14} \mathrm{H}_{11} \mathrm{O}_{3}, \mathrm{HO}\right)$, and Damolic, the composition of which last is unknown.

413. The determination of the mode and place of origin of the urinary constituents, and especially of the urea and uric acid, are points of considerable interest. The solution of this question, however, demands great skill

1 Vogel and Neubatier, On the Urine, New Syd. Soc Transl., 1863, p. 18.

2 Kreatinin $\mathrm{C}_{8} \mathrm{H}_{7} \mathrm{~N}_{3} \mathrm{O}_{2}+4 \mathrm{HO}$ becoming $\mathrm{Kreatin} \mathrm{C}_{8} \mathrm{H}_{11} \mathrm{~N}_{3} \mathrm{O}_{6}$.

3 Kreatin $\mathrm{C}_{8} \mathrm{H}_{11} \mathrm{~N}_{3} \mathrm{O}_{6}$ becoming Urea $\mathrm{C}_{2} \mathrm{H}_{4} \mathrm{~N}_{2} \mathrm{O}_{2}$ and Salcosin $\mathrm{C}_{6} \mathrm{H}_{7} \mathrm{NO}_{4}$.

4 Mcissner, Centralblatt, 1868, p. 275.

5 Begomolofi, Centralblatt f. d. II ded. Wiss., 1875, n. 210.

6 Pflüger's Archiv, Bd. iv, p. 497.

7 Centralblatt, f. d. Med. WViss., 1871, p 369.

8 Idem, 1871, p. 465.

30 See also Schunck, Proceed. of Roy. Society, 1867, vol. xvi, p. 73.

31 'Thudichum, Chronical Physiology, 1872, p. 187, gives directions for obtaining Urochrom, Uromelanin, Uropittin, Omicholein, Omicholic acid, and Xanthin, which last Sclierer and Neubaner also considered to be present in the urine.

12 Memoirs of Manchestor Mrd. Sioc, vol. xiv, p. 293. See also Kletzinsky, Heller's Archiv, vol. vi, p. 414; and Thudichum, Brit. Med. Journ., Nov. 5th, 1864. 
in chemical analysis, and the evidence is at present in an extremely unsatisfactory state. As regards the mode of origin of urea, its composition shows clearly that it procecds from the disintegration of the albuminous or nitrogenous constituents of the tissues and blood. It was at one time consid. ercd that it was generated entirely at the expense of the muscular tissue; but as no one has yct succeded in extracting urea from muscle, and as muscular exertion, even when violent and protracted, causes little or 110 increase in the amount eliminated, and as the substances that we know result from the disintegration of unscular tissue, as kreatin and kieatinin, are either not at all, or not easily, converted into urea, and even when ingested are eliminated unchanged, without causing any augmentation in the amount of urea, whilst a large increase quickly follows the ingestion of nitrogenous food when the body is at rest, there seem to be good grounds for admitting that only a portion of the urea discharged can proceed from that disintegration to which the muscles, in common with all other animal structures of high organization, are liable, and that another and much larger portion is derived from the decomposition and disintegration of the albuminous compounds that are constantly being consumed in naintaining the activity of the great glandular and cellular organs of the body, ${ }^{1}$ the ultimate results of the oxidation -urea, carbonic acid, and water-being the same. The question of the place of origin of the urea is still more difficul to answer. Up to a very recent period it was universally held that the kidneys constituted a kind of filter by which certain products of the disintegration of the tissues were separated from the blood and discharged from the body. M. Picard's experiments, which showed that urea is uniformly present in the blood (2-4 parts in 10,000), and in larger proportion in the renal arterial than in venous blood, and those of Gréhant, ${ }^{2}$ showing that after ligature of the ureters the amount of urea in renal venous blood becomes exactly equal to that in renal arterial blood, have been commonly referred to in support of this view, the small quantity present being attributed to the care with which the system was freed from this excretory product. Lately, however, an attempt has been made to prove that urea is formed fron the secondary products of the disintegration of the tissues, such as kreatin, kreatinin, uric acid, hypoxanthin, and taurin, in and by the kidney itself, upon the following grounds: ${ }^{3}$ First, that extirpation of the kidneys is followed by only a trifling increase in the proportion of urea present in the blood, though the proportion of kreatin and other lower stages of the oxidation of nitrogenous compounds is augmenter both in the blood and muscles; secondly, that after ligature of the ureters, the renal organs remaining intact, there is considerable increase in the amount of urea contained in the blood; thirdly, tlat the ingestion of kreatin with the food produces an increase of the excretion of kreatinin and urea; fourthly, that on rubbing down kreatin with the substance of the kidney, it is rapidly converted into urea ; and lastly, that there is reason for believing that the cclls covering the glomeruli exercise a secreting function,

1 On this view the "luxus eonsumption" of Voit and others, which was considered to eonsist in the oxidation of the nitrogenous eonstituents of the food in the blood previous to their conversion into tissue, has no existence.

2 See atstract of Memoir in Humphry and Turner's Journal of Anat. and Phys., 1871, p. 216.

3 See Munk, Deutsehe Klinik, 1862, p. 299; Oppler, Virchow's Archiv, 1861, Bd. xxi, p. 260; Subbotin, Henle and Meissner's Zeitsehrift, Bd. xxviii, 1866, p. 114; and Zalesky, Untersuchungen über den Uramischen Process. Sehultzen and Nencki (Zeits. f. Biologie, 1872, Bd. vii, p. 124) believe that some of the intermediate stages between Albumen and Urea are represented by Glyeol, Leucin, and Trrosin. But Küssner has clearly shown that Tyrosin eannot be regarded as an anteedent of Urea (Centralblatt, 1875, p. 216). 
and are not merely adapted for the elimination of water, since these glomeruli are abundantly distributed through the kidneys of birds, the urine of which animals is semisolid, whilst it is impossible to obtain a trace of uric acid from their blood. Now, in opposition to some of these statenents are the observations of G. Meissner, ${ }^{1}$ who, by analyzing large quantities of blood, obtained unmistakable evidence of the prescnce of uric acid in that of the bird (goose), and shows by calculation that it is possible for all the uric acid excreted by the animal to have been separated from the blood passing through the kidney in a given time. In the course of his experiments, Meissner found so much uric acid in the liver, and so little in other organs, that he came to the conclusion that the liver was the seat of its formation in birds. ${ }^{2} \mathrm{On}$ extending his researches to mammals, he found that here also the liver presented on chemical analysis a larger proportion of the essential urinary constituent urea than any other organ. Hence he concludes that it procecds from the disintegration of the hremoglobin of effetc blood-corpuscles into urea, glycogen, and biliary coloring matter; and adduces pathological evidence, derived from the obscrvations of Frerichs, Städeler, and Harley, to the effect that in acute and chronic atrophy of the liver it is either greatly diminished or wholly absent. Heynsius further adduced in support of this view the fact that more urea can be obtained from a liver which has been removed from the body for some hours and kept at a temperature of $104^{\circ} \mathrm{F}$. than from a fresh one, and $\mathrm{Cyon}^{3}$ maintained that the blood which was passed through the liver of a living animal is richer in urea after its passage than before. These statements have, howcver, becn again called in question by Gscheidlen in an elaborate essay ${ }^{4}$ upon the subject, and his experiments have led him to the conclusion that no single organ can be fixed upon as exclusively producing urea, but that it is formed in the system generally. It is remarkable that though it ean be detected in the blood, liver, spleen, kidneys, brain, and eye, it does not appear to be present in the muscles. Gréhant ${ }^{5}$ finds that after extirpation of the killneys, the amount of urea in the blood undergoes progressive increase, proportionate in fact to the quantity that would have been excreted had the kilneys been in action; he finds also that after ligature of both ureters the same accumulation of urea takes place, and that the renal venous blood, contrary to Picard's statement, contains less urea than renal arterial blood, whilst after ligature of both ureters the proportion of urea in the arterial and renal venous blood is equal. There seems therefore to be good reason for believing that the urea is simply excreted by and not formed in the kidncys. ${ }^{6}$ In reference to the origin of urea from kreatin, Meissner states, in opposition to Munk, ${ }^{7}$ that he has found no increase in the amount of urea when kreatin or kreatinin were given with the food, or otherwise introduced into the blood. In all instances these substances were discharged either unaltered, or merely with conversion of some of the kreatin into kreatinin. Voit ${ }^{8}$ also declares himself opposed to the vicw that the formation of urea occurs at the kidncys, cxcept in so far as

1 Centralblatt, $1868, \mathrm{pp} .226$ and 275.

2 Pawlinoff' (Centralblatt, 1873, p. 241) has satisfied himself that uric aeid is not formed in but only exereted by the kidneys.

3 Centralblatt, 1870, p. 580. For a good résumé of all this diseussion, see Parkes's Leetures, in the Lancet, 1871 , vol. i, p. 467.

4 See abstraet of his memoir in Centralblatt, 1871, p. 630.

5 Centralblatt, 1870, p. 249.

.6 See the corroborative experiments of Rosenstein, Centralblatt, 1871, p. 353; Falek, Virchow's Arehiv, Bd. liii, 1871, p. 282; Gseheidlen, Studien über den Ursprung des Harnstotis im Thierkörper, Leipzig, 1871.

7 Deutsche Klinik, 1862, p. 299.

8 Centralblutt, 1868, p. 468. 
that it may take place to some slight cxtent from a conversion of kreatin; though when this was given with food it was eliminated partly unchanged and partly converted into kreatinin. He found an increase in the quantity of urea in the blood, and also discovered it in the muscles, both after cxtirpation of the kidneys and after ligature of the ureters: the amount being larger in proportion to the lateness of the period at which death occurred, and on that account it was smaller in amount after ablation of the kidncys. In one instance, after cxtirpation had been performed, he collected the whole of the retained urea, and obtained 5.3 grammes, whilst if the animal had been allowed to live, he would have elininated 5.8 grammes in the same space of time. The:e was cortainly no increase of kreatin after either extirpation or ligature. The respiration of oxygen diminishes the quantity of urea in the urine, ${ }^{1}$ notwithstanding that it augments the activity of the combustive processes, and might therefure be expected to increase it. A possible explanation is that it probably leads to the combustion of the urea itself and its conversion into carbonic acid, ammonia, and water. The nonincrease of urea in the urine when violent excrtion is made is, perhaps, explicable on the same view. On the whole, the results of recent researches seen to show that urea is formed in the tissues generally, including the renal, and with the exception perhaps of the muscular, and that thus entering the blood from many quarters, it is filtered off by the kidneys, the secreting cells of which have a special affinity for it.

414. Besides its organic materials, the urine contains a considerable a monnt of Suline matter; the excretion of which, in a state of solution, appears to be one of the principal offices of the kidney. Various saline compounds are being continually introduced with the food ; and others are formed within the system, by the oxidation of the sulphur and phosphorus of the tissues or of the food, and by the combination of the sulphuric and phosphoric acids thus formed, with alkaline and earthy bases which the food may contain, usually in a state of combination with weaker acids which are otherwise disposed of. Thus the saline compounds found in the urine are to be regarded as partly proceeding from the retrograde metamorphosis of the materials of the tissues, after these have served their purpose in the economy, and partly from that of such components of the food as, being superfluous, do not undergo organization. But the kidney also serves as the channel for the elimination of saline conipounds introduced into the system per se; these being sometimes normally present in the body, but ingested in too large an amount, as is often the case with common salt; whilst, on the other hand, they may be altogether foreign to the composition alike of its solids and its fluids.-The Allkaline Sulphates usually constitute, as we have seen $(\$ 410$, at least 10 per cent. of the whole solid matter of the urine. Being always in solution, however, they never make their presence known by the formation of sediments, and are only to be detected by chemical tests. The causes which influence their amount have been carefully studied by Dr. Bence Jones; who has shown that they vary (like urca) with the amount of food ingested, and with the degree of nervo-muscular activity put forth ; as might be anticipated from the fact, that, under ordinary circumstances, the sulphuric acid is entirely formed within the system, by the oxidation of the sulphur of the protein-compounds, the bases being furnished by the alkaline carbonates or phosphates of the blood. A portion of the sulphur is, however, eliminated by the bowels in the form of taurin. In Mr. Weston's case the average excretion of sulphuric acid for five days before his long walk of $317, \frac{1}{2}$ miles in five days was 38.37 grains, for the five days of the walk 53.50 grains, and for the five days after the walk 49.02

1 Pitter, Revue Scientif., 1872, p. 91. 
grains. In regard to the effects of exercise on the excretion of acids by the urine, Klüpfe ${ }^{1}$ found that it was augmented to the extent of 44.8 per cent. by exercise, whilst Sawicki ${ }^{2}$ obtained only variable and chiefly negative results. When sulphuric acid or soluble sulphates are taken into the system per se, they partly find their way out of it by the kidneys; the proportion of sulphuric acid in the urine being for a time augmented, although the increase is not considerable until some hours have elapsed after the introduction of these substances into the stomach. ${ }^{3}$ They are not increased on a non-nitrogenous diet by exercise (Parkes). The absolute amount of sulphuric acid varies from 35 to 50 grains per diem.-The amount of Alkaline. Phosphates in the urine is usually about half that of the alkaline sulphates. The acid of these also is ordinarily generated within the system, by the oxidation of the phosphorus originally introduced in the protein-compounds; and thus, as in the case of the sulpliates, the quantity of them which is excreted by the urine bears a certain relation to the amount of these compounds ingested as food, and also to the amount of muscular tissue which has undergone disintegration by exercise. But it further appears that there is a special relation between the quautity of the alkaline phosphates in the urine, and the amount of disintegration of the nervous tissue; as might have been suspected from the fact, that this tissue is distinguished by the very large proportion of phosphorus, united with fatty acids, which it contains. And a marked incrcase of these salts is observed in those inflammatory diseases of the brain, in which there is reason to believe that an unusually rapid disintegration of its texture is taking place. ${ }^{4}$-The Earthy Phosphates usually bear but a snall proportion to the Alkaline; but their presence in the urine comes to be of great importance with reference to the precipitates which they form in particular conditions of that secretion. From the researches of Dr. Bence Jones (loc. cit.) it appears, that the quantity of these phosphates in the urine chiefly varies with the amount of them contained in the food, into many articles of which they enter largely, ${ }^{5}$ but he has also ascertained that their formation within the system is determined by the presence of their bases; for if any earthy salt, a little chloride of calcium or sulphate of magnesia for instance, be taken into the system, the quantity of earthy phosphates in the urine undergoes an increasc. The small quantity of carbonate of lime taken into the system with the food, or set free by the slow disintegration of the osseous tissue, is probably excreted in Man almost entirely in the form of phosphate; although of the much larger amount ingested by herbivorous aninals, a considerable proportion is excreted in the urine in its original state. The Earthy Phosphnates, although insoluble in water, are soluble in atl acid liquids; and they are held in solution in Urine, like the urates, by the acid phosphate of soda. Their precipitation in an alkaline state of the urine is owing to the want of this

1 Hoppe-Seyler's Chem. Unters, 1868, Heft 3.

2 Pfluger's Archiv, Bd. v, p. 28\%.

3 Dr. Bence Jones in Philusophical Transactions, 1849.

4 Sce Dr. Bence Jones's valuable series of Papers in the Philosophical Transactions for 1845,1847 , and 1850 , and in the Medico-Chirurcical Transactions for 1847 and 1850 ; also Byasson, Op. cit., p. 612. It is curious to observe, that whilst the increase in the alkaline phosphates in Inflammatory affections of the nervous centres is very marked, there appears to be a positive diminution of them in Delirium Tremens. A certain allowance must be made, however, for the abstinence from food, which will of itsclf occasion a reduction in the quantity excreted.

5 The experiments of Neubaur (Journal f. pract. Chem., 1866, p. 96), Riesel (HoppeSeyler, It ed. Chem. Untersuch., IIeft 3, 1869), and Soborow (Centralblatt, f. d. Med. Wis.s., 1872, p. 609) all show that when tuken in excess the salts of lime are very rupidly and completely eliminated by the urine, the whole being discharged in the course of a few liours. 
solvent, not to an excess in their production; for, as Dr. Bence Jones has pointed out, that excess of alkaline and earthy phosphates in the urine which constitutes the true "phosphatic diathesis," is generally coincident with a highly acid state of the urine. In Mr. Weston's case before alluded to the average excretion of the phosphoric acid was 50.14 grains per diem for the five days before the walk, for the five days of the walk $76.6 \%$ grains, and for the five days after the walk 56.89 grains. The excretion of phosphoric acid is not increased by exercise on a non-nitrogenous diet (Parkes). The absolute amount excreted per diem on a mixed diet varies from 54 to 78 grains (Genth).--The only other inorganic saline constituent of the Urine, whose quantity gives it importance, is Chloride of Sodium. By far the larger proportion of this is doubtless derived directly from the food; but little being furnished by the disintegration of muscle, which will set free potash rather than soda. The amount eliminated by the urine is consequently subject to great variation, it being the function of the Kidneys to remove whatever is superfluous, so as to prevent the blood from becoming overcharged with this substance. In Ranke's experiments on his own person, the quantity discharged varied from 75 to 523 grains daily; ordinarily it varies from 200 to 350 grains. Of the chloride of sodium introduced as food, a part appears to undergo decomposition in the system, whereby hydrochloric acid is furnished to the gastric fluid, and soda to the bile; much of this acid, however, must reunite with its base in the alimentary canal, so that the chloride of sodium thus regenerated will be absorbed with the products of the digestive operation. Its quantity is increased by muscular exertion (Byasson). Dr. Flint found the average amount daily excreted during five days in the person of Mr. Weston to be 159.45 grains for 5 days previous to a walk of $317 \frac{1}{2}$ miles. During the walk the average was 65.08 grains, and during the five days after the walk 312.40 grains per diem. The quantity is decreased on a non-nitrogenous diet (Parkes). It is much diminished after profuse sweating (Ranke). -Although Nitric Acid can scarcely be regarded as a normal constituent of the Urine, yet the investigations of Dr. Bence Jones appear to show that it is formed by a combustive process within the body, whenever ammoniacal salts are introduced into the system; its amount, however, being very small. He has also found that it is generated after the ingestion of small quantities of urea; a fact which affords some confirmation to the doctrine of Frerichs, that urea may undergo decomposition into carbonate of ammonia, whilst still circulating in the current of blood.-The presence of Oxalic Acid in the urine (in combination with Lime) has been usually regarded as a pathological phenomenon, consequent upon an irregular performance of the retrograde metamorphosis of the tissues; but there can be no doubt that it may also result from the presence of soluble salts of oxalic acid in certain articles of vegetable food. ${ }^{2}$ - The Gases found in the Urine have been examined by Planer $^{3}$ and Bernard. ${ }^{4}$ Planer found in one instance 7, and in another 16 per cent. of gas. The following Table gives the percentage composition of the gases obtained:

1 Philosophical Transactions, 1851. - It is right to state, however, that this doctrine has been called in question by some eminent authorities, who deny the validity of the test for nitric acid employed by Dr. Bence Jones.

2 See Dr. Golding Bird on Ürinary Deposits.

3 v. Gorup-Besanez, Physiolog. Chenı., 1862, p. 526.

4 Leçons, vol. i, 1859 , p. 347. 


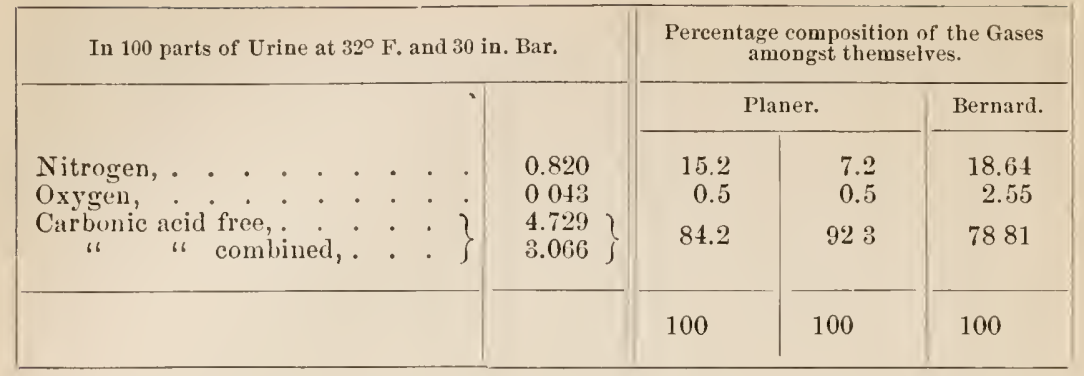

About one-third of the carbonic acid was combined, the remaining twothirds were free.

415. The ordinary acid reaction of the Urine appears to be due, not to the presence of any free acid, but to the conversion of the basic phosphate of soda into the acid phosphate, by the subtraction of a part of the base, which occurs when uric, hippuric, lactic, or other free acids come into contact with the former substance. There is no adequate reason to believe, that, in the healthy state, there is ever any other cause than this; although in morbid urine, free organic acids are almost certainly present.' It has been shown by the researches of Dr. Bence Jones, ${ }^{2}$ with whose observations those of Roberts ${ }^{3}$ and Brunton ${ }^{4}$ generally agree, that the acid reaction is far from being constant in its degree, even when an ordinary mixed diet is steadily employed ; for that it varies at different periods of the day, increasing and decreasing inversely with the acidity of the stomach. Thus the acidity of the Urine decreases soon after taking food, whilst that of the Stomach is increasing, and attains its lowest limit about three to five hours after a meal, when, therefore, absorption is being most actively performed. An alkaline reaction is often observed in the urine at this period, which, according to Dr. Roberts, is due to the presence of fixed alkali ; this occasions a precipitation of earthy phosphates, rendering the urine turbid, though the quantity of uric acid at this period is always large. The acidity then gradually increases, whilst that of the stomach is decreasing; and attains its highest limit after a fast of some hours, when the stomach is quite empty, and its secretion neutral. If no food be taken, the acidity does not decrease, but remains at nearly the same point for ten or twelve hours. When animal food was alone employed, the diminution of the acidity after a meal was more marked and continued longer than when a mixed diet was eaten (apparently on account of the greater demand for acid in the stomach); and the acidity did not rise quite so high after fasting, as with a mixed diet. On the other hand, when the diet was purely vegetable, the diminution of the acidity of the urine was never such as to render it absolutely alkaline, although its acidity was reduced to the point of neutrality; and the increase of its acidity after fasting was sometimes very considerable, though by no means so marked as the decrease of alkalescence.- These diurnal variations in the acidity of the urine make it highly probable, that corresponding variations occur in the alkalescence of the blood ; such diumal variations being produced by the quantity of acid separated from it, and poured into the stomach for the purpose of dissolving the food. The introduction of dilute sulphuric acid into the stomach, even

1 Sce Prof. Lehmann's Physiological Chemistry (Cavendish Socicty's ed.), vol. ii, pp. 404-406.

2 Pliilos. Transact., 1849.

3 Memoirs of Manchester Phil. Society, 1859.

4 Digitalis, p. 62. 
in large doses, was not found to produce any decided change in the acidity of the urine; the only pereeptible effect being a slight diminution of the rlccrease which takes place after taking food, and a slight augmentation of the increase after fisting. On the other hand, the use of liquor potassa in large doses lessens the acidity of the urine, preventing it from rising after fasting to the height it would otherwise attain, and increasing its alkalescence after a meal ; but it does not render the urine by any means constantly alkaline, nor does it hinder the variations produced by the state of the stomach from being very evident. Tartaric acid in large doses temporarily increases the acidity of the urine, causing it to rise considerably higher than usual after a fast, but not preventing that which is passed a few hours after food from becoming alkaline. Tartrate of potash in large doses, on the other hand, has a marked effect in rendering the urine alkalescent; still, it does not prevent the usual recurrence of the acidity some hours after a meal.-The Urine of Herbivorous animals is almost invariably alkaline; partly because their food contains a large quantity of alkaline and earthy bases, in combination with eitric, tartaric, oxalic, and other acids, which are decomposed within the systenl; and partly because the amount of sulphuric and phosphoric acids, generated as products of the oxidation of the elements of the tissues or of the surplus food, is not sufficient to neutralize them. Such is the condition which occasions the alkalinity of Human Urinc, when a portion of the acid which wonld otherwise show a predominance is directed into another channel; and it is exaggerated in those states, in which, either from the irritating nature of the food, or from the irritable condition of the stomach, an undue quantity of acid is poured out into that viscus; so that, its reaction being habitually acid, that of the urine becomes habitually alkaline. Such a state of the urine must be carefully distinguished, as Dr. Bence Jones has pointed out," from that in which the alkalescence is due to the prescnce of volatile, and not to that of fixed alkali ; the difference being easily recognizable by the influence of the liquid upon reddened litmus-paper, for the restoration of its blue color is permanent in the latter case, but only transitory in the former. The alkalescence due to the presence of volatile alkali is due to the decomposition of urea, whilst the urine is yet within the bladder, through the agency of morbid secretions of that viscus; and it disappears when this organ returns to its healthy state. On the other hand, the alkalescence from fixed alkali proceeds from disordered action of the stomach, which is usually connected with disorder of the gencral system; and it persists until this can be remedied. In both forms of alkalescence, there is a precipitation of earthy phosphates; but in the alkalescence from fixed alkali, the precipitate usually consists almost entirely of phosphate of lime; whilst in that from volatile alkaki, the amorphous sedinent of phosphate of lime is mingled with prismatic crystals of the phosphate of ammonia and magnesia. These precipitates may be obtained from healthy urine, by adding to it a solution of potash or of anmonia ; and the decomposition of such urine, which begins to take place very soon after it leaves the body, gives rise to the same precipitation, by the production of carbonate of ammonia at the expense of its ureat.

416. Thus, then, we have seen that the Kidneys serve as the special instruments for depurating the Blood of those highly-azotized compounds, which are formed in the system by the decomposition of the materials of the albuminous and gelatinous tissues, and also by that of the non-assimilated components of the food. We have seen also, that they serve for the removal of certain excrementitious compounds, of which carbon is a principal in- 
gredient; and these, although normally present in but small amount, may undergo a marked increase in disease, especially when the liver is insufticiently performing its functions, or the respiratory process is obstructed. Further, we have been led to regard the Kidneys as the emunctory, not only for the superfluous water of the blood, but also for those saline compounds, which, having been introduced into the system or generated within it, in larger amount than is compatible with the normal constitution of the blood, or than is required for the reparation of the solids of the body, or for the production of its fluid secretions, are only fitted for elimiuation. On this point a very elaborate series of researches was made by Wöhler, ${ }^{1}$ who showed that of the soluble salts taken into the circulation, those are most readily excreted which produce a determination of blood towards the kidneys, whereby an increased quantity of liquid is filtered off through the outlet which they affiord. This statement is to be extended from saline compounds, to such other soluble matters as are not eliminated by preference through other channels, or are present in too large an amount to find their way out thence with sufficient rapidity, as Sugar and Lactic acid. In like manner, too, the system makes an effort to free itself (so to speak) from various substances altogether foreign to it, which have been introduced into the circulating current by absorption, and which would be injurious if retained; the rate at which it does so, being in a great degree dependent upon the functional activity of the Kidneys ( $\$ \$ 220,221$ ).

417. It is a most important fact, in a Dietetic and Therapeutic point of view, that the metamorphic process, of which the greater part of the constituents of the urine are the products, should be capable of retardation or of acceleration by the presence of other substances in the blood. The former appears to be the operation of thein, which is the active principle of Tea and Coffee. From various experiments, ${ }^{2}$ it appears that the use of these substances, by retarding the "waste" of the system, diminishes the demand for food, and makes a limited amount of it go further $;^{3}$ and this conclusion seems fully borne out by experience. ${ }^{4}$-The like results happen, according to Dr. Böcker, under the use of small quantities of Alcohol frequently repeated; as much as $13 \frac{1}{3}$ grammes less urea being excreted daily, when a teaspoonful of proof spirit was taken seven or eight times a day, than when water alone was drank. It does not hence follow, however, that Alcohol can be used as advantageously for this purpose as Tea or Coffee; in fact, it may be doubted whether it is so much by diminishing the "waste" of matter, as by interfering with the duc elimination of its products, that Alcohol occasions a diminution in the weight of the urinary solids. For, although it does not appear to effect any marked diminution, but rather an increase in the climination of ccrtain forms of excrementitious natter which have been reccived back into the blood, and especially of the hydrocarbonaceous products ( $\$ 311$, vi), yet very cogent evidence is supplied by the experience of $Z y$ motic diseases, that the very same cause produces an aceumulation of fermentable azotized substances in the blood $(\$ 71)$. - It seems not unlikcly that the almost instinctive eraving for Tobaceo among a large proportion of man-

1 Muller's Elements of Physiology, translated by Baly, p. 589.

2 Böcker, Archiv des Vereins tuir gem. Arbeit zur Förd. der Wiss. Heilk., 1854; and Julius Lehmann, Annal, der Chem. und Pharm., Bd. Ixxxviii.

3 Dr. Ed. Smith (Proceed. of Roy. Soe., 186il) found the deerease in the elimination of ureat after the use of tea (which had the greatest effeet) and eoffee, to be but slightly marked after the first day or two.

4 Voit, from experiments with coffice on a $d o g$, was led to a different result; and eonsiders that this substanee possesses but little influenee on the exeretion of urea. See Henle and Mcissner, Bericht, 1860, p. 397. 
kind, arises out of its possession of a power of retarding the metamorphosis of the tissues; since we find that men, when supplied with this article, can far better sustain being put upon a short allowance of food, than when destitute of it.

418. Of the substances that accelcrate the metamorphosis of the tissues, and thus augment the solids of the urine, the Alkalies and their carbonates and Chloride of Sodium are those whose action is best known; these (with such of thcir salts as are formed by acids which are decomposed in the blood into the carbonic, such as the acetates, tartrates, and citrates) have a solvent action on the albuminous compounds generally, and tend to break up these compounds into simpler forms of combination. Hence it seems likety that their presence in the Blood in increased amount, will tend to hasten the retrograde metamorphosis of the tissues; their chemical force bcing exerted, not merely upon those which are already in a state of disintegration, but also upon those which, being disposed to degenerate, cannot exercise that resisting power which they possess when in a state of complete vital activity. ${ }^{1}$ The operation of Liguor Potasse in health, in acute rheumatism, and in chronic diseases, has been carefully studied by Dr. Parkes; ${ }^{2}$ and he has given satisfactory evidence that it causes an increase in the solids of the urine generally, but especially in the urea and in the amount of the sulphuric and phosphoric acids; thus clearly showing that it hastens the metanorphosis of some of the albuminous structures of the body. Similar results were obtained by Dr. Golding Bird, ${ }^{3}$ from the employment of acetate of potash.It does not appear, however, that the excretion of the urinary solids is augmented by those "diuretic" medicines, which cause a larger amount of liquid to be passed off through the Kidneys, merely by determining an increascd flow of blood to them. On the contrary, it would seem as if, by producing congestion and irritation, they sometimes interfere with the normal process of secretion; so that the quantity of solid constituents is actually decreased, notwithstanding the large augmentation in the watery part of the urine. ${ }^{4}$ This very important fact has been demonstrated by Prof. Krahmer, ${ }^{5}$ who gives the following as the result of his observations upon the amounts excreted in 24 hours, after the administration of diuretics to persons in health :

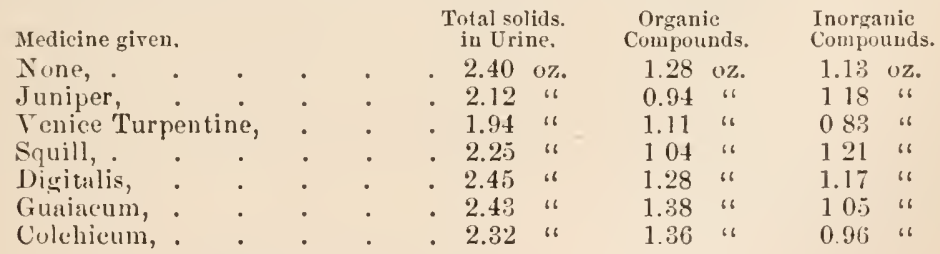

It seems highly probable that the "critical evacuations" of urine, as of sweat, or fecal matter, on which the older physicians were accustomed to lay great stress, are really charged,with noxious substances, of which the blood is thus depurated; and that great benefit would f'requently arise in practice from the use of the "alterative diuretics," as suggested by Dr. G. Bird, where (as in chronic rheumatism, gout, etc.) there is reason to believe that a

1 Sce Voit, On the Action of Common Salt, ete., Munich, 1860.

2 Brit. and For. Med.-Chir Review, vols. xi, xiii, xiv.

3 See his Lectures on the Influence of Researches in Organic Chemistry on Therapeutics, in Medical Gazettc, 1848, vol. xlii, p. 230.

4 In the case of Digitalis Dr. Brunton found there was a con-ilurahle absolutio, though not relutive, increase in the amount of urea eliminuted. Sue Bruntun, On Digitalis, p. 42, 1868 .

s Heller's Archiv, Dec. 1817. 
quantity of malassimilated matter exists in the system, of which it is important to get rid. In many such cases, indeed, clinical observation had alrearly established the benefit derivable from such medicines, witlout affording the rationale of it. The urine as it is secreted trickles drop by drop into the bladder, a musculo-membranous receptacle capable of holding from one to three pints, from which it is discharged at stated periods. The bladder is composed of two muscles opposer in action, the detrusor urinæ, which forms the greater part of the membranous bag, and the sphincter vesicxe, which forms its neck. Both are chiefly composed of unstriated muscular tissue, though some fasciculi of striated muscle are found in the sphincter, and both are under the governance of nervous centres situated in the lumbar portion of the spinal cord, though they may also be influenced by the will. Under ordinary circumstances the escape of the urine is prevented by the moderate contraction or tone of the sphineter vesice, to overcome which in the rabbit, the pressure of a column of water of from 16 to 20 inches in height, ${ }^{1}$ and in the dog of about 30 inches (Giannuzzi and Nawrocki) is required. On section of the lower part of the spinal cord, or of the vesical nerves, the pressure of a column of water of only five or six inches in height is sufficient to force a passage for the fluid through the sphincter. The concordant observations of Masius ${ }^{2}$ and Budge ${ }^{3}$ show that the motor centre of the bladder is situated at or about the level of the fourth lumbar Vertcbra in animals. In connection with the motor centre there appears to be a sccond or inhibitory centre also situated in the lumbar region, for Goltz has shown ${ }^{4}$ and observations on man furnish corroborative evidence that neither incontinence nor retention of urine need necessarily follow division of the spinal corl ; but that in some instances, the subjects of this injury can hold their water for several hours, and discharge it at regular intervals-that is to say, that whilst the bladder is filling, some influence restraining the action of the detrusor is exerted, which from analogy there is reason to believe proceeds from an inhibitory centre, till the excitation of the accumulated urine becomes so strong as to stimulate the notor centre and overpower the inlibitory centre. Goltz observed, and the experiment might be useful in cases of lesion of the spinal cord in man, that the application of a cold wet sponge to the anus caused immediate expulsion of the urine, either by stimulating the motor centre and inducing contraction of the detrusor, or by paralyzing the inhibitory centre, and thus effecting the relaxation of the sphincter, and removing any obstacle to the respondence of the detrusor to the stimilus of the moderate accunulation of urine in the bladder. Daily experience teaches that the will can exert an influence both on the motor and inhibitory centres situated in the lumbar region of the cord.

\section{Of the Skin-Cutaneous Transpiration.}

419. The Skin is the seat of various secretions,-as the Sebaceous, Ceruminous, and Odoriferous, - for each of which it is provided with special organs; but these lave reference chicfly to its own protection, or to some other local purpose; and the only one which can be regarded as truly excrementitions, is the Transpiration of aqueous fluid holding certain matters in solution. The elimination of this fluid from the blood is effected by the Sudoripurous glandulie (Fig. 182), which essentially consist of long convoluted tubes ( $a, a)$, rarely single, but usually multiplied by repeated dicliotomous

1 Kupressow, Pflüger's Arehiv. 1872, Bd. v, p. 291.

2 Bulletin de l'Acad. Roy. de Belgrique, 1868, p. 491.

3 Virchow's Archiv, 1858, Bd. xv, p. 115.

4 I'llüger's Archiv, 1873, p. 474. 
subdivision (2), sometimes also giving off short creal processes before their termination. These are seated rather beneath the Corium and in the niclst of the subcutaneous adipose tissue, than in the substance of the skin itself, and the gromerulus is always invested by a sheath of smooth muscular tisene (Kranse). ${ }^{1}$ The tubuli of each gland are lined throughout with a single layer of columnar epithelium, and unite so as to form but one duct; and this passes upwards through the Cutis and Cuticle, in a somewhat corkscrewlike mamer (3), to open upon the surface of the latter (4), which it usually reaches obliquely, so that the outer larer of the Enidermis forms a solt of little valve. which is litted by the secreted fluid as it issues forth. These glandulae are diffused in varying proportions over the entire surface of the body. According to Mrr. Erasmus Wilson, ${ }^{2}$ as many as 3528 of them exist in a square inch of surface on the palm of the hand; and since every tube, when straightened out, is about a quarter of an inch in length, it follows that, in a square inch of skin from the palm of the hand, there exists a length of tube equal to 882 inches, or 732 feet. The number of glandulie in other parts of the Skin is sometimes greater, but is generally less than this; and, according to Mr. Wilson, about 2800 may be taken as the average number of pores in each square inch throughout the body. Now the number of square inches of surface, in a man of ordinary stature, is about 2500 ; the total number of pores, therefore, may be about seven millions; and the length of the perspiratory tubing would thus be $1,570,000$ inches, or nearly 28 miles, or would represent a solid mass about cqual to one-third of a kidney (77 cub. cent., Krause).

420. Although a separation of fluid by this extensive glandular apparatus is continually taking place, yet this fluid, being usuatly carried off in the form of vapor as fast as it is separated, does not ordinarily accumulate so as to become sensible. If, however, from the increased amount of the secretion, or from the condition of the surrounding air as regards temperature and moisture, the whole fluid thus poured ont should not evaporate, the residue forms minute drops

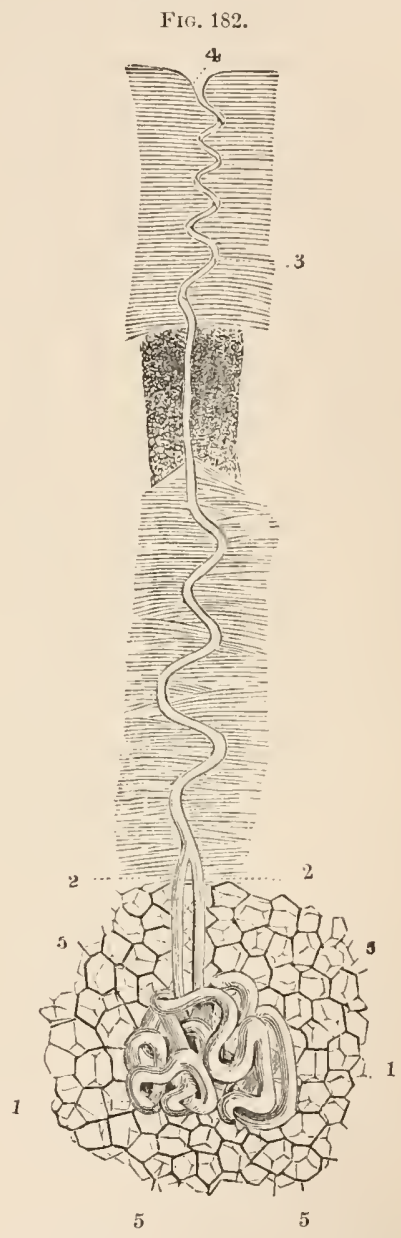

Sudoriparous Gland from the palm of the hand, magnified 40 diam.: 1,1 , contorted tubes, composing the gland, and uniting in two excretory ducts, 2, 2, which unite into one spiral canal that perforates the epideruis at $c$, and opens on its surface at 4 ; the gland $i$, imbedded in fat-vesicles, which a re seen at 5,5 . upon the surface of the skin. Thus the Sudoriparous excretion may take 
the form either of sensible or of insensible transpiration; the latter being eonstant, the former oecasional. When eollected in the fluid state, sweat is a colorless liquid, possessing a peculiar odor according to the part of the skin from which it is obtained, and more or less turbid from the presence of sebaceous matter and epidermal seales, which constitute from 0.2 to 0.3 per eent. of the whole amount of the excretion. Its reation is usually acid, though Gillibert ${ }^{1}$ and Favre found that after protracted sweating it became neutral or even alkaline. Its acidity appears to be due to the presenee of certain volatile acids, as the acetic, butyric, and formic; to which, and possibly to the metacetonic and eapric acids, we are probably to attribute the sour smell which it possesses in some disordered states of the system. The substances which have been found to be constant constituents of the sweat are, water, fat, various volatile fatty aeids in addition to those already mentioned, urea and inorganic salts, amongst the ehief of whieh are the chlorides of sodium and potassium, the alkaline phosphates and sulphates, the earthy phosphates, and iron. That it is a true secretion, and not a mere transudate, is shown by the entire absenee of albumen, except under very unusual conditions, and then only occasionally. ${ }^{2}$ Other eonstituents of the sweat, whose presence is not eonstant, or the nature of which has not been satisfactorily determined, are, the salts of ammonia, of lactie aeid, and of the hydrotic acid of Favre, and certain pigmentary substanees of various shades. In disease, urie acid, grape-sugar, albumen, and biliary eoloring matters, have been found; and when taken with the food, benzoic acid (partly converted into hippuric), suceinic, cinnamie, and tartarie acids, arsenious and arsenic acids, with iodine and iodide of potassium, have been recovered in the sweat. Funke ealculates that about 11 grains of nitrogen are daily eliminated by the skin through the desquamation of the epithelial scales. He also found urea (as was first stated by Dr. Landerer ${ }^{3}$ ) to be a constant eonstituent. In one experiment, the entire quantity of perspiration for the whole body for 1 honr being 3320 grains, $6 \frac{1}{2}$ grains were found to be present. If the secretion had continued at the same rate for $2+$ hours, $157 \frac{1}{2}$ grains of urea would have been eliminated, containing $73 \frac{1}{2}$ grains of nitrogen. Under ordinary circumstances, however, it is probable that a very much smatler quantity is thus eliminated. From the general uniformity in the proportion of solids to 100 parts of sweat, obscrved by Funke, it is obvious that, with an increase in the quantity of fluid exereted by the skin, there is also an augmented excretion of solisls; and to the defieiency whieh is thus produeed in the salts of the blood may be partly assigned the debilitating effeets of profuse perspirations. Other causes, however, probably eoneur in producing those effects. Thus the great fatigue which is experieneed as a consequence of musenlar exertion in a heated atmosphere, may fairly be set lown to the diminished activity of the respiratory process at high temperatures $(\$ 811, i)$, and the eolliquative sweating of heetic fever is obviously not a cause but a eonsequenee of, though it may also react upon and increase, the debilitated state of the general system. The proprotion of solid matter eontained in different specimens differs very greatly; thus, according to Anselmino, it varies between 5 and 12.5 parts in 1000 ; the observations of Favret give 4.43 parts per 1000 as the proportion eontained in nearly nine gallons which

1 Gillibert d'Héreourt, Gaz Méd. de Lyon, Mai, 1853, Riev. Méd., $185 \%$.

${ }^{2}$ See Lrube, Virchow's Arehiv, Bd. xlviii, pp. 181, 301; and Archiv f. Klin. Med., Bd. vii, p. 1.

3 Heller's Arehiv, Bd. iv, p. 196. See also Deininger, Deutsch. Arehiv f. Ḱlin. Med, 1870, Bd. rii, p. 587.

4 Archives Génér. de Méd., 1853, 5me Sér., tom. ii, pp. 1-12. 
he had collected; whilst those of Schottin ${ }^{1}$ maise it as high as 22.4 parts per 1000, of which, huwever, 12 parts consisted of epithelium and insoluble matters.

421. The cutire amount of fluid which is "insensibly" lost from the Cutaneous and Pulmonary surfaces was estimated by Seguin at 18 grains per minute; of which $11^{\circ}$ grains pass off by the skin, and 7 by the lungs. Funke, with two stuclents, made numerous experiments upon the amount and characters of the Sweat excreter from the hand and forearm under different circumstances. In these experiments the arm was inclosed in a caoutchouc hag, and each experiment lasted for one or two hours. It was found that the largest quantity of sweat obtained from the forearm and hand nuder favorable circumstances, in one honr, was 740 graius, which wonld, in 24 hours, supposing the secretion to continue at the same rate, amount to about $2 \frac{1}{2}$ lbs. But, from accurate measurements, Funke ascertained that the ratio of the superficies of the forearm and hand to that of the bolly generally was as 1:17; so that if the perspiration took place contimuously and at the same rate from the whole surface of the body, upwarks of $42 \mathrm{lbs}$. might he discharged in 24 hours. On the other hand, the minimum quantity excreted by the hand and forearm was 48 grains per hour, which would amount to 1152 grains in 24 hours, and this, multiplied by 17 , would give $2 \frac{3}{4} \mathrm{lbs}$. for the amount eliminated from the whole body in 24 hours. It was found, however, that different regions of the borly gave off, in proportion to their surface, very different quantities of fluid: thus, in no instance was the amount discharged by the leg equal to that given off by the arm. Moreover, the three experimenters furnished very differcut proportions of sweat under the same circumstances: thus, with active exercise in the sun, the proportion between them was as $1: 2.3: 4.4$, and in another experiment as $1: 1.7: 2.06$. Funke dliws the conclusion from his experiments, that the entire amount of. perspiration from the whole body may fluctuate from about 2 ounces ( 819 grains) to about 29 ounces $(12,588$ grains) per hour, the quantity of solid residue varying from 14.25 to 107.57 grains per hour. Favre, by taking largequantities of warm drinks, and exposing the body to a high temperature, collected no less than 2560 grammes, or above $5 \frac{1}{2} \mathrm{lbs}$. of water in $1 \frac{1}{2}$ hours. It is difficult to give an average for the 24 hours when the variations are so great; but it may, perhaps, be estimated at about 2 lbs., the exhalation of aqueous vapor by the lungs being rather less than $1 \mathrm{lb}$. ( $\$ 318)$. An interesting series of observations has recently been published by Dr. Victor Weyrich ${ }^{3}$ upon the relative amounts of insensible perspiration under different conditions. The instrument he employed was a modification of Daniell's hygrometer; and his experiments extended over more than a year. He found that variations of temperature betwecn $55^{\circ}$ and $70^{\circ}$ F., when the body was clothed, produced little effect; but every $1^{\circ} \mathrm{C}$. $\left(=1 \frac{4}{5}^{\circ} \mathrm{F}\right.$.) above $70^{\circ} \mathrm{F}$. occasioned an increase of 2 per cent. in the total amount of vapor exhaled, and for every $1^{\circ} \mathrm{C}$. below $55^{\circ} \mathrm{F}$. there was a diminution of from 1 to $1 \frac{1}{2}$ per cent. He observed that the effects of the relative moisture of the air wcre in great measure concealed by variations in temperature, so that the highest averages of insensible perspiration occur-

1 Archiv für Physiol. Heilkunde, Bd. ii, pp. 73-104.

${ }^{2}$ Beiträge zur Kenntniss der Schweiss Secretion; Moleschott's Untersuchungen zur Naturlehre, u. s. w.. iv, p. 36.

3 Die unmerkliche Wasserverdunstung der Menschlichen Haut, Leipzig, 1862. See abstract in Med.-Chir. Rev., 1863, rol. ii, p. 359. Sec also Röhrig, Die Physiologie der Hautathmung, Deutsche Klinik, 1872, No. 23; and Erismann, Zur Physiologie der Wasserverdunstung von der Haut, in Zeitschrift f. Biologie, Bd. xi, pp. 1-i8, 1875 . 
red, not with the lowest, but with moderate amounts of moisture in the air. The minimum amount of perspiration always occurred on rising in the morning, being then 25 per cent. below the average. The maximum amount was climinated at noon, when it rose to 52 above the minimum. Food invariably increased the cutaneous transpiration, coffee and tea having a particularly powerful influence. The increase occurrerl soonest after breakfast, but was greatest and most permanent after dinner. Moderate muscular or mental exertion slightly increased the amount of parspiration, but fatigue and exhaustion produced a considerable decrease. Violent muscular effort raised it to 77 per cent. above the mean; severe intellectual labor, 42 per cent. During sweating, the rise was equal to 116 per cent. over the mean, but after sweating it fell even to 26 per cent. below the mean. The amount of insensible perspiration varies greatly with the conditions of the atmosphere, and of the body itself, in respect to cxposure, food, exercise, and activity of other secretions; and these variations, as we shall hereafter see $(\$ 424)$, have a most important share in the regulation of the temperature of the body. According to Garrod,' sweating begins when standing at rest at about $86^{\circ} \mathrm{Fahr}$. Exact observations on this point, however, in which not merely the temperature, but the hygrometric state of the air should be precisely determined, are much wanting; the best hitherto recorded being those marle by Dr. Southwood Smith," at the Phonix Gas Works, in which the former element only was carefully noted. These observations were made upon eight of the workmen employed in "drawing" and "charging" the retorts, and in making up the fires, during which they are exposed to intense heat; the men were accurately weighed in their clothes, immerliately before they began, and after they had finished their work; and in the interval between the first and second weighings, they were not allowed to partake of any solid or liquid ingesta, nor to part with urine or fieces.

Experiment I. Nov. 18th, 1836. Day bright and clear. Temperature of the air in which the men worked, $60^{\circ}$ Fahr. Barometer 29.25 in. to 29.4 in. Duration of labor, 45 minutes.-Average loss of weight, 3 lbs. $6 \mathrm{oz}$.; maximum, 4 lbs. $3 \mathrm{oz}$; mininum, 2 lbs. 8 oz.

Experiment II. Nov. 25th, 1836. Day foggy, with scarcely any wind. Temperature of the air $39^{\circ}$ Fahr. Barometer 29.8. Duration of labor, 75 minutes. Average loss of weight, 2 lbs. 2 oz.; maximum, 2 lbs. $15 \mathrm{oz}$; minimum, $14 \mathrm{oz}$.

Experiment III. June 3d, 1837. Day exceedingly bright and clear, with little wind. 'Temperature of the air, $60^{\circ}$. Duration of labor, 60 minutes. Average loss of weight, 2 lbs. 8 oz.; maxinum $3 \mathrm{lbs}$; mimimum, $2 \mathrm{lbs}$.

Experiment IV. On the same day, two other men worked in an unusually hot place for 70 minutes; the loss of weight of one of these was $4 \mathrm{lbs} .14 \mathrm{oz}$; and of the other 5 lbs. $2 \mathrm{oz}$.

Although the individuals subjected to those experiments were not in all instances the same, yet there was enough of identity among them to atmit of the certain inference, that the amount of fluid lost must be influenced by the state of the individual system, as well as by that of the surrounding medium. Thus in the second experiment, Michael Griffiths lost 2 lbs. $6 \mathrm{oz}$, and Charles Cahell 2 lbs. $15 \mathrm{oz}$; whilst in the third, Michael Griffiths lost $3 \mathrm{lbs}$, and Charles Cahcll only $2 \mathrm{lbs}$. It is probable that the amount of liquid ingested not long previously, might have a considerable influence on the quantity lost by transpiration under such circunstances.-The most recent investigator into the conditions affecting the evaporation of fluid 
from the body is Erismann, ${ }^{1}$ who examined them both in the dead and in the living borly. In the dead borly lie found that the amount of fluid evaporatjug from a given area of the skin was the same whether the under surface was in contact with serun or with water, and whether the vessels were fully injected with watcr or not. The amount incrased rapidly with temperature and with the dryncss of the air, but it made little difference whether 1000 or 6000 litres of air passed over the surface in a given time. Evaporation took place most actively from those parts which contained many sweatglands; the skin of the sole of the foot, for example, which contains, according to Krause, 2685 sweat-glands in the square inch, yielding nearly double the anomnt of insensible perspiration as compared with the skin of the belly, which has only 1136 in that area, notwithstanding the much greater thickness of the cpithelium in the former situation. A dead borly (the size of which is not given) of a woman lost 617.6 grains in 24 hours, the temperature being $63^{\circ} \mathrm{F}$, and the amount of aqueous vapor in the air 64 per cent. (as compared with saturation). Experiments nude upon the living body slowed that the most important external factor in deternining the anount of evaporation was the relative dryness or moisture of the air. Next came the temperature, and then the ventilation ol amount of air blowing over the surfice. The imbibition of a large quantity of hot fluid, by filling the vessels and increasing the pressure, augmented the evaporation. It was also increased by work, even though sweating did not occur. Considerable difference of opinion exists as to whether the insensible perspiration is discharged by the surface of the skin generally (Krause, Donders), or whether this is not the exclusive province of the sweat glands. Erismann adduces many reasons in favor of the latter view, and it may at least be admitted that the greater part of the "insensible" and all the "sensible" perspiration is eliminated by these glands.

422. That the Cutaneous excretion is to a certain extent vicarious with the [rinary in regard to the amount of fluid eliminated, has been generally arlmitted, and is probably true; but the observations of Weyrich have shown that under similar conditions, avoiding extremes, both excretions risc and fall together, and that, consequently, no deductions can be drawn as to the amount of perspiration given off from any estimates of the volume of urine discharged. IVe must not disregard the circumstance, however, that these two excretions are to a certain extent vicarious, in regard to the elimination of the products of the "waste" of the system. Leube" has in particular shown that in certain affections of the kidneys the skin exudes urea, phosphoric acid, and chlorine in excess, whilst the quantity of these compounds appearing in the urine is correspondingly diminished. "The share which the Skin has in this office has probably been generally underrated. As we have seen $(\$ 421)$, there is reason to believe that at least 100 grains of azotized matter are excreted from it daily; and any cause which checks this excretion must throw additional labor on the kidneys, and will be likely to produce disorder of their function.-From the experiments of Scharling and Hannover, it would appear that the proportion of Carbonic acid elininated by the Skin is to that discharged by the Lungs as $1: 38$. Aubert, however, gives a nuch smaller proportion, viz., as $1: 200$ (see p. 395). Reinhardt ${ }^{3}$ estimates the daily amount of Carbonic acid eliminated by the whole skin of an adult, by calculation from experiments made on one of his alms, at from 33 to 36 grains, and Röhrig found that the skin of one alm yielded half a grain of Carbonic Acid gas per hour. The secreting action of the

1 Erismann, Zur Physiologie der Wasserverdunstung von der Hatu, in the Zeitschrift f. Biulogrie, Bd. xi, 1875 , pp. 1-78.

2 Deutsche Archiv f. Klin. Mcd., Bd. vii, p. 1. 3 Zeits. für Biol., 1869, p. 28. 
Skin is influenced by general conditions of the vascular and nervous systems, which are as yet ill understood. It is quite certain, however, that through the influence of the latter the secretion may be excited or suspended; this is seen on the one hand in the state of syncope, and in the effects of depressing emotions, especially fear, and its more aggravated condition, terror; and on the other, in the dry condition of the skin during states of high nervous excitement. It is possible that, in some forms of fever, the suppression of the perspiration is a cause, as well as an effect, of disordered vascular action; for there are several morbid conditions of large parts of the surface, in which the suppression of the transpiration appears to be one of the chief sources of danger, having a tendency to produce congestion and inflanmation of the internal organs. The operation of some poisons, like tobacco and jaborandi, induces copious sweating. From the experiments of Dr. Fourcault, which have been coufirmed by Valentin, ${ }^{1}$ it appears that complete suppression of the perspiration in animals, by means of a varnish applied over the skin, gives rise to a state termed by him "cutaneous asphyxia;" which is marked by imperfect arterialization of the blood, and considerable fall of temperature; and which, as it produces death in the lower animals, would probably do the same in Man. A partial suppression by the same means gives rise to febrile symptoms, and to albuminuria. ${ }^{2}$ Other symptoms that have been ohserved are tremors, hypersesthesia, and subsequently ansesthesia of the - skin, increased reflex excitability, tetanic cramps, movements of rotation of the whole body, paralysis of the bladder (Feinberg), ulcers in the stomach in consequence of extensive extravasations, and diffise parenchymatous inflammation of the kidneys (Socoloff). ${ }^{3}$ In Valentin's experiments it was found that removal to a room of high temperature $\left(71^{\circ}\right.$ to $140^{\circ} \mathrm{F}$ :h $\mathrm{r}$.) was followed by remarkable temporary improvement in the condition of the animals, sensibility and voluntary motor power being reacquired, and in some instances food being taken. Death, however, always ultimately occurred. Laschkewitsch ${ }^{4}$ regards the effects produced as analogous to those seen in paralysis of the vaso-motor nerves, where a hyperamic condition of the ressels is present, and the animal loses heat rapidly, and more in proportion to the smallness of its size. He denies that the cause of death is asplyxia, but attributes it to cold, and refers in support of his view to the fact that death may be deferred or prevented by wrapping the animal in cotton-wool. Lang ${ }^{5}$. has pointed out that crystals of the triple phosphates, which he attributes to the decomposition of urea, may be found in all parts of the body after death by suppression of the perspiration. He considers the animals die from uranic poisoning. Feinberg, ${ }^{6}$ on the other hand, refers the symptoms to the irritation of the cutaneous nerves caused by the stiffening of the varnish, which leads to vascular disturbances and paralysis, and secondarily to an affection of the spinal cord. The poisonous nature of the cutaneous sccretion is well shown in an experiment made by Röhrig, ${ }^{7}$ who found that the injection at noon of $3 \frac{1}{2}$ cem. of fresh filtered human sweat into the external jugular vein of a rabbit caused the temperature to rise from $99.2^{\circ} \mathrm{F}$. to $104.3^{\circ}$ during the evening, whilst the pulse rose from 192 per minute to 326 , and the respirations from 82 to 105 . On the following morning, the temperature remaining the same, the cardiac beats were 315 , and the respiration 215

1 A rchiv für Physiolog. Heilk, Bd. ii, 1858, p. 433.

2 See his important treatise, Causus Générales des Maladies Chroniques, ete., 1844; and Brit. and For. Med. Rev., vol $\mathrm{xx}$, pp. 106-108.

3 Sucoloff, C'entralblatt, 1872, p. 688.

5 Archiv d. Heilliunde, 1872, Bd. xiii, p. 277.

6 C'entrulblatt f. d. Mred. Wiss, 1873 , p. 545.

7 Beiträge zur Physiologie der Haut, Jalırb. f. Balneologie, 1873, Bd. i, p. 1. 
in the minute; after this it gradually returned to the normal in the course of the dar. During the febrile state the urine containesl albuncn. There can be no doubt whatever, that imperfect action of the Cutancous glandulie, conseguent upon inactive habits of life and want of ablution, is a very frequent source of disorder of the gencral system; occasioning the accumulation of that decomposing organic matter in the blood, which it is the special office of these glandulæ to eliminate. Hence the due maintenance of health requires that this excretion should be promoted by the use of the natural and appropriate means just referred to ; and this is the more neccsary, when from any eause the function of the kidneys is imperfectly performed. There are many diseased state, moreover, in which there appears to be a special determination of the materies morbi to the Skin; and in which, therefore, the use of means that promote the cutaneous excretion constitutes the most efficient method of eimninating it from the blood. ${ }^{1}$

\section{CHA P T ER XII.}

EVOLUTION OF IIEAT, IIGHT, AND ELECTRICITY.

\section{General Considerations.}

423. TuE scries of Nutritive operations which has now been passed in review has been shown to consist in the continual appropriation, by the Animal organism, of certain "organic compounds" or "alimentary materials," which have been generated for its use by Plants; and in the constant restoration of their elcments to the Inorganic world, either in the very same forms of combination in which they originally cxisted there, or as products of incipient decay, by whose further decomposition those simple binary compounds will be reproduced. And thus, so far as the material components of the Organic Creation are concerued, the agency of Vegetable life is employed in withdrawing them from the Mineral world, and that of Animal life in returning them to it, after they have served their purpose in the living structure. But if we examine into the source of those active powers or "forces," on whose operation every change, no less in the organized body, than in what is commonly designated as "inert" matter, is dependent, we shall find that they are all traceable to the solar radiations. It is by the action of the Light and Heat of the Sun upon the Vegetable germ, that it is crabled to exercise its wonderful transforming capacity, whereby it extracts carbon, hydrogen, nitrogen, and oxygen, from the carbonic acid, water, and ammonia furnished by the atmosphere or the soil ; and that it converts these into the albuminous, saccharine, and oleaginous componnds, which are the destined food of Animals. And it is under the influence of Heat chiefly derived from the same source, that the greater number of tribes of

1 The praetieal value of active diaphores in many fobrile diseas's, is well understood by the native fractitioners among the Negroes of the Guinea (iont; who, alcording to Dr. Daniell (Medical 'Topography and Native Diseases of the Gulf of Cininea, pp. 119-20), make use of it most succesfully in the treatment of artynamie remittent fevers. Dr. Daniell states that having himself had abundant experience of its efficacy, he has no doubt of its superiority in these cases to the ordinary praticn of venesection, saline purgatives, large doses of calomel, etc. And he bat roputtedly stated that one great secret of preserving health in tropical climates, lies in due attention to the cutaneous functions. 
Animals are enabled to apply these compounds to the purposes of organization; and that, through the peculiar instruments thus constructed, those various kinds of Vital Force are evolved, whose operations a re so different from any which we witness in the Inorganic world. Accordingly we observe that the "rate of life" in this larger proportion of the Animal kingdom, is regulated, as in Plants, by the amount of Heat supplied to the organism from external sources; and that, when the external temperature is reduced below a certain point, there is an entire cessation of all vital activity. But there are certain tribes, especially Birds and Mammals, which possess the power of generating Heat within themsclves, to such a degree as to render the rate of their vital processes almost entirely independent of external influences; and there is probably no one species that can exercisc this power more effectually, and through a greater range of external conditious, than Man is able to do. Of this we shall presently have evidence. The evolution of Jight, again, is by no means an unusual phenonrenon among the lower tribes of Animals; but where it does occur, it usually appears to have some special purpose, as is obvious enough in the case of the glow-worm and other luminous Insects. But the luminosity which is occasionally exhibited in Man must be regarderl as an altogether abnormal phenomenon, whose physiological interest arises out of the peculiurity of the circumstances under which it presents itself.-Of the degree in which Electricity is generated in the living body, we know comparatively little. There can be no doubt that a disturbance of Electric polarity takes place in every action of Organic as weli as of Inorganic Chemistry; and thus that every molecular change in the Animal as well as in the Vegetable organism must involve an alteration in its electric condition. But it would seem that in the Animal body generally, these alterations are made to balance each other so exactly, that no considerable disturbance of the elcetric equilibrium ordinarily takes place in the organism as a whole; and it is only in certain peculiar cases (as in the Electric Fishes) that a provision exists for the gencration of Electricity in considerable amount and intensity, with a view to some special purpose. In the Human subject, however, an extraordinary production of free electricity, as of Light, occasionally presents itself; and this, taken in connection with other evidence, would seem rather to indicate a departure from the bulance usually maintained between the opposite electrical changes continually taking place, than to be due to the introduction of any extraordinary sources of electric disturbance.

\section{Evolution of Heat.}

424. All the vital actions of the body of Man, as of that of "warmblooded" animals generally, require an elevated temperature as a condition of their performance; and the high degree of constancy and regularity which is observable in these actions, appears to depend in great degrce upon the provision which the organism contains within itself, for the maintenance of that temperature at a fixed standard. This constancy and regularity are most renarkably exhibited in the various periodical changes to which the body is subject both in health and in discase; the uniformity of whose recurrence is due to a corresponding uniformity in the rate of vital action taking place in the interval. Thus, as will be shown hereafter, the perior of parturition is in great degree determined by the maturation of the fretal structures; and the miformity of the time which this requires (like the corresponding uniformity in the period of development in the embryo birl) may be fairly attributed to the regularity of the supply of Heat, which is the power that especially determines the formative operations. For the periods 
of all sinilar phenomena in "cold-blooded" aninals, which have comparatively but feeble power of maintaining an independent temperature, exhibit no such uniformity; ret even in the lowest Vertebrata, according to $\mathrm{Mr}$. Gulliver, ${ }^{1}$ the temperature of the body is from $2^{\circ}$ to $5^{\circ}$ warmer than that of the melium in which they live. Heat, which is a mode of motion, is generated whenever stronger chemical affinities than those which were previousby in action are satistied; hence the temperature rises in muscles that are made to contract, and in glands when they are in the active performance of their function. The liver, spleen, kidneys, and glands of the intestinal tube, ${ }^{2}$ with the brain, ${ }^{3}$ the muscles during exercise, and the blood ${ }^{4}$ itself are the chief generators of heat in the body, because in all these parts active processes of oxidation are taking place by which the constituents of these organs and tissues are reduced to lower and more stable planes of composition and a certain amount of force is set free in the form of heat. We shall now inquire, in the first place, into the amount of heat thus generated by Man ; and then into the sources of its production.

425. Our present knowledge of the ordinary 'Temperature of the Human Body under different circumstances, is due to the investigations of a multitude of observers, references to many of which will be found in Wunderlich's exhaustive treatise. A series of observations made by Dr. J. Davy ${ }^{5}$ included 114 individuals of both sexes, of different ages, and anong various races and different latitudes, and under various temperatures; the external temperature, however, was in no instance very low, and the variations were by no means extreme. The mean of the ages of all the individuals was 27 years. The following is a general statement of the results, the temperature of the body having been ascertained by a thermometer placed under the tongue :

Temperature of the air, . $60^{\circ}$

16
66
66
16
16

Mean of all the experiments,.

Highest temperature of air,

Lowest temperature of air, $60^{\circ}$

$78^{\circ}$

$795^{\circ}$

$80^{\circ}$

$822^{\circ}$

$74^{\circ}$

$82^{\circ}$

$60^{\circ}$
Average temperature of the body, .

" "

64

"6

"

Mean of all the experiments,

Highest temperature of body,

Lowest temperature of body; $98.28^{\circ}$

$9815^{\circ}$

$988.5^{\circ}$

$99.21^{\circ}$

$\$ 9.67^{\circ}$

$\$ 99^{\circ}$

$100^{\circ}$

$102^{\circ}$

$96.5^{\circ}$

From this we see that the variations noted by Dr. Davy, which were evidently in part the consequence of variations in external temperature, but which were also partly attributable to individual peculiarities, amounted to $5 \frac{1}{2}$ degrees; the lower extreme might be found to undergo still further depression, if the inquiries were carried on in very cold climates. Wunderlich ${ }^{6}$ gives as the result of the numerous observations made by himself and others of late years, a lower mean temperature than Dr. Davy, and states that the

I Lecture IX, Icd. Times and Gaz, Jan. 17th, 1863.

2 See Winternitz, in Stricker's Mfed. Jahrbücher, 1871, p. 180.

3 Heidenhain, Pfluger's Archiv, Bd. iii, p. 504. Funke, Physiologie, 1853, p. 306.

4 See Gamgee, On Heat Generated in the Blood during Arterialization, Brit. Assoe. Repurts, 1871 .

5 Sce Anatomical and Physiologieal Rescarches. Wunicrlich's treatise has bcen translated by Dr. Woodman for the New Sid. Society. See also Brown-Séquard (Journal de la Physiolorie, 1859, p 549), whose experiments essentially corroborate those of Dr Dary, as well as the older ones of MII. Eydoux and Souleyet (Comptes Rendus, 1838, p. 457 ), exespt that he found a greater difference in the temperature of the men be examined, though the variation of the atmospherie temperature was mueh less.

6 Loe. eit., p 82. 
range of normal temperature in the axilla is from $97.25^{\circ}$ Fahr. to $99.5^{\circ} \mathrm{F}$., and that the mean normal temperature is $98.6^{\circ} \mathrm{F}$. The mean temperature appears from Dr. Crombie's observations ${ }^{1}$ to be a little higher in the natives of India. It is also higher in Icelanders, ${ }^{2}$ whilet it is as mueh as $2.5^{\circ} \mathrm{F}$. lower in Africans. ${ }^{3}$ Sex and Pregnancy in women make no differenee in the mean temperature, though a slight augmentation of $0.3^{\circ} \mathrm{F}$. is observed during labor pains. Amongst the most important of these variations that occur in the temperature of the body are those rependent upon Age, Period of the day, Exereise or Repose, Ingestion of Food or Drink, and External Temperature.

I. The temperature of Infants just born, according to the observations of Andrab, Dr. Davy, MI. Roger ${ }^{4}$ and Dr. G. C. Holland, ${ }^{5}$ is somewhat higher than that of adults, ${ }^{6}$ provided that they are placed in conditions favorable to its sustenanee; but, as will be shown hereafter, infants and young ehildren are very inferior to adults in their power of resisting the depressing influenee of external cold. Their temperature before birth is a trifle higher than that of the mother's uterus or vagina. ${ }^{7}$ When examined immediately after birth by a thermometer in the axilla, it is nearly $100^{\circ}$; but it quiekly $\left(2\right.$ hours $\left.^{8}\right)$ fatls to about $95.5^{\circ}$, and gradually rises in the course of the next twenty-four hours to about $97.7^{\circ}$ in weakly subjects, and to $99.5^{\circ}$ in strong infants. Between four months and six years of age, M. Roger found the average temperature to be $98.9^{\circ}$; and, between six and fourtcen years of age, $99.16^{\circ}$. Dr. Finlayson ${ }^{9}$ stated that from 300 observations made on ehildren he had satisfied himself that in them there was a minimum from about 10 P.M. to 3 A.M., a gradual rise during the early morning hours, a maximum during the day, and a tolerably rapid fall during the early part of the evening. The average range of temperature amonnted to more than $3^{\circ} \mathrm{Fahr}$, and this variation he believes eannot be explained by reference to the dinmal range in the temperature of the air, to the influence of daylight, of museular exertion, of food, or of sleep, but is simply an expression of a law of daily periodicity affeeting the borly. ${ }^{10}$ - The Temperature of aged persons, from the observations of Dr. J. Davy, does not seem to be below that of persons in the vigor of life, provided that there be no external depressing influenees; but they seem, like infants and young children, to have less power of resisting external cold, the temperature of their bodies being more easily and considerably reduced by it than is that of adults; and hence probably it has happened, that popular opinion assigns to them an habitually inferior temperature.

II. A slight diurnal variation in the temperature of the body appears usually to take place, quite irrespeetively of external heat or cold; but this does not seem to be very eonstant either in its period or its degree, and is

1 Indian Annals of Med. Science, No. xxxii.

2 Thomsen, Ueber Krankheiten aut Iskand, ete, p. 24.

3 Livingstone, Travels in South Africa, p. 509.

4 A rehiv. Gén. de Méd, $1844 . \quad 5$ Inquiry into the Laws of Life, 1829.

6 Dr. W. F. Edwards (On the Influence of Physical Agents on Life, p. 115) gives as the result of his observations, which were only ten in number, that the temperature of infants is lower than that stated above; but it is obvious that these observations were made during the period of depression which occurs in the first few days, whilst the respiratory function is becoming established

7 Bäirensprung, Müller's Archiv, 1851. Sce also Andral, Comptes Rendus, t. lxx, 1870, p. 825 .

8 Dr. J. Maclagan, Transact. Roy. Soc, of Eilinb, 1870; abstract in Lancet, Aug. 13 th, 1870, p. 243 .

9 In a paper read before the Phil. Soe. of Glasgow. Dec. 3d, 1873.

10 Sitz (Jahrb. f. Kind.-heilk., Bd. iv, 1871, p. 414) is in accord with Finlayson. 
seldom very considerable. The concurrent olservations of Dr. Davy, Dr. IV. Osle, ${ }^{1}$ Dr. Jürgensen, ${ }^{2}$ and Dr. Casey, ${ }^{3}$ show that the body is warmest in the morning and coldest at night. Dr. Ogle found that the temperature rose from morning till late in the afternoon, after which it fell till bedtime. The lowest temperature occurred about daybreak. The average diumal variation was about $1.5^{\circ}$ Fahr. The minimum temperature noticed was $97^{\circ}$ at 5.30 A.M., in winter. The maximum was $100.6^{\circ}$, whilst in a Turkish bath of $120^{\circ}$. The extreme oseillation of temperature, therefore, was not morc than $3.5^{\circ} \mathrm{F}$. in health. Dr. Jürgensen found the diurnal variation to anount to from $1.8^{\circ}$ to $3.6^{\circ} \mathrm{F}$; the minimum occurred from $1.30 \mathrm{~A}$. s. to 7.30 . The temperature then, with some fluetuation, rose till 4 r.M., when it attained its maximum, which lasted till 9 P.M. ; and after this it again fell. Dr. Casey found his mean temperature during the day to be $98.07^{\circ} \mathrm{F}$., the mean range of temperature $1.61^{\circ} \mathrm{F}$. The maxinum rauge $2.5^{\circ}$. The maximum temperature was at 7.30 P.x. Sydney Ringer and P. Stewart ${ }^{4}$ give the average maximum temperature for persons under twenty-five years of age at $99.1^{\circ}$ Fahr., of those over forty $98.8^{\circ} \mathrm{F}$. They find the period of highest temperature extends from 9 A.M. till 6 P.M., the lowest is about inidnight. These observations eorrespond well with what has already been pointed out with regard to the relative activity of the respiration ( $\$ 311$, viii and $\mathrm{ix}$ ) and eirculation at different periods of the twenty-four hours. As a rule the temperature of the two sides of the body is alike, but Blake ${ }^{5}$ has observed that the right side is sometimes as mueh as $1^{\circ} \mathrm{F}$. higher than the left duriug exertion, espeeially in the sun.

III. That an inercase in the heat of the body is produced by exercise, and that repose tends to its reduetion, is a matter of familiar experience; but the observations of Dr. Davy show that there is scarcely any pereeptible difference in the heat of the deepscated parts, the augmentation and depression being confiued to the extremities. Thus, on one oceasion recorded by him, the temperature of the air of the room before walking being $60^{\circ}$, that of the feet (shown by a thermometer placed between the toes) being only $66^{\circ}$, that of the thermometer under the tongue being $98^{\circ}$, and that of the urine being $100^{\circ}$, - the temperature after a walk in the open air at $40^{\circ}$, the exereise having diffused a feeling of gentle warmth through the boty, was $96.5^{\circ}$ in the feet, $97^{\circ}$ in the hands, $98^{\circ}$ under the tonguc, and $101^{\circ}$ in the urine. So, on another oeeasion, the temperature having been $66^{\circ}$ in the room, $75^{\circ}$ in the feet, $81^{\circ}$ in the hands, $98^{\circ}$ under the tongue, and $100^{\circ}$ in the urine,-after a walk in air at $50^{\circ}$ the temperature was $99^{\circ}$ in the feet, $98^{\circ}$ in the hauds, $98^{\circ}$ under the tonguc, and $101.5^{\circ}$ in the urine. These effeets are, therefore, in all probability, ehiefly due to an inerease in the energy and frequency of the heart's contractions, by which means the warm blood is driven with greater velocity through the extreme eapillaries, imparting its heat to the surrounding parts. Mareet ${ }^{6}$ found in the ascent of Iont Blane that when at rest the temperature of the body did not vary

: St. George's Hospital Reports, vol. i, p. 221. Dr. Ogle's experiments were made on two healthy adults; the temperature being taken by introducing a warmed selfregistering themometer three or four times a day under the tongue, and retaining it in that position for several minutes. They extended over a year.

2 Deutsches Archiv f. Klin. Med., Bd. iii, p. 166. Dr. Jürgensen's experiments extended over three days, and consisted in reading off at intervals of five minutes the indications of a thermometer permanently retained in the rectum at a depth of about two inches.

3 Lancet, vol. i, 1873, p. 200.4 Proceed. of the Roy. Soc., vol. xvii, p. 287.

5 E. Blake, Med. Times and Gazette, Oct. 1871.

6 Archiv. des Sci. Physiques, t. xxxvi, p. "247. 
very much at different heights. In the ascent, as Lortet ${ }^{1}$ observed, the internal temperature of the borly fell during exercise, especially when the stomach was empty, and the skin was freely perspiring - to a degree, indeed, that was almost proportional to the height ascender. When the feeling of malaise, so often complained of by Alpine travellers, or mal de montagne, was most evident, the temperature was lowest, and the sensation was best removed and the temperature raised by frequent ingestion of food. The observations of Clifford Allbutt ${ }^{2}$ do not support the statements of Lortet, for he found that with one or two exceptions the tendency of exercise in Alpine climbing was to elevate the temperature. The forenoon rise occurred earlier, and the evening fall had often reached the night-level at 9 P.n. The difference was probably owing to the different pliysique of the two observers. Passive novement (swinging or rocking for fifteen minutes) was found by Manassein" to lower the tenperature of rabbits about $1^{\circ}$ Fahr., even when they were carefully protected from draught. The depression reached its maximum half an hour after the swinging had ceased, and lasted for two hours. The experiments of various observers, moreover, have shown that a certain amount of heat is developed during the active contraction of muscular tissue, the rise in temperature of a muscle like the Biceps, after a few powerful contractions, being as much as $1^{\circ}$ Fahr.; and this increase in temperature may be regarded as due to the increased energy of the chemical changes, and in some measure also to the mechanical effects of friction, ete., taking place in the contracting muscle. It is remarkable that voluntary increase of the frequency and extent of the respiratory movements for the space of ten minutes, or suspension of the respiration at the end of a full inspiration, alike produce a decline in the temperature of the blood, as shown by that of the skin over the radial artery; in the former case amounting in Mi. Lombard's ${ }^{4}$ experiments to as much as $2^{\circ}$ Fahr. Perhaps in this case, as Drs. Wilson Philip, Hastings, and C. J. B. Williams have pointed out takes place in the performance of artificial respiration, the cooling effect of the air introduced is greater than the warming effect of the respiratory processes to which it becomes subservient. Coincidentally with such iucrease of the respiratory movements, however, there is diminution of the force and tension of the pulse, as shown by the sphygmograph, which may to some extent explain the fall. It thus appears that the temperature of the body is not raised by exercise to the extent that might be expected, its increase beyond a certain point heing provided for by more rapid breathing, the quicker circulation of the blood through the skin, and consequently quicker cooling by radiation, sweating, ete., so that, as IV underlich observes, the opposing conditions of the loss of force by mechanical work and by quicker cooling, and on the other hand the overplus through augmented chemical action, compensate each other in health, amd the final difference of temperature during rest and during lubor is extremely trifling.

IV. The influence of ingestion of food upon the temperature of the borly was found, in Dr. Ogle's and in Dr. Jürgensen's experinents, to cause a slight elevation of the temperature both of the mouth and of the rectum, unless wine were consumed, when a decline occurred. Dr. Jürgensen observed no change beyond a slight depression of the mean diurnal temperature after fasting for 26 hours; but when the abstinence was prolonged to a period of 152 hours, the mean diurnal temperature rose and the usual period of de-

1 Centralblatt, 1869, p. 781 .

2 Journal of Anatomy and Physiology, 1873, vol, vii, p. 117.

3 Pftüger's Arehiv, Bid. iv, 18\%1, p. 283.

4 Brown-Séquard, Arehives de Physiologie, t, i, 1868, p. 479. 
pression did not occur. Drs. Ringer and Rickards' have shown that, excepting in those who are much accustoned to its use, the ingrestion of alcohol in considerable doses causes a remarkable dininution of temperature, amounting in some cases to about $3^{\circ}$ Fahr. In rabbits, the injection of aleohol into the rectum caused a depression of the animal heat amounting to $15^{\circ}$. They found that alcohol in various doses produces only slight and temporary depression of the temperature of febrile persons; and consequently that although when indicated, it will act to some extent bencficially in virtue of its power to cause some diminution of the temperature, yet it cannot bring the temperature of febrile persons to that of health. The experiments of Dr. IV. Ogle, ${ }^{2}$ and of 'T'scheschichin, ${ }^{3}$ are confirmatory of the preceding results. Dr. Ogle found that tea caused an elevation of temperaturc. Common experience leals to the conclusion, that after a meal, as after exercise, there is greater warmth in the extrennities; but Dr. Davy's observations show that, in his own person, whilst resident in England, there was usually an appreciable depression inmediately after dinner, though in Barbadoes the effect of a moderate meal was to produce an elevation. In both cases, however, Dr. Davy obscrved that the ingestion of wine had a positively depressing influence on the temperature of the body, which increased with the quantity taken; and it may have been the constant employment of wine with his dinner, which was the real cause of the depression observed in England.

v. The influence of external temperature is sufficiently apparent in the observations already cited; for although external cold may act in a different degree on different individuals, according to their respective ages, powers of resistance, ete., sometimes, when its action is bricf, causing a slight increase of temperature, yet there is ample proof that on the whole a continued exposure to it reduces the temperature of the body somewhat below its ordinary standarl, whilst continued exposure to heat occasions a slight elevation in the temperature of the borly. The influence of cold is, of course, most powerfully exerterl when the body is at rest; and under such circumstances Dr. Davy found the temperature of his own body to be reduced, on an average of four observations, to $96.7^{\circ}$, the average temperature of the surromnding air having been $37^{\circ}$. On comparing the bodily temperature of different individuals working in rooms of various temperatures in the same factory, Dr. Davy found the tongue thermometer rise to $100^{\circ}$ in one man, and to $100.5^{\circ}$ in another who had been working for some hours in a room at $92^{\circ}$; whilst it was $99^{\circ}$ in a young woman who worked in a room at $73^{\circ}$, and only $97.5^{\circ}$ in another who worked in a temperature of $60^{\circ}$. Dr. Schuster found the effects of baths of different kinds, as hot water and douche baths, was to eause an elevation of temperature, and to increase the rapidity of the pulse. Horvath, in experiments on rabbits, found that when they are cooled down by snow to $73^{\circ} \mathrm{F}$. the heart beats rarely, excitation of the vagus is inoperative, the intestines are motionless and non-excitable, asplyyxiation causes neither augmentation of the blood-pressure nor cramps, but all these phenomena are reversed when the temperature is raised to $100^{\circ}$ Fahr. ${ }^{5}$ The lowest temperature to which Horvath ${ }^{6}$ succeeded in cooling puppies with subsequent lestoration was $40^{\circ}$ Fahr. as measured by a thermometer in the rectum.-The effects of seasonal change are less marked in Man, than they are in the lower animals, which are more exposed to extremes of temperature; but it seems principally exerted in modifying the heat-producing power. For it has been shown by Dr. W. F. Edwards, that warm-blooded animals

1 Proceed. of the Roy. Med.-Chir. Soc., vol. v, 1866, p. 209.

2 Op. cit., p. 238.

3 Reichert's Archiv, 1866, p. 151.

4 Virchow's Archiv, Bd. xliii, p. 60, 1868.

5 Horvath, Wien. Akadem., 1870, No. 11. '6 Centralblatt, 1871, p. 513. 
are more speedily killed by extreme cold in summer than in winter; and it seems probable, therefore, that we are partly to attribute the peculiar chilling influence of a cold day in summer, and the oppressiveness of a warm day in winter, to the seasonal change in the body itself; although the effect is doubtless referrible in part to the effect of contrast upon our own feelings.?

426. The usual Temperature of the body occasionally undergoes considerable alteration in disease; and this in the way cither of increase or of diminution. Thus in maladies which involve an acceleration of pulse and a quickening of the respiration, the teniperature is generally higher than usual, even though a large portion of the lung may be unfit for its function. This is often renuarkably seen in the last stages of phthisis, when the inspirations are extremely rapid, and the pulse so quick as scarcely to admit of being counter; the skin, in such cases, often becomes almost painfully hot. On the other hand, in diseases of the contrary character, such as " morbus coeruleus," asthma, and cholera, the temperature of the body falls; a reduction to $78^{\circ}$ having been noticed in the former maladies, and to $67^{\circ}$ in the latter. The range observed by M. Andral in diseases which less affected the calorifying function, was from $95^{\circ}$ to $107.6^{\circ}$; and by M. Roger (loc. cit), in diseases of children, from $74.3^{\circ}$ to $108.5^{\circ}$. Prof. Dunglison ${ }^{2}$ speaks of having seen the thermometer at $106^{\circ}$ in scarlatina and typhus; and Dr. Frances Hone $\mathrm{e}^{3}$ found it to stand at $104^{\circ}$ in two individuals in the cold stage of an intermittent, whilst it afterwards fell to $101^{\circ}$, and subsequently to $99^{\circ}$, during the sweating stage. Dr. Elwards mentions a case of tetanus, in which the temperature of the body rose to $110_{4}^{3 \circ}$. The following observations have been made on this subject by M. Donné; in a casc of puerperal fever, the pulse being 168 , and the respirations 48 per minute, the temperature was $104^{\circ}$; in a casc of hypertrophy of the heart, the pulse being 150 , and the respirations 34 , the temperature was $103^{\circ}$; in a case of typhoid fever, the pulse bcing 136 , and the respirations 50 , the temperature was $104^{\circ}$; and in a case of phthisis, the pulse being 140 , and the respirations 62 , the temperature was $102^{\circ}$; on the other hand, in a case of janndice, in which the pulse was but 52 , the temperature was only $96.40^{\circ}$; but the same temperature was obscrved in a case of diabetes, in which the pulse was 84 . These limited observations, whilst they clearly indicate that a general relation exists between the temperature of the body and the rapidity of the pulse, also show that this relation is by 110 means invariable, but that it is liable to be affected by several causes, of which our knowledge is as yet very slight. Pcrsistent high temperature of the borly $\left(105^{\circ}-110^{\circ}\right)$ in febrile affections usually indicates a fatal issue. The highest temperature yct ohserved has been reported by Dr. J. Teale, of Scarborough, who in a case of injury to the spine from a fall registered the remarkable temperature of $122^{\circ}$ Fahr., the pulse being

1 Iany of the lower animals, as the Marmot and Dormouse, hibernate during the winter, and their state has been very earefully examined by Valentiu and by Horvath (Centralblatt, $1872, \mathrm{pp} .706,721$, and 737 ). Horvith's experiments were eondueted on Marnots (Spermophilus eitillus), which exist in large numbers in Russia. In captivity he finds that during the winter they sleep for about four days and then wake for four days. During the sleeping period they ean be eoled down to such a degree that a thermometer introdued into the rectum to the depth of an ineh and a half indicuted only $3^{\circ} \mathrm{F}$. above the freezing-point. The temperature rose rapidly after the aninal awoke, so that in the eourse of an lour it was $3^{\circ} \mathrm{F}$. higher, at the close of the seeond hour $9^{\circ} \mathrm{F}$. lighter, and at the end of the next half hour about $27^{\circ}$ F. The eatuse of this remarkable elevation of temperature is aeeording to Horvath searecty explicable on the ordinary ehemical theory of ealorifiention, since neither the repiration nor the musculur movements were correspondingly augmented.

2 Human Physiology, 7th edit., vol ii, p. 22.5.

3 Medienl Facts and Experiments, London, 1759.

4 Archiv. Gén. de Méd., October, 183.5. 
120. ${ }^{1}$ In this instance the patient recovered. ${ }^{2}$ Jacobson, ${ }^{3}$ from experiments marle with thermo-electric instruments, has satisfied himself that the temperature of intensely inflamed skin and muscles never runs as high as the temperature of the inner parts of the body, which is quite in accordance with the dictum of John Hunter, that local inflammation cannot raise the temperature higher than the degrec of warmth found at the centre of the circulation. It is still doubtful whether the augmented temperature observed in febrilc disenses is due to diminished elimination or to increased production of heat, but considering the large excess of heat that is developed during the.crisis of fevers there scems to be reason for believing that Leyden's view in favor of excessive production of heat is correct. ${ }^{4}$ - It is not a little remarkable that the temperature of the body should frequently rise considerably after death; and this not merely in such cases as Cholera, in which it has undergone an extreme depression during the latter part of life; but even in the case of febrile disorders, in which the temperature during life has been above the usual standard. This has been ascertaincl by Dr. Bennet Dowler, ${ }^{5}$ of New Orleans, on the bodies of those yellow fever subjects which have already been referred to as exhibiting a remarkable degree of molecular life after somatic death $(\$ 263)$. In one casc, for example, the highest temperature rluring life was in the axilla, $104^{\circ}$; ten minutes after death, it had risen to $109^{\circ}$ in the axilla; fifteen minutes afterwards, it was $1133^{\circ}$ in an incision in the thigh ; in twenty minutes, the liver gave $112^{\circ}$; in one hour and forty minutes, the heart gave $109^{\circ}$, and the thigh in the former incision $109^{\circ}$; and in three hours after the removal of all the viscera, a new incision in the thigh gave $110^{\circ}$. It is curious that the maximum heat obscrved after death should have been in the thigh, and the minimum in the brain. The postmortem rise in temperature appears to be essentially due to the passage of the muscles of the body into the state of rigor mortis, a change that is associated with chemical action analogous to that occurring during contraction, and accompanied by a corresponding elevation of temperature. ${ }^{6}$ Ackermann has pointer out that the post-mortem rise may in part be dne to the persisteuce of the heat-producing chemical changes in the deeper parts of the borly, whilst the radiation and loss of heat from the surface by evaporation is reduced by the contraction of the cutaneous vessels, and $1 W_{\text {uuderlich suggests }}$ that it may be also in some measure owing to the paralysis of that part of the nervous system which inhibits or regulates the generation of heat, supposing such centre to cxist.

427. Although there appears to be, for all kinds of animals, a distinct limit to the variations of bodily temperature, under which their vital operations can be carried on, this limitation does not prevent certain species from existiug in the midst of great diversities of external conditions; since they

1 Lancet, March 6th, 1875.

2 According to Lewitzky the febrile condition that follows the injection of putrid fluids into the blood is not due to the Bacteria that are prescnt in such fluid Centralblatt, 1873, p. 723 ; see also Naunyn, abstract in idem, p. 731.

3 Virchow's A rehiv, Bd. li, Heft 2.

4 See Milner Fothergill's paper read before the Mcdical Socicty of Lnndon, Pamphlet, 1873.

5 Westrm Journal of Medicine and Surgery, June and Oet. 1844 ; cited in Philadelphia Medical Examiner, June, 1845, and in Prof. Dunglison's Human Physiology, 7th edit., vol. ii, p. 718 .

${ }^{6}$ See the papers of Walther, Centralblatt für die Med. Wiss., 1867, p. 391; Wunderlich, A rehiv d. Heilkunde, Bd. v, p 205 ; Huppert, idem, Bd. viii, p. 321; Fick and Dybkowsky, Vierteljabrschrift d. Zurich Naturf. Gesellsch., 1867 ; Ackermann, Deutsche Archiv f. Klin. Med., Bd. ii, p. 359 ; Valentin, d. Post-mort. temp.-steigerung Dissert. Leipzig, 1869. 
have within themselves the power of eompensating for these, in a very extraordinary degree. The power seems to exist in Man to a higher amount than in most other animals; since he cannot only support, but enjoy life, under extremes of which either would be fatal to many. In many parts of the tropical zone, the thermonteter rises every day, through a large portion of the year, to $110^{\circ}$; and in British India it is said to be seen occasionally at $130^{\circ}$. On the other hand, the degree of cold frequently sustained by A retic voyagers, and quite endurable under proper precautions, appears much more astoni-hing; by Captain Parry the thermometer has been seen as low as $-55^{\circ}$, or $87^{\circ}$ below the freezing-point; by Captain Franklin at $-58^{\circ}$, or $90^{\circ}$ below the freezing-point; and by Captain Back at $-70^{\circ}$, or $102^{\circ}$ below the freezing-point. In both cases, the effect of the atmospheric tenperature on the body is greatly influeneed by the condition of the air as to motion or rest: thus, every one has heard of the almost unbearable oppressiveness of the "siroceo," or hot wind of Sicily and Italy, the actual temperature of which is not higher than has often been experieneed without any great discomfort when the air is calm; and on the other side, it may be mentioned that, in the experience of many Aretic voyagers, a temperature of $-50^{\circ}$ may be sustained, when the air is perfectly still, with less ineonvenience than is eaused by air in motion at a temperature fifty degrees higher. ${ }^{1}$ 'This is quite conformable to what might be anticipated on physieal prineiples.

428. Again, the degree of moisture contained in a heated atmosphere, makes a great difference in the degree of elevation of temperature whieh may be sustained without inconvenience. Many instances are on record, of a heat of from $250^{\circ}$ to $280^{\circ}$ being endured in dry air for a considerable length of time, even by persons unaccustomed to a particularly high temperature; and persons whose occupations are sueh as to require it, can sustain a much higher degree of heat, though not perhaps for any long period. The workmen of the late Sir F. Chantrey were aceustomed to enter a furnace in which his moulds were drier, whilst the floor was red-hot, and a thermometer in the air stood at $350^{\circ}$; and Chabert the "Fire King" was in the habit of entering an oven the temperature of whieh was from $400^{\circ}$ to $600^{\circ} .^{2}$ It is possible that these feats might be easily matched by many workmen who are habitually exposed to high temperatures; such as those employed in Iron-foundries, Glass-houses, and Gas-works. In all these instances, the dryness of the air facilitates the rapid vaporization of the fluicl whose seeretion by the Cutaneous glandula is promoted by heat applied to the surface;

1 The Author las been informed by Sir John Riehardson, that in his last Aretic Expedition, whilst at winter quarters, he was aecustomed to go from his sitting-room to the magnetie observatory at a short distanee (about an ordinary street's breadth), withsut feeling it neeessary even to put on a great eout; although the temperature of the former was about $50^{\circ}$, and that of the air throum which he had to pass to the latter was $-50^{\circ}$, the difference being $100^{\circ}$. This immunity from ehilling influence was ehiefly attributable to the dimness and stillness of the atmosphere; but it is worthy of note that Sir J. lichardion and the whole of his party on this expedition abstained entirely from aleoholie liquors; and the Author las reeeived his personal assurance, that his experience on this vecasion fully bore out his previous eonviction, that continued severe cold is much better borne without recourse to these stimulants, than unfler the employment of them.

2 'The wonderful feats performed by many individuals from time to time-of dipping the hamd into melted lead, laying hold of a red-hot iron, ete. -late been recently shown by $\mathbf{I I}$. de Butiony to be explicable upon very simple principles. For in all such eases at thin film of aqueous fluid in the "spheroidal state" intervenes between the skin and the lesated surfaee; and a hand which is naturally damp, or which has been slightly moistened, may be safely passed into the stream of molten iron als it fluws from the furnace; as was demonstrated by M. de Boutigny at the mecting of the British $\Lambda$ ssoeiation at Ipswich in 1851 . 
and the large amount of caloric whieh is eonsumed in this change, is for the most part withdrawn from the body, the temperature of which is thus kept down. By some experimenters, as by Ackermann, ${ }^{1}$ an attempt has been made to show, that the lungs as well as the skin, constitute a regulating mechanism for preserving an equality of the temperature in warm-blooded animals; since if an animal be exposed to a gradually increasing temperature its temperature rises, but its respirations also increase in number, quite apart from the deficiency of oxygen or incrense of carbonie acid in the blood, and ultimately a form of dyspnee is produced, due sinply to heat. ${ }^{2}$ The inereased number of respirations on exposure to warm air docs not, aeeording to Riegel, ${ }^{3}$ occur in rabbits and dogs in which the spinal cord has been divided high up, and the temperature of the animal continues to rise. In Riegel's experiments on animals under the influence of woorara, and in which artificial respiration was maintained, all conditions of the experiment remaining the same, the temperature invariably fell in proportion as respiration was quickened. It is difficult to say whether the power of generating heat which the body possesses is eapable of being self-regulated or governed in eonformity with the external conditions that may at any time be present; that is to say, whether when the body is exposed to eold more heat is produced, and when to heat, less. Liebermeister ${ }^{4}$ found that in a eold bath, or on exposure of the surface to eool air $\left(54^{\circ}-70^{\circ} \mathrm{F}\right.$.), the temperature of the interior of the body in the first instance rose slightly or remained stationary, though it fell after long immersion or exposure. It fell also after removal from the cooling influence. This he explained by considering that the body possesses the power of generating more heat when required, though this power is limited; whilst the seeondary fall, when there is no longer any withdrawal of heat, is due to the eooling of the blood circulating in the capillaries of the cool skin. Kering ${ }^{5}$ endeavored to furnish a further proof by showing that with increase of extermal heat, or by preventing the body from losing its temperature, a diminished production of heat takes plaee. Jurgensen ${ }^{6}$ and Senator ${ }^{7}$ oppose these statements, and maintain that when the body is exposed to eold, there is no increased production of heat, but the superficial vessels contraet, and a badly conducting superfieial layer of tissue exists, so that the blood in the deeper organs is prevented from giving off its heat, and thus with unaltered production of heat may rise in temperature. As soon as the exposure to cold ceases, the cutaneous vessels dilate, and the blood circulating through the cooled part leads to a fall of temperature. Funke ${ }^{8}$ considers that the rapid rise that occurs in the temperature of the body in animals that have been thoroughly cooled, when placed under favorable circumstances, is in favor of Liebermeister and Kering's views. Exposure to intense eold eauses a fall of the temperature of the whole body from the first, and vice versî during exposure to a hot bath. The temperature may rise above that of the bath. ${ }^{3}$

1 Archiv f. Klin. Med, Bd. ii, p. 361. See Woodman's A bst. of Riegel's paper in Lond. Med. Record, 1874, p. 744 .

${ }^{2}$ See also Fick and Goldstein, Ueber Warmdyspncea, Inaug. Abhand, Würzburg, Verhand., 1871.

3 Virchow's Archiv, Bd. lxi, Heft 3.

4 Archiv für Anatomie u. Physiol, 1860, pl. 520 and $589 ; 1861$, p. $28 ; 1862$, p.

661 ; Arehiv f. Klin. Medicin, Bd. v, p. 217.

5 Experiment. Beiträg. zur Kenntniss d. Wärmeregulirung Diss., Dorpat, 1864.

6 Deutsch. Archiv f. Klin. Med., Bd, iv, n. 323.

7 Virchow's Archiv, Bd. xlv, p. 351; Bd. 1, p. 354 \& Physiologie, 1873, p. 308.

9 Schuster, Deutsche Klinik, 1864, pl), 216, 229, 248; Röhrig and Zuntz, Pflüger's Archiv, Bd. iv, p. 57; Murri, Del potere regulatore della temperatura animale; Pamplilet, Firenze, 1873 ; Rosenthal, Centralblatt, 1872, p. 840. 
429. Exposure to a very elevated temperature, however, if continued for a sufficient length of time, does produce a certain elevation of that of the body; as might be expected from the statement a already made, in regard to the variation in the heat of the body with changes in atmospheric temperature $(\$ 425)$. In the expcriments of MM. Berger and Delaroche, ${ }^{1}$ it was found that, after the body had been exposed to air of $120^{\circ}$ during $17 \mathrm{~min}$ utes, a thermometer placed in the mouth rose nearly $7^{\circ}$ above the ordinary temperature; it may be remarked, however, that as the body was immersed in a close box, from which the head projected (in order to a voil the direct influence of the heated air on the temperature of the mouth), the air had probably become clarged with the vapor exhaled from the surface, and had therefore somewhat of the effects of a moist atmosphere. At any rate, the temperature of the body does not appear to rise, under any circumstances, to a degree very much greater than this. In one of the experiments of Drs. Fordyce and Blagden, ${ }^{2}$ the temperature of a Dog, that had been shut up for half an hour in a chamber of which the temperature was between $220^{\circ}$ and $236^{\circ}$, was found to have risen from $101^{\circ}$ to about $108^{\circ}$. MM. Delaroche and Berger tried several experiments on different species of animals, in order to ascertain the highest temperature to which the body could be raised without the destruction of life, by inclosing them in air heated from $122^{\circ}$ to $201^{\circ}$, until they died: the result was very uniform, the temperature of the body at the end of the experiment only varying in the different species between $11^{\circ}$ and $13^{\circ}$ above their natural standard: whence it may be inferred, that a sudden elevation to this degree must be fatal. ${ }^{3}$ This elevation would be obtained comparatively soon in a moist atmosphere; partly because of the greater conducting power of the medium, but principally on account of the check which is put upon the vaporization of the fluid secreted by the skin. Even here, however, custom and acquired constitution have a very striking influence; for whilst the inhabitants of this country are unable to sustain, during more than 10 or 12 minutes, immersion in a vapor-bath of the temperature of $110^{\circ}$ or $120^{\circ}$, the Finnish peasantry remain for half an hour or more in a vapor-bath, whose temperature finally rises even to $158^{\circ}$ or $167^{\circ}$. Pouchet ${ }^{4}$ las endeavored to show that, when sniall animals are exposed to cold, death results from changes occurring in the blood-corpuscles; Walther ${ }^{5}$ has referred the fatal issue to anæmia of the nervous systen. But Bernard, ${ }^{6}$ who has made many experiments on this point, attributes it to the toxic influence of heat on the striated muscular tissue, which speedily occasions the arrest of the cardiac and respiratory movements. Death occurs in cold-blooded aninals on sudden exposure to a temperature of from $98^{\circ}$ to $102^{\circ} \mathrm{F}$., in Mammals on exposure to a temperature of $109^{\circ}-111^{\circ} \mathrm{F}$, and in Birds of $120^{\circ}-122^{\circ} \mathrm{F}$. On examination the heart is found to have stopped, though it long continues to beat in ordinary asphyxia, and neither it nor any of the striated muscles respond to electrical or other stimuli, whilst cadaveric rigidity, due apparently to coagulation of the myelin, sets in with wouderful rapidity. The unstriated muscular fibres secm to be powerfully stimulated by these degrecs of heat.

1 Expériences sur les Effits qu'une forte Chaleur produit sur l'Economie; Paris, 1805 ; and Journal de Physique, tomes Ixiii, lxxi, et lxxvii.

2 Philosophical Transactions, 1775.

3 Bernard (Comptes Rendus de la Société de Biologie, 1859, p. 51) attributes the death of the animals in these and similar experiments to a condition analogous to rigor mortis of the hat being established. He found the auricles filled with blood, but the ventricles firmly contracted and empty.

4 Journal de l'Anatomie, Jan. 186t;.

6 Centralblatt, April, 1866.

6 Legons, in the Revue Scientitique, 1871, p. 183 et seq. 
The blood is dark and contains little oxygen ( 1 or 2 per cent.). Both Dr. Davy ${ }^{1}$ and Pouchet found that completely congelated animals were incapable of being restored to life.-Aceurate cxperiments are yet wanting to determine the influence of humidity on the effects of cold air. From experiments on young Birds incapable of maintaining their own temperature, of which sonse werc placed in cold dry air, and others in cold air charged with moisture, it was found by Dr. Edwards that the loss of heat was in both instances the same; the effect of the evaporation from the surface in the former case, being counterbalanced in the latter by the depressing influence of the cold moisture. This influence, the existence of which is a matter of ordinary experience, is probably exerted directly upon the Nervous system.

430. Having thus considered the general facts which indicate the faculty possessed by the living system, in Man and the higher Animals, of keeping up its temperature to an elevated standard, and of preventing it from being raised much beyond it by any degree of external heat, we have next to inquire to what this faculty is due. ${ }^{2}$ - It may be stated as a general fact, that every change in the condition of the organic components of the body, in which their elements enter into new combinations with Oxygen, must be a source of the devclopment of Heat. And as we have seen that a considerable part of the carbonic acid and water which are exhaled in Respiration, is formed within the body by the metamorphosis of its own tissues, and that this metamorphosis is promoted by the active exercise of the nervo-muscular apparatus, it follows that in animals whose habits of life are peculiarly active, whilst the temperature of the surrounding medium is sufficiently high to prevent its exerting any considerable cooling influence over them, the combustive process thus maintained may be adequate for the maintenance of the temperature of the borly at its normal standard. This seems to be the case with the great Camivorous quadrupeds of warm climates, and with certain races of Men who lead a life of incessant activity like theirs. But whenever the cooling influence of the atmosphere is greater, or the retrograde metamorphosis of tissuc takes place with less activity, some further supply of heat-producing material is required; and this is derived either directly from the food, or from a store previously laid up in the body. Although the albuminous and gelatinous components of the food may be made, by decomposition within the body, to yield saccharine and oleaginous compounds which serve as an immediate pabulum to the combustive process $(\$ \S 78,344)$, yet this metamorphosis involves a great waste of valuable nutritive material; and the needed supply is much more advantageously derived at once from those farinaceous or oleaginous substances, which are furnished in abundance by the Vegetable kingdom, the latter also by Animals. No reasonable doubt can any longer be entertained, that the production of Heat by the combustive process is the purpose to which a large proportion of these substances is destined to be subservient in the bodies of Herbivorous animals and of Man ; and the results of experience in regard to their relative heat-producing powers, are in precise accordance with the indications afforded by their chemical composition.

431. Our knowledge of the dependence of all the vital processes in warm-

1 Proceed of the Roy. Soc., 1866, p. 250.

2 It was affirmed by Dr. Granville (Phil. Trans., 1825) that the temperature of the uterus during parturition sometimes rises as high as $120^{\circ}$. In some observations made at the Philadelphia Hospital, however, at the desire of Prof. Dunglison, the temperature of the uterus was not lound to be mueh above that of the vagina; the former being, in three eases, $100^{\circ}, 102^{\circ}$, and $106^{\circ}$, whilst the latter was $100^{\circ}, 100^{\circ}$, and $105^{\circ}$. (Prof. Dunglison's Human Physiology, 8th edit., vol. i, p. 602 ) 
blooded animals upon the Heat of their bodies, and of the dependence of their calorifying power upon the due supply of material for the combustive process, has received some remarkable additions from the experimerits of M. Chossat upon Starvation. ${ }^{1}$ He found that Birds, when totally deprived of food and drink, suffered a progressive, though slight, daily diminution of temperature. This diminution was not so much shown by a fall of their maximum heat, as by an increase in the diurnal variation, which he ascertained to occur even in the normal state $(\S 425$, II). The average variation in the inamitiated state, was about $6^{\circ}$ (instear of $1 \frac{1}{2}^{\circ}$ ) gradually increasing as the animal became weaker ; morcover, the gradual rise of temperature, which should have taken place between midnight and noon, was retarded; whilst the fall subsequently to noon commenced much earlier than in the healthy state; so that the average of the whole day was lowered by about $4 \frac{1}{2}^{\circ}$, between the first and the penultimate days of this condition. On the last day, the production of heat diminished very rapidly, and the thermometer fell from hour to hour until death supervened ; the whole loss on that day being about $25^{\circ}$ Fahr., making the total depression about $29 \frac{1}{2}^{\circ}$. This depression appears, from the considerations to be presently stated, to be the immediate cause of Death.-On examining the amount of loss sustained by the different organs of the body, it was found that 93 per cent. of the Fut had disappeared; being all, in fict, which could be removed; whilst the nervous centres scarcely exhibited any diminution in weight $(\S 78)$. From the constant coincidence between the entire consumption of the fat, and the depression of temperature,-joined to the fact that the duration of life under the inanitiating process evidently varied (other things being equal) with the amount of fat previously accumulated in the body,-the inference seems irresistible, that the ealorifying process depended chicfly on the materials supplied by this substance. Whenever, therefure, the store of combustible matter in the system was exhausted, the inanitiated animals died, by the cooling of their bodies consequent upon the loss of calorifying power.

432. That this is the real explanation of the fact, was shown by the results of a series of very remarkable cxperiments performed by M. Chossat, with the purpose of testing the correctness of this view. When inanitiated animals whose death seemed impending (death having actually taken place in scveral instances, whilst the preliminary processes of weighing, the application of the thermometer, ctc., were being performed), were subjected to artificial heat, they were almost uniformly restored from a state of insensibility and want of muscular power to a condition of comparative activity; their temperature rose, their.muscular power returned, they flew about the room, and took foorl when it was presented to them; and if the artificial assistance was sufficiently prolonged, and they were not again subjected to the starving process, most of them recovered. If they were left to themselves too early, however, the digestive process was not performed, and they ultimately died. $U_{p}$ to the time whon they began to take food, their weight continued to diminish; the secretions being renewed, under the influence of artificial heat, sometimes to a considerable amount. It was not until digestion had actually taken place (which, owing to the weakened functional power, was commonly many hours subsequently to the ingestion of the food), that the animal regained any power of generating heat: so that, if the external source of heat was withdrawn, the body at once cooled ; and it was not until the quantity of food actually digested was sufficient to support the wants of the body, that its independent power of

1 Recherehes Exprérimentales sur l'Inanition, Paris, 1843 ; an analysis of this work will be found in the Brit. and For. Med. Rev., April, 1844. See also H. Senator, in Reichert and Du Bois-Reymond's Archiv., 1872, p. 1. 
calorification returned. It is to be remembered that, in such cases, the resources of the body are on the point of being completely exhausted, when the attempt at reanimation is madle; consequently, it hats nothing whatever to fall hack upon ; and the leaving it to itself at any time until fresh resonrces have been provided for it, is consequently as certain a cause of death, as it would have been in the first instance.

4:3. It can scarcely be questioned, from the similiarity of the phenomena, that Inanition, with its consequent depression of temperature, is the immediate cause of death in various Disenses of Exhaustion; and it seems probable that there are many cases in which the depressing canse is of a temporary nature, and in which a judicions and timely application of artificial heat might prolong life until it has passed off, just as artificial respiration is serviceable in cases of narcotic poisoning ( $\$ 221$ ). It is especially, perhaps, in those forms of Fever, in which no decided lesion can be discovered after death, that this view has the strongest claim to reception; and the beneficial result of the administration of Alcohol in such conditions, and the large amount in which it may be given with impunity, may probably be accounted for on this principle. That it acts as a specific stimulus to the Nervous system, camnot be doubted from its effects on the healthy body; but that it serves as a fuel to keep up the calorifying process, appears equally certain. ${ }^{1} \quad$ Its great efficacy in such cases seems to depend upon the readiness with which it will be taken into the circulation, by a simple act of endosmotic imbibition, when the special Absorbent process, dependent upon the peculiar powers of the cells of the villi $(\$ 135)$, is in abeyance. There is no other combustible fluid, whose miscibility and whose density, relatively to that of the Blood, will permit of its rapid absorption by the simple physical process adverted to.

434. That the oxidation of certain components of the food or of the tissues is the fundamental source of Animal Heat, is further indicated by the close conformity which we everywhere find between the activity of the Respiratory process and the amount of Heat which is generated; and this is not merely when we compare different tribes of animals with each other, but also when we compare the amount of oxygen absorbed and of carbonic acid exhaled by the same individuals under different degrees of external temperature $(\S 311, \mathrm{I})$. For we find that the system possesses within itself a regulating power, by which the combustive process is augmented in activity when the cooling influence of the surrounding medium is considerable, so that this influence is resisted; whilst the internal fire (so to speak) is slackened, whenever the temperature of the outer air rises so much as to render the same generation of heat no longer requisite. The appetite for food, and especially for those particular forms of it which best afford the combustive pabulum, varies in the same degree; and thus, when supplied with appropriate nutriment, Man is able to brave the severest cold, without suffering any considerable depression in his bodily temperature.-It would seem that the Cutaneous Respiration ( $\$ 313)$, small as its anount is, promotes those molecular changes on which the maintenance of Animal Heat depends; for it was found by MM. Becquerel and Breschet, ${ }^{3}$ and Socoluff, that when the hair of Rabbits was shaved off, and a composition of ghe, suet, and resin (forming a coating impermeable to the air) was applied to the whole surface, the temperatnre rapidly fell, notwith-

1 See the articles written by M. Baudot in L'Union Médicale for Nov. 1893.

2 The Author has stated the verr striking results of observations which he has had the opportunity of making upon this point, in his Essay on the Physiology of Temperance and Total Abstinenee, $\% 213$.

3 Cumptes liendus, October, 1841. These experiments were repeated and confirmed by Magendie (Gazette Médiealc, Dec. 6th, 1813).

4 Centralblatt, 1872, No. 44. 
standing the obstacle thus offered to the evaporation of the sweat, whereby, it might be supposed, the temperature of the body would be eonsiderably elevated. In the first rabbit, whieh had a temperature of $100^{\circ}$ before being shaved and plastered, it had fallen to $89 \frac{1}{2}^{\circ}$ by the time the material spread over him was dry. An hour afterwards, the thermometer placed in the same parts (the nuuscles of the thigh and ehest) had deseended to $76^{\circ}$. In another rabbit, prepared with more care, by the time that the plaster was dry, the temperature of the body was not more than $5 \frac{1}{2}^{\circ}$ above that of the surrounding medium, which was at that time $692^{\circ}$; and in an hour after this, the animal died. The varnish appears to aet by inereasing radiation. Dr. Sanderson ${ }^{1}$ found that a rabbit, which in the normal state gave off only 3 heat-units in ten minutes, gave about 20 after varnishing, notwithstanding that in the former case its temperature was eonstant at $39.5^{\circ} \mathrm{C}$, while in the other it sank from $36^{\circ}$ to $25^{\circ}$. In Socoloff's experiments, albumen rapidly made its appearance in the urine, and tetanie eonvulsions oeeurred before death. Neither wrapping the animal in wool, nor enmpelling it to breathe oxygen, prevented the fatal result. After death a diffused parenehymatous inflammation of the kidneys was observed, and ulcers were found in the stomach eonsequent upon profound extravasation. These experiments and observations place in a very striking point of view the importanee of the eutaneous surface as a respiratory organ, even in the higher animals; and they enable us to understand how, when the aerating power of the Lungs is nearly destroyed by disease, the heat of the body is kept up to its natural standard by the aetion of the skin. A valuable therapeutic indication, also, is derivable from the knowledge whieh we thus gain, of the importanee of the cutaneous respiration; for it leads us to perceive the desirableness of keeping the skin moist, in those febrile diseases in which there is great heat and dryness of the surfaee, since aeration eannot properly take place through a dry membrane. Of the relief afforded by eold or tepid sponging in sueh eases, experienee has given ample evidenee.

435. It has been held that the Chemieal theory of Calorification is insufficient to aceount for the total amount of Heat generated by a warm-blooded animal in a given time; this assertion being founded upon the experimental results obtained by M. Dulong. MM. Favre and Silbermann ${ }^{2}$ have shown, however, that the original estimates require correetion for the true calorifie equivalents of earbon and hydrogen; and that this eorreetion having been made, the heat produeed by the combustion of the Carbon which is eontained in the carbonie aeid expired, and by the eombustion of such a proportion of the Hydrogen eontained in the exhaled water as nay be fairly considered to have undergone oxygenation within the system (\$318), proves to be adequate to compensate for that which wonld be dissipated by the evaporation of all the water transpired from the skin and lungs, and also to maintain the temperature of the body itself in an atmosphere of ordimary coolness. And to the combustion-heat of carbon and hydrogen, we should also add that of those relatively minute quantities of Phosphorus and Sulphur, which also mndergo oxidation within the system $(\$ 414)$, whereby a small additional amount of heat must be generated.-Through whatever diversity of combinations or suecessive stages of oxidation these elements respeetively pass, in their progress to complete or final oxidation, it may be regarded as an indisputable fact, that they give out precisely the same amount of heat in the whole, as if they had undergone the most rapid combustion to the same degree of oxida-

1 Irandbook for the Physiol. Yabor., 1873, p. 333.

2 See their Memoirs, Des Chaleurs de Combustion, in Comptes Rendus, tom. $x x$, xxii. 
tion in pure oxygen; and thus almost every moleeular ehange in the body, but pre-eminently those which are eoncemed in the disintegration of its textures, and in the elimination of their products by Respiration, participate in the funetion of Calorification.-The experiments of Ranke, ${ }^{1}$ male upon himself, furnish perhaps the best data on whieh the absolute amount of heat developed in the body can be calculated; and they are by so mueh the more to be depended upou, as the results agree well with the determinations of Frankland on the amount of heat developed by various kinds of aliment during the act of eombustion. It may be remarked that the age of Ranke vas twenty-four, his height about six feet, and his weight $154 \mathrm{lbs}$. The first experiment was made to determine the amount of heat developed on mixed food. The ingesta and the egesta were equal in amount, the weight of the body remaining the same. The numbers represent grammes:

Exp. I.-Production of heat on the first day of total abstinence from food (commeneing 23 hour's after the last meal), the ingesta ( $i . e$, eonsumption of the body itself) caleulated from the egesta:
Ingesta, in Grammes.
54.45 Albumen.
195.94 Fat.
Egesta.
18.3 Urea.
0.24 Uric Acid.

From these data it may be caleulated that the daily production of heat amounted to 2012.8 calories.

Exp. II.-Production of heat on meat diet, the deposition of flesh in the body, and the eonsumption of fat being ealeulated from the exeretions:

Ingesta.

$1832 \mathrm{grm}$. of Meat, of which only $1300 \mathrm{grm}$.

underwent disintegration.

$\left.\begin{array}{l}70 \mathrm{grm} \text {. Fat of Food, } \\ 75.14 \text { Fut of Body, }\end{array}\right\} 145.14$ Fat.
Egesta.

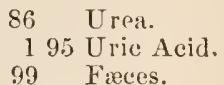

86 Urea.

99 Freces.

The daily produetion of heat produeed here was 2799.5 ealories.

Exp. III.-Production of heat on non-nitrogenous diet, consumption of albumen and deposit of fat in the body calculated from the excreta:

Ingesta, in Grammes.

51.55 Body Albumen.

150.00 Fat, of which 81.5 were deposited.

300

So that only 68.5 were burnt off.

Stareh.

100 Sugar.

The daily production of heat was here 20.59.5 ealories. With mixed diet the daily production was about 2200 calories.

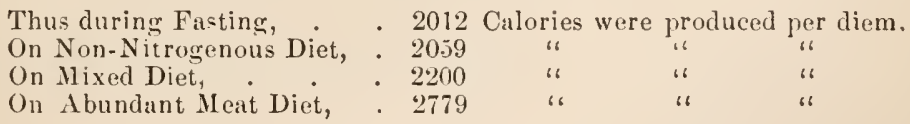

Aeeording to Senator, ${ }^{2}$ a dog weighing about 12 lbs., fed on a pound of meat per diem, gave off, 16-26 hours after food, 12-14 ealories per hour, during whieh time it excreted from 52 to 57 grains of carbonic acid gas. After fasting for 48 hours, it gave off 11.6 ealories, and eliminated 51.7 grains of $\mathrm{CO}_{2}$, whilst two hours after digestion it gave off 21 calories, and eliminated 79.8 grains of $\mathrm{CO}_{2}$.

The average of Ranke's experiments on himself gave the number of ealories produced per diem at 2200 , which is a quantity suffieient to raise 44 
pounds of water from the freezing to the boiling-point. Hel mholtz estimated the amount at $2700 .^{1}$ The mode in which the heat produced is applied, has been estimated as follows:

To the elevation to the temperature of the body of the food ingsested, To the warming of the air breatled, .

To the vaporization of the water discharged by the linge, ${ }^{*}$ :

To the radiation from the body and evaporation from the skin,

2.6 per eent.

5.2 "

14.7 "

775 "

In this calculation Helmholtz estimated that one kilogramme of water (= $2.2 \mathrm{lbs}$ avoird.) in evaporating from the skin and lungs took up or required 582 calories, its temperature being already nearly $100^{\circ} \mathrm{F}$. Fond was considered to be upon the average about $20^{\circ} \mathrm{F}$. cooler than the temperature of the body, and to require the same amount of heat to warm it as water. Barral" gives a somewhat different estimate, and considers that of the total heat produced in a man at rest, which, in accordance with $\mathrm{Helm}$ holtz, he estimates at 2706.076 calories, 699.801 , or 25.85 per cent., are lost in the water evaporaterl from the skin and lungs; 100.811 , or 3.72 per cent., in warning the air breathed ; 52.492 , or 1.94 per cent., in warming the food; 33.020 , or 1.22 per cent., in the solid and fluid excreta; and 1819.952 , or 67.22 per cent., hy radiation and conduction and mechanical work. Béclard ${ }^{3}$ estimates that a man daily develops sufficient heat to raise 5.5 lbs. of water from $32^{\circ}$ to $212^{\circ} \mathrm{F}$.

436. The influence of the nervous system upon the temperature of the borly is well shown by the effects of section of the spinal cord. These effects, however, are not constant, for such lesion is sometimes followed by an elevation, and sometimes by a decline in the temperature. Thus, a case is recorded by Sir B. Brodie ${ }^{4}$ in which the spinal cord having been so seriously injured in the lower part of the cervical region that the whole of the nerves passing off below were completely paralyzed, the heat of the body, as shown by a thermometer placed in the groin, was not less than $111^{\circ} \mathrm{F}$.; and this, notwitlistanding that the respiratory function was very imperfectly perforned, the number of inspirations being considerably reduced, and the face livid. Similar cases have been recorded by other observers. On the other hand, when the spinal cord has been divided experimentally in animals, Sic B. Brodie $^{5}$ and others have shown that the temperature of the body usually falls with rapidity, even when artificial respiration is steadily maintained. This difference, however, is probably due to the secondary conditions of the experiment, for it is to be particularly noted that scetion of the spinal cord below the medulla oblongata paralyses the vaso-motor centre, and consequently produces hypersemia of the capillaries of the body generally-a condition that would necessarily lead to increased production of heat. On the

1 Or rather $2,700,000$, but he considered a calory to be the quantity of heat required to raise 1 gramme of water $1^{\circ} \mathrm{C}$., instead of 1 kilogramme, which is 1000 grammes.

2 Stat. Chim. des Animax. Paris, 1850.

3 Physiol., 1862, p. 561.

4 Med. Gaz., June, 1836 , and Physiolog. Rescarches, p. 121.

5 Philostphical Trans., 1811, 1812, and Physolorieal Researelies. Sec atso the confirmatory experiments of MII. Le Gullois, Anutes de Chimie, 1817, and CEuvres, t. ii, Chossat, Mémoire sur l'Influence du Śyst. Nerv. sur la Chaleur Animale; and Ticheschichin, Reichert's Arehiv, 1866, ip. 151-179. C. Brornard, Comptes Rendus, 1853, t. xxxvi, Pr. 414 and 632. S'chiti, Untersuchmen, Heft 3 ; Physol. d. NorvenSystem, 185.5. Brown-Séquard, Revue Scientif, 1871, p. 288. The romarkable case reeorded by Intchinson, Lancet, 1875 , vol. i, p. 713 ; and that by Dr. Teale, alrcady refirred to. Heidenhain, Uober Einwirkungen des Nerven-system auf die Körpertenperatur, in P'fliger's Arehiv, Bd. iii, p. 504; and WVeir Mitchell, Brown-Sequard's Alehives of Ścient. and Pract. Med., 1873, No.4. Sehreiber, Pflüger's Archiv, Bd. viii, $187-$, p. 576 . 
whole, there scems to be no strong rcason for admitting the existence of an inhibitory centre for the production of heat in the spinal cord, which is paralyzed on dirision of the cord, and for which some authors have contended. In M. 'Tscheschichin's cxperiments, section of the pneumogastrics was not observer to produce any remarkable effect upon the development or distribution of the animal heat in rabbits-at least not until those pathological conditions which have been already described (\$ 305), as resulting from their section, had become established. Various pathological phennmena indicate that the withdrawal of nervous influence from any part of the body usuilly tends to produce a depression of its temperature, and this especially in the cremitics; thus II:. II. Eurle found the temperature of paralyzed limbs slightly lower than that of sound limbs; so Prof. Dunglison has noticed that in one ease of hemiplegia of five months' standing, the temperature of the axilla was $96_{2}^{10}$ on the sound side, and $96^{\circ}$ on the paralyzed; whilst that of the hand was $87^{\circ}$ on the sound side, and only $792^{\circ}$ on the paralyzed; and in another case of only a fortnight's duration, the temperature of the axilla was $100^{\circ}$ on the sound side, and only $98 \frac{1}{4}^{\circ}$ on the paralyzed, whilst that of the hand was $94^{\circ}$ on the sound side, and $90^{\circ}$ on the paralyzed. ${ }^{2}$ According to Folet, ${ }^{3}$ the temperature of the paralyzed side soon after an attack of hemiplegia is $1.8^{\circ} \mathrm{Fahr}$. above that of the opposite side; but, when atrophy supervenes, the temperature falls again. The elevation is quite independent of the seat of the lesion of the nervous system.

437. Locul Vuriations. - The blood is the means by which the uniformity of the temperature of the borly gencrally is maintained, and its mass enables it to equalize the variable amounts that are produced in the several glands and muscles it traversos, according to whether they are in an active or in a quiescent condition. IVamed during its passage through the abdominal and tholacic viscera, which are in constant functional activity, and which are prevented from cooling by the thick layer of fat that covers the abdominal parietes, the blood carries a high temperature to the extremities, where it becomes gradually reduced, owing to radiation and conduction. If the heat be prevented from escaping from the surfice of the body by radiation or evaporation, as in cases where the large size of the animal causes the capillaries of the skin to bear a comparatively small proportion to those of the body generally, or when the animal possesses a thick coating of wool or fat, or is kept in a marm atmosphere, ${ }^{4}$ the temperature rises to a high degree: when the opposite conditions are present, the temperature falls. The great importance of the supply of blood to any part in maintaining its temperature is well shown by the experiments of M. Claude Bernard, from which it appears that an elevation of temperature constantly takes place on one side of the face, when the trunk which unites the Sympathetic ganglia of the neck on that side is cut through; this increase being not only perceptible to the touch, but showing itself by a thermometer introduced into the nostrils or ears, even to the extent of from $7^{\circ}$ to $11^{\circ}$ Fahr. When the superior cervical ganglion is removed, the same effect is produced, and with yet greater intensity. This difference is maintained for many months, and is not apparently connected with the occurrence of inflammation, congestion, nedema, or any other pathological change in the tissues, though the sensibility of the parts thus affected is no less augmented than their temperature; moreover, it is not prevented from manifesting itself by the division of any of the cerebro-spinal nerves of the face. This exaltation of temperature, there can 
be no doubt, is sufficiently explained by the relaxation of the walls of the smaller arteries (producing a state resembling a permanent "blush"), and the consequent increase in the flow of blood through the part, which has been shown by Dr. Aug. Waller to result from this operation. (See \$ 254.) A curious experiment made by Bernard tends to show that the quantity of blood taken up by any one organ is supplied to it at the expense of another; and that the excess of heat developed at one point of the body is compensated for by a diminution in some other part. He found that on making a section of the Sympathetic in the neck of a Rabbit, both of whose ears had previously a temperature of $95^{\circ} \mathrm{F}$., the temperature rose to $100^{\circ} \mathrm{F}$. on the side on which the scetion was made, whilst it fell to $91^{\circ} \mathrm{F}$. on the opposite side. When, however, the peripheral end of the cut nerve was galvanized, the temperature fell in the corresponding ear, and rose in the opposite one. ${ }^{1}$ Local variations of temperature occur in the various organs in consonance with the changes in the circulation in them resulting from the active performance of their duties, or their state of repose. In some instances, however, such variations seem to be independent of changes in the supply of blood. ${ }^{2}$ Thus Schiff ${ }^{3}$ has shown that irritation of a sensory nerve in a dog under the influence of woorara, and therefore incapable of performing muscular movements, causes increase of the temperature of one or the other hemisphere of the brain, and was independent of changes in the circulation, since it occurred even as late as twelve minutes after the heart's action had ccased. Even irritation of the nerves of special scnse will produce this effect, for it was distinctly perceptible in a thoroughly woorarized dog before which an umbrella was suddenly opened. In accordance with this, though perhaps other circumstances lead to the increase of temperature, is the observation made by Bernard, ${ }^{4}$ that if the foot of a dormouse be pinched whilst in a state of hibernation, the temperature rises almost immediately as much as from $60^{\circ}$ to $70^{\circ} \mathrm{F}$. In opposition to it is the statement made by Horvath, ${ }^{5}$ that irritation of a sensory nerve causes depression of the temperature in the rectum. ${ }^{6}$ Horvath having observed that mere binding of a rabbit so that it could not nove, caused a gradual fall of temperature, sometimes to as much as $3^{\circ}$ Fahr., at first attributed it to its cramped condition; but further experiments led him to conclude that it was due to the pain expericnced by the animal when its limbs were tightly bound. Funke ${ }^{7}$ states that intellectual exertion causes an increase of temperature in the brain. A considerable fill of temperature occurs during the narcotic condition induced by chloroform ${ }^{8}$ which is probably partly due to its depressing influence upon the circulation, as well as to its direct action upon the blood-corpuscles. In like manner in poisoning by woorara, which C. Bernard has shown first paralyzes the vaso-motor nerves, causing dilatation of the cutaneous capillarics, and consequent increased loss of heat, and at the same time, a retardation of the movements of the heart and respiratory muscles, a decline of temperature is constantly observed. Jacobson and Landré ${ }^{9}$ have shown that there is similarly a decline in the temperature of the rectum. [Bernard considers that the muscular and nervous systems are important sources of heat. In the extremitics and on the surface of the body the venous blood is always cooler

1 Bernard, Leçons, 1859, fème Leçon.

2 Many instances of local variations in disease have been eolleeted by Wunderlieh.

3 Archives de Physiologie, 1870, p. 198.

5 Centralblatt, 1870 , p. 546.

4 Rev. Scient., 1871, p. 288.

7 P'hysiologie, 1873, p. 306.

8 Sce Seheinesson, Dissert. über d. Einfluss d. Chloroform : quoted by Funke, Physiologie, 1872, p. 308.

9 Nederland. $\Lambda$ rehiv v. Genees en Naturk., Bd. ii, p. 355. 
than the arterial; but in the cavities of the body this law is reversed, as between the crural vein and artery there is a difference of one degree, and very ncal the bifulcation of the aorta and vena cava, the difference is only eighttenths of that just mentioned. Immediatcly above the opening of the renal veins, the blood of the vena cava and aorta have the same temperature, which Bernard terms the real point of temperature. The inferior vena cava's blood is warmer than that in the arteries; that of the superior vena cava is cooler.

Bernard believes that the vaso-dilators are calorific nerves, whilst the vaso-constrictors are frigorific.

Prof. H. C. Wood, Jr., belicves that in the pons or above it, there is a nerve centre whose function it is to inhibit the production of animal heat. This centre does not act directly upon the tissues, but probably through a controlling influence over centres in the cord, which regulate the chemical activities. The action of the centre is supposed to be analogous to the reflex inhibitory centre of Setschenon. $]^{1}$

438. We have now to inquire whether the power of generating Heat is possessed by the Human subject in an equal degree at all ages; this question being very different from that of the ordinary temperature of the body at the various periods of life; since an individual who can maintain a high temperature when the surrounding air is moderately warm, may have very little power of bearing continued exposure to severe cold. Important analogical evidence on this point has been supplied by the experiments of Dr. WV.F. Edwards upon the lower Mammalia, Birds, etc. ${ }^{2}$ It appears from these to be a general fact, that, the younger the animal, the less is its independent calorifying power. Thus the development of the embryo of all Oviparous animals is entirely dependent upon the amount of external warmth supplied to it. There are many kinds of Birds, which, at the time they issue from the egg, are so deficient in the power of generating heat, that their temperature rapidly falls when they are removed from the nest and placed in a cold atmosphere; it being shown by collateral experiments, that the loss of heat was not to bc attributed to the absence of feathers, nor to the extent of surface exposed in consparison with the bulk of the body; and that nothing but an absolute deficiency in the power of generating it, would account for the fall of temperature. This is quite conformable to facts well ascertained in regard to Mammalia. The foetus, during intrauterine life, has little power of keeping up its own temperature; and in many cases it is much dependent on external warmth for some time after birth. The degree of this dependence, however, differs greatly in the various species of Mammalia, as among Birds; being less, in proportion as the general development is advanced. Thus, young Guinea-pigs, which can run about and pick up food for themselves almost as soon as they are born, are from the first independent of parental warmth; whilst, on the other hand, the young of Dogs, Cats, Rabbits, ete., which are born blind, and which do not for a fortuight or more acquire the same development with the preceding, rapidly lose their heat when withdrawn from contact with the body of the mother.

439. In the Human species, it is well known that external warmth is necessary for the Infant, its body rapidly losing heat when exposed to the chilling influence of a low temperature; but the fact is too often neglected (under the erroneous ideas of "hardening" the constitution) during the early years of childhood. It is to be carefully remembered, that the development of Man is slower than that of any other animal, and that his calorifying power is closely connected with his general bodily vigor; and though

2 On the Influence of Physical Agents on Life, part iii, chap. $i$. 
the infant becomes more independent of it as development advances, it is many years before the standard can be maintained without assistance, throughout the ordinary vicissitudes of external tenperaturc. Especial care is required with regard to the maintenance of the bodily heat by artificial warmth, in the case of children prematurely born; for the earlier the period of embryonic life, the less is the power of calorification that exists for some time after birth. The temperature of a seven months' child, though well swathed and near a good fire, was found by Dr. W. Edwards, within two or three hour's after its birth, to be no more than $89.6^{\circ}$. And in some of the recorded instances in which the birth has taken place before the complction of the sixth month, it has not been found possible to maintain the warmth of the infint by exposure to the radiant heat of a fire, the contact of the warm body of another person being the only effectual means of keeping up its temperature.-The fullest measure of calorifying power is possessed by adults; but cven in them it is sometimes weakened by previous exertion, so that death by the cooling of the body may oceur, when the body is cxposed to cold of no great intensity, but in a state of exhaustion of nervous power; a fact which remarkably confirms the views advanced in the preceding paragraph. A decrease of calorifying power takes place in advanced age. Old people complain that their "blood is chill;" and they suffer greatly from exposure to cold, the temperature of the whole body being lowered by it.

440. These facts have a very interesting connection with the results of statistical inquiries, as to the average number of deaths at different seasons ; the following are recorded by M. Quetelet, ${ }^{1}$ as occurring at Brussels, the mean monthly mortality at each age being reckoned as 100 .

\begin{tabular}{|c|c|c|c|c|c|c|c|}
\hline & & $\begin{array}{c}\text { First } \\
\text { month. }\end{array}$ & $\begin{array}{c}2-3 \\
\text { years. }\end{array}$ & $\begin{array}{l}8-12 \\
\text { years. }\end{array}$ & $\begin{array}{l}25-30 \\
\text { years. }\end{array}$ & $\begin{array}{l}50-65 \\
\text { year's. }\end{array}$ & $\begin{array}{r}90 \text { years } \\
\text { and above }\end{array}$ \\
\hline January, . & . & 1.39 & 1.22 & 1.08 & 1.0 .5 & 1.0 & 1.58 \\
\hline February, & . & 1.28 & 1.13 & 1.06 & 1.04 & 1.22 & 1.48 \\
\hline March,. & . & 1.21 & 1.30 & 1.27 & 1.11 & 1.11 & 1.25 \\
\hline April, . & . & 102 & 1.27 & 1.34 & 1.06 & 1.12 & 0.96 \\
\hline May,. & . & 0.93 & 1.12 & 1.21 & 1.02 & 0.93 & 0.84 \\
\hline June,. . & . & 0.83 & 0.94 & 0.99 & 1.02 & 0.85 & 0.75 \\
\hline July, , . & . & 0.78 & 0.82 & 0.88 & 0.91 & 0.77 & 0.64 \\
\hline August. . & . & 0.79 & 0.73 & 0.82 & 0.96 & 085 & 0.66 \\
\hline September, & . & 0.86 & 0.76 & 081 & 0.95 & 0.89 & 0.76 \\
\hline October,. & . & 0.91 & 0.78 & 0.76 & 0.93 & 0.90 & 074 \\
\hline November, . & . & 093 & 0.91 & 0.80 & 0.97 & 100 & 1.03 \\
\hline December, & . & 1.07 & 1.01 & 0.96 & 0.97 & 1.15 & 1.29 \\
\hline
\end{tabular}

We see from this table that, during the first months of infant life, the external temperature has a very marked influcnce; for the average mortality during each of the three summer months being 80 , that of January is ncarly 140, and the average of Febrinary and March is 125 . This is confirmed by the result obtained by MM. Villermé and Mihne-Eslwards, in their researches on the mortality of the children conveyed to the Foundling Hospitals in the different towns in France; for they not only ascertained that the mortality is nunch the greatest during the first three months in the year, but also that it varies in different parts of the kingdom, accorling to the relative severity of the winter. ${ }^{2}$ As childhood advances, however, the winter mortality di-

1 Essai de Ply ysique Soniale, tom. i, p. 197.

2 Dr. Emerson has shown that, in the Southern and Middle States of North America, the high summer temperature is the greatest cause of Infant mortality : the 
minishes, whilst that of the spring undergoes an increase; this is probably due to the greater prevalence of certain epidemics at the latter scassun; for the same condition is observed, in a still more remarkable degree, betwcen the ages of 8 and 12 years, - the time when children are most severely affected by such epidemics. As the constitution acquires greater vigor, and the bodily structure attains its full devclopment, the influcnce of the scason upon mortality bccomes less apparent; so that at the agre of from 2.5 to 30 years, the difference between the summer and winter mortality is very slight. The difference reappears, however, in a very marked degrce, at a later period, when the general vigor, and the calorifying power, undergo a gradual dininution. Between the ages of 50 and 65, it is ncarly as great as in early infancy; and it gradually becomes more striking, until, at the age of 90 and upwards, the deaths in January are 158, for every $74 \mathrm{in} \mathrm{July}$ (a proportion of $2 \frac{1}{2}$ to 1 ); and the average of the three winter months is 145 , whilst that of the three summer months is only 68 , or less than one-half:The results of the comparisons which have now becu carried out for many successive years in the Reports of the Registrar-Greneral, between the rariations in the weekly rate of mortality in the Metropolis and the range of atmospheric temperature, present a close coincidence with the foregoing: it being especially to be noted, that the rate of mortality (save during the prevalence of any fatal epidemic) is almost invariably the highest during the winter months; that the increase of deaths at that period is most marked amongst children and old people; and that any extraordinary severity of winter cold constantly produces a great augmentation in the mortality, the weekly number of deaths rising from the average of 1100 (or thereabouts) to 1600 or even 1800 , when the mean temperature of the week remains six or eight degrees below the freezing-point.

\section{Evolution of Light.}

441. Although the evolution of Light from the living Human subject is an exceptional phenomenon, which has only been observed in morbid states of the body, yet its occasional occurrence is fraught with interest to the Physiologist, on the one hand from its relation to the Luminosity so common among the lower animals, and on the other from the indications which it affords of the possibility of the formation, even during life, of peculiar phosphuretted compounds, which, being products of incipient decomposition, have been usually supposed to be generated only after death.-There is no doubt that luminous exhalations frequently ascend from burial-grounds; and that the superstitions of many nations respecting "corpse-lights" lave to this extent a foundation in fict. A very decided luminosity has becn observed to proceed from dissecting-room subjects, the light thus evolved being sufficient to render the forms of the bodies, as well as those of muscles and other dissected parts (which are peculiarly bright), al most as distinct as in the daylight. That this proceeds from the production of a peculiar phosphorescent compound, is shown by the fact, that the luminosity may be communicated to the fingers or to towels, etc., by contact with the luminous

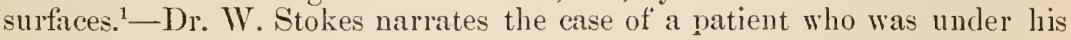

proportion of deaths during the tirst year of ehildhood oceurring in the months of June, July, and August, being about four times greater than that occurring during the same months in any subsequent year up to the age of 20 . The winter mortality under the seeond year scareely exeeeds the average of subsequent years. (Amer. Jour. of Med. Sei., Nov. 1831.)

a See Sir Herbert IIarsh, on the Evolution of Light from the Living Human Subject (Dublin, 1842), p. 20.-From this interesting pamphlet most of the statements in this paragraph are derived. 
observation, some years since, in the Old Meath Hospital, having been admitted on account of an enormous cancer in her breast, which was in an advanced stage of ulceration, the edges being irregular and everted; every part of the base and edges of this eavity was strongly phosphorescent, the light being sufficient to enable the figures on a watch-dial to be distinguished within a few inches; and here also it appeared that the luminosity was due to a particular exudation from the exposed surface. Three cases are recorded by Sir H. Marsh, in which an evolution of light took place from the living body, without any such obvious source of decomposition; all the subjects of these cases, however, were in the last stage of phthisis; and it can scarcely be doubted that here, as in other diseases of exhaustion, incipient disintegration was taking place during the later periods of life $(\S 80)$. The light in each case is described as playing around the face, but not as directly proceeding from the surface; and in one of these instances, which was recorded by Dr. D. Donovan, ${ }^{1}$ not only was the luminous appearance perceptible over the head of the paticnt's bed, but luminous vapors passed in streams through the apartment. It can scarcely be doubted that it was here the breath which contained the luminous compound, more especially as it was observed in one of the cases to have a very peculiar smell ; and the probability that the luminosity was due to the presence of phosphorus in progress of slow oxidation, is greatly increased by the fact already referred to $(\S 319)$, that the injection of phosphuretted oil into the bloodvessels gives rise to a similar appearance. In repeating this experiment, Sir H. Marsh states, that when half an ounce of olive-oil, holding two grains of phosphorus in solution, was injected into the crural vein of a dog, a dense white vapor began to issue from the nostrils even before the syringe was completely empticd, which became faintly luminous on the removal of the lights; and the injection being repeated with the same quantity, the expiration immediately became beautifully luminous, resembling jets of palecolored flame pouring from the nostrils of the animal. And the luminosity which has been occasionally observed in the urinc, ${ }^{2}$ may fairly be imputed to an increase in the quantity of unoxodizerl phosphorus which it seems normally to contain; its liberation taking place at a more rapid rate than its conversion into plosphoric acid, cither through excessive excretion or through inpeded respiration. ${ }^{3}$ A case has been recorded by Kaster (loc. cit.), in which the body-linen was rendered luminous by the perspiration, alter any violent cxercise; and here, too, the cause may be presumed to have been the same.-On the whole, then, we may conclude the occasional evolution of Light from the Human subject to be the consequence (when not an electrical phenomenon) of the production of a phosphorescent compound at the expense of the disintegrating tissues; which compound passes off through one of the ordinary channels of excretion.

\section{Evolution of Electricity.}

442. When the vast variety of changes of condition to which the components of the living body are subjected during the performance of its vital

1 Dublin Vedienl Prese, Jan. 15th, 1840.

2 Cusper's Woehensclurift, 1849, No.15.-A case has been put on record (IBiehner's Jiepert., Bd. viii, p. 342), in which the urine and semen of a patient who was under treatment for impotence and sperantorrlea, and who was empleying phosphorus as a remedy both internally and extermally, were observed to he luminous.

3 The large proportion of intemperate subjacts, amonin those who exhibit this phenomenon, secms to eonfirm the view already axpressed. that the habitual presence of Alcohol in the blood interferes with the oxidation and elimination of excrementitious mutters. 
operations, and the impossibility of the occurrence of any of these without some disturbance of Electric equilibrium, ${ }^{1}$ are duly considered, the wonder is, not that such disturbance should be occasionally so considerable as to make itself apparent, but that it should be ordinarily so obscure as only to be detected by the most careful search, and with the assistance of the most delicate instruments. The researches of Prof. Mattencei, M. Du Bois-Reymond, and others, however, have now made it apparent, that there are no two parts of the body (save those which correspond on the opposite sides), whose electrical condition is precisely the same; and that the differences between them are greatcr in proportion to the diversity of the vital processes which are taking place in them, and to the activity with which these are being carried on. ${ }^{2}$ - It is by the comparison of the electric states of different secreting surfaces, that such departures from equilibrium are most readily demonstrated. 'Thus, Donné found that the skin and most of the internal membrames are in opposite electrical states; and Mattencei observed a considerable deflection of the needle of a delicate galvanometer, when the liver and stomach of a rabbit were comected with its platinum electrodes. ${ }^{3}$ More recently, Mr. Baxter has found that if one of the electrodes be placed upon any part of the intestinal surface, and the other be inserted into the branch of the mesenteric vein proceeding from it, a decided deflection of the needle is produced, indicating a positive condition of the blood; but that no effect is produced when the second electrode is inserted into the artery of the part, instead of into its vein. These effects were found to cease after the death of the animals ; and could not be attributed, therefore, to mere chemical differences between the blood and the secreted product; but must have arisen from electric disturbance taking place in the very act of secretion. ${ }^{*}$ Scontetten and Shettle, again, have found arterial blood to be positive in its relations to venous blood.- That the process of Nutrition, as well as of Secretion, in parts which are undergoing rapid molecular change, gives rise to electric disturbance, is proved by the experiments of Matteucci and Du Bois-Rey-

1 There is probably no instance of chemical union or decomposition, in which the Electrie condition of the bodies concerned is not altered. Simple change of form, from solid to liquid, or from liquid to gaseous, is attended with electric disturbance; and this is greatly increased when any separation takes place between substances that were previously united, as when water containing a small quantity of saline matter is caused to evaporate and to leave it behind. Heat, again, is continually renerating Electricity ; for not only is a current produced by the heating of 1 wo dissimilar metals in contact, but also by the unequal heating of two parts of the same har ; and though the effect is most striking in the case of metals, it is by no means limited to them. And so constantly is Electricity generated by the retardation of motion, as in friction, that it is not possible to rub together any two substances, excepting those which are of the most perfect homogeneity (such as the fractured surfaces of a broken bar), without the production of Electric change as well as of Heat.

${ }^{2}$ Having had an opportunity of witnessing some of the experiments made by $\mathrm{Mr}$. Du Bois-Reymond with a magneto-electrometer of extraordinary sensitiveness, the Author can bear his personal testimony to the fact, that the electricity even of the corresponding fingers of the two hands is very seldon equally balanced, and that the existence of even the slightest scratch or abrasion of surfuce upon one of them produces a very marked disturbance.

3 See II. Becquerel's Traité de l'Electricité, tom. i, p. 327, and tom iv, p. 300. From his rescarches on the cectrical organs of the Torpedo, Prof. Babuchin (Centralblatt, 1870, p. 241) arrives at the conclusion that they are essentially muscles in which the proper muscular or contractile substance is absent, and conversely he regards muscles as electrical organs, in which muscular fibres are introdured betweren the electrical septa. Marey (Comptes Rendus, Ixxiii, pp 918 and 958) found the period of latent excitation of the lectrical apparatus of the torpedn to be $\frac{1}{60}$ th of a second, whilst that of the muselcs of the frug is $\frac{1}{8} 0^{t}$ th.

4 Philosuphical Transactions, 1848, p. 243.

5 An Essay on the Electricity of the Blood, 1867. 
mond, upon the relative electrical states of different parts of muscles and nerves. If the two extrenities of a Muscle, remover from the body of an animal very recently killed, be applied to the two electrodes of a delicate galvanometer, there is usually some deflection of the needle; this being greater, in proportion to the difference in the arrangement of the muscular and tendinous elements at the two extremities. Although the direction of the current is constant for each muscle, yet there is no constant relation between the direction of the currents and the position of the muscles in the body; thus in the gastrocnemius of the Frog's leg, the direction is from the foot towards the body, whilst in the sartorius it is the reverse. Taking all the muscles of a part together, however, there is usually such a want of balance between the opposite currents, that a constant current is establisher in the direction of the strongest and most numerous of the separate muscular currents; this, in the Frog, passes uniformly from the hind feet towards the head, and was at one time supposed to be peculiar to that animal; but a similar current may almost always be detected in other animals. The muscular current grows feebler and feebler, the longer the muscle has been removed from the body; it is affected by any agents which tend to lower its vitality, and becomes extinct as soon as its contractility ceases. From the experiments of MI. Du Bois-Reymond, it may be concluded that the current in the arm of Man, when at rest, is from the shoulder towards the points of the fingers. (The special conditions of the "Nervous" and "Muscular" currents will be hereafter fully considered in the chapters devoted to the Nerves and Muscles respectively.)

443. Some of the most important parts of the body being thus in a state of constant disequilibrium with regard to each other, it is not surprising that the Electrie state of the whole should be ordinarily in disequilibrium with that of surrounding bodies. This difference, however, is usually prevented from manifesting itself, in consequence of the restoration of the equilibrium by the free contact which is continnally taking place between them ; and it is for the most part only when the Human body is insulaterl, that it becomes apparent. The galvanometer is then affected, however, by the contact of one of its electrorles with the person insulated, and the other with any neighboring uninsulated body; and also by the contact of the electrodes with the hands of two persons both insulaterl, who join their other hands together, a difference in the electrical states of the two individuals being thus indicated. The electricity of Man is most commonly positive, and irritable men of sanguine temperament have more fiee electricity than those of phlegmatic character. The electricity of women is more frequently negative than that of men. There are persons who scarcely ever pull off articles of dress which have been worn next the skin, without sparks and a crackling noise being produced; especially in dry weather, when the electricity of the body is retained, instead of being rapidly dissipated as it is by a damp atmosphere. The effect is usually heightened, if silk stockings and other silken articles have been worn, since these act as insulators. It is duubtless in part sttributable to the friction of the articles of dress against each other and against the body ; but we can scarcely doubt that it is partly due to the generation of electricity in the borly itself, since it bears no constant relation to the former of these supposed canses. Thus a Capuchin friar is mentioned by Dr. Schneider, ${ }^{1}$ who, on removing his cowl, always found a number of shining erackling spatis to pass from his scalp; and this phenomenon continued still perceptible after a three weeks' illness.-The most remarkable case of the generation of Electricity in the Human subject at present known, was 
recordel some years since in America. ${ }^{1}$ 'The subject of it, a larly, was for many months in an electric state so different from that of surrounding bodies, that whencver she was but slightly insulated by a carpet or other feebly conducting medium, sparks passed between her person and any object she approached; when most favorably circumstanced, four sparks per minute would pass from her finger to the brass ball of the stove at the distance of 1: inch. From the pain which accompanied the passage of the sparks, her condition was a source of much discomfort to her. 'The circumstances which appeared most furorable to the generation of the electricity, were an atmosphere of about $80^{\circ}$, tranquillity of mind, and social enjoyment ; whilst a low temperature and depressing cmotions diminisher it in a corresponding degree. The phenomenon was first noticed during the occurrence of an Aurora Borealis; and though its first appearance was sudden, its departure was gradual. Yarious experiments were made, with a view of ascertaining if the electricity was generated by the friction of articles of dress; but 110 change in these seemed to modify its intensity.

\section{CHA PTER XIII.}

OF THE FUNCTIONS OF THE CEREBRO-SPINAL NERVOUS SYSTEM.

\section{General Summary.}

444. The Nervous System of Man, like that of all other Animals, is composerl of ganglionic centres and nerve trunk; the former (Figs. 183, 184) being essentially composed of "vesicular substance," made up of cells which

FIG. 183 .

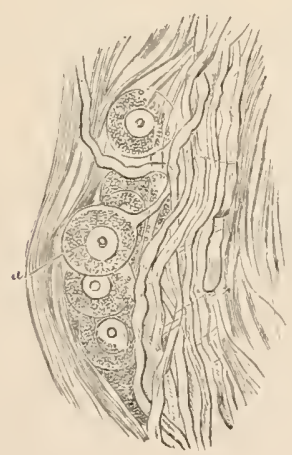

FIG. 184.

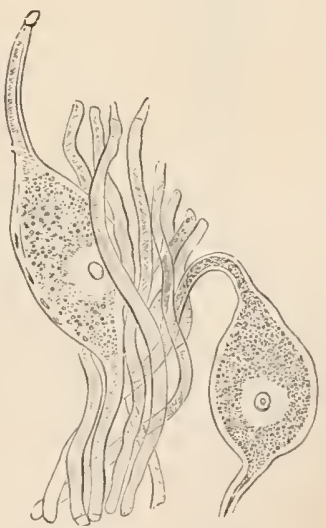

FIG. 183.-Microscopic Ganglion from Heart of Frog.

FIG, 184.-Bipolar Ganglionic Cells and Nerve-fibres fiom the Ganglion of Fifth Pair in Lamprey.

may be spheroidal, fusiform, caudate, stellate, or of almost any variety of shape; the latter consisting entirely of "nerve-fibres," which, in their most completely developed state, are tubular. If the structure of an ordinary nerve like the Median be examined, it will be found to consist of an investjng membrane of connective tissue, or perineurium, in which small vessels 
and nerves ramify. From the internal surface of this, processes are given off" which divide the nerve into smaller bundles or funiculi. And these funiculi, according to Ranvier, are invested by an epithelium exhibited at Fig. 185, consisting of large flat cells. Thesc are considered by some observers to represent the lining of a lymphatic space. ${ }^{1}$ On further dissection, the individual fibres may be separated from one another, and in the porfectly fresh state appear as clear, transparent, and highly refractile threads, in which no trace of structure can be discoverer. After short exposure to the action of air, water, and other reagents, a kind of coagulation occurs, and it then appears that each fibre is composed of a very delicate sheath,

FIG. 185.

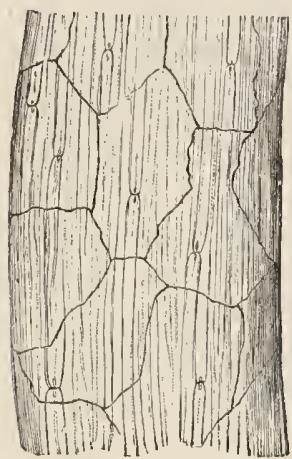

FIG. 186.

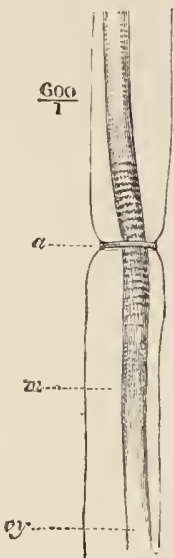

Fig. 185,-Funiculus of a mouse after impregnation with nitrate of silver. Large flat epithelial cells are secn covering its surface. The explanation of the small crosses is secn by reference to the next figure.

FIG. 186.--Nerve-fibre from the sciatic nerve of the rabbit after the action of nitrate of silver: $a$, ring formed l,y thickened nembrane of Schwann; $m$, white substance of Schwann rendered transparcnt ly glycerin; $C y$, cylinder-axis, which just above and below the level of the annular constriction presents the strice of Frommann.

the sheath of Schwann, or ncurilemma (1, Fig. 187), within which is an oleaginous material termed the white or medullary substance of Schwann (2), whilst the core or centre is formed by an albuminous round or flattened thread, the axis-cylinder, or primitive band (3). Ranvier ${ }^{2}$ de-

Frg. 187. scribes certain annular constrictions (Fig. 186) on all medullated $3-\quad$ nerve-fibres at intervals of about $\frac{1}{2}$ th of an inch, which nay be brought into view with various reagents, as the picro-carminate of ammonia and osmic acid, and which he thinks are caused by a thickcning of the membrame of Schwann. The constrictions appear to divide the white substance of Schwann into segments, each containing a nucleus. The cylinder-axis runs continuously through the constriction without presenting any trace of segmentation, except that when the fibre is treated with nitrate of silver, it presents a laminated aspect, just above and below the constriction. No such constrictions arc presented by the fibres

1 Tamamschef, Centralblatt für die MIed. Wiss., 1872, p. 593, who also gives a comparative table of the action of various reagents on the cylinder-axis and on albumen. See also A. v. Török, Würzburg Physikal-Med. Verhand., Bł. iii, 41.

2 Brown-Séquard's Archives de Physiologie, 1872, p. 129, No. 2. Sachs, Centralblatt, 1873, p. 578. An account of Ranvier's discovery will be found in the Lancet, 1872 , vol. i, p. 477. 
of Renak, or the non-medullated fibres. The nuclei lie between the menbrane of Schwann and the white substanee of Schwann, in which last they are included. They are surroumded by a layer of albuminoid substanee, which does not stain witl perosmic aeid. In the ganglion-cells eontained in the brain and spinal eord, and in the ultimate peripheral ramifications of the nerves, both the neurilemma and the white substanee of Sehwann beeome indistinct or wholly disappear, whilst the axis-cylinder has been observed to break up into filnils of extreme tenuity, termed primitive nerve-fibrils ; ${ }^{1}$ these are represented in Fig. 189, $a$. The olcaginous eomposition of the white or medullary subtance is shown by its ready solubility in cther. It possesses great refingibility, is extremely extensible, but inelastie, and of a peculiar viscid nature, so that when its continuity is interrupted it has little or no tendency to return to its original

Fig. 189.

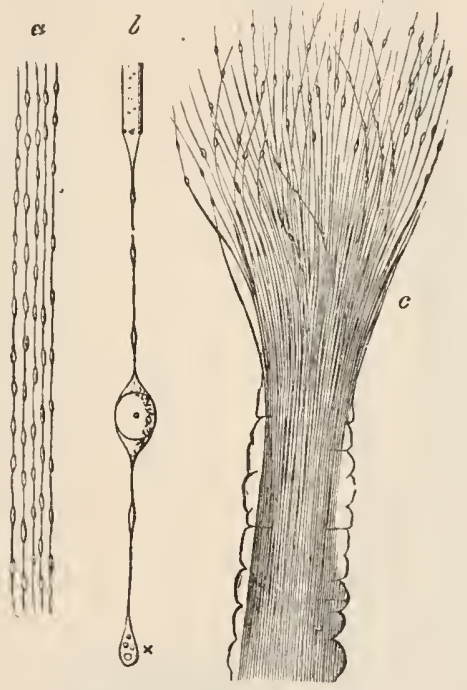

FIG. 188.- $a$, Axis-cylinder, showing its fibrillar structure; at the upper part, $x, x$, it is seen to arise from a ganglion-cell, $a$, only partially represented, and to become incrusted by a medullary sheath at $a^{\prime} ; b$, naked axis-eylinder, from the dorsal region of the spinal cord of the ox. The medullary sheath has been removed.

FIG. 189.-Primitive nerve-fibrils: $a$, from the nervous fibre-layer of the retina; $b$, from the external granular layer of the retina, showing at $x$ a larger raricosity, resulting from imbibition; $e$, from the olfactory nerve of the pike, showing a thick nerve inclosed in a sheath breaking up into fibrillæ.

FIG. 188 .

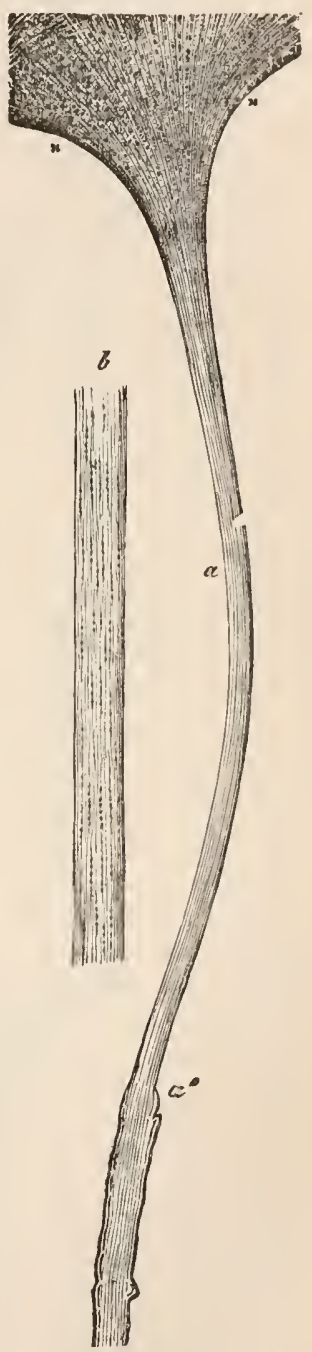

position. ${ }^{2}$ The peculiar appearances it presents in polarized light have led Klebs ${ }^{3}$ to maintain that it consists of, or eontains, doubly-refracting bodies

1 See Max Schultze, Art. on The Histology of the Nervous System, in the first volume of Stricker's Human and Comparative Histology, Syd. Soe. Trans., 1870, p. 147.

2 See Lockhart Clurke's Observations on the S'srueture of Nerve-fibre, in Journ. of Med. Sei., vol. viii, p. 1.

s Quoted in Kühne's Phys. Chemie, 1868, p. 339. 


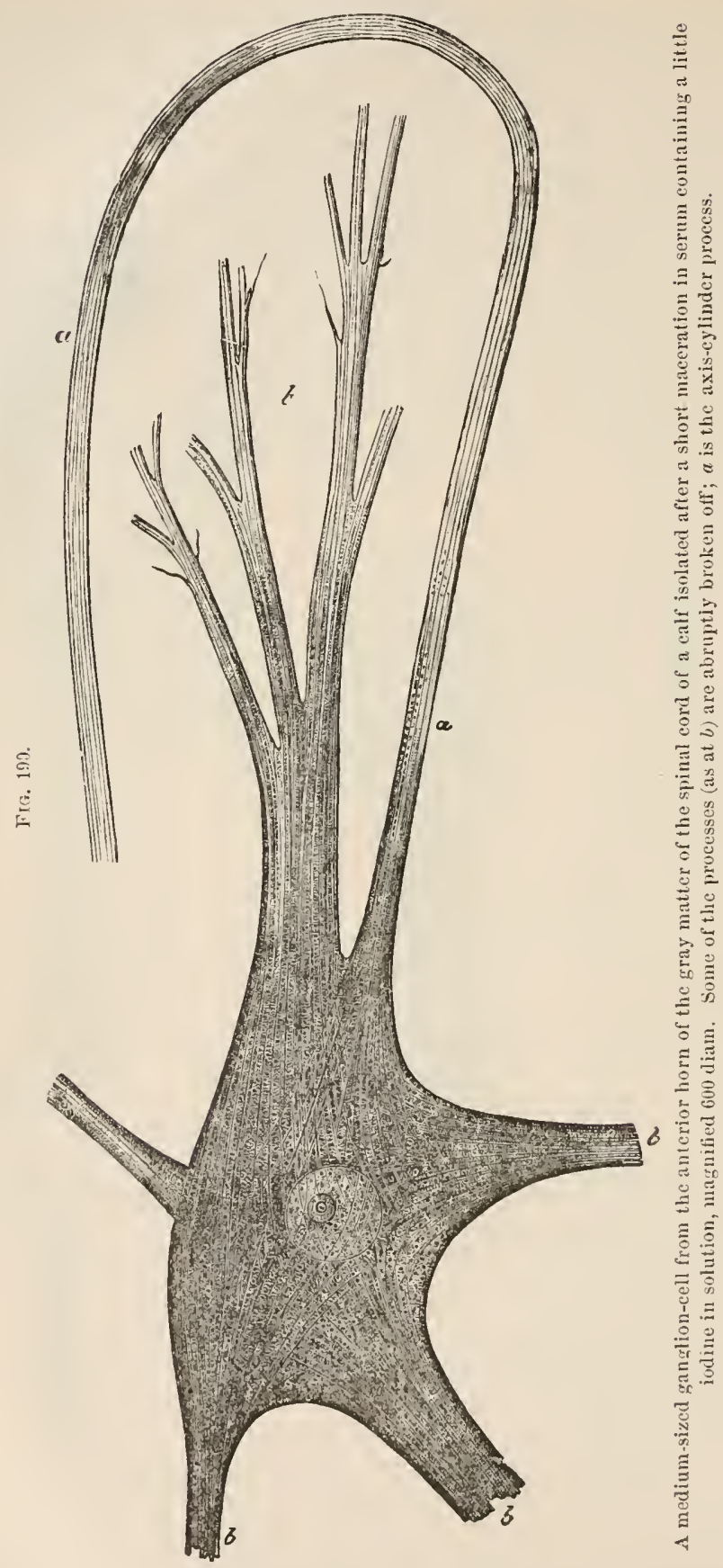


(crystalline particles), the optic axes of which are arranged radially to the primitive band. 'The cylinder-axis is insoluble in ether, and further differs from the white substunce of Schwam in readily staining with carmine. The sympathetic nerves contain some fibres that are of a paler color than those thit constitute the majority of the cerebro-spinal nerves, and are further chanacterized by the absence of a double contour, and by presenting nuclei in their conrse, but fine dark-erged fibres are abundant ${ }^{1}$ these are believed by some observers to consist of bundles of minute fibrils. 'The diameter of ordinary nerve-fibres varies from the $\frac{1}{1500}$ th to $\frac{1}{20} \frac{1}{000}$ th inch, but the ultimate tibrils above alluded to do not exceed, according to Dr. Beale, $\frac{1}{50}$ th to $50 \frac{1}{0}$ on th of an inch. On carefurl treatment with various hardening solutions, the latter may he isolated, but soon imbibe water and present varicose enlargements (Fig. 189). These increase in size till the film becomes unrecognizable and disapliears. The precise mode in which the nerves terminate peripherally, can scarcely be said to be accurately known in any instance perhaps, with the exception of the Pacinian corpuscles. In the case of the motor nerves and of the nerves of special sense, considerable differences of opinion exist (which will be hereafter more particularly referred to), as to whether there is a terminal plexus, or whether the nerves end in loops or in free extremities, or become continuous with gland or muscle-ceils. Dr. Klein, in following ont the nerves of the Cornea, seems to have satisfied himself, that in this part at least, the fibres end in free extremities, which run up between the cells. Nerve-fibres are divided into afferent or centripetal, which convey impressions to a nervons centre or ganglion; efferent or centrifugal, which comduct impressions from a centre; and central or intramesial Nerves. The Centripetal nerves are subdivided into the sensory nerves and excito-motor nerves, the former conveying impressions which are usually perceived or felt by the individual, whilst those conveyed by the latter are often unperceived. The Centrifugal fibres are subdivided into motor nerves, distributed to museles, both striated and unstriated, secretory fibres distributed to glands, and inhibitory nerves, which are capable of arresting or preventing the contraction of muscular tissue. The existence of fibres capable of causing active elongation of muscular fibre is still sub judice. Nerve-cells vary much in their form, size, and structure. The simpler kinds are round or oval, the larger polygonal and stellate, and it is probable that all possess a nucleus, and give off one, two, or more prolongations, that either intercommunicate with the processes of other cells, or become continnous with the cylindes-axis of a nervefibre (Fig. 190), gradlually acquiring a neurilemma, and the white substance of Schwann. In some instances, as in the cells of varions parts of the spinal cord (Fig. 191), the subdivision and ramification of the prolongations, which are sometimes called protoplasmic processes, are very remarkable, a close network being formed which pervades the adjoining portion of the nervous tissue. In other instances, only one or two processes can be traced, the cells being then termed mini- and bipolar. In the sympathetic ganglia of the firog and other animals Dr. Beale, whose researches have been fully confirmed by subsequent inquirers, has observed nerve-cells of great complexity of stiucture, the chief microscopic features of which are shown in Fig. $192, A$. Such cells are pyriform and nucleated, and from their pointed extremity two fibres arise $(a, b)$, which, on reaching the vervous bundle to which they are distributed, run in opposite directions, thus affording sone support to the view maintained by Dr. Beale, that every nerve-fibre, how-

I See S. Mayer, Art. Sympathetic System of Nerves, in Stricker's Histology, vol. ii, p. 552 . 
ever long its eourse may be, is a loop arising in, and returning to, the same cell. One of the fibres $(a)$ is usually straight, penetrates into the interior of the eell, and appears like a stalk to the cell; the other $(b)$, which is sometimes double at first, seems to arise from the exterior of the eell, and winds spirally for two or three times round the former. Both fibres at first resemble the cylinder-axis of ordinary nerve-fibres, and both may subsequently beeome dark-bordered, or remain pale, fibres. The spiral fibres bear large oblong nuclei in their course. The deseriptions given by Arnold and Courvoisier are in accordanee with that by Dr. Beale, except that

FIG. 191.

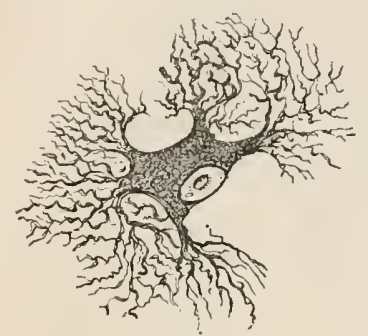

FIG. 192.

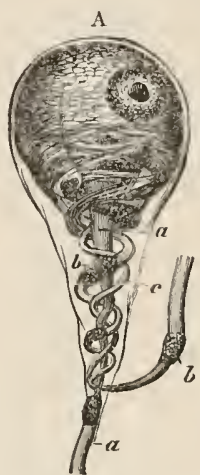

I

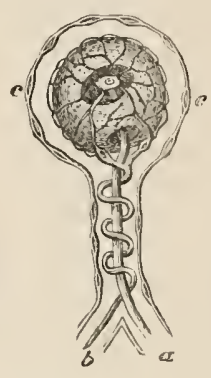

FIG. 191.-Stellate Nerve-cell, from the nucleus cervicis cornu (posterior vesicular column) of a fœetus of six months $\times 420$,

Fig. 192.-Structure of Ganglionic Nerre-cell. A, According to Dr. Beale, B, According to Aruold.

they state they lave traced the straight fibre into the nuclcus, and the spiral fibre into a plexus on the exterior of the cell, but whieh may ultimately be traced into the nueleolus (Fig. 192, B), so that the two fibres are continuous with one another through the nueleus and nueleolus. The whole eell is invested by a nueleated capsulc of eonneetive tissuc, proceeding from and continuous with the sheath of Schwann investing the nerve-fibres with whieh it is in connection. ${ }^{1}$ All our knowledge of the strueture and endowments of the ganglionic centres and nerve-trunks renders it probable that they bear a complementury relation to each other; the Vesicular substance having for its office to originute changes, whieh it is the function of the Fibrous to eonduct.

445. Regeneration of Nervous Structure.-If a nerve be divided by a sharp instrument, and the cnds placed in apposition, they will reunite, with complete restoration of function. ${ }^{2}$ The mion is aecomplished by the efficion of gelatinous lynph, in whieh connective-tissue and elastic fibres form, by

1 For a fuller description of these structures, sec Quain and Slusrpey's Introd. to Anat., p. exliii ; Dr. Beale, Philoswph. Transact., 18633, p. j433; Courvisier, Centralblatt, No. 57, 18f7; Frantzel, Virchow's Archiv, 1867, Bd. xxxvii, p. 549; Arnold, id., Bd. xli, 1. 178 ; Schultze, Inc: cit.

${ }^{2}$ Cruickshank, 1776. Funtama, 1778. Michrehis, 1785. Haighton, Phil. Trans, 1795; Vulpian, Leçons sur la Physiologie du systeme Nerveux, Paris, 1866 ; Forseber, Rauvier, Comptes Rendus de l'Acadómie des Sciences, 1873, "491; Brnecke, Virchow's Archiv, 1873, Bd. Ivii, 1. 49t5; Laveran, Thèe de Strasbourg, quoted in Demarquay, I) la Récgénération des Orgumes et des Tiswles, in which the various views of Schiff, Vulpian, Landry, Ranvier, Kölliker, and others are woll griven; IIjelt-Otto, Virehow's Archiv, $x i x, p .35: 2$, and E. Oehl, sul proeesso di Rigenerazione dei Nurvi recisi. Puvia, 1864, 8vo. 
which the continuity of the perincurium is restored. According to some, bipolar cells are developed within this shcath, the processes of which unite to form the axis-cylinders of new nerves; the mednllary sheath being subsequently developed around them. But Ranvier maintains that the fibres of the peripheric stump atrophy, and that the new fibres proceed from the axiscylinder of the centric stump which make their way through the cicatrix into the degenerated fibres, or run in the connective tissue of the peripheric stump. The changes that occur in the fibres after section are, that they become cloudy, and their margins are less defined. These changes are woll marked on the eighth day, and soon after the medullary substance becomes divided into scoments, and a kind of coagulation takes place in it, with deposit of fat-globnles. In the course of a month or six weeks the medullary substance is reduced to a mass of extremely fine granular molecules of fatlike dust, which finally disappear, and the sheaths collapse. Whether the cylinder-axes remain for a long time unaltered, as Schiff ${ }^{1}$ maintains, or also undergo absorption, as Ranvier believes, is still doubtful. The time that elapses before the newly-formed tissue can fulfil the function of a nerve in transmitting sensory and motor impulses is given by varions authors at from 7-15 days for the first traces, and 30-90 days for complete return of sensation and motion. ${ }^{2}$ According to Schiff, ${ }^{3}$ regeneration of the pneumogastrics may occur even when two inches have been excised. It is questionable whether, after extirpation of a ganglion, new ganglionic corpuscles can be formed; yet, in Brown. Séquard's experiments upon pigeons, it was found that the whole spinal cord would reunite after division, with almost complete restoration of function. The distal extremity of a nerve separated from its centre by section undergoes fatty degeneration, ${ }^{4}$ whilst the proximal portion retains for a considerable period its normal characters, indicating, according to Waller, that the ganglion-cell with which it is in relation exercises a certain influence over its nutrition.

446. As regards the chemistry of the Nerves, it has bcen fonnd that the Brain contains about 75 per cent. of water, and 25 of solid residue, of which about 15 parts consist of fatty substances, 7.5 of albuminous compounds, 1.5 of salts, and 1 of extractive inatters. The proportions of these constituents, however, are different in other parts of the nervous system; the amount of water, for instance, varying firm 70 (in the white) to 85 per cent. (in the gray substance). The fat contained in the gray matter is always much smaller in quautity than that in the white. According to Peilowsky, ${ }^{5}$ when dried the gray substance contains more than half of its weight of albumen, the white only one quarter. The gray substance (dried) contains 18.7 of Cholesterin and fat, and 0.5 of Cerebrin, the white 51.9 of the former, and 9.5 per cent. of Cerebrin. Amongst the chief constituents of the cerebral substance, in addition to Cerebrin, is Lecithin, with the products of its deconposition, viz., glycerin, phosphoric and oleo-phosphoric acids, and other fatlike substances containing phosphorus and soluble in ether, palmitic acid, small quantities of ordinary fat, and volatile fatty acids. Besides these, the following substances are enmmerated by v. Gorup-Besanez, ${ }^{6}$ an albuminous substance resembling Myosin, a substance analogous to Elastin, small quantities of a soluble albuminous substance, coagulating at $147^{\circ}$ F.; Inosite, Sarkin, Xanthin, Kreatin, Lactic, Uric, and Phosphoric acids, and their combinations with Potash, Lime, and Magnesia; Silicic Acid,

1 Comptes Rendus de l'Académie des Sciences, Mars 6th, 1854.

2 Descot, Thèse Inaugurale, 1822 ; Paget, Surgical Pathology.

3 Vierordt, Physiologie, 186il, p. 44.

6 Pflüger's Archiv, 1873, p. 369.

${ }^{4}$ See Schitf, Physiologie, p. iii.

6 Phys. Chemie, 1875, p. 697. 
Oxide of Iron, Fluorine, small quantities of Alkaline Sulphates, and lastly Chloride of Sodium. The quantity of Phosphorus is very large, amounting, according to Bursarelli, ${ }^{1}$ to from 1.352 to 1.790 per eent. Perfectly fresh nerves, when at rest, possess a neutral or perhaps slightly alkaline reaction. ${ }^{2}$ According to Ranke, they become acid after tetanus. The white substance of the brain and spinal cord is also feebly alkaline or neutral. After exhausting work and after death it is acid. The gray substance is always acicl."

447. As regards the general relations of the principal Centres of the Nervous System of Man, it is only requisite here to remark, that those which make up the Cerebro-Spinal portion of the apparatus have such an intimate structural relation to each other, and so much more frequently aet eonsentaneously than separately, that, notwithstanding the abundant evidence of the diversity of their respective endowments, there is considerable difficulty in the determination of their special funetions ; since the destruction or removal of any one portion of the Nervous system, not only puts a stop to the phenomeua to which that portion is directly subservieut, but so deranges the general train of nervous activity, that it often becomes impossible to ascertain, by any such method, what is its real share in the entire performance.-In this difficulty, however, we may advantageously have recourse to the study of the structure and actions of those forms of the Nervous System presented to us among the lower animals, in whieh its ganglionie centres are fewer and less intimately eonnecterl, and in which, therefore, it is more easy to gain an aequaintance with their several endowments. And from an extensive survey of these, we seem able to deduce the following conclusions, which afford the most valuable guidance in the study of the Nervous System of Man :

I. The Nervous System, in its lowest and simplest form, may consist of but a single gauglionic centre, ${ }^{5}$ with afferent and motor nerves, whose function is essentially internuncial; impressions made upon the afferent fibres exciting respondent or" "reflex" movements in the inuseles supplied by the motor, without any necessary intervention of conscionsness. - Such movements are properly distinguished as excito-motor.

II. A simple repetition of sueh gauglionie eentres may exist to any extent, without heterogeneousness of function, or any essential departure from the morle of action just indicated ; each of these centres may be speeially connected by afferent or motor fibres with one segment or division of the body, and may minister peculiarly to its actions; but the several centres may be so intinately connected by commissural fibres, that an impression made upon the afferent nerves of any one of them may excite respondent motions in other segments. - This we see effected through the annular gangliaterl eord of the higher Ratliata, and through the longitudinal gangliated cord of the Articulata; the disposition of the ganglia and of their comnecting eords, having reference simply to the general plan of the borly.

III. A higher form of Nervous System is that in which there is multiplica-

1 Sid. Soc. Year-book, 1861, 1. 32.

2 See Heidenhan, Studien des P'hys. Jnstit. zu Breshan. 1868, p. 248; and Liebreich, in Tageblatt der Natur-firsch Versamm. zu Frankfürt, 1867.

3 G-cheidlen, Archiv f. P'hysiol., Bal. viii, 1873, 1. 17:2.

4 For a gencral view of the fincts on which these conclusions are based, see Princ. of Comp. Phys., chatp. xiii"

5 It may, perbaps, be doubted whether any Animal really exists possesing such a norvous systom, and yet not endowed with conscionseness. It $i$-quite certain, however, that animals do exist (the Tumicated Mollusen for example) in which the actions above referred to are the only ones of which we have any distinct evidence from observation of their habits. 
tion of similar parts which are to be alike supplied with nervous power, but to the exercise of a diversity of functions, through the instruncentality of diflerent structures: thus, in the higher Articulated and Molluscous tribes, we find ganglionic contres specially set apart for the actions of deglutition and respiration, as well as for those of locomotion; but their modus operandi is still the samc, these actions being all "excito-motor," that is, bcing performed through the "reflex" agcucy of their several ganglionic centres, without the necessary intervention of consciousness. These centres are connected with each other commissurally, when they are required to act with consentaneousness; and it is frequently to be observed in the most developed forms of each type, that they come into actual coalescence, their functional distinctness being still indicated, however, by the distribution of their nervetrunks.

Ir. In all but the very lowest Invertebrata, the Nervous System includes, in addition to the foregoing, certain ganglionic centres, situated in the neighborhood or the entrance to the digcstive cavity, and connected with organs, which, firom their more or less close resemblance to our own instruments of special sense, we conclude to be organs of sight, smell, hearing, etc. Now as we know fiom our own experience, that impressions made upon these organs produce no influence on our actions unless we bccome conscious of them, and as the Invertebrata possess no distinct ganglionic centres of a higher character, it seems to be a legitimate inference, that these "scnsorial" ganglia are the instrumeuts by which the animals furnished with them are rendered cognizant of such impressions, and through which the sensations thus called into existence serve to prompt and direct their movements. What is commonly designated as the "brain" of Invertebrata (more properly their "cephalic ganglia") cannot be shown to consist of anything else than an ascemblage of sensorinl centres; and its actions appear to be entirely of a "reflex" character, such of the movements of these animals as are not cxcitomutor, being performed (there is strong reason to believe) in direct respondence to sensations excited by internal or external impressions. Such movements, therefore, may be designated as sensori motor or consensual. Like the preceding, they do not appear to involve the participation either of Emotion, Reason, or WVill; and the proportion which they bear to the actions of the excito-motor kind, seems to correspond pretty closely with the relative development of the cephalic ganglia and of the rest of the nervous system, as is very obvious when the larva aud imago states of Insects are compared.However disjointed the various "excito-motor" centres may be amongst each other, we uniformly find them counected with the "sensory" ganglia by commissural tracts; and this anatomical fact, with many phenomena which observation and experiment upon their actions have brought to light, makes it apparent, that besides the reflex actions which are performed through their own direct instrumentality, the sensory ganglia have a participation in those performed through other ganglionic centres. Thus it seems probable that a stimulus transmitted downwards from the sensory ganglia, to one of the ganglia of the trunk of a Centiperle, excites the efferent nerves of that ganglion to call into contraction the muscles supplied by them, just as the excitor influence arriving at that ganglion through its own afferent nerves would do.

448. The whole Nervous System of Invertebrated Animals, then, may be regarded as ministering entirely to purely reflex action; and its highest development, as in the class of Insects, is coincident with the highest manifestations of the "instinctive" powcrs, which, when carcfully examined, are found to consist entirely in movements of the excito-motor and sensori-motor kiuds. When we attentively consider the habits of these animals, we find 
that their actions, though evidently adapted to the attainment of certain ends, are very far from evincing a desigued adaptation on the part of the beings that perform them, such as that of which we are ourselves conscious in our own voluntary movements, or which we trace in the operations of the more intelligent Vertebrata. For, in the first place, these actions are invariably performed in the same manner by all the individuals of a species, when the conditions are the same; and thus are obviously to be attributed rather to a uniform impulse, than to a free choice; the most remarkable examples of this being furnished by the economy of Bees, Wasps, and other "social" Insects, in which every individual of the community performs its appropriate part, with the exactitude and method of a perfect machine. The very perfection of the adaptation, again, is often of itself a sufficient evidence of the unreasoning character of the beings which perform the work; for, if we attribute it to their own intelligence, we must almit that this intelligence frequently equals, if it does not surpass, that of the most accomplished Human reasoner.' Moreover, these operations a re performed without any guidance from experience; for it can be proved in many cases, that it is inpossible for the beings which execute them to have received any instruction whatever; and we see that they do not themselves make any progressive attempts towards perfection, but that they accomplish their work ats well when they first apply themselves to it, as after any number of repetitions of the same acts. It is interesting to observe, moreover, that as these instinctive operations vary at different periods of life, so there is a corresponding variation in the structure of the Nervous system. 'Thus we see that, in the larva of the Insect, these operations are entirely directed towards the acquisition of food; and its organs of sense and locomotive powers are only so far developed as to serve this purpose. But in the imago or perfect Insect, the primary object is the continuance of the race; and the sensorial and motor endowments are adapted to enable the individual to seek its mate, and to make preparations (frequently of a most elaborate kind) for the nurture of the offspring.- Hence we can scarcely fail to arrive at the conclusion, that the adapticeness of the instinctive operations of Insects, etc., lies in the original construction of their nervous system, which causes particular movements to be executed in direct respondence to certain impressions and sensations. And this view is confirmed by the comparison of such movements with those which, in the Human subject, are most directly concerned in the maintenance of the life of the individual, and in the perpetuation of the race. For we lave the evidence of our own consciousness in regard to these, that, however obvious their purpose may be, and however complete their adaptation to that purpose, they are performed, not with any notion of that purpose, but at the prompting of an irresistible impulse which is not only independent of all intelligent appreciation of the result, but may produce its effect without even affecting the consciousuese of the agent. Thus the infint seeks the nipple, and puts its muscles into suctorial action, without any knowledge, derived from experience, that by so doing it will relieve the uneasy feeling of hunger; and if we could imagine a man coming into the world with the full possession of all his fuculties, we may feel tolerably certain that he would not wait to eat until he had learned by experience his dependence upon food. We shall see that arlult animals whose Cerebral hemispheres have been removed, will eat food that is put into their mouths, although they will not go to seek it; and this is the case with many Human idliots. When the functions of the Brain are destroyed, or in partial abeyance, as in fever, we often observe a remarkable return to the instinctive

1 See Prine, of Comp. Phys., 4th edit., p. 694. 
propensities in regard to food ; and the Physician frequently derives important guidance with respect to the patient's diet and regimen (particularly as to the administration of wine), from the inclination or disinclination which he manifests. So, in regard to the intercourse of the sexes, the impulse which prompts to it loes not arise from a knowledge of the ultimate purposes which it is designed to answer; and the higher powers of the mind are only so far coneerned in it, that when the action of the instinctive impulse has led to the formation of a clefinite idea of the objeet of desire, the Intelligence is prompterl to take means for its gratification.'

449. Thus, then, the type of psychical perfeetion among Invertcbrated animals, which is manifested in the highest degree in the Social Insects, consists in the exelusive development of the Instinctive faeulty-that is, of automatic power: of a very simple kind; in virtue of which, each indivirlual performs those aetions to whieh it is directly prompted by the impulses arising out of impressions nade upon its afferent nerves, without any selfeontrol or self-direetion; so that it must be regarded as entirely a creature of neessity, performing its instrumental part in the economy of Nature, from no design or will of its own, but in aceordanee with the plan originally devised by its Creator.

450. On turning to the Vertebrated series, on the other hand, we find that its type of psychical perfeetion, as shown in Man, consists in the highest development of the Reason, and in the supreme domination of the Will, to which all the "automatie" actions, save those which are absolutely essential to the maintenance of the Organic funetions, are brought under subjection; so that each individual beeomes not only a thinking and refleeting, but a self-moving and self-eontrolling agent, whose aetions are performed with a definite purpose which is distinctly before his own view, and are adapted to the attainment of their end hy his own intelligence. This, however, is only true of Man in his most elevated state; and not only in ascending the Vertebrated seale, but also in watehing the progressive cvolution of his mental faculties during the earlier periods of his life, may we trace a regular gradation, from a eondition but little (if at all) in advanee of that of the higher Invertebrata, up to that which is displayed in the noblest examples of Humanity. Through the cntire series, however, we pereeive that the Exeitomotor and Sensori-motor portion of the Nervous system ( $\$$ 453) eonstitutes its fundamental and essential part; serving not nierely as the instrument whereby those actions are performed, which are as necessary among the higher aninals as they are among the lower, for the maintenanee of the Organie functions; but also as the immediate recipient of all those impressions from without, by which the higher operations of Mind are exeited, and as the exeeutant of the actions which proeeed from them. But as we ascend the Vertebrated seale, or as we watch the progressive psychical development of the Infant, we find it becoming more and more obvious that the actions are prompted, not so much by simple sensations, as by ideas or notions of the objects to which they relate; these ideas being founded, in a large proportion of instanees, upon the results of past experience, and the eourse of

1 TVe have not, perhaps, any right to affirm that there is nothing whatever analogous in the Invertebrata to the Keasoning powers and Will of higher animals; but if these facultics have any existence among them, they inust be resarded as in a merely rudimentary state, corresponding with the undeveloped condition of the Cerebrum. The only distinct indicution of intelligence displayed by Invertebruta, is the slight degree of capacity of "learning by experience" which some of them disulay; this capacity being hmited to the mere formation of associations between the psychical called up by different objects of sense, which we observe to be the tirst stage in the development of the mental powers in the Human infant. 
action being shaped in accordance with it. In the acts of animals of a still higher grade, as in those of the Child, we can scarcely fail to perceive the manifestation of reasoning processes analogous to those which we ourselves perform, and the expressions of some of those emotional states of which we are ourselves conscious. The superaddition of these more elevated endowments, in the Vertebrated series, is coincident with the addition of a peculiar ganglionic centre, the Cerebrum, to the Sensori-motor apparatus; and the relative proportion which the former bears to the latter, both as to size and to complexity of structure, corresponds so closely with the degree of predominance which the Intelligence possesses over the Instinctive propensities, that it is scarcely possible to doubt that the Cerebrum is the instrument through which this higher form of psychical power is exercised. Much of this exercise, however, may still be cutomatic in its nature; for so long as the current of thought and feeling flows on in accordance with the direct promptings of Suggestion, and without any interference from Volition, may it be considererl as a manifestation of the "reflex" activity of the Cerebrum, which takes the form of a mental instinct. This reflex activity manifests itself not only in the psychical operations themselves, but also in muscular movements; and these, when they proceed from simple ideas without any excitement of feeling mity be designated as ideo-motor: whilst if they spring from a passion or enotion, they are termed emotional. The mental iristincts, however, are by no means as invariable in the different individuals of the same species, as are what maly be termed the physical Instincts of that inferior part of the nervous apparatus, which is more closely connected with the maintenance of the Organic life; the particular changes which any given suggestions will excite in each, being partly determined by original constitution, and partly by acquired habits.

451. The superiority of the Mind of Man over that of the most elevaterl among the lower animals, consists not only in the far greater variety and range of his fitculties, but yet more in that dominant power of the IVill, which enables him to utilize them with the highest effect. In so fir as the course of his thoughts and feelings is the mere result of the action of external impressions upon an organization having certain respondent tendencies, must he be considered as irresponsible for his actions, his character being formed for instead of $b y$ him ; but in so far as he can exert a Volitional power of directing his thoughts and controlling his feelings, may he rise superior to circumstances, make the most advantageous use of the Intellectual fiteulties with which he maty be endowed, and bring his Moral character more and more into accordance with the highest type which his nature may be capable of attaining in its present sphere of existence. Notwithstanding the evidences of rationality which many of the lower animals present, and the manifestations which they display of emotions that are sinilar to our own, there is no gromnd to believe that they have any such controlling power; on the contrary, all observation seems to learl to the conclusion, that they are under the complete donnintion of the ideas and emotions by which they may be for the time possessed, and have no power either of repressing these by a forcible atct of Will, or of turning the attention, by a like voluntary effort, into another channel. In this respert, then, their condition resembles that of the Dreamer, the Somnambule, or the Insane patient, in all of whom this voluntary control is suspended, and who (when their ninds are susceptible of exterial impressions) may be so "played upon" by the suggestion of idleas, that any respondent action consistent with the ordinary mental state of the individual may be evoked by an appropriate stimulus; just as we see in the case of animals that are trained to the performance of particular sets of 
movements, which are executed in respondence to certain promptings conveyed to them through their sensorimm. Now betwcen the complete want of this controlling power of the IVill, and the most perfect possession of it, every intermediate gradation is presented by the several individuals which make up the Human specics; some persons being so much acenstomed, in consequence of the wealkness of their. Will, to act directly upon the prompting of every transient impulse, that they can searcely be said to be voluntary agents; and others allowing certain dominant ideas or habitual feelings to gain snch a mastery over them, as to exercise that determining power which the IVill aloue ought to cxert. This gradation may be perfectly traced in children, in whose education the development of the faculty of "self-control" should be a leading object; and it is also displayed in certain phases of mental Imbecility, which result from a deficiency of the power of voluntarily fixing the attention upon any object of conscionsness, and of thus withdrawing it cither from external objects that tend to distract the mind, or from notions it has arlopted which hold it in subjection.

452. When we apply oursclves to the study of the Cerebro-Spinal Nervous centres of Man, we find ourselves peculiarly liable to be misled by the great development which the Ccrebrum presents, both as to size and to complexity of structurc, in proportion to the other centres; and thus it has happened that, through the too cxclusive attention commonly paid to Human. Anatomy, the meaning of the facts bronght to light by dissection has hecn very commonly misapprehended, aud many of the physiological interpretations based upon them have becn completely ncgatived by more cxtended inquiry.-It is only, in fact, by studying the Cerebro-Spinal apparatus in its lowest, as well as in its highest form, and by bringing the intervening grades into comparison with both extremes, that it is possible to establish what are its fundamental or essential, and what its accessory parts; and in this way only can such a correspondence be established between the development of a particular structure and the manifestation of a psychical endowment, as may enable the latter to be attributed with any degree of probability to the former. In fact there is no part of the Human Organism, as to which the advantages of such a comparison are so striking, or" in which the value of the "experiments ready preparer for us by Nature" is so much above that of the results of artificial mutilations.

453. Cerebro-Spinal Nervous Centres.--Under the guidance, then, of these principles, we find that we may distinguish, as the fundamental part of the Cerebro-spinal apparatus of Man, the Cranio-Spinal Axis, consisting of the Spinal Cord, the Medulla Oblongata, and the Sensory Ganglia, and altogether constituting the centrc of automatic movement.-The Spinal Cord, consisting of a tract of vesicular natter inclosed within strands of longitudinal fibres, and giving off successive pairs of intervertebral nerves which are connected at their roots with both of these components, is obviously homologous with the gangliated ventral column of the Articulata, chiefly differing from it in the continuity of the ganglionic substance which occupies its interior; and each segmental division of it, which serves as the centre for its own pair of nerves, may be considered, like each ganglion of the ventral column of the Articulata, as a repetition of the single "pedal" or locomotive ganglion of the Mollusca.-The Medulla Oblongata consists of a set of strands, which essentially correspond with the cords that pass round the nesophagus in Invertebrated animals, connecting the cephalic ganglia with the first subosophageal ganglion; but as the whole cranio-spinal axis in the Vertebrata lies chove the alimentary canal (the trunk being supposed to be in a horizontal position), there is no such divergence of these strauds, the only 
separation between them being that which is known as the "fourth ventricle." Interposed among the comnissural fibres of the Medulla Oblongata, however, are certain collections of vesicular matter, which serve as the ganglionic centres, governing the calibre of the vessels, and for the movements of respiration and deglutition, the latter corresponding with the "respiratory" and "stomato-gastric" ganglia of Invertebrated animals. This incorporation of so many distinct centres into one system, would seen destined in part to afford to all of them the protection of the vertebral column; and in part to secure that consentaneousuess of action and that ready means of mutual influence, which are peculiarly requisite in beings in whom the activity of the Nervous system is so predominant. Thus the close connection which is established in the higher Vertebrated animals between the respiratory and the general locomotive apparatus, is obviously subservient to the nse which the former makes of the latter in the performance of its functions; whilst, on the other hand, the control which their encephalic centres possess over the actions of the respiratory ganglia, enables the Will to regulate the inspiratory and expiratory movements in the manner required for the acts of vocalization.- Under the term Sensory Ganglia, may be comprehended that assemblage of ganglionic masses lying along the base of the skull in Man, and partly included in the Medulla Oblongata, in which the nerves of the "special senses," Taste, Hearing, Sight, and Smell, have their central terminations; and with these may probably be associated the two pairs of ganglionic bodies known as the Corpora Striata and Thalami Optici, into which may be traced the greater proportion of the fibres that constitnte the various strands of the Medulla Oblongata, and which secm to stand in the same kind of relation to the nerves of Touch or "common sensation," that the Olfactive, Optic, Auditory, and Gustative ganglia bear to their several nervetrunks.

454. Now it is not a little interesting that this Cranio-Spinal axis, which represents in Vertebrated animals the whole nervous system of the Invertebrata (with the exception of the rudiment of the Sympathetic which they posscss), should exist in the lowest known Vertebrated animal without any superaddition, and should be sufficient for the performance of all its actions. Such is the case in the curious Amphioxus, a little fish which presents not the slightest trace of either Ccrebrum or Cerebellum, and in which even the sensory ganglia and the organs of special sense lave only a rudinentary existence; and in which, too, the spinal cord is composed of a series of granglia that are obvionsly distinct from each other, although in close approximation. And even in the lower Cyclostome Fishes, the condition of the nervous centres is very little above this, save as regards the larger develonment of the sensory ganglia.-This condition has its parallel, even in the Human species, in the case of Infants which are occasionally born without either Cerebrum or Cercbellum; snch have existed for several hours, or even days, breathing, sucking, crying, and performing various other movements; and there is no physiological reason why their lives should not be prolonged, if they be nurtures with sufficient care.

45.5. In Man, however. as in all the higher Vertebrata, we find supcrimposed (as it were) upon the Sensory ganglia, and constitnting the principal mass of the Encephalon, the bodies which are known as the Cerebrul Hemispheres, or Hemispheric Ganglia. Now when these are so greatly developed as to cover in and obscure the Sensory ganglia to the degree which presents itself in Man, it is not surprising that the fundamental importance of the latter should not be generally recognized; in Fishes, however, the proportion between the two sets of eentres is entirely reversed, the rudiments of the Cere- 
bral Hemispheres (Fig. 193, 13) being usually inferior in size to the Optic ganglia (c) alone. Indeed, of the pair of ganglionic masses to which that designation is usually applied, it may be almost positively staterl, that the greater part is liomologous with the Corpora Striatia of the Human Brain; it being only in the higher Cartilaginous fishes, that a ventricular cavity exists in each of these bodics, separating the thin layer of true Cerebral substance which overlies it, from the ganglionic mass which forms its floor. Between these two extremes, a regular gradation is presented in the intermediate tribes.-Now it is a point especially worthy of note, that no sensory nerves terminate directly in the Cerebrum, nor do any motor ucrves issue from it; and there seems a strong probability that there is not (as formerly supposed) a direct continuity between all or even any of the nervefibres distributed to the body, and the Medullary substance of the Cerebrum. For whilst the nerves of "special" sense have their own gauglionic centres, it camnot be shown that the nervous fibres of "general" sense, which either enter the craniun as part of the cephalie nerves, or which pass up from the Spinal cord, have any higher destination than the Thalami Optici. So the motor fibres which pass forth from the cranium, either into the cephalic nerve-trunks, or into the motor columns of the spinal cord, though commonly designated as Cerebral, cannot be certainly said to have a higher origin than the Corpora Striata. And we shall find strong physiological as well as anatomical ground for the belief, that the Cerebrum has no communication with the external world, otherwise than by its connection with the Sensori-motor apparatus; and that even the movements which are usually designated as "voluntary" are only so as regards their original source, the stimulus which calls the nuscles into contraction being even then immediately issued from the Cranio-Spinal axis, as it is in the movements prompted by the reflex stimulation of an external impression.

456. Wherever a Cerebrum is superimposed upon the Sensory Ganglia, we find another ganglionic mass, the Cerebellum, superimposed upon the Medulla Oblongata. The development of this organ bears a general, but by no means a constant relation to that of the Cerebrum; for in the lowest Fishes it is a thin lamina of nervous matter on the median line, only partially covering in the "fourth ventricle;" whilst in the higher Mammalia, as in IIan, it is a mass of considerable size, having two lateral lobes or hemispheres in addition to its central portion. The direct eommunication which the Cerebellum has with both columns of the Spinal cord, and the comparatively slight commissural connection which it possesses with the higher portions of the Encephalic centres, justify the supposition that it is rather concerned in the regulation and co-ordination of the actions of the former, than in any proper psychical operations; and it will hereafter be shown that the various kinds of evidence afforded by Comparative Anatomy, by Experimental inquiry, and by Pathological observation, all tend to support this view of its function.

45\%. Now although every segment of the Spinal Cord, and every one of the Sensory Ganglia, may he considered, in common with the Cerebrum, as a true and independent centre of nervous power, yet this independence is only manifested when these organs are separated from each other; either 
structurally - by actual division; or finctionally-by the suspension of the activity of other parts. In their state of perfect integrity and complete functional activity, they are all (at least in Man) in such subordination to the Cerebrum, that they only minister to its actions, except in so far as they are subservient to the maintenance of the Organic functions, as in the automatic acts of hreathing and swallowing. With regard to every other action, the Vill, if it possesses its due predominance, cau exercise a determiniug power; keeping in check every automatic impulse, and repressing the promptings of emotional excitement. And this seems to result from the peculiar arrangement of the nervous apparatus; which causes the excitor impression to travel in the uproard direction, if it meet with no interruption, until it reaches the Cerebrum, without exeiting any reflex movements in its course. When it arrives at the Sensorium, it makes an inıpression on the consciousness of the individual, and thus gives rise to a sensation; and the change thus induced, being further propagated from the sensory ganglia to the Cerebrum, becomes the occasion of the formation of an idea. If with this idea any pleasurable or painful feeling should be associated, it assumes the character of an emotion: aud either as a simple or as an emotional idea, it beconres the subject of intellectual operations, whose final issue is in a volitional determination, or act of the WVill, which may be exerted in producing or checking a muscular movement, or in controlling or directing the current of thought.

458. But if this ordinary upwart course be anywhere intermped, the impression will then exert its power in a transverse direction, and a "reflex" action will be the result; the nature of this being dependent upon the part of the Cerebro-Spinal axis at which its ascent had been checkel. Thus, if the interruption be produced by division or injury of the Spinal Cord, so that its lower part is cut off from communication with the encephalic centres, this portion then acts as an independent centre; and impressions made upon it through the afferent nervcs proceeding to it from the lower extremities, excite violent reflex movements, which, being thus produced without sensation, are designated as "excito-motor."-So, again, if the impression should be conveyed to the Sensorium, but should he prevented by the removal of the Cerebrum, or by its state of functional inaction, or by the direction of its activity into some other chamnel, from calling forth ideas through the instrumentality of the latter, it may react upon the motor apparatus by the "reflex" power of the Sensory ganglia themselves; as seems to be the case with regard to those locomotive actions which are maintained and guided by sensations during states of profound abstraction, when the attention of the individual is so completely concentrated upou his own train of thought, that he does not perceire external objects, although his movements are obviously guided through the visual and tactile senses. Snch actions, being dependent upon the prompting of sensations, are "sensori-motor" or "consensual." -But further, even the Cerebrum responds automatically to impressions fitted to excite it to "reflex" action, when from any cause the Will is in abeyance, and its power cannot be exerted either over the muscular system or over the direction of the thoughts. Thus in the states of Reverie, Dreaming, Somnambulism, ets., whether spontaneous or artificially induced, ideas which take possession of the mind, and from which it camnot free itself, may excite respondent movements; and this may happen also when the force of the Idea is norbidly exaggeraterl, ancl the WVill is not suspended, but merely weakened, as in many forms of Insinity.

459. The goneral views here put forth in regard to the independent and connected actions of the several primary divisions of the Cerebro-Spinal apparatus, may perhaps be renlered more intelligible by the following 
table, which is intended to represent the ordinary course of operation when the whole is in a state of complete functional activity, and the character of the "reflex" actions to which each part is subservient, when it is the highest

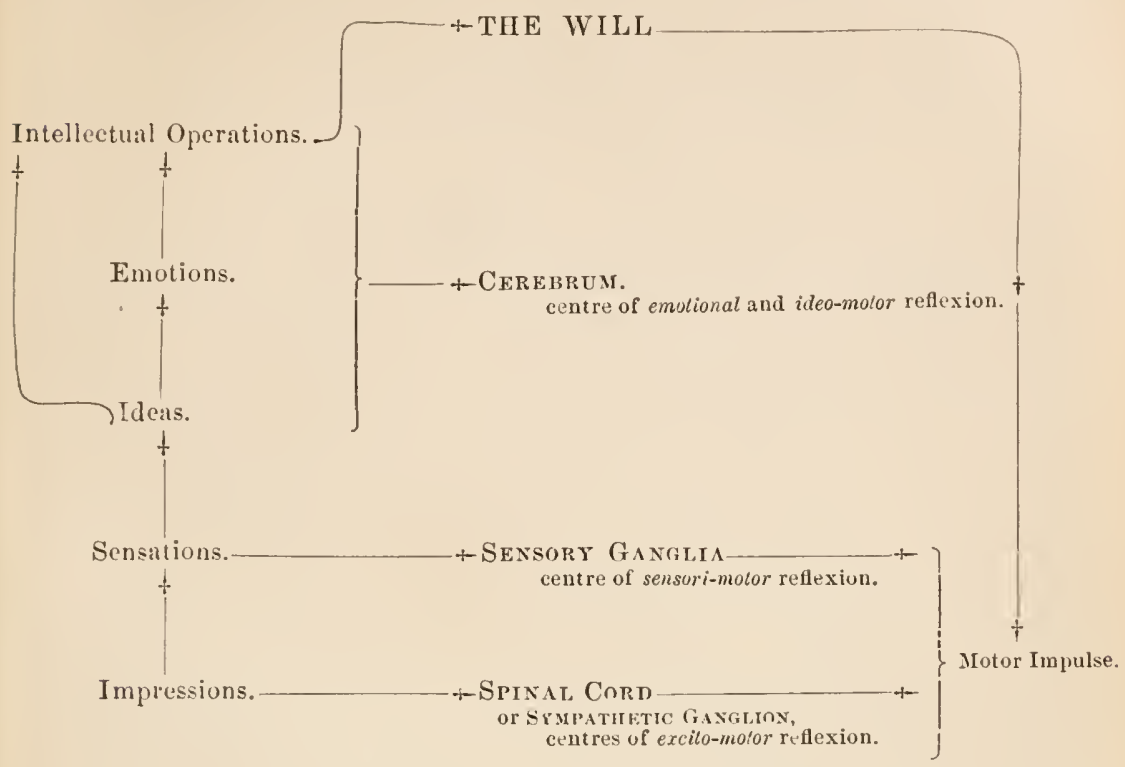

centre that the impression ean reach. The directing power of the Will seems to be most strongly exerted over those actions which are most closely connceted with psychical changes, and which are exclusively Cerebral in their seat. It has been already pointed out, that the Cranio-Spinal axis not merely serves as the channel for the reception of the impressions which excite the activity of the Hemispheric ganglia, and as the instrument whereloy the result: of their operation are brought to bear upon the muscular system; but that it is also the centre of reflexion through which various automatic movements are called forth, that are immediately concerner in the maintenance of the organic functions. The impressions which excite these movements do not in general pass on to the Cerebrum; for we nuly perceive them when we specially direct our attention to them, or" when they exist in unusual potency. Thus we are unconscious of the "besoin de respirer" by which our ordinary novements of respiration are prompted; and it is only when we have refrained from breathing for a few seconds, that we experience a sensation of uneasiness which impels us to make forcible efforts for its relief. Notwithstanding, however, that the Cerebrum is thus unconcerned in the ordinary performance of those antonatic movements, yet it can exert a certain degree of control over many of them, $s$ as even to suspend them for a time, though in no instance can it carry this suspension to such an extent as seriously to disarrange the Organic functions; thus, when we have voluntarily refrained from breathing for a few seconds, the inspiratory impulse so rapidly increases in strength with the continuance of the suspension, that it at last overcomes the most powerful effirt we can make for the repression of the movements to which it prompts $(\S 300$, note). Now in this and similar cases it would seem as if the Will interfered to prevent that direct transverse passage of the stimulus from the afferent to the efferent nerves through 
the Cranio-Spinal axis, which constitutes the ordinary line of action for impressions having their origin in the necessities of the Organic or Vegetative life of the individual. That the Will should have a certain degree of control over these movements, is necessary in order that they may be rendered subscrvient to various actions which are necessary for the due exercise of Man's psychical powers; but that they should not be left dependent upon its exercise, and shonld even be exccuted in opposition to it when the wants of the systcm imperatively demand their performance, constitutes a wise provision for sccuring Life against the chance of inattention or momentary caprice.

460. The Cerebro-Spinal system is intimately blended with another set of ganglionic centres and nerve-trunks, scattered in different parts of the body, but mutually connected with each other; this is commonly termed the sympathetic system; but not unfrequently, from the position of its principal centres, and their evident functional relation to the apparatus of Organic life, the Visceral system. To this system we are probably to refer, not only the Semilunar and Cardiac ganglia (which seem to be its principal centres), with the chain of cranial, cervical, thoracic, lumbar, and sacral ganglia, which are in ncarer connection with the Ccrebro-spinal system; but also numerous minute ganglia, which are to be found on its branches in various parts. Moreover, the ganglia upon the posterior roots of the Spinal nerves, and those upou the roots and trunks of certain Cranial nerves, may be ranked with considerable probability under the same category; and if such be the case, those fibres contained in the Cerebro-spinal nerves, which have these as their ganglionic centres, must also be accounted as belonging to the Sympathetic system. On the other hand there unquestionably exist numerous fibres in the Visceral system, which proceed into it from the Cerebrospinal system ; these, however, are not uniformly distributed, for somc of the Visceral nerves contain few or none of them, whilst in others they are numerous. The branches by which the Sympathctic system communieates with the Cerebro-spinal, and which were formerly considered as the roots of the Sympathetic system, seem to contain fibres of both kinds; i. e., Cerebrospinal fibres passing into the Sympathetic, and Sympathetic fibres passing into the Cerchro-spinal. The latter are chiefly, if not entirely, transmitted into the anterior branches of the Spinal nerves; the posterior branches being apparently supplied with sympathetic fibres from the ganglia on their own posterior roots. Somc of thesc last fibres also pass from the Cerebro-spinal into the Sympathetic system. By these communications, the two systems of fibres are so blended with each other, that it is impossible to isolate them.The branches procceding from the Scmilumar ganglia are distributed upon the vessels of the abdominal viscera; and those of the Cardiac ganglia upon the heart and vessels proceeding from it. The latter seem to accompany the arterial trunks through their whole course, ramifying minutely upon their surface; and it can scarcely be doubted that they exercise an important influence over their functions. What the nature of that influenec maty be, however, will be a subject for future inquiry (chap. xvii). It is so evidently connected with the operations of nutrition, secretion, ctc., that the designation, "nervous system of organic life," as applied to this system, does not secm objectionable, provided that we do not understand it ats denoting the dependence of these functions upon it.-The interpenctration of the Cerehro-spinal system by the Sympathetic is strongly marked by these two circumstances, - that, in some of the lower Vertebrata, the distribution of their trunks cannot be separately distinguished; and that, even in the highest, some of the Glands, of which the secretion is most directly influeneed by the condition of the mind, are supplied with most of their nerves from 
the ccrcbro-spinal system, the lachrymal and sublingual glands receiving large branches from the fifth pair, and the mammary glands from the intereostal nerves.

461. Cerebro-Spinal Nerve-Trunks.-IIaving thus considered the principal attributes of the ganglionic centres of the Cerebro-spinal system, we have next to inquirc into those of the nerve-trunks which are connected with them. It is only in the Vertebrata, that the difference between the afferent and efferent fibres of the nerves has been satisfactorily determined. The merit of this discovery is almost entirely due to Sir C. Bell, who was led to it by a chain of reasoning of a highly philosophical character ; and although his first experiments on the Spinal nerves were not satisfactory, he virtually determined the respective functions of their two roots,- the posterior as sensory (afferent), the anterior motor (efferent),-by experiments, and by pathological observations upon the Cranial nerves, some of which contaiu only onc class of fibres to the exclusion of the other, before any other physiologist came into the field. ${ }^{1}$ Subsequently his general views were confirmed by the rery decided experiments of Müller; but until very recently, sonte obscurity hung over a portion of the phenomena. It was from the first maintained by Magendie, and has been subsequently asserted by other physiologists, that the posterior and anterior roots of the nerves were both concerned in the reception of impressions and in the production of motions ; for that, on touching the posterior roots, not only the sensibility of the animal seemed to be affected, but muscular motions were excited; aud that, when the anterior roots were touched, the animal gave signs of pain, at the same time that convulsive movements were performed. These physiologists were not willing, therefore, to admit more than that the posterior roots were especially seusory, and the anterior especially motor. But the knowledge we now possess of the "reflex" function of the Spinal Cord euables the former portion of these phenomena to be easily explained. The motions excited by irritating the posterior roots are found to be entirely dependent upon their connection with the Spinal Cord, and upon the integrity of the anterior roots and of the trunks into which they enter; whilst they are not checked by the separation of the posterior loots from the peripheral portion of the trunk : it is evident, therefore, that excitation of the posterior roots does not act immediatcly upon the muscles, through the trunk of the nerve which they contribute to form; but that it excites a reflex motor impulse in the Spinal Cord, which is propagated through the anterior roots to the periphery of the system.The converse phenomenon of the apparent seusibility of the auterior roots of the Spinal Nerves has been recently investigated and satisfactorily explained by M. Brown-Séquard. If these roots be irritated, the animal usually gives signs of uneasiness; but if they be divided, and the cut ends nearest the centre be irritated, none such are exhibited: whilst they are still shown when the farther ends are irritated, but not if the posterior roots are divided. According to M. Brown-Séquard, ${ }^{2}$ these phenomena are simply due to the circumstance, that on irritating the distal extremities of the anterior roots the muscles supplied by them are thrown into a state of cramp, and pain is experienced from the violent compression of the extremities of the sensory nerves, which of course is no longer felt when the roots of the latter are divided.

462. Every fibre, there is reason to belicve, runs a distinct course, between the contral organ, with one of the cclls of which it is conuected at one extremity, and the organ of sense, muscle, or other tissue, in which it either

1 See British and Foreign Med. Review, vol. ix, p. 140, ete.

${ }^{2}$ Lectures on the Pbysiology of the Central Nervous System, 1860, Lecture i. 
terminates or forms a loop at the other; in the terminal ramifications of the nerves, however, a subdivision and plexiform arrangement of the fibres is frequently observable. Although the fascieuli vecasionally intermix and exehange fibres with one another (as occurs in a plexus), the fibres themselves never inosculate. Each fibre would seem, therefore, to have its appropriate office, which it cannot share with another.-Several objects appear to be attained by the plexiform arrangement. In some instances it serves to intermix fibres, which have endowments fundamentally different; for example, the Spinal Aecessory nerve, at its origin, appears to be exelusively motor, and the roots of the Pneumogastric to be exclusively afferent; but by the early admixture of these, a large number of motor fibres are imparted to the Pneumogastric, and are distributed in variable proportion, with its different branches; whilst a few of its sensory filaments seem to enter the Spinal Accessory.-In other instanees, the object of a plexus appears to be to give a more advantageous distribution to fibres, which all possess corresponding endowments. Thus the Brachial plexus mixes together the fibres arising from five segments of the spinal cord, and sends off five prineipal trunks to supply the arm. Now if eaeh of these trunks had arisen by itself, from a distinct segment of the spinal eord, so that the parts on which it is distributed had only a single ennneetion with the nerrous eentres, they would have been much more liable to paralysis than at present. By means of the plexus, every part is supplied with fibres arising from several segments of the spinal eord; and the funetions of the whole must therefore be suspended, before complete paralysis of any part cau oecur from a cause which operates above the plexus. Such a view is borne out by direet experiment; for it has been ascertained by Panizza that, in Frogs, whose Crural plexus is much less enmplieated than that of Mammalia, seetion of the roots of one of the three nerves which enter into it, produces little effeet on the general movements of the limb; and that, even when $t$ wo are divided, there is no paralysis of any of its actions, all being weakened in a nearly similar degree. ${ }^{1}$ All eonsideration of the mode in which we make use of our museles, and of the power which we have over them, leads to the eonclusion that each ganglionie eentre has a specific and limited sphere of influence, producing eertain movements and no others; hence, for the execution of a variety of morements in harmonious eombination with each other, it seems requisite that the nerrous supply of each muscle should be derived from several different centres; and thus it is, that the complication of plexuses comes to be related to the variety of movements of the parts supplicel through them. It is not a little interesting to remark, that arrangements of a similar kind present themselves anong the higher Invertebrata.

463. The following statements, in which the doctrines of Prof. Muller ${ }^{2}$ are adopted with some modifications and additions, embody the greneral principles ascertained by experiment, respeeting the transmission of Sensory and Motor impressions along the nerves whieh respectively minister to them. Their rationale will be at once understood, from the facts alrealy mentioned, in regard to the isolated character of eaeh fibril, and the identity of its endownents through its whole eourse.

1 Striking illustrutions of the importanee of the plexiform erommunicution of nerves are atforded by such cases as that recorded hy Mr. Savory (Lameret, Lug lst, 18i8), where, afterexcision of a portion of the muscule spiral nerve, the sensibility of the part supplied by it, thougl impaired, was still to some extent retained, in eonsequence probubly of the communieations that cxist betwoen the radinl and external coltancous nerves in the forenrm. Sae also WV Gull, Gulstonian Leetures (on the Nervous sys=tem, in II edical T'imes, $1849, \%$. 37\%?

2 Elcments of Physiology, trunslated by Dr. Baly ; lp. 68', 686. 
I. When the whole trunk of a sensory nerve is irritated, a sensation is produced, which is referred by the mind to the parts to which its hranches are ultimately distributerl; and if only part of the trunk be irritaterl, the sensation will be referred to those parts only which are supplicel by the fibrils it contains. - This is evidently caused by the production of a change in the sensorium, corresponding with that which would have been transmitted from the peripheral organs of the nerves, had the impression been made upon them. Such a change only requires the integrity of the affierent trunk between the point irritated and the sensorium, and is not at all rlependent upon the state of the peripheral yart to which the sensations are referrer, for this may have been paralyzed by the division or other lesion of the nerve, or nay have been altogether separated as in amputation, or the relative position of its parts may have been changed as in autoplastic operations. So, when different parts of the thickness of the same trunk are separately and successively irritated, the sensations are successively referred to the several parts supplied by these divisions. This mat be easily shown by compressing the uhnar nerve in different directions, where it passes at the inmer side of the elbow-joint. - Still the mind undoubtedly does possess a certain power of discriminating the part of the nerve-trunk on which the impression is made; for whilst this impression is such as to produce sensations that are referred to its peripheral extremitics, pain is at the same time felt in the spot itself; and it would scem as if slight impressions are only felt in the latter situation, at least in the normal condition of the trumk or tibre. Thus, as it has been well remarked by Volkmann, "if a needle's point be drawn in a straight line across the back, or the thigh, or any part in which the nerves are widely placed, the mind perceives the line of irritation as a straight one; whereas, if it referred all impressions to the ends of irritated fibres, this morle of irritation should be felt in sensations variously scattered about the line, at the points where the rerve-fibres crossed by the needle terminate."

Ir. 'The sensation produced by irritation of a branch of the nerve is confined to the parts to which that branch is distributed, and does not affect the blamches which come off from the nerve higher up.- The rationale of this law is at once intelligible; but it should be mentioned that there are certain conditions, in which the irritation of a single nerve will give rise to sensations over a great extent of the body. This "raliation of sensations" seems rather due, however, to a particular state of the central organs, than to any direct communication anong the peripheral fibres.

111. In general the motor influence is propagated only in a centrifugal direction, and not in a retrograde course. It may originate in a spontaneous change in the central organs, or it may be excited by an impression conveyed to them through afferent nerves; but in both cases its law is the same. There is, however, a well-known experiment termed the "paradoxical contraction of muscle," which shows that motor nerves nay under certain circumstances convey impressions centripetally. If a motor nerve be selected which divides into two branches (as for example the sciatic of the frog, which divides above the bend of the knee into the tibial and peroneal branches), and a galvanic stimulus be applied to either of these branches, this having been first divided above its insertion in to the muscles, the electrotonic state will be developed, not merely in the portion of the trunk continuous with that branch, but also in that which is continuous with the other branch, as will be made apparent by the contraction in the muscles supplied by the latter. That this experiment may be free from the possible fallacy resulting from the excitement of reflex action, the trunk of the sciatic nerve should be divided high up, or

1 Kirlies und Paget's Handbook of Physiology, p. 375. 
the spinal cord be destroyed.-Lastly the occurrence of the negative oscillation of the current, that is to say the disappearance of the normal current which exists in both sensory and motor nerves, on excitation of these nerves by any stimulus, affords an additional proof that the particles of nerves can conduct in either direction. In the same way, although as a rule sen:ory impressions are only conducted towards the new centres, yct some evidence has been obtained to show that they may conduct in an opposite dircction. Thus, MM. Philippeaux and Vulpian ${ }^{1}$ hivided the hypoglossal and lingual nerves, which are conveniently placed for the experiment, and applied the peripheric extremity of the hypoglossal to the centric extremity of the lingualis. They found that in a few weeks union took place, and that the muscles of the tongue might be excited to contract by an electrical current applied to the linguatis or scnsory nerve. MII. Philippeanx and Vulpian drew the conclusion that when the properties of the hypoglossal are abolished by section the lingualis after the lapse of some time acquires motor fibres it did not previously possess. It is to be observed, however, that although the fibres can thus conduct an electrical stimulus there is total loss of voluntury control over the lingual muscles, and if the operation be performed on both sides the animal is rendered permanently incapable of protruding his tongue. In Bidder's experiments," microscopical examination of the nerves showed that the peripheric extrenity of the lingualis consisted exclusively of nervefibres which had undergone fatty rlegeneration, whilst in the peripheric portion of the hypoglossal which had united with the centric of the lingualis, the greater number of the fibres presented their nornal characters. And this accorded with the fact that, when the nerve was cut during life, the animal gave marked indication of pain, and the same side of the tongue was convulsed.

Iv. When the whole trunk of a motor nerve is irritated, all the muscles which it supplies are caused to contract. This contraction evidently results from the similarity between the effect of an artificial stimulus applicel to the trunk in its course, and that of the change in the central organs by which the motor influence is ordinarily propagated. But when only a part of the trunk or a branch is irritated, the contraction is usually confined to the muscles which receive their nervous fibres from it; in this instance, as in the other, there is no lateral communication between the filbrils.

464. Determination of the Functions of Nerves. - Various methods of determining the functions of particular nerves present themselves to the Physiological inquirer. One source of evidence is thaw from their peripheral dixtribution. For example, if a nervous trunk is found to lose itself entirely in the substance of Muscles, it may be inferred to be chiefly, if not entirely, motor or efferent. In this manner Willis long ago determined that the Third, Fonrth, Sixth, Portio dura of the Seventh (or Fatcial), and Ninth cranial nerves, are almost entirely sulservient to nuscular movement; and the same had been observed of the fibres procecting from the small root of the Fifth pair, before Sir C. Bell experimentally determined the double function of that division of the nerve into which alone it enters. Again, where a nerve passes through the muscles, with little or no ramification among them, and procceds to a Cutaneous or Mucous surface on which its branches are minutely distributed, there is equal reason to believe that it is of a sensory or rather of an afferent character. In this manner Willis came to the conclusion, that the Fifth pair of cranial nerves differs from those previously mentioned, in

I MM. Ihilippeaux and Vulpian, Comptes Rendus, 1860, t. ii, p. 363, and idem, t. iii, p. 58 Auchiv. Gén. de Médıcino, July, 1863, p. 122. See also Gluge and Thiernrs:se. Brown-séquard's Journal de la Pliysiologie, 1859, t. ii, p. 686.

2 Reichert's Arehiv, $1865, \mathrm{p} 246$. 
being partly sensory. Further, where a nerve is entirely distributed upon a surface adapted to recive impressions of a special kind, as the Schneiderian membrane, the retina, or the membrane lining the internal ear, it may be inferred that it is not capable of transmitting any other kind of imprescions; for experiment has shown that the speciul sensory nerves lo not possess common semsibility. The case is different, however, in regard to the sense of tastc, which originates in impressions not far removed from those of ordinary touch; and it is probable that the same nerves minister to both.- Inatomical evidence of this kind is valuable also, not only in reference to the functions of a principal trunk, but even as to those of its several branches, which, in some instauces, differ considerably. 'Thus, some of the branches of the Pueumogastric are especially motor, and others almost exclusively afferent; and anatomical examination, carefully prosecuted, not only assigns the reasons for these functions, when ascertained, but is in itself nearly sufficient to determine them. For the superior laryngeal branch is distributed almost entirely upon the mucous surface of the larynx, the only muscle it supplies being the crico-thyroid; whilst the inferior laryngeal or recurrent is almost exclusively distributed to the muscles. From this we might infer, that the former is an afferent, and the latter a motor nerve; and experimental inquiries (as we have seen, $\$ 301$ ) fully confirm this view. In like manner it may be shown, that the Glosso-pharyngeal is chiefly an afferent nerve, since it is distributed to the surface of the tongue and pharynx: and scarcely at all to the inuscles of those parts; whilst the pharyngeal branches of the Pueumogastric are chiefly, if not entirely, motor (\$\$9). Lower down, however, the branches of the Glosso-pharyngeal cease, and the oesophageal branches of the Pneumogastric are distributed both to the mucous surface and to the muscles, from which it may be inferred that they are botlo afferent and motor ; a deduction which experiment confirms $(\$ 90)$. - We perceive, therefore, that much knowledge of the function of a nerve may be obtained from the attentive study of its ultimate distribution; but it is necessary that this shuuld be very carefully ascertained, before it is made to serve as the fommation for physiological inferences. As an example of former errors in this respect, may be mentioned the description of the Portio dura of the Seventh (or Facial) at first given by Sir. C. Bell; for he incorrectly stated it to be distributed to the skin as well as to the muscles of the face, and erroneously regarded it as in part an afferent nerve, subservient to respiratory impressions as well as to motions. In the same mauner, from inaccurate observation of the ultimate distribution of the Superior Laryngeal nerve, it was long regarded as that which stimulated to action the constrictors of the glottis.

465. But the knowledge obtained by such anatomical examinations alone is of a very general kind; and requires to be made particular, to be corrected and modified, by other sources of information. One of those relates to the commection of the trunks with the central organs. 'The evidence derived from this source, however, is seldom of a very definite character; and, in fact, Plysiologists have rather been accustomed to judge of the finctions of particular divisions of the nervous centres by those of the nerves with which they are connected, than to draw aid from the former in the determination of the latter. Still, this kind of examination is not without its use, when there is reason to believe that a particular tract of fihrous structure has a certain function, and when the office of a nerve whose roots terminate in it is doubtful. Here, again, however, very minute and accurate examination is necessary, before any sound physiological inferences can be drawn from facts of this description; and many instances might be adduced to show, that 
the real connections of nerves and nervous eentres are often very different from their apparent ones.

466. Most important information as to the funetions of partieular nerves may be diawn from experimentul inquiries; but these also are liable to give fallacious results, unless they are proseeuted with a full knowledge of all the precautions necessary to insure suc'cess. Some of these will be here explained. In the first place, the endowments of the trunk and of the roots of a nerve may differ; owing to the admixture, in the former, of fibres derived by inosculation from another nerve $(\S 463)$. Henee, in order to attain satisfactory results, a comparative set of experiments should always be made upon each.- A nerve-trunk may be too hastily eonsidered as motor, on account of the excitation of muscular movements by irritation of its trunk, whilst still in connection with its centre; for such novements may be ealled forth, not only by the direct influenee of the nerve upon the museles, but also by reflex stimulation acting through the ganglionie centre upon some other nerve. The real nature of such movements can only be determined by dividing the trunk, and then irritating each of the eut extremities. If, upon irritating the end separated from the eentre, muscular contractions are produced, it may be safely inferred that the nerve is, in part at least, of an efferent character. Should no such result follow, this would be improbable. If, on the other hand, muscular movement should be produced by irritating the extremity in comnection with the centre, it will then be evident, that it is occasioned by an impression conveyed towards the centre by this trunk, and propagated to the muscles by some other; in other words, to use the language of Dr. M. Hall, this nerve is an "exeitor" of motion, not a direet motor nerve. The Glossopharyngeal has been satisfactorily determined, by experiments of this lind, performed by Dr. J. Reid $(\$ 89)$, to be chiefly, if not entirely, an aflerent nerve.-It has been from the want of a proper mode of experimenting, that the functions of the posterior roots of the Spinal nerves have been regarded as in any degree motor. If they be irritated, without division of either root, motions are often excited; but if they be divided, and their separated trunks be then irritated, no motions ensue; nor are any movements produeed by irritation of the roots in connection with the spinal cord, if the anterior roots have been divicled. Henee it appears that these fibres do not posiess any direct motor powers, but that they convey impressions to the eentre, which are reflecter to the muscles through the anterior roots.-The same diffieulties do not attend the determination of the sensory endowments of nerves. If, when the trunk of a nerve is pricked or pinched, the animal exhibits signs of pain, it may be eoncluded that the nerve is eapable of reeeiving and transmitting sensory impressions from its peripheral extrenity. But it not unfrequently happens that this eapability is derived by inosculation with another nerve; as is the ease with the Facial, which is sensory after it has pasecd through the parotid gland, having received there a twig from the Fifth pair.

467 . The fallaeies to which all experiments upon the nerves are subject, ariving from the partial loss of their power of receiving and convering inpressons, and of exciting the muscles to aetion, after death, are toc obvious to require more particular mention here; yet they are frequently overlooked. Of a similar description are those arising from severe clisturbance of the system, in consequence of operations; which also have not been enough regarded by experimenters. - As a general rule, negative results are of less value than positive, but very careful diserinination is often required to determine what ure negative, and what positive results. Each particular ease has its own sonres of fillacy, which require to be logically serutinized; and the only satisfactory proof is derived fron the eoncurrence of every kind of evidence which 
the nature of the inquiry admits of. Thus in the determination of the functions of a particular nerve-trmuk, it should be shown that a certain effect is constuntly produced by its excitation (under the conditions laid rown in the preceding paragraph), and that a corresponding in terruption in the action to which it is hence inferred to be subservient, takes place when its continuity has been interrupted; by this double proof, the Glosso-pharyngeal and the P'neumogastric are shown to be the principal, but not the sole, excitors of the movements of Deglutition and Inspiration respectively. But the evidence afforded solely by the interruption of a particular function, after the division of a certain nerve, or the destruction or removal of a nervous centre, is by no means so satisfactory; for this may be occasioned rather by the general effects of the operation, than by the simple lesion of the nervous apparatus. In order to get rid, so firr as possible, of this source of fillacy (which particularly affects experiments upou the Encephalic centres, and upon the influence of the nerves upon the viscera), it is clesirable to perform comparative experiments, in which the general injury shall be as nearly as possible the same, and the only difference shall lie in the lesion of the nervous system; and to subtract from the entire result all that can be thus shown to be attributable to the general disturbance produced by the operation. But even then, it may happen that the function is only suspended for a time, by the shock which has been induced by the injury to the nerve; and if it should be subsequently renewed without any reunion of the trunk, we have the most convincing proof that whatever degree of participation the nerve may have in it, the action is not essentially dependent upon the integrity of that portion of the nervous apparatus. Such we have seen to be the ease, in regard to the relation of the Pneumogastric nerves to the secretion of gastric fluid in the walls of the stomach (113).

468. All our positive knowledge of the functions of the Nervous System in general, save that which results from our own consciousness of what passes within onrelves, and that which we obtain from watching the manifestations of disense in Man, is derived from observation of the pisenomena exhibited by animals made the suljects of experiments; and in the interpretation of these, great caution must be exereised. - In the first place it must be constantly borne in mind, that, except through the movements consequent upon them, we have no means of ascertaining, whether or not particular changes in the Nervous System, whose character we are endeavoring to determine, are attended with sensation ; since we have no power of judging whether or not this has been excited, save by the cries and struggles of the animal made the subject of experiment. Now although such cries and struggles are ordinarily considered as indications of pain, yet it is not right so to regard them in every instance; and the only unequivocal evidence is derived from observation of the corresponding phenomena in the Human sulject; since we can there ascertain, by the direct testimony of the individual affecterl, what impressions produce sensation, and what excite movements independently of sensation. Further, we are not justified in assuming that Consciousness is exeited by an irritation, still less that Intelligence and Will are caller into exercise by it, merely because movements evidently tending to get rid of its source are performed in respondence to it. We know that the contractions of the heart and alimentary tube are ordinarily excited by a stimulus, without any sensation being involved; and these morements, like all that are concerned in the maintenance of the Organic functions, have an obvious design, when considered either in their immediate effects, or in their more remote consequences. The character of adaptiveness, then, in Muscular movements excited by external stimuli, is no proof that they are performed in obedience to sensation; much less that they have a voluntary character. 
In no case is this adaptiveness more remarkable, than in some of those aetions, which are not only performed without any effort of the will, but which the will caunot imitate. This is the ease, for example, with the act of Deglutition $(\$ \$ 87,88)$, the muscles eoneerned in which eannot be thrown into contraction by a voluntary impulse, being stimulated only by impressions convered from the mucous surface of the fanees to the Medulla Oblongata, and thence reflected along the motor nerves. No one can swallow, without producing an impression of some kind upon this surface, to which the muscular movements will immediately respond. Now it is impossible to eonceive any movements more perfectly adapted to a given purpose, than are those of the parts in question; and yet they are independent, not only of volition but of sensation, being still performed in cases in which conscionsuess is completely suspenderl or entirely absent. 'The aet of Sucking in the infant, again, is one in which a number of muscles are ealled into combined contraction, in a manuer which shows a complete adaptation to a given purpose; and yet it is impossible to suppose this adaptation to be purposice on the part of the infant itself; more especially as it is shown both by the occurrence of monstrosities, and by experinients made with this object, that no part of the Cranio-spinal axis ahove the Medulla Oblongata is necessary to it. And in the acts of Coughing and Sneezing ( $\$ 303$ ), we have additional examples of the most adaptive morements, executed by a marvellous eombination of separate muscular aetions, with the obrious purpose of removing sources of irritation from the air-passages; and yet we know by personil experience, that this eombination is not marle with any design of our own.

469. The activity of the nervous ganglia and of the nervons cords is alike ealled into action by the application of stimuli. These vary in their nature, and whilst some, as electrical eurrents, chemical agents, and mechinical pressure, ean excite all nerves to action, others, like the vibrations of light and soumd, odorous emanations, and heat, appear to be only capable of exciting nerves whose intimate structure especially adapts them for responding to the impressions made by these delieate yet active agents. Although the eonducting power of the Nerves for electrical currents is many thousand times less than metallic threads, electricity appears to be a stimulus that very readily affects them, whatever may be their function; exciting not only the various sensory nerves, but being also the most powerful agent with which we are acquainted for inducing the eontraction of mnscles when applied to the motor nerves that supply them. The effects of electricity upon nerves differ remarkably according to whether a eontinuous or an induced current is employed. A continnous current passed across a nerve at right angles occasions no contraction; but if it be directed up or down the nerre, contraction commonly occurs at the moment of closing and opening the eurrent, though none during its steady and uniform passage. With an induced or interrupted current, on the contrary, the nerve heing kept in a constant state of excitation, the muscles smpplied by it pass into a state of permanent or tetanic contraction. With a continuous cnrrent, contraction is observed to take place, not only at the moment of elosing and opening, but also when any sulden change, either of increase or deerease, occurs in the intensity of the transmitted current. The ubservation of these plenomena has led to the establishment of a law of nerve physiology, which was originally lair down by Du bois-Reymond, that the excitation of a nerve is effected not so much by the alsolute amomnt or intensity of the stimulus that is applied to it, but by the modification of this anount from one moment to another. In other words, the excitation of any nerve caused by a stimulus is greater the more rapilly the resulting changes are produeed, or the greater they are in 
a griven time; and on the contrary, whatever may be the nature of the stimulus applied, whether mechanical, chemieal, thermic, or electrical, neither sensition in a sensory nerve nor motion in a motor nerve is produced when the passage from one grade of intensity to another is extremely gentle. If for example mechanical prossure be so applied to a motor nerve as that commencing with the slightest possible contact it may steadily and continuonsly increase in force even till the nerve be killed at that spot, no convukions occur in the muscles to which the nerve is distributed. ${ }^{1}$ Muscular contraction only supervenes where the change in the amount of pressure, whether greater or less than that previously present, is so sudden as to prodnce a kind of shock. In proportion to the energy of the shock or vibration of the particles of the nerve is the effect produced on the muscles; thus we see that tetanic convulsions may be induced hy violent extension of a nerve, and that the whole body of a decapitated Frog can sometimes be rendered rigid by throwing it on the ground. In a similar manner, whilst the surden application of a ligature or of heat to a sensory nerve produces acute pain, numbness passing into entire insensibility is the only effect if they be gradually applierl, and the same holls good for all other kinds of stinuli. In all instances the passage of a nerve from a state of rest to one of functional activity is accompramied by changes in the chemical constitution of the tissue, and it has been shown that whilst the substance of the brain, spinal cord, and nerves is feebly alkaline or neutral when at rest, it becomes distinctly acid after long and exhausting activity. ${ }^{3}$ The molecular and chenical changes seem to be more readily induced in sensory than in motor nerves, the latter requiring more powerful stimulation to call them into play than the former, their equilibrium in other words heing more stable. Chauveau has endeavored to explain the effects of electrical currents on the supposition that they produce a mechanical commotion in the particles of the nerve. Hence induced currents, which are currents of high tension, and therefore prodnce a nore powerful shock or series of shocks, constitute stronger stimuli than continuous currents, in which the quantity of electricity is large. ${ }^{5}$ On applying a continuous current to a nerve contraction takes place in the muscle it supplies, and a similar contraction occurs at the moment when the current is broken, because at these periods, in accordance with Du Bois-Reymond's law, there is a sudden change in the molecular constitution of the nerve. When the interruptions of a continuous current are about twenty in the second, the muscle has not time to relax between the periods of breaking and making contact and passes into a state of tetanus. The induced currents which are developed in a secondary coil on closing and opening the current in a primary coil, as in the instruments of ordinary construction, are always of short duration, and the molecular movement produced in the nerve is correspondingly rapid and sudden. The duration of the opening current does not exceel $0.0042^{\prime \prime}$, whilst the duration of the closing current is $0.0114^{\prime \prime}$. The closing current is comparatively weak, its proportion to the opening current being as $1: 6$, the latter being of higher tension and of shorter duration. Chemical stimuli act but slowly on nerves, which we may attribute to the sheath of the fibres affording a certain anount of protection

J Schiff, Physiologis, 1839 , p. 94.

2 See Heinzinann. Ueber die Wirkung sehr allmähliger Aenderungen thermische Reize auf die Empifindungsnerven, Pflüger's Archiv, Bd. vi, p. 2:2.

3 By Funke, Gscheillın, and Ranke, Centralblatt, 1869, p. 97.

4 Chauveau, Brown-Séquard's Journ. de la Physiologie, 1859, p. 576.

5 For an account of the action of induced and continuous eurrents on bealthy and on paralyzed nerve and muscle respectively, see Onimus, Robin's Journal de l'Anatomie, $18 \% 4$, translated in full in the Practitioner, 1874-75. 
to the conteuts. The scnsory nerves appear to be inuch more readily acted on, and by a much greater range of chemical agents, than the motor nerves; powerful stimuli for the latter are, however, found in solutions of Soda and Potash, even when not exceeding 2 per cent., in those of Nitrate of Potash and of $\mathrm{Hydrochloric}$ acid, containing 20 per cent., and in concentrated solutions of Ammonia and Alcohol (90 per cent.); the latter, however, rapidly killing the nerve at the point where they have becn applied. Bisulphicle of carbon, the cthereal oils, and concentrated mineral acids kill the nerve at once, without producing convulsions. I IVater applied to nervetrunks excites no muscular contractions, but if injected into the vesscls distributed to a muscle induces very violent convulsions, which are believed by Schiff to be due to the direct effect of the water upon the delicate terminations of the nerves in the muscles. Withdrawal of water from the nerves, if effected gradually, produces no effect, but if accomplished rapidly, produces tetanus. ${ }^{2}$ As regards thermic irritation as a stimulus for the nerves, it has been shown by Weber that the sensory nerves do not perceive positive temperature, but only variations in the degree of heat of external objects. The influence of variations of temperature on motor nerves has been investigated by Eckhard, who has shown that a temperature of about $130^{2} \mathrm{~F}$. produces convulsions in frogs, which, however, soon cease: the irritability of the nerves being then lost, though upon cooling they occasionally regain it. Sudden exposure to a temperature of about $25^{2}$ F. also produces convulsions. ${ }^{3}$ Temperatures intermediate to these limits do not occasion convulsions, but the nerve soon loses its irritability when exposed to those near either the higher or the lower extreme.

470 . During life, and in the healthy state, the excitability of a motor nerve gradually diminishes from its origin to its distribution in the muscte, so that a stimulus of determinate intensity produces a morc energetic contraction of a muscle in proportion to the distance from the muscle that it is applied to the nerve, or, as it is expressed by Pflüger, in proportion to the length of the myopolar portion of nerve. 'Thus Budge found that to produce the same effect, $i$. e., the same amount of contraction-it was neccsary to apply a stimulns of more than double the strength close to a muscle, than was reyuisite if the stimulus were applied to the portion of nerve near its origin. The question arises whether the nerve is itself more cxcitable at the parts ncarer the centre, or whether the stimulus does not gain force in its descent, and produce, like an avalanche, an effect greater in proportion to the distance it has traversed. Pflüger expresses himself decisively in fivor of the latter supposition. Yet it seems opposed to our ordinary notions of the resistance offered to the passage of eurents by conductors, and the phenomenon appears to be more readily explicable on the supposition that the structure of the nerve, and especially of its sheath, may be more delicate in those parts which arc more protected, and that it consequently there more readily responds to impressions. After death the excitability of the nerves dies out centrifugally, the part in proximity to the nuscles remaining longest excitable; hut Roscnthal has shown that immediately after death the excitability of the nerve is for a short period considerably exalted, and that this exaltation is shorter in duration in proportion to the rlistance of the portion of nerve examined from the muscle. According to Ochl, if the

1 Schiff, Physiologrie, 18i9, p. 101.

2 Hartes, Zoltschrift f. Rat. Med., Bd. vii, p. 219. 122 .

s Eekhard, Zeitschrift f.' Riat. Med., Bd. x, p. 165; and IIarless, ibid., Bd. viii, p.

4 Anmali Universali, tom. cxc, 1864, p. 465; 1865, p. 601, and Lombard, Med.Chir. Rev, Jall. 1869. 
needle of a sensitive thermo-electric apparatus be made to traverse a large nerve like the sciatic, a marked increase of temperature occurs at the moment that its functional activity is excited by mechanical or electrical excitation.

471. The rapidity with which sensory and motor impressions are transmitted through the Nerves of the living body is apparently so great, and the means of estimating it at our disposal so few, that it is doubtful whether we shall ever be able to determine it with accuracy; but the ingenuity of Helm. holtz has cnabled hin to ascertain with sone precision the rate at which the change induced by the passage of an electrical current is propagated along a sulall portion of a nerve. The following figure and description deserve

FIG. 194.

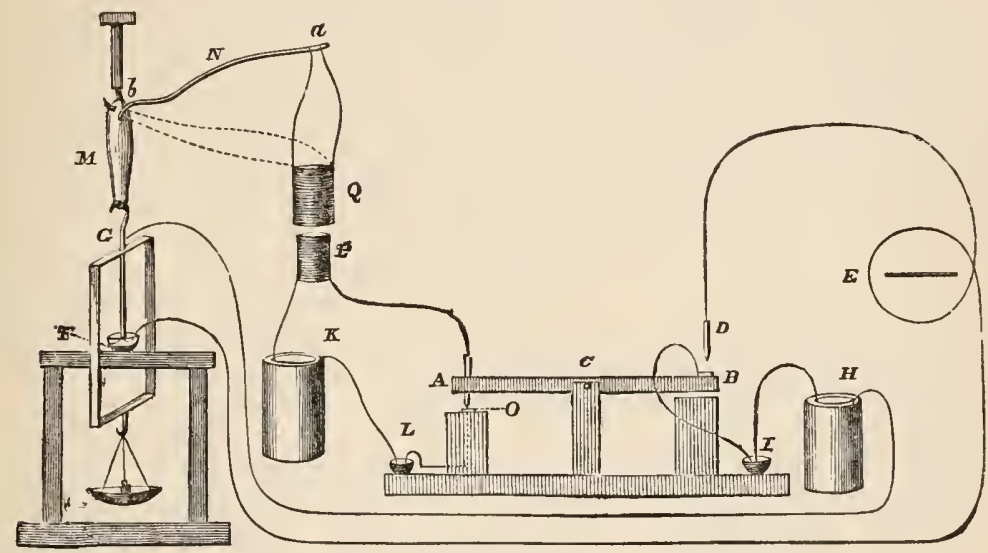

attention, since they exhibit the mode in which physical research can be applied to the most recondite questions of animal life. It is required to measure the time which any excitation takes to travel from the cut end $\alpha$ of the nerve $\mathrm{N}$ to its point of entrance $b$ into the nuscle r. As the means of excitation, Helniholtz employs an instantaneous induction current in the following mode: At the moment that a constant current passing through the coil $\mathrm{P}$, from the hattery $\mathrm{k}$, is broken, an instantancous induced current passing in the same direction is excited in 2 ; this is the stimulus acting on the nerve at $a$. The time-measuring current is formed by a second battery II, into some part of whose circuit a galvanometer $\mathbf{E}$ is introduced. It is requisite that the closure of this current should be precisely coincident with the opening of the inducing current from $\mathrm{K}$, by which the induced current at $\mathrm{Q}$, or the stimulus, is produced; this is effected by the lever $\mathrm{A} \mathrm{B} \mathrm{C}$, whose arm $\mathrm{A}$ rests on the metal plate 0 and completes the circuit K L A P. If now the metal point $D$ be forcibly pressed on $\mathrm{B}$, the time-measuring current passing through $\mathrm{H} \mathrm{I}$ B D E F G will be closed; but at the same instant, from the depression of the arm $\mathrm{B}$, the stimulus will be applied to the nerve through the opening of the inducing current $\mathrm{K} \mathrm{L} \mathrm{A} \mathrm{P}$, which is the result of the elevation of the arm A. But as soon as the stimulus has reached the muscle $x$, after traversing the nerve $\mathrm{x}$ the nuscle contracts, raising with it the hook $\mathrm{G}$, which just dips into the cup of mercury $F$, and consequently breaking the time-measuring current proceeding from the battery ir. The extent to which the galvanometer needle has been deflected indicates the time during which the current has been flowing through the circuit II I B D E F G, that is, the time which has 
intervenerl firom the instant of the application of the stimulus to the nerve at $a$, to the moment when the contraction of the muscle breaks that current. A portion of this time. is occupied in the transmission of the stimulus from the point $a$ to the muscle, and a portion, termed the period of latent excitation, elapses before the muscle responds to the stimulus. In order to ascertain the duration of the former period, the experiment is repeated with this alteration, that the stimulus is applied at $b$, and again the extent to which the needle is deflected is read off; the difference between the two observations then gives the time occupied by the stimulus in passing from $a$ to $b$. From numerous experiments with this instrument, Helmholiz arrived at the conclusion that in the Frog, at a temperature between $52^{\circ} \mathrm{F}$. and $70^{\circ} \mathrm{F}$., the rapidity of the propagation of impressions along motor nerves was from 81 to 126 feet per second, and he estimates the rapidity for human nerve at somewhat more than 200 feet per secoucl. ${ }^{1}$ Other observers have obtained the following results: Hirsch, ${ }^{2} 34$ metres (111.5 feet); and Schelske, ${ }^{3} 29.6$ metres (98.t feet) per second in the Frog. Marey, ${ }^{4}$ from 12 to 15 metres ( 36 to 48 feet) per second in the same animal in winter. Dunders and De Jaager, ${ }^{5} 26.09$ metres ( 88 feet) for the sensory nerves of Man. And Kohlrausch $^{6}$ also from experiments on Man, at 94 metres ( 308.3 feet) per second. Still more recently Helmholtz, ${ }^{7}$ in experiments conducted with Herr Baxt, obtained the number 33.905 (111.22 feet) for Man, whilst Place and Van West ${ }^{8}$ found that the mean velucity in man was 53 metres $(17+$ feet) per second. In these experiments as well as in those of Munk it was found that the rapidity of transmission is greater in the peripheral than in the more centrally situated portions of the nervous system. [Bloch states that the rapidity of the sensory current in man is, for the corrl, 194 metres per second, and for the nerves 132 metres per second. $]^{9}$ Colin ${ }^{10}$ has noticed that if the sympathetic ganglia are strongly irritated, reflex movements are immediately produced; but when the excitation is more feeble, a longer time elapses before the movements occur. M. Hirsch has even attempted to determine the relative rapidity with which impressions are transmitted through the nerves of sight, hearing, and touch; and the following table gives his conclusions,

\begin{tabular}{|c|c|c|c|}
\hline \multirow[b]{2}{*}{ Sense. } & \multicolumn{2}{|c|}{ Hirseit. } & HANKLT." \\
\hline & $\begin{array}{c}\text { Physiological } \\
\text { time. }\end{array}$ & $\begin{array}{c}\text { Mean } \\
\text { variation. }\end{array}$ & $\begin{array}{l}\text { Physiological } \\
\text { time. }\end{array}$ \\
\hline $\begin{array}{l}\text { 1. Hearing, } \\
2 \text { Visual perception of a spark, } \\
\text { 3. Visual perception of the transit of a star, } \\
\text { 4. Touch (left hand), } \cdot \cdot \cdot \cdot \cdot \cdot \cdot \cdot\end{array}$ & $\begin{array}{l}0149 \\
0.200 \\
0077 \\
0.182\end{array}$ & $\begin{array}{l}+0.025 \\
+0.016 \\
+0.1125 \\
\pm 0016\end{array}$ & $\begin{array}{l}0.1505 \\
0.2057 \\
0.1546\end{array}$ \\
\hline
\end{tabular}

1 Aceording to Troitzky, with feeble currents the naximum veloeity of propagation is between $50^{\circ}$ and $68^{\circ} \mathrm{Fahr}$, the rapidity being greatly reduced when the nerve (in the Frog) is warmed to $86^{\circ}$ or cooled to $0^{\circ}$ Fahr. With strong currents the influnce of the temperature umon the ennductivity of the nerves diminishes or becomes altorether imperceptible (Pfïger's Arehiv, Bi, viii, Heft xii). Both these exp.riments and the antecedent ones of Helmbitz and Baxt (Ionutsberieht d Berlin Acad., 1870, p. 184) show that the influence of temperature must not be overlooked in examining the conduetivity of nerves.

2 Noleschutt's Untersuch., Bd. ix, 1868, p. 183.

3 Rieichert's Archiv, 1864, p. 151.

5 Noderlandsch. Arehief, Bil. i, p 518.

- Henle, P’tintter's Zrits., Bd. xxviii, 1866, p. 190.

7 Berichte der Berliner $\Lambda$ kadem., 1867, p. 229. 8 Paüger's Arehiv, Bd. iii, p. 424.

9 [Chieago Journat of Mental Disenses, vol. ii.]

10 Comptes liendus, 1861 , tom. i, p. 969.

11 Ber. d. k. Suchs. Gesell. der Wiss., Feb. 1866. 
in which the term "Plyssiological time" signifies the period oecupied in the perception of the impression, and in the origination of the motor impulse and cxecution of the muscular novement by which the time was registered.

Thus it will be observed that the perception and registration of an unexpected appearance (spark) occupies much more time than the perception of a slowly-ilwaited one (transit observation), and nne-third more than even the perception of a sound ; but the mean variation in the latter case is considerably greater. The value of such experiments in affording information respecting the rapidity of conduction of sensory nerves is, however, but small, since the total or physiological time oceupied includes: 1 . The time required for the reception of the sensation at the integument. 2. The time required for its transmission through the sensory nerve. 3. The conversion of the sensory impulse into a motor inpulse. 4. The transmission of this impulse through the motor nerve, and lastly, the execution of the muscular contraction, each of which events may occupy a variable time.

47.2. Electrical Phenomena in Nerve and iruscle.-The electrical phenomena prescnted by the nerves and muscles are in many respects so similar that it will prevent repetition if they are here considered together. ${ }^{1}$ When a small piece of a nerve-trunk or a cylindrical or fusiform muscle is cut out from the recently killed body, and is so placed upon the electrodes of a Galvanometer that it touches one of then with its surfice (or natural longitudinal section), and the other with its cut extrenity (or artificial transverse section), a considerable deflection of the index is producerl, the direction of which always indicates the passage of a current from the interior to the exterior of the nerve-trunk, or from the longitudinal section through the galsanometer wire and galvanometer to the transverse -section. This is shown diagrammatically in Fig. 195. It is indifferent in regardel to the direction of the current, "whether the central or the peripheral cut extremity be applied to the electrode ; and in fact the most powerful effect is obtained by doubling the nerve in the middle, and applying both transverse sections to one electrode, whilst the lnop is applied to the other. On the other hand, if the two cut extremities be applied to the two electrodes respectively, no deciled effect is produced; and the same neutrality exists

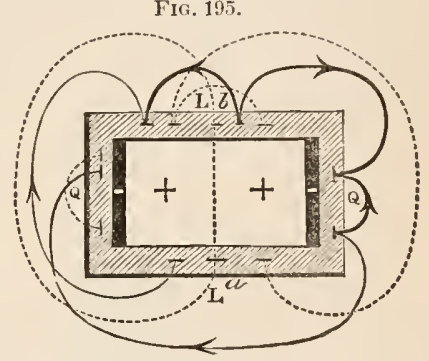

This figure is intended to show the direction of the currents in a columnar portion of nerve or muscle. I, longitudinal section: Q. transverse section $a b$, the equator. The harbed lines indicate the dircetion, and their thickness the force of the currents established, where the electrodes of a gaivanometer are applied to the corresponding surfaces. The dotted lincs show inoperativc arrangement: between any two points of the surfice of the trunk, equidistant from the middle of its length or equator ( $a b$, Fig. 195); but if the points be not equidistant, then a deflection is produced, indicating that the parts nearer the middle are positive to those nearcr the extremities. It has not been found possible, owing to the small size of the nerve-trmass cxperimented on, to test in a similar manner the relative state of different points of their transverse section; but there can be little doubt, from the complete conformity which exists in other respects between the nervous and muscular currents, that the

1 The principal works to be comsu!ted on this subject are Du Bois-Reymond, Untersuchungen über thierische Electricitat, in which a complete list of all previous works is contained; Wundt, Untersuchungen zur mechanik der Nerven und Nerven centren, 1871 ; Munk, Hermann, Pflugrer, and others, in Pfüxer's Archiv f. gesammte Physiolog., 1868-1875; Onimus, Archives de Physiologie, 1874. 
same law will be found to prevail in the former as in the latter case, namely, that the points nearer the surface are positive to those nearer the centre. There is no difference between the motor and the sensory nerves in regard to the direction of this current, the existence of which has been proved by M. Du Bois-Reymond, not only by the galvanometer, but also by the excitement of entractions in the limb of the galvanoscopic frog.-The "nervous current," like the nuscular, must be considered as derived from the electromotive action of the molecules of the nerve; and it seems quite unquestionable, that every integral particle of the nervous substance must be a centre of electro-motor action, and must contain within itself positive and negative elements; and the variations both of intensity and direction in the nervous current, under certain circumstances, are so sudden and so extensive, that it appears impossible to account for them by any change of larger heterogenenus elements, or in any other way than by assuming corresponding changes of position in almost infinitely small centres of action. It is indifferent what form is assigned to these electro-motive molecules; but it would seem that they must have two negative polar zones, and a positive equatorial zone; a conibination of such elements being able to produce all the electrical effects of a nerve in a state of rest. It seems altogether best to suit the phenomena, to suppose that each of these peripolar molecules is formed by the combination of two dipolar molecules, touching each other by their positive poles,as in the suljoined table, which represents a band of four series, A, B, C, D, each series containing four dipolar molecules:

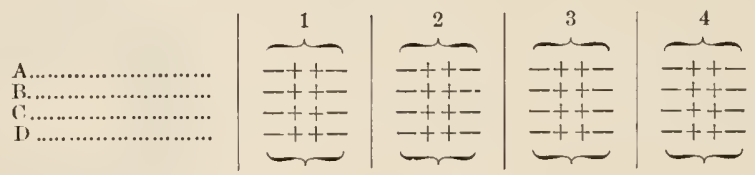

The relative position of these scts of molecules may, however, under certain . circumstances, be changed; and the very remarkable modification of the "nervous current," which has been shown by M. du Buis-Reymond to follow severe injuries of the nerve by mechanical, chemical, or themal agencies, appear's to be attributable to such an alteration. If, for instance, a piece of hot metal be brought near to the nerve without touching it, the nervous current will be scen to diminish rapidly, and to have its direction reversed, during which the property possessed by the nerve of conveying irritation to the muscle, though somewhat impaired, will not be destroyed; and if, whilst in this abnormal state the nerve be divided, every transverse section is found neutral or positive to the longitudinal section, insteal of negative. If the nerve-trunk be then placed between muscles, so as to recover its natural moisture, it will at the same time recover its usual electromotive power. The same phenomenon is often exhibited in wintcr, when the frogrs serving for experiment have been exposed to cold. 'The muscle or nerve is then said to present a "parelectrononie" behavior, and Du BoisReymond explains it by assmming that in the case of muscle there is a layer of muscle in contact with the tendon which acts electro-motorially in an opposite direction, and this equals, or even over-compensates, the normal current. 'To represent this parelectronomic layer, it is only requisite to take away the ultimate molecule of the dipolar inolecule, when the last one will turn its positive side to the surfice. Accorling to M. Du Bois-Reymond, the current shown by the entire nerve, when made to form part of a circuit, is only a derived enrent prodnced by ineomparably more intense currents circulating in the interior of the nerve aromo these ultimate particles, varying greatly in intensity according to the mode in which these particles are 
arranged; but, generally speaking, increasing both with the length and with the thickness of the nerve. Ranke $e^{1}$ has also shown that the lactic aeid generated in nerve and muscle consequent upon the active discharge of function, suffices to abolish and even reverse the ordinary nerve current, which is again restored when the acid is neutralized by an alkali. In the nerves the axis-cylinder, and in muscle the internediate substance is the seat of the most active ehemieal ehanges, and beeomes acid; the doubly refraeting muscle substance, and the doubly refracting substance of Schwann remain alkaline. Ranke holds that at the point where a stimulus is applied to a nerre, an inereased metamorphosis takes place, accompanied by the formation of lactie acid, which causes regular variation of the muscle current, and a state of inereased irritability in the nerves. Hermam is at issue with Du Bois-Reymond on several points. He contends s' that in perfeetly uninjured animals the museles, when at rest, are absolutely destitute of any current, and that all eurrents that ean be made manifest are due to injury inflieted on the tissue, leading to its more rapid oxidation at the point injured, followed by death. This part then becomes negative to the remainder of the nerve. This view has been sharply eriticized by E. Du Bois-Reymond and Munk. We have now to follow II. Du Bois-Reymond through his investigations on the ehange in the eondition of the "nervous eurrent," whilst the nerve is in a state of functional activity, whether motor or sensory.

473. Electrotonus of Du Bois-Reymond.-Elcetronus is the alteration produeed in the electromotor condition of the whole of the nerve by the passage of a constant current from a battery through part of it. If a portion of nervetrunk be so placed (Fig. 196), that it touches one of the electrodes by its

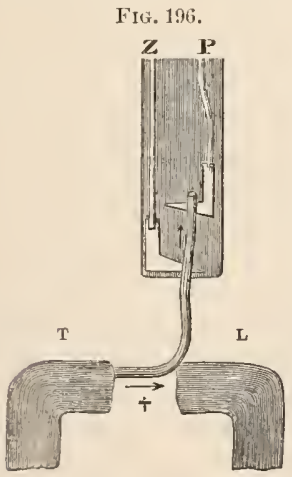

Fig. 197.

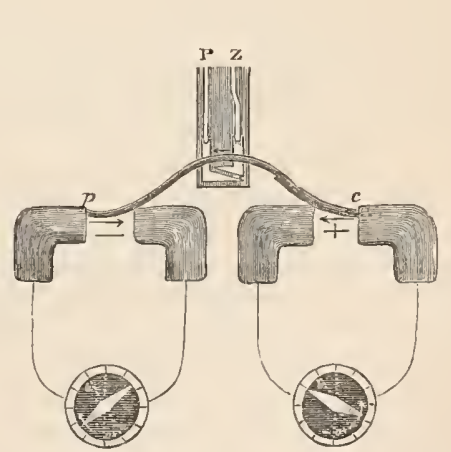

transverse section (which may be designated $\mathrm{T}$ ), and the other by its surface or longitudinal section ( $\mathrm{L}$ ), and a portion of its continuation be included in a galvanie cireuit, so that a current shall pass in the direetion $\mathrm{Z}-\mathrm{P}$, which is the same in its direction as that between $\mathrm{T}-\mathrm{L}$, then the intensity of the "nervous current" $\mathrm{T}-\mathrm{L}$, as indicated by the deflection of the needle of the galvanometer, will be found to undergo an increase; whilst on the other hand, if the electric eurrent be passed in a contrary direetion $\mathrm{P}-\mathrm{Z}$, the intensity of the "nervous current" $\mathrm{T}-\mathrm{L}$ will decrense. - The portion $\mathrm{Z}-\mathrm{P}$ of the nerve, whieh is included in the electric eireuit, is termed the excited portion, and the current passed through it is the cxciting current; on the other hand, the portion $\mathrm{T}-\mathrm{L}$ ineluded between the eleetrodes of the galvanometer 
is the derived portion; and the altered condition of this part, whieh is produced by the extraneous current (this current having been experimentally proved by M. Du Bois-Reymond to exert no influenee of its own on the galvanoncter), is termed the electrotonic state of the nerve. When the intensity of the "nervous eurrent" is inereased, the nerve is said to be in the positive phase of this eleetrotonie state; and when it is diminished, the nerve is in the negutive phase of that state.-By a proper arrangement, the same exciting current may be made to produce the positive phase in one part of a nervetrunk, and the negative phase in another. Thus if the two extremities of a nerve (Fig. 197, $p$ and $c$ ) be so connected with two galvanometers that both shall develop the "nervous eurrent," and an intermediate portion be exeited by the transmission of an electric current in the direction $z-P$, the nervous current in the "derived" portion $c$ will be increased in intensity, whilst that in the portion $p$ will be diminished. Hence it may be inferred, that when any portion of the length of a nerve is traversed by an eleetrie current, besides the usmal eleetro-motive aetion of the nerve, a new eleetro-motive action takes place in every point of the nerve, by a polarization of its electromotive elements, whieh aetion has the same direetion as the exeiting current itself: and a current is thus produeed in the "derived" portion, which is added to the original "nervons eurrent" at that end of the nerve at whieh the direetion of this new current and of the nervous current eoincide $(c)$, and is subtracted at that end at whieh the direetions are different $(p)$. The intensity of the eleetrotonic condition is found to be materially affected by the distance at which the nerve is examined from the point where the "exeiting current" is applied, being always nuch greater near that point than at a considerable distance from it. It is also powerfully influeneed by the strength of the exeiting current, and by the length of the portion of nerve through which that current passes, inereasing in intensity with stronger eurrents, and diminishing in proportion to the length of nerve the current has to traverse. These variations in the intensity of the "nervous current" eontinue as long as the "exeiting eurrent" lasts, and soon cease when the eircuit of that current is broken; a slight enfeeblement of the normal nerve current being apparent for some time after both phases of electrotonus. It is to the induction of the electrotonie state in the nerve supplying it, that the contraction of a muscle is dne, which ensues on the completion of the cireuit; and to the cessation of this state, that the museular eontraction is due which is consequent upon the interruption of the cireuit. Hence the electrotonie changes in the eondition of nerves may be observed without previously dividing them.- When, on the other hand, a nerve is "tetanized" by passing an interrupted and alternating eurrent through a portion of it, the effect is, as in the case of musele, to produee a diminution in its own proper eurrent; the needles of both galvanometers, in the arrangement last described, being defleeted to the negative side, instearl of one going baek to zero and the other having its positive deflection inercased, as happens when the "cxcited portion" is subjected to a continuous and miform current. The same negative variation of the nervous eurrent has been demonstrated by M. Du Bois-Reymond in nerves tetanized by other means, as by the use of strychnia. And the phenomena both of the "eleetrotonic state" and of the "negative valiation," are precisely the same, whether motor or sensory nerves be subjected to the experiment; thus making it appear that nerveforee may be transuitted in either direction along each of these orders of nerves.

474. Elcctrotonus of Pflïger.-Pflïger has investigated with mueh care the changes that oeeur in the excitability of a nerve in a state of electrotonus, or, in other words, through a portion of which an electrieal eurrent is passing. 
Under such circumstances the nerve may be considered to be divided into two parts, an intrapolar and an extrapolar portion, the latter being again subdivided into that portion situated nearer the nervous centres than the current, or central, and that situated between the current and the muscle, or distal, of the current, the latter being sometimes also called the myopolar portion. As the positive pole of an electrical current is termed the anode, and the negative the cathode, Pflüger has applied the terms anelectrotonus and cathelectrotonus to distinguish those conditions establisherl in the portions of nerve in the immediate vicinity of the poles of a constant battery. He has shown that the intrapolar portion of nerve is divided into two zones (Fig. 198); in one of these, situated at and near the Positive pole, the excitability of the nerve is diminished, whilst in the other, situated at and near the Negative pole, the excitability is increased. The extent of the portion of nerve in which the excitability is lowered, the positive or anelectrotonic zone, is small in proportion to the weakness of the current; whilst the negative or cathelectronic zone, in which the excitability is exalted, is correspondingly large; so that, with very weak currents, nearly the whole of the intrapolar portion of the nerve is in a state of exalted excitability, whilst with strong currents the intrapolar portion of the nerve is almost wholly in a state of depressed excitability. The same conditions of exalted or depressed excitability also extend for a cousiderable clistance beyoud the poles$i$. e., in the extrapolar portions of the nerves in both directions. 'The mode of determining the variations in the excitability of the nerve at the two poles may be understood with the aid of the diagram (Fig. 198). In Fig. 199, c C

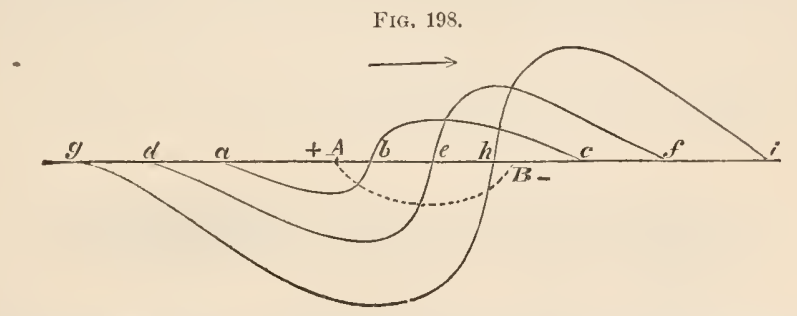

$\Lambda$, the Positive, $\mathrm{r}$, the Negative Pole of a constant current applied to a nerve. $a, b, c$, a curre, showing the effects of a weak current; $d, e, f$, of a stronger current; $g, h, i$, of a very strong current. The portion of the curve below the line shows the degree and extent of the depression, the part above of the exaltation of the excitability of the nerve.

represents the poles of the constant or polarizing currents by means of which the state of electrotonus is established, and $\mathrm{R} R$ those of the exciting current, or that by means of which the excitability of the nerve is tested; the latter may be replaced by a mechanical stimulus or by a chemical stimulus. Eckhard employed a solution of common salt. Before throwing the nerve into an electrotonic state by the application of the poles of the constant current, a few trials are made to ascertain what is the weakest stimulus which, when applied at $d$, will produce coutraction in the muscle. When this is known, the constant current is applied, and it will then be found that if the direction of this be as in Fig. 199, either a much weaker stimulus applied at $d$ will produce contraction in the muscle, or the same stimulus will produce a much more vigorous contraction, in either case showing that the excitability of the nerve has been increased. This is expressed by the curve $b, e, g$. If an electrical stimulus is employed, the current should be passed in the direction indicated, as in that case it would tend to relluce the influence of the cathode of $\mathrm{C} \mathrm{C}$, and by so much render the results obtained more striking. This 
constitutes Pflüger's extrapolar centripetal cathelectrotonus. By a similar mode of proceeding, the excitability of the nerve behind the ascending current, or in the myopolar portion, which is under the influence of the positive

FIG. 199.

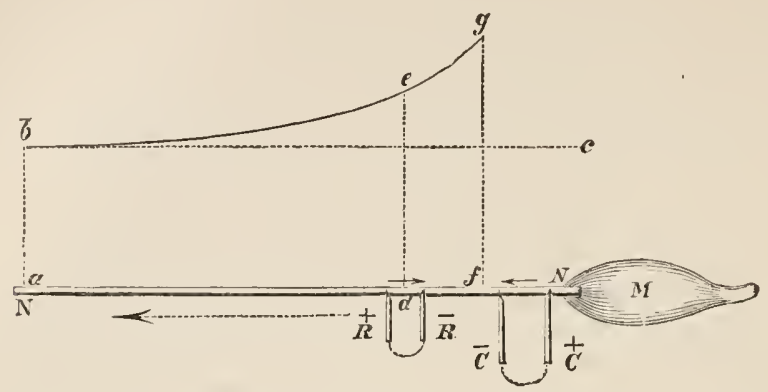

$\mathrm{N} \mathrm{N}$, represents a nerve; $\mathrm{m}$, a muscle; $\mathrm{c} \mathrm{C}$, the positive and negatice poles of a constant current. a $f$, extrapolar portion of nerve. $d$, point to which a stimulus, here represented by $\mathrm{R} R$, the positive and negative poles of an interrupted current, but which may be replaced by a mechanical or chemical excitant, is applied. $b, c$, indicates the line of normal cxcitability, supposed for the sake of simplicity to be equal throughout the whole length of the nerve, though in reality it is greater, and should therefore ascend towards $b$. $b, e, g$, indieates the curve of augmented excitability in the extrapolar portion of nerve, the amount of incrcase being greatest at the cathodc-as at $g$, less marked at $e$, and falling to its ordinary amount at $b$.

pole of the constant current, c c, can, as by the curve $f, e, c$, in Fig. 200, be shown to be remarkably diminished. This constitutes Pflüger's extrapolar

FIG. 200.

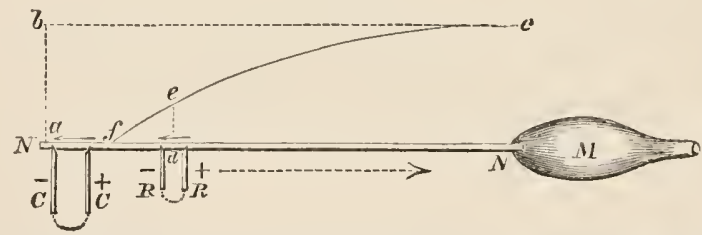

Centrifugal Extrapolar Anelectrotonus. The references are the sume as in the last figure except that a $f$ represents the intrapolar portion of the nerve, and that the curve of diminished excitability is represented by $f, e, e$; the lowest degree being at the anode, $f$, and the nerve gradually recovering its normal excitability towards $c$.

centrifugal anelectrotonus. The curve, $g, e, c$, in Fig. 201, shows the variation in the excitability in the myopolar portion of the nerve, when the Nega-

FIG, 201.

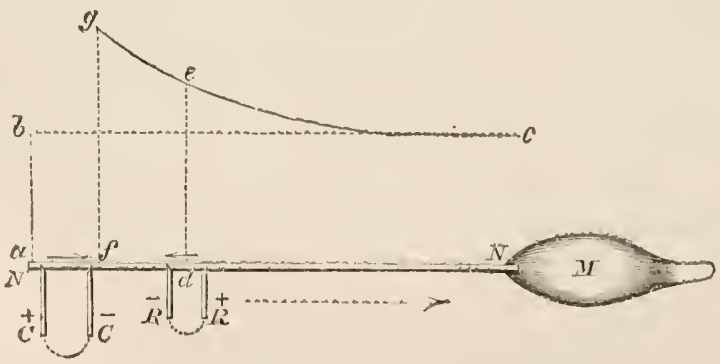

Extrapolar Centrifugal Cathelectrotonus. The increase in the cxcitability of the nerve is shown by the curve, $g, e, e$, to be greatest $\mathrm{ln}$ the vicinity of the cathode of the polarlzing current, $\mathrm{c}, \mathrm{C}$. 
tive pole is next the muscle. Lastly, Fig. 202 shows the condition of excitability in the nerve in centripetal extrapolar anelectrotonus. Pflüger found that in all these cases the strength of the polarizing current was of great importance, and that within certain limits the increase of excitability near the cathode, and the decrease near the anode, augmented; but that, if these

FIG. 202.

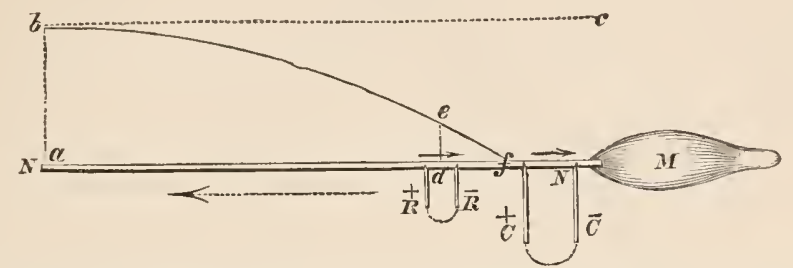

Centripetal Extrapolar Anelectrotonus. Here, as is indicated by the curre, $b, e, f$, the excitability of the nerve falls as the positive pole or anode of the polarizing current is approximated.

limits be passed, and currents of much greater strength than usual were cmployed, the phenomena were less marked, and at length failed altogether to occur. From an examination of the curved lines in the precerling figures, it will also be seen that the excitability of the nerve varies with the distance of the part examined from the electrode, the increase or diminution being always greatest at the eathode and anorle respectively, whilst the effect diminishes as these are receded from. There is one other circumstance that affects the excitability of the nerve, namely, the length of the intrapolar portion ; and it would appear the longer this is, the greater is the extent and degree of the excitability of the nerve around the cathode. As regards time, the state of increased excitability always attains its full intensity with great rapidity. Thus much for the variations of excitability in a nerve rendered electrotonic.

475. The increase of electro-motive power that occurs in the vicinity of the positive pole, and the depression in that of the negative, has already been noticed. Another alteration effected in the nerve by the induction of the electrotonic state, is a variation in the velocity with which it will conduct impressions; this, according to $\mathrm{V}$. Bezold, being invariably diminished. Dr. Rutherford, however, ${ }^{1}$ finds that if eurrents of medium streugth instead of the strong ones employed by V. Bezold be used, the negative pole quickens the rate at which the nervous influence is transmitted, whilst the positive pole retards it. As the general result of these researches, it appears then that the conditions present in a nerve, through a portion of which a closed continuous current is passing, and which is, therefore, in a state of electrotonus, are snch that at the anode or positive pole of the current there is an exaltation of the intensity of the ordinary nerve-current (positive phase), and depression of the excitability (anelectrotonus), and of the conductivity or velocity of transmission of impressions. On the contrary, at the cathode there is constantly a depression of the intensity of the ordinary nerve-current (negative phase), and coincident exaltation of the excitability (cathelectrotonus) and of the conductivity. ${ }^{2}$

476. From the foregoing observations it will be intelligible that the action

1 Humphry and Turner's Journal of Anat. and Phys., vol. ii, 1868, p. 95.

2 A very different explanation of the phenomena of eleetrotonus, founded on chemical considerations, has been suggested by Hermann (see his Untersuchungen, published at Berlin in 1867); but his views have been vigorously assailed in an able paper by Du Bois-Reymond, in the Berichte der Berlin Akadem., 1867, p. 597. 
of electrical currents applied to nerves in producing muscular contraction is liable to many variations, and that numerous circumstances must be taken into consideration before an explanation can be given of any particular phenomenon. Thus it has long been well known that though contraction of a muscle usually occurs at the noment of opening and closing a current of electricity transmitted through its motor nerve, yet that this is not constant, the contraction failing sometimes at the moment of closing and sometimes at the moment of opening the current. The singularity of this phenomenon has attracted the attention of many observers; and the names of Ritter and Nobili, Matteucci, Du Bois-Reymond, Eckhard, and Pflïger deserve especial mention for the light which they have thrown upon this obscure and difficult department of physiology. From their observations and from those of many other experimenters, it is now Fig. 203. Fig. 204. ascertained that the effects produced upon the muscle are de-

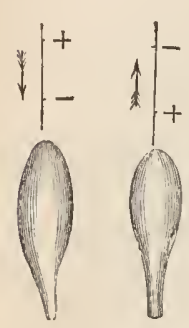
pendent-first, upon the direction of the electrical current passed through the nerve, whether centrifugal-i.e., from the origin to the periphery of the nerve (Fig. 203), or centripetal-i.e., from the periphery towards the origin (Fig. 204); secondly, upon the state of excitability of the nerve; and thirdly, upon the strength of the current. Ritter and Nobili, in whose observations the strength of the current was disregarded, endeavored to show that a definite succession of results followed the application of the electrical stimulus, according to the direction and the excitability of the nerve. Ritter, operating on Frogs, the excitability of whose nerves departed slowly after death or excision, was able to distinguish six stages; whilst Nobili, operating in the warmer climate of Italy, could distinguish only four. The following tabular arrangement taken from Funke will show the relations of the contraction of the muscle to the degree of excitability remaining in the nerve, and to the direction of the current:

\section{Ritter and Nobili's Law of Contraction.}

\section{$\mathrm{C}$ indicates closure of the current; $\mathrm{O}$ indicates opening of the current, or breating contact.}

\begin{tabular}{|c|c|c|}
\hline $\begin{array}{l}\text { Grade of excitability of } \\
\text { the nerve. }\end{array}$ & Ascending or Centripctal current. & $\begin{array}{l}\text { Desccuding or Centrifugal } \\
\text { current. }\end{array}$ \\
\hline I. (Ritter), . $\}$ & $\begin{array}{l}\text { C, Contraction, } \cdot \cdot \cdot \cdot \cdot \cdot \cdot \\
\text { O, Rest, } \cdot \cdot \cdot \cdot \cdot\end{array}$ & $\begin{array}{l}\text { C, Rest. } \\
\text { O, Contraction. }\end{array}$ \\
\hline II. (Ritter), · $\}$ & $\begin{array}{l}\text { C, Contraction, } \\
\text { O, Slight Contraction, } \cdot \cdot\end{array}$ & $\begin{array}{l}\text { C, Slight Contraction. } \\
\text { o, Contraction. }\end{array}$ \\
\hline$\left\{\begin{aligned} \text { III. } & (\text { Ritter }), \\
\text { I. } & \text { (Nobili), }\end{aligned}\right.$ & 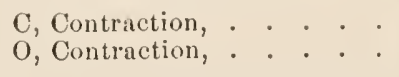 & $\begin{array}{l}\text { C, Contraction. } \\
\text { O, Contraction. }\end{array}$ \\
\hline$\left\{\begin{array}{l}\text { IV. }(\text { Ritter }), \\
\text { II. (Nobili), }\end{array}\right.$ & 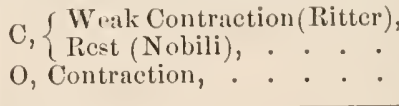 & $\begin{array}{l}\text { C, Contraction. } \\
\text { O, Slight Contraction. }\end{array}$ \\
\hline$\left\{\begin{array}{c}\text { V. } \\
\text { III. (Notter), }\end{array}\right.$ & 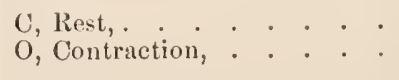 & $\begin{array}{l}\text { C, Contraction. } \\
\text { O, Rest. }\end{array}$ \\
\hline$\left\{\begin{array}{l}\text { VI. (Ritter), } \\
\text { IV. }(\text { Nobili), : }\end{array}\right.$ & $\begin{array}{lllllll}\text { C, Rest,. } & \cdot & \cdot & \cdot & \cdot & \cdot & \cdot \\
\text { O, Rest,. } & \cdot & \cdot & \cdot & \cdot & \cdot & \cdot\end{array}$ & $\begin{array}{l}\text { C, Slight contraction. } \\
\text { O, Rest. }\end{array}$ \\
\hline
\end{tabular}


Fron this table it is apparent that in the highest grade of excitalility of the nerve, the centripetal current induces contraction only on closure of the current, none occurring on opening it. Contraction on opening the current first happens in the second stage-i.e., when the cxcitability of the ncrve is somewhat diminished, and then only weakly. In the third stage of excitability of Ritter, the first of Nobili, the vigor of the opening and closing cuntraction is about equal. In the fourth grade, the closing contraction is weak, the opening strong. In the fifth stage, thcre is no contraction on closurc, but it occurs on opening the current; whilst in the sixth and last stage no contraction follows cither the closure or the opening of the current. For the descending or ccisuifugal current, the phenomena present themselves in an inverse order, -in the first or highest stage of excitability, there is contraction only on opening the current-then weak contraction on closure, as well as contraction on opening-then contraction of cqual strength at both periods-then contraction at both periods, though weaker on opening the current-then contraction only on closure; and finally, in which respect it differs slightly from the effects of the centripetal current, weak contraction on closure of the eurrent. From the preceding table, the statement of Nobili, who only experimented during the last four stages of irritability, becomes intelligible, that there is cssentially only one strong contraction for each direction of the current; an opening contraction being the most marked with the centripetal current, and a closing contraction with the centrifugal current.

477. Heidenhain ${ }^{1}$ and Pflüger, ${ }^{2}$ in following up this train of research, now showed that in freshly-prepared nerves, whose excitability was therefore of the highest grade, the law of contraction was dependent upon the strength of the current; and the phenomena have been thus formularized by Pflüger :

\begin{tabular}{|c|c|c|c|c|c|}
\hline \multirow{2}{*}{\multicolumn{3}{|c|}{ strength of current. }} & \multicolumn{3}{|c|}{ Direction of current. } \\
\hline & & & Centripetal. & & Centrifugal. \\
\hline Weak, . & $\cdot \cdot$ & - & $\begin{array}{l}\text { C, Contraction, } \\
\text { O, liest,. . }\end{array}$ & $\cdot \cdot \cdot$ & $\begin{array}{l}\text { C, Contraction. } \\
\text { O, Rest. }\end{array}$ \\
\hline Moderate, & $\cdot \cdot$ & . & $\begin{array}{l}\text { C, Contraction, } \\
\text { O, Contraction, }\end{array}$ & . : & $\begin{array}{l}\text { C, Contraction. } \\
\text { O, Contraction. }\end{array}$ \\
\hline Strong,. . & . $\cdot$ & . & $\begin{array}{l}\text { C, Pest, . } \\
\text { O, Contraction, }\end{array}$ & $\begin{array}{l}\cdot . \\
\cdot .\end{array}$ & $\begin{array}{l}\text { C, Contraction. } \\
\text { O, Weak Contraction. }\end{array}$ \\
\hline
\end{tabular}

Thus beginning with currents so feeble that no contraction was induced either on making or on breaking contact in very excitable nerves, Pflüger found that on passing a slightly stronger, but still weak current, in a centripetal direction, contraction first occurred on closure, but none on opening. With currents of moderate strength, contraction occurs both on closing and opening the current; and lastly, if the current exceeds a certain strength, no contraction occurs on closing, though it is well marked on opening the current. If the same experiments are repeated with the centrifugal current, we obtain with the weakest current contraction on closure alone (exceptionally also on opening); with moderately strong currents, contraction both on

1 Heidenhain, in Archiv f. Phys. Heilk., 1857, p. 442.

2 Pflüger, Archiv f. Path. Anat., Bd. xii ; and Untersuchungen über d. Physiologie des Electrotonus, Berlin, 1859. 
opening and closure; and with strong currents, the elosing contraetion preponderates with centrifugal eurrents, and the opening eontraction with eentripetal. As regards the reactions of sensory nerves, it is maintained by Pfluger that the effeets produeed by eleetrical stimulation are dependent upon the foree of the current, exeept that, as might be expected from the direction in which they ordinarily eonduet their impressions, a kind of inverse relation exists.

478. Those who hold with Hermann and Onimus, with whom Ranke is to some extent in aeeord, that many of the electrie phenomena presented by nerve and musele are dependent upon ehemical action, extend this view to the explanation of the different conditions of eleetrotonus. Onimus, ${ }^{1}$ for example, refers to an experiment made by Matteueci, which consists in covering a platinum wire a yard in length with tow. The wire is dipped in salt, and arranged as in the experiment for showing electrotonies. 'On passing a eurrent of electricity through a given portion of it, a strong electrotonic eondition is established, even at a listance of eighteen inches or more. It would hence appear that the eleetrotonic state is not one that is peculiar to the nerves. ${ }^{2}$ They further offer a very simple explanation of the anelectrotonie and catheleetrotonic zones of Pfliger. They contend that the passage of an eleetric current through a nerve is attended by an eleetrolytie action resulting in the formation of acids around the positive pole and of alkali around the negative, whieh is suffieient to explain all the phenomena, sinee aeids lower whilst alkalies exalt the excitability of the nerve. Pflïger, from the results of his experiments, laid down the following law: $A$ eertain length of nerve being given, this is exeited by the supervention of eathelectrotonus and by the disappearanee of anelectrotonus; but it is not excited by the disappearanee of catheleetrotonus nor by the supervention of ainelectrotonus. This law has been slightly modified by Cyon, who formulates it as follows: A nerve is excited when its moleenles pass from their ordinary state to one of greater mobility (eathelectrotonus), or when they pass from a state of less mobility (aneleetrotonus) to the ordinary state. The nerves do not, on the eontrary, experience any excitation, either when they pass from their ordinary to a state of less mobility (aneleetrotonus) or on their passage from a state of greater mobility (cathelectrotonus) to their ordinary state. ${ }^{3}$ Onimus maintains that all these alternations of commotion which have received so much attention at the hands of numerous observers are explicable by remembering two well-established facts-First, that the descending or direct eurrent is that which acts most energetically on motor nerves, or, in other words, the deseending eurrent is that which most strongly calls forth muscular eontraetion; and seeondly, that every current when applied to a nerve determines a current in the opposite direetion at the moment of its cessation. Thus each time that a nerve is eleetrified with an ascending eurrent a descencling current is developed at the moment of breaking in the interior of the nerves, and eontrariwise at the moment when a descending eurrent is broken an ascending current is formed. In accordance with this, Onimus gives the subjoined table, obtained by electrifying nerves withont the direct application of the poles to the nerve, which he contends interferes with the results, since it causes local electrolytic action. It will be seen to resemble the scheme given by Nobili.

1 Robin's Journal de l'Anatomie, 1874.

2 Ranke, however, states explicitly that neither moist conductors, nor the muscles, nor dead nerves, exhibit the phenomena of electrotonus. P'hysiologie, 1872, p. 674.

3 Cyon, Princeps d'Electrothérapie, 1873, p. 103. 


\begin{tabular}{|c|c|c|c|}
\hline & Descending current. & & Aseending current. \\
\hline 1. Period, $\left\{\begin{array}{l}\text { Closure, } \\
\text { Opening, . }\end{array}\right.$. & $\begin{array}{l}\text { Contraction, . } . ~ \\
\text { Contraction, . }\end{array}$ & . & $\begin{array}{l}\text { Contraction. } \\
\text { Contraction. }\end{array}$ \\
\hline 2. Period, $\left\{\begin{array}{l}\text { Closure, } \\
\text { Opening, }\end{array}\right.$ & $\begin{array}{l}\text { Contraction, } \\
\text { Fecble Contraction,. }\end{array}$ & . & $\begin{array}{l}\text { Fecble Contraction. } \\
\text { Contraction. }\end{array}$ \\
\hline 3. Period, $\left\{\begin{array}{l}\text { Closure, } \\
\text { Opening, : }\end{array}\right.$. & 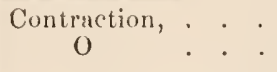 & : & $\begin{array}{c}\mathrm{O} \\
\text { Contraction. }\end{array}$ \\
\hline 4. Period, $\left\{\begin{array}{l}\text { Closure, } \\
\text { Opening, }\end{array}\right.$ & $\begin{array}{ccc}\text { Contraction, } & \cdot & \cdot \\
O & \cdot & \cdot\end{array}$ & . & $\stackrel{\mathrm{O}}{\text { Fceble Contraction. }}$ \\
\hline 5. Period, $\left\{\begin{array}{l}\text { Closure, } \\
\text { Opening, }\end{array}\right.$ & $\begin{array}{l}\cdot . \\
.\end{array}$ & . & $\stackrel{\mathrm{O}}{\text { Fecble Contraction. }}$ \\
\hline
\end{tabular}

Thus, in the first period, the excitability of the nerve being undiminished, contraction of the muscle takes place as soon as this molecular state of the nerve undergoes alteration, which occurs both at the moment of closure and of breaking of the current; but by degrees, as the excitability of the nerve diminishes, contraction takes place only on the closure of the descending current, and on the opening of the ascending current. But the breaking of the ascending current is equivalent to the formation of a descending current, that is to say, that with these two directions the muscle only contracts with a descending current. In the same way, at the moment of breaking a descending current an ascending current is formed which remains without action on the muscles like the ascending current of the battery. At the fourth period the ascending current only gives the contraction of opening when the current has been applied for some time, for then the (descending) polar current becomes more energetic. At the fifth period, when the current of the battery no longer gives any contraction, this may still be sometimes obtained by the polar current. Thus Onimus maintains that by taking into consideration the formation of a polarizing current, and the greater action of the descending current, all the phenomena of Pflüger's alternations armit of ready explanation.

The subject of clectrotonus, however, must not be dismissed without a notice of the work which Dr. Radelifte las reently been doing in this direction. ${ }^{1}$ Dr. Radcliffe does not agree with Du Bois-Reymond, in thinking that the electrotonic movements of the niedle are to be accounted for by the nervecurrent being modified by the voltaic current. He questions some of the old fact, and brings forward several new facts; and he has certain explanations to offer which, to say the least, are as simple as those to which attention has been already directed.

(a) Le calls attention in the first place to certain facts which make it difficult to believe that the electrotonic movements of the needle have to do, as Du Bois-Reymond supposes, with chunges in the nerve-current, produced by the action of the electrotonizing current upon the nerve.

One such fact, which is brousht to lisht by simply going on a little further with the ordinary experiments upon fresh nerves, is this, that the movements in question continue for a long time after the fiual disappearance of the nerve-current.

Another fact of like import is this, that movements of the needle in all respects like those of electrotonus, are to be observed, not only when there is no nerve-current in the nerve to be moditied, but even when the nerve itsclf is taken away, and another bad conductor used in its stead. If', for example, a piece of common liempen

1 Drnamics of Nerve and Muscle, post 8vo.; Macmillan \& Co., 1871; Tital Motion a Mode of Physieal Motion; in the Press. 
string, moistened with water or saliva, be made to take the place of the nerve, the needle moves, as it moves under the action of cleetrotonus, when the nerve is acted upon, as it moves under the action of anclectrotonus it the anode be next the aralvanometer, as it moves under the action of cathelectrotonus if the cathode be in this position. And so also if cotton thread, or silk thread, or a thread-like strip of gutta-percha, similarly moistenel with water or saliva, be substituted for the piece of conmon hempen string, the movements of the ncedle belonging to electrotonus being always produced if only the voitaic eonditions for produeing them are provided.

Here, too, is the place to mention another fact, which is really complementary to the facts which have been mentioned; namely, this, that electrotonic movements of the needle are not met with when the experiments for producing them are repeated upon a pieee of metal wire; for unless this fact be taken in connection with the other, it is very difficult to say why these movements should be present in some cases and absent in others.

Shortly before these facts were bronght to light by the independent inquirics of Dr. Radilife, Matteucei had also disenvered-First, That electrotonic morements of the needle are to be obtained, not only from living nerve, but also from dead nerve, as well as from narrow strips taken from the substance of brain or bladder; and, secondly, that such movements are not to he obtained if the body experimented on be a wire of amalgamated zine, eovered with cotton or linen thread, and soaked in a saturated solution of sulphate of zine; and thus, with this strong additional evidence in their favor, the facts under ennsideration cannot well be called in question.

It is very plain, then, that the electrotonic movements of the needle are not to be referred to modification of the nerve-current produced by the voltaie current, but it is not easy in get beyond this negative conclusion. Matteucei refers them to polarization, their absence in the ease of the amalgamated zine wire, coated with thread soaked in salurated solution of sulphate of zine, arising, as he believes, from the firet that such wire is umpolarizable; but this view does not account for the absence of these movements, when the wire employed in the experiment is made of eopper, or silver, or platinum, without anythini being done to it to prevent polarization. Dr. Radcliffe has another way of accounting for the presence or abiener of the movements in question: for the presence, by supposing that the frec electricity which is liberated at the voltaie poles when nerve or other bad conductor is placed between them, may so overflow towards the gatvanometer, and inte the coil, as to act upon the needlc and make it move, as it moves in anelectrotonus, if this free electricity be positive, as in cathelectrotonus, if negative; and for its absence when a good conductor like wire is plateed between the poles, by supposing that in this case there is no overflow of free electrieity from either of the poles towards the gatranometer and into the eoil, for tha simple reason, that the presence of the good conductor between the poles prevents the liberation of free electricity at the poles; and in justification of this view, he points to the fact that similar movements of the needle may be actually brought about by passing free electricity through the coil, and that this free clectricity is actually present when electrotonic movements are present, and absent in the cointring ases.

Movements of the needle strictly corresponding with the elcetrotonie movements may be enued by the electricity set free by mans of a frictional machine, if this electricity be made to pass through the eoil of the galvanometer in the way in which it is supposerl to pass in electrotonus, the movement agreeing with that of anclectrotonus when the elcetricity is positive, and with that of catheleetrotonus when it is nogative; and thus there is no intrinsic improbability in the notion that the electrotonic movements of the needle ma be brought about by the action of free electricity.

There is also very conchisive evidence to show that the two electrotonic regions are actually charged as they are supposed to be charged in the case where the eleetrotonic movements of the nealle are present, the aneloctrotonic positively, and the eathelectrotonic negratively, and that these charges are absent when the movements are absent. 'Thus, if a long piece of nerve be stretehed ont upon a plate of paraflin, with its middle portion lying across the poles of a voltaic lattery, the state on closing the circuit, as mude known by touching the nerve here and there with the electrode belonging to the insulated pair of quadrants of the new quadrant electrometer, is found to be that which is shown in the accompanying figure (Fing. 205), the anclectrotonic region, which is left $1 \mathrm{n}$-lnaded, being charged positively as is indicated by the doutted line with the + signs over it; the cathelectrotonic region, which is shaded, being charexel nuratively, as is indiented by tho dotted line with the - signs over it as a state of charge, the derree of which is cqual to that of the pole outside the pole, but not so inside the pole; for inside the pole it falls regularly from the pole, where it is 
at its height, to a point milway between the poles, where the two clectrotonic regions meet, and where the charge is at zero.

FIG. 205.

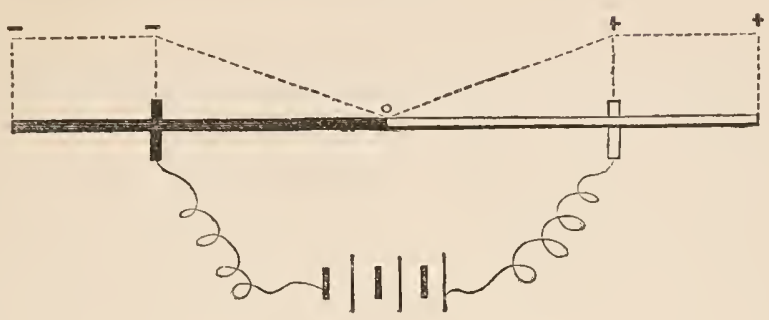

And as in this case so in that in which a galvanosenpie frog is arranged and examined in the same manner as that in whieh the nerve was arranged ard examined in the last experiment, for (as is sbown in the same way in the next figure) it is found that the two corresponding halves of the frog and of the nerve, are in precisely the same predicament as to charge: thus-

FIG. 206.

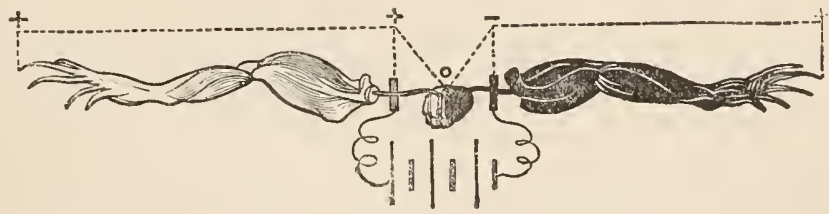

On the other hand, if a wire be made to take the place of the nerve or galvanoscopic frog, all these evidences of charge are wanting, unless it be that there is some impediment to the frec passage of the eurrent betwcen the poles, from insufficient contret with the poles, from want of conductive capacity in the wire, or from some other cause.

These then are the facts. Movements of the needle, like those belonging to electrotonus, are eaused by the passage of free Franklinic electrieity throush the coil. There is an outflow of free electrieity from the voltaic poles in the case where electrotonic movements of the needle are present. There is no such outflow when these movements are absent. And so it may bc that the electrotonic movements of the needle which are observed when the electrodes of the galvanometer are placed anywhere (not on the nerve merely) in the course of this outflow, are nothing more than the natural eonsequences of the passage of free electricity into the eoil from the voltaic polc which happens to be nearest to it ; the free electrieity passing through the coil from one elcetrode of the gilvinnometer to the other (from that which is nearest to the voltaic pole to that whieh is furthest from the pole), rather than direetly along the nerve from one electrode to the other, for the simple reason that it meets with less resistanee in the coil than in the nerve. It carnot well be otherwise, for it is not to be supposed that the outflow of free eleetricity in this ease should not act upon the needle in the very same way as that in whieh the outflow of free eleetrieity from a frietional machine las been seen to aet.

(b) In order to be surc as to the facts with which he has to do in the next place, Dr. Padeliffe employs two methods of inquiry.

The first method is that which is carried out more simply than the second, but it is less exhaustive. In it a galvanoscopic frog is arranged upon a plate of paraffin with its two limbs stretehed out in opposite directions, and with the two exposed nerves resting at their middle, as in the last figure, upon the two voltaie poles, and then a state of slight tetanu. is set up in both the limbs simultaneously by applying a drop of strong solution of salt to the nerve on caeh side where it lies beyond the pole, or else by faradizing with very feeble currents at the same spot. Until the limbs are slightly tetanized the voltaic eircuit is open, and there is consequently no eleetrotonus; when the limbs are slightly tetanized, the voltaic circuit is closed, first with 
two or more elements inchuded in it, and then with only one element, and electrotonus is set up by so doing-anelectrotonus in the limb and nerve on the one side, cathelectrotonus in the limb and nerve on the other side. And this is what happens when this is done. If there are two or more voltaic elements in the circuit the establishment of electrotonus, by elosing the circuit, is attended bv the cessation of telanus in both limbs-in the limb on the side of eathelectrotonus, as well as in the limb on the side of anelectrotonus. If only a single element be employed in setting up electrotonus by closing the cireuit, the tetanus is suspended in the limb on the side of anclectrotonus, but in the limb on the side of eatheleetrotonus, instead of being suspended, the tetanus is sometimes (not always) exagrerated. These are the ficts. The electrotonic results vary in this manner with the strength of the electrotonizing current. The tetanus is suspended alike in anelectrotonus and cathelectrotonus under the action of the stronger currents, but not to the same degree, for on comparing the results of the action of the stronger currents with those of the weaker, the inevitable inference is that the contraction-antagonizing power of the weaker currents is less marked than that of the stronger. And this is all that is to be learnt from this method of inquiry, except this, - that the eontractions eonsequent upon opening and closing the voltaic cirruit continue for a longer time on the side of anelectrotonus than on that of cathelectrotonus.

The second method of inquiry differs from the first in the substitution of a eouple of rheoscopic limbs (one for each of the two elcctrotonic states) for the galvanoscopie frog, and in the measurement of the movements of the gastrocnemius during electrotonus by an apparatus consisting of a platform with an insulating gutta-percha top to it, a serics of multiplying wheels, a graduated scale, an index, and a string which has to be attached at one end to the tenrlo-Achillis, and at the other to a hanging weight just heavy enough to put the gastroenemius gently on the streteh, and which, by resting at is middle in the grooved rim of the wheel by which the other whects are driven, obliges the index to move in face of the graduated scale this way or that, as the mucle happens to lengthen or shorten. Where the object is to exhibit the action of anelectrotonus. one of the rheoscopic limbs (the other is reserved for the experiment in catheleetrotonus) is fixed on the platform by passing a pin through the knee-joint into the gutta-percha top, and then, after tying the string of the measuring apparatus to the tendo-Achillis, and arranging the sciatic nerve so that it lies across the voltaie poles, with the anorte next the muscle, a drop of solution of salt is applied to the nerve between the anode and the knee, or else the action of feeble faraditic eurrents is brought to beur upon the same spot. Where the object is to cxhibit the action of cathelectrotonus, the same arrangements are made for the other rheoscopic limb, with the single differenee, that the cathode, not the anode, is now next the muscle. And this is all that has to be donc in either case, except to wait until the muscles are slightly tetanized, and then to set up the state of electrotonus by closing the voltaic circuit, first with two or more elements included in it, and then with one element only.

And this is what happens: In the case of the limb which is under the action of anelectrotonus, the setting up of the elcctrotonic state is seen to have the effect of suspending the tetanns, and of causing, in addition, the index of the measuring apparatus to move in a way which phinly shows that the gastrocnemius is stightly clongated, and the only difference between the action of the stronger and weaker electrotonizing currents is in this, - that the muscular elongation produced by the latter is somewhat less marked in degree.

In the case of the limb which is under the action of cathelectrotonus, the results are the same as those which were noticed under the action of anelectrotonus, if two or more voltaic elements were employed in produeing the elcetrotonic state. The tetanus is suspended in both cases atike, and in both eases atike there is also muscuhar elongation-to the same degree even. But the results are nut the same when a single voltaic element is marle use of in producing the electrotonic state, for in this case, insteal of being suspended, the tetanus, as is plainly seen by the movement of the in. dex of the apparatus, is often exargerated to a consillerable degree by the clectrotonus.

These, then, are the facts which are brought to light by carrying out these methods of inquiry, and the question is how to account for then. How is the suspension of tetanus, and the muscular elongation consequent upon electrotonus, to be acounted for? What is the explanation of the exagrgeration of tetanus which may happen in cathelectrotonus? How is it that anelectrotonus his a greater power of suspending contration than cathelectrotonus? Why do the contractions eonsequent upon opening and closing the voltaic circuit come to an end sooner under the aetion of cathelectrotonus than under that of anclectrotonus? And these questions are not looked upon as unanswerable. 
The natural electrical state of nerve and muscle during the state of rest, according to Dr. Radcliffe, is one in which the fibres are electro-motive elements in the state of open eircuit, the coats being charged positively, and the contents negatively by electro-motive action. While charged in this manner the condition of the muscle is that of relaxation or elongation; when this charge is discharged contraction is the result; and the broad conclusion is that the state of relaxation or elongation is consequent upon the prescnce, just as the opposite state of contraction is consequent upon the ab. scnce of this charge, the clarge operating by setting up a state of mutual repulsion among the muscular molecules, the discharge doing its work by allowing the attraction force or forces inherent in the pluysical constitution of the nolccules to come in to play. Hence it is not altogether unintelligible that the artificial charge belonging to the electrotonic states may set up a state of muscular elongation which is greater than that which is natural to the muscle, for the simple reason that the artificial charge is greater than the natural charge, and that it may at the same time act like the natural charge in inhibiting contraction. Hence the exaggeration of tetanus in cathelectrotonus may be not altogether unintelligible, for if contraction is only the passive return from a previous state of elongation consequent upon charae, it follows that the contraction in electrotonus may be greater than that which is natural to the muscle, for the simple reason that there is in electrotonus a greater degree of elongation bcfore the contraction than that which is natural to the muscle. And hence, too, the cxplanation of the fact, that contraction is inhibited more effectually by anelectrotonus than by cathelectrotonus, and that the contraction on closing and opening the cireuit continues for a longer tine under anelectrotonus than under catlelectrotonus, for these differences after all may be nothing more than the nutural consequence of the way in which the action of the artiticial charge agrees with that of the natural charge in the one case, and disagrees in the other, the + artiticial clarge imparted to the outsides of the fibres in anelectrotonus agreeing with the + charge which is matural to these parts, and so favoring the continuance of that natural state of charge which at once inhibits contraction and allows of contraction; the - artificial charge imparted to the outsides of the fibres in eathelectrotonus disagreeing with the charge which is natural to these parts, and being, on this account, unfavorable to the continuance of that natural state of charge which at once counteracts contraction and makes contraction a possibility. In a word, the explanation of the lunger or shurter continuance of the contraction which happens in this case in the elosing and opening of the circuit is the same as that which Dr. Radelifie applies to the explanation of the longer or shorter continuance of the same contraction under the "inverse" and "direct" currents; for in this latter ense the evidence goes to show that the differences in question lrave to do, not with differences in the direction of the current, but with differences in the charge associated with the current, the + charge associated with the "inverse" current being favorable to the continuance of the contraction, the charge associated with the "direct" current being unfavorable.

\section{Of the Spinal Cord and Medulla Oblongata; - their Structure and Actions.}

479. In our more detailed consideration of the functions of the several divisions of the Nervous System, it is desirable, for several reasons, to commence with the Cranio-spinal Axis; which, as already pointed out, may be considered as constitutiug the fundamental portion of this apparatus. The entire Axis is divided into its Cranial and its Spinal portions, the passage of the Cord through the "foramen magnum" of the occipital bone being considered to mark the boundary between them; and although the separation of the Medulla Spinalis from the Medulla Oblongata, whicl is thus established, is in itself purely artificial, yet it will be found to correspond completely with the natural division founded on their respective physiological attributes.

480. The Spinal Cord, ${ }^{1}$ which extends from the margin of the foramen

1 The sketch given in the text of the Anatomy of the Spinal Cord: is chiefly derived from the statements of Prof. Kölliker, in his Mikroskopische Anatomie (Bd. ii, $\xi \xi$ 115, 116), and of Mr. J. L. Clarke, in the Philosophical Transactions, 1851, 1853 , and 1859 ; but Gerlach gives an excellent account of it in Stricker's Hum. and Comp. Histology, Syd. Soc. Transl., vol, ii, p. 327 . 
magnum to the first or second lumbar vertebra, and which is prolonged as the filum terminale to the extremity of the sacral canal, is almost completely divided by the anterior and posterior median fissures (Fig. 207, $a, p$ ), into two lateral and symmetrical halves. The "anterior median fissure" (a) is more distinct than the posterior, being wider at the surface; but it only penetrates to about one-third of the thickness of the Cord, its depth increasing, however, towards its lower part. The sides of the "posterior median fissure" $(p)$, on the other hand, are in closer approximation; but the division commonly extends to about half the thickness of the cord, being deeper towards its upper than towards its lower end. The two halves, therefore, are only united by a commissural band, which occupies the central part of the cord ; and this is traversed by the "Spinal canal" $(f)$, which is continued downwards from the fourth ventricle, is about $\frac{1}{100}$ th of an inch in

FIG. 207.

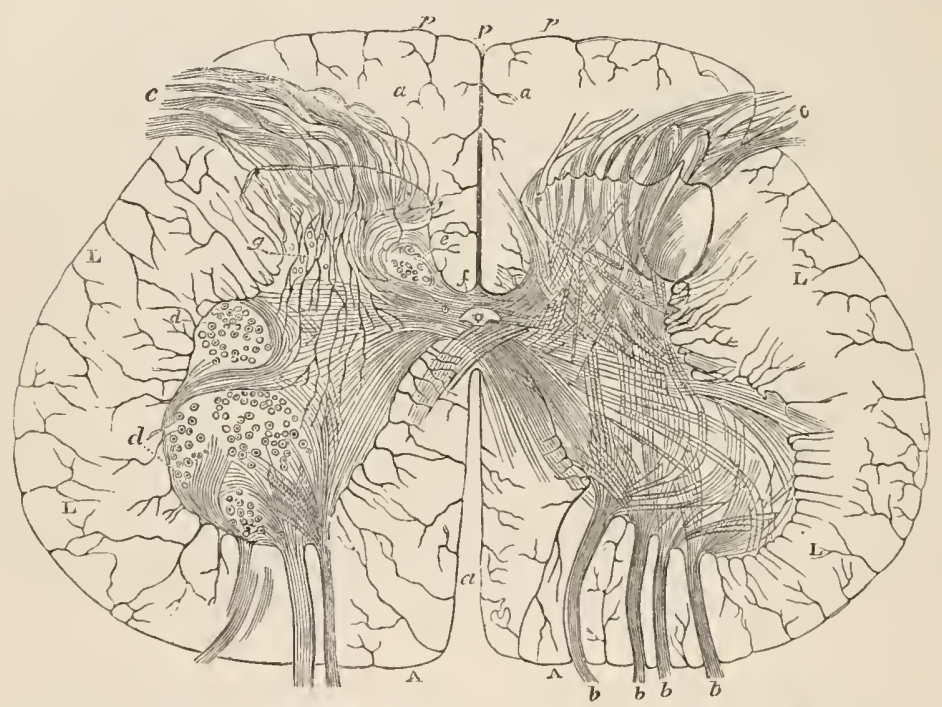

Transverse section of Spinal Cord; through the middle of the lumbar enlargement, sliowing on the right side the course of the nerve-roots, and on the left the position of the prineipal tracts of resicular matter: A, A, anterior columns; P, P, posterior columns; L, L, lateral columns; a, anterior unedian fissure; $p$, posterior median fissure; $b, b, b, b$, anterior roots of spinal nerves; $c, c$, posterior roots; $d, d$, tracts of vesicular matter in anterior column; $e$, tracts of vesicular matter in postcrior column, termed by Jacubowitsch the "sympathetic" column or tract; $f$, central canal, surrounded by the gray commissure; $g$, substantia gelatinosa of Rolando.

diameter, and according to Mr. Lockhart Clarke, is lined with a Jayer of columnar ciliated cells, whose attached extremities taper into delicate fibres, becoming continuous with the fibres of the comnective tissue of the white columms. - At a little distance from either side of the posterior median fissure, and corresponding with the line of attachment of the posterior roots of the nerves, is the posterior lateral furrow; a shallow, longitudinal depression, which markis out the "posterior columns" of the Cord $(\mathbf{P}, \mathrm{P})$ as distinct from the "antero-lateral columns." $\Lambda$ corresponding furrow has been sometimes clescribed as traversing the Cord in the line of the anterior roots

1 The strueture of the "filum terminale" is in every respeet essentially the same as that of the proper spinat Cord, save that no nerve-roots are connected with it. 
of the ncrves on either side; but this can scarcely be said to have a real existence; and the separation of the "antero-lateral columns" into the "anterior" and the "lateral" columns $(\Lambda, A$ and $\mathrm{L}, \mathrm{L})$ is only marked externally by the attachment of the nerve-roots. It is made more obrious internally, howerer, by the peculiar distribution of the gray matter, which, though by no means uniform throughout the Cord, usually presents (in a transverse section) the form of two somewhat crescent-shaped masses, whose convexities are turned towards each other, and are connected by the gray commissure, whilst their cornua are directed toward the surface of the cord. The posterior peak on each side nearly reaches the posterior lateral furrow, whilst the anterior, though the larger cornu, docs not approach quite so near the surface. The gray matter is enveloped by the white substance of the columns, which are entirely composed of nerve-tubes, whose general direction is longitudinal.-The Spinal Cord of Man is by no means of uniform dimensions in every part of its length; and the proportions which the gray and white substances bear to one another in different parts, are extremely diverse. Two principal enlargements are seen in the cervical and lumbar regions, at the origins of the large nerves forming the brachial and crural plexuses; and these enlargements are chiefly due to an increase of the gray substance, which is comparatively deficient in the intervals. On the other hand, there is a regularly progressive increase in the white substance, as we proceed from the lower to the higher portion of the eord; and this fact of itself serves to indicate the probability, that the longitudinal columns serve (as formerly supposed) to establish a direct connection betwcen the Encephalic centres and the roots of the Spinal nerves.

481. The gray matter or vesicular substance of the Spinal Cord, which is best seen in transverse section (Figs. 207 and 208), is by no means uniform in its texture throughout. Its anterior cornua, which are thicker and shorter than the posterior, are of a uniform gray color; and they consist of large well-dereloped nerve-cells (d, Fig. 207 and l, Fig. 208), which usually present many radiating processes, onc of which always passes into the anterior root of the nearest spinal nerve; whilst another ascends on its own side, and others form communications either with adjoining cells or with those in the horn, or on the opposite side of the Cord. The cells of the anterior horn connected together in this way form groups which may reasonably be supposed to constitute centres for the numerous fibres distributed to each musele, so that an impulse of the wili or other stimulus acting upon one of the cells may excite the whole to equal and consentanevus action, and thus abolish the necessity that would otherwise exist for every cell to possess its own motor fibrc. The central portion, which contains the canal, and which also forms the commissure, has a similar composition; but the cells are smaller, though still having long branching radiations; and the fibres are extremely fine, their tubularity being often indistinguishable. The anterior portion of the commissure, however ( $n$, Fig. 208, $i$, Fig. 209), is purely fibrous, and is distinguished by some as the "white commissure;" it does not, however, form an imnediate connection between the two anterior columns, but brings cach of them, as will be presently seen, into relation with the vesicular matter of the anterior cornu of the opposite side. The posterior cornu (Fig. 208, $g h$ $i j)$, longer and narrower than the anterior, is divided by Mr. Lockhart Clarke into two parts, the Caput and the Cervix Cornu. The Caput Cornu $(g h)$, or bulbous extremity of the horn, consists of an outer and comparatively transparent gelatinous portion $(g)$, the substantia gelatinosa of Rolando, and of an inner and more opaque portion $(h)$. The former contains nervecells of various shape and size, often multicaudate, the caudate prolongations being continuous with nerve-tubules of small average size (varying 
from $5 \frac{1}{5000}$ to $\bar{z} 0 \frac{1}{000}$ of an inch), rumning transversely, longitudinally, and obliquely. Mingled with these are bloodvessels and some connective tissue. The inner or anterior portion of the Caput also contains longitudinal fibres, to which its opacity is chiefly due; transverse fibres which are continuous with the posterior roots of the nerves and with the longitudinal column of the cord, and cells which are for the most part of small size. ${ }^{1}$ Gerlach ${ }^{2}$

FIG. 208.

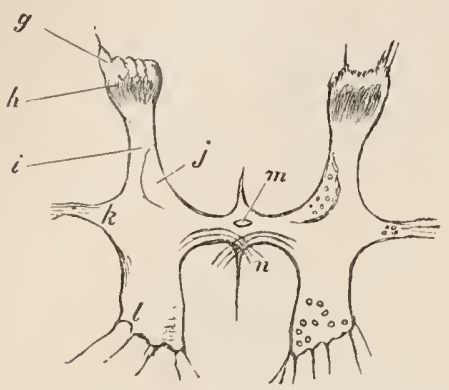

F16. 208.-Transverse section of the gray substance of the flumin Spinal Cord at the level of the first Dorsal Nerves; $g$, gelatiuous substance of Caput Cormu; $h$, dark interior of Caput Cornu; $i$, Cervix Cornu, containing, $j$, the posterior resicular column; $k$, the tractus intermedio-lateralis; $l$, Anterior Cornu; $m$, Central Canal; $n$, Anterior Decussating Commissure.
FIG. 209.

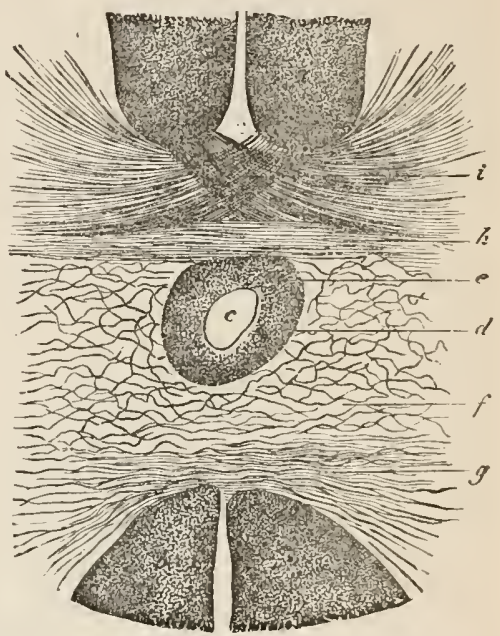

Fir. 209.-Mcdian portion of a transverse section of the spinal cord of a child six months old, from the lower part of the cervical regiou, treated with the double chloride of potassium and gold. Magnifled 50 diameters. $a, a$, anterior columns, $b, b$, posterior columns, $c$, central canal. $d$, line indicating the epithelum of the ecntral canal. $e$, connective tissue surrounding the contral canal. $f$, nervefibre plexus around the central canal, $g$, posterior transverse fibres of the gray commissure. $h$, anterior transverse fibres of the gray commissure, $i$, decussation of fibres in the anterior white commissure.

obscrves that the median portion of the gray substance of the spinal cord, the so-called gray commissure, is composed of several distinct histological divisions. Situated slightly in front of the exact centre is the central canal, Fig. 209, c, lined by columnar epithelial cells, Fig. 209, d, which rest on a membranc composed of comnective tissue or ependyma tolerably free from nerve-fibres, Fig. 209, e. Anteriorly to this, and immediately behind the white conmmissure, Fig. 209, $i$, are the anterior commissural fibres that $(g)$ immerliately bound the sulcus longitudinalis posterior in the middle line and the posterior columns laterally. The cilia of the columnar cells of the central camal are only present in chiddhool. A remarkable columm of ganglionic cells constituting the inner and anterior part of the Cervix Cornu $j$, and extending from the lower part of the cord to the middle of the cervical cnlargenent, where it terminates, has been described by Mr. Clarke under the term of the posterior vesieular column. 'The point of junction of the anterior and poisterior cornua $(k)$ is termed by the same observer the tractus intermedio-lateralis. It extends from the upper roots of the eighth cervical nerves to the lowest part of the dorsal region, but is most prominent about the first and sccond dorsal nerves. The posterior vesicular columms,

1 See Lockhart Clarke, Phil. Trans., 1858, p. 249.

2 Art. Spinal Cord, in Striclier's Human and Comp. Histology, vol. ii, p. 355, 1872. 
on the other hand, are largest at the lowest part of the dorsal region. The delicately granular vucleated substance which intervenes between the cylinder-axes of the gray substance of the spinal cord, and forms the greater part of it, was termed "neuroglia" by Virchow, "reticulum" by Kölliker, "granular basement-substance" by Henle, "spongy substance" by Schultze, and is belicved by Henle, ${ }^{1}$ Robin, ${ }^{2}$ and others to be quite distinct from connective tissue, not only in function, but in microscopical characters, and in its chentical reactions. Gerlach ${ }^{3}$ and Frey, ${ }^{4}$ however, still describe it as a special form of connective tissue. It is chiefly found at the periphery of the nervous centres, where it forms a cortical envelope around the central canal of the cord (forming the noyau periépendymaire of the French writers) on the two surfaces which bound the posterior median fissure, and lastly, around the posterior cornua, where it forms the gelatinous substance of Rolando. It is described by Gerlach ${ }^{5}$ and Lockhart Clarke as a material of finely granular aspect, like the matrix of hyaline cartilage, with little clumps of cytoid particles scattered through it, which seem to be in connection with the cells lining the central canal, and with the pia mater. Pervading every part of the neuroglia of the gray substance of the cord, except that lying in immediate proximity to the central canal, is a close plexus of extremely fine fibres, chiefly derived from the processes of the nerve-cells just described. The bloodvessels of the central parts of the nervous system are stated by $\mathrm{His}^{6}$ to be surrounded by a loose sheath, between which and the proper external coat lymph-corpuscles are perceptible. These spaces he consider's to represent the lymphatic systcm of these parts, which are otherwise destitute of this system of vessels.

482. The connection of the Nerve-roots of the Spinal Nerves with the several components of the Cord, and the course of the fibres after entering it, may be made out partly by means of sections, and partly by following the course of individual fibres by ordinary microscopical dissection. ${ }^{7}$ The following is an outline of the information which may thus be gained from a comparison of transverse and longitudinal sections (Fig. 207 et seq.).-The bundles that form the Posterior roots (Fig. 207, c, c; Fig. 210, P, P, P ; Fig. $211, g)$ consist of three kinds, which differ from each other partly in direction, and partly in the size of their component filaments. The first kind, Fig. 210, $a, a, a$ (which are more numerous in the upper part of the Cord), enter the posterior columns horizontally; and then, taking a longitudinal direction down the Cord, send fibres into the anterior gray substance ( $\mathrm{x}$ ), of which some bend upwards, and others downwards; part apparently becoming continuous with fibres of the anterior roots; whilst another part lose themselves among the fibres of the anterior columns, in which they may either proceed continuously to the head, or may pass along for a limited distance only, to emerge in the nerve-roots of some other segment. The second kind of bundles, $b, b, b$, also traverse the posterior columns horizontally and obliquely inwards; their further course may be best traced in a transverse section (Fig. 207). These fasciculi, which are composed of re-

1 Centralblatt, 1869, p. 117.

2 Anatomie et Physiolocrie Cellulaires, 1873, p. 117.

3 Stricker's Hum. and Comp. Histol., Syd. Sue. Trans., vol. ii, p. 33 J.

4 Histoling, Barker's Transl., p. 575.

5 Centralbiatt, 1867, Nos. 24 and 3.5.

6 sicbold and Kölliker, Z'itschrift, Bd. xv, 1865, p. 127.

$7 \mathrm{Mr}$. J. L. Charke has suceceded, by the adoption of a peeuliar method of preparation (for whieh see Phil. Trans., 1868, p. 321), in making sectious of considerable thickness sufficiently transparent to allow the course of the tibres, and the contour of the norve-eells and their prolongations, to be distinetly made out. 
markably fine and delicate fibres, interlace so as to form with each other an intricate plexus; and from this, straight and distinet bundles enter the posterior cornua along their whole breadth, crossing the "substantia gelatinosa"

FIG. 210.

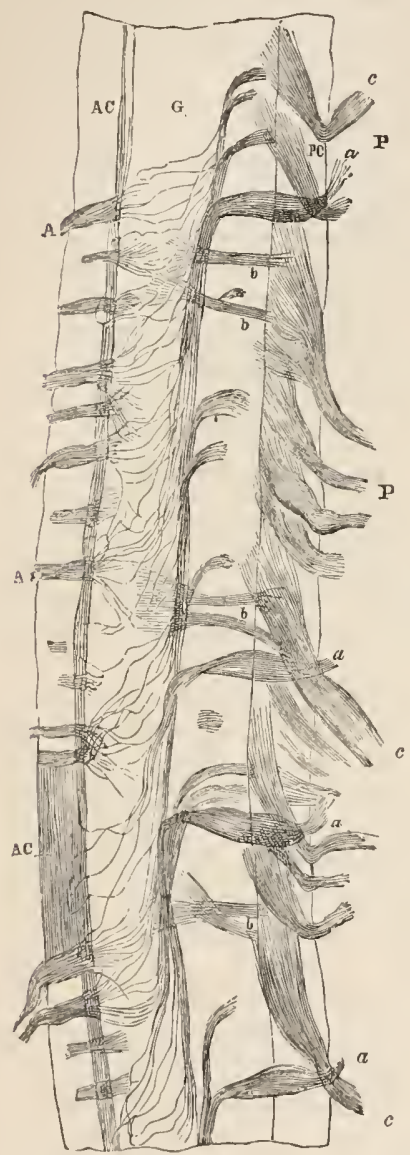

Longitudinal seetion through Cervieal enlargement of Sininal Cord of Cat: A c, anterior white columus; $\Lambda c^{\prime}$, portion, showing the arrangement of the longitudinal fibres; P C, posterior white columus: $i$, gray substanee between them (the vesiches omitted, to avoid obscuring the eourse of the fibres); $\Lambda$, anterior roots of the nerves; r, posterior roots, cousisting of thiree kiuls, the first, $a$, erossing the posterior columus horizontally, and then passing oblinuely downwarls, across the gray substiuce, into the anterior columus; the second, $b$, traversing the posterion columus horizontally, and then losing themselves in the gray substance; the third, $c$, for the most part beconing continuous with the longitulinal fibres of the posterior columu; all, or almost all, ultimately entering the gray substance. both obliquely and at right angles. Having thus entered the vesicular substance of the Cord, some of the fibres become connected with multipolar ganglionic cells; others, after traversing it, emerge from it again, into either the posterior columns, or the posterior portion of the lateral columns ; others pass towards the transverse conmissure, through which they seem to make their way to the posterior and lateral columns of the opposite side; and others, again, form a fine network, which cxtends towards the anterior cornua. Of the fibres of a third set (Fig. 210, $c, c, c$ ), a part secm to become dircetly continuous with the fibres of the posterior columns; the larger proportion of them, however, cross these columns obliquely upwards, and enter the gray substance at different points; after passing into which, they can no longer be clearly follower, although some of them appear to form loops and then return to the white columns.-The fasciculi of fibres which constitute the anterior roots [Figs. 207, $211, b, b, b$; Fig. $210, A, A]$, on the other hand, traverse the anterior columus of the Cord nearly horizontally, and in straight and distinct bundles, which do not interlace with each other until they reach the anterior cornua of the gray substance; on entering this, they break up into smaller bundles and separate fibres, which diverge in various directions; many unite with the large multipolar ganglionic cells of the anterior horns of the gray substance; some passing out again into the anterior, and others into the lateral columns of the same sile; others again pass towards the anterior part of the commissure, in which they cross over to the opposite side, entering its anterior and lateral columns; a considerable number plunge into the central substance of the gray cormu, and of these some become longitudinal, passing equally upwards and downwards, 
whilst others seem to traverse it horizontally, so as to come into relation [not improbably into actual continuity] with the posterior roots.'

483. Thus we see that there are two very distinct courses pursued by the Root-Fibres of the Spinal Nerves, in the substance of the Corl; the first transerese, the second longitudinal. The fibres belonging to the former category traverse the Cord horizontally or obliquely, and appear to pass out in the other set of roots connected with the same segment, either on its own or on the opposite side of the median fissure. Of those belonging to

FIG, 211.

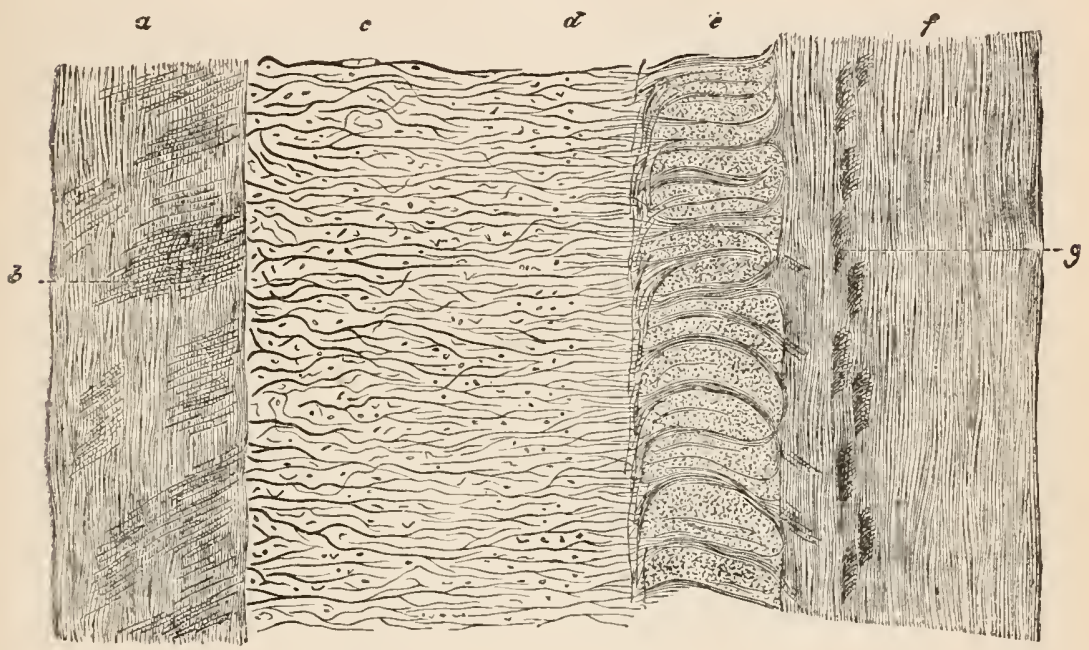

Antero-posterior section through the lumbar enlargement of the human spinal cord, treatcd witl chloride of gold and potassium. Magnified 30 diameters, $a$, anterior columns; $b$, anterior ruots of the nerves traversing the anterior columns obliquely; $c$, anterior cornu; $d$, posterior cormu, with the rertical fasciculi ascending in front of the subntantia gelatinosa; $e$, substantia gelatinosa, traversed by horizontal fasciculi; $f$, posterior column; $g$, posterior nots of the nerves divided transversely in consequence of their lateral entrance.

the latter, a small part appears to connect the posterior roots directly with the posterior columus, without passing into the vesicular substance; but the remainder of those belonging to the posterior roots, first enter the gray matter of the Cord, and then emerge from it either into the posterior column, or into the posterior part of the lateral columu of their own or of the opposite

1 Those who are desirous of pursuing the structure of the Spinal Cord in more detail than can possibly be given in an elementary treatise like the present, are referred to the important work published by Stilling in 18.56, entitled Netie Untersuehungen über den Bau des Rüekenmarks, in 3 parts, with an Atlas; alio to the Untersuch. über den feineren Bau des Central Nervensystum des Mensehen, by J. v. Lenhossek, Wien, 1855; to the researehes of Bidaler and Kupfter, Ueber die Textur des Rückenmarks, Leipzig, 1857 ; to the valuable paper's in the Philosophieal Transactions for 1851, 1853, 1858, part i, p. 231, 1859, part i, p. 437, by J. Lockhart Clarke; to the Translation by the Sidenham Socinty of the "reatise of Schröder v. d. Kolk, 1859; and to the essays of Dr. C. Frommann, Untersueh. üb. die Norm. u. Path. Anat des Rückenmarks, Jena, 1864, 4 plates; the work of .J. Luys, Recherehes sur le Système Nerveux Cérébro-spinal, Paris, 1865, and Gerlueh, in Stricker's Human and Comp. Histology, Syd. Soe. Trans., 1872, p. 327. 
half of the Cord; and, in like manner, all the longitudinal fibres belonging to the anterior roots first enter the vesicular substanee, and either terniuate in the ganglionie cells in the anterior horn or re-enter the anterior column, or the anterior part of the lateral column, of the same or of the opposite side.

48t. The observations of Mr. Clarke show elearly that some of the fibres of the anterior roots never beeome longitudinal, and these, accordingly, have no other ganglionie eentre than the vesicular substance of the segment of the Cord with which they eome into immediate relation; they also render it extremely probable, that many of the longiturlinal fibres of both roots pass eontinuously upwards to the Encephalon, most of them after traversing the gray nueleus, but some of those of the posterior roots without even entering the vesicular substance, so that these cannot have their ganglionic eentre in the Cord at all. If the latter be among the fibres whieh pass up through the Posterior Pyramids into the sensory traet of the Crura Cerebri, their true ganglionie centres are the Thalami Optici.

485. That sueh is the real arrangement, is very strongly indieated by the analogous conformation of the gangliated cord of Artieulated animals; for it may be stated with tolerable certainty, that some of the root-fibres of their nerves pass along the purely fibrous tract of that eord (which is far more readily separated from the vesieular, than it can be in Vertebrata), directly to the cephalic ganglia, which they thus bring into direct eommunication with all the nerve-trunks connected with the gangliated eord; but that others, also beeoming longitudinal, and rumning along those portions of the cord which intervene between and connect the ganglia of the differcnt segments, pass into the nerve-trunks that emerge from ganglia at a distanee of one, two, three, or more segments above or below : whilst a large proportion of the root-fibres have their ganglionic eentres in the ganglia whieh they respectively enter; and, after eoming into relation with its vesieular substance, pass out again, either on the same or on the opposite side of the median plane. ${ }^{1}$ Now the purely fibrous traet of the ventral eord of the Articulata terminates in the Ceplialie ganglia, which are homologous, as already remarked ( $\$ 447$, iv), not with the whole Eneephalon of Tertebrata, but with their "sensory ganglia" alone; and thus analogy would lead us to suppose, that the fibrous strands of the Spinal Cord do not pass on continnously to the Cerebrum, but really extend no further upwards than the Corpora Striata, Thalani Optiei, and the other ganglionie eentres in eonnection with then which lie along the floor of the eranial cavity. This view will be hereafter shown (Seet. 3) to be in harmony with anatomical and physiological fatets, which indicate that the Cerebrum only receives its impulses to action throngl the medium of the Sensory Ganglia, and that it reaets npon the muscular apparatus only through the same chamnel. That some of the afferent fibres of the spinal nerves should ascend continuously upwards to the ganglia of tactile sense, in Man and other Vertebrat:a, as well as in Articulated animals, would seem a legitimate deduction from the fact, that such continuity obviously exists between the olfactive, visual, and auditory nerves, and their respective ganglionic eentres, no intermediate apparatus of vesieular matter being interposed in their eourse; and, as we have scen ( $\$ 48 \%)$, the existence of such a continnity in regard to a part of the fibres of the posterior roots of the nerves, is mate cxtremely probable by the researehes of Mr.J.L.Clarke.$A$ very remarkable confirmation, too, has been afforded to the doetrine of the

1 See Prine of Comp. Phys., ? 648. - The important facts here referred to have been chichly substantiated by the rescarehes of $\mathrm{II}$. Newport and M. Günther. 
constitution of the Spinal Cord here advocated by the Pathological researches of Dr. Ludwig Türck ;" who has shown that certain lesions of the Encephaton produce a degeneration of nerve-tissue in particular tracts, which may be traced continuously down the Spinal Cord usually in the anterior colunin of the side affected, and in the laterul columu of the opposite side; whilst, on the other hand, local lesions of the Spinal Cord, as from caries of the vertebre, or from the pressure of tumors, produce a like degeneration in certain tracts of the posterior columus, and sometimes also of the lateral columns, ascending towards the Encephalon. Thus it appears that the posterior fasciculi are liable to this secondary degencration in the centripetal direction only, and the anterior in the centrifugal direction only; the degeneration taking place, in each case, in the direction in which they ordinarily transmit nerve-force. The mixel endowments of the luteral columns are also indicated by these phenomena.

486. We are not required, however, by the adoption of this view of the constitution of the Spinal Cord, to regard its Cephalic fibres as of a different order from those which pass from one of its own segments to another; for, considering the whole of the Cranio-spinal axis as one series of centres, receiving the terminations of all the nerves, its longitudinal fibres are equally commissural, whether they establish the connection between the nerve-roots and vesicular matter of two aljacent segments, or whether they bring into the same structural relation the parts which are furthest removed in position. And thus we may regard all inmpressions upon the afferent nerves as first operating upon it (affecting the consciousness, or not, according as they reach the Sensory Ganglia, or are arrested in their progress thither); and all motor impulses, whether purely reflex, or originating in volitional direction or emotional excitement, as issuing immediately from it through the motor trunks. - If such be the case, it does not seem at all improbable that there should be a difference in differcnt tribes of animals, as to the proportion. of fibres which have their centres in the Spinal Cord and in the Sensorial. centres respectively; for in those whose ordinary moventents of progression, etc., are independent of sensation, being performed through the reflex. action of the spinal cord, it might be expected that the chief connection of the spinal nerve should be with its own ganglionic substance, and that the bulk of the fibrous columns should be composed of commissural fibres resembling those which intervene between the separate portions of the ganglionic tract of the ventral cord of Articulata; whilst in like manner it might be anticipated that in man, so large a part of whose movements are performed in obedience to a mental stimulus and under the guidance of sensation, the longitudinal strands should be chiefly composed of fibres that directly connect the Sensorial centres with the roots of the spinal ucrves. Such a difference would appear, from the comparative researches of MM. Volkmann and Kölliker, to exist between the structure of the Spinal Cord of the Horse and that of 1 [an.

487. The Medulla Oblongata, ${ }^{2}$ or cranial prolongation of the Spinal Cord,

1 See his Memoir, Ueber secondäre Erkrankung einzelner Rïckensmarkssträinge und ihrer Fortsetzungen zum Gehirne, in Denkschriften der Kaiserliehen Akadenie der Wissenschaften, Wien, 1851; aho Zutsehrift der Gesell. der Aertze zu Wien, Band ix, Heft 10.

2 For good aecounts of the anatomy of the IIedulla Oblongata, see Dr. John Reid, in Edinb. Med. and Surg. Jour., 1811, Mr. L. Clarke in the Phil. Trans, 1858, val. i, and 1868, Pt. i, and Dr. John Dean, 8ro, 1863; Sehröder v. d. Kolk, Syd. Suc. Trans.; Meynert, Art. Brain of Mummalia in Stricker's Hum. and Comp. Histology, Syd. Soe. Trans., vol. ii, 1872 , p. 367. 
which brings it into counection with the Encephalic centres, is distinguished by the peculiar arrangement of its fibrous strands and of its nuclei of gray matter; and also by the peculiar distribution and endowments of the nerves connected with it. The anatomical boundaries usually assigned to it are the Pons Varolii above ${ }^{1}$ and the Occipital foramen below; but these limits are purely artificial, and for physiological purposes the course of its fibres must be traced much higher. The part thus marked out has a bulblike form, and presents, like the Cord of which it is the continuation, a posterior and an anterior median fissure. The former is deep and narrow, extending to the posterior border of a layer of conmissural fibres which fornis the floor of the anterior fissure. The latter is wider and less deep; and its continuity with the anterior fisure of the Spinal Cord is interrupted by the decussation of the Anterior Pyramids, which is marked externally by the crossing of from three to five bundles of fibres from each side over to the other. This decussation may be considered as the physiological boundary between the Medulla Oblongata and the Spinal Cord. 'The surface of each lateral half is furrowed by grooves, which assist in

FIG. 212.

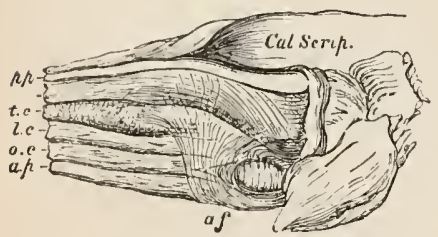

Lateral view of the Medulta Oblongata: $a p$, anterior pyramid ; o e olivary column; $l c$, lateral columin; $\ell c$, tubercle of Rolando, or tuberculo-cinereo; $c r$, corpus rest iforme; $p p$, posterior pyramid; $a f$, arciform fibres; Cul. Scrip., calamus seriptorius. marking out the several strands of nervefibres that may be distinguished on either side: these are-I. The Anterior Pyramids, or Corpora Pyramidalia; II. The Olivary Bodies, or Corpora Olivaria; III. The Lateral Colununs; iv. The Tubercles of Rolando, or Tuberculi Cinerei; v. The Restiform Bodies, or Corpora Restiformia, otherwise called Processus à Cerebello ad Medullam Oblongatam; vi. The Posterior Pyramids, or Corpora Pyramidalia Posteriora. (See Fig. 212.) - The connections of these with the Brain above, and with the Spinal Cord below, will be presently traced. The resicular sulstance, on the other hand, is principally aggregated in three pairs of ganglionic centres; of which the anterior forms the nucleus of the Olivary body, the lateral of the Restiform, and the posterior of the Posterior Pyramiclal.

488. The Anterior Pyramids (I) consist entirely of fibrous structure and establish a communication between the "motor tract" (Fig. 213, $n t$ ) of the Crura Cerebri, and the anterior and antero-lateral columns of the Spinil Cord. The principal part of their fibres decussate; and these, as they piss from above downwards, dip away from the anterior surface of the Cord, and commect themselves with its midlle or lateral columns, instead of with its anterior, as was pointed out by Rosenthal, ${ }^{2}$ and more filly described by Dr. J. Reid $;^{3}$ and some fibres are stated by $\mathbf{M r}$. J. L. Clarke, ${ }^{4}$ to pass into the posterior colunns and posterior gray substance. A small part of the fibres of the pyramidal columns, however, do not decussate, but proceed downwards on the same side, into the corresponding anterior columns of the Spinal Cord.-II. The Olivary borlies are composed of fibrous strands, inclosing a large gray motor nucleus (Fig. 213,og) on either side. The upward

1 From which it is separated later,ally in animals by a broad band termed the Trapezim, but in man by a groove; the trapezium forminar the posterior border of the Pons. See I. Clarke, l'roweed. Roy. Soe., vol. xi, p. 360.

2 Fin Beitrag atr Encephalotomie, Weim:ar, 1815.

3 Eilinb. I ed. and Surg. Journ., Jan. 1811; and Physiol., Pathol., and Anat. Riserarehes, chatr. vii.

I Phil. Trans., 1858, p. 238 ; see also Meynert, op. cit, p. 5:8. 
continuation of the former divides, while passing through the Pons Varolii, in to two bands, one of which proceeds upwards and forwards as a part of the "motor tract" $(m t)$ of the Crus Cerebri, whilst the other $(o)$ proceeds upwards and backwards to reach the Corpora Quadrigemina $(\mathrm{C}, \mathrm{D})$. The Olivary columns are continuous inferiorly with the anterolateral columms of the Spinal Cord. Their vesicular nucletis, which is known as the "Corpus dentatum," and which appears first amongst the network of fibres into which the anterior cornu is resolved and the outer portion of the anterior column seenis to be intimately connected with all the surrounding parts of the Medulla, chiefly through the arciform system, which will presently be described; and $\mathrm{Mr}$. Lockhart Clarke, though he has never been able to trace any immediate connection between the cells of the nuclear laminse and the roots of the nerves-even in the case of the hypoglossal nerves which pass directly through them-yet is inclined to

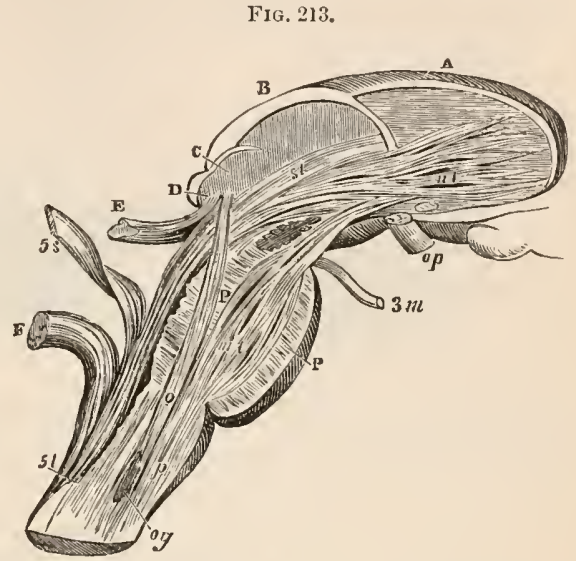

Dissection of the Medulla Oblongata, to show the connections of its several strands: $\mathbf{A}$, eorpus striatum; $\mathbf{B}$, thalamus opticus; C, D, corpora quadrigemina: E, commissureconnecting them with the cerebellum; $F$, corpora restiformia; $\mathrm{P}, \mathrm{P}$, pons Varolii; $s t, s t$, sensory tract; $m t, m t$, motor tract; $g$, olicary tract; $p$, pyramidal traet; $o g$, olirary ganglion; o $p$, optic nerve; $3 \mathrm{~m}$, root of the third pair (motor); $5 \mathrm{~s}$, sensory root of the fifth pair. regard them as the co-ordinating centres for the different ganglia or nuclei of the Medulla Oblongata. ${ }^{1}$ Schröder v. d. Kolk is disposed from many considerations to regard these bodies as the nervous centres on which the symmetrical movements required in speech or the articulation of the voice are essentially dependent. ${ }^{2}-$ III. The lateral columns (le, Fig. 212), Fuisceaux intesmédiaires of Longet, decussate below with the anterior pyramids. Ascending, they assume the form of triangular columns, the apex of each appearing at the surface, the base being opposed to the one of the opposite side, and projecting, covered with gray substance, into the floor of the fourth ventricle. Behind, they are in contact with the restiform bodies, and in front with the olivary bodies. At their upper part they trifurcate, one portion curving outwards to enter the middle peduncle of the cerebellum, the other two separating from one another to allow of the passage of the superior peduncles of the cerebellum and part of the restiform columns, the inner one ultimately reaching the cerebral peduncles; the outer one forms a transverse commissure behind the Corpora Quadrigemina.-IV. The gray tubercle of Rolando ( $t c$, Fig. 213$)$ is simply the expanded extremity of the posterior cormu of the gray substance of the Spinal Cord, now appearing on the surface.- $\mathrm{v}$. The Restiform bodies each consists of fibrous strands (F, Fig. 213) inclosing a gray nucleus. The fibrous strands pass upwards into the Crura Cerebelli; whilst below they are chiefly continuous with the posterior columns of the Spinal Cord, having also some connection with the posterior part of the middle columns. These Cerebellar columns, moreover, communicate with the anterior columns of the Spinal 
Cord by a band of "arciform" fibres, whose eomnections were first distinctly deseribed by Mr. Solly $;^{1}$ of these there is a superficial set which unites itself with the pyramidal columms, and a deep set which comes into rclation with the olivary.-VI. The Posterior Pyramids are scarcely distinguishable externally from the Restiform bridies, of which they were formerly described

FIG. 214.

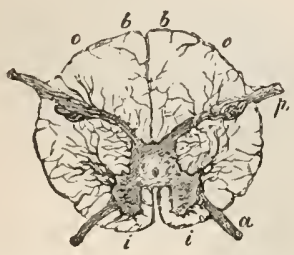

FIG. 215.

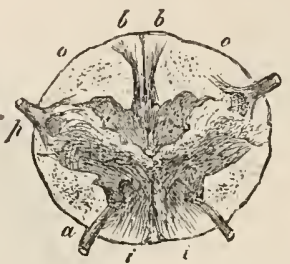

FIG. 216.

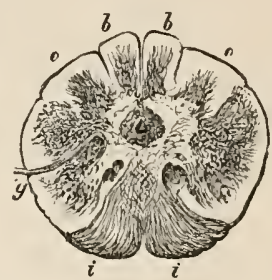

FI(i, 214-S.ction made opposite First Pair of Cervical Nerves.-The following references indicate the same parts in Figs. 217-223: $a$, anterior ; $p$, posterior root of Spinal Nerve; $i, i$, anterior white columu; 0 , posterior white column beluw, but in the higher sections restifurm bohy ; $b b$, posterior py ramids: e, gray Tubercle of Rolando: $H_{g}$, Hypoglossal Nerve; Sp. Ac., spinal Accessory Nerve; $V$, Pneumogastric Nerve; gp, Glosso-pharyngeal Nerve.

FIG. 215.-Section passing through upper fibres of origin of First Pair of Cervical Nerves.

FIG. 216.- Section passing a quarter of an inch below Olivary bodies.

as a constituent part; they form, however, the immediate boundaries of the posterior median fissure; and whilst superficially marked off from the Restiform bodies by a slight groove, are more completely scparated from them by their anatomical relations to the parts above and below. Their fibres establish a connection between the sensory traet $(s t, s t)$ of the Crura Cerebri, and the posterior part of the lateral eolumns of the Spinal Cord, some of them passing also into its posterior eolumis. These fibrous tracts are stated by Mr. Solly ${ }^{2}$ and Dr. Radclyffe $\mathrm{Hall}^{3}$ to decussate, partially, at least, whilst passing through the Pons Varolii. The arciform fibres ( $a f$, Fig. 212) here seen erossing the Medulla nearly at right angles, just below the olivary bodies, which indeed they partly eover, have been shown by Mr. J. L. Clarke to be only a superficial portion of a very important and extensive order of commissural fibres (wcll seen in Figs. 217-219), the bulk of which is mueh more deeply placerl, and which not only connect the opposite halves of the Medulla Oblongata by traversing the raphé, but at the same time form the means of conmunication between all the parts of each separate half, the netlike arrangement of the fibres being everywhere interspersed with innumerable cells of varied shape and size, from which many of the fibres may be seen to arise.-The gradual development of the several centres of gray substance in the Medulla Oblongata, and the rehations whieh they bear to the Cerebral nerves, most of which take their origin from this part of the spinal axis, may be rendered intelligible by a comparison of the following diagrams.

The first section here shown (Fig. 214) is made at the level of the lower fibres of origin of the first Spinal nerves. On conpraring the shape and position of the gray substance with its appearance, as shown in Fig. 207, it will be observed that the whole of the gray substance is here placed more anteriorly in that section; that the posterior white eolumns ( $o$ and $b$ ) are of large size, whilst the anterior and antero-lateral columns are compara-

3 Kindiub. Med. and Surg. Journ., July, 1817, plate vii. 
tivcly small. In Fig. 215 the gray substance is seen to have relatively increased in size, but to have become somewhat broken up. On each side of the posterior median fissure a remarkable longitndinal column $(b)$, containing gray matter in its interior, termed the "pyramidal column," is beginning to appear; a sccond swelling, sitnated on the Cervix a little morc externally to that just mentioned, indicates the commencing appearance of the restiform nucleus; still more externally, the Caput Cormu may be scen to be detached and thrown aside from the rest as a distinct mass, which is traversed successively by the vagus and glosso-pharyngeal nerves, and then becomes the principal nucleus of the sensory root of the fifth pair. The decussation of fibres proceeding from the deeper part of the lateral column (between $p$ and $a$, Fig. 214) to form the anterior columns is also here well seen, and the central gray substance has reassumed a triangular form. In the ncxt section (Fig. 216), made about $\frac{1}{4}$ of an inch below the olivary bodies, the gray matter of the posterior pyramids $(b)$ on either side of the posterior median fissure, is seen to have considerably increased in size; the slight swelling at the basc of the Cervix is also now much larger, and has become the gray nucleus of the restiform bodies (o), whilst what was the Caput Cornu is puslied still further forwards, and forms a great mass of gray matter at the side of the cord known as the Gray Tubercle of Rolando (e, Figs. 217, 218). The commissural direction and arrangement of the fibres of the anterior pyramids are also still apparent. They come principally from the central gray substance, and scarcely at all from the lateral columns. On making a section just below the olivary bodies (Fig. 217), the gray matter is found to occupy almost the whole of the posterior pyranids $(b)$, and a large portion of the restiform bodies $(o)$, whilst a most delicate and complex system of interlacing fibres surrounds the central canal. The gray tubercle of Rolando having increased in size and reached the surface of the Medulla, appcars

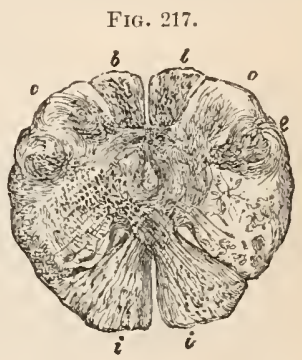

Section inmediately below Olivary bodies. as a dark streak ( $t, c, \mathrm{Fig} .212)$; the portion of the anterior column which does not decussate has been left white on the right side of this drawing. Two minute dark spots may be noticed near the bottom of the posterior fissure; these are imbedded in the mass of cells forming the chief ganglionic centres of the spinal accessory nerve, though other and extremely tine rootlets belonging to these nerves may be traced arising from the lateral gray substance and base of the anterior cornu of the spinal cord or tractus intermedio-lateralis, and issuing with the posterior roots of the Spinal nerves as low down as the sixth or seventh cervical vertebra. Fig. 218 is taken from a section made through the lower part of the Olivary body. The postcrior pyramids $(b)$ still contain much gray matter, and the restiform nucleus and gray tubercle of Rolando are strongly defined. The small central canal has become closely approximated to the bottom of the posterior median fissure, and on either side of it are the ganglionic masses from which the spinal accessory nerve takes its origin, whilst immediately in fiont of it are two dark spots containing large multipolar cells indicating the ganglia of origin of the hypoglossal nerve, other fibres of which last, like those of the spinal accessory nerve, may be traced downwards, and arise firm the upper remains of the anterior cornu, whilst a few of the superior fibres cross the raphé. Anteriorly the windings of the corpus dentatum or olivary nucleus are visible, with a reniarkable set of ganglionic cells indicated by 
G, constituting the vaso-motor centre, ${ }^{1}$ and termed the antero-lateral nucleus. These are connected together by a network in the lateral column, and by nerve-fibres from the Tubercle of Rolando. The whole central part of the gray substance of the Medulla is shown to be composed of commissural bundles constituting the deep system of arciform fibres described by Lockhart Clarke. The decussation of the anteriur pyramids is here much diminished; for the fibres they derive from the lateral columns, which at first were

FIG. 218 .

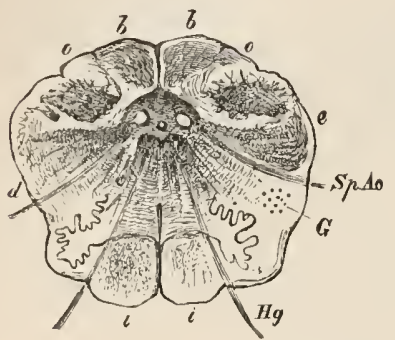

FIG, 219.

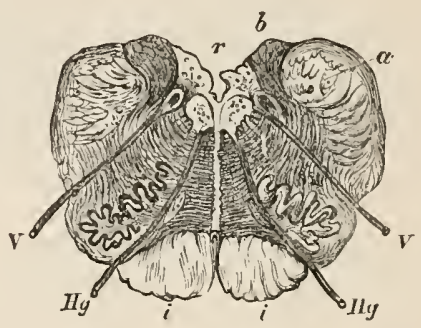

FIG. 218.-Section through lower part of Olivary body.

FIG. 219,-Section through point of Calamus seriptorius.

their principal source, have become comparatively few; whilst those that proceed from the posterior columns and central gray substance have bcen gradually increasing in number, though not in a corresponding proportion. The section shown in Fig. 219 is carried through the Medulla just at the point of the Calamus Scriptorius, and shows that the hypoglossal ganglia have retreated somewhat backward, pushing the mass of ganglionic cells from which the spinal accessory arose, but which now constitute the origin of the Pneumogastric Nerves (v), to some extent outwards. ${ }^{2}$ The po-terior pyramidal $(b)$ and restiform ganglia $(a)$ love increased in size, and by their lateral expansion form nearly one continuous mass on each side of the Medulla, which, from the close interlacement of their fibres, presents a spongy appearance, numerous cells being contained in the interstices. In a recent paper read before the Royal Society, Mr. Lockhart Clarke ${ }^{3}$ lias made one or two additions to the foregoing statement which may be here noticed and will be understoor from an examination of Fig. 220 . It will there be seen that between the hypoglossal and spinal accessory nuclei, the cells of which are intimately comnected together by communicating processes, a small group of cells exist (7x), forming the attenuated point of a fusiform tract which, augmenting as it ascends, insinuates itself betrecn the hypoglossal and the spinal accessory, now become the vagal nucleus (n), and that still higher (c) it has attained a large size and forms in conjunction with another sulall vesicular tract, also situated to the imuer side of the hypoglossal nerve, the fisciculus teres, which lies on either side of the median line. This tract constitutes the nucleus of the seventh. Intimately connected with the nucleus of the seventh and with that of the glosso-pharyngeal by means of lomg fibres are the cells which form the motor tract of the fifth, and which may be traced below the level of the middle of the olivary borlies. The section displayed in Fig. 221 is carried through the upper part

1 I)ttuar, Ludwig's Arbeiten fur $1873, \mathrm{p} .115$.

2 'The vesicular eolumn which gives wrigin to the fibres of the spinat accessory, becomes the centre for the Vagus abent the level of the middle of the olivary bendies.

3 lhil. 'Trans., 1868, it. i, ץ. 283. 
of the Medulla Oblongata, and shows the Glosso-pharyngeal arising at a higher level, but from the same series of ganglionic cells as those from which the Spinal Accessory and Pneumogastric roots have successively arisen, and which are now sunk beneath two new masses of vesicular sub-

FIG, 220.

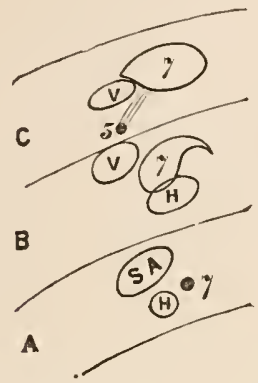

FIG. 221.

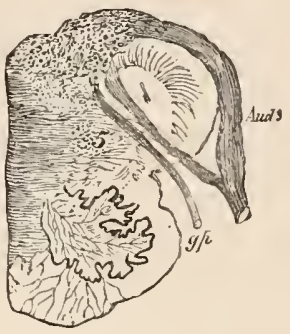

FIG. 220.-Diagram showing the position of the Nuclei in the Medulla Oblongata: $a$, at the end of the lower third of the olivary body $b$, at the middle of the olivary body; $c$, at the upper extremity of the olivary body; II, Hypoglossal; s A, Spinal Accessory; v, Vagus; 7, Portio dura; 5 , Motor root of the fifth.

Fig. 221.-Section through upper part of the Medulla Oblongata.

stance from which the Auditory nerves take their origin. The Auditory nerve itself is seen to divide into two portions, one curving round the side of the Medulla, and forming the well-known transverse elevation on the floor of the Fourth Ventricle, to terminate in the inner or posterior auditory nucleus and to some extent in the outer nucleus, the other dipping into the substance of the cord in front of the Restiform body to reach the outer nueleus formed by the summit of the posterior pyramid and apparently by

FIG. 222.

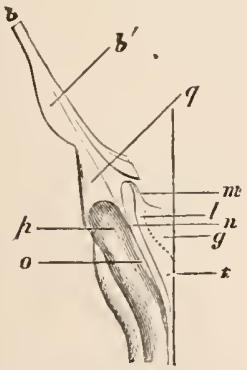

FIG, 223,

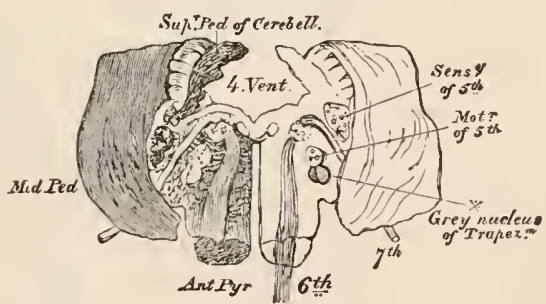

FIG. 222.-Longitudinal section of the Medulla Oblongata: 0 , pyriform gray substance of the restiform and post-pyramidal bodies; $p$, superfieial gray substance of the restiform body ; $b$, posterior pyramid; $b^{\prime}$, its gray substance; $g$, vagal nucleus; $t$, sjinal accessory nucleus; $n$, slender column particularly connected with the glosso-pharyngeal aud with the vagal and spinal accessory roots of origin.

FIG. 223.-Section made through the summit of the Medulla Oblongata.

part of the nucleus of the Pneumogastric nerve. The ganglionic cells which give origin to the motor root of the fifth nerve are here very apparent. If the parts just described are examined in longitudinal section the appearances are those shown in Fig. 222, and are thus described by Mr. Lockhart Clarke. ${ }^{1}$ If the posterior pyramirl $b, b^{\prime}$ (on the left side) be carefully

1 Researches on the Intimate Structure of the Brain. Secund Series. Phil. Trans.

Part i, 1868, p. 267. 
dissected from the restiform body from below upwards, and be thrown forwards, the tract will be exposed from which the spinal accessory and pneumogastric nerves arise. The part indicated by $t$ is the nucleus of the spinal accessory nerve. The oval mass, $g$, marked off by the dotted line, is the inner and posterior portion of the vagal nucleus. Continuous with the preceding, and exposed at the point of the calamus scriptorius by the divergence of the posterior pyramid, $l$, is its inner and more anterior portion, covered like the spinal accessory nucleus, $t$, lower down, by the posterior pyramid, as seen in Figs. 218 and 219 . Its upper point, $m$, forms the principal nucleus of the glosso-pharyngeal nerve. Along the outer and anterior part of this gray tract is a slender longitudinal white columm, which is lorlged as it were in a groove, and which tapers to a point as it descends obliquely inwards along the base of the posterior pyramid to the mesial line. In its upward course it lies along the inner edge of the pyramid, and joins those fibres of the latter which pass into the anterior or outer auditory nucleus. On the outer side of this slender white column is a somewhat fusiform mass of gray substance $(0)$ imbedded in the inner side of the restiform body, and exposed by the removal of the posterior pyramid. From the upper extremity of this mass at thin but broad layer of fibres, mixed with some gray substance $(p)$, radiates upward and outward on the restiform body. The deep origins of the fifth, sixth, and Portio Dura of the seventh, are further shown in the section Fig. 213. The sixth and Portio Dura seem to form almost a loop, and to be continuous with each other through a common ganglionic centre from whence they arise, situated above but in the same line with that of the hypoglossal, and both may be traced to the superficial gray layer of the fasciculus teres, but each of these nerves has besides a separate nucleus of its own. When the portio dura of the seventh nerve reaches the firsciculus teres, as shown in Figs. 223, 225, it runs longitudinally down the medulla, and after a very short course agrain bends tramsversely forward to form a loop along the side of the median furrow. The summit of this curve constitutes the longitudinal bundle of fibres, of which the ovil eut end is seen united by a bridge in the figure just below the words fourth ventricle (Fig. 223). The loop incloses the nucleus common to it and the sixth, and the lower arm of the loop in its course forwards divides like a brush into separate fibres, which plunge into the motor nucleus of the fifth nerve, and into the superior olivary body, or gray nucleus of the trapczium. As regarls the sixth, the lower fibres arise from the ganglion conmon to it and the portio dura of the seventh, and also from the gray matter of the fasciculus teres, whilst the upper fibres arise from the upper and inner part of the common ganglion, which may here be regarded as a separate centre or nucleus, as the outer portion from which the portio dura previously arose, has become much attenuated, and ceases to give origin to the fibres of that nerve. The close rclation which exists between the nuclei of origin of the hypoglossal, glossopharyngeal, spinal accessory, vagus, facial, and trigeminal nerves, is of much interest, and serves to explain certain symptoms accompanying varions forms of paralysis, in which the muscles concerned in deglutition, vocalization, articulation, and expression are affected. The motor and sensory roots of the fifth are separated from one another at their origin by the Portio Dura. The connection of the motor root with the glosso-pharyngeal nucleus and with the fasciculus teres or nucleus of the seventh, has alrearly been noticed. The Posterior or Sensory root rums down throngh the front of the gray tubercle or caput cormu posterior, which may be reganded as the contimuation of its nucleus, and is in most intimate relation with the fibres of origin of the vagus and glosso-pharyngeal nerves, which pass through this portion of the fifth nerve. The origins of the fourth pair of Cerebral nerves have 
been shown by Mr. Lockhart Clarke to be traceable on either side through the thin lamine constituting the Valve of Vieussens, and through the columns forming the lateral boundaries of the Aqueduct of Sylvius, to near the floor of the fourth ventricle; whilst the third nerve, the apparent origin of which is from the locus niger of the Cerebral perluncles, has been followed by Stilling to a gray nucleus underlying the Aqueduct of Sylvius, and has been shown by Clarke to be in close relation with the gray tubercle into which the sensory root of the fifth penetrates, and the nucleus common to the portio dura and abducens nerves. In order to complete the description of the origins of the Cerebral nerves, it is only requisite here to mention that the second pair, or Optic nerves, arise from the posterior part of the Optic thalami and from the Corpora Quadrigemina; whilst the first pair, or Olfactory nerves, arise by three roots, the outer one appearing to be connecterl with the Corpus Striatum of its own side, the inner one with the Lamina Cinerea in front of the Optic commissure, and the middle one springing from a gray nucleus in front of the anterior perforated space.-It will thus be seen that the whole series of the Cephalic nerves, when followed to their origin, arise from gray ganglionic centres situated along the floor of or just below the fourth ventricle and the base of the brain. These, there can be little doubt, are more or less intimately connected with one another by longitudinal and transverse commissural fibres, and establish the exist-

FIG. 224 .

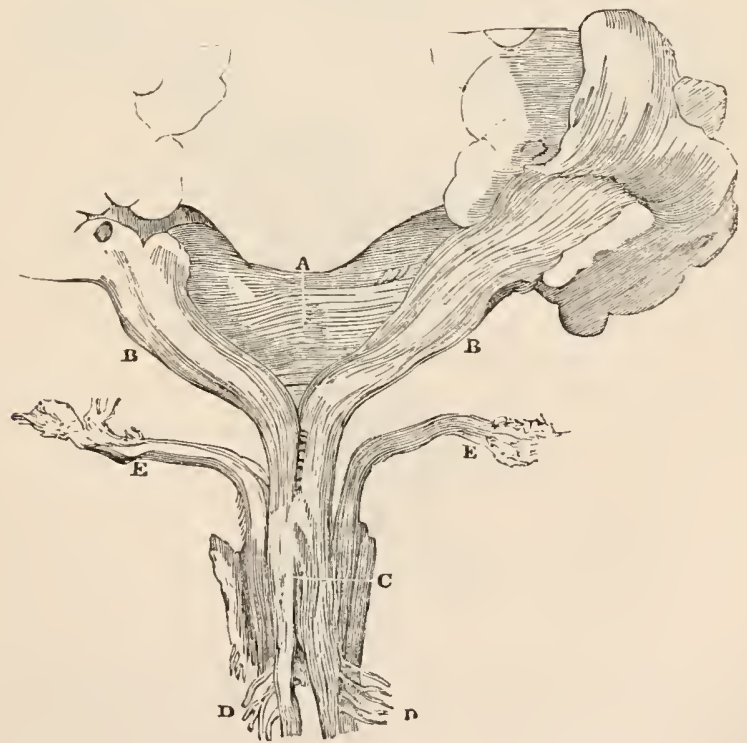

Course of the Scnsory tract according to Sir C. Bell: A, Pons Varolii; B, B, sensory tract separated; C, union of posterior columus; D, D, posterior roots of spinal nerves; E, sensory roots of fifth pair.

ence of a Sensory tract, the activity of which is of fundamental importance, as will hereafter be shown, in the origination of ideas and of a certain class of morements which may be termed "consensual " or "sensori-motor." The Pons is chiefly composed of transverse fibres which constitute the great conımissure of the Cerebellum; and are an extension of the arciform fibres of the medulla oblongata; and these fibres not only surround the longitudinal 
bands which connect the Cerebral mass with the Spinal Cord, but pass through them so as in some degree to isolate the two lateral halves from one another, and to form a complete septum between the anterior and posterior portions of each. These anterior and posterior tracts of the Crura Cerebri are prob-

FiG. 225.

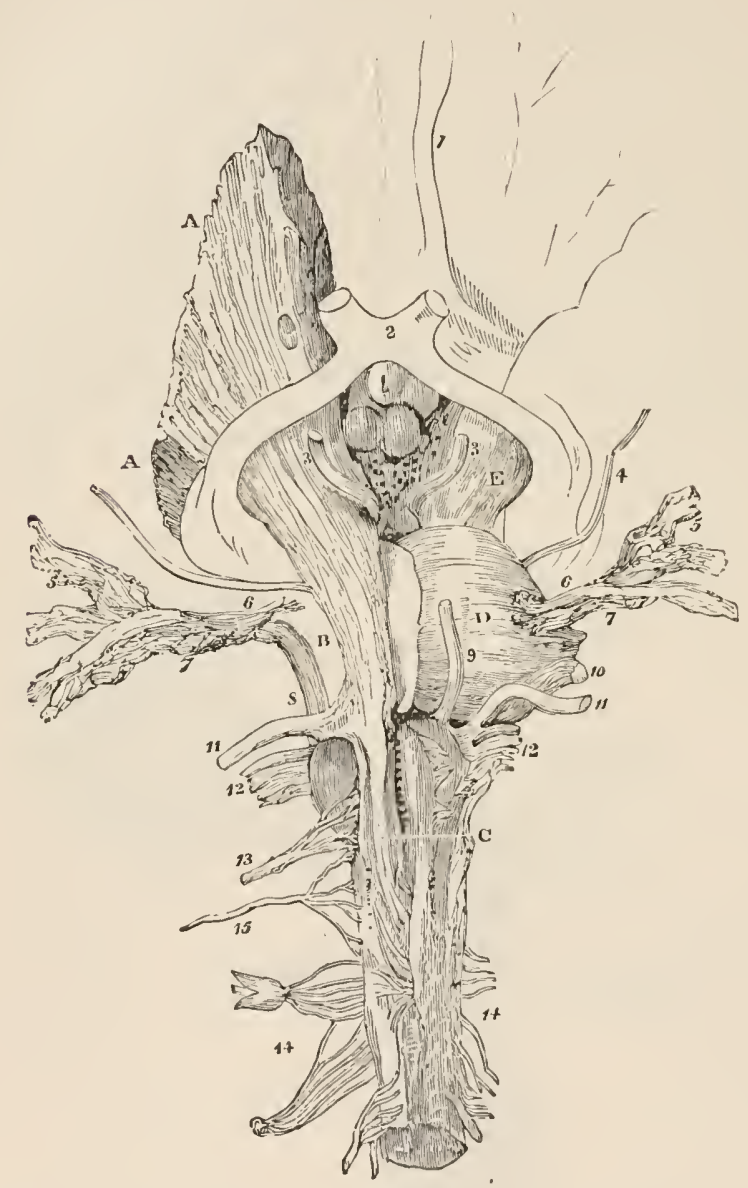

Course of the Motor tract, according to Sir C. Bell: A, A, fibres of the Iremisphere, conrerging to form the anterior portion of the crus cerebri; 1 , the samc tract, where passing the crus cerebri ; $c$, the right l'yramidal body, a little above the point of decussation; D, the remaining part of the l'ous Varolii, a portion having been dissected ofl to expose 13.-1, olfactory nerve, in outline; 2 , union of optic nerves; 3,8, notor oculi ; 4,4 , patheticus; 5,5 , trigeminus; 6 , 6 , its muscular division ; 7,7 , its sensory root; 8 , origin of sensory root from the postcrior part of the medulla oblongata; 9 , abduccus oculi; 10 , auditury neve; 11 , fucial nerve; 12 , eighth pair; 13 , hypglossal; 14, spinal ncrves; 15 , spinal accessory of right side, separated from par vagum and glosso-pltaryugeal.

ably essentially sulservient to the motor and sensory functions. The gray substance of the Pons is arranged in a peenliar manner. Its cells are generally round, oval, or fusiform, and of about the $\frac{1}{15} \overline{5}$ th of an inch in diameter, and are so comneeted with nerve-fibres in ehains or bundles as to form 
a complete network, the principal chains of which have in general a longitudinal extcnsion, and follow the course of the longitudinal fascieuli of the anterior pyramids. The general relations of the Sensory tract were represented by Sir Charles Bell in the accompanying diagram (Fig. 224), in which the Medulla is opened on its posterior aspect, the restiform columns separated and turned aside so as to bring into view the posterior pyramids, some of the fibres of which may be traced upwarls into the Thalami Optici, whilst they pass through the posterior pyramids into the posterior portion of the lateral columns, and also into the posterior columns of the Spinal Cord. It will be seen, however, from the foregoing description, that the posterior and lateral columns of the Cord to a great cxtent terminate in the lower part of the Medulla Oblongata, and that the posterior pyramids and restiform bodies, with their gray nuclci, are essentially new formations, the real function of which is as yet only partially determined. The Motor tract (Fig. 22.5) is brought into view by simply raising the superficial layer of the Pons, and following upwards and downwards the longitudinal fibres which there present themselves. These fibres may be traced upwards into the Corpora Striata, and downwards into the anterior pyramids and a portion of the olivary columns, so that they connect the Corpora Striata with the anterior, and with the anterior portion of the lateral columns of the Spinal Cord.

489. Nerves of the Spinal Axis.-With the Spinal Cord (in its limited sense) there are concerned thirty-one pairs of nerves; each of which corresponds to a vertebral segment of the body, and has two sets of roots, an anterior and a posterior, differing in their functional endowments, as already described $(\$ 461)$. The anterior roots are usually the smaller; and this is particularly the case with those of the cervical nervcs, in which the posterior roots are of remarkable comparative size. In the first Cervical or "suboccipital" pair, the anterior roots are sometimes wanting; but there is then a derivation of fibres from the Spinal Accessory, or from the Hypoglossal, or from both. The two roots of the ordinary Spinal nerves unite immediately beyond the ganglion, which is situated on the posterior onc; and the trunk thus formed separates immediately into two divisions,- - the anterior and posterior,- - each of which contains both afferent and motor fibres. These divisions, of which the anterior is by far the larger, proceed to the anterior and posterior parts of the body respectively; and are chiefly distributed to the skin and the muscles. The anterior branch is that which communicates with the Sympathetic nerve.- In addition to these, however, as we have seen, the cranial prolongation of the Spinal Axis is the centre of all the cephalic nerves, the functions of which, since they are for the most part distinguished by the peculiarity of their endowments, require to be separately noticed.

490. The pair of nerves commonly designated as the Fifth of the Cephalic series, or as the Trigeminus, is the one which more nearly resembles the ordinary Spinal nerves, than does any other of thosc originating within the cranium. It possesses two distinct sets of roots, of which one is much larger than the other; on the larger root, as on the posterior and larger root of the Spinal nerves, is a distinct ganglion, known as the "Gasserian," and the fibres arising from the smaller root, the number of which has been estimated at 9000 to 10,000 , do not blend with those of the larger, until the latter have passed through this ganglion. The trunk of the nerve separates into three divisions, - the Ophthalmic, the Superior Maxillary, and the Inferior Maxillary; and it can be easily shown, by careful dissection, that the fibres of the smaller root pass into the last of these divisions alone. When the distribution of this nerve is carefully examined, it is found that the first and second divisions of it proceed almost entirely to the Skin and Mucous surfaces, only 
a very small proportion of their fibres being lost in the muscles; whilst of the branches of the third division, a large number are distinctly Muscular. Hence analogy, and the facts supplied by anatomical research, would lead to the conclusion that the two first divisions are nerves of sensation only, and that the third division combines sensory and motor endowments. Such an inference is fully borne out by experiment. When the whole trunk is divided within the cranium by the penetration of a sharp instrument (which Magendie, by frequent practice, was able to accomplish), evident signs of acute pain are given. After the incision has been made through the skin, the animal remains quiet until the nerve is touched; and when it is pressed or divided, doleful cries are uttered, which continue for some time, showing the painful effect of the irritated state of the cut extremity. The common sensibility of all the parts supplied by this nerve is entirely destroyed on the affected side. The jaw does not hang loosely, because it is partly kept up by the muscles of the other side; but it falls in a slight rlegree; and its movements are seen, when carefully observed, to be somewhat oblique. If the trunk be divided on cach side, the whole head is deprived of sensibility; and the animal carries it in a curious vacillating manner, as if it were a foreign body.-If the anterior or Ophthalmic branch only be divided, all the parts supplied by it are found to have lost their sensibility; but their motions are unimpaired; and all experiments and pathological observations concur in attributing to it sensory endowments only. The only apparent exception is in the case of the naso-ciliary branch, since there is good reason to believe that the long root of the ciliary ganglion and the long ciliary nerves possess motor powers; but these appear to be derived from the Sympathetic or from the $3 \mathrm{~d}$ pair. When the whole nerve, or its anterior branch, is divided in the rabbit, the pupil is exceedingly contracted, and remains immovable; but in dogs and pigreons it is dilated. The pupil of the other eye is scarcely affected; or, if its dimensions bc changed, it soon returns to its natural state. The eyeball, however, speedily becones inflamed; and the inflammation usually runs on to suppuration and complete disorganization. The commencement of these changes inay be commonly noticed within twenty-four hours after the operation; and it is probable they nay in part be attributed to the want of the protective secretion, which is necessary to keep the mucous surface of the eye in its healthy condition, and which is not formed when the sensibility of that surface is destroyed; since, as Snellin has shown, if the eye be carefully protected from the action of extermal and injurious agencies, no ill effects are observed. Patholorical evidence, however, is not wanting to show that the fifth exerts some influcnce over the nutritive processes in the parts it supplics, which is probably transmitted through the vaso-motor nerves it contans. ${ }^{2}$ 'The Superior Muxillary branch, considered in itself, is equally destitute of motor cudownents with the ophthalmic ; but its connection with other nerves, through the spheno palatine ganglion, or lather its anastomosing twigs, ${ }^{3}$ may introduce a few motor fibres into it.-The Inferior Maxillary branch is the only one which possesses motor as well as sensory endownents from its origin; but its different sublivisions possess these endowments in varying proportions, some being almost cxclusively motor, and others as completcly of a sensory character. The latter is probably the nature of the Lingual branch; and there seems good reason to believe, as will hereafter be shown (\$ 493$)$, that this ministers not only to the tactile sensibility of the tongue, but to the

1 Anu. d'O('ulist., 186; , t. liii, p. 178.

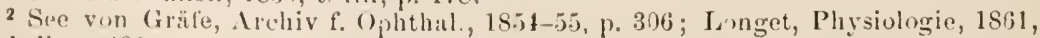
vol. ii, p. 48 ;

3 Since the ganglion has been shown by Prérost to be surely sensory. Séquard's Archivés de Physiol., 1868, pp. 7 and 207.)

(Brown- 
sense of Taste. The muscles put in action by this division, are solely those concerned in the masticatory movements.-The Chorda Tympani, though essentially destined to excite the submaxillary gland to action, cither directly or indirectly, contains motor nerves, distributed to the muscles of the Tongue." The 5th pair is connected, in different parts of its course, with a number of small ganglia belonging to the Sympathetic system. One of the most interesting of these ganglia is the Ophthalmic or Ciliary (Fig. 226, 29), which is the centre whence the eyeball derives its supply of nerves, sensory, motor, and sympathetic. This ganglion derives its sensory fibres by its "long root" from the nasal branch of the Oplithalmic division of the 5 th pair; its motor fibres, by the "short root" from the $3 \mathrm{~d}$ pair; whilst by another small root, it is connected with the cavernous plexus of the Sympathetic system, ${ }^{2}$ and is thus brought into relation with the Spinal axis; for, according to Budge, ${ }^{3}$ these fibres of origin for the Sympathetic nerve arise from two centres: first, from the Spinal Cord between the 6th cervical and the $2 \mathrm{~d}$ dorsal vertebra (a part which he terms the Centrum Cilio-spinale Inferius), the fibres from which pass upward in the great cord of the Sympathetic; and secondly, from another centre situated in the Medulla Oblongata, in immediate proximity to the origin of the Hypoglossal nerve, the fibres from this source passing into the superior cervical ganglion. Valentin maintains that some of the fibres of the Inferior Cilio-spinal ganglion ascend in the trunk of the Pneumogastric. ${ }^{4}$

491. The Third, Fourth, and Sixth pairs, together make up the apparatus of motor nerves, by which the muscles of the Orbit are called into action. The 3d pair supplies the levator palpebre, the superior, inferior, and internal recti; the circular fibres of the Iris and the Ciliary Muscle, or Tensor

1 See Vulpian, Gazette Hebdomadaire, 1873, No. 3.

2 The functions of this ganglion have been made the subject of particular investigation by Dr. C. Radelytfe Hall (Edinb. Med. and Surg. Journal, 1816-48), whose most imjiortant results are as follows:

1. The size of the ciliary ganglion is always in direct proportion to the activity of the iris, which in turn always bears a direct relation to the strength and acuteness of vision, and to the nocturnal habits of the animal, and implies a proportionate development of the internal vascular apparatus of the eye.

2. The ganglion is always more intimately connected with the $3 \mathrm{~d}$ pair than with any other; the size of the short root being always in direct relation to that of the gangtion, and the ganglion being sometimes a mere swelling on the trunk of the nerve.

3. The fibres derived from the 5th pair do not terminate in the ganglion, but pass onwards through it to the eiliary plexus.

4. In the Rabbit, the iris receives fibres from the 6 th pair which do not pass through the ganglion; and it is through this that the contraction of the pupil is produced in that animal by irritation of the 5th pair, which will not produce any effect upon the pupil of the Dog, Cat, or Pigeon, so long as it does not affect the brain to the extent of producing vertigo, nor affect the visual sense in any other way.

5. Irritation of the 5th nerve does not in any animal affect the action of the iris, affer the division of the ccrebral connections of all the other ocular nerves [this is denied by Budge], so that its influcnce over the movements of the iris must be rcflected through the encephalie eentres, not through the ophthalmic ganglion.

6. The function of the ganglionic centre itself, as a part of the Sympathetic system, seems to be to bring the "organic aetions" of the eyeball, expecially its supply of blood, into harmony with its functional activity; this harmony being produced by the passage of the eerebro-spinal nerves through the ganglion, which exeites the synergetic action of its own vesieles and nerve-fibres.-Irritation of the $3 d$ pail of werves produces contraction of the pupil ; irritution of the cervical portion of the Sympathetic, dilatation. On the other hand, paralysis of the $3 \mathrm{~d}$ nerve is followed by dilatation; paralysis of the cervical sympathetic (as by section), by contraction of the pupil.

3 Physiologie, 1862, p. 767.

4 Sce Schiff, Physiologie, p. 376. 
choroidea. Seetion or paralysis of the $3 \mathrm{~d}$ oeeasions drooping of the upper eyelid (ptosis); external strabismus, persistent dilatation of the pupil, and aeeommodation of the eye for distant objects. The 4 th nerve is eonfined to the Superior Oblique, and the 6 th to the External Reetus. The number of fibres in the $3 \mathrm{~d}$ nerve is about 15,000 , in the 4 th about 1100 , in the 6 th from

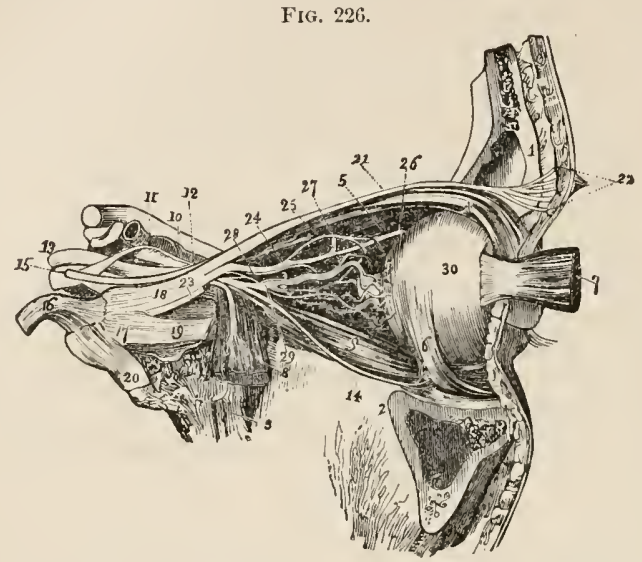

The Nerves of the Orbit seen from the outer side; 1 . Section of the frontal bone; immediatcly behind the numeral is the frontal sinus, and, in front, the integument. 2. The superior maxillary bone; the section in front of the numeral exhibits the maxillary sinus. 3. Part of the sphenoid bone. 4. The levator palpebre and superior rectus muscles, 5. The superior oblique muscle. 6 . The inferior oblique muscle. 7. The ocuiar half of the external rectus muscle drawn forwirds. 8. The orbital half of the external reetus muscle turned downwarts. On this muscle the sixth nerve is seen dividing into branches. 9. The inferior rectus musele. 10. The optic nerve 11. The internal carotid artery enıerging from the cavernous sinus. 12. The ophthalmic artery. 13. The third nerve. 14. The branch of the thirl nerve to the inferior oblique musele. Between this and the sixth nerve (8) is scen the branch which supplies the inferior rectus; its branch to the ophthalmic ganglion is seen proceeding from the upper sicle of the trumk of the nerve, at the bottom of the orbit. 15. The fourth nerve. 16. The trunk of the fifth nerve. 17. The Gasserian ganglion. 18. The ophthalmic nerve. 19. The superior maxillary nerve, 20. The inferior maxillary nerve. 21. The frontal nerve. 22. Its division into branches to supply the integument of the forehead. 23. The lachrymal nerve. 24. The nasal nerve; the small nerve seen in the bifurcation of the nasal and frontal nerve, is one of the branches of the upper division of the third nerve. 25. The nasal nerve passing over the internal rectus muscle to the anterior cthmoidal foramen. 26. The infra-trochlear nerve. 27. A long ciliary branch of the wasal; another long ciliary branch is seen proceding from the lower aspeet of the nerve, 2s. The long root of the ophthatmic ganglion, proceeding from the nasal nerve, and receiving the sympathetic root which joins it at an acute angle. 29. The ophthaluic ganglion, giving off from its forepart the short ciliary nerves. 30 . The globe of the eye.

2000 to $2500 .^{1}$ The third and fourth nerves present some traces of sensibility, which in the former nerve is probably derived from the 5th. Chanvea ${ }^{2}$ observes that the deep or intra-cerebral portions of the motor nerves are quite incapable of being excited to action by direct stimulation; though on applying irritation to them at the point where they emerge from the cerebrum, movements ean always be induced.-The peeuliar mode in which those motor nerves ordinarily excite the museles to aetion, under the guidance of the visual sense, will be considered in the next Seetion. Although commonly ranked as eephalie nerves, they have no direet comnection with the Cerebrum; their real origin being from the upper part of the Spinal Axis. The roots of the $3 d$ pair may be traeed into direet eonnection with

1 Rosentlal, De Numero atque Mensura Microsep. Fibrillarum, Breslau, 1815.

2 Journal de la Physiologie, tom. v, 1862, p. 272. 
the Corpora Quadrigemina; a fact of considerable physiological importance, as will hereafter appear.-The chief actions of a purely reflex nature to which this group of nerves ordinarily ministers, are the government of the diameter of the pupil, which is accomplished through the Third pair; and the rolling

FIG, 227.

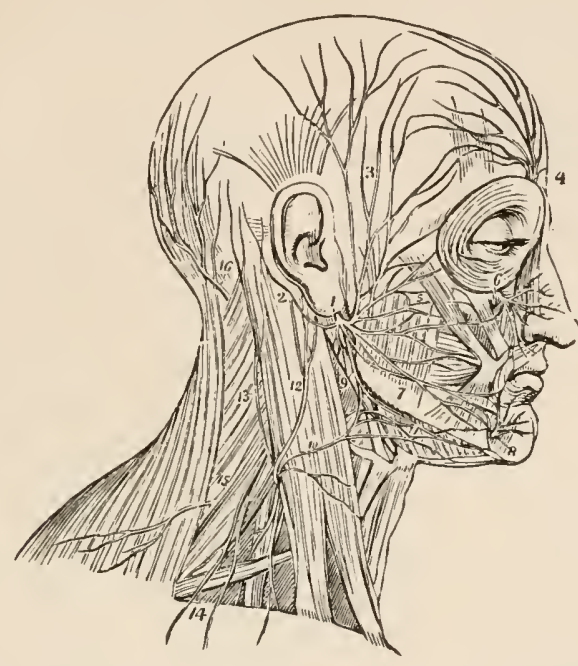

The distribution of the Facial Nerve, and the branches of the Cervical Plexus: 1. The facial nerve, escaping from the stylo-mastoid foramen, and erossing the ramus of the lower jaw ; the parotid gland has been remored in order to show the nerve more distinctly. 2. The posterior auricular branch: the digastric and stylo-mastoid filaments are seen near the origin of this branch. 3. Teuporal branches, communicating $w i t h(4)$ the branches of the frontal nerve. 5. Facial branches, communicating with (6) the infra-orbital nerve. 7. Facial branches, communicating with (8) the mental nerve. 9. Cervicofacial branches, communicating with (10) the superficialis colli nerve, and forming a plexus (11) orcr the submaxillary gland. The distribution of the branches of the facial in a radiated direction over the side of the facc, constitutes the pes anserinus. 12. The auricularis magnus nerve, one of the ascending branches of the cervical plexus. 13. The occipitalis minor, ascending along the posterior border of the sterno-mastoid muscle. 14. The superficial and deep descending branches of the cervical plexus. 15. The spinal accessory nerve, giving off a branch to the external surface of the trapezius muscle. 16. The occipitalis major nerve, the posterior branch of the second cervical nerve.

of the eyeball beneath the upper lid during sleep, as well as in the efforts of sneezing, coughing, etc. But irregular movements of the eyeballs, which must be referred to the same group, are continually seen to accompany various abnormal forms of convulsive action.

492. The Portio Dura of the 7th pair, or Facial Nerve, containing about 4000 to 4500 nerve-fibres, was shown by Bell to be a motor nerve, chiefly distributed to the muscles of the face; it has hence been termed the Nerve of expression. In its passage through the Aqueductus Fallopii, it presents a gangliform enlargement, which is connected by the N. petrosus superficialis major with the sphenn-palatine ganglion of the 5 th, and by the N. petrosus superficialis ninor with the otic ganglion.-By these branches the palatine muscles supplied by these ganglia receive their motor power, and some sensory fibres enter the facial, thus accounting for its sensibility when cut at its exit from that canal. It is also connected with the tympanic nerve of Jacobson proceeding from the glosso-pharyngeal, with the auricular of the Pneumogastric, and with the upper cervical nerves. The Portio Dura, besides the muscles of the face, supplies the stapedius, the auricular, occipital, stylohyoid, and 
the posterior belly of the digastric muscles. It does not supply the muscles of mastication. Its chorda tympani branch joins the lingual of the fifth, and has been shown by Bernard to be the nerve by which the subniaxillary gland is excited to active secretion, while another branch is distributed to the parotid ( $\$ 101)$.- Experimental as well as anatomical researches leave no doubt that the Portio Dura is the general motor nerve of the face; ministering to the influence of Volition and of Emotion, and also being the channel of the reflex movements concerned in respiration, as of other automatic actions of the muscles.

493. Although the functions of the Glosso-Pharyngeal nerve have been heretofore alluded to in part, several questions still remain to be discussed in regard to thcm. Reasons have been given for the belief, that it is chiefly an afferent nerve, scarcely having any direct power of exciting muscular contraction, but conveying impressions to the Medulla Oblongata, which produce reflex movements of the motor uerves concerned in deglutition ( $\$ 89)$. ${ }^{1}$ This view of this function was deduced by Dr. J. Reid from minute anatomical investigation, and from a large number of experiments. Some experimentcrs assert that they have succeeded in exciting direct muscular actions through its trunk; but these actions seem to be limited to the stylopharyngei, palato-glossi, and superior constrictor muscles. ${ }^{2}-$ Much controversy has taken place on the question, whether this nerve is to be regarded as ministcring, partly or exclusively, to the sense of Taste; and many high authorities have ranged themselves on each side. The question involves that of the function of the Lingual branch of the 5th pair; and it is partly to be decided by the anatomical relations of the two nerves respectively. The Glosso-pharyngeal is principally distributed on the mucous surfice of the fauces, and on the back of the tongue; but, according to Valentin, it sends a branch forwards, on either side, somewhat beneath the lateral margin, which supplies the edges and inferior surface of the tip of the tongue, and inosculates with the Lingual branch of the 5th. On the other hand, the upper surface of the front of the tongue is supplied by this Lingual branch. The experiments of Dr. Alcock, whose conclusions are borne out by D)r. J. Reid, decidedly support the conclusion, that the gustative sensibility of this part of the tongue is chiefly due to the latter nerve, being evilently impaired by division of it. On the other hand, it is equally certain that the sense of taste is not destroyed by section of the Lingual nerve on each side; and it seems also well ascertained, that it is impaired by section of the Glossopharyngeal nerve.-The pathological evidence bearing upon this point appears somewhat contradictory. Numerons cases have been recordell, ${ }^{3}$ in which both common and gustative sensation were destroyed in the parts of the tongue supplied by the 5th pair, when that nerve was paralyzed; in some of these, the loss of the sense of taste appeared to extend itself to the base of the tongue, but then there was evidence that the Glosso-pharyngeal was involved in the paralysis. On the other hand, cases of paralysis of the 5 th pair are related by Mr. Noble and by Vogt, ${ }^{4}$ in which commom sensation was lost, whilst the sense of taste remained in the same parts; and Mr. Noble relates another ease, ${ }^{5}$ in which there wats loss of taste without impairment of common sensation. The cases of Mr. Noble and Vogt would seem

3 See ulso Vulpian, Rıv. des Cours Seient., t. iii, p. 754.

${ }^{2}$ Su. Chauveati, Journal de Physiologric; Brown-Séquard, 1862, t. v, p. 209.

3 Soe rspreially the cuses recorded by lombers, in Müller's Areliv, 1838, Heft

iii ; Todd and Bowman, in Playsiologrienl Anatomy, vol. i, p. 445; and Dixon, in Med-Chir. 'Trans., vol. xxviii.

- Medical (razette, Oct. 25th, 1834; and Müller's Archiv, 1840, p. 72.

5 Mrdical Gazctte, Nov. 21st, 1835. 
to indicate that the 5th pair does not minister to the sense of Taste; but, as Dr. J. Reid has justly observed, we have no evidence that all the filaments of the 5th pair sent to the tongue were affected; and there is believed to be no case on record, in which the whole of the 5th pair, or of its third branch, was found to be diseased after death, and in which during life the sense of Taste had been retained in the anterior and middle parts of the tongue. Hence these cases only serve to indicate what is probable on other grounds; viz., that the filaments which convey gustative impressions are not the same with those that minister to common sensation.-On the whole, then, it seems to be proved by anatomical and experimental evidence, that both the Glosso-pharyngeal and the Fifth pair ninister alike to the tactile and to the gustutive sense; and there is nothing in the pathological facts just noticed, that militates against this conclusion. There seems good reason to believe the Glosso-pharyngeal to be exclusively the nerve, through which the impressions made by disagreeable substances taken into the moutl are propagated to the Medulla Oblongata, so as to produce nausea and to cxcite efforts to vomit. The number of fibres in this nerve is about 3500 .

494. The functions of the Preumogastric nerve at its roots have been made the subject of particular examination by various experimenters; sone of whom (for instance, Valentin, Longet, and Morganti) have concluded that it there possesses no motor power, but is entirely a sensory or rather an afferent nerve. According to these, if the roots, containing about 4000 smaller and 5000 larger tubules, be carefully separated from those of the Glosso-pharyngeal, and (which is a matter of sonie difficulty) from those of the Spinal Accessory nerve, and be then irritated, no movements of the organs supplied by its trunk can be observed: whilst, if the roots be irritated when in connection with the nervous centres, muscular contractions, evidently of a reflex char-

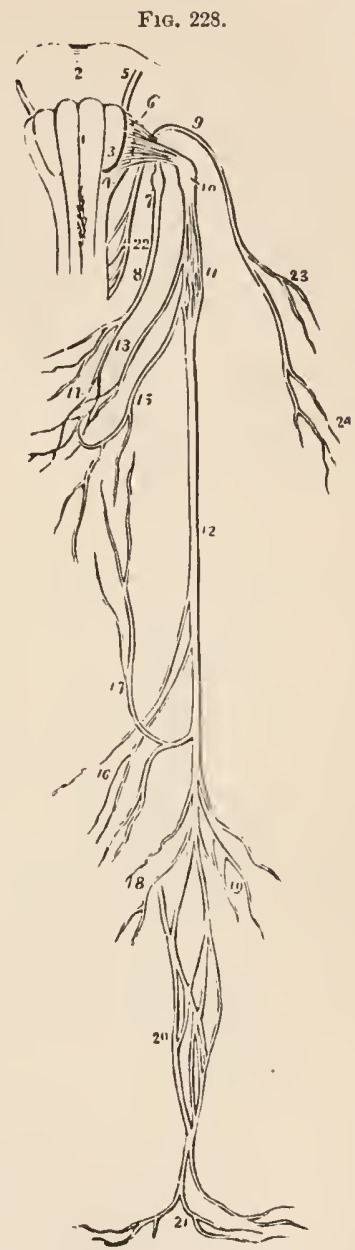

Origin and Distritution of the Eighth Pair of Nerves: $1,3,4$. The Medulla Oblongata. 1. The Corpus Pyramidale of one side. 3. The Corpus Olivare. 4. The Corpus Restiforme. 2. The Pons Varolii. 5. The Facial Nerve. 6. The origin of the Glosso-pharyngeal nerve. 7. The ganglion of Andersch. 8. The trunk of the nerve. 9. The Spinal Accessory nerve. 10. The ganglion of the Pneumogastric nerve. 11. Its plexiform ganglion. 12. Its trunk, 13. Its pliaryngeal branch forming the pharyngeal plexus (14) assisted by a branch from the glosso-pharyngeal (8) and one from the superior lary ngeal nerve (15). 16. Cardiac branclies. 17. Recurrent laryngeal branch. 18. Anterior pulnonary branches. 19. Posterior pulmonary branches. 20. Esophageal plexus. 21. Gastric branches. 22. Origin of the Spinal Accessory nerve. 23. Its branches distributed to the sternomastoid muscle. 24. Its branches to the trapezius musele. 
acter, result from the irritation ; and strong evidence of their sensibility are also given. It has been further asserted that, when the roots of the Spinal Accessory nerve are irritated, no indications of sensation are given; but that the muscular parts supplied by the Pneumogastric, as well as by its own trunk, are marle to contract, even when the roots are separated from the nervous centres; so that these roots must be regarded as the channel of the motor influence transmitted to them from the Medulla Oblongata. Where the Pneumogastric swells into the jugular ganglion, an interchange of fibres takes place between it and the Spinal Accessory; and it seems clear that the pharyngeal branches, which are among the most decidedly motor of all those given off from the Pneunogastric, may in great part be traced backwards into the Spinal Accessory. But, on the other hand, an equally numerous and trustworthy set of experimenters (among whom may be mentioned J. Reid, Müller, Volkmann, Stilling, Wagner, Chauveau, ${ }^{\prime}$ and Bernard ${ }^{2}$ ) are opposed to this opinion; maintaining that the Pneumogastric has notor roots of its own; and affirming that irritation of the roots of the Spinal Accessory produces little or no effect on the muscles supplied by the trunk of the Par Vagum. In the careful experiments of MII. v. Kempen and Thiernesse, ${ }^{3}$ the causes of these discrepancies have been elucidated, for they have shown that if irritation be applied to the roots of cither Spinal Accessory or Pncumogastric nerves, contractions occur in the essophagus, in the constrictor muscles of the pharynx, and in the internal muscles of the larynx; and in addition, when the Spinal Accessory roots are irritated, in the trapezius and sterno-mastoid muscles. If, however, the roots of the Pneumogastric nerves be divided, and irritation be again applied to the roots of the Spinal Accessory, no movements are observed execpt in the trapezius and sternomastoid inuscles. Hence it would appear that in the former instance, the resophageal and laryngeal movements were occasioned by a reflex action conveyed to the Medulla Oblongata by centripetal or sensory fibres in the Spinal Accessory, and reflected down to the muscles by motor fibres in the Pneumogastric nerves, the communication bctween the two nerves bcing effected by a chain of ganglionic nerve-cells in the Medulla. This vicw receives strong confirmation from another series of experiments performed by M. v. Kenipen, who found that if the supposed communication in the Medulla between the two nerves were divided by a transverse section carried between their respective origins, irritation of the posterior cut surface of the Medulla or of the roots of the Spinal Accessory wats only followed by movements in the stcrno-mastoid and trapezius muscles; whilst, when the same irritation was applied to the upper extremity of the Medulla or to the roots of the Pneumogastric, contractions occurred in the muscles of the pharynx and larynx. Hence we may conclude that the Pneumogastric itself contains the motor fibres which act on the muscles of the pharynx, asophagus, and larynx; although it probably receives additional motor fibres from the Spinal A cecssory, and supplies that nerve with afferent fibres.

495). 'There can be no doubt that the trunk of the Pnemogastric is to be considered as a nerve of double entownents; although it is ecrtain that these cudowments are very differently distributed amongst its branches. That the nerve is capable of conveying those impressions which become sensations when communicated to the sensorium, is experimentally prover by the faret, that, when its trunk is pinched, the animal gives signs of acute pain; but it is also evident from the painful consciousncss we occasionally

1 Chauveau, Journal de Physiologie, 1862, pp. 190 and 203.

8 Bernard, Recherches Expériment. sur les Fonctions du Nerf Spinal, etc., 1844, p. 30 .

s Bulletin de l'Acad. Roy, de Méd. de Belgique, 1863, tom. xvi, p. 184. 
have, of an ahnormal condition of the organs which it supplies. Thus, the suspension of the respiratory movcments gives rise to a fceling of the greatest uneasiness, which nust be cxcitch by impressions conveyed through this nerve from the lungs; and an inflamed statc of the walls of the air-passages causes the contact of cold and dry air to produce distressing pain and irritation; yet of the ordinary impressions conveyed from these organs, which are concerned in producing the respiratory movements, and in regulating the actions of the glottis, we are not conscious. The same may be said of the portion of the nerve distributed upon the alimentary tube; for the pharyngeal branches are almost exclusively motor, the afferent function being performed by the glosso-pharyngeal; whilst the osophageal and gastric are both afferent and motor, conveying impressions which excite reflex movements in the muscles of those parts, but which do not hecome sensations ex. cept under extraordinary circumstances. - The participation of this nerve in the operations of Deglutition, Digestion, Circulation, and Respiration, and the effects of injury to its trunk or branches, have already been considered in the account of thosc functions. ${ }^{1}$

496. In regard to the functions of the Spinal Accessory nerve, also, there has been great differcnce of opinion; the peculiarity of its origin and course having led to the belief, that some very especial purpose is answered by it. It may be said to have three roots of origin (Lockhart Clarke)-one from the anterior gray substance of the Spinal Cord, a second from the nuclcus of the Hypoglossal nerve, and a third from the tract of vesicular substance in the Medulla Oblongata, common to it and the Vagus nerve. The trunk contains from 2000 to 2500 tubules. The predominance of motor fibres in its roots, its inosculation with the Pneumogastric, and its probable reception of sensory fibres from the latter, whilst imparting to it motor filaments, have been already referred to $(\$ 494)$. As its trunk passes through the foramcn lacerum, it divides into two branches; of which the internal, after giving off some filanients that assist in forming the pharyngcal branch of the Pneumogastric, becomes incorporated with the trunk of that nerve; whilst the external proceeds outwards, and is finally distributed to the sternomastoid and trapezius muscles, some of its filaments inosculating with those of the cervical plexus. When the external branch is irritated, before it perforates the sterno-mastoid muscle, vigorous convulsive movements of that muscle and of the trapezius are produced; and the animal does not give any signs of pain, unless the nerve be firmly compressed between the forceps, or be included in a tight ligature. Hence it may be inferred that the functions of this nerve are chiefly motor, and that its sensory filaments are few in number. Further, when the nerve has been cut across, or firmly tied, irritation of the lower end is attended by the same convulsive movements of the muscles: whilst irritation of the upper end in connection with the spinal cord, after section of the Pneumogastric Ncrves $(\$ 494)$, is unattended with any muscular movement. Hence it is clear that the motions in the stcrnomastoid and trapezius muscles, occasioned by irritating it, are of a direct, not of a reflex character; though the movements which occur in the laryngeal and pharyngeal muscles, on irritation of the centric extremity, are unquestionably reflex in their nature.-According to Sir C. Bell, the Spinal Accessory is a purely Respiratory nerve, whose office it is to excite the involuntary or automatic movements of the muscles it supplies, which share in the act of respiration; and he states that the division of it paralyzes, as muscles of respiration, the muscles to which it is distributed; though they

1 For a careful inquiry into the effects of section of this nerve in producing pulmonary lesions, see Boddärt, Journ. de la Physiologie, t. v, pp. 442 and 527. 
still perform the voluntary movements, through the inedium of the spinal nerves. Both Valentin and Dr. J. Reid, however, positively deny that this is the case; and Dr. Reid's method of experimenting was well adapted to test the truth of the assertion. ${ }^{1}$ The functions of this nerve have been made the subject of special examination by M. Cl. Bernard $;^{2}$ who has arrived at the conclusion that the Spinal Accessory is essentially a motor nerve, whose action is not exclusively requisite for the ordinary movements of respiration, these being provided for by the Pneumogastric and ordinary Spinal nerves; but that its special function is to bring the respiratory movements into accordance with the requirenents of Animal life, adapting the actions of the muscles of the larynx and thorax to the production of voice, or to general muscular effort. The internal branch, which is specially distributed, with the fibres of the Pneumogastric, to the pharynx and larynx, is peculiarly subservient to the former of these purposes; and the external to the latter. This conclusion is sufficiently in accordance with the results obtained by other experimenters, to be received as a probable explanation of the facts which have been observed by them.

497. The Hypoglossal nerve, or Motor Linguce, is the only one which, in the regular order, now remains to be considered. This nerve contains from 4500 to 5000 nerve-fibres. That the distribution of this nerve is restricted to the nuscles of the tongue, is a point very easily established by anatomical research; and accordingly we fiud that, long before the time of Sir C. Bell, Willis had spoken of it as the nerve of the motions of articulation, whilst to the Lingual branch of the 5th pair he attributed the power of exercising the sense of taste; and he distinctly stated, that the reason of this organ being supplied with two nerves, is its double function. The inference that it is chiefly, if not entirely a motor nerve, which has been founded upon its anatonical distribution, is supported also by the nature of its origin, which is usually from a single root, corresponding to the anterior root of the Spinal nerves. Experiment shows that when the trunk of the verve is stretched, pinched, or galvanized, violent motions of the whole tongue, even to its tip, are occasioned; and also that similar movements take place after division of the nerve, when the cut end most distant from the brain is irritated. In regard to the degree in which this nerve possesses sensory properties, there is some difference of opinion among plysiologists, founded, as it would secm, on a variation in this respect between different animals. Indications of pain are usually given when the trunk is irritated after its exit from the cranium; but these may proceed from its free anastomosis with the cervical nerves, which not improbably impart sensory fibres to it. But in some Mammalia, the hypoglossal nerve has been found to possess a small posterior root with a ganglion; this is the case in the $\mathrm{Ox}$ and Cat, and also in the liabbit; and in the latter aninal, Valentin states that the two trunks pass out firom the cranium through separate orifices, aud that, after their exit, onc niay be shown to be sensory, and the other to be motor. Hence, this nerve, which is the lowest of those that originate in the cephalic prolongation of the spinal cord generally known as the Medulla Oblongata, approaches very closely in sone animals to the regular type of the spinal nerves; and though

I See his Physiol., Pathol, and Anat. Researehes, p. 151; and Edin. Med. and Surg. Journ., Jun. 1838.

2 Recherches Expérimentales sur les Fonetions du Nerf Spinal, in Archives de Médecine, 1844. See ulso M. Bernard's Leçons sur la Phys. du Système Nerveux, tom ii, 1. 279 et seq., 1858; M. Vulpian, Rev. des Cours Seient., tom. iii, 1. 754; and Hadenhain, Stud. des Plyysolog. Inst. zu Breslau, 1865, p. 115. Heidenhain and schitf think the Spinal Aceessory ministers to both the ordinary respiratory and to the phonetic movements of the larynx. 
in Man it still manifests an irregularity, in having only a single root, yet this irregularity is often shared by the first cervical nerve, which also has sometines an antcrior root only. ${ }^{1}$ The Hypoglossal nerve is distributed not merely to the tongue, but to the muscles of the neck which are concerned in the movements of the larynx; and the purpose of this distribution is probably to assnciate them in those actions which are necessary for articulate speech. Though all the motions of the tongue are performed through the medium of this nerve, yet it would appear, from pathological phenomena, to have at least two distinct connections with the nervous centres; for in many cases of paralysis, the masticatory movements of the tongue are but little affected, when the power of articulation is much injured or totally destroyed; and the converse may be occasionally noticed. When this nerve is paralyzed on one side, in hemiplegia, it will be generally observed that the tongue, when the patient is directed to put it out, is projected towards the palsied side of the face: this is due to the want of action of the lingual muscles of that side, which do not airl in pushing forward the tip; the point is consequently directed only by the muscles of the other side, which will not act in a straight direction, when unantagonized by their fellows. It is a curious fact, however, that the Hypoglossal nerve seems not to be always palsied on the same side with the Facial, but sometimes on the other. This has been suggested to be due to the origination of the roots of this nerve from near the point at which the pyramids of the medulla oblongata decussate, so that some of its fibres come off, like those of the spinal nerves, without crossing, whilst others are transmitted to the opposite side, like those of the higher cephalic nerves; and the cause of paralysis may affect one or other of these sets more particularly. Whatever may be the validity of this explanation, the circumstance is an interesting one and well worthy of attention." The Hypoglossal nerve, according to Vulpian, ${ }^{3}$ contains vaso-motor fibres, the irritation of which causes the vessels supplying the submaxillary gland to contract. Its section is followed by the dilatation of these vessels.

498. The general homology of the Cephalic nerves, considered with reference to the ordinary Spinal, constitutes a study of much interest. It appears, from what has been already stated, that the Pneumogastric, Spinal Accessory, Glosso pharyngeal, and Hypoglossal ncrves, may be considered nearly in the light of ordinary Spinal nerves. They all take their origin exclusively in the Medulla Oblongata ; and the want of correspondence in position between their roots and those of the Spinal nerves, is readily accounted for, by the alteration in the direction of the columns of the Spinal cord, which not only decussate laterally, but, as it were, antero-posteriorly $(\$ 488)$. The Hypoglossal, as just stated, not unfrequently possesses a sensory in addition to its motor root. The Glosso-pharyngeal, which is principally an afferent nerve, has a small motor root; but most of the motor fibres which answer to it are to be found in the Pneumogastric. That the Pneumogastric and Spinal Accessory together represent a Spinal nerve, may be regarded as probable from what has been already said of their relations.-Leaving these nerves out of the question, therefore, we proceed to the rest. Comparative anatomy, and

1 See Vulpian's E-say on the Posterior or Ganglionic Root of the Hypoglossal Nerve in various Animals, Journal de la Physiologie, 1862, p. 5.

2 It may be questioned, however, whether the Hypoglossal is really paralyzed on the opposite side from the Facial in such cases. An instance has been communicated to the Author by Dr. W. Budd, in which the hypoglossal nerve was completely divided on one side; and yet the tip of the tongue, when the patient was derired to put it out, was sometimes directed from and sometimes towards the palsied side; showing that the muscles of either half are sufficient to give any required direction to the whole.

3 Gaz. Hebdomaduire, 1873, No. 21. 
the study of Embryonic development, alike show that the Spinal Cord and Medulla Oblongata constitute the most essential part of the nervous system in Vertebrata; and that the Cerebral Hemispheres are superadded, as it were, to this. At an early period of development, the Encephalon consists chiefly of four vesicles, which correspond with the ganglionic enlargements of the nervous cord of the Articulata, and mark four divisions of the Cerebro-Spinal axis; and, in accordance with this view, the Osteologist is able to trace, in the bones of the cranium, elcments which present an analogy to those that would form four vertebre, in a much expanded and altered condition. The four pairs of nerves of special sensation,-Auditory, Gustatory, Optic, and Olfactory,-make their way out through these four cranial vertebræ respectively. At a later period of development other nerves are interposed between these; which, being intervertebral, are evidently more analogons to the Spinal nerves, both in situation and function. A separation of the primitive fibres of these takes place, however, during the progress of development, so that their distribution appears irregular. Thus the greater part of the sensory fibres are contained in the large division of the Trigeminus; whilst of the motor fibres, the anterior set chiefly pass forwarls as the Oculo-motor and Patheticus; and of the posterior, some form the small division of the Trigeminus, and others unite with the first pair from the Medulla Oblongata to form the Facial. This last fact explains the close union which is fonnd in fishes and some Amphibia, between that nerve and those proceeding more directly from the Medulla Oblongata. According to Valentin, the Glosso-pharyngeal is the sensory portion of the first pair from the Melulla Oblongata, of which the motor part is chiefly comprehended in the Facial nerve. Although we are accustomed to consider the Fifth pair as par éminence the Spinal nerve of the head, the foregoing statements, founded ipon the history of development, ${ }^{1}$ show that the nerves of the Orbit really belong to its motor portion; they may consequently be regarded as altogether forming the first of the intervertebral nerres of the cranium. The Facial and Glosso-pharyngeal appear to constitute the second; whilst the Par Vagnm and Spinal Accessory, forming the thirel pair, intervene between this and the two Spinal, of which the Hypoglossal may be considered as the first.

499. Functions of the Spinal A.xis.-In considering the functions of the Spinal Cord, we have to regard it under two aspects; -in the first place, as a conductor of nervous force between the Nerve-trunks and the Encephalic centres; and in the second place, as itself an independent centre of nervous power. As a mere conductor of nervous force, its functions are the same as those of a nerve-trunk : ${ }^{2}$ for if it be divided, all the parts of the body which are solely supplied by nerves coming off' below the point of section are completely paralyzed, as fur as regarls sensibility and voluntary movement; no impressions made upon them having the least power to affect the conscionsness, and no excrtion of the will being able to determine contraction of their muscles. This state of paraplegia, which may be experimentally induced in animals, is frequently exhibited in Man as a result of injury or of disease which seriously implicates the Spinal Cord; and as it has been shown that among the lower animals complete reunion of the Cord may take place after complete division, as indicated by the entire restoration of its functional powers and the complete redintegration of its structure, so have

1 On this point, as well as on the functions of the Cephalic nerves grenerally, see Prof. Valentın, De Funetionibus Nervormm Curebralium et Nervi Symputhici, Birna, 1839.

2 Vulentin (1)ie Zurekungsgesetze des lebenden Nerven und Iluskcls, 1863, p. 86) observes that the whole spinal cord behaves like a larire nerve on applying etectrical stimulation to it, though its irritability is very rapidly exhansted.

${ }^{3}$ See the admirable researches of iI. Brow-Séquard, in Gazette Médicale, 1819, 
we reason to believe that a similar regencration may take place to a considerable cxtent in Man, this being markerl by the gradual return of sensibility and power of voluntary movement in the lower limbs which had been at first completely paralyzed. This regeneration is of course less likely to occur in cases of disease, when the parts around are in an unlrealthy state, than when the paralysis is due to injury, which all the restorative powers of the system are engaged in repairing; but it is to be remembered, that as the injuries which are likely to cause such lesions of the Cord are nearly alway's attended with severe concussion (it being very rare for the Cord to be accidentally wounded by the penetration of a sharp instrument between the vertebrie, in the mode in which experiments are made upon animals), some of their first effects are attributable to the shock which it has sustained; so that the partial recovery which takes place at an early period, must not be regarded as the result of regeneration of nervous tissue, which requires a much longer time for its completion.- The conducting porer of the entire Spinal Cord being thus established, we have next to inquire whether any difference in endowment can be shown to exist in its sercral columns.

500. The Spinal Cord considered as a Conductor of Sensory Impressions and Iotor Impulses - The Posterior Columns. - The concurrent testimony of nearly all observers shows that the postcrior columns are highly sensitive, the slightest irritation applied to their surface causing the animal to give indications of pain; whilst, after division, irritation of their cut surfaces not only causes pain, but in many instances convulsive movements also occur. Experiments, moreover, can be made, which demonstrate that the pain is attributable, not to the fibres of the columns themselves, but to the posterior roots of the nerves which traverse them. Thus, if the Spinal Cord be exposed, and a few nimutes allowed to elapse to permit the effects of the mere exposure to pass off, the sensibility of the skin of the hind limbs may be shown to be everywhere perfect. If a section be now made through the posterior columns (C P, Fig. 229) by passing a tenaculum from side to side, and cutting down upon it, and any nerve (s) comnected with a part of the cord below the section be stimulated as by

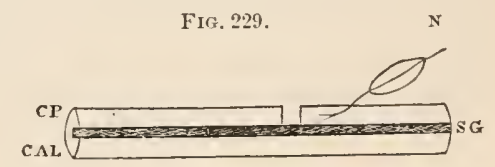

$\mathrm{N}$, Nerve.

P C, or C P, Posterior Column.
GS, ors G, Gray Substance.

CAL, Autero-lateral

Column. pricking, the cries and movements of the animal show clearly that the conduction of sensory impressions is not materially interfered with. On the other hand, if after the same preliminary proceedings, the whole of the Spinal Cord be divided transversely (caL, sg, Fig. 230), with the exception of the posterior columns (cp), it will be found that the sensibility of the posterior limbs is entirely abolished. "It is clear, therefore, that the posterior columns do not constitute the continuation of the posterior roots. The circumstance that after division of these columns the surface of both the caudal and cephatic segments of the cord are acutely sensitive, is considered by M. Brown-Séquard to be due to the fact that some of the sensory fibres of the posterior roots (Fig. 238) ascend, whilst others descend a little way in these columns before crossing to the opposite side. There is good reason, then, for believing that the proper fibres of the posterior columns are insensitive, and it seems not improbable that they consist esscutially of commissural fibres (F, Fig. 238), which run longitudinally, and bring different segments of the

No. 45, and 1850, No. 30 ; also the Comptes Rendus de la Société de Biologie, 1849, 1850 . 
cord into connection, thus aiding in the co-ordination of complex novements. For, in the first place, if the posterior columns are divided at several

FIG. 231.

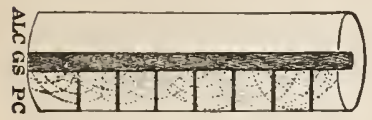
successive places, it will be found that the movements of locomotion become more and more disordered in proportion to the number of the sections (Fig. 231), whilst it is well known that locomotor ataxy, in which affection the power of locomotion and of co-ordinating movements is remarkably impaired, is associated with diseasc of these colunms. Schiff,' however, concludes from his expcriments that the posterior columns are essentially destined to conduct tactile scnsations as opposed to those of pain or pressure $;^{2}$ since every lesion of these columns causes a permanent loss of tactile sensation, at least when the lesion is in the lower part of the cervical and the dorsal part of the cord.

Antero-laterul Columns.-These columns are chiefly composed of longitudinally rumning fibres ( $m$, Fig. 238) which conduct volitional impulses to the groups of motor cells (L, Fig. 238) in the auterior cornua of the gray substance; but in part also of fibres proceeding from these cells and running

FIG. 232.

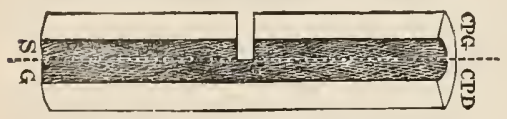
transversely to emerge as the anterior ronts of the spinal nerves. Some anatomists, as Schröder, admit the existence of longitudinal commissural fibres (indicated by dotted lines in Fig. 238) serving like those of the posterior columns to bring different segments of the cord into connection. The volitional motor fibres, though responding readily to their natural stimulus, answer but slowly to direct irritation. Feeble indications of sensibility can be obtained on irritating them, which has been attributed by Claude Bernard to the presence of recurrent fibres from the posterior roots. If a section of the cord be made, as in Fig. 229, dividing the posterior columns alone, the animal is still capable of moving all the muscles of its posterior limbs voluntarily. But if the anterior and

1 Centralblatt, 1872, p. 774. See also Lond. Med. Record, Jan 15th, 1873.

2 Schiff urees with sanders Ezn, who has found that the tactilis fibres of the posterior roots in the lumbar region run obliquely upwards for two or three inches before they enter the pusterior eolumus. The pusterior columns of the lumbar region in animals (dogs) contain the taetile nerves of the organs of generation, pelvis, unus, and tait. The tuctile nerves of the feet lie in other regions of the cord. Hence lesions of the posterior columns in the upper part of the fumbar segment cause paralysis of tactile sensation in the region of the anus, while the sensation and antion of the posterior extremities remain nornal. In the region situated above the last three cervical vertebra there is a strand of white substance in the lateral eohmn which scrwes as the path by which the sensory impresions exciting the thoracic movements in respiration are condueted. Lesions of these strands eatuse abolute and permanent paralysis of the respiratory movements, never compensited by any of the other parts of the cord. Section of the lateral column in the ulpel cervical region eauses, along witl a ereater or less insensibility to thetile inpressions, complete immobility of the ribs during respiration. Schift's investigations into the functions of the batral columne in the doral region have satisfied him that they do not contain the conductors of the sensory inpresions of pain or of pressure for the hinder extrenities. These are conveyed through the central and lateral gray substance of the eord. The lateral gray substance of the right side in man, the dos, and rabit specially, and perhaps also exclusively, conducts the sensations of pain of the opposite posterior limb, and vice versa. Cats, however, form an exception to this rule, for in the cord of these animals the sensory paths do not decussate. Sohiff believes that in lesions of almost any part of the cord a compensatory assmption of the functions of the injurect parts by tho e left intact may take place. The only exception being in the ase of the posterior columis. 
lateral columns be divided, all power on the side of the scetion is lost. [Dr. Woroochiloff in experimenting on rabbits by dividing the cord at the last dorsal vertebra, arrived at the conclusion that all the channels of motor and sensory impressions are in the latcral columns. ${ }^{1}$ ] Some diminution, though not entire abolition of voluntary control over the movements of the posterior extremities of the same side is caused by division of the posterior columns and gray substance; the reason of this result is clear from an examination of Fig. 233. It is herc seen that the section of the antero-lateral colmmn $(a, b)$ divides all the fibres connecting the motor cells in the anterior horns of the gray substance with the brain; whilst section of the gray substance and posterior columns $(c, d)$ only destroys a certain number of the cells and their communications with the brain, those above and below remaining uninjured, and therefore retaining their activity.

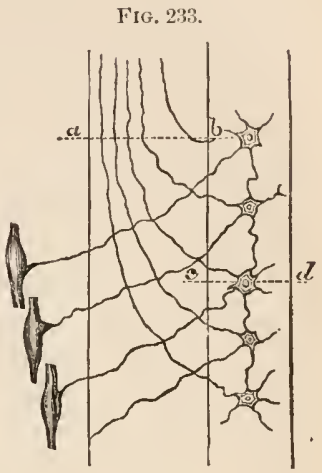
The section of one antero-lateral column does not produce quite complete paralysis of the parts on the same side supplied by nerves issuing from the cord behind the section, and it would seem probable that some of the motor fibres run in the anterior parts of the gray substance.

The Gray Substance of the Spinal Cord.-The gray substance of the cord is undoubtedly the channel through which most sensory impressions are conducted to the brain, and in it are contained at different levels those groups of ganglionic cells or nerve-centres, which preside over certain special functions. It is remarkable that it does not respond to direct stimulation, and that, notwithstanding that it contains so many sensory fibres, it may be pricked, pinched, or otherwisc irritated, without any indications of pain heing given by the animal. This peculiarity, first pointed out by V. Deen, has led Schiff to apply the term resthesodic ${ }^{2}$ to it, and he believes that it is capable of conducting in any direction either transversely or longitudinally. That sensory impressions are chiefly conducted throush the gray substance, is shown on the one hand by retaining it intact, whilst all the white columns are divided (Fig. 234), when the sensibility of the hind limbs will be found to be but slightly impaired; and on the other hand by divilling the gray substance alone (Fig. 235), when the sensitiveness of the posterior extremities will be found to be entirely lost. But it can be further shown by experiment, that the sensory fibres of the posterior roots of the spinal nerve do not ascend on their own side, but cross over to the opposite side, either immediutely, or after a short ascending or descending course. Thus, if a series of sections be carried from without inwards, the first of which divides the cord as far as to the imaginary line A, Fig. 235, and the succeeding cuts be made progressively deeper and deeper as to $\mathrm{B}, \mathrm{C}, \mathrm{I}$, and $\mathrm{E}$, it will be found on testing the sensibility of the ani-

FIG. 234.

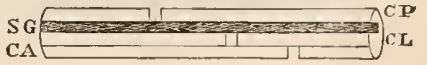

1 [Recent Reportin Physiology, hy H P. Bowditch, M. D., Ludwig's Arbeiten, 74.]

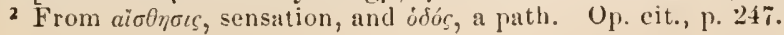


mal, that the hind limb of the side opposite to that on which the section is made, becomes progressively less and lcss sensitive, till at last when the section has passed a little beyond the middle line it is entirely lost. But if the nerve-fibres ministering to common sensation on both sides decussate in the spinal cord, it must follow, that on making a longitudinal section from above downwards, along the whole length of the cord, dividing it into two lateral halves, sensibility of both sides of the body should be totally extinguisher, for such a section would obviously divide all the sensory nerves, and, according to M. Brown-Séquard, this is actually the result obtained. Other observers, however, as Oré, ${ }^{1}$ Longet, and Schiff, though admitting there is great diminution of sensibility after a longitudinal division of the cord, maintain that distinct evidence of the conduction of sensory impressions may still be obtained; and it seems probable from their experiments, that some few fibres may ascend in the gray substance or in the posterior white columns of their own side. Perhaps the discrepancies in the results of the operation in the hands of different experimenters are due to different animals having been used; for MI. Brown-Séquard has himself observed, that the decussation of the sensory fibres is neither so complete or immediate in Reptiles and Birds as in Mammals; and he has further noticed, that it docs not seem to be so perfect in the lumbar as in the dorsal region. ${ }^{2}$ The important experiments nade by M. Brown-Séquard show clearly that whilst the sensory fibres of the posterior roots in part run at once to the oppositc side of the gray substance, some of them ascend and others descend for a short distance in the gray substance before decussating. 'Thus, if in one animal the posterior columns be divided above the origin of a particular pair of nerves, and the posterior columns be then dissected back for a short distance (Fig. 236), whilst in a second aninal a section be marle immediately below the origin of the same pair of nerves, and the same dissection be madc (Fig. 237), in the former case the flap will only communicate with the

FIG. 2:36.

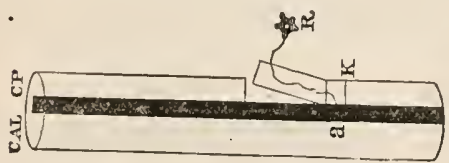

FIG. 237.

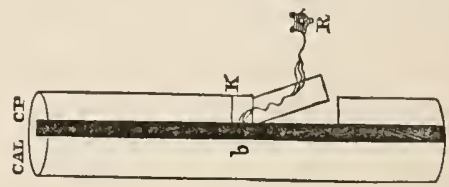

gray substance by its lower extremity, and in the latter by its upper extremity. In both instances the animal will continue to give indications when the nerve (R) is pinched, that sensory impressions are still conveyed to the sensorium ; thus showing that sonc of the fibres descend whilst others ascent in the posterior columns, for some distance before entering the gray substance, following in the two cases the course marked in the figures by the lines $\mathrm{k}, \mathrm{a}, \mathrm{r}, \mathrm{b}$. By making sections beginning at $\mathrm{k}$, two centimetres from the point to which the posterior column had been reflected, where sensation was found to be still acute, and gradually approximating the attached portion of the posterior column till sensation was found to be abolished, BrownSéquard ascertained that in the dog the posterior roots after their entry into the posterior columns sprearl upwards and downwards for a distance of 4 or 5 centimetres, or from an inch and a half to one inch and threc-quarter's before entering the gray substance. The sensory fibres which enter motor ganglionic cells of the anterior cornua, and are subservient to reflex acts, 
seem to decussate nearly in the same plane as that at which they enter the cord. It would appear that the smallest longitudinal column or transverse layer of the gray substance remaining intact, may serve to a certain limited cxtent as a means for the conduction of the sensory impressions of either sidc. The central portions of the gray substance are the most effective in the transmission of sensations, much more so at all events than either the anterior or posterior cornua (Brown-Séquard).

501. M. Brown-Séquard has adduced ${ }^{2}$ very strong evidence in favor of there being special conductors in the spinal cord for the sensations of touch, pain, tickling, and temperature, besides thosc conveying motor impulses, none of which can convey other sensations than their own, and he considers that clinical facts demonstrate that each of these four species of sensory nerves occupies a distinct part of the cord, those coming from the inferior extremities, and a great part of the trunk forming a group which in the upper part of the cervical region is placed behind those proceeding from the thoracic members, all of which decussate in the spinal cord. Dittmar ${ }^{3}$ even goes beyond this, and contends that there are special fibres which respond only to mechanical, chemical, and electrical stimuli respectively. They exert, he thinks, a reflex action through the vaso-motor centre upon the ressels, producing increase of blood-pressure. M. Brown-Séquard ${ }^{4}$ has also satisficd himself by experiment that the nerve-fibres employed in making muscles contract in fits of epilepsy are quite distinct from voluntary motor nerve-fibres, and that whilst the voluntary motor nerve-fibres are chiefly in the anterior gray and white parts of the cord, the others are chiefly in the lateral column, and this is in accordance with the observation of M. Charcot, that inflammation (sclerosis) of the lateral column of the spinal cord is invariably accompanied by strong muscular spasms. The conductors ministering to the muscular sense, on the other hand, like those which envey the mandates of the will to the nuuscles and the vaso-motor nerve, do not decussate in the cord. The conductors for impressions of temperature in the dorsal region of the cord and in the cervical enlargement appear to occupy the central parts of the gray substance; the conductors of impressions of pain are more disseminated, and are found in the lateral and posterior parts of the gray substance, whilst the conductors of the impressions of touch and tickling are chiefly situated in the anterior parts of the gray substance. A very remarkable result of section of one-half of the Spinal Cord is that, besides the anasthesia which is established on the opposite side of the body, there is produced a state of exalted sensibility or hyperastlyesia on the same side. ${ }^{5}$ This condition, made apparent by the cries of the animal on the slightest pricking or pinching of the skin, begins to appear a few hours after the operation, rapidly attains its full intensity, and continues to be well marked for from 17 to 22 days in dogs, and from 12 to 16 days in cats ; after which, according to Schiff, it gradually decreases, until at length the sensibility falls below its normal acuteness. M. Brown-Séquard has, howevcr, observed it to persist in guinea-pigs, though not in a very high degree of intensity, for mauy months after the operation. The cause of this phenomenon has not been accurately determined. It is certainly accompanied by an increased flow of blood and increased temperature of the parts to which the nerves are distributed, and hence may be due to paralysis of the

1 See Masius and Vanlair, Centralblatt, 1870, p. 1.

2 Sce his Journal de Physiolngie, 1863-1865; Archives de Physiologie, 1868.

3 Ber. d Sachs. Gesell. d W iss., 1870, p. 18.

4 Lancet, 1870 , vol, i, p 2.

${ }^{5}$ See Brown-Séquard, Central Nervous System, 1860, p. $19 .{ }^{6}$ Op cit., p. 275. 
vaso-motor nerves. Considerable differences undoubtedly exist in the position of the motor tracts in different parts of the Spinal Cord ; and M. BrownSéquard ${ }^{1}$ concludes from his numerous cxperiments on the effects of section, that whilst, in the dorsal region, all parts of the Spinal Cord except the posterior columus are employed in the conveyance of the orders of the Will to the muscles, in the upper part of the cervical region most of these conductors are in the lateral colunins, and in the gray substance between these and the anterior columns, the latter here having little share in the transmission of such impulses. The same observer has satisfactorily shown that the fibres which transmit motor impulses decussate almost exclusively at the lower part of the Medulla Oblongata. (See $a r$, Fig. 239.) - Hence if a section of one-half of the Spinal Cord be made (as at 3, Fig. 239), loss of movement on the same side occurs, in consequence of the division of the ascending motor fibres $(a r)$

FIG. 238.

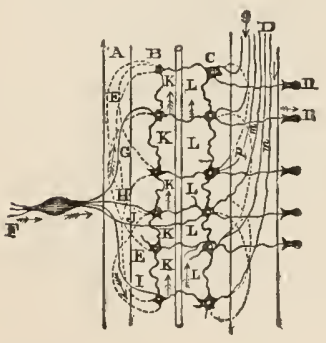

FIG. 239 .

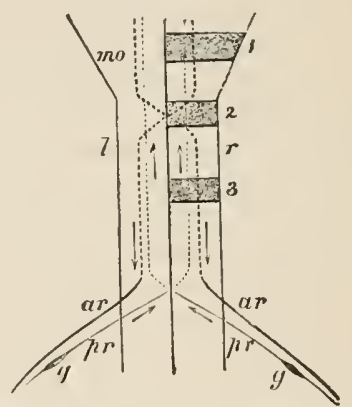

Fig. 238.-A, Posterior Column. B, Posterior horn of gray matter. C, Anterior horn of gray matter. D, Antero-lateral column. E, Loop-fitures of the posterior column proper. F, A posterior nerve-root. (2) Ascending faseiculns of this root. II, Direct fasciculus. I, Descending fasciculus. J, Reflex motor root. K, Chain of sensory cells. I, Chain of motor cells. $m$, Eneephalic fibrey of the auterior columns. N, Auterior nerve-roots. D, Loop fibres of the auterior roots.

Fig. 239.-Diagram showing the course of the Motor and Sensory Fibres in the Spinal Cord and M edulla Oblongata.

from the anterior roots; whilst if the section be madc at the level of the decussation of the anterior pyramids (as at 2), paralysis of the muscles of both sides is produced ; lastly, if a section be made a littlc higher (as at 1), paralysis of the muscles of the opposite side results. Numerous fibres belonging to the anterior roots undoubtedly decussate throughout the greater part of the Spinal Cord; but these are probably destined, as suggested by Brown-Séquard, to be channcls for the conveyance of reflex actions. Schiff proposes the term "kinesorlic" substance" for the material by which notor impulses are conveycd along the Spinal Cord, on the ground that when directly stimulated the movements performed are few and imperfect; and he thinks that as with the "sesthesodic substance," so with the "kinesodic substance," the smallest portion is capable of transmitting motor impulses in any direction. From the results of the foregoing experiments, which are fairly in accordance with the microscopic analysis of the eord given by Lockhart Clarke (\$ 481) and others," it may be concluded,-1. That sensory impressions are conducted to the spinal cord by the posterior roots of the spinal nerves; that the fibres of these routs divcrge on entering the cord, some passing directly across to the

1 Op. cit., p. 46.

2 From kíujoss, motion, and jós, a path.

3 For confirmatory evidence, see Mr. Brown-Séquard's treatise; Sehiff, Op. cit.; H. Sander's, Henle and Meissner's Bericht. 
opposite side, others running upwards and downwards for the spaee of half an inch or more in the posterior columns before deeussating; and that, having deeussated, these fibres run from below upwards in the gray substance of the cord. 2. That the motor nerves run for the most part in the anterior and antero-lateral columns, and that they deeussate at the lower part of the medulla oblongata. 3. That there are special eonductors for particular sensations as for touch, pain, tickling, and temperature, whieh deeussate in the eord, whilst there are others, viz., those whieh convey motor impulses to the muscles, and to the vessels, as well as those ministering to the nuscular sense, which do not decussate.

502. The Cord as an Independent Centre.-We have now to eonsider the Spinal Cord as an independent eentre of nervous power, and to inquire whether the movements which are exeited through its "reflex" activity necessarily involve sensation. These movenients are most characteristically displayed, when the Spinal Cord is eut off from communication with the higher Nervous centres; probably rather because the nerve-foree excited by the impression reacts through the Spinal ganglion to which it is eon reyed, when it can no longer pass on to the Encephalie centres $(\$ 459)$, than because (as some suppose) the impulse to reflex movement is ordinarily neutralized and rendered inoperative by an effort of the Will. It is true that those reflex actions of the Spinal Cord, which are necessary to the maintenance of Organic life, and which are equally performed whether the Spinal axis be in communieation with the higher Encephalic centres or not, are eontinually modified or temporarily suspended by the Will; but this is only when we eonsciously bring the Will to bear upon them; and it is no less certain that we are not eontinually making any such exertions, in order to antagonize movements, which (as we learn from Pathological evidence ${ }^{1}$ ) would be enntinually excited but for this nentralizing influence, if such a doctrine were correet.-The readiest demonstration of the independent power of the Spinal Cord, is derived from the motions exhibited by the limbs of animals, when irritation is applied to them after seetion of the Spinal Cord at some point above the entranee of their nerves; the faet that these movements are reflected through the Cord, and are not the produet of direct stimulation applied to the part irritated, being shown by their complete eessation when the nerve-trunks are divided, or the substance of the Spinal Cord is broken down. Thus, if a frog be deeapitated, its body remains supported on its limbs in the usual position, and will reenver this if it be disturbed; irritation of the feet will eause it to leap; and tickling the cloaca with a probe will exeite efforts to push away the instrument. ${ }^{2}$ It is to be

1 See, for example, the ease of Softening of the Spinal Marrow, reeorded by Dr. Nairne in the Med.-Chir. Trans, vol. xxxiv; in which a portion of the Curd at least an ineh fong, situated opposite the third and fourth dorsal vertebræ, was "so soft that the slightest pressure of the finger broke it up," being nearly in a fluid state through its whole thickness; yet the patient felt pain in his lower limbs, showing that the power of upward transmission remained; and although he had lost all Voluntary control over the museles of the lower part of the body, yet they were affeeted with incessant choreic movement (which, aceording to Dr. Hughlings Jaekson, Edin. Med. Journ., Oct. 1868, p. 294, originates in embolism of the vessels of the Sensory Ganglia), and these movements were affeeted in such a marked manner by emotions, as plainly to indicate a dononward transmission of motor power.

2 It has been pointed out by Messrs. Todd and Bowman (Physiologieal Anatomy, vol. $i, p .315)$, that the Spinat Cord of the male trog, at the season of eopulation, naturally possesses a state of most extraordinary exeitability. The thumb of each anteriur extremity at this season beeomes eonsiderably enlarged, as is well known to Nuturalists. "This enlargement is eaused prineipally by a eonsiderable development of the papillary structure of the skin which eovers it; so that large papilla are formed all over it. A male frog, at this season, has an irresistible propensity to 
observed that a slight irritation applied to the peripheral extremities of the afferent nerves, is a more powerful excitor of reflex action than a much stronger impression, which occasions acute pain, applied to their trunks; thus Mr. Grainger found that he could remove the entire hind leg of a Salamander with the scissors, without the creature moving, or any muscular contraction being produced, if the Spinal Cord had been first diviled; yet that by irritation of the foot, especially by heat, in an animal similarly circumstanced, violent convulsive actions were exciterl in the legs and tail. This fact is important, not only as showing the comparatively powerful effect of impressions upon the cutaneous surface, but also as proving how little relation the amount of reflex action has to the intensity of sensation. The different kinds of reflex action have been well formulated by M. Küss. ${ }^{1}$ They may be classified according to the direction in which both the centripetal and the centrifugal impulse passes. 1. All ordinary reflex actions take place both centripetally and centrifugally through spinal nerves, examples being afforded in deglutition, coughing, sneezing, walking, etc., and in pathulogy by vomiting, tetanus, epilepsy, 2. A second class almost as numerous includes those reflex actions which take place centripetaily through a cranio-spinal nerve, and centrifugally through a motor nerve of the sympathetic system, and most frequently a vaso-notor branch. As examples of this kind of reflex action may be given the excitation of the salivary and gastric glands, blushing or pallor of the skin, ercetion, certain movements of the iris, certain modifications in the beats of the heart, and, in pathology, some of those phenomena which in consequence of the difficulty of explaining their production, are called metastatic, as certain forms of ophthalmia, orchitis, and coryza, due to reflex hyper:emia, and certain cases of amaurosis, paralysis, paraplegia, etc., due to reflex ancomia. 3. A third class comprehends those reflex actions in which the centripetal nerve is a sympathetic nerve, and the centrifugal a cranio-spinal. Most of these actions are pathological, and are represented by the convulsions that occur from the intestinal irritation produced by worms, reflex eclampsia, hysteria, ete. A physiological instance of this form occurs in respiration, the vagus or sensory nerve being a kind of transition nerve, bridging over the interval between the sympathetic and the cranio-spinal nerves, so far as its pulmonary branches are concerned. 4. Lastly, there are reflex actions in which both the centripetal and centrifugal conductors are branches of the sympathetic system. Such are the obscure actions that preside over the secretion of the intestinal juices, those which unite the various generative functions, the dilatation of the pupils owing to worms, and many pathological phenom-

eling to any object, by seizing it between his anterior extremities. It is in this way that he seizes upon, and elings to the female; fingr his thumbs to eareh side of her abdomen, and remaining three for werks, until the ova have becn eompletely expelled. An eflort of the will alone could not keep up the grasp uninterruptedly for so long a time; yet so firm is the hold, that it can with difficulty be relaxed. Whatever is brought in the way of the thumbs, will be cauglit by the forcible eontraction of the anterior limbs; and henee we often find frogs elinging blindly to a piece of wood, or a dead fista, or some other sub-tance which they may chance to meet with. If the tinger be placed between the anterior extromitios, they will grasp it firmly; nor whlt they relax their grasp until they are separated by foree. If the animal be deenpitated whilst the finger is within the errasp of its anterior extremulies, they still continue to hold on firmly. The posteriol half of the body ma be cut away, and get the anterior extremities will still cling to the finger; but immediately thit the segment of the Cord, from which the antrior extrenities derive their nerves, has been removed, all their motion eeases. Tlis eurious instinet only exists during the period of sexual cxciument; for at other periods the exeitability of the anterior extremitios is considerably less than that of the posterior."

1 Cours de Physiologie, 1873, p. 62. 
ena. From experiments on frogs and other animals Pflüger has laid down the following "laws" of reflex action:

1. The Law of Unilateral Reflection.-In accordance with this law it follows that when in consequence of irritation of one or more sensory nerves movement takes place on one side, it is always on the sume side as that to which the irritation was applied.

2. The Law of Symmetry.-It may further be demonstrated that when the impression is sufficiently strong to be irradiated to the muscles of the opposite side, these are always congenerous with those excited to action on the irritated side.

3. The Law of Intensity.-The movements on the irritated side are sometimes equalled in intensity by those of the opposite side, but if they are not equal they are always of inferior vigor.

4. Law of Reflex Irradiation. - Lastly, in the Spinal Cord, the motor nerve excited is always on the same plane as the sensory nerve that has bcen irritated, but if the sensory irritation be so powerful as to be propagated beyond this point, it always affects the nerves above and never those below. In the casc of the reflex movements due to the encephalon, however, the irradiation takes place from above downwards towards the Medulla Oblongata, which possesses the power of generalizing all reflex movements; whenever the irradiated excitation in its upward course reaches the Medulla Oblongata, all the nerves arising from the encephalon are affected.

It is noticeable also that the reflex activity is greatest in young animals. It varies in the different classes of animals. appearing to be most strongly developed in Birds, then in Mammals, and least in Fishes. It is exalterl by opium, alcohol, and nicotin, and especially by strychnia. It is diminished by acetate of zinc, chloral hydrate, hydrocyanic acid, belladonna, digitalis, ${ }^{2}$ and bromide of potassium. ${ }^{2}$ Like other parts of the nervous system the cells ministering to reflex action can be exhuusted by effort and require rest to recover their properties. The experiments of Küssnaul and Tenner ${ }^{3}$ show that interruption of the blood-supply, contrary to what might be expected, has a tendency to exalt the reflex excitability of the spinal cord, though to a much less extcnt than the nervous centres in the Brain and Medulla Oblongata. Complete suppression of the blood-supply to the Spinal Cord rapidly causes complete paralysis. [Setschenow has discovered that nerve-centres which inhibit reflex action are seated mainly in the thalami optici and corpora quadrigemina. ${ }^{4}$ ] Reflex acts are greatly enfeebled, or are altogether absent, when the blood is overcharged with oxygen, so that the reflex contractions consequent on the administration of strychnia, brucia, thebaia, and caffein are suppressed in animals to which they have been given by vigorous artificial respiration. ${ }^{5}$ The time occupied in the performance of a reflex act is dependent upon the strength of the stimulus, being very rapid when the stinulus is powerful. ${ }^{6}$ Exner, experimenting on the reflex act of winking (the movement of the lids being excited by the application of a spark to the cornea), found that with a weak spark the time in man was

1 Weil, Centralblatt, 1871, p. 889.

2 Meihuisen, Centraiblatt, 1873, p. 88.

3 On the Nature and Origin of Epiteptiform Convulsions, New Syd. Soc. Translation, 1859 , p. 54.

- [l'hysiologische Studien über die Hemmungs-mechanismen für die Reflexthätigheit des Rückenmarks im Gehirne des Frosches, von Dr. J. Set-chenow. Neue Virsuche am Hirn und Rückenmark des Frosches, von Dr. J. Setschenow und B. Paschutin.]

5 See Leube and Uspensky, Centralblatt, 1868, pp. 41 and 677; Uspensky, Reichert and Du Bois-Reynond's Arehiv, 1868, p. 401.

6 Rosenthal, Studien über Reflexe, Monatsberieht d. Berlin. Akad., 1873, p. 104 ; and Exner, Pflüger's Archiv, 1874, p. 526. 
$0.0555 \mathrm{sec}$, whilst with a powerful shock it was only $0.0471 \mathrm{sec} \cdot{ }^{\cdot}$ The time occupied in the performance of a reflex act on the same side of the body as that on which the irritation is applied is shorter than on the opposite side, and the longer period required in the latter instance is termed the "period of reflex conduction." This also becomes very short, or almost imperceptible, when the irritation applied is very strong. Exhaustion of the Spinal Cord prolongs the duration of the "reflex time." The strength of the stimulus has no influence on the rapidity of the conduction in peripheral motor nerves.

503. That the movements executed by the limbs of the lower animals, when these are no longer connected by the Spinal Cord with the Encephalon, but remain in nervous connection with the Cord itself, do not take place through the intermediation of sensation, might be supposed to be sufficiently proved by the simple fact, that division of the Cord in Man, and hence by inference in the lower animals, reduces the parts below to a state of complete insensibility. But, on the other hand, the very performance, by decapitated animals of inferior tribes, of actions which har not been witnessed in Man under similar circumstances, has been held to indicate, that the Spinal Cord in them has an endowment which his does not possess. The possibility of such an explanation, however unconformable to that analogy throughout organized nature, which, the more it is studied, the more invariably it is found to guide to truth, could not be disproved. Whatever experiments on decapitated animals were appcaled to, in support of the doctrine that the Encephalon contains the only seat of sensibility, could be met by a simple denial that the Spinal Cord is everywhere as destitute of that endowment as it appears to be in Man. The cases of profound Sleep and Apoplexy might be cited as examples of reflex action without consciousness; but these have been met by the assertion, that in such conditions, sensations are felt, though they are not remembered. It is difficult, however, to apply such an explanation to the case of Anencephalous human infants (in which all the orlinary reflex actions have been exhibited, with an entire absence of brain), without supposing that the Micdulla Oblongata is the seat of a sensibility which we know that the lower part of the Spinal Cord does not possess; and of this there is no evidence whatever.-Experiments on the lower animals, then, and observation of the phenomena manifested by apoplectic patients and anencephalous infants, might lead to the conclusion that the Spinal Cord does not itself possess sensibility, and that its reflex actions are independent of sensation. At this conclusion, Unzer, Prochaska, Sir G. Blane, Flourens, and other physiologists had arrived; but it was not until special attention was directed to the sulject by Dr. M. Hall, that facts were obtained by which a positive statement of it could be supported. For the question might have been continually asked,-If the Spinal Cord in Man be precisely analogous in function to that of the lower Vertebrata, why are not its reflex phenomena manifested, when a portion of it is severed from the rest by discase or injury? The answer to this question is twofold. In the first place, simple division of the cord with a sharp instrument leaves the separated portion in a state of much more complete integrity, and therefore in a state much more fit for the performance of its peculiar functions, than it ordinarily is after disease a) violent injury; and as the former method of division is one with which the Physiologist is not likely to meet in Man as a result of accident, and which he camnot experimentally put in practice, the eases in which reffex actions would be manifested are likely to be comparatively few. But secondly, a sufficient number of such instances have now been accumulated, to prove that the oceurrence is by no means so rare as might have been supposed; and that nothing is required but patient observation, to throw a great. 
light on this interesting question from the phenomena of disease. $\Lambda$ most valuable collection of such cases, occurring within his own experience, has been published by Dr. W. Budd ; ${ }^{1}$ and the leading facts observed by him will be now enumerated.

504. In the first case, Paraplegia was the result of angular distortion of the spine in the dorsal region. The sensibility of the lower extremities was extremely fceble, and the power of voluntary motion was almost entirely lost. "When, however, any part of the skin is pinched or pricked, the limb that is thus acted on jumps with great vivacity; the toes are retracterl towards the instep, the foot is raised on the heel, and the knee so flexed as to raise it off the bed; the limb is maintained in this state of tension for several seconds after the withdrawal of the stimulus, and then becomes suddenly relaxed." "In general, while one leg was convulsed, its fellow remained quiet, unless stimulus was applied to both at once." "In thesc instances, the pricking and pinching were perceived by the patient; but much more violent contractions are excited by a stimulus, of whose presence he is unconscious. When a feather is passed lightly over the skin, in the hollow of the instep, as if to tickle, convulsions occur in the corresponding limb, much more vigorous than those induced by pinching or pricking; they succeed one another in a rapid series of jerks, which are repeated as long as the stimulus is maintained." "When any other part of the limb is irritated in the same way, the convulsions which ensue are very feeble, and much less powerful than those induced by pricking or pinching." "Convulsions, identical with those alrearly described, are at all times excited by the acts of defecation and micturition. At these times, the convulsions are much more vigorous than under any other circumstances, insomuch that the patient lias been obliged to resort to mechanical means to secure his person while engaged in these acts. During the act of expulsion, the convulsions succeed one another rapidly, the urine is discharged in interrupted jets, and the passage of the freces suffers a like interruption." The convulsions are more vigorous, the greater the accumulation of urine; and involuntary contractions occur whenever the bladder is distended, and also when the desire to relieve the rectum is manifested. "In all these circumstances, the convulsions are perfectly involuntary; and he is unable, by any effort of the will, to control or moderate them." This patient subsequently regained, in a gradual manner, botl the sensibility of the lower extremities, and voluntary power over them; and as voluntary power increased, the susceptibility to in voluntary movements diminished, as did also their extent and power.-This case, then, exhibits an increased tendency to perform reflex actions, when the control of the Brain was removed; and it also shows that a slight impression upon the surface, of which the patient was not conscious, was more efficacious in exciting reflex movements, than were others that more powerfully affecter the sensory organs.-It should be added that, in the foregoing case, the nutrition of the lower extremities was not impaired, as it is in most cases of paraplegia ; the rationale of this phenomenon, which is to be constantly observed when the reflex actions of the part remain entire, will be understood by reference to $\S \S 360,512$. In another case, the paralysis was more extensive, having been produced by an injury (resulting from a fall into the hold of a vessel) at the lower part of the neck. There was at first a total loss of voluntary power over the lower extremities, trunk, and hands; slight remaining voluntary power in the wrists, rather more in the elbows, and still more in the shoulder's. The intercostal muscles did not participate in the movements of respiration. The sensibility of the hands and feet was greatly impaired. There were no 
retention of urine, and involuntary evaeuation of the faees. Recovery took plaee very gradually; and during its progress, several remarkable phenomena of reflex aetion were observed. At first, tickling one sole excited to movement that limb only which was acted upon; afterwards, tickling either sole excited both legs, and, on the 26th day, not only the lewer extremities, but the trunk and upper extremities also. Irritating the soles, by tickling or otherwise, was at first the only method, and always the most effieient one, by whieh eonvulsions could be exeited. From the 26th to the 69 th day, involuntary movements in all the palsied parts continued powerful and extensive, and were exciter by the following eauses: in the lower extremities only, by the passage of flatus from the bowels, or by the contact of a cold urinal with the penis; eonvulsions in the upper extremities and trunk, attended with sighing, by plucking the hair of the pubes. On the 41st day, a hot plate of metal was applied to the soles, and was found to be a more powerful excitor of movement than any before tricd. The movements eontinued as long as the hot plate was kept applied; but the same plate, at the eommon temperatnre, excited no movements after the first eontaet. Though the contact was distinctly felt by the paticnt, no sensation of heat was pereeived by him, even when the plate was applied hot enough to eause vesieation. At three different intervals the patient took one-eighth of a grain of stryehnia three times a day. Great inerease of susceptibility to in voluntary movenents immediately followed, and they were exeited by the slightest causes. No convulsions of the upper extremities could ever be produeed, however, by irritating their integument; thongh, under the influence of strychnia, pulling the hair of the head or tickling the chin would oecasion violent spasmodic actions in them. Spontaneous convulsions of the palsied parts, which oeeurred at other times, were more frequent and more powerful after the use of strychnia. On the first return of voluntary power, the patient was enabled to restrain in some measure the excited movements ; but this required a distinet effort of the will ; and his first attempts to walk were curiously affected by the persistence of the susceptibility to exeited involuntary movements. When he first attempted to stand, the knees immediately beeame forcibly bent under him; this action of the legs being excited by contact of the soles with the ground. On the 95 th day this cffect did not take place until the patient had made a few steps; the legs then had a tendeney to bend trp, a movement which he counteracted by rubbing the surface of the belly; this rubling exeited the extensors to action, and the legs became extended with a jerk. A few more steps were then made, the mancuvre was repeated, and so on. This susecptibility to involuntary movements from impressions on the soles gradually diminisher ; and on the 141st day the patient was able to walk about, supporting himself on the back of a ehair which he pnshed before him; but his gait was unsteady, and much resembled that of chorea. Sensation improved very slowly: it was on the $53 \mathrm{~d}$ day that he first slightly perceived the heat of the metal plate.- Now, in this case, the abolition of common sensation was not so complete as in the former instance; but of the peculiar kint of impression which was found most efficacious in exciting reflex moventents, no conscionsness whutever was experienced. Not less interesting was the circumstance, that convulsions eould be realily cxcited by inpressions on surfaces above the seat of injury: as by pulling the hair of the sealp, a sudden noise, and so on. This proves two important points: first, that a lesion of the Cord may be such as to interecpt the transmission of voluntary influenee, and yet may allow the transmission of that reflected from incident nerves. Secondly, that all influenecs from impressions on ineident nerves a re diffised through the Cord; for, in the instance aldineed, the reflected influcnec was undoubtedly not made to deviate into the Cord by the morbid condition of that organ, but 
followed its natural course of diffusion, being rendered manifest in this case by the convulsions which were exciter, in consequence of increased activity of the motor function of the Cord. It is further interesting to remark, that, in the foregoing case, the reflex actions were very feeble during the first seven days, in comparison with their subsequent energy; being limited to slight movements of the feet, which could not always be excited by tickling the soles. (In another case of very similar character, it was three days after the accident before any reflex actions could be produced.) It is evident, then, that the Spinal Cord must have been in a state of concussion, which prevented the inanifestation of its peculiar functions, so long as this effect lasted; and it is easv, therefore, to perceive, that a still more severe shock might permanently destroy its power, so as to prevent the exhibition of any of the phenomena of reflex action.

50.5. So many cases of this kind have now occurred, that it may be considered as a demonstrated fact, that the Spinal Cord, or insulated portions of it, mav serve in Man, no less than in the lower animals, as the centre of very energetic reflex actions, when the Encephalic power which ordinarily operates through it is suspended or destroyed, or when it is prevented from influencing the Spinal nerves by such an injury to the Cord above their points of connection with it, as prevents the transmission of nervous polarity : and it is further evident that these movements are not more dependent upon Sensation than they are upon the Will, since they may be excited without the consciousness of the individnal, even when this is filly directed to the part. ${ }^{1}$ And we thus have adequate ground for the assertion, that the morements which may be called forth by stimulation in the states of profound Sleep or Coma, are not to be held to indicate that conscious sensation is even monentarily excited; since we know that the reflex power of the Spinal Cord may be called into action by impressions which do not travel onwards to the sensorium, or which are powerless to affect the consciousness even when they arrive there. These abnormal reflex actions of the Spinal Cord of Man, though often powerful, have much less regularity and apparent purposiveness, than have the movements executed by the lower Vertebrata (as the Frog, $\S 501$ ) after decapitation or section of the cord; the latter approaching, in respect to these qualities, to the reflex novements of Articulater Animals-as is well seen in the following experiment, which is much relied on by those who hold that the Spinal Cord is the seat of sensorial functions. ${ }^{2}$ If a frog be decapitated and acetic acid be applied over the internal condyle of the femur, the animal will wipe away the acid with the foot of the same side; but if this be cut off, after some ineffectual efforts, and a short period of hesitation, it will perform the same action with the fout of the opposite side. The explanation seems to be that (in accordance with the laws laid down by Pflüger) when the skin of one side of the body is irritated the motor nerves of that side respond to the impression, but this

1 The Author is informed by his friend Mr. Paget, that among the notes left by John Hunter (which furnisbed some of the materials for the admirable Catalogue of the Pathological portion of the Hunterian Museum drawn up by Mr. Paget), there was the record of a case of paraplegia, in which it appeared that Hunter bad witnessed reflex movements of the leg- in which sensation did not participate. When the patient was asked whether he felt the irritation by which the motions were ex('ited, he significantly reptied-glaneing at his limbs,- "No, sir ; but you see $m y$ legs do."

2 See Pflüger, Diß sensorizchen Functionen des Rückenmarks, Berlin, 1853; see also an able review it the Med-Chir. Review for Jun. 1864, in which the above experiment is quoted. The doctrine of the ind prendent volitional as well as sensorial power of the Spinal Cord is ingeniously sustained in Mr. G. H. Lewes's Physiology of Common Life, vol. ii ; whilst the opposite side is taken in a review upon that work contained in the Med.-Chir. Review, vol. xxvi, 1860, p. 423. 
being prevented and the sensory impression continuing, the impression is radiated to the motor ganglia of the opposite side, and these muscles are accordingly brought into play. We have here exhibited the results of a nrechanical disposition of parts, and not the operation of a conscious intelligence. It must not hence be inferred, however, that there is any essential difference in the endowments of the Spinal Cord, between Mau and the lower animals; or that any psychical agency exists in the latter case which is wanting in the former. We have already seen that the existence of even the most perfectly-adapted combination of different muscular actions, all obviously bearing upon a definite object, cannot in itself justify our attributing this combination to design or voluntary choice on the part of the organism that executes it $(\S 448)$; whilst, on the other hand, to remove these movements in any case from the category of automatic actions, would be to assign to the Spinal Cord a power of consciously selecting and directing them, such as we have every reason for believing to be limited to the higher parts of the Cerebro-spinal centres. Now the very uniformity of the movements in question, or the slight variation in effect which has been observed to follow the application of different stimuli, is itself an indication that they do not proceed firom any purposive choice, but depend upon the special endowments of those centres of reflex action, whence the impulses that call them forth immediately issue to the nerves; and hence the more marked adaptiveness of the reflex actions performed by many of the lower tribes of animals, can only be held to iurlicate that a larger share of such adiptation is effected in them by what may be termed the mechanism of their nervous centres, and that less is left to voluntary choice and direction, which can only be safely trusted where a considerable amount of intelligence exists to guide it;--a conclusion which accords well with what has been already stated respecting the structural differences that seem to exist betwcen the

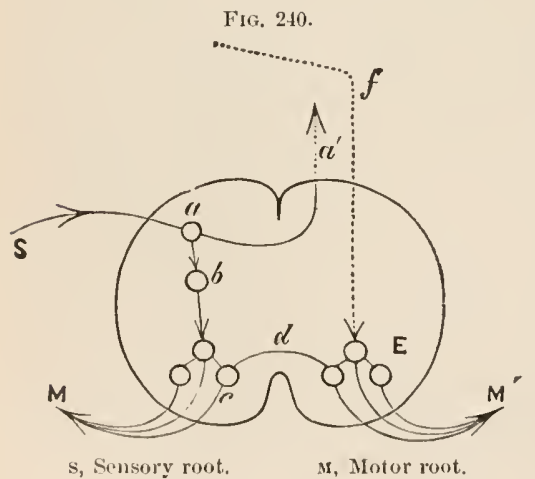

The ordinary contsc of a sensory impression to the brain is through the ganghion eell, $a$, and fitire, $a^{\prime}$, which erosses to the opposite half of the cord. In the event of this being divided, the impression is transmitted through an intermediate ganglion cell, b, to group of motor cells in tle anterior cornu, $c$, and is thence tramsmitted through a motor nerve, $\mathrm{M}$, to the musch:s of the same side. If the fmpression be still strougir, the unseles of the opposite side are ealled into reflex action through the communicating fibre, dl. The group of motor cells may also be called into action by the voluntary nerve, $f$, which decussates at the lower part ol the Mredulla Oblongata.
Spinal Cord of Man and that of the inferior Vertebrata $(\$ 486)$. If we endeavor to combine the results obtained in pathological cases and those observed after experimental sections of the Spinal Cord with the cvidence derived from microscopical investigation, it would seem probablc that the sensory or centripetal nervous fibres terminate in the ganglionic cells of the posterior horns of the gray substance of the cord (Fig. 240). From these processes are given off;, one of "which ascends on the opposite side to the sensory ganglia at the base of the Brain, whilst others terminate in cells that are in direct connection with those lying in the anterior horus of the gray substance. Generally speaking, sensory impressions follow the former and simplest path, and any movements that may oceur are directed by and subordinate to the will; but if these ascending fibres are divided, then the purely reflex action of the Spinal Cord is exhibited, and the impression is transmitted to one cell or 
to a group of cells communicating with those in the anterior horn of its own side. If the impression be strong, it is transmitted to the opposite side through the connecting fibres that pass from the cells of onc anterior horn, or possibly of one posterior horn to those of the other. The motor cells of the Cord are brought into communication with the Brain through the intermediation of the cells in the Corpora Striata. A peculiar condition described by Schiff ${ }^{1}$ as Analgesia may here be alluded to. It consists in the retention of the capability of perceiving sensations of touch, though the most severe injuries to nerves produce no sensations of pain $(\$ 504)$. This condition may be induced, according to Schiff, by division of the whole Spinal Cord with the exception of the posterior columns, also by rapid abstraction of blood; and it may be observed in the early stages of the administration of ether or chloroform. It seems to be questionable, however, whether this is not rather to be considered as a state of blunted common scnsibility. There can be little doubt respecting the origin of vaso-motor fibres from the Spinal Cord, by which the calibre of the vessels and the temperature of the parts supplied by them is regulated. Finally, physiological experiments have shown that in animals at least (rabbits), and the experiments are supported by the result of pathological investigations in man, there is a genito-urinary centre presiding over the sexual movements, and those of micturition, which occupies the lower part of the cord $(\$ 276)$. As a sequel to the preceding consideration of the Spinal Cord as a conductor of motor and sensory impressions, and as an independent centre, the following summary by M. BrownSéquard $^{2}$ of the results in Man of any injury damaging the whole transverse thickness of a small portion of one lateral half of the cord is instructive. There may be observed under these circumstances: A. On the same side1. Paralysis of voluntary motion; 2. Hyperesthesia for sense of contact, for tickling, for pain, and for temperature in the paralyzed parts; 3. An anæsthetic zone of small extent, corresponding to the parts supplied by nerves which take their origin from that part of the Spinal Cord situated immediately below the lesion; 4. Hyperesthesia in a greater or less extent of surface above the zone of diminished sensibility; 5 . Absolute or relative elevation of temperature in the paralyzed parts, and often also in those parts of which the sensibility is exalted, but not in the parts which are not paralyzed; 6 . Phenomena indicating paralysis of the origins of the great synipathetic nerve in the neck, when the lesion has occurred in the cervicobrachial enlargement. B. On the opposite side-1. Complete anrsthesia as regards contact, tickling, pain, and temperature in the parts which correspond to those that are paralyzed on the opposite side; 2 . Perfect preservation of the voluntary movements and of the muscular sense;. 3 . A zone of exalted sensibility of small extent and feeble in degree, situated in the parts above those the sensibility of which is diminished. From his numerous observations, he bclieves he is justified in drawing the conclusion already stated $(\$ 500,501)$, that complete decussation of the conductors of the various kinds of sensibility occurs in the cord, with the exception of those only conveying the muscular sense.

506. The endowments of the Medulla Oblongata do not seem to differ from those of the Spinal Cord in any other respect, than in the special nature of the reflex movements to which it ministers. This part of the Cranio-Spinal Axis has been regarded by some Physiologists, indeed, as the peculiar seat of vitality; since, although the other Encephalic masses may be withdrawn

1 Physiologie, 1859, p. 252.

2 Journal de la Physiologie, vol. vi, Oct. 1863, published in Decenber, 1865, pp. 124, 232, and 581; and Archives de Physiologie, 1868, p. 610. 
from above, and nearly the whole of the Spinal Cord may be removed from below, without the destruction of life, yet a complete stop is put to the current of vital action when the Medulla Oblongata is destroyed. But the dependence of the vital activity of the body generally upon the functional integrity of this part of the nervous system, is simply consequent upon the fact that the Medulla Oblongata contains the chief ganglionic centre of the Respiratory movements $;^{1}$ upon the continuance of which, as already shown (chap. ix, sect. 3), the continuance of the Circulation is dependent, and with this, the maintenance of the Organic functions generally. Where, however, as in the Frog, the respiratory activity of the skin is equal to or greater than that of the lungs, the removal of the Merlulla Oblongata is not attended by fatal results, and M. Brown-Séquard ${ }^{2}$ has kept frogs thus mutilated alive for eight months. Besides the respiratory the following Gauglionic centres are situated within the Medulla Oblongata. 1. The centre of mastication. 2. The centre of deglutition. 3. The centre of mimetic expression. 4. The centre of speech - so far as this is connected with the movements of the lips, tongue, and larynx. 5. The centres governing the movements of the heart (accelerating and in hibitory ganglia). 6. The greater part of the vaso-motor centre. 7. The cilio-spinal centre. According to Burge this centre, which governs the movements of the iris, is partially, and according to Salkowsky wholly, imbedded in the Medulla Oblongata. It is remarked by Mr. Lockhart Clarke $^{3}$ that it is probable the Olivary bodies are not only the centres through which different movements are co-ordinated for expressing the passions and emotions, but that they are the motor centres through which different movements are effected by sudden, violent, or peculiar impressions on the special senses; for they are intimately connected with all the sensory ganglia of the Medulla, - with the gray tubercle (trigeminus), the ragal nucleus, the post pyramidal and restiform nuclei (auditory ganglia), and the corpora quadrigemina (optic ganglia) - through the fillet, and not improbably with the parts about the root of the olfactory bulb, since he has been able to trace the olivary columns nearly to the anterior perforater space. As regards the functions of the several strands composing the Medulla Oblongata, little is known, excepting that the anterior pyramids are the conductors for voluntary motor imprulses. The Corpora Restiformia, which constitute the inferior perduncles of the Cerebellum, do not appear, according to M. Brown-Séquard, to give passage to any of the conductors of sensory impressions proceeding from the trunk, limbs, or hear. It is remarkable, however, that after they have been transversely divided, hyperasthesia is produced in cvery part of the trunk and limbs.

507. Hence the Spinal Cord, with its Encephalic prolongation, may be said to supply by its "reflex power" the conditions requisite for the maintenance of the various muscular movements which are essential to the continunce of the Orgamie processes; and, as Dr. Hatl has pointed out, it especially governs the various orifices of ingress and egress.-Thus, the act of Deglutition is entirely dependent upon the Spinal $\mathbf{A}$ xis and the nerves proceeding from it; the Vill being in no other way concerned in it, than by originating the necessary stimulus; and even sensation not being a necessary link in the chatin of' excito-motor action $(\$ \$ 88-90)$. The action of the carliac sphincter, again,--and probably that of the pyloric sphineter also,-is dependent upon its nervous comection with the Spinal Axis; and is entirely

1 Brown-sequard considers that the whole base of the Eneephalon in Man is implicated in Respiration (Centrul Nervous System, p. 191).

2 Central Nervous System, 1860, p. 191.

3 Philusophical Transations, 1868, p. 319.

I Ibid., p. $2 \pi$. 
regnlated withont sensorial excitement $(\$ 90)$. And there is much reason to believe that certain of the movements of the stomach itself are in like manner dependent upon its connection with the Medulla Oblongata $(\$ 91)$, although there is evidence that it possesses an independent motor activity of its own. The movenents of the Intestinal tube are unquestionably influenced by the Spinal Cord, although perhaps in some measure independent of it (\$92-93); and the sphincter which surrounds its orifice of egress is undoubtedly placed under its guardianship, although partly subjected (in Man) to the control of the Will.' The same may be said of the expulsor muscles concerned in the act of Defecation; and of the expulsors and splincter which effect and control the act of Urination (\$99)._Looking, ${ }^{2}$ again, at the movements which are subservient to the Respiratory process, we find that all those which are essential to its regular maintenance are performed through the intermediation of the Spinal Axis alone; that the Will has only such a limited power over them as to bring them into harmony with its other requirements, as in the acts of vocalization and in extraordinary muscular exertions; and that the stimulus by which they are commonly maintained does not even affect the consciousness, the "besoin de respirer" only becoming sensible when the respiratory process is being imperfectly performed ( $\$ 294-$ 296). Not ouly are the ordinary lespiratory movements performed through this channel, but the aperture of the Glottis is regulated by it, in everything that concerns the respiration; and either by its spasmodic closure against the entrance of unfit substances, or by the expulsor effort of cough. ing which is exciterl by them when they do find their way into the air-passages, these passages are kept free from solid, liquid, or gaseous particles, whose presence in them would be injurious. As the great centre governing the force and frequency of the cardiac contractions, and the calibre of the ressels throughout the system, the spinal axis exerts an influence that is felt in every part of the borly over the processes of secretion and of mutrition.-In the expulsion of the Generative products also, the reflex power of the Spinal Cord takes an important share. Budge ${ }^{3}$ has demonstrated the existence of a genito-spinal centre (in rabbits) in that portion of the Spinal Cord which lies opposite the fourth lumbar vertebra; for on irritating this part, contractions of the rectum, bladder, and vasa deferentia occurrer. The same effects are produced on irritating the ganglion of the Sympathetic nerve lying on the fifth lumbar vertebra, which receives communicating branches from this part of the cord; and the influence of the nervi erigentes aud common pudendal nerves observed by Eckhard, on the erection of the penis and emissio seminis, has been already fully detailed (\$276). The muscular contractions which produce Emissio Seminis are excito-motor in their nature; being independent of the Will, and not capable of restraint by it when once fully excited; and being (like those of Deglutition) excitable in no other way than by a particular local irritation. It has been shown by experiment, and also by pathological observation, that the separation of the lower portion of the Spinal Corl from the upper does not prevent these movements from being exciter, although the act is then unaccompanied with sensation, which proves that sensation is not essential to its performance; on the other hand, the power of emission is annihilated by destruction of the lower portion of the Spinal Cord, or by section of the nerves which

1 See Mrasius's Recherches Expérimentales, Bulletin de l'Académie Royale de Belgique, ze sér. t. xxv, No. 3, 1868.

2 See Goltz, Pflügrer's Archiv, 1873, p. 474; and Wernich, Centralblatt, 1873, p. 5.33.

3 Comptes Rendus de l'Acad. des Scien, 1858, p. 586; Physiologie, 1862, p. 14 ; and Pflüger's Archiv, 1872, Bd. vi, p. 309. 
supply the genital organs. The act of Parturition, however, seems to be less dependent upon the Spinal Cord ; for, as will be shown hereafter (chap. xviii, sect. 3 ), the contractions of the Uterus, which are alone sufficient to expel the foetus when there is no considerable resistance, are not to be regarded as altogether "reflex;" and it is only in the co-operation of those associated muscles which come into play in the second stage of labor, when the head is passing through the os utcri and is engaged in the pelvic cavity, that the ascistance of the Spinal Cord and its nerves is called in. These movements, like those of Defecation, may be to a certain extent promoted or restrained by voluntary effort; but when the exciting influence (the pressure of the head against the parietes of the vaginal canal) has once been fully brought into operation by the uterine contractions, the Will has little power over them, either in one way or the other. The antagonizing influence of the sphincter vagine seems, like that of the sphincter ani, to be dependent upon the Spinal Cord; and thus it happens that when its tension and that of other muscular parts has been destroyed by death, whilst the uterus still retains its contractility, the power of the latter has sufficed for the completion of the parturient process, the child being expelled after the respiratory movements have ceased. [Goltz and Frensberg have shown that in the lunbar portion of the cord a centre for the innervation of the uterus is scated.-Masius and Vanlair state that feeble excitation of the superior third of the lumbar portion of the cord causes an active dilatation of the anns, and an elevation of the tail ( $\mathrm{dog}$ ), whilst moderate irritation of the middle third caused a contraction of the sphincter, and a lowering of the tail. An intense irritation of the one or the other of these parts causes these actions to become rhythmical. They hold that the rhythmic centre contains mainly the ano-spinal centre. $\left.{ }^{1}\right]$

508. The Spinal Axis is not merely the instrument whereby the movements escential to the maintenance of the organic functions are sustained; it is also subservicnt to other muscular actions, whose character is essentially protective. Thus it was ascertained by Dr. M. Hall ${ }^{2}$ that, if the functions of the Brain he suspended or destroyed without injury to the Spinal Cord and its nerves, the Orbicularis muscle will contract, so as to occasion the closure of the eyclids, upon their tarsal margin being touched with a feather. 'This fact is interesting in several points of view. In the first place, it is a charracteristic example of an adaptive action, oceuring under circumstances in which volition cannot be imagined to guide it, and in which there is no valid reason to believe that sensation directs it. Further, it explains the almost irresistible nature of the tendency to winking, which is performed at short intervals by the contraction of the Orbicularis muscle; this is evidently a reflex action, capable of being in some degree restrained (like that of respiration) by the will, but only until such at time as the stimulus (resulting perlatps from the collection of ninute particles of dust upon the cyes, or from the dryness of their surface in consequence of evaporation), beconces too strong to be any longer resisted. The nervous chamel through which this action is performed, is completed by the first branch of the Fifth and the Portio Dura of the Seventh. A gain, we have in sleep or in apoplexy an example of this purely spinal action, unbalanced by the influence of the will, which, in the waking state, antagonizes it by calling the levator palpebre into action. As soon as the will ceases to act, the lids droop, and close over the eye so as to protect it; and if those of a sleeping person be sepa-

1 [Chicago Jour. of Nervous Diseases, vol. ii ]

2 II moirs on the Nervous System, 1837, p. 61 . 
rated hy the hand, they will be found presently to return. Here, as in studying the respiratory and other movements, we are lerl to perceive that it is the Brain alone which is torpid during sleep, and whose functions are affected by this torpidity. As Dr. M. Hall very justly reniarks, "the Spinal system never sleeps;" it is constantly in activity ; and it is thus that, in all periods and phases of Life, the movements which are essential to its continued maintenance are kept up without sensible effort.-The closure of the pupil against a strong light, is another movement of the same protective tendency. The contraction of the pupil is innrerliately caused by the Third pair, or Motor Oculi, as is easily shown by irritating the trunk of that nerve and observing the result; but the stimulus which excites it is conveyed through the Optic nerve. Yet although the contraction of the pupil is usually in close accordance with the sensation occasioned by the impression of light upon the retina, yet there is evidence to prove that the sensation of light is not always necessary; for even when the sight of both eyes has been entirely destroyed by anaurosis, the normal actions have been witnessed in the pupil, in accordance with the varying degrees of light impinging on the retina. Such cases seem to indicate that the motion results from an impression upon the retina, which impression being conducted to the Sensorium ordinarily produces a sensation ; but that even where no sensation is produced, on account of a disordered state of the part of the ganglionic centre in which the Optic nerve terminates, if the central tract which connects that nerve with the Third pair retains its integrity, the reflex contraction of the pupil may still be excited through it. The rarity of the occurrence is easily accounted for, by the fact that in most cases of amaurosis the disease lies in the retina or in the trunk of the nerve, and thereby checks both its spinal and its encephalic actions.-Although we are not at present acquainted with any similar protective movements in the Human being, designed to keep the organ of Hearing from injury, yet there can be little doubt that those which we are constantly witnessing in other animals possessed of large external ears, are reflex actions excited by the irritation applied to them. In regard to the Nose, we find a remarkably complex action-that of Sneezingadapted to drive off any cause of irritation (\$304). The stimulus is conveyed, in this case, not through the Olfactory nerve, but through the Fifth pair; so that it is not dependent upon the excitement of the sensation of Smell. The act of Coughing, also, may be regarded as of a protective character ; being destined to renove sources of irritation from the air-passages. Many of the automatic movements performed by the limbs of Frogs and other animals, when their connection with the brain has been cut off $(\$ 501)$ appear destined to remove these parts from sources of irritation or injury ; and they may thus be rightly placed under the same category.

509. The fact that Sensation is very commonly associated with the reflex action we have been considering, being produced by the impression that excites them, has led many to suppose that it necessarily participates in them; a doctrine which we have seen to be untenable. But the question not unnaturally arises, why Sensation should so constantly participate in these operations, if not essential to them ; and the answer to this question is to be found in the fact, that it is only through sensation that a higher set of actions, mental and bodily, is callerl into play, which is essential to the continued maintenance of those belonging to the present category. Illustrations of this truth might be drawn from any of the functions already noticed; but the ingestion of food will supply us with one of the most apposite. We have seen that the act of Deglutition is in itself independent of sensation; anything that comes within the grasp of the pharyngeal constrictors being conveyed downwards by their reflex contraction, just as anything 
which touches the arms of a Polyp is entrapped by them and drawn into the stomach. But this action is attended with scnsation, in the ordinary condition of the higher Animal, apparently in order that guidance may be thus afforded in the performance of those other movements of prehension, mastication, etc., by which the food may be brought within reach of the apparatus of deglutition; and the sensations which are linked with these are among the influences which prompt to those higher mental operations, whereby food is provided for the digestive apparatus to make use of. The Zoophyte is dependent for its supplies of aliment upon what the currents in the surrounding fluid, or other chances, may bring into its neighborhoorl; and if these should fail, it starves. The anencephalous Infant, again, can swallow and even suck; but it can execute no other movements adapted to obtain the supply of food continually necessary for its maintenance, because it has not a mind which sensations could awake into activity. The sensation connectcd with excito-motor actions has not only this important end, but it frequently contributes to enjoyment, as in Suction and Emissio Seminis. The sensation accompanying the actions of this class, moreover, frequently affords premonition of danger, or gives excitement to supplementary actions destined to remove it, as in the case of Respiration; for wherc anything interferes with the dne discharge of the function, the uneasy sensation that ensues occasions unwonterl movements, which are morc or less adapted to remove the impediment, in proportion as they are guided by judgment as well as by consciousness. Again, sensation often gives warning against inconvenience, as in the excretory functions; and here it is very evident, that its purpose is not only (if it be at all) to excite the associated muscles neccsiry for the excretion, but actually to make the Will sct up the antagonizing action of the sphincters $(\S 99)$.

510. We have now to inquire how far the independent action of the Spinal Cord is concerned in the general muscular movements of Man, and especially in the locomotive actions of his inferior extrenities. On this point, it is obvious that we must not be guided by the analogy of the lower animals; since the locomotive and other movements of Min are for the most part rolitional and purposive, and he has to acquire by expericnce that control over his muscular apparatus which is nccessary to enable him to perform them ; whilst in Invertebrata generally, and in a large part of the lower Vertehrata, it is evident that the movements of progression, etc., which are characteristic of each species, come under the general category of automatic actions, and are provided for in the original organization of its nervous centres, being performed without any education, and under circumstances which render the notion of a purpose on the Animal's own part quite untenable. In so far as these instinctive movements require the guidance and direction of scnsations, they must be referred to the "consensual" group; but clear evidence is afforder by the continuance of many of them after the removal of the centres of sensation, that they are excito-motor in their character, and that they require no higher ecntre than the ganglia which correspond to the Spinal Cord of Man. ' There can be little doubt that the halitual movements of locomotion, and others which have become "secondarily automatic," may be performed by Man (under particular circumstanecs) through the agency of the Spinal Cord alone, under the guidance and direetion of the Sensorial centres, or even withont such guidance; the required condition being, that the influence of the Cerebrum shall be entirely withdrawn. Thus, numerous instances are on record, in which soldiers have continued to march in a sounl sleep; and the Author has bcen assured by

1 See Princ. of Comp. Phys., $8 \& 649-654$. 
an intelligent witness, that he has seen a very accomplished pianist complete the performance of a piece of music in the same state. ${ }^{1} A$ case has been mentioned to him by his friend Dr. William Budd, of a patient laboring under the form of epilepsy in which there was simply a temporaly suspension of consciousness without convulsion, who, whenever the paroxysm canle on, persisted in the kind of movement in which he was engaged at the moment; and thus on one occasion fell into the water through continuing to walk onwards, and frequently (being a shoemaker by trade) wounded his fingers with the awl in his hand, by a repetition of the movenent by which he was enteavoring to pierce the leather. Such facts as these add great strength to the probability, that when the Cerebral power is not suspended, but merely directed into another channel, as in the states of Reverie or Abstraction, and the attention is entirely drawn off from the movements of locomotion, the continuance of these is due to the independent autonatic action of the Spinal Cord, the direction being given to them loy the Sensory Ganglia. This point, however, will be more fully considered hereafter; at present it may be remarked, that, when a regular train of movements is being performed under such conditions, every single action may be probably regarded as affording the stimulus to the next; each contact of the foot with the ground, in the act of walking, exciting the muscular contractions which constitute the next step; ${ }^{2}$ and each movement of the musician prompting that which has customarily followed it, after the same fashion.

511. Now in all these cases it seems reasonable to infer that the same kind of connection between the excitor and notor nerves comes to be formed by a process of gradual developnent, as originally exists in the nervous systems of those aninals whose movements are entirely automatic; this portion of the nervous system of Man being so constituted, as to grow to the mode in which it is habitually called into play. Such an illea is supported by all that we know of the formation and persistence of habits of nervo-muscular action. For it is a matter of universal experience that such habits are far more readily acquired during the periods of infancy, childhood, and yout!, than they are after the attainment of adılt age; and that the earlier they are acquired, the more tenaciously are they retained. Now it is whilst the organism is growing most rapidly, aud the greatest amount of new tissue is consequently being formed, that we should expect such new connections to be most readily established; and it is then, too, that the assimilative processes most readily take on that new mode of action ( $\$ 336$ ), which often becomes so completely a "second nature," as to keep up a certain acquired morle of nutrition through the whole subsequent life. It is an additional and most important confirmation of this view, to find that when a nervetrunk las been cut across, the re-establishment of its concluctive power, which takes place after a certain interval, is effected, not by the remion of the divided fibres, but by the development of a new set of peripheral fibres in the place of the old ones (which undergo a gradual degeneration), this development proceeding from the point of section, and the central fibres

I In playing by memory on a inusical instrument, the muscular sense often surgosts the sequence of movements with more certainty than the auditory; and since the infressions derived from the muscles may prompt and regulate successional movements, without affecting the consciousness, there is no such improbability in the above statement as might at first sight apper.

2 'The truth of this view seems to the Author to be strongly supported by observation of the mude in which Infants learn to walk: fur it may often be observed that long before they can stand, they will instnctively perform the movements of walking, if they be so supported that the feet touch the ground. 
remaining unaltered. ${ }^{-}$-That an actual continuity of nerve-fibres, however, is not requisite for the establishment of those connections between excitor and motor nerves, in which the central organs take part, seems probable from the fact, that under particular circumstances we find the influence of such impressions radiating in every direction, and extending to nerves which they do not ordinarily affect. Still there can be no doubt that the nerveforce is disposed to pass in special tracks; and it seems probable, that whilst some of these are originally narked out for the automatic movements, others may be gradually worn in (so to speak) by the habitual action of the Will; and that thus, when a train of sequential actions primarily directed by the Will has been once set in operation, it may continue without any further influence from that source.

512. Another nanifestation of the independent power of the Spinal Cord is seen in its influence on Muscular Tension.-The various muscles of the body, even when there is the most complete absence of effort, maintain in the healthy state of the system a certain degree of firmness, by their antagonism with each other; and if any set of muscles be completely paralyzed, the opposing muscles will draw the part on which they act out of its position of repose; as is well seen in the distortion of the face which is charactcristic of paralysis of the facial nerve on onc side. This condition has been designated as the tone of the Muscles; but this term renders it liable to be confounded with their tonic contraction, which is also concerned in maintaining their firmness, but which is a manifestation of the simple contractility of their tissue, and is exhibited alike by the striated and the non-striated forms of muscular fibre, but more especially by the latter. On the other hand, the condition now alluded to, which may perhaps be appropriately termed their tension, is the result of a moderate though continued excitement of that contractility, through the nervous centres. It has been proved by $\mathrm{D}_{i}$. MI. Hall that the Nuscular 'Tension is dependent, not upon the influence of the Brain, but upon that of the Spinal Cord, as the following experiments demonstrate: "Two Rabbits were taken: from one the head was removed; from the other also the head was removed, and the spinal nuarrow was cautiously destroyed with a sharp instrument: the limbs of the former retained a certain degree of firmness and clasticity; those of the second were perfectly lax." Again: "The limbs and tail of a decapitated Turtle possessed a certain degree of firmmess or tonc, recoiled on being drawn from their position, and noved with energy on the application of a stimulus. On withdrawing the spinal marrow gently out of its canal, all these plicnomena ceaserl. The limbs were no longer obedient to stimuli, and became perfectly flaccid, having lost all their resilience. The sphincter lost its circular form and contracted statc, becoming lax, flaceid, and shapeless. The tail was flaceid, and unmoved on the application of stimuli.". It is further reniarked by Messrs. Todd and Bowman, that "a decapitated frog will continue in the sitting posture through the influence of the spinal cord; but immediatcly this organ is removed, the linbs fall apart."-This operation of the Spinal Cord is doubtless but a peculiar manifestation of its ordinary reflex function. A curious experiment by M. Brown-Séquard ${ }^{3}$ shows that this effect is not duc to loss of contractility in the muscles; for although, after division of the Spinal Cord, there is a temporary diminution in their power, after a short interval the muscles, when stimulated to contract, will not only raise an equal but even a greater weight than before, the effect lasting in licalthy

1 See Dr. Waller's important researehes on the Reproduetion of Nervous Substance, in Mroller's Archiv, 1852, Heft iv.

2 Memoirs on the Nerrous System, 1837, p. 93.

3 Comptes Rendus, 1847. 
frogs for 24 hours or more. 'Thus, two frogs, A and B, had weights fastened to the lind legs until they were unable to raise them; the weighting amounted in each case to 925 grains. Immediately after division of the Cord they were able to raise-

\begin{tabular}{|c|c|c|c|c|c|c|c|c|}
\hline & $\begin{array}{l}5 \text { minutes } \\
\text { after. }\end{array}$ & $\begin{array}{l}15 \text { minutes } \\
\text { alter. }\end{array}$ & $\begin{array}{l}25 \text { minutes } \\
\text { after. }\end{array}$ & $\begin{array}{l}1 \text { hour } \\
\text { after. }\end{array}$ & $\begin{array}{l}2 \text { hours } \\
\text { after. }\end{array}$ & $\begin{array}{l}4 \text { hours } \\
\text { after. }\end{array}$ & $\begin{array}{l}24 \text { hours } \\
\text { after. }\end{array}$ & $\begin{array}{l}48 \text { liours } \\
\text { after. }\end{array}$ \\
\hline A, 308 grains, & 694 & 925 & 1223 & 2003 & 2160 & 2160 & 2214 & 2314 \\
\hline B, 154 srains, & 463 & 617 & 925 & 1540 & 1851 & 20113 & 2160 & 2160 \\
\hline
\end{tabular}

We shall hereafter see how much the influence of the Will in producing the active contraction of a muscle, is dependent upon sensations received from it; and it seents highly probable that the impression of the state of the muscle, conveyed by the afterent fibres proceeding from it to the Spinal Cord, is sufficient to excite this state of moderate tension through the motor nerves arising from the latter. Such a view derives probability from the fact, which must have fallen under the observation of almost every one, that most reflex actions become increased in energy, if resistance be made to them. Of this we have familiar examples in the action of the expulsor muscles which operate in defecation, urination, and parturition, if, when they are strongly excited, their efforts be opposed by spasmodic contraction of the sphincters, or by mechanical means. Many forms of convulsive movement exhibit the same tendency, their violence being proportional to the mechanical force used to restrain them. Here it is evident that the impression of resistance conveyed to the Spinal Cord is the source of the increased energy of its motor influence; from which we may fairly infer that the moderate resistance occasioned by the natural antagonism of the muscles, is the source of their continued and moderate tension, whilst they are under the influence of the Spinal Cord. This constant though gentle action serves to keep up the nutrition of the muscles which are paralyzed to the will; and this is still more completely maintained, if the portion of the nervous centres with which they remain connected be so unduly irritable, that the muscles are called into contraction upon the slightest excitation, and are thus continually exhibiting twitchings, startings, or more powerful convulsive movements. It is upon the continuance of the nutrition of the muscles, that the persistence of their contractility depends; and hence the Spinal Cord has an indirect influence upon the peculiar property, which is more likely to be retained when the muscle is still subject to the influence of the Spinal Cord, though cut off from that of the Brain, than when it is completely paralyzed by the entire severance of its connection with the nervous centres.

\section{Of the Sensory Ganglia and their Functions.-Consensual Movements.}

513. At the base of the Brain in Man, concealed by the Cerebral Hemispheres, but still readily distinguishable from them, we find the series of ganglionic masses which have been already mentioned as being in direct connection "ith the nerves of Sensation, and which appear to have functions quite independent of those of the other components of the Encephalon. These are the Olfactory and Optic ganglia (Corpora Quadrigemina), with the Auditory and Gustatory centres contained in the IIedulla Oblongata. The structure of the Corpora Quadrigemina has been shown by Mr. Lockhart Clarke to consist of nerve-cells, together with oblique, transverse, and 
longitudinal nerve-fibres resting on an arched transparent lamina, which forms the roof of the Sylvian Aqueduct. A large proportion of the Optic tract is connected with the nates. - But besides these, at the base of the Cerebral Hemispheres, we find two other large ganglionic masses on either side, through which nearly all the fibres appear to pass that connect the Hemispheres with the Medulla Oblongata: namely, the Thalami Optici and the Corpora Stricta. Now, although these are commonly regarded in the light of appendages merely to the Cerebral Hemispheres, it is evident from the large quantity of vesicular matter they contain, that they must rank as andependent ganglionic centres; and this view is supported alike by the evidence of Comparative Anatomy, and by that afforded by the history of Development. For it is certain that the size of the Thalani Optici and Corpora Striata presents no more relation, in different tribes of animals, to that of the Cerebrum, than does that of the ganglia of Special Sense; and they may even present a considerable development, when the condition of the Cerebrum is quite rudimentary. Thus, in the Osseous Fishes, a careful examination of the relations of the body which is known as the Optic lobe (Fig. 19:3, c) makes it apparent that this is the representative, not merely of the proper Optic ganglion of Man, but also of the Thalamus Opticus; whilst, again, the mass which is designated as the Cerebral lobe (B) is chiefly homologous with the Corpus Striatum of higher animals. The nature of the latter body is made apparent, in the higher Cartilaginous Fishes, by the presence of a ventricle in its interior; the floor of this cavity being formed by the Corpus Striatun, whilst the thin layer of nervous matter which forms its roof is the only representative of the Cerebral hemisphere. So in the human embryo of the sixth week, we find a distinct vesicle for the Thalani Optici, interposed between the vesicle of the Corpora Quadrigemina and that which gives origin to the Cerebral Henrispheres; whilst the Corpora Striata constitute the floor of the cavity or ventricle which exists in the latter, this being as yet of comparatively small dimensions.-Now, as already pointed out ( $\$ 488$ ), we may distinguish in the Medulla Oblongata and Crura Cerebri, a sensory and a motor tract, by the endowments of the nerves which issue from them. The sensory tract nay be traced upwards, until it almost entirely spreads itself through the substance of the Thalamus. Moreover, the Optic nerves and the peduncles of the Olfactory may be shown to have a distinet connection with the Thalami, the former by the direct pasaage of a portion of their roots into these ganghia, and the latter through the medium of the Fornix. Hence we may fairly regard the Thatumi Optici as the chief focus of the Sensory nerves, and more especially as the ganglionic centre of the nerves of common sensation, which ascend to it from the Melulla Oblungata and Spinal Cord.-On the other hand, the Corpora Striata are implanted on the Motor tract of the Crura Cerebri, which descend into the Pyramidal columns; and their relation to the fibres of which that tract is composed, appears to be essentially the same as that which the Thalami bear to the sensory tract. - The Corpora Striata are connected with each other, on the melian plane, by the anterior commissure; and the Thalami Optici, by the soft and the posterior commissures. The Corpus Striatum and Thatanus Opticus of the same side are very closely connecter by commissural fibres, stretching from one to the other; and, if the preceding iccount of the respective offices of these bodies be correct, they may be regarded as having much the same relation to each other as that which exists between the posterior and anterior peaks of vesicular matter in the Spinal Cord ;' the latter issuing motor im-

1 This was tirst pointed nut by Messrs. Todd and Bowmun, in their Physiological Anutomy, vol. i, pp. $347-350$. 
pulses in respondence to sensations excited through the former. They are also intimately connected with other ganglionic masses in their neighborhood, such as the "locus niger," and the vesicular matter of the "tuber anmulare;" which, again, are in close relation with the vesicular matter of the Medulla Oblongata.

514. It has been commonly supposed that the fibres of the Crura Cerebri, after entering the Corpora Striata and Thalami Optici, pass continuously through these bodies, receiving "reinforcements" of additional fibres from their ganglionic matter; and that they then radiate to the internal surface of the gray matter of the Cerebral Hemispheres. Such would certainly be the conclusion to which a superficial examination of their course would lead. But very strong reasons have recently been advanced for the belief, that the fibres of the Crura Cerebri for the most part, if not entirely, terminate in the vesicular substance of the Corpora Striata and Thalami Optici and that the radiating fibres of the Hemispheres take a fresh departure from these ganglia, serving, in fact, the part of commissures to connect their vesicular substance with that of the Cerebrai ganglia. ${ }^{1}$ And this view, as we shall hereafter see, is in complete accordance with the existence of a very decided physiological separation between these two sets of organs.-Altogether it is very evident, that a series of true ganglionic centres exists at the base of the Encephalon, which are really as distinct from either the Cerebrum or Cerebcllum as the latter are from each other; and as these centres are in immediate connection with the nerves both of special and of general Sense, they may be appropriately designated the Sensory Ganglia.-An inqury into the distribution and endowments of their nerves will assist us in the determination of the functions of the central organs in which they terminate.

515. Nerves of Special Sense.-Through the First pair, or Olfactory nerve, are transmitted the impressions made by odorous emanations upon the surface it supplies; and it is not susceptible to impressions of any other kind. Anatomical examination of the distribution of this nerve proves that it is not one which dircctly conveys motor influence to any muscles, since all its branches are distributed to the inembrane lining the nasal cavity; and experimental inquiry leads to the same result, for no irritation of the perluncles or branches excites any muscular movement. Further, no irritation of any part of this nerve excites reflex actions through other nerves. Again, it is not a nerve of "common" sensation; for animals exhibit no signs of pain when it is subjected to any kind of irritation. Neither the division of the nerve, nor the destruction of the olfactive ganglia, seems to inconvenience them materially. 'They take their food, move with their accustomed agility, and exhibit the usual appetites of their kind. The "common" sensibility of the parts contained in the olfactive organ is in no degree impaired, as is shown by the effects of irritating vapors; but the animals are destitute of the sense of smell, as is shown by the way in which these vapors affect them; for at first they appear indifferent to their presence, and then suddenly and vehemently avoid them as soon as the Schneiderian membrane becomes irritated. Moreover, if two dogs, with the eyes bandaged, one having the olfactory nerves and ganglia sound, and the other having had them destroyed, are brought into the neighborhood of the dead body of an animal, the former will examine it by its smell; whilst the latter, even if he touches it, pays no attention to it. This experiment Valentin' states that he has repeated several times, and always with the same results. Further, common observation

1 See especially Messrs. Todd and Bowman's Physiological Anatomy, vol. i, p. 277; and Prof. Kölliker's Mikroskopische Anatomie, Bd. ii, \& 118.

2 De Functionibus Nervorum Cerebralium, etc., Bernæ, 1839. 
shows that sensibility to irritants, such as snuff, and acuteness of smell, bear no eonstant proportion to one another; and there is ample pathological evidenee, that the want of this sense is eonnected with some morbid eondition of the olfaetory nerves or ganglia.-It is well known that Magendie has maintained, that the Fifth pair in some way furnishes eonditions requisite for the exercise of the power of smell; asserting that, when it is cut, the animal is deprived of this sense. But his experiments were made with irritating vapors, which excite sternutation or other violent museular aetions, not through the Olfactory nerve, but through the Fifth pair; and the experiments of Valentin, just related, fully prove that the animals are not sensitive to odor's, strictly so ealled, after the Olfactory nerve has bcen divided. The aeuteness of the true sense of smell is lessened by section of the Fifth pair; but this is because the Schneiderian membrane is then no longer duly moistcned by its proper secretion, and when lry it is less susceptible of the impressions made by those minute particles of odorifcrous substances, to which the exeitement of the sensation must be referred. A number of eases have, however, been colleeted by Claude Beruard, and especially a well-authenticated one (Marie Lemmens), in whieh, whilst no failure of the sense of smell was observed during life, the eomplete absenee of the olfaetory nerve was ascertained on post-mortem examination.

516. That the Seeond pair, or Optic nerve, has an analogous character, appears alike from anatomieal and experimental evidence. No chemical or mechanieal stimulus of the trunk produees direct museular motion; nor does it give rise, so far as ean be ascertained, to indieations of pain; whence it may be coneluded that this nerve is not one of "eommon" sensation. That the ordinary sensibility of the eyeball remains, when the funetions of the Optie nerve are completely destroyed, is well known; as is also the fact, that division of it puts an end to the power of vision. Valeutin states that, although the Optic nerve may, like other nerves, be in appearanee completely regenerated, he has never been able to obtain any evidenee that the power of sight has been in the least degree reeovered. He remarks that animals suddenly made blind exhibit great mental disturbanee, and perform many unaecustomed movements; and that the complete abscnee of the power of vision is easily aseertained. Morbid changes are sometimes observed to take plaec in eyes whose Optie nerve has becn divided; but these are by no means so constant or so cxtensive, as when the Fifth pair is paralyzed; and they may not improbably be attributed to the injury oeeasioned by the operation itself, to the parts within the orbit.

517. The Optic nerve, though analogous to the Olfactory in all the points hitherto mentioned, differs from it in one important respect: that it has the power of conveying impressions which excite reflex muscular motions. This is especially the ease in regard to the Iris, the ordinary actions of whieh are regulated by the degree of light impinging on the retina. The fibres of the optie nerve that reflectorially excite the branches of the third nerve distributed to the Iris undergo complete decussation in the chiasma optici.' When the Optie nerve is divided, contraction of the pupil takes plaee; but this ducs not ocenr if the connection of this nerve with the third pair, through the nervous centres, be in any way intermpted. After such division (if complete), the state of the pupil is not affected by variations in the alegree of light impinging on the retina; exeept in particular cases, in which it is influenced through other chamels. Thus, in a patient suffering under anaurosis of onc eye, the pupil of the affected cyc is often found to vary in size, in accordance with that of the other eye; but this effeet is due to the aetion 
of light on the retina of the sound eye, which produces a motor change in the third pair on both sides. Further, as already shown ( $\$ 508)$, the impression only of light upon the retina may give rise to contraction of the pupil, by reflex action, when the Optic nerve is itself sound; whilst no sensations are received through the eye, in consequence of disease in the sensorial portion of the nervous centres. Although the contraction of the pupil is effected by the influence of motor fibres which proceed to the sphincter of the Iris from the third pair of nerves, through the Ophthatmic ganglion, its dilatation, as we shall hereafter see, depends upon the influence it derives from the Sympathetic system, of which that ganglion forms a part.-Besides the contraction of the pupil, another action of a "reflex" character is produced through the Optic nerve; namely, the contraction of the Orbicularis muscle under the influence of strong light, or when a foreign body is suddenty brought near the eye. But this cannot be excited without a consciousness of the visual impression; in fact, it is a movement of a "consensual" kind, produced by the painful sensation of light, which gives rise to the condition well characterized by the term photophobia. The involuntary character of it must be evident to every one who has been engaged in the treatment of diseases of the eyes; and the effect of it is aided by a similarly involuntary movement of the eyeball itself, which is rotated upwards and inwards, to a greater extent than the Will appears able to effect-Another reflex movement excited through the visual sense is that of Sneezing, which is induced in many individuals by the sudden exposure of the eyes to a strong light: of the purely automatic character of this movement there can be no question, since it cannot be imitated voluntarily; and that it is not excito-motor, is proved by the fact that it is not excited unless the light be seen. ${ }^{1}$

518. There is a further peculiarity, of a very marked kind, attending the course of the Optic nerves; this is the crossing or "decussation" which they undergo more or less completely, whilst passing between their ganglia and the eyes. In some of the lower animals, in which the two eyes (from their lateral position) have entirely different spheres of vision, the decussation is complete; the whole of the fibres from the right optic ganglion passing into the left eye, and vice versa. This is the case, for example, with most of the Osseous Fishes (as the cod, halibut, etc.); and also, in great part at least, with Birds. ${ }^{2}$ In the Human subject, however, and in animals which, like him, have the axes of both eyes directed to the same object, the view entertained by many excellent anatomists and microscopists up to a recent period was that suggested by Hannover, ${ }^{3}$ namely, that the posterior border of the Optic Chiasma is formed exchusively of commissural fibres, which pass from one optic ganglion to the other, without entering the real optic nerve; whilst the anterior border of the Chiasma is composed of fibres, which seem, in like manner, to act as a commissure between the two retince; passing from one to the other, without any connection with the optic ganglia. The tract which lies between the two borders, and occupies the middle of the Chiasma, Hannover considers to be the true Optic Nerve; and in this he thought that a portion of the fibres decussates, whilst another portion passes directly from each Optic ganglion into the corresponding eye. The fibres proceeding from the ganglia to the retinse, constituting the proper Optic Nerves, he distinguished into an internal and an external tract. Of these the external, on each side, he maintained, passes directly onwards to the eye of that side; whilst

1 A ratient was for some time in the London Hospital, in whom there was sueh an undue impressibility of the retina, that she could not remain in even a moderate light without a continual repetition of the act of Sneezing.

2 See Solly on The Human Brain, 2 d edit., p. 288.

3 Das Auge, 1852. 
the internal crosses over to the eye of the opposite side. The distribution of these two sets of fibres in the retina of each eye respectively, would thus be such that, as Mr. Mayo concluded, the fibres from either optic ganglion is listributed to its own side of both eyes; the right optic ganglinn being thus exclusively connected with the outer part of the retina of the right eye, and with the inner part of the retina of the left; whilst the left optic ganglion is connected exclusively with the outer side of the left retina, and with the inner side of the right. Now as either side of the eye receives the images of objects which are on the other side of its axis, it follows, if this account of the distribution of the nerves be correct, that in Man, as in the lower animals, each ganglion receives the impressions of objects situater on the opposite side of the body. The recent researches of Biesiadecki, Mandelstamm, and Michel, ${ }^{3}$ have thrown much doubt upon this view, and seem to prove that the decussation of the optic nerves is complete in Man, though the fibres pursue a wavy course, which might readily lead to the assumption of the existence of the commissures and tracts above mentioned. In full accordance with this is the observation of M. Brown-Séquard that section of one optic nerve causes complete amaurosis of the opposite eye, whilst an anteroposterior section of the chiasma produces complete blindncss of both eyes. The purpose of this decussation may be, to bring the visual impressions, which are so important in directing the movements of the body, into proper harmony with the motor apparatus; so that the decussation of the motor fibres in the pyramids being accompanied by a decussation of the optic nerves, the same effect is produced as if neither decussated, which last is the case with Invertebrated animals in general. The view maintained by Hannover receives some support from the interesting observation of Mr. Towne, that a blending of two colors occurs if their images are simultaneously presented to the inner side of one retina and the outer side of the other retina, but not otherwise. ${ }^{5}$

519. The functions of the Auditory nerve, or Portio Mollis of the Tth, are easily determined, by anatomical examination of its distribution, and by observation of pathological phenomena, to be analogous to those of the two precerling. Atropliy or lesion of the trunk destroys the sense of Hearing; whilst irritation of it produces auditory sensations; but does not occasion pain. From experinents made upon the nerve before it leaves the cranial cavity, it appears satisfactorily ascertained that this nerve is not endowed either with common scnsibility or with the power of directly stimulating muscular movement. Nor can any obvious reflex actions be executed by irritation of this nerve; but it seems nevertheless by no means improbable, that the muscles which regulate the tension of the Tympanum are caller into action by impressions made upon it and reflected through the auditory ganglion, in the same manner as the diameter of the pupil is regulated through the optic nerve. In the involuntary start, however, which is oceasioned by a loud and sudden sound, we have an example of a consensuch movement excited through the Auditory nerve, which is evidently analogous to the closure of the eyes to a strong light. In certain morbidly inpressible states of the nervous system, as will be presently shown ( $\$ 533$ ), the effect of sounds on the motor apparatus is far more remarkable. - It has been

1 Wien. Akad. Sitz.-ber, Bd. xlii, 18fil, p. 86 .

2 Centralblatt f. d. Med. Wiss., 1873, No. 22.

3 A rehiv f. Ophthalmol., Bd. xix, Heft 2, 1873.

4 Brown-śéquard, Arehives de Physiolorie, 1872, p. 261.

6 For additional facts bearing on this sulject, see the observations of Mr. Towne, On the Str.roseopre and Stereoscopic Results, in Guy's Hospital Reports for 1862, p. 62 , and 1863 , p. 103. 
attempted by Flourens to show, that the division of the Auditory nerve which proceeds to the Semicircular canals, has functions altogether different from that portion which supplies the Vestibule and Cochlea. This inference, lowever, is grounded only upon the movements exhibiter by animals in which these nerves are irritated; which movements are capable of a different explanation $(\S 526)$.

520. The nerves which minister to the sense of Taste are destitute of the peculiarities which distinguish the preceding; being no other than certain branches of ordinary afferent nerves-the Fifth Pair and Glosso-pharyngeal (\$ $\$ 490-493)$ - the peculiar cndowments of which seen to depend rather upon the structure and actions of the papille at their peripheral extremities, than upon anything special in their own character; for, as in the case of the ordinary nerves of "common" sensation, mechanical irritation applied to them calls forth indications of pain.-From the observations and cxperiments of M. Cl. Bernard, ${ }^{1}$ it appears that the facial nerve (portio dura of the $7 \mathrm{th}$ ) supplies some condition requisite for the sense of Taste, through the branch known as the Chorda Tympani, which is the motor nerve of the Lingualis muscle and Submaxillary gland $(\$ 105)$. When paralysis of the Facial exists in Man, the sense of taste is very much impaired on the corresponding side of the tongue, provided that the cause of the paralysis be seated above the origin of the Chorda Tympani from its trunk. Similar results have been obtained from experiments upon other animals. The effect may possibly be attributable to the secretion of Saliva being interfered with.

521. Nerves of Common Sensation.-To the sense of Touch all the afferent nerves of the body (sare the nerves of special sense) appear to minister ; in virtue-according to the doctrine already propounded $(\$ 485)$ - of the direct connection of certain of their fibrils with the Sensorium commune. But the degree in which they are capable of producing Sensations does not bear any constant relation to their power of exciting reflex actions. Thus, the Glossopharyngeal is not nearly so sensitive as the Fifth pair ; though more powerful as an excitor nerve. The Par Vagum appears to have even less pcwer of arousing sensory changes; although it is the most important of all the excitors to reflex action. So again, the afferent nerves of the inferior extremities, in Man, are less concernerl in ministering to sensations, than are those of the superior; and yet they appear to be much more efficient as excitors to muscular movement. - These differences may be accounted for, by supposing that the proportion which the fibres having their centre in the ganglionic matter of the Spinal Cord, bears to that of the fibres which pass on to the Sensorium, is not constant, but is liable to variation in different nerves; the former predominating in the Par Vagum and the Glosso-pharyngeal, whilst the latter are more numerous in the Fifth pair, and in most of the Spinal ncrves.

522. Motor Nerves.-No motor nèrves issuc from the Sensory Ganglia with the same directness that afferent nerves procecd towards them; but the reflex actions of these centres find a ready channel in the motor nerves of the Cranio-spinal axis generally. For, as we have seen $(\S 513)$, the motor tract of the Crura Cerebri, which is in connection with the motor Encephalic nerves, and also (through the vesicular substance of the Spinal Cord) with the anterior roots of the Spinal nerves, passes up into the Corpora Striata and Corpora Quadrigemina. Although the direct connection of the other ganglia of Special Sense with the Motor columns is at present a matter of presumption only, yet this presumption is strongly supported by the analogy of the Optic ganglia; the distinctness of this connection 
in their case being easily accounted for, when it is remcmbered in how great a degree the general movements of the body are guided by the visual sense.

523. Functions of the Sensory Ganglia.-We have now to consider what deductions may be drawn with regard to the functions of the Sensory Ganglia in Man, from the facts supplied by Comparative Anatomy, by Experimental inquiry, and by Pathological phenomena. The determination of these functions may seem to be the more difficult, as it is impossible to makc any satisfactory experiments upon the ganglionic centres in question, by isolating them completely from the Cerebral Hemispheres above, and from the Merlulla Oblongata and Spinal Cord below. But the evidence derived from Comparative Anatomy appears to be in this case particularly clear; and, rightly considered, affords us nearly all the information we require. In the series of "experiments prepared for us by nature," which is presented to us in the descending scale of animal life, we witness the effects of the gradual change in the relative development of the Sensory Ganglia and Cerebral hemispheres, which are presented to us in descending through the Vertebrated scale; and the results of the entire withdrawal of the latter, and of the sole operation of the former, which are exhibited in the higher Invertebrata (sec $\$ \$ 447,450){ }^{1}$ - Thus we are led by the very cogent evidence which Comparative Anatomy supplies, to regard this series of Ganglionic centres as constituting the real Sensorium; each ganglion having the power of rendering the Mind conscious of the impressions derived from the organ with which it is connected. If this position be denied, we must either refuse the attribute of consciousness to such animals as possess no other Encephalic centres than these; or we must belicve that the addition of the Cerebral hemispheres, in the Vertebrated series, alters the endowments of the Sensory ganglia,-an idea which is contrary to all analogy.

524. So far as the results of Experiments can be relied on, they afford a corroboration of this view. The degree in which animals high in the scale of organization can perform the functions of life, without any other centres of action than the Ganglia of Special sense, the Medulla Oblongata, and the Cerebellum, appear's extraordinary to those who are accustomed to regard the Cerebral Hemispheres as the centre of all energy. From the experiments of Flourens, ${ }^{2}$ Hertwig, ${ }^{3}$ Magendie, ${ }^{4}$ Longet, ${ }^{5}$ and others, it appear's that not only Reptiles, but Birds and Mammals, may survive for many weeks or even months (if their physical wants be duly supplied) after the removal of the entire Cerebrum. It is difficult to substantiate the existence in them of actual sensution; but some of their movements appear to be of a higher kind than those resulting from mere excito-motor action. One of the most reniarkable phenomena exhibited by such a being, is the power of maintaining its equilibrium, which could searcely exist without

1 It is worthy of special rotice, that the development of the Cephalic gangria in the Invertebrata always boars an exact proportion to the developmint of the eyes; the other organs of special sen:e heing compuratively undeveloped; whilst these, in all the higher classes at least, are instruments of great perfeetion, and are evidently connected most intimately with the direction of the movements of the animals. Of this fact we have a remarkable illustration in the history of the metamorplosis of Inseets; the eyes being almost rudiuentary, and the Cephalic ganglia comparatively small, in most Larve; whilst buth these orgatus attuin a high development in the Imago, to whose actions the fueulty of simht is essential.

2 Recherehes Expérimentales sur les Propriétés et les Fonetions du Système Nerveux, $2 d$ edit., 1845 .

s Exper. de effect. lax-ion. in partibus Encephali, Berol., 1826.

4 Lecons sur les Functions du Sistène Nerveux, Paris, 1839.

5 'Truité de P'hysiologie, tom. ii, partie 2, 1860, p. 411. 
consciousness. If it be laid upon the back, it rises again; if pusherl, it walks. If a Bird thus mutilated be thrown into the air, it flics; if a Frog be touched, it leaps. It swallows food and liquid, when they are placed in its mouth; and the digestive operations, the acts of excretion, etc., take place as usual. In the case of a Pigeon experimented on by Malacorps, which is recorded by Magendie, there appears sufficient proof of the persistence of a certain amount of sensation. Although the animal was not affected by a strong light suddenly made to fall upon i's eyes, it was accustomed, when confined in a darkened or partially-illuminated room, to seck out the light parts; and it avoided objects that ley in its way. In the same manner, it did not seem to be affected by sudden noises; but at night, when it slept with its eyes closed and its head under its wing, it would raise its head in a remarkable manner, and open its eyes, on the slightest noise; speedily relapsing into a state of complete unconsciousness. Its principal occupation was to preen its feathers and scratch itself. And Longet mentions that a Pigeon from which he had removed the entire Cerebrum, gave many indications of consciousness of light; for not only did the pupil contract, but the lids closed, when a strong light was suddenly made to fall upon the eye, the animal having been previously kept in darkness; and when a lighted candle was made to move in a circle before it, the animal executed a corresponding movement with its head. - The condition of such beings seems to resemble that of a Man, who is in a slumber sufficiently dcep to lose all distinct perception of external objects, but who is yet conscious of sensations, as appears from the movements occasioned by lights or by sounds, or from those which he executes to withdraw the body from an uneasy position.

525. The results of other experiments made upon the Sensory ganglia themselves, and upon the organs from which they derive their impressions, confirm this view; by showing that the ordinary movements are seriously perturbed, and that in some instances a new set of automatic movements is induced, when the normal relations between the sensory and motor apparatus are disarranged. Of the functions of the ganglia of special sense, those of the Corpora Quadrigemina are the chief which have been examined experimentally. The researches of Flourens and Hertwig have shown, that the connection of these bodies with the visual function, which might be inferred from their anatomical relations, is thus substantiated. The partial loss of the ganglion on one side produces partial loss of power and temporary blindness on the opposite side of the body, without necessarily destroying the mobility of the pupil ; but the removal of the larger portion, or complete extirpation of it, occasions permanent blindness and inmobility of the pupil, with temporary muscular weakness on the opposite side. This temporary disorder of the muscular system sometimes manifests itself in a tendency to move on the axis, as if the animal were giddy. No disturbance of consciousness appears to be produced; and Hertwig states that he never witnessed the convulsions, which Flourens mentions as a conscquence of the operation, and which were probably occasioned by his incision having been carried too deeply. As Longet has justly remarked, it is difficult, if not impossible, to remove one or both of these ganglionic masses, without doing such an injury to the Crura Cerebri on which they repose, as shall in great degree account for such disturbed movements (\$529). Irritation of one of the Tubercula

1 It must not be forgotten that, in such experiments, the severity of the operation will of itself occasion a suspension or disturbance of the functions of parts that remain ; so that the loss of a power must not be at once inferred from the absence of its minifestations. But the persistence of a power, after the removal of a particular organ, is a clear proof that it cannot be the peculiar attribute of that organ. 
Quadrigemina has bcen observed, both by Flourens and Longet, to produce contraction of the pupils of both eyes. Budge has corroborated Flourens's statements, adding that it is ouly when the lesion affects the inner part of the corpora quadrigemina, that paralysis of the Iris occurs, and that this paralysis is on the side opposite to the lesion. Renzi admits therc is temporary, but denies there is permanent loss of contractility of the Iris. Knoll ${ }^{1}$ found that irritation of the anterior pair of the corpora quadrigemina caused dilatation of both pupils, but especially of that of the same side. Lesions of the corpora quadrigemina were without effect on the iris, as long as the optic tracts were untouched, but when these were damaged between the corpora quadrigemina and the chiasma, paralysis of the opposite iris occurred, while lesions of the optic nerve on the distal side of the chiasma caused paralysis of the iris of the same side, showing that the fibres of the optic nerve which excite reflectorially the iridal branches of the third nerve, undergo complete decussation in the chiasma. Knoll operating on Rabbits, did not observe any alteration in their motility after injuries inflicted upon the corpora quadrigemina.-These results of experiments are partly confirmed by Pathological phenomena in Man; for there are many instances on record, in which blindness has been one of the consequences of diseased alterations in one or both tubercles; and in some of the cases in which the lesion extended to parts seated beneath the tubercles, disturbed movements were observed.The subscrvience of these bodies to the exercisc of the visual sense, appears, on the whole, to be the point best established in regard to their functions; and considering the degree in which this sense is concerned in the regulation of the general movements of the body, it is not surprising that lesions of its centre should occasion a perversion of these movements. This appears the more probable from the fact that, in animals whose Sensory ganglia bear so large a proportion to the whole Encephalon that we must luok upon them as the principal centres of motor activity, instead of being chiefly concerned (as in Man) in the mere guidance of movements whose origin is Cerebral, lesions of the organ of sense from which the impressions that excite the sensori-motor impulses are derived, produce a corresponding disturbance. This Flourens found that a vertiginous movement may be induced in Pigeous by simply blinding one eye; and Longet produced the same effect by evacuating the humors of the eye.

526. It is probably on the same principle, that we are to account for the remarkable results obtained by Flourens ${ }^{2}$ from section of the portion of the Auditory nerve proceeding to the Senicircular canals. Scetion of the horizontal semicircular canal in Pigeons, on both sides, induces a rapid jerking horizontal movement of the head, from side to side; and a tendency to turm to one side which manifests itself whenever the animal attempts to walk forwards. Section of a vertical canal, whether the superior or inferior, of both sides, is followed by a violent vertical movement of the head. And section of the horizontal and vertical canals, at the same time, causes horizontal and vertical movements. Section of either canal on one side only, is followerl by the same effect as when the canal is divided on both sides; but this is inferior in intensity. The movements continue to be performed during scveral montls, but cease immediately if the thalami optici be removed (Löwenberg). In Rabbits, section of the horizontal canal is followed by the same movements as are exhibited by P'igeons; and they are even more constant though less violent. Section of the anterior vertical canal

1 Centralblatt f. d. Med. Wiss, 1872, p. 265.

2 Op. cit. Ses also Bötteler, Centralblatt f, d. Med. Wiss., 1873, p. 72; and Löwenberg, idem, p. 278; Waldeyer, idem, 1872, p. 385. 
causes the animal to make continued forward "somersets;" whilst section of" the posterior vertical canal occasions continued backward "somersets." The movements cease when the animal is in repose; and they recommence when it begins to move, increasing in viulence as its motion is more rapid.-Thesc curious results are supposed by MI. Flourens to indicate, that the nerve supplying the semicircular canals does not minister to the sense of hearing, but to the direction of the movements of the animal; whilst M. Cyon ${ }^{1}$ refers them to the circumstance that in order that an animal should preserve its equilibrium, it should have a correct idea of the position of its own head, and that the scmicircular canals supply this information in conscquence of each canal having a definite relation to space. But they are more rationally cxplained upon the supposition, that the normal functions of the semicircular canals is to indicate to the animal the direction of sounds, and that its movements are partly determined by these; so that a destruction of one or other of them will produce an irregularity of movement (resulting, as it would seem, from a sort of giddiness on the part of the animal), just as when one of the eyes of a bird is covered or destroyed, as in the experiments previously cited. Goltz, ${ }^{2}$ however, has recently inaintained that the position of the head is judged of by the animal from the pressure exerted by the endolymph on one side or the other of the semicircular canals; and that when the endolymph has escaped by section of the canals, neither the eye nor the muscular sense can supply the deficiency-the movements of the body are on this view secondary, and are due to the inability of the animal to judge of its relation to surrounding objects from the position of its head ; on the other hand, according to Cyon, ${ }^{3}$ a definite perception of the position of the head is necessary to the maintenance of equilibrium; and this perception has its origin in the semicircular canals, each canal having a certain determinate relation to certain grades of position. The derangement of motion consequent upon division of the semicircular canals, Cyon classifies under three heads: 1 . Derangements of equilibrium, as a direct result of the injury. 2. Violent movements, resulting from the irritation consequent on the abnormal sense of liearing induced thereby. 3. Consecutive symptoms, occurring some days after the operation, from the resulting inflammation of the cerebellum.

527. The numerous experiments which have been made for the purpose of determining the functions of the Thalami Optici and Corpora Striata, have not yielded any very satisfactory results; and this on account of the impossibility of completely isolating them in such a manner as to limit the operation (whether this be section, removal, or irritation) to them alone. Thus it is impossible to remove them, either separately or conjointly, without first removing the Cerebral Hemispheres; and the Thalami cannot be entirely removed, without dividing the stratum of fibres which traverse their deeper portion in their passage to the Corpora Striata. The Thalami Optici have not that relation to the visual sense which their designation would imply; for (according to the affirmation of Longet), they may be completely destroyerl in Mammals and Birds, without destruction of sight or loss of the activity of the pupil. And irritation of one or both of them produces no contraction of the pupil. It seems probable, therefore, that the loss of sight with dilatation and immobility of the pupil, which is frequently observed in cases of apoplectic effusions into the substance of the Thalami, is really due to the compression of the Optic nerves which lie beneath them. These bodies appear, however, to possess a very decided influence on the

1 Pflüger'ș Archiv, Bd, viii, p. 325.

2 Ibid., Bd. iii, 1870, p. 172.

3 See also abstract, Knapp's A rchives of Ophth. and Otol., 1874, p. 137. 
power of voluntary movement; for although an animal maintains its balance, and can be made to move onwards, after the removal of the Cerebral Hemispheres, and even after the removal of the Corpora Striata, yet if either of the Thalami Optici be removed, the sensibility and power of voluntary movement are destroyed on the opposite side of the body, and the animal consequently falls over to that side (Longet). If, instead of the entire removal of one of the Thalani, an incision be made in it without the previous removal of the Cerebrum, the animal keeps turning to one side in a circular manner (évolution du manége): according to Longet and Lafargue, this movement is directed in the rabbit towarls the opposite side; whilst Flourens states that in the frog its direction is towards the injurerl side; and according to Schiff ${ }^{1}$ the destruction of the three anterior fourths of this organ in the rabbit determines this movement towards the injured side, whilst that of the posterior fourth determines the movenient towards the oppositc side. Brown-Séquard attributes the rolling movenrents in many of these cases to certain muscles being in a state of spasm, in other instances to vertigo. No mechanical irritation of the Thalani produces either signs of pain or muscular movement; and this fact might at first appear to negative the doctrine that these organs are the ganglia of common sensation. ${ }^{2}$ But it must be borne in mind that the production of pain by mechanical injuries is by no means a universal phenomenon in the case of the nerve-trunks which minister to sensation, - the olfactive, optic, and auditory nerves being exempted; and it need occasion still less surprise, therefore, that a nervous centre should be destitute of this kind of impressibility, which we have seen to be wanting also in the Spinal Cord.

528. The effects of lesions of the Corpora Striata a re less distinctly marked. It was affirmed by Magendie that there exists in them a motor power which excites backward movement, and that a corresponding power of exciting forward movement exists in the Cerebellum; that these two powers ordinarily balance one another; but that if either organ be removed, the power of the other will occasion a continual autonatic movement, the removal of the Corpora Striata causing an irresistible tendency to forward progression, whilst the division of the peduncles of the Cerebellum (according to hims) occasious the reverse moventent. These assertions, however, have not been confirmed by other experimenters. According to Longet, ${ }^{3}$ Schiff, ${ }^{4}$ and Lafargue, ${ }^{5}$ the results of removal of the Corpora Striata with the anterior part of the Cerebral hemispheres, are for the most part negative ; for the animal usually remains in a state of profound stupor, although still retaining the erect position; and it is only when irritated by pinching or pricking, that it will cxecute any rapid movements. No mechanical irritation of the Corpora Striata produces either signs of pain or muscular movement. Burlon-Sanderson ${ }^{6}$ has shown that by direct irritation of the Corpus Striatum, movements of the muscles of the opposite side can be produced, and that there is a certain correspondence in the groups of muscles that can thus be called into play, and those that are excited by irritation of lefinite regions of the intact cerehral hemispheres: on irritating the deepest part of the Corpus

1 Romer and Wunderlich's Archiv für Physiol. Heilkunde, 1846, \& 667.

2 Nothnagel (Centralblatt., 1874, p 577) in a recent paper states that from numerous experiments on Rabbits hr has satisfed himself-1. That the optic thalani have nothing to do with the innervatuon of voluntary movements. 2. That after their extirjution, no disturbance of cutaneous sensibility ean be demonstrated. And 3 . That they appesar to have a definite relation to the muscular semso

3 Op. cit. SDu vi motoriâ baseos Encephali, Bockenhemii, 1845.

5 Essai sur la Valeur des Localisations Encéphaliques, etc., Tỉèse Inaug., Paris, 1838.

6 Centrablatt, 1874, p. 513. 
Striatum, the animal opened its mouth, and alternately thrust out and retracted the tongue. ${ }^{1}$

529. When the fibrous tracts which connect these ganglionic masses with the Medulla Oblongata, and which are commonly (but erroneously) designated as the Crura Cerebri, are completely divided, the result, as inight be anticipated, is the annililation of sensibility and of the power of voluntary movement in the body generally. ${ }^{2}$ When, however, the Crura Cerebri of a rabbit are not completely divided, but one of them is partially cut through a little in front of the Pons Varolii, the animal is said by Longet and Schiff to exhibit a constant tendency to turn towards the side opposite to that of the lesion, so that it performs the circular évolution dumanége; the diameter of its circle of movement being smaller, in proportion as the incision approaches the edge of the Pons. But if one of the Crura be completely divided, the animal then falls over on the opposite side; the limbs of that side being paralyzed to the influence of the Encephalic centres, though they may be still caused to exhibit reflex motions. Hence it appears that the circular movements which are performed after incomplete lesions of the Crus Cerebri and Thalamus Opticus of either side, are due to the weakening of the sensori-motor apparatus of the opposite side, whereby the balance of the muscular actions of the two sides is destroyed. Nearly the same results have been obtained on this point by Longet, Lafargue, and Schiff: Afunasieff ${ }^{3}$ found that in the course of two or three weeks an animal in which one of the cerebral peduncles had been divided, was able to run straight forward. The section causes complete paralysis of the oculo-motorius on the same side, and imperfect paralysis of the facial nerve on the opposite side. It also produces diminished sensibility of the body and head, and contraction of the arteries, which lasts for 10 or 15 days, and is more marked in the ear of the same side. At the moment of section the blood-pressure is increased, and the pulse slowed, and in half an hour the temperature of the body falls $3^{\circ} \mathrm{F}$. Division of both peduncles destroys the power of voluntarily relaxing or constricting the sphincter ani, as well as of relaxing the constrictor urethre.

530. Considerable importance is attached by some Physiologists to the part of the Encephalon known as the Tuber Anmulare, to which the name of Mesocephale has also been given. This is not altogether synonymous with the Pons Varolii, as some Anatomists have represented it; for, while the latter consists of transverse fibres which form the commissure between the hemispheres of the Cerebellum, surrounding and passing between the longitudinal fibres of the Sensory and Motor tracts which constitute the Crura Cerebri, the Tuber Anuulare (which exists in animals whose Cerebellum has no hemispheres) is a projection from the surface of the proper Medulla Oblongata, containing a considerable nucleus of vesicular matter. M. Brown-Séquard ${ }^{*}$ has drawn the fullowing conclusions respecting the functions of this part of the Encephalon, chiefly based on pathological evidence: -1. That the restiform bodies and their prolongations into the Pons, and

1 Hitzig (Centralblatt, 1874 , p. 548) criticizes Dr. Sanderson's statements.

2 It is considered by Longet that these functions are not completely destroyed, because the animals on whom this operation has been performed still retain some power of movement, and respond by cries to impressions that ordinarily produce pain. There is no proof, however, that such actions are other than "excito-motor ;" they certainly cannot in themselves be admitted as proving the persistence of consciousness in the lower segment of the Cerebro-Spinal axis. (See Brown-Séquard, Central Nervous System, 1860, p. 225; and Schroeder v. d. Kolk, Syd. Soc. Trans., 18.59, p. 76.)

3 Wien. Med. Wochens., pp. 137, 153, 169, and 185.

4 Journ. de la Physiol, vol. i: p. 762 ; vol. ii, p. 121. 
into the Cerebellum, are not, as has been supposed, the eonduetors of sensory impressions. 2. That whilst hyperesthesia oceurs on the same side of the body when the Spinal Cord is injured, especially in its posterior part, it appears on the opposite side of the body when a section is made either of the anterior or posterior surface of the Pons; and this he believes to favor his view of the decussation of the sensory fibres in the Cord, and to be opposed to the old view of the decussation of these fibres below the Tubercula Quadrigemina, or in the substance of the Pons itself. 3. The transmission of sensory impressions in the Pons appears to be ehiefly effected by its eentral portion, whilst the anterior portion is chiefly instrumental in the conduction of the mandates of the Will to the Museles. The experiments of Longet led him to the eonclusion, that the Tuber Annulare, the strueture of which is very complicated, is an independent centre of sensation and of motor power; but they do not afford any clear information as to its special attributes. He states, however, that convulsive movements are excited by irritating it, and especially by the transmission of an eleetric eurrent through its substance. These movements, however, according to the testimony of Dr. Todd, appear to be of a different character from those which are excited by the application of the same stimulus to the Spinal Cord and Medulla Oblongata ; for he states that while the eonvulsions excited by the transmission of the current of the magneto-electric machine through the parts just named, are tetanic, the museles being thrown into a state of fixed contraetion,- those which ensue when the current is transmitted through the region of the Mesocephale and Corpora Quadrigemina, are epileptic, being combined movements of alternate contraction and relaxation, flexion and extension, affecting the nuscles of all the limbs, of the trunk, and of the eyes, which roll about just as in epilepsy. ${ }^{1}$

531. The evidence afforded by Pathology regarding the functions of these Ganglionie masses is not altogether self-consistent; but this arises, probably, from the eireumstance that the effects of morbid changes (particularly of sanguineous effusions) in any part of the Eneephalon, extend themselves to other parts than those in which the obvious lesions are found; as is abundantly proved by the great variety of phenomena which present themselves as the results of lesions apparently similar, and by the similarity of the phenomena that are frequently eonsequent upon lesions of very different parts. It is established by abundant evidence that disease of the Corpora Striata, or 'Thalami Optici, or hamorrhage into these bodies produces hemiplegia, or paralysis of the opposite side. 'This paralysis, however, is not uniform, but afteets chiefly the arm and leg, and in a less degree the face, whilst sensation is usually unly slightly affeeted, or eseapes altogether. An ingenious attempt has been matie by Dr. Broadbent ${ }^{2}$ to explain the phenomena observed in these eases. He observes that the relative situation of the two ganglia (Corpus Striatum and Optie Thalamus) will in some measure account for the circumstance that sensation so frequently escapes when motor power is lost; since the Corpus Striatum - the motor ganglion - is in front of and external to the Thalamus, and may therefore easily be extensively damaged without involving the latter, or the fibres passing from it to the Cord. The Thalamus-the sensory gancrlion -on the other hand, lying behind the Corpus Striatum, and upon the fibres connecting it with the Cord, ean seareely be seriously affected without injury to these fibres or the Corpus Striatum itself. Again, the Optie Thalamus, according to hypothesis, standing with respeet to the Corpus Striatum in the

I Lumleian Lectures, On the Pathology and Treatment of Convulsive Diseases, in Medical Gazette, May 11th, $18 t 9$.

2 Med.-Chir. Rev., A pril, 1866. 
relation of a sensory to a motor nerve-nucleus, it would almost follow that severe injury to the former would paralyze the latter by inhibitory influence, even when the injury was confined to the Thalamus, and did not reach the Corpus Striatum directly or indirectly. Lastly, the experiments of M. BrownSéquard ntay be referred to, as showing that in the case of the Spinal Cord, a very much more complete destruction of the gray matter is requisite to destroy sensation entirely than is requisite for the abolition of the power of motion. Dr. Broadbent considers that the partial character of the paralysis may further be referred to the mode of functional activity of the muscles affected as compared with those which escape, and believes it may be shown that where the muscles of the corresponding parts on opposite sides of the body constantly atet in concert, and seldom if ever independently, the nerve nuclei of these muscles are so connected by commissural fibres as to be pro tanto a single nucleus. This combined nucleus will have a set of fibres from each Corpus Striatum, and will usually be called into action by both; but it will also be capable of being excited by either singly, though more or less completely according as the commissural connection bet ween the two halves is more or less perfect. In support of this statement, it may be observed that those muscles which are commonly associated in their movements like the ocular muscles, are not paralyzed; those of the cheek, on the other hand, exhibit a degree of independence of action, and are slightly paralyzed; and lastly, the muscles of the arm and leg, which are almost completely independent in their action, are most severely affected. It is found also that in unilateral couvulsion or spasm, the movements are bilateral in those parts which escape paralysis in Hemiplegia - i.e., the combined nucleus transmits the irregular one-sided impulse along the nerves of both sides.

532. In employing the information derived from the foregoing sources, as a guide in the inquiry into the part pertormed by the Sensory Ganglia in the ordinary operations of the Cerebro-Spinal system, we have to distinguish, as in the case of the Spinal Cord, between their operation as independent centres, and their action in subservience to the Cerebrum, which is superposed upon them.- We have seen reason to conclude that, in their former capacity, they are to be regarded as the true seat of Sensation (i.e., the material instruments through which the consciousness becomes affected by external impressions), and as the instrument, in virtue of their own " reflex" power, of that class of Instinctive or Automatic movements, which require to be prompted and guiled by sensations, and which camnot, therefore, be referred to the excitomotor group. But although it is sufficiently obvious that such movements constitute the highest manifestations of Animal life in the Invertebrata geuerally, and that they are but little modified by any higher principle of action even in the lower Vertebrata, yet it is no less obvious that in adult Man, in whom the Intelligence and Will are fully developed, we have comparatively little evidence of this independent reflex action of the Sensory Ganglia: all those automatic actions which are immediately necessary for the maintenance of his Organic life, being provided for by the excito-motor portion of the apparatus, so that although sensation ordinarily accompanies most of them, it is not essential to them; whilst those which are necessary to provide more remotely for its requirements, are for the most part committed to the guidance of his Reason. For the impressions which have been brought by the afferent nerves to his Sensorium, and which have there produced sensations, do not in general react at once upon the motor apparatus (as they do in those animals in which the Sensory Gauglia are the highest of the nervous centres), but usually transmit their influence upwards to the Cerebrum, through whose instrumentality they give rise to ideas and reasoning processes, which operate upon the motor apparatus either emotionally or volitionally. And it is for 
the most part only when this upward transmission is checked, either by the non-development or the funetional inaetivity of the Cerebrum, or by its complete oceupation in some other train of aetion,- - or, on the other hand, when the reflex action of the Sensory ganglia is called into play with unusual potency,that we have any manifestations of the sensori-motor or consensual mode of operation in Man, that are at all eomparable in variety or importanee to those instinetive aets whieh are so remarkable in the lower animals ( $\$ 448)$.

533. Still, sufficient evidenee of the existenee of this class of reflex movements may be drawn from observation of the actions of Man in his ordinary condition; examples of it being furnished (as we have seen) by the closure of the eyes to a dazzling light, the star eaused by a loud and unexpected sound, and the sneezing excited by sensory impressions on the Sehneiderian membrane or on the Retina. To these may be added the vomiting produeed by various sensory impressions, as a sight of a loathsome object, a disagreeable smell, a nauseous taste, or that peeuliar feeling of want of support which gives rise to "sea-siekness," especially when combined with the sight of continually shifting lines and surfaces, whieh itself in many individuals disposes to the same state; the involuntary laughter which is excited by tiekling, and also that which sometimes bursts forth at the provocation of some sight or sound to whieh no ludicrous idea or emotion can be attaehed; the yawning which is excited by an internal sensation of uneasiness (usually arising from cleficient respiration), or by the sight or sound of the act as performed by another ; and those involuntary movements of the body and limbs, excited by uneasy sensations (probably muscular), which are commonly designated as "the fidgets." When the reflex activity of the Sensory ganglia is more strongly excited, in consequenee either of an unusual potency of the sensory impressions, or of an unusual excitability of this part of the nervous centres, a much greater variety of sensori-motor aetions is witnessed. The powerful involuntary contraction of the orbicularis and of the museles which roll the eyeball upwards and inwards, in cases of excessive irritability of the retina $(\$ 517)$, is one of the best examples of this kind; but another very eurious illustration is afforded by the involuntary abridgment of the excito-motor actions of respiration, when the performanee of these is attended with pain, the dependenee of this abridgment upon the direet stimulus of sensation, rather than upon voluntary restraint, being obvious from the faet that it often presents itself on one side only, a limitation which the Will cannot imitate. Again, there are certain Convulsive disorders which appear to depend upon an undue exeitability of these centres, the paroxysus being excited by impressions whieh act through the organs of sense, and are not thus operative unless the patient be eonscious of them; thus in Hydrophobia, we observe the immediate influence of the sight, sound, or contaet, of liquids, or of the slightest eurrents of air, in exciting muscular contractions; and in many Hysteric subjeets, the sight of a paroxysm in another individual is the most certain means of its induction in thenselves. A remarkable case of this general exaltation of purely sensorial excitability has been reeorded by Dr. Cowan, who gives the following account of its phenomena, which can searcely be referred to any otlier than this category. "The shadow of a bird crossing the window, though the blind and bed-curtains are elosed, the displacement of the sinallest portion of the wick of a candle, the slightest change in the firelight, induce a sudden jerking of the spinal muscles, extending to the arms and legs when violent, and this without the slightest mental emotion of any kind beyond a conseiousness of the movement. At times the vocal organs are implicated, and a slight ery, quite involuntary, takes place. At these periods she is unusually susceptible of all noises, especially the least expeeted and least familiar. Movements in the next 
house inaudible to others, the slightest rattle in the lock of a door, tearing a morscl of paper, and a thousand little sources of sound not to be catalogned, induce results similar to those of visual impressions."

5:34. It is, however, when the Cerebrum is not in a state which renders it capable of receiving and acting upon Sensorial impressions, that we find the independent reflex activity of the Sensory ganglia most strikingly displayed. Thus in the Infant for some time after its birtl, it is obvious to an attentive observer, that a large part of its movements are directly prompted by sensations to which it can as yet attach no distinct ideas, and that they do not proceed from that purposive impulse which is essential to render them voluntary. This is well scen in the efforts which it makes to find the nipple with its lips; being probably guided thereto at first by the smell, but afterwards by the sight also; when the nipple has been found, the act of suction is purely excito-motor, as already explained. So in the Idiot whose brain has never attained its normal development, the influence of sensations in indirectly producing respondent movements is obvious to all who examine his actions with discrimination; and a remarkable case has been described, ${ }^{2}$ in which an entire, though temporary suspension of Cerebral power, reducing the subject of it to the condition of one of the lowest Vertebrata, gave a very satisfactory proof of the independent action of this division of the Encephalic ccntres.

535. But we do not require to go so far in search of characteristic examples of this kind of reflex action; since they are afforded by the performance of habitual movements, which are clearly under Sensorial guidance, when the Cerebrum is occupied in some train of action altogether disconnected with them. An individual who is subject to "absence of mind," may fall into a reverie whilst walking the streets; his attention may be entirely absorbed in a train of thought, and he may be utterly unconscious of any interruption in its continuity; and yet duriug the whole of that time his limbs shall have been in motion, carrying him along the accustomed path, whilst his vision shall have given to those movements the direction. which is requisite to guide him along a particular line, or to move him out of it for the aroidance of obstacles. As already pointed out ( $\$ 510)$, there seems strong reason for regarding the ambulatory movements of the limbs as in thenselves excito-notor; but the guidance of these movements by the visual sense indicates the participation of the Sensorium in this remarkable performance.-It has becn maintained by some Metaphysicians and Physiologists, that these "secondarily automatic" actions always continue to be voluntary, because their performance is originally due to a succession of volitional acts, and because, in any particular case, it is the Will which first excites them, whilst an exertion of the Will serves to chcck them at any time. But this doctrine, involves the notion that the Will is in a state of pendulum-like oscillation between the train of thought and the train of movement; whereas nothing is more certain to the individual who is the subject of both, than that the former may be as uninterrupted as if the body were perfectly at rest, and his reverie were taking place in the quietude of his own study. And as it commonly happens that the direction taken is that in which the individual is most in the habit of walking, it will not unfrequently occur that if he had previously intended to pursue some other, he finds himself, when his reverie is at an end, in a locality which may be very remote from that towards which his walk was originally destined; which would not be the case, if his movements had been still under the purposive direction of the will. And although it is perfectly true that these 
movements ean be at any time eheeked by an effort of the will, yet this does not really indicate that the will has been previously engaged in sustaining them; since, for the will to act upon them at all, the attention must be reealled to them, and the Cerebrum must be liberated from its previous selfoecupation. And the gradual eonversion of a volitional into an automatie train of movements, so that at last this train, once started, shall continue to run down of itself, will be found to be less improbable than it would at first appear, when it eomes to be understood that the meehanism of both sets of aetions is essentially the same, and that they merely differ as regards the nature of the stimulus which originally exeites them $(\$ 544)$. That the same automatie movements are not excited by the same sensations, when the Cerebrum is in its ordinary state of functional eonneetion with the Sensorium, is a fact entirely in harmony with the prineiple already laid down $(\$ \$ 457,458)$. The eomplete oeeupation of the mind in other ways, as in elose conversation or argument, or even (it may be) in the voluntary direetion of some other train of museular movenents, is no less favorable than the state of reverie to that independent action of the Automatic eentres which has been now deseribed.

536. In the state of entire functional aetivity of the nervous eentres of Man, however, there ean be no doubt that the operation of the Sensory Ganglia is entirely subordinated to that of the Cerebrum; and that it furnishes an essential means of connection between the aetions of the Cerebrum on the one hand, and those of the organs of Sense and Motion on the other, by the eombination of which the Mind is brought into relation with the external world. For, in the first place, it may be affirmed with certainty that no mental action can be originally excited, save by the stimulus of Sensations; and it is the office of the Sensory ganglia to form these out of the impressions brought to them from the organs of sense, and to transmit such sensorial changes to the Cerebrum. But they have a no less important partieipation in the downward aetion of the Cerebrum upon the motor apparatus; for no voluntary action ean be performed without the assistance of a guiding sensation, as was first prominently stated by Sir C. Bell. ${ }^{1}-I_{11}$ the majority of eases, the guiding or controlling sensation is derived from the muscles themselves, of whose eondition we are rendered eognizant by the sensory nerves with which they are furnished; but there are certain eases in which it is ordinarily derived from one of the special senses, and in whieh the "museular sense" can only imperfectly supply the deficiency of such guidanee; whilst, again, if the "muscular sense" be deficient, one of the speeial senses may supply the requisite information. [Sachs hats demonstrated that there are nerves of muscular sense, and that the perecption of a contraction is probably due to a mechanical irritation of sensitive nerves, which run between and around the musenlar fibres. ${ }^{2}$ ] The proof of this neeessity is furnished by the entire impossibility of making or sustaining voluntary efforts, without a guiding sensation of some lind. Thus, in complete anresthesia of the lower extrenities, without loss of muscular power, the patient is as completely unable to walk as if the motor nerves had also been paralyzed, unless the deficient sensorial guidanee be replaced by some other; and in similar affections of the upper extremities, there is a like inability to raise the limb or to sustain a weight. But in snch eases, the deficiency of the "muscular sense" may be made good by the visual; thus, the patient who eamot feel either the eontact of his foot with the ground, or the muscular

1 Sec his chapter, On the Nervous Circle which connects the Voluntary Muscles with the Brain, in his work, On the Nervous Systcm of the Human Body.

${ }^{2}$ [Recent Progress in Physiology, by Prof. II. P. Bowditch ] 
effort he is making, can manage to stand and walk by looking at his limbs; and the woman who cannot feel the pressure of her child upon her arms, can yet sustain it so long as she keeps her eyes fixed upon it, but no longer, - the muscles ceasing to contract, and the limb drooping powerless, the moment that the eyes are withdrawn from it. Thus it is, too, that when we are about to make a muscular effort, the amount of force which we put forth is governed by the mental conception of that which will be required, as indicated by the experience of former sensations; just as the contractions of the muscles of vocalization are regulated by the conception of the sound to be produced. Hence, if the weight be unknown to us, and it prove either much heavier or much lighter than was expected, we find that we have put forth too little or too great a muscular effort.

537. There are two groups of muscular actions, however, which, although no less voluntary in their character than the foregoing, are yet habitually guided by other sensations than those derived from the muscles themselves. 'These are, the movements of the Eyeball, and those of the Vocal apparatus. The former are directed by the visual sense, ${ }^{1}$ by which the action of the muscles is guided and controlled, in the same manner as that of other muscles is directed by their own "muscular sense;" and hence it happens that, when we close our eyes, we cannot move them in any required direction without an effort that strongly calls forth the inuscular sense, by which the action is then guided. In persons who have become blind after having once enjoyed sight, an association is formed by habit between the muscular sense and the contractile action, that enables the former to serve as the guide after the loss of the visual sense; but in those who are born perfectly blind, or who have become so in early infancy, this association is never formed, and the eyes of such persons exhibit a contiuual indeterninate movement, and cannot by any amount of effort be steadily fixed in one spot, or be turned in any definite direction. A very snall amount of the visual sense, however, such as serves merely to indicate the direction of light, is sufficient for the government of the movements of the eyeball.-In the production of rocal sounds, again, that nice adjustment of the muscles of the Larynx, which is requisite to the giving forth of determinate tones, is ordinarily directed by the auditory sense: being learned in the first instance under the guidance of the sounds actually produced; but being subsequently effected voluntarily, in accordance with the mental conception (a sort of inward sensation) of the tone to be uttered, which conception cannot be formed, unless the sense of hearing has previously hrought similar tones to the mind. Hence it is that persons who are born deaf are also dumb. They nay have no malformation of the organs of speech; but they are incapable of uttering distinct vocal sounds or musical tones, because they have not the guiding conception, or recalled sensation of the nature of these. By long training, however, and by imitative efforts directed by muscular sensations in the larynx itself, some persons thus circumstanced have acquired the power of speech; but the want of a sufficiently definite control over the vocal muscles is always very evident in their use of the organ.- It is very rarely that a person who has once enjoyed the sense of hearing, afterwards becomes so completely deaf as to lose all auditory control over his vocal organs. An example of this kind, however, has been communicated to the public by a well-known author, as having occurred in himself; and the record of his experiences ${ }^{2}$ contains many points of much interest. The deafness was the

1 See Dr. Alison's Memoir on the Anatomical and Physiological Inferences from the Sudy of the Nerves of the Orbit, in Trans, of Roy. Soc of Edinb., vol. $x \nabla$.

2 See the Lost Senses, by Dr. Kitto, vol, i, chapters 2 and 3. 
result of an accident occurring in childhood, which left him for some time in a state of extreme debility; and when he made the attempt to speak, it was with considerable pain in the vocal organs. This pain probably resulted from the unaccustomed effort which it was necessary to make, when the usual guidance was wanting; being analogous to the uneasiness which we experience, when we attempt to move our eyes with the lids closed. His voice at that time is described as being very similar to that of a person born deaf and dumb, but who has been taught to speak. With the uneasiness in the use of the vocal organs, was associated an extreme mental indisposition to their employment; and thus, for some years, the roice was very little exercised. Circumstances afterwards forced it, however, into constant employment; and great improvement subsequently took place in the power of vocalization, evidently by attention to the indications of the muscular sense. It is a curious circunistance fully confirming this view, that the words which had beeu in use previously to the supervention of the deafness, were still pronounced (such of them, at least, as were kept in employment) as they had been in childhood; the nruscular movements concerned in their articulation having still been guided by the original auditory conception, in spite of the knowledge derived from the information of others that such pronunciation was erroneous. On the other hand, all the words subsequently learned were pronounced according to their spelling; the required associations between the muscular sensations and the written signs being in this case the obvious guide.

538. It is through the "muscular sense," in combination with the visual and tactile, that those movements are regulated which are concerned alike in ordinary progression, and in the maintenance of the equilibrium of the body. That the visual sense has, in most persons, a large share in this regulation, is evident from the simple fact, that no one who has not been accustomed to the deprivation of it, can continue to walk straight forwards, when blindfolded, or in absolute darkness, towards any point in the direction of which le may have been at first guided. But the blind man, who has been accustomed to rely exclusively upon his muscular sense, las no difficulty in keeping to a straight path; and moves onwards with a confidence which is in remarkable contrast with the gait of a man who has been deprived of sight for the occasion only. In fact, as Mr. Mayo has well remarked, ${ }^{1}$ in our ordinary movements, "we lean upon our eyesight as upon crutches."- When our vision, however, instead of aiding and guiding us, brings to the niind sensations of an antagonistic character, our movements become uncertain, from the loss of that power of guidance and control over them which the harmony of the two sensations ustally gives. Thus a person unaccustomed to look dowu heights, feels insecure at the top of a tower or a precipice, although he linows that his body is properly supported; for the roid which he sees below him contradicts (so to speak) the tactile sensations by which he is made conscious of the due equilibrium of his body. So, again, although any one can walk along a narrow plank, which forms part of the floor of a room, or which is elevated but a little alove it, without the least difficulty, and even without any consciousness of eflort, if that plank be laid across a chasm, the bottom of which is so far removed from the eve that the visual sense gives no assistance, even those who have braced their nerves against all emotional distraction, feel that an effort is requisite to maintain the eqnilibrium during their passage over it; that effort being aidled by the withdrawal of the eycs from the abys below, and the fixation of them on a point beyond, which at the same time helps to give steadiness 
to the movements and distracts the mind from the sense of its danger. The degree in which the "muscular sense" is alone sufficient for the guidance of such movements, when the mind has no consciousness of the danger, and when the visual sense neither affords aid nor contributes to distract the attention, is remarkably illustrated by the phenomena of Somnambulism; for the sleep-walker traverses, without the least hesitation, the narrow parapet of a house, and crosses narrow and insecure planks, clambers roofs, etc., under eireumstances that clearly indicate the nature of the guidance by which he is directed.-The dependence of our ordinary power of maintaining our equilibrium, upon the combiuation of the guiding sensations derived through the sight and the touch, is further well illustrated, as Mr. Mayo has pointed out (lnc. cit.), by what happens to a landsman on first going to sea. "It is long before the passenger acyuires his 'sea legs.' At first, as the ship mores, he can hardly keep his feet; the shifting lines of the ressel and surfitce of the water unsettle his visual stability; the different inclinations of the planks he stands on, his muscular sense. In a short time he learns to disregard the shifting inages and changing motions, or acquires facility in adapting himself (like one on horseback) to the different alterations in the line of direction in his frame." And when a person who has thus learned by habit to maintain his equilibrium on a shifting surface, first treads upon firm ground, he feels himself almost as much at fault as he did when he first went to sea, and it is only after being some time on shore, that he is able to resume his original manner of walking. Indeed, most of those who spend the greater part of their time at sea, acquire a peculiar gait, which becomes so habitual to them that they are never able to throw it off.

539. But, further, there is very strong physiological evidence that the Sensory Ganglia are not merely the instruments whereby our voluntary movements are directed and controlled, in virtue of the guiding sensations which they furnish, but that they are actually the inmediate centres of the motor influence which excites muscular contractions, in obedience to impulses transmitted downwards from the Cerebrum. It has usually been considered that the Cerebrum acts directly upon the museles, in virtue of a rirect continuity of nerve-fibres from the gray matter of its convolutions, through the Corpora Striata, the motor tract of the Medulla Oblongata, the anterior portion of the Spinal Cord, and the anterior roots of the nerves; and that in the performance of any voluntary movenient, the Will determines the motor force to the muscle or set of muscles by whose instrumentality it may be produced. To this doctrine, however, the anatomical facts already stated constitute a very serious objection; for the motor tract cannot be stated with certainty to have any higher origin than the Corpora Striata; and it is impossible to imagine that the fibres which converge towards the surface of these bodies from all parts of the Cerebrum, can be so closely compacted together as to be included in the motor columns of the Spinal Axis. The fict would rather seem to be, that these converging fibres bear the same kind of anatomical relation to the Corpora Striata and the other Sensorial centres of motor power, as do the fibres of the afferent nerves which proceed to them from the retina, the Schneiderian nembrane, and other peripheral expansions of nervous matter; and hence we might infer that the nerve-force geverated in the convolutions, instead of acting immediately on the motor nerves, is first directed towards the Autonatic centres, and excites the sane kind of motor response in them, as would be given to an impression transmitterl to them through a sensory nerve. We shall find that such a view of the structural arrangements of these parts is in remarkable aceordance with their functional relations, as indicated by careful analysis of the mechanism of what is commonly regarded as "voluntary" movement. The 
Cerebrum may thus call the motor apparatus into action, as the instrument either of $i$ deas, of emotions, or of volitional determinations; but we must limit our present examination to voluntary movements alone, these having been usually regarded as in such complete antagonism to those of the automatic group, that even separate sets of nerve-fibres have been thought requisite to account for the transmission of these two distinct orders of motor impulses to the nuscles.

540. Now, in the first place, it may be asserted, with some confidence, that no effort of the WVill can exert that direct influence on the muscles, which our ordinary phraseology, and even the language of scientific reasoners, woukd seem to imply; but, on the other hand, that the Will is solely concerned in determining the result; the selection and combination of muscular movements required to bring about this result, not being effecter by the Will, but by some intermediate agency. If it were otherwise, we should be dependent upon anatomical knowledge for our power of performing the simplest movement of the body; whereas we find the fact to be, that the man who has not the least idea of the mechanism of muscular action, can acquire as complete a command over his movements, and can adapt them as perfectly to the desired end as the most accomplished anatomist could do. Further, we cannot, by any exertion of the will, single out a particular muscle, and throw it into contraction by itself, unless that muscle be one which is alone concerned in an action that we can voluntarily perform; and even then we single it out by willing the action. Thus we can put the levator palpebre in action by itself; but this we do not by any conscious determination of power to the muscle itself, but by willing to raise the eyelids; and it is only by our anatomical knowlerge that we know that but a single nuscle is concerned in this movement. So far as our own consciousness can inform us, there is no difference between the mechanism of this action and that of the flexion of the knee- or elbow-joint; and yet in these latter movements several muscles are concerned, not one of which can be singled out by any effort of the will, and thrown into action separately from the rest.- The idea that the will is directly exerted upon the muscles called into action to produce a particular movement, nay scem to derive some support from the sense of musculer effort of which we are conscious in making the exertion, and which we refer to the muscles which are concerned in it; but this sense of effort is nothing else than the "muscular sense" alrearly alluded to, which has its origin in the state of tension of the muscles, and which is no more an indication of mental effort directed to them, than the sensation of light or sound is an indication of a determination of voluntary power to the cyes or ears.

541. There are two eases, already referred to under another head, in which it is very easy to show that the Will is concerned with the result alone, and is not dircetly exerted upon the instruments by which that result is brought about: these are, the movements of the Eyes, and the production of Vocal tones. In neither of them are we conscious of any effort in the muscular apparatus, unless the contraction be earried beyond its accustomed extent; the ordinary movements being governed, as already remarkerl, not by the muscular sense, but by the visual and auditory senses respectively.Nothing can be more simple, to all appearance, than the act of turning the eyes upwards or downwards, to one side or the other, in obedience to a determimation of the Will; and yet the Will does not impress such a determiuation upon the muscles. That which the Will really does, is to cause the eychalls to roll in a given direction, in accordance with a visual sensation; and it is only when there is an object towarls which the eycs can be turned, that we ean move them with our usual facility. When the eyelicls are closed, and we attempt to roll the globes upwards or downwards, to one 
side or to the other, we feel that we can do so but very imperfectly, and with a sense of effort referred to the muscles themselves, - this sense being the result of the state of tension in which the muscles are placed by the effort to move the eyes without the guiding visual sensation. Now, on the other hand, the Will may determine to fix the eyes upon an object; and yet this very fixation may be only attainalole by a nuscular movement, which novement is directly excited by the visual sense, without any exertion of voluntary power over the muscles. Such is the case when we determinately look steadily at an object, while we move the head horizontally from side to side; for the eycballs will then be moved in the contrary direction by a kind of instinctive effort of the external and internal recti, which tends to keep the retine in their first position, and to prevent the motion of the images over them. So, when we look steadily at an object, and incline the head towards either shoulder, the eyeballs are rotated upon their antero-posterior axis (probably by the agency of the oblique muscles) apparently with the very same purpose, - that of preventing the images from moving over the retinæ (see chap. xv, sect. 3). Now we cannot refuse to this rotation any of the attributes which really characterize the so-called voluntary movements; and yet we are not even informed by our own consciousness that such a movement is taking place, but know it only by observation of others, or by the reflection in a mirror.

542. The muscular contractions which are concerned in the production of Vocal tones, are, in like manner, always accounted voluntary; and yet it is easy to show that the IVill has no direct power over the muscles of the larynx. For we cannot raise or depress the laryux as a whole, nor move the thyroid cartilage upon the cricoid, nor separate or approximate the arytenoid cartilages, nor extend or relax the rocal ligaments, by simply willing to do so, however strongly. Yet we can readily do any or all these things, by an act of the Will exerted for a specific purpose. "We conceive of a tone to be produced, and we will to produce it; a certain combination of the muscular actions of the larynx then takes place, in most exact accordance with one another; and the predetermined tone is the result. This anticipated or conceived sensation is the guide to the muscular movements, when as yet the utterance of the voice has not taken place; but whilst we are in the act of speaking or singing, the contractile actions are regulated by the present sensations derived from the sounds as they are produced.-It can scarcely but be admitted, then, that the Will does not directly govern the movements of the Larynx; but that these movenents are immediately dependent upon some other agency.

543. Now what is true of the two preceding classes of actions, is equally truc of all the rest of the so-called voluntury movements; for in each of them the power of the $\mathrm{W}$ ill is really limited to the determination of the result; and the production of that result is entirely dependent upon the concurrence of a "guiding sensation," which is usually furnished by the very muscles that are called into action. It is obvious, therefore, that we have to seek for some intermediate agency, which executes the actions determined by the IVill; and when the facts and probabilities already stated are duly considered, they tend strongly in favor of the idea that even voluntary movements are executed by the instrumentality of the Automatic apparatus, and that they differ only from the automatic or instinctive in the nature of the stimulus by which they are excited,- -the deternination of the Will here replacing, as the exciting cause of its action, the sensory impression which operates as such in the case of an instinctive movement, and which is still requisite for its guidance.

544 . This view of the case derives a remarkable confirmation from the 
analysis of two classes of very familiar phenomena: the first consisting of cases in which movements that are ordinarily Automatic are performed by Voluntary determination, or simply in respondence to an Idea; the second consisting of those in which movements originally Voluntary come by habit to be Automatically performed.-Of the first class, the act of Coughing is a good example. This action, which is ordinarily automatic, may also be excited by a voluntary determination; such a determination, however, is directed to the result, rather than exercised in singling out the different movements and then combining them in the necessary sequence; and the Will thus scems obviously to take the place of the laryngeal or tracheal irritation, as the primum mobile of the series, which, in its actual performance, is as automatic in the latter case as in the former. So, again, we know that many of the automatic movements which have been already referred to as examples of the sensori-motor group ( $\$ 533)$, and which the Will cannot call forth, may be performed in respondence to ideas or conceptions, which are Cerebral states that seem to recall the same condition of the Sensorium ats that which was originally excited by the Sensory impression. Thus it is well known that the act of Vomiting may be induced by the remembrance of some loathsome object or nauscous taste, excited by some act of "suggestion ;" and the Author has known an instance in which a violent. fit of sea-sickness was brought on by the sight of a vessel tossed about at sea, which reealled the former experience of that state. So the Hydrophobic paroxysm may be exeited by the mention of the name of water, which of course calls up the idea; and a tendency to yawn is in like manner frequently induced by looking at a picture of yawners, or by speaking of the act, or by voluntarily commencing the act, which may then be automatically completed. - The automatic performance of actions which were originally voluntary has already been fully liscussed ( $\$ 537$ ); and we have therefore only to remark here, that the filct very strongly supports the view now advanced, as to the singlents's of the mechanism which serves as the instrument of both classes of actions, and the essential uniformity of its operation in the two cases.-It would be difficult to explain either set of phenomena satisfactorily, on the hypothesis that there is a "distinct srstem" of fibres for the volitional and for the automatic movements; since it is not readily to be conceived how a set of movements originally performed by the one can ever be transferred to the other; whilst, on the other hand, it is casy to understand how the same motorial action may be excited in the automatic centres, either by an crternal impression conveyed thither by an afferent nerve from a Sensory surface (as that of the irritation in the airpassages which excites the act of eoughing), or by a stimulus proceeding from the convoluted surface of the Cerehrnm, and conveyed along those connecting fibres which Reil with great sagacity termed the "nerves of the internal senses."

545. To sum up, then, we scem justified in concluding that the CranioSpinal Axis of Man and other Vertebrata,-consisting of the Sensory Ganglia, Medulla Oblongata, and Spinal Cord,-is (like the chain of cephalic and ventral ganglia of Articulata with which it is homolngous) the inmediate instrument of all sensorial and motor changes; that by its sole and independent action are produced all those movements which are ranked as antomatic or iustinctive, these being performed in respondence to external impressions which may or maly not affect the eonsciousness; but that when acting in subordination to the Cerebrum, the Cranio-Spinal Axis transmits upwards to it the influence of Sensorial changes, and receives from it the downward impulses, which it direets antomatically into the appropriate chatnnel for the execution of the movements which the Mind has directed. 
The number of purely antomatic actions diminishes in proportion to the development of the Cerebrum, and to the subjection of the Automatic apparatus to its control; but even in Man, those most closely connected with the maintenance of the organic functions, or most necessary for the conservation of the bochily structure, remain quite independent of any mental agency, and most of them do not require consciousness for their excitation. But if the activity of the Cerebrum be suspended or be otherwise directed, without any affection of the automatic apparatus, movements which have long been liabitually performed in a particular sequence, may be kept up, when the will has once set them in action, through the automatic mechanism alone; the impressional or sensational change produced by each action, supplying the stimulus which calls forth the next.-It may further be concluded that the Sensory Ganglia, which are the instruments whereby we are rendered conscious of external impressions, are also the seat of those simple feelings of pleasure and pain which are immediately linked on to that consciousness: for it can scarcely be doubted that such feelings must be associated with particular sensations, in animals that have no ganglionic centres above these; since we must otherwise regard the whole series of Invertebrated tribes as neither susceptible of enjoyment, nor capable of feeling pain or discomfort. And it likewise seems probable that the Sensory Ganglia are also the seat of those perceptional acts, which bring the consciousness into direct relation with the external object that arouserl the sensation; since the recognition of externality seems evident in the actions of the tribes just referred to.' A few remarks may here perhaps appropriately be introduced, indicating the effects of lesion of the several ganglia at the base of the brain from above downwards. In the event of lesion, as hremorrhage, occurring in front of or above the corpora striata, no paralysis either motor or sensory is observed unless the damage be very great. The intellectual faculties are probably always more or less affected, though it may not be easy to determine in what mode or to what degree. As will subsequently be shown, if the posterior frontal convolutions, especially of the left side, be affected, aphasia is likely to occur. If the hemorrhage occur in the Corpus Striatum, there is motor paralysis of the opposite side only. If in the Thalamus Opticus, there would be motor paralysis of the opposite side, with more or less paralysis of sensation. If in the Crus Cerebri there would be paralysis of the opposite side, which might be either motor or sensory, or both. If the muscles of the eye be paralyzed, it is on the same side, and would chiefly affect those supplied by the third. If in the Pons, there would be paralysis of motion or of sensation, or of both, of the opposite side of the body and the same side of the face,--in those muscles mainly supplied by the 5th and 7th, that is - there would be crossed paralysis. If in the Medulla Oblongata, the great centres of respiration, deglutition, etc., would be affected, and a fatal issue soon occurs.

\section{Of the Cerebellum, and its Functions.}

546. The Cerebellum is an organ which, though confined to the Vertebrated sub-Kingdom, is yet in peculiarly intimate relation with the Automatic apparatus. In that highest state of development which it presents in IIan, we find it to consist of two lateral lobes or hemispheres, composed of nerve-fibres

I It may here be remarked that the torm Sensation is now understood to imply the simple eonsciousness of an impression, whilst Pereeption refers that impression to something out of the ego. For the production of a Sensation a conseious state of the mind is all that is required; but for the exercise of the Perceptive power a certain degree of attention is requisite. 
invested in a very peeuliar manner by vesieular substanee, and of a central lobe, also eontaining a combination of the vesieular and fibrous substances, which is known under the designation of the "vermiform proeess." The hemispheres are eonneeted with each other not only by this eentral lobe, but also by the fibrous eommissure which passes beneath the Medulla Oblongata, and is known as the "Pons Varolii." The commissural fibres form part of

FIG, 241.

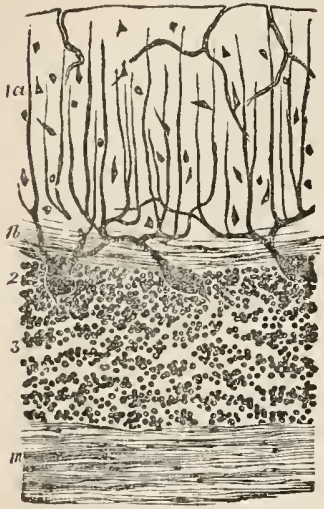

Transparent section from the cortex of the Cerebellum of Man.

1 a. External portion of the pure gray layer.

1 b. Internal portion of the pure gray layer with fusiform cells and fibre areu atie.

2. The layer of Purkinje's cells.

3. The layer of gramules.

$m$. Medullary lamina. the "Crura Cerebelli;" but another portion is formed by the strands which conneet the Cerebellum with the anterior and posterior columns of the Spinal Cord and Medulla Oblongata $(\$ 488)$; and in addition to these, we find a fascieulus of fibres passing between the Cerebellum and the Corpora Quadrigemina, the "iter a eerebello ad testes." The perlunele of its hemispheres on either side contains a mass of gray matter, the "eorpus rhomboideum," or, "dentatum," which seems to be a ganglionie eentre for the fibres that pass upwards to it from the Spinal Cord. There are, then, three masses of gray matter in the eerebellum - that of the eortex, the dentated nuelei, and the roof-nuelei of Stilling, situated in the medulla of the Vermiform proeess. The aeeompanying figure (Fig. 241) exhibits the appearance presented when a scetion of the eortex of the Cerebellum is examined, and it will be seen that it differs considerably from that of the Cerebrum given on $\mathrm{p}$. $690 .^{1}$ The inquiries of Engel ${ }^{2}$ have shown that the development of the Cerebellum is completed in infaney, and remains maltered up to the 50th year, after which the number of the lamellie, especially of the superior vermiform proeess, begin to dinninish.

547. When we examine into the relative development of the Cerehellum in the different classes of Vertebrata, we find that it presents some very remarkable differences. ${ }^{3}$ In its simpler forms, this organ is found to eonsist entirely of the representative of the central lobe of the Human Cercbellum, the hemispheres not making their appearanee until we have aseended to the class of Birds. On ascending the scale of Mammiferous animals, on the other hand, we eannot but be struek with the rapid advanee in the proportional size of the Cerebellum, which we observe as we rise from the lowest (which are surpassed in this respect by many Birds), towards Man, in whom it attains a development which appears enormous, even when contrasted with that of the Quadrumana. In proportion, in faet, as the extremities aequire the power of prehension, and together with this a power of applieation to a

1 For an admirable deseription of the II uman Cerebellum, see Stilling's Esiay on the Structure of the Organ. Cassel, 1867. Also Deiter's Untersuch. üb. Gehirn, v. Rückenmark, 1865; Meynert, in Stricker's IIum. and Comp. Histology, vol. ii, 1872, 1. 512; IIallich, Archivf. Microsenp. Anat., Bd. vi, p. 191.

2 Wien. Medizin. Wochens., 1863, No. 33.

3 See l'rine of Comp. Phys., \& 635. - Fuller information on this point will be found in M. Serres's Anat. Comp. du Cerveau, and M. Leuret's Anat. Comp. du Système Nerveux.-Foraceneral discussion of the evidence aflorded by Comparative Anatomy in regard to the functions of the Cerebellum, see the Brit. and For. II ed. Rev., vol. xxii, pp. 58J-541. 
great variety of purposes,-still more, in proportion as the animal becomes capable of maintaining the erect posturc, in which a constant muscular excltion, consisting of a number of most elaborately combiner actions, is required,-do we find the size of the Cerebellum, and the complexity of its structure, undergoing a rapid increase. Thus, even between the Dog and the Bear there is a marked difference; the latter being capable of remaining for some time in the erect posture, and often spontaneously assuming it; whilst to the former it is anything but natural. In the semi-erect Apes, again, there is a very great advance in the proportional size of the Cerebellum; and those which most approach Man in the tendency to preserve habitually the erect posture also come nearest to him in the dimensions of this organ.-Thus on looking at the size of the Cerebellum, in relation to the general motor activity of the Vertebrated classes respectively, and especially taking into account the variety of their respective movements, and the number of separate muscular actions which are combined in each, we can scarcely help noticing that it is in the tribes which are most distinguished in these resperts, that the largest Cerebellum is usually found. Now it is evident that Man, although far inferior to many of the lower animals in the power of performing various particular kinds of movement, far surpasses them all in the number and variety of the combinations which he is capable of executing, and in the complexity of the combinations themselves. Thus, if we attentively consider the act of walking, we shall find that there is scarcely a muscle of the trunk or extremities which is not actively concerned in it; some being engaged in performing the necessary movements, and others in maintaining the equilibrium of the body which is disturbed by them. On the other hand, in the Horse or Camel, the muscular movements are individually numerous, but they do not require nearly the same perfect co-ordination. And in the Bird, the number of muscles employed in the movements of flight, and in directing the course of these, is really comparatively small; as may at once be perceived, by comparing the rigidity of the skeleton of the trunk of the Bird with that of Man, and by remembering the almost complete inactivity of the lower extremities during the active condition of the upper. In fact, the motions of the wings are so simple and regular, as to suggest the idea, that, as in Insects, thcir character is more reflex than voluntary, - an idea which is supported by the length of time during which they can be kept up without apparent fatigue, and also by the important facts already mentioned ( $\$ 524)$, which experimental research has disclosed.

548. We have next to inquire what evidence can be drawn from Experimental investigations on the same subject; and in reference to this it is desirable to remark, in the first place, that the experimental mode of inquiry is perhaps inore applicable to this organ than to other parts of the Encephalon, inasmuch as it can be altogether removed with little disturbance of the actions immediately essential to life, the animals soon recovering from the shock of the operation, and seeming but little affected except in some easily recognized particulars. The principal experimenters upon this subject have been Rolando, Flourens, Magendie, Hertwig, Longet, Schiff, Brown-Séquard, and Wagner. It is not to be expecter that there should be an exact conformity among the results obtained by all. Every one who has been engaged in physiological experiments is aware of the amount of difference caused by very minute variations in their circumstances; in no department of inquiry is this more the case, than in regard to the Nervous System; and such differences are yet more likely to occur in experiments made upon its ccutres, than in those which concern its trunks.-The investigations of Flourens

1 Recherches Expérim. sur les Propriétés et les Fonctions du Système Nerveux. 
seem the most clear and deeisive in their results; and of these we shall accordingly take a general survey. He found that, when the Cerebellum was mechanically injured, the animals gave no signs of sensibility, nor were they affected with convulsions. When the Cerebellum was being removed by successive slices, the animals became restless, and their movements were irregular; and by the time the last portion of the organ was eut away, the animals had entirely lost the power of springing, flying, walking, standing, and preserving their equilibrium,-in short, of performing any combined muscular movements, which are not of a simply reflex character. When an animal in this state was laid upon the back, it could not recover its former posture; but it fluttered its wings and did not lie in a state of stupor. When placed in the ereet position, it staggered and fell like a drunken man,-not, however, without making efforts to maintain its balauce. When threatened with a blow, it evidently saw it, and endeavored to a void it. It did not seem that the animal had in any degree lost voluntary power over its several muscles; nor did sensation appear to be impaired. The faculty of combining the actions of the muscles in groups, however, was completely destroyed; except so far as those actions (like that of Respiration) were dependent only upon the reflex function of the Spinal Cord. The experiments afforded the same results, when made upon eaeh class of Vertebrated animals; and they have been since repeated, with nearly eorresponding effeets, by Bonillard, Hertwig, and by many other experimenters. ${ }^{1}$ Wagner found that the ehief symptoms produced in Pigeons from which he had removed the whole or the greater part of the Cerebellum were-1. A remarkable tendency on the part of the animal to throw itself on one side, and to keep the legs eompletely extended, with an indisposition to move them, though it was still evidently capable of flexing them by an effort of the will. 2. Torsion of the head on tle neck. 3. Persistent trembling of the muscles of the body generally, resembling paralysis agituns. 4. Vomiting frequently accompanied by liquid alvine evacuations; and 5 . The animals became thinner, the feathers fell off', and the temperature was much depressed. No symptoms were observed having reference to the generative organs. The perception of sensations and the performance of psychical operations appeared to be perfect; and though the voluntary control over the muscles was somewhat impaired, it was manifestly not altogether lost. Hertwig, and especially Dalton, ${ }^{2}$ have moreover shown that in pigeons a very eonsiderable portion (two-thirds) of the Cerebellum may be removed with so little disturbance of the voluntary movements, that after a few days the effects were searcely, if at all perceptible. Lussana observes that the results of irritation of the Cerebellum are usually vomiting, cephalalgia, convulsions, and affections of the pupil, strabismus, amblyopia, etc.; and lie believes that in every case of extensive disease of the Cerebellum there are eoncurrent symptoms of disorder of the muscular novenents, indicative of defect or absence of the "muscular sense."

549. It was further affimed by Magendie, that the removal of the Cerehellum, or the infliction of a deep wound in its substance on both sides, ocersions the animal to move backurds as if by an irresistible injulse; and this lie attributed to the retrogracle power of the Corporat Striata, which now acts without its due balanee. That such a movenent does sometimes present itself after such injuries as have been diescribed, cannot be questioned, the

1 See Wagner, in Brown-Séquard's Journal do la Physiol., 1861, Pp. 225 and 401; Juscana iu idem, 186\%, 1. 418, 1863, p. 170; M M. Leven and Ollivier, Arehiv. Gén. de Med., Nov. and Dec. 18ti2; Dalton, American Journal of Med. Secience, 1861, vol. xli, 1. 89; Brown-Séquard, Central Nervous System, 1800.

2 Amer. Juurn. of Hed. Sciences, 1861, vol. xli, p. 83. 
fact having been confirmed by other experimenters; but it is a phenomenon of such rarity, that it cannot be rightly considered as having any direct dependence upon the injury of the Cerebellum, but must be rather set down to some accidental complication or concurrent disturbance; more especially since, as already pointed out $(\$ 545)$, the function attributed by Magendie to the Corpora Striata has no real existence.-But the results of section of one of the Crura Cerebelli, which were first obtained by Magendie, are much more constant; for the performance of this operation causes the animal to fall over upon one side, and to continue rolling upon its longitudinal aris, even as fast (in some instances) as sixty times in a minute, the movement going on for many days without intermission. There is a remarkable difference in the statements of different experimenters, however, as regairds the direction of this rolling movement; for whilst Magendie and Müller affirm that it takes place towerds the injured side, Longet and Lafargue asiert that it talses place from the injured side towards the opposite side. This discrepancy appears, from the experiments of Schiff," to be due to a difference in the locality of the section; for he states that if the peduncle be divided from behind, the animal turns towards the side on which the section is made; whilst if the section be made in front, the animal turns from that side towards the opposite one. This difference is explained by Longet, by the difference in the course of the anterior and posterior fibres of the peduncles: for according to him, the former communicate with the decussating, and the latter with the non-decussating portion of the motor tract; so that, when the former are injured, the animal loses control over the muscles of the opposite side, and when the latter, over the muscles of the same side. This rolling movement is attributed by some to the continued activity of the muscles on one side, now unbalancerl by that of the muscles on the other; but if such were the case, as Longet justly remarks, it ought to occur more frequently than it does in cases of ordinary hemiplegia; and, according to that experimenter, observation shows that it rather depends on a twisting movement of the spinal colnmn, especially affecting its anterior portion, and dragging the posterior (as it were) after it. ${ }^{2}$ Thus MI. Brown-Séquard, ${ }^{3}$ who has shown that similar rolling movements may be produced by lesions of other parts of the uervous centres, as the Spinal Cord, Medulla Oblongata, and Pons, observes that the movements do not resemble those effected by voluntary muscles; but that, in consequence of the tonic contraction into which some muscles are thrown, the trunk and neck of the animal are twisted as far as the bones will permit, into the form of a corkscrew. He attributes the phenomena in question, which the animal evidently endeavors to check, to the irritation of a peculiar set of nerve-fibres not usually employed by the will, the division of which does not cause paralysis, though they may serve as the conductors of powerful motor impulses to special groups of muscles. IIM. Leven and Ollivier, operating on guinea-pigs, found that pricking the Cerebellum produced well-marked movements of rotation, usually proceeding from the side injured towards the opposite side. They did not observe any disorders of the alimentary canal similar to those noticed by Wagner and others, after ablation of portions of the Cerebellum. Hitzig ${ }^{+}$found that by electrical stimulation of the lobes of the vermiform process, he was able to cause the eyes to turn to the right or left, or one upwards and the other downwards.

550. The information supplied by Pathological phenomena, when inter-

1 De vi motoriâ haseos encephali inquisitiones experimentales, Bockenhemii, 1845.

2 See his Traité de Physiologie, tom. ii, p. 408, 1860.

3 Central Nervous Srstem, 1860, p. 193.

4 Untersuchungen über das Gehirn., 1874. 
preted with the cautions formerly referred to, is found on the whole to coincide with that obtained from experiment. In the first place, it fully supports the conclusion, that the Cerebellum is not in any way the instrument of psychical operations. Inflammation of the membranes covering it, if confined to that part, does not produce delirium; and its almost complete destruction by gradual softening does not appear necessarily to involve loss of intellectual power. "But," remarks Andral, "whilst the changes of intelligence wcre variable, inconstant, and of little importance, the lesions of motion, on the contrary, were obscrved in all the cases [of softening] except one; and in this it is not quite certain that motion was not interfered with." Yet the result of Andral's analysis of as many as ninety-three cases of disease of the Cerebellum, ${ }^{1}$ is not favorable to the doctrine to which the results of experiments seem to point: but, as it has been justly remarked by Longet, the effects of the disease are only partly comparable to those of experiment; since in a large proportion of chronic disorders, the changes consist in the formation of a new product, such as a tubcrcular or cancerous deposit, or a cyst of some kind, the gradual development of which is quite consistent with the continucd functional activity of the organ, as we sce by parallel phenomena elsewhere; whilst in those instances in which hemorrhage occurs, this usually occasions either complete apoplexy or local paralysis, by its effects upon other organs. Still, screral cases of chronic disease of the Cerebellum have been observerl, in which unsteadiness of gait, withont paralysis, or only giving place to paralysis at last on the occurrence of hamorrhage, was a very marked syinptom; $;^{2}$ and these afford a strong confirmation of the doctrine bascd on the experimental researches already referred to. In a few cases in which both lobes of the Ccrebellum have been seriously affected, the tendency to retrograde movement has been observed; and instances are also on record, of the occurrence of rotatory movement, which has been found to be connected with lesion of the Crus Cerebelli on the same side. ${ }^{3}$ So far as they can be relied on, therefore, the results of the three methods of investigation bear a very close correspondence; and it can scarcely be doubted that they afford us a near approximation to truth.

5.51. It must not be allowed to pass unnoticed, that some Physiologists (as Foville, Pincl-Grandchamp, and Dugès) have regarded the Cerebellum as the centre of common Sensation; chiefly on the ground of its connection with the posterior columns of the Spinal Cord and of the manifestations of pain which are called forth by touching the restiform columns. Although these facts may lead ns to admit that the Cerebcllum is connected with the sensorial centres, and event that it is itsclf $a$ seat of sensibility, yet it is impossible to regard it as the exclusive seat of sensibility, consistently with the finets with which experiment and pathological observation supply us; since neither the removal of the entire organ by operation, nor its complete destruction by disease, ${ }^{4}$ has been found to involve any loss of the ordinary sen-

1 Sre his Clinique Médicule, 2ème élit., tom. v, p. 735.

2 Two such cases are recorded by Mr. Dumn in the Med.-Chir. Trans, vol, xxxii, and another by Dr. Cowan in the Prov. Med. and Surg. Journ., April 16th, 1845; and the Author has been made acquainted with several others, by gentlemen under whose cornizance they have fallen. See also various papers by II ughlings Jackison in Mr. 'I'ines and Guzette.

${ }^{3} \Lambda$ enllection of stleh cases has been made by Dr. Paget, in his paper on Morbid lihythmical Hovements, in the Edinb. II ad and Surg. Journal, 1847, vol. Ixvii.A case once fell within the Author's knowledge, in which a state of this kind, that lastrel for some hours, appeared to depend upon an attack of Indigestion; the srmptoms being completely relieved by vomiting, and no further indication of Encephalic disorder manifesting itself.

- See the well-known case recorded by Combetti, in the Revue Médicale, t. ii, p. 57. 
sorial powers.-There would seem much more probability in the idea, that it is the special seat of the "muscular sense," which has so important a share in the guidance of the co-ordinated movements $(\$ 536)$; and this notion derives confirmation from the marked structural connection which exists between the Cerebellum and the Optic Ganglia (corpora quadrigemina), the purpose of which nay be not unfairly surmised to be, to communicate the guirlance of the visual sense to the organ by which the co-ordination of notions is effected, in the same manner as the impressions appertaining to the "muscular" sense" are transmitted upwards by the Restiform columns." The chief objection to such a view, would seem to lie in the strong similarity between the "muscular" sense and "common" or "tactile" sensation, which makes it difficult to conceive that they should have different seats in the Sensorium commume. But this difficulty is diminished if not removed by the reflection, that the Restiform columns appear to have the same endownents as the renainder of the Sensory tract derived from the posterior columns of the Spinal Cord; and that no explanation can be given of their extreme sensitiveness to impressions (as shown by experiment), unless it be admitted that the organ in which they terminate is itself a centre of a form of sensation elosely allied to that of the common or tactile kind. Possibly, however, the true termination of these fibres is in the "corpus dentatum" of the Crura Cerebelli; and the Cerebellum may react upon impressions thence transmitted to it, without being itself the instrument of communicating such impressions to the consciousness. ${ }^{2}$ Dr. Laycock ${ }^{3}$ states that the considera-

1 This view, sugrested many years since by the Author, has been recently supported in the able papers by if. Ph. Lussana in the Journal de la Physiolocrie, tom. v, 1862, p. 48t, and tom. vi, p. 169 ; and also by Mr. Robert Dunn, in his Essay on Physiological P-yehology (London, 18.58), who also places the centre of the muscular sense in the corpus rhomboidale of the Cerebellum.

2 M. Frown-Séquard (Juurn. de la Physiol., vol, i, 1858, p. 535) and Wagner (Op. cit.) have arrived at almost purely negative results in regard to the function of the Cerebellum. The former experimenter holds that this orisan is not a nervous centre for sensitive impressions nor for conseiousness, nor is it even a part through which the conductors of motion or of sensation pass; for he believes that no idca, emotion, or voluntary act is suppressed as a con-equence of lesion of its structure. Hence he maintain-, that it is not a centre for the faculty of balaneing or en-ordination of the symmetrical movements of the body, and that when paralysis is oberved after lesion of its strueture, it is occasioned (when the paralysis is on the opposite side of the body) by concurrent lesions of other parts, as the Pons Varolii, the Iedulla Oblongata, or the Cerebral peduncles; whilst, when the parilysis is on the same side, it is usually duc to irritation of certain parts of the Cercbellum reacting on other parts of the Encephalon, though even from this caute the paralysis may sometimes occur on the opposite side. Though he does not admit it to be a centre for auditory or visual impressions, he acknowledges that it has a s, ceial influence on vision, having collected 60 cases of anaurosis aceompanying disca-e of its structure. (See also on this point the work of Lusana, Luys, and Renzi.) He las, in a more recent paper (Journ. de la Phys., 1862. tom. v, l. 486), attributed the various effects of Curebellar lesion, as amaurosis, vomiting, cephalalgria, dilatution of the pupil, general or local convulsive movements, epileps, hemiplegia, general debility and disordered movements, contraction of particular muscles, strabismus, hyperæesthesia, noises in the cars, and exaggeration of the sexual desire, to irritation of the Cerebellum, and not to loss of function. He compares these effects with those produced by worms in the intestines. Wagner believes that this organ may become the puint de départ of a direct (not reflex) irritation for certain organic muscles, as for those of the abdominal viscera, generative organs, and also, probably, for the heart. Schiff, at the conclusion of his section on the Cerebellum, states simply that "the functions of this organ are still unknown;" whilst Lussana, in the essay already quoted, finishes by observing that the musculur. sense and the erotic sense are the two essential functions of the Cerebellum. Prideaux, Med. Times and Gaz., 1864, ii, p. 340 , adduces evidence to show that the lateral lobes are the centres of cutaneous sensibility, whilst the central lobe is the centre of nuscular sensibility.

${ }^{3}$ Ned. Times and Gaz, July 12th, 1873. 
tion of a large and varied series of faets have led him to the conelusion that the Cerebellum with its conneetion downwards along the medulla oblongata and spinal cord, and upwards into the hemispheres, is the great trophic centre. This eentre may be excited to funetional aetivity, not only by afferent impressions from the borly, whether eonscionsness be coincident or not, but also by afferent impressions from the vast periphery of the cerebral hemispheres, and in this case also whether consciousness be eoincident or not; in short, that the eerebral hemispheres are not functionally restricted to intellectual processes, as is generally held, nor the eerebellum to musetilar co-ordination, but that both conjointly influence the whole of the organic processes.

55.2. We have now to examine, however, another doetrine regarding the functions of the Cerebellum, which was first propounded by Gall, and whieh is supported by the Phrenologieal sehool of physiologists. This doctrine, that the Cerebellum is the organ of the sexual instinet, is not incompatible with the other; and by some it las been held in combination with it. The greater number of Phrenologists, howerer, regard this instinet as the exclusive function of the Cerebellum; and assert that they can judge of its intensity by the degree of development of the organ. We shall now examine the evidence in support of this position, afforded by the three methods of inquiry which have been already indieated.-In the first place it may be remarked, that the sexual propensity is very closely eonnected with various Emotional states of mind, to whieh "organs" are assigned by Phrenologists, and of which the Cerebellum is universally admitted to be the seat; sueh for instance as "love of offspring," "adhesiveness," and (in the lower animals more particularly) "embativeness;" whilst in Man it has a continual operation upon the reasoning faculties and the Will. Tet the anatomieal counections of the Cerebellum are peculiarly unfavorable to any sueh influence; these being, as we have seen, rather with the lower than with the higher portion of the Ccrebro-spinal axis.-Again, the results of fair observation as to the comparative size of the Cerebellum in different animals, can searcely bc regarded as otherwise than very mifivorable to the doctrine in question. ${ }^{1}-$ It is asserted, however, that the results of observation in Man lead to a positive conelusion, that the size of the Cerebelhnm is 'a measure of the intensity of the sexual instinet in the individual. This assertion has been met by the counter-statement of others, that no sueh relation exists. It is unfortunate that here, as in many other instances, eaeh party has registered the observations favorable to its own views, rather than those of an opposite character; so that until some additional evidence of a less partial nature shall have been collected, we must eonsider the question as sub judice. It may be safely affirmed, however, that no evidenee upon the aftirnative side of this proposition has yet been addueed, which can be in the least degree satisfactory to the nind of any Anatomist who is eompetent to judge of its value. For nearly all the observations which have been paraded by Phrenologists in support of Gall's doctrine, have been based, not upon the actulal determination of the size or weight of the Cerebellum in different intividuals, but upon an estimute of its proportional development from the external conformation of the skull. Now any one who has even cursorily exannined those principal types of cranial conformation which are characteristic of some of the chicf subdivisions of the Human speeies, must perceive that there is a no less chatracteristic difference between these difierent types in the occipital, than there is in the frontal region. For whilst the occipital projection is much greater in the "prognathous" skull than it in the "ellipti-

1 See Brit. and For. Medical Review, vol. xxii, pp. 535-541. 
cal," it is as much less in the "pyramidal;" and thus while the first would be considered, according to phrenological rules, to hold a much larger Cercbcllum, this organ in the latter would be regarded as necessarily very small. Now there is not only as much evidence of a strong development of the sexual propensity, in the characters and habits of the pyramidal-sliulled Asiatics, as there is in regard to the elliptical-skulled Europeans, or the prognathous Negroes; but there is also anatomical evidence to show that the size of the Cerebellum in the different races bears no relation whatever to the degree of projection of the occiput; for the plane of this organ being somewhat oblique in the elliptical skull, is horizontal in the prognathous, and nearly vertical in the pyramidal, while the size and anatomical relations of the organ are not in the least degree affected by this difference in its position. - - Hence it may be safely affirmed, that no evidence with regard to the relation asserted to exist between the size of the Cerebellum and the intensity of the sexual propensity, has any value, save that which is drawn from the positive determination of the former by measure or weight.

553. Among the arguments adduced by Gall and his followers in proof of the connection between the Cerebcllum and the sexual instinct, is one which would deserve great attention, if the filcts stater could be relied on. It has been asserted, over and over again, that the Cerebellum, in animals which have been castrated when young, is much smaller than in those which have retained their virility,-being, in fact, atrophied from want of power to act. Now it is unfortunate that vague assertion, founded on estimates formed by the eye from the cranium alone, is all on which this position rests; and it will be presently shown how very liable to error such an estimate must be. The following is a result of a series of observations on this subject, suggested by M. Leuret, ${ }^{2}$ and carried into effect by M. Lassaigne: The weight of the Cerebellum, both absolutely and as compared with that of the Cerebrun, was adopted as the standard of comparison. This was ascertained in ten Siallions, of the ages of from nine to seventeen years; in twelve Mares, aged from seven to sixteen years; and in twenty-one Geldings, aged from seven to seventeen years. The average weight of the Cerebrum in the Stullions was 433 grammes; the greatest being $485 \mathrm{gr}$, and the least (which was in a horse ten ycars old) being $3.50 \mathrm{gr}$. The average weight of the Cerebellum was $61 \mathrm{gr}$. ; the greatest being $6.5 \mathrm{gr}$., and the least $56 \mathrm{gr}$. The average proportion borne by the weight of the Cerebellum to that of the Cerebrum, was, therefore, 1 to 7.07 ; the highest (resulting from the very small Cerebrum) being 1 to 6.25 ; and the lowest (resulting from an unusually large Cerebrum) being 1 to 7.46 . Throughout it might be observed, that the variation in the size of the Cerebellum was much less than in that of the Cerebrum.- In the twelve Mares, the average weight of the Cerebrum was $402 \mathrm{gr}$; the highest being $432 \mathrm{gr}$., and the lowest $363 \mathrm{gr}$. That of the Cerebellum was $61 \mathrm{gr}$.; the highest being $66 \mathrm{gr}$. (which was in the individual with the smallest Cerebrum), and the lowest $58 \mathrm{gr}$. The average proportion of the weight of the Cerebellum to that of the Cerebrnm was 1 to 6.59 ; the highest being 1 to 5.09 , and the lowest 1 to 7 . The proportion was, therefore, considerably higher in the perfect female than in the perfect male.In the twenty-one Geldings the average weight of the Cerebrum was $419 \mathrm{gr}$.; the highest being $566 \mathrm{gr}$., and the lowest $346 \mathrm{gr}$. The average of the Cerebellum was $70 \mathrm{gr}$; the highest being $76 \mathrm{gr}$., and the lowest $64 \mathrm{gr}$. The

1 The Author's statements on this point are based on the very decided assertions of his late friend, Prof. Retzius, of Stoekbolm, who paid speeial attention to this inquiry.

2 A nat. Comp. du Système Nerveux, ton. i, p. 427. 
average proportion was, therefore, 1 to 5.97 ; the highest being 1 to 5.16 , and the lowest 1 to 7.44 . It is curious that this last was in the individual which had the largest Cerebellum of the whole; but the proportional weight of the Cerebrum was still greater-Bringing together the results of these observations, they are found to be quite opposed to the statement of Gall. The weight of the Cerebrum, reckoning the Cerebellum as one, is thus expressed in eaeh of the foreguing descriptions of animals :

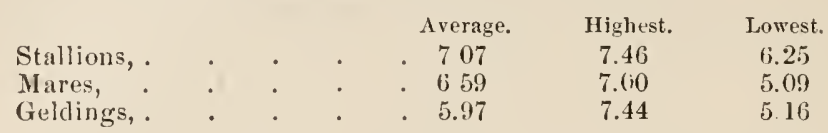

The average proportional size of the Cerebellum in Geldings, therefore, is so far from being less than that which it bears in entire Horses and Mares, that it is positively greater; and this depends not only on diminution in the relative size of the Cerebrum, but ou its own larger dimensions, as the following eomparison of absolute weights will show :

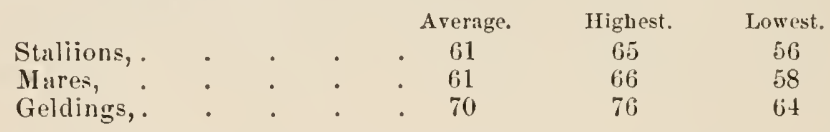

The difference is so remarkable, and appears, from examination of the individual results, to be so constant, that it cannot be attributed to any accidental eireumstance arising out of the small number of animals thus examined. The average weight of the Cerebellum in the ten Stallions and twelve Mares is seen to be the same, and the extremes differ but little in the two; whilst the average in the Geldings is more than one-seventh higher, and the lowest is considerably above the average of the preeeding, while the highest far exeeeds the highest among the entire Horses. It is curious that Gall would have been much nearer the truth, if he had said that the dimensions of the Cerebrum are usually reduced by castration ; for it appears from the following table that such is really the ease:

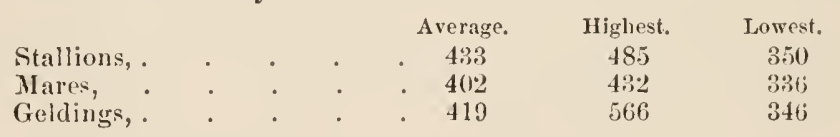

The weight of the largest Cerebrum of the Gelding is far above the highest of the Stallions; but it seems to have been an extraordinary ease, as in no other was the weight above $490 \mathrm{gr}$. If this one be exeluded, the average will be reducerl still further, being then about 412 ; this may be seen, by looking over the whole table, to give a very fair irlea of the usual weight in these animals, which is therefore less, by abont one-t wentieth, than the average in the Stallion.- The increased size of the Cerebellum in Geldings may perhaps be accounted for, by remembering that this class of horses is solely employed for its muscular power, and that the comstant exercise of the organ is not unlikely to develop its size; whilst Stallions, being kept especially for the purpose of propagation, are much less applied to occupations which call forth their motor activity.

554. It is asserted, however, by the followers of Call, that very strong evidence of the truth of this doetrine is afforded by Pathologieal phenomena: exeitement of the genital organs, manifesting itself in priapism, turgescenee of the testes, and seminal emissions, being an ordinary concomitant of some forms of apoplexy in whieh the Cerebelhum is affeeted; whilst in 
other cases of disease or injury involving extensive destruction of the substance of the organ, there has been a complete abatement of sexual desire. The proportion of recorderl cases of disease of the Cerebellum, however, in which any affection of the genital organs has been noticed, is extremely small; for out of 178 cases which have been collected by Burdach, ${ }^{1}$ only 10 , or searcely more than 1 in 18 , presented any symptoms that tended to indicate a functional relation between the Cerebellum and the Genital organs. The same physiologist affirms that similar affections present themselves when the Cerebrum is the seat of the lesion; and there seems a strong probability that it is solely to the conncetion of these organs with the Spinal Cord, that such affections of the genital apparatus are due. Fur erection of the penis has been noticed in a far larger proportion of cases in which the Spinal Cord itself has been the seat of the lesion; thus in 15 cases in which the cervical portion of the Cord was affected, erection of the pen is was observed in 8 ; and in 13 cases of lesion of the dorso-lumbar portion of the Cord erection of the penis took place in $3 .^{2}$ It is well known that erection of the penis and emissio seminis are not infrequent phenomena of death by hanging; and this fact accords fully as well with the idea that the affection of the sexual organs is consequent upon lesion of the Cranio-Spinal axis, as with the doctrine that it is due to disordered functions of the Cerebellum.It has been suggesterl by Serres, ${ }^{3}$ who collecter seven cases in which excitement of the genital organs was coincident with apoplexy of the merlian lobe of the Cerebellum, that while the lateral lobes or hemispheres may be connected with the loconotive function, the median lobe may be the organ of the sexual instinct. Several cases have been recorded, in which some such relation appeared to be indieaterl; and the Author has been made acquainted with at least $\operatorname{six}^{4}$ in which an extraordinary salaeity developed itself at an advaneed period of life, whilst, concurrently with this, or following upon it, there was that kind of unsteadiness of gait which may be held to indicate chronic disease of the Cerebellum. In one of these cases of which the history aurl post-mortem appearances have been carefully recorded by Mr. Dunn, ${ }^{5}$ there was strong evidence that the excitement of the sexual propensity was eoineiclent with the irritative stage of incipient disease in the central lobe of the Cerebellum, and that the abatement of the propensity was in like manner coincident with the subsequent destruction of its substance; whilst the advance of the disease into the lateral lobes was marked by impairment of the power of eo-ordination of movement. But with regard to all such cases, and others that may be ranked in the same category, ${ }^{6}$ the objection of Pétrequin ${ }^{7}$ holds good, that when disease or injury affects the median lobe

1 Vun Baue und Leben des Gehirns (Lripzig, 1819-26), Bd iii

2 See the Traité des Maladies de la Mü̈lle Epinière of M. Ollivier (d'Angers), 3ènc édit., tom. jii, 316.

3 Anatomie Comparée du Cerveau, tom. ii, pp. 601, 717.

4 Four such cases eame under the notice of his firiend, the late Dr. Simpson of Torli.

5 Medico-Chirurgieal Transactions, vol. xxxii.

6 Thus a case has been communicated to the Author by Mr. Turley, of Woreester, in which the sexual desire, which had been always strong through life, but which had been eontrolled within the limits of deceney, manifested itself, during a period of some months preceding death, in a most extraordinary degree; on post-mortem examination, a tumor was found on the Pons Varolii.-And he las been informed of anothar case by Dr. Evanson (formerly of Dublin), in which a young officer, on the eve of narriage, having received a blow on the occiput by a fall from his horie, became impotent, without "ny other disorder of his bodily or mental powers; and in the distress consequent upon this discovery, eommitted suicide on the morning fixed for lis wedding.

7 Sur quelques points de la Physiologie du Cervelet et de la Moëlle Epinière, in Gaz. Médieale, 1836, tom. iv, p. 546. 
of the Cerebellum, the Medulla Oblongata is almost certain to be implicated in it ; so that, as the evidence already referred to clearly indieates the existence of a special relation between the genital organs and the upper part of the Spinal Axis, no positive proof is afforded by them that any portion of the Cerebellum has any special eonnection with the generative function.

555. The Author is fir from denying in toto, that any peculiar comnection exists between the Cerebellum and the Genital system; bnt if the evidenee at present alduced in support of the Phrenologieal position be held sufficient to establish it, in defianee of so many opposing eonsiderations, we nust bid adien to all safe reasoning in Physiology. The weight of testimony appears to him to be quite decided, in regard to the conncetion of the Ccrebellum with the regulation of the motor function; and as an additional argument in favor of this view, it may be stated, that the lobes of the Human Cerebellum undergo their most rapid development during the first few years of life, when a large number of complex voluntary movements are being learned by experience, and are being assoriated by means of the muscular sensations accompanying them; whilst in those animals whieh have, inmediately after birth, the power of regulating their voluntary movements for definite objects, with the greatest precision, the Cerebellum is more fully developed at the time of birth. In both instances it is well formed and in active operation (so far as ean be judged of by the anount of eireulation throngh it), long before the sexual instinct manifests itself in any perceptiblc degree.But neither doetrine need be maintained altogether to the exclusion of the other; and there are many among the Phrenologists of the present day, who hold, with Serres, that whilst the hemispheres of the Cerebellum possess the endownents now generally assigned to them by Physiologists, the central lobe is conneeted with the Genital function. It has been shown by Dr. N. S. Davis, ${ }^{1}$ however, that there is no perceptible difference in the dimensions of this central lobe, any more than in those of the hemisphcres, between Bulls and Oxen; and no proof has yet been offered, save that afforded by the pathological evidenee just referred to, that any such endowment is possessed by it. That in some way or other, however, either the central portion of the Cerebellum, or some part of the Medulla Oblongata, has a special conneetion with the Generative funetion, appears to the Author to be indicated with tolerable elearness by several of the Pathological phenomena already eited. The circumstance, too, of which he has frequently been isssured, that great application to gymmatie excreises diminishes for a time the sexual vigor, and even totally suspends desire, seems worthy of consileration in reference to such a view; for if the C'erebellum be really connceter with both kinds of function, it does not seem nnreasonable that the excessive employment of it upon one should diminish its energy in regard to the other.-An analysis of the nature of the Sexual propensity, however, suggests the conclusion that we are not to look in this part of the Encephalon for anything else than a seat of the scxual sensation; the character of which seems to be sufficiently different from that of mere tactile sensation, to require a distinct ganghionic centre. Such a rentre would be likely to be placed in the line of the other sensory ganglia, and in close connection with them.

5.56. As in the ease of other sensations, the Sexnal, when morlerately exeited, may give rise to ideas, emotions, and desires, of which the Cerebrum is the seat; and these may react on the muscular system through the Intelligence and Will. But when inordinately excited, or when not kept in restraint by the Will, the sexual sensations will at once call into play respondent movements which are then to be regarded as purely automatic; this is 
the case in Nymphomania and Satyriasis in the Human subject; and it is probably also the ordinary mode of operation of this sense, in such of the lower aninals as have not psychical power enough to form a conception of an absent object of gratification, and cannot, therefore, be said to have sexual dexires. Thus, like other sensations, it may act either intelligentially or automatically; giving rise to ideus, by transmission to the Cerebrum, which icleas, associated with pleasurable fechings, originate desires that stimulate the Reasoning powers to devise means for their gratification, and excite the Will to the necessary actions; or, by its immediate action upon the motor apparatus, producing respondent movements.-Of this double modus operundi we seem to have sufficient evidence. For among many of the lower tribes of animals, at the time when the gencrative organs are in a state of functional activity, the presence of an individual of the opposite sex indicated by the sight, smell, hearing, or tonch, immediately excites the whole train of instinctive actions concerned in the reproductive operation; whilst we have no cvidence in them of any voluntary exertion, resulting from the existence of a dcsire entertained in the absence of the object, and intended for the gratification of that desire. In Man, on the other hand, the principal operation of the sexual sensations is in awakening desires and affections, which serve as excitements to the intelligence and as motives to the $\mathrm{W}$ ill; and it is only, under ordinary circumstances, when the two sexes have been thus brought into close relation, that the direct reaction of the scxual sensation manifests itself in automatic movements. In cases, however, in which this sensation is excited in unusual strength, it may completely overmaster all motives to the repression of the propensity, and may even cntirely remove the actions from volitional control; and a state of a very similar kind exists in many Idiots, in whom the sexual propensity exerts a chominant power, not because it is in itself peculiarly strong, but because the intelligence being undeveloped, it acts without restraint or direction from the Will.

\section{The Cerebrum, and its Functions.}

557. We come, in the last place, to consider the functions of that portion of the Nervous Centres, which is evidently, in Man, the predominant organ of his whole system; being not merely the instrument of his Reasoning faculties, but also possessing a direct or indirect control over nearly all the actions of his corporeal frame, save those purely vegetative processes which are most completely isolated from his animal powers. WVe should be in great danger, however, of coming to an erroneous conclusion as to the real character of the Cerebrum and of its operations, if we confined uurselves to the study of the Human organism; and the history of Physiological science shows that every advance of knowledge respecting its functions has tended to limit them, whilst at the same time rendering them more precise. Thus the Brain (this term, in the old Anatomy, being chiefly appropriated to the Cerebrum) was once accounted not merely the centre of all motion and sensation, but also the source of all vitality ; the different processes of nutrition, secretion, etc., being maintained, it was supposed, by a constant supply of " animal spirits," propagated from the brain, along the nerves, to each individual part. The more modern doctrine, that the Sympathetic System has for its special function to supply the nervous influence requisite for the maintenance of the functions of Organic life, was the first step in the process of limitation; still the Brain was regarded as the centre of all the Animal functions; and no other part was adnitted to possess any power independently of it. $13 y$ experiments and pathological observations, the porvers of the Spinal Cord as an independent centre of action were next established; and it was thus shown 
that there is a large class of motions in which the Brain has no concern, and that the removal of the Cerebral hemispheres is not incompatible (even among the higher Vertebrata) with the prolonged maintenance of a sort of inert and scarcely conscious life. Still, it has been usually maintained, and with great show of reason, that the Cerebrum is the instrument of all psychical operations, and the originator of all the movenents which could not be assigned to the reflex action of the Spinal Cord. An attempt has been made, however, in the preceding pages, to show that this view is not correct; and that there is a class of actions, neither excito-motor nor voluntary, hut directly consequent upon Sensations, and constituting (with the excito-motor) the truly instinctive actions, which may be justly assigned to certain ganglionic centres not less independent of the Cerebruni than is the Spinal Cord itself. It has been further pointed out that the Cerebrum must be considered in the light of an nrgan superadded for a particular purpose or set of purposes, and not as one which is essential to life; that it has no representative among the Invertebrata (except in a few of the highest forms, which evidently present a transition towards the Vertebrated series); and that, at its first introduction in the class of Fishes, it evidently performs a subordinate part in the general actions of the Nervons System. Hence, whatever be the function, or set of functions, we assign to the Cerebrum, we must keep in view the special character of the organ ; and we must never lose sight of the fact, that its predominance in Man does not deprive other parts of their independent powers, although it may keep the exercise of those powers in check, and may considerably modify their manifestations.

558. Before proceeding to inquire into the Physiology of the Cerebrum, we may advantageously take notice of some of the leading features of its structure. ${ }^{1}$

In the first place, it forms an exception to the general plan on whieh the elements of ganglionic centres are arranered; in having its vesicular substance on the exterior, instead of in the central part of the mass. The purpose of this is probably to allow the vesicular matter to be disposed in such a manner as to present a very large surface, instead of being aggregated together in a more enmpart mass; and by this means to admit, on the one side, a more ready aceess of the blond vessels which are so essentia! to the functional operations of this tissue, as well ats a more realy eommunieation, on the other, with the vast number of fihres by which its influence is to be proparated. There is no reason whatever to believe, that the relative functions of threvescular and fibrous substances are in the least altered by this change in their rebative position; indeed, the results of observation upon the phenomena of disordered Cerebral action are sueh as to afford deeided confirmation to the duetrine now generally aecepted, that the action of the Vesicular matter constitutes the somrce of nervous power, whilst the Fibrous structure bas for its office to conduct the influenee thus generated to the points at which it is to operate. The purpose of this arrangement is further evideneed by the fact, that, in all the higher forms of Cerebral structure, we find a provi-ion for a still greater extemsion of the surface at which the vesicular matter and the bloodvessels may come into relation; this being "ffected by the plication of the layer of vesicular inatter into "convolutions," into the sulei between which the highly vascular nembrane known as the "pia matep" dips down, sending multitudes of small vessels from its immer surface into the eortical substance. The eonvolutions of the Brain ${ }^{2}$ are extrenely complieated in their arrangement, but they ean be divided into groups by certain easily reognized fissures, and are individually identified and named. The more important of them only need be deseribed here. The outer and under surfuce of each hemisphere is divided into five lobes as follows. Traeing the deep

1 For further details of the minute anatomy of the Cerebral substance, see Loekhart Clarke in the Proceedings of the Royal Society, vo?. xii, No. 57.

${ }^{2}$ For neeurate description of whieh see Prof. Turner's P'amphlet, 1866; Gratiolet, Sur les Plis Cérébraux de l'Homme, ete., 1854; L. Marsluall on the Brain of a Bushwoman, ete., Proe. Roy. Soe, 1863, Quuin and Slatpey's Anatomy, vol. ii, p. 531, and Eeker's pamplilet on the Convolutions of the Brain. 
Srlvian Fissure outwards upon the external aspeet of the hemisphere it is seen to bifurate, one braneh running upwards, the other almost horizuntally backwards. Anterior to the Sylvian Fissure we have the frontal labe, between its two branehes the parietal lobe, below the posterior braneh the temporo-sphenoidal lobe, and forming the pusterior extremity of the hemisphere the occipital lobe, while eoncealed within the Fissure of Sylvius is the central labe, more commonly known as the Island

FIG. 242,

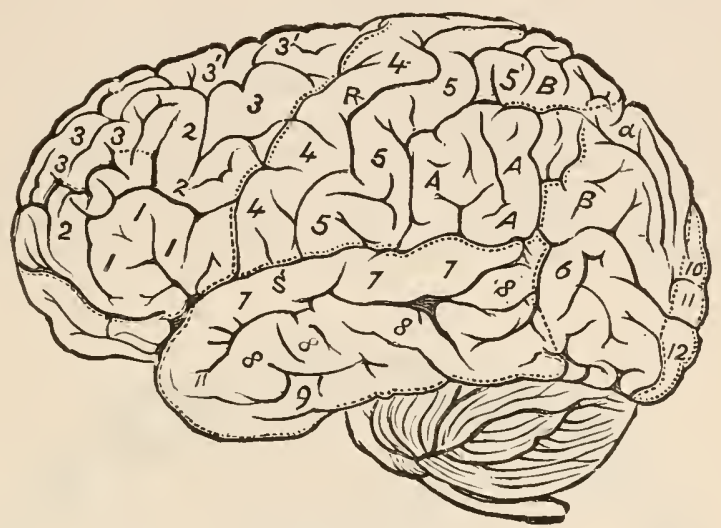

Brain of Man.

1, 2, 3, Frontal convolutions.

7, 8, 9, Temporo-sphenoidal convolutions.

$A$ is the supramarginal lobulc; $\mathrm{B}$ is the postero-parietal lobule; and $B$ is on the bridging or anpectent convolutions; R, Fissure of Rolando; E, parieto-occipital fissure.
$4,5,6$, A \& B, Parietal convolutions. $10,11,12$, Occipital convolutions.

of Reil. This last presents a few short and almost straight $₫ y$ ri radiating from the inner end of the tissue ealled the Gyri operti. The four other lobes are ach made up of three more or less tortuous grri. The frontal eonvolutions have a horizontal direetion, and form three tiers, named respeetively the superior, middle, and inferior frontal convolutions, the superior close to and parallel with the great longitudinal fissure, the inferior resting upon the orbital plate of the frontal bone. It is the posterior part of this inferior frontal eonvolution which has been said to be the seat of the faeulty of language, and disease here to be one of the eauses of aphasia. The convolutions of the parietal lobe are nearly vertieal, and run up to the margin of the longitudinal fissure; between the first or anterior and the seeond is a well-marked sulcus, which appears early in the development of the brain, and is eal'ed the Fissure of Rolando. The temporo-sphenoidal grri are again almost horizontal, lying parallel to the horizontal braneh of the Sylvian Fissure. The oceipital lobe is small and not well defined, a series of short irregular eonvolutions ennneeting it with the parietal lobe. These have reeeived the name of annectent or brideing gyri; the eonvolutions of the oeeipital lobe it-elf are irregularly lorizontal, and its anterior limit is a sulcus whieh issues from the longitudinal fissure, and is ealled the parieto-neeipital fissure. On the opposed flat surfiees of the hemispheres the prineipal eonvolutions seen are the marginal convolutions, whieh form the margin of the great longritudinal fissure and the gyms fornicatus, which eneireles the corpus callosum, eounmoncing anteriorly near the anterior perforated space, and terminating at the point of the temporosphenoidal lobe. By some anatomists these two great convolutions lave been subdivided.

559. The Cortical substance or "gray matter" of the Hemispheres essentially consists of that vesicular nerve-substance, which, in the Spinal Cord, as in ganglionic masses generally, is found to occupy the interior. Its usual thickness is about one-fifth of an inch; but considerable variations present themselves in this respect, as also in the depth of the convolutions. Thus the plications are deepest, and the layer of "gray matter" the thickest, during the period of greatest nervous energy, that is, in middle life ; in infancy and 
in old age, the ennvolutions are simpler and have fewer undulations, and the thickness of their cortical substance is much inferior; and the same is true of the adult brain of some of the least eultivated races of mankind. The structure of the cortical substanee has been most carefully inve-tigated by Mrr. Lockhart Clarke. ${ }^{1}$ The convolutions present on section at least seven layers of nervous substance, the enncentric arrangement of which is most conspicuous at the extremity of the posterior lobe, and is rendered apparent by a slight difference in hue. In this situation all the nerve-cells are small, but differ eonsiderably in shape, and are much more abundant in some layer's than in others. In the superficial Jayer, which is pale, they are round, oval, fusiform, or angular, but are not numerous. The second layer is darker, and is densely crowded with eells of similar form and size, mingled with others that are pyriform and lie with their tapering ends either towards the surface or parallel with it, in ennneetion with fibres which run in eorresponding direetions. The broader ends of the pyramidal cells give off two or more pro-

FIG. 24:3.

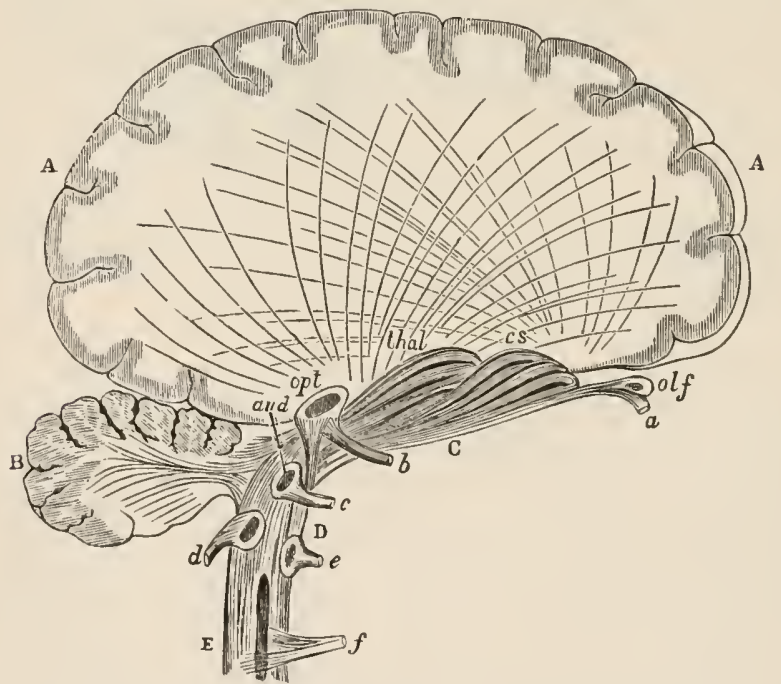

Diagram of the mutual relations of the principal Encenhalic centres, as shown in a vertical section: $\Lambda$, Cerebum ; , Ccrebellum; c, Sunsori-motor tract, including the Olfactive ganglion olf, the Optic opt, and the Auditory aud, with the Thalani Optici thal, and the Corpora Striata $c s$; 1), Medulla Oblongata; ह, Spin:ll Corl; $-a$, olfactive nerve; $b$, optic; $c$, anlitory; $d$, phemmogastric ; $e$, hy poglossal ; $f$, spinal : fibres of the medullary substance of the Cerebrum are shown, connecting its ganglionic surface with the Sensori-notor tract.

eesses whieh run partly towards the eentral white axis of the eonvolutions, and partly horizontally along the plane of the layer. The third layer is of a much paler color. It is erossed at right angles by narrow and elongated groups of small cells and nuclei, internediate to which are bundles of fibres racliating towards the surfice from the central white axis of the ennvolutions.

1 See l'roceed. of Roy Soc, vol. xii, No. 57, and Dr. Mandsley's Physiology and Patholugy of the Mind, $1868, \mathrm{p}$. 60, from which last the aceount in the text is taken. $\Lambda$ good description of threstructura of the brain is also given by Aindt in Sclualtze's Archiv, BA, iii, p. 41, 1867. Soe also Cloland, Quart. Journ. of Mieroscop. Sei., 1870, p. 126; and II eyrort, in Stricker's IItuman and Comp Histology, vol. ii, p. 382; Gerlach, Centralblatt, 1872, p. 273; Rindfleisch, Centralblatt, 1872, p. 277. 
The fourth layer contains broader and more regularly arranged gronps of cells and nuclei, which together with the bundles of fibres between then present a distinctly fanlike arrangement. The fifth layer is pale, with a similar structure, but with the fanlike appearance less distinct. The sirth layer is reddish-gray, and contains similar cells to those above described with others that are rather larger. The elongated groups of cclls are fewer in number. Its deep surfice blends with the central white axis of the convolution, into which its cells are seattered for some distance. The seventh layer is the central white stem or axis of the convolution, which gives off on cvery side bundles of fibres that radiate outwards, beconing excecdingly fine as they reach the surface, in consequence of some of the fibres terminating in the cells of the different layers, whilst others bend round and run horizontally, either crossing the convolution transversely, or running longitudinally in the same direction. Besides these fibres which form the central white axis of the convolution, another set springing from the same source converge or rather curve inwards from opposite sides to form arches along some of the gray layers. They appear to be partly continuous with those of the radiating or divergent set which bend round to follow a similar course. All these fibres establish an infinite number of communications in every direction, between different parts of each convolution, between different convolutions, and between these and the central white substance. In other central convolutions situated more anteriorly the layers are less pronounced, and instead of all the cells of the several layers being small, a certain proportion of much larger cells are found chiefly occupying the two internal layers. These cells are pyramidal, with quadrangular bases directed towards the central white substance, and each gives off four or more processes which run partly towards the central white axis, and partly parallel with the surface of the convolution to be continuous with arciform fibres. The processes frequently subdivide into minute branches, which form part of the network between them. The apical extremity runs straight outwards, and gives off minute branches which are lost like the process itself in the surrounding network. Slight modifications occur in the vesicular structure of other convolutions. It is interesting to note that $\mathrm{Mr}$. Clarke was unable to perceive any difference whatever between the cells of the convolutions in Man and those of the ape tribe.

Professor Mrynert, in an elaborate essay, has reently given an anatomical description of the hrain, of whieh the following is an outline. Many points, however, are liere unavoidably omitted, especially those relating to the structure of the medulla oblongata and pons, for which the reader is referrecl to the original article contained in the second volume of Stricker's Manual of Histology, translated for the Sydenham Soeiptr.

Professor Meynert points out that the peripherie nerves of the body eolleetively eonverge towards the gray matter of the eerebral eavities, spinal cord, and medulla oblongata, and that after passing through these with more or less interruption or sermentation in the ganglion eells, they divergo to terminate in the great expansion of gray sub-tanee which forms the cortex of the cerebral hemispheres. The entire eolleetion of fibres be terins the "Projwction system," and eommences its description not with the peripherie nerves, but from the hemispheres of the eerebrum and cerebellum. He divides it into three links, with three masses of gray matter. The first inss of gray matter is the cortax of the carebrum and cerebellum ( $C \mathrm{CH}$ and $C b$, Fig. 244), and the first link of the projection system is represented essentially by the corona radiata $(C R)$, which consists of fibres extending from the eerobral cortex to the ganglionie masses of the eorpus striatum and optic thalamus $(L N, C N$, OT ), which constitute the seeond mass of gray matter. The second link of the projection system is eomposed of fibres that extend from theso ganglia to the graty substance around the eentral eavities, which is the third gray mass, and is represented by the system of the crus eerebri. The third link is formeil by the nerves which arise from the above-named gray substance of the eentral cavities, beginning with the 
origin of the third pair of eerebral nerves in the gray matter around the aqueduet of Sylvius to the nuelens of origin of the low crmost eveey geal nerve of the spinal cord.

spraking generally, the cortex of the cerebrum presents five lamina (Fig. :-45). The first is principally eomposed of an equally punetated matrix, with a few small stellate colls, and near its surfuce numerous fine varicose nerve-fibres decussating in all direetions. The matrix Neynert considers to consist chiofly of a non-nervous substance. It has been ealled ependyma formation by Rokitansky, neuroglia by Virehow, eonneetive tissue hy Kölliker, coalesced ganglion eell-substance by Henle and R. Wagner, gelatinous substance by Clarke, and molcenlar substanee by Kupfer. The second is a layor of elose-set, small pyramidal eorpuseles; the third is a layer of large pyramidal corpuscles; the fourth is a layer of small, elose-set, irregularshaped eorpuces; and the fift is a layer of fusiform corpuscles.

FIG. 244

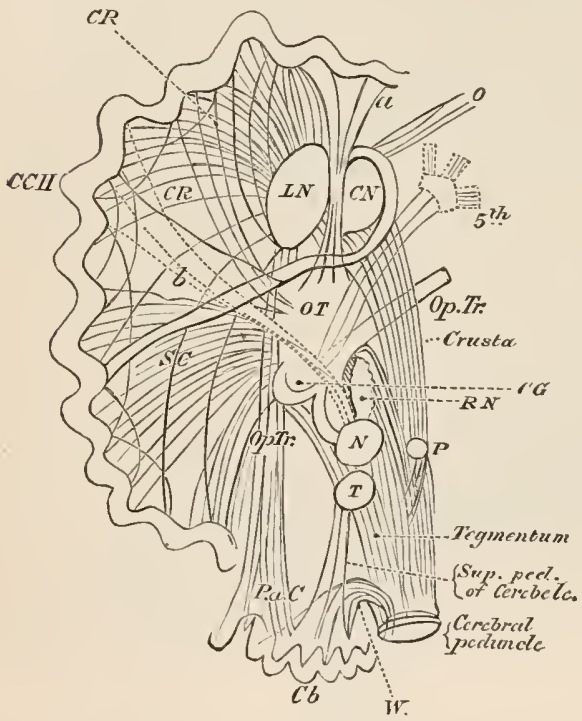

FIG 245 .

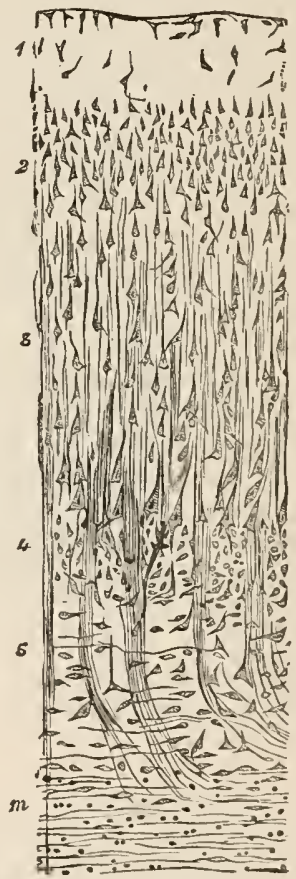

Fif. 244.-CCH, Cortex of the cerebral hemispheres, the convolutions of which are secn to he connected by arcuate connecting fibes. $C b$, Cortex of cerebellum. $C R$, Corona rathata, consisting of fibres extenling from the cortex cercbri to $L N$ and $C N$, the lenticular and caudate nuclei of the corpus striatum, and io $O T$, the optic thalamus. The posterior cxtremity of the optic thalamus presents two cnlargenents, the corpus geniculatum externum and internum, which is seen to be connected with the optic tracts. The letters Op. Tr. are placed on a hand of fibres that are helievel to rmn directly from the cortex cerebri to the cortex cerebelli. SC, Stria cornea, or tienia semicirculitis. R.Y, Red nuclens of tegmentum. $N$, Nates. $T$, Testis. $P$, Pineal gland, $b$, Fibres passing diretly inlo the tegmentum from the cortex cerebri. $P a C$, The band of fibres to the right of these letters are part of the superior peduncle of the cerchellum.

Fis. 215.- Transparent section of a furrow of the thirt central eonvolution of $\mathbf{M}$ an, $\times 100$ diam. 1. Layer of seattered smail cortical corpuscles. 2. Layer of close-set, small pyramiclil, cortical corpuseles. 3. Layer of large pyramidal corpuseles. 4. Layer of snill, close-set, irregnlarly shaped, cortical corpuscles (granulc-like formation). 5. Layer of fusiform cortical corpuscles. m, Mledullary layer.

The different parts of the same hemisphere are eonneeted, first, by the numerous intercommunieating proeesses of the cells; and, spcondly, by a system of areuate fibres of different lengths lying immediately beneath the eortex. The eorresponding 
parts of the opposite hemispheres are conneeted by the transverse fibles of the eorpus callosum. The cortex of the cerebrum is connected with that of the cerebellum by fibres passing directly from one to the other.

The corpus striatum consists of two nuelei, a smaller one-the caudate or intraventricular nucleus ( $C N$, Fig. 244) - and a larger or extraventricular one, named the lenticular nucleus $(L N)$. The caurate nucleus is essentially connected with the olfactory lobe and bulb by connecting fibres $(O)$, and is consequently small in man as compured with many animals

The fibres forming the first link of the projection system, and conneeted with the lenticular nucleus, are-1. Those proeeding from the internal surface of the whole length of the cerebral hemisphere, but ehiefly from the frontal lobes, 2. The stria cornea $(S C)$ proceeding from the apex of the temporal lobe to the anterior region of the corpus striatum. 3. Then in addition there are the fibres entering the optic thalamus-namely, $a$. Those arising from the frontal lobe and passing straight back between the caudate and lenticular nuelei of the corpus striatum ( $\alpha$, Fig. 244). b. Those proceeding from the walls of the Sylvian fissure and from the temporal lobes $b$ (inferior pedunele of optic thalamus). $c$. Fibres from the striatum zonale; and lastly, $d$, Those proceeding from the cortex of the gyrus fornicatus, constituting the ascendin prillar of the fornix (superior peduncte of optic thalamus). The fornix itself is the prijection fasciculus of the cortex passing to the anterior cminence of the optic thalami.

The deeper-lying part of the optic thalamus receiving the corona radiata contains many cells, and constitutes the red nucleus of the tegmentum, $R N$. This red nueleus is the first internode of a tract that originates in the eortex of the cerebrum in a fanlike form, and stretehes to the eortex of the cercbellum. The processus a crebello ad eerebrum is a free segment of this conneeting tract between the two eortical substances. Beneath the above-mentioned fan is a second more slender fan of the corona radiata, which is applied to the substance of Soemmering. Posteriorly the optic thalani are connceted with the optie tracts. The optic traets are also connecterl just as if they were a poltion of the eorona radiata with the brachium of the infurior corpus quadrigeminum. The optic tracts and nerves, therefore, are not peripheric nerves, but the retina, like the olfactory bulb, is, so to speak, an outlying portion of the cortex cerebri.

The second link of the projection system is formed by the system of the crus cerebri, which is divided into two layers with some intermediate gray substance. The inferior or anterior layer, named the crusta, proceeds from the eorpus striatum; the superior or posterior layer, named the tegmentum, ehiefly from the optie thalamus. In addition to the fibres proceeding from the two nuclei of the corpus striatum, the crusta eontains others derived from the substantia nigra of the ventricles, fibres (shown in dotted outline) which come directly from the occipital and temporal lobes. The size of the cerebral hemispheres, of the lenticular nueleus, and of the crusta cerebri, are all proportionate to one a nother, but there is no relation between the size of the crusta and of the tegmentum. On the contrary, the tegmentum of the crus with its ganglia, espeeially the eorpora quadrigemina, and corpora genieulata interna, alle more larkely developed in propertion to the smallness of the cerehral lobes. The tegmental fibres proceeding from the optie thalamus are reinforeed by others from the posterior commissure - the anterior and posterior eorpus geniculatum, the cortex cerebelli, and the pineal gland, those from the latter sourec decussating with those of the opposite side. The innermost fibres of the erusta, after decussating in the middle line, terminate peripherically in the central graysubstance of the ventricle surrounding the aquaductus sylvii in the nates, penetrating at this point into the nueleus common to the third and fourth nerves. The most external fascieulus of the erusta passes through the deeussution of the pyramids of the medulla oblongata, into the posterior eolumn of the spinal cord.

The tegmentum is charaeterized by its connection with the optic tracts and fifth pair of nerves on the one hand, and with the motor columns of the spinal cord on the other, forming a region where sensory impressions are reflected as motor impulses. The fact that the ganghia of the crusta have no eonnection with sensorial peripherie expansions, suggests that they owe their power of exciting motor impulses to another source-namely, to the eonditions of excitation of the certebral lobes.

The organization of the crusta is eompleted near the anterior part of the thalamus. That of the tegmentum just below the corpora quacigemina, the lowest of its ganglia of origin.

A large group of the radiating fibres procecding from the occipital lobes converge to the ganglia of origin of the tractus opticus-i.e., the external and internal corpora geniculata, and the corpora quadrigemina, forming a remarkably thick medullary 
lanina (optic radiations of Gratiolet). This mass associates itself with the posterior and external faseiculi of the crusta of the erus cerebri. But the most external faseiculus of the erusta, as just stated, passes through the decussation of the prramids of the medulla oblongati, into the posterior column of the spinal cord, and eonsequently the posterior roots of the spinal nerves are represented in the same lobes of the hemispheres as the radiations of the optie traet. It is remarkable that these lobes also recoive the fibres proceeding from the olfaetory bulb and lobe. Another group of fibres frum the cortex pass to the corpora quadrigemina, forming the brachia of the nates and testes.

The pineal grand is a ganglion of origin of the tegmentum, and is plaeed over the deensation of the tegmenta of the opposite sides.

At the level of the pons is a large and important region where the brachia of the cerebellum interlace with the projertion system, and from this point the third link of the projection system descends. The superior peduncle is eomposed partly of fibres of the enrona radiata, proceeding directly from the cortex of the cerebral hemispheres; and partly of the fitres from the optic thalamus and corpus striatum, all of which decursate so that the superior peduneles form a horseshoe closed in front whieh corresponds with the nates and testes. They constitute the connecting system of the cerebellum. The middle pedunele of the cerebellum is best understond by remembering that every faseieulus of the crusta terminating in the anterior division of the pons is represented by two fasciculi of the opposite middle peduncle of the eerebellum, of which one runs through the superficial, the other through the deep layer of transverse fibres of the pons.

The inferior peduncle of the cerebellum consists of fibres passing from the cerebellum to the posterior columns of the spinal eord, and ineludes -1 . The corpus restiforme; 2. The internal division of the inferior crus eerebri; and 3 . The fuscieulus cuneatus and slender fiseiculus

The gray substanee of the central cavities is a eentre from which a large number of nerve-roots take origin. It lines the third ventricle, surrounds the aqueduct of Sylvius, expands itself in the cavity of the fourth ventricle, and incluses the eentral canal throughout the spinal cord; from it the third, fourth, and succeeding eerebral and atl the spinal nerves in sueeession take origin, and these eonstitute the third link of the projection system. The third nerse may in fact be taken as the type of the projeetion system of Meynert. The first link eonsists of fibres extending from the cerebrum to the lentieular nucleus; the seeond link from the lenticular nucleus to the nuelens of origrin of the third nerve in the gray substance of the third rentricle of the opposite side, and the third link being the nerve itself.

The eerebelfum represents a loop or sling, the curves and sinuosities of which establish very indirect eonnections between the cerebrum and the nerve-roots. 'T'lie auditory nerve is almost entirely lost in it, and it has extensive eonnections with the optic nerve. The crusta of the ccrebral pedunel', whieh descending, is continued into the pyranids of the medulla oblongata, is at least three times the size of the pyramids, and this diminution is due to the termination of many of the fibres of the crusta in the ganglion eells of the pons, from whence fibres arise that pass into the middle peduncles of the cerebellum. A motor function untst therefore be uttributed to the ecrebellum, even from this point of view alone. For no other view can be taken than that the impulses conducted from the eortex to the corpus striatum and the lenticular nucleus, besides their conduction into the spinal cord, at the same time give rise to definite moles of activity of the cerebeltum.

The medulla oblongata consists of a prolongation of the anterior and posterior trict of the erus cerebri, and of the crus cerebelli, together with much scattered gray matter in its substance, and a layer on its surface, the gray matter of the fourth ventricle representing the gray matter of the central cavities.

560. The weight of the entire Encephalon in the adult Male usually ranges between 40 and $60 \mathrm{oz}$, the average being about $50 \mathrm{oz}$.; and in the Female from 36 to $50 \mathrm{oz}$, the average being about $45 \mathrm{oz}^{1}$ 'The maximum

1 The average of both sexes differs, however, in the various races of mankind. Dr. Davis (Proceedings of the Royal Soeiety, Jan. 23d, 1868) found the mean of the

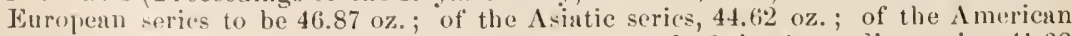
series, $44.730 \%$; of the Afriean series, $44.3 \mathrm{nz}$; and of the Australian series, 4138 o\%. Dr. Thumam (Journal of II (nntal Seience, April, 1866) gives 49 oz as the average weight of the European brain, whilst in distinguished men it amounts to $54.6 \mathrm{oz}$. 
of the healthy brain seems to be about $64 \mathrm{oz}$, and the minimum about 31 o\%. But in cases of Idiocy, the amount is sonetimes much below this; as low a weight as $20 \mathrm{oz}$. having been recorded.-It appears, from the investigations of M. Bourgery, that the relative sizes of the different component elements of the Human Encephalon are somewhat as follows. Dividing the whole into 204 parts, the weight of the Cerebrun will be represented by about 170 of those parts, that of the Cerebellum by 21 , and that of the Medulla Oblongata with the Optic Thalami and Corpora Striata by 13. The weight of the Spinal Cord would be, on the sane scale, 7 parts. Hence the Cerebral Hemispheres of Man include an amount of nervons matter, which is four times that of all the rest of the Cranio-Spinal mass, more than eight times that of the Cerebellum, thirteen times that of the Medulla Oblongata, etc., and twenty four times that of the Spinal Cord.- The absolute weight of the cerebral hemispheres varies according to Meynert from 17,000 to 21,600 grains. The average weight of the whole Encephalon in proportion to that of the borly, in man, taking the average of a great number of observations, is about 1 to 36 . This is a much larger proportion than that which obtains in most other animals; thus the average of Mammalia is staterl by II. Leuret to be 1 to 186 , that of Birds 1 to 212 , that of Reptiles 1 to 1321, and that of Fishes 1 to 5668 . It is interesting to remark, in reference to these estimates, that the Encephalic prolongation of the Medulla Oblongata in Man (being about one-sixteenth of the weight of the whole Encephalon) is alone more than twice as heavy in proportion to his borly, as the entire Encephalon of Reptiles, and ten times as lieavy as that of Fish.-But there are some animals in which the weight of the Encephalon bears a higher proportion to that of the body than it does in Man ; thus in the Blueheaded Tit, the proportion is as 1 to 12 , in the Goldfinch as 1 to 24 , and in the Fieldmouse as 1 to 31 . It does not hence follow, lowerer, that the Cerebrum is larger in proportion; in fact, it is probably not nearly so large; for in Birds and Rodent Mammals, the Sensory Ganglia form a very considerable proportion of the entire Encephalon. M. Baillarger has shown that the surface and the bulk of the cerebral hemispliere are so far from bearing any constant proportion to each other in different animals, that notwithstanding the depth of the convolutions in the Human Cerebrum, its bulk is $2 \frac{1}{2}$ times as great in proportion to its surface as it is in the Rabhit, the surface of whose Cerebrum is smooth. The entire surface of the human cerebrum is estimated by lim at about 670 square inches. - The specific gravity of the Brain has been made the subject of careful research by Dr. Bastian, who finds the average of the gray substance to be 1.030 , and of the white 1.040 .

561. The Encephalon altogether receives a supply of Blood, the anount of which is very remarkable, when its comparative bulk is considered; the proportion which goes to it being, according to the estimate of Haller, as much as one-fifth of the whole mass. The manner in which this blood is conveyed to the brain, and the conditions of its distribution, offer some peculiarities worthy of notice. The two Vertebral and two Carotid arteries, by which the blood enters the cavity of the cranium, have a more free communication by anastomosis than any similar set of arteries elsewhere; and this is obviously destined to prevent an obstruction in one trunk firom interrupting the supply of blood to the parts through which its branches are chiefly distributed,- the cessation of the circulation through the nervous matter being immediately productive of suspension of its functional activity. ${ }^{1}-\mathrm{N}$ ot

${ }^{1}$ M. Robin (Journal de la Physiologie, vol. ii, p. 537) has described an accessory tissue around the capillaries of the brain, in the space between which and the proper Tunica adventitia, free nuclei, fatty masses, and granules of hamatosin, are observable. M. Robin seems to be of opinion that these are the lymphatics of the brain. See also Stricker in idem, 1867, p. 652 . 
only must there be a sufficient supply of blood, but it must make a regulated pressure on the walls of the vessels. Now the Eneephalon is differently eircumstanced from other vascular organs, it being inclosed within an unyielding bony case $(\$ 275)$; and we find a special provision for equalizing the bulk of the contents of this cavity, and for eounterbalancing the results of differences in the functional aetivity of the brain and in its supply of blood, in the existenee of a fluid which is found beneath the arachnoid, both on the surface of the brain and spinal cord, and in the ventricles of the former. The amount of this "cerebro-spinal fluid" seems to average about two ounces; but in cases of atroply of the brain, as much as twelve ounces of fluid may sometimes be obtained from the eranio-spinal cavity; whilst in all instances in which the bulk of the brain has undergone an increase, whether from the production of additional nervous tissue, or from undue turgeseence of the vessels, there is either a diminution or a total absence of this fluid. It appcars from the experiments of Magendie (to whom our knowledge of its importance is chiefly due), that its withdrawal in living animals eauses great disturbance of the cerebral functions, probably by allowing undue distension of the bloodvessels; it is, however, capable of being very rapidly regenerated; and its reproduetion restores the nervous centres to their natural state-As the cerebro-spinal fluid can readily find its way from the subaraehnoid spaees of the crunial cavity into those of the spinal, and as it is no less readily absorbed than reproduced, it evidently serves as an equalizer of the amount of pressure within the cranial cavity; admitting the distension or contraction of the vessels to take plaee, within eertain limits, without any considerable change in the degree of compression to which the nervous matter is subjected. 'That this uniformity is of the greatest importanee to the functional exercise of the brain, is evident from a few well-known fatets. If an aperture be male in the skull, and the protruding portion of the brain be subjected to pressure, the immediate suspension of the activity of the whole organ is the result; in this manner, a state resembling profound sleep ean be induced in a moment, the normal activity being renewed as momentarily so soon as the pressure is withlrawn. ${ }^{1}$ This phenomenon has often been observerl in the Human subject in eases in which a portion of the cranial envelope has been lost by disease or injury. The various symptoms of Cerebral disturhance which are due to a state of general Plethora, are evidently owing to an excess of pressnre within the vessels; but an undue diminution of pressure is no less injurious, as appears from the disturbanee in the Cerebral functions which results from the very opposite cause-namely, a depresion of the power of the heart, or a deficiency of blood in the vessels.It is of peculiar importance to bear in mind the disturbance of the Cerebral functions occasioned by variations of internal pressure, when we are endeavoring to draw inferences from the phenomena presented by disease.

562. We shall now proceed with our Physiological impuiry into the funetions of the Cerebrum; and shall appeal, as before, to Human and Comparative Anatony, to Experiment, and to Pathology, for our chief data.The anatomical relations of the Cerebrum to the other Encephalic centres, clearly demomstrate that it is not one of the essential or findamental portions of the Nervous system; but a superadded organ, reeciving all its impulses to action from the parts below, and operating upon the body at large through them. And its great bulk, joinel to its position at the summit of the whole apparatus, - the vesicular substance of its convolutions affording a termination to the fibres in connection with it, and not being for the most

1 Schiff states that the Indian snake-eharmers are aeeustomed to produee rigidity of the body in these animals by pressure on the oeciput. 
part only traversed by them, as is the case with that of all the lower centres, clearly mark it out as the highest in its functional relations, and as ministering, so far as any material instrument may do, to the exercise of those psychical powers, which, in Man, exhibit so remarkable a predominance over the mere animal instincts. This conclusion is fully borne out, when we extend our inquiries from Human to Comparative Anatomy ; for with some apparent exceptions, which there would probably be $110 \mathrm{great}$ difficulty in explaining if we were in possession of all the requisite data, there is a very close correspondence between the relative development of the Cerebrum in the several tribes of Vertebrata, ${ }^{1}$ and the degree of Intelligence they respectively possess,-using the latter term as a comprehensive expression of that series of mental actions which consists in the intentional adaptation of means to ends, based on definite ideas as to the nature of both. It is not always easy to say, in the case of the lower animals, what parts of their actions are to be attributed to automatic impulse (i.e., to be considered as Instinctive), and what should be regarded as the results of Intelligence. 'The character of Intelligent actions, however, as compared with Instinctive (\$563), is usually shown (1) in the variety of means which are adopted to conpass the same ends, and this not merely by different individuals and by successive generations, but by the same individual at different times; $(2)$ by the intprovement in the mode of accomplishing the object, which results from the intelligent use of experience, and from the greater command of means which is progressively attained; and (3) by the conformity of the means to altered circumstances, so that the character of adaptiveness is still maintained, however widely the new conditions may depart from those which must be considered as natural to the species.

563. The difference between actions which proceed from the Intellectual faculties prompted by the instinctive propensities, and those of a purely Instinctive character, is well seen in comparing Birds with Insects. The Instinctive tendencies of the two classes are nearly of the same kind; and the usual arts which both exhibit in the construction of their habitations, in procuring their food, and in escaping from danger, must be regarded as intuitive, on account of the uniformity with which they are practiced by different individuals of the same species, and the perfection with which they are exercised on the very first occasion. But in the adaptation of their operations to peculiar cireumstances, Birds display a variety and fertility of resource, far surpassing that which is manifested by Insects; and it can scarcely be doubted by those who attentively observe their habits, that in such adaptations they are often guided by real intelligence. This must be the case, for example, when they make trial of several means, and select that one which best answers that purpose; or when they make an obvious inprovement from year to year in the comforts of their dwelling; or when they are influenced in the choice of a situation by peculiar circumstances, which in a state of nature can scarcely be supposed to affect them. The complete domesticability of many Birds is in itself a proof of their possessing a certain degree of intelligence; but this alone does not indicate the possession of more than a very low amount of it; since many of the most domesticable animals are of the humblest intellectual capacity, and seem to become attached to Man, principally as the source on which they depend for the supply of their animal wants. But there are certain tribes of Birds, especially the Parrots and their allies, which possess an extraordinary degree of educability, and which manifest a power of performing simple acts of 
reasoning, that are quite comparable with those of a child when first learning to talk.

564. This development of the Intelligence under the influence of Man, and in accordance with his habits rather than with the original habits of their species, is yet more remarkahle in the case of those Mammals whose instincts lead them to attach themselves peculiarly to him, and whose powers of reasoning are called forth in adapting themselves to the new circumstances in which they are thus placed. The actions of a Dog, a Horse, or an Elephant, are evidently the result, in many instances, of a complex train of reasoning, differing in no essential respect from that which Man would perform in similar circumstances; so that the epithet "half-reasoning," commonly applied to these animals, does not express the whole truth; for their mental proeesses are of the same kind with those of Man, and differ more in the degree of comprehensiveness of their data and conchusiveness of their inferences, than they do in their essential character. We lave no evidence, however, that any of the lower animals have a voluntary power of directing their mental operations at all similar to that which man posserses; these operations, indeed, seem to be of very much the same character as those which we perform in connected dreams, different trains of thought commencing as they are suggested, and proceeding according to the usual laws until some other disturb them.-Although it is customary to regard the Dog and the Elephant as the most intelligent among the lower animals, it is not certain that we do so with justice; for it is very possible that we are misled by that peculiar attachment to Man, which in them must be termed an instinct, and which enter's as, a motive into a large proportion of their actions; and that, if we were more acquainted with the psychical characters of the higher Quadrumana, we should find in them a greater degree of mental capability than we now attribute to them. One thing is certain, that the higher the degree of Intelligence which we find characteristic of a particular race, the greater is the degree of variation which we meet with in the characters of individuals; thus everybody knows that there are stupid Dogs and clever Dogs, ill-tempered Dogs and good-tempered Dogs,-as there are stupid Men and clever Men, ill-tempered Men and goor-tempered Men. But no one could distinguish between a stupid Bee and a ('lever Bee, or between a good-tempered Wasp and an ill-tempered Wasp, simply because all their actions are prompted by an unvarying Instinct.

565 . In estimating the relative development of the Cerebrum in different tribes of Animals, and in comparing this with their relative intelligence, it must be borne in mind that the size of the organ does not, considered alone, afford a mcaus of accurate judgment as to its power. For the quantity of vesicular matter which it contains affords the only fair criterion of the latter; and of this we must jutge, not merely by the superficial area, bint by the number and depth of the convolutions and by the thickness of the cortical layer. Again, there are many reasons why it is not fair to estimate the relative development of the Cerebrum by the proportion which it bears to the whole bulk of the animal; and, on the whole, the most accurate basis of complarison would probably be afforded by the relation between the bulk of the Cerebrum and the diancter of the Spinal Cord. In making any such comparison, however, the Thalami Optici, Corpora Striata, and Corpora (2uadrigemina should be excluded from the estimate for reasons now sufficiently apparent; and the bulk of the Cerebrum proper shonld be alone determined, cither by weight or by the displacement of liquid.-Bnt the Cerebrum varies in different classes and orders of Vertebrata, not merely in proportional size, but also in the relative devclopment of its anterior, middle, and posterior lobes. This is a point of very great importance, in deter- 
mining the value to be assigned to the organologieal system of Gall and Spurzheim and their followers. The Cerebrum of the Oviparous Vertebrata is not a miniature representative of that of Man, as a whole, but only of his anterior lobes; as is sufficiently obvious from an examination of its connections with other farts, and from the abscuce of any other commissural connections between its two hemispheres than those which are afforded by the Sensory Ganglia. It is in the Implacental Mammals that we find the first rudiments of the middle lobes of the Cerebrum, and of the proper intercerebral commissure, the Corpus Callosum; and even in the Rudents this is but very imperfectly developed. As we ascend the Mammalian series, we find the Cerebrum becoming more and more elongated posteriorly by the development of the middle lobes, and the intereerebral commissure becomes more complete; but we must accend as high as the Carnivora, before we find the least vestige of the posterior lobes; and the rudinent whieh these possess is so rapidly enlarged in the Quadrumana, that in some of that group the posterior lobes are as fully developed in reference to the Cerebrum as a whole, and as completely eover in the Cerebellum as in the Human subjeet. ${ }^{1}$ - The attention which has yet been given to this department of inquiry has not hitherto done more than confirm the statement already made with regard to the general correspondence between the development of the Cerebrum and the manifestations of Intelligenee; very deeided evidenee of which is furnished by the great enlargement of the Cerebrum, and the corresponding alteration in the form of the Cranium, which present themselves in those races of Dogs most distinguished for their educability, when eompared with those whose condition approxinrates most closely to what was probably their original state of wildness.

566. This general inference drawn from Comparative Anatomy, is borne out by observation of the Human species. When the Cerebrum is fully developed, it offers innumerable diversities of form and size among various individuals; and there are as many diversitics of eharaeter. It may be doubted if two individuals were ever exactly alike in this respect. That a Cerebrum which is greatly under the average size is incapable of performing its proper functions, and that the possessor of it must necessarily be more or less idiotic, there can be no reasonable doubt. On the other hand, that a large, well-developed Cerebrum is found to exist in persons who have made themselves conspienous in the world in virtue of their intelleetual aehievements, may be stated as a proposition of equal generality. In these opposite cases, we witness most distinctly the antagonism between the Instinctive and Voluntary powers. Those unfortunate beings in whom the Cerebrum is but little developed, are guided almost solely by their instinetive tendencies, which frequently manifest themselves with a degree of strength that would not have been supposed to exist; and oeeasionally new instincts present

I It has been asserted by the followers of Gall, that the development of the Cerebrum from belind forwards, as above described, is rather apparent than real: the whole organ being in faet pushed backwards by the exeessive development of the anterior lobe. But the anatomieal distinetion between the anterior and nidlle lobes is sufticiently obvious externally; and that of the middle and postcrior lobes is also clearly marked out by the development of the posterior eornua of the lateral ventricles, and the situation of the hippocampus major. Hence the facts above stated do not admit of any such interpretation; and they are fully borne out by the history of the Enbryonie levelopment of the Cerebrum in Man, whieh preeisely follows the above plan.- It is not here denied that the anterior lobe of the Human Cerebrum is remarkable for its great extension forwards; but still, the diffirence betwoen the Cerobrum of Man and that of the lower Mammalia consists mueh rather in the proportional development of the posterior lobes, than in that of the anterior. 
themselves, of which the Human being is ordinarily regarded as destitute. ${ }^{1}$ On the other hand, those who have obtained most influence over the understundings of others, have always been large-brained persons, of strong intellectual and volitional powers, whose emotional tendencies have been subordinated to the reason and will, and who have devoted their whole energy to the particular objects of their pursuit.-It is very different, however, with those who are actuated by what is ordinarily termed genius; and whose influence is rather upon the feelings and intuitions, than upon the understandings of others. Such persons are often very deficient in the power of even eomprehending the ordinary affairs of life; and still more commonly they show an extreme want of judgment in the management of them, being under the immediate influence of their passions and emotions, which they do not sufficiently endeavor to control by their intelligent will. The life of a "genius," whether his bent be towards poetry, music, painting, or pursuits of a more material character, is seldom one which can be held up for imitation. In snch persons, the general power of the mind being low, the Cerebrum is not usually found of any great size.-The mere comparative size of the Cerebrum, however, affords no accurate measure of the amount of mental power; for we not unfrequently meet with men possessing large and wellformed hearls, whose psychical capability is not greater than that of others, the dimensions of whose crania have the same general proportion, but are of much less absolute size. Large brains, with deficient activity, are commonly found in persons of what has been termed the phlegmatie temperament, in whom the general processes of life seem in a torpid and indolent state; whilst small brains and great activity betoken what are known as the sanguine and nervous temperaments.

567. Having now inquired into the evidence of the general functions of the Cerebrum, which may be derived from examination of its Comparative development, we proceed to our other sources of information, Experiment and Pathological phenomena. The electrical excitability of the hemispheres was experimentally demonstrated by Fritsch and Hitzig, ${ }^{2}$ who found that on the application of a galvanic stimulus to particnlar regions of the surface of the hemisphere, certain definite muscular movements occurrer on the opposite side of the body, such as flexion, extension, and rotation of the limbs, and also movement of the facial muscles. Their earlier experiments were made on dogs, and the constant currents applied were feeble. The contraction on making the current was greater than that on breaking it. They adduced various reasons against the supposition that the movements were due to mere conduction of the stinulus to-distant centres, amongst the more important of which were the feebleness of the currents employed, the close approximation of the electrodes, the bad conductivity of the brainsubstance, the occurrence of contractions on the opposite side of the body, and their non-appearance when the position of the electrodes was slightly altererl. In further researches Hitzig ${ }^{3}$ believed he was able to establish the existence of a distinct centre for the several movements of the eves, coincirling with a part of the Facialis centre, and especially that part imnervating the protective nuscles of the eye. He subsequently ${ }^{4}$ found in experiments on monkeys that the anterior cerebral convolution constitutes the true motor

1 A remarkable instance of this was published some years sinee: A perfectly idiotic crirl, in Paris having been seduced by some misereant, was delivered of a child without assistance; and it was found that she had grawed the umbilical cord in two, in the samo manner as is practiced by the lower animals. It is scarcely to be supposed that she land uny iden of the object of this separation.

2 Reiehert's Archiv, 1870, p. 300.

Berliner Klin. Wuchenschr., 1874, No. 6.

3 Ibid., 1873, p. 397. 
part of the cortex of the cerebrum, the several centres lying in it from the median fissure downwards to the Sylvian fissure. He maintained that about $3 \mathrm{~mm}$. from the median line is the centre for the posterior extremity of the opposite side, and about $3 \mathrm{~mm}$. further outwards that for the anterior extremity. Seven nmm. beyond this laterally is the centre for a part of the muscles associated with the visual organs, and close to the Sylvian fossa a fourth centre governing the muscles of the mouth, tonguc, and jaw of both sides. Weak currents applied to the parietal and frontal regions were not followed by any movements. In a still more recent short communication ${ }^{1}$ he states that he had found lesion of the posterior convolutions (occipital) of the cerebral hemispheres produces blindness of the opposite eye and paralytic dilatation of the corresponding pupil. Soon after the appearance of the first series of observations made by Fritsch and Hitzig, their results were confirmed and extended by Ferrier ${ }^{2}$ in his experiments with the Faradic current in reference to the theories of epileptic discharges propounded by Hughlings Jackson. He defined on the surface of the brain of cats, rlogs, and rabbits the different centres from which various movements of the limbs, face, mouth, and tongue, eyes, ears, etc., could be definitely and distinctly excited. Carrying his investigations to the brain of monkeys, Ferrier ${ }^{3}$ has
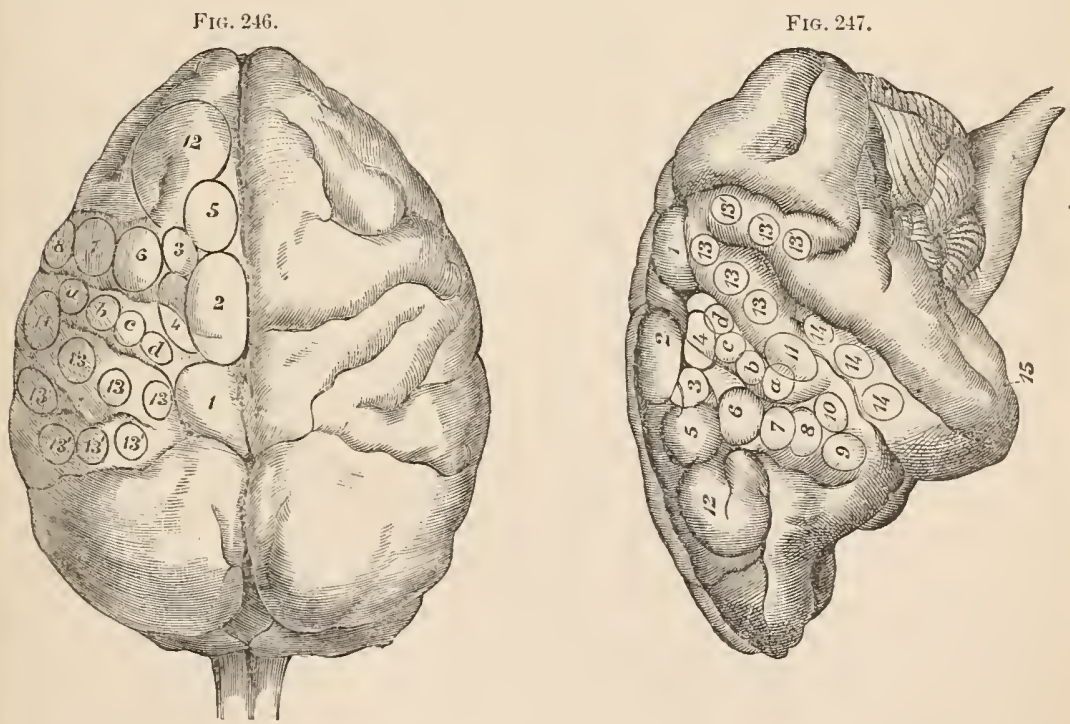

Diagram of the Brain of Monkey to show the effects of elcctrical stimulation of certain points as given in the text. In each instance the effects produced resulted from the application of the two electrodes to the area circumscribed by the circle.

mapped out the following regions, the stimulation of which gives results which may thus be briefly stated (see Figs. 246, 247): 1. Movement of the hind foot as in walking; 2. Complex movements of the hind leg, consisting chiefly in adduction of the foot to the middle line; 3. Movements of inind foot and tail ; 4. Action of the latissimus dorsi; 5. Extension forward of the arm: $a, b, c, d$. Different aspects of combined muscular movements of the hand and wrist, which in their completest action cause closure of the fist; 6 . Action of the biceps, supination and flexion of forearm; 7. Elevation of the upper

2 West Riding Asylum Lieports, vol. iii, 1873. ${ }^{3}$ Proc. Roy. Soc., No. 161, 1875. 
lip-zygomatic action ; 8 . Conjoint action of the elevators of upper lip and depression of lower; 9 . Opening of the mouth and protrusion of the tongue; 10. The retraction of tongue (these movements have a bilateral charactcr); 11. Action of platysma; 12. Elevation of the eyebrows and eyclids, dilatation of the pupsils, and turning the head to the opposite side; 13. Eyes directed to the opposite side and upwards, with usually contraction of the pupils; 13 . Similar action, but the eyes usually directed downwards; 14. Retraction of the opposite car, head turns to the opposite side, the cycs widely openerl and the pupils dilated; 15 . Stimulation of this region, which corresponds to the tip of the uncinate convolution, causes torsion of the lip and nostril of the same side. The antero-frontal and occipital regions give no rcsult on stimulation; nor does the island of Reil react to the stimulus. Stimulation of the corpora striata caused tonic spasin of the whole of the muscles of the opposite side, and consequently a condition of pleurusthotonos. Stimulation of the optic thalamus was negative. Considerable difference of opinion exists among expcrimenters as to the real signification of the results thus obtained by galvanic or Faradic stimulation of the surfice of the hemispheres. Fritsch and Hitzig and Ferrier regard them as the result of excitation of the gray matter of the cortex, while others regard them as the result of conduction of the current to the motor ganglia. Dupny ${ }^{1}$ and also Carville and Duret have attempterl to prove that the actions exerted arc due to diffusion and conduction to underlying motor ganglia and motor strands. Dr. Burdon-Sanderson ${ }^{2}$ has also shown that when the gray matter corresponding to the centres definch by Hitzig and Ferrier is removed, yet the same actions are produced by exciting the medullary fibres which proceed from these to the corpus striatum. This fict has also been stated by other subsequent experimenters. Ferrier ${ }^{3}$ arcues that the rcsults cannot be explained by conduction, on the ground that in a state of anæsthesia sufficicut to prevent any manifestation on stimulation of the surfice of the brain, the corpora striata still remain excitable; whence, unless it be assumed that chloroform annihilates the conductivity of the medullary fibres to the electric stimulus, the results should be obtained as before. The definitencss and predictability of the results, aidl also the fact that stimulation of the island of Reil, which is nearest the corpus striatmm, causes no action, even though the rest of the brain is excitable, seem to dispose of ubjections on the gromnd of conduction or diffision. Even thongh a certain amount of diffusion of the current beyond the points of contact of the elcetrodes be proved, it would scem that a certain intensity is requisite to produce stimulation, and the possibility of differentiating centres in cluse proximily to each other wonld seem to prove the finct of localization. In reference to the experiments of Dr. Sinderson, Ferrier argnes that as the corpus striatum contains in an integrated form the centres individually differentiated in the hemispheres, it is quite in acenrdance with the explanation given by Hitzig and himself to suppose that stimulation of the medullary cone of fibres should cxcite the same movements as result from functional activity of the corresponding cortical centres. Consilcrable diversity of opinion exists as to what relation these cortical centres have to the motor phenomena which are manifested on stimulation. Fritsch and Hitzig are of opinion that they are in some way related to the muscular scusc, on the gromul that after the ablation of the limb-centres in clogs, the animals so operated on do not suffer from paralysis of the limbs, but merely appear to have lost consciousness of the position of the limbs, and hence place them in irregular and munatural attitudes. This view is also supported by Noth-

1 Examen de quelques Points de la Phrsiologie du Corvanu, Paris, 1873.

2 Proc. lioy. Suc, $1873 . \quad 3$ IVest Riding Asylum Reports, vol. iv, 1874. 
nagel from the results of his experiments in the injection of ehromic acid into the brain cortex. ${ }^{1}$ Schiff ${ }^{2}$ regards the movements resulting from stimulation of the lemispheres as of a reflex nature, but denies the existence of ccntres which exert any direct influence on the muscles of animal life. $\mathrm{He}$ describes the results of ablation of these centres as due to the loss of muscular sense in the parts. Hermann, ${ }^{3}$ though admitting the fact of definite morements being excited hy localized stimulation of certain cortical regions, denies that this proves the existence of motor centres in the hemispheres, and grounds his opinion on the fact that dogs recover perfectly from the effects of destruction of the so-called motor centres of the limbs, and regain complete control of their movements. The interpretation which Ferrier puts upon his experiments differs essentially from any of the foregoing. $\mathrm{He}$ regards the movements which result from stimulation as indications of excitation of centres concerned in voluntary or purposive action, or of centres of expression and sensation. The motor portion of the brain is situated anteriorly and corresponds with the medullary expausion of the fibres from the corpus striatum, while the sensory portion corresponds with the medullary expansion from the optic thalamus. The destruction of a motor centre causes paralysis of voluntary motion in respect to the actions which are excited by stimulation of the same centre. This paralysis, however, is only complete in cascs of movements which are quite independent of each other. It is seen more especially in the case of the monkey, which, like man, is capable of highly complex and independent movements. In dogs and quadrupeds grenerally, owing to the fact of the movements being usually associated on both sides, the destruction of a motor centre in one hemisphere does not cause complete voluntary paralysis. Under the influence of the other hemisphere action of both siles may be caused by the agency of the lower ganglia. Hence a dog may rapilly recover from the paralysis of voluntary motion, which manifests itself immediately after the destruction of the motor centres in the opposite hemisphere. This explanation is in accordance with the theory of Dr. Broalbent, who accounts for the fact that paralysis from brain disease affects the arm more than the leg, owing to the bilateral coordination in each hemisphere of movements usually associated together. Hence the motor centres in the brain are regarded by Ferrier as the differentiated apparatus of voluntary muscular action. At the same time they form what he terms the motor substrata of intellect, by being the centres of memory of muscular actions. Hence he explains how the loss of speech is

1 Nothnagel (Virchow's Archiv, Bd lvii, p. 184, and lviii, p. 420) found on inject ing a solution of chromic acid intn a point about $14 \mathrm{~mm}$. (half an inch) from the anterior extremity of the cerebral hemsphere in rabits, and about $\frac{1}{12}$ tl of an inch from the median fiscure, that the opposite forepaw dragred in walking, and could be placed in the most awkward positions without th+ animal resentiner it, or attempting to withdraw it. It was, however, neither insensible nor paralyzed, it only appeared to have lost its muscular sense. A similar spot influencing both the fore und hind legs exists at the outer extremity of the ayrus post-frontalis. The affection is transitory and disappears in a few wreks Other motor paralyses were observed with injections made into various parts of the white substance. He finds a spot near the niddle and inner part of the corpusstriatum, which when injured leads in the course of a few minutes to violent leaping and springing forward movements, which continue for a quarter or half an hour till the animal drops exhausted; he terms this spot the nodus cursorines. Injury to a spot situated at the posterior extremity of the single sulcus of the brain of the rabbit. is followed by similar springiner novements, which after a few minutes case cutirely. Nothnagel found that ablation or de-truction of the lenticular nucleus was followed by the same effccts us removal of the cerebral hemisphere of the same side. See ulso Fournie, Comptes Rend., t. lxxvii, No. 5 .

2 Archiv f. Experiment. Pathol. und Pharmakologie, 1874, Bd. iii.

3 Archiv f. Physiologie, Bd. x, 1875. 
associated with the destruction of that part of the brain which is the centre for the movements of articulation. As regards sensory localization, Ferrier has recently concluded a series of experiments on monkeys in which he claims to have localized the regions of special sense. These regions he regards as the centres of sensory perception as distinct from the centres of sensory impressions or sensori-motor action. The following is an abstract of these later researches, in which also attempts have been made to ascertain the functions of those parts of the hemispheres which do not react to stimulation: ${ }^{1}-1$. Ablation of the frontal regions which give no reaction to electrical stimulation is without effect on the powers of sensation or voluntary motion, but causes marked impairment of intelligence, and of the faculty of attentive observation. 2. Destruction of the gray matter of the convolution dividing the fissure of Rolando, causes paralysis of voluntary motion on the opposite side of the body; while lesion circumscribed to special areas in these convolutions, previously localized by the author, causes paralysis of voluntary motion, limited to the muscular action excited by electrical stimulation of the same parts. 3. Destruction of the angular gyrus ( $p l i$ courbe) causes blindness of the opposite eye, the other senses and voluntary motion remaining unaffected. This blindness is only of temporary duration, provided the angular gyrus of the other hemisphere remain intact; when both are destroyed, the loss of visual perception is total and permanent. 4. The effects of electrical irritation and the results of destruction of the superior temporo-sphenoidal convolution indicate that they are the centres of the sense of hearing. 5. Destruction of the hippocampus major and hippocampal convolution abolishes the sense of touch on the opposite side of the boty. 6. The sense of smell (for each nostril) has its centre in the gubernaculum cornu Ammonis or tip of the uncinate convolution on the same side. 7. The sense of taste is localized in a region in close proximity to the sense of smell, and is abolished by destructive lesion of the lower part of the temporosphenoidal lobe. (The action is crossed.) 8. Destruction of the optic thalamus causes complete anæsthesia of the oppositc side of the body. 9. Ablation of the oceipital lobes produces no effect on the special senses or in the powers of voluntary motion, but is followed by a state of depression and refusial of food not to be accounted for by mere constitutional disturbance consequent on the operation. The function of these lobes is regarded as still obscure, but considered as in some measure related to the systemic sensation. Their destruction does not abolish the sexual appetite. 10. After removal both of the frontal and occipital lobes an animal still retains its faculties of special sense and the power of voluntary motion. In the cxperiments made by the committce of the New York Society of Neurology and Electrology, including Drs. Dalton, Aruold, Beard, Flint, and Mason, ${ }^{2}$ results confirmattory of Hitzig's observations were met with. 'They found that all the centres of motion for the anterior and posterior limbs are situated in the convolution imncdiately surrounding the frontal fissure which runs transversely to the longitudinal fissure. The centres for flexion and cxtension of the anterior and posterior limbs were always found in the external part of the praefrontal convolution just anterior to this fissure, and in the post-frontal convolution just behind it. In a majority of cases those for the anterior limbs were situated more in front, near the outer extremity of the frontal fissure, and those for the posterior limbs more posteriorly and inwarks, but their cxact positions varied somewhat in different cases. The centre for flexion of the head and neck in the median line is in the lateral and anterior part of

1 Exporiments on the Brain of Monkeys, seeond series, read beforo the Royal Socisty, May 131h, 1875. Abstract of Croonian Lecture.

2 Reported in New York Med. Journ., March, 1875. 
the prefromtal convolution, where it leads downwards and outwards; that for flexion of the head with rotation towards the side of the stimulus is in a part of the convolution situated still farther towards the front and downward, so as to be invisible in a view of the brain taken from above. The centre for the facial muscles is in a region situated on the lateral part of the liemisphere immediately abont the supra-Sylvian fissure. ${ }^{1}$-The effects of the entire removal of the Cerebral Henispheres have been already stated ( $§$ 524). So far as any inferences can be safely drawn from them, these fully bear out the conclusion that the Cercbrum is the organ of Intelligence; since the animals which have suffered this mutilation appear to be constantly plunged in a profound sleep from which no irritation ever seems able to rouse them into full activity, although they give manifestations of consciousness. It would be wrong hence to infer, however, as some have done, that such would be the natural condition of an animal without a Cercbrum; since it is obvious that much of the disturbance of the sensorial powers which is occasioned by this operation, is fairly attributable to the laying open of the cranial cavity, to the disturbance of the normal vascular pressure, and to the injury nccessarily done to the parts which are left, by their severance from the Cerebrum. Inence the persistence of consciousness after the entire removal of the Cerebrum, - which proves that the Cerebrum is not its seat, or at least not its exclusive seat, - is a far more important fact than the positive destruction of psychical power which is conscqnent upon the operation. So far as they can be trusted, however, the results of such mntilations bear out the views already put forth, as to the superardded and non-essential character of the Cerebrum; and justify us in applying to the higher animals the inferences to which we should be led by the contemplation of those forms of the nervous system in which no Cerebrum exists. There is nothing, therefore, to oppose the conclusion, that whilst sensations may be felt, and sensori-motor actions excited, independently of the Cerebrum, ${ }^{2}$ the presence of this organ is essential to the formation of ideus or notions respecting the objects of scnsc, and to the performance of those psychical operations for which ideas furnish at once the material and the stimnlus to activity.

568. The information afforded by Pathological phenomena is far from being definitc. ${ }^{3}$ Many instances are on record in which extcnsive disease has occurred in one Henisphere, so as almost cntirely to destroy it, without either any obvious injury to the mental powers, or any interruption of the influence of the mind upon the borly. But there is no case on record of any such severe lesion of both henisplieres, in which morbid phenomena were not evident during life. It is true that, in Clironic Hydrocephalns, a very remarkable alteration in the condition of the Brain sometimes presents itself which might a priori have been supposed destructive to its power of activity ; the ventricles being so enormously distended with fluid, that the cerebral matter has seemed like a thin lanina spread over the intcrior of the enlarged cranium. But there is no proof that absolute destruction of any part was thus occasioned: and it wonld seem that the very gradual nature of the change gives to the structure time for accommodating itself to it. This, in fact, is

1 For other recent researches on this subject see Beaunis, Gazette Médicale de Paris, No. 30, 1872; Fournie, Recherches Expérimentales, 1873; Crichton Brown, Brit. Med. Journ., 1875, p. 447.

2 It is worthy of remark, that M. Flourens, who in the first instance maintaised that sensation is altogether destroyed by the remoral of the Cerebrum, has substituted, in the Second Edition of his Researches, the word perception for sensation; aplarently implying exactly what is maintained above.

3 For abundant evidence on this point see MI. Brown-Séquard, Archives of Scient. and Pract. Med., vol. i, 1873, p. 255. 
to be noticed in all diseases of the Encephalon. The partial or entire absence of the commissure from congenital malformation reducing the Cerebrum (in this respect) at least, to the level of that of the Marsupial Quadruperl or of the Bird is by no means an unfrequent cause of deficient intellectual power. In an interesting case recorded by $\mathbf{M r}$. Paget, ${ }^{1}$ in which the middle portion of the fornix and the whole of the septum lucidum were absent, with a very thin and short corpus callosum, the subject had been a servant girl, and had during life betrayed a peculiar want of forethought and power of judging of the probable result of things, but her memory was good, and she possessed an ordinary amount of knowledge. A similar case has been recorded by Mitchell Henry. ${ }^{2}$ The mental deficiencies in this and in most of the few other cases of which the details have been recorded, seem to have been of the same order; and this is exactly what might have been anticipated; since the deprivation of these parts takes away that which is most characteristic of the Cerebrum of Man and of the higher Mammalia; their intellectual operations being peculiarly distinguished by that application of past experience to the prediction of the future, which constitutes one of the highest efforts of intelligence.-A sudiden lesion, that may be so trifling as to escape observation unless this be very carefully conducted, will occasion very severe symptoms; whilst a chronic disease may gradually extend itself, without any external manifestation. It will usually be found that sudden paralysis, of which the seat is in the Brain, results from some slight effusion of blood in the substance or in the neighborhood of the Corpora Striata; whilst, if it follows disorder of long standing, a much greater amount of lesion commonly presents itself. In either case, the paralysis occurs in the opposite side of the body, as we should expect from the decussation of the Pyramids; but it may occur either on the sane, or on the opposite side of the face, - the cause of which has already been explainerl. The disturbance of the Cerebral functions occasioned by those changes in its nutrition which are commonly included undel the general term Inflammation, presents a marked diversity of character according to the part it affects. Thus it is well known that the Delirium of excitement is usually a symptom of inflammation of the cortical substance or of the membranes of the Hemispheres. This is exactly what might be anticipated from the foregoing premises, since this condition is a perversion of the ordinary mental operations, which are dependent mpon the instrumentality of the vesicular matter; and it is evidently impossible for the membranes to be affected with inflammation, without the nutrition of this substance being impared, since it derives all its vessels directly from them. On the other hand, inflammation of the fibrous portion of the Cerebrum is usually attended rather with a state of torpor, than with excitement; and with dininished power of the will over the muscles. It is stated by Foville, that in acute cases of Insanity, lie has usually found the cortical substance intensely red, but without adhesion to the membranes; whilst in chronic cases it is indurated and adherent; but where the insanity has been complicated with Paralysis, he has usually found the medullary portion indurated and congested.

569. The numerous and interesting obervations which have been made during the last few year's on loss of the ficulty of language, or rather of intellectual expression, ${ }^{3}$ are of great interest in reference to the Physiology of the Brain. It is commonly associated with Right Hemiplegia, and in a large proportion of the cases examined after death, disease has been found in the posterior part of the third or inferior frontal convolution of the left hemisphere; hence the conclusion has been drawn that the fiaculty of lan-

3 See $A$ phasia, Agraphia, ete, in the Year-Books of the New Sydenham Society. 
guage has its seat in this particular convolution. Language, however, is coextensive with thought, and the third left frontal convolution is not the seat of language as a ficulty of the mind, but simply an important link in the nervous mechanism of speech. Dr. Hughlings Jackson ${ }^{1}$ has pointed out that lauguage may be intellectual or emotional, and that when all power of expressing ideas in words is lost, an entire phrase may be uttered under entotion. Intellectual language again or intellectual expression he shows to be a department of educated movements in general, and gives reasons for believing that the entire hemisphere is concerned in its evolution. It conflicts with all preconceived notions that the left side of the brain should alone have to do with the expression of ideas in language, but this seems to be clearly demonstrated by Pathology. P. Broca and Dr. Moxon have explained it by supposing that the side of the brain only is educated, and Gratiolet's observation that the left frontal convolutions are developed before the right, has been adduced in support of this view, which, however, cannot be said to be established. The mechanism of speech and thought may be represented as follows. Impressions derived from sensory surfaces generally (Gs, Fig. 248) and from the organs of special sense (OA) are translatel in the sensor'y ganglia of the base of the brain (OT) into sensations. These sensations transmitted upwards to the cortex of the hemispheres here give rise to perceptions, or the intellectual recognition of the external causes of the sensations; by combination again of the different perceptions derived from a given object an idea or complete intellectual representation of the object is formed, with which is associated a name. The "perceptive centres" (Bistian) in which simple perceptive recognition takes place (PC) are probably situated near the margins of the hemisphere where the convolutions are directly connected by fibres with the central gauglia, while ideas are supposed to be formed in the convolutions remote from the margins, many of which receive no fibres from the central ganglia or crus, but are connected by arcuate fibres with the marginal convolutions and with each other. Up to the present the mechanism described is that concerned in the reception of impressions and the formation and association of ideas. When these ideas are to be expressed in worls the proposition is formulated, and the phrase mentally rehearsed in the higher convolutions, and transmitted for verbal expression to the third left frontal gyrus, the function of which is to provide the appropriate words or motor symbols in which the idea is to be clothed, and call into action through the corpus striatum the motor nervenuclei in the medulla which are concerner in articulation and phonation. The third left frontal convolution is thus the first step on the way out for words, and damage here leaves the subject of it able on the one hand to understand what is said, to form ideas, and even to rehearse propositions in his mind, and on the other hand able

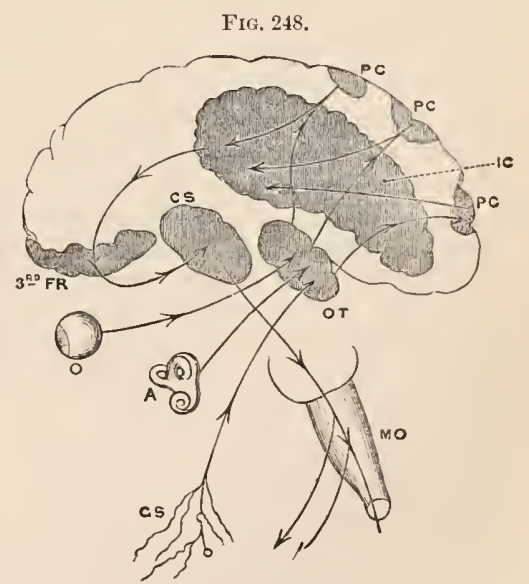

A. Auditory nerves. o. Optic nerve. Gs. General sensory surface. OT. Optic thalamus PC. Perceptional centre. Ic. Ideational centre. cs. Corpus striatum. 3 FR. Third frontal convolution. Mo. Medulla oblongata. 
to execute all the movements required for articulation and phouation, though, from the breach in the mechanism for translating ideas into words, he is speechless. This is pure Aphasia, but cases unconıplicated by further damage are rare, while speechlessness of a totally different character is often confounded with Aphasia. The nervous mechanism may, in fact, be injured at different points. Below the third frontal convolution, lesion in the Corpus Striatum may cause impairment of articulation, or in the medulla or its nerves more or less complete loss both of phonation and articulation (alalia). Here the speechlessness is simply from motor paralysis, but other forms of speechlessuess arise from lesions in the cerebral or mental mechanism. Cases have been met with in which a man could speak and writc correctly while unable to read a single word even of what he had himself written, or to name the most familiar object shown to him; the association by which the visual perception called up the name was broken. Let the association betwecn the auditory perception and the name be similarly broken, and we have the explanation of the perplexing cases ${ }^{1}$ in which a patieut has lost all comprehension of articulate sounds, and neither understands what is said to him nor what he says, while he responds promptly to signs, and appears to be intelligent. These are forms of Amnesia or loss of memory for words, but there are other more common forms of Amnesia in which a patient understands spoken words, but cannot recall them mentally so as to rehearse a plirase or proposition in his mind. Very frequently a degree of Amnesia is associated with Aphasia, the various degrees and combinations of loss of memory for words and loss of memory how to say words depending upon the region and cxtent of cortex involved, or upon the severance of fibres counecting together different sets of convolutions. Again, in extensive disease of the Cortex there is no speech because there is no idea; this is dementia or mutism.

570. The general result of pathological in vestigation is, that the Cerebrum is the instrument of all those psychical operations, which we include under the general term Intellectual, whilst it also affords, in part at least, the instrumental conditions of Emotional states; and that all those muscular movements which result from voluntury determinations, or which are directly consequent upon emotional cxcitement, have their origin in its vesicular substance, though the motor impulse is immediately furnished by the Cranio-Spinal apparatus, upon which the Cerebrum plays ( $\$ 547$ ). It does not hence follow, however, that the Cerebrum has such a dircet relation to the Mind, that the consciousness is immediately and necessarily affected by changes taking place in its own substance; and, however startling the proposition may at first sight appear, that the organ of the intellectual opcrations is not itself endowed with conscionsness, a careful consideration of the relations of the Cerebrum to the Sensory Ganglia will tend to show that there is no a priori absurdity in such a notion. For if the connection of the vesicular matter of the Cerebral Hemispheres with the Sensorial Centres, be anatomically the same as that which exists between these centres and the Retina or any other peripheral expansion of vesicular matter in an organ of sense, which we have scen that it is $(\$ 564)$, - and if the sanc kind of ehange may be excited in the Sensorial Centres by an impression from each source, which has been shown to be a matter of common occurrence ( $\$ 546)$, it can scarcely be deemed unlikely that the Scusorial Centres should be the seat of consciousness, not merely for the impressions transmitted to them by the nerves of the external senses, but also for the impressions brought to them by the "nerves of the internal

1 See Broadbent, Med.-Chir. Trans., 1872-5, to whom the Editor is indebted for mueh aid in drawing up this section, and for the Figure by which it is illustrated. 
seuses," as we mat designate (after Reil) the radiating fibres of the Cercbral Hemisplicres ( $\$ 564)$. And there is on the other hand an a priori improbability that there should be two seats of consciousness, so fir removed from onc another as the Sensory Ganglia and the vesicular surface of the Hemispheres (for to their medullary substance no such attribute can be assigned with the least probability); an idea which is quite at variance with that very simple and familar class of phenomena, which consists in the recollections of sensations. For the remembered scnsition is so completely the reproduction of the original, that we can hardly suppose the seat of the two to be different; yet the act of recollection is clearly Intellectual, and therefore Cerebral; consequently, if we admit that the Sensory Ganglia are the scat of the original sensation, we can scarcely but admit that they are also the seat of thit which is reproduced by the Cercbral act,-a view which is fully confirmed by the occurrence of automatic movements as consequences of its recall ( $\$ 546)$. And a careful analysis of our own nental operations will often supply cvidence of the evolution of results, such as ordinarily proceed from intellectual action, without any conscionsness on our own parts of the steps whereby these are attained.

571. Without presuming, then, to affirm positively what cannot be proved, it may be stated as a probable inference fron the facts already referred to that the Sensory Ganglia constitute the seat of consciousness, not merely for impressions on the Organs of Sense, but also for changes in the cortical substance of the Cerebrum; so that, until the latter have reacted downwris upon the Scnsorium, we have no consciousness either of the formation of ideas, or of any intellectual process of which these nuy be the subjects.Ideas, Enotions, Intcllectual operations, etc., have of late been frequently designated as "states of consciousness;" and this psychological description of them is in full harmony with the physiological account here given of the material conditions under which they respectively occur. For as a Sensation is a state of consciousness excited through the instrumcutality of the Sensorium, by a certain change $(e, g$. ) in the condition of the Retina, it is not difficult to understaud how a change in the condition of the Cerebrum may excite, through the same instrumentality, that state of conscionsness which may be termed Ideational, ${ }^{1}$ or that another change maty produce the Enotional consciousness, another the Intuitional cousciousness, another the Logical consciousness. And although it may be thought at first sight to be a departure from the simplicity of Nature, to suppose that the Cerebrum should require another organ to give us a consciousness of its operations, yet we have the knowledge that the Eye does not give us visual consciousness, nor the Ear auditory consciousness, unless they be connected with the Sensory Ganglia; and in the end (the author feels a strong assurance) it will be found much simpler to accept the doctrine of a common centre for sensational and for what may be distinguished as mental consciousuess, than to regard two centres as distinct. ${ }^{2}$

1 The Author ventures to use this term, the meaning of whieh requires no explanation, on the authority of Mr. James Mill, who remarks, - "As we say Sentation, we might alsosay Ideation; it would be a very useful word; and there is no objection to it, except the pedantic habit of decrying a new term. Sensation is the general name for one part of our constitution [or rather for one state of our eonseiousness], Ideation for another." (Analysis of the Human Mind, vol. i, p. 42)-If the use of the substantive Ideation be admitted, there can be no reasonable objection to the adjective ideational.

${ }^{2}$ An interesting and suggestive paper by Mr. Loekhart Clarkc, On the Nature of Volition, will be found in Nos. 7, 8, and 9 of the Psychological Journal for 18i:2. 


\section{Of Sleep and Somnambulism.}

572. It is a peculiar feature in the Physiology of the Cerebral and Sensorial Ganglia, that their activity undergoes a periodical suspension, more or less complete; the necessity for this suspension arising out of the fact that the exercise of their functions is in itself destructive to their substance, so that, if this be not replaced by nutritive regeneration, they specdily become incapacitated for further use. An ingenious theory of the cause of sleep has been advancerl by Sommer, ${ }^{1}$ founded on the observations of Pettenkofer and Voit already alluded to $(\S 308, \mathrm{xr})$. Sommer observes that if, as the experiments of Pettenkofer appear to show, oxygen is gradually being storect up during sleep, a period will probably arrive when it exists in such cxcess as materially to aceelerate the metamorphosis of the nervous and other tissues, and as a consequence awakening oecurs. On the other hand, during the waking state the stored up oxygen is gradually eliminated, as shown by the large proportion of carbonic acid given off, until at length when all the excess has been consumed, exhaustion and general relaxation is experienced accompanied by the desire for slecp. This view has been expressed at considerable length by Pflüger," who suggests that the waking state is maintained by the violent oscillations almost comparable to sniall explosions taking place in the molecules of the cerebral substance, owing to the combination of the intramolecular oxygen with the carbon of the tissue. These vibrations radiatc outwards far and wide along the nerves in all directions. As the oxygen is gralually used up, the explosions become feebler, the activity of all nervous processes less, mental operations are conducted with less evergy, the exhausted and quiescent nerves are no longer easily aroused by impressions from without, aud sleep results. On Dr. Cappie's ${ }^{3}$ theory the links in the causation of sleep are, first, that there is diminished molecular activity of the cerebral cclls, whilst coincidently there is a change in the capillary circulation of the brain, so that less blood is supplied to it, and it consequently occupics less space. But as the brain-case must be constantly full, the veins of the pia mater undergo gradual and proportional distension, and although the absolute quantity of blood and the amount of internal pressure remain unaltered, the direction of the pressure is morlificel. It is less from within, and more on the surface of the organ, and with altered direction of pressure the continued exercise of function is incompatible. This riew is quite in accordance with the interesting rescarches of Mr. Arthur Durhan ${ }^{4}$ on the condition of the circulation in the Brain chring slecp, which have shown that the brain is then in an essentially bloodless conclition, aud that not only the quantity but the rapiclity of movement of the blood in the vessels is materially diminished; and this is corroborated by the observations of Dr. J. Hughlings Jackson on the ophthalnoseppic condition of the Retina during sleep, ${ }^{5}$ the optic disk being then whiter, the arteries smaller, the veins sonewhat larger, and the neighboring part of the retina more anenic, than in the waking state. In ordinary profound sleep there is a state of complete unconseionsness, so far as external phenomena are concerned; no ordinary impressions upon the organs of sense being either felt or perceived; although an extraordinary impression, or even an habitual one upon which the attention has been previonsly fixed as that at which the

1 Henle and Pfeufler's Zeits. f. lat. Med., Bd. xxxii, 1868, p. 214.

2 l'llïner's Archiv, 1875, p. 468.

3 ('ирит, The Causation of Sleep, 1872, p. 32.

4 Guy's Huspital Ruports, Third Series, vol. vi.

5 Sece Royal Lond. Uphth. Hosp. Reports. 
slumberer is to awake himelf ( $\$ 580)$, occasions a renewal of sensorial activity. It is in this capability of being aroused by extcrnal impressions, that the chief difference lies betwcen Sleep and the abnormal condition of Coma, whether this arise from the influence of pressure or effusion within the cranium, or be consequent upon the poisoning of the blood by narcotic substances, or follow a previous state of abnormal activity of the brain, such as Delirium. Between these two conditions, however, every gradation nıa be seen; as in the gradually increasing torpor which results from slow effusion within the cranium, the gradual loss of susceptibility to external impressions which is observed on the application of Cold to the nervous centres, as in the interesting experiments of Dr. Richardson and Dr. Weir Mitchcll, ${ }^{1}$ or after an overdose of a narcotic, as well as in the intensification of ordinary sleep which is consequent upon extreme previous fatigue. But it is a matter of doubt, whether the suspension of sensorial conscionsness is equally complete as regards internal or Cerebral changes; for some are of opinion that, even in the most profound sleep, we still dream, although we may not remember our dreams; whilst others (and among these the Author would rank himself) consider that dreaming is a mark of imperfect sleep, and that, in profound ordinary sleep, the Cerebrum in common with the Sensory Ganglia, is in a state of complete functional inactivity. When Dreaming takes place, there is usually a less complete exchusion of sensory impressions, although the perceptive consciousness may be entirely suspender: so that the course of the dream may be influenced by them, although the mind is not conscious of them as such ( $\$ 584$ ). If this be the true account of the case, we may consider that in profound Sleep the functional activity of the Cerebrum and of the Sensory Grunglia is alike suspended; but that in Dreaming the Cerebrum is partially active, whilst the Sensorium is in such a condition of receptivity for Cerebral (subjective) impressions that the mind becomes directly conscious of them, though it only becontes conscious of (objective) impressions nade upon the Organs of Sense, after their influence has been transmitted through it to the Cerebrum, and has been, as it were, reflected back by that organ. It is, in fact, by their influence upon the current of ideas, and not by their power of exciting sensations, that we recognize their operations under such circumstances.

573. The state of sleep is one to which there is beyoud doubt a periodical tendency ; for, when the waking activity has continued during a considerable proportion of the twenty-four hours, a sense of fatigue is usually experienced, which indicates that the brain requires repose; and it is only under some very strong physical or moral stimulus, that the mental energy can be sustained through the whole cycle. In fact, unless some decidedly abnormal condition of the Cerebrum be induced by the protraction of its functional activity, Sleep will at last supervene, from the absolute inability of the organ to sustain any further demands upon its energy, even in the midst of opposing influences of the most powerful nature. ${ }^{2}$ That the strongest Volitional determination to

1 See for Dr. Richardson's experiments, Medical Times and Gazette, 1867, vol. i, p. 489 et seq.; and for tlıose of Dr. Mitchell, the American Journal of Medical Science, 1867 , p. 102 .

2 Thus it is on reeord, that during the heat of the battle of the Nile, some of the overfutigued boys fell asleep upon the deck; and during the last attack upon Rangoon, the Captain of one of the war-steamers most actively engaged, worn out by the excess of continued mental tension, fell asleep, and remained perfectly unconscious for two hours, within a yard of one of his largest guns, which was being worked encrgetically during the whole period.-So even the severest bodily pain yiclds before the imperative demand occasioned by the continued exhaustion of the powers of the sensorial centres; thus Damiens slept upon the rack, fluring the intervals of his cruel sufferings; the North American Indian at the stake of torture will go to sleep on the 
remain awake is forced to give way to Slcep, when this is required by the exhaustion of nervous power, must be within the experience of every one; and the only way in which the IVill can even retard its access, is by determinately fixing the consciousness upon some definite object, and resisting every tendency in the thoughts to wander from this. It does not appear to be of any consequence, whether this exhaustion be produced by the active exercise of volition, reflexion, emotion, or simple sensation; still we find that the volitional direction of the thoughts in a course different from that in which they tend spontaneously to flow, is productive of far morc exhaustion than the automatic activity of the mind; whilst, on the other hand, the excess of automatic activity, whether as regards the intellectual operations or emotional excitement, tends to prevent sleep. This is particularly the case when the feelings are deeply interested; thus the strong desire to work out a result, or to complete the survey of a subject, is often sufficient to keep up the intellectual activity as long as may be requisite (a state of restlcssness indeed being often induced, which prevents the access of sleep for some time longer); so, again, allxiety or distress is a most frequent cause of wakefulness; and it is generally to be observed that the state of suspense is more opposed to the access of sleep, than the greatest joy or the direst calamity when certainty has been attained. ${ }^{1} \quad$ But although an excess of automatic activity is opposed, so long as it continues, to the access of sleep, yet it cannot be long protracted without occasioning an extreme exhaustion of nervous power, which neccsitates a long period of tranquillity for its complete restoration.

574 . Whilst, however, the necessity for Sleep arises out of the statc of the nervous system itself, there are certain external conditions which favor its access; and these, in common parlance, are termed its predisposing causes. Among the most powerful of these, is the absence of sensorial impressions; thus darkness and silence usually promote repose; and the cessation of the sense of muscular effort, which takes place when we assume a position that is sustained without it, is no less conducive to slumber. There are cascs, however, in which the contimance of an accustomed sound is necessary, instead of positive silence, the cessation of the sound being a complete preventive of sleep; thus it happens that persons living in the neighborhood of the noisicst mills or forges cannot readily sleep elsewhere. Such cases are referable either to the influence of habit, which causes the attention of the individual to be more attracted by the suspension of the sonnd than by its contimuance; or to the fact that the monotonous repetition of scusorial impressions is often more favorable to slcep than their complete absence. Thus it is within the experience of every one, that the droning voice of a heavy reader on a dull subject is often a most effectual hypuotic; in like mamer, the ripple of the calm ocean on the shore, the sound of a distant waterfall, the rustling of foliage, the hum of bees, and similar inpressions mpon the auditory sense, are usuaily favorable to sleep; and the muscular and tactile senses may be in like minner affected by a uniform succession of gentle movements, as we sec in the mode in which nurses "hush off" infants, or in

least remission of agony, and will slumber until the fire is applied to awaken him ; and the Madieal Practioner has frequent illustrations of the same faet.-That the continued demand for muscular activity is not incompatible with the aceess of slecp, is obvious from what has been already said of the persistenee of the automatic movements in that condition; it is well known that, previonsly to the shortening of the hours of work, factory children frequently fell asleep while attending to their machines, although well aware that they should ineur severe punishment by doing so.

: Thus it is a common observation, that criminals under sentence of death sleep badly so long as they entertain any hopes of a reprieve; but when onee they are satisfied that thrir death is incritable, they usually sleep more soundly, and this even on the very last night of their lives. 
the practice of gently rubbing some part of the body, which has been successfully employed by many who could not otherwise compose themselves to sleep. The reading of a dull book acts in the same mode through the visual sense; for the cyes wander on from line to line, and from page to page, receiving a series of sensorial impressions which are themselves of a very monotonous kind, and which only tend to keep the attention alive in proportion as they excite intcresting ideas.

575. In these and similar cases the influence of external impressions would seem to be exerter in withdrawing the mind from the distinct consciousness of its own operations (the loss of which is the transition-state towards that of complete unconsciousness), and in suspending the directing power of the Will. And this is the case, even where the attention is in the first instance voluntarily dirceted to them; as in some of the plans which have been recommended for the induction of sleep, when there exists no spontaneous disposition to it. In other methods, the attention is fixed upon some internal train of thought, which, when once set going, may be carried on automatically; such as counting numbers, or repeating a French, Latin, or Grcek verb. In either case, when the sensorial consciousness has been once steadily fiscd, the monotony of the impression (whether received from the Organs of Sense, or from the Cerebrum) tends to retain it there; so that the Will abandons, as it were, all control over the opcrations of the mincl, and allows it to yield itself up to the soporific influence. This last method is peculiarly effectual when the restlessness is dependent upon some mental agitation; provided that the Will has power to withdraw the thoughts from the exciting subject, and to reduce them to the tranquillizing state of a mere mechanical repetition.

576. The access of Sleep is sometimes quite sudden ; the individual passing at once from a state of complete mental activity to one of entire torpor. More generally, however, it is gradual; and various intermediate phases may be detected, some of which bear a close resemblance to the state of Reverie. The same may be said with regard to the transition from the state of Sleep to that of wakeful activity ; and this also may be sudden and complete, although it usually consists of a succession of stages-the complete consciousness of the individual's relation to the external world, and the power of directing his thoughts and actions to any subject about which he may be required to exert himself, being the last to return to him. There may be a rapid alternation of these different states; the loss and recovery of the waking consciousness bcing many times repeated in the course of a few minutes, when the circumstances are such as to prevent the access of profound sleep by the recurrence of sensory impressions; as when a man on horseback, wearied from want of rest, lapses at every moment into a dozing state, from which the loss of the balance of his body as frequently and sudden arouses him; or when a man going to sleep in a sitting posture, gradually loses the support of the muscles which keep his head erect, his head droops by degrees, and at last falls forward on his chest, and the slight shock thence ensuing partially arouses and resteres his voluntary power, which again raises the head. Similar fluctuations occur in the sensory perceptions; and these may be often artificially induced by very simple means. "We find, for example, one condition of sleep so light, that a question asked restores consciousness enough for momentary understanding and reply; and it is an old trick to bring slecpers into this statc, by putting the hand into cold water, or produce some other sensation, not so active as to awaken, but sufficient to draw the mind from a more profound to a lighter slumber. This may be often repeated, sleep still going on; but make the sound louder and more sudden, and complete waking at once ensues. The same with 
other sensations. Let the sleeper be gently touched, and he shows sensibility, if at all, by some slight muscular movement. A ruder touch excites more disturbance and motion, and probably changes the current of dreaning; yet sleep will go on; and it often requires a rough shaking, particularly in young persons, before full wakefulness can be obtained." . . . "It is certain that the faculties of sensibility and volition are often unequally awakened from sleep. The case may be stated, familiar to many, of a person sleeping in an upright posture, with the hearl falling over the breast; in whom sensibility is suddenly aroused by some external impression, but who is unable, for a certain time, to raise his heal, though the sensation produced by this delay of voluntary action is singularly distressing." These various cases, it is justly remarked by Sir H. Holland, ${ }^{1}$ depending severally on the intensity of sleep, and on the kind and degree of the external exciting causes, will be found to explain many of those so-called Mesmeric phenomena, which are offered to us under a widely different interpretation. And it may be here remarked, that among those intermediate stages between sleep and waking, which either occur spontaneously, or can be induced in numerous individuals by very simple processes, there are several which exhibit peculiarities that are not in themselves in the least degree less remarkable, than are those which are regarded with so much wonder by the uninformed observer, when induced by the asserted Mesmeric influence, and paraded as specimens of its power.

577. It is unquestionable that the supervention of Sleep may be promoted by the strong previous expectation of it; and this is true, not merely of ordinary sleep, but of the states of artificial Reverie and Somnambulism formerly described. Every one knows the influence of habit, not only in regard to "time," but also as to "place and circumstance," in predisposing to Sleep. Thus, the celebrated pedestrian, Captain Barclay, when accomplishing his extraordinary feat of walking 1000 miles in as many successive hours, obtained at last such mastery over hinself that he fell asleep the instant he lay down. And the sleep of soldiers, sailors, and others, who are prevented by "duty" from obtaining regular periods of repose, but are obliged to take their rest at short intervals, may be almost said to come at command; nothing more being necessary to induce it, than the placing the body in an easy position, and the closure of the eyes. It is related that the Abbé Faria, who acquired notoriety through his power of inducing somnambulism, was accustomed merely to place his patient in an arm-chair, and then, after telling him to shut his eyes and collect himself, to pronounce in a strong voice and imperative tone the word "dormez," which was usually successful. The Author has had frequent opportunities of satisfying himself, that the greater success which attended the "hypnotic" mode of indueing somnambulism, in the hands of Mr. Braid, its discoverer, than in that of others, partly lay in the mental condition of his subjects, who came to him for the most part under the confident expectation of its production, and were further assured by a man of very determined will, that it could not be resisted." And it is one of the inost curious phenomena of the state of indnced Reverie, absurdly called "biological," that, in many subjects at least, sleep may be induced in a minute or less, by the positive assurance, with

I See his excellent chapter, on Sleep, from which the above extraets are taken, in his Medical Notes and Reflections, and his Chapters on Mental l'hysiolngy.

2 A very amusine instunee in which sleep having been previously indued by the ordinary "mesmerie" and then by the "hypnotic" processes, was brought on by the simple belief that a new process was being put in practice, will be found in the Brit. and For. Med. Rev., vol, xix, p. 477. 
which the mind of the individual becomes possessed, that it will and must supervene.

578. The influence of previous mental states is yet more remarkable in determining the effects produced upon the sleeper by different sensory impressions. The general rule is, that habitual impressions of any kind have much less effect in arousing the slumberer than those of a new or unaccustomerl character. An amusing instance of this kind has been related to the Author, which, even if not literally true, serves extremely well as an itlustration of what is unquestionably the ordinary fact. A gentleman who had taken his passage on board a ship of war, was aroused on the first morning by the report of the morning gun, which chanced to be fired just above his berth; the shock was so violent as to cause him to jump out of bed. On the second morning he was again awoke, but this time he merely started and sat up in bed; on the third morning the report had simply the effect of causing him to open his eyes for a moment and turn in his bed; on the fourth morning it ceased to affect him at all; and his slumbers continued to be undisturbed by the report so long as he remained on board. It often happens that sleep is terminated by the cessation of an accustomed sound, especially if this be one whose monotony or continuous repetition had been the original inducement to repose. Thus, a person who has been read or preached to sleep, will awake, if his slumber be not very profound, on the cessation of the voice; and a naval officer, sleeping beneath the measured tread of the watch on deck, will awake if that tread be suspended.-In this latter case the influence of the simple cessation of the impression will be augmented by the circumstances next to be alluded to, which has received too little attention from writers on this subject, but which is of peculiar interest both in a physiological and psychological point of view, and is practically familiar to almost every one.

579. The awakening power of sensory impressions is greatly modified by our habitual stute of mind in regard to them. Thus, if we are accustomed to attend to these impressions, and our perception of them is thus increased in acuteness, we are much more easily aroused by them than we are by others, which are in themselves much stronger, but which we have been accustomed to disregard. Thus, most sleepers are aroused by the sound of their own names uttered in a low tone, when it requires a much louder sound of a different description to produce any manifestation of consciousness. The same thing is seen in comatose states; a patient being often found capable of being momentarily aroused by shouting his name into his ear, when no other sound produces the least effect.-The following circumstance, communicated to the Author by the late Sir Edward Codrington, is a most apposite illustration of this principle. When a young man, he was serving as signal lientenant under Lord Hood, at the time when the French fleet was confined in Toulon harbor; and being desirous of obtaining the favorable notice of his commander, he devoted himself to his duty (that of watching for signals made by the lookout frigates) with the greatest energy aud perseverance, often remaining on deck nineteen hours out of the twenty-four, with his attention constantly directed towarks this one object. During the few hours which he spent in repose his sleep was so profound that no noise of an ordinary kind, however loud, would awake him; and it used to be a favorite amusement with his comrades to try various experiments devised to test the soundness of his sleep. But if the word "signal" was even whispered in his ear, he was instantly aroused, and fit for immediate duty.-The influence of habitual attention is shown as much in the effect produced by the ccssation, as in that of the occurrence, of sensory impressions. Thus, in the case of the naval officer aroused by the suspension of the measured tread of the 
watch over his head, the knowledge possessed during the waking state, that this suspension is either an act of negligence which requires notice, or indicates some unusual occurrence, doubtless angments the effect which the discontinuance of the sound would of itself produce.

580. It is not requisite, however, that the sound should be one habitually attended to during the hours of watchfulness; for it is sufficient if it be one on which the attention has been fixed as that at which the slumberer is to arouse himself. Thus the medical man, even in his first profound sleep after a fatiguing day's work, is aroused by the first stroke of the clapper of his night-bell; and to those who are accustomed to rise every morning at the sound of an alarm clock, the frequency and regularity of the occurrence do not diminish, but rather increase, the readiness with which it produces its effect, provided that the warning be promptly obeyed. On this usually depends the efficiency of the awakening sound; if it be regarded as a thing to which there is no occasion to give heed, it very soon ceases to produce any effect, the entire peal not being sufficient to awake the sleeper; whilst, on the other hand, the first stroke is enough to break the repose of him who is impressed with the effectual desire of profiting by the warning. And thus it may happen that, of two persons in the same room, either shall be at once aroused by a sound which produces no disturbance in the slumbers of the other. To this influence of previous impressions, whether habitual, or but once forcibly made, we are also to refer the spontaneous termination of the state of sleep at particular times, without any sensorial excitement from external impressions. Thus, many persons who are accustomed to rise at a particular hour, wake regularly at that hour, whether they have gone to rest carly or late; so that the act of spontaneously awakening is no proof that the desirable amount of repose has been obtained. But what is more remarkable is, that many individuals have the power of determining, at the time of going to rest, the hour at which they shall rise, so as to awake from a profound sleep at the precise time fixed upon. In others, however, the desire to rise at a particular hour only induces a state of restlessness throughout the night, destroying the soundness of the slumbers; the individual a wakes many times in the night, with the belief that the hour is past, and very possibly oversleeps it after all, the system being worn out by the need of repose.

581. The Amount of Sleep required by Man is affected by so many conditions, especially age, temperoment, habit, and previous exhaustion, that no general rule can be laid down on the subject.-The condition of the fotus in utero may be regarded as one of continual shumber; the apparatus of Animal life being completely secluded from all stimuli which could arouse it into activity, whilst the energy of the Organic functions is entirely directerl to the building up of the fabric. On its first entrance into the world, the infant continues to pass the greater part of its time in slumber; and this is particularly to be noticed in cases of premature birth, the seven months' child seeming to awake only for the purpose of receiving food, and giving lout little heed to external objects, whilst even the eight months' child is considerably less alive to sensory impressions than one born at the full time. The excess of activity of the constructive over the destructive operations, which characterizes the whole period of infancy, childhood, and adolescence (chap), $\mathrm{xx}$ ), requires that a larger proportion of the diurnal cycle shall be passed in sleep (during which the former may be carried on without hin(lrance), than is requisite when adult age has been attained, the two sets of changes being then balanced; and the amount of sleep to which the system shows itself disposed, gradually diminishes from three-fourths to one-half, and fiom one-half to one-third, or even to one-quarter, of the twenty-four hours. It is to be noticed that the sleep of children or young persons is not 
only longer than that of adults, but is also more profound. On the other haind, as age advances, and the bodily and mental activity of the waking state decreases, a smaller amount of sleep suffices; or, if the slumber be protracted, it is usually less deep and refreshing. It may be noticed, however, that very old persons usnally pass a large proportion of their time in sleep, or rather in a sort of heavy doze, especially after meals; as if, in consequence of the want of energy of their nutritive operations, a very long period of repose is necessary to repair the waste which takes place during their short period of activity. - In regard to the influence of temperament, it may be remarked that a plethoric habit of body, sustained by full diet, usually predisposes to sleep, provided that the digestive powers be in a vigorous condition; persons of this constitution freqnently pass nine or ten hours in slnmber, and maiutain that they cannot be adequately refreshed by less. Ou the other hand, thin wiry people, in whom the "nervous" temperament predominates, usnally take comparatively little sleep, notwithstanding the greater activity of their nervous system when they are awake; but their slumber, while it lasts, is generally very deep. Persons of "lymphatic" temperament, heavy passionless people, who may be said to live very slowly, are usually great sleepers; but this is rather because, through the dulness of their perceptions, they are less easily kept awake by sensorial or mental excitement, than because they really require a prolonged cessation of activity. As they are half asleep during the waking state, so it would appear that the constrnctive operations must be far from active while they are asleep, sn little do they seem restored by the repose.-The amount of sleep, ceteris paribus, required by individuals, is very greatly influenced by habit; and, contrary to what we might anticipate, we find that the briefest sleepers have usually been men of the greatest mental activity. Thus Frederick the Great and John Hunter are said to have only required five honrs' sleep out of the twenty-fonr; and Geueral Elliott, celebrated for his defence of Gibraltar, is recorded not to have slept more thau four hours out of the twenty-four. It may be doubted whether it would be possible for any one to sustain a life of vigorous exertion upou a smaller allowince than this; and the general fact is, that from six to eight hours of repose, out of every twenty-four, are required to keep the system of an adult in a state of healthful activity. The influence of habit may be brought to bear upon the protraction, as well as on the abbreviation, of the usual period. Thus Quin, the celebrated actor, could slumber for twenty-four hours successively; and Dr. Reid, the metaphysician, could take as much food, and afterwards as mnch sleep, as were sufficient for two days. - It is needless to dwell npon the obvious fact, that other things being equal, the amount of sleep required by man is proportional to the amount of mental exertion pnt forth during the waking hours; since this is an obvious result of what has been laid down as the eause of the demand for sleep. It may be remarked, however, that we must not measure the amount of sleep by its durution alone, since its intensity is a matter of equal importance. The light slumber which is disturbed by the slightest sounds, cannot be as renovating as the profound sopor of those whom no ordinary noise will a wake.

582. There are certain states of the Encephalic centres, in which there is an entire absence of Sleep; and this may continue for many days, or even for weeks or months. Insomnia is, for instance, one of the characteristics of acute Mania, and may also exist in various forms of Monomania; it is usually, also, one of the symptoms of incipient meningeal inflammation; and it may constitute a specific disease in itself. In all these cases, however, the preponderance of the destructive processes over the constructive mauifests itself, sooner or later, in the exhaustion of the mental and bodily 
powers. Thus Mania, when prolonged or frequently recurring, subsides into Dementia ; and if it continue for any length of time, is sure to be followed by a great sense of wretchedness and prostration, frequently accoinpanied by continual restlessness. Such effects, too, in a less aggravated degree, result from habitual deficiency of sleep; whether this be due to emotional excitement which keeps repose at bay, or to a voluntary detcrmination to keep the intellect in activity. This is a very common occurrence anong industrious students, who, with a laudable desire for distinction, allow themselves less than the needed quantum of repose. Headache, tension, hcat, throbbing, and various other unpleasant sensations in the head, give warning that the brain is being overtasked; and if this warning be not taken, sleep, which it was at first difficult to resist, becomes even more difiicult to obtain; a state of general restlessness and feverish excitement is induced; and if, in spite of this, the effort be continued, serious consequences in the form of cerebral inflammation, apoplexy, paralysis, fever, insanity, or loss of mental power, more or less complete, are nearly certain to be induced. Some individuals can sustain such an effort much longer than other's, but it is a great mistake to suppose that they are not equally injured by it; in fact, being possessed with the belief that they are not suffering from the exertion, they frequently protract it, uutil a sudden and complete prostration gives a fearful demonstration of the cumulative effects of the injurious course in which they have been persevering. Those, consequently, who are earlier forced to give way, are frequently capable of accomplishing more in the end.- In regard to the degree of protraction of sleep which is consistent with a healthy state of the system in other respects, it is difficult to speak with certainty. Of the numerous well-authenticated instances on record, in which sleep has becn continuously prolonged for many days or even weeks, it is enough here to state that they cannot be regarded as examples of natural slecp; the state of such persons being more closely allied to hysteric coma. An unusual tendency to ordinary sleep generally indicates a congested state of the brain, tending to apoplexy; and it has been stated that apoplexy has been actually induced by the experimental attempt to ascertain low large a proportion of the diurnal cycle might be spent in sleep.-Thus, on either side, inattention to the dictates of Nature, in respect to the amount of sleep required for the renovation of the system, becomes a source of disease, and should therefore be carefully avoided.

583. Dreuming. - IVe liave hitherto spoken of Sleep in its most complete or profound form; that is, the state of complete unconsciousness. But with the absence of consciousness of external things, there may be a state of mental activity of which we are more or less distinctly cognizant at the time, and of which our subsequent remembrance in the waking state varies greatly in completeness. 'The chief peculiarity of this state of dreuming appears to be, that there is an cntire suspension of Volitional control over the current of thought, which flows on automatically, sometines in a uniform coherent order, but more commonly in a strangely incongruous sequence. The former is most likely to occur when the mind simply takes up the train of thought on which it hat been engaged during the waking hours, not long previously; and it may even lappen that, in conscquence of the frechom from distraction resulting from the suspension of extcrnal influences, the Reasoning processes may thus be carrich on during sleep with unusual vigor and success, and the Inagination may develop new and larmonious forms of beanty. ${ }^{2}$ The

1 Such, for example, as that of Samuel Chilton (Phil. Trans., 1694), and that of Mary Lyall (Trans. of loy. Soc. of Edinb., 1818).

2 Thus, Condoreet saw in his dreams the final steps of a dificult ealeulation which had puzzled him during the day; and Condillac tells us that, when engaged in his 
more general fact is, however, that there is an entire want of any ostensible coherence between the ideas which successively present themselves to the consciousness; and yet we are completely unaware of the incongruousness of the combinations which are thus formed. It has been well remarked that "nothing surprises us in dreams." All probabilities of "time, place, and circumstance" are violated; the dead pass before us as if alive and well; even the sages of antiquity hold personal converse with us; our friends upon the antiporles are brought upon the scene, or we ourselves are conveyed thither, without the least perception of the intervening distance; and oceurrences, such as in our waking state would cxcitc the strongest emotions, may be contemplated without the slightest feeling of a paintul or pleasurable nature. Facts and events long since forgotten in the waking state, and remaining only as latent impressions, on the Cerebrum, present themselves to the mind of the dreamer; and many instances have occurred, in which the subsequent retention of the knowledge thus reacquired has led to most important results. ${ }^{2} \quad$ But one of the most remarkable of all the peculiarities in the state of dreaming, is the rapidity with which trains of thought pass through the inind; for a dream in which a long series of events has seemed to occur, and a multitude of images has becn successively raiserl up, has been often certainly known to have occupied only a few minutes, or even seconds, although whole years may seem to the dreamer to have elapsed. There would not appear, in truth, to be any limit to the amount of thought which may thus pass through the mind of the dreamer, in an interval so brief as to be scarcely capable of measurement; as is obvious from the fact, that a dream involving a long succession of supposed events, has often distinctly originated in a sound which has also awoke the sleeper, so that the whole must have passed during the almost inappreciable period of transition between the previous state of sleep and the full waking consciousness." Hence it has been argued by some, that all our dreams really take place in the momentary passage between the states of sleeping and waking; but such an idea is not consistent with the fact, that the course of a dream may often be traced by observing the successive changes of expression in the countenance of the dreaner. It seems, however, that those dreams are most distinctly remembered in the waking state which have passed through the mind during the transitional phase just allnder to; whilst those which occur in a state more allied to Somnambulism, are more completely isolated from the ordinary consciousness.- There is a phase of the dreaming state which is worthy of notice as marking another gradation between this and the vigilant state; that, namely, in which the dreamer has a consciousness that he is dreaming, being aware of the unreality of the images which present themselves before

Cours d'Etude, he frequently developed and finished a subjeet in lis dreams, whieh he had broken off bcfore retiring to rest. Coleridge relates of himself that his fragment Kubla Khan was composed during sleep, whieh had eome upon him whilst reading the passage in Purchas's Pilgrimage, on which the portieal dencription was founded, and was written down immediately on awking, "the images rising up before him as things, with a parallel production of the corresponding expressions, without any sensation or eonseiousness of effort."

I See a number of such eases in Dr. Abercrombie's Inquiries concerning the Intelleetual Powers.

2 The only phase of the waking state in which any such intensely rapid sueeession of thoughts presents itself, is thit which is now well attested as a frequent occurrence, under circumstanees in whieh there is imminent danger of death, espeeially by drowning; the whole previous life of the individual seeming to be presented instantaneously to his view, with its every important incident vividly inpressod on his eonsciousness, just as if all were combined in a picture, the whole of which eould be taken in at a glanee. 
his mind. He may even make a voluntary and successful effort to prolong them if agreeable, or to dissipate them if unpleasing; thus evincing the possession of a certain degree of that directing power, the entire want of which is the characteristic of the true state of Dreaming.

584. But the sensibility to external impressions may not be entirely suspended in Dreaming; and it is curious that even where sensations are not recognized by the mind of the dreamer as proceeding from external objects, they may affect the course of its own thoughts; so that the character of the dreams may be in some degree predetermined by such an arrangement of sensory impressions as is likely to modify them. This is especially the case in regard to the dreamy state induced by certain narcotics, such as the Hachisch (a preparation of Cannabis Indica), employed for this purpose in the East; for the emotional condition of the individual under its influcnce is entirely under the control of external impressions; so that those who give themselves up to the intoxication of the fantasia, take care to withdraw themselves from everything which could give their delirium a tendency to melancholy, or excite in them anything else than feelings of pleasurable enjoyment. ${ }^{1}$ Moreover, there are certain forms of ordinary Dreaming, in which the whole succession of thought and feeling (which is made manifest by the words occasionally uttered, or by the play of countenance, or by the more active movements of the dreamer) may be governed by extcrmal suggestion ; as, for example, in the well-known case of the officer who amused his friends by acting his dreams during the expedition to Louisburgh, the conrse of these dreams being capable of direction by whispering into the sleeper's ear, especially if this was done by a friend with whose voice he was familiar. ${ }^{2}$ Such forms of Dreaming constitute a transition to the state of Somnambulism.

585. Somnambulism.-The phenomena of Sommambulism are so various, that it is difficult to give any general definition that shall include the whole; but it is a condition which is common to all forms of this state, that the controlling power of the Will over the current of thought is entirely suspended, and that all the actions are directly prompted by the ideas which possess the mind ; and the differences chiefly arise out of the mode in which the succession of ideas is directed, this being in some cases a coherent sequence through the whole of which some one dominant impression may be traced, whilst in other instances it is more or less completely determinable by external suggestions. These two forms are thus parallel to the states of spontaneous $\mathrm{Ab}$ straction and artificial Reverie (Electro-Biology) respectivcly; but differ from them both in this essential feature,- - that they oceur in a state of consciousness so far distinct from the ordinary waking condition, as not to be connected with it by the ordinary link of Memory; and that although the course of thought in Somnambulism usually manifests the directing influence of previous habits, and the knowledge of persons and things possessed during the waking state may be readily brought before the mind, yet nothing which occurs during the state of Somnambulism is ever retraced spontaneously, or can be brought back by an act of recollection. Impressions upon the nervous system, howcver, are sometimes left by strong enotional excitement, which

I See the Author's urticle, Sleep, in the Cychop. of Anat. and P'hys, vol, iv, pp. 688-690; and Morea, Du Hachisch et de Mlienation Mentale, Etudes Psyehologiques, 1. 67 .

'This case is detailed by Dr. $\Lambda$ bererombie (Inquiries eoncerning the Iutelleetual Powers, 5th ed., p. 277), on the authority of Dr. Grogory, to whom it was related by a gentleman who witnessed it. A case of a very similar nature, the subjeet of whieh was a medieal student at Edinburgh, is related in Smellie's Philosophy of Natural History. 
give rise to subsequent feelings of discomfort, of whose origin the individual is entirely unconscious. ${ }^{1}$ - In the first of the phases just referred to, a train of reasoning is often carried out with remarkable clearness and correctness, and its results expressed in appropriate language, or otherwise acted on. Thus, a mathematician may work out a difficult problem, an orator may make a speech appropriate to the occasion on which he supposes himself to be called up, or an author may compose and commit to writing poetry or prose, upon the subject which occupies his thoughts. But it is a frequent defect of the intellectual operations carried on in this condition, that through the complete absorption of the attention by one set of considerations, no account is taken of others which ought to modify the conclusion; and this, although it nay be palpably inconsistent with the teachings of ordinary experience, is not felt to be so, unless the latter should happen to present themselves unbidden to the thoughts.

586. The second of the phases above mentioned, which is especially seen in the artificial Somnambulism induced by the (so-called) Mesmeric process, or by the fixed gaze at a near object (as practiced by Mr. Braid under the name of Hypnotism), is essentially the same as that of the "biological" condition, save in the different relation which they respectively bear to the waking state; for there is the same readiness to receive new impressions through the senses (the visual sense, however, being generally in abeyance), and the same want of persistence in any one train of ideas, the direction of the thoughts being entirely determined by the suggestions which are introduced from without. In either of these extreme forms of Somnambulism, and in the numerous intermediate phases which connect the two, the consciousness seems entirely given up to the one impression which is operating upon it at the time; so that whilst the attention is exclusively directerl upon any object, whether actually perceived through the senses, or brought suggestively before the mind by previous ideas, nothing else is felt. Thus there may be complete insensibility to bodily pain, the somnambulist's whole attention being given to what is passing in his mind; yet in an instant, by directing the attention to the organs of sense, the anresthesia may be replaced by ordinary sensibility; or, by the fixation of the attention on any one class of sensations, these shall be perceived with most extraordinary acuteness, whilst there may be a state of complete insensibility as regards the rest.-Thus, the Author has witnessed a case in which such an exaltation of the sense of Smell was manifested, that the subject of it discovered without difficulty the owner of a glove placed in his hand, in an assembly of fifty or sixty persons; and in the same case, as in many others, there was a similar exaltation of the sense of Temperature. The exaltation of the Muscular Sense, by which various actions that ordinarily require the guidance of vision, are directed independently of it, is a phenomenon common to the "mesmeric" with various other forms of artificial as well as of natural Somnambulism. The Author has repeatedly seen Mr. Braid's "hypnotized" subjects write with the most perfect regularity, when an opaque screen was interposed between their eyes and the paper, the lines being equidistant and parallel; and it is not uncommon for the writer to carry back his pen or pencil to dot an $i$ or cross a $t$, or make some other correction in a letter or word. Mr. B. had one patient who would thus go back and correct with accuracy the writing on a whole page of note-paper; but if the paper was moved from the position it had previously occupied on the table, all the

1 See a very curious example of this kind, which fell under the Author's own observation, narrated in the article Sleep, in the Cyclop. of Anat. and Phys., vol. iv, p. 693. 
corrections were on the wrong points of the paper as regarded the actual place of the writing, though on the right points as regarded its previous place; sometimes, however, he would take a fresh departure, by feeling for the upper left-hand corner of the paper, and all his corrections were then made in their right positions, notwithstanding the displacement of the paper.-So, again, when the attention of the somnambulist is fixed upon a certain train of thought, whatever may be spoken in harmony with this is heard and appreciated; but what has no relation to it, or is in discordance with it, is entirely disregarded.

587. It is among the most curious of the numerous facts which Mr. Braid's investigations upon artificial Somnambulism have brought to light, that the suggestions derived from the "muscular sense" have a peculiar potency in determining the current of thought. For if the face, body, or limbs be brought into an attitude that is expressive of any particular emotion, or that corresponds with that in which it would be placed for the performance of any voluntary action, the corresponding mental state, that is, either an Emotional condition affecting the general direction of the thoughts, or the Idea of a particular action, is called up in respondence to it. Thus, if the hand be placed upon the vertex, the Somnambulist will frequently, of his own accord, draw his body up to its fullest height, and throw his hearl slightly back; his countenance then assumes an expression of the most lofty pride, and the whole train of thought is obviously under the domination of this feeling; as is manifested by the replies which the individual makes to interrogatories, and by the tone and manner in which these are delivered. There the first action does not of itself call forth the rest, it is sufficient to straighten the legs and spine, and to throw the head somewhat back, to arouse the emotion, with its corresponding manifestation, in its full intensity. If, during the most complete domination of this emotion, the head be hent forwards and the borly and limbs be gently flexed, the most profound humility then takes place. So, again, if the angles of the mouth be gently separateil from one another, as in laughter, a hilarious disposition is immediately generated ; and this may be made to give place to moroseness, by drawing the eyebrows towards each other and downwards upon the nose, as in frowning.' So, again, if the hand be raised above the head, and the fingers be flexed 11 pon the palm, the idea of chimbing, swinging, or pulling at a rope is called up in such as have been used to such kinds of exertion; if, on the other hand, the fingers be flexed when the arm is hanging down at the side, the idea suggested is that of lifting a weiglit; and if the same flexure be mate when the arm is advanced forwards in the position of striking a blow, the idea of fighting is at once aroused, and the Sommambulist is very apt to put it into inmediate execution. ${ }^{2}$

1 The Anthor has not only repeatedly witnessed all these effects, as produced by Mr. Braid upon "hypnotized" subjects, of whom severul had novor bex.n previously in that comdition, and had no idea whatever of what was expected from them; but he has bren assured by a most intelligent medical friend, who has paid special attention to the psychologiend part of this inquiry, that having subjeeted humself to Mr. Braid's practice, and having been only partially thrown into the "hypuntic" state (in faet, "biologized"), he distinctly remembers everything that was done, and ein retrace the uncontrollable effect 1 pon his emotional state, which was produeed by this management of his muscular appuratus.

20 one oeension on which alue Anchor witnessed this result, a violent bluw was struck, which elaneed to alight upon a second somnambulist within reach; his combativeness being thereby excited, the two closed, and began to belabor one another with such energy, that they were with difficulty separated. Althumh their passions were at the moment so strongly exeited, that even when separated they continued to utter furious denuneiations against each other, yet a little discreet manipulation of their muscles soon ealnied them and restored them to perfeet good humor. 


\section{CHA PTER XIV.}

\section{OF THE ORGANS OF THE SENSES, AND THEIR FUNCTIONS.}

\section{Of Sensibility in General.}

588. We have seen that the conscious Mind is affected by inpressions made upon the corporeal organism, or, in other words, that Sensation is produced, through the instrumentality of a certain part of the Encephalon termed the Sensorium, which is the general centre of the nerves both of "special" and of "common" sensibility: the former connect it with the special Organs of Sense, the latter with the body generally, to the several parts of which they are by no means uniformly distributed, some tissues being altogether destitute of then. Those parts of the body which are endowed with sensory fibres, and impressions on which, therefore, give rise to sensation, are ordinarily spoken of as sensible; and different parts are said to be sensible in different degrees, accordiug to the strength of the sensation produced by a corresponding impression on each. In accordance with the general fact of the dependence of all Nervous action on the continuance of the Circulation of the blood, it is found that the sensory nerves are distributed pretty much in the same proportion as the bloodvessels: that is to say, in the non-vascular tissues,-such as the epidermis, hair, nails, cartilage, and bony substance of the teeth,- - no nerves exist, and there is an entire absence of sensibility; and in those whose vascularity is trifling, as in the case with bones, tendons, ligaments, fibrous membranes, and other parts whose functions are simply mechanical, and even with serous and areolar membranes, there are few nerves, and the sensibility is dull. Many of these textures are acutely sensible, however, under certain circumstances; thus, although tendons and ligaments may be wounded, burned, etc., without much consciousness of the injury being aroused, they cannot be stretched without the production of considerable pain; and the fibrous, serous, and areolar tissues, when their vascularity is increased by inflammation, also become extremely susceptible of painful impressions. All very vascular parts, however, do not possess acute sensibility; the muscles, for instance, are furnished with a large supply of blood, to enable them to perform their peculiar function; but they are not sensible in by any means the same proportion. Even the substance of the brain, and of the nerves of special sensation, appears to be destitute of this endowment; and the same may be said of the mucous membranes lining the interior of the several viscera, which, in the ordinary condition, are much jess sensible than the membranes that cover those viscera, although so plentifully supplied with blood for their especial purposes. 'The most sensible of all parts of the body is the Skin, in which the sensory nerves spread themselves out into a minute network; and even of this tissue, the sensibility differs greatly in different parts (\$594). - The organs of Special Sensation become, by the peculiar character of the nerves with which they are supplied, the recipients of impressions of a particular kind: thus, the Eye is sensible to light, the Ear to sound, etc.; and whatever amount of ordinary sensibility they possess, is dependent upon other sensory nerves. The eye, for example, contrary to the usual notions, is a very insensible part 
of the borly, unless affected with inflammation; for though the mucous membrane which covers its surface, and which is prolonged from the skin, is acutely sensible to tactile impressions, the interior, with the exception of the Iris, is by no means so, as is well known to those who have operated much on this organ. And the common sensory nerves which supply certain parts of the body, are adapted to receive and convey to the mind impressions of particular kinds, with much greater readiness than they communicate those of a different description; thus the sensibility to tickling is much greater on some parts of the surface than on others; and this kind of excitement, applied to the genitals or to the nipple, produces sensations of a most peculiar order.

589. An active Capillary Circulation being essential to the sensibility of every part supplied with nerves, any cause which retards this deadens the sensibility, as is well seen with regard to Cold; and, on the other hand, an increase in its energy produces a corresponding increase in the sensibility, as is peculiarly evident in the "active congestion" which usually precedes and accompanies inflammation. A diminution or increase of sensibility to external impressions may arise, however, not only from an abnormal state of the circulation in the organ or part itself, but from the similar conditions affecting that part of the Sensorium in which the impressions are received. Thus in those various conditions of the Encephaton, in which either a stagnation of the circulation, or an abnormal state of the blood (such as that produced by anæsthetic agents), occasions a diminished functional activity in the Sensorial centres, this is marked by obtuseness to sensory impressions; on the other hand, in active congestion of the brain, the most ordinary cxternal impressions produce sensations of an unbearable violence; and in that peculiar condition of the nervous system known under the name of Hysterical, the patients often manifest the same hyperesthesia, even when the circulation is in a feeble, rather than in an excitcl state. ${ }^{1}$ It is remarkable that the sensibility of the nucous membranes lining the interual organs, is less exalted by the state of inflammation, than is that of most other parts ; and in this arrangement we may trace a wise aud beneficent provision; since, were it otherwise, the functions necessary to life could not be performed withont extreme distress, whenever a very noderate amount of disorder might exist in the viscera. If a joint is inflamed, we can give it rest; but to the actions of the alimentary canal we can give little voluntary respite.

590. It is through the medium of Sensation that we acquire a knowledge of the material Universe around us, by the psychical operations which its changes excite in ourselves. The various kinds or modes of Sensation suggest to us various ideas regarding the properties of matter; and these properties are known to us, only through the changes which they produce in the several orgatns. It is well known that instances exist, in which, from some imperfection of the organization, there is an incapacity for distinguishing colors or musical tones, whilst there is no want of sensibility to light or sound; and that some persons are naturally endowed with a nucle greater ramge of the sensory facultics, than that possessed by others. Hence it does not seem at all improbable, that there are properties of matter of which none of our senses can take immediate cognizance; and which other beings might be formed to perceive, in the same manner as we are sensitive to lighlit, sound, etc. Thus many animals are affected by atmospheric changes, in

1 The influence of toxic agents introduced into the blood, in producing Ana-thesia and Hyperasthesia, constitutes a very wide fleld of inquiry, the investigution of which has been ably commenced by Dr. Anstic, in his interesting work on Stimulunls and Nareotices (London, 1864). It is remarkable that Lead and Alcohol should be capable of inducing cither of these states. 
such a manner that their actions are regarded by Man as indications of the probable state of the weather; and the same is the case in a less degree with some of our own species, who are peculiarly susceptible of the like influences. - Now the most universal of all the qualities or properties of Matter, on which, in fact, our notion of it is chiefly founded, is its occupation of space, producing a more or less complete resistunce to displacement ; and this quality is that through which alone any knowledge of the external world can be obtained by a large proportion of the lower Animals; contact between their own surface and some material body, being required to produce sensation. We shall presently see, however, that the idea of the shape of a borly which we form from the touch, results from a very complex process, such as animals of the lower grades can scarcely be supposed to exercise. There can be little doubt that, next to the mere sense of resistance scnsibility to temperature is the most universally diffused through the Animal kingdom; and probably the consciousness of luminosity is the next in the extent of its diffusion. $^{1}$ It is probable that the sense of taste (which has a close affinity to that of touch) exists very low down in the animal scale, being obviously of great importance in the selection of food; but the Anatomist has no means of ascertaining where this refinement exists, and where it does not; since the orgaus of taste and touch are very similar. The sense of hearing does not seem to be distinctly present among the Invertebrate animals, except in such as approach most nearly to the Vertebrata; it is not improbable, however, that sonorous vibrations may produce an effect upon the system of those animals which do not receive them as sound. The sense of smell, which is concerned with one of the least general properties of matter, appears to be the least widely diffuserl among the whole; being only possessed in auy high degree by Vertebrated animals, and being hut feebly present in a large proportion of these.

591. Besides the various kinds of sensibility which have been just enumeratcd, there are other's which are ordinarily associated together, along with the sense of material resistance (and its several morlifications), and the sense of temperature, under the head of Common Sensation; but several of them, especially those which originate in the body itself, can scarcely be regarded in this light. Such are the feelings of hunger and thirst; that of nausea ; that of distress resulting from suspended aeration of the blood; that of "sinking at the stomach," as it is vulgarly but expressively described, which results from strong mental emotion; the sexual sense, and perhaps some others.-Now in regard to all these, it is impossible in the present state of our knowledge to say, whether their peculiarity results from the particular constitution of the nerves that receive and convey them, or ouly from a modification of the impressing causes, from the particular endowments of their ganglionic centres, and firom the inode in which they operate. Thus we have no evidence whether the nervous fibrils which convey from the lungs the sense of distress resulting from deficient aeration, are of the same or of a different character from those which convey from the surface of the air-passages the sense of the contact of a foreign body. But as we know that all the trunks along which these peculiar impressions travel, do min-

1 There is gond reason to believe, from observation of their habits, that many animals ure susceptible of the influence, and are directed by the guidance of light, whose organs are not adapted to receive true visual impressinns, or to furm optieal images; and such would seem to be the function of the red spots, frequently scen on prominent parts of the lower Articulata and Nollusca, and even of some Radiata. Wherever these are of sufficient size to allow their structure to be examined, they are found to be largely supplied with nerves, but to be destitute of the peculiar organization which ulone constitutes a true eye. 
ister to ordinary sensation, whilst the nerves of truly "special" sensation are not sensible to tactile impressions, it is evident that the probability seems in favor of the identity of the fibres which minister to these sensations, with those of the usual sensory character. We shall see that with regard to the sense of Temperature, there is strong evidence that its peculiarity partly depends on the specialty of the apparatus by which impressions are received at the peripheral extremities of the tactile nerves, and partly upon some peculiarity in the transmitting fibres.

592. There are certain external agencies which can excite changes in the Sensorium through sevcral different channels; the sensation being in each case characteristic of the particular nerve on which the impression is made. Thus pressure, which produces through the nerves of common sensation the feeling of resistance, is well known to occasion, when exerted on the eye, the sensation of light and colors; and, when made with some violence on the ear, to produce "tinnitus aurium." It is not so easy to excite sensations of taste and smcll by mechanical irritation; and yet, as was shown by Dr. Baly, ${ }^{1}$ this may readily be accomplished in regard to the former. The sense of nausea may be easily produced, as is familiarly known, by mechanical irritation of the fauces. Electricity still more completely possesses the power of affecting all the sensory nerves with the changes which are peculiar to them ; for, by proper management, an individual may be made conscious at the same time of flashes of light, of distinct sounds, of a phosphoric odor, of a peculiar taste, and of pricking scnsations, all excited by the same cause, the effects of which are modified by the respective peculiarities of the instruments through which it operates.-But although there are some stimuli which can produce sensory impressions on all the nerves of sensation, it will be found that those to which any one organ is peculiarly fitted to respond, produce little or no effect upon the rest. Thus the ear cannot distinguish the slightest difference between a luminous and a dark object. A tuningfork which, when laid upon the ear whilst vibrating, produces a distinet musical tone, excites no other sensation when placed upon the eye than a slight jarring feeling. The most delicate touch cannot distinguish a substance which is sweet to the taste, from one which is bitter; nor can the taste (if the communication between the mouth and the nose be cut off') perceive anything peculiar in the most strongly odoriferous bodies.-It may hence be inferred that no nerve of special sensation can, by any possibility, take on the function of another. ${ }^{2}$

\section{Sense of Touch.}

593. By the scnse of Touch, as commonly understood, is meant that modification of the common sensibility of the borly, of which the Cutaneous surface is the special scat. The Skin is peculiarly adapted for th is purpose, not merely by the large amount of sensory nervous fibres which are distributed in its sulstance, but also by its possession of a papillary apparatus in which these nerves for the most part terminate, or rather commence. The papille

1 Trumblation of Müller's Elements of Physiology, p. 1062, note.

2 It does not, however, seem $u$ thing altogrether incredible, that impressions powerfully arousing one sense may consentameously exeite another sense, and in evidenec of ilis Nusmbumer, Monatschrift f. Ohrenheiliund, March, 1873, records the faet, that loth he and his brother can perceive certain eolors when the auditory nerve is pow rfully "xcited by certain sounds. In one brother "a" on the piano produces thesubjective impression of dark Prussian blue, in the other brother it produces dark yolluw. Simo of the colors, though differing in the two brothers, are not produeed by any sound. 
are little elevations of the surface of the cutis, usually simply conical or clavate in form (Fig. 249), but sometimes presenting numerous summits. On the palmar surface of the hand, they are arranged in lows; and they are there so numerous that (according to E. H. Weber) as many as 81 compound, or from 150 to 200 simple papillse, are contained within the area of a square (Paris) line. The papillie are also very numerous, though without any definite arrangement, on the red surface of the lips, on the penis of the male, on the labia minora and clitoris of the female, and on the nipples of both sexes; but elsewhere they are scattered more widely apart. Each sensory papilla receives one or more nerve-fibres from the plexus which is formed by the inosculation of the ranifications of the cutaneous nerves (Fig. 249);

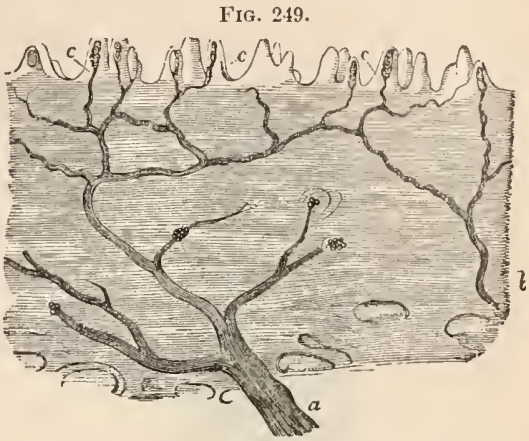

Vertical Section of the Skin of the palmar surface of the forefinger (treated with a solution of caustic soda), showing the branches of cutaneous perves, $a, b$, inosculating to form a terminal plexus, of which the ultimate ramifications pass into the cutaneous papillie, $c, c, c$. and these nerve-fibres seen to tcrmi-

nate (at least in the papillie of the palm of the hand and of the lips, and in the simple papilla of the tongue) in a peculiar "axile body," which occupies the principal part of the interior of the papilla (Fig. 250). With regard to the nature of this body, there has been considerable discussion between Prof. Wagner, its discoverer, and Prof. Kölliker ' ${ }^{1}$ the former regarding it as an organ altogether sui generis; whilst the latter maintains that it is nothing else than a mass of homogeneous connective-tissue with an cxternal layer of imperfectly-rleveloped elastic tissue, and that it is essentially similar to the bundles of fibrous tissue encircled by elastic fibres, which are to be found in the substance of the cutis. 'This last view is in the main supported by Mr. Huxley, who regards the "axile body" as formed by the continuation and increased development of the neurilemma of the nerve-tubes which enter the papilla, and as bearing a close relation to the "Pacinian bodies." The recent observations of Rouget, Biesiadecki, and Thin seem to show that the tuctile corpuscles really represent the specially modified termination of a

1 For details in regard to the strueture of the corjusculat taetus and the terminations of the taetile nerves, see Prof. Waguer in the Göttingen Gelehrte Naehriehten for Feb. 1852, and Müller's Archiv, 1852, Heft 4; Prot. Kölliker in Zeitseh. für WVissemsch. Zuol., Jume, 18.52, and in his Mik Anat., Bd. ii, p. 24; Dalzell, in Edin. Mouthly Journal, March, 18.53; Eeker, Icon., Physiol., plate xvii ; Leydig, ML̈̈ller's Archiv, 1856, p. 50, and Schultze's Archiv. f. Iie. A nat., 1868, p. 195; Grrach, Mikroskop. Siudien, Erlangen, 18.58; Krause, Die Terminal Körperchen der pinfach Sensibeln Nerven, Hanover, 1860 ; Huxley, in Cyclop. of Anat. Physiol., Suppl., Art. Tegument. Organs, 1859, p. 503; Meissner, Beiträge, plute i, Figs. 6 and 8; Henle, Handb. der System. Anut., 1862, Bd. ii, p. 13; Fiek, Lehrb. der Anat. der Simues Organe, 1862, p. 22; Tomsa, Wien Med. Woehens., 1865, Bd. xv, p. 53 ; Rouget, Alchiv. de Physiol., 1868, p.598; Miehelson, Centrulblatt, 1869, p. 446; G. Ciaceio, Molesehott's U'ntersuch., Bd x, p. 579 ; J. Schöhl, Schultze's Arehiv, Bd. vii, p. 260, and viii, p. 295; Th. Eimer, Idem, Bd. vii, p. 181; L. Stieda, Idem., Bd. viii, p. 274; W. Beil, A bst. in Centralblatt, 1872, p. 692; Sertoli, A bst. in Centralblatt, 1872, p 692; Budge, Centralblatt, 1873, p. 594; Langerhans, Schultze's Arcliv, Bd. ix, p. 730 ; Jobert, Comptes Rendus, 1874, p 820; G. Thin, Journ. of Anat. and Phys., 1874, p. 30 ; Biesiadecki, in Strieker's Hum. and Comp. Histology, vol. ii, p. 232; Grandry, Jurnal de l'Anatomie, t. vi, 1870, n. 390

" Sce his Memoir, On the Structure and Relation of the Corpuscula Tactus, in the Quarterly Journai of Mieroscopical Science, vol. ii, p. 1. 
single medullated nerve-fibre. The nerve runs without division sometimes only as far as the lower pole, sometimes as far as the middle, and sometimes even to the extremity of the eorpusele, frequently winding around it onee or

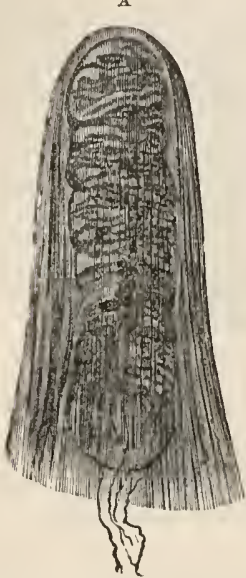

FIG. 250.

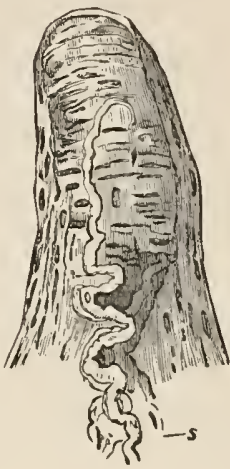

Tactile Papillæ from the Skin of the palmar surface of the forefinger, showing the tactile corpuscles or "axile bodies :" $A$, in the natural state; $B$, treated with acetic acid.

twiee, and eonstrieting it at these points. The nerve at length suddenly loses its medulla and ean no longer be traeed, so that the termination of the axiseylinder is unknown. The corpusele further presents eertain transverse elements (Fig. $250 \mathrm{~B}$ ), which are the nuelei of oblong eells, and anastomose with eaeh other by means of prolongations of elastie tissue fibres. The eapsule of the eorpusele is formed by a eireular layer of elastie tissue formed by the anastomosing processes of eells. ${ }^{1}$ That the axile eorpuseles of Wagner are intimately assoeiated with proper nervous tissue, is clearly shown by the fatty degeneration they undergo on seetion of the nerves supplying them. In a majority of so-ealled nerve-papilla one or more eapillary loops may easily be demonstrated. A very simple form of the axile bodies has been described by Krause as oceasionally oceurring in the eonjunetiva, lips, and

Fig, 251.

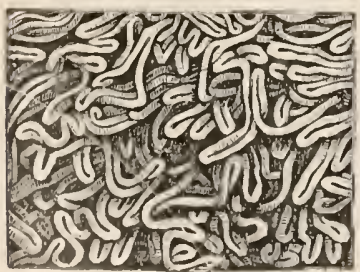

Capillary lonjs in Cutaneous papillie at margin of lips. soft palate, in the tongue, and in the glans penis and glans elitoridis. Here the nerve forms a "terminal button or knob," eonsisting of a delicate sheath dotted with nuclei and filled with granular plasma, into which the cylinder-axis of the nerve enters terminating by a simple blunt extremity. In the Pacinian bodies, the number of which in Man is estimated by Rauber to be $21+2,{ }^{2}$ a more complex strueture is met with than in either of those just mentioned, the chief difference being that instead of a single sheath, there are many investing eapsules; a spaee

1 Dr. Beale appears to duubt the termination in any instance of sensory nerves by free extremities; for he has evorywhere obtained demonstrative evidence of a network, the fibres being often of extrardinary tenuity. He believes that in the papillae of the skin, and even in the Pacinian bokles, after bocoming connected with nuclei or corpuseles the nerve-tibres turn or loop back to the cell from whence they originate.

2 Untersuch. München, 1867. 
being, however, always left between the innermost one and the extremity of the nerve, in which a fluid or scmifluid substance is contained. As the "corpuscnla tactus" and "Pacinian bodies" are only to be found in the papilla of those parts which are distinguished for acuteness of tactile sensibility, we cannot regard them as essenticl to the exercise of the sense of touch; their function, either being to intensify tactile impressions, where delicacy of touch is peculiarly required, or perhaps to supply information in regard to variations in the strength of certain stimuli, as those of temperature or pressure.

594. The relative sensibility of different parts of the Skin may bc in some degree judged of by the results of the observations of Prof'. E. H. Weber ; whose mode of ascertaining it was to touch the surface with the legs of a pair of compasses, the points of which were gnarded with pieces of cork, and then (the eyes being closerl) the legs were approximated, until they were brought within the smallest distance at which they conld be fclt to be distinct from one another, which has been termed by Dr. Graves "the limit of confusion."-The following are some of the measurements taken:

Point of tonume,

Palmar surface of third phalan $x$,

Red -urface of lins,

Palmar surface of second plialanx,

Palinar surface of metacar-

Tip of the nose. • • . .

Dursum and edge of tongue,

Part of lips covered by skin,

Pulm of hand, . . . . .

Skin of cheek, . . . . .

Extremity of great toe, . . 5 "6

Hard palate, . $\frac{1}{2}$ of a line.

1 line.

2 lines.

216

316

3 "

4 16

466

56

616

6 "6
Dorsum of hand,

Mucous menbrane of gums,

Luwer part of forehead, .

Lower part of occiput, .

Back of hand,

Vertex,

Skin over patella, . . . . 16 "

" sacrum, . . . 18 "

"6 acromion, * . • 18 "

Dorsum of fout. • . . . 18 "

Skin over sterrum, . . . 20 "

Skin beneath oceiput, . . 24 "

Skin uver spine, in back, . 30 "

Midale of the thigh, . . . 30 "

It is curious that the distance between the legs of the compasses, as well as the rapility of their motion when they were lightly drawn over the skin, seemed to be greater (although really so much less), when it was felt by the more sensitive parts, than when it was estimated by parts of less distinct sensibility. With the extremities of the fingers and the point of the tongue the distance could be distinguished most easily in the longitudinal direction ; on the dorsum of the tongue, the face, neck, and extremities, the distance could be recognizerl best when the points were placed transversely. As a general fact, it seems that the sensibility of the trunk is greater on the median line both before and behind, and less at the sides. Differences in the temperature and weight of bodies were, according to Prof.' Weber's observations, most accurately recognized at the parts which were determined to be most sensible by the foregoing method of inquiry. ${ }^{3}$ - It has been since

1 In proof of which, various ingenious experiments have been made by Kranse (see Zeitschrift für Rat. Med., xvii, p. 278). He explains their presence in the mosentery of the Cat as connected with the mechanism and arrangement of the viscera required for the act of springing.

2 For similar experiments performed by Dr. Ballard, see Lancet, 1862, vol. i, p. 303. Dr. Ballard found that in the hand the tip of the index finger was the most, the dorsal surface of the base of the fifth metacarpal bone the least, sensitive part; the limit of confusion in the former being 0.35 of a line, in the latter 5 lines.

${ }^{3}$ See his Mrmoir, De Pulsu, Respiratione, Auditu, ct Tuctu, Lipsire, 1834. Sre also Recherehes sul la Nature, la Distribution, et l'Organe du Sens Tactile, by M. H. Belficld-Lefèrre, Paris, 1837; and Prof. Valentin's Lehrbuch der Physiolicie des Menschen, Bd. ii, 566.- In the Author's article, Touch, in the Cyclopadia of Anat- 
found, however, by Prof. Valentin, who has followed up and extended Prof. Weber's observations, that a consilerable amount of individual variation exists in regard to the "limit of confusion " some persons being able to distinguish the points at one-half or even one-third of the distances required by others. Czermak ${ }^{1}$ has drawn attention to many curious facts in relation to the "sense of space," or "locality" possessed by the skin; and has particularly shown that two points nay be much more closely approximated, and yet distinguished as two, if they are applied one after the other, than if they are applied together. The delicacy of the sense of touch is diminished if the skin be either artificially or naturally stretched; hence the skin of the belly is less sensitive during pregnancy than under ordinary circumstances, and this may aiso in some measure serve to explain the diminution in sensibility which occurs in the passage from childhood to adult age, though the difference is no doubt partially due to the increased thickness of the epithelium. The theory of the sense of tonch which has been suggested by Fick, is that each nerve-fibril breaks up into a pencil of fine filaments at the periphery, which are distributed over a certain space, perhaps on the average about $\frac{1}{25}$ th of an inch in diameter. An impression made upon any

FIG. 252.

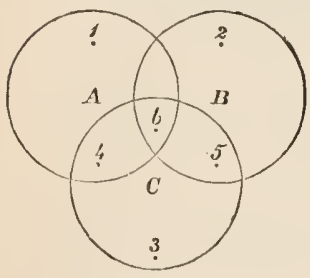
one of these filaments conveys the same sensation to the sensorium, providing no other nerve be distributed to the same space; but this hardly ever occurs, and hence compound sensations arise, by which our perception of the precise spot of the skin tonched by a point is accuratcly determined. Thus, if we suppose the distribution of nerves to be represented by the circles A, B, C (Fig. 252), single sensations would be produced if a point were applicel at 1,2 , or 3 , but a compound sensation would be produced if contact were made at 4 or 5 , fir the fibrils of two nerves, $A$ and $C$, or B and $C$, would be implicated; whilst if the impression were made at 6 , a still more complex sensation would arise, for then the peripheral branches of three of these nerves would be affected; in all instances a difference in the character of the impression capable of recrognition by the mind being producer. It is obvious that the closer these "sensory circles" are, and the more intimately the branches of different nerves are intercalated with one another, the greater will be the acenracy of the sense of locality of that part, or, in other words, the greater will be the facility with which minute differences in the precise spot tonched will be appreciateil. The experiments of Dr. Paulus show that the sensitiveness of the skin of the lower extremity, in accordance with a theory propounded by Vierordt, increases with its distance from the axis of rotation of the limb, or, in other words, from the proximal joint, and with the freedom witl which its morements can be cxecuter. The leg is thus more sensitive than the thigh, the foot than the leg, and the toes than the foot, the sensitiveness in each division acrain augmenting from its own proximal joint, exrept in the single ease of the leg proper, where the minimum acuity is opposite the centre of the tibia; but this, as Paulus points ont, really favors Tierorlt's theory, since, muler different circunstances, sometimes the upper and some-

omy and Pliysiology, vol. iv, p. 1169, will be found a Table including the whole serios of observations made by Profs. Wober and Valentin, the maxima and minima of the latter being stated, as well as the means.

'Sitz.-ber. der Wiener Akall, Bd. xvii, p. 563, Bd. xxiv, p. 231 ; and Moleschott's Untersuch., Bal. i, p. 188.

2 Paulus, Zuit-chrift f. Biologie, Bd. vii, p. 237; see also Kottenkamp and Ullrich, idem, Bu, vi, p. 37 . 
times the lower part of the leg moves through the greatest are. In the arm the increase of sensitiveness firom the shoulder to the tips of the fingers is as $1: 24$; in the leg as $1: 8 \frac{1}{2}$, which may be accounted for by the greater rapidity required in the movements of the arm as conpared with those of the leg.

595. As already stated $(\$ 590)$, the only idea communicated to our minds by the sense of 'Touch, when exercised in its simplest form, is that of Resistance; and it is by the various degrees of resistance which the sensory surface encounters, of which we partly judge by the muscular sense ( $\$ 5.38)$, that we estimate the hardness or softness of the body against which we press. It is only when cither the sensory surface or the substance touched is made to change its place in regard to the other, that we obtain the additional notion of crtension or space; this also being derived from the combination of the muscular with the tactile sense. By the impression made upon the papillie, during the movement of the tactile organ over the body which is being examined, the roughness, smoothness, or other peculiar characters of the surface of the latter are estimated. Our knowledge of form, however, is a very complex process, requiring not merely the exercise of the sense of tonch, but also great attention to the muscular sensations. - It is chiefly, as formerly remarked, in the variety of movements of which the haud of Man is capable, that it is superior to that of any other animal; and it cannot be doubted that the sense of Touch thus employed, affords us a very important means of acquiring information in regard to the external world, and especially of correcting many vague and fallacious notions which we should derive from the sense of Sight, if used alone. On the other hand, it must be confessed that our knowledge would have a very limited range, if this sense were the only medium through which we could acquire ideas. It is probably on the sensations communicated through the Touch, that the idea of the material world, as something external to ourselves, chiefly rests; but this idea is by no means a logical deduction from our experience of these sensations, being rather an instinctive or intuitive perception directly excited by them.

596. Various experimenters ${ }^{1}$ have endeavored to determine the accuracy with which the Skin can appreciate impressions of weight or pressure when unassister by the "muscular sense," that is when the part experimented on is well sapported, as when the hand is laid upon a table. Aubert and Kammler found that on the face and dorsal surface of the upper extremity, the pressure of a portion of elder-pith, presenting a surface of nearly onethird of an inch square, and weighing only $\frac{1}{3} \mathrm{~d}$ of a grain (2 mgrm.), coukd be distinguished; whilst the tips of the fingers required a weight, presenting the same superficies, of $\frac{1}{3} d$ of a grain or more, and the tocs as much as 8 grains, before any sensation of pressure was felt. The presence of the minute hairs on the face was, however, found materially to influence its sensibility, since when these were shaved off it was much diminished.-According to Weber, differences in the amount of pressure are more accurately distinguished if they are applied successively to the same point, than if they are estimated coetaneously. The interval, however, must not be more than a few seconds, unless the difference be considerable. Thus when 4 ounces and 5 ounces were'successively applied, an accurate judgment of the difference might be made after 90 seconds; but the difference between 14.5 and 15 ounces could not be accurately determined after 40 seconds. If the bare sense of pressure were assisted by the muscular sense, as in cases when the hand was unsupported, much finer discrimination was always displayed.

${ }^{1}$ Aubert and Kammler, Molcschott's Untersuch., Bd.v, p. 145; Dohrn, Zeits. f. Rat. Med., 1860. 
Thus on lifting a cloth in which weights were concealed, Weber found that ten people eorrectly indicated that a weight of 80 ounces was heavier than one of 78 ounces. Both Weber and Feehner ${ }^{1}$ appear to have satisfactorily shown that with light weights smaller differences are perceived than with heavy weights. Thus supposing that ounce weights are distinguishable in the ratio of 29 to $30,-i . e$, that a weight of 29 ounces can be discriminated whell attentively examined from one of 30 ounces, a whole ounce requiring to be added or subtracted before certainty is attained;- when druchms are employed the same ratio still subsists, so that in this instance the removal or addition of one drachm to a weight of 30 drachms can be aecurately appreciated. Meissner has drawn attention to the fact, which must be familiar to most persons, that if the hand or foot be immersed in warm water or mereury, the only sensation experienced is that of a ring surrounding the limb at the surface of the fluid. This effect is, as he suggests, probably due to the circumstance that the pressure is applied in sneh cases with perfeet uniformity over the part immersed, and therefore eauscs no disturbance of the nervous elements, the tactile sense being only exeited at the line where the pressure produced by the fluid is exchanged for that of the air.- Valentin ${ }^{2}$ has endeavored to ascertain the duration of a monentary excitation of the sense of 'Touch by rolling a spiked wheel over the skin; when slowly rotated, the contact of each spike was clearly diseerned; but when only $\frac{1}{4} 0$ th of a second intervened between the suecessive blows, they could no longer be distinguished.-That the conditions under whieh eertain of the modifications of common sensation operate, are in some respects different from those of ordinary Touch, is very easily shown. Thus, the feeling of tiekling is excited most readily in parts which have but a low tactile sensibility, namely, the armpits, flanks, and soles of the feet; whilst in the points of the fingers, whose tactile sensibility is most acute, it cannot be excited. Moreover, the nipple is very moderately endowed with ordinary sensibility; yet by a particular kind of irritation, a very strong feeling may be excited through it.A gain, in regard to Temperature, it is remarked by Weber that the left hand is more sensitive than the right; although the sense of toueh is undoubtedly the most acute in the latter. He states that if the two hands, previously of the same temperature, be plunged into separate basins of warm water, that in which the left hand is immersed will be felt as the warmer, even though its temperature is somewhat lower than that of the other. In regard to the sensations of heat and eold, he points out another eurious faet, - that a weaker impression made on a large surfice, scems more powerful than a stronger impression made on a small surface; thus, if the forefinger of one hand be immersed in water at $104^{\circ}$, and the whole of the other hand be plunged in water at $102^{\circ}$, the cooler water will be thonght the warmer; whence the well-known faet, that water in which a finger ean be held, will scald the whole hand. Hence it also follows, that minute differences in temperature, which are impereeptible to a single finger, are appreciated by plunging the whole hand into water; in this mamner a difference of one-third of a degree may readily be detected, when the same hand is placed successively in two vessels. T'he judgment is more accuratc, when the temperature is not much above or much below the nsual heat of the body; just as sounds are best discriminated, when neither very aente nor very grave.

597. Whether the chamnels for the conduction of sensations of pain, tickling, and temperature are distinct from those of touch is still doubtful. 'The

I Elemente der Psychophysik, 1860.

2 Ueber die Dauer der Tasteindrücke, Archiv f. Physiol. Heilk, Bd. xi, p. 438. 
pathological observations of M. Brown-Séquard ${ }^{1}$ strongly support the view that such separate conductors do exist, and he cven believes he has demonstrated that the nerves conducting these four kinds of impression from the inferior extremities and greater part of the trunk after decussation arc situated in the upper part of the Spinal Cord, behind the corresponding group belonging to the upper limbs and the ncek; and Horvath ${ }^{2}$ has made the curious observation, that if the fingers be kept for some time in alcohol, only a few degrees $\left(8^{\circ}\right)$ above the freezing-point, whilst the tactile sensibility is retained, the prick of a needle is not felt. The experiments made by Weber ${ }^{3}$ to determine whether there are special conductors for temperature, in which he applied spatulas of different temperature $\left(48^{\circ}\right.$ and $122^{\circ} \mathrm{F}$.), to the surface of the skin denuded of its integument by a burn, and found that only pain was experienced, are of little value. It is remarkable, however, that we cannot excite impressions of heat or cold by direct application to the trunks of nerves which we know must conduct such impressions; for the parts of the skin, immediately beneath which lie large nerve-trunks, are not more sensitive to moderate heat and cold than are any others; whilst a greater degree of either is felt as pain, not as a change of temperature. Thus, a mixture of ice and water applied over the uhnar nerve, affects it in fifteen seconds, and produces severe pain, having no resemblance to cold, and such as cannot be excited by the same degree of cold applied to any other region. So the nerve of the tooth-pulp is equally and similarly affected by water of $43^{\circ}$ and of $112^{\circ}$; either application causing a pain exactly similar to that excited by the other, or to that produced by pressure. The same is true of the impressions received through the skin itself, when they pass beyond certain limits of intensity ; thus, the sensation produced by touching frozen mercury is said to be not distinguishable from that which results from touching a red-hot iron. Wislicenus ${ }^{4}$ and Fick, moreover, found that sensations of heat, even in the most sensitive parts of the body, were sometimes mistaken for those of contact. Thus in the case of the hand, an erroneous conclusion was arrived at six times out of 105 trials, and on the back twelve times in 30 experiments. The perception of variations of temperature does not extend in the nucous membranes far beyond their external orifices. Thus, Weber found that on drinking a tumbler of water $32^{\circ}$, he felt the cold water in the mouth and pharynx, but its passage into the stomach could not be perceived. There was, it is true, a slight scnsation of cold in the gastric region, but as it only occupied the situation of the anterior wall of the stomach, it was attributable to the abstraction of heat from the abdominal integuments in contact with this. On drinking three glasses of milk at $158^{\circ}, 145^{\circ}$, and $140^{\circ}$, the sensation of heat could not be traced lower down than that of the cold in the previous experiment. In like manner, the injection of fourteen ounces of water at $65^{\circ}$ into the rectum produced scarcely any sensation of cold, though on its return, a few minutes afterwards, a distinct feeling of cold at the anus. When water at so low a temperature as $45.5^{\circ} \mathrm{F}$. was injected, the first feeling excited was a sensation of cold in the immediate neighborhood of the anus, and then a feeble movement in the borrels; but, a little time afterwards, there was a faint sensation of cold, especially in the anterior wall of the abdomen. This sensation, however, remained after the return of the water; and may hence be attributed to the abstraction of warmth from the abdominal integuments, which was proved to have taken

1 Archives de Physiologie, 1868, vol. i, p. 610; see also Sieveking, Med.-Chir. Rev., 1858, p. 280; Spring, Presse Médicale, 1864, No. xxxiv.

2 Centralblatt, 1873, p. $208 . \quad{ }_{3}$ Mlüler's Archiv, 1849, p. 273.

4 Henle and Meissner's Bericht, 1859, p. 632. 
place, the temperature of the surface being lowered $3^{\circ}$. So, again, if the cavity of the nose be filled with cold water, the coldness is only perceived in the parts of the cavity which are most endowed with the proper tactile sense, namely, the neighborhood of the nostrils and of the pharynx; and it is not at all discernible in the higher part of the cavity, which is especially subservient to the olfactory sense. But when the water injected is very cold $(e . g$, $41^{\circ}$ ), a peculiar pain is felt in the upper part of the nasal fosse, extending to the regions of the forehead and the lachrymal canals; this pain, however, is altogether different from the sense of coldness. In Nothnagel's ${ }^{1}$ extensive series of experiments it was found that slight differences of temperature are most acutely recognized between $80^{\circ}$ and $91^{\circ}$ Fahr. The eyelids, cheeks, and temples can distinguish variations amounting to not more than from $0.4^{\circ}$ to $0.2^{\circ} \mathrm{C}$. The hand and finger are about equally sensitive, but are less so than the forearm, and this again is exceeded by the upper arm, which can distinguish a difference of $0.2^{\circ} \mathrm{C}$, and the same holds good of the foot, leg, and thigh.

598. The improvement in the sense of Tonch, in those persons whose dependence upon it is increased by the loss of other senses, is well known; and the remarkable circumstance noticed by Volkmann, ${ }^{2}$ that the increased sensitiveness which results from frequent experiments made upon one side of the body is experienced also in the nerve-fibres distributed to the opposite and exactly symmetrical parts, seems to show that the improved delicacy of the sense is to be in part attributed (as already remarked) to the increased attention which is given to the sensations, and in part, it may be surmised, to an increased development of the tactile organs themselves, resulting from the frequent use of them. The process of the acquirement of the power of recognizing elevated characters by the touch, is a remarkable example of this improvability. When a blind person first commences learning to read in this manner, it is necessary to use a large type; and every individual letter must be felt for some time, before a distinct iden of its form is acquired. After a short period of diligent application, the individual becomes able to recognize the combination of letters in words, without forming a separate conception of each letter; and can read line after line, by passing the finger over each, with considerable rapidity. When this power is once thoroughly acquired, the size of the type may be gradually diminished; and thus blind persons may bring themselves, by sufticient practice to read a type not mnch larger than that of an ordinary large-print Bible. The casc of Saunderson, who, although he lost his sight at two years old, became Professor of Mathematics at Cambridge, is well known; amongst his most remarkable faculties, was that of distinguishing genuine medals from imitations, which he could do more accurately than many connoisseurs in full possession of their senses. Several instances are recorded of men who became eminent as Sculptors after the loss of their sight, and who rere particularly successful in modelling portrait-busts; hence, it is obvious, not merely the tactile but the muscular sensibility must be greatly augmented in acuteness by the habit of attending to it. 'The porver of immerliate recognition of individuals by the slightest contact of the hands, even after long periods of time, which most blind and deaf persons lave displayed, is one of the most curious examples of the mode in which tactual perceptions will impress themselves on the memory, when they are habitually attended to. As an example of the correct notions which may be conveyed to the mind, of the forms and surfaces of a great variety of objects, and of the sufficiency of these notions for accurate com-

1 Deutsches Archiv f. Klin. Med. Bd. ii, p. 284.

${ }^{2}$ Volkmann, Ueber den Einfluss der Ubüng auf das Erkennen Raümlicher Distanzen, Bericht der Sachs. Gesell., 1858. 
parison, the Author may mention the case of a blind friend of his own who has acquired a very complete knowledge of Conchology, both recent and fossil; and who is not only able to recognize every one of the numerous specimens in his own cabinet, but to mention the nearest alliances of a shell previously unknown to him, when he has thoroughly examined it by his touch. Hany similar instances might be cited, one of the most remarkable being that of John Gough, who, although blind, was a noted botanical collector, and earned his livelihood as a land-surveyor. Several cases are on record ${ }^{1}$ of the acquirement by the blind of the power of distinguishing the colors of surfaces which were similar in other respects, and, however wonderful this may seem, it is by no means incredible. For it is to be remembered, that the difference of color depends upon the position and arrangement of the particles composing the surface, which render it capable of reflecting one ray whilst it absorbs all the rest; and it is quite consistent with what we know from other sources, to believe that the sense of Touch may become so refined, as to communicate a perception of such differences. ${ }^{2}$

\section{Sense of Tuste.}

599. The sense of Taste is that by which we distinguish the sapid properties of bodies. The term as commonly understood, inclindes much more than this; being usually employed to designate the whole of that knowledge of the qualities of a body (except such as is purely tactile), which we derive through the sensory apparatus situated within the mouth. But it will be hereafter shown that a considerable part of this is dependent upon the assistance of the olfactive sense $(\S 603)$; which is affected, through the posterior nares by the odorous emanations of all such bodies as are capable of giving them off; and the indications of which are so combined with those of the true gustative sense, as to make an apparently single impression upon the Sensorium. Moreover, there are certain sensorial impressions received through the organ of taste, which are so nearly allied in their character to those of touch, as to render it difficult to specify any fundamental difference between them; such are the pungent sensations produced by mustard, pepper, the essential oils, etc.; all of which substances, when applied for a sufficient length of time to any part of the cutaneous surface, produce a sensation which can scarcely be distinguished from that excited through the organ of taste, in any other way than by its inferior intensity, and by the absence of the concurrent odorous emanations. The taste of such substances might therefore, perhaps, be considered as the composite result of the impressions made upon the sensorium through a refined and acute fouch, and by the effect of their odorous emanations upon the organ of smell. After making full allowance, however, for all such as can be thus accounted for, there remains a large class of pure sapors, of which we take cognizance without the assistance of smell, and which are altogether dissimilar to any tactile impressions; such are the bitter of quinine, the sour of tartaric acid, the sweet of sugar, the saline of common salt, ete. 'The smell can give us no assistance in distinguishing small particles of these bodies, since they are

1 A mong the best-authenticated of these, is that of a lady who became blind, and afterwards deaf, in consequence of an attack of confluent small-pox; cited in Dr. Kitto's Lost Senses, vol. ii, p. 79, from the Annual Register for 1758.-Dr. Kitto's treatise may be referred to, as containing a large collection of interesting cases of a similar description.

2 For some additional details in regard to the sense of touch, see the Author's article Touch, in the Cyclopedia of Anatomy and Physiology, vol. iv. 
either entirely inodorous, or so vearly as only to be recognizable through its means when in large masses; and the most refined touch cannot affurd any indication of that kind of difference among them, of which we are at once rendered cognizant by taste.-Of all the "special" senses, however, that of Taste is most nearly allied to that of touch, as appears from several considerations. In the first place, the actual contact of the object of sense with the organ through which the impression is received, is necessary in the present case, as in the preceding. Again, it appenrs from the considerations formerly adduced ( $\$ 493)$, that there is no special nerve of Taste; for the gustative impressions upon the front of the tongue are conveyed by the Lingual branch of the Fifth pair, and the branches of the Facial running in the Chorda tympani," whilst those made upon the back of the organ are conveyed by the Glosso-pharyngeal, both of which nerves also minister to common sensibility; and pressure on the trunk of either of these nerves gives rise to pain, which is not the case with either the olfactory, the optic, or the auditory nerves. Moreover, the papillary apparatus, through which the gustative impressions are made upon the extremities of these nerves, is essentially the same in structure with that of the skin. ${ }^{2}$

600 . For the Gustative nerve-fibres to be impressed by the distinctive properties of sapid substances, it appears requisite that these substances should be brought into immediate relation with them, and that they should penetrate, in the state of solution, through the investments of the papilla, into their substance. This would seem to be proved by the two following facts: first, that every substance, whether solid, fluid, or gaseous, which possesses a distinct taste, is more or less soluble in the fluids of the mouth, whilst substances which are perfectly insoluble do not make their presence known in any other way than through the sense of touch; and, second, that if the most sapid substance be applied in a dry state to the papillary surface, and this be also dry, no sensation of taste is excited. Hence it may be inferred that in the reception of gustative impressions, a change is produced in the molecular condition of the nerve-fibres, or, to use the language of Messrs. Torld and Bowman, their polarity is excited by the direct agency of the sapid matter itself. This change may be induced, however, both by electrical and by mechanical stimulation. If we make the tongue form part of a galvanic circuit, a peculiar sensation is excited, which is certainly allied rather to the gustative than to the tactile, and which does not seem to be due (as was at one time supposed) to the decomposition of the salts of the saliva. And, as Dr. Baly has pointed out, ${ }^{3}$ " if the end of the finger be made to strike quickly, but lightly, the surface of the tongue at its tip, or

1 Lussana, Centralblatt f. d. Med. Wiss., 1871, p. 233.

2 For some pathological cases bearing upon the question of the implieation of the chorda tympani in the sense of taste, see Inzani and Lussanna, in the Annali Universali di Ind., 1862, pp. 282-322; Stich, in Henle ard Meisner's Berieht, 1857, p. 588 ; whilst for experimental eridence to the same effect, see Schiff, Unterstreh. zur Naturlehre, Bd. x, p. 406, and E. Neumann. Königsberger Medic. Jahrb., Bd. iv, p. 1. The two former observers believe the ehorda tympan to be the true nerve of taste for the anterior part of the tongue, by which sweet, saline, piquant, and aromatie flavors are distinguished, whilst the mineral aeids, astringents, bitters, pungents putrefactive, and disgusting flavors are ehiefly perceived through the glosso-pharyngeal. Schiff, Physiologie, 1859 , p. 403, thinks the Glosso-pharyngeal nerves are espreially adapted to perceive bitter, and the Fifth nerves aeid tastes. IInos, Centralblatt, 1867, No.46, reeords a case where modifications of the sence of taste in the forcpart of the tonguc resulted from pressure on the chorda tympani, oceusioned by the use of one of 'Toynbec's artificial tympana.

3 'Translation of il üller's Physiologie, p. 1062, note. 
its edge near the tip, so as to affect not the substance of the organ, but merely the papillie, a taste sometimes acid, somctimes saline, like the tastc produced by electricity, will be distinetly perccived. The scusation of taste thus induced will sometimes continue several seconds after the applicition of the mechanical stimulus." On the other hand, as Wagner has truly remarked, if the surface of the tougue near the root be tonched with a clean dry glass rod, or a drop of distilled water be placed upon it, a slightly bitterish sensation is produced; and this, if the pressure be continued, passes into that of nausea, and if the pressure be increased, even excites vomiting. The feeling of nausea nuy bc excited by mechanical irritation of any part of the surfacc of the fauces or soft palate; and this feeling is certainly much more allied to that of taste than to that of touch. Further, it has becn observed by Henle, tliat if a small current of air be directed upon the tongue, it gives rise to a cool saline taste like that of saltpetre. Thus we find that the peculiar effects of sapid substances upon the nerves of taste may be imitated to a certain extent by other agencies; and it also appears that the sensations excited by these vary according to the part of the gustative surface on which they operate; mechanical or electrical stimulation of the front of the tongue giving rise to a kind of saline taste, whilst mechanical stimulation applied to the back of the tongue and fauces excites the feelings of bitterness and nausea.-One of the conditions requisite for the due exercise of the gustative sense, is a temperature not departing far on either side from that which is natural to the body. It appears from the experiments of Prof. E. H. Weber, that if the tongue be kept immersed for nearly a minute in water of about $12.5^{\circ}$, the taste of sugar brought in contact with it, either in powder or solution, is no longer perceiverl; the sense of touch, usually so delicate at the tip of the tongue, bcing also renclered inperfect. A similar imperfection of taste and touch was produced by intmersing the tongue for the same length of time in a mixture of water and broken ice.

601. The surface of the Tongue is undoubtedly the special seat of gustative sensibility in Man; though the sense of Taste is not by any meaus restricted to that organ, being diffused in a less degree over the soft palate, the arches of the palate, and the fauces. It is on the tongue alone, however, that the papillary apparatus is fully developed; and its structure has bcen so carefully examined and described by Messrs. Todd and Bowman, that little remains to be added to their account of it.-The lingual papilla may be divider, in the first place, into the Simple and the Componnd, the former of which had previously escaped obscrvation, through not forming any apparent projection. The Simple papillae are scattered in the intervals of the compound, over the general surface of the tongue; and they occupy much of the surface behind the circumvallate variety, where no compound papillæ exist. They are completely buried and concealed beneath the continuous sheet of epithelium, and can only be detected when this membrane has been removed by maceration; they are then found to have the general characters of the cutaneous papilla. The Compound papilla are visible to the naked eye; and have been classified, according to their shape, in to the circumvallute, the fungiform, and the filiform. The circumvallate or calyciform papillse are eight or ten in number, and are situated in a $\mathrm{V}$-shaped line at the base of the tongue. Each consists of a central flattened circular projection of the mucous membrane, surrounded by a tumid ring of about the same elevation,

1 IIüller's Archiv, 1847, s. 342.

2 Physiological Anatomy and Physiology of MIan, vol, i, chap. xv. 
from which it is separated by a narrow circular fissure. The surface of both centre and border is smooth, and is invested by scaly epithelium, which conceals a multitude of simple papillæ. The fungiform papillæ, varying in

FIG. 253.

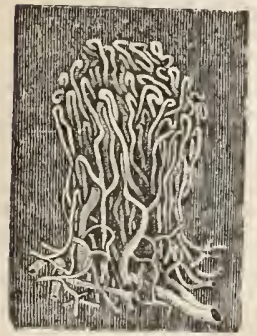

Capillary plexus of fungiform papilla of the Tongue. number from 160 to $290,{ }^{1}$ are scattered singly over the tongue, chiefly upon its sides and tip. They project considerably from the surface, and are usually narrower at their base than at their summit. They contain a complex capillary plexus (Fig. 248), the terminal loops of which enter the numerous simple papilla that clothe the surface of the fungiform body. Amidst these lie nerve-tubes, which probably terminate in free extremities between the epithelial cells, the epithelium itself being so thin as to allow the red color of the blood to be seen throngh it. In this manner they are readily distinguished from the filiform papillæ, among which they lie. The filiform papillæ, like the preceding, contain a plexus of capillaries and a bundle of nervefibres, both terminating in loops, which enter the simple papille that clothe the surface of the compound body; but instead of being covered with a thin scaly epithelium, they are furnished with bundles of long pointed processes, some of which approach hairs in their stiffiness and structure. These are immersed in the mucus of the mouth, and may be moved in any direction, though they are generally inclined backwards.- The simple papillie, which occur in an isolated manner, may not improbably be tactile; while those which are aggregated in the circumvallate and fungiform bodies, doubtless minister to the sense of Taste, this being most acute in the situations wherein they most abound. With regard, however, to the office of the filiform papills, there. seems much reason to coincide in the opinion of Messrs. Todd and Bowman: "The comparative thickness of their protective covering, the stiffiness and brushlike arrangement of their filanentary productions, their greater development in that portion of the dorsum of the tongue which is chiefly cmployed in the moventents of mastication, all evince the subservience of these papillse to the latter function, rather than to that of taste; and it is evident that their isolation and partial mobility on one another, must render the delicate touch with which they are endowed more available in directing the muscular actions of the organ. The almost manual dexterity of the organ, in dealing with minute particles of food, is probably provided for, as far as sensibility conduces to it, in the structure and arrangement of these papilla. It may be added, that the filiform papillie of Man seem to be the rudimentary forms of those horny epithelial processes which acquire so great a development in the tongues of the Carnivora, and which are of such importance in the abrasion of their food. The mode of termination of the gustatory nerves has been the subject of much recent rescarch. Eugehmann² describes the glosso-pharyngeal nerves in Man and Mammals as terminating in peculiar

1 Szabadföldy, Virchow's Arehiv, xxxviii, p. 177.

2 Stricker's Manum of Histology, New Sydenhmm Soeiety, 1873, vol. iii, p. 1, where a complete biblingraphy of the subjet is given. The principal English referenees are Waller, Philosophical Transitet, 1847; Lionel Beale, idem, 1865, and Qunrt. Journ. of Mieroseop. Sci., 1869; and R. L. Maddox, Month. Microscop. Journal, 1869. And since the date of Engelmann's artiele, the following papers have "preared: Ajtai, Arehiv f. Mie. Anat, Bd. viii, p. 455; Ditlevsen, Undersögelse, cte., Copenhagen, 1872; $\Lambda$ bstrat in Sehwalbe's Jahresbericht, 1872; Hönigschmeid, Zeitsch. für Wiss. Zool., Bd. xxiii, p. 414; Sertoli, Gazetia Med.-Vet., Anno iv, Liep. ubd. 
organs, termed gustatory bulbs, or taste-buds. These are flask-shaped bodies (Fig. 254), which are disposed in a zone encircling the sides of the papillse circumvallatie (Fig. 2.5), a few being also found on the outer wall of the vallecula, or that which looks towards the papillie. Schwalbe estimated the number present in one circumvallate papilla of the Sheep at 480 , and in one such papilla from the $\mathrm{Ox}$ at 1760. They are also found, but more irregularly distributed, upon the fungiform papillæ. The bulbs are composed of groups of cells (Fig. 254), which occupy flask-shaped cavities in the mucous membrane. The bottom of the cavity is formed by the fibrous layer of the mucous membrane, its sides are composed of cells, and the slender short neck perforates the corneal lamina, opening on the surface by a small circular mouth, which may be called the gustatory pore. The length of the bulb is about 0.080 of a millimetre. The gustatory bulbs, which completely fill these spaces, are composed of two kinds of cells. Of these the outer, or investing cells (Fig. 254), from 1.5 to 30 in number, are fusiform, have a well-defined nucleus, and are arranged concentrically

FIG. 255.

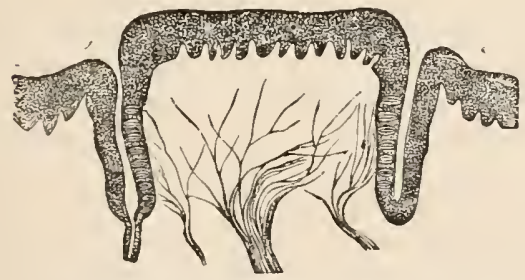

FIG. 255.-Transverse section through a circumvallate papilla of a Calf, showing the arrangement of the gustatory bulbs.

FIG. 256.-Termination of the gustatory nerres of the Frog. Ramification of a nerve-fibre in the nerve-cushion. Two goblet cells are seen, one columnar, and ten forked cells. (Chromic acid and glycerin. Mag. 600 diam.)
Fig. 254.

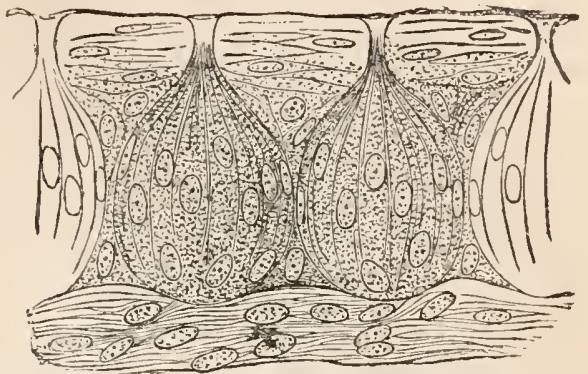

from the lateral gustatory organ of the Rabbit. Mag. 450 diam. 
which one or more fasciculi are given off, that run up the axis of the papilla, and then break up into numerous fine branches which stream out towards the epithelium. In the Frog, cylindrical papillæ are present, which are composed below of loose, and near their free extremity of compact, connective tissue, forming a nerre-cushion; upon each of these lies a gustatory disk, the structure of which is analogous to that of the gustatory bulb, being resolvable into goblet and columnar supporting or protecting cells, and forked cells, which appear to be the continuation of the non-medullated nerve-fibres (Fig. 256 ).

602. The simple application of a sapid substance to the gustative surface is usually sufficient to excite the sensation; and if this application be restricted to one particular spot, we are able to recognize its place more or less distinctly. In this respect, then, the gustative impression resembles the tactile; for whilst we camnot by our own consciousness, distinguish the parts of the retina or of the auditory apparatus on which visual or auditory impressions are made, we can make this distinction in regard to the surface which is supplied by the nerves of general sense. From the careful experiments of Stich and Klaatsch,, ${ }^{1}$ supported as they are by the results of other observations, we are now enabled to define with some accuracy the exact seat of the sense of taste. It exists over the whole surface of the posterior third of the dorsum of the tongue, on the under surface of the tip, and in a band or line, about one-quarter of an inch broad, running along its edge. The sense is also well defined in the posterior part of the hard palate, and in that portion of the soft palate which is near the bone, and lastly, in the anterior pillars of the fauces. The middle and anterior part of the dorsum, the gums, posterior pillars of the fauces, and the inner surface of the lips, possess no sense of taste, though exquisitely sensitive to tactile impressions. Bitters and acids appear to be the substances of which the dilution or attenuation mav be carried to the greater extent, without ceasing to excite sensations of taste, providing a sufficient volume of the solution be introduced into the mouth. Thus, according to Valentin, one part of extract of aloes or of sulphuric acid in 900,000 of water, and even one part of sulphate of quinine in 1,000,000 of water, may be distinguished if heedfully compared with perfectly pure water. The contact of a sapid substance much more readily excites a gustative sensation, when it is made to press upon the papilla, or is moved over them. Thus there are some substances whose taste is not perceived when they are simply applied to the central part of the dorsum of the tongue, but of whose presence we are at once rendered cognizant by pressing the tongue against the roof of the mouth. The full flavor of a sapid substance, again, is more readily perceived when it is rubbed on any part of the tongue, than when it is simply brought in contact with it, or pressed against it. Even when liquids are received into the mouth, their taste is most completely discrininated by causing them to move over the gustative surface: thus the "wine-taster" takes a small quantity of the liquor into his mouth, carries it rapilly over every part of its lining membrane, and then ejects it. It is not improbable that this exaltation of the usual effects is simply due to mechanical caluses; the salpid particles being brought by the pressure or movement into more rapid and complete operation on the nerve-fibres, than they would be if simply placed in contact with the papillie. 'The rapidity with which sapid impressions are perceived has been made the subject of a series of experiments by Vintischgau and Hönigschmied." The substances used were bisulphate of

1 Archiv f. Path. Anat., Bd. xiv, 1858, p. 225, and Bd xviii, p. 80 .

${ }^{2}$ Pflüger's Archiv, 1875, pp, 1-48. 
quinine, sugar, common salt, and diluted phosphoric acid. A small brush, about one-third of an inch square, was applied to the surface of the tongue. On being applied, an electrical current was made, which was broken by a movement of the hand as soon as the taste was perceived. When the tip of the tongue was thus excited, the following times were obtained: Common salt, 0.1598 sec.; sugar, 0.1639 ; phosphoric acid, 0.1676 ; quinine, 0.2351 .

603. The impressions made upon our consciousness by a large proportion of sapid substances are of a complex kind ; being in part derived fronı their odorous emanations, of which we take cognizance through the organ of Smell. Of this any one may convince himself by closing the nostrils, and inspiring and expiring through the mouth only, whilst holding in the mouth, or even rubbing between the tougue and the palate, some aromatic substance; for its taste is then scarcely recognized, although it is immediately perceived when its effluvia are drawn into the nose. It is well known, too, that when the selsibility of the Schneiderian membrane is blunted by inflammation (as in an ordinary "cold in the head"), the power of distinguishing flavors is very much diminished. In fact, some physiologists are of opinion that all our knowlerge of the flaror of sapid substances is received through the Smell; but this, as already shown, would not be a correct statensent; and there are cases on record in which the sense of Smell has been entirely lost, without any impairment of the true sense of Taste. ${ }^{1}$

604. Taken in its urdinary composite acceptation, the sense of Taste has for its object to direct us in the choice of food, and to excite the flow of mucus and saliva, which are destined to aid in the preparation of the food for Digestion. Among the lower animals, the instinctive perceptions connected with this sense are much more remarkable than our own; thus an omnivorous Monkey will seldom touch fruits of a poisonous character, although their taste may be agreeable; and animals whose diet is restricted to some one kind of food will decidedly reject all others. As a general rule it may be stated, that substances of which the taste is agreeable to us are useful in our nutrition, and vice vers $\hat{\imath} ;^{2}$ but there are many signal exceptions to this.-Like

I An interesting case of this kind, occurring in a Negro who had gradually lost the characteristic hue of his skin, and had acquired the fair complexion of a European, has been put on record by Dr. J. C. Hutchinson.-The Olfactory nerve scemed to be entirely paralyzed, whilst the branches of the Fifth Pair retained their integrity ; so that, whilst the proper sense of smell was entirely lost, a pungent burning sensation was excited by irritating vapors, and the application of snuff induced sneezing. Notwithstanding this deficiency, the sense of Taste, properly so called, did not seem to be impaired; for substances which possessed neither odor nor pungency could readily be discriminated, even though their tastes were not widely different. (See Amer. Journ. of Med. Sci., Jan. 1852.)

2 It is justly remarked by Sir H. Holland (Medical Notes and Reflections, p. 85) that, "In the majority of instances of actual illness, provided the real feelings of the patient can be certainly ascertained, his desires as to food and drink may be safely complied with. But undoubtedly much eare is needful that we be not deceived as to the state of the appetite, by what is merely habit or wrong impression on the part of the patient, or the effect of the solicitation of others. This class of sensations is more nurtured out of the course of nature, than are those which relate to the temperature of the body. The mind beconics much more deeply engaged with them; and though in acute iliness they are generally submitted again to the natural law, there are many lesser cases where enough remains of the leaven of habit to render every precaution needful. With such precautions, however, which every physician who can take schooling from experience will employ, the stomach of the patient becomes a valuable guide; whether it dictate abstinence from a recurrence of food; whether much or little in quantity; whether what is solid or liquid; whether much drink or little; whether things warm or cold; whether sweet, acid, or saline; whether bland or stimulating to the taste." Further, Sir H. Holland remarks: "It is not wholly para- 
other senses, that of Taste is eapable of being rendered more aente by education; and this on the principles already laid down in regard to Touch. The experieneed wine-taster ean distinguish differences in age, purity, plaee of growth, ete., between liquors that to ordinary judgments are alike; and the epieure ean give an exact determination of the spices that are eombined in a partieular sauce, or of the manner in whieh the animal on whose flesh he is feeding was killed. As in the ease of other senses, moreover, impressions made upon the sensory surfaee remain there for a eertain period; and this period is for the most part longer than that which is required for the departure of the impressions made upon the eye, the ear, or the organ of smell. Every one knows how long the taste of some powerful substanees remains in the mouth; and even of those which make less deeided impressions, the sensations remain to sueh a degree that it is difficult to eompare them at short intervals. Hence if a person be blindfolded, and be made to taste substanees of distinet, bnt not widely-different flavors (sueh as various kinds of wine or spirituous liquors), one after another in rapid sueeession, he soon loses the power of discriminating between them. In the same manner, the difficulty of administering very disagreeable medieines may be sometimes got over, by either previously giving a powerful aromatie, or by combining the aromatie with the medicine; its strong impression in both eases preventing the unpleasant taste from exeiting nausea.

\section{Sense of Simell.}

605. The Nasal passages may be eonsidered as having, in air-breathing Vertebrata, two distinct offices; for they eonstitute the portal of the Respiratory organs, and have for their office to take eognizanee of the aeriform matter as it enters them, and to give warning of that which would be injurious (this being effected by the instrumentality of the Fifth pair), whieh receives the impressions of gaseous irritants, and excites the act of sneezing to expel them; whilst they also contain the organ of Smell, which is formed by the distribution, over a certain part of their membranous wall, of the Olfactory nerve, which is suseeptible of being impressed by Odorous emanations. Of the nature of these emanations the Physieal Philosopher is so completely ignorant, that the Physiologist eannot be expeeted to give a definite aceount of the mode in which they produce sensory impressions. Although it niay be surmised that they consist of partieles of extreme minuteness, dissolved as it were in the air, and although this idea seems to derive confirmation from the fact that most orlorous substanees are volatile, and vice versâ,-yet the most delicate experiments have failed to diseover any diminution in weight, in eertain substanees (as nunsk) that have been impregnating a large quantity of air with their effluvia for several years; whilst there are some volatile fluids, such as water, which to Man are entirely

doxical to say that we are anthorized to give greatest heed to the stomach, when it suggrests some seeming extravaganec of diet. It may be said that this is a mere cleprivation of the sense of taste; but frequently it expresses an actual need of the stomach, either in aid of its own funetions, or indirectly (under the mysterious law just referred to) for the effecting of ehanges in the whole moss of blood. It is a geod practical rule in such cases to withlsold assent, till we find after a certain lapse of time that the same desire continues or strongly reeurs; in which ease it may grenerally be taken as the index of the fitness of the thing desired for the actual state of the organs. In the parly stage of recovery from long gastric fevers, I recollcet many enrious instinees of sueh contrariety to all rule being aequieseed in, with manifest good to the patient. Dieteties must become a mueh more exact branch of knowledge, before we ean be justified in opposing its maxims to the natural and repeated suggestions of the stomaeh, in the state either of health or disease." 
inodorous. Nearly all the vegetablc otors belong to one or other of three categories-namely, hydrocarbons, aldehydes, or etliers. Many of them are capable of being artificially formed, and they present good examples of Isomerism. Thus the essences of turpentine, citron, bergamot, neroli, juniper, savin, laveuder, cubebs, peppermint, and cloves, all have the same composition, $\mathrm{C}_{10} \mathrm{H}_{16^{\circ}}$. Amongst the odoriferous essences that are ranged by chemists in the class of aldehydes are those of mint, rue, bitter almonds, cunmin, anise, fennel, canella, and meadow sweet. The ethers are very varied and complex in constitution. Linneus arranged odors into seven classes: Aromatic (laurel leaves); fragrant (jasmine); ambrosial (musk); alliaccous (garlic); fetid (stinking goose-foot); repulsive (solanaceer); and nauseous odors. Such an arrangement is very imperfect, not including, for example, such well-marked odor's as those of tar gas. ${ }^{1}$

606. The tractus olfactorius is exclusively composed of medullated nervefibres which have a sheath of Schwann. It terminates on each side in the Olfactory ganglion, from which the Olfactory nerves pass down in the form of very numerous minute threads, which form a plexus upon the surface of the Schneiderian or pituitary membrane (Fig. 257). The filaments composing this plexus are described by Messrs. Todd and Bowman ${ }^{2}$ as differing widely in structure from those of the ordinary cephalic nerves; they coutain no white substance of Schwann, are nucleated and finely-granular in texture, and altogether bear a close resemblance to the gelatinous form of nerve-fibres (Fig. 257). The mode in which these nerves terminate has recently been the subject of close investigation by Hoyer, ${ }^{3}$ Schultze, ${ }^{4}$ Lockhart Clarke, ${ }^{5}$ Babuchin, ${ }^{6}$ Paschutin, ${ }^{7}$ Cisoff, ${ }^{8}$ and Martin. ${ }^{9}$ Their distribution appears to be limited to the membrane covering the upper third of the septum of the nose, the superior turbinated bone, aud perhaps the upper part of the middle turbinated bone; together with the upper wall of the nasal cavities beneath the cribriform plate of the ethnoid

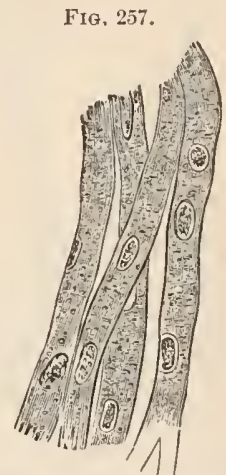

Fibres of ultimate ramifications of Olfactory Nerve of Dog. bone; all which surface is covered (as Messis. Todd and Bowman have pointed out) with an epithelium of a rich sepiabrown hue, constituting the regio olfactoria of Babuchin. According to Schultze these epithelial cells are divisible into two sets: one of these (a, Fig. 258) may be described as terminating externally by truncated flat surfaces which cannot be observed to be covered by any nembrane separate from the contents of the cell. The contents themselves appear to consist of protoplasm, presenting a yellowish granular appearance in the outer part, whilst at the lower part an oval nucleus lying in clear protoplasm can be readily distinguished. Towards thcir attached extremity these cells become

1 See an interesting paper on Odors, by F. Papillon, in Pharmaceut. Journ., Nov. 16 th, 1872, p. 383; also Laneet, 1870, p. 847.

2 Physiologieal Anatomy, vol. ii, p. 9.

3 Henle and Meissner's Bericht, 1857, p. 27.

4 Untersuehungen über den Bau der Nasenschleimhaut, Halle, 4 to.

5 Zeits. f. Wissens. Zool., Bd. xi. For an abstract of this paper, see Med.-Chir. Review for 1862, vol. i, p. 521. Sce also Exner, Sitz. d. k. Akad. zu Wien, 1870 and 1872. Exner denies the distinetness of the two forms of cells described below.

6 Stricker's Human and Comp. Histology, Syd. Soc. Trans., 1873, p. 201, vol, iii.

7 Leipziger Physiol. Arbeiten, 1873, p. 41.

8 Centralblatt für die $11 \mathrm{~cd}$. Wissenschaften, 1874, p. 689.

9 Journ, of Anat. and Physiol., vol. viii, 1874, p. 39. 
attenuated, and can be traced inwards for a considerable distance, when they expand into a broad flat sheet or plate, which, whilst it frequently presents a granular appearance, is never colored. The processes which pass off from this sheet appear to be continuous with the fibres of the submucous connective tissue. Towards the margin of the true olfactory region, cells (c, Fig. 258) in every respect analogous to those just described are found, excepting only that they present a well-defined

Fig. 258.

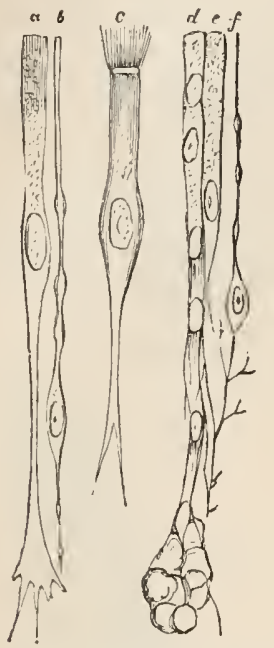

Cells of the Olfactory Mucous Membrane: $a, b, c$, after schultze; $d, e, f$, after Lockhart Clarke. band or seam at their free extremity, which is surmounted by a circle of cilia.-The cells of the second set (b, Fig. 258) have been described by Schultze and Babuchin as continuations of the nerves, and have hence been termed by them "Olfactory cells." They are thin, fibrous- or rodlike bodies, terminating at the same level as the proper epithelial cells in a leash of long fine cilia (Babuchin), and presenting when traced inwards a large oval nucleus and a series of moniliform or varicose swellings which are directly continuous with outrunners of more deeply-seated nerve-cells. Closely analogous appearances have been seen and described by Lockhart Clarke, who states that the Olfactory Nerve-fibres on reaching the base of the epithelial layer divide into finer and still finer branches, to form a network with numerous interspersed nuclei, through which they are probably connected with the "Olfactory cells" ( $f$, Fig. 258), although he has never been able satisfactorily to convince himself of such comnection. The proper epithelial cylinders $(d, e)$ are connected at their bases with the septa formed of connective tissue belonging to the subepithelial glandular layer.-The remainder of the nasal surface is supplied by the Fifth pair only, and is not endowed with sensibility to odors, although it is susceptible of irritation from such as are of a pungent nature; and hence it is that we cannot distinguish faint odors, unless, by a peculiar inspiratory effort, we draw the air charged with them to the upper part of the nose. In animals living in the air, it is a necessary condition of the exercise of the sense of Smell, that the odorous matter should be transmitted by a respiratory current through the nostrils, and that the membrane lining these should be in a moist state. Hence, by breathing through the mouth, we may avoid being affected by odors even of the strongest and most disagreeable kind; and in the first state of a catarrh, when the ordinary nucous secretion is suspended, the sense of Smell is blunted from this cause, as it afterwards is from the excess in the quantity of the fluid, which prevents the odoriferous effluvia from coming into immediate relation with the sensory extremities of the nerves. Hence we may easily comprehend how section of the Fifth pair, which exerts a considerable influence over the secretions, will greatly diminish the acuteness of this sense, and will have the further effect of preventing the reception of any impressions of irritation from acrid vapors, which are entirely different in their character from true odorous impressions, and are not transmitted through the Olfactory nerve ( $\$ 515)$.

607 . The importance of the sense of Smell among many of the lower Animals, in guidiug them to their food, or in giving them warning of danger, and also in exciting the sexual feelings, is well known. To Man its utility is comparatively small under ordinary circumstances; but it may be greatly 
increased when other senses are deficient. Thus, in the well-known case of James Mitchell, who was blind, deaf and dumb, from his birth, it was the principal means of distinguishing persons, and enabled him at once to perceive the entrance of a stranger. It is recorded that a blind gentleman, who had an antipathy to cats, was possessed of a sensibility so acute in

FIG. 259.

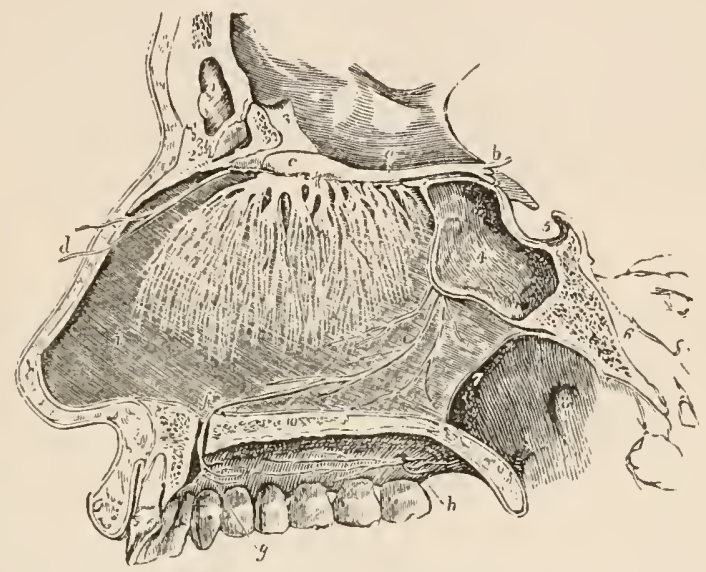

Distribution of the Olfactory Nerve on the Septum Nasi. The nares have been divided by a longitudinal section made immediately to the left of the septum, the right nares being preserved entire.1. The frontal sinus. 2. The nasal bone. 3. The crista galli process of the ethmoid bone. 4. The sphenoidal sinus of the left side. 5. The sella turcica. 6. The basilar process of the splenoidal and occipital bones. 7. The posterior opening of the right nares. 8. The opening of the Eustachian tube in the upper part of the pharynx. 9. The soft palate, divided through its middle. 10. Cut surface of the hard palate. $a$. The olfactory peduncle. $b$. Its three roots of origin. $c$. Olfactory ganglion, from which the filaments proceed that spread out in the substance of the pituitary membrane. $d$. The nasal nerve, a branch of the ophthalmic nerre, descending into the left nares from the anterior foramen of the cribriform plate, and dividing into its external and internal branch. e. The naso-palatine nerve, a branch of the sphenopalatine ganglion, distributing twigs to the mucous membrane of the septum nasi in its course to $(f)$ the anterior palatine foramen, where it forms a small gangliform swelling (Cloquet's ganglion) by its union with its fellow of the opposite side. $g$. Branches of the naso-palatine nerve to the palate. $h$. Posterior palatine nerres, $i, i$. The septum nasi.

this respect, that he perceived the proxinity of one that had been accidentally shut up in a closet adjoining his room. Anong Savage tribes, whose senses are more cultivated than those of civilized nations, more direct use being made of the powers of observation, the scent is almost as acute as in the lower Mammalia: thus it is asserted by Humboldt, that the Peruvian Indians in the middle of the night can distinguish the different races, whether European, American Indian, or Negro; and the Arabs of the Great Desert are said to be able to distinguish the smell of a fire thirty iniles off.-The quantity of some odorous bodies which is capable of exciting a distinct perception of smell, must in some instances be exceedingly small. A very minute trace of sulphuretted hydrogen is readily recognized, and according to Valentin, one part of bromine in 200,000 of air conmunicates an unpleasant odor to the latter, whilst in the case of musk a proportion not greater than one part in $13,000,000$ of air is still perceptible.-The agreeable or disagreeable character assigned to particular odors, is by no means constant amongst different individuals. Just as many of the lower animals pass their whole lives in the midst of odors that are to Man (in his civilized condition at least) in the highest degree revolting, and will even refuse to 
touch food until it is far advaneed in putridity, so do we find that men who are compelled by circumstances to live upon putrescent food, come at last to relish it most when it is furthest advanced in decomposition ( $\$ 71)$; and the most refined epicures among highly eivilized communities scem to find pleasure in similar odors and savors, which to ordinary tastes are anything but agreeable.-As to the length of time duriug which impressions made upon the organ of Smell remain upon it, no certain knowledge can be obtained. It is difficult to say when the effluvia themselves have been completely removed from the nasal passages, since it is not unlikely that the odorous particles (supposing such to exist) are absorbed or dissolved by the mueous secretion; it is probably in this manner that we may account for the faet, well known to every medical man, that the cadaverous odor is frequently experienced for many days after a post-mortem examination. ${ }^{1}$

\section{Sense of Vision.}

608. The objects of this sense are bodies from which Light proceeds either beeause they are luminous in themselves, or because they reflect the light that proceeds from other bodies. Whether this light is transmitted by the actual emission of luninous particles, or by the propagation of undulations analogous to those of sound, is a question that has been long keenly debated amongst Natural Philosophers; but it is of little consequence to the Physiologist which is the true solution, since he is only concerned with the laws aceording to which the transmission takes place, which are the same on both theories. These laws it may be desirable here briefly to recapitulate.

609. Every point of a luminous body sends off a number of rays, which diverge in every direction, so as to form (as it were) a cone, of which the luminous point is the apex. So long as these rays pass through a mediun of the same density, they proceed in straight lines; but if they enter a medium of different density, they are refracted or bent,-towards the perpendicular to the surface at the point at which they enter, if they pass from a rarer into a denser medium,-and from the perpendicular, when they pass from a denser medium into a rarer. It is easily shown to be a result of this law, that, when parallel rays passing through air fall upon a convex surfice of glass, they will be inade to converge; so as to meet at the opposite extremity of the diameter of the circle, of which the curve forms part. If, instead of continuing in the glass, they pass out again, through a second convex surface, of which the direction is the reverse of the first, they will be made to eonverge still more, so as to meet in the centre of eurvature. Ratys which are not parallel, but which are diverging from a foeus, are likewise inale to eonverge to a point or focus; but this point will be more distant from the lens, in proportion as the object is nearer to it, and the angle of divergence consequently greater. The rays diverging from the several points of a luminous objeet, are thus brought to corresponding feei; and the places of all these foci hold exactly the same relation to each other, with that of the point from which the rays diverged; so that a perfect inlage of the objeet is formed upon a sereen held in the foeus of the lens. This image, however, will be inverted; and its size, in proportion to that of the objeet, will depend upon their respective distances from the lens. If their distances be the same, their size will also be the same; if the object be distant, and the image uear, the latter will be much the smaller; and vice versû.

1 This may partly be attributed also to the efluvia adhering to the dress. It las been remarked that dark eloths retain these more strongly than light. For some sensible olservations on the sense of smell in the diagnosis of disease, see D. W. Crompton, in the Birmingham Medieal lieview, No. viii, Oet. 1873, p. 251, and No. ix, p. 23. 
610. There are two circumstances, however, which interfere with the perfection of an image thus formed by a convex lens. The one is, that if the lens constitute a large part of the sphere from which it is taken, the rays which fall near its margin are not brought to a focus at the same point with those which pass through its centre, but at a point nearer the lens. This difference, which must obviously interfere greatly with the distinctness of the image, is termed Spherical Aberration; it may be corrected by the combination of two or more lenses, of which the curvatures are calculated to balance one another, in such a manner that all the rays shall be brought to the same focus; or by diminishing the aperturc of the lens by means of a stop or diaphragm, in such a manner that only the central part of it shall be used. The latter of these methods is the only one employed, where the diminution in the amount of light transmitted is not attended with inconvenience. The nearer the object is to the lens (and the greater, therefore, the angle of divergence of its rays), the greater will be the spherical aberration, and the more must the aperture of the diaphragm be reduced in order to counteract it.-The other circumstance that interferes with the distinctness of the image, is the unequal refrangibility of the differently colored rays which together make up white or colorless light; the violet being more bent from their course than the blue, the blue more than the yellow, and the yellow more than the red; the consequence of which will be, that the violet rays are brought to a focus much nearer to the lens than the blue, and the blue nearer than the red. If a screen be held to receive the image in the focus of any of the rays, the others will make themselves apparent as fringes round its margin. This difference is termed Chromatic Aberration. It is corrected in practice, by conbining together lenses of different substances, of which the dispersive power (that is, the power of separating the colored rays) differs considerably. 'This is the case with flint and crown-glass, for instance,- - the dispersive power of the former being much greater than that of the latter, whilst its refractive power is nearly the same; so that, if a convex lens of crown-glass be united with a concave of flint whose curvature is much less, the dispersion of the rays effected by the former will be entirely counteracted by the latter, which diminishes in part only its refractive power. ${ }^{1}$

611. The refractive surfaces of the eye are three in number, and may be regarded as spherical, though the cornea has been shown to be slightly ellipsoidal. The radius of the first refracting surface, which is that of the cornea, is about $7.5 \mathrm{~mm}$; of the second, which is the auterior surface of the lens, varies from $7.8-9 \mathrm{~mm}$; and of the third, which is the posterior surface of the lens, from 5.3 to $6.9 \mathrm{~mm}$. The distances between these are: from the anterior surface of the cormea to the anterior surface of the lens varies from 2.9 to $3.1 \mathrm{~mm}$. ; the distance from the anterior surface of the cornea to the

1 The most important recent work on the optical relations of the eye is Hel mholtz's Handbuch der Physiologischen Optik, Leipzig, 1867. MM. Hüppel and Grünhagen have shown (Archives für Ophthalmol., Bd. xiv, p. 219) that the ordinary pressure of the contents of the globe of the eye in the cat is sufficient to support a column of mercury of from $22-24 \mathrm{~mm}$. in height. When the third nerve was irritated the pressure rose from this average to $70-90 \mathrm{~mm}$., which was apparently due to the contraction of the recti and obliquus superior. Irritation of the branches supplying the sphincter iridis and ciliary muscle exerted no influence. Excitution of the cervical sympathetic was followed by a primary exaltation and a secondury diminution of pressure. The former effect, amounting to 1-6 mm., was probubly due to the con traction of the orbital muscle; the latter appeared to result from contraction of the ocular vessels. Monniki (Tonometers en Tonometrie, Inaug. Dissert,, Abst. in Syd. Soc. Year-Book, 1871-72, p. 339) ascertained that the tension of the eyc varied within rather wide limits. It is normal when a pressure of 150 to 225 grains produces a depression of $\frac{1}{4}$ of a millimetre. 
posterior surface of the lens, from $7.1-7.5 \mathrm{~mm}$. The thickness of the lens therefore varies from 4 to $4.6 \mathrm{~mm}$. The distance from the postcrior surface of the lens (Knapp) to the retina is about $13 \mathrm{~mm}$. The coefficient of refraction is for the lens 1.455, and for the vitreous and aqueous humors 1.3366 . In order that the course of a ray of light may be followed in any system of refractive media, it is necessary that the position of the five cardinal points should be known-namely, that of the two principal points, which are the points where the principal refracting surfaces are cut by the axis; that of the two nodal points, or those points in the refractive media to which a ray of light is directed before, and appears to proceed from, after its refraction; and lastly, of the focal, or rather of the two focal points, one behind the lens and the other in front of the cornea. The relative positions of these cardinal points are as follows:
1. Principal point, $2.1746 \mathrm{~mm}$. behind the anterior surface of the cornea.
2. Principal point, 25724 "
1. Nodal point, 0.7850 "
2. Nodal point, 0.3602 "
2. Focal point,
14.6470
1. Focal point,
128326

" in front of the posterior surface of the lens.

The two principal points thus lie at $0.4 \mathrm{~mm}$. distance from one another, nearly in the middle of the anterior chamber of the eye. The two nodal points, also about $0.4 \mathrm{~mm}$. from each other in the posterior part of lens; the second focal point for parallel rays close to or in the retina. The two nodal points lie so close to one another that they may be regarded as single, and visual rays passing through them as rectilinear. In like manner, the two principal surfaces may be regarded as marked in the spherical surface, $h h$ (Fig. 260), which represents the refactive surface of the eye. Every point of a retinal image corresponds to a point of the object; and if it be desired to determine which are the corresponding points of the object and of the image, it is only requisite to join them by a line passing through the united nodal point. The retinal images are consequently inverterl.

612 . The Eye may be regarded as an optical instrument of great perfection, adapterl to produce on the surface of the Retina, a complete inlage or picture of luminous objects brought before it ; in which the forms, colors, lights, and shades, ete., of the object are all accurately representerl. By the different refractive powers of the transparent media through which the rays of light pass, and by the curvatures given to their respective surfaces, both the Spherical and Chromatic aberrations are corrected in a degree sufficient for all practical purposes; so that, in a well-formed cye, the picture is quite

FIG. 260.

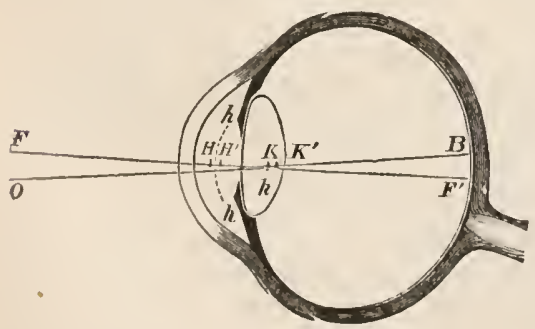

F $F^{\prime}$, Axis of the Eye; II I', Principal points; к $\mathrm{K}$, Nodal points; $h h$, Principal refracting surface; o $\mathrm{B}$, Visual ray. retina, but would converge towards a point behind it; whilst ou the confree from haziness and from false colors. The power by which it adapts itself to variations in the distance of the object, - $\mathrm{so}$ as to form a distinct image of it, whether it be six inches, six yards, or six miles off,-is extremely remarkable, and cannot be regarded as hitherto completely explained. It is obvious that, if we fix upon any distance as that for which the eye is naturally adjusted (say 12 or $1+$ inches, the distance at which we ordinarily read), the rays proceeding from an object placed nearer to the eye than this would not be brought to focus upon the 
trary, the rays from an object at a greater distance would meet before they reach the retina, and would have again diverged from each other when they impinge upon it; so that, in either case, vision would be indistinct. Now, two methods of adaptation suggest themselves to the Optician. Either he may vary the distance between the refracting surface and the screen on which the image is formed, in such a manner that the latter shall always be in the focus of the converging rays; or, the distance of the screen remaining the same, he may vary the convexity of his lens, in such a manner as to adapt it to the distance of the object. The mode in which this adaptation is effected in the Human Eye has been carefully investigated by Czermak, Helmholtz, and others. According to the calculations of Olbers, based on the ascertained refractive powers of the media of the eye, the difference between the focal distances of the images of two objects, the one so far off that its rays are parallel, and the other at the distance of only four inches from the eye, is about 0.143 , or one-seventh of an inch; but as the usual range of distinct vision does not extend to objects brought within six or seven inches, the amount of change required in the relative places of the refracting bodies and the retina would not ordinarily exceed a line. It has been thought that this change might be produced by an alteration in the convexity in the cornea, or by an elongation of the globe of the eye generally, or by both methods in combination; but a strong counter-argument to these opinions is derived from a case which came under the observation of v. Gräfe, in which the power of accommodation was preserved, although from paralysis of the Third Nerve all the ocular muscles were paralyzed, except the external rectus and the superior oblique. There is much more ground for the belief that a change of form and perhaps of place is effected in the crystalline lens, by the action of the ciliary muscle and the erectile tissue of the ciliary processes; for not only can it be shown that the contraction of the

FIG. 261.

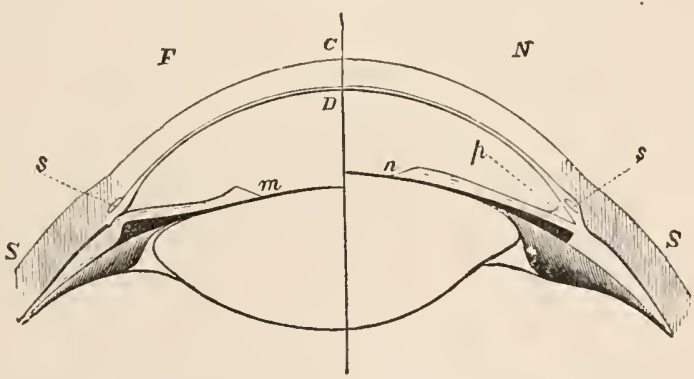

c, Cornea; s, Sclerotic; $F$ C x, Vertical plane of the Cornea; B C D, Axis of the Eye; $s s$, Canal of Schlemm; $p$, Angle formed by the Iris and Cornea, or margin of anterior Chamber; $m$, Position of Iris, and curvature of Lens in an Eye conrerged for parallel rays, distant vision, or negative accommodation; $n$, Position of Iris, and curvature of lens required for near objects, or for positive accommodation.

ciliary muscle would tend to compress the lens, but the fact that this muscle is peculiarly powerful in the predaceous Birds, which are distinguished for their great range of vision, and which have, in their circle of osseous sclerotic plates, an unusually firm point of attachment for it, is a strong argument in favor of this doctrine. ${ }^{1} \quad$ Further, the almost entire loss of the power of adapting the eye to distances, which is experienced after the removal of the Crystalline lens in the operation for Cataract, is a marked indication that

1 See on this subject, Messrs. Todd and Bowman's Physiological Anatomy, vol. ii, p. 27; and Dr. Clay Walluce on The Adjustment of the Eye to Distances, New York, 1851. 
some change in the place or figure of this body is the principal means whereby the ordinary adaptation is effected. The precise changes which occur in the interior of the Eye when it is accommodated for viewing near objects, or during positive accommodation, have bcen determined by Helmholtz ${ }^{1}$ with an instrument that he has terned an Ophthalmometer, the principle of which consists in examining the reflexion from the various ocular merlia of two flames: alterations in the relative position and figure of these can be readily perceived and measured, furnishing the data for the requisite calculations. By this means it has been ascertained that the essential alteration is a changc effected in the figure of the lens by muscular effort, which increases its thickuess in the antero-posterior diameter, the convexity of the anterior surface in particular undergoing a considerable augmentation ( $n$, Fig. 260), and by a forward movement approximating the cornea; whilst the convexity of the posterior surface is but slightly modified, and undergoes scarcely any change of place. The return of the lens to its original figurc after the cessation of the effort by which it has been accommodated for near objects is probably effected by its own elasticity, which is certainly very considerable. The other and clearly secondary changes which have been observed are a contraction of the circular fibres of the Iris, making the pupil smaller-the pupillary edge of the Iris at the same time moving forwards, and the attached or peripheral edge $(p)$ backward. The forward movement of the plane of the iris amounts, according to Knapp, ${ }^{2}$ to about $\frac{1}{1}$ th $_{2}$ of an inch. Lastly, according to Becker, ${ }^{3}$ the points of the ciliary processes retire from the edge of the lens.The object fulfilled by the contraction of the pupil in adaptation of the Eye for near objects, is evidently to cxclude the outer rays of the cone or pencil, which, from the large angle of their divergence, would fall so obliquely on the convex surface of the eye as to be much affected by the spherical aberration, and thus to allow the central rays only to enter the eye, so as to preserve the clearness of the image; the principle being exactly the same as that on which the optician applies a stop behind his lenses, which reduces their aperture in proportion to the shortness of their focal distance. The channel through which this action is effected, is evidently the same at that through which the convergence of the eyes is produced, namely, the inferior branch of the 'Third pair of nerves; to the action of which, the scusations received through the retina seem to afford the immediate stimulus, in the same manner as they do to the ordinary variation in the diameter of the pupil under the influence of light; but the voluntary determination to fix the vision upon the object, is the original source of the action. That the prescuce of the Iris is not indispensible for the performance of positive accommodation, is shown by the fact that, in a patient from whom Gräfe removed the whole Iris, this faculty remained perfect; and a sinilar power has been observed to exist in cases of congenital absence of the Iris. ${ }^{4}$ During negative accommodation,-in other words, in viewing distant objects, - the lens $(m)$ becomes flattened, the external margin of the iris is brought for-

'A full confirmation of Helmboltz's statement, with a good historical résumé of the whole subject, will be found in Prof. Allen Thomson's Phenomena and Mechanism of the Foeal $\Lambda$ djustment of the Eye to Distinet Vision at Different Distances (pamphlet), and a still more complete exposition of all points connected with the Anatomy and Plyysiology of the Eye in Grafe und Sämisch's Handbucla der gersmmten Augenlacilkuide, 1874-75.

2 Arehiv f. Ophthalmol, Bd. vi, Abtheil. ii, p. 1.

${ }^{3}$ See his interesting paper in Braun, Duchek, and Schlager's Medizin. Jahrb., 1864, p. 1.

4 Sie Dr. Soelberg Welts's instruetive paper, On the Paralysis of the Muscles of the Eye, in the Oplathulmic Hospital Reports, vol, ii, 1859-1860, p. 199. 
ward, the pupil dilates under the intuence of the dilatator papilla, which is innervated by the Sympathetic nerve, and the tips of the ciliary processes are approximated to the margin of the lens. The main instrument in effecting these changes in the Eye appear's to be the Ciliury Muscle, the structure and attachments of which were first clearly lescribed by Mr. Bowman. It consists of unstriped muscular fibre, partly arranged in a circular manner, the innermost fibres running parallel to the margin of the Cornea $(d$, Fig. $262)$, and partly disposed radially $(a)$, the fibres of the latter portion of the muscle appearing to be connected at their origin with the posterior elastic lamina of the Cornea, and externally or posteriorly being partly inserted into the Iris, forming the pillars of the Iris (Ligamentum pectinatum iridis), partly into the Sclerotic bounding the canal of Schlemm (s, Fig. 261), and partly and chiefly into that part of the outer surface of the choroid tunic, which corresponds to the ciliary processes. The mode and effects of the

FIG, 262.

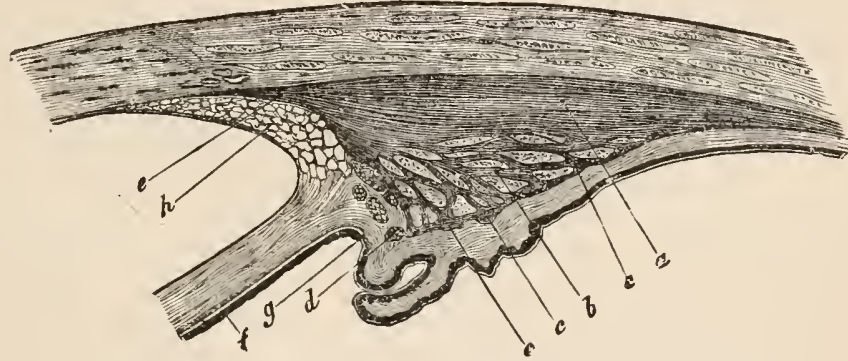

Section of the Ciliary Region of the Eye in Man. $a$. Meridional muscular fasciculi of the musculus ciliaris. $b$. Deeper seated radiating fasciculi. $c, c, c$. Annular plexus, d. Annular muscle of Yüller. $f$. Muscular lamina on the posterior surface of iris. $g$. Muscular plexus at the ciliary border of the Iris, e. Annular tendon of the musculus ciliaris. $h$. Ligamentum pectinatum.

contraction of this muscle have not been determined with perfect certainty ; some, as Brücke, believing the anterior attachment to be the origin, or fixed point, towards which in contraction the posterior extremity is drawn; others, as Donders, that the posterior border is the truc origin; and others again, as Helmholtz, considering that both extremities are movable. According to Cramer, Donders, H. Müller, and others, the lens, when arlapted for viewing infinitely-distant objects, is at rest, and it is only when near objects are looked at that a change is effected in the figure and position of the lens; Cramer attributing this effect especially to pressure exerted by the iris, and H. Müller to the ciliary muscle. Helmholtz, Arlt, and Jäger consider that the lens is flattened in viewing distant objects, through the traction exerted by an elastic membranous zonula attached to its edge. When the ciliary muscle contracts, which occurs in viewing near objects, the posterior border of the zonula is drawn forward, and its tension, and therefore the flattcning power it exerts upon the lens, is diminished. A third supposition has been advanced by Henke and Langenbeck ${ }^{1}$ to the effect that a muscular effort is required in arranging the Eye for viewing both near and distant objects, the former being accomplished through the contraction of the circular fibres, the latter through that of the radial fibres ${ }^{2}$ but a strong argument against this

1 Henle and Meissner's Bericht, 1860, p. 561.

2 An opinion to which Giäfe seems alio to have been led from a comparison of the effects of belladonna and opium upon the iris and upon the ciliary muscle (as indicated by the power of accommodation) respectively. See also Warlomont, Annales d'Oculistique, t. 73 , p. 195. 
view is derived from the circumstance that no fatigue is experienced from prolonged direction of the Eye to distant objects, whilst the employment of the visual power upon near objects for some time is accompanied with a sense of effort, and is followed by fatigue. The movement which effects the change of form of the crystalline lens, is performed in obedience to Volition, and is guided by sensation; yet we are not conscious of performing it, all that we will being the result: and thus we have another apposite illustration of the really automatic nature of what are termed "vohntary movements" generally $(\S 540)$. The time occupied in accommodating the Eye for near objects is greater than that required for adapting it to view distant objects. According to Aby the period occupied in changing the accommodation from 17 to $4 \frac{1}{2}$ inches is about 2 seconds, whilst in changing it from $4 \frac{1}{2}$ to 17 inches only 1.2 seconds are required. Vierordt, however, ${ }^{1}$ states that he was able to effect the accommodation from 60 feet to $4 \frac{1}{2}$ inches in about nine-tenths of a second, and from $4 \frac{1}{2}$ inches to 60 feet in about seven-tenths of a second. Differences in age, and in amount of practice, are probably the chief causes of such variations in the results of different observers; accommodation for near objects being always accomplished more slowly with the advance of years. The adaptation of the Iris for variations in the intensity of light is still slower.-In healthy, or as Donders terms them, "emmetropic" eyes, the limits of clear vision lie between two points, the "near-point" and the "far-point." The former, very near the eye in infancy, gradually recedes with advancing age; and Fellenberg ${ }^{2}$ has shown, that at 10 years of age it is $2 \frac{2}{3}$ inches distant from the front of the cornea ; at 20 years of age, $3 \frac{5}{9} \mathrm{in}$.; at $30,4 \frac{4}{5}$ in.; at $40,6 \frac{5}{7}$ in. ; at $50,12 \mathrm{in.}$; at 60,24 in.; and at 70,144 incbes. The "far-point" for healthy eyes is infinitc distance, or in other words, the refractive media of healthy eyes in a condition of repose are adapted to bring parallel rays to a focus on the retina. The extent of the range of vision for each eye is very considerable, amounting, according to Korm and Förster, ${ }^{3}$ in the horizontal direction, to an are of $130^{\circ}$, and in the vertical to an are of $110^{\circ}$. $^{4}$ The actual rotation of the globe, or as Schuur-

1 Henle and Meissuer's Bericht, 1857, p. 547.

2 Canstatt's Jahresbericht for 1862 , p. 157.

3 Ibid., p. 157.

4 Landolt (II perimetro e la sua applicazione, Quaglino's Annal. d'Ottalmologia, G(mnajo, 1872) gives rather higher numbers, viz., $135^{\circ}$ for the horizontal and $120^{\circ}$ for the vertical are; and Uschakoff (Reichert and Du Bois-lieymond Archiv, 18i0, p. 454) and Reich (Gräfe and Sämisch, Handb. der Augenheilkunde, Bd. iii, 1874, p. 59) higher still, namely, in the horizontal meridian, max $142^{\circ}$, min. $137^{\circ}$; and in the vertical, max. $120^{\circ}, \mathrm{min} .114^{\circ}$. The field of vision is smaller in myopes and rather larger in liypermetropes than in healthy or emmetropic eyes. Helmholtz gives as average numbers derived from his observations the following value to the varying optical constunt and cardiual points. 'The numbers, where not otherwise expressed, represent the distance from the anterior surface of the cornea in millimetres:

Radins of curvature of cornea,

liadius of curvature of anterior surface of lens,

Rudius of curvature of posterior surface of lens,

Situation of anterior surface of lens,

$$
\text { of posterior, }
$$

Focal distanee of lens,

Posterior tocal distanee of the cye,

Anterior fienl distance of the eye,

Position of unterior focal point,

Position of first chice point,

Position of second rhief point,

Position of first nodal point, .

" second,

" posterior focul point,

In aceommodation

For distance. For near objects.

0
8

10

6

3.6

7.2

43.707

19.875

14.858

12.918

1.9403

2.3563

6.957

7.373

22.221
6

5.5

32

7.2

33785

$17.75 \%$

13.74

11.241

2.0330

2.4919

6.515

6.974

20.248 
man $^{1}$ terms it, the mean excursion of a healthy or emmetropic eye from the central point is inwards $45^{\circ}$, outwards $42^{\circ}$, upwards $34^{\circ}$, and downwards $57^{\circ}$.

613. When both eyes are fixed upon an olject their axes converge so as to meet it; and the degree of convergence is, of course, altered by variations in the distance of the ohject; since, when the object is very remote, the optic axes are virtually parallel, whilst its approach causes them to incline towards each other, and this the more rapidly as the object is brought nearer, the increase being the greatest when it has arrived within the orlinary distance of distinct vision. Here, again, we have an example of the automatic nature of voluntary actions; for the convergence of the cyes that may be produced by this gradual approximation of an object on which the eyes are kept fixed by an exercise of the IVill, far exceerls that which most individuals can induce by an effort made directly for the purpose; and if, when an object has thus been gradually approximated to within a few inches of the nose, the voluntary fixation be intermitted, and the optic axes be allowed to regain thcir parallelism, they can seldom be brought to converge again upon it, without repeating the whole process.-It has been thought, from the close accordance between the changes required for the adaptation of the eyes to distinct vision at different distances, and the alterations in the direction of the optic axes which are required to bring the two eyes to bear upon objects at varying degrees of proximity or remoteness, that the former of these movements is in some degree dependent upon the latter, or, at any rate, that the two proceed from a common motor impulse. But that the convergence of the axes is not itself in any way the occasion of the alteration of the focus of the eye, is shown by these two facts: first, that the adaptation is as perfect in a person who only possesses or uses one eye, as it is when both are employed; and second, that some persons possess the power of altering the focus of the eyes by an effort of the will, whilst the convergence remains the same.

614. The ordinary forms of defective vision, which are known under the names of Myopia and Hypermetropia, or "shortsightedness" and "longsightedness," are entirely attributable to defects in the optical adaptation of the eye. As already stated, the healthy, or emmetropic Eye, when at perfect rest, is adapted to focus parallel rays on the retina (A, Fig. 263). If, however, a near object be looked at, since the rays proceeding from it are divergent, it is obvious that without some change in the media the image, iustead of being focussed on the retina, would be focussed behind it. The Eye, however, by its power of accommodation, due to the action of the ciliary muscle in causing the lens to become thicker, is capable of effecting this alteration; and it is by an effort that increases with the proximity of the object that all near objects are seen. In Hypermetropia (c), or longsightedness, either the Eye as a whole is flattened from before backwards, or the lens is too flat, or both conditions may be present together. In either case, even parallel rays are not brought to a focus on the retina, much less divergent rays, such as those coming from near objects. It requires, in fact, muscular effort to bring parallel rays to a focus on the retina, and a very great effort, which cannot long be maintained, to bring divergent rays. The patient consequently complains of pain after a few minutes reading or writing. To remedy this state the eyes are placed in a passive state by the instillation of atropia; the strongest glass is then given, which produces distinct vision of distant objects (objects at 20 feet or more), or, in other words, which will focus parallel rays on the retina. In Myopia (D) either the Eye is too long in the antero-posterior direction, or the lens is too thick, or both

1 Gräfe and Sämisch, Handbuch d. ges. Augenbeilkunde, Bd. iii, p. 233, 1874. 
eonditions eoneur, and parallel rays striking the cornea are brought to a foeus in front of the retina, and after deeussating form a circle of dispersion on this membrane. All distant objects, therefore, are seen obseurely. On

Fig. 563 .

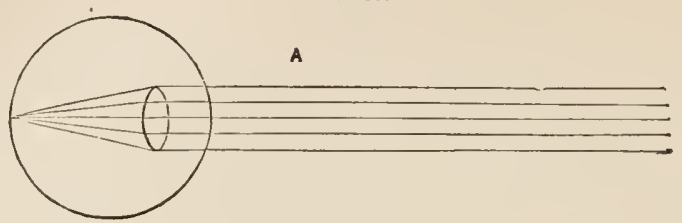

Emmetropic Eye. Parallel rays focussed on the retina.

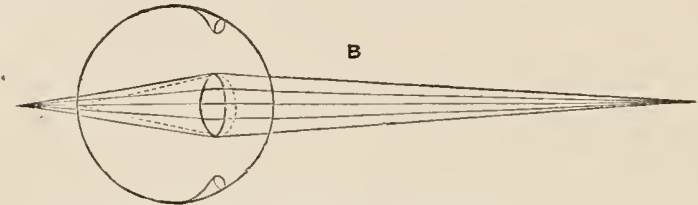

Emmetropic Eye. The dotted lines showing how accommodation for the diverging rays of near objects is effected.

the other hand, the patient ean see objects close to his eye, beeause the rays are there highly divergent. This condition may be remedied by placing a coneave lens in front of the eye, which causes the rays of light to become divergent, and they are not, therefore, brought to a focus so soon in the in-

FIG. 264.

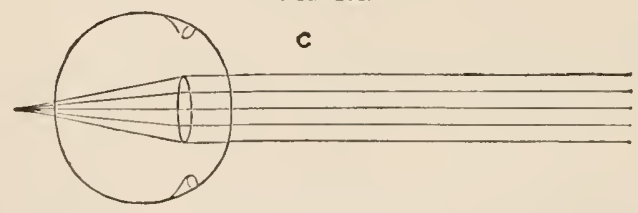

Hypermetropic Eye.

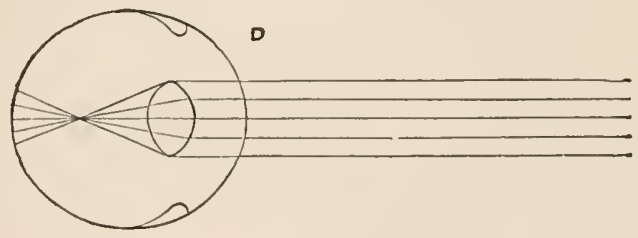

Myopic Eye.

terior of the eye. An interesting experiment, eapable of a practical applieation in determining whether a given eye is normal or ametropic, and whether the ametropia is myopic or hypermetropic, is that known as Scheiner's experiment (Fig. 265); in this a card or thiu piece of metal, perforated with two small holes, the distance between which must be less than the diameter of the pupil, is placed before the eye. If the eyes be normal, two cireles of light will be seen, which overlap one another to a certain extent, and in this brighter part all objects appear single, because the rays are anited upon the retina at $c$. If, however, the axis of the eye be too long, as in Myopia, and the retina be at $p q$, the rays will have crossed, and double 
images will be seen in the central part of the field of vision; whilst if the axis of the eye be too short, as in Hypermetropia, the rays will not have united, and double images will also be seen. By placing a piece of red or green glass over one of the holes, as at $g$, it is easy to determine whether the ray passing through that hole has or has not crossed. "The term "presbyopia," as limited by Donders, simply expresses a deficient power of accommodation in the eye, resulting from increased density of the lens, or from defective power of the ciliary muscle, so that the "near-point" recedes beyond a certain point, arbitrarily fixed by Donders for the sake of convenience at eight inches. The effects of atropin upon the eye are very remarkable, not only in dilating the pupil to the utmost in the course of from twenty to twenty-five minutes, but in completely paralyzing the power of accommodation, so that the "near-point" becomes gradually more and more distant, till at length it coincides with the "far-point." The Calabar bean, on the contraly, causes extreme contraction of the pupil in the course of from thirty to forty minutes, the "far-point," and in many eyes the "nearpoint" also, becoming approximated to the eye, though the power of accommodation is never altogether lost. Both of these agents appear to exert a stimulating as well as a paralyzing influence on the nerves supplied to the Iris ; atropin paralyzing the third and exciting the sympathetic nerve, whilst the Calabar bean paralyzes the sympathetic and excites the third." - The term astigmatism ${ }^{3}$ ( $\alpha$, privative, $\sigma: \zeta \mu \alpha$, a point) has been applied by Professor Whewell to a condition of the eye (first observed in himself by Professor Airy) in which there is an inequality in the refractive power (owing to difference in the degree of curvature either of the cornea, or of the lens, or of both) between the horizontal and vertical meridians of the eye. There is a consequent incapacity on the part of the eye to collect all the rays of light entering it to one exact focus; this has been shown by Donders to be of common occurrence in those who are otherwise healthy. The asymmetry is usually of such a uature that with each degree of accommodation horizontal lives are seen distinctly at a point nearer to the eye than vertical lines, showing that the vertical meridian has a shorter focal distance than the horizontal. This condition may be remedied by the use of the so-called cylindrical glasses.-Many other interesting inquiries, respecting the action of the eye as an optical instrument, suggest themselves to the Physical philosopher; but the foregoing are the chief in which the Physiologist is concerned; and we shall now proceed, therefore, to consider the share which the nervous apparatus performs in the phenomena of vision.

615. The Optic Nerve, at its entrance into the eye, divides itself into numerous small fasciculi of ultimate fibrils; and these appear to spread themselves out, and to inosculate with each other by an exchange of fibrils, so as to form a netlike plexus, which constitutes the inner layer of the Retina (Fig. $266,7)$ in immediate contact with the "limitary membrane" (8). There is considerable difficulty, however, in the precise determination of the course

1 See Thompson, Amer. Jour. Mcd. Sci., A pril, 1870.

2 See the Essays of Rogow, in Henle and Pteuffer's Zcitschrift, Bd. xxix, 1867, p. 1; Bernstein in idem, p. 35; Dr. Argyll Robertson on Calabar Baan, Trans. of Royal Soc. of Edin., vol. xxiv; V. Gräfe, Archiv f. Ophth., Bl. ix, Heft iii, p. 87

3 Sce Donders's Astigmatismus, ete. (Berlin, 1862); the Oration delivered by Mr. Z Laurence before the North London Medical Society, 1863, and his papers in the Med. Times and Gazette for 1862-63; also Mr. Wharton Jones's abstract of paper read before the Royal Society, in Proceedings of the Royal Society for 1859, vol. x, p. 374 .

4 An excellent account of the historical development of our knowledge of the structure of the retina, from the year 1856 to the year 1868, is given by Krauss, in Robin's Journal, vol. vi, 1869, p. 438. 
of the nerve-fibres in the Retina, on account of their minute size, their softness, and the alteration in their characters that takes place during mounting. Although uniformly much smaller than ordinary nerve-fibres, they present considerable diversities in size, the largest of them being only about $\frac{1}{6000}$ th of an inch in diameter, whilst the smallest are no more than from $\overline{3} 0000$ th to $5 \overline{5} \frac{1}{000}$ th of an inch. It is considered by Mr. Bowman that, like the fibies

FIG. 265.

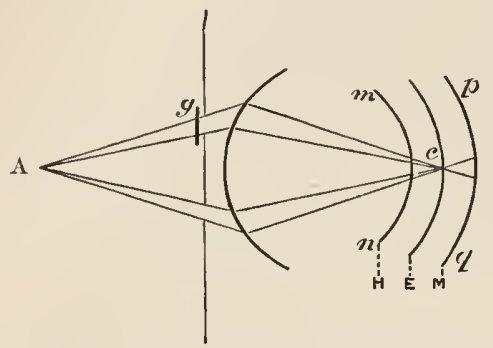

FIG. 265.-Scheiner's Experiment. A, souree of light ; E, position of retina in regard to the foeus, $c$, of the rays entering through two apertures in a eard, one of which is covered with a colored glass, $g$, in an emmetropic eye; $H$, position of the retina, $m n$, in a bypermetropic eye; $M$, position of retina, $p q$, in a myopic eye.

FIG. 266.-Vertical Section of Retina of the Human Eye; 1 , bacillar layer; 2 , onter granular layer; 3 , intermediate fibrous layer; 4, inner granular layer; 5, finely-granular gray layer; 6 , layer of nerve-ceils; 7 , layer of fibres of optic nerve; 8 , limitary membrane.
FIG. 266.

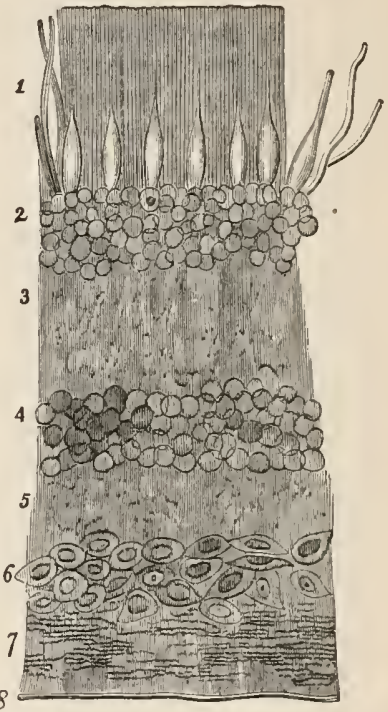

of the Olfactive nerves ( $\$ 606$ ), they consist of axis-cylinders without shcaths. They do not form a continuous fibre-layer at the yellow spot. Externally to the stratum of nerve-fibres, which may be called the Optic layer, is a vesicular stratum called the ganglionic layer (Fig. 267, 3), which consists of a finely granular matrix, wherein are imbedded nerve-cells resembling those of the nerve centres, and having, like them, one, two, or a variable number of processes, some of which appear to become continuous with the fibres about to be described; at the macula lutea all the ganglion-cells are bipolar. It is to these fibrons and vesicular layers of the Retina, which together make up the analogue of the cortical substance of the Cerebrum, that the principal supply of blood is distributed by the minute capillary network which is spread out through their substance. Immediately external to the ganglionic layer is the internal molecular layer (4), or the layer of gray vesicular nutter of Mr. Bowman, the peculiar appearance of which is due to the admixture of a very fine plexus of spongy connective tissue given off from certain radially runing supporting fibres, with nerve-fibrils of immeasurable minuteness. This again is succeeled by the layer of inner granules (5), which contains two distinct kiuds of nucleated cellular clenents, one of which is imberlded in radially arranged nerve-fibres, and the other in similarly disposed fibres of connective tissue; next comes (6) the external molecular or granulated layer, consisting of a thin layer of fine plexiform tissue, inclosing a few nuclei and smooth cells, with coarser fibres ruming parallel to the surface of the retina. 'The external granule-layer (7), which consists of a thin layer of granules, lying in a finely striated matrix of con- 
nective tissue, in which extraordinarily fine fibrils are imberded, running obliquely or parallel to the surface of the retina, and attached to the peripheric processes of the internal granules, and to the fibres of the rods and cones; and finally the layer of rods and cones (9), often also called the bacillary layer, or after its discoverer, Jacob's membrane. The rods are cylindrical bodies, with a length at the back of the Eye in Man of fifty to sixty micromillimetres, and a diameter of two nicromillimetres, but becoming shorter anteriorly. Distributed at regular intervals between the rods, except at the macula lutea and ora serrata, are the flask-shaped cones. The distance between two cones amounts on an average to eight or ten millimetres, the intervening space being occupied by three or four rods in a straight line. In both structures two essentially different segments are distinguishable. (See Fig. 268.) The distinction is most marked in the cones, in which the outer

Fig. 267 .

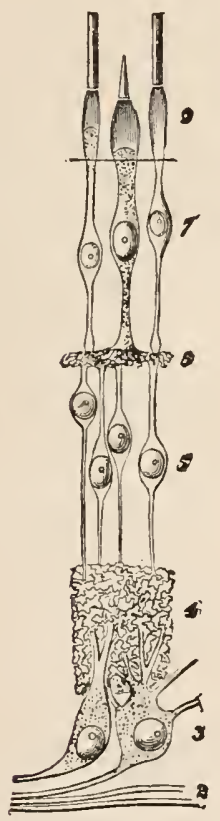

Fig. 268.

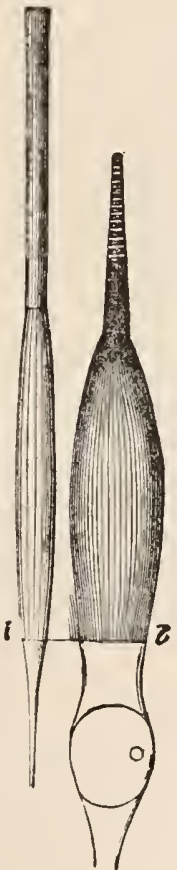

FIG 269.

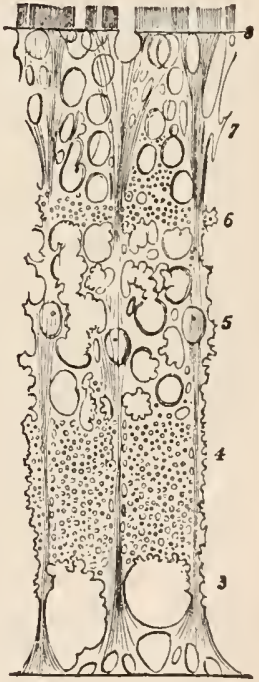

FIG. 267.-Diagrammatic representation of the connections of the nerve-fibres in the Retina. 1. Membrana limitans interna. 2. Optic nerve-fibre layer. 3. Layer of ganglion-cells. 4. Internal grannlated or molecular layer. 5. Internal granule-layer. 6. External granulated or molecular layer. 7. External granule-laycr. 8. Membrana limitans exterior. 9. Bacillary layer, or layer of rods and cones.

FIG. 268.-Rod and cone from the Retina of Man preserved in a two per cent. solution of perosmic acid, to show the fine fibres of the surface, and the different lengths of the internal segment. The outer segment of the cone is broken up into disks, which, however, are still adherent to one another; at the base of the cone are seen a few fine hairs ( $\times 1000$ diam.).

FIG. 269.-Diagrammatic representation of the connective tissue of the retina as secn near the ora serrata. The numbers correspond to those of the several layers of the retina shown in Fig. 267.

segment is conical and highly refractile, whilst in the rods the segment is usually regularly cylindrical. The plane of junction of the two segments is more anterior in the cones than in the rods. After removal from the body the outer segments of both the rods and cones undergo a kind of coagula- 
tion, imbibe water, and break up into a series of disks. Subsequently they undergo further changes of form, the final result being a spheroidal body resembling certain myelin drops. When well preserved they exhibit also a longitudinal and very fine striation. Ritter, Hensen, and others think that an axial fibre can be seen in the outer segnent of the rods. The internal segments of both rods and cones exhibit a fine longitudinal striation on their surface, which are rather channellings or fibres, probably the latter, since they both surround the base of the inner segment, and protrude from its outer extremity, inclosing the base of the outer segment in a kind of cradle. Hensen and some others believe that an axial fibre may be seen in the $i n$. temal segnient of the rods in some animals, but such fibres are not visible in man. The nucleated cone-granule is a bipolar cell, the peripheric process of which is the cone itself, whilst the central extremity arises from the external molecular layer, by the coalescence of a number of fine fibrils. The rods and cones, the latter of which present in many animals, as in birds and reptiles, a drop of brilliant-colored oily substance at their peripheric extremities, are the terminal organs of the optic nerve-fibres; but it still remains undecided whether the fibrils in the interior of the inner segments stand in connection with the nerve-fibrils of the fibres in question. The outer segment may possibly represent a non-nervous physical accessory apparatus. It is remarkable that section of the optic nerve in the living animal is followed by degeneration of all the elements of the retina except the bacillary layer, which thus searcely seems to belong to the true nerve-tissues. The layer of hexagonal pigment-cells, commonly termed the pigment epithelium of the choroid, belongs both physiologically and morphologically to the retina. The outer segments of the rods and cones are so closely cmbraced by them, in well-preserved specimens, that they will rather separate from the internal segments or fracture through their substance than become detached from them. The proper nervous structures of the retina are permeated and supported by a stroma of connective tissue, which is bounded externally and intemally by the membrane limitantes, the external limiting membrane corresponding to the inner extremity of the rods and cones or line of detachment of Jacob's membrane; and the internal limiting membrane (8) resting on the hyaloid. The supporting connective tissue (Fig. 269) is closely atlied structurally to that of the hrain and spinal cord, which has been named Neuroglia by Virchow. By Schultze it is termed spongy connective tissue. It fills up the interspaces between the ganglion-cells, granules, and nerve-fibres, and consists of radial supporting fibres (most constantly found in the internal granule-layer) and oval homogeneous nuclei.

616. 'There are two spots in the Retina, in which the arrangement of the foregoing components is essentially different; and from these differences, important physiological conclusions may be drawn. One of these is the slight eminence at which the Optic nerve enters, which is a little below and internal to the posterior extremity of the axis of the eye. 'The other is the "yellow spot of Soemmering," which is situated in the exact centre of the retina. The modifications undergone by the Retina at the maeula lutea and fovea centralis are considerable. Nearly in the axis of vision an intensely yellow pigment is deposited between the elements of the different layers, with the exception of the bacillar and external granular layer. The centre of the yellow spot is depressed anteriorly (Fig. 270) to form the fovea centralis. The retina is thicker at the macula lutea, of course, excepting at the fovea centralis, than in the adjoining parts, and is at the same tine softer and more prone to post-mortem change, probably in consequence of the deficiency of the radial supporting connective tissue. The layer of the ganglion-eells and internal division of the external granule-layer, are the layers 
that are most obvinusly thickenerl. On the other hand, there is no continuous layer of nerve-fibres beneath the membrane linitans interna. The rods are altngether deficient, their place being taken by the cones, which become longer and narrower, and are closely packed. The course pursued by the cone-fibres changes as compared with other parts of the retina from a radial to a horizontal direction. At the fovea all the layers of the retina, with the exception of the cones and external granules, diminish to a minimum.It is not a little remarkable, that the point of the entrance of the Optic nerve should be deficient in the power of receiving distinct visual impressions (\$ 634$)$; whilst the "yellow spot," the position of which according to Landolt is $3.905 \mathrm{~mm}$. to the outer side of the optic disk, and $0.785 \mathrm{~mm}$. higher, is the most sensitive portion of the entire Retina.' And hence it seems unequivocally to follow, that these impressions cannot act primarily upon the nerve-fibres, - a conclusion which harmonizes with the fact, that the fibres of the optic nerve are superimposed upon each other in the stratum which they form, in such numbers that it is not conceivable that they should be the prinary recipients of luminous impressions, since their transparency must allow rays of light to penetrate from one portion of the layer to another. The bacillary layer was formerly regarded as a reflecting apparatus, having for its purpose to stop the further passage of light, and to intensify its influence on the true retina; but since its connection with the proper nervous elements of the retina has been established, there seems much ground for believing (with Prof. Kölliker) that its rods and cones are the primary recipients of luminous impressions, and that they communicate their condition to the fibres of the optic nerve, by means of their own delicate fibrous prolongations, which seem to come into more or less direct connection with its ultimate ramifications.

617. The limits of Human Vision, as regards the minuteness of the objects of which it can take cognizance, have been investigated by Professor Ehrenberg, with the view of calculating the ultimate power of the Microscope. $^{2}$ In opposition to the generally received opinion, Ehrenberg arrived at the conchusion that, in regard to the extreme limits of vision, there is little difference amongst persons of ordinarily good sight, whatever may be the focal distance of their eyes. The smallest square magnitude usually visible to the naked eye, either of white particles on a black ground, or of

1 Aubert and Förster (v. Gräfe's A rehiv f. Ophth., Bd. vii, 1860, p. 152) have shown that the aenteness of vision in receding from the fovea centralis does not diminish in coneentric eircles, but more quickly above and below, and more gradually towards the out and the inside. They found also that the more remote any object was from the optie axis the larger it must be to be recognized, and further, that a small objeet in proximity to, the eye ean be recognized at a greater distance from the axis than a larger object remote from the eye. The measure of aeuteness of vision in general use amongst ophthalmie surgeons is a series of letters, the thickness of which is onefifth of their height, and which are placed at such a distanee that they subtend an angle of 5 '. 'The distance $d$ at whieh such letters are still distinctly recoguized divided by the distanee $D$ at which they subtend an angle of $5^{\prime}$ expresses the sharpness of vision. Thus, if the letters $C$, or $\mathbf{G}$, or $B$, be made of sueh a size that at 20 feet they subtend an angle of $5{ }^{\prime}$, and can be read at that distanee, the vision of the experimenter is perfect, $\mathrm{V}=\frac{d}{\mathrm{v}}$ or $\frac{2 \mathrm{l}}{20}=1$; but if he ean only see them at 10 feet, his vision $=\frac{10}{20}=\frac{1}{2}$; if only at 5 feet his $\mathrm{V}=\frac{5}{20}=\frac{1}{4}$, and so on. The absolutely smallest visual angle at whieh any object can under exeeptionally favorable circumstanees be seen subtends an angle of $50 \%$. (Hirschmann, 1867.)

2 Taylor's Scientific Memoirs, vol. i, p. 576. See also Helmholtz, Physiolog. Optik., 1860. 
black upon a whitc or light-colored ground, is about the $\frac{1}{405}$ th of an inch. It is possible, by the greatest condensation of light, and excitement of the attention, to recognize magnitudes between the $\frac{1}{4}, 0$ th and $\frac{1}{54}$ th of an inch, but without sharpness or certainty. Bodies which are smaller than these cannot be discerned with the naked eye when single, but may be seen when placed in a row. Particles which powerfully reflect light, however, may be distinctly seen, when not half the size of the least of the foregoing; thus gold-dust of the fineness of $\frac{1}{1}{ }^{1} 5^{t h}$ of an inch, may be discerned with the naked eye in common daylight. The delicacy of vision is far greater for lines than for mere points; since opaque threads of $\frac{1}{49} \delta$ th of an inch in diameter (about half the diameter of the Silkworm's fibre) may be discerned with the naked eye, when held towards the light. The size of the retinal image in these cases must be exceedingly small. In some of Bergmann's experiments it was found that black and white checkers of $\frac{1}{25}$ th of an inch square could be discerned at such a distance that the retinal image of each

FIG. 270.

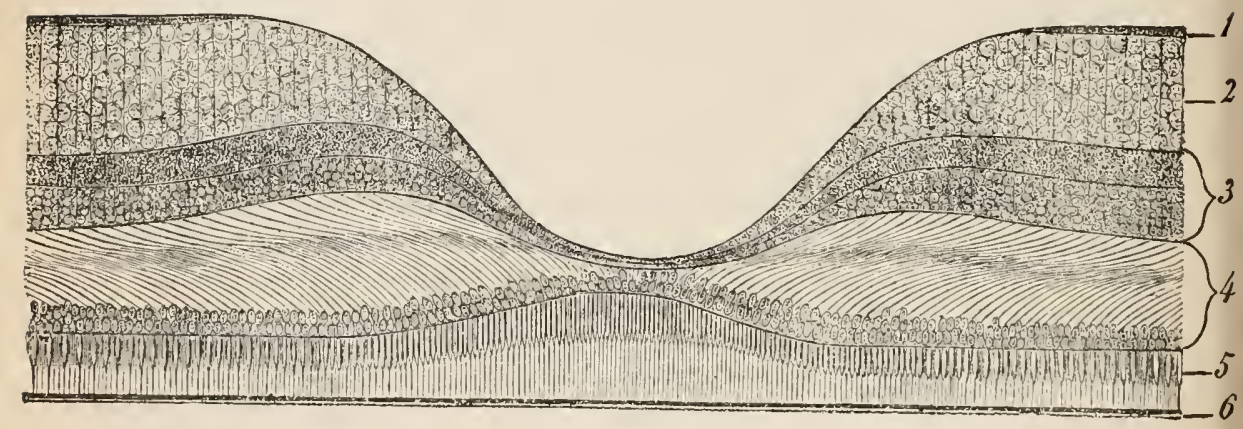

Diagrammatic section through the macula lutea and fovea centralis of the Retina of Man. 1. Optic nerve-fibres. 2. Ganglion-cells. 3. Internal granulated (molecular) layer and Internal granule-layer. 4. External granulated (molecular) layer, External fibrous layer, and Exterual granule-layer. 5. Rods and cones. 6. Pigment layer.

square could not have exceeded half the diameter of one of the cones of the bacillary laycr. ${ }^{2}$ - The degree in which the attention is directed to them, has a great influence on the rearliness with which very minute objects can be perceived; and Ehrenberg remarks that there is much greater difference imongst individuals in this respect, than there is in regard to the absolute limits of vision. Many persons can distinctly see such objects, when their situation is exactly pointed out to them, who camnot otherwise distinguish them; and the same is the case with persons of acuter perception, with respect to objects at distances greater than those at which they can sce most elearly. "I myself," says Ehrenberg, " camnot see $\sum^{1} 7_{0}^{1}$ th of an inch, black or white, at twelve inches' distance; but having found it at four or five inches' distance, I can remove it to twelve inches, and still see the object plainly." Similar phenomena are well known in regard to a balloon or a faint star in a clear sky, or a ship in the horizon: we casily see them after they have been pointed out to us; but the faculty of readily descrying objects depends on the habit of using the eyes in search of them, and of at-

1 Elirenberg mentions that he obtuined the finest particles of gold by seraping gilt brass; by filing pure gold, he always obtained much coarser particles.

2 Henle and Meissner's Bericht, i857, 1. 559. 
tending to the sensory impressions thus received ( $\$ 637$ ). Aubert ${ }^{1}$ found that the excitability of the retina for extremely feeble stimuli rapidly attained a high degree when a dark room was entered, though a slight increase in sensitiveness continued to take place for a considerable period if the sojourm in it were protracted. A wire heated by electricity was first discovered when at a temperature of about $666^{\circ} \mathrm{F}$. In another series of experiments he found that the feeblest illumination of the field of vision that could be recognized was about equal to that of the planet Venus when brightest, or to the white light of day admitted into a chamber through an opening forty-one seconds square. Small surfaces, however, always require considerably greater illumination, in order that they should be perceived, than large.

618. The amount of light admitted to the eye is regulated by the contraction and dilatation of the Pupil, the smallest diameter of which is about $\frac{1}{20}$ th, and its largest about $\frac{1}{3} \mathrm{~d}$ of an inch. The muscular structure of the Human Iris is entirely of the non-striated kind, being composed of the elongated fibre-cells, with staff-shaped nuclei which are characteristic of that variety. Part of these are so disposed as to form a circular sphincter (Fig. $271, a$ ), which can be readily seen in the iris of the white rabbit, or in the blue iris of man from which the uvea has been removed, immediately surrounding the pupillary margin to the breadth of about one-third of a line. The fibres of this sphincter are not absolutely parallel, especially at the outer margin, where they seem to become continuous with those of the radiating fasciculi $(b b)$, which may be traced from this sphincter (though usually with difficulty) to the outer margin of the iris, sometimes anastomosing with each other in their course. ${ }^{2}$ The contraction of the annular fibres, whereby the diameter of the pupil is diminished, is effected, as already explained ( $\$ 491)$, through the instrumentality of the Third pair of nerves; the contraction of the radiating fibres, on the other hand, whereby the pupil is dilated, is under the government of the cervical portion of the Sympathetic, being called forth (as MM. Budge and Waller have shown ${ }^{3}$ ) by irritation of the trunk of the Sympathetic in the neck, or of the lower part of the cervical portion of the Spinal Cord, by the magneto-electric apparatus; whilst section of the Sympathetic produces a permanent contraction of the pupil, the action of the Third pair being then no longer antagonized. It

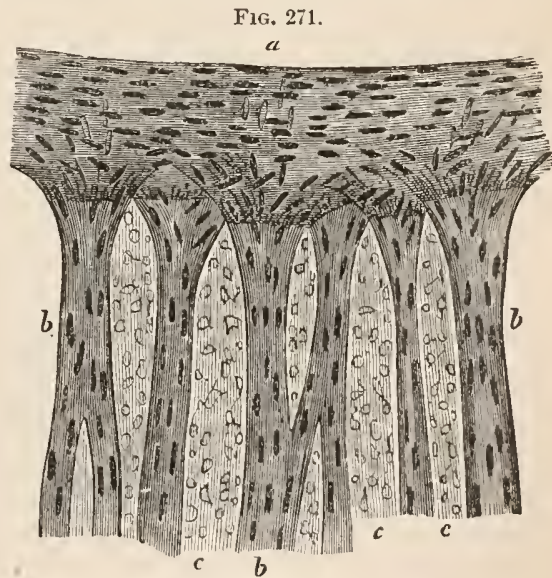

Museular structure of the Iris of a White Rabbit: $n$, sphincter of the pupil; $b, b$, radiating fasciculi of dilator muscle; $c, c$, connective tissue with its corpuseles. appears, from other experiments, that the fibres through which this movement is effected, pass through the Gasserian ganglion, and are distributed to the eye by the oplathalmic branch

1 Physiologie der Netzhaut, 1864.

2 See Prof. Kölliker's Mikroskopische Anatomie, Bd. ii, 8272 ; and Joseph J. Lister's Observations on the Contractile Tissue of the Iris, in Quart. Journ. of Microscop. Science, vol. i, p. 8. See Lancet, vol. i, 1870, pp. 127 and 211 .

3 Gazette Médicale, 1851, Nos. 41, 44. 
of the Fifth pair ( $\$ 490)$. The contraction of the Pupil is a reflex action, induced by excitation of the retina, and acting through the nervous circle formed by the optic nerves and tracts, and the third pair of cerebral nerves. It answers the purpose, as we have seen, not merely of excluding superfluous light from the eye, but also of cutting off the most divergent rays when the object is brought near the refracting surface ( $\$ 612)$, and of thus preventing the indistinctness of vision which would result from their admission. For, although, when the Eye is at rest, parallel rays come to a focus on the Retina, divergent or convergent rays proceeding from any point come to a focus either behind or in front of that membrane, forming upon it what is termed a "circle of dispersion ;" but by cutting off the outermost rays and permitting the entrance of those only which are nearly parallel, the magnitude of such circles is materially dininished, and vision correspondingly improved. It is interesting to observe that contraction of the pupil is effected with greater rapidity than dilatation, a matter of some importance in sudden alternations from light to darkness. Contraction of the pupil may also be produced by powerfully converging the optic axes, as in squinting inwards; by strong accommodation of the eyes for near objects, and, as already stated, by certain poisons, as the Calabar bean, nicotin, opium, etc--MI. BrownSéquard ${ }^{1}$ has shown that the Irides of various animals may be directly affected by Heat and Light. Thus if the eyes of dogs, cats, or rabbits, either soon after death, or shortly after their removal from the body, be suddenly exposed to an alteration of temperature amounting to $50^{\circ}$ or $60^{\circ} \mathrm{F}$., if the pupil be contracted, it expands, though on the contrary, if it be in the first instance dilated, it speedily contracts. These effects of heat have not been observed either in Man or the Mammalia during life. As regarls the direct action of Light, Brown-Séquard found that the Irides of eels and frogs which had been removed for several (even sixtecn) days from the body in winter, as well as the Irides of mammals and birds for a short time after death, contracted on exposure to the light of the sun or of a candle; this effect being produced even when the posterior half of the eye had been cut off, and when, therefore, there could have becn no reflex action. The yellow rays appeared to have the greatest energy. These remarkable phenomena prove, at all events, that the contraction of the pupil is not, as has vccasionally been maintained, exclusively due to vascular turgescence. The cause of the effect produced by Light is difficult to explain, but that occasioned by Heat may perhaps be attributed, as Brown-Séquard suggests, to the circumstance that a contracted miscle has less power than one in a statc of extcusion, so that if a stimulus act equally on both, when previously nicely balanced in point of strength, the uncontracted muscle will exert the greater force, and consequently overpower the contracted muscle. Dilatation of the pupil may be caused by strong irritation of sensory nerves, and occurs during violent muscular effort, and in dyspnoea, as well as from the action of belladonna.

619. The sense of Vision depends, in the first place, on the excitenent of our sensitional consciousness by the ocular picture impressed upon the retina, which represents the outlines, lights and shades, colors, and relative positions of the objects before us; and all the idcas respecting the real forms, distances, ctc., of borlies, which we found upon these data, are derived through the perceptions, either instinctively or experientially suggested by sensations. Many of these ideas are derived through the combination, in our minds, of the Visual perceptions, with those derived from the sense of Touch. Thus, to take a most simple illustration, the idea of smoothness is one essentially

1 Journal de la Physiologie, 1859, vol, ii, p. 294. 
tactile; and yet it constantly occurs to us, on looking on a surface which reflects light in a particular manner. But if it were not for the association which experience leads us to form, of the connection between polish as scen by the eye, and smoothness as felt by the touch, we should not be able to determine, as we now can do, the existence of both these qualities, from an inıpression communicated to us through either sense singly.-The general fact that, in Man, the greater part of those notions of the external world, by which his actions in the adult state are guided, are acquired by the gradual association of the two sets of perceptions derived through the Sight and through the Touch, is substantiated by amply sufficient evidence; this being chiefly derived from observations made upon persons born blind, to whom sight has been communicated by an operation, at a period of life which enabled them to give an accurate description of their sensations. The case recorded by Cheselden is one of the most interesting of these. The youth (about twelve years of age), for some time after tolerably-distinct vision had been obtained, saw everything flat as in a picture, simply receiving the consciousness of the impression made upon his retina; and it was some time before he acquired the power of judging, by his sight, of the real forms and distances of the objects around him. An amusing aneclote recorded of hint, shows the complete want which there is in Man, of any natural or intuitive connection between the ideas formed through visual and through tactile sensations. He was well acquainted with a Dog and a Cat by feeling, but could not renımber their respective characters when he save. them; and one day, when thus puzzled, he took up the Cat in his arms, and felt her attentively, so as to associate the two sets of ideas, and then setting her down, said, "So, puss, I shall know you another time." - A sinilar instance has come under the Author's own knowledge; but the subject of it was scarcely old enough to present phenomena so striking. One curious circunstance was remarked of him, which fully confirms (if confirmation were wanting) the view here given. For some time after his sight was tolerably clear, the lad preferred finding his way through his father's house (to which he had been quite accustomed when blind) by touch rather than by sight, the use of the latter sense appearing to perplex instead of assisting him ; but, when learning a new locality, he employed his sight, and evidently perceived the increase of facility which he derived from it. ${ }^{1}$ - The actions performed by many newborn animals do not constitute any valid objection to the view that such visual perceptions are for the most part acqnired by Man; for all that is indicated by them is, that certain sensations give rise to movements adapted to supply the wants to which they relate; and they do not afford any proof that definite notions, such as we entertain, of the forms and properties of external objects, are possessed by the animals which exhibit them.- We shall now examine, a little more in detail, into the means by which we gain such notions, and the data on which they are founded.

620. The first point to be determined, is one which has been a fruitful source of discussion,-the cause of erect vision, the picture upon the retina being inverted; and with this is connected the general question of the origin of our Sense of Direction.-The difficulty which has been raised in regard to the former subject, is rather apparent than real ; being founded on an erroneous notion of the nature of the Visual sense. For it seems to have been supposed that we look at the retinal picture with the "mind's eye," just as

1 The question has been proposed, whether a person born blind, who was able by the sense of Touch to distinguish a cube from a sphere, would, on suddenly obtaining his Sight, be able to di-tinguish them by the latter sense. This question was answered by Locke in the negative; and, as appears from the facts above stated, with justice. 
we look at the picture formed by a Camera with the bodily eye; and that our consciousness must be thereforc impressed by its discordance with the information which we receive through our sense of Touch. Some philosophers, indeed, have actually gone so far as to assert that the Infant must at first see everything inverted, and that the erectness of visual objects is only learncd by the corrective experience gained by touching and handling them. But such is clearly not the case; for the visual perception is obviously not a mere transfer of the sensorial impression, but is a mental state excited by it, and therefore related to it as an effect to its cause; and we know no reason why it should be less natural for the retinal picture to suggest to the mind the notion of erect position, than for it to have the contrary effect. Moreover, it will appear from investigations to be hereafter detailed $(\S 635)$, that there is in the eye a common "centre of direction," through which all lines must pass, that are drawn from any points of an external object to the corresponding points of its retinal image ; and that we immediately refer the cause of the excitation of any spot of the retina by a luninous impression, to an objective source in the "line of direction" which passes from that spot through the centre of direction; so that, in virtue of this "law of visible direction," as all the lines of direction crosis each other both vertically and laterally, the formation of an inverted image upon our retina suggests to our minds the representation of the object in its erect position, and the same reversal takes place also in regard to its two sides, which are transposed in the retinal picture. A peculiar arrangement of the receptive apparatus, which seems to be subservient to this mental appreciation of direction, has becn already noticed $(\S 615)$.

621. The cause of Single Vision with the two Eyes has, in like manner, been the subject of much discussion; and here, too, the difficulty is rather apparent than real, having for its foundation the idea that the mind looks at the two retinal pictures as at two separate objects, instead of being impressed by a certain state of the Sensorium, which may be excited through the instrumentality of either eye, or through that of both in combination. Some have even asserted, under the influence of this idea, that we do not really employ both eyes simultancously, but that the mind is affecterl by the image communicated by one only; which might secm to be confirmed by the fiact sufficiently well ascertained respecting the alternate use of the two eyes, when they are looking through two differently-colored media. But of this assertion a complete disproof is afforded by the knowledge we now possess ( $(623)$, that our appreciation of the solid forms of bodies depends on the combination by the Mind, of the images simultaneously suggested by the two pictures; and that our knowledgre of distances is in great part obtained in like manner.-Attempts have been made to explain the phenomena of Single Vision by the peculiar decussation of the Optic Nerves formerly described $(\S 518)$; it being supposed that only one Optic Ganglion would be affected by an impression nuade upon both Retine." 'This cxplanation, however,

With regurd to the precise situation of this "eentre of direction," there is a want of aeeordance among those who have attempted to determine it; some having placed it in the eentre of the pupil, others in the centre of the crystalline lens, ithers ut various distances between this and the centre of the globe, and others anong them Sir D. Brewster) in the centre of the globe. This last notion, with the "law of visible direction "founded upon it, - which affirms that every objeet is seen in the direction of the perpendicular (or radius) to every point of the retina which is impressed -is so munifestly wrong, that it is difficult to eoneeive how it could ever have been entertained by men of scienee. The experimental investigations of Listing indicate a point near the centre of the erystatline as the "centre of dircetion" ( 8609$)$.

2 This deeussation seenis to be even more complete than was form.rily supposed, for in various experiments made by Dr. Watler upon the effects of section of one optic 
even supposing the fact to be as stated, would be far from affording the solution of the problem; and it would be entirely inapplicable to that very important series of phenomena to be next described, which show how large an amount of information we derive, not from the repetition, but from the differ. ence, of the sensory impressions made by the same object upon our two retina; and which indicate that here, as in the case of erect vision, the mental interpretation of the sensory impressions is a process altogether removed from the simple affection of the consciousness by those impressions, and is not to be accounted for by any structural arrangements of the Sensorial apparatus. One condition of single Vision, however, seems to be this, that the two images of the object should be formed on parts of the two retinse which are accustomed to act in concert; and habit appears to be the chief means by which this conformity is produced. There can be no doubt, however, that double images are continually being conveyed to the Sensorium; but that, from their want of force and distinctness, and from the attention being fixed on something else, we do not take cognizance of them. This may be shown by a very simple experiment. If two fingers be held up before the eyes, one in front of the other, and rision be directed to the more distant, so that it is seen singly, the nearer will appear double; while, if the nearer one be regarded more particularly, so as to appear single, the more distant will be seen double. A little consideration will show, therefore, that our minds must be thus continually affected with sensations, which cannot be united into the idea of a single image; since, whenever we direct the axes of our eyes towards any object, almost everything else will be represented to us as double; but we do not ordinarily perceive this, from our minds being fixed upon a clear and distinct image, and disregarding, therefore, the vague undefined inages formed by objects not in the visual focus. Of this it is very easy to satisfy one's self. It has been found by Gehler, J. Miiller, and others, that those objects which do not appear double when a given point is fixedly regarded are situated in a certain circular line, termed the Horopter, of which the chord is formed by the distance between the eyes, whilst the magnitude of the circle is determined by three points, namely, by the two eyes and the point towards which their axes converge. Prof. Helmholtz, however, considers that generally the Horopter is a line of double curvature, produced by the intersection of two hyperboloids, or exceptionally, of two plane curves; and that when we look straight forward to a point of the horizon, the Horopter becomes a horizontal plane passing through our feetbeing, in fact, the ground on which we are standing. The form and situation of the Horopter appear to be of great practical importance in enabling us to judge with accuracy of the shape and distance of those objects which are situated in it. ${ }^{1}$ - The above experiment, moreover, makes it evident that

nerve, it was found that the Optic Tract upon the same side as the lesion, showed no signs of degeneration, whilst that of the opposite side soun underwent disorganization with the exception of a few strands on the inner and posterior aspect; thus countenancing the opinion that there are commissural fibres passing between the corpora quadrigemina of the two sides, but negativing the view that some of the tibres from each retina run to the corpora quadrigemina on their own side. Dr. Waller is inclined to think, therefore, that the decussation is complete. It is importunt to observe, that in these experiunents the anterior portion of the divided nerve, with the retinal elements, remained unchanged for many weeks. See Proceedings of the Royal Society, vol. viii. On the other hand, the reader may refer to some curious cases of partial Amaurosis recorded by Mr. Towne in the Guy's Huspital Reports for 1863 , p. 127.

1 See Müller's Physiology, translated by Dr. Baly, vol. ii, p. 1196; also the Croonian Lecture for 1864, delivered before the Royal Society, by Professor Helmholtz, in rol $x$ iii of the Proceedings of the Royal Suciety, and Dr. H. Kaiser, in Archiv $f$. $U_{\text {phth. }}$, Bd. xv, 1869 , p. 75. Dr. Kuiser, who hus treated the subject analytically, 
double vision cannot result from want of symmetry in the position of the images upon the retina, to which some have attributed it; for it answers equally well, if the line of the two fingers be preeisely in front of the nose, so that the inclination of both eyes towards either objeet is equal; the position of the images of the second object must then be at the same distance on either side from the central line of the retina, and yet they are represented to the mind as double. Hence, too, it seems clear that singleness of vision in an object that is looked at, is also dependent in part upon the convergence of the optic axes in that object $(\$ 613)$; and that this is the case appears further from a curious experiment devised by Prof. Wheatstone, in which two similar objects are made to seem as one, when they are placed in the line of eonvergence. This is aecomplished by looking through two tubes, placed before the right and left eyes respectively, at two similar objects of any deseription, placed near the farther extremities of the tubes; if, now, these objects be slightly approximated, so that the axes of the tubes (still direeted towards them) meet in a point beyond, the mind is impressed with the image of only a single object, and this appears to be removed back to the point of convergence.

622 . On the mode in whieh our notion of the solid forms and relative projection of objects is acquired, great light has been thrown by the interesting experiments of Professor Wheatstone. It seems perfectly evident, both from reason and experience, that the flat pieture upon the retina, which is the inmediate source of our sensation, could not itself convey to our minds any notion but that of a corresponding plane surface. In fact, any notion of solidity, whieh might be formed by a person who had never had the use of more than one eye, would entirely depend upon the combination of his visual and tactile sensations. This view is fully eonfirmed by the case already referred to $(\$ 619)$, as recorded by Cheselden. The first visual idea entertained by the youth was, that the objects around him formed a flat surface, whieh touched his eyes, as they had previously been in contact with his hands; and after this notion had been corrected, through the education of his sight by his touch, he fell into the converse error of supposing that a picture, which was shown to him, was the object itself represented in relief on a small scale.-But where both eyes are cmployed, it has bcen aseertained by Professor Wheatstone, that they concur in exciting the perception of solidity or projeetion, whieh arises from the mental combination of the two dissimilar pictures formed upon the two retinx. It is easily shown, that any near object is scen in two different modes by the two eyes. Thus let the reader hold up a thin book, in such a manner that its back shall be exactly in front of his nose, and at a moderate distance from it; he will observe by elosing first one eye and then the other, that his perspeetive riew of it (or the manner in which he would represent it on a plane surface) is very different, ae-

states that the interior system of the Horopter is an liyperbole of equal dimensions for each eye; one of the radii of which pasees through the fovea centratis and never passes through the punctum caeum; its summit is found at the side of the fovea. The real axes have the same angle between them as that of the two retinal horizons; their inclination on this does not diller mueh from half a right angle. In individual cases it is found that for a point of fixation situated at an infinite distance the Horopter becomes at spherical surfice with an infinite radius. Thus in looking at a star all the stars are found on the Horopter. For a point of fixation situated in the primary position of the retinal plane the Horopter becomes reduced to a circte, the eircle of the IIoropter of $M$ iuller passing through the centre of each globe and the fixed point. For a point of fixation situated in the median plane, the Horopter is an ellipse situated in a plane which biscets the angle formed by the visual plane and the primary prosition.

1 Philosophical Transactions, 1838 and 1852. 
cording to the eye with which he sees it. With the right eye he will see its right side, very much foreshortened; with the left he will gain a corresponding view of the left side; and the apparent angles, and the lengths of the different lines, will be found to be very different in the two views. On looking at either of these views singly, no other notion of solidity can be acquired from it, than that to which the mind is conducted, by the association of such a view with the touch of the object which it represents. But it is capable of proof, that the mental association of the different pictures upon the two retinæ, does of itself give rise to the idea of solidity. This proof is afforded by Professor Wheatstone's ingenious instrument, the Stereoscope, first described by him in $1838 .^{2}$

623. The Stereoscope in its original form essentially consists of two plane mirrors, inclined with their hacks to one another, at an angle of $90^{\circ}$. If two perspective drawings of any solid object, as seen at a given distance with the two eyes respectively, such as those at $\mathrm{A}$ and $\mathrm{B}$, Fig. 272, be so placed before these mirrors, one before each, that their two images shall be made to fall upon the corresponding parts of the two retinæ, in the same manner as the two images formed by the solid object itself would have done, the mind will perceive, not a single representation of the object, nor a confused blending of the two, but a projecting or receding surface, the exact counterpart of that from which the drawings were made. ${ }^{2}$ The solid form is forcibly

FIG. 272.

$\mathbf{A}$

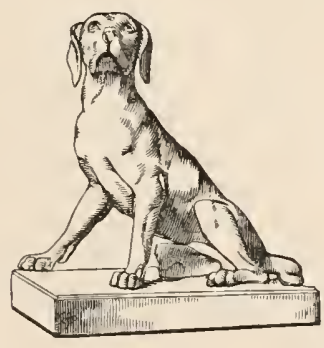

B

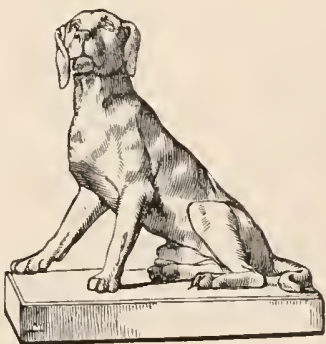

impressed on the mind, even when outlines only are given, especially if these be delineations of simple geometrical figures, easily suggested to the mind; and it may be readily shown that the very same outline will suggest different conceptions, according to the mode in which they are placed. Thus in

1 Various modifications of this instrument have been subsequently introduced; and there is one whieh has come into very extensive use, in which the two monocular pictures placed side by side, as in Figs. 272, 273, are viewed by the two eyes respectively through two halves of a convex leus. The great advantuge of this instrument is its portability, and its enlargement of the pictures by the magnifying power of the lenses; but it is limited to pictures of small size, siriee the distance between corresponding points of the two pietures must not exceed the distanee between the centres of the two eyes; and it is ineapable of many adaptations which can be mude with the mirror-stereoscope. In the Stercomonoseope of Claudet the idea of relief is obtained by looking with both eyes at once on a iround glass plate at the image produced by the coalescence of the two images of at stereoscopic slide, each refraeted by a separate lens. (See Proceed. of Royal Soeiety, vol. ix, 1857-59, p. 194.)

$\&$ The most striking effeet is produced by two Photographie pictures, taken at the same tine by two cameras, so placed that their axes shall form the same angle with each other as that which the axes of the two eyes would form when looking at the same object. This adaptation, though the credit has been assumed by others, was originally devised by Prof. Wheatstone. 
Fig. 273, the upper part of figures A, B, when combined in the Sterenscope, excite the idea of a projecting truncated pyramid, with the small square in the centre, and the four sides sloping equally away from it; whilst the lower pair of figures, C, D, which are the same as the upper, but transferred to the opposite sides, no less vividly bring before the mind the visual conception of a receding pyramid, still with the small square in the centre, and the four sides sloping equally towards it.-Professor Wheatstone has further shown, by meaus of the Stereoscope, that similar images, differing to a certain cxtend in magnitude, when presented to the corresponding parts of the two retiux, give rise to the perception of a single object, intermediate in size between the two monocular pictures. Were it not for this, objects would appear single only when at an equal distance from both eyes, so that their pictures upon the retinie are of the same size; which will not happen unless they are directly in frout of the mediau line of the face. Again, if pietures

FIG. 273 .
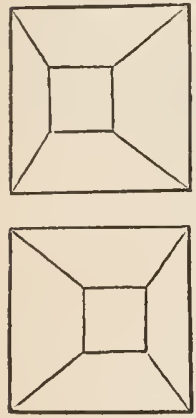

C
B
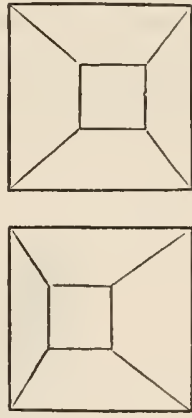

1) of dissimilar objects be simultaneously presented to the two eyes, the consequence will be similar to that which is experienced when the rays coine to the eye through two differently colored media; the two images do not coalesce, nor do they appear permanently superposed one upon the other; but at one time one image predominates to the exclusion of the other, and then the other is seen aloue; and it is ouly at the moment of change that the two seem to be intermingled. It does not appear to be in the power of the Will, Professor Wheatstone remarks, to determine the appearance of either; but if one picture be more illuminated than the other, it will be seen during a larger portion of the time. If, however, the differences in the two pictures be such that the Mind can reconcile them, an intermediate conception is formed; thus if two photographic portraits be taken at the proper angle for the Stereoscope, not sinultaneously but consecutively, and the "sitter" alter his expression in the interval, so that one of the portraits represents him with a smilc, and the other with a frown, the Stereoscopic image will present an intermediate expression of placidity.-Many other curious experiments with this simple instrument are relater by Professor Wheatstone; and they will go to confirm the general conclusion, that the combination of the dissimilar images furnished by the two eyes is a mental act, the resultant of which, in the case of all objects that are near enough to be seen in different perspective with the two eyes, is a mental image (referred to the visual sense) possessing the attributes of solidity and projection. In regard to distant objects, however, the difference in the images formed by the two eyes is so slight that it cannot aid in the determination; and hence it is, that whilst we have no difficulty in distinguishing a pieture, however well painted, from a solid object, when placed near our eyes (since the idea which might be suggested by the inage formed on one eye will then be corrected by the other), we are very liable to be misled by a delineation in which the per-

1 It is a remarkable illustration of this principle, that a photographic representation of a lundscape, building, etc., when viewed with one eye at a moderate distance, 
spective, light and sliade, etc., are faitlifully depicted, if we are placed at a distance from it, and are prevented from perceiving that it is but a picture. ${ }^{1}$ In this case, however, a slight movement of the head is sufficient to undeceive us; since by this movement a great change would be occasioned in the perspective view of the object, supposing it to possess an uneven surface; whilst it scarcely affects the image formed by a picture. In the same manner, a person who only possesses one eye, may obtain, by a slight motion of his head, the same idea of the form of a body which another would acquire by the simultaneous use of his two eyes. ${ }^{2}$

624. Our appreciation of the relative Distances of near objects seems to be derived in like manner from the mental combination of the perceptions derived from the dissinilar pictures upon the two retine, assisted by the sensations derived from the muscles of the eyeballs, which are put in action to bring the optic axes into the requisite convergence. How much our right estimation of the relative distances of objects not too far removed from the eye, depends upon the joint use of both eyes, is nade evident by the fact, that, if we close one eye, we find ourselves unable to execute with certainty many actions (such as threading a needle, or snuffing a candle) which require its guidance. In proportion as the object is approximated to the eyes, slight differences of distance produce marked differences in the degree of convergence, and these are readily appreciated so as to afford the means of very nice discrimination; whilst, on the other hand, in proportion as they are removed further and further, do the optic axes approach parallelism, and the power of appreciating differences of distance is lost. It is the usual opinion that the muscnlar sensation which accompanies the inclination of the optic axes, immediately suggests the notion of the distance of an object; and that our appreciation of its size depends upon a secondary interpretation of the magnitude of its picture on the retina, on the basis of this notion. But it would appear from the experiments of Prof. Wheatstone, that the reverse is the case; the sensation of convergence assisting in the first instance to determine the size, and the appreciation of distance being a secondary judgment based on this foundation $(\$ 627)$. - The power of estimating distance from the foregoing data, lowever, is obviously, in Man, not an intuitive but an acquired endowment; for it is evident to any observer, that infants, or older persons who have but recently acquired sight, form very imperfect ideas respecting the distance of objects; their attempts to grasp bodics which attract their attention being for a long time unsuccessful, so that they only gradually learn to ineasure distances by the sight, through the medium of the touch. And it seems to follow from this, that even the notion of "projection," which we seem necessarily to form when looking at a solid object within a moderate distance, or at a properly adjusted pair of Stereoscopic pictures, is not derived from an original intuition, but is the result of the association of our visual with our tactile experience, very early in life, so as to constitute a "secondary intuition" on which all our subsequent appreciation of projection is based.

frequently brings the real scene fur more forcibly before the mental vision than when it is looked at with both eyes; since, in tle latter case, the mind cannot avoid perceiving the flutuess of its surface; whilst in the former, the perspective, and the distribution of the lights and shadows, are free to suggest to the mind the relative distances and projections of the several parts.

1 This delusion has been extremely complete, in some of those who have seen the panoramic view of London in the Colosseum. A lively and interesting account of it is given in the Journal of the Parsee Shipbuilders, who visited England some years ago.

${ }^{2}$ For many interesting experiments with the stereoscope, see Mr. T. Towne in Guy's Hospital Reports, for 1862 and 1863. 
625. In regard to remote objects, our judgment of Distance is chiefly founded upon their apparent size, if their actual size be known to us ; but, if this be not the case, and if we are so situated that we cannot judge of the intervening space, we principally form our estimate from that effect of different degrees of remoteness upon the distinctness of their color and outline, which is known to Artists as "aerial perspective." Hence this estimate is liable to be greatly affected by varying states of the atmosphere, as is particularly known to every one who has visited rarmer climates; where the extreme clearness of the air sometimes brings into apparently near proximity a hill that rises some iniles beyond a neighboring ridge (the intervening space being hidden, so as not to afford any datum for the estimate of the distance of the remote hill), whilst a slight haziness carries its apparent distance to three or four times the reality. Additional means of judging of the distance of remote objects pointed out by Aubert, ${ }^{1}$ are found in their parallax or apparent change of place, on the alteration of our own position with regard to them, and in the rate of movement, both absolute and relative, of the objects themselves, if they happen to be in motion.

626. Our cstimate of the Size of a remote object is partly dependent upon the visual angle under which we see it, and partly upon our estimate of its distance. ${ }^{2}$ The "visual angle," formed by imaginary lines drawn from the eye (Fig. 274, A) to the extreme points, B, C, of the object, is the measure of the dimension of its image upon the retina ; and it is obvious that, if two objects, B C, D E, the former twice the length of the latter, be placed at the same distance, the visual angle $\mathrm{B} \mathrm{A} \mathrm{C}$ being twice as great as the angle $\mathrm{D} \mathrm{A} \mathrm{E}$, the image of $\mathbf{B}$ C upon the retina will be twice as long as that of $\mathrm{D} E$, and the mind will estimate their relative sizes accordingly. But if the distance of the object $\mathrm{D}$ E from the eye be diminished to one-half, so that it is brought into the position $\mathrm{F} \mathrm{G}$, its visual angle, and consequently the size of its image on the retina, will now be equal to that of $\mathrm{B} \mathrm{C}$; and the estimate we form of the relative sizes of the two, will entirely depend upon the idea we entertain of their relative distances. Hence any circumstance which modifies that idea, produces a corresponding difference in our estimate of their size; so that the apparent size of an object, seen under a given visual angle, may be estimated as larger or smaller than the reality, according as we suppose it to be more or less distant than it really is. Of this we have a familiar instance in the fact, that if we meet a child whilst we are walking across a common in a fog (the flatness of the ground not giving us much power of estimating the intervening space), it appears to have the stature of a man, and a man secms like a giant; for the indistinctness of outline causes the mind to conceive of the figures as at a greater distance than they really arc, and their apparent dimensions are augmented in like proportion. For if the object F G (Fig. 274) be mentally earried back to the distance of I $\mathrm{E}$, being still scen under the visual angle $\mathrm{FA}$ G (or B A C), it will appear to possess the length B C instead of $\mathrm{D}$ E. On the other hand, if the object $\mathrm{B} \mathrm{C}$ were to be mentully brought forward into a position $\mathrm{K} \mathrm{L}$, its apparent sizc being still determined by its visual angle, it will secm to be reduced to the lengtle $\mathrm{F}$ G. That our estimate of the Size of near objects, however, depends upon a more direct

I Thysiologie der Netzhaut, 1864, p. 17.

2 When oljects are so remote that we lave no means of even approximately estimating their distance, we have no measure whutever of their size. Thus, the Sirn and the Monn are of nearly the same apparent size to us, though one is about four humdred times the distance of the other; and we may eover eithar disk with a sixpence held near the eye, so as to be seen under the same visual angrle; but we do not possess the least power of estimating the actual sizes of these objecis, save by a ealculution bused on a knowledge of their relative distances. 
process, seems to be a necessary inference from the following very ingenious experiments, made by Professor Wheatstone with a modification of his MirrorStereoscope, devised for separately testing the influence of the two conditions, namely, the magnitude of the retinal picture and the degree of convergence

Fig. 274 .

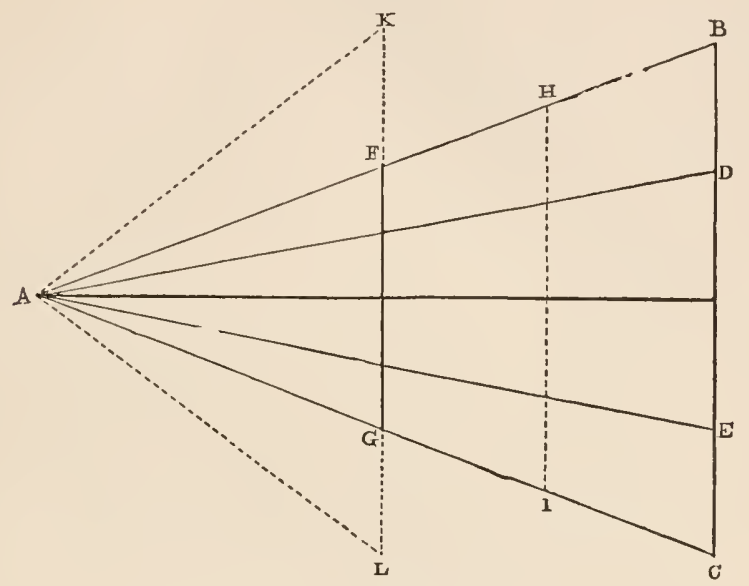

of the optic axes, -which are ordinarily in action together. When an object is moved nearer to or farther from the eye, its perceived or estimated magnitude undergoes no change. But if two pictures, placed in the mirrorsterenscope, be made to move to and from the mirrors, in such a manner as to vary their distances from these (and therefore from the eyes), without altering the angle of convergence, their perceived magnitudes are augmented and reduced, in precise proportion to the increased and diminished sizes of the retinal pictures. Conversely, if the two pictures be made so to change their places in regard to the mirrors (by moving in a horizontal circle, of which the middle point between the mirrors is the centre), that the angle of convergence is increased or diminished, as it would be if the object were brought nearer to the eyes or removed farther from them, the perceived magnitude of the pictures is altered in an inverse manner; being reduced when the angle of convergence is increased, and increased when the inclination of the optic axes is lessened so as to approach parallelism. Thus it appears that the absence of alteration in the perceived magnitude of an object as ordinarily seen at varying distances, is the result of the inverse action of these two kinds of suggestion; for the enlargement of the retinal picture when acting alone, occasions an increase in the perceived magnitude, whilst an increase of convergence, taking place by itself, diminishes the perceived magnitude; and thus as these alterations occur simultaneously when an object is approximated to the eye, its dimensions seem to undergo no change; as will also be the case when, by the removal of the object to a greater distance, these conditions are again made to vary simultaneously, though in a contrary direction.-It may further be remarked, that in the first of the foregoing experiments, the picture whose perceived magnitude is undergoing enlargement or diminution in consequence of the alteration of its retinal magnitude, seems evidently to be approaching or receding; yet if we fix our attention on it when it is stationary, at any instant, it appears to be at the same distance at one time as at another,- the effect being very much like 
that of the Phantasmagoria, in which the alteration in the size of the images on the screen suggests the notion of their approach or recession, although we are quite sensible that the distance of the screen from our eyes remains constantly the same. In the second experiment, on the other hand, the picture whose perceived magnitude is undergoing diminution or enlargement in consequence of increase or lessening of the angle of convergence, does not appear either to approach or recede, and yet, when attentively regarded in different fixed positions, it is felt to be at different distances. Hence, as Professor Wheatstone observes, convergence of the optic axes suggests fixed distance to the mind, whilst variations of retinal magnitude suggest change of distance; and, however paradoxical it nay seem, "we may perceive an object approach or recede, without appearing to change its distance, and an object to be at a different distance without appearing to approach or recedc." $-\mathrm{A}$ like alteration in apparent size is produced when two pairs of figures (such as those given in Fig. 273), the effect of one of which is to suggest a projecting, and that of the other a receding form, are viewed at the same time in the ordinary Stereoscope. For it will be observed that the relative size of the parts which appear to project is reduced, whilst that of the apparently receding parts is angmented; as is particularly the case with the square truncated end of the pyramid, which is estimated by most persons as fron one-third to one-half larger in each of its dimensions in the receding, than it is in the projecting pyramid, notwithstanding that the actual sizes of the squares in the two sets of figures are precisely the same. For supposing H I (Fig. 274) to represent the real side of one of the small squares, which becomes the truncated end of the pyramid; when this is brought forward by the mind into the position $\mathrm{K} \mathrm{L}$, as the truncated top of a projecting pyramid,

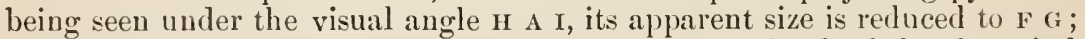
whilst, on the other hand, the very same square, carried back by the mind to the distance D E, as when it forms the truncated end of the receding pyramid, is mentally enlarged to the dimensions B c, the visual angle $\mathrm{B}$ A C being the same as $\mathrm{H} \mathrm{A}$. .

627. The large share which the Mind has in the interpretation of even such visual impressions as seem to us neccssarily to induce particular perceptions, is further shown by a very remarkable class of phenomena, termed by Professor Wheatstone (their discoverer) Conversions of Relief. The simplest example of this class is presented by the alteration in the visual pioduct of the same Stereoscopic pictures, when their positions are transposed. Thus the very same diagrams, which as placed in the upper part of Fig. 273 , bring before the mind's eye the conception of a projecting pyramid, when changed to the position which they occupy in the lower part of that figure, call up the image of a receding pyramid. And a corresponding effect is produced by the reversal of any other pair of Stereoscopic pictures; all that should project being made to recede, all that should recede being made to project, provided the converse has any mcaning which the Mind can readily appreciatc.-But the same effects may be produced, if the objects themselves are looked at by an instrument devised by Professor Wheatstone, and termed by him the Pseudoscope; the optical effect of which is, to reverse the ordinary visual relations between the near and distant parts of an object; the two conditions described in the preceding paragraph being combined inversely, so that as an object or part of an object is nearer the eye, its larger picture on the retina is accompanied by a diminished convergence of the optic

1 See Philos. Transact., 1852, pp, 2-5. The Author thinks it well to add, that he has himself verified the above very eurious results; which are scarcely less valuable contributions to the Physiology of Binocular vision, than those earlier attained by the sume eminent experimentalist. 
axes. When the impression of a seal is looked at with this iustrument, it is converted into the representation of the seal itself; or, if the seal be looked at, it presents the figure raised in relief, as in its ordiuary impression. So, the inside of a cup or basin appears as a solid convex body; whilst the outside appears depressed and concave. A bust regarded in front becomes a deep hollow mask; whilst the interior of the cast of a face presents the appearance of the face in its ordinary relief. A china vase, ornamented with colored flowers in relief, seems like a vertical section of the interior of such a vase, with hollow impressions of the flowers. The base of a brain seems concave, like the interior of the base of the skull which is its reflex; and the latter seems convex and projecting, like the base of the brain.-These and similar appearances are not always immediately perceived ; and some present themselves much more readily than others. Those converse forms which we are accustomed actually to see, or which have a meaning that the mind can easily apprehend, are those which are most readily perceived. Thus, the illusion which may be produced with a bust or with the cast of a face, is not obtainable even by a lengthened pseudoscopic contemplation of the real face, which we cannot conceive of as thus "turned inside out." Another very interesting fact is, that those to whom the illusion does not at first present itself, usually find it suddenly come upon them after a little time, especially if they should have directed their minds to the imaginary conception of the object under its changed aspect. And, further, when the conversion has taken place, the natural aspect of the object continues to intrude itself, sometimes suddenly, sometimes gradually, and for a longer or shorter interval, when the converse will again succed it. This is due to the involuntary alternation of the attention, between the conception suggested to the mind by the visual impressions derived from both eyes, and that which is derived from either eye singly; the latter, moreover, harmonizing with and being strengthened by our recollection of the object as we have seen it before, or (if it be new to us) by our notion of its natural appearance. A remarkable illusion in respect to the direction of lines is exhibited in the accompanying diagram (Fig. 275), construeted by Zöllner, which if regarded vertically, and still more if at an angle of $48^{\circ}$ from the perpendicular with one eye, presents the following peculiarities: Firstly, the dark longitudinal lines do not appear to be parallel, but to converge above and below alternately; secondly, the two halves of each oblique stria, traversing a longitudinal line, do not appear to be, as they really are, continuous with one another, but the lower half seems to be displaced downwards; and thirdly, sometimes, though not always, a stereoscopic effect is perceived, as though the lines were drawn on a sheet of papel folded longitudinally. Hering ${ }^{2}$ explains this by a train of reasoning too long to be here inserted, but to the effect that all acute angles under $60^{\circ}$, on account of the natural curvature of the retina, appear less than they really are.

628. The persistenee during a certain interval of impressions made upon the retina, gives rise to a number of curious visual phenomena, which can be here only briefly adverted to. The prolongation of the impression will be governed, in part, by its previous duration: thus when we rapidly move an ignited point through a circle, the impression itself is momentary, and remains but for a short period: whilst, if we have been for some time looking at a window, and then close our eyes, the impression of the dark bars traversing the illumiuated space is preserved for several seconds. One of the

2 Funke's Lehrbuch der Physiologie, vol. ii, 1866, p. 416. 
results of this persistence is the combination into a single image, of two or more objects presented to the eye in successive movements; but these must be of a kind which can be united, otherwise a confused picture is produced. Thus in a little toy, called the Thaumatrope, which was introduced some years ago, the two objects were painted on the opposite sides of a card, - a bird, for instance, on one, and a cage on the other; and when the card was made (by twisting a pair of strings) to revolve about one of its diameters, in such a manner as to be alternately presenting the two sides to the eye at minute intervals, the two pictures were blended, the bird being seen in the cage. A far more curious illusion, however, was that first brought into notice by Professor Faraday; who showed that, if two toothed wheels, placed

Fig, 275.

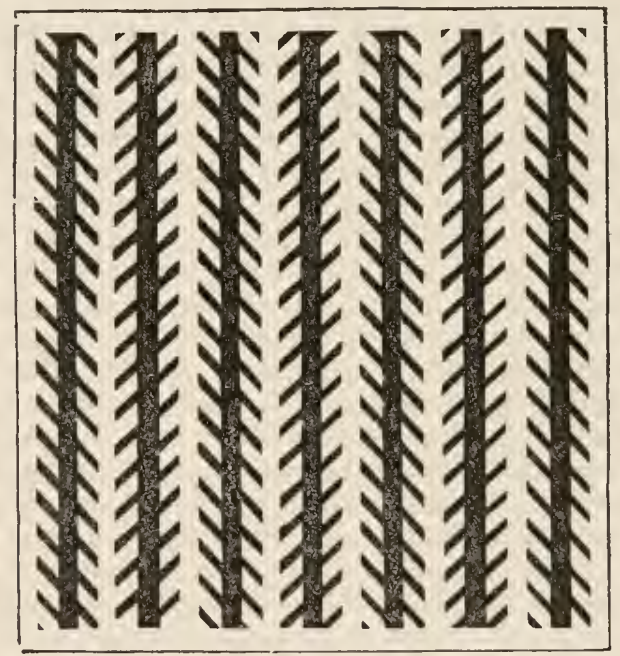

one behind the other, be made to revolve with equal velocity, a stationary spectrum will be seen; whilst if one be made to revolve more rapidly than the other, or the number of teeth be different, the spectrum also will revolve. The same takes place when a single wheel is made to revolve before a mirror, the whecl and its image answering the purpose of the two wheels in the former case. On this principle, a number of very ingenious toys have been constructed: in some of these, the same figure or object is seen in a variety of positions; and the successive impressions, passing rapidly before the eyc, give rise hy their combination to the idea that the object is itself moving through these positions. ${ }^{-}$- It is interesting to remark, moreover, that when

1 A very beautiful "philosophieal toy" was shown to the Author some years since, by its inventor, Mr. Roberts, the eelebrated machinist of Manchester; consisting in an apparatus by which it was made possible to read words printed on a card, although the eard iteolf wats made to revolve on its axis even 40,000 times in a minute. The principle of its construetion was simply this, - that the eye eanght a suceession of glimpaes of the eard, through a narrow slit before which a disk with a single correspondine ferforation was made to revolve; the rate of movement of this disk being so acljusted to that of the card, that whenever the eye caught sight of the latter, it was momentarily in the same prosition, so that, by the suceesion of transient impresions thus made upon the retina, the words printed on the curd could be distinctly rend. 
the eye has been for some time contemplating an object in motion, and is then directed towards stationary objects, these appear for a short time to have a like movement. Any railroad traveller may try this simple experiment, by first lookiug at the hedges, etc., which he is rapidly passing, and then at some part of the interior of the carriage itself, especially one which presents a series of parallel lines. But when the impression of movement has been of longer duration, its effects are less transient; thus a person who has been for some time on board ship, sees the floors, walls, and ceiliugs of his apartments on shore in a state of continual up and down motion, even for some days after he has landed. This would seem to be rather a sensorial than a retinal phenomenon.

629. When the Retina has been exposed for some time to a strong impression of some particular kind, it secms less susceptible of feebler impressions of the same kind. Thus, if we look at any brightly luminous object, and then turn our eyes on a sheet of white paper, we shall perceive a dark spot upon it ; the portion of the retina which had been affectel by the bright image, not being able to receive an impression from the fainter rays reflected by the paper. The dark spectruin does not at once disappear, but assumes different colors in succession,- - these being expressions of the states through which the retina is passing, in its transition to the natural condition. If the eye has received a strong impression from a colored object, the spectrum exhibits the complementary color $;^{1}$ thus, if the eye be fixed for any length of time upon a bright red spot on a white grouud, and be theu suddenly turned so as to rest upon the white surface, we see a spectrum of a green color:The same explanation applies to the curious phenomeuon of "colored shadows." It may not unfrequently be observed at sunset, that, when the light of the sun acquires a bright orange color from the clouds through which it passes, the shadows cast by it have a blue tint. Again, in a room with red curtains, the light which passes through these produces green shadows. In both instances, a strong impression of one color is made on the general surface of the retina; and at any particular spots, therefore, at which the light is colorless but very faint, that color is not perecived, its complement only being visible. The correctness of this explanation is proved by the fact, that, if the shadow be viewed through a tube, in such a manner that the colored ground is excluded, it seems like an ordinary shadow. It is not unlikely that, as Müller suggests, the prerlominant action of one color on the retina disturbs (as it were) the equilibrium of its condition, and excites in it a tendency to the development of a state correspouding to that which is produced by the impression of the complementary color; for the latter is perceived, as he remarks, even where it does not exist; as when the eye, after receiving a strong impression from a colored spot, and bcing directed upon a completely dark surface or into a dark cavity, still perceives the spectrum. This change, indeed, extends beyoud the spot on which the impression is made $(\$ 633)$; for, as is well known to Artists, the seusory impression produced by any color is greatly affected by neighboring hues. Thus, if four strips of colored paper, or any other fabric, A, B, C, D, 一 two of them, A, B, of one color (e.g., red), and the other two, C, D, of some different color (e.g., blue), - be laid side by side at intervals of about half an inch, the hues of the two central strips B, $\mathrm{c}$, will be decidedly modified by each

1By the "complementary" color is meant that which would be required to make white or colorless light, when mixed with the original: thus red is the complement of green (which may be made by mixing'yellow and hlue); blue is the complement of orange (red and yellow); and yellow of purple (red and blue); and vice versâ in all instances. 
other's proximity, each approximating to the hue of the complementary color of the other; so that instead of

$\begin{array}{cccc}\underset{\text { red }}{\mathrm{A}} & \mathrm{B} & \begin{array}{c}\mathrm{C} \\ \text { red }\end{array} & \begin{array}{c}\mathrm{D} \\ \text { blue, }\end{array} \\ \underset{\text { red }}{\mathrm{A}} & \underset{\text { we shall see }}{\mathrm{B}} & \mathrm{C} & \mathrm{D} \\ \text { orange-red } & \text { greenish-blue } & \text { blue. }\end{array}$

In the experiments of Mandelstamm, ${ }^{1}$ it was found that the acuteness of perception of the eye for slightly different shades of color was greatest in the yellow spectrum, and then successively less in the blue, green, indigo, and finally in the red, in which it was least. ${ }^{2}$ Lamansky ${ }^{3}$ finds that the sensitiveness of the eye for color is greatest in the order green, yellow, and blue, and least for red. With faint illumiuation blue is better seen than red, and green and yellow than blue. In commencing atrophy of the optic nerve, red color blindness first appears. Lamansky finds the time requisite for the reception of red three times greater than that for blue. Kunkel, however, ${ }^{4}$ states that the order of rapidity of perception is, red $(0.0573$ sec. $)$, blue $(0.0916 \mathrm{sec}$.$) , and green (0.133 \mathrm{sec}$.$) . The time requisite for distinct vision$ of a line is extreniely brief. From experiments with the Electric Spark, O. N. Rood ${ }^{5}$ estimates it for a black line at not more than four billionths of a second. The means by which differences of color are recognized are at prescnt unknown. Young suggested that there might be different nerves, each having the power of discriminating one of the fundamental colors, but the structure of the Retina gives no support to this view. The laminated structure observed by Max Schultze in the proximal extremitics of the rods and cones may possibly have some relation to this power, for if the laminæ possessed a different refractive power in the several rods aud cones, they would only transmit light of a certain color.

630. The observations of Schultze seem to point clearly to the conchusion that the perception of colors is due to the cones and not to the rods, for not only is the fovea centralis of the human eye, where cones alone are present, the part most acutely sensitive to variations of color, but in animals of nocturnal habits like the owl and the bat, no cones are discoverable, and we may conclude that vision in them is reduced to the quantitative perception of light; or, in other words, to the differences between shades of light and darkness. A simple experiment shows that our notions of color are, like those of temperature, relative and not positive, for although when a pair of smoked glasses are worn before the eyes, surrounding objects at first appear strongly tinged with their color, very short experience euables the wearer to distinguish between different colors, and he sees or seems to himself to sce white objects of a fine white color, until he undeceives himself by removing them.

631. Upon the properties of the Eye in regard to Color, are founded the laws of harmonious coloring, which have an obvious analogy with those of musical harmony. All complementary colors have an agrccable effect when judiciously disposed in combination; and all bright colors, which are not complementary, have a disagrceable effect, if they arc predominant: this is

1 Archiv f. Ophthalmol., Bd. xiii, Abtheil. ii, p. 399.

2 A remarkable phenomenon of recurrent vision is described by Prof. Young in Amer. Jumn. of Sci., vol. iii, No. 16.

3 v. Gräfe's Archiv, Bd. xvii, p. 123.

- Innd. Med. Record, 1874, P. 710.

5 American Juurn. of Science and Art, ser. 3, vol. ii, p. 159. 
especially the case in regard to the simple colors, strong combinations of any two of which, without any color that is complementary to either of them, are extremely offensive. Painters who are ignorant of these laws, introduce a large quantity of dull gray into their pictures, in order to diminish the glaring effects which they would otherwise produce; but this benefit is obtained by a sacrifice of the vividness and force, which may be secured in combination with the richest harmony, by a proper attention to physiological principles. ${ }^{1-}$-Some persons whose visual powers are excellent in every other respect, are more or less deficient in the power of discriminating colors. This defect (which is now commonly known as "Daltonism," from the name of the distinguished philosopher who was himself the subject of it) may be so complete, that nothing can be perceived save different degrees of light and shadow; more commonly, however, it exists only with regard to particular colors, especially such as have a complementary relation to one another, so that persons thus affected are unable $(e . g$.) to distinguish ripe cherries a mong the leaves of the tree, save by their form; whilst in some individuals it does no more than confuse colors that are nearly related, sucl as green and blue, especially when they are seen by artificial light. ${ }^{2}$

632. The three fundamental colors, as was originally shown by Thomas Young, are red, green, and violet. The most common form of color-blindness is that for the red rays, which in some cases is incomplete, so that whilst brilliant reds can be distinguished from other colors, low tones are not recognized from gray or black. Purkinje long ago showed that the periphery of the Retina exhibited defective perception of the different colors, red light appearing gray; yellow, green; green, bluish ; but blue and violet unaltered. The ordinary form of color-blindness would therefore seem to be only an extension of the want of perceptivity normal in the periphery of the Retina. ${ }^{3}$ Niemetschek ${ }^{4}$ has shown that the affection may either be congenital or acquired, and that whilst the retina and refractive media are usually healthy, and the sharpness of vision is normal, there is more or less disturbance or lesion of those portions of the frontal convolutions which intervene between the orbits.

633. The impressions made by luminous objects upon the Retina are not precisely confined to the spots upon which their rays impinge, but extend themselves to a greater or less distance around; which phenomenon has been termed irradiation. Thus if we make a circular white spot upon a black

1 This subject has been most carefully and elaborately investigated by M. Chevreul, whose recent Treatise on Colors has almost exhausted the inquiry into the mode in whicb the Visual sense of Man is affected by them. For a general view of the nature and attributes of Light, see Art. Light, by Sir J. Herschel, in the last edition of the Encyclopæedia Metropolitana.

2 See especially the Memoir of Prof. Secbeck, in Poggendorff's Annalen, Bd. xlii (1837) ; that of Prof. Wurtmann, in Taylor's Scientific Memoirs, vol. iv, n. 156; Ir. Pule's case, recorded in the Proceedings of the Royal Society, 1856-57, vol. viii, p. 172, and the interesting commentary upon it by Sir J. Herschel, in idem, vol. x, p. 72. Sce also Preyer, Centralblatt, 1869, p. 72. A difference appears to exist between the effects of reflected and transmitted light in cases of color blindness. See Jeaffreson, Lancet, 1872, pp. 601, 670. Clarke, idem, p. 635.

3 For an interesting case in which the patient was affected with monocular green blindness and could yet see blue, though this color, if it were a mixture of green and violet, ought to have appeared violet to him, see Preyer, Centralblatt, 1872, No. 8 ; see also Lebert, Klin. Monatschr. f. Augenheilk., 1873, p. 867. The observations of Schelske (Gräfe's Archiv, Bd. ix, Heft iii, p 41) and Woinow (idem, Bd. xvi, Heft $i, p .200$ ) have shown that the peripheral parts of the retina are, even in healthy persons, insellsible to red, and perhaps to green, the latter color being perceived as yellow. See also Rählmann, Abst. in Centralblatt, 1873, p. 357.

- See Prag. Vierteljahrs., Bd. c, 1868, p. 224. 
ground, and a black spot of precisely the same dimensions upon a white ground, the former will seem to be eonsiderably larger than the latter; apparently because the excitation of the retina by the luminous impression tends to spread itself in eaeh case over the adjaeent 1 on-exeited spaee. Hence it is that we are able to distinguish any small magnitudes, such as letters or the lines of a diagram, at a mueh greater distance when they are marked in white on a blaek ground, than when inscribed in black upon a white ground. Another curious ease of the same kind has been noticed by Sir D. Brewster." "If we shut one eye, and direct the other to any fixed point, sueh as the head of a pin, we shall see indistinetly all other objeets within the sphere of vision. Let one of these objects thus indistinctly seen, be a strip of white paper or a pen lying on a green cloth. Then, after a short time, the strip of paper, or the pen, will disappear altogether, as if it were entirely removed; the impression of the green cloth upon the surrounding parts of the retina, extending over that part of it which the image of the pen occupied. In a short time the vanished image will reappear, and again vanish; when both eyes are open, the very same effeet takes place, but not so readily as with one eye. If the object seen indistinctly is a blaek stripe on a white ground, it will vanish in a similar manner. When the object seen obliquely is luminous, sueh as a candle, it will never vanish entirely, until its light is much weakened by being plaeed at a great distance; but it swells and contracts, and is eneireled by a nebulous halo."

634. The power of receiving and transmitting visual impressions is by no means uniformly diffused over the entire Retina. In the whole field of vision which at any time lies before us, we only see with perfeet distinetness that part to whieh the axes of our eyes are directed, and of which the image, therefore, is formed upon the "yellow spot" $(\$ 616)$. Nevertheless we have a sufficiently distinct percejtion of the remainder of the field, to enable us to judge of the relations of the objects whieh are distinctly seen to those which surround them; and the mobility of our eyes enables us, under the guidanee of our visual sense $(\$ 541)$, to direct the most sensitive spot of the retina to every part of the field in suecession, not only without effort, but even almost without the eonseiousness that we are doing so.-Generally speaking, the indistinctness of vision for objects seen out of the axis of the eye, increases with the distance of their images from the eentral point; or, in other words, the impressibility of the several parts of the retina diminishes, according to their distanee from the "yellow spot." For a small space around it, however, the vision is tolerably aecurate, and the extent of this cirele of elear "indirect vision," as it is termed, varies in different people; Volkmann, for instance, can read an entire word by the light of a single electrical spark, and must therefore have instantaneously a direet and perfect perception of every part of it, whilst by others only a letter or two can be distinguished. It appcars also from the experiments of Aubert and Förster, ${ }^{2}$ and of Heymann, ${ }^{3}$ that when the Eye is aecommodated for near objeets, the limits of clear lateral pereeption are inereased, or at lcast the perceptibility of that cirele is intensified; so that of two objeets which throw images of equal size on the Retina, the smaller and more approximated one is distinctly perceived at a greater distance from the yellow spot that the larger and more distant objeet. But there is one part of the retinal surfaee, nancly, the seat of entrance of the Optic Nerve, whieh is renarkable for its imperfeet receptivity; as is shown by the following experiment. Ixet two

1 Treatise on Optics, in Lardner's Cyclopadia, p. 296.

2 Archiv f. Ophthalmol., Bd. iii, p. 1.

3 Actu Academ. C.L. C.G. Naturio Curiosorum, Dresden, 1864. 
black spots be made upon a piece of paper, about four or five inches apart; then let the left eye be closed, and the right eye be strongly fixed upon the left-hand spot; if the paper be then moved backwards and forwards, so as to change its distance from the eye, a point will be found at which the righthand spot is no longer visible, though it is clearly seen when the paper is brought nearer or removed further. In this position of the eye and the object, the rays from the right-hand spot cross to the nasal side of the globe, and fall upon the point of the retina which has just been mentioned. If the same experiment be tried with candles, the image will not entirely disappear, but will become a cloudy mass of light. It is not correct to say, as is sometimes done, that the retina is not impressible by light at this point; since, if such were the case, we should see a dark spot in our field of view whenever we use only one eye, which is not the case. The fact seems rather to be, that this portion of the retina is very inferior to the surrounding parts in its receptivity for luminous impressions; whilst, on the other hand, there is an unusual tendency to the extension of their condition to it by "irradiation" ( $\$ 633)$; so that, in the experiment just described, if the black spots be made upon a colored ground, this color will take the place of the spot which disappears. ${ }^{1}$

635. That an electrical current is produced when light is allowed to fall upon the Retina, was first establisherl by Holmgren. ${ }^{2}$ He observed an oscillation of the needle of the galvanometer under these circumstances in all vertebrates except Fishes. In the Frog the oscillation is positive, but in all others it is negative, but positive when the light is withdrawn; the yellow rays are the most active in this respect. The subject has been also taken up by Dewar and HCKendrick, ${ }^{3}$ who have corroborated and extended Holmgren's observations. The impression made by rays of light upon the Retina may be to a certain extent imitated by other physical agencies, which thus give rise to various subjective visual phenomena. Advantage has recently been taken by Dr. Serre, ${ }^{4}$ of the power of mechanical pressure to produce luminous spectra, for the investigation of the "law of visual direction" $(\$ 620)$; and the results which he has obtained are of very great interest. When any part of the globe of the eye is compressed (the experimenter being in a completely darkened room), a luminous figure is seen to be projected in the direction opposite to the spot pressed upon. Its form varies according to that of the compressing body, and to the degree in which the retina is affected by it. Thus if the pressure be made by the point of the finger, or by any other circular surface, upon a part of the globe over the interior of which the retina is continuous, the spectrum or phosphène (as it is termed by Dr. Serre), is also circular; if the compressing body, on the other hand, be square at its extremity, the "phosphène" is also square; and if it be triangular, the "phosphèue" is triangular too. But if the pressure be made near the anterior erge of the retina (which is what most commonly happens, unless the most favorable situation be designedly chosen), the figure of the "phosphène" is incomplete; and the degree of its deficiency corresponds with the proportion of the area of compression that does not lie over the retinal expansion. Hence there can be no hesitation in regarding the production of this spectrum as the immediate result of the affection of the sensorium by

1 The diameter of the blind spot as obtained by experiment on the living eye is $1.55 \mathrm{~mm}$. (Listing); $1.616 \mathrm{~mm}$. (Hannover and Thomsen); $181 \mathrm{~mm}$. (Helmholtz). The diameter of the optic disk, according to Weber, in the dead subject, varies from $2.10 \mathrm{~mm}$. to $1.72 \mathrm{~mm}$.

2 See Abstract in Humphry and Turner's Journal of Anat. and Phys., 1872, p. 225.

3 See Humphry and Turner's Journal of Anat. and Phys., 1873, vol. vii, p. 275.

- See his Essai sur les Phosphènes. Paris, 1853. 
the pressure of the retina; and as it seems to our perceptive consciousuess to have a distinct objective existence, and as its position bears a constant and definite relation to that of the portion of the retina on which the impression is made, it seems obvious that any such affection of the retina not only immediately suggests to our minds the notion of an exterual objective cause of the impression, but also indicates to our consciousness the direction of the object.-But further, besides the principal " phosphène," another, of smaller dimensions, is usually to be seen, in a direction nearly the same as that on which the pressure is made; this is the result of the transmission of the pressure to the opposite side of the globe, by an alteration of its figure and of the position of its contents, which corresponds to the fracture of the skull by contre-coup. "The form of this smaller or secondary "phosphène" is not affected by the cause which sometimes renders the larger or primary spectrum incomplete; since, as we cannot anywhere apply pressure to the living Human eye, save on some part of its anterior hemisphere, the "contre-coup" will always take place at the opposite spot in the posterior hemisphere, over which the retina is continuous, save at the entrance of the optic nerve. By an extensive series of observations upon the relation of the positions of the primary and secondary "phosphènes," both to each other and to the seat of compression, Dr. Serre has deduced the important conclusion, that the lines joining the imaginary spectra and the spots of the retina upon whose affection they respectively proceed, pass through a common "centre of direction," whose position is in the middle of the crystalline lens. And hence it seems to be a legitimate conclusion, that our sense of the relative directions of external objects is derived from a kind of mental projection of each point of the retinal image, in the line which joins it to this "centre of direction."

636. Another very curious subjective phenomenon of Vision, is the representation which, under particular circumstances, we may mentally obtain of the retina itself; as in the following experiment, first devised by Purkinje, and known by his name. "If in a room otherwise dark, a lighted candle be moved to and fro, or in a circle, at a distance of six inches before the eyes, we perceive, after a short time, a dark arborescent figure ramifying wrer the whole field of vision; this appearance is produced by the vasa centralia distributed over the retina, or by the parts of the retina covered by those vessels. There are, properly speaking, two arborescent figures, the trunks of which are not coincident, but on the contrary arise in the right and left divisions of the field, and immediately take opposite directions. One trunk belongs to each eye, but their branches interscet each other in the common fiell of vision. 'The explanation of this phenomenon is as follows: $13 y$ the movement of the candle to and fro, the light is made to act on the wholc extent of the retina, and all the parts of the membrame which are not inmediately covered by the vasa centralia are feebly illuminated ; those parts, on the contrary, which are covered with those vessels, cannot be acted on by the light, and are perceived, therefore, as dark arborescent figures. These figures appear to lie before the cye, and to be suspended in the field of vision;" " and as the vessels appear magnified, and display a remarkable parallactic gliding movement over the visual fiekd, data are afforled by which H. Miiller has calculated that the true percipient surface of the retina must be situated at a certain distance firom the vessels, corresponding in fact with the bacillar layer." We have thus another demonstration of the fact,

1 Mülter's Eilements of Physiology (Baly's 'Translation), p. 1163.

2 For the explanation of various other entoptieal phenomena, see James Jago, B.A., in l'roeedings of the Royal Society, vol. viii, p. 603. He observes that the long beams of light whieh issue from flames regurded with "winking eyes" proeed from little bars of fluid along the margins of the lids. 
that, in ordinary Vision, the immediate object of our sensation is a certain condition of the retina, which is excited by the formation of a luminous image.

637. The visual power is susceptible of extraordinary improvement, through the habitual direction of our attention to the effects produced upon our consciousness by the impressions transmitted to the Sensorium from the Eye; and this improvement may take place, either in regard to the quickness and realiness with which objects generally are perceived, or in the faculty of discriminating the slightest differences in form, shade, color, etc., or of discerning bodies of extreme minuteness. In regard to all these points it may be noticed that the habit of attention to any particular class of objects, sharpens the discriminating power for that class alone; and that it is usually rather the mental than the corporeal vision which undergoes improvement. Thus the seaman who makes out the "loom of the land," where the landsman can discern nothing but an indefinite haze above the horizon, or who can distinguish the size, rig, and course of a vessel, which the landsman can but just see as a formless speck, does so in virtue of the aptitude of his mind for receiving suggestions from minute indications such as pass unnoticed by those who have not been accustomed to form their ideas upon the same kind of experiences. And the Microscopist, who is constantly on the outlook for the various forms of organic structure with which his mind is faniliar, discerns these without difficulty or hesitation, where an ordinary observer sees nothing but a confused jumble of tissue. Extremely slight variations in the relative illumination of two objects can readily be discerned. According to Arago ${ }^{1}$ the difference can be perceived when it amounts to no more than about $\frac{1}{64}$ th, according to Volkmann when it is from $\frac{1}{60}$ th to $\frac{1}{100}$ th, to Steinheil $\frac{1}{3} \mathrm{~s}$ th, and to Masson, $-\frac{1}{2} \mathrm{t}_{0}$ l. Aubert ${ }^{2}$ has shown that these variations in the results obtained by different observers are probably due to their having employed different amounts of illumination; since the perception of slight variations is much greater, within certain limits, with moderately bright than with feeble illuminating powers.-It is interesting to observe that the power of descrying objects at vast distances appears to be hereditarily possessed by two races of men, the Mongols of Northern Asia, and the Hottentots of Southern Africa, both of which liabitually dwell on vast plains that seem to stretch without limit in every direction. It seems probable that this power was in the first instance acquired by habit in every case; and that, as frequently happens with acquired peculiarities which are kept up by constant use in successive generations, ${ }^{3}$ it has become fixedly liereditary.

\section{Sense of Hearing.}

638. In the Ear, as in the Eye, the impressions made upon the sensory nerve are not at once produced by the body which originates the sensation; but they are propagated to it, through a medium capable of transmitting them. We obviously take cognizance by the mind, therefore, not of the sonorous object, but of the condition of the auditory nerve; and all the ideas we form of sounds, as to their nature, intensity, direction, etc., must be based upon the changes which they produce in it. The complex contrivances which we meet with in the organ of Hearing among higher animals, are evidently intended to give them greater power of discriminating sounds than is possessed by the lower tribes; in which last it is reduced to a form

${ }^{3}$ See Princ, of Comp. Physiol., \& 620. 
so simple that it may be questioned whether they can be said to possess an organ of hearing, if by this term we imply anything more than the mere consciousness of sonorous vibrations. - There is a considerable difference, however, between the Eye and the Ear, in regard to the special purposes for which they are respectively adapted. In the former we have seen that the whole object of the instrument is to direct the rays of light received by it, in such a manner as to occasion them to fall upon the expansion of the optic nerve in similar relative positions, and with corresponding proportional intensities, to those which they posscssed when issuing from the object. We have no reason to believe anything of this kind to be the purpose of the Ear; indeed it would be inconsistent with the laws of the propagation of sound. Sonorous vibrations having the most various directions, and the most unequal rates of succession, are transmitted by all media without modification, however numerous their lines of intersection; and wherever these undulations fall upon the auditory nerve, they must cause the sensation of corresponding sounds. Still it is probable that some portions of the complex organ of hearing, in Man and in the higher animals, are more adaptcd than others to receive impressions of a particular character; and that thus we may be especially informed of the direction of a sound by one part of the organ, of its musical tone by another, and some other of its qualities by a third.

639. A single impulse communicated to the Auditory nerve through an appropriate apparatus, seems to be sufficient to excite the momentary sensation of sound; but most frequently a series of such impulses is concerned, there being but few sounds which do not partake, in a greater or less degree, of the character of a tone. Any continuous sound or tone is dependent upon a succession of impulses; and its acuteness or depth is governed by the rapidity with which these succeed one another. It is not difficult to ascertain by experiment, what number of such impulses or undulations are required to give every tone which the ear can appreciate. Thus if, as in the instrnment termed the Syren, a circular plate with a number of apertures at regular intervals be made to revolve over the top of a pipe through which air is propelled, a succession of short puffs will be allowed to issue from this; and, if the revolution be sufficiently rapid, these inpulses will unite into a definte tone. In the same inanner, if a spring be fixed near the edge of a revolving toothed wheel, in such a manner as to be caught by every tooth as it passes, a succession of clicks will be heard ; and these too, if the revolution of the wheel be sufficiently rapid, will produce a tone. The number of apcrtures in the plate which pass the orifice of the pipe in a given time, or the number of teeth which pass the spring, being known, it is easy to see that this must be the number of impulses required to produce the given tone. Each impulse produces a double vibration, forwards and backwards (as is seen when a string is put in vibration, by pulling it out of the straight line); hence the number of single vibrations is al ways double that of the impulses.- The maximum and minimum of the intervals of successive pulses, still appreciable by the ear as determinate musical sounds, have been determined by MI. Despretz. ${ }^{1}$ According to this observer the number of complete vibra-

I Comptes Rendus, tom. xx, p 1214. Hermann, Grundriss der Plysiologie, 1867, gives the limits at 40 and 16,000 double vibrations; Helmholtz at 16 and 38,000 single vibrations, or about 11 octaves. Blake (Boston Iled. and Surg. Jouru., 1872, vol. $x, N(20)$ found that children of $12-13$ years of age conld perceive a note produced by 40,960 single vibrations at a distance of 34 feet. Young persons of $18-20$ years the sume only at a distance of $13-16$ feet, but a note produced by 36,864 simple vibrutions at 34 feet. Adults of 28-30 yeurs eould only hear at 34 feet a note produced by 32,768 vibrations. The deepest tone of orchestral instruments is the $\mathrm{E}$ of 
tions required to produce an appreciable musical sound, in persons endowed with an acute sense of hearing, may vary from 8 for the lowest, to 36,500 for the highest note. From some observations of Dr. Wollaston, it seems probable that the ears of different individuals are differently constituted in this respect; some not being able to hear very acute tones produced by Insects, or even Birds, which are distinctly audible to others. Again, the sound resulting from 16 impulses per second is not, as has been usually supposerl, the lowest appreciable note; on the contrary, M. Savart has succeeded in rendering tones distinguishable, though they can scarcely be ternied musical, which are produced by only 7 or 8 impulses in a second; and continuous sounds of a still deeper tone could be heard, if the individual pulses were sufficiently prolonged. In regard, however, to the precise time during which a sonorous impression remains upon the ear, it is difficult to procure exact information, since it departs more gradually than do visual impressions from the eye. This is certain, however, - that it is much longer than the interval between the successive pulses in the production of tones; since it was found by M. Sirvart, that one or even several teeth might be removed from the toothed wheel, without a perceptible break in its sound,-showing that, when the tone was once established, the impression of it remained during an intermision of some length.

640. A very recondite investigation into the theory of Acoustics, and especially into the conditions on which the distinct qualities of musical tones depend, has recently been undertaken by Hclmholtz. ${ }^{1}$ It is possible, he observes, to produce sounds consisting of only a single primary or fundamental note; the fundamental note of a sonorous body being the lowest tone which it yields when the whole of it is in vibration together; but in by far the greater number of instances, sounds however produced, and whether musical in their character or not, are compounded of the fundamental note and a number of secondary, collateral or harmonic notes; and the peculiar quality or timbre of particular instruments appeurs to be determined by a variation in the mode of grouping of the secondary sounds. Eitch such group Helmholtz desiguates a "sound color." In a series of experiments upon the vowel sounds, $a, e, i, o$, and $u$, he has remarked that we distinguish them from one another ${ }^{2}$ by the harmonic sounds which accompany the chief or fundamental uote, and he endeavors to render this evident by the following experiments. He terms the fundamental note the first (1), whilst the harmonics $(2,3,4,5,6$, etc.) are notes produced by two, three, four, five, or six times the number of vibrations of the fundamental note. This, taking the middle $\mathrm{C}$ of the piano as the fundamental note, the harmonics will be $\mathrm{C}_{2}$ (octave) $\mathrm{G}, \mathrm{C}_{3}$ (double octave) $\mathrm{E}_{3} \mathrm{G}_{3}$, etc. Now if the vowel $a$ be sung $2 \quad 3 \quad 4 \quad 5 \quad 6$

close to a piano with the damper up, not only will the wire corresponding to the fundamental note be thrown into vibration, but also the wires corresponding to the $3 \mathrm{~d}$ and 5 th harmonics, or those vibrating three times and five times as often as the fundamental note, and also more feebly the $2 \mathrm{~d}$, 4 th, and 7 th harmonic notes. When the vowel 0 is sung, the $3 d$ harmonic note vibrates somewhat more weakly than when $a$ is sung; the $2 \mathrm{~d}$ and 5 th harmonics very weakly. With $u$ the fundamental note vibrates alnost alone; the third harnonic very feebly. With $e$ the $2 \mathrm{~d}$ larmonic wire is

the double Bass with $41 \frac{1}{4}$ vibrations, the highest the $\mathrm{d}^{\mathrm{v}}$ of the Piccolo flute with 4752 vibrations (Tyndall).

1 Die Lehre von den Ton-empinindungen als physiologische Grundlage für die Theorie der Musik, Braunschweig. 1862.

2 It must be borne in mind that the German pronunciation of the vowels is here implied. 
thrown into powerful vibration, but the higher harmonics are scarcely produced. With $i$, as with $u$, it is difficult to pronounce it loudly enough to excite vibrations in any but the fundamental note; the $2 d$ and $3 d$ harmonics, however, appear to aid in determining the clear character of the note, and slight vibrations may be observed in the 5th harmonic. The wires of the piano in these instances may be said to analyze the vocal sound into its secondary elements or partial notes; and Helmholtz has shown that the same result may be attained by placing in connection with the ear a series of glass vessels, producing by their vibration harmonic notes, and ascertaining with which note or kind of note they resonate most powerfully. In another series of experiments, instead of analyzing the vocal sounds as above mentioned, Helmholtz endeavored to produce them synthetically, by accompanying a given fundamental note with its several harmonics. This was accomplished by a system of tuning-forks, arranged in harmonic series, which could be thrown into vibration at will in various order. Thus the fundamental note of the first tuning-fork, resembling the vowel $u$, the vowel sound or musical color o was produced if the harmonics 2 were powerfully, and 3 and 4 were weakly sounded; $e$ was produced by the $3 \mathrm{~d}$ octave resonating powerfully with the fundamental note, the 2 harmonic note moderately, and the 4 and 5 harmonics feebly, and so on for the other vowel sounds.-The power which we possess of distinguisbing the characters belonging to similar notes produced by different instruments, appears, therefore, to be due to a kind of analysis being performed by the ear, sinilar to that effected by the wires of the piano; and we shall see that it is not unreasonable to attribute this function especially to the branches of the auditory nerve distributed upon the lamina spiralis of the cochlea. It may be said, indeed, to have received direct confirmation from the observations of Hensen ${ }^{1}$ upon the auditory hairs on the free surface of a Decapod Crustacean (Mysis). These were seen under the microscope to vibrate in certain groups corresponding with the special note sounded in their vicinity. In the case of the human ear very effective "damping apparatus" must exist, since through the greater part of the musical scale a trill of ten alternate notes in the second can be distioctly differentiated, which would be confused if the sensation of each note persisted much longer than the sound itself.

641. The essential part of an Organ of Hearing is obviously a nerve endowed with the peculiar property of receiving sonorous undulations, and of transmitting their effects to the Sensorium. This nerve is spread out over the surface of a delicate membrane which lincs the Vestibule and its prolongations; and this menbrane incloses a fluid, which is the medium whereby the sonorous vibrations received through the external ear are communicated to the nerve. We learn from an examination of the comparative structnre of the auditory apparatus in the lower animals, and from the study of its development in the higher, that the part which, being most constantly present, and being also the earliest in its development, may be considered as the most esscntial, is the sinple Vestibular eavity; which exists where there are no vestiges either of Semicirculitr Canals, or Cochlea, or of Tympanic apparatus. Such a condition presents itself in some of the higher Invertebrata and in the lowest Fishes; but as we ascend the Vertebrated series, we find the semicircular canals growing out (as it were) of the Vestibule in Fishes, a Tympanitic apparatus superadded in Reptiles, and a Cochlea first acquiring a more than rudimentary development in the class of Birds, although only presenting in Mammalia that characteristic form 
from which it derives its name. ${ }^{1}$ In regard to the mode in which the ultimatc subdivisions of the Auditory nerve are distributed upon the lining membrane of the labyrinth, the observations of Rüdinger and others have demonstrated that there are certain spots named cristre acusticin in the ampullie and maculie acustice in the sacculi, which are of a yellowish color. The epithelium of these parts presents two forms of cells, of which one is columnar and supporting, whilst the other is fusiform (Fig. 276), and secms

FIG. 276.

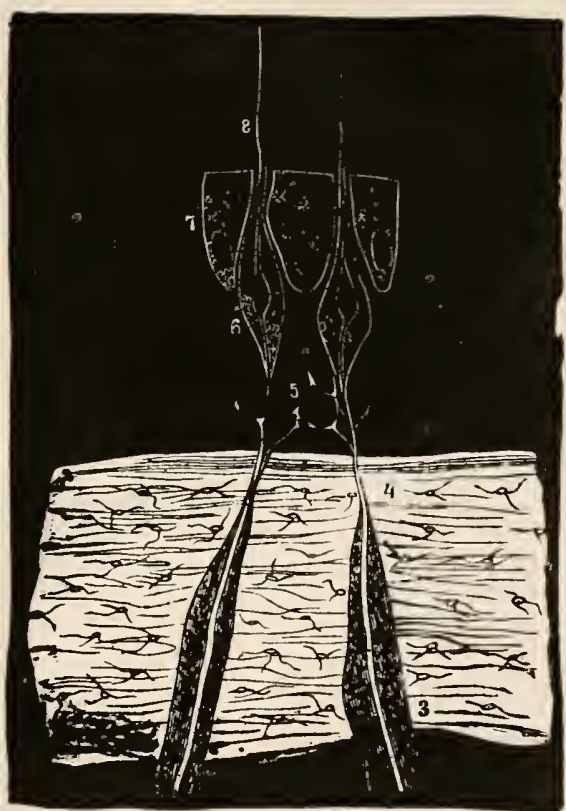

Diagram of the mode of termination of the auditory nerve in the ampullæ and sacculi. 1, cartilage of the wall of the ampulla; 2, structureless basement-membrane; 3 , doubly-contoured nerve-fibre; 4 , axis-cylinder traversing the basement-membrane; 5 , plexiform union of fine nerve-fitres with interspersed nuclei; 6 , fusiform cells, with nucleus and dark fibre in their interior; 7 , supporting cells; 8 , auditory hairs.

to represent the terminal organs of the vestibular nerves. The fusiform cells are each connected at their base with a branch of the auditory nerve, and terminate in a long hair-like process. They contain a certain amount of yellowish pigment. The structure of the cochlea has recently been materially elucidated by the extraordinarily minute and delicate dissections of Corti, ${ }^{2}$ Schultze, Kölliker, and others, and may readily be understood from

1 For a more detailed sketch of the Comparative Anutomy of the Organ of Hearing, see the Author's Prineiples of Comparative Phyiology. 6.3. 711-714.

2 See his Memoir in Kölliker and Siebold's Zeits. für wiss. Zonlogie, 1851, Bd. iii, Heft 1; also Prof. Kölliker's Mikroskop. Anutomie, Bd. ii, \& 289, and his Munual of Microseopie Anatomy, 1860; Fick, Anat. u Physiol. der Sinnes Organe, 1862, \%. 122; Rüdinger, Das Gehör-organe, Münehen, 1867, with an Atlas of Photographs; Reiehert, Ablund. d. k. Akad. der wiss. zu Berlin; C. Hasse, On the MLde of Termination of the Acnustic Nerves in Birds, in the Göttingen Nuehriehten, 1867, and Kölliker's Zeits., Bd. xvii, p. 598; Pritchard, in Monthly Mieroscop. Journ., 1873, 
an examination of Figs. 277 and 278, the former of which represents a section through one of the coils of the cochlea, whilst the latter shows in par-

FIG. 277.

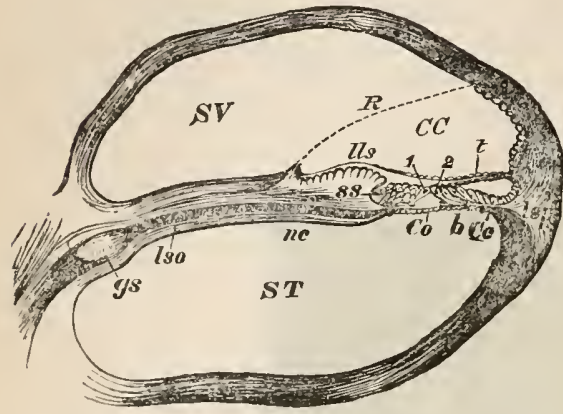

FIg. 277.-Section through one of the eoils of the Cochlea. ST, scala tympani ; sv, scala restibuli; $\mathrm{cc}$, eanalis cochlec ; $\mathrm{r}$, membrane of Reissner, consisting of a single layer of nucleated flattened cells, extending from just behind the teeth of the limbus to the upper part of the ligament of the Cochlea; lls to $l s p$, lamina spiral is membranacea; $l l s$, limbus laminæ spiralis ; $s s$, suleus spiralis; $g s$, ganglion spirale seated on $n c$, the nervus corblearis, indicated by the black line; lso, lamina spiralis ossea; $l$, membrana tectoria; $b$, nembrana basilaris; $C o$, organ of Corti; $l s p$, ligamentum spirale; $C c$, cells of Claudius; 1 , lroximal rod of Corti ; 2, distal rod of Corti.

FIG. 278.-Vertical section of the organ of Corti in the Dog, magnified 890 diameters. $a-b$, homogeneous layer of the membrana basilaris; $u$, its vestibular layer, corresponding to the strix of the zona pectinata; $v$, tympanal layer, with nuclui, granular cell protoplasm, and transverse sections of fibrils of eonnective tissue; $a$, labium tympauienm of the erista spiralis; $a^{2}$, continuation of the tympanum periosteum of the lamina spiralis ossea; $c$, thickencd commencement of the membrana basilaris inmediately external to the passage of the nerres, $h$; $d$, vas spirale; $e$, bloodvessel; $f$, nerve fascieuli; $g$, epitbelium of the suleus spiralis internus (not well preserved); $i$, an internal hair-cell; $k$, its basal proeess; surrounding the latter, above the point of emergence of the nerves, are a few nuclei and a finely granular mass into which the nerve-fibres stream (granule-layer); $l$, inner part of the capitular lamina of the internal pillar and hairs of the interual hair-cell; $m$, eapitula of the two pillars juincl together,-the body of the external pillar has here been cut through its middle; behind it the body and basc, $o$, of the next pillar eome into view; $n$, hase with nueleated remains of protoplasm of the internal pillar; $p, q, r$, three external hair-cells (only traces of the hairs preserved), the first one alone eomplete, of the two others only the heads are seen; $t$, basal portion of two other hair-cclls; $z$, 11 ensen's supporting eell; $l-l$, lamina reticularis; $w$, a nerve-fibre passing to the first hair-cell, $p$, which ean be followed bencath the areh to the point of emergence of the nerves.

ticular the details of the part known as the organ of Corti. The ultimate branches of the auditory nerve appear also, as in the labyrinth, to termi-

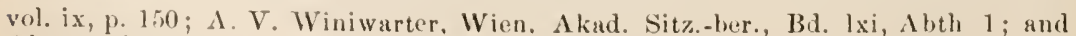
Abstract in Centralblatt, 1870, p. 8.53; Gottstein, Contralblutt, 1870, 1). 6.2.5, und 1872, p. 385 ; and Rülinger and IValdeyer, in Stricker's IItm. and Comp. II istologr, Sry. Soc. 'Trans., 1s73, vol. iil, in which notiees of all recent literature upon the subject will be lound. 
nate in hair-cells (see Fig. 278). The number of the arches of Corti is estimated by Kölliker at 3000 , or about 33 to each half note of the ordinarily audible seven octaves.

642 . In order to gain any definite idea of the uses of different parts of the Ear, it is necessary to bear in mind that sounds may be propagated a mongst solicl or fluid bodies in three ways: by reciprocation, by resonance, and by conduction. -1 . Vibrations of reciprocation are excited in a sounding body, when it is capable of yielding a musical tone of definite pitch, and another borly of the same pitch is made to sound near it. Thus if two strings of the same length and tension be placed alongside of each other, and one of them be sounded with a violin bow, the other will be thrown into reciprocal vibration; or if the same tone be produced near the string in any other manner, as by a flute or a tuning-fork, the same effect will result.-2. Vibrations of resonance are of somewhat the same character; but they occur when a sounding body is placed in connection with any other, of which one or more parts may be thrown into reciprocal vibration; even though the tone of the whole be different, or it be not capable of prorlucing a definite tone at all. This is the case, for example, when a tuning-fork in vibration is placed upon a sound-board; for even though the whole board have no definite fundamental note, it will divide itself into a number of parts, which will reciprocate the original sound, so as greatly to increase its intensity; and the same sound-board will act equally well for tuning-forks of several different degrees of pitch. When a snaller body is used for resonance, however, it is essential that there should be a relation betweeu its fundamental note and that of the sonorous body; otherwise no distinct resonance is produced. Thus, if a tuning-fork in vibration be held over a column of air in a tube, of such a length that the same note would be given by its vibration, its sound will be reciprocated. And if it be held over a pipe, the column of air in which is a multiple of this, the column will divide itself into that number of shorter parts, each of which will reciprocate the original sound, and the total action will be one of resonance. But if the length of the pipe bear no such correspondence with the note sounded by the tuning-fork, no resonance is given by the column of air it contains. - 3 . Vibrations of conduction are the only ones by which sounds can strictly be said to be propagated: these are distinguishable into various kinds, into which it is not requisite here to inquire. It should be renarked, however, that all media, fluid, liquid, or solid, are capable of transmitting sound in this nanner; a vacuum being the only space through which it cannot pass. The transmission is usually much more rapid through solid bodies than through liquid; and through liquid than through gaseous. The greatest diminution in the intensity of sound is usually perceived when a change takes place in the medium through which it is propagated, especially from the aeriform to the liquid.

643. The retailed application of these principles has been most elaborately worked out by Professor Müller; and the following statement is little more than an abstract of the results of his experimental iuvestigations; of which the first series bears specially on the case of those animals, which, living immersed in water, receive the sonorous undulations through that mediun. The labyrintl of such as possess a distinct organ of hearing, is either entirely inclosed within the bones of the head, as in the Cephalopoda and in the Cyclostome and Osseous Fishes; or, its cavity being prolonged to the surface of the body, it is there brought into communication with the conducting medium by means of a membrane, besides receiving the vibrations through the mediun of the solids of the body, as is the case in Cartilaginous Fishes and Crustacea: I. Sonorous vibrations, excited in water, are imparted with con- 
siderable intensity to solid budies.-II. Sonorous vibrations of solid bodies are communicated with greater intensity to other solid bodies brought in contact with them than to water; but with much greater intensity to water than to atmospheric air.-III. Sonorous vibrations are communicated from air to water with great difficulty, this difficulty very much exceeding that with which they are propagated from one part of the air to another; but their transition from air to water is much facilitated by the intervention of a las membrane extended between them.- Iv. Sonorous vibrations are not only imparted from water to solid bodies with definite surfaces which are in contact with the water, but are also returned with increased intensity by these bodies to the water; so that the sound is heard loudly in the vicinity of those bodies, in situations where, if it had its origin in the conducting power of the water alone, it would be faint.-v. Sonorous undulations, propagated through water, are partially reflected by the surfaces of solid bodies.-vi. Thin membranes conduct sound in water without any loss of its intensity, whether they be tense or lax.-VII. When sonorous vibrations are communicated from water to air inclosed in membranes or solid bodies, a considerable increase in the intensity of the sound is produced, by the resonance of the air thus circumscribed.--VIII. A body of air inclosed in a membrane, and surrounded by water, also increases the intensity of the sound by resonance, when the sonorous undulations are communicated to it by a solid borly.

644. Animals living in air are nearly always provided with an opening into the vestibule, the fenestra ovalis, covered by a thin membrane; and generally with a Tympanic apparatus also. The following experimental results bear upon the manner in which the Ear of such animals is affected by sound: Ix. Sonorous unchlations, in passing from air directly into water, suffer a considerable diminution in their strength; while on the contrary, if a tense membrane exist between the air and the water, the sonorous undulations are communicated from the former to the latter medium with great intensity.$\mathrm{x}$. The sonorous vibrations are also communicated without any perceptible loss of intensity from the air to the water, when, to the membrane forming the medium of communication, there is attached a short solid boly, which occupies the greater part of its surface, and is alone in contact with the water.XI. A small solid body, fixed in an opening by means of a border of niembrane, so as to be movable, communicates sonorous vibrations from air on one side to water or the fluid of the labyrinth on the other, much better than solid media not so constructed. But the propagation of sound to the fluid is rendered much more perfect if the solid conductor, thus occupying the opening, is by its other end fixed to the middle of the tense mentbrane which has atmospheric air on both sides.-The fact stated in $\mathrm{Ix}$ is evidently one of great importance in the physiology of hearing; and fully explains the nature of the process in those animals which receive the sonorous vibrations through air, but which have no tympanic apparatus. In $x$ we have the eluciclation of the action of the fenestra ovalis, and of the movable plate of the stapes which occupies it, in animals living in air but destitute of tympanic apparatus; this is naturally the case in many $A$ mphibia; and it may happen as the result of clisease in the Human subject. In xI we have a very interesting demonstration of the purpose and action of the tympanum, in the more perfect forms of the auditory apparatus.- We are now prepared to inquire, in somewhat more of detail, into the actions of the different parts of this apparatus; and it will be better to commence with those of the Mriddle and Internal Ear, the accessory organs being afterwards considered.

645. The Membrana Tympani consists of three layers: an extermal one continuous with the cutis of the external meatus, and consisting of dermoid tissue with a covering of epidermic cells; an internal, which is extremely thin, 
continuous in like manner with the mucous membrane lining the tympanic cavity, and also composed of dermoid tissue and epithelium; and a middle layer, which, according to Mr. Toynbee, ${ }^{1}$ nay be separated into two distinct lamine whose fibres run in contrary directions, those of the external layer (which is the stronger of the two) radiating from the malleus towards the peripheral ring to which they are attached, whilst those of the internal are ammular. The fibres of which these laminæ are composed appear to be tendinous; and the membrane as a whole is almost inextensible. Mr. Toynbee points out the existence of a tubular ligament, inclosing the tendon of the tensor tympani muscle; and considers that the membrane is maintained by this ligament in a state of moderate tension, the assistance of the muscle being only required to augment this. - The function of the Membrana Tympani seems obviously to be the reception of sonorous undulations from the air, in such a manner that it may be thrown by them into a reciprocal vibration, which is communicated to the chain of bones, and, as is shown in the accompanying little diagram, through them to the membrane of the fenestra ovalis. Helmholtz las shown that the curvature of the membrana tympani, whilst it diminishes the amplitude of the vibrations, increases their force. In its usual state, this membrane is scarcely on the stretch; and this is found by experiment to be, for a small membrane, the best condition for the propagation of ordinary undulations. This is easily rendered sensible in one's own person; for an increased tension may be given to the membrana tyn pani, either by holding the breath and forcing air into the Eustachian tube, so as to distend it from within, or by exhausting the cavity, so as to cause the external air to make increased pressure upon it; and in either case, the hearing is immediately found to become indistinct. It is observed, however, that grave and acute sounds are not equally affected by this action; for the experimenter renders himself deaf to grave sounds, whilst acute sounds are heard even more distinctly than before. This fact is readily understood, by referring to the laws of Acoustics already mentioned. ${ }^{2}$ The greater the tension to which the membrana tympani is subjected, the more acute will be its fundamental tone; and as no proper reciprocation can take place in it to any sound lower than its fundamental tone, its power of repeating perfectly the vibrations proper to the deeper notes will diminish. The nearer a sound approaches to the fundamental note proper to the teuse nembrane, the more distinctly will it be heard. On the other hand, when the membrane is in its naturally relaxed condition, its fundamental note is very low, and it is capable of repeating a much greater variety of sounds; for, when it receives undulations of a higher tone than those to which the whole membrane would reciprocate, it divides itself into distinct segments of vibration, which are separated by lines of rest; and every one of these reciprocates the sound, ${ }^{3}$ at the same time rendering it more intense by multiplica-

1 Philosophical Transactions, 1851.

2 See the Experiments of Schapringer (Wien. Akad. Sitz.-ber., Bd. lxii, 1870), who possessed the faculty of voluntarily contracting his tencor tympani.

3 This is very easily proved by experiment on a membrane stretched over a resonant cavity; for if light sand be strewed upon it, and a strong musical tone be produced in its vicinity, the nembrane will immediately be set in vibration, not as a whole (unless its fundamentul note be in unison with that sounded), but in different segments of which every one reciprocates the sound; from the vihrating parts, the sand will be violently thrown off; but it will settle on the internediate lines of rest, which are known us the nodal lines, forming a variety of curious figures. See also Donders on the sound colors of the vowels, in Douders and Berlius, Archiv f. d. Holland. Beiträre zur Nutur und Heilkunde, Bd. iii, p. 446. By means of a modification of Scott's form of König's phonautograph, Donders obtained very beautiful pictures or series 
tion ( $\S 642)$. These facts enable us to understand the influence of the tensor tympani muscle, in augmenting the tension of the membrane, and thus enabling it to vibrate in reciprocation to sounds having a great variety of fundamental notes. It appear's to be antagonized by the stapedius, the contraction of which scems to diminish the tension of the membrana tympani, and to take off pressure from the fluid of the labyrinth. These two muscles conjointly may be considered to rcgulate the transmission of sonorous undulations to the fluid of the internal sac, preventing it from being too violently affected by loud sounds, in the same manner that the iris regulates the admission of light to the eye $(\S 612)$; and the analogy extends also to their nervous supply, the stapcdius being excited to action by a branch of the Facial, whilst the tensor tympani receives its nerves from the Otic ganglion. ' They are probably put into conjoint action when we are listening for faint sounds, so as to bring the tympanum into the state of tension best adapted to reciprocate them; whilst by a like preparation, the concussive effects of a loud sound that is anticipated, are more effectually moderated than when it strikes the ear without warning. It is probably owing to an imperfect action of these muscles, that some persons are deaf to grave sounds, whilst they readily hear the more acute. Helmholtz ${ }^{2}$ observes, that by the transference of the vibrations of the tympanum to the much smaller incmbrane of the fenestra ovalis, mechanical power is gained for the cstablishment of vibrations in the comparatively incompressible fluid of the labyrinth. He observes also that the inferior aspects of the articular surfaces of the malleus and incus are furnished with small teeth, so arranged that when the malleus moves outwards the articular surfaces easily separate as far as the somewhat loose capsule will allow, whilst when the malleus moves inwards these two bones become firmly locked. The result of this is, that when air is blown into the tympanic cavity, the membrana tympani can move outwards without dragging the stapes out of the fenestra ovalis.

646. The uscs of the Tympanic Cavity are very obvious. One of its purposes is to render the vibrations of the membrane quite free; and the other, to isolate the chain of bones in such a manner as to prevent their vibrations from being wcakened by diffusion through the surrounding solid parts. As to the objects of the Eustachian Tubc, opinions bave been much divided. Many of these opinions, however,-such as the one most commonly cntertaincd, that it serves the same purpose as the holc in an ordinary drum, removing an inperliment to the free vibration of the membrane that would be offered by the complete inclosure of the air within,-are at once negatived by the fact, which seems to have been demonstrated by Mr. Toynbec and Dr. Jago, ${ }^{3}$ that the guttural orifice of the tube is usually closed, being only opened during the act of swallowing. ${ }^{4}$ The principal object of the Eustachian tube (which is always found where there is a tympanic cavity) secms to be the maintenance of equilibrium between the air within the tympanum

of curves, representing complieated vibrutions, not only of the roeals, but also of the notes proluced by the passare of these into eonsonants; of the sound colors of various musieal instruments, and of various notes, - all of which present curves of nppropriate form. See also 'Tyndall's work, On Sound, 1867, for a full résumé of ull rocent researches, also Squire on The Quality of Musical Sounds, Quart. Journ. of Soi., $1865,1) .600$.

I See Mr. C. Brooke in Lnneet, 1843, p. 380; and Mr. Toynbee in Brit. and For. Med.-Chir. Ruv., vol. xi, p. 235.

2 Ueber die Mechanik der Gehörknöchenchen, Pflüger's Arehiv, 1868. Sre Humphry and 'Tumer's Jourmal of A natomy, vol. iii, 18t8, 1. 219; also Buck, New York Med. Journ., June, 1874.

3 see his very interenting essnys in the Med.-Chir. Review, 1867, pp. 175 and 496.

1 Luc. cit., and I'roceedings of tho Royal Society, 1852. 
and the external air; and Dr. Jago holds that the normally closed condition is a provision against the ingress of aerial undulations from the throat, which, if admitted, would threaten the inembrana tympani with incessant oscillatious, and that as the moment seized for bringing the tympanum into communication with the fauces must be one in which there can be no respiratory current, the period selected is the instant of swallowing, at which instant there is a compulsory suspension of respiration; so that neither shouting, singing, whistling, nor coughing can be performed. ${ }^{1}$ It also has the office of conveying away mucus secreted in the cavity of the tympanum, by means of the vibratile cilia which clothe its lining membrane; and the deafness consequent on occlusion of this tube, is in part explicable by the accumulation which then takes place in the cavity. From what has been stated, it is evident that sonorous undulations in the air will be propagated to the fluid contained in the labyrinth-through the tympanum, the chain of bones, ${ }^{2}$ and the membrane of the fenestra ovalis to which the stapes is attacherlwithout any loss, but rather an increase of intensity. It is of great importance, as Dr. Jago has shown, that the external surface of the membrani tympani should be clean and free from moisture, since if it be rendered moist the power of hearing is immediately lessened; and since its inner surface is continually moist, an additional argument is furnished for the view that sonorous undulations are chiefly conveyed through the ossicula, and not through the air contained in the tympanum. Wliy water should be chosen as the mediun through which the impression is to be made upon the nerve, it is impossible for us to say with anything like certainty, in our present state of ignorance, as to the physical character of that impression. But the problem being to communicate to water the sonorous undulations of air, the experinental results already detailed satisfactorily prove that-whilst this may be accomplished, in a degree sufficient for the wants of the inferior animals, by the simple interposition of a membrane between the air and the fluid-the tympanic apparatus of the higher classes is most admirably adapted for this purpose. The fenestra ovalis is not, however, the only channel of conmunication between the tympanum and the labyrinth; for there is in most aninals a second aperture, the fenestra rotunda, leading into the cochlea, and simply covered with a membrane. It is generally supposed that, the labyrinth being filled with a nearly incompressible fluid, this second aperture is necessary to allow the free vibration of that fluid; the membrane

1 Lucæ (Archiv f. Ohrenheilk., Bd. iii, p 186) maintains that exchange of air in the tympanum takes place during the ordinary acts of respiration, and that it is not linited to the instant of swallowing. Sce Zuckerkandl, Zur Anat. u. Physiol der Tuba Eustachiana, Monatssch. f Ohrenheilk., Dec. 1873, and Knapp's Archives of Ophth. and Otol., 1874, vol. iv, No. 1, p. 126.

2 For pupers showing that sounds are chiefly conducted through the bones of the tympanum, see J. Jago, in Proceedings of Royal Society, 1857-59, vol. ix, p. 134; and J. Toynbee, in idem, 1859-50, vol. $x, p .32$. See also on this point Dr. Gustav Brunnen, on The Connection between the Ossicles of Hearing, in Knapp's Archives of Ophthalmology and Otology, vol. iii, No. 2, p. 145, and Burnett, Monthly Journal of Aural Surgery, July, 1871 ; Politzer, Archiv f. Ohr'nbeilk, Bd.iv, Heft 1. Buck, however (Hinton's Report on Otolngy, Med.-Chir. Rev., April, 1873, p. 489), found, on measuring with a micrometer the little lines into which starch-granules scattered over the ossicula are thrown, that the vibrations of the malleus are twice as large as those of the incus, and four times as large as those of the stapes, hence the intensity of the sound-waves apjears to undergo diminution on their passage from the membrana tympani to the labyrinth. The views of Muller, admitting waves of condensation and rarefaction, are supported, in part at least, by Hensen and Schmidekum (Untr.rsuch. d. Kinder. Instituts, 1869) and Henke (Zeits. f. rat. Med., Bd. xxxi), who fastened glass threads to the ossicula, and observed great variation in the amplitude of the vibrations, which were sometimes vertical and sometimes transverse 
of the fenestra rotunda being made to bulge out, as that of the fenestra ovalis is pushed in. It may be easily shown by experinent, however, as well as by reference to comparative anatomy, that no such contrivance is necessary; for sonorous undulations may be excited in a non-elastic fluid, completely inclosed within solid walls at every part, except where these are replaced by the membrane through which the vibrations are propagated; and this is precisely the condition, not only of Invertebrated animals, but even of Frogs; in which last a tympanic apparatus exists, without a seeond orifice into the labyrinth. Moreover, it is certain that the vibrations of the air in the cavity of the tympanum must of themselves act upon the membrane of the fenestra rotunda; and this is perhaps the most direct manner in which the fluid in the cochlea will be affected, although it will ultimately be thrown into much more powerful action, by the transmission of vibrations from the vestibule. For it has been satisfactorily deternined by experiment (xIr), that vibrations are transmitted with very much greater intensity to water, when a tense membrane, and a chain of insulated solid bodies capable of free movement, are successively the conducting media, than when the media of communication between the vibrating air and the water are the same tense membrane, air, and a second membrane; or, to apply this fact to the organ of hearing, the same vibrations of the air act upon the fluid of the labyrinth with much greater intensity, through the medium of the chain of auditory bones and the fenestra ovalis, than through the medium of the air of the tympanum and the membrane closing the fenestra rotunda, which last, it is maintained by Dr. Jago, has little if any influence in the transmission of sounds to the internal Ear.-The fenestra rotunda is not to be considered as having any peculiar relation with the cochlea, since, in the Turtle tribe, the former exists without the latter.

647. It is obviously in the Labyrinth, as a whole, that the sonorous vibrations are brought to bear upon the Auditory nerve spread out to receive them. In regard to the special functions of particular parts of the labyrinth, however, no certainty can be said to exist. The membrane which lines its cavities not only contains a liquid (the endolymph), but is also separated from the osseous wall by another collection of liquid, the perilymph, so that it is suspended, as it were, in a liquid which bathes both its surfaces. In the cavity of the Vestibule, which is subdivicled by a membranous partition into two, are round small masses of coneretionary particles, collectively named otoconia, or ear-powder; these are obviously the rudiments of the otoliths, or ear-stoncs, whose presence, in animals with a less perfect auditory apparatus, seems ncedful to intensify the undulations.-It is commonly sup)posed that the Scmicircular Canals have for thcir peculiar function, to receive the impressions by which we distinguish the dircetion of sounds; and it is certainly a powerful argument in support of this view, that, in almost cvery instance in which these parts cxist at all, they hold the same relative positions as in Man, their three planes being nearly at right angles to one another. The idea, however, must be regarded as a mere speculation, the value of which cannot be decided without an increased knowledge of the laws according to which sonorous vibrations are transmitterl but it receives a certain degrec of confirmation from the curious movements witnessed by M. Flourens ${ }^{2}$ after section of one or other of these canals (\$526).-Regarding the special function of the Cochlea, there is precisely the sane uncertainty. It has been surmised hy M. Dugis, that by the Cochlea we are especially

1 And confirmed by Loewenberg (A rehives of Ophthalmology and Otology, vol. iii, No. 2, p. 31, 1874), who attributes them to irritation, and not to paralysis of the nerves. 
enabled to estimate the pitch of sounds, particularly of the voice; and he adduces, in support of this idea, the fact, that the development of the cochlea follows a very similar proportion with the compass of the voice. This is much the greatest in the Mammalia; less in Birds; and in Reptiles which have little true vocal power, the cochlea is reduced to its lowest form, disappearing entirely in the Amphibia. That there should be an acoustic relation between the roice and ear of each species of animal, caunot be re-

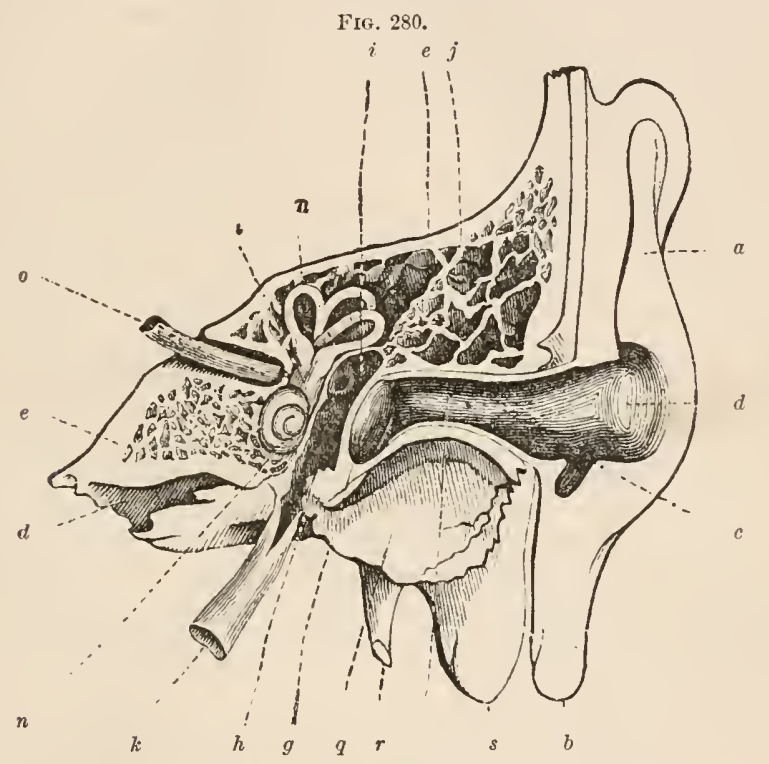

Vertical Section of the IIuman Ear, the internal portions on an enlarged scale : $a, b, c$, external ear; ( $l$, entrance to auditory canal, $f ; e, e$, petrous portion of temporal bone; $g$, membrana tyunpani; $h$, cavity of the tympanum, the chain of bones being removed; $i$, openings from this cavity into the cells, $j$, excarated in the bone; on the side opposite the membrana tympani are seen the fenestra ovalis and rotunda; $k$, Eustachian tube; $l$, vestibule; $m$, semicircular canals; $n$, cochlea; $o$, auditory nerve; $p$, canal for carotid artery; $q$, part of glenoid fossa; $r$, styloid process; $s$, mastoid proeess.

garded as improbable; and the speculation of M. Dugès derives confirmation from the researches of Helmholtz, who appears to consider that the function of the cochlea stands in intimate relation with our power of discriminating differences in the quality of sounds. This will naturally follow from his demonstration that the timbre depends upon the harmonic combinations; if it be the function of the cochlea to discriminate pitch. According to his observations, the individual branches of the auditory nerve are only capable of distinguishing simple, pendulum-like vibrations; but, as already stated ( $\$ 640$ ), all ordinary sounds are compound in their nature, the fundamental note being accompanied by harmonies; these throw corresponding fibres into vibration, and produce an impression which may be likened to a color. The analogy which exists between the power of distinguishing colors and that of discrininating musical tones has long been recognized; and whilst we find that some persons are endowed with the latter, which is commonly known as a "musical ear," in a degree that renders it a source of great discomfort to them (since every discordant sound is a positive torment), others are altogether destitute of it,-the deficiency being very analogous to the "color- 
blindness" formerly described ( $\$ 631$ ). It is not a little curious, that the two defects are oecasionally coexistent in the same individuals. ${ }^{1}$

[The late Dr. Samuel Jaekson, Professor of the Institutes of Medicine in the University of Pennsylvania, thought that the semieireular canals aeted by suppressing the sonorous undulations or vibrations of the lymph of the vestibule, which are the immediate excitants of the sense of hearing. They arrest the waves of reflexion, whieh would neeessarily occur in a simple cavity, wholly limited by plane surfaces, as the vestibule would be without these appendages, and as is the case with the rudimentary vestibule or internal ear of the Invertebrata. The production of mere sound or noise of different intensities would result from refleeted undulatory vibrations maintained in the labyrinthic fluid, while the perception of immense numbers of fine and delieate tones, and varying qualities of sound, now so characteristic of the hearing of man and the higher animals, would be rendered impossible in the confusion of vibrations to and fro in the fluid of the labyrinth, but for the semieireular canals, by which they are suppressed. These canals, in the apparatus of hearing, were eonsidered by Dr. Jaekson as corresponding, in funetion, with the pigmentum nigrum of the ehoroid eoat in the organ of vision. The preeise mode in whieh this suppression is accomplished, will be better appreciated by following up Dr. Jackson's comparison:

"The two senses and their apparatus are homologous. The essential phenomena and laws of each are identical. The knowledge of those of the one sense demonstrates those of the other. The conditions of perfeet vision and perfect hearing are the same. They are, 1st. The existence of separate, independent, sensitive spaces or sections of the retina for distinct images and perceptions of visual impressions. Volkmann estimates these to be 0.0005 $\mathrm{mm}$; and others at ${ }_{50 \overline{0}} \frac{1}{000}$ of an inch. 2d. A single distinct impression made by the molecular vibration of the ether, the excitor of the sense of sight.

"The above conditions are obtained $(a)$ by the special anatomical arrangement of the retina; $(b)$ by the refracting apparatus of the globe of the eye, that coneentrates the undulatory rays of the ether, proceeding from every point of a visual object, on the distinct, sensitive points or spatees of the retina; $(c)$ by the suppression of the undulatory vibrations, immediately they have excited an impression on the retina, by the black pigment of the choroid eoat. Their reflection from the exterior surfaee of the sclerotic coat, and reiterated excitement of the retinal surfaees, is thus prevented. In Albinos the pigment of the choroid is either deficient or absent, and the eonsequence is indistinet vision in daylight, from the general excitement of the retina by the reflected undulations of the ether oecupying the globe of the eye.

"The same eonditions are obtained in hearing: 1st. By the aulitive nerve being decomposed into its separate filaments and ganglionic vesicles, amounting to some thousands, and spread out in a manner to receive single, individual impressions in the membranous vestibule, ampulla, and on the lamina spiralis of the eoehlea. 2d. By the molecular undulations or vibrations excited in the fluids, perilymph and endolymph, by the sonorous undulations commnnieated by the stapes, oceupying the fenestra ovalis. From this point they radiate in expanding waves of mndulations, strike on, and pass through the membranous vestibule and anpulle, on which the filaments of the vestibular braneh of the auditive nerve are arranged, producing a single, distinct

1 See a collection of such cases by Dr. Pliny Earke, in Amer. Journ. of Hed. Sci., vol. $x \times \times v$. 
impression, rcinforced by the resonance of the superimposed otoconire, and exciting a single aud distinct impulse and perception of sound. These bodlies act like the sounding-board of the piano. The sonorous vibration having thus completed its office, the spccific excitation of the sense of hearing must, like that of the visual vibration, cease, or be suppressed. This occurs, in part, in the ampulla, but mostly in the semicircular canals.

"The vibrations of the endolymph, reaching the ampullæ, are partially broken and weakened at their openings: those entering the ampullae again expand, losing thereby their impetus, and either die away against the membranous walls, or come in coutact with the vibrations of the perilymph or their exterior. The two can scarcely be in perfect consonance of expansion or condensation, and interference ensues, by which they are suppressed. In this mode all the feebler vibrations are terminated. Those of greater force enter simultaneously the two opposite openings of the semicircular canals. The orifices and commencement of each canal differ as to size and form, and consequently each entering wave of undulatory vibration is modified, thus losing their consouance of expansion, and when they meet interference and suppression result. Reflection of sonorous vibrations is completely provided against.

"Parallel couditions exist in the cochlea. Its two canals-the superior scala vestibuli, and the inferior scala tympani-are filled with lyıph fluid, continuous aud identical with that of the vestibule. The first, the scala vestibuli, is the principal seat of hearing. On its lamina spiralis is expanded a sentient nervous structure, the recipient of the sonorous vibrations excitative of the sense of hearing. It is the homotype of the retina of the eyc. The scala tympani furnishes space for spreading out the filaments of the nerve, but the terminal extremities pass through the membranous spiral lamina, to be incorporated with the sentient organ of hearing in the superior canal or scala vestibuli. The filaments of the inferior canal or scalia tympani are mere conductors of the nervous excitement of the auditive sentient membrane. The scala tympani, similar to the semicircular canals, has no direct connection with the production of hearing. It is the homotype of the semicircular canals, and performs the same office.

"The sonorous vibrations, starting from the stapes and fenestra ovalis, rushing into the adjacent opening of the scala vestibuli, excite, by their inpulse, the auditory membrane or retiua, spread over its lamina spiralis, and reach its termination, where it opens into the scala tympani. Feeble vibrations may subside spontancously by exhaustion from their extension. The stronger pass on into the scala tympani, where they fade away, or are suppressed by the interference of vibrations entering the inferior canal by the fenestra rotunda from the tympanum. The condition for perfect hearing, for the distinct perception and appreciation of the finest tones and notes, so that each vibration shall make but one, single, distinct impression, and then. be suppressed, is thus amply fulfilled.'

"Analogous provisions are perceived to exist in the tympanum, to preserve in that cavity the perfect wave systems of undulations, indispensable to the perfection of the sense of hearing. Vibrations existing in air, contained in a cavity with plane walls, would continue to be reflceted from side to side, producing confused sounds or noise. The air in the tympanum is thrown into vibrations by impulses of the membrani tympani. They are commuuicated, pure, and in perfect accord, to the membrane of the fenestra rotunda. This curious and beautiful result is effected in the following manner: on one side the tympanum communicates, by numerous openings, with the mastoid cells communicating with one another. All the vibrations impinging on this side are suppressed in the mastoid cells. Those that reach 
the opposite side are swallowed up and lost in the Eustachian tube. All resonance and reflection of vibrations are suppressed, and the wave-systems of sonorous vibrations traverse the tympanum undisturbed, enter, with augmented force, the lymph fluid of the scala tympani, and meet the corresponding undulations coming from the scala vestibuli, from which both systems are suppressed by interference.

$$
\text { * } * * * *
$$$$
* \quad *
$$

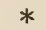

*

"The small space through which the vibrations pass, and the rapidity of their movements in fluids, cause the impressions they make on the nervous sentient organ, and the perceptions they excite, to appear as an instantaneous act. The mind has cognizance of them, however diversified they niay be, as a unity of sounds simultaneously instant in action; whence it forms the compound idea of perfect harmony.

"An analogous phenomenon occurs in vision. When a body, composed of different forms and colors, is presented to the eye-as a bouquet of flowers, a landscape, or picture-each different form, color, tint, and shading, are perceived blended, but perfect and distinct, forming the image of a single object. Yet thousands of ether vibrations are traversing the eye, and are exciting each a separate, distinct impression, without confusion, on the retina, and as many distinct and separate perceptions, from which a corresponding compound idea of a single object is formed by the mind."]

648. We have now to consider the functions of the accessory parts, - the External Ear, and the Meatus. The Cartilage of the external ear may propagate souorous vibrations in two ways; by reflection, and by conduction. In reflection, the concha is the most important part, since it directs the reflected undulations towards the tragus, whence they are thrown into the auditory passage. The other inequalities of the external ear cannot promote hearing by reflection; and the purpose of the extension of its cartilage is evidently to receive the sonorous vibrations from the air, and to conduct them to its source of attachment. In this point of view the inequalities become of importance; for those elevations and depressions upon which the undulations fall perpendicularly, will be affected by them in the most intense degree; and in consequence of the varied form and position of these inequalities, sonorous undulations, in whatever direction they may come, must fall advantageously upon some of them.-The functions of the Meatus appear to be threefold. The sonorous undulations entering from the atmosphere are propagated directly, without dispersion, to the membraua tympani; the sonorous undulations received on the external ear are conveyed along the walls of the meatus to the membrana tympani; whilst the air which it contains, like all iusulated masses of air, increases the intensity of sounds by resonance. That in ordinary hearing, the direct transmission of atmospheric vibrations to the membrana tympani is the principal means of exciting the reciprocal vibrations of the latter, is sufficiently evident; the undulations which directly enter the passage, will pass stritight on to the membrane; while those that enter obliquely will be reflected from side to side, and at last will fall obliquely on the membrane, thus perhaps contributing to the notion of direction. The power of the lining of the meatus to conduct sound from the external ear, is made evident by the fact that, when both ears are closely stopped, the sound of a pipe having its lower extremity covered by a membrane, is heard more distinctly when it is applied to the cartilage of the external ear itself, than when it is placed in contact with the surface of the head. The resonant action of the air in the tube is easily demonstrated, by lengthening the passage by the introduction of another 
tube; the intensity of external sounds, and also that of the individual's own voice, as heard by himself, is then much increased.

649. Many facts prove, however, that the fluid of the Labyrinth may be thrown into vibration in other ways than by the Tympanic apparatus. T'hus in Osseous Fishes, it is only by the vibrations transmitted through the bones of the head, that hearing can take place. There are many persons, again, who can distinctly hear sounds which are thus transmitted to them; although, through some imperfection of the tympanic apparatus, they are almost insensible to those which they receive in the ordinary way. It is evident, where this is the case, that the nerve must be in a state fully capable of functional activity; and on the other hand, where sounds cannot thus be perceived, there will be good reason to believe that the nerve is diseased. Urbantschitsch ${ }^{1}$ finds that there are three deaf-spots in each ear, or spots in which a vibrating tuning-fork passed in front of the ear is not heard. The two chief areas have the form of two little triangles, one of which extends forwards and upwards, the other backwards and upwards.

650. The power of distinguishing the direction of sounds appears to be, in Man at least, for the most part acquired by habit; for it is some time before the infant seems to know anything of the direction of noises which attract his attention. Our judgment as to this point is probably assisted, in most cases, by a difference in the intensity of the sensations received through the two ears respectively; but since we have a certain power of appreciating direction when one ear alone is used, this power must depend upon an exercise of perceptive discrimination (which is probably acquired, rather than intuitive) in regard to the impressions which we receive through its means; and it has been already mentioned that the Semicircular canals (\$ 647) appear to furnish the instrumentality by which our ninds are enabled to take cognizance of such differences. - The idea of the distance of the sonorous body is another acquired perception, depending principally upon the loudness or faintness of the sound, when we have no other indications to guide us. In this respect there is a great similarity between the perception of the distance of an object, through the Eye by its size, and through the Ear by the intensity of its sound. When we are acquainted with the usual intensity of its sound, we can judge of its distance; and vice versû, when we know its distance, we can at once form an idea of its real strength of tone from that with which our ears are inpressed. In this manner, the mind may be affected with corresponding deceptions through both senses; for as, in the Phantasmagoria, the figure being gradually diminished while its distance remains the same, it appears to the spectators to recede (the illusion being more complete if its brightness be at the same time diminished); so the effect of a distant full nilitary band gradually approaching, may be alike given by a corresponding crescendo of concealed instruments. It is upon the complete imitation of the conditions which govern our ideas of the intensity and direction, as well as of the character, of sounds, that the deceptions of the Ventriloquist are founded. A very curious instance of the degree in which our auditory interpretation is affected by other sense-perceptions, is afforded by the "Ghost" exhibition which has recently been so popular; for it is scarcely possible to avoid referring to the place where they seem to be made, sounds which are really produced elsewhere.

651. The Auditory sense, like the visual, may vary considerably among different indiviluals, both as regards its general acuteness, and as respects its discriminative power for particular classes of impressions. Much depends upon the habit of attention to its indications; and thus it comes to 
pass, that the power of hearing very faint sounds and of recognizing their souree becomes augmented to a wonderful degree in those individuals who are obliged to trust to the knowledge thus acquired for the direetion of their own actions; whilst, in like manner, the power of distinguishing slight differences in the piteh of sounds, may be so eultivated (where it is not eongenitally deficient) as to attain an intensity that seems very extraordinary to those who have not aecustomed themselves to listen for them. The general cultivation of this sense is perhaps most remarkable in blind persons, who have euabled themselves, by reliance npon it, to walk about freely, even in the crowded thoroughfares of the metropolis; and who are not only able to judge of the habits of individuals whom they meet, by the sound of their footsteps (at once recognizing, for instance, the footstep of a policeman on duty), but can even tell when they are passing a stationary object (such as a lamp-post), provided it be as high as the ear or nearly so, by the reverberation of the sound of their own footsteps, and ean diseriminate between a lamp-post and a man standing still in the position of one, by the same means. ${ }^{1}$ The effect of habitual attention in inereasing the diseriminative power for impressions of one particular kind, is perhaps best seen in the ability which is possessed by certain Conductors of orchestral performances, to detect the slightest departure from time or tune in the sound of any one of (perhaps) a hundred instruments that are simultaneously sounding, and to fix without hesitation upon the faulty instrumentalist. Seebeck, indeed, affirms that accomplished musicians can detect a difference in pitch between two sounds whieh only differ by $\frac{1}{120}$ th in the number of their vibrations. ${ }^{2}$ According to the researehes of MLI. Renz and Wolff, ${ }^{3}$ our faculty of estimating differences in the intensity of sounds is mueh less perfect. When the intensities of two sounds are to one another as 7 to 10 , the difference can be distinguished, but not when they are in the relation of 9 to 10. The advantage resulting from the simultaneous employment of the two ears in distinguishing minute differences in the intensity and pitch of sounds, is well shown in the experiment suggested by M. Weber, of holding two watches in the hand before one ear, when it will be found that the suecessive sounds can be distinctly heard, though they cannot be distinguished one from the other, whilst if one be held in front of each ear the two sounds can be clearly discriminated.

652. Facts of mueh interest have been ascertained, some of which have been already alluded to ( $\$ 471)$, in regard to an oeeasional difference in the rapidity of the perception of sensory impressions received through the Eye and through the Ear respectively. These facts are the result of comparisons made amongst different Astronomical observers, who may be watching the same visual phenomenon, and "timing" their observations by the same clock; for it has bcen renarked, that some persons see the same occurrence, a third or even a half of a second earlier than others. There is no reason to suppose from this, however, that there is any difference in the rate of transmission of the sensory impressions in the two nerves. The fact seems rather to be, that the Sensorium does not readily perceive two impressions of different kinds with equal distinetness; and that, when several such impressions are made on the senses at the same time, the mind takes cognizance of one only, or perecives them in suecession. When, therefore, both sight and hearing are directed simultaneously to two objects, the communication of the impression through one sense will necessarily preeede that made by

1 See the account of a blind boot-lace seller given by Mr. H. Maybew, in his London Labor and the London Poor, vol. i, p. 402.

2 See Ludwig, Physiologie, vol. i, p. 380 ; and lẻelard, Physiol., 1862, p. 1858.

3 Archivf. Phys. Heilk., 1856. 
the other. The interval between the two sensations is greater in some persons than in others; for some can receive and be conscious of many impressions, seemingly at the same moment; whilst in others, a perceptible space must elapse. The "personal equation" of each observer in an Observatory has, therefore, to be determined and allowed for."

653. Amongst other important offices of the sense of Hearing, is that of supplying the sensations by which the Voice is regulated. It is well known that those who are born entirely deaf, are also dumb; that is, they do not spontaneously or initatively form articulate sounds, though not the least defect may exist in their organs of voice. Hence it appears that the vocal muscles are usually guided in their action by the sensations received through the Ears, in the same manner as other muscles are guided by the sensations received through themselves; but when the former are deficient, the action of the vocal muscles may be guided by the latter ( $\$ 537)$. - That the perceptions obtained by the auditory nerve should be capable of being more quickly perceived and registered than those received through the optic is not surprising, since the course of the former is much shorter than that of the latter. The following table gives the results of several observers in regard to the physiological time of the several senses of sight, hearing, and touch; or in other words the whole tern occupied between the occurrence of an event and its registration :

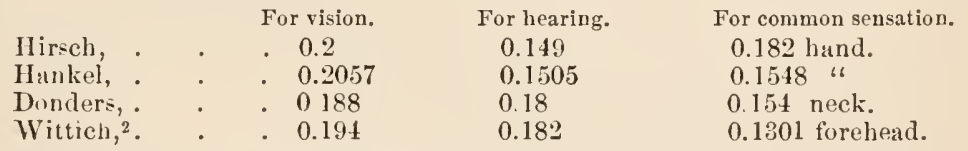

By subtracting the physiological time for auditory impressions from those for optical impressions, it appears that the rapidity of the conduction of sensory impulses is comparatively slow. On the highest estimate not exceeding 7.35 metres per second, and on the lowest, amounting to only 1.068 metres per second.

The Measure of Sensations. - The observations made by Weber ( 8594$)$ and others on the several senses, have led to the cstablishment by Fechner of a psycho-physical law $w^{3}$ applicable to the quantitative sensations of temperature, pressure, muscular cxertion, sound, light, and of fatigue. At tirst sight it would seem impossible to measure a sensation, but inasmuch as the excitution of any nerve which leads to sensation is caused by external or physical conditions which we can vary or quantitatively determine, we possess in this a means of measuring sensations. 'Thus, if a weight of half an ounce be held in the hand, and another half ounce be added, a difference is instantly felt; but the addition of half an ounce to twenty pounds is not appreciated. The same is true of light and sound. It would hence appear that for an excitation

1 In all the best Observatories, an arrangement is now made for rccording observations which supcrsedes the necessity of timing them by simultaneous attention to the clock. The observer who is watching the transit of a star (for example) across the meridian, simply presses a button at the moment when he witnesses its contact with the cross wire. This pressure breaks an electric circuit, which is so connected with a chronometer as to stop it instantancously, and thus automatically to record the precisc time of the phenomenon. Since this plan has been adopted, it has been found that the "personal equation" nearly or altogether disappears; thus confirming the view given above as to its dependence on the distraction of the attention between the two ribjects of perception. For interesting papers on the subject of this paragraph, see Much, On the Sense of Time in the Ear, Moleschott's Unters., Bd. x, 1866, Heft 2. Also Mach, On the Accommodation of the Ear, in idem, p. 201.

2 Sec Von Wittich's paper in Henle and Meissner's Zeitschrift, 1868, Bd. xxxi, p. 87.

3 Fechner, Elemente der Psychophysik, 2 vols., Leipsic, 1860; Detbœuf, Recherches Théoriques et Expérimentales sur la Mesure des Sensations, Bruxelles, 1873; Ribot, La Psychologie Physiologique en Allemagne, in La Rev. Scient., No. 24, 1874. This section is ehiefly drawn from Wundt, Physiologie, 1873. 
to be felt, it must be proportionately more feeble as the excitation to which it is added is fceble, and stronger in proportion to the strength of the original or primary excitation. Hence the conclusion may be drawn that the intensity of a sensation increases, not directly in proportion to the intensity of the excitation that produces it, but in some other ratio. Now it may be asked, what proportion does the inerease in the intensity of the sensation bear to the increase in the intensity of the stimulus? And in order to aequire this knowledge, three methods of experimentation have been adupted, named by Fechner respectively the method of the smallest perceptible differences, the method of true and false estimates, and the method of mean error. The first method consists in this: Two weights, $A$ and $B$, are to be compared. If they are nearly alike, they may be judged to be equal; if the difference bc considerable, it will casily be recognized. If the difference $d$ between $A$ and $B$ be gradually incrcased or gradually diminished, a point will be arrived at when the differenee is only just discernible, and the smaller the difference perceptible, the more acute is the sensibility of the subject. The second method consists in taking two weights, the difference between which is so small that an error in judgment is possible. In proportion as the difference increases, the number of accurate conclusions will augment at the expense of the inaccurate ones. If the total number of experiments be 100 , and the number of true estinates be 70 , we have the proportion $\frac{70}{100}$ established by the comparison of the two weights A and B. Now suppose a weight $\alpha$ to be given, we seek to determine the weight $b$, which compared with $a$ will give the same proportion of 70 . Cases of indecision must be placed half to the account of the true and half to the account of the false estimate. The third method consists in taking a weight, $A$, exactly determined by balance, and it is sought by the judgment alone to fix on another weight which is judged equal to the first. In gencral the second weight differs from the first by a quantity, $d$, whieh is small in proportion to the acuteness of the sensibility of the subject. This experiment is frequently repeated, the positive and negative errors added, the signs being neglected. The total is divided by the number of trials, and the mean error is thus obtained. By the employment of one or other of these methods the following results are obtained :

Sensution of Weight. - The hand is extended und supported, the eyes are bandaged, and successive weights, as a drachm, an ounce, a pound, etc., are placed upon it. On each weight various small additional weights are placed till a distinet difference is pereeived. The results of numerous experiments by the first method have shown that a very simple relation is maintained, viz., that whatever may be the weight originally placed on the hand, it requires an addition of onc-third of that weight to enable a distinet difference to be perceived.

Sensation of Muscular Effort.-This is a much more delicate means of estimating differences of weight than the foregoing, since not only does the sense of pressure, but the sense of nuseular effort guide the judgment; and experiments have shown that an additional weight of $1 \frac{6}{10}$ ths can be deteeted, $i . e$., a weight of 6 grains added to 100 grains, or of 60 grains to 1000 , is perceptible.

The Sensation of Temperature seems to follow the same law as that of simple pressure vithout muscular exertion, an addition of one-third being requisite to be perceived. In regard to light, photometrical experiments have shown that the intensity of a candle or other source of light must be inereased ${ }_{1}^{1}{ }_{0}$ th in order that the increase should be perceptible. For the sensation of sound, the increase or dininution must be equal to one-third Renz and Wolff found that for two sounds to be clearly distinguished they must be in the relation of $100: 72$. The proportion given by Volkmann is $4: 3$, which equals $100: 75$.

From all this it would appear that if $\mathrm{S}$ represent the value of the minimum perceptible sensation, the second possible sensation would be for tactile impressions $\mathbf{S}+$ $\frac{1}{3} ;$ for muscular eflort, $S+\frac{1}{15}$; for temperature, $S+\frac{1}{3}$; for light, $S+\frac{1}{100}$; for sound, $S+\frac{1}{3} ;$ and the results of nurnerous experiments are as follow :

Constant proportionals.

Touch $\frac{1}{3}$,

M[uscular effort $\frac{1}{17}$,

Temperature $\frac{1}{3}$.

Sound $\frac{1}{3}$,

Light Iำ,
Perceptible minimum.

Pressure of $0.002 \mathrm{grm}$. to $0.05 \mathrm{grm}$, according to the region of the bedy to be experimented on. (A ubert.)

Contraction of the internal rectus of the eye to the extent of $0.004 \mathrm{~mm}$.

(The heat of the skin being taken at $18.4^{\circ}$ Cent.) $1_{8}^{\circ}$ Cent. (? $\frac{1}{1}$, Fechner.)

Ball of cork weighing $0.001 \mathrm{grm}$. falling $0.001 \mathrm{~m}$. on a plate of glass, the ear bring at a distance of 91 millimetres, 34 inches. (Schaf häutl.)

Illumination of black velvet by a candle at a distance of 8 fect 7 inches. (Volkmann.) 
In secking to find a law which shall express the general relation of excitation and of sensation, it is to be noted that we possess a knowledge of the two necessary elements, namely, the measure of the constant proportional and the measure of the smallest perceptible sensation. The first supplies the unit for dividing the standard into equal parts, the second serves to graduate it, since it determines the zero and renders it tit for use. This may be understood by reference to the following firure: In a line, $X$, of indefinite length, a zero, 0 , is noted. This answers to the minimum of sensation. Starting from the point 0 , the line $x$ is divided into equal parts, 1,2 , 3 , 4 , ete, which represent the increments of sensation. From the point 0 , a line, $0 b$, of any length is drawn; it represents the minimum stimulus, say the $\frac{1}{50}$ th of a gramme if sensations of pressure are under consideration. Now, since the constant proportional, that is to say, the smallest perceptible difference $=\frac{1}{3}$ for pressure, a line

FIG. 281.

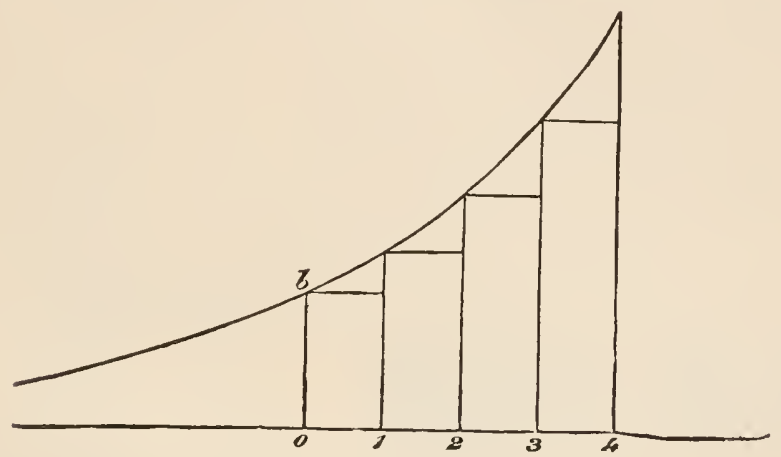

drawn from the puint 1 must equal the line $0 b$ plus $\frac{1}{3}$ of this line; from the point 2 a line equal to the line 1 , plus $\frac{1}{3}$ of 1 ; from the point 3 a line equal to 2 , plus $\frac{1}{3}$ of 2 ; and from the point 4 a line equal to 3 , plus $\frac{1}{3}$ of 3 . The third added is thus always an increasing quantity, and as the vertical lines have necessarily the same relation to one another as the weights they represent, it is clear that the differences of length between the line 0 and the lines 4, 5, 6, etc, indicate what weight must be employed in order that the perceptible difference should be quadrupled, quintupled, ete. The psycho-ph ysical law which Fechner has deduced from this is that within certain limits sensation increases as the logarithms of the stimulus; in other words, sensations inerease as the logarithms, whilst the excitations increase as ordinary numbers. If we represent the stimulus as $R$ and the corresponding sensation as $S$, while $C$ represents the constant proportional, then $S=C$ log. $R$ when the minimum stimulus is taken $=1$. This psycho-physical law only holds good within a certain limit. Beyond this the sensation increases more and more slowly, and soon a maximum excitation is reached, beyond which the relation between stimulus and sensation no lunger obtains.

\section{CHAP'TER X.}

ON THE STRUCTURE AND FUNCTIONS OF MUSCULAR TISSUE.

\section{Structure of Muscular Tissue.}

654. THE capability of executing movements effecting change of place or of form is a power that is so widely distributed through the animal body, that it has been questioned whether every cell or mass of germinal matter does not possess it at some period of its development. The gradual alteration of shape exhibited by the white corpuscles of the blood ( $\$ 177$ ), by 
the corpuscles of lymph $(\S 154)$ and pus $(\$ 377)$, by the salivary corpuscles ( $\S 102)$, and connective tissue $(\S 40)$, and by pigment ${ }^{1}(\S 39)$, and cartilagecells, as well as the rhythmical protoplasmic movements observed in the eggs of osseous fishes, ${ }^{2}$ represent, perhaps, the simplest modes in which this power is displayed. The movements presented by the greater number of these cells, or corpuscles resemble those performed by the germinal mass of which an Anroba is composed, the form altering from round to oval or guitar-shaped, and processes being thrust out at various points into which the body of the corpuscle is again drawn, by which a veritable locomotion is effected. The movements occurring in the fission and cleavage of cells appear to belong to the same category. In all these instances the inotions are usually slow and interrupted, but are rendered more energetic and lively by warnth and electricity, and are retarded by cold. In Dr. Ransom's experiments, the presence of oxygen in the surrounding medium was found to be requisite for the exercise of the property of the rhythmic contractility possessed by the food yolk, as well as of the fissile contractility of the formative yolk, whilst, on the other hand, the presence of carbonic acid rapidly checked, or altogether arrested them. ${ }^{3}$ The several movements here alluded to appear to be of the same kind as those observed in the contraction of muscle, only that the power is generally diffused through the whole of the cell or mass of germinal matter, instead of being limited to an organ of definite structure; just as in some of the lower animals the power of perceiving light seems to be diffused through the body, when no distinct organ of vision has as yet been developed.

655. A second kind of movement is presented by the cells of ciliated epithelium ( $\$ 39$ ), which line parts of the respiratory and genito-urinary apparatus in man, and in him appear to have as their office the establishment of currents directed' towards the exterior of the body in the fluids covering the surface of these membranes; whilst in animals they frequently constitute important agents in effecting locomotion, and in the procurement of food. The vibrations, which are upwards of 700 per minute, ${ }^{4}$ do not appear to be in any way under the control of the nervous system, since they persist long after somatic death. When they have becomc languid they can be made to recur with vigor for a short time by the addition of a small quantity of a dilute solution of potash or acetic acid. Carbonic acid gas soon arrests the movements, but the admission of oxygen gas leads to their renewal, ${ }^{5}$ and this alternate action may be kcpt up for two or thrce times; when they have stopped they can also be renewed by the attion of induced currents of electricity. The vibratile motions presented by the spcrmatozoa appear to be of the same nature as those of ciliated epithclium, and cach zooid may be regarderl as a cell, provided with a single cilium. Neither in these cells nor in the corpuscles mentioned in the foregoing section are any morphological character's discernible. ${ }^{6}$

1 The nigment-colls in the skin of the frog appour, from the experiments of Mr. Lister, Phil. 'Irans., 1858, to be in some measure under the influence of the nervous system, and the black particles in them when set free by the rupture of the eell, exhibit remarkable quivering novements, termed Brunonian movements.

${ }_{2}$ W. H. Ransom, M.D., Ilumphry and 'Turner's Journ. of Anat. and Physiol., vol. i, p. 237.

3 See also Rossbach, Die rhythm. Bewegung-erschein. der einfachsten Organism und ilır Verhalten eregen physikal. agent. und Arzneimittel, in Verhand. d. Phys.Med. Gesellseh. in Wïrzburg, Bd. ii, p. 179; Abst. Centralblatt, 1872, p. 490.

4 Engalmann, Centralblatt, $1867, \mathrm{No} .42$.

5 see Kühne, Schnltze's Areliv, Bd. ii, 1867, p. 372, and Klein, in Sanderson's P'hysiological II andbook, 1873, p. 21.

6 Unless indeed the stria deseribed by Dr. A. Stuart (Zeits. f. rat. Med., Bd. xxx, 
656. Putting aside these cases, however, all the sensible movements of the body are effected by one or other of two forms of tissue to which the term muscular has been applied. The first of these, termed the smooth or unstriped variety of muscle, consists of flattened bands, which are stated by Kölliker to be composed of long, fusiform cells (Fig. 282), with one or often two elongated oval nuclei, which become staff-shaped after death. ${ }^{1}$ Around the nucleus is a little finely granular protoplasm, which extends for some distance in the axis of the fibre; the length of the cells varies from $\frac{1}{125}$ th to $5^{1}$ th of an inch, and their breadth from $\frac{1}{56} \frac{1}{2}$ th to $\frac{1}{1} \frac{1}{2} 5^{\text {th }}$ of an inch. This form of muscular tissue is found in a nearly pure state, unmixed with other tissue, in the nipple, corium, intestinal canal, bladder, prostate, vagina,

FIG. 2S2

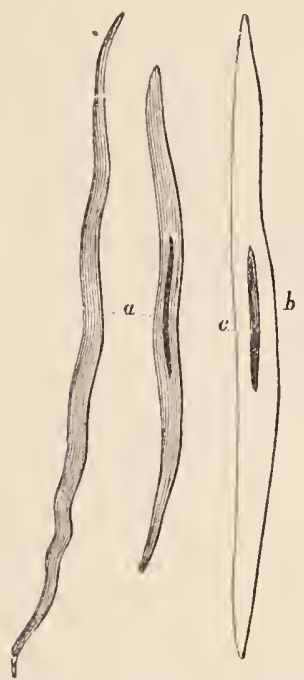
and in the smaller arteries, veins, and lymphatics; and mingled with much areolar, fibrous, and elastic tissue in the trabecule of the spleen and corpora cavcrnosa, the dartos, the circular fibres of the larger arteries and veins, the urethra, Fallopian tubes and uterus, in the trachea and bronchi, and in the ciliary muscle of the eye, the choroid coat, and the iris.

FIG. 283.

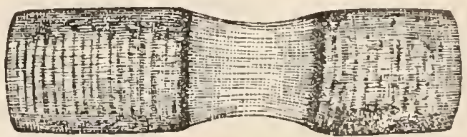

Fig. 282.-Fusiform cells of Smoolh Muscular Fibre, from the renal vein of Man:- $a$, Two cells in their natural state, one of them showing the staff-shaped nucleus; $b$, a cell treated witl acetic acid, with its nucleus $c$ brought strongly into view.

FIG. 283.-Muscular Fibre broken across, showing the untorn Sarcolemma, connecting the fragments.

657. The second variety of Muscular tissue presents transverse strix under the nicroscope, and occurs in all those muscles that are usually termed "voluntary," though its presence in the heart, rectum, and pharynx shows that it is not limited to these alone. On examining the structure of a striated muscle it is found to be easily separable into coarser or finer fasciculi connected by means of areolar tissue, and these on more minute dissection can be shown to consist of transversely striated polygonal fibres with three or five angles, having, in Man, an average diameter of $\frac{1}{4} 0_{0}$ th of an inch. The fibres frequently terminate by free pointerl extremities in the muscle, and occasionally divide; at other times they become continuous, either abruptly or by imperceptible gradation, with tendinous or strong connectivetissue fibres. ${ }^{2}$ In the case of the heart, the tissue is stated by Eberth ${ }^{3}$ and

p. 288), as cxtending from the base of each cilium to the nuclcus and attached extrenity of the cell, are to be regarded as representing extremely fine museular fibres. Dr. Stuart's observations were made on the cells of the ciliated epithelium of certain species of Eolis. He has counted from 41 to 60 bands in each cell, and describes the nucleus of the cell as being moved hither and thither by their contraction

1 Schwalbc, Sehultze's Archiv f. Microscop. Anat., Bd. iv, p. 392, pl. xxiv.

2 As in the tongue, Hyde Salter, in Cyclop. Anat. and Phys., vol, iv, p 1132. Hoyer, however, maintains that in such instanees the transparent fibres in which the museular fibres apparently terminate are in reality contractile. See Reichert's Archiv, 1859, p. 481.

3 Virchow's Archiv, 1866, Bd. xxxvii, p. 100. 
Schweigger-Seidel ${ }^{1}$ to be composed of transversely striated oblong cells, often forked at their extremities, and containing one or several nuclei $(\$ 233$, Fig. 119). The divarication of the terminal portions and the occasional presence of lateral processes, give rise to the illusory appearance, described by Skey and others, of anastomoses occurring between the fibres. ${ }^{2}$ The length of the fibres in the Sartorius varies, according to Krause, from onethird of an inch to one inch and a half; whilst, according to Dr. Nicol, ${ }^{3}$ in the small muscles of the hand they are coequal with the length of the muscle, and in the muscles of the forearm vary from $\frac{1}{25}$ th of an inch to one inch. During life the fibres of striated muscle appear to be semi-transparent and of soft consistence. ${ }^{4}$ After death each fibre can be split either longitudiually iuto fibrille, the number of which has been estimated at six or seven hundred, or transversely into a series of disks; the average diameter of the fibrille is $\frac{1}{9400}$ th of an inch in man, and they are bound together by a transpareut sheath, the sarcolemma (Fig. 283) ${ }^{5}$ (between which and the contractile substance is sometimes, as in the muscular fibres of the crab, a distinct layer of protoplasm). On the surface of the sarcolemma and sometimes in the interior of the fibre are nuclei, contaiuing one or more nucleoli, and readily brought into view by the action of acetic acid. According to some observers these are to be regarded as the remains of the original cells from which the muscular fibres were developed; others have regarded them as centres from whence new inuscular fibres may originate; others, as the corpuscles of the connective tissue distributed through the muscle, and therefore as centres of nutrition analogous to the lacuna of bone; and still more recently it has been maiutained that they are in connection with the ultimate terminations of nerves. The exact structure of the fibrille is still doubtful. Under high powers of the microscope they

1 Stricker's Hum. and Comp. Histology, Syd. Soc. Transl., vol. i, p. 244.

2 It is usually stated that no sarcolemma exists around the cardiac muscular fibres. Winkler, however, describes it as being present in the form of an extremely delicate membrane. Rejchert's Archiv, 1867, p. 221.

3 Schmidt's Jahrbücher, Bd. cxxxii, 1866, p. 148.

4 Kühne (Physiol. Chemie, 1868, p. 281; also Marey, Rev. des Cours Scient., tone iii, p. 797) observed a Nematoid worm (Myoryctes Weissmannii), move with apparent freedom in the interior of a fibre. The movements of the worm displaced the stria, which as it passed onward resumed their natural position. Besides this evidence of the semifluid nature of the contents of the fibre, it has been found that when a current of clectricity is passed through a few muscular fibres, the substance of the muscle accumulates around the ncgative pole, indicating a certain freedom of movement in the constituent particles.

5 The following authorities may also be consulted: Schwalbe, Ueber den fein. Bau d. Muskelfasern wirbelloser Thiere, Schultze's Archiv, Bd. v, p. 205; Ratzel, Histol. Unters. Zcits, f. wiss. Zool., Bd. xix, p. 257; Schneider, Ueber die Muskeln der Nematoden, idem, p. 281; Grenacher, Ueber die Muskelelemente von Gordius, idern, p. 287; Montgomery, Zur Frage über die Struct. v. Contract. quergest. Muskelfasern, Centralblatt, 1870, p. 163; Ranvier, Note sur la Structure intime du Tissue Musculaire, in French Translution of Frey's Histology, 1870, p. 366 , and Comptes Rendus, t. Ixxvii, 1873; Merkcl. Ier quergestreifte Muskel, Max Schultze's Archiv, Bd. viii, 1872, p 244; Dönitz, Beitrage zur Kéentniss der quergestreifte Mu-kelfasern, Reichert's A rchiv, 1871, p. 434; Wagener, Ueber die Querstrcifen den Muslieln, Sitzungsber. d. Gesell. zur Marburg, 1872, pp. 25, 117, 141; Grummach, Struktur der Muskelfasern bei den Insekten, Centralblatt, 187\%; Engelmann, Mic. Untersuch. u. d. qurgestreifte Muskelsutıstanz, P'füger's Archiv, Brl. vii, pp. 33 and $155 ;$ Sachs, Jie querstreifte Muskelfasern, Reichert's Archiv, 1872, p. 607; Kratue, Göttingen Nachrichten, $A$ ug. I868, p. 357 ; Zeits. f. Biolocrie, Bd. v, 1869, 1. 414; and 'Pfügx's Archiv, 1873, Bd. vii, p. 508; Floegel, Schultze's A rehiv, Bd. viii, 1871, p. 69, and Med.-Chir. Rev., 1872, p. 520; Hénocque, Lancet, 1870, vol. i, p. 812; Hensen, Arbeiten aus dem Kiel Physiolog. Institut., 1868; Dwight, Month. Mic. Jour., vol. xii, p. 29. 
appear to consist of alternate rectangular light and dark particles, constituting the "sarcous elements" of $M \mathrm{r}$. Bowman. The dark particles are thicker than the light ones, and in consequence of their being less easily acted on by dilute hydrochloric acid and gastric juice, can be obtained in a detached or separate state aftcr short exposure to the action of either of these fluids. Brïcke has described the dark particles as refracting light doubly (anisotropous) whilst the clear intervening substance is only singly refractile (isotropous). ${ }^{1}$ Dr. Martyn, ${ }^{2}$ in examining a fortunate specimen of muscular tissue under a very high power (1200 linear), observed large and small sarcous elements to occur alternately, as had previously been described by Busk and Huxley $;^{3}$ the smaller one evidently corresponding to the faint transverse line traversing the clear space long ago perceived and described by Dr. Sharpcy and the Author, from careful observation of Mr. Lealand's preparations. Careful accounts of the structure of striated muscle have recently been given by Engelmann ${ }^{5}$ and by Schäfer. ${ }^{6}$ The former observer describes each fibre as being, when fresh, almost perfectly transparent and homogeneous, but speedily undergoing a kind of coagulation, which is hastened by the addition of any reagent, and results in the appearance of a series of superimposed disks, varying in their thickness and their action on light. These confer upon the tissue its peculiar striated aspect, and the following Figure (284) exhibits them in a diagrammatic form; the septal or intermediate disk, $\mathrm{z}$, he describes as resembliug a homogeneous membrane, which with sharp focussing forms the darkest stria of the fibre; water and various reagents make it granular or beady, though the fibre may still retain its contractile power. It is doubly refracting, and its greatest thickness (in Articulata) is $0.0008 \mathrm{~mm}$. It is highly elastic-i. $e_{\text {. }}$, is compressed and extended with difficulty. It corresponds to the septum between two compartments of muscular fibre if that view of the structure of muscular fibre be taken. The sarcolemma presents either an annular groove, or an elevation where it is attached to it, and the connection between the two is usually firm. 2. The isotropal layer between the septum and the collateral or secondary disk is almost immeasurably thin. 3. The secondary or collateral disk (n), Flögel's "granule-layer," has a thickness of $0.002 \mathrm{~mm}$. This is usually separated from the auisotropal substance by a thin layer of isotropal substance, but is sometimes fused with it, as can easily be determined by polarized light, the anisotropal substance then appearing much thinner, since the collateral disk presents but feeble indications of double refraction. It adheres less firmly to the sarcolemma than to the septal disk. In breaking a fibre across mechanically, the rupture commonly occurs between the collateral and the

1 Brücke further regards the dark particles as uniaxial positive crystals, having their axes parallel to the direction of the fibres, and as being conıposed of minute solid doubly-refracting particles, which he terms disdiaclasts. See Stricker's Hum. and Comp. Histology, Syd. Soc. Trans., vol. i, p. 235, 1870.

2 Beale's Archiv, 1862, p. 227.

3 Notc to Kölliker's Man. of Hum. Histology, Syd. Soc. Trans., vol. i, p. 239.

4 Dr. Iracnamara (Med. Times and Gazette) describes the muscular fibres of the chameleon when examined with the highest powers $\left(\frac{1}{50}\right)$ as composed of a sheath of sarcolemma containing two longitudinal flat bands, connected by a spirally wound band, the shadow or the approximation of two coils of which forms the transverse strix. Between the horizontal bunds are open spaces, as is shown by their never becoming stained with carmine. M. Rouget (Brown-Séquard's Journ, de la Physiologie, and Med.-Chir. Rev.; see also Comptes Rendus, 1867, pp 1128, 1232, and 1i6) regards the elementary fibrilla of striated muscles as being a spirally twisted ribbon, of which the coils, ordinarily separated from one another or stretched, approxinate on the removal of all exciting and nutritive conditions.

5 Pflüger's Archiv, Bd. vii, pp. 33-71.

6 Philosoph. Transact, 1873, p. 429. 
transverse disks. In mammals the septal or intermediate and the collateral disks appear to be fused together. 4. The isotropal layer between the secondary and transverse disks in Vertebrate has a thickness of $0.001 \mathrm{~mm}$., and in Arthropods of 0.0015 . This is very soft, but still not fluid, as Kühne thought. 5. The layer of anisotropal substance consisting of two transverse and a median disk $(m)$. This layer after the action of many reagents appears to be formed of solid doubly refracting rod-like elements, the so-called sarcous elements, muscle prisms or rodlets, which are imbedded in a softer, singly refracting amorphous substance. (Fig. 285). The rods, according to Engelmann, are certainly not preformed elements. The account given by

FIG, 284.

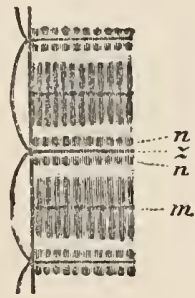

FIG. 285.

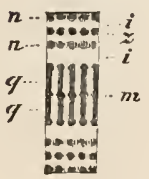

Fig. 286.

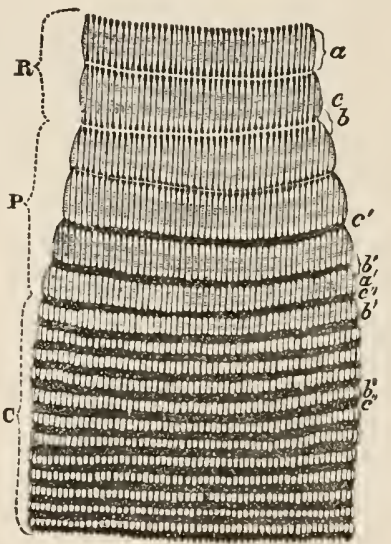

FIG. 284.-Structure of striated muscular fibre after Engelmann, ${ }^{1}$ from Telephorus melanurus. Cutaneous muscle from the abdomen. $m$, median disk; $n$, secondary disk; $z$, intermediate disk, magnified 1000 diam. The sarcolemma is seen on the left side.-Frx. 285, from Astacus fluviatilis. Heat tetanus. $n$, secondary disk; $z$, intermediate disk; $i$, isotropous disk between transverse and secondary disk; $i$, isotropous disk betwcen sccondury and intermediate disk; $m$, median disk; $q, q$, transverse disk. The sarcous elements are swollen at their extremities, and at their centres. Magnified 1000 diam.

Frf. 286.-Muscular fibre undergoing contraction. $R \mathbf{R}$, portious still at rest; $\mathbf{P} \mathbf{P}$, contraction proceeding; c, contracted portion; $a a^{\prime}$, dim stripes; $b b^{\prime} b^{\prime \prime}$, bright stripes; $c c^{\prime} c^{\prime \prime}$, lincs formed by rodheads.

Schäfer differs considerably from the foregoing. He describes a muscular fibre as consisting of a ground substance, appearing at first sight to be composer of a series of alternately dim and bright disks, and of a vast number of minute rod-tike particles, tis which he applies the term muscle-rods, which are closely arranged side by side, with their long axes parallel to the axis of the fibre, so as to form by their juxtaposition as many series as there are disks of dim substance in the fibre. The main part or shaft of each musclerod is imbedded in and traverses a disk of dim substance, while the ends, which are enlarged into little knobs or heads, extend into the bright disks. These little knobs form the line of dots which has long been described as existing in the middle of each bright stripe. When the fibre is somewhat extended this line appears double, owing to the separation of the heads of the two successive series of muscle-rods which meet in the middle of the bright substance. In the state of absolute rest (n, Fig. 286) the rocts are uniformly cylindrical without terminal enlargements, and in this case only 
a longitudinal fibrillation is to be seen in the fibre, all trace of transverse striping having disappeared. In the normal state of slight tension, however, $(P)$, the rod heads make their appearance, and with them the bright substance by which they are surrounded, so that the dim ground-substance now presents a transversely striated aspect. In contraction of the muscle the heads of the rods become enlarged at the expense of the shaft, the ends of the several muscle-rods thus approaching one another, and forming with the heads of the next scries of muscle-rods, a dark transverse band crossing the bright stripe. As the contraction proceeds the dark bands approximate to one another, the bright borders encroach upon the dim stripe, which finally disappears, so that its place is taken by a single transverse bright stripe (c). Contracted muscle consequently shows alternate dark and bright stripes, the former, however, being due to the enlarged juxtaposed extremities of the rods, the light on the other hand being mainly composed of the ground-substance which has become accumulated in the intervals between their sbafts. Examined by polarized light, the muscle-rods give indications of being isotropous or singly refracting, whilst the remainder of the fibre is anisotropous. The latter is probably the true contractile part, whilst the rods are merely elastic structures, serving to restore the fibre to its original length. The muscles receive a free supply of blood, especially during action, ${ }^{1}$ the

FIG. 287.

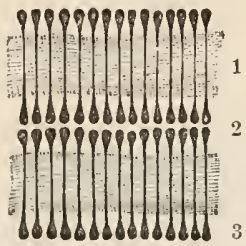

FIG. 287.-Diagram representative of Mr. Schäfer's view of the structure of muscular fibre.
1. Dim substance.
2. Bright stripe.
3. Muscle-rods.

FIG. 288.

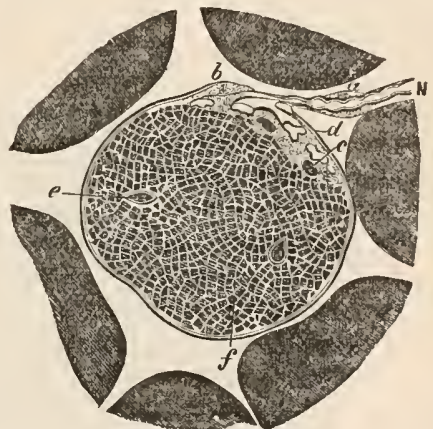

FIG. 2SS.-Transverse section of one of the muscles of the thigh of the Lacerta agilis, inade whilst frozen, and magnified 400 diameters. $\mathrm{N}$, nerve. M, unscular fibre, surrounded by portions of six others. $a$, Nucleus of the nerve-sheath; $b$, nucleus of the sarcolemma; $c$, section of nucleus of terminal plate of nerve; $d$, transverse section of terminal plate, surrounded by granular material; $e$, transverse section of muscle-nuclei; $f$, fine fat-drops. The angular dark particles are sections of groups of sarcous elements; the clear intervening spaces represent the fluid isotropal part of the nuscle-substance.

capillary vessels being arranged in oblong meshes; but their lymphatics are either altogether absent or exceedingly few in number. ${ }^{2}$ - The mode of termination of the nerves in muscle has also recently been the subject of much investigation. ${ }^{3}$ According to Kühne and Engelmann, the motor nerves divide and subdivide till the fibres run alone or only in bundles of two or three on the outside of the muscular fibres. After a short course, however, they penetrate the sarcolemma, losing at the same time their sheath, which

1 Sezelkow, Centralblatt, 1870, p. 691.

2 Teichmann, Das Saugader System, 1861, p. 100.

3 See Kühne, Ueber dic peripheric Endorgane del Motor Nerven, 1862 ; Engelmann, T. IV., Untersuch. üb. d. Zusammenhang v. Nerv-u. Muskel-fascr, Leipzig, 1863; Kölliker, Croonian Lecture, 1852; Beale, Archives of Medicine, vol. iii, 1862, p. 246; Philosophical Transactions, 1863 ; Croonian Lecture, 1865 ; and Distribution of Nerves to Voluntary Muscles: an Anatomical Controversy. Pamphlet, Churchill, 1865. 
becomes continuous with the sarcolemma, and the white substance of Schwann; whilst the axis-cylinder, dipping in amongst the fibrillæ, terminates in a nerve-plate or disk, which melts by imperceptible gradations into the tissue of the muscle itself. Cohuheirn, ${ }^{1}$ whilst agreeing with Kühne in admitting the penetration of the sarcolemma by the nerve-fibres, represents these as branching and dividing to a considerahle extent. Kölliker, and Beale and Krause, ${ }^{2}$ on the other hand, deny the penetration of the sarcolemma by the ultimate branches of the motor nerves, the two former observers describing them as forming a plexus, composed of pale fibres of extraordinary tenuity ( $\overline{1} \frac{1}{0} 000$ th of an inch), intermingled with many nuclei lying on and ramifying over the fibres. Mayo describes a similar plexus within the sarcolemma, whilst Krause admits the plate, but believes it to be outside the sarcolenina. The three accompanying drawings will render the views of Kühne, Cohnheim, and Beale intelligible. The proportion of nervefibres to muscular fibres varies considerably. ${ }^{3}$ Tergast, finds in the ocular muscles of the Sheep, that there is one nerve-fibre to about 6 or 7 muscular fibres. In the ocular muscles of Man, there are about 3 nerve to 7 muscular fibres. In the biceps of a young Dog there is one nerve-fibre to 83 muscular fibres; in the sartorius of the same animal 1 to $40-60$. In the cutaneous pectoral of the Frog, the proportion is $1: 23-27$ (Reichert); in the abductor digiti quinti pedis $1: 40$; in the sartorius $1: 16 \frac{1}{2}$; in the ocular muscles of the same animal, $1: 10$. In the caudal muscles of the Mouse, 1:28-29.

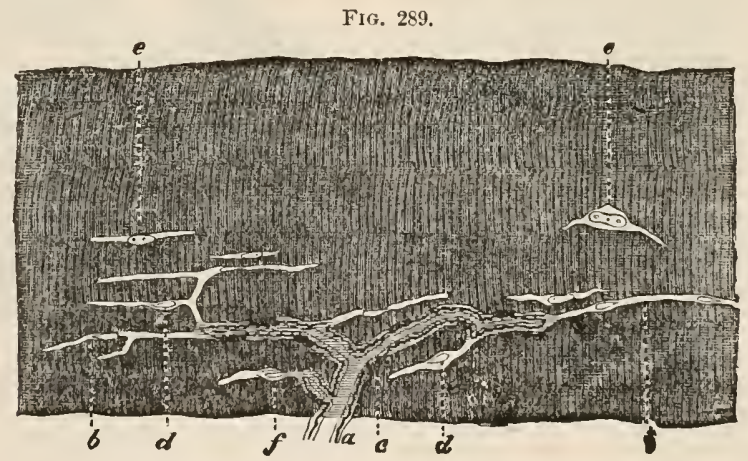

Muscular Fibre, with termination of Motor nerve, from the Gast rocnemius of the Rana esculenta: $a$, terminal pencil of a dark-border d nerve-fibre; $b$, intra-muscular naked axis-cylinder; $c$, uucleus of the ncurilemma; $d$, clavate extremities of the nerve; $e$, spaces of the muscle-nuclei; $f$, terminal knob of nerve, with contral fibre and vesicular dilatation of the nerve. (After Cohmheim.)

658. Chemical Composition of Muscle.-The muscles of cold-blooded animals are well adapted for chemical investigation on account of the slowness with which they undergo change. If the muscles of such an animal, after the removal of all blood from the tissue by the injection of a very weak solution of common salt, be subjected to pressure, a neutral or weakly alkaline fluid is obtained, termed "muscle-plasma," which soon undergoes spontaneous coagulation, and separates into two parts, - a semisolid portion termed myosin $(\$ 53)$, and a fluid serum, which at ordinary tempcrature quickly acquires an acid reaction. In the latter, as obtained from various animals by different chemists, there have been discovered: 1 . Various albuminous compounds; small quantities of pepsin (Brücke); and a substance

${ }^{3}$ See Tergast, Schultze's Archiv f. Microscop. Anatomie, Bd. ix, p. 36. 
analogous to ptyalin (Piotrowski). 2. A coloring matter similar to, if not identical with, hæmoglobin. 3. Creatin ( $\$ 54)$, and perhaps creatinin, ${ }^{1}$ hypoxanthin or sarkin, xanthin, and taurin. 4. Inosinic and uric acids. 5. Sugar,

FIG. 290.

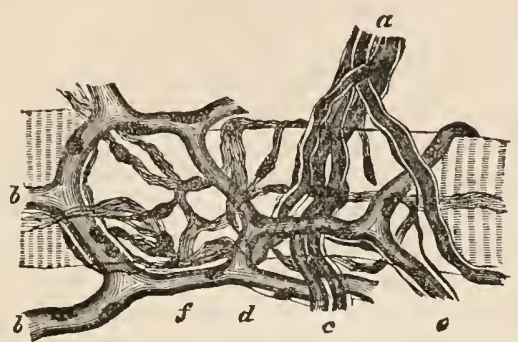

Portion of an elementary Muscular Fibre from one of the abdominal muscles of the White Mouse, with four dark-bordered fibres $(a)$ crossing orer its surface. A capillary vessel, $b$, is also seen with fine nerve-fibres distributed to it. To avoid confusion, a few only of the transverse markings of the muscle are represented. Two of the dark-bordered nerve-fitres (c), pass over the elementary fibre, to be distributed to adjacent fibres. One dark-bordered fibre (over $d$ ) is lost among several pale nucleated fibres. Pale nucleated fibres are seen ramifying in several places upon the surface of the elementary fibre, but beneath the dark-burdered nerve-fibres and capillaries. It will be observed that a fine fibre, which seems at the upper part of the figure to be but one of the outlines of the tubular membrane of one of the dark-bordered fibres, leaves the dark-bordered fibre and passes to the capillary vessel (over $e$ ). This arrangement, in which a dark-bordered nerve-fibre distributed to muscle divides into branches, one of which passes to a vessel, while the other ramifies upon a muscle, is frequent. The capillaries, darkbordered nerve-fibres, and pale nucleated tibres here represented, can be completely stripped off from th:e surface of the sarcolemma without tearing that membrane. Of the structures, therefore, represented in this drawing, not one, according to Dr. Beale, can lie beneath the sarcolemma. $(\times 700$.) (After Beale.)

inosite, glycogen, and dextrin. 6. An isomeric modification of lactic acid, termed para- or sarco-lactic acid, acetic, formic, and butyric acids. 7. Salts, which, as obtained from the residue of broth, consist in 100 parts $^{2}$ of

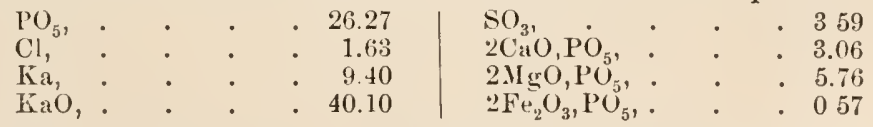

8. A small proportion of fat. 9. Water, carbonic acid, and oxygen gases; and, lastly, various compounds derived from the tissues which are inseparably united with the muscular tissue, as protagon proceeding froln the nervous, gelatin from the connective, and elastin from the vascular tissue. The composition of nuuscle as a whole is thus given by Kühne, after Lehmann:

Water, . . . . . . . . . $74.0-800$

Solid constituents, . . . . . . . . 26.0-200

Albuminous substances insoluble in water (myosin, sarco-

lemma, nuclei, vessels, and elastic fibres), . . . 15.4 - . 17.7

Gelatin,

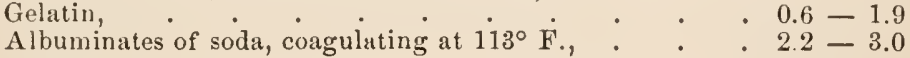

Creatin,

Fat,

Lactic acid,

Phosphoric acid,

Potush,.

Soda,

Chloride of Sodium,

Lime,

Magnesia,

1 Naurocki, Fresenius's Zeits. f. Analyt. Chemie, 1865, p. 330, denies the presence of the latter, or that any conversion of creatin into creatinin occurs during exercise.

2 Kühne, Physiol. Chemie, 1868, p. 307, in which work a very complete account of the chemistry of muscle is contained. 
The percentage proportion of nitrogen in the flesh of different animals has been shown by Petersen, ${ }^{1}$ to vary: thus mutton contains 3.15 ; veal, 3.18 ; pork, 3.25 ; beef, 3.29 ; and horseflesh, 3.48. Its amount in dried muscular tissue varies from 11.88 to 15.07 per cent. According to Danilewsky ${ }^{2}$ tetanized muscle yields a little morc nitrogen to warm alcohol, which dissolves the products of its disintegration, than muscle at rest. Amongst these is lecithin. Muscular tissue, whether living or dead, absorbs oxygen, and eliminates carbonic acid, ${ }^{3}$ though more energetically in the former case than in the latter. The specific heat of muscle exceeds that of water, and is higher than that of any known solid or fluid body. ${ }^{4}$ It is, on the other hand, an exceedingly bad conductor of heat.

659. Development of Mruscular Tissue.-In Man, according to Mr. Lockhart Clarke, ${ }^{5}$ Muscular Fibre can first be distinguished about the 4 th or 5 th week of utero-gestation. In a fœtus of three-fourths of an inch in length, it forms a gelatinous mass consisting of fibres and nuclei imbedded in a scmifluid granular blastema. In the formation of the fibres, granular processes of condensed blastema extend from the sides or from around the nuclei, which are subsequently bounded by an investing substance in the form of a baud or fibre, sometimes plain, but sometimes longitudinally fibrillated. In these bands the transverse striation first makes its appearance, and only subsequently cxtends through the central band or axis. The muscular fibres vary in size at different parts, and they may sometimes be seen to increase in diameter by the adhesion of fresh nuclei and fresh processes of blastema. A very similar account has been given by Mr. Savory for the Mammalia generally, ${ }^{6}$ except that in his observations the nuclei, at first irregularly distributed, were found to arrange themselves with great regularity in single rows, almost in contact with one another, the fibres being formed by the development of two nearly transparent bands inclosing and bounding the rows of nuclei; subsequently the nuclei began to scparate from one another, and ultimatcly broke up into granules and disappeared. The striation began within the border and gradually extender to the centre. Increase in the size of the fibres was effected by the addition of fresh blastema to the outer side of existing fibres. The observations of Braidwood ${ }^{7}$ and of Eckhard ${ }^{8}$ are, on the whole, confirmatory of the observations of Mr. Clarke and Mr. Savory; and it would hence appear that the cssential features of the process occur not in the nuclei, nor in cells, as was originally maintained by Sch wamn, but in a material which may be regarded as intercellular substance; and Mr. Lockhart Clarke regards even involuntary muscular fibres as by no means the product of a nucleated cell, but rather as a kind of ccll-formation, presenting at first a nucleus incrusted with blastema, around which an investing sarcous substance represcnting the ccll-wall is subsequently dcveloped. ${ }^{9}$

660. The frequently renewcd exercise of muscles, by producing a detcrmination of blood towards them, occasions an increase in the nutrition; so that

1 Zeits. f. Biologie, Bd. vii, Heft' 2.

2 Centralblatt, 1872, p. 433.

${ }^{3}$ Du Bois-Reymond; G. Liebir: Hermann. See the Grundrise der Physiol. of the hatter author, 1867, p. 21\%; R. Gseheidlen, Pllüger's Arehiv., Bd. viii, p. 506.

4 Adamkiewiez, Centralblatt, 1874, No.22.

b l'roceedings of the Royal Society, vol, xi, No. 48.

6 See Part ii of the Phil. 'Trans. for 1855. See also Petrowsky, Centralblatt, 1873, p. 769.

i Mled.-Chir. Rev., 1866, p. 447.

8 Zeitsch. f. rat. Med., Bd. xxix, p. 55.

9 Dr. Wilson Fox (Phil. Trans, 1865-66) has, however, resuscitated the older view of Lebert, Kölliker, and others, that the fibres of musele proceed from the cells of the embryo, the contents of which become fibrillated, whilst the cell-wall becomes the sarcolemma. 
a large amount of new tissue is developed, and the muscles augment in size and vigor. This is true not only of the whole muscular system when equally exercised, but also of any particular set of muscles which is more used than another. Of the former we have an example in those who practice a system of gymnastics adapted to call the various muscles alike into play; and of the latter in the limbs of individuals who follow any calling that habitually requires the exertion of either pair, to the partial exclusion of the other, as the arms of the smith or the legs of the opera dancer. But this increased nutrition cannot take place unless an adequate supply of food be afforded; and if the amount of nutritive material be insufficient, the result will be a progressive diminution in the size and power of the muscles, which will manifest itself the more rapidly as the amount of exertion, and consequently the degree of waste, is greater. Nor can it be effected if the exercise be incessant, for it is during the intervals of repose that the reparation of the muscular tissue occurs; and the Muscular system, like the Nervous, may be worn out by incessant use. The more violent the action, the longer will be the period of subsequent repose required for the reparation of the tissue; and the longest time will of course be requisite when (as sometimes occurs) the contractility of the muscle is so completely exhausted by excessive stimulation that no new manifestation of it can be excited. It docs not appear improbable that there is a provision in some Muscles, as the Heart and Respiratory muscles, by which the nutrition is carried on with unusual activity during the short period of repose which intervenes between two successive contractions. Moreover, the muscular tissue, like all the softer and more decomposable portions of the organized fabric, has a limited term of existence; and hence, even if its contractility be not called into exercise, it undergoes a gradual disintegration, so sonn as all the nutritive changes of its fibres are completed. This change seems to be a necessary consequence of the high temperature of the bodies of warm-blooded animals; for it does not occur with nearly the same rapidity in cold-blooded animals, nor in the hibernating condition of certain warm-blooded Mammalia ; indeed, when the temperature of the body is reduced to within a few degrees of the freezing-point, no chemical change seems possible in muscle-its spontaneous decay and its vital activity being alike checked. Now, when a muscle or set of muscles in a warm-blooded animal is reduced to a state of prolonged inactivity, from whatever cause, its supply of blood is diminished, and its spontaneous decay is not compensated by an equally active renewal; so that in time, the characters of the structure are changed, and its distinguishing properties are no longer presented. Thus it was found by Dr. John Reid ${ }^{1}$ that in a rabbit, a portion of whose sciatic nerve had been removed on one side, the muscles of that leg were but very feebly excited to contraction by galvanism after the lapse of seven weeks. The change in their nutrition was evident to the eye, and was made equally apparent by the balance. The muscles of the paralyzed limb were much paler, smaller, and softer than the corresponding muscles of the opposite leg, and they scarcely weighed more than half-being only 170 grains, whilst the others were 327 grains. It was found also that a perceptible difference existed in the size of the bones of the leg, even after so short an interval had elapsed; the tibia and fibula of the paralyzed limb weighing only 81 grains, whilst those of the sound limb weighed 89 grains. On examining the muscular fibres with the microscope, it was found that those of the paralyzed leg were considerably smaller than those of the sound limb, presenting a somewhat shrivelled appearance, and that the longitudi-

1 Edinb. Montbly Journ. of Med. Science, May, 1841 ; and Physiological, Anatomical, and Pathological Researches, p. 10. 
nal and transverse strie were much less distinct. So in persons whose lower extremities have been long disused, the muscles first become pale and flabby ; their bulk gradually diminishes; their contractile force progressively decreases, and at last departs almost entirely; and their proper structure is replaced by a deposit of fat, in which few or no striated muscular fibres can be detected. But muscles that have for some time remained in this condition may be gradually brought back to their original state by exercise, provided that the feeblest contractility remains; for every action which they can be made to perform determines an augmented flow of blood through the tissue, and gives rise to an improvement in its nutrition, which in its turn increases its contractility, and renders it capable of more vigorous action. This principle is of great importance in the treatment of the various forms of paralysis (especially the hysterical), in which the muscles are thrown out of use by the suspension of the functional power of the nerves; for when the latter have recovered their capacity, the muscles refuse obedience to their stimulation, and can only be brought to act by persevering and judiciously contrived exercise.

661. Muscles exist in two states, the elongated and the contracted; the former is usually termed their state of rest, in which they immediately respond to the application of stimuli, whether direct or indirect, by passing into the active state of contraction. ${ }^{1}$ The physical, chemical, and electrical properties of muscles differ considerably in these two states.-In contraction the muscles become shorter and thicker, aud diminish slightly in volume. Their elasticity and electrical relations are modified, and heat ${ }^{3}$ and sound are produced. They absorb more oxygen. They give off, as alrcady stated, more carbonic acid. Their reaction changes from neutral or feebly alkaline to acid, which, according to Ranke, ${ }^{4}$ is due to the development of lactic acid. They contain more creatin, grape sugar, and fat, and less glycogen. ${ }^{5}$ From the expcriments of Helmholtz, ${ }^{6}$ which have been corroborated by Ranke, it appear's that the muscles of frogs long subjected to the action of an interrupted current of electricity yield from 20 to 24 per cent. less of extractives soluble in water, whilst those soluble in alcohol increase to a corresponding amount; the muscles also respond differently to electrical shocks. In tetanus the muscles of the extremities, if the blood-current through them be preserved, become more watery (Ranke). This is particularly the case with the heart.

1 Dr. Radeliffe (see his Epileptie and other Convulsive Diseases of the Nervous System, 3d edit., 1860, and his Leetures on Epilepsy, Pain, and Paralysis, 1864) has, however, addueed many arguments to show that the ordinarily received statement above given should be reversed, and that the state of elongation should be regarded as the really active eondition of museular fibre, in whieh all its vital properties and peeuliarities are most strongly marked, whilst the state of eontraction is due to its being left to the influenee of the attraetive forees inherent in its moleeules, the most energetie operation of which is seen in the rigor mortis. Aeeording to Lavdovsky (Centralblatt, 1871, p. 769) the unstriated musele fibres of Leeehes and Worms, when stimulated, first elongate and beeone attenuated, and then eontraet and beeome thiekened. The number of suceessive eontraetions that ean be made to occur per minute in isolated musele-eells varies from $10-20$, whieh is the ordinary number, to $36-40$, which only happens in very lively animals.

${ }^{2}$ Harless, A bhand. Ilüneh, Akad., 1862, p. 357. Luige Fasei, Virehow's Jahresbericht, 1867, p. 80 .

3 In rigor mortis, Fiek, in Vierteljahrseh. der Naturf. Gesell. in Zurieh, 1867, with Dybkowsky, observed a rise of $0.05^{\circ}-0.07^{\circ} \mathrm{C}$, and they attribute the rise in temperature sometimes observed in bodies after death, to this souree, the museles then beeoming rapidly stiff.

4 Reichert and Du Bois-Reymond's Arehiv, 1863, p. 422. See also his work on Tetanus, Leipzig, 1865.

5 Weiss. Wien. Akad. Sitz-ber., Bd. lxvi, p. $28 t$.

6 Müller's Archiv, 1845. 
The quantity of albumen diminishes, though only to an inconsiderable extent (Helmlioltz, Ranke, Nawrocki). The Heart in the case of the Dog in comparison with the muscles of the extremities contains much less albumen. The heart yields much more warm alcohol and less watery extract than the quiescent, and even than the tetanized muscles of the extremities. The alcoholic extract of tctanized muscle, and especially of the heart, contains more nitrogen than that of quiescent muscle. ${ }^{1}$ It is remarkable that highly oxygenated blood, such as is the condition of the blood in apnoa, renders both the nerves and muscles unexcitable. ${ }^{2}$

662. Numerous experimenters $s^{3}$ have shown that the contraction of muscular tissue is accompanied by the production of a considerable amount of heat. Thiry and Meyerstein found that on tetanizing the gastrocnemius of a frog for ten minutes the temperature rose $0.073^{\circ}-0.119^{\circ}$ Centigrade, or about one-fifth of a degree Fahr. Helmholtz estimated the rise of temperature in the same case at rather less than one-third of a degree Fahr. In warm-blooded animals the heat generated is much greater. Billroth and Fick $^{4}$ observed a rise of $5^{\circ} \mathrm{C}$, or more when tetanus was maintained for ten minutes. The degree of heat developed is dependent upon the tension of the muscle, upon the amount of work done, and upon the condition of freshness or exhaustion of the muscle. With the increase of the tension the amount of heat generated is augmented, so that a muscle contracted to the utmost, supposing its excitability and the stimulus to remain the same, develops the maximum of heat; hence the whole amount of heat generated increases with the amount of work done, though a portion is derived from the contraction of the muscle itself. 'The temperature falls rapidly with increasing exhaustion, and the amount generated is inappreciable to our present means of research before the muscle has quite lost its power of contraction. Solger and Meyerstein and Thiry have observed that at the commencement of contraction a muscle becomes sensibly cooler than before. This effect lasts several seconds, and may perhaps be attributed to a diminution of the specific heat of muscle in contraction ; it is followed by a gradual increase in temperature, which, if the muscle be tetanized, continues for some time after contraction has ceased; and proceeds, in all probability, partly from the continuance of a more energetic process of oxidation, indicated by the increased production of carbonic acid, and partly from an increased flow of blood through the vessels of the muscle. According to Meyerstein and Thiry, the amount of leat generated is always in proportion to the amount of work done; whilst Heidenhain maintains that the relation between the two is inverse after a certain point has been reached. He notices also that less heat is developed if the muscle be allowed to shorten, and thus to perform work, than if it be prevented from shortening, and this may reasonably be explained on the

1 See Danilewsky, Centralblatt, $18 \overrightarrow{\imath 2}$, p. 433 ; and Grützner, Ueber einige Chem. React. des thät. u. unthät. Muskels., PAüger's A rchiv, Bd. vii, p. 254, who shows that quiescent muscle is capuble of oxidizing pyrogallic acid, whilst tetanized muscle is incapable.

2 See v. Bezold and Blöbaum, in the Wurzburg. Physiol. Untersuch., Heft 1, p. 66, and Mayer and Basch, Sitz. d. kais. Acad. d. Wiss. zu Wien, 1870, p. 837 . For the phenomena of exhaustion in muscle, soe Volkmann, in Plüger's Archiv, Bd, iii, p. 372 .

${ }^{3}$ Helmholtz, Müller's Archir, 1848, p. 144; Solger, Studien des Physiolog. Instituts. zu Breslau, 1863 , p. 125; Meyerstein and Thiry, Zeits. für rat. Med., Bd. xx, 1863 , p. 45; Heidenhain, Essuy on the Theory of M usrular Force, Breslau, 1864, and Mechanische Leistung, Wärme-entwicklung und Stoffumsatz, 1864; Dybkowsky and Fick, Vierteljahrschrift der Naturforsch. Gesell. in Zurich, 1867; Schiffer, PAüger's Archiv f. Physiol., 1868 ; and MI üller's Archiv, 1868, p. 442.

- Wundt, Physiologie, 1873, p. 536. 
supposition that during the active alternate contraction and elongation of the fibrcs the circulation through the vessels is more rapid, so that the heat locally produced is carried off by the blood.- The peculiar sound heard duriug the contraction of striated muscle may be perceived, as suggested by Dr. Wollaston, ${ }^{1}$ by placing the tip of the little finger in the ear, and contracting the muscles of the ball of the thumb, or by powerfully exerting the muscles which close the jaw. It resembles the distant rumbling of carriagewheels, or an exceedingly rapid and faint tremulous vibration, which, when well marked, has an almost metallic tone. From various experiments made upon himself and others, Professor Haughton estimates that the number of vibrations varies from 32 to 36 per second. The sound may be readily conceived to depend upon the friction of the elements of the muscle, one upon another, which must thus be perpetually taking place so long as it continues in a state of activity, an explanation that receives support from the observation of Helniholtz, that the pitch of the note may be made to vary by exciting contraction in the muscle with an interrupted current, the shocks of which succeed one another with varying rapidity.-The amount of shortening which a muscle will undergo, bears a direct relation to the resistance; and by opposing a sufficient resistance, the contractile power of the muscle may be powerfully exerted without any contraction taking place. Under ordinary circumstances the striated muscles do not contract much more than one-third of their length, being restrained by the mechanical arrangements of the bones and joints, and by the antagonistic muscles. But if a long muscle of a frog be removed firom the body and powerfully stimulated, it will contract to one-fifth of its original length. The unstriped fibres will contract under favorable circumstances to about one-third of their length.

663. Muscles, whether in the contracted or elongated state, possess a certain amount of elasticity. By this term is meant that force by which the particles of any substance, after being approximated to or separated from one another, strive to regain their original position. The clasticity of muscular fibre is small, but remarkably perfect; for although it is extended considerably by a light weight, it recovers itself completely on the removal of the extending force. ${ }^{2}$ Like that of India-rubber, it is augmented by heat. ${ }^{3}$ That it is exceedingly small, even during life, is shown, as Mansvelt has observed, ${ }^{4}$ by the fact, that in cases of paralysis of the third nerve the pupil is for some days brought quite into the middle of the space between the eyelids solely through the elastic contraction of the rectus internus; a proof that its antagonist, in a state of elongation, exercises no force worth speaking of. On appending a small weight to a vertically-suspended fresh muscle, it at first elongates suddenly and considerably (the primary cxtension), then much more slowly (the secondary cxtension). On removing the weight, the same phenomena appear in inverse order; a considerable primary, and a more gradual and smaller secondary retraction. With small weights the increase in length is proportional to the wcight ; with heavicr weights a greater proportional weight is required to produce the same amount of extension, as is shown in the following experiment made by $\mathrm{Weber}^{5}$ with the Hyoglossus of a Frog:

1 Philosoph. Trans., 1811.

2 IIeidenhain, Studien, Berlin, 1856; and Wundt, Müller's Archiv, 1857.

3 Schmulowitseh, Centrablatt, 1870, p. 609.

4 See a Review of his work in the Mled.-Chir. Rev., for 1864, p. 443 , vol. i.

6 Wagner's IIandwörterbuch, Bd. iii, p. 54. See ako Volkmann, PHüger's Arehiv, Bd vii, 1873, p. 15. Fick, l'flüger's Mrehiv, 1871, 13d. iv, p. 301, finds that the elasticity of muscle varies with each degree of contraction. 


\begin{tabular}{|c|c|c|c|}
\hline $\begin{array}{c}\text { Weight in Grammes } \\
\text { successively applied to } \\
\text { the Muscle. }\end{array}$ & $\begin{array}{c}\text { Length of the Muscle } \\
\text { in Millimetres. }\end{array}$ & \multicolumn{2}{|c|}{ Extension. } \\
& - & In Man. & Per cent. \\
1.3 & 24.9 & $\ldots$ & $\ldots$ \\
23 & 30.0 & 2.3 & 20 \\
33 & 32.3 & 1.1 & 7 \\
43 & 33.4 & 0.8 & 2 \\
5.3 & 34.2 & 0.4 & 1 \\
\hline
\end{tabular}

Mansvelt, however, deduces as the principal result of his experiments, that living muscle is, at least within certain limits, extended in proportion to the increase of the weights, each fibre elongating about 1 per cent. of its length for each 65th of a grain weight appended to it. According to Wundt, the weight which is required to extend a fresh muscle of 1 square millimetre $\left(\frac{1}{25}\right.$ th of an inch) sectional area, twice its length, is $2 \mathrm{oz}$. The muscles are constantly in a state of slight tension, as is shown by the separation of their extremities when cut; but it would obviously have seriously interfered with their action had a high degree of elasticity been conferred upon them, since antagonistic muscles would have had this, in addition to all other resistances, to overcome, before movement could be effected. Weber has shown that the extensibility of muscles increases during contraction. He applied a weight of 115 grains to an elongated muscle. On the addition of another weight of $15 \frac{1}{2}$ grains, the amount of extension which took place was about $\frac{1}{1+4}$ of its length; but on repeating the same experiment with a contracted muscle, the extension was as much as $\frac{1}{79}$ of its length, showing that the extensibility was greater in the latter case than in the former. The exhaustion of a muscle greatly increases its extensibility up to a certain point, after which it again diminishes. Thus, when a portion of muscle was weighted with 115 grains, its greatest extension occurrer when it had been made to contract 43 times; whell weighted with 193 grains, after 23 contractions; and lastly, when weighted with 424 grains, at the 8 th contraction. It was even found that, by appropriate weighting, a muscle on being stimulated to contract might actually become longer instead of shorter.

664. Electrical Relations of Muscle.-As we have already seen in the Nerves $(\$ 472)$, so in the Muscles it is easy to furnish evidence of electrical disturbance. The conditions of the "Muscular current" have been made the subject of special investigation by M. Du Bois-Reymond; and the following is an outline of the results at which he has arrived, for the due comprehension of which, however, it is requisite that the terms entployed by him should be first defined. - The entire muscle being composed of a mass of fibres, having a generally parallel direction, and attached at their extremities to tendinous structure (which has in itself but little or no electro-motor power, but is a conductor of electricity), it follows that the tendon or tendinous portion of a muscle represents a surface formed by the bases of the muscular fibres considered as prisins, which may be designated its natural transverse section. On the other hand, the fleshy surface of the muscle, which is formed only by the sides of the fibres considered as prisms, may be rega rded as the natural longitudinal section of the muscle. Again, if a muscle be divided in a direction more or less perpendicular to its fibres, an artificial transverse section will be made; whilst if the muscle be torn lengthways in the direction of its fibres, an artificial longitudinal section will be made; and 
these artificial sections show the same electric conditions with their corresponding natural sections. Now, experiments repeated in a great varicty of modes demonstrate, that every point in the natural or artificial longitudinal section of a muscle is positive in relation to every part of its transverse section, whether natural or artificial; and hence a current is passing in the muscle from the transverse to the longitudinal section (Fig. 195). The most powerful influence on the galvanometer is produced, when a portion of the surface (or natural longitudinal section) of a muscle is laid upon one of the electrodes, and a portion of the surface formed by cutting the muscle across (or artificial transverse section) is placed against the other. When the two tendinous extremities of a muscle whose form is symmetrical or nearly so, are placed against the electrodes, the deflection of the needle of the galvanometer is but slight; and the same is the case with two transverse sections taken at equal distances from the two ends of the muscle, and also with two points of the longitudinal section, which are equally distant from the middle of its length. But if the two points of the longitudinal section applied to the electrodes be not equally distant from the centre of the muscle, then the point which is nearest to the centre is positive to the one which is nearest to the end; and, in like manner, when the different parts of the transverse section are tested in regard to each other, the points lying nearest the surface of the muscle are found to be positive to those nearest its interior. The intensity of the current, however, between any two points in the same section-whether transverse or longitudinal-is always incomparably less than that of the currents which are obtained between two points in different sections, one in the longitudinal and the other in the transverse. These results may be obtained, not merely with the entire Muscle, but with insulated portions of it; and even, as we are assured by M. Du Bois-Reymond, with a single primitive fasciculıs. It has been suggested by Hermann that the key to the electrical opposition which exists between the artificial transverse and the artificial longitudinal section is probably to be found in the action of oxygen on the muscular tissue, the surface exposed by the cut being more rapidly acted on, as compared with the longitudinal section, which is protected by more or less fascia, and by the sarcolemma of the fibres. In favor of this view it is to be observer that the more rapidly after removal from the body the electrical relations of the natural longitudinal and artificial transverse sections, or in other words of the tendon and the surface of the muscle, are tested, the slighter is the difference found to exist between them; indeed, if the examination be made sufficiently early, especially if the animal has been kept in the cold, it will be found either that no difference exists between them, or that the tendon and a portion of the muscle near its longitudinal axis are positive in regard to the surface of the muscle.

665. That a change in the electric state of a Muscle takes place in the act of contraction had been ascertaincd by the experiments of Professor Matteucei ; but as he was only able to detect this by the galvanoscopic frog (the galvanometer which he employed not giving unquestionable indications of it), he was not able to detcrmine its nature with accuracy. This has been accomplished, however, by MI. Du Bois-Reymond ; who has shown that during contraction the muscular current is not increased (as supposed by Matteucei), but is diminished and even reduced to zero. In order to exhibit this phenomenon satisfactorily, it is found advantageous to cause the muscle to contract powcrfully or uninterruptedly for as long a time as possible-that is, to tctunize it; and this may be effected by acting violently on its nerve by heat, chemical agents, or a succession of electric shocks; or by poisoning

1 See his successive Memoirs in Phil. Traus., for 1845, 1847, and 1850. 
the animal with strychnia. In whatever mode the tetanized state is induced, the same result follows, - the needle of the galvanometer passes over to the negative side. Ranke ${ }^{1}$ has noticed the remarkable fact that dead muscle is a better conductor of electricity than living, and that the conducting power of muscle exhausted by exercise is also increased. This he attributes to the accumulation of the products of disintegration, and especially to that of lactic acid. Living muscle conducts electricity about three million times worse than mercury, and fifteen million times worse than copper.

666 . The rapidity with which the mandates of the Will are conmunicated to and executed by the Muscles is immeasurable; but Helinholtz has shown that if an electric spark, whose duration does not exceed one ${ }_{6}^{\frac{1}{0}} \frac{1}{0}$ th or $\frac{1}{700}$ th of a second, be allowed to strike a portion of fresh muscle, a measurable period, amounting to $\frac{1}{100}$ th or $-\frac{2}{100}$ ths of a second, intervenes before the commencement of contraction. This he terms the period of latent contraction or excitation. At the commencement of the contraction which succeeds, an instantaneous electrical discharge occurs, lasting less than the $\frac{1}{100}$ th of a second, and comparatively weak, but still probably equivalent to that of the electric organ in fishes. ${ }^{2}$ The contraction which then takes place is not sudden and complete, but is divisible, according to Klünder, ${ }^{3}$ into four stages, in the first of which the movement of contraction commences and slowly increases; in the second there is great increase in the rapidity of the contraction; the third is the period of maximum rapidity, and in the fourth there is a diminution of the rapidity. The first period can be much protracted by heavy weighting, and the last period is very variable. Klünder

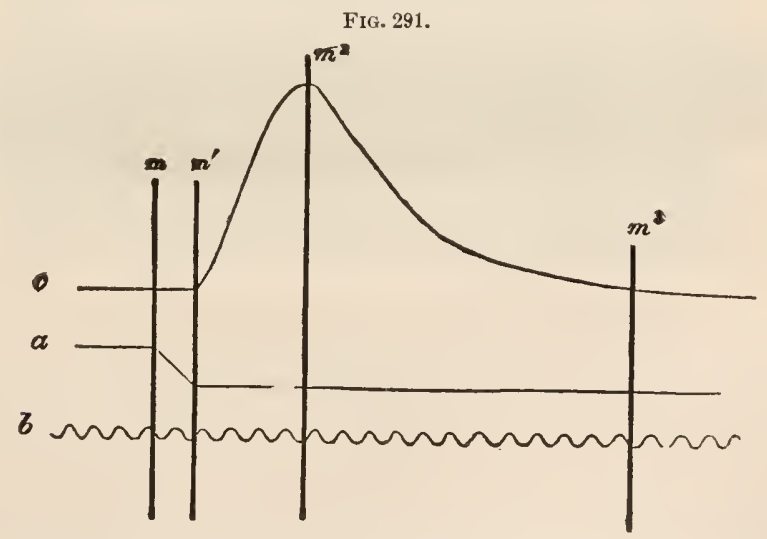

Diagram of a muscle curve as drawn on a travelling surface. $c$, the line described by the point of the lever connected with the muscle; $a$, the line described by marking lever; $b$, the line described by the tuning-fork. The vertical line, $m$, marks the moment of stimulation; $m^{\prime}$, the beginning, $m^{2}$, the maximum, and $\mathrm{m}^{3}$, the end of the contraction of the muscle.

gives as the duration of the latent excitation of fresh and lively muscle $\frac{3}{400}$ ths of a second, but when exhausted and heavily weighted it rises to $T_{1}^{1} \pi^{\text {th }}$ th of a second; previous extension of the muscle diminishes the duration of the latent excitation, as Helmholtz also found. ${ }^{*}$ The true curve of con-

1 Tetanus, Leipzig, 186.5.

2 See Donders's Essay on the Constituents of Food, translated by Dr. Moore, Dublin, 1866, p 14, where it is quoted as the observation of Meissner, and as corroborated by v. Bezold.

3 Up. cit., p. 129.

4 Ranvier (Comptes Rendus, lxxvii, p. 1105, and Archiv. de Physiolog., t. vi, p. 1) 
traction at its middle portion represents a parabola modified by the elasticity of the muscle. The perior of time which elapses from the instant that the stimulus is applied until the contraction is complete, increases generally with the amount of shortening, with the heaviness of the weight, and with the exhaustion of the muscle. In the Frog the entire time occupied in the contraction and subsequent elongation of a muscle is about one-third of a seeond, of which

The period of latent excitation amounted to
6 "6
6

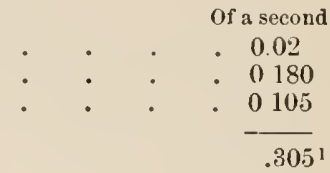

From the results of various experiments, Helmholtz satisfied himself that to develop their greatest force, muscles require a longer time than when slight efforts only are made. ${ }^{2}$

667. Mechanism of Muscular Contraction.-From the inquiries of $\mathrm{Mr}$. Bowman, it appears that the act of contraction usually commences at the extremities of the fibre; but it frequently occurs also at one or more intermediate points. The first appearance is a spot more opaque than the rest, caused by the approximation of a few of the dark points of some of the fibrillr; this spot usually extends in a short time through the whole diameter of the fibre; and the shading caused by the approximation of the trausverse strix increases

FiG. 292.

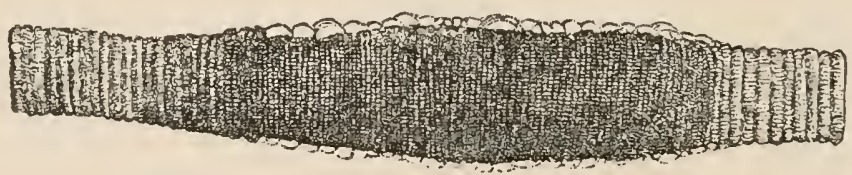

Muscular Fibre of Dytiscus, showing the contracted state in the centre; the strix approximatcd; the breadth of the fibre increased; and the myolemma raised in bulle on its surface.

in intensity. The stria are found to be two, three, or four times as numerous in the contracted as in the uncontracted part, and are also proportionally narrower and more delicate. The line of demarcation between the contracted and uncontracted portions is well defined; but as the process goes on, fresh strixe are absorbed as it were from the latter into the former. The contracted part augments in thickness, but not in a degree commensurate with its diminished length, so that its solid parts lie in smaller compass than before,the fluid which previously intervened between them being pressed ont in bullse under the sarcolemma. Narey and Aeby have shown that when a muscle is excited by passing a current of electricity through it, every part contracts simultancously, as proved by the identity in point of time of trac-

has pointed out various differences between the white and the red museles of the rabbit, and amongst others, that the period of latent excitation of the white nutuseles of the rubbit is $\frac{1}{83} d$ of a second, whilst for the red muscles it is as much as $\frac{1}{18}$ th of a second.

1 See Helmholtz in Müller's $\Lambda$ rchiv, 1850, 1852; and Volkmann, in Leipzim. Berichte Math. Phys. Class., 1851. Place has more recently (Nederland. Archief, Bd. iii, 1867, Heft 2) estimated the period of latent excitation in the musclus of frogs at only 0.005 sec., and he fincls the rapidity of propagation of the excitation through muscles to be about one meter per second.

${ }^{2}$ For a very minute investigation on this point, sce Klünder, Ucber den zeitlichen Verlauf der IIuskelzuckung, in the Arbeiten uus dem Kieler physiologischen Institut., 1868, pp. 107-130. 
ings taken with levers attached to different parts. In like manner, when the nerve supplying a muscle is excited the whole muscle appears to contract simultaneously, and this is explained by Aeby on the supposition that the contraction commences at the point of entry of each terminal twig of the nerve, and propagates itself away from this point in both directions. As these points of entry are distributed very irregularly in neighboring fibres, the swelling appears to be uniform throughout. In one of his experiments, a muscle of a frog is taken, the motor nerve of which bifurcates as it enters. One of the divisions is cut, and the main trunk excited. It is then found that that portion of the nuscle which is supplied by the intact nerve contracts simultaneously throughout, whilst in the remaining portion a wave is propagated that travels at precisely the same rate as the contraction that occurs when mechanical irritation is applied to a given point of a fresh muscle. The rapidity of this last is given by Aeby, ${ }^{1}$ for the muscles of frogs at about 40 inches per second, Bernstein ${ }^{2}$ estimated it far more highly at nearly 13 feet per second, and quite recently Hermamn, ${ }^{3}$ operating on the nuscles of frogs, both with and without woorara, gives the rapidity at 2.698 metres per second, or about 9 feet. M. Marey ${ }^{4}$ has lately shown by means of his deli-

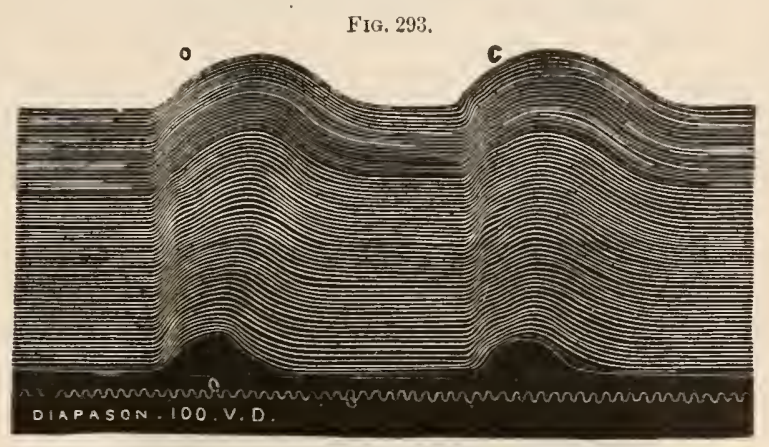

cately constructed registering apparatus, that a contraction of a muscle which follows the application of a sudden stimulus, as of an electric spark, differs remarkably from the contraction induced by a voluntary impulse. In the former instance the contraction is sudden and single, especially if the muscle be quite fresh, beconing slower as the muscle experiences fatigue. This is clearly shown in the preceding woodcut, which represents the tracing obtained on a rapidly rotating circular disk from a nuscle made to contract by the opening and closing of a galvanic current. Two contractions, or, as M. Marey terms them, impulses or shocks (secousses) are exhibited. One series (o) corresponding to the period of opening of the induced current, the other of closing (c). The line traced at the botton of the figure by a diapason vibrating 100 times (double vibrations) per second

1 Untersuchungen über die Fortpflanzungsgeschwindigkeit der Reizung, etc., Braunschweig, 1862. See also v. Bezold, Meissner's Jahresbericht, 1860, p. 482; Engelmann, Jenaische Zeits., Bd. iv, p. 30.5; Place, Onderzoek. ged. in het Phys. Lab. der Utrecht Hoogeschool, Bd. ii, Recks i, p. 135; Valentin, Plüger's Archiv, Bd. iv, p. 115.

2 Uritersuchungen, ete, Heidelberg, 1871, p. 76.

3 Plügrer's Archiv, Bd. x, 1875 , p. 54.

4 See his Lectures on Self-registering Apparatus, in the Revue des Cours Scicntifiques, tom. iii. 
enables the duration of each of the impulses to be estimated. The arrangement of the apparatus is such that the lower lines represent the tracing obtained when the muscle is in the perfectly recent state, whilst the upper ones represent it when more or less exhausted. It will be noticed that for each galvanic shock there is a single instantaneous contraction represented by an elevation with rounded summit, and that the period of ascent corresponding to the period of shortening of the muscle (on the left) is more rapid than the period of descent of the line, the latter corresponding to the period of relaxation. In proportion as the muscle becomes fatigued three peculiarities may be noticed: the duration of the contraction or shock augments; the period of ascent becomes prolonged, and the height of the wave or the amount of shortening of the muscle increases. This last, however, is ouly transient, since, if the tracings be continued, the wave height diminishes though its width continues to increase. The tracings present the same features whether the excitation be applied to the nerve supplying the muscle, or to the muscle itself. It is very interesting to remark that the phenomena of exhaustion are not produced in the living body within moderate limits, indicating that reparation is constantly taking place. Of all the muscles of the body, the heart alone in its ordinary contraction gives a tracing corresponding to that obtained from a voluntary muscle on the application of an electrical shock - that is to say, the heart constitutes the only instance where each contraction is definite and single, and it presents the same characters in all animals. In all other instances, what is termed a muscular contraction consists of a series of shocks or impulses, as shown in Fig. 294, in which

FIG. 294.

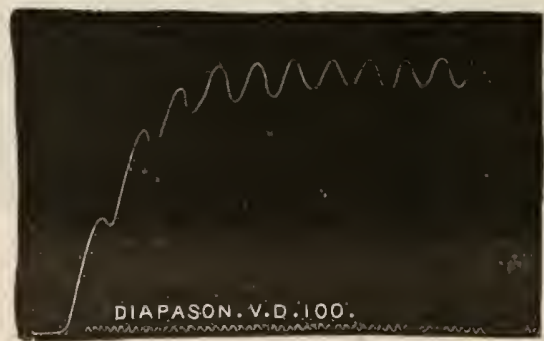

a tracing is shown such as may be obtained from a muscle caused to contract by a voluntary effort, or to which excitations at regular intervals are applied. Here the effects of the successive shocks are in the first instance superadded to one another till a certain degree of contraction is obtained, which remains permanent with that amount of stimulation. If the electrical or mechanicall ${ }^{1}$ excitations are made to succed cach other more rapidly (Fig. 295), the successive shocks unite morc quickly and completely, and the total contraction is greater in degree. Finally, if the excitations are repeated more than a certain number of times per second, varying with the animal and the state of the muscle, the several shocks fuse completely into one another, and tetanus is produced in which no vibration is perceptible (Fig. 296). The muscles of different animals respond differently to clectrical excitation. In the case of the bird, ${ }^{2}$ permanent contraction or tetanus is not

1 As in Heidenhain's mechanieal Tetano-motor, in which a little hammer is set in motion by an electro magnetic current, and a tetanic condition can be established in the museles which will last for two minutes or more, till the irritability of the nerve is destroyed.

2 Marey, Rev. des Cours. Scient., vol. iv, 1867, p. 215. 
produced until more than 75 shocks are communicated in a second, whilst the muscles of a tortoise are tetanized with only three shocks per second. Ranvier ${ }^{1}$ found considerable difference in the reaction of the white and red muscles of rabbits to induce electricity. Thus the semitendinosus (a red unscle) excited for one-seventh of a second with a current that was inter-

FIG. 295.

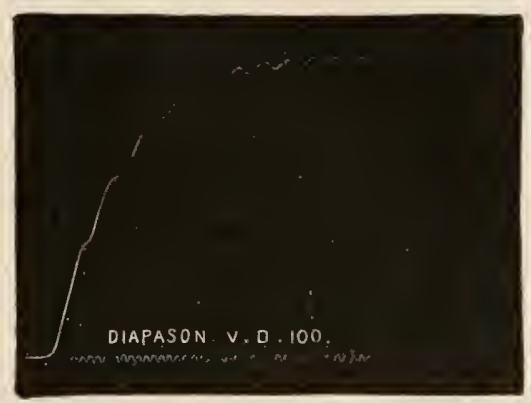

rupted 357 times in a second, passed at once into a state of tetanus, and its myographic tracing exhibited a continuous and uniform elevation. The adductor longus on the other hand (a pale muscle), stimulated in the same way, showed as many elevations and depressions as there were interruptions of the current.

668. The contractility of the muscles may be called into play either directly by stimuli applice to the tissue itself, or indirectly by agents exciting the motor nerves. The contraction which follows in the latter instance is termed by Schiff neuro-muscular, and in the striated muscles is sudden,

FIG. 296.

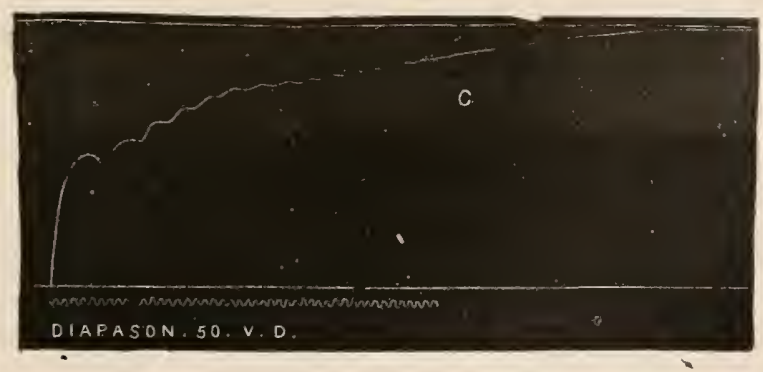

general, and energetic; but when mechanical irritation is directly applied to a muscle, the tissue itself responds to the stimulus, producing what Schiff has termed idio-muscular contraction. It may be observed in the manner first described by Dr. Stokes ${ }^{2}$ by percussing the pectoralis muscle of emaciated patients, or by drawing the back of a knife across a muscle after all signs of irritability on the application of stimuli to the motor nerve have ceased; it then presents itself as a swelling or intumescence a few lines broad and high, but varying with the strength of the blow, lasting for four

2 On Diseases of the Chest, p. 397. 
or five seconds, and showly disappearing. A further phenomenon has been noticed in the same muscles by Auerbach ${ }^{\mathbb{1}}$ after an energetic blow; namely, a wave or undulating contraction, proceeding from either side of the local intumescence of Schiff, and propagating itself to the extremity of the muscle at the rate of about eighteen inches per second. The breatdh of the waves is about a quarter of an inch at their base, and they gradually die out as they spread from the point struck. It is doubtful whether both of these appearances are not due simply to a prolonged contraction of the muscle, resulting from exhaustion of its contractility at the excited spot.

669. Sudden variations of temperature induce persistent contraction of muscular tissue; thus the legs of a frog, dipped into water at a temperature either as high as $130^{\circ}$ or as low as $25^{\circ}$ Fahr., become tetanized. V. Bezold ${ }^{2}$ and Prevost have found that in a certain stage of Veratrin poisoning the muscles respond to a single electric shock, not with a single short contraction, but with a persistent tetanic contraction; and, according to Weyland, the same results from the action of Sabadillin, Delphinin, Emetin, and Aconitin. ${ }^{3}$ As regards chemical agents, some appear to act with equal energy in producing contraction, whether applied to the muscle or to the motor nerve, as solutions of potash and soda; others, as creosote, alcohol, pure lactic acid, and glycerin, act on the muscle through the nerve, but possess little stimulating power when directly applied to the muscle; and others again excite energetic contraction when made to act immediately on the muscle, but scarcely operate through the nerve, as sulphate of copper and ammonia. ${ }^{4}$ Kühne $^{5}$ remarks that all those bodies which coagulate the muscle plasma, as dilute acids and alkalies, act as powerful stimulants to muscles even when very dilute. The metallic salts, as a rule, require to be in a stronger state of concentration. He thinks that each part as it contracts, generates material (paralactic acid) which again acts as an excitor to the next adjoining layer.

670. Muscular Irritability is deadened by many substances, and especially by those which have a narcotic or sedative action on the nervous system. In carbonic acid gas, hydrogen, carbonic oxide, or sulphurous acid gas, muscles contract very feebly, or not at all, when stimulated; whilst in oxygen they retain their irritability longer than usmal. Narcotic substances, such as a watery solution of opium, when applied directly to the muscles, have an immediate and powerful effect in diminishing or even destroying their irritability; this effect is also produced, though in a less powerful degree, by injecting these substances into the blood. In the same manner venous blood charged with carbonic acid, and deficient in oxygen, has the effect of a poison upon the muscles, diminishing their irritability, when it continues to circulate through them, to such a degree that they sometimes lose it almost as soon as the circulation ceases, as is seen in those who have died from gradual and therefore prolonged asplyxia. The unfavorable influence of venous blood is also shown in the Morbus Coeruleus, patients affected with which are incapable of any considerable muscular exertion. Although most of the stimuli which occasion the contraction of muscles, when directly applied to their fibres, operate also when applied to their motor nerves, the same does not hold good in regard to those agents which diminish irritability. It is a

'A blınd. der Schleswig. Gesellseh., 1861, p. 294.

2 Centrablatt, 1869, p. 600.

s See for an extensive series of researehes on this point, including the action of Tartar Emetic, Upas Antiar, Caffein, Chtoroform. Napellin, Quinine, and other drugs, Buchheim and Eisenmenger in Eckhard's Beiträge zur Anat. u. Physiol, Bd. v, 1871, p. 73 .

'See I)r. Duflin's paper, On Muscular Contraction, in Beale's Archises of Medicine, vol. iii, p. 147; and Kühne in Archiv f. Anat. und Physiologie, 1859, p. 213.

5 Physiol. Cliemie, 1868, p. 311. 
fact of some importance in relation to the disputed question of the connection of muscular irritability with the nervous system, that when, by the application of narentic substances to the nerves, their vital properties are destroyed, the irritability of the muscle may remain for some time longer, showing that the latter must be independent of the former.-The effects produced by the Wonrara and Upas Antiar poisons in this respect are exceedingly curious, and have been carefully studied by Bernard ${ }^{1}$ and others. Woorara, Conia, and, as Drs. Crum Brown and Fraser ${ }^{2}$ have shown, the Sulphates and Iodides of Methyl-Strychnium, Methyl-Brucium, MethylThebaium, Methyl-Codeium, and Methyl-Morphium, all act directly njon the motor nerves, whilst Cyanide of Potassium and the poison of the Upas Antiar abolish the irritability of the muscular tissue itself. The evidence given by Bernard in proof of this last statement is very satisfactory, for he has shown that the cause of death after the administration of a sufficient dose of Woorara is the cessation of the respiratory movements owing to paralysis of the motor nerves; for not only has it been proved by v. Bezold that by this agent the rapidity of the conduction of stimuli through the motor nerves is greatly reduced and ultinately abolished, but it is certain that perfect recovery nay take place if artificial respiration be maintained for a sufficient length of time to enahle the poison to be eliminated from the system or decomposed within it; whilst in foetuses, and during the earlier stages of existence of fishes and other animals that are not directly depcident upon muscular movements for the aeration of their blood, this being accomplished by the umbilical vesicle, little or no injurious effect is experienced, the animals continuing to swim about in a watery solution of the poison without apparent inconvenience. That the sensory nerves are not affected seems to be proved by the experiments of Kölliker and Funke, who observer that reflex actions could readily be excited in parts kept fiee from the circulation of poisoned blood by the ligature of their vessels, on pricking or pinching the skin of parts poisoned by the admission of blood containing Woorara. The influence of the poison seens to be first felt by the peripheral extremities of the motor nerres, and its paralyzing effect gradually extends centripetally through the trunks. - An additional argument may be mentioned in favor of the essential independency of muscular irritability, in the circunstance that, although spontaneous movements occur in the muscles of enibryos, the muscles cannot, in the earlier periods of foetal life, be incited to contract by stimuli directly applied to their nerves.-Dr. Harless ${ }^{3}$ again found that when the nervous system had been rendered, by the inhalation of ether, utterly incapable of conveying a galvanic stimulus applied either to the nervous centres or to the nerve-trunks, the same stimulus applied directly to the muscles would immediately throw them into powerful contraction. Various other experinenters have shown that when the nerves supplying the muscles of a limb are divided and the animals are allowed to live, excitants applied to the nerves beyond the point of division fail to produce muscular contraction long before they cease to do so when applied to the muscles themselves. Hence it is obvious that the activity of the Nervous system is not essential to the manifestation of the characteristic endowment of the Muscular.

671. The contractions of the Heart present some differences from those of

1 See his Lecture in Med. Times and Gazotte, 1860, vol. ii; also A. v. Bezold in Monatsberich der Berlin. Akad., 1859; und Martin-Magron and Buisson in Journal de la Physiologie, 1860 .

2 Transact. if the Roy. Soc of Edinb., 1868. A paper of great value on the connection between chemical constitution and physiological action.

3 Müller's Archiv, 1847, Bd. ii. 
ordinary striated muscular tissue, probably depending upon the peculiar arrangement of its fibres, whereby the contraction of one set gives a mechanical stimulation to others; for the muscular substance of a large part of the organ is thrown into rapid and energetic contraction by a stimulus applied at any one point, and this contraction is speedily followed by relaxation, which is again succeeded by a number of alternating contractions and relaxations. ${ }^{1}$ Each contraction, however, has been shown to be equivalent to a single shock in an ordinary striated muscle ( $\$ 667)$. On the other hand, if we apply a similar irritation to a portion of non-striated fibre, as that of the Intestinal Canal, the fasciculus which is stimulated will contract less suddenly, but ultimately to a greater amount; its relaxation will be less speedy, and before it takes place, other fasciculi in the neighborhood begin to contract; their contraction propagates itself to others, and so on. In this manner consecutive contractions and relaxations may be produced through a considerable part of the canal by a single prick with a scalpel. Again, in the muscular structure of the Bladder and Uterus (when the latter is fully developed), direct irritation excites immediate and powerful contractions, which extend beyond the fasciculus actually irritated, and produce a great degree of shortening; but they do not alternate in the healthy state with any rapid and decided elongation. Similar phenomena may be observed on irritation of the smaller arteries. In order to obtain the full contraction of a muscle by irritation applied to the nerves, it is requisite that the stimulus should be applied for a certain length of time; thus Budge ${ }^{2}$ found that when an electric current was passed through the cervical region of the spinal cord 'of a rabbit for the space of half' a second, the pupil dilated about oné-sixth of an inch; but on continuing the application for three seconds, dilatation occurred to the extent of nearly one-third of an inch. In all cases relaxation speedily alternates with contraction, unless the operation of the stimulus be continued-as when an electric current is propagated without internission along the nerve-trunks-in which case the contraction lasts as long as the stimulus is continuously applied, but ceases as soon as it is withdrawn. The singular "inhibitory" effiets produced by irritation of some nerves, as the pneumogastric and splanchnic, have already $(\$ 244,96)$ been alluded to; but further expcriments are still required before it can be admitted that any nerve can really transmit a "stimulus to relaxation" on the part of the muscle to which it is distributed. The general fact that relaxation alternates with contraction at no long intervals is most evident in the rhythmical movements of the Heart, ${ }^{3}$ and in the peristaltic action of the Intestinal Canal ; since in these parts the whole or a large proportion of the fibres seem

1 Ray Lankester (Pfluger's Archiv, 1871, p. 315) has shown that the muscular tissue of the Heart is characterized by containing hemoglobin.

2 Pliysiologie, 1862 , p. 650 .

3 Some curious rhythmieal movements have been observed by M. Brown-Séquard (Gaz. Med., 1849) in the diaphragm, in the intercostals, and in some of the muscles of locomotion, both after death and after section of their nerves during life. These inovements could not be in any way dependent upon reflex action, because they took place wh"n the miscles were completely cut off from the nervous eentres, sometimes to the number of from 5 to 20 in a minute, and for as long as a quarter of an hour after death; and oceasionally reeurred in living animals for many months afterwards, especially when the respiration was impeded and the circulation hurried. Of a similar mature are the vibratory movements of the museles of the tongue witnessed by Schitt after section of the Hyoglossals (Plysiologie, 1859, p. 177); and we may perhaj is refer to the same category the trembling movements of the hands and head in old age, in certain forms of paralysis, and in habitual drunkards and smokers. All these cases furnish evidence of a tendency to rhythmical movements in the aruscles themselves, altogether independent of the excitement to action which they receive through the nervous system. 
to contract together, and then shortly relax. But this is probably no less true of the individual fibres of those muscles which are kept in contraction by a stimulus transnitted through their nerves; since none of them appear, under ordinary circumstances at least, to remain in a contracted state for any length of time, a constant interchange of condition taking place among the fibres, some contracting while others are relaxing, and vice versa. It is difficult to speak with confidence, however, in regard to the condition of the individual fibres of a muscle that is thrown into a state of continued spasmodic contraction. Whether the individual fibres in such instances maintain a state of contraction without intermission, or whether the contraction of the entire muscle is kept up by a continual interchange of the fibres actually engaged, is a very curious subject for inquiry.

672. Muscles do not lose their Irritability inmediately on the general death of the system, which must be considered as taking place when the circulation ceases without the power of renewal; in cold-blooded animals it is retained much longer after this period than in the higher Vertebrata, in some instances attaining its highest degree long after death has occurred, ${ }^{1}$ whilst in the latter it frequently disappears within an hour. The muscles of young aninals generally retain their irritability for a longer time than those of adults; on the other hand, those of Birds lose their irritability sonner than those of Mammalia. Hence, as a general rule, the duration of the irritability is inversely as the amount of respiration. From experiments on the bodies of executed criminals who were previously in good health, Nysten ascertained that in the human subject the irritability of the several muscular structures disappears in the following time and order: The left ventricle of the heart first, the intestinal canal at the end of 45 or 55 minutes, the urinary bladder nearly at the same time, the right ventricle after the lapse of an hour; the cesophagus at the expiration of an hour and a half, the iris a quarter of an hour later; the muscles of animal life somewhat later; and lastly, the auricles of the heart, especially the right, which in one instance contracted under the influence of galvanism $16 \frac{1}{2}$ hours after death. It will be presently shown that the departure of the irritability is essentially dependent upon the cessation of the circulation, and that it may be prevented from disappearing, and may even be recalled after it has ceased to manifest itself, by transmitting a current of arterial blood through the muscles. Kronecker ${ }^{2}$ has endeavored to establish certain laws of muscular exhaustion to this effect: 1 . That if a muscle be overloaded with a definite weight, and irritated at equal intervals by equal induction shocks, the height of the contractions form an arithmetical series, in which the constant difference depends only on the interval of time. 2. The diminution in the height of the contractions is independent of the weight, and only depends on the interval between two contractions. ${ }^{3}$

673. We find, however, that sudden and severe injuries of the Nervous centres have power to impair, directly and instantaneously, or even to destroy the contractility of the whole Muscular system; so that death immediately results, and no irritability subsequently remains. It is in this manner that the sudden destruction of the brain and spinal cord, especially of

1 See on the whole subject of the Irritability of Muscles, a grood paper by Dr. Norris in Humphry and Turner's Journ. of Anat., vol. i, p. 217. See also B. W. Richardson's Croonian Lecture on Muscular Irritability after Systemic Death, Abst. in Lond. Med. Record, June 18th, 1873.

2 See abstract of his paper in the Journal of Anatomy and Physiology, vol. vi, 1872 , p. 241 .

3 See in regard to the irritability of muscles after systemic death, B. W. Richardson, Proceed. Roy. Soc., 339, 1874. 
the latter, occasions the immediate cessation of the heart's action, though they may be gradually removed without any considerable effect upon it. Severe concussion has the same effect; hence the syncope which immediately displays itself. It is sometimes an important question in forensic medicine, whether an individual who has died from the effects of a blow upon the head, could have moved from the place where the blow was inflicted. If there be found, as is frequently the case, no sensible disorganization of the brain, the death must be attributed to the concussion, and must have been in that case immediate. If, on the other hand, effusion of blood has taken place within the cranium to any considerable extent, it is probable that the first effects of the blow were in some degree recovered from, and that the circulation was re-established. It is not essential, however, that the impression should be primarily made upon the Cerebro-spinal system. The wellknown fact of sudden death not unfrequently resulting from a blow on the stomach, especially after a full meal, without any perceptible lesion of the viscera, clearly indicates that an impression upon the widely-spread cœliac plexus of Sympathetic nerves (which will be much more extensively communicated to them when the stomach is full than when it is enpty) may cause the immediate cessation of the heart's action, in the same manner as a violent injury of the brain or spinal cord. ${ }^{1}$ In all these cases the whole vitality of the system appears to be destroyed at once; for the processes which would otherwise succeed to the injury, and which after other kinds of death less sudden in their character, produce evident changes in the part of the surface that has immediately received it, are here entirely prevented. An instance is on record in which a criminal under sentence of death determined to anticipate the law by self-destruction. Having no other means of accomplishing his purpose, he stooped his head and ran violently against the wall of his cell; he immediately fell dead, and no mark of contusion showerl itself on his forehead. The same absence of the usual results is to be noticed in the case of blows on the stomach. The influence of severe impressions on the nervous system in diminishing, when it does not altogether destroy, nuscular irritability, is well seen in the operation of severe injuries affecting vital organs, or extending over a large part of the surface, in depressing the heart's action; to which attention has already been directed $(\$ 241)$.

674. From a general consideration of the phenomena of Irritability, we can scarcely do otherwise than acquiesce fully in the doctrine of Haller, which involves no hypothesis, and which is perfectly conformable to the analogy of other departments of Physiology. He regarded every part of the body which is endowed with irritability as possessing that property in aud by itself; but considered that the property is subjected to excitement and control from the nervous system, the agency of which is one of the stimuli that can call it into opcration. It may be desirable briefly to sum up the fitets by which this doctrine is supported. 1 . The existence in vegetables of irritable tissues, which are exciterl to contraction by stimuli clirectly applied to themselves, and which can be in no way dependent upon or influenced by a nervous system. 2. The existence in animals of a form of muscular tissue which is especially connected with the maintenance of the organic functions, and which is much more readily excited to action by direct stimulation than it is by nervous ageney. 3. The fact that by the agency of these the organic functions may go on (so long as their requisite conditions are supplied) after the removal of the nervous centres (of the Cerebro-spinal system at least), and when these were never present; rendering

1 For examples of this see Lancet, 1870, vol. i, p. 276. 
it next to certain that their ordinary operations are not dependent upon any stimuli received through the nerves, but upon those directly applied to themselves. 4. The persistence of irritability in muscles, for some time after the nerves have ceased to be able to convey to them the effects of stimuli ; this is constantly seen in regard to the Sympathetic system of nerves, and the muscles of organic life upon which they operate; and it is shown, by the agency of narcotics, to be true also with respect to the Cerebro-spinal system and the muscles of Aninal life. 5. The continuance of irritability in the muscles after their complete isolation from the nervous centres, so long as their nutrition is unimpaired; and the effects of frequent exercise in preventing the impairment of the nutrition and the loss of irritability. 6. The recovery of the irritability of muscle, when isolated from the nervous centres, after it has been exhausted by repeated stimulation: this also depends upon the healthy performance of the nutritive actions. 7 . The existence of certain poisons which appear to possess a directly depressing effect on the conducting power of motor nerves, without exerting any influence upon the irritability of muscles $(\$ 670)$. 8. The existence of certain tracts of muscular tissue, as those, for instance, of the walls of the umbilical vessels, which, according to Virchow, whilst possessing considerable irritability, show no trace of nervous tissue. In the words of Dr. Alison, then, "the only ascertained final cause of all endowments bestowed on nerves in relation to muscles in the living body, appears to be not to make muscles irritable, but to subject their irritability in different ways to the dominion of the acts and feelings of the mind"-to its volitions, emotions, and instiuctive determinations. ${ }^{1}$

675. There can be no question that the condition most essential to the maintenance of muscular contractility is an adequate supply of arterial blood. It is well known that when a ligature is applied to a large arterial trunk in the IIuman subject, there is not only a deficiency of sensibility in the surface, but also a partial or complete suspension of muscular power, until the collateral circulation is established. The same result has been constantly attained in experiments upon the lower aninals; the contractility of the muscle being impaired or altogether extinguished when the flow of blood into it was arrested, and being recovered again when the supply of blood was restored.-The various experiments of M. Brown-Séquard ${ }^{2}$ on this subject are still more satisfactory, as showing that the contractility of muscles, whether of the striated or smooth variety, may not only be restored by the transmission of aerated blood through them, after it has entirely ceased, but that this may even occur when it has given place to cadaveric rigidity. Thus he found that when he connected the aorta and vena cava of the body of a rabbit which had been some time dead, and in which the cadaveric rigidity had already manifested itself for between ten and twenty minutes, with the corresponding vessels of a living rabbit, so as to re-establish the circulation in the lower extremities, the rigidity disappeared in from six to ten minutes, and in two or three ninutes afterwards the muscles contracted on being stimulated. He subsequently made similar experiments upon the muscles of a decapitated criminal; the hand being selected as a convenient part for the purpose. It was not until nearly $12 \frac{1}{2}$ hours after death that all traces of irritability had left the muscles, and the injection was not com.

1 For a good résumé of the arguments for and against the theory of independent irritability in muscles, see a paper by Dr. H. N. Maclaurin in Edinb. Med. Journal, July, 1863.

2 See Gazette Médicale, 1851, Nos. 24 and 27 ; and Journal de la Physiologie, 1858, vol. $\mathrm{i}, \mathrm{pp} .95,353,729$. For some more reeent experiments, see $\mathbf{M}$. Robin in his journal de l'Anatomie, 1869, p. 69. 
menced until 45 minutes after this, cadaveric rigidity having appeared in the interval. About half a pound of human blood, which had been defibrinated and freely exposed to the air so as to acquire the arterial tint, was then injected at intervals for about thirty-five minutes; ten minutes after the last injection the greater number of the muscles were found to be irritable, and these remained so for two hours, after which the contractility gradually departerl, and was succeeded by cadaveric rigidity. The blood, which had been injected in an arterialized condition, issued from the vessels quite dark; and as this occurred over and over again, the change of hue could not be attributed to anything else than the reaction between the blood and the tissues. - Similar experiments were made, twenty-seven hours after death, upon the muscles of the foot of the same criminal, but with an entirely negative result, save that the blood which was injected returned of a considerably darker hue. ${ }^{1}$-Still more recent experiments have shown, that in order that the muscles should retain their elongated condition, it is necessary that they should be supplied with arterial blood, the passage of venous blood through their capillaries immediately inducing contraction. This was remarkably exemplified in an experiment made by M. Brown-Séquard upon a pregrant rabbit, in which the injection of venous blood into the uterine vessels immediately excited the organ to contract, and caused the expulsion of two or three foetuses, whilst on injecting arterial blood all signs of contraction immediately passed off. It is doubtful whether the stimulus to contraction in these cases is the presence of carbonic acid, or whether, as Dr. Rarlcliffe ${ }^{2}$ supposes, it is not rather to be attributed to a deficiency of oxygen, the readmission of which restores the vital properties of the muscle and induces its elongation. The latter view is certainly supported by the violent convulsions which occur in aninals that are bled to death; and even the convulsions which are witnessed in asphyxia, when the contracted state of the small arteries ( $\$ 324)$ and the consequent diminished transmission of blood through the capillaries are borne in mind, are not unfivorable to it. Dr. Radeliffe has adduced the interesting experiments of Dr. George Harley upon the influence of the ardition of strychuia and brucia to blood, as cseentially confirmatory of his view; since these poisons dininish the capacity of the blood to absorb oxygen, and their action may thus be said to be equivalent to a copious loss of blood.

676. Whilst the Irritability of Muscles is gradually departing after death, it not unfrequently shors itself under a peculiar form; for, instead of producing sudden contractions, speedily followed by relaxation, the application of stimuli then occasions slow and somewhat prolonged contractions, the relaxation after which is tardy. This form of contraction is seldom scen in adult Mammalia, except (as will be presently shown) when death has taken place from certain diseases that have a special influence on the blood and muscular system; but it is stated by M. Brown-Séquard ${ }^{4}$ to present itself more constantly in young animals, and to be (so to speak) an exaggeration of the ordinary modus operandi of their muscles, which during life are much

\footnotetext{
I In Robin's experiments upon decapitated criminals, the heart could be made to recommence its rhythmical contraction by blowing air into its eavities upwards of one hour and a quarter after execution. The contractions continued lor eight minutes. Rosenthal (Wien. Med. Press, 1872, Nos. 18 and 19) found that the muscles of the trunk and extremitics lose their irritability and cease to respond to fiudo-electrical excitation within a period varying from 90 to 180 minutes after death.

2 In whose work on Epileptic and other Convulsive Affections of the Nervous System (3d edit., 1861) much original and interesting information on the subject of muscular contructility will be found.

3 See Lancet, 1856 .

4 Gazette Médicale, December 22d, 1849. See also Norris, loc. cit.
} 
more slowly thrown into contraction by mechanical stimuli than they are in adults. - The most remarkable manifestations of it yet observed, lowever, have been witnessed after death from Cholera and Yellow Fever; for in these cases the muscular contractions, though capable of being excited by mechanical stimulation applied to the muscles themselves, are frequently spontaneous, and sometimes give rise to movenients strongly resembling the ordinary actions of the living state. In regard to the occurrence of this phenomenon, after death from yellow fever, several interesting observations have been recorded by Dr. Bennet Dowler, of New Orleans. ${ }^{.}$In one case, the subject of which was an Irishman, aged twenty-eight, the following series of movements took place spontaneously not long after the cessation of the respiration; first the left hand was carried by a regular motion to the throat, and then to the crown of the head; the right arm followed the same route on the right side; the left arm was then carried back to the throat, and thence to the breast, reversing all its original motions, and finally the right hand and arm did exactly the same. Similar phenomena have been described by Mr. N. B. Ward, Mr. Helps, and Mr. Barlow, ${ }^{2}$ as occurring in the bodies of cholera patients. Mauy circumstances indicate that these movements were due to the inherent contractility of the muscles, and were not in any degree dependent upon the operation of the nervous system; and Mr. Dowler proved experimentally, by completely separating limbs which exhibited these movements from the trunk of the body, that the influence of the nervous system was not in any degree essential to their production.

677. The Rigor Mortis, or Cadaveric rigidity of the muscles, is essentially the result of the coagulation of myosin (which, according to Michelsohn, is due to the action of a ferment). ${ }^{3}$ It begins immediately after all indications of irritability have departed, but before any putrefactive change has commenced. The supervention of the rigidity is not usually prolonged much beyoud seveu hours, though a tetanic state at first sight resembling it inay occasionally be observed to occur instantly after death from some peculiar conditions of the nervous and muscular systems at the moment. In other instances twenty or even thirty hours may elapse before it shows itself. Its general duration is from tweuty-four to thirty-six hours, but it may pass off much more rapidly, or it may be prolonged to four or six days. It first affects the neck and lower jaw, then the trunk, then the upper extremity, and finally, the muscles of the lower extremities. In its departure, which is immediately followed by decomposition, the same order is followed. It is remarkable that it is equally intense in muscles which have been paralyzed by Hemiplegia, or whose nerves have been previously severed, provided that no considerable change has taken place in their nutrition. It was the opinion of Mr. Hunter that death from exhanstion by hunting, as well as by lightning, completely prevents the post-mortem rigidity of muscles, and the coagulation of the blood. But the observations of Gulliver ${ }^{4}$ have proved that in animals killed by hunting and by fighting, the rigor mortis is greatly hastened, and that the blood does coagulate. He found that deer, foxes, and hares became quickly stiff after being hunted to death; and that game fowls, exhausted and worried to death by fighting, become quite stiff, and have the blood coagulated in their hearts within twenty-eight minutes after the last fatal wound. The immersion of Batrachian reptiles in water at a temperature of about $120^{\circ}$ kills them instantly, when their muscles become imme-

\footnotetext{
1 Experimental Researches on the Post-mortem Contractility of the Muscles, 1816.

2 see Mr. F. Barlow's Observations on the Muscular Contractions which occasionally occur after Death from Cholera, in Med. Gazette for 1849-50.

3 Journ. of Anat. and Phys, 1874, p. 213.

4 Edinb. Med. and Surg. Journ., Oct. 1818.
} 
diately very stiff. Indeed it may be said that all circumstances which tend to exhaust or depress the irritability of the muscles, such as death by slow and wasting disease, violent muscular exertion immediately before death, or powerful electrical shocks passed through the motor nerves, induce the early appearance and speedy departure of this state-putrefaction subsequently appearing and progressing rapidly. On the other hand, when the general energy has been retained up to a short period before death, as in persons who die from an accidental cause, or in animals the irritability of whose muscles has been augmented by cold, cadaveric rigidity sets in late and lasts long, and putrefaction also appears late and progresses slowly. Muscles deprived of blood by the ligature of their arteries, or brought into contact with distilled water, ammonia, dilute acids, alkaline salts, metallic salts, alcohol, or chloroform (all of which produce coagulation of the myosin, whilst some of them act on the other albuminous constituents of muscle), pass into a state closely analogous to, if not identical with Rigor mortis; and within certain limits their powers can be restored by the readmission of a current of duly oxygenated or arterial blood. The contractile force exerted in Rigor mortis, according to Hermann and Walker, ${ }^{1}$ is generally less than, though sometimes fully equal to, or even greater than that which the muscle can exert on strong electrical excitation. - The condition of the muscles in post-mortem rigidity is in many respects different from that of the contraction which occurs during life. In the former the shortening is persistent and uniform, the elasticity of the tissue is increased ${ }^{2}$ and when it is induced by Heat, a distinct diminution in the bulk of the muscle occurs; it feels firm and hard, and there are no signs of electrical disturbance. In the latter, on the contrary, the contraction is intermittent, and there is, as we have seen, a diminution in the amount of the elasticity and of firmuess, and evidence of a change in the state of electrical tension (negative variation).- In Rigor mortis the muscles generally have an acid reaction; but this is not always the case, and the two conditions are therefore independent of each other. ${ }^{3}$ According to Ranke ${ }^{4}$ and Hermann, living muscle absorbs far more oxygen than dead; as is shown in the following table:

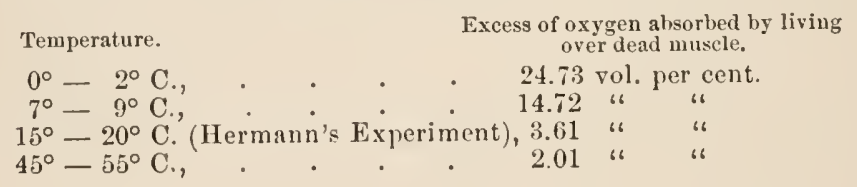

The absorption here indicated is clcarly of a physiological nature, since it steadily diminishes with increasing elevation of temperature, which hastens the death of the muscle, and would prove favorable to any purely chemical changes.

678. It was formerly customary to divide the Muscles into two groups, termed the "voluntary," and "in voluntary," corresponding to the "striated" and "non-striated" tissuc respectively, bit there are various circumstances which show that this system of classification camnot be consistently maintained. It is quite true that all the Muscles of Organic Life may be truly styled "involuntary;" for although they are capable of being influenced by emotional and ideational states of mind, yet the Will camnot exert any

1 Pflügrer's Archiv, Bd. iv, 1871, p. 182.

2 There seems to be some difference of opinion on this point, Hermann and Walker (Pflüger's A rchiv, 1871, vol. jv, p. 182) maintaining that muscles in rigor mortis possess a greater extensibility than contraeted muscles.

3 Wundt, P'hysiologie des Menschen, 187R, p 476.

- Die Lebensbedingungen der Nerven, 1868, p. 33. 
direct influence upon them, only affecting them indirectly by its power of determining these states. But over those Muscles, also administering to the organic functions, and doing so in obedience to impulses purely automatic, which are called into action by the Cranio-Spinal nerves, the Will, as we have seen, exerts some power; and such, therefore, cannot be properly regarded as involuntary, since the Will can influence their state; whilst they are far from being truly voluntary, since the Will cannot control their tendency to automatic action beyond a certain limited amount $(\S 294)$. On the other hand, every one of the MLuscles usually styled voluntary, because ordinarily called into action by the Will, is liable to be thrown into action involuntarily; either by an Excito-motor stimulus, as in tetanic convulsions, or by Consensual action, as in tickling, or Emotionally, as in laughter or rage, or simply Ideationally, as in somnambulism and analogous states. Hence although there are certain groups of muscles which are more frequently acted on by the Will than by any other impulse, and certain others which are more frequently played on by the Emotions, and so on, it becomes obvious that every muscle called into contraction by the Cranio-Spinal nervous system, is capable of receiving its stimulus to movement from any of these sources; the nerve force transmitted along the motor fibres, being issued either from the Spinal Corl, from the Sensory Ganglia, or from the Cerebrum, as the case may be, but being in its nature and effects the same in every instance.

679. The grouping or combination of muscular actions, which takes place in almost cvery movement of one part of the body upon another, must be attributed, not to any peculiar sympathy among the Muscles themselves, but to the mode in which they are acted on by the Nervous Centres. This is most obriously the case with regard to those of the primarily automatic cliss; but it can scarcely be doubtful as to those of the secondarily automatic kind $(\$ 510)$, such as walking, which, though at first directed by the Will, comes by habit to be performed under conditions essentially the same with the preceding; and when it is borne in mind that even in voluntary movements the Will cannot single out any one muscle from the group with which it usually co-operates, so as to throw this into separate contraction, but is limited to deternining the result $(\S 540)$, it seems pretty obvious that even here the grouping is effected by the endowments of those Automatic centres from which all the motor impulses immediately proceed to the muscles, and not by Cerebral agency. In fact, the wholc process by which we acquire the power of adapting our muscular actions to the performance of some new kind of movement,- as in the case of an infant learning to walk, a child learning to write, an artisan learning some occupation which requires nice manipulation, a musical performer learning a new instrument, and so on,is found, when attentively studied, to indicate that the Will is fir from having that direct and immediate control over the contractions of the Muscles, which it is commonly reputed to possess; and that the operation really consists in the gradual establishment of a new grouping of the separate actions, in virtue of which, the stimulus of a Volitional determination, acting under the guidance of the muscular sensations ( $\$ 536)$, henceforth calls into contraction the group of muscles whose agency is competent to carry that determination into effect. For, however amenable any set of muscles (as those of the arm and hand) may have become to the direction of the Will, in any operations which they have been previously accustonsed to perform, it is only after considerable practice that they can be trained to any method of combined action which is entirely new to them; and even if we attempt to bring our anatomical knowledge into use for such a purpose, by mentally fixing upon certain muscles whose action we wish to intensify and to associ- 
ate with those of others, we find that such a method of proceeding affords no assistance whatever, but rather tends to impede our progress, by drawing off the attention from the "guiding sensations" (visual, muscular, etc.), which are the only regulators that can be depended upon for determining the dne performance of the volitional mandate.-Hence we are led by these considerations, as by those stated in the preceding paragraph, to the conclusion that the agency which directly affects the muscles is of the same kind, and that it operates under the same instrumental conditions whatever be the primal source of the motor power. And in watching the gradual acquirement of the capacity for different kinds of movement, during the periods of Infancy and Childhood in the Human subject, we find everything to confirm this conclusion. For it becomes obvious that the acquirement of Voluntary power over the movements of the limbs, is just as gradual as it is over the direction of the thoughts; all the activity of the body, as well as of the mind, being in the first instance automatic, and the Will progressively extending its domination over the former, as over the latter, until it brings under its control all those muscular movements which are not immediately required for the conservation of the body, and turns them to its own uses. ${ }^{1}$

\section{Of the Symmetry and Harmony of Muscular Movements.}

680. It might have been not unreasonably supposed, a priori, that those muscles would have been most readily put to simultaneous contraction which correspond to each other on the two sides of the body; in other words, that symmetrical movements would be those most readily performed. Such, however, is by no means the case; for in many of our most familiar actions we consentaneously exert different muscles on the two sides of the body. This is nowhere more clearly slown than in the various movements that are required for the performance of the different acts of locomotion, and which may here be briefly noticed. In order to maintain the body in the erect posture, simple as the effort appears, the concurrent action of many muscles is required, as is clearly shown not only by the numerous and futile trials made by children before the power of balancing is acquired, but by the impossibility of placing a dead body in this position without support. In standing the legs are more or less extended; and the weight of the trunk is transmitted through the femora and the tibire and fibulæ to the astragali. These, with the other tarsal and metatarsal boncs, form an elastic arch on either side, which, whilst allowing the great superincumbent pressure to be borne with ease, enables each foot to accommodate itself to irregularities of the surface of the ground, and at the same time breaks the shoek or jar which would otherwise be experienced in the various movements of walking,

1 The aptitude which is acquired by practice, for the performanee of eertain actions that were at first aceomplished with difficulty, seens to result as much from a structural change which the continual repetition of them occusions in the Muscle, as in the habit which the Nervous system acquires of exeiting the movement. Thus almost every person lcarning to play on a musical instrument finds a difliculty in causing the two slorter fingers to move independently of eaeh other and of the rest; this is particularty the case in regard to the ring finger. Any one may satisfy himsolf of the diflieulty by laying the pulm of the laand flat on a table, and rasing one finger after the other, when it will be found that the ring finger ean seareely be lifted without disturbing the rest,- - evidently from the difficulty of detaching the netion of the portion of the exterson communis digiturum, by whieh the movement is produced, from that of the remainder of the muscle. Yet to the practiced musician, the command of tha Will over all the fingers becomes nearly alike; and it can seareely be doubted that some ehange in the strueture of the muscle, or a new development of its nerve-fibres takes place, which favors the isolated operation of its several divisions. 
running, or leaping. The centre of gravity of the whole borly lies, according to Weber, in the promontory of the sacrum; but, according to Meyer, in the canal of the second sacra! vertebra. As long as a perpenticular line drawn from this point to the earth drops within the hasis formed by the feet, the ercet posture can be maintained with comparative ease; if it drop outside that basis, the subject must inevitably fall. The chief muscles called into play in the standing position are those which keep the heal vertical on the spinal column, as the recti, obliqui, sterno-mastoids, splenii, complexus, etc., the extensors of the spine, as the erectores spinæ and their prolongations, and the extensors of the thigh and leg; but the opposite muscles are, as a sailor would express it, "taut" and ready to contract instantancously and unconsciously on the slightest indication of loss of equilibrium.

681. Walking.--In this movement the body, supported in a nearly vertical position, alternately rests on the right and left leg; the limb upon which it does not rest swinging forward, like a pendulum, in a remarkahly regular manner, just sufficiently bent to avoid contact with the ground. This is not effected, however, quite apart from muscular action, since, as M. Duchenne has shown, certain muscular paralyses (of flexor nuscles) prevent the oscillation from occurring. ${ }^{1}$ If we examine the successive movenents which occur in making two steps, it will be found that if the subject be standing firmly with the left leg in advance, the first act consists in raising the leel of the right foot, which is accomplished by the gastrocnemius and soleus muscles; and the weight of the whole body thus raised is by the simultaneous contraction of the psoas and iliacus muscles of the left leg thrown over to the left side, resting for an instant upon the left foot. At this period all the extensors of the left leg, the glutæi, the quadriceps extensor femoris, the tibialis anticus, etc., are powerfully contracted. The right leg, the toe of which is the last part which touches the ground, now swings forward, the knee and hip joints being just sufficiently bent to enable the foot to clear accidental irregularitics of the surface. Lastly, the right heel is planted on the ground in front, and is immediately followed by the whole surface of the foot; but coincidentally with this occur the elevation of the left heel and the throwing over of the weight of the trunk to the right side, which is followed by the swinging forward and implantation of the left foot, and so on alternately. The weight of the legs in the act of swinging forward has been shown by Weber to be materially diminished by the pressure exerted by the atmosphere in retaining the head of the femur in the acetabulum. The ordinary rate of movement in walking for each person is to an important extent regulated by the length of the leg, and the consequent duration of its pendulun-like oscillation. Various compensatory movements in walking oceur in order to maintain the equipoise of the body ; amongst the most important of these are the movements of the arms, for whilst the right leg is swinging forwards, the twisting of the trunk which occurs at this period would bring the right shoulder forwards, but the right arm at this monent swings backwards and the left forwards, and by thus gencrating a force in the opposite dircetion neutralizes this tendency. A corresponding compensation takes place when the left leg swings forward, and this is effected by a good walker without any sensible lateral twisting of the trunk. ${ }^{2}$ The whole body rises and falls to a small amount ( $1 \frac{x}{4}$ inch) in walking, etc. The trajectory of any fixed point of the body, as the pubis, nay, according to the formula of MI. Carlet, be inscribed in a hollow half cylinder with its concave portion upwards, at the base of which lie the minima, and on the sides of which the

1 Duchenne (de Boulogne), Physiologie des Mrouvements, Paris, 1867, p. 386.

2 See Bishop in Cyclop. of Anat. and Phys, vol. iii, p. 460. 
maxima terminate tangentially. M. Carlet, ${ }^{1}$ who has lately bestowed much attention on the movements of locomotion in man, divides each step into two parts-one, during which both feet are in contact with the ground (temps du double appui), and the other when the body is supported by one foot alone (temps de l'appui unilateral). A. Period of Double Contact.-1. At the beginning of the period of double contact, when the foot in front only touches the ground with the heel, the posterior leg is stretched, and rests only on the extremities of the metatarsal bones and the phalanges. The knee of the front leg is extended or slightly flexed. The bicotyloidean axis is oblique, from before backwards, and from above downwards. 'The trunk descends at the same time that its lateral and forward inclination diminishes. 'The pubis is turned towards the side of the posterior leg. 2. In the middle of the period of double contact, that is to say when the front foot begins to touch the ground along its whole length, the posterior leg only touches it with its phalanges. The knee of the fore leg is rather more bent. The position of the bicotyloidean axis is the same as before. The trumk has gained its lowest position. The pubis is situated above the axis of the path to be pursued. 3 . At the end of the period of double contact, that is when the posterior leg only touches the ground by the ends of its phalanges, the front leg has begun to extend the kuee-joint. The bicotyloidean line is oblique as before. 'The trunk begins to be raised at the same time that it inclines forwards and to the side. The pubis is directed obliquely towards the side of the front leg. B. Period of Single or Unilateral Contact.-1. At the beginning of this period, that is when the posterior foot is about to quit the ground, and the front foot is planted flat, the supporting leg continues to open or extend the knee-joinit, whilst the opposite one begins to be flexed. The bicotyloidean axis is oblique, but from before backwards only, being otherwise horizontal; the trunk begins to rise at the same time that it inclines forwards and to the side. The pubis is directed obliquely outwards, towards the side of the leg in front. 2. In the middle of the period of unilateral support, that is when the heel of the supporting leg quits the ground, it extends the articulation of the knee to the utmost. In the leg that is suspended in the air, on the contrary, the knee is flexed to its maximum amount. The bicotyloidean axis is always oblique, but from above downwards only. It lies in a vertical plane, and its lower extremity corresponds to the supporting limb; the trunk has reached its greatest elevation and at the same time its inclination forwards and to the side is at its maximum. The pubis is at its maximum of obliquity as regards the path pursned on the side of the supporting leg. 3. At the close of the period of unilateral support, that is, when the supporting leg touches the ground only by its metatarso-phalangeal portion, and the free $\mathrm{leg}$ has passed the mirldie of its period of oscillation, the anklejoint of the supporting leg extends or opens whilst that of the knec remains at its maximum of extension. The bicotyloidean axis bccomes again oblique from before backwards, and from above downwards; but its obliquity is now in the opposite dircction, and the limb which was in front aud above in the period of double contact, is now behind and below. 'The trunk descents at the same time that its forward and lateral inclination diminishes. The pubis approximates the axis of the path. If the length of the steps increases, their duration in general diminishes, whilst the falling of the trunk and its inclination always augment. The number of steps in a given time, or the pace of walking, is partly dependent upon the length of the legs, aud

1 Carlet, Essais expérimentals sur la Locomotion, in the Annales des Sei. Nat., 1872. The reader nuy also refer to Marey's Animal Mechanism, vol. xi, of the International Scientific Series, and to Pettigrew's Animal Locomotion, vol. vii, of the same series. 
partly upou direct nuscular effort: the longer the leg, the slower will be the oscillation; but by planting the foot on the ground when it has only passed through one-half of its natural oscillation, the succession of steps, and consequently the rapidity of progress, can be materially increased, without much effort. In very quick walking almost every muscle in the body is brought into play ; the trunk is considerably inclined forwards, partly for the purpose of resisting and compensating for atmospheric pressure, but chiefly to enable the hip-joints to be carried low, thus increasing the extent of ground which can be covered by each step, whilst at the same time the number of steps is greatly increased by muscular effort; the period during which both feet are resting on the grouid together being considerably shortened. In an experiment made by Mr. Vasey, the length of whose leg was thirty-four inches, in walking at the rate of four miles an hour, 2000 steps were male every fifteen minute:; the length of each step must therefore have been 2.64 feet, and the time of each step 0.45 second. MI. Carlet has shown that the muscular effort in walking, as indicated by the backward push, supposing the weight of the individual to be about 150 pounds, does not surpass 45 polinds additional, though it is much greater in leaping and running.-Quick walking passes by insensible gradations into running, the period in which the body rests upon both feet becoming shorter and shorter, until at length there is a period between successive steps, during which the body moves forward unsupported by either foot. According to Weber, the vertical undulations of the trunk in running vary from ${ }_{4}^{3}$ ths to $\frac{4}{5}$ ths of an inch, the duration of the step from $\frac{1}{4}$ th to $\frac{1}{5}$ th of a second, of which time the body swings unsupported in the air $\frac{1}{1}$ th of a second, the time of descent being $\frac{1}{15}$ th of a second. - In leaping, the extensor muscles are brought into extremely vigorous action, and the act may be accomplished either by the alternative or the simultaneous action of the legs, as seen in the "hop, step, and jump" of children. The essential difference in leaping and running is, that in leaping the body is raised so high from the ground, and for so long a period, that the leg or legs have time to complete their full arc of oscillation, and consequently cover the utmost space of ground possible. 'The extent of the leap is of course dependent upon the muscular energy of the individual.

682. Now it is plain that the grouping of the muscular movements in these different instances arises out of its felt conformity to the end in view, and that it is regulated by the guiding sensations which indicate to us the progression and balance of the body. The infant, in learning to walk, is prompted by an instinctive tendency to put one foot before the other, as may be noticed at a very early period, when it is first held so as to feel the ground with its feet; and in attempting to balance itself when first left to stand alone, it moves its arms with a like intuitive impulse, not based upon experience. All that experience does, in either case, is to give that precise adjustment to the muscular action, which makes it perfectly conformable to the indications afforded by the muscular sensations. Thus, if we advance each arm with its corresponding leg, we feel that the balance of the body is not nearly as readily maintained, as it is when we advance the arm with the leg of the opposite side; and thus, without any design or voluntary determiuation on our parts, the former comes to be our settled habit of action. This kind of adjustment, in the case before us, is by no means limited to the muscles of the limbs; for there is scarcely any muscle of the trunk or head, that is not exerted with some degree of consentaneous energy, however un-

1 The subject of the locomotion of Man has been particularly investigated by the Profs. WVber, whose work entitled Mechanik der menschlich. Grehwerkzeuge (Göttingen, 1836) has been translated in Jourdan's Encyclopédie Anatomique, tom. ii. See also the Art. Motion, by Mr. J. Bishop, in Cyclop. of Anat. and Physiol., vol, iii. 
consciously to ourselves, in the act of walking. The difficulty which would attend the voluntary harnonization of all these separate actions, is remarkably evinced by the fact, that no mechanist, however ingenious, has ever succeeded in constructing an automaton that should walk like Man; the alternate shifting of the ceutre of gravity from one side to the other, upon so small a base as the human foot affords, simultaneously with the movement in advance, constituting the great difficulty of biped progression. But all this adjustment is effected in our own organism for us, rather than by us; the act of harmonization, when once fully mastered, being attended with no effort to ourselves; but the whole series of complex movements being performed in obedience to the simple determination to walk, under the automatic guidance of the senses, which instantly reveal to us any imperfection in the performance.-The same view extends itself readily to other combinations of dissimilar and non-symmetrical movements, which are less natural to Man, but which may be readily acquired artificially if they all harmonize in a common purpose, and are under the guidance of the same set of sensations. Thus, the performer on the Organ uses the several fingers of his two hands to execute as many different movements (in very different positions, it may be) on the "manual" keys: one of his feet may be on the "swell" pedal, and the other may be engaged in playing on the "pedal "keys; but all these diverse actions are harmonized by their relation to the same sct of auditory sensations; and if the result be not that which the performer anticipated, an immediate correction is made.-The preferential use of the right arm and leg is not easily explicahle. Dr. Pye Smith ${ }^{1}$ refers it to the principle of the "survival of the fittest." contending that in warfare those who advance the right side would in the long run be exposed to less risk of fatal wounds. Dr. Ogle ${ }^{2}$ however, points out that the right extrenities are used preferentially by other animals, as the monkey and parrut, and refers it to the fact that the left hemisphere receives a freer supply of blood than the right. It may to some extent procecd from imitation, and to sume extent also be the result of education.

683. It would be casy to multiply instances of the same kind, all illustrative of the general principle, that the facility with which we voluntarily combine different movements is chiefly determined, not by their symmetrical character, but by their conformableness to a common end, and by the hamony of their griding sensations with reference to that end $;^{3}$ but it will be desirable to dwell particularly on the Movements of the Eye, as presenting certain points of peculiar interest, some of which have an important bearing on Surgical practice.-It will be recollected that in the Human Orbit, six muscles for the movements of the eyeball are found; the four Ricti, and the

1 Guy's Hosp. Rep., 1871.

2 Repro of Med.-Chir. Soe, Laneet, 1871, p. 449. See also, for seatterert Notes and Ohservations on this subjeet, Laneet, 1870 , vol. i, pl. $526,557,660 ; 1871$, vol i, p. 495; vol. ii, pp. 49 and $11 \mathrm{i}$; Buchanan, Theory of the Right Hand, Eulinbursh Med. Journ., 186\%, and l'amphlet, Glasgow, $186 ; 2$.

3 'Two simple examples, however, may be cited, of the difficulty which attends the simultaneous performanee of movements that are not harmonious. If we attempt to (.) (evate one erelid whilst we are depressing the other, we find that a considerable effort is required to aceomplish the action, although the elevation or depressine of both eyclicl: together is performed with so little effurt that we are scarcely conseious of it; and the difficulty is increased if we half shut both eyes, and then iry to close one and to open the other. So if we try to move our two hands as if they were simultaneonsly winding eord in opposite directions upon two reels placed in front of us, we shall find oursolves unable to do so without a eonstant exercise of the attention, and even then but slowly and with diffieulty; ulthough the very same movements may be seprrately performed, or both hands may be made thus to move in the same direction, with the greatest facility. 
two Oblique muscles. The precise actions of these are not easily established by experiment on the lower animals; for in all those which ordinarily maintain the horizontal position, there is an additional muscle, termed the retractor, which embraces the whole postcrior portion of the globe, and passes backwards to be attached to the bottom of the orbit. ${ }^{.}$If the origin and insertion of the four Recti muscles be examined, however, no doubt can remain that each of them, acting singly, is capable of causing the globe to revolve in its own direction, - the superior rectus causing it to roll towards the nose,-and so on. A very easy and direct application of the laws of mechanics will further make it evident to us, that the combined action of any two of the Recti muscles must cause the pupil to turn in a direction intermediate betreen the lines of their single action; and that amy intermediate position may thus be given to the eyeball by these muscles alone. In two directions, however, their combined action is supplemented by the oblique muscles. The superior oblique rotates the eve downwards and outwards; the inferior oblique upwards and outwards. Another important operation of the oblique muscles is to maintain the parallelism of the vertical meridians of the two eyes in certain movements, for it is found that whilst the external and internal recti merely turn the eyes outwards and inwark, without deflecting the vertical meridian, the superior and inferior recti, in consequence of the obliquity of their muscle planes, not only rotate the eye respectively upwards and downwards, but deflect the upper extremity of the vertical meridian, the former inwards, the latter outwards. But the oblique muscles also deflect the vertical meridian, the superior turning the upper extremity of the vertical meridian inwards, the inferior outwards, and therefore by co-operating with the recti, are able to preserve the parallelism of the vertical meridians of the two eyes, as shown in the following table:

Morement

Tpwards,

Downwards,

Inwards,

Outwards,

Upwards and inwards,

Upwards and outwards,

Downwards and inwards,
Is effected by the

Superior rectus, aided by the inferior oblique.

Inferior rectus, aided by the superior oblique.

Internal rectus.

External rectus.

Suprior and internal recti muscles, aided by the inferior oblique.

$\{$ Superior and cxternal recti museles, aided by the inferior oblique.

$\{$ Inferior and internal recti musc!es, aided by the superior oblique.

Downwards and outwards, Inferior and external recti, aided by the superior oblique.

684. On studying the Voluntary movements of the Eyeballs, we are led to perceive that they are not so much symmetrical as harmonious-that is to say, the corresponding muscles on the two sides are rarely in action at once; whilst such a harmony or consent exists between the actions of the muscles of the two orbits, that they work to one conmon purpose, namely, the direction of both eyes towards the required object. They may be a rranged nnder two groups; the first comprising those which are alike harmonious and symmetrical; the second including those which are harmonious but not symmetrical. To the first group belong the following: 1. Both cyeballs are elevated by the contraction of the two Superior Recti.-2. Both eyeballs a re depressed by the conjoint action of the Inferior Recti muscles.-3. Both are drawn directly imwards, or inwards and dowmwards, as when we look at an object placed on or near the nose: this movement is effected by the action of the Internal Recti of the two sides, with or without the Inferior Recti. It is

1 See Alfred v. Gräfe, Klinische Analyse der Motilituts-störungen des Auges, and v. Gräfe's Archiv f. Ophthalmologie, Bd. i-iii. 
evidently symmetrical, but might seem at first sight not to be harmonious, because the eyes do not move together towards one side or the other; it is, however, really harmonious, since it directs their axes towards the same point. ${ }^{1}-\mathrm{Now}$ it is to be observed, with regard to these movements, that we can never effect them in antagonism with each other, or with those of other muscles. We cannot, for example, raise one eye and depress the other; nor can we raise or depress one eye, when we adduct or abduct the other. The explanation of this will be found in the fact, that we can never, by so doing, direct the eyes to the same point.-The harmonious but unsymmetrical novements, forming the second class, are those in which the Internal and External Recti of the two sides are made to act together, either alone or in conjunction with the Superior and Inferior Recti. They are as follows: 4. One eye is marle to revolve directly imvards by the action of its Internal Rectus, whilst the other is turned outwards by the action of its External Rectus.-5. One eye is made to revolve upwards and inwards, by the conjoint action of the Superior and Internal Recti ; the other upvards and outwards, by the conjoint action of the Superior and External Recti.-6. One eye is made to revolve dowmords and inwards, by the conjoint action of the Inferior and Internal Recti; the other downwards and outwards, by the conjoint action of the Inferior and External Recti.-In these movements, two different muscles, the Extermal and Internal Recti, are called into action on the two sides, with or without the Superior and Inferior Recti; but they are so employed for the purpose of directing the axes of the eyes towards the same point; and although, as just noticed, we can put the two Internal Recti in action together, we cannot voluntarily cause the two External Recti to contract together, it not being possible that any object shonld be in such a position as to require this action for the dircetion of the axes of the eyes towards it.

685 . 'The greater number of the foregoing movements may be performed unconsciously to ourselves, in obedience to a Voluntary determination to keep the direction of the eyes fixed, instead of to give motion to the eyeballs. Thus, if we gaze steadily at an object in front of us, and then depress the head forwarls on its transverse axis, the eyeballs roll upwards upon their transverse axes (1) by the action of the Superior Recti, without our being aware of it; so if, whilst still maintaining the same fixed gaze, we raise the head into the vertical position and then depress it backwards, the eyeballs are rolled downwards (2) by the action of the Inferior Recti; if, under the same conditions, the head be made to rotate on its vertical axis from side to side, the eyeballs will be made to roll on their vertical axes in the contrary directions by the External and Internal Recti (4) of the two sides respectively; so, by causing the head to move obliquely in the opposite directions, the reverse oblique movements ( 5 and 6 ) of the eyeballs are made to take place by the eontinued fixation of the vision upon the same object. To these we have to add one more action, which cannot be called forth in any other mode-nancly, that rotation of the two eyes upon their antero-posterior axes, which takes place probably by the instrumentality of the Oblique muscles, when we incline the heal to one side or the other by rotating it upon its antero-posterior axis. In all these movements, as in the preceding, the

I Some persons can effect this voluntarily to a greater extent than ot lers ; but fiven then, they en only accomplish it by fixing the graze upon some olject siturted betwern the oyes; and mannot eall the adductor muscles into combined action in prect darknoss, or if the lids be closed. Even those who have the lrast power of etfeeting this extreme convergence by at onee direeting the eyes towards a very noar object, ean accomplish it by locking ut an object plaeed at a moderate distance, anul gradually bringing this nourer to the nose, keeping the eves standily fixed upon it. The unwonted character of the movement is shown in this, - that it can only be maintained, even for a short time, by a strong effort, produeing a sense of fatigue. 
IVill directs the result; and there is no other difference between them than that which arises out of our consciousness of a change in the one mase, and our unensciousness in the other. It may here be remarked that Professor Helmholtz has recently adopted the same view as that just expresserl in regard to the nature of the volitional direction and the influence of the guiding sensations; in corroboration of which he further mentions the important fact ascertained by Donders and himself, that by the use of a prism before one eye, both eyes may be made to move outwards, or one up and the other down, - still under the same fundamental law.-The truly involuntary movements of the eyeballs, however, are performed under very different conditions; there being here no purposive direction or fixation of the gaze; and the muscular contractions not being determined by visual sensations, but being called forth by nerve force excited in sone remote part. Of this we have an example in the normal revolution of both eyes upwards and inwards, which takes place in the acts of coughing, sneezing, winking, etc.; but far more remarkable illustrations are presented in those abnormal movements of the eyeballs, occurring in Convulsive diseases, in which there is neither harmony nor symmetry.

686. It has been stated to be a condition of single and distinct vision, that the usual axes of the eyes should be directed towards the object, in order that its picture should be thrown upon the parts of the two retinæ which are accustomed to act together ( $\$ 621)$; but as this cannot take place without the guidance of visual sensations, the movements of the eyeballs are wanting in harmony whenever the visual power has been deficient from birth. This is most remarkably the case, where the deficiency has becn so complete that not even light ean be distinguished; but the movements are frequently very far from being harmonious, in cases of congenital cataract, where a considerable amount of light is evidently admitted, but where no distinct image can be formed; and in such cases, the movements are most harmonious where the object is bright or luminous, and more vivid impressions are therefore made upon the retinx. It is no objection to this doctrine to say, that persons who have become blind may still move their eyes in a harnonious manner; since the habit of the association of particular movements having been once acquired, the guidance of the muscles may be effected by sensations derived from themselves, in the manner in which it takes place in the laryngeal movements of the deaf and dumb ( $\$ 537)$; and, as a matter of fact, a want of consent may often be observed where the blinchess is total. The peculiar "vacant" appearance, which may be noticed in the countenances of persons completely deprived of sight by amaurotic or other affections, which do not alter the external aspect of the eyes, seems to result from this,-that their axes are parallel, as if the individual were looking into distant space, instead of presenting that slight convergence which must always exist between them, when the eyes are fixed upon a definite object. This convergence, which is of course regulated by the Internal Recti, varies in degree according to the distance of the object; and it is astonishing how minute an alteration in the axes of the eyes becomes perceptible to a person observing them. For instance, $A$ sees the eyes of $B$ directed towards his face, but he perceives that $\mathrm{B}$ is not looking at him; he knows this by a sort of intuitive interpretation of the fact, that his face is not the point of convergence of 'B's eyes. But if $\mathrm{B}$, who might have been previously looking at something nearer or more remote than A's face, fix his gaze upon the latter, so that the degree of the convergence of the axes is altered, without the general direction of the eyes being in the least affected, the change is at once perceived by the person so regarded;

1 In his Croonian Lecture, Proceedings of the Royal Society, April 14th, 1864, p. 193. 
and the eyes of the two then meet.-It is an interesting confirmation of the principles here advocated, that when binocular vision cannot be obtainerl by directing the true axes of the eyes towards the object, as happens when an opaque spot exists upon the centre of the cornea, or an artificial pupil has been firmed at the margin of the iris, there is an automatic tendency to the neutralization of the mischief, by such an action of the muscles as shall turn the virtual axis of the affected eye (that is, the axis in which the rays most directly enter the globe) towards the object, thus producing Strabismus, but not Double Vision.

\section{Energy and Rapidity of Muscular Contraction.}

687. The energy of Muscular contraction is of course to be most remarkahly observed, in those iustances in which the continual exercise of particular parts has occasioned an increased determination of blood towards them, and in consequence a permanent increasc of their bulk (\$334, IIr). This has been the case, for example, with persons who have gained their livelilood by exhibiting feats of strength. Much will, of coursc, depend on the mechanically advantageous application of muscular pewer; and in this manner effects may be produced, even by persons of ordinary strength, which would not lave been thought credible. In lifting a heavy weight in each hand, for examplc, a person who keeps his back perfectly rigid, so as to throw the pressure vertically npon the pelvis, and only uses the powerful extensors of the thigh and calf, by straightening the knees (previously somewhat flexed), and bringing the leg to a right angle with the foot, will have a great advantage over one who uses his lumbar muscles for the purpose. A still greater advantage will be gained by throwing the weight more directly upon the loins, by means of a sort of girdle, shaped so as to rest upon the top of the sacrum and the ridges of the ilia; and by pressing with the hand upon a frame so arranged as to bring the muscles of the arms to the assistance of those of the legs: in this manner, a single Man of ordinary strength may raise a weight of 2000 lbs. ; whilst few who are unaccustomed to such exertions, can lift more than 300 lbs. in the ordinary mode. A man of great natural strengtl, however, has been known to lift $800 \mathrm{lbs}$. with his hands; and the same individual performed several other curious feats of strength, which secm deserving of being here noticed. "1. By the strength of his fingers, he rolled up a very large and strong pewter dish. 2. He broke several short and strong pieces of tobacco-pipe with the force of his middlc-finger, having laid them on the first and third finger. 3. Having thrust in under his garter the bowl of a strong tobacco-pipe, his legs being bent, he broke it to pieces by the tendons of his hams, without altering the bending of the knee. 4. He broke such another bowl between his first and scond fingers, by pressing them together sideways. 5. He lifted a table six feet long, which had lialf a hundred-weight hanging at the end of it, with his teeth, and held it in that position for a considerable time. It is true, the ficet of the table rested acrainst his knees; but as the length of the table was nuch greater than its height, that performance required a great strength to be exerter by the muscles of his loins, neck, and jaws. 6. He took an iron kitchen poker, about a yard long, and threc inches in circumference, and holding it in his right hand, he struck it on his bare left arm between the elbow and the wrist, till he bcnt the poker nearly to a right angle. 7 . He took such another poker, and, holding the ends of it in his hands, and the middle of it against the back of his ncck, he brought botlı ends of it together before him ; and, what was yet nore difficult, he pulled it straight again." 1 Haller mentions 
an instance of a man, who could raisc a weight of 300 lbs., by the action of the clevator numseles of his jaw; and that of a slender girl, affected with tetanic spasms, in whom the extcusor numseles of the back, in the state of tonic contraction or opisthotonos, resisted a weight of $800 \mathrm{lbs}$. laid on the abdonien with the absurd intention of straightening the body.

688. Absolute Force of Muscle.-The mechanical power exerted by muscle in contraction may be calculated as in any mechanical machine by multiplying the weight lifterl by the height to which it is raised. Weber obtained the following values for the muscle of a frog:

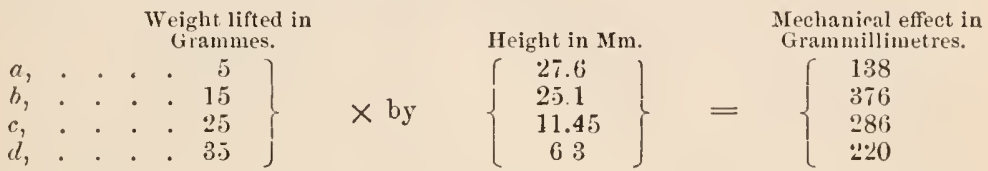

That is to say, that 138 grammillimetres are equal to 5 grammes raised $27.6 \mathrm{~mm}$. or to 27.6 grammes raised $5 \mathrm{~mm}$. It will be seen from the table that the mechanical effect increases to a certain point with the weighting, and then gradually diminishes: it was found that different muscles had their maximum at difrerent weightings. - The power of the muscles appears to vary in different animals, being greatest in proportion to their size in Insects. ${ }^{1}$ The relation of the nuscles of the same animal to one another is very simple, the weight which can be raised, as Professor Haughton " states, being proportional to the area of the cross section of each muscle, and may even be estimated by the cross section of the tendon that conveys its influence to a distant point; whilst it is obvious that a given weight can be raised higher in proportion to the length of the muscle. The most natural measure of the maximum of force which is exerterl when the muscle is in its highest state of excitability is the amount of work it can accomplish under the influence of the strongest stimulus. But this, as is shown above, is found to vary with the degree of weighting; and it is, therefore, advantageous to adopt another measure to which the term "absolute musclc-force" may be applied. ${ }^{3}$ This is represented by the weight, which is exactly equivalent to the contractile power of the muscle when stimulated to its utmost, or, in other words, which the muscle, when most strongly stimulated, is just incapable of raising. The absolute muscle-force for the square centinetre of the muscles of the frog was estimated by IV eber at 692 grammes. Rosenthal ${ }^{4}$ gives a higher number for the muscles of the same animal, estinating it at from 2300 to 3000 grammes per square centimetre of cross section for the adductor magnus and semi-membranosus, and from 1000 to 1200 grammes for the gastrocnemius; whilst for the square centimetre of the muscles of man Henke and Knorz have estimated it at from 6000 to 8000 grammes; and Koster ${ }^{5}$ at about 10,000 grammes per square centinetre for the muscles of the leg, and 7400 for those of the arm. Haughton's estimate ${ }^{6}$ agrees very closely with those of Henke and Knorz, since he considers the absolute muscle-force of the muscles of the human arm to be $94.7 \mathrm{lbs}$, of the leg to be 110.4 lbs., and of the abdomen to be $107 \mathrm{lbs}$. for the square inch of sectional area, which reduced to French measure ${ }^{7}$ would amount to about

1 Sre Plateau, Revue Suisse, t. xxv, 1866, p. 87, who states that the Donacia nymphau can overcome a resistance equal to 42 times its own weight.

2 Proceedings of Royal Society, 1867, No. 94

3 See Hermunn, Grundriss der Phwiologie, 1867, p. 238.

- Comptes Rendus, tom. Ixiv, p. 1143. $\quad 5$ A rehief Nederland, Bd. ii, No. 2.

6 Procuedings of the Royal Society, 1867, No. 94.

7 Taking lae square inch at 6.45 square centinetres and the pound avoirdupois at 45359 grammes. 
7700 grammes for the square centimetre. Mr. H. F. Baxter ${ }^{1}$ found from his experiments that 1 grain of frog's muscle is on the average capable of raising a weight of 608 grains through a space of $\frac{1}{6}{ }_{3} \mathrm{~d}$ of an inch, though considerable differences exist in regard to sex, age, and general condition of the animal. Thus he found that whilst 1 grain of the muscle of male frogs could raise 656 grains, 1 grain of the muscle of fentale frogs could only raise 579 grains. Again, in March and April 1 grain of frog's muscle raised 445 grains $\frac{1}{5} \frac{d}{3}$ of an inch high, in June and July 608 grains.2 This agrees with the observation of Schmulewitsch, ${ }^{3}$ that within certain limits the higher the temperature of muscle, the more work is it able to perform with equal weighting and stimulus. Fick ${ }^{4}$ finds the power possessed by 1 grain of frog's muscle to be 5000 millimetre-granimes for one single contraction. Haughton ${ }^{5}$ estimates that one ounce of the human heart will lift 20.576 lbs. through a height of one foot per minute, and that $1 \mathrm{lb}$. av. weight of human muscle is capable of lifting 1.56 ton through 1 foot before it is exhausted. Mr. Baxter's experiments also show the interesting circumstance that whilst there is a loss of weight in the animal during prolonged nuscular contraction, there is an increase of weight in the individual muscles experimented on.-It is to be recollected, that the mechanical application of the power developed by muscular contraction to the movement of the body, is very commonly disadvantageous as regards force: being designed to cause the part moved to pass over a much greater space than that through which the muscle contracts. Thus the Temporal muscle is attached to the lower jaw, at about one-third of the distance between the condyle and the incisors; so that a shortening of the muscle to the amount of half an inch, will draw up the front of the jaw through an inch and a half; but a power of 900 lbs. applied by the muscle, would be required to raise $300 \mathrm{lbs}$. bearing on the incisors. In the case of the forearm and leg, the disproportion is much greater; the points of attachment of the nuscles by which the knee and elbow-joints are flexed and extended, being much closer to the fulcrum, in comparison with the distance of the points on which the resistance bears. Professor Haughton has also shown that there is a loss in the force applied by the muscles of various animals in consequence of the friction of their tendons, which amounts in man to 35 per cent., in the niastiff to 41 per cent., and in the kangaroo to 61 per cent. It may be instructive to append here the estimates made by different observers of the amount of work that a man weighing about $150 \mathrm{lbs}$. can with vigorous exertion accomplish in the course of a day of eight hours. The French assume as a work-unit the force that is requisite to raise 1 kilogramme (=2.2 lbs.) 1 metre $(=39.37$ in. $)$ high in one second of time:

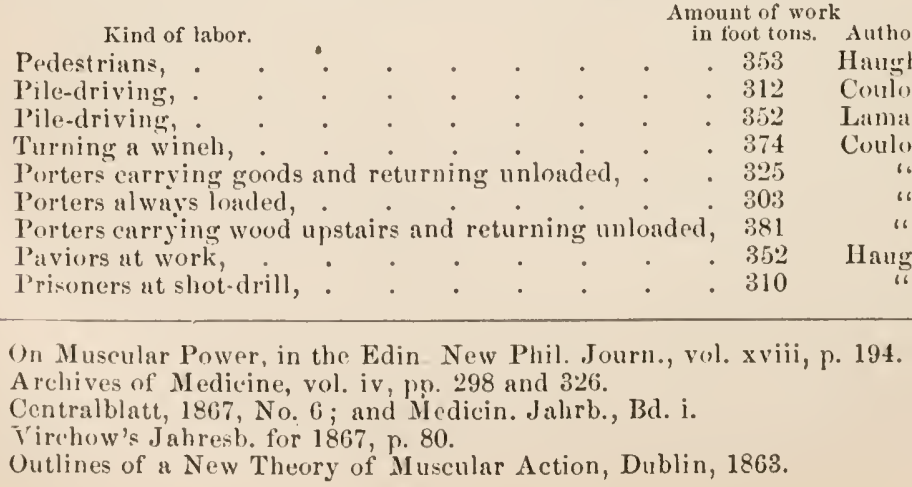


The mean of these estimates is $340.2 \mathrm{ft}$. tons, or $762,048 \mathrm{ft}$. pounds $=$ 105,605 kilogrammetres, which closcly accords with the cstimate of Professor Donders. ${ }^{1}$ In his address at the meeting of the British Association, at Oxford, Professor Haughton estimated the daily external work of a working man at 353.75 foot tons, and adds 133 foot tons for the work requisite to maintain the circulation and respiration. Ranke ${ }^{2}$ gives the following table from Redtenbacher :

The amount of work accomplished in eight hours in

1. Man, weighing on the average 70 kilog., working without

\begin{tabular}{|c|c|c|c|c|c|c|c|}
\hline & machine, & . & $\cdot$ & . & • & - & $316,8 \cap 0$ \\
\hline 66 & with a lever (Hebel), & - & • & . & - & & 158,400 \\
\hline 6 & with a windlass (Kurbel), & - & • & 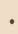 & - & • & 184,320 \\
\hline 66 & with a whinsey or gin, & - & - & • & - & $\theta^{\circ}$ & 207,360 \\
\hline 6 & with a treadwheel, . & - & ${ }^{\circ}$ & - & - & ${ }^{\circ}$ & 241,920 \\
\hline & with an inclined plane, 24 & . & • & • & • & . & $3+5,600$ \\
\hline
\end{tabular}

2 Horse, weighing on the average 280 kilog., working without a maehime,

$2,102,400$

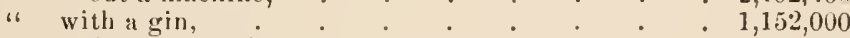

3. Ox, weighing on the average 280 kilog., without machine, . . . . . . . $1,382,400$

" with a gin, . . . . . . . 1, . . . . . 2,200

4. Mule, weighing on the average 230 kilug., without machine, . . . . . .

"with gin, . . . . . . . .

5 Ass, weighing on the average 168 kilog., without ma-

$1,497,600$

777,500

$81,4,000$

316,800

Reducing these results to a general measure for a given weight, Ranke estimates that-

$1 \mathrm{kilog}$. of human muscle works in 1 see., without machine, $0.157 \mathrm{kilog}$.

\begin{tabular}{|c|c|c|c|c|c|}
\hline 66 & $0 x$ & 66 & 66 & 66 & 0.172 \\
\hline " & ass & 66 & 6 & 66 & 0.178 \\
\hline 6 & mule & "6 & "6 & 66 & $0.2 \div 2$ \\
\hline "6 & horse & 16 & 16 & 16 & $0 \div 61$ \\
\hline
\end{tabular}

He calculates eight hours' walking to be equivalent to $200,000 \mathrm{kilogr}$.

689. Sources of Muscular Force.-Muscle has been defined by an able chemist to be a machine by which heat is converted into mechanical force; and the results of numerous recent researches tend to show that the source of the primary heat is to be looked for in the oxidation of both the nitrogenous and of the non-nitrogenous constituents of the blood ; the combination taking place partly and principally within the bloodvessels (Heaton), but partly also in those portions of the blood which, escaping from the vessels, supply the tissue with the materials requisite for its nutrition. That nitrogenous substances are oxidized during muscular exertion is sufficiently proved by the necessity that exists for their free supply in groups of men, as navvies, prizefighters, etc., who have to maintain severe and protracted exertion, as well as by the fact ascertained by Parkes $(\$ 411)$ and Flint $(\S 411)$, that a slight increase in the amount of the products of the disintegration of the nitrogenous constituents of the body does take place during exercise, whether the diet have contained a regulated amount of nitrogen, or has been wholly restricted to non-nitrogenous substances. That the force daily exerted by the muscles of a laboring man is, however, not exclusively

1 See Dr. Moor's translation of his paper in Humphry and Turner's Journal of Anatomy, vol. i, 1867 , p. 168.

2 Grundzüge der Physiologie, 1868. 
derived from the combustion of the nitrogenous constituents of his muscles or of his blood, is proved by the circumstance that the elimination of urea, which niay be regarded as the final product in the animal body of the decomposition of the albuminoid compounds, is by no means proportional to the amount of force expended ; and secondly, by the fact that evell allowing a large margin for errors of calculation and experiment, the absolute quantity of nitrogen eliminated by the body represents an amount of albuminous matcrial the combustion of which is insufficient to account for the muscular force that is gencrated with even moderate exertion. That the oxidation of the non-nitrogenous materials of the blood occurs during work, to furnish the heat which the muscles transform into mechanical force, is shown first, by the greatly increased amount of carbonic acid contained in the venous blood of a contracting muscle, as compared with a muscle at rest (Sczelkow, $\$ 194)$; secondly, by the increased elimination of carbonic acid and water that occurs during exercise (E. Suith, §311); thirdly, by the fuct that in some animals, as in bees (Verloren), as well as in man (Fick, Parkes) a considerable amount of exertion can be tcmporarily undertaken on a diet containing little or no nitrogen, as sugar and fat, though it has been clearly shown that if the diet be exclusively confined to non-nitrogenous material, weakness and weariness soon supervene, quickly followed by complete muscular exhaustion (Hammond, Savory, Parkes). It may be remarked, also, that in those nations, and in those animals, that are well supplied with nitrogenous compounds in their food, a superior physical condition is produced, enabling them to maintain scvere exertion for a longer period, and also to exert, when occasion may require, more vigorous effirt for a shorter period, than those whose diet is of a poorel quality, or contains less nitrogen in an easily assimilable form. - The precise seat of the oxidation camnot be held to be decisively ascertained, and some, but not very satisfactory, evidence has becn brought forward to show that it takes place within the vessels.-The chemical facts connected with the contraction of muscle have been ingeniously woven by Hermann' into the following theory. He supposes that muscle contains a store of a complex nitrogenous material in a state of solution. It is unstable, and in the act of disintegration develops force. The products of its disintegration are, inter alia, carbonic acid, paralactic acid (possibly, as Ranke believes, sugar aud fut), and an albuminous compound which in the living muscle is gelatinous, but soou coagulates into a solid substance (Myosin). When at rest the disintegration proceeds slowly, but it is rendered more energetic by elevation of temperature within certain limits, and is induced instantly by certain "irritants." As the muscle-substance is gradually consumed by exertion, it is requisite for the maintenance of its characteristic properties that a constant circulation of blood shonld take place through its vessels, by which means not only may oxygen and fresh supplics of nutritive material be brought to it, but the products of its disintegration, the prescnce of which seriously impairs its contractile powers, may be removerl." The power of the nuscles appears to be capable of being

1 Grundriss der Physiologie, 1867, p. 226. See also Schenk, Archiv f. Exper. Path., 187t, Bd. ii, p. 21.

2 'The realor will find much interesting information on the several views of the origin of muscular force, with references to previous writers, in Playfair's Essay on the Food of Man in Riclation to his useful Work, Edinb., 1865; IJeaton's Ersay on the Function of the Blood in Mi,scular Work, Phil. Mag., 1867; Donders, On the Comstituents of Food in their Relation to Miscular Work and Animal Heat, translated by Dr. Mourn, Dublin, 186if; Parkes's Essays on the Elinination of Nitrogen by the Kidneys (Procedings of the lioyal society, 1867, Nos. 89 and 94); Procerd. Roy. Soc.. land., 1874, No. 150, and P'rofessor Haughton's Address at the Meeting of the British Mrdical Association, 1868. 
increased by the passage of a continuous electrical current through the nerves supplying them. ${ }^{\circ}$ Thus Dr. Poore has shown that in a case where a man could hold his arm outstretched for six minutes, when the current was used he could go on for thirteen minutes. So also eight successive squeezes of the dynamometer without galvanism gave 388 pounds, and the same number with galvanism 477 pounds. Similar observations have been made by Heidenhain and Remak, who have termed such currents "refreshing" or "restorative."

690. The rapidity of the changes of position of the component particles of muscular fibres, may, as Dr. Alison justly remarks, ${ }^{2}$ be estimated though it can hardly be conceived, from various well-known facts. The pulsations of the heart can sometimes be distinctly numbered in children, at more than 200 in the minute; and as each contraction of the ventricles occupies only half the time of the whole pulsation, it must be accomplished in $\frac{1}{4} 0$ th of a minute, or $z_{z}^{3}$ ths of a second. Again, it is certain that, by the movements of the tongue and other organs of speech, 1500 letters can be distinctly pronounced by some persons in a minute: every one of these must require a separate contraction of muscular fibres; and the production aurl cessation of each of the sounds, implies that each separate contraction must be followed by a relaxation of equal length; each contraction, therefore, must have been effected in $\frac{1}{30 \overline{0}}$ th part of a minute, or in $\frac{1}{50}$ th of a second. Haller calculated that, in the limbs of a dog at full speed, muscular contractions must take place in less than $\frac{1}{2} \frac{1}{0}$ th of a second, for many minutes at least in succession.-All thcse instances, however, are thrown into the shade, by those which may be drawn from the cliss of Insects. The rapidity of the vibrations of the wings may be estimated from the musical tone which they produce; it being easily ascertained by experinents, what number of vibrations are required to produce any note in the scale $(\S 639)$. From these data, it appears to be the necessary result, that the wings of many Inscets strike the air many hundred or even many thousand times in every second.-The minute precision with which the degree of muscular contraction can be adapted to the designed cffect, is in no instance more remarkable than in the Glottis. The musical pitch of the tones produced by it, is regulated by the degree of tension of the chordce vocules, which are possessed of a very considerable degree of elasticity ( $\$ 697$ ). According to the observations of $M$ Muller, ${ }^{3}$ the a verage length of these, in the male, in a state of repose, is about ${ }_{100}^{73}$ ths of an inch; whilst in the state of greatest tension it is about $\frac{93}{100}$ ths; the difference therefore being $\frac{20}{100}$ ths, or one-fifth of an inch: in the female glottis, the average dimensions are about ${ }_{100}^{51}$ ths and $\frac{63}{10} 0$ ths respectively; the difference being thus about one-eighth of an inch. Now the natural compass of the voice in most persons who have cultivater the vocal organ, may be stated at about two octaves, or 24 semitones. Within each semitone, a singer of ordinary capability could produce at least ten distinct intervals; so that of the total number, 240 is a very moderate estimate. There must, therefore, be at least 240 different states of tension of the Vocal Cords, every one of which is producible by the will, without any previous trial; and the whole variation in the length of the cords being not more than one-fifth of an inch, even in man, the variation required to pass from one interval to another, will not be more than $\frac{1}{2} \frac{1}{0}$ th of an inch. And yet this estimate is much below that which might be truly made from the performances of a practiced vocalist. ${ }^{4}$

1 See the experiments of Dr. Poore, Practitioner, January, 1873.

2 Cyclopedia of Anatomy and Physiology, Art. Contractility.

3 Eilements of Physiology. Baly's translation, p. 1018.

4 It is said that the celebrated IIadame Mara was able to sound 100 different in. 


\section{CH A P T ER X VI.}

\section{OF THE VOICE A N D SPEECH.}

\section{Of the Larynx and its Actions.}

691. THE sounds produced by the organ of Voice constitute the most important means of communication between Man and his fellows; and the power of Speech has, therefore, a primary influence, as well on his physical condition, as on the development of his mental faculties. It is necessary to bear in mind that Vocal sounds, and Speech or articulate Language, are two things entirely different; and that the former may be produced in great perfection, where there is no capability for the latter. Hence, we might at once infer that the instrument for the production of vocal sounds is distinct from that by which these sounds are modified into articulate speech; and this we easily discover to be the case, the voice being unquestionably produced in the larynu, whilst the modifications of it by which language is

FIG. 297.

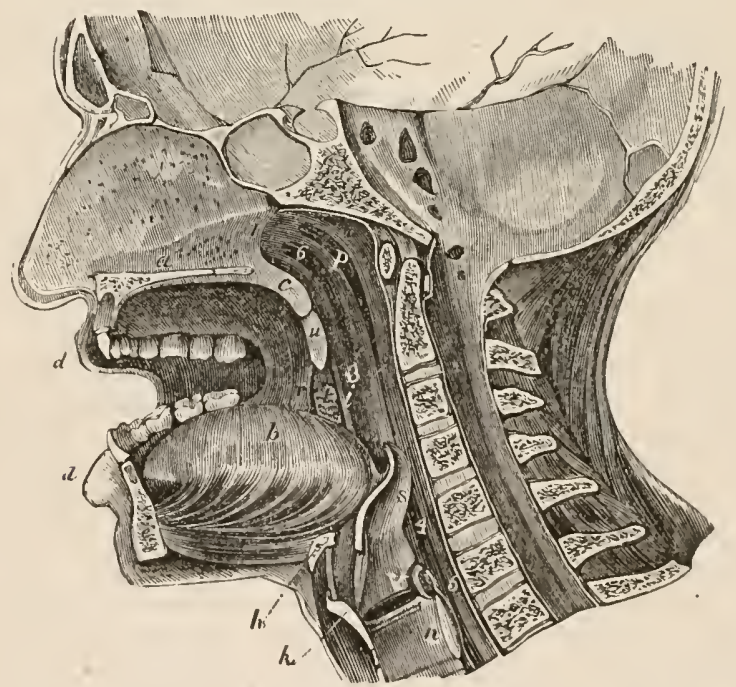

Nedian Section of Mouth, Nuse, Plıarynx. aud Laryux: $a$, septum of nose; below it, section of hard balate; $b$, tongue; $c$, scetion of velum pendulum jalati; $d, d$, lips; $u$, uvula; $r$, anterior areh or pillar of fauces; $i$ posterior arch; $\ell$, tonsil; $p$, pharynx; $h$, nyoitl bone; $k$, thryoid cartilage; $n$, cricoid cartilage; $s$, epiglottis; $v$, glottis; 1 , posterior opening of nares; 3 , isthmus fuccum ; 4 , stuerior opening of laryux; 5, passage into cesophagus; 6 , mouth of right Eustachian fube.

formed, are effected for the most part in the oral cavity.-The structure and functions of the former, then, first claim our attention. It will be remembered that the Trachea is surmounted by a stout cartiknginons ammulus, termed the Cricoid cartilage (Figs. 298, 299, А в, Fig. 300, $r u \mathrm{x} w$ ); which

tervals between each tone. The compass of hor voiee boing at least three octaves, or 21 tones, the total number of intervals was 2100 , all comprised within an extreme variation of one-(ighth of an inch; so that it might be said that she was able to determine the contractions of her veal mu-cles to nearly the seventeen-thousandth of an inch. 
serves as a foundation for the superjacent mechanism. This is embraced (as it were) by the Thyroid (Figs. 298, 299, E C G, Fig. 300, G E II), which is articulated to its sides by the lower horns (Figs. 298, 299, c), round the extremities of which it may be considered to turn as on a pivot. In this manner, the lower front border of the Thyroid cartilage, which is ordinarily separated by a small interval (Figs. $298,299, m n$ ) from the upper margin of the Cricoid, may be made to approach it or to recede from it; as any one may easily ascertain, by placing his finger against the little depression which may be readily felt externally, and observing its changes of size, whilst a range of different tones is sounded; for it will then be noticed that, the higher the note, the more the two cartilages are made to approximate, whilst they separate in proportion to the depth of the tones. ${ }^{1}$ Upon the upper surface of the back of the Cricoid, are seated the two snall Arytenoid cartilages (Figs. 298, 300, F F); these are fixed in one direction by a bundle of strong ligaments, which tie them to the back of the cricoid; but they have some power of moving in other directions, upon a kind of articulating surface. The direction of the surface and the mode in which these cartilages are otherwise attached, cause their movement to be a sort of rotation in a plane which is nearly horizontal but partly downwards; so that their vertical planes may be made to separate from each other, and at the same time to assume a slant-

FIG. 298.

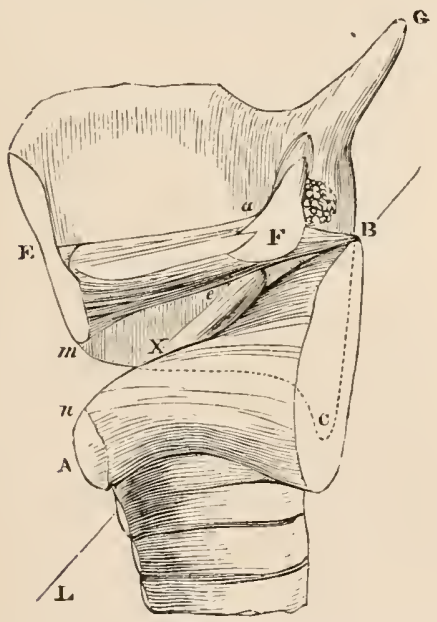

FIG. 299.

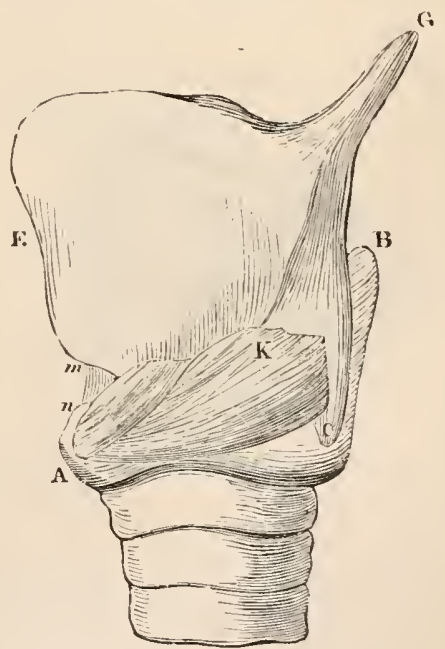

External and Sectional views of the Larynx: A $n$ B, the cricoid cartilage; E C G, the thyroid cartilage ; $G$, its upper horn; $c$, its lower horn, where it is articulated with the cricoid; $F$, the arytenoid cartilage; E F, the vocal ligament; $\mathbf{A}$, crico-thyroideus muscle: $\mathbf{F}$ e $m$, thyro-arytenoideus muscle; $\mathbf{x} e$, cricnarytenoideus lateralis; $s$, transverse section of arytenoideus transversus; $m n$, space between thyroid and cricoid ; B L, projection of axis of articulation of arytenoid with thyroid.

ing position. This change of place will be better understood, when the action of the muscles is described. To the lower part of the anterior surface of the Arytenoid cartilages are attached the chordee vocales or Vocal Ligamients (Fig. 298, E F, Fig. 300, T v), which stretch across to the frout of the Thyroid cartilage; and it is upon the condition and relative situation of these ligaments that their action depends. It is evident that they may be ren-

1 In making this observation, it is necessary to put out of view the general movement of the Larynx itself, which the finger must be made to fulluw up and down. 
dered more or less tense, by the movement of the Thyroid eartilage thus deseribed; being tightened by the depression of its front upon the Crieoid eartilage, and slackened by its elevation. On the other hand, they may be brought into more or less elose apposition, by the movement of the Arytenoid cartilages; being made to approximate nearly, or to reeede in sueh manner as to eause the rima glottidis to assume the form of a narrow $V$, by the revolution of these cartilages.- We shall now inquire into the aetions of the muscles upon the several parts of this apparatus; and first into those of the larynx alone.

692. The depression of the front of the Thyroid cartilage, and the eonsequent tension of the Vocal Ligaments, is oceasioned by the conjoint action of the Crico-thyroide $i^{1}$ (Fig. 299, A K) on both sides; and the ehief antagonists to these are the Thyro-arytenoidei (Fig. 298, $\mathrm{F} m$, Fig. 300, v $k f$ ), whieh draw the front of the thy roid back towards the arytenoid eartilages, and thus relax the voeal ligaments. These two pairs of nuscles may be regarded as the prineipal gavernors of the pitch of the notes, whieh, as we shall hereafter see, is almost entirely regulated by the tension of the ligaments; their aetion is assisted, however, by that of other muscles presently to be mentioned. ${ }^{2}$ The arytenoid cartilages are made to diverge from each other, by means of the Crico-arytenoidei postici (Fig. 300, $\mathrm{N} l$ ) of the two sides, whieh

FIG. 300 .

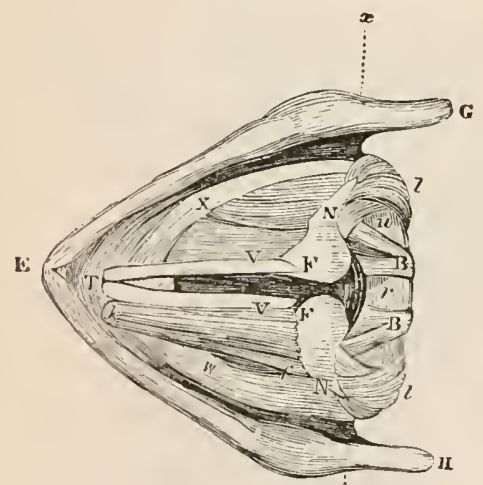

z

Bird's-eye vitw of Larynx from above: (f) 1 , the thy roid eartilage, embracing the ring of the crieoid, $r u \times x$, and turning mon the axis, $x z$, which passes throngh the lower horus, c, Fig. 298; y F, s F, the arytenoid cartilages, eonneeted by the arytenoidens transversus; $T v, T$, the voeal ligaments; $x, x$, the right erico-arytenoideus lateralis (the left being removed); v $k f$, the left thy ro-arytenoideus (the right being ronoved); $\mathrm{N} l, \times l$, lle erieo-arytenoidei postici ; I), 13 , the erico-arytenoid liganents. proeeed from their outer eorners, and turn somewhat round the edge of the Crieoid, to be attached to the lower part of its baek; their aetion is to draw the outer eorners backwards and downwards, so that the points to whieh the vocal ligaments are attached are separated from one. another and the rima glottidis is thrown open. This will be at nnce seen from the succeeding diagram, in whieh the direction of traction of the several muscles is laid down.The action of these muscles is partly antagonized by that of the Cricoarytemoidei laterales ( $\mathrm{Fig} .300, \mathrm{x} \mathrm{x}$ ), which run forwards and downwards from the outer corners of the Arytenoid cartilages, and whose eorrtraction tends to bring their anterior points into the same straight line, depressing them at the same time, so as thus to close the glottis. These muscles are assisted by the Arytenoidens transversus (Fig. 300), which eonnects the posterior faces

I For a careful inve-tigation in regard to the precise mode in which the cricothyroid acts. see Jelentfy, Pllüger's A rehiv, 1873, vol. vii, p. 86.

2 I)r. P. Martyo has idduced varions observations to show that the Thyroid body exerts an important infuence on the pitch of the notes, by giving a certain firmness, rigidity, and tension to the larynx. He also suggests that this body muy act as a loader, renderingr the vibrations of the voeal eords slower and longer, and the tone in consequence, futler, luteler, and deeper, thus compensating for the small size of the larynx; finally he believes that it aids, by its changes in shape, bulk, and denaty, in producing the wonderful qualities of modulation and expression peeuliar to the human voice. See l'roeedings of the Royal Society, vol. viii, p. 315. 
of the Arytenoid cartilages, and which, by its contraction, draws them together. By the conjoint action, therefore, of the Crico-arytenoidei laterales and of the Arvtenoideus transversus, the whole of the adjaccnt faces of the Arytenoid cartilages will he approximated, and the points to which the vocal ligaments are attached will be depressed.-But if the Arytenoideus be put in action in conjunction with the Crico-arytenoidei postici, the tendency of the lattcr to separate the Arytenoid cartilages being antagonized by the former, its backward action only will be exerted; and thus it may be caused to aid the Crico-thyroidei in rendering tense the vocal ligaments. This action will be further assisted by the Sterno-thyroidei, which tend to depress the Thyroid cartilage by pulling from a fixed point below; ${ }^{1}$ and the Thyro-hyoide $i$ will be the antagonists of these, when they act from a fixed point above, the $\mathrm{Os}$ Hyoides being secured by the opposing contraction of several other muscles.The respective actions of these muscles will be best comprehended by the following table:

\section{Govern the pitch of the Notes.}

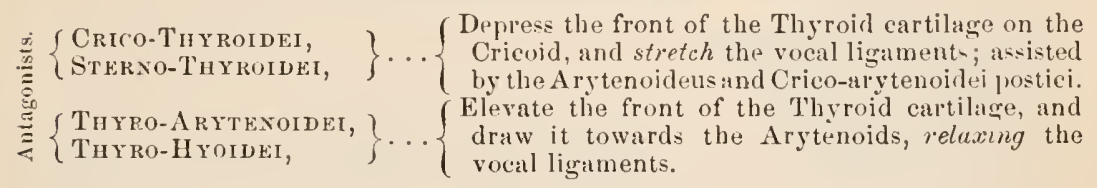

\section{Govern the aperture of the Glottis.}

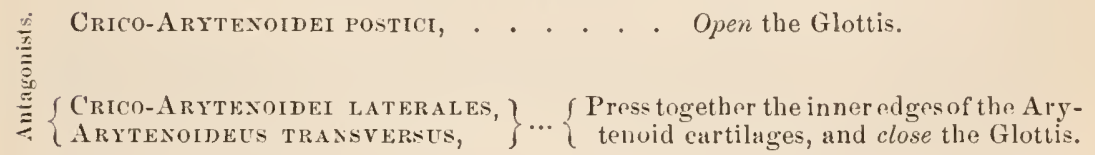

693. The muscles which stretch or relax the Vocal cords are entirely concerned in the production of Voice: those which govern the apertire of the Glottis have important functions in connection with the Respiratory actions in general, and stand as guards (so to speak) at the entrance to the lungs. These separate actions are easily made evident. In the ordinary condition of rest, it seems probable that the Arytenoid cartilages are considerably separated from each other; so as to cause a wide opening to intervene between. their inner faces and between the vocal ligaments, through which the air freely passes; and the vocal ligaments are at the same time in a state of complete relaxation.- - We can close the aperture of the Glottis by an exertion of the will, during either inspiration or expiration; and its closure by an automatic impulse forms part of the acts of Coughing and Sneezing ( $\$ 304)$, besides giving rise to those more prolonged impediments to the ingress and egress of air, which have been already noticed as resulting from disordered states of the Nervous system. With these actions, the muscles which regulate the tension of the vocal ligaments have nothing to do; and we have seen that they are performed by the instrumentality of the Preumogastric or proper Respiratory nerve $(\$ \$ 301,302)$. The appearances which present themselves when the interior of the Larynx is examined during life are, according to Prof. Czermak, that in the almost semilunar

1 These are not usually reckoned among the principal muscles concerned in regulating the voice; but that they are so, any one may convince himself by placing his finger just above the sternum, whilst he is sounding high notes; a strong feeling of muscular tension is then at once perceived. 
space bounded by the posterior wall of the Pharynx (Fig. 302) and the base of the tongue, the upper curved free edge of the epiglottis $(e)$ is seen, its lateral portions just touching the posterior pharyngeal wall, and its central

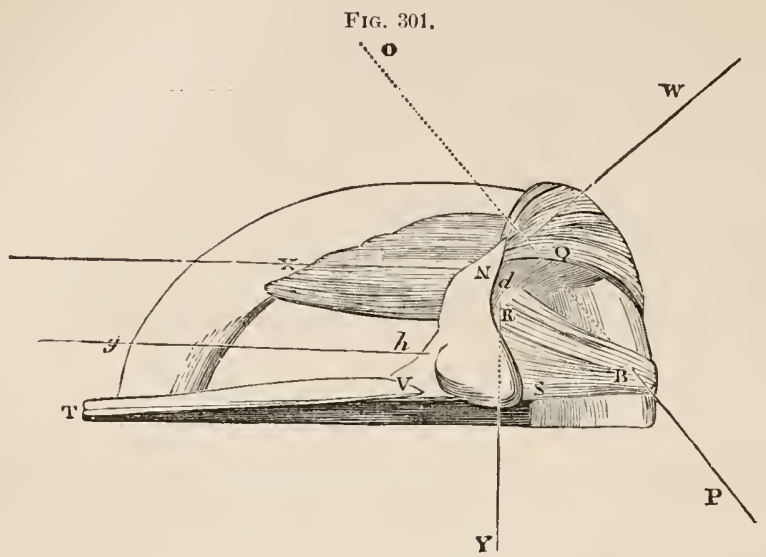

Part of Fig. 300 enlarged, to show the Direction of the Muscular Forces which act on the Arytenoid cartilage. N v s, the right Arytenoid cartilage; $T$ v, its vocal ligament; $\mathrm{B} R \mathrm{~S}$, bundle of liganents uniting it to Cricoid ; o $P$, projection of its axis of articulation; $h g$, direction of the action of the Thyroarytenoideus; $\mathrm{N} \mathrm{x}$, direction of Crico-arytenoideus lateralis; $\mathrm{N} \mathbf{w}$, direction of Crico-arytenoideus posticus; $\mathrm{N}$ Y, direction of Arytenoideus transversus.

portion arehing forwards, so as to leave an interval for the passage of air in the median line. Near the centre of the cleft between the upper border of the epiglottis and the walls of the pharynx, a transverse band or cushion (c)

FIG. 302.

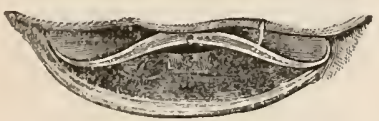

Fig. 303.

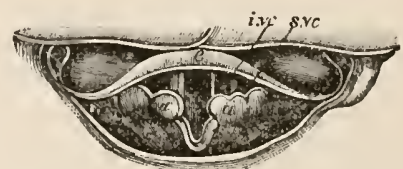

Fur, 302,-Condition of the Larynx as seen by the Laryngoscope duriug tranquil respiration: e, epiglottis; $x$, fissure-like opening of resophagus; $c$, fold of mucous membranc bounding the opening of the glottis posteriorly, and extending between the tubercles of the cartilages of Sintorini.

FIa. 303,-Conllition of the Larynx during the cmission of the broad rowel sound (A): $a$, cartilages of Santoriui sumounting the arytenoid cartilages; e, epiglottis; $i v e$, inferior or true vocal cord; $s v e$, superior or false vocal cord of right side.

is also scen, of a reddish color, and formed by the edge of the fold of mucous membrane sustained between the two separated arytenoid eartilages $(a a)$. The anterior outline of the fold is concave in front, and forms with the superior border of the epiglottis, which is coneave behind and situated a little higher, a narrow transversely-elliptical fissure. If the vowel $a$ be now sounded as in ah or eh, the semilumar space behind the base of the tongue is enlarged, the epiglottis rises and separates from the posterior wall of the pharynx, the glottis beeomes widely opened, and a considerable portion of the anterior wall of the trachea ean be pereeived. A small rounded swelling situated to the outer side of the tubereles of Santorini, which was previously concealed by the lateral border of the epiglottis, now also comes into view. The movements of the arytenoid cartilages during the production of vocal sounds ean be very distinctly observed by the laryngoseope, and the aceount 
given by Professor Czermak possesses considcrable interest, since it fully corroborates the views derived from theory and experiment on the dead subject, which had been expressed before the introduction of the instrument. As soon as we wish to utter a sound, the two arytenoid cartilages raise themselves in the fold of mucous membrane which covers them, and approach ove another with surprising mobility. This movement effects the approximation of the vocal cords, and consequently the constriction of the Glottis (Fig. 303). The study of the mode of formation of the gravest chest-sounds is extremely difficult, on account of the arytenoid cartilages becoming elevated and rapidly approaching one another until they come almost into complete contact, whilst they bend under the border of the depressed epiglottis in such a manner that the latter, as viewed by the laryngoscope, entirely conceals the interior of the Larynx. According to Mandl ${ }^{i}$ the opening of the glottis in the production of the decpest notes is ellipsoidal. Duriug the emission of the most acute sounds, the Glottis is contracted in a linear form (Fig. 304); on each side we perceive the vocal cords, distinguished by their whitish-yellow color, and a little to the outer side is a narrow groove indicating the position of the ventricles of Morgagni. Further outwards again are the false or superior vocal cords. These parts, with the erected arytenoid cartilages, the epiglottis pulled upwards and forwards, and the aryteno-epiglottidian ligaments, together form a short and stiff tube situater above the Glottis; the whole appearing, from the sensation we experience during the experiment, to be in a state of very great teusion. ${ }^{2}$

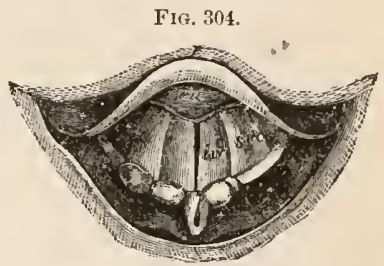

Condition of the Larynx during the emission of a high or aeute sound: $e$, epiglottis; $c u$, cushion of epiglottis; i. $v c$, true vocal cord; $s v c$, false vocal cord.

That the aperture of the glottis is greatly narrowed during the production of sounds, is easily made evident to one's self, by comparing the time occupied by an ordinary expiration, with that required for the passage of the same quantity of air during the sustenance of a vocal tone. Further, the size of the aperture is made to vary in accordance with the note which is being produced; of this, too, any one may convince himself, by comparing the times during which he can hold out a low and a high note; from which it will appear that the aperture of the glottis is so much narrowed in producing a high note, as to permit a far less rapid passage of air than is allowed when a low one is sounder. According to Kempelen no sound is elicited when the distance betwcen the Chordx Vocales exceeds $\frac{1}{1} 0$ th to $\frac{1}{1}$, th of an inch. 'The muscular movements concerned in the act of vocalization, appear to be called forth by the instrumentality of the motor fibres, partly derived from the Spinal Accessory nerve, which are contained in the Pueumogastric $(\$ 496)$.

694. We have now to inquire what is the operation of the Vocal Cords in the production of sounds: and in order to comprehend this, it is necessary to advert to the conditions under which tones are produced by instruments of various descriptions having some analogy with the Larynx. These are chiefly of three kinds: strings, flute-pipes, and reeds or tongues.-The Vocal Ligaments were long ago compared by Ferrein to vibrating strings; and at first sight there might seem a considerable analogy, the sounds which both

1 Wien. Acad Sitz.-ber., Bd. 1xii, p. 764, and Traité pratique des Maladies du Larrnx et du Pharynx, Paris, 1872.

2 On the Laryngoscope, Syd. Soc. Trans., 1861, pp. 37-8; see also The Laryngoscope, by George D. Gibh, ML.D, London, 1863. Murell Mackenzie, M.D., The Use of the Laryngoscope, 3d edit., 1869. 
producc being elevated by increased tension. This resemblance disappears, however, on more accurate comparison; for it may be easily ascertained by experiment, that no string so short as the vocal ligaments could give a clear tone at all to be compared in depth with that of the lowest notes of the human voice; and also, that the scale of changes produced by increased tension is fundamentally different. When strings of the same length but of different tensions are made the subject of comparison, it is found that the number of vibrations is in proportion to the square roots of the extending forces. Thus, if a string extended by a given weight produce a certain note, a string extencled by four times that weight will give a note in which the vibrations are twice as rapid; and this will be the octave of the other. If nine times the original weight be employed, the vibrations will be three times as rapid as those of the fundainental note, producing the twelfth above it. Now by fixing the larynx in such a manner that the vocal ligaments can be extended by a known weight, Müller has ascertained that the sounds produced by a variation of the extending force do not follow the same ratio; and therefore the condition of these ligaments cannot be simply that of vibrating cords. Further, although a cord of a certain length, which is adapted to give out a clear and distinct note equal in depth to the lowest of the human voice, may be made by increased tension to produce all the superior notes (which, in stringed instruments, are ordinarily obtained by shortening the strings), it does not follow that a short string, which, with molerate tension, naturally produces a high note, should be able, by a diminution of the tension, to give out a deep one; for, although this might be theoretically possible, yet it cannot be accomplished in practice; since the vibrations become irregular on account of the diminished elasticity. ${ }^{1}$ These considerations are in themsclves sufficient to destroy the supposed analogy; and to prove that the Chorda Vocales cannot be reduced to the same category with vibrating strings.

695. The next kind of instrument with which some analogy might be suspected, is the flute-pipe, in which the sound is produced by the vibration of an elastic column of air contained in the tube; and the pitch of the note is determined almost entirely by the length of the column, although slightly modifier by its diameter, and by the nature of the embouchure or mouth from which it issues. This is cremplified in the German Flute, and in the English Flute or Flageolet; in both of which instruments the acting length of the pipe is determined by the interval between the embouchure and the nearest of the side apertures; by opening or closing which, therefore, a modification of the tone is produced. In the Organ, of which the greater number of pipes are constructed upon this plan, there is a distinct pipe for every note; and their length increases in a regular scale. It is, in fact, with flute-pipes as with strings, - that a diminution in length causes an increase in the number of vibrations, in a sinply inverse proportion; so that of two pipes, one being half the length of the other, the shorter will give a tone which is the octave above the other, the vibrations of its column of air being twice as rapid. Now there is nothing in the form or dimensions of the columu of air between the larynx and the mouth, which ean be conceived to render it at all capable of such vibrations as are required to produce the tones of the Human voice; though there is some doubt whether it be not the agent in the musical tones of ecrtain Birds. The length that would be required in an open pipe to give the lowest $\mathrm{G}$ of the ordinary bass voice, is nearly six

1 Thus it would be impossible to produce good bass notes on the strings of a Violin, by diminishing their tension; the lengtl afforded by the Violoncello or Double Bass is requisite. 
feet; and the couditions necessary to produce the higher notes from it, are by no means those which we find to exist in the process of modulating the human voice.

696. We now come to the third class of instruments, in which sound is produced by the vibration of reeds or tongues; these may either possess elasticity in themselves, or be made elastic by tension. The "free" reeds of the Accordion, Concertina, Seraphine, Harmonium, etc., are examples of instruments of this character, in which the lamina vibrates in a sort of frame that allows the air to pass out on all sides of it through a narrow channel, thus increasing the strength of the blast; whilst in the Hautboy, Bassoon, etc., and in the Organ pipes of similar construction, the reed covers an aperture at the side of one end of a pipe. In the former kind, the sound is produced by the vibration of the tongue alone, and is regulated entirely by its length and elasticity; whilst in the latter its pitch is dependent upon this conjointly with the length of the tube, the column of air contaiued in which is thrown into simultaueous vibration. Some interesting researches on the effect produced on the pitch of a sound given by a reed through the union of it with a tube, have been made by M. W. Weber; and, as they are important in furnishing data by which the real uature of the vocal organ may be determined, their chief results will be here given.-I. The pitch of a reed may be lowered, but canuot be raised, by joining it to a tube. II. The sinking of the pitch of the reed thus produced is at the utmost not more than an octave. III. The fundamental note of the reed thus lowered may be raised again to its original pitch by a further lengthening of the tube, whilst by a further increase it is again lowered. Iv. The length of tube necessary to lower the pitch of the instrument to any given point, depends on the relation which exists between the frequency of the vibrations of the tongue of the reed, and those of the columu of air in the tube, each taken separately.From these data, aud from those of the preceding paragraph, it follows that if a wiud instrument can, by the prolongation of its tube, be made to yield tones of any depth in proportion to the length of the tube, it must be regarded as a flute-pipe; whilst if its pitch can only be lowered an octave or less (the embouchure remaining the same) by lengthening the tube, we may be certain that it is a reed instrument. The latter proves to be the case in regard to the Larynx.

697. It is evilent from the foregoing considerations, that the action of the Laryux has more analogy to that of reed instruments, than it has to that either of vibrating strings, or of flute-pipes; and though there would seem, at first sight, to be a marked difference in character between the vocal ligaments and the tongue of any reed instrument, this difference is really by no means considerable. In a reed, elasticity is a property of the tongue itself, when fixed at one end, the other vibrating freely; but by a membranous lamina, fixed in the same mauner, no tone would be produced. If such a lamina, however, be made elastic by a moderate degree of teusion, and be fixed in such a manner as to be advantageously acted on by a current of air, it will give a distinct tone. It is observed by Müller, that membranous tongues made elastic by tension may have either of three different forms: I. That of a band extended by a cord, and included between two firm plates, so that there is a cleft for the passage of air on each side of the tongue. II. The elastic membrane may be stretched over the half or any portion of the end of a short tube, the other part being occupied by a solid plate, between which and the elastic membrane a narrow fissure is left. III. Two elastic membranes may be extended across the mouth of a short tube, each covering a portion of the opening, and having a chink left open between them.-This last is evidently the form most allied to the Human Glottis; 
but it may be made to approximate still more elosely, by prolonging the membranes in a direction parallel to that of the eurrent of air, so that not merely their edges, but their whole planes shall be thrown into vibration. Unon this principle, a kind of artificial glottis has been constructed by Mr. Willis; the conditions of action and the effeets of whieh are so nearly allied to that of the real instrument, that the similar charaeter of the two ean seareely be doubted. The following is his deseription of it. "Let a wooden pipe be prepared of the form of Fig. 305, a, having a foot, c, like that of an

Fig. 305.
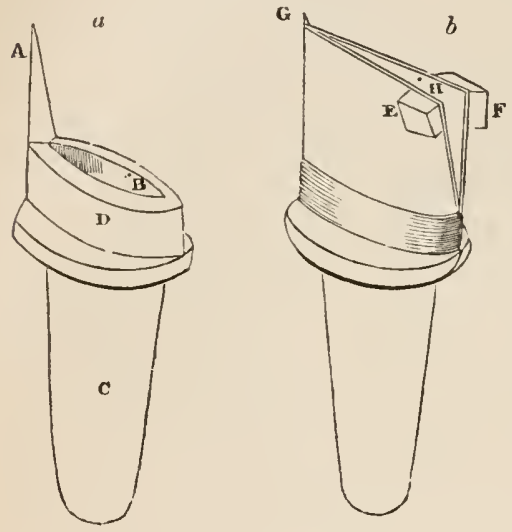

Artificial Glottis. organ-pipe, and an upper opening, long and narrow, as at $\mathrm{B}$, with a point, A, rising at one end of it. If a piece of leather, or, still better, of sheet India-rubber, be doubled round this point, and seeured by being bound round the pipe at D with strong thread, as in Fig. $305, b$, it will give us an artificial glottis with its upper edges $\mathrm{G}$ H, which may be made to vibrate or not, at pleasure, by inclining the planes of the edges. A couple of pieces of eork, E F, may be glued to the eorners, to make them more manageable. From this maehine various notes may be obtained, by stretching the edges in the direetion of their length $\mathbf{G} \mathbf{H}$; the notes rising in piteh with the increased tension, although the length of the vibrating edge is increased. It is true that a scale of notes equal in extent to that of the human voice cannot be obtained from erlges of leather; but this seale is much greater in Indiarubber than in leather, and the elastieity of them both is so much inferior to that of the vocal ligaments, that we may readily infer that the grcater seale of the latter is due to its greater elastic powers." By other experimenters the tissue forming the middle coat of the arteries has been used for this purpose, in the moist statc, with great sueeess; with this, the tissuc of the vocal ligament is nearly identical. It is worthy of remark that, in all such experiments, it is found that the two membranes may be thrown into vibration, when inclined towards each other in various degrees, or even when they are in parallel planes, and thcir edges only approximate; but that the least inclination from each other (whieh is the position the vocal ligaments have during the ordinary state of the glottis, § 693), eompletely prevents any sonorous vibrations from being proluced.

698. The pitch of the notes produced by memhranous tongues may be affected in several ways. Thus, an inerease in the strength of the blast, whiel has little influenee on metallie reeds, raises their pitch very considerably; and in this manner the note of a membranous reed may be raised by semitones, to as much as a fifth above the fundamcutal. The addition of a pipc has nearly the same effect on their pitch, as on that of mctallic reeds; but it cannot easily be determined with the same precision. Several different notes may be produeed with a pipe of the same length; but there is a certain length of the column of air, which is the one best adapted for eaeh tone. It has been recently asecrtained, moreover, that the length of the pipe prefixed to the reed has a eonsiderable influenee on its tone, rendering it deeper in proportion as it is prolonged, down to nearly the oetave of the fundamental 
note; but the pitch then suddenly rises again, as in the case of the tube placed bcyond the reed. The researches of Müller, however, have not succeeded in establishing any very definite relation between the lengtlis of the two tubes in regard to their influence on the pitch of the reed placed between them.

699. From the foregoing statements, it appears that the true theory of the Voice may now be considered as well established in regard to this essential particular, - that the sound is the result of the vibrations of the true vocal cords, which take place according to the same laws with those of metallic or other elastic tongues; and that the pitch of the notes is chiefly goverued by the tension of these lamina. ${ }^{1}$ With respect, however, to the mode and degree in which these tones are modified by the shape of the air-passages both above and below the larynx, by the force of the blast and by other concurrent circumstances, little is certainly known; but no doubt can be felt that these modifications are of great importance, when we observe the great amount of muscular action which takes place consentaneously with the production of vocal tones, and which scems designed to alter the length and tension of the various parts of the vocal tube, so that they may vibrate synchronously with the vocal cords. Thus, during the ascent of the voice from the deeper to the higher notes of the scale, we find the whole larynx undergoing an elcvation towards the base of the cranium, the thyroid cartilage being drawn up within the os hyoides, so as even to press on the epiglottis, at the same time the small space between the thyroid and cricoid cartilages, or crico-thyroid chink, is closed by the depression of the front of the former upon the latter ( $\$ 691$ ); the velum palati is depressed and curved forwards; and the tousils approach one another. The reverse of all these movements takes place during the descent of the voice.-A very important adjunct to the production of the higher notes has been pointed out by Müller, as being afforded by the modification in the space included between the two sides of the thyroid cartilage, which is effected by the thyro-arytenoidei. He had experimentally ascertained that the introduction of a hollow plug into the upper end of the pipe beneath his artificial larynx (and therefore just below the reed), by dininishing its aperture, produced a considerable elevation of the tone. The action may be imitated in the human larynx, when made the subject of experiment, by compressing the thyroid cartilage laterally; and in this manuer the natural voice cau be made to extend through a range that could otherwise be only reached by a falsetto. The influence of the prefixed and superadded tubes, in modifying the tones produced by the Human larynx, has been fonnd by Prof. Müller not to be at all comparable to that which they exercised over the artificial larynx; the reason of which difference does not seem very apparent. It appears, however, that there is a certain length of the prefixed tube-as there is a certain distance of the vibrating lamine, and a certain length or form of the tube above-which is most favorable to the production of each note; and the downward movement

1 It is considered, however, by Mr. Bishop (Cyclop. of A nat and Physiol., vol, iv, p. 1486), that the vocal apparatus combines the properties of a stretched cord, a usembranous pipe with a column of air vibrating in it, und a reed; and is the perfect type, of which these instruments are only imperfect adaptations. The Author is unable, however, to deduce from $\mathrm{Mr}$. Bishop's previous statcments the grounds upon which he makes this assertion; and does not understand how any instrument can combine the actions of strings and of tongues, the laws of whose vibration are so different. That the column of air in the air-passages is thrown into vibration consentaneously with the production of sound by the vocal cords, and intensifies that sound by reciprocation, can scarcely be doubted; but the reasons previously given appear to the Author sufficiont to disprove the notion that this vibration is at all more essential to the production of the vocal tone, than it is in the reed-pipe of an organ. 
of the whole vocal organ, which takes place when we are sounding deep notes, and its rise during the elevation of the tones, have been supposed to answer the purpose of making this adjustment in the length of the trachea; but this requires the supposition that the real length of the trachea is shortened whilst it appears extended-for which there seems no foundation. It is considered by $\mathrm{Mr}$. Wheatstone that the column of air in the trachea may divide itself into "harmonic lengths," and may produce a reciprocation of the tone given by the vocal ligaments $(\S 6+2)$; and in this manner he considers that the falsetto notes are to be explained. It may be added that the partial closing of the epiglottis seems to assist in the production of deep notes, just as the partial covering of the top of a short pipe fixed to a reed will lower its tone; and that something of this kind takes place during natural vocalization, would appear from the retraction and depression of the tongue, which accompany the lowering of the front of the head when the very lowest notes are being sounded. The experiments of Savart have shown, that a cavity which only responds to a shrill note, when its walls are firm aud dry, may be made to afford a great variety of lower tones, when its walls are moistened and relaxed in various degrees. This observation may probably be applied also to the trachea.

700. The falsetto is a peculiar modification of the voice, differing from the "chest-voice," not merely in the higher pitch of its notes, but also in their quality; its tones being less reedy, and more like the "harmonic notes " of stringed and wind instruments. In some individuals, the chestvoice passes by imperceptible gradations into the falsetto, whilst in others the transition is abrupt; and some persons can sound the same notes in the two different registers, these notes forming the upper part of the scale of the chest-voice, and the lower part of the falsetto. ${ }^{1}$ - With regard to the theory of the production of the falsetto-voice, there has been considerable difference of opinion amongst Physiologists; and it cannot be regarded as fully determined. By Magendie and Mayo it was maintained that these tones are produced by the vibration of the vocal cords along only part of their length, the rima glottidis being partly closed; and this explanation is consistent with the fact, that a far smaller quantity of air is required for sustaining a falsetto note, than for a note of the ordinary register, even though they should be of the same pitch. By Müller and Garcia," again, it is asserted that in the production of the falsetto notes, merely the thin border of the glottis vibrates, since the fibres of the lateral crico-arytenoid muscle remains inactive, whilst the lips of the glottis, stretched by the horizontal bundle of the thyro-arytenoid, come in contact by their edge alone, and offer little resistance to the air. In the chest-voice, on the contrary, the contraction of the lateral crico-arytenoids gives a rotatory movenent to the cartilages, and increases the depth of the surface of contact of the two ligaments, and it is to this circumstance that the peculiar amplitude of the notes of the chest-register is attributable. Mandl has demonstrated that both these doctrines are correct; and that in the production of falsetto notes, the

1 Thus a gentleman of the Author's aequaintance has a bass voice of $\mathrm{u}$ hursh, reedy charater, ranging from the $D$ below the buss elef to the $D$ above it ( $t$ wo oetaves); whilst his faketto, which is remarkable for its clearness and smoothness, ranges from the $A$ on the highest line of the bass elef to the $E$ in the highest space of the troble elef. Hence there are five notes eommon to the two registers, and the entire voice ranges through more than three octaves; but fronı want of a gradual passage from one to the other, this gentleman ean only sing buss parts with his ehest-voice, or alto purts with his fulsetto, the tenor senle extending above the range of ore, and below that of the other.

2 Proeecdings of the Royal Society, vol. vii, p. 408 
false or upper vocal cords apply themselves to the true rocal cords in front, behind, and to the sides, so that the middle portion of the true cords alone vibrates; whilst by the contraction of the arytenoidei muscles the cords are brought into close apposition ${ }^{1}$ with each other for part of their length, their thin elges only being in vibration in the remainder. It has been pointed out by Mr. Bishop (loc. cit.), that at the moment of transition from the "chest-voice" to the "falsetto-roice," the crico-thyroid chink, which was closed during the production of the highest note of the former, suddenly opens on the production of the lowest note of the latter; thus indicating that the vocal cords are relaxed in the passage from the one to the other, as must be the case, if, for the production of the same note, they be only put in vibration along a part of their length; so that it would not seem improbable that the cause of those differences in the mode of transition which have been already noticed, lies in the differences in the proportional amount of the vocal cords which is thus thrown out of use by the partial approxinution of the two lips of the rima glottidis. It is further remarked by $\mathrm{Mr}$. Bishop, that, in the passage from the chest to the falsetto-voice, the larynx descends from its previously elevated position, and gradually rises again with the ascending scale of falsetto notes; and he mentions a case of double fulsetto, in which a third register existed, and in which the relaxation of the vocal cords and the descent of the larynx were observed at its commencement, as at the commencement of the second or ordinary falsetto register." The pressure of the air within the Trachea during the production of voice is considerable. Cagniard de Latour observed in a man with a tracheal fistula, that the pressure indicated by a manometer when the patient called out at the top of his voice, was equal to a column of water 38 inches in lieight; when he spoke at his usual pitch, to one of 5 inches; and when he sang a high note, to one of about 8 inches. The deepest notes the human Larynx is capable of producing have about 80 double vibrations in the second, the highest about 992; the former occurring in bass, the latter in soprano voices. Donders ${ }^{3}$ gives the limits at 44 vibrations, corresponding to the $F$ of the lowest bass voice, and 1408 for the highest note corresponding to the highest $f^{\prime \prime \prime}$ of the soprano, which includes five octaves.

701. The various muscular actions which are employed in the production and regulation of the Voice, are called forth by an impulse which has been shown ( $\$ 537,5+2)$ to be really automatic in its operation, and to be completely under the influence of guiding sensations, although usually originating in a Volitional determination, or giving expression to Emotions or simply to Ideas. This, however, has been proved to be also true of all $\mathrm{V}_{\mathrm{O}}$ litional movements; so that the production of vocal tones constitutes no real exception. It may be safely affirmed that the simple utterance of sounds is in itself an Instinctive act; although the combination of these, whether into music or into articulate language, is a matter of acquirement, which is much more readily made by some individuals than by others. No definite tone

I See also Ch. Bataille, Nour. Rech. sur la Phonation, Paris, 1861.

2 An entirely different theory of the falsetto has been given, however, by $\mathbf{M}$ M. Pétrequin and Diday (Gazette Médicale, 1844), who consider that the falsetto notes are not produced by the vibration of the vocal cords, but are really "flute-notes," formed by the vibrations of the column of air to which the rima glotidis then serves as the embouchure. This view harnonizes well with some of the phenomena of the falsetto voice; but it is open to the objections already stated in rogurd to the flute theory generally. It may be added that some have attempted to show that the falsetto depends upon a peculiar action of the parts above the laryn ; but for this doctrine there is no foundation whatever.

3 Dr. Moore's Translution in Humphry and Turner's Journ. of Anat. and Plysiology, vol. i, 1867, p. 173. 
can be produced by a Voluntary effort, unless that tonc be present to the consciousness during an interval-however momentary-either as immediately produced by an act of Sensation, recalled by an act of Conception, or anticipated by an effort of the Imagination. When thus present, the Will can enable the muscles to assume the condition requisite to produce it; but under no other circumstances does this happen, except through the particular mode of discipline by which the congcnitally deaf may be trained to speak. Such persons are debarred from learning the use of "Voice in the ordinary manner; for the necessary guidance camnot be afforded, either through sensations of the present or conceptions of the past, and the imagination is entirely destitute of power to suggest that which has been in no shape experienced. But they may be taught to acquire an imperfect speech, by causing them to imitate particular muscular movements, which they may be made to see; being guided in the imitation of those movements, in the first place by watching their own performance of them in a looking-glass, and afterwards by attending to the muscular scusations which accompany them. Many instances, indeed, are on record, in which persons entirely deaf were enabled to carry on a conversation in the regular way; judging of what was said by the movements of the lips and tongue, which they had learned to connect with particular syllables; and regulating their own voices in reply, by theic voluntary power, guided in its exercise by their muscular sensations. ${ }^{1}$

\section{Of' Articulate Sounds.}

702. The larynx, as now described, is capable of producing those tones of which Voice fundamentally consists, and the sequence of which becomes Music; but Speech consists in the modification of the laryngeal tones, by other organs intervening between the Glottis and the Os externum, so as to produce those articulate sounds of which language is formed. It cannot be questioned that Music has its language; and that it is susceptible of expressing Emotional states of the mind (among those, at least, who have been accustomed to associate these with its varied modes) to even a higher degree than articulate speech. But it is incapable of addressing the Intellect, by conveying definite ideas of objects, properties, actions, etc., in any other way than by a kind of imitation, which may be compared to the signs used in hieroglyphic writing. These ideas it is the peculiar province of Articulate Language to convey; and we find that the vocal organ is adapted to form a large number of simple sounds, which may be readily combined into groups, forming words. The number of combinations which can be thus produced is so inexhaustible, that every language has its own peculiar scries; no difficulty being found in forming new ones to express new ideas. There is considerable diversity in different languages, even with regard to the use of the simplest of these combinations; some of them are more easy of formation than others, and these accordingly enter into the composition of all languages; whilst of the more difficult ones, some are employed in one language, some in another-no one language possessing them all. Without entering into any detailed account of the mechanism required to produce each of these simple sounds, a few general considerations will be offered in regard to the classification of them; and the peculiar defect of articulation termed Stammering will be briefly treated of.

703. Vocal sounds are divided into Vowets and Consonants; and the distinetive characters of these are usually considered to be, that the Vowels are produced by the Voice alone, whilst the sound of the Consonant is formed 
by some kind of interruption to the voice, so that they cannot be properly expressed unless conjoined with a vowel. The distinction may be nore correctly laid down, however, in this manner: the Vowel-sounds are continuous tones, modified by the form of the aperture through which they pass out; whilst in sounding Consonants the breath suffers a more or less complete interruption in its passage through parts anterior to the larynx. Hence the really simple Vowel-sounds are capable of prolongation during any time that the breath can sustain them; this is not the case, however, with the real Diphthongal sounds (of which it will presently appear that the English $i$ is one); whilst it is true of some Consonants. It seems to have been forgotten by many of those who have written upon this subject, that the laryngeal voice is not essential to the formation of either vowels or consonants; for all may be sounded in a whisper. It is very evident, therefore, that the larynx is not primarily concerned in their production; and this has been fully established by the following experiment. A flexible tube was introduced by M. Deleau through his nostril into the pharynx, and air was impelled by it into the fauces; then, closing the larynx, he threw the fauces into the different positions requisite for producing articulate sounds, when the air impelled through the tube became an audible whisper. The experiment was repeated, with this variation,-that the laryngeal sounds were allowed to pass into the fauces; and each articulated letter was then heard double, in a proper voice, and in a whisper. Observations ${ }^{1}$ made by Professor Moore upon those who from some cause are unable to transmit the air which has passed through the trachea and aperture of the glottis into the mouth, have demonstraterl (1) that the larynx is the seat of vocalization forthe vowels $a$ in all its forms, $i$ long, o long, and the pure aspirate; also for the short vowels which are to some extent explosive, as $i$ in sit, $o$ in not, and $e$ in err, though the last can also be made in the front part of the mouth. With the exception of the pure breathing and the short vowels all these sounds receive a finish in the pharynx, nose, and mouth. (2) That the vorrels $e$ long and oo, the diphthong eu, which is made up of these two elements, and all the consonants, are made above the larynx.

70t. That the Vowels are produced by simple modifications in the form of the external passages, is easily proved both by observation and by imitative experiment. When the mouth is opened wide, the tongue depressed, and the velum palati elevated, so as to give the freest possible exit to the voice, the vowel $a$ in its broadest form (as in $a h$ ) is sounded. ${ }^{2}$ On the other hand, if the oral aperture be contracted, the tongue being still depressed, the sound oo (the Continental $u$ ) is produced. If attention be paid to the state of the buceal cavity, during the pronunciation of the different vowel sounds, it will be found to undergo a great variety of modifications, arising from varieties of position of the tongue, the cheeks, the lips, and velum palati. The position of the tongue is, indeed, one of the primary conditions of the variation of the sound; for it may be easily ascertained that, by peculiar inflexions of this organ, a great diversity of rowel sounds may be produced, the other parts remaining the same. Still there is a certain position of all the parts, which is most finvorable to the formation of each of these sounds; but this could not be expressed without a lengthened description. The following table, slightly altered from that of Kempelen, expresses the relative dimensions of the buccal cavity and of the orifice for some of the principal of

1 See the interesting paper of Prof. E. M. Moore, New York Medical Record, vol. vii, 1872 , p. 49.

${ }^{2}$ This sound of the vowel $a$ is searcely used in our language, though very common in most of the Continental tongues; the nearest approaeh to it in English is the $a$ in fur; but this is a very pereeptible modification, tending towards au. 
these; the number 5 expressing the largest size, and the others in like proportion:

Vowel.

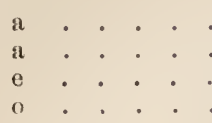

Sound.

as in $a h$

as in name

as in theme

as in cold.

as in cool.
Size of oral opening.

Size of buccal cavity.

These are the sounds of the five vowels, $a, e, i, o, u$, in most Continental languages; and it camnot but be admitted that the arrangement is a much more natural one than that of our own vowel series. The English $a$ has three distinct sounds capable of prolongation; - the true broad $a$ of $a h$, sligh tly modified in far; the $a$ of fate, corresponding to the $e$ of French; and the $a$ of fall, which should be really represented by au. This last is a simple sound, though commonly reckoned as al diphthong. In Kempelen's scale, the oral orifice required to produce it would be about 3 , and the size of the buccal cavity 4. ${ }^{2}$ On the other hand, the sonnd of the English $i$ camnot, like that of a true vowel, be prolonged ar libitum; it is in fact a sort of diphthong, resulting from the transition from a peculiar indefinite murmur to the sound of $e$, which takes its place when we attempt to continue it. The sound oy or oi, as in oil, is a good example of the true diphthong; being produced by the transition from an to $e$. In the same manner, the diphthong ou which is the same with ow in owl, is produced in the rapid transition from the broad $a$ of $a h$, to the oo of cool. - Iuch discussion has taken place as to the true character of $y$, when it commences a word, as in yet, yawl, etc., some having maintained that it is a consonant (for the very unsatisfactory reason that we are in the habit of enploying a rather than an, when we desire to prefix the indefinite article to such words), whilst other's regard it as a peculiar vowel. A slight attention to the position of the vocal organs during its pronunciation, makes it very clear that its sound in such words really corresponds with that of the long (English) $e$; the pronunciation of the word yawl being the same as that of Eaul, when the first sound is not prolonged, but rapidly transformed into the second. The sound of the letter $w$, moreover, is really of the vowel character, being formed in the rapid transition from oo to the succeeding vowel; thus wull might be spelt öoal. Miny similar difficulties night be removed, and the conformity between spoken and written language might be greatly increased (so as to render far more easy the acquirement of the former from the latter), by due attention to the state of the vocal organs in the production of the sinple sounds.

705. It is not very difficult to produce a tolerably good artificial imitation of the Vowel sounds. 'The method adopted by Heluholtz of combining the fundamental note with various harmonics for each vowel has been already referrel to $(\$ 640)$. By Kempelen it was accomplished by means of an India-rubler ball, with an orifice at each end, of which the lower one was attached to a reed: by modifying the form of the ball, the different vowels could he sounderl during the action of the reed. He also employed a short

1 The short vowel sounds, as $a$ in fut, $e$ in met, o in pot, ete, are not eapable of prolongation.

2 The node of making a determination of this kind may here be given, for the sake of example. If the broad $a$ be sounded, the mouth and fauces bring opened wide, and we contraet the oral orifice by denrees, at the same time slightly elevating the point of the tongue, we gradually come to the sound of au; by still further contraeting the orifice, and again depressing the tongue, we form oo. On the other hand, in sunding $e$, the tongue is raised nearly to the roof of the mouth; if it be depressed, without the position of the lips being ultered, au is given. 
funncl-tike tube, and obtained the different sounds by corering its wide opening to a greater or less extent. This last experiment has been repeated by Mr. Willis; who has also found that the vowcl sounds might be initated, by drawing out a long straight tube from the reed. In this experiment he arrived at a curious result: with a tube of a certain length, the series of vowels, $i, e, a, o, u$, was obtained by gradually drawing it out; but if the length was increased to a certain point, a further gradual increase would proluce the same sequence in an inverted order, $u, o, a, e, i$; a still further increase would produce a return to the first scale, and so on. When the pitch of the reed was high, and the pipe short, it was found that the vowels $o$ and $u$ could not be distinctly formed,- - the proper tone being injured by the clongation of the pipe necessary to produce them; and this, Mr. Willis reniarks, is exactly the case in the Human voice, most singers bcing unable to pronounce $u$ and $o$ upon their lighest notes.

706. The most natural primary division of the Consonants, is into those which require a total stoppage of the breath at the moment previons to their being pronounced, and which, therefore, cannot be prolonged; and those in pronouncing which the interruption is partial, and which can, like the vowel sounds, be prolonged ad libitum. The former have received the designation - of explosive; and the latter of continuous.-In pronouncing the explosive conconants, the posterior nares arc completely closed, so that the exit of air through the nose is altogether prevented; and the current may be checked in the mouth in three ways, - by the approximation of the lips, - by the approximation of the point of the tonguc to the front of the palate, - and by the approximation of the middle of the tongue to the arch of the palate. In the first of these modes we pronounce the letters $b$ and $p$; in the second $d$ and $t$; in the third, the hard $g$ and $k$. The difference between $b, d$, and $g$, on the one hand, and $p, t$, and $k,{ }^{1}$ on the other, seems to depend on this,that in the former group the approximating surfaces are larger, and the breath is sent through them more strongly at the moment of opening than in the latter. The continuous consonants may be again subdivided, according to the degree of freedom with which the air is allowed to make its exit, and the compression which it consequently experiences. I. The first class includes those in which no passage of air takes place through the nose, and in which the parts of the mouth that produce the sound are nearly approximated together, so that the compression is considerable. This is the case with $v$ and $f$, which are produced by approximating the upper incisors to the lower lip, and which stand in nearly the same relation to cach other as that which exists between $d$ and $t$, or $b$ and $p$. The sibilant sounds, $z$ and $s$, also stand in a similar relation to each other; they are produced by the passage of air between the point of the tongue and the front of the palate, the teeth being at the same time nearly closed. The simple sound sh is formed by narrowing the channel between the dorsum of the tongue and the palate; the former being elevated towards the latter through a considerable part of its length. If, in sounding $s$, we raise the point of the tongue a very little, so as to touch the palate, the sound of $t$ is evolved; and in the same manner $d$ is produced from $z$. This class also includes the th; which, being a perfectly simple sound, ought to be cxpressed by a single letter, as in Greek, instead of by two, whose combination does not really produce anything like it. For producing this sound, the point of the tongue is applied to the back . of the incisors, or to the front of the palate, as in sounding $t ;{ }^{2}$ but whilst key.

1 For the sake of proper comparison; this letter should be sounded not as kny but

" Hence it is easy to understand the substitution of $t$ or $d$, for the English $t$, by foreigners. 
there is complete contact of the tip, the air is allowed to pass out around it.II. In the second class of continuous consonants, including the letter's $m, n$, $l$, and $r$, the nostrils are not closed; and the air thus undergoes very little compression, even though the passage of air through the oral cavity is almost or completely checked. In pronouncing $m$ and $n$, the breath passes through the nose alone; and the difference of the sound of these two letters must be due to the variation in the form of the cavity of the mouth, which acts by resonance. The letter $m$ is a labial, like $b$; but in the former the nasal passage is open, the mouth remaining closed, whilst in the latter the nose is entirely closed, and the sound is formed at the moment of opening the mouth ; hence the passage from $m$ to $b$ is made with great facility. The same correspondence exists between $n$ and $t$, or $n$ and $g$ (the particular part of the tongue approximated to the palate not being of much consequence in the pronullciation of $n$ ); and hence it is that the transition from $n$ to $t$, or from $n$ to $g$, is so easy that the combinations $n t$ and $n g$ are found abundantly in most languages. The sound of $l$ is produced by bringing the tip of the tongue into contact with the palate, and allowing the air to escape around it, at the same time that a vocal tone is generated in the larynx; it differs therefore from th in the position at which the obstruction is interposed, as well as in the slight degree of compression of the air which it involves. The sound of the letter $r$ depends on an absolute vibration of the point of the tongue, in a narrow current of air forced between the tongue itself and the palate. ${ }^{1}$ III. The sounds of the third class are scarcely to be termed consonants, since they are merely aspirctions caused by an increased force of breath. These are $h$, and the guttural $c h^{2}$ of most foreign languages (the Greek $\%$ ). The first is a simple aspiration; the second an aspiration modified by the elevation of the tongue, causing a slight obstruction to the passage of air, and an increased resonance in the back of the mouth. The sound would become either $g$ or $k$, if the tongue, whilst it is being produced, were carried up to touch the palate. ${ }^{3}$

707. These distinctions come to be of much importance, when we apply ourselves to the treatment of defects of articulation. Great as is the number of muscles employed in the production of definite vocal sounds, the number is much greater for those of articulate language; and the varieties of combination which we are continually forming unconsciously to ourselves, would not be suspected without a minute analysis of the separate actions. Thus, when we utter the explosive sounds, we check the passage of air through the posterior nares in the very act of articulating the letter; and yct this important movement commonly passes unobserved. - We must regarl the power of forming the several articulate sounds which have been adverted to, and their simple combinations, as so far resulting from intuition, that it ean in general be more readily acquired by early practice than other actions of the same complexity; but we find that among different Races of Men, there exist tendencies to the production of different sounds, which, though doubtless influenced in great degree by early habit (since we find that children, when first learning to speak, form their habits of vocalization in great de-

1 Donders describes no less than four modes in which the letter $r$ can be made. 1 , by the lips; 2 , by the tongue; 3 , by the uvula; and 4 , by some part bet ween this and the chordac vocules. The $r$ as ordinarily but distinctly pronounced, is produced by about thirty vibrations of the tongue in the second. The uvular $r$ by from nineteen to twenty-eirht.

2 The English $c h$ is merely a combination of $t$ with $s h$; thus chime might be spelt tshime.

3 The general classification froposed by Dr. Marshall Hall has been here adopted, with some moditication as to the details. 
gree in aeeordanee with the examples amidst which they are placed), are certainly also dependent in part upon eongenital eonstitution; as we often see in the ease of children anong ourselves, who grow up with certain peculiarities of pronmeiation, not thus derived from imitation, of which they do not seem able to divest themselves.

708. It is in want of power to combine the different museular actions coneerned in vocalization, that the defeet termed Stammering essentially consists. Many theories regarding the nature of this impediment have been proposed; and there can be little doubt that it may be attributed to a great variety of exciting causes. A disordered action of the nervous centres must, however, be regarded as the proximate cause; though this may be (to use the language of Dr. M. Hall) either of centric or of excentric origin,that is, it may result from a morbid condition of the ganglionie centre, or from an abnormal impression conveyed through its afferent nerves. When of eentrie origin (and this is probably the most general case), the phenomena of Stammering and Chorea have a close analngy to each other; in faet, stammering is frequently one of the modes in which the disordered eondition of the nervous system in Chorea manifests itself.-It is in the pronunciation of the Consonants of the explosive elass, that the stammerer experiences the greatest difficulty. The total interruption to the breath which they occasion, frequently beeomes quite spasmodic ; ${ }^{1}$ and the whole frame is thrown into the most distressing semi-convulsive movement, until relieved by expiration. In the pronunciation of the contimuous Consonants of the first elass, the stammerer usually prolongs them by a spasmodie eontiuuance of the same action; and there is in eonsequenee, an inmpeded, but not a suspended respiration. The same is the case with the $l$ and $r$ in the seeond class. In pronouneing the $m$ and $n$, on the other hand, as well as the aspirates and rowels, it is sometimes observed that the stammerer prolongs the sound by a full and exhausting expiration. In all these cases, then, it seems as if the museular sense resulting from each particular eombination of actions, became the stimulus to the involuntary prolongation of that state. It is possible that the defect may result, in some instanees, from malformation of the parts about the fauces, producing an abnormal stimulus of this kind in some particular positions of the organ; and such cases may be really benefited by an operation for the removal of these parts. But the effect of sueh an operation is eertainly exerted in most cases through the mind of the patient; the expectation of benefit from it tending to improve his command over the museles of voealization, whieh Emotional excitement always impairs; and the improvement is usually proportional to the eonfidenee which he has been led to feel in the result. The siightest disturbance of the feelings is suffieient in most stammerers to induee a eomplete perturbation of the roeal powers; the very fear that stammering will occur, particularly under eircumstances which render it peeuliarly annoying, is often sufficient to bring it on in a predisposed subject; and the tendency to consensual imitation sometimes occasions stammering, in individuals (especially children) who never show the slightest tendeney to it except when they witness the diffienlty in others.

709. The method proposed by Dr. Arnott for the prevention of Stammering, consists in the conneetion of all the words by a voeal intonation, in sueh a manner that there shall never be an entire stoppage of the breath. It is justly remarked by Müller, however, that although this plan may afford some benefit, it eannot do everything; since the main impediment oeeurs in

1 By Dr. Arnott this interruption is represented as taking place in the larynx: that such is not usually the case, the Author believes that a little attention to the ordinary phenomena of voice will satisfactorily prove. 
the middle of words themselves. One important remerlial means, on which too much stress cannot be laid, is to study carefully the mechanism of the articulation of the difficult letters, and to practice their pronunciation repeatedly, slowly, and analytically. The patient would at first do well to practice sentences from which the explosive consonants are omitted; his chief difficulty, arising from the spasmodic suspension of the expiratory movement, being thus avoided. Having mastered these, he may pass on to others, in which the difficult letters are sparingly introduced; and may finally accustom himself to the use of ordinary language. One of the chief points to be aimed at, is to make the patient feel that he has command over his muscles of articulation; and this is best done, by gradually leading him from that which he finds he can do, to that which he fears lie cannot. The fact that stammering people are able to sing their words better than to sperk. them, has been usnally explained on the supposition that, in singing, the glottis is kept open, so that there is less liability to spasmodic action; if, however, as here maintained, the spasmodic action is not in the larynx, but in the velum palati and the muscles of articulation, the difference must be due to the direction of the attention rather to the muscles of the larynx than to those of the mouth.-One of the most important objects to be aimed at in the treatment of stammering, consists in the prevention of all Emotional disturbance in connection with the act of Speech; and this requires the exercise of the voluntary power over the direction of the thoughts, in the following morles: 1. To reduce mental emotion, by a daily, hourly, habit of abstracting the mind from the subject of stammering, both while speaking, and at other times. 2. To avoid exciting mental emotion by attempting unnecessarily to read or speak, when the individual is conscious that he shall not be able to perform these actions without great distress. 3. To elude mental emotion, by taking advantage of any little artifice to escape from stammering, so long as the artifice continues to be a successful one.-Much may frequently be done, also, by constitutional treatment, adapted to improve the general vigor of the nervous system. ${ }^{1}$

\section{CHA P'TER X VII.}

ON THE INFLUENCE OF THE NERYOUS SYSTEM ON THE ORGANIC FUNCTIONS.

710. Or the modes in which the Nervons System influences the Organic Functions, a great part have been already considered; for it has been shown to be concerned in providing the merhanieal conditions, either immediate or remote, under which alone these functions can be performed ; so that, when its activity ceases, they cannot be inuch longer maintained. But the influence of the Nervous System is not alone exerter upon the motor or eontractile tissues of the body ; for there is good evidence that it has a direct operattion upon the molecular changes which constitute the functions of Nutrition, Secretion, ete.; and this view may be admitted to its fullest extent, without

1 See on the subject of Stammering and its Treatment, a nsefal pamphtet under this title, by Bace. II ed. Oxon., 1850; and $\mathrm{Mr}$. Bishop's treatise, On Articulate Sounds, and on the Causes and Cures of Impediments of 'speech. 
our being thereby led to regard the processes in question as depcndent upon Nervous agencr, - a doctrine for which there seems no valid fommlation. Throughout the animal body, it may be observed that, the more Vegretative the nature of any function, the less is it under the influence of the Nervous System, save where that influence is required to bring it into harmony with other functions, sometimes by exciting, sometimes by checking, and sometimes by otherwise modifying them, very much in the way that a rider guides and controls the movements of his horse.- It is evident that this influence must be principally exerted through the Sympathetic or Tisceral system of nerves, since a large proportion of the organs on which it operates are supplied by no other; and hence this apparatus has been commonly designated the "Nervous system of organic life," as distinguishing it from the Cerebro-spinal system, which is the "Nervous system of animal life." There is, however, no such parallelism between them as this designation would imply; for whilst the operations of the Cerebro-Spinal system essentially constitute the Animal life of the individual, those of the Sympathetic cannot be fairly said to do more than control and direct those of Nutrition and Secretion.- $\mathrm{W}$ e shall now inquire into the structure and relations of the Sympathetic System; and shall then exanine the nature of the actions which there seems reason to attribute to it.

711. Sympathetic Nervous System.-That collection of scattered but mutually connected ganglia and nerves, of which this apparatus is made up, may be rangerl under the following groups: 1. The isolated ganglia and nerves in immediate connection with the Viscera, which seem to be the chief centres of the system; these form three principal plexuses, the Cardiac, the Solar, and the Hypogastric. 2. The double chain of Prevertebral ganglia, with connecting cords, which lies in front of the Vertebral column, and which communicates on the one hand with the Spinal nerves, and on the other with the before-named plexuses. Under this head we should probably rank the minute Cranial ganghia, which are situated in the neighborbood of the Orgaus of Sense, and in imnediate connection with the branches of the Fifth pair that proceed to them; these are the ophthalmic, otic, spheno palritine, and submaxillary ganglia. 3. The ganglia on the posterior roots of the Spinal nerves; under which head we are probably to rank not only the Gaserian ganglion of the Fifth pair, but also the ganglia near the roots of the Pneumogastric and Glosso-pharyngeal nerves. - The trunks of the Sympathetic are male up of different orders of fibres; some of these having their central termination in the vesicular matter of the Sympathetic ganglia themselves, whilst others are derived from the Cerebro-spinal system. The former, which are all of the "gelatinous kind," are most abundant in the great Visceral plexuses; but they may be traced from the prevertebral ganglia into the Spinal nerves, part of them proceeding to the ganglia on their posterior roots (whence fibres are given off that mingle with their spinal fibres), whilst other parts enter the anterior roots and mingle with their fibres. On the other hand, the latter, which are of the "tubular" kind, are derived by the same cords of communication (these being commonly termed the "roots" of the Sympathetic, but being really commissural hands that bring the two systems into connection) from both roots of the Sipinal nerves, and pass through the prevertebral ganglia into the Sympathetic system, without undergoing any ostensible change. Thus it appears that the Cerebro-spinal and

1 It must be carefully borne in mind, that, although the proper Sympathotic fibres are all "gelatinous," yet that the Cerebro-Spinal system contains "crelutinous" fibres of it: own, which are very abundant in some parts. An account of Kuttner's and Remak's views on the structural relations of the prevertebral ganglia, will be funnd in the Medico-Chirurgical Review, 1868. 
Sympathetic systems interpenetrate one another; each having its own series of ganglionic centres, and of trunks connected with them ; but each system transmitting its fibres into the trunks of the other, so as to be peripherally distributed with their ramifications. Giannuzzi ${ }^{1}$ has made a special study of the rami communicantes of the great sympathetic cord in Mammals by the Wallerian method-that is, by dividing particular roots of the spinal cord, and after the lapse of a certain period examining the rami communicantes microscopically with the objcct of determining whether any, and if any, what amount of degeneration of the nerve-fibres had taken place. The results of his observations are that, with the exception of a few fibres, the fibres of the rami communicautes are entirely derived from the spinal cord, or at least have their nutritive centres in the posterior spinal ganglia, and in the spinal cord. The few exceptional fibres are characterized by their great delicacy and the want of double contours, and pass from the sympathetic ganglia through the rami to the roots of the spinal cord. They may be entirely absent. The number of motor fibres sent by the spinal cord to the Sympathetic is greater than the number of sensory fibres. Giannuzzi has also ascertained that the trophic influence of the spinal cord extends along the nerves derived from the spinal cord after they have traversed a sympathetic ganglion. Arnd ${ }^{2}$ describes the ganglia of the Srmpathetic as composed of an apparently homogeneous matrix, through which granules giving off from 2 to 4 fine processes, are distributed. According to Fräntzel, ${ }^{3}$ the cells of the sympathetic and of the spinal ganglia are invested by a capsule of connective tissue formed by an expansion of the neurilenma of the nerves, which is lined by a layer of parement epithelium. Beale, Arnold, and others describe a single straight fibre emerging from the nucleus of each sympathetic cell ( $\$ 444)$, and a spiral fibre that appears to be in connection with the surface of the cell, and which, after winding for a few turns round the straight fibre, pursues an opposite direction; such cells must be regarded as bipolar. There is some doubt whether the cells of the spinal ganglia present this structure or not; Schwalbe and Courvoisier ${ }^{5}$ having only been able to discover one fibre originating from each cell ; the cells of these ganglia are therefore unipolar.

712. The connections and distribution of the principal trunks and branches of the Sympathetic system may be concisely stated as follows: In the cervical portion of the sympathetic the presence of the following nerve-fibres appears to have heen satisfactorily demonstrated. ${ }^{6} \quad 1$. Vaso-motor nerves for the corresponding half of the head, that probably arise from a centrc situated in the medulla oblongata, which governs the tone not only of these vessels, but of the entire vascular system throughout the body. 'This ganglionic centre is constantly in action. Its influence can be abolished by section of the spinal cord in the cervical region, and may be reflectorially depressed, as Cyon and Ludwig have shown, by irritation of the depressor nerve, which is a centripetal branch of the vagus ( $\$ \$ 242,244,245)$. A local depression of its influence may be also reftectorially induced by irritation of the sensory nerve supplying any part, whikt its action may be excited through the agency of carbonic acid. 2. Fibres distributed to the dilator pupillae, that probably arise fiom the oculo-pupillary or cilio-spinal centre, seated in the

1 Ricerche esequite nel erabinetto di Fisiologia della Ri. Universita di Siena, 1872, p. 51. See also Mayre, Wien. Akad. Sit\%-ber., Bd. Ixvi, Abth. 3, p. 52.

2 Sichultze's Archiv f. Mic. Anat., Bd. x, p. 208.

3 Virclow's Archiv, 1867, , 549.

6 lbid, Bd. ii, p 18, and Bd. iv, p 125.

6 See Hermann, Grundriss der Physiokgrie, 1867, p. 424.

7 Löven, Ludwig's Arbeiten aus der l'liysiolog. Anstalt zu Leipzig, 1861, p. 1. 
medulla oblongata,-a centre that, like the preceding, is in a constant state of activity, and is influenced in a manner similar to the respiratory and vasomctor centres; hence in dyspnoea the pupil dilates, and the vessels distributed to the eve contract. 3. Secretory fibres for the salivary glands, irritation of which contracts the ressels and modifies the characters of the secretion, whilst section is followed by dilatation of the vessels. 4. Fibres possessing an accelerating, and others exerting a depressing influence on the heart. The former, according to MM. E. and M. Cyon, energe by the third branch of the inferior cervical ganglion; whilst the first and second branches constitute the roots of the depressor nerve. 5. Fibres passing to the central cerebro-spinal organs, which reflectorially stimulate the nerves retarding the action of the heart. As regards the thoracic portion of the sympathetic trunk, Otto Nasse ${ }^{1}$ and Bernard only obtained negative results from its division or excitation. The superior thoracic ganglion gives accelerator fibres to the heart. The plexus cardiacus, arising from the thoracic sympathetic, also receives branches from the vagus and the depressor nerves. 'The splanchnic nerves, which arise from the lower six thoracic ganglia, contain fibres exerting an inhibitory, and others exerting an exciting influence ${ }^{2}$ over the movements of the intestine; secretory fibres acting on the kidneys (Beruard); vaso-motor nerves influencing the calibre of the whole abdominal system of vessels; ${ }^{3}$ and lastly, centripetal fibres exerting reflectorially an inhibitory influence on the action of the heart. The abdominal portion gives off numerous branches which aid in forming the coliac, mesenteric, renal, suprarenal, spermatic, and hypogastric plexuses, and these, when irritated, occasion movements in the parts to which they are distributed, as the intestine (small and lar@e), hladder, ureters, uterus, vesiculæ seminales, spleen, etc., partly by their direct action on the muscular fibres, partly by modifying the supply of blood to them." Of the ophthalmic ganglion $(\$ 490)$, the branches are distributed, not merely to the iris, whose radiating fibres are made to contract through their instrumentality, as already explained ( $\$ 618$ ); but also to the vascular apparatus of the eyeball, and especially to the ciliary processes, which seem to possess a sort of erectile character. The otic ganglion, which communicates with the third division of the Fifth pair and with the Glossopharyngeal, may be considered, from the distribution of most of its branches to the teusor tympani and circumflexus palati muscles, as ministering to the exercise of the sense of Hearing, in somewhat the same mode that the ophthalnic ganglion seems to do to that of vision (\$645). The spheno-palatine ganglion (Fig. 259, $f$ ), whose connections are with the Fifth and the Facial nerves, seems in like manner to minister, by the distribution of its branches on the mucous niembrane of the nasal cavity and the palate, to the senses of Smell and Taste. It has been shown by Prévost ${ }^{5}$ to be purely sensory in its function. Of the submaxillary ganglion, which also is chiefly connected with the Fifth and the Facial nerves, the branches proceerl almost entirely to the Submaxillary gland, and according to Pflüger ${ }^{6}$ and Palladino, ${ }^{7}$ terminate in the gland-cells. 6. The fibres which arise from the ganglia on the posterior roots of the Spinal nerves (if really belonging to the Sympathetic sys-

1 Essays on the Physiology of the Movements of the Intestine. Pampliet, 1866.

2 Pflüger, Nasse, loc. cit. The splanchnic nerves (Bidder, Reichert, and DuboisReymond's Archiv, 1869, p. 472) in the cat contain three kinds of fibres, viz., 1 , Brnad medullated fibres, often collected into fasciculi; 2 , Slender medullated fibres; 3 , Slender Remak's fibres.

3 v. Bezold, Untersuch. passim Cyon, and Ludwig, Arbeiten, etc , 1867.

$\checkmark$ See Nasse, loc. cit.

5 Brown-Séquard's Archives de Physiologie. tom. i, p 207.

6 Loc. cit. $\quad{ }_{7}^{7}$ Abstract in Centralblatt, 1873, p. 782. 
tem) must be distributed along with the branches proceeding from the trunks which they help to form; as must also a part of those fibres which are sent from the proper Sympathetic ganglia into the roots of the same nerves, a large part of them, however, being distributed upon the bloodvessels of the Spinal Cord itself.

713. If, then, it be inquired what inferences we are entitled to draw respecting the functions of the Sympathetic system of nerves, from our knowledge of its Anatomical distribution, we are at once justified in replying that the muscular tissue which directly enters into the formation of the vessels, and especially of the smaller arteries, is supplied essentially from this source. In accordance with this, it is found that excitation of the sympathetic nervous ganglia, whether by direct or reflex irritation, leads to contraction of the ressels, and consequent diminution in the activity of all organic processes, such as secretion, nutrition, growth, and devclopment; their paralysis, as is well seen in cases of section of the cervical sympathetic, disclosing itself by the establishment of the opposite conditions. Again, it is certain that a large proportion of the Muscular apparatus which directly ministers to the Organic functions, - that, namely, which surrounds the alimentary canal from the stomach downwards, with the gland-ducts which open into it, and that, also, which forms the walls of the bladder and uterus, of ureters and Fallopian tubes-receives no other nervous supply; and, consequently, that of whatever motor influence these parts may receive from Mental states or from excitation not applied to themselves, this system of nerves must be the channel. The same may be said, too, in regard to that greater portion of the Glandular apparatus, which is exclusively supplied by the Sympathetic nerve, and chiefly by the plexuses that embrace its bloodvessels; since any such alterations in its rate of activity, or iir the character of its products, as depend upon conditions of Mind, can be brought about through no other instrumentality. - It is not a little remarkable, howerer, that those portions of the Muscular apparatus of Organic life, which most obviously exhibit in their action the influence of the Nervous system, both in their respondence to emotional states and in their "sympathy" with disturbance in other functions, - namely, the Heart and the stomach,- - derive a considerable part of their nervous supply directly from the Cerebro-spinal system. And it is still more significant, that most of those Glands whose function is occasional, and whose states of activity are most obviously influenced by affections of the Mind, are specially supplicd by Cerebro-spinal nerves, in addition to the Sympathetic plexuses which they receive on the walls of their bloodvessels: thus, the Lachrymal and Salivary glands are supplied with branches of the Fifth and Facial nerves; and the Mammary glands by branches of the Intercostals. It cannot but be deemed highly probable, then, from this circumstance alone, that the inflnence of mental states upon the function of Secretion may be exerted through the nerves of the Cerebro-spinal system, as well as through those of the Sympathetic.

714. It aust be in virtue of the conncetions of the Sympathetic with the Cerebro-spinal system, that the parts which are solely supplied with nerves from the former, are calpable of transmittingsensory impressions to the Sensorium. It is true that, under ordinary cireumstances, these parts are insensible: that is, inpressions marle upon them do not travel onwaris through the Spinal (Cord to the Eneephalon; but their sensibility is acutely manifested in morbirl states, in which the impressions seem to be propagated further tham usial, in virtue of their greater potency. That it is the office of the ganglia on the roots of the Spinal nerves to "cut off" sensation," that is, to prevent the further transmission of sensory impressions, is an old doetrine; and there seems much reason to believe that this may be effected by 
the free conmunication between onc ganglion-cell and another, which is established through the vesicular substance of a ganglion, so that the whole force of ordinary impressions on the nerve-fibres is lost in diffusion anong the rest of their contents. The same principle seens to apply to the motor fibres; for there are cases which show that when fibres obviously belonging to Cerebro-spinal nerves pass through Sympathetic ganglia, they do not so rapidly or so surely transmit motor impulses, as when they have no such relation to ganglia. ${ }^{\text {. }}$

715. The effects of section and of galvanization of the cut extremities of the sympathetic nerve in the neck, have been earefully investigated by Bernard, Wraller, Brown-Séquard, ${ }^{2}$ and others. On dividing the nerve, the bloodvessels of that side of the hear dilate, and with the freer current of blood which is then established through the eapillaries, an increase of the vital properties of all the tissues on the same side of the head is associated. Thus the sensibility of the retina for light appears to be augmented, whence follow contraction of the pupil, retraction of the globe of the eye, partial closure of the eyelid, and projection of the membrana nictitans (where present) with increased flow of tears. The temperature and sensibility of the skin, and the cutaneous secretions, are also much increased,-the temperature in some of Dr. Waller's experiments ${ }^{3}$ rising as much as $18^{\circ}$ Fahr., and the skin in some of M. Bernard's being bathed with perspiration. 'The color of the renous blood assumes a brighter hue, and its coagulation is more rapid. The muscles respond more readily to weak, and more energetically to strong stimuli, and retain their irritability longer; rigor mortis consequently sets in more slowly and endures for a longer period; hypertrophy of the facial bones has been noticed by Sehiff, and Benedikt has observed a similar result to oecur in certain muscles; whilst it further appears from Suellen's researches ${ }^{5}$ that even the inflammatory and reparative processes, as the effusion of serum, the formation of pus, the absorption of effused blood, and the cicatrization of wounds, take place with very much greater energy and rapidity. On the contrary, when the upper cut extremity of the nerve is galvanized, all these phenomena are reversed; for now, as a consequence of the contraction of the bloodvessels and the diminished supply of blood which ensues, the vital properties of the tissues are diminished, the pupil dilates, the eyelid is widely opened, the temperature and sensibility of the parts decrease, the contractile power of the muscles is less strongly marked, their normal galvanic current is feeble, and eadaveric rigidity sets in quickly and soon passes off, putrefaction immediately supervening. The effects produced by section of the Sympathetic in the neck are much more strongly marked when the cerveal ganglia are destroyed, and Bernard ${ }^{6}$ states that closely similar results follow section of the Sympathetic nerves distributed to the vessels of the extremities. In these latter experiments he found that division of the roots of the spinal nerves within the spinal canal, though abolishing sensation and motion in the limb beyond, yet produced no effect upon .its temperature; whilst if after such section the sciatic or brachial nerves were divided, an immediate exaltation of temperature ensued; clearly showing that the nerve-fibres devoted to the conduction of sensory and motor impulses issuing from the spinal cord had been joined by a third set of fibres,

1 See Messrs. Kirkes and Paget's Handbook of Physiology, p. 421).

2 See Leetures on the Central Nervous System, 1860, lectures ix and $\mathbf{x}$.

3 Comptes Rendus, 1853.

4 Electro-therapie, Wien, $1868, \mathrm{p} 88$.

5 Henle and Meissner's Bericht, 1857, p. 373.

6 Sce Gazette Hebdomad., Auût, 1862 ; Comptes Rendus, vol. ii, 1862 ; and Journal de la Physiologie, vol. v. 
either proceeding directly from the sympathetic ganglia, or through and beyond these from some part of the cerebro-spinal system, the office of which is to preside over the contraction of the vessels and calorification. A further corroboration of this view was obtained by experiments in which the lumbar gauglia of the Sympathetic were destroyed, when the vascular changes and the incrcase of temperature in the lower limb were observed without the occurrence of any paralysis. Dr. Waller has shown that some of the results of irritation of the cervical portion of the sympathetic may be made apparent during life by pressure of the point of the finger behind the ramus of the jaw, though they are associated with other phenomena proceeding from irritation of the pneumogastric. The more important symptoms observed were dyspnoa, cardiac and gastric disturbance, tingling and heat of the ear, lasting for upwards of half an hour, and in one instance dilatation followed by contraction of the pupil. Dr. Waller ${ }^{2}$ has also ingeniously shown the effects of paralysis of the vaso-motor nerves of the arm in the living body, by applying a freezing mixture to the ulnar nerve at the elbow; the effect in the first instance being to produce a fall of temperature equal to about $0.5^{\circ} \mathrm{C}$. in the two inner fingers; but as the vaso-motor nerves became paralyzed, the temperature gradually rose until it attained a height of from $5^{\circ}$ to $6^{\circ}$ C. above that of the outer fingers; the difference between the outer and inner fingers appeared to be partially attributable to a decrease in the temperature of the former as well as to an increase in that of the latter, owing to the diversion of part of the blood of the radial into the ulnar artery. The effects of percutaneous excitation of the sympathetics in man by means of electricity are very slight, consisting only, according to MII. Eulenberg and Guttman, ${ }^{3}$ of an almost inappreciable dilatation of the pupil, and a lowering of the frequency of the pulse. As the smaller vessels contract, there is probably an increase of pressure in the larger ones, but it must be remembered tliat it is difficult to irritate the ccrvical Sympathetic without coincidentally exciting the vagus-depressor nerve of Cyon, the laryngeal norve, and descendens noni, which may materially influence the result. The vaso-motor nerves of the upper extremity do not proceed from the spinal cord, in common with the sensori-motor nerves forming the brachial plexus, but issue from it at a much lower point, namely, between the third and seventh dorsal nerves. The vaso-motor ncrves for the lower extrcmities spring from the adjoining dorsal roots, and not from those which form the sciatic plexus. The chief vaso-motor of the body which supplies all the vessels distributed to the viscera is the splanclnic nerve, and by reason of the large quantity of blood these vessels can contain the splanchnic nerve plays the principal part in the distribution of the blood generally in the body. ${ }^{4}$ If it be irritated, the blood is driven in large quantity into the vessels of the head and limbs, whilst if it be paralyzed the blood accumulates in the viscera, and the lead and extremities are rendered an:emic. Burge ${ }^{5}$ maintains that the small arteries throughout the body can be made to contract by electrical irritation of the pedunculus cercbri, which, therefore, he regarls as the centre of the rasomotor nerves, but there can now be no question that the principal raso-motor centre is, as already stated ( $\$ 25 t)$ situated in the medulla oblongati.

716. It is very difficult to give a satisfactory explanation of the dilatation observerl in the vessels of certain regions of the borly when the nerves supplying them are irritated. The most marked instances of such dilatation

1 Procedings of the Royal Society, vol. xi, p. 302.

2 Ibid., 1. 436 .

3 Die l'athologie des Sympathicus, 1873, p. 202.

- Sree Cyon, Electrothrapie, 1873, p. 203.

6 Pflüger's Archiv, Bd. vi, 1872, p. 303. 
are seen in the ressels of the submaxillary gland when the chorda tympani, and in those of the penis when the nervi erigentes are stimulated. In the lattcr case, if the nerves of both siles be cut, erection of the penis on sexual excitement or by mechanical irritation of the sensory fibres in the pudendal nerves is rendered impossible; yet if the distal extremities of the nerves be irritated, the corpora carcrnosa swell, and the copious flow of bright-colored blood that follows an incision into them, shows that the circulation has been greatly increased in activity. Claude Bernard ${ }^{1}$ was at first disposed to admit a dircet dilating action of the nerves, and Schiff" seems still to believe in the possibility of such an influence. It involves, however, the view that muscular fibres can be caused to eiongate by irritation of their nerves, which is contrary to all analogy. Others have suggested that the phenomena are due to the contraction of the small veins, or in the case of the penis, to contraction of the trabecule of the corpora cavernosa impeding the return of blood; but against this it has been shown that erection does not follow ligature of the principal veins. MI. Legros ${ }^{3}$ again believes that they are due to an exaggeration of the ordinary peristaltic action of the smaller arteries, but it is not easy to understand how this could act in the absence of valves. It is not improbable that two conditions co-operate in producing the increased flow of blood in the instances adduced above. On the one hand, as is especially seen in the case of the submaxillary gland, irritation of the chorda tympani may augment the attraction of the tissue of the gland for the blood, and thus act in producing a vis a fronte, and on the other, as oceurs more particularly in the case of the penis, the nervi erigentes exert, when stinulated, an inhibitory influence over the ordinary vaso-motor and constricting nerves exactly comparable to that of the vagi over the movements of the heart.

717. It can only be through the Nervous System that the Muscular apparatus of Organic life is acted upon by states of Mind. Although 110 exertion of the Vill can produce any effect upon any part of it, yet there are various organs whose muscular walls are influenced on the one hand by Emotional states, and on the other by the state of Expectant Attention. The Heart sympathizes so much with the emotions, that the language of almost all civilized nations refers to it as the seat of the "feelings" $(\$ 241$ et seq.); but we have as yet no certain evidence whether this influence is transmitted through the Sympathetic or through the Pneumogastric nerve. The former seems the more probable channel, when we bear in mind that it can be through the sympathetic alone that those alterations in the diameter of the bloodvessels take place which give rise to the blush of modesty or shame, or to the pallor which alternates with this in many states of mental agitation. ${ }^{4}$ So, again, the influence of Emotional states is strikingly manifested in the production of the peculiar turgescence of the Erectile tissues $(\$ 276)$; and here we have a striking example of the utter powerlessness of the Will in the well-known fact, that no amount of sexual desire will produce

1 C. Bernard, Leçons sur les Liquides de l'Organisme, t. i, p. 230 ; and Revue Scientitique, 1872 , p. 119.

"2. M. Schiff, De l'Inflammation, 1873.

3 Ch. Legros, Des Nerfs Vasomoteurs, Thèe, Paris, 1873, p. 67. For other papers bearing on this subject, see Eckhard, Beitrage zur Anatomie, Abhand. vii, 1863 ; Lovén, Ludwig's A rbeiten, 1866, p. 1 ; Kolliker, Wurzburger Verhandlungen, Bd. ii; Goltz, Pflüger's Archiv, 1873, p. 346; Brown-Séquard, Leçons sur les Nerfs Vasomoteurs, pp. 25-65; v. Wittich, Virchow, Archiv, 1866, t. xxxvii, p. 93 ; Heidenlaain, Pflüger's Archiv, Bd. v, p. 40; Vulpian, L'Appareil Vasumoteur, 1875, p. 160 .

${ }_{4}$ The pallor of extreme fear or terror is probably due rather to a state tending to Syncope, arising from a partial failure of the Heart's action. 
erection, if the mind be possessed with any feeling of doubt or apprehcnsion as to the existence of the sexual ability. The muscular walls of the Alimentary canal seem frequently to be excited to increased action by agitating emotions; but it may be doubted how far this is a primary effect of the mental state, or how far it is consequent upon the influence of that state upon the Secretions poured in to the canal $(\$ 725)$. - The influence of the state of expectant attention, as of the emotions, is strongly manifested in the case of the Heart; the action of which, as Sir H. Holland has remarked, "is often quickened or otherwise disturbed by the mere centring the conscionsness upon it, without any emotion or anxiety. On occasions where its beats are audible, observation will give proof of this, or the physician can very often infer it while feeling the pulse; and where there is liability to irregular pulsation, such action is seemingly brought on, or increased, by the effort of attention, even though no obvious emotion be present."' There can be no doubt that the movements of the lower part of the Alimentary Canal are capable of being affected in a similar manner; since we may frequently trace the rapid descent of the fecal mass into the rectum, when we expect to be shortly able to discharge it; and it is in great part in this mode, that habit operates in producing a readiness for defecation at particular times, and that brearl-pills and other supposititious purgatives unload the bowels. ${ }^{2}$

718. Trophic Nerves. - The existence of a special system of nerves possessing a direct influence on the process of nutrition, though suggesterl by other writers, was first clearly enunciated by Samuel of Leipsic, anth has been so warmly supported by Duchenne, that he has declared that "if trophic nerves did not exist, it would be necessary to invent them." The positive facts which have led to their admission are, however, comparatively few, and in fact may ahmost be considered as limited to the single one, demonstrated by Ludwig, that certain glands can be excited to action by the stimulation of their nerves independently of their blood supply. (Saliva, \$10.5.) The view taken by Samuel ${ }^{3}$ is that the so-called trophic nerves arise from the ganglia on the posterior roots of the spinal nerves and run centrifugally to

1 Chapters on Mental Physiology, p. 16.

2 The duthor may mention the two following enses, which have fallen within his own knowledge, as curious illustrations of the influence of mental states if pon the movements of the alimentary eanal. - The first of these oecurred in the person of at literary man. of a somewhat hypoehondriacal temporament, who had been troubled with continued co-tiveness, for which he hat been aceustomed to take an aperient pill daily. Fincting that this eeased to have its u-ual effect, and beiner foaltul of inereasing his regular dose, he applied for advice to a practitioner, who, having had formare cxperience of what Mental agency alone would do, determined to try its effect in this instance. Seating his patient before him, with the abdomen uncovered, he desired him to fix his attention intently upon his abdominal sensations, and wsured him that in a short time he was quite certain that he would begin to feel amorement in his bowels, which would end in a eopious evacuation. He himself did uothing but look steadily at his pationt, with an air of great determination and confidence, and point his finger at the abdomen, moving it along the areh of the colon, and (as it were) in the course of the convolutions of the small intestines, so as to aid the pationt in fixing his attention upon them. In a short time the expected movements werefolt, and a copious evacuation soon followed; and for some time afterwards, the bowets continued to act freely without medieine.- In the other ease, a Leeturer at a publin Institution was seized with a strong impulse to defecation during his lecture; atrd was greatly ineonvenieneed by the effort necessary to restrain it. Before every subseguent lecture in the same place, the same imputse returned upon him, notwithstanding that he might have previously unlouded his bowels elsewhere. In this case, there was obviously a state of apprehension combined with the simple antieipation; but the influence of the latter is shown by the fuct, that in no other place did this individuat experienee the imputse in question under the like circumstances.

3 Die trophische Nerven, 1860. 
the tiscues. When irritation is applied to them, it causes increased activity of all the nutritive changes, cell-growth in particular taking place with abnormal rapidity. On the contrary their paralysis, as by section, leads to diminished activity in the uutritive operations, and atrophy. In proof of these statements Samuel adduced the results of many experiments showing that if a rough fragment of bone be passed beneath the sciatic nerve stretching it like a cord and producing continual irritation of its fibres, the thigh, leg, and fuot swell in the conrse of 24 or 36 hours. The whole limb below the scat of irritation of the nerve becomes hyperesthetic, its temperature rises, and an ill-smelling discharge takes place from the wound, all circumstances indicating the increased activity of the various processes both of nutrition and disintegration. In like manner laryngitis may be produced by irritating the superior laryngeal nerves, and after death the mucous mcmbrane is fonnd swollen and reddened; so by irritation of the Vagi, just below their exit from the skull, the symptoms and pathological conditions characterizing pneumonia may be obtaincel, and by irritating the spinal cord with a bristle dipped in croton oil passed through it in such a direction as to affect the posterior ronts of the spinal nerves at the level of the last dorsal vertebra, he observed great hyperienia, tumefaction, and elevation of temperature in the lower limbs. ${ }^{1}$ Dr. Axmann found that when the spinal nerves of frogs were divided on the distal side of their prevertebral ganglia, the nutrition of the parts supplied by them was much more injuriously affected than it was when the section was marle between the ganglia and the spinal cord. A large number of pathological cases are on record which certainly appear to support the views of Samuel. One of the most typical is that given by Sir James Paget in his lectures on Nutrition, on the authority of Ir. Hilton: "A man was at Guy's Hospital, several years ago, who, in consequence of fracture of the lower end of the radius, repaired by an excessive quantity of new bone, suffered compression of the median nerve. He had ulceration of the thumb, and of the fore and middle fingers, which had resisted various treatment, and was cured only by so binding the wrist, that the parts on the palmar aspect heing relaxed, the pressure on the nerve was removed. So long as this was done, the ulcers became and remained well; but as soon as the man was allowed to use his hand, the pressure on the nerves was removed, and the ulceration in the parts supplied by it returned."2 In the American war a special Hospital having been set aside for injuries and diseases of nerves, the surgeons, Messrs. Mitchell, Morehouse, and Keen, had large opportunities of observing the effects of such lesions. The conditions they fonnd to occur in the parts below the seat of injury were atrophy of muscles, and various subacute inflammatory states indicated by tumefaction and congcstion, oedema, thickening of the cuticle and glossiness of the skin, cracks and fissures in it, bed-sores, eczema, curved and talonlike nails, retraction of the skin of the ungual phalanx and exposure of the matrix, painful swelling of joints and altered or arrested secretions (Sweat). Bärensprung again has satisfactorily shown that in some cases of Herpes, at least, the ganglia on the posterior roots of the spinal nerves are inflamed, and Vandyke Carter ${ }^{3}$ lias pointed out that in cases of leprosy the cutancous

1 See also for corroborative experiments, Laborde and Leven, Gaz. Médieale, 1870; Vulpian, Brown Séquard's A rehives, $187^{\circ}$, p. 384

2 Similar eases are given by $\mathbf{M}$. Gillette in the Dictionnaire Eneyelopédique, by M. Charcot in Brown-Séquard's Archives de Physiologie, and Mr. I'Anson, Lancet, 1871. vol. ii, p. 913; by Hutchinson, in the London Hospital Reports for 18666 ; by Sehiefferdecker, Edis, and a storehouse of such facts in the work of Messrs. Mitchell, Morehnuse, and Keen, On Gunshot Wounds and other Injuries of Nerves.

${ }_{3}$ British and For. Il ed.-Chir. Rev., 18133, January. 
affection is often limited to ecrtain nerve regions, and that post-mortem examination has shown that the nerves in question are swollen and affected with hypertrophy of the interstitial conneetive tissue. And as the cutaneous affection commences with anæsithesia, it seems probable that the nerves are primarily affected. Then again there are the remarkable phenomena observed and described by Snellen, Sehiff, and many others, ${ }^{1}$ which follow intracranial section of the fifth pair of nerves, and which consist in the occurrence of conjunctivitis within a few hours of the operation, the discharge of a thick puriform mucus, haziness, ulceration, and ultimately sloughing of the cornea, and the loss of the eye on the same side as that on which the nerve has been divided. Lastly, there are the atrophic changes which oecur in muscles when a motor nerve is divided, and which have been described with great minuteness by M. Vulpian, ${ }^{2}$ by Erb, and others, the fibres losing their transverse strice, and gradually undergoing fatty degeneration, whilst the nuclei of the sarcolemma and the interstitial connective tissue undergo hypertrophy. Thus it would at first sight appear there is a large amount of evidence proving the direct influence of the nervous system on the processes of nutrition.

719. It is not less certain, however, that weighty evidence can be addueed to show that the nervous system is not required for the due performanee of the nutritive processes, and has little or no direct action upon them, the pathological phenomena above mentioned as concurrent with their persistent irritation, or consequent on their paralysis, resulting from changes in the supply of blood, which again are eansed by the action of the vaso-motor nerves upon the vessels. In proof of this it may be observed, in the first place, that nutrition and the proeesses which minister to it, as absorption, assimilation, eireulation, secretion, the fixation of new material, and the disintegration and removal of the old, are all actively performed by plants, though there is no evidence of the existence of such a rudimentary nervous system in the vegetable kingdom. Again, in many of the lower forms of animal life, as well as in the more lowly organized tissues of the higher animals, such as eartilage, fat, and eonnective tissue, few or no nerves are present, and nervous inflnence, if perceptible at all upon the process of nutrition in them, must therefore be indireet. Thirdly, daily experience shows that even in the higher animals, sensory nerves may be divided without any failure in the processes of nutrition of the parts they supplied. ${ }^{3}$ In regard to motor nerves, the experiments of Reid marle long ago showed elearly that although atrophy of muscle follows seetion if the limb be allowed to remain quiescent, yet that the muscles retain all their characters if they are methodically exereised by passive movement, or by the action of the electrical current. Brown-Séquard reeords eases where mixed nerves ${ }^{4}$ have been divided without apparent alteration being produced either in the tempcrature or in the nutrition of the parts beyond. Lastly, even with regard to the sympathetie there is evidence that section of its trunk on one side in the nerk, if anything, improves rather than deteriorates nutrition on the same sicle of the heatl, for the vaso-motor system being paralyzed, the current of blood becomes freer, causing the hair on that side to grow more rapidly in the mammal, and the lateral half of the comb of the eock to hypertrophy, whilst injuries heal more rapidly, and the tissues, as in the case of the cornea

1 See especially Sinitzin, Centralblutt für die Med. Wiss., 1S71, p. 160.

2 Brown-séquard's Arehives, 1872 , p. 753.

3 See case by Vanzetti (Brown-Séquard's Archives, 1872, p. 15\%), in which the lingual nerve was resected on one side, and in thrce months after the organ still pre. served its normal form, color, and nutrition.

4 Arehives, 1869. 
especially, are more tolerant of irritation and injury ; and such cases as those recorded by Dr. Carnochan and Dr. Conner, ${ }^{1}$ where Meckel's ganglion was extirpated, and no apparent mischief followed, show that some other conditions than the mere abolition of the function of the sympathetic ganglia must be present in order that impairment of nutrition may take place.

720. It is to be observed, morcover, that whilst some of the phenomena above alluded to are inexplicable on the supposition that the blood supply is interfercel with, possibly by persistent contraction of the bloodvessels, in others there may have been some interference with the lymphatic system, the relations of which to the nerves is at present unknown, whilst others again admit of a different explanation. Take, for example, the case of the eve after division of the fifth nerve. The experiments of Bütner and Meissner, ${ }^{2}$ v. Bezold, ${ }^{3}$ v. Hippel, and others, have shown that if the eye be carefully covered and protected from external lesion, no pathological lesions occur after the section, whilst if it be exposel, ulceration soon sets in. Here it is probable the loss of sensibility of the cornea leads to drvness, and the entrance of foreign bodies, in consequence of the ordinary act of winking being neglected, and such dryness is a predisposing cause to inflammation. In a case under the care of the Editor, in which the fifth was paralyzed on both sides, one eye was wholly lost, but in the other incomplete ptosis occurred, and the inflammation was long linited to the part of the cornea exposed in the half-shut condition. In this part a deep ulcer formed, whilst the rest of the cornea was perfectly bright and transparent, and the iris was not implicated till a very late period. In like manner Brown-Séquard has shown that many of the effects which may be observed to follow injuries of the nerves of the extremities, may be referred to a want of power on the part of the animal, both to perceive and to withdraw them from irritating and depressing conditions (cold, wet, and pressure). It must be remembered also that many of Mitchell's cases were severe gunshot wounds, and that the bloodvessels and other tissues besides the nerves were always implicated. ${ }^{4}$

721. The influence of particular conditions of the Mind, in exciting, suspending, or modifying various Secretions, is a matter of daily experience. The Lachrymal secretion, for example, which is continually being formed to a small extent for the purpose of bathing the surface of the eye, is poured out in great abundance under the moderate excitement of the emotions, either of joy, tenderness, or grief. It is checked, however, by violent emotions; hence in intense grief, the tears do not flow; and it is a well-known indication of moderated sorrow when the gush takes place, this very act affording a further relief. The flow of Saliva, again, is stimulated by the sight, the smell, the taste, or even by the thought of food, especially of "such as is of a savory character. On the other hand, violent emotion may suspend the salivary secretion; as is shown by the well-known test, often resorted to in India, for the discovery of a thief amongst the servants of a family, - that of compelling all the parties to hold a certain quantity of rice in the mouth during a few minutes, - the offender being generally distinguished by the comparative dryness of his mouthful at the end of the ex-

1 Amer. Journ. of Med. Sci, October, 1870, and New York Med. Journ., No. 69, p. 579 .

2 Berichtüb. die Fortsch. d. Phys, 186\%, p. $41 \%$.

3 Deutsche Klinik, 1867.

4 Ludwig and Hafiz, Arbeiten, 1870 ; Practitioner, x, 1873, p. 146. See also Hermann Schulz, Ueber den Einfluss der Nervendurchschneidung auf Ernährung, Centralblatt f. d. Med. Wiss., 1873, p. 708 ; Joseph Reichert's Archiv, 1872, No. 2; Fischer, Journ. of Anat. and Physiolog., vol. vi, p. 222; Vulpian, Comptes Pendus, 1872, t. $\operatorname{lxx}$, No. 15. 
pcriment. There is much rcason to believe that the secretion of Gastric fluid is affected, in the same manner as that of the saliva, by the impressions made by food upon the senses; for it has been ascertained by Bidder and Selimidt ${ }^{1}$ that it is copiously effused into the stomachs of dogs that have been kept fasting, when flesh or any other attractive food is placed before them. That the secretion, on the other hand, is entirely suspended by powerful mental emotion, seems almost certain, from the well-known influence which this has in dissipating the appetite for food, and in suspending the digestive process when in active operation. As a cheerful state of feeling, on the other hand, seems to be decidedly favorable to the performance of the digestive function, it probably exerts a beneficial influence, as to both quantity and quality, on the secretion of gastric fluid. Of the influence of mental states on other secretions concerned in the reduction and appropriation of the food (such as the Biliary, Pancreatic, and intestinal fluids), neither observation nor experiment has as yet afforded any satisfactory information. It is a prevalent, and perhaps not an ill-founded opinion, that melancholy and jealousy have a tendency to increase the quantity, and to vitiate the quality, of the Biliary fluid. Perhaps the disorder of the organic functions is more commonly the source of the former emotion than its consequence; but it is certain that the indulgence of these feclings produces a decidedly morbific effect by disordering the digestive processes, and thus reacts upon the nervous system by impairing its healthy nutrition. A copious secretion of fetid gas not unfrequently takes place in the intestinal canal, under the influence of any disturbing emotion; or the usual fuid secretions from its walls are similarly disordered. The tendency to Defecation which is commonly excited under such circumstances, is not, therefore, due simply to the relaxation of the sphincter ani (as commonly supposed); but is partly dependent on the unusually stimulating character of the freces themselves. The same may be said of the teudency to Micturition, which is experienced under similar conditions; the change in the character of the urine becoming perceptible enough among many animals, in which it acquires a powcrfully-disagreeable odor under the influence of fear, and thus answers the purpose which is effected in others by a peculiar sccretion. The halitus from the Lungs is sometimes almost instantaneously affected by bad news, so as to produce fetid breath. The odoriferous secretion of the Skin, which is much more powerful in some individuals than others, is increased under the influence of certain mental emotions (as fear or bashfulness), and commonly also by scxual desire. The Sexual secretions themselves are strongly influenecd by the condition of the mind. When it is frequently and strongly directed towards objects of passion, these secretions are increased in anount, to a degree which may causc them to be a very injurious drain on the powers of the system. On the other hand, the active employment of the mental and bodily powcrs on other objects, has a tendency to render less active, or even to check altogether, the processes by which they are claboratel. ${ }^{2}$

1 Op. cit., p. 35.

2 'This is a simple Physiological fact, but of high Moral application. The Author would say to those of his younger readers, who urge the wants of Nature as an excuse for the illicit gratification of the sexual passion, "Try the effects of close mental application to some of those ennobling pursuits to which your profession introduces Jou, in combination with vigoruus bodily exercise (for the effects of which see ? 555), before you assert that the appetite is unrestrainable, and act upon that assertion." Nothing tends so much to increase the desire, as the continual durection of the mind towards the objects of its gratitication, especially under the favoring influence of sedentary habits; whilst nothing so effectually represses it, as the determinute exercise of the mental faculties upon other objects, and the expenditure of nervous energy 
722. No Secretion so strongly manifests the influence of the Nervous system, and especially of Emotional states, both upon its quantity and its quality, as that of the Mammary glands. Although the production of Milk, when once established, continually goes on in the breasts of a nursing female, yet it is obviously accelerated in the first instance, and augmented afterwards, by the mechanical irritation of the nipple produced by the suction of the infant; and this alone (or in combination with the strong desire to furnish milk) has been effectual in producing the secretion in girls and old wonen, and even in men. Again, in the nursing female the secretion is often suddenly augnented by the sight of the infant, or even by the thought of him in absence, especially when associated with the idea of suckling; this gives rise to the sudden rush of blood to the gland, which is known by nurses as the draught, and which may probably be attributed to a dilatation of the Mammary arteries, through the instrumentality of their Sympathetic nerves, analogous to that which takes place in the act of blushing ( $\$ 717$ ).-Although we are continually witnessing indications of the powerful influence of Emotional states upon the qualities of the Mammary secretion, yet it is probable that such influence is not at all peculiar to the milk; and that we only recognize it more readily in this case, because the digestive system of the Infant is a more delicate apparatus for testing it than any which the Chemist can devise; affording proof; by disorder of its function, of changes in the character of the secretion which no examination of its physical properties conld detect. The following remarks on this subject are abidged from Sir A. Cooper's valuable work on the Breast: "The secretion of milk proceeds best in a tranquil state of mind, and with a cheerful tempcr; then the milk is regularly abundant, and agrees well with the child. On the contrary, a fretful temper lessens the quantity of milk, makes it thin and sernus, and causes it to disturb the child's bowels, producing intestinal fever and much griping. Fits of anger produce a very irritating milk, followed by griping in the infant, with green stools. Grief has a great influence on lactation, and consequently upon the child. The loss of a near and dear relation, or a change of fortune, will often so much diminish the secretion of milk, as to render adventitious aid necessary for the support of the child. Anxiety of mind diminishes the quantity, and alters the quality of the milk. The reception of a letter which leaves the mind in anxious suspense, lessens the draught, and the breast becomes empty. If the child be ill, and the mother is anxious respecting it, she complains to her medical attendant that she has little milk, and that her infant is griped and has frequent green and frothy motions. Fear has a powerful influence on the secretion of milk. I an informed by a medical nun who practices much among the poor, that the apprehension of the brutal conduct of a drunken husband will put a stop for a time to the secretion of milk. When this happens, the breast feels knotted and hard, flaccid from the absence of milk, and that which is secreted is highly irritating; and some time elapses before a healtly secretion returns. Terror, which is sudden and great fear, instantly stops this secretion." Of this two striking instances, in which the secretion, although previously

in other channels.-There scems to be something in the process of training young men fur the Medical Profession, which encourages in them a laxity of thought and expression on these matters, that too frequently ends in the laxity of principle and of action. It inight have becn expected that thosc who are so continually wituessing the melancholy consequences of the violation of the Divine Law in this particular, would be the last to break it themselves; but this is unfortunately very far from being the case. The Author regrets being obliged further to remark, that some works which have issued from the Medical press, contains much that is calculated to excite, rather than to repress, the propensity; and that the advice sometimes given by practitioners to their patients, is immoral as well as unscientific. 
abundant, was completely arrested by this emotion, are detailed by Sir A. Cooper. "Those passions which are generally sources of pleasure, and which, when moderately indulged, are conducive to health, will, when carried to excess, alter, and even entirely check, the secretion of milk."

723. There is even evidence that the Mammary secretion may acquire an actually poisonous character, under the influence of violent mental excitement; for certain phenomena which might otherwise be regarded in no other light than as simple coincidences, appear to justify this inference, when interpreted by the less striking but equally decisive facts already mentioned. "A carpenter fell into a quarrel with a soldier billeted in his house and was set upon by the latter with his drawn sword. The wife of the carpenter at first trembled from fear and terror, and then suddenly threw herself furiously between the combatants. wrested the sword from the soldier's hand, broke it in pieces and threw it away. During the tumult, some neighbors came in and separated the men. While in this state of strong excitement, the mother took up her child from the cradle, where it lay playing, and in the most perfect health, never having had a moment's illness; she gave it the breast, and in so doing sealed its fate. In a few minutes the infant left off sucking, became restless, panted, and sank dead upon its mother's bosom. The physician who was instantly called in found the child laying in the cradle, as if asleep, and with its features undisturbed; but all his resources were fruitless. It was irrecoverably gone." 1 In this interesting case, the milk must have undergone a change which gave it a powerful sedative action upon the susceptible nervous system of the infant.- The following, which occurred within the Author's own knowledge, is perhaps equally valuable to the Physiologist, as an example of the similarly fatal influence of undue emotion of a different character; and both should serve as a salutary warning to mothers, not to indulge either in the exciting or in the depressing passions. A lady having several children, of which none had manifested any particular tendency to cerebral disease, and of which the youngest was a liealthy infant a few inonths old, heard of the death (from acute hydrocephalus) of the infant child of a friend residing at a distance, with whom she had been on terms of close intimacy, and whose family had increased almost contemporaneously with her own. The circumstance naturally made a strong impression on her mind; and she dwelt upon it the more, perhaps, as she happened, at that period, to be separated from the rest of her family, and to be much alone with her babe. One morning, shortly after having nursed it, she laid the infant in its cradle, aslecp and apparently in perfect health; her attention was shortly attracted to it by a noise; and on going to the cradle, she found her infant in a convulsion, which lasted a few moments and then left it dead. Now, although the influence of the mental emotion is less unequivocally displayed in this case than in the last, it can scarcely be a matter of doubt; since it is natural that no feeling should be stronger in the mother's mind

1 Dr. Von A numon, in his treatise, Die ersten IItterpfliehten und die erste Kindespflege, quoted in Dr. A. Combe's exeellent little work on The Management of Infancy.-Similar facts are reeorded by other writers. Mr. Wardrop mentions (Laneet, No 5lfi), that having rentoved a small tumor from behind the ear of a mother, all welt well, until she fell into a violent prssion; and the ehild, being suckled soon afterwards, died in convulsions. He was sent for hastily to see another ehild in eonvulsions, after taking the breast of a nurse who had just been severely reprimanded; and he was informed by Sir Riehard Cruft, that he had seen many similar instanees. Three others are reeorded by Burdach (Physiologie, \& 52.) ; in one of them, the infant was seized with convulsions on the right side and hemiplegia on the left, on sucking immediately after its nother had met with some distlessing oecurrenee. Another ease was that of a puppy, which was scized with epileptic eonvulsions, on sucking its mother after a fit of rage. 
under such circumstances, than the fear that her own beloved child should be taken from her, as that of her friend had been; and it is probable that she lrad been particularly dwelling on it, at the time of nursing the infant on that morning.-Another instance, in which the maternal influence was less certain, but in which it was not improbably the immerliate cause of the fatal termination, occurred in a family nearly related to the Author's. The mother had lost several children in early infancy from a convulsive disorder; one infint, however, survived the usually fatal period; but whilst nursing him one morning, she had been strongly dwelling on the fear of losing hin also, although he appeared a very healthy child. In a few minutes after the infant had been transferred into the arms of the nurse, and whilst she was urging her mistress to take a more cheerful view, directing her attention to his thriving appearance, he was seized with a convulsion fit, and died alınost instantly. Now although there was here unquestionably a predisposing cause, of which there is no evidence in the other cases, it can scarely be doubted that the exciting cause of the fatal disorder is to be referred to the mother's anxiety. This case offers a valuable suggestion, - which, indeed, would be afforded by other considerations, that an infant under such circumstances should not be nursed by its mother, but by another woman of placid temperament, who has reared healthy children of her own.

72t. There is abundant evidence that a sudden and vinlent excitement of some depressing Emotion, especially Terror, may produce a severe and even a fatal disturbance of the Organic functions; with general symptoms (as Guislain ${ }^{1}$ has remarked) so strongly resembling those of sedative Poisoning, as to make it highly probable that the blood is directly affected by the Emotional state, through Nervous agency; and, in fact, the emotional alteration of various secretions, just alluded to $(\$ \S 721,723)$, seems much more probably attributable to some such affection of the blood, than to a prinary disturbance of the secreting process itself. Although there can be no doubt that the habitual state of the Emotional sensibility has an important influence upon the general activity and perfection of the Nutritive processes,as is shown by the well-nourished appearance usually exhibited by those who are free from mental anxiety as well as from bodily ailment, contrasted with the "lean and hungry look" of those who are a prey to continual disquietude, - yet it is not often that we have the opportunity of observing the production of change in the nutrition of any specific part, by strong emotional excitement. In the two following cases, the correspondence of the effects to their alleged causes may have been only casual ; and a much larger collection of facts would be neeled to establish the rationale here arlvanced as probable. But so many analogous though less strongly-marked phenomena are presented in the records of medical experience, and the influence of the Emotions upon the products of Secretion is so confirmatory, that there does not seem any reasonable ground for hesitation, in admitting that the same explanation may apply here also. The first of these cases, cited by Guislain (loc. cit.) from Ridard, is that of a woman who, after seeing her daughter violently beaten, was seized with great terror, and suddenly became affected with gangrenous erysipelas of the right breast. But a still more remarkable example of local disorder of nutrition, occasioned by powerful emotion, and determined as to its seat by the intense direction of the attention to a particular part of the body, is narrated by Mr. Carter." "A lady who was watching her little child at play, saw a heavy window-sash fall upon its hand, cutting off three of the fingers; and she was so much overcome by

1 Leçons Orales sur les Phrénopathies, tom. iii, pp. 165-168.

2 On the Pathology and Treatment of Hysteria, p. 24. 
fright and distress as to be unable to render it any assistance. A surgeon was spcedily obtained, who, having dressed the wounds turned himself to the mother, whom he found seated, moaning, and complaining of pain in her hand. On examination, three fingers, corresponding to those injured in the child, were discovered to be swollen and inflamed, although they had ailed nothing prior to the accident. In four-and-twenty hours incisions were made into them, and pus was evacuated ; sloughs were afterwards discharged, and the wounds ultimately healed."

725. The influence of the state of expectant attention, in modifying the processes of Nutrition and Secretion, is not less remarkable than we have already seen it to be in the production or morlification of Muscular movements ( $\$ 717)$. It seems certain that the simple direction of the conscionsness to a part, independently of emotional excitement, but with the expectation that some change will take place in its organic activity, is often sufficient to induce such an alteration; and would probably always do so, if the concentration of the attention were sufficient. The most satisfactory exemplification of this principle has been given by the experiments of $\mathrm{I}_{\mathrm{r}}$. Braid, who has succeeded in prorlucing very decided changes in the secretions of particular organs, by the fixation of the attention upon them in the "hypnotic" state ( $\$ 586)$. Thus he brought back an abundant flow of milk to the breast of a female who was leaving off nursing from defect of milk, and repeated the operation upon the other breast a few days subsequently, after which the supply was abundant for nine months; and in another instance he induced the catamenial flow on several successive occasions, when the usual time of its appearance had passed. It is not requisite, however, to produce the state of Somnambulism for this purpose, if the attention can be sufficiently drawn to the subject in any other mode; thus $\mathrm{Mr}_{\mathrm{r}}$. Braid ${ }^{1}$ has repeatedly produced the last-named result on a fentale who possessed considerable power of mental concentration, by inducing her to fix her thoughts upon it for ten or fifteen ninutes, so as to bring on a state of Abstraction.- Now the effects which are producible by this voluntary or determinate dircction of the consciousness to the result, are doubtless no less producible by that invol. untary fixation of the attention upon it, which is consequent upon the eager expectation of benefit from some curative method in which inplicit confidence is placer. It is to such a state that we may fairly attribute most, if not all, the cures, which have been worked through what is popularly terned the "imagination." The cures are real facts, however they may be explained; and there is scarcely a malady in which amendment has not been produced, not merely in the estimation of the patient, but in the more trustworthy opinion of medical observers. by practices which ean have had no other effect than to direct the attention of the sufferer to the part, and to kecp alive his confident expectation of the cure. The "charming away" of warts by spells of the most vulgar kind, the imposition of royal hands for the cure of the "evil," the pawings and strokings of Valentine Greatrakes, the manipulations practicerl with the "metallic tractors," the invocations of Prince Hohenlohe, et hoc gemus omne,-not onitting the globulistic administrations of the Infinitesimal doctors, and the manipulations of the Mesmerists, of our

1 See his important Memoir on Hypnotie Therapenties, in Edinb. Monthly Journal, July, 1853. - Of the reality of this last result, the Author has had an opportunity, through Mr. Braid's kindness, of personally satisfying himeelf.

2 1)r. Huygarth, of Bath (in conjunction with Mr. Richard Smith, of Bristol) tested the value of Perkins's metallic tractors, by substituting two pieces of wool painted in imitation of them, or even a pair of tenpenny nails disguised with sealingwax, or a couple of slatepencils; which they found to possess all the virtues that were claimed for the real instruments. 
own times,-have all worked to the same end, and have all been alike successful. It is unquestionable that, in all such cases, the benefit derived is in direct proportion to the faith of the sufferer in the means employed; and thus we see that a couple of bread pills will produce copious purgation, and a dose of red poppy syrup will serve as a powerful narcotic, if the patient have entertained a sufficiently confident expectation of such results. ${ }^{1}$

726. This state of confident expectation, however, may operate for evil, no. less than for good. A fixed belief that a mortal disease had seized upon the frame, or that a particular operation or system of treatment would prove unsuccessful, has been in numerous instances (there is no reason to doubt) the rirect cause of a fatal result. Thus M. Ridard relates the case of a man, thirty years of age, who was affected with stone in the bladder, and who saw a patient die by his side, after being operated upon for the same complaint. The man's imagination became excited; his thoughts were constantly fixed upon the operation which he himself expected to undergo, and upon the probable death that would follow; and, in fact, without any operation at all, he died at the end of a month, affected with gangrene botl of penis and scrotum. Hence also it is, that the morbid feelings of the Hypochondriac, who is constantly directing his attention to his own fancied ailments, tend to induce real disorder in the action of the organs which are supposed to be affected.- In the same category, too, may be placed those instances (to which alone any value is to be attached), wherein a strong and persistent impression upon the mind of a Mother, has appeared to produce a corresponding effect upon the development of the fotus in utero. In this case, the effect (if admitted to be really exerted) must be prorluced upon the maternal blood, and transmitted through it to the foetus ; since there is no nervous communication between the parent and the offspring. There is no difficulty, however, in understanding how this may occur, after what has been already stated ( $\$ 219$ ) of the influence of minute alterations in the Blood in determining local alterations of nutrition.

\section{CHAPTER XVIII.}

\section{OF GENERATION.}

\section{General Character of the Function.}

727. HAVIxG now passed in review the rarious operations which are concerned in maintaining the life of the individual, we have next to proceed to those which are destined to the perpetuation of the race by the production of successive generations of similar beings. The question of the occurrence of spontaneous generation is one that has received great attention during the last few years, but the opinions that have been expressed both for and against it are still sub judice. No doubt can be entertained that under all ordinary circumstances fluids containing organic substances in solution or suspension when exposed to temperatures between $40^{\circ}$ and $100^{\circ}$ or $110^{\circ} \mathrm{F}$., and more rapidly as the mean temperatures of $70^{\circ}$ and $80^{\circ}$ are approxi-

1 A remarkable and thoroughly well-attested case of the cure of a fistula lachrymalis which had advanced so far as to involve disease of the bones of the nose, is recorded in the History of the Portroyalists. 
mated, exhibit evidences of life. 'The fluid-such, for instance, as an infusion of turnip, carrot, meat, cheese-becomes cloudy, from the formation or separation of an infinite number of minute molecules, almost unresolvable by the highest microscopic powers. Soon Bacteria, or small rod-shaped bodies appear, which exhibit movements of a slow oscillating character, then more swiftly moving monads and vibrios, and, finally, infusuria of various forms and more complex structure. Two views have been alvauced to explain the development of these lowly organized beings. On the one hand, the panspermists maintain that the air is crowded with spores so small as to be imperceptible to the highest microscopic powers, and which, falling on suitable soil, as into noist solutions of organic substances, inmediately begin to increase and multiply; and they point to the fact that the purer the air, whether it be that obtained on high mountain-tops, or which has been filtered through cotton-wool, or has been made to pass through red-hot tubes, the less likely is the solution, if protected by closing the mouth of the vessel in which it is contained, to become the seat and focus of life. On the other hand, the heterogenists contend that, as on the Darwinian theory pusher to its furthest limit, the whole animal and vegetable kingdoms may be derived from some simple form, which must have originated from the action of light and heat, or of heat alone, on the inorganic materials of which the earth is composed, it is not unlikely that the same process is constantly bcing repeated when the appropriate conditions are present; and they point as additional arguments in favor of their view, to the circumstances that, whatever may be the care taken in filtering the air admitted to organic infusion, and even when a boiling temperature has been maintained for several minutes with hermetic closure of the vessel during the process of ebullition, it is, in many cases, impossible to prevent the development of bacteria, though the absence or great diminution of air or rather of oxygen thus vecasioned prevents them forming in any considerable numbers. They refer also to the extraordinary numbers in which the bacteria appear-numbers which they believe to be incompatible with their production from the spores supposed by the panspermists to be floating in the air; and, lastly, they refer to valious experiments which seem to show that the lowest forms of life may be germinated in solutions, consisting exclusively of inorganic compounds. When it is considered how difficult it is to preserve the air admitted to the solution used in these experiments in a perfect state of purity, and our ignorance of the amount of heat which the spores of the lower organisms can bear exposure to without destruction, it would seem at present that it is safest to hold the doctrine of panspermism, thongh it must be admitted to present several points of considerable difficulty. ${ }^{\circ}$

728. Among Plants, and the lower tribes of Animals, a multiplication of independent beings takes place without any sexual process whatever, by a process of gemmation or "budding" from the parent stock; these "buds," at first entirely nourished by it, gradually become less and less depcndent upon it, and at last detach themselves and maintain a separate existence. Now this process may be regarded as essentially the same with that of the multiplication of cells by subdivision, which is one of the most ordinary operations of growth and development; and it is peculiar in nothing else than this,- - that the newly formed structure, instcad of remaining as a constituent and dependent part of the parcutal fabric, is capable of living independently of it, and of thus existing as a distinct individual when

1 The student will find a very full discussion, with an historical résumé of this subject, in Dr. Bustian's Beginnings of Life, 1872; Burdon Sanderson, Nature, vol. viii, p. 478; Heuzinga, Samuelsun, Putzeys, and Gscheidlen, in Pflüger's Archiv for 1873 and 1874 . 
spontaneously or artificially detached. Among the higher tribes of Animals, as in Man, this mode of reproduction, which is merely a multiplication of the individual, and not a real Generative process, does not present itself, at least in the adult state; for in no instance do we find that a part of the borly separated from the rest can develop the organs which are neccssary for the sustenance of its existence; and the power which the organism possesses, of regencrating parts which it has lost by disease or accident, is restrained within very narrow limits $(\$ 361)$. But there is good ground to believe, that such a multiplication by subdivision may take place at that earliest period of cmbryonic life, at which the germ is nothing else than a mass of cells, wherein no distinction of parts has as yet manifested itself; and that the production of two complete individuals, held together only by a connecting band, may arise from some cause which determines the subdivision of the germinal mass, at the period when its grade of development corresponds with that of the Hydra or Planaria. And this view of the case is confirmed by the facts already stated $(\$ 361)$ in regard to the higher degree of the regenerating power during embryonic life, infancy, and childhood, as compared with that which remains after the development of the fabric has been completed.

729. The proper act of Generation in Man, as in the Animal and Vegetable Kingdons generally (see Prixc. of Comp. Pнys., chap. xi), uniformly involves the union of the contents of two peculiar cells, which may be designated as the "sperm cell," and the "germ cell ;" and, as in all higher Animals, the "sperm cell" develops in its interior a self-moving spermatozoon; whilst the "germ cell" (germinal vesicle) whose contents are fertilized by the spermatozoon, is imbedded in a mass of yolk destincd for the early nutrition of the embryo thence originating: so that this embryo, if supplied with the requisite warmth, as well as drawing into itself the aliment stored up for it, gradually evolves itself into the likeness of its parent. Therc is a great difference, however, among the different tribes of Animals, as to the degrce of assistance thus afforded to the embryo; the general rule being, that the higher the form which the embryo is ultimately to attain, the longer is it supported by its parent. Hence we find the embryos of most Invertebrated animals coming forth from the egg in a condition very unlike their perfect type, and only acquiring this after a long succession of subsequent alterations, which frequently involve a complete change of form, or metamorphosis. In Fishes, however, the embryo, though far from having completed its embryonic development at the time of its emersion from the egg, does not differ so widely from the adult type. In Birds, there is a provision for a much more advanced development; the store of nutritious matter, or "yolk," being so large as to allow the whole series of changes requisite for the formation of the complete chick to take place before it leaves the egg. In the Manmalia, on the contrary, the quantity of yolk contained in the ovum is very small, but the embryo is ouly dependent upon it for the materials of its increase during the earliest stages of its evolution ; for it speedily forms a special connection with the parent structure, by means of which it is enabled to receive a contiuual supply of newly prepared aliment, so as to be supported at the expense of this until far advanced in its development. Some approaches to this arrangement are met with among certain of the lower animals, but it is only in the higher Mammalia that it is completely carried out; and it is only in this class, too, that we find a supplemental provision for the nutrition of the offspring after it has come forth into the world. A considerable difference in the ova of different animals further exists, as was first shown by Reichert, in the circumstance that in some the whole yolk undergoes segmentation, and is applied directly to the formation 
of the embryo; whilst in others, only a portion is so segmented, the remainder being as it were a store of food which is gradually taken up in the process of development. The former kind of egg consists, therefore, altogether of germ yolk; the latter of a small germ yolk, and a large food yolk. The former has been called "holoblastic," the latter "meroblastic." The former is found in Man and Mammals, Batrachians, Cyclostome Fishes, the lower Crustacea, Arachnida and Mollusca, Annelids, Worms and Radiate animals; the latter in Birds, Amplibia, Fishes, Cephalopods, and the higher groups of Crustacea and Arachnida. In many of the lower tribes of animals, the fertilization of the ova is accomplished without any sexual congress; the spermatic fluid effused by the male, coming into direct contact with the ova previously depositer by the female; but in all the higher tribes, as in Man, the spermatic fluid is conveyed into the oviducts of the female, so as to impregnate the ovum shortly after it has quitted the ovarium, or even before its final escape from it.

\section{Action of the Male.}

730. The Spermatic fluid of the Male is secreted by glandular organs, known as Testes. Each of these consists of several lobules, which are separated from each other by processes of the Tunica Albuginea that pass down

FIG. 306.

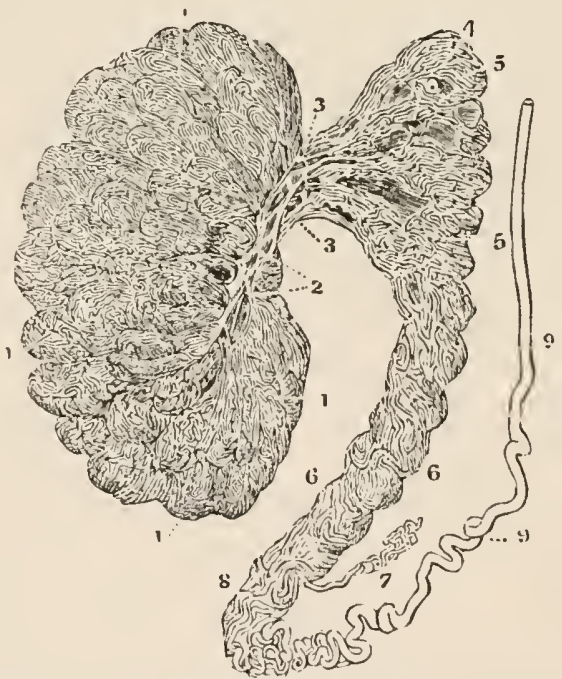

Tuman Testis, injected with mercury as completely as possible; 1,1 , lobules formed of seminiferous tuhes; 2 , rete test is; 3 , vasi efferentia $; 4$, flexures of the eflerent vessels passing into the head; 5,5 , of the epididymis; 6 , body of the epididymis; 7 , appendix; 8 , caula; 9 , vas deferens.

between them, and also by an extremely delicate membrane (described by Sir A. Cooper under the name of Tunica Vasculosa) consisting of ninute ramifications of the spermatic bloodvessels united by areolar tissue. Each lobule (Fig. 306, 1 1) is composed of a mass of convoluted tubuli. seminiferi, throughout which blood vessels are minutely distributed. The lobules differ greatly in size, sone containing one, and others many of the tubuli; the total number of the lobules is estimated at about 450 in each testis, and that of the tubuli at 840 . The walls of the tubuli are firmer than those of similar gland-canals elsewhere; for outside the basement-membrane on which the epithelium rests, they have a tolerably firm but extensible en- 
velope, composed of an indistinctly fibrous connective tissue with longitudinal nuclei. They are lined by peculiar branched and anastomosing cells, ${ }^{1}$ and occupying the lumen of the tube are other cells, which may be referred to two types, one possessing dark gramnlar nuclei and the other containing clear nuclei. The cells present evidences of undergning rapid multiplication, and exhibit amœboid movements. The convolutions of the tubuli are so arranged that each lobule forms a sort of cone, the apex of which is directed towards the rete testis (2); and when they have reached to within a linc or two of this, they cease to be convoluted, several unite together into tubes of larger diameter, and these enter the rete testis under the name tubuli recti. The mode in which the tubuli terminate at the large end of the lobule has not been clearly made out, owing partly to the number of their anastomoses; it is probably either by cecal endings or by loops. The diameter of the tubuli is for the most part very uniform; in the natural condition they seem to vary from about the $-\frac{1}{195}$ th to the $\int_{\frac{1}{70}}$ th of an inch; but when injected with mercury, they are distended to a size ncarly double the smaller of these dimensions.-The rete testis (2) consists of from seven to thirteen vessels, which run in a waving course, anastomose with each other, and again divide, being all connected together. The vasa efferentia (3), which pass to the head of the epididymis, are at first straight, but soon

FIG. 307.

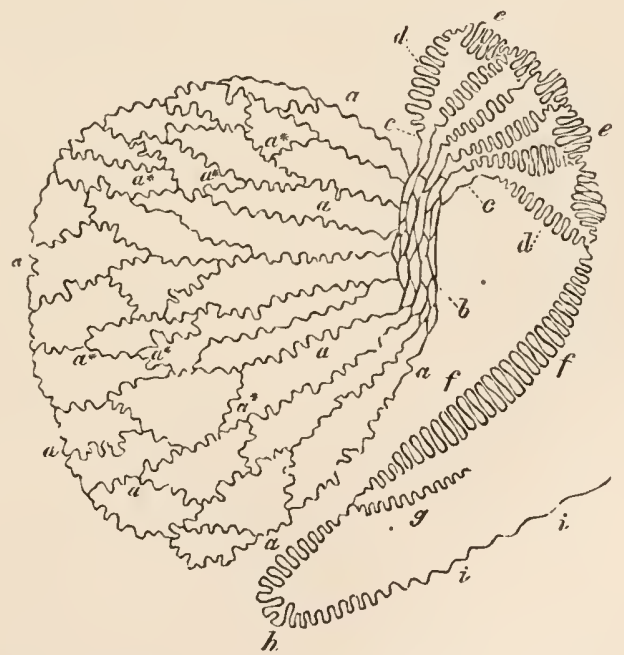

Plan of the structure of the Test is and Epididymis: $a, a$, seminiferous tubes; $a^{*}, a^{*}$, their anastomoses; the other references as numbercd in the last figure.

become convoluted (4), each forming a sort of cone, of which the apex is directed towards the rete testis, the basc to the head of the epididymis (5). The number of these is stated to vary from nine to thirty ; and their length to be about eight inches. The epididymis itself (6) consists of a very convoluted canal, the length of which is about twenty-one fcet. Into its lower extremity, that is, the angle which it makes where it terminates in the vas deferens, is poured the secretion of the vasculum aberrans or appendix (7); which seems like a testis in miniature, closely resembling a single lobule in its structure. Its special function is unknown. The nerves of the testis are

1 Lavalette St. George, Stricker's Handbook of Histology, Syd. Soc. Trans., 1872, vol. ii, p. 139. 
stated by Letzerich ${ }^{1}$ to pierce the membrana propria of the tubuli seminiferi, and end in a more or less irregular pyramidal inass of protoplasm, in which lie clear elliptic nuclei. The ends of the fibres, therefore, lie in close relation to the outer layer of secreting cells.

731. The fluid secreted by the Testis is invariably alkaline in Man, and is mingled, during or previously to its emission, with fluid secreted by the Vesiculre Seninales, the Prostate, Cowper's glands, ete. ; and it cannot, therefore, be obtained pure, but by drawing it from the testicle itself. No accurate analysis of it has been made in the human subject; but Kölliker ${ }^{2}$ has made the following analysis of it in the Bull and Stallion:

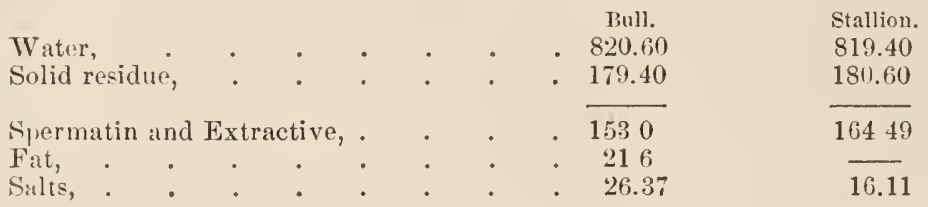

And Frerichs, ${ }^{3}$ on examining the contents of the Testes of a Rabbit, a Cock, and a Carp, found pure Semen to be a milky fluid of a mucous consistence, and neutral or slightly alkaline reaction. The imperfectly developed Spermatozoa are composed of an albuminous substance, the quantity of which diminishes with their progress towards maturation; so that the perfectly developed semen contains no albuminous compound. On the other hand, the principal component substance of the mature Spermatozoa is the same with that which is the chief constituent of the Epithelia and of the Horny tissues generally-namely, the "binoxide of protein" of Mulder. Besides this, the spermatozoa contain about 4 per cent. of a butter-like fat, with some phosphorus in an unoxidized state (probably combined with the fat as in the phosphorized fats of the blond-corpuseles and of nervous matter), and about 5 per cent. of phosphate of lime. The spermatozoa evince little tenlency to decomposition, and offer considerable resistance to the action of sulphuric, nitrie, hydrochloric, and acetic acids, and to caustic alkalies at ordinary temperatures. The fluid portion of the secretion is a thin solution of mucus, which, in addition to the animal matter, contains clitoride of sodium, and small quantities of alkaline sulphates and phosphates. When allowed to evaporate spontaneously, crystals appear, which are composed either of ammoniaco-magnesian phosphate, or, as Böttcher thinks, of albumen. The peculiar odor which the Semen possesses does not appear to belong to the proper spermatic fluid; but is probably derived from one or other of the sccretions with which it is mingled.- The product of the secretion of each Testis is conveyed away by a single vas deferens (9), which is a cylindrical canal, having, within its fibrous wall, a layer of non-striated muscular fibre, and being lined by a proper mucous membrane. The vas deferens, ascending into the abdominal calvity as a part of the spermatic cord, reaches the fundus of the bladder; and there it comes into proximity with the Vesiculu Seminulis of its own side, with whose duct it unites to form the ejaculatory duct which terminates on the verumontanum of the urethra. It has been commonly supposed that the vesicule seminales stand to the vasa deferentia in the same light that the gall-bladder stands to the hepatic duct, namely, as a receptacle into which the seminal fluid may regnrgitate, and within which it may accmunlate; but (as Hunter was the first to maintain) this is not the case, since the fluid that is found in them is not semen, and but rarely contains even a small admixture of scminal fluid. ${ }^{4}$ Moreover, these organs are not

1 Virchow's Archiv, March, 1868. 2 v. Gorup-Besanez, 1862, Phys. Chem., 1) 424.

${ }^{3} \Lambda \mathrm{rt}$. Semun, in Cyclop. of Anat. and Physiol, vol. iv, p. $50 t$.

4 See Art. Vesicule Seminales, in Cyclop. of Anat. and Physiol., vol. iv, p. 1431. 
simple vesicles, but have a sacculated glandular character; and their secretion seems to he of a mucous nature. Into the same part of the urethra is discharged the secretion of the Prostate Gland, which is poured forth by a number (15-20) of separate ducts into a depressed fossa on either side; of the nature of this secretion scarcely anything is known; and it can be only surnised that its use, like that of the fluid of the vesicula seminales, is to dilute the seminal fluid, and to give it such an increase of bulk that it may be more effectually conveyed within the female passages. It seems probable, indeed, that a certain dilution of the fluid secreted by the testes may be a condition of its power of fecundation; since it has been ascertained by Mr. Newport, that too copious an application of spermatozoa to an ovum is absolutely unfavorable to their action.- That in some way or other both these glandular bodies serve as accessory organs of generation, may be inferred from the fact, that in animals which have only a periodical aptitude for procreation, they undergo an alternate increase and decrease, corresponding with the periodical enlargement and diminution of the testes themselves. The essential peculiarity of the Spermatic fluid, however, consists in the presence of a large number of very minute bodies, the spermatozoa, which, from their nsually remaining in active motion for some time after they have quitted the living organism, have been erroneously considered as proper Animalcules. The Hunan Spermatozoon (of which representations are given in Plate I, Fig. 1; whilst some of the principal forms in other animals are shown in Fig. 308) consists of a little oval flattened "lhead" $5 \mu$ in length, an intermediate portion $6 \mu$ in length, from which proceeds a long filiform "tail" gradually tapering to the finest point, of $50 \mu$ in length. The whole is perfectly transparent; and nothing that can be termed "structure" can be satisfactorily distinguished within it. ${ }^{1}$ Its movements are principally executed by the tail, which has a kind of vibratile undulating motion; they may continue for many hours after the emission of the fluid; and they are not checked by its admixture with other secretions, such as the urine and the prostatic fluid. Thus, in cases of nocturnal emission, the Spermatozoa may not unfrequently be found actively moving through the urine in the morning; and

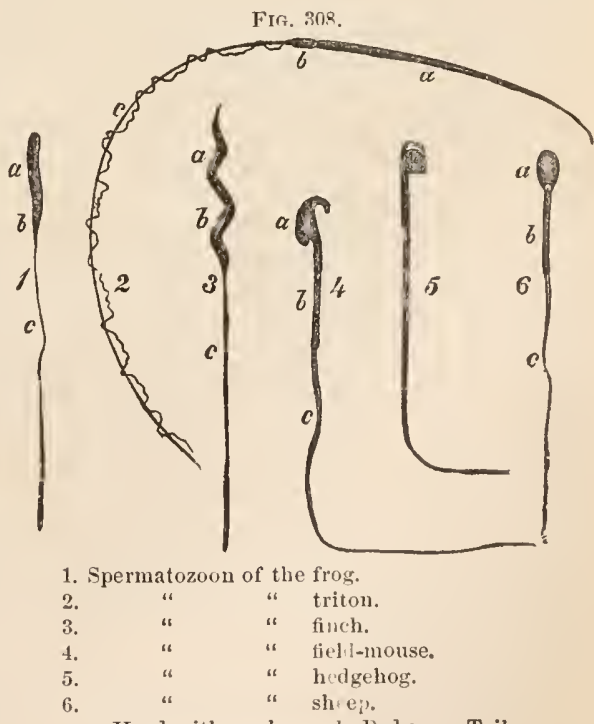

a. Head with nucleus, b. Body. c. Tail.

1 The characteristic forms of the spermatozon of the various classes of the vertebrata, are beautifully represented by Schweigger-Seidel in Max Schultze's Mlikroskop. Anat., Bd. i, p. 309. He describes each spermatozoon as consisting of a head, body, and tail the latter, as in some tritons, having a membrane attached to it, which performs undulatory inovements. Grohe (Virchow's Archiv, Bd. xxxii, p. 401) attributes the novements of the spermatozoa to the contractile protoplasm contained in the "head" of the zooid; Bizzozero to that in the cilium or tail. See also v. Lavalette St. George, Art. Testes, in Stricker's Hum. and Comp. Histulugy, Syd. Soc. Trunsl., 1872, vul. ii, p. 149. 
those contained in the seminal flivid eollected from females that have just copulated, are frequently found to live many days. As in the case of eiliated epithelium, the movements are rapidly arrested by weak acids, whilst they arc stimulated by alkaties. They cease when the spermatozoa are exposed to a temperature of $120^{\circ} \mathrm{F} .,^{1}$ but frozen spermatozoa recommenee movements on being thawed. Their presence may be readily deteeted by an observer familiar with their appcaranee, and furnished with a Microseope of sufficient power, even when they have long ceascd to move, and are bruken into fragments; and the Physician and the Medieal Jurist will frequently derive mueh assistanee from an examination of this kind. Thus, cases are of no uncommon occurrence, especially among those who have been too mueh addicted to sexual indulgence, in whieh seminal emissions take plaee unconsciously and frequently, and produec great general derangement of the health ; and the trie nature of the complaint is obseure, until the fact has been detected by microseopic examination. Again, in charges of rape, in whieh evidenee of aetual emission is required, a mieroseopic examination of the stiffencd spots left on the linen will seldom fail in obtaining proof if the aet have been completed: in such cases, however, we must not expeet to meet with more than fragments of Spermatozoa; but these are so unlike anything else that little doubt need be entertained regarding them. It has been proposed to employ the same test in juridieial inquiries respecting doubtful cases of death by suspension, seminal emissions being not unfrequent results of this kind of violence; but there are many obvious objections which should prevent much eonfidence being plaeed in it. ${ }^{2}$

732. The mode of evolution of the Spermatozoa, ${ }^{3}$ which are undoubtedly true produets of the formative action of the organs in which they are found, and cannot be ranked in the same eategory with Animalcules, probably varies in different animals, so that in one the entire sperm-eell with all its parts is converted into a Spermatozoon (Sehweigger-Seidel); in another the Spermatozoon proceeds exelusively from the nucleus (Kölliker), and in another it originates from the nueleus which remains at the head, and the eellprotoplasm whieh develops into the tail (v. Lavalette St. George). ${ }^{4}$ Besides the eells already deseribed numerous molecules are found in the semen. $\mathrm{Mr}$. Gulliver deseribes them as resembling oil-particles, and varying in dianeter from $\overline{2} 00_{0}^{1}$ th to $\overline{8}_{0}^{1} \overline{0}$ th of an inch. They are atways present, but are particularly abundant in birds and reptiles, when the testes begin to enlarge in spring, and become seanty as soon as the spermatozoa are completely developed. And the same is true for Man just before and after the attainment of the age of puberty.

733. That the Spermatozoa are the essential clements of the spermatic fluid, may be reasonably inferred from several consilerations. There are some cases in which the "liquor seminis" is altogether absent, so that they eonstitute the sole clement of the semen; whilst, on the other liand, they are

1 See Bizzozero, Annali Universali, vol. clxxxvii.

2 See the Author's Artiele Asphyxia, in the Library of Practieal Medicine, and the authorities there refiorred to.

3 For researches on the development, ete, of the Spermatozoa, see the elaborate Article Semen, in the Cyelop of Anat. and Physiol, hy Drs. Wagner and Trackart, l'rof. Kölliker's Manual of Microseopic Anatumy, 1860 ; Schweigrger-Seidel in Max Schultze's Archiv f. Mikroskop. Anut., Bd. i, p. zo9; Lavalette St. George, Strickrr's Ituman and Comp. Histolugy, vol, ii, 18i2, p. 131; Merkel, Reichert's Arehiv, 1871, 1. 644. Neumann (Centraiblatt, 187:2, 1. 881) eontends that Spermatozor are merely detached eilia developed from the epithelial colls lining the tubuli testis. See v. Ehiner, also Reichert's Archiv, 1872, p. 251); Henle, Handbuch, Bd. ii, 1). 356.

1 Köliker's views on the development of thespermatozoa are illustrated in Plate I, Figs. 2 and 3. 
never wanting in the semen of animals capable of proereation; but are absent, or imperfectly developed, in the semen of hybrids, whieh are nearly or entirely sterile. II oreover, it may be eonsidered as certain that the absolute contact of the spermatozoa with the ovum is requisite for its fecundation; whilst, on the other hand, if the spermatozoa be earefully removed from the liquor seminis by filtration, the latter is entirely destitute of fertilizing power.' Hence the presence of the Liquor Seminis must be ensidered as merely incidental; and as answering some seeondary purpose, either in the developnent or in the conveyance of the Spermatozoa. Henle ${ }^{2}$ observes that whilst the Spermatozoa retain their vitality even in extreme old ace, they are frequently absent in the seminal fluid of those suffering from disease. ${ }^{3}$

734. The power of proereation does not usually exist in the Human Male before the age of from 14 to 16 years; and it may be ennsidered probable that no Spermatozoa are produced until that period, although a fluid is secreted by the testes. At this epoch, which is ordinarily designated as that of Puberty, a considerable change takes place in the bodily eonstitution; the sexual organs undergo a much increased development; various parts of the surface, especially the chin and the pubis, become eovered with hair; the larynx enlarges, and the roice becomes lower in pitch, as well as rougher and more powerful; and new feelings and desires are awakened in the mind. Instances, however, are by no means rare, in which these changes oeeur at a much earlier period; the full development of the generative organs, with manifestations of the sexual passion, having been observed in chilitren but a few years old. The procreative power may last, if not abused, during a very prolonged period. Undoubted instances of virility at the age of more than 100 years are on record; but in these eases, the general bodily vigor was preserved in a very remarkable degree. The ordinary rule seems to be, that sexual power is not retained by the male to any eonsiderable amount, after the age of 60 or 65 years.

735. To the nse of the sexual organs for the eontinuance of his race, Man is prompted by a powerful instinctive desire $(\$ 556)$, which he shares with the lower animals. This Instinct, like the other propensities, is exeited by sensations; and these may either originate in the sexual organs themselves, or may be excited through the organs of special sense. Thus in Man it is most powerfully aroused by impressions conveyed through the sight or the toueh; but in many other animals, the auditory and olfactory organs communicate impressions which have an equal power; and it is not improbable that, in eertain morbidly exeited states of feeling, the same may be the ease in ourselves. Loealized sensations have also a very powerful effect in exeiting sexual desire, as must have been within the experience of almost every one; the faet is most remarkable, however, in cases of Satyriasis, which

I This point was completely established by the researches of Mr. Newport (Phil. Trans., 1851), who repeated and conflumed the experimental results previously obtained by Spallanzani and by Prevost and Dumas.

2 Anatomie des Menschen, p. 357.

3 This observation has been supported by Mantegazza and Bozzi, who found that in 88 cases of various forms of disease, on examination of the Testis, the spernutozua were deficient in both organs in 1:2 cases, and in one tostis in 9 cases, whilst this could only be referred to organic lesion of the testis in 2 cases. Gulliver, On the Semen and Seminal Tubes of Mammals and Birds (Proc. Zool. Soc., July, 1842 ; and Edin. Med. and Surg. Journ., 1843, vol. lx, p. 158), also gives many examples of the absence of spermatozoa in cases of disease in Man and the lower Animals, and in birds during the winter. He has found that the spermatozoa of a purticular genus may ditter remarkably in chemical and other characters. 'Thus in the Fringillidae they are quickly dissolved by acetic acid and other reagents, which have no action on the club-shaped spermatozoa of Hirundinida. 
disease is gencrally found to be connected with some obvious cause of irritation of the generative system, such as pruritus, active congestion, etc. That some part of the Encephalon is the seat of this as of other instinctive propensities, appears from the considerations formerly adduced; but that the Cerebellum is the part in which this function is specially located, cannot be regarded as by any means sufficiently proved $(\$ \S 554,556)$. The instinct when once aroused (even though very obscurely felt), acts upon the mental faculties and moral feelings; and thus becomes the source, though almost unconsciously so to the individual, of the tendency to form that kind of attachment towards one of the opposite sex, which is known as love. This tendency cannot be regarded as a simple passion or emotion, since it is the result of the combined operations of the reason, the imagination, and the moral feelings; and it is in this ingraftment (so to speak) of the psychical attachment, upon the mere corporeal instinct, that a difference exists between the sexual relations of Man and those of the lower animals. In proportion as the Human being makes the temporary gratification of the mere sexual appetite his chief object, and overlooks the happiness arising from spiritual communion, which is not only purer but more permanent, and of which a renewal may be anticipated in another world,- does he degrade himself to a level with the brutes that perish. Yet how lamentably frequent is this degradation.

736. When, impelled by sexual excitement, the Male seeks intercourse with the Female, the erectile tissue of the genital organs becomes turgid with blood ( $(276)$, and the surface acquires a much ircreased sensibility; this is especially acute in the Glans penis. By the friction of the Glans against the rugous walls of the Vagina, the excitement is increased; and the impression which is thus produced at last becomes so strong, that it calls forth, through the medium of a ganglionic centre, probably situated in the lower portion of the Spinal Cord, a reflex contraction of the muscular fibres of the Vasa Deferentia, and of the muscles which surround the Vesiculæ Seminales and Prostate gland. These receptacles discharge their contents into the Urethra; from which they are expelled with some degree of force, and with a kind of convulsive action by its own Compressor muscles; whilst they are prevented from passing back into the bladder, according to Kobelt, by the great distension of the Verumontanum which occurs during the period of erection. Now although the sensations concerned in this act are ordinarily most acutely pleasurable, there appears sufficient evidence that they are by no means cssential to its performance; and that the impression which is conveyed to the Spinal Cord need not give rise to a sensation, in order to produce the reflex contraction of the Ejaculator muscles ( $\$ 507)$. The high degree of nervous excitement which the act of coition involves, produces a subsequent depression to a corresponding amount; and the too frequent repetition of it is productive of conscquences very injurions to the general health. This is still more the case with the solitary indulgence, which (it is feared) is practiced by too many youths; for this substituting an unnatural degree of one kind of excitement for that which is wanting in another, cannot but be still more trying to the bodily powers. The secretion of seminal fluid being, like other secretions, very much under the control of the nervous system, will be increased by the continual direction of the mind towards objects which awaken the sexual propensity $(\S 725)$; and thus, if a frequent discharge be occasioned, whether by natural or unnatural excitement, a much larger quantity will altogether be producerl, although the amount emitter at cach period will be less, and its due perfection will not be attained, the fluid under such circumstances being found to contain an unduly large proportion of immature seminal cells. The formation of 
the secretion seems of itself to be a much greater tax upon the corporeal powers than might have been supposed a priori: and it is a well known fact, that the highest degree of bodily vigor is inconsistent with more than a very molerate indulgence in sexual intercourse; whilst nothing is more certain to rerluce the powers, both of borly and mind, than excess in this respect. -These principles, which are of great importance in the regulation of the health, are but expressions of the general law (which prevails equally in the Vegetable and in the Animal kingdom), that the Development of the Individual and the Reproduction of the Species stand in an inverse ratio to each other.

\section{Action of the Female.}

737. The essential part of the Female Generative system, is that in which the Ova are prepared; the other organs are melely accessory, and are not to be found in a laige proportion of the Animal kiugdom. In many of the lower animals, the Ovarium consists of a loose tissue containing many areolre, in which the Ova are formed, and from which they escape by the rupture of the cellwalls; in the higher animals, as in the Human female, the substance of the Orilrium is firm and compact, and consists of a nucleated, tough, fibrous, connective tisstie, with much intersper:ed fusiform muscular tissue forming what is known as the stroma. It originates in a small outgrowth of the inner surface of the IVolffian body, the regular columnar epithelial investment of which, probably derived from the epiblast, and contrasting strongly with the flattened epithelium of the rest of the peritoneal cavity, is thickened at this spot. The epithelium is the rudiment of the Graafian follicles and ova, whilst the outgrowth is destined to form the vascular stroma of the ovary. As development proceeds the cells

FIG. 309.

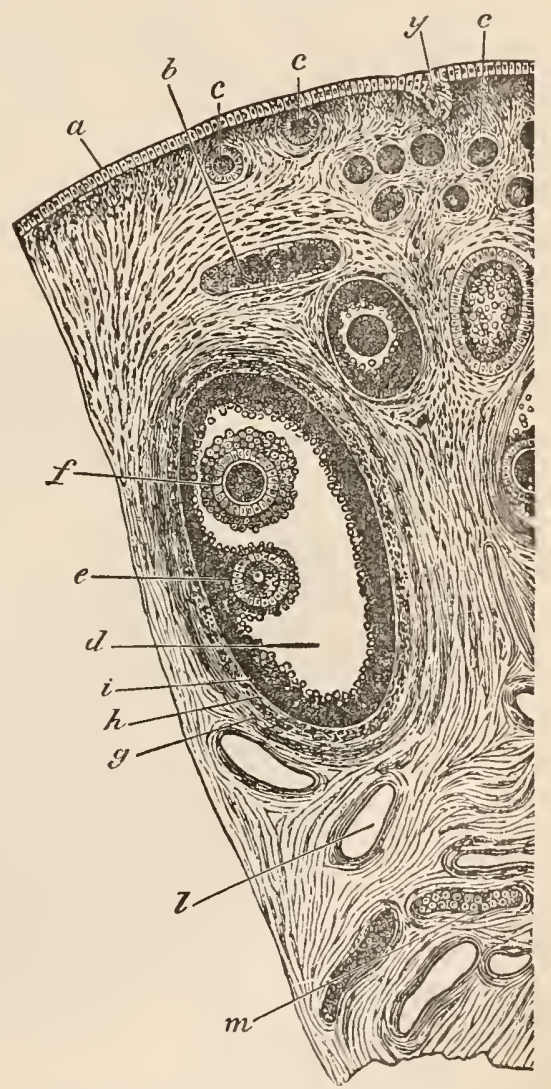

From the ovarium of an old bitch. $a$, germ epitleliun; $b$, ovarial tube; $c, c$, young Graafin follicles; $d$, older fullicle; $e$, discus proligerus, with orum; $f$, epithelium of a second ovum in the same follicle; $g$, fibrous tunic; $h$, tunica propria folliculi; $i$, epithelium of the fullicle (membrana granulosa). of the superficial columuar, or so-called germ epithelium multiply, and single cells or groups of cells, rouud, ovoid, or tubular, come to be inclosed in the tissue of the ovary by delicate vascular processes which shoot forth from the stroma. These cells constitute the primordial ova, ${ }^{1}$ each of which is there-

1 For the literature of the Histology of the Ovaries up to 1871, see Art. Ovary and Paruvarium, by IV. Waldeyer, in Stricker's Hum. and Comp. Histology, Syd. Suc. 
fore a persistent cell of a peculiar epithelial formation. When mature a primordial ovum has a diameter of $200 \mu$, (and since $\mu$ represents a micromillimetre or 0.0000032809 of an inch, $200 \%$ would equal .00065618 , or about $5^{\frac{1}{2}}$ th of an inch), and is contained within a capsule termed the Graafian follicle or ovisac. ${ }^{1}$ In a large Graafian follicle we may distinguish a connectivetissue investing membrane, which is composed of two layers, the trunica fibrosa (g, Fig. 309) and the tunica propria folliculi $(h)$; the latter is lined on its intermal surface by stratified columnar epithelium $(i)$, constituting the epithelium of the follicle or membrana gramulosa. The membrana granulosa is collected around each ovum into a disk-like investment termed the discrus proligerus (e, Fig. 309), and the remainder of the follicular cavity contains a clear fluid, the liquor folliculi. The earliest rudiment of every orum consists of a simple cell with soft granular protoplasm uninclused by a membrane, a nucleus and a nucleolus. The protoplasm of the primordial cell is termed the formative or principal yolk, since it alone undergues segmenta-

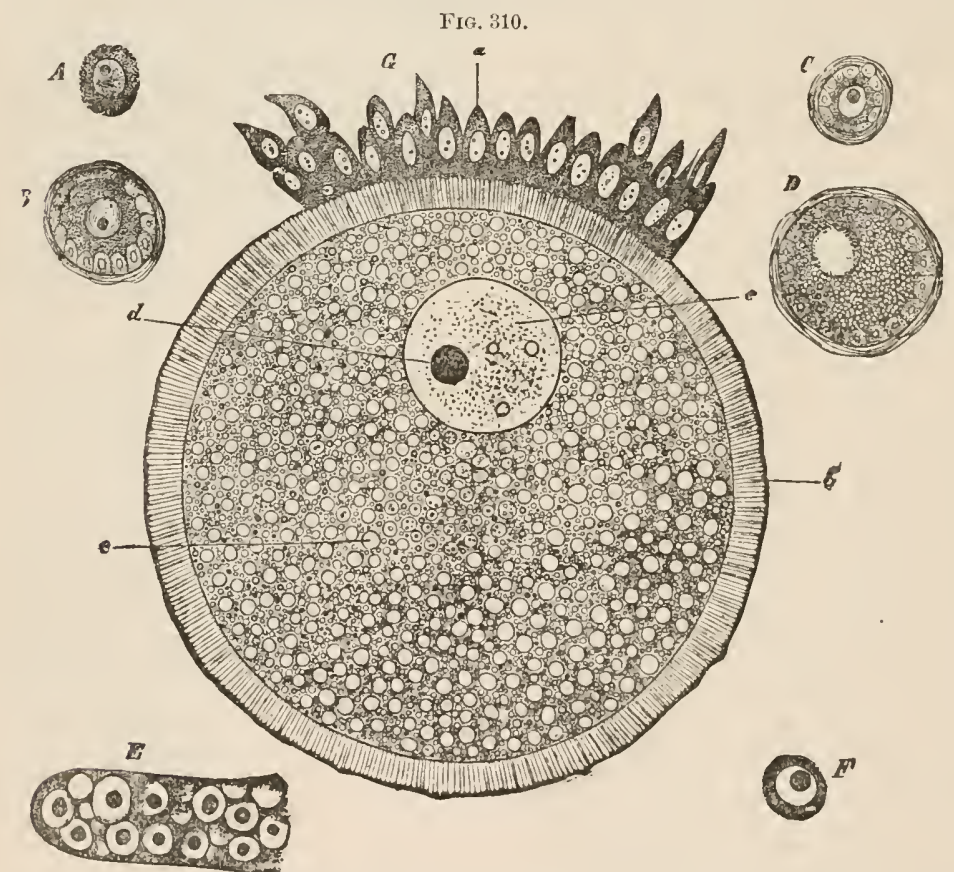

$A$, primordial egg of Man, from an eight months' fotns: $B$, primordial egg of Rabbit ; $C$, primordial follicle of a Pigeon; $D$, a somewhat older follicle from a l'igeon, slrowing commencing formation of seeondary yolk; $E$, blind end of the ovary of an Ascaris nigro-venosa, showing germinal vesicle, germinal spot, and iu some instances, a schrön's granule in a dilluse mass of protoplasm; $F$, egg of $A$ scaris nig. from about the inidale of the ovary.

$G$, an Ovan from the Gratian Follicle of a Rabbit. $a$, epithelimm of the orum, part of the diseus proligerus; $b$, radially striated zona pellueida; $c$, germinal vesicle; $d$, germinal spot; $e$, yolk.

tion and development. The mucleus is termed the grerminal vesicle (Vesicvla germinativa) (c, Fig. $310 ; v q$, Fig. 311), and the nucleolus, the germinal spot (Macula germinativa) (d, Fig. 310; tg, Fig. 311). Whilst still within

Transl., 1872, vol. ii, p. 16t. Since then there have appeared Kapff, Reichert's Archiv, 1872, p. 518, denying, and Romiti, Schultze's Archiv, Bd. x, p 201, and Born. Reichert's Archiv, 1874 , p. 118, corroborating Waldeyer's histological obsrrations.

1 Barry, Researches in Embryology, 1st series, in Philos. Transact., 1838. 
the Graafian follicle the ovum becomes surrounded by a series of secondary formations, which are collectively to be regarded as products of the follicular epithelium. To these belong the vitelline membrane or membranc inclosing the yolk, which on account of its thickness and peculiar transparency has received in Mammalia the distinctive appellation of Zona pellucida (b, Fig. 310; mv, Fig. 311), and the food yolk or secondary yolk. The zona pellucida in Mammals appears to be perforated by numerous fine pores, which confer upon it a striated aspect; it is highly elastic, and when torn with neelles the edges roll back and the contents issue in a stream. It resists to a considerable degrec the action of acids and alkalies. When mature the Human Ovum is extremely minute; not measuring above $\frac{1}{120}$ th of an inch in diameter, and being sometimes no more than half that size. The diameter of the germinal vesicle of the Human Ovum has not yet been ascertained, owing to the difficulty of isolating it from the yolk; in the ovum of the Rabbit, it is about $7^{\frac{1}{2}} \pi$ th and in the Guinea-pig about $\frac{1}{8} \pi_{0}$ th of an inch; and that of the germinal spot, in the Mammalia generally, is from $\frac{1}{36} \overline{0}$ th to $\frac{1}{1300}$ th of an inch.

738. In Plate I, Fig. 4, is represented the condition of the Graafian vesicles in various stages of development, as they are seen imbedded in the fibrous stroma of the ovarium, in a thin slice from the ovary of a sow three

FIG. 311.

A

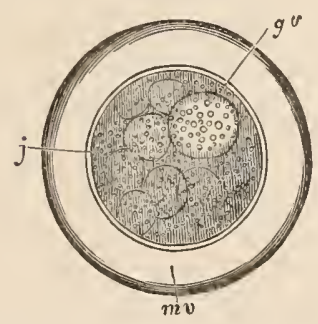

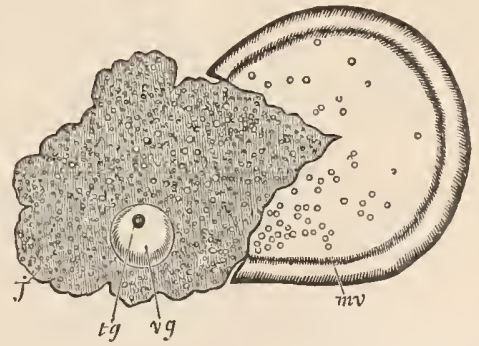

Constituent parts of Mammalian Ovum: A, entire; B, ruptured, with the contents escaping; $-m v$, vitelline membrave; $j$, yolk; $v g$, germinal vesicle; $t g$, germinal spot.

weeks old. The ovum at first occupies the centre of the Graafian vesicle, but it subscquently removes to its periphery; and, when the contents of the ovisac are undergoing maturation, prior to their escape, the ovum is always found on the side of it nearest to the surface of the ovary. The proper Ovisac, whose wall is formed of a non-vascular membrane, is surrounded by a vascular layer, whicl is formed by a condensation of the ordinary stroma of the ovarium; it is this which is usually described as the outer layer of the Graafian vesicle.

739. A continual change seems to be taking place in the contents of the Ovarium during the greater part of life; certain of the Ovisacs or Graafian vesicles, and their contents, successively arriving at maturity, whilst others degenerate and die. According to the valuable inquiries of Dr. Ritchie, ${ }^{1}$ it appears that even during the period of childhood, there is a continual rupture of ovisacs and discharge of ova, at the surface of the ovarium. The Ovaria are studded with numerous minute copper-colored maculæ, and their surface presents delicate vesicular elevations, which are occasioned by the most matured ovisacs; the dehiscence of these takes place by minute punctiform

1 London Medical Gazette, 1844. See also Foulis, Brit. Med. Journ., 1875, p. 841. 
openings in the peritoneal coat, and no cicatrix is left. At the period of puberty, the stroma of the ovarium is erowded with ovisacs; which are still so minute, that in the $\mathrm{Ox}$ (aeeording to Dr. Barry's computation) a cubic

FIG. 312.

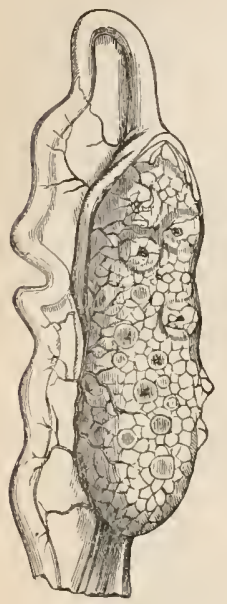

Ovarium of the Rabbit, at the period of Heat; showing various stages of the extrusion of ova. inch would eontain 200 millions of them. The greatest advance is seen in those whieh are situated nearest the surface of the Ovarium; and in sueh, the Graafian vesicle, with its two eoats, may be distinctly traced. In those animals whose aptitude for conception is periodieal, the development of the ova to sueh a degree that they beeome prepared for feeundation, is periodieal also. This development is made evident, when the parts are examined in an animal which is "in heat," by the projection of the Graafian vesieles from the surface (Fig. 312); and it eonsists not merely in an increase of size, but in certain internal changes presently to be deseribed $(\$ 744)$.

740. In the Human female, the period of Puberty, or commencing aptitude for procreation, is usually between the 13 th and 16 th years; it is generally thought to be somewhat earlier in warm elimates than in cold, ${ }^{1}$ and in densely populated manufacturing towns than in thinly peopled agricultural distriets. The mental and bodily habits of the individual have also considerable influence upon the time of its oeeurrence; girls brought up in the midst of luxury or sensual indulgence, undergoing this ehange earlier than those reared in hardihood and self-denial. The ehanges in which puberty consists, are for the most part eonneeted with the Reproduetive system. The extermal and internal organs of generation undergo a eonsiderable inerease of size; the mammary glands enlarge; and a deposition of fat takes place in the mamme and on the pubes, as well as over the whole surface of the body, giving to the person that roundness and fulness, whieh are so attrative to the opposite sex at the period of commeneing womanhood. The first appearanee of the Catamenia nsually occurs whilst these ehanges are in progress, and is a decided indieation of the arrival of the period of puberty; but it is not unfrequently delayed much longer; and its absence is by no means to be regarded as a proof of the want of aptitude for proereation, since many women have borne large families without having ever menstruated. 'The Catamenial diseharge, as it issues from the uterus, appears

1 It has been stated, by almost all physiological writers, that women (like fruits) reach maturity, und that menstruation commences, mueh carlier in hot climates, particularly between the tropics, than in temperate nnd very co!d countries. From many ciaborate and interesting papers which lave been published within a few years, however, especially from those of Mr. Roberton of Manchester (collected in his Essnys on Menstruation, and on Pruetical Midwifery, 1851), it would seem that the natural period of puberty in tenjperate climates occurs in a much more extended range of nges, und is much more equally distributed through that range, than others have alleged; and that, in other countries, the supposed parallel between plants and fruits does not hold good. The fuct seems to be, that this, like other periodic phenomena of warm-blooded animals, is but little influenced by extermnl temperature, simply because the rate of arowth and development, of which these phenomena are the exponents, is determined by the temperature of the body itself, not by that of the surrounding medium. Still it is quite possible that external warmtli may have a sliwht influence in determining early puberty; sinee, as already shown, it tends to maintain a somewhat ligher degree of bodily heat (8 425). According to Szukitz, the average age at which the catamenia nppear amongst German women is $15 \frac{1}{2}$ years; according to Brierre de Boismont, it occurs a year earlier in Parisian grirls. See Henle mond Meissner's Bericht, 1857; p. 606. 
to be nearly or quite identical with ordinary blood; but in its passage through the vagina, it becomes nixerl with the acid mucus exuded from its walls, which usually deprives it of the power of coagulating. If the discharge should be profuse, however, a portion of its fibrin remains unaffected, and chots are formed. In cases in which, by the death of women at this period, an opportunity has been afforded for the examination of the lining membrane of the uterus during menstruation, it is found to be unusually turgid with blood, the vcins in particular being much distended, and opening upon the internal surface by capillary orifices, to which valvnles are occasionally found attached. ${ }^{1}$ Hence it is scarcely correct to designate the menstrual flux as a "sccretion;" although there is reason to think that it may carry off, besides blood, certain matters which would be appropriate to the formation of a Decidual membrane ( $\$ 751)$, but which, if not so employed, become, excrementitious.-The interval which usually elapses between the sllcessive appearances of the discharge, is about four wceks; and the duration of the flow is from three to six days. There is great variety in this respect, however, among the inhabitants of different climates, and among individuals; in general, the appearance is more frequent, and the duration of the flow greater, among the residents in warm countries, and among individuals of luxurious habits and relaxed frame, than anong the inhabitants of colder climes, or among individuals inured to bodily exertion. The first appearance of the discharge is usually precerled and accompanied by considcrable general disturbance of the system, especially pain in the loins and a sense of fatigue in the lower extremities; and its periodical return is usually attended with the like symptoms, which are more or less severe in different individuals.

741. Much discussion has taken place respecting the causes and purposes of the Menstrual flow; and modern inquiries have thrown great light upon them. The state of the female generative system, during its continuance, appears to be analogous to the heat or periodic sexual excitement of the lower animals; some of which have a sero-sanguinolent discharge at that period, and among many of which the ova are entirely extruded by the female before the spermatic fluid of the male reaches them, this occasionally taking place even in Birds. There is good reason to believe that in the Human female the sexulal feeling becomes stronger at the period of menstruation; and it is quite certain that there is a greater aptitude for Conception immediately before and after that epoch, than there is at any intermediate period. Observations to this effect were made by Hippocrates, and were confirmed by Boerhave and Haller; indeed, coitus immediately after menstruation appears to have been frequently recommended as a cure for sterility, and to have proved successful. This question has been made the subject of special inquiry by M. Raciborski; who affirms that the exceptions to the rule-that conception occurs immediately before or after, or during menstruation-are not more than 6 or 7 per cent. Indeed, in his latest work on the subject, ${ }^{2}$ he gives the details of fifteen cascs, in which the date of conception could be accurately fixed, and the time of the last appearance of the catamenia was also known; and in all but one of them, the correspondence between the two periods was very close. Even in the exceptional case, the catamenia marle their appearance shortly after the coitus; which took place at about the middle of the interval between the two regular periods. When conception occurs immediately before the menstrual period, the catamenia sometimes appear, and sometimes are absent; if they appear, their duration is generally less than usual. The fict that

1 See Whitehead, On Abortion and Sterility, pp. 13-37.

2 Sur la Ponte des Mammifères, Paris, 18t1. See also Lancet, 1871, vol. i, p. 421. 
conception often takes place immediately before the last appearance of the catamenia (and not after it, as commonly imagined), is one well known to practical men.-Numerous cases have been collected by Mr. Girdwood, Dr. Robert Lee, MMI. Gendrin, Negrier, Raciborski, and others, in which the menstrual period was evidently connected with the maturation and discharge of ova $;^{1}$ but the most complete observations yet made on this subject, are those of Dr. Ritchie (loc. cit.). He states that about the period of puberty a marked change usually takes place in the mode in which the ovisacs discharge their contcnts; but that this change does not necessarily occur simultaneously with the first appearance of the catamenia; as in some cases the conditions which obtain in the period before puberty, are extended into that of menstruation. The ovaries now receive a much larger supply of blood; the ovisacs show a great increase in bulk and vascularity, so that, when they appear at the surface of the ovary, they present themselves as pisiform turgid elevations; and the discharge of their contents leaves a much larger cicatrix, and is accompanied by an effusion of blood into their cavity, with other subsequent changes to be presently described. It would appear, however, that although such a discharge takes place most frequently at the menstrual period, yet the two occurrences are not necessarily coexistent; for menstruation may take place without any such rupture; whilst, on the other hand, the maturation and discharge of mature ova may occur in the intervals of menstruation, and even at periods of life when that function is not taking place. Perhaps the most correct general statement on the subject would be this: that there is a periodic return of Ovarian excitement, which tends to the maturation and extrusion of ovules, though it may not always reach that point; whilst there is also a periodic turgescence of the vessels of the lining membrane of the Uterus, which tends to the production of a decidual membrane; - but that these two periods, thongh usually coincident, are not necessarily so ; and that either change may occur without the concurrence of the other.

742 . The duration of the period of aptitude for procreation, as marked by the persistence of the Catamenia, is more limited in Women than in Míen, usually terminating at about the 4.5 th year; it is sometimes prolonged, however, for ten or cven fifteen years further; but cases are rare in which women above 50 year's of age have borne children. ${ }^{2}$ There is usually no menstrual flow during pregnancy and lactation; in fact, the cessation of the catamenia is generally one of the first signs indicating that conception has taken place. But it is by no means uncommon for them to appear once or twice subsequently to conception; and in some women there is a regular monthly discharge, though probably not of the usual character, through the whole period. Some very anomalous cases are on record, in which the catamenia never appeared at any other time than during pregnancy, and were then regular. The absence of the catamenia during lactation is by no means constant, cspccially if the period be prolonged; when the menstrual discharge oceurs, it may be considered as indicating an aptitude for conception; and

1 Such at least appears to be the legitimate inferenee from the state of the Ovaries; but the eases are very few in which the extruded Ora have been found in the female passages. 'Two such cases (one of them, however, not altogether satisfuctory) were recorded by Dr. Letheby, in Philos. Transact., 1852.

2 Dr. Mitthews Duncan has elfarly shown (Trans. Roy. Soc. of Edin., vol. xxiii, p. 168) that the total fertility of fertile women diminishes as the age at whieh marriage takes plaee increases. Sterility is rare amongst those marying between the ages of 20 and 24 , but abont 7 per eent. of those marrying between 15 and 20 are sterile. These last, however, where fertile, bear more ehildren than those marrying at alater date. 
it is well known that, although pregnancy seldom recurs during the continuance of lactation, the rule is by no means invariable.

743. The function of the Female, during the coitus, is essentially passive. When the sexual feeling is strongly excited, there is a considerable degree of turgescence in the erectilc tissue surrounding the vagina, and composing the greater part of the nympha and the clitoris; and there is an increascd secretion from various glaudular follicles. ${ }^{1}$ But these changes are by no means necessary for effectual coition; since it is a fact well established, that fruitful intercourse may take place when the female is in a state of narcotism, of somnambulism, or even of profound ordinary sleep. It has been supposed by some that the os uteri dilates, by a kind of reflex action, to receive the semen; but of this there is but little evidence. The introduction of a small quantity of the fluid just within the vagina, appears to be all that is absolutely necessary for conception; for there are many cases on record in which pregnancy has occurred, in spite of the closure of the entrance to the vagina by a strong membrane in which but a very small aperture existed. That the spermatozoa make their way towards the ovarium, and fecundate the ovum either before it entirely quits the ovisac or very shortly afterwards, appears to be the general rule in regard to the Mammalia; and their power of movement must obviously be both vigorous and long continued to enable them to traverse so great an extent of mucous membrane, especially when it is remembered that they ascend in opposition to the direction of the ciliary movement of the epithelial cells, and to the downward peristaltic action of the Fallopian tubes, which may generally be noticed in animals killed soon after sexual intercourse.- We shall now consider the changes in the Ovum and its appendages, by which it is prepared for fecundition.

744. Up to the period when the Ovum is nearly brought to maturity, it remains in the centre of the ovisac or inner layer of the Graafian follicle; and it is supported in its place by the "membrana granulosa," which is continuous with its proligerous disk. The movement of the ovun towards the surface, which has been already referred to as a part of the changes by which it is prepared for fecundation, appears from the observations of $\mathrm{V}$ alentin to be due to the following cause: In the immature ovisac, the space between its inner layer ald the ovum is for the nost part filled up with cells; these, however, gradually dissolve away, especially on the side nearest the surface of the ovary; whilst an albuminous fluid is effused from the deeper part of the ovisac, which pushes the residual layer (forming the discus proligerus) before it, and thus carries it against the opposite wall. At the same time, there is a gradual thinning away of the various envelopes of the Graafian follicle, as well as of its own walls, in the situation of its most projecting part; and thus it is preparing to give way at that point, for the discharge of the contained ovum. Before rupture takes place, however, the ovisac itself

1 The glands of Duverney, which were very accurately described by Professor Tiedeman (1840), and subsequently by M. Huguier in the Arelives d'Anatomie (1847), seem to be analogous to Cowper's glands, and like then are sometimes wanting and differ in size. In advanced age they are said to diminish in size, and even to disappear. They are present in the females of all animals, where Cowper's glands exist in the males. They seerete a thiek, tenacious, grayish-white fluid, whieh is emitted in large quantity at the termination of the sexual act, most likely from the spasmodic contraction of the constrietor vagine muscle, under which they lie. Its admixture with the male semen has been supposed to have some eonneetion with impregnation; but no proof whatever has been given that any such admixture is necessary. It seems not improbable, however, that it may serve, like the prostatie fluid of the male, to give a dilution to the seminal fluid that is favorable to its action $(3,731)$. These glands were probably known to the ancients; and it is doubtless their seeretion which Hijpocrates and others describe as the fernale semer. 
undergoes a considerable change. Its walls become more vascular externally, and are thickencd on their interior by the deposit of a fleshy-looking sub-

FIG. 313.

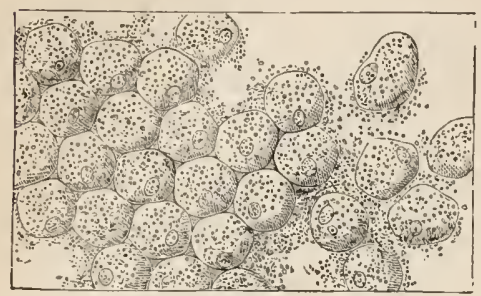

Cells forming the original substance of the Corpus Luteum. stance, which in many of the lower Mammalia is of a reddish color, whilst in the Human female it is rather of a yellowish hue. This substance, known as the Corpus luteum, is at first entirely composed of an aggregation of cells (Fig. 313), and may, in fuct, be considered as an increased development, or hypertrophy, of the "membrana granulosa " or epithelial lining of the ovisac; many of its cells, however, especially those in apposition with the enveloping wall of the follicle, undergo a more or less complete transformation into fibres; and thus a gradual transition is established between the cellular substance of the interior of the mass, and the fibrous stroma of the Ovarium itselt.' In most domestic quadrupeds, this growth, which sprouts like a mass of granulations from the lining of the ovisac, is often so abundant, if the ovum be impregnated, as not only to fill the cavity of the ruptured vesicle, but even to protrude from the orifice on the surface of the ovary; this orifice subsequently closes, aud the contained growth becomes gradually firmer, its color changing from red to yellow. In the Human female, however, as in the Sow, this new formation is at first less abundant; it does not form mammillary projections from the interior of the ovisac, but lies as a uniform layer

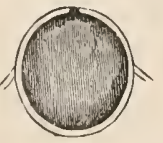

$a$

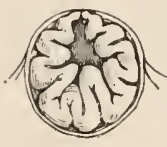

e

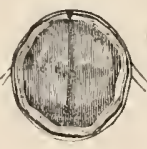

$b$

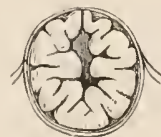

Successive stages of the formation of the Corpus Luteum, in the Graafian follicle of the Sow, as seen

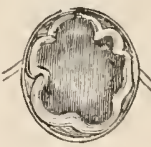

$c$

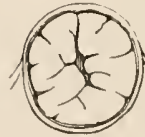

马

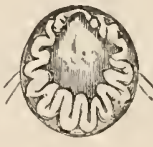

d

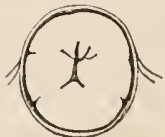

$h$ in vertical scction: at $a$ is shown the state of the follicle immediately after the expulsion of the ovum, its cavity being filted with blood, and no ostensille increase of its epithelial liniug having yet take'n place; at $b$, a thickening of this lining has become apparent; at $c$, it begins to present. folds which are deepened at $d$, and the clot of blood is absorbed pari passu, and at the same time decolorized; a continuance of the same process, as shown at $e, f, g, h$, forms the Corpus Lutcum, with its stellate cicatrix.

upon its lining; and this is thrown into wrinkles or folds, in consequence of the contraction of the ovisac (Fig. 314, $a-d$ ). An irregular cavity is thus at first left in the interior of the ovisac, after the discharge of the ovum; but

1 By some observers, as Köliker, the principal part of the new growth is regarded as the result of a hypertrophy of the internal layer of the fibrous membrane of the original follicle, which, eren before the expulsion of the ovum, becomes loosened in texture and angmented in thiekness. The fact seems to be, that, as in the ease of the Malpighian bodies of the Spleen $(3212$, iii), there is no distinet line of demarcation between the fibrous wall and the cellulur contents of the folliele. 
this gradually diminishes, partly in consequence of the increased growth of the yellow substance, and partly owing to the general contraction of the orisic, until it is at last neally obliterated or reduced to a sort of stellate cicatrix $(e-h)$. An effusion of blood usually takes place into this cavity, in the Human female, at the time of the rupture of the ovisac; but the coagulum which is left, takes no share in the formation of the yellow body. It generally loses its coloring matter, and acquires the characters of a fibrinous clot; and this may either for'm a sort of membranous sac lining the cavity, or it may become a solid mass occupying the centre of the stellate cicat rix. ${ }^{1}$

745 . The later part of the history of the Corpus Luteum is greatly influenced by the impreguation or non-impregnation of the Ovum whose extrusion it has followed.- If conception do not take place, the corpus luteum seldom attains a size greater than that of a small pea, and is very commonly less than this; and it begins to dininish about the time of the next menstruation, its shape, which was at first globular, becoming somewhat collapsed and flattened. This diminution is due in the first instance to the absorption of part of its contained coagulum, which usually at the same time loses part of its coloring matter; but contemporaneously with this, there is an increase in the proper yellow substance, which also becomes brighter in color from the presence of a large quantity of oleaginous matter in its cells. Soon, however, the yellow substance becomes softer and more friable, showing less distinctly the markings of its convolutions; whilst at the same time it becomes more intimately connected with the neighboring tissues. The central coagulum becomes a faint, whitish, stellate cicatrix; and the yellow substance assumes various irregularities of form, and gradually decreases in size. As a general rule, the corpus lutenm of the non-pregnant female is reduced within six or eight weeks to a very insignificant size; but it may then remain almost unchanged for many months; so that, in the ovaries of females who have menstruated regularly, numerous obsolete corpora lutea may be distinguished.-But if, on the other hand, the discharged ovum should be fertilized, and pregnancy should supervene, the corpus luteum instead of reaching its maximum of development in three or four weeks, and then undergoing atrophy, continues to develop itself for a considerable period, and does not, in fact, become very decidedly retrograde, until after the termination of gestation. This difference relates not only to its size, but also to its aspect and general characters. Its size appears to be usually greatest between the third and the sixth months of pregnancy; it retains its globular or only slightlyflattened form; and it continues to give to the touch a sense of considerable resistance and solidity. The convoluted wall of yellow substance becomes much thicker in proportion to the space in its interior; so that whilst in the non-impregnated female its thickness never exceeds one-eighth of an inch, and is usually much less, that of the pregnant female measures as much as from three-sixteenths to one-fourth of an inch. This substance, moreover, acquires a firmer and more highly organized structure; but instead of presenting an increased brightness of color, it fades to a dusky and indefinite hue. As, from the time that impregnation takes place, the periodical activity of the ovary is suspended, no new vesicles protrude themselves from its surface until after the completion of gestation; and even those which, at the date of conception, happened to be more or less prominent, appear again to recede. Hence, if the period of preguancy be at all advanced, the corpus lutem is not found, like that of menstruation, in company with unruptured vesicles in active process of development. After parturition, the corpus

1 This process was first accurately described by M. Pouchet, in his Thérie Positive de l'Ovulation Spontanée, 1847. 
Iuteum rapidly diminishes; though its characteristic structure is still to be distinguished for many months, by close inspection. ${ }^{1}$

746. The foregoing differences (whose ordinary existence may be considered as well established, although it may not be affirmed that they present themsclves characteristically in each individual case) are probably to be attributed to the increased determination of blood which takes place to the wholc Generative apparatus, when it is in a state of exalted functional activity. It is a question, however, of much scientific interest, and one that occasionally becomes of importance in Juridical investigations, what degree of rescmblance may exist between the corpus luteum which is formed after the mere cxtrusion of an ovule, and that which has been modified by the supcrvention of pregnancy. For it is unquestionable that an unusual development of the fibro-cellular substance may sometimes occur without impregnation ; whilst, on the other hand, the changes which usually follow impregnation may take place so much less characteristically than usual, that the corpus luteum, even at the middle period of pregnancy, may be no larger than that which is often found where pregnancy has not occurred. These variations, which seem mainly to depend upon differences in the degrce of vascular excitement of the ovaries accompanying and succeeding the extrusion of ova, render it impossible to draw any definite line of demarcation, by which we may at once determine what are, and what are not, the results of conception; but the following practical rules, deduced from a consideration of all the circumstances yet known, may be laid down for the guidance of those who find it desirable to have some standard of judgment: "1. A Corpus Lutcum, in its earliest stage (that is, a large vesicle filled with coagulated blood, having a ruptured orifice, and a thin layer of yellow matter in its walls), affords no proof of impregnation having taken place.-2. From the presence of a Corpus Luteum, the opening of which is closed, and the cavity reduced or obliterated, only a stellate cicatrix remaining, alsn no conclusion as to pregnancy having existed, or fecundation having occurred can be drawn, if the Corpus Luteum be of small size, not containing as much ycllow substance as would form a mass the size of a small pea.-3. A sinilar Corpus Luteum of larger size than a common pea, would be strong presumptive evidence, not only of impregnation having taken place, but of pregnancy having existed during scveral wceks at lcast; and the evidence would approximate more and more to complete proof, in proportion as the size of the corpus luteum was greater."'

747. Since the discharge of natural Ova from the ovaries takes place as independently of sexual intercourse in the Human female (and in the Mammalia generally) as it does in those animals whose ova are fertilized out of the body, it secms unnecessary that the seminal fluid should reach the ovariun in order to effect the fertilization of the ova, since this end may be answered by the contact of the two in the Fallopian tubes, or even in the Uterus itself. From the experiments of Bisclioff, lowever, it appears that in rabbits, bitches, and probably in most other Mammalia, sexual union usually takes place previously to the escape of the ova from the ovary, and that sufficient time often clapses for the seminal fluid to reach the ovary beforc their extrusion occurs: in such cases, therefore, it would scem probable

1 See espeeially the Prize Essay of Dr. J. C. Dalton, On the Corpus Luteum of Menstruation and Pregnaney, in the Transact. of the Ameriean Medieal Association for 1851, and separately reprinted, Platadelphia, 1851; and the excellent seetion on Reproduction, in his Human Physiology, Philadelphia, 186t; also, the essay of $\mathrm{M}$. His in Schultze's Arehiv, Bd. i, p. 181, in which references to the prineipal works on the subject will be found.

2 See Dr. Baly's Supplement to Müller's P'hysiology, p. 57. 
that fecundation is effected at the ovary itself. That such occasionally happens in the Human female, seems to be unequivocally proved by the occurrence of tubal or even of ovarian foctation ; the ovum having received the fertilizing influence immediatcly upon quitting the ovisac, or even before it has entircly extricated itself from the ovary, and having been in some way checked in its transit towards the uterus, so that its development has taken place in the spot at which it has been arrested. It is affirmed by Bischoff that by the time the ovum reaches the uterus, or even the lower end of the Fallopian tube, its capacity for impregnation is lost; but this assertion chiefly rests on the cessation of sexual desire observed in those animals in which, after death, the ova were found in these situations. There is every reason to belicve that this is not the case in the Human female; for although the sexual desire may be the strongest about the period of the maturation and escape of the ova, yet it is by no means wanting at other times; and the occasional occurrence of cases in which impregnation has taken place from a single coitus in the middle of the interval between the menstrual periods, shows either that the ovum may retain its capacity for impreguation for some time after its escape from the ovary, or that its maturation and extrusion are not by any means invariably coincident with the menstrual period. ${ }^{1}$ The ova, when set free from the ovaries by the rupture of the ovisacs and the giving way of their several envelopes, and surrounded by the cclls of the membrana granulosa, are received by the fimbriated extremities of the Fallopian tubes, which, during the period of sexual excitement, appear to be closely applied to the surface of the ovaries. Their conveyance along the Fallopian tubes is probably due in part to the peristaltic movement of their walls, and in part to the action of the cilia which clothe their internal surface.

748. The object of the changes which have been already described, is to bring the Ovum within the reach of the fecundating influence, and to convey it into the uterus after it has been fertilized; we have now to consider the changes of the Ovum itself, which take place during the same epoch.At about the same period that the ovum moves towards the periphery of the Graafian follicle, the germinal vesicle moves towards the periphery of the yolk; and it always takes up its position at the precise point of the zona pellucida which is nearest the ovisac, and which is closest, therefore, to the surface of the ovary. Moreover, the germinal spot is always on that part of the germinal vesicle which is in closest contact with the zona pellucida. Thus, the germinal spot is very near the exterior of the ovary; but it is separated from the peritoneal coat of the latter, by a thin layer of its stroma forming the external wall of the Graafian follicle, by the ovisac forming its internal membrate, and by the zona pellucida. As soon as these give way, there is nothing to prevent the spermatozoa from coming into direct contact with the ovum, even before it quits the ovisac. That such contact is an essential condition of fecundation, there is every reason to believe; although as to the precise manner in which it operates, we are at present in the dark. There can be no doubt that it is in the contact of the spermatozoa with the ovum

1 See a ease of this kind reeorded by Dr. Oldham in the Medieal Grazette, July 13 th, 1849. - Instances are eertainly not unfrequent, in which eonception bas taken place five or six days after the eonelusion of the menstrual period; the Author has himself known onc in which this occurred, after the menstrual flow itself had persisted for a week. It has been urged that the known fertility of Jewish females, who abstain from sexual intereourse for eight days, or even thirteen days, after the termination of the eatamenia, is opposed to the idea that the menstrual period is that of "heat;" but there is reason to believe that this is to be aecounted for in another way, namely, by the usual oecurrenee of conception from intercourse immediately before the access of the eatamenia. (See Mr. Girdwood, in the Lancet, Dec. 14th, 1844.) 
( $\$ 747$ ), and in the changes which occur as the immediate consequence of that contact, that the act of Fecundation essentially consists. The most recent observations of the late Mr. Ncwport upon the process of impregnation of the Frog (some of which the Author, through the kindness of Mr. Newport, had the opportunity of verifying) showed that the spermatozoa become imbedded in the gelatinous envelope of the ovum, within a few seconds after they come into contact with it; and that they then absolutely pass through the vitelline menbrane, in to the interior of the Ovum, ${ }^{1}$ where they probably undergo a gradual diffluence; and thus the product of the "sperm-cell" may be absorbed into the "germ-cell," and may intermingle with its contents, the Spermatozoon being nothing else than an embodiment of the fertilizing material developed within the sperm-cell, which is endowed with a temporary power of movement in order that it may find its way to the Ovum. - In the Osseons Fishes it has been shown by Dr. Ransome that the Spermatozoa pass through a minute opening in the external membrane of the ova, termed the micropyle. A similar opening has bceu observed by Müller and others in Insects, Acephatous Mollusks, and in several Echinodermata; and its use, as Dr. Allen Thomson has suggested, is probably to facilitate the fecundation of ova possessed of very thick external coverings. A micropyle has not been seen in any of the Mammalia, though the point has been closely investigated by Reichert in the Guinea-pig. It has been remarked by Mr. Newport, that Spermatozoa whose spontaneous motility has ceased, no longer possess the fecundating power; and this fact concurs with other phenomena to indicate, that it is not only a certain material, but a vital force of which that material is (so to speak) the vehicle, which is required to effect this most important opcration.

749. The precise share which the Germinal Vesicle performs in the changes which take place in the ovum about the period of fecundation, has not yet bcen satisfactorily deternined. According to Dr. Barry (loc. cit.), the germinal vesicle becomes filled with a new development of cells, which sprout, as it were, from its nucleus (the germinal spot); and after fecundation, a pair of cells is seen in the space previously occupied by the pellucid centre of the nuclcus, which is developed at the expense of the rest, and is the true foundation of the embryonic structure. This view is to a certain extent confirmed by the observations of Wagner on the ova both of Frogs and Mammalia, and by those of Vogt on those of the Rana obstetricans; both of which lead to the belief that such a process of cellformation does take place within the germinal vesicle, but that, instead of the further development bcing carried on within the germinal vesicle, as

1 Philos. Transact, 1853, pp. 266-281.-Prof. Bischoff, the highest authority on this subjet, who had disputed the validity of all previous observations on the penetration of the spermatozoa into the interior of the Ovum, fully confirmed those of II. Newport; whose lamented death prevented him from enjoying the satisfiction which this testimony to his aceuracy would have atjorded him.- See also Dr. Barry, in Philos. Transact., 1840, p. 533 ; and Dr. Pansome, in Proceed. of Roy. Soe., Nov. 23d, 1854. Bischoff' (Henle and P'eutier's Zeits, 1865, p. 268) eonsiders that in by far the majority of eates, the act of feeundation oceurs whilst the ovum is traversing the Fallopian tube. According to Coste, the duration of the passage of the egg through the oviduct of the fowl varies from four to six hours, and of its retention in the cloaca four hours. The influence of a single act of coition in the fowl, according to the same observer, may extend to from five to six eggs, which may be hid during the cleven to seventeen subsequent days. Harvey extended the influence even to twenty eggs. His agrees with coste, and observes, that in all probability these eggs were impregnated at different periods; and hence some of the variations in point of development of the cicatricula may proeed. His has also observed that the eggs of fowl, laid in the middle of summer, are more advanced, and develop with greater rapidity than those laid towards the end of autumn. 
maintained by Dr. Barry, this ruptures and sets free the cells that had heen developed in its interior, which are now dispersed through the yolk whose ulterior changes take place under their influence. Mrr. Newport's view is nearly the same as this; and he states that, in the Frog, this dissolution of the germinal vesicle and diffusion of its contents take place as a preparation for fecundation, and not in consequence of it. ${ }^{1}$ That the germinal vesicle is no longer to be seen when the metamorphoses of the yolk have commenced, is now universally admitted; but with regard to the antecedent process just described, there is still a want of accordance amongst Embryologists, its existence being altogether denied by Bischoff, who maintains that the germinal vesicle simply dissolves away shortly after coition. The Author is strongly inclined to believe, however, from his own observations, as well as from a priori considerations based on the history of Vegetable fertilization, that there is a devclopment of cells within the germinal vesicle, at the time of its maturation; and that it is by the influence of the spcrmatic fluirl upon one of these cells, after it has been set free in the midst of the yolk by the rupture or diffluence of the germinal vesicle, that the first cell of the embryonic fabric is generated. ${ }^{2}$

750. Having thus noticed the principal points of the history of the development and impregnation of the Ovum, we shall proceed to consider the provisions made for the Nutrition of the Embryo, through the Generative apparatus of its female Parent, up to the time of parturition; deferring the history of its own Development for that separate consideration which the importance of this subject demands $(\$ 4)$. - A bout the time that the ovum is leaving the ovary, the cells of the proligerous disk which inmediately surrounds the zona pellucida become club-shaped; their small ends being applicd to the surface of the ovum, so as to give it somewhat of a stellate appearance. According to Bischoff, these cells entirely disappear from the ovum of the Rabbit as soon as it has entered the Fallopian tube: whilst in the Bitch they become round, and continue to invest the ovum in this form throughout its whole transit to the uterus. During its passage, the ovun acquires a sort of gelatinous envelope, which is inclosed in a membrane of fibrous texture, termed the Chorion. This envelope is probably of an albuminous nature, corresponding with the "white" of the Bird's egg; whilst the fibrous texture of the chorion seems to be produced like the nembranous basis of the egg-shell of the bird, by the exulation of fibrin from the lining membrane of the Fallopian tube or oviduct. The outer layer of this envelope, in the egg of the Birl, is consolidated by the deposition of particles of carbonate of lime in its areola; and none of it undergoes any further organization. The Chorion of the Mammal, on the other hand, is destined to undergo changes of a much higher order, which adapt it for participating to a most important degree in the nutrition of the included embryo. The first of these changes consists in the extension of the cellular surface of the nembrane into a number of villous prolongations, which give it a spongy or shaggy appearance (Fig. 318); these serve as absorbing radicles, and form the channel through which the embryo is nourished by the fluids of the parent, until a more perfect communication is formed by the subsequent extension of vessels into them.

751. We have now to speak of the changes in the Uterus which take place in consequence of Conception, and which prepare it to receive the ovum. Of these the most important is the formation of the Membrana Decidua, so called from its being cast off at each parturition. Professor

1 Philos. Trans., 1851, p. 178.

2 See Huxley, on Development of Pyrosoma, in Linn. Trans., vol. xxiii, p. 227 ; and Ann. Nat. Hist., Ser. 3, vol. v, pp. 29-35. 
Turner has pointed out, that as soon as the ovum is received into the uterus the mucous membrane swells. The ciliated epithelium often, though not always, loses its columnar form, and the cells multiply in order to cover the increased surface. The subepithelial tissue increases enormously, which is due to the multiplication and development of the corpuscles which are

FIG. 315 .

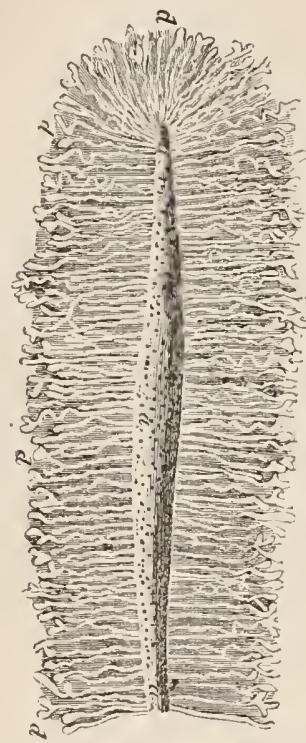

FIG. 316 .

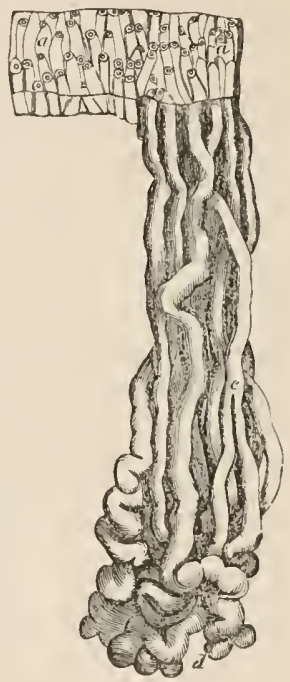

FIG. 315.-Section of the Lining Membrane of a Ifuman Uterus at the period of commencing pregnancy, twice the natural size; showing the arrangenent and other peculiarities of the glands, $p, p, p$. with their orifices, $a, a, a$, on the internal surface of the organ.

Fig. 316.-A portion of Fig. 315 more enlarged; showing the convoluted extremities of the tubular glanculæ.

abundantly distributed throngh its tissue. The branched glands naturally present, as seen in vertical sections, are separated to a much greater distance from each other in consequence of the growth of the subepithelial tissue, and are augmented in size. The whole membrane becomes much more vascular. On its surface pitlike depressions may be seen, which were formerly thought to be the enlarged mouths of the glinds, but which Professor Turner has ascertained to be new-formed pits or crypts in the interglandular tiscue. Into these erypts the villi of the chorion penetrate.

752. The Deciduous membrane is found at a later period to consist of two layers: the Decidue vera lining the uterus, and the Decidua reflexa covering the exterior of the ovum. The observations of M. Coste and Dr. Farre show that there is considerable resemblance between the two at an early period, and from their observations and those of Reichert, ${ }^{1}$ it would appear that when the ovum enters the uterus, it becomes attached to some part of a triangular area of the decidua vera, on which numerous cotyledonary elevations or islands exist. The spot at which the ovum is attached (Fig. 317) ceases to grow, but a remarkable development of primary and secondary papillary processes takes place in the adjoining islands, in consequence of which a cup-shaped depression is formed, in which the ovum is lodged. The 
growth of the margin of the cup over the free surfice of the ovum, closes in the chamber and forms the membrana decidua reflexa ${ }^{1}$ (Fig. 318), by which the ovum is entirely eovered about the twelfth or thirteenth day. At

Fic. 317.

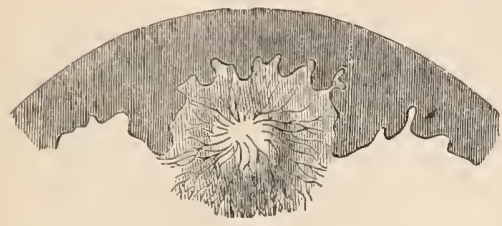

First stage of the formation of the Decidua reflexa around the ovum.
FIG. 318.

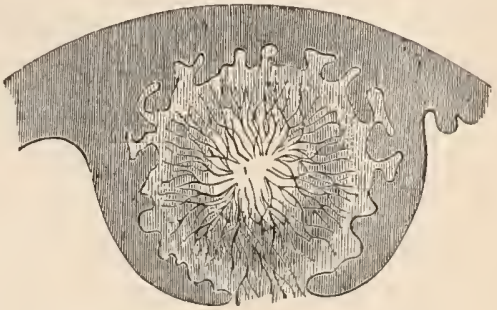

More advaneed stage of Decidua reflexa.

the margin of the eotyledonary island, the uterine mucous membrane is smonth, and shows the widened orifices of the uterine glands. Some utricular glands are also found opening on the inner eoncave surface of the reflexa, the rest of the surface being covered with a short, non-ciliated eylindrical epithelium. As the ovum increases in size, the eavity between the decidua vera and the decidua reflexa, or, as it is sometimes termed, the uterine ehamber, graduilly diminishes, and by the end of the third month either the two layers come into contaet and are henceforth indistinguishable - the whole cavity of the uterus being oceupied by the fœetal chamber-or, as Dr. Farre suggests, the decidua reflexa may, after first becoming extremcly attenuated, ultimately entirely vanish.

753. The surface of the Ovum, thus surrounded by the double layer of the deciluous membrane, and during the first three or four weeks lying loose in the foetal chamber, is rendered shaggy by the growth of villous tufts from the surface of its investing Chorion (Fig. 319), by which it begins to be attached to the walls that surround it. Eaeh of these tufts, as was first pointed out by Prof. Goodsir (loc. cit.), is composed of an assemblage of nucleated cells, which are found in various stages of development; and these are always inclosed within a layer of basement-menbrane, whieh seems to be itself composed of flattened cells united by their edges. At the free extremity of each villus is a bulbous expansion, the eells eomposing which are arranged round a central spot; and it is at this point that the most active proeesses of growth take place, the villus elongating by the development of new eells from its germinal spot, and (like the spongiole of the plant) drawing in nutriment from the soil in which it is imbedded. - In its earliest grade of development, the

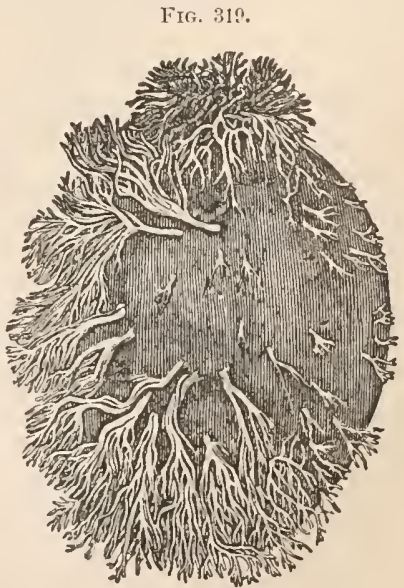

Entire Ifuman Orum of eighth week. sixteen linns in length (not reckoning the tufts); the surface of the Chorion partly smooth, and partly rendered shaggy by the growth of tufts.

1 See Turner's Report, Journal of Anatomy and Physiology, vol. viii, p. 168. 
chorion and its villi contain no vessels; and the fluid drawn in by the tufts is communicated to the cmbryo by the absorbing powers of the germinal membrane of the latter. But when the tufts are penetrated by bloodvessels, and their communication with the embryo becomes more direct, the means by which they communicate with the parent are found to be still essentially the same; namely, a double layer of nucleated cells, one layer belonging to the foetal tuft, and the other to the vascular maternal surface. It is from these elements that the Plicenta is formed. ${ }^{\mathrm{I}}$

754. The first stage in this process consists in the extension of the Fotal vessels into the villi of the Chorion over its entire surface, in the manner hereafter to be detailed; so that the nutriment which these villi imbibe, instead of being merely added to the albuminous fluid surrounding the yolkbag, is now conveyed directly to the embryo. This-the earlicst and simplest mode by which the Fotus effects a new comection with the parentis the ouly one in which it ever takes place in the lower Mammalia, which are hence properly designated as "non-placental," rather than as ovo-viviparous. In the higher Mammalia, however, there soon occurs a great extension of the vascular tufts of the foetal chorion, at certain points; and a corresponding adaptation, on the part of the uterine structure, to afford them

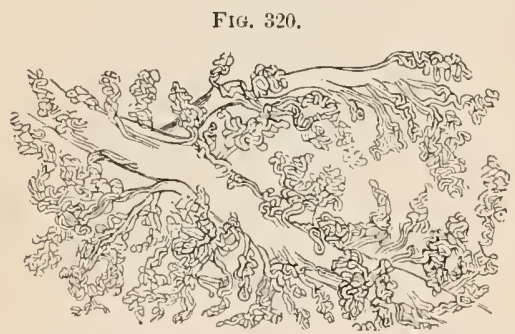

Portion of the ultimate ramifieations of the umbilical vesscls, forming the Fotal Villi of the Placenta.

an increased supply of nutritious fluid. These specially prolonged portions are seattered in the Ruminantia and some other Nammalia, over the whole surface of the chorion, forming what are termed the " cotyledons;" but in the higher orders, and in Man, they are concentrated in one spot, forming the Placenta. In some of the lower tribes the maternal and the foutal portions of the placenta may be very easily separated; the former consisting of the thickened Decidun, and the latter being composed of the protonged and ranifying muscular tufts of the Cho-
FIG. 321

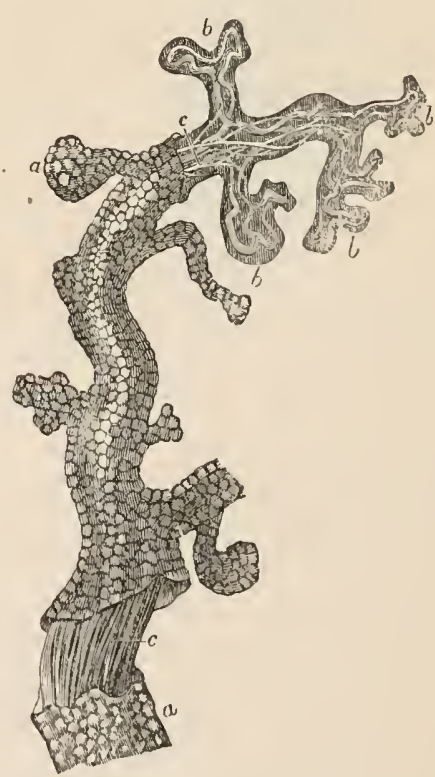

Portion of one of the Fretal Villi, about to form part of the Placenta, highly magnified: $a, a$, its eellular eovering; $b, b, b$, its looped vessels; $c, c$, its basis of eonnective tissne.

I The Placenta varies in form to a eonsiderable extent in different animals. In Cetacea and in many Unerulata, as the Horse and Zabra, the villi project from all purts of the chorion, aud thrir placenta is eonsequently termed diffuse. In Carnivora, in Soals, in the Elephant and Hyrax, the villi are only drvelopeal in a ring or zone around the chorion, and the placenta is therefore called zonary. In Rumiunts the villi are drveloped in eertain spots, irearularly distributed over the chorion, forming the cotyledonoms placenta. Finally, in Man and in Rodents the villi are limited to a singlespot, and the Placenta is thence termed discoil. See Report of Turner's Lectures delivered at the College of Surgeons, in Lancet for June, 1875. 
rion, dipping down into it. But in the Human placenta, the two elements are mingled together through its whole substance.-On looking at the foctal surface of the Human placenta, we perceive that the umbilical vessels diverge in every direction fron the point at which they enter it; and their subdivisions form a large mass of capillaries, arranged in a peculiar manner (Figs. 320, 321), and constituting what are known as the fretal villi. Each villus contains one or more capillary loops, communicating with an artery on one side, and with a vein on the other; but the same capillary may pass into several villi, before re-entering a larger vessel. The capillaries of the villi are covered, as in the chorion, by a layer of cells (Fig. 321, $a, a$; Fig. 322, e), inclosed in a basement-membrane; but the foetal tuft thus formed is inclosed in a second series of envelopes (Fig. 322, $a, c, e$ ), derived from the maternal portion of the placenta, - a space (ips) being left, however, between the two, at the extremity of the tuft.

755. Whilst the fotal portion of the Placenta is thus being generated by the extension of the vascular tufts of the Chorion, the maternal portion is formed by the enlargement of the vessels of the Decidua, between which they dip down. "These vessels assume the character of sinuses; and at last

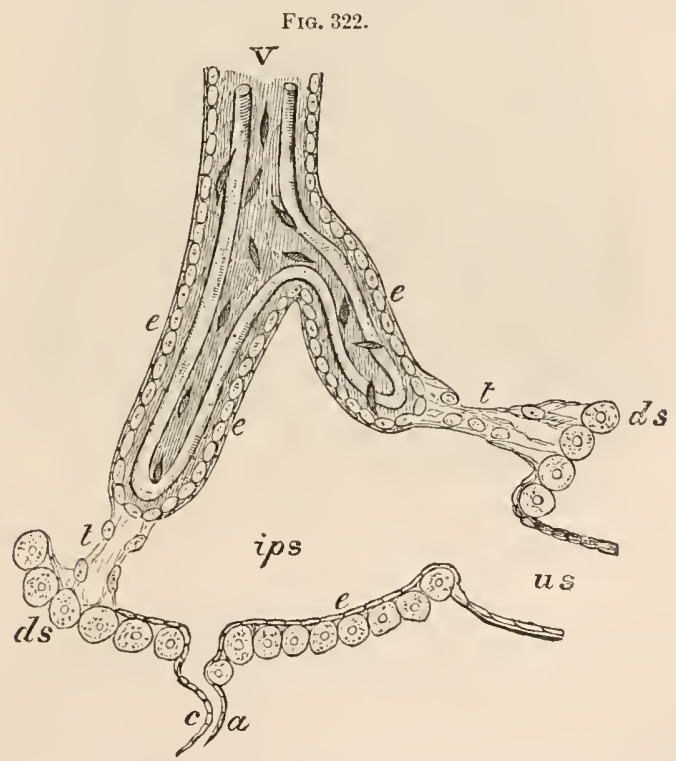

V, Placental Villus, consisting of gelatinous connective tissue with corpuscles; in its interior are seen the foetal bloodvessels forming loops; $e, e$, epithclium investing the Villus, beneath which is a layer of cells forming the occluding lamina; $d, s$, decidua serotina; $c$, $a$, curling artery; $u s$, uterine sinus; $t, t$, trabecula ; ips, intra-placental maternal blood sinus.

swell out (so to speak) around and between the villi; so that finally the villi are completely bound up or covered by the membrane which constitutes the walls of the vessels, this membrane following the contour of all the villi, and even passing to a certain extent over the branches and stems of the tufts. Between this membrane, or wall of the enlarged decidual vessels, and the internal membrane of the villi, there still remains a layer of the cells of the decidua." 1 In this manner is formed the maternal portion of the

1 Prof. Gondsir's Anatomical and Pathological Observations, p. 60. Prof. Turner (Journ. of Anat. and Physiology, 1873, p. 130) has recently demonstrated, however, 
placenta, which may be regarded in its adult state (as well pointed out by Dr. J. Reid ${ }^{1}$ ) in the light of a large sac formed by a prolongation of the inner coat of the uterine vessels; against the foetal surface of which sac the tufts just described may be said to push themselves, so as to dip down into it, carrying before them a portion of its thin wall, which constitutes a sheath to cach tuft. Now as every extension of the uterine vessels carries the decidua before it, every one of the vascular tufts that dips down into it will be covered with a layer of the cellnlar structure of the latter; and the foetal portion of each tuft will thus be generally inclosed in a layer of matemal cells and basement-membrane (Fig. 322, $a, b, c) .{ }^{2}$ The whole interior of the

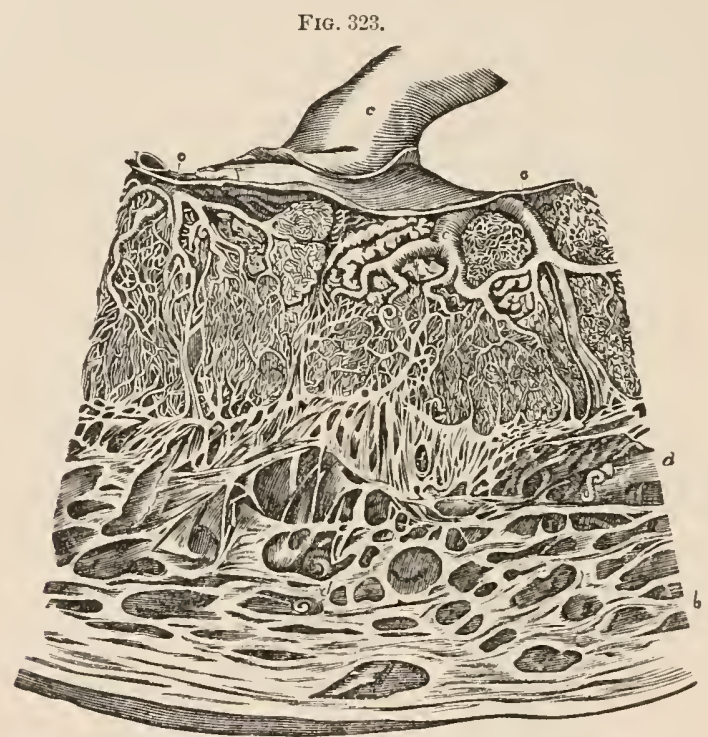

Section of a portion of a fully-formcd Placenta, with the part of the Uterus to which it is attached: $a$, umbilical cord; $b, b$, section of uterus, showing the venous sinuses; $c, c, c$, branches of the umbilical vessels; $d, d$, curling arteries of the uterus.

Placcntal cavity soon becomes (Fig. 323) intersected by numerous tufts of foetal vessels disposed in fringes, and bound down by reflexions of the delicate membrane that forms its proper wall; just as the intestines are held in their places by the reflexions of the peritoneum that covers them. 'This view was snggested to Dr. Reid by the very interesting fact, that the tufts of foctal vessels not unfrequently extend beyond the uterine surfice of the placenta, and dip down into the uterine sinuses, where they are still covered and held in their places by reflexions of the same membrane. All the bands which connect and tie down the tufts are formed of the same clements as the envelopes of the tufts themselves; namely, a fold of the lining membrane of the decidual sinuses, and a layer of the ccllular decidua.

that the decidua serotina does not form a complete and continuous membranous septum between the uterus and placenta, but that its continuity is in various loealities interrupted to allow of the penctration of many of the placental villi into the uteroplacental vessels, into which they project free and naked.

1 Edlin. Med. and Surg. Journ., Janmary, 1841; and Anat, Phys, and Pathol. Researches, chap, viii.

2 See Turner, Observations on the Strueture of the Human Placenta, in Humphry and Turner's Journal of Anatomy and Physiology, vol. vii, 1873, p. 120, in which the literature of the subject will be found. 
756. The Materual blood is conveyed into the Placental cavity by the "curling arteries" of the utcrus (Fig. 322, c, $a$, Fig. $323 d$ ); and is received back from it into the large vcins that are commonly designated as sinuses (Figs. 323, 324, $b, b$ ). "The utero-placental sinus system of veins is so related to the placenta as to communicate with the interior of the cotyledons, either at the outer edge of the placenta, where the so-called circular sinus lies, or where the sinuscs lie within the intercotyledonary decidual dissepiments, or where they come into contact with the literine face of the placenta, close to the plane of entrance of the primary decidual dissepiments into its substance. The communication is not as if the sinuses terminated abrnptly by open mouths, as has usually been described, but rather by possessing cribriform apcrtures in their walls as they lie in contact with the placenta. From the relation of the sinuses to the margins of the cotyledons, whilst the curling arteries penetrate their uterine surface near their centre, the stream of maternal blood passes through each cotyledon from its centre to its circumference, and is effectually brought into contact with the whole of the foetal villi." The foetal vessels (Fig. 322, e, e; Fig. 323, c, c) being bathed in this blood, as the branchire of aquatic animals are in the water that surrounds them, not only enable the foetal blood to exchange its venous character for the arterial, by parting with its carbonic acid to the matermal blood, and receiring oxygen from it; but they also serve as rootlets, by which certain uutritious elements of the maternal blood (prohably those composing the liquor sanguinis) are taken into the system of the fotus. In this, they closcly correspond with the villi of the intestinal canal; and there is this further very striking analogy, 一that the nutrient matcrial is selected and prepared by two scts of cells, one of which (the maternal) transmits it to the other (the foetal), in the same manner as the epithelial cells of the intestinal villi seem to take up and prepare the nutrient matter, which is destined to be still further assimilated by the cells that float in the circulating current. It is probable, too, that the Placenta is to be regarded as au excreting organ; serving for the removal, through the maternal bluod, of excrementitious matter whose continued circulation throngh the blood of the foetus would be prejudicial to the latter. And it will be in this mode that the blood of the mother may become impregnated with substances, or impressed with attributes, originally belonging to the male parent; so as to impart these to the products of subsequent conceptions by a different father $(\$ 769) .{ }^{1}$ There is no more direct communication between the mother and foetus than that which is afforded by this immersion of the foetal tufts in the maternal blood; all the observations which have been supposed to prove the existence of real vascular continuity, having been falsified by the extravasation of fluid, probably consequent upon the force used in injecting the vessels. Moreover, the different size of the blood-corpuseles in the fotus and in the parent shows the non-existence of any such communication.

757. The formation of the Placenta, in the manner just describer, commences in the latter part of the second month; during the third, the organ acquires its proper character; and it subsequently goes on increasing, in accordance with the growth of the Ovum. Towards the end of the term of gestation, however, it becomes more dense and less vascular; owing, it would seem, to the obliteration of several of the minuter vessels, which are converted into hard fibrous filaments. The vessels of the Uterus undergo great enlargement throughout, but especially at the part to which the placenta is

1 See, for various proofs that the mother may be poisoned through the presence of noxious substances in the blood of the foetus, the Essay by Mr. Savory, entilled An Experimental Inquiry into the Effect upon the Mother of Poisoning the Føetus, London, 1858. 
attached; and the blood in moving through them produces a peculiar murmur; which is usually distinctly audible at an early period of pregnancy, and may be regarded (when due care is taken to avoid sources of fallacy), as one of its most unequivocal positive signs. The "placental bruit" is thus described by Dr. Montgomery:" "The characters of this phenomenon are, a low murmuring or somewhat cooing sound, resembling that made by blowing gently over the lip of a wide-mouthed vial, and accompanied by a slight rushing noise, but withont any sensation of impulse. The sound is, in its return, exactly synchronous with the pulse of the mother at the time of examination; and varies in the frequency of its repetitions, with any accidental variation which may occur in the maternal circulation. Its situation does not vary during the course of the same preguancy; but in whatever region of the uterus it is first heard, it will in future be found, if recognized at all,for it is liable to intermissions, - at least, we shall occasionally be unable to hear it where we have already heard it a short time before, and where we shall shortly again recognize it. According to my experience, it will bé most frequently heard about the situation of the Fallopian tube of the right side; but it may be retected in any of the lateral or anterior parts of the uterus." That the cause of this sound exists in the Uterus itself, is distinctly proved by the fact, that it has been heard when that organ was so completely anteverted, that the fundus hung down between the patient's thighs. A sound so much resembling this as to be scarcely distinguishable from it, may be occasioned, however, by a cause of a very different nature,-namely, an abdominal tumor, pressing upon the aorta, iliac arteries, or enlarged vessels of its own ; and, in doubtful cases, it is necessary to give full weight to the possibility of such an explanation. The sound may be imitated at any time, by pressing the stethoscope on the iliac arteries. The placental bruit has been not unfrequently heard in the eleventh week; but it cannot generally be detccted before the fourth month, when the fundus uteri rises above the anterior wall of the pelvis.

758. The increase in the size of the Uterus, which takes place pari passu with the enlargement of the ovum, is accompanied with a remarkable augmentation in the amount of its substance. $U_{p}$ to about the fifth or sixth month, not only its cavity, but the thickness of its walls is progressively added to ; from that time to the end of gestation, the thickness of the walls diminishes whilst the cavity increases, but not in an equal proportion; and at the conclusion of parturition, its solid bulk is estimated at about twentyfour times that of the unimpregnated Utcrus. The augmented volume of the organ is chiefly due to the increased development of its Muscular coat, which is composed of the fusiform cells with staff-shaped nuclei, that make up the "non-striated" muscular fibre elsewhere. According to Prof. Kölliker, a vast amount of new fibres are generated during the early months of pregnancy; but there is at the same time an extrandinary increase in the size of those previously formed, their length heing multiplied from seven to eleven times, and their width from twice to five times. After the sixth nonth the origination of new muscular fibres seems to cease, but the augmentation in the size of those already gencrated seems to continue. The conncetive tisue which unites the muscular fibres also increases during pregnancy, and becones more distinctly fibrous. ${ }^{2}$ It has been shown by Dr. Lee, ${ }^{3}$ in his beantiful preparations and drawings, that the Nerves of the Uterus, which are

1 Signs of Pregnancy, p. 121.

2 See Kölliker's Ianual (Syd. Soc. Ed.), vol. ii, pp. 258, 259.

3 Phil. Trunsuct. 1811, 181: $, 1846,1819$. 
deriver from the inferior mesenteric plexus and the middle sacral nerves, also undergo a great augmentation during pregnancy. Simultancously with the enlargement of the uterus, the Mammary gland and its appendages undergo a fuller development; and from this a valuable, but not unequivocal, indication of pregnancy may be drawn. Occasional shooting pains in the Mamma are not unfrequently cxperienced within a short period after conception; and more continued tendemess is also not unusual. A sense of distension is very commonly experienced at about the end of the second month ; and from that time a distinct "knottiness" usually begins to present itself, increasing with the advance of pregnancy. In many instances, however, these mamnary sympathies are entirely absent; and they may be simulated by changes that take place in consequence of various affections of the uterus. A change of color in the areola is a very common, but not an invariable, occurrence in the early months of pregnancy; but another sign is afforded by the areola and nipple, which is of more value because more constant,namely, a puffy turgescence, and an increased development of the little glandular follicles, or tubercles, which commonly secrete a dewy moisture.Iany other changes in the constitution occur during pregnancy; indicated by the buffiness of the blood, the irritability of the stomach, and the increased excitability of the mind. All these however, are discussed with sufficient amplification in works on Obstetric Medicine.

759. The act of Conception, being one of a purely organic nature, is not itself productive of any sensation on the part of the mother; but therc are some women in whom it is attended with certain sympathetic affections, such as faintncs, vertigo, etc., that enable them to fix upon the particular time at which it has taken place. From that period, however, the mother has no direct consciousness of the change going on in the uterus (save by the effects of its increasing pressure on other parts), until the occurrence of what is termed "quickening." This is generally described as a kind of fluttering movement, attended with some degree of syncope or vertigo. After it has once occurred, and has strongly excited attention, it is occasionally renewed once or twice, and then gives place to the ordinary movements of the foetus. Not unfrequently, however, no movement whatever is felt, until near the end of the term of gestation, or even through the whole of it. As to the cause of the sensation, Obstetricians are much divided; and no satisfictory account has been given of it. It has been vulgarly supposed to be due to the first movement of the foetus, which was imagined then to become possessed of an independent life; and the English law recognizes the truth of this doctrine, in varying the punishment of an attempt to procure Abortion, according to whether the woman be "quick with child" or not; and in delaying execution when a woman can be proved to be so, though it is made to proceed if she is not, even if she be unquestionably pregnant. Whether or not the first sensible motions of the foetus are the cause of the peculiar feeling in question, there can be no doubt that the embryo has as much independent vitality before, as after, the quickening. From the time that the ovum quits the ovary, it ceases to be a part of the parent, and is dependent on her only for a dne supply of nourishment, which it converts by its own inherent porvers into its proper fabric. But this dependence cannot be said to cease at the moment of quickening: for the connection must be prolonged during several weeks, before the foetus becomes capable of sustaining life

1 Korner, Heidenhain's Stud. des Physiol. Instit. zu Breslau, 1865, p. 109 . For the Histology of the Virgin Uterus, see Kreitzen, in Landzert's Beiträgre zur Anat. and Phys, St. Petersburg, 1872, vol. i, p. 1, and Centralblatt, 1873, p. 117. 
without such assistance. The earliest pcriod at which this may occur, will be presently considered $(\S 764){ }^{1}$

760. At the conclusion of about forty weeks, or (less correctly) nine solar months ${ }^{2}$ from the period of conception, the time of Parturition arrives. In this act, the muscular walls of the Uterus are primarily concerned; for a kind of peristaltic contraction takes place in them, the tendency of which is to press the contents of the cavity from the fundus towards the os uteri, and finally to expel them; and this contraction is alone sufficient to empty the uterus, when no impediment is presented to the exit of the foetus, as we see in the occasional occurrence of post-mortem parturition. It is, in fact, in the contraction of the fibres of the fundus and body of the uterus, and in a relaxation of those about the cervix (which relaxation is something quite different from a mere yielding to pressure, and is obviously a vital phonomenon that marks a peculiarity in the actions of this part), that the first stage of an ordinary labor essentially consists. ${ }^{3}$ There is no proof whaterer that these changes are dependent upon nervous influence; in firct, there is much evidence that the parturient action of the uterus is not the result (as some have maintained it to be) of a "reflex" action of the Spinal Cord, but is due to its inherent contractility ; for numerous instances have occurred in which normal parturition has taken place, notwithstanding the destruction of the lower part of the Cord, or the existence of a state of eomplete paraplegia which marked its functional inactivity; and the continuance of the peristaltic action for some time after somatic death, when neither the Cerebro-spinal nor the Sympathetic system can afford any supply of nervous power, is a yet more satisfactory proof of the same position." -Nevertheless, it seems quitc certain that inuscular contractions of the Uterus may be induced by reflex action; for in no other way can we account for numerous phenonena, which distinctly mark the opcration of renote causes acting through the nervous system; such as the induction of uterine

1 A case recorded by Dr. J. R. Beck (Med. and Surg. Reporter, 1872, No. 15), serens: to show that the Uterus may participate rather actively in the process of impregnation, as he observed tho os uteri to open and close with considerable ("norgy on mechanical stimulation. Oter and Schlesing(r (Stricker's Med. Jahrb., 18i:-2) have shown that powerful contractions of the uterus are yroduced by the circulation of dy-pncic arterial blood, partly owing to exeitation of some centre for the uterine nerven existing in the cranium, and partly owing to irritation of excitable tirsue in the uterus itselt; and schlesinger has further shown (Stricker's II Jahrb., 1873, 1. 1) that uterine contractions can also be indueed by electric excitation of the centric extremity of a divided dorsal norve. (For other experiments on the reflex contraction of the uterus after irritation of sensory nerves, sce Spiegelbers, Zuit. f. rat.

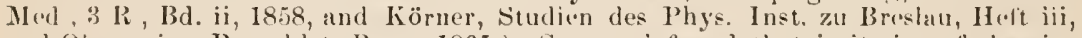
and Ohermoier, Pamplilet, Bumn, 1865.) Seanzoni found that irritation of the nipples, which, according to Luschka, contain so many tactile and Pacinian corpurches, causes contraction of the uterus. The nerveplexus on the aortat is an important but not the only channet for the conduction of these motor impulses.

2 Allhough "nine months" is usually spoken of as the term of Gestation, yet the real torm of forty werks exceeds this by from five to seven days, acorrling to the month inchuded. The mole of reckoning customary among women, i- to date from the middle of the month after the last apjearance of the Catamenia: lut it is certain that Comception is much more likely to take place soon alfer they have ceased to flow, or even just before their aceess, than in the intervening period $(\xi 741)$; so that, in most instances, it would be most correct to expect labor at forty weeks and a fiew days atter the last recurrence of the menses. -The period of Quickening may be relied on in some wonmen, in whom it ocenrs with great regularity in a certain week of pregnatucy; but in seneral there is great latitude as to the time of its occurrence. The usual or average time seoms to be about the eighteenth weck of gestation

3 Soe a paper corroborating this statement, by Arthur Scott Dunkin, M D, in Edinb. Med. Journal, vol. ii, 1860, p. 523.

t Sec cases recorded in Lancet, 1872, vol, i, pp. 517, 596. 
contractions by the dash of cold water on the abdominal surface, by the injection of cold water into the vagina, by the ingestion of cold water into the stomach, or even by dipping the hand into cold water, or again by the suctorial application of the infant's lips to the nipple, by the introduction of the hand into the vagina, by violent movements of other parts of the body, and by various other means. This general fact has an important prictical bearing; since there are various oceasions on which it is most important to life that the previously flaceid uterus should be exciterl to vigorous contraction, for the sake of accelerating parturition or of suppressing hamorrhage; whilst, on the other hand, it is often no less important to be able to prevent or to antagonize the operation of causes which would prematurely induce uterine contractions, to the destruction of the offspring and the danger of the mother.

761. When, in the normal act of Parturition, the head has so far marle its way through the os uteri as to begin to distend the lower part of the genital canal, a new kind of expulsive effort is superadded to that of the Uterus itself'; the assistance of the Expiratory muscles being then called in $(\$ \overline{507})$, through the intermediation of the Spinal Cord, which is probably excited to this action by the stimulus thus applied to the afferent nerves of the compressed parts; and it is chiefly by the instrumentality of these muscles that the normal act of parturition is usually completed. The same action which expels the foetus, generally also detaches the placenta; and if the uterus contract with sufficient force after this has been thrown off", the orifices of the vessels which communicate with it are so effectually closed, that little or no hamorrhage takes place. If, however, the uterus does not contract, or relaxes after having contracted, a large amount of blood may be lust in a short time from the open orifices. For some little time after parturition, a sero-sanguineous discharge, termed the lochia, is pourerl out firom the uterus; and this commonly contains shreds of the deciduons mentbrane which had not been previously detached, together with a quantity of fat-globules, and other products of disintegration of the uterine tissue $(\$ 3.51){ }^{1}$ Within a few weeks after delivery, the uterus regains (at least in a healthy subject) its previous condition; part of its newly generated muscular fibres seen to disappear altogether, whilst the others shrink to their ordinary dimensions; and the portion of its mucous membrane which had been thrown off as Decillua, seens to be to some extent reprorluced, according to the researches of Dr. Matthews Duncan and M. Robin, even before delivery occurs, so that the muscular tissue of the Uterus is never left completely denuded. ${ }^{2}$

762. As to the reason why the period of Parturition should be just forty weeks after the occurrence of Conception, we know nothing more than we do of that of similar periodical phenomena in the history of the life of Man and of other living beings; all of which must be consirlered as occasional manifestations of changes that are constantly in progress, whose rate, being dependent upon the degree of Heat supplied, is so uniform in warm-blooded

In addition to the evidence above referred to, of the rapid occurrence of fatty degeneration of the uterine structure ufter parturition, the Author may mention that he has been informed by Dr. Rotzius (Professor of Midwifery at Stockloolm) that he has detected a large number of fat-glubules in the urine of puerperal women. Is it not possibla-it maty be further asked-that some of the oleaginous matter so copiously pourt forth by the Mammary glands, nay be derived from this source? Such an eenomy of nutrient material ivould be consistent with what we elsewhere meet with; and the idea is conformable to tin. fact that the proportion of butyrin in the milk is nuch grater in the earlier, than in the later months of lactation.

2 See Iluxley's Elements of Comp. Anatomy, 186t, p. 107. 
animals, as to secure a very close conformity to a common standard. ${ }^{1}$ There is evidence that the occurrence of the uterine nisus may be induced by a variety of causes, scveral of which probably concur in the normal act of Parturition. For, in the first place, the state of development of the muscular substance of the Uterus can scarcely be without a considerable influence on this operation. We see it undergoing a gradual augmentation during the period of pregnancy, without any demand being made upon its functional activity ; it gradually becomes more and more irritable, contractions being far more readily excited in it by electrical or other stimulation, in the later than in the earlier months of pregnancy; and at last this irritability seems to reach its acme, in virtue of the nutritive changes which have been progressively taking place in it, and to discharge itself in one powerful effort. Certain preparatory changes are known to be taking place in the Uterus itself, during the last two or three weeks of gestation ; for its upper part contracts more closely around its contents, as if it were bracing itself up for the coming encounter; whilst there is a greater disposition to relaxation of its lower part, as also in the soft parts surrounding the orifice of the pelvis, so that the whole mass descends. It is well known that there is far less aptitude for dilatation in the os uteri before this change has taken place; so that premature labors are frequently rendered very difficult and tedious by the resistance which the foetus encounters from the soft parts, notwithstanding that its smaller size enables it to pass more readily through the pelvic canal. - That the parturient effort, however, is not solcly dependent upon the state of development of the uterus, appears from several considerations; and, in the first place, from the very curious fact that, in cases of cxtra-nterine foetation, contractions resembling those of labor take place in its walls. In fact, what may be termed the maturation not merely of the Uterus, but also of its Embryonic contents, - - a condition analogous to that which precedes the dropping of ripe fruit, and which is acquired by the completion of the developmental process, - appears to have more influence in determining the normal parturient effort, than any other cause which can be assigned. The Placenta of the fully developed fintus, indecd, is sonewhat in the condition of the footstalk of a ripening fruit; that is, having attained its full evolution as an organ of temporary function, its connection tends to become dissevered in virtuc of the further changes which take place in itself, quite irrespectively of any external agency. ${ }^{2}$ This is very strikingly evinced by the fact, that when the uterus contains two fretuses, and one of them is expelled,-either in consequence of impeded devclopment or disease in itself, or becausc it has attaincd its own full term of development (as in cases of superfotation, $\$$ 766),-the other, if its development at this period is far from complete, is often retained, and gocs on to its full term, its placenta not being detached in the first parturient effort, because it was not then prepared for the separation. It is obvious that this view affords a rational explanation of the occurrence of uterine action in cascs of extra-uterinc futation; for, if the condition of the placental attachnent furnish its exciting cause, it will do so equally, whether the placenta be attached to the lining of the uterus, or to

1 This may be best illustrated by the analogy of a Leyden jar which is being charged by the continuous action of an Electrical Machine, and which is so arranged as to discharge itself spontaneously whenever the disturbance in its equilibrium at. tains a certain intensity. If the movement of the machine be uniform, and other conditions remain the same, the discharge will take place at regular intervals.

2 Such a change may be easily verified in the Placenta of many of the lower animals, such as the Cat, in which the fotal and maternal portions remain more distinct from cach other than they do in the IIuman female; for these become far more casily separable us the period of parturition draws ncar than they are at any previous time. 
that of the Fallopian tube, or to any other organ. It is an additional indication that the inmediate stimulus to the parturient effort of the uterus is given by some change in the condition of its foetal convectious, that the term of gestation seems capable of being prolonged by peculiarities in the constitution or rate of development of the foetus, which are derived from the male parent; for it was ascertained by the late Earl Spencer, ${ }^{1}$ that of 75 cows in calf' by a particular bull, the average period was $288 \frac{1}{2}$ days, instead of 280 ; none of these having gone less than 281 days, and two-fifths of them having exceeded 289 ilays. $^{2}$

763. Various states of the constitution, especially that which is designated as "irritability," may induce the occurrence of the parturient effort at an earlier period; and this constitutes Premature Delivery or Abortion, according as the child is or is not viable $(\$ 764)$. There are some women in whom this regularly happens at a certain month, so that it seems to be an action natural to them; but it should always be prevented, if possible, being injurious alike to the nother and to the child; and this prevention is to be attempted by rest and tranquillity of mind and body, and by a careful aroidance of all the exciting causes which may produce uterine contractions by their operation on the Nerrons system $(\S 760)$. Among the causes of Abortion, however, the death of the foetus, or an abnormal state of the placcntal structure, is one of the most common; and thus we have another very distinct proof of the influence which the state of the contents of the uterus has on the induction of the parturient effort.

764. The question of the extreme limits of the period of Gestation, is one of great importance both to the Practitioner and to the Medical Jurist.-In regard to the shortest period at which Gestation may terminate, consistently with the viability of the Child, there is still a great degree of uncertainty. Most practitioners are of opinion that it is next to impossible for a foetus to live and grow to maturity, which has not nearly completed its seventh month; but it is unquestionable that infauts born at a much earlicr period have lived for some months, or even to adult age. It is rare in such cases, however, that the date of conception can be fixed with sufficient precision to enable a definite statement to be given. Of the importance of the question, a case which some time since occurred in Scotland affords sufficient proof: A vast amount of contradictory evidence was adduced on this trial; but, on

1 See Dr. J. C. Hall, in Medical Gazette. May 6th, 1842.

2 The very ingenious doctrine has been propounded by Dr. Tyler Smith (Parturition, and the Principles and Practice of Obstetrics, London, 1819), that the exciting cause of Parturition is to be found in the recurrence of the periodical excitement of the wrary, acting by reflection on the uterus through the spinal system of nerves, the orarian nerves being the excitors, and the uterine the motors; this excitenent continuing during the entire period of gestation, and giving a sprecial tendency to abor. tion at each return; and acting with such potency at the eleventl recurrence as then to induce the parturient effort. He assigns no other cause, however, why this eleventh recurrence should be so mueh more effectual than the rest, than that by this time there is a much greater aptitude to contration in the uterus itself, and in increased readiness to be thrown off on the part of the placenta, - conditions which seem to the Author to be in themselves adequate to account for the result. Dr. 'Tyler Smith's hypothesis is distinctly negatived by the following fuets: 1 . The period of gestation, although commonly a multiple of the menstrual interval, is by no means constantly so; the former often remaining normal, when the latter is shorter or longer than usual. 2. Parturient efforts take place in the uterus, notwithstanding the previous removal of the lower part of the spinal cord. 3. The removal of the ovaries in the later part of gestation does not interpose the least check to the parturient action, as Prof. Simpson of Edinburgh has experimentally ascertained.-The Author considers himself fully justified, therefore, in asserting that this hypothesis does not posses: the slightest elaim to be entertained as even a possible one; and would rufer, for a more detailed examination of it, to the Brit. and For. Mled.-Chir. Review, rol, iv, p. 1. 
the general rule of accepting positive in preference to negative testimony, it seems that we ought to consider it possible that a child may live for some months, which has been born at the conclusion of 24 weeks of gestation. In the case in question, the Presbytery decided in favor of the legitimacy of an infant born alive within 25 weeks after marriage. ${ }^{1}$ A very interesting case is on record, ${ }^{2}$ in which the mother (who had borne five children) was confident that her perior of gestation was less than 19 weeks; the facts stated respecting the development of the child are necessarily very imperfect, as it was important to avoid exposing his body, in order that his temperature might be kept up; but three weeks after his birth, he was only 13 inches in length, and his weight was no more than $29 \mathrm{oz}$. At that time, according to the calculation of the mother, he might be regarded as corresponding with an infant of 22 weeks or 5 months; but the length and weight were greater than is usual at that period, indicating that he was probably born at about the 25th week. It is an interesting feature in this case, that the calorific power of the infant was so low, that artificial heat was constantly needed to sustain it; but that under the influence of heat of the fire he evidently became weaker, whilst the warmth of a person in bed rendered him lively and comparatively strong. During the first week it was cxtremely difficult to get him to swallow; and it was nearly a month before he could suck. At the time of the report, he was four months old, and his health appeared very good.-Another case of very early viability has been more recently put on record by Mr. Dodd: $:^{3}$ in this, as in the former instance, the determination of the child's age rests chiefly on the opinion of the mother; but there appears no reason for suspecting any fallacy. The child seems to have becn born at the 26th or 27th weck of gestation; and having been placed under judicious management, it has thriven well.-One of the most satisfactory cases on record, is that detailed by Dr. Outrepont ${ }^{4}$ (Professor of Obstetrics at Wurtzburg), and stated by Dr. Christison in his evidence on the casc first alluded to. The evidence is as complete as it is possible to be in any case of the kind; being derived not only from the date assigned by the mother to her conception, but also from the structure and history of the child. The gestation could have lasted only 27 weeks, and was very probably less. The length of the child was $13 \frac{1}{2}$ inches, and its weight was 24 oz. Its development was altogether slow; and at the age of eleven years, the child seemed no more advanced in body or mind than most boys of seven years old. In this last point, there is a very striking correspondence with the results of other observations upon premature children, nude at an earlier age.-A very remarkable case has becn since put on record by Dr. Barker of Dumfries, ${ }^{5}$ in which the child is affirmed to have been born on the 158th day of gestation, or in the middle of the twenty-third week after intercourse. Its size, weight, and grade of development were conformable to the asserted period: for it weighed only $16 \mathrm{oz}$., and measured 11 inches; it had only rudimentary nails, aud scarcely any hair except a little of reddish color on the back of the hearl; the eyelids were closed, and did not open until the second day; the skin was shrivelled. When born it was wrapped up in a box and placed before the fire. The child did not suek properly until after the lapse of a month, and did not walk until she was ninetcen months old. Three year's and a half afterwards this child was in a thriving state, and very healthy but of small make; she then weighed $29 \frac{1}{2} \mathrm{lbs}$.

1 Report of Procedings anain-t the Rev. Fergus Jardine, Edinburgh, 1839.

2 Edinb. Med. and Surg. Jurnal, vol, xi.

3 Provincial Medical and surgicat Journal, vol, ii, p. 474.

4 Henke's Zeitsebrift, Bd. vi.

5 Medical Times, Sept. Fth and Oct. 12th, 1850. 
765. A like uncertainty exists with regard to the degree of protraction of which the ordinary duration of Gestation is capable.- Many obstetric practitioners, whose experience should give much weight to their opiniou, maintain that the regular period of 40 weeks is never extended by more than two or three days; whilst, on the other hand, there are numerous cases on recorrl, which, if testimony is to be believed at all (and in many of these, the character aud circumstances of the parties place them above suspicion), furuish ample evidence, that Gestation may be prolonged for at least three weeks beyond the regular term. ${ }^{1}$ In one case, iudeed, recorded by Liegard, ${ }^{2}$ pregnancy was believed to have lasted 330 days. The English law fixes no precise limit; and the decisions which have been given in our courts, when questions of this kind have been raised, have been mostly formed upon the collateral circumstances. The law of France provides that the legitimacy of a child born within 300 days after the death or departure of the husband shall not be questioned; and a child born after more than 300 days is not declared a bastard, but its legitimacy may be contested. By the Scotch law, a child is uot declared a bastard, unless born after the tenth month from the death or departure of the husband.-Very important evidence on this subject is afforded by investigations on the lower animals, which are free from niny sources of fallacy that attend human testimony. The observations of Tessier, which were continued during a period of forty years, with every precaution agaiust inaccuracy, have furnished a body of results which seems quite decisive. In the Cow, the ordinary period of gestation is about the same as the Human female; but out of 577 individuals, no less than 20 calved beyond the 298th day, aud of these, some went on to the 321st, making an excess of nearly six weeks, or about one-seventh of the entire period. Of 447 Mares, whose natural period of gestation is about 335 days, 42 foaled between the 359 th and the 419 th days, the greatest protraction being thus 84 days, or just one-fourth of the usual term, Of 912 sheep, whose natural period is about 151 days, 96 yeaned beyond the $153 \mathrm{~d}$ day; and of these, 7 weut on until the 157 th day, making an excess of 6 days. Of 161 Rabbits, whose natural period is about 30 days, no fewer than 25 littered between the. $32 \mathrm{~d}$ and the $35 \mathrm{th}$; the greatest protraction was here one-sixth of the whole period, and the proportion in which there was a manifest prolongation was also nearly one-sixth of the total number of individuals. In the incubation of the common Hen, the duration of which must be entirely deternined by the rate of embryonic development, Tessier found that there was not unfrequently a prolongation to the amount of three days, or one-seventh of the whole period.-In regard to Cows, the observations of 'Tessier have been confirmed by those of Earl Spencer, who has published $^{3}$ a table of the period of gestation as observed in 764 individuals; he considers the average period to be 284 or 285 days; but no fewer than 310 calved after the 285th day; and of these, 3 went on to the 306 th day, and 1 to the 313 th. It is curious that among the calves born between the 290 th and 300 th days, there was a decided preponderance of males,-these being 74, to 32 females; whilst all of those born after the 300 th day were females. The additional series of observations subsequently made by Earl Spencer, in regard to the constant protraction of the period in 75 cows in calf by a particular bull, has been already noticed $(\$ 762)$. - A nother series of observations has been published by Mr. C. N. Bement of Albany, U. S.,

1 A good collection of such cases will be found in Dr. Montgomery's excellent work on the Signs of Pregnancy, and in Dr. A. Taylor's Medical Jurisprudence.

2 Gaz. des Hôpitaux, 1859.

3 Journal of the English Agricultural Society, 1839.

4 American Journal of the Medical Sciences, October, 1845. 
who has recorded the period of gestation of 62 cows. The longest period was 336 days; the shortest, 213 days. The average period for male calves was 288 days; and for females 282 days.-On the whole it may be considered, that in regard to the Human female, the French law is a very reasonable one; there being quite sufficient analogical evidence to support the assertions of females of good character, having no motive to deceive, which lead to the conclusion that a protraction of at least four weeks is quite possible, and that a protraction of six weeks is scarcely to be denied. ${ }^{1}$

766. There is another question regarding the function of the Female in the Reproductive act, which is of great interest in a scientific point of view, and which may become of importance in Juridical inquiries; namely, the possibility of Superfotation, that is, of two distinct conceptions at an interval of greater or less duration; so that two foetuses of different ages, the offspring perhaps of different parents, may exist in the uterus at the same time.-The simplest case of Superfoetation, the frequent occurrence of which places it beyond reasonable doubt, is that in which a female has intercourse on the same day with two males of different complexions, and bears twins at the full time; the two infants resembling the two parents respectively. Thus, in the Southern States of America, it is not uncommon for a black woman to bear at the same time a black and a mulatto child; the former being the offspring of her black husband, and the latter of her white paramour. The converse has occasionally, though less frequently, occurred; a white woman bearing at the same time a white and a mulatto child. There is no difficulty in accounting for such facts, when it is remembered that nothing has occurred to prevent the uterus and ovaria from being as ready for the second conception as for the first; since the orifice of the former is not yet closed up; and, at the time when one orum is matured for fecundation, there are usually more in nearly the same condition.-But it is not easy thus to account for the birth of two chiidren, each apparently mature, at an interval of five or six months; since it might have been supposed that the uterus was so completely occupied with the first ovum, as not to allow of the transmission of the seminal flud necessary for the fecundation of the second. In cases where two children have been produced at the same time, one of which was fully formed, whilst the other was small and seemingly premature, there is no occasion whatever to imagine that the two were conceived at different periods; since the smaller foetus may have been "blighted," and its development retarded, as not unfrequently happens in other cases. Nor is it necessary to infer the occurrence of superfoetation in every case in which a living child has been produced a month or two after the birth of another; since the latter may have been somewhat premature, whilst the former has been carried to the full term. But such a difference can scarcely be, at the nost, more than $2 \frac{1}{2}$ or 3 months $;^{2}$ and there are several cases now on record, in which the interval was from 110 to 170 days, whilst neither of the children presented any indication of being otherwise than mature. ${ }^{3}$

767. Whatever be the precise nature and history of the Fecundating process, there can be no doubt that the properties of the Germ depend upon conditions, both material and dynamical, supplied by both Parents. This is

1 See espeeially two cases, 183 and 184 , detailed by Dr. Muphy in his Report of the Obstetric Practice of University College 11 ospital for 1844 ; and another ease since publisher by him in the Medical Gazette for 1849 , vol. xlviii, p. 683 .

${ }_{2}$ For an interesting case of superfotation, where the differenee in the age of the two foetuses was about three months, see a Report made by Drs. Harley and l'anner to the Obstetrical Society, Lancet, vol. ii, 1862 .

3 See the Article Superfoetation, in Dr. Beck's Elements of Medical Jurisprudence, and R. B. Schultze in the Jenaische Zeits., Bd. ii, 1865, p. 1. 
most obviously show by the fusion of the characters of the parents, which is exhibited by hybrids between distinct species or strongly-marked varieties among the lower animals, such as the Horse and Ass, the Lion and Tiger, or the rarious brceds of Dogs; or in the offspring of parents belonging to two strongly-contrasted Races of Men, such as the European on the one hand, and the Negro or American Indian on the other.-It has long been a prevalent ilea that certain parts of the organism of the offspring are derived from the male, and certain other parts from the female parent; and although $n o$ universal mle can be laid down upon this point, yet the independent observations which have been made by numerous practical " "breeders" of domestic animals (both mammils and birds), seem to establish that such a tendency has a real existence; the characters of the Animal portion of the fabric being especially (but not exclusively) derived fiom the male parent, and those of the Organic apparatus being in like manner derived from the female parent. The former will be chiefly manifested in the exterual appearance, in the general configuration of the head and limbs, in the organs of the senses (including the skin), and in the locomotive apparatus; whilst the latter show themselves in the size of the body (which is primarily determined by the development of the viscera contained in the trumk), and in the morle in which the vital functions are performed. Thus the mule, which is the produce of the male ass and the marc, is essentially a modified ass, haring the general configuration of its sire (slightly varied by equime peculiarities), but having the rounder trunk and larger size of its dam; on the other hand, the himn, which is the offspring of the stallion and the she-ass, is essentially a modified horse, having the general configuration of the horse (though with a slight admixture of asinine features), but being a much smaller animal than its sire, and thus approaching its dam in size, as well as in the comparative narrowness of its trunk. The influence of the female on the general "constitution," and especially on the fattening, milking, and breeding qualities of the offspring, is asserted to be proved by the history of several races of sheep and cattle, which have been most distinguished in these respects. ${ }^{1}$ - But however general this rule may prove to be as regards the lower animals, it is by no means universal; for instances are by no means unfrequent, in which the multiple progeny of one conception divide between them the characters of the parents in very different morles. Thus, in a case in which a Setter-bitch, having been "lined" by a Pointer, bore three pups, two of these pups seemed exclusively to resemble the father, appearing to he perfect Pointers in configuration, and growing up with the habits of that race; whilst the third seemed equally to resemble its mother, being apparently a true Setter both in structure and instinct. Yet notwithstanding this apparent restriction, it subsequently appearecl that the pointer-pups must have had something of the setter in their constitution, and the setter-pup something of the pointer. For one of the Pointer-pups (a male) having been matched at the proper age with a Pointerbitch of pure breed, one of the pups borne by the latter was a true setter, exactly resembling its paternal grandmother, and another was setter-marked ; and the Setter-pup (a female) having been lined by a Setter-dog of pure breed, there were among its litter of pups two pointers resembling their maternal grandfather.- The same variety presents itself to even a creater degree in the human species. For in almost every large family (and some-

1 See Walker, On Intermarriage; Orton on The Phrsiology of Breeding, in the Neweastle Chronicle, March 10th, 1854; and Dr. Alex. Harvey, On the Relutive Influence of the Male and Female Parents in the Reproduction of the Animal Species, in Erlinb. Monthly Journ., Aug. 1854; and especially Darwin, On the Variation of Species under Domestication, 1868. 
times even where there are no more than two children), ${ }^{1}$ it will be observed that the likeness to the father predominates in some of the children, and the resemblance to the mother in others. Still it is rare to meet with instances in which some distinctive traits of both parents may not be traced in the offspring; these traits often showing themselves in peculiarities of manner and gesture, in tendencies of thought or feeling, in proneness to particular constitutional disorders, etc., even where there is no personal resemblance, and where there has been no possibility that these peculiarities should have been gained by imitation. And even when they are overborne, as it were, in the immediate progeny, by the stronger influence derived from the other side, they will often reappear in a subsequent generation (as in the case just cited), constituting the phenomenon known as Atavism.

768. The influence of both Parents on the constitution of the Offspring is strikingly manifested, not merely in the admixture of their characters normally displayed by the latter, but also in the tendency to the hereditary transmission of perverted modes of functional activity which may have been habitual to either. The diseases which are usually consiltered to be most prone thus to reappear in successive generations, are Serofula, Gout, Syphilis, and Insanity; but it can scarcely be doubted that many others might be added to this list. ${ }^{2}$ The predisposition may have been congenital on the part of the parents, or it may have been acquired by themselves, as in the case of Epilepsy transmitted by guinea-pigs in whom the sciatic nerve has been divided, to their young [Eugene Dupuy has found that guinea-pigs, in which the cervical Sympathetic has becn cut, transmit the peculiar changes produced by such section]; and in no case is this more obvious than in the influence of Alcoholic excesses on the part of one or both parents, in producing Idiocy, a predisposition to Insanity, or weakness and instability of Mind, in the children, this being especially the ease where both parents have thus transgressed. Thus out of 359 Idiots, the condition of whose progenitors could be ascertained, it was found that no fewer than 99 were the children of absolute drunkards; and there was reason to believe that a large proportion of the parents of the remainder were more or less intemperate, only about a quarter of the whole number of idiots having been found to be the chillren of parents who were known to be temperate. ${ }^{3}$ And it is perfectly well known to those who are conversant with Insanity, that of all the "predisposing causes" of that disorder, habits of intemperance on the part of either or both parents are among the most frequent.-The intensification which almost any kind of perversion of Nutrition derives from being common to both parents, is most remarkably evinced by the lamentable results which too frequently accrue from the marriage of individuals nearly related to each other, and partaking of the same "taint." Such results must have fallen within the knowledge of almost every one possessing an extended field of observation; but they are brought out with fearful vividness by the unerring test of properly-collected Statistics. For ont of the 359 idiots just referred to, 17 were known to have been the children of parents nearly re-

1 One of the most remarkable cases of this kind known to the Author, is that of two Sisters, who seem to rosemble each other in no one point of cunficuration or mental eharacter; but of whom one bears a most striking resemblance, both in person and in mind, to her Fathrer whilst the othor no less strikingly resembles her Mother. The only peculiarities which at ail indicate their relationship, are a gouty diathesis which they both inherit from their fathor, and an idiosyncrasy in rearard to opium, of which neither is able to take even a small dose (in any form whatever) without vomiting.

2 See the vary interesting and suggestive Chapter, On Hereditary Disease, in Sir H. IIolland's Medical Notes and Reflections.

3 See Dr. Howe's Report on Idioey to the Legislature of Massachusetts, 1848. 
lated by blood; and this relationship was susperted to have existed in several other cases, in which positive information could not be obtained. On examining into the history of the 17 families to which these indivicluals belonged, it was found that they liad consisted, in all, of 95 children; that of these no fewer than 44 were idiotic, 12 others were scrofulous and puny, 1 was deaf, and 1 was a dwarf. In some of these families, all the children were either idiotic, or very scrofulous and puny; in one fannily of 8 chitdren, 5 were idiotic. ${ }^{1}-$ But it does not seem requisite for the production of very imperfect offspring from the intermarriage of near relations, that any decided "taint" should exist in the parents; for the Author's own observations and inquiries lead him to conclude that the same danger results when there is any strong personal or mental "idiosyncrasy," such as is often seen to run through the members (both male and female) of a particular family, causing them to be at once recognized as belonging to it, by those who have been familiar with other members. ${ }^{2}$ This liability probably does not exist to nearly the same degree, where the parents, although nearly related, differ widely in physical and in psychical characters, through the predominance of elements which have been introduced by their non-related parents; as, for example, wheu a man strongly resembles his father rather than his mother, marries the daughter of his mother's brother, who, on her part, resembles her own mother rather than the father. But the case previously cited $(\$ 767)$ gives warning that even here the "family idiosyucrasy" may exist in a powerful degree, though in a latent form, and may seriously affect the constitution of the offspring. It is quite as common to meet with Atavism in the transmission of hereditary disease, as in the reproduction of "family likeness."

1 See Dr. Howe's Report, p. 90. An Abstract of this Report is given in the Amer. Journ. of ILed. Sci, April, 1849. - The fullowing works may also be referred to as containing information upon the important subject of the effects upon the offspring of marriagcs of consanguinity: M. Boudin in the Annales d'Hygiene, vol. xviii, lp. 6-82, who observes that the deaf mutes of consanguineous origin are from twelve to fiftecn times as numerous as they would be if the infirmity were equally distributed among the offspring of consanguineous and other marriages; Dr. Bemiss in the Journal of Psychological Medicine for 1857, p. 368, who supplies facts and argumonts against such marriages; Dr. Mitchell in the Edinb. Med. Journ. for 1862, p. 872, who considers idiocy to be an espccially frequent consequence of the marriagc of blood relations, and agrees with $\mathbf{M}$. Boudin in regard to the frequency of deaf mutism in the offspring; M. Cadiot in the Comptes Rendus, vol. ii, 186i), p. 978; M. Angelon in idem, vol. i, 1864, P. 166; and Dr. E. Dally in the Anthropological Revicw for Ilay, 1864. Amonest the Editor's own immediate relations there have been five marriages between first cousins, from which have proceeded thirtythrce children; of these eight have died, one from tcething, two from croup, and one from hooping-cough (all injudiciously fed), one from accident, one from cyanosis, and two from well-marked scrofulous disease; the last two occurred in the same family, and were the only offepring of an extremely obese father and a highly scrofulous mother. The surviving children are of unumally healthy and tine growth. See also a Liader in Lancet, 1870, vol ii, p. 898. The Editor, therefore, from these and other observations, fully accords with the observations of Dr. G. W. Childs in the Medico Chir. Review for 1862, vol. i, p. 461, who, in criticizing Dr. Bemiss's Essay, renarks that the marriages of blood relations have no tendency, per se, to produce degeneration of race, though they have a tendeney to strengthen and develop in the offepring individual peculiarities of the parents, both mental and physical, whether morbid or otherwise.

2 A most lamentable instance of this kind, which happened some rears agro in a family well known to the Author, was the occasion of his tirst directing his attention specially to this point. Two first cousins, posscssing a strong "family idiosynerasy," but no definitc "taint," having married, four children were born, each of which was distinguished by some marked defect of organization or perversion of function, one being deaf and dumb, another serofulous, a third idiotic, and a fourth epileptic. 
769. Attention has recently been directed to a very curious class of phenomena, which show that where the mother has previously borne offspring, the influence of its father may be impressed on her progeny afterwards begotten by a different parent: as in the well-known case of the transmission of Quagga-marks to a succession of colts, both of whose parents were of the species Horse, the mare having been once impregnated by a Quagga male; ${ }^{1}$ and in the not unfrequent occurrence of a similar phenomenon in the Human species, as when a widow who marries a second time, bears children strongly resembling her first husband. Some of these cases appear referable to the strong mental impression left by the first male parent upon the female; but there are others which seem to render it more likely that the blood of the female has imbibed from that of the fotus, through the placental circulation, some of the attributes which the latter has derived from its male parent; and that the female may communicate these, with those proper to herself, to the subsequent offspring of a different male parentage. ${ }^{2}$ - This idea is borne out by a great number of important facts; and it serves to explain the circumstance well known to practitioners, that secondary syphilis will often appear in a female during gestation or after parturition, who has never had primary symptoms, whilst the father of the child shows no recent syphilitic disorder. For if he have communicated a syphilitic taint to the foetus, the mother may become inoculated with it through her offspring, in the manner just described. As this is a point of great practical importance, it may be hoped that those who have the opportunity of bringing observation to bear upon it, will not omit to do so.

770. There seems good reason to believe, moreover, that the attributes of the Germ are in a great degrce dependent, not merely upon the habitual conditions of the Parents which have furnished its original components, but even upon the eondition in which those parents may be at the time of sexual congress. Of this we have a remarkable pronf in the phenomenon well known to breeders of animals, that a strong mental impression made upon the female by a particular male, will give the offspring a resemblance to him, even though she has had no sexual intercourse with him $;^{3}$ a circumstance for which there is no difficulty in accounting, on the hypothesis already put forth regarding the dynamical relation of mental states to the Organic processes (chap. xvii). And there is no improbability, therefore, in the idea that the offepring of parents ordinarily healthy and temperatc, but begotten in a fit of intoxication on both sides, would be likely to suffer permanently from the abrogation of the reason, which they have temporarily brought upon thenselves. - On the whole, then, we seem cntitled to conclude, that the attributes of the embryo will be influenced in a most important degree by the entire condition (as relates both to the organic and the psychical life) of both parents at the tinc of the sexual congress; and it is probably on account of the perpetual changes taking place in the bodily and mental state of each individual (his condition at any one tine bcing the general resultant of all those changes), that we almost constantly witness marked differences between children born at successive intervals, however strong may be the "family likeness" among them; whilst the resemblance between twins is almost invariably much closer. ${ }^{5}$

I'bilosophical Transactions, 1821

2 See an interesting discussion of this question, by Dr. Alex. Harvey, in the Edinb. Monthly Journ., Oct. 1849, and Oct. and Nov. 1850; and in lis pamphlet, On a Permarkalble Etfiet of Cross-breeding, Edinb., 1851.

3 See Harvey, loc. cit.

4 See acase of this kind related by MIr. G. Combe, in the Phrenological Journal, vol, viii, p. 471 .

5 Where twins are very unlike one another, it will usually be found that the dis- 
771. When it is borne in mind that during the entire period of gestation, the Embryo is deriving its nutriment exclusively from the blood of the Mother, and that the condition of this fluid in relation to her own processes of Nutrition and Secretion, is subject to a very marked influence from her own mental states (chap. xvii), it cannot fairly be thought improbable, that the developmental processes of the Embryo should be powerfully affected by strong Emotional excitement on her part. Among the facts of this class, there is, perhaps, none more striking than that quoted by Dr. A. Combe from Baron Percy, as having occurred after the siege of Landau in 1793. In addition to a violent cannonading, which kept the women for some time in a constant state of alarm, the arsenal blew up with a terrific explosion, which few could hear with mnshaken nerves. Out of 92 children born in that district within a few months afterwards, Baron Percy states that 16 died at the instant of birth; 33 languished for from eight to ten months, and then died; 8 became idiotic, and died before the age of five years; and 2 came into the world with numerous fractures of the bones of the limbs, probably caused by irregular uterine contractions. Here then is a total of 59 children ont of 92 , or within a trifle of 2 out of every 3 , actually killed through the medium of the Mother's alarm, and the natural consequences upon her own organization; an experiment (for such it is to the Physiologist) upon too large a scale for its results to be sct down as mere "coincilences." No soundly judging Physiologist of the present day is likely to fall into the popular error of supposing that "marks" upon the Infant are to be referred to some transient though strong impression upon the imagination of the Mother; but there appear to be a sufficient number of ficts on record, to prove that habitual mental conditions on the part of the Mother may have influence enough, at an early period of gestation, to produce evident bodily deformity, or peculiar tendencies of the mind $(\$ 726)$. The error of the vulgar notion on this subject, lies in supposing that a sudden fright, speedily forgotten, can exert such a continual influence on the nutrition of the Enbryo, as to occasion any personal peculiarity. ${ }^{2}$ 'The view here stated, is one which ought to have great weight, in making manifest the importance of careful management of the health of the Mother, both corporeal and mental, during the period of pregnancy ; since the ultimate coustitution of the offspring so much depends upon the influences then operating upon its most impressible structure.

\section{Development of the Embryn.}

772. The history of the evolution of the Germ, from its first appearance as a single cell lying in the midst of the yolk, to the time when it presents the form and structure characteristic of its parent species, and is capable of maintaining an independent existence-including the details of the progressive development of each separate organ, from its first appearance as an

similarity is due to the predominance of the characters of the futher in one, and of those of the mother in the other; as in the case of the Pointer and Setter previously cited $(\& \quad 767)$.

1 On the Management of Infuncy, p. 76 .

2 For some valuable observations on this subject, sce Montsomery, On the Signs of Pregnancy.-Numerous cases were recorded a few years since (especially in the Lancet and Provincial Medical Journal) in which malformations in the Infunt appeared distinctly traccable to strong impresions nuade on the mind of the Muther some months previously to parturition; these impressions having hecn persistent during the remaining period of pregnancy, and giving rise to a full expectation on the part of the llotlier that the child would be affected in the particular manner which actually occurred. Of one very striking case of this kind, the Author is personally cognizant, it having oceurred in the family of a near conncetion of his own. 
aggregation of simple cells formed by the duplieative subdivision of the primordial vesicle, to that stage of completeness in which it is able to bear a part in the vital economy of the new being-and embracing, also, the suecession of changes in the provisions for the nutrition of the embryo in the successive phases of its existence, and the adaptations of its general organization to each respectively-constitutes one of the most interesting departments of Physiologieal Science, and one which has of late years received a peculiar degree of attention. It is a branch of the inquiry, however, which has, and seems likely to have, less practical bearing than any other; for neither as regards the preservation of the body in health, nor its restoration from disease, is it easy to see what direct benefit the most exact knowledge of Embryonic Development is likely to afford. The chief subjeet on which it throws light, is that of Congenital Malformations and Deficiencies; many of which are now distinctly traceable to arrest or irregularity of the developmental processes; sume of them, indeed, to excess ( $\$ 357)$. For these reasons, the topic before us will be passed over much more lightly in the present Treatise, than its seientific importanee might seem to demand; and all that will be here attempted, will be a mere sketch of the mode in which the evolution of the germ takes place, this being followed in the first instance as a whole, whilst its principal organs will be afterwards separately considered as they successively present themselves.-This sketch, however, will serve to convey an idea of the nature of the process, and to illustrate its conformity in Man to that great law of progress from the general to the special, which is equally manifested in the development of every other organized being.

773. When we first discern the primordial cell which is to evolve itself into the Animal organism, we can trace nothing that essentially distinguishes it from that which might give origin to any other form of organie structure; its condition, in fact, being alike in all, and permanently represented by the humblest single-celled Plants and Aninals. The carliest stage of its development consists in simple multiplieation by "duplicative subdivision" of its contents, so that a mass of cell-like bodies comes to be produced, amidst the several components of which no differenee can be traced; and this also finds its parallel among the simpler organisms of both kingdoms. Soon, however, this homogeneous condition gives rise to a heterogeneous one; the further ehanges which different parts of this mass undergo, not being of the same uniform eharaeter, so that a marking out of organs, or instrumental parts adapted for different purposes in the economy, comes to be discernible. A marked divergence occurs, however, at a very early period, according to whether the whole contents of the ovum undergo segmentation, and are directly converted into the growing embryo, or whether only a portion is thus segmented, the remainder forming a bag over which vessels are developed, effecting the absorption of its eontents, and thus enabling it indirectly to participate in the process of development. Animals in which the former arrangement holds are termed holoblastie, and are represented by Mammals generally, Batrachia and Cyclostomata amongst the Vertebrata, and by the simpler forms of Crustacea and Arachnida, the Annelida, lower Mollusca, Entozoa, and Radiata amongst the Invertebrata. The animals in which the latter arrangement lolds are termed meroblastic, and are represented by the Monotremata, Birds, scaly Amphibia, Plagiostomous and T'eleostean fishes amongst the Vertebrata, and by the higher orders of Crustacea and $A$ rachnida, and by Cephalopoda amongst the Invertebrata. In the fowl, aceording to His (loe. eit., p. 39), the whole of the nervous system, the whole of the museular system (both striated and unstriated), the true epithelial structures, and the glands proceed from the development of the morphological 
elements of the cicatricula, whilst the blood and the connective tissues proceed from the so-called white yolk. The organs whose distinctness first becomes apparent, are not (for the most part) those which we trace in the completed structure, but have a merely temporary character; being evolved either as a sort of scaffolding or framework for the building up of the more permanent parts, or with a view to the nutrition of the embryo during the evolution of these. Although the first indications of heterogeneousness in the general mass are of nearly the same kind in all animals-consisting in the formation of a blastodermic membrane (composed, however, of nothing else than layers of cells) upon its exterior, which serves as a sort of temporary stomach, whilst a large part of the included mass undergocs liquefaction, and serves as the nutrient material for the tissues which are to be evolved from it-yet indications are very speedily manifested of the primary division of the Animal kingdom of which the new being is a member; thus, in the case of the Human embryo, as of that of all Vertebrated animals, the first outline of the permanent organization is shown in the "primitive trace" which marks out the line of the vertebral column (Plate II, Fig. $11)$; and in this we very soon discern the foundations of the separate vertebre (Fig. 12,e). But there is nothing at this period to distinguish the germ of Man from that of any other Vertebrated animal, this early part of the developmental process being carried on upon the same plan in every member of that subkingdom; and it is not until we meet with indications of one of the plans which are peculiar to the respective classes of that subkingdom, that we can discover whether the germ in course of evolution is to become a Mammal, Bird, Reptile, or Fish. So, even when it has been recognized as belonging to the Mammalian class, there is at first nothing to distinguish it from that of any other Mammal; and it is only with the advance of the developmental process that indications successively present themselves, which enable us to distinguish, one after another, the characters of the order, the family, the genus, the species, the variety, the sex, and the individual - the more special features progressively evolving themselves out of the more general, which is the expression of the law of development common to all Organized beings.

774. With this progressive alteration in the condition of the embryo itself, a very remarkable series of alterations is proceeding, pari passu, in the mode in which it is supplied with nutrient material, and in the provisions for the aeration of its circulating fluid.- The first evolution of the germ takes place entirely at the expense of the yolk: of which, however, the store contained in the Mammalian ovum is very small. The whole of this is very speedily incorporated in the substance of the germ, by the peculiar process to be presently described; and there is no residual store of "food-yolk," such as that which, in the Bird, serves for the nutrition of the embryo during the whole remainder of the developmental process, by being gradually absorbed into the substance of the blastodermic membrane, and there converted into blood. The Mammalian ovum, however, from the time it reaches the Uterus, is furnished with a new supply of nourishment, in the fluid secreted by the Decidual membrane; and for the absorption of this, it is particularly adapted by the villosities which develop themselves from its own external envelope. These, at first entirely destitute of bloodvessels, are subsequently penetrated at a certain part of the surface, by the foetal capillaries brought to them by an organ, the Allantois, which is developed in Birds as the temporary instrument of respiration ; and thus is originated the foctal portion of the Placenta, of whose formation an account has already been given ( $\$ \S 753-$ 755). From the time that this organ is completed, up to the birth of the Infant, the embryo draws its nutrient materials direct from the maternal 
blood, though not receiving that blood as such into its own organism; and it is through the same medium that the aeration of its own blood is effected, its pulmonary apparatus being as yet inoperative. Its circulating system, arranged in accordance with these requirements, presents many peculiarities which mark its foetal character; and the alteration in the course of the blood, which takes place as soon as the respiratory organs come into play, constitutes the essential difference between intra-uterine and extra-uterine life. If, as sometimes happens, the lungs of the newborn infunt expand but imperfectly or scarcely at all, the circulation continues to be carried on in a greater or less degree, upon its intra-uterine plan; and this, when the placenta is no longer capable of supplying the needed aeration, is incompatible with the persistence of life.

775. The early stages of the development of the Embryo in Vertebrata are much better known in the Bird than the Mammal, on account of the facilities that the eggrs of these animals offer for examination, and it will he expedient, therefore, to describe the course of events in them: noting the principal differences that have been ohserved in the process as it occurs in the higher class.' A newly-laid hen's egg is composed of a shell (Firg. 324, s), composed of an organic basis impregnated with calcic salts, and perforated by vertical canals, through which an interchange of gases can take place. The shell is lined by two layers of membrane (Fig. $324, \mathrm{sm}$, ism), which early separate from each other at the broad end to form the airchamber. Beneath the shell-membrane is the white of the egg, or albumen (Fig. $324, w)$; and stretching from near the two extremities of the egg to the opposite surfaces of the yolk, are two twisted portions of rather firmer albumen, termed the chalaze $(c h, e)$, which perhaps serve to keep the yolk in position. The yolk is inclosed in the vitelline membrane (vt), and by fiar the largest portion of it is composed of yellow yolk (yy) which consists of spheres, never containing a nucleus, but filled with minute, highly refractile granules. The yellow yolk is surrounded by a thin layer of a lighter-colored yolk, the white yolk (wy), which, dipping into it at one point, forms a flaskshaped mass in its interior. 'The white yolk also forms a series of concentric layers (halones) in the substance of the yellow yolk. It is composed of spherules, for the most part smaller than those of the yellow yolk, with a highly refractive nucleus-like body in the interior of each, and of larger

1 In the following acenunt, Foster and Balfour's Elements of Embryology has been taken as a guide, and to this exeellent work the student is referred for details that considerations of space preclude from being here inserted; bnt other works and researches which may be studied are those of Rathke, On the Development of the Snake, 1839, and of the Tortoise, 1848; of Kiolliker (Müller's Archiv, 1842, p. 68) and Bagge (De Evolut. Strongyli et Ascarid, Diss. Inaug., 1841) on the ova of Eutozon; Kölliker's Entwiekelungsgesehichte des Mensehen, 1861 ; those of v. Buer, On the Development of the Fish, 1835 ; those of Mr. Newport (Philos Transact., 1851) and Dugres (Recherches sur les Batraciens, 1835) on the ova of Butrachia; those of Bischnff (Entwickelungsgeschichte des Hundes-eies, 1845) on the ova of the Bitch; those of Remak on the Vertebrata (Untersuch, üher die Entwickel. res Wirbelthiere, Borlin, 1855); of Reiehert on the (iuinea-pig (Boitrïge zur Entwickelungegeschichte des Meerschweinchens), Monatsbericht d. Akad. Berlin, 1860; of Leuckart, contained in Wagner's Iandwörterbuch der Physiologie, art. Zeugulag; of Allen Thomson, in the art. Ormm, in the supplementary volume to Todd's Cyelop. of Anatomy and Pliysiology, 18.59; of Huxley, in the Croonian Iuecture for 18.5, and in his Lectures on the Filements of Comparative Anatomy, 1864; of Coste (Histoire Génér. et Partic. du Développement des Corps Organisés, 1847-18.99); of Pander, Beitrüge zur Entwick. d. Iühnehens; of His, Untersuchungen uber die erste Anhage des Wirbelthierlibes, Leipzig, 18fis; of v. Bencden, Recherehes sur la composition et la signification de I'(Enf, 1870; of Oellacher, Schultze's Archiv f. mic. Anat., Bd. viii, 1872; Goethe, On the Development of the Bombinator igneus, 1875, and of Parker's various papers, On the Development of the Skull, in Philosophical Transactions. 
spheres, each of which contains a number of splierules similar to the smaller spherules; it presents also some vicuoles in the region of the cicatricula. At the point where the white yolk dips into the yellow yolk is a depression, which is occupied by a small white disk, about the sixth of an inch in diameter, termed the blestoderm or cicatricula $(b l)$. The disk is always uppermost when the egro is opened from the side, in consequence of the lighter specific gravity of this part of the vitellus. A typical cicatricula presents

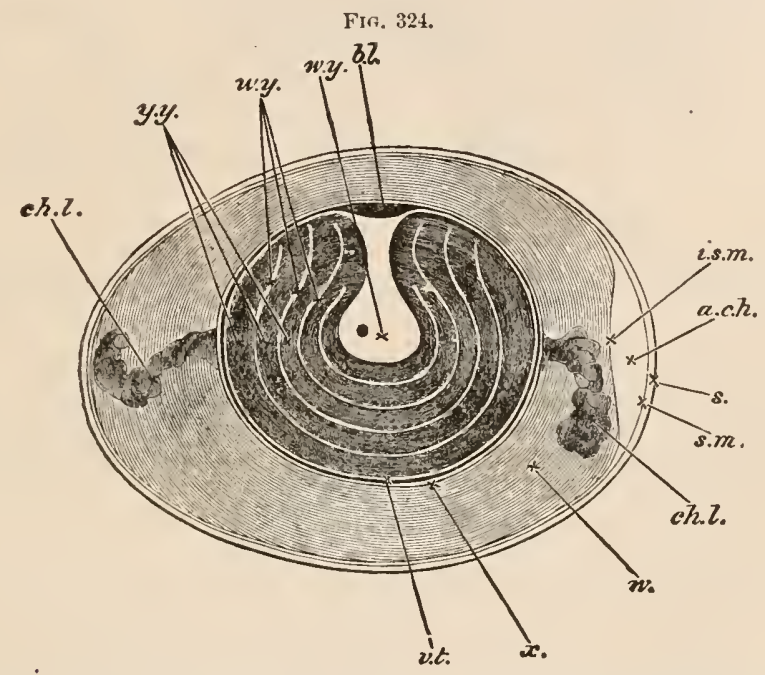

Diagrammatic Section of an Unincubated Fowl's Egg: $b$, blastoderm; $u y$, white yolk. This consists of a central flask-shaped mass and a number of layers concentrically arranged around this; $y y$. yellow yolk; $v t$, vitelline uncmbrane; $x$, layer of more fluid albumen immediately surrounding the yolk; $w$, albumen, consisting of alternate denser and more fluid iayers; $c h l$, chalaza; ach, air-chamber at the broad cnd of the egg. This chamber is merely a space lct between the two layers of the shellmembrave. ism, internal layer of shell-membrave; $s m$, external layer of shell-membrane; $s$, shell.

an outer white rim, or area opaca, a circular transparent area, or area pellucilla, and a more or less well-marked central opacity. The area opaca and central opacity appear to be dne to the disposition of the white yolk beneath the blastoderm, whilst in the part corresponding to the area pellucida, the blastoderm is separated from the white yolk by a space, filled with a little fluid. Imbedded in the protoplasm of the germinal disk is a globular or ellipsoidal highly refractile borly, termed the germinal vesicle; in the interior of which, again, is a small body, the germinal spot.

776. Before being lail, and at about the time when the shell is being formed around the egg, the cicatricula or germinal disk undergoes a remarkable process, termed segmentation. This commences witl the formation of a furrow, which is quickly crossed by another at right angles, and soon by others (Fig. 325). The examination of hardened specimens shows that the segmentation is not confined to the surface, but extends through the mass of the blastoderm, and that it takes place not only by vertical but by horizontal furrows, that is, by furrows parallel to the surface of the disk. The original germinal disk is thus broken up into a number of small masses of protoplasm, which are smallest in the centre of the disk, and upon the surface; the smaller size of the superficial layer foreshadowing the subsequent division of the blastoderm into two layers. The disk having undergone seginentation becomes separated from the white yolk, on which it has hitherto been lying, by a space containing fluid, termed the segmentation cavity (see 
Fig. 327), and with this a distinction becomes apparent between the upper and lower layers of the segmentation masses. Those of the upper or superficial series assuming a columnar form, and presenting well-defined nuclei, arrange themselves side by side, and constitute a kind of membrane (Fig.

FIG. 325.
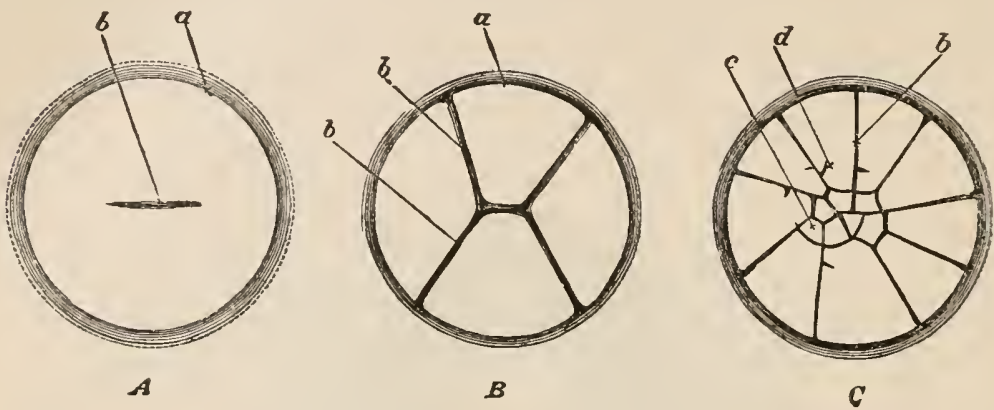

$A$ represents the earliest stage. The first furrow, $b$, has begun to make its appearance in the eentre of the germinal disk. In $B$ the first furrow is eompleted right across the disk, and a second sinilar furrow nearly at right angles to it has appeared. The disk thus hecomes divided somewhat irregularly into quadrants by four (half) furrows. In a later stage $(C)$ the meridian furrows $(b)$ have increased in number from four, as in $B$, to nine, and eross furrows have also made their appearance. The disk is thus cut up into small ceutral $(c)$ and larger peripheral $(d)$ segments. Severai new cross furrows are seen just beginning, as ex. gr. close to the end of the line of referenee $(d)$.

$326, a)$; whilst those of the lower series remain larger $(b)$, have no nucleus, or only an indistinct one, and form rather a close irregular network than a distinct membrane. A few of the cells of this layer, constituting the so-called formative cells (bd, Fig. 327) becoming detached, fall to the bottom of the. segmentation cavity, and rest on the white yolk. This is the usual condition

FIG. 326.

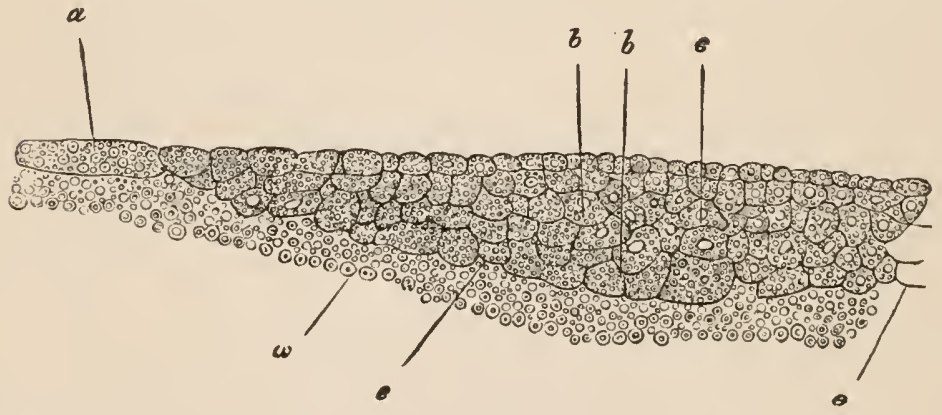

Section of the Germinal Disk of a Fowl during the later Stages of Segmentation. The seetion, whieh represents rather more than half the breadth of the blastoderm (the middle line being at $c$ ), shows that the upper and central parts of the disk'segment faster than those below, and at the periphery. In the majority of segments a nucleus ean be secn, and one is probably present in all. The segments contain a number of highly refraeting spherukes. In the central part of the blastoderm the upper cells have eommenced to form a distinct layer. No segmentation eavity is present. $a$, large peripheral cell; $b$, larger eclts of the lower parts of the blastoderm; $c$, midd line of blastoderm; $e$, edge of the blastoderm adjoining the white yolk; $w$, whitc yolk.

of the blastoderm at the time that the egg is laid. The future development of the chick takes place entirely in the area pellucida. In the course of a few hours after being laid the blastoderm of the fecundated egg, in consequence of the flattening of the lower cells of the mesoblast and the development of nuclei in their interior, presents a division into three layers (Fig. 
327 )-an upper, middle, and inferior-termed respectively the epiblast $(A)$, mesoblast (B), and hypoblast (C). It also begins to spread circularly over the vitellus, so that instead of appearing as a mere disk it forms an investment

FIG. 327.

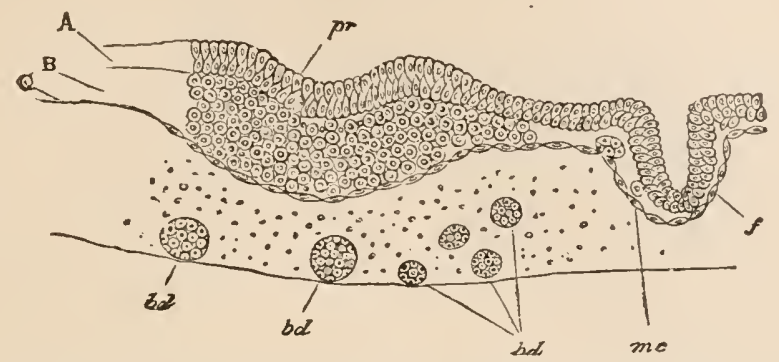

Section of a Blastoderm at right angles to the long axis of the Embryo after eight hours' ineubation. Taken about midway between the front and hind end. A, Epiblast; B, Mesoblast; c, Hypoblast; $p r$, primitive groove; $f$, fold in the blastoderm, probably produced by the action of the eliromic acid; $m c$, mesoblast cell-the line points to one of the peripheral mesoblast cells lying between epiblast and hypoblast: $b d$, fornative cells. The following are the chief poiuts represented in the section: (1) The thickening of the mesoblast underneath the primitive groove $p r$, even when it is hardly at all present at the sides of the groove; (2) The hypoblast, c, early formed as a single layer of spindle-shaped cells; (3) The so-called segmentation eavit 5 , in which eoagulated albumen is present. On the thoor of this are the large formative cells $d$. The line of separation between the epiblast and mesoblast is too strongly marked in the ligure.

for the yolk beneath the vitelline membrane, which, however, only becomes complete towards the close of the period of incubation. The bag thus produced is chiefly formed by the growth of the area opaca, but in part, also, by that of the area pellucida, which gradually assumes an oval and then a pearshape. In the centre of the area pellucida a longitudinal thickening is now seen, termed the primitive streak, which is formed by the multiplication of the cells both of the epiblast and of the mesoblast, but chiefly of the mesoblast, and this, again, is quickly marked by a rimple, the primitive groove ( $p r$, Fig. 328). This is the first indication of the embryo, which in its further development is formed by a folding off of the area pellucida from the rest of the blastoderm; though it may be mentioned incidentally that the primitive groove early disappears without entering directly into the formation of any part of the embryo. The first indication of the folding off of the embryo consists in the formation of a crescentic furrow (Fig. 328 , the first dark crescent above the line $\boldsymbol{A})$ at a point which corresponds to the head of the embryo, and very shortly afterwards tail and lateral folds form, which give rise more and more distinctly

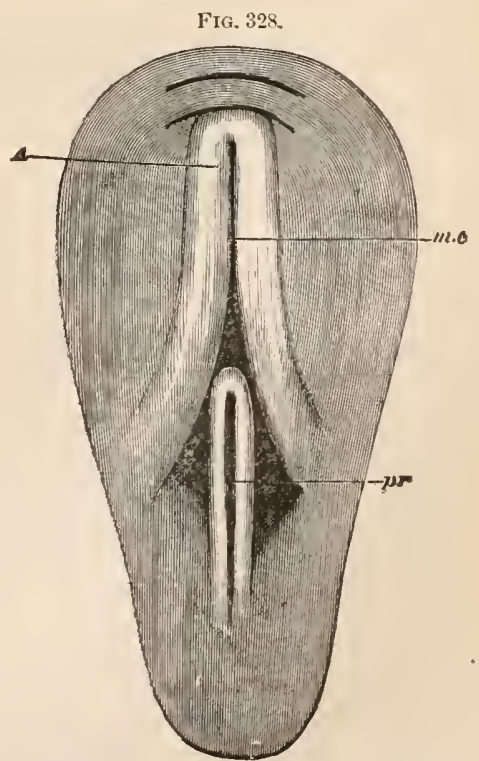

Surface view of the Pellucid Area of a Blastoderm of 18 hours. None of the opaque area is shown, the pear-shaped outline indicating the limits of the pellucid area. to the appearance of a small tubular sac seated upon and connected by a 
continually narrowing hollow stalk (the vitelline duct) with the germinal sac of the blastoderm which incloses the yolk. Soon after the appearance of the primitive streak and groove the mesoblast undergnes a cleavage into two lamina over its whole extent, with the exception of that part that lies just beneath the axis of the embryo. The upper layer of the mesoblast unites with the epiblast, the lower layer with the hypoblast, and the yolk thus comes to have a double investment beneath the vitelline membrane. In the first formation of the head, tail, and lateral folds, both layers are equally involved, but, as shown in Fig. 329, the lower leaf is folded in more rapidly than the upper one, and a space-the pleuroperitoneal cavity ( $p p$, Fig. 329) appears between them. The upper or outer layer forms the somatopleure ( $F S_{0}$ ), and subsequently gives rise to the borly walls of the embryo. The lower or inner layer forms the splunchnoplenre $(S p)$, and its opposite folds meeting sooner than those of the upper layer, constitute the intestinal tube. At about the sixteenth hour a thickening of the mesoblast occurs in front of the primitive groove, ending in frout as the headfold (Fig. 328 A, Fig. 329 ). The surfice of this is marked by a groove ( $m$ c, Fig. 328), termed the medullary groove, the sides of which $(A)$ constituting the medullary folds or lamince dorsales, gradually arching over till they meet and fuse, inclose the medullary canal. Immediately beneath the groove the cells form a flattened cylindrical rod-the notochord, which is the precursor of the vertebral column.

Formation of Amnion and Allantois.-Coincidently with the formation of the headfold, a second fold (Fig. $329, A \mathrm{~m}$ ) appears a little in front of it,

Fig. 329.

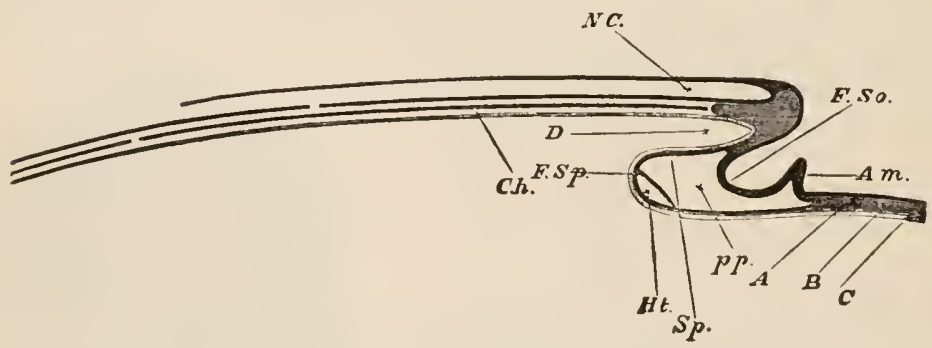

Diagrammatic Longitudinal Section through the Axis of an Embryo. FSo, Fold of the somatopleure. FS p Fold of the splanchnopleure. The line of reference, $F S O$, is placed in the lower bay, ontside the embryo. The line of $D$ is placed in the upper bay, inside the embryo; this will remain as the alimentary eanal. Both folds $(F S O, F S p)$ arc parts of the headfold, and are to be thought of as contiunaly travelling ouwards (to the left) as development proceeds. $p p$, Space between somatopleure and splanch noplcure; pleuroperitoneal cavity. A $m$, Commencing (head) fold of the amnion. The tailfold has not yet appeared. $N C$, Ncural canal, closed in front, bint as yet open behind. The section being taken in the middlc line, the protovertebre are of course not shown. In front of the notochord is seen a mass of uncleft mesoblast, which will eventually form part of tỉe skull. D, Commencing foregut, or front part of the alimentary canal. A, Epiblast. $B$, Mesoblast. C, IIypoblast.

and soon others arise at the tail end and sides of the embryo, which, unlike the head-fold, are formed exclusively of the somatopleure-i.e., of the epiblast and a thin layer of mesoblast, and gradually rising, bend over the body of the embryo (Figs. 331, $d, e ; 334, a f$ ), and coalesce (c, Fig. 332). These are the ammiotic folds. Each fold necessarily consists of two limbs. After their coalescence the septum disappears and two spaces exist: one which is continuous with the pleuroperitoneal cavity between the outer and inner limbs, and one between the imner limb and the body of the embryo. The former is the space into which the allantois or respiratory organ of 
the embryo projects; the latter is the amniotic sac, and is subsequently filled by the amniotic fluid. The allantois (Fig. $333, c$ ) is not formed till the $2 d$ or 3d day, when it appears as a bud thrown out by the splanchnopleure
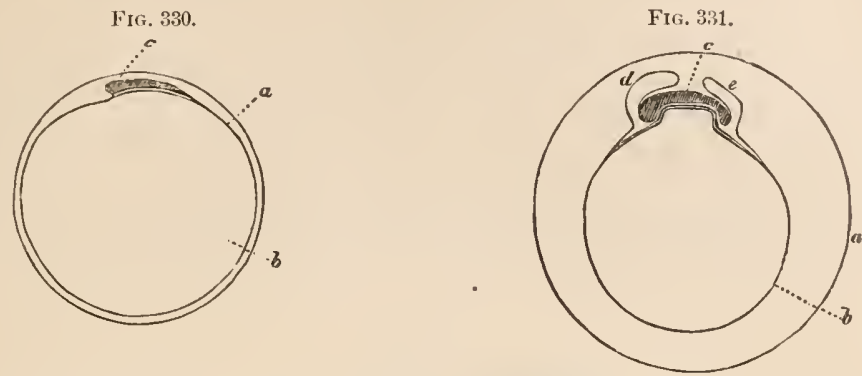

Fig, 330.-Plan of early Uterine Ovum. Within the external ring, or zona pellucida, are the serous lamina, $a$; the yolk, $b$; and the incipient embryo, $c$.

FIG. 331.-Diagram of Ovum at the commencement of the formation of the Amnion: $a$, chorion; $b$, yolk-sac; $c$, embryo; $d$ and $e$, folds of the scrous layer rising up to form the amnion.

close to its junction with the somatopleure at the hinder end of the embryo, and gradually insinuating itself first into the pleuroperitoneal cavity, and then between the true and false amniotic sacs, it curves over the embryo
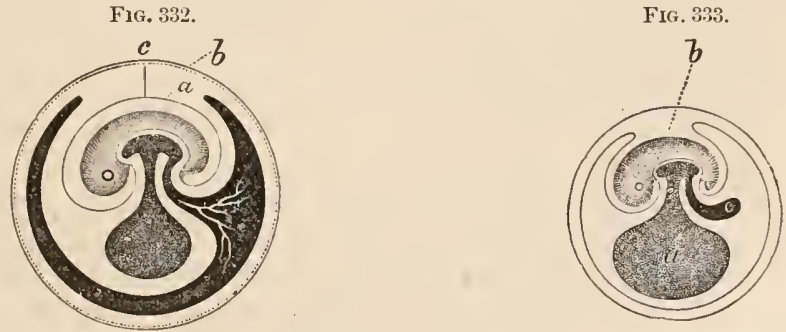

Fig. 332,-Fecundated Egg of Fowl with Allantois nearly completed: 1, Inner lamina of amniotic fold; $b$, outer lamina of the same; $c$, point where the amniotic folds come in contact with each other; the allantois is seen penetrating between the inner and outer lamina of the amuiotic fold.

Fif. 333.-Feundated Egg, showing formation of Amnios and Allantois: $a$, Umbilical vesicle; $b$, amniotic cavity ; $c$, allantois.

(Fig. 332), and is separated from the outer air only by the shell vitelline membrane and the thin false amnion. It is composed of a layer of columnar cells derived from the hypoblast, of a layer of cells derived from the undivided mesoblast, and of an epithelial investment derived fiom the mesoblast of the splanchnopleure. It receives at an early period brauches from the iliac arteries, which subsequently constitute the umbilical vessels, and are developed in an extension of the mesoblast cells of the area opaca, known as the vascular area.

The first rudiment of the heart in the chick appears as a solid thickening of the mesoblast of the splanchnopleure just beneath the anterior extremity of the foregut. It soon becomes hollow, and receives behind the blood of the two omphalo-mesaraic veins, which ramify over the yolk-sac, 
whilst in front it gives off the two aortre, which bend round the front end of the foregut and gain its upper side, when they turn back and run in the inesoblast on each side of the notochord to the tail. About the middle of the embryo each gives off a large omphalo-mesenteric artery, which is distributed over the pellucid and vascular areas, from whence the blood is returned by the omphalo-mesaraic veins (Fig. 340, R.Of.A, L.Of). At the close of the first day the protrovertebra begin to form in the uncleft portion of the mesoblast near the middle line, which is called the vertebral plate. The first one that inakes its appearance is the body of the third or second cervical, others soon becoming segmented off the vertebral plate both before and behind. At this time the forepart of the medullary canal with its optic and cerebral vesicles, which has hitherto been straight, begins to curve over the antcrior ex-

FIG. 334 ,

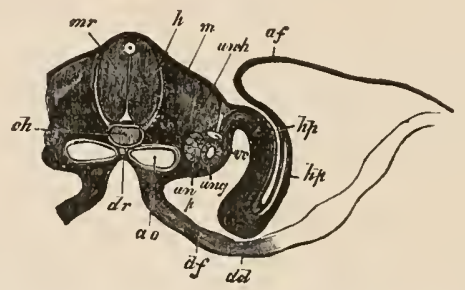

Transverse section of the Embryo of a Fowl at the beginning of the third day of incubation $\times 90$ -100 : ch, chorda dorsalis; uwh, undivided mesoblast, in which the protovertebre are subsequently developed; $h_{p}$, somatopleure; $d f$, intestinal fibrous lamina; $d d$, intestinal glandular lamina; $d r$, primitive intestinal groove; $h$, eorneal lamina (the line in the drawing extending a little too far); $m r$, medullary tube (spinal cord); $m$, muscular lamina; $p$, pleuroperitoneal cavity; $a f$, fold of the amnios; $a 0$, primitive aorta; $v e$, vena cardinalis; un, Wolffian body; ung, duct of the Wolffian body.

tremity of the notochord, which is the commencement of the cranial flexure; and soon after the whole embryo becomes curved upon itself. On the third day certain fissures or clefts, termed the visceral or branchial clefts, appear, developing in succession to the number of four from before backwards, and from within outwards. The anterior border of each forms a visceral or branchial
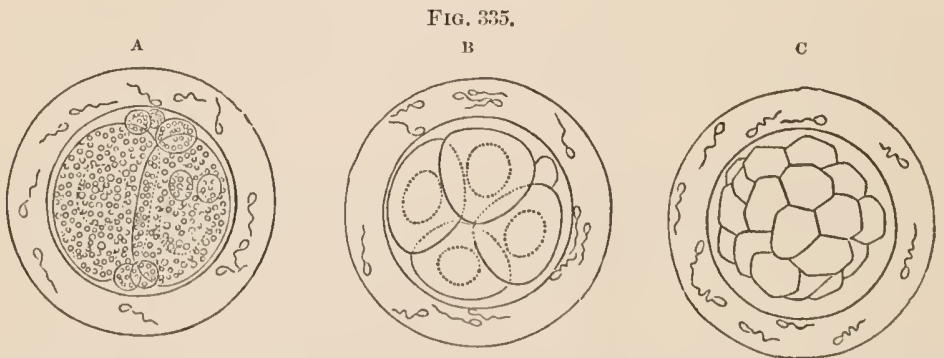

Progressive stages in the Segnentation of the Yolk of the Mammalian Ovum : A, its first division into two halves; $\mathrm{B}$, subdivision of eaeh half into two; $\mathrm{c}$, further subdivision, produeiug ummerous segments.

fold, so that there are five folds. The first pair form the inferior maxillæ, and by a pair of buds they give off from their upper border, the superior maxillas. Other structures are formed in the remaining folds, which will hercafter receive mention $(\S \S 795,800)$. 
Having proceeded thus far with the development of the chick, we may now return to the early stages of the development of the Mammalian ovum. The ovum of the Mammal differs from that of the bird, in not presenting the same differentiation into white and yellow yolk and cicatricula, but resentbles the cicatricula in undergoing complete segmentation. It is originally composed of yolk spheres diffused in protoplasm, and contains a germinal vesicle and spot. As the egg ripens the vesicle comes to be nearer and nearer to the surface, and before impregnation occurs, and probably as a consequence of the contractile power of the protoplasm, is squeezed out from it, and lies between it and the zona pellucida. Here it undergoes segmentation, but its further changes are unknown, except in so far that the products of its division do not appear to stand in any genetical relation to the nuclei of the primary segmentation spheres. ${ }^{1}$ These are derived from the division of the yolk, which takes place in a manner essentially similar to that of the cicatricula of the Avian egg (Figs. 335 and 336 ), the ovum ultimately

FIG. 336.

$\mathbf{A}$

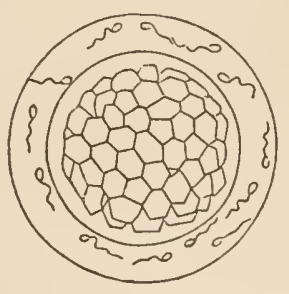

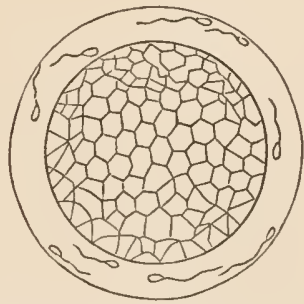

Later stage in the Segmentation of the Yolk of the Mammalian Orum: at A is shown the "mulberrymass" formed by the minute subrivision of the ritelline spheres; at $\mathrm{B}$, a further increase has brought its surface into contact with the vitelline membrane, against which the spherules are flattened.

acquiring a mulberry-like aspect, and by the time of its arrival into the uterus the whole cavity of the vitelline membrane or Zona pellucida being occupied by minute spherules of yolk. ${ }^{2}$ The outermost cell-like products of the segmentation of the ovum assume a definite arrangement, and form a kind of membrane within or beneath the Zona pellucida, named by Bischoff the blastodermir vesicle. This increases rapidly in size, and becomes filled with fluid furnished by the uterus. When it has attained to ${ }^{3 \prime \prime}$, in the ovum of the Rabbit, a round spot begins to be distinguished by its white opaque appearance; this is the Area germinativa (Plate I, Fig. 6). The Area germinativa continually increases in extent and thickness by the formation of new cells, and soon exhibits a differentiation into an upper and a lower layer (Plate I, Figs. 5 and 6), and the lower layer again speedily divides into two. Thus, the same succession of layers-an outer or epiblastic, a middle or me-

1 Oellacher, Max Schultze's Archiv, Bd. viii, p. 1, 1872.

2 A rotation of the yolk at this period, for which the presence of oxygen appears to be a necessary condition (see Dr. Ransom, Humphry and Turner's Journal of Anatomy, vol. i, 1867, p. 237) was observed by Dr. Ransom in the ova of the Gasterosteus, and was soon after noticed in the Pike by Reichert, in the frog by Ecker, and subsequently in the Rabbit and Guinea-pig by Bischoff. The cause of this singular morement is still unknown, and though Bischotf stated that he had seen cilia in the rabbit on the outer surface of the yolk, he was unable to satisfy himself of their presence in the guinea-pig. 
soblastic, and an internal or hypoblastic layer-is seen as in the egg of the fowl, and the process of development is in all essential respects in its early stages identical with that of the egg of the Bird. From the epiblast the brain and spinal cord, the special modifications of the nerves ministering to special sense, as the Retina, Auditory hairs, etc., and the epidermis with its epithelial prolongations into the mouth, salivary ducts, and cloaca, are derived. The mesoblast gives origin to the muscles, bones, connective tissue, and dermis, the cerebro-spinal and sympathetic nerves, the genito-urinary, and the chylopoietic system, and, lastly, from the hypoblast arise the epithelium of the digestive canal and of the ducts of the glands connected with it (except the salivary), as wcll as the cells constituting the parenchyma of the liver and pancreas, and the epithelium of the respiratory apparatus. Whilst this is progressing the fine membrane covering and inclosing the blastodermic vesicle begins to show small mammillary eminences, whence the name which has been suggested for this membrane, of Chorion primitivum or Hembrana ovi externa. The ovum at this period, therefore, consists of the external villous nembrane or primitive chorion; of the blastodermic vesicle, composed of two layers; and of the cellular yolk. As in the Bird, the area germinativa at its first appearance has a rounded form, but it soon loses this, first becoming oval and then pear-shaped (Plate II, Fig. 11). The centre becomes clear, and constitutes the area pellucida, and this is bounded by a more opaque circle, the area opaca. The first appearance of the cmbryo in the form of the primitive trace with the subsequent elevation of the lamina dorsales, their junction in the middle line, and expansion anteriorly into three vesicles (Plate II, Fig. 126), afterwards to be developed into the prosencephalon, mesencephalon, and epencephalon; the formation of the amnion by the growth of two folds of the epiblast, and the growth of the allantois into its cavity differ in no essential respect from the similar processes in the chick, though the allantois never attains the same degree of development in

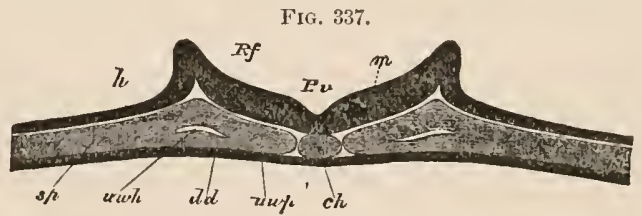

Transverse section through the Embryo of the chick at the close of the first day of incubation, magnified abont 100 diameters: $c h$, chorda dorsalis; $h$, external serous or corveal layer; m, medullary portion of serous layer; $P v$, primitive groove between the dorsal lamiuse $I f$ and $m$; dd, intestinal epithelial or glandular layer (mucous layer); uep, prevertebral miss, in which the primary or protovertebre are formcd, and winch is continuous with the middle lamina, $s p$; woh, fissure in the widlle limiua, presenting the first indication of the pleuro-peritoneal eavity, and of the subsequent division of the middle lamina into two layers.

the mammal. A microseopic examination of the Amniotic membrane in the Human subject shows that it consists of an inner layer of tessellated epithelium, and an outcr layer, which even at the fourth week presents spindleformed corpuscles, and at the seventh wcek has become well-marked connective tissue. In some animals it is provided with muscular fibres, and performs distinct movements; but it never in any species possesses proper vessels. From its mode of formation, the Ammion is directly continuous with the skin of the embryo, and the Amniotic liquor in which the foetus floats occupies the space bctween the inner layer and the skin.

777. As the development of the embryo progresses, the walls of the abdomen and the coats of the intestines begin to be formed by the bending 
downwards and forwards of the lateral portions of the blastodermic vesicle. In Fig. 3:38, the mode of the development of the abdominal cavity is seen, its parietes being former by the somatopleure, composed of the epiblast with some mesoblast $(b h)$, whilst within it the deep groove of the intestines $(d)$ appears, the walls of which or splanchnopleure are composed of two laminie, the mesoblast $(d f)$, and the hypoblast $(d)$, passing into the corresponding lamine of the blastodermic vesicle, which already form the vitelline sac. The incipient intestine is maintained in its place by the mesentery, which begins to be formed out of a prolongation of the mass lying in front of the chorda dorsalis, in which lie the now symmetrical aorta $(s a)$ and the cardinal vein $(v c)$, and which is obviously only a thickened portion of the connecting band between the parietal lamina and the intestinal fibrous layer.-During the same period, a very important provision for the future support of the embryo begins to be made, by the development of Bloodvessels and the firpmation of Blood. Hitherto, the embryonic structure has been nourished by direct absorption of the alimentary materials supplied to it by the yolk ; but its increasing size and the necessity for a more free communication between its parts than any structure consisting of cells alone can permit, call for the development of vessels through which the nutritious fluid may be conveyed. These vessels are first seen in the vascular area or that part of the germinal membrane which immedialely surrounds the embryo. ${ }^{1}$ In their earliest stage of development these vessels appear as two arcus aorte, proceeding from the anterior part of the heart, which after a short course in the forward direction, bend backwards to unite in a single, short, symmetrical aortic tube, from which again two branches almost immediately arise, the arterice vertebrales posteriores, or primitive artæ. These, lying beneath the chorda dorsalis, extend to the posterior part of the body of the embryo, dividing ultimately into the omphalo-nesaraic, or Vitelline vessels (Fig. 340, R.Of.A, L.Of.A; see also Plate II, Fig. 13) which form a close network, bounded by a circular channel termed the Vena or Sinus terminalis. This network or vascular area soon extends itself, and the vessels finally spread over the whole of the membrane that contains the yolk. At the anterior part of the embryo the two extremities of the circular channel form the Vence omplalo-mesaraice, which discharge their contents into the back part of the heart.-At this period the Yolk-sac is entirely separated in the Mammalia, by a constriction of the portion which is continuous with the abdomen of the enbryo (Fig. $343, b$ ); and it is known from that time under the name of the Umbilical Vesicle (Plate I, Fig. 10, i). The communication, however, remains open for a time through the "vitelline duct ;" and even after this has been cut off, the trunks which connect the circulating system of the embryo with that of the vascular area are discernible. The two first veins, then, that are developed, are the Venæe omphalo-mesaraice, which belong not to the body of the embryo itself, but to the germinal area, and open by a short tube common to both into the posterior extremity of the Heart (Fig. 339, I, om). Subsequently by the extension of their branches over the yolk-sic they become the vitelline vessels, still opening by two veins into the heart, and effecting the absorption of the yolk. With the formation of the intestine, however, the vessel of the right side disappears, the left alone remaining

1 According to His (loc. cit., p. 95), Wolff, and Pander, in the chick a peripherical vessel around the germinal area, and othors in the area opaca, first appear, whilst at. various points small colored mases, surrounded by a membrane or blood-islands are developer. Both the vessels and the hlond proceni directly from the white or germyolk The formation of the vessels precedes that of the heart, and is quite independent of it. 
(Fig. 339, 2, $\mathrm{om}^{\prime \prime}$ ), which is soon joined by a small mesenteric vessel from the intestine (Fig. 339, 3, m). Before this is accomplished, however, the Allantois has been developed, and to this organ the large branches pass from the Iliac Arteries, which are named umbilical arteries; the blood returning from it after aeration enters the two Venæ umbilicales which pass forwards and open into the common trunk of the Venæomphalo-mesenterica (Fig. 339, I, $u^{\prime} u^{\prime \prime}$ ). The Venæ umbilicales rapidly increase in size, preponderating so much over the only remaining Vena omphalo-mesenterica, into which they originally discharge their contents, that the latter now appears to be merely a tributary branch. As the Liver becomes developed it surrounds the trunk of the umbilical vein (Fig. 339, 3), which soon forms

FIG. 338.

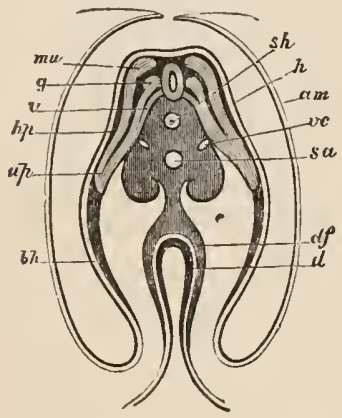

FIG. 338.-Transverse section made through the body of the Embryonic Fowl, near the umbilicus, on the fifth day of incubation: $s \bar{h}$, sheath of the chorda dorsalis; $h$, epiblast; $a m$, amnios completely closed; $s a$, secondary aorta; $v c$, vena cardinalis; $m v$, muscular lamina; $g$, spinal ganglion; $v$, anterior root of the spinal nerve; $h p$, mesoblast; $u p$, prolougation of the mesoblast into the abdominal wall (protovertebral lamina of Remak, visceral lamina of Rejchert); $b h$, somatopleure, or primitive wall of the abdomen, composed of the external, serous, or epiblastic lamina, and of a layer of inesoblast ; $d f$, internal layer of mesoblast, in which the fibrous membranes of the intestines are developed; $d$, hypoblast. The mass around the chorda is that in which the protovertebre are developed; it contains the ressels anteriorly, and in front, in the middle line, is prolonged as the mesentery.

FIG. 339.-Diagram of the formation of the Venæ Omphalo-mesaraice and Umbilicales; 1 . At the time of the first appearance of the umbilicales and the commencement of the omphalo-mesaraicie. 2. At the time of the first appearance of the hranches to and from the liver, and the diminution of the omphalomesenteric vessels. 3, 4. At the period of completc fotal circulation in 1, omphalo-mesaraic trunk; in 2,3 , remains of it ; in 4, vein of the yolk-sac alone; om ' right and om" left vena omphalo-mesarticie; $u$, trunk of the umbilical vein ; $u^{\prime}$ right and $u^{\prime \prime}$ left vena umbilicalis ; dc, ductus Cuvieri ; $j$, jugularis ; $c$, cardinalis; $l$, liver; $h a$, hepaticse advehentes; $h r$, hepatice revehentes; $m$, mescnteriea; $d a$, ductus venosus $A$ rantii ; $c i$, cava inferior ; $p$, vena portæ; $l$, lienalis ; $m$, mesenterica superior.

a twofold system of tubes within that gland, the one conveying the blood to the liver, the Vence hepatice advehentes; the others returuing the blood from the gland substance to the umbilical vein again, and constituting the Vense hepatice revehcntes. The right umbilical vein now disappears, and the blond returning from the placenta altogether traverses the left vein, which soon takes up a median position ; the remains of the omphalo-mesaraic vessel ( $\mathrm{om}$, Fig. 339, 4 ), together with branches $(\mathrm{m})$ derived from the intes- 
tine, ultimately come to open into the right vena hepatica advehens of the umbilical vcin, and thus constitute the origin of the portal vein. That portion of the umbilical vein which lies between the two systems of hepatic branches just mentioned, remains throughout the whole of fietal life, and is termed the Ductus venosus Arantii. It was formcrly believed that the nutrient matter of the yolk passes directly through the vitelline duct, into the (future) digestive carity of the embryo, and is from it absorbed into its structure; but therc can now be little doubt, that the vitelline vessels are the real agents of its absorption, and that they convey it through the general circulating system, to the tissues in process of formation. They correspond, in fact, to

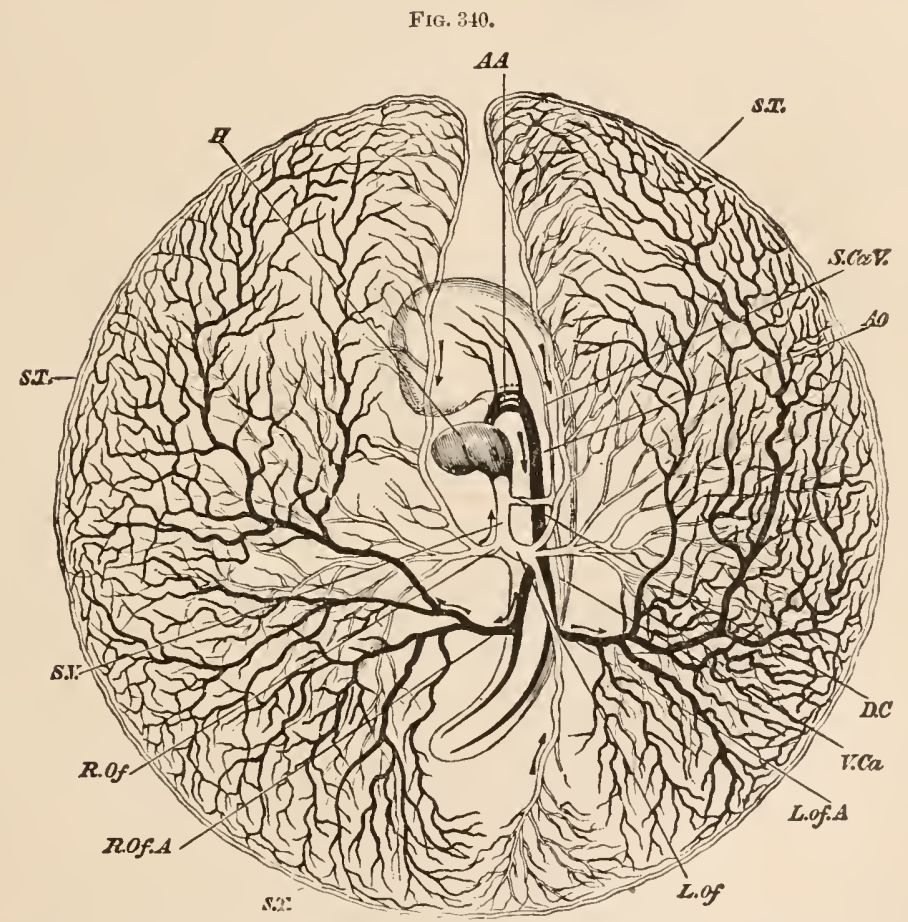

Diagram of the circulation of the Yolk Sac at the end of the third day: $H$, Heart. $A A$, the $2 d, 3 d$, and 4 th Aortic Arches; the first has become obliterated in its median portion, but is continued at its proximal end as the external Carotid, and at its distal end as the interual Carotid. Ao, Dorsal Aorta. R.Of.A, and L.Of.A, Right and left omphalo-mesaraic arteries. S.T., sinus terminalis. R.Of and L.Of, Right and left omphalo-mesaraic veins. S. $V$, sinus venosus. D.C, Ductus Cuvieri. S.Ca.V and V.Ca, Superior and inferior Cardinal Veins.

the Mesenteric veins of Invertebrated animals, which are the solc agents in the absorption of nutriment from their digestive cavity ; and the blastodermic vesicle to be regarded as the temporary stomach of the embryo,--remaining as the permanent stomach in the Radiated tribes.

778. The first rudiment of the Mammalian Heart, which is the earliest of the permanent organs of the embryo that comes into functional activity, consists of an aggregation of cells, forming a thickening of the mesoblast beneath the anterior portion of the intestinal canal, and lying in the general pleuroperitoneal cavity (Fig. $329, H$ ), the innermost cells becoming de- 
tached, float in the newly formed cavity as the first blood-corpuscles, whilst

FIG. 311 .
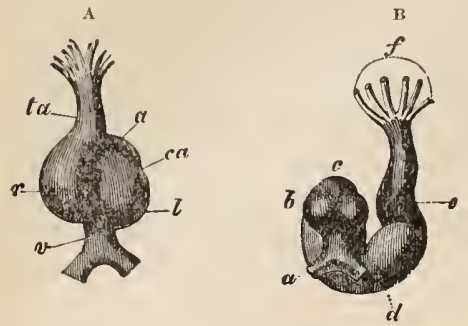

A. Heart of the Embryo of a Rabbit seen from before: $t a$, truncus arteriosus; $l$, left ventricle; $r$, right ventricle; $a$, auricle; $v$, venous sinus.

B. The same heart seen from belind: $a$, vense omphalo-mesaraice; $d$, right auricle; $e$, bulbus aortse; $f$, the six aortic arches; $e$, atrium; $b$, auriculie.

15th-18th day in the Human Embryo it bech the arteries. Aloct the (Plate II Fir 1\%, doubly bent upon itself (Plate II, Fig. 13, $d$, and Fig. $3+1,1, B$ ), one loop corresponding to the arterial, the other to the venous portion. After this, two slight enlargements (b) are observed in the venous bend; and the arterial bend separates into two parts by a long line of division. The two enlargements represent the auricles, and receive the venæ omphalo-mesaraicæ $(a)$, which run outwards in the folds of the Splanchnopleure. Above, they open into the atrium (c), which leads to the right ventricle $(d)$, and this again into the bulbus aorte. The circulation is at first carried on exactly upon the plan which is permanently exhibited by Fishes. The Anrta subdivides on either sicle of the neck into three or four arches (Figs. $340,346, e, e^{\prime}, e e^{\prime \prime}$ ), which are separated by fissures much resembling those forming the entrances to the gill-cavities of Cartilaginous Fishes; and these arches reunite to form the dcscending aorta, which transmits branches to all parts of the body. The vesscls as well as the blood-corpuscles proceed from processes thrown out by mesoblastic cells, which unitc to form a protoplasmic network containing nuclei at the point from which the processes starterl. The nuclei multiply and form nodal points, and those occupying the centre of these nodal points become colored, and constitute the corpuscles, whilst the outer ones remain imbedded in granular protoplasm and form the vessel-wall, and thus a network of vessels containing blood-corpuscles is produced (Foster and Balfour). Such is the first phase or aspect of the Circulating Apparatus, which is common to all Vertebrata during the earliest period of their development, and which may, therefore, be considered as its most general form. It remains permanent in the class of Fishes; and in them the vascular system undergoes further development on the same type, a number of ninute tufts being sent forth from cach of the arches, which enter the filaments of the gills, and are thus subservient to the aeration of the blood. In higher Vertebrata, however, the plan of the circulation is afterwards entirely changed, as will be presently deseribed, by the formation of new eavities in the heart, and by the production of new vessels; it is incorrect, therefore, to speak of the vascular arches in their necks as branchial arehes, since no branchice or gills are ever developed from them. The elefts between them may be very distinctly seen in the Human Fotus towarls the end of the first month; during the second, they usually close up and disappear.

779. With the evolution of a Cireulating apparatus, adapted to absorb 
nourishment from the store prepared for the use of the Embryo, and to convey it to its different tissues, it becones necessary that a Respiratory apparatus slould ako be provided, for depurating the blood from the carbonic acid with which it becomes charged during the course of its circulation. 'The temporary Respiratory apparatus now to be described, bears a strong resemblance in its own character, and especially in its vascular connections, to the gills of the Mollusea; which are prolongations of the external surface (usually near the termination of the intestinal canal), and almost invariably receive their vessels from that part of the system. This apparatus, which is termed the Allantois, sprouts forth from the splanchnopleure close to its junction with the somatopleure, at first as a little mass of cells, which soon exhibits a cavity (probably originating in the liqucfaction of the cells of the internal part), so that a vesicle is formed (Figs. $342,343, g$ ), which looks like

FIG. 342 .

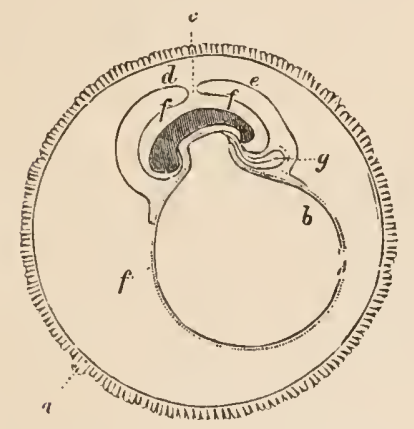

FIG. 343 .

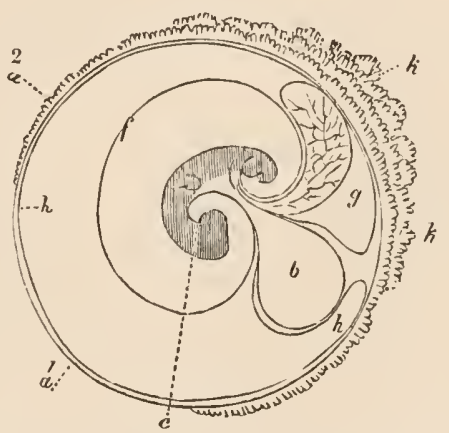

FIG. 342.-Diagram of an early Human Orum, showing the Amnion in process of formation and the Allantois beginning to appear : $a$, chorion; $b$, vitelline mass surrounded by the blastodermic vesicle; $c$, embryo; $d, e$, and $f$, external and interual folds of the serous layer, forming the amnion; $g$, incipient allautois.

Fig. 343.-Diagram of a Human Ovum in second month, showing the completion of the sac of the Amnion, and a fu:ther development of the Allantois : a 1, smooth portion of chorion; $a 2$, villous portion of chorion; $k, k$, elongated villi, beginning to collect into l'lacenta; $b$, vitelline or umbilical vesicle; $c$, embryo; $f$, amnion (inner layer); $g$, allantois; $h$, outer laycr of amnion, coalescing with chorion.

a diverticulum from the lower part of the digestive cavity. The outer cells are composed of mesoblast, the internal of hypoblast. 'This vesicle, in Birds, has been shown by Vulpian ${ }^{1}$ to be possessed of a distinct contractile power, and soon becomes so large as to extend itself around the whole yolksac, intervening between it and the membrane of the shell, and coming through the latter into relation with the external air; but in the embryo of Mammalia, the allantois, being early superseded by another provision for the aeration of the blood, seldom attains any considerable dimensions. Its chief office here is to convey the vessels of the embryo to the Chorion; and its extent bears a pretty close correspondence with the extent of surface throngh which the Chorion comes into vascular connection with the decidua. Thus, in the Carnivora, whose placenta extends like a band around the whole ovum, the allantois also lines nearly the whole inner surface of the chorion; on the other hand, in Man and the Quadrumana, whose placenta is restricted to one spot, the allantois is small, and conveys the fœtal vessels to one portion only of the chorion. When the vessels have reached the chorion, 
they ramify in its substance, and send filaments into its villi; and in proportion as these villi form that connection with the uterine structure which has been already described $(\$ \$ 752-755)$, do the vessels increase in size. They then pass directly from the foetus to the chorion; and the allantois, being no longer of any use, shrivels up, and remains as a ninute vesicle only to be detected by careful examination. The same thing happens in regard to the umbilical vesicle, from which the entire contents have bcen by this time withdrawn; and from henceforth the fotus is completely dependent for the materials of its growth upon the supply it receives through the Placenta, which is conducted to it by the vessels of the umbilical cord. This state of things is represented in Figs. 344, 345, n $n^{\prime}, o o^{\prime}$.-The Allantois is commonly said to give origin to the Urinary Bladder; but this organ is really formed by an enlargement of the upper part of the uro-genital sinus ( $\$ 787)$, with which the allantois communieates by a duct which gradually shrivels, only a vestige of it remaining permanent, to form the Urachus or suspensory ligament of the bladder, by which this is connected with the umbilicus. Before this takes place, however, the Allantois is the receptacle for the secretion of the Corpora Wolffiana, and also for that of the true Kidneys, when they are formed.

780. It will be seen from the succeeding diagram, that the Amnion forms a kind of tubular sheath around the umbilical cord; it is continuous at the unbilicus with the integument of the foetus; and at the point where the cord enters the placenta, it is reflected over its internal or foetal surface. It thus forms a shut sac, resembling that of the pleura, arachnoid, etc.; and it contains a fluid known as the liquor amnii, which consists of water holding in solution a small quantity of casein, creatin, lactic acid, grape sngar, ${ }^{1}$ and saline matter, and resembles, therefore, very diluted scrum. During the first two months of gestation, the amnion and the inner lining of the chorion (which is really the reflected layer of the amuion, Fig. $343, h$, just as the lining of the abdominal cavity is formed by the perituncum) are separated by a gelatinous-looking substance; which probably aids in the nutrition of the embryo, previously to the formation of the placenta. This is absorbed during the second month; and the ammion is then found immediately beneath the chorion.-In the Umbilical Cord, when it is completely formerl, the following parts may be traced. 1. The tubular sheath afforded by the Amnion. 2. The Umbilical Vesicle (Fig. $34 t, t$ ), with its pedicle, or vitelline duct. 3. The Vasa Omphalo-XCesaraica $(q, r)$, or mesenteric vesscls of the embryo, by which the yolk was absorbed into its body; these accompany the pedicle, 4. The Urachus, and remains of the Allantois. 5. The Vasa Umbilicalia $(n n, o)$, which in the latter period of gestation, constitute the chief part of the Corl. These last vessels consist in Man of two arteries and onc vein. The arteries are the main branches of the Hypogastric; and they convey to the placenta the blood which has to be acrated, and otherwisc revivificd, by being brought into relation with that of the mother. The vein returns this to the foetus, and discharges a part of it into the Vena Porte, and a part directly through the Ductus Venosus into the Vena Cava.

781. A change in the type of the Circulating system of the foetus, from that at first prescuted by it (\$777), takes place at a very early period. Between the fourth and eighth weck the venous portion of the heart bccomes nuch cnlarged, and a septum begins to be forned which gradually divides the single ventricular cavity into two, the separation bcing completed at the seventh week. The septum of the auricles commences in the eighth week,

1 Hoppe-Seyler, Handbueh der Chem. Anal., 1867, p. 502. 
but remains incomplcte throughout the whole of foetal life, the opcning being termed the foramen ovalc. Contemporaneously with the formation of these scpta, a transformation occurs in the arrangement of the Arterial trunks proceeding from the heart, which ends in their assumption of the form they present until the end of Fotal life; and this undergoes but a slight alteration, when the plan of the circulation is changed at the moment of the

FIG. 344 .

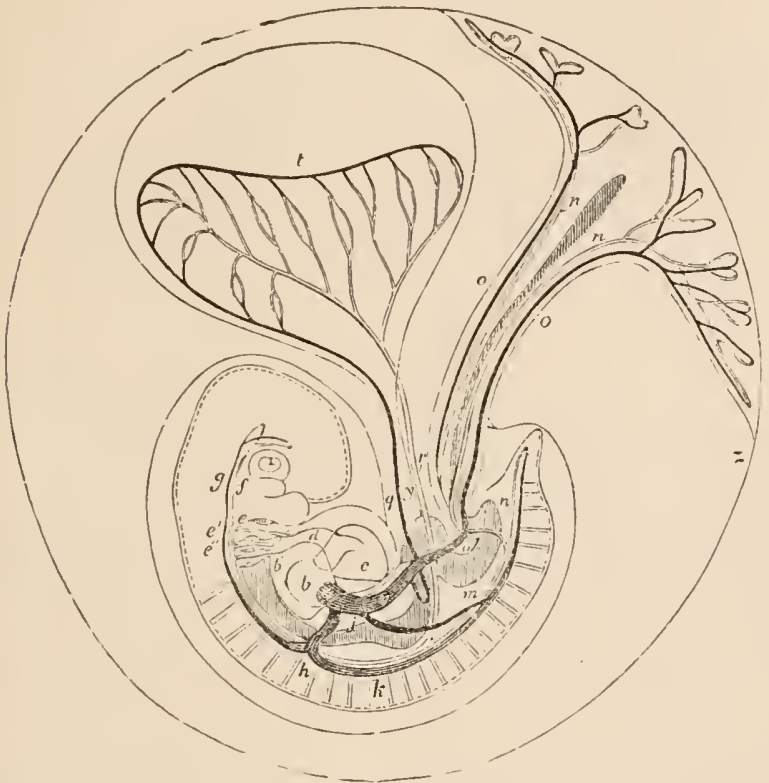

FIG. 345 ,

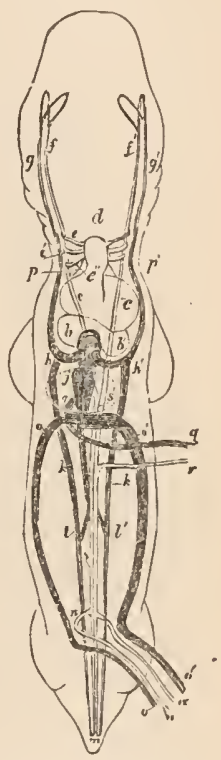

Fig. 34t.-Diagram of the Circulation in the Human Embryo and its Appendages, as seen in profile frow the riglit side, at the commencement of the formation of the Placenta.

FIG. 345.-The same, as seen from the front: $a$, renous sinus, receiving all the systemic reins; $b$, right auricle: $b^{\prime}$, left auricle; $c$, right ventricle; $c^{\prime}$, left ventricle; $d$, bulbus aorticus; subdividing into $e, e^{\prime}, e^{\prime \prime}$, branchial arches; $f, f^{\prime}$, arterial trunks formed by their confluence; $g, g^{\prime}$, vena azygos superior; $h, h^{\prime}$, confluence of the supcrior and inferior azygos; $j$, vena cava inferior ; $k, k^{\prime}$, vena azygos inferior; $m$, descending aorta; $n, n$, umbilical arteries proceeding from it $: o^{\prime}, 0$, umbilical veins ; $q$, omphalo-mesaraic rein; $r$, omphalo-mesaraic artery, distributed on the walls of the vitelliue vesicle, $t$; $v$, duetus venosus; $y$, vitelline duct; $z$, chorion.

first inspiration. The number of aortic arches on each side, which was five at first, soon becomes reduced in the Mammalia to three, ly the obliteration of the two highest pairs. The Bulbus Aorticus is subdivided by the adhesion of its walls at opposite points into two tubes, of which one becomes the origin of the aorta, and the other that of the pulmonary artery, and of the three remaining pairs of vascular (branchial) arches, the third, being connected with the aortic trunk, contributes, with portions of the two highest pairs, to the formation of the external and internal carotid arteries; whilst of the second pair, the arch on the right side forms the innominate and the beginning of the right subclavian, and the other becomes the arch of the aorta, and contributes to form the left subclavian. The lowest pair is entirely obliterated on the right side. On the left, it gives off the pulmonary artery, and remains throughout foetal life in communication with the aorta, 
as the Ductus Arteriosus. ${ }^{1}-\mathrm{A}$ knowledge of these different stages in the development of the Heart and Arterial system enables us to explain many of the malformations which they oceasionally present in Man; these being for the most part due to arrest of development, whereby the cireulating apparatus is permanently fixed in conditions that are properly charaeteristic of cold-blooded animals. And it is interesting to remark, too, that the varieties which not unfrequently present themselves in the arrangement of the
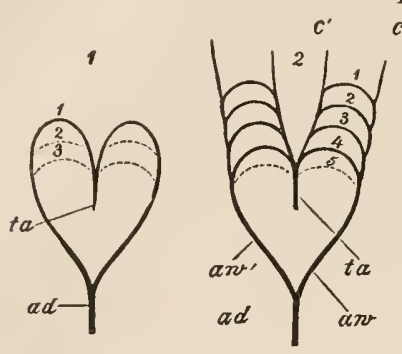

FIG. 346.
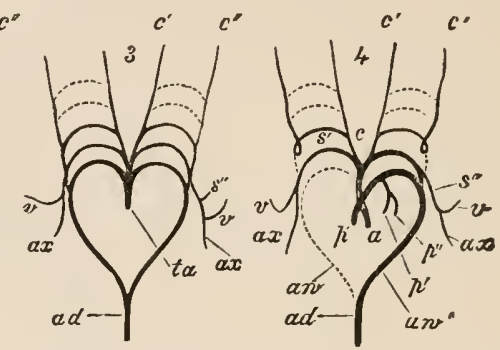

1. Truncus arteriosus, with one pair of aortic arches, and dotted outlines indicating the future position of the second and third pairs. 2. Truncus arteriosus, with four pairs of aortic arches and indications of the fifth. 3. Truncus arteriosus, with the threc posterior pairs of aortic arches, from which the permanent vessuls of the embryo are developed, with dotted outlines showing the position of the two (now) obliterated anterior arches. 4. Permanent arterial trunks in their primitive form, the obliterated portions still shown in dotted outline. 1-5. Primitive aortic arches; $a$, aorta; $p$, pulmonary artery: $p^{\prime}, p^{\prime \prime}$, brauches to the lungs; $a w^{\prime}$, root of thorucic aorta $(a d)$ on left side; aw, obliterated root springing from right side; $s^{\prime}, s^{\prime \prime}$, subclavian artery; $v$, vertebral; ax, axillary ; $c$, common carotid; $c^{\prime}$, external carotid; $c^{\prime \prime}$, interual carotid. In the chick the part $s^{\prime}$ has been observed to atrophy, the vessel $c$ becoming the external, and $c^{\prime}$ the internal carotid artery.

principal trunks given off from the Aorta, find their analogues in the arrangements that are normally characteristic of some one or other of the Mammalia.

782. The Tenous system of the body generally undergoes changes which are even more remarkable than those of the arterial trunks. In its earliest condition, it has been aseertained by Rathke ${ }^{2}$ to present essentially the same type in the embryos of all Vertebrated animals; the peculiarities of eaeh group being acquired hy a proeess of subsequent transformation. There is at first a pair of anterior venous trunks (Figs. 344, 345, $g, q^{\prime}$ ), receiving the bluorl from the head, and a pair of posterior trunks $\left(k, k^{\prime}\right)$, formed by the confluence of the veins of the trunk, of the Wolffian bodies, ete.; the former are persistent as the jugular veins; the latter remain separate in most Fishes, where they are designated the eardinal veins; but in Min (as in warm-blooded Vertehrata generally), they are only represented by the vene azygos, major and minor, ${ }^{3}$ which coalesce into a conmon trunk for a considerable part of their length. Onc of the anterior trunks and one of the posterior unite on either side, to form a canal which is known as the Ductus Cuvieri; and the ducts of the two sides coalesee to form a shorter main canal, which enters the auriele, at that time an undivided eavity. This common eanal is absorbed into the auricle at an early period, in all Vertebrata above Fishes; and after the scptum auriculorum is formed, the two Cuvierian ducts separately enter the right auriclc. 'This arrangement, is persistent in Birds and the inferior Mammals, in which we find two Vene

: Kölliker, Entwickelungsøeschiehte des Menschen, p. 409.

2 Ueber den Bau und die Entwickelung des Venensystens der Wirbuthiere, 1838.

3 See Müller's Vergleichende Anatomie der Myxinoiden, Berlm, 1840. 
Cava superiores, entering the right auricle separately; but in the higher Mammalia and in Man, the left duct is obliterated, and the right alone remains as the single Yena Cava superior, a transverse communicating branch being formed, to bring to it the blood of the left side. ${ }^{1}$ The double Vena Cava sometimes presents itself as a monstrosity in the Human subject. Is the anterior extremities are developed, the subclavian reins are formed to return the blood from them; and these discharge themselves into the jugulars. The Omplalo-nesaraic vein (Fig. 34t, $q$ ), which has been alrealy ( $\$ 776$ ) shown to be formed by the confluence of the veins of the yolk-bag and intestinal canal, passes by itself, with the two Cuvierian ducts, into the auricle. The upper part of this remains to constitute the upper part of the Inferior Cava (Figs. $344,345, j$ ), the lower portion of which arises between the IVolffian bodies, and originally enters the onphalo-mesenteric vein above the liver. The Inferior Cava, which receives the hepatic rein, is gradually enlarged by the reception of most of the veins from the inferior part of the trunk and the lower extremities, and the Vena Azygos is reduced in the same proportion; in some rare cases of abnormal formation, lowever, the vena cava fails to be developed, and then the blood from the lower parts of the body is conveyed to the superior cava through the system of the vena azygos.

783. The following is the course of the Circulation in the mature Fotus. The fluid brought from the Placenta by the umbilical vein, is partly convered at once to the ascending Cava by means of the ductus venosus, but chiefly flows through the vena portæ into the Liver, whence it reaches the ascending Cava by the hepatic vein. Having thus been transmitted through the great depurating organ, the Placenta, and the great assimilating organ, the Liver, ${ }^{2}$ it is in the condition of arterial blood; but, being nixed in the great vessels with that which has been returned from the trunk and lower extrenities, it loses this character in some degree by the time that it arrives at the Heart. In the right auricle, which it then enters, it would be also mixed with the venous blood brought thither by the descending Cava; were it not that a very curious provision exists to prevent (in great degree, if not entirely) any such further dilution. The Eustachian valve has been foumd, by the experiments of Dr. J. Reid, ${ }^{3}$ to serve the purpose of directing the arterial blood, which flows upwards from the ascending Cava, through the foramen ovale into the left auricle, whence it passes into the left ventricle; whilst it also directs the venous blood, that has been returned iby the descending Cava, into the right ventricle. IVhen the ventricles contract, the arterial blood which the left contains is propelled into the ascending Aorta, and supplies the branches that proceed to the head and upper extremities, before it undergoes any admixture; whilst of the venous blood contained in the right ventricle, part is transmitted by the Pulmonary artery to the lungs, but another (and probably by far the larger) part finds its way through the Ductus Arteriosus into the descending Aorta, mingling with the arterial current which that vessel previously conveyed, and passing thus to the trunk and lower extremities. Hence the head and superior extremities,

1 See the elaborate Menoirs, On the Development of the Great Anterior Yeins of Man and Mammalia (1'hil. Trans., 185'), by Mr. J. Marshall; who has further shown that some vestiges of the original arrangenent may be traced even in the normal condition of the venous sy-tem in the adult.

2 It does not seem probablc that the depurating action of the Liver can be encrgetically pertorned during foetal life; and its large dimensions and copious supply of blood appear rather to be referable to its function as a blrod-making gland.

3 Edinb Med. and Surg. Journal, vol. xliii; and Anat., Plsyiol., and Pathol. Researches, chap. ix. 
whose development is required to be in advance of that of the lower, are supplied with blood nearly as pure as that which returns from the placenta;

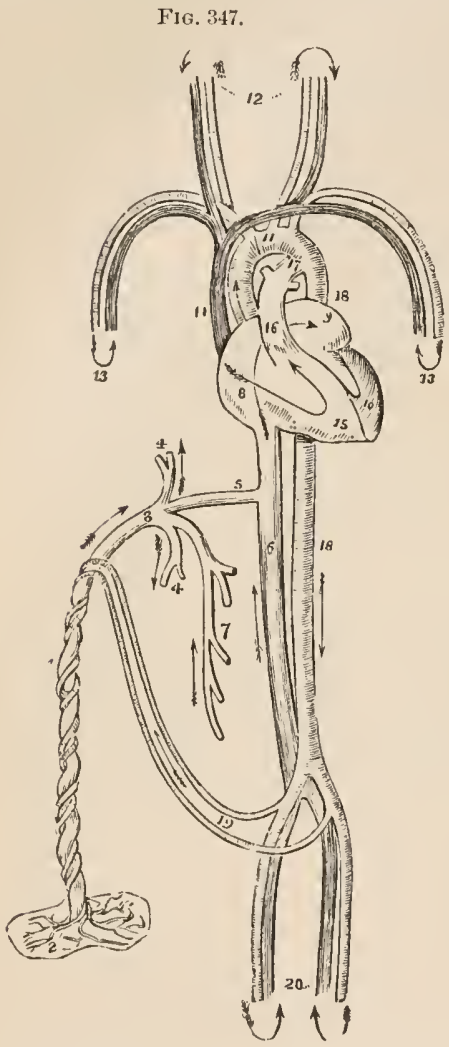
whilst the rest of the body receives a mixture of this with what has previously circulated through the system; and of this mixture a portion is transmitted to the placenta, to be renovated by coming into relation with the maternal

Fif. 347.-Diagram of the Fotal Cireulation. 1. The umbilieal eord, consisting of the umbilieal vein and two umbilical arteries, proceeling from the placenta (2). 3. The umbilical vein dividing into thee bratiehes; two $(4,4)$ to be distributed to the liver, and one $(5)$, the duetus venosus, which enters the inferior vena eava (6). 7. The portal vein, returning the blood from the intestines, and uniting with the right hepatic braneh. 8 . The right auricle; the eourse of the blood is denoted by the arrow proceeding from 8 to 9 , the left auricle. 10. The left ventriele; the blood following the arrow to the areh of the aorta (11), to be distributed through the branches given off by the ateh to the head and upper extrmities. The arrows 12 and 13 represent the return of the blood from the head and upper extremities tlirough the jugular and subclavian reins, to the superior vena eara (14), to the liglit auricle (8), and in the course of the arrow through the rirht rentriele (15), to the puluonary artery (16). 17. The ductus arteriosus, which appears to be a proper eontinuation of the pulmonary artery; the offsets at each side are the right and left pulmonary arteries cut off. The ductus arteriosus joins the desceuding aorta !18, 18), which divides into the eommon iliaes, and these into the internal iliaes, whieh becone the umbilical anteries (19), and returu the blood along the umbilisal cord to the placenta, and the external iliacs (20), which are continued into the lower extrenities. The arrows at the termination of these ressels mark the return of the venous blood by the veins to the inferior eava.

fluid.-At birth the course of the current is entirely changed by the cessation of the circulation through the Placenta, and by the enormous increase in the quantity transmitted to the Lungs, which takes place immediately on the first inspiration: the Ductus Venosus and Ductus Arteriosus soon shrivel into ligaments; the Foramen Ovale becomes closed by its valve; and the circulation which was before carried on upon the plan of that of the ligher Reptiles, now becomes that of the complete Bird or Mammal. ${ }^{1}$ It is by no menus unfrequent, however, for some arrest of development to prevent the completion of these changes; and various malformations, involving an imperfect discharge of the function, may hence resnlt. From the above description it is obvions that the chief propelling power in the circulation of the Foetus is the right heart; the force of the left heart bcing chicfly spent in propelling a due supply of blood to the head and upper extremitics; and an interesting observation of Langer ${ }^{2}$ is in accordance with this, for he has shown that the walls of the right ventricle in the futus are as thick as those of the left, whilst those of the right auricle are even thicker and more mus-

I For causes of closure of the Ductus Arteriosis, see Walkhoff, IIenle and Pfeifter's Zeitschrift, Bd. xxxvi, p 109. 328.

2 Zur Anatomie der Fötalen Kreislauforgane, Zeits. der Gesell. d. Wien, xiii, p. 
cular than those of the left auricle. This condition lasts for some days after birth, when the left heart gradually attains the superiority in thickness which is usual in adults.

784. The Alimentary Canal has bcen shown ( $\$ 777)$ to have its origin in the blastodermic vesicle; being a portion pinched off (as it were) by the infolding of the splanchnopleure from that part of it which is just bcieath the spinal column of the embryo, whilst the remainder, which is at that time the largest part of it, forms the vitelline or umbilical vesicle. In its earliest form it is merely part of a long narrow tube (Fig. $348, m$ ), nearly straight,

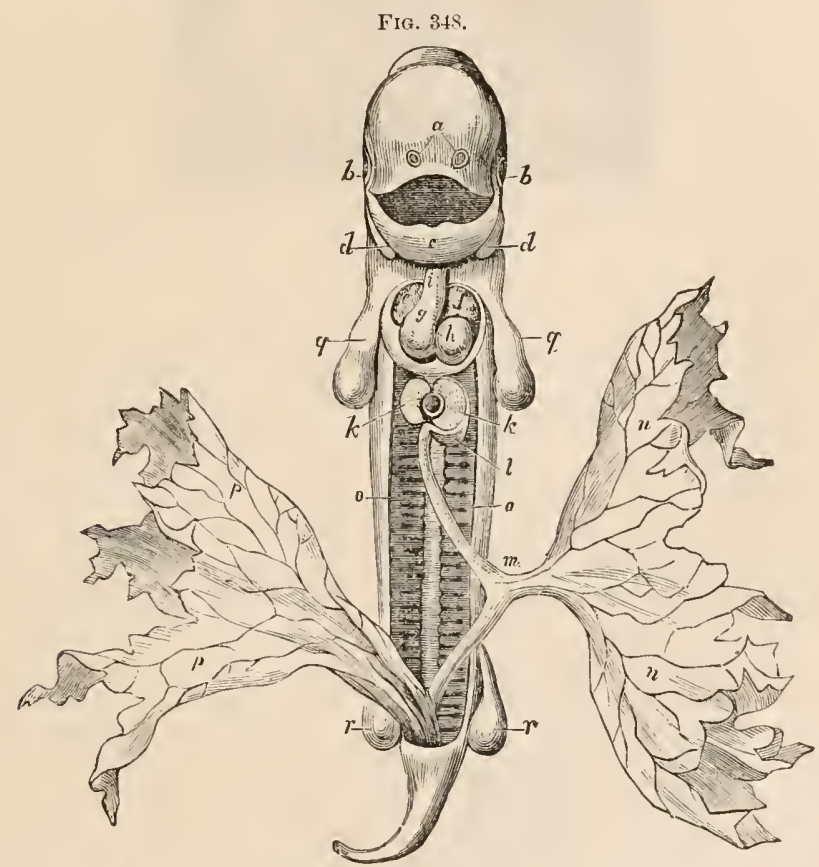

Embryo of Dog, 25 days after last copulation: $a, a$, nostrils ; $b, b$, eyes ; $c, c$, first visceral arches, forming the lower jaw ; $d, d$, sceond visceral arches; $e$, right auricle; $f$, left auricle $g$, right ventricle; $h$, left ventricle; $i$, aortic bulb; $k, k$, liver, between the two lobes of which is seen the divided orifice of the omphalo-mesenteric vein; $l$, stomach; $m$, intestine, communicating with the umbilical resicle $n, n$; 0,0 , corpora Wolfiana; $p$, allantois ; $q, q$, anterior extremities ; $r, r$, posterior extremities.

and communicating with the umbilical vesicle $(n, n)$ at about the niddle of its length; thus it may be regarded as composed of the union of two divisions, an upper and a lower. At first, neither mouth nor anus exists; but these are formed early in the second month, if not before. The tube gradually manifests a distinction into its special parts, œsophagus, stomach, small intestine, and large intestine; and the first change in its position occurs in the stomach, which, originally disposed in the line of the body, afterwards takes an oblique direction. The curves of the large and small intestine present themselves at a later period. It is at the lower part of the small intestine, near its termination in the large, that the entrance of the vitelline duct persists; and a remnant of this canlal is not unfrequently preserved throughout life, in the form of a small pouch or diverticulum from that part of the intestine.

785. In immediate connection with the intestinal tube, we find the first 
rudiments of the Liver, which is formed in the chiek at about the 60 th hour of incubation by the thickening of the meso- and hypoblastic cells in the wall of the duodenum, at the spot at which the hepatic duct is subsequently to discharge itself. This thickening (Fig. 349), which is situated a little

FIG. 349.

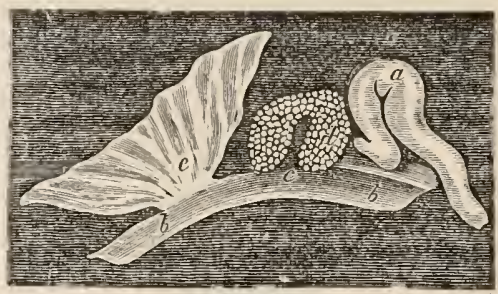

Origin of the Liver from the intestinal wall, in the embryo of the Fowl, on the fourth day of incubation: $a$, heart; $b$, intestine; $c$, everted portion giving origin to liver; $d$, liver; $e$, portion of vitelline vesicle.

behind the heart, soon presents two diverticula which embrace the meatus venosus or united trunk of the omphalo-mesaraic veins, which, as it passes between them, exhibits numerous small bulgings. Towards the end of the third day, aceording to Foster and Balfour, there may be observed in the greatly thickened mesoblastic investment of each diverticulum a number of solid eylindrical masses of cells which are apparently outgrowths from the hypoblast of the divertieulum. These unite and form a network; the mesoblast eontained in the meshes becoming at the same time largely converted into bloodvessels. In addition to this network of solid hypoblastic eylinders, the diverticula also send out hollow proeesses lined with hypoblast. On the fourth day, the two masses meet beneath the meatus venosus. The bloodvessels of the mesoblast enter into communication with the meatus venosus. "It may soon be observed that in those vessels which are comnected with the posterior part of the liver the stream of blood is directed from the meatus venosus into the network of the liver. In those connected with the anterior part the reverse is the ease; here the blood flows from the liver into the meatus venosus. The thick network of solid cylinders represents the hepatic parenchyma of the adult liver, while the hollow processes of the denticula are the rudiments of the biliary ducts." (Foster and Balfour.) As this is going on, the hepatic mass is gradually removed to a distance from the wall of the alimentary canal ; and the ceceum is narrowed and lengthened, so as to becone a mere connecting pediele, forming, in fact, the main trunk of the hepatic duet.- In the IImman embryo, the formation of the Liver begins at about the third week of intranterine existenee; the organ is from the first of very large size, when compared with that of the body; and between the third and fifth weeks, it is one-half the weight of the entire embryo. It is at that period clivided into several lobes. By the third lunar month, the liver extends nearly to the pelvis, and almost fills the abdomen; the right side now begins to gain upon the left: the gall-bladder makes its first appearance at this time. The subsequent changes chiefly consist in the eonsolidation of the viseus, and the diminution of its proportional size. $U_{p}$ to the periou of birth, however, the bulk of the liver, relatively to that of the entire body, is much greater than in the adult; the proportion being as 1 to 18 or $20 \mathrm{in}$ the newborn ehild, whilst it is about 1 to 36 in the adult; and the difference between the right and left lobes is still inconsiderable. During the first year of extrauterine life, however, a great change takes place; the right 
lobe increases a little or remains stationary, whilst the left lobe undergoes an absolute diminution, being reduced nearly one-half; and as, during the same period, the bulk of the rest of the body has been rapidly increasing, the proportion is much more. reduced during that period, than in any subsequent one of the same length. According to Meckel, the liver of the newly-born infant weighs one-fourth heavier than that of a child eight or ten months old; and as the weight of twe whole body is more than doubled during the same time, it is obvious that the change in the proportion of the two must be principally effected at this epoch. The liver seems to be engaged during foetal life, in the depuration of the blood (as appears from the acumulation of meconimm, which is chiefly altered bile, in the intestinal canal at birth); but at the same time it is serving as a blood-making organ, containing many free nuclei and protoplasmic masses, ${ }^{1}$ and this is probably its principal function before birth. The general history which has just been given of the development of the Liver, seems equally applicable to the other glands that are evolved from the mesoblast and hypoblast forming the parietes of the Alimentary canal, such as the Salivary glands and Pancreas ; since they all seem to commence in little masses of cells, formed by an increased development, at certain spots, of the layers of blastema which originally constituted its wall; and whilst the cells of the mesoblast give origin to the proper vesicles of each gland, its ducts and tubuli, those of the hypoblast form their epithelial lining.-The development of the Spleen and of the Suprarenal, Thymas, and Thyroid bodies, has been already described $(\$ \S 215,217,220)$.

786. The Lungs are also developed from the mesoblast in immediate relation with the upper part of the Alimentary canal, their first rudiments shooting forth as a pair of budlike processes (Fig. 350, a) from the under or anterior surface of the osophageal portion. 'These rere originally and currectly described by Von Bär as hollow, and as being in reality direrticula from the tube itself. They gradually increase in size, extending downwards by the multiplication of their component cells in that direction; and their cavities at first communicate with the pharynx by separate apertures; these, however, as the channels are elongated into tubes, coalesce to form the trachea, and the pulmonary organs become removed to a distance from their point FIG. 3\%0,
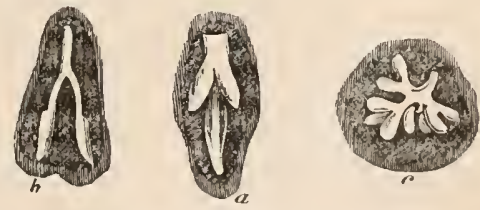

First appearance of the Lungs: $a$, in a Fowl at four days; $b$, in a Fowl at six days ; $c$, termination of bronchus in a very young l'ig. of exit (Fig. 350, $b$ ).- The first appearance of the Lungs in the Chick takes place towards the close of the third day, and in the Human embryo at about the sixth reek. Their surface soon becomes studded with numerous little wartlike projections, which are caused by the formation of corresponding enlargements of their cavity; thcse enlargements sson become prolonged, and develop corresponding budlike enlargements from their sides; and in this manner the form of the organs is gradually changed, a progressive increase in their bulk taking place from above downwards, in consequence of the extension of the bronchial ramifications of the single tube at the apex. At the same time, however, a corresponding increase in the amount of the parenchymatons tissue of the lung is taking place; for this is deposited in all the interstices between the bronchial ranifications, and might be com-

\footnotetext{
1 Schenk, Centralblatt, 1869, p. 865.

2 See Schenk, Anat. Phys. Untersuch., Wien, 1872. Abstract in Centralblatt, 1873, p. 35.
} 
pared with the soil filling up the spaces anongst the roots of a tree. It is in this parenchyma that the pulmonary vessels are distributer; and the portion of it which extends beyond the terminations of the bronchial tubes, seems to act as the nidus for their further extension. It can be easily shown that, up to a late period of the development of the lungs the dilated terminations of the bronchi constitute the only air-cells (Fig. 350, c); but, as already mentioned, the parenchyma subsequently has additional cavities formed within it.-It is a fact of some interest as an exanple of the tendency of certain diseased conditions to produce a return to forms which are natural to the foetal organism, or which present themselves in other animals, that up to a late period in the development of the Human Embryo, the lungs do not nearly fill the cavity of the chest, and the pleura of each side contains a good deal of serous fluid.

787. The embryological development of the Urinary organs in Vertebrated animals is a subject of peculiar interest; owing to the correspondence which may be traced between the transitory forms they present in the higher classes, and their permanent condition in the lower. In this respect, there is an evident analogy with the Respiratory system. The first appearance of anything resembling a Urinary apparatus in the Chick, is seen towards the close of the second day in the forn of a group of cells projecting on either side from the mass of uncleft mesoblast on the outside of the protovertebre into the somewhat triangular space formed by the epiblast above, the upper and outer angle of the protovertebræ on the inside, and the mesoblast on the outside. In consequence of the cells assuming a radiated arrangement and separating at their common point of junction, a canal closed anteriorly is formed, which extends from about the fifth protovertebra towards the posterior extremity of the embryo, and quickly descends towards the pleuroperitoneal cavity. On the second half of the third day the duct appears as a long canal, extending on each side of the spinal column, from the region of the heart, towards the allantois (Fig. $348, o, o$, seen also in transverse section in Fig. 334, ung); on the sides of this are a

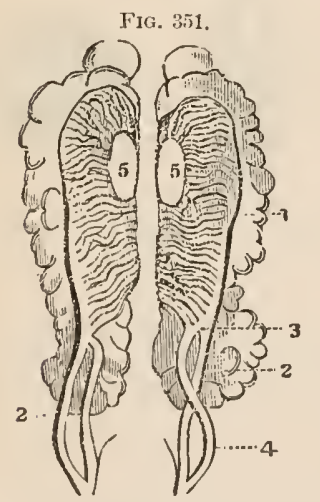

State of the Trinary and Genital Apparatus in the early emliryo of the Bird: 1, corpora Wolfhana; 2, 2, their excretory ducts; 3 , kidueys; 4 , ureter ; 5 , 5, test cs.

they give place to the truc Kidneys, the devclopment of which commences in the Chick about the sixth day. The first part of these bodies to be formed is their duct or ureter, which begins to appear about the 80-100th hour, and 
is at first situated behind that of the Wolffian duct. from which it is constricted off: At first both open together into the Cloaca, but by the sixth day the two ducts have independent openings. From the upper end of the ureter diverticula are given off $(c)$, which seem to sprout from the outer edges of the Wolffian bodies, but which are really independent formations, springing from a mass of blastema behind them; and as they gradually increase in size and advance in development, the Wolffian bodies retrograle; so that at the end of foetal life, the only vestige of them is to be found as a shrunk rudiment, situated (in the male) near the testes, to which their excretory ducts serve as the outlets, becoming the "vasa deferentia."-About the end of the fourth day a furrow is formed on each side by an involution of the germinal epithelium below the projection formed by the Wolffian body. The sides of the furrow arch over and unite to form Mïller's duct, which at first unites with the Wolffian duct near the entrance of the latter into the cloaca, but subsequently separately and above it. The duct of Müller on the right side (in the Fowl, the left with the corresponding nvary disappearing), is never closed in in front, and remains in the female as the oviduct. In the male it is almost entirely obliterated on both sides. The history of the development of the Urinary organs in the human embryo, seems to correspond closely with the foregoing. The $\mathrm{W}_{\text {olffian }}$ bodies begin to appear towards the end of the first month; and it is in the course of the seventh week, that the true Kidneys first present themselves. When at their greatest development, the Corpora Wolffiana are the most vascular parts of the body next to the liver; four or five branches from the arta are distributed to each, and two veins are returned from each to the vena cava. The upper arteries and their corresponding veins are afterwards converted into the Renal or emulgent vessels; and the lower into the Spermatic vessels. From the beginning of the third month, a diminution takes place in the size of the Wolffian bodies, pari passu with the increase of the Kidneys; and at the time of birth scarcely any traces of the former can be found. At the end of the third month, the Kidneys consist of seven or eight lobes, the future pyramids; their excretory ducts still terminate in the canal, the sinus urogenitulis, which receives those of the Wolffian bodies (subsequently to become the vasa deferentia), and of the Fallopian tubes ; and this opens, with the rectum, into a sort of Cloacr, analogous to that which is permanent in the oviparous Vertebrata. The Kidneys are at this time covered by the Suprarenal capsules, which equal them in size; about the sixth month, however, these have decreased, whilst the kidners have increased, so that their proportional weight is as 1 to $2 \frac{1}{2}$. At birth, the weight of the Kidneys is about three times that of the Suprarenal capsules, and they bear to the whole body the proportion of 1 to 80 ; in the adult, however, they are no more than 1 to 240 . The lobulated appearance of the kidney gradually disappears; partly in consequence of the condensation of the areolar tissue which connects its different portions, and partly through the development of additional tubuli in the interstices.-The Urinary Bladder is formed quite

1 Although it has been usually considered that the Vasa Deferentia of the male and the Fallopian tubes of the female are homologous organs, yet this does not seem really to be the case; for the former are derived from the excretory ducts of the Wolffian bodies, whilst the latter are independent formations, which ars found to enexist with seminal ducts at an early period of clevelopment, alike in male and in female embryos. (See Kobelt, Der Nebeneierstock des Weibes, Heidelber's, 1847.) The duets of the Wolffian bodies, although subsequenty distprearing in the fomales of most Mammals, remain permanent as "Gaertner's canals" in the female Ruminants and Pig. 
independently of the secreting apparatus, being an enlargement of a portion of the pars urinaria of the "urogenital sinus" (\$789).

788. The essential parts of the Generative apparatus, namely, the Testes in the male, and the Ovaria in the female, are first developed in such immediate proximity with the Corpora Wolffiana (Fig. 351,e,e), that they have been supposed to sprout forth from them; this, however, is not really the case, as they have an independent origin in the intermediate mass of mesoblastic blastema (termed by Foster and Balfour the genital ridge), from which the Wolffian body and Kidneys have successively been differentiated. They make their first appearance in the Chick, as delicate strix on the Wolffian bodies, about the fourth day; at which period no difference can be detected between the Testes and the Ovaria, which originate in precisely the same manner. The superficial cells proceeding originally from the epiblast acquire special characters, and, as alreaty deseribed ( $\$ 737$ ), become invested and inclosed by an outgrowth of the stroma of the ovary, and constitute the primordial ova. In the Human embryo, the rudiments of the sexual organs-whether testes or ovaria-first present themselves soon after the kidneys make their appearance, that is, towards the end of the 7 th week. They are originally much prolonged, and seem to consist of a kind of soft, homogeneons blastema, in which the structure characteristic of each organ subsequently develops itself. The Testis gradually assumes its permanent form; the epididymis appears in the tenth week; and the gubernaculum (a membranous process from the filamentous tissue of the scrotum, analogons to the round ligament arising from the labium and attached to the ovary in the female), which is originally attached to the vas deferens, gradually fixes itself to the lower end of the testis or epididymis. The Wolffian duct remains as the vas deferens of the male. The Testes begin to descend at about the middle period of pregnancy; at the seventh month they reach the inner ring; in the eighth they enter the passage; and in the ninth they usually descend into the scrotum. The canse of this descent is not very clear: it can scarcely be due merely, as some have supposed, to the contraction of the gubernaculum; since that does not contain any fibrous strueture until after the lowering of the testes has commenced. It is well known that the testes are not always found in the scrotum at the time of birth, even at the fill period. Upon an examination of 97 new-born infants, Wrisberg found both testes in the scrotum in 67 , one or both in the canal in 17 , in 8 one testis in the abdomen, and in 3 both testes within the cavity. Sometimes one or both testes remain in the abdomen during the whole of life; but this circumstance does not seem to impair their function. ${ }^{1}$ This condition is natural, indeed, in the Ram.-The Ovary undergoes much less alteration, either in its intimate structure, or in its position. Its efferent canal (which, as just stated, is not the representative of the vas deferens of the male, but is the duct of Mïller) renains detached from it, presents a frec terminal aperture, and constitutes the Fallopian tube. The Uterus (which was formerly supposed to be formed by the coalescence of the Fallopian tubes), is now known to be derived, like the Vagina, from the genital portion of the "uro-genital sinus" ( $\$ 789$ ), which is formerl exactly on the same plan in both sexes alike, at an early period of foctal development, and receives at its upper extremity the termination of the Fallopian tubes. In the Female, this canal increases in size, and a marked separation is established between its lower or vaginal portion and its npper or uterine portion. The former opens in to the undivided portion of the uro-genital sinus, which also receives

1 A case occurrel within the Author's knowledge, in which both testes remuined in the abdomen until the tenth year, and then descended. 
the terminations of the urethra and of the Wolffiian ducts, and which remains permanently unclosed. In the Male, on the other hand, the simns genitalis makes no advance in development, and diminishes in relative size; so at the period of foetal maturity, it is only discoverable as the vexicula mostatica, which has been supposed until recently to be an appendage to the prostate gland. A transverse constriction in this canal marks out its vaginal from its uterine portion; the former having exactly the same relation as in the female to the terminations of the urethra and of the Wolffian ducts (vasa deferentia) in the "urogenital sinus," which is subsequently closed in, however, so as apparently to form a continuation of the urethral canal; and the latter, in those Mammals whose females have a "uterus bicornis," exhibiting a like divarication into two lateral halves. ${ }^{1}$

789. The history of the development of the external Organs of Generation in the two sexes, presents matter of great interest, from the light which is thrown by a knowledge of it upon the nalformations of these organs, which are among the most common of all departures from the normal type of Human organization.-Not only is the distinction of sexes altogether wanting at first; but the conformation of the external parts of the apparatus is originally the same in Man and the higher Mammalia as it permanently is in the Oviparous Vertebrata. For, about the 5th or 6th week of embryonic life, the opening of a cloaca may be seen externally, which receives the termination of the intestinal canal, the ureters, and the efferent ducts of the sexual organs; but at the 10th or 11th week, the anal aperture is separated from that of the genito-urinary canal or "uro-genital siuus," by the development of a transverse band; and the uro-genital sinus itself is gradually separated by a like process of division, into a "pars urinaria" and a "pars genitalis," the former of which, extending towards the urachus, is converted into the urinary bladder. A partial representation of this phase of develupment is found in the permanent condition of the Struthious Birds and of the Implacental Mammalia. The external opening of this caual is soon observed to be bounded by two folds of skin, the rudiments of the labia majora in the female, and of the two halves of the scrotum in the male; whilst between and in front of these, there is formed an erectile body, surmounted by a gland, and cleft or furrowed along its under surface. This body in the female is retracted into the genito-urinary canal, and becomes the clitoris, whilst the margins of its furrow are converted into the nymphæ or labia minora; and these bound the "atrium vaginæ" or "vestibule," which receives the orifices of the urethra, of the vagina, and of Gaertner's canals when they are present, and which exactly represents, therefore, the "sinus genitalis" of the early embryo. In the male, on the other hand, this sinus is nearly closed in at a very early period, by the adhesion of the two folds of integument which bound it, forming that portion of the genito-urinary canal (improperly. termed the "urethra") which receives the orifices of the vesical or true urethra, of the genital sinus (vesicula prostatica), and of the vasad deferentia; the erectile body increases in prominence, and becomes the penis; whilst the margins of the furrow at its under surface unite (at about the 14th week), to form the anterior continuation of the now contracted genito-urinary canal, which is commonly termed the spongy portion of the urethra. The following table,

1 See Prof. E. Weber's Zưätze zur Lehre vom Batue und den Verrichtungen der Geschlechtsorgane, Leipzig, 1846; und Dr. Leuckurt's Art. Tesicula Prostatica, in Cyclop. of Anat. and Physiol, vol. iv - It was supposed by Prof. Weber that the vesicula pro-tatica is the homologue of the uterus alone; but the Author considers it to have been satisfactorily established by the researches of Dr. Leuckart, that it answers to the uterus and vagina conjointly. 
extraeted from the admirable thesis of Dr. W. M. Banks, ${ }^{1}$ gives elearly the origin and homologies of the several parts of the urino-genital system in the two sexes:

\section{THE WOLFFIAN BODY ITSELF.}

In the Female.

Fragmentary tubes and canalicules disposed in the neighborhood of the Parovarium.
In the Male.

Organ of Giraldès and some of the tubules adhering to excretory duct, forming the vasa aberrantia.

\section{NEW STRUCTURE ON SUMMIT OF WOLFFIAN BODY.}

Parovarium.

Globus major.

\section{MÜLLER'S DUCTS.}

Ampulla forms the fimbriated end of the Fallopian tube.

From ampulia to round ligament forms the Fallupian tube itself.

From round ligament to genital cord forms the cornua uteri

When united in genitul cord they form the uterus and vagina.
Ampulla forms the hydatid of Morgagni.

From ampulla to gubernaculum forms small cysts running from the hydatid of Morgagni down the side of the epididymis.

From grubernaculum to genital cord forms cornua of the organ of Weber.

When united in genital cord they form the organ of Weber.

\section{EXCRETORY DUCTS OF WOLFFIAN BODIES.}

Gaertner's canals.

Diverticula in them.
Vas deferens, body and globus minor of epididymis.

Broad and saceulated ends of the vasa deferentia.

EXTERNAI, ORGANS.

Clitoris.

Pars intermedia.

Lubia majora.

Bulbus vestibuli.

Lubia minora.

Vestibulum vaginæ.
Penis.

Corpus spongiosum.

Selotum.

Bulb.

Cutaneous covering of the urethra.

SINUS URO-GENITALIS.

Membranous portion of the urethra, and a sinall part of the prostatic.

790. Now in a large proportion of eases of so-ealled Hermaphrodism, there has been either a want of completeness in the development of the Male organs, so that they present a greater or less degree of resemblance to those of the female; or the developmental proeess has gone on to an abnormal extent in the Female organs, so that they eome to present a certain degree of resemblance to those of the male.-One of the most common malformations of the male organ is "hypospadias," or an abnormal opening of the urethra at the base of the penis, arising from ineompleteness in the closure of the edges of its original furrow. But when the developmental proeess has heen checked at an early period, the uro-genital sinus may retain

1 Prize Thesis, Elinburgh, 1864. On the Wolffin Bodies of the Fotus, and their remains in the Adult, inchuding the Development of the Generative System. For the latest observations on Müller's and the Wolfian ducts, sce C. Semper, Central. blatt, $1875, \% .466$. 
more nearly its original character, and may have a wide external opcning beneath the root of the penis, so as to resemble the female vagina, whilst the penis is itself destitute of any trace of the urethral canal; in some of these cases, arain, the testes have not descended into the scrotum; whilst the absence of beard, the shrillness of the voice. and the fulncss of the manme, have contributed to inpart a feminine character to these individuals, their male attributes, however, being determined by the seminiferous character of the essential organs, the testes. ${ }^{1}$ - In the fimale organs, on the other hand, a greater or less degree of resemblance to those of the male may be produced by the enlargenent of the clitoris, by its furrowing or complete perforation by the urethra, by the closure of the entrance of the vagina and the cohesion of the labia, so as to present a likeness to the unfissured perineum and scrotum of the male, by the descent of the ovaries through the inguinal ring into the position of the male testes, and by the imperfect development of the uterus and manmie; with these abnormalities are usually associated roughness of the voice and growth of hair on the chin, and a psychical character more or less virile.-True Hermaphrodism, in which there is an absolute combination of the essential male and female organs in the same individual, is comparatively rare. It may occur unler the forms of lateral hermaphrodism, in which there is a genuine ovary on one side and a testis on the other, in which case the external organs are usually those of a hypospadic male; transverse hermaphrodism, in which the external and internal organs do not correspond, the former being male and the latter female, or vice versa; and double or vertical hermaphrodism, in which the proper organs characteristic of one sex have existed, with the addition of some of those of the other: this is the rarest of all, and it is not certain that the coexistence of testes and ovaria on the same side has ever been observed in the Human species. ${ }^{2}$

791. IVe have now to follow the course of the development of the principal organs of Animal life; and shall first notice that of the Skeleton. ${ }^{3}$ The

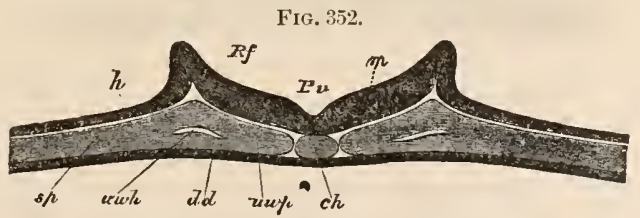

Transverse section through the Embryo of the Chick at the close of the first day of incubation, inagnified about 100 diameters. ch, chorda dorsaiis; $h$, external serous or corneal layer; $m$, medullary portion of serous layer; $P v$, primitive gruove belween the dorsal laminæ $R f$ and $m$; $d l$. intestinal epithelial or glandular layer (mucous laycr); uup, prevertebral mass, in which the primary or protovertubre are formed, and which is continuous with the middle lamina, sp; uch, fissure in the middle lamina, presenting the first indication of the pleuro-peritoneal cavity, and of the subsequent division of the middle lamina into two layers.

first differentiation of parts that occurs in the middle lamina of the blastodermic vesicle (Fig. 352), is the formation of a solid cartilaginous rod, termed the notochord or chorda dorsalis $(c h)$, which extends throughout the whole length of the future vertebral column, and along the base of the

1 The vesicula prostatica has presented un unusual development in some of these cases; see Prof. Weber (loc. cit.), and Prof. Theile's Account of a Case of Hypnspadias, in Müller's Archiv, 1847.

z On this subject, sea Prot. Simpson's Article Hermaphrodism in the Cyclop. of Anat. and Phys, vol. ii.

3 See Buffour, Studies from the Physiol. Lab of Cambridge, Pl I. 
cranium as far as the space between the auditory capsules, or even to that point which subsequently becomes the pituitary fossa. The chorda dorsalis is originally composed of nucleated cells, that in the first instance lie in contact with one another, but are soon separated by the development of intercellular substance or matrix, the whole being inclosed by a delicate sheath. The chorda dorsalis, though permanent in the lowest fishes, is only a transitory structure in Man and all the higher vertebrata. Soon after the laying down of this cartilaginous rod, the portion of the middle lamina which immediately surrounds it (uwp, Fig. 352, uw, Fig. 353) becomes detached; and in the portion so scparated the first rudiments of the vertebræ appear in the form of rings surrounding the chorda dorsalis. More cxternally, the middle layer, passing outwards and downwards, and forming what is known as the Ventral Lamina, subdivides into two by a split or fissure $(s p)$, which is the first indication of the pleuroperitoneal cavity, the external or parietal layer $(h p l)$ joining with the epiblast to form the somattopleure or walls of the abdomen with their contained structures, and ultimately meeting on the median line and inclosing the abdominal cavity in the same way that the dorsal laminze inclose the spinal cord, whilst the inner layer, uniting with the hypoblast $(d f)$ develops the muscular and fibrous layers of the intestinal canal, the innermost layer or hypoblast $(d d)$ producing the proper epithelium of the ducts and portions of the parenchyma of the several glands connected with the intestine. At this period the primitive aortæ (ao) and the first urinary organs or Wolffian bodies $(u v h)$ begin to be formed. These, as just stated, are developed in the material situated externally to the chorda dorsalis, constituting a portion of the middle lamina of the blastodermic vesicle ( $u$, Fig. 353 ), which now becomes separate and

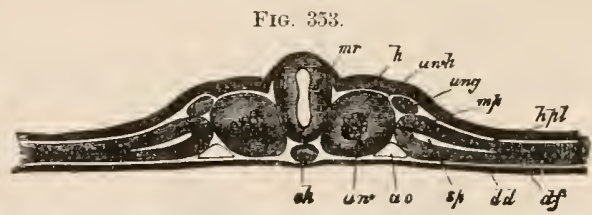

Transverse section made through the Embryo of a Fowl at the thirty-sixth hour of incubation, 100. $c h$, clsorda do rsalis; $h$, cxternal lamína; $m r$, luedullary tube (spinal cord); dd, intestinal glandular layer; $a w$, prevertebral mass; $a u h$, incipient cavity in the same; $s p$, split in the middle lamina, dividling it into an external or parietal lamina, hpl, and an internal or fibrous layer, $d f$, which are connected by a median lamina, $m p$. The position of the Wolfian bodies is represented by $u n g$, and of the primitive aorta by ao.

distinct from the remainder. Soon after this period the prevertebral masses (uw) extend themselves so as to cmbrace the chorda dorsalis below and the spinal cord above; the part where the two sidcs unite above being calted by Rathke the membrana reuniens superior, or membranous vertebral arch. i portion of the prevertebral mass atso insinuates itself between the chorda dorsalis and the spinal cord, so that the former is entirely invested by it, and a complete vertebral column is formed, though still only membranous, presenting two tubes, the one postcrior, formed by the arches, and inclosing the spinal cord, the other anterior, investing the chordal dorsalis. In the membranous arches a histological differentiation takes place, by which, on the other hand, the cartilaginous arches arc developed, and on the other, the anterior and posterior roots of the spinal nerves (v, g, Fig. 338).

792. The formation of cartilage constitutes the second stage of the development of the vertebral column. It commences about the sixth or seventh week of foetal life, and rapidly extcnds over the bodies of the future ver- 
tebre, so that already in the eighth week, a complete cartilaginous column with the membranous intervertebral ligament is forned; the chorda dorsalis now lecomes attenuated and begins to disappear in the bodies of the vertebra (Fig. 354), whereas it still remains distinct in the Ligamenta intervertebralia, and consequently presents a mouiliform appearance. The formation

Firi, 354 ,

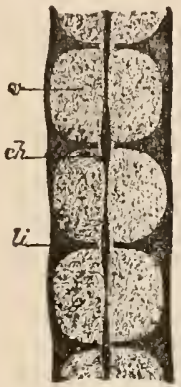

FIG. 355 .

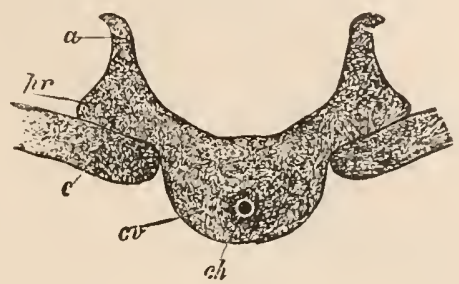

FIG. 354.-Diagram showing the attenuation of the rhorda Dorsalis in the middle of the bodies of the vertebre whilst preserving its original diameter in the intervertebral spaces: ch, chorda dorsalis; $v$, body of rertebra; $l i$, intervertebral substance.

FIG. 355.--Diagram showing the position of the chorda dorsalis in the body of the vertebra and the formation of the neural arches; $c h$, chorda dorsalis; $c v$, body of the vertebra; $a$, neural arch or neurapophysis; $c$, rib; $p r$, transverse process.

of cartilage, which, according to Robin, ${ }^{1}$ is everywhere developed before the substance of the brain and spinal cord, takes place much more slowly in the vertebral arches, not being more advanced at the eighth week than is shown in Fig. 355 ; so that at this period the medulla spinalis and its ganglia are only covered by the membrana reuniens superior. The arches first meet and inclose the medulla in the dorsal region; in the fourth month this is completed throughout the column, and, except in the coccygeal region, where no arches are developed, the form of the future vertebra, in which ossification has already commenced, is perfect. The development of the atlas is irregular, its body, which is originally traversed by the chorda dorsalis, as shown by Rathke and Robin, becoming connected, not with its proper arch, but with the body of the axis forming the odontoid process of this vertebra. The ossification of the vertebra begins at the end of the second or the beginning of the third month, with three centres for each vertebra, one for the body and one for the arch on each side. These parts, however, do not unite till the second year after birth. Accessory centres of ossification are subsequently formed at the tips of the spinous and transverse processes, and in the form of thin leaves at the upper and lower surfaces of the bodies, which resemble the epiphyses of the long bones. The cartilages of the ribs do not develop at once in their whole length, but gradually from the spine towards the sternum. Their ossification proceeds contemporaneously with those of the vertebra from one centre for each rib, the anterior extremities of the upper seven uniting together to form a broad cartilaginous band, which constitutes one lateral half of the sternum, the two halves subsequently uniting from above downwards. An arrest of this mode of development explains the monstrosity called "Fissura Sterni," a case of which, in the person of M. Groux, excited so much interest in this country. The morphological relations of the several parts constituting the shoulder girdle in man appear, 
according to the investigations of Mr. Parker, ${ }^{1}$ to be as follows. Beginning with the scapula, the thin epiphysial ossification running along the vertebral border is the supra-scapular bone, well shown as segmented from the scapula in the ray and sturgeon, and large, but not quite segmented off from the scapula proper in the frogs. The whole intraspinous portion of the bone represents the scapula proper forming the greater portion of the scapula of the bird, but best differentiated as a distinct bone in the iguana and turtle. The acromion process, with the whole of the spinous process, constitutes the mesoscapula, which is seen partly segmented from the body of the scapula in the pangolins, but is well shown also in the iguana. The neck of the bone and the articular facet forming the glenoid region have a separate internal ossification in the frog and toad. The coracoid process forms a large separate bone in the ovipara, and in monotremes, of which only the part corresponding to the head is developed in the human subject, which speedily coalesces with the other elements forming the scapula. The portion of bone around the coracoid notch, with the forepart of the supraspinous fossa, is the prescapula. It is well seen as a distinct bar above the glenoid cavity in certain lizards, and exists as a separate cartilage, even in tlie cat. The cartilaginous extremities of the clavicle are remnants of a primary rod of cartilage developed independently of the clavicles. The outer or mesoscapular segment becomes attached to the acromion by fibrous tissue, and an imperfect synovial articulation. The inner segment divides into two, of which the outer portion becomes attached to the true clavicle, whilst the intermal portion, corresponding to the omo-sternum (or so-called episternum) of frogs, becomes converted into fibro-cartilage. The clavicle itself is a parosteal bar which has grafted itself on a delicate rod of cartilage. ${ }^{2}$

793. In order to facilitate the comprehension of terms now very generally employed both in Human and Comparative Anatomy in regard to the parts of a vertebra, the following description is here appended. The complete typical vertcbra (Fig. 356, A) essentially consists, according to Prof. Owen, ${ }^{3}$ of the centrum, around which are arranged four arches inclosed by processes in comnection with it, viz., superiorly, the neural arch, which incloses the neural axis, and is formed by a pair of "neurapopliyses" $(n, n)$ and a ncurat spine $(n s)$; inferiorly the hamal arch, which is in like special relation with the centres of the circulation, but may be expanded around the Visceral cavity generally, and which is formed of a pair of "hæmapophyses" $(h, h)$ and the "hæmal spine" (hs); and two lateral arches, inclosing vascular canals, which are bounded by the "diapophyses" $(d, d)$ and the "parapophyses" $(p, p)$, and are completed by the "pleurapophyses" $(p l, p l)$. Of these elements, the centrum is the most constant; and next to these are the neural arches, which we find in every part of the vertebral column through which the neural axis passes, and which are enormously developed in the cranial segments, in accordance with the high development of their nervous mass. The hromal arches are often almost entirely deficient, as in the cervical and lumbar vertebre of Man and the Mammalia; but in the dorsal vertebre they are very largely developed, and the elements of the lateral arches are

1 See his important and extensive series of observations in the Monograph on the Structure and Davelopment of the shoulder Girdle and Sternum in the Vertebrata, 18ti8, published by the Ray Society.

2 Mr. Parker differentiates three kinds of ossification ; "endostosis," occurrirg in the substance of hyaline carlilage; "ectostosis," when the bony dejosit oceurs in the "lmost structureless inner hywr of the periosteum ; and "parostosis," when the bone is formed in the skin, subcutaneous fibrous mesh, or in aponeuroses.

3 See his A rehetype Sketeton, his Lectures on Conmarative Anatomy, and his Discourse on the Nature of Limbs. 
brought into eonnection with them, so as to form the inclosure of the visceral cavity (Fig. 356, в). From the pleurapophyses are occasionally developer a pair of "diverging appendages" $(o, \alpha)$, which are well seen in the ribs of Birds; and these are considered by Prof. Owen to be the fundamental elements of the bones of the "extremities" or "limbs," those of the anterior extremity being on his view the diverging appendages of the occipital vertebra, and those of the posterior extrenity standing in the same

FIG. 356.
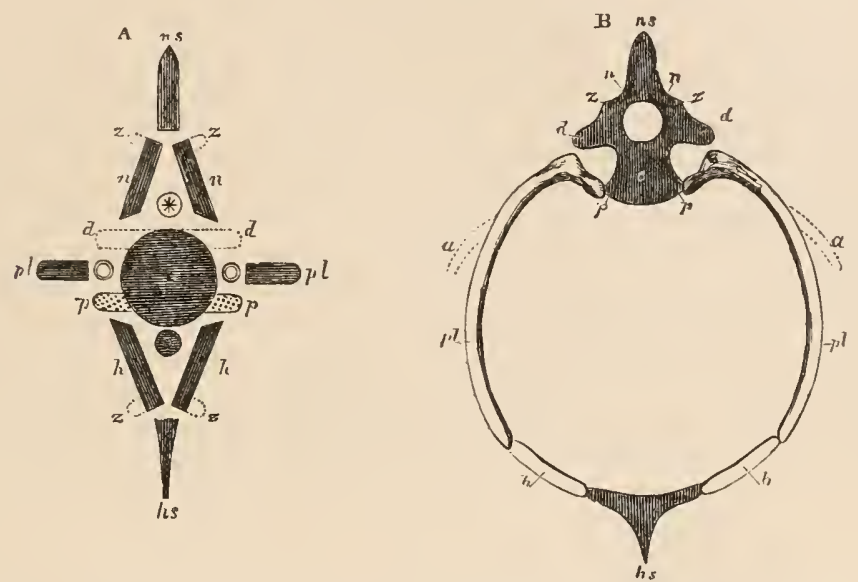

Elements of a Vertebra according to Prof. Owen: A, ideal typical vertebra; B, actual thoracic vertebra of a Bird ; $c$, centrum, giving off $d, d$, the diapophyses, and $p, p$, the parapophyses; the neural areh, inclosing the spinal cord, * is formed by $n, n$, the neurapophyses, and $n s$, the neural spine; the hrmal arch, inclosing the great centres of the circulation, is formed by $h$, $h$, the hæmapophyses, and $h s$, the hæmal spine. From both the neurapophyses and hæmapophyses may ue given of the zygapophyses, $z, z$. The lateral arches, which may inclose the vertebial arteries, 0,0 , are completed by the pleurapophyses, $p l$; these in $B$ are bent downwards, so as to form part of the hrmal arch, and give off the diverging appendages, $a, a$.

relation to one of the sacral vertebræ. The number of the segments analogous to Vertebre entering into the skull has been a subject of much discussion among those who adopt the "vertebral theory" of its composition; but Prof. Owen agrees with Goethe and Oken (the original propounders of that theory) in fixing the number at four, which corresponds with the points of ossification, succeeding each other in a linear series, that, though absent in the earlier, are apparent in the later stages of the development of the Encephalon, namely (procecding from behind forwards), the Encephalon, the Mesencephalon, the Prosencephalon, and the Rhinencephalon (Fig. 362); and also corresponding with the number of the nerves of special sense, the Auditory, Gustative, Optic, and Olfactory, which issue from this part of the neural axis with the same segmental regularity that the ordinary sensorimotor nerves do elsewhere.

794. In the development of the Skull the same three stages may be traced as that in the Vertebral column, namely, the membranous, the cartilaginous, and the osseous; the result of the first two forming what is now called the Primordial Cranium. In the first stage, the membrane of the Cranium is formed from the anterior part of the prevertebral plates (uwh, Fig. 353), which shoot forwards in front of the pointed extremity of the Chorda dorsalis or Notochord, and throw out processes on either side, that, arching upwards, ultimately form a case for the brain. An essential difference from 
those which, as we have just now seen, inclose the Spinal Cord, is however already visible, in the perfect continuity and absenee of any trace of segmentation in the hasal mass. The form assumed by this deposit at a very early period is diagrammatically shown in Fig. 357, $c$ representing the atlas, or last segment of the true vertebral column, formed round the notochord, $a$, which terminates at the point $g$, where the pituitary body subsequently appears. In front of the atlas $c$, and also, like it, surrounding the notochord, a large quantity of blastema is laid down, to which is attached anteriorly a pair of rods, $g$, termed the trabeeulæ cranii, that separate to inclose the pituitary fossa, and reunite in front of it to form a solid mass, the nasal frontal process. From the margins of this great basal mass of the primordial cranium, a mentbranous investment rises up to cover the intracranial nervous centres. This membranous eranium, which accurately invests the rudimentary brain, is not long persistent, but soon becomes partially converted into eartilage; the ehange commencing at the base in the Human foetus at least as early as the second month, whilst the upper part retains its membranous eondition until a much later period. 'The prinordial erauial axis of Man, therefore, consists of three parts: 1. A membranous roof; 2. Chiefly membrauous lateral walls; and 3. A cartilaginous base.--The third, or osseous stage of development, is attained by four different processes, namely: 1. By direct ossification of a portion of the eartilage of the primordial eranium ; 2. By part of the eartilage remaining unaltered ; 3. By the disappearance of a sniall part of the primordial cartilage; and 4. By

FIG. 357.

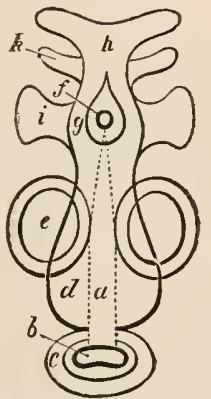

FIG. 358 .

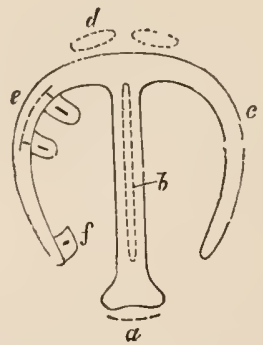

FIG. 357.-Cartilaginous basis Cranii : $a$, chorda dorsalis; $b$, foramen magnum; $c$, atlas ; $d$, lateral lnvesting cartilaginous mass; $e$, auditory eansule; $f$, pituitury body ; $g$, trabeeula eranii ; $h$, frontal nasal process; $i$, alie majores; $k$, ala minores of the sphenoid bone.

Fig. 358.-Vertical transverse section of anterior portion of the Primordial basis eranii : $a$, position of vomer; $b$, perpendieular lamina of ethmoid ; $c$, right ala of the eartilage, from whieh the turbinal bones, $e$ and $f$, are seen projecting on the opposite side; $d$, nasal bones.

the deposition of new bone in the form of opereular, or splint bones, on the exterior of the primordial cranium. The first point of ossification appears immediately in front of the foramen magnum about the ninth week, and is the rudiment of the basilar portion of the oecipital bone; a seeond (sometimes double) point forms in the third month at the forepart of the Sella turciea, and is the rudiment of the basi-sphenoid, or posterior portion of the sphenoid bone. Still more anteriorly, but a little later in point of time, a third double eentre of ossification may be seen, which is the eommencement of the presphenoid, and in front of this again an ossification commences about the midclle of foetal life, which subsequently becoming greatly extended in a vertieal direction, forms the perpendicular plate of the ethmoid. With each of these centres of ossification, situated along the floor or base of the 
skull, a superior areh is eonneeted, eomposed of bones analogous to the laminie and spines of the vertebre, and, like them, inclosing and protecting the nervous mass within. The formation of the superior arch in connection with the basi-occipital centre eommences at an early period, by the appearanee of two additional ossifying points in the cartilage on either side of the foramen magnum, which develop into the eondyloid and lateral portions of the occipital bone or ex-occipitals; whilst the crown of the arch, or supra-occipital bone, represented in the adult by the broad expanded plate, is formed by two osscous points in cartilage, and one or two in the membrane immediately above the eartilage that subsequently coalesce. The upper arch of the basisphenoid begins as a bony deposit in the cartilage representing the great wings of the sphenoid bone, or ali-sphenoids ( $i$, Fig. 357); and the crown of this arch, formed by the parietals, is exclusively produced, not by intraeartilaginous, but by intra-membranous ossifieation. A third upper areh is conneeted with the pre-sphenoid by the ossification of the projections of the pre-sphenoid $(k)$, representing the ale minores of the sphenoid or orbitosphenoids, the crown of this arch also, the frontal bone, developing by intramembranous ossification, like the parietal and supra-oecipital bones. The most anterior of the eentres of ossifieation that appears in the basal eartilage of the skull, forms the lamina perpendicularis of the ethmoid (b, Fig. 358), and is seen in vertical section in Fig. 358. At an early period the eartilage sends out two proeesses, $c, e$, which inelose the nasal fosse. The superior and middle turbinals (opposite $e$ ) are developed as outgrowth from this cartilage. The inferior turbinal $(f)$ is of later date. The nasal bones, $d, d$, are developed as opercular bones in the membrane covering the primitive eartilage, and overlie the nasal cartilage; whilst at the base of the eartilage, but developed from membrane, is the vomer $(a)$. The remaining bone which enters into the formation of the skull is the Temporal, the development of which, formerly much misunderstood, has been very earefully investigated by Prof. Huxley, Mr. Parker, and others; from whose inquiries it appears that the squamosal portion, like the parietal and frontal bones, is developed from membrane. Below this, and developed from fibro-eartilage, a ring of bone appears incomplete above, forming the auditory meatus, and termed the tympanic bone. Finally, there are three eentres of ossification, for which Mr. Huxley proposes the terms, prootic, epiotic, and opisthotic. The prootie lics behind the foramen ovale, and forms the petrosal bone or petrous portion of the temporal. The epiotic surmounts the posterior vertical semieircular eanal, and forms the mastoid portion of the temporal; whilst the opisthotie is continuous with the ossifieation which primitively surrounds the fenestra rotunda, and forms the floor of the Tympanum, lying in front of the point of exit of the eighth pair of nerves.

795. The development of the Faee next claims our attention. It proceeds from three parts, two of which are symmetrical and the third single. The former are the first pair of visceral arches (a, Fig. 359), sometimes termed the mandibular areh, from which the superior maxillary process is budded off on each side. The asymmetrical part is the frontal process, with its alæe or internal nasal processes (seen on each side of $n f$, Fig. 360 ), the development of which into the turbinals, covered by the nasals, has been already alluded to. The two lateral halves of the first visceral arch (1, Fig. 359) uniting in the middle line, form the rudinent of the lower jaw, and originally eonsist of two parts on each side, one of which, the inferior maxillary process, is cartilaginous, and becomes converted at its base into the malleus (b, Fig. 361), whitst its distal portion is prolonged downwards and forwards in the form of a slender rod, known under the name of Meekel's Cartilage, on the outer side of which the lower jaw $(d)$ is developed as a splint bone. 
The lower jaw thus stands in the same relation to Meekel's Cartilage that the opereular bones do to the primitive cranial bones; and it originally eonsists of two halves, united by a kind of synchondrosis, which does not ossify till after birth.- The malleus, whieh is the homologue of the quadrate bone of Birds, ossifies in the fourth month from the surface inwards, whilst Meckel's cartilage dies away, exeept near its root, which ossifies into the processus gracilis, or long process of the malleus. The superior maxillary

FIG. 359.

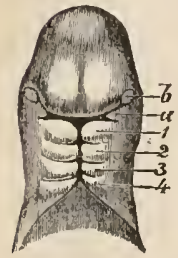

FIG. 360 .

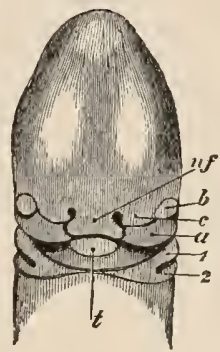

FIG. 361 .

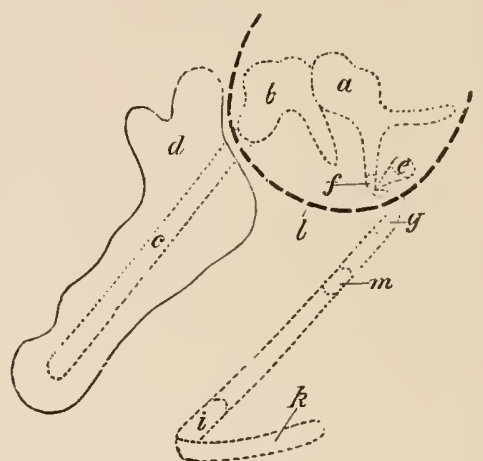

Fig, 359.-Human Embryo at the end of the third week: 1, 2, 3, 4, the visceral arches; $a$, the maxillary process; $b$, the cye.

FI; 360,- Human Embryo at the close of the fifth wcek: 1 and 2, the first two visceral arches; $a$, the superior maxillary process; $b$, the eye; $c$, the lateral naso-frontal process; $n f$, the naso-frontal process; $t$, the tongue.

Fig. 361.-Diagram of the first and secoud post-stomal (visceral) arches of Human Enbryo: $a$, iucus; the line $f$ points to the apex of the second arch, containing the os orbiculare; $b$, malleus; the tip of the long process is the apex of the first visceral arch; $c$, Meckel's cartilave; $d$, dentary; $e$, stapes; $f$, os orbiculare; $g$, upper hyoid cartilage; between $g$ and $e$ is the rudiment of the stapedius muscle; $m$, middle hyoid cartilage; $i$, rudiment of the cornu minus of os hyoides; $k$, basi-hyal; $l$, tympauic anuulus.

process ( $a$, Fig. 360) of the first visceral arch furnishes near its base the Pterygoid (k, Fig. 361) and distally the Palatine (i) bones, whieh begin to ossify in nascent or simple cartilage at about the elose of the second month. The superior maxillary and zygomatic bones each ossify from one centre, at the end of the sccond month; and these, together with the lachrymal bones, are to be regarded as opercular bones. With regard to the intermaxillary bone, it is probable that this is developed from two ossific centres in the membrane, independently of the superior maxilla, though they join with it about the middle of the third month. ${ }^{1}$ Kolman, ${ }^{2}$ however, describes it as originating from the frontal proeess by two halves, which subsequently unite. The Vomer bears the same relation to the base of the septum nasale; it appears in the third month, and has then the form of a scmi-canal. At first, the mouth is a wide cavity, which is subsequently divided into a respiratory and digestive cavity by the lateral growth of the superior maxillary processes of the first visceral arch; thus constituting partitions on either sidc, ealled Palate plates, which after the eighth week begin to coalesee from before backward. $\Lambda \mathrm{n}$ arrest of development at this period produces the deformity termed Cleft palate. The second visceral or hyoid arch is originally in eonnection with the base of the skull, near the posterior sphenoid bone, but 
subsequently becomes segmented off, its apex or proximal portion remaining as the incus and os orbiculare in Man (which represent the hyomandibular and symplectic of Fish), whilst its distal portion is converted into the styloid process of the temporal bone and cornu minus of the hyoid with the intervening membranous part (Fig. $361, g, m, i$ ). The stapes proceeds from a cartilage developed in the fenestra ovalis, and is probably a periotic clement. In the third visccral arch, which corresponds with the first branchial arch of Ichthyopsida, the cormu majus of the hyoid bone is developer on each side, ossifying in the cighth month.

796. From the foregoing brief outline of the development of the skull, it will be seen that no segmentation of the cartilaginous basis takes place at all analogous to that which occurs in the vertebral column at the same period of its development; and therefore, as Mr. Huxley observes, it is impossible to admit the existence of a series of cranial vertebrie, and still less to define their several parts by means of terms especially adapted to the description of those bones which constitute the spinal column. At the same time, a very superficial investigation of the process of ossification leads to the conclusion that this takes place in such a manner as to produce a series of segments which are the niore closely analogous to those of the vertebral column the more posteriorly they are situated, as we see in the occipital and sphenoid segments; whilst in those that are more anterior the modification of structure is so great, that scarcely any trace of the form of a vertebra remains, as appears in the case of the pre-sphenoid and ethmoidal segments.

797. Within the Craniospinal canal thus formed, the rudiment of the Cerebrospinal axis is found, at first under a very different aspect from that which it subsequently presents, especially as regards the relative proportion of its different segments. According to the investigations of Bidder, Kupffer, and Kölliker, in Man and Birds, the spinal cord consists, after the clo-

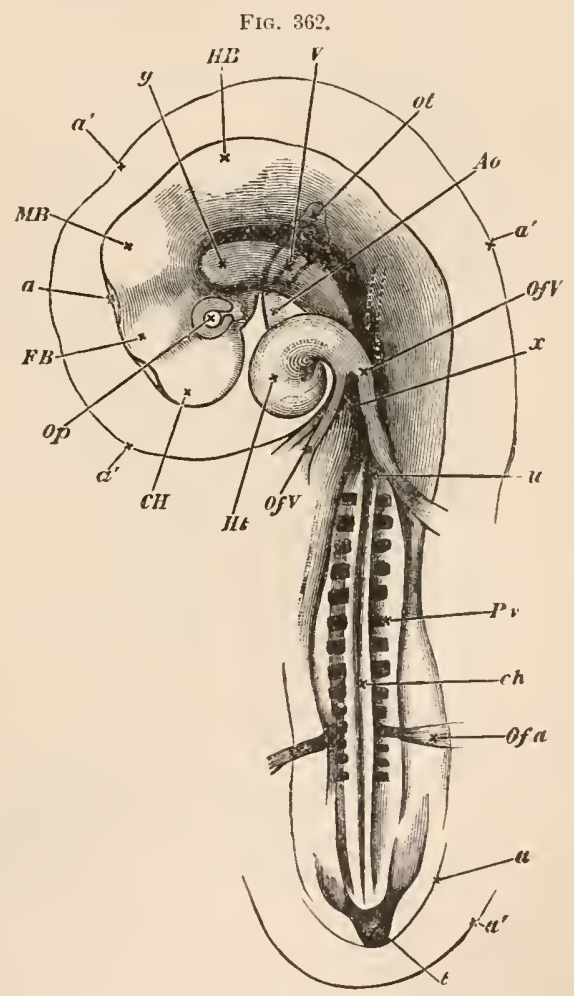

$a^{\prime}$, The outer amniotic fold or false amnion; $a$, the true amnion ; $t$, tail ; $C H$, cerebral hemisphere ; $F B$, fore brain or vesicle of the third ventricle; $M B$, unid-hrain; $H B$, hind brain; $o p$, optic vesicle; ot, otic vesicle; of $\downarrow$, Omp'ralo-mesa raic veins forming the venous roots of the heart; $H t, \mathrm{~h}$ art, now completely twisted on itself; $A O$, bulbus arteriosus, the thin aortic arches dimly seen uniting into the aorta, still more dimly seen as a eurved dark line running along the body ; the other eurved dark line by its side ending near the reference $y$ is the notochord, $c h$; of a, omphalo-mesaraic arteries; $P e$, protor -rtebra $x$ is placed at the point of dirergence of the splanchopleure folds. The blind foregut begins here and extends about ul' to $y$. 
of a canal surrounded by cells arranged in a radiating manner. These separate into an external layer composed of gray matter, and into an inner layer constituting the epithelium of the canal. The white substance appears later than the gray, and is unquestionably developed from it. In the first instance it consists of four cords or strands arranged in pairs, which subsequently become connected in front by a white commissure. ${ }^{1}$ According to the researches of Lockhart Clarke, in Man, Mammalia, and Birds, ${ }^{2}$ the spinal cord, in its earlier stages of development, consists of a ranal surrounded by a homogeneous layer of small cells or nuclei, which are not distinguishable from each other in appearance, and are so closely aggregated as to seem in actual contact. This layer continues to increase in clepth, and undergoes a differentiation into two-an inner or epithelial, and an onter or gray, layer; while at the same time the small cells of both layers are uninterruptedly connected by a continuous network of fibres which forms between them. As development progresses, a diversity of structure ensues in the gray substance; the cells or nuclei of the anterior gray substance becoming much larger than those of the posterior, and being connected by a coarser and more granular network. From these nuclei are developed a number of large roundish or irregular but adjacent cells, with thick nucleated walls, which are connected with the surrounding network, and have precisely the same appearauce as the connective tissue of parts external to the cord. It appears, then, that in these early stages of development, there are at least two kinds of free nuclei in the gray substance of the cord. One of these kinds appears to develop the general network of tissue which pervades the entire structure, but proceeds no further; whereas each nucleus of the other kind, while connected with this network as well as with nerve-fibres, develops a nucleated eell, with a nucleated wall, which is still connected, and ultimately blended, with the surrounding reticular structure. Through the inedium of this intervening reticular structure, the walis of the nerve-cells, the walls of the bloodvessels, the processes of the epithelium, and the pia mater on the surface of the cord, are all uninterruptedly continuous with each other; and since the processes of nerve-cells constitute the axis-cylinders of the vaso-motor nerves distributed to parts external to the cord, $\mathrm{MIr}$. Clarke thinks it probable that some of those processes which are lost by subdivision in the intervening nucleated and reticular tissue within the cord, are the means of transmitting nerve power to that tissue, and throngh that, to the coats of its bloodvessels, from which, by their direct connection with them, the nerve-cells, in return, receive their supply of nutriment.

798. In the Bird the medullary folds become closed in front, during the early part of the second day, the posterior part remaining open for a short time, as the "sinus rhomboidalis." The anterior extremity is dilated into a bull, and forms the first cerebral vesicle. Two projections are formed at the sides which gradually become stalkerd, and constitute the optic vesicles. At the close of the sccond day the medullary canal presents two more dilatations, separated from each other and from the first cercbral vesicle by constrictions, so that instead of a single cercbral vesicle there are now, in addlition to the optic vesicles, a series of them one behind the other. The most anterior of these, or first cercbral vesicle, is developed into the fore-brain, the second into the mid-brain, and the third into the hind-brain. Before the end of the second day the first cercbral vesicle has begun to bud oft' two small vesicles in front; these are the vesicles of the cerebral henispheres, which subsequently become the most conspicuous part of the brain. As these are formed the fore-brain, with the cerebral and optic vesicles, becomes

1 Kölliker, Entwisk., p!. 259, 260.

2 Phil. Trans., 1862, p. 911 et seq. 
slightly bent downwards over the antcrior extremity of the notochord, and this is the commencement of the cranial flexure. The cavity in the interior of each of the two vesicles of the cerebral hemispheres originating in the manner just described, constitutes the lateral ventricle, whilst the cavity of the fore-brain from which they wcre budded off renains as the cavity of the third ventricle, or, as Foster and Balfour term it, the "'tween brain." On the summit of the 'tween-brain the rudiment of the pineal gland makes its appearance, whilst the floor is produced into the "infundibulum," which joins the pituitary body. The roof of the mid-brain becomes developed into the enrpora bigemina or optic lobes in Birds, but in to the corpora quadrigemina in Mammals; its floor is formed by the crura cerebri, and its cavity becomes reducerl to the iter a tertio ad quartum ventriculum. In the mid-brain or third cerebral vesicle a constriction appears in the course of the third day, which inclicates a division into the cerebellum in front, and the medulla oblongata behind. The fundamental parts of the brain are thus fairly mapperl out in Birds on the third day. In Mammals the series of vesicles above described are distinctly visible at about the sixth week, and in the small proportion which the Cerebral Hemispheres bear to the other parts, in the absence of convolutions, in the deficiency of commissures, and in the general simplicity of structure of the whole, there is a certain correspondence between the brain of the Human embryo at this period and that of a Fish; but the rescmblance is much stronger between the foctal brain of the Fish and that of the Mammal ; indeed, at this early period of their formation, the two could scarcely be distinguished; and it is the large amount of change which the latter undergoes, as compared with the former, that causes the wide dissimilarity of their adult forms. At about the 12 th week, we find the Cerebral Hemispheres much increased in size, and arching-back over the Thalami and Corpora Quadrigemina (Fig. 363); still, however, they are destitute of convolutions, and are imperfectly connected by commissures; and there is a large cavity yet existing in the Corpora Quadrigemina, which freely communicates with the Third Ventricle. In all these particulars, there is a strong analogy between the condition of the brain of the Human embryo at this period and that of the Bird.-Up to the end of the $3 \mathrm{~d}$ month,

FIG. 363 .

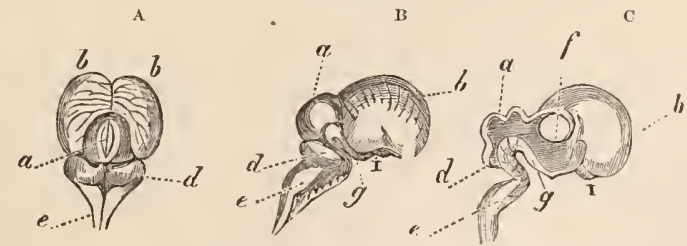

Brain of Human Embryo at twelfth week: A, seen from behiud; B, side riew; c, sectional view; $a$, corpora quadrigemina; $h, h$, hemispheres; $d$, cerebellum; $e$, medulla oblongata ; $f$, optic thalmus ; $g$, floor of third reutricle; $I$, olfatory nerve.

the Cerebral Hemispheres present only the rudiments of anterior lobes, and do not pass beyond that grade of development which is permanently characteristic of the Marsupial Mammalia, the Thalami being still but incompletely covered in by them. During the 4 th and part of the 5th months, however, the middle lobes are developed from their posterior aspect, and cover the Corpora Quadrigemina; and the posterior lobes, of which there was no previous rudiment, subsequently begin to sprout from the back to the middle lobes, remaining separated from them, however, by a distinct furrow; even in the brain of the mature foetus, and sometimes in that of older persons. In these and other particulars, there is a very close corre- 
spondence between the progressive stages of development of the Human Cerebrum, and those whieh we eneounter in the ascending series of Mammalia.

799. The development of the Eye $e^{2}$ eommenees by a protrusion from the lower and posterior part of the anterior eerebral vesicle, the eavity of the protrusion being eontinuous with that of the vesiele itself; very soon, how-

FIG. 364.
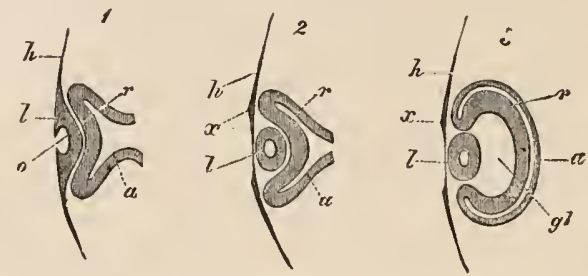

Longitudinal section of the Eye of Embryo Fowl : 1, from an embryo at ahout the 65th hour of ineubation; 2 , from an embryo a few hours older; 3 , from an embryo at the 4 th day of incubation: $h$, epiblast; $l$, lens in Fig. 1 , still connected with the corneal lamina, aud possessing a small eavity $(0)$ in its interior,-in Figs. 2 and 3 it is seen detached but still hollow; $r$, int roverted portion of the primitive optic venicle, subsequently becoming the retina; $a$, posterior part of the optic vesicle, which, according to Remak, probably becomes the choroid coat, eiliary processes, and iris, and in Figs. 1 and 2 is still connected with the brain by the hollow optic nerve; $x$, thickening of the epillast around the spot froin which the lens has detached itself; $g l$, vitreous body.

ever, it loses all ennneetion with the Cerebral Hemispheres, and opens exelusively into the "third ventriele." $A$ s soon as the primitive optie vesiele has assumed its permanent position, the Epiblast over it beeomes thickened (Fig. 36t, 1), whilst the subjacent wall of the optie vesiele beeomes indented, and at length so far pushed in as to form a sae eomposed of two layers, the edgres of which surround the lens (Fig. 36t, 2). This sae is the "seeondary optie vesicle" or "eup." The anterior thicker layer (Fig. 364, 3, r) is developed into the retina, the posterior $(a)$ beeomes the hexagonal tessellated pigment layer of the choroid. The doubling in of the primary optie vesiele is so eondueted that a slit remains for a short time, termed the choroidal fissure, throngh whieh a portion of mesoblast gains entrance into the interior of the vesicle. The thickened layer of the epiblast $(e)$ beeoming detaehed constitutes the lens, a thin layer of the epiblast still remaining, which forms the epithelium of the eornea. The mesoblast surrounding the optic vesicle gradually forms a distinet investment for it, of whieh the outer part eonstitutes the selerotie and cornea, and the inner the proper tissues and vessels of the choroid, whilst another portion penetrating more deeply eonstitutes the suspensory ligament and eapsule of the lens, and the vitreons. The choroid only reaches as far ats the edge of the lens at first, and no traee of Iris ean at that time be diseovered. At the end of the seeond month the iris, at first represented by a eolorless lamina in which pigment is afterwards deposited, grows out from the edge of the ehoroid, and insinuates itself between the lens and the eornea. The development of the anterior half of the Retina eeases during the latter part of footal life, and this part is gratually transformed into the Pars eiliaris, which in the adult does not eontain any nervous element. The Macula lutea is not present in the embryo, nor

1 See an account of the observations of Prof. Retzius on the Development of the Curebrum, in the Archives d'Anatomie Gémérale et de Pliysiolocrie, $18+6$.

2 Siee the excrllent Memoir of the late Mr II. Gray in the Philosophionl Transactions, 1850; Kölliker, Entwickel. Aes Menseben, 1861, p. 273; Peter Young, On the 1hevelopment of the Eye in the Chick, Med.-Chir. Rev., 1858; vol. xxii, 1). 187 ; and Klebs, in Virchow's Archiv, Bd. xxviii. 
in the new-born infant. The optic nerve, which is at first hollow, gradually beeomes solicl by the growth of fibres which fill its cavity. The Chiasma appears at an early period, and results from the fibres of the one stalk growing over into the attachment of the other. This takes place soon after the deposition of pigment in the outer wall of the optic cup, and about the same time the fibres at the neck of the optic cup grow forward and become connecterl with the retina, over whose internal surface they spread (Foster and Balfour).

800. Development of the Ear.-The ear makes its first appearance in the Fowl on the second day, as an involution of the Epiblast over the hindbrain; and the pit thus formed hecomes converted into a sae by the narrowing and closure of its mouth. This sac is the "otic vesicle," and is lined by epiblast and surrounded by mesoblast. By the outgrowth of the vesicle in different directions the semicircular canals and cochlea are developed, the mesoblast forming both their membranous and osseous walls, whilst the epiblast remains as their epithelial investment, and consequently forms the proper auditory apparatus of hair cells, etc. The auditory nerve arises from the mesoblastic layer near the optic vesicle, and in this respect is in marked contrast with the optic nerve. In Man the vesicles are first foand about the 4th week, possessing an epithelial lining derived from the epiblast: these are the Vestibula. The vesicles or vestibules then close and become pyriform; and the small end pushes out a hollow, club-shaped process, "processus vestibuli," which is connected with the dura nater, its peduncle passing through the Aquseductus vestibuli to the Atrium. Soon afterwards the Cochlea makes its appearance as a process from the vestibule, shooting in an antero-inferior direction. The Semicircular Canals are at first straight tubes, receiving their characteristic curvature and ampullae at a later period. The remaining portion of the vestibule forms the Fovea hemispherica and the Fovea hemi-elliptica. The petrous portion of the temporal bone is developed from the mesoblast surrounding the labyrinth, which subsequently becomes cartilaginous (8th week). In MIan the cochlea makes one entire turn in the 8th week; at the end of the 3d month the canal is complete. The spiral lamina is not completed till after the 6th month.-The modiola and the spiral lamina only ossify in the last months. The Middle Ear (including the external meatus, tympanum, and Eustachian tube) is formed by the partial closure of the first branchial cleft at the 4 th week. At the $3 \mathrm{~d}$ month the ossicula are formed, and are then seen lying over, not in, the tympanic cavity, imbedded in gelatinous tissue. The Eustachian tube remains closed during the whole of foetal life by gelatinous tissue, the cartilaginous portion being formed at the 4 th month. The mastoid cells only appear at puberty. The membrana tympani is at first very thick, and horizontal in position.The External Ear is developed from the Annulus tympanicus, a small bone which can be separated at birth, and gradually elongates. The cartilage and auricle are formed from the skin that surrounds the outer opening of the first branchial cleft. The auditory capsule is developed, according to Huxley, from three separate ossifications arising in the periotic cartilaginous mass,-an anterior ossification, the prootic, a superior and posterior one, the epiotic, and an inferior and posterior one, the opisthotic. Of the three ossicula auditûs, the stapes is a separate periotic nucleus of cartilage. It is the equivalent of the base of the columella of air-breathing ovipara. The incus, with the os orbiculare, is the proximal portion of the second visceral arch. In the lower Vertebrata, it is represented by the hyomandibular. The malleus is the proximal portion of the first visceral arch, and is the modified os quadratum of fish, reptiles, etc. The processus gracilis, at an early period of foetal life, is the cartilage of Meckel, and meets its fellow in 
the middle line below the mouth, forming a perfect primordial lower jaw. The first proper visceral cleft is the mouth ; the second (or first of the older embryologists) is the tympano-Eustachian passage, in which the outer and middle ear are developed; the third and fourth and fifth (sccond to fourth of anthors) are early closerl, but remain in Branchiate Vertebrata.

801. Organ of Sinell.-According to Baer, the nasal fossa are at first distinct from the oral cavity, subsequently conmunicate with it, and are finally divided into two portions, of which one becomes the respiratory portion of the nasal cavity, whilst the other forms the true olfactory portion and labyrinth of the Nose. In the Chick the olfactory vesicles make their appearance towards the end of the third day beneath the vesicles of the cerebral hemispheres. The epiblast orer these becomes indented to form the nasal pits, which subsequently become connected with the olfactory vesicles and mouth. In the Human subject two depressions, the nasal fosse, are well marked at the end of the 4 th week. In the 6 th week these fosse communicate below with the oral carity by a groove. At the end of the $2 d$ month the groove closes, and the labyrinth communicates with the most anterior part of the oral cavity by means of two narrow orifices, which are themselves rapidly closed by the formation of the palate dividing the nose from the mouth, slight traces of them remaining in adult life in the Nasopalatine foramen. At the 10th week the posterior uasal orifices are formed on either side of the Septum. The Labyrinth is wholly developerl from the epiblast investing the nasal fosse. It is fully formed at the close of the $3 \mathrm{~d}$ month, though the accessury cavitics of the frontal, sphenoidal, and ethmoidal sinuses, with the antrum of Highmore, are yet absent, and are not completed till after the 6 th month. The outer nosc begins to grow out from the nasal part of the primordial cranium about the end of the $2 \mathrm{~d}$ month. In the $3 d$ month the nasal orifices are closed by a gelatinous plug, which disappears after the 5th month, and seems to consist of mucus and epithelial plates. As to the sinare of the nervous system, we have already seen that the olfactory tract and bulb are cvolutions of the 1st brain-vesicle, and nothing is known in respect of the devclopment of the nerves from the bulb. Here also, therefore, the corncal laycr plays an important part. It is, however, never shut off' as a closed vesicle. The several steps of the development of this organ are met with in the various classes of animals: the small closed fossa remind us of Fishes; the short nasal ducts opening into the anterior part of the mouth, of Batrachians, etc.

802. The cxtremities (Fig. $348, q q, r r$ ) appcar in Man about the fourth wcek, as small and undivided stumps from the lateral platc; those of the upper cxtremity appearing first: a division into two principal parts takes place in the fifth week; onc of which is broarl, and shows about the fifth wcek four indentations; the other is more cylindrical, and subdivides into a fore and upper arm about the eiglith week. The two extremities arc very similar in form up to this period, their distinctive characters only appearing well marked at the third month. All the bones which cnter into their composition pass through stages of development similar to those that have been already described as occurring in the bones of the vertebral column and skull. In the first instance only a soft blastema or indifferent tissuc appears in the place of the finture bone; but this gradually develops into cartilage, the conversion being complete about the cnd of the sceond or the commencement of the third month, and in the cartilage again points of ossification make their appcirance, with grcat though not ahsolute precision, for cach bone, not only as regards number, but also as to time and position. ${ }^{1}$ 
803. Of Sex.-The conditions on which the differentiation of sex immediately depend are as yct extremely obseure. M. Mare Thury, ${ }^{1}$ who has paid great attention to this subject in cattle, has arrived at the conclusion (which, however, demands much confirmatory evidence for its establishment) that the sex of the progeny of a particular act of sexual intercourse is dependent upon the period of menstruation (in women), or of rut (in animals), at which the impregnation of the ovum takes place. If this occur at the conmencement of the period, the offspring will invariably be a female; if towards the close, male: the cause of the difference being the more advanced stage of maturation of the ovum in the latter case, owing to its having been for a longer period exposed to the warmth of the body of the mother. Ploss ${ }^{2}$ attributes the sex of the child to the quantity and quality of the nutriment received by the mother during pregnancy, since from a review of various countries, and a comparison of the relative numbers of males and females born, he finds that when the food is abundant and plentiful, the proportion of females rises; whilst, under opposite conditions, males are most frequent. In mountainous countries the number of males also increases relatively. 'Preussen (loc. cit.), however, on the other hand, considers that better and more abundant food is required by the mother for the protection of males.-There is strong statistical evidence that the relative numbers of Males and Females are in some way influenced by the relative ages of the parents. The following table expresses the average results collected by M. Hofacker ${ }^{3}$ in Germany, and by Mr. Sadler ${ }^{4}$ in Britain; between which it will be seen that there is a very striking general correspondence, although both were drawn from a too limited series of observations. The numbers indicate the proportion of Male births to 100 Females, under the several conditions mentioned in the first column :

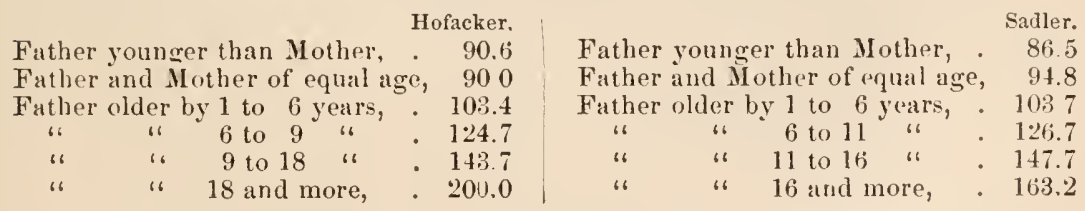

From this it appears, that the more advanced age of the Male parent has a very decided influence in occasioning a preponderance in the number of Male infants; and this tallies with the fact, that taking the average of the whole of Europe, over which (as a general rule) the state aud customs of society bring about a decided preponderance of age, among married couples, on the side of the husband, the proportion is about 106 males to 100 females. This does not hold good, however, in regard to illegitimate offspring, the parents of which may generally be presumed to be more nearly on an equality in this respect; and it is curious that the proportion of these has averaged 102.5 males to 100 females, in places where the proportion of legitimate births was $105^{\frac{3}{4}}$ males to 100 females.-We are not likely to obtain data equally satisfactory in regard to the influence of more advanced age on the part of the Female parent, as a difference of 10 or 15 years on that side is not so common. If it exist to the same extent, it is probable that the same law would be found to prevail in regard to Female children born under such cireumstances, as will be stated $(\S 804)$ with respect to the Male,-namely, that the inortality is greater during embryonic life and early

1 Notice on the Law of Production of Sexes, etc., Pamplulet, 1863.

2 Henle and Meissner, 1860, p. 210.

3 Annales d'Hygiène, October, 1829.

4 Law of Population, vol. ii, p. 343. 
infancy, so that the preponderanee is reduced. Even at birth there is a manifold difference in the physieal conditions of infants of different sexes; for, in the average of a large number, there is a decided preponderance on the side of the Males, both as to the length and the weight of the body. And it seems not improbable that this differenee has a decided influence upon the greater loss of life in the aet of parturition, whieh oeeurs anong Malc infants.

I. The Length of the body in fifty new-born infauts of eaeh sex, as aseertained by Quetelet, ${ }^{1}$ was as follows:

\begin{tabular}{|c|c|c|c|c|c|c|}
\hline From & 16 to 17 & inches ${ }^{2}$ (French), & & $\begin{array}{c}\text { Males. } \\
2\end{array}$ & $\begin{array}{c}\text { Females. } \\
4\end{array}$ & $\begin{array}{c}\text { Total } \\
6\end{array}$ \\
\hline " & 17 to 18 & " & . & 8 & 19 & 27 \\
\hline "6 & 18 to 19 & " & . & 28 & 18 & 46 \\
\hline " & 19 to 20 & “ & . & 12 & 8 & 20 \\
\hline "6 & 20 to 21 & "6 & • & 0 & 1 & 1 \\
\hline
\end{tabular}

From these observations, the mean and the extremes of the Lengths of the male and female respectively, wcre calculated to be:

Males.

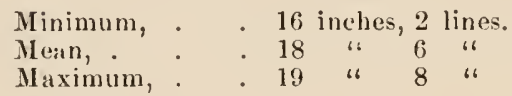

Females.

16 inches, 2 lines.

18 " $1 \frac{1}{2}$ "

Notwithstanding that the maximum is here on the side of the Female (this being an accidental result, which would probably have been otherwise had a larger number been examined), the average shows a difference of $4 \frac{1}{2}$ lines in favor of the Male.

II. The inequality in the Weights of the two is even more remarkablc; the observations of $\mathrm{M}$. Quetelet ${ }^{3}$ were made upon 63 male and 56 female infiants.

\begin{tabular}{|c|c|c|c|c|c|c|c|}
\hline \multicolumn{3}{|c|}{ Infants weighing from } & & & Males. & Females. & Total. \\
\hline $1 \mathrm{t}$ & to $1 \frac{1}{2}$ & kilog. ${ }^{4}$ & . & . & 0 & 1 & 1 \\
\hline $1 \frac{1}{2} \mathrm{t}$ & to 2 & ") & . & . & 0 & 1 & 1 \\
\hline $2 t$ & to $2 \frac{1}{2}$ & " & . & . & 3 & 7 & 10 \\
\hline $2 \frac{1}{2} \mathrm{t}$ & to 8 & " & . & . & 13 & 14 & 27 \\
\hline $3^{2} \mathrm{t}$ & to $3 \frac{1}{2}$ & " & . & . & 28 & 23 & 51 \\
\hline $3 \frac{1}{2} \mathrm{t}$ & to 4 & “ & . & • & 14 & 7 & 21 \\
\hline $4 \mathrm{t}$ & to $4 \frac{1}{2}$ & " & . & . & 5 & 3 & 8 \\
\hline
\end{tabular}

The extremes and means were as follows:

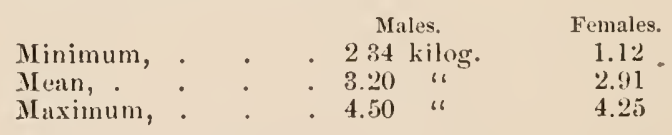

III. The average Weight of infants of both sexes, as determined by these inquiries, is 3.05 kilog., or $6.77 \mathrm{lbs}$; ; and this corresponds almost exactly with the statement of Chaussier, whose observations were made upon morc than 20,000 infants. The mean obtained by him, without reference to distinction of "scx, was $6.75 \mathrm{lbs}$; the maximum loeing $11.3 \mathrm{lbs}$, and the minimum 3.2 lbs. ${ }^{5}$ The average in this eountry is probably rather higher; according to

1 sin. l'Homme, tom. ii, p. 8.

2 The French inch is about one-fifteenth more than the English.

3 Op. cit., tom. ii, p. 35.

4 The kilogramme is equal to 2.22 lbs. avoirclupois.

5 These numbers have been erroneously stated in many Physiological works, owing to the difference between the French and English pound not having been allowed for. 
Dr. Joseph Clarke, whose inquiries were made on 60 males and 60 fenales, the average of Male children is $7 \frac{1}{3} \mathrm{lbs}$, and that of Females $6 \frac{2}{3} \mathrm{lbs}$. He adds that children which at the full tine weigh less than $51 \mathrm{lbs}$. rarely thrive; being generally feeble in their actions, and dying within a short time. Several instances are on record, of infants whose weight at birth exceeded $15 \mathrm{lbs}$. It appears that healthy females, living in the country, and engaged in active but not over-fatiguing occupations, have generally the largest children; and this is what might be expected a priori, from the superior energy of their nutritive functions.

804. There appears to be, from the first, a difference in the Viability (or probability of life) of Male and Fenale children; for, out of the total number born dead, there are 3 Males to 2 Females: this proportion gradually lessens, however, during early infancy; being about 4 to 3 ' during the first

FIG. 365 .

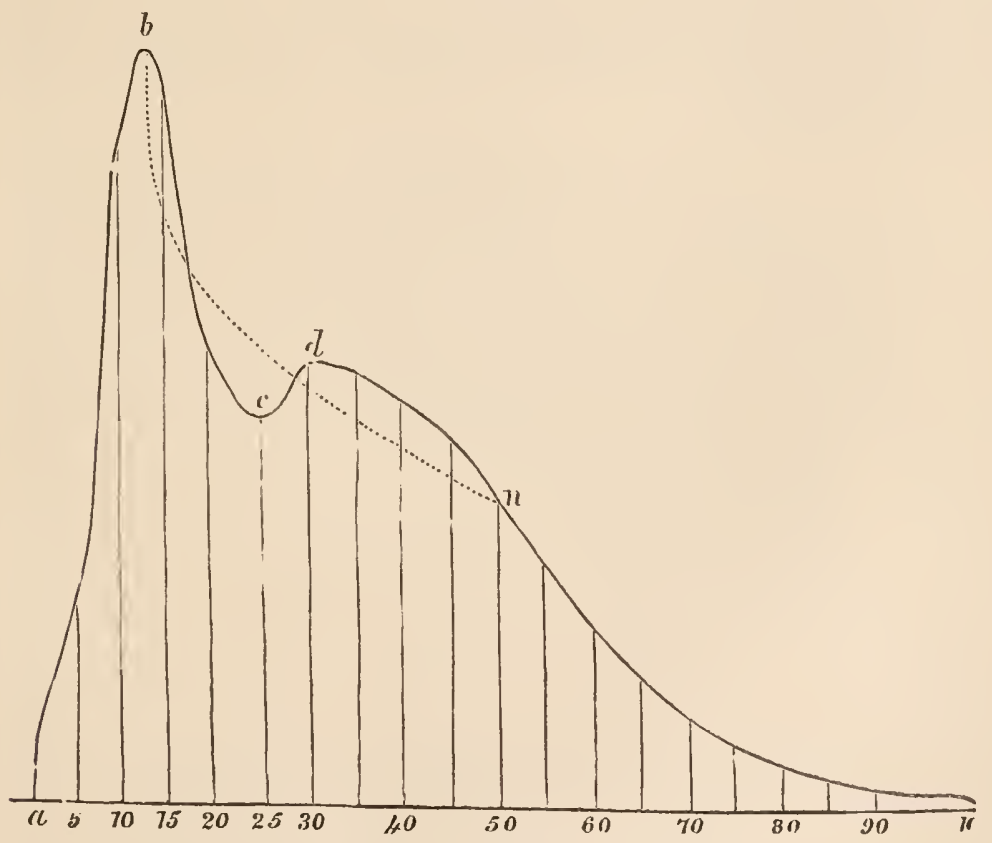

Diagram representing the Comparative Viability of the Male and Female at different Ages.

two months, and about 4 to 5 during the next three months; after which time the deaths are nearly in proportion to the numbers of the two sexes respectively, until the age of puberty. The viability of the two sexes continues to increase during childhood; and attains its maximum between the 13 th and 14th years. For a short time after this epoch has been passed, the rate of mortality is higher in Females than in Males; but from about the age of 18 to 28 , the mortality is much greater in Males, being at its maximum at 25 , when the viability is only half what it is at puberty. The fact is a very striking one; and shows most forcibly that the indulgence of the passions not only weakens the health, but in a great number of instances is the cause of a very premature death. From the age of 28 to that of 50 , the mortality 
is greater and the viability less on the side of the Female; this is what would be anticipated from the inereased risk to which she is liable during the parturient period. After the age of 50 , the mortality is nearly the same for both.-These faets have been expressed by Quetelet ${ }^{1}$ in a form which brings them prominently before the eye (Fig. 365). The relative viability of the Male at different ages is represented by a eurved line; the elevation of whieh indicates its degree, at the respeetive periods marked along the base line. The dotted line, which follows a different curve, represents the viability of the Female. Starting from $a$, the period of birth, we arrive at the maximum of viability for both at $b$ : from this point, the Female curve steadily descends towards $n$, at first very rapidly, but afterwards more gradually; whilst the male eurve does not descend quite so soon, but afterwards falls much lower, its minimum being $c$, which corresponds with the age of 25 years. It afterwards aseends to $d$, which is the maximum of viability subsequently to the age of puberty; this point is attained at the age of 30 years, from which period up to 50 , the probability of life is greater in the Male than in the Female. In the deeline of life, there seems little or no differenee for the two sexes.

FIG. 366.

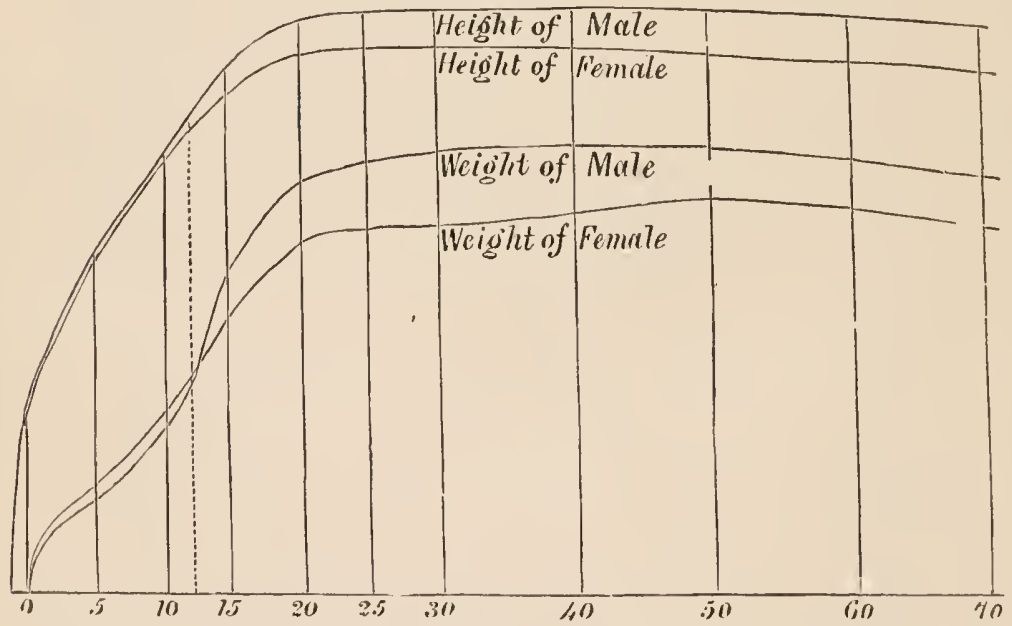

Diagram representing the Comparative Heights and Weights of the Male and Female at different Ages.

805. Similar diagrams have been construeted by Quetelet, to indicate the relative Heights and Weights of the two sexes at different ages (Fig. 366). In regard to Height it may be observed, that the inerease is most rapid in the first year, and that it afterwards diminishes gradually; between the ages of 5 and 16 years, the annual inerease is very regular. The difference between the Height of the Male and Female, which has been already stated to present itself at birth, eontinues to increase during infuncy and youth; it is not very decided, however, until about the 15 th year, after which the growth of the Female proeeeds at a mnch diminished rate, whilst that of the Iale continues in nealy the same degree, until about the age of 19 years. It appears, then, that the Female comes to her full development in regard to Height, earlier than does the Male. It seems probable, from the obser- 
vations of Quetelet, that the full Height of the Male is not gencrally attainerl until the age of 25 years. At about the age of 50 , both Nalc and Fenale undergo a diminution of their stature, which continues during the latter part of life.-'The proportional Weight of the two sexes at clifferent periods, corresponds pretty closely with their height. Starting from birth, the predominance then exhibited by the Male gradually increases during the first few years; but towards the period of puberty, the proportional weight of the Female increases; and at the age of 12 year's, there is no difference between the two sexes in this respect. The weight of the Male, however, then increases much more rapidly than that of the Female, especially between the ages of 15 and 20 years; after the latter period, there is no considerable increase on the side of the Male, though his maximum is not attained mntil the age of 40 ; and there is an absolute climinution on the part of the Female, whose weight remains less during nearly the whole period of childbearing. After the termination of the parturient period, the weight of the Female again undergoes an increase, and its maximum is attained at about 50. In old age, the weight of both sexes undergoes a diminution in nearly the same degree. The average Weights of the Male and Female that have attained their full development, are 20 times those of the new-born Infants of the two sexes respectively. The Heights, on the other hand, are about $3 \frac{1}{1}$ times as great. ${ }^{1}$

806. The chief differences in the Constitution of the two sexes, manifest themselves during the period when the Generative function of each is in its greatest vigor. II Iny of these distinctions have been alrearly allurled to; but there are others of too great inportance to be overtooked; and these chiefly relate to the Nervous System and its functions. There is no obvious structural difference in the Nervous System of the two sexes (putting aside the local peculiarities of its distribution to the organs of generation), save the inferior size of the Cercbral Henispheres in the Female. This difference, which is not observed in other parts of the Encephalon, is readily accounted for on the principles formerly stated $(\$ 566)$, when we compare the psychical character of Woman with that of Man; for there can be no doubt that-putting aside the exceptional cases which now and then occur-the intellectual powers of Woman are inferior to those of Man. Her intuitive powers are certainly greatcr than his; her perceptions are more acute, her apprehensions quicker; and she has a remarkable power of interpreting the feelings of others, which gives to her, not only a much more ready sympathy with them, but that facility in guiding her actions so as to be in accordance with them, which we call tact. This tact bears a close correspondence with the unconscious adaptiveness to particular ends, which we see in Instinctive actions. Notwithstanding the superiority of her perceptive faculties, her capability of sustained mental exertion is much less; and though her vicws are often peculiarly distinguished by the clearness and decision which result from the strength of her intuitive sense, they are generally deficient in that comprehensiveness which brings the whole case to be jurlged of, and which is consequently necessary for their stability. With less of volitional power than Man possesses, she has the emotional in a much stronger degree. The emotions, therefore, predominate; and more fiequently become the leading springs of action, than they do in Man. By their direct influence upon the bodily frame, they prodluce changes in the Organic functions, which far surpass in degree anything of the same kind that we ordinarily witness in Man; and they thus not unfrequently occasion symptoms of an anomalous kind,

1 For an excellent treatise on The Stature and Bulk of IIan in the British Isles, see John Beddoe, Pamphlet, 1870, pp. 191. 
which are very perplexing to the Medical pratitioner, though very interesting to the Physiological observer. But they also aet as powerful motives to the Will; and when strongly called forth, produce a degree of vigor and determination, which is very surprising to those who have usually seen the individual under a different aspect. But this vigor, being due to the strong exeitement of the Feelings, and not to any inherent strength of Intellect, is only sustained during the persistenee of the motive, and fails as soon as this subsides. The feelings of Woman, being frequently ealled forth by the oeeurrences she witnesses around her, are naturally more disinterested than those of Man; his energy is more eoncentrated upon one objeet; and to this his Intelleet is direeted with an earnestness that too frequently either blunts his feelings, or carries them along in the same channel, thus rendering them selfish.-In regard to the inferior development of her Intellectual powers, therefore, and to the predominance of the Instinetive, Woman must be eousidered as ranking below Man; but in the superior purity and elevation of her Feelings, she is as highly raised above him. Her whole eharaeter, Psyehical as well as Corporeal, is beautifully arlapted to supply what is defieient in Man ; and to elevate and refine those powers which might otherwise be directed to low and selfish objeets.

\section{Of Lactation.}

807. The new-born Infant in the Human speeies, as in the class of Mammalia generally, is supplied with nourishment by a secretion elaborater from the blood of its maternal parent, by certain glandular organs known as the Mammary. The structure of these, which has been thoronghly investigated by Sir A. Cooper ${ }^{1}$ and Mr. Birkett, ${ }^{2}$ is extremely simple. Eacl gland is eomposed of a number of separate glandules, whieh are eonnected together by fibrous or faseial tissue, in such a manner as to allow a eertain degree of mobility of its parts, one upon another, which may accommodate them to the aetions of the Peetoralis musele wherenn they are bound down; and the glandules are also connected by the ramifications of the lactiferous tubes, which intermingle with one another in sueh a manner as to destroy the simplicity and uniformity of their divisions, although they rarely inosculate. The mamillary tubes, or terminal ducts contained in the nipple, are usually about ten or twelve in number; they are straight, but of somewhat variable size; and their orifices, whieh are sitnated in the centre of the nipple, and are usually coneealed by the overlapping of its sides, are narrower than the tubes themselves. At the base of the nipplc, these tubes dilate into reservoirs, which extend beneath the arenla and to some distanee into the gland, when the breast is in a state of lactation. These are mueh larger in many of the lower Mammalia than in the Human female, in whom their use is to supply the immediate wants of the child when it is first applied to the breast, so that it shall not be disappointerl, but shall be indueerl to proceed with sucking until the "draught" be necasioned (\$722). From each of these reservoirs commence five or six branches of the lactiferous tubes, each of which speedily subdivides into smaller ones; and these again divaricate, until their size is very mueh reduced, and their extent greatly inereased (Fig. 367). These, like the reservoirs and mammillary tubes, are eomposed of a fibrous coat lined by a mucous membrame; the latter is highly vascular, and forms a seeretion of its own, whieh sometimes colleets in eonsiderable quantity when the milk eeases to be produeed. The smaller subdivisions of

1 On the Anatomy of the Breast, 1810.

2 The Diseases of the Breast, and their Treatment, 1850. See also Giannuzzi, livista Scientif. del $\mathrm{Akad}$ de Fisiocritici, ii, p. 38. 
the lactiferous tubes proceed to distinct lobuli in each glandule; so that when a branch of a nammillary tube has been filled with injection, its attached lobules, if separated from each other by long maceration, are like a bunch of fruits clustered upon a stalk (Fig. $36 \dot{8}$ ). When the lactiferous tubes are

Fig. 367.

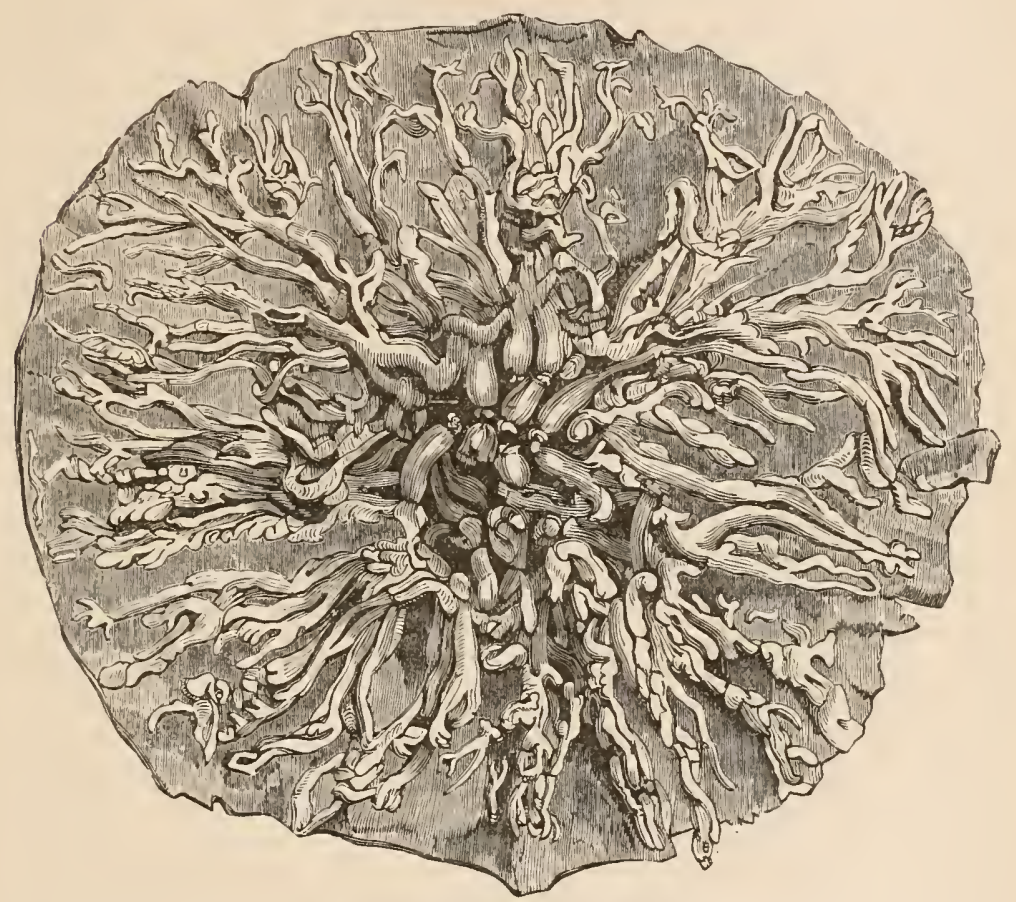

Distribution of the Milk-ducts in the Mamma of the Human Female, during lactation; the ducts injectcd with wax.

pursued to their ultimate distribution, they are found to terminate in follicles, whose size, in full lactation, is that of a hole pricked in paper by the point of a very fine pin, so that, when distenderl with quicksilver or milk,

FIG. 368 .

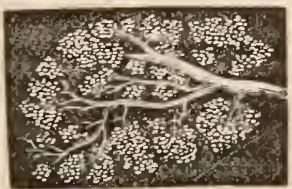

FIG. 369.

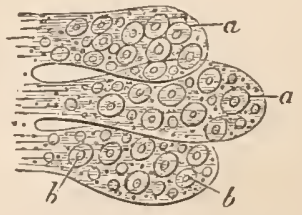

FIG, 368.-Termination of portion of Milk-duct in a cluster of follicles; from a mercurial injection ; enlarged four times.

FIG. 369.-Ultimate follicles of Mammary gland, with their secreting cells, $a, a$, and nuclei, $b, b$.

they are just visible to the naked eye; at other tines, however, the follicles do not admit of being injected, though the lactiferous tubes may have been completely filled. They are lined by a continuation of the same membrane 
with that which lines the ducts; and this possesses a high vascularity. The artcries which supply the glandules with blood, become very large during lactation; and their divisions spread themselves minutely on the follicles. From the blood which they eonvey, the milk is secreted and poured into the follicles, whence it flows into the ducts. The inner surface of the milk-follicles, in common with other glandular structures, is covered with a layer of epithelium-cells (Fig. 369), as was first observed by Prof. Goodsir; and these, being scen to contain milk-globules, may without doubt be regarded as the real agents in the secreting process. Absorbent vessels are seen to arise in large numbers in the neighborhood of the follicles; their function appears to be, to absorb the more watery part of the milk contained in the follicles and tubes, so as to render it more nutrient than it is when first secreted; and also to relieve the distension which would occur, during the absence of the child, from the continuance of the secreting process.

808. The Manmary gland nay be detected at an early period of foetal existence; being easily distinguishable from the surrounding parts by the redness of its color and its high vascularity, especially when the whole is injected. At this period it presents no difference in the male and female; and it is not until near the period of puberty that any striking change manifests itself, the gland continuing to grow, in the one sex as in the other, in proportion to the body at large. At about the age of thirtcen years, however, the enlargement of the gland commences in the Female; and by sixteen, it is greatly evolved, and some of the lactiferous tubes can be injected. At about the age of twenty, the gland attains its full size previous to lactation; but the milk-follicles cannot even then be injecter from the tubes. During pregnancy, the mamme receive a greatly increased quantity of blood. This determination often commences very carly, and produces a fceling of tenderness and distension, which is a valuable sign (where it exists in connection with others) of the commencement of gestation $(\$ 758)$. A true lacteal secretion usually commences about the third or fourth month of preguancy, and may be obtained by pressure carefully applied. This may be turned to useful account, in diagnosing cases of conccaled or doubtfiil pregnancy from cases of simple suppression of the catamenia; but it will not serve to distinguish true pregnancy from spurious, or from the distension of the utcrus by tumors. ${ }^{1}$ The vascularity of the gland continues to increase during pregnancy; and at the time of parturition its lobulated character can be distinctly felt. The follicles are not, however, developer sufficiently for injection, until lactation has commenced. After the cersation of the catamenia from age, so that pregnancy is no longer possible, the lactiferous ducts continue open, but the milk-follicles are incapable of receiving injection. The substance of the glandules gradually disappears, so that in old age only portions of the ducts remain, which are usually loaded with mucus; but the place of the glandules is commonly filled up by adipose tissue, so that the form of the breast is prescrvect. Sir A. Cooper notices a curious change, which he states to be alnost invariable with age-namely, the ossification of the arteries of the breast, the large trunks as well as the branches, so that their calibre is greatly diminished or even obliterated.

809. The Mammary glaud of the Male is a sort of miniature picture of that of the Female. It varies extrenely in its magnitude; being in some persons of the size of a large pea ; whilst in others it is an inch, or even two inches, in diametcr. In its structure it corresponds cxactly with that of the female, but is altogether formed on a smaller scale. It is composed of

1 Sre a valuable paper by D. Peddie, On the Mammary Secretion, in the Edinb. Mouthly Journal, Aug. 1848. 
lobules containing follicles, from which ducts arise; and these follicles and ducts are not too minute to be injected, although with difficulty. The evolution of the gland goes on pari passu with that of the body, not undergoing an increase at any particular period; it is sometimes of considerable size in old age. A fluid, which is probably nucus, may be pressed from the nipple in many persons; and this in the dead body, with even more facility than in the living. That the essential character of the gland is the same in the male as in the femalc, is shown by the instances, of which there are now several on record, in which infants have been suckled by men $(\$ 790)$.

810. Althougl the state of functional activity in the Mammary gland is usually limited to the epoch succeeding Parturition, yet this is not invariably the case; for numerous instances are on record, in which young women who have never borne children, and even old women long past the period of childbearing, have had such a copious flow of milk as to be able to act as efficient nurses. ${ }^{1}$ In these cases, the strong desire to furnish milk, and continued irritation of the nipple by. the infant's mouth, seem to lave furnished the stimulus requisite for the formation of the secretion, and it has been found that this is usually adequate to restore the secretion, after it has been intermitted for some months during the ordinary period of lactation, in consequence of disorder or debility on the part of the mother, or any other cause ; so that where her condition renders it advisable that she should discontinue nursing for a time, the child may be withdrawn and the milk "dried up," with a confident expectation that the secretion may be reproduced subsequently. ${ }^{2}$ Dr. McWilliam mentions in his report of the Niger Expedition, ${ }^{3}$ that the inlabitants of Bona Vista (Cape de Verd Island) are accustomed to provide a wet-nurse in cases of emergency, in the person of any woman who has once borne a child and is still within the age of childbearing, by continued fomentation of the mamme with a decoction of the leaves of the jatropha curcas, and by suction of the nipple.-The most curious fact, however, is that eveu Men should occasionally be able to perform the duties of nurses, and should furnish an adequatc supply of infantile nutriment. Several cases of this kind are upon record, ${ }^{4}$ but one of the most recent and authentic is that given by Dr. Dunghison. "Professor Hall, of the University of Maryland, exhibited to his Obstetrical class, in the year 1837, a colored man, fifty-five years of agc, who had large, soft, well-firmed mamme, rather more conical than those of the female, and projecting fully seven inches from the chest; with perfect and large nipples. The glandular structure seemed to the touch to be exactly like that of the female. This man had officiated as wet-nurse for several years in the family of his mistress; and he represented that the secretion of milk was induced by applying the children intrusted tis his care, to the breast during the night. When the

1 A colleetion of such cases is given in Dr. Dunglison's Human Physiology, 7th edit., vol. ii, p. 513.

2 see an recount of $\mathrm{M}$. Trousseau's experience on this point, in L'Union Médicale, 1852, No. 7 ; and paper by Dr. Ballou in the Amer. Journ. of Med. Sui, Jan. 1852.

3 II dieal Gazette, Jan. 1847.

4 See the ease described by the Bishop of Cork, in the Philosophical Transactions, vol. xli, p. 813; one mentioned by Sir John Franklin (Narrative of a Journey to the Polar Sea, p. 157); and one whieh fell under the notice of the eelebrated traveller Humboldt (Personal Narrative, vol. iii, p. 58).

5 Human Physiolngy, 7th edit., vol, ii, p. 514. Dr. Dunglison also mentions that in the winter of 1849-50, an athletie man, twenty-two years of age, presented himself at the Jefferson Medieal College at Philadelphia, whose left mamma withunt any assignable cause, bad beeome greatly developed, and seereted milk copiously. - It may be added that a laetescent fluid, apparently presenting the eharacter of true inilk, may frequently be expressed from the mammary glands of infants. (See Dublin Medieal Press, April 17th, 1850) 
milk was no longer required, great difficulty was experienced in arresting the secretion. His genital organs were fully developed." Corresponding facts are also recorded of the male of several of the lower animals.

811. The secretion of Milk consists of Water, holding in solution Sugar, various Saline ingredients, and the peculiar albuminous substance terined Casein ; and having Oleaginous particles suspended in it. Its reaction is sometimes alkaline, sometimes neutral, and somctimes acid. Cow's milk is usnally, and the milk of Carnivora always, acid, ${ }^{1}$ from the presence of fiee lactic acid. The constitution of this fluid is made evident by the ordinary processes to which it is subjected in domestic economy. If it be allowed to stand for some time, cxposed to the air, the greater part of the oleaginous globules come to the surface, being of less specific gravity than the fluid through which they are diffused: this is especially the case with the larger faceted globules, which have been hence distinguished as "cream globules." The cream thus formed does not, however, consist of oily particles alone; but includes a considerable amount of casein, with the sugar and salts of the milk. These are further separated by the continued agitation of the cream; which, by rupturing the envelopes of the oil-globules, separates it into butter,

\section{FIG. 370.}

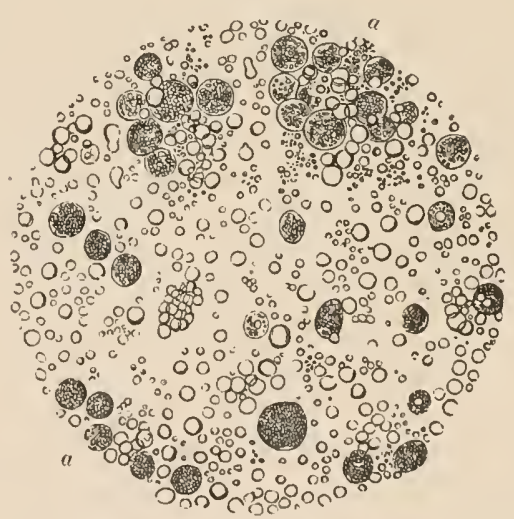

Microscopic appearance of Human MIilk, with an intermixture of Colostric corpuscles at $a a$, and elsewhere.

formed by their aggregation, and buttermilk, containing the cascin, sugar, ctc. A considerable quantity of casein, however, is entangled with the olcaginous matter, and this has a tendency to decompose, so as to render the butter rancid; it may be separated by keeping the butter meltcd at the tempcrature of $180^{\circ}$, when the casein will fill to the botton, leaving the buttcr pure and much less liable to change.-The milk, after the cream has been removed, still contains the greatest part of its casein and sugar. The amount of casein and of fat increases when milk is allowed to stand for twenty-four hours, the former at the expense of the albumen, ${ }^{2}$ and the latter under the influence of fungi. Thus Kemmerich found in colostrum immediately after withdrawal $31 \frac{1}{4}$ parts of casein, and $43 \frac{1}{2}$ parts of albumcn, but after the lapsc of 24 hours these proportions were reversed, the quantities

$1 \mathrm{~V}$. Gorup-Besanez, $\mathrm{p}$ 388. See in regard to the Comparative Chemistry of the Cow and Goat, Bogomoloff, Centralblatt, 1871, p. 62.5 .

${ }^{2}$ Kemmerich, Pflüger's Archiv, Bd. ii, p. 401. 
being 42.4 of casein and 30.6 of albumen. ${ }^{1}$ If it be kept long enough, a spontancous change takes place in its composition; the sugar is converted into lactic acid, and this coagulates the casein, precipitating it in suall flakes. The same precipitation may be accomplished at any time by the addition of an acid; all the acids, however, which act upon albumen, do not precipitate casein, as will presently be pointed out in detail; the most effectual is that contained in the dried stomach of a calf, known as remet. The whey left after the curl has been separated contains a large proportion of the saccharine and saline matter that entered into the original composition of the milk; this may be rearlily separated by evaporation.

812. When Milk is examined with the Microscope, it is seen to contain a large number of particles, of irregular size and form, suspended in a somewhat turbid fluid (Fig. 370); these particles vary in size from about the ${ }_{1}{ }_{2} \gamma_{0}$ th to the $\frac{1}{30}$ th of an inch; and they are termed "milk globules." They are not affected by the mere contact of ether or alkalics; but if these reagents are shaken with them, an immediate solution is the result. The sane effect happens if they are first treated with acetic acid. Hence it is evident that the globules consist of oily matter, inclosed in an envelope of some kind; and an extremely delicate pellicle may, in fact, be distinguished, after the removal of the oily matter by ether, or after the globules have been ruptured and their contents pressed out, by rubbing a drop of milk between two plates of glass. No proof of the organization of this pellicle has, however, been detected; and it is probably to be regarded as the simple result of the contact of oil with albuminous matter. ${ }^{2}$-Besides these milk-globules, other globules of much smaller size are seen in milk; and these present the peculiar movement which is exhibited by molecules in general. Most of them seem to consist of oily matter not inclosed in an envelope, as they are at once dissulved when the fluid is treated with ether, but, according to the statements of Donné, it would seem that a portion of them are composerl of casein, suspended, not dissolved, in the fluid.- The colostrum, or milk secreted during the first week after delivery, is described by Dr. Davy, in the case of the cow, as being of a rich yellow color, less fluid than the milk of a later period, of a higher specific gravity (1075), slightly acid, and containing large oil-globulcs, a few irregular flakes, probably epithelium scales, a little grauular matter like curd, and a small number of granular corpuscles, the largest of which are about the $\overline{5}_{0}$ th of an inch in diameter (Fig. $370, a a$ ). It congulates on being heater to about $163^{\circ} \mathrm{F}^{3}$ The granular corpuscles, when maintained at a temperature of $100^{\circ} \mathrm{F}$, exhibit feeble anoeboid movements (Stricker and Schwarz). They are probably epithelial cells of the mammary ducts which have undergone fatty degencration." The chemical composition of the solids of the colostrum, as compared with the milk of a subsequent perior, is well given in the following percentage table by Dr. Tolnuatschefi: $:^{5}$

\begin{tabular}{|c|c|c|c|c|c|c|c|c|c|}
\hline & & & & & Age. & Temperament. & Albumen. & Fat. & Sugar. \\
\hline 4 th & ay a & fter delivery, & & • & 23 & Fair, mid. stature, & 4.188 & 2.471 & 433 \\
\hline 6 th & "، & "6 & & . & 22 & Large, fuir, strong, & 2.0 .50 & 3.177 & 576 \\
\hline $15 \mathrm{th}$ & " & " & & . & 22 & Large, dark, strong, & 2077 & 2.939 & 5.90 \\
\hline $36 \mathrm{tl}_{1}$ & ، & "6 & . & . & 34 & Large, fair, strong, & $1.10 t$ & 1.713 & 6.26 \\
\hline
\end{tabular}

1 For a discussion on the resemblanees and differences betwren Casein and Alkalialbuminate, sec Soxlet, Journ. f. Pratet. Chemie, 1872, Bd. vi, p. 1.

2 The presenee of an albuninous envelope to the oil-glubules floating in milk has been called in question by Kehrer, Archiv f. Gynreeol., Bd. ii, 1871, p. 1 (see also Zahn, Pflüger's A rehiv, 1869, p. 598), but is maintained by Sehwalbe, Max Schultze's Arehiv, Bd. viii, p. 269.

3 See atso Bermard, Leçons, vol. ii, 1859, p. 224.

4 See Reinhardt, Alsstruct in Edin. Juurn., Feb. 1848.

${ }^{6}$ Hoppe-Seyler, Med. Chem. Unters., 1867, p. 272. 
Physiologically considered, ${ }^{1}$ the most marked peculiarities of the colostrum in the cow are the concentration of nutritive matter in it; the greater facility with which it coagulates by rennet as compared with older milk, and its greater power of resisting change when exposed to the action of air. All of these are qualities which may be eminently serviceable, viewing it as the first food of the young animal. Thus its easy coagulability nay be adapted to the comparatively weak gastric juice of the young animal. Its power of remaining semifluid, and of resisting change may adapt a part of it to the intestines, to promote the removal of the meconium; whilst its concentration as nutritive matter may permit it to fulfil the same office for the young mammal as the food-yolk for the oviparous vertebrate. According to Beruard, ${ }^{2}$ the Colostrum of the Human female contains a very large quantity of albumen, since it coagulates en masse when it is heated. At a later period none can be discovered by this method; but if sulphate of magnesia be added, all the casein and the butter will be thrown down, and on filtration will be left on the filter with the sulphate of magnesia; the filtrate will then contain the albumen and the sugar of milk, and will coagulate on heat. All the larger globules of nil may be removed by repeated filtration; and the fluid is then nearly transparent. This, in fact, is the simplest way of separating the oleaginous from the other constituents of the milk; as but little casein then adheres to the former. The transparent fluid, which has passed through the filter, contains nearly the whole amount of the casein of the milk; but even in this fluid there are found globules too minute to be kept back by the filter, whose chemical reactions mark them as oleaginous.

813. We shall now consider the chemical characters of each of the foregoing ingredients.-The Oleaginous matter of milk principally consists of the ordinary components of fat; but it also contains another substance peculiar to it, designated as butyrin, to which the peculiar smell and taste of butter are due; this yields in saponification three volatile acids, of strong animal odor, to which Chevreul has given the names of butyric, caproic, and capric acids. These peculiar acids are not only formed when the butyrin is treater with alkalies; but are produced by the ordinary decomposition of this principle, which is favored by tine and moderate warmth. The Casein of Human milk, however, by sone chemists regarded as only a combination of albumen with soda, is usually said to be much less precipitable by acids than is that of the Cow; very commonly resisting the action of the mineral acids, and even that of the acetic; but being always coagulated by remnet, though the curd is long in collecting. On this point, however, there has been much discremancy of statement, on which the experiments of Mr. Moore ${ }^{3}$ throw some light. It appears from the results obtained by him, that Human Milk forms with most acids two sets of compounds, one of them soluble in water, the other insoluble; the latter being formed only when the quantity of acid is large in proportion to the casein. Thus, when two fluid ounces of Cow's milk were boiled with a single drop of nitric acid, complete coagulation of the casein at once took place; but when two fluid drachms of Hunan milk were treated in the sane manner, no coagulation occurred, though the casein was at once thrown down by a solution of ferrocyanide of potassium ; the same quantity of milk, with five drops of the acid, formed a coagulum which was not very manifest until after the lapse of five hours, but was very complete, the serous fluid not being found to contain any casein by testing it with ferrocyanide of potassium; and it required ten drops of nitric acid to produce

1 Physiological Researehes, by J. Dary, M. D., F.R.S., 1863, p. 141.

2 l.ę̧ons, vol. ii, 1859 , p. 224.

3 Dublin Quart. Journ, of Med. Sci., vol. vii, p, 280. 
immediate coagulation. The quantity of acid necessary to produce coagulaticn sufficiently rapid to be immediately visible, will vary with the anount of easein present in the particular specimen of milk, 5 drops in some instances producing a coagulation as rapid as that produced by 10 drops in others. In no specimen did Mr. MIoore fail to produce coagulation by adding a sufficiency of acid. Acetic acid without heat produces in Human milk a slow separation of soft flaky coagula; but when heat is employed, a more perfect coagulation is produced by small, than by large quantities of this acid. Rennet does not seem to act upon the casein of Human milk, unless an acid be also present. In several of these particulars, as well as in its small proportional amount, the Casein of $\mathrm{A} s \mathrm{~s}$ 's milk bears a closer resemblance to that of Human milk than does that of the Cow.-The Sugar of Wilk, which may be obtained by evaporating whey to the consistence of a syrup, and then setting it aside to crystallize, forms four-sided prisms, whose composition is $\mathrm{C} 24, \mathrm{H} 19, \mathrm{O} 19+5 \mathrm{HO}$. In many of its properties it bears a close resemblance to Glucose or Grape sugar, into which it is readily converted by the agency of dilute sulphuric or hydrochloric acid, or by the acetic or citric acids. It is readily made to pass into the lactic and butyric fermentation, by the appropriate fements; but is with difficulty brought to undergo the vinous fermentation.-The Saline matter contained in milk, ap. pears to be nearly identical with that of the blood; with a larger proportion of the phosphates of lime and magnesia, which amount to 2 or $2 \frac{1}{2}$ parts in 1000. These phosphates are held in solution chiefly by the casein, which seems to have a power of combining with them even greater than that of albumen: the presence of a minute proportion of free alkali also assists their solution. A small portion of iron in the state of phosphate, together with the chlorides of potassium and sodium, may also be detected in milk. ${ }^{1}$

814. The proportion of these different constituents is liable to great variation, from several causes. Thus, the whole amount of the solid constituents may vary from 86 to 138.6 parts in 1000 ; the difference being partly due to invidual constitution, but in great part also to the amount and character of the ingesta. The average seems to be between 100 and 120 parts. The following table ${ }^{2}$ will serve to indicate the usual composition, as well as the ordinary variations occurring in Human milk:

\begin{tabular}{|c|c|c|c|c|c|c|c|}
\hline & $\begin{array}{l}\text { Joly } \\
\text { and } \\
\text { Filhol. }\end{array}$ & Bödecker. & Griffith. & Doyère. & Simon. & $\begin{array}{c}\text { Henry } \\
\text { and } \\
\text { chevallier. }\end{array}$ & Brunner." \\
\hline Water, & .874 .6 & 882.2 & 875.00 & 873.8 & $861.8-914.0$ & 879.5 & 900 \\
\hline Sugar of Milk, . & . 68 & $6+.6$ & 6176 & 70.0 & $39.2-62.4$ & 65.0 & 62.0 \\
\hline Fat, . . . . & . 47.5 & 31.0 & 25.41 & $3 \circ .8$ & $8.0-54.0$ & 35.5 & 17.3 \\
\hline Albumen, Casein, etc. & . 9.8 & 19.0 & 12.68 & 16.4 & $19.6-45.0$ & 15.2 & 6.3 \\
\hline Salts, .... & . 11 & 3.3 & 1.55 & 1.8 & $1.6-2.7$ & 4.5 & $\mathbf{1 4 . 0}$ \\
\hline
\end{tabular}

Sehukowsky ${ }^{5}$ gives 30 per 100 as the average proportion of oleaginous matters in the milk of Russian women. Milk contains about' 3 per cent. of its volume of Gas, having a percentage composition of 55.15 of Carbonic acid, 40.56 of Nitrogen, and 4.29 of Oxygen. It further appears from the analyses of Simon, that the proportion of the different ingredients is liable to variation according to the time which has elapsed since parturition. The quantity of Casein is at its minimum at the commencenent of lactation, and then gradually rises until it attains a nearly fixed proportion. The

1 Haidlen in Annalen der Chemie und Pharmacie, Bd. xlv, p. 1ti3.

2 Canstatt's Jahresbericht, $1860 . \quad 3$ Henle and Meissner's Bericht, 1857, p. 329.

4 Brunner, Pflüger's Archiv, Bd. vii, 1873, p. 421.

5 Pflüger's Archiv, 1874, Bd. viii, p. 597. See also Lowit for a comparison of the results obtained by analyzing nulk un the several ways recommended by 'Trummer, Hoppe-Seyler, and Schukowsky, in Pflüger's Archiv, 1874, Bd. ix, p. 65. 
quantity of Sigar, on the contrary, is at its maximum at first, and gradually diminishes. The amount of Butter (as appears from the wide extremes shown in the above tables) is more variable than that of any other constituent.-That some of the variations, moreover, are due to the character of the ingesta, and others to the external temperature, amount of exercise, and other circumstances affecting the individual, is proved by the inquiries of Dr. Playfair upon the Milk of the Cow. He has shown that the amount of butter depends in part upon the quantity of oily matter in the food, and in part upon the amount of exercise which the animal takes and the warmth of the atmosphere in which it is kept: exercise and cold by increasing the respiration, eliminate part of the oily matter in the form of carbonic acid and water; whilst rest and warmth, by diminishing this drain, favor its passage into the milk. The proportion of Casein, on the other hand, is increased by exercise. Dr. Playfair's experience on this head seems to correspond with the results of common observation in Switzerland; for where the cattle pasture in very exposed situations, and are obliged to use a great deal of muscular exertion, the quantity of butter yielded by them is very small, whilst the cheese is in unusually large proportion; but these same cattle, when stall-fed, give a large quantity of butter and very little cheese. It is quite possible, moreover, that particular breeds of cattle may yield milk of a richer quality than others. Thus Vernois and Becquerel ${ }^{1}$ found that Tyrolese, Dutch, and Swiss cows give milk containing from 7 to nearly 10 per cent. of butter, with much casein and albumen; whilst the cows in the immediate neighborhood of Paris furnished a poor milk, containing only 3.6 or 3.7 per cent. of butter, and little casein. The total amount of solid matter in the milk diminishes with age, being most abundant in nursing women of from 15 to 20 years, and smallest in those of from 35 to 40 years of age.

815. The change which naturally takes place from the condition of Colostrum to that of true Milk, during the first week of lactation, is a very important one. The Colostrum has a purgative effect upon the child, which is very useful in clearing its bowels of the meconium that loads them at birth; and thus the necessity of any other purgative is generally superseded. Occasionally, however, the colostric character is retained by the milk during an abnormally long period; and the health of the infant is then severely affected. It is important to know that this may occur, even though the milk may present all the usual appearances of the healthy secretion; but the microscope at once detects the difference. ${ }^{2}$ The return to the character of the early milk, which has been stated to take place after the expiration of about twelve months, seems to indicate that Nature designs the secretion no longer to be encouraged; the mother's milk cannot then be so nutritious to the child as other food $;^{3}$ and every medical man is familiar with the injurious consequences to which she renclers herself liable, by unduly prolonging lactation." Cases are not unfrequent, however, in which the secretion continues as long as there is a demand for it; and sometimes quite independently of this. It is the habit among some nations, to suckle the children until they are three or four years old, and to continue doing so even though another

1 L'Union Médicale, xi, No. 26.

2 See Donné, Du Lait, en particulier celui des Nourrices, and Brit. and For. Med. Review, vol. vi, p 181.

3 On the whole subject of Infant Nutrition, the Author would strongly recommend the excellent little work of Dr. A. Combe, formerly referred to.

4 (One of these, which has partieularly fallen under the Author's notiee, is debility of the retina, sometimes proceeding to complete anum rosis; this, if treated in time, is most commonly relieved by discontinuance of laetation, generous diet, and quinine. 
pregnancy should supervene ${ }^{1}$ so that the older child is only displacel by the arrivial of another infant. And it scems to be chiefly amoug those who lave thus forced the mammary gland into a state of unnaturally persistent activity, that the spontaneous and irrepressible flow continues, after the demand for it las ceased. ${ }^{2}$

816. It is very interesting to observe that Milk contains the three classes of principles which are required for human food, the Albuminous, the Oleaginous, and the Saccharine; and it is the only secreted fluid in which these all exist to any considerable amount. It is, therefore, the food most perfectly adapted for the young animal; and is the only single article supplied by nature, in which such a combination exists. Our artificial combinations will be suitable to replace it, just in proportion as they imitate its character; but in none of them can we advantageously dispensc with milk, under some form or other. It should be remembered that the Saline ingredients of milk, especially the phosphates of lime, magnesia, and iron, have a very important function in the nutrition of the infant, affording the material for the consolidation of its bones and for the production of its red blood-corpuscles; and any fluid substituted for milk, which does not contain these, is deficient in essential constituents. It is very justly remarked by Dr. Rees, ${ }^{3}$ that, of all the secreted fluids, Milk is most nearly allied in its composition to Blood.

817. The proportion of the different ingredients in the Milk of different animals, is subject to considerable variation; and this fact is of much practical importance in guiding our selection, when good Human milk cannot be conveniently obtained for the nourishment of an infant. The first point to be inquired into, is the quantity of solid matter contained in each kind; this may be determined either by evaporation, or by the specific gravity of the fluid. The specific gravity of Human Milk is stated by Dr. Rees (loc. cit.) to vary between 1030 and 1025 ; others, however, have estimated it much lower. That of the cow appears to be usually about the same; that of the cream, however, being 1024, and that of the skimmed milk about 103.5. The variation will in part depend (as in the case of the urine) upon the quantity of fluid ingested, and in part, it is probable, upon the manner in which the milk is drawn; for it is well known to milkers, that the last milk they obtain is much richer than that with which the udder is distended at the commencement. The quantity of solid matter obtainable from Cow's Milk by evaporation, seems to be usually considerably greater than that yielded by Human Milk; and there is also a considerable difference in the relative proportions of their ingredients, there being far more casein and less sugar in the milk of the Cow, than in that of the Human female. The following table exhibits the a verage proportions of the different ingredients, in the Milk of various animals frons which that fluid is commonly obtained; these proportions, however, are liable to wide variations:

1 See Erman's Travels in Siberia (translated by Cooley), vol ii, p. 527; and the Narrative of the United States Expedition, vol, ii, p. 138

2 Thus Dr. Green has publislied (New York Journ. of Jed. and Surg., Sept. 1844) the case of a lady, w. 47, the mother of four ehildren, who had un abundant supply of milk for twenty-seven years previously. A period of exuetly four years and a half occurred between each birth; and the ehildren were permitted to take the breast until they were running about at play. At the time when Dr. Green wrote, she had been nine years a widow, and was obliged to bave her breasts drawn daly, the seeretion of milk being so eopious.

3 Cyelopedia of Anatomy and Physiology, Art. Milk. 


\begin{tabular}{|c|c|c|c|c|c|c|c|}
\hline & & $\begin{array}{l}\text { Woman. } \\
\text { (Simon.) }\end{array}$ & $\begin{array}{c}\text { Cow. } \\
\text { (Simon.) }\end{array}$ & $\begin{array}{c}\text { Goat. } \\
\text { (Chevallier.) }\end{array}$ & $\begin{array}{c}\text { Sheep. } \\
\text { (Chevallier.) }\end{array}$ & $\begin{array}{c}\text { Ass. } \\
\text { (Simon.) }\end{array}$ & $\begin{array}{c}\text { Mare. } \\
\text { (Luiscius.) }\end{array}$ \\
\hline Water, & . & . 890 & 860 & 868 & 856 & 907 & 888 \\
\hline Sulics, & - & . 110 & 140 & 132 & 144 & 95 & 112 \\
\hline Butter, & . & $\overline{25}$ & 38 & 33 & 42 & 12 & 8 \\
\hline Cascin, & . & 35 & 68 & 40 & 45 & 16 & 16 \\
\hline Sugar and & Extructiv & 48 & 30 & 58 & 50 & 65 & 17. \\
\hline Fixed Salt & $\mathrm{ts}, \quad$. & 2 & 6 & 6 & 7 & & 88 \\
\hline
\end{tabular}

It appears from this, that, whilst the milks of the Cow, Goat, and Sheep have a general correspondence with each other, those of the Ass and Mare are fluids of very dissimilar character, containing a comparatively small proportion of casein, and still less butter, but abounding in sugar. Henee it is that they are mueh more disposed to ferment than other milk; indeed the sugar of Mare's milk is so abundant, that the Tartars prepare from it a spirituous liquor, to which they give the name of koumiss. Although no milk more nearly approaches that of the Human female, in the proportion of its ingredients, than that of the Goat, its casein forms a peculiarly dense curd, which does not suit the stomach of the infant; besides which, the milk is tainted with the peeuliar odor of the animal, whiel is more intense if the individual be dark-eolored. The milk of the Ass, though differing in the proportion of its ingredients, seems to bear a closer approximation in properties ( $\$ 813)$. The milk of the Cow will usually answer very well for the food of the infant, if care be taken to dilute it properly, according to the age of the ehild, and to add a little sugar. Where there is an apprehension of an early failure in the supply of Milk, the Author has found it alvantageous to eommence feeding the Infant once a day with this mixture, soun after the first month; the number of its meals may be progressively increased, until it beeomes entirely independent of its parent, witlout any abrupt transition; and at the same time the proportion of water and of sugar may be diminished, in aecordance with the natural change whieh takes place in the milk of the mother during the progress of lactation $(\S 812)$.

818. From what has been stated of the elose correspondence between the elements of the Blow and those of the Milk, it is evident that we can scarcely expect to trace the existence of the latter, as such, in the circulating fluid. To what degree the change in which their elaboration consists, is accomplished in the Manmary gland, or during the course of the cireulation, there is no certain means of aseertaining. It is evident that the seeretion camnot serve as the channel for the deportation of any element, the accumulation of which would be injurious to the system; since it does not oceur in the Male at all, and is present in the Female at particular times only. Yet there is reason to believe that if, whilst the process is going on, it be suddenly ehecked, the retention of the material in the blood, or the reabsorption of the seereted fluid, is attended with injurious consequenees. Thus if, when the milk is first secreted, the child be not put to the breast, an accunulation takes place, which, if not relieved, oceasions great general disturbanee of the system. 'The narrowness of the orifiees of the milk-tubes obstruets the spontaneoms exit of the fluid, especially in mimipara; the reservoirs and ducts beeome loaded; further secretion is prevented; and a state of eongestion of the vessels of the gland, tending to inflammation, is induced. 'The accompanying fever is partly due, no doubt, to the local disturbance; but in part also, there seems reason to believe, to the reabsorption of the milk into the hlond; this eannot but be injurious, since, although but little altered, the constitution of milk is essentially different, especially in regard 
to the quantity of crystallizable matter (sugar) which it contains.-Cases of the vicurious secretion of nilk are not numerous; and in no instance is there any proof that the elements of the fluid were pre-existent in the blood. Some of the most curious are those in which it has been poured out from a gland in the groin; but it is probable that this was in consequence of the existence of a real repetition, in that place, of the true mammary structure; this being the situation of the mammx in many of the inferior animals, of which the homologues in man are usually undeveloped. ${ }^{1}$

819. Of the quantity of Milk ordinarily secreted by a good Nurse, it is difficult to form a correct estimate ${ }^{2}$ since the amount which can be artificially drawn, affords no criterion of that which is secreted at the time of the "draught" (\$ 722). The quantity which can be squeezed from either breast at any one time, and which, therefore, must have been contained in its tubes and reservoirs, is about two ounces. The amount secreted is greatly influenced by the mental and physical condition of the female, and also by the quantity and character of the ingesta. In regard to the influence of the mental state upon this secretion, ample details have already been given (\$s 722, 790). With respect to the physical state most favorable to the production of an abundant supply of this important fluid, it may be stated generally, that sound health, a vigorous but not plethoric constitution, regular habits, moderate but not fatiguing exercise, and an adequate but not excessive amount of nutritious food, furnish the conditions most required. It is seldom that stimulating liquors, which are so commonly indulged in, are anything but prejudieial; and even where, as sometimes unquestionably happens, an improvement in the condition both of mother and infant is the immediate result of the moderate employment of them, it is questionable

1 The following is a more unequivocal case of vicarious secretion; and it is peculiarly interesting as exhibiting the injurious affects of the reabsorption of the secretion, and the relief which the sy:ten experienced whon it was separated from the blood by the new channel. " $\Lambda$ lady with a delicate constitution (with a predisposition to juleum(nia) was prevented from suckling her child, as she desired, by the folluwing circumstance. Soon aft $r$ her delivery she had a severe fever, during which her breasts hecame very large and hard; the nipples were swollen and firm; and there was cvidently an abundant secretion of milk; but neither the sucking of the infunt, nor any artificial means could draw a single drop of fluid from the swollen glands. It was elear that the milk-tubes were closed; and as the breasts continued to grow larger and more painful, purgatives and other means were employed to check the secretion of milk. After three days the fever somewhat diminished. and was replaced by a constarit cough, which was at first dry, but sonn after was followed by the expectoration of simple mucus. After this, the cough diminished in severity, and the expectoration became casy ; but the sputa were no longer mncous, but were commised of a liquid, which had all the physical chatracters of genuine nulk. 'This continued for fiftecn days; the quantity of milk expectorated amounting to thrce ounces or more in the twenty-four hours. The breasts aradually diminislied in size; and by the time that the expectoration ceased, they had regained their natural dimensions. The same complete obstarle to the flow of milk from the nipples recurred ufter the births of four children successively, with the same sequelse Aitor thesixth, she had the same symptoms of fever, but this time they were not followed by bronchitis or the expectoration of milk; she had in their stead copious sweiting =, which, with other severe symptoms, reduced her to a cachectic state, and trrminated fatally in a fortnight." (Bulletino delle Scienze Mediche, April, 1839; and Brit. and For. Med. Review, Jan. 1810.)

2 For an estmate by M. Guillot, founded on the comparative weight of the Infant before and after lactation, see L'Union Médicale, 18.52, No. 16. The total amount cminsidred by IIons. Guillot to be ustally drawn in the twenty-four hours, varies from $32 \mathrm{oz}$. to $64 \mathrm{oz}$. (apoth.); but his estimates are vitiated by the extraordinary frequency of the lactations observed, the infunt being put to the breast from 25 to 30 times in the twenty-four hours. 
whether the remote effect is not of a reverse nature. ${ }^{1}$ Their modus operandi, when they are really benefieial, seems to lie in promoting the digestive process, and in thus aiding in the appropriation of those nutritive materials which eonstitute the real source of the solid constituents of the milk.

820. The influence of various Medieines upon the milk is another important question, which has not yet been sufficiently investigated. As a general rule, it appears that most soluble saline eompounds pass into the milk as into other secretions; but there are many exceptions. Common salt, the sesquicarbonate of soda, sulphate of soda, iodide of potassium, oxide of zine, trisnitrate of bismuth, and sesquioxide of iron, ${ }^{2}$ have been readily detected in the milk, when these substances were experimentally administered to an Ass; and ordinary experience shows that the Human infant is affeeted by many of these when they are administered to the mother. The influence of mereurial medicines taken by the mother, in removing from the infant a syphilitic taint possessed by both, is also well known. The vegetable purgatives, especially castor oil, senna, and colocynth, have little effect upon the milk; hence they are to be preferred to the saline aperients, when it is not desired to act upon the bowels of the ehild.

\section{CHA PTER XIX.}

OF THE DIFFERENT BRANCHES OF THE HUMAN FAMILY, AND THEIR MUTUAL RELATIONS.

\section{General Considerations.}

821. Ox taking a general survey of the Human race, it is natural, in the first place, that we shonld proeed to inquire into the evidenee at present possessed of its antiquity, and into the physical and social conditions which prevailed in the most remote periods of which any information ean be acquired; and secondly, that we should endea vor to aseertain whether the origin of the race is attributable to a single pair whose offspring have peopled the earth, or whether there may not have been a plurality of parents or of eentres from which the reniarkably different nations that are now in existence have sprung. The question of the remote Antiquity of Man, though long ago suggested, has only of late years, on account of the numerous facts which seem to lend support to it, awakened a lively spirit of philosophic inquiry. When onr attention has been direeted to it, however, it soon appears that no subject possesses a deeper interest than the relation in which Man stands to the organie world around him--both aninal and vegetable; whether he was originally ereated with his eorporeal powers, and the intellectual faculties to which they minister already developed to their highest extent, and eapable of the greatest results that have been achieved in subsequent times; or whether he is not rither to be regarded as the erown and acme of a long process of development eommeneing with fur simpler organisms, which, under the protracted operation of external agents, and in accordance with the law of continuous descent with modification through nat-

1 See the Author's Physiolngy of Temperanee and Total Abstinenee, ? 208.

2 See Bistrow, On the Passage of Iron in to the Milk, Virchow's Arehiv, xlv, 98. 
ural selection, whereby those animals that are the strongest and best adapted for the special conditions of life present at any time, supplant, and ultimately exterminate the less perfectly constituter, has at length culminater in a creature that even now, howsoever noble in reason and infinite in faculties, yet presents a transitory condition only to some more exalted phase of existence. The facts on which this opinion rests are of various character and weight, and a few only of the more important can here be alluderl to. We have seen that in the earliest stages of the development of the embryo of the Human subject, which in this respect presents a character common to all animals, a single cell is alone discoverable; this receiving an accession of energy from the spermt-cell, and being placed under favorable conditious for the acquisition of the materials requisite for growth, soou undergoes subdivision; and in the cellular mass thus formed a differentation of parts takes place, by which the various organs and tissues of the body are successively evolved. In the higher forms of the animal creation we have further seen, that at certain transitory stages of development a close analogy exists with the permanent conditions of creatures occupying a lower position in the scale; and that, whilst throughout the whole a wonderful unity in the process is clearly discernible, each species presents certain characteristic features which are peculiar to itself. This, it is supposed, may have occurred in the history of the world. A few great types may have becu originally formed, which, in the lapse of ages, owing to the action of external agents, as light, heat, and food, and to the perpetuation of accidental varieties especially adapted to these external conditions, have gradually resulted in the infinitely varied species that now surround us. ${ }^{1}$ With this extraordinary similarity in the process of development throughout the whole animal kingdom, which seems very difficult to account for upon the theory of a separate creation for each species, it cannot be a matter of surprise that close bonds of alliance should be found in the adult period of life cven amongst the most dissimilar creatures. The Birds, for instance, appear to be a singularly well-defined and separate group; yet the rese urches of Mr. Parker ${ }^{2}$ have shown that in their osseous system they possess affinities with every other class of the Vertebrata; so that, whilst presenting the closest analogies to Reptiles, and especially to the Lacertilian group, they anticipate, on the one hand, various Mammalian characters, and on the other recede, as it were, below Reptiles, retaining different Ichthyic points of structure, which are not, as a rule, found in that class. And thus it has ever been found, that the more closely the structure of even the most aberrant forms of auimal life has been investigated, the wider have been the affinities discovered, often explaining what was previously obscure in the structure of others, whilst at the same time the more complete has been the proof that no real isolation of a species, much less of a genus or family, exists. It is indeed probableand this is a point on which $\mathrm{Mr}$. Darwin lays great stress-that were it possible to reprorluce the entire series of forms now become extinct, a regular gradation would be presented from the lowest to the highest; and hence that, as Dr. Hooker has maintained, ${ }^{3}$ we are indebted for our means of resolving plants into limitable geuera aud orders simply to the extinction of the forms by which they were originally connecter. The reason that the intermediate links have not been discovered, is owing essentially to the imperfection of the geological record. Of that great book, comparatively few leaves have

1 For a full exposition of this theory, see Darwin, On the Origin of Species by Means of Natural Selection, etc., 1859.

2 See his paner on the Usteology of the Gallinaceous Birds and Tinnamous, in the Trans. of the Zoulogical Society for Nov. 25th, 1862.

3 Introduction tu the Flura of New Zealand, 1853. 
as yet been deciphered; whilst even under the most favorable circumstances, and with the largest amount of information that can be obtained from this source, it is certain that the softness of the tissues of many animals will have presented an effectual obstacle to their preservation. ${ }^{1}$ It is obvious that if this mode of explanation of the production of species be extended to its utmost limits, we may reach the extreme of simplicity; for it may well be said, that if a few types only are needed, these may again be reduced in number to a greater and still greater degree, until at length we arrive at that which is common to all at some stage of their existence-the single nucleated cell-a structure which comprehends the totality of the life of some animals and vegetables, and is constantly met with as the earliest stage of development of all; whilst the whole superstructure of both kingdoms niay be considered to proceed from a gradual process of development and differentiation of this primary and most simple organization. It is but just to remark, however, that Prof. Owen, one of the best authorities on this subject, has in a recently published work advanced a different explanation of the origin of species. He states ${ }^{2}$ that, "being unable to accept the volitional hypothesis, or that of impulse from within, or the selective force exerterl by outward circumstances," he deems "that a minutc tendency to deviate from parental type operating through periods of adequate duration is the most probable nature, or way of operation, of the secondary law, whereby species have been derived one from the other."

822. By those who embrace the developmental theory, numcrous facts have been recently collected, tending in the first place to prove that Man has existed for many thousands of years upon the face of the earth; and secondly, that the morc remote the period at which he can be proved to have existed, the ruder, more savage and degraded, both in a social and a structural or physical point of view, was his condition. In regard to the former point, very strong evidence has recently been obtained by the discovery of Human remains intermingled with those of extinct animals, as the Manmoth, Cave Bcar, and woolly Rhinoceros, in the breccias of various caverns, as in those of Liége and Eugis; whilst in other instances where no bones have bcen discovered, perhaps in consequence of the practice of burning the dearl, almost equally unexceptional evidence has been obtained from the discovery of works of art fashioned by Human hands, as in the flint implements found buried in the drift at Abbeville in Picardy and at St. Acheul near Amiens, and those found at. Hoxne in Suffolk, and in Brixham Cave near Torquay. ${ }^{3}$ In these instances the geological position of the remains, as well as the circumstance of their being accompanied by the boncs of so many

1 The oeeurrenee of a few cascs where the conditions have been favorable, as in the instance of the Tellina of the Fresh water Chalk Formation of Steinheim mentioned by Oscar Sehmidt (in his. Descendenzlebre, $1873, \mathrm{p} .87$ ), is highly sugrgestive in this print of view. Here the deposit from a small inland lake may be divided into about forty petrographieally distinguishable layers, and throughout the whole series the varieties of Planorbis multiformis are distributed in such a manner that individual layers are eharaeterized as successive strata by the exclusivo oceurrence, or by the predominance of one or more varieties, which within the layer remain constant or slightly variable, but towards the limits of the next layer lead by transition to the suceceding forms. The forms diverge so greatly, and are so constant in the main zones, that in aceorlanee with the old conehological practice they would be $n$. ruservedly elaimed as species, if the eonneeting links were not too eonspieuous and the territory too eircumicribed, and if the geofogical period-which must, however, be reckoner by thousand; of years-were not considered too insignificant. Similar statements may be innde in respeet to the Amminites.

2 Comp. Anat. and Physiol. of Vertebrates, 1860, p. 807.

3 For full informution respecting which, see the Antiquity of Man, by Sir Charles Lyell, 1863. 
extinct aninals, alike point to a remote antiquity. In particular, a very close investigation of those found at Moulin Quignon, near Abbeville, by MI. Boucher de Perthes and others, has been made by Mr. Prestwich, ${ }^{1}$ who has show'n that although some doubts may exist respecting the authenticity of the Human jawbone and some of the flint implements recently discovered there, yet that the genuineness of other flint implements cannot be doubted, and that the age of the gravel beds in which they have been discovered is perfectly well determined as belonging to an early Quatemary or Post-pliocene period, dating before the excavation of the valley of the Somme, and consequently to a period when the physical character of the country wore a very different aspect from that which it now presents.

823. Nor can the circumstance be disregarded, that in the oldest existing monuments, as on those of Amenophis, of Horus, and of Rhameses, ${ }^{2}$ sculpture and painting, amongst the latest of the fine arts in their development, had attained to so high a degree of perfection anongst the Egyptians, that the types of the Human race there depicted may still be referred to as $\mathrm{ex}^{-}$ cellent portraitures of some of the still existing varieties, - the Jew, the Mongol, and the Ethiopian being readily distinguishable. For this indicates, on the one hand, the wonderful permanence of particular types, and so far constitutes an argument against the Specific Unity of Man on the assumption that his duration upon the earth has not exceeded, as ordinarily computed, some 6000 ycars; whilst if we estimate the period occupied in the progress to a high degree of civilization in these old times by the rate at which it has advanced in the history of modern European nations, we find it requisite to armit the lapsc of a much longer period than is usually allowed, and of a long sequence of antecedent generations. In all the nations of Western Europe, in France, in England, in Germany alike, it has taken many centuries to rear the modern fahric of civilization; and the ultimate results obtained by ancient nations, however imperfectly they may be known to us, do not appear to be of so extraordinary a nature as to lead us to attribute to them a superior, if even an equal, neasurc of intellectual endowments with ourselves, nor on that account to admit that their progress in mental culture may have been more rapid. ${ }^{3}$

824. The evidence tending to show that the most ancient races of Man possessed a materially lower type of organization than those at present in existence, is not by any means sufficient to enable any general conclusions to be drawn respecting the truth of the developmental theory, or to show that there have been transitional links between the higher Apes and Man. In the most remarkable cranium yet discovered, that of the Neanderthal, which has been most carefully exanined by Prof. Huxley, the forehead is indeed unusually low and retreating, the supraorbital ridges prominent, and the bones remarkably thick. Yet its cubic capacity does not appear to he materially less than that of many crania that might be selected from modern nations; and hence, as Mr. Huxley adds, the first traces of the primordial stock whence Man has proceeded need no longer be sought by those who entertain any for'm of the doctrine of progressive development in the newest tertiaries, but must be looked for in an epoch more distant from the age of the Elephas primigenius (mammals) than that is from us.

825. Many interesting facts have recently come to light, which, whilst

1 see Phil. Transact, 1860 , p. 277 ; Proc. of the Royal Society, vol. xii, 186i2, n. 38 ; and Quarterly Journal of the Geological Socicty, Nov, 1st, 1863, vol, xix, p. 497.

2 see Sumuel IIorton, Crania Egyptiaca, Philad., 1844; and the works of Champollion and Rosellini: Paul Broca, On the Phenomena of Hybridity in Man, Journal de la Physiol, vol. iii, 1861.

3 Sir Charles Lyell, Antiquity of Man, p. 89. 
furnishing corroborative geological evidence of the antiquity of Man, afford important means of estimating the material and social conditions of his existence in these distant epochs. The most interesting evidence upon these points is derived from the Danish Peat Mosses. These, which are of considerable depth, varying from 30 to 40 feet or more, have been the result of the slow formation of ages; and from the extraordinary preservative power which they possess, have become the receptacles or depositories of a series of objects, from which, by a process of inductive reasoning, the most valuable conclusions can be drawn. On the surface of the soil of Denmark at the present time there flourish magnificent forests of Beech trees, numerous trunks of which are found in the superficial layers of the Peat, mingled with those of other trees, as the Alder, the Aspen, and the Birch. With these are found various instruments constructed of iron, a metal requiring a considerable amount of technical skill in its extraction, partly on account of the chemical processes to which the ores have to be subjected, and partly on account of the extremely high temperature required for its fusion or welding. These tools are accompanied by the skulls of men presenting close analogies to the present Scandinavian type, of whom, indeed, they may be considered as the early ancestors. Below the Beeches, the trunks of Oaks are found, and iron instruments cease to appear, being replaced by those of bronze. Mr. Lubbock ${ }^{1}$ has adduced various considerations to show that these workers in bronze, which is composed of copper and tin, were of Eastern origin, and were perhaps allied to the modern Hindoo, with whom they agreed in the form of the head, in the practice of burning the dead, in their leading a pastoral and agricultural life, as evidenced by the associated remains of sheep, oxen, and pigs, and in using cylindrical as well as cubic dice. Still lower in the Peat the scene once more changes; the trunks of Pines now abound, and with these have been discovered crania belonging to a wholly different race-a race who were ignorant of even the simplest processes of metallurgy, and were only able to fashion, thongh often with great skill and ingenuity, a series of stone or flint instruments-hammer, chisel, saw, adze or dagger-and who were probably a hunting and fishing nation, burying their dead in tumuli or barrows. Additional information has been gained respecting this race, or the races coeval with them, by the investigation of the Swiss Lake Habitations, the piles supporting which have been found in the lakes of Zurich, Constance, and Geneva; and still more by careful exanination of the Danish "Kitchen-middings." In the former the same succession of Iron, Bronze, aind Stone eras appears to have succeeded one another; whilst the latter seem to be refuse heaps, composed of oysters, cockles, nussels, periwinkles, and other molhusca, which have been thrown out around their habitations by men of the Stone period. The crania of this race are small and round, with overhanging eyebrows. The remains of dogs and various wild animals are found in the middings, which, with the canoes, and the bones of deep-sea fish, as the cod and herring, seem to show that this ancient people lived by hunting and fishing.

826. In pursuing the second branch of our inquiry, it is apparent that amongst the various tribes of Men which people the surface of the globe, and which are separated from all other animals by the characters formerly described (chap. ii.) therc are differences of a very striking and important nature. They are distinguishable from cach other, not only by their language, dress, manners and eustons, religious belief, and other acquired peculiaritics, but by the physical conformation of their bodies; and the difference lies not merely in the color of the skin, the nature of the hair, the

I Natural History Review, 1861, p 489. 
form of the soft parts (such as the nose, lips, etc.), but in the shape of the skull and of other parts of the bony skeleton, which might be supposed to be less liable to variation. Now it is clearly a question of great scientific interest, as well as one that considerably affects the mode in which we regard the races that differ from our own, whether they are all of one species,that is, descended from the same or from similar parentage,-or whether ther are to be considered as distinct species, the first parent of the several races having had the same differences among themsel ves as those which are now exhibited by their descendants.

827. In order to arrive at a just conclusion on this subject, it is necessary to take a very extensive survey of the evidence furnished by a number of different lines of inquiry. Thus, in the First place, it is right to investigate what are the diseriminating structural marks, by which species are distinguished among other tribes of animals. - Secondly, it should be ascertained to what extent variation may proceed among races which are historically known to have had a comnon parentage, and what are the circumstances which most favor such variation.-Thirdly, the extreme variations which present themselves among the different races of Men, should be compared with those which occur among tribes of animals known to be of the same parentage; and it should be questioned, at the same time, whether the circumstances which favor the production of varieties in the latter case are in operation in the former.-Fourthly, where it is inpossible to trace back distinct races to their origin, it is to be inquired how far agreement in physiological and psychological peculiarities may be regarded as indicating specific identity, even where a considerable difference exists in bodily conformation; and this test, if it can be determined on, has to be applied to Man.Fifthly, it must be attempted by a detailed examination of the varieties of the Human race themselves, to ascertain whether their differences in confornuation are constant; or whether there are not such occasional manifestations, in each race, of a tendency to assume the characters of others, as to prevent any definite lines being drawn between the several tribes which together make up the (supposed) distinct species.-An investigation so comprehensive could not be followed out, even in the most cursory manuer that would be consistent with utility, within the limits of the present work; and no more will be attempted, therefore, than an indication of the principal points of difference among the several Races of Men, and a statement of the results of inquiry into their degree of constancy in each of the principal groups which they have been thought to mark out. ${ }^{1}$

828. The differential characters on which those have relied who have sought to establish the existence of a plurality of species among Mankind, are both Anatomico-Physiological, and Psychological. Under the former head rank the color of the Skin, the texture of the Hair, and the conformation of the bony Skeleton, especially the Skull. The latter consist in the superiority claimed for some races over others, in Intellectual power, and in Moral aud Religious capacity. The former group will be the one first considered,

829. The Color of the skin exists in the Epidermis only; and it depends

1 The whole of this investigation hus been must elaborately, and in the. Anthor's opinion most successfully worked out by Dr. Prichara, in his profound and philo. sophical Treatise on the Physical History of $\mathrm{M}$ an. For a more concise view of Dr. Prichard's argument, with some additional considerations not embraced in it, the Author maty refer to his own article on the Varieties of the Human Species, in the Cyclop. of Anat. and Phys., vol. iv.-See also Dr. R. G. Latham's Natural History of the Varieties of Man; and his shorter Essuy on the Varieties of the Human Species, in Orr's Circle of the Sciences, vol. i. 
upon the admixture of pigment cells with the ordinary epidermic-cells; all the varied hues presenterl by the different races of men being due to the relative amount of these cells and to the particular tint of the pigment which they form. It would be easy, by selecting well-marked specimens of each race, to make it appear that color affords a character sufficiently distinctive for their separation ; thus, for example, the fair and ruddy Saxon, the jetblack Negro, the olive Mongolian, and the copper-colored North American, might be considered to be positively separated from each other by this character,- - propagated, as it seems to be, with little or no perceptible change, from generation to generation. But although such might appear to be the clear and obvious result of a comparison of this kind, yet a more careful and comprehensive survey tends to break down the barrier that would be thus established. For, on tracing this character through the entire family of Man, we find the isolated specimens just noticed to be connected by such a series of links, and the transition from one to the other to be so very grarlual, that it is impossible to say where the lines are to be drawn between them. There is nothing here, then, which at all approaches to those fixed and definite marks, that are always held to be requisite for the establishment of specific distinctions among other tribes of animals.

830. But further, there is abundant evidence that these distinctions are far from being constantly maintained, even in any one race. For among all the principal subdivisions, albinoism, or the absence of pigment-cells, occasionally presents itself; so that the fair skin of the European may present itself in the offspring of the Negro or of the Red man. ${ }^{1}$ On the other hand, instances are by no means rare of the unusual developinent of pigment-cells in individuals of the fair-skinned races; so that parts of the body are of a dark-red or brown hue, or even quite black. Such modifications may seem of little importance to the argument; since they are confined to individuals, and may be put aside as accidental. But there is ample evidence that analogous changes may take place in the course of time, which tend to produce a great variety of shades of color, in the descendants of any one stock. Thus, in the great Indo-European family (part of the Cancusian race of Blumenbach), which may be unquestionably regarded as having had a common origin, we find tribes with fair complexion, yellow hair, and blue eyes,-others presenting the xanthous or olive hue,-and others decidedly black. A similar diversity may be seen anong the American races, which are equally referable to one common stock; and it exists to nearly the same

I A very curious example of change of color in a Negro has been recorded on unquestionable authority. - The suliject of it was a negro slave in Kentucky, aet. 45, who was born of black parents, and was himself perfectly black until 12 years of ace. A that time a portion of the skin, an inch wide, encircling the cranium just within the edge of the hair, gradually changed to white; also the hair oceupying that heality. A white spot next alpeared near the inner canthus of the left eye; and from this the white color gradually extended over the face, trunk, and extremities, until it covered the entire surface. The eomplete change from black to white occupied about ten years; and but for his hair, which was erisped or woolly, no one would have supjosed at this time that his progenitors had offered any of the characteristics of the Negro, his skin presenting the healthy vascular appealance of that of a fair-compleximed European. When he was about 22 years of age, however, dark coppercolored or brown spots liegan to appear on the face and hands; but these have remained limited to the portions of the surface exposed to light. About the time that the black color of his skin began to disapprear, he completely lost his sense of smell ( $\& 603$, note); and since he has become white, he has had measles and hooping-cough aseond time. (See Dr. Hutehinson's account of this ease, in the Ainer. Journ. of Med. Sci.. Jan. 1852) A case of partial disappearance of the black color of the

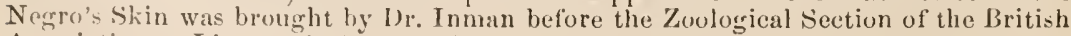
$\Lambda$ ssociation at Liverjoul, Sept. 1854. 
extent among the African nations, which appear to be similarly related to each other.' It may be freely admitted that, among European colonists settled in hot climates, such changes do not present themselves within a few generations; but in many well-known instances of earlier colonization, they are very clearly manifested. Thus the wide dispersion of the Jewish nation, and their remarkable isolation (maintained by their religious observances) from the people among whom they live, render them peculiarly appropriate subjects for such observations; and we accordingly find that the brunette complexion and dark hair, which are usually regarded as characteristic of that race, are frequently superseded, in the Jews of Northern Europe, by red or brown hair and fair complexion; whilst the Jews who settled in India some centuries ago, have beconne as dark as the Hindoos around them.

831. The relation of the complexions of the different Races of Mankind to the climates they respectively inhabit, which is established by an extended comparative survey of both, leads to the general conclusion that the intertropical region of the earth is the principal seat of the darkest races, whilst the region remote from the tropics is that of the fairer races; and that the climates approaching the tropics are generally inhabited by nations which are of an intermediate complexion. It is important to observe, however, that no regular gradation of tint can be observed in passing from the equatorial to the polar regions. MI. Paul Broca ${ }^{1}$ has particularly pointed out that the Esquimanx of Greenland, the Lapps and Finns of Europe, and the Samoyedes and Kamschatkans of Asia, all of them nations inhabiting the most northern regions of the habitable globe, present a deep olive complexion, dark straight hair, and dark eyes; being considerably deeper in the than the Chinese, Burmese, Cochin-Chinese, and Malays, although these are situated so much nearer the equator, and are exposed to the rays of a far fiercer sun. The same conclusion is forced upon us by a survey of the various nations inhabiting the western shores of America ; for if we trace them in succession from Behring's Straits to Patagonia, we shall find that under the same latitude as Norway there dwells a race whose color is yellowish-brown, mixed with red; under that of England a perfectly white race (Vancouver's Islanders), under that of France a red race (Oregon), under that of Spain and Algeria a black race (California). From thence as far as the equator, under the same latitude as Guinea and Soudan, are races of a merely brown tint, much lighter than the inhabitants of those regions. Lastly, the races which occupy the littoral region extending from the equator to Tierra del Fuego, present a brown tint, becoming lighter as the colder regions are approximater; but are suddenly succeeded, under the rigorous climate of Patagonia, by one or more blackish or altogether black races. To these observations it may be added that high mountains, and countries of great elevation, are generally inhabited by people of a lighter color than are those of which the level is low, such as swampy or sandy plains upon the seacoast. These distinctions are particularly well seen in Africa, where the tropics almost exactly mark out the linits of the black complexior of the inhabitants; and where the deepest hue is to be seen among the Negroes of the Guinea Coast, whose residence unites both the conditions just mentioned, whilst the mountainous regions in their immediate vicinity are inhabited by tribes of a much lighter aspect.

832. The nature of the Hair is perhaps one of the most permanent cliaracteristics of different races, and a division has been established between the

1 In his paper on Hybridity, in M. Brown-Séquard's Journal de la Physiologie for 1858 , p. 462 . See for many analogous instances, $J$. Craufurd, in the Transactions of the Ethnological Society, vol. i, p. 364 . 
Ulotrichi with crisp or woolly hair, and the Leiotrichi with smooth hair. With few exceptions (Andaman Islanders) the Ulotrichi are also dolichocephalous. They are represented by the Negroes and Bushnen of Central and Southern Africa, and the Negritos of the Malay Peniusula and Archipelago, and of the Papuan Islands. The Leiotrichi are divisible into the Australioid group, the Mongoloid group, the Xanthochroic group (Slavonians, Teutons, Scandinavians), and the Melanochroic group (Iberians and black Celts of Western Europe). ${ }^{3}$ In regard to its color the same statements apply as those just made with respect to the color of the skin ; the variety of hue being given by pigment-cells, which may be more or less developed under different circumstances. But it has been thought that its texture affords a more valid ground of distinction; and it is commonly said that the substance which grows on the head of the African races, and of some other dark-colored tribes (chiefly inhabiting tropical climates), is wool and not hair. This, however, is altogether a mistake; for microscopic examination clearly demonstrates that the hair of the Negro has exactly the same structure with that of the European; and that it does not bear any resemblance to wool, save in its crispness and tendency to curl. Moreover, even this character is far from being a constant one; for, whilst Europeans are not unfrequently to be met with, whose hair is nearly as crisp as that of the Negro, there is a great variety amongst the Negro races theniselves, which present every gradation firm a completely crisp (or what is termed woolly) hair, to merely curled or even flowing locks." A similar observation holds good in regard to the natives of the islands of the great Southern Ocean, where some individuals possess crisp hair, whilst others of the same race have it merely curled.

833. It has been supposed that varieties in the configuration of the Skeleton would afford characters for the separation of the Human races, more fixcd and definite than those derived from differences in the form, color, or texture of the soft parts which clothe it; and attention has been particularly directed to the skull and the pelvis, as affording such characters. It has been generally laid down as a fundamental principle, that all those nations which are found to resemble each other in the shape of their heads must needs be more nearly related to each other, than they are to tribes of Men which differ from them in this particular. But if this principle be rigorously carried out, it will tend to bring together races which inhabit parts of the globe very remote from each other, and which have no other mark of affinity whatever; whist, on the other hand, it will often tend to separate races which every other character would lead us to bring together. It is to be remenbered, moreover, that the varieties in the conformation of the skeleton, presented by the breeds of domesticated animals, are at least equal to those which are manifested in the conformation and color of their soft parts; and we might reasonably expect, thereforc, to meet with similar variations annong the Human races. It is probable, however, that climate has not so much influcnce in producing such changes in the configuration of the body, as the peculiar liabits and mole of life of the different races; and Dr. Prichard has pointed out a very remarkable relation of this kind, in regand to the principal types of form presented by the Skull. These differ from each other to such an extcnt, that if the antcro-posterior cliameter be

1 See Huxley, The Anatomy of Vertebrated Animals.

2 It is a very eommon mistake, espeeially in the United States, to consider Negro as s.ruonymous with African. So far is this from being the fact, that, as Dr. Latham justly romarks, "the true Negro area, the aran vecupied by men of the black skin, thick lipe, and woolly hair, is exeredingly small; as small in proportion to the rest of the continent, as the area of the district of the stunted Hyperboreans is in $A$ sia, or that of the Lapps in Europe." (See ? 8351,853 ) 
taken at 100 , the transverse diameter varies from 98 or 99 to 62 . The number expressing the proportion of the transverse to the longitudinal dianeter of the brain-case is termed the cephalic index. Those people who possess crania with a cephalic index of 80 and above are called brachycephali; those with a lower index are dolichocephali. ${ }^{1}$

834. Among the rudest tribes of Men, hunters and savage inhabitants of forests, dependent for their supply of food on the accidental produce of the soil, or on the chase-among whom are the most degraded of the African nations, and the Australian savages-a form of head is prevalent, which is most aptly distinguished by the term prognathous, indicating a prolongation, or forward extension of the jaws (Fig. 371). This character is most strongly marked in the Negroes of the Gold Coast, whose skulls are usually so formed as to give the idea of lateral compression. The temporal muscles have a great extent, rising high on the parietal bones; the cheek-bones project forward, and not outward ; the upper jaw is lengthened and projects forwards, giving a similar projection to the alveolar ridge and to the teeth; and the lower jaw has soniewhat of the same oblique projection, so that the upper and lower incisor teeth are set at an obtuse angle to each other, instead of being nearly in parallel planes, as in the European. Fron the shape of the

FIG. 371.
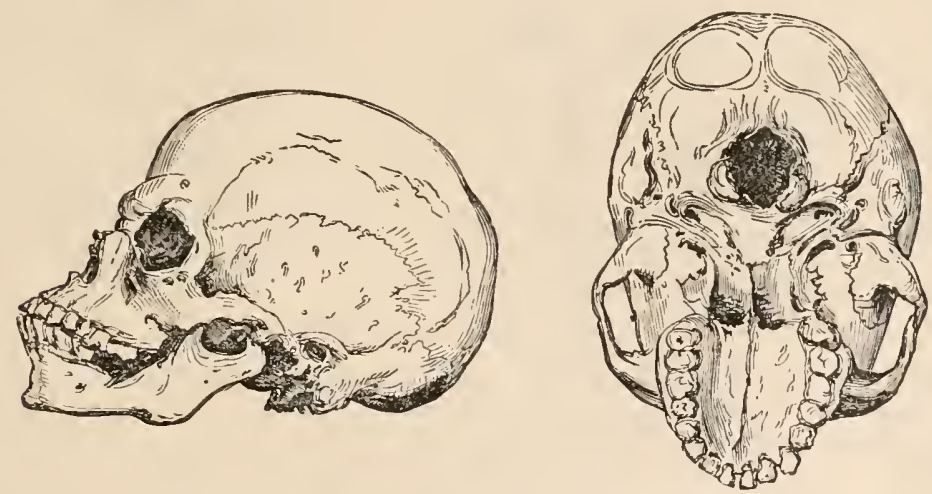

Profile and basal views of the Prognathous Skull of a Negro.

upper jaw alone would result a marked diminution in the fucial angle, measured according to the method of Camper; but this diminution is far from being sufficient to approximate the Ethiopian races to the higher Apes, as some have supposed it to be $(\S 24)$. Independently of the diminution of the facial angle resulting from the projection of the upper jaw, it is quite certain that in the typical prognathous skull there is a want of elevation of the forehead; but it does not appear that there is a corresponding diminution in the capacity of the cranial cavity, the retreating for'm of the forehead being partly due to the general elongation of the skull in the antero-posterior direction. Nor is it true, as stated by some, that the position of the foramen magnum in the Negro is decidedly behind that which it holds in the European, in this respect approaching that of the Apes (\$21); since, if due allowance be made for the projection of the upper jaw, this aperture is found to have the same position in the prognathous skull as in the oval one-namely, exactly behind the transverse line bisecting the antero-posterior diameter of the base of the cranium. 'The prognathous skull is further remarkable for the large development of the parts connected with the organs of sense, especially those

1 Huxley, Anatomy of Vertebrated Animals, p. 495. 
of smell and hearing. The aperture of the nostrils is very wide, and the internal space allowed for the distribution of the olfactory nerve is much latger than in most European heads; the posterior openings of the nasal cavity are not less renarkable for their width, than the anterior. 'The external auditory meatus is also peculiarly wide and spacious; and the orbital cavities have been thought to be of more than ordinary capacity,-Dut this last is by no means a constant character.

835. A second type of cranial conformation, very different from the preceding, belongs principally to the Nomadic races which wander with their herds and flocks over vast plains; and to the tribes which creep along the shores of the Icy Sea, and live partly by fishing, or in part on the flesh of their reindeer. This form, designated by Dr. Prichard as the pyramidal (Fig. 372), is typically exhibited by various nations of Northern and Central Asia; and is seen in an exaggerated degree in the Esquimaux. Its

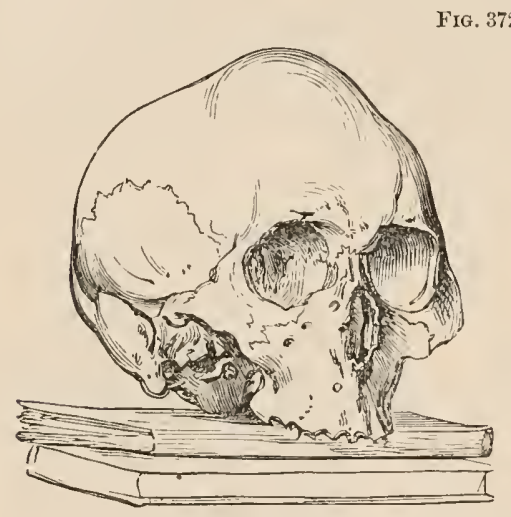

FIG. 372 .

Front and basal views of the Pyramidal Skull of an Esquimaux.

most striking character is the lateral or outward projection of the zygoma, which is due to the form of the malar bones. These do not project forwards and downwards under the eyes, as in the prognathous skull; but take a lateral or outward direction, forming, with the zygomatic process of the

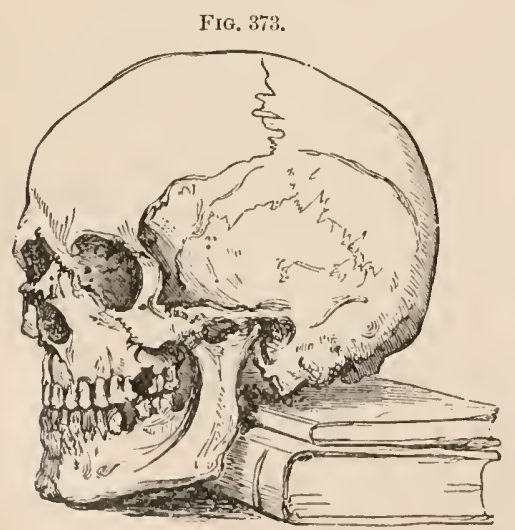

Oval Skull of a European. temporal bone, a large rounded sweep or segment of a circle. From this, in connection with the narrowness of the forehead, it results that lines drawn from the zygonatic arches, tonching the temples on either side, insteal of being parallel (as in Europeans), meet over the forehear, so as to form with the basis a triangular figure. The upper part of the face being remarkably flat, the nose also being flat, and the nasal bones, as well as the space between the eyebrows, heing nearly on the same plane with the cheek-bones, the triangular space bounded by these lines nay be compared to one of the faces of a pyramid. The orbits are large and deep; and the peculiar conformation of the bones which surround it, gives to the aperture of the lids an appear- 
ance of obliquity, - the inner angle seeming to be directed downwards. The whole face instead of prescuting an oval form, as in most Europeans and Africans, is of a lozenge-shape. The greater relative development of the zygomatic bones, and of the bones of the face altogether, when compared with the capacity of the cranium, indicates in the pyramidal skull a more ample extension of the organs subservient to sensation; the same effect being thus produced by lateral expansion, as by the forward extension of the facial bones in the prognathous skulls.

836. The most civilized races, - those which live by agriculture and the arts of cultivated life, - all the most intellectually inprover nations of Europe and Asia,-have a shape of the head which differs from both the preceding, and which may be termed oval or elliptical. This at once approves itself as a more symmetrical form; no part having an excessive proninence; whilst, on the other hand, there is nowhere an appearance of undue flattening or compression. The liead is altogether of a rounder shape than in the other varieties, and the forehead is more expanded; while the maxillary bones and the zygomatic arches are so formed as to give the face an oval shape, nearly on a plane with the forehead and cheek-bones, and not projecting towards the lower part. Owing to the more perpendicular direction of the alveolar processes, the front teeth are fixed in planes which are nearly or quite parallel to each other. The principal features in this form of craniun are those of a negative character; the chief positive distinction is the large development of the cranial cavity, and especially the fulness and elevation of the forehead, in proportion to the size of the face: indicating the predominance of the intellectual powers over those merely instinctive propensities which are more directly connecterl with sensations. Among European nations, the Greeks have probably displayed the greatest symmetry and perfection in the form of the head; but various departures may be traced towards the preceding forms, when we compare the crania of different races, and even of individuals, belonging to the same stock, - some approaching the pyramidal form of the Northern Asiatics, whilst others approximate to the prognathous type of the Negro.

837. The influence of habits of life, continued from generation to generation, upon the form of the head, is remarkably evinced by the transition from one type to another, which may be observed in nations that have undergone a change in their manners and customs, and have made an advance in civilization. Thus, to mention but one instance, the Turks at present inhabiting the Ottoman and Persian empires, are undoubtedly descended from the same stock with those Nomadic races which are still spread through Central Asia $(\S 849)$. The former, however, having conquered the countries which they now inhabit, eight centuries since, have gradually settled down to the fixed and regular habits of the Indo-European race, and have made corresponding advances in civilization; whilst the latter have continued their wandering mode of life, and can scarcely be said to have made any decided advance during the same interval. Now the long-since civilized Turks have undergone a complete transformation into the likeness of Europeans; whilst their nomadic relatives retain the pyramidal configuration of the skull in a very marked degree. Some have attributed this change in the physical structure of the Turkish race to the introduction of Circassian slaves into the harems of the Turks; but this could only affect the opulent and powerful amongst the race; and the great mass of the Turkish population have always intermarried among themselves. The difference of religion and nianners must have kept them separate from those Greeks whom they subdued in the new Ottoman countries; as in Persia, the Tajiks, or real Persians, still remain quite distinct from their Turkish rulers, 
belonging to a different sect among the Mussulmans, and commonly living apart from them.- In like manner, even the Negro head and face may become assimilated to the European, by long subjection to similar influences; thus, in some of our older West Indian Colonies, it is not uncommon to meet with Negroes, the descendants of those first introduced there, who exhibit a very European physiognomy; and it has even been asserted that a Negro belonging to the Dutch portion of Guiana may be distinguished from another belonging to the British settlements, by the similarity of the features and expression of each to those which respectively characterize his masters. The effect could not be here produced by the intermixture of bloods, since this would be made apparent by alteration of color.-But not only may the pyramidal and prognathous types be elevated towards the elliptical; the elliptical may be degraded towards either of these. Want, squalor, and ignorance have a special tendency to induce that diminution of the cranial portion of the skull, and that increase of the facial, which characterize the prognathous type ; as cannot but be observed by any one who takes an accurate and candid survey of the condition of the most degrarled part of the population of the great towns of this country, but as is seen to be pre-eminently the case with regard to the lowest classes of Irish immigrants. ${ }^{1} \quad A$ certain degree of retrogression to the pyramidal type, is also to be noticed among the nomadic tribes which are to be found in every civilized community. Among these, as has been remarked by a very acute observer, ${ }^{2}$ "According as they partake more or less of the purely vagabond nature, doing nothing whatsoever for their living, but moving from place to place, preying on the earnings of the more industrious portion of the community, so will the attributes of the nomarle races be found more or less marked in them; and they are all more or less distinguished for their high cheek-bones and protruding jaws;" thus showing that kind of mixture of the pyramidal with the prognathous type, which is to be seen among the lowest of the Indian and Malayo-Polynesian race.

838. Next to the characters derived from the form of the head, those which are founder upon the form of the pelvis seem entitled to rank. These have been particularly examined by Professors Vrolik and Weber. The former was led by his examiuations of this part of the skeleton, to consider that the pelvis of the Negress, and still more that of the female Hottentot, approximates to that of the Simix in its general configuration; especially in its length and narrowness, - the iliac bones having a more vertical position, so that the anterior spines approach one another much more closely than they do in the European; and the sacrum also being longer and narrower. On the other hand, Prof. Weber ${ }^{3}$ concludes, from a more comprehensive survey, that no particular figure is a permanent characteristic of any one race. He groups the principal varieties which he has met with, according to the form of the upper opening into oval, round, four-sided, and wergeshaped. The first of these is most frequent in the European races; the second, among the American races; the thirl, most common among the Mongolian nations, corresponds renarkably with their form of head; whilst the last chiefly occurs among the races of ' $\dot{A}$ frica, and is in like manner conformable with the oblong compressed form usually presenterl by their cranium. But although there are particular shapes which are most prevalent in each race, yet there are numerous individual deviations, of such a nature that every variety of form presents itself oceasionally in any given race.

1 See the Dublin University Ingaine, No. xlviii,

2 Mr. Henry Mahew, in London Labor and the London Poor, p. 2.

3 Die Lahre von din Ur- und Riacenformen der Schatedel und Becken des Menschen; Düsseldorf, 1830. 
839. Other variations have been observed by anatonists, between the different races of Mankind, in the relative length of the bones, and in the shape of the limbs; but these also seem to have reference to the degree of civilization, and to the regularity of the supply of wholesome nutriment. It is generally to be observed that the races least improved by civilization, like the uncultivated breeds of animals, have slender, lean, and elongated limbs ; this may be especially remarked in the natives of Australia. In nearly all the less civilized races of Men, the limbs are more crooked and badly-former than the average of those of Europeans; and this is particularly the case in the Negro, the bones of whose legs bow outwards, and whose feet are remarkably flat. It has been generally believed that the length of the forearm in the Negro is so much greater than in the European, as to constitute a real character of approximation to the Apes. The difference, however, is in reality extremely slight, and is not at all comparable with that which exists between the most uncultivated races of Men and in the lighest Apes $(\$ 27)$. And in regard to all the peculiarities here alluded to, it is to be observed that they can only be discovered by the comparison of large numbers of one race with corresponding numbers of another; for individuals are found in every tribe, possessing the characters which distinguish the majority of the other race. Such peculiarities, therefore, are totally useless as the foundation of specific characters; being simply variations from the ordinary type, resulting from causes which might affect the entire race as well as individuals.-The connection between the general form of the boly, on the one hand, and the degree of civilization (involving the regular supply of nutriment) on the other, is made apparent, not merely by the improvement which we perceive in the form, development, and vigor of the frame, as we advance from the lowest to the most cultivated of the Human races; but also by the degradation that is occasionally to be met with in particular groups of the higher tribes, which have been subjected for several generations to the influence of depressing causes. Of such degradation, occurring under circumstances that permit its successive steps to be traced, we have a remarkable example in the conversion of certain tribes of the Hottentot race into Bushmen ( $\$ 8.54$ ); and there is very strong ground for the belief that similar influences have operated at a more remote period, in the production of the peculiar characters of the Guinea-coast Negroes and Australian Bushmen.

840. Independently, however, of the obvious modifying influence of exterual circumstances, much allowance must be made for that tendency to variation, which presents itself, more or less, in all those races of animals, which possess such a constitutional capability of adaptation to changes in climate, habits of life, etc., as enables then to live and flourish under a variety of conditions. Thus we find that the offspring of any one pair of domesticated animals do not all precisely agree among themselves, or with their parents, either in bodily conformation or in psychical character; but that individual differences, as they are termed, exist among them. Now, as this tendency to variation cannot be clearly traced to any influence of external circumstances, it is commonly distinguished by the term "spontaneous;" but as there is no effect without a cause, and as the widest differences of this kind present themselves in those races which are most obviously amenable to the influence of external conditions, we seem justified in attributing them to agencies operating unostensibly upon the parents, either previously to their intercourse, or at the time of coition $(\$ 768)$, or in the female during the period of uterogestation (\$ 771). The difference between wild and domesticated animals in regard to color affords a very good illustration of this general fact; for the uniformity among the former is no less 
remarkable than the want of constancy among the latter; and whilst variety of color soon gives place to uniformity, when domesticated races return in any considerable degree towards their primitive state, ${ }^{1}$ it very speedily derelops itself in races which are undergoing the converse process. ${ }^{2}$

841. Now it is by taking advantage of those "spontaneous" departures from the ordinary type, which present features of value to the breeders of domesticated aninals, that new races are developed from time to time among these; any strongly marked peculiarity which thus appears in only a single individual, being usually transmitted to some of its offspring, and being almost certainly perpetuated when both parents are distinguished by it, as happens when the products of the first procreation become capable of brecding with each other. ${ }^{3}-$ Now there can be no hesitation in admitting, that the tendency to the so-called "spontaneous" variation prevails in the Human race to a greater degree than in any other; since we find most remarkable diversities in features, complexion, hair, and general conformation, anong the offspring of the same parentage; whilst more special modifications of the ordinary type, such as the possession of six fingers on each hand and of six toes on each foot are of no unfrequent occurrence. Under ordinary circumstances, these modifications tend to disappear as often as they occur; the free intermixture of those members of the race which possess them, with those which depart less from the ordinary type, tending to nerge them in the general average. But there can be no reasonable doubt that if the same kind of segregation were practiced among Mankind, which is adopted by the breeders of animals for the purpose of perpetuating a particular variety,if, for example, the members of a six-fingered family were to intermarry exclusively with one another,--any such variety would be permanently established as a new race. Now if it be borne in mind that the influence of a scanty population, in the early ages of the Human race, by isolating different families from each other, and causing intermarriages among cren the nearest relatives, would have been precisely the same with that which is now exercised by the breeders of animals, we see one reason why the varieties which then arose should have a much greater tendency to self-perpetuation than those which now occasionally present themselves. And when, too, it is borne in mind, that the change.in external conditions induced by migration would thus operate not only upon the parents but upon the offspring, and would have a continual influence in so modifying the constitution of the latter that the peculiarities thus acquired by them would be transmitted in yet greater intensity to their progeny, there is no real difficulty in account-

1 This has been especially notieed in the dogs, horses, eattle, sheep, and logs introdueed by the Spaniards into South America.

2 Thus Mr. T. Bell informs us (British Quadrupeds, 2d edit., p. 203), that an Australian bitch, or dingo, in the Zoologieal Gardens, had a litter of puppies, the father of which was also of that breed; both parents had been taken in the wild state, both were of the uniform reddish-brown eolor whieh belongs to the raee, and the mother had never bred before; but the young, generated in confinement and in a half-domestieated state, were all more or less spotted.

3 See the history of the introduetion of the ancon breed of sheep, eharacterized by a peeuliar eonformation of its limbs, in Massaehusetts, given by Colonel Hutchinson in the Plil. Trans. for 1813.-A sinilar aceount has been more lately given by Prof. Owen (in a Leeture delivered before the Society of Arts, Dee. 10th, 1851), respeeting the reeent introduction of a new breed of merino slieep, distinguished for tlie long, smooth, straight, and silky character of the wool, and now known as the Mauchamp breed.-In both instances, the breed originated in the spontaneous appearance of a male lamb possessing the peculiarities in question ; from its offspring sueh a selection was made by the breeder, as enabled him to bring together males and females, brith of which were distinguished by them; and in their progeny, the peculiarities uniformly appeared. 
ing, upon the strictest physiological principles, for the widest of those departures from one common type of conformation, which we encounter in our survey of the different Races of Mankind. ${ }^{1}$

842 . Hence we are led to conclude, that, so far as regards their Anatomical structure, there is no such difference among them as would justify to the Zoologist the assertion of their distinct origin. But further, although the comparison of the structural characters of the Human races does not furnish any positive evidence of their descent from a common stock, it justifies the assertion that even if their stocks were originally distinct, there could have been no essential difference between then; the descendants of any one such stock being able to assume the characters of another. This, as already remarked, can be proved by historical evidence in regard to a sufficient number of tribes, to justify the saine assertion with respect to others, whose languages, customs, habits of thought, etc., have an affinity strong enough to warrant us in regarding them as descendants of the same stock, whilst their physical conformation is widely different. Each principal geographical area, which is so isolated from others as to render it probable, a priori, that its population has extended from one centre,--such as the Continent of Africa, or America,-contains races of very diversified physical characters, whose linguistic affinities make it almost certain that they must have had a common descent; and thus, in whatever mode the types of the principal varieties are selected, they are found to be connected by so gradual a series of intermediate or transitional forms, that it is impossible to draw any such line of demarcation between them, as would be required by a soundly judging Naturalist for the boundary of distinct species.

843 . A very important confirmation of this view, is afforded by the essential agreement which exists among the different Races of Mankind in regard to their Physiological history; the variations which they present not being greater than those which we meet with between the different individuals of any one race. Thus, we not only find the average duration of life to be the same (making allowance for circumstances which are likely to ind uce disease), but the various epochs of life,--such as the times of the first and second dentition, the period of puberty, the duration of pregnancy, the intervals of the catamenia, and the time of their final cessation,-present a marked general uniformity, such as does not exist among similar epochs in the lives of species that are nearly allied but yet unquestionably distinct. Further, the different races of Mankind are all subject to the same diseases, both sporadic, endemic, and epidemic; the only exceptions being those in which the constitution of the race has grown to a certain set of influences (as that of the Negro to the malaria which generate certain pernicious fevers in the European), producing an hereditary immunity in the race, which is capable of being acquired by individuals of other races, by a process of acclimatization commenced sufficiently early. ${ }^{2}$ The most important physiological test, however, of specific

1 For a masterly digest of the analogical evidence furnished by the changes known to have been thus produced among domesticated animals, and of the modifications which particular tribes of men can be shown to have undergone within the historic period, see Dr. Prichard's Physical Hi-tory of Mankind, and his Natural History of Man; see also the summary given by the Author in the Cyclop. of Anat. and Physiol, vol. iv, pp. 1301-1339; and Darwin, The Variation of Animals and Plants under Domestication, 1868.

2 'This view of the immunity of the Negro race from certain forms of fever which are very fatal to Europeans, is justified, the Author believes, by all the facts known upur the subject. Much nay be set down, as he is assured by Dr. Daniell, to the better adaptation of the Negro habits of life to their climate; and Europouns who exercise due caution (especially in regard to the functions of the skin), may preserve an immunity scarcely less complete. Dr. D. himself, having been taken prisoner by 
unity or diversity, is that furnished by the Generative process. It may be considered as a fundamental fact, alike in the Vegetable and in the Animal kingdom, that hybrid races originating in the sexual connection of individuals of two different species, do not tend to self-perpetuation; the hybrids being nearly sterile with each other, although they may propagate with either of their parent races, in which the hybrid race will soon merge; whilst, on the other hand, if the parents be themselves varieties of the same species, the hybrid constitutes but another variety, and its powers of reproduction are rather increased than diminished, so that it may continue to propagate its own race, or may be used for the production of other varieties, almost ad infinitum. It appears that, among Plants, hybrids originating between undoubtedly distinct species, sometimes reproduce themselves for two or three generations, but do not continue beyond the fourth. Amongst animals, the limits of hybridity between parents of distinct species are more narrow, since the hybrid is totally unable to continue its race with one of its own kind ${ }^{1}$ and although it may propagate with one of its parent-species, the progeny will of course approach in character to the pure breed, and the race will speedily nerge into it. In Animals, as among Plants, the mixed offsprings originating from different races within the limits of the same species generally exceed in vigor, and in the tendency to multiply, the parent-races from which they are produced, so as to gain ground upon the older varieties, and gradually to supersede them. In this manner, by the crossing of the breeds of our domesticated animals, many new and superior varieties have been produced. The general principle is, then, that beings of distinct species, or descendants from stocks originally different, cannot produce a mixed race which shall possess the capability of perpetuating itself; whilst the union of varieties has a tendency to produce a race superior in energy and fertility to its parents.-The application of this principle to the Human races leaves no doubt with respect to their specific unity; for, as is well known, not only do all the races of Men breed freely with each other, but the mixed race is generally superior in physical development, and in tendency to rapid multiplication, to either of the parent stocks; so that there is much reason to believe that, in many countries, the mixed race between the Aborigines and European colonizers will ultimately become the dominant power in the community. This is especially the case in India, South America, and Polynesia.

844. The question of Psychicul conformity or difference among the Races of Mankind, is one which has a most direct bearing upon the question of their specific unity or diversity; but it has an importance of its own, even greater than that which it derives from this source. For, as has been argued with great justice and power, ${ }^{2}$ the real Unity of Mankind does not lie in the consanguinity of a conmon descent, but has its basis in the participation of

onc of the Negro tribes at un early age, and having spent two years among them, seems to have been thoroughly acelimatized; and has subsequently passed many yours on the most unhealthy parts of the cuast, without experiencing any severe attacks of illness, and in the enjoyment of very good general health.-It is sometimes maintained that the Negro race possesses such a complete exemption from the Yallow Fever of the United States, as marks its speeifie diflerence; such, however, is not constantly the ease, since Negroes oceasionally suffer from it; and their compurative immunity scems fairly attributable to the constitutional peculiarity acquired by their A frican progenitors, and capable of being acquired by Europeans also.

1 One or two instances lave been stated to oceur in which a Mule has produced offupring from union with a similat animal; but this is certainly the extreme limit, since wo one has ever maintaind that the race can be continued further than the second generation without admixture with one of the parent specios.

2 See the New Qurterly Review, No. xv, p. 131; and au Article by Prof. Agassiz in the Cliristian Examiner, Boston (N. E) , 1850. 
every race in the same moral nature, and in the community of moral rights which hence becomes the privilege of all. "This is a bond which cvery man feets more and more, the farther he advances in his intellectual and moral culture, and which in this development is continually placed upon higher and higher ground: so much so, that the physical relation arising from a common descent is finally lost sight of, in the consciousness of the higher moral obligations." It is in these obligations, that the moral rights of men have their foundation; and thus " while Africans have the hearts and consciences of human beings, it could never be right to treat them as domestic cattle or as wild fowl, if it were ever so abundantly demonstrated that their race was but an improved species of ape, and ours a degenerate kind of god."-The Psychical comparison of the various Races of Mankind is really, therefore, in a practical point of view, the most important part of the whole investigation; but it has been, nevertheless, the one most imperfectly pursued, until the inquiry was taken up by Dr. Prichard. The mass of evilence which he has accumulated on this subject, however, leaves no reasonable doubt that no more "impassable barrier" really exists between the different races with respect to this, than in regard to any of those points of nstensible diversity which have been already considered; the rariations in the positive and relative development of their respective psychical powers and tendencies, not being greater, either in kind or degree, than those which present themselves between individuals of our own or of any other race, by some members of which a high intellectual and moral standard has been attained. The tests by which we recognize the claims of the outcast and. degraded of our own or of any other "highly civilized" conımunity, to a common humanity, are the same as those by which we should estimate the true relation of the Negro, the Bushman, or the Australian, to the cultivated European. If, on the one hand, we admit the influence of want, ignorance, and neglect, in accounting for the debasement of the savages of our own. great citics, - and, if we witness the same effects occurring under the same conditions anong the Bushmen of Southern Africa ( $\$ 854$ ), - we can scarcely: hesitate in admitting, that the long-continued operation of the same agencies has had much to do with the psychical as well as the physical deterioration of the Negro, Australian, and other degraded races. So, on the other hand, if we cherish the hope that the former, so far from being irreclaimable, may at least be brought up to the standard from which they have degenerated, by means adapted to develop their intellectual faculties and to call forth the higher parts of their moral nature, no adequate reason can be assigned why: the same method should not succeed with the latter, if enployed with sufficient perseverance. It will be only when the effect of education, intellectual, moral, and religious, shall have been fairly tested by the experience of many generations, in conjunction with the influence of a perfect equality in civilization and social position, that we shall be entitled to speak of any essential. and constant psychical difference between ourselves and the most degraded. beings clothed in human form. All the evidence which we at present possess leads to the belief, that under a vast diversity in degree and in modes of manifestation, the same intellectual, moral, and religious capabilities exist in all the Races of Mankind; so that, whilst we may derive from this conformity a powerful argument for their zoological Unity as a species, we are aiso directly led to recognize their community of moral nature with ourselves, and to admit them to a participation in our own rights.

845. Most iniportant assistance is afforded in the determination of the real affinities of different Races, by the study of their Languages. This, however, is a department of the inquiry so far beyond the limits of Physiological science, that it must be here dismissed with a bare mention of those results, 
to which the zealous pursuit of it by a large number of philosophic Philologists seems undoubtedly to tend.-There can be no reasonable doubt that, as a general principle, the affinities of races are more surely indicated by their languages than by their physical features; and the experienced philologist is generally able to discriminate those resemblances, which may have arisen out of the introduction of words or of modes of construction from the one into the other, by conquest, commercial intercourse, or absolute intermixture, from those which are the result of a community of origin. And thus are supplied those means of tracing the past history of races, which are seldom afforded by written records, or even (at least with any degree of certainty) by traditional information. It is to be borne in mind that the affinities of languages are indicated, not merely by verbal resemblance, but by the similarity of their modes of grammatical construction, or the methods by which the relation between different words that constitute sentences is indicated. The nost positive evidence is of course afforded, when a conformity exists both in the vocabularies and in the modes of construction of two languages; but it frequently happens that although the conformity cxists in regard to one of these alone, yet the evidence which it affords is perfectly satisfactory. Thus, there are many cases in which the vocabularics are so continually undergoing important changes (the want of written records not permitting them to acquire more than a traditional permanence), that their divergence becomes so great, even in the course of a few generations, as to prevent tribes which are by no means remotely desceuded from a common ancestry, from understanding one another; whilst yet the system of grammatical construction, which depends more upon the grade of mental development and upon habits of thought, exhibits a remarkable permanence. Such appears to be true of the entirc group of American languages; which seem, as a whole, to be legimately referable to a common stock, notwithstanding their complete verbal diversity. On the other hand, when two languages or groups of languages differ greatly in construction, but present that kind of verbal correspondence on which the philologist feels justified in placing most reliance (namely, an essential conformity in those "primary words" which serve to represent the universal ideas of a people in the most simple state of existence), that correspondence may be held to indicate a community of origin if it can be proved that it has not been the result of intercourse between the two families of nations subscquently to their first divergence, and if it seems probable on other grounds that their separation took place at a period when as yet the grammatical development of both languages was in its infancy. Such appears to have been the case with certain of those groups of languages whose distinctness can be traced back historically for the longest period. - It is evident, then, that Philological inquiry nust be looked to as one of the chief means of determining the question of radiation from a single centre or from multiple centres; and it is a remarkable fact, that the linguistic affinity and the conformity in physical characters frequently stand in a sort of complemental relation to cach other, each being the strongest where the other is weakcst; so that, by one or other of these links of connection, a close relationship is indicated between all those families of nations under which the several races appear to be most naturally grouped.

\section{General Survey of the Principal Varietics of the Human Species.}

846. The distribution of the Races of Mankind under five primary varieties, according to their respective types of cranial conformation, as first pro-

1 The changes, or stages of growth and development, through which all languages probably pass have been traced in a most interesting manner by Prof. Max IIüller, in his Lectures on the Science of Language, 1861 ; see Lectures ii and viii. 
posed by Blumenbach, is still so commonly receiver, notwithstanding the distinct proof which has been given of the fallacious nature of its basis, that it will be desirable to explain his terms, and at the same time to show how far the information subsequently acquired has tended to modify his arrangement. - The first of these varieties, which is considered to be distinguished by the possession of the oval or elliptical ${ }^{1}$ type of cranial conformation, was designated Caucasian by Blumenbach, on two grounds : first, because he considered the Caucasian people (of whom the Georgians and Circassians are best-known examples) as presenting its physical characters in the greatest perfection; and second, because it was supposed that the Caucasian range of mountains night be regarded as the centre or focus of the races belonging to it. Neither of these ideas, however, is correct; for whilst the oval form of cranium is presented with fully as great beauty and symmetry by the Greeks, it seems now to be almost certainly determinable by the evidence of language, that the Georgian and Circassian nations are really of Mongolian origin, and consequently have no direct relation of affinity with the other nations usually ranked as belonging to this variety; and the evidence of history and tradition, so far from pointing to the Caucasian range as the original centre of radiation of the race, accords with that of language in assigning its locality much nearer to Central Asia. It would be most desirable, therefore, that some other designation should be substituted for that given by Blumenbach; were it not that the present state of our knowledge requires the entire abandonment of his doctrine, that the races agreeing in this type of conformation are mutually connected by community of descent. For, even within the limits of Europe, we find at least two nations,the Turks, and the Magyars or true Hungarians, - whose crania are characteristically oval, and which are yet undoubtedly of Mongolian origin ; and although sone allowance must be made, in regard to the change which has taken place among the former, for the influence of intermixture, with other races, yet there is no reason to believe that any such influence has operated among the Magyars, whose blood seems to have been transmitted with remarkable purity from the time when they settled in Hungary about ten centuries since. In Asia, we find this type presented not merely by the Persian and other Indo-European races, but also by the Syro-Arabian and by the larger proportion of the inhabitants of Hindostan; yet the SyroArabian races are more nearly related to the African stock ( $\$ 8 t 8)$ than to that from which most of the present inhabitants of Europe have sprung; and there is good reason to believe that the great mass of the existing inhabitants of India are of Mongolian descent $(\$ 850)$. It will be necessary, therefore, to consider the nations which present the so-called Caucasian type of cranial conformation, under several distinct heads. No uniformity exists amongst them in regard to color ; for this character presents every inter-

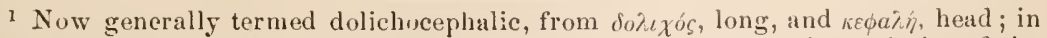

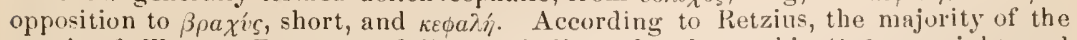
people of Western Europe are dolichocephalic and orthognathic (optos, upright, and

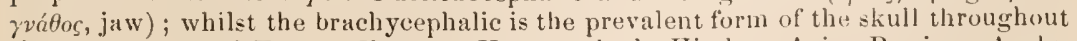
the great extent of Eastern Europe. He rogards the Hindons, Arian Persians, Arabs, and Jews, with the Tungusians and Chinese, a being examples of Asiatic dolichocephali, the last two being proguathic ( $\pi \rho \dot{o}$, forwards, and yvatos, jaw), the former orthognathic; whilst the Samoiedes, Turks, Circasians, Affihans, Laicars, Tartars, Mongolians (both of Asiatic Russia and Mongolia), and Malays, are all progratlic brachycephali, and constitute the prevailing type. On the continent of Australia and in Van Diemen's Land, all the savage tribes are frognathic dolichocephali. See his Glance at the Present State of Ethnology with reference to the Form of the Skull, in the Medico-Chir. liev., for 1860 , vol. $x \times v$, p. 503, and vol. xxvi, p. 215. 
mediate gradation between the fair and florid tint, with light-red or auburn hair, of the Northern European, to the dusky or even black hue of the races bordering on or lying between the Tropies. The hair is generally long and flexible, with a tendency to curl; but considerable variety presents itself with regard to this particular. The conformation of the features approaches more or less closely to that which we are accustomed to regard as the type of beauty.

847. 'T'he first place, in a more natural distribution of the Human Races, must undoubtedly be given to that which is designated by Dr. Prichard as the Arian, and which is often termed the Indo-European; including the collective body of European nations, with the Persians, ${ }^{1}$ Affghans, and certain other nations of the south western portion of the Asiatic continent, ${ }^{2}$ near to which their original focus appears to have been. The great bond of connection between these nations, lies in their languages; which in spite of great diversities, present a certain community of character that is recoguized by every philologist. The family which is most dissimilar to the rest (the typical Celt contrasting remarkably with the types of the Germanic group, both in physical conformation and in psychical characters) is that formed by the Celtic nations; but these are undoubtedly like the others, of Eastern origin, as was first shown by Dr. Prichard ; ${ }^{3}$ though they appear to have detached themselves from the common stock at an earlier period in the development of its language. The Indo-Germanic languages are obviously all formed upon the same base with the ancient Sanskrit, if not upon the Sanskrit itself; and they are united alike by community in many of the most important "primary words," and by general similarity in grammatical construction. The existing Lettish or Lithuanian dialect presents a very near approach to the original type; and the Old Prussian, a dialect spoken as late as the sixteenth century, had a still closer alliance to the ancient Zend or Median, which seems to have been a very early derivation from the Sanskrit, and which is the basis of the language now spoken in Persia.-But there is evidence that, notwithstanding the mutual affinities of the Indo-Germanic languages, every one of then has been modified by the introduction of extraneous elements: thus, in those of Western Europe, there is a considerable admixture of Celtic; whilst in others, there are traces of more barbaric tongues. In fact, there can be little doubt that Europe had an indigenous population, before the immigration of the Indo-German or even of the Celtic tribes; and of this population it seems most probable that the Lapps and Finns of Scandinavia, and the Euskarians (or Basques) of the Biscayan provinces, are but the remnant. The former of these tribes, which is undoubtedly of Mongolian origin, once extended much further south than at present; and with regard to the latter, whose nearest linguistic affinities are also with the tongues of High Asia, there is anple historical proof that they had formerly a very ex-

1 The modern Persians are a very mixed raee, in which Turkish and Arab cle. ments hargely participate. The most perfect representutives of the origial stock (whose purity of descent seems to have been maintained from the time of their original migration into their present locality, by the physical obstacles which lave: cut them off from intercourse with their nearest neighbors) are believed to he the Kiafirs of Kafirstan, a fair-skinned, light-haired race inlabiting the impracticable mountain country on the watershed between the Oxus and the northwestern sources of the Indus. The Tajiks of Bokhara aloo keep up the ancient lineage and language, although their country is ruled by people of 'Turkish descent.

${ }_{2}$ The population of Hindostais lats been commonly arecounted as belonging to this division; but the more intiuate the kuowledge attanel of its character and languares, the more does it lead to the eonclusion that the great mass of this population is really of Mongolian deseent ( 8 850).

3 On the Eastern Origin of the Celtic Nutions, 1831. 
tensive distribution through Southern Europe. It would not seem improbable, then, that the advance of the Indo-European tribes from the southeast corner into Central Europe, separated that portion of the aboriginal (Mongolian) population which they did not absorb or destroy, into two great divisions; of which one was gradually pressed northward and eastward, so as to be restricted to Finland and Lapland; and the other southward and westward, so as to be confined at the earliest historic period to a part of the peninsula of Spain and the South of France, gradually to be driven before the successive irruptions of the Celts, Romans, Arabians, and other nations, until their scanty remnant found an enduring refuge in the fastnesses of the Pyrenees. ${ }^{1}$ - The Indo-Germanic race is unquestionably that which has exercised the greatest influence on the civilization of the Old World; and it seems indubitably destined to acquire a siunilar influence in those newly-found lands which have been discovered by its enterprise. With scarcely an exception, as Dr. Latham has justly remarked, the nations belonging to it prescnt an encroaching frontier : there being no instance of its pernanent displacement by any other race, save in the case of the Arab dominion in Spain, which lias long since ceaser ; in that of the Turkish dominion in Turkey and Asia Minor, which is evidently destined to expire at no distant period, being upheld for merely political purposes by extraneous influence; and in that of the Magyars in Hungary, who only maintain their ground through their complete assimilation to the Indo-Germanic character. It is a remarkable fact, that in most cases in which this race extends itself into countries previously tenanted by people of an entirely different type, the latter progressively decline and at last disappear before it, provided the climate be such as enables it to maintain a vigorous existence; this is pre-eminently the case in North and South America, in Australia, in New Zealand, and in many of the smaller Polynesian islands. And where the climate is less favorable to the perpetuation of the race in its purity, an intermixture with the native blood frequently gives origin to a mixed race, which possesses the developed intellect of the one, and the climatic adaptiveness of the other, and which appears likely ultimately to take the place of both.

848. The Syro-Arabian or Semitic nations agree with the preceding in general physical characters, but differ entirely in the structure of thcir language, and for the most part in vocabulary also, though recent researches seem to indicate that certain roots of the Semitic and Indo-Germanic languages have a decided affinity. It seems quite certain, however, that the linguistic affinities of the Semitic nations are rather with the African than with the IndoEuropean races; and so strong is the link of connection thus established, that by Dr. Latham they are ranked with the former under the general designation Atlantide, ${ }^{2}$ whilst Mr. Norris, whose authority upon all such subjects is deservedly great, is strongly disposed (as he has himself informed the Author) to consider them an essentially African people.-The original seat of this race, however, is commonly reputed to have been that region of Asia which is intermediate between the countries of the Indo-European and of the Egyptian races; having as its centre the region watered by the great rivers of Mesopotamia. Several of the nations primarily constituting this group have become extinct, or nearly so; and the Arabs, which originally formed but one subdivision of it, have now become the dominant race, not

1 This view, which was sugrested by the Author in the Brit. and For. Med. Rev, Oct. 1847, without the knowledge that it had been elsewhere propounded, has been put forth with considerable confidence by Dr. Latham (Varieties of Mrn, 1850), as having originated with Arndt and been adopted by Rask, distinguished Scandinavian ethnologists.

2 See his Varieties of Man, 1850, p. 469. 
only throughout the ancient domain of the Svro-Arabian nations, but also in Northern Africa. In the opinion of Baron Larrey, who had ample opportunities for observation, the skulls of the Arabian race furnish, at present, the most complete type of the human head; and he considered the remainder of the physical frame as equally distinguished by its superiority to that of other races of men. The different tribes of Arabs present very great diversities of color, which are generally found to coincide with variations in climate. Thus the Shegya Arabs, and others living on the low countries bordering on the Nile, are of a dark-brown or even black hue; but eren when quite jetty, they are distinguished from the Negro races by the brightness of their complexions, by the length and straightness of their hair, and by the regularity of their features. The same may be said of the wandering Arabs of Northern Africa; but the influence of climate and circumstances is still more strongly marked in some of the tribes long settled in that region, whose descent may be traced to a distinct branch of the SyroA rabian stock, namely, the Berber, to which belong the Kabyles of Algiers and Tunis, the Tuaryks of Sahara, and the Guanches or ancient population of the Canary Isles. Amongst these tribes, whose affinity is indisputably traceable through their very remarkable language, every gradation may be seen, from the intense blackness of the Negro skin, to the more swarthy hue of the inhabitants of the South of Europe. It is remarkable that some of the Tuaryk inhabitants of particular Oases in the great desert, who are almost as insulated from communication with other races as are the inhabitants of islands in a wide ocean, have hair and features that approach those of the Negroes; although they speak the Berber language with such puritv as to forbid the idea of the introduction of these characters by an intermixture of races. The Jews, who are the only remnants now existing of the once-powerful Phœnician tribe, and who are now dispersed through nearly every country on the face of the earth, present a similar diversity; having gradually assimilated in physical characters to the nations among which they lave so long resided $(\S 830)$.

849. The second prinary division of the Human family, according to the arrangement of Bhmenbach, is that commonly termed Mongolian. The real IIongols, however, constitute but a single and not very considerable nember of the group of nations accepted under this designation; which is, therefore, by no means an appropriate onc. The original seat of these races appears to have been the great central elcvated plain of Asia, in which all the great rivers of that continent have their sources, whatever may be their subsequent direction. Taken as a whole, this division is characterized by the pyramidal form of the skull, whose antero-posterior diameter scarcely exceeds the parietal, and by the broad, flat face and prominent cheek-bones; by the flattening of the nose, which is neither arched nor aquiline; by the eyes being drawn npwards at their outer angle; by the xanthous or olive complexion, which sometimes becomes fair, but frequently swarthy; by the scantiness and straightness of the hair, and deficiency of beard; and by lowness of stature. These characters, however, are exhibited in a prominent degree only in the more typical members of the group, especially those inhabiting Northern and Central Asia; and may become so greatly modified, as to cease altogrether to be recognizablc. Such a modification has been remarkably effected in the case of a part of the Turkish people, now so extcnsively distributed. All the most learned writers on Asiatic history are agreed in opinion, that the Turkish races are of one common stock; although at present they vary in physical characters, to such a degree that, in some, the original type has been altogether changed. Those which still inhabit the ancient abodes of the race, and preserve their pastoral nomadic life, pre- 
sent the plysiognomy and general characteristics which appear to have belonged to the original Turkomans; and these are decidedly referable to the so-called Mongolian type. Before the Mohanımerlan era, however, the Westem Turks or Osmanlis had adopted more settled habits, and had made considerable progress in civilization ; and their adoption of the religion of Islam incited them to still wider extension, and developed that spirit of collquest, which, during the Middle Ages, displayed itself with such remarkable vigor. The branches of the race, which, from their long settlement in Europe, have made the greatest progress in civilization, now exhibit in all essential particulars the physical characters of the European model; and these are particularly apparent in the conformation of the skull.-Another marked departure from the ordinary Mongolian type, is prescuted by the Hyperborean tribes inhabiting the borders of the Icy Sea; these have for the most part a pyramidal skull, but their complexion is swarthy and their growth is pcculiarly stunted; and they form the link that connects the ordinary Mongolide with the Lapps and Finns of Europe on one side, and with the Esquimaux of North America on the other. The Ugrian division, which migrated towards the northwest at a very early period, planted a colony in Europe, which still tenants the northern Baltic countries, forming the races of Fims and Lapps. In the time of Tacitus, the Finns were as savage as the Lapps; but the former, during the succeeding ages, became so far civilized, as to exchange a nomadic life for one of agricultural pursuits, and have gradually assimilated with the surrounding people; whilst the Lapps, like the Siberian tribes of the same race, have ever since continued to be barbarous nomades, and have undergone no elevation in physical characters. The same division gave origin to the Nagyars or Hungarians; a warlike and energetic people, unlike their kindred in the North; in whom a long abode in the centre of Europe has, in like manner, developed the more elevated characters, physical and mental, of the European nations.

850. The nations inhabiting the Southeasteru and Southern portions of Asia, also, appear to have had their origin in the Mongolian or Central Asiatic stock; although their features and form of skull by no means cxhibit its characteristic marks, but present such departures from it, as are elsewhere observable in races that are making advances in civilization. The conformity of the Mongolian type is most decidedly shown by the nations (collectively termed Seriform by Dr. Latham), which inhabit China, Thibet, the Indo-Chinese peniusula, and the base of the Himalayan range; these are associated by certain linguistic peculiarities which distinguish them from all other races; that prinitive condition of human speech, in which there is a total absence of inflections indicative of the relation of the principal words to one another, being apparently preserved with less change in the tongues of these people, than in thcse of any other. The Chinese may be physically characterized as Mongolians softened down; and in passing from China towards India through the Burmese empire, there is so gradual a transition towards the ordinary Hindoo type, that no definite line of demarcation can be anywhere drawn.-The inhabitants of the great peninsula of Hindostan have been commonly ranked (as already remarked) under the Cancasian race, both on account of their physical conformity to that type, and also because it has been considered that the basis of their language is Sanskritic. It is certain, however, that this conclusion is incorrect with regard to a very large proportion of the existing population of Iudia ; and there is strong reason to believe that no part of it bears any real relation of affinity to the Indo-European group of nations, except such as may be derived from a slight intermixture. Thus, the Tamulian, which is the dominant language of Southern India, is undoubtedly not Sanskritic in its origin (although con- 
taining an infusion of Sanskritic words), but more closely approximates to the Seriform type; and many of the hill tribes, in different parts of India, speak peculiar dialects, which, though mutually unintelligible, appear referable to the same stock. Now it is among this portion of the population of India, that the greatest departure presents itself from the Caucasian type of cranial formation, and the closest conformity to the Mongolian; the cheekbones being more prominent, the hair coarse, scanty, and straight, and the nose flattened; sometimes, also, the lips are very thick, and the jaws project, showing an approximation to the prognathous type. Now in the opinion of Dr. Latham and Mr. Norris, the various dialects of Northern India (of which the Hindostani is the most extensively spoken) are to be regarded as belonging, in virtue of their fundamental nature, to the same group with those of High Asia, notwithstanding the large infusion of Sanskritic words which they contain; this infusion having been introduced at an early period by an invading branch of the Arian stock, of whose advent there is historical evidence, and whose descendants the ordinary Hindoo population have been erroneously supposed to be. According to this view, then, the influence of the Arian invasion upon the language and population of Northern India was very much akin to that of the Norman invasion upon those of England; the number of individuals of the invading race being so small in proportion to that of the indigenous population as to be speedily merged in it,-not, however, without contributing to an clevation of its physical characters; and a large number of new words liaving been in like manner introduced, without any essential change in the type of the original language. And thus the only distinct traces of the Arian stock are to be found in the Brahminical caste, which preserves (though with great corruption) the original Brahminical religion, and which keeps up the Sanskrit as its classical language; it is certain, however, that this race is far from being of pure descent, having intermingled to a considerable extent with the ordinary Hindoo population. There is but little to remind us of the Mongolian type in the countenances of the Hindons, which are often remarkable for a symmetrical beauty that only wants a more intellectual expression to render them extremely striking; some traces of it, however, may perhaps be found in the rather prominent zygomatic arches which are common amongst them ; but the cranial portion of the skull presents no approach to the pyramidal type, being oftcn very regularly elliptical. There is a remarkable differcnce in the color of the different Hindoo tribes; some being nearly as dark as Negroes, others more of a copper color, and others but little darker than the inhabitants of Southern Europe. ${ }^{1}$

851. According to the usual mode of dividing the Human family, the Ethiopian or Negro stock is made to include all the nations of Africa to the southward of the Atlas range. But, on the one hand, the Hottentots and Bushmen of the southern extremity constitute a group which is strongly distinguished by physical characters from the rest of the African nations; so, again, the region north of the Great Desert is mostly occupied by Semitic tribes $(\$ 848)$ : the scattcred population of the Great Desert itself is far from being Negro in many of its features; the valley of the Nile, at least in its middle and lower portions, including Egypt, Nubia, and even Abyssinia, is inhabited by a group of nations which maty be designated as Nilotic, and which presents a series of gradational transitions between the Negroes and Kaffres and the Semitic races; a large portion of the arrea south of the

I For many interesting particulars respecting the physical characters and habits of the wild tribes of the Veddahs of Ceylon, see a paper by J. Bailey in the Transactiuns of the Ethnological Society, vol. ii, p. 278. 
Equator is occupied by the Kaffre tribes and their allies, which cannot be truly designated as Negroes: so that the true Negro area is limiteal to the western portion of the African continent, including the alluvial valleys of the Seneral, the Gambia, and the Niger, with a narrow strip of Central Africa, passing eastwards to the alluvial regions of the Upper Nile. Even within this area, the true Negro type of conformation, such as we see in the races which inhabit the low countries near the Slave Coast, consisting in the combination of the prognathous form of skull with receding forehead and depressed nose, thick lips, black woolly hair, jet black unctuous skin, and crooked legs, is by no ineans universally prevalent; for many of the nations which inhabit it must be ranked as subtypical Negroes; and from these the gradation in physical characters is by no means abrupt, to those African nations which possess, in a considerable degree, the attributes which we are accustomed to exclude altogether from our idea of the African race. Thus, the race of Jolof near the Senegal, and the Guber in the interior of Sudan, have woolly hair and deep black complexions, but fine forms and regular features of a European cast; and nearly the same may be said of the darkest of the Kaffres of Southern Africa. The Bechuma Kaffres present a still nearer approach to the European type; the complexion being of a light brown, the hair often not woolly but merely curled, or even in long flowing ringlets, and the figure and features having much of the European character.-There is no group, in fact, which presents a more constant correspondence between external conditions and physical conformation, than that composed of the African nations. As we find the complexion becoming gradually darker, in passing from Northern to Southern Europe, thence to Forth Africa, thence to the borders of the Great Desert, and thence to the intertropical region where alone the dullest black is to be met with,--so do we find, on passing southwards from this, that the hue becomes grarlually lighter in proportion as we proceed further from the equator, until we meet with races of comparatively fair complexions among the nations of Southern Africa. Even in the intertropical region, high elevations of the surface have the same effect as we have seen them to produce elsewhere, in lightening the complexion. Thus the high parts of Senegambia, where the temperature is moderate and even cool at times, are inhabited by Fulahs of a light copper color, whilst the nations inhabiting the lower regions around them are of true Negro blackness: and nearly on the same parallel, but at the opposite sicle of Africa, are the high plains of Enarea and Kaffi, of which the inhabitants are said to be fairer than the natives of Southern Europe.

852. The languages of the Negro nations, so far as they are known, appear to belong to one group; for although there is a considerable diversity in their vocabularies (arising in great part from the want of written records which would give fixity to their tongues), yet they seem to present the same grade of development and the same grammatical forms; and various proofs of their affinity with the Semitic languages have been developed, these being afforded by similarity alike of roots and of grammatical construction. The Semitic affinity of the Negro nations is further indicated in a very remarkable manner, by the existence of a variety of superstitions and usages among the Negroes of the Western const, closely resembling those which prevail also among the Nilotic races whose Semitic relations are most clear, as well as among branches of the Senitic stock itself; and thus we seem to have adequate proof of the absence of any definite line of demareation, in regard either to physiological or to linguistic characters between the Negro race, and one of those which has been hitherto considered to rank among the most elevated forms of the Caucasian variety.-Nor is there anything in the 
psychical character of the Negro, which gives us a right to separate him from other races of Mankind. It is true that those raees which have the Negro character in an exaggerated degree, are uniformly in the lowest stage of soeiety, being either ferocious savages, or stupid, sensual, and indolent ; such are most of the tribes along the Slave Coast. But, on the other hand, there are many Negro Statess, the inhabitants of whieh have attained a considerable degree of improvement in their soeial condition; such are the Ashanti, the Sulima, and the Dahomans of Western Africa, also the Guber of Central Suckan, among which a eonsiderable degree of eivilization has long existed ; the physieal characters of all these natious deviate considerably from the strongly marked or exaggerated type of the Negro; and the last are perhaps the finest race of genuime Negroes on the whole continent, and present in their language the most distinct traces of original relationship to the Syro-Arabian nations. The highest civilization, and the greatest improvement in physical characters, are to be found in those African nations which have adopted the Mohammedan religion; this was introdueed, three or four centuries since, into the eastern portion of Central Africa ; and it appears that the same people, which were then existing in the savage eondition still exhibited by the pagan nations further south, have now adopted many of the arts and institutions of civilized society, subjecting themselves to governments, praetieing agriculture, and dwelling in towns of considerable extent, many of which contain 10,000 , and some even 30,000 inhabitants; a eireumstance which implies a considerable advaneement in industry, and in the resources of subsistence. This last faet affords most striking evidence of the improvability of the Negro raees; and, taken in eonnection with the nuany instances that have presented themselves, of the advance of individuals, under favorable circumstanees, to at least the average degree of mental development among the European nations, it affords clear proof that the line of demarcation, whieh has been supposed to separate them intellectually and morally from the races that have attained the greatest elevation, has no more real existence than that whieh has been supposed to be justified by a difference in physical characters, and of which the fillacy has been previously demonstrated.

853. The southern portion of the Afriean continent is inhabited by a group of nations, which (as already mentioned) recede more or less deeidedly from the Negro type in physieal characters, and whieh seem connected together by essential community of language, as branches of the stock of which the Kaffres may be considered the stem. In this warlike nomadic people, which inhabit the eastern parts of South Africa, to the northward of the Hottentot eountry, so great a departure from the ordinary Negro type presents itself, that many travellers have assigned to thein a different origin. The degree of this departure, however, varies greatly in the different Kaffre tribes; for whilst some of them are black, woolly-headed, and deeidedly prognathous, so as obviously to approach the modified Negroes of Congo in general aspect, others recede considerably from the typical prognathous races, both in eomplexion, features, and form of head, presenting a light brown eolor, a high forehead, a prominent nose, and a tall, robust, well-shaped figure. Thic thick lips and blaek frizzled hair, however, are generally retained; thougl the hair is sometimes of a reddish color, and becomes flowing; and the features may present a European cast. But even among the tribes which depart most widely from the Negro type, individuals are found who present a return to it; and it is interesting to renark, that the people of Delagoa Bay, though of the Kaffre race (as indieated by their language), having been degraded by subjugation, approach the people of the Guinea Coast in their physical eharacters. In filct, between the most elevated 
Kaffre and the most degraded Negro every possible gradation of physical and psychical characters is presented to us, as we pass northwards and westwards from Kaffiaria towards the Guinea Coast; and we meet with a similar transition, although not carried to so great an extent, as we pass up the eastern coast.-The languages of the Kaffies and other allied tribes are distinguished by a set of remarkable characters, which have been consilered as isolating them from nther African tongues. According to Dr. Latlan, however, these peculiarities are not so far without precedent elsewhere as to establish the very decided line of demarcation which some have attempted to draw; and may be regarded, in fact, as resulting from the fuller development of tendencies which manifest themselves in other African languages.

854. The Hottentot race differs from all other South African nations, both in language and in physical conformation. Its language cannot be shown to possess distinct affinities with any other stock $;^{1}$ but in bodily structure there is a remarkable admixture of the characters of the Mongolian with those of the Negro. Thus the face presents the very wide and high cheek. bones, with the oblique eyes and flat nose of the Northern Asiatics; at the same time that, in the somewhat prominent muzzle and thick lips, it resembles the countenance of the Negro. The complexion is of a tawny buff or fawn color, like the black of the Negroes diluted with the olive of the Mongols. The hair is woolly, like that of the Negroes, but it grows in small tufts scattered over the surface of the scalp (like a scrubbing-brush), instead of covering it uniformly: thus resembling in its comparative scantiness that of the Northern Asiatics. It is most interesting to observe this remarkable resemblance in physical characters, between the Hottentots and the Mongolian races, in connection with the similarity that exists between the circumstances under which they respectively live; and it is not a little curious that the Hottentot, as the Mongol, should be distinguished by the extraordinary acuteness of his vision ( $\$ 854)$. No two countries can be more similar than the vast steppes of Central Asia and the karoos of Southern Africa ; and the proper inhabitants of each are nomadic races, wandering through deserts remarkable for the wide expansion of their surface, their scanty herbage, and the dryness of their atmosphere, and feeding upon the milk and flesh of their horses and cattle. Of the original pastoral Hottentots, however, comparatively few now remain. A large proportion of them have been gradually driven, by the encroachnents of the Kaffies and of European colonists, and by internal wars with each other, to seek refuge among the inaccessible rocks and deserts of the interior; and have thus been converted from a mild, unenterprising race of shepherds, into wandering hordes of fierce, suspicious, and vindictive savages, treated as wild beasts by their fellow-men, until they become really assimilated to wild beasts in their habits and dispositions. Hence have arisen the tribes of Bushmen or Bosjesmen, which are generally regarded as presenting the most degraded and miserable condition of which the. Human race is capable, and have been supposed (but erroneously) to

$1 \mathrm{It}$ is eonsidered by some, that the Hottentot language is a degraded Kaffre, as the Bushman language is a degrader Hottentot; but the Author is informed by Mr. Norris that he sees no valid ground for this as-umption; the affinities of the Hottentot language being rather, in his opinion, with the languages of High Asia, although the eomneeting links are extremely slight Such as they are, however, they tend to confirm an idea sugersted to the Author some years since by the malked reproduction of so many Mongotian characters in the Hottentot race, - that is the remnant of a migration from Asia, earlier than that in which the great bulk of the $A$ frican nations have their origin; and that it has been driven down to the remotest corner of the contiuent. just as the aboriginal (Mongolian) population of Southwestern Europe secms to have been driven back by the Indo-European immigration ( 8817 ). 
present resemblances in physical characters to the higher Quarlrumana. This transformation has taken place, under the observation of eye-witnesses, in the Koranas, a tribe of Hottentots well known to have been previously the most advanced in all the improvements which belong to pastoral life; for having been plundered by their neighbors, and driven out into the wilderness to subsist upon wild fruits, they have adopted the habits of the Bushmen, and have become assimilated in every essential particular to that miserable tribe.-It appears, however, from the inquiries of Dr. Andrew Smith, that this process of degradation has been in operation quite independently of exterual agencies; nearly all the South African tribes who have made any advances in civilization being surrounded by more barbarous hordes, whose abodes are in the wildernesses of mountains and forests, and who constantly recruit their numbers by such fugitives as crime and destitution may have driven from their own more honest and more thriving communities; and these people vary their mode of speech designedly, and even adopt new words, in order to make their meaning unintelligible to all but the members of their own association. This has its complete parallel in the very midst of our own or any other highly civilized community; all our large towns containing spots nearly as inaccessible to those unacquainted with them, as are the rude caves or clefts of hills, or the burrows scooped out of the level karroo, in which the wretched Bushman lies in wait for his prey; and these being tenanted by a people that have been well characterized as les classes dangerenses, which, as often as the arm of the law is paralyzed, issue forth from the unknown deserts within which they lurk, and rival in their fierce indulgence of the most degrading passions, and in their excesses of wanton cruelty, the most terrible exhibitions of barbarian inhumanity. Such outcasts, in all nations, purposely adopt, like the Bushmen, a "flash" language; and in their general character and usages there is a most striking parallel. ${ }^{1}$

855. The American nations, taken collectively, form a group which appears to have existed as a separate family of nations from a very early period in the world's history. They do not form, however, so distinct a variety, in regard to physical characters, as some anatomists have endeavored to prove; for, although certain peculiarities have been stated to exist in the skulls of the aboriginal Americans, yet it is found on a more extensive exanination, that these peculirrities are very limited in their extent,--the several nations spread over this vast continent differing from each other in physical peculiarities as much as they do from those of the Old Work, so that no typical form can be made out anong them. In regard to complexion, again, it may be remarked, that, although the native Amcricans have been commonly characterized as "red men," they are by no means invariably of" a red or coppery hue, some being as fair as many European nations, others being yellow or brown, and others nearly, if not quite, as black as the Negroes of $A$ frica ; whilst, on the other hand, there are tribes equally red, and perhaps more deserving that epithet, in $\Lambda$ frica and Polynesia. Our ordinary notion of the Anerican races, having bcen chiefly founded upon the characters of those tribes of "Indians" with whom European settler's first came into contact, proves to be no more applicable to the inlabitants of the Continent generally, than are the character's of the Negro to the population of $\Lambda$ frica as a whole $(\$ 851)$. - In spite of all this diversity of conformation, it is believed that the structure of their languages affords a decided and clearly marked evidence of relationship between them ( $\$ 845)$. Notwith-

1 See London Labor and the London Poor, p. 2. 
standing their diversities in mode of life, ton, there are peculiarities of mental character, as well as a number of ideas and customs derived from tradition, which seem to be common to them all; and which for the most part indicate a former elevation in the scale of civilization, that has left its traces anong them even in their present depressed condition, and still distinguishes them from the sensual, volatile, and almost aninalized savages that are to be met with in many parts of the Old Continent.-The Esquiniaux have been regarded as constituting an exception to all general accounts of the physical characters of the American nations; for in the configuration of their skulls, as also in their complexion and general physiognomy, they conform to the Mongolian type, even presenting it in an exaggerater degree; whilst their wide extension along the whole northern coast of America, through the Aleutian Islands, and even to the Continent of Asia, certainly lends weight to the idea that they derive their origin from the Northern Asiatic stock. But the increased acquaintance which has been recently gained with the tribes that people the northeastern portion of the American Continent, has clearly shown that no physical separation can be established between the Esquimaux and the Indian proper; the one form graduating so insensibly into the other, as to make the distinction between the two groups there as difficult as on the western side it is easy. Hence the existence of the Esquimaux population in this situation affords a complete link of transition between the Asiatic and the American nations, in the precise region in which the geographical relations of the two continents would lead us to expect it.

856. It now remains for us to notice the Oceanic races which inhabit the vast series of islands scattered through the great ocean that stretches from Madagascar to Easter Island. There is no part of the world which affords a greater variety of local conditions than this, or which more evidently exhibits the effects of physical agencies on the organization of the human borly. Moreover, it affords a case for the recognition of affinities by means of language, that possesses unusual stability; since the insulated position of the various tribes that people the remote spots of this extensive tract prevents them from exercising that influence upon each other's torms of speech, which is to be observed in the case of nations united by local proximity or by frequent intercourse. Tried by this test, it is found that the different groups of people inhabiting the greater part of these insular regions, although so widely scattered and so diverse in physical characters, are more nearly connected together than most of the families of men occupying continuous tracts of land on the great continents of the globe. A probable explanation of this remarkable affinity has been afforded by the careful investigation of the Flora and Fauna of these regions ${ }^{1}$ by Dr. Hooker and Mr. Wallace; whose observations furuish strong evidence that most important and extensive geological changes have taken place since the islands scattered over that region have been peopled by their existing inhabitants. The western and eastern halves of the Indian archipelago, the former containing Sumatra and Borneo, the latter including Celebes and New Guinea, are separated at their nearest approximation by the Straits of Lombok, which are no more than fifteen niles wide: the Fauna of the former is essentially Asiatic, that of the latter essentially Australian; and there is no other intermixture between

1 See the Introductory Essav to the Flora of New Zealand, hy Dr. J. D. Hookrr, 185.3, and his Flora of Australia, its Origin, Affinities, and Distribution, 1859 . Also Mr. A. R. Wallace, On the Zoological Goograpby of the Malay Archipelago, in the Pruceedings of the Linnæan Society for Novmber, 1859 ; and the review of these works in the Mcdico-Chir. Pev. for 1860, vol. $x x v, p .371$. 
them than sueh as a very limited migration aeross this narrow channel will readily aceount for. Now the various portions of the Indian provinee are still conneeted by a vast submarine plain, whieb extends over the whole of the Java Sea, the Straits of Malaeea, the Gulf of Siam, and the southern part of the China Sea, at a depth of not more than three hundred feet, abruptly terminating at its limits in an unfathomable ocean. An elevation of the sea bottom to this amount, therefore, would nearly double the extent of tropical Asia; and there is every probability that the eontinent was thus extended before that last great elevation of the voleanie range of Java and Sumatra took place, whieh (aeeording to the general faet first brought into notice by Mr. Darwin, of an altcration of bands of elevation and depression) was eoineident with the subsidenee that separated those islands from Borneo on the one side, and from the continent of Asia on the other. On the other hand, the great Paeifie Continent of which New Guinea and Australia are doubtless fragments, and whieh (as Dr. Hooker has rendered probable by botanical considerations) onee conneeted Australia and New Zealand with South Ameriea, seems to have extended itself as far westward as the Moluccas; and its submeryence, produeing the limitation and separation of the great islands of the South Sea, seems to have taken plaee before the rise of the tropical Asiatic continent. There are even indieations that the tropieal Indian Continent extended so near to what is now the coast of Afriea, that the Isle of Bourbon and the Mauritius, perhaps even Madagascar, were outlying portions of it; and if the submergence whieh formed the bed of the present Indian Oeean should have taken plaee subsequently to the time when those countries beeame inhabited by Man, we have a rational explanation of the faet whieh has perplexed all ethnologists, and whieh the hypothesis of migration ean scarcely be stretched far enough to aeeount for,- - that both the Fauna and the languages of Madagascar are rather Malayo-Polynesian than Afriean in their fundamental affinities.

857. The inhabitants of Oceania seem divisible into two principal groups, whieh are probably to be regarded as having constituted distinet races from a very early period; these are the Malayo-Polynesian race, and the Negritos or Pelagian Negroes. The Malayo-Polynesian group is by far the more extensive of the two; and eomprehends the inhabitants of the greater part of the Indian and Polynesian Arehipelagoes, with the peninsula of Mralaeea (which is the centre of the Malays proper), and perhaps the inhabitants of Madagascar. These are all closely united by affinities of language. The proper Malays bear a strong general resemblance to the Mongolian raees, and this resemblance is shared, in a greater or less degree, by most of the inhabitants of the Indian Archipelago. They arc of a darker complexion, as might be expeeted from their proximity to the equator; but in this complexion, yellow is still a large ingredient. The Polynesian branch of the group presents a mueh wider diversity ; and if it were not for the eommunity of language, it might be thought to eonsist of several raees, as distinet from eaeh other as from the Malayan braneh. Thus the Tahitians and Marquesans are tall and well made; their figures eombine graee and vigor; their skulls are usually remarkably symmetrical; and their physiognomy presents much of the European east, with a very slight admixture of the ficatures of the Negro. The eomplexion, espeeially in the females of the higher classes who are sheltered from the wind and sun, is of a clear olive or brunette, such as is common among the natives of Central and Sonthern Europe; and the hair, though gencrally black, is sometimes brown, or auburn, or cven red or flaxen. Anong other tribes, as the New Zealanders, and the Tonga and Fricndly Islanders, there are grcater diversities of eonformation and hue; some being finely proportioned and vigorous, others comparatively small and 
feeble; some being of a copper-brown color, others nearly black, others olive, and others almost white. In fact, if we once admit a strongly markerl difference in complexion, features, hair, and general configuration, as estahlislying a claim to original distinctness of origin, we must admit the application of this hypothesis to almost every group of islands in the Pacific,-an idea, of which the essential community of language seems to afford a sufficient refutation. Among the inhabitants of Madagascar, too, all of which speak dialects of the same language, some bear a strong resemblance to the Malayan type, whilst others present approaches to that of the Negro.

8.58. The Negrito or Pelagian Negro races must be regarled as a group altugether distinct from the preceding; having a marked diversity of language; and presenting, more decidedly than any of the Malayo-Polynesians, the characters of the Negro type. They form the predominating population of New Britain, New Ireland, the Louisiade and Solomon Isles, of several of the New Hebrides, and of New Caledonia; and they seem to extend westwards into the mountainous interior of the Malayan Peninsula, and into the Andaman Islands in the Bay of Bengal. ${ }^{1}$ The Tasmanians, or aborigines of Yan Diemen's Land, who are now almost completely externinated, undoubtedly belonged to this group. Very little is known of them, except through the reports of the people of Malayo-Polynesian race inhabiting the same islands; but it appears that, generally speaking, they have a very inferior physical development, and lead a savage and degraded life. There is considerable diversity of physical characters among them; some approximating closely in hair, complexion, and features, to the Guinea Coast Negroes; whilst others are of yellower tint, straight hair, and better general development. The Papuans, who inhabit the northern coast of New Guinea and some adjacent islands, and who are remarkable for their large bushy masses of half-woolly hair, have been supposed to constitute a distinct race; but there is little doubt that they are of hybrid descent, between the Malays and the Pelagian Negroes.-To this group we are probably to refer the Alfourous, or Alforian race, which are considered by some to be the earliest inhabitants of the greater part of the Malayan Archipelago, and to have been supplanted by the more powerful people of the preceding races, who have either extirpated them altogether, or have driven them from the coasts into the mountainous and desert parts of the interior. They are yet to be found in the central parts of the Moluccas and Philippines; and they seem to occupy most of the interior and southern portion of New Guinea, where they are termed Endamenes. They are of very dark complexion; but their hair, though black and thick, is lank. They lave a peculiarly repulsive physiognomy; the nose is flattened, so as to give the nostrils an almost transverse position; the cheek-bones project; the eyes are large, the teeth prominent, the lips thick, and the mouth wide. The limbs are long, slender, and misshapen. From the close resemblance in physical characters between the Endamenes of New Guinea and the aborigines of New Holland, and

1 An interesting paper, On the Mincopie Pace of the Anduman Isles, by Professor Owen, will be found in the Transactions, of the Ethnological Society for 1863, p. 34. They appear to be amongst the most degraded of the Human species, possessing no notion of a Supreme Being, nor of a future existence, nor any sense of decency or shame; they are of diminutive size, yet the cranium is well formed, of an oval type, with rather receding forebead, and they ure skilful in making knives of glass and iron cast up from wrecks. They possess considerable powers of imitation, and are active in running, climbing, and swimming. They are not cannibals. Prof. Owen concludes that they are the aborigines of these islands, but remarks that antecedent generations may have coexisted with the slow and gradual geological changes which have obliterated the place or continent of their primitive origin. 
from the proximity between the adjacent coasts of these two islands, it may be surmised that the latter belong to the Alforian race; but too little is known of the language of either to give this inference a sufficient stability. In the degradation of their condition and manner of life, the savages of $\mathrm{New}$ Holland fully equal the Bushmen of South Africa; and it is scarcely possible to imagine human beings existing in a condition more nearly resembling that of brutes. But there is reason to believe, that the tribes in closest contact with European settlers are more miserable and savage than those of the interior; and even with respect to these, increasing acquaintance with their language, and a consequent improved insight into their modes of thought, tend to raise the very low estimate which has been formed and long maintained, in regard to their extreme mental degradation. The latest and nost authentic statements enable us to recognize among them the same principles of a moral and intellectual nature, which, in more cultivated tribes, constitute the highest endowments of humanity; and thus to show that they are not separated by any impassable barrier, from the most civilized and elevated nations of the globe.-There are many indications, indeed, that the Negrito race is not so radically distinct from the Malayo-Polynesian, as the marked physical dissinilarity of their respective types, and the apparent want of conformity between their languages, would make it appear. For as, on the one hand, some of the subdivisions of the latter prescnt a decided tendency towards that prognathous character and depth of complexion which are typical of the former, so among the former do we not unfrequently meet with a lighter shade of skin, a greater symmetry of skull, and a considerable improvement in form and feature. And although no very close relationship can be discovered between the Negrito and Malayo-Polynesian languages, yet it has been pointed out by Mr. Norris that a much more decided relationship exists between the Australian and Tamulian ( $\$ 850)$; and remote as this connection seems, the circumstance adds reight to the idea, that the native Australians (with other Negrito tribes) are an offset from that southern branch of the great nomadic stock of Central Asia, which seems early to have spread itself through the Indo-Chinesc and the Indian Peninsulas, and to have even there shown an approximation to the prognathous type.

859. Looking, then, to the great diversity which exists among the subordinate groups of which both these divisions consist, and their tendency to nutual approximation, it cannot be shown that any sufficient reason exists for isolating them from each other; and, as already remarked $(\$ 857)$, there scems no medium between the supposition that cach island had its aboriginal pair or pairs, and the doctrine that the whole of. Occania has been peopled from a common stock. Looking, again, to the very decided approximation which is presented by certain Oceanic tribes to the Mongolian type, and this in locatities which, on other grounds, might be regarded as having received the first stream of migration, the possibility, to say the least, can scarcely be denied, that the main land furnished the original stock, which has undergone various transformations subsequently to its first dispersion; these having been the result of climatic influence and mode of life, and having been chiefly influenecd as to degree by the length of time during which the transforming causes have been in operation. At any rate, it may be safely affirmed, that the Oceanic races are not entitled by any distinctive physical peculiarity, to rank as a group which nust have necessarily had an original stock distinct from that of the Continental nations. 


\section{CHA PTER XX.}

\section{OF THE MODES OF VITAL ACTIVITY CHARACTERISTIC OF DIFEERENT AGES.}

860. Althovgh from the time when the Human being comes into the world, to the final cessation of his corporeal existence, the various functional operations of Organic life are carried on with ceaseless activity, whilst those of Animal life are only suspended by the intervals of repose which are needed for the renovation of their organs, yet there are very marked differences, not only in the degree of their united activity, but also in the relative degrees of energy which they severally manifest, at different epochs. These differences, taken in connection with the modifications in the size and conformation of the body with which they are in relation, mark out the whole term "f life into the various "Ages," which are commonly recognized as seven-namely, Infancy, Childhood, Youth, Adolescence, Manhood, Decline, and Senility. For Physiological purposes, however, a less minute subdivision is equally or perhaps more appropriate; namely, the three great periods of Growth and Development, of Waturity, and of Decline. The first comprehends the whole of that series of operations, by which the germ evolves itself at the expense of the nutriment which it appropriates from external sources, into the complete organism, possessed not merely of its full dimensions, but of its highest capacity for every kind of functional activity ; this includes, therefore, the epochs of Embryonic life, Infancy, Childhood, Youth, and Adolescence, all of which are characterized by an excess of the constructive over the destructive changes taking place in the organism. The second period ranges over the whole term of Manhood, in which the organism, having attained its complete development, is brought into vigorous and sustained activity; and in which it is maintained in a condition fitted for such activity, by the equilibrium which snbsists between the operations of redintegration and of disintegration. The third period commences with the incipient failure of the bodily powers, consequent upon the diminished activity of the constructive powers, as compared with that of the changes which involve degeneration and decay; this diminution begins to manifest itself during the latter part of Middle Life, before Old Age can properly be said to commence; and it continues in an increasing ratio through the whole "decline of life," until the reparative powers being exhausted, Death supervenes as the necessary termination of that long succession of phenomena of which Life consists.

861. Although the organization of the body at each epoch may be truly said to be the resultant of all the material changes which it has undergone during the preceding periods, yet it is scarcely possible to take an enlarged view of the case, without perceiving that we must look for the cause of this succession in those dynamical conditions, the presence of which is the distinguishing attribute of living structures. Every constructive act, whether this consist in Growth ( $\$ 331$ ) or in Development ( $\$ 332$ ), not merely requires materials for the new tissue produced, but depends upon the active operation of a formative power, without whose agency these materials would remain unorganized. In our examination into the source of the formative power which we see thus operating in every individual organism (chap. i), we found it traceable to the Physical Forces to which it is subjected (Heat being 
the one which seems to bear most directly upon the formative operations); these forces being metamorphosed, so to speak, into the constructive force of the living body, in virtue of the peculiar endowments of its material substratum,- just as an Electric current transmitted through the different nerves of Sense, produces the sensory impressions which are characteristic of each respectively ( $\$ 592)$; or as the same current, transmitted through one form of Inorganic matter, produces Light and Heat, through another, Chemical Change, or through another, Magnetism. But we must also recognize in the Organism at large, as well as in every integral part of it $(\$ 330)$, a certain capacity for growth and development-which is the original endowment of its germ-which not only determines the mode in which it shall progressively evolve itself iuto the fabric characteristic of its species and sex, but also shapes the peculiarities of the iudividual,-which serves also to bring about the perpetual reconstruction that is needed for its continued maintenance, and is peculiarly manifested in those reparative processes which make good losses of its substance resulting from injury or disease,-and of which the cessation, by preventing any further metamorphosis of Physical into Vital force, causes the constructive powers to fail altogether, so that the Organism is resolved back by these very forces into the various forms of Inorgauic matter at the expense of which it had been built up.

862. Now this "germinal capacity" is most strikingly displayed during those earliest periods of existence, in which growth and development alike are taking place most rapidly; in fact, the further we go back in the history of intrauterine life, the more energetic do we perceive its manifestatious to be. For when we look simply at the increase from the minute point that constitutes the first perceptible germ, to the mature foetus of 6 or 7 pounds weight, we see that at no other period of existence can that increase be compared in its rate, with that which presents itself during the nine months that follow conception; and if we go more into detail, we find that it is yet more remarkable in the earlier than in the later months (\$ 864$)$. So, again, it is in the first few weeks of embryonic life, that the foundation is laid of most of its permanent organs, in the midst of an apparently homogeneous mass of cells; whilst in the succeeding weeks, these rudiments are evolved into the semblance of the forms they are subsequently to present, and a differentiation of tissues begins to show itself in their several parts; so that the developmental process is so far advanced at little more than half the term of gestation, that the foetus may even then, under favorable circumstances, maintain an independent existence $(\$ 764)$. The rate of increase becomes progressively slower during the advance from infancy to maturity; and the energy of the developmental process is comparatively enfeebled, being limited to the perfectiug of structures whose foundations had been previously laid, and in no instance manifesting itself normally in the evolution of a new part or organ. Now as there is no limit (in the well-nourished individual) to the supply of Food and Warmth, it follows that this gradual decliue of formative activity must be due to a diminution of the capacity for that activity, inherent in the organism itself; and this diminution is still more strongly marked by that entire cessation, both of increase, and of further developmental changes, which constitutes the termination of the first period. For the orgauism which has attained that stage of its existence, has so far lost the formative capacity which characterized its earkier years, that, however copions the supply of food, however abundant the generation of heat, it can theuceforth to no more than maintain its norinal condition, and can effect this for only a limited term of years. It seems a necessary sequence of this series of phenomena, that the time should come, when, after a period of gradual decline, the germinal capacity of the organ- 
ism should be so much reduced as no longer to suffice for the maintenance of its own integrity; and whenever such is the case, the termination of its existence as a living body must be the necessary result. Hence we find that there is a natural limit, not only to the size and development of the organism, but also to the duration of its life. And although that limit in each case is subject to variation amongst individuals, partly in consequence of diversity of external conditions, but partly (it may be surmised) through differences in the measure of germinal capacity possessed by each, yet there is a limit also to these variations, so that the character of the species is never departed from.

863. Period of Growth and Development.-The general history of the first part of this period, that of Embryonic existence, has already been so fully given, that it is only necessary here to remark briefly in regard to the character of its vital operations, that the whole nisus of its activity is directed rather to the performance of the vegetative or organic than to that of the animal functions; the action of the heart, and the occasional reflex movements of the limbs, being its only manifestations of nervo-muscular power. And thus it seems to be that the formative capacity is greater during embryonic life, than at any subsequent period, and greater in its earlier than in its later stages; so that we have not only evidence of an extraordinary power of regenerating parts which have been lost by disease or accident, as seen in attempts at the reproduction of entire limbs after that "spontaneous amputation" ( $\$ 361$ ); but there is also not unfrequently an absolute excess of productive power, as shown in the development of supernumerary organs, which may even proceed to the extent of the complete duplication of the entire body, by the early subdivision of the embryonic structure into two independent halves ( $\$ 357$ ).- It is to be noticed, also, that the embryo derives its supply not merely of food, but also of heut, from its maternal parent; and it is probably owing especially to the constancy with which this force operates, that the period of embryonic development is so uniform in Man (as in warm-blooded Animals generally), by comparison with the corresponding developmental periods in Plants and cold-blooded Animals, these being entirely determined by the degree of heat to which the embryos are subjected.

864. It is frequently of great importance, both to the Practitioner and to the Merlical Jurist, to be able to determine the age of a Fotus from the physical characters which it presents; and the following table has been framed by Devergie ${ }^{1}$ in order to facilitate such determination. It is to be remarked, however, that the absolute length and weight of the Embryo are much less safe criteria than its degree of development, as indicated by the relative evolution of the several parts which make their appearance successively. Thus it is very possible for one child born at the full time to weigh less than another born at 8 or even at 7 months; its length, too, may be inferior; and even the position of the middle point of the body is not, taken alone, a safe criterion, since it is liable to variation in individuals. ${ }^{2}$

Embrys three to four weeks. -It has the form of a serpent; its length from 3 to 5 lines; its hrad indicated by a swelling; its caudal extremity (in which is seen a white line, indicating the continuation of the medulla spinalis) slender, and terminating in the umbilical cord; the mouth indicated by a cleft, the eyes by two black joints; members begin to appear as nipple-like protuberances; liver occupies the whole abdomen; the bladder is very large; the chorion is villous, but its villosities are still diffused over the whole surface.

Embryo of six weeks.-Its length from 7 to 10 lines; its weight from 40 to 75 grains;

1 Médecine Légale, 3ème édit., tom. i, p. 279.

2 See, on this lust point, Moreau in Lancette Française, 1837; and Dr. A. Taylor in Guy's Hospital Reports, 1842. 
face distinct from cranium; aperture of nose, mouth, eyes, and ears perceptible; head distinct from thorax: hands and forearms in the middle of the length; fingers distinct; legs and feet situated near the anus; clavicle and maxillary bone present a point of ossification; distinct umbilicus for attachment of cord, which at that time consists of the omphalo-mesaraic vessels, of a portion of the urachus, of a part of the intestinal tube, and of filaments which represent the umbilical vessels; the placenta begins to be formed; the chorion still separated from the amnion; the umbilical vesicle very large.

Embryo of two months.--Length from 16 to 19 lines ; weight from 150 to 300 grains; elbows and arms detached from the trunk; heels and knees also isolatcd; rudiments of the nose and of the lips; palpebral circle beginning to show itself; clitoris or penis apparent; anus marked by a dark spot; rudiments of lungs, spleen, and suprarcnal capsules; cecum placed behind the umbilicus; digestive canal withdrawn into the abdomen; uracluus visible; osseous points in the frontal bone and in the ribs ; chorion commencing to touch the amnion at the point opposite the insertion of the placenta; placenta begins to assume its regular form ; umbilieal vessels commence twisting.

Emtryo of three months. - Length from 2 to $2 \frac{1}{2}$ inches; weight from $1 \mathrm{oz}$. to $1 \frac{1}{2} \mathrm{oz}$. (Troy); head voluminous; eyelids in contact by their free margin ; membrana pupillaris visible; mouth closed; fingers completely separated; inferior extremities of greater length than rudimentary tail; elitoris and penis very long; thymus as well as suprarenal capsules present; crecum placed below the umbilicus; cerebrum 5 lines, cerebellum 4 lines, medulla oblongata $1 \frac{1}{2}$ line, and medulla spinalis $\frac{3}{4}$ of a line in diameter; two ventricles of heart distinct; the decidua reflexa and decidua uterina in contact; funis contains umbilical vessels and a little of the gelatin of Wharton; placenta completely isolated ; umbilical vesicle, allantois, and omphalo-mesaraic vessels have disappeared.

Fotus of four months. - Length 5 to 6 inches; weight $2 \frac{1}{2}$ to 3 oz.; skin, rosy, tolerably dense; mouth very large and open; membrana pupillaris very evident; nails begin to appear; genital organs and sex distinct; cecum placed near the right kidney; gall-bladder appearing; meconium in duodenum ; creal valve visible; umbilicus placed near pubis; ossieula auditoria ossitied; points of ossification in superior part of sacrum ; membrane forming at point of insertion of plucenta on uterus; complete contact of chorion with amnion.

Fatus of five months - Length 6 to 7 inches; weight 5 to $7 \mathrm{oz}$.; volume of head still comparatively great; nails very distinct; hair beginning to appear; skin without sebaccous covering; white substance in cerebellum; heart and kidneys very voluminous; crecum situated at inferior part of right kidney; gall-bladder distinet; germs of permanent teeth appear; points of ossitication in pubis and calcaneum; meconium has a yellowish-green tint, and occupies comnencement of large intestine.

Fotus of six months.-Length 9 to 10 inches; weight $1 \mathrm{lb}$; skin presents some appearance of fibrous structure; eyelids still agglutinated, and membrana pupillaris remains; sacculi begin to appear in colon; funis inserted a little above pubis; face of a purplish red; hair white or silvery; sebaceous covering begins to present itself; meconium in large intestine; liver dark-red; gall-bladder contaius serous fluid destitute of bitterness; testes near kidneys; points of ossification in four divisions of sternum; middle point at lower end of sternum.

Fotus of seven months. - Length 13 to 15 inches; weight 3 to 4 lbs.; skin of rosy hue, thick and fibrous; sebaceous covering bcgins to appear; nails do not yet reach extremities of fingers; eyelids no longer adherent; membruna pupillaris disappearing; a point of ossification in the astragalus; meeonium occupies nearly the whole of large intestine; valvule conniventes begin to appear; crecum placed in right iliac fossa; left lobe of liver almost as large as right; gall-bladder contuins bile; brain possesses more consistency; testicles more distant from kidneys ; middle point at a little below cind of sternum.

Foetus of eight months. - Length 14 to 16 inches; weight 4 or 5 lbs.; skin covered with well-marked sebaccons envelope; nails reach extremitics of fingers; membrana pupillaris becomes invisible during this month; a point of ossification in last vertebra of sacrum; cartilage of inferior extremity of femur presents no centre of ossification; brain has some indications of convolutions; testicles descend into inguinal ring; middle point nearer the umbilicus than the sternum.

Foetus of nine months, the full term.-Length from 17 to 21 inches; weight from 5 to $9 \mathrm{lbs}$, the uverage probably about $6 \frac{1}{2} \mathrm{lbs}$. ; head covered with linir in greater or less quantity, of from 9 to 12 lines in length; skin covered witl sebaceous matter, especially at bends of joints; membrana pupillaris no longer cxists; external auditory meatus still cartilaginous; four portions of occipital bone remain distinet; os hyoides not yet ossitied; point of ossification in the centre of cartilage nt lower ex- 
tremity of femur; white and gray substances of brain become distinct;-liver descends to umbilicus; testes have passed inguinal ring, and are frequently found in the scrotum; meconium at termination of large intestine; middle point of body at umbilicus, or a little below it.

865. From the time of its entrance into the world, the condition of the Human infant is essentially changed. It is no longer supplied with nutriment by the direct transmission of organizable materials from the circulating fluid of the mother to its own; but obtains it by the processes of digestion, absorption, and assinilation, which involve the establishment of new modes of vital activity in its own organism. In order, however, that the change may not be too sudden, the nutriment provided by Nature for the early period of infautile life, is such as to occasion the least possible demand upon its vital powers for the preparation of the organizable material which is required for its further growth aud development. But the transition is a most important one in another particular; the infant is now thrown in a great degree upon its own resources for the generation of its Heat; and this it is enabled to accomplish by the combustion of a portion of its food, which is specially provided for the purpose, this combustion being promoted by the arrangements for that active Respiration, which now supersedes the very limited aeration of its circulating fluids that was sufficient during foetal life. In the movements of the respiratory muscles and of the walls of the alimentary canal, we have a new source of expenditure of vital force, and of destruction of tissue; and this expenditure is progressively augmented as the motions of the body and limbs become increasingly active. Thus we find that the fornative powers are not exercised during Infancy and Childhood, solely in the construction and angmentation of the fabric (as they were during embryonic life), since there is a constant demand upon them for its maintenance; and this demand becomes greater and greater, in proportion to the activity of the Animal powers. These, at first called into exercise by the stimulus of sensory impressions upon the Nervous system, are speedily brought into very energetic operation. This operation is of au extremely limited character, being at first purely sensorial, and for some time afterwards simply perceptive. But the whole Nind (such as it is) being given up to it, habits of observation are formed, which are never subsequently lost; the infant learns how to use his Organs of Sense; and he also acquires those powers of interpreting their indications, which become so completely ingrafted into his nature, as henceforth to seem a part of it. Although this Education of the Senses will necessarily go on, even without any intentional assistance on the part of others, yet it is in the porrer of the Mother or Nurse to promote it effectually, by supplying objects of various kinds which the Infant may look at and grasp, and by not abruptly interfering (by the too speedy withdrawal of such objects) with the process by which the visual and tactile perceptions are blended and harmovized ( $\$ 619)$. - The Nervous system of the Infant, although thus called into extraordinarily energetic activity, cannot long sustain that activity; a very large measure of Sleep is required for the restoration of its speedily exhausted powers, and auy unusual excitement of them tends to injurious disturbances of its nutrition. It is owing to this peculiar susceptibility of the Nervous system of the infant to external influences, that medicines (especially narcotics) which exert a special influence upon that system, are so peculiarly potent in their effects at this period of life, that the greatest caution is needed in their administration.

866. The most important developmental change which occurs in Infancy, after the complete establishinent of the extrauterine circulation $(\S 783)$, is the completion and eruption of the first set of teeth; the greater part of whose formation, however, has taken place before birth. These "milk" or" 
"deeiduous" teeth, 20 in number, usually make their appearance in the following order: The four eentral Incisors first present themselves, usually about the 7 th month after birth, but frequently mueh earlier or later; those of the lower jaw appear first. The lateral Ineisors next show themselves, those of the lower jaw eoming through before those of the upper; they usually make their appearanee between the 7 th and 10th months. After a short interval, the anterior Molars present themselves, generally soon after the termination of the 12 th month; and these are followed by the Canines, which usually protrude themselves between the 14th and 20th months. The posterior Molars are the last, and the most uneertain in regard to their timc of appearance; this varying from the 18 th to the 36 th month. In regard to all exeept the front teeth, there is no settled rule as to the priority of appearance of those in the upper or under jaw; sometimes one preeedes, and sometimes the other; but in general it may be stated, that whenever one makes its appearanee the other eannot be far off. The same holds good in regard to the two sides, in which development does not always proeed exactly pari passu.-The period of Dentition is sometimes one of considerable risk to the Infant's life, and this espeeially when an irritable state of the nervous system has been brought about by unsuitable food, un wholesome air, or some other eause of disordered health. In such eases the pressure upon the nerves of the gum, which necessarily preeedes the opening of the sae and the eruption of the tooth, is a fruitful source of irritation; produeing disturbanee of the whole system, and giving origin to Convulsive affections whieh are not unfrequently fatal. These have been particularly studied by Dr. M. Hall, who reeommends the free use of the gum-laneet, as a most inportant means of prevention and eure; but the Author has no doubt that too much attention has been given to the immediate souree of the irritation, and too little to the general state of the system; and that eonstitutional treatment, espeeially ehange of air, and improvement of the diet, is of fundamental importanee. In infants whose general health is good, and who are not overfed, Dentition is usually a souree of but very trifling disturbance; a slight febrile aetion, lasting only for a day or two, being all that marks the passage of the tooth through the capsulc, and its eruption through the gum taking place without the least indieation of suffering or disorder. Any existing malarly or abnormal tendeney, however, is pretty sure to be aggrarated during the "eutting of the teeth;" and it is therefore of the greatest eonsequenee that the infant should be withdrawn during this period firom all injurious influences; and that no irregularity of diet, or deficicney of fresh air and exereise, should operate to its disalvantage.

867. Although there are no well-marked divisions between the periods of Childhood, Youth, and Adoleseenee, through all of whieh we witness the eontinuance of the proeesses of Growth and Development (though in a gradually-deereasing ratio), yet we may appropriately distinguish each as the epoch of one of those important ehanges whieh tend towards the eompletion of the fabric; namely, Childhood as ranging through the greater part of the period of the seeond Dentition,- Youth as charaeterized by that increased evolution of the sexual organs, and by those general constitutional ehanges aeeompanying that cvolution, which altogether constitute Puberty,and Adolcscence as distinguished by that entire consolidation of the Osseous skelcton, which is not eompleted until the full stature las been attained. It will be convenient first to eonsider what is eommon to all these periods; and then to notice the features by which they are severally characterized.

868. The passage from Infuncy to Childhood may be regarded as marked by the eruption of the "deciduous" Teeth; by the termination of that direct supply of food to the off:pring, which is afforded until then by the mammary 
secretion of the mother; by the dawn of the Intellectual powers, manifcsted in the first efforts at speaking; and by the acquirement of sufficient control over the muscular apparatus, to render it subscrvient to the increasing desire which then displays itself for independent Locomotion. All these advances usually take place simultancously, or ncarly so, during some part of the second year; some Infants being much more forward than others, both in "cutting their teeth" and in learning to walk and to talk. When they have been completed, the Child enters upon a life which is in many respects new. The alteration of its diet involves a much higher activity of all the organs which are concerned in making blood; whilst its greatly increased amount of exertion, both of body and mind, gives occasion to a morc rapid disintegration of the nervous and muscular tissnes, and hence to a higher activity of the Excretory organs. This will, of course, progressively augment, in proportion as the Nervo-muscular apparatus is brought, with advancing years, into nore vigorous and more prolonged exercise; until, with the attainment of adult age, the disintegration of these tissues comes to be the chief source of the Fxcrementitious products. But during the whole period of increase, there is another source of demand for nutritive activity, in that perpetual reconstruction of the fabric (involving a sort of continual pulling down and rebuilding on a larger scale, all the old materials being carried away as useless) which is a necessary condition of its growth : but this demand of course slackens with the diminution of the rate of increase; and at last it ceases altogether, just when the other attains its maximum. Hence the demand for food, on the one hand, and the amount of excretory matter set free from the body, on the other, are remarkably large during the whole of this perior : the child, as every one knows, consuming far more nutriment than the adult, in proportion to the wcight of their respective bodlies; and the like being true of the quantity of carbonic acid exhaled from the lungs ( $\$ 311$, III), and of the urea given off from the kidneys ( $\$ 411)$.-That the germinal capacity, though inferior to that of the embryo, still persists in a high degree during the period of childhood and youth, is shown in the readiness with which the effects of injuries and disease are recovered from; for although the regeneration of lost parts does not take place to nearly the same extent as during early embryonic life, yet up to a certain point it is effected with great completeness, and with much greater rapidity than at later epochs. It is still, in fact, rather in the exercise of formative power, than in the production of nervo-muscular vigor, that the vital force of the earlier part of this period is displaycd; and we may readily trace such a relation of reciprocity between these two modes of its manifestations, as is strongly indicative of the community of their source. For it is familiar to every observer, that, when the growth of a child or a young person is peculiarly quick, his nervo-muscular energy is usually feeble, and his power of endurance brief, in comparison with that which can be put forth by one whose frame is undergoing less rapid increase. And we observe, moreover, that the capacity of resistance to depressing influences of various kinds, which is a no less decided manifestation of the vital powers of the organism (secing that these influences are of such a kind as to tend towards its death), is possessed by the latter in a far higher degree than by the former. 'This is remarkably the case in regard to privation of food and depression of external temperature; under which, too, children and young persons succumb much more speedily than adults.

869. It is most interesting to trace, during the progress of the development of the bodily fabric, the gradual expansion and invigoration of the Mental powers. The acquirement of language constitutes the most im- 
portant step in the development of the ideational eonseiousness; and it is easy to reeognize in the psyehical manifestations of Children, the further progress of that development. The formation of Associations between ideas takes place with extraordinary readiness and tenaeity during the earliest period of ehildhood; and these exereise so much influence over the succession of the thoughts during the whole remainder of life, that "the force of early associations" has beeome proverbial. Out of these associations arise, on the one hand, Memory and Imagination; on the other hand, those simple processes of Reasoning which are neeessary to the development of a higher class of ideas. Thus the mind passes from those primary notions of individual objects which are direetly suggested by sense-perceptions, to those abstract ideas of their qualities, which enable them to reeognize those qualities elsewhere, notwithstanding the existenee of differenees in other respeets; and thence to those general ideas, in which the abstraetions are embodied. In all these processes, the child-mind seems to be so entirely eoncentrated upon the partieular subjeet of its thoughts, as to be "possessed" by it for the time, almost as completely as a "biologized" subjeet is by his dominant idea ; and no prolonged study of it is required to justify the statement, that its operations are for some time entirely automatic, and that the acquirement of Volitional eontrol over them, on the part of the individual, is a very gradual proeess. As a general rule it may be laid down that the aetivity with which the formation of new ideas takes place in the ehild, and the rapidity with which the attention transfers itself from one objeet to another, prevents any single state from fixing itself durably in the consciousness, so that the Memory preserves but faint traees of the greater part of what passes through the mind; and it is (for the most part) only when the same thoughts are frequently recurred to, that they take root (so to speak) in the psyehical nature. Still we oeeasionally find that partieular impressions exert a very powerful influence on the subsequent eourse of thought and feeling; and there is good reason to believe that even where the consciousness loses its hold over them, impressions of a transient nature may leave such traces in the Brain, that they may be reprodueed at any future time when the appropriate suggestion may happen to be supplied.- Whilst the ideational consciousness is thus being expanded and elevated, the Emotional part of the Psyehical nature is rapidly acquiring a greater range and intensity of aetion. The infant and young ehild give ample evidenee in their aetions, of the several forms of Emotional Sensibility which eonnect themselves with Sensational and Pereeptive states; but no sooner does the development of Ideas eommenee, than the various modifications of "feeling" attaeh themselves to these; and thus almost every thought that is not a purely intelleetual abstraction, comes to possess more or less of an Emotional character. Here, again, we traee the powerful influenee of early impressions; for notwithstanding that the state of feeling which is habitual to each individual may depend in great degree upon his original constitution, yet it is unquestionable that it is largely influeneed (espeeially in its assoeiation with particular elasses of ideas) by sympathy with the like states in those anong whom the child reeeives its early edueation. It is of peculiar importanee, therefore, that this exanıle should be such as it is wholesome for the ehild to imitate; since it is upon the habits of feeling thus early formed, that the happiness and right eonduet of after life mainly depend. This statement (which applies with yet greater foree to the MLoral Sense) may at first seem ineonsistent with the well-known faet that the Enotions of ehildren are peculiarly transient in their charaeter, even when they are violently excited; one state of feeling giving place to another, even of the most opposite kind, 
under the influence of some new impression or of some cliange in the direction of the ideas. But the same general principle applies to this case, as to the formation of habits of thought; namely, that although individual impressions are more speedily dissipated from the minds of children than from those of adults, yet that when impressions of the same kind are frequently repeated, the brain grows to them in such a manncr that they come to take part (as it were) in its ordinary working; and thus, by establishing a particular mode of nutritive assinilation, they tend to perpetuate this acquired habit, of whatever nature it be.-The right training of the Enotional tendencies, and all the higher uses of the Intellectual Faculties, depend in great degree, as may readily be shown, upon the influence of the Will in directing the current of thought and feeling; and this becomes greater and greater, if rightly cultivated, with the advance of years, so that the psychical powers, whilst themselves acquiring an increase of vigor and comprehensiveness, are brought more and more under the control of the individual, and can be utilized in any way in which he may choose to employ them. Thus with a diminishing mobility of thought and excitability of feeling, the Mind becomes more and more capable of sustained and determinately concentrated activity; and is at the same time progressively acquiring that store of familiar experiences, which not only constitutes the basis of all attainments in special departments of knowledge, but supplies (when judiciously used) that "common sense" by which we form most of our judgments and direct most of our conduct.-During this period, moreover, the Muscular apparatus of Animal life, whose actions are at first purely automatic, is brought more and more under the direction of the Mind, so as to express its ideas, its feelings, and its volitions. And it is whilst this transference is going on, that new habits of action are most readily formed, and when once formed, are durably impressed upon the organism $(\$ \S 510,545,679)$.- The excess which must exist, during the whole of this period, in the constructive over the destructive activity, and the large amount of the latter which (as already shown) arises out of the very nature of Growth, in addition to that which proceeds from the increased activity of the Animal functions, necessitates a much larger proportion of repose than suffices for the adult; but this necessity diminishes with the progress of years, for the reasons already mentioned; and thus we find that whilst the young child passes 16 or 18 hours a day in sleep, half that time suffices for the youth just entering on manhood.

870. The Second Dentition, consisting in the replaccment of the deciduous or "milk" Teeth by the permanent Teeth that succeed them, which is the most important developmental change that occurs during the period of Childhood, normally commences in the 7 th or 8 th year: the germs of the new teeth, however, are formed long previously, having their origin in a process of gemmation from the tooth-sacs of the temporary teeth, which takes place at a very early period in the development of the latter. The three permanent Molars on either side of each jaw, however, have no such origin : since they do not replace temporary teeth. The first pair, which usually make their appearance behind the temporary molars, either contemporaneously with, or a little anteriorly to, the first shedding of the deciduous teeth, are really "milk" teeth, so far as their origin is concerned, since they are developed from primitive tooth-sacs: on the other hand, the second true molars, which afterwards come up behind them, are evolved from tooth-sacs which hold the same relation to those of the first, as the tooth-sacs of the other permanent teeth do to those of the deciduous teeth which they replace; and the third true molars, or dentes sapientice, bear the like relation to the sccond. Although the eruption of the true molars is so long postponed, yet the 
foundation of them is laid at an earlier period ; for the papilla of the first is distinguishable at the 16 th week after conception, that of the second at the 7 th month after birth, and that of the third at the 6 th year. In the successive replacement of the "milk" teeth by the "permanent" set, a very regular order is usually followed. The middle Incisors are first shed and renewed, and then the lateral Incisors. The anterior " milk" Molars next follow; and these are replaced by the anterior Bicuspid teeth. Abont a year afterwards, the posterior "milk" Molars are shed, and are replaced in like manner by Bicuspid teeth. The Canines are the last of the "milk" teeth to be exchanged; in the succeeding year, the second pair of the true Molars appear; but the third pair, or dentes sapientice, are seldom developed until three or four years subsequently, and often much later.

871. It has been proposed ${ }^{1}$ (and from the evidence adduced in its favor, the proposition would seem entitler to considerable attention) to adopt the successive stages in the Second Dentition, as standards for estimating the physical capabilities of Children, especially in regard to those two periods which the Factory Laws render it of the greatest importance to determine: namely, the ages of nine and thirteen years. Previously to the former, a Child is not permitted to work at all; and up to the latter, it may be only employed during nine hours a day. The necessities or the cupidity of Parents are continually inducing them to misrepresent the ages of their children; and it has been found desirable, therefore to seek for some test, by which the capability of the Child may be determined, without a knowledge of its age. A standard of Height has been adopted by the Legislature for this purpose; but upon grounds which, physiologically considered, are very erroneous; since, as is well known, the tallest children are frequently the weakliest ( $\$ 868)$. According to Mr. Saunders, the degree of advance of the Second Dentition may be regarded as a much more correct standard of the degree of general development of the organic frame and of its physical powers; and it appears from his inquiries, that it may be relied on as a guide to the real age in a large proportion of cases; whilst no serious or injurious mistake can ever arise from its use. It may happen that local or constitutional causes may have slightly retarded the development of the Teeth; in which case the age of the individual would rather be underestimated, and no harm could ensue ; on the other hand, instances of premature development of the Teeth very rarely, if ever, occur; so that there is little danger of imputing to a Child a capability for exertion which he does not possess, as the test of height is continually doing. Moreover, if such an advance in Dentition should occur, it might probably be regarded as indicative of a corresponding advance in the development of the whole organism; so that the real capability would be such as the teeth represent it.-The following is Mr. Saunders's statement of the Ages at which the "permanent" Teeth respectively appear: The first true Molars usually present themselves towards the end of the seventh year. Occasionally one of them protrudes from the gum at 6 , or more frequently at $6 \frac{1}{2}$ years of age; but the evolution of the whole of them may be regarded as an almost infallible sign of the Child being 7 years old. In other instances, where the tooth on one side of the mouth is freety developed, it is fair to reckon the two as having emerged from their capsules; since the development of the other must be considered as retarded. This rule only holds good, however, in regard to tceth in the same row ; for the development of the teeth in either jaw must not be inferred

1 The Teeth a Test of Age, eonsidered with reference to the Factory Children. By Edwin Saunders. 
from that of the corresponding teeth in the other. With this understanding, the following table will probably be very near the truth:

Central Incisors cleveloped at

Lateral Incisors, .

First Bicuspid,

Sccond Bicuspid, .

Canines,

Second Molars,

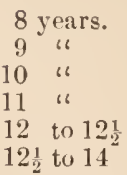

The following are the results of the application of this test, in a large number of cases examined by Mr. Saunders. Of 708 children of nine years old, 530 would have been pronounced by it to be near the completion of their ninth year; having the central, and either three or four lateral, incisors fully developed. Out of the remaining 178, it would have indicated that 126 were $8 \frac{1}{2}$ years old, as they presented one or two of the lateral Incisors; and the 52 others would have been pronounced 8 years old, all having three or four of the central Incisors. So that the extreme deviation is only 12 months; and this in the inconsiderable proportion (when compared with the results obtained by other means) of 52 in 708, or $7 \frac{1}{3}$ per cent. Again, out of 338 cliildren of 13 years of age, 294 might have been pronounced with confidence to be of that age; having the Canines, Bicuspid, and second Molars, either entirely developed, or with only the deficiency of one or two of either class. Of the 44 others, 36 would have been considered as in their thirteenth year, having one of the posterior molars developed; and 8 as near the completion of the twelfth, having two of the Canines, and one or two of the second Bicuspid. In all these instances the error is on the farorable side,- - that is, on the side on which it is calculated to prevent injury to the objects of the inquiry; in no instance did this test cause a Child to be estimated as older or more fit for labor than it really was. ${ }^{1}$

872. The period of Youth is distinguished by that advance in the evolution of the Generative apparatus in both sexes, and by that acquirement of its power of functional activity, which constitutes the state of Puberty. Of the principal changes in which this consists, in the two sexes respectively, an account has already been given $(\$ \$ 734,740)$; and it is merely requisite here to add, that this augmented development can only be rightly regarded as preparatory to the exercise of these organs, and not as showing that the aptitude for their exercise has already been fully attained. It is only when the growth and development of the individual are completed, that the procreative power can be properly exerted for the continuance of the race; and all experience shows that by prematurely and unrestrainedly yielding to the sexual instincts, not merely the generative power is early exhausted, but the vital powers of the organism generally are reduced and permanently enfee-

1 The value of this test, as compared with that of Hcight, is manifested by a striking example adduced by Mr. Saunders. The height of one lad, J. J., aged 8 years and 4 months, was 4 feet and $\frac{3}{4}$ of an inch; that of another boy, aged 8 years and 7 months, was only 3 feet $7 \frac{1}{4}$ inches. According to the standard of height adoptcd by the Factory Commissioners (namely, 3 feet 10 inches), the taller lad would have been judged fit for labor, whilst the shorter would have been rejected. The Dentition of the latter, however, was further advanced than that of the former; for he had two of the lateral Incisors, whilst the former had only the central; and the determination of their relative physical powers, which would have been thus formed, would have been in complete accordance with the truth. The elder boy, though shorter than the other by $5 \frac{1}{2}$ inches, possessed a much greatcr degree both of corporcal and mental energy, and his pulse was strong and regular; whilst that of the younger lad, who was evidently growing too fast, was small and frequent. -An instance even more striking has comc under the Author's own observation. 
bled; so that any latent predisposition to disease is extremely liable to manifest itself; or the bodily vigor, if for a time retained with little deterioration early undergoes a marked diminution.

873. After the attainment of Puberty, no marked alteration takes place in the organism, save the continuance of its increase in stature, usually for a few years longer $(\S 784)$; which increase is the chief manifestation of the excess of the germinal capacity, that has not yet expended itself in the building up of the fabric. But so long as this increase is going on, there is a want of that solidity and compactness of the organism which seem only attainable when growth has ceased; and the attainment of which, being essential to the highcst manifestations of vigor and endurance, marks the final completion of its development. Of this we have the best illustration in the Osseous system; whose completion, being postponed until all further growth has ceased, may be fairly considered as marking the final stage in the development of the organism, and as therefore characterizing the period of Adolescence.-Commencing with the Vertebral Column, we find that whilst the "body" and "neural arches" of each vertebra become consolidated in early childhood, the spinous and transverse processes are completed by separate "epiphyses," the ossification of which does not commence until after puberty, and tinc final union of which with the body of the bone may not occur until the age of twenty-five or thirty years. About the same time, there is formed and added to each surface of the body of the vertebra a smonth annular plate of solid bone, which covers a portion that was previously rough and fissured. During this period, the consolidation of the Sacrum is proceerling: the component vertebræ of which remain separate up to about the sixteenth year, and then begin to unite from below upwards, the union of the two highest being completed by about the twenty-fifth or the thirtieth year; whilst at the same time thin osseous plates are formed on either side of the coalesced mass, which seem to represent the epiphyses of the transverse processes of its component vertebræ, and like them are finally joined on to the body of the bone. The ossification and coalescence of the Coccygeal vertebrie take place at a still latcr period. Each rib in like manner has two epiphyses, one for the head and the other for the tubercle; the ossification of which begins soon after puberty, whilst their union with the body of the bone is not completed until some years aftcrwards. The five pieces of which the stcrnum consists, though themselves completely ossified, remain separate until after the age of puberty; when their union commences from below upwards, as in the sacrum, not being always completed, however, even in old age, by the junction of the first piece to the rest of the bone. The ossification of the Ensiform cartilage does not commonly begin until after the age of puberty; and it is usually not entirely completed cven in very advanced life.- The ossific union of the separate elements of the Bones of the Skull $(\$ \S 794,795)$, is usually completed within a few years after birth; but therc are some parts which not unfrequently remain distinct during the greater portion of life, and which may even never coalesec; such is the case with the two halves of the Frontal bone, which oftcn remain permanently divided by a continuation of the sagittal snture, and with the Styloid process of the temporal bone. In the Upper extremities we find the Scapula presenting three epiphyses, onc for the coracoid process, onc for the acromion, and one for the lower angle of the bone; the ossification of which begins soon after puberty, their union with the body of the bone taking place between the ages of twenty-two and twenty-fivc years. The Clavicle lias an epiphysis at its sternal end, which begins to form between the eighteenth and twentieth ycars, and is united to the rest of the bonc a few vears later. The consolidation of the Humerus is completed rather carlicr; the large picce at the upper end, which is formed 
by the coalescence of the ossific centres of the head and two tuberosities, unites with the shaft at about the twentieth year; whilst its lower extremity is completed by the junction of the external condyle and of the two parts of the articulating surface (previously united with each other), at about the seventeenth year, and by that of the internal condyle in the year following. The superior epiphyses of the Radius and Ulna unite with their respective shafts at about the age of puberty ; the inferior, which are of larger size, at about the twentieth year. The epiphyses of the Metacarpal and Phalangeal bones are united to their principals at about the twentieth year.- - In the Lower extremities the process of ossification is completed at nearly the same periods as that of the corresponding parts of the upper. The consolidation of the Ilium, Ischium, and Pubis, to form the Os Innominatum, by the ossification of the triradiate cartilage that intervenes between them in the acetabulum, does not take place until after the period of puberty; and at this time additional epiphyses begin to make their appearance on the crest of the ilium, on its anterior inferior spine, on the tuberosity of the ischium, and on the inner margin of the pubes, which are not finally joined to the bone until about the twenty-fifth year.

874. The rapid increase in Viability which shows itself in both sexes up to the age of puberty, its rapid decline from that point, and its subsequent increase in the male up to the age of thirty, have been already pointed out ( $\$ 84)$. The disorders to which the organism is most subject during the several periods which have now been considered, are by no means the same for each. In early Childhood, when there is a great demand for the activity of the Digestive and Assimilative functions, and these have to be exercised upon nutriment to which their organs are not yet accustomed, we find derangements of those organs to be among the most common of all maladies; these may be serious enough in themselves to coinstitutc dangerous and even rapidly fatal diseases; but even when they do not take these acute forms, a foundation is often laid, in habits of perverted Nutrition thence arising, for disorders of a more chronic nature (especially those depending on the Tubercular diathesis, §378), which may not manifest themselves for many years afterwards. The peculiar activity of the nervous centres, which is prolonged from Infancy into early Childhood, involves a continued liability to derangements of their nutrition or of their functions; and thus it happens that in young children of scrofulous temperament, it is either in the mesenteric glands, or in the brain or its membranes, that tubercular deposit first takes place. The second Dentition, like the first, is often accompanied with a grcat deal of constitutional disturbance; especially in such individuals as are suffering from defective Nutrition, or from an irritable state of the Nervous System. In the former case there is a special proncness to Tubercular disease ${ }^{1}$ in the latter, to Epilepsy, Chorea, or some other form of disorder of the nervous centres, the connection of which with Dentition is shown by its abatement when that epoch has passed. A large part of the sickness and mortality, however, which presents so high a rate during the whole period of Childhood, is due to various forms of Zymotic disease, especially the Exanthemata and Infantile Remittent Fever, and to their sequelce. ${ }^{2}$-The attainment of Puberty

1 It is a very significant circumstance, that of the many specimens of the Anthropoid Apes which have been brought alive into this country, not one has survived its second dentition; and that, in almost cvery case, it has been by tubcrcular disease that their lives have been thus prematurely cut off.

2 The effects of affluence and poverty on the duration of life at this period are remarkably shown by the deductions of Caspar of Berlin, who states as the result of his inquiries that of 1000 children born in the families of affluent persons, 911 attained the age of 15 years; whilst of 1000 raupers, only 584 survived to that age. (Béclard, Physiologie, 1862, p. 594.) 
in the Male sex is not usually attended with any specific tendency to disease: nor would it probably be in the Female, if her mode of life were more accordant with the rules of health. Although disorder of the Menstrual function is one of the most common phenomena of female youth, yet it is undoubtedly to be looked upon more frequently as a symptom of general defect of nutrition (and especially of an impoverished condition of the blood), than as itself constituting a disease. The extraordinary reduction in the probability of life, indicating a large mortality, during the years which immediately succeed puberty, seems to depend in great degree, in the Male, upon the premature use of his generative powers, and upon his entrance upon the active employments of life before his constitution has reeeived that invigoration which results from the completion of his bodily development; whilst in the Female it is very commonly attributable to the accumulation of unhealthy influences, which begin to "tell" upon the powers of her system, when its germinal capaeity no longer ministers to its active regeneration. It is then, in both sexes, though from causes whose immediate nature is different, that the Tubercular diathesis is prone to develop itself with peeuliar intensity, and that, by fixing upon the Respiratory organs, it produces the most rapidly fatal alterations in structures whose integrity is essential to life.

875. Period of Maturity.--The cessation of growth, and the completion of the developmental processes, which indicate the attainment of Manhood, are accompanied by a marked inerease in the general vigor of the organism, and by a special augmentation in the power of endurance in the exercise of the Animal faculties. With the exception of those parts of the fabric whose utility was confined to the earlier periods of its development, we fiud every organ now presenting its greatest capacity for sustained activity; and thus it is from the eharacters whieh each presents at this period, that we base our ideas of its typical perfection of strueture and composition. All the previous changes whieh the organism has undergone, both as a whole and in its separate parts, concur to the attainment of this perfection, as we have especially seen in regard to the evolution of the solid framework of the body; and every subsequent change, as we shall presently perceive (877), involves a deterioration from it. The whole nisus of development, during this period, appears to be direeted towards the maintenance of the organism in the state which it had acquired at its commencement; by the regeneration of its tissues as fast as they undergo disintegration, and by the renovation of its vital force in proportion as this is expended. There is no longer any capacity for the production of new organs, and comparatively little for the augmentation of those already existing; the increase of the Uterine and Mammary structures, during the period of gestation, being the most important examples of formative power, and these presenting themselves in the sex in which there is least of nervo-muscular activity and of general vigor. We should infer, then, that the "germinal capacity" is now on the decline; and this further appears from the diminished energy and completeness with which the reparative processes are performed, as compared with the mode in whieh they are executed during the period of growth. There is consequently a less demand for alimentary material (allowanee being made for the augmented bulk of the body) than during the previous periods; and the dependence of life upon a constant supply of aliment is far less close. Moreover, the ordinary rate of waste or degeneration of tissue is now much less rapid than during the period of growth; for we have seen that decay and removal, in the latter case, are anong the very conditions of increase; whilst in the former, they proceed, for the most part, only from the expenditure of the vital powers of the tissues, consequent upon their functional activity. Hence it is upon the degree in which the Animal powers are exercised, that the denand 
for food chiefly depends in the $\Lambda$ dult; the sole purpose of the Organic or Vegetative operations being (so to speak) to keep the apparatus of Animal life, now fully developed, in working order. The relative activity of the different parts of this apparatus is now somewhat modified. The observing faculties no longer possess the same pre-eminence; the emotional sensibility is less readily excitcd; but the intellectual povers now act, in the modes which have become habitual to them, with a sustained vigor and completeness which they never previously possessed. And so, whilst the muscles are not so easily excited to contraction, and new combinations of movement are acquired with far more difficulty than during the period of growth and development, the force which they can generate by their contraction is augmented, and this force can be kept up for a much longer time in adults than in younger subjects.

876. The duration of the period over which this "maintenance" may be protracted, without any sensible deterioration, depends in great degree upon the due observance of all the conditions of hcalth. If the various mental and bodily faculties are duly exercised, without being overtasked,-if an amount of sleep adequate to their periodic renovation be regularly taken,if a sufficicnt but not excessive quantity of wholesome food be ingested at appropriate intervals, -if the functions by which the blood is prepared, and those by which it is kept in purity, be duly performed,-if all such noxious agents as foul air, strong alcoliolic liquors, tobacco-smoke, be kept at a distance,-and there be no constitutional predisposition to disease on the one hand, nor any exposure to extraneous morbific causes on the other,-it may be fairly anticipated that the bodily and mental vigor may be sustained with little deterioration during a long succession of years. The circunstances that most tend to premature decline, are, on the one hand, excessive cxertion either of the mental faculties or of the generative power; or, on the other, undue indulgence in food, or in stimulating drinks, or in any practice that tends to disorder the Organic functions, especially by exciting them to undue activity. Every one who, in any of these modes, may "live too fast," is almost certain to pay the penalty in an abbreviation of his term of vigorous activity; which may be either brought to a sudden and final close by fatal disease, or may be prematurely reduced by more gradual decay. And this tendency will of course be more decided, the greater is the amount, and the larger the combination, of those departures from the Laws of Health which give rise to it.

877. Period of Decline.-The decline of life exhibits a much more obvious diminution of the whole vital power of the organism; for not only is its formative activity now greatly reduced, but its nervo-muscular energy and general vigor progressively diminish, and its generative power becomes enfeebled, or ceases entirely ( $\$ 734,742)$. Of this diminution in formative power we have evidence in the entire absence of any attempt at new development, in the less perfect and more tedious manner in which the losses of substance occasioned by disease or injury are recovered from, and in the grarlual deterioration of the organism in general. The tissues which are rendered effete by their functional activity, are not any longer replaced in their normal completeness; for either the quantity of new tissue is inadequate, so that the bulk of the organs is obviously reduced; or their quality is rendered imperfect by the production of structures in various phases of degencration, in place of those which had been previously developed in the fullest completeness. The inferiority of Nervo-nuscular energy and of general vigor are thus evidently the result of the deficiency, and not (as in the period of growth) of the excess, of formative power, and in proportion as the "waste" of the tissues, consequent upon their functional activity, is 
more rapid than their renovation, a progressive loss of substance must take place. The forms of Degeneration most commonly met with in advanced age, are the fatty and the calcareous. The former $(\$ 351)$ is extremely prone to show itself in those organs whose integrity of structure is peculiarly important to health, and whose deterioration interferes directly with the vital properties of their component tissues. Thus we observe it in the Muscular apparatus generally, but pre-eminently in the walls of the Heart; and in proportion as its contractile fibre has been replaced by particles of fat, must the vital energy of any muscle be lowered. So, again, we find the same degeneration in the Liver, Kidney, and other parts of the Glandular apparatus; the proper secreting action of which is impaired in the ratio of the substitution of fat for the proper Glandular elements. But it may also lead to most serious derangements of the vital functions, by its interference with the purely mechanical actions of certain parts of the organism; thus, fatty degeneration of the walls of the Bloodvessels is one of the most frequent causes of those extravasations of blood in the nervous centres, which give rise to the apoplexy and to the various forms of paralysis so common among the aged; and the same change occurring in the Bones, gives them that peculiar brittleness which they frequently exhibit in advanced periods of life. That general decline of the vital powers, which has received the name of "climacteric disease," appears traceable to the same source."-The tendency of the calcareous degeneration (which especially affects the Cartilaginous and Fibrous tissues) is almost exclusively to interfere with the mechanical adaptations of the organism ; producing an injurious rigidity in various structures which require a greater or less amount of flexibility for the normal performance of their functions. Thus it is very common for the cartilages of the ribs to become ossified in advanced life, so as to interfere with the free movement of the walls of the thorax; and the thyroid cartilages of old people are frequently converted into bone, producing a roughness of the voice, and deficiency of the power of modulating it. The intervertebral substance (which is partly cartilaginous and partly fibrous) not unfrequently becomes solidified in the lumbar region, as do also the spinal ligaments, so that several of the lower vertebre are firmly anchylosed to each other and to the sacrum; and a like change often takes place in the pelvic articulations, so that the pelvis and the lower part of the spine become one continuous mass of bone, destitute of flexibility or yieldingness in any part. In like mamner the cranial sutures often become obliterated, and calcareous deposits occur in the duplicatures of the dura matter forming the falx and tentorium. A large amount of this kind of change may take place without any serious interference with the organic functions, although it tends to curtail the Animal powers. When the calcareous degeneration, however, extends itself to the vital organs, the interruption which it occasions in their actions may be fatal; thus, next to fatty degeneration, there is probably no more frequent cause of failure of the lieart's action, or of extravasation from the bloodvessels, in old persous, than ossification of the valvular apparatus of the former, depriving it of the flexibility which is essential to its proper action, or the fibrous walls of the latter, imparting to them a brittleness which predisposes to rupture. ${ }^{2}$

878. Thus, then, with the advance of Old Age, the organism becomes progressively more and more unfit for the active performance of its vital

1 See Culliver in the Transact. of Roy. Med.-Chir. Soc., 1843; and in Edin. Med. and Surg. Journ., 1843; Mr. Barlow's General Observations on Fatty Degeneration, in the Mledical Times and Gazette, May 15th, 1852.

8 A good account of these changes will be found in the Practical Treatise on the Diseases and Infirmities of $\Lambda$ dvanced Life, by Daniel Maclachan, M.D., 1863. 
operations; a gradual weakening is observable in the Mental as well as in the Corporeal energy; and a retardation becomes obvious in the current of Organic life. The mind is far less active than in the periods of Maturity; the perceptions are dull, the feelings comparatively obtuse (save where some dominant emotion has gained possession, through the previous habit of yielding to it), the intellectual powers cannot be so readily put in action, and the imagination loses its vividness. There are few instances in which any great works, either literary or artistic, have been executed after the age of threcscore. Still the experience of a long life gives value to the judgment; and the counsels of the old, where the bearings of the question can be fully understood, deserve the respect of the young, more especially in cases wherc temporary ardor of feeling tends in the latter to supersede the dictates of their calmer reason.-The mental torpor is correlated, there seems no reason to doubt, with changes in the condition of the Nervous substance, which impair its original activity; and like changes, occurring in the Mluscular substance, diminish its capacity for physical exertion. Hence there is, on the one hand, a marked diminution in the demand for food; on the other, a like diminution in the rate of the excretory processes, as is seen especially in the exhalation of carbonic acid ( $\$ 311$, III) and in the excretion of Urea $(\S+11)$ : and in accordance with all these reductions, there is a greatly diminished power of sustaining the heat of the body, the temperature of which consequently becomes liable to a serious depression from external cold. This retardation of vital activity gradually becomes more and more marked, until, if neither accident nor disease should intervene, the current stops of itself; the formative power seems to undergo a progressive exhaustion, until no assistance from artificial heat, no supply of the most nutritious food, can any longer avail for the generation of new tissue; the nervo-muscular energy gradually dechines, until at last even those actions ou which the circulation and respiration entirely depend can no longer be performed; and with the cessation of these functions, the Life of the entire organism becomes extinct. - Such we may consider to be the mode in which Death normally occurs. Various abnormal influences, however, remain to be considered, which may bring about this final result at an earlier period, and in different modes (chap. xxi).

\section{CHA PTER XXI.}

\section{OF DEATH.}

879. WE have seen it to be inherent in the very nature of Vital Action, that it can only be sustained during a limited period by any Organized body; for although the duration of certain structures may be prolonged, and their vital properties retained, almost indefinitely, yet this is only when the withdrawal of all extraneous agencies has reduced them to a condition of complete inactivity. The Organized fabric, in fact, is at the same time the instrument whereby Vital Force is exercised, and the subject of its operation; and of this operation, decline is no less a constituent part than development, and Death is its necessary sequence. Hence, in the performance of each one of those Functions whose aggregate makes up the Life of Man, the particular organ which ministers to that function undergoes a certain loss by the de- 
cline and death of its component tissues; and this the more rapidly in proportion to the activity of the changes which are effected by their instrumentality. But if the regenerative processes be also performed with due vigor, no deterioration of the organ is manifested, since every loss of substance is compensated by the production of an equivalent amount of new and similar tissue. This regenerative power, however, gradually diminishes with the advance of years; and thus it happens that the entire organism progressively deteriorates $(\$ 877)$, and that Death at last supervenes from a general failure of the vital powers, rather than from the perversion or cessation of any one class of actions in particular.

880. But Death may occur at any period of Life, from some local interruption produced by disease or injury in the regular sequence of vital actions; such interruption extending itself from the part in which it commences to the organism in general, in virtue of that intimate mutual dependence of one function upon another, which is characteristic of all the higher orders of living beings. The death of the body as a whole, which may be appropriately designated Somatic ${ }^{1}$ death, becomes a necessary consequence of the death of a certain part of it, or Molecular death, only when the cessation of activity in the latter interferes with the elaboration, the circulation, or the depuration of the Blood, which supplies not merely the nutritive pubulum to every part of the organism, but also the oxygen which is essential to the activity of the Nervo-muscular apparatus. Thus, even in the higher animals, the death or removal of the limbs, although they may constitute (as in Man) a large proportion of the fabric, is not necessarily fatal; because it involves no interruption, either in the nutritive operations of the viscera, or in the sensorial functions of the brain. ${ }^{2}$ On the other hand, the destruction of a certain minute portion of the Nervous centres, or such a lesion of the Heart's structure as would be trivial in almost any other organ, may be the occasion of immediate death; because these changes arrest the Respiratory movements, or interfere directly with the action of the Heart so as to bring the flow of blood to a stand. It sometimes happens, however, that life may be prolonged after the death or removal of some important organ, in consequence of the power which some other possesses of discharging its functions; thus we find that in Man the kidncys seem occasionally to take upon themselves the elimination of the constituents of bile from the blood ( $\$ 385)$; and in the Frog the skin can perform part of the office of the lungs, so as to effect the aeration of the blood in a sufficicut degree to prolong life for some time, unless the temperature be elcvated. ${ }^{3}$

881. But although the vital activity of every part of the body is dependent upon a duc supply of circulating fluid, yet this dependence is usually not so close as to involve the immediate suspension of vital activity, or Molecular Death, in every part, whenever the general Circulation shall have bcen brought to a stand. For we have distinct evidence of the persistence

I This term was first suggested by Dr. Prichard, in place of the less aceurute term "systemic" whieh was previously in use. (See Cyclop. of Anat. and Physiol., vol. i, p. 791.)

2 The Author has been informed by Dr. Daniell that it is not at all uncommon in Negroes who are in the last stage of the adynamic fevers of the Afriean coast, for death and deeomposition to extend gradually upwards from the extremities to the trunk; so that the former may be in a state of absolute putreseenee, before the respiration and circulation have been brought to a stand, and he learns from Prof. Jackson, of Philadelphia, that he has nore than once witnessed the same oeeurrence.

3 That such camnot take place in Man, is due uot merely to the fur less complete adaptation of his skin for the aeration of the blood, but also to the differenee in the type of his circulation, which eauses the arrest of blood in the pulmonary vessels to produee a stugnution of the entire eurrent. 
of vital changes in various organs and tissues of the body, after the deatl of the body at large; as is manifested in the performance of ciliary and of muscular movements, in acts of secretion and perhaps even of nutrition, ${ }^{1}$ in the maintenance of the local circulation ( $\$ 261)$, and in the generation of animal heat $(\$ 42 t)$; and the fact is even yet more remarkibly manifested in the remion (even after the lapse of some hours) of parts that have been entirely severed, such as finger's or tocs, noses or ears, by adhesion bctwcen the cut surfaces when brought into apposition, which could not take place if the severed part were already dead.

882. The permanent and complete ccssation of the Circulating current, which essentially constitutes Somutic Death, may be directly or indirectly consequent upon several distinct causes. In the first place, it may be due to failure in the propulsive power of the Heart, which constitutes Syncope. This failure may occur either $(a)$ in consequence of a loss of the proper irritability of the Muscular tissue, or $(b)$ through the supervention of a "tonic spasm," the organ remaining rigidly contracted without its usual alternation of relaxation. The phenonena attending death in the two cases are not dissimilar, when the loss of irritability is sudden and immediate (as when it arises from violent impressions on the nervous system); for the individual suddenly turns pale, falls back or drops down, and expires with onc gasp. But under the former condition, the heart is found flabby, sometimes empty, sometimes distended with blood, both cavities being equally filled; whilst in the latter the heart is contracted and hard, containing little or no blood, as when in the state of rigor mortis.-The cause of the loss of irritability, when sudılen, usually lies in the influence of a "shock" transmitted through the Nervous system, and originating either in some severe lesion of its central organs or of its peripheral expansion $(\$ 244)$, or in a deficiency of its supply of blood or diminution of its usual pressure (such as is produced by rapid detraction of blood, especially in the erect posture, by the rapid removal of the fluid in ascites without the substitution of artificial pressure, or by suddenly rising into the erect posture, after prolonged recumbency, ${ }^{2}$ still more, after long stooping), or in some powerful mental emotion, either exciting or depressing. A more gradual effect of the same kind is produced by severe lesions of the internal organs (such as rupture of the uterus), which often prove fatal by the general "collapse" thus induced, rather than by the disturbance which takes place in their own proper functions; and this seems to be the usual modus operandi of corrosive poisons, whose effect upon the heart's action resembles that produced by severe burns of the surface in children. The influence of the proper sedative poisons, however,- - such as digitalis, tobacco, aconite, and upas,--seems to be directly exerted, through the blood, upon the tissue of the heart itself; and the same is probably the case with some of those "morbid poisons," whose introduction into the system gives rise to diseases of the most intensely arlynamic type, such as Maligant Cholera, in which the "collapse" is out of all pro-

1 Thus Mr. T. Bell mentions (History of British Reptiles, p. 61), that having been engaged in the careful dissection of the poison apparatus of a large lattle-nake, although the animal had been dead for some hours, and the head had becn taken off immediately after death, yet the poison continued to be secreted as the dissection proceeded, so as to require to be occasionally dried off with a bit of sponge.-A growtl of Hair is said to have becn noticed in several instances after death; and if the temperature of the surrounding medium be not too low for the vital activity of the hair-bulbs, there seems no adequate reason why this should not takc place.

2 Hence it is that great caution should be exercised in allowing patients who are convalcscent from acute diseases to rise into the crect position, many cases of fatal syncope having been thus induced. The state of general debility, and the continued rccumbency both fuvor this result, especially in persons advanced in iife. 
portion to any local lesion. But, again, the loss of the Heart's irritability may be a gradual process, resulting from the deterioration of its tissue by fatty degeneration or by simple atrophy; and this last condition may be due to deficiency of blood, as happens in chronic starvation and diseases of exhaustion, in which the failure of the circulation seems duc to the weakening of the heart's power and to the lowering of the quantity and quality of the blood, acting as concurrent causes, the condition thus induced being appropriately designated Asthenia. In all cases it is to be observed that when the Vital powers have been previously depressed, a much slighter impression on the Nervous system is adequate to produce Syncope, than would be required when it is in a state of full vigor.-The causes of the tonic spasm of the heart have not been clearly made out; but it seems producible, like the more comnon form of Syncope, by agencies operating through the Ncrvous system; thus it has supervened upon the ingestion of a large quantity of cold water into the stomach.

883. Somatic Death may be occasioned, secondly, by an obstruction to the flow of blood through the capillaries of the lungs, constituting Asphyxia (\$323); and this may be consequent upon a disordered state of the lungs themselves, or upon suspension of the respiratory movements through affections of the Nervous centres. It is in this mode that most fatal disorders of the Nervous System produce death, except when a sudden and violent impression occasions a cessation of the lieart's power; thus in Apoplexy, Narcotic Poisoning, etc., death results from the paralyzed condition of the Medulla Oblongata; whilst in Convulsive diseases, the fatal result generally ensues upon a spasmodic fixation of the respiratory muscles.-Thirdly, Somatic death may be occasioned by a disordered condition of the Blood itself ( $\$ 204$ ), which at the same time weakens the power of the Heart, inspairs the activity of the Nervous system, and prevents the performance of those changes in the systemic Capillaries, which afford a powerful auxiliary to the circulation. This is death by Necremia. ${ }^{1}$-Fourthly, Somatic death may result directly from the agency of Cold, which stagnates all the vital operations of the system. Where the cooling is due to the agency of an cxtremely low external temperature, which acts first upon the superficial parts, there is reason to think that the congestion of the internal vesscls thereby induced, occusions a torpid condition of the Nervous centres, and that the cessation of the Circulation is immediately due to Asphyxia. But when the cooling is gradual, and the loss of heat is almost equally rapid throughout, it is obvious that the stagnation must be universal, and that no cessation of activity in any one part is the occasion of the torpor in the functions of the remainder. It is in this manner that death ordinarily results from Starration, and not by the weakening of the heart's action, as commonly supposed; the proof's of this have been already stated $(\$ 431)$.

884. As a general rule, we find that the more active the clianges which normally take place in any tissue during life, the more speedily does its Moleculur Death follow Somatic Death, the requisite conditions of its vital action being no longer supplicd to it. 'Thus we obscrve that in Cold-blooded animals, the supcrvention of Molecular upon Somatic death is much less speedy than it is in Birds and Mammals. This seems due to two causes. In the first place, the tissues of the former, being at all times possessed of a lower (legrec of vital activity than those of the latter, are disposed to retain it for a longer time; according to the principle already laid down. And secondly, as the maintenance of a high temperature is an essential comlition of the vital activity of the tissues of IV arm-bloorled animals, the rapid cool-

1 See Dr. C. J. B. Williams's Principles of Medicine, 3d edit., p. 553. 
ing of the body after Somatic death is calculated to extinguish it specdily; and that this cause has a real opcration, is evinced by the influence of artificial warmth in sustaining the vital properties of separated parts- The rapidity, however, with which Molccular death follows the cessation of the general circulation, will be influenced by a varicty of causes; but especially by the degree in which the condition of the solids and fluids of the borly has been impaired by the mode of death. Thus in Necremia, Asthenia, and death by gradual cooling, Molecular and Sonatic death may be said to be simultaneous; and the same appear's to be true of death by sudden and violent impressions on the Nervous system ( $\$ 244)$. But in many cases of death by causes which operate by producing a more gradual syncope or Asphyxia, the tissues and blood having been previously in a healthy condition, Molecular death may be long postponed; and we cannot be quite certain that it has supervened until signs of actual decomposition present themselves.

885. When Molecular death takes place in an isolated part, it must result from some condition peculiar to that part, and not prinarily affecting the body in gencral. Thus we may have Gangrene or Mortification of a limb as a lirect result of the application of severe cold, or of an agent capable of producing chemical changes in its substance, or of violent contusions occasioning mechanical injury; or, again, from an interruption to the current of nutritive fluid; or, further, from some ill-understood stagnation of the uutritive process, which manifests itself in the spontaneous death of the tissues without any assignable cause, as in some cases of senile gangrene. Sometimes we are enabled to trace this stagnation to a disordered condition of the circulating fluid; as in the gangrene resulting from the continued use of the "ergot" of rye or wheat; but we can give no other account of the almost invariable commencement of such gangrene in the extremities, than we can of the selection of lead, introduced into the blood, by the extensors of the forearm. If Mortification or Molecular Death be once establi-hed in any part, it tends to spread, both to contiguous and to distant portions of the body. Thus we have continually to witness the extension of gangrene of the lower extremities, resulting from severe injury or from the use of the ergot, from the small part first affected, until the whole limb is involved; and this extension is easily accounted for, by our knowledge of the tendency of organic substances in the act of decomposition, to produce a similar change in other organic substances subjected to the influence of proximity to them. And the propagation of the gangrenous tendency to remoter parts, is obviously due to the perversion of the qualities of the Blood, which results from a similar cause. ${ }^{1}$

886. It is quite certain that an apparent cessation of all the vital functions may take place, without that entire loss of vitality which would leave the organism in the condition of a derd borly, liable to be speedily disintegrated by the operation of chemical and physical agencies. The state of Syncope is sometimes so complete that neither can the heart's action be perceived nor any respiratory movements be observed, all consciousness and power of movement being at the same time abolished; and yet recovery has spontaneously taken place, which could scarcely have been the case if all vital action had been suspended.-It is not a little remarkable, that certain individuals have possessed the power of roluntarily inducing this condition. The best authenticated case of this kind is that of Col. Townsend, which was de-

1 On the proximate causes of Death, see especially the Art. Death, by Dr. Symonds, in the Cyclop. of Anat. and Phys., vol. i ; the first chapter of Prof. Alison's Outlines of Pathology and Practice of ILedicine, and Dr. C. J. B. Williams's Principles of Medicine, $3 d$ edit., pp. 536-557. 
scribed by Dr. George Cheyne, ${ }^{1}$ who was himself the witness of the fact. But statements have been recently made respecting the performances of certain Indian Fakeers, which are far more extraordinary; it being demonstrated, if these assertions are to be credited, ${ }^{2}$ that the Human organism may not only be voluntarily reduced to a state resembling profound collapse, in which there appears to be nearly a complete suspension of all its vital operations, but may continue in that condition for some days or even weeks, until, in fact, means are taken to produce resuscitation.-Another form of apparent death, the existence of which appears to be well authenticated, is that sometimes designated as "Trauce" or "Catalepsy," in which there is a reduction of all the Organic Functions to an extremely low ebb, but in which consciousness is still preserved, whilst the power of voluntary movement is suspended; so that the patient, though fully aware of all that is being said and done around, is unable to make the least visible or audible sign of life. ${ }^{3}$ It is impossible, in the present state of our knowledge, to give any satisfactory account of these states; but some light appears to be thrown upon them by certain phenomena of artificial somuambulism, "liypnotic" or "mesmeric" ( $(586)$; for in this condition, there is sometimes an extraordinary retardation of the respiratory movements and of the pulsations of the heart, which if carried further, would produce a state of complete collapse; and its self-induction is suspected by Mr. Braid to be the secret of the performance of the Indian Fakeers just referred to.

887. The signs by which real is certainly distinguishable from apparent Death are not numerous, a large proportion of those commonly relied on being fallacious; but they are conclusive.-In the first place, it is to be remarked that no reliance is to be placed, for the reasons already mentioned, upon the apparent cessation of the Heart's action and of the Respiratory movements; since the reduction of these to so low a condition that they are no longer distinguishable, is by no ineans incompatible with the persistence of vitality. It has been suggested, however, that the persistence of the circulation in its feeblest degree may be rendered manifest by the application of a ligature to a finger, which will become swollen on the distal side if

1 See his Treatise on Nervous Diseases, p. 307

2 See a eolleetion of these cuses, clireetly abtained from British officers who had been eye-witnesses of them in India, by Mr. Braid, in his Observations on Tranee, or Human IJibernation, 1850.-In one of these, vouched for by Sir Claude M. IV ade (formerly political agent at the Court of Runjeet Singh), the Fakeer was buried in an underground cell, under striet guardianship, for six weeks; the budy had been twiee dug up by liunjeet Singh during the period of interment, and had been found in the same josition as when first buried.-In another ease, narrated by Lieut. Boileau in his Narrative of a Junrey in Rajwarra, in 1835, the man lad been buried for ten days in a grave lined with masonry and eovered with large slabs of stone, and strictly guarded; and he assured Lieut. Boileau that he was ready to submit to an internent of atwelvemonth's duration if desired. - In a third case, narrated by Mr. Braid, the trial was made under the direet superiutendence of a litish ofticer, a period of nine days haviug been stipulated for on the part of the devotee; but this was shortened to three at the desire of the offieer, who feared lest he slould ineur blame if the result was fatal. - The appearanee of the body when first disintered, is described in all instances as having boenquite corpse-like, and no pulsution could be deteeted at the heart or in the arteries: the mouns of restoration cmployed were chiefly warmth to the vertex and friction to the body and limbs.-It inay be remarked that the possibility of the protraction of such a state (supposing that no deception vitiates the authenticity of the narratives referred to) ean be much better eomprehended as oceurring in India than as taking place in thiseountry; since the warmth of the tropical atmosphere and soil would prevent any serious loss of heat, such as must soon oceur in a colder clinate, when the processes whereby it is generated are brought to a stand.

3 Several such eases are recorded in Dr. II. Mayo's Letters on the Truths contained in Popular Superstitions, and also by Mr. Braid, op. eit. 
the heart still continues to act. ${ }^{1}$ A surer test, however, is afforded by the condition of the Muscular substance; for this gradually loses its irritability after real Death, so that it can no longer be excited to contraction by electrical or any other kind of stimulation; and the loss of irritability is succeeded by the appearance of calaveric rigidity. So long, then, as the muscle retains its irritability and remains frec from rigidity, so long we may say with certainty that it is not dead; and the persistence of its vitality for an unusual period affords a presuniption in favor of the continuance of some degree of vital action in the body generally: whilst, on the other hand, the entire loss of irritability, and the supervention of rigidity, afford conclusive evidence that death has occurred. The most satisfactory proof, however, is given by the occurrence of putrefaction; this usually first manifests itself in the blue-green coloration of the cutaneous surface, especially the abdominal; but it speedily becomes apparent in other parts, its rate being usually in some degree of accordance with the external temperature, though also much influenced by the previous condition of the solids and fluids of the body, these having been sometimes left by diseased actions in a state that renders them peculiarly prone to disintegration ( $\$ 80)$.

888. With the final restoration of the components of the Human Organism to the Inorganic Universe, in those very forms (or nearly so) in which they were first withdrawn from it, the Corporeal Life of Man, of which it has been the object of the foregoing Treatise to sketch the leading features, comes to a final close. But the Death of the Body is but the commencement of a new Life of the Soul; in which (as the religious physiologist delights to believe) all that is pure and noble in Man's nature will be refined, elevated, and progressively advanced towards perfection; whilst all that is carnal, selfish, and degrading, will be eliminated by the purifying processes to which each individual must be subjected, before Sin can be entirely subjugated, and Death can be completely "swallowed up of Victory."

1 See also Norris, Humphry and Turner's Journal of Anat, and Physiology, vol. i, p. 217. 
ON MR. SORBY'S SPECTRUM ANALYSIS OF THE BLOOD.

In addition to the observations made in the text, it may be remarker that the scale of measurement adopted by Mr. Sorby is obtained by means of two small Nicol's prisms and an intermediate plate of quartz. Mr. Sorby observes in his paper, contained in the "Proceelings of the Royal Society," for 1867, that if white light passing through two such prisms without the plate of quartz be examined with the spectrum microscope, it of course gives an ordinary continuous spectrum, but if a thick plate of quartz or selenite be placed between the prisms, with the axis of $45^{\circ}$ to the plane of polarization, though no difference can be seen in the light with the naked eye the spectrum is entirely changerl. The light is still white, but it is made up of alternate black and colored bands, evenly distributed over the whole spectrum. The number of these depends upon the thickness of the depolarizing plate, so that we may have if we please almost innumerable fine black lines, or fewer broader bands, black in the centre and shaded off at each side. Hence, as the number of divisions depends on the thickness of the interference plate, it became necessary to determine what number should be adopted. The number 12 was selected for the number of divisions purely for the sake of convenience. This number is easily counted, and the sodium line D comes very accurately at $3 \frac{1}{2}$. The centre of the bands is black, and they are shaded off gradually at each side, so that the shaded part is about equal to the intermediate bright spaces. Taking then the centres of the black bands as $1,2,3$, etc., the centres of the bright spaces are $1 \frac{1}{2}, 2 \frac{1}{2}, 3 \frac{1}{2}$, ete., the lower edges of each $\frac{3}{4}, 1_{4}^{3}$, etc., and the upper $1_{4}^{\frac{1}{1}}, 2 \frac{1}{4}$, ete. $\mathrm{W}$ e can easily divide these quarters into eighths by the eye, and this is as near as is required, corresponding as nearly as possible to $\frac{1}{10}$ th part of the whole spectrum visible under ordinary circumstances by gaslight and daylight. Absorption-bands at the red end are best seen by lamplight, and those at the blue end by daylight. On this scale the position of some of the principal lines of the solar spectrum is about as follows:

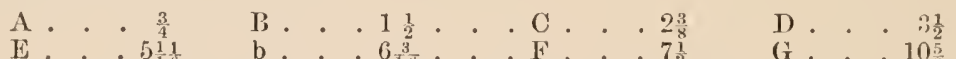

Mr. Sorby further remarks, that in order to describe spectra he lias devised a simple notation, employing types in constant use, by which it is casy to give a single line in all the essential particulars that would otherwise require a long and tedious description, or a number of drawings and woodeuts. 'The intensity of the absorption is expressed by the following types:

Not at all shaded,

Very slightly sliuded, $\bullet \cdot \cdot \cdot \cdot$

Decidedly sliaded,

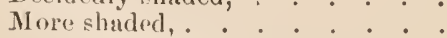

Strongly shaded, but so that a trace ?

of color is still seen, .....

Still darker, . . . . . . .

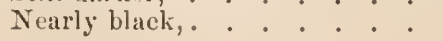

Blank space.

Dots with wide spaee.

Dots closer together.

Very elose dots.

Three hyphens closo.

Single dush.

Duuble dash. 
Fxcept when specially requisite, only the symbols . . ., - -, -, are employed for the sake of simplicity, and then as signs of their relative rather than of the absolute amount of absorption, and it is assumed that there is a gradual shading off from one tint to the other, unless the contrary is expressed. This is done by a small vertical line over the figure, which shows that there is a well-marked division between them. Definite narrow absorption-bands are indicated by * printed over their centre. This will be better understood by a description of the spectrum of deoxidized Homatim.

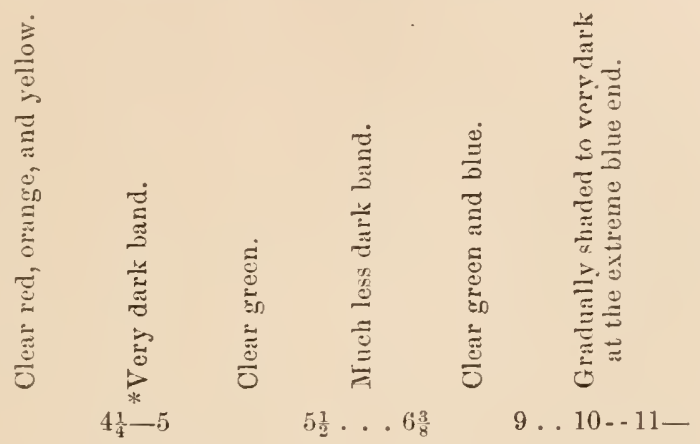

The reader will now be enabled to understand the accompanying notation of the figure on page 249 .

1. Sorby's standard spectrum.

2. Oxidized hemoglobin,. . . . . . . $3 \frac{5^{*}}{-} 4 \frac{3}{8} \quad 4_{4}^{3} \frac{*}{4} 5_{4}^{3} \quad 8 .-9-$

3. Hrmoglobin with $\mathrm{CO}_{2}$, . . . . . . . $3 \frac{3}{4}{ }^{*} 4_{2}^{1} \quad 4_{8}^{\frac{7}{*}}-5 \frac{7}{8} \quad 8 .-9-$

4. Deoxidized hemuglubin, . . . . . $3 \frac{3}{8} \ldots 4 \frac{1}{8} \div 5 \frac{1}{4} \quad 9-10-$

5. Bloodstain several years old,. . . . . . $1 \frac{7}{8} \ldots 2 \frac{7}{8} \quad 3 \frac{1}{2},-4-$

6. Acid solution of hæmatin, . . . . . $1 \frac{1}{2} \ldots 2 \frac{1}{2} \quad 3 \frac{1}{2} .4-$

7. Ammoniacal solution of hæmatin,. . . . $3 \frac{1}{2},-4-$

8. Deoxidized ammoniacal hematin, . . . . $4-55 \frac{3}{8} *-6 \frac{3}{8} 9 .-10-$ 



\section{INDEX OF AUTHORS REFERRED TO.}

Abererombie, Dr., on dreaming, 717

Accolas, on glycogeny, 48:

Achecharumow, M., on action of aconitina on heart, 316

Ackermann, on digitalis, 317 note; on postmortem rise of temperature, 535 ; on regulating mechanism for heat, 537

Adaukierriez, on muscle. 808 note

Adawiik, on inhihition of heart's action, 309 ; on vaso-motor nerves, 328

Addison, on effects of ablation of suprarenal capsules, 223: on emigration of white corpuscles, 460

Adrian, H., on secretion of saliva, 148; on gastric juice, $16: 3$

Aeby, Dr. C., on structure of capillaries, note, 343

Aeby, on usucular contraction, 816,817 ; on action of intercostals, 370 note

Afanassieff, on development of blord-corpuscles. 251 ; on respiration, 398 ; on lesion of crura cerebri, 661

Agassiz, Prof., on psychical conformity of hutuan races, 998 note

Airy, Prof, on astigmatism. 753

Ajtai, on gustatory nerves, 736 note

Akos, Puky, on Brünuer's glands, 177

Aladoff, on glycogeny. 487,488

Albert, temperature of heart, 234

Alcock, Dr., on lingual nerves, 620

Alison, Prof.. on asphyxia, 407 note; on suppression of bile, 4811 note; on guiding sensation, 667 ; on rapidity of muscular movements, 843

Allbutt, Dr. Clifford, on animal heat, 532

Allen and Pejys, on elimination of carbonic acid, 392

Althaun, on intracranial pressure, 358

Ammon, Von, on influence of nerves on secretion, 876

Ancell, Mr., on the blood, 236 note

Andral $\mathrm{H}$., on composition of blood in cachexia, 267 ; in scurvy, 268 ; on relative capacity of cardiac ventricles, 294 ; on temperature in disease, 534 ; on cerebellum, 678

Andral and Givarret. MM., on alteration of blood in disease, 265 ; on respiration, 389 , 396

Angelon, on consanguineous marriages, 919 nete

Anselmino, on solids in sweat, 522

Anstie, Dr. E., on alcohol, 117 ; on elimination of alcohol, 2st note; on stimulants and narcotics, 722 note

Arago. Prof., on sensibility of retina, 779

Arantius, on action of intercostals, 371 note
Arloin and Tripier, on inhibition of heart's action, 309 note, 314

Arlt, Prof, on accommodation of eye, 749

Arndt. M.. on ganglia of sympathetic, 864

Arnold, Dr., on excitation of cerebrum, 702

Arnoli, MI, on development of spleen, 222 ; on suprarenal bodies, 222 ; on erectile tissue, 359 ; on regeneration of corneal epithelium, 449 ; on nerve lesion, 558 ; on sympathetic nerves, 864

Arnott. Dr., on Venous circulation, 355 ; on stammering, $86 \mathrm{I}$

A rnstein, on action of Calabar bean on heart, 317, note

Ascherson, on haptogen membrane, 256

Asp, on effect of division of spinal cord on heart, 322 ; on vaso.motor centres, 327 ; on structure of liver, $\$ 72,474$

Aubert, Dr. H., on respiration, 395 ; on cutaneous respirition, 525 ; on acuteness of vision, 759,768 ; on sense of touch, 798

Aubert and Förster, on lymphatic system, 206 ; on acuteness of vision, 757 ; on eccentric vision, 776

Aubert and Kammler, MII., on cutaneous sensibility. 729

Aubert and Roever, on inbibition of heart's action, 309 note; on vaso-motor centres, 328

Auerbach, on lymphaties of intestines, 137, 206 ; on structure of capillaries, 344 ; on idio.muscular contraction, 820

Auspitz, on absorption of solid bodies, 200, 204

Axmann, on trophic nerves, 871

Babington, Dr., on buffy coat of blond, 273

Babuchin, Prof., on electrical apparatus of torpedo, 551; on olfactory nerves, $7+1$

Bichl, on respiration, 401

Back, Captain, on low temperature, 536

Badoud, on innervation of heart, 315; on pressure of blood in pulmonary artery, 338

Baer, Von, on developinent, 924 note

Bagge, Dr., on development of entozon, 924

Bailey, J., on the Cingalese, referred to, 1006 note

Baillarger, M., on relative weight of cerebrum, 693

Bain, his method of artificial respiration, 407

Bakewell, Mr., on red corpuseles of Ifindu, 266

Bilfour, on development of blood-corpuscles, 251 ; on hermaphrodism, 951 note

Ballard, Dr. E., on tactile sensibility, 727 
Bıllou, Dr., on suspended lactation, 973 note

Baly, Dr., on mechanical excitation of olfuctive and gustatory senses. 724,734

Banks. Dr. W. M., on homologies of different parts of the urinary apparatus, 950

Binting, Mr., his mode of reducing obesity, 428

Barclay. Captain, his power of sleep after exercise, 712

Bärensprung, on temperature of foetus, 530 ; on trophic nerves, $87 \mathrm{l}$

Barker, Ir.. his case of short gestation, 914

Barlow, Mr. F., on post-mortew morements in cholera patients, 827

Barral. M., on exeretion of carhonic acid, 396 ; on hest produced in bindy. 544

Barruel, M.. on odor of blood, 253

Barry. Dr. Martin, on Gratifin follicle, 890 ; on number of oxa, 842 ; on penetration of sperniatuzoa into ovum, 900 note

Bary, Sir D, on circulation in veins, 354

B:trth and Roger, on length of cardiac sounds, 304

Bartholinns, on intercostal muscles, 371

Barwell. on articular cartilage, 69

Basch, Von, on intestinal movements, 140 ; on influence of oxygenated blood on muscle, 811 ; on action of nicotin on heart, 317

Bashau, on uræmia, 497

Bastian. Dr., on development of cells, 59 ; on wigrition of white corpuscles, 460 ; on spe cifie giavity of brain, 693 ; on perceltive centres, 705 ; on spontaneous generation, 880

Butaille, M., on phonation, 855 mote

Butulnt, M., on effects of disease on animal lieat, 541

B:ıuer, on absorption of albumen in rectum, $1 \times 0$

Baxt, M., on rapiflity of motor impulses, 582

Baxter, Mr.. on disturbance of electric equilibrium in organic processes, 551 ; on absolute force of in uscle. 840

Bayer, M.. on protagon, 87

Beale, Prof. L, ou constitution and developInent of cells, 59 ; on cardio-motor ganglia, 306 ; on nerves of capillaries, 344,345 ; on structure of liver, 471, 473; on kidney, 495 ; on structure of nerves, 557,558 ; on nerve-endings in skin. 726 ; in tongue. 736 note; on sympathetic ganglia, 864; on cous. position of thyus 226

Bestrd, Dr.. on excitation of cerebrum, 702

Bealu and Maissiat, MM., on respiratory uns. eles, 371

Beaunont, Dr., on seuse of satiety, 111 ; on movements of stomich, 133; on secretion of gistric juice, 159; on disorilered states of the stouach, 161 ; on gastric digestion, 16316 it

Beck. Ir., on participation of uterus in parturition, ! 10 note: on superfoctation, 916 note

Becker, Von, on absorption of sugar. 199 ; on visual accommodiation, 748

Béclirl, M., on quantity of food required, 105 ; on osmosis, 195 ; on absorption of fit. 199 ; on composition of blond of portal vein, 263 ; on erectile tissue. 359 ; on total hent prorluced by bondy, 544

Becquerel and Breschet, MM., on cutaneous re-pirition, 541

Becquerel and lodier, on composition of blood, 253 ; ditto, in disease, $265,266,268$
Beddoe, on stature and bulk of Man, referred to, 969 note

Berbie, Dr., on albuminuria, 495 note

Beil, on corpuscula tactûs, 725 mile

Belajeff, M., on lymplaties of heart, 296 ; on respiration of g:ıses, 40:3

Belfielıl-Lefèvre, M., on tirctile sensibility, 727

Bell, Sir C., on guiding sensations, 128; on motor nerves of respiration, 379 ; on distinet functions of anterior and posterior roots of spinal nerves, 571 ; on ceplialic nerves, 574 , 575 ; on spinal accessory nerve, 623 ; on guiding sensations, 666

Bell, Mr. T., on secretion of serpent poison after death, 1033; on Austrilian dingo, 996

Bement, Mr., his eases of protracted gestation, 915

Bemiss, Dr., on hereditary mental disease, 919 note

Benerlen. Von, on development, 924 note

Benedikt, M., on effects of division of the sympathetic, 867

Belieke, on uyelin, 87 ; on cholesterin, 97

Benuett, Prof. J. H., on derelopment of cells, 59 ; on bile, 176 ; on production of bloodcorpuscles in ductless glindis, 2:30; on devel. opment of red corpuscles, 252 ; on !eucocythamia, 267 : on bile, 482

Béruril, on Brïnner's glands, 172 ; on venous eirculation, 355

Berg, on respiration, 392

Berger and Delaroche, MM., on experiments on animal heat, 5.38

Berireron, on heart, 315

Berginann, Dr., on respiration in nitrogen, 347 ; on acuteness of vision, 758

Bernard, M. Claude, on hydrocarbonaceous compounds, 94; on glycogen. 95; on gistric juice. 121 ; on movements of intestines, 138 ; on siliva, 148, 149; on gastric digestion, 15.3 ; on composition of gastric juice, 156 , 158 ; on pancreatic juice, 168,161 ; on bile, 175 ; on temperature of blood, 233 ; on urea in blood, 231 ; on durttion of life of blood-corpuscles, 250 ; on wases of hlond, 258 , 261 ; on color of blool, 2 ti2; on blood of hepatic and portal veins, 264 ; on gravitation of red corpuscles of blood during life, 271 ; on fibrin in inflummation. 278 ; on irritibility of endocnrlium, 298, 307; on inhibition of heart's action, 314; on action of sulphocyanide of potassium on heirt. 315, 317 ; his differential thermometer, 335 ; his carliometer, 336 ; on arrest of respiration, 378 ; nu asphyxia, 404 ; on hepatic circulation, 479; on glyeogeny, 483, 486: on albuminuria, 495; on gases of urine, 515 ; on deatl by heat, 5.38 ; on animal heat, 546 , note; 545,546; on motol roots of vilgi, 1322 ; on spinal accessory, 624 ; on alfactive ganglia, 652 ; on relation of facial nerve to sense of taste, 655 ; on woorara, 821; on sympathetic nerve, 865 ; on section of syıpathetic, 867 ; on dilating nerves, 869

Bernharit, temperature of heart. 234 note; on inhibition of heart's action, 30! note

Bermstein, M., on panereatic fluid, 169; on lymph, referred to, 217 ; on rapidity of muscular contraction, 817; on Calabar bean, 753 note

Bert, on gases of blood, 258,261 ; on respiration of tissues, 362 ; on contritctility of 
lungs. 367 ; on respiratory movements, 369 , 374,$378 ;$ on respiration of oxygen, 394, 398,403 ; on aspbyxia by drowning, 404, 405

Bertolus, on rapidity of blood eurrent, 342

Berzelius, his analysis of saliva, 145 ; of coloring witter of blood, 247

Besanez. v. Gorup-, see Gorup Besinez, v. Bever. M. K. on vaso motor centre, 327

Bezold, Ton A. M., on the innervation of the heart, 309. 314: on the action of woorara on beart, 312 ; on the action of atropin on lieart, 316 . note, 317 ; on viso motor centre, 327 ; on influence of oxygen on muscle. 811; on action of reratria on muscle 820 ; on electrotonus, 589 ; on trophic nerves, 873

Bihra. Ton, on anilysis of teeth, 76

Bulder, on inoveulents of deglutition, 129; on secretion of salira, $14 \mathrm{~S}$; on pancreatic fllid, $169 ;$; on bile. 175. 176; on frees, 183; on eardio-motor anglia, $30 h^{\circ}$; on atetion of woorara on ragus, 317 mote; on elimination of carbonic acid, 390 ; on tilney, 490 note; on union of motor with sensorv nerves, 574 ; on synipathetic of eat, 865 mote

Bidider and Schmidt. on quantity of 1 ruph, 216 ; on intestinal juice, 178: on exeretion of hile, 176, 183: on nutrition, 421 mote, 425,426 ; on effects of fit on bile, 481 ; on troplice nerves, 874

Biesiarlecki, Prof , on organisms in blood, 268 ; on liver, 475 ; on optic chiasma, 654 ; on eorpusecula tactîs, 725 note.

Billing. Dr.. on sounds of beart, 305 note

Billruth. Dr. T., on spleen, 218 ; on heat developed in tetanus, 811

Binz, on alcohol, 117; on action of quinine on white corpuscles, 243

Bird Dr. Golrling, on action of acetates on urine, 519 ; on action of cliuretics, 519

Birkett, Mr., on the anatomy of the breast, 970

Birsch. llirschfeld, on organisms in blood, 268

Bischoff, Prof., on developınent of spleen, 222 ; on penetration of ovum by spermatozoa, 900 wote; on embryonic development of mimmals. 924; on rotation of yolk, 9.31

Bischoff. M., on inorganic compounds, 99 ; on intestinal dicestion, 182 ; on respiration, 395 ; on quantity of bile secreted. 481 mote; on iumpregnation 899,900

Bischoff and Voit. MM., on gelatin diet, 103 ; on general nutrition. $421,427,428$; on calorific value of starch, $4: 35$

Bishop. Mr., on motion, 83.3 note; on physiol$0 \mathrm{gy}$ of voice, 85.3 ; on stammering, 862 note

Bizio, II , on glyeogen, 485

Bizot, MI, on relative size of right and left ventricles. 294, 295

Bizzozero, M., on lyıpbatic glands, referred to, 207 ; on myeloplaxes, 228 ; on spermittozoa, 886 ; on fatty degeneration of muscle, 439

Bligden, Dr., experiments on animal heat, 5.38

Blainville, on coagulation of blood in ressels, 275

Blake, Prof., on quantity of blood. 232 note, on action of various poisons on heart, 317 note; on rapidity of circulation, 318 ; on animal heat, 531; on limits of audible sounds, 780 mote

Blane, Sir G., on reflex acts, 636
Blasius, on the metals fonnd in tho body, 80

Blöbaum, on action of atropin on heart, 316 motr; on action of oxyrenated blood on musele, 811

Blondlot, on gastric jnice, 159; on the bile, 175 note: on faces, 186

Blumenbacb, Prof., on races of mankind, 1001 , 1004

Blundell, on inanition, 12 :

Bobrik, on effects of acils on beart, 307

Bock, on cells of liver, 475

Bocker. Dr., on influence of tea, 120, 518 ; on influence of diet on urine, 504,518

Bodlärt, Von, on lesions produced by section of rilui, fi2: note

Bïdecker, on the eomposition of inilk, 977

Bućhat, on thyroid body, 226

Boehm, on inhibition of herrt's action, 308 mote; on action of poisons on heart, 316, 317 note

Boerhanve, on intercostal inuscles, 371

Boroljubow, on grises of bile, 477

Bugomoloff, on pigments of bile and urine, 510

Brileiu, Lieut., 1033 note

B sileaı. Castelnau. M , on insufticient diet at the Mrison Ceritrale of Nîmes. 125

Bois Reymonil. M. Du. on electrical listurbance in organic procesees, 551,552 ; his law of nerve excitation, 578 ; on electrical phenomena in nerves, 583. 584 wote; on electrotonus. 585 ; on museular current, 813 ; on muscle, 818 inte

Bull, on strueture of tenilon, 64 ; on structure of salivary glitnds, 144

Borelli, on intercostal muscles, 371

Borsirelli, on amount of pbosphorus in brain, 560

Böttcher, on blood, 236 mute; on blood-eryst:1s, 245,245 ; on lesions of semicirculir canals, 658

Bouchardat and Sindra*, M.M., on composition of blood of inesenteric veins. 263

Boucher de Perthes, M., on flint implements, 985

Bourlin, M., on hereditary disease, 919 mote

Bouillaud, M. $_{\text {, }}$ on ventricles of heart, 294 , 295

Bourdon, M. on voluntary arrest of respiration. 380 note

Bourgery, on weight of brain, $69:$

Boussingault, M., on advantilge of salt in food, 99; on excretion of nitrogen, 399

Boutigny, M. De. on bad conductibility of aqueous vanor, 536 note

Bowman, Mr. on uneous membrane of stomich. 153: on machanism of museular contraction, 816 ; on structure of liver, 474 ; on kiılney, 490 mote, 492-194; on ciliary muscle, 749 ; on retina, 754 ; on muscle, 803.

Boyer, on relative capacity of cardiac ventricles, 294

Bozzi, M., on spermatozoa, 887 unte

Braconnot, on air of large towns, 410

Brail, Mr., on liypnotisin, 712, 719; on influence of nervous system on the organic functions, 878

Briadwood, Mr., on development of muscle, 808

Braune, case of artificial anus, 141, 180

Brettnuer and Steinacb, MM., on epithelial cells of villi, 190 
Breuer, on respiration. 376,377

Brewster, Sir D., on spectrum analysis of blood, 248; on law of visible direction, 762

Breymann, on vaso motor centre, 327

Brierre de Boismont, on time of appearance of catamenia, 892

Bright, Dr., on fitty discharges, 172 note

Brinton, Dr. W., on stomach and intestines, referred to, 133 note

Bristowe. Dr., on tumors of uterns, 443

Brittan, Dr, on cholera at Bridgewater, 116 nute.

Broadbent. Dr., on inorganic constituents of borly. 98 ; on sounds of heart, 305 ; on lesions of optic thalami and corpora striata, 662 ; on paralysis, 701 ; on apbasia, 706

Broea, M. P, on developinent of cells, 59 ; on aphasial, 705

Brodie, Sir B., on tobacen, 119; on action of nervous system on animal heat. 544

Brondgeest, M..*on action of ehloroform on heart, 316 mote

Brooke, Mr. C., on osmosis, 195 ; on otic ganglion, 788

Brown. Dr. Crum, on action of various com. pounds on nerve and muscle, 821

Brown. Robert, on molecular inotion, 57

Brown-Séquard, on suprarenal capsules, 223 on formation of fibrin, 278 ; on vaso-motor centres, 327 ; on reflex action through vasomotor centres, 328 ; on resuiratory nerve. centres. 374 ; on motor nerves of respiration, 379 ; on aspbyxia, 404 ; on renal circulation, 493,499 ; on animal heat. 529 note, 544 note, on regeneration of nerve-tissue, 559; on recurrent sensibility of anterior roots of spinal nerves, 571 ; on glosso.pharyngeal nerve, 620 ; on restoration of function of spinal cord after division, $626^{\circ}$; on functions of posterior columns, 627 ; on oourse of fibres in spinal cord, $6: 30-632$; on effects of section of one lateral half of spinal cord, $6+1$; on medulla oblongata, 642 ; on corpora restiformia, 642 ; on muscular tension, 648 ; on section of optic tract, 654 ; on lesion of thalani, 660 ; on functions of mesocephalon. 661 ; on cerebellum, 677 ; on channels for various sensutions, 731 ; on irritability of muscle, 525,826 ; on rhythmical movements in diaphragin and intercostals, 822 ; on action of light on iris, 760 ; on restoration of mus. cular irritability, 825 ; on effects of $\mathrm{sy}^{\prime}$ ш thetic, 867

Brozeit, on quantity of blood, 232

B uce, Mitchell, on structure of tendons, 64

B'uch, l'rof., on absorption of fat, 129

Bruicke, on eolor of blood, 233; on red corpuscles of blood, 235 ; on congulation of blool, 274 ; on salivary glands, 145 ; on glyeogen, 95,485 ; on mueous membrane of stomilch, 154 ; on pepsin, Ifil); on intestinal digestion, 179 ; on faces, 186 ; on villi, 190 mote; on l'eyerian glands, 210,211 note; on musele, 803,806

Brunn, on suprarenal capsules, 223

Brumen, on ossicula "uulitûs, 789

Brunner, on glands of intestines, 167

Brunton, Dr., on splanchnies, 140; on composition of the nucleus of the white corpuscles, 243 ; on purgatives, 176 ; on elimination of snake-poison, 284,291 ; on action of lieat on heart, 308, 309; on aetion of atropin on heart, 312 ; on digitalis, 316,519 ; on influ. ence of position on pulse, 320 ; on rhyth mical movements of vessels, $326^{\circ}$; on vaso-motor nerves, 328 ; on action of calomel, 482 ; on glycogen, 485 ; on acids of urine, 516 ; on genito-spinal centre, 643

Bryden, report on choleri, 287 note,

Buchanan, Dr., on coagulation of blood, 275277 ; on left-handedness, referred to, note, $834 ;$ on force of the heart, 302, 436

Buchbeim, on action of drugs on muscle, 820 ; on action of woorara on heart, 317 mote

Buchbeimer, on osmosis. 195

Buck, Dr., on ossicula auditûs, 788

Bucquoy, on effects of atmospheric pressure on heart, 321

Budd, Dr G., on liver, 480, 481

Budd, Dr. W., on symmetrical diseases, 281 ; on local inflammation, 455 ; on bypoglussal, 625 ; on paraplegia, 637 ; on epilepsy, 647

Budge, Prot. J., on deglutition, 129 ; on movewents of intestines, 138 ; on gastric juice, 163 ; on bile, 175 ; on irritability of heart, 298 ; on action of poisons on he:ırt, 317 note ; on influence of various circumstances on pulse, 321 ; on dynamics of eirculation, 334 ; on intercostal nuscles, 370 ; on ciliospinal centre, 642,868 ; on corpuscula tactûs, 725 mote.

Budge and Waller, Drs., on influence of nerves on pupil, 759

Burdich, on quantity of blood, 232 ; on forua. tion of fat, 433 ; on vicarious secretion of urine, 467, 468; on cerebellum. 683 ; on influence of nerves on secretion. 876

Burkart, M., on arrest of respiration, 378 ; on laryngeal nerves, 330,382

Burkhart, on bile, 174

Burnett, on os-icula auditîs, 789 mote

Burrows, Dr. G, on intracranial blood circulation. $3 i 8$ note

Busch, on cessation of gastric movements during sleep. 135; case of injury of intestine, $141,171,172,178$; on absorption, 19s

Busk, Mr. G., on alteration of blood in scurvy, 266 ; on muscle, 81)3

Busse, on elimination of carbonic acid, 392

Büttner, on trophic nerves. 873

Byasson, M., on excretion of urea, 507; of uric acid, 508 ; of phosphates, 514

Cadiot, on effects of consanguineous marriages, 919 uste

Cagniard de Latour, on pressure on trachea in phonition, 855

Calleniler, on development of thyroid gland, 227 ; on development of ficial hones, 958

Carnochan, on trophic nerves, 873

Carter, Mr., on troplic nerves, 877

Carter, Vilndyke, on trophic nerves, 871

Chevreul, M., on colors, 775 nole

Chilıs, Dr., on consinguineous inarriages, 919 note

Chossat, his experiments on inanition 122

Clarke, Dr. J. Luckhart, on structure of nerves, 555 ; on spinal cord, $597,601,632$; on medulla oblongita, $605-615$; on origin of spinal accessory nerve, 623 ; on cilio-spinal centre, $6+2$; on structure of corpora quadriremina, 649 , on the nature of volition, referred to, 707 note; on functions of olivary bodies, 555 ; on structure of eerebrum, 686, 6s9: on the olfuctory nerves, 741 ; on development 
of muscular fibre, $80 S$; on development of cerebro-spinal axis, 960

Clarke. Dr. Joseph, on infantile mortality, 412 ; on weight of new born infunts, 967

Clitudet, Mr., his stereomonoscupe, 765 nole

Cleliınd, Prof., on action of intercostals, 370 ; on cerebral convolution, 688 "ote

Cloetta. MI, on chemical composition of lungtissue. 366

Cloez, M., on taurochloric acid in suprarenal capsules, 480

Clowes, on pepsin and pancreatic ferment, 170

Coates, on inbibition of heart's action, 308 note, 314

Coathupe, Mr., on amount of air respired, 386

Codrington, Sir E., case of. 713

Cihnleim, M., on pancreatin, 171 ; on migration of white corpuscles, 217,460 ; on spleen, 222 ; on structure of capillaries, referred to, 343 ; on atuylolytic ferment, 486 ; on ending of motor nerves in muscle, 803

Coleridge, S. T., his aut omatic mental activity, 716

Colin, on quantity of pancreatic fluid, 169; on digestion of fat, 172; on absorption of salts, 192 ; on intricostal muscles, 370 ; on rapidity of impulses conducted by sympathetic, 582

Collard de Martigny, M., on respiration in nitrogen, 397

Collins, Dr., on infantile mortality, 412

Combe, Dr. A., on digestion, 161 note; on influence of vassion on mammary secretion, 876 mole; on influence of mother on foetus, 921 ; on infant nutrition, 921 note

Combe, Mr. G., on result of sexual intercourse in state of intoxication, 921 "ole

Combetti, his case of destruction of cerebellum, 678 note

Conner, Dr., on trophic nerves, 873

Conte, Prof. Le, on correlation of force, 31

Cooper, Sir A., his experiments on coagulation of blood in ressels, 274 ; on influence of emotions on maminary secretion, 875 ; on structure of mammary gland, 970

Copland, Dr., on antiphlogistic regimen, 126

Corfe, Mr., on water at Wolverton, 116 nole

Cork, Bishop of, his case of lactation by male, 973 noty

Cornil, M., on movements of leucocrtes, 60 ; on structure of capilaries, referred to, 313 ; on respiratory nurmur, 372

Corti, Marquis, on cochlear nerve, 783

Corvisirt, on pepsin. 157,159 ; on the functions of the pancreas, 169 ; on bile, 173

Costa, on intestinal digestion, 179

Coste, M., on decidua reflexa, 902 ; on development of embryo, referred to, 924 note

Coulomb, M., on amount of work performed by body, 436

Courvoisier M., on structure of ganglionic cells, 558, 864

Cowan, Dr., his case of consensual movements, 664 ; of apuplexy of cerebellum, 678 note

Coxwell, Mr., his balloon ascents, 38

Cozé, on glycogeny, 488

Cramer, Dr., on phenomena accompanying positive accommodation, 749

Crane, Rev. IV., on consumption of alcohol, 116

Craufurd, on the colors of different races of man, 989 nate

Cravford, Dr., on color of blood, 262
Crisp, on spleen, 218

Croce-Spinelli on oxygenation of blood in balloon ascents, 38

Crombie, Dr., on animal heit, 530

Crompton. on sense of smell as an aid in diagnosis of disease, 744 note

Cruickshank, on regeneration of nerres, 558

Crum, Brown, on action of poisuns on motor nerves. 821

Cruveilhier, relative capacity of cardiac ven tricles, 294

Cunningham, on germs in air, 411,450

Cunze, M., on action of arsenious acid on heart, 316 note

Curling, Mr, his cases of hypertrophy of the fingers, 442 nole; on atrophy of bone, 445

Currie, Dr., on eutaneous absorption, 201

Cuvier, on the hand, 39 ; on the intercostal muscles. 370

Cyon, M. E., on influence of vagus on heart, 311 ; on action of salts and reids ou heart, 316 wole; on glycogeny, 487

Cyon, M. M , on action of heat on heart, 308310 ; on innervation of heart, 315 ; on vasomotor centres, $327,328,865$; on vasomotor nerves, 328 ; on rapidity of blood current in arteries, 342 ; on venous circulition, 354 ; on urea, 512 ; on electrotonus, 592 ; on section of semicircular canals, 659 ; on sympa. thetic nerve, 864,869

Czajewicz, M., on the derelopment of fat, 67

Czermak, Dr. J., on deglutition, 129 ; on influence of ragus on beart. 214 ; on retirdition of pulse, 333 ; on causes of dyspnoen, 375 ; on sense of touch, 728 ; on accommodation of the eye, 747 ; on luechanism of voice, 847 Czerny, ou rectal digestion, 180

Dally, Dr. E., on consanguineous marriages, 919 note

Dilton, Dr. J. C., on quantity of food required. 111 ; on quantity of salivit, 147,148 ; on gastric digestion of living aniuals, lfif; on rate of secretion of bile, $176^{\circ}$; on effects of ablation of spleen, 221 ; on biliary acids, 93,$475 ;$ on spectrum of bile, $676 ;$ on the cerebellum, 478; on excitation of cerebral conrolutions, 702 ; on corpus luteum, 898

Dalzell, on tactile papillæ, 725

Diniell, Dr., on fevers, 291 note; on diaphore sis, 525 mote; on African ferers, 997 note; on death of fever patients, 1032 note

Dinilewsky, on lecithin, 86 , on pancreatin, 171 ; on nuscle, 808 ; on chemistry of contracted muscle, 811

Dillwin, Mr. Charles, on the rariation of species under domestication. 983 notr; on geological changes in human period, 1012

Discy, Mr. Norris E., on effects of disease of suprarenal capsules, 223

Davies, Dr. H., on size of cardiac orifices, 304

Jivis, Dr. N. S, on central lobe of cerebellum, 684 ; on weight of brain, 692

Davy, Dr. J., on venous bue of arterial blood, 233,262 ; on effects of loss of blood, 257 ; on temperature of human body, 529,530 ; on death by cold, 5.31

Dean, on medulla oblongata, 605

Deen, Von, on gray substance of spinal cord, 629

Deininger, on urea in sweat, 522 nute

Deiters, on cerebellum, 674 note 
Delafond, on absorption, 190

Delaroche and Berger, MM., their experiments on endurance of heat, $5: 38$

Delbouf, on the measure of sensation, 797 note

Ileleau, M., on vocal sounds, 857

Deluarquay, on regeneration of tissues, 450 , $55 \mathrm{~s}$

De Morgan, Mr., on removal of bone by absorption, 438

Denis, on eromposition of blood, 255 ; on coagulation, 277

Desiguliers, Dr., his examples of muscular power. $8: 38$

Descot, M., on regeneration of nelves, 559

Despretz, M., on musical notes, 780

Devergie, M., on presence of lead in muscle. 283 ; on charncters of embryo, at different periods, 1017

Dewar and McKendrick, on electrical disturbance caused by light, 777

Diakonow, M., on cerebrum, 86 ; on pancreatic peptones, 173

Didily, on filsetto voice, 855 note

I)iemerbröck, on action of intercostals, 370

Ditlevsen, on gustatory nerves, $7: 36$ mote

Dittmar, on effect of division of spinal cord on beart, 322 ; on vasomotor centre, 327,328 , 610

Dixon, Mr., on nerves of taste, 620 note

Dobell, on pancreatin, 173

Dubroslawin, on intestinal digestion, 179

Dobiynin, on allantois, 929

Dobson, Mr., his experiments on the spleen, 221

Dock, on glycogeny, 484,485

Dodd, Mr., his case of early viability, 914

Dogiel. M., on sounds of heart, 305 ; on rapidity of blood current in arteries, 341 ; on lymphatic absorption, referred to, 200 ; on action of ehloroform on heirt, 316 wote

Dïhmen, on dyspnoes, 375

Londers, Prof, on development of connective tissue, 65 ; on action of pancreas on chyme, 172 ; on action of bile on chyne, 172; on absorption of solid particles, 200 : on duristion of the action of the heart, 299 ; on inhibition of heart's action, 309 note, 311 ; on capacity of capillary system, 347 ; on expiratory foree, $367 ;$ oil quintity of urine, 498 ; on perspiration, 525 ; on sound colors, 787 note; on linits of pitch of vocal sounds, 855 ; on the letter $r, 860$; on rupillity of transmission of motor impulses through nerves, 582 ; on absolute muscle force, 841 ; on astiguatisu, 753; on pluenomena nceompanying positive accommodition, 749 ; on the limits of clear vision in bealth. 750 ; on the symuetrical movements of the eye, $8: 37$

Jiinitz, on muscle, 8112 note

Donkin, Dr. A. Scott, on parturition, 910 note

Donı é, M., on temperature in disease, 534 ; on development of electricity in living body, 551; on human milk, 978 note

Jonovan, Dr., on Irish starvation, 124; on evolution of light, 550

1) 0 rnellas, on vomiting, 136

Duwler, Dr. liennett, on blood's movement after death, 348 ; on post-mortem elevation of temperature, 535; on post-mortein move. ments, 827

Doyire, M., on the composition of milk, 977

Iriluer, Prof, on the capillary circulation, 352

Dreschfeld, on vasomotor centre, 327
Drozdoff, on migration of white corpuscles, 461

Lubreuil and Lerros, MM., on influence of sulphocyanide of potassium on heart, 315

Duchenne, on intercostals. 370 note; on respiritory nerve centres, 374 ; on locomotion, 831 ; on trophic nerves, 870

Duffin, Dr., on the stimuli affecting nerve and muscle respectively, 820 )

Dugès, M., on function of cerebellum, 678 : on function of cochlea, 791 ; on'the ova of batrachia, referrell to, 924 note

Dulong, M., on value of stareh, 435 ; on ealorifiention, 542

Dunglison, Prof., on gastric juice, 156 note; on sounds of heart, 305 ; on temperature in disease. 534 ; heat of uterus in parturition, 539 note; on temperature of paralyzed limbs, 545

Dumas, on formation of fat, 432

Duncan, Dr., on rapidity of blood current, 341 note

Duncan, Dr. MI, on epithelial lining of uterus luring pregnaney, 911 ; on fertility of females, 894 note

Dunn, Mr., on automatic actions, 127 ; his cases of apoplexy of cerebellum, 678 notf, ti8:

Dupré, M. A., on animal quinoidine, 93 ; on alcohol, 117; on rapidity of absorption from stomach, 192; on eliuination of alcohol, 234 note

Dupuy, M., on injection of cerebral substance inte veins, 275 ; on electrical excitition of cerebrum, 700; on the transmission of disorlered states of system in guineat-pigs, 918

D'Urbain. on gases of blood. 258-260

Durbam, Mr. A., on the condition of the circulation in the brain during sleep, 358, 708

Dural, on intercostil muscles, 370 ; on regeneration of tissues, 450

Dwight, on muscle, 802 note

Dybkowsky, M., on lymphatic absorption, 210 ; on movement of lymph, 216 ; on action of antiaris on heart, 316 ; on post-mortem rise of temperature, 5:35; on rise of teinperature in rigor mortis. 810,811 ; on respiration of hydrogen phosphide, 402

Drondi, on deglutition, $12 y$

Earle, Mr. I., on temperature of paralyzed limbs. 545

Earle, Dr. Pliny, on want of power to diseriminate musical notes, 792 mote

Eberbard, on absorption of solid particles, 200

Ebertb, M., on suprirenal capsules, 22: ; on muscular fibres of beart, 295 ; on lyuphatics of heart, 296 ; on structure of small arteries, 323 ; on structure of eapillaries, $34.3,3.15$; on structure of veins, 353 ; on biliary ducts, $473 ;$ on muscular tissue of heart, 801

Ecker, Prof., on pituitary lody, 227; on convolutions of cerebrum, 686 note; on nerves of touch, referred to, 725 note; on rotation of yolls, $9: 31$

Eekhard, Prof., on salisa, 148, 150 ; on absorption, 195 ; on earliomotor ganglia, 307 ; on rhythuical contration of veins, 355 note, on influence of nervous sysiem on erection, 359,643 ; on rlyeosuria, 487 : on electrotonus, 587 ; on levelopment of muscle, 808 ; on influence of changes of temperature on nerves, 580

Edwards, M., on absorption, referred to, 169 
Edwards, Dr. W., on irritability of heat in young animals, 297 ; on respiration in hydrogen. 397 ; nn absorption and elimination of uitrogen, 399 ; on temperature in tetanus, 534 ; on temperature of infants, 5.30 mote, on seasnnal viariation of calorific power, 533 ; on influence of moist air, 539 ; on inferior calorifying power of young animals, 547, 548

Egerton, Sir Philip, on effect of castration on buck, 282

Ehreuberg, Prof., on limits of vision, 758

Eichhorst, on absorption from reetum, 180

Eicliwald, on fibrin, 277

Eimer, M. T., on epithelial cells of villi, 192 note; on corpuscula tâctûs, 725 note

Einbrodt, M., on inlluence of respiration on heart, 339

Eiselt, M., on presence of pus-corpuseles in air, 285

Eiseminenger, on action of various drugs on musele. 820

Eliotson, Dr., on number of respiratory move. ments, 374

Elson, Dr., on action of cinchonin on heart, 316 , note

Emerson, Dr., on infintile mortality, 548, note

Emminghaus, on transadutes, 457 ; on flow of lymph. 461

Enderlin, on frees, 182

Engel, M., on development of cerebellum, 674

Engelmann, M., on intestinal movements, 135 ; on gustatory bulbs, 736 ; on ciliary movements, $800 ;$ on muscle, 8112 mote; on motor nerves, 805

Erb, on fatty degeneration of muscle, 439,872

Erichsen, Prof., on rate of absorption, 192 ; on effects of ligature on coronary artery, 297 ; on asphyxi:1, 35l note, 407 note

Erismann, on perspiration, 523,525

Erman, on protracted lactation, 979

Estor and St. Pierre, MM., on gases of blood, 258 mote, 260, 361

Eulenberg and Guttmann, MM., on action of bromide of potassium on heart, 316 nore; on exeitation of the sympathetic, 8 hs

Euleuberg. MI, on absorption of salts, 192 ; on action of nicotin and quinine on heart, 316 note

Evanson, Dr., his case of abolition of sexual desire, 683 note

Ewald, on salivary glands, 143,151 ; on dyspnoea, 375 ; on gly cogen, 488

Exner, on time of reflex acts, 635 ; on olfactory cells, 741 mote

Eydoux and Soulyet, on animal beat, 529

Fabre and Silberınann, MM., on heat of combustion, 542

Fagge and Stevenson, Drs., on action of poisons on heart, 316

Fiarer, effects of ablation of spleen, 229

Falek, on origin of urea, 512

Faraday, Prof., on visual illusions, 772

F arr, Dr. W., on zymotic affections, 285

Furre, Dr. Arthur, on decidua refexa, y03; on uterine sinuses, $90: 3$

Fasci, L. M., on muscular contraction, 810

Farre, M., on solids of sweat, 522 ; on calorific equivilents, 542

Fayrer, Dr., on elimination of snake.poison, 284 ; on snake-bites, 288,291
Fechner, Dr. G. Th., on the appreciation of weight, 730 ; his psycho-physical law, 797

Feinberg, on suppression of cutaneons respiration, 526

Fellenberg, Dr. C., on recedence of near-point with advaneing age, 750

Feltz, on migration of white corpuseles 460 ; on pigments of bile and blood, 478 ; on jaundice, 480

Fernet, M, on gases of blood, 258, 259

Ferrier, Dr, on electrical excitation of cerebral convolutions, 649

Fick and Wislicenus, MM., on elimination of nitrogen by the urine, 38, 101, 505

Fick, Prof. A., on secretion of gastric juice, 157 ; on action of spartein on heart, 317 inte; his spring kymograph, 338 ; on heat dyspnoe, 537 ; on cochlea. 783 ; on work on nonnitrogenous diet, 842 ; on nerves of touch, referrerl to, 725 note; on sense of touch, 728 ; on sensations of temperature, 731 ; on rise of temperature in rigor mortis, 535.810; on elasticity of muscle, 812 ; on absolute mus. cle force, 840

Figuier, on gl ycogeny, 484

Finlayson, Dr., on temperature of infants, 530

Fischer, on trophic nerves, $87: 3$

Fleischmann, on freces, 182 note

Flem

Flês, Di., his case of atrophy of liver and panereas, 173

Flint, Dr. Austin, on cholesterin and stercorin, 97 ; on the state of the rectum previous to defecation, 141 note; on secretion of bile, 176 ; on stereorin, 182 ; on semilunar valves of heart, 303 ; on bile-ducts, 474 ; on jaundice, 480 ; on effects of exercise on urea, 506 ; on salts of urine, 515 ; on excitution of cerebral hemispheres, 702

Fliggel, on muscle. 802 note

Flourens, M., on enlargement of arteries with pulse, 329 ; on noeud vital, 374 ; on reflex action, 636 ; on removal of cerebrum, 656 , 657 note; on functions of corporil quadrigemina. 637 : on auditory nerve, 655,658 ; on cerebellum, 675

Flower, Prof, on comparative anatomy of liver, 470

Fodéré, on inanition, 127

Folet, M., on temperiture of paralyzed parts, 545

Fontana, on regeneration of nerves, 558 note

Ford, Mr., his case of absorption in ovarian dropsy, 203

Ford, Hutson, on alcohol in blood, 254

Forlyce and Blagilon, Drs., their experiments on endurance of heat, 538

Förseher, on nerve regeneration, 558 note

Förster, on perimetritis, 750

Foster, Dr. M., on amylolytic power of pancreatic fluid, $17 \mathrm{I}$; on revelopment of blondcorpuscles, 251; on cardiu-motor ganglia, 307,309 ; on heart of snail, 312 ; on glycogen, 485 ; on presence of amyloid substince in entozoa, 485 ; on development of bird, 924-96:3

Foster and Balfour, Drs., on development of fowl, 924,944

Fothergill, on digitalis, 317 note; on temperature in dixease, 535

Fouremit, Dr., on eutaneous asphyxia, 526

Fournice, on excitation of cerebral convolutions, 701 
Foville, M., on function of cerebellum, 678 ; on condition of brain in insanity, 704

Fowler, on inanition, 124

Fox, Dr. Wilson, on development of muscle, 808 note

Franke, on calorific value of stareh, 435

Frankland, Dr., on disintegration of muscle, 101 ; on effective energy of various substances, $4: 35$; on work performed by body, 436

Franklin, Sir J., on temperature, 536 ; his case of lactation by mile. 973 wore

Frantzel, M., on nerve.cells, referred to, 558 , 864

Fraser, Dr. T. R., on physiological action of Calabar bean, 307,316 ; on action of various cornpounds on nerve and muscle, 821

Frerichs, Prof., on digestion of gelatin, 103; on composition of saliva, 145 ; on action of pancreatic juice, 171 ; on composition of bile, 476 ; on meconium, 481 mole; on glycogeny, 483 ; on kidney, referred to, 451 note; on excretion of urea, 507,512

Frey, Prot., on structure of lymphatic glands, 207,208 ; on lecithin, 86 ; on protagon, 87 ; on bloodressels of Peyerian glands, 211 ; on biliary ducts, 473,475 ; on kidneys, referred to, 490 mite; on nearoglia, 601

Friedlinder, on action of heart, 306

Friedleben, M., on composition of thymus gl:ınd, 226

Fritsch, on electrical excitation of brain, 698

Fröllich, on influence of position on pulse, 320

Frommann, Dr. C., on structure of spinal cord, referred to, 603 mote

Fudikowski, on proportion of iron in hæmoglobin, 254

Furke, Dr. Otto, on colorless corpuscles in bluod of splenic veia. 229 ; on absorption of fat, 199 ; on absorption of peptone, 199; on perspirition, 522,523 ; on regulating mechanism for heat. 537 ; on temperature of brain, 546 ; on reation of nerve, 579 ; on effects of woorara on motor and sensory netves, 317 nole, 821

Gaetghens, on glycogeny, 490

Gairdner, Dr. IV. T., on contractility of bronchial tubes, 367 ; on kidneys, 490 note

Galal,in, on sphygmograph. 330 ; on sphygmographic tracings. 331,332

Gall, on a mative function of cerebelluın, 680 ; on comparative development of cerebrum, 697

Gallway, Mr. Brooke, on unbealthy inflamma. tions. 458 mote

Gamgee, Mr., on effects of consumption of diseased meat, 115 ; on bile, 176 ; on specific heat of blood, 234 ; on influence of nitrites on blood, 250 ; on ripidity of blood current, 341 ; on temperature of blood, 529

Garcia, on filsetto voice, 854

Garrod, A. H., on active dilatation of heart. 299 mote; on cardiographic tracings, 301 mote; on sphygnograph, 330 note

Garrod, Dr., on salines of blool in cholera, 269 ; on uric acid in blood, 508 ; on sweating, 524

Gelatin Commissions, report of, 103

Geltowsky, on action of quinine on white corpuscles, 243
Gendrin, on maturation of ova, 894

Genersich, on lywphatic system, 206 mote; on effects of morement on flow of lymph, 461 note

Genth, on excretion of uric acid, 508 ; of salts, 515

Gerbor, on molecular base of chyle, 213 mote

Gerlach, on structure of kidney, referred to, 490 mote, 493 ; on spinal cord, 597,601 ; on cerebrum, 688 mote; on nerves of touch, referred to, 725 mote

Ghert, Von, on effects of exertion on respiration and circulation, 374

Giannuzzi, on vomiting, 135 ; on pressure under which the urine is secreted, 520 ; on sympathetic nerve, 864 ; on conditions affecting the seeretion of salivi, 150; on lymphatics of glandular organs, referred to, 206; on mammary gland, 970 mote

Gibb. Dr. G., on the laryngoscope, referred to, 849 note

Gilbert and Lawes, Messrs, on the mode of fattening anim:ıls, 432,433

Gilchrist, $\mathrm{Dr}^{r}$, on water dressing, 452 note; on effects of section of vagi, 376

Gillette, on deglutition, 130; on trophic nerves, 871 mote

Gillibert and Favre, MM., on perspiration, 522

Girdwood, Mr., on periodical discharge of ova, 894,899

Glaisher, Mr., his balloon ascents, 322,394

Gluge and Thiernesse, on union of sensory with motor nerves, 574

Gmelin, on bile, 175

Gobley, on myelin, 87 ; on urea in blood, 264

Goethe, on development of blood-corpuseles, 251

Goldstein, on effect of temperature on respiration, 376 ; on heat dyspican, 537

Golgi, on fatty degeneration of muscle, 439

Goll, on rapidity of flow of urine, 449

Goltz, on movements of intestine, 1.39 ; on influence of nervous system on absorption. 217 ; on action of poisons on heart, 317 mite; on erection, 359 ; on mirration of white cor. puscles, 461 ; on nervous centre of bladder, 520,643 ; on section of semicireular canals, 659 ; on vaso-motor nerves, sis note

Golt $z$ and Frensberg, on the uterine centre. 644 Goodman, on coagulation of fibrin, 278

Goodsir, Prof., on absorption by intestinal villi, . 189 ; ou structure of kilney referred $t 0,490$ mote; on structure of decidua, 905 ; on villi of chorion, 903

Gordon, on ventricles of heart, 294

Gorup.Besanez, v., on pancreatic juice, 168 ; on action of bile on starch, 17t; on lymph, 212 ; on thymus gland, 226 ; on coloring matter of the blrod, 248; on composition of the blood, 252 ; on gases of blood, 261 ; on composition of the bile, 476 ; on urine. 502 ; on composition of nervous tissue, 559 ; on renction of milk, 974 wote

Gottstein, on cochlea, 783

Giäfe, A. Von, on movements of the eye, 835 wate; on glyeageny, 487

Grïfe, Prof. Von, on paralysis of fifth nerve, 616; his case of paralysis of the thirl nerve, 747 ; bis case of removal of iris, 748 ; on Calabar bean, 75:3

Graham, Prof., on colloids, 82, 196; on gastric juice, $156,166^{\circ}$; on osmosis, 194 
Grandeau, M., on effects of injecting salts into blowd, g9, 307

Grindry, M., on corpuscula tactîs. 725 note

Granville, Dr., on heat of uterus in parturition, 5.39 note

Gratiolet, M., on suprarenal capsules, 223 ; on aphasia, 705

Graves, Dr, on limit of confusion in touch, 727

Gray, Mr. H., on structure and development of spleen, 218; on development of suprarenal bodies, 223 ; of thyroid body, 227 ; on functions of spleen, ete., 229 ; on blood of portal and hepatic veins, 26:3; on developinent of eye, 962 note.

Green, D:., on protracted lactation, 979 note

Greenhow, Dr., on disease in town districts, 286 ; on treatment of burns, 452

Gregory, Dr., his case of suggested dreaming, 718 note

Gréhunt, on gasfs of blood, 258, 403; on vital eapacity of chest, 385 ; on amount of tidal air, 386 ; on urea in blood, 511,512

Grenacher, on muscle, 802 note

Griffith, Mr., on the composition of milk, 977

Grohe, on spermatozoa, 885

Groner, on formation of fit, 433

Groux, M., his case of fissure of the sternum, 953

Grove, Prof., on the correlation of the physical forees, 37 note

Gruby and Delafond, MM., on cells of intes. tinal vilii, 190 note

Griinewaldt and Schroeler, on composition of gastric fluid, $15 b^{\circ}$; quantity of gastric fluid, 159 note

Grunuisch, on unusele, 802 note.

Gi iitzner, on secretion of saliva, 151 ; on chem. istry of contracted mus.le, 811

Gscheidlen, un quantity of blood, 232 ; on raso. motor centre, 327 ; on origin of urea, 512 . on albuminuria, 497 ; on reaction of nerves, 560,579 ; on luuscle, s08 note; on sponta. neous generation, 88i)

Gubler, on relation between coloring matters of bloor and bile, 477

Guillot. M., on amount of milk secreted, 981 nole

Guislitin, M., on influence of emotions on nutrition, 877

Gull. Dr., on uses of plexuses of nerves, 572 mote

Gulliver, Mr., on molecular base of chyle, 212 , 213 ; on spleen, 220 ; on thymus gland, 225 ; on red corpuscles of blond, 235,237 ; on quantity of $1 \mathrm{ymph}$, referred to, 216 ; on colorless corpuscles, 242 ; on congulation of blcod, 272-274; on buffy co:tt, 276 ; on elasticity of lungs, 367 ; on temperature of fish, 529 ; on post-mortem rigidity, 827 ; on fitty degenerntion of arteries, 434 note; on disappearance of spermatozoa in disease, 886

Gundlach, on formition of fat, 432

Guuning, on vaso-motor centre, 326

Gunther, on gangliated cord of articulata, 604 ; on termination of nerve-fibres in ganglia, 604 note

Guttuann, on action of potassium bromide on heart, 316

Guy, on influence of sex on pulse, 319 ; on infiluence of iuuscular exertion on pulse. 319

Guyot, M., on treatment of wounds by hot air, 452
Hadlich, on cerehellum, 674 note

Ilaeckel, on protista, 58

II:fiz, on trophic herses, 87:3 nole

If:aighton, on nerve regeneration, 5.58 note

Hales, on ubsorption, referred to, 217 ; on dy. namics of eirculation, 3.35 ; on the force of the heart's contriction, 336 ; on rate of blood's morement in capillaries, 346

H:ılford. 1)r. G. B, on influenee of snake-poison on blockl, 269-276, 2s8, 291; on the movements and sounds of the heart, 299, 304, 305

H:all, Dr. C. Radelyffe, on vital capacity of lungs, 385 ; on decussition of posterior pyrauidls, 608 ; on ciliary ganglia, 617 note

II:Il, Dr. J. C., on protricted gestation. 913

Hall. Dr. M., on deglutition, li:2; on aetion of sphincters. 142 ; on eireulation in acardiace fotus. 349 wote; on stimulus to respiratory movelsent, 378 ; his mode of artificinl respiration, 4107 note; on reflex action of spinal cord, $636,6+2,6+4$; on muscular tension, 648 ; on articulate soutuds, 860 nole; on stinumering, stil

Haller, on quitntity of blood in the body, 2.32 ; on relative capacity of earliac ventricles, 294 ; on rapidity of museular movements, 843 ; on respiratory pulse, $35 \pm$; on vicarious secreicon of urine, 467,468

II Iliwachs, on hippuric acid, 509

H.umberger, on action of intereostals, 370

IL unmarsten, on lymph, 21:3; on tension of carbonic acid in blood and lymph, 213; on thow of lyinph, 46)

H umuond. Di, on diet of gum, 101 ; on diet of albumen, 102, 495 nole; on effects of alcohol, 118; on effects of tobilco, 119; on action of carroval on heart. 316 ; on condi. tion of circulation in brain during sleep, $35 \mathrm{~s}$; on nutrition, 428 ; on urine, 500 ; on musele, 842

Hämpe'n, on albuminuria, 497

Hanket, M., on velocity of sensory impulses, $58: 3$

Hannover, Dr., on exhalation of carbonic acid, 393 ; on eliuination of carbou by skin, 525 ; on optic chiasuna, 65:3.

Harles:, Dr., on muscular contraction, 810 ; on effect of withdriwal of witer from nerves, 580; on effect of ether on motor nerves and on muscles, 821

Harley, Di. G., on appearance of salts in saliva, 145 ; on quantity of saliva, 147 ; on quantity of gastric juice, 159; on eff cts of ablation of suprarenal bodies. 223 ; on glycogeny, 453, 4S5; on effects of strychnis on absorptive power of blood for gases, 826 ; on coloring matter of urine, 512 ; on superfœtation, 916 note

Hatung, on the pneumngastric nerve, 134 nole Harvey, Dr. Alex., on relatire influence of male and feuale parents, 920 nor ; on influence of foetal bloorl on maternal, 920

Harzer, on osmosis, 195

Il:1ssull, on thymus, 225

Hilsse, on spleen, 219 ; on structure of ear, referred to, 78:3

Hastings, Dr., on eapillary circulation, 353 ; on animal heat, $53: 2$

Haughton. Prof. $S$, on work aone by leart, 302 ; on work done by muscles of respiration, 373 ; on amount of work done in and by the body, 436,437 ; on excretion of urea, 
505,507 ; on the sound accompanying muscular contraction, 812 ; on the contractile energy of muscle, 839

Havers, on bone, 71

II:Iygarth. Dr., on tnetallic tractors, 878 note

Heaton. Mr., on seat of oxidizing processes, $437,8.2$

Heidenhain, M., on cells of salivary glands, 151 ; on gastric gland cells, 151; on pancreatic cells, 169 ; on restorative currents of electricity, 843 ; on temperature of heart, 234 ; on gases of blood, 259 ; on action of woorara on beart, 317 mote; on vase-motor centre, 327 ; on structure of liver, 472 ; on pressure of bile, 477 ; on action of nerves on liver, 482 ; on kidney, 493 ; on temperature of brain, 529 ; on animal heat, 544 note, 546 mote: on reaction of nerves, 560 ; on law of muscular contraction, 591 ; on function of spinal accessory nerve, 624 note; on muscles, 811 ; his tetinomotor, 818 ; on vasomotor nerves, 869

Heiderhain and Bı̈̈cke, on absorption, 199 ; on gastric follicles, 152 ; on epithelial cells of sinall intestine, 190 wote

Heinemann, M., on action of strychnia on beil, 317 note

Heintz, on kreatin and kreatinin, 510

Heinzmann, on theruic extitation of nerves, 579

Heitzmann, on cartilage, 68

Heiberg, on regeneration of epithelium, 449

Heller, on migration of white corpuseles, 460 ; on excretion of nrea, 507

Helmboltz, Prof. H., on conservation of en erury, 38 wote; on muscular force of heart, 302 ; on calorification, 436 ; on absolute anount of heat produced in body, 544 ; on rapidity of transmission of motor impulses, 581 ; on accommodation of the eye, 745,749 ; on optical constants, 750 note; on the horopter, 763,764 ; his theory of acoustics, 781; on membrana tyıpani, 788 ; on function of enchlea, 791 ; on period of latent excitation, 815 ; on chemical changes and rise of temperature during ususculir contraction, 811 ; on volitional movements of the eye, 837

Helys, Mr., on post-mortem movements in cholera patients, 827

Ilelvetius, on vicarious secretion of urine, 468

Henke and Langenbeck, on accommodation of the eye, 749

Henke, MI., on ossicula auditâs, 789 ; on absolute muscle force. 8:39

Henle, Prof., on gistric glands, 151 ; on solvent power of gastric juice, 158 ; on kidney, referred to, 490 mote; on neuroglia, 601 ; on helicine arteries, 359 note; on nerves of touch, 725 not?

Henneberg on elimination of carbonic acid, $3 ! 2$

IIennoberg and Stohmann, on nutrition, 421

ITénucque, M., on muscle, 812 mote

Henry, Mr. Mitchell, his unse of deficient commissures, 704

Henry and Chevallier, MM., on the composition of inilk, 977

Iensen and Cobnleim, on influence of nervous system on glycogeny, 977

Hensen, M., on ly mph, 213; on glycogeny, 484, 486 ; on structure of retina, 756 ; on audi. tory hairs of ernstacea, 782 ; on waves in ear, 789 ; on muscle, 802 note
IIensley, Dr., on heart, 294

Herapatb, Dr. W. B., on lead-poisoning, 116

Herbst, on action of pancreatic juice, 172 ; on quantity of blood, $2: 32$; on awount of tidal :iir, 396

IIering, on pigment cells, 62 ; on gases of blood, 260 ; on action of fifth nerve on heart, 314 ; on quantity of blood expelled by ventricles, 319 ; on vasomotor centre, 328 ; on tubercu. losis, 463 note; bis experiments on the circulation, 319 ; on biliary ducts, $472,476^{\circ}$; on optical illusion of Zollner, 771

IIermann, Dr. L., on intestinal movenents, 140 ; on gises of blood. 258 urte; on action of intercostals, 370 ; on poisonons gases, 402 ; on nutrition, 421 note; on influence of nervous system on quantity of nrine, 498 nute; on electrical phenomenil in nerves, 583 , note 585 ; on electrotonus, 592 ; on electric stimnlation of cerebrum, 701 ; on muscle force, 842 ; on limits of audible sounds, 780 ; on electrical current in muscle, 814 ; on wuscle, 808 note; on rigur mortis, 828

Hernite (L'), M., his osmotic experiment with fluid septum, 195

IIerschel, on spectrum analysis of blood, 248

IIerschel, Sir J., on light, referred to. 775 note

Hertwig, M., on removil of cerebrum, 656 , $657 ;$ on cerebellum, 676

Heubel, on lyıph, 217

Heuzinga, on spontaneous generation, 880 note Hewson, on red corpuscles of blood, 231 ; on production of red corpuscles in spleen and thymus, 229 ; on congulation of blood, 272

IIeymann, on eccentric vision, $77 b^{\circ}$

Heynsius, on pirments of bile and urine, 510

Hill, Sir G.. on eutaneous absorjtion, 202

Hiller, on"organisms in blood, 269

Hilston, on ammonia in snake-bites, 288

llippel, Von, on trophic nerves, $87: 3$

Hirsch, on rapidity of transmission of sensory impressions, 582,583

Hirschmann, M., on gases of blood, 260,361; on structure of lung-tissue. 36.4

IIirt, on the relative proportion of white and red corpuscles in the blood, 244 ; in splenic blood, 229 ; in blood of splenic vein. 264

His. M., on structure of $1 y m u h_{\text {at }}$ tic glands, 206 , 211 ; on development of blood-corpuscles. 251 ; on corpus luteum, 898 note; on development, 924 ; on devolopment of chick; 933 note

IIitzig, on lesion of erus cerebri, 661 note; on cerebellum, 677 ; on electrical excitation of cerebrisl convolutions, 698

Ijelt, Otto M., on regenerition of nerves, 558

Hofacker, on proportion of sexes, 965

II f funann, on formation of fat, 432

II offmann, M., on cutaneous absorption, 199 ; on regeneration of epithelium, 44 !

IIolland, Dr. G. C., on temperature of infants, 530

IIolland, I)r. II.. on sleep, 712 ; on instinctive choice of food, etc., 739 wote; on influence of expectant attention on involuntary moveInents, 870 ; on hereditary diseases, 918 mote

IIolin, M., on suprarenal bodies, 222

llolues, on action of ergot on heart, 317 nole

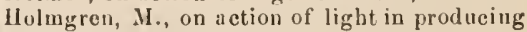
electrical disturbance, 777

Home. Dr. F., on temperiture in disense, 534

Howolle, M., on absorption by skin, 203 
Honigschınied, on sense of taste, 735

lloker, Dr., on relation between pulse and respiration, 374 note

Hooker, Dr. J D., on the theory of continuous developuent, 983 ; on the flora and fituna of New Zealand and Australia, 1011 note

Hoppe, Dr. F., on spectrum analysis of blood, 248,249 ; on effects of breathing a highly rarefied atuosphere, 394

Hoppe-Seyler, on composition of cartilage, 70 ; on effects of ingestion of calne sugar, 158; on decomposition of bile in the intestines, 182 ; on hremelobin, 247 ; on fibrin, 277 ; on gises of blood, 361 ; on glyeogeny, 485 ; on respirntion of poisonous gises, 402 ; on composition of liquor amnii, 938

IIorvath, on movements of intestine, 140 ; on animal heat, 533,545 ; on anæsthesia by cold, $7: 31$

Houckgeest v. Braam, on intestinal movements, 138

Houston, Dr., on circulation in acardiac foetus, 349 wote

Howe, Dr., on education of Laura Bridguan, 56 ; on idiotcy, 918 note

Howship, in lacunæ of bone, $4: 38$

Iloyer, on pigment-cells, 62 ; on development of lyinph-corpuscles, 227 ; on muscular fibre, S01 nole; on the olfactory nerves, 741

Huber, on formation of fat, 432

Hibbenet, on gastric juice, 156 note, 162 note, on pincreatic juice, 171; on succus enterieus, 172

Hiifner, on kidney, refered to, 490 note

Huguier, M , on Daverney's glands, 895 note

Humboldt, Von, on sense of smell in Peruvians, $7+3$

Hunter, John, on coagulation of blood, 272 , 277 ; on assumption of male plumige by female pheasant, 252 ; his doctrine of lyulphatic absorption, 204; on muscular contractility of arteries, 324 ; on elasticity of arteries, 324 ; on retardation of blood by curves in vessels, 334 ; on temperature in disease, 535 ; on hypertrophy from augmented supply of blood, 442 ; on healing prucesses, 443,453 ; his case of paraplegia, 639 note, on post-mortem rigidity, 827 ; on vesicula seminales, 884

Huppel and Grünhagen, on intraocular pressure, 745

Hïppert, on glycogeny, 490 ; on death by cold $5: 35$

Huschke, on kidneys, 492

Huss, Dr., on chronic alcoholism, 119 note, 440 note

Hutchinson, Col., on ancon breed of sheep, 996 nole.

Hutchinson, Dr. J., on elastic tension of lungs, 367 ; on action of intercostal museles, 370 ; on forces of inspiration and expiration, 37:; on vital capacity of chest, 385 ; its relation to beight and weight, 386 ; on amount of air insnired, 386 ; on limit of suspension of respiratory movements, 405

Hutchinson, Jr., his caso of lost sense of smell, 739 note; on change of color in Negro, 9S8 note

Hutchinson, Mr. Jonathan, his cases of nerve lesion, 544 ; on nerve lesions, 871 note

Huxley, Mr. T. H, on agamic development of aphis, 29 ; on cranium of man, 46,47 ; on fossil remains of man, 51 note; on the zoo- logical relation of man with the lower animals, 45 et seq. ; on teeth, 78 ; on structure of spleen, 218 ; cases of diffuse inflammation, 290 ; on tactile papilla, 725 ; on muscular fibre, 803 ; on the development of the ovuiu in pyrosoma, referred to, 91) 1 mole; on development of embryo, 924 note; on development of skull, 957 ; of ear, 963 ; on the Neanderthal cranium, 985

I'Anson, on nerve lesions, 871 note

Inman, Dr., on partial bleaching of Negro's skin, 988 note

Inzani and Lussana, on nerves of taste, 734 note

Irminger, M., on biliary ducts, 473, 475

Isaacs, on kidneys, referred to, 490 , note 493

Jaager, M., on rapidity of transmission of impulses through motor nerves, 582

Jickson, Dr., on vital capacity of lungs, 385 note; on gradual death in adynamic fevers, 1032 note; on the analogy between hearing and sight, 792

Jackson, Dr. J. H., on choreic movements, 533 ; on cerebellum, "rote, 678 ; on agraphia and aphasia, 705 ; on the condition of the circulation in the retina during sleep, 708

Jacobson, M., on temperiture of heart, 234 ; on pressure of blood in reins, 355 note; on temperature in inflamed parts, 535 ; on effects of woorara on animal heat, 546

Jacubowitsch, on saliva, 145

J.lfe. M., on stercobilin, 182 ; on urobilin, 478 Jäger, Von, on accorumodation of the eye, 749

Jago, James, on entoptical phenomena, referred to. 778 note; on tympanic cavity, 789

Jaminet, M., on action of compressed air, 321 , 394

Jardine, Rev. Fergus, case of, 914 note

Jeaffreson, Mr., on Daltonism, 775 note

Jeffreys, Mr. J., on inspired air, 384,387 note

Jelenffy, on cricothyroid muscle, $\$ 46$

Jendrassik, on thymus gland, 224

Jobert, M., on corpuscula tactûs, 725 note

Johnson, Dr. J., on structure of kidney, referred to, 490 note; on albuminuria, 496 note

Johustone, Dr., on conversation of deaf and dumb, 856

Jolly, M., on intracranial pressure, 358

Joly, M., on condition of iror in blood, 246

Joly and Filhol, MM., on the composition of wilk, 977

Jolyet, Dr., on nerres implicated in deglutition, 131

Jones, Dr., on condition of prisoners in Fort Sunter, 125

Jones. Dr. Bence, on aniınal quinoidine, 93 ; on rapidity of absorption by stomach, 192 ; on gastric juice. 158 ; on emulsification by bile, 174 note; on production of nitric acid in the body, 515 ; on sulphates in urine, 514; on phosphates in urine, 514 ; on acidity of urine, 508 ; on alkalescence of urine, 513 , 515,516 .

Jones, Dr. Handfield, on fatty degeneration, 439 mote; on tumors, 443 ; on fibroid degeneration, 459 note

Jones, Mr. Wharton, on lymphatic beart of eel, referred to, 216 ; on red corpuscles of 
blond, 235; on development of red corpuscles, 252 ; on granular cells, 279 ; on white corpuscles, 280 ; on rhythmical movements of reins in hat s wing, 326 ; on structure of spleen, 218 ; on effects of stimuli on the smaller arteries, 325 ; on retardation of capillary virculation by stream of carbonic acid, 351 ; on astigmatism, 75.3; on rhythmical contraction of veins, 355

Joseph. on trophic nerves, 9:37

Jurasz, on action of bile and urea on blood. cor,uscles, $2: 36$

Jürgensen, Dr., on temperature of the body, 531,537

Jurin, Dr., on absorption of vapor, 202

Kaiser on the horopter, 76.3

Katumler and Aubert, on sense of weight, 729 Kiapff, on ovaries, 889

Kaster, on evolution of light by body, 550

Kiauffuann and Rosenthal, MM., on action of sulphuretted hydrogen on lieart, 316,402 nute.

Kaupp, on quantity of urine, 498 note; on excretion of urea, 507

Kiellie, Dr., on the intracranial circulation, 358

Kemmerich, on action of potassium chloride, gy

Kempelen, on vocal sounds, 849, 857

liempen and Thiernesse, MM., on roots of vigi, 622 ; on union of sensory with motor nerves, 622

Kering, on regulating mechanisin for heat, $5: 37$

Keuchel, on inbibition of heart's action, 309

Kiernan, Mr., on structure of liver, 471

Kiliın, on fatty degeneration of uterus after parturition, $4: 39$

King. Mr. T. W., on triscupid ralve, 303

Kinkead. on panereatin. 173

Kirlkes, I)r., on freces, 181 ; on effects of disease of suprarenal olgans, 223

Kitto, Dr., on guiding sensations, 667 ; his cases of acute tactile sensihility, 733

Iilaatsch, seat of sense of taste, $7: 38$

Kilapp, Dr. W. H., action of strychnia on the blood pressure, 327

Kílebs, ou absorption of insoluble substances, 200

Klein, on goblet cells, 62 ; on gastric glands, 154; on lymphitic system, 205 note; on serous membranes, 209,211 ; on thymus, 225 ; on action of reagents on blool, 2.36 ; on white corpuscles, 241; on development of blood-corpuscles, $25 \mathrm{I}$; on nerves of capillaries, 344 ; on lymplatics of lungs, 360; on migration of white corpuscles, 462 ; on nerve-endings in cornea, 5.57

Kiletzinsky, on saliva, 146; on absorption by skin, 203 ; on urine. 510 note

Kílug, on action of alcobol, 119

Kilunder, on innscular contraction, 815

Kilipfel, on acids of urine, $5 / 4$

Knapp, on lens, 746 ; on accommodation of the eyc, 748

Kinoll, on reflex actions through optic nerve, 652 ; on effects of lesion of corpora quadrigemina, 158

Knor\%, M., on absolute muscle force, 839

Kiobelt, Dr., on emissio seminis, 888; on Fallopian tubes and $\mathrm{Wolfian}$ bodies, 947 note
Köblrausch, M., on rapidity of transmission of impulses through motor nerves, 582

Kölk. Schroeder van der, on coagulation of blood in vessels, 274

Kölliker, Prof., on osteoclasts, 72 ; on splanch. nics, 140; on structure of gastric follicles, 151,153 ; on rate of secretion of bile, 176 ; on muscular structure of intestinil villi, 189 ; on structure of Peyerian glands, 211 ; on structure ot spleen, 218 ; on suprarenal bodies, 222 ; on thymus. 225 ; on structure of lyuphatic glands, 206 ; on proportion of colorless corpuscles to red, 257 ; on action of woorara on lieart, 317 note; on structure of arterial walls, 323 ; on diameter of capillaries, 344 ; on veins, 353 nute; on erectile tissue, 359 ; on lungs, 363 ; on giant cells, 438 ; on muscular fibres of bronchial tubes, 363 ; on biliary luets, 473 ; on starch in test of tunicatis, 483 ; on structure of lridney, 490,493 ; on spinal cord, 597 ; on neuroglia, 601; on connecion of corpora striata and thalatui optici with cerebrum, 651 note; on tactile papillx, 725 ; on termination of motor nerves. 806 ; on structure of iris. 759 ; on cochlear nerve, 78:3 note; on action of wooraril on motor nerves, 821 ; on unstrialed muscular tissue, 801 ; on analysis of semen, 854 ; on evolution of speruatozon, 886 ; on corpus luteum, 896 wote; on augmentation of uterine substance in pregnancy, 908; on development of rasculir system, 940; on development of cranio-spinal axis, 559 ; on developuent of eye, 962

Konig. un salts of bone, 434

Koopmans, un digestion of albumen, 157

Korn and Forster, MM., on the range of vision, 750

Korner, M., on temperisture of heart, 234 ; on nerves of uterus. 909

Koster, M., on absolute muscle force, 839

Kottmeier and Kithe, MM., on secretion of bile, 479

Kowilewsky, on spleen, 218 note; on inhibitory nerves of heart, 309 note; on ratiatious of arterial pressure, 328 ; on elimination of carbonic acid, 393 ; on respirition of oxygen, 403 ; on bile. 477

Iirahmer, Prof., on action of diuretics, 519

Firatschuer, ou aution of fifth nerve on heart, 314 ; on vaso-motor centre, 328 ; on arrest of respiration. $37 \mathrm{~S}$

Kirause, Prof., on villi, 187 ; on lymph, 216 , 218 ; on sudoriparous glands, 521,525 ; on the nerves of touch, referred to, 725 note, 727 ; on leng1h of uuscular fibre, 802

lirauss, on structure of retina, 75.3 note

Kreitzen, on histologry ot virgin uterus, 909 note

liroger, on quantity of pancreatic fluid, 169?

Krolow, on digestive action of intestinal gl:unds, 178

Kironecker, laws of uuscular exhanstion, 823

Kubne, Dr., on leucin, 88; on casein, 8:3; on temperature of saliva, 145 ; on rajidity of gastrie digestion, 14l; on action of panere. atic juice on pejtones, 173 ; on respiration, 40I; on bile, 48I; on blood crystals, referred to, 245, 248; on ciliary movements, 810 ; on blood, 236 ; on glyeogeny, 485 ; on hippuric acid, 509 ; ou muscle, $802,806,820$; on tuode of termination of motor nerves. 806: on effects of stimuli applied to muscle and nerve respectively, 820 
Kunkel, on rapidity of perception of color, 77.4

liuffer, on the development of nervous system, 959

Jupresson, on pressure of urine in bladder, 520

Kiiss, on lungs. 364,366 : on interenstil muscles, $37 n$; on regeneration of cornenl epithelium, 450 ; on laws of reflex action, 634

Kiissmaul and Tenner, on intracranial circulation, 358 ; nn the effects of anauia on reflex excitabiiity of cord, 635

Kussner, on formation of urea, 511

Kiithe, on bile, 177,479

Kuttner, on sympithetic nerve, 863 note

Ki $y$ ber, on spleen, 221

Laborde and Leven, on trophic nerves. 871

L: boulbène, composition of blood in disease, 267

Laennec, relative capacity of cardiac rentri cles, 294 ; on duration of sounds of beart, 304

Lafurgue. M., on lesion of thalami optici, 660 on corvora striata, 660 ; n cerebellum, 677

Laffer, on reubsorption of bile, 176

Lilmandé. M., on amount of work performed by the body, 436

Laminsky, on perception of color, 774

Linderer, $\mathrm{D} \cdot$., on urea in sweit, 522

Landois, on duration of actions of heart, referred to, 299; on action of heart on respiration, 371

Landolt, on perimetry, 750

Lanilié, on aetion of woorara on animal heat. 546

Langer, on foetal heart, 942 ; on helicine arteries, 359 note

Lalıgerbans, on structure of pancreas, 167 ; on corpusculin tictûs, 725 note

Langhans, on blood erystals. 248

Lankester, Dr., on various diet sciles, 112

Linkester, Dr. Rily, on hæunglobin in heart, 822 : in plasma of blool of invertebrata, 246

Laptschinsky, on organisms in blood, 458

Larrey. Baron, on Syro-Arabian race, 477,1004

Laschkewitsch, on suppression of cutaneous respiration, 524

Lassagne, on quantity of saliva, 147

Latham, Dr., on seurry at Millbank, 125

Lath:ım. Dr. R. G., on varieties of men, 987, note; on Negro area, 990 mote; on Indo-Germanic race, 1003; on Syro-Arabian race, 10113: on Seriform race. 1005 ; on population of Irdia, 1006 ; on liaffre language. 10119

Latschenberger, on structure of pincreas, 167 ; on rectal digestion, 180

Laurence, Mr. J. Z., on astigmatism referred to, $75: 3$ no'e

Laurent, on action of byoscyamin on heart, 317 note

Lavalette, St. George, on testes, 883 ; on spermatozoa, $886^{\circ}$

Lardovsky, on musculir contraction, 810

Liveran, on nerve regenerition. 558 note

Layeock, Dr., on vicarious secretion of urine, 467 ; on cerebellum, 679

Leared, Dr., on sounds of heart, 305

Lebert, on Daltonism, 775 mote

Lebon, on inanition, 126

Lecanu, M., on coloring matter of blond, 247 on eomposition of blood, 255 ; on fat in blood, 268,440
Le Conte. Prof, on the correlation of forces, 31

Lee, Dr. R., on carclio-motor ganglia. 306 ; on nerves of liver, 476 ; on periodical discharge of ovis, 894 ; on nerves of uterus. 908

Lee. Mr. H.. on the effect of allmixture of pus with blood, 275,276

Lee, Mr. W., on preventible disease, 413

L - anllois, relative capicity of cardiac ventricles, 294 ; on animal beat, 544

Leyg, on vicarinus secretion of bile, 469 ; on glycogeny, 4.88

Legrus, on dil ting nerves, 869

Legros and Dubreuit, on action of poisons on heart. 315: on viso-1uotor nerves, 329

Legros and Onimus, on movements of leucosytes, 59 ; on intestinal morements, 137,139 , $140 ;$ on purgatives. 140 ; on erection, 359

Lehmann. Prof, on solution of blood corpus. cles, 236 ; on coloring inatter of blood. 247 ; on hrematin crystals, 247 ; on composition of purtal and hepatic venous blood, 264; on respiration. 389 note; on formition of $\mathrm{f}_{\mathrm{ilt}} \mathrm{t}$ 4333 ; on alkiline silts of blood, 268 ; on saliva, 146 ; on gistric juice, 159 ; on pancreatic fluid, 172 ; on composition of bile, 477 ; on origin of bile, 481 ; on glyeogeny, 483 ; on composition of urine, 500 ; on its acid reaction, 516

Lehmann. Dr. Julius, on influence of coffee, 121, 518; on faftening animals, 43.3

Leily, Dr., on strueture of liver, 470 note

Leigh, on the air of towns, +10

Lenhossek, on spinal cord. 603 note

$\mathrm{L}$,nz, M., on digestion of fats by pancreatic juice, 172

Lepine. MI. on net of romiting, 135

Letellier, M., on influence of external temperature on production of earbonic acid, 388

Letheby, Dr., on elimination of narentic poisons, 284: on discharge of ovules in menstruation, 894 note

Letzerich, M., on absorptive organs of villi, 191; on nerres of testis, 894

Leube, on nutrition, 180 mote; on perspiration, 522,525 ; on reflex action, 635

Leucknit. Dr., on spermatozoa, 886 unte; on development of embryo, 924 note; on vesicula prostatica, 949

Leuret and Mitirié, MY., on influence of age on pulse, 319

Leuret. M. an comparative anatomy of cerebellum, 6it note; on comparative size of cerebellum in geldings, ete.. 681 ; on relittive weight of encephalon. 693

Leren and Ollivier, MM., on functions of the cerebellum, 676

Leven, M., on influence of caffein and thein on action of heart, 120,316 note; on effects of division of inferior laryngeal nerve, 380

Lewes. Mr. (7. H., on the sensorial power of the spinal cord, referred to, 639 note

Lewis, Dr., on org:ırisins in blood, 268; on spores in air, 450,458

Lewitzky, on temperature of disease, 53.5

Ley, Dr. H., his case of disordered respiration, 379

Leyden, on action of phosphoric acid on hent, 307

Leydig, Dr., on structure of spleen, 218; on nerves of touch, referred to, 725 mote

Lichtenfels, on influence of various eircumstances on pulse, 320 
Liebermeister, on action of heat on heart, 307 ; on regulating inechanism for heat, $5: 37$

Liebig, Dr. G., on exhalation of carbonic acid from muscle, 398

Liebig, Prof., on manufacture of beef tea, 108 on ilmount of food required, 112 ; on nature of fecal matters. 194 ; on puroatise action of saline solutions, 194 note; on action of muscles on oxygen and carbonic acid, 361 ; on formation of fat, 432 ; on amount of carbon excreted, 396

Liebreich, on reaction of nerre-tissue, 560

Liegard; on duration of pregnancy, 915

Lieutaud, on relative capacity of cardiac rentricles, 295

Limpricht, M., on presence of amyloid substance in muscle, 485

Lining, on absorption of vapor, 202

Linnæus, bis division of odors, 741

Lister, Mr. J.J., on pigment cells, 62,800 ; on splanchnics, 139 ; on inhibition of heart's action, 309 mote; on the coagulation of the blood, 274; on employınent of carbolic acid for wounds, 451 ; on the early stages of inflammation, referred to, 463 note; on structure of iris, 759 note

Liversidge, on eomposition of pepsin and pancreatic ferment, 170

Livingstone, on temperature of Africans, 530

Lombard, on animal beat, 5:32

Longet, M., on quantity of gastric juice, 162 on effects of division of the pneumogastrics on stomach, 162; on contractility of bronchial tubes, 367 ; on automilic centres of respiration, 374 ; on albuminuria, 496 ; on spinal cord, 630 ; on lesion of erus cerebri, 661 ; on roots of pneumogastric, 621 ; on removal of cerebrum, 656,657 ; on functions of corpora quadrigemina, 658 ; on thalami, optici, 660 ; on corpora striata, 661 ; on tuber annuliıre, 662 ; on cerebellım, 677

Loos, on action of wooraril on heart, 317 note

Lortet, M., his hamitochometer, 342 ; on movements of leucocytes, 60 ; on respiration, 395 ; on animal beit, 5.32

Lossen, on metals found in the body, 80 ; on respiratory movements, 371 ; on elimination of carbonic acid and imınonia by the breath, 392,401

Lossnitzer, M., on intestinal fistula, 180 note

Lostorfer, on organisms in blood, 269

Lovén, on rhythmical movements in vessels, 326 ; on vaso-motor centre, 327,329 ; on griant cells of bone, $4: 88$; on sympathetic nerve, 869

Löwenberg, on lesion of th:1lani optici, 658 ; on section of semicireular eamis. 791

Lower, relative capacity of cardiac carities, 294

Liowig, on glycoureny, 48:

Lmbbock, Mr., on the D.mish pent-mosses, 986 Luex, on Eustachian tube, 789

Luchsinger, on glyeugeny, 485

Lndwitg, Prof. on absorption by Iynphatics, 200; on sounds of heart. 30.5 ; on eardiomotor ganulia, 306; on effects of increased pressure on heart, 307; on innervation of he.1rt, 311, 315; on influence of position on pulse, 320 ; on vaso-motor contre, 327,328 ; his kymographion. 336 ; on pressure in arteries, 338 ; his Stromuhr, 339; rapillity of blood current in arterics, 341 ; on tension of carbonic acid in lungs. 39s; on calorific value of starch, 435 ; on killney, referreil to, 490 note, 492 ; on trophic nerves, 873 note; on rapility of circulation in capillaries. 340 ; on rapidity of flow of urine, 498; on move. ments of stomach, 135; on saliva, 148, 149

Luschka. M., on nerves of pericardium, 296 ; on pituitary and coceygeal bodies, 227

Lu.k, on glycogeny, 490

Lussana, M. P., on reabsorption of bile, 482 ; on the cerebellum, 676 ; on nerves of taste, 734 note

Luys, on spinal cord, 603 mote; on cerebellum, 679

Lyell, Sir Charles, on the antiquity of man, 985

Macartney, Prof., on the healing processes, 449,452 ; on treatment of wounds by steum, 451

MacDonnell, on glyeogenic function of liver, 484. 489

Mackillavry, M., on biliary duets, 473 ; on structure of liver, 475

Micgregor, Mr., on elimination of carbonic acid, 393

Mach, M., on sense of time in the ear, referred to, 797 note; on sphyøuograph, 330

Mack, on hippuric acid. 509

Mackenzie, Dr., on the laryngoscope, 849 mote Maclachlin, Dr. D., on the diseases of advanced life, 1030 note

Miclagan, on temperature of infants, 530

Maclimrin, Dr. H. N., on independent irritability of muscle, referred to, 825 note

Maclean, Mr., on St. Kilda, 412

Maenamara, Dr., on muscle, 803

MeWillian, Dr., on artificial lactation, 973

Madclen, Dr. W. H., on curaneous absorption, 202 ; on puluonary absorption, 401; on tuberculosis, 463 mote

Madlox, on ending of gustatory nerres, 736 note

Magendie, M., on act of vomiting, 135 ; on intestinal mases. 184 ; on alteration of blood in disease, 265; on bloorl, 270 ; on action of intercostals. $37(1)$; on albuminous urine, 496 note; on cutaneous respiration, 5.11 ; on roots of spinal nerves, 571 : on removal of cerebrum, 656 ; on cerehellum, 676 ; on effects of withdrawal of cerebro-spinal fluid, 694 ; on fillsetto voice, 854

Magoiorani, on spleen, 221

Milhomed, on sphy rmograph, 330

Malassez, number of red eorpuscles, 239 ; nuin. ber of red corpuscles in lead-poisoning, $28: 3$

Mileolm, Mr., on excretion of earbonic acid, 393

Mily, on cholepyrrhin, 477 ; on pigments of bilo and urine, 510

Manassein, on action of reagents on blood corpuceles, 237 mote; on size of red corpuseles in fever, 238 ; on animal beat, 532

Mandelstamm, on optic commissure, 654 ; on perception of color. 774

II andl, on glot tis, 849 ; en falsetto voice, 854

Minsvelt, on elasticity of in uscle, 812

Manteriz\%, on number of red corpuseles, 266 ; on eorculation of blood, 277 ; on arrest of respirition. 378 ; on uramia, 497 ; on spermatozo:h, 887

Mara, Mad, her compass of voice, 814 mote

Marc, M., bis ease of suspended animation, 40.5 nole

Marcet, Dr.. on composition of tissues, 81 : on chronic alcoholiswus, 117 note; on compo- 
sition of blood in disense, 268; on animal heat, 531 : on composition of faces, 18I-183 Marchand. M, his analysis of urine, 500

Marey, M., on the movements of the heart, 299; his carliogriph, 301; on character of cardiac contraction, 303,305 ; his sphygmo. graph, 330, 3:31; on the dynamies of the circulation, 334, 335 note; on movements of respiration, 369,374 ; on torperio, 551 ; on rapiclity of transmission of imsulses along motor nerves, $5 S_{2}$; on muscle, 802 ; on phe. nomena of muscular contraction, 816,817 ; on locomotion. 832.

Märker, on elimination of carhonic acid, 392 ; on spontaneous ventilation, 409

Marsh, Sir 11., on evolution of light, 550

Marshill. Mr, on brain of Bushivoman, 686 ; on development of veins, $9+1$ note

Martin, Dr., on olfectory nerves, 741

Martin-Magron, on action of poison on muscle, 821

Martyn, Dr., on structure of muscular fibre, 803

Martyn. Dr. P., on the functions of the thyroid body in regard to the voice, 816 note

M.sius, on g:ınglionic centre of rectum, $1+1$, 643 ; of bliulfer. 520,643 ; on stercobilin, 182,478 ; on pigments of bile and urine, 510

Masoin, on inhibition of heart's action, 309, 314

Mason, Dr., on excitation of cerebral convolution, 702

Massiat, on intercostal uuscles, 370

Masson, on sensitiveness of retina, 779

Mathieu and D'Urbain, MM., on gases of blood, 258, 259, 2h0, 394

Matschersky, on formation of hippuric acid, referled to, 509 note

Mattencei. Prof., on disturbance of electric equilibrium in organic processes, 551,552 ; on development of electricity by muscular contraction. 814

Maudsley, Di., on convolutions of brain, 688 note.

Mayer, Dr., on the correlation of force, 37 ; on spleen, 221 ; on ric.ırious secretion of urine, 468

Mayer, Dr. S., on intestinal movements, 140. 141 ; on increase of fibrin in blond after repeated bleedings, 265 ; on biliary ducts, 473

Mayer, M., on action of oxygenated blood on muscle, 811 ; on action of electricity on heart. 307 ; on vaso-ınotor centre, 328 ; ou seat of nxillizing processes, 437

Mahew, Mr. IIenry, on acuteness of hearing in blind, 796 note; on numadic races, 994, 1010 note

Mayo, Mr. H., on optic chiasma, 654; on guirling sensations, 669 ; on falsetto voice, 854 ; on muscle, 806

Meckel, on cardiac ventricles, 294 ; on relative weight of liver, 945

Meibuisen, on action of bromide of potassium on reflex excitability of cori, 6:35

Meissner, Prof, on sympathetic ganglia in walls of intestine, 137; on peptones, 158-173; on action of woorila on vigus, 317 nute; on creatinin, 510 ; on presence of uric acid in blnod. 512 ; on nerves of touch, referred to, 725 note, 730 ; on trophic nerves. 873

Meissner and Shephard, on origin of hippuric aci 1,509

Melsens, on metals in blood, 255
Mendelssoln, mechanism of respiration, 384 note

Mensonides, on absorption of solid particles, 200

Merkel on muscle, 802 note; on spermatozoa, 886 mole

Metschnikoff, on inhibition of heart's action, 309 note

Meyer, II., on bone. 70

Meyer, on gases contained in blood, 258, 259, 260 ; on centre of gravity of body, 831 ; on innervation of heart, 312

Meyerstein and Thiry, on loss of heat at commencement of muscular contraction, 811

Meynert, on medull: oblongata, 605 ; on cerebellu11, 674 note; on structure of cerebrum, 689

Mialhe, M. on salivary secretion, 1tS; on osınosis, 197 note; on albuninuria, 263

Mich:telis on nerve regeneration, 558 nole

Michel, on optic ehiasma, 654

Michelson, on rigor mortis, 827 ; on corpuscula tactûs, 725

Miescher, nn vaso-motor centre, 327

Mill, Mr. James, on ideation, 707 note

Miller, Prof., on lead-poisoning, 283 ; on com. position of air, 387

Millon, on the metals contained in blood, $25+$

Milner, on digestion, 181

Milne-Edwarits, Prof. H., on irrigation of tissues, 217 ; on influence of season on mortality of children, 548

Mitchell, Dr., on hereditary dicease, 919 note

Mitchell, Dr. Weir, on nerve lesions, 54t; on action of cold on nervous centres, 709 ; on trophic nerves, 871

Mitivié on influence of age on pulse, 319

Mohamed, Etfendi Hafiz, on museular tissues of heart, 324

Mohl, on protoplasin, 57

Moleschott, on proportion of colorless corpuscles to red, 243 ; on size of pulmontury aircells, 365 note

Monniki, on tension of eye, 745 no/p

Montgomery, Dr., on muscle, 802 note: on placental bruit, 908; on duration of pregnancy, 915 mote; on influence of mother on foetus, 921 nole

Ioore, Mr., on easein of human milk, 976

Moore, Prof., on rocalization, 857

Moos, M., on glycogeny, 497 ; on sense of taste, $73+$ note

Moreau, M., on hachisch, 718 note; on deter inination of age of foetus, 1017 note

Mnrginti, on roots of vigus, 621

Morrison. on osteophatus cells, 438

Inrton, Dr. S., on the antiquity of man, 985

Mosler, on effects of extirpation of splecn, 228; on effects of large potations of water, 116

Mnugeot, M., on absorption by skin, 203

Moura, Dr., on deglutition, 129,130

Moxon, Dr., on aphasia, 705

Mulcler, on coloring mitter of hlood, 247

Miiller, C. W., on influence of pressure on res. piration, 394

Muller, Dr. H., on accommodation of the eye,

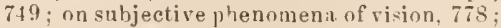

Muller, J. IT. M., on the structure of cells, 59 ; on the spleen. 218; on the thyroirl boly, 227 ; on spectrum analysis of blood, 248 ; on gases of bloor, 258: on pressure of blood, 338; on respiration, 398 
Miiller. Prof. Max, on the science of language, referred to. 1000 nute

Miiller. Prof., on rate of secretion of bile, 176 ; on blowd, 271; on size of eapillaries, 344; on capillary circulation, 35.3 ; on erectile tissue, 359 ; on respiration in hydiogen, 397 ; on respiration of oxygen. 403 ; on action of nervous system on liver, 482 ; on roots of spinal nerves, 571 ; on laws of nervous transmission, 572 ; on motor roots of pneumo. gastric, 622 ; on cerehellum, 677 ; on the horopter, $76: 3$; on complementary colors. 773 ; onsuljective phenomena of vision. 778 ; on acoustic principles of heitring, 785 ; on novements of rocal eords, 843 ; on mechan. ism of voice, 850 ; on tnicropvli, 900 ; on renous system of fi-hes, 940 note

Munk, Dr., on action of phosphoric acid on heart, 307 ; on rapidity of motor impulses. 582 ; on electrical pbenomena in nerves, 583, 5.5 ; on origin of urinary constituents, 511 , 512

Murphy, Prof., his cases of protracted gestation, 916 note

Murri, on animal heat, 5.37

Nairne, Dr., his case of softening of spinal cord. $6: 3: 3$ note

Naoumoff on respiration of oxygen gas. 403

Nisse, Prof. on movements of stomich, 139 141 ; on respiratory centres, 375 ; on quantity of bile, 175 ; on specific gravity of blood. $23:$; on influence of nerves on movement of lymph, 217; on fat in blood, 253; on symparhetic nerre in tborax. 86.5 ; on influence of food on recretion of liver, 481 ; on unove. ments of intestine, 865 mote

Naunyn, on temperature in disease. $5.35,545$

Niwrocki, on kreatin and kreatinin, 89 ; on gases contained in blonl. 260 ; on chemistry of contracted muscle. 811; on vasomotor centre, 327 ; un pressure under which the urine is secteted, 520 ; on muscle, 807 note

Nedretski, on organisuns in blool, 269

Negrier, on maturation of ova, 894

Neill, on rilli of stounach, 154

Nencki, on cxeretion of urei, 507

Nepreu, on orginisms in blood. 269

Nessler, on respiration. 411]

Nenbaluer. on myelin, 87 ; on urine, 501,510 ; referred to, 510

Teufeld, on action of antiaris on heart, 316

Neuminn, on developinent of white corpuscles in the marrow of borres. 227

Nemminn, on the teeth, 75 ; on chorila tympani, 734 note; on spermatozon, $\$ 8.5$ note

Newport, Mr.. on insects, 37 ; on bluorl-corpuseles of iusects, 279; on incrouse of curbonic acid exereterl by exercise, 3i) ?; on nervous ganglia of articulatia, referred to. 604 uste; on fertilizing power of sperniatozo: $885,887,900 ;$ on embryonic developinent of bitrichia, 924 note

Nieol, I)r., on leneth of inuseular fibres, 802

Niemetschek, on D łltonisın, 775

Nobili, his law of muscular entration. 590

Noble, Mr., his cases of paralysis of tith pair. 6201

Noll, on pressure of lymph in lyıphatics, 216

Norris, Dr., on irritability of muscle, 82:3 note; on emigration of white corpuscles, 460

Norris, Mr., on Syro-Arabian race, 1003; on population of India, 1006; on Hottentot language, 1006 note; on Australian langruage, 1014

Nothnagel, M., on lesion of optic thalami, 660 wole; on effects of lesion of cerebral convolutions. 701

Nowirk, un nutrition, 425 note

Nuel, on inbibition of heart s action, 309

Nunneley, on action of poisons on heart, 317 note.

Nissbaumer, his case of excitation of optic centres by sound. 724

Nysten, on excretion of carbonic acid. 393; on vicarious secretion of arine, 467,468

O'Beirne, on defecation. 141

Obermeier, on organisms in bluod, 269; on uterine contractions. 910 note

Oedmannson, on absorption by lymphatics, 200 Oehl. M. on saliva, 145,147 ; on regeneration of nerves, 558 note; on increase of temperature in nerves during action, $5 \mathrm{SO}$

Oellicher, on developruent of chick, 924 note, 931

Oesterlen, on absorption of solid particles, 199

Ogle. Dr. IV., on action of belladionna on lieart of rabbits, 317 nots; on temperature of the borly, 531-5:3; on preferential use of right hand, 834 ; on glyeogeny, 489

Oid/mann, on lympontic glands, 209; on spleen, 221

O'dham, Dr., on period of conception, s99 note

Ollivier, M., on heart, 315 ; on albuminuria, 496 ; on urine, 499 ; on cerebellum, 677

Onimus. on moveruents of leucocytes. 59 ; on intestinal movements, 137,139 ; on purgatives, 140 ; on action of electrical currents on nerves, 579, 58:3 note; on electrotonus, 592

Oppler, Mr., on origin of urinary constituents, 511

Oié, M.. on absorption by skin. 20.3 : on course of sensory fibres in spinal eord. 630 ; on ligature of hepatic centres, 479

Ornellas (D'), on vomiting, 136

Orth, on organisus in blood, 269

Orton, Mr., on physiology of breeding, 917 note

Oser. on action of nicntin on heart, 317 note; on uterine contration, 910

Ott, Dr. I. on action of lobelina on the pneumogastrics, 317 ; on the action of thebain on the visomotor centres, 328

Ouluont, on action of hyoseyamin and datura on heirt, 317 note

Ontrepoint, Dr., his case of early viability, 914

Overbeck, on albuminnris, 496

Uwen, Prof., on the divisions of the mammalin. founded on the brain, 40 ; on autliropoid apes, 47 ; on structure of cerebrum in man, 52 ; on typical vertebra, 954; on cranial vertcbra, 95.5; on Matuhamp breed of sheep, 996 note; on the Mincopie race of the Andaman isles, 1013 note

Owsjannikow, on vasomotor centre, 327

Pagenstecher. on intracranial pressure, 358

Piaget, Dr., on morbid rbythmical tuovements, 678 note

Paret, Sir Janes, on alteration of blood in disease, 265; on retarded coagulation of 
blood, 273 ; on colorless corpuscles. 280 ; on symuetrical disuses, 281 ; on complementiry nutrition, 2s2; on local deternining causes of infi+mumition, 290; on contractile movements of leart, 297 ; on effects of me. chanical irritation on smaller arteries, 325 , note; on eapillary circulation, 351 note, 352 ; on formative power of individurl parts, 4:38; on fatiy dezeneration of lymph, 439,440 ; on exuriation of dead parts, 440 ; on tamors, 443; on reparative power, 447 ; on in. cipient changes in atrophy, 446 ; on healing processes, 445, 451; on iuflam:nation, 449; on Incalization of inflammatory action, 455 ; on heat of iuflammontion, 456 ; on lymph products of influmitron. 4is; on tuberculosis, 46:3 note; on cancerous cachexia, 463 mitr; on regeneration of nerve-tissue. 559 ; his case of deficient commissures, 704 mole; on influence of nerrous system on nutrition. 871

Pallodino, on nerve ending in salivary glands, 865

Pander, on development of ressels, 933

Panizza, on uses of plexuses. 572

Panum, Dr, on inaution, 123: on metals in bloou, 255 "are; on aetion of hest on heart, 307,304 ; on respiration. 392, 394; on sinitary condition of Faroe Islands, 115

Paquelin, on condition of iron in the blood, 246

Parent-Duchatelet, M., on inhalation of sul. phuretted hydrogen, 402

Parisot, on cutilleous absorption, 203

Pirker. Mr. Lingston, on mercurial inbalation, 411:3 note

Parker, Mr. W. K., on different moles of ossification, 954; on the development of the temporil bone, 957

Parkes, Di., on suprarenal capsules, 223; on excretion of nitrogen. 101 ; on choler: 266 ; on nutrition, 423,430 : on influence of liq. potassa on solich of urine. 519 ; on quantity of urine, 498 ; on entuposition of urine, 502 ; on ejiuination of urea, 505,506 ; on eliuination of phosphates by urine. 515 ; of sulphates, 514; on uuscle force, 842

Parry. Captain, on resi-tance to cold, 5.36

Paschutin, on ptyalin, 148; on intestinal digestion, 178 ; on pressure of $1 y \mathrm{mph}$. in lyuphatics, 217 mote; on action of wooraril or [yıph, 46]

Pasteur. M., on earbonic acid contained in the intestine, 18.3; on presence of germs in air, $285 ;$ in prevention of feruentation by filtrition of air, 285

Paton, Ir., on sounds of heart, 305

Paulus, Dr., on tactile sensibility, 729

Pary, Dr., on self-ligestion of stounab, 158 ; on amyloid substance in blood, 254 ; on gly cogreny, 484-494)

Pawliniff, on origin of urea, 512

Payen, M., on economy of almixture of unimal and regetable ford. 105 ; on composition of inuscle of heilt, 107

Peddie, Dr., on mimmary secretion, referred to, 876 mote

Pelikan and Dybkowsky, on action of Tanghinia on heart, 316

Pennock, on influence of age on pulse, 319

Percy, Baron, on siege of Landil u, 921

Percy. Dr.. on ahsorption of alcohol, 193

Peremeschko, M., on structure of spleen, 218,
222 ; on nerves of thymus gland, 225, 226 ; on pituitiry hody, 227

Perrin, on elimination of carbonic acid, 390

Petersen, on muscle. 808

Pétrequin, M. . on function of cerebellum, 683 ; on filsetto voice, 855

Petrowsky, on coluposition of brain, 559

Pettenkoter, M., on cholera, 26 if mote; on ventilation. 409 ; his respiration apparatus, 414 ; on nutrition, 42I- 424

Pettenkofer and Voit. on elinination of carbonic acid, 390,$393 ;$ on air in relation to clothing, 409 ; on respirntion in air charged with carbonic acid, 410 ; onl cnuse of sleep, 708

Peyrani, on action of bile on fit, 172; on renal circulation, 499

Pfeiffer, on blood eurrent in the lung 3. 357

Pfliiger, on composition of saliva, 146; on mode of termination of nerves in salivary glands, 143, $865 ;$ on nerves of pancreas, $167 ;$ on effects of irritation of splanchnic nerves, 139 ; on gases of blood, 259,230 ; on influence of varus on he:ırt, 309.312 ; on cause of dyspnoe 1,375 ; on respiration, 378 , 396 ; on nerves of liver. 476 ; on electrical phenomena in nerves, $5 \mathrm{~s}: 3$; on electrotonus, 5.97 ; his lin of inusculir contraction. 59l, 592; nn anelectrotonus : ind cothelectrotonus, 587-590; on spinal enro, 639; on eause of sleep, 708 ; on sympathetic ganglia, 865

Philip, Dr. Wilson, on independent action of heart, 309, 312; on eapillary cireulation, 353 ; on animal heat, $5: 32$

Philippeaux and Vulpian, on union of sensory with motor nerves, 574

Philippeaux, on the spleen, 221

Picard, M., on proportion of urea in renal, arterial, and venous blool, $231,264,511$

Pickford, on effects of temperature on heart, 307

Picot, on migration of white corpuscles, 460 ; on uræmia, 497

Pincus, on effects of section of nerres on stomach. 139

Pinel-Grandchamp, M., on function of cerebellum, 678

Piotrowski. M, on composition of muscle, 807

Pircher, on urine, 502

Place. M , on rapidity of motor impulses, 582 ; on duration of latent excitation in inuscle, 816

Pliner, on gases of intestinal canal, 183; on gases contained in urine, $5 ! 5$

Plateau, M., on muscular power of insects, 839 Plattner, on quantity of bile, 175

Playfair, Dr. L., on absolute amount of work performed by boly, 436 ; on relation of food to work, 842 note; on eomposition of nilk, 978

Ploss, on the cause of variation of sex, 965

Plnsz, on ferment of blond, 254; on albuminous coinpounds of liver, 475

Poggiale, on blond of unbilical artery, 255

Poisseuille, M., on urea in blood, 264; his experiments or influence of viscidity ou capillary flow, 270 ; on the rate of circulation, 318 ; on muscular contrictility of arteries, 326 ; on extinction of pulse ware, 334 ; on discharge of fluid through tubes of different dianeter, 334 mote; on lateral pressure of blood within arteries, 336 ; his hamadynamometer, 336 
Poisseuille and Lefort, MM.. on presence of sugar in various pirts of the body, 48:

Pokrowski, M.., on action of carbonic oxide on heart, 316 note

Polaillon, on action of inea on heart. 317 note

Pole, Mr., his case of color blindness, 775 note

Pollack, on quantity of urine, 498

Polli. Dr., on effect of loss of blood, 257 ; on congulation of blood, 272, 274

Poore, Dr., on inerease of muscular power by electricil currents, 84 :

Portal, on carliac ventricles, 294

Pouchet, M., on death by cold, 538, 539; on ovulation, 897 note

Pravaz, on action of compressed air on pulse, 321

Prestwich, Mr. J., on the flint implements of Moulin-Quignon, 985

Preussen, on the cause of variation of sex, 965

Prévist and Dumas, MM., on fertilizing power of spermatozoa, 887 note

Prévost, on action of veratrin, 820 ; on fifth nerve, 616, 865

Preyer. M., on action of hydrocyanic acid on heart, 250 mote, 316 ; on globin, 244, 250; on blond crystals, $245,247,248$; on gases of blood, 259; on Dilltonism, 775 note

Pribram, on vaso-motor centre, 328

Prichard, Dr., on varieties of man, 987 note; on typical forms of skull, 992 ; on chinges in domesticited animals, 997 mote; on psychical conformity of human races. 999; on Celtic ianguages, 1002; on somatic death, 1032

Pritehard, Dr. U., ou cochlea, 783

Pruchiska, on reflex acts, $6: 36$

Prout, Dr., on acid of gastric juice, 156 ; on secondary digestion, 214 ; on quantity of urine, 498 ; on its specific gravity, 500

Prussak, on enigration of white corpuscles, 460

Puky Akos, on Briiuner's glands, 177

Purkinje, Prof., on retina, 775 ; optical experiment of, 778

Purves, on emigration of white corpuscles, 460

Putnam, on vasomotor centres, 327

Putzeys, on spontaneous generation, 880 note

Pye Smith, on preferential use of right liand, 834

Quain and Sharney, on nerve-tissue, 558

Quekett, Mr. J., on elastic tissue in fæces, 181 nute

Quetrlet, M., on rate of respiration at different iges, $37: 3 ;$ on influence of seisons on mortality, 548; on length and weight of new. born infints, 966 ; on viability of male and female, 967 ; on relative heights and weights of inile and female at different ages, 968

Quincke, on digestion, 179; on blood-current in the lungs, 357 ; on animal heat, 545

Rabutean, on uræmia, 497

Racilorski, Ml., on periodical discharge of ova, 8:):

Radeliffe, Dr. C. 13., on the electrical phenomena presenterl by nerve and muscle, 594; on muscular irritability, 826 ; on muscular contrinetion, 810

Radriejewsky, on tyrosin, $S S$; on action of purgatives, 140 ; on formation of fit, 432
Rählmann, on perception of color by retina, 775 note

Rainey, Mr. G., on structure of lungs, 363 note

Ranke, Prof. Von, on secretion of saliva, 150; on muscular force of heart. 302 ; on elinination of carbonic acid in the fasting state, 396 ; on proportion of constituents of body to each nther, 421; his experiments on nutrition, 421 uste, 422-428; on pure meat diet, 427 ; on amount of heat prodnced in the body, 436, 543; on excretion of uric acid, 508 ; on excretion of salts, 515 ; on reaction of nerve-tissue, $560,570,585$; on chemical changes in inuscle during contraction, 810, $842 ;$ on relative conductivity of dead and living muscle for electricity, 815 ; on absorptive power of dead and living muscle for oxygen, 828

Ransom, Dr., on rotation of yolk, 800 ; on fertilization, 931

Ransome, on mechanism of respiration, 371 ; on expired air, 401; on fertilization. 900

Ranvier atd Cornil, on structure of capillaries, referred to, $: 34: 3$

Ranvier, on difference between white and reil muscles, 815,819 ; on effects of division of nerves on flow of lymph. 461; on secretion of saliva. 151; on migration of white cor. puscles. 461 ; on structure of nerve-fibres, 554 ; on nerve regeneration, 558 note; on miscle. 802 note

Rathke, $\dot{D}^{\circ}$, on development, referred to, 924 "ute; on development of venous system, 940

Rauber, on Pacinian bodies, 726

Ravitsch, on influence of nerves on stomach, $16: 3$

Rawitz. Dr., on components of freces, 181

Rayer, M., on albuminous urine, 496 note

Recklinghiusen, M., on lymphatic system, 205 , 210 ; on pressure of blond in veins, 355 note; on lymphatic glands, 207

Redfern, Dr., on atrophy of cartilage, 446

Rerlwond. on colloids, 196

Rees, Dr. G. O, on red corpuscles of blood, 236 mote; on composition of chyle and lymph, 213; on composition of milk, 979

Registrar-General's report on influence of cold on mortality, 549

Regnault and Reiset, MM., on absorption of oxygen, 393 ; on absorption and exhalation of nitiogen, 400

Reich, on perimetry, 750

Reichert, on liliary ducts, 473 ; on structure of ear, referred to, 78.3; on serulutition of orum. 881 ; on the development of the guineapig, 924 mote

Reid. Dr. John, on sense of hungor, 121 ; on llerves of lleglutition, 131 ; on movements of stmmacl, 134; on restoration of dizestion after section of pneumogastrics, 162,163 ; on influence of nerves on secretion, 163 ; on re-excitement of heart's action by relief of distension, 304 ; on retardation of systemic circulation in asphyxia, 351 wete; on funetion of pneumogastric in respiration, $376^{\circ}$; on laryige:1 nerves, 380 ; on results of $\mathrm{sec}$ tion of pneumorastrics, 3SI, 383 ; on aspliyxia, 407 ; his case of hypertrophy of a limb, 442 note; on atrophy firom disuse, 446 ; ou structure of medulla oblongatir, 6105 ; on functions of glosso-pharyngeal, 576,620 ; or nerves of taste, 621 ; on motor roots of pneu- 
mogastric, 622 ; on spinal accessory, 624 ; on effects of exercise on the nutrition of muscle, 809 ; on structure and connections of placenta, $906 ;$ on Eustachian ralve, 941

Reil. on nerves of internal senses, 707

Reinhard, on cutaneous respiration, 525

Reinhardt, on respiration, 395 ; on colostric corpuscles, 975

Reiset. M., on respiration, 393,400

Remak. Dr., on protoplasm, 57 ; on cardiomotır ganglia, 306 ; on restorative currents of electricity, 843 ; on sympathetic nerve, Sfi3 note; on the development of the vertebrita, 924 mote

Renz and Wolff, on appreciation of intensity of sound, 796

Renzi, on effects of lesion of corpora quadrigemina, 658 ; on cerebelluin, 679

Report of Committee of Medico-Chirurgical Society on hypodermic injection, 204 note

Retrius, Dr., on fat in urine after parturition, 911 note; on ethnology in connection with the form of the skull. 1001 note; on variations in position of cerebellum, 681 note

Reveil, M., on absorption by skin, 203

Reverdin, on treatment of ulcers, 450

Reynoso, on diabetes, 488

Ribot, M., on the measure of sensations, 797 rote

Richardson, Dr. B. W., on effects of cold applied to nervous structures, 709 ; on museular irritability, 823; on the cause of the coagulation of the blood, 401

Richardson, Dr. J.G., on red corpuscles of bloor, 235 note; on white corpuscles, 241 note

Richardson, Sir J., on endurance of cold, $5: 36$ note

Ridard, M., on influence of emotions on nutrition, 877

Riegrel, Dr., on rhythmical movements of vessels, $326:$ on respiratory movements, 326 note; on effects of artificial respiration on animal heat, 537

Riesel, on excretion of salts, 514

Riess, on organisms in blood, 269 note,

Rindfleisch. on awyloid compounds, 87 ; on lungs, 364 ; on cerebrum, 688

Ringer, Sydney, on alcohol, 117 ; on animal he 1 t, 531

Risler, M.. on the absorption of bumors, 31

Ritchie. Dr., on evolution of ova, 891, 894

Ritter, on action of blood-corpuscles in respiration, 398 ; on pigments of blood and urine, $47 \mathrm{~S}$; on jaundice, 480 ; his law of muscular contractions, 590 ; on structure of retina, 756

Ritthauser. on nutrition, 425 note

Roberts, Dr. W., on influence of various reagents on blood.corpuseles, 236 ; on specific gravity of urine, 500 ; on acidity of urine, 516

Roberts, Mr.. his apparatus for reading cards in rapid motion, 772 note

Robertson, Dr. Argyll, on Calabar bean, 753 note

Roherton, Mr., on menstruation, 892 note

Robin, M., on developiuent of cells, 59 ; on myeloplexus, 228,438 ; on neurnglia, 601 ; on irritability of musele, 825 notr; on helicine arteries, 359 note; on lymphaties and capillaries of the brain, 693 note; on de. cidua, 911

Robinson, Mr., on strength of bone, 72 ; his experiments on absorption, $195,196,217$; on transudates, 457 ; on albuminous urine, 496 mote

Roger, M.. on temperature of infants, 531,534

Rogow, M., on action of Calabar bean, referred to. 753 mote

Röhrig, on action of biliary acids on leart. 307 ; on ligatures of hepatic artery, 479 ; on perspiration, 523 note; on cutaneous respiration, 525,526 ; on animal heat, 537

Rokitansky, Prof, on fitty degeneration, 440 note; on inflammatory deposits, 458

Rolando, M., on cerebellum, 675

Rollett, on nuclei, 59; on blood, 236 ; on blood-crystals, 245, 248

Rotbberg, Dr., on nerves of taste, referred to, 620 note

Romiti, on ovaries, 889

Rood, Dr. 0. N., on rapidity of pereeption. 774

Rosece, Dr., on coluposition of the air of London, 410

Rosenstein, on uræmia, 497

Rosenthal, on influence of pneumogastrics on lungs, 367,377 ; on effects of hydrogen-sulphide on heart, 316 note, 402 ; on inhibitory influence of superior larsngeal nerves on respiratory aets, 381,382 ; on medulla oblongata, 606 ; on retention of irritability by nerve after death, 580 ; on retention of irritability by muscle after death, 826 note; on absolinte muscle force, 839

Rossbach, on action of poisons on heart, 317 mote; on rhythmical movements, 800

Rostan, M., on starvation, 124

Rouget, MI., on zo-amyline, 48t, 485 ; on helicine arteries, 359 wote; on corpuscula tactûs, 725

Roussin, on hippuric acid, 509

Routh, Dr., on puerperal fever of Vienna, 236 note

Röver, on vasomotor centre, 327 note. 329 note

Rudinger, M., on structure of ear, 703

Ruge, on gases of large intestine, 184

Rugenberg, M., on influence of vagus on lungs, 367

Ruble, on vomiting. 136

Rummell, on excretion of urea, 503

Rutherford, Prof, on biliary secretion, 176 ; on actions of heart, 301 mote; on influence of vigus on the heirt, $309,310,314$; on vasomotor centre, 328 ; on the action of calomel on the liver, 482 ; electrotonus, 589

Sabatier, on action of intercostals, 370 ; on respiratory murmur, 372 ; on relative capacity of cardiac rentricles, 294

Sachs, M., on absorptive organs of villi, 192 ; on structure of nerves, 554 ; on nerves of musculitr sense, 666 ; on muscle, 802 note

Sidler, Mr., on pressure of hlood in veins, 356 note; on proportion of sexes, 965

Salkowsky, on cilio-spinal centre, 642

Salomon, on glycogeny, 485,489

Salter, Dr. Hyde, on cause of respiratory murmur, 372 ; on mode of termination of museu. lar fibre, 801 note

Samuel, on trophic nerves, 870

Sanuelson, on spontineous generation, 880 note Sinders, Ezn, on posterior roots of nerve, 629 Sanilers, Dr., on structure of spleen. 218 mote Sanders, H., on functions of spinal axis, $6: 32$

Sanderson, Burdon, Prof., on phenomena of circulation, 234 ; his cardiograph, 301 ; on 
vasomotor nerves, 328 ; on sphygmograph, 330 note; on means of exhibiting capillary circulation, 343 no'e; on extent of respiratory movetuents, 371 ; on action of vagi on respiration, 377, 384; on asphyxia, 406; on formation of small-pox pustule, 462 ; on $\mathrm{cu}$. taneous respiration, $5+2$; on lesion of crus cerebri, 6 tio; on electrical excitation of cerebrum. 700; on spontaneous generation, 880

Sanderson, Dr., on influence of respiration on heart, $3: 39$

Sanson, on glycogeny, 484

Sappey, M., on number of gastric follicles, 151 ; on accessory venæ portarum, 479

Sirokow, on nutrition, $4: 3 \mathrm{I}$

Saunders, Mr. E, on dentition, 1024

Saunderson, Prof, case of, $7: 32$

Savart, M., on production of musical tones, $7 \$ 1,854$

Saviotıi. on pigment cells, 63 ; on rbythmical uorements of vessels, 326

Savory, Mr. W. S.. on effects of non-anotized diet, 101, 8t2; on forces aiding the eirculation of the blood. referred to, 352 note: on advantage of plexiform arrangement of nerves, 572 note; development of musculitr fibre, 808; on effects of poironing the foetus on mother referred to, 907 mote

Sawicki, on acils of urine, 514

Scanzoni on uterine coutractions, 910 mote

Schäfer. on development of red corpuscles, 251 ; on muscle, 803,804

Sehilpringer, on tensor tympani, 787

Scbarlau, on fat in blood of lluukards, 440 mote

Scharling, Prof., on excretion of carbonic acid from lungs, 388, 391; from skin, 395; on aluount of carbon excreted by skin, 525 ; on omichuyl, 502

Scheffer. on effects of deprivation of water, 123

Seheinesson, on animal heat, 546

Schelske, M., on action of heat on heart, 307 ; on rapidity of trinsıission of impulses through motor nerves, 582 ; on perception of color by retina, 775 note

Scherk, on respiration. 401; on nutrition. 425 note; on liver, 475 note; on spectrum of bile, 478 ; on muscle force, 842 ; on development of pancreas, 945

Scherer and Neubiner, on the presence of xinthin in urine, 510 note

Scheremetjewsky, on oxidation in blood, 398 ; on diabetes, 494 note

Seherer, Prof., his test for inosite, 95

Schiefferdecker, on nerve lesions, 871 note

Schiff, Prof, on mechanisin of voluiting, 135 ; on morements of stomith, 134; on nerve centres goverling movements of stomach, 135; on -illira, 145, 150; oll effects of section of vagus nerve on voutuiting, 162; on digestive action of bile, 174; on digestive puwers of intestinal fluid, 179; on innervation of heart, 309 note. 315 ; on rlythmical enntrace tioms of smaller vessels, $326 ;$ on vasomotor nerves, $329 ;$ on respiratory nerve centres, 374 ; on dyspnoea. 376 ; ou arrest of respiratiou, 378, 384; on structure of liver, 475 ; on reabsorption of bile, 481 ; on glyengeny, 486,488 ; on albuminuria, $496 ;$ on influence of medulla on kidneys, 496 ; on influence of the nervous system on developinent of heat, 544 note; on regeneration of nerve, 558 note; on spinal corrl, 628 ; on nnalgasia, 641 ; on stimulation of central hemispheres, $701 ;$ on sympathetic. 867 ; on action of bile on involuntary muscle, 175 ; on effects of ligature of coronary arteries on heart, 297 ; on rhythmical contractions of heart, 298 ; on rhythmical contraction of veins, 355; on effects of ligature of hepatic artery, 479 ; on effects of virious stimuli on motor nerves, 579, 580; on course of sensory fibres in spinal cord, 628 ; on asthesodic substance, 629 ; on kinesodic substance. 632 ; on lesion of thalami optici, 660; on corpora striata, fifll; on cruria cerebri, 661 ; on cerebellutu, 677 ; on hypnotisın. 694 ; on nerves of taste, 734 note; on in u*cular contraction. 819 ; on thythmical morements. 822 note; on the sympathetic. 867

Schiffer, on beat developed during muscular contrution, 811

Schleisner, Dr, on sanitary condition of Icel:and, 412 note

Schlemmer, on Brunner's glands, 177

Scblesinger, on action of strychnia on bloodpressure, 327 ; on uterine contrictions, 910 mote

Schmidekam, on ossicula audit n̂s, 789

Schmidt, A., on fibrin, 8:3; on salts of saliva, 147 ; on quanticy of gastric juice, 159; on action of pancreatic juice on starch, 171; on serretion of bile, 176 ; on intestinal juice. 178; on ha'loglobin. 246 ; on ecagulation of blond. 277 ; on fibrin, 277 ; on elimination of earbonic acid, 390,398 ; on presence of starch in test of tunicata, 483 ; on glycogeny, 48:

Schinidt and Kiröger, on quantity of pancreatic flui,l, 169

Schmidt, Dr. H. D., on derelopment of blood. corpuscles, 251; on liver, 475 nute

Schinierleherg, on action of pnisons on heart, 312 mote, 316 note; on innervation of heart, 315

Schinulowitsch, M., on relation between muscle force and temperature, 812

Schneider, Dr., his case of electric disturbance, 552

Schöhl, on corpuscula tactôs. 725 note

Sebiffer, on gilses of blood, 260

Schöpffor, on clycogeny, $4 \$ 5$

Sehottin, on solids of sweat, 523

Schreger, on absorption by eutaneous lymphaties, 20:?

Sebroder, on presence of germs in the air, 285 Schrneder, Van der liolk, Prof., on spinal cord, 603 note; on functions of olivary bodies, 607

Schuh, on deglutition, 129

Schultze, Prof. M., on development of connective tissue, 65 ; on structure of nerve fiorils, $5: 36$, on neurowlia, 601 ; on the olfactory nerves. 741 ; on the structure of the cochlea, 783; on muscular tissue, 802 note

Schultzen, on excretion of urea. 507,511 note Shulz, on trophic nerves, 873 note

Schulze, 1)r. F. E. on structure of lungs, 363, 361,366 ; on elimination of carbonic acid, 393

Subunck, on eoloring matter of urine, 510 note Schuster, on snimal beat, $5333,5: 37$

Schutzenberger, on nutrition, 421

Schuurman, on mean excursion of eye, 750

Sehwilbe, on Brunner's glands, 177 ; on unstriated muscular tissue. 801 note; on striated unseular tissue, 802 note; on origin of nerves from cells, 864 
Schwann. Prof., on derelopment of connective tisslle, 6.5 ; on division of bile duct. 175; on structure of nerves. 554 ; on muscle, 806

Schweigger-Seidel, on lymphatics, referred to. 200 ; on nerves of pericardium, 245: on ganglia of heart, 306 note; on muscle of heart, 802 : on structure of spleen, referred to, 218 ; on spermatozoa, 855 nole

Scoutrtten, on electricity of the blood, 551

Sczelkow, on gises of blood, 260 ; on pressure of blood in veins, 356 ; on muscle, 805 note, 842

See, M., on fibrin, 277

Seebeck, on Diltonisin, 775 note; on appreciation of minute differences in pitcb of sounds, 796

Seebeck and Wartmann, on Daltonism, 775 note

Seegen, on nutrition, 421 note, 425 note, 426

Seguin, on amount of sweat, 523

Senac on relative size of cardiac ventricles. 294 ; on action of intercostals, 370

Senator, on glycogeny, 490 ; on regulsting mechanism, 5.37 ; on effects of starvation on heat, 540; on atnount of heat produced by body. 543

Serre. Dr., on phosphènes, 777

Serres, M.. on compirative anutomy of cere bellum, 674 note; on its pathology, 683

Sertoli, on gases of blood, 259 ; on corpuscula taetûs, 725 note

Setschenow, on color of blood, 233 ; on gases of bloorl. 259, 260; on inhibition of heart's action, $30 y$ note; on blood in asphyxia, 407 note; inhibitive centre for refl $: \mathrm{x}$ action, 635

Severé, Dr., on influence of gastric juice on alcoholic fermentution, 162

Shirpey, Prof., on structure of bone, 72, 74 ; on pulp-carity of the teeth, 75 ; on spectrum analysis of blood, 249 ; on action of poison of manganja on beirt, 316 ; on structure of muscular fibre, 8013

Shettle, Dr., on electricity of the blood, 551

Sibson. Dr., on actions of heart, 299,302 ; on sounds of heart, 305 ; on action of intercostals. 370 note; on mechanism of respiration, 369 nole, 384 mote

Sievekıng, Dr., on cbanuels of sensation, 731

Siewert, on nutrition, 425 note

Sikorski. on lympbaties of lungs, 366

Silbermann, on caloric equivalents of carbon and hydrogen, 542

Silvester, Dr. H. R., on nature of the spleen, 229 note; his mode of artificial respiration for the asphy xiated, 407

Simon, Dr., on analysis of saliva, 145 ; on com. position of uneconium. 481 ; on specific cravity of urine, 500 ; on variations in urine, 500 ; on viriations in milk, 977 ; on milk of different animals, 980

Simon, Mr., on coagulation of blood in the vessels, 274,275 ; on thymus gland, 226 ; on cancerous eacbexia, 415 note; on general pathology, 292 note; on inflammation, 463 note

Simpson, Dr., on patbology of cerebellum, 683 note.

Simpson, Prof. on analogy between puerperal and surgical fever, 287 ; on regeneration of limbs, 448; on hermiphrorlisa, 451 note.

Sinitzin, on lesion of the fitth nerve, 872 note

Sion, Dr., his case of fit in the blood, 268

Sitz, on temperature of infants, 530
Sivel, on respiration of $0 x y g e n, 38$

Skey. Mr. on muscular fibre, 802

Sklarek, M. on action of arsenious acid on heirt, .316 note

Skrebitsky, on quantity of pancreatic juice, 169

Sloan, Dr., his case of abstinence, 127

Sinee, Mr. A. H.. on gases of blood, 261 ; on artificial production of fibıin, 83. 278

Sroith, Dr. Andrew, on Bushmen, 10!()

Suith, Dr. Angus, on the air of Minchester, 286,410

Smith. Dr. Edward, on relation of carbonic acid expreed to muscular effort, 37 ; on bealthy dietary, 108, 113; on elınination of alcobol. 118 ; on quantily of freces, 181 ; on circumstances affecting the rapidity of the pulse, 320,321 ; on quantity of air respired per dieın, 386, 387; on aununt of e:trbonic acid eliminated per diem. 3s8; on circumstances affecting the quantity of cambonic acid eliminated, $383,395,842$; on elimination of carbonic acid by lungs and skin, 400 ; on effects of seison on flow of urine, 502 ; on quantity of urea, 498 ; on hippuric acid, 509 ; on influence of tea and coffee on urine, 518

Smith. Dr. F. G., on acid of gastric juice, 156 ; on temperature of stomach during digestion, 162 ; on effects of gastric digestion, 166

Smith, Dr. R. M., on acid of gistric juice, 156 Swith, Dr. Southwood, on eutaneous absorption, 201 ; on cutaneous transpiration, 524

Smith, Dr. Tyler, on cause of parturition, 913 note

Smith, Mr. R. A., on pulmonary exhalation, 401

Smith, Mr. Richard, on metallic tractors, 878 note

Snelien, on influence of protection after section of the sympathetic, 616 ; on effects of section of the sympathetic upon reparative processes, 867,872

Soborow, on excretion of calcic salts, 514

Socoloff. on suppression of cutaneous respira. tion, $526,5+2$

Solger, on heat evolved during contration of inuscle, 811

Solly, Mr. S., on medulla oblongata, 608 ; on optic ehiasma, 653 no'e

Solyet, M., on action of quinine on beart, 316 note

Sominer, M., on eause of sleep, 708

Sorby. Mr., on spectrum analysis of the blood, $249,1038,1034$

Southey, Dr. Reg, on tuberculosis, referred to. 463 ; on resiels of kidneys, referred to, 493

Spallanzani, on respiration of hydrogen, 397 ; on fertilizing power of spermitozoi, 887 note Speck, on fit in blood, 268

Spencer. Earl, his case of protracted gestation, 913,915

Spiegelberg, on albuminuria, 497 ; on reflex action of nterus, 910 note

Spigelius, on action of intercostals, 370 note

Squirey, Lr., on effects of coffee, 120

Squire, on quality of musical sounds, 787

Stackman. on quantity of bile, 175

Städeler, on coloring mitter of bile, 477 ; on excretion of urea, 512 ; on carbonaceous acids of urinary extractire, 510

Stannius, his experiment on heart, 306 
Stark, Dr., on chemical composition of bone, 72

Stefan, on elimination of carbonic acid, 392 ; ratio of liver weight to budy weight, 470

Stein, on erectile tissue, $35 y$

Steinberg, on quantity of blood, 232

Steinbauser, his case of artificial anus, 180

Steinheil, on perceptibility of different degree of illumination, 779

Steinıanu, on velocity of blood current in arterics, 341 ; on venous circulation, 354

Stewart, P., on animal heat, 531

St. George, Lavaletie, on spermatozoa, 883

Stezinsky, on vaso-motor centre, 326 note

Stich, on nerves implicated in sense of taste, 734 note

Stieda, M., on structure of spleen, 218; on corpuscula tactûs, 725

Stilling, on erectile tissue. 359 ; on structure of spinal cord, 603; on motor roots of pneumogatstrics. 622 ; on cerebellum, 674 note; on mode of termiuation of gustatory nerves, 642

Stoff, on spleen, 219

Stokes, Dr., on spectrum analysis of the blood, 248,249 ; on evolution of light, 549 ; on muscular contraction, 819

Stokes, Prof. G., on spectrum analysis of the blond, 249

Stoney, Butler, on saiiva, 147

Strassburuh, on gases of blood, 258 note; on respiration, 399

Strach, on respiration, 401

Strecker, on biliary acids, 477

Stricker, Dr., on temperature of heart, 234; on organisms in blood, 269; on capillary circulation, 343,345 ; on migration of white corpuscles, 460 ; on lymphatics of mesentery, 345

Stuart, Prof. A., on ciliary movement, 800 nole

Subbotin, M., on formation of fat, 432 ; on origin of urinary constituents, 511

Sutschinsky, on action of Calabar bean on heart, 317 note

Symonils, Dr., on death, referred to, 1035 note

Szukitz, on date of appearance of catamenia, 892

Tamamscheff, on structure of nerve-fibre, 554

Tinner, Dr., on a case of superfotation, 916 note

Tanquerel, M., on lead-poisoning, 283 note

Tarchanoff, on migration of white corpuscles, 461 ; on excretion of pigments of bile and blood, 478

Taylor, Dr. A., on poisonous change in meat, 115 note; on protracted gestation, referred to, 915 ; on age of foetus, 1 (1)17 note

Teale, Dr. J., his case of incroised temperature in clisense, 5:34, 544 note.

Teichunan, on the lymphatics of the stomach, 154 ; on the lymphatic system, 206; on the villi, 187 ; on lyınpatic glinds, 207 ; on Peyerian glands, 211; ou homin crystals, $2+7,2+8 ;$ on lymplaties of liver, 475 ; of muscle, 805

Tenner, on intracranial circulation, 358

Tergast, on nerves of muscle, 806

Tessier, M., his cases of protracted gestation, 915

Thatekrah, Mr., on coagulation of blood in the vessels, 274; on proportions of clot and serum, 276
Thanhoffer, on absorption of fats, 190

Theile, Prof., on hypospadias, 951 note

Thiernesse and v. Kempen, on union of motor with sensory nerves, 574 ; on roots of vigi, 622

Thin. Dr., on corpuscula tactûs, 725 notf

Tbiry, M., on intestinal juice, 178; on innervation of heart, 315 ; on temperature of tetanized muscle, 811; on vasomotor centre, 327 ; on dyspnoea, 375 ; on respiration, 401

Thomas, on migration of white corpuscles, 460 Thompson, Dr., on diagnosis of myopia and presbyopia, 753

Thomsen, on temperature of Icelanders, 530

Thouson, Prof. A., on focal adjustment of the eye, 748 wote; on double monstrosity, 444 note; on micropyle, 900 ; on development of embryo, 924 note

Thomson. Dr. Murray, on cutaneous absorption, 20:3

Thudichum, Dr. J. L. W., on chemical composition of nerve-matter, 87 ; on lutein, 89 ; on Liebig's extract of meat, 108; on coloring matter of bile, 477 ; on urine, 499,501 , $50 \mathrm{~s}$ wote; on hippuric acid, 509

Thurnam, on weight of brain, 692

Thury, M. Marc, on the cause of difference of sex, 965

Tibbitts, on uræmia, 497

Tiedemann and Gmelin, MM., on action of bile in digestion, 175 ; on absorption frou alimentiry canal, 194

Tieffenbach, on diabetes, 488

Tiegel, on ferment in blood, 254 ; on glyco. geny, 484

Tigger. on action of heat on heart, 307

Tod, Mr., on duration of irritability of heart. 297

Todd and Bowman, on structure of mucous membrane of stomach, 153 ; on structure of liver, 471 ; on nerves of tiste, 620 note; on peculiar excitability of frog, 63:3 note; on muscular tension, 648 ; on corporil striata and thalami optici, 650 ; on functions of uesocephalon, 651 ; on papillæe of tongue, $7: 35,736$; on olfactory nerve, 741

Toldt, on adipose tissue. 68

Tomes, Mr., on removal of bone by absorption, 438

Tommasi, Prof., on influence of altitude on pulse, 321

Tomsa, on lyinph, 217, 218; on tactile corpuscles, 725

Török, Von, on structure of nerve-fibre, 554

Towne, Mr., on the stereoseope, 727 note; on partial auaurosis of the retina, 654,762

Townsend, Col., case of, 1035

Toynbee, Mr., on structure of kidney, referred to, 490 note; on membrana tyrupani and its muscles, 787, 788

Traill, Dr., on fat in the blood, 268

Traube, MI., on action of earbonic oxide on lieart, 316 mole; his curves of arterial pressure, 328,340 ; on causes of dyspncea, 375 ; on arrest of respiration, 378 ; on uræunia, 497 ; or respiration of poisonous gases, 402

Treviranus, Prof., on couplemental nutrition, 281

Troitzky, on velocity of motor impulses, 582

Trousseau, M., on suspended lactation, 973 nole

Truhart, on action of poisons on heart, 312 mols

Trutschel, on nerves of stomach, $\mathbf{1 5 5}$ 
Tschaussow, on movements of pigment cells, 63

Tscherinoff, M. . on glycogeny, 484,489

Tscheschichin, M., on temperature of the body, 533,544

Turck. I)r., on pathological changes in spinal cord. 605

Turley, Mr., his case of excessive sexual desire, 68:3 note

Turner, Prof., on bronchial system of vessels, 366 ; on arrangement of convolutions of brain, 686 ; on placenta, 904

Tyndall, Prof., on germs in air, 411, 450 ; on sound, 780,787 mote

Tyson, ou glycogeny, 490 note; on kidney, 495

Unzer, Prof., on reflex action, 636

Urbain (D), on gases of hlood, 258, 259, 260, 394

Urhantschitsch, on "Deaf spots," 795

Uschakoff, on perimetry, 750

Uspensky, on reflex action, 635

Ustimowitsch, on renal circulation, 498

Valentin, Prof, on inanition, 123; on move ments of stomach, 134 ; on bile in fæees. 183 ; on pancreatic juice, 171 ; his estimate - of amount of blood, 232 note; on amount of blood discharged from heart, 318 ; on rate of blood's movement in capillaries. 346 ; on erectile tissue, 359 ; on excitability of mucous surface of trachea and bronchi, 381 ; on quantity of air respired, 386; on cutaneous respiration, 526 ; on post-mortem rise of temperature, 535 ; on glosso-pharyngeal, 620 ; on roots of pneumogastric, 621 ; on spiual accessory, 624 ; on hypoglossal, 624 ; on cephalic nerves generally, 626 ; on olfactory nerves, 652 ; on behavior of spinal cord in regard to electric currents, 626 ; on selise of touch, 728, 730 ; on sense of taste, 738

Vanlair, on stercobilin, 182,478 ; on pigments of hile and urine, 510

Vanner, his estimation of the quantity of blood, 232

Vanzetti, on trophic nerves, 872

Vasey, on locomotion, $8: 33$

Verdeil, on composition of ashes of blood, 254

Verloren, M., on derivation of force from farinaceous compounds, 437,842

Vernois and Becquerel, on the composition of milk, 978

Verson, on structure of thyroid body, 227 ; on structure of villi, 190, 192

Vesalius, on action of interenstals, 370

Vierordt, on food, 111 ; on quantity of blood, 232 ; on amount of hlood expelled by ventricles, 318 ; his hæunatochometer, 340 ; on rite of circulation, 319 ; on dynamies of cir. culation, 334 ; on rate of circulation in capillaries, 346 ; on respiratory movements, 364 , 384 note; on amount of tidal air, 386 ; on percentage of carbonic acid in expired air, 387 ; on circumstances affecting this, 387393 ; on work performed by hody, 436 ; on syectrum notution, 478 ; on tactile sensibility, 728 ; on rapiaity of accommodation, 750

Villemin, M., on inoculability of tubercle, 463 note
Villermé, M., on influence of season on mortality of children, 548

Vintschgin, on sense of taste, 738 ; on conversion of starch into sugir by salivit, 148

Virchow, l'rof. R., on development of eonnec. tive tissue, 65 ; on myelin, 87 ; on lympl. 212 ; on hrematoidin crystals, 248 ; on connective tissues, 345 ; on griant cells of horn, 438 ; on fitty degeneration of uterus after parturition. 439 ; on inflitmmatory processes, $453-454,463$; on the relation between the coloring matter of blood and hile, 477 ; on corpora anylicea, 486 ; on veuroglia, 601

Vivenot, on effects of compressed air on beart, 321,394

Vogel, on the urine, 507

Vogt, his cases of paralysis of fifth pair, 620

Voit, Prof., on defecation, 141; on action of bile on fats, 172 ; on quantity of bile, 176 ; on rectal absorption, 181$)$; on quantity of bili:ıry acids, 182, 481 note: on fæees, 185 ; on respiratory movements, 371 ; on elimination of carbonic acid, 393 ; on elimination of nitrogen, 399 ; on nutrition, $42 \mathrm{I}-125$; on uramia, 497 ; on the effects of coffee, 120 ; on origin of urea, 505 ; on influence of coffee on urine, 518 nole

Volkmann, Prof., on sounds of heart, 304 ; on amount of blood discharged from heart, 318 ; on riate of pulse in the aged, 319 note; on the influence of stature on the pulse, 319 ; on dilatation of arteries with pulse wave, 329 ; his hrmodromometer, 340 ; on rate of movement of hlood in arteries, 340 ; his kyınographion, 336 ; lateral pressure of blood within arteries, 3336 ; on rate of blood's movement in capillaries, 346 ; on contractility of lungs, 367 ; on discrimination of sensory impressions, 573 ; on spinal cord, 605 ; on motor roots of pueumogastric, 622 ; on improvability of sense of touch, 732 ; on phenomena of exhaustion in wuscle, 811 note; on perceptibility of different degrees of illumination, 779,798 ; of temperiture, 798

Von Ammon, Dr., on influence of passion on manmary secretion. $\$ 76$ note

Vrolik, Prof., on double monstrosity, 444 note; on varieties in form of pelvis, 994

Vulpian, M., on nerves implicated in deglutition, 131; on action of woorara on heart, 317 nute; on vasomotor centre, 327 nute; on vasomotor nerves, $329,869,873$; on structure of capillaries, 345 ; on belicine arteries, 359 ; on rhythmicil contriction of reins, 355 ; on nerve regeneration, 558 note; on chorda tympani, 617 ; on glosso-pharyngeal nerve. 620 ; on hypoglossitl nerve, 624 , 625 ; on presence of taurocbolic acid in suprarensil capsules, 480 ; on allantois, 937

Wade, Sir C., his ease of trance, 1036 note

Wagener, on muscle, 802 note

Wagner, Prof., on rhythiuical contraction of veins, 355 ; on resections, 448 ; on motor roots of pneumogastric. 622 ; on the cere. bellum, 675 ; on tactile papillæ, 725,726 ; on spermitozoa, 886

Waldeyer. Dr., on teeth, 79 ; on development of bone, 74 ; on lesion of semicircular cilnals, 658 note; un cochlea, 783 ; on ovaries, 889 
Walker, Mr. A., on intermarriage, 917 note; on rigor unortis, 828

Wallace, Mr. Alf. Russell, on the fauna of the Malay Arehipelago, 10/1 note

Walkhoff, on duclus arteriosus, 942 mote

Wallace, Dr. Clay. on adaptition of eye to distances, 747 note

Waller, Dr. Aug.. on migration of white enrpuscles, 266,460 ; on effects of section of nerses on their structure, 559 ; on regeneration of nervestructure, 648 ; on influence of sympathetic on walls of arteries, 326 ; on effects of dirision of the sympathetic, 867 ; on ending of gustatory nerves, 736 mote; on heat, 546 ; on pupil, 759 ; on decussation of the optic nerves, 762 note

Walshe, Dr., on cancerous eachexia, 464 note

Wulther, Dr., on death by culd, 535,538

Ward, Mr. N. B, on post-mortem movements in choleri patients, 827

$\mathrm{W}^{\prime}$ ardrop. Mr., on influence of passion on matumary secretion, 876 mote

Warnecke, on urea, 507

Wartmann and Seebeck, on Daltonism, 775 note

Waters. Dr., on the structure of the lungs, 363,364 ; on caluse of respiratory muriuur, 372

Watson, Dr., on absorption of vapor, 202

Webar, Profis., on arrest of heart's action by stimulating pueumogastries, 309 ; on effects of electro-magnetic current on small arteries, 326 ; on diameter of capillaries, 344 ; on rate of bloot's movement in eapillaries, 346 ; on effects of electricity in capillary circulation, 350 ; on erectile tissue, 359 ; on strus. ture of liver, 473 ; on perceptivity of nerves for heat, 580 ; on size of pulmonary air-cells, 365 ; on tactile papillæ, 725 ; sensibility, 727 ; on sppreciation of weight, 730 ; on appreciation of temperature, 730 ; on sensibility of tongue, 727,735 ; on special conduetors for temperature, 731 ; on perception of sounds, $796^{\circ}$; on elasticity of inusele, 812 ; on ceritre of sravity of the body, 8.31 ; on morements of locomotion, 83.3 ; on mechani. cal power of muscle, $8: 39$; on sounds of vi. brating reeds. 851 ; on vesicula prostatica, 951 note; on varieties of form of pelvis, 994

Weigelin, M., on exeretion of urea after exertion, 506

Weikart, on urea, 502

Weil. on action of digitalis in increasing reflex excitability, 635

Weinmann, on quantity of pancreatic fluid, 1f9

Weiske, on salts of bones, 434

Weiss, on grlyengen in muscle, 95 ; in liver, $485-488 ;$ on clative eapacity of ventricles of heart. 294; 011 quatity of 1 ymph, $216^{\circ}$; on the rite of its inovements, 216

Weissmann, on hippuric acid, 509

West, $V$ :u, on rapidity of motor impulses, 582

Wieslerholrl, on expiresl air, 401

Welcker. his method of determining the quantity of blood, 232 ; estimate of aerating surfuce in lungs, 388

Wells, llr., on eolor of blood, 262

Wells, Dr. J. Soelberg, on the eye, referred to, 748 110

Wellyel, on teeth, 79

Weston, Mr.. experiments made on during exeıcise, 506
Westphalen, on quantity of bile. 175

Weyland, on action of various prisons on heart, 317 mote; on nuscular contraction, 820

Weyrich, on insensible persuiration, 387, 400, 523 ; on tension of watery rapor in expired air, 400

Wheatstone, Prof., on binocular vision, 764767 ; on estiuation of size, 769 ; on the pseudoseore, 770; on filsetto voice, 854

Whewell. Prof. W., on astigmatisı, 75:3

White, Mr., his ease of reproduction of supernumerary thumb, 448 wote

Whitehead. Mr., on menstrual fluid, 893

Willin, on absineuce, 127

Willemin, on cutaneous absorption, 203

Williams Dr. C. J. B., on destruction of bloodcorpuscles. 267 ; on elimination of morbid poisons, 292 wote; on force required to propel the blood, 293 note; on sounds of heart, 304 ; on venous circulation, 356 ; hisexperiments on the tonicity of blondressels, 356 ; on contratetility of bronchial tubes, 366 ; on animal heat. 532 ; on death from necremia, $10: 34$ note; on proximate causes of death, 1035 note

Williıms, Dr. R., on morbid poisons, 29l, 292

Williams, Dr. T., on the structure of the lungs, 363

Willis, Dr., on functions of cranial nerves, 574,624

Willis, Mr., his artificial glottis, 852 ; on vowel sounds, 859

Wilson. Mr. E., on sudoriparous glandule, 521

Winiwarter, on cochlea, 783

Winkler, M., on muscular fibres of heart, 802 mole

Winogradoff., on diabetes, 498

Win-low, on relative enpacity of ventricles of heirt, 294; on action of intercostals, 370

Winternitz, on temperature of riscera, 529

Wintrich, on influence of ragus on lungs, 307

Wislicenus and Fick. MM., on excetion of nitrogen by the urine, 101 ; on sensition of he: t, $7: 31$

Wistinghausen, on influerce of bile on prounting "bsorption, 174, 195

Wittich, Von, on pepsin, 84 ; on influence of sympathetic on salivary glands, 145 ; on ferment of saliva, 146 ; on ferment of bile, 478 ; on glyengeny, 484; on visomotor nerves, 869 note

Wohler, on excretion of soluble salts, 518

Woinow, on perception of color by retina, 775 mote

Waif, on secretion of bile, 176

Wolfberg, on gises of blood, 258 ; on respiratory processes, $39 ! 9$

Wolff, on osseous tissue, 70 ; on development of vessels, 9.33

IVollistou. Dr., on the sound aceompanying mu*cular contriction, 812

Wood, on action of veratria on heart, 317 note; on the heat centre, 547

Wrisberg, on quantity of blood, 232 ; on vicarious secretion of urine, this

Wunderlich, on evolution of heat. $529,5.32$; on post-mortem rise of temperature, $5: 35$; on local variations of temperature in disease, $54 i^{\circ}$

Wunlt, on pancreatic juice, 168 ; on action of oxygen on heart, 307 ; wn ivfluence of rigus 
on heart. 309 ; on influence of woorara on heart. 315 ; on elasticity of arteries, 323 note; on influence of respiration on blood pressure. 339 ; on action of intercostal muscles, 370 ; on electrieal phenomena in nerves, 583 ; on extensibility of muscle, 813 ; on reation of muscle in rigor mortis, 828

Wurtz, on lynph, 213

Wyss, 0 .. on hiliary ducts, 473 note

Wywolzoff, M., on lymphatics of lungs, referreul to, 206,366

Yarrell, Mr., on assumption of male plumage by female, 282
Young, Dr. Peter, on the development of the eve in the chick. 962 note

Young, Dr., on fundamental colors, 775

Zalesky, M., on origin of urinary constituents, 511

Zanarelli, on fat in the blood, 265

Zander, on succus entericus, 179

Zenker, on the relation between the coloring matter of blood and bile, 477

Zeviani, on vioarious secretion of urine, 468

Zöllner, M.. example of optical illusion, 771

Zuckerkandl, on Enstachian tube, 789 note

( Zundt, on animal heat, 537 



\section{INDEX OF SUBJECTS.}

Aberration, chromatic and spherical, 745

Abortion, 913

Abscesses, formation of , $459-463$

Absolute amount of hent produced in the body, 435

Absolute muscle force, 839

Absorbent Cells, 191, 206

Absorbent Glandula, 207

Absorbent Vessels, 186

ABsorption, general nature of the function, 186 ; organs effecting, 186,192

From Alimentury Camnl, by Bloodvessels, 192,193 ; by Lacteils, 188; circum stances iffecting rate of, 195

From body in genpral. by Lymphaties, 200 ; by Skin, 201; by Sanguiferous system, 193 ; by Lungs. 401

Of Albumen, 201 ; of Fats, 199 ; of Salts, 197 ; of Solid Bodies, 199

of Vapors, 202

of Effete Tissues, 345

Abstinence from Food, duration of life under, 127

Acaraiac Foetus, movement of blood in, 349

Accessory Nerve, origin of, 611,622 ; fune tions of, 62:

Accommodation of the Eye, phenomena accompanying, 746 ; action of ciliary muscle in, 749 ; time required for, 750

Acidity of Gastric Juice, cause of, 156

Acidity of Urine, causes of, 516

Arids of Bile, 477

Aconitina, action of, on heart, 316 note, 317

Acousties, theory of, 781

Adaptation of the Eye to objects at different distances, 746-750

Adipose tissue, structure of, 66 ; uses of, 67 ; development of, 67

Adhesion, reparation of wounds by, 448 ; secondary, 449

Adolescence, characteristics of, 1020,1026

Asthesodic substance, 629

Afferent nerve-fibres, 560

African Races, 1006

After sensations, $729,744,772$

$A$ ge, influence of, on composition of blood, 255 ; on rate of pulse, 319 ; on exeretion of carbonic acid, 389 ; on nutritive activity, 417 ; on exeretion of urea, 50$) 2$; on power of ealorification, 530 ; on rate of growth, 969 ; on rate of mortality, 1029

Ases, different, characteristics of, 1015 ; fotal life, 1017 ; infincy, 1019 ; chillhood, 1020 ; youth, 1025 ; adolescence. 1026 ; maturity, 11328 ; decline, 1029; old age. 1030

Air, composition of, 387 note; total quantity breathed, 357 ; effects of rarefaction of, on
Man, 394 ; alterations in, by Respiration, $3 S 7$ (see RESPIRATION); effects of insufficient supply of, 404 ; amount required, 409 ; ventilation of, 409 ; effects of breathing impure, $408-113$

Air-cells of the Lungs, 364

Air-sacs of the Lungs, 364

Alalia, 706

Alhinoisın, 988

Albumen, compounds of, 81 ; importance of, in diet 104-110; digestion of. 163 ; feeble dialyzing power of, 197 ; assimilation of. 86 ; gastric digestion of, 157 ; pancreatic digestion of, 173 ; normal proportion of, in Blood, 253 ; variations of, in disease, 249 ; uses of, 80, 431 ; transudation of 457,495 ; conversion of, into fat, 433

Albuminous constituents of food, 104 ; importance of admixture of, with oil and stareh, 108 ; digestion of, $158,166,173,181$; influence of, on exeretion of urea, 428, 505 . metamorphosis of, in the body, 435

Albuminuria, 496

Alcohol, quantity of, consinmed in England, 116 ; injurious results of habitual use of, 118; rapid absorption of, through animal nombranes, 194 ; its tendency to produce fitty degeneration, 439 ; on kilney, 508. 518 ; use of, in fever, 541

Alfourou Race, 101:

Aliment, 100 , see Fod

Alimentary Cinal, development of, 933, 943

Alkalies, effect of, on urine, 516

Alkaline Phosphates in hlood, 254; in urine, 514

Alkuline Sulphates in urine, 513

Alkalinity of Blood, importance of, 378

Alkalinity of Urine, eauses of, 517

Allantoin, 91

Allantois, development and uses of, 9.37

Alreolar passages of lungs, 364

Alveoli of lungs, 364

Amanita muscaria, action of, 284

American Races, 1010

Ainnesia, 706

Amnion, development of, 928 ; liquor of, 932 , 938

Amphioxus, nervous system of, 566

Anylaceous substances, digestion of, 184, 171, 179

Amylnid substance of the liver, 87, see Glycogrny

Anilgesia, 641

Andaun Isles, Mincopie Race of, 1013 note

Ancenist, state of blood in, 266

Ancon breed of sheep, 996 note

Anelectrotonus, 586; extrapolar centrifugal, 588 ; extrapolar ceutripetal, 588 
Animal Heat, 528, see Hert, Animal

Antero-luteral columns of spinal eord, 628

Antiaris Toxicaria, action of, on Heart, 316

Antiperistaltic action, nature of, 133

Aorta, development of, $933-936$

Apes, differences between man and, 39

A phasia, 706

Aphides multiplication of, 29

Apnoea, 375

A poplexy, predisposition to, 266

Apparatus, Pettenkofer's respiration, 414

Apparent Death, 1035

Apyrenæmata, 2.37

Arib Pace, 1004

Arciform fibres of Medulla Oblongata, 608

Arcbeneephala, 40

Area Germinativa, 931

Area Pellucidil, 932

Area Vascular, 933

Areolinr tissue, $6: 3$

Arian Rice, 1002

Arrest of Development, 417 ; of circulating apparatus, 938 ; of sexual organs, 950 ; of the sternum, 953 ; of visceral arches of face, 958

Arruw Poison of Borneo, action of, on heart, 316 nute

Arsenic, action of, on heart, 316 note; elimination of from body, 283

Arseniuretted Hydrogren, action of, on Blood, 402

Arterial Blood, differential characters of, 257261 ; cause of color of, 261; absence of, a cause of muscular contraction, 296,825

Arterial System, first development of, 933 ; subsequent changes in, 938

Arteries, movement of Blood in, 323 ; properties of coats of, 323 ; irritability of, 324 ; contractility, 324 ; influence of elemical and other stimuli upon, 325 ; influence of nerves upon, 326 ; elasticity of, 324 ; pulsation of, 326.329 ; influence of nervous system on, 326 ; lateral pressure of blood in, 336 ; rate of movement of blood in, 340

Arthritic diathesis, 110

Articulate Sounds, production of, 856,862 ; vowels, 856,857 ; consonants, 859

Artificial giottis. 852

Arytenoid Cartilitges, 845 ; movements of, 845

Asphysia, nature of, 375 ; pitholozy of, 404 ; in relation to capillary circulation, 350 ; death by. 404; phenomena of, 406 ; gases contained in the blool in, 407 note

Asplyyxia, Cutaneous, 526,541, 542

Assimilition. 187; performed by Liver, 476 ; by Abiorbent system, 209; by Vitscular glands, 218

Associated movements, $830-838$

Asthenia, death by, 103 t

Asthma, sposmodic contriction of bronchial tubes in, 366

Astiømatism, 753

Atavism, 918

Atlantidio, 1003

Atrophy, 445

Atropin, action of, on heart, 316 note.

Attention, effect of, on acuteness of Touch, 732 ; on Taste. 740 ; on Smell, 742 ; on Vision, 779 ; on 11 earing, 795

Attention, Expectant, production of More. ments by. 878 ; influence of, on Organic func tions, 870

Auditory Ganglia, 611, 649
Auditory Nerves, 654 ; ultimate distribution of. 782 ; effects of section of 658

Automatic activity of Spinal Cord, 633-649; of Sensory Giunglia, 6 $\$ 9-673$

Axile Burlies, of tactile papillæ, 725

Axis, Spinal, 597

Azygos Veins, 940

Balance of vital economy, 421-440; see Vital Econom?

Barium, netion of salts of, on heart, 316 note

Bisque Rice, 1002

Beer, as i beverage, 117

Berber Race, 1004

Bile, secretion of, by hepatic cells, 469, 476; excreluentitious character of 481 ; essentially formel from prodnets of disintegration. and in and by the liver itrelf, 480 ; bnt partly from newly absorbed materials, 48I; its relation to fitty and albuminous comprounds. 481 ; action of calomel on, 482 ; influence of nervous system on, 482 ; vicarious secretion of, 469 ; composition of, 476 ; qu:ıntity of, 175 ; its uses in digestion, 174 ; aids the $a b$ sorption of fitt, 174 ; antiseptic properties of, 174; its reabsorption from intestine, IS2, 482 ; spectrum of 478,479 ; origin of chief constituents of, $48 \mathrm{I}$; its presence in fieces, 183, 481 mote

Bile-piginent, 477 ; its passage into urine, 478

Biliary cells 470,473

Bilifulvin, 477

Bilifuscin, 477

Bilihumin, 477

Biliprascin, 477

Bilirubin, 477

Biliverdin, 477

liastoderm, 925, 931

Bind persons, acuteness of touch in, 732 ; improvement of heiring in, 795

BLOoD, general character and purposes of. 230 ; quantity of, 231 ; urea in, 231,233 ; temperature of in rarious parts, 233 ; color of, $2: 3$; specific heat of, $2: 34$; mieroscopical cliaricters of, $2: 34$; crystals of, 244 ; spectrum analysis of, 248 ; pneumatology of, 257

Commsition of, in Health, 252 ; modification of, by age, 255 ; by sex, 255 ; by food and drink, 256 ; by loss of blond, 257 ; differences of Arterial and Venous. 257 ; peculiarities of portal blood, 258. 261, 2633; of mesenteric blood. 263 ; of splenic blood, 257,263 ; of hepatic rein, 264 ; of renal vein, 264

Compesition of, in Disease, 264, 270; increase of fibrin, 265 ; diminution of fibrin, 265 ; incrense of red corpuseles, 266 ; diminution of rerl corpuseles, 267 ; incre:se of eolorless corpuscles, 267 ; diminution of albumen, 267 ; increase of fitty matter, 268 ; altered proportion of salts, 269 ; of water, 269 ; presence of prisons in, 283

Corpussles of, Red; form, size, and aspect of, 235 ; eomposition of, 235 ; influence of rengents on, 235,236 ; tendeney to aggrogation of, 240 ; production and disintegration of, 250 ; embryonic development of. 251,936 ; subsequent development of, from lymph-corpuseles, 252 ; change of color in, by respiration, 262 ; their uses, 279 ; variations in amount of, in disoase, 
266 ; mutual attraction of, in coagulation, $2+1), 270$; adlucsion of, to walls of ressels, 3.51)

Corpuscles of. Colorless; form, size, and aspect of, 241 ; peculuar movements of, in capillaries, 241 ; action of reagents of, 242 ; numerical proportion of, to rel, 243 ; development of, into red. $25 \mathrm{I}$; their uses, 279 ; their variations in number, 244; multiplication of, in disease, 267

Pressure of. ngainst arteries, 326,338

Properties of, Physiral. 233

Propertits of, rital. 270; congulation of (see Corgulation), 270 ; nses of fibrin of, 278 ; uses of corpuscles of, 279 ; uses of fitty constituents of, $67,43.3$; uses of inorganic components of, 434 ; purification of, by excretory processes. 466; composition of determines modes of nutrition, 280 ; Life of. 280 ; self-maintaining power of: 283 ; elimination of poisons from. 28.3-285; contamination of, by morbid poisons, 286292

Rate of Propulion of, by heart, 318; rate of movement of, ihrough arteries, 340 ; through capillaries, 346 ; through veins, 353

Blood-relatious, effects of marringe of, 919

Bloodvessels, Absorption by, from alimentary canal, 192, 194; from body in general, 200 ; influence of state of, on coagulation of contained blood, 274; see Arteries, Copillarirs, reills

Bone, structure and growth of, 70-74; Brachycephali, 1001 note

Borveo arrow poison, action on heart, 316 wote

Brain, of Man, compared with that of Apes, 53; arrangement of convolutions of. $52-55$, 686; development of. 960 ; see Cerebrum, Cerebellum, and Sensury Ganglin

Brinchial Arches, 936

Breal, bad economy of exclusive diet of, 105

Breeds of Animals, origiuation of new, 996

Bright's disease of Kidney, 495 ; state of blood in, 268

Bromide of potassium, action of, on beart, 316 nute

Bronchial tubes, structure of, 36.3 ; contractility of, 366 ; vessels, 366

Bronzing of the skin, 223

Brumner's Glinds, 177

Brunnonian movements, 57

Buffy cont of blood, 276

Bulbus arteriosus, 940

Busbmen, of Southern Africa, 1009

Cadaveric rigidity, 827

Caffein, action of, on leart. 316 note

Calabar bean, action of, on heart, 316 note; effect of solution of, on eye, 75:3

Calcutta, black hole of, 407

Calomel, action on liver, 482

Calorifying Power, sources of, 541. 54.; see Heat

Calory, definition of, 544 note.

Cinmp Sumter, state of prisoners in, 125

Cancerous growths, 464

Capacity for progress, a characteristic of Man, 56

Capillaries, structure of, 343,344 ; diameter of, 344 ; arrangement of, 346 ; rate of morement of blood through, 346 ; its variations,
347 ; its independence of heart's action, 348 ; its regulation by couditions operating in capillaries themselves, :348-352; iufluence of nervous system on, 352 ; influence of shock on, 353

Caput cornu of the gray substance of the spinal cord, structure of, 599

Carbonic Acid and oxide gases, action of, on beart, 316 note

Carbomic Acidl, in Blood, 258, 25!; sonrces of production of, in system, 311,313 ; action of, on henrt, 316 note; its exchange for oxyen in respiration, $38 \tau$; eircumstances affecting quantity generated, 388, 392; carbonic oxide, action of, on heart, 316 mote; seat of origin of, 397 ; extraction of, from skin. 395 ; eliuination of, in atmosphere of nitrogen or hydrogen, 396

Cardiac jlexus of Sympathetic, 863

Cirdiogriph, 301,302

Carnivorous animals, excretions of, 426

Carroval, action of poison of, on heart, 316

Cartilage, structure and growth of, 68

Casein of Nlilk, 83, 976

Castration, influence of, on growth of hair and borns, 232

Catalepsy, cases of, 1036

Cathelectrotonus, 587 ; extrapolar centripetal, 588 ; extrapolar centrifugal, 558

Caucasian Race, 988, 1001 ; variety of color in, 989

Cells, structure and mode of incrense of, 58

Cells, parement or tessellated, 60

Cells, columnar or cylindrical, 61

Cells, spheroidal, 61

Cells, chalice, cup, or goblet, 62

Cells, piginent, 62

Cells, nerve, $55:-557$

Celtic Race, 10102

Cephalic Gianglia of Invertebrata, 561

Cephalic Nerves, general character and rela. tions of, $6 ! 5$

Cerbellum, peculiar to Vertebrata, 673 ; structure and relations of, 673 ; relative development of, in different animals, 674 ; results of experiwents on, 675 ; pathological phenomena of, 677 ; functions of, $679-685$

Cerebrin, 86

Cerebro-spinal fluid, 694

Cel elro. Spinul system, see Nervous System, Crrebellum, Cerehrum. IIedulla O'slonguta. Seusory Gangliu, spmenl Cord

Cerphrum, peculiar to Vertebrata, 5633, 685: arrangement of cunvolutions of, 52,54 , 686 ; structure of, 686 ; its inferion ity in lower Vertebrat:ı, 696 ; its relative size in different animals, 693 ; its vast predominance in Man, 693; itsauatomical structure, 686-692; its weight, 693 ; its supply of blood, 693; lymphatics of, 693 note; development of, 961

Functions of, 694; its relation to intelligence is contrasted with Instinct, 695 ; electrical excitibility of hemispheres, 698 ; Hitzig's experiments on, 698 ; Ferrier's experiments on, 699; motor centres in. 699-71) ; effects of its removil, 703 ; information deducible from its pathology, 703 ; its functional connection with Seusory Ganglia, 707

Cervix cormu of the gray substance of the spinal cord, 599, 600

Chalazz, 924

Chalice-cells of lungs, 363 
Change of matter required for performance of Organic functions, $415-421$

Childhood, characteristics of, 1020 ; diseases of, 1020

Chimp:ınzee, comparison of, with Man, 41-54

Chloride of Sodium in blood, 254; in urine, 502,515

Chloroforw, action of, on heart, $3 i 6$ note

Chlorosis, state of blood in, 266 ; treatment of, 266 note

Chorda dorsalis, 951

Cholepyrrhin, 478

Choleri, state of blood in, 266; influence of putrescent food in developing, 115-124; influence of imperfect respiration in developing, $408-413$

Cholesterin, 97 ; in Bile, 477 ; in Blood, 253

Cholic Acid, 93, 477 ; Choleic Acid, 477

Cholin, $86^{\circ}$

Chondrin, 85

Chrrdæ Vocales, regulation of their tension, $845-847$; nature of their action, 850

Chorion, formation of, 903

Chromatic A berration, 745

Chyle, composition of, 213 ; microscopic cliaracters of, 212,213 ; issinalation of, $2: 5$

Chyme, formation of, by digestive process, 167

Cicatricula, 925

Cicatrizalion, process of, 449-462

Ciliary ganglion, 617

Ciliary movement, son

Ciliary unscle, function of, 749

Cilio spinal centre, 1542

Cinchonine, action of, on Heart, 316 note

Circulation, 292 ; generil plan of, 292, 293 ; action of Heart in, 29:-322 (see Heart); action of Arteries in, 293-360 (see Arte. ries); action of Cilpillaries in, 34:3 (see Capillarips); action of Veins in, 353$\$ 57$ (see Veins)

Peculiarity of, in Cranium, 357, 606; in Liver, 357 ; in Lungs, 357 ; in Erectile tissues, 358

In Fotus, early type of, 93.3 ; change in plan of, 938 ; plan of, in mature foetus, 941

Civilization, influence of, on form of skull, 994 ; on body in general, 995

Claremont, lead-poisoning at, 116

Cloacil, 947

Coagulable Lymph, effused for reparation, 450 ; in inflatumation, 457

Cougulutim of Blood. 270 ; essentially due to solilification of fibrin, 270 ; an act of vitality, 271 ; occusional deficiency of, 272 ; retardation of. 272 ; elfect of external influ. ences on, 272 ; influence of rest, 273 ; influence of wirmth, $27:$; effect of neutral sults, 273 ; effect of exclusion of atmosphere, 273 ; iutluence of depressed vitality or death of vessels, 274 ; influence of admixture of dend matter, 274 ; varying proportions of serum and clot, $276^{\circ}$; formation of buffy coat in, 276

Coccygeal gland, 227

Cochlea, structure of, 784 ; functions of, 791

Cochlear nerve, ristribution of, 794

Cueliac gituglia, effects of extirpation of, 163

Coffee, composition of, 120 ; effects of use of, 120, 518

Coition, share of Male in, 887 ; of Female, 895

Cold, influence of, on tonicity of arteries, 3.31 ; power of resisting, variation of, with age, 5.30 ; power of generating, 548 ; death by, $535,540,1034$

Collagen, 84

Colloids, properties of, 83,197 ; diffusion of, 196

Colon, use of sacculi of, 141

Colostrum, 975, 976, 978

Color of Blood, cbanges of, 231, 233, 243, 261

Color of Skin, variation of, in Man, 987

Colors, want of power to discriminate, 775 ; production of complementary. 773; modification of, by juxtaposition. $77: 3$

Colorless corpuseles, 241 ; see Blood

Commissures of Cerebrum, 697 ; absence of, 70.4

Complemental Nutrition. doctrine of, 282

Complementary Colors, 773

Conception, act of, 909

Conduction of sonorous vibrations, 785

Congestion, venous, causes of. 356

Conia, action of, on heart, 317 note; on motor nerves, 821

Connective tissues, 63,295

Consciousness, seat of, in Sensory Ganglia, 656

Consensual movements, 649,653

Constituents of body, proportion of, to each other, 421

Conversions of Relief, 770

Convolutions of Brain, arrangement of, 52 , 686 ; functions of. 698

Co-ordination of Movements, the probuble function of the Cerebellum, 674-679; intluence of habit on, 829

Cord, Spinal, structure of, 597-605 ; as a conductor of motor impulses and sensory im. pressions, 627 ; as an independent centre, 633

Coronary Arteries of Heart, effects of ligature of, 297

Corpora Amylacen, of Virchow, 486; Malpighiana, of Kidney, 492-494; of Spleen, 219,229

Corpora Olivaria, 606

Corpora Pyramidalia, 606

Corpora Quadrigemina, 649; their functions, 657

Corpora Restiformia, 606, 642

Corpora Striat:a, 650 ; functions of, 655,659 ; connection of, with Cerebrum, 691

Corpora IVolffiana, $94 t^{3}$

Corpus Callosum, 691, 697; cases of deficiency of, 704

Corpus Dentatum, 674

Corpus Luteum, formation of, 896

Corpuscles of Blood, red, 235, 241; white, 241 ; see Blood

Corpuscles of Chyle, 212, 215 ; their transformation into blood-corpuscles, 215,243

Correlation of force, doctrine of, 37 note

Cougling, act of, 381,382

Cranial vertebre, 956

Cranio-spinal Axis, the fundamental portion of the Cerebro-spinaI System, 597 ; development of 959 ; see Medulla Oblongutu and Spinal Cord

Craninm of Man, compared with that of Apes, $43-52$; peculiarity of circulation in, 357 , 693

Crassamentum, 234, 270 ; proportion of to serum, 2\%6

Creatin and Creatinin, $88,89,510$ 
Critical eracuations, 519

Crura Cerebri, motor and sensory tracts of, 614 ; effects of section of, 661

Cruorin, 249

Crying, act of, 352

Crystals of Blood, 244, 245

Crystallin, 86

Crystalloids, properties of, 196

Cup cells of lungs, 363

Curara, its eficets on muscles, 821 ; on pancrests, 169 ; see Hoorara.

Outaneous Aspbyxia, 542

Cutaneous Respiration, 526, 541

Cutaneous Transpiration, 455-458; see Sudoriparons Excretion

Cystin, 91

Cysts, piliferous and dentigerous, 444

Cytodes, 58

Cytoplasm.

Daltonism, 775

Daturia, action of, on IIeart, 317 note

Deaf and Dumb, 667, 919

Deaf.spots, 795

Death, the necessary consummation of Life, 1031 ; somatic, 1032 ; molecular, 1032 ; apparent and real 1036 ; signs of, 1036

Decidua, formation of 902 ; its share in forination of placenta. 904

Decline, period of, 1029

Defecation, act of, 142,644

Degentration. continual, of liring tissues, 415 ; of mu:cle, $4: 38$; of bone, $4: 38$; of teeth, 438 ; increased tendency to, in inflammation, 454 ; of $1 \mathrm{rmph}$ and its products, 458

Degenerntion, Calcareous, 1030

Degeneration, Fatty, 439 ; favored by habitual use of aleoholic liquors, 117,439 ; tendency to, during period of decline, 1030 ; of Uterus, 439,912

Deglutition, act of, 129 ; nerves of, 131

Delphinin, action of, on heart, 316 note

Dentition, first, 75 ; second, 1023

Depressor nerie of lleart, 313

Determinations of Blood, local, causes of, 347

Deutencephalon, development of, 961

Development, a source of demand for nutrition, 416 ; its difference from growth, 417 ; arrest of, $417,940,950,953,958$; period of, 1017

Development of Envbryo, general plan of, 922 ; earliest stages of', 924; segmentation of yolk, 925; rotition of yolk, 931; formation of Blastodermic vesicle, 931 ; foundation of Vertebral column and Nervous centres, 927, 9:32; development of Amnion, 928, 932; first appearance of Tessels, 929 ; Vitelline vessels, 93:3; Umbilical vessels, 9333; Неpatic ressels, 934; Ductus renosus, 935 ; Heart and Arterial system. 935; Allantois, $9: 37$; second form of circulating system, 438; Bulbus aorticus and aortic arches, 939 ; Venous system, 940; Aiimentary canal, 943; Liver, 944 ; Spleen and other vascular glands, 221 ; Lungs, 946 ; Urinary organs, 946 ; Generative apparatus, 945; Mammary gland, 972 ; Skeleton, 951; Vertebral colunn, 95:3; Skull, 955; Nervous centres, 960 ; Eye and Ear, 962, 96:3 organ of smell, 964 ; of the Extremities, 964

Diapedesis of red corpuscles, 459

Dicrotous Pulse, 331
Diet. Animal, 104; Vegetable, 105 ; nixel, 105 ; of trainers, 114 ; different scales of, 112 ; influence of, on composition of Biod, 256 ; on Respiration, 389 ; on Excretion generally, 421 ; on composition of Urine, 503

Diet seales, various, 112

DigESTION :

\section{Buccul, 147}

Gastric, a process of chemical solution, 151 , 157,163 ; time required for, 164 ; action on azotized substances, 165 ; influence of various conditions on, 166

Intestiual, influence of pancreatic fluid in, 170 ; of bile in, 173 ; of suceus entericus, 177 ; its universal efficucy, 179

Digitalis, action of, on heart, 316 mote, 317

Dingo, Australian, breeding of, $9 \div 6$ note

Direction of sounds, judgment of, 795

Direction, risual sense of, 762,778

Direction, Centre of, 762

Discus proligerus, 890

Disdiaclasts, 803 note

Disintegration of Tissues, 415,438

Distance, adaptation of eye to, 746 ; visual appreciation of, 766 ; auditory appreciation of, 795

Diuretics, effect of, on urine, 519

Diurnal Variation, of pulse, 321 ; of respiration, 390 ; of temperature, 5.30

Dolichocepbali, 1001

Dormant Vitality, 26 note

Dreaming, $709,713,716$

Urink, water the natural, 116 ; influence of, on composition of blood, 256 ; effects of Alcoholic, 116, 119, 439

Dublin Lying in Hospital, mortality in, 412

Ductless Glands, structure and functions of, 218,230

Ductus Arteriosus, 940, 942

Duetus Cuvieri, 940

Ductus Venosus, 942

Duration, relative, of different parts of the Organism, 438; of ufter-sensations, 729,730 , 771

Duverney's Glands, 895 note

Dyspnoei, causes of, 375

Ear, external, 794; mentus. 794, middle, 786 ; internal, 786 ; development of, 963 ; see Heuring, Organ of

Eirthy Phosphates in urine, 500. 514

Economy: balance of rital, 421 ; see Titul E'onomy

Elfective energy of various compounds when consumed in the body, $4: 35$

Efferent nerve-fibre $3,557,571$

Egesta, chemical composition of, for one day, 423 ; relative proportion of, discharged by different excretory orgins, 123,424

Ejaculatio Seminis, 858 ; its inclependence of sensition, 64:3

Elistic Tissue, 65

Elastin, 85

Elasticity of Arteries, 324 ; of Veins, 35.3 ; of Lungs. 367 ; of walls of Chest, 372 ; of Muscular Tissue, 512

Election, seats of, 280

Elerticity, Evolution of, in living boily, 550 ; connection of, with nutritive and secretory operations, 551 ; Muscular current of, 813 ; disturbance of, in muscular contraction, 815 ; 
Nervous current of, 583 ; disturbance of, in nervous action, 584

Electricity, Influence of, on coagulation of the blood, 272 ; on heart, 307 ; on arteries, 326 ; on mesocephale, 661 ; on brain, 698-703; on nerves of special sense, 724

Electrotonus, 585

Embryo, development of, 921 ; see Development

Eubryonic life, peculiarities of, 1016

Euetin, action of, on heart, 317 note

Emmetropia, 751

Emigration of white corpuscles, 459

Emotions, excitation of, by muscular suggestion, 706 ; their action on organic functions, 875 ; influence of, ou stanmering, 861

Endosmometer, 194

Enteric fluid, digestive power of, 177

Epidemic Diseases, predisposition to, in state of Blood, 285; from putrescent food, 115 , 124 ; from putrescent water, 116 ; from alcoholic liquors, 118; from starvation, 125 ; from insufficient respiration, 408 .

Epithelial cells of Skin, serous and mucous weubranes, 60 ; of salivary glands, 144 ; of gastric follicles, 152; of Villi, 61, 187, 191

Epithelial tissues, exuviation and replacement of, 438

Epithelium, 60.

Epithelium, ciliated, fil

Fpithelium, columnar or cylindrical, 61

Epithelium, cup, 62

Epithelium, goblet, 62,

Epithelium, ribbed, 61

Epithelium, spheroidal. 61

Epithelium, regeneration of, 449

Epithelium, tessellated, 60

Erectile tissues, circulation in, 358

Erection, nerves influencing, 358, 359

Erect Vision, cause of, 761

Ergot, action of, on IIeart, 317 mote

Esquimaux Race, 989 ; pyramidal skull of, 992 Ethiopian Race, 1006

Eupucea. 375

European Nations, 1002

Euskarian Language, 1002

Eustachian Tube, functions of, 788

Eustachian Valve, uses of, 941

E.crito motor Actions of Spinal Axis, 63:3; their independence of sensation, $637-640$; their adiptive character, 640 ; their relation to the Urganic function, 642 ; their subser-. vience to locomotion, 646 ; their establishment by habit, 646 .

Excretion, general nature of, 465 ; sources of demand for, 465 ; staties of, $466-469 ; \mathrm{com}$ plementary relation of different modes of, 466,467 ; forms of, 468

Exercise, influence of, on excretion of carbonic acid, 390 ; on composition of urine, $51) 4$; on teiuperature of body, $5: 31$

Exhalation of aqueous vapor, from Lungs, 400 ; from Skin, 524 ; from dead body, 525 ; frigorifie elfect of, 536

Exhaustion, Muscular, laws of, 823

1 Canses of leatli by, $540,548,1033$

Expectant attention, 870,878

Expiration, movements of, 371 ; force required for, 372

Externality, elementary notion of, 673

Extructive, of Blood, 254, 255; of Urine, 510

Extrauterine linelation, 848

Exulatious, reparative, 450 ; inflammatory, $449-451$
Exuviation of effete Tissues, 437

Eye, optical structure of, 746 ; adaptation of, to distance, 746 ; nervous organizition of, see Retina; use of, in Vision, see Vision; development of, 961

Eyes, convergence of axes of, in object, 767 $769,837-838$; novements of, clirected by visual sense, $566-669$; relation of 1 Vill to, 670 ; harmony and sywmetry of. $834-838$

Facial Angle of Man and Apes, 47

Facial nerve, deep origin of, 612,613 ; distribution and functions of, 019

Frees, composition of, 181 ; expulsion of, 141 , 643 ; average daily quantity of, 182

Filkeers, Indian, apparent death of. 1036

Fallopian Tubes, development of, 947-950; passage of spermatozoa through, 895 ; passage of ova through, 899 ; forwation of chorion in, 901

Falsetto Voice, nature of, 854

Farinaceous constituents of food, 94, 100, 147, 170,178 ; importance of, in production of muscular force, 434

Firoese islanders, diet of, 115

Fat, structure, uses, and development of, 6668,434 ; increase of, in divease, 268 ; a unount of, in blood, 253; importance of, in cell formation, 434; in old age, 1)29; in Chywe, emulsification of, 171 ; in Frees, 181 ; pro. duction of, in Liver, 474 ; effects of, when taken with meat, 427 ; proluction of, from stareh, 433; from albuwen, 43:3; proportion of, in brain, 559 ; in nerves, 559 ; in museles, 807

Fatty degeneration, 439

Fechner's Psycho-physicul law, .797-799

Feeundation, seat of, $\$ 99$; act of, 900

Female, physiological peculiarities of, see $S$ x s; mental constitution of, 969 ; length and weight of, at birth, 968 ; subsequent increase of, 969 ; viability of, 968 ; puberty of, 892 ; iufluence of, on pringeny, 917-922; on sex, 965 ; share of, in Geberition, see GeNEIRATION

Fenestra ovalis and rotunda, 759

Fever, alterations of blool in, 265 ; sources of predisposition to, 285,286 ; wortulity frow, 413

Fibrin, 83, of blood, artificial formation of, 278 ; origin of, 277 ; normal proportion of $25:$; inereased proportion of, in arterial blool, 257-261; in splenic rein, 263; aug. mentition of in inflummition, 265; dimi. nution of, in adyuamic diseases, 266 ; its coigulation, 270 (see Corgulation); its uses, 278 ; destruction of, at kidney, 278

Filrin of Chyle, 213

Fibrin of Lymph, 213

Fibrinous effusions of Inflammation, 278,457 ; conservative nature ol, 449

Fibrinogenous substance, 277

Fibrimplastic substance, 277

librous tissue, 63

Fufth pair of Nerves, origin of, 612 ; distribution and functions of, 615 ; its action in mastication, 129; in deglutition, 130) influenee on salivary secretion, 148 ; in respiration, 375; its agency in taste, 617,620 ; in smell, 652,742

Filiform rapillø of tongue, 736

Finulsh Race, 989 
Fish, Brain of, compared with Man's, 567, 650

Flute-pipes, laws of, 850

Foerus, first circulation in. $933-935$; second, $438-943$; mode of determining age of, 1017 , 1018 : size and weight of; st hirtl, 967 ; development of organs in (see Devtopment).

Food, the primary source of neuro-muscular energy, 38: classification of components of, 100,103 ; saccharine constituents of, 100 ; oleaginous constituents of, 101 ; albuminous coustituents of, 102 ; gelatinous constituents of, 103 ; proportions of carbon and nitrogen in different articles of, 105 ; calorific and histogentic vilue of, 10.3 ; most economical cotnlinations of. 105 ; composition of various kinds of, 106,107 ; relative value of animal and vegetable, 109,110 ; quantity of, needed by Min, 111, 112; importance of purity of, 115 ; consequences of deficiency of. 122, 127 ; prehension and ingestion of, 127 ; relatire digestibility of different kinds of, 164 ; in. fllence of nature of, on commosition of blood, 253,256 ; on respiration, 389 ; on exeretion, 503,516

Foot of Man, compared with that of Apes, 43

Form, mode of acquiring knowledge of, by Touch, 729; by Vision, 761

Formentice Pomer, of individual parts, 437 ; excess of, in hypertrophy, 441; deficiency of, in atrophy, 445 ; manifestation of, in re. parative process, 447 ; deficiency of, in inflimmation, 448 ; its greater energy in earlier than in later periods of life, 448,1016

Fornix, 691

Fourth pair of Nerves, origin, 612 ; distribution, $\$ 17$

Fraunhofer's lines of Spectrum, 249

Frigorification, influence of cutaneous exhalation in, 524

Funcions, Vital, see ABsorption, Assimila tion, Circulation, ele.

Fungi, action of light upon, 31

Fungiform papilla of Tongue, 736

Ganglia, structure of, 553 ; see Nervous SrsTEM

Ganglia of Sympathetic system, 863

Gaol at Nîmes, mortality in, 125 note

Gases. found in the alimentary camal, 183 ; in the blood, 257 ; in the urine, 515

Gasserian ginglion, 615 ; its influence on $\mathrm{nu}$ trition, 863

Gistric Follicles, structure of, 153

Gastric Juice, composition of, 155,156 ; conditions of its secretion, 158,159 ; quantity of secreted daily, 159 ; influence of nerrous system on, 162. 874 ; solvent puwer of, 163.166

Gelatin, 84 ; uses of, as food, 102 ; feeble dialysing power of, 196

Generation, general nature of, 879,880 ; provisions for its performance, $880-\$ 82$

Action of Wale in, 882 ; structure of testes, 882 ; characters of seminal fluid, 884 : 11:ture and evolution of Spermatozo:1, 885 ; essential importance of Spermatozon in fecundation, 886,887 ; puberty, epoch of. 887 ; of sexual desire, 887 ; coition, 888

Action of Female in, 589 ; structure of Ovum, 889 ; evolution of ovum, 890 ; period of puberty, 892 ; menstrual discharge, 892 ; coincident ovulation, 894 ; duration of pro- creating period, 894 ; her function in enition, 895 ; maturation of ova, 895 ; eorpus luteum, 896 ; fecundation of ovum. 899 ; consequent changes, 901 ; formation of chorion. 901 ; formation of lecidua, 901; of villi of chorion, 904 ; of foctil tufts, 904 ; of Placenta, 904; changes in Uierus during gestation, 908; quickening, 909 ; parturition, act of, 911 ; period of, 912 ; superfotation. 916; see Lactation, .14ammury Gland, Milk

Influence of Parents on progeny, 916 ; effects of near relationstip of, 917 ; influence of Male on subsequent offspring, 920 ; effects of state of parents at time of coneeption, 920 ; subsequent influence of Mother, 879 . 921 ; influence of Ages of parents on Sex of progeny. 965

Embryouic Devrlopment, see Devetopment of Embryo

Generation, organs of, their development, 947, 948

Germinal capacity, variation of, at different ages, 1016

Germinal Matter, 57

Germinil Spot. 890

Germinal Vesicle, $\$ 90$

Gestation, ordiuncy term of, 910 ; abbreviated, 913; protracted, 915

Ghost exhibition, deceptive effect of, on hearing, 795

Glands, Assimilating, of Absorbent System, 207 ; their functions, 20s; vasculer, 218; their functions, 228 ; salivary, 143 ; gastric, 151 ; pancreatic, 167 ; liver, 469 ; kidney, 490 ; Brinner's, 177

Glands, Secretirg, essential nature of, 465

Globulin. 86

Gilus:o-Pharyngeal Nerre, origin of, 612 distribution and functions of, 620 ; its instrumentility in deglutition, 131 ; in sense of taste, 620,655

Glottis, regulation of, 847 ; artificial, 852

Glycin, 93

Glycocholic acid, 93

Glycogene and Glycogenic substance. 95, 482; composition of, 95 ; theories of origin of, 489

Glycogeny and Glycogenic function of the liver, 482 ; influence of nervous system upon, 486 ; effects of medicinal agents on, 488

Goblet cells of lungs, 363

Gurilla, comparison of, with M:ın, 39-57

Graafian follicle, 890 ; formation of ovum within, 891, 892; escape of orum from, syl; subsequent changes in, 895

Grinulation of wounds, $450-453$

Grape sugar, 94

Gray substance of Spinal Cord, 629

Growth, period of, 1017

Growth, a source of demand for nutrition, 416 ; excess and deficiency of, $441-444$; its difference from development, 417 ; formative atctivity during periol of, 1017

Guaclus, their weat diet, 104

Guanin, 92

Guiding sensations, 666 ; essential to regulation of certain movements, as to those of the eye, fi67; those of the larynx, 667,796

Gum, effects of diet of, 101

Gustatory Ganglia, $60 y$

Gustatory Nerves, 654. 734

Gyri operti of Brain, 687 
Habit, influence of, in establishing excito.motor actions, 647 ; on sensori-motor actions, 6035,763 ; on impressions on sleeping persons, 713 ; on amount of sleep required, 715 ; on co-ordination of muscular wovements, 829

Hachisch, effects of, 718

Hreına dromometer, 340

Hæmady namometer, 336

Haenatin crystals, 247

Hamatochometer, 340

Hæmito-crystallin, 86

Heinatoglobin crystils of blood, 244

Hruin erystals of blood, 247

Hamoglobin, 86

Hæumorhage, predisposition to, $27 \mathrm{~S}$

Hair, charicters of, in different Races, 989

Hilones of vitellus, 924

Hand of Man, peculiar attributes of. 41

Harmony of Muscular movements, 830

Haversian canals of Bone, 71

Healing Processes, different forms of, 447

Hearing, physical conditions of, 779

Organ ot', its essential structure. 782 ; its adaptation to laws of propagation of sounds, 782 ; structure and functions of tympanic appiratus, 786 ; of labyrinth, 783 ; of externitl ear and meatus, 794 ; development of, 963

Sense of, 779 ; discrimination of pitch of tones. 791 ; estimate of direction of sounds, 795 ; estimate of distance, 795 ; influence of babitual attention on acuteness of, $79 h$, 797: rapidity of perception hy, coupared with vision, 797 ; use of, in regulating voice, 671,796

Heart, general functions of, 292; comparison of right with left ventricle, 294 ; valves of, $295 ;$ unscular fibres of, 295 ; nerses of, 296 ; arratigement of muscular fibres in, 294; irritability of, 297 ; rhythmical movements of, 298 ; moveinents of, 298 ; force exerted by, 302 ; course of blood through, 30:3; sounds of, 304 ; influence of nervons system on, 306 ; excito-motur system of. 306 ; effects of temperature on, $30 \overrightarrow{7}$; effect of virious poisons on, 307 ; effects of electrical currents 01,307 ; nerves, inlibitury, 309 ; nervus depressor of, 313 ; nerves, acceleriting. 314; action of poisons on, 315; quintity of blond expelled by, 317 ; number of pulsations of, 319 ; peculiarity in contritctions of, 818,822 ; first development of, 935 ; subsequent changes in, 938

Heat, importance of, in growth and development, 29, 30; influence of, on vital action, 528 ; on period of gestation. 980 ; endurance of extremes of, 538 ; its production in Iluman boty, 529 ; sources of variation of, $529-$ 5.34 ; alteritions of in disease, 5.34 ; liberation of, after death, 535 ; sources of, 539 ; loss of, the cause of death by starvation and exluasting liseases, 540 ; partial depentence of, on cutaneous respirition, 541 ; absolute amount of:, produced in the body, 435, 542 ; influence of nervous systom on, 544 ; local variations of, 545 ; inferior power of generating, at earliest and latest periods of life, 547

Heat centre, location of, 547

Jleat tetanus. 820

Ileight at different ages, 968

Ilelleborus niger and riridis, action of, on heart, 316
Hepatic Artery, 472

Hepatic Cells, 474

IIepatic Parenchyma, arrangement of, 474

Hepatic Vein. 472,479; blood of, compared with portal, 264

Hepatin, 484 ; see Glycogemy

IIerbivorous animals, excretions of, 517

IIereditary Transınission of maladies, $91 \mathrm{~S}$

Hermaphrodism, 950

Heterologous growths, 464

lliccough, act of, 382

IIindostan, languilges and people of, 1085

Hippuric Acid, 90 ; its presence in the Blood, 254 ; in Urine, 5015119

Horopter, nature of, 763

Hottentot kace, 1009

IIumus, absorption of, by plants, 31

Hunger, indicates necessity for aliment, 120 ; immediate source of sense of, 120

Hybrid Races, question of fertility of, 998

llybrids, influence of pilrents on, 917

Hydrocyanic Acid Gas, action of, on Heart, 316 wote

Hydrocirbonaceous compounds, 94

Hydrogen, antimonide, phosphide, and sulphile, action of, 402

IIydrogen, respiration in, 398

Hyoscyamine, action of, on heart, 317 note

11 ypermetropia, 751

Hy pertrophy, 416, 442; conditions of, 441; shown in production of tumors, 444 ; in supernumerary parts, 444

Hypnotism, 719

Hypochondriasis, operation of, 879

Hypogastric plexus of Sympathetic, 563

IIy pospadias, 950

Hypoglossal Nerve, origin of, 610, 624

Hypoxinthin, 92

IIysteria, exalted sensibility in, 664

Hysterical Ischuria, 467

Icelanders, freedom of, from tuberculosis. 169 ; liability of, to zymotic diseases, 411 , 412

Idiocy, preslominance of instinet in, 697,698 ; cinuses of, 918, 919

It]io-muscular contraction, 819

Illamination, relative perceptibility of, 779

Inanition, 123; balance of vital economy in, 425 ; effects of, on temperature, 441

India, population and languages of, 1002

Inclirect vision, 776

Indo-European Race, 1002

Infuricy, characteristies of, 1019

Infunts, temperature of. 530 ; inferior prower of genorating beat in, 546 ; length and weight ot, at birth, 966,1018

Inflammation, increase of fibrin of blood in, 265 ; a perverted form of nutritive process, 448 ; albesive, 449 ; modelling process in, 450); importance of exclusion of at during repair accompanied by, 452 ; its relations 10 hypertrophy and atrophy, 454 ; cuuses of, 454; phenomena of, 454 ; state of blood in, 457 ; characteristic effusions of, 457 ; unhealthy forms of, 463

Inflanınitory effusions, different characters of, $281), 457$

Infundibula of Iungs, 364

Ingesta, arerage chemical composition of, for one day, $42: 3$

Inhibitory influence of the nerrous system on 
intestine, 138 ; on heart, 309 ; on respiratory muscles, 381

Ince (poison d'), action of, on heart, 317 note

Inorg:unic constituents of Body, 98 ; of Blood, 254 ; their uses, 434 ; of Úrine, 501, 502, 513

Inosite, 95

Insaliration, 143

Insects, automatic actions of, 561,562

Inspiration, morements of, 369 ; force required for, 372 ; cause of first, 378

Inspiration-letunus, 378

Instinet, contrasted with Reason, 888

Intelligence, nature of, as opposed to instinct, 563 ; degree of, conformable to size and development of Cerebrum, 694-698

Intestinal Canal, wovements of, $12 \bar{\imath}$; influence of Sympathetic nerves on, 134-13S ; influence of mental states on, 870 ; development of, 943

Intestinal Juice, 177 ; its use in digestion, 178

Intestinal Secretions, influence of nervous systein on, 873

Involuntary morements, 828; influence of Sympithetic on, 867

Iris, structure of, 759 ; movements of in accommodition of Eye. 748, 749; effects of heat and light upon. 760 (see Pupil)

Irradiation of iupressions on retina, 775

Irrigation of the tissues effected by lymph, 217

Irritability of Heart. 297 ; of Arteries, 324 ; of muscular tissue, 820-825

Jaundice from reabsorption of bile, 468

Jewish Females, period of conception in, 899 note

Jewish Nation, 1004; varied complexion of, 989

Kaffre Race, 1007,1008

Feratin, 85

lidney, structure of, 490,491 ; tubuli uriniferi of, 492 ; circulation in, 493 ; Corpora Milpighiana of, 493; secreting cells ot; 492 , 493 ; elimination of water by, 498 ; of soluble matters generally, 502 ; two fuctors occusioning secreting action of, 498 ; excretory function of, 498-520; development of, 946 (see $($ rine)

Kinesodic substance, 632

Kireitin, 88,510

Kreatinin, 89,510

K ymograph, 336

Labyrinth of Ear, functions of, 780-784

Lachrymal secretion, influence of mental states on, $87: 3$

Lactution, 970-977; change of quality of milk in course of, 975,976 ; extraordinary prolongation of, 978 ; by males, 973

Lacteuls, origin of, in villi, 187 ; absorption by, 189; glandulæ of, 207 ; contents of, 212 (see Cleyle)

Lactic acid, origin and relatinns of, 96 ; presellce (f, in gastric fluid, 155

Lacuna of bone, 70

Lamina spiralis, structure of, 784

Laminæ dorsales, 932

Landeau, effects of siege of, 921

Language, the expressiou of ideas, 705,855
Languages of different races, cssential conformity in, 1000; Americut, 1010; Bushunan. 1009 ; Celtic, 1002 ; Euskarian, 10112 ; Hindoo, 1006; Hottentot, 1006 ; Indo-Germanic, 1002; Kuffre, 10018; Malayo-Polynesian, 1012 ; Negro, 1007 ; Negrito, 1013; Sanskritic, 1006; Seriform, 1005 ; SyroArabian, 1003 ; Tamulian, 1005

Lanugo of fotus, 281

Lapps, Race of, 10115

Larynx, structure of, 844 ; muscular actions of, 846 ; precise adjustment of, 844 ; their dependence on guiding sensations, 667, 671, 843 ; nerves of, $378,622-624$; production of sounds by, 853 ; theory of the voice, 853 ; fillsetto notes, 854

Latent excitation, period of, in muscle, 815

Laterill vision, 776

Lil ughing, act of, 382

Laws of reflex action, 635

Laws of unilateral reflection. 635

Laws of symmetry, 6.35

Litws of intensity. 635

Laws of reflex irradiation, 635

Leid, poisoning of water by, 116 ; cumulative action of. 284

Lecithin, 86, 477

Left.handedness, 834

Leiotrichi, 990

Lencæmi:ı, 228

Leucin, 87

Leucocytes, movements of, 60 ; origin of, from bone marrow, 227

Life, nuture of, 25 ; distinguishing features of, 26-29; multiplication of, 27,28 ; importance of Heat in developinent of, 29,30 ; influence of Light upon, 31; final purpose of, in plants, 32 ; various inanifestations of, in animals, 33, 34; manifestation of, in rlerelopment, 35 ; in production of heat, 35.31 ; sensuri-motor activity, 37 ; correlation of the physical forces in the acts of, 37-39; of the blood, 251

Liglut, evolution of, from living body, 549

Lightning, deith by, effect of on blood, 272

Limbs, nature and development of. 964 ; at. tempted reproduction of, in foetus, 448

Limits of Vision, 757

Liquor Amnii, 9.32, 938

Liquor Sanguinis, 234

Lithic acid, 508 (see Uric Acill)

Liver, structure of, 469 ; general plan of, in lower animals, $469-471$; in Mlan, 471 ; arrangement of bloodvessels in, 471 : biliary ducts in, 473 ; parenchyma of, 474 ; lymphatics of, 475 ; developuent of, 944 ; double function of, $\$ 82$

Assimilating action of, 263,490 ; production of glycogen and sugar by, 4\$2; of red corpuseles by, 485

Exeretory action of, 485 ; formation of bile by, 476 (see Bile)

Lohelina, action on pneumogastrics, 317

Lochia, 911

Locomotion, movements of, 8:31

Londonderry steamer, case of, $40 \mathrm{~s}$

Loss of Blood, influence of, on composition of blood, 257

Luminosity, of living body. 550

Lings, structure of, 363 ; entractility of bronchial tubes of, 366 ; elasticity of, 367 ; force required for their distension, 372 ; mecbanisu of their expansion, 368 ; capacity 
of, 385 ; changes in, from section of pneumogistrics, 376 ; development of, 945

Lutein, 89

Luxus consumption of fool, 432

Ly mph, composition of, 212 ; wicroscopic characters of, 212 ; sonrces of, 204,216 ; paths pursued by, 209 ; forces effecting the movement of, 216 ; pressure of, against the walls of the lymphatics, 217 ; influence of nervous system on auount of, 218 ; causes of variations presented by, 218

L,ymph Corpusrles, charicters of, 212

Lymph, Congulable, effusion of, in inflamma tion, 457 ; oonservative nature of, 462 ; fibrinous and corpuscular forms of, 458 ; legenerations of, 459 ; formation of pus in, 462

Lymph Paths, superficial and deep, 208, 209

Lymplutics, origin of, 206 ; distribution of, in stomach, 155 ; in intestines, 186,187 ; in nervous centres, 206, 693 mote; in spleen, 221 ; in liver, 475; in kiclneys, 495 ; in heart, 296 ; in lungs, 306 ; glandula of, 207 ; absorption by, 216 ; contents of, 212 (see L.ympll)

Macula lutea, 756

Migenta, action of solutions of, on blood.corpuscles. 236

Magyar Race, 1003

Maintenance of organism, 415 ; during period of maturity, 1028

Malayo-Polynesian Race, 1012

Male, rudimentury uterus in, 949 ; rudimental manmary gland in, 972 ; laetation by, 973; influence of, on progeny, 917; on sex, 965 ; size and weicht of at birth, 966 ; subse. quent increase of, 968 ; viability of, 967 ; juberty of, 887 ; bis chalacter as compared with female, 969 ; share of, in generation (sce GENERATION)

Maliennant growilis, 464

Malpighim Budies, of Kidney, 492, 49:3; of isleen, 220

Mammary Glund, structure of, 970, 972, 835 ; functional activity of, 977 ; influence of mental states upon, 875 ; secretion of, 974 (see Milk)

Mav, Distinctive Chalaters of. 39 ; hand of. 41,42 ; foot of, 42 ; crinturu of, 43. 44; vertebril column of; 47 ; lower extremities of 42,50 ; fircial augle of, 47 ; $110 y 0$ ogery of, $51-52$; visceral allutatus of 52 ; britin of, $52-55$; subordination of senses to intelligence of, 55 ; jeculiar amlaptability of, 55 ; slow gruwth of 55 ; uental endowments of, 56 ; articulate speech of, 55 ; eapacity for 1)ogress, 56,57

Han. Elochs of Life of, 1015; embryonic life 1016 ; infancy, 1019; childhood, 1020; yonth, 11125; adolescence, 1026; maturity, 1028 ; decliue, 1029

Man, Valieties of, $881-894$ : see Color, Mair, Jangnage, Pelvis, Races, Skull, and Varicties Manchester, ormanic matter in air of. 410)

Mansanja, action of poison of, on heart, 316

Manometer, differential, 335

Mara, Mad., ral ge of voice of, 843 note

Narriages of consanguinity, 918,91!

Marrow, red, the seat of cell formation, 227

Mastication, act of, 128 ; nerves of, 129

Maturity, eharacteristics of, 1028
Mauchamp breed of Sheep, 996 note

Meit, bad economy of exclusive diet of, 105 ; effects of diet of. on balanee of vital econolny, 428 ; effects of liseased, 115

Meconium, nature of, 481 note

Medulle Oblonguta, structure of, 605-609. gray substauce of, 615 ; origin of various nerves from, 611-614; motor tract of, 609; sensory tract of, 613 ; special endowments of, 641: see Spinal Cord

Medulla Spinulis, 597, 548; see Spinal Cord

Medullary fulds or laminæ, 928

Melanin, 132

Membrina Granulosa, 890.895

Membrana Tympani, strueture and uses of, 787

Menstruation, period of, 892 ; persistence of, 894

Mesencephalon, functions of, 661; develop. ment of. 960

Mesenteric Blood, special characters of. 263

Mesenteric Glandulæ, structure of, 189, 190 , 207,208

Mesmeric state, 719

Mesucephale, effects of section of, 661 ; effeets of electric current on, 662,663

Metals entering into composition of the body, 80

Metamoruluosis of matter, required in Organie functious, 418

Metirst asis of Secretion, 467

Migration of white corpuscles, 241,459

Mill, secretory appsiritus of, 970 ; supply of 972 ; constituents of, 974-980; microscopi. cal charicters of, 975 ; variations in their proportions, 977 ; influence of inental states on, 875 ; varieties of, iu different inimals, 977 ; relation of, to blood, 980); reabsorp. tion of, 981; vicarious secretion of, 981 ; quantity of, secreted, 875 ; passage of medicines, etc., into, 875

Milk, Sugir of. 95,977

Millbank Prison, ecurvy at, 125

Millon's Ragrent, 82

Mineopie Race of the Andaman Isles, 1013 incte.

Mixp of Man, its distinetive characteristics, $55,5 t i: 3$; its influence on Organic func. tions. 866,873 ; variation of, at different periods of life, $899,901,908$

Enotional activity of, $568,706,869$

Idio.dyn:ımic activity of. 568

Mixed diet, econoury of, 104; importance of, 105

Molleling process, 450 ; tueans of promoting, 451

Molecular Death, 1032

Mongolian liace, in Europe, 1003 ; in India, 1004,1005

Monstrosities, by excess, 441 ; by arrest of development, $417,940,950,953,958$

Morbid Poisons, 283 (see Poisuns. Morhid)

Mortility, preventible, of England. 414

Mortality, relative, at different seisous, 548 ; at diflerent iges, 1031

Mother, influence of mental states of, on foetus, 919, 121; ou mammary secretion, 875

Motor nerves, laws of transmission through, 557, 571; see Eifferent Nervefibres

Motor Truct of Nedulla Oblongata, 614

Muein, s5

Mule, charaeters of, 917 ; sterility of, 998 note

Minscle-rods, 8114

Muscarin, aetion of, on heart, 316 note 
Muscles, limited term of life of, 419,809 : degencration of, 419,420 ; hypertrophy of, Stis; atrophy of, 809 ; electric current of: 70.3

Musical tones, theory of, 780

Muscular apparatus of organic life, 801 ; of animal life, sol

Museular Tissue, various forms of. 801,802 ; structure of unstriated, 801; structure of striped, 802 ; distrihution of motor nerves in, 806 ; distribution of blood to striperl form of, 809 ; lymphatics of, 806 ; chemical composition of, 806 ; chemical changes in, induced by exhustion, 809 ; development of, 808 , nutrition of. 809 ; limited duration of. 419, 809; elongated and contracted conditions of 810 ; phenomena accompanying contraction of, 810 ; elasticity of, 812 ; electrical relations of, 813 ; mechanism of mus. culil contraction, $81 \mathrm{fi}$; idio-musculir contraction of, 819 ; neuro-nuscular enntraction of, 819; peculiarity of that of Heart, 8119 , 818; tetaum of, 818 ; various stimuli inducing contraction of, 820 ; examples of rhythmical movement of, 822 ; irritability of, 820 ; agents destroying irritability of, 820; effects of shock in destroying irrita bility of. 823 ; proofs of essential independence of irritability of. 825 ; necessity of due supply of arterial blood for maintenance of irritability of, 825 ; spontaneous and postmortem wovements in, 827 ; rigor uortis of, 827

Muscular Movements, increase of contractile power of, after section of spinal cord, 648 ; post-mortem, 827 ; voluntary and involuntary, 828 ; grouping of, 829 ; symmetry and harmony of, 830 ; energy and rapidity of 838 ; absolute muscle force, 839 ; sources of muscular force, 841; rapidity nt, 843; precise adjustment of, 84:3; (see Muscular Sense)

Muscular Sense, 668 ; nerves of, 666 ; its participation in voluntary movements. 670 ; its exaltation in Somnambulism, 719

Muscular Suggestion, its influence in Somnambulism, 718

Muscular Tension, influence of Spinal Cord on, 648

Myelin. 87

Mivelopliques, 228, 438

Myenteric plexus, 137

Myopia, 751

Myosin, 85, 806

Navy, diet scale of 112

Necramia, death br, 1034

Negrito Race, 1013

Negro, change of color in. 988 note

Negro Rices, color of, 988 ; hair of, 989 ; skull of, 991; uodification of its form by cicilization, 993; pelvis of, 994; immunity from fever of, 997 note; geographical range and varieties of, 1006

Nerium Oleander, action of, on Heart, 316

Nerve-force, laws of transmission of, 572

Nerves, electric current in. 593

Nervous Srstex, 55.3 ; influence of, on Animal Heat, 554; general arrangement of, 554 ; regeneration of nervous tissue, 558 ; chemistry of, 559 ; autom tic character of. in Invertebrata, 561; distinguished in
Vertebrata by Cerebrum and ministering to Intelligence, 562

Cerchro-spiual system, principal divisions of, 565 ; Cranio-Spius!l Axis, 597 ; Sensory Ganclia, 649: Cerebral Hemisphere, $686^{\circ}$ Cerebellum. 673 ; general course of action of, 565; reflex operatious of sepurite narts, 569: subordination of these to the Will, 569; relations of to Sympathetic system, 570; influence of, on Anim:l Heat. 871 ; on Organic functions. Sti2: see Cerebellum, Cerphrulu. MLedullu Oblongata. Sunsory Gunglia. Sivimel Corrl, Conscionsuess. Emotions, E.teito-motor Actions. Irton-mestor Artions. Iurellertural Fice ulties, Reflex Arfions, Seuseri-molor Actims. Volirionul Artions

Symputhetir System. generil structure of, Sti.3: Cerebro-Spinal fibre: in, 863.864 ; connection and distribution of principal trunks, 864 ; results of section anil of irritation of symp thetic, 867 ; fibres, dilating vessels, 869 ; action of, on apparatus of organic life, 869 ; their instrumentality in sensition in museular contraction. $870^{\circ}$ on musular elongation, 869 ; action of, on intestinal canal, 137. 162; on heart, 306 ; on bloodvessels. 326 ; on uterus, 865.888 ; nn iris. 759.864 ; proper fibres of, $863:$; influence of, on Secretion generally, 673 ; on secretion of saliva, 148, I49; on secretion of gastric juice, 162 ; on $111-$ trition, 871 ; on animal heat, 545 ; reflex actions of, 6.35

Trumks, entowments of, $5 h 0$; afferent and efferent, 560 ; use of plexuses of, 572 ; litws of transmission in, 573 ; modes of determining their functions, 574-577; action of various stimuli on. 578 ; rapility of ronduction of electrical stimulus by, 581 ; electrical phenomena in, 50:3; electrotonic conclition of, 585 ; electro-motor properties of, 581

Nervous Tissue, chemistry of, 87 ; limited dura. tion of, 419 ; atrophy of. 446 ; reparation of, 5.58

Nicotin, action of, on heart, 316 note, 317

Nîmes, prison of, mortality at, 125

Nitric Acid, in urine, 515

Nitrngen, its presence in blool, 25s; exhalation and absorption of, 400 ; excretion of, 424,505

Notochord, formation of, 952

Nuclein. 86

Nutritlox, general nature of 280,415 ; de. pendent on pabulum in blood, 415 ; complenental doctrine of, 282 ; sources of demand for, in increase, 416 ; in development, 416 ; conditions of its performunce, 420 ; interstitial and superficial, 438; varying activity of, 441 ; at different periods of life, 1021 , 1028,1031 ; ahnolmal derrees of, 411 ; peculiar phises of. in reparation of injuries. 447; abnormal forms of, 454 ; inflammation at.d its results, 454; tuberculosis, 46:3; tualignant growths, 464; influence of nervous system on, 871 ; electric disturbance in. 551

Oblique Muscles of Eye, function of, 835 Observation, active in inf.ıney, 1021

Observations, astronomical, mode of recording, 796 
Oceanic Race, 1011

Ocular Speetra, 77:3-778

Odoriferous secretion of Skin, influence of nervous system on, 874

Odorous matter in Blood, 234

Odors, nature of, 740 ; varieties of, 740,741

Esophagus, movements of, in swallowing, 129, 130

Old Age, characteristies of, 1029 ; temperature in, 530 ; diminished power of generating beat in, 548

Oleaginous constituents of food, 96 ; digestion of, 171, 174; absorption of, by investing cells of Villi, 189-200 rote

Olfuctive Cells, 741, 742

Olfactive Ganglia, 649,651

Olfactive Nerves, $613,651,740$; distribution of, 741

Dlivary bodies, 606

Omphalo-mesaraic vessels, 930,934

Ophthalmic branch of Fifth Pair, 616, 759 , 760

Ophthalinic Ganglion, 615, 865

Optic Commissure, 653

Optic Ganglia, 649

Optic Nerves, endowments of, $652,653,744$; distribution of $75: 3$; defreient sensibility at entrance of, into globe of eye, $75 h^{2}$

Optic Thalami, 650 ; functions of, 659

Ourang-outang. comparison ot', with Man. 39-57

Osmosis, 194; various phenomena of, 194-195; of constituents of food, 198, 200

Ossification. completion of, a mark of Adolescence, 1026

Otic ganglion, 86.5

Oval Skull, 993

Ovarium, structure of, 859 ; development of, 889 ; evolution of nvisacs witbin, 891 ; discharge of ova from. 891

Overerowding, a predisposing cause of zymotic disense, $407-114$

0 visac, 891

Ooum, structure of primordial, 890 ; evolution of, 891 ; maturation and discharge of, 891 ; fertilizition of, 900 ; first changes in, 90); subsequent changes in, see Decelopment of Embryo

Oxalic Acid, action on heart, 316 note; in urine, 515

Oxygen, a mount of, in blood, 258 ; stimulating effect of, on heart. 307

Oxygen, sources of demand for, 360,363 ; (juantity of, required, 387 ; exchange of earbonic neid for, 387 ; $\theta$ xeretion of, 424 ; respiration in, $261,394,403$

Pancreas, structure of. 167 ; nerves of, 167 ; levelopment of, 167

Panereatic fluid. composition of, 168; changes ill the cell, 169 ; quantity of, 169 ; infuence of nervous system on, 170 ; action of, on stareh, 170; on fit, 171 ; on albumen, 173

Papilla, tactile, 724, 725; gustative, 736-739

Patpuan Rice, 1013

Par Vagum, origin, 610 ; distribution, 620 (seo Pnermogastrir Verve)

Paralyzed limbs. lemperature of, 545

Parapeptones, formation of, from albumen, $158,17: 3$

Paruplegir, peculiar cases of, $6: 37$

Purents, influence of, on proreny, 918; see (ieneriton, Iifluence of Purents
Parotid Gland, 143 ; secretion of. 144

Parturition, act of, 644,910 ; regular period and causes of, 910 ; premature, 913 ; retarded, 915

Passion, influence of, on secretion of Milk, 875

Paupers, dietary of, 112

Pelagian-Negro Ritce, 1013

Pelvis, form of, in different Races, 874

Pepsin. 84, 157

Peptones, formation of, from albuminous compounds, $86,158,173$; osmotic energy of, 197

Perceptive centres of cerebrum, 705

Periodical phenomena, 528, 707, 911

Peristaltic inovement of intestines, 137 ; effects of renous blood on, 140 ; effects of irritation of virious parts of nervous system on, 138 ; influence of mental states on, 870

Persistence of sensory impressions, tactile, 729 ; gustative, 740 ; olfictive, 743 ; visual, 771

Personal equation, 797

Perspiration, 521-526 (see Suloriparous Ex. cretion)

Personal Equation of Astronomical observers, 796

Pettenkofer's test for the biliary acid. 93

Peyerian glandulæ, strueture and relations of, $189,190,210$

Phthisis, influence of, on Pulse, 320

Phosphates, Alkaline. in blood, 254; in urine, 500,514

Phosphates, Earthy, in arine, 501, 515

Phosphènes, investigation of, 777

Phosphorus, elimination of, by breath, 401 , 550 ; by urine, 514

Phosphorescence of living body, 550

Phrenolngical doetrine, of Cerebollum, 650 ; of Cerebrum, 696

Physical Basis of Life, 57

Pigment cells, 62

Piteh of Sounds, appreciation of, $79 t$

Pitch of Voice, regulation of, 848

Pituitary bolly, 227

Placenta, formation of foetal portion of. 904 ; of maternal portion, 906

Placental muruur, 908

Platyrrline Apes, comparison of thumb of, with that of Min. 41

Pleuroperitoneal cavity, 928

Plexus myentericus, 137

Pneumatology of the blood, 257

Pneumogastric Nerve, origin of 610 ; gonera distribution and endowments of, 621 ; its instrument:1lity in deglutition, 131 ; in hunger and sitiety, 121 mote; $\mathrm{its}$ influence on secretion of gratric fluid, and on movements of stomach, 140, 162; on movements of heart, 309 ; its iction as excitor of respiration, 374,378 ; its influence on larynx, 380 ; effects of section of, $3 \times 2$

Pointer and Setier, peculiar breeding of, 917

Points, foeal, of the eyo, 746

Points, nodil, of the eye, 746

Points, prineipal, of the eye. 746

Poisons, mode of action of, 283 ; their passage inte the cireulation, 282 ; elimination of, from blool, 291

Poisons, Morbid, their substantive existence, 285; some ceneraterl within the system, 2 28; zymotic, 285 ; predisposition to their activity, 296 ; eolarse of action of, 259 ; alteration of blood by, 259 ; recuvery of blood from, 290 
Polynesian Races, 1012

Pons Varolii, structure of, 613 ; effects of section of, 661

Portal Yein, blood of, 263 ; comparison of, with blood of hepatic vein, 263 ; its distribution in Liver. 471

Portio dura, origin of, 611,612 ; functions of: 619,620

Positive accommodation of the eye, 749

Posterior coluuns of spinal cord, 627

Potash, effect of, on ariue, 519

Pot assium-broinide, action on heart, 316 note

Pregnancy, signs of, 908,909 (see Gestution)

Prehension of food, movements of, 127

Presbyopia, 753

Pressure of Blood in arteries, 336 ; in reins, 354 ; increased during inspiration, 340 ; influence of, on secretion of urine, 498

Primitive streak and groove, 927

Prisons, diet-seale of. 112 (see Gaols)

Prognatbous Skull, 991

Projection of objects, visual appreciation of, 764

Proportion of several constituents of body to each other, 421

Prosencephalou, development of, 960,961

Prostate Gland, function of, 850

Protagon, 87

Proteids, 81

Protricted Gestation, 915

Pseuiloseope, 770

Psycho-physical law, Fechner's, 797-799

Ptyalin, 84, 146

Puberty, the characteristic of Youtb, 1026 ; in femile, 892 ; in male, 892 ; diseases of. 1026

Puerperal Fever, predisposing causes of, 286

Pulse, Arterial, 329 ; varieties of, 332 ; 1 ode of propagation. of, 332 ; rapidity of propagation of. 334 ; rate of, under different conditions, 319 ; proportion of, to respiratory morements, 374 ; dicrotous, 331

Pulse, Respiratory, 340

Pulse, Venous, 354, 355

Pupil, action of, $75 !$; relation of, to Third Pair, 748 ; to Syinpathetic. 865

Purpura, state of blood in, 266

Pus, formation and characters of, 450, 457, $459-462$; influence of, on coagulition of blood, 275

Putrescent Food, injurious consequences of, 115 ; Water, injurious effects of, contaminated, II6

Pyin, 85

Pyrainidal Skull, 992

Pyramids of Medulla Oblongata anterior, 606 ; posterior, 608

Pyrenamata, 237

Python, temperature of, during incubation, 35 note

Quadrmmana, comparison of, with Man, 39-57 Quagga, transmission of marks of, 920

Quickening, act of, 909

Quinine, action of, on heart, 316 note

Quinoidine, animal, 93

Races, origination of new, 996

Rures of Mankind. American, 1010: Arvan or Indo Europea1n. 1002; Berber, 1004; Bushman, 1009; Caucusian, 1001; Crltic, 1002; Hindostanic, 1006 ; Hottentot, 1009 ; Kaffre,
1008; Mongolian. 1004: Malayo-Polynesian, 1012 ; Negro. 1006 ; Ocennic, 1011; Pela. gian-Negro, 1013; Seriform, 1005 ; SyroArabian, 1003.

Range of vision, extent of, 750,779

Rapidity of transmission of impulses through motor nerves, 581; through sensory, 582, 797 ; of Muscular movements, 815

Rattlesnake, poison of, secretion after death, 1033 note.

Reciprocation of sonorous vibrations, 785 ; by membrana tympani, 787

Red Corpuscles, 235 (see Blond)

Reeds, vibrating, laws of, 851

Reflex Actions, general nature of, 633 ; laws of 635 ; circumstances augmenting actirity of, 635; of Spinal Cord, 633-641 (see Exritomotor Actions) ; of Sensory Ganglia, 656 (see Sensori.motor Actions).

Refraction, laws of, 744

Regimen (see Dift, Food)

Relations, near, tendency of their marriage to produce imperfect progeny, 9]8, (919

Relief of surfaces, visual appreciation of, 764767 ; eonversion of, 770

Reparation of injuries, 447 ; completeness of, in lower animals, $4+7$; limitations of, in higher, 447 ; most energetic and complete in earliest periods of life, 448 ; not dependent on inflammation, 448 ; by immerliate union, 449 ; by adhesion, 449 ; by undelling process, 452 ; by suppurative granulation, 453 ; by secondary adhesion, $45: 3$

Reproduction of limbs in foetus, 445 ; of lower jaw, 448 ; of epithelium, 449

Resonance of sounds, 78.5

ResplRation, general nature of the function, 360 ; sources of demand for, 3633 ; apparatus of, 363 (see Lumgs); mechanism of nets of, 368

Mocements of 369 ; rate and extent of, 371 ; force exerted in, 372 ; waintenance of, by nervous system, 374 ; exeitor nerves of, 374 ; motor nerves of, 379 ; modifications of, 381 ; effects of compression and rarefaction of air on, 394. 395

Effects of, on Air, 384; amount of air consumed. 385 ; changes in its jroportions of oxygen and carbonic acid, 357; quantity of carbonic acid imparted to, :54-392; changes in proportion of nitrngen. 399 ; watery vapor imparted $t 0,400$; absorption from, 4111

Effects of, on Bloor, 257-262

Consequences of Suspension of, 404

Effects of D.firiency of, shown in predisposition to zymotic disease, 408 ; predi=position to spasuodic diseases, 411 ; excess of mortality attributable to, +12 ; apparitus of Pettenkofer for experiments on. $41 t$

Respiration of hydrogen, 403 ; of nitrogen, 403 ; of oxygen, 403

Respiritory Pulse, 354

Restiform bodies, 606

Rete atvllum and rete angustum of intestina? lyw phatics, 187, 185

Retia mirabilia of lymphatics, 206

Retilla. structure of, $75.3-757$; most sensitive point of 756,776 ; leas sensitive point of, 756. 776 ; persistence of impressions on. 771 ; irralialion of impressions on, 775 ; spectric produced by pressure on, 777 ; cirrulation in, rendered visible, 778 ; development of, 961 
Rhinencephalon, development of, 960

Rhythuical movements of heart, 298; (see Hrart); of ressels, 328,329 ; of diaphragm, 376 ; of unstriped muscles, 821

Rigor Mortis, 827

Rotifera, asplanchnic character of males of, 33 note

Rudimental parts, uses of, 281

Sabadillin, action of, on heart, 317 mote

Saccharine constituents of food, 94 ; digestion of, 170

Saccharine inatter in blood, 254, 483

Sicculi of Colon, use of, $1+1$

St. Killa, inortality at. 412

St. Martin, case of, $156,158,159-162$

Silive composition of, 145,147 ; different kinds of. 145-148; uses of, 147; influence of nervous systen on, 148-151 ; quantity of, secreted dilily, 147; influence of kind of food upon quantity of, 147

Salivary Glands, 143

Salts, common, advantage of. in food, 98 ; Neutral. influence of, on clunge of color of blood, 262; in retarding coagulation of blood, 273

Salts of Biood, normal proportion of 264 ; variations of, in disease, 269 ; uses of, 434

Salts of Cirire, 500, 504; of Saliva, 145,147

Singuifirution. process of, 205,230 ; share of Liver in 205; of Absorbent System, $206-$ 21S; of Ductless filands, 218-220

Sanguinarin, action of, on heart, 317 note

Sanskritic languages, 1002

Sarcode, 57

Sirkin, 92

Sitiety, sense of, 111

Scab, formation of, 450 ; nrtificial, 452

Scurvy, causes of, 109 mote; state of blood in, 267 ; at Millbank, 125

Secondarily-Automatic actions, 645-648, 665, 672

SECRETION. its relation to Excretion, 465,466 ; vicarious relation between that of skin and kidneys, 467; influence of nervous system on, s7i; continutunce of after death, 412 ; metnstasis of, 46:; see Bile. Gastric Juice. Mtilk, Prucrentic Fluid, Suliva, Trine, ete.

Segurutition of vitellus.

Self eontrol, see Volition

Seinicirculir Cinals, functions of $790-794$; effects of section of, 6.58

Seminal fuid, charileters of 884

Semilic lince, 100:3

Sensation, its seat in the Sensorium, 566,649 , 664 ; general. 651, 721; special, 651, 721 ; dependence of, on eapillary circulation, 722 ; various kinds of: 723 ; excitement of, by electricity, 724 ; by mechanicul impressions, 724

Sensutions, their seat in Sensory Ganglia, 656

Seusibility, unseular, $7: 32$

Sensibility, tactile, relative, of different parts of skin, 727,728

Sensmi motor Actions, their correspondence with the instinctive of lower aniuals, $561-$ 563.3 ; thair independence of the Cerebrum, 656 ; their estahlishment by babit, 665,763

Sensorium, its special seat in the Sensory Giıngliil, 656

Sensory Grourlir, genersl structu-e and relations of, 566,649 ; their nerves, $65 \mathrm{I}-655$; their relative predominance in lower animals, $563,566,567,655$; functions of, 656 ; the probable seat of Sensation for external impressions, 656 (see Sensation); also for Cere. bral chinges, 707 ; reflex functions of, 663 (see Sellsori motor Actions); their participation in voluntiry actions, 646

Sensory Nerves, lisws of transmission through, 572 ; see Afferent Nerre-fibres

Sensory Tract of Medulla Oblongata, 614

Seriform Race, 1005

Serous layer of Germinal membrane, 814

Serous effusions of Inflammation, 457

Serum, 234, 271; proportion of to crassamenti1m, 276 ; transudation of. 457

Setter and Pointer. peculiar breeding of, 917

Seventh Pair of Nerves, 619 ; deep origin of, 610

Sex of Fotus, causes of, 965

Srxps. proportional number of, 465 ; differences in getleril development of, 966 ; in viability, 967 ; in composition of blood, 255 ; in pulse, 319 ; in respiration, 389 ; in psychical character, 969

Sexual sensition, probable seat of, 685

Sheep, new breeds of, 996 note

Shock, effect of. on heart, 314; on eapillary circulation, 35:3

Sighing. act of, 381

Single Vision, conditions of, 762,837

Sinus rhomboidalis, 960

Six-fingered f:ı milies, 996

Sixth Pair of Nerves, 617 ; deep origin of, 612

Size, visual apprecintion of, 768

Skeleton, development of, 952

Skin, structure of, 520 ; color of, its variation in M:ı, 988; absorption by, 2013; respuiration by, 395 ; transpiration from, 525

Skull, forms of, in different rices, 990 ; prognathous. 991 ; pyramidal, 992; oval. 993

Strep, definition of, 708 ; thenry of carre of, 708 ; circulation in the brain during, 708 ; dreaning during. 709 ; necessity for. 709 ; periodicity of, 709 ; predisposing influences to, 710 ; means of inducing, 711 ; incess of, 711 ; intermediate states between sleeping and wilking. 711 ; influence of expectation and habit in inducing, 712 ; influence of $\mathrm{im}$. pressions on the mind of the sleeper, 713; a mount of, required by $\mathrm{M} i n, 714$; cases of absence and rleficiency of, 715 ; undue protriction of 716

Simell, sense of, $645,648,651,652$; nerves of, 7411 ; their distribution, $740-742$; conditions of, $7+1$; uses of, 742 ; improvement of, 743 ; modification of, by habit, 743; duration of improssions on, 744 ; its purticipation in Trste, 744 ; exaltation of, in Somnambulism, 719

Snake, temperature of, during incubation, 35 note

Sneezing, net of, 382

Sohbing, act of. 382

Solar plexus of Syınpathetic, 863

Soliclity, perception of, 764

Somatic Doath, 1033

Soinatopleure, 928

Somnambulism, relations of, to sleep and reverie, 718 ; suspension of volition:l] control in, 718; phenomenn of, 719 ; mesmeric, 719

Sound accompanying muscular contraction, 812

Sounds, propagation of, 780 ; means of deter 
mining direction of, 790.795 ; distance of, 795 ; pitch of, 791 ; nature of musical, 781 Sounds of Heart. 304

Sound Colors, 781

Spartein, action of, on heart, 317 note

Specific identity or dirersity of Human Races, question of, 987,1000

Speech, participatiou of central organs in, 000

Spectrum Analysis of the Blood, 248

Spectrum of Bile, 478,479

Spermatozon, nature and evolution of, 885 ; essential importance of, in fecundation. 887

Spheno-palatine ganglion, 865

Spheno-palatine ganglion of Sympatbetic, 863

Spherical Aberration, 745

Sphincters, action of, 141,643

Sphygınographs, construction of various, 330 , $3: 31$

Sphygmographic tracing of the cardiac moveuents, 301 ; of arterial pulse. 331

Spinal Accessory Nerve, deep origin of, 609 ; distribution and functions of, 62:3

Spinal Coid, structure of, 597 : external conformation of, 598 ; resicular substance of, 599 ; fibrous strands of, 602 ; connection of, with nerve roots, 601

Functions of, 626 ; as a conductor of seusory impressions and of motor impulses, 627 ; as an independent centre, 633 ; its proper reflex actions, 6.34 ; their relation to the Organic functions, 642 ; their protective chitracter, 644 ; their subservience to loco. motion, 644; its influence on Muscular tension, 648 ; development of, 840

Spinal Nerves, 615 ; double function of their roots, 571 ; their connection with the Spinal Cord, 571

Splanchnic nerves, 328

Splanchnopleure, 928

Spleen, structure of, 218-221; chemical composition of, 221 ; lymphaties of, 221 ; nerves of, 221 ; chemical composition of, 226 ; development of, 221 ; fuuctions of, 222,226 ; blood of, 263

Splenic Blood, 263

Stammering, nature of, 861 ; treatment of, 861

Stapedius, functions of, 788

Starch, a constituent of food, 94, 100; its transformation by saliva, 148 ; by pancreatic Aluid, 170 ; by intestinal Aluid, 179; importance of, in protecting other tissues from the action of oxygen, 428,434 ; production of fut from, 432

Starvation, effects of, $124-127$; death by, 124 ; Chossat's experiments ou, 124, 540 ; acute, 124 ; slow, 125

Stercorin, 97

Stereoscope, 765

Stethometer, Sanderson's recording, 371

Stimuli, action of various, on nervous system, 518

Stomash, movements of, 132-136; netion of, in vomiting, 1:35; influence of pneumogas. tric on, 134, 162; influence excited by sympathetic upon, 163; 1 $\mathrm{ymphatics}$ of, 154 ; secreting follicles of, $151-155$; nerves of, 155 ; villi of, 154 ; secretion of gastric juice by, 155-158; digestion in, 156-166; temperature of, during digestion, 162

Strabismus, pathology of, 838

Strength, feats of: 839

Strings, vibrating, laws of, 849

Stroma of blood-corpuscles, 236
Strychnia, action of, on heart, 316 noe, 317 ; action on blood-pressure after section of spinal cord, 327

Sublingual Gland, 146,148 ; secretion of, 146

Subuaxillary Ganglion of Sympathetic, 856

Submaxillary Gland, 146 ; secretion of, 148

Succinic Acid, 96

Snecus Entericus, 177 ; its use in digestion, 178

Sucking, act of, 578

Sudoriparous Excretion, conposition of, 520 ; quantity of, 522 ; vicarious with urinary, 498,525 ; consequences of suppression of, 526 ; frigorifying effect of, 524

Sudoriparous Glandulæ, $52 \theta$

Sugar, a constituent of the body, 94 ; formation of, in liver, 483 ; passage of, into urine, after lesions of nervous system, 487

Sugar, Grape, 94

Sugar, Milk, 95

Sugar, Muscle, 95

Sulphates, Alkaline, in urine, 500,573

Sulphocyanide of Potassium, in the Salisa, 146

Sulphuretted Hydrogen Gas, action of on Heart, 316 nole

Superfoetation, 9 If

Supernumerary Parts, 442-448

Suppuration of wounds, $45:$

Suprarenal bodies. structure of, 222 ; development of, 223; function of, 228 ; effects of ablation of, 223 ; effects of disense of, $22: 3$

Surgical Fever, predisposing causes of, 287

Swallowing. act of, 129

Symmetrical disenses, 280

Sympatertir System, ganglia of, 863 ; struc ture of rami communicantes, 864 ; myenteric ganglia of, 137

Syncope, death by, 1033

Suntonin, 83, 157

Syro-Arabian Race, 1003

Tactile corpuscles, 725

Tamulian Language, 1005, 1014

Tanghinia venenifera, action of poison of, on Heart, 316

Tannic acid, action of solutions of, on blood corpuscles, $2: 36$

Taste, ganglion of. 610,612 ; nerves of, 617 , 621 ; Sense of, 733 ; special conditions of, 734 ; seat of, 735,736 ; papillæ of, 736 ; varying acuteness of. 738 ; rapidity of, 738 ; participation of smell in, 739 ; objects and uses of, 739 ; improvement of, by habit, 740 ; cases of loss of, 739 mite

Taurin. 480

Taurocholic acid, 93, 418

Tea, composition of, 120 ; influence of, on urine, 518

Teeth, structure of, 75 ; deciduous exuviation of, 418 ; development of, 1021 ; developuent of permanent. 1024

Temperature, normal, of man, 529

Temperature, normal, of infants, 530

Temperature, normal. of agerl persons. 5:30

Teuperature, diurnal variation of, 530

Temperature, effects of exercise on, 5:31

Temperature, effects of ingestion of food on, 532

Temperature, effects of external cold on, 53:3

Temperature, effects of disease upon. 534

Temperature, effects of moisture in air on, 536

Temperature, rise of, after death, 535 
Temperature, extremes of, endured by man, 538

Temperature, sense of, 730

Temperature, of the blood in different parts of the body, 2:33

Tension of Muscles, influence of Spinal Cord on, 648

Tensor tympani, functions of, 788

Testes, structure of, 882 ; development of, 948

Tetinomotor, Heidenhain's, $\$ 18$

Tetanus, 818

Thalami Optici, 650; their relation to Cerebrum, 650 ; their functions, 659

Thebain, action on vasomotor centre, 328

Thein, action of, on heart, 316 mote; effect of, on urine, 518

Third Pair of Nerves, 617

Thirst, immediate source of sense of, 122 ; death by, 124

Thymus Gland, structure and development of, $224-226$; function of, 228,230

Thyroid Gland, chemical constituents of, 226 ; structure of, 226 ; development of, 227 ; function of, $228-230,846$ note

Tobacco, influence of, on body, 119

Tongue, papilla of, 735-738; sensory nerves of, $612,616,620,736,737$; motor nerves of, 624 (see Taste)

Tongues, vibrating, laws of, 851

Touch, ganglia of, 650 ; nerves of, 570 ; Sense of, 724 ; papillæ of, 724,725 ; varying acuteness of. 727 ; theory of sense of, 728 ; dura. tion of impression of, 729 ; knowledge acquired by, 729 ; improvement of, by prictice and attention, 732 ; coubination of, with visual sense, 766

Toxic Disenses, general pathology and therapeutics of, 281-289, 291

Trainers, diet of, 114 note

Trance, causes of, 1036

Traube's curves, 328, 340

Tricuspid valve, imperfect closure of, 30.3

Trigeminus, 615 (sea Fifth Pair)

Trisum Nuscentium, mortality from, 412

Trophic Nerves, 870

Tuber Annulare, effects of section of, 662 ; effects of electric current on, 662

Tubercle, nature of, 463

Tubercula Quadrigemina, 649,657

Tubercular Diathesis, 463; inoculability of, 4 fi.3 note; manifestation of, at different ages, 11228

Tubes, effects of various conditions on flow of liquids through, 334,335 , note

Tumors, their relation to hypertrophies, 443 ; malignant. 289

'Turkisb Race, 1004

Tympanic apparatus, structure and uses of, $786-790$

Typhoil fever, alteration of blood in, 265

Tyrosiu. 88

Ulotrichi, 990

Uubilic:al cord, structure of, 938

Umbilical vessels, 938

Upas Autiar poison, action of on beart, 316 ; on motor nerve, 821

Urachus, 9:38, 949

Uremia, pathology of, 496

Urea, 91; its ordinary proportion in urine, $500-503$; influence of inanition on excretion of, 426 ; sources of, 510 , various circum- stances affecting quantity of, $503-507$; its presence in blood, $264,502,511$; in sweat, 522,525 ; consequences of its non-elimination, 496

Uric acid, 89 ; its ordinary proportion in urine, 507 ; variations in its amount, 508, 509; sediments produced by, 509

Urination, act of: $142,519,643$

Urime, secretion of, 490 ; excrementitious character of, 490,518 ; physical properties of, 497 ; quantity of, 498 ; circumstances affecting quantity, 498 ; specific gravity of, 500 ; composition of, 501; influence of inanition on, 425,427; coloring ratter of, 510 ; gases contrined in, 516 ; differences of, with age, 503 ; influence of diet on, 503 ; influence of diuretic medicines on, 504, 519; Organic components of, 501 (see Urea, Uric Acid. etc.); acidity of, 516 ; alkalinity of, 517; Inorganic components of, 513; sugar in, 486 ; lactic acid in, 513 ; vicarious secretion of, 468

Urobilin, 478

Uro-genital sinus, 949

Uterine Glandulae, 902

Uterns. inherent motility of, 909 ; increase of, during pregnancy, 908 ; action of, in parturition, 911 ; temperature of, in parturition, 539 ; subsequent degeneration of, 439,911 ; embryonic development of, 948 ; rudimentary, of male, 949

Vaccine virus, nature of, 285, 289

Valves of Heart, 303 ; difference of mitral and tricuspid, 303 ; sounds produced by tension of, 304,305

Vao poison, iction of, on heart, 316

Vilpor aqueous, absorption of, 202,402 ; exhalation of, 4010

Variation, tendency to, 995

Varieties of Mlan, their essential conforinity in structure, 987 ; in physiolngical characters, 997 ; in psychical endowments, 998 ; in languages, 999 (see Races)

$\checkmark$ ascular Area, 9.33

Vasomotor centre, 327,868

Vasomotor nerves, 327, 758, 865,868

Vegetibles, fresh, an essential article of diet, 109

Vegetarianism, 106

Veins, structure of, 353 ; movement of blood in, 353 ; causes of motion of blood in, 354 ; congestion in. 356 ; on muscle, 820 ; development of first set, 933; of second set, 940

Venous Blood, differential characters of, 233 , 257. 262 ; causes of variation of color in, 202: influence of, on intestines, 140; on respiration, 375

Ventilition, 409

Ventricle of Heart, effect of pregnancy on left, 294

Veratria, action of, on Heart, 317 note

Vertebra, ty jic:sl, 954

Vertebra, cranial, 955

Vertebral Column of Man, comparison of, with that of Apes, 47 ; first indications of, 952, 95:3

Vesicula Prostatica, its real inport, 949

Vesicula Seminales, function of, 858

Vesicular nerve-substance, 553

Vessels, blood, development of, 933, 936

Vestibule of Ear, 782 
Viability, early, of foetus, 913 ; relative, of two Sexes, 967

Villi, intestinal, structure of, 61, 187; of stomach, 154

Tision, ganglia of, 650 ; nerves of, 652,753 ; Sense of, 744, 780 ; optical conditions of, 744 747 ; defects in, 745 ; accommodation of, for varying distances of objects, 748 ; nervous apparatus of, $753-757$; limits of, 757 ; use of in combination with touch, 761 ; erect, eause of, 762,763 ; single, conditions of, 762 ; appreciation of solid forms by, 764 ; of dis. tances, 767 ; of size, 768 ; conversions of relief, 770 ; persistence of impressions, 771 ; complementary colors, 773 ; colored shadows, 773 ; acuteness of perception for colors, 776 ; rapidity of perception, 774 ; want of power to distinguish colors, 775 ; irradiation of impressions, 775 ; vanishing of images, 776 ; perception of laterally situated objects by, 776 ; imperfect perceptivity of optic disk, 777 ; electrical current induced by light, 777 ; phosphènes, 777 ; representations of vessels of retira itself, 778 ; improvement of, by attention, 779 ; importance of, in guiding movement, 668 ; appreciation of varying amounts of illumination by, 779

Tital Economy, balance of, 421,440 ; ordinary diet, 421 ; in inanition, 425 ; with pure meat diet, $42 S$; with meat and fat, 429 ; with sugar and meat, 429 ; differences between Carnivora and Herbivora, in respect to, 429 ; changes undergone by albumen in maintaining, 81,430 ; changes undergone by fat in maintaining, 68 ; changes undergone by sugar and starch in maintaining, 93,434 ; application of inorganic constituents of the food to maintenance of, 434 ; work done in and by the body, 434; substitution of new tissue for old in, 437 ; necessity of due supply of nervous power for maintenance of, 440 Vitelline Duct, 928, 933.

Vitelline Vessels, 9:3:3

Vitellus, 925 ; its segmentation, 925, 93।

Voice, ordinary, mode of production, 85 ; falsetto, 854

Volition, fixation of attention by, in states of Dreaming and Somnambulism, 716-718

Volitional. Actions, their source in the Cerebrum, 706

Voluntary Novements, their dependence on guiding sensations, 666,667 ; performed by instrumentality of Sensori-Motor apparatus, 669 ; not in themselves distinguishable from involuntary movements, 829 ; but result from an impulse originating in Cerebrum, 706

Voiniting, act of, 135

Vowel sounds, 856 ; diserimination of, 858

\section{Walking, movements executed in, 8.31}

Water, the natural drink of Man, 116; effects of drinking large quantities of, 116 ; effects of impurity of, 116 ; effects of deprivation of, 123 ; normal proportion of, in Btood, 253; alterations in, 257 ; transudation of, by Kidney, 498

Water-dressing of wounds, 451

Weight, appreciation of, 729,730

White Corpuseles, 241 ; see Bloorl, Colorless Corpuscles

Wolffian bodies, 948

Woorara poison, influence of, on secretion of Saliva, 151 ; action of, on Heart, 3।5, 316 note; action of, on Animal heat, 547 ; effect of, on motor nerves, 821

Xanthin, 92

Yawning, act of, 382 ; consensual suggestion of, 382

Yellow Fever, elevation of temperature after death from, 535 ; continuance of eapillary circulation in, 348; immunity of Negroes from, 997 note.

Yellow Spot of Retina, 754, 756, 776

Yolk of Egg, of fowl, structure of, 925 ; of fish, rotation of, 931

Youth, characteristics of, 1025

Zo-amyline, 484

Zona pellucida, 931

Zymogen, 170

Zymotic poisons, 285; predisposition to. in consequence of state of blool, 286-2s9; from bad air, 286; from putrescent food, 115 ; from putrescent water, 116 ; from aleoholic liquors, 118; from starvation, 124; from deficiency of respiration, $408-411$; tendency of the system to eliminate, 291 



\section{IENRY C. LEA'S}

(LATE LEA \& BLANCHARD'S,

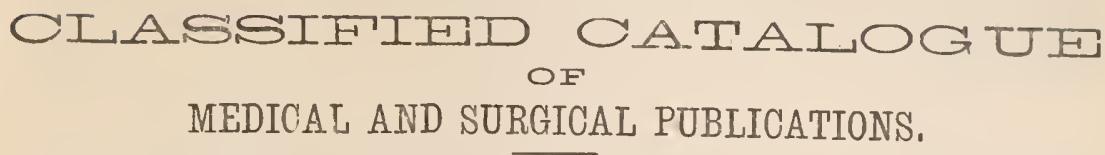

In asking the attention of the profession to the works advertised in the following pages, the publisher would state that no pains are spared to secure a continuance of the confidence earned for the publications of the house by their careful selection and accuracy and finish of execution.

The printed prices are those at which books can generally be supplied by booksellers throughout the United States, who can readily procure for their customers any works. not kept in stock. Where access to bookstores is not convenient, books will be sent by mail post-paid on receipt of the price, but no risks are assumed either on the money or the books, and no publications but my own are supplied. Gentlemen will therefore in most cases find it more convenient to deal with the nearest bookseller.

An Irdustrated Catalogue, of 64 octavo pages, handsomely printed, will be forwarded by mail, post-paid, on receipt of ten cents.

Nos. 706 and 708 Sansos St., Philadelphia, April, 1877.

HENRY C. LEA.

ADDITIONAL INDUCEMENT FOR SUBSCRIBERS TO

THE AMERICAN JOURNAL, OF THE MEDICAL SCIEXCES.

THREE MEDICAL JOURNALS, containing over 2000 LARGE PAGES, Free of Postage, for SIX DOLLARS Per Annum.

\section{TERMS FOR 1877:}

The American Journal of the Medicat. Schences, and Five Dollars per annum, The Medical News axd Library, both free of postage, $\}$ in advance.

\section{$O R$}

'Tue American Journal of the II edical Sciences, published quarterly (1150 pages per anuum), with

The Medical News and Librars, monthly (384 pp. per annum), and per annum,

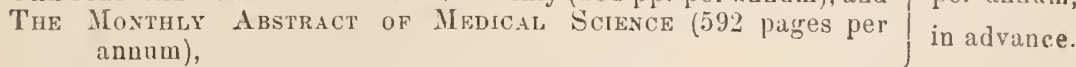

* Advance-paying subscribers can obtain at the close of the year cloth covers for each volume of the Journal (two annually), and of the Abstract (one annually), free by mail, on receipt of ten cents for each cover.

\section{SEPAIATE SUBSCRTPTIONS TO}

The American Jodrnal of the Medical Sciexces, when not paid for in advance, Five \ollars.

The Medical News and Library, free of postage, in advance, One Dollar.

The Monthly Asstract of Medical Science, free of postage, in advance, Two Dollars and a Half.

It is manifest that only a very wide circulation can enable so vast an amount of valuable practical matter to be supplied at a price so unprecedentedly low. 'I'he pub. lisher, therefore, has much gratification in stating that the very great favor with which these periodicals are regarded by the profession promises to render the enterprise a permanent one, and it is with especial pleasure that he acknowledges the valnable assistance spontaneously rendered by so many of the old subscribers to the "JounNAL," who have kindly made known among their friends the advantages thus offered, and have induced them to subscribe. Relying upon a continuance of these friendly exertions, he hopes to be able to maintain the unexampled rates at which thesa works 
are now offered, and to succeed in his endeavor to place upon the table of every reading practitioner in the United States the equivalent of three large octavo volumes, at the comparatively trifling cost of Six Hol.tars per anmum.

'These periodicals are universully known for their high professionatstanding in their several splieres.

I.

\section{THE AMERICAN JOURNAL OF TIIE MEDICAL SCIENCES,}

\section{EuITED BY ISAAC HAYS, M.D.,}

is nublished Quarterly, on the first of January, April, July, and October. Each number contains nearly three hundred large octavo pages, appropriately illustrated wherever necessary. It has now been is:ued regularly for over fifry years, during nearly the whole of which time it lias been under the control of the present editor. 'Thronghont this long period, it has maintained its position in the highest rank of medical periodicals both at home and abioad, and has received the cordial support of the entire professiom in this country. A mong its Collaborators will be found a large number of the most distinguished names of the profession in every section of the United States, rendering the department devoted to

\section{ORIGINAI, C () M M U I A T IONS}

full of varied and important matter, of great in terest to all practitioners. 'Thus, during $18 i f$, articles have appeared in its pages from over oue hundred gentlemen of the highest standing in the profession throughout the United States.*

Following this is the "Review Departane," containing extended and impartial reriews of all important new works, together with numerous elaborate "ANALYTICAL and Bibliographical. Notices" of nearly all the medical publications of the day.

This is followed by the "QUARTERLY SUMMARY OF IMPROVEMENTS AND DIACOVERIES in tue Medical sciences," classilied and arranged under different heads, presenting a very complete digest of all that is new and interesting to the physician, abroad as well as at home.

Thus, during the year 1876, the "Journal" furuished to its subseribers 9 4 Original Communications, 129 Reviews and Bibliographical Notices, and 22.8 articles in the Quarterly summaries, making a total of over Four Hundred and Fifry articles emanating from the best professional minds in America and Europe.

'That the efforts thus made to maintain the high reputation of the "Jovrsar" are successful, is shown by the position accorded to it in both America and Europe as a nationat exponent of medical progress:-

Anerica contiunes to titie a great place in this rowed matter it contains, and has establisbed for cians of journals (1uarterlies), at the bead of which itself a reputation in every country wliele medicine

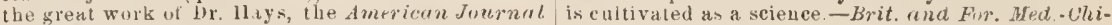
of the Merieal Sciences, still holds its gronnd, as our rurg Review, April, 1871.

quotitions have often proved - Dublin Med. Press Ithis, if not the best, is one of the best.conducted aud Circulur, Jan. 31, 1s72.

(1) Euglish periodical the Loncet, and of American the Atw. Jourual of the Bleclicul Sciences, a re to be regarded is necesmitles to the readiag practitioner.N $Y$. Medicul Guztte, Jan. 7, isil.

'libe dinerian Journal of the Medical Sciences yields to none in the amount of original and borinedical quarterlies in the English language, and the present um uber is not by any means nulerior to its predecensors. - Loudon Luncet, A $11 \mathrm{~g} 23,1873$

Almost the only one that circulates everywhere, all over the Unton and in Europe.-London Medical T'imes, sejut. 5, 1 b6s.

And that it was specifically included in the award of a nedal of merit to the Publisher in the Vennal Hixhibition in $18: 3$.

the subscription price of the "A merican Journat, of the Medical Sctrances" has never been raised during its long career. It is still Five Voldaks per anum ; and when paid lor in advance, the subseriber receives in addition the "MEdreal, News AxD Library," making in all about 1500 large octavo pages per annum, free of pustage.

II.

\section{THE MEDICAL NEWS AND LIBRARY}

is a monthly periodical of 'Thirty-two large octavo pages, making 384 pages per andum. Its "Nows DnPARTMEN" presents the current information of the day, with Clinical Leetnres and Hospital (t)anings; while the "Llbrary 1)Epartment" is devoted to publishing standard works on the various branches of medical science, paged

* Com nunications ire invited from gentlemen in all parts of the country. Elaborate articles inserted by the Edator are jod for by the l'ublisher. 
separately, so that they ean be removed and bound on completion. In this muner subscribers have received, without expense, such worlis as " W'atson's l'rat'tre,"

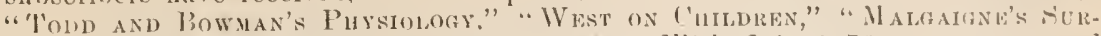

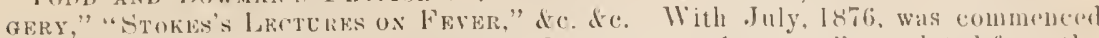

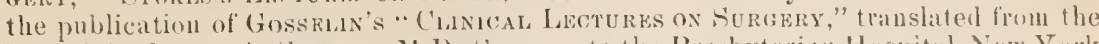
French by Lew 1 A. Strmson, M.1), Surgeon to the Presbyterian Hospital, Now York (see p. 26). Gentlemen commencing their snbseriptions with 187\%, can obtain the portion of "Gossbidx" issued in 1876 for Fifty cents, if remitted promptly.

As stated above, the subscription price of the "MEDICAL Nows ani limbary" is OxE DOLLa per aunum in advance; and it is furnished without charge to all andrance paying subscribers to the "American Journal of tire Ml hical Sciences."

\section{III.}

\section{THE MONTHLY ABSTRACT OF MEDICAL SCIENCE.}

The "IIoxthuY ABstract" is issued on the first of every month, each number containing forty-eight large octaro pages, thus furnishing in the course of the year about six hundred pages. 'The aim of the ABstract will be to present a careful condensition of all that is new and important in the medical journalism of the world. and all the prominent professional periofleals of both hemispheres will be at the disposal of the Editots. 'T'o show the manner in which this plan has been carried out it is sufficient to state that during the year 1876 it contaiued-

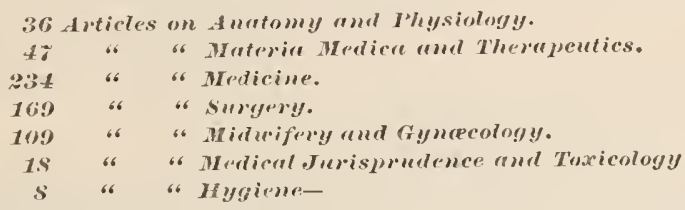

making in all Six HuxDred and 'TWENTY-ONF articles in a single year.

'The subscription to the ". Monthly Abstract," free of postage, is Two Dollars AND A HALF a year, in advance.

As stated above, however, it will be supplied in conjunction with the "AMrRicas Journal of the M EDical scimices" and the "Medicat. News and Library," making in all about 'T'WENTY-oNe HuxdRED pages per anum, the whole free of postage, for Six Dollars a year, in advance.

Those who desire to have complete sets, can still procure Vol. I. July to Decem ber, 1874 , I vol. Sro., cloth, of about 300 pages, for $\$ 150$, and Vol. II, and 111 . for 1875 and 1876,1 vol. 8 vo of about 600 pages cloth, for $\$ 300$ each.

In this effort to bring so large an amount of practical information within the reach of every member of the profession, the publisher coufidently anticupates the firiendly aid of all who are interested in the dissemination of sound medicial literature. He trusts, especially, that the subscribers to the "AMGRICAN M EDICAL Joursal" will call the attention of their acquaintances to the advantages thus offered, and that he will be sustained in the endeavor to permanently establish medical periodical literature on a footing of cheapness never heretutore attempted.

\section{PREMIUM FOR OBTAINING NEW SUBSCRIBERS TO THE "JOURNAL."}

Any gentleman who will remit the amount for two subscriptions for $187 \%$, one of which must be for a new subsriber, will receive as a PREMun, free by mail, a copy of "Flint's Essars ox C'onservative 11 molcine" (for advertisement of which see p. 15),

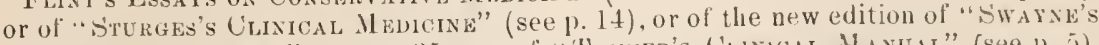
Obstetric Aphorisus" (see p. "25). ol of "'T'anner's Ulinical Manual" (see p. j), or of "Unambers's Restorative Medicine" (see p. 18), or of "West ox Nerrous DISORDERS OF ChHLDREN" (see page 21 ).

* * Gentlemen desiring to avail themselres of the advantages thins offered will do well to forward their subscriptions at an early day, in order to insure the receipt of

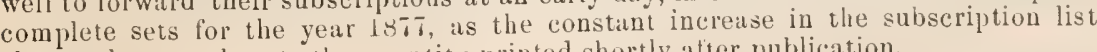
almost always exhausts the quantity printed shortly after publication.

to 'The safest mode of remittance is by bank check or postal money orler, drawn to the order of the undersigned. Where these are not accessible, remittances for the "JOURNAL" may be made at the risk of the publisher, by forwarding in REGLSTERED letters. Address,

HENRY C. LEA,

Nos, 706 and 708 Sansom St., Philadelpuia, Pa. 
UNGLISON (ROBLEY), M.D.,

Late Professor of Institutes of Medicine in Jefferson Medical College, Philadelphia.

MEDICAL LEXICON; A Dictionary of Medical Science: Containing a concise explanation of the various Subjects and Terms of Anatomy, Physiology, Pathology, Hygiene, Therapeutics. Pharmacology, Pharmacy, Surgery, Obstetrics, Medical Jurisprudence, and Dentistry. Notices of Climate and of Mineral Waters; Formules for Officinal, Empirical, and Dietetic Preparations; with the Accentuation and Etymology of the Terms, and the French and other Synonymes; so as to constitute a French as well as English Medical Lexicon. A New Edition. Thoroughly Revised, and very greatly Modified and dugmented. By Richard J. I'Unglison, M.D. In one very large and hand. some royaloctavo volume of over 1100 pages. Cloth, $\$ 650$; leather, raised bands, $\$ 750$. (Just Issued.)

The object of the author from the outset has not been to make the work a mere lexicon or dictionary of terms, but to afford, under each, a condensed view of its various medical relations, and thus to render the work an epitome of the existing condition of medical science. Starting with this view, the immense demand which has existed for the work has enabled him, in repeatod revisions, to augment its completeness and usefulness, until at length it has attained the position of a recognized and standard authority, wherever the language is spoken.

Special pains have been taken in the preparation of the present edition to maintain this en. viable reputation. During the te $n$ years which have elapsed since the last revision, the additions to the nomenclature of the medical sciences have been greater than perhaps in any similar period of the past, and up to the time of his death the author labored assiduously to incorporate every. thing requiring the attention of the student or practicimer. Since then, the editor has been equally industrious, so that the additions to the vocabulary are more numerous than in any previous revision. Es lecial attention has been bestowed on the accentuation, which will be found narked on every word. The typ graphical arrangement has been much improved, rendering reference much more easy, and every care has been taken with the mechanical execution. The work has been printed on new type, small but exceedingly clear, with an enlarged page, so that the additions have been incorporated with an increase of but little over a hundred pages, and the volume now contains the matter of at least four ordinary octavos.

A hook well known to our readers, and of which excry American ought to be proud. When the learned author of the work passed away, probalily all of us ferred lest the hook should not maintain its place in the adraucing science whose terms it defiries. Fortunately, Dr. Riclard J. Dunglison, having assisted his father in the revision of several editions of the work, and having been, therefore, trained in the methods and imbued with the spirit of the book, has heen able to edit it, not in the patchwork manner so dear to the lient of book editors, so repulsive to the taste of intelligent book readers, but to edit it as a work of the kind should be edited-to carry it on steadily, withont jar or interrujtion, aloug the groores of thought it has tratvelled during its lifetime. To show the magnitude of the task which Dr. Dunglison has assumed and carried through, it is only necessary to state that more than six thousand new suhjects have heen added in the present edition. Without oceupying nore space with the theme, we congratulate the editor on the successful completion of his lators, and hope he may reap the wellearmed reward of profit and honor--Ihala. Med. Times, Jan. 3, $187 \pm$.

About the first book purchased by the medical student is the Medical Victionary. The lexicon explanatory of technical terms is simply a sine qua non. In a acience so extensive, and with such collaterals as medicine, it is as much a necessity also to the practising pliysician. T'o meet the wants of students and nost pliysicians, the dictionary must be condensed while comprehensive, and practical wlile perspicicious. It was because Dunglison's met these iudications that it becullue at once the dictionary of gencral use wherever melicine was itudied in the English languace. In no former revision lave the alterations and additions bees. so great. More than six thousand new sutjects and ternis have beev adder. The chief terms have been sot in hlack letter, while the derivatives follow in small eaps; an arragement which grestly facilitates reference. We may kafely confirm the hope ventured by the editor "that the work, which possesses for him a filial as well as an individus] interest, will be found wortby a continuance of the position so long accorded to it as a standard authority."-Cincinnati Clinic, Jan. 10, 1574.

We are glad to see a new edition of this invaluahle work, and to find tlat it has beeu so thoroughly revised, and so greatly improved. Tlie dictionary, in its pre sent torm, is a m dical library in itself, and one of which every physician should be possessed. $-\Lambda$. I. Med. Journal, Feb. 1874.

With a history of forty years of unexampled succes and universal indorsement hy the nuedieal profession of the western coutinent, it would he presumption in any living medical American to essay its review. No re. viewer, however uble, can add to its faule; no captious critic, however cautic, can remove a single stone from its tirm and enduring foundation. It is destined. as a colossal monument, to perpetuate the solid aud richly deserved tame of Robley bunglison to coming genera tions. The large additions made to the voeatsulary, we think, will be welcomed hy the profesion as supplying the want of a lexicon fully up with the march of sci. euce, which has heen inereasingly felt for some years past. The accenturtion of terms is rery completc, and, as far as we have been able to examiue it, very excel lent. We hope it may be the means of securing greater uniformity of pronunciation among nedical ben.- At. lanta Med and Surg.Journ., Feh. 1874

It would he mere waste of words in 0.8 to express unr admiration of a work which is so aniversally and deservedly appreciated. The most adinirable work of its kiud in the English language. - Flasgoro Mredieal Journal, January, 1866.

A work to which there is no equal in the Englls anguage. - Edinburgh Medical Journal.

Few works of the class exhihit a grander monumen f patient research and of scientific lore. The extent of the sale of this lexicon is sutticient to testify to its asefulness, and to the great service conferred hy Dr. Robley Dunglison on the profession, and indeed on thers, hy its issue.-Londun Lancet, Ma y 13, 1865

It has the rare merit thatit certainly has no rival in the English language for accuracy and extent of refereuces.-London Medical Gazetie.

$H^{O B L Y N}(R I C H A R D$ D.), M.D.

A DICTIONARY OF THE TERMS USFD IN MEDICINE AND THE COLLATERAL SCIENCES. Revised, with numerous additions, by IsAAC HAYB, M.D., Editor of the "American Journal of the Medical Sciences." In one large royal $12 \mathrm{mo}$. volume of over 500 double-columned pages; cloth, $\$ 150$; leather, $\$ 200$

It th the best book of definitions we have, and ongbt always to he epontbe student'e table.-809ther' Med. and Surg. Journal. 


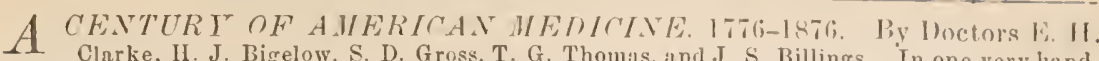
Clarke, II. J. Bigelow, S. D. Gross, T. G. Thomas, and J. S. Billings. In one very hand. some 12 mo. rolume of about 350 pages : cloth, $\$ 225$. (Just liealy.)

This work has appeared in the pages of the American Journal of Hedical Sciences during the year 1876. As a detaile account of the development of metlical science in America, ly gentle. men of the highest authority in their respectire departments, the profession will no doubt wel. come it in a form adapted for preservation and reference.

One of the most charming souvenirs of the year, just passed, is the roln me before us. Although in. tended as an especial offering to the American medical profession, this work is likely to awaken more than national interest. A record of nedical discovery, medical literature, distinguished nedical men, of the last hundred years, the work munt be regarded as one of permanent value; dealing as it does with the history of uedicine in the United States, it will ineiviably he used and largely quoted by the future medical histographers of all countries. As a book it can also be commended to the non-professioual public, and Te sliall be much surprised if its sale does not far surpass the most sanguine expectations ofitweuterprising publisher. Nogentleman's lihrary is conplete without it. Aकhistorical reports the various papers couposing the work have never beeu equalled ou this aide of tha Atlantic. The publisher bas displayed rare perspicuily in his choice of edi. tors; certainly no more coin petent group of medical men in this country could havebeta selected. But the review is becoming tooloug and we must drop our pen, only saving. in conclusiou, to our numerous readers, buy a cony of this hook if you wish to pass your leisure hours pernsingsomethivg inteusely interesting aud, at the sametime, wonderfully instructive,-Cincin. Lancet and Observer, Dec. ' 76.

ROD IELL (G.F). F.R.A.S. s.e.

A DICTIONARY OF SCIENCE: Comprising Astronomy. Chem. istry, Dynamics, Eleetricity, Heat, Ilydrodynamics, Iydrostaties, Light, Misgnetism, Mechanics, Meteorology, Pneumatics, Somnd, and Statics. Preceded by an Essay on the History of the Physical Sciences. In one handsome octavo volume of 694 pages, anu many illustrations: cloth, $\$ 5$.

NEILL (JOHN), M.D., and $S_{\text {Prof. of the Institutes of Bredicine in the }}^{\text {MITH }}$

A A A A TICAT COMPEVDIUY OF THE TARIOUS BRANCHES OF MEDICAL SCIENCE; for the Use and Examination of Students. A new edition, revised and improved. In one very large and handsomely printed royal $12 \mathrm{mu}$ volume, of about one thousand pages, with 374 wood cuts, cloth, $\$ 4$; strongly bound in leather, with raised bands, $\$ 475$.

\section{FARTSHORNE (HENRT), M. D., \\ Professor of Hygiene in the University of Pennsylvania.}

A CONSPECTUS OF THE MEDICAL SCIENCES; containing Handbooks on Anatomy, Physiology, Chemistry, Materia Medica, Practical Medicine, Surgery, and Obstetries. Second Edition, thoroughly revised and improved. In one large royal $12 \mathrm{mo}$. volume of wore than 1000 closely printell pages with 477 illustrations on wood. Cloth, $\$ 425$; leather, $\$ 500$. (Lately Issued.)

The work before us has already successfully assert. od its claim to the confidence and favor of the profession: it bnt remains for us to say that in the present editiou the whole work has heen fully overhauled and brouglit up to the present status of the science.Atlanta Hed. and Surg. Journal, Sept. 157t.

The $\pi$ ork is intended as an aid to the medical studeut, aud as such appears to adinirably fulfil its ohject by itsexcellent arrangement, the full compilation of facts, the perspicuity aud telseuess of lauguage, and the clear and instructive illustrations in sisme purts of the work-Americun Journ. of Pharmacy, Philadelphia, July, 157t.

The volume will be found useful, not only to stu dents, but to many others who may desire to refresh their memories with the smallest possible expend.ture of tiue. - N Y Mert. Journal, Sept. 1S7t.

The student will fiud this the most couvenient ar $d$ useful book of the kind ou which be citn lav his hand.-Pacific Med rn't S'urg. Journ., A ug. 1S7t

This is the hest bouk of its kind that we liave ever examiued. It is an houest, accurate, aud coucise compend of medical sciences, as fairly as posible representing their present cordition. The chauges and the additious have heen so judicious and thorough as to render it, so far as it goes, entirely trustworthy. If students must bave a conspectus, they will be wire. to procure that of Dr Hartshorne.-Detroit Rev. of Med and Pharm., Aug $157 t$.

LUDLOW (J.L.), M. D.

A MANUAL OF EXAMINATIONS upon Anatomy, Physiology, Surgery, Practice of Medicine, Obstetrics, Materia Medica, Chemistry, Pharmacy, and Therapeutics. To which is added a Medical Formulary. Third edition, thoroughly revised and greatly extended and enlarged. With 370 illustrations. In one bandsowe royal $12 \mathrm{mo}$. volume of 816 large pages, cloth, $\$ 325$; leather, $\$ 375$.

The arrangement of this volume in the form of question and answer renders it especially suitable for the office examination of students, and for those preparing for graduation.

\section{TANNER (THOMAS HA W'KES), M. D., \&. .}

a MANUAL OF CLINICAL MEDICINE AND PHYSICAL DIAG. NOSIS. Third American from the Second London Edition. Revised and Enlarged by Trubury Fox, M. D., Physician to the Skin Department in University College Hospital, \&c. In one neat volume small $12 \mathrm{mo}$, , of about 375 pages, cloth, $\$ 150$

*** On page 3, it will be seen that this work is ,ffered as a premium for proc 7 ring new subcribers to the "A MERICAN JoURNAL OF THE MEDICAL J́CIENCES." 
Lecturer on Anatomy at St. George's Hospital, London.

ANATOMY, DESCRIP'IVE AND SURGICAL. The Drawings by H. V. Carter, M. D., late Demonstrator on Anatomy at St. George's Hospital; the Disseotions jointly by the Autror and Dr. CARTER. A new American, from the fifth enlarged and improved London edition. In one magnificent imperial octavo volume, of nearly 900 pages, with 465 large and elabornte engravings on wood. Price in cloth, $\$ 600$; leather, raised bands, $\$ 700$. (Lately Published.)

The author has endeavored in this work to cover a more extended range of subjects than is eas. tomary in the ordinary text-books, by giving not only the details necessary for the student, but also the application of those details in the practice of medicine and surgery, thus rendering it both a guide for the learner, and an admirable work of reference for the active practitioner. The en. gravings form a special feature in the work, many of them being the size of nature, nearly all original, and having the names of the various parts printed on the body of the cut, in place of figures of reference, with deseriptions at the foot. They thus form a complete and splendid series, which will greatly assist the student in obtaining a clear idea of Anatomy, and will also serve to refresh the memory of those who may find in the exigencies of practice the necessity of recalling the details of the dissecting room; while combining, as it does, a complete Atlas of Anatomy, with a thorough treatise on systematic, deseriptive, and applied Anatomy, the work will be found of essential use to all physicians who receive students in their offices, relieving both preceptor and pupil of much labor in laying the groundwork of a thorough medical education.

Notwithstanding the enlargement of this edition, it has been kept at its former very moderate price, rendering it one of the cheapest works now before the profession.

Theillustrations are beaulifully executed, and reu-| From time to time, as successive editions have ap. der this work an indispensahle adjnuct to the library peared, we have had much pleaxure in expressing of the surgeon. This remark applies with great force the general judginent of the woudertal excellence of to those surgeons practising at a distance from our Gray's A uatimy.-Cincinnati Lancet, July, 1870.

lajge cities, as the opportunity of refreshing their meinory by actual dissection is not always altainable.Clanada Mod Journal, Aug. 1870.

The work is toowell known and appreciated hy the profession to need any comment. No medical man can afford to he without it, if its only merit were to serre as a reininder of that which so soon hecomes forgotten, when not called into frequent use, viz., the relations and names of the complex organism of the human hody. The present cdition is much improved. -California Med. Gazette, July, 1870.

Gray's Anatomy has heen so long the standard of perfection with every student of anatomy, that we need do no more thau call attention to the improvement in the preseut edition.-Detroit Review of Med. and, Pharm., Aug. 1870.

Altogether, it is unquestionably the most complete and serriceable text-book in anatomy that has ereI heen presented to the student, and forms a striking contrast to the dry and perplexing volnmes on the name subject through which their predecessors strng gled in days gone hy. $-N$. Y. Med. Record, Jnne 15 1870 .

To commend Gray's Anatomy to the medical pro. fession is almost as mnch a work of supererogation as it wonld be to give a favorahle uotice of the Bible in the religious press. To say that it is the most complete and conreniently arranged text-hook of its kind, is to repeat what each generation of stndent. has learned as a tradition of the elders, and verified hy personal experience. $-N \quad \boldsymbol{Y}$. Med. Gaxette, Dec. 17,1870

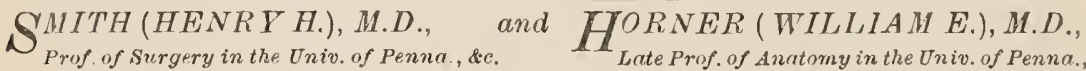

AN ANATOMICAI A TLAS, illustrotive of thy in the Uiv. of Penna., a

Human Body. In one volume, large imperial octavo, eloth, with about six hundred and fifty beautiful figures. $\$ 450$.

The plan of this Atlas, which renders it so pecn- the kind that bas yet appeared; and we mnst add liarly convenient for the student, and itw superh ar- the very heantiful manner in which it is "got ap," tistical execution, bave heenalready pointed out. We is so creditahle to the country as to he flattering to must congratulate thestudent upon the completion our national pride.-American Medical Journal. of this Atlas, as it is the most convenient work of

\section{SCHAFER (EDW'ARD ALBERT). M.D. \\ Assistant Professor of Phyciology in University College, London.}

A COURSE OF PRACTICAL IHISTOLOGY : Being an Introduction to the Use of the Microscope. In one handsome royal 12 uro. volume of 304 pages, with numerous illustrations: eloth, $\$ 200$. (Just Ready.)

We are very muel, plenvel with the hook, which teaslies the student simply low to use his instruments ant conduce his stutice without going tintuer into the microscopic anatony of the tiscues and oreans than is alsolutely necesary. What we particularly praiso in it is the way in which it takes the student hy the hand, as it were, showing him what to do, and cxplaining simply, but thoroughly. how to do it.-Bessin Mled. and Surg. Journ., April, 1877.

It is deveterl wholly to the unc of the microseope in the study of histology. It is a very thoromgh and pric

HORNER'SSI'ECIAL, A ATOMY A ND HISTOLOGY Eighth edition, extankiralv ravisad and modifar In 2 vols. $8 v 0$., of over 1000 pages, with more thall 300 wond-cnts: cloth. $\$ 6$ on

Hol)fis' PRACTICAT, DISSECTIONS Second Edition, tholoughly revised. In one neat royal 12 mo. volume, balf bonnd, 8200.

SIIARPEY AND RIAIN'S IIUMAN ANATUMY Reviked, with Notes and Adlitions, ly Jesspu Laspr, M. D., Professor of Anatomy in the Uuiversity of

tical little haudbook of the best methods of making lisfological preparations nnd examining llem under the microacope- $-1 m$ Jisura. of Microseopy, May, 1sit.

From first to last the book slinws that it lias heen unde by one who is accustomed to teraching the subjoet abnut which lie writes, and has praetical knowlerlere of the ohstuctes and dificultes to ba met with. We heartily recommend the rolume to those who wish : concise and roliable haudbook.-New Remedies, May 15, $18 \pi$.

Pennoylvania Complete in two large octavo vol. nues of about 1300 pages, will 511 illustrations: eluth, \$6 on

MACLISL'S SURGICAL ANATOMT In one volume, very largeimperial quarto; with fis largeandsplendid plates, drawn in the best style and beatifilly colored, containing 190 flgures; many of then the size of life; together with coplous explanatory letter-press. Sirongly and handsomely bound in cloth. Price $\$ 1+00$ 
WILSON (ERASMUS), F.R.S.

A. SYS'TEMGF HUMAN ANATOMI, General and Special. Eelited by W. H. Gоввеснт, M. D., Professor of General and Surgical Anatomy in the Medical Col. lege of Obio. Illustrated with three bundred and ninety-seven engravings on wood. In one large and handsome octavo volume, of over too large pages; cloth, $\$ 400$; leather, $\$ 500$.

The publisher trusts that the well-earned reputation of this long-established favorite will be more than maintained by the present edition. Besides a very thorough revision by the author, it has been most carefully examined by the editor, and the efforts of both bave been directed to in. troducing everything which increased experience in its use has suggested as desirable to render it a complete text-book for those seeking to obtain or to renew an acquaintance witb Human Ana. toing.

IEATH (CHRISTOPHER), F. R. C.S.

Teacher of operative Surgery in University College, London.

PRACIICAL ANATOMY: A Manual of Dissections. From the Second revised and improved London edition. Edited, with additions, by W. W. KEEN, M. D., Lecturer on Pathological Anatomy in the Jefferson Medical College, Philadelphia. In one handsome royal 12 mo. volume of 578 pages, with 247 illustrations. Cloth $\$ 350$; leather, \$4 00 .

Dr. Keen, the American editor of this work, in his preface, says: "In presenting this American edition of 'Heath's Practical Anatorny,' I feel that I have been instrumental in supplying a want loug felt for a real dissector's maunl, "and this assertion of its editor we deem is fully justified, after an examina tion of its contents, for it is really an excellent work. Indeed, we do uot hesitate to say, the best of its clas: with which we rre acquainted; rexembling Wilson In terse aud clear description, excelling viost of the so-called practical anatonical dissectors in the ecope of the subject and pructical selected matter.

In reading tlis work, oue is forcibly impressed with the great paius the anthor takes to impress the subfect upon the mind of the student He is full of rare snd pleasing little derices to aid memory in main-

taining its hold upon the slippery slopes of anatomy -St. Louis Merl. and Surg. Jucrnial, Mar. 10, 1S71.

It appears to us certain that, as a guide in dissection, and as a work containing facts of anatomy in brief and easily understood form, this manual is complete. This work coutains, also, very perfect illustrations of parts which can thns be mure easily understood and studied; in this respect it compares favorably вith works of mucl greater pretensiun. Sucb wanuals of anatomy areal ways favorice workt with medical students. We would earnestly recom. mend this one to their attention; it has excellence which make it valuahle us a guide in disspeting, a well as in studying anatomv. - Buffubo Medieal and Surgical Journal, Jan. 1871.

\section{BELLAMY (E.), F.R.C.S.}

THE STUDENT'S GUIDE TO SURGICAL ANATOMY : A TextBook for Students preparing for their Pass Examination. With engravings on wood. In one handsome royal $12 \mathrm{mo}$, volume. Cloth. $\$ 225$. (Lately Published.)

We welcome Mr. Bellamy's work, as a contribution to the study of regional anatomy, of equal value to the student ad the surgeon. It is written in clear and concise etyle, and its practical suggestions add largely to the interest attaching to its technical details - ihicago Med. Examiner, Malcli 1, 1s74.

We cordially congratnlate Mr. Bellamy upon having produced it - Med. Times and Gaz
We canuot too highly recommend it.-Student's Jourual.

Mr. Bellamy has spared no pains to produce a really reliable studeut" $*$ guide to surgical anatumyone which all caudilales for surgical degrees niay consult with advaniage, and which possesses much orivinal matter. - Med. Press and circular.

CLHLAND (JOHN), M.D.,

Professur "f Anrtomy and Physiology in Queen's College, Gulway.

A DIRECTORY FOR THE DISSECTION OF THE HUMAN BODY In one small volume, royal 12 mo. of 182 pages : cloth, $\$ 125$. (Now Ready.)

This work makes no pretensions to be a manual of descriptive anatomy, the aim of the author being to furnish such instruction as will enable the stulent to make the most of his opportunities in a practical course of dissections. It in nowise supersede? the ordinary text-books of analomy, but in conjuction with them, will afford, in a clear and compendious form, the infor. mation required as a guide in the dissecting-room. The author is well known as one of the most experienced practical anatomists in Great Britain, and has here recorded the results of many years: assiduous labor in guiding beginzers through this arduous part of their training.

The distinguinhed Professor of Anatomy in Galway has done guod work by the publication of this mall rolume. brery student of anatomy workiugin the dissectiug roun must often have felt the waut ot a short, cuncise, aud handy guide to bis work. This lie will find iu the "Directory." The directions are short, not overlnaded with facts, and canedsily be read orer before begiuning a part, so that in a short time it working plan of the proposed method of procedure is bruught clearly before the student's iniud. We cor dialty recum mend every dissector :o provide himself at once with this shortbut involuable "Iirectory. -Edin. Med. Journ., Feb. 1877.

HARTSHORNE (HENRY), M.D.,

Professor of Hygiene, ete, in the Univ. of Penna.

HANDBOOK OF ANATOMY AND PIIYSIOLOGY. Second Edi tion, revised. In one roval $12 \mathrm{mo}$. volume, with 220 wood-cuts; cloth, $\$ 175$. (Just Issutd.)

This is a plain, convenient, dissecting gnide, to be used over the subject. As sucli, it will comment it selt to the student by the luvid composition and di. tiuct directious of the author.-Med. and. Surg. Reporter, Feb. $1 \leq 77$

This volume does not interfere with the text-books in comm on use, but merely supplements them, and prepares the dissector for many practical dificulties that are aut to perplex the inexperiencad. It is of a courenient size forcarrying in the pucket, a ai sbould be in the possession ot every student of uedicine. r. Y. Med. Journ., Harch, is 7 .

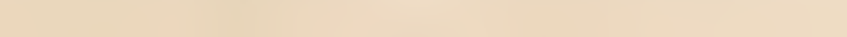


CAKPENTER (WILLIAM B.), M.D., F.R.S., F.G.S., F.L.S.,

PRINCIPLES OF HUMAN PHYSIOLOGY; Edited by Henry Power, M.B. Lond., F.R.C.S., Examiner in Natural Sciences, University of Oxford. A new A merican from the Eighth Revised and Enlarged English Edition, with Notes and Addi. tions, by Francis G. Smith, M. D., Professor of the Institutes cf Medicine in the University of Pennsylvania, etc. In one very large and handsome octarovolume, of 1083 pages, with tro plates and 373 engravings on wood; cloth, $\$ 550$; leather, \$6 50. (Nov Ready.)

The great work, the crowning labor of the distinguished author. and through which so nany generations of students have acquired their knowledge of Physiology, has been almost metamorphosed in the effort to acapt it thoronghly to the requirements of modern science. Since the appearance of the last American edition, it has bad several revisions at the experienced hand of Mr. Power, who has modified and enlargerl it so as to introduce all that is important in the investigation $=$ and discoveries of England, France, and Germany, resulting in an enlargement of about one-fourth in the text. The series of illustrations has undergone a like revision, a large proportion of the former ones having been rejected, and the total number increased to nearly four hundred The thorough revi:ion which the work has so recently received in England, has rendered unnecescary any elaborate additions in this country but the American Editor, Professor Smith, has introduced such matters as his long experience has shown him to be requisite for the student. Every care has been taken with the typographical execution, and the work is presented, with its thousand closely, but clearly printed pages, as emphatically the text-book for the student and practitioner of medicine-the one in which, as heretofore, especialcare is directed to show the applications of phy iology in the various practical branches of medical science. Notwithstanding its very great enlargement, the price has not been increased, rendering this ne of the cheapest works now before the professiun.

What an enormons labor the editor has had to perform. incorporating into the text the isolated discoveries. and observations of various authors in the lifferent depart ments of physiology, may be partly gathered from bi prefice. Such editing is, indeed, a most arduous task and one to which but few would aspire, for the reputation fained is by no means proportionate to the labor cxpendeal. In this case the work has been well and faithfully done, and no mean skill has been exhibited in introducing so much that is new, and leaving the work so thoroughly "Carpenter's Physiology", after all.Ohis Mth. and Surg.Journ., Feb. 1877 .

"Good wine neerls no bush" says the proverb, and an old aud faithful servant like the " big" Carpenter, as carefully brourht down as this edition has been by $\mathrm{Ir}$. Henry Power, needs little or no comnendation by us. Such enormous advances have recent'y been made in our physiological knowledge, that what was perfectly new a year or two agro. looks now as if it had been a received and established fact for years. In this encyclopadic way it is unrivallel. Ilere, as it seems to us, is the great value of the book: one is safe in sending a studeut to it for information on almost any given subject, perfectly certain of the fulness of information it will convey, and well satisfitd of the accuracy with which it will there be found stated.-London Med. Times and Guzetle. Fel), 17,1876 .

Thus fully are treated the strncture and functions of all the important orguns of the body, while there are chap. ters on sleep and somnambulism; chapters on ethnolory : a full spction on creueralion. and abundant references to the curiosilies of physiology, as the erolution of light, beat, electricity, etc. In short, this new exlition of Carpenter $i$, as we have said at the start, a very euryclopedia of molern physiology.-The Clinic, Feb. 24, 1877.

The merits of "Carpenter's l'hysiology are so widely known and appreciated that we need only alluile brietiy to the fact that in the latest edi'ion will be found a coniprehensive embodiment of the results of recent jibysio. lorical investiration. Care has been taken to preserve the practical character of the original work. In fart the entire work has been brought up to date, snd liurs evilence of the amount of labor that has been bestowed upon it by its distinguished editor, Mr Ilenry Power. The American clitor las made the latest additions. in order fully to cover the time that has elapsed since the last English edition- $-Y$. Med. Journal, Jan. 1SiT.

A more thorough work on physiology could not be found. In this all the facts discovered by the late researches are noticed, and neither student nor practitioner should be without this exlsustive treatice on an impntant elementary branch of medicine.-1tlanta Med. and Surg Journal, Dec. 1876.

We regurd it, as a text-book, as near perfect as could be, and a book of reference of the greatest value to the practitioner. the student, and the lecturer. - Washville Journ. of Medicine and Surgery, Dec. $15 i 6$.

\section{KIRKES (WILLIAM SENHOOSE), M.D.}

A MANUAL OF PHYSIOLOGY. Edited by W. Morrant BaKer, M.D., F.R.C.S. A new American from the eighth and improved London edition. Witb about two hundred and fifty illustrations. In one large and handsome royal $12 \mathrm{mo}$. $\nabla \circ]$. ume. Cloth, \$325; leather, \$3 75. (Lately Issued.)

Kirkes' Physiology has long been known as a concise and exceedingly conrenient text-book, presenting within a narrow compass all that is important for the student. The rapidity with which successive editions have followed each other in England has enabled the editor to keep it thoroughly on a level with the changes and new discoveries made in the science, and the eighth odition, of which the present is a reprint, has appeared so recently that it way be regarded as the lutest accessible exposition of the subject.

On the whole, there is very little in the book, gertext-books of Carpenter or Marshall. The book which either the student orpractitioner will not find is admirably adapted to be placed in the hands of of practical value and consistent with our prenent students. -Boston Med. and Surg. Journ., A pril 10 , knowledge of this rapidly changing ecience; and we 1873.

have no hesitation in expressing our opinion that

this eighth edition is one of the best handbooks on physiology which we have in our language, $-N, Y$. Med. Record, April 15, 1873.

This volume migbt well he need to replace many of the physiological text-books in use in this coun try. It represents more accurately than the works of Dalton or Flint, the prenent state of onr knowl. edge of most physiological questions, while it is mnch less bulky and farmore readable than the lar.

In its enlarged form it is, in our opinion, still the best book on physiology, most useful to the student. - Plila. Med. Times, Aug. 30, 1873.

This is undonbtedly the best work for stndents of physiology extant.-Cincinnoti Med. Nezes, Sept. '73.

It more nearly represents the present condition of physiology than an y other text-book on the subject. Detroit Rev. of Med. Pinarm., Nov. 1873. 
DALTON (J. C.), M.D.

Professor of Physiolngy in the College of Physicians and Surgenns, New York, \&c.

A TREATISE ON HUMAN PHYSIOLOGY. Designed for the use of Students and Practitioners of Medicine. Sixth edition, thorouglaly revised and enlarged, with three hundred and sixteen illustrations on wood. In one very benutiful octavo vol. ume, of over 800 pages. Cloth, $\$ 550$; leather, $\$ 650$. (Just Issued.)

From the Preface to the Sixth Edition.

In the present edition of this book. while every part has received a careful revision, the original plan of arrangement has been changed only so far as wis necessary for the introluction of new material.

The aditions and alterations in the text, requisite to present concisely the growth of positive physiological knowledge, huve resulted in spite of the author's earnest efforts at condensation, in an increase of fully fifty per cent. in the uatter of the work. A change, however, in the typographical arrangeuent has accommodated these additions without undue enlargement in the billk of the volume.

The new ehemical notation and nomenclature are introduced into the present edition, $a s$ hav ing now so generally taken the place of the old, that no confusion need result from the change. The centigrade system of measurements for length, volume, and weight, is also adopterl, these measurements being at present almost universally employed in original physiological in vestigations and their published accounts. Temperatures are given in degrees of the centigrade scale, usually accompanied by the corresponding degrees of Fahrenheit's seale, inclosed in brackets.

NEW Iork, Septeuber, 1875.

During the past few ycars sereral new works on physiology, aud new editions of old works, have appeasci, compering for the favor of the medical student, but none will rival this new edition of Dalton. As now enlarged of reference for the practitioner.-Chicago Med. Jown. and Examiner, Jan. I 876.

Prof. Dalton has discussed conflicting theories and couclusions legarding physiolngical questions with a fuimess, a fulness, and a conciseuess which lend freshness and rigor to the cntire bnok. But his discussinns have heen so guarded by a refusal of almission to those speculative and theoretical explanations. which at best exist iu the minds of observers themselves as only pro. babilities, that noue of his readers need be lerl into grave errors while making them a study.-The Medical Record, Feb. 19, 1876.

The revision of this great work has hrought it forward with the physiological arlvances of the day. and renders it, as it has ever heen, the finest work for studenis extant.-Nushrille Journ. of Mol. and Surg., Jan. 1876.

For clearness and perspicuity, Dalton's Physiology comurended itself to the stuitent years ago. and was a pleasant relief from the verbose productious which it supplanterl. Pliysioligy has. however. made many ad. vances since then-ant while the style has becn preservell intact, the work in the prasent edition has been brought ulr fully abreast of the times. The new chemical polation and nomenclature hare also been introdured into the present edition. Notwithsianding the multiplicity of text-books on physiology, this will lose none 6,1875 .

f its old time popularity. The mechanical execution of the work is all thit could be desired.-Peninsular Journal of Medicine, Dec. 1875.

This ponular texlobook on physiology comes to us in its sixth elition with the addition of about fifty per cent. of uew matter, chiefly in the departments of pathologicul chemistry and the nervous system. where the principal advances have been realizel. With so thorough resixion aud additions, that keer the work well up to the times, its continued poprularity may bo confidently pretlicted, notwitlstanding the comperition it may encouter. The pub!isher's work is admirably done.-St. Louis Mell, und Surg. Journ, Dec. 1575

We heartily welcome this, the sixth edition of this almirable text book. than which there arc none of equal brevity more valuable. It is cordially recommended by the Professor of Physiology in the University of Louisiand, as by all competent terchers in the United States and wherever the English language is reat, this book has been appreciated. The present edition, with it 316 admiraoly executed illustrations, has been carefully revised and very much enlarued, although its bulk loes not seem perceptibly increased.-New Orleans Medical and Surgical Journal, March, 1876.

The present edition is very much superior to every other, not only in that it briugs the subject un to the times, but that it doss so more fully and satisfactorily than any previous editiou. Take it altogether, it remains, in our humble opinion. the best text book on pliysiology in any land or language.-The Clinic, Nov.

UNGLISON (ROBLEY), M.D.

Professor of Institutes of Mudicine in Jefferson Medical College, Philadelphia.

HUMAN PHYSIOLOGY. Eighth edition. Thoroughly revised and extensively modified and enlarged, with five hundred and thirty-two illustrations. In two large and handsomely printed octavo volumes of about 1500 pages, clotb, $\$ 700$.

\section{CEHMANN (C. G.)}

PHISIOLOGICAL CHEMISTRY. Translated from the second edi. tion by Georgk E. DAY, M. D., F. R. S., \&c., edited by R. E. Rogers, M. D., Professor of Chemistry in the Medical Department of the University of Pennsylvania, with illustrations selected from Funke's Atlas of Physiologieal Chemistry, and an Appendix of plates. Com. plete in two large and handsome octavo volumes, containing 1200 pages, with nearly two hundred illustrations, cloth, \$600.

\section{B T THE SAME AUTHOR.}

MANUAL OF CHEMTCAL PHYSIOLOGY. Translated from the German, with Notes and Additions, by J Cueston Morris, M. D., with an Introductory Essay on Vital Force, by Professor SAmukL JACKson, M. D., of the University of Pennsyl. vania. With illustrations on wood. In one very handsome octavo volume of 336 pages. alnth, 8225

MARSAALI'S OETLINFS OF PHYSIOLOGY, HUMAN AND COMPAKATIVE. With Additione hy Fraxcis GokNex Suith, M.D. With numerous il. lnstrations In oue large and handsome octaro volume, of 1026 pages: cloth, $\$ 650$; leather raised bands, $\$ 760$. 


\section{A TTFIELD (JOHN), Ph.D.,}

\section{Professor of Practical Chemistry to the Pharmaceutical Snciety of Great Brituin, \&c.}

\section{CHEMISTRT, GENERAL, MEDICAL, AND PHARMACEUTICAL ;} including the Chemistry of the U.S. Pharmacopoia. A Manual of the General Principle? of the Science, and their Application to Medicine and Pharmacy. Seventh American edition, reviser from the Sixth English edition by the author. In one handsome royal $12 \mathrm{mo}$. volume of 668 pages, with 87 illustrations: cloth, $\$ 275$; leather, $\$ 325$ (Just Issued.)

This work has received a very careful rerision at the bands of the author, resulting in aconsiderable increase in size, together with the addition of a handsome series of illustrations. Notwithstanding these improvements, the price has been maintained at the former very moderate rate.

A book which has lassod through six erlitions ju nine verars nweds from journalists only such an nouncement. as are necessary to ksep the profession aware of the continued interest of the author in his progeliy; we, therefore, are content with the rommendation that the bunk before us is brought sbreast of the times.-Philn. Hed. Times, Oct. 28, 18.6.

A fter having nsed it as a text-hook in the lahoratory of the Philadelplitia (Oollege of Pharmacy during the last five rears. We (*un speak from our own experience, and testify to its intrinsie value in the instruction of the stulent. The more we have used it, the more we were pleased with it. and on the apperance of a new, re rised. and enlared edition. wc take ocearion to again eorrlially recommend it, beliering lluat for the practical instrurtion of pharmaceutical students in ehenixtry it las 110 superinr in the Euglish language.- - Jin. Journ. of Pharm. Nov. 1876 .

The bonk. by a well arranger system, introluces the student into the Science of Chemistry, giring lim at each step sufficieut information to enathe hiw to perfurm experiment: with his own hands; the cxperiments are partly of synthetical and partly of aualytical interest: in this way the editor sucece ls alinirally iu aves liur a dry monotonous en umeration of tacts. The variety which he rives is certainly well calculated to prevent the reader from getting tired. This variety. however. is not such as to bewilder the mind. nor are the experinents descrihed calculated only to serve a pleasant pastime. 'The stulent who reals the look anil excemes the experimeuts mentioned, eannot help but feel thepily interesterl in the subject. and indeed, will, goin through the practical work. find it a rery acreealble recreation.-Cincinnati Clin ic, Oct. 28,1876

It brings up our knowleige of the subject to the pre sent date, and has been enriched with numerous wond engravings il]ust rative of apparat $u$ and modes of $w 0 r^{\circ} \mathrm{K}$ The arrangement of the work is admirable. and to each element its more inportant compounds used in medicineor pharnaey are given, togetlier with hoth syntheticul and nualytical reactions. The systematic analysi of emmpounds. suhstanees or fluids is also troated of. and copious tables are given showing the morles of systematically separating tha different elements from one another-Canndu Med. and Surg. Journ., Nov. 1-76.

As a compart manual of the ceneral princisles of the science and their applications in medicino and phar macy, it has no rival, and the frequent aud thorougl revision it receives liecps it in all respects up with the times The Amprienn edition, which eovers the United States Pharmacopria, is prepared undel the author's supervision - Brston Journal of Chemistry. Now 1\$i6.

Admirably alanted to the useof medical stulents. Atlanta Med. Journ., Oct. 1576.

\section{FOWNES (GEORGE), Ph.D.}

A MANUAL OF ELEMENTARY CHEMISTRY; Theoretical and Practical. With one bundred and ninety-seven illustrations. A new American, from the tenth and revised Londion edition. Edited by RoBERT BRIDGES, M. D. In one large royal 12 mo. volume, of about 850 pp., cloth, $\$ 275$; leather, $\$ 325$.

This work ta so well known that it seems almost ther work that has greater claims on the physician, onerfluous for us to speak about it. It has been a pharmacentist, or student, than this. We eheprfully lavorite text-hook with wedical studeuts for years, recommend it as the best text-hook on elementary and its popularity has in no respect diminished, shemistry, and hespeak for it the careful attention Whenever we have heen consulted hy medical stu- if students of pharmacy. - Chicago Phurmacist, Ang. dencs, a.s has frequently occurred, what treatise on 1869

chemistry they shonld procure, we have alwaye recommeuded Fownes', for we regarded it as the best. There no work that combines so many excellen- for by eager teacners of chemistry. In its new garb. ces. It is of convenient size. not prolix, of plain and under the oditorship of $M r$. Watts, it las resumed perspienons diction. contains all the most recent its old place as the most successful of text-hooks.discoveries, and is of moderate price.-Cincinnati Indirn Medienl Gozette. Jan. 1, 1869

Mod. Repertrry, Aug. 1869.

It $w$ ill continne, gs heretofore to hold the flrst ran

Large additions have heen made, especially in the to a text-book for students of medicine.-Chicas department of organic chemistry, and we know of no Mrd. Exrminer, Aug. 186\%

\section{BOWMAN (JOHN E.), M. D.}

PRACTICAL HANDBOOK OF MEDICAL CHEMISTRY. Edited by C. L. Buoxam, Professor of Practical Chemistry in King's College, London. Sixth American. from the fourth and revised English Edition. In one neat volume, royal 12 mo. pp. 351, with numerousillustrations, cloth, $\$ 225$.

$B^{Y}$ THE SAME AUTHOR (Intely Issued)

INTRODUCTION 'TO PRACTICAL CHEMISTRY, INCLUDING ANALYSIS. Sixth American, from the sixth and revised London edition. With numerous illustrations. In one neat vol, royal $12 \mathrm{mo}$, cloth, $\$ 225$.

KXAPP'S TECHNOLOGT ; or Chemistry Applied to the Arts, and to Manufietnres With Ameriean additions hy prof. Waliter Je. Jouxson In two very handseme octava rolumes, with 500 wood pngravings, $c$ loth, $\$ 600$

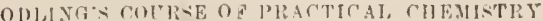
arraged far the ['se of Medica] stulentx. With
Illustrations. From the Funrth and Revised London Eulition. In one weat $12 \mathrm{mo}, \mathbf{v o l}$, cloth, $\$ 2$ GAILA)WAYS MAXUAI, OF RUAITTATIVE ANAL Ysis From the Fifth Inulon Edition. In one $12 m$ o. vol., witlillustrations; cloth, \$2 50. (Just Issued.) 
BLOKA.U (C.L.),

\section{CHEMISTRY, IXORGANIC AND ORGANIC. From the Second Ian.}

don Edition. In one very handsome octavo volume, of 700 pages, with about 300 illustra. tions. Cloth, $\$ 400$; leither, $\$ 500$.

It has been the author's endeavor to produce a Treatise on Chemistry sufficiently compreliengive for those studying the science as a hranch of general ellucation, and one which a stulent may use with advantage in pursuing hischemical studies at one of the colleges or merlical schools. The special attention devoted to Metallurgy and some other branches of Applied Chemistry reuders the work especially useful to those who are being educated for employment in manufacture.

We have in this work a complete and mostexcel- iccasion to refresli their memories on any moint re. lent text-bonk for the use of schools, and can heart. latiug to it. In a word, it is a bow to ba read by all ily recommend it as euch.-Boston Hed. and Surg. who wish to kuow what js the chemistry of lhe preJourn., Mdy 28,1574 .

It is seldom that iu the same compass so complete and interesting a compeudium of the leading facts of chemistry is offered.-Druggists' Circulur, Nor. '73

The above is the title of a work which we can most conscientiously recommeud to stndents of chemistry. It is as easy gis a work on chemistry could he made. at the sume lime that it presents a full account of that scipnce as it now stands. We have spoken of the work asadmirably adanted to the wants of students it is quite as mell suited to the requirements of prac titioners who wish to review their chemistry, or have sent day-American Practitioner Nov, 1573.

One of the best text-books of chemixtry yet pub. lished-Chicago Med Journ., Not. 1578 .

This is an excellent work, well adapted for tlie beginner and the advanced studeut of chemistry. $-A m$. Joura of Pharm, Nov. IS7:3

Prof. Bloxam possesses pre-eminently the inestimable gift of perspicuity. It is a pleasure to read his hooks, for he is capable of makiug very plain what other authors frequently hare left very obscure. Va. Clinical Record, Nov. 1573.

(YLO MES (FRANK), D.Sc., Lnndom.

Senimr Scienre- Ifaster at the High Schonl, Nencastle-under Lyme, etc.

AN ELEMENTARY TREATISE ON PRACTICAL CHEMISTRY AND QUALITATIVE INORGANIC ANALYSIS. Specially sdapted for Use in the Lahoratories of Schools and Colleges and by Beginners. From the Second and Reviserl English Edition, with about fifty illustrations on wood. In one very handsome royal $12 \mathrm{mo}$. volume of 376 pages: cloth. \$2 50. (Just Ready.)

It has been my aim thronghout to give all necessary directions so fully and simply as to reduce to a minimum the amount of assistance required from a teacher. The language emplnyed has been rendered simple and intelligible by avoiding the unnecessary use of scientifis terms and by explaining or paraphrasing in ordinary rords any such terms when introduced for the first time. The directions how to wnrk and the description of the preparation and use of anparatus bave been given more fully than is usual. . . The introduction as appendices into this edition of the reactions and methods of detection of the rarer elements and of the use of the spectroscope with a spectrum chart, will, it is believed, render the book wore useful to advanced students."-Preface.

The arrangement in tabular form of all special analytical processes has enabled the author to compress a very large amount of instruction within reason able compass, and in a form exceedingly clear and intelligible, rendering the volume one especially suited for practical work in the laboratory, or for the guidance of students deprived of the assistance of a teacher.

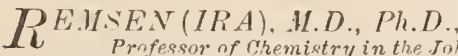

PRINCIPIES OF THEORE'ICAL CHWMSTRY, with sperial reference to the Constitution of Chemical Compounds. In one handsome royal $12 \mathrm{mo}$. vol. of orer 232 pages: cloth, \$1 50. (Now Ready.)

This volume ia devoted to the principles npon which the theretical structure of urulern chemi-try is lnapel. and as surl it is a very vatuahle addition to our literature. insomuch as it diseuses, in a c'ear and com re. hemsise munner, the varions livs g.verning chemic 1 combination and decompnsition. and the virions therrios whi-h have heen advanced for explaining announred facts. In our opinion. the wrrk will prove to be a raluable aid to the chomical stment who would faniliarize himsalf with the thioriex of the science that have lod to m'ny important discoveries.-Am Journ. if Pharm.. June. $18 \div$.

Inut few of the recent text-hooks on this suhject pre-

aent even a passable synopsia of the develonment and status of ehemical theories. To supply this deficiency. this little work of Prof liemsen was evilently prepareil. and from a ha-ty glauec over its pagne we are saticfied that the author has succeeled aduirably. -The Phar. macist May. $187 \%$.

It is an almirable presentation of the leading lnc. trines of modern cbemistry If some suljects serm briefly treaten, it is simply becanse fol little is really known about them, and the a a'bor lias had the raro gonl sense bot to lumber hiz pages with unprofitahles eprenlations and mere " gucsses at the trutll." - Buston Jinrn of Chem., May, $15 \div 7$.

\section{WOHLER AND FITTIG.}

OUTLINES OF ORGANIC CHEMISTRY. Translated with Additions from the Eighth German Edition. By Ira Ressen, M.I., Ph.D., Professor of Chemistry and Physics in Williams College, Mass. In one handsome volume, royul 12 mo. of $550 \mathrm{pp}$, cloth, $\$ 3$.

As the numerous editions of the original attest, this work is the leading text-book and standard authority throughout Germany on its important and intricate subject-a position won for it hy the clearness and conciseness which are its distinguishing characteristics. The translation has heen executed with the approbation of Profs. Wöbler and Fittig, and numerous additions and Iterations have been introduced, so as to render it in every respect on a level with the inost advanced condition of the science. 


\section{DARRISH $\left(E D W^{r} A R D\right)$, \\ Late Professor of Materin Mredica in the Philadelphin College of Pharmacy.}

A TREATISE ON PHARMACY. Designed as a Text-Book for the Student, and as a Guide for the Physician and Pharmaceutist. With many Formulæ and Prescriptions. Fourth Edition, thoroughly revised, by Thom AS S. WIEGAND. In one handsome octavo volume of 977 pages, with 280 illustrations; cloth. \$5 50; leather, \$6 50 (Lately Issued.)

The delay in the appearance of the new U. S. Pharmacopoia, and the sudden death of the author, have postponed the preparation of this new edition beyond the period expected. The notes and memoranda left by Mr. Parrish have been placed in the hands of the editor, Mr. Wiegand, who has labored assiduously to embody in the work all the improvements of pharmaceutical sci. ence which have been introduced during he last ten years. It is therefore hoped that the new edition will fully maintain the reputation which the volume has heretofore enjoyed as a standard text-book and work of reference for all engaged in the preparation and dispensing of medicines.

of Dr. Parrisl's gleal work on pharmacy it only an honored place ou our own bookshelves.-Dublin remains to be said that the editor has accomplished Her. Pressand Circular, Ang. 12, 1s7t.

his work so well as to muintain, in this tonrth edition, the high standard of excellence which it bad attained in previons editions, nnder the editorship of its accomplished author. This has not been accom. plished without much labor, and many additionsand improvements, involving changes in the ar'angemeut of the several parts of the work, and the addition of much new matter. With the modifications thns effected it coustitutes, as now presented, a compeudium of the science and art indirpensable to the pharmacist, and of the utmost ralne to every practilione of uedicine desirous of familiarizing himself with the pharmaceutical preparation of the articles which he prescribes fur bis patients. - Chicago Med. Journ. July, 1874 .

The work is eminently practical, and has the rare merit of being rendable and interesting, while it preserves a strictly scientific character. The whole work reflects the greatest credit on author, editor, and publisher It will cunvey someidea of he liberality $w \mathrm{bich}$ has been bestowed upon its prodnctiou wheu we mention that there are no less thau 2 socarefully execnted illustrations. In conclusion, we hearily recommeud the rork, not only to phalmacists, bnt also to the multitude of medical practitioners who are olliged to compound their own medicines. It will ever hold

We expressed our opinion of a former edition i erms of nnonalified praise, and we are in no mood to detract from that opinion in reference to the pre. sent edition, the preparation of which has fallen into competent hands. It is a book with which no pharmacist can dispense, and from which no physician can fail to derive much information of value to him in practice.-Pacific Mte. and Surg. Journ., Juue, '74.

With these few remarks we heartily commend the work, and have no doubt that it will naiutain its old reputation as a text-hook for the stndent, and a work of reference for the more experienced physician and pharmacist.- Chicago Med. Examiner, June 1.5, 1874 .

Perhaps one, if not the most important book upon phalmacy which lias appeared in the English langnage has emanated from the transatlantic press. "Parrish's Pharmacy" is a well-known work on this side of the water, and the fact shows ns that a really useful work never become: merely local iu its fame. Thanks to the judicious editing of Mr. Wiegand, the posthumous edition of "Parrish" has been saved to the public with all the matnre experience of its author, and perliaps none the worse for a dash of uew blood.-Lond. Pharm. Journal, Oct. 17, 1874.

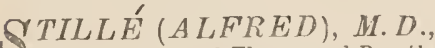

10 Professor of Theory and Practice of Medicine in the Oniversity of Penna.

THERAPEUTICS AND MATERIA MEDICA; a Systematic Treatise on the Action and Uses of Medicinal Agents, including their Description and Historz. Fourth edition, revised and enlarged. In twolarge and handsome 8 vo. vols, of about 2000 pages. Cloth, $\$ 10$; leather, $\$ 12$. (Lately Issued.)

The care bestowed by the author on the revision of this edition has kept the work out of the market for nearly two years, and has increased its size about two hundred and fifty pages. Not withstanding this enlargement, the price has been kept at the former very moderate rate.

It is unnecessary to do much more than to an- of the present editiou, a. whole cyclopedia of theraannce the appearace of the fouth edition of this well known and excollent work-Brit. and For. Med.-Chir. Revitw, uct 1575 .

For all whodesire a conplete work on therapcutics and inateria medica for retorence, in cases involving medico-legal questions, as twell as for information concerning renedial agents, 1)r. Stille's is "por r.xcellence" the work. The work heing out of print, by the exhanstion of former editions the anthor has laid the profession under renewed obligations, hy the carcful revision, important additions, and timcly re issuing a work not exactly snpplemented by any other in the Luglish language, it in any lunguage. The mechanical execution handsonely sustais the well.known skill and goou taste of the publinher.St. Lowis Merl. and Surg. Journal, loec 1574.

The prominent feature of Dr. Stille s great work is sound good sen-e. It is lesrned, hut its learning is of inferior value compared with the dineriminating judgment which is show ly its atuhor inthe dis. cussion of his subjects, and which renders it a trustworthy suide in the sick-room.- $-1 w$. Practitimer, Jan. 1 975 .

From the publication of the first edition "Stille's Therapeutics" has been one of the chassics; its absence trom our libraries would create a vacum which conld be filled by no other work in the lit nguage, and its presence supplies, in the two volumes peutics.-Chicrgo Iedical Journal, Feb. 157.5

The unarnifcent work of Professor Stille is kuown wherever the English language is read, aud the art of medicine cnltivated; known so well that no encu-

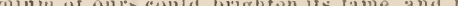
vorable criticism could tarnish itsraputalion. - Philarlel phia Mert. Times; Dec. 12, 157t

The rapid exhanstion of three editions and the nnivernal favor will which the wotk has been received by the luedical professiou, are suflicient ploof of its excellence as a reptertory of practical ind nseful information for the physician. The edition before us fully sustains this rerdict, as the work has been careinlly revincd and in some portions rew ritten, bring. ing it up to the prerent time by the admission of chloral and croton chloral nitrite of amyl, bichloricle of metlylene, mothylic ether, lithimm .com. pounds, golseminum, and other romcdies, $-A m$. Jouru of Pharman, Feb. 1875.

We can hardly almit that it has a riral in the multitud of its citations and the fulness of its re. search into clinical histuries, and we nust asigign it a place in the physician's library; not, indered, as fully ropreating the present mate of knowledge in pharmacolynamies, but a hy far the most complete treatise upon the clinical and practical side of tre question.-Boston Mtd. and. Surg. Journal, Nov. 5, $1 \leqslant 71$. 
ILLE (ALFREI) , II.I), LI, II. Prof of Theor!l and Practice of Glinical Miect. in Unix. of $P$ a.

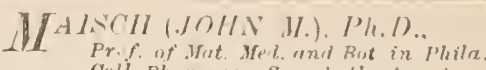
Coll. Phommery, Secy in the Aunericen Plermacentichl Assuciation.

THE NATIONAT, DISPENSATORI : Embracing the Chemistry, Botany, Materia Medica, Pharmacy, Pharmacodynamies, and Therapeutics of the Pharmacepoaias of the United States and Great Britain. For the Use of Physieians and Pharmaceutists. In one handsome oetavo volume, with numerous illustrations.

The want has long been felt and expressed of a work which, within a uorlarate compass, should give to the phrsician and pharmicentist an authoritative exposition of the Pharmateo. poias from the rxisting standpoint of medical and phar un tcentical scienee. For severitl vears the authors have been earnestly engaged in the preparation of the present volume, with the hope of satisfying this want, and their labors are now suficiently advanced to enable the pub. lisher to promise its appearance during the coming season. Their distinguisherl reputation in their respective departments is a guarintee that the work will fulfil all reasonable expectation as a guide in the selection, compounding, dispensing, and medicinal uses of drugs, complete in all respects, while convenient in size, and carefully divested of all unnecessary and obsolete matter.

\section{GRIFFITH (ROBERT E.), M.D.}

A UNITERSAL FORMULARY, Containing the Methods of Pxє paring and Administering Officinal and other Medicines. The whole adapted to Physiciars and Pharmaceutists. Third edition, thoroughly revised, with numerous additions, by Joil M M Maisci, Professor of Materia Medica in the Philadelphia College of Pharmacy. In one large and handsome octavovolume of a oout 800 pages, cloth, $\$ 450$; leather, $\$ 550$. (Lately Issued.)

As a comparative riew of the United States, the British, the German, and the French Pharmacopoias, together with an immense amount of unofficinal formulas, it affords to the practitioner and pharmaceutist an aid in their daily avoentions not to be found elsewhere, while three indexes, one of "Diseases and their Remedies," one of Pharmaceutical Nimes, and a cieneral Index, afford an easy key to the alphabetical arrangement alopted in the text.

The young practitioner will find the work in raluable in suggenting eligible modes of admini-tering many remedies.-Am. Journ. of Pharm., Feb. 157t.

Onr copy of Griffith's Formulary, after long use, first in the dispensing shop, and ifterwards in our medical practice, bad gradnally fallen behind in the onward march of materia medica, pharmacy, and therapeutics, until we had ceased to consult it as a daily book of reference. So completely lids Prof Maicb reformed, remodelled, and rejurenated it in the new edition, we sball gladly welcome it back to our table again beside Du uglison, Webster, and Woud \& Bache. The publisher could not have been more fortunate in the selection of an editor. Prof. Maisch is eminently the man for the work, and he has done it thoroughly and ably. To ennmerate the alterations, amendments, and additions would be au end. less task; everywhere we are greeted with the evidences of his labor. Following the Formulary, is an addendum of nseful Recipes, Dietetic Preparations, List of Incompatibles, Posological table, tahle of Pharmacentical Names, Oficinal Preparations and Directions, Poisons. Antidotes and Treatment, and coptous indices. which afford ready access $t$, aill parts of the work. We unhesitatingly commend the book as being the best of its kind, within our knowledge - Atlanta Med. and Surg. Journ., Feb. 1874.
To the drugrist a good formulary is simply indis pensable, and perhaps no formulary ha been in re extensively used than the well-known work before us. Many physicians have to offciate, also, as itruegists This is true especially of the country physician, and a work which shall teach him the means by which to administer or combine his remedies in the most efficacisus and pleasant manuer, will always hold its place upon his slielf. A firmulary of this kiud is of benefit atio to the city physician in largest practice.-Cincinnati linic, Feb. 21, 1574.

The Formulary has already proved itself acceptitble to the medical profession, and we do not hesitate to say that the third edition is much improved, and of greater practicul valne, iu consequeuce of the careful rerisiou of Prof Majsch.-Chicago Med. Examiner, March 15, 1874 .

A more complete formulary than it is in its present form the pharuacint or physician could hardly desire To the first some such work is indispen-ih ble, and it is hardly lese esvential to the practitioner who compounds his own medicines. Much of what is contained in the introluction onght to be cuta mitter to memory by every student of ineliviue. A * a help to physicians it will be found invalnahle. and doubtless will unke its way into libraries uot already supplied with a standard work of the kind. - The Ameriean Practitioner, Louisville, July,' 't.

FLLIS (BENJAMIN), M.D.

THE MEDICAL FORMULARY : being a Collection of Prescriptions derived from the writings and practice of many of the most eminent physicians of America and Europe. Together with the usual Dietetic Preparations and Antidotes for Poisons. The whole accompanied with a few brief Pharmaceutic and Medical Observations. Twelfth ed..

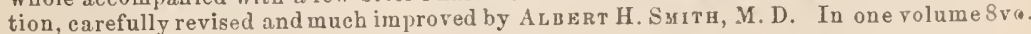
of 376 pages, cloth, $\$ 300$.

DUNGLISON'S NEW REMEDIES, WITH FORMULA FOR THEIR PREPARATION AND ADHINIST'RATION. Serenth edition, with extensive additions. One vol, 5vo., pp. 770 ; cloth. \$t 100

WHATTO OBSERVEATTHE BEDSIDE AND AFTEK Deatg in Medical Cases. Published under the \&uthority of the London Society for Medical Obser. vation. From the second Londonedition. 1 vol. royal 12 mo. cloth. $\$ 100$
CIRISTISON'S DISPENSATORY. With copioumad-

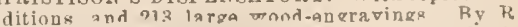
Ehlesemld Griffith, M. D. Onevol. Svo., pp. ifoo; cloth. $\$ 4$ m

CARPENTER'S PRIZE ESSAT ON THE USE OF A rcoholic Liquora is HEalth $\triangle$ ND DIsease. New edition, with a Preface by D. F Cospte. M.D., and explanations of scientific words. In one neat 12 ruo. volums, pp. 178, cloth. 60 cents. 
GHN TITK (SA MUEL), M.D.

Assistrnt Physicirn to the London Hospital.

THE STUDENT'S GUTDE 'TO MEDICAL DIAGNOSIS. From the

Third Revised and Enlarged English Editior. With eighty-four illustrations on wood. In one very handsome volume, royal $12 \mathrm{mo}$, , eloth, $\$ 225$. (Just Issued)

Of the many gnido-books on medical diagnosis, cise, practical unanner, well calculated to assist the clamed to be written for the special instructuon of studeut in forming a correct, thorough, and systemstmilents, this is tho hest. The anthor is evidently a atic method of exanivation and diaguosis of diseane. well read and accumplistied pbysician and he knows The illusirations are numerous, and finely expcuted. how to each practic l mediciue. The charm of sim- Those illustrative of the microscupic appearance of plicity is not the lea-t int resting feature in the man- morbid timsue, fe., are especinlly clear and distinct. per in wlich l) Fennick convey inetruetion. There a few books uf this mize on priterica! medicine that contain to much and convey it so well as the volume before us I is a buok we can siucerely lecommend to the student fir directinstruction, and to the practilioner as a ready aud nseful aid to his memory.Arn. Journ. of Syphilograyhy, Jan. 187 t.

It covers the ground of medieal diagnosis in a con-

-Chicugo Mrd. Examiner, Nov 1 is.

So far superior to any offered to students that the colleges of this country slould recomineud it th their respetive elasse8.-N. O. Med. anot Surg. Journ., March, Is7t

This little book ought to he in the possession of every medical st ndeut.-Boston Medical and Surg. Journ., Jan. 15, $157 t$

\section{GREEN (T. HENRY), M.D.} Lecturer on Palhology and Morbid Anatomy at Charing-Cross Hospital Medical School.

PATHOLOGY AND MORBID ANATOMY. Second American, from the Third and Enlarged English Edition With numerousillustrations on Wood. In one very handsome octavo volume of over 300 pages, cloth. $\$ 275$ (Just Issued.)

This usetul and convenient uauual has alrealy; this, for a work which has already gained a deservedly rearloerl a tlirirl elition, and we are glad to find that, al hough it las grown somewhat larger, it still remain. a little book, and we are inclined to forgive the incrase in sixe on account of the valuable allitions which the author bas male both to tle printed matter aud to the illustrations 'lloe new illustrations, drawu by Mr. Collings from preparations by Ur. Cireen himself. are very good. and the care aud trouble exprnded by the antho in the preparation of this edition will an doht increased the popularity of his book, ereat though it alreacly is. The London Practitinner, Feb. 1876.

We oberve that the whole $\mathrm{h}:$ : s ben carefully revised, that a considerable addition luas leen made to the illutrations, and that nuch new matter has been adued. We have not space for noting each of the additions that have been uade, and it is quite unecessary 10 attempt solit reputation. It is enourh to say that it has been brongh thorouglily up to the knowledre of the present day, and that the student can have no better or sate cruide to pathology and unerbil anitomy than Dr. Green's book.-Loni. Times and Gaz.. Sept. 1875.

The autbor of this valuable little work is to be congratulated on the demand for it that has already called for a third edition. It atfords gratifying testitnony to its ralue and populitrity as a text-bouk. it possesses furiher all thove qualities whiob reuder such a work popular among moludents. It is written in clear and concise laugrage, it is coufined almost entirely to st ctements of taet $s$, theoretical views hav ing for tlie nust part been kept out of sight, and it is above all fully and exceedingly well illustrated London Lancet, Aug 2, 1875 .

GIUGE'S ATLAS OF PATHOLOGICAL HISTOLOGY Trauslated, with Notes and Additions, hy Josepr LEIDX, M. D. In one volume, very large imperial quarto, with 320 copper-plate figures, plain and colored, cloth, $\$+00$

LA ROCHE ON YELLOWV FEVER, considered in it Historical, Pathological, Etiological, and Therapeo tical Relatioum. In two karge and haudsome octaro volumea of nearly 1500 prges, eloth. $\$ 700$

HOLLAND'S MEDICAL NOTES AND REFLEC TIONs. 1 vol. $8 \nabla 0 .$, pp. 500 , eloth. $\$ 350$
LAYCOCK'S LECTURES ON THE PRINCIPLES AND Methods of Medical Observation and RB BEARCH. For the nse of advauced students and junior practitioners. In one very neat royal $12 \mathrm{me}$ volume, cluth. \$1 00

BARLOW'S MANUAL OF THE PRACTICE OF MEDICINE. With Additions hy D. F. CONDIB, II 1 vol, 8vo., pp. 600. eloth. \$2 50.

TODD'S CLINICAL LECTURES ON CERTAIN ACUT B Diseafes. I u oue neat octavo volume, of 320 pages, cloth. $\$ 250$

STURGES (OCTAVIUS), M.P. Cantab.

Felluw of the Roynl (*ollege of Physicians, \&c. \&.c.

AN INTRODUC'TON TO TIIE S'TUDY OF CLINICAL MEDICINE. Being a Guide to the Investigation of Disease, for the Use of Students. In one handsome $12 \mathrm{mo}$. volume, cloth, 125 . (Lutely Issued.)

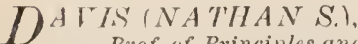

Prof. of Principles and Prantice of Medicine, etc., in Chirago Mert. College.

CIINICAI, IEC'TURES ON VARIOUS I.MPUR'TAN'T IDSWASES; being a collection of the Clinical Lectures delivered in the Medical Wards of Mercy Ilospital, Chicago. Elited by Frank H. D.IVIs, M V. Second edition, enlarged. In one handsome royal $12 m 0$. volume. Cloth, \$1 75. (Lately Issued.)

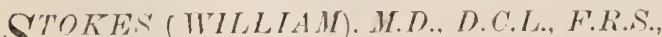

10 Retims Profesarm of Physic in the Unin. of Dublin, sc.

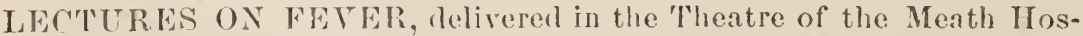

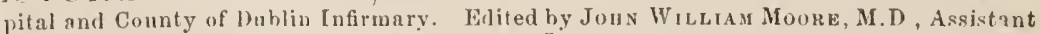
Physing to the Cork Street Fever IIospital. In one neat octavovolume. Cluth. \$2 00. (Jilst Issuerl) 
FliNT (AUSTLN), M.D.

Professor of the Principles and Practice of Medicine in Bellevee Med. Collegt, N. $Y$

A TREATISE ON THE PRINCIPLES AND PRACICE OF MEDICINE; designed for the use of Students and Practitioners of Medicine. l"urth edition, revised and enlarged. In one large and closely printed octavo voluule of alonut 1100 pages; cloth, $\$ 600$; or strongly bound in leather, with rilised bands, $\$ 700$. (.Iust Issurt.)

By common consent of the English and American medisal press, this work has been assigned to the highest position as a complete and compendious text-book on the most advancerl enndition of medical science. At the very moderate price at which it is offered it will be found one of the oheapest volumes now before the profession.

This axctllent treatise on medicine lias acyuired for it-elf in the Trited States a reputation similar tu that enjoyed iu Fingland by the adnuirable lectures of Sir Thomas Watsun. It may not porsese the same charm of style, but it has like solidity, the fruit of loug and patient observation, and presents kindred moleratiou and eclecticism. We have referred to many ot the most important chapters. and find the re rision spoken of in the prefuce is a genuine one, and that lleanthor has very fairly bronght no lis inat'er to the lerel of the knowledge of the prakent dity. The work has this great recommendution, that it is in one volume, and therefore will not be soterrifying to the student as the bulky volnmes which geveral of our English text-bunks of medicine have deretoped in to. -British and Fureign Med-Chir. Rev., Jun. Is7t

It is of course unnecessary to introdnce or enlngize this now standard treatise. All the colleges recom mend it as a text-book. and there are few libraries in whict one of its editions is not to he found. The presentedition has been enlarged and rerised to bring it up to the anthor's present level of experience and reading. His ow n clinical studies and the latest contrihntions to medical literature both in this country and in Encope, lave received careful attention, so that some portions liave been entirely rewritten, and about seventy pages of new matter have been added. - Chicago Vod Journ., Jnne, 1873.

Has nevel been surpassed as a text-book for stu-

dents and a book of read y reference for practionners. The furce of its logic, its simple nud practical teachings, hare left it without a rival in the field -.1 . Med Record, Sept 1.5, lsit

Flint : Practice of Madicine las hecomeso fixed in it pesitions a a Amprican text look that little newd he said beyond the anmoncemsnt of a new edition. It may, however, he ploner to kay that the athar has improsed the ocraxiun to iuredince the litest contributions of inedical literature tingether with the results of his own continteal clinical observations. Notxo extended as many of the stanclard works on practice, it still is snfficiently complece for all ordinary reference. and we do not know of a moreconvenient work for the husy general practitioker. Cineinnali Luncet and fisererer, June, 1573

Prof Flint, in the fonrth edition of hisgreat work, has performed a labor reflectiug $m$ nch credit upou himself, and eonferring a lasting henefit upon the profession. The whole work slows evidenco of thorough revision, so that it appeals like a new houk witten expressly for the times Forthfgeneral practiri oner and student of medicine, WA cannot recommord the hook in too strong terms - N. I Med. Jisur.. Sept '73.

It is given to very few men to tread in the steps of Austin Flint, whose rirgle volume an medicine, hough hereand there defective, is a masierpiece of lucid condensation and of general grasp of an enormonsly wide subject - Lond. Pructitioner, Dec. '7s.

\section{B T THE SAME ADTHOR.}

ESSAYS ON CONSERTATIVE MEDICINE AND KINDRED TOPICS. In one very bandsome royal $12 \mathrm{mo}$. volume. Cloth, $\$ 138$. (Just Issued.)

This little work comprises a numiber of pssays written at rarious times for medical journals and sipties. It is unnecessary ro say aught in regard to the sty le in which they are written. for Dr. Flint is familiar as a hou-e. holil worl to the profession. Ilis name is a vuaruntee that the subjects are treated in a masterly manner. The followin snlyect = aredisenssed: Conserrative metlicine, as anplied to therapentics and hyciene. medicine in the past. the present, and the future, alimentation in dispast. the present, and asease, on the agency of the ntind in

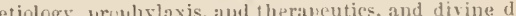
sirm, as exemplified in tle natural listory of lispases. A more suguestive collection of topies it would be diffi enlt to conceive The sssity on conservative merlicine are peculiarly valuable. The author in these takes a rery cummoin-sense view of the treaturent of disease, and shows the necessity of "rouservine" to the fulle-t extent the strength of lhe sy-tem in oriler to devise the lest results from the mis medicatrix nuture.-Penissular Mrl. Jouriz, Oct. 1 sit.

\section{WTATSON (THOMAS), M.D., \&c.}

LECTURES ON THE PRINCIPLES AND PRACTICE OF PHYSIC. Delivered at King's College, London. A new American, from the Fifth re vised and enlarged English edirion. Edited, with additions, and ceveral hundred illustraations, by Henry Hartshorne, M.D., Professor of Hygiene in the University of Pennsylv. nia. In two large and hanilsome 8 ro. vols. Cloth, $\$ 900$; leather, 81100 . (Lriely Published.)

It is a subject for congratulation and for thanktul- apprecialed, that it is scarcely necpenty to do nevs that sir Tlumas Watson, during a period of com- more than call attention to the special adrantages parative leinore, after a long laburious, and mort of the last over previnus editions "The anther parative hourable professional career. while refaining fare hined with wonderfulforenric elounence has exerted possession of his bigh mental facultier, shatd have he enployed the opportunity tusubmit his Lectures oxtrom His clinical descriptions of most dima more thorongh rerision than was pusible during of physicidns. His chincal description on this scure the earlier and busier period of his life. Carefully eases have never heen equatled in the future. The passing in reriew some of the most intricate and im. at least his work will hise loug in the fut de. The portant pathological and practical que timan. the results of hisclear insight and his calm judgment ar now recorded for the benefit of mankind, in language which, for precision, vigor, and clarsiral elegance, has rarely been equalled, and never surpassed The re. vision has eridently been most carefully done, and the results appear in almost every page--Brit. Med. Journ., Oct. 14, 1871 The lectures are so well known and so jnstly $\mid \begin{aligned} & \text { no } \\ & 1872\end{aligned}$ ook. Amer Journ. of Syuhilogrophy. July, $15 i 2$

Matnrity of yearz, extenkive observaicon, profound resedrch, and yet coutiuuons enthusiasin. liarecombined $t$ rive us in this latest edition a model of profescion the mode of cotnonuication. But this classic napd no eulngin of onrs.-Chicago Merl. Journ., July,

\section{DUNGLISON, FORBES.TWEEDIE, AND CONOLLT}

THE CYCLOPEDIA OF PRACTICAL MEDICINE: comprising Treatises on the Nature and Treatment of Diseases, Materia Medica and Therapeutice, Disenses of Whomen and Children, Medical Jurisprudence, \&c. Ac. In four large super-roys octavo volumes, of 3254 double-columned pages, strongly and bandsomely bound in leather, $\$ 15 ;$ eloth, $\$ 11$. 
BRISO WE (JOHN SYER), H.D, FR.C.P.

Physiciun and Joint Lecturer on Mearime, St. Thrmas's Hospital.

A MANUAL ON THE PRACTICE OF MEDICINE. Editer, with Additions, by James II. Iluichissos, M.D., Physicinn to the Penna. Hospital. In one handsome octavo volume of ver 1100 pages: cloth, $\$ 550$; leather, $\$ 650$. (Non Ready.)

In the effort of the author to render this volume a complete and trustworthy guide for the student and practitioner be has covered a wider field than is customary in text-hooks on the Practice of Medicine, and has sedulously endeavored to present each smbject in the light of the most uodern developments of observation and treatment. So much has been done of late years to enlarge our knowledge of disease by imfroved methods of diagnosis, and so many new agen. cies have been called into service in treatment, that a condensed and compendious work, thoroughly on a level with the advince of medical science, can hardly fail to prove of value to the profession. In the present volume this has been so completely acomplished that the Editor has found it necessary only to make such additions as seemed requisite to present in more detail matters in which the practice of this country differs from that of Europe.

Tue busy practiriouer will ho able by its pernsal of conciseness at the expense of completeness. A to keep shreast with the great progress which rcien. superficial survey even shows that, as a text-book, tifie wedicine has made within the past few year $=$, it is far in advance of those publiched ouly a few and fur whirh he lias neither the time, norfrequently years ago; and a more careful examination of :ome the vpportunty to consult larger treatises, mono. Of itrections-such. for example, as the onederoted graphs and journals. While all of it is deserviug of to diseases of the nervoussystem, demonstratesthat high praise, we must particularly commend the por- in provinces which have accomplished the greatest tion devoted to nervons diseyses, which is very com- advances of late years, the author has kept his work plete, and well represents the present state of on $r$ quite abreast with the lahors of the most reliahle knowledge on this inportant suhject. The style of cl nicalobservers Featuresquitenusualina purethe workisplain and lncid; thongh condensed, it is ly medicaltreatise are included in the shupe of exnever bald Contr)rersy is avoided, andillustra- cellent clianters on diseases of the skin, the affections tive cases are omitted in order to giveroom to prac- of the genito-nrinary organs in females, which can tical teachiug. As an accurate and praiseworthy but resultin lessening the tendency on the part of the guide it is of the highest order of merit, and though gener.I practitioner to neglect thei nportant elasses it will not probahly supersede in this country br. of complaints with the teeling that, like derangeFlint's admirahle treatise, it has the advantage of we uts of the chief organs of the special senses, they emhodyiosthediscoveries andimprovements which an better he managed by specialists. - Nero Remehave been made siuce the last i-sue of that work. - dits, Nov. 1876.

Buston Hed. and Surg. Journ, Des. 7, 1876.

We recommend highly this book, and feel justi-

The style is clear, the matter and method good. Whoever buys this hook gets as complete a repre sentation of modern medicine as has been, and prohably can he, put inside of one thou-and pages of sinilar size and type-The Medical Tines, Philadelphia, Dec. 9, 1876 .

Upon reading it our filst emotion was tha: of snr prise-surptise mingled with pleasnre, to perceive that, notwi hatanding the same work had heendone hy somany, it yet could be done so much better. In 70.56 pages the authur has compressed the most complete treatise mpon the theory and practice of medicine we have ever seen. Almoit every disease known to the profession, including many but tomod in similar works, is treated of As a hand-book for stude $\mathrm{a}^{\prime} \mathrm{s}$, therefure, we do not think it has an equal in the Eaglish language while older members of the profession ma consult it with equal pleasnreano protit. The style is remiarkably clear, platn and tamiliar, and is perfectly comprehensihle to the least cultivated, while the most bighly cultured can hardly fail to he pleased at the purity of its Euglish. -Physicirn and Surgern, Baltimore, Nov. 1576.

It isinpossible to look over its yages withou being impressed with the anount of information which they havo heen inade to coutain, with no appearauce

fied in duing so hy the thought that, of its class it is the best we have yet seen. The judicions renarks of the Americin editor add very mnch to the value ot the work; his jealons guard orer American medicine is most prajiewortly, in fact, on only complaint is that so little of his own well-known style appears - Obstet. Journ, of Grent Britain ana Ireland, American Supplement, Nor. 1876

It nay, therefore, he assumed with some slow of probubility, that the author has keyt in mind the special nepls of medical students. Nor is the expeetation disappointed when we open the book. But it innst not les assumed that this volume is for students ouly, who are readiu for examinations. It well deseryes a place in the library of every pliysician, and of every practitioner of the medical art. The work is one wlich wil greatly enlance the ruthor's reputation. We noplyesy that it will be the favorite tior the London and other nuirersities, und the College of Physicians, whitst many who ncver. pass these examinations, hut content themselved with hall and college, will be irlat to purchase a bonk wheh, once acepuired they will not wish to part with, lint will carry with them to their resilence in the conntry. or to the distant colony. on boarel ship. and "ven in the knapsack on the mareh with troops-Lond. Iferl. Record. Dec. 15,1876

FARTSHORNH (IENRI), M. U

\section{Professor of Hygiene in the Univ rsity of Pennsylvania.}

ESEENTIALS OF THE PRINCIPLES AND PRACTICE OF MEDI.

C $\perp$ N. A bandy-book for Students and Practitioners. Fourtbedition, revised and im. proved. With about one hundred illustrations. In one handsome royal $12 \mathrm{mo}$ rolume, of about 500 pages, cloth, $\$ 263$; half bound, $\$ 288$. (Just Issued.)

The thorough manner in which the author bas labored to fully represent in this favorite handbook the most advanced condition of practical medicine is shown by the fact that the present edition contains more than 250 additions, representing the investigations of 172 authors not referred to in previous editions. Notwithstanding an enlargement of the pnge, the size has been increased by sixty pages. A number of illustrations have been introdnced which it is hoped will facilitate the comprebension of details by the reader, and no effort has heen smared to make the volume worthy a continuance of the very great favor with which it has hitherto been received.

As a liandbook, which elearly setk forth the Esisen. TIA I,S of the PRIXCIPI.EK AND PKACTICE OY MEDICINE, We do not know of its equal. - Vu. Mrd. Monthly.

As a brief, condensed, but comprehensive hand. hook, it cannot he improved n pon-Clhicago Mrot Exrininer, Nov. 1.5, 187 !

The work is brunght fully ap with all the recent adrances in medicine, is almirahly condensed, and yet sufliciently explicit for all the puposesintended, thus making it by fur the hest work of its character ever publimbed.-Cucinnati clinic, Oct. 24, 1874 .

Without doubt the hest hook of the kind published in the linglish lanumage, - St. Lou is Med. and Surg. Journ, Xuv. 1Sit. 
FOTHERGILL (J. MILNER), M.I. Edin., M.R.C.I. Imm.

THE PRACTITIONER'S HANDBOOK OF TREATMENT; Ol, the Principles of Therapeutics. In onevery neat octavo volume of about 550 pages : cloth, \$4 00. (Now Reary.)

It may be said that the scope of this work is not dissimilar to that of the well known "Principles of Medicine," by Dr J. C. B. Williams, now long out of print, which in its day net with such nnusual acceptance. More practical in its character, however, it seeks to loring to the aid and elucidation of positive therapeutics, the vast accumnlation of scientific ficts and theories made by the present generation, pointing out the measures to he adopted at the hedside and establishing them on firm rational grounds. Such a work, by a first-rate man, and fully up to the advanced condition of science, cannot fail to prove of the utmost service to both student and practitioner.

Our frimds will find this a rery readable book : and that it sheds lish upon every theue it touches, causing the practitiozer to feel more certain of his diagno:is in diflicult cases. We confidently coniniend the work to our reader's as one worthy of careful perusal. It lighis the "ay over obscure and difficult rassess in merlical practice. 'The chayter on the circulation of the blood is the most exhaustisc aud iustructive to be found. It is a ho li esery practitioner neets, and would hatre, if he kuew how suzgestive and helpful it would be to him.-St. Louis Mled. and Surg. Jenur + ., A pril. 187.

The object is one of the most inuportant wlich a medical writer can propose to hinn-elf. fir therapeutics is the goal of melicine, aud the plan is an excellent one. in justice to Dr. Fotherrill we ought to say that he has adhered to his plan throughout the work will tidelity. and has acenniplished bis object. with a rare degree of success. We hesrtily comumend his look to the nledical student as an honest and infeligent guide through the mazes of theraveutics, aud assure the practitioner who has grown gray in the haruess that he will derive pleasure and instruction from its perusal. The imperfections and errors which we bave noticed are few and uniniportant. On the other hand, the excellences are many and pateut. Valuable suggestions aud material for thought abound throughout. The chapters on body heat and ferer, inflamuation, action and inaelion. and the urinary system are partieularly good. The descriptions of patho. logical conditions, and the character of the therapeutic measures alviset tive evillence of sound clinical ohservalion,-Bostom Med, and Surg. Jourmul, Mar 8. 1877.

The strong good sense, the rasy st.yle, the practical el aracter of his instruction, are qualities in the anthor which commend hin to Americun physicians. In the

volume hefore us Dr. Fothergill appears in lijs luest

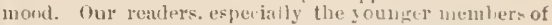
the profession. will fiul this a most smyrestive and useful hook. There are tew old practitioners who will not lie benefited by its nernsul. Ife commend it to all chasses of ritders, with the espression of leelief that those who buy it will le hardly content to chss it until the last leaf is turnel over.-Cin'mnati Chnic. Mar. 3. 1s7t. It is our honest convie:ion, nfter a careful perw:al of this goodly octaro. thent it reprrsents a great aluoumt of farnest thought and pamstaking work, and is therefore one of those hooks which foth descrve aud ure likuly to survive. This book, although written ostensib: yor the young and inexperieneed, may he very protituly st udied hy those who have been ijratioing their lin fession more or les-empirically for thirty or forty yess:. We particularly recommed the chapters on i'ulilic and l'rivate Hygiene, food in litealth and Jll-llealth. and the Couclusion-the Medical Man at the Bed-ide The last is hizh-toned, and iudjates much slirewchess of observation. Our space will not admit of further quotalion. We content ourselves with agriu reeomuenaiug the book very eordially - Eltin. Med. Jomm., Jan $157 \%$.

It is of great adrantage to the practitiouer to have general principles to guicle him. and that he shonld not, wlen confinted with an assuublage of patluslosical symptoms. be at the merey of an unreasoned experience of a similar ease. or be ohliged to swear in zerbumagistri. lle will find reasons in this work for not lookiug upon drugs, as grouled in tixed and unalteralle eategories, but hearn when and why he may give opium tu cause puration. and ecastur oil to eheck it. We stronily reecmmend it to our reaters.- The Lundon Practitioner, Jau. 1 , 7 .

\section{LINCOLN (D.F.). H.D.}

\section{Plusician to the Deprriment of Neromus Diseases, Boston Dispensrry.}

ELECTRO-THERAPEUTICS; A Concise Manual of Medical Electricity. In onevery neat royal $12 \mathrm{mo}$. volume, cloth, with illustrations, $\$ 150$. (Just Issued.)

This little book is, considering its size, one of the rery best treatisesiu the language on the subject that has come to our notice, pos-essing, anung others, the rare merit of dealiug avowedly and actually with principles, mainly. rather than with practical details,

\begin{abstract}
thereby supplying a real waut, instead of helping merely to flood the literary uarket Dr. Lincoln's style is usuilly rematkalily clear, and the whole book is rearlable and interesting.-Buston Med. and Surg. Journ., July 23, 157 .
\end{abstract}

\section{POBERTS (WILLIAM), M. D.}

\section{2t Licturer on Medicine in the Manchester School of Medicine, \&c.}

A PR.ACTICAL TREATISE ON URINARY AND RENAL DIS. EASES, including Urinary Deposits. Illustrated by numerous cases and engravings. Seoond American, from the Second Revised and Enlarged London Edition. In one largo and handsome octavo volume of 616 pages, with a colored plate; cloth, $\$ 450$. (Lately Published.)

The most completeand practical treatike npon renal and a host of other well-known writers npon this snbdiseases we have examined It is peculiarly adapted to the rants of the majority of American practition. ers from its clearness and simple announcement of the fucts in relation to diagnosis and treatment of nrinary divorders, and contains in condensed form the investi gations of Bence Jones, Bird, Beale, Hassall. Prout thological, as indicated to the naked ey. as well us by microscopical and chemical in restigitions, are concisely represented both by description and hy well executed engravings. - Cincinnati Journ. of Ifed.

ECTURES ON THE STUDY OF FEVER. BY A HcDsox, M.D., M.R.I.A., Physician to the Meath Hospital. In one vol. 8ro., cloth, $\$ 250$.

A TREATISE ON FEVER. BY ROBERT D LIONB, IN C C. In one octaro volumo of 362 pages, cloth, \$2 25 .

CLINICAL OBSERVATIONS ON FUNCTIONAL
NERYOUS DISORDERS BvC. HANDFIELD JONES, II. D. Physiciau to St. Mary's Hospital, se. Second American Edition. In one handsome octaro volnme of 348 pager, clnth, $\$ 32.5$

BASHAM ON RENAL DISEASES: a Clinical Guido to their Diagnosis and Treatment, With lllustrs. tions. In one $12 \mathrm{mo}$. rol. of $30 \pm$ pages, cloth, 200 . 
$F^{L I N T}(A \operatorname{USTIN})$, M.D.,

Professor of the Principles and Practice of Medicine in Bellevue Hospital Med. College, $N$. $Y$.

PHTHISIS: ITS MORBID ANATONY, ETIOLOGY. SYMPTOMATIC EVENTS AND COMPLICATIONS, FATALITY AND PROGNOSIS, TREATMENT, AND PHYSICAL DIAGNOSIS; in a series of Clinical Studies. By AUstiN Flixt, M.D., Prof. of the Principles and Practice of Medicine in Bellerue Hospital Med. College, New York. In one handsome octavo volume: \$3 50. (Just Issued.)

This volume, containing the results of the author's extended ohservation and experience on a suhject of prime importance, cannot hut have a claim ujon the attention of every practitioner.

This book contains an analysis. in the anthor's lueid style. of the votes whicli he has male in several hundred cases in hospital and private practice. We conl menil the book to the nerusal of all interested in the study of this disease.-Boston Med. and Surg. Journal, Feh 10, 1 s76.

The name of the author is a sufficient guarantee that this hook is of practical value to both student and prac-

titioner. While the author takes ssue with many of the lealing minds of the day on important questions arisin in the sturly of phthisis, the strong testimnisy of expe rience and authority will have great weinht with the seeker atter truth. As the result of clinissl sturly. the work is unequalled.-St. Lonis Ned. and. Surg Journul, Mareh, 1876.

\section{$B^{Y}$ THE SAME AUTHOR. (Now REAdy)}

\section{A MANUAL OF PERCUSSION AND AUSCULTATION; of the} Physical Diagnosis of Diseases of the Lungs and Heart, and of Thoracic Aneurism. In one bandsome royal 12 mo. volume: eloth, $\$ 175$.

In this little work the ohject of the author has been to present in a clear and compact form the existing condition of physical exploration, showing the manner of conducting it and the diagnostic value of the several signs therehy elicited.

This manual, from so experieuced a pen as that dent or practitinner who is somewhat rusty on the of its anthor, conld not he otherwise than concise. "physical signs" it will prove just the book he clear, atud practical. It is all these, and to the stu- wats.-Merl. and Surg. Reporter. Ang. $19,1876$.

\section{BI THE SAME AUTHOR.}

A PRACTICAL TREATISE ON THE DIAGNOSIS, PATHOLOGY, AND TREATMENT OF DISEASES OF THL HEART. Second revised and enlarged edition. In one octavo volume of 550 pages, with a plate, eloth, $\$ 4$

Dr. Flint chose a difficult snhiect for his researches, una clearest practical treatise on those snhjects, and and has shown remarkahle puwers of observation should he in the hands of all practitioners and stu and refection, as well as great industry, iu his treat- lents. It is a credit to Anerican medical literature. ment of it. His hook must he considered the fullest -Amer. Journ. of the Med. Sciences, July, 1860.

\section{$B^{Y}$ THE SAME AUTHOR}

A PRACTICAL TREATISE ON THF PHYSICAL EXPLORA. TION OF THE CHEST AND THE DIAGNOSIS OF DISEASES AFFECTING TIIE RESPIRATORY ORGANS. Second and revised edition. In one handsome octavo volume of 595 pages, eloth, \$4 50 .

Dr Flint's treatise is one of the most trustworthy incy to over-refinement and unnecessary minnteness gnides which we can consult. The style is clear and vhich characterizes many works on this same sub. distinct, and is also concise, being free from that tend- ject.-Dublin Medical Press, Feb. 6, 1567.

WILLIAMS (C.J. B.), M.D.,

Senior Consulting Physicion to the Hospitul for Consumption, Brompton.

PULMONARY CONSUMPTION; Its Nature, Varieties, and 'Treat. ment. With an Analysis of One Thousand Cases to exemplify its duration. In one neat octavo volume of ahout 350 pages, cloth, \$2 50. (Lately Published.)

CHAMBERS (T. K.), M.D..

Consulting Physirien to St. Mary's Hospital, London, dec.

A MANUAL OF DIET AND REGIMEN IN HEALTH AND SICKNESS. In one handsome octavo volume. Cloth, $\$ 275$. (Just 1ssued.)

DlPHTILRIA; its Nature and Treat $n$ ent, with an account of the History of its Prevalence in various Contries. By D. D SuADF, M. D. Secoud and revised edition. In one neat royal $12 \mathrm{mo}$. volume, cluth, कै। 2:;

WALSHE ON THE DISEASES OF THE HEART ANI GREAT VESSEIS. Third American edition. In

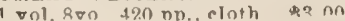

FULLER ON DISEASES OF THELUNGS AND AIRPAssaglis. Their Pathology, Physical biagnosis, Symptoms, and Treatment. From the seewnd aud revised Englixh colition. In one hamelsome octavo volume of abont 500 pages: cloth, $\$ 350$.

LA ROCHE ON PNEUMONIA. 1 vol. 8vo., cloth, of 500 pager Price\$3 00.

8MITH ON CONSUMPTION ; ITS EARIT AND RE-

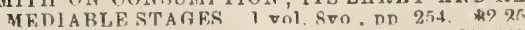
LECTURES ON THE DISEASES OF TIE STOMACII. With an lutroduction on its A natomy and Pliynio. logy. By WILLIAM BRINTON, M.D., F.R.s. From the second and enlarged Londonedition. With il lustrutions ul wood ln one handsome octivo volume of about 30 pages: cloth, $\$ 32:$.

CHAMbEHS'S RESTORATIVE MEIICINE. An II veirn Anunal Oration. With Tro Sequels. In one very handsome vol. small 121110 , cluth, \$il 00 Fux ox TIIE DISEASES OF THE STHUACH: Beins the Whird Elition of the "Dingnosis and 'l'rentnent of the Variaties of Dyspepsia." lieviced nud Fnlared. With Illustratious. In nue handsoue octavo volume: eloth. \$3 200 (Just lssued)

PAVY'S TREATISE ON THE FUNCTION OF DIGESTION ; its Disorders and their Treatment. Froul the kpcond London edition. In one handsume volume, small octarn, cloth, s.200

PAVY' TILATISE (IN FOOD) AND HETETICS loysiologically and Therapenticaliy Considered. In one handsome octaro volume of uearly 600 pages, clotb, $\$ 175$. 
BUWSTEAD (FREEMAN J.), M.D.

Professor of Venereal Disenses at the Col. of Phys. and Surg., Nein Xork, dec.

THE PATHOLOGY AND TRFA'TMENT OF TENERFAL DISEASES. Including the results of recent investigations upon the subject. Thirl erlition, revised and enlarged, with illustrations. In one large and handsome octavo volulue of over 700 pages, cloth, $\$ 500$; leather, $\$ 600$.

In preparing this standard work again for the press, the author has subjected it to a very thorough rerision. Many portions bave been rewritten, and uluch new matter adiled, in oriler to bring it completely on a level with the most advanced condition of syphilography, but by careful solupression of the text of previous editions, the work has been increased by only sixty-four juges. The labor thus bestowed upon it, it is hoped, will insure for it a continuance of its position as a complete and trustworthy guide for the practitioner.

It is the most complete book with which we are ac- wuch special commendationas if its predecexsors had quainted in the language. The latest views of the unt been published As a thoronghly practical hook best authorities are put forward, and the information on a class of diseises which form a large sliare of Is well arranged-a great point for the student, and nearly erery physician's practice, the volume before still more for the practitioner. The suhjects of vis- us is iy far the hest of which we have kuowledge. ceral syphilis. syphilitic affectione of the eyes, and $N Y$. ifedicel Gizatte. Jiar. 28, 1871

the treatment of syphilis hy repeatedinoculations. are It is rare in the history of medicine to find any one very fnlly discusked.-London Lanert, Jan. 7, 1971. book which contains all that a practitioner nepds to

Dr. Fixmstead's work is alrealy so univerally kuow; while the possessor of "l3umstead on Vene. snown is the best treatise in the Euglish language ou real “ ias uo occision to look outside of its covers for venereal diseases, that it ma reem alnost - uperti u- aything practical counected with the riaguosic. his. ons 10 say more of it than that a new edition has been tory, or treatment of these affections.- $N$. $Y$. Medical issned. But the anthor's industry has rendered this Junrmal, March, 1871

gew edition virtually a new work, and so merits as

\section{COLLERIER (A.), BCUMTEAD (FREEMAN J.),}

$\begin{aligned} & \text { Sergeon to the Hopital du Midi. } \text { Professon of Venereal Distasws in the } \\ & \text { Physirians and Surgeons. N. }\end{aligned}$

AN ATLAS OF VENEREAL DISEASES. 'Translated and Frliterl hy FreEMAN J. BuMSTEAD. In ene large imperial 4 to. volume of 328 pages, double-columns, with 26 plates, containing about 150 figures, beautifully colored, many of them the size of life; strongly bound in cloth. $\$ 1700$; also, in five pa-\$s, stout wrappers, at $\$ 3$ per part.

Anticipating a very large sale for this work, it is offered at the very low price of THRE DOL. LARS a Part, thus placing it within the reach of all who are interesterl in this department of praotice. Gentlemen desiring early impressions of the plates would do well to order it without delay.

A specimen of the plates and text sent free by mail, un receipt of 25 cents.

We wish for once that our proviuce was uot restrict- n it eud, we do not know a single medical work, - d to methods of treatment, that we inight say something of the exquisite colored plates in this volume. - Limiton Practitioner, May, 1869

As a whole, it teaches all that can he tanght by means of plates and print.-Lmdon Lancet, March LS, 1569 .

Snperior to anything of the kiud ever hefore issued on this continent.-Canadr Merl. Journal, March, '69.

The practitioner who desires to understand this braneh of medicine thoroughly should obtain this, the most complete and best work ever published.Dominion Mra. Journal, May, 1.64.

This is a work of master hauds on both sides. II Cullerier is scarcely secoud to, we think we may truly sqy is a peer of the illustrious and renerahle Ricord, $x$ hile in this country we do not hexitate to say that Dr. Bumstead, as an authority, is without a rival Assuring our readers that these illustrations tell the whole history of venereal disease, from its inception which for its kind is unore uecsesary for them to have. -California Med. Frazette, March. 1569.

The most splendidly illustrated work in the lanzuage, and in our opinion far inore useful than the Fench original $-A m$. Journ. Merl. Seieneses. Jan.' 69.

The fifth and concluding number of this magnificent work has reacked us, and we have uo hesitation in sa ying that its illa-trations surpass those of prerious uniuherk. - Bost Med and Surg. Jl, Jan. 141869

Other writers besides M. Cullerier have given us a good account of the diseases of $w$ hich he treats, but uo one has furnished us with sucls a complete series of illustrations of the venereal dikesses. There is, however, an additional interest and ralne possessed by the volnme before us: for it is an A merican reprint and translation of M. Cullerier's work, with incidental remarks by one of the most eminent American syphilographers, Mr. Bumstead. - Brit. and For. Herlien-rhir. Review, July, 1869

TEF (HENRI)

Prof. of Surgery at the R.vyal. College of Surgeons of Englond etc.

LECTURES ON SYPIIIIS AND ON SOME FOR.MS OF LOCAL DISEASE AFEECTING PRINCIPALLY TIIE ORGANS OF GENERATION. In one handsome octavo volume : cloth; $\$ 225$. (Lately Published.)

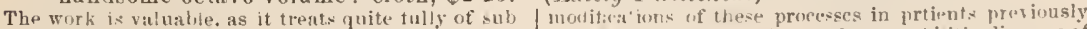
jests which are not dwelt upon in the systematic works cyphi itic: primary amd secondary symi itic dicases of

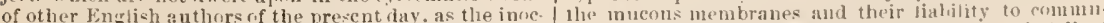

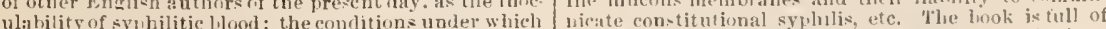
the secretions of primary and secondary syphitio man. clinical materiat illustrating thest tojucs, original or the secretions of primary and secondary syphilitic man. the morbid processes produced by such inoculation; the

fILL (BERKELEI),

Surgeon to the Lock Hospital, London.

ON SYPHILIS AND LOCAL CONTAGIOUS DISORDERS. In one handsome octaro volume: cloth, \$3 25.

TEISSL (H.), MD.

A COMPLETE TRE A TISE ON TENEREAL DISEASES. Translated from the Second Enlarged German Edition, by Frederic R. Sturgis, M.D. In one octavo volume, with illustrations. (Preparing.) 

FOR (TILBURY), M.D., F.R.C.P., and T. C. FON, B.A., M.R.C.S.,

EPITOMIE OF SKIN DISEASES. WITH FORMULA. For STUDeNTS AND PRActitioners. In one handsome $12 \mathrm{mo}$. volume, of 120 pages: cloth, $\$ 1$. (Now Ready.)

A veryelear and eoncise description is given of the / quite practieal. The early chapters, treating of eleelementary lesions and the author's remarks on the mentary nuatters, in the study of skin diserses. are very general cbaracter, complications, and modifications of good. and the list of formulat is excellent.-Archices of eruptions, torrther witl the ir practical hints on the ex- Clinicul Surgo $y$. Dec. $] 8 \% 6$.

amination of skin diceases, will he of great assistance If doctors neclect the study of diseases of the skin, it to the novice in tbis lepartment of melicine. We know will not lue for lack of onportunities of instruction. Tbis of no other which, in so little space. contains so nu uch little handhook contains wonderfully eondensed knowreliable information. $-N$. I. Med. Journ., Dec. 1876. | ledge that cannot but be most useful to erery one wbo

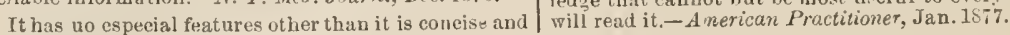

WILSON (ERASMUS), F.R.S.

ON DISEASES OF THE SKIN. With Illustrations on wood. Sev* enth American, from the sixth and enlarged English edition. In onelarge octavo volume of over 800 pages, $\$ 5$.

A SERIES OF PLATES ILLUSTRATING “TILSON ON DISEASES OF THE SKIN;" consisting of twenty beautifully executed plates, of which thir. teen are exquisitely colored, presenting the Normal Anatomy and Pathology of the Skin, and embracing accurate representations of about one hundred varieties of disease, most ol them the size of nature. Price, in extra cloth, $\$ 50$.

Also, the Text and Plates, bound in one handsome volume. Cloth, $\$ 10$.

\section{$B^{Y}$ THE SAME AUTHOR.}

THE STUDENT'S BOOK OF CUTANEOUS MEDICINE and DIs. FASES OF THE SKIN. In one very handsome royal 12 mo. volume. $\$ 350$.

\section{MELIGAN (J.MOORE), M.D., M.R.I.A.}

ATLAS OF CUTANEOUS DISTASFS. In one beautioful quarto volume, with exquisitely colored plates, \&c., presenting about one hundred varieties of disease. Cloth, $\$ 550$.

The diagnosis of eruptive disease, hewever, under to whicb the particular case may belong. Wbile all circumstunces, is very diffcult. Nevertheless, ooking over the "Atlas" we have been indnced to Dr. Neligan has certainly, "as far as possible," given ixamine also the "Practical Treatise," and we are a faithful and accurate representation of thisclass of inclined to consider it a very superior work, cons diseases, and there can be no doubt that tbese plates bining accurate verbal description with sonnd views will be of great use to tbe student and practitioneriu of the pathology and treatment of eruptive diseases. drawing a diagnosis as to the class, order, and species -Glasgow Med. Journal.

HILLIER (THOMAS), M.D.,

Plysicinn to the Skin Department of Iniversity College Hospital, \&c.

HAND-BOOK OF SKIN DISEASES, for Students and Practitioners. Second American Edition. In one royal $12 \mathrm{mo}$. volume of $358 \mathrm{pp}$. With Illustrations. CJoth, \$2 25.

We can conscientionsly recommend it to the student; the style is clear and pleasant to read, the matter is good, and the descriptions of disease, witb the modes of treatment recommended, are frequently 1llnstrated with well-recorded cases, - London Med. Times and Gazette, A pril 1, 1865.

A NDERSON (MCCALL), M.L.

Physician to the Dispensary for Skin Diseases, Glasgow, \&c.

ON THE TREATMEN'T OF DISEASES OF THE SKIN. With an Analysis of Eleven Thousand Consecutive Cases. In one vol. 8vo. \$1. (Lately Published.)

\section{GMTH (EUSTACE). M.D., Physician to the Northoest London Free Dispensary for Sick Children.}

\section{A PRACTICAL TLEATISE ON THE WASTING DISEASES OF}

INFANCY AND CHILDHOOD. Second American, from the second revised and enlarged English edition. In one handsome octavo volume, cloth, 250 . (Lately Issued.)

Tbis is in every way an sdmirable book. The / scribed as a practical handbook of the common dismodest title whicb the author has chosen for it scarce. eases of children, so numerous are the affections con ly conveys an adequate idea of the many subjects sidered either collaterally or directly. Wo are npon which it treats. Wasting is so coustant an at. acquainted with no safer guide to tbe treatment of tendant upon the maladies of childhood, that a trea- children's diserses, and few works gire the insight tise n pon the wastiug diseases of children must neces. into the physiological and other peculiarities of chil. sarily embrace tbe consideration of many *ffections dren that Dr. Smith's book does.-Brit. Med. Journ., of wich it is a symptom; and this is excellentlywell April 8, 1871.

done by Dr. Smith. Tbe book inight fairly be de. 
GMITH (J.LEWIS), M. D.,

Professor of Mrmbirl Anatomy in the Bellevue Hospilal Med College, $N$ Y.

A COMPLETE PRAC'TICAI, TREA TISE ON THE DISEASES OF

CHILUREN. Third Edition, revised and enlargerl. In one handsome octavo volume of 720 pages. Cloth, $\$ 5$; leather, $\$ 6$. (Just Issued.)

The eminent success which this work has achieved has enoourager the author, in fire faring this third edition, to render it even more worthy than heretofore of the faror of the professinn. It has been thoroughly revised, and very considerable additions have heen made tlironghout. To accommodate these the volume has been printerl in a smaller type. so as to jirevent any notable increase in its size, and it is presented in the hope that it maly attain the jusition of the Americun text book on this important dejartment of medical science.

This work took a stand as an authority from its firs elition will contirm and ald to its reputatiun. IInving appearance. and erery one interestel in studying the been brought up to the preapnt mark in the rajil addiseases of which it treats is desirous of knowing what rance of nedical science, it is the best work in our improvements are apparent in the successive editims. language, on its rmme of topies. for the $A m e r i c a n$ prac The princinal adilitions to which we reter. and which titioner.-I'ucific Med. and Sulg. Journ.. Fub. 1-i6.

will be the distiuguishing features of the third edition. Dr. Smith's visenses of Children is certainly th" most are chapters on diphtheria cerebro-spinal meuingitis, valuable work on the subjects treated that ihe practiand rötleln. The former disease is considered much tinner can provide himself with. It is fully abreast more in detail thau formerly, and a great amount of with every advance: it should be in the lands of prac very practical information is added, and altogether it is titinners generally, whils, because of the roncisenes one of the most comprehensive and one of the best writ- and clearness of style of the writing of the autlur, every ten chapters of the subject we have thus far read. His professor of diseases of children. if he has not already description of cerebro-spinal meningitis. founded also done so, should sdopt this as bis text-book.- ${ }^{\circ} \alpha$. Itedical for the most part on personal experience. is aclmirably clear aud exhaustive - The Ned. Record. Feb. 19, 1876.

In presenting this deservedly popular treatise for the third time to the profession, Dr. smith bas giren it a careful preparation, which will uake it of derjuled superiority to either of the former editions. The position of the anthor. as physicion and consultant to several large ehildren's hospitals in New York eity, has furuished him with ronstant ocensions to put bis treatment to the test, and his work has at ouce that practical and thoughtful tone which is a marked characteristic of the best productions of the Americau medical press.- Med. and Surg. Reporter, Feb. 1576.

The former editions of this book hare given it the highest rank among works of its class, and the present

\section{Honth7y, Feb. 1876.}

The third edition of this really valuable work is now before us, with a lundred vages of additional matter, an altered size of page, new illustrations. and new type. of the diseases treaterl of for the first time. we notice rötheln and cerebrospinal ferer. which latrly prevailed in enidemie form in some parts of the country. The article upon diphtheria, containing the latest derelopments in the pathology and treatment of that dreal dis ease, which so lately raraged our country, if peculiarly interesting to every practitioner. We gladly welenme this standard work. and rbeerfully reconimend it to our readers as the best on this subject in the Jnerlish language-Nasheille Journal of Med. and Surgtry, Jarch, 1876 .

\section{CONDIE (D. FRANCIS), M.D.}

A PRACTICAL TREATISE ON THE DISEASES OF CHILDREN. Sixth edition, revised and a ugmented. In one large octavo volume of nearly 800 closely. printed pages, cloth, $\$ 525$; leather, $\$ 625$.

The present edition, which is the sisth, is fully up | teachers. As a whole, however, the work is the best to the timesin the discussion of all those pointsin the American one that we have, and in its special adapta. pathology and treatment of infantile diseases which tion to American practitioners it certainly has no have been bronght forward by the Germau and French $\mid$ эqual. - New Fork Med. Record, Jarch 2, is6s.

\section{YITEST (CHARLES), M.D.}

Physician to the Hospital for Sick Children, \&.c.

\section{LECTURES ON THE DISEASES OF INFANCY AND CHILD.}

HOOD. Fifth American from the six th revised and enlarged English edition. In one large and handsome octavo volume of 678 pages. Cloth, $\$ 450$; leather, \$5 50. (Just Jssued.)

The continued demand for this work on both sides of the Atlantic, and its translation into German, French, Italian, Danish, Dutch, and Russian, show that it fills satisfactorily a want extensively felt by the profession. There is probably no man living who can speak with the anthority derived from a more extended experience than Dr. West, and his work now presents the results of nearly 2000 recorded cases, and 600 post-mortem examinations selected from among nearly 40,000 cases which have passed under his care. In the preparation of the present edition he has omitted much that appeared of minor importance, in order to find room for the introduction of arditiona matter, and the volume, while thoroughly revised, is therefore not increased materially in size.

Uf all the English writers on the diseases of chil-| liring uuthorities in the difficultepartuent of med dren, there is no one so entirely satisfactory to us as $\mid \mathrm{cdl}$ seieuce in which he is most widely known.Dr. West. For years we have held his opinion as $/$ Boston Med. and Surg.Journal.

Judicial, and have regarded bim es one of the highest

\section{BY THE SAME AUTHOR. (Lately Issued.)}

ON SOME DISORDERS OF THE NERTOUS SYSTEM IN CIILN. HOOD; being the Lumleian Lectures delivered at the Royal College of Physicians of Lon. don, in March, 1871. In one rolume, small $12 \mathrm{mo.}$, cloth, $\$ 100$. 
THOMAS (T. GAILLARD), M. D.,

Professor of Obstetrics, \&e, in the College of Physicians and Surgeons, N. Y., \&e.

A PRACTICAL TREATISE ON THE DISEASES OF WOMEN. Fourth edition, enlarged and thoroughly revised. In one large and handsome octavo volume of $\$ 00$ pages, with 191 illustrations. Cloth, $\$ 500$; leather, $\$ 600$. (Just Issued.)

The autbor has taken advantage of the opportunity afforded by the call for another edition of this work to render it worthy a. continuance of the very remarkable favor with which it has been received. Every portion has been subjected to a eonscientious revision, and no labor has been spared to make it a complete treatise on the most advanced condition of its important subject.

A work which has reached a fourth alition, and that, tno, in the short space of five yests, has achiever a remuation which places it almost beyond the reach of criticism, and the favorable opinions which we have alrcady expressed of the former elitions sectu to re quire that we should to little nore than annomme this new issue. We raunot refrain from saying that, as a practical work, this is seeond to none in the kng lish. or. indeed, in any other language. The arrauscwent of the contents, the admirably clear nianner in which the subject of the differential diacnosis of geveral of the cliceases is handled, lenve nothing to lie desired by the prastitioner who wants a thoroughly clinieal work, one to which he ean refer in liffienit cases of doubttul diagnosis with the certainty of gaining light ant instruction. Dr. Thoman is a man with a very clear hewl and deciled views. and there sums to be nothing which be so much dislikes as hazv notions of diagnosis anil blind routine and mureasonahle therapeuties. The student who will thorourbly study tlis book anul test its principles by clinical olservation. will certainly not be guilty of these fault.s.-London Lancet, Feb. 13.157 .5 .

The latest edition of this well-kuown text-hook retains the exsential chiracters which rendered the earliest so deservedly popular It is still pre-eminently a practical manual, intended to courey to studeutsin a clear aud frrcible mauner a sufficiently complete outline of gynacology. la a word, we should sat that auy oue who inteuded to make a special study of gynrecology could hardly do hetter than to begin with a minute perusal of this book, and that any one who iutended to keep gynacology subordinate to geaeral prantice, should bardly fuil to have il ou liand for future reference. $-N$. $Y$. Med. Journ.. Jan. 1875 .

Reluctautly we are obliged to close this unvatis factory notice of so excelleut a work, and iu cunclu. fion would remark that, as a teacher of $g y n s e c o l o g y$, hoth didactic and clinical, Brof Thomashascertainly titkeu the lead far ahead of his ennfrères, and as an author he certaiuly has met with unu-na! and mer. ited success. - Am Journ. of Olstrtrics, Nov. 1874.

This volume of Prof. Thonas in its revised form is classical withuut being pedantic, full in the details of audomy and palhology, withont ponderous transtation of nages of German literatnre, describes dictiuctly the details and difficulties of each operatiou, withont wegrying and useless minutia, and is iu all respects a wirk worthy of coufidence, justifying the high reqard in which its distinguished a nthor is held by tbe profession. $-A \mathrm{~m}$. Supplement, Obstet. Journ. Oet 1s7t.

Professor Thomas fairly took the Profession of the United States by atorn when his book first made its appearance early in 1565 . Its reception was simply enthusiastic, notwithstanding a few adverne critjcista- from on transatlantic brethreu, the first large edition wis rapidly exllaunted, aud in six muuths a second one was issized, aud in two years a third one was unu in nced and publinled, and we are now promised the fourth. The popularity of this work was not ephemeral, aud its success wax unprecedeuted in the a nuals of Americau medical literature six years is a long period in medical scientific researcb, but Thomas's work ou "Disea-es of Womeu" is still the leading native production of the United States. The order, the matter, the abseuce of theoretical disputativeness, the fairuess of statement, aud the elegance of diction, preserved thrunghout the entire rag ae of the bouk, indicate that Protessor Thomas did not overestimate bis powers when he conceised the idea and executed the work of $\mathrm{pr}^{\mathrm{w}}$ duciug a new treatis $\theta$ npon direases of womeu-Prop. PALLE, in Louis. ville Med. Journel, sept. 1574.

\section{OARNES (ROBERT), M. D., F. R.C.P.}

\section{A CLINICAL EXPOSITION OF THE MEDICAL AND SURGI-} CAL DISEASES OF WOMEN. In one hand some octavo volume of about 800 pages, with 169 illustrations. Cloth, $\$ 500$; leather, $\$ 600$. (Just Issued.)

Dr. Bitrues is not only a practitioner of exceptioually large opportunities, which he lras used well, but he has kept litmelf informed of what has beeu haid and lune by others; aud he lias in tha present vol ume judiciousy used this kuowledge. We cau strougly recommend Dr. Baraes is work to the gyasecolöical student and practitiouer.-N. Y. Med. Rec ord, Juue 15, 187 \&

We cun only repeat tbat, as a thoroughly sound, pructical, clinical treatise, we know of no lingliali work whicl can compare to this of Dr. Barues. To the sin-called specialist, as well as to the general practitionor, it will prove a most useful guide,-Londun Linert, Jau. $10,107 \mathrm{t}$.

In conelnsion, we must expressonr convietion that, iu viev: of the wide ringe of subject- compressed into a siugle volume, this book is ahnirable for the conciseness and clearness with which practical points a re trpated, and evidently from a large experience. For stndeuts, and, incleed, for a good uauy of thuse who for want of time canuot, or for wat of inclination will not, be stndents, it is a safe and satisfactory guide, aud no ne who attempts to treat the diseakes neculiar to women cau itforit to be without it. 'The volume is profusely illustrated: many of the

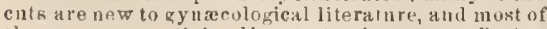
them are essentisl adjuncts to the text.-Boston Med. and Surg. Journ, April 17, 1S7t.

Dr. Burnes'n preseut work is a maguificent contribution to the literaturc of that branch of the profese sion with which hisuame has so long been lounoraly connected. (') attempt, huwevar, an exhanstive a alysis of so volumiuous a treatise wonld eary us far beyoud all reatsouable bousds - Glasgoio red. Journ., July, is 1 .

Embodying thelongexperlence and persousl obser vation of une of the greatent of living leachersin dis gases of women, it seems pervaded by the presence of the author, who speaks directly to the realer, and ipeaks, too, as one having anthority Ancl yet, notwithstanching this distinct personality, there is nothang narrow as to time, place, or iudividuals, in the ripws presented, aud iu the iustructions ziven; Dr. Barnes las been an atteutivestudent, not ouly of Eucopean, but also of A melican literature, pertainiug to liseases of females, and enrichedthis ow experience by treasures theuce gatliered; lo seeus as fauliar, or example, with the writiogs of Sims, Entmet, Thomas, and Peaslee. as if these enineut men were his contrymen a ad colleggues, and gives them id credit which unst he gratifying to every Anerican pliysiciau.-Am Journ. Merl. Sei., April, 1574.

Thronghout the whole book it is impossible not to feel that the anthor has spontaneously, conacientionsly, and fearlessly performed histask. He goes direct to the point, and does not loiter on the way to gossip or quarrel with other anthors. Dr. Barnes's book will be eagerly read all over the world, and will everywhere be admired for its comprehensiveness, honasty of purpose, and ability - The Ohstet. Journ. of Freat Britain and Ireland, Mal'cl, 1874. 
HODGE (HUGH L.). M.D.,

Emeritus Professon of Ohstetries, \&c., in the University of Pennsylornia.

ON DISEASES PECUIAAR TO WOKEN; including Displarements

of the Uterus. With original illustrations. Second exlition, revisell and enlarged. It one beantifully printed octavo volume of 531 pages, cloth, $\$ 450$.

From Prov. W. H. BrForn, of the Rush 3ftical College, Chicngo.

The book bears the impress of a master hand, and must, as its predecessor, prove acceptahle to the profession. In diseases of women Dr. Horlge has established a school of treatment that has become world. wide in fame.

\section{WJEST (CHARLES), M.D.}

LECTURES ON THE DISEASES OF TOMEN. Third American, from the Third London edition. In one neat octavo volume of about 550 pages, cloth, $\$ 375$; leather, \$4 75 .

As a writer, Dr. West stands, in our opinion, se- seekingtruth, and one that will convince the stadent cond ouly to Watson, the "Macaulay of Medicine;' that he has committed himself to a candid. safe, и $\mathrm{\square d}$ he posesses that happy faculty of clothing instruc. valuableguide.-N. A. Med.Chirurg Reviezn.

tion in easy garments; combining pleasure with proft, he leads his pupils, in spite of the a acient pro verb, along a royal road to learning. His work is one which will not satisfy the extreme on either side, bn it is one that will please the great majority who are

Professor Hodge's work is truly sn original one rou beginnjog to and, conkertuently now our cru pe. :ase its pages without legruing something upw. AR a contribution to the xtuly of women 'p dimeatsen, it la nf great value, and is abunilantly uhle to staud un ft. ow n merits. $-N$. Y. Fedical Record, Sept. 15, 1 stis.

We have to say of it, briefly and decidedly, that 11 is the best work on the subject in any language, and that it stamps Dr. West as the facile yrinceps of British obstetric authork.-Edinburgh Mfed. Journal.

DEWEES'S TREATISE ON THE DISEASES OF FE MALES. With illastratione. Eleventh Edition with the Author's last improvementsand correc tions. In one octavo volnme of 536 nages. wit\} plates, cloth. $\$ 300$

CHURCHILL ON THE PUERPERAL FEVER AND OTHER. DISEASES PECDLIAR TO WOMEN 1 vol. 8vo., pp. 450 , cloth. $\$ 250$.
ASHWELL'S PRACTICAL TREATISE ON THE DISEASES PECULIAR TO WOMEN. Third American, from the Third and revised London edition. 1 vol. sro., pp. 528, cloth. \$3. 50

MEIGS ON THE NATURE, SIGAS, AND TREAT. MENT OF CHILDBED FEVER. 1 vol, Svo., pp. 365 , eloth. $\$ 200$.

\section{TANNER (THOMAS H.), M.D.}

ON THE SIGNS AND DISHASES OF PREGNANCY. First America! from the Second and Enlarged English Edition. With four colored plates andillustration: on wood. In one handsome octavo volume of about 500 pages, cloth, $\$ 425$.

With the immense variety of subjects treated of We recommend obstetrical students, young and and the ground which they are made tocover, the im. old, to have this volume in their collection. It cor possibility of giving an extended review of this truly tains aot onls a fair statement of the signs, 8 ymptom remarkable work must be apparent. We have not a and diseaser of preguancy, but comprises in addition single fault to find with it, and most heartily com- much interesting relative matter that is not to b mend it to the careful study of every physician who fonnd in uns other work that we can name. Edin wonld not only always be sure of his diagnosis of burgh Mert. Journal, Jan. 1868.

\section{THE OBSTETRICAL JOURNAL. (Free of postage for 18iT.)}

THE OBSTETRICAL JOURNAL of Great Britain and Ireland; Including MIDwfery, and the DISEASES of Women AND INFAsts. With an Americar Supplement, edited by J. V. IxGHAM, M.D. A monthly of about 80 octaro panges very handsomely printed. Subseription, Five Dollars per annum. Single Numbers, 5 cents each.

Commencing with April, 1873, the Obstetrical Journal consists of Original Papers by Brit ish and Foreign Contributors; Trinsactions of the Ohstetrieal Srocieties in Fnglanil and abroad Reports of Hospital Practice; Reviews and Bibliogriphical Notices: Articles and Notes, Edito rial, Historical, Forensic, and Miscellaneous; Selections from Journals; Correspondence, \&c Collecting together the vast amount of material daily accumulating in tbis important and ra pidly improving department of medical science. the value of the infurmation which it pre sents to the subscriber way be estimated from the character of the gentlemen wbo have alrends

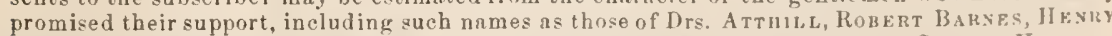

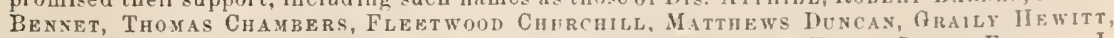
Braxton Hicks, Alfred Meadows, W. Leishas, Alex. Simpson, Trqer Smith, Edwari) J TILT, SPENCER WELLS, \&c. \&c. ; in short, the representative men of British Obstetrica and Gynæ. cology.

In order to render the OBstetrical Jounsal fully adequate to the wants of the Americar profession, each number contains a Supplement devoted to the arlvances male in Obstetrics and Gynacology on this side of the Atlantic. This portion of the Journal is under the editorial charge of Dr. J. V. INGnAM, to whom editorial communications, exchanges, books for re. view, \&c., may be addressed, to the care of the publisher.

* * Complete sets from the beginning can no longer be furnished, but subscriptions can com. mence with Vol. IV., A pril, 1876, or with January, 1877. 
PLAYFAIR (IT. S.), M.D., F.R.C.P.

Professor of Obstetric Medicine in King's College, ete. ftc.

A TREATISE ON THE SCIENOE AND PRACTICE OF MIDTIFERY. In one handsome octavo volume of 576 pages, with 166 illustrations: cloth, $\$ 400$; leather, \$5 00. (Just Issued.)

The stulent aud also the busy practitioner will find here a rich mine frow which he may nbtain valuable information to aid him iu his attenctance on the pu-rperal female 'The whole chapter unon the manarement of a natural labor is by itxelt worth the price of the book. Indeed, authors generally seem to reuard this matter as of trivial imvortauee, as though it were a thing too well known to nced elucidation, while they dwell at great and tiresome length upon malpresentation-, milformations, ete, matters which so rarely are encoun ered hy the general practitioner but we might continue at still oreater length, so fiscinating have we found this book of Dr. Play fair's. We would earnestly recommend it to all our readers as a book which should occusy a prominent position on their shelves, and one, too, which they should coustantly and carefully study. -Med. und Surg. Feporter, Sept. 30, 1876.

The author's reputation was sufficient to warraut grent expectations. when lis fir theouning work wus announced. and its appenrance has caused no disapp intment It deals in a masterly way with unny dispuled points, and gives conelusions which it would be dilfieult to gniusay. The work is the must valuable acquisition to the sulject on which it treats which lias beeu giren the profession in a long time, and in saying this we do not forget the many admirable treatises which have recently upyenred. No practitioner can afforil to be without it - Peninsular Journ. of Med., Sept. 1875.

The hirh reputatiou already wou by Dr. l'layfuir in this special department of medicine is a suffivient guarantet? for the meritorious character of this work. Every page is rejlete with iuteresting and iustructive matter, containing the very latest information resurding the subject of ob-tetrics, tinll of hints of the greatest practical value. This work will find. we predict. a larue and ready sale The book is profusely illustrated with valuable wood-cuts, and is printed in heautiful type.-Cincinnati Lancet and Olserver. Nov. 1876.

This is pre-cmincntly a work alapted th the wants of students, and will do more towand accomplisling the profession at larue iu that nurticularbrunch of medicine than any other work in the field of ob-tetric litcrature. In praise of this work ton un uch cinnot be said - in ad verse criticism very little. We alvise every student aud ever. graluate to obtiin it, and hope, ere long, to see it adopted as the principal text book of obstetric mediciue in every college in the United states. - Nashville Med. and Surg. Journ., Oct. 1876.

HODGE (HUGH. L.), M.D.,

Emeritus Profes.sor of Midwifery, \&e, in the University of Pennsylvania, \&c.

THE PRINCIPLES AND PRACTICE OF OBSTETRICS. IIIU. trated with large lithographic plates containing one hundred and fifty-nine figures from original photographs, and with numerous wood-cuts. In one large and beautifully printed quarto volume of 550 double-columned pages, strongly bound in cloth, $\$ 14$.

The work of Dr. Hodge is something more than a obstetricians. Of the Americun works on the snbject Imple presentation of his particular. riews in the de- itis decidedly the best. - Edinb. Med. Jour., Dec. '64. partment of Obstetrics; it is something more than an We have read Dr. Hodge o book with great plen ordinary treatise on midwifery; it is, in fact. a cyclo-sure, and have much satisfaction in expressing on padia of midwifery. He has aimed to embody in a commendation of it as a whole. It is certainly highly single volnme the whole science and art of Obstatrics instructive, and in the main, webelieve, correct. The An elaborate text is combiued with accurate aud va. great attoution which the anthor has devoted to the ried pictorial illustratious, so that no fact or principle mechauism of parturition, taken along with the con. Is left nustated or nnexplained.-Am. BLed. Times, clusions at which he hus arrived, point, we think, Sept. 3, 1864 .

conclusively to the fact that, in Britain at least, the

It 18 very large, profusely and elegantly illustrated, doctrines of Naegele bave been too blindly recelved. and is fitted to take its place near the works of great - Glasgow Med. Journal, 0ct. 1864.

* * Specimens of the plates aud letter-press will be forwarded to any address, free by mail, on receipt of six cents in postage stamps.

THE PRINCIPLES AND PRACTICE OF OBSTETRIC MEDICINE AND SURGERY, in reference to the Process of Parturition. A new and enlarged edition, thoroughly revised by the author. With additions by W. V. KEATING, M. D., Professor of Obstetrics, \&c., in the Jefferson Medical College, Philadelphia. In one large and handsome imperial octavo volume of 650 pages, strongly bound in leather, with raised bands; with sixty-four beautiful plates, and numerous wood-cuts in the text, contrining in all nearly 200 large and beautiful figures. $\$ 700$.

\section{CHURCHILL (FLEETWOOD), M. D., M.R.I.A.}

ON THE THEORY AND PRACTICE OF MIDWIFERY. A new American from the fourth revised and enlarged London edition. With notes and additions by D. Francis CoNDie, M. D., author of a "Practical Treatise on the Diseases of Children," \&c. With one hunlred and ninety-four illustrations. In one very handsome octavo volume of nearly 700 large pages. Cloth, $\$ 400$; leather, $\$ 500$.

AONTGOMERY'S EXPOSITION OF THE SIGNS AND SYMPTOMS OF PREGNANCY. With two exq̨isisite colored plates, a nd numerons wood.cuts. In 1 vol. 8vo., of nearly $600 \mathrm{pp}$, cloth. $\$ 375$.
RIGBY'S SYSTEM OF MIDWIFERY. With Notes and Additional Illustrations. Second American odition. One volnwe octavo, cloth, 422 pages. $\$ 250$. 
CEISHMAN (WLLLAM), M.D.,

Kegius Professor of Midwifry in the University of Rlasgon, de.

A STSTEM OF MIDIFERY, INCIUDING THE DISEASES OF PREGNANCY AND TIIE PUERPERAL STATE. Second American, from th Sermi and Revised English Edition, with additions by Joux S. PAnur, M. D., (1)sletriciun to the Philadelphia Ilospital, de. In one large and very bandsume octavo volume of wor 700 pages, with about two hundred illustrations: cloth, \$5; leather, \$6. (Jutely Issued)

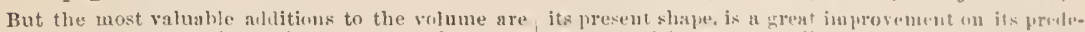

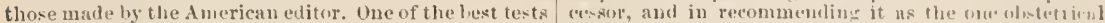

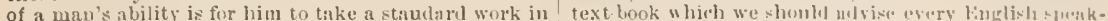
our profession. Jike this of lor. Leishman. and materially in practitioner and stmlent to buy.-Amerieun Jour. improve it. Mauy a one, with more ambition than wis. doun. has attempted it with uther books and failed. liut Dr. Parry las suceedel nost utmirably. We know no obstctrical work that has anything better ou the use of the forceps than that which lir. larry has given in this, and nowork that has the rutional and intelligent views upou lactation with which he has anriched this. llaving used "Leishman" for two yeurs as a text book for studeuts, we can cordially commend it. and are quite satisfied to coutinue such use now.-Am. Practitioner, Mar. 18j6.

This new edition decidedly confirms the opinion which we expressed of the first ellition of the work, in the May. 1874. number of this Jourual. that this is "the best molern work on the sul,ject in the Enrlish language." The excellent practical notes eontributed by Dr. Pary refer principally to the use of the foucens. lactation. and the puerperal diseases, and are inteuded to increase the use fulness of the work in this country. An entirely new chapter on diphtheria of puerperul wounds has becn added (Dr. P. has hat unusual experieuce in this form of puerperal fever), and also a number of illustrations of the principal obstetrical instruments iu nse in America. We have no lositatiou in saying that the work, ju nal of Olsterics, lieb. 1 76 .

l'rhaps the most useful one the stulent can promure. Some important ahlitions have leen male by the editor, in order to adapt the work to the professim in tlis comu. try, and sonu new llustrations have bern introulucud, to represent the obstetrical mstruments conerslly (1mployed in American practice. In its present form, it is an exceedingly valuable book for both the student uttd

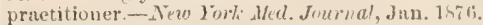

Iu alout two years after the issue of this excellnt treative a second edition has been ealled for. Wi reward the treatios as thoroughly somm and pructical. and one which may with confilence be consulted in any enter gincy.-The London Lancet, Dis: 11, 1evó.

The appearance of a second edition of this system is the fultiluent of the prophecy which we male in a former review, that the book wis clestined to "luetolue a favorite." The alditiuns by Dr. l'irry are usually not abumlant, but certain plnces which are pinted out as the weak part of Dr. Leishmun's hatndicraft hass linn grently strensthened by abundant and rery judicious addenda.-Philud. Hed. Times, Dec. 25, 1875.

SWA TNE (JOSEPH GRIFFITHS), M.D.,

Physician-Accoucheur to the British Genernl Hospital, \&c.

OBSTETRIC A PIORISMS FOR THE USE OF STUDENTS COM. MENCING MIDWIFERY PRACTICE. Second American, from the Fifth and Revised London Edition with Additions by E. R. Htтchins, M. D. With Illustrations. In one neat $12 \mathrm{mo}$. volume Cloth, \$1 25 (Lately Issued.)

* * See p. 3 of this Catalogue for the terms on which this work is offered as a premium to subseribers to the "AMERICAN Journal of THE MEDICAL Sciences."

J

Professor and Director of the Gynacologicul Clinic in the University of Rostock

A COMPLETE TREATISE ON 'THE PATHOLOGY A IT 'TREAT. MENT OF CIILDBED, for Students and Practitioners. Translated, with the consent of the author, from the Second German Edition, by JAMes ReAD CHADWICK, M D. In nne netrovo volume. Cloth, $\$ 400$. (Jicst Issued.)

We feel quite sure that the profesion of this country meface, to supply a want arising from the rery brief will weleome - Cincinmati lled. Neros, June. 1876.

In Germany this treatise is reiarded as a standaril authority in tlis branch of medicine. and as it colstains the refent advmnces in the pathologr and treatment of diseases that pertain to the puerperal condition. will be glarlly received liv a large portion of the profes

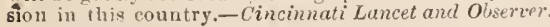
June, 1870 . () hatefrics, in which respect. it seems the protession in his country is not different from oura, and to fill a blank the subject alrealy in the present standpoint of scirnce. 'The the field. and the present standpoint of scirice. The throurlout of eareful study and practistal experience. ts its tille imulies it is a manual rathej than a treatise. - Herican. Journal of Med. Sciences, A pril, 1-71.

This work was written, as the author tells us in hi

\section{PARRT (JOHN S.). M.D.,}

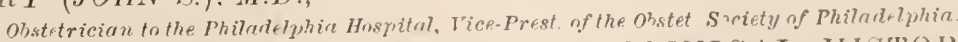

ENTRA-UTERINE PREGNANCY: ITS CLINICAT, HSTORI, DIAGNOSIS, PROGNOSIS, AND TREATMENT. In one handsome octavo volume. Cloth, \$2 50. (Lately Issued.)

It is with genuine satisfiction, therefore. that werear the work before us. which is far in adrance of any monograph upon the subject in the English langunge. and exceeding very much, in the number of cases upon which it is based, we helieve, any work of the kinl iver published. The author has giren great care and stndy to the work, and has handled his statistirs with iudgto the work. and has hand w so that, whatever was to be gained from them he has garned and added to our knowledge on lie suh jeet. We owe the autlior murb for giving ws a clenr. readable book unon this topie. Ile has, so far $a$ - it i at present possible, renoved the obscurity attunding certain points of the subjeet. He has brought order

out of something very like chans.-Philadelphia Mod. Times. Hivb. 19, 1876.

In this work Dr. P'arry has adder a most valuable eontribution to obatetrie literature, aud one which uests a want lone felt by those of the profession whil have ever treen called upon to loal with this elas of cares. Bustom Vol. and Surg. Journ. Wurch 9. 1niti.

This work. heing as near as possible s eollection of the exuriences of many permons, will afford $x$ most $u=c \cdot f u$ exporiences of for this unst guale, both in tiafnosis anc treatment interesting and fatal malady We think it shouhl the hands of all physicians pr. 
GROSS (SAMUEL D.), M.D.,

Professor of Surgery in the Jefferson Medical College of Philadelphia.

A SYSTEM OF SURGERY: Pathological, Diagnostic, Therapeutic, and Operative. Illustrated by upwards of Fourteen Hundred Engravings. Fifth edition, carefully revised, and improved. In two large and beautifully printed imperial octavo volumes of about 2300 pages, strongly bound in leather, with raised bands, \$15. (Just Issued.)

The continued favor, shown by the exhaustion of successive large editions of this great work, proves that it has successfully supplied a want felt by American practitioners and students. In the present revision no pains have been spared by the author to bring it in every respect fully up to the day. To effect this a large part of the work has been rewritten, and the whole enlarged by nearly one-fourth, notwithstanding which the price has been kept at its former very moderate rate. By the use of a close, though very legible type, an unusually large amount of matter is condensed in its pages, the two volumes containing as much as four or five ordinary octavos. This, combined with the most careful mechanical execution, and its very durable binding. renders it one of the cheapest works accessible to the profession. Every subject properly belonging to the domain of surgery is treated in detail, so that the student who possesses this work may be said to bave in it a surgical library.

We have now brought our task to a conclusion, and have seldom read a work with the practical value of which we have been more impressol. Every chapter is so emcisely put togetler, that the busy practitioner. when in difficulty, can at once find the information he requires. His work, on the contrary, is ensmololitan, the surgery ut the world being fully represented in it. The work, in fact, is so lis torically umpejudiced. and $=0$ eminently practien, that it is aluost. a talice compliment to say that we helieve it to be destined to occupy a foremost place as a work of reference, while a syst m of $s u$. gery liket tie present system of suruery is the gractire of surgeons. The printing and bindiug of the work is unexceptionable; indeed, it contrasts, in the latter respect, remarkally with English melical and surgical cloth-boum! ouhlications, which are generally so wetchediy stitched as to require re-binding before tliey are any time in use.-Dub. Sourn. of Mre. Sci, March, 18it

Dr. Gross's Surcery, a great work, has beconne stil greater, bnth in size and merit, iu its most recent form. The dilference in actual number of pages is not more than 130 , but. the size of the page having been increaced to what we believe is technieally termed " elephart." there has been room for considerable additions, which, togetler with the nlterations, are improvements.-Lond. Lancet, Nor. 16. 1872.

It combines, as perfectly as possible, the qualities of a text-burk ant work of reference. We think this last edition ct (iross's "Inrgery," will confirm his title of

"Primus inter. Pures." It is learned, scholar-like, methodical, precise. and exhaustive. Wie scarcely think any living man could write so complete and fanltess a treatice, or romprehend more solid, iustructive matter, in the given number of pares. The labor must lase been immense, and the work gives evidence of great fowers of mind, and the hiyhest orcler of intellertual likripline and nethodical disposition. and arrangement of acyuired knowledge and personal experience.- $\boldsymbol{N} . \boldsymbol{Y}$ Hed Journ.. Feb 1573

As a whole, we reyard the work as the representative "System of Surrery" in the English lan range.-St. Louis IVediral ard Surg. Juurn., Uet. 1572.

The two magnificent volumes before us afford a very complete siew of the suruical knowledge of the day. Some years ago we bad the pleasure of jresuntion the first edition of fiross's surgery to the profession as a work of unrivalled excellence; and now we have the result of years of experience, labor, and stndy, all condensed upon the great work before us. A nd to students or practitioners desirons of enriching their lilorary with $a$ ireasure of reference, we can simply commencl the purchase of these two volumes of immense research Cincinnati Lancet und Obsrter, sejt. 1-72.

A complete system of surrery-not a mere text-book of operations, but a scientific aconnt of surgical theory and practice in all its departments.-Brit, and For. Med. Chir, Rev, Jan. 1873.

\section{BY THE SAME AUTHOR.}

A PRAC'TICAL TREATISE ON THE DISEASES, INJURIES, and Malformations of the Urinary Bladder, the Prostate Gland, and the Urethra. Third Elition, thoroughly Revised and Condensed, by SAmuel WV. Gross, M.D., Surgeon to the Philadelphia Ilospital. In one handsume octavo volume of 574 pages. with 170 illus trations: oloth, \$4 50. (Now Ready.)

The editor has availed himself of the opportunity afforded by the call for a new edition of this work to thoroughly revise nnd render it in every respect worthy of its position as a standard au. thority. lieing in great part rewritten, the olportunity has been taken to condense it as much as possible, so that it will be found reduced in size, while yet containing the latest views on the subjects discussed.

This work is a very valuable aldition to surgical lite rature, and will be fomd nseful to all who may rofer to it.-Jimmal of Vervous ond Jental Jisesse, Uct. 1876

'The bouk is fully up to the times, and we know of no monograph on the sulject of mrinsm diseases that i: fuller and more complete than the mie under notice.Ginein. Lancel and observer, Ine. 1-ib.

$1 t$ is a valuable and exhnustive truatise on the surgery of the arinary orgmo, brought fully up to the existing state of our knowlolge. A perusal of its 574 pares will aninly repay the: investigator. - l'ac fic lled. ard sury. Journ, Nov. 1s76.

Nothing neml he suid to eommend this stanlard work to the profession. It has long becis cousilereal one of the nost valuable from the pen of the distingnisied anthor The erlitor has done his work ably and fitill. fully. and severnl of the (hapters, by no means the lenst useful mes, are from his pen: as a momormpl repre. suluting alt the snigery of the parts of whicls it treats, it lias nosnperiorin out tongue.-Wed and Surg lie. porter, (1).t. 2], 1×76.
For refurence and general information, the uhsiciau

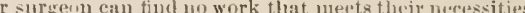
more thoronghly than this, a revised olition of an ex(e)lent treatise. and no medisal library shoull be will out it, liejelete with handsome illustruti. ns and grood ileas. it has the unusal advantage of bolng edxily comprobended, hy the reasonable and practical manner in whel the varions subjests are syatematizel ane arransel We heartily recomment it to llo profiseion as a valunhle aldition to the important liternture of diserses of the urinary organs.-Itlanta J/rd Jourk., Wet. 1576 .

It is with pleasure we now again take up this old work in a decitedly new dress. Inderel, it must le reugarded ns " new book in very many of its parts. Thu chapers. on "Dineases of the Bladier." "l'roslate budy." anut "Lithotomy", are slidendil specimens of clescriptive wribing: while the chapter on "stricture" is one of the most contise aml elean lant we have ever read - Vew Jork Mted. Journ., Nov. 1576. 


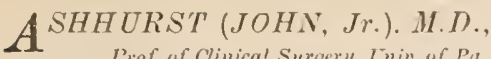

I'mf. of Clinical Surger!. Thiv of $P$ a. Surgeon to the Episengel Herspitul, Philadelphir.

THE PRINCIPLES AND PRACTICH OF SURGHRY. In one

very large and handsome octavo volume of about 1000 pages, with nearly 550 illustrations, cloth, $\$ 650$; leather, raised bands, $\$ 750$.

Its author brs evidently tested the writings and ppinions of others Ife isconservatire, but mot hide. experiences of the past and present in the cructble bound by antlurity. His atyle is clear, elegant. and of a careful, analytic, and bonorable mind, and futh-| scholarly. 'The wi rk is an admirabletext-bork, and fnlly endeavored to brins his work up to the level of a useful bonk of reference. It is a creslit to Anperican the highest standard of practical surgery. Ho is professinual literature, and one of the first rije fruits frauk and defuite, and gives us opinions, and gene. If thesoil fertilized hy the hlood of our late nulaplly rally sound ones, instead of a mere resumé of the var.-N. Y. Hed Record, Feb. 1, 1872.

\section{HOLMES (THMOTHY). H.D., \\ surgenn to st George's Ifospital, Londinn.}

SURGERT, ITS PRINCIPLES AND PRACTICE. In one handsome octavo volume of nearly 1000 pages, with 411 illustrations. Cloth, $\$ 6$; leather, $\$ 7$. (Just Issued.)

We helieveit to be by far the best surgical text-book that we have, insomncli as it is the complete-t, and the one most thoroughly lrought up to the kuowledge of the present day. All who will gire this book the careful pernsal that it dererves and rernires, shether studeat or practitioner, will agree with us, llt $\times t$, from the happy way in which justice is done, both to the principles and practice of surgery, from the care with which its pages are brought n l to modern date, from the respect whteh is paid all along $t$ " the opialons of otliers, it deserves to take the first place among the text.books on surgery. - British Hed. Journ., Dec. 25, 1975 .

This is a work which has heen looked for on both sides of the Allantic with much interest. Mr. Holmes is a surgeon of large and raried experience, and one of the best known, and perliaps the mont billiant writer npon surgical subjects in England. It is a book for students - and an admirable one-and for the busy general practitioner It will gireastudent all the knowledge needed to pass a rigid examination. The book fuirly justifies the high expectation that were formed of $j t$. Its style is clear and forcible, eveu brilliant at times, and the cunciseness neerl.d

THE PRINCIPLES AND PRACTICE OF SURGERY. By WILIA и PiRria, F.R S E, Profe-sor of sinrgery in the [tnirersity of Aberdenn. Edited by $\mathrm{J}_{\text {мн }} \mathrm{x}$ Neill, M D., Professor of Surgery in the Penua to bring it within its proper limits has not impaired it ofurce anc distiactuess. $-N$. Y. Hed. Record, April $1 \frac{1}{2}, 1976$.

It will be found a most excellent epitoue of sur. gery by the general practilioner who has nol the time togiveattention to more minuleand extended works, and to the medical student. In fict. we know of no one we car more cordial y recommend. The author has acceeded well in gioing a plaiu and proctical ancount ot each surgical iojury and disease, aud of the treatment which is most commonly advisable. It will no doubt becone a popular work in the profe-sion. and especially as a text-hook.-Cincinnati Mer. News, a pijl, 1806.

In poiut of literary structure we bave no words but those of praise to write of Dr. Holmes's book tlis diction is always graceful and clear, and he usnally works with sreat con-cientionsness. There is much independence of tho $1 \mathrm{ght}$ and a herltby disposition to resis the tevdency to walk in old tracks simply becanse they areold. On the whole, he has donphis ivork iu a manner for which it wonld be ungenerous not to give bim very high credit judeed.-Dublin Jucrn. Med., ()et. 1576.

Meaical College, Surgeon to the Pennsylrania Hos. pital, \&c. In oue rary bandsome octavo volume of 750 payes, with 316 illustrations, cloth, $\$ 375$.

\section{BIGELOW (HENRY J.). M. D.}

Professor of Surgery in the Mnssanihusetts Med. College.

ON THE MECHANISM OF DISLOCATION AND FRACTURE OF THE HIP. With the Reduction of the Dislocation by the Flexion Method. With numerous original illustrations. In one very handsome octavo volume. Cloth, $\$ 250$.

\section{HAMILTON (FRANK H.), M.D., \\ Professor of Frnctures and Dislocations, \&e., in Bellevue Hosp. Med. College, New York.}

\section{A PRACTICAL TREATISE ON FRACTURES AND DISLOCA-} TIONS. Fifth edition, revised and improved. In one large and handsome octavo rolume of nearly 800 pages, with 344 illustrations. Cloth, $\$ 575$; leather, $\$ 675$. (Nou, Ready.)

This work is well known, abroad as weil as at home, as the highest authority on its important subject-an authority recognizerl in the courts as well as in the schools and in practice-and again manifested, not only by the demand for a fifth edition, but by arrangements now in pro. gress for the speedy appearance of a translation in Germany. The repeated revisions which the author has thus had the opportunity of making hare enabled him to gire the most careful consideration to every portion of the volume, and he has sellulously endeavored in the present issue, to perfect the work by the aid of his own enlarged experience and to incorporate in it whatever of value has been added in this department since the issue of the fourth edition. It will therefore be found considerably inproved in matter, while the most careful attention has been pilid to the typographical execution, and the volume is presented to the profession in the confident hope that it will more than maintain its very distinguished reputation.

There is nn hetter work on the subject in existence than that of Dr. H.tonilton. It sluould be in tle posses. sion of every general practitioner and surgeon.-The Am. Jinurn. of Obstetrics. Feb. 15:0.

The value of a work like this to the practical jhysician and suryeon can bardiy be over-estimated. smil the necessity of haring such a book rerised to the latest dates, not merely on account of the practical importance of its teachings, but also by reason of the melico lean bearings of the eases of which it treats. and whell hare recently been the subject of useful papers ly lor 11 anilton and others, is sufticiently obvings to erery one The present volume seems to amply fill all the requi-ites. We ean safely recommend it st the hest of its kin.l in the English lanugure, azul not excelled in suv otleer.Journ. of Nerious and Mental Diseuse, Jan 1576. 
H. RICHSEN (JOHN E.),

THE SCIENCE AND ART OF SURGERY; being a Treatise on Sur. gical Injuries, Diseases, and Operations. Revised by the author from the Sixth and enlarged English Edition. Illustrated by over seven hundred engravings on wood. In two large and beautiful octavo volumes of over 1700 pages, eloth, $\$ 900$; leather, $\$ 1100$. (Lately Issued.)

These are only a few of the points in which the states in his preface, they are not confined toany one presentedition of Mr. Erichsen's work surpasses its portion, but are distributed generally through the predecessors. Thronghout there is evidence of a subjects of which the work treats. Certainly one of laborious care and solicitude in seizing the passing the most valiable sections of the book seems to ns to knowledge of the day, which reflects the greatent be that which treats of the diseases of the arteries credit on the author, and much enhances the valne and theoperative proceedings which they necessitate of his work. We cun only admirethe industry which in few text-books is so much carefnlly arranged iuhas euabled Mr. Erichsen thus to succed, amid the formation collected.-London Med. Times and Gaz., distractions of active practice, in producing emphatic- Oct. 26 , IS72.

ally THE book of reference and study for British pructitioners of surgery.-London Lancet, Oct. 26, 1572.

Considerahle changes have been made in this edition, and nearly a hundred new illustrations have been added. It is dificult in a sinall compass to point out the alterations and additions; for, as the author

The entire work, complete, as the great English treatise on Surgery of our ow time, is, we can assure our readers, eyually well adapted for the most junior student, and, as a book of reference, for the ad vanced practitioner -Dublin Quarterly Journal.

SEEY'S OPERATIVE SURGERY. In I vol. SVo. cl., of 5.50 pages; with abont 100 wood-cnts. \$326 COOPER'S LECTURES ON THE PRINCIPLES AND

PraCtICE OF SURGERY. In 1 vol. $8 \nabla 0$ cloth, 7.50 p. \$2. GIBSON'S INSTITUTES AND PRACTICE OF SCRGERI. Eighth edition,.improved and altered. With thirty-four plates. In two haudsome octavo volumes, about 1000 pp. , leather. raised baud . \$6 6 ก.

MIILEli's PRIYCIPLES OF SURGERY. Fourtl American, from the Third Ediuburgh Edition. In one larre svo. vol. of 700 pares, with 340 illustratious : cloth, $\$ 375$.

MILLER'S PRACTICE OF SURGERT. Fourth American, from the last blinburgh lidition lievised by the American editor. In one large svo. vol. of vearly 700 pages, with 3 it illustrations: cloth, $\$ 375$.

\section{DRUITT (ROBERT), M.R.C.S., \&. .}

TIE PRINCIPLES AND PRACTICE OF MODERN SURGERY. A new and revised American, from the eighth enlarged and improved London edition. Illugtrated with four hundred and thirty-two wood engravings. In one very handsome octavo volume, of nearly 700 large and closely printed pages, cloth, $\$ 400$; leather, $\$ 500$.

All that the surgical student or practitioner conld practice of surgery are treated, and so clearly and desire.-Dublin Quarterly Journal.

It is a most admirable book. We do not know when we have examined one with more pleasure..Boston Med. and Surg. Journal

In Mr. Druitt's book, thongh containing only some seven hnndled pages, both the principles and the perspicuously, as to elncidate every important topic. We bave examiued the book most thoroughly, and can say that this success is well merited. His book, moreover, possesses the inestimable advantages of baviug the subjects perfectly well arranged and clas. sified, and of being written in a style at once clear ind succinct.-Am. Journal of Med. Sciences.

CYOS.ELIN (L.)

Professor of Surgery in the Faculty of Medicine, Paris, tc.

CIINICAL LFCTURWS ON SURGER. Delivered nt the Hospital of La Charité. Translated from the French by LEwis A. STrusox, M D., Surgeon to the Presbyterian IIospital, New York. With illustratious. (Publishing inthe Metical Neu's and Library, commencing with the July No. 1876.)

\section{SUMINART OF CONTFITIS.}

Part I. Surgtcal. Diseases of You' H-S Lectires.

II. FiACTURFS OF THE LIMBS-18 Lectures.

III. Tracmatic Osteltis A.XD Ni.cromis-2 Lectures

It will be seen from this brief abstract of the contents that these Lectures treat of subjects which are of daily interest to the practitioner, while some of them hardly receive in the text.books the attention which their importance deserves. The very distinguished reputation of the author and the practical manner in which he has handled the topics before him are sufficient assurance that this work will he in every way satisfictory to the subscribers of the "MEDlcaL NEwS AND LI. BRARY" and that it will in no sensedetract from the character of the very valuableseries of books which have occupied the Library Department of the "NEWs" during the last thirty-three years.

\section{BRIAN'T (THOMA.S), F.R.C.S., \\ Surgeon to (ruy's Hospital.}

THE PRACTICE OF SURGERY. With over Five Hundred Engravings on Wood. In one large and very bandsome octavo volume of nearly 1000 pages, cloth, \$6 25 ; leather, raised bands, \$7 25. (Lately Publushed.)

Again, the athor gives us his own practice, his/sidered calmly and fairly, hut Mr. Bryant's are own beliefs, audillustrutes by his own cases, or those adopted. Thus the work is not a coupilation of treated in Guy's Hospital. This feature adds joint other writings; it is not an encyclopredia, but the emphusis, and a solidity to his statements that inspire plain statements, on practical points, of a nan who confidence. One feels himelf almost by theside of has lived and hroullied and hud his being in the the snrgeon, seeing lis work and bearing his liring richest surgiral experience.-Detroit Revituof Med. words. The riews, etc, of other surgeons are cou- and Pharmacy, August, 1873.

ASITON ON TUE DISEASES, INJURIES, AND MAL FO [L.MATION: (1) THERECTIM AND ANUS; with remarks on Ilabitual Con-tipation. Second American, from the fonrth and enlerged loudon Edition. With illuctraions. Iu one $8 v 0$ vol, of 287 pages, cloth, $\$ 325$
ARFENT ON BANDAGING AND OTIER OPER. TIONS OF MINOR XURGERY. New edition, with an additional chapter on Military Snrgery One 12 mo. vol. of 353 puges, with 181 wood-cuts. Cloth \$1 75 . 
BROWNE (EDCARA.),

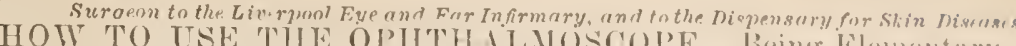
HOW TO LSE THE OPIITHALMOSCOPE. Beine Lilenentary Instructions in Ophthalmoscoly, arranged for the Use of Students. Witl thirly.five illustra. tions. In one small volume royal $12 \mathrm{mo}$. of 120 pages: clotl, $\$ 1$. (Now liculy.)

The information is given in a very concise. but we may. also ald, in a rery cleitr and forcil le wanuer Many if the dingrams that illustrate the text are criminal und ingenions in their construction, aud very iustructive.Edin. Nerl. Juturn.

It is by 110 means an easy rask to write a good ele mentary work ou a dilicult sulject. The author nust not only posass a conprelieusive and accurate know. ledge of it, but must be able to express himself iu rimple and easily intelijuble terms. Ile renuires tu have the power of seizing the essential fact and placing them iu a striking light betiore the reader He must not wenry hius with lougr liscussions, nor confuse him by the mul. tiplirity of defalls: he oust be short. but clear. The little look hefore us fultils tliese reutuirements in a very eati-factory uander. The explanations are grveu in a

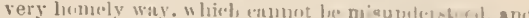

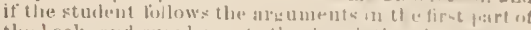
the donok, and sopplements tha deseriptions liy p ramal

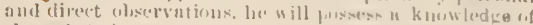

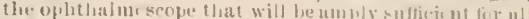

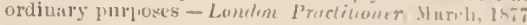

Especiul cure is taken to make the studint famitia

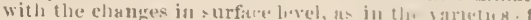

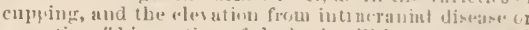
mevitis. 'I his portion of the l ouk will le foul a l1-4-le to a larger atulivence thun Hat Mr. Browne professed ly adclressed - Med.-Chrr Quarkily lier.

We congratulate the authur on so success fully arrom

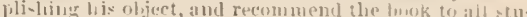
dents interested in this varticular liue of study. - y/e. and surg. lingorter, June 2, 18it.

CARTER (R. BRUDENELL), F.R.CS.

Ophthalmic Surgeon to st Grorge $s$ Henpitat, te.

A PRACTICAL TREATISE ON IJSEASES OF TIE ETE. Edited, with test-types and Additions, by John Grees, M.D. (of St. Louis, Mo).). In one handsome octavo volume of about 500 pages, and 124 illustrations. Cloth, 5375 . (Just Rearly.)

Dr. Green, whose reputation and experience in this department are well known, has giren this work a very careful revision, and has introduced much matter which will be found of importance to the prictitioner. As his system of test-types is the one recommerded by the author, they have been inserted in the volume in a shape which will admit of their being detached and mounted for convenient office use.

These test-types, on a sheet for mounting, can be had separate, price 25 cents.

It would he difficult for Mr. Carter to write an uniu- in riew, aud presents the subject iu a clear and concise struetive book, and inspossible for him to write an un- manner. easy of comprehensiun, and hewce the arure interesting one. Even on subjects with which he is not valuable. Wie would especially comment, howerer. as. bound to be familiar, he can discourse with a rare degree worthy of high praise, the mainer iu which the the-r. of clearness a ud effect. Our readers will therefore not leutics of disease of the eye is elaborated, for here the be surprised to learn that a work by him on the Diseases author is particularly clear and practical, where othcir of the Eye unkes a very valuable addition to ophthal- writers are unfortunately too often dencient. I'he fiun. mic literature. . . The hook will remain oue useful chipter is devoted to a discussiou of the uses and schecalike to the general aud the special practitioner. Not tion of spectacles, and is admirably compact, 1 lain, und the least valuable result.which we expect trom it is that useful, especially the paragraphs on the treatuent of

It will to soue considerable extent despecialize this bril- ureabyopia and uy onia. I u conchsiou, our thanks are iant tepartaunt of meliciue.- London Lincet, Oct. 30 , 150.

It is with great pleasure tbat we can endorse the work as a most valuable contribntion to practical ophthalmology. Mr. Carter ueverdeviates from the end he has due the author for many useful hints in the groat $\sim n b$ ject of ophthalwic surgery and therapentics, a fielu where of late years we gleab but a few grains if rou

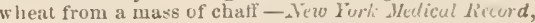
Uct. 23,1575

\section{MIELLS ( J. SOELBERG),}

Professor of Ophthalnnology in King's College Hospital, \&e.

A TREATISE ON DISEASES OF THE EYE. Second Americal, from the Third and Revised London Edition, with additions; illustrated with numerous engravings on wood, and six colored plates Together with selections from the Test-types of Jaeger and Snellen. In one large and very handsome octavo volume of nenrly 800 pages ; cloth, $\$ 500$; leather, $\$ 600$. (Lately Published.)

On examining it carefally, one is not at all sur- lucid and fow

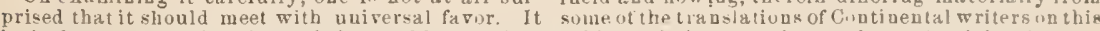
is, in fact, a comprehensire and thoroughly practical subjects thai are to the torket. special pain. are treatise ou di-eases of the eye, settiug forth the prac- taken to explaih, at leagth, those subjects which are tice of the leading oculists of Eurupe and America, particularly diticult of cumprehensiun to the lieginand givingthe author's own opiniussandpreferences, uer, as the use of the ophthalmoscope, the interprewhich are quite decided and worthy of high consid. tation of its initges, etc. The book is prufunely and eratiou. The third Englisb editiun, from which this ab y illustrated, and at the end are to be foumd is taken, having been revised by the author, com- excelleutcolured ophthalmoscupic figures, which are prises a notice of all the more recent adraces nade copies of sume of the plates of Lielireich 's aduirable in ophthilmic science. The style of tle writer is atlid.-Kringra City Med. Jiurn., Juue, 1sit.

CAURENCE (JOHN Z.), F.R.C.S.,

Editor of the Ophthalmic Review, \&c

A HANDY-BOOK OF OPHTHALMIC SURGERY, for the use of Practitioners. Second Edition, revised and enlarged. With numerousillustrations. In one very handsome octavo volume, cloth, \$2 75 .

TA WSON (GEORGE), F. R. C.S., Engl., Assistant Surgeon to the Royal London Ophthalmic Hospital, Moorfields, \&c.

INJURIES OF THE EYE, ORBIT, A VD EYELIDS: their Immediate and Remote Effects With about one hundred illustrations. In one rery hand. some octavo volnme, cluth, $\$ 35 \mathrm{v}$ 
Aurd? Surg to the Presb. Hosp., Surgeon-inethargenf the Infir. for Dis of the Ear, Phila.

THE EAR, I'TS ANATOMY, PIIYSIOLOGY, AND DISEASES. A Practical Treatise for the Use of Mellical Students and Practitioners. In one hand. some octavo volume, with numerous illustrations. (In Press.)

Recent progress in the investigation of the structures of the ear, and advances ma. ${ }^{2} e$ in the modes of treating its diseases, would seem to render desirable a new work in which all the resources of the most advanced science should be placed $a^{t}$ the disposal of the practitioner. This it has been the aim of Dr. Burnet to accomplish, and the advantages which ha has enjoyed in the special study of the subject are a guarantee that the result of his labors will proye of service to the profession at large, as well as to the specialist in this department.

\section{THOMPSON (SIR HENR Y), \\ 1 Surgeon and Professor of Clinical Surgery to Dniversity College Hospital.}

LECTURES ON DISEASES OF THE URINARY ORGANS. With illustrations on wood. Second American from the Third English Edition. In one neat octavo volume. Cloth, $\$ 225$. (Just lssued.)

My aim has been to produce in the smallest possible compass an epitome of practical knowledge concerning the nature and trentment of the diseases which form the subject of the work; anl I venture to believe that my intention has been more fully realized in this volume than in either of its predecessors - Author's Prefice.

\section{$B^{Y}$ THE SAME AUTHOR.}

ON THE PATHOLOGY AND TREATMENT OF STRICTURE OF THE URETHRA AND URINART FISTULE. With plates and wood-cuts. From the third and revised English edition. In one very handsome octavo volume, cloth, $\$ 350$. (Lately Published.)

$B^{Y}$ THE SAME AUTHOR. (Just Issued.)

THE DISEASES OF THE PROSTATE, THEIR PATHOLOGY

AND TREATMENT. Fourth Edition, Revised. In one very handsome octavo volume of 355 pages, with thirteen piates, plain and colored, and illustrations on wood. Cloth, \$3 75.

\section{TAYLOR (ALFRED S.), M.D.,}

1 Lecturer on Hed. Jurisp. and Chemistry in Guy's Hospital.

MEDICAL JURISPRUDENCE. Serenth American Edition. Edited by John J. Reese, M.D., Prcf. of Med. Jurisp. in the Univ, of Penn. In one large octavo volume of nearly 900 pages. Cloth, $\$ 500$; leather, $\$ 600$. (Lately Issuerl.)

To the members of the legal and medical profession, in behalf of a wurk on inedical jurisprudence by an it is unuecessaly to say auythiug commendatory of author wh's is almost universallyesteented to be the Taylor's Meduct Jurioprudeuce. We tnight as well best atuthority on this specialty in ourlatuguage. (1) undertake to speak of the nerit of Cinity's Plead. this puint, huwever, we will sy that we cumsider bl. ngs.-Chicugi" Legal Neros, Oet. 16, 18\%..

Little caube added to what lias already been said of this mlandard work of Dr. Taylor"s. As a manal it is doubtless the must comprehearive extat, meeiing fully the demands of the student of mediciue aud law.-IVestern Lancet, Nov. 1073.

It is beyoud question the inust attractive as well as most relinble manual of medical juringudence published in the Euglion language.-Am. Journal of Syphiligraphy, ict. 1873 .

It is altogether siperfuous for us to offer anything Titylor to be the saffest medico-legal anthority to fol. low, ingeneral, with which we are acuaniutediuauy lituguage.-Vu Clin. Recrrd, Nov. 1573.

This lastedition of the Manual is piobably the best of all, as it couraius more material and is worked np to the latert viows of the author as expressed in the last edition of the Principles. 1)r. Reese, the editur of the Manual, has done everything to make his work acceptable to his nedical countrymeu. $-N$. $Y$. Med. Record, Jau. 1;, $137 t$.

\section{$B^{Y}$ THE SAME AUTHOR.}

\section{THE PRINCIPLES AND PRACTICE OF MEDICAL JURISPRU.}

LENCE. Second Edition, Revised, with numerous Illustrations. In two large octavo volumes, eloth, $\$ 1000$; lenther, $\$ 1200$

This great work is now recognized in England as the fullest and most authoritative treatise on every department of its important subject. In laying it, in its improved form, before the American profession, the publisher trusts that it will assume the same position in this country.

\section{$B^{Y}$ TIIE SA.HE AUTHOL. (New Edilion-Just lswed.)}

\section{POISUNS IN RELATION TO MEDICAL JURISPRUDENCE AND}

MLDLUNE. Third American, from the Third and Revised English Edation. In one large vetavo volume of $\$ 30$ pages; eloth, $\$ 550$; leather, $\$ 650$.

To the members of the lenral nnd medical profession ethition of the Principles Dr. Reesc, the editor of the it is unneessary to say angthing commendatury of Manual, las done everything to inake his work aceept-

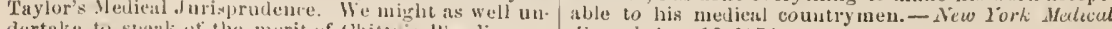
dertake to speati of the marit of Chity s. Pesulings.Chicugo Legal Niws, Uet. 16, 1873.

This latst adition of the Manual is protubly the best of all, as it contains nors material and is workest up to tho latest views of the author as explessed in lhe last líccord, di11. 15, 1874

It is beyond question the most attrative us well as must retiable manum of medicnljurisprudencepublished in the binglish language.-Americun Journal of syphilosrophy, Uct. 1873. 


\section{TUKE (DANIEL HACK), M.D.}

Joint author of "The Manual of Psychological Mredicine," \&c.

ILLUSTRATIONS OF THE INFLUENCE OF THE MINT UPON

THE BODY IN HEALTH AND DISEASF. Desigued to illustrate the Action wf the

Imagination. In one handsome octavo volume of 416 pages, cloth, \$3 25. (Just Issued.)

The object of the author in this work has heen to show not only the effect of the unind in cassing and intensifying disease, but also its curative influence, and the use which ma be made of the imagination and the emotions as therapeutic agents. Seattered facts bearing "pon this subject have long been familiar to the profession, but no attempt has hitherto been made to collect and systematize them so as to render them available to the practitioner, by estalilisling the several phenomena upon a scientific basis. In the endenvor thus to convert to the use of legitimate medicine the means which have been employed so suecessfully in wany systenus of quackery, the author has produced a work of the highest freshness and interest as well as of permanent value.

\section{RLANDFORD (G. FIELDING), M.D., F.R.CP.}

\section{Lecturer on Psychological Medicine at the School of St. George's Hospital, \&c.}

INSANITY AND I'TS TREATMENT: Lectures on the Treatment, Medical and Legal, of Insane Patients. With a Summary of the Laws in force in the United States on the Confinement of the Insane. By IsAAC RAY, M. D. In one very handsome octavo volume of 471 pages; cloth, $\$ 325$.

This volume is presented to meet the want, so frequently expressed, of a comprehensive treatise, in moderate compass, on the pathology, diagnosis, and treitment of insanity. To reuder it 0. more value to the practitioner in this country, Dr. Ray has added an appendix which affords information, not elsewhere to be found in so accessible a form, to physicians who may at any moweat be called upon to take action in relation to patients.

It satisfies a want which must have been sorely actually seen in practice and the appropriate treatfelt by the hasy general practitioners of thiscountry. ment for them, we find in Dr. Blandford's work a It takes the form of a manual of cliuical descriptiou considerable advance over previous writiugs un the of the various forms of insanity, with a description subject. His pictures of the various tinrus ul uental of the mode of examining persous suspected of in- disease are su clear and goud that no reader can fail saity. We call particular attention to this feature to be struck with their superiority to thuse given in of the book, as giving it a unique vilue to the gene. rdinary manuals in the Euglixh litnguage or (so fus ral practitioner. If we pass from theoretical conside- as our own reading extends) in any otber. $-L u n d o r$ rations to descriptions of the varieties of insanity as Practitioner, Feh. 1871.

WINSLOW (FORBES), M.D., D.C.L., \&c.

ON OBSCURE DISFASES OF THE BRAIN AND DISORDERS

OF THE MIND; their incipient Symptoms, Pathology, Diagnosis, Treatment, and Prophylaxis. Second American, from the third and revised English edition. In one handsome octavo volume of nearly 600 pages, eloth, $\$ 425$

\section{LEA (HENRY C.).}

SUPERSTITION AND FORCE: ESSAYS ON THE WAGER OP LAW, THE WAGER OF BATTLE, THE ORDEAL, AND TORTURE. Second Elition, Enlarged. In one handsome volume royal $12 \mathrm{mo}$. of nearly 500 pages; cloth, $\$ 275$. (Lately Published.)

We know of no single work which contains, in so interesting phases of human society and progres, mall a compass, so much illustrative of thestrangest The fulness aud breadth with which he has carried out bis comparative survey of this repulsise tield o.

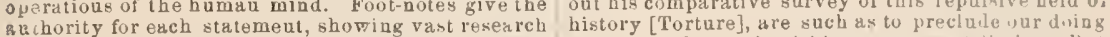
and wouderful industry. We advise uur confreres justice to the work within our prenent limits. Bnt to read this book aud ponderitstenchings. - Chicago here, as throughout the volume, there will be fuund Med. Journal, Aug. 1870.

As a work of curious inquiry on certain outlying points of obsolete law, "Superstition and Force" i. one of the most remarkuble books we have met with -London Athenceum, Nov. 3, 1566

He has thrown a great deal of light upon what mast be regarded as one of the most instructive as well as a wealth of illustration and a critical srasp of the philosophical import of lacts which will reuder Mr. Lea's labors of sterliug value to the binturical stadent.-London Saturdicy Kevieu, ()ct. s, isiu.

As a book of ready reference on the $m$ abject, it is of the highest vulue.-Weglmingter Ritvie1D, Uct. 1567.

\section{7) THE SAME AUTHOR. (Late y Published.)}

STUDIES IN CHURCH HISTORT-THE RISE OF THE TEM. PORAL POWER-BENEFIT OF CLERGY - EXCOMMUNICATION. In one large royal $12 \mathrm{mo}$. volume of $516 \mathrm{pp}$. eloth, $\$ 275$.

The story was never told mure calmly or with, literury phenomenon that the head of one of the first greater learning or wiser thought. We duubt, indeed, If any other study of this field can he compared with this for clearness, accuracy, aud power. - Chicag Examiner, Dec. 1870.

Mr. Lea's latest work, "Stadies in Chnrch History," fully sustains the promise of the tirst. It deals with three subjects-the Temporal Power, Benefit of Clergy, and Excommusicatiou, the record of which hus a peculiar importance for the Englisb btudent, and is a chapter ou Ancient Law likely to be regarded as final. We cain hardly pass from our mentiou of such works as these-with which that un "sicerdotal Celibacy" should he included-withur noilag the Americun houses is also the writer of nome of its no

Mr. Lea bis done great honor to himmif and this country by the atiuirable works be lism written on ecclesiological and cuguate subjects. We hare already had vocusion to commend hin "sujermtimon aud Force" and his "History of sacerdstal Celibicy." Force" and his "History of Sacerdutal Celluacy. thod of dealing with topics and in the thoroughaeabguality sofrequently lacking in Amprican a uthorswith which they are investigated.-N. Y. Jonrual of Psychol. Medicine, July, 1570. 


\section{N EX TO CATALOGUE.}

A aedican Jonrnal of the Medical Sciences Ahstract, Falf-Yearly, of the Med Sciences Anatomical Atlas, by Smith and Horner

Anderkon on Diseases of the Skin

Ashoou on the fiectum and Anus.

Attield's Chemistry

Ashwell on Diseases of Femaler.

Ashburst's Surgery

Burnett on the Ear

Barnes on Diseases of Women

Bellamy's Surgical Anatomy

Bryant's Practical Surgery

Bloxam's Chemixtry

Blandford on Insanity

Basham on Reual Diseases

Brinton on the Stomach

Bigelow on the Hip

Barlow's Practice of Medicine

Bowman's (Jubn E.) Practical Chemistry

Bowman's (John E.) Medical Chemintry

Bristowe's Practice

Bumstead on Venereal.

Bumstead and Cullerier's Atlas of Venereal

Carpenter's Hurau Physiology

Carpenter's Comparative Physiology

Calpenter on the Use and Abuse of Alcohol

Carter on the Eye

Cleland's Dissector

Clowes' Chenistry

Century of American Medicine

Chambers on Diet and Pegimen

Chambers's Restorative Medicine

Christisou and Grittith's Dispensatory

Cburchill's System of Midwifery.

Churchill on Puerperal Fever

Condie on Diseases of Children

Cooper's (B. B.) Lectures on Surgery

Cullerier's Atlas of Venereal Diseases

Cyclopedia of Practical Medicine.

Dalton's Human Physiology

Davis' Clinical Lectures

Dewees on Diseases of Females

Dewees on Diseases of Children

Druitt's Modern Surgery

Dunglison's Medical Dictionary

Dunglison's Human Physiology

Dunglison on New Remediek

Ellis's Medical Formulary, by Smith .

Frichren's System of Surgery

Fenwick's Dlagnosis

Flint on Respiratory Organs.

Flint on the Heart

Plint's Prictice of Medicine.

Flint's Essay :

Flint on Phthisis

Flint on l'ercussinn

Fothergill's Handbook of Treatment

Fownes's Eleuentary Cliemistry

Fox on Diseases of the stomach

Fox on Diseases of the Skin

Fuller on the I, ungs. \&

Green's Pathology and Morhid Anatomy

Gibson' Surgery

Ginge's Pathological Histology, by Leidy

Galloway'\& Qualitative Analyois.

Gray's Auatomy

Grithth's (P. k.) Universil Formulary

Gross on Urinary (Organs

Gross on Foreign Budies in Air-Passagen

Gross's Principles and Prantice of surgery.

Gosselin's Clinical Lectures on Surgery

Hamilton on Dislocations and Fractures

Hartshorne's Essentials of Medicine

Hartshorne's Conspectus of the Medical Sciences

Hartbliorne's A naturny and I'ligriology

Heath's Practical Anacomy

Hoblyn's Medical Dictionary

Hodge on Woinen

Hod ge's Ohstetrics.

Houges" Practical Dissection

Holland's Medical Notes and Reflections

Holines's sinrgery

Horner's Anatomy and Histology

Hadson on Fevers.
PAGE

1 Hill on Venereal Diseases

PAQB

Iillier's Handhook of skin Disegses - 20

6 Jones (C. Handtield) on Nervous Disorders : 17

20 Kirkes' Physlology . . . . 8

25 Knapp's Chemical Technology . 10

10 Lea' 6 Superstition and Force 31

23 Led 8 Studiesin Church History . : : 31

27 Lee on syphilis.

30 Linculn on Electro-Therapentics . 17

22 Leishman's Midwifery

7 La Roche on Yellow Fever.

$2 s$ La Roche on Pneumonia, \&c.

11 Laurence and Moon's Ophthalmic Surgerz . . 39 awson on the Eye Laycock on Medical Ohyervation. ehmann's Physiological Chemistry, 2 vols. Lehmann's Cliemical Physiology . $\quad \cdot \quad \cdot 9$

aclise's Surgical Anatomy

Medical News and Lib

Meigs on Puerperal Fever

Iiller's Practice of Surgery .

tgomery on Pregnancy

eill and Smith's Compendium of

astetrical Journal

Practical Chemistr

Pary on Digestion

Parrish's Practical Pharmacy

Pirrie's System of Surgery

Play fair's Midwifery

nain and Sharpey's Anatomy, by Leidy.

Roberts on Urinary Diseases. 17

Ramsbotham on Parturition

Remsen's Principles of Chemistry

Rigby's Midwifery

Rudwell's Dictionary of Science

Swayne's Obstetric A phorism 8

'argent's alinor Surgery

horey and o 28

skey's Operative Surgery

lade on Diphtheriagery

chinfer's Histology

Smith (J. L.) on Children

Smitl (H. H.) and Horner's Anatomical Atlas

Smith (Edward) on Consumption.

unith on Wasting Diseases in Children

tillé \& Maisch's Dispensatory

Stokes on Fever

anner on Pregnancy

'aylor' ' Medical Jurisprudence

Tay lor on Poisone.

uke on the lnfluence of the Mind

Thomas on Diseanes of Females.

Thompson on Urinary Organs

Thompnon on Strictnre

hompsou on the Prostate

Todd on Acute Diseares.

Watson's l'ractice of Physic

Vells on the Eye

Vest on Diseasen of Fernales

Vest on Diseases of Child ren

Vest on Nervous Disorders of Children

Villams on Consuntiun 18

Wilsus on Consumption

Wilson's Human Anitomy

ilson's liater on Diseares of the $8 \mathrm{kin}$

Wilson's Fater on Disearen of the skin 


. 




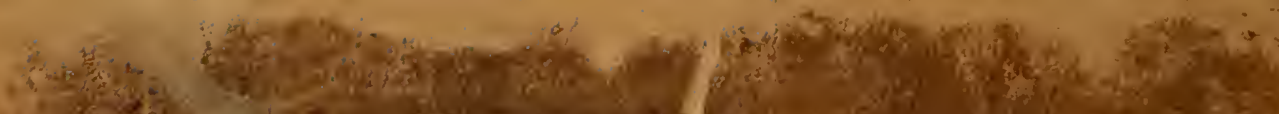

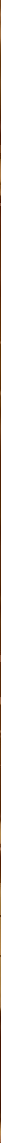

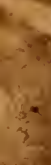

